
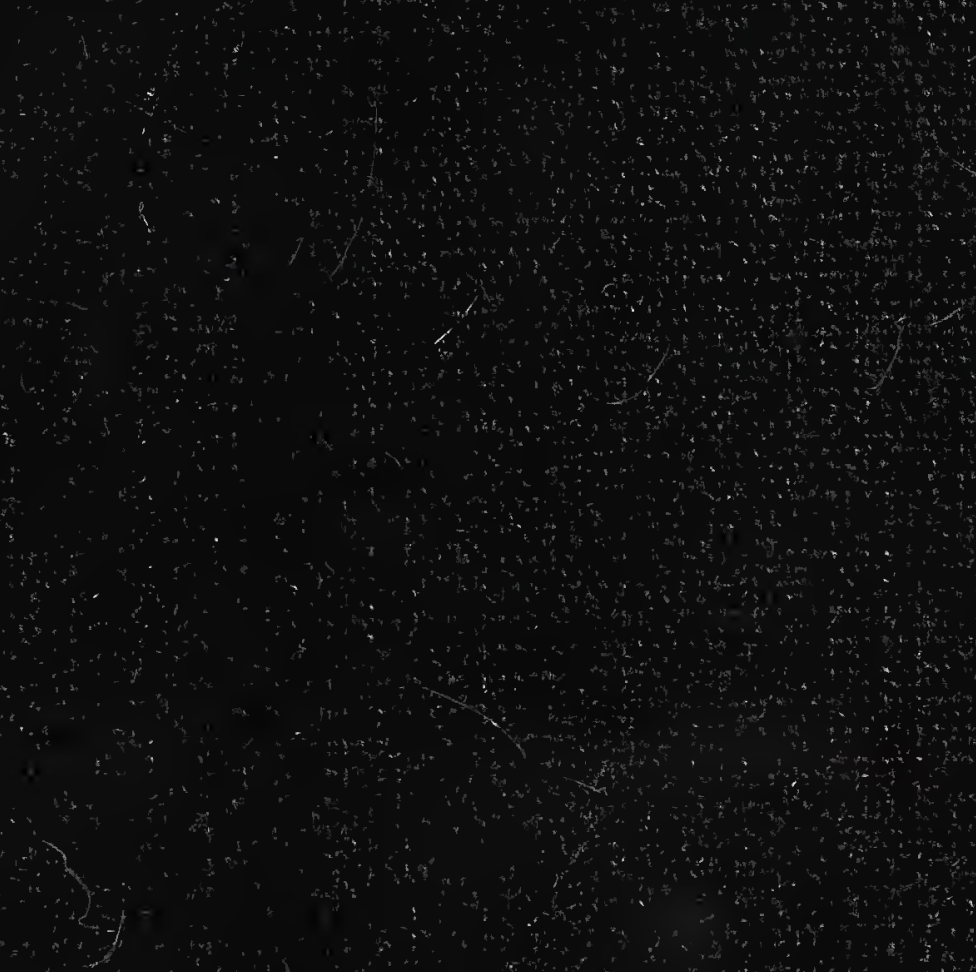

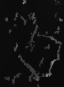
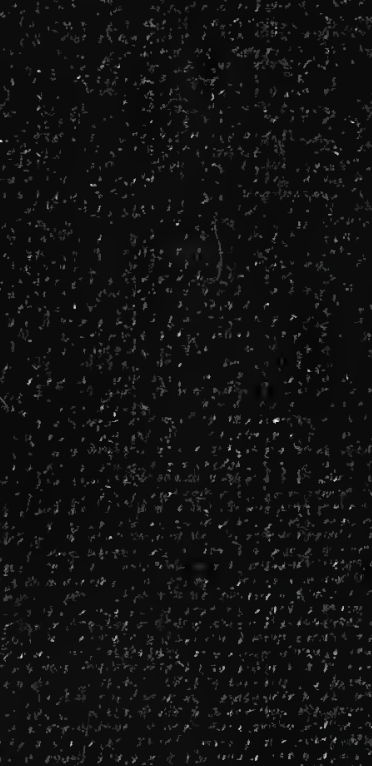


\title{
DAKOTA
}

\section{WOWAPI WAKAN。}

\author{
THE \\ HOLY BIBLE,
}

IN THE

\section{LANGUAGE OF THE DAKOTAS:}

'TRANSLATED OUT' OF

THE ORIGINAL TONGUES;

BY THOMAS S. WTLLTAMSON AND STEPHEN R: RIGOS, MISSTONARTES.

\section{NEW YORK:}

AMERICAN BIBLE SOCIETY, INSTITUTMD IN THE TEAR 1816.

bakata $8 v a$.

$$
1.887 .
$$




\section{WOWAPI WAKAN WOWAPI KIN,}

QA

WICOWOYAKE TONAKA.

WOWAPI WAKAN TANNI.

Wicoicağe

Wicowoyake.

Wicoicage . . . 50

Eyanpaha

Wicowoyake.

Hdinanpapi . . . . . . 40

Lewi Toope . . . . . . 27

Wicayawapi . . . . 36

Woope Itakihna

Dowanpi . . . . 8

Josuwa • . . . . . 24

Isaya . . . . . . : . 66

Jeremiah . . . . . 52

Wayacopi . . . . 21

Rute

I. Sansiel

II. Samuel

4

Wicaśtayatapi 22

II. Wicaśtayatapi . . . . 25

I. Anpetu Oyakapi . . . 29

IT. Anpetu Oyakapi . . 36

Wicaceya . . . . 5

Ezekiel . .. . . 48

Daniel . . . . 12

Hosea . . . . . . 14

Joel • . . . . . 3

Amos . . . 9

Obadiah . . . . . . 1

Jonah . . . . . . . . 4

Mika . . . . . . . 7

36 Nahum . . . . . . 3

- . . . 10

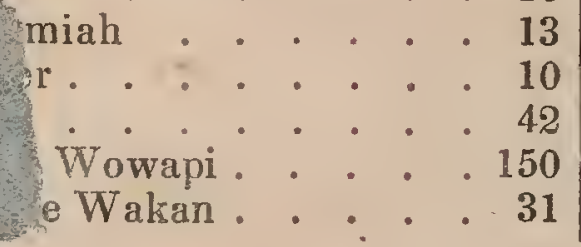

Habakuk . . . . . . 3

Zephaniah . . . . 3

Haggai . . . . . . 2

Zekariah . . . . 14

WOWAPI WAKAN TECA.

Matheos . . . . . 28

Markos . . . . . . 16

Lukas . . . . . . . . 24

Johannes . . . . . 21

Ohanyanpi . . . . 28

Roma

I. Korinth

II. Korinth

Galatie

Ephesos

Philippi

Kolosse

I. Thessalonike

II. Thessalonike
I. Timotheos

II. Timotheos

Titos

Philemon.

Hebrew

Jakob .

I. Inyan

II. Inyan .

6

6

4

4

5

3
I. Johannes

II. Johannes

III. Johannes

Judas

Wayuotanin . 


\section{W I C O I C A G E.}

\section{WICOWOYAKE 1.}

1 Otokahe ekta Wakantanka mahpiya kin maka kin ahna kaga.

2 Unkan maka kin tanton śni, qa takudan ohnaka śni, qa otpaza ośbe kin akan wanke ca, Wakantanka Taniya kin mini kin aman.

3 Unkan Wakantanka, Ojanjan kta, eya. Unkan ojanjan.

4 Unkan ojanjan wanke cin, he Wakantanka waśte e wanhdake ca, Wakantanka ojanjan kin otpaze cin kici yukinukan ehnaka.

5 Qa Wakantanka ojanjan kin, Anpetu eciya, otpaze cin iś, Hanyetu eciya. Unkan ohtayetu, qa ohanhanna he anpetu tokaheya kin hee.

6 Unkan, Okotonyan wanke kte, mini kin okitahedan, qa mini kin mini kin yukinukan kte, Wakantanka eya.

7 Unkan okotonyan kin Wakantanka kage ca, mini okotonyan kuyatanhan kin, qa mini okotonyan akantanhan kin kici yukinukan. Unkan ecetu.

8 Unkan okotonyan kin he Wakantanka, Malipiya eciya. Unkan olitayetu, qa ohanhanna anpetu icinonpa kin hee

9 Unkan, Mahpiya kin ihukuya mini wanke cin icunonpa kawitaya kte, ca taku puze cin taninyan wanke kte, Wakantanka eya. Unkan ecetu.

10 Unkan taku puze cin he Wakantanka, Maka eciye ça, mini kiwitaya kin he, Miniwanca Gen. eciya, qa he Wakantanka waśte e wanhdaka.

11 Hehan Wakantanka heya, Maka kin wato icaliye kte, peji kin he su icahye kte, waskuyeca can kin he waskuyeca icahye kte, waskuyeca mahen su yuke kte, ocaje otoiyohi su kin icaliye kta, maka akan, Wakantanka eya. Unkan ecetu.

12 Unkan maka kin wato aicaga, peji kin ocaje otoiyohi su aicage ca, can kin waskuyeca aicaga otoiyohi mahen su kin yukan ece. Unkan he waśte e Wakantanka wanhdaka.

13 Unkan olitayetu, qa ohanhanna. he anpetu iciyamni kin hee.

14 Unkan Wakantanka heya, Mahpiya okotonyan kin ekta taku iyoyanpa yuke kte, on anpetu hanyetu kici yukinukanyan un kte ça, heon woyaka unpi kte, makoncage, anpetu, omaka, henakiya.

15 Qa malipiya okotonyan kin ekta hena iyoyanpa un kte, maka kin iyoyam ye kte, eya. Unkan ecetu.

16 Wakantanka wiiyoyanpa nom tankinyanyan kaga, tuka uman iyotan tanka kin he anpetu en ounye kite ca uman aoptetu kin he hanyetu en ounye kte; wicanhipi nakun.

17 Hena malipiya okotonyan kin ekta Wakantanka ehnaka, maka kin iyojanjan kta e hecon.

18 Anpetu hanyetu ko ohinniyan ounye wicakiya, qa ojanjan kin otpaze cin kici yukinukan- 


\section{WICOICAGE.}

ounye kiya. Unkan he wa; e Wakantanka wanhdaka.

19 Unkan olitayetu, qa ohansanna he anpetu icitopa kin hee. 20 Unkan Wakantanka heya, Mini kin taku niyake ota icaliye kta, qa taku kinyan maka kin iwankam mahpiya okotonyan kin ohna okinyanpi kte.

21 Hecen Wakantanka hogan tankinyanyan oicaliye, ça taku niyake, taku mini oicage cin ocaje hiyeye cin owasin, hena mini icalikiye ca, taku kinyan hupahu tonyan ocaje otoiyohi. Unkan he Wakantanka waśte e wanhdaka.

22 Hena Wakantanka yawaśte qa hecen ewicakiya, Icagapi qa ihduotapo, qa miniwanca kin ojudan yakonpo, qa taku kinye cin maka akan ihduotapi kte.

23 Unkan ohtayetu, qa ohanhanna he anpetu icizaptan kin hee.

24. Hehan Wakantanka heya, Maka kin taku niyake oicage cin iyecen icaliye kte ; woteca, watutka, wamanica, henakiya ocaje otoiyohi, eya. Unkan ecetil.

25 Hecen wamanica ocaje otoiyohi, woteca ocaje otoiyohi, qa taku maka asdohan owasin ocaje otoiyohi, henakiya Wakantanka wicakage, ca he waśte e Wakantanka wanhdaka.

26 Hehan Wakantanka hecen eya, Unkiye iyeuncecapi qa ouncage unkitawapi kin en wicaśta unkagapi kta, qa miniwanca ekta hogan oicage cin wicayuhe kte, mahpiya ekta taku kinye cin nakun, qa woteca qa maka kin ocowasin, qa watutka taku maka akan sdohan, ocaje owasin yuhe kta.

27 Wakantanka eyaya iye iyececa wicaśta wan kaga, Wakan- tanka ouncage iyececa kaga; wica winyan kici wicakaga.

28 Qa Wakantanka wicayawaśte qa, Icagapi, qa ihduotapo, qa maka kin ojudan iciyapo, qa denakiya wicayuha yaunpi kta, miniwanca ekta hogan oicage, ca malipiya ekta taku kinye cin, qa taku niyake maka aśkanśkan oicage cin owasir, tawa wicaya po; Wakantanka ewicakiya.

29 Unkan, Ito taku maka akan waicaliya suton wojupi owasin cicupi, can waskuyeca suton oicage cin owasin, hena nakun; hena woyute yayapi kta.

30 Tuka taku maka akan ni un kin, malipiya taku okinye cin, qa taku maka aśkanśkan kin, taku niya un kin owasin, hena peji wato owasin woyute wicawaqu, Wakantanka eya. Unkan ecetu.

31 Unkan Wakantanka taku kage cin owasin wanhdaka; unkan iyotan waśte. Unkan ohtayetu qa ohanlianna he anpetu i ciśakpe kin hee.

\section{WICOWOYAKE 2.}

1 Hecen mahpiya kin maka kin iyahna, qa taku ohnaka hiyeye cin owasin tanyan yuśtanpi.

2 Unkan anpetu iciśakowin, Wakantanka tohtani kage cin owasin ayuśtan, qa anpetu iciśakowin kin en tohtani kage ciqor etanhan okihpa.

3 Qa Wakantanka anpetu ici.. śakowin kin he hdawaśte, qa hduwakan. Tohtani Wakantanka kage cin owasin anpetu kin he en ayuśtan, qa okilipa, heon etanhan.

4 Malipiya maka ko kagapi kin, Jehowa Wakantanka maka mahpiya ko kage cin, anpetu kin he en, woicage oyakapi kin dee. 


\section{WICOWOYAKE 2.}

5 Can hiyeye cin owasin maka kin en he śni itokam, peji tinta oicage cin owasin uye śni itokam, Jehowa Wakantanka nahahin maka kin amagaju ye śni, qa wicaśta maka kicanye kte cin wanica.

$6 \mathrm{Qa}$ maka kin etanhan po wankantkiya u, qa maka itohnake kin owancaya acuya.

7 Hehan Jehowa Wakantanka, maka mdu kin etanhan, wicaśta wan kage, ça poge olidoka ohna ipoh iyeya hecen wicaśta nagi ni un kin icaga.

8 Unkan Jehowa Wakantanka, Eden heciya wihinanpe cin ekta, wojupi wan kage ça wicaśta kin he en chnaka.

9 Qa Jehowa Wakantanka can kin owasin tona owanyag waśte, qa tona woyute waśte aicage cin, maka kin etanhan icahya, qa wojupi kin cokaya, can wiconi wan kage ca, can wan on taku waśte taku śica ko sdonyapi kin he nakun en.icahya.

10 Unkan can wojupi kin hpan ye kta e, watpa wan Eden etanhan uye ca hetanhan ointpa tom icaga.

11 Ointpa tokaheya kin Piśon eciyapi; he Hawila makoce kin owancaya ohomniya.

12 Heciya mazaskazi yuke, ca mazaskazi makoce kin he en iyeyapi kin he waśte. Heciya Bedola, qa ihe wicaśake iyececa.

13 Watpa inonpa Gition eciyapi; he Kuś makoce kin ohna iyaya.

14 Qa watpa iyamni kin Hedeqel eciyapi; he Aśur makoce kin wiyohiyanpata kiya kaduza. Qa watpaitopa kin Yuphrate hee.

15 Unkan Jehowa Wakantanka Adam icu, qa Fden wojupi kin he kicanye ca awanyake kta e, en ehnaka.
16 Qa Jehowa Wakantanka wicaśta kin hecen eciya, Can wojupi kin owasin etanhan icakiś iciye śni yate kta.

17 Tuka can wan, taku waśte taku śica. ko on sdonyapi kin de etanhan yate kte śni; tohan hetanhan yate cinhan anpetu kin he en nite kta.

18 Hehan Jehowa Wakantanka, Wicaśta kin de iśnana un kin he śica, wanji iye iyececa wecage kta, eya.

19 Wanna Jehowa Wakantanka, maka kin etanhan tinta wamanica owasin wicakaga, mahpiya etkiya taku kinye cin ko owasin, qa Adam en u wicakiya, token caś wicaton kte cin sdonye kta e heon. Unkan token Adam owasin caś wicaton, hecen taku ni un kin otoiyohi caje wicayatapi.

20 Hecen Adam woteca owasin caś wicakiton, mahipiya ektakiya taku kinye cin ko owasin, tinta wamanica nakun owa$\sin$; tuka Adam ookiye iye iyececa wanjidan iyeyapi śni.

21 Unkan Jehowa Wakantanka woiśtima tanka.wan Adam ahinlipaye ya, unkan iśtima. Unkan Wakantanka cutuhu kin wanji yujon icu, qa conica kin ecen paohduta iyeya.

22 Qa Jehowa Wakantanka cutuhu kin, wicaśta etanhan icu qon on winyan wan kage, ca wicaśta kin en kai.

23 Unkan, Mihu kin etanhan de hu ye ca, micehpi kin etanhan cehpi ya. De wicaśta kin etanhan icupi kin, heon de winohinca eciyapi kta, Adam eya.

$24 \mathrm{He}$ etanhan wicaśta atkuku hunku kici awicayuśtan, qa tawicu kin en ikoyag içiye kta, hecen cehipi wanjipidan kta. 


\section{WICOICAGE.}

25 He ehan Adam tawicu kici napin oge iciton śni yakonpi; tuka iśtecapi śni.

\section{WICOWOYAKE 3.}

1 Wanna wamanica hiyeye cin owasin Jehowa Wakantanka wicakage cin, wamduśka kin hecedan ksapa: qa wanuduśka kin winyan kin heciya, Can wojupi kin en can otoiyohi etanhan yatapi kte śni awicakehan Wakantanka eya he?

2 Unkan winyan kin wamduśka kin heciya, Can wojupi en can waskuyeca aicage cin hena untapi kta ce.

3 Tuka can wanjidan wojupi cokaya he cin, he taku aicage cin heceedan, Ihnuhan yatapi qa odutanpi kin, hecanonpi kinhan nițapi kta ce, Wakantanka eya ce. 4 Unkan wamduśka kin winohinca kin hecen eciya, Nițapi kte śni tuka heya ce;

5 Anpetu kin en he yatapi kinhan niś eya iśta nimdezapi, qa Taku wakan iyenicecapi, taku waśte taku śica ko sdonyayapi kte cin he Wakantanka sdonya, he etanhan heya ce.

6 Unkan can kin waskuyeca woyute waśte, owanyag waśte, qa wicimdeza ksam wicaye kte cin he, winohinca wanyake cehan waskuyeca kin icu, qa yute ça hihnaku kin qu, qa iś eya yuta.

7 Unkan napin iśta mdezapi, qa tancodan yakonpi kin, hehan sdonkiciyapi, qa suken can ape heca kagegepi, qa on oge içitonpi.

8 Unkan anpetu kin cusni hehan, Jehowa Wakantanka ho kin wojupi kin ohna mani kin he nahonpi, qa Wakantanka itohnake kin etanhan wojupi can kin ehna naicihmanpi.
9 Hehan Jehowa Wakantanka Adam kipan, qa heciya, Tukten yaun he?

10 Unkan Adam ayupte ca, Niho kin nawahon qa kowakipe ca namicibibe, tancodan waun kin heon etanhan, eya.

11 Unkan tancodan yaun kin tuwe oniciyaka he? Can wanjidan etanhan yute śni ciśi qon, hetanhan yata he? eya.

12 Unkan Adam heya, Winohinca mayaqu hee, qa mici un kin, iye can kin etanhan maqu, qa wata ce.

13 Unkan Jehowa Wakantanka winohinca kin heciya, Tokeca hecanon he? Unkan, Wamduśka kin malnaye ca wata ce, winohinca kin eya.

14 Unkan Jehowa Wakantanka wamduśka kin hecen eciya, Niye decanon, qa heon woteca watutka ko owasin, niś nana niyaśicapi. Itpi kin on maka kin asdohan yaun qa tohan yani kin hehanyan maka ece yate kta.

15 Qa detanhan niśs winohinca kin kici toka kiciya yaunpi kta, qa winohinca cinhintku kin nicinca kici toka kiciya yaunpi kta. He pa kin nicuwa kta, qa niś he siyete lin be yakuwa kta.

16 Hehall winohinca kin heciya, Iyoniciśice ca ihduniśake cin nina mduota kta. Iyokiśinya cinca yaton, qa nihihna cantiheyaye ca iye wowidag niye kta.

17 Ủnkan wicaśta kin heciya, Nitawin kin token eniciye cin anayagoptan, qa can wan etanlian yute śni ciśi qon, etanhan yate cin heon niye on etanhan maka kin yaśicapi. Taku aicage cin on htayani qa hecen yate kta, tohan yani kin hehanyan.

18 Wapepeka toka hu ko icah niciye kta, qa peji maka aicage cin yate kta. 


\section{WICOWOYAKE 4.}

19 Niite tenimni kin on aguyapi yahdute kta, maka inicu kte cin hehanyan. Maka kin etanhan inicagapi nakaeś, maka mdu kin henica qa maka kin ekta icicawin yahde kta.

20 Hehan Adam iye tawicu kin, Ewe eya caś kiton; taku ni un kin owasin he ina yanpi kin heon etanhan.

21 Unkan Jehowa Wakantanka Adam tawicu kin kici wakihdaka okde wicakicage ça oge wicakicaton.

22 Qa Jehowa Wakantanka heya, Wicaśta kin wanna unkiye wanji he iyeuncecapi, taku waśte taku śica ko sdonya, heon ihnuhan nape yekiye ca wiconi can kin etanhan icu, qa yute ca owihanke wanin ni kte cin.

23 Heon Jehowa Wakantanka wicaśta kin Eden wojupi kin etanhan iyog iyeya; maka kin etanhan icage cin he kicanye kta ece.

24 Hecen wicaśta kin tankan iyeya, qa can wiconi canku kin awanyake kta e, Eden wojupi wiyohiyanpa tanhan Kerubim maza sagye ideya śkanśkan un ko ewicalide.

\section{WICOWOYAKE 4.}

1 Unkan Adam tawicu kin Ewe sdonya, unkan ihduśake ca Qain he ton, qa, Jehowa etanhan wicaśta wan mduha ce, eya.

2 Qa ake ihduśake ca sunkaku Abel ton. Unkan Abel tahinca wanuyanpi wilian wicakiya, qa Qain maka kin kicanyan.

3 Unkan omaka ihanke kin hehan Qain waskuyeca maka aicage cin hee Jehowa wakiyuśna.

4 Unkan Abel tahinca wanuyanpi tawa tokaheya tonpi wan, ihdi koya wośna. Unkan Jeho- wa Abel taku walkiyuśna kin ko, akicitonwan.

5 Tuka Qain taku wakiyuśna ko akicikta śni. Unkan Qain canteptanye ca itohnake tokeca. 6 Unkan Jehowa Qain heciya, Tokeca canniniye ca itohnake enicetu śni?

7 Tanyan ecanon kinhan ihanilktapi kte śni he? Tuka tanyan ecanon śni kinhan woahtani tiyopa kin en yanka. Tuka niye qe cantiheniye kta qa niśs wowidake yaye kta.

8 Unkan Qain sunkaku Ảbel okiya, qa wojupi ekta napin yakonpi qehan najin hiyaye ça surikaku Ábel kikte.

9 Unkan Jehowa Qain heciya, Nisunka Abel tukte e he? Unkan, Sdonwaye śni. Ecin misunka kin he awanhdag waun he? eya.

10 Unkan token yahan he? Nisunka we kin maka kin etanhan ho umakiya.

11 Qa wanna maka kin nisunka we kin ninape etanhan icu kta e i kin hdukawa kin he etanhan niyaśicapi ce.

12 Detanhan maka kin yakicanyan eśta, taku ota ical niciye kte śni. Maka kin de akan onuniyan qa najica yaun kta ce, eya. 13 Unkan Qain Jehowa heciya, Wawalitani kin he tanka kin kajujupicaśni.

14 Anpetu kin dehan maka kin detanhan iyog iyemayaya, qa nitoye kin inahbe wakiye kta, maka kin akan onuniyan qa najica waun kta, qa tuwe kaśta iyemaye cinhan makte kta.

15 'Tuka Jehowa heciya, Tuwe Qain kte kinhan, śakowin akihde wośice akipe kta. Qa Jehowa Qain wapetog ton, hecen on tuwe wanyaka eśta ktepi kte śni. 
16 Unkan Qain Jehowa itoye kin etanhan inapa, Eden wiyohiyanpa tanhan makuce wan, Nod eciyapi kin, he en ounyan.

17 Qa Qain tawicu lkin sdonya, unkan ihduśake ca Henok ton. Unkan Qain otonwe wan kage ca Henok eya caś kiton, cinhintku caje kin iyecen.

18 Unkan Henok cinca wan kicitonpi, Irad hee. Unkan Irad Mecujael cinkśiya. Unkan Mecujael Metuśael cinkśiya. Unkan Metuśael Lamek cinkśiya.

19 Unkan Lamek winohinca nom. wicayuza. 'Tokaheya kin A da eciyapi, qa iyokihe Zila eciyapi.

20 Unkan Ada Jabel ton; he tona wakeya otipi, qa wanuyanpi awanhdakapi kin, hena ateyapi.

21 Qa sunkaku Jubal eciyapi. Tona candowankiyapi cotanka ko, yahotaninpi kin, hena he ateyapi.

22 Unkan Zila he Tubal Qain ton. Taku maza zi on kagapi, qa maza sapa on kagapi ko owasin, iye onspe qa kaga. Qa Tubal Qain tawinohtin Nahama hee.

23 Unkan Lamek tawicu Ada Zila kici hewicakiya, Miho kin nahonpo, Lamek tawicu kin mioie kin anagoptanpo. Wicaśta wan wakte, on camapapi, qa kośka wan on kiunimiciya ce.

24 Qain śakowin akihde tokiconpi kinhan, Lamek wikcemna śakowin sanpa śakowin tokiconpi kta ce, eya.

25 Unkan ake Adam tawicu kin sdonya; unkan cinca wan ton, qa, Wakantanka cinca tokeca wan maqu, Abel Qain kte qon hee kiya, eye ça Set eya caś kiton.

26 Unkan Śet iś eya cinca wan kicitonpi, qa Enoś eya caś kiton. Hehan tokaheya wicaśta kin Jehowa caje kin hoyekiyapi.

\section{WICOWOYAKE 5.}

1 Adam wicowazi wowapi kin dee. Wakantanka Adam kage cehan, taku wakan ouncage iyecen ical kiya.

2 Wica winyan ko wicakage ca wicayawaśte, qa wicakage cehan Adam eya caś wicaton.

3 Unkan Adam waniyetu opawinge sanpa wikcemna yamni ni, qa cinca wan iye ouncage iyecen kicitonpi, qa Set eya caś kiton.

$4 \mathrm{Qa}$ Set tonpi kin he iyohakam, Adam waniyetu opawinge śahdogan ni, qa cinca wica winyan ko kicitonpi.

5 Hecen anpetu owasin Adam ni un kin hena waniyetu opawinge napciwanka sanpa wikcemna yamni, hehan ta.

6 Unkan Śt waniyetu opawinge sanpa zaptan ni, qa Enoś kicitonpi.

$7 \mathrm{Qa}$ Śet Enoś tonpi kin iyohakam waniyetu opawinge śahdogan sanpa śakowin ni, qa cinca wica winyan ko kicitonpi. 8 Hecen anpetu owasin Śst ni un kin hena waniyetu opawinge napciwanka sanpa ake nonpa, hehan ta.

9 Unkan Enoś waniyetu wikcemna napciwanka ni, qa Qenan kicitonpi.

10 Qa Qenan tonpi kin iyohakam Enoś waniyetu opawinge śahdogan sanpa wikcemna sanpa zaptan ni, qa cinca wica winyan ko kicitonpi.

11 Hecen anpetu owasin Enoś ni un kin hena waniyetu opawinge napciwanka sanpa zaptan, qa hehan ta. 


\section{- WICOWOYAKE 6.}

12 Unkan Qenan waniyetu wikcemna śakowin ni, qa Mahalele kicitonpi.

13 Qa Qenan Mahalele tonpi kin iyohakam waniyetu opawinge śahdogan sanpa wikcemna topa ni, qa cinca wica winyan ko kicitonpi.

14 Hecen anpetu owasin Qenan ni un kin hena waniyetu opawinge napciwanka sanpa wikcemna, hehan ța.

15 Unkan Mahalele waniyetu wikcemna śakpe sanpa zaptan ni, qa Jered kicitonpi.

16 Qa Mahalele Jered tonpi kin iyohakam waniyetu opawinge śahdogan sanpa wikcemna yamni ni, qa cinca wica winyan ko kicitonpi.

17 Hecen anpetu owasin Mahalele ni un kin hena waniyetu opawinge śabdogan sanpa wikcemna napciwanka sanpa zaptan, hehan ța.

18 Unkan Jered waniyetu opawinge sanpa wikcemna śakpe sanpa nonpa ni, qa Henok kicitonpi.

19 Qa Jered Henok tonpi kin iyohakam waniyetu opawinge sahdogan ni, qa cinca wica winyan ko kicitonpi.

20 Hecen anpetu owasin Jered ni un kin hena waniyetu opawinge napciwanka sanpa wikcemna śakpe sanpa nonpa, hehan ța.

21 Unkan Henok waniyetu wikcemna śakpe sanpa zaptan ni, qa Metuśela kicitonpi.

$22 \mathrm{Qa}$ Henok Metuśela tonpi kin iyohakam waniyetu opawinge yamni Wakantanka opeya mani, qa cinca wica winyan ko kicitonpi.

23 Hecen Henok anpetu tawa owasin waniyetu opawinge yamni sanpa wikcemna śakpe sanpa zaptan.
24 Qa Henok Wakantanka opeya mani, qa en un śni, Wakantanka he ikikcu nakaeś.

25 Unkan Metuśela waniyetu opawinge sanpa wikcemna śakowin sanpa śahdogan ni, qa Lemek kicitonpi.

26 Qa Lemek tonpi kin iyohakam Metuśela waniyetu opawinge śakowin sanpa wikcemna śahdogan sanpa nonpa ni, qa cinca wica winyan ko kicitonpi.

27 Hecen anpetu owasin $\mathrm{Me}$ tuśela ni un kin hena waniyetu opawinge napciwanka sanpa wikcemna śakpe sanpa napciwanka, hehan ta.

28 Unkan Lemek waniyetu opawinge sanpa wikcemna śahdogan sanpa nonpa ni, qa cinca wan kicitonpi.

29 Qa, Jehowa maka kin yaśice cin he nape on unkicanyanpi, qa htaunnipi kin en unkikiyapi kte cin dee ce, eye ça Nowa eya caś kiton.

30 Qa Lemek Nowa tonpi kin iyohakam waniyetu opawinge zaptan sanpa wikcemna śakowin sanpa zaptan ni, qa cinca wica winyan ko kicitonpi.

31 Hecen anpetu owasin Lemek ni un kin hena waniyetu opawinge śakowin sanpa wikcemna śakowin sanpa śakowin, hehan ta.

32 Unkan Nowa wanna waniyetu opawinge zaptan, hehan Sem, Ham, qa Japet, kicitonpi.

\section{WICOWOYAKE 6.}

1 Hehan wicaśta maka akan ota ayapi, qa cunwintkupi kicitonpi.

2 Unkan Wakantanka cinkśi wicaye cin wicaśta cunwintkupi kin hena e waśte wanwicayaka- 


\section{WICOICAGE.}

pi, qa tona cinpi kin hena etanhan, winohinca wicryuzapi.

3 Unkan Jehowa heya, Wicaśta kin wicacelipi kin heca heon wahtanipi en mitaniya he kici owihanke wanin ounye kte śni, tuka anpetu tawa kin hena waniyetu opawinge sanpa wikcemna nonpa kta.

4 Unkan anpetu kin hena icunhan, maka kin akan wazise yakonpi, qa Wakantanka cinkśi wicaye cin wicaśta cunwintkupi kin wicayuzapi, qa cinca kicitonpi kin, hena eepi he iyohakam wicaśta waśakapi, wanakaju tanhan wicaśta nina caje wicayatapi.

5 Unkan wicaśta maka akan wahtanipi kin ota e, Jehowa wanyaka, anpetu osan wicocante oze okah otoiyohi ecedan śica.

6 Unkan wicaśta maka akan icali wicaye cin heon, Jehowa iyopeiçiye ça cante iyokiśin ic̣iya.

$7 \mathrm{Qa}$, Wicaśta icah wicawaye cin, maka itohnake kin etanhan wicawakahinte kta ; wicaśta, qa woteca, qa watutka, qa taku malipiya ektakiya kinyan un kin henakiya icah wicawaye cin heon iyopemiciya ce, Jelowa eya. 8 Tuka Jehowa Nowa wanyake ca wacin en yuza.

9 Nowa wicoicage oyakapi kin dee. Nowa wicaśta olian owotanna, qa hecetu wicoicage tawa kin hen, qa Nowa Wakantanka opeya mani.

$10 \mathrm{Qa}$ Nowa cinca yamni kicitonpi, Śem, Ḣam qa Japet.

11 Unkan Wakantanka itokam maka kin honwin ce, qa maka owancaya nina waboticapi.

12 Unkan Wakantanka maka kin wanyaka, unkan houwin; wicacehpi owasin maka akan iye tacankupi kin honwin kiyapi ce.
13 Unkan Wakantanka Nowa heciya, Taku cehpi yukan owasin owihanke kin mitokam u ce; iyepi kin on maka kin waboticapi on ojudan; qa maka kin etanhan ihang wicawaye kta.

14 Wazi can on wata wan icicaga wo. Mahentu kin ośkiśkeya yakage kta, qa mahen tanhan akapa tanhan ko, canśin apawinta wo.

15 Qa hecen yakage kta. Wata ohanske cin wiciśpa opawinge yamni, ohdakinyan kin wiciśpa wikcemna zaptan, qa obosdatu kin wiciśpa wikcemna yamni kta.

16 Qa wata kin en ojanjan hdepi yakage kta, qa wankantuya wiciśpa wanjidan en yahduśtan kta. Wata tiyopa kin cuwi kin ekta yakage kta, owanka tokaheya, inonpa, qa iyamni yakage kta.

17 Wanna miye maka akan minitan waye kta, heon taku cehpi yuke cin niyake iyeye cin owasin mahpiya ihukuya, ihang waye kta. Taku maka akan un kin owasin te kta.

18 Tuka wicotakuye mitawa kin niye en nici wahdusuta kta, wata kin en oyape kta nicinca om, nitawin, nicinca tawicupi kin, henana om.

19 Qa taku niya un kin owasin, taku cehpi yukan hiyeye cin ocaje otoiyohi, nom nom mdoka wiye iyahnahna, en owicayahmake kta; ni wicayaye kta e niye kici wata kin en upi kta.

20 Taku kinye cin token ocaje, woteca token ocaje, wamanica maka akan unpi kin token ocaje, owasin ocaje otoiyohi nom nom niyake wicaduhe kta e niye en upi kta.

21 Qa niye taku yutapi kin ocaje otoiyohi etanhan icu, qa 


\section{WICOWOYAKE 7.}

mnayan wo; hecen taku yutapi anihduhe, ca woteca kin iś iyacinyan wicayakihduhe $k$ ta.

22 Unkan Nowa Wakantanka token eciye cin, owasin anagoptan, qa ecen econ.

\section{WICOWOYAKE 7.}

1 Unkan Jehowa Nowa heciya, Niye, tiyohnaka nitawa kin owasin om, wata kin en opa wo; wicoicage kin de en mitokam owotanna yaun kin wanciyaka ce.

2 Woteca wakaśoteśni ocaje otoiyohi mdoka wiye ahnahna śakowinwin iyacu kta, qa woteca wasśapapi kin, hena nom nom mdoka wiye kici iyacu kta.

3 Taku malipiya ektakiya kinye cin nakun śakowinwin, mdoka wiye ahnahna maka akan aicagapi e niyake wicaduhe kta.

4 Ehake anpetu śakowin, hehan maka kin amagaju waye kta, qa taku ni un wakage cin owasin maka kin owancaya etanhan wakahinte kta ce.

5 Unkan Nowa, Jehowa token eciye cin owasin ecen econ.

6 Nowa tonpi kin ehantanhan waniyetu opawinge śakpe hehan maka kin akan minitan.

7 Qa Nowa cinkśi wicaye om, qa iye tawicu, cinkśi wicaye cin tawicupi ko, hena owasin om minitan mini kin itokapa tanhan wata kin en opa.

8 Woteca wakaśoteśni, qa woteca waaśapapi kin, taku kinye cin, taku maka asdohan unpi ko owasin,

9 Nom nom mdoka wiye ahnahna Nowa en hipi, wata kin en; Wakantanka Nowa econ śi qon he iyecen.

10 Unkan anpetu śakowin hehan maka kin akan minitan aya.
11 Waniyetu opawinge śakpe hehanyan Nowa ni un kin, wi icinonpa, anpetu iake śakowin kin, hehan śbe tanka kin wakoniya hiyeye cin owasin yuomdecapi, qa mahipiya owanyeye hdepi kin owasin yuzamni ehdepi.

$12 \mathrm{Qa}$ anpetu wikcemna tom, hanyetu wikremna tom, hehanyan naka kin ahinheya.

13 Anpetu kin he en Nowa, qa Śem, qa Ham, qa Japet, Nowa cinkśiwicaye cin, Nowa tawicu kin nakun, cinca tawicupi yamni om, wata kin en hiyupi ;

14 Hena qa wamanica ocaje owasin, woteca ocaje owasin, watutka tona maka asdohan unpi ocaje owasin, taku kinyan ocaje owasin, zitkadan owasin taku śun yukan owasin,

15 Nom nom hipi, Nowa ekta wata kin en, taku cehpi yuke cin woniya niyake yuke cin owasin,

16 Hena en hiyupi; mdoka wiye ahnahna taku celipi yuke cin owasin etanhan upi; Wakantanka econ śi qon he iyecetu. Unkan Jehowa tiyopa kin onataka.

17 Unkan anpetu wikcemna tom maka kin ahinheye ca, minitan tanka aya; unkan wata kin okapon maka kin iwankam iyaya.

18 Unkan mini kin waśagya aye ca maka kin akan nina ihduota, unkan wata kin mini kin aokapota.

19 Unkan mini kin nina hiin waśagya, maka kin akan, heon he pajodan owasin, tona mahpiya ihukuya un kin hena aminitan.

20 Wiciśpa ake zaptan iwankam mini kin aye, ça paha kin aminitan.

21 Unkan taku cehpi yuke cin 
owasin, taku maka aśkanśkan un kin, taku kinyan, qa woteca, wamanica, qa watutka tona maka kin akan sdohanpi kin owasin tapi, wicasta iyulipa nakun tapi.

22 Taku maka puze cin akan ni, taku poge on niya un kin, owasin tapi.

23 Unkan taku hiyeye cin maka akan un kin owasin kahin- tapi, wicaśta, woteca, watutka, mahpiya zitkadan, owasin maka kin etänhan wicakahinta, qa Nowa iśnana qa tona wata kin ohna om un kin henana okaptapi.

24 Anpetu opawinge sanpa wikcemna zaptan mini kin maka kin akan waśagya.

\section{WICOWOYAKE 8.}

1 Hehan Wakantanka Nowa kiksuye, ça wamanica woteca ko owasin, iye kici wata ohna yakonpi kin hena; qa Wakantanka tate wan maka kin akan iyayupte ya, qa mini kin ayuśtan. $2 \mathrm{Qa}$ minilidoka owahinapeye cin onatakapi, mahpiya owanyeye kin hena koya, qa magaju mahpiya etanhan kin he ayuśtan.

3 Unkan mini kin maka kin etanhan kihda, anpetu opawinge sanpa wikcemna zaptan, hehan mini kin oyahe aya.

$4 \mathrm{Wi}$ iśakowin, anpetu iake sakowin wi kin en, hehan wata kin Ararat he kin en azi.

5 Unkan mini kin iyoopta ye ca oyahe aya, wi iwikcemna kin hehanyan; wi iwikcemna kin anpetu tokaheya kin he en, he paha kin taninyan hiyeya.

6 Unkan anpetu wikcemna tom henakeca, hehan Nowa wata kin owanyeye kage ciqon, he yuhidoka.

7 Qa kangi wan tankan iyaye ya, unkan iyaye ça ohnihdeya un, mini kin maka kin etanhan oyahe kin hehanyan.

8 Mini kin maka itohnake kin etanhan wanna pus aya; wanyake kta e wakiyedan wan nakun tankan iyaye ya.

9 Tuka wakiyedan kin tukten sicuha iyahe kte cin iyeye śni, mini kin maka kin owancaya akan un nakaeś: qa Nowa en wata kin ekta hdi; unkan nape kin kiyugate ca wata kin en ikikicu.

10 Qa ake anpetu śakowin ape, qa hehan ake wakiyedan wan wata kin etanhan iyaye ya.

11 Unkan ihtayetu he ehan wakiyedan kin hdi, qa wihdi can ape wan yapa hdi; unkan Nowa mini kin maka kin etanhan wanna pus aye cin sdonya.

12 Unkan ake anpetu śakowin tokeca ape, qa hehan wakiyedan wan tankan iyaye ya, unkan icimana hdi śni.

13 Unkan Nowa tonpi kin ehantanhan waniyetu opawinge śakpe qa itokaheya kin, wi tokaheya, qa anpetu tokaheya, hehan mini kin maka kin akapatanhan puza, unkan Nowa wata kin akahpe ciqon yuhidoke ça, maka itohnake kin wanna puza wanyake.

$14 \mathrm{Wi}$ inonpa kin, anpetu iake śakowin kin, hehan maka kin puza.

15 Unkan Wakantanka Nowa okiye ca,

16 Wata kin etanhan ya wo, niye, qa nitawin, qa nicinca, qa nicinca tawicupi kin niye kici;

17 Taku niyake niye kici un kin ko owasin, taku cehpi yukan owasin, taku kinyan, woteca, watutka tona maka asdohan unpi kin owasin, tankan awicayaku kte, hecen maka akan cinca 


\section{WICOWOYAKE 9.}

kagapi kte ca icagapi, qa ihduotapi kta ce, eciya.

18 Unkan Nowa tankan iyaye ca, cinca nakun, tawicu, cinca tawicupi koya.

19 Taku niyake owasin, wamanica owasin, qa taku kinyan owasin, taku maka akan sdohan un kin owasin, ocaje otoiyohi wata kin etanhan inanpapi.

20 Unkan Nowa wahna wośnapi wan Jehowa kicaga qa, woteca wakaśoteśni otoiyohi etanhan, qa taku kinyan wakaśoteśni ocaje otoiyohi etanhan icu, qa wawicayuśna, qa huhnali wicaya, wahna wośnapi kin akan. 21 Unkan Jehowa waśtemna kin omna, qa Jehowa cante kin ekta heya, Wicaśta kin heon maka kin ake mdaśice kte śni; ehaeś wicaśta kin hokśiyoqopa kin ehantanhan cante oze śica ece, tuka icimana taku niya un kin owasin ibang waye kte śni, hecamon qon iyecen.

22 'Tohanyan maka kin wanke cin hehanyan wojupi qa coyapi, qa sni qa didita, qa modoketu qa waniyetu, qa anpetu qa hanyetu hena ayuśtanpi kte śni ce.

\section{WICOWOYAKE 9.}

1 Unkan Wakantanka Nowa, cincawicaye cin ko, wicayawaśte qa, Icagapi qa ihduotapi, qa maka kin owancaya ojudan yapo ;

2 Qa taku maka aśkanśkan, taku malipiya okinye cin ko owasin, maka watutka owasin, qa mini owanca hogan owasin, itonnipapi qa ikonipapi kta, hena owasin ninape kin。 en nicupi ce.

3 Taku niya, qa śkanśkan kin owasin woyute nitawapi kta ; peji wato iyecen hena owasin ciẹupi.
4 Tuka we, cehpi wiconi kin hee, yatapi kte śni.

5 Qa awicakehan we nitawapi kin on yanipi kin awakite kta, wamanica otoiyohi nape kin etanhan awakite kta, wicaśta nape kin ko etanhan, otoiyohi hunka wanjitku nape kin etanhan wicaśta wiconi kin he awakite kta.

6 Wakantanka iye ouncage iyecen wicaśta kin kaga; heon tuwe wicaśta weye cinhan, he wicaśta eciyatanhan weyapi kta. 7 Qa niyepi icagapi, qa maka kin owancaya ounyanpi, qa he ohna ihduotapo, ewicakiya.

8 Qa Wakantanka Nowa, cinca wicaye cin ko, owicakiye ca ;

9 Tho miye wicotakuye mitawa ciciyasuta qa nicinca nihektam unpi kte cin om.

10 Nakun taku niya un kin, niyepi om unpi kin, taku kinyan, woteca, qa maka wamanica owasin, tona niye om wata kin etanhan inanpapi kin, taku maka akan ni un kin owasin om.

11 Niyepi om wicotakuye mitawa wakaga, qa taku celipi yukan owasin minitan mini on icimana awihnuni waye kte śni, qa detanhan maka ihang ye kta on, icimana minitan kte śni, ewicakiya.

$12 \mathrm{Qa}$, Wicoicage owasin, hehanyan niyepi en, qa taku ni un kin owasin en, wicotakuye wakage cin wowakta kin dee.

13 Mitinazipe kin mahpiya śoka en ewehnake ca he wicotakuye maka kin waqu kin, wowakta kin hee kta.

11 Qa tohan maka kin malipiya śoka wan ahanzi waye cinhan, malipiya soka kin ekta mitinazipe kin tanin kta:

15 Qa wicotakuye mitawa weksuye kta, niyepi om, qa taku 


\section{WICOICAGE.}

ni un kin owasin om, qa taku cehpi yuke cin owasin awihnuni $\mathrm{kta} e$, detanhan icimana minitan kte śni.

16 Itazipa kin mahpiya śoke cin en yanke kta, qa wicotakuye Wakantanka kici, qa taku maka akan niya un kin taku cehpi yuke cin owasin om, owihanke śniyan un kte cin, he weksuye kta e itazipa kin wanwahdake kta ce, Wakantanka eya :

17 Qa, Taku cehpi yuke cin maka akan owasin, wicotakuye wicawaqu kin wowakta kin hee kta, Wakantanka Nowa eciya.

18 Unkan Nowa cinca wicaye cin, wata qon etanhan inanpapi kin deepi, Sem, qa Ḣam, qa Japet. Unkan Ham Kanan atkuku kin hee.

19 Hena yamni Nowa cinca kin eepi, qa hena etanhan maka kin owancaya enanakiya iyayapi.

20 Unkan, Nowa maka kin kicanyan aye ca hastanhanka iyuwi hu hde.

21 Qa hetanhan miniśa yatke ca witko, qa wakeya ohna tancodan un.

22 Unkan Ham Kanan atkuku kin hee, atkuku tancodan un kin he wanhdake ca cincu nom tankan yakonpi kin, owicakiyaka.

23 Unkan Śem Japet kici, śina wan icupi, qa napin hiyetepi kin akan ehnakapi, qa iheyata manipi, qa ateyapi tancodan un kin akahpapi ; itepi kin iheyata unpi, hecen ateyapi tancodan un kin wanhdakapi śni.

24. Unkan Nowa, miniśa kin etanhan kikta, qa cinhintku hakakta kin taku ecakicon qon sdotkiya ;

25 Qa heya, Kanan yaśicapi kta. Wowidake wowidag yapi kta, cinyc wicaye cin he yuhapi kta.

26 Jehowa Śem taku wakan tawa kin yawaśtepi nunwe. Kanan wowidake yuhapi kta.

27 Wakantanka Japet yuota kta, qa Sem tawakeya kin ohna Japet ounye kta, qa Kanan wowidake yuhapi kta:

28 Unkan Nowa, minitan qon iyohakam, waniyetu opawinge yamini sanpa wikcemna zaptan ni.

29 Hecen Nowa anpetu tawa owasin, waniyetu opawinge napciwanka sanpa wikcemna zaptan hehan ța.

\section{WICOWOYAKE 10.}

1 Nowa wicowazi kin dee. Nowa cinca kin, Śem, 广̇am, qa Japet: Unkan minitan qon iyohakam, hena cinca kicitonpi.

2 Japet cinca kin Gomer, qa Magog, qa Madai, qa Jawan, qa Tubal, qa Meśek qa Tiras.

3 Unkan Gomer cinca kin, Aśkenas, qa Ripat, qa 'I'ogarma.

4 Unkan Jawan cinca kin, Eliśa, qa 'Tarśiś, Kitim, qa Dodanim.

5 Hena Hetne wita tawapi kin wicakicipamnipi, makoce tawapi kin en, otoiyohi iapi kin, token wicowazi kin, hecen oyate kin en.

6 Ḣam cinca kin, Kuś, qa Mizarim Egupton hee, Put, qa Kanan.

7 Unkan Kuuś cinca kin, Seba, qa Cawila, qa Sabta, qa Rahama, qa Sabteca. Unkan Rahama cinca kin Śba, qa Dedan.

8 Unkan Ku'ś Nimrod kicitonpi, he tokaheya maka akan waśaka aya.

9 Iye waayatesa Jehowa ito- 
kam waśalie cin hee; heon etanhan, Waayatesa waśaka Jehowa itokam, Nimrod iyecen, eyapi kin.

10 Unkan wokiconze tawa tokaheya kin Babel hee, qa Erek, qa Akad, qa Kalne Sinar makoce kin en unpi.

11 Makoce kin he etanhan iyaya, qa Aśur, Niniwe kage ça Rehobot otonwe Kala nakun;

$12 \mathrm{Qa}$ Niniwe Kala kici otahedan Resen otonwe tanka wan hee.

13 Unkan Mizarim Egupton hee cinca kicitonpi kin Ludim, qa Anamim, qa Lehabim, qa Naptuhim,

14 Qa Partusim, qa Kasluhim, hetanhan Piliśtim, qa Kaptorim inanpapi.

15 Unkan Kanan cinca kicitonpi Zidon, he tokapa, qa Het,

16 Qa Jebusi kin, qa Amori kin, qa Girgiśi kin,

17 Qa H̊iwi kin, qa Hareqi kin, qa Sini kin,

18 Qa Aradi kin, qa Zemari kin, qa Hamati kin ; qa hehan Kanani wicowazi kin yuomden iyayapi.

19 Qa Kanani makoce tawapi kin dee, Zidon etanhan Gerar ektakiya de cin Gaza etu, qa hetanhan Sodom, qa Gomora, qa Adma, qa Zeboim Lasa ekta.

20 Ham cinca wicaye cin hena eepi, wicowazipi kin iyececa, oyatepi tamakocepi kin en, iapi kin iyecen.

21 Unkan Japet tokapa kin sunkaku Sem, he cinca kicitonpi, Heber cinca wicaye cin owasin ateyapi kin hee.

22 Sem cinca wicaye cin, Elam, qa Aśur, qa Arpakśad, qa Lud, qa Aram.

23 Unkan Aram cinca wicaye cin Uz, qa Hul, qa Geter, qa Maś.
24 Unkan Arpakśad Śela kicitonpi, qa Śsela Heber kicitonpi. 25 Unkan Heber cinca nonpa kicitonpi; tokapa anpetu tawa kin en maka kin akipam icupi kin heon Peleg eciyapi, qa sunkaku kin Joktan cajeyatapi.

26 Joktan cinca wicaye cin Almodad, qa Śelep, qa Hatsarmawet, qa Jera ;

27 Qa Hadoram, qa Uzal, qa Diqela ;

$28 \mathrm{Qa}$ Obal, qa Abimahel, qa Seba ;

29 Qa Opir, qa Ḣawila, qa. Jobal, hena owasin Joktan cinkśi wicaya.

30 Meśa etanhan de cin, Seper he wan wiyohiyanpata wanke cin, hehanyan ounyanpi.

31 Śem cinca wicaye cin hena eepi ; wicowazipi, qa wicoie hduhapi kin iyecen oyatepi kin tamakocepi kin en ounyanpi.

32 Nowa cinca wicaye cin wicowazipi kin heepi, oyatepi kin en. Hena etanhan maka kin owancaya oyate enanakiya iyayapi minitan qon iyohakam.

\section{WICOWOYAKE 11.}

1 Hehan maka kin owancaya wicaiha wanjidan, qa iapi ko wanjidan.

2 Qa wiyohiyanpata ihdaka unpi, qa Śinar makoce kin he en, omdaye wan iyeyapi, qa en eyakonpi.

3 Qa otoiyohi takodaku hekiciyapi, Ihopo, maka omdoton unkagapi, qa śpan unkiyapi kta ce, eyapi. Hecen inyan hee kiya maka omdoton kin he icupi, qa upśija hee kiya bitumen icupi.

4 Qa ake hekiciyapi, Ihopo, otonwe wanji unkagapi kte ca nakun conkaśke wan, he ointpa kin mahpiya iyahdeye kta, qa 
WICOICAGE.

caje unkicagapi kte; heconkupi śni kinhan. maka kin owancaya omdecaheya unkiyayapi kta.

5 Unkan, Jehowa otonwe kin, inatake ko, Adam cinca wicaye cin kagapi kin wanyake kta e kun hiyu.

$6 \mathrm{Qa}$, Ehaeś oyate wanjidan, qa owasin iapi wanjidan yuhapi, qa de tokaheya econpi, qa detanhan taku kaga kecinpi owasin takudan tehike dapi kte śni.

7 Iho, kun unyanpi, qa iapi kin icicahi unyanpi kta ; kinhan iyakitedan iapi nakicilionpi kte śni, Jehowa eya.

$8 \mathrm{Qa}$ hetanhan Jehowa, maka kin owancaya, yuomden ye wicaya; unkan otonwe kagapi qon ayuśtaupi.

$9 \mathrm{He}$ etanhan caje kin Babel eciyapi ; heciya Jchowa maka kin owasin iapi kin yuicicahi, qa hetanhan maka kin owancaya yuomden enanakiya ye wicaya.

10 Sem wicowazi wowapi kin dee. Śem waniyetu opawinge sanpa nonpa ni, qa hehan Arpakśad kicitonpi, minitan qon iyohakam waniyetu nonpa.

11 Śem Arpakśad tonpi kin iyohakam, waniyetu opawinge zaptan ni, qa cinca wica winyan ko kicitonpi.

12 Unkan Arpakśad waniyetu wikcemna yamni sanpa zaptan ni, qa Sela kicitonpi.

13 Qa Arpakśad, Śela tonpi kin iyohakam, waniyetu opawinge tom sanpa yamni ni, qa cinca wica winyan ko kicitonpi.

14 Unkan Sela waniyetu wikcemna yamni ni, qa hehan $\mathrm{He}$ ber kicitonpi.

15 Qa Śla Heber tonpi kin iyohakam, waniyetu opawinge tom sanpa yamni ni, qa cinca wica winyan ko kicitonpi.

16 Unkan Heber waniyetu wi16 kcemna yamni sanpa topa ni, qa Peleg kicitonpi.

17 Qa Peleg tonpi kin iyohakam, Heber waniyetu opawinge tom sanpa wikcemna yamni ni, qa cinca wica winyan ko kicitonpi.

18 Unkan Peleg waniyetu wikcemna yamni ni, qa Reyu kicitonpi.

19 Qa Peleg, Reyu tonpi kin iyohakam, waniyetu opawinge nonpa sanpa napeiwanka ni, qa cinca wica winyan ko kicitonpi. 20 Unkan Reyu waniyetu wikcemna yamni sanpa nonpa ni, qa Serug kicitonpi.

$21 \mathrm{Qa}$ Serug tonpi kin iyohakam, Reyu waniyetu opawinge nonpa sanpa śakowin ni, qa cinca wica winyan ko kicitonpi.

22 Unkan Serug waniyetu wikcemna yamni ni, qa Nahor kicitonpi.

23 Qa Nahor tonpi kin iyohakam, Serug waniyetu opawinge nonpa ni, qa cinca wica winyan ko lkicitonpi.

24 Unkan Nahor waniyetu wikcemna nonpa sanpa napciwanka ni, qa Tera kicitonpi.

25 Qa Nảhor Tera tonpi kin iyohakam, waniyetu opawinge sanpa wikcemna sanpa napciwanka ni, qa cinca wica winyan ko kicitonpi.

26 Unkan Tera waniyetu wikcemna śakowin ni, qa Aberam, qa Nahor, qa Haran kicitonpi.

27 Tera wicowazi wowapi kin dee. Tera iye Aberam, Nahor, qa Haran kicitonpi. Unkan Haran Lot kicitonpi.

28 Unkan Haran, iye atkuku, Tera itokam ta, Ur Kaśdim heciya, makoce en tonpi kin he en ța.

29 Unkan Aberam, qa Nahor winohinca yuzapi. Aberam ta- 


\section{WICOWOYAKE 12.}

wicu caje kin Sari, qa Nahor tawicu caje kin Milka eciyapi. Haran he cunwintku iye Milka Iska ko ateyapi.

30 Tuka Sari cinca ton śni un, cinca wanica.

31 Unkan Tera iye cinhintku Aberam ikikcu, qa takojatpaku, Lot he Haran cinhintku, qa takośku Sari iye cinhintku A beram tawicu kin hee. Hena om Ur Kaśdim etanhan iyaya, Kanan makoce kin ekta ye kte, ca Haran ehan hipi qa hen hiyakonpi.

32 Qa Tera anpetu tawa kin waniyetu opawinge nonpa sanpa zaptan henakeca, qa Haran hen Tera ta.

WICOWOYAKE 12.

1 Unkan Jehowa Aberam heciya, Nita makoce kin etanhan ya wo, nitakuye etanhan, qa niyate ti kin etanhan, makoce wan wanyag ciciye kte cin he ekta ya wo.

2 Kinhán oyate tanka icah ciye, ca ciyawaśte, qa nicaje kin tanka wakage kta; qa wowaśte yaun kta;

3 Qa tona niyawaśtepi kin hena wicamdawaśte, qa tuwe niyaśice cin he mdaśice kta, qa niye en wicowazi tona maka akan unpi kin owasin yawaśtepi kta ce.

4 Unkan Aberam iyaya, Jehowa eciye ciqon he iyecen, qa Lot opa. Aberam wanna waniyetu wikcemna śakowin sanpa zaptan, Haran etanhan iyaye çehan.

5 Qa Aberam tawicu Sari ikikcu, qa iye cincu cinhintku Lot nakun, qa taku içihdepi, taku tonpi kin owasin, wicanagi tona

- Haran en wicatonpi ko, qa unhdaka yapi, Kanan makoce kin ektakiya, qa Kanan makoce kin en hipi.

6 Qa Aberam makoce kin ohna ya, Sekem ounye cin etu, More utuhu kin en. Unkan hehan Kanani kin makoce kin en unpi.

7 Unkan Jehowa Aberam en tanin iciye ca, Wicowazi nitawa kin makoce kin de waqu kta ce, eciya. Unkan Aberam hen wahna wośapi wan, Jehowa tanin iciye cin he kiciga.

8 Qa hetanhan unhdaka ya Betel iwiynhiyanpatanhan he wan wanke cin, Betel wiyohpeyata, qa Hai wiyohiyanpata otahedan en e wakeya, qa heci wahna wośnapi wan kage ça Jehowa caje kin hoyekiya.

9 Qa ake Aberam unhdaka itokah kiya ihdaka ya.

10 Unkan makoce kin he en wicakilian, qa Aberam Egupta ekta apamahde ya, hen yanke $k$ ta, makoce en un qon nina wicaakihan nakaeś.

11 Qa Egupta ekta wanna hi kte cehan, tawicu Sari heciya, Winohinca owanyag waśte henica sdonwaya;

12 Qa Egupton oyate kin wanniyakapi kinhan, De tawicu kin ee ce, eyapi, kta, qa miye maktepi lkta qa niye niniyanpi kta.

13 Ceciya ce, tawinohtin ciya keya wo; hecen tanyan waun kte ca, niye eciyatanhan minagi kin ni kta.

14 Qa Aberam Mizarim, Egupta hee, en hi qehan, Egupton oyate kin tawicu kin owanyag waśte hinca e wanyakapi.

15 Unkan Paro taakicita tancan winohinca kin wanyakapi, qa Paro en yatanpi, qa winohinca kin Paro ti kin en un kte cin icupi.

16 Qa iye kin on Aberam tanyan ecakiconpi; unkan tahin wa17 


\section{WICOICAGE.}

nuyanpi yuha, tatanka nakun, qa śuktanka śonśonna mdoka wiye ko qa ookiye wica winyan ko, qa camo hena owasin.

17 Unkan Jehowa Paro oyu. tan, Sari Aberam tawicu kin on etanhan, Paro tiyohnaka tawa kin koya wowayazan tanka on wicakaśtaka.

18 Unkan Paro Aberam kico, qa heciya, Tokeca hecamiyecon? He nitawin kin tokeca omayakidake śni he?

19 De mitankśi ce, ehe cigon he tokeca heha he? Hecen miś mduze kta iwacu tuka. Tuka nitawin wanhdaka wo. Ehdaku qa hunktiya wo.

$20 \mathrm{Qa}$ Paro wicaśta tawa kin hena he iwahokonwicakiya, unkan hde śipi, tawicu taku yuhe cin ko owasin.

\section{WICOWOYAKE 13.}

1 Unkan Aberam Egupta etanhan iyaya, iye tawicu kici, qa taku yuhe cin ko owasin, Lot nakun opa, itokah makoce kin etu.

2 Qa Aberam wijica hinca, wanuyanpi, mazaska, qa mazaskazi ota yuha.

3 Qa itokah maknce kin oti qon ohna ihdaka ku, Betel etu, wakeya iticage ciqon Betel qa Hai otahedan heciya;

4 Tokag ehan wahna wośnapi kage ciqon he ekta, qa hen Aberam Jehowa caje kin hoyekiya.

5 Unkan Lot Aberam kici ihdaka un kin he tahinca, qa tatanka wakeya ko yuha.

6 Qa witaya tonwanyanpi kte cin makoce kin iyowinwicakiye śni, ehaeś wanuyanpi ota yuhapi, heon witaya ounyanpi kta okitpanipi.
7 Unkan Aberam wanuyanpi wihan wicakiyapi kin qa Lot wanuyanpi wilian wicakiyapi kin akinicapi. Unkan hehan Kanani kin, Pcrazi kin ko makoce kin en ounyanpi.

8 Unkan Aberam Lot heciya, Unhdokinica kte śni, wihan wicakiya mitawa kin, qa wihan wicakiya nitawa kin nakun akinicapi kte śni, huinka wanjin unkiciye cin.

9 Makoce ocowasin nitokam wanke śni he? Ceciciya ce, miye etanhan kinukankiya ya wo. Niś catka tanhan de cinhan ıniś etapa tanhan, qa niś etapá tanhan kinhan miś catka tanhan mde kta ce.

10 Unkan Lot wankan etonwe, ca Jordan iyomdaye kin ocowasin Zohar itato owancaya mini yukan, (Sodom Gomora Kici Jehowa ihangye cin itokam,) Jehowa tamaga kin iyecen, qa Egupta makoce kin iyecen.

11 Qa Lot Jordan ohna makoce kin owasin kahnige ça, Lot wiyohiyanpata kiya unhdaka ya, hecen otoiyohi hunka wanjitku kin etanhan kinukankiya iyayapi.

12 Aberam Kanan makoce kin en ounyan, qa Lot omdaye kin otonwe kin en ounye, ca Sodom en wakeya iticaga.

13 Unkan Sodom wicaśta kin wicaśtapi śni, qa Jehowa en nina wahitanipisa.

14 Unkan Lot Aberam etanhan kinukankiya iyaye cin, he iyohakam Jehowa Aberam heciya, Iśta kin yuwankan ikikcu, qa toki yaun kin ihdukśan etonwan wo ; waziyata, qa itokaga, qa wiyohiyanpata, qa wiyohpeyata.

15 Makoce kin de wandake cin sitomniyan ciçu kte ça, wicowa- 


\section{WICOWOYAKE 14.}

zi nitawa nakun owihankeśniyan.

16 Qa wicoicage nitawa kin maka wiyaka sukaza iyenaka wakage kta. Wicaśta wan maka wiyaka sukaza yawa okihi, hecinhan wicoicage nitawa nakun yawapi kta ce.

17 Najin qa makoce kin ohanske cin, qa ohdakinyan kin ecen omani wo, he cicu kta ce, eya.

18 Unkan Aberam ihdake ca Mamore utuhu kin he Hebron en wanke cin ekta i, qa en ounye ca hen wahna wośnapi wan Jehowa kicaga.

\section{WICOWOYAKE 14.}

1 Unkản Amrapel Ś́sinar en wicaśta yatapi ounye cin he ehan, iye qa Ariyok Elasar en wicaśta yatapi, qa Kedorlahomer Elam en wicaśta yatapi, qa Tidal Goim en wicaśta yatapi ozuye kagapi.

2 Bera Sodom en wicaśta yatapi, qa Birsa Gomora en wicaśta yatapi, qa Śinab Adma en wicaśta yatapi, qa Śemeber Zeboim en wicaśta yatapi, qa nakun Bela, Zohar hee, he en wicaśta yatapi, hena owasin azuwicayapi.

3 Sidim mdaye kin, mini skuya mde kin hee, en hena owasin ecipapi.

4 Waniyetu ake nom, hehanyan Kedorlahomer wowidake wicaya, tuka iake yamni kin hehan kipajinpi.

5 Unkan waniyetu iake topa, hehan Kedorlahomer qa wicaśta yatapi owicape ciqon owasin upi, qa Repaim kin Aśteret Qarnayim en wicakaśtaka, qa Zuzim kin Ham en, qa Emim kin Qiratayim mdaye kin en, hena owasin wicakaśtakapi.
6 Ḧori kin nakun, Sehir he tawapi kin en Paran utuhu kin hetu, he hopuza kin en un.

7 Qa hdicupi, Miśpat wakoniya, Qadeś hee en, qa Ameleqi tamakocepi kin owasin awihnunipi, Amori kin tona Hazazon Tamar en ounyanpi kin nakun.

8 Hehan Sodom en wicaśta yatapi, qa Gomora en wicaśta yatapi, qa Adma en wicaśta yatapi, qa Bela Zohar he en wicaśta yatapi, qa Zeboim en wicaśta yatapi hena owasin, zuya iyayapi, qa Sidim mdaye kin en kicizapi.

9 Kedorlahomer Elam en wicaśta yatapi, qa Tidal Goim en wicaśta yatapi, qa Amrapel Sinar en wicaśta yatapi, qa Ariyok Elasar en wicaśta yatapi, wicaśta yatapi ece, uman topa uman zaptan ecipapi.

10 Unkan Sidim mdaye kin ohna bitumen woha ota, qa Sodom en wicaśta yatapi Gomora en wicaśta yatapi henios najicapi, qa ohinhpayapi, qa umanpi kin, tona nipi kin, he onapapi.

11 Unkan Sodom Gomora ko woyuha, taku yutapi ko yuhapi qon, owasin icupi qa kihdapi.

12 Lot Aberam cincu cinhintku kin Sodom en un kin nakun, taku tawa ko owasin icupi, qa hecen hdapi.

13 Unkan wicaśta wan okicize etanhan u, qa Aberam Heberi kin wokiciyaka, utuhu oju Mamore Amori tawa kin en un; Mamore Eśkol Aner kici hunka wanjin wicaye cin, qa hena yamni Aberam kici dakon kiciyapi.

14 Unkan Aberam sunkaku wayaka ahdapi kin he nakilion, hehan wicaśta opawinge yamni sanpa wikcemna sanpa śahdogan, iye ti kin en icagapi, qa onspewicakiyapi kin hena awi- 


\section{WICOICAGE.}

caye ça wicaśta yatapi qon, Dan hehanyan wicakuwa.

15 Qa hanyen taokiye kici anawicatan, qa wicakaśtake ca owicakuwa, Coba Damaskos icatka tanhan wanke cin hehanyan.

16 Qa woyuba qon owasin eyaku; sunkaku Lot, qa taku tawa ko owasin, winohinca oyate ko owasin ahda.

1\% Qa Kedorlahomer, qa wicaśta yatapi owicape ciqon wicakaśtakapi kin etanhan hdi kin, hehan Sodom wicaśta yatapi kin itkokim ya; Kaksiza mdaye kin ekta Wicaśta yatapi takaksiza kin hee.

18 Unkan Melkizedek Salem en wicaśta yatapi, Taku wakan otancanke wakiyuśnapi kin, he aguyapi miniśa ahna Aberam kahi ;

19 Qa yawaśte, qa heya, Wakantanka otancanke mahpiya maka ko ocowasin tawa kin, he Aberam yawaśte nunwe.

20 Qa Wakantanka otancanke kin, toka niyanpi kin nape kin en onihnake cin he yawaśtepi nunwe, eya. Unkan taku owasin etanhan iwikcemna kin qu.

21 Unkan Sodom wicaśta yatapi kin Aberam heciya, Oyate kin micu wo, qa woyuha kin he owasin icu, qa yuha un wo.

22 Unkan Aberam Sodom wicaśta yatapi kin heciya, Jehowa Wakantanka otancanke kin mahpiya maka ko ocowasin tawa kin, he ekta nape ye wakiya.

23 Taku nitawa kin etanhan hahonta wanjidan, hantpa wanjidan eśta iwacu kte śni, qa Aberam wawokihi wakaga ehe kte śni.

24 Tuka kośka taku yutapi kin hecehnana, qa Aner Eśkol qa Mamore wicaśta omicipapi kin hena eepi, onśpa tawapi kin ikikcupi nunwe, eya.

\section{WICOWOYAKE 15.}

1 Hena henakeca hehan, owanyake wan en Jehowa oie kin Aberam en hi, qa heciya, Aberam ihmuhan koyakipe cin ; wahacanka nitawa qa taku iyotan tanka yahduhe kte cin he miye ce.

2 Unkan Aberam heya, Jehowa Itancan taku mayaqu kta he? Miś micinca manica qa wati kin taku ohnaka kin Eliezer Damaskon he yuha.

3 Qa Aberam heya, Miye cinca mayaqu śni, qa wicaśta wan wati kin en tonpi kin, he taku mitawa owasin yuhe kta.

4 Unkan Jehowa oie kin hoyekiya, De taku nitawa owasin yuhe kte śni ce. Tokeśta nitezi kin etanhan inanpe kte cin be taku nitawa kin owasin yube kta ce, eya.

5 Qa tankan u śi, qa heciya, Mahpiya ekta etonwe ca wicanhpi kin yawa oyakihi hecinhan hena yawa wo. Qa nicinca kin he iyenakecapi kta ce, eciya.

6 Unkan Aberam Jehowa oie kin wicada, qa he woorvotanna kiciyawapi.

7 Unkan Jehowa heciya, Makoce kin de cicu, qa yahduhe kta e Ur Kaśdim etanhan u ciciye cin, Jehowa he miye ce.

8 Unkan, Jehowa Itancan, tokiya tanhan wahduhe kte cin sdonwakiye kta he? eya.

9 Unkan, Pte wan waniyetu iyamni, qa tatokadan wan waniyetu iyamni, qa tamdoka wan waniyetu iyamni, hena owasin imicu wo, qa wakiyedan wan nakun, tin wakiyedan wan iyahna. 


\section{WICOWOYAKE 16.}

10 Unkan hena owasin ikikcu, qa cokaya okiwicakasdece-ça wobaśpe kin owasin iciyotakons ehnaka, qa zitkadan kin hena baśpe śni.

11 Unkan taku kinye cin woteca wicakte qon akan kun upi, unkan Aberam ham wicaya.

12 Unkan anpetu wi aisinyan iyaye kte cin, hehan woiśtima tanka wan Aberam ahinhpaye ca nakun otpaza wohitike hinca.

13 Unkan Aberam lieciya, Wowicake eciyatanhan he sdonya wo, nicinca makoce wan tawapi śni e en waniyetu opawinge tom ounyanpi kte, unkan wowidag wicayapi, qa iyoyag wicayapi kta.

14 Unkan oyate wan wicayuhe kte cin he mdaco kta, unkan hehan woyuha ota yuha hinanpapi kta.

15 Tuka niye hunkake wicayaye cin ekta tanyan yahde kte ca, pa niska waśte kinahan nihapi kta.

16 Qa wicoicage itopa kin, hehan deciya hdipi kta ce. Amori kin woalitani kin nahahin iyatahdepi śni ce.

17 Unkan wi iyaya hehan nina otpaza, qa oceti izita wan, petijanjan ideya wan ko, taku okicasdece ciqon itoopteya iyaya.

18 Anpetu kin he en Jehowa wicotakuye wan Aberam kicage ca heya, Makoce kin de Egupta watpa etanhan, watpa tanka Yuphrate eciyapi hehanyan nicinca wicawaqu kta.

19 Keni kin, qa Qenizi kin, qa Qadmoni kin,

20 Qa Ceti kin, qa Perazi kin, qa Repaim kin,

21 Qa Amori kin, qa Kanani kin, qa Girgaśi kin, qa Jebusi kin.
WICOWOYAKE 16.

1 Unkan Aberam tawicu kin Sari cinca kiciton śni, qa Egupton wikośka wan yuha, Hagar eciy api.

2 Qa Sari Aberam heciya, Tho Jehowa miye onamataka; ceciye, wikośka wan mduhe cin he ekta ya ye; okini cinca miciton kta, eya. Unkan Aberam Sari oie kin anagoptan.

3 Unkan Sari Aberam tawicu kin, he wikoślka tawa, Hogar Egupton kin icu, qa Aberam hihnaku kin tawicu kta e qu; wanna waniyetu wikcemna hehanyan, Aberam Kanan makoce en un qehan hecon.

4 Unkan Aberam Hagar en i, unkan ihduśake ca, wanna ihduśaka wanhdake çehan, yuhe cin he iśta kin on ihakta śni.

5 Unkan Sari Aberam heciya, Sicaya ecamiconpi kin he niye en oiyanihde. Miye wikośka wan mdulie cin he cicu, nimaku kin ekta, unkan ihduśaka wanhdake ca iśta kin on ihamakta śni, miye niye kici unkiyotahedan Jehowa yaco kta ce.

6 Unkan Aberam Sari heciya, Tokeśta wikośka nitawa kin he ninape kin ohna un, token iyonicipi ecen ecakicon wo. Unkan Sari iyoyag ya; unkan najica iyaya.

7 Unkan Jehowa taohnihde wan Hagar tinta kin en iyeya, mini hdoka wan ikiyedan, Sur canku kin ohna mini hdoka he cin hee.

8 Qa heya, Sari tawikośka Hagar, tokiya tanhan yau he? qa toki da he? Unkan, Sari mayuha itoye kin etanhan nawajica ce, eya.

9 Unkan Jehowa taohnihde kin heciya, Niyuhe cin ekta ici21 
cawin hde, ça nape kin ihukuya eicihde wo.

10 Kinhan nicinca ota wakage kta, qa ota kin heon yawapi kte śni, Jehowa taohnihde kin Hagar eciya.

$11 \mathrm{Qa}$, Tho ihduniśake cin cinca wanji yaton kte, ca Iśmayel eya caś yakiton kta; nicakije cin Jehowa nanition kin heon etanhan.

12 Kinhan iś ikce wicaśta kin heca kta. Wicaśta owasin nape apalıa wicayanke kta, qa iś wicaśta owasin nape apaha yankapi kte, ca hunka wanjin wicaye cin owasin itokam ounye kte, Jehowa ohnihdeye cin eciya.

13 Unkan Wakantanka wanmayake cin he deciya awakita he? eye ca, Jehowa okiye cin, he Wakantanka wanmayadake cin, eya caśton.

14 Heon wakoniya kin he, Tuwe ni qa wanmayake cin tawakoniya eciyapi; he Qadeś qa Bered otahedan wanka.

15 Unkan Hagar Aberam cinca wan kiciton, qa Aberam cinca Hagar ton kin he Iśmayel eya caś kiton.

16 Aberam wanna waniyetu wikcemna śahdogan sanpa śakpe, Hagar Iśmayel Aberam kiciton kin hehan.

\section{WICOWOYAKE 17.}

1 Unkan Aberam wanna waniyetu wikcemna napciwarka sanpa napciwanka, hehan Jehowa Aberam en tanin iciye ca, Taku wakan iyotan waśake cin he miye; mitokam omani qa iyaonpepica śni un wo.

2 Kinhan odakonciciye kta qa, iyakicuya ciyuota kta, eciya.

3 Innkan Aberam pustag ehpe- içiya ; unkan Wakantanka okiye ca heya,

4 Odakonciciya qa oyate ota ate niyanpi kta;

5 Qa detanhan Aberam eniciyapi kte śni, tuka Abereyam nicaje ee kta; oyate ota ate niyanpi kte cin cicaga ce.

6 Qa nina yuota ciciye ça, oyate cicage kta, niye etanhan wicaśta yatapi inanpapi ktá.

7 Qa miye niye kici wicotakuye cicage kta, qa taku nitawa nihektam u kte cin hena koya, hecen wakage kta, tohanhanyan wiconi kte cin, hehanhanyan hecetu kta, hecen wakan mayada kta, qa nicinca nihektam u kte cin hena owihanke wanin wakan madapi kta.

8 Makoce en ihdaka yaun kin, Kanan makoce kin he owasin cicu kta, qa tona enitanhan u kte cin hena, qa owihanke wanin tawayapi kta qa taku wakan mayanpi kta.

9 Qa, niye wicotakuye mitawa kin yahduhe kta, niye, nicinca nihektam upi kte cin hena koya, wicoicage tawapi kin en.

10 Qa wicotakuye mitawa miye, qa niye kici, qa nicinca nihektam u kte cin hena koya, yahduhapi kte cin he dee ce. Tona wica un kinhan hena bakihdayapi kte.

11 Ce inkpa ha kin banicihdayapi kta qa odakonciciyapi wowapetokton kin hee kta.

12 Wicoicage nitawapi kin tona wica owasin yatipi kin ohna tonpi, qa nicinca etanhan śni eśta, tuka oyate tokeca cinca, qa mazaska on opetonpi kin owasin, cincatonpi ehantanhan anpetu iśahdogan balidayapi kta.

13 Tuwe yati kin ohna tonpi qa mazaska nitawa on opetonpi kin he bahdayapi kta, qa oda- 
konciyapi, nicehpi kin en he wicotakuye owihanke wanice kta.

14 Tuwe wica balidayapi śni, ce inkpa ha kin bakihdayapi śni kinhan, wicotakuye mitawa naksa, heon wicaśta kin he oyate tawa kin etanhan baśpapi kta, Wakantanka Abereyam eciya.

$15 \mathrm{Qa}$ detanhan Sari nitawin kin Sari cajedate kte śni, Sara caje kin hee kta ce.

16 Qa he mdawaśte kte ca, hetanhan cinca wan cicu hite ca, cinca niciton kte cin he nakun indawaśte kte ca, oyate ota nakun wicaśta yatapi tanka hetanhan inanpapi kta, Wakantanka Abereyam eciya.

17 Ünkan Ábereyam pustag ehpeiciye ça iha, qa cante kin mahen heya, Wicaśta waniyetu opawinge cinca kicitonpi kta he? qa Sara waniyetu wikcemanapciwanka cinca wan ton kta he?

18 Hehan, Tokin Iśmayel nitokam ni un, Abereyam Wakantanka eciya.

19 Unkan Wakantanka heya, Han ; awicakehan Sara nitawin cinca wan niciton kta, qa Izak eya caś yakiton kta, qa wicotakuye mitawa kin he kici wahdusuta kta; cinca wicaye kte cin ihektam u kte cin, hena koya wicotakuye owihanke śniyan.

20 Iśmayel on nakun nacilion, on mdawaśte kta, cinca ota icahye wakiye ça iyakiçuya yuota wakiye kta, wicaśta yatapi ake nom kicitonpi kte ca, oyate tanka icaliye wakiye kta.

21 Tuka Izak kici wicotakuye mitawa kin wahdusuta kta, detanhan omaka wanjica kinhan, makoncage kin de en Sara ton kta.

22 Wakantanka ie ca ohiniki- ye cin, hehan Abereyam itokam wankan ikiyopta.

23 Unkan Abereyam cinhintku Iśmayel ikikcu, qa nakun tona iye ti kin ohna wicatonpi kin, tona maza ska iye tawa on opewicaton kin hena koya orvasin, tona wica iye ti kin ohna yakonpi kin hena, anpetu kin he en ce inkpa ha kin bawicakihdaya, Wakantanka eciye cin he iyecen.

24 Abereyam wanna waniyetu wikcemna napciwanka sãnpa napciwanka hehan iye ce inkpa ha kin bakilidayapi.

$25 \mathrm{Qa}$ cinlintku Iśmayel waniyetu ake yamni hehan ce in$\mathrm{kpa}$ ha kin bakihayapi.

26 Abereyam cinhintku Iśmayel kici, anpetu wanjidan en bawicahdayapi.

27 Qa tiyohnaka wicaśta owasin, ti kin ohna wicatompi, qa oyate tokeca etanhan opewicatonpi kin hena koya, owasin Abereyam kici bawicahdayapi.

\section{WICOWOYAKE 18.}

1 Unkan Mamore utuhu kin heciya, Abereyam wakeya tiyopa kin ekta iyotankehan yanke, ca wiyotanhan hehan Jehowa tanin içiya.

2 Unkan Abereyam wankan etonwan, qa wicaśta yamni itokam najinpi wanwicayake ca, wakeya tiyopa .kin etanhan itkowicakipe kta e inyang iyaye ca, maka kin en canpeśka makehdeya inajin.

3 Qa, Itancan ni iśta kin iyokipi ciya hecinhan ceciciya ce, nitaokiye kin etanhan sam iyaye śni wo.

4 Mini onge aupi on siha hdujajapi, qa can kin ihukuya ozi içiyapo. 


\section{WICOICAGE.}

5 Kinhan aguyapi onśpa cicaupi kta. Nicantepi kin iwakiśakapo, heon nitaokiyepi kin en yahipi, qa hehan idadapi kta ce, eya. Unkan token ehe cin ecen econ wo, eyapi.

6 Unkan Abereyam wakeya kin en ohankoya hda, Sara ti kin ekta qa, Aguyapi iyutapi yamni kohanna icu qa pasuta qa aguyapi hmiyanyan kaga wo, eya.

7 Hchan Abereyam wanuyanpi estä inyang ye ca, ptejincadan wan cepa qa waśte ikikcu, qa he kośka wan qu; unkan inahiniyan pata.

8 Unkan pte asanpi qa pte asanpi ihdi, qa ptejincadan pata qon ikikcu, qa wicitokam ehde, qa iye wicikiyedan najin can kin ihukuya. Unkan wotapi.

9 Qa Sara nitawin kin toki un he? eciyapi. Unkan, Wakeya ohna yanka ce, eya.

10 Unkan, Detanhạn omaka akihde kinhan, ake niye en cihi kta qa awektunje kte śni. Hehan nitawin Sara cinca wan ton kta. Unkan Sara wakeya tiyopa kin ohna wicaśta kin ihektam yanka tuka he nahion.

11 Wanna Abereyam Sara kici wanakaś wotapi, napin kanpi ; winohinca ayakonpi kin he, Sara wanna ecece śni un.

12 Heon Sara cante mahen iha qa, Wamakanka hehan, qa mayuha iś nakun wicalinca eśta imduśkin kta he? eya.

13 Unkan Jehowa Abereyam heciya, Tokeca e Sara ilia qa, Awicakehan wamakanka hehan cinca waton kta he? eya he?

14 Jehowa taku wanji okitpani tukte $\mathrm{e}$ he? Tohantu kte cin ake niye en cihi, qa Sara hokśidan wan ton kta.
15 Hehan Sara kokipe ca heon anakilibe ca, Iwaha śni ce, eya. Unkan, Hiya, iyaha ce, eya.

16 Hehan wicaśta qon heciya tanhan najinpi, qa Sodom ektakiya etonwanpi ; unkan Abereyam awicaye kta e om iyaya.

17 Unkan Jehowa heya, Taku ecamon kte cin he Abereyam anawakihbe kta lie?

18 Abereyam iś oyate tanka, qa waśaka un kte ça iye eciyatanhan oyate maka ohnaka owasin yawaśtepi kta;

19 Qa de sdonwakiye, cinca wicaye cin, tiyohnaka kin iyahna taku owotanna qa ecetu econ wicaśi kta, qa Jehowa tacanku kin okicipapi kta, hecen Jehowa Abereyam token wahoye cin owasin kicicahi kta.

20 Unkan Jehowa heya, Sodom qa Gomora ceyapi kin he tanka, qa wahtanipi kin tehika e nawahon, heon

21 Nakaha kun mde ca ceyapi kin mahiyohi kin ocowasin iyececa econpi kinhan sdonwaye kta, qa ecece śni kinahan sdonwaye kta ce, eya.

22 Unkan wicaśta qon hetanhan iyayapi, qa Sodom en ipi, qa Abereyam nahahin Jehowa itokam yanka.

$23 \mathrm{Qa}$ Abereyam ikiyadan hinajin qa, 'Tona ohan owotanna wahtanipisa om ihang wicayaye kta he?

24 Okini wicaśta owotanna wikcemna zaptan otonwe kin en unpi eśta ihang yaye kta he? Wicaśta owotanna wikcemna zaptan kin hena on, otonwe en unpi kinhan, otonwe kin itonyape kte śni he?

25 Wicaśta ohan owotanna walitanipisa om ihang wicayaye kta seca; tokadan hecanon kte śni. 'Tona owotanna wahtani- 
pisa iyecen ecawicakiconpi kịn he iyonicipi śni. Maka kin owancaya wayaco un kin he woyaco econ kte śni he? eya. 26 Unkan Jehowa heya, Wicaśta owotanna wikcemna zaptan Sodom otonwe en iyewaye cinhan, hena on otonwe kin ocowasin itonwape kta ce.

27 Unkan Abereyam ayupte ca, Maka mdu qa cahota hemaca qeyaś mayuhe cin taku ewakiye kta on iapi iwacu.

28 Okini wicaśta owotanna wikcemna zaptan kin en zaptan ope kte śni seca; zaptanna kin hena on otonwe kin ocowasin ihang yaye kta he? eya. Unkan, Ihang waye kte śni, hen wikcemna tom sanpa zaptan iyewaye cinhan, eya.

29 Unkan ake ie kta e hda, qa, Okini hen wikcemna tom iyewicayapi kta, eya. Unkan, Wikcemna topapi on ecamon kte śni, eya.

30 Unkan, Mayuha ceciciye canniye maye śni wo; iwae kta ce. Okini wikcemna yamni hen iyeyapi kta seca, eya. Unkan, Wikcemna yamni hen iyewicawaye cinhan ecamon kte śni, eya.

31 Unkan, Tokin Mayuhe cin taku ewakiye kita e epen. Okini wikcemna nonpa hen iyeyapi kta seca, eya. Unkan wikcemna nonpa on ihang waye kte śni ce, eya.

32 Unkan, Itancan ceciciye canniye maye śni wo; wancadan iwae kta ce. Okini wikcemna en iyeyapi kta seca, eya. Unkan wikcemna on ihang waye kte śni ce, eya.

33 Unkan Jehowa Abereyam okiya ohinikiye cin hehan toki iyaya, qa Abereyam ekta hda.

\section{WICOW OYAKE 19.}

1 Unkan htayetu ehan ohnihde wicaye cin nom Sodom en hipi ; he icunhan Lot Sodom tiyopa kin en iyotankehan yanka, unkan Lot wanwicayake ca itkowicakipe kta najin hiyaya, qa wicitokam patuś inajin.

2 Qa hewicakiya, Itancan ceciciyapi, wati kin en yapo, he wowidake mayaduhapi, heon hanyetu kin de wati kin en yukanpo. Siha kin hdujaja po, qa hanlianna yelstapi, qa tokiya dapi hecinhan ekta katinyan yapo, ewicakiya. Unkan, Hiya, ocanku kin de ohna hanyetu osan unyakonpi kta, eyapi.

3 Tuka nina cinwicakiya; unkan kici kipi. 'Ti kin ti mahen ipi, unkan aguyapi napohye codan śpan ye ca nakun wowicakihan; unkan yutapi.

4. Iwankapi kta itokam, Sodom otonwe wicaśta kin owasin tipi kin he aohduteyapi, hokśidan wicahinca ko owasin, otonwe ihanke anokatanhan, henana otonwe ohnaka kin owasin kawitaya iheya.

5 Qa Lot kipanpi, Wicaśta nom hanyetu kin de yati en hipi kin tukte epi he? Tankan u wicaśi wo; sdonwicunyanpi kte, eyapi.

6 Unkan Lot ti kin etanhan inanpe, ca tiyopa kin ecen icu,

7 Qa, Hunka wanjin ciyapi, ceciciyapi ce, ihnuhan hecen śicaya ecanonpi kin.

8 Micunkśi nonpapi kin nahahin wicaśta sdonye śni yakonpi, heniyos eiçupi, qa token yacinpi ecen wicayakuwapi kta, tuka wicaśta kin dena conkaśke mitawa ohanzi ihukuya hipi kin heon takudan ecawicakiconpi śni po, ewicakiya. 


\section{WICOICAGE.}

9 Unkan, Tokan hiyaya wo. Wicaśta kin de oyate tokeca, tuka den un kta wacin, qa hi qa he unyacopi wacin. Heon ihomeca niye iyotan śicaya unnicuwapi kta, oyate kin eyapi, qa Lot nina paśkicapi qa tiyopa kin kaptujapi kta e en yapi.

10 Unkan ohnihde unpi kin tiyopa kin yuganpi, qa Lot ti mahen hdicu yapi, qa tiyopa kin onatakapi.

11 Unkan oyate kin wicaśta ciștina wicaśta tanka ko, oyate otonwe ohnaka kin owasin, tiyopa kin en hiyeye cin hena iśta gonge wicayapi, heon tiyopa kin yutantan akitapi.

12 Unkan ohnihde unpi kin Lot heciyapi, Nakun den takuyaya yukan he? takoś yaye cin nicinkśi, niçunkśi, qa taku tona otonwe kin ohna duhe cin, de etanhan om tankata inanpa wo.

13 Otonwe kin de ihang unyanpi kta, heon unhipi ; oyate kin de owasin woahtani hoyapi, qa Jehowa itokam oiyahde iciyapi, heon otonwe kin de owihanke ye unhipi.

14 Unkan Lot tankata inanpe, ca wicaśta takoś wicaye kte cin, hena hewicakiya, Otonwe kin de etanhan tankata inanpapo; Jehowa otonwe kin de ihanke ye kta ce. Tuka takoś wicaye kte cin Lot cețunhdapi.

15 Anpao hinanpa, unkan ohnihde unpi kin Lot inahni yapi, qa, Najin wo; nitawin ehdaku wo, qa nakun nicunkśi nonpa den unpi kin, okini otonwe wahtani kin en awihnuniniyanpi kta nace.

16 Tuka ihduwiyeyapi śni ; unkan ohnihde unpi nape etanhan wicayuzapi, Lot, qa tawicu, qa cunwintku nonpa nape kin wicayuzapi ; Jehowa hena onśi26 wicakida, he etanhan otonwe kin tankan ewicayayapi.

17 Otonwe tankar awicaipi qa uman heciya, Napa wo, ni içiya wo. Ihnuhan nihektam eyatonwe cin. Omdaye kin ohna tuktedan inajin śni. Ḧe kin heciya onapa wo ; hecen yani kta ce.

18 Unkan Lot hewicakiya, Hiya, Itancan ceciciya ce:

19 Wowidake yaya nitokam wopida iyeiçiya, qa nitowaonśida kin icantoyahnake cin he miye. Tuka he onawape kte cin owakitpani kta. Okini taku śica hiyohimaye ca mate kta, kowakipa.

20 Heon ceciciya, otonwe wan cistina den aśkadan he cin, hee iyowahi kta owakihi kta. Ceciciya, heci ye mayan wo; cistina tuka hecen on minagi kin ni kta.

21 Unkan, He wopida kin aciyupte kta; otonwe cistina kin he ihang waye kte śni.

22 Onapa wo; inahni wo. Tohan ehan yai śni hehanyan token wahan kte śni, eciya. He etanhan otonwe kin he Zohar eciyapi.

23 Wi toka hinanpa hehan Lot Zohar iyohi.

24 Unkan hehan Jehowa magaju ya, Sodom Gomora heniyoza kiya inyan zi peta ko Jehowa mahpiya eciyatanhan ahinhe wicaya.

25 Otonwe kin hena owihanke wicaya, omdaye ko ocowasin, qa tona otonwe kin en ounyanpi, qa makoce kin hen peji koya.

26 Tuka Lot tawicu kin hakikta, unkan tancan kin tokeca hinhde ca miniskuya icu.

$27 \mathrm{He}$ icunhan, hanhanna Abereyam kikta, qa Jehowa okiye ciqon en etkiya ya. 


\section{WICOWOYAKE 20.}

28 Qa Sodom, Gomora, makoce ihdukśan koya atonwan; unkan makoce kin he etanhan śota wan, maza śdoyapi oceti śota iyececa, wankantkiya inanpe cin wanyaka.

29 Jehowa Omdaye otonwe kin hena, owikanke ye cin he icunhan, Abereyam kiksuye ca otonwe ohna Lot ounye cin ihang wicaye cin hetanhan Lot tankan iyaye ya.

30 Unkan Lot Zohar etanhan itawankanhde ye,ca he wan akan cunwintku napin om e ounyan, Zohar he en un kte cin he wikopa heon, qa makohdoka wan cunwintku napin om oti.

31 Unkan tokapa kin he tankaku kin hecen eciya, Ate unye cin wanna wicahinca, qa maka ohnaka wanna wicaśta wanica, maka akan econpi qon iyecen, tuwedan unkiye en hi kte śni.

32 Tho we, ate miniśa yatke unkiye kta, qa kici unwainke kte; hecen on ate etanhan wicoicage unhdoyapi kta.

33 Hanyetu, unkan atkuku miniśa yatke kiyapi. Tokapa kin he tokaheya atkuku kici iwanka, tuka atkuku kin cunwintku en hiwanke cin he sdotkiye śni, nakun kikia kin.

34 Thanhanna tokapa kin he tankaku kin heciya, Hinhan ate kici imunka; ecin ake hanyetu kinhan, miniśa yatke unkiye kte ca niśs ito kici nunke kte, hecen on ate etanhan wicoicage unhdoyapi kta.

35 Unkan ake ihanyetu, unkan atkuku miniśa yatke kiyapi ; iś ito hakakta kin atkuku kici iwanka. Iś ake cunwintku en hiwanke cin sdotkiye śni, qa kikta kin nakun.

36 Hecen Lot cunwintku napin atkuku etanhan hokśin itpihnakapi.

37 Tokapa kin hokśidan wan ton qa Moab eya caś kiton. He Moab oyate ate yapi anpetu kin dehan aiyahdeya.

38 Unkan hakakta kin iś eya hokśidan wan ton qa, Benami eya caś kiton. He Amon cinca kin anpe dehan aiyahdeya ate yapi.

\section{WICOWOYAKE 20.}

1 Hehan Abereyam makoce itokaga kin ekta ihdaka ye ca, Qadeś qa Śur otahedan iyotanke ça Gerar en ounyan.

$2 \mathrm{Qa}$ Abereyam tawicu Sara ke ca, Mitánkśi kin dee ce, eya. Unkan Gerar wicaśta yatapi Abimelek, he ekta ye wicaśi qa Sara icu.

3 Unkan hanyen, Wakantanka Abimelek ekta hi, qa wowihanmde wan en heciya, Tho nite, winohinca iyacu kin he wicaśta wan tawicu kin heca nakaeś.

4 Tuka Abimelek nahahir Sara ikiyedan wanke śni, qa heya; Itancan oyate owotanna wan he nakun te wicayaye kta he?

5 Mitankśi kin ree, emakiye śni he? qa winyan kin iś, Timdo waya ce, emakiye śni he? Micante kin ecedan qa minape iyecetu kin on hecamon.

6 Unkan Wakantanka wowihanmde kin en heciya, Míś nakun nicante ecedan kin en hecanon kin sdonwaya qa, heon ecihdaku, miye en wayahtani kte śni, qa dutan kte cin iyowin ciciye śni. 7 Qa wanna, iho, wicaśta qon tawicu kin kicu wo, iś wicaśta wokcan kin heca, kinhan niye on cekiye kta, hecen yani kta; tuka ake yecu śni kinahan nițe kte ca nakun taku nitawa kin owasin, he sdonya wo. 


\section{WICOICAGE.}

8 Unkan Abimelek hanhanna hin kikta, qa ookiye wicayuhe cin owasin wicakico, qa hena owasin owicakiyaka: Unkan wicaśta kin nina kokipapi.

9 Unkan Abimelek Abereyam kico qa, Tukeca e hecaunyeconpi ? Qa niye en wawahtani kin tukte e on woalitani tanka wan miye qa oyate mitawa ko iyahde unyayapi? Woccon wan econpi kta iyecece śni tuka hecamiyecon, eciya.

$10 \mathrm{Qa}$, Taku wandaka on hecen ecanon he? Abimelek Abere- yam, eciya.

11 Unkan A bereyam heya, Tuwedan deciya Wakantanka ohoda śni qa mitawin on maktepi kta kepce cin heon hecamon;

12 Qa awicakehan tankśi waya ce. Ate waye cunwintku kin hee, tuka ina tawa śni, qa mitawin ee kta mduza.

13 Qa Wakantanka ate ti kin etauhan ihdaka ye maye cehan winyan qon hewakiya; Taku waśte ionśimayada kte cin dee ce. Makoce owasin tokiya kaśta en unki kinhan, Timdo emakiya wo, epe ciqon, eya.

14 Hehan Abimelek tahin wanuyanpi ikikcu, qa tatanka qa hokśidan wicinyanna ko iwicakikcu qa Abereyain qu; tawicu Sara nakun kicu.

15 Qa Abimelek heya, Mitamakoce nitokam wanka ce; tukten niiśta iyonicipi kinhan hen iyotanka wo.

16 Qa Sara heciya, Tho nitimdo mazaska kektopawinge waqu; iho he niiśta akahpe kte cin ee, tona nici unpi kin owasin en, qa tokan nakun owasin en; hecen Sara iyopeyapi.

17 Hehan Abereyam Wakantanka icekiya; unkan Wakantanka Abimelek asni yan, tawicu kici qa wikośka yuhe cin owa sin. Unkan cinca tonpi.

18 Jehowa, Sara Abereyam tawicu kin on etanhan, Abimelek tiyohnaka tawa owasin tamnipi kin suksuta onawicataka tuka qon.

\section{WICOW OYAKE 21.}

1 Unkan Jehowa heye ciqon, he iyecen Sara ekta hi, qa Jehowa, eciye ciqon, he iyecen ecakicon.

2 Unkan Sara ihduśake ca Abereyam okanta cinca wan kiciton; Wakantanka eye ciqon iyehantu qehan.

3 Unkan Abereyam cinhintku kicitonpi, Sara ton kin he, Izak eya caś kiton.

4 Qa Abereyam Izak bakihidaya anpetu iśahdogan tonpi kin ehantanhan, Wakantanka econ śi qon iyecen.

5 Abereyam wanna waniyetu opawinge, hehan cinhintku Izak kicitonpi.

6 Unkan Sara heya, Wakantanka iha mayan, qa tona nahonpi kin imiciyuśkinpi kta.

7 Qa Sara hokśiyoqopa azin kiye kte cin, tuwe Abereyam eciye kta he? wicahinca tuka cinca weciton kin, eya.

8 Unkan hokśidan kin tanka aye ça azin ayaśtan kiyapi. Unkan Izak azin ayaśtan kiyapi anpetu kin he en, Abereyam wohe ca wicota wicakico.

9 Unkan Hagar Egupton kin cinhintku Abereyam kiciton kin he, wowilialia kin he Sara wanyake ca;

10 Wikośka kin de cinhintku kin iyahna tankan ye wicaya ye. Wikośka kin de cinhintku kin, micinkśi Izak kici woyuha tawaye kte śni, eya. 


\section{WICOWOYAKE 21.}

11 Unkan oie kin he, Abereyam iśta kin en tehike linca, cinhintku kin heon etanhan.

12 Unkan Wakantanka Abereyam heciya, Wikośka duhe cin, qa hokśidan kin on etanhan, niiśta kin en teliike śni nunwe. Taku Sara eniciye cin owasin ecen ho kin anagoptan wo. Izak he en wicoicage nitawa kin caje yatapi kta.

13 Wikośka cinhintku kin nicinkśi kin hee, heon he nakun oyate wan icali wakiye kta ce.

14 Unkan Abereyam hanhianna hin kikta, qa aguyapi mini apalita wan ahna icu, qa Hagar qu, tahpa kin akan ehnaka, hokśidan nakun qa toki ye śi. Unkan iyaye ça Berśeba tinta kin onuni.

15 Unkan mini apahta kin etanhan mini wanna yahepapi, qa hokśidan kin canliaka wan ihukuya elipekiya ;

16 Qa iyaye ca iyotakons iyotanka kitana tehan, wanhinkpe kihiyeyapi hehanyan: Hokśidan te kte cin wanwahdake kte śni ce, eya; heon aisinyan iyotanke ça hoyeye ça ceya.

17 Unkan Wakantanka hokśidan ho kin nahon, qa Wakantanka taohnihde mahpiya eciyatanhan Hagar kipan, Hagar taku yaka he? Wakantanka he oyanke kin etanhan hokśidan ho kin nahon. Kokipe śni wo.

18 Najin qa hokśidan kin ikikcu qa, nape kin on hduha wo. Iye oyate tanka wan icali wakiye kta ce, eya.

$19 \mathrm{Qa}$ Wakantanka winyan iśta kin yulidoka, unkan minilidoka wan wanyake ca ekta i, qa mini apahta kin iyatahde ye ça hokśidan kin yatke kiya.

-20 Unkan Wakantanka hokśidan kin kici un; hecen tanka icage ca tinta kin en ounye ça itazipa on waoka.

21 Qa Paran tinta kin en ounye ca hunku kin Egupta makoce kin etanhan, tawicu kte cin kiciyuza.

22 Unkan hehan Abimelek qa takkicita tancan Pikol henioza Abereyam heciyapi; Taku ecanon kin owasin en Wakantanka oniciya.

23 İho hecen eya wo, Wakantanka namalion; cihnaye kte śni, nicinkśi nitakoja ko wicawahnaye kte śni, taku waśte ecamiyecon kin iyecen ecacicon kta, makoce en ounwaye cin nakun.

24 Unkan, Miś ecen eya wakonze kta ce, Abereyam eya.

25 Hehan minilidoka wan Abimelek taokiye kin kipi qon, he Abereyam cajeyate ca he on Abereyam Abimelek iyopeya.

26 Unkan, Tuwe hecon kin sdonwaye śni, qa niś nakun omayakidake śni, nakun miś he nawahion śni, nakaha heceyedan, eya.

27 Unkan Abereyam tahinca wanuyanpi pte wanuyanpi ko ikikcu, qa hena Abimelek qu; unkan napin odakota wan kicicagapi.

28 Hehan Abereyam tahinca cinca wiyedan śảkowin akipam ewicahde.

29 Unkan Abimelek Abereyam heciya, Tahinca wiyedan śakowin kinukan ewicayahde kin he taku he.

30 Unkan, Minilidoka kin de miś waqe cin he yuotaninpi kte cin, heon tahinca wiyedan śakowin kin hena minape kin etanhan iyacu kta, eya.

31 Unkan heon etanhan makoce kin he Berśeba eciyapi, napin heciya Wakantanka namation eya, ekiciyapi. 


\section{WICOICAGE.}

32 Unkan Berśeba hen odakota wan kicicagapi; hehan Abimelek najin taakicita tancan nakun, qa Piliśtim tamakocepi kin ekta hdapi.

33 Unkan Abereyam Berśeba heciya taśkoju wan oju, qa hen Jehowa Taku wakan owihanke wanica hoyekiya.

$34 \mathrm{Qa}$ Abereyam Piliśtim tamakocepi kin en anpetu ota ounyan.

\section{WICOWOYAKE 22.}

1 Unkan hena owasin iyohakam, Wakantanka Abereyam iyutan ye ça heciya, Abereyam, eya houkiya. Unkan, Tho miye ce, eya.

2 Unkan, Nicinkśi heceyedan waśte yakidake cin Izak he icu, qa Moriya makoce kin ekta ye ça heciya. he wan ociciyake kte cin he akan petan wahduśna wo, eya.

3 Unkan Abereyam hanhanna hiin kikta, qa śuktanka śonśonna aqin kiton, qa kośka nom iwicakikcu cinhintku Izak nakun, can on wośna kte cin he kakse ca, najin qa hena om, makoce tukte en Wakantanka cajeyate ciqon heciya iyaya.

4 Anpetu iyamni Abereyam wankan etonwe ca, tukten ke cin he tehan tanhan wanyaka.

5 Qa Abereyam kośka wicayuhe cin hewicaliya, Den iyotankapo śuktanka śonśonna iyahna, qa miś hokśidan kici kan unkipi kinhan canpeśka makehdeya unkanpi, qa den dukanpi kin en unhdipi kta.

6 Qa Abereyam can on wośna lste cin icu, qa cinhintku Izak akan ehnake ca peta isan ko nape kin en icu, qa sakim iyayapí.

7 Unkan Izak atkuku Abereyam kici okiye ça, Ate, eya.
Unkan, Micinkśi nawahon ce, eya. Unkan, Iho peta can ko yukan, tuka woteca kin wośnapi on tukte e he? eya.

8 Unkan, Micinkśi Wakantanka tahin wanuyanpi wakiyuśnapi on okide kta, eya. Hecen sakim yapi.

9 Qa wanna tukten Wakantanka ye śi qon hen hiyohipi, qa hen Abereyam wahna wośnapi wan kage ca, cinhintku Izak iyakaśke ca wahna wośnapi kin akan ekibnaka, can kin iwankam.

10 Qa cinhintku țe kiye kta e nape kiyugate ca isan kin ikikeu.

11 Hehan mahpiya kin eciya tanhan Jehowa ohnihde ye cin kipan, Abereyam, Abereyam, eya. Unkan, Nawahon ce, eya.

12 Unkan, Hokśidan kin elita ninape kin ye kiye śni, qa takudan ecakicon śni wo. Wanna niye Wakantanka ikoyape cin sdonwaya ce; nicinkśi heceyedan, tuka mayaqu kta wicayada he etanhan, eya.

13 Hehan Ábereyam wankan etonwe ca, inyun ilieyata tamdoka wan otehi ohna he kin on ikoyag najin, he wanyake ca, Abereyam ekta i, qa tamdoka kin icu, qa cinhintku kin hee kiya hee petan wośna.

14. Qa Ábereyam makoce kin he, Jehowa wiwanhdake kta, eya caś ton; heon Jehowa he tawa kin akan tanin ic̣iye kta ce, nahahin eyapi.

15 Unkan mahipiya kin eciya tanhan Jehowa ohnihde ye cin inonpa akihde Abereyam kipan ; 16 Miye kaeś caje mihdate Jehowa eya; Taku ecanon kin de nicinca wanjidan tuka itonyakipe śni ;

17 Heon wowaste on ciyawa- 


\section{WICOWOWAKE 23.}

śte kta, nicinca iyakiçua yuota wakiye kta. Mahpiya wicanhpi iyena, qa miniwanca kahda wiyaka sukaza iyeye cin iyena, taku nitawa iyacin kte ça, nicinca toka wicayapi kin otonwe tawapi kin yuhapi kta.

$18 \mathrm{Qa}$ mioie kin anayagoptan kin heon nicinca kin on maka kin oyate owasin wicayawaśtepi kta ce, eya.

19 Unkan Abereyam kośḱa wicayuhe cin ekta hda; unkan najinpi qa yuwitaya Berśeba ekta hdapi ; qa Abereyam Berśeba en ounyan.

20 Hena owasin iyohakam Abereyam hecen eya okiyakapi ; Milka he nakun nicinye Nahor he cinca kiciton.

$21 \mathrm{Uz}$ tokapa kin hee, qa sunkaku Buz, qa Qemuel Aram he atkuku ;

$22 \mathrm{Qa}$ Kesed, qa Ḣazo, qa Pildaś, qa Idlap, qa Betuel.

23 Unkan Betuel he Rebeka kicitonpi. Hena śahdogan kin Milka he Nahor Abereyam cincu kin kiciton.

24. Unkan tawicu tokeca kin, Ruma eciyapi he Teba, qa Gaham, qa Talios, qa Mahaka hena wicaton.

\section{WICOWOYAKE 23.}

1 Unkan Sara waniyetu opawinge sanpa wikcemna nonpa sanpa śakowin henakeca, waniyetu kin hena Sara ni.

2 Hehan Sara ta, Arba otonwe kin heciya, İebron Kanan makoce kin etu hee. Unkan Abereyam Sara on iyokiśice ça akiceye kta e en hi.

3 Hehan Abereyam tawicu te cin itokapa tanhan najin qa, Het cinca wicaye cin owicakiya.

$4 \mathrm{Qa}$, Miś wicaśta ihdaka waun qa aśkatudan nicipi wahimdo- tanka, wicaśta hnakapi mduhe kta e niyepi om maqupo; kinhan makite cin mitokapa tanhan wehnake kta ce, eya.

5 Unkan Het cinca wicaye cin ayuptapi, qa Abereyam heciyapi ;

6 Itancan anaungoptanpo: Wicaśta yatapi wakan unkiyepi cokaya henica. Wicaśta hnakapi unhapi kin tukten iyonicipi kin nicițe cin en kihnaka wo. Unkiś wanjidan kaśta wicaśta hnakapi unhapi kin hen nicite cin yehnake kta e tehinda kte śni.

7 Unkan Abereyam najin qa Het cinca wicaye cin oyate makoce yuhapi kin wicitokam apatuja.

8 Qa owicakiye ca, Makita mitokapa tanhan wehnake kte cin he iyonicipipi hecinhan anamagoptanpi, qa Epron 'Zohar he cinhintku cin makiyapo.

9 Kinhan Makpela imnija ohdoka yuhe cin, tamaga ihanke en un kin, mazaska iyenakeca kin heon maqu kte cinhan, niyepi cokaya wicaśta hnakapi wan mduhe kta ce, ewicakiya.

10 Unkan Epron Het cinca wicaye wicehna ounyan; qa Epron. Heti kin Abereyam ayupta ; Het cinca wicaye cin, otonwe tiyopa ohna upi kin hena owasin nahonpi;

11 Hiya, Itancan namahion wo. Maga kin ciçu; imnija olidoka en un kin he nakun cicu. Mitaoyate cinca wicaye cin wanmayakapi he ciçu. Nicițe cin kihnaka wo, eya.

12 Unkan Abereyam oyate makoce tawapi kin wicitokam patuja.

$13 \mathrm{Qa}$ ia, Tho amayadupte cinahan, namakion wo. Maga kin on mazaska ciẹu kta. Icu wo; kinhan makite cin wehnake kta, 


\section{WICOICAGE.}

Epron eciya, oyate makoce yuhapi kin hena nationpi.

14. Unkan Epron Abereyam ayupte ça heciya ;

15 Itarican namahon wo. Maga kin mazaska opawinge topa iyehantu ce ; tuka unkiyotahedan he taku? Nicițe cin ekihnaka wo.

16 Unkan Epron ie cin he Abereyam anagoptan, qa mazaska opawinge tom wopeton icupi kin heca Abereyam aspe ye ton qa qu, he Epron Het cinca wicaye cin nahonpi cajeyate ciqon hee.

17 Unkan Epron tamaga Makpela en wanka, Mamore iyotakons he qu; maga kin imnija ohdoka he en wanke cin he nakun, qa can tona he en han qa tona ihdukśan he cin he nakun owasin ;

18 Abereyam tawa kte cin, Het cinca wicaye cin tona otonwe tiyopa kin ohna yapi kin he wanyakapi.

19 Hehan Abereyam tawicu Sara ekihnaka; Makpela maga imnija ohdoka kin he en, Mamore ikiyedan, Hebron Kanan makoce kin etu hee.

20 Unkan maga imnija ohdoka iyahna, Abereyam wicaśta hnakapi on yuhe kte cin, Ḣet cinca wicaye cin qupi.

\section{WICOWOYAKE 24.}

1 Unkan Abereyam wanna wicahinca omaka ota; unkan Jehowa taku owasin en Abereyam yawaśte.

2 Unkan Abereyam he taokiye tiyohnaka tawa tokapa kin, taku yuhe cin owasin awanyag un kin heciya; Ninape kin miceca ihukuya ekihnaka wo ;

3 Kinhan, Jehowa Taku wakan mahpiya maka ko yuhe cin namahion, eye ciciye kta, Kanani oyate om manke cin cunwintkupi kin etanhan micinkśi on winohinca iyacu kte śni.

4 Tuka mitamakoce qa mitakuye kin hena ekta de kte ca, hetanhan micinkśi Izak on winohinca iyacu kta, kehe kta ce, eya.

5 Unkan, taokiye kin heya, Okini winohinca kin makoce kin de ekta omape kta tawatenye kte śni ; hecinhan makoce etanhan yau qon, nicinkśi ake ekta ye wakiye lita he?

6 Unkan, Ihnuhan micinkśi icicawin heciya ye yakiye cin.

7 Taku Wakan mahpiya yuhe cin, ate ti kin etanhan qa makoce wan en matonpi kin etanhan, imacu qa omakiye ca, Makoce kin de nicinca waqu kta ce, eya konza, he taohnihde kin nitokam ye śi kta, kinhan micinkśi kin on heciya tanhan winohinca wan iyacu kta.

8 Winohinca kin onipe kta tawațenye śni, hecinhan iyakonze kin de on iyaonpepicaśni yaun kta, tuka micinkśi heciya ye yaye kte śni ce.

9 Unkan taokiye qon nape kin iye yuhe cin Abereyam ceca kin ihukuya ekihnake ca ecell eya konza.

10 Qa ookiye kin, iye yuhe cin camo tawa kin etanhan, camo wikcemna, qa iye yuhe cin taku waśte tawa kin owasin etanhan icu, qa hena yuha iyaye ca Nalior otonwe kin elrta i, Aram watpa otahedan etu.

11 Qa otonwe kin itankan minilidoka ikiyedan, camo kin canpeśka makehdeya inajin wicakiya, htayetu mini huwe ipi eca iyehantu.

12 Qa heya, Jehowa Abereyam 


\section{WICOWOYAKE}

mayuhe cin Wakan nida ceciciya, nakaha tanyan ihuni makiye ca Abereyam mayuhe cin he wowaśte ecakicon ye.

13 Minilidoka kin ekta nawajin ; qa otonwe kin wicaśta cunwintkupi kin mini huwe upi kta.

14 Qa wikośka wan tuwe kaśta hewakiye kta; Wakiśkotpa nitawa kin au wo, mini mdatke kta ce; unkan, Yatkan ye, qa camo nitawa kin nakun yatke wicawakiye kta, eye cinhan, tokin nitaokiye Izak yuhen yakahinige cin hee, kinhan mayuhe cin wowaonsida ecayecon sdonwayen.

15 Unkan iś ia nahalin ayaśtan śni ehan, Rebeka u, Abereyam cincu Nahor tawicu Milka he cinhintku Betuel he cunwintku kin hee, wakiśkotpa hiyeta onpe ca $u$.

16 Wikośka owanyag waśte hinca, hokśiwina, qa wicaśta tohini sdonye śni, minilidoka kin ekta kun ye ca wakiśkotpa kin ojudan icu qa wankan hiyu.

17 Unkan ookiye qon itkokim inyang ye ca, Wakiśkotpa duhe cin etanhan mini onge yatke makiya wo, eya.

18 Unkan, Itancan yatkan ye, eye ca wakiśkotpa kin nape kin on kun akihde, qa yatke kiya.

19 Unkan ayaśtan hehan, Camo nitawa kin nakun hena on mini awau kta, yatkan ayaśtanpi kin hehanyan, eya.

$20 \mathrm{Qa}$ inah̆ni qa wakiśkotpa kin cankaślkotpa tanka kin okaśtan, qa inyanka miniholoka kin ekta mini huwe ya heon, qa camo kin owasin mini wicakahi.

21 Unkan wicaśta kin yuśinyaye ca taku eye śni, canku ohna $u$ kin he Jehowa ohinniyan tanyan ikiyuśtan kta hecinhan he sdonye kta.
22 Unkan camo kin mini yatkan ayaśtanpi, hehan wicaśta qon mazaskazi maza oin tanka, mazaska hanke ivecen tke, he icu qa nakun maza huhu nom mazaska wikcemna iyecetu, hena owasin wikośka nape kin en ye kiya;

$23 \mathrm{Qa}$, Tuwe hunkake yaya he? Omakiyaka wo, niyate ti kin ohna unkiwankapi kta okan. he? eya.

24 Unkan, Milka cinhintku Betuel Nahor kiciton kin he cunwintku kin miye ce, eya.

$25 \mathrm{Qa}$, Peji puze ça taku yutapi ko ota, qa nakun wankapi kta okan ce, eciya.

26 Unkan wicaśta qon pamahdedan yanke ca Jehowa cekiye ca,

27 Jehowa Abereyam mayuhe cin taku wakan da kin he yawaśtepi nunwe. Towicake towaonśida ko mayuhe cin ektakiya ayuśtan śni, tuka mayuha sunkaku ti kin canku kin ohna Jehowa amau ce, eya.

28 Unkan wikośka kin dus hde ca iye hunku ti kin en hena owasin oyaka.

29 Rebeka timdoku wan yukan, Laban eciyapi, qa Laban iś dus iyaya wicaśta qon ekta minihdoka kin en.

30 Laban oin tanka, qa maza huhu tankśitku nape kin akan wanyake ca Rebeka tankśitku oie ye cin, Wicaśta kin hecen emakiya eye cin he nation qa, hehan wicaśta qon minilidoka kin ekta, camo kin icahda najin kin en hi.

31 Qa heya, Jehowa he niyawaśte kin u wo. Tokeca tankan nayajin he? Miś tipi kin wanna wiyeya wakaga, camo yukanpi kte cin nakun.

32 Unkan wicaśta qon tipi kin 33 


\section{WICOICAGE.}

ekta hi; unkan camo kin kiyuśke ça peji puza taku yutapi ko camo kin qu, qa mini on siha hdujaja kta wicaśta om hi kin nakun hdujajapi kta e au.

33 Qa woyute nakun qu. Unkan, l'aku on wahi kin owahdake śni kinhan onśpadan wate kte śni ce, eya. Unkan, Ia wo, eya.

34 Unkan, Abcreyam tahokśidan wan he miye :

35 Qa Jehowa he mayuhe cin nina yawaśte, qa tahin wanuyanpi qu, qa pte, qa mazaska, qa mazaskazi, qa wicaśta winyan ko wowindag wicaye cin, qa camo, qa śuktanka śonśonna, hecen wicaśta okinihan.

36 Qa mayuhe cin tawicu kin Sara cinca wan ton, mayuha wanna wicahinca hehan he kiciton, unkan taku yuhe cin owasin kicu.

37 Qa Kanani makoce tawapi kin en manke cin he cunwintkupi kin etanhan micinkśi on winohinea duze ktc śni :

38 Tuka hunkake wicawaye cin tipi kin ekta de kte ca, takúwicawaye cin etanhan micinkśi on winohinca wan duze kta ce, mayuhe cin eya konza, keyemaśi.

39 Unkan, Okini winohinca kin mici u kte śni, mayuhe cin ewakiya.

40 Unkan, Taku wakan wada Jehowa itokam mawani kin, he taohnihde wan nici ye śi kte ça, mitakuye qa ate ti kin etanhan, winohinca wan micinkśi on duze kta e, canku yaye cin tanyan ihuni niciye kta ce.

41 Tuka taku eya konze ciciye cin nihiyahde kte śni, takuwicawaye cin ekta de cinhan, qa nicupi śni kinhan, hehan taku eya konze ciciye cin iyahde niciye kte śni, emakiya.

42 Unkan nakaha minilidoka

$$
34
$$

kin exta wahi qa hepa, Jehowa Abereyam mayuhe cin he wakan nida, canku ohna wau kin tanyan ihuni mayakiya hecinhan; 43 Tho miś miniȟdoka kin icahda nawajin qa wikośka wan mini huwe hiyu qa, Wakiśkotpa duhe cin etanhan mini onge yathe makiya ye, ewakiye kta.

44 Unkan, Yatkan ye, qa nakun camo nitawa kin mini wicawakahi kta ce, emakiye cinhan, winohinca wan mayuhe cin cinhintku yuze kta e Jehowa kahinige cin bee kte.

45 Miś cante mahen ia nahahin mdaśtan śni, unkan inyun Rebeka hinanpe ca, minihdoka kin ekta kun i qa mini icu; unkan, Tokin yatke mayakiyen, ewakiya.

46 Unkan tawakiślkotpa kin inahniyan kun ahi qa, Yatkan ye, qa camo nitawa kin nakun woyatke wicawaqu kta ce, eya ; unkan mdatke ça camo kin nakun yatkanpi.

47 Unkan imonge ca, Tuwe cunwintku niyan he? ewakiya. Unkan Betuel cunwintku be miye, Nahor cinhintku Milka kiciton kin hee. Hehan oin tanka ite kin akan ewahnaka, maza huhu nakun nape kin akan.

48 Qa pamahdedan manke ca Jehowa cewakiya, Jehowa Abereyam mayuhe cin taku wakan da kin he mayuhe cin cinhintku kin on, mayuhe cin sunkaku cunwintku iwacu kta e canku wicaka ohna amau kin he mdatan.

$49 \mathrm{Qa}$ niyepi wanna wowaonsida wowicake ko mayuhe cin ecayeconpi kte cinhan omakiyakapo, qa ecayeconpi kte śni kinhan omakiyakapo: etapa tanhan mduhomni kta qa iś catka tanhan, eya. 


\section{WICOWOYAKE 25.}

50 Unkan Laban Betuel ko ayuptapi qa Taku kin de Jehowa etanhan u qa taku śica qa iśs taku waśte unkeniciyapi kta unkokitpanipi ce, eyapi.

51 Tho Rebeka nitokam un; icu qa hda wo. He niyuhe cin cinhintku kin yuze kta, Jehowa oie ye cin iyececa.

52 Unkan Abereyam taokiye kin iapi hena nalion qehan, Jehowa ohoda kta e makata patuś iyaya.

53 Hehan ookiye qon mazaska oin qa mazaskazi oin ikikcu, wokoyake nakun, qa hena Rebeka qu, timdoku hunku ko taku tehika wacaqu.

54 Hehan wotapi qa wayatkanpi, iye wicaśta opapi kin hena koya. Wankapi qa hanhanna kiktapi qa, Mayuhe cin ekta hdicu mayan wo, eya.

55 Unkan timdoku hunku ko, Wikośka unkicipi yanke kte, wikcemna can hehanyan, hehan ye kta ce, eyapi.

56 Unkan, Jehowa iś canku mitawa kin tanyan ihuni mayan heon mayutehanpi śni po.' Mayuhe cin ekta kibde mayanpo, ewicakiya.

57 Unkan, Wikośka kin unkicopi qa, iye i kin etanhan unkiwangapi kta ce, eyapi.

58 Qa Rebeka kipanpi, qa, Wicaśta kin de kici de kta he? eciyapi. Unkan, Mde kta ce,"eya. 59 Unkan Rebeka tawinolitinpi kin ye yapi, qa azinkiye ciqon, qa Abereyam taokiye, qa wicaśta tawa nakun.

$60 \mathrm{Qa}$ Rebeka yawaśtepi qa, Unkitawinohtinpi kin he niye, kektopawinge oyawa tanka icaga wo, qa cinca wicayaye kte cin toka wicayapi otonwe kin yuhapi kte, eciyapi.

61 Hehan Rebeka najin, wi- kośka yuhe cin nakun, qa camo akan iyotankapi, qa wicaśta qon kici iyayapi. Hecen ookiye qon Rebeka icu qa kihda.

62 Wanná Izak minilidoka, Tuwe ni un kin wanmayaka tawa kin hetanhan $u$, qa makoce puze cin en iyotanka.

63 Qa htayetu ca Izak cekiye kta e manin ya, hehan wankan etonwe ca camo upi kin wanwicayaka.

64 Rebeka nakun wankan etonwe ca Izak wanyake ça camo kin etanhan ipsica.

$65 \mathrm{Qa}$ ookiye kin heciya, Wicaśta wan itkounkipapi hewoskan omani kin he tuwe? Unkan, Mayuhe cin hee, ookiye kin eya. Unkan ite akalipe wan icu qa aihdahpa.

66 Unkan ookiye kin, taku token econ kin owasin Izak okiyaka.

67 Hehan Izak iye hunku Sara tawakeya kin mahen Rebeka tin ye śi, qa yuze ca tawicu kin waśte kidaka. Hecen Izak iye hunku Sara te cin iyohakam iwacintonhnag yapi.

\section{WICOW OYAKE 25.}

1 Hehan ake Abereyam winohinca wan yuza, Qetura eciyapi. 2 Unkan cinca kiciton kin dena eepi, Zimran, qa Jokśan, qa Medan, qa Midian, qa Iśbak, qa Śuha.

3 Unkan Jokśan iś Śseba qa Dedan kicitonpi. Unkan Dedan iś Aśurim, qa Letuśim, qa Lumim cinkśi wicaya.

4. Unkan Midian cinca wicaye cin, Epa, qa Heper, qa Ḧlanok, qa Abida, qa Eldaha. Hena owasin Qetura cinkśi wicaya.

5 Unkan Abereyam taku yuhe cin iyulipa Izak qu. 
6 Tuka winohinca uman cinca Abereyam kicitonpi kin hena Abereyam taku wicaqu, qa nahahin iye ni un kin wiyohiyanpata makoce kin ekta ye wicaśi, cinhintku Irak etanhan.

7 Abereyam anpetu tawa kin waniyetu ni un kin dena ce, waniyetu opawinge sanpa wikcemna śakowin sanpa zaptan, hehanyan ni.

8 Hehan Abereyam niya śni ta iyaya, pa ska waśte, qa wicahinca imna; hehan taoyate kin ekta okipa yapi.

9 Qa cinca wicaye cin Izak Iśmayel kici kihnakapi; Makpela imnija ohdoka kin en Mamore itokam, Zohar Heti he cinhinthu Epron tamaga qon en.

10 Maga wan Abereyam Ḣet cinca wicaye cin opewicakicaton, he en Abereyam hnakapi, tawicu Sara kici.

11 Unkan Wakantanka, Abereyam te cin iyohakam, cinhintku kin Izak yawaśte, qa Izak Tuwe ni un qa wanmayake cin minihdoka tawa kin ekta ounyan.

12 Hagar Egupton kin Sara tawikoślka kin he Abereyam cinca wan kiciton, Abereyam einhintku Iśmayel wicoicage tawa kin dee.

13 Iśmayel cinca wicaye cin cajepi kin deepi, wicowazipi qa cajepi kin iyececa. Iśmayel cinca tokapa kin he Nebayot, hehan Qedar, qa Adbel, qa Mibśam;

14 Qa Miśma, qa Duma, qa Masa ;

15 Hada, qa Teman, Jetur, Napiś qa Qedma.

16 Hena Iśmayel cinkśi wicaya; toki tipi qa tonwanyanpi kin ecen eciyapi, wicaśtayatapi ihdawapi ake nom, taoyatepi kin om.
17 Iśmayel ni un kin waniyetu kin dena ee, waniyetu opawinge sanpa wikcemna yamni sanpa sakowin, henakeca; hehan niya śni ta iyaye ça taoyate kin ekta okipa yapi.

18 Hunka wanjin wicaye cin owasin wicehna ta. Hawila etanhan Śur itokam un kin ektakiya de cin qa hetanhan Aśur etu makoce kin he en ounyanpi.

19 Unkan Izak Abereyam cinhintku wicoicage tawa kin dee, Abereyam he Izak kicitonpi.

20 Unkan Izak wanna waniyetu wikcemna topa, hehan Rebeka yuza, he Betuel Arami kin he cunwintku, Aram Mdaye kin etanhan, Laban Arami kin tawinohtin kin hee tawicu kta e yuza.

21 Qa Izak tawicu kin cinca ton śni kin heon, Jehowa icekiya. Unkan Jehowa anakicigoptan, hecen Rebeka Izak tawicu kin ihduśaka.

22 Unkan hokśiyoqopa Rebeka mahen akinicapi; unkan, De taku hwo hecetu kta hecinhan token on hemaca he? eye ca Jehowa iwange kta e ekta $\mathrm{i}$ :

23 Unkan, Nitamni kin mahen oyate nonpa, qa nitezi kin etanhan oyate nonpa inanpapi kta, qa oyate wan waśaka keś oyate uman sanpa waśake kta, qa hakakta kin he tokapa kin wowidake yuhe kta ce, Jehowa eciya. 24 Unkan anpetu cinca ton kte cin wanna henakeca, qa inyun tamni kin mahen cekpa yukan.

25 Unkan tokapa kin hiyu owancaya gi, pte ha śina iyecen; unkan Esa eya caśtonpi.

26 Hehan sunkaku kin hiyu, qa nape kin Esa siyete kin yus un; heon Jakob eya caś kiton. Hena tonpi kin ehan, Izak waniyetu wikcemna śakpe. 


\section{WICOWOYAKE 26.}

27 Unkan hokśipidan tanka icagapi, qa Esa wotihni wayupika, wicaśta hewoskan un kin heca, tuka Jakob wicaśta wahbadan wakeya oti.

28 Unkall Izak Fisa waśte kidaka, taku o kin yuta heon. Tuka Rebeka Jakob waśte kidaka.

29 Unkan Jakob wahanpi ohe cin icunhan Esa tinta kin etanhan u qa watuka un;

$30 \mathrm{Qa}$, Akilian mate kta heon wahanpi śa kin de onge maqu wo, mdatke kta ce, Esa Jakob eciya. Heon $\mathbb{E}$ dom eya caje yatapi.

31 Unkan, Watonikapa kin he nakaha maqu wo, Jakob eya.

32 Unkan Eisa, Wanna mațe kta qa watomakapa kin de taku okihi kta he? eya.

33 Unkan Jakob, Nakaha Wakantanka icajeyan emakiya wo, eya. Unkan Wakantanka icajeyan eciya. Hecen Esa watokapa tawa kin he Jakob qu.

34. Unkan Jakob omnica hanpi aguyapi kici Esa qu, unkan yute ca yatkan qa najin, qa toki iyaya. Hecen Esa watokapa kin ihakta śni.

\section{WICOWOYAKE 26.}

1 Unkan makoce kin he en wicaakihan tokeca wan, Abereyam anpetu tawa icunhan wicaakihan tokaheya qon he iyohakam. Unkan Izak Piliśtim tawicaśta yatapi Abimelek eciyapi ekta i, Gerar etu.

2 Unkan Jehowa iye en tanin içiye ça heciya, Egupta ekta de kte śni ce, makoce wan ociciyake kte cin hen yanka wo.

3 Makoce kin de en ounyan wo, kinhan nici waun qa ciyawaśte, qa makoce kin dena owasin ciçu kta, nicinea ko wokonze Abere- yam niyate konza ewakiye cin he wahdusuta;

4 Qa nicinca yuota wakiye kta mahpiya wicanhpi sukaza iyenaka, qa makoce kin dena owasin nicinca wicawaqu kta, qa oyate maka kin ohnaka owasin nicinca kin on yawaśtepi kta.

5 Nakaeś Abereyam miho kin anamagoptan qa mitawoahope, mitawokonze, mioie, qa mitoope kin hena yuhe cin heon etanhan. 6 Unkan Izak Grerar en ounyan.

7 Unkan wicaśta heciya tipi kin tawicu kin on iwangapi ; unkan, Mitankśi kin dee ce, eya. Rebeka owanyag waśte, qa iye on okini wicaśta deciya yakonpi kin maktepi kta ecin heon, Mitawin dee eye kte cin itonpa.

8 Unkan wanna anpetu ota hen yanke cehan, Piliśtim wicaśta yatapi Ảbimelek ojanjan hdepi wan etanhan eyokasin qa Izak tawicu Rebeka kici śkata e wanwicayaka.

9 Hehan Abimelek Izak kico qa, Awicakehan nitawin hee. Tokeca, Mitawinohtin dee ehe ciqon he? eya. Unkan okini iye on mate kta epce cin heon hepa ce, Izak eya.

10 Unkan, De taku ecaunyeconpi he? Wanna ecadan oyate etanhan wicaśta wan nitawin kici iwanke kta unkanś, taku śica iyahde unyayapi kta tuka ce, Abimelek eya.

11 Qa Abimelek oyate tawa owasin iwakta wicaya, Tuwe wicaśta kin de yutan, qa iś tawicu yutan kinhan te kta ce, eya.

12 Unkan, Izak makoce kin he en woju, qa omaka kin he en opawinge akihde kamna. Hecen Jehowa Izak yawaśte.

13 Unkan wicaśta kin tanka 
qa ohinniyan tanka aya, wijica hinca.

14 Qa oiçihde, tahinca, qa pte wanuy anpi, qa ookiye ota yuha; heon Piliśtim icekinpi.

15 Unkan minilidoka, tona atkuku taokiye qapi qon atkuku Abereyam ni qehan, hena owasin Piliśtim aohduteyapi, maka okatapi.

16 Unkan Abimelek Izak heciya, Unkiyepi etanhan toki iyaya wo, waunśakapi keś niś sam iyeya waniśaka ce.

17 Unkan Izak hetanhan iyaye ça Gerar kaksiza kin he en eti, qa hen iyotanka.

18 Qa minilidoka atkuku Abereyam ni kin icunhan qapi qon, qa Abereyam te cin iyohakam Piliśtim kin hena aohduteyapi kin, hena ake Izak qe ça Abereyam caś ton qon hena iyecen Izak caje yata.

19 Qa Izak hokśidan wicayuhe cin kaksiza ohna qapi qa, en minicaduza minihdoka wan iyeyapi.

20 Hehan Gerar wanuyanpi wihan wicakiyapi tawa kin, Izak wanuyanpi wihan wicakiyapi tawa kin om akinicapi qa, Mini kin he unkitawapi ce, eyapi; heon minihdoka kin he Esek Izak caś ton, heciya kiyuśepi kin heon.

21 Unkan ake minilidoka tokeca wan qapi; lunkan he on nakun alkinicapi, heon he Sitna caśton.

$22 \mathrm{Qa}$ hetanhan ihdaka ye ça minilidoka tokeca wan qapi, qa he on akinicapi śni. Unkan he Rehobot eya caś kiton; Wanna Jehowa tankaya unkiyukanpi kaga makoce kin en, heon unkicagapi kta ce, eya.

23 Unkan hetanhan itawankanhde ye ça Berśeba ekta i.
24 Unkan hanyetu kin he en Jehowa tanin ic̣iye ça heciya, Niyate Abereyam taku wakanda kin he miye ce. Wikopeśni un wo; niyate Abereyam mitaokiye kin heon nici waun, qa ciyawaśte, qa nicinca yuota wakiye kta ce.

25 Unkan kakiya wahna wośnapi wan kage ca Jehowa caje kin hoye kiye ca, kakiya wakeya oti, qa kan Izak taokiye kin minilidoka wan qapi.

26 Hehan Abimelek Gerar etanhan Izak en hi; iye takodaku Ahuzat, Pikol taakicita tancan koya.

27 Unkan, Śice mayadakapi qa niyepi kin etanhan toki iyaye mayaśipi, qa tokeca en mayahipi he? Izak ewicakiya.

28 Unkan, Unkanitonwanpi qa Jehowa nici un kin he wanunyakapi qa, Tho wokonze yuke kte, unkiyotahedan qa odakonkiciyapi unnicagapi lita ce, unkeyapi.

29 Hecen unkiś unniyutanpi śni, qa taku waśte ecedan ecaunniconpi, qa wounkiyapi iyaye unniśipi kin he iyecen, niś dehan Jehowa niyawaśte, taku śica ecaunyeconpi kte śni, eyapi.

30 Unkan wowicakihe ça wotapi qa wayatkanpi.

31 Qa ihanhanna kiktapi qa konza ekiciyapi, napin hunka wanjitku kici heconpi qa, Izak kihde wicaśi. Unkan wookiye iyayapi.

32 Anpetu kin he en Tzak taokiye kin en hipi, qa minilidoka qapi kin he okiyakapi qa, Mini iyohi unyanpi ce, eyapi.

33 Unkan, Konzapi eya caś kiton. Heon anpetu kin de hehanyan otonwe kin heciya un kin Berśeba eciyapi.

34 Unkan Esa wanna waniye- 


\section{WICOWOYAKE 27.}

tu wikcemna topa, hehan Beri' Hieti kin he cunwintku Judit, qa Elon Heti he cunwintku Basmat, henios wicayuza. Hena napin on, Izak Rebelia ko cante śicapi.

\section{WICOWOYAKE 27.}

1 Unkan Izak wanna wicahinca iśta kin mdeze śni, hecen wawanyake sni; hehan Izak cinhintku tokapa kin Esa kipan qa, Micinkśi, eya. Unkan, Iho miye ce, eya.

2 Ũnkan, Wanna wicamahinca, qa tohan mate kte cin sdonwakiye śni.

3 Ceciya ce, nakaha wipe ikikcu wo, wanju itazipa ko ikikcu, qa hewoskan ye ça tado imakihni wo.

4 Qa mate kte cin itokam, minagi kin niyawaśte kta e, tado skumna taku waśte wadaka heca micage, ça makau wo. Wate kta ce, eya.

5 Unkan Rebeka Izak cinhin. tku Esa okiye cin he nahon. Unkan Esa atkuku kin on wotihni kta e hewoskan iyaya.

6 Hehan Rebeka cinhintku Jakob heciya, Tho niyate Wisa nicinye okiya nawahon;

$7 \mathrm{Qa}$, Tado makau qa taku skumna waśte micaga wo; wate kta qa mațe śni kin itokam Jehowa itokam ciyawaśte kta ce, eciya.

8 Heon micinkśi token econ ciśi miho kin anamakigoptan ye.

9 Ecadan wanuyanpi ekta ye ca tatokadan cinca nom waśte imakicu ye, kinhan tado skumna wecage kta, niyate waśte daka iyececa.

10 Unkan niyate te cin itokam niyawaśte kta e en ayai kta; unkan yute kta ce.

11 Unkan, Jakob hunku kin
Rebeka heciya; Ecah micinye Fisa wicaśta hin śma heca, qa niś wicaśta śduśduta hemaca.

12 Okini ate mayutan kte cinhan wicahnayesa wan iyececa iyemaye kta, hecinhan mayašicapi lin he iyahde miçiye kta, mayawaśtepi kin hee kte śni ce. 13 Unkan, Micinkśi niyaśicapi kin he miye en amaupi nunwe. Tokeśta miho kin anamakigoptan, qa imakicu ye, hunku kin eciya.

14. Unkan ekta ye ça ikikcu qa hunku kin en au; unkan hunku kin tado skumna atkuku waśte dake cin iyecen kaga.

15 Hehan Rebeka śina waśte wan, cinhintku tokapa Esa he tawa ti kin ohna yuhe cin he icu, qa cinhintku hakakta Jakob in kiya.

16 Qa tatokadan cincadan ha kin he Jakob nape kin, qa tahu śduśduta kin akan ehnaka.

17 Qa tado skumna kage ciqon aguyapi koya cinhintku Jakob nape kin en qu.

18 Unkan atkuku kin en au qa, Ate, eya. Unkan, Tho micinkśi ni tuwe be? eya.

19 Unkan Jakob atkuku kin heciya, Esa nicinksi tokapa kin he miye ce. Token emayakiye cin ecen ecamon ce. Ceciciya najin qa iyotanka wo; qa ninagi kin mayawaśte kta e tado awahi kin yuta wo, eya.

20 Unkan, Micinkśi token inahniyan iyeyaya he? Izak cinhintku kin eciya. Unkan Jehowa wakanyada kin he itkomakim u kiya heon etanhan, eya.

21 Unkan, Micinkśi mikiyedan u wo, ciyutan kta ce, Esa micinkśi kin de niye qa iś dee śni uman tukte sdonwaye kta, Izak Jakob eciya.

22 Hehan Jakob atkuku Izak 
ikiyedan hinajin, unkan yutan qehan, Ho kin Jakob ho kin hee, tuka nape kin Esa nape kin eepi, eya.

23 Nape kin hin śma cincu Esa nape kin iyececapi; heon etanhan iyekiye śni, qa Jakob yawaśte.

24 Esa micinkśi kin de niye he ? eya iwanga. Unkan, Han he miye ce, eya.

25 Unkan, Mikiyedan u wo. Minagi kin niyawaśte kta e, taku micinkśi o kin wate kta ce, eya. Unkan ikiyedan hinajin, unkan wota, miniśa nakun en au; unkan yatkan.

26 Hehan atkuku Izak, Iho micinkśi mikiyedan u qa i imaputaka wo, eciya.

27 Unkan en ye ca i iputaka, unkan wokoyake omna kin he omna, qa yawaśte qa, Micinkśi omna kin he tinta wan Jehowa yawaśte omna kin he iyececa.

28 Qa Wakantanka rrahipiya cu kin nicu kte ca nakun maka kin wasna qa aguyapi qa miníśa ko ota.

29 Oyate wowindag wicayaye kta nitokam wicaśta yatapi makata ehpeiciyapi kta. Nihunka wanji yuha un wo, qa nihun cinca wicaye cin nitokam patujapi kta, tuwe niyaśice cin yaśicapi kte, qa tuwe niyawaśte kin yawaśtepi kta ce, eya.

30 Wanna Izak Jakob yawaśte hdaśtan, unkan Jakob atkuku Izak itoye kin etanhan kitana aisinyan iyaya, hehan cincu Esa wotihni kin etanhan hdi.

$31 \mathrm{Qa}$ iś nakun tado skumna kage ça atkuku kin en ahi, qa atkuku kin heciya, Ate najin qa nicinkśi taku o kin etanhan yuta wo; ninagi kin mayawaśte kte cin heon etanhan.

32 Unkan atkuku Izak, $\mathrm{Ni}$ tu- we he? eciya. Unkan, Nicinkśi tokrpa Esa he miye ce, eya.

33 Unkan Izak woyuśsinyaye tanka hinca on nina y uśinyaya ; Token tuwe tado ihni qa makahi, unkan owasin etanhan wata, yahi śni ehan, qa mdawaśte qa nakun iye yawaśtepi kta ce, eya.

34 Esa atkuku oie kin nalion hehan nina ceye ca śicahowaye ca, Ate miś nakun mayawaśte ye, atkuku kin eciya.

35 Unkan, Nisunka hi qa wohnaye kin eciya tanhan niyawaśtepi kin icu, eya.

36 Unkan, Jakob eciyapi caje kin iyecetu śni he? Wanna nonpa yuśna mayan; watumakapa kin he tokaheya ki qa nakaha mayawaśtepi kin icu ; eye ca, Woyawaśte wan miyecipatan śni he, eya.

37 Unkan Izak ayupte ca, Ecah ohiniciye kte he wakage, ca hunka wanjin wicaye cin owasin wicayuhe kta waqu, aguyapi miniśa ko yuhe kta waqu, qa dehan micinkśi taku ecacicon kta he? Esa eciya.

38 Unkan, A te woyawaśte kin wanjidan duha he? Miś nakun mayawaśte wo, ate, Esa atkuku kin eciye ça, Esa panyanhan ceya.

39 Unkan atkulku Izak ayupte ça, Maka wasna kin ohna ounyaye kte ca mahpiya cu kin aniu kte ; 40 Qa nitacanhipi kin on yani kte ca nisunka wowidag niye $\mathrm{kta}$; tuka tohan waśaka inicage cinhan iye tawanapin nitahu kin etanhan dukse kta ce, eciya. 41 Unkan Esa Jakob s̉ice kidaka, woyawaśte kin on atkuku kin yawaśte kin heon etanhan, qa Esa cante kin mahen heyä; Ate aceyapi kte cin anpetu kin hena wanna ikiyedan qa, hehan misunka Jakob wakte kta ce. 


\section{WICOWOYAKE 28.}

42 Unkan Rebeka he cinhintku tokapa token ie cin he okiyakapi, unkan ekta ye si qa, cinhintku hakakta Jakob kico qa, Tho nicinye Esa niye tokicon qa nikte kta e oiciya ce.

43 Tho micinkśi miho kin anamakigoptan ye. Najin qa timdo Laban en Haran ektakiya najica ya ye.

44 Qa timdo kici nanke kta anpetu tonana; nicinye canniye niye cin ayuśtan kin hehanyan.

45 Nicinye wocanniye aniyuśtan qa, taku ecayecon akiktonje cin hehantu, kinhan hetanhan icicu kta e wahociye kta ce. Ehaeś token on etanhan anpetu wanjidan en niye napin makitaninpi kte śni he? eciya.

46 Unkan Rebeka Izak heciya, Wani kin he wanna owihanketa, Het cunwintku wicaye cin on etanhan, Jakob winohinca wan dena iyececa, Het cunwintku kin etanhan, yuze cinhan token on wani kta he, eya.

\section{WICOWOYAKE 28.}

1 Hehan Izak Jakob kipan, qa yawaśte qa wahokonkiye cea, Kanan cunwinkupi kin etanhan winolinca duze kte śni.

2 Najin Aram Mdaye kin ekta ya wo, nihun atkuku Betuel ti kin ekta, qa hetanhan timdoku Laban cunwintku kin etanhan winohinca wan yuza wo.

$3 \mathrm{Qa}$ Taku wakan iyotan waśake cin niyawaśte, qa iyakiçuya yuota niciye kta, qa oyate ota yaun kta.

4 Qa Abereyam yawaśtepi kin niçu, makoce wan en ounyaye cin Wakantanka Abereyam qu qon he nicinca or yahduhe kta, eciya.

5 Hecen Izak Jakob ye śi; unkan iyaya Aram Mdaye kin ekta, Betuel cinhintku Laban Arami kin en, Jakob Esa kici hunkupi kin Rebelka timdoku kin hee.

6 Unkan Izak Jakob yawaśte, qa Aram Mdaye kin ekta ye śi kin, heciya tanhan winohinca wan yuze kta, qa yawaśte qehan, Kanan cunwintkupi kin etanhan winohinca duze kte śni ce, eciye cin he Esa wanyaka.

7 Unkan Jakob atkuku hunku kici anawicagoptan, qa Aram Mdaye kin ektakiya ya.

8 Unkan Kanan cunwintkupi kin iye atkuku Izak jśta kin en śicapi e Esa wanyake ceehan ;

9 Esa Ísmayel ekta i, qa Abereyam cinhintku lśmayel cunwintku Mahalat, Nebayot tawinohitin kin he yuza, tawicu nonpa tuka he nakun yuza.

10 Unkan Jakob Berśeba etanhan iyaya Hiaran ektakiya.

11 Qa toki i kin hen iwanka, wi wanna iyaya nakaeś, qa inyan hen yanke cin etanhan icu, qa ipahin ekihnake ca heciya iśtima.

12 Qa wihanmde ca inyun taku iyadipi wan makata han, qa pa kin mahpiya kin elkta iyohiya; unkan Wakantanka ohnihde wicaye cin adipi qa kun hiyupi.

13 Qa inyun Jehowa iwankam najin qa, Niyate Abereyam taku wakan da qa Izak taku wakan da kin Jehowa he miye ce. Makoce akan nunke cin he cicukta nicinca koya.

14 Qa nicinca maka watuśekśeca sukaza kin iyenakapi kta, eniciciya idade kta wiyohipeyata, qa wiyohiyanpata, qa waziyata, qa itokaga, qa niye nicinca koya en wicowazi tona maka akan unpi kin owasin yawaśtepi kta.

15 Iho miś nici waun, qa toki 


\section{WICOICAGE.}

da eśta awanciyake kta, qa makóce kin de ekta acihdi kta, ehpeciye kte śni, tohan taku ociciyaka wahduśtan śni kin hehanyan, eya.

16 Unkan Jakob wihanmde cin etanhan kikta qa, Awicakehan Jehowa den yanka, tuka miś sdonwaye śni, eya.

17 Hecen kokipe ça, Oyanke kin de itonpapi kta tuka ce, Wakantanka ti kin qa mahpiya tiyopa kin dee śni he? eya.

18 Qa hanhanna hehan Jakob najin qa inyan wan ipahin ehnake ciqon he icu, qa wokiksuye kte cin ehde, qa he pa kin akan wihdi akaśtan.

19 Qa oyanke kin he Betel, (Taku Wakan ti kin) eya caśton, tuka tokag ehan otonwe kin he Luz eciyapi.

20 Unkan Jakob wokonze wan içiconze ca heya, Wakantanka mici un kinhan, qa canku kin de ohna mde cin he ohna awanmayake cinhan, qa aguyapi wate kta maqu qa wokoyake komayake kta nakun;

$21 \mathrm{Qa}$ ate ti kin ekta tanyan wahdi hecinhan, Jehowa eceedan wakanwada kta ce.

22 Qa inyan wokiksuye ewehde kin de Wakantanka tipi tawa kta ce, qa taku mayaqu kte cin owasin etanhan, iwikcemina kin ciçu kta ce.

\section{WICOWOYAKE 29.}

1 Hehan Jakob Wiyohiyanpata cinca tamakocepi kin elatakiya siha on mani iyaya.

2 Qa etonwe ça inyun tinta ohna minihdoka wan, qa tahin wanuyanpi optaye yamni heciya minilidoka kin icahda wankapi, minilidoka kin he etanhan optaye kin mini wicaqupi ece. Un- kan minihdoka i kin akan inyan tanka wan yanka.

3 Unkan hen optaye kin owasin mniciyapi eca, minitidoka i kin akan tanhan inyan kin yuptanyanpi qa, tahinca kin mini wicaqupi ca inyan kin hen yanke kte cin minilidoka i kin akan ehnakapi.

4. Unkan, Hunka wanjin ciyapi tokiya tanhan yaunpi he? Jakob ewicakiya. Unkan, Haran unketanhanpi ce, eyapi.

5 Unkan, Laban Nahor cinhintku sdonyayapi he? ewicakiya. Unkan, Han he sdonunyanpi ce, eyapi.

6 Unkan, Zaniyan un he? ewicakiya. Unkan, Zaniyan un, nakun wanyaka wo; cunwintku Rahel tahin wanuyanpi kin om hiyu ce, eyapi.

7 Unkan, Anpetu nahahin tanka ihan. Wanuyanpi mniciyapi kte cin nahahin iyehantu śni. Tahinca mini wicaqupi qa wilian wicakiyapo, eya.

8 Unkan, Unkokitpanipi ce ; optaye kin owasin mniciyapi kin, hehan inyan kin minihdoka i kin etanhan yuptanyanpi kinhan, hehan tahinca kin mini wicunqupi kta ce, eyapi.

9 Om wohdaka icunhan, Rahel atkuku tahinca tawa om hi; wihan wicakiya nakaeś.

10. Hecetu unkan Jakob, iye hunku kin he timdoku Laban cunwintku Rahel he wanyake ca, hunku timdoku kin Laban tahinca tawa nakun, qa Jakob ikiyedan i qa, inyan qon mini hdoka i kin akan tanhan yuptanye ca, hunku kin he timdoku Laban tahinca tawa mini wicaqu.

11 Qa Jakob Rahel i iputake ca ho taninyan ceya.

12 Qá Jakob Rahel heciya, 


\section{WICOWOYAKE 29.}

Niyate sunkaku kin hemaca, Rebeka cinhintku kin he miye ce. Unkan inyang hde ça atkuku okiyaka.

13 Unkan Laban he tawinolitin cinhintku kin Jakob taku ohdake cin nalion qehan, itkokim inyang ye ca, poskin yuze ca, i iputake ca ti kin timahen u śi. Unkan Jakob Laban hena taku kin owasin okiyaka.

14 Unkan, Mihu, qa micelipi kin he niye ce, Laban Jakob eciya. Unkan anpetu tona wi wanjidan en un kin kici yanka.

15 Unkan Laban Jakob heciya, Hunka wanjin ciye cin on ituya wowidag ciye kta he? Taku iyuwin yacin kin he omakiyaka wo, eya.

16. Wanna Laban cunwintku nonpa, tokapa kin Leha eciyapi, qa hakakta kin Rahel eciyapi.

17 Qa Leha iśta kin wankadan; tuka Rahel okah waśte owanyag waśte hinca.

18 Unkan Jakob Rahel waśte dake ca, Rahiel nicunkśi hakakta kin he on waniyetu śakowin wowidag mayaye kta, eya.

19 Unkan he cicu kinhan waśte kta; wicaśta tokeca waqu kinhan waśte kte śni. Mici ti wo, Laban eya.

20 Unkan Jakob Rahiel on waniyetu śakowin okiya; tuka he waśte dake cin on iśta kin en anpetu tonana yawa.

21 Hehan, Mitawin maqu wo, kici imunke $\mathrm{kta}$, anpetu kin wanna henakeca ce, Jakob Laban eciya.

22 Unkan Laban otonwe kin wicaśta owasin mnawicaye ça wowicakihan.

23 Qa otpaza hehan cunwintku Leha he icu, qa Jakob en au. Unkan kici wanka.

24 Unkan Laban wikośka wan yuhe cin Zilpa, he icu qa cunwintku Leha wikośka yuhe kta e qu.

25 Ihanhianna inyun Leha hee, qa Jakob Laban heciya, Ratiel on ociciye śni he? 'Tokeca mayahnayan he?

26 Unkan, Hakakta kin tokaheya qupi, qa hehan tokapa kin deciya hecen econpi śni ;

27 Anpetu śakowin kin de ihuniyan wo; kinhan he nakun cicu kta, tokata waniyetu śakowin tokeca omayakiye kte cin heon etanhan, Laban eya.

28 Unkan Jakob ecen econ, qa śakowin kin he ihuniyan. Unkan Laban cunwintku Rahel he tawicu kta e qu.

$29 \mathrm{Qa}$ wikośka wan yuhe cin Bilha, he Laban cunwintku Rahel wikośka yuhe kta e qu.

30 Unkan Jakob Rahel kici wanke ca, nakun Rahel waśte dake ça, ake waniyetu śakowin uman Laban cajeyate ciqon he yuśtan.

31 Unkan Leha śice dakapi kin he Jehowa wanyake ca, Lieha tamni kin yuhidoka, tuka Rahel cinca ton śni.

32 Unkan Leha ihduśake ca, cinca ton, qa Ruben eya caś kiton; Makiyuśepi kin Jehowa wanyaka, unkan dehan mihihna waśte madake kta ce, eya.

33 Qa ake ihduśake ca cinca ton, qa, Śice madapike cin he Jehowa nation, qa cinca kin de nakun maqu, eye ca, Śimeyon eya caś kiton.

34 Qa ake ihduśake ca cinca ton qa, Wanna detanhan mihihna tinsa mahduze kta: Wanna cinca yamni weciton, eye, ca Lewi eya caś kiton.

35 Unkan ake ihduśake ca cinca ton qa, Dehan Jehowa mdatan kta ce, eye ca, Juda eya caś 


\section{WICOICAGE.}

kiton. Hehan cinca ton kin ayuśtan.

\section{WICOWOYAKE 30.}

1 Unkan Rahel Jakob cinca kiciton śni e wanhdake ca, Raliel he cunku inakiwizi qa Jakob heciya, Cinca maqu ye, hecanon śni kinhan mate kta ce.

2 Unkan Jakob canniye ye ça, Rahel heciya, Miye Wakanmatanka kecanni he? Iye taku tamni ton kin onanitaka ce.

3 Unkan, Iho wikośka mduhe cin Bilha he ekta ya ye ; unkan miśiyoto kin akan cinca ton kinhan, iye etanhan cinca waton kta ce;

4 Eye ca wikośka yuhe cin Bilha he tawicu kta e qu. Unkan Jakob he en i.

5 Unkan Bilha ihduśake ca. Jakob cinca kiciton.

6 Unkan Wakantanka mayaco qa, nakun houwaye cin namalion, qa cinca wan maqu, Raliel eye caa, Dan eya caś ton.

7 Ủnkan ake Rahiel tawikośka Bilha ihduśake ca cinca icinonpa Jaknob kiciton.

8 Unkan Wakantanka omakiye ça micun kici litawani, qa ohiwaya ce, Raliel eye ça, Neptali eya caś ton.

9 Unkan Leha cinca sanpa ton śni e wanhdake cehan wikośka y uhe cin Zilpa icu, qa Jakob tawicu kta e qu.

10 Unkan Leha wikośka yuhe cin Zilpa, he Jakob cinca kiciton.

11 Unkan, Wicota kta, Leha eye ca, Gad eya caś ton.

12 Unkan Leha wikośka yuhe cin Zilpa Jakob cinca icinonpa kiciton.

13. Unkan, Wopida mayanpi, cunwintku unpi kin mayawaśtepi kta ce, Leha eye ça, Aśer eya caś ton.
14 Unkan aguyapi baksapi kin icunhan Ruben magata iyaye ca, dudaim iyeye ca hena hunku kin ekta kai. Unkan Rahel Leha heciya; Nicinkśi dudaim an kin etanhan maqu ye.

15 Unkan, Mihihna yaki kin he taku cistina naceca, micinkśi dudaim tawa kin, he nakun iyacu lita he? eciya. Unkan, Nicinkśi dudaim tawa kin he on hanyetu kin de nici iwanke kta ce, eya.

16 Unkan hitayetu hehan, Jakob maga tanhan hdi; unkan Leha itkokim inanpe ca, Miyahna yau kta, micinkśi dudaim tawa kin hena on opeciton ce, eya. Unkan banyetu kin he kici wanka.

17 Unkan Wakantanka Leha anagoptan: unkan ihduśake ca cinca izaptan Jakob kiciton.

18 Qa, Wikokśa mduhe cin he mihibna waqu kin heon, Wakantanka iyunwin maqu, Leha eye ça, Isakar eya caś kiton.

19 Unkan ake Leha ihduśke ca cinca iśakpe Jakob kiciton.

$20 \mathrm{Qa}$, Nakaha Wakantanka taku waśte itumakilian, mihihna cinca śakpe weriton, heon detanhan mici ti kta ce, eye ça, Zebulon eya caś kiton.

$21 \mathrm{Qa}$ he iyohakam cinca winyan ton qa, Dina eya caś kiton. 22 Unkan Wakantanka Rahel kiksuye ca Wakantanka anakicigoptan, qa tamni kin yuhdoka.

23 Unkan ihduśake ca cinca wan ton qa, Taku iyamaonpapi qon Wakantanka wanna emicihdaku ;

24 Qa Wakantanka cinca tokeca wan nakun maqu kta, eye ca, Josep eya caś kiton.

25 Unkan Rahel Josep ton kin hehan, Jakob Laban heciya, 


\section{WICOWOYAKE 30.}

Wanna hde mayan wo. Mitamakoce qa toki manke kte cin ekta wahde kta.

26 Mitawin micinca ko maqu wo, wahde kta ce; hena on token htawani, qa wowindag mayaye cin niś sdonyaya ce.

27 Unkan, Tokin niiśta kin en iyocicipin, niye on etanhan Jehowa mayawaśte wahdukcan.

28 Taku on omayakiye kta atayedan omakiyaka wo; hecece cinhan ciẹu kta ce, Laban eciya.

29 Unkan, Niś token ociciye ca, nitawanuyanpi kin token mici unpi qon sdonyaya.

30 Wahi kin itokam taku cistina duhe ciqon, qa wanna ota aye ça, misiha kin eciya tanhan Jehowa niyawaśte. Unkan wanna tohan wati ohnaka kin on taku micicage kta he? eya.

31 Unkan, Taku cicu kta he? eya. Unkan Jakob heciya, Takudan mayaqu kte śni, tuka taku kin de ecanon kinhan ake tahinca nitawa kin awanwicamdake kta.

32 Nakaha wanuyanpi owasin ehna mawani kta, qa tona hdehdega qa hdehdeze cin iyog iyewicawaye kta, tahinca wanuyanpi kin tona gigi kin owasin, qa tatokadan tona hdehdege ca hdehdeze cin heniyos akipam ewicawahde kta; qa tokata tahin wanuyanpi ehna tona gigi, qa tatokadan ehna tona hdehdega hdehdeza ko, hena iyunwin mitawa kta.

33 Unkan tokata miohan owotanna mihduotanin kta; taku mitawa nitokam $u$. kinhan, tatokadan tona hdehdegapi śni, qa hdehdezapi śni, qa tahin wanuyanpi ehna tona gigi śni kin hena owasin mawanon kehe kta.

34 Unkan, Tokin token ehe cin hecetun, Laban eya.
35 Qa anpetu kin he en tatokadan mdoka tona hdehdeza hdehdega ko, qa tatokadan wiye tona hdehdege ca hdeśkaśka kin owasin, tona akan hin san kin hena koya owasin, akipam ewicahdaku, tahin wanuyanpi ehna tona gigi kin nakun owasin, qa hena cinkśi wicaye cin nape kin en wicaqu.

$36 \mathrm{Qa}$ anpetu yamni imani, iye Jakob kici ihehanyan kaga. Unkan Laban woteca optaye ihe cin hena Jakob, wihan wicaki ya.

37 Qa Jakob can sakadan icu, waga teca qa can su, qa uma hena owasin etanhan icu, qa ha kin pago hdeza, ska tanin kta e hecen hdehdeza kaga.

38 Qa watpadan tukten wanuyanpi mini yatkanpi kin hena ohna, can sakadan pago qon ehde, wanuyanpi itokapa tanhan, unkan wanuyanpi yatke upi en kiyuhapi ece.

39 Hecen can sakadan qon ekta wanuyanpi kin kiyuhapi, qa wanuyanpi hdehdeza hdehdega hdeśkaśka ko wicatonpi.

40 Unkan Jakob tacincadan yukinukan ewicahnake ça, wanuyanpi itepi kin taku hdeza ektakiya ewicahde, Laban wanuyanpi gigi kin owasin, qa wanuyanpi tawa kin yukinukan ewicahde, Laban tawanuyanpi kin kici ewicahde śn.

41 Qa tohan wanuyanpi waśakapi kiyuhapi eca, Jakob can sakadan qon watpadan ohna wanuyanpi iśta kin wicitokam ehde ; can sakadan kin ekta kiyuliapi kta e hecon.

42 Tuka wanuyanpi wankapidan eca, ehde śni, hecen tona wankapi kin hena Laban tawa, qa tona waśakapi kin hena Jakob tawa. 


\section{WICOICAGE.}

43 Hecen wicaśta kin tanka hinca icage ça wanuyanpi ota ton, qa nakun winyan taokiye, qa hokśidan,- qa camo, qa śuktanka śonśonna.

\section{WICOWOYAKE 31.}

1 Hehan, Taku ate unyanpi tawa qon he owasin Jakob icu, qa taku ate yuhe ciqon etanhan, woyuha tanka kin de owasin içicaga, Laban cinkśi wicaye cin eyapi kin Jakob nation.

2 Qa Laban ite kin he nakun Jakob wanyaka, qa iye ektakiya wanna tokeca.

3 Nakun, Niyate makoce tawapi kin ekta, qa takuwicayaye cin ekta hda wo, kinhan nici waun kta ce, Jehowa Jakob eciya.

4 Heon Jakob tuwe ekta ye śi qa, tawicu napin Rahel Leha kici, tinta kin heciya, tawanuyanpi kin ekta wicakico.

5 Qa, Niyatepi kin wanna tokeca amatonwe cin wanmdaka, tuka ate taku wakan da kin mici un.

6 Qa token owakihi ohinniyan niyatepi kin owakiya sdonyayapi ;

7 Tuka niyatepi kin mahnaye ca, wikcemna akihde taku maqu kte cin yutokeca, tuka kiunni maye kte cin Wakantanka iyowinye śni. ?

8 Kakell, Hdehdegapi kin hena iyunwin duhe kta ce, eye cehan, waunyanpi kin owasin hdehdegapi kin heca ece wicatonpi ; qa, Hdehdezapi kin hena iyunwin nitawa kta eye cehan, hehan wanuyanpi owasin hdehdezapi heca ece wicatonpi ece.

9 Hecen Wakantanka niyatepi tawanuyanpi kin ki ece, qa he maqu.
10 Wanuyanpi kin kiyukapi eca wiwahanmde ca, ewatonwe ca, inyun tamdoka hdehdeza hdehdega hdeśkaśka hecapi ko, wanuy anpi akan adipi e iśta on wanmdaka.

11 Nakun wiwahanmde ca, Wakantanka taohnihde ye cin hemakiya; Jakob. Unkan, Tho miye ce, epa.

12 Unkan, Iśta yuwankan ikikcu qa, tamdoka wanuyanpi adipi kin awicatonwan wo; hdehdeza hdehdega hdeśkaślka hecapi ; token Laban ecanicon kin he owasin wanmdaka ce.

13 Taku wakan Betel en tanin içiye cin he miye, hen wokiksuye sdayaye ca, hen taku konza emayakiya. Wanna najin, qa makoce kin de etanhan, iyaye ca taku wicayaye cin ekta hda wo, eya.

14 Unkan Rahiel Leha ko ayuptapi ; Ate ti kin ohna taku unhapi kte ca taku unkitawapi kte cin yukan he?

15 Oyate tokeca unhdawapi śni he? Wiyopeunyanpi, qa nakun mazaska unkitawapi kin owasin yusota.

16 Heon woyuha ate unyanpi kin etanhan Wakantanka ki kin he iyuhpa unkiye unkitawapi, qa unkicincapi tawapi ce. Tho wanna token Wakantanka econ niśi kin owasin ecen econ ye, eyapi.

17 Unkan Jakob najin, qa cinca tawicu ko owasin camo akan ewicahnaka,

$18 \mathrm{Qa}$ atkuku Izak en Kanan makoce kin ekta kihde kta e tawanuyanpi kin owasin awicaya, woyuha icicage cin, qa taku tonpi kiton kin, taku Aram Mdaye kin en ihdamna kin owasin.

19 Wanna, Laban tahinca kin hduśda iyaye cehan, Rahiel he 
atkuku terapim tawa kin manon.

20 Unkan Jakob Laban Arami kin cante kin manon, najica iyaya, okiyake śni nakaeś.

21 Hecen najica, taku tawa kin owasin hduha najin, qa watpa kin iyuwege ca, Gilead he kin ek takiya etonwan.

22 Unkan anpetu iyamni kin hehan, Jakob wanna najica Laban okiyakapi.

23 Unkan hunka wanjin wicaye cin wicakico, hena om okide ye ca, śakowin can icimanipi hehan, Gilead he kin en kihdegapi.

24. Unkan, Wakantanka hanyen Laban Arami kin en hi qa, wihanmde cin en heciya, Ihnuhan taku waśte taku śica uman tukte kaśta eyakiye cin, eya.

25 Unkan Laban Jakob kihdege çehan, Jakob he kin en wakeya oti, qa Laban hunka wanjin wicaye cin om Gilead he kin hiyahanpi.

26 Qa Laban Jakob heciya, Taku tokanon micante kin mayahnaye ça, micunkśi canlipi on wayaka iyecen awicayahda.

$27 \mathrm{He}$ tokeca $\mathrm{e}$ hecanon he? Anamayakilibe ca, maniçinon, omayakidake śni. Omayakidaka unkanś wiyuśkinyan iyaye ciye ça, cicidowan, qa cancega candowankiyapi ko ciciyahoton kta tuka hecanon.

28 Micinca wica winyan ko i iwicawaputake kte, iyowin mayakiye śni. Wanna witkoya hecanon.

29 Dehan taku śica ecacicon kta nape wamaśaka, tuka niyate taku wakan da kin hinhan hemakiya; Ihnuhan Jakob taku waśte taku sica uman tukte kaśta eyakiye cin, eya.

30 Wanna niyate ti kin ekta yahde kte hinca, tuka tokeca
Taku wakan mitawa kin maya. non he? eya.

31 Unkan Jakob waayupte ca, Kowakipe cin heon, qa okini nicunkśi kin hena mayaki kta naceca ce epe cin heon hecamon;

32 Taku wakan nitawa kin tuwe kici iyeyakiye cinhan; he ni kte śni. Hunka wanji unye cin wicitokam, taku nitawa mici un kin, tukte e he, iyukcan qa ikikcu wo. Rahel hena manon tuka Jakob he sdonye śni, qa heciya.

33 Hehan Laban Jakob tawakeya kin en ti mahen i, Leha tawakeya kin nakun, qa wikośka nonpa tawakeyapi kin; tuka iyekiye śni; hehan Laban Leha tawakeya kin etanhan hdinanpe ça, Rahel tawakeya kin en i.

34. Tuka Rahel terapim kin icu, qa camo aqinpi kin en ehnake ciqon, qa akan iyotanka. Unkan Laban wakeya kin owancaya yutan qa iyekiye śni.

35 Unkan atkuku kin heciya, Itancan nitokam nawajin owakitpani, hececa śta canniye maye śni ye. Winohinca ayakonpi kin hemaceca ce. Unkan nina akita tuka terapim kin iyekiye śni.

36 Unkan Jakob canniye ca, Laban kige, Taku śica ecamon qa wawahtani kin tukte e he, on hecen mayakuwa?

37 Mitawahpaya kin owasin mayakidutan, wakśica yati kin etanhan wanji iyeyaye cin tukte e he? takuwicunye cin wicitokam ehnaka wo; hecece cinhan uman tukte unkitawa kta yukcanpi nunwe.

38 Waniyetu wikcemna nonpa kin dena nici waun, tuka tawiyedan nitawa kin kpapi śni, qa, nitawanuyanpi tamdoka kin hena wate śni.

39 Taku yahdecapi kin niye 47 
en cicai sni, he miye piya wakaga ce. Hanyen manonpi kin, qa anposkan manonpi kin he koya, minape kin etanhan mayakida.

40 Kaken waun, anposkan ipuza mața, qa hanyen osni; woiśtima miiśta kin amayuśtan.

41 Miye waniyetu wikcemna nonpa kin yati kin en wowidag mayaye; waniyetu ake topa nicunkśi nonpa on, qa waniyetu śakpe nitawanuyanpi kin on, ociciye ca, taku mayaqu kte cin wikcemna akihde mayadutokan.

42 Ate taku wakan da kin, Abereyam taku wakan da kin qa Izak Tokokipe kin, mici un kin; hecetu śni unkanś wanna cokadan kihde mayaśi kta tuka ; mawahbadan kin qa minape hitanipi kin he Wakantanka wanyake ca, hinhan iyopeniyan ce, Jakob Laban eciya.

43 Unkan Laban waayupte ca, Jakob heciya, Cinca winyan kin dena micunkśi eepi, qa hokśidall kin dena micinca eepi, qa wanuyanpi kin dena wanuyanpi mitawa eepi, qa taku niye wanyahdake cin he iyulipa mitawa ce. Tuka de micunkśi qa iś cinca wicatonpi kin dena, nakaha taku ecawicawecon tata he?

44 Tokin wanna wicoun unkicagen, miye qa niye, hecen waayatanin unkiyotahedan yuke kta.

45 Unkan Jakob inyan wan icu, qa wokiksuye e pasdata:

$46 \mathrm{Qa}$, Inyan icupo, Jakob hunka wanjin wicaye cin ewicakiya. Unkan inyan icupi, qa paha wan kagapi qa, hen paha kin akan wotapi.

47 Unkan paha kin he, Igar sahaduta Laban eya caśton; tuka Jakob he Galed eya caśton.

48 Unkan Laban heya, Anpe dehan paha kin de unkiyotahedan waayatanin kta; Galed Waayatanin paha kin he ka, paha kin he eciyapi.

49 Qa, Micunkśi wicayakiduśe, qa winohinca tokeca duze cinhan, wicaśta tuwe he atonwe kta unkici un śni, unkiyotahedan Wakantanka he waayatanin kta.

50 Tohan kinukankiya unkiyaye cirhan Jehowa unyacopi kta, Laban eye ca, Wayaco caś ton.

51 Qa, Wanyaka wo, paha kin de, wokiksuye unkiyotahedan ewehde kin de;

52 Paha kin waayatanin, wokiksuye kin de waayatanin, taku śica on paha kin de kapeya imdamde ça niye en cii kte śni, qa niś kapeya yahihdu qa hiyohi mayaye kte śni.

53 Abereyam taku wakan da kin, Nahor taku wakan da kin, hunkake wicayapi taku wakan dapi kin unyacopi kta, Laban Jakob eciya. Unkan Jakob iye atkuku Izak Tokokipe kin cajeyan konza.

54. Hehan Jakob he kin akan wośnapi wan wakiyuśna, qa agùyapi yutapi kta e hunka wanjin wicaye cin wicakico. Unkan aguyapi yutapi qa he kin en wankapi.

55 Unkan ihanhanna Laban kikta qa iye cinca wica winyan ko i iwicaputake ca, wicayawaśte qa, hehan Laban tohe kin ekta kihda.

\section{WICOWOYAKE 32.}

1 Unkan Jakob tacanku kin ohna iyaye ca, Wakantanka ohnihde wicaye cin iktokim hipi.

2 Unkan Jakob wanwicayake cehan, Wakantanka wicobe ta- 


\section{WICOWOYAKE 32.}

wa kin dee ce, eye ça oyanke kin he Mahianaim caś ton.

3 Hehan Jakob Edom wojupi kin Sehir makoce kin etu, cincu Esa ti kin ekta, ohnihde wicaye cin ye wicaśi.

$4 \mathrm{Qa}$ wahokonwicakiye ca, Itancan mitawa Esa hecen eyakiyapi kta ce, eya; Laban kici wati qon dehantu.

5 Qa pte, qú śuktanka śonśonna, qa tahinca, qa hokśidan wikośka ko, ota wicamduha, qa onśimayada kta e itancan ociciyag ye wicawaśi, nitaokiye Jakob eya.

6 Unkan Jakob ohnihde wicaye cin hdipi qa, Nicinye Esa ekta unkipi unkan iś nitkokim u qa, wicaśta opawinge tom opapi ce, eyapi.

7. Hehan Jakob nina kokipe ca, Coyate kici un kin nonpakiya ewicakihde, tahinca, pte, camo, ko owasin ośpaye nonpa wicakaga.

8 Qa Rsa ośpaye wanji en hi qa hena wicakte kinhan, ośpaye uman okapte cin inaśdoke lita ce, eya.

9 Hehan Jakob heya, Abereyam ate waye wakan nida, qa ate Izak wakan nida Jehowa niye, Nitamakoce, qa takuwicayaye cin ekta hda wo, kinhan taku waśte ecacicon kta ce, emayakiye ciqon;

10 Miye nitowaonśida qa iewicayake cin owasin nitaokiye ecayecon kin aopten waun; sagye kin heceyedan lıduha Jordan watpa kin de imduwege ça, wanna ośpaye nonpa imacaga.

11 Wanna cinye nape kin etanhan emahdaku wo; Esa nape kin etanhan; hi kinhan cinca hunkupi kin kici mikte kta kowakipa ce.

12 Niye, Ohinniyan taku waśte ecacicon kte ca, wiyaka mini wanca kahda sukaza utkana on yawapica śni, iyenaka nicinca wakage lita ehe ciqon, eya.

13 Unkan hanyetu kin he hen wanka, qa taku cincu Esa qu kte cin ikilicu, taku nape en hiyu ;

14 Tatokadan wiye opawinge nonpa, qa mdoka wikcemna nonpa, tahin wanuyanpi wiye opawinge nom mdoka wikcemna nonpa ahna ;

15 Camo azinkiyapi wikcemna yamni cincapidan om, pte wikcemna tom, qa tatanka wikcemna, śuktanka śonśonna wiye wikcemna nonpa cincadan wilkcemna ahna.

16 Qa ookiye wicayuhe cin woteca otoiyohi kinnukan yuhe wicaśi, qa, Optaye otoiyohi yukinukan awicahiyayapo, ewicakiya.

17 Qa tokaheya kin wahokonwicakiya, Tohan cinye itkonicipapi kinhan, qa, Tuwe tawa niyan he? qa toki da qa taku nitokam un kin he tuwe tawa he? eya iniwange cinhan:

18. Hehan, Nitaokiye Jakob dena tawa, tuka itancan mitawa Esa qu kta; unkan iś nakun unkihektam u ce, ehapi kta ce, ewicakiya.

19 Unkan inonpa, qa iyamni, qa nakun owasin tona optaye ihakam yapi kin, Esa iyeyayapi kinhan oie kin hena iy ecen eyakiyapi kta ce :

20 Nakun, Nitaokiye Jakob unkihektam u ce, ehapi kta ce, ewicakiya. Taku waqu kin mitokapa tanhan ye cin, hecen ite kin iyokipi waye kta, qa hehan ite kin iyowinmakiye kta ce, eya.

21 Unkan taku qu kin, he tokata iyokipta; tuka iś hanyetu kin he taobe kin om wanka. 


\section{WICOICAGE.}

22 Qa hanyetu kin he en, najin qa tawicu nonpa kin iwicacu qa cinca wicaye cin ake wanji, qa Jabok oiyuwege kin en iyuwega.

23 Qa iwicakikcu, qa watpa kin iyuweh wicaye ca, taku tawa kin owasin iyuweh wicakiya.

24 Qa Jakob iśnana hekta yanka, unkan wicaśta wan anpao kin hehanyan kici kiihduśpa.

25 Qa wicaśta kin tokadan ohiye śni e wanhdake cehan, cecunte okihe kin en yuza; unkan kici kiihduśpapi kin icunhan, Jakob cecuntośtan kin papśon iyaya.

26 Unkan, Amayuśtan wo; wanna anpao hinanpa ce, eya. Unkan, Mayadawaśte śni kinhan, aciyuśtan kte śni ce, eya.

27 Qa, Token eniciyapi he? eya. Unkan Jakob emakiyapi ce, eya.

28 Unkan, Nicaje Jakob eniciyapi kte śni. Detanhan Israel eniciyapi kła, Wakantanka wicaśta ko, kici kinihduśpe ca niye ohiyaya ce, eciya.

29 Ünkan, Tokin nicaje. kin omayakidaken, Jakob eya iwanga. Unkan, Token on etanhan micaje kin inonga he? eye ca hen yawaśte.

30 Unkan, oyanke kin he, Ite wakan, Jakob eya caś ton. Taku Wakan ite icitkokim wanmdaka eśta minagi lkin zaniyan un ce, eya.

31 Unkan Ite wakan iyokipte cehan, anpetu wi hinanpa, qa Jakob ceca kin on huśte.

32 Heon etanhan Israel cinca wicaye. cin anpetu kin dehan ceca śkotpa kin akan kan kiksuye śni qon he yutapi śni; Jakob ceca śkotpa kin akan kan kiksuye śni kin he oyutan kin heon etanhan.

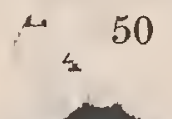

\section{WICOWOYAKE 33.}

1 Unkan Jakob wankan etonwe ça inyun, Esa u, wieaśta opawinge tom kici wanwicayake ca, hokśiyoqopa kin akipam ewicakihde, Leha kici, qa Rahel kici, qa wikośka nonpapi kin om.

2 Qa wikośka kin cinca wicayapi kin om tokaheya ye wicaśi, qa hena ihektapa tanhan Leha cinca wicaye cin om, qa hena ihektapa tanhan Rahel Josep kici.

3 Qa iye owasin wicitokam ye ca, cincu ikiyedan u kin icunhan śakowin akihde patuja.

4. Unkan, Esa itkokim inyanke ca, nape kin yuze ca tahu kin akan elipeiciye ca i iputaka, qa napin ceyapi.

5 Hehan Esa wankan etonwe ca, tawicu cinca wicaye cir ko wanwicayake ca, Dena token takuyaya he? eya. Unkan, Wakantanka towaonśida kin on nitaokiye cinea qui kin dena eepi ce, eya.

6 Hehan wikośka kin cinca wicayapi kin om ikiyadan hipi, qa patujapi.

7 Hehan Leha cinca wicaye cin om ikiyadan hi qa patujapi; qa ehake Josep Rahel kici ikiyadan hipi, qa patujapi.

8 Unkan, Optaye kin dena owasin itkowicawakipe cin, token yaka he? eya. Unkan, Ma. yuhe cin iśta kin iyokipi ciye kta e heon.

9 Unkan, Misunka taku ota wahduha ce. Taku nitawa kin hduha un wo, Esa eya.

10 Unkan, Hiya niiśta kin iyokipi ciye cinhan, minape kin etanhan taku waqu kin iyacu kta, nitohnake Wakantanka itohnake iyecen wanciyake ça iyocicipi kin heon etanhan. 


\section{WICOWOYAKE 34.}

11 Tokin taku ciyawaśte kin en aniupi kin he iyacun. Wakantaka onśimada ece, qa taku owasin mduha, Jakob kitanyan eya; unkan icu.

$12 \mathrm{Qa}$ heya, Ihdaka unye ça miye tokaheya mde kta ce.

13 Unkan, Hokśiyoqopa wankapidan e mayuhe cin sdonye ca, nakun tahinca pte ko ihduśaka micicapi qa, anpetu wanjidan keś awicapapi kinhan, wanuyanpi owasin țapi kta.

14 Tokin itancan nitaokiye itokam yahden, qa miś wanuyanpi mitokam token manipi, qa hokśiyoqoqa kin token manipi kin, ecen iwahnanna mde kta, mayuhe cin ekta Sehir en wai kin hehanyan.

15 Unkan, Iho oyate mici unpi kin etanhan wanjikśi nici ehpewicawaye kta ce, Esa eya. Unkan tokeca e, mayuhe cin iśta kin iyocicipi hecinhan, eya.

16 Unkan anpetu kin he en, Esa tacanku kin ohna Sehir ektakiya kihda.

17 'Tuka Jakob Sukot ekta unhdaka $\mathrm{i}$ qa, hen tipi içicage ca, taku tawa kin nakun ohanzi hdepi wicakicaga; heon otonwe kin he Sukot eya cajeyatapi.

$18 \mathrm{Qa}$ Jakob Aram Mdaye kin etanhan u qehan, Śkem otonwe tawa kirn Kanan makoce kin etu zaniyan hi, qa otonwe kin itokam ticaga.

19 Qa makoce onśpa, tukten wakeya iticage cin, Sekem atkuku Hamor cinca wicaye cin napepi kin etanhan opewicakicaton, mazaska opawinge nom wicaqu.

20 Unkan hen wahna wośnapi wan kage ca, El Israel ta-Wakantanka ỉin eya caśton.

\section{WICOWOYAKE 34.}

1 Hehan Dina Leha he cunwintku Jakob kiciton kin, he makoce wicinyanpidan wanwicayake kta e toki iyaya.

2 Unkan wicaśta yatapi ihdawa Hamor Hiwi kin he cinhintku Śkem, he, wanyake ça icu qa kici wanka, hecen wieyaku.

3 Qa Śsem nagi kin Dina Jakob cunwintku kin en nina iyaskape ça wikośka kin waśte dake ça, wikośka cantohnag ye cin ecen okiya.

$4 \mathrm{Qa}$, Wicinyanna kin de miciyuza wo, Śekem iye atkuku Ḣmor eciya.

5 Unkan cunwintku yuaśapapi kin he Jakob nakihon, tuka cinkśi wicaye cin tinta ekta wanuyanpi om yakonpi, qa hdipi kin hehanyan Jakob inina yanka.

6 Unkan Ḣamor Śsekem atkuku kin Jakob kici okiye kta e en'i.

7 Unkan Jakob cinkśiwicaye cin tinta kin etanhan hdipi, qa he nahonpi, qa iyokiśicapi ; nina canniye yapi, Jakob cunwintku kin kici iwankapi : hecen econpi kte śni tuka, Israel witkoya ecakiconpi heon etanhan.

8 Unkan Hamor hewicakiya, Micinkśi Śekem nagi kin nicunkśipi kin iyaskapa; he tawicu kta e qupo.

9 Kinhan takuunkiciyapi kta; nicunkśipi kin hena unqupo, qa niś cunkśi wicunyanpi kin wicayuzapo.

10 Qa unkiyepi om dukanpi kta, makoce kin nitokam un kta ce, en unpo qa makoce kin en wopetonpi qa he yuhapo.

11 Qa Śekem wikośka atkuku timdo wicaye cin ko hewicakiya; Cantemakiyapo, kinhan token emayakiyapi kin ecen cicupi kta. 


\section{WICOICAGE.}

12 Wikośka kin mitawin un kta e mayaqupi kinhan, wohpayapi iyakiçuya tanka mayakidapi, taku qupi tanka eśta ; token emayakiyapi kin ecen ciçupi kta.

13 Unkan Jakob cinkśi wicaye cin tawinohtinpi kin Dina yuśapapi qon kiksuyạpi, qa heon Śekem he atkuku Hamor kici hnayeya awicayuptapi.

14 Qa, Taku hececa econpi unkokitpanipi. Wicaśta wan ha iyotan kin bahdayapi śni kin heca tankśi unyanpi kin unqupi kinhan, he wiśten unkiçiyapi kta naceca.

15 Decehnana on unkaniyuptapi kta; unkiś baunkihdayapi kin, niś nakun tona wica owasin henicecapi kinhan;

16 Hehan cunkśi wicunyanpi kin unniçupi kta, qa nicunkśipi kin wicunyuzapi kta, qa nicipi oununyanpi qa oyate unwanjipidan kta.

17 Tuka taku de en anaunyagoptanpi śni kinhan, baniçilidayapi śni kinhan, cunkśi unyanpi kin he unkikikcupi, qa toki unkiyayapi kta ce, ewicakiyapi.

18 Unkan, Ḣamor Śsekem H்amor cinhintku kici wicoie kin he waśte dakapi.

19 Qa kośka kin Jakob cunwintku kin cantiheya, heon taku eyapi kin kohanna econ. Iye atkuku ti kin ohna yakonpi kin hena owasin iyakapeya kinihanpi.

20 Hehan Ḣamor iye cinhintku Śekem kici otonwe tawapi kin ekta kipi, qa otonwe tawapi kin wicaśta om wohdakapi, qa heyapi,

21 Wicaśta kin dena unkiyepi om wokiyapi, heon makoce kin en ounyanpi qa, hen iciyopeyapi kte. Ito makoce kin wicitokam tankaya un kinhan, cunwintkupi kin wicunyuzapi kta, qa cunkśi wicunyanpi kin wicunqupi kta.

22 Tuka decehnana on wicaśta kin wicadapi kta; wiciye bakihdayapi kin he iyecen unkiye tona wica owasin baunkilidayapi kinhan; unkiye om ounyanpi, qa oyate unwanjipidan kta.

23 Decehnana en anawicungoptanpi kinhan, unkiyepi om ounyanpi kta; kinhan tawanuyanpi, qa taku yuhapi kin owasin, taku tonpi koya unkitawapi kte śni he? eyapi.

24 Unkan wicaśta tona otonwe tiyopa kin omanipi kin hena owasin, Hamor iye cinhintku Śkem kici anawicagoptanpi, qa bakicildayapi, tona wica otonwe tiyopa kin omanipi kin owasin.

25 Unkan anpetu iciyamni kin yazampi kin icunhan, Jakob cinhintku kin nonpa, Śineyon Lewi kici Dina timdo wicaya, tacanhpipi kin ikikcupi, qa kokipeśniyan otonwe kin tatpe ipi, qa tona wica owasin wicak tepi.

26 Ḣamor iye cinhintku Śekem ko canhipi hi kin on wicaktepi, qa Dina Śsem ti kin etanhan ehdakupi qa hdohdapi.

27 Hehan Jakob cinkśi wicaye cin wicakahugapi kin en ipi, qa, otonwe wan tankśitkupi kin yuśapapi qon he ocowasin wicakipi ;

28 Tahinca, qa tatanka, qa súktanka śonśonna, taku otonwe kin ohna un, taku magata un kin ko owasin icupi.

29 Taku yuhapi qon owasin taśiceca tawicupi ahna nakun wayaka icupi, qa taku tipi kin ohna iyeyapi kin owasin icupi. 


\section{WICOWOYAKE 35.}

30 Hehan Jakob Śimeyon Lewi kici hewicakiya, Iyoyag mayayapi, śicamna mayakagapi makoce wojutipi kin wicitokam, Kanani, qa Perazi kin, qa miye matonana hecen tamatpe mniciyapi, qa maktepi kta, hecen miś wati ohnaka ko owasin awimahnuni kita.

31 Unkan wihomnipi kin iyecen tankśi unyanpi kin ecakiconpi kta iyececa he? eyapi.

\section{WICOWOYAKE 35.}

1 Hchan Wakantanka Jakob heciya, Najin qa Betel ekta itawankanlide ye ça, hen ounyan wo. Nicinye Esa itohnake kin etanhan nayajice cehan, Taku wakan, niye en tanin iciye cin, he wahna wośnapi wan hen kicaga wo.

2 Unkan Jakob tiyoknaka tawa, qa tona kici unpi kin owasin hewicakiya; Taku wakan tokeca duhapi kin, hena owasin yutokan iyewicayapo; piiciyapi qa wokoyake teca ihduzapo;

3 Qa najinpo, Betel ekta itawankanhde unyanpi kta ce. Heciya wahna wośnapi wan wakage kta, anpetu wan iyomakiśice cehan, Taku wakan namahon, qa canku ohna imdamde cin mici ye cin, he wecage kta ce, eya.

4 Unkan Taku wakan tokeca yuhapi kin hena owasin Jakob qupi, oinpidan noge oinpi kin herra koya. Unkan hena owasin nahma, Śkem ekta utuhu wan he cin, he ihukuya.

5 Hehan ihdaka iyayapi, qa Jehowa otonwe ihdukśan unpi kin yuśinye wicaya; hecen $\mathrm{Ja}$ kob cinkśi wicaye cin wicakuwapi sni.

b' Unkan Jakob, iye oyate ope- ya un kin koya owasin, otonwe wan Luz eciyapi, Betel hee, Kanan makoce kin en, he ekta ipi.

7 Qa hen wahna wośnapi wan kage ca, oyanke kin he El Betel eya caś ton, cincu etanhan najica iyaye cehan, heciya iye en Wakantanka ihdutanin kin, heon etanhan.

8 Hehan Debora Rebeka azin kiye ciqon ta, unkan Betel hukun utuhu he cin, he ihukuya hnakapi, qa he, Utuhu oceyapi, eciyapi.

9 Wanna Jakob Aram Mdaye kin etanhan hiyu, hehan ake iye en Wakantanka tanin ic̣iye ça yawaśte.

10 Qa, Tokata Jakob nicaje qon eniciyapi kte śni, detanhan Israel eya cajeniyatapi kta, Wakantanka eciye ca, hecen Israel caś ton.

11 Qa, El Iyotan waśaka he miye; ihduota qa cinca ota yuha wo; oyate qa, oyate obe ota niye etanhan unpi kta, qa wicaśta yatapi ninite kin etanban inanpapi kta.

12 Qa makoce wan Abereyam Izak kici wicawaqu qon, he niye ciçu kte ca nicinca nihektam unpi kte cin, makoce kin he wicawaqu kta ce, Wakantanka eciya.

13 Qa oyanke kin en, Wakantanka okiye ciqon hetanhan wankantkiya ikiyopta.

14. Unkan tukten okiye ciqon, he en Jakob wokiksuye wan ehde, inyan wokiksuye qa, wośnapi wan akaśtan, wihdi nakun akaśtan.

15 Qa oyanke kin en, Wakantanka okiye ciqon, he Jakob Betel eya caś ton.

16 Hehan Betel etanhan ihdakapi, qa Eprata ikiyadan hipi, 


\section{WICOICAGE.}

hehan Rahiel hokśiksuye ẹa, kitan seh cinca ton.

17 Wanna kitan ecinyan cinca ton, hehan, Ihnuhan koyakipe cin, cinca kin de wica e nakun duhe kta ce, cincatonkiyesa eciya.

18 Unkan wanna te kta, nagi kin iyaya icunhan, Benoni eya caś kiton ; tuka atkuku kin Benjamin eciya.

19 Hehan Rahel ta, unkan Eprata, Betlehem hee, canku kin ohna hnakapi.

20 Qa Jakob wokiksuye wan ohna hnakapi kin ekta ehde. Rakiel ohna hnakapi wokiksuye kin dehantu eciyapi.

21 Hehan Israel unhdake ca, Eder conkaśke kin akotanhan ewakeya.

22 Unkan Israel makoce kin he en ounye cin icunhan, Ruben iye atkuku tawicu Bilha ekta i, qa kici iwanka. Unkan Israel he nakithon.

23 Jakob cinkśi wicaye cin ake nonpapi ce. Leha cinkśi wicaye cin, Ruben, Jakob cinhintku tokapa kin hee, Śmeyon, Lewi, Juda, Isakar, Zebulon henakeca. 24. Rahel cinkśi wicaye cin Josep, qa Benjamin.

25 Qa Bilha, Rahel tawikośka, cinkśi wicaye cin Dan, qa Neptali.

26 Qa Zilpa Leha tawikośka kin, cinkśi wicaye cin, Gad, qa Aśer. Henakiya Jakob cinkśi wicaya Aram Mdaye kin en wicatonpi.

27 Hehan Jakob iye atkuku kin ekta ki, Arba otonwe, Ḧebron hee, ekta Mamore etu hen Abereyam ounyan, qa Izak nakun.

28 Wanna Izak anpetu tawa waniyetu opawinge sanpa wikcemna śahdogan.
29 Hehan Izak ta, qa taoyate kin en okipapi, wicahinca qa anpetu kin wanna imna. Unkan cinkśi wicaye cin Esa, Jakob henios kihnakapi.

\section{WICOW OYAKE 36.}

1 Esa, Edom hee, wicowazi tawa kin dee.

2 Esa Kanan cunwintku kin etanhan winohinca nom wicayuza, Elon Heti kin cunwintku Ada, qa Zibeon Hiwi kin cunwintku Ana he cunwintku Aholibama henioza.

3 Qa Iśmayel cunwintku Basmat, Nebayot tankśitku he nakun yuza.

4 Unkan Ada he Esa kiciton Elipaz hee : qa Basmat he Ruhel ton.

5 Qa Aholibama he Jehus, qa Jalam, qa Qora, wieaton. Esa cinkśsi wicaye cin, Kanan makoce kin en wicatonpi kin hena eepi.

6 Hehan Esa iye tawicu kin iwicacu, qa cinca wicaye cin wica winyan ko, qa tiyohnaka tawa wicanagi owasin, qa tawanuyanpi taku yuhe cin ko owasin, tuku tawa Kanan makoce en ton kin iyuhpa, qa sunkaku Jakob itohnake kin etanhan ya, makoce tokeca wan ekta.

7 Taku yuhapi kin he odota, heon witaya iyotankapi kin okitpanipi, wanuyanpi ota yuhapi kin heon, makoce kin en ounyanpi kte cin iyowinwicakiye śni.

8 Unkan Esa Sehir he kin en iyotanka, Esa he Edom eciyapi. 9 Qa Sehir he kin en Edom oyate ateyapi Esa wicoicage kin dee.

10 Esa cinkśi wicaye cin cajepi kin dena ee, Elipaz Esa ta- 
WICOWOYAKE 36.

wicu Ada he cinhintku, qa Ruhel Esa tawicu Basmat he cinhintku.

11 Unkan Elipaz cinkśi wicaye cin dena eepi ; Teman, Omar, Zepo, Gatam, qa Kenaz.

12 Unkan Elipaz Esa cinhintku Timna nalimana yuze cin he Ameleqe Elipaz kiciton. Esa tawicu Ada cinkśi wicaye cin hena eepi.

13 Unkan Ruhel cinkśi wicaye cin dena eepi ; Naliat, qa Zera, qa Śama, qa Miza. Esa tawicu Basmat cinkśi wicaye cin hena eepi.

14 Unkan Aholibama Zibeon cunwintku Ana he cunwintku kin Esa yuza. Unkan he Esa ciuca kiciton kin dena eepi; Jehus, qa Jalam, qa Qora.

15 Esa cinca kin itancan unpi kin dena eepi. Esa cinhintku tokapa Elipaz cinkśi wicaye cin, Ternan itancan, Onar itancan, Zepo itancan, Qenaz itancan,

16 Qora itancan, Gatama itancan, Ameleqe itancan. Fidom makoce kin en Elipaz itancanyan unpi kin hena eepi, qa hena Ada cinkśi wicaya.

17 Unkan Esa cinhintku Ruhel cinca kin dena eepi : Nahat itancan, Zera itancan, Śama itancan, Miza itancan, Ruhel itancanyan unpi kin hena eepi, Edom makoce kin en, Esa tawicu Basmat hena cinkśi wacaya.

18 Unkan Esa tawicu Aholibama he cinca kin dena eepi; Jehus itancan, Jalam itancan, Qora itancan, Ana cunwintku Aholibama Lisa yuze cin itancan ton kin hena eepi.

19 Esa, Edom hee, cinkśi wicaye cin hena eepi, qa itancan yuhapi kin heepi.

20. Makoce kin he en iyotan- kapi qon Sehir Hori kin cinca dena eepi ; Lotan, qa Ś Sobal, qa Zibeon, qa Ana, qa Diśon, qa Ezer, qa Diśan.

21 Sehir cinkśi wicaye cin, Edom tamakioce kin en, Hori kin itancanyan unpi kin hena eepi.

22 Unkan Lotan cinkśi wicaye cin Hori, qa Heman, qa Lotan tawinohtin kin 'Timna ee.

23 Unkan Śobal cinkśi wicaye cin dena eepi ; Alan, qa Manahat, qa Ebal, qa Śepo, qa Onan. 24 Unkan Zibeon cinkśi wicaye cin dena eepi, Aya qa Ana; Ana kin de atkuku Zibeon taśunka śonśonna wilian wicakiye cehan hopuza en wakoniya kata iyeya.

25 Ana cinhintku kin Diśon hee, qa Aholibama Ana cunwinku kin ee.

26 Qa Diśon cinkśi wicaye cin dena eepi, Hemdan qa Ĺśsan, qa Jiteran, qa Keran.

27 Unkan Etzer cinkśi wicaye cin dena eepi, Bilhan, qa Zawan, qa Aqan.

28 Diśon cinkśi wicaye cin dena eepi, Uz qa Aran.

29 Hori kin itancanyan unpi kin dena eepi; Lotan itancan, Śbal itancan, Zibeon itancan, Ana itancan,

30 Diśon itancan, Etzer itancan, Diśan itancan; Hori kin itancanyan unpi kin, token Sehir makoce kin en itancan wicayawapi kin hena eepi.

31 Israel cinca kin nahahin wicaśta yatapi wanica, Edom makoce kin wicaśta yatapi wicayawapi kin dena eepi.

32 Behor cinhintku Bela Edom en wicayube cin, qa otollwe tawa Dinaba eciyapi.

33 Qa Bela ța, unkan hee kiya Zera cinhintku Jobab Bozra 


\section{WICOICAGE.}

etanhan wicaśta yatapi yawapi.

34. Qa Jobab ta, unkan hee kiya Ḧuśam Teman makoce kin etanhan, wicaśta yatapi yawapi.

35 Qa Houśam ta, unkan hee kiya Hadad Bedad cinhintku wicaśta yatapi yawapi. Iye Midian oyate kin wicakaśtaka, Moab tinta kin ohna qa otonwe en ti kin Awit eciyapi.

36 Qa Hadad ta, unkan hee kiya Samla, Masrika etanhan, wicaśta yatapi yawapi.

37 Qa Samla ta, unkan hee kiya Saul, Rehobot watpa kin ohna wanke cin he etanhan, wicaśta yatapi yawapi.

38 Qa Saul ta, unkan hee kiya Balhenan $A$ kbor he cinhintku wicaśta yatapi yawapi.

39 Qa Balhenan Akbor cinhintku kin ta, unkan hee kiya Hadar wicaśta yatapi yawapi. Otonwe tawa Pahu eciyapi; qa tawicu kin Mehetabel eciyapi, Matred cunwintku Mezahab cunwintku.

40 Esa itancan wicayawapi kin hecen ewicakiyapi, wicowazipi kin iyececa, qa tonwanyanpi kin iyecen cajewicayatapi ; Timna itancan, Alwa itancan, Jetet itancan,

41 Aholibama itancan, Ela itancan, Pinon itancan,

42 Qenaz itancan, Teman itancan, Mibsar itancan,

42 Magdiyel itancan, Iram itancan. Edom itancan wicayawapi kin hena eepi, tonwanyanpi kin iyecen, tamakocepi kin en; Edom Esa ate yapi.

\section{WICOWOYAKE 37.}

1 Unkan Kanan makoce kin en Jakob atkuku unhdaka un 56 qon, makoce kin he en Jakob iyotanka.

2 Jakob wicoicage wowapi kin dee, Josep wanna waniyetu ake śakowin, hehan wanuyanpi wihan wicakiya cinye wicaye cin om, qa Bilha qa Zilpa napin atkuku wicayuze cin, hena cinkśi wicayapi kin om, hokśidan kin un qa taku śica eyapi kin ateyapi kin en ahda.

3 Unkan Isıael, cinkśi wicaye cin owasin sam iyeya, Josep waśte kidaka wanna wicahinca ehan kicitonpi kin heon etanhan, qa onhdohda hanska wan Josep kicaga.

4 Unkan ateyapi kin, cinkśi wicaye cin owasin sam iyeya Josep waśte kidake cin he cincu wanhdakapi, qa wokiya okiyapi kte cin okihipi śni.

5 Unkan Josep wowihanmde wan ihanmna, qa cincu owicakiyaka; unkan sam iyeya śice kidakapi.

6 Unkan, Thopo wowihanmde wan iwahanmde cin de nahonpo.

7 Maga ekta aguyapi paunhtapi, unkan inyun pawahte cin bosdan najin hiyaya, unkan payahtapi kin ihdukśan najin hiyaye ca, pawahte cin itokam makata ehpeiciyapi, ewicakiya.

8 Unkan cinye wicaye cin heciyapi, Ehanqon tawaunyayapi kta he? qa iś wowidake unyaduhapi kta he? Qa iyakapeya śice kidakapi, wihanmde ciqon oie ko heon.

9 Unkan ake wowihanmde tokeca wan ihanmde ca, ake cincu kin owicakiyaka. Ake wiwahanmde ca inyun anpetu wi, hanyetu wi, qa wicanlipi ake wanji mitokam makata elipeiciyapi, ewicakiya.

10 He atkuku cincu ko owicakiyaka; unkan atkuku he iyo- 


\section{WICOWOYAKE 37.}

pekiye ca, Wowihanmde wan iyahanmde cin de taku hwo? Miye qa nihun nicinye ko owasin nitokam makipusdiya ehpeunkiçiyapi kta he? eciya.

11 Unkan cincu kin icekinpi, tuka atkuku kin wicoie kin he awakicin un.

12 Hehan cincu kin ateyapi tawanuyanpi kin wilian wicakiyapi kta e Sekem ekta ipi.

13 Unkan Israel Josep heciya, Nicinye Śkem ekta wawihan kiya unpi śni he?' Tho wo hena ekta ye ciśi kta ce. Unkan, Ho miye ce, eciya.

14 Unkan, Tho ekta de ca nicinye wanuyanpi ko zaniyan yakonpi hecinhan wanhdake ca, hośi makahdi wo, eciya. Unkan Hebron kaksiza kin etanhan iyaye ca Śkem ekta i.

$15^{\circ}$ Qa tinta onuni; unkan wicaśta wan wanyake ça, Den taku ayakita he? eya iwanga.

16 Unkan, Cinye wicawaye cin awicawakita ce. Ceciye tukten wilian wicakiyapi kin omakiyaka wo, eya.

17 Unkan wicaśta qon, Wanna detanhan iyayapi; Dotan elita unyanpi kta ce, eyapi nawahon ce, eya. Unkan Josep cinye wicaye cin wicihakam ye ça Dotan en iyewicaya:

18 Unkan tehantanhan wanyakapi qa wicikiyedan u śni kin itokam, nahmana țe yapi kta awacinpi.

$19 \mathrm{Qa}$ otoiyohi hunka wanjitku kin hekiciyapi, Wanyakapo; wihanmdesa kin de wanna u.

20 Thopo dehan unktepi, qa makohdoka wan ohna ehpeunyanpi kte ca, Wamanica ocin śica wan he temya ce, unkeyapi kinhan, wihanmde ciqon toketu kte cin wanunyakapi kta ce, ekiciyapi.
21 Ruben he nalion qa, napepi kin etanhan ehdaku kta e, Unktepi kte śni, eya.

22 Napepi kin etanhan ehdaku kte ca, atkuku kin en akiyahde kta e Ruben hewicakiya; Weyapi śnipo. Woha hewoskantuya wanke cin de ohna iyeyapo, tuka ninapepi on apapi śnipo.

23 Unkan kaketu, Josep iye cineu najinpi kin en hi qehan, taonhidohida yuśdokapi, onhdohda hanska un kin hee;

24 Qa Josep icupi, qa wolia wan en iyolipeyapi, tuka woha kin takudan obnaka śni, mini wanica.

25 Qa aguyapi yutapi kta e iyotankapi, qa pa yuwankan ikikcupi qa, Iśmayeli optaye wan Gileyad eciyatanhan u kin wanwicayakapi, camo yuhapi kin taku waśtemna canśin pejihuta koya qinpi, Egupta ekta kun yapi kta.

26 Unkan Juda hunka wanjin wicaye cin hewicakiya, De sunka unyanpi unktepi kinhan, we kin naunhimanpi eśta taku unkihdamnapi kta he?

27 Ihopo, Iśmayeli kin dena en wiyopeunyanpi kte. De sunka unyanpi qa kici celpi unwanjipidan kin heon, nape on unkatapi kte śni, eya. Unkan hunka wanjin wicaye cin anakigoptanpi.

28 Hehan wicaśta wopeton hecapi Midiani en hiyayapi. Unkan Josep yuzapi, qa woha qon etanhan yuwankan ehdakupi, qa mazaska wikcemna nonpa on Josep wiyopeyapi. Unkan Iśmayeli kin Josep opetonpi, qa Egupta ekta ayapi.

29 Unkan Ruben woha qon ekta hi, unkan Josep en un śni, heon tawnkoyake hdupota, 30 Qa hunka wanjitku kin en 57 


\section{WICOICAGE.}

wicahdi qa, Hokśidan kin tanin śni ce, miś toki imdarnde kta hwo, ewicakiya.

31 Unkan Josep taonhidolida qon icupi qa tatokadan mdoka wan ktepi, qa we kin on oputkanpi.

32 Hehan tuwe onlidohda hanske cin ahide śipi qa ateyapi kin kahipi qa heciyapi; De iyeunyanpi ce. Ito de nicinkśi onhidolida tawa qa iś tawa śni uman tukte hecetu hecinhan iyukean wo.

33 Unkan iyekiỷe ca, Micinkśi taonhidohda qon dee. Wamanica śica wan he temya. Ehanqon Josep wanna yapotapi ce, eya.

34 Unkan Jakob tawokoyake hdupote ça, waśihda qa anpetu ota cinhintku kin akiceya.

35 Unkan cinca wicaye cin owasin wica winyan ko magagaye wacinpi, tuka iś magaga yapi cin śni, qa, Iyomakiśica ecen micinkśi en Hades ekta mde kta ce, eye ca cinhintku kin akiceya:

36 Unkan Midiani kin Egupta en Josep wiyopeyapi ; unkan Potjpar Paro taakicita tancan opeton.

\section{WICOWOYAKE 38.}

1 Hena owasin hecetu, unkan Juda hunka wanjin wicaye cin etanhan apamahde ye ca, Adulami wicaśta wan Hira eciyapi ekta i ;

$2 \mathrm{Qa}$ hen Juda Kanani wicaśta wan, Śula eciyapi, he cunwinthu wanyake ça yuze ça en i.

3 Unkan ihduśake ca cinca wan ton; unkan Er eya caś kiton.

4 Unkan ake ihduśake ça, cinca wan ton qa, Onan eya caś kiton.

5 Qa ake cinca wan ton qa,
Śela eya caś kiton. He ton kin ehan Kezib en un.

6 Unkan Juda iye cinhintku tokapa kin Fr, winohinca wan, Tamar eciyapi yus kiya.

7 Unkan Er Juda cinhintku tokapa kin he śica e Jehowa wanyake ca, Jehowa he te ya.

8 Hehan Juda Onan heciya, Nicinye tawicu qon ekta ye ca, he yuza wo. Hecen nicinye cinkśi ye kte cin yakage kta ce.

9 Unkan cinca kin he iye tawa yawapi kte śni Onan sdonye, ca cincu cinca kicage kte śni e cincu tawicu qon en i eca, maka kin atpapson.

10 Unkan taku econ kin he śica e Jehowa wanyake ca, he nakun te ya.

11 Hehan Juda iye takośku kin Tamar heciya, Wiwazica niyate ti kin en yanka wo, micinkśi Śla tanka icage cin hehanyan. Okini iś nakun cinye wicaye cin iyecen te kta kecin, heon hecen eya. Unkan Tamar kihde ca atkuku ti kin en yanka.

12, He iyohakam anpetu ota, qa Śuha cunwintku Juda tawicu kin wanna ta ; unkan Juda wanna magaga yapi, qa Timnat ekta tahin wanuyanpi tawa yuśdapi kin ekta itawankanhde ya, iye takodaku Hira Adulami kin kicica.

13 Unkan Tamar heciyapi, Tho nitunkan tahin wanuyanpi tawa hduśda kta e Timnat ekta itawankanhde ya ce, eyapi.

14 Unkan Tamar iyoyakeca wokoyake hduśdoke ça, ite ahahipe on aihdahpe ca, Timnat canku iyahde kin he icahda taninyan iyotanka ; Śla wanna tanka, tuka qupi śni he wanyaka, heon hecon.

15 Juda he wanyaka ite aihda- 


\section{WICOWOYAKE 39.}

hpe cin heon winolinca wihomni heca kecin;

16 Qa canku kin etanhan ekta i, qa takośku kin hee kin sdonye śni heon, Tokin unwanken, eciya. Unkan unwanke ca, taku mayaqu kta he? eya.

17 Unkan, Miś wanuyanpi kin etanhan tatokadan cincadan wan nicahipi waye kta, eya. Unkan, $\mathrm{Au}$ wicayakiye cin itokam taku mayaqu kinhan, eya.

18 Unkan, He cicu kta e sdonyaye kte cin on etanhan taku e nakaha cicu kta yacin he? eya. Unkan, Maza huhu duhe cin ikan iyahna, qa nakun nitacanhpi ninape ohna duhe cin, eya. Unkan hena qu qa, kici wanka; unkan iye etanhan ihduśaka.

19 Qa najin qa hde ça ite akahpe hduśdoke ca ake waśihda.

20 Unkan Juda taku qu qon, winohinca nape kin etanhan ehdaku kta e, takodaku Adulami kin tatokadan cincadan aye śi, tuka iye winohinca qon iyeye śni.

21 Qa wicaśta heciya yakonpi kin iwicawanga; Witkowin canku ohna taninyan iyotanke ciqon tukte e he? eya. Unkan, Tohini witkowin wan deciya yanke śni, eyapi.

22 Unkan ihdamna, qa Juda ekta i qa heciya; Winohinca qon iyewaye śni qa, nakun wicaśta heciya yakonpi kin, Witkowin walijidan tohini deciya un śni ce, eyapi.

23 Unkan, Yuha un nunwe. Tatokadan cincadan kin de aye ciśi tuka iyeyaye śni ; sanpa unkakite cinhan, okini wowihaha unke kta, Juda eya.

24 Unkan hetanhan wi yamni hehan, Nitakoś Tamar wawicihaha econ, qa wanna wawiciha- ha kin etanhan ihduśaka ce, Juda eciyapi. Unkan, 'Tankan aupo; huhinage kta ce, eya.

$25 \mathrm{He}$ aupi kin icunhan tunkanku hecen wahoya, Tokin maza huhu kin de ikan iyahna, qa canhipi kin de, dena tuwe tawa imiyecidukcan. 'Tuwe dena tawa ye cin, wicaśta kin he etanhan ihdumaśaka ce, eya.

26 Unkan Juda hena iyekiye ca, Winohinca kin he ohan owotanna miś hemacece śni ; he micinkśi Śla waqu śni kin heon etanhan, eye ca hetanhan icimana winohinca qon sdonye śni. 27 Unkan wanna cinca ton kte cehan, inyun tezi mahen cekpa yukan.

28 Qa tonpi kin icunhan, wanji nape kin $q u$; unkan cinca tonkiye cin he nape kin icu, qa taku duta iyakaśke ca, De tokaheya hinanpe kta ce, eya.

29 Unkan nape kin ehdaku, liehan inyun cincu hiyu. Unkan winohinca kin heya, Token payahdeca; Opalideca lin de anicipe nunwe, eye ca, Parez eya caś ton.

30 Hehan sunkaku taku duta nape kin akan yuhe cin he hiyu; unkan he Zara eya caś ton.

\section{WICOWOYAKE 39.}

1 Unkan Iśmayeli kin Josep Egupta ekta ayapi. Unkan Potipar Egupton wicaśta kin heca, Paro taakicita tancan kin he aupi kin Josep opewicakicaton.

2 Unkan Jehowa Josep lkici un. Unkan taku econ kin owasin tanyan ihuni ye ca iye yuhe cin Egupton ti kin en yanka.

3 Unkan Jehowa kici un, qa taku nape econ kin owasin Jehowa tanyan yuśtan kiye cin he yuhe cin wanyaka. 


\section{WICOICAGE.}

4 Unkan Josep yuhe cin okiye ca iyokipi ya; unkan tiyohnaka tawa owasin awanyag śi, qa taku tawa owasin nape kin en qu.

5 Unkan tipi tawa, qa taku tawa owasin awanyag śi kin ehantanhan, Jehowa Josep on etanhan Egupton tiyohnaka kin yawaśte, qa taku ti ohnaka, qa tamaga ekta. wanke cin ko owasin, Jehowa yawaśte kin akan un.

6 Hehan taku tawa owasin Josep nape kin en ehpeye ca, iś takudan awakicin śni, aguyapi hdute cin heceedan. Unkan Josep owanyag waśte, tancan ite ko waśte.

7 Hena owasin hecetu; unkan hehan yuhe cin tawicu kin Josep atonwe ça, Mici wanka ye, eya.

8 Tuka wicada śni qa yuhe cin tawicu kin heciya; Hiya, mayuhe cin taku tawa owasin minape kin en qu, qa taku tipi olnaka kin mici un kin iye sdonye śni.

9 De tipi kin ohna tuwedan iyamakapa śni ; qa nihihna miye etanhan takudan tpatan śni, niś nana ulyuze cin heon etanhan, qa token woahtani tanka kin de ecamon, qa Wakantanka en wawahtani kta he? eya.

10 Unkan winohinca qon anpetu owasin heciya, qa kitan hinca, tuka Josep anagoptan śni, kici iwanke śni qa ecaca kici un śni.

11 Unkan kaketu, anpetu wan Josep taku tokon kta e ti mahen i ehan, wicaśta hen tipi kin tuwedan timahen un śni.

12 Unkan winohinca qon Josep taśina kin iyahpaye ça, Mici iwanka ye, eya; tuka śina kin winohinca nape kin etanhan éhpeya naśdog hdicu, qa tankan iyaya.
13 Unkan nape kin etanhan śina ehpeya tankan naśdog hdicu kin he winyan kin wanyake ca,

14 Hehan wicaśta tona ti kin ohna tipi kin hena wicakipan, qa hewicakiya, Wanyakape, Heberi wicaśta wan den unkahdipi, unkan wiśtenunyanpi cin. Manke cin en mahi qa mici wanke kte linca, tuka ho tankakiya nina waśicahowamda.

15 Nina ho tankakiya waśicahowamde cin he nahon, qa wapan qehan, mitankiyedan śina ehpeya naśdog tankan iyaya ce, eya.

16 Qa yuhe cin hdi kte cin hehanyan śina qon, itankiyedan ehnaka.

$17 \mathrm{Qa}$ eye ciqon owasin ake ecen okiyaka, Heberi hokśidan unyakahdipi kin he imaha kta e mikiyadan $u$.

$18 \mathrm{Qa}$ ho tankakiya waśicahowamde ceehan mitankiyedan śina elipeya naśdog tankan iyaya ce, eya.

19 Unkan yuhe cin he tawicu oie kin, Hokśidan nitawa kin hecen ecamicon, eciye cin he nalion hehan cantiyahdeya.

$20 \mathrm{Qa}$ yuhe cin Josep icu, qa wicaśta yatapi tona kaśka wicahnake cin tipi wan en kaśka wicahnakapi kin he en Josep kaśka ehnaka. Unkan wicakaśka tipi kin en yanka.

21 Unkan Jehowa Josep kici un qa, towaonśida kin hiyohiya qa wicakaśka tipi kin itancan kin he Josep wacin en yus kiya.

22 Unkan wicakaśka tipi itancan kin, tona wicakaśka tipi kin en kaśka wicahnakapi kin owasin, Josep nape kin en qu. Unkan taku hen econpi kin owasin Josep econ wicakiya.

23 Hecen Jehowa Josep kici 


\section{WICOWOYAKE 40.}

un, qa taku econ kin owasin tanyan yuśtan kiya; heon wicakaśka tipi itancan kin, taku Josep nape en yuhe cin hena takudan awanhdake śni.

\section{WICOWOYAKE 40.}

1 Hena owasin hecetu, unkan hehan Egupta wicaśta yatapi tawayatkekiye tawohekiye ko, wicayuhe cin Egupta wicaśta yatapi kin en wahtanipi.

2 Hecen Paro akicita nom wicayuhe cin canniye wicaya, wayatkekiyapi tancan, qa wohekiyapi tancan kin henioza.

3 Qa akicita tancan tipi tawa wicakaśka tipi kin tukten Josep kaśka hnakapi yanke cin he en awanyag wicakiyapi kta e ewicahnaka.

4. Unkan akicita tancan kin he Josep hena awanwicayag kiya, unkan owicakiya. Unkan anp’etu ota kaśľa hnakapi ecen yukanpi.

5 Hehan Egupta wicaśta yatapi tawayatkekiye, tawohekiye ko, wicakaśka tipi kin ohna kaślka wicahnakapi, hanyetu wanjidan en kinukan wowihanmde ihanmnapi, otoiyohi wihanmnapi kin iyukcanpi kin iyecen.

6 Hehan ihanhanna Josep en wicahi qa iyokiśicapi kin wanwicayaka.

7 Qa Paro taakicita wicakaśka tipi kin, iye yuhe cin tipi tawa kin he en iye kici unpi wiwicawanga; Tokeca nakaha ite iyoyag dukanpi he? eya.

8 Unkan wowihanmde wiunhanmnapi, tuka tuwe iyukcan kte cin den wanica ce, eciyapi. Unkan wiyukcan kin Wakantanka hee śni he? Wiyahanmnapi kin omakiyakapo, Josep ewicakiya.
9 Hehan wayatkekiyapi tancan kin wihanmde ciqon ohdaka qa, Wiwahanmde cin en hastanhanka iyuwi wan mitokam har. 10 Qa adetka yamni wiyuwi aicage ça ape wahica ko icali ye, qa iyage hastanhanka suton yapi.

11 Hehan Paro wiyatke tawa kin minape ohna mduha, qa hastanhanka kin iwacu, qa Paro wiyatke tawa kin ohna mduśkice ca Paro nape kin en wiyatke kin ewehde, eya.

12 Unkan Josep heciya, Wiyahanmde cin he kaken ka. Adetha yamni qon anpetu yamni ee.

13 Ehalke yamni can Paro nipa kin yuwankan inicu kte ça nanke ciqon ake en anihde kta; unkan tokaheya wayatkeyakiye ciqon wicohan kin ake ecen ecanon kta, Paro nape kin en tawiyatke kin yaqu kta.

14 Hena hecetu kinhan miksuya wo. Tokin tanyan yaun kinhan wowaśte ecamiyecon, Paro en caje mayadaten qa tipi kin de etanhan hinanpe mayayen.

15 Awicakehan Heberi tamakocepi kin etanhan mamanonpi, qa deciya takudan ecamon śni on makohdoka kin den emahnakapi kta, eya.

16 Hehan wohekiyapi tancan kin wiyukcan waśte e wanyake ca Josep heciya; Miś nakun wiwahanmde ca inyun, aguyapi makanopiye yamni mapa kin akan.

17 Qa makanopiye akantu kin ohna Paro tawoyute ocaje owasin wohekiyapi kage cin. Unkan zitkadan hena temyapi, makanopiye mapa kin iwankam un kin hetanhan.

18 Unkan Josep ayupta; He kaken ka. Makanopiye yamni kin anpetu yamni eepi. 
19 Ehake yamni can Paro pa kin yuwankan inicu qa, can akan otke niye kta; hehan zitkadan nicehpi kin etanhan yutapi kta.

20 Unkan iyamni can, anpetn en Paro tonpi kin he kiksuyapi kta e wowidag wicaye cin owasin wowicakihe, ca wayatkekiyapi tancan wohekiyapi tancan henioza wowidake wicaye cin wicehna hdinanpe wicaya.

$21 \mathrm{Qa}$ wayatkekiyapi. tancan kin wayatke wicakiye cigon wicohan ake hecon śi ; unkan wiyatke kin Paro nape kin en qu.

22 'Tuka wohekiyapi tancan kin otke ya, Josep iwicakiciyukcan qon iyecen.

23 Unkan wayatkekiyapi tancan kin Josep kiksuye śni, tuka akiktonja.

\section{WICOWOYAKE 41.}

1 Hehan tanhan waniyetu nonpa hehan Paro wihanmna. Unkan iho wakpa kahda inajin.

2 Qa inyun wakpa kin etanhan, pte sakowin owanyag waśte qa cepa heca hinanpapi, qa tinta en wihanpi.

3 Qa hena ihektapa tanhan pte tokeca śakowin owanyag śica qa tamaheca hecapi, wakpa etanhan hinanpapi, qa pte umanpi qon ehna wakpicahda najinpi.

$4 \mathrm{Qa}$ pte owanyag śica tamaheca hena pte owanyag waśte cepapi śakowin qon temwicayapi. Unkan Paro kikta.

5 Alze iśtima qa inonpa wihanmna. Unkan inyun wamnaheza hu wanjidan wahuwapa śakowin suton, qa waśteśte aicaga.

$6 \mathrm{Qa}$ hena iyohakam wahuwapa tokeca śakowin hinanpa, tuka śikśica qa wiyohiyanpa tanhan tate on śnija.
7 Qa wahuwapa conica ton śni kin wahuwapa suton qa ojugjudan qon owasin temya. Paro hecen wihanmde ca hehan kikta.

8 Unkan ihanhanna qehan $\mathrm{Pa}$ ro nagi kin iyokiśice ca, Egupton en pejihuta wicaśta qa wicaśta ksapapi kin owasin wicakico, qa wihanmde ciqon Paro owasin owicakiyaka; tuka tuwedan yukcan okihi śni.

9 Hehan Paro wayatkekiyapi tancan kin ie ca, Anpe dehan wawalitani kin weksuya ce.

10 Paro taokiye kin canniye wicaye ca, akicita tancan tipi kin en kaśka mahnaka, miye qa wohekiyapi tancan kin he nakun.

11 Unkan hanyetu wanjidan en wiunhanmnapi, miye iye kici kinukan, wihanmnapi iyukcanpi kin iyecen wiunhanmnapi.

12 Unkan hen unkicipi kośka wan Heberi kin heca, akicita tancan tahokśidan kin he wiunhanmnapi kin unkokiyakapi, unkan iye hena iyukcan otoiyohi wiunhanmnapi kin iyecen unkiciyukcanpi.

13 Unkan unkiciyukcanpi kin ecetu; miye ake wiyatke yuhe makiye ca uman kin otke ya.

14 Hehan Paro Josep huwe ye wicaśi, unkan wicakaśka tipi kin etanhan kiyuśkapi, hehan putin hin hdasan, qa wokoyake tokeca kicun qa Paro yanke cin en hi.

15 Unkan Paro Josep heciya, Wowihanmde wan iwahanmna, unkan he yukcan kta okihi tuwedan iyewaye śni, tuka wihanmnapi niś nayahon unkan idukcan oyakihi keyapi nawahon.

16 Unkan Josep ayupte ça, Miye ee śni, Wakantanka eqe toketu kin tanyan oniciyake kta ce, eciya. 


\section{WICOWOYAKE 41.}

17 Unkan Paro ie ça, Wiwahanmde ca watpa hutata kin nawajin ;

$18 \mathrm{Qa}$ inyun wakpa kin etanhan, pte śakowin cepa, owanyag waśte hinanpapi, qa tinta kin en wilianpi.

19 Unkan hena iyohakam pte tokeca śakowin tamaheca, owanyag śikśica hinanpapi ; tamahenheca śica hena iyececa, Egupta makoce kin en tohini wanmdáke śni.

20 Qa pte tamahenheca śice cin pte śakowin cepa tokaheya qon temwicayapi.

21 Unkan tan mahen iyayapi kin hehan, tan mahen iyayapi kin sdonye pica śni; otokahe ekta śikśica taninpi qon nahahin hececapi. Unkan hehan wekta. $22 \mathrm{Qa}$ ake wiwahanmule ca inyun wamnaheza bu wanjidan wahuwapa śakowin hanskaska waśteśte aicage cin wanmdaka.

23 Hehan ake wahuwapa śakowin cikcistina, wiyohiyanpata tateyanpa kin on śnijapi, qa co wanica hinanpapi.

24 Qa wahuwapa cikcistina wahuwapa śakowin waśteśte qon owasin temyapi. Unkan wicaśta wiyukcan heca owicawakimdaka, tuka miciyukcanpi śni.

25 Hehan Josep Paro heciya, Paro wihanmde cin hena okonwanjidan, Wakantanka token econ kte cin he Paro okiyaka.

26 Pte śakowin waśte qon, hena waniyetu śakowin ee; qa wahuwapa sakowin waśteśte qon, hena nakun waniyetu śakowin ee, wowihanmde kin hena wanjidan.

$27 \mathrm{Qa}$ pte śakowin tamaheca, qa śice cin umanpi kin iyohakam hinampapi kin, hena waniyetu śakowin ee, qa wahuwapa śako- win cikcistina wiyohiyanpata tateyanpa kin on śnija kin hena nakun, waniyetu śakowin wicaakihan kte cin hee.

28 Parn taku ewakiye cin he dee. Wakantanka taku econ kte cin he Paro wanyag kiya.

29 Hecetu kta, toka ta waniyetu śakowin hehanyan, Egupta makoce kin owancaya taku owasin iyakicuya icage kta.

30 Qa hena iyohakam waniyetu sakowin wicaskilian kta, qa Egupta makoce kin en taku iyakicuya icage kte ciqon akiktunjapi kte ca, wicaakihian kte cin makoce kin awihnuni kta.

31 Unkan hehan wicaakilian kte cin iyotan tehike kte cin makoce kin en, heon wipipi qon sdonyapi kte śni.

32 Qa wicoie kin de Wakantanka yuecetu kte ça, wanna kohanna Wakantanka econ kta, heon Paro nonpa akihde wihanmna.

-33 Qa wanna Paro wicaśta wan ksape ca wayupika akite ça, Egupta makoce kin yuhe kiya nunwe.

$34 \mathrm{Qa}$ Paro akicita wicakage ca makoce kin en wicahdusuta kte; unkan waniyetu śakowin wipipi kta hena icunhan, taku makoce aicage kte cin owasin izaptanptan icupi nunwe.

35 Hecen waniyetu sakowin waśteśte kte cin hena icunhan, woyute ocaje owasin kamnapi kte, Paro nape kin ihukuya, tonwanyanpi kin en aguyapi pahipi kte cin he woyute awanyakapi nunwe.

$36 \mathrm{Qa}$ waniyetu śakowin wicaakihan kte cin Fgupta makoce kin en hena. on, taku yutapi kihnakapi kinhan, makoce kin wicaakilian kte cin on awihnuni kte śni, eya. 


\section{WICOICAGE.}

37 Unkan Paro ookiye wicaye cin ko wicoie kin he waśte dakapi.

38 Hehan Paro iye taokiye kin hewicakiya; Wicaśta wan Wakantanka taniya en un kin de iyececa iyeunyanpi pica he?

39 Qa Paro Josep heciya, Wakantanka de owasin sdonye niciye cin, niś nana widukcan qa yaksapa, tuwedan iyenicece śni. 40 Niś wati kin awanmiyecidake kta, qa oyate mitawa owasin oie ananigoptanpi kta. Oiyotanke kin en hecedan iciwankam waun kta.

41 Qa wanyaka wo, Egupta makoce kin owasin yuhe ciciya ce, eya.

42 Hehan Paro maza napcupe hduśdoke ca Josep nape kin ohna iyeye ca, minihuha ska waśte koyag ye ca, mazaskazi wanapin wan napin kiya.

43 Qa carpahmihma yuhe cin etanhan canpahmihma inonpa kin he ohna iyotang ye ca, Itokam canpeśka makehde inajinpo, ieyanpaha eyapi, qa Egupta makoce kin owasin yuhe kiyapi.

44 Qa Paro Josep heciya, Paro miye ce. Oyate kin tuwedan iye cinka takudan econ kte śni. Niś nana token econ wicayaśi kin hecetu kta ce.

45 Qa Paro Josep, Wicoicage nikiye cin, eya caś ton, qa On otonwe kin en wośnapi kage cin, Potipera he cunwintku Asenat tawicu kta e qu. Unkan Josep Egupta makoce kin ehna iyaya.

46 Josep, Fgupton wicaśta yatapi Paro itokam najin qehan, wanna waniyetu wikcemna yamni qa, hehan Josep Paro itokapa tanhan inanpe ca Egupta makoce kin owancaya iyoptapta iyaya.
47 Unkan waniyetu wipipi kin hena icunhan, makoce kin napohnahnaka icah ya.

48 Qa waniyetu śakowin Egupta makoce kin en, taku yutapi owasin pahipi, qa tonwanyanpi kin en kibnakapi; otonwe otoiyohi ohna maga ihdukśan un kin etanhan woyute otonwe kin en kihnakapi.

49 Qa Josep, miniwanca kahdaya wiyaka wanke cin iyecen, aguyapi ota hinca pahi, yawapica śni nakaeś yawapi kte cin ayaśtanpi.

Ło Unkan Jusep cinca wica nonpa kicitonpi, waniyetu wicaakihan kin itokam, Asenat Potipera On en wośnapi kage cin he cunwintku kin hena Josep kici ton.

51 Iyomakiśice ciqon owasin, qa ate ti kin owasin Wakantanka akiktunś mayan, eye ca tokapa kin Manaśe eya caś kiton.

52 Qa, Makoce en kakiś mayanpi qon, he en Wakantanka taku icah mayan, eye ca iyokihe Epraim eya caś kiton.

53 Unkan waniyetu śakowin wipipi kin Egupta makoce kin en wanna henakeca.

54 Qa waniyetu śakowin wicaakihan kte cin wanna en au, Josep eye ciqon hecetu. Unkan makoce owasin en wicakihan, tuka Egupta makoce kin en 0wancaya aguyapi yukan.

55 Unkan Egupta makoce kin owancaya akihanpi kte ccehan, oyate kin aguyapi on Paro hoyekiyapi. Uikan, Josep ekta yapi qa, token econ niśipi kin ecen econpo, Paro Egupton owasin ewicakiya.

56 Wanna maka ohnaka owancaya wicaakihan, hehan Josep aguyapi opiye kin owasin hdu- 
hdoke ca, Egupton taku yutapi | iyewicakiya, tuka iye Josep iyewicaqu; Egupta makoce kin en wicaakihan tehika aye nakaś.

$5 \%$ Unkan maka owancaya etanhan, Egupta ekta Josep en taku yutapi opeton hipi, maka kin owancaya nina wicaakitian ece.

\section{WICOWOYAKE 42.}

1 Hehan Egupta makoce kin en aguyapi yuke cin Jakob wallyake ça cinkśi wicaye cin hewicakiya, Tokeca ecin opakicihta dukanpi he?

2 Ihopo Egupta heciya aguyapi yukan keyapi nawation. Ecin kutkiya ekta yapi qa heciya tanhan woyute opeunkicatonpo, kinhan unnipi qa unțapi kte śni ce, eya.

3 Unkan Josep cinye wicaye cin wikcemna qon aguyapi opetonpi kta e Egupta makoce kin ekta kutkiya ipi.

4 Tuka Benjamin Josep sunkaku kin ope śni, Okini taku śica akipe kta naceca, Jakob eye ça hecen ye śi śni.

5 Ünkan Kanan makoce kin en wicaakilian, heon uman hipi kin om, Israel cinkśi wicaye cin woyute opeton hipi.

6 Wanna makoce kin en Josep itancanyan un, qa makoce kin ohna oyate hiyeye cin owasin taku yutapi wicaqu kin Josep hee. Unkan cincu qon en hipi, qa itokam ite makipusdiya makata ehpeiciyapi.

7 Unkan Josep wanwicayake ca cincu iyewicakiya, tuka wicitokam ihdutokeca, qa icanksiya owawicakiya qa, Tokiyatanhan yaupi he? eya iwicawanga. Unkan Kanan makoce kin etanhan taku yutapi opeton unhipi ce, eyapi.

8 Hecen Josep eqe cincu kin Ex. kiyapi śni.

9 Hehan Josep wowihanmde ihanmde ciqon kiksuye ca, Makoce iwanyakapi kin henicapi, qa makoce wanna śdayehna wanke cin he iwanyag yahipi ce, ewicakiya.

10 Unkan, Hiya itancan hecetu śni. Hokśidan nitawa woyute opeton unhipi.

11 Wicaśta wanijidan owasin cinkśi unyanpi. Unkiye iewicaunkapi ; hokśidan nitawa kin makoce iwanyakapi kin heuncapi śni ce, eciyapi.

12 Unkall, Hiya makoce śdayehna wanke cin he iwanyag yahipi ce, ewicakiya.

13 Unkan, Hokśidan nitawa hunka wanjin unkiciyapi ake unnonpapi ; Kanan makoce kin en wicaśta wanjidan ate unyanpi, qa hakakta kin he anpe dehan ate unyanpi kin kici yanka, qa wanjidan tanin śni, eyapi.

14 Unkan, Makoce iwanyakapi kin henicapi ; eya eciciyapi qon he hecetu ce.

15 Deciya tanhan niyukcanpi kta. Paro ni un kin nisunkapi cistinna kin he hi śni kinhan detanhan tokidan dapi kte śni.

16 Ihopo, niyepi kin wanjidan sunka yayapi kin hduwe ye śipo, qa nioiepi kin yahduwicakapi kin hehanyan kaśka dukanpi kta. Hecen niyukcanpi kta, hecetu śni kinhan, Paro ni un kin makoce iwanyakapi kin henicapi kta, Josep ewicakiya.

17 Qa iyamni can hehanyan witaya onatag wicahnaka.

18 Anpetu iciyamni hehan Josep hewicakiya, Wakantanka kowakipa ce. Kaken e econpo qa ni unpo.

19 Wicayakapi kinhan, hunka wanjin yayapi kin wanjidan ka65 


\section{WICOICAGE.}

śka yanke kta, tipi kin de onatag nihnakapi kin he en, qa niye umanpi kin ihopo, tiyohnaka nitawapi kin wicaakilian kin on woyute akiyahdapo.

$20 \mathrm{Qa}$ sunka yayapi cistina kin he miye en makaupo, hecen nioie yahduwicakapi kinhan nitapi kte śni. Unkan ecen econpi.

21 Qa iyakitedan hekiciyapi, Ehanqon waunhtanipi. Sunka unyanpi wacin iyokiśin wanunyakapi qa ceunkiyapi, tuka anaungoptanpi śni, heon wocante śice cin de unhiyahdepi ce, eyapi.

22 Unkan Ruben ayupte ca, Hokśidan kin en wahtanipi śnipo eciciyapi śni he? tuka anamayagoptanpi śni; unkan ecin iye we kin wanna wiunwangapi kin he dee ce, eya.

23 Unkan Josep he nahon sdonyapi śni. Taku ewicakiya eca wicaśta wan ie ska kiya ece nakaeś.

24 Tuka Josep wicitokapa tanhan toki ye ca ceya. Hehan icicawin en wicahdi qa, taku ewicakiye ca, hehan umanpi kin etanhan Śimeyon icu qa, iśtapi kin wicitokam pakilita.

25 Hehan Josep wojuha tawapi kin aguyapi on ojuwicakicitonpi kta, qa mazaska tawapi otoiyohi wojutonpi kin en owicakicihnakapi kta; waneya nakun wicaqupi kta, keya. Unkan hecen ecawicakicon.

26 Unkan śuktanka śonśonna kin taku yutapi qin wicakiyapi qa hdapi.

27 Qa tukten kiwankapi kin, wanji taśunke śonśonna wo qu kta e wojutonpi kin hduhdoka; unkan inyun wojutonpi i kin en tamazaska kin yanka.

28 Unkan hunka wanjin wica- ye cin hewicakiya, Mazaska mduhe ciqon ake micupi. Wanyakapo, wojutonpi mitawa kin en ohnakapi ce. Unkan owasin icanwankapi qa ikopapi qa, De taku Wakantanka ecaunkiconpi hwo, ekiciyapi.

29 Qa Kanan makoce kin ekta ateyapi Jakob en hdipi, qa token akipapi qon owasin okiyakapi.

30 Makoce yuhe cin he ihnuhana icanksiya taku unkekiciyapi, qa makoce kin iwanyag unkipi iyecen ecaunkiconpi.

31 Tuka, Ohan unkowotanpi qa makoce iwanyakapi kin heuncapi śni ;

32 Hunka wanjin unkiciyapi ake unnonpapi hena owasin ate unwanjipidan, wanjidan tanin śni, qa hakakta kin he anpe dehan Kanan makoce kin en ate unyanpi kici yanka ce, unkekiyapi.

33 Unkan, Ohan oniwotanpidan kinhan, detanhan sdonwaye lita ce. Hunka wanjin yayapi kin wanjidan den mici yanke kta, qa yatipi kin en wicaakihan kin on, woyute icupi qa ekta hdapo.

34 Qa sunka yayapi hakakta kin he makaupo. Kinhan ma. koce iwanyakapi kin henicapi śni, qa ohan oniwotanpidan kin sdonwaye kta ce, qa hehan, hunka wanjin yayapi kin de cicupi kta; kinhan makoce kin den wopeyatonpi kta ce, nrakoce yuhe cin unkekiciyapi ce, eyapi.

35 Hehan wojutonpi kin tokokadapi; unkan inyun mazaska apahtapi qon, owasin wojutonpi kin en yanka. Owasin ateyapi kin kici mazaska apahtapi qon wanhdakapi, qa inihanpi.

36 Hehan Jakob ate yapi kin hewicakiya; Miye micinca ma- 


\section{WICOWOYAKE 43.}

yakipi, Josep tanin śni, qa Śimeyon tanin śni, qa Benjamin iyacupi kta; hena owasin iyokiśin mayanpi.

37 Unkan Ruben he atkuku kin heciya, He minape kin en maqu wo. Miś niye en awahdi kta ce. He niye en awahdi śni kinhan, micinca nom kața iyewicaya wo, eya.

38 Tuka, Micinkśi kin de nicipi ye kte śni ce. Cincu wanna țe ça iś nana okaptapi, qa canku ohna dapi kin he tahepi Benjamin taku śice cin akipe cinhan, mapa ska kin Hades ekta iyoki- śin yemayayapi kta ce, eya.

\section{WICOWOYAKE 43.}

1 Wanna makoce kin en wicaakihan tehika aya.

2 Unkan aguyapi Egupta etanhan ahdipi gon temyapi, hehan ateyapi kin hewicakiya, Ake ekta yapi qa taku yutapi onge opeunkicitonpo.

3 Unkan Juda ayupte ca, Wicaśta qon, Nisunka nicipi $h i$ śni kinhan miite kin wanmayadakapi kte śni ce, nina kitanyan unkekiciyapi.

4 Hecen niś sunka unyanpi kin unkicipi ye yaśi kinhan kun unyanpi, qa woyute opeunnicitonpi kta.

5 Tuka, niś ye yaśi kte cin tawatenya ye śni kinhan, kun unyanpi kte śni. Nisunkapi kin ope śni kinhan, miite kin wandakapi kte śni ce, wicaśta kin unkekiciyapi ce, eya.

6 Unkan, Tokeca nisunka wanji yuke cin, wicaśta kin oyakidakapi qa śicaya ecamiyeconpi he? Israel eya.

7 Unkan, Wicaśta kin atayedan wicowazipi kin unkiwangapi, qa heya, Niyatepi kin naha- hin ni he? Nisunka wanji yukan he? Unkan owasin wicoie kin hena ecen unkokiyakapi. Ecin token on, Nisunkapi kin makaupo, eye kte cin sdonunyanpi kta he? eyapi.

8 Qa, Kośka kin mici ye śi wo, kinhan naunjinpi qa unyanpi kta; hecen unnipi kta, unkiye niye unkicincapi ko owasin untapi kte śni.

9 Miś lie awanmdake ca ninape kin etanhan mayakida kta. Niye en cicicahdi śni, qa nitokam ewehde śni kinhan, anpetu owasin, Niye en wawahtani kemakiyapi kta.

10 Ye unkapinpi śni unkanś, wanna dehan inonpa unhdipi kta tuka ce; Juda atkuku Israel eciya.

11 Unkan, Hecetu hecinhan kaken e econpo. Makoce kin de waskuyeca tukte iyotan waśte kin wojuha duhapi kin ohna yuha yapo, canśin onge, qa hastanhanka hanpi tiktica onge, qa taku waśtemna, qa pejihuta yatan, hma qa uma, henakiya wicaśta kin yaqupi kta.

12 Mazaska nakun oiyopeye nom, nape kin ohna icupo, mazaska wojutonpi ohna yahdohdipi qon he koya, nape ohna adapi kta, he wanun econpi naceca.

13 Nisunkapi kin nakun icupi, qa najinpi qa wicaśta qon ekta ake yapo.

14 Qa wicaśta kin cante niciyapi qa hunka wanjin yayapi kin, uman kin he ku si kte, Benjamin koya, Taku wakan Otancanke ionśinidapi kte. Miś micinca makipi kinhan hecen makipi kta, ateyapi Israel ewicakiya.

15 Hecen wicaśta kin taku ikce qupi kte cin he icupi, qa mazaska nape ohna icupi; qa 


\section{WICOICAGE.}

Benjamin kici inajinpi, qa Egupta ekta kun yapi qa Josep itokam inajinpi.

16 Unkan Josep wanwicayaka, Benjamin kici, qa taokiye wan tipi awanyake cin he héciya; Wicaśta kin dena tin awicaye ca, wanuyanpi wan pata, qa śpanyan wo. Wiyotanhan hehan wicaśta kin dena om wawate kta ce.

17 Unkan wicaśta kin token Josep eye cin owasin ecen econ, qa Josep ti kin ti mahen u wicaśi.

18 Unkan Josep ti kin ti mahen awicaipi kin heon wicaśta kin kokipapi qa, Mazaska tokaheya wojutonpi unkitawapi kin ohna unhdohdapi qon, heon anauntanpi, qa taku iyaunkonpapi kta e unkicopi, qa wayaka unyuzapi kta unkiye śuktanka. śonśonna unhapi koya, eyapi.

19 Qa Josep ti kin awanyake cin he en ikiyedan hinajinpi, qa tipi tiyopa kin en okiyapi.

20 Qa, Itancan otokahe ekta taku yutapi opeuntonpi kta e kun unhipi.

21 Qa owanka qon, en unkiwankapi, qa wojutonpi unhduhdokapi, unkan mazaska unkahipi qon otoiyohi wojutonpi unkitawapi i kin ohna yanka, mazaska aspeunkiye unkitonpi qon he iyececa, he owasin nape ohna unnicicahipi.

$22 \mathrm{Qa}$ mazaska tokeca on taku yutapi opeuntonpi kta e nape ohna yuha unhipi. 'Tuwe mazaska unkahipi qon, unkitawojutonpi kin ohna iyolipeye cin sdonunyanpi śni ce, eyapi.

23 Unkan, Tanyan yaunpi kta ce. Wikopapi śni po. Taku wakan yadapi kin niyatepi ta Wakantankapi kin hee wojutonpi nitawapi kin ohna woyuha 11içupi. Mazaska nitawapi qon miye en makahipi, eye ça hehan Simeyon wicitokam hinanpe ya. 24 Qa Josep ti kin ti mahen u wicaśi, qa mini wicaqu; unkan siha hdujajapi, qa śuktanka śonśonna tawapi kin nakun taku yutapi wicaqu.

25 Unkan, Hen aguyapi yutapi kta keya nalionpi, heon wiyotanhan hehan Josep hdi kte cin he itokam taku ikce qupi kte cin owasin wiyeya ehnakapi.

26 Unkan Josep tiyata hdi hehan taku ikce qupi kte cin, nape ohna Josep en ti mahen aupi, qa itokam makipusdiya elipeiciyapi.

27 U̇nkan, tanyan unpi hecinhan iwicawange ça, Niyatepi kin wicahinca cajedatapi qon nahahin ni he? tanyan un he? eya.

28 Unkan, Nitaokiye ate unyanpi kin he nahahin ni, qa tanyan un ce, eyapi qa patujapi qa makata ehpeiciyapi.

29 Unkan Josep en etonwe ca, sunkaku Benjamin kici hunku wanjidan kin he wanhdake ca, Sunkayayapi cistina miye en cajedatapi qon be dee he? eye ça, Micinkśi Wakantanka cantonihnake kte, eya.

30 Qa sunkaku kin en cante kin śkanśkan he cin heon Josep inahniyan tukten ceye kta akite ça wankan tipi ekta i, qa ceya.

31 Hehan ite kin hdujaja qa hdinanpe ça ihduhe ça, Aguyapi ehnakapo, eya.

32 Unkan aiyog Josep qupi, qa hunka wanjitku kin iś aiyog wicaqupi, qa Egupton tona hen wotapi kin aiyog wicaqupi ; Egupton Heberi om aguyapi yutapi okihipi śni nakaeș, heconpi kinhan iśten iciyapi kta.

33 Unkan Josep itokam iyotankapi, tokapa kin watokapa kin iyecen, qa hakakta kin ci-

68 
stina un kin iyecen, qa wicaśta qon iyakitedan yuśinyayapi.

34 Taku yutapi iyacinpi otoiyohi wicaqu, tuka Benjamin taku tawa tanka umanpi taku tawapi zaptan akihde heon. Unkan kici yatkanpi, qa iyuśkinpi.

\section{WICOWOYAKE 44.}

1 Unkan Josep tuwe tipi tawa awanyake cin heciya, Wicaśta kin wojuha yuhapi kin en taku yutapi oju wo ; tohan qin okihipi kin hehanyan, qa mazaska aupi kin owasin otoiyohi tawo"jutonpi i kin ohna ehnaka wo.

2 Qa hakakta kin tawojutonpi i kin ohna mazaska wakśica mitawa kin he oyahnake kta, mazaska woyute iyopeye ahi kin he iyahna. Unkan token Josep eciye cin, ecen econ.

3 Anpao hehan hde wicaśipi, wicaśta taśunke śonśonna koya.

4. Wanna otonwe kin etanhan kinanpapi kitanna tehan hdapi, hehan Josep wicaśta tipi tawa awanyake cin heciya; Najin qa wicaśta qon tawicapa wo, qa wicayehdege cinhan, He tokeca tanyan ecaniconpi kin itkom śicaya ecanonpi?

5 Mayuhe cin taku ohna wayatke ca on ayate cin dee śni he? Taku ecanonpi kin he śica, ewicakiya wo.

6 Unkan ewicakihdege ça wicoie kin hena ewicakiya.

7 Unkan, Itancan tokeca e hecen eha he? Hokśidan nitawa token heconkupi kta he?

8 Mazaska wojutonpi i kin ohna iyeunyanpi qon he ake, Kanan makoce kin etanhan unnicicahipi kin sdonyaya. Hehan ecin token on etanhan niyuhe cin ti kin etanhan mazaska qa iś mazaskazi maunnonpi kta he?
9 Hokśidan nitawa uman tukte kaśta he yuha iyeyaye cinhan te kia, qa unkiye owasin wowindag unyayapi kte, eyapi.

10 Unkan, Wanna token ehapi kin hecetu kte. Tuwe he yuha iyewakiye cinhan wowidake waye kta, tuka umanpi kin iyaonpepicaśni yaunpi kta, eya.

11 Unkan owasin inaliniyan wojutonpi kin makata pahpapi qa, otoiyohi wojutonpi hduhdokapi.

12 Unkan tokapa kin tawojutonpi kin en tokaheya akite ça hakakta kin ecen owecinhan yuśtan. Qa Benjamin tawojutonpi kin ohna wakśica kin iyeya.

13 Unkan wokoyake kin hdupotapi qa owasin śuktanka śonśonna qin wicakiyapi, qa icicawin otonwe kin ekta ipi.

14 Hehan Juda, hunka wanjin wicaye cin om, Josep ti kin en ipi. Unkan iye nahabin hen yanka, qa he itokam owasinmakata ehpeiciyapi.

15 Unkan woecon kin de taku ecanonpi hwo? Wicaśta tuwe hemacece cinhan ayate cin okihi sdonyayapi śni he? Josep ewicakiya.

16 Unkan Juda heya, Mayuha token unkaniyuptapi kta he? Taku unkeyapi kta, qa tokiya tanhan unhduecetupi kta he? Waunhtanipi qon wanna Wakantanka iyeunyanpi. Iho, Itancan wayaka unyaduhapi, wakśica kin yuha iyeyapi qon qa unkiyepi owasin nakun, eya.

17 Unkan, Hecamon kte cin Wakantanka iyomaki śni nunwe. Wiyatke yuha iyeyapi qon wicaśta kin he, hecedan wowindag waye kta; tuka niyepi wookiye on niyatepi kin ekta hdapo, Josep eya.

18 Unkan Juda ikiyedan hina- 


\section{WICOICAGE.}

jin qa heya, Itancan ceciya ce, hokśidan nitawa canniye maye śni wo. Mayuhe cin Paro iyeniceca. Tokin hokśidan nitawa taku epe cin nayahorı.

19 Mayuhe cin hokśidan nitawa wiwicanonga; Niyatepi yuke ça nisunkapi yukan he? ehe ciqon.

20 Unkan itancan hecen unkeniciyapi; Han ate unyanpi kin wanna wicahinca, qa cinhintku cistina kin wicahinca ehan tonpi kin he kici yanka, qa cincu kici hunku wanjidan qon he ța, hecen iśnana okaptapi, unkan atkuku cantekiya ce, unkeyapi.

21 Unkan, Nisunkapi kin makaupo, wanmdake kta ce, hokśidan nitawa kin ewicayakiye ciqon.

22 Unkan, Itancan hokśidan kin atkuku kin ehpeye kte cin okitpani, he atkuku ehpeya u kinhan, atkuku kin te kta ce, unkeniciyapi qon.

23 Ünkan, Nisunkapi cistina kin he kici kun yaupi śni kinhan, ake miite kin icimana wandakapi kte śni, hoksidan nitawa unkeyakiyapi.

24. Unkan hokśidan nitawa kin ate unyanpi kin ekta itawankanhde unhdapi, qa he en token iyae cin owasin unkokiyakapi.

25 Unkan, Ake ekta yapi, qa woyute onge opeunkicatonpo, ate unyanpi kin eya.

26 Unkan, Sunka unyanpi cistina kin de ope cinhan unyanpi kta ce ; tuka iye ope śni kinhan apamahde unyanpi kte cin unkokitpanipi. Sunka unyanpi hakakta kin kici unyanpi śni kinhan, wicaśta qon itohnake kin wanunyakapi kte śni ce, unkeyapi.

27 Unkan hokśidan nitawa ate 70 unyanpi kin heunkiciyapi, Mitawin cinca nom nana miciton e sdonyayapi.

28 Tuka uman kin mitan tanhan toki iyaye ca, Ehanqon yapotapi ce, epe ciqon ehantanhan wanwahdake śni.

29 Qa wanna de nakun mitan tanhan toki adapi kta, qa tahepi taku śice cin akipe cinhan pa maska iyokiśica Hades ekta amayadapi kta ce, eya.

30 Unkan dehan kaketu kta ce. Nitahokśidan ate unyanpi kin ekta unhdapi, qa iye nagi kin hokśidan nagi kin en ihdaśke ca hokśidan kin ope śni kinhan;

31 Ate unyanpi kin hokśidan tanin śni kin wanhdake cinhan te kta. Hecen wowindag unyayapi kin hokśidan nitawa ate unyanpi kin pa ska kin iyokiśica Hades ekta kun unkayapi kta.

32 Hokśidan nitawa miye hokśidan kin ate wakida qa hewakiya; Niye cicicahdi śni kinhan, ate niye en wawahtani ohinniyan kecanni kta ce, epa.

33 Unkan wanna ceciciye, hokśidan kin hee kiya den manke ca mayuhe cin wowindag mayaye kta, qa hokśidan kin cinye wicaye cin om itawankanhde hde kta.

34 Hokśidan kin omicipe śni kinhan ate ekta itawankanhde wahde kte cin owakitpani. 'Ta$\mathrm{ku}$ śica ate ahinhpaye kte cin he wanmdake kte cin tawatenwaye śni, eya.

\section{WICOWOYAKE 45.}

1 Hehan Josep tona en najinpi kin owasin wicitokam ihduhe kta okihi śni, qa panyanban hewicakiya, Wicaśta owasin mitokapa tanhan tankan iyayapo. Hecen Josep hunka wanjin wi- 


\section{WICOWOYAKE 45.}

caye cin en sdonye iciye cehan, tuwedan kici yanke śni.

2 Hehan Josep hotaninyan ceya.

Unkan Egupton he nahonpi, $\mathrm{Pa}$ ro tiyohnaka tawa kin nakun nahonpi.

3 Unkan Josep hunka wanjin wicaye cin hewicakiya, Josep he miye ce, Ate nahahin ni he? eya ; tuka cincu itokapa tanhan yuśinyayapi qa ayuptapi kte cin okitpanipi.

4 Unkan, Ihopo, mitan kiyedan upo, Josep hunka wanjin wicaye cin, ewicakiya. Unkan kiyadan hinajinpi. Unkan, Josep nisunka Egupton ekta wiyopeyayapi qon he miye ce.

5 Qa dehan wiyopemayayapi kin on iyokiśin iciyapi śnipo, qa icanniye kiciyapi śnipo. Wanikiye makage la ta Wakantanka u makiya ce.

6 Wanna waniyetu nonpa wicaakihan maka kin ohna, qa tokata waniyetu zaptan yumdupi kte śni, qa woksapi kte śni ce.

7 Taku maka akan ecicihnakapi, qa taku iyotan tehika etanhan ni ciyapi kta e Wakantanka nitokain u makiya ce.

8 Wanna deci u makiyapi kin he niyepi ee śni. Wakantanka liee hecon qa, Paro ate maye ca tiyohnaka tawa kin owasin itancan makiyapi, qa Egupta makoce kin owancaya wowindag wicawaye kta e emahde.

9 Inahnipo, qa ate ekta itawankanhde hdapi, qa heciyapo ; Nicinkśi Josep hecen eya; Wakantanka Egupta owasin yuhe makiya ce. Tho kun en mahi qa yutehan śni wo.

10 Kinhan Gośen en ounyaye ca mitan kiyedan yaun kta ce. Niye nicinca qa nicinca cinca wicayapi, tahin wanuyanpi nita- wa, pte nitawa ko, qa taku duhe cin owasin ;

11 Kinhan wo ciçu kta : nahahin tokata waniyetu zaptan wicaakihan kte cin heon, yau śni kinhan, okini niwahpanica kta nace, niye yati ohnaka kin, qa taku nitawa ko owasin.

12 Ihopo, niiśtapi kin misunka Benjamin iśta kin nakun mii kin on ociciyakapi kin he wanmayahdakapi.

13 Egupta en wowitan mduhe owasin, qa taku wandakapi ko owasin, ate okiyakapo, qa inahniyan ate deciya kun aupo ;

14 Eye ça sunkaku Benjamin poskin yuze ca ceya. Unkan Benjamin cincu tahu kin akan ceya.

15 Hehan hunka wanjin wicaye cin owasin i iwicaputake ça wicahduha ceya. Unkan cinye wicaye cin kici wohdakapi.

16 Wanna Josep hunka:wanjin wicaye cin hipi ce, eya oyakapi kin, Paro tiyohnaka tawa kin nahonpi, qa Paro ookiye wicaye cin ko he waśte dakapi.

17 Qa Paro Josep heciya, Hunka wanjin wicayaye cin hecen ewicakiya wo. Kaken econpo; wanuyanpi duhapi kin qin wicakiyapi, qa Kanan makoce kin eli ta hdapo.

18 Qa niyatepi tiyohnaka nitawapi kin ko owasin, icupi qa en maupo ; kinlıan Egupta makoce kin en taku waśte yuke cin ciçupi kta qa, taku iyotan waśte makoce aicage cin yutapo.

19 Qa niye hecen econ niśipi. Nitaśicecapi nitawinpi ko ol Egupta makoce kin etanhan canpahmihma yuha hdapi, qa niyatepi kin kici wicahduha upo.

20 Tuka wahpaye duhapi kin he awakicinpi śnipo. Taku wa- 


\section{WICOICAGE.}

śte Egupta makoce ohnaka kin owasin nitawapi kta ce.

21 Unkan Israel cinca kin ecen econpi, qa Josep canpahmihma wicaqu, Paro eya econ śi qon iyecen, waneya tahepi yutapi kta nakun wicaqu.

$22 \mathrm{Qa}$ owasin wokoyake iyohi wicaqu, tuka Benjamin mazaska opawinge yamni qu, qa wokoyake owasin zaptanptan nakun.

$23 \mathrm{Qa}$ śuktanka śonśonna wikcemna taku Egupta aicage cin qin wicakiya, qa nakun śuktanka, śonśonna wiye wikcemna wamnaheza, qa aguyapi śpan, woyute atkuku waneya yuhe kte cin qin wicakiye ca, hena owasin atkuku kin en ahde wicaśi.

24 Qa hunka wanjin wicaye cin kihde wicaśi qa, Ihunhan tahepi taku ayakinicapi kin, ewicakiya: Unkan hdapi.

25 Egupta makoce kin etanhan itawankanhde hdapi, qa Kanan makoce kin ate yapi Jakob yanke cin ekta lripi.

26 Qa heciyapi, Josep nahahin ni, qa Egupta makoce kin owasin yuha ce, eyapi. Unkan cetonwicahda qa wacin hnuni.

27 Hehan Josep oie ewicakiye cin owasin okiyakapi, qa canpahmihma ohna iye ihdaka ye kta e Josep ahde wicaśi qon hena wanyake cehan, Jakob ate yapi cante kin kimdeza.

28 Qa Israel heya, Tho henana Josep micinkśi nahahin ni. Mațe śni wanhdag mde kta ce.

\section{WICOWOYAKE 46.}

1 Hehan Israel ihdaka, iye take tawa ko owasin, qa Berśeba en hi qa, atkuku Izak taku wakan da kin wośnapi wakiyuśna.
2 Unkan Wakantanka hanyetu wowanyake wan en Israel heciya, Jakob, Jakob, eya. Unkan, De iniye ce, eya.

3. Unkan, El niyate ta Wakantanka kin he miye. Egupta en de kte cin ikope śni wo. Hen oyate tanka icah ciciye kta ce.

4 Miye Egupta ekta ciyahna kun mde ca ake acihdi kta, qa Josep nape kin niiśta kin akan aniputake kta ce, eya.

5 Unkan Jakob Rierśeba etanhan inajin. Unkan Israel cinkśi wicaye cin taśicecapi, qa tawicupi, qa Jakob ate yapi kin, henakiya canpahmihma Jakob aupi kta e Paro wicaqu qon, hena ohna yuha yapi.

6 Qa tawanuyanpi, qa tawahpayapi, taku Kanan makoce kin en tonpi kin ikikcupi qa Egupta ekta ihdaka ipi. Jakob taku tawa ko owasin;

7 Cinkśi wicaye cin, qa sanpa cincapi, cunkśi wicaye cin qa cinhintku cunkśi wicayapi kin, taku tawa ko owasin, Jakob kici Egupta ekta ipi.

8 Israel cinca kin Egupta en ipi kin, decen ewicakiyapi, Jakob qa iye cinca, Jakob cinhintku tokapa kin Ruben eciyapi.

9 Qa Ruben cinkśi wicaye cin Ḣanok, qa Palu, qa Herron, qa Karmi.

10 Unkan, Śimeyon cinkśi wicaye cin; Jemuel, qa Jamin, qa Ohad, qa Jakin, qa Zohar, qa Saul, he Kanani winohinca wan ton.

11 Unkan Lewi cinkśi wicaye cin Gerśon, qa Qehat, qa Merari.

12 Unḱan Juda cinkśi wicaye cin Er, qa Onan, qa Śela, qa Perez, qa Zera; tuka Er Onan kici Kanan makoce kin en țapi ; 
qa Perez cinkśi wicaye cin Hீezron, qa Hamul.

13 Unkan Isakar cinkśi wicaye cin Tola, qa Puwa, qa Job, qa Simron.

14 Unkan Zebulon cinkśi wicaye cin Sered, qa Elon, qa Jalel.

15 Hena Leha cinkśi wicaye ca Jakob kiciton, Aram Mdaye kin hen, cunwintku Dina nakun, cinca wica winyan ko wicanagi owasin wikcemna yamni sanpa yamni.

16 Gad cinkśi wicaye cin Zipeyon, qa Hayi, qa Śsuni, qa Ezebon, Eri, qa Arodi, qa Areli.

17 Unkan Aśer cinkśi wicaye cin Jimma, qa Jiśwa, qa Jiświ, qa Beriya, qa Sera tawinohitinpi. Unkan Beriya cinkśi wicaye cin Ḣeber, qa Malkiyel.

18 Hena Zilpa, Laban iye cunwintku Leha qu qon, cinkśi wicaya. Hena Zilpa Jakob kiciton wicanagi ake śakpe.

19 Rahel Jakob tawicu kin cinkśi wicaye cin Josep, qa Benjamin.

20 Unkan Josep cinkśi wicaye cin Manaśe, qa Epraim hena Asenat, Potipera On otonwe kin en wośnapi kage cin he cunwintku, Egupta nakoce kin en Josep kiciton.

21 Unkan Benjamin cinkśi wicaye cin, Bela, qa Bered, qa Aśbel, Gera, qa Naaman, Eri, qa Roś, Mupim, qa H̃upim, qa Ared.

22 Hena Rahel cinkśi wicaye ca Jakob kiciton, wicanagi owasin ake topa.

23 Unkan Dan cinkśi wicaye cin Huśim.

24 Unkan Neptali cinkśi wicaye cin Jahzel, qa Guni, qa Jezer, qa Śilem.

25 Bilha, he Laban iye cunwintku Rahel qu qon, hena Ja- kob kiciton, wicanagi cinkśi wicaye cin owasin śakowin.

26 Wicanagi Jakob nite kin etanhan inanpapi, (Jakob cinca tawicupi kin hena yawapi śni) Jakob kici Egupta ekta ipi kin wicanagi owasin wikcemna śtkpe sanpa śakpe.

27 Unkan Josep cinkśi wicaye cin Egupta en kicitonpi kin, wicanagi, nonpa. Jakob wicowazi Egupta en hi qon, wicanagi kin owasin wikcemna śakowin.

28 Wanna Jakob Juda tokata ye śi, Josep en, Gośén etu itkokim u kte cin heon. Unkan Gośen makoce kin en hipi.

29 Unkan Josep suktanka canpahmihma koyag wicakiye ca atkuku Israel itkokipe kta e Gośen etu i, qa wanhdake ça poskin hduze ça tahu akan tehan ceya.

30 Unkan Israel Josep heciya, Nahahin yani kin, nitohnake kin he wanciyaka, heon dehan mața eśta tehike kte śni.

31 Unkan Josep cinye wicaye cin, qa atkuku tiyohnaka tawa kin owasin hewicakiya: Wahde ca Paro owakimdake kta, Hunka wanjin wicawaye cin, qa ate tiyohnaka tawa kin Kanan makoce kin en unpi qon, wanna en mahipi.

32 Qa wicaśta kin wanuyanpi wihan wicakiyapi kin hecapi, wicaśta wanuyanpi yuha unpi kin iś hecapi, qa tahinca pte ko, qa taku tawapi kin owasin awicahipi.

33 Hecen tohan Paro nicopi, qa winiwangapi qa, Wicolitani tukte wanji opiniçiya he? eye cinhan;

34 Hehan kaken ehapi kta ce, Hokśidan unyaduhapi kin, wanuyanpi awanwicunyakapi ece ; 
WICOICAGE.

unkiś uncistinpidan ehan tanhan heuncapi, qa hunkake wicunyanpi kin hecen opiiçiyapi ece, ehapi kta; hecinhan Gośen en idotankapi kta. Tona wanuyanpi wihan wicakiyapi kin hena orvasin Egupton wahte wicadapi śni.

\section{WICOWOYAKE $4 \%$.}

1 Hehan Josep hde ca Paro okiyake ça, A te qa hunka wanjin wicawaye cin, qa tahinca tawapi, pte tawapi ko; qa taku tawapi owasin, Kanan makoce kin etanhan upi, qa wanna Gośen makoce kin en ahi tipi, eya.

2 Qa hunka wanjin wicaye cin etanhan wicaśta zaptan iwicacu, qa Paro itokam ewicahde.

3 Unkan, Wicohtani tukte wanji opiniçiyapi he? Paro Josep hunka wanjin wicaye cin ewicakiya. Unkan, Hokśidan nitawa wanuyanpi wihan wicunkiyapi, unkiś hunkake wicunyanpi koya, Paro eciyapi.

4 Qa, Makoce kin en ounyanpi kta e unhipi ce, Kanan makoce kin heciya wicaakihan wanna tehika; wanuyanpi unhapi ko takudan yutapi śni, peji wanica; heon ceunniciyapi Gośen makoce kin en hokśidan nitawa unkiyotankapi kte, Paro eciyapi.

5 Unkan Paro Josep heciya, Wanna niyate qa hunka wanjin wicayaye cin niye en hipi ;

6 Egupta makoce kin owasin nitokam wanka. Makoce kin tukte iyotan waśte kin, hen niyate hunka wanjin wicayaye cin ko iyotanke wicakiya wo. Gośen makoce kin he en iyotankapi kte ca, wanjikśi minihecapi sdonwicayaya hecinhan, hena wanuyanpi mitawa kin awanyag wicakiya wo.
7 Unkan Josep iye atkuku Jakob u kiye ca Paro itokam ehde. Unkan Jakob Paro yarva. śte.

8 Unkan, Waniyetu anpetu tona yani he?' Paro Jakob eciya. 9 Unkan, Waniyetu anpetu ihdaka wani kin hena waniyetu opawinge sanpa wikcemna yamni. Waniyetu anpetu wani kin hena tonana qa śikśica. Hunkake wicawaye cin waniyetu anpetu ihdaka nipi qon iyehan wani śui ce, Jakob Paro eciya.

10 Hehan Jakob Paro yawaśte, qa Paro itokapa tanhan kinanpa.

11 Unkan Josep atkuku hunka wanjitku ko, makoce tukte iyotan waśte kin, Rameses makuce kin he en, iyotang wicaśi, qa Egupta makoce kin en maga wicaqu, Paro hecen econ śi qon, he iyecen.

12 Qa Josep atkuku, hunka wanjin wicaye cin, qa atkuku wicowazi kin owasin, taku yutapi wicaqu, taśiceca iyacinyan aguyapi wicaqu.

13 Unkan wicaakilian kin iyotan telika aye cin, heon makoce kin owancaya aguyapi wanica. Wicaakitian kin on Egupta makoce, Kanan makoce ko, awihnuni aya.

14. Unkan aguyapi opetonpi kin he Josep wiyopeye cin, heren mazaska talku Fupta makoce kin en iyeyapi, Kanan makoce en nakun mazaska iyeyapi kin owasin, Josep kamna, qa mazaska kin Paro ti kin en ahiju.

15 Unkan wanna Egupta makoce kin etanhan, Kanan makoce kin etanhan ko, mazaska kin wanna henakeca, hehan Egupton Josep en ahi qa, Aguyapi unqupo. Tokeca e nitokam 


\section{WICOWOYAKE 47.}

unțapi kta he? Ecin mazaska wanna unnicapi kin, eciyapi.

16 Unkan, Wanuyanpi duhapi kin maqupo. Mazaska wanice cinhan nitawanuyanpi kin on aguyapi ciçupi kta ce, Josep eya.

17 Unkan tawanuyanpi kin Josep en ahipi ; śuk tanka, tahinca, pte, qa śuktanka śonśonna, henakiya on, waniyetu kin he aguyapi wicaqu.

18 Waniyetu kin he wanna ihunipi, qa waniyetu iyokihe ake Josep en hipi qa, Itancan anaunkihmapi kte śni, mazaska wanna ecaca wanice ca woteca wanuyanpi owasin itancan duha. Unyuhapi kin itokam takudan unkohdaptapi śni, tancan maga kici ehake hecehnana unhapi.

19 Tokeca awiunhrumpi kin wandake kta unkiye, maga unhapi ko owasin he? Opeuntonpo unkiye unkitamagapi koya. Aguyapi unyaqupi kinhan Paro wowindag unyanpi kta, unkiś maga unhapi koya. Taku unkojupi kta nakun unqupo; kinhan unnipi qa unțapi kte śni, qa unkitamagapi kin hewoskan wanke kte śni ce, eyapi.

20 Hecen Egupton wicaakihan kin on iyotan iyekiyapi, qa wicaśta otoiyohi owasin tamagapi kin wiyopekiyapi; unkan Josep Egupta makoce kin owasin $\mathrm{Pa}$ ro opekiciton, qa Paro makoce kin owasin tawa ya.

21 Qa oyate kin he Egupta makoce ihanke kin anokatanhan otonwe tokeca ohna iyotang wicakiya.

22 Wośnapi kagapi kin henana tamagapi kin wiyopeyapi śni ece. Wośnapi kagapi kin taku yutapi onge Paro wicaqu ece, qa taku Paro wicaqu kin he yutapi, heon tamagapi kin opeton śni.
23 Qa Josep oyate kin hewicakiya, Thopo nakaha opecitonpi niyepi nitamagapi ko, Paro tawa niyanpi kta. Ihopo de wojupi kin cicupi qa makoce kin oyajupi kta.

24 Qa kaketu kta, tohan taku aicaga eca, owasin idutapi qa iyutapi tomtom yahduhapi kta, hetanhan ake maga kin woyajupi qa he yatapi kta, niye, nitaśicecapi qa tona yatipi kin ohna yakonpi kin hena owasin he yutapi kta; tuka iyutapi izaptanptan kin owasin Paro yaqupi kta ce, eya.

25 Unkan, Itancan ni unyayapi iyounnicipipi kte; hecen Paro wowindag unyanpi kta.

26. Unkan wicoope kin de Josep ope wicakiya, qa anpe dehan hececa, Egupta makoce kin en wiyutapi izaptanptan kin Paro tawa ya. Wośnapi kagapi tamagapi kin henana hecapi śni, henana Paro tawa ye śni.

27 Unkan Israel Egupta makoce kin ohna, Gośen makoce kin en iyotanke ca, maga yuhapi qa icagapi qa nina ihduotapi. 28 Qa Jakob Egupta makoce kin en waniyetu ake śakowin ni, hecen Jakob anpetu tawa kin waniyetu ni un kin, waniyetu opawinge sanpa wikcemna topa sanpa sakowin henakeca.

$29 \mathrm{Qa}$ anpetu en Israel te kte cin he wanna aśkadan, hehan cinhintku Josep kico qa, Ceciciya iyocicipi kinhan ninape miceca kin ihukuya kiyugata wo; kinhan wowaonśida wowicake ko ecamiyecon, qa Egupta makoce kin en mayahnake kte śni; 30 'Tuka Egupta makoce kin etanhan amayade ca, ate wicawaye cin ohna hnakapi kin ohna mayahnake kta; hecen hena om imunke kta ce, eciya. Unkan, 


\section{WICOICAGE.}

Miś token ehe cin ecen ecamon kta ce, eya.

31 Unkan Wakantanka cajeyate ca emakiya wo, eya. Unkan Wakantanka cajeyate ça eciya. Unkan Israel can sagye ipa kin akan pamahdedan wocekiye eya.

\section{WICOWOYAKE 48.}

I Unkan hena owasin iyohakam hehan, Tho niyate wayazanka ce, Josep eciyapi, qa cinhintku napin Manaśe Epraim kici hduha ekta i.

2 Unkan Jakob okiyakapi, $\mathrm{Ni}$ cinkśi Josep niye en u ce, eyapi. Unkan Israel wakiśag içiye ça owinja kin akan iyotanka.

3 Qa, El Iyotan waśake cin Kanan makoce kin heciya Luz ekta miye en ihdutanin, qa mayawaśte,

4 Qa hemakiya, Miye wawicahyo cicage, yuota ciciye ça, oyate obe ota cicage ca makoce kin de nakun cicu kta, nicinca nihakam upi kte cin owihankeśniyan tawapi kta ce, emakiya.

5 Qa wanna nicinca nonpa, Egupta makoce kin en nicitonpi, Egupta ekta niye en cihi śni kin itokam, Epraim Manaśe kici, hena mitawa ce, Ruben Ś́ meyon kici iyecen, tawa wicawaye kta ce.

6 Qa taku nitawa kin hena iyohakam nicitonpi kte cin hena nitawapi kta, tuka cinye wicayapi kin eciyatanhan, makoce tawapi kin en caś wicatonpi kta.

7 Miye Aram Mdaye kin etanhan wau qon, hehan Rahel makița, Kanan makoce kin en, canku ohna Eprata etanhan makoce iyutapi kin wanjidan, qa heciya owehnaka Fiprata, Betle- hem eyapi kin hee, canku kin ikiyedan, eya.

8 Hehan Israel Josep cinkśi wicaye cin wanwicahdake ca, Dena tuwepi he? Jakob Josep eciya.

9 Unkan, Wakantanka cinca deciya maqu kin dena eepi, Josep atkuku kin eciya. Unkan, Ceciciya ce, napin makau wo, wicawahdawaśte kta ce, eya.

10 Wanna Israel wicahinca heca on iśta gonga, wanyaka okitpani. Unkan en awicahi, unkan poskin wicahduze ca i iwicaputaka. 11 Israel Josep heciya, Niite kin eqeś wanwahdake kte cin epce śni, unkan wanna icah wicayaye cin hena, Wakantanka wanwicahdag mayan.

12 Unkan Josep hupahu kin etanhan inanpe wicaye ca, ite kin maka kin etkiya patuja.

13 Qa napin wicahduza, Epraim Josep nape etapa kin en, Israel catka kin ektakiya, qa Manaśe iye nape, catka kin en, Israel etapa kin ektakiya; hecen atkuku kin on awicai.

14 Unkan Israel kiyugate ca nape etapa kin Epraim pa kín aputaka, he hakakta tuka, qa nape catka kin Manaśe pa kin akan he tokapa tuka, nape yukcanyan ye kiya.

15 Qa Josep yawaśte qa heya, Wakantanka ate wicawaye $A$ bereyam Izak kici itokam manipi qon, he Wakantanka matonpi kin ehantanhan anpe dehanyan won mayan kin ;

16 Ohnihde un kin taku śica owasin etanhan opemakiton kin he, hokśipidan kin wicayawaśte kte, micajeyan qa ate wicawaye cin Abereyam Irak kici icajeyan ewicakiyapi, qa maka kin ohna nina ihduotapi kte, eya.

17 Unkan atkuku nape etapa 


\section{WICOWOYAKE 49.}

kin Epraim pa kin aputake cin he Josep wanyake ca, śice dake ça atkuku nape lkin yuze ca, Epraim pa kin etanhan Manaśe pa kin etkiya ye kiye kta tuka;

18 Qa, Hecetu śni ate, de tokapa.kin ee. Iye pa kin nape eni.tapa kin on aputaka wo, Josep atkuku kin eciya.

19. Unkan sdonwaya. Micinkśi sdonwaya ce. He nakun oyate kta qa he tanka kta, qeyaś sunkaku iyotan tanka kta qa cinca wicaye kte cin oyate ota kta ce ;

20 Eye ca anpetu kin hehan wicayawaśte qa, Nicajeyan Israel ihdawaśtepi qa, Wakantanka Epraim qa Manaśe iyecen icali niyan nunwe, eyapi kta ce, eya. Hecen Epraim Mànaśe itokam cajeyata.

21 Hehan Israel Josep heciya, Anagoptan wo. Miye mate lita, tuka Wakantanka nicicapi, qa ate wicayayapi tamakocepi kin ekta anihdapi kta.

22 Qa miye makoce onśpa, Amori nape kin etanhan mitacanhipi mitinazipe kin iyahna on iwacu qon, he hunka wanjin wicayaye cin iyakapa ciçu, eciya.

\section{WICOWOYAKE 49.}

1 Qa Jakob cinkśi wicaye cin wicakico qa heya, Mniciyapo, tokata anpetu yeye cin token nihiyahdepi kte cin ociciyakapi kta.

2 Jakob cinkśi wicaye cin witaya upi qa anagoptanpo. Israel niyatepi kin he anakicigoptanpo.

3 Ruben micinkśi tokapa kin he niye, mitowaśake mitowookihi tokaheya kin iyotan wicimdeza iyotan suta.

4 Mini iyecen nihduhepicaśni, lıeon initancan kte śni. Niyate ohehde kin ayadi qa hehan mitowinja kin duśapa ce.

5 Ślmeyon Lewi kici hunka wanjin kiciyapi. Tacanhipi kin wipe wicakisa kin heepi.

6 Canteptanyanpi qehan wicaśta wan litepi, qa iyokipi içiyapi kta e oinatake wan oqapi ; heon wohdakapi kin en minagi kin ye kte śni, qa omniciye tawapi kin en wowitan mitawa un śni nunwe.

7 Wicocanniye tawapi kin yaśicapi nunwe, waditaka ce, towahanicidapi kin he nakun, wohitika ce; Jakob en yukinukan wicawakiye ca Israel ohna yuomden iyaye wicawakiye kta.

8 Juda niye hunka wanjin wicayaye cin niyatanpi kta. Ninape kin toka niyanpi tahu kin akan niyate cinkśi wicaye cin nitokam patujapi kta.

9 Mnaja cincadan wan Juda heca. Wicayapotapi kin etanhan micinlsśi nayajin. Mnaja iyecen canpeśka makehde wanka, qa mnaja wiye wan iyecen, tuwe he pahice kta lie?

10 Juda etanhan maza sagye yutokanpi kte śni, tuka cadotahedan wicaśta yatapi yuke kta, Ślo hi kin helıanyan, qa iye en oyate kin mniciyapi kta.

11 Taśunke śonśonna hastanhanka iyuwi kin en iyakaśkahan, qa taśunke sonśonna cinca kin hastanhanka waśte hinca iyuwi kin ekta, taonhdohda kin miniśa on hdujaja kta qa taśina hastanhanka we kin on.

12 Iśta kin miniśa on śa kte ça hi kin pte asanpi on ska kta.

13 Zebulon miniwanca huta kin en ti qa iye en wita wata oihuni kta, qa Zidon otonwe kin hehanyan yuhe kta.

14 Isakar śuktanka śonśonna 77 
waśake cin heca wan, conkaśke otahedan makan wanka.

15 Okihpapi kin he waśte kin, qa makoce kin wiciyokipi kin he wanyake ca qin kta e tahpa kin qu, hecen wayaka wicohtani kin econ.

16 Dan Israel wicoun wan iyecen taoyate kin wicayaco kta.

17 Wamduśka wan canku tukte ohna yapi kte cin ohna naicilibe ca, śuktanka siyete kin yahitaka on tuwe akan yotanke cin itunkam hinhipaye kta Dan hecece kta.

18 Jehowa woyuśke nitawa kin awape.

19 Ozuye wan Gad azuye kta, tuka ihakam iye azuwicaye kta.

20 Aśer taaguyapi kin waśte qa wicaśta yatapi woyute wiciyokipi kin wicaqu kta.

21 Neptali tamdoka kiyuśkapi kin heca iapi wicimdeza ia.

22 Josep adetka waicahya ece, adetka waicahya mini lidoka icahda, taadetka kin conkaśke iyadipi.

23 Wanhinkpe yuhapi kin hena iyaonpapi qa kigepi qa śicaya kuwapi.

24 Tuka tinazipe kin sutaya han, Jakob waśagye cin towaśake kin eciya tanhan nape isto kin yuwaśakapi ce. Heciya tanhain Israel taimnija $q a$ wo wicaqu kin hee;

25 Niyate Taku wakan da kin eciya tanhan." Iye oniciye ca Iyotan waśake cin iye niyawaśte kta, mahpiya wankan tanhan wowaśte kin, ośbe kin ihukuya wanke cin wowaśte kin, aze tezi ko wowaśte kin nicu kte.

26 Niyate wicayawaśte kin he wawokihika, he ohinniyan he cin isanpa. Paha owihanke wanice cin taku wiciyokipi aicage cin he Josep pa kin en, qa tuwe hunka wanjin wicaye cin etanhan yukinukanpi qon, pesdete kin en unpi kte.

27 Benjamin śunktokeca yatesa heca anpao kte cin hehanyan yute kta ece; htayetu eca wawicaki kin pamni kta.

28 Israel wicoun ake nonpa kin hena owasin heepi, qa hecen ate yapi kin ewicakiye ca wicahdawaśte, otoiyohi towaśte kin iyecen wicayawrśte.

$29 \mathrm{Qa}$ hecen wahokonwicakiya, Miś oyate mitawa kin en ope mayanpi kta, ate wicawaye cin om emahnakapo, imnija ohdoka maga wan Epron Heti kin tawa qon en un kin, he en.

30 Kanan makoce kin etu, Mamore itokam, Makpela maga kin en imnija ohdoka wanke cin he ohna. Abereyam wicaśta ohna hnakapi kte cin he tawa kta e maga kin he Epron Heti kin he opekicaton.

31 Hen Abereyam tawicu Sara kici wicahnakapi, hen Izak tawicu Rebeka kici wicahnakapi, qa hen miś Leha wehnaka.

32 Maga kin he imnija olidoka ohna wanke cin ko, Het cinca wicaye cin opewicakicaton qon, ewicakiya.

33 Hecen Jakob cinkśi wicaye cin wahokonwicakiye cin ayaśtan qehan, siha kin ohehdepi kin en ehdaku qa ta; unkan taoyate kin ekta okipe yapi.

\section{WICOWOYAKE 50.}

1 Hehan Josep atkuku ite kin akan ehpeiciye ca i iputake ca ceya. 2 Qa Josep taokiye peji huta wicaśtapi kin atkuku yuliwin śni waśtemna ye wicaśi. Unkan peji huta wicaśta kin Israel waśtemna yanpi; anpetu wikcemna tom hecakiconpi. 
3 Tona yuhwin śni waśtemna yanpi eca hehanyan . yuśtanpi ece. Unkan Egupton anpetu wikcemna śakowin Jakob aceyapi.

4 Anpetu hena aceyapi kin wanna iyokiptapi, hehan Josep Paro tiyohnaka tawa kin hewicakiya, Wanna waśte mayadapike cinhan miye makapi qa $\mathrm{Pa}-$ ro itokam hecen eyapo.

5 Ate hecen emakiya, Tho miś wanna mate kta ce. Kanan makoce kin heciya ohna hnakapi wan micice cin he ohna mahnaka wo, eye ça Wakantanka cajeyate maśi. Unkan tokin wanna itawankanhde mde ca ate wehnaken, kinhan wahdi kta.

6 Unkan Paro ayupte ça, Itawankanhde ye ca niyate kihuaka wo, konza eye niśi qon iyecen.

7 Unkan Josep atkuku kihnake kta e itawankanhde ye ca Paro taokiye kin owasin opapi, tiyohna hunka wicayapi, qa Egupta makoce kin hunka wicayapi ko uwasin.

8 Qa Josep tiyohnaka tawa, qa hunka wanjin wicaye cin atkuku tiyohnaka tawa owasin; taśiceca qa tahinca, pte ko yuhapi kin henana Gośen makoce kin en kihnakapi.

9 Canpahmihma qa wicaśta śuktanka akan yotankapi ko opapi, hecen ośpaye tanka hinca.

10 Unkan Atad tahocoka kin ekta ipi he Jordan akasanpa wanka, qa heciya woceye tanka anpetu śakowin atkuku kin nina aceyapi.

11 Unkan makoce wojutipi kin Kanani hena Atad tahocoka ohna ceyapi kin he wanyakapi qa, Egupton de nina ceyapi ce, eyapi; heon oyanke kin he $\mathrm{E}$ gupton oceyapi kin eciyapi, he Jordan akasanpa wanka.
12 Hecen cinkśi wicaye cin token econ wicaśi qon, ecen ecakiconpi.

13 Qa cinkśi wicaye cin, hena Kanan makoce kin ekta hduha yapi, qa Makpela maga kin en imnija ohdoka wanke cin he ohna kihnakapi; Mamore itokam; maga kin he Abereyam Epion Heti kin etanhan opekicaton wicaśta ohnahnakapi tawa kta e hecon.

14. Unkan Josep Egupta ekta hda, atkuku hnakapi kin iyohakam; iye hunka wanjin wicaye cin, qa tona iye om atkuku hnakapi kta e itawankanhde yapi qon owasin.

15 Unkan Josep cinye wicaye cin ate yapi kin te cin, heon wikopapi qa heyapi, Olkini Josep śicaya unkuwapi qa iye en taku śica ecaunkiconpi qon iś owasin tokicon kta.

16 Qa hecen Josep okiyag wicaśipi ; Niyate te cin itokam hecen wahokonunkiyapi.

17 Josep kaken eyakiyapi kta, Tokin nicinye wahtanipi kin wicayecicajujun. Śsicaya ecaniconpi tuka niyate ta Wakantanka kin wowindag wicaye cin wahtanipi qon kajujun; eya ce, eyapi. Unkan Josep wicoie okiyakapi kin on ceya.

18 Hehan Josep cinye wicaye cin iye en ipi, qa itokam elpeiçiyapi qa, Iho unyaduhapi ce, eciyapi.

19 Unkan, Ihnuhan ininihanpi kin: Miś Wakantanka hemaceca he?

20 Niyepi kin śicaya ecamicon wacanipi, tuka Wakantanka waśte kta e cin, oyate ota ni wicaye kta anpe dehan iyecen hecon ce.

21 Heon nakaha inihanpi śnipo. Miś wo ciçupi kta niyepi $7 \dot{9}$ 


\section{WICOICAGE.}

nitaśicecapi ko, ewicakiye ça, | kin de etanhan itawankanhde ye hecen wicakihna qa cantowi- niyanpi kta; malsoce wan Abecahnaka.

22 Josep Egupta en ounyan; iye atkuku tawicoun koya, qa Josep waniyetu opawinge sanpa wikcemna ni.

23 Qa Josep Epraim cinca takojatpaku, qa sanpa cinca wanwicahdake ca nakun Manaśe cinhintku Makir cinca kin hena Josep śiyoto akan wicahduha.

24 Hehan Josep hunka wanjin wicaye cin hewicakiya; Miś mate kta tuka Wakantanka niyepi en nihipi kte ça, malsoce cakiye cin he ekta.

25 Qa Josep Israel cinca kin konza ewicakiya, Awicakehan Wakantanka niyepi kin en nihipi kta, qa mihu kin detanhan ayahdapi kta ce, eya.

26 Hehan Josep ța iyaya. Wanna waniyetu opawinge sanpa wikcemna hehan. Unkan iye tancan yuhwin śni waśtemna yanpi, qa Egupta makoce kin en can ohna knakapi wan ohna hnakapi. 


\section{HDINANPAPI.}

\section{WICOWOYAKE 1.}

1 Wanna Israel cinca Jakob kici Egupta ekta hipi cajepi dena eepi, otoiyohi tiyohnaka om hipi.

2 Ruben, Simeon, Lewi Juda,

3 Isakar, Zebulun, qa Benjamin,

4 Dan qa Naptali, Gad qa Aśer.

5 Unkan wicanagi Jakob ceca etanhan inanpapi kin owasin wicanagi wikcemna śakowin, qa Josep eqe wanna Egupta en un.

6 Unkan Josep ta cincu ko owasin, nakun tona kici icagapi kin owasin.

7 Unkan Israel cinca kin nina icagapi, qa ihduotapi, qa waśaka hinca ayapi, qa nina ota ayapi, on makoce kin ow ancaya unpi.

8 Unkan Egupta en wicaśta yatapi tokeca wan najin, he Josep sdonye śni.

9 Unkan oyate tawa hewicakiya, Inyun, Israel cinca oyate kin unkiyepi sam iyeya otapi qa waśakapi.

10 Ito wacinksamya econ wicunkiyapi kta, okini ihduotapi, qa ozuye wan tatpe unhipi kinhan iś eya toka unyanpi om kokijuyapi kta, qa azuunyanpi qa makoce kin etanhan hdinanpapi kta, eya.

11 Unkan tawaqinpi on waśaka śni wicakiyapi kta e wohtani itancan yuhe wicakiyapi. Unkan opiye otonwe, Piton qa Rameses Paro kicagapi.

12 Unkan token iyokiśin wicayapi kin hecen ihduotapi, qa ica- gapi, qa Israel cinca kin on etanhan nina kokipapi.

13 Unkan Egupton Israel cinca kin nina htani wicakiyapi.

14 Qa wohtani tehika owasin econ wicakiyapi on wiconi tawapi pa wicakagapi upśija en, qa maka omdoton en qa wohtani owasin tehiya econ wicakiyapi.

15 Unkan Egupton wicaśta yatapi Heberi cincatonwicakiyapi wanji Ś́sera eciyapi qa unman Pua eciyapi kin hena hewicakiya;

16 Heberi winohinca cinca ton wicayakiyapi eca, qa can akan iyotankapi wanwicadakapi eca cinca wica kinhan te yayapi kta, tuka he winyan kinhan eqe ni kta.

17 Tuka cincatonwicakiyapi kin Wakantanka kokipapi qa token Egupton wicaśta yatapi kin econ wicaśi ecen econpi śni, tuka cinca wica kin ni wicayapi.

18 Unkan Egupton wicaśta yatapi kin cincatonwicakiyapi kin wicakico, qa hewicakiya, Tokeca decen ecanonpi qa cinca wica kin ni wicayayapi he? eya.

19 Unkan cincatonwicakiyapi kin Paro heciyapi, Heberi winohinca kin Egupton winohinca kin iyececapi śni ye, tuka minihecapi qa cincatonwicakiye cin en wicahi śni itokam cincatonpi heon heconkupi yé.

20 Unkan Wakantanka cincatonwicakiyapi tanyan ecawicakicon, unkan oyate kin ihduotapi qa waśaka hinca ayapi.

21 Unkan cincatoriwicakiyapi

Exod. 


\section{HDINANPAPI,}

kin Wakantanka kokipapi lieon tipi wicakicaga.

22 Unkan Paro oyate tawa owasin taku wanji econ wicaśi, Cinca wica kin owasin wakpa kin en elipewicayayapi kta, tuka winyan kin, owasin niwicayayapi kta ce, eya,

\section{WICOWOYAKE 2.}

1 Unkan wicaśta wan Lewi tiyohnaka etanhan Lewi cunwintku wan ekta i qa yuza.

2 Unkan winohinca kin ihduśake ca cinca wan ton, qa hokśidan waśte e wanhdake ça wi yamni nakihma.

3 Hehan sanpa nakihma okihi śni, qa huliba wakiśkotpa wan icu qa bitumen canśin ko on apawinte ca he ohna hokśiyoqopa kin okihnake ca wakpaicahda psa en ehnaka.

4 Unkan tankeku token ecakiconpi kte cin sdonye kta e itehanyan inajin.

5 Unkan Paro cunwintku ihdujaja kta wakpa ekta i, qa tawikośka wakpa hutata kin omanipi ; qa wakiślkotpa kin psa ehna wanyake ca tawikośka kin he huwe ye śi.

6 Qa yulidoke ça hokśiyoqopa wanyaka. Unkan inyun hokśiyoqopa kin ceya. Unkan onśida qa, Heberi cinca wan dee, eya.

7 Unkan, Heberi winohinca waazinkiye cicipan mde ca hokśiyoqopa azin niciye kta ye, tankeku Paro cunwintku kin eciya. 8 Unkan, Ya ye, Paro cunwintku eciya. Hecen wiciyanna kihde ca hokśiyogopa hunku kin kipan.

9 Unkan, Hokśiyoqopa kin de ahda, qa azin miciciya ye, kinhan cicicajuju kte ye, eya. Un- kan winohinca kin hokśiyoqopa ikikeu qa azinkiya.

10 Unkan hoksidan tanka icaga. Unkan Paro cunwintku kin kahi, hecen he ciniśi ya, qa miniyatanhan iwacu eya, heon Mowis eya cajehdata.

11 Unkan Mowis tanka icage cin he iyohakam kaketu; Mowis hunkawanjitku wicaye cin ekta i, qa token qin wicakiyapi atonwan, qa Egupton wicaśta wan Heberi wicaśta iye sunkaku wan kte wanyaka.

12 Qa anokatanhan ihduhomni, qa wicaśta wanica wanyake cehan, Egupton kin he kte, qa wiyaka mahen nahma.

13 Qa inonpa can tankan i, unkan inyun Heberi wicaśta nom kicizapi, unkan, Tokeca nitakoda ayapa he? śicaya econ kin eciya.

14. Unkan, Tuwe wicaśta yatapi, qa wayaco tawa unyayapi kta e nicaga he? Ḣtanihan Egupton yakte kin he iyecen mayakte kta he? eya. Unkan Mowis kokipe ca awicakehan wicoie kin de sdonyapi ce, eya.

15 Unkan Paro wicoie kin de nahon qa Mowis kte kta e akita, unkan Mowis najica, Paro ite kin etanhan qa Midian makoce kin en yanke ça miniyowe wan akan iyotanka.

16 Unkan Midian wawayuśna kin cunwintku śakowin atkukupi tahinca tawa mini yatke wicakiyapi kta e hipi, qa etanhan icupi, qa wakiśkotpa ojudan yapi.

17 Unkan wilianwicakiyapi heca en hipi qa nape wicayapi ; unkan Mowis najin, qa owicakiye ca tahinca tawapi mini wicaqu.

18 Unkan atkukupi kin Ruel en hdipi ; unkan, Tokeca nakaha ecadan yahdipi he? eya. 


\section{WICOWOYAKE 3.}

19 Unkan, Egupton wicaśta wan wilian wicakiyapi etanhan eunhdakupi, qa nakun mini unkicicupi, qa tahinca kin mini wicaqu, eyapi.

20 Unkan tukte he? tokeca wicaśta kin elipe yayapi he? kicopo, aguyapi yute kta ce, eya.

21 Unkan wicaśta kin he kici ounye kta Mowis iyokipi ; unkan cunwintku Zipora tawicu kta e qu.

22 Unkan cinca wan kiciton, unkan, Oyate tokeca tamakoce kin en manka ce, eye ça heon Gersom eya caślkiton.

23 Unkan anpetu ota iyohakam, Egupton wicaśta yatapi ta. Unkan Israel cinca kin śica howayapi wolitanipi kin on, qa wolitanipi kin on ceyapi kin he wankantuya Wakantanka ekta i.

24 Unkan Wakantanka śica howayapi kin nahon, qa Abereham, qa Izak, qa Jakob om wicotakuye kage ciqon he kilssuya.

25 Qa Wakantanka Israel cinca kin awicatonwan, qa Wakantanka sdonwicaya.

\section{WICOWOYAKE 3.}

1 Unkan Mowis iye tunkanku Jetro Midian wawayuśna tahinca tawa awanwicayake ca tahinca hopuze cin iheyata awicaye ca Wakantanka paha tawa kin $\ddot{H}$ oreb ekta $\mathrm{i}$.

2 Unkan Jehowa ohnihde kin otehi wan cokaya, peta ide wan en ihdutanin he wanyaka; unkan inyun otehi peta en itkon, tuka hulinage śni.

3 Unkan, Ito ekta mde ca wowanyake tanka kin he, tokeca otehi kin hulinage śni he wanmdake kta, Mowis eya.

4 Unkan wanyake kta e u kin he Jehowa wanyake ca Wakan- tanka otehi cokaya tanhan kipan, qa Mowis, Mowis, eya. Unkan, Iho miye, eya.

5 Unkan, Ihnuhan deciya ikiyedan yahi kinhan. Maka kin tukten nayajin kin he wakan ce; heon nisiha etanhan hanpa hduśdoka wo;

6 Qa miś nihunkake taku wakandapi kin he miye, Abereham taku wakanda qa Izak taku wakanda kin, qa Jakob taku wakanda kin he miye ce, eya. Unkan Mowis Taku Wakan atonwe kta kokipa, heon ite kin aihdahpa.

7 Unkan, Egupta en oyate mitawa toiyokiśicapi kin he wanmdake, ca wicakahapapi kin on śicahowayapi kin he nawalion qa wayazanhdapi kin sdonwaya.

8 Qa Egupton napepi kin etanhan ewicawahdaku qa makoce kin he etanhan, makoce tanka qa waśte, makoce wan ohna pte asanpi qa canhanpi tiktica kaduze cin he, Kanani, qa Ḣeti, qa Amori, qa Perazi, qa Hiwi, qa Jebusi ounyanpi kin, heciya awicamde kta e kun wahi ce.

9 Hantuke, Israel ceyapi kin wanna en mahi, qa iyokiśicapi kin token Egupton iyokiśin wicayapi kin he nakun wanmdaka. 10 Heon iho wanna oyate mitawa, Israel cinca kin Egupta etanhan hdinanpe wicayaye $\mathrm{kta}$ e Paro ekta ye ciśi kta ce, Jehowa eya.

11 Unkan, Miś matuwe he on Paro ekta mde ca Israel cinca kin Egupta etanhan hdinanpe wicawaye kta, Mowis Wakantanka eciya.

12 Unkan heya, Awicakehan nici waun, qa ye ciśi kin de etanhan sdonyaye kta, oyate kin Egupta etanhan hdinanpe wicayaye iyohakam he kin de akan Wakantanka ohoyadapi kta ce. 


\section{HDINANPAPI,}

13 Unkan Mowis Wakantanka heciya, Iho Israel cinca kin en wai, qa nihunkakepi Taku Wakandapi kin he niyepi elsta u maśi, epe cinhan; hehan, Token eciyapi emakiyapi kinhan, taku epe kta he?

14. Unkan, Taku waun kin he waun ce, qa Israel cinca kin hecen ewicayakiye kta, Waun kin he niyepi en u maśi ce, Wakantanka Mowis eciya.

15 Qa nakun Wakantanka Mowis heciya, Israel cinca kin hecen ewicayakiye kta, Jehowa nihunkakepi Taku Wakan dapi kin, Aberaham Taku Wakan da kin, qa Izak 'Taku Wakan da kin qa Jakob Taku Wakan da kin he niyepi ekta u maśi ce. Micaje kin hee owihanke wanin qa wicoicage yeye cin hecen milksuyapi kta.

16 Ekta hde ça Israel hunkayapi kin mniciye wicayakiye ca hecen ewicayakiye kta; Jehowa nihunkakepi wakandapi kin he miye en ihdutanin, Aberaham qa Izak qa Jakob Taku Wakan dapi kin hemakiya; Awicakehan wanciyakapi qa Egupta en token ecannionpi kill.

17 Qa Egupton iyokiśin niyanpi kin etanhan hdinanpe ciyapi kta, Kanani qa Hiti qa Amori qa Perazi, qa Hiwi qa Jebusi tamakocepi kin ekta, makoce wan pte asanpi qa canhanpi tiktica on kaduze cin he ekta; epa ce.

18 Qa niho kin nanicilionpi kta, qa niś Israel hunkayapi kin om Egupton wicaśta yatapi kin en yaipi kta, qa Heberi Taku Wakan dapi kin Jehowa unkakipapi, heon tokin anpetu yamni oicimani hopuze ekta unyanpi, qa Jehowa Wakan undapi kin taku waunkiyuśnapin, eyakiyapi kta.
19 Unkan miye he sdonwaya, Egupton wicaśta yatapi kin dapi iyowinniciyapi kte śni, qa nape kin waśake kte śni.

20 Qa minape kin yewakiye ça taku tehilhika mitawa Egupton cokaya ecamon kta, hena owasin on awicawape kta he iyohakam ye niśipi kta.

21 Qa Egupton kin oyate kin de cante wicakiyapi he wakage kta, hecen yaupi kinhan cokadan yaupi kte śni.

22 Tuka winohinca otoiyohi tuwe ikiyedan ti kin, qa tuwe iye ti kin ohna ti kin, he etanhan mazaska oinpi qa mazaskazi oinpi qa wokoyake da kta, qa nicincapi wica winyan ko hena un wicayakiyapi kta, hecen Egupton wawicayakipi kta.

\section{WICOWOYAKE 4.}

1 Unkan Mowis ayupte ca, Ehaeś wicamadapi kte śni, qa Jehowa niye en ihdutanin śni, eyapi kta, hecen maho kin nahonpi kte śni, eya.

2 Unkan Jehowa heciya, Ninape ohna yanke cin he taku he? Unkan, Cansakadan, eya.

3 Unkan, Makata ehpeya wo, eya. Unkan makata ehpekiya qehan wanmduśka icaga ; unkan itokapa tanhan Mowis najica.

4 Unkan, Ninape hdugate ca sinte kin yuza wo, Jehowa Mowis eciya. Unkan nape hdugate ca he yuza, hehan nape kin ohna cansakadan icaga.

5 Heon Jehowa iye hunkakepi Taku Wakan dapi kin, Abereham Taku Wakan da, qa Izak Taku Wakan da, qa Jakob Taku Wakan da kin he niye en ihdutanin kin he wicadapi kta.

6 Qa nakun, Ikpi kin ohna nape ye kiya wo, Jehowa eciya. 


\section{WICOWOYAKE 4.}

Unkan nape ikpi kin ohna ye kiye ca chdaku; unkan inyun nape kin ska, wa iyececa.

7 Unkan, Ninape ake niikpi ohna ye kiya wo, eya. Unkan ake nape ikpi kin ohna ye kiye ca ikpi etanhan ehdaku, qa inyun ake iye cehpi kin iyececa.

8 Unkan kaketu kta, wicanidapi kte śni, qa wowapetokeca tokaheya ho kin wicadapi kte śni eśta, wowapetokeca unman ho kin wicadapi kta.

9 Qa wowapetokeca nonpa kin dena nakun wicadapi śni kinhan qa niho kin nalionpi kte śni kinhan, wakpa kin etanhan mini iyacu, qa maka puze cin ayakaśtan kta, qa mini wakpa etanhan iyacu kin he maka puze cin akan we icu kta ce, eya.

10 Unkan, Itancan ceciciya ce, miś wicaśta wamdapike śni, nitaokiye kici woyahdake cin ehautanhan nakun he itokam; tuka i matke, qa ceji matke, Mowis Jehowa eciya.

11 Unkan Jehowa heciya, Tuwe wicai kin kaga he? qa ia okitpani, qa nogetpa, qa wawanyake cin, qa iśta gonge cin? Jehowa he niye śni he?

12 Heon wanna ekta ya wo, unkan nii kin kici waun, qa token ehe kte cin he onspe ciciye kta ce.

13 Unkan, Itancan ceciciya, Tuwe nape kin on ye yaśi kte cin he ye śi ye, eya.

14 Hehan Jehowa tocanniye kin Mowis aide qa heya, Aaron Lewi kin he nicinye heca śni he? Iye wayapika he sdonwaya, qa nakun, iho wanna itkonicipe kta u ce; qa wanniyake cinhan cante kin iyuśkin kta.

15 Qa he taku eyakiye kta, qa i kin ohna wicoie kin yeyakiye kta, qa miś nii kici waun kta, qa iye i kin kici, qa token ecanonpi kta he onspe ciciyapi kta.

16 Qa iye niye on oyate kin taku ewicakiye kta, qa hecen iye nii kin ee yakiye kta, qa iye Taku Wakan niyuhe kta.

17 Unkan cansakadan kin de ninape ohna iyacu kta, qa he on wowapetokeca ecanon kta.

18 Unkan Mowis iye tunkanku Jetro ekta kihde ca heciya, Ito mde ca mihunkawanji Egupta ohna unpi kin ekta wahde ca nahanhin ni unpi kinhaniw anmdake kta ce. Unkan, Zaniyan hda wo, Jetro Mowis eciya.

19 Wanna Midian ohna Jehowa Mowis heciye ciqon, Iho Egupton ekta hda wo, wicaśta tona ninagi akitapi qon hena owasin tapi ce.

20 Unkan Mowis iye tawicu qa cinhintku napin ewicahdaku, qa śuktanka śonśomna akan iyotangwicakiye ca Egupta makoce kin ekta kihda; qa Mowis Wakantanka cansakadan tawa kin nape kin ohna icu.

21 Unkan Jehowa Mowis heciya, Egupta ekta yaki kinhan waktaya un wo. Wowapetokeca owasin ninape ohna cicu kin Paro itokam ecanon kta, qa miś Paro cante kin mdusuta kta, hecen oyate kin kihde wicaye kte śni.

22 Qa Paro hecen eyakiye kta, Jehowa hecen eya, Israel micinkśi tokapa kin hee.

23 Qa heciciya, Micinkśi omakiye kta hde śi wo; qa hde kta teyahinda kinhan nicinkśi tokapa te waye kta ce.

24 Unkan, kaketu tahepi tukten iwankapi kin en Jehowa akipe ca te ye kta cin.

25 Unkan Tipora wanhi wan icu, qa cinhintku ce inkpa ha kin bakihdaya, qa siha kin ekta 


\section{HDINANPAPI,}

ehpeye ça, Awicakehan we wicaśta takuciya ye, eya.

26 Unkan he ayuśtan hehan, Bahdayapi on etanhan we on takuciye ye, eya.

27 U.ikan Jehowa Aaron kaken eciye ciqon, Mowis itkokipe kta e iyr ya wo, hopuze cin ekta, unkan yyaye ca Wakantanka he tawa kin ekta akipe ca i itputaka.

- 28 Unkan Jehowa yeśi kin, oie kin owasin, qa wowapetokeca econ śi kin owasin, Mowis Aaron okiyaka.

29 Unkan Mowis iyaya Aaron kici, qa Israel cinca hunkayapi kin owasin mniciye wicayapi.

30 Qa wicoie Jehowa Mowis eciye ciqon owasin Aaron ewicakiya, qa wowapetokeca kin econ, oyate kin wicitolram.

31 Unkan oyate kin wicadapi ; qa Jehowa Israel cinca kin en wicahi, qa iyokiśieapi kin wanyake cin he nationpi qehan patujapi qa cekiyapi.

\section{WICOWOYAKE 5.}

- Unkan iyohakam Mowis qa Aaron Paro en hipi, qa heciyapi, Oyate nitawa hewotahedan wohanpi wan micicagapi kta e iyowin wicakiya wo, Jehowa Israel Taku Wakan dapi kin eya ce.

2 Unkan Paro heya, Jehowa he tuwe on ho kin nawation, qa Israel ye wicawaśi kta he? Jehowa sdonwaye śni qa Israel amduśtan kte śni ce, Paro eya.

3 Unkan heyapi, Heberi Taku Wakan dapi kin unkakipapi, ceunniciyapi, iyowinunkiyapi, hopuza ekta anpetu yamni unyanpi, qa Jehowa Taku Wakan undapi waunkiciyuśnapi kte, okini makośica qaiś canhipi on iyaunkihpayapi kta.

4 Unkan, Tokeca Mowis qa 86
Aaron oyate kin wicohtani ayuśtan wicaya kiyapi he? Nitawaqinpi kin ekta hda po, Egupton wicaśta yatapi kin ewicakiya.

5 Qa, Inyun makoce oyate kin wanna ota ce, qa tawaqinpi kin kpahpe wicayakiyapi, Paro eya. 6 Qa anpetu kin ne Paro oyate wicakahapapi, qa itancanpi kin econ wicaśi qa hewicakiya,

7 Dehanyan oyate maka omdoton kagapi kta e peji puza wicayaqupi ece, tokata ecanonpi kte śmi. Iye yapi qa peji puza mnakiyapi kta.

8 Qa dehanyan maka omdoton iyuta kagapi kin he kah wicayakiyapi kta, duoptetupi kte śni; kujapi nakaś, heon loo yeyapi qa, Ito unyanpi qa Taku Wakan undapi kin waunkiciyuśnapi kta, eyapi.

9 Wicaśta kin wohtani tehika econ wicayakiyapi kta, hecen htanipi $\mathrm{kta}$, qa wicoie ecinśniyan ihaktapi kte śni ce.

10 Unkan oyate wicakahapapi kin, qa itancanpi kin tankan ipi, qa oyate kin hewicakiyapi; $\mathrm{Pa}-$ ro hecen eya, Peji puza ciçupi kte śni ce.

11 Niś hunktiya po, qa peji puza tukten iyeyayapi kin hetanhan ikikcu po, qa hitayanipi kin takudan yuoptetupi kte śni.

12 Hecen oyate kin Egupta makoce kin owancaya enanakiya iyayapi, qa peji puza hee kiya aguyapi hu kin mnayanpi.

13 Unkan wicakahapapi kin inahni wicayapi, qa Nitohtanipi kin hduśtan po; anpetu otoiyohi peji yuke ciqon he iyecen, eyapi.

14. Unkan Israel cinca itancanpi kin Paro wicakahapapi kin yuhe wicakiyapi kin hena awicapapi qa, Tokeca maka omdoton kahi niśipi kin btanihan qa 


\section{WICOWOYAKE 6.}

nakaha duśtanpi śni, hekta ecannonpi qon he iyecen.

15 Hehan Israel cinca itancanpi kin upi, qa Paro ho yekiyapi, qa heyapi, 'I'okeca nitaokiye hecen ecawicayecon he?

16 Peji puza takudan nitaokiye unqupi śni ; Maka omdoton kaga po; unkekiyapi, qa nitaokiye unkapapi tuka, oyate nitawa kin hena ee taku sica econpi.

17 Unkan, Niśnikujapi, nikujapi ce, heon, Unliyayapi qa Jehowa waunkiciyu napi kta, ehapi.

18 Heon wania hunktiya po, qa htani po. leji takudan nicupi kte śni, qa maka omdoton iyenaka yakaga $f_{a} \mathrm{kta}$, eya.

19 Unkan, Anpe u otoiyohi maka omdoton yaka api qon he duoptetupi kte śni, cvicakiyapi qehan, taku śica el a unpi Israel

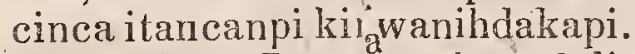
20 Unkan Paro danhan hdinanpapi qehan, Me vis Aaron kici, canku ohna r inpi, unkan itkowicalkipapi.

21 Qa hewicaki,tpi, Jehowa anitonwanpi qa waj co kta. $\mathrm{Pa}$ ro iśta kin ohna qa aokiye iśtapi kin ohna ounmjepi śicamna unyakagapi, qa n repi kin en isan wan on unkter sta wicayaqupi ce.

22 Unkan Mowis thowa ekta ihdamna, qa heya, nican tokeca oyate kin de, śtína ecawicayecon, qa tokeca ${ }_{\{0}$ ta ye mayaśi he?

23 Qa nicajeyan $\mathrm{P}$ b takewakiya ekta wahi kin $\mathrm{C}$ antanhan oyate kin de taku śi ecawicakicon, qa dehanyan co ate nitawa ecaca wicayak śke śni, eya.

\section{te.}

WICOWOYAal 6 .

1 Unkan Jehowa Mo, i, heciye, Ito token Paro eca son ktel heciya; cin he wandake kta. Nape waśaka on ye wicaśi kta, qa makoce tawa etanhan nape waśaka on wicakahape kta.

2 Unkan Wakantanka Mowis kici wohdaka, qa heciya, Jehowa he miye.

3 Qa Abereham qa Izak qa Jakob en Taku Wakan waśaka mihdutanin, tuka micaje Jehowa he sdonmayanpi śni.

4 Qa nakun wicotakuye mitawa wicaweciyusuta; makoce tawapi śni ohna ihdakapi kin he, Kanan makoce kin he wicawaqu kta.

5 Nakun Israel cinca śicahowayapi kin he nawahon, Egupton wowidag wicayapi kin he on, qa wicotakuye mitawa kin weksuya.

6 Heon Israel cinca kin hecen ewicakiya wo, Jehowa he miye, qa Egupton waqin niciyapi kin ihukuya tanhan hdinape ciyapi kte, ca htani niciyapi kin etanhan ecihdakupi kta; qa isto hdugata qa woyaco tanka on opecitonpi kta.

7 Qa oyate mitawa kta e ciyuzapi kta, qa Taku Wakan yadapi-kin he miye kta, qa Jehowa wakan yadapi Egupton waqin niciyapi ihukuya tanhan hdnape niyanpi kin he miye, sdonyayapi kte.

8 Qa makoce wan Abereham qa Izak qa Jakob wicawaqu kta kepa, qa minape wankan yewakiya, he ekta aciupi, qa tawayayapi kta e cicupi kta ce, Jehowa he miye.

9 Unkan Mowis Israel cinca kin hecen ewicakiya; tuka toksape kicaksapi, qa wicohtani telika, heon Mowis anagoptanpi śni.

10 Unkan Jehowa ie ça Mowis 


\section{HDINANPAPI,}

11 Paro Egupton wicaśta yatapi kin ekta ya wo; qa iye tamakoce kin etanhan Israel cinca kin ye wicaśi kta, keciya wo.

12 Unkan Mowis Jehowa itokam ie ca, Inyun, Israel cinca kin namalionpi śni, qa iha bamakilidayapi śni hecen token Paro namalion kta he? eya.

13 Unkan Jehowa Mowis Aaron kici Israel cinca kin ekta, qa $\mathrm{Pa}$ ro Egupton wicaśta yatapi kin ekta ye wicaśi, qa Egupta makoce kin etanhan hdinape wicaye kta, kewicakiya.

14 Hunkake wicayapi tiyohna.. ka itancanpi kin dena eepi. Israel cinca tokapa kin Ruben, he cinca kin Hanok, qa Pallu, qa Hezron, qa Karmi; Ruben wicowazi kin hena eepi.

15 Simeon cinca kin, Jemuel, qa Jamin, qa Ohad, qa Jakin, qa Zohar, qa Kanani winohinca wan cinca Saul; Simeon wicowazi kin dena eepi.

$16 \mathrm{Qa} \mathrm{Lewi} \mathrm{cinca} \mathrm{cajepi} \mathrm{wicoi-}$ cagepi kin iyececa; Gerśom, qa Qohat, qa Merari. Qa waniyetu Lewi ni kin opawinge sanpa waniyetu wikcemna yamni sanpa śakowin.

17 Gerśom cinca kin Libni, qa Śimi wicowazi tawapi kin iyececa.

13 Qa Qohat cinca kin Amram, qa Izhar, qa Hebron, qa Uziel ; qa waniyetu Qohat ni kin waniyetu opawinge sanpa wikcemna yamni sanpa yamni.

19 Qa Merari cinca kin, Mahli, qa Muśi. Lewi wicowazi kin hena eepi wicoicage tawapi kin iyececa.

20 Unkan Amram iye tunwicu Jokebed e yuza; unkan he Aaron, qa Mowis kiciton; qa waniyetu Amram ni kin hena wariyetu opawinge sanpa wikcemna yamni sanpa śakowin.
21 Qa Izhar cinca kin Qora, qa Nepeg, qa Zikri.

22 Unkan Uziel cinca kin Miśael, qa Elizapan, ya Sitri.

23 Unkan Acron Aminadab cunwintku, Nahsón tawinohtin, Eliśeba yuza; ankan Nadab, qa Abihu, qa Eleazar, qa Itamar hena kiciton!

24 Unkan Gora cinca kin Aśer qa Elqana, qa Abiasap; Qorahi wicowazipi kin hena eepi.

25 Unkan Aaron cinhintku Eleazar, Putiel cunsintku kin etanhan wanji yuzi ; unkan he $\mathrm{Pi}$ nehas kiciton. Lewi ateyapi kin itancanpi kin h:na eepi, wicowazipi kin iyececı.

26 Egupta m.koce etanhan Israel cinca kinobe tawapi ecekcen hdinape ricaya po, Jehowa tuwe ewicakie ciqon, he Aaron qa Mowis den eepi.

27 'Tuwe Isr el cinca kin Egupta etanhan hinape wicaye kta, Paro, Eguptin wicaśta yatapi eciyapi qon, Mowis qa Aaron hena eepi.

$28 \mathrm{Qa}$ anpqu wan Jehowa Mowis Egupta nakoce kin ohna taku eciya heen kaketu.

29 Unkan ehowa ie ca, Mowis heciya, Jebwa he miye, taku eciciye cinowasin Paro Egupton wicaśr yatapi eciya wo, eya.

30 Unka, Inyun iha bamakilidayapi śr, heon Paro namahon kte śni, $\mathrm{N}$ wis, Jehowa itokam, eya.

\section{WTOWOYAKE 7.}

1 UnkarJehowa Mowis heciya, Wan $\mathrm{Pa}$ taku wakan niye kta e cicaga qa Aaron nicinye ie yakiye lit.

2 Niś tru eye ciśi kin owasin ecen eh kta, qa nicinye Aaron Paro iyeamakocepi kin etanhan 


\section{WICOWOYAKE $\%$.}

Israel cinca kin kihde wicaśi kta, eciye kta.

3 Tuka miś Paro cante kin mdusuta kta, qa Egupta makoce kin ohna wowapetogtokeca mitawa, qa taku woyuśinya wahduota kta.

4 Tuka Paro nanilionpi kte śni, hecen Egupton akan minape ewahnake kte ça woyaco tankinkinyan on Israel cinca kin, oyate mitawa, obe mitawa kin, Egupta makoce kin etanhan hdinape wicawaye kta.

5 Hecen Jehowa he miye Egupton sdonyapi kta, minape Egupton akan ye wakiye ca wicacokaya tanhan Israel cinca kin hdinape wicawakiye cinhan.

6 Unkan Mowis qa Aaron Jehowa token econ wicaśi kin owasin ecen econpi.

7 Unkan Mowis waniyetu wikcemna śahdogan, qa Aaron waniyetu wikcemna śahdogan sanpa yamni, hehan Paro en wohdakapi.

8 Unkan Jehowa ie ça Mowis Aaron kici hewicakiya;

9 Tohan, Wowapetokeca kin kpazo po, Paro eniciyapi kinhan, Cansakadan ikikcu, qa Paro itokam elipe kiya wo; Aaron eyakiye kta; unkan wamduśka icage kta.

10 Unkan Mowis qa Aaron Paro en hipi; qa token Jehowa econ wicaśi kin ecen econpi, qa Aaron cansakadan kin elipe kiya, Paro itokam, qa taokiye wicitokam; unkan wamduśka icaga.

11 Unkan Paro nakun wicaśta ksapa qa pejuta wicaśta wicakico, unkan Egupton pejuta wicaśta iś eya taku wakanyan ohanyanpi on iyecen econpi.

12 Qa otoiyohi cansakadan ehipe kiya; unkan wamduśka ica- gapi, tuka Aaron cansákadan tawa kin he cansakadan tawapi kin napca.

13 Unkan Paro cante kin ihdusuta, qa nawication śni, Jehowa eye ciqon he iyecen.

14 Unkan Jehowa Mowis heciya. Paro cante kin tke, oyate kin ye wicaśi wicada śni.

15 Tho hanhanna Parn mini ekta i lita; ekta ya wo, qa wakpa hutata itkokim nayajin kta, qa cansakadan wamduślta icage ciqon he ninape ohna iyacu kta.

16 Qa heyakiye kta, Jehowa Heberi Taku Wakan dapi kin niye ekta u maśi qa, Mitaokiye, oyate mitawa kin, hopuze cin ekta ye wicaśi wo, eniciye maśi ; tuka dehanh wanayahon śni.

17 Ito Jehowa hecen eya, Jehowa he miye, de etanhan sdonyaye kta. Miś cansakadan minape ohna mduhe cin on mini wakpa ohna un kin awape kta; hecen mini kin we icu kta.

18 Qa hogan wakpa ohna yakonpi kin tapi kta, qa wakpa kin śicamna kta, hecen Egupton wakpa mini kin yatkanpi hitihdapi kta.

19 Unkan Jehowa Mowis heciya, Aaron heciya wo, Cansakadan ikikcu; qa Egupton mini tawapi ektakiya nape hdugata wo; wakpa tawapi ektakiya, qa tawakpadanpi ektakiya, qa cokan tawapi ektakiya, qa minikiwitaya tawapi ektakiya, hecen hena we icu kta; qa Egupta makoce kin owancaya we yuke kta; nakun can-opiye ohna qa inyan opiye ohna.

20 Unkan Mowis qa Aaron token Jehowa econ wicaśi kin he iyecen econpi, qa cansakadan qon yuwankan icu, qa mini wakpa ohna un kin apa, he Paro wanyaka, qa taokiye wanyakapi he89 


\section{HDINANPAPI,}

cen mini wakpa ohna un kin owasin we icu.

21 Qa hogan wakpa ohna yakonpi kin țapi, qa wakpa kin śicamna, qa Egupton mini wakpa etanhan yatkanpi okihipi śni ; qa Egupta makoce kin owancaya we yukan.

22 Unkan Egupton pejuta wicaśta iś eya taku wakanyan ohanyanpi on iyecen econpi, hecen Paro cante kin ihdusuta, qa nawicahon śni, Jehowa eye ciqon he iyecen.

23 Unkan Paro ihdamna, qa ti kin ekta kihda, qa he nakun ekta cante kin ye kiyje śni.

24 Unkan Egupton owasin mini wakpa etanhan yatkanpi okihipi śni, heon mini yatkanpi kta e wakpa icahda qapi.

25 Unkan Jehowa wakpa kin apa ehantanhan anpetu śakowin wanna henakeca.

26 Unkan Jehowa Mowis heciya, Paro ekta ya, qa heciya wo; Jehowa hecen eya, Oyate mitawa omakiyapi kta ye wicaśi wo.

27 Tuka yapi kta teyahda kinhan, iny un makoce nitawa owancaya hnaśka on awape kta.

28 Qa wakpa kin hnaśka ota icah ye kta, hecen hinanpapi qa yati kin en hiyupi kta, qa tipi ohna inonke cin mahentuya, qa owinja nitawa akan, qa nitaokiye tipi kin mahen, qa onna aguyapi śpanyayapi kin en; qa oyaptapi wopiye nitawapi kin en ;

29 Qa niye en, qa nitaoyate kin en, qa nitaokiye owasin en, hnaśka wankan hiyupi kta.

\section{WICOWOYAKE 8.}

1 Unkan Jehowa Mowis heciya, Aaron hecen eciya wo; Cansakadan hduha ninape hdugata wo, wakpa kin ektakiya, qa wakpadan kin ektakiya, qa cokan ektakiya, hecen hnaśka kin Egupta makoce kin akan hinanpapi kta.

2 Unkan Aaron Egupton mini tawapi ektakiya nape hdugata, unkan hnaśka kin hinanpapi qa Egupton tamakocepi kin akahpapi.

3 Unkan pejuta wicaśta wakanyan ohanyanpi ece on hecen econpi, unkan hnaślia kin Egupta makoce kin akan hinanpapi.

4 Unkan Paro Mowis Aaron kici wicakico qa, Jehowa cekiyapo, hecen hnaśka kin yutokan kta; miye etanhan qa oyate mitawa etanhan; kinhan oyate kin ye wicawaśi kta, qa Jehowa wakiciyuśnapi kta, eya.

5 Unkan Miye on ihdatan wo; tohantu kte, niye qa nitaokiye, qa nitaoyate wocekiye eciciyapi kta, qa hnaśka awihnunipi kta; niye etanhan qa yati kin etanhan; wakpa kin heceedan ohna ihanpi kta? Mowis Paro eciya. 6 Unkan, Heyakecinhan, eya ; Unkan heya, Jehowa Wakan undapi kin he tuwedan iyececa śni sdonyaye kta e heon token ehe cin hecetu kta;

7 Qa hnaśka kin aniyuśtanpi kta, qa yati kin, qa nitaokiye, qa oyate nitaws, wakpa heceedan ohna ihanpi kta.

8 Qa Mow is qa Aaron Paro etanhan inanpapi, qa Mowis Jehowa hoyekiya; hnaśka Paro en hiyuye ciqon heon etanhan.

9 Unkan Mowis eye cin he iyecen Jehowa econ, qa hnaśka kin tapi, tipi kin etanhan, qa tonwanyanpi kin etanhan qa maga etanhan.

10 Unkan hena mnayanpi paha ota, unkan makoce kin śicamna. 11 Unkan iyozi yukan he Paro

90 


\section{WICOWOYAKE 8.}

wanyake ca cante kin ihdutke, qa nawication śni, Jehowa eye ciqon he iyecen.

12 Unkan Jehowa Mowis heciya, Aaron heciya wo, Cansakadan ye kiye ca makamdu kin apa wo, hecen Egupta makoce kin owancaya hoponkadan icage kta.

13 Unkan hecen econpi, qa Aaron cansakadan hduha nape hdugate ca makamdu kin apa, hecen hoponkadan icaga, wicaśta akan qa woteca akan, Egupta makoce kin owancaya makamdu kin owasin hoponkadan icaga.

14. Unkan Pejuta wicaśta taku wakanyan ohanyanpi on he iyecen econpi hoponkadan hinanpe yapi kta, tuka okihipi śni; hececa eśta hoponkadan yukan, wicaśta akan qa woteca akan.

15 Unkan Pejuta wicaśta kin Wakantanka napsukaza kin dee, Paro eciyapi; tuka Paro cante kin ihdusuta, qa nawicalion śni; Jehowa eye ciqon he iyecen.

16 Unkan Jehowa Mowis heciya, Hanhanna hin kikta, qa Paro itokam inajin wo, iho mini ekta inanpe kta, qa heyalkiye kta; Jehowa hecen eya, Oyate mitawa ye wicaśi wo, hecen omakiyapi kta.

17 Tuka niye mitaoyate kin ye wicayaśi śni kinhan, ito miś tatawamduśka ye wicawaśi kta, niye en, qa nitaokiye en, qa nitaoyate en, qa yatipi kin en; hecen tatawamdnśka kin Egupton tipi kin ojun yapi kta, qa maka akan yakonpi kin he nakun.

18 Qa anpetu kin he en, Gośen makoce kin akan mitaoyate yakonpi kin he mdukinukan kte, he ohna tatawamduśka wanice kta; hecen maka cokaya kin Jehowa he miye sdonyaye kta.
19 Qa oyate mitawa oyate nitawa iyececapi kte śni wakage kta. Heyakecinhan wowapetokeca kin de tanin kta.

20 Unkan Jehowa hecen econ, qa tatawamduśka tehika Paro ti kin ekta hipi; qa taokiye tipi kin, qa Egupta makoce owancaya en, makoce kin awihnuni tatawamduśka kin on.

21 Hehan Paro Mowis Aaron kici wicakico, qa heya, Hunktiya po, makoce kin olina Taku Wakan yadapi kin wakiciyuśna po.

22 Unkan Mowis heya, Hecen econkupi kta iyecetu śni. Jehowa Wakan undapi waunkiciyuśnapi kin he Egupton wahte dapi śni. Inyun Egupton taku wahte dapi śni iśtapi kin itokam waunyuśnapi kinhan inyan on unkininpi kta.

23 Anpetu yamni imanipi hewoskantu kin ohna unyanpi, qa Jehowa Wakan undapi kin waunkiciyuśnapi kta, unkekiyapi qon he iyecen.

21 Unkan Paro heya, Ye ciśipi kta qa hewoskantu ohna Jehowa Wakan yadapi kin wayeciduśnapi kta, tuka sanpa tehan idadapi kte śni. Wocekiye emiciciya po.

25 Unkain Mowis heya, Ito miś niye etanhan inawape ca Jehowa cewakiye kta; unkan tatawamduśka, kin yutokan lkta, Paro etanhan, qa taokiye etanhan, qa taoyate etanhan; tuka ihnuhan Paro ake wahnayan, qa oyate kin Jehowa wakiyuśnapi kta ye wicaśi śni.

26 Hehan Mowis Paro etanhan tankan inanpe ca Jehowa/cekiya. 27 Unkan Jehowa Mowis eye ciqon he iyecen econ, qa tatawamduśka kin yutokan, Paro etanhan, qa taokiye etanhan, q 


\section{HDINANPAPI,}

taoyate etanhan, wanjidan ihe śni.

28 Tuka Paro dehan nakun cante kin ihdutke, qa oyate kin ye wicaśi śni.

\section{WICOWOYAKE 9.}

1 Unkan Jehowa Mowis heciya, Paro ekta ya wo, unkan heyakiye kta; Jehowa Heberi Wakan dapi kin hecen eya, Oyate mitawa omakiyapi kta ye wicaśi wo.

2 Qa yapi kta teyahinda, qa nahanhin sutaya wicaduze cinhan;

3 Ito Jehowa nape kin wanunyanpi nitawa tinta ohna yakonpi kin akan un kta, śuktanka en, śuktanka śonśonna en, camo en, pte en, qa tahinca en makośice rehilka hinca kta.

4 Qa Jehowa Israel tawanunyanpi, qa Egupton tawanunyanpi otahedan yukinukan kta, hecen Israel cinca taku tawapi kin owasin etanhan takudan te kte śni.

5 Nakun tohantu kte Jehowa yaotanin, qa heya; heyakecinhan Jehowa wicoie kin de econ kta, makoce ohna.

6 Unkan ihanhanna wicoie kin he econ; unkan Egupton tawanunyanpi kin owasin tapi, tuka Israel cinca tawanunyanpi wanjidan țe śni.

y Unkan Paro tuwe ekta ye śi, unisan inyun, Israel tawanunyanpi kin wanjidan țe śni, tuka cante kin ihdutke qa oyate kin ye wicaśi śni.

8 Unkan Jehowa Mowis Aaron kici hewicakiya, Maza śdoyapi oceti cahota kin ninape ohnakapi kin icu po, qa Mowis he mahpiya ektalkiya kadada iyeye kta, Paro iśta kin itokam.

9 Qa he watuśekśeca kta, Egup92 ta makoce kin owancaya, qa siyaka wicao ton icahye cin heca kta, wicaśta akan, qa woteca akan, Egupta makoce kin owancaya.

10 Unkan Maza śdoyapi oceti etanhan cahota icupi, qa Paro itokam inajinpi, qa Mowis he mahpiya ektakiya kadada iyeya. Unkan he śiyaka wicao ton icah ye cin heca, wicaśta en, qa woteca en.

11 Unkan śiyaka wicao on etanhan pejuta wicaśta kin Mowis itokam najin okitpanipi; nakaś śiyaka wicao pejuta wicaśta en, qa Egupton owasin en.

12 Tuka Jehowa Paro cante kin yusuta, hecen nawicahon śni, Jehowa Mowis eciye ciqon he iyecen.

13 Unkan Jehowa Mowis heciya, Hanhannahin kikta, qa Paro itokam inajin wo, qa heyakiye kta; Jehowa Heberi Wakan dapi kin hecen eya, Oyate mitawa ye wicaśi wo, unkan ohomadapi lita.

14 Dehan wowayazan mitawa owasin nicante ekta hiyu waye kta, qa nitaokiye en, qa nitaoyate en, hecen maka kin owancaya tuwedan iyemaceca śni sdonyaye kta, heon.

15 Nakaha minape ye wakiye ca acipe kta, qa oyate nitawa makośice on, qa maka kin etanhan nitanin kte śni ;

$16 \mathrm{Qa}$ awicakehan heon najin ciye, mitowaśake kin niye en wahdutanin kta; qa micaje kin maka kin owancaya oyakapi kte.

17 Dehanyan niś nihduwankantuya, oyate mitawa en, qa yapi kta iyowin wacayakiye śni.

18 Ito miś heyakecinhan dehantu Egupta ohna hinhewaye kta, wasu tehika hinca anpetu tokaheya en ounyanpi ehantan- 


\section{WICOWOYAKE 10.}

han ecen dehanyan, tohinni hececa śni.

19 Heon wanna ye wicaśi, qa nita wanunyanpi kin nape wicaya wo, qa taku nitawa tinta en un kin owasin, wicaśta, qa woteca tona tinta ohna yakonpi, qa tipi en mnawicayapi śni, hena owasin wasu ahinhewicaye kta, unkan tapi kta.

20 Paro taokiye tuwewe Jehowa oie kin ikope cinhan iye taokiye, qa tawanunyanpi tipi kin ekta awicahdi.

21 Tuka tuwe Jehowa oie kin ekta cante kin ye kiye śni kinhan, taokiye qa tawanunyanpi kin tinta ohna elipe wicaya.

22 Unkan Jehowa Mowis heciya, Mahpiya ektakiya nape hdugata wo, hecen Egupta makoce owancaya wasu yuke kta, wicaśta akan, qa woteca akan, qa tinta wato owasin akan, Egupta makoce ohna.

23 Unkan Mowis cansakadan hdugata mahpiya ektakiya, unkan Jehowa hoton, qa wasu hiyuya, qa peta maka ainyanka, hecen Jehowa wasu Egupta makoce ahinhe kiya.

24 Unkan wasu, qa peta wasu kici icicahiya tehika hinca, Egupton oyate yukan ehantanhan makoce owancaya ohna tohinni hececa śni.

25 Qa Egupta makoce kin owancaya wasu kin taku tankan un kin owasin apa, wicaśta, qa woteca, qa tinta wato kin owasin apa, qa wasu kin can iheye cin owasin kawega.

26 'Tuka Gośen' makoce kin Israel cinca ohna yakonpi kin, heceedan ohna wasu wanica.

27 Unkan Paro tuwe ekta ye śi, qa Mowis Aaron kici wicakico, qa hewicakiya; Dehan wawahtani, Jehowa hee ohan owo- tanna tuka miś qa oyate mitawa unśicapi.

28 Jehowa cekiya po, qa henakeca kta, sanpa Wakantanka hoton kte śni, qa wasu wanice kta'; unkan ye ciśipi kta, qa sanpa owanji nayajinpi kte śni.

29 Unkan Mowis heciya, Otonwe etanhan inanwape cinhan Jehowa ektakiya nape wahdumdaye kta hecen hoton kin henakeca kta, qa wasu kin sanpa wanice kta; heon Jehowa maka kin tawaya sdonyaye kta.

30 Tuka niye qa nitaokiye dehanyan Jehowa Wakantanka yakinihanpi kte śni sdonwaya.

31 Unkan hahonta on kagapi, qa barle kin hena kawankapi; nakaś barle kin wanna itka hinanpa, qa hahonta on kagapi wahica.

32 Tuka aguyapi hu kin qa wamnaheza kin hena kawankapi śni, nakaś hena oical tehan.

33 Unkan Mowis Paro etanhan otonwe itankan inanpe ça nape hdumdaya, Jehowa ektakiya ; unkan hotonpi kin qa wasu kin anapta, qa magaju maka kin sanpa ahinhe śni.

34 Unkan magaju kin qa wasu kin qa hotonpi kin anaptapi, $\mathrm{Pa}$ ro wanyake ca ake wahtani, qa cante kin ihdutke; iye qa taokiye nakun.

35 Hecen Paro cante kin ihdusuta, qa Israel cinca kin ye wicaśi śni, Jehowa Mowis on eye ciqon be iyecen.

\section{WICOWOYAKE 10.}

1 Unkan Jehowa Mowis heciya, Paro ekta ya wo, miśs iye cante kin mdutke, qa taokiye cantepi kin nakan; hecen wicacokaya wowapetokeca kin dena wahdu tanin kta, heon letanhan. 9.3 


\section{HDINANPAPI,}

2 Qa hecen Egupta ohna taku wakanyan owahanmda, qa wowapetokeca mitawa ecawicawecon kin hena nicinkśi, qa nitakoja owicayakidake kta, nogepi ohna, qa Jehowa he miye sdonyayapi kta.

3 Unkan Mowis qa Aaron Paro en hipi, qa heciyapi, Jehowa Heberi Wakan dapi kin hecen eya, Tohanyan mitokam nihduhukuya tawațenyaye kte śni he? Oyate mitawa ye wicaśi wo, unkan omakiyapi kta.

4 Tuka mitaoyate yapi kta teyahinda kinhan, ito heyakecinhan miś psipsicadan ota nitamakoce en hiyu waye kta.

5 Unkan maka itohnake kin akahpapi kta, hecen tuwe maka kin wanyake kte śni, qa taku nahanhin ecen han, taku wasu kin onicicaptapi kin he temyapi kta, qa maga ohna can nitawapi kin tona camni uye cin owasin temyapi kta.

6 Qa yati kin ohna otapi kta, qa nitaokiye tipi kin owasin, qa Egupton owasin tipi kin ohna otapi kta, niyatepi qa niyate ateyapi kin takudan he iyececa wanyakapi śni, makka akan unpi ehantanhan ecen anpetu kin de iyehantu; eya qa ihduhomni qa Paro etanhan inanpa.

7 Unkan Paro taokiye heciyapi, Tohanyan wicaśta kin de unhmunkapi kta he? Wicaśta kih Jehowa wakan dapi kin okiyapi kta e ye wicaśi wo ; Egupta awihnuni nahanhin sdonyaye śni he?

8 Unkan ake Mowis, Aaron kici Paro en hiyuwicayapi, unkan hewicakiya, Hunktiyapo, Jehowa Wakan yadapi kin okiya po; tuwewe dapi kta he?

9 Unkah Mowis heya, Kośka, wicahinca ko unyanpi kte, unki- cincapi wica winyan ko opapi kta, tahinca pte ko hduha unyanpi kta, Nakaś Jehowa wounkicihanpi kta.

10 Unkan hewicakiya, Niś nitaśicecapi ko ye ciśipi kta e Jehowa nicipi un kte. Wanyaka po; nitokam taku śica yukan.

11 Hecetu śni do. Wicaśta tanka kin wanna yapo, qa Jehowa okiyapo yacinpi qon hee. Unkan Paro itokapatanhan ham wicayapi.

12 Unkan Jehowa Mowis heciya, Egupta makoce ektakiya nape hdugata wo, psipsicadan on, unkan Egupta makoce kin akan hiyupi kta, qa makoce wato kin owasin temyapi kte, taku wasu kin okapte cin iyuhpa.

13 Unkan Mowis cansakadan kin hdugate, Egupta makoce kin ektakiya; unkan Jehowa wiyohiyanpa tanhan tateyanpa makoce en hiyuya, anpetu kin he osan, qa hanyetu osan, qa ihanhanna wiyohiyanpa tanhan tateyanpa kin psipsicadan hiyuya.

14 Unkan psipsicadan kin Egupta makoce owancaya iwankam iyayapi, qa Egupta ihdukśan owancaya iyahanpi, tehika hinca, hena itokam psipsicadan hececa wanica, qa iyohakam hececapi kte śni.

$15 \mathrm{Qa}$ makoce itohnake kin owancaya akahpapi, qa makoce kin aotpas yapi, qa makoce wato kin owasin temyapi, qa can waskuyeca wasu okapte cin nakun owasin; hecen Egupta makoce owancaya can akan, qa tinta peji ohna takudan to ihe śni

16 Unkan Paro inaliniyan Mowis Aaron kici wicakico, qa heya, Wawalitani, Jehowa Wakan yadapi kin en, qa niyepi nakun en. 


\section{WICOWOYAKE 11}

$17 \mathrm{Qa}$ wanna tokin wawahtani kin nakaha heceedan miyecicajujun, qa Jehowa Wakan yadapi kin cekiya po, hecen wiconte kin de heceedan miciyutokan kta.

18 Unkan Paro etanhan inanpe ca Jehowa cekiya.

19 Unkan Jehowa tateyanpa kin yuhomni wiyohpeya tanhan suta hinca, qa he psipsicadan icu, qa Mde śa en iyohpe wicaya, Egupta makoce owancaya psipsicadan wanjidan ihe śni.

20 Unkan Jehowa Paro cante kin yusuta unkan Israel cinca kin ye wicaśi śni.

21. Unkan Jehowa Mowis heciya, Mahpiya ek takiya nape hdugata wo, hecen Egupta makoce akan otpaza kta, qa otpaza kin yutanpica kta.

22 Unkan Mowis mahpiya ektakiya nape hdugata, hecen Egupta makoce kin owancaya otpaza soka hinca yיkan, anpetu yamni. 23 Tuwedan sunkaku wanhdake śni, qa tuwedan towinja kin etanhan najin śni, anpetu yamni ; tuka Israel cinca owasin tipi kin ohna ojanjan wicayukan.

24 Unkan Paro Mowis kico qa heya, Hunktiyapo, Jehowa okiyapo nitaśicecapi nakun onipapi kta. Tahinca nitawapi qa pte nitawapi kin heceedan owanji yakonpi kta.

25 Unkan Mowis heya, Wośnapi, qa wohuhnahyapi nakun hduhe unyakiyapi kta, hecen Jehowa Wakan undapi waunkiciyusnapi kta.

26 Qa nakun wanunyanpi unkitawapi opapi $\mathrm{kta}$, taśake wanjidan ihe kte śni. Hena etanhan Jehowa Wakan undapi kin ounkiyapi kta. Nakaś unkiś ekta unkipi śni hehanyan taku on Jehowa ounkiyapi kta sdon unkiyapi s̉ni.
27 Unkan Jehowa Paro cante kin yuśuta; unkan ye wicaśi tawațenye śni.

28 Qa Paro heciya, Mitan tanhan hunktiya wo. Ihnunhan miite kin ake wandake cinhan. Tohan miite wandake cinhan anpetu kin he en nite kta.

29 Unkan Mowis heya, Token ehe cin hecetu kta. Niite kin ake icimana wanmdake kte śni.

\section{WICOWOYAKE 11.}

1 Wanna Jehowa Mowis heciye ciqon, Ehake wowayazan wanjidan Paro akan hiyu waye kta, qa Egupton akan. He iyohakam detanhan ye niśipi kta, tohan ye niśipi kinhan ocowasin detanhan nicahapapi kta.

2 Wanna oyate nogepi ohna kewicakiya wo, qa wicaśta otoiyohi takodaku etanhan, qa winohinca tuwe kodaye cin etanhan mazaska oinpi, qa mazaskazi oinpi kidapi kta.

3 Unkan Egupton kin oyate kin cante wicakiye Jehowa kaga. Nakun Mowis wicaśta kin tanka hinca, Egupta makoce ohna, Paro taokiye wicitokam, qa oyate kin wicitokam.

4 Unkan Mowis heya, Jehowa hecen eya, Hanyetu cokaya miś Egupton cokaya inanwape kta.

5 Qa tuwe caske owasin Egupta makoce ohna tapi kta Paro cinhintku tokapa oiyotanke tawa akan iyotanke kte cin etanhan, wikośka wiyukpan icahda iyotanke cin cinhintku tokapa kin aiyahdeya; nakun woteca cinca tokaheya wica tonpi kin owasin.

6 Qa Egupta makoce owancaya woceye tanka kta; he iyececa hektapatanhan wanica, qa tokata ake he iyecece kte sni. 


\section{HDINANPAPI,}

7 Tuka Israel cinca owasin ekta śunka wanjidan keś ceji hduśkan kte śni, wicaśta qa woteca unman tukte ekta. Hecen Egupton, qa Israel cinca kin otahedan Jehowa yukinukan sdon yayapi kta.

8 Qa nitaokiye dena owasin en mahipi qa miye en patujapi kta, qa Toki iyaya ye niye, qa oyate nihukuya unpi kin owasin, emakiyapi kta, qa he iyohakam toki mde kta, eye ca Paro nina canniye cin etanhan inanpa.

9 Wanna Jehowa Mowis heciye ciqon, Mita wowapetokeca Egupta makoce ohna yuotapi kta; heon Paro nanihonpi kte śni.

10 Unkan Mowis Aaron kici wowapetokeca kin dena owasin Paro itokam econpi, unkan Jehowa Paro cante kin yusuta, heon iye tamakoce etanhan Israel cinca kin ye wicaśi śni.

\section{WICOWOYAKE 12.}

1 Wanna Jehowa Mowis Aaron kici Egupta makoce kin ohna hewicakiye ciqon.

2 Wi kin de wi itancan dawapi kta; omaka wi kin de tokaheya dawapi kta ce.

3 Israel omniciye owasin hecen ewicakiya po; Wi kin de anpetu iwikcemna kin tipi otoiyohi on tacincadan ikikcupi $\mathrm{kta}$, ateyapi tipi kin iyececa.

4 Tuka tiyohnaka tonana on tacincadan yutapi okihipi śni kinhan, iye qa tuwe ikiyedan ti kin he kici icu kta, wicanagi yawapi iyecen, wicaśta otoiyohi token yute kta okihi, tacincadan on dawapi kta.

5 Tacincadan waśte, mdoka waniyetu wanjidan kta, taliin wanunyanpi, qa iś tatokadan etanhan iyekcupi kta.
6 Qa wi kin de anpetu iaketopa kin, hehanyan kaśka yahduhapi kta, qa hitayetu otahedan, Israel omniciye owasin he patapi kta.

7 Qa we kin etanhan icupi qa tośu tiyopa anokatanhan, qa iwankam amnimnipi kta, tipi ohna he yutapi kte cin he akan.

8 Qa hanyetu kin he en cehpi kin peta on ceonpapi yutapi kta, aguyapi onapohye codan, qa peji pa kici he yutapi kta.

9 Hetanhan ongedan saka qa mini ohna ohanpi yatapi kte śni, tuka petan ceonpapi; pa kin qa huha śupe kici yatapi kta.

10 Hetanhan ihankanna hehanyan oyahdaptapi kte śni; qa ihanhanna hehanyan ongedan oyaptapi kinhan, he peta on huhnah yayapi kta.

11 Qa hecen yatapi kte, nite ipiyag yakitonpi, qa siha hanpa oyakihanpi, qa sagye nape ohna yahduhapi kta, qa inahniyan yatapi kta; Jehowa toacakśin kin hee.

12 Qa hanyetu kin de Egupta makoce opta mde ca tona tokapa Egupta makoce ohna, wicaśta woteca ko owasin awicawape kta, qa Egupton taku wakan dapi kin owasin akan woyaco ecamon kta. Jehowa he miye.

13 Unkan tipi ohna dukanpi kin hena we kin on wapetog yakitonpi kta, hecen we kin wanmdake ca niwankam acakśin mde ca Ëgupta makoce kin awape cinhan wowayazan on nițapi kta iyonihipi kte śni.

14 Unkan anpetu kin de wokiksuye duhapi kta, qa he ohna wohanpi Jehowa woyecihanpi kta; nitoicagepi ohua wokage, owihanke wanica wohanpi yayapi kta.

15 Anpetu śakowin aguyapi 


\section{WICOWOYAKE 12.}

onapohye codan yatapi kta; anpetu tokaheyr awicakehan yatipi kin etanhan onapoliye dutokanpi kta. Nakaś anpetu tokaheya etanhan anpetu iśakowin kin hehanyan tuwe kaśta onapoliye yute cinhan, wicanagi kin he Israel etanhan yutokanpi kta.

16 Anpetu tokaheya kin en wicakicopi wakan, qa anpetu iśakowin en wicakicopi wakan duhapi kte, anpetu kin hena en wohtani talzudan econpi kte śni, tuka wicanagi iyohi taku yute kta wiyeya kagapi kta, heceedan ecanonpi kta.

17 Qa onapohye codan wohanpi kin yapatanpi kta, nakaś anpetu kin de en obe nitawapi kin Egupta makoce etanhau hdinanpe ciyapi, heon anpetu kin de yapatanpi kta, nitoicagepi yeye cin wokage owihanke wanica.

$18 \mathrm{Wi}$ tokaheya, anpetu iaketopa, htayetu etanhan aguyapi onapohye codan yatapi kte, wi anpetu wikcemna nonpa sanpa wanjidan hitayetu kta hehanyan. 19 Anpetu śakowin onapoliye yatipi kin ohna iyeyapi kte śni, nakaś hehanyan tuwe taku napohyapi yute cinhan wicanagi kin he oyate tokeca qa iś makoce he en tonpi kin anman tukte kaśta, Israel omniciye etanhan yutokanpi kta.

20 Takudan napoliyapi yatapi kte śni. Yatipi kin owasin ohna aguyapi napolyapi śni yatapi kta, eya.

21 Unkan Mowis Israel hunkayapi kin owasin wicakico, qa hewicakiya, Ekta hdapo, qa wicoun nitawapi on tacincadan ikikcupo, qa woacakśin kin patapo.

22 Qa peji hota opahte wan iyacupi kta, qa we kin tiyopa icahda un kin he en oyaputkanpi, qa tośu tiyopa anokatanhan, qa iwankapatanhan ayamnimnipi kta, we tiyopa icahda un kin he on. Unkan ihanhanna kin hehanyan tuwedan iye tiyopa etanhan inanpe kte śni.

23 Hecen Jehowa Egupton wicakaśtaka hiyaye kta, qa tośu tiyopa anokatanhan qa iwankam hena akan we kin wanyake cinhan Jehowa tiyopa kin acakśin kta, qa waihang ye cin he anipe kta e yatipi en hiyu iyowinkiye kte śni.

24 Unkan wicoie kin de yapatanpi kta, he wokage owihanke wanica niye qa nicinca duhapi kta.

25 Qa hecetu kta, tohan makoce wan Jehowa niçupi kin ekta yaipi, eye ciqon iyecen, wohtani kin de oyapapi kta.

26 Qa tohan nicincapi kin, Wohtani kin de ecannonpi kin he taku he? eniciyapi kinhan;

27 Hehan hehapi kta, Woacakśin Jehowa wakiyuśnapi kin dee, Iye Egupton wicakaśtake ceehan, Egupta makoce ohna Israel cinca tipi kin acakśin, qa untipi kin patan ce. Unkan oyate kin patujapi qa ohodapi.

28 Unkan Israel cinca kin ekta hdapi, qa token Jehowa Mowis Aaron kici econ wicaśi kin he iyecen econpi.

29 Unkan kaketu, hanyetu cokaya hehan Jehowa tona Egupta makoce ohna caske owasin wicakaśtaka, Paro cinhintku tokapa toiyotanke akan iyotanke kta etanhan, wayaka wicakaśka tipi ohna yanke cin cinhintku tokapa aiyahdeya, qa woteca cinca tokapa nakun owasin.

30 Unkan Paro hanyen kikta, iye qa taokiye owasin, qa Egupton owasin. Unkan Egupta
Ex.
97 


\section{HDINANPAPI,}

ohna śicahowayapi tanka, nakaś tipi tukte tuwedan țe śni wanica.

31 Unkan hanyen Mowis, Aaron kici wicakico, qa heya, Najinpo, oyate mitawa wicehnatanhan inanpapo, niye qa nakun Israel cinca kin owasin, qa hunktiyapo, Jehowa okiyapo ehapi qon iyecen.

32 Nakun tahinca nitawapi qa pte nitawapi kin ikikcupo, ehapi qon iyecen; nakun miś eya mayawaśtepo.

33 Unkan Egupton iyowicapaśtakapi, qa owasin unțapi se eyapi, heon oyate kin makoce etanhan ye wicayapi kta inahnipi.

34 Unkan oyate kin aguyapi mdu kin nahanhin napoliyapi śni ikikcupi, wakśica towokoyakepi ohna pahtapi tahpapi kin akan.

35 Qa Israel cinca kin Mowis eye ciqon he.iyecen econpi, qa Egupton etanhan mazaska oinpi, qa mazaskazi oinpi, qa wokoyake dapi.

36 Unkan Egupton kin oyate kin cante wicakiyapi kin he Jehowa kaga; heon wicaqupi, unkan taku Egupton tawapi yuha iyayapi.

$3 \%$ Qa Israel cinca kin Rameses etanhan ihdakapi, Sukot ekta, wicaśta kektopawinge opawinge śakpe Huninyunkenken manipi qa śicecapi kin hena wicayawapi śni.

38 Qa oyate tokeca wicota opapi qa tahinca qa pte, wanuyanpi ota hinca.

39 Qa aguyapi mdu Egupta etanhan yuha hdinanpapi kin he śpanyanpi, aguyapi hmiyanyan he napohyapi śni, ecin Egupta etanhan nape wicayapi, qa owanji unpi okihipi śni, ya nakun waneya ic̣icagapi śni, nakaś.

40 Israel cinca Egupta en iyo98 tankapi kin wanna waniyetu opawinge topa sanpa wikcemna yamni en ounyanpi.

41 Qa waniyetu opawinge topa sanpa wikcemna yamni owihanketa, anpetu kin he en, Jehowa obe tawa owasin, Egupta etanhan hdinanpapi.

42 Hanyetu kin de Jehowa on awacinpi kta; Egupta makoce etanhan hdinanpe wicaya, heon Israel cinca kin owasin wicoicage yeye cin ecekcen Jehowa hanyetu tawa kin he awacinpi kta.

43 Unkan Jehowa Mowis Aaron kici hewicakiye ciqon; Woacaksin wokonze kin dee, oyate tokeca cinca kin tuwedan hetanhan yute kte śni.

44 Tuka wicaśta otoiyohi taokiye mazaska on opetonpi, he bayahdaye cinhan, hehan hetanhan yute kta.

45 Tuwe oyate tokeca makoce en ti, qa iś tohtani opeyaton eśta he yute kte śni.

46 Tipi wanjidan ohna he yutapi kta, qa celipi kin ongedan tipi kin he etanhan tankan adapi kte śni, qa huhu kin wanjidan duwegapi kte śni.

47 Israel omniciye ocowasin heconpi kta.

48 Qa tuwe oyate tokeca niye kici ounye ca woacakśin Jehowa on ope kte cinhar, tona wica iye ti kin ohna owasin bahdayapi kte, hehan ikiyedan hi, qa hecon kta; hecen tuwe makoce ohna tonpi kin iyececa kta; tuka bahdayapi śni tuwedan hetanhan yute kte śni.

49 Tona makoce en tonpi, qa oyate tokeca niyepi ehna ounyanpi kin wicoope wanjidan yuhapi kta.

50 Unkan token Jehowa Mowis qa Aaron econ wicaśi kin he iye- 


\section{WICOWOYAKE 13.}

cen Israel cinca kin owasin econpi.

51 Unkan anpetu kin he Jehowa Israel cinca kin obe tawapi kin ecekcen, Egupta makoce kin etanhan hdinanpe wicaya.

\section{WICOWOYAKE 13.}

1 Unkan Jehowa ie ca Mowis beciya,

2 Tona caske owasin miciyuwakan wo, Israel cinca kin ehna tona winyan tamni nahdoke cin wicaśta woteca ko owasin mitawa.

3 Unkan Mowis oyate kin hewicakiya, Anpetu kin de kiksuya po, he en Ëupta makoce kin etanhan, wayaka tipi kin etanhan yahdinanpapi, Jehowa nape waśaka on hetanhan hdinanpe niyanpi, heon takudan napohyapi yutapi kte śni.

4 Aguyapi itka hinanpe, Abib wi kin anpetu kin de yahdinanpapi.

5 Unkan makoce wan Jehowa nicu kta e niyate wokonze on ewicakiya, Kanani qa Hiti kin, qa Amori kin qa Hiwi kin qa Jebusi kin tamakocepi kin he en Jehowa hiyuniye cinhan, makoce wan ohna pte asanpi qa canhanpi tiktica kaduze cin he ohna, wi kin de en wicohan kin de ecannon.kta.

6 Anpetu sakowin hehanyan aguyapi napohyapi śni yate $\mathrm{kta}$, qa anpetu iśakowin kin Jehowa wohanpi kicagapi kta.

7 Aguyapi napohyapi śni, anpetu śakowin yutapi kta, qa aguyapi napohyapi nicipi wanyakapi kte śni, qa onnapohyapi kin makoce nitawapi kin ohna wanyakapi kte śni.

8 Qa anpetu kin he nicinkśi oyakidake ça heyakiye kta,
Egupta makoce etanhan wau qehan Jehowa taku ecamicon heon de ecamon.

9 Unkan he ninape akan wowapetokeca duhe kta, qa niiśta otahedan wokiksuye kta, hecen Jehowa toope kin nii kin ohna un kta ; nakaś nape waśaka on Jehowa Egupta etanhan hiyu niyan.

10 Heon wokonze kin de omaka iyehantu ca oyape kta, waniyetu otoiyohi.

11 Unkan tohan Jehowa Kanani makoce kin ekta aniye cinhan, qa he niçu, niś qa nihunkakepi eniciya qon he iyecen ;

12 Hehan winyan cinca tokapa kin owasin, Jehowa on dutokan kta, qa wanunyanpi nitawa cinca tokapa mdoka kin owasin Jehowa tawa kta.

$13 \mathrm{Qa}$ śuktanka śonśonna cinca tokapa kin owasin opeyakiton $k$ ta, tahinca cinca wan he iyopeyakiye kta, qa opeyakiton śni kiuhan pakin yakakse kta; qa wicaśta nicincapi kin tona caskepi owasin opeyakiton kta.

$14 \mathrm{Qa}$ kaketu kta, tokata tohan nicinca, De taku hwo? eya iniwange cinhan, hehan heyakiye kta, Nape waśaka on Egupta etauhan, wayaka tipi kin etanhan, Jehowa hdinanpe unyanpi.

15 Unkan unhdapi Paro katinyan tehinda; heon Jehowa tona caskepi Egupta makoce ohna owasin wicakte, wicaśta cinca tokapa, qa nakun woteca cinca tokapa, heon tona caskepi owasin Jehowa wawakiyuśna, qa micinca caske opewakiton, ehe kita. $16 \mathrm{Qa}$ he ninape akan wowapetokeca kta, qa ite akahpe niiśta otahedan niciyuke kta, nakaś nape waśaka on Jchowa Egupta etanhan hdinape niyanpi. 
17 Unkan kaketu, Paro oyate ye wicaśi qehan Wakantanka Pilistim tamakocepi canku kin ohna awicaye śni, he ptecedan tuka okini oyate ozuye wanyakapi. kinhan iyope ic̣iyapi qa Egupta ekta hdapi kta, eya.

18 Heon Wakantanka oyate kin wicayuhomni, qa Mde-śa hopuze canku kin ohna awicaya; unkan Israel cinca kin ipiyag kitonpi Egupta makoce kin etanhan inanpapi.

19 Unkan Mowis Josep huhu kin yuha hda, nakaś Israel cinca kin Taku Wakan icajeyan wicaśi qa heya, Awicakehan Wakantanka en nihipi kta, qa huhu mitawa yuha detanhan inayapapi kta.

20 Unkan Sukot etanhan ihdakapi, qa liopuze kin icahda Elam en etipi.

21 Unkan Jehowa wicitokam anpa eca malipiya bosdata wan ohna, canku kin ohna ye wicaya, qa hanyetu eca peta bosdata, hecen anpetu hanyetu ko, mani okihipi ece.

22 Anpetu eca malipiya bosdata ewicakicihdaku śni, qa hanyetu eca peta bosdata wicitokapa tanhan.

\section{WICOWOYAKE 14.}

1 Unkan Jehowa ie ca Mowis heciya,

2 Israel cinca kin decen ewicakiya wo ; Ihdamnapi qa Hahirot i kin itokam etipi kta, Migdol qa Mde kin otahedan, Baal Zepon itokapatanhan he iyotakons, mde icahda eyatipi kta.

3 Unkan, Israel cinca kin makoce ohna nunipi hew oskan onawicataka, Paro eye kta.

4 Hecen Paro cante kin mdusuta kta, unkan tawicape kta; he- cen Paro qa ozuye tawa kin owasin etanhan wowitan waton kta; qa Jehowa he miye Egupton sdonyapi kta, eya. Unkan hecen econpi.

5 Unkan oyate kin najicapi kin Egupton wicaśta yatapi kin okiyakapi, hehan Paro cante kin, qa taokiye cantepi kin oyate ekta ayuhomnipi, qa tokeca de econkupi, qa Israel wowidag wicunyanpi qon tokan ye wicunśipi hwo? eyapi.

6 Qa canpahmihma aqin kicaton qa taoyate kin hduha eyaya.

7 Qa canpahmihma opawinge śakpe kahnili icu, qa Egupton tacanpahmihma owasin, qa otoiyohi ohna wicaśta yamni.

8 Unkan Jehowa Egupton wicaśta yatapi kin Paro cante kin yusuta; hecen Israel cinca kin tawicapa; tuka Israel cinca kin nape hduwankan iyayapi.

9 Unkan Egupton kin tawicapapi, qa Paro śuktanka tawa owasin, canpahmihma qa śuktanka akan iyotankapi, qa ozuye tawa kin wicakihdegapi, mde icahda wankapi, Hahirot i kin ekta Baal Zepon iyotakons.

10 Unkan Paro ikiyedan hi qehan, Israel cinca iśta wankan ikikcupi, unkan inyun Egupton wicihakam natan au, heon nina kokipapi, qa Israel cinca kin Jehowa hoyekiyapi.

$11 \mathrm{Qa}$ Mowis heciyapi, Egupta ekta wicaliapi wanica nace, heon Hewoskan ohna untapi kta e hetanhan hiyu unyayapi he? Tokeca de ecaunyeconpi, qa Egupta etanhan hiyu unyayapi he?

12 Oie wan Egupta en unkeniciyapi qon dee seca. Unkayuśtanpo, hecen Egupton wowidag unyanpi kta, unkeyapi. Egupton wowidag unyanpi kin hee 


\section{WICOWOYAKE 14.}

waśte, qa Ḣewoskan unțapi kin hee śica.

13 Unkan Mowis oyate kin hewicakiya, Ihnuhan koyakipapi kin. Owanji najin po, hecen Jehowa woehdaku ecanionpi kte cin he wandakapi kta ; Egupton token nakaha wandakapi, he iyecen ake icimana wanwicadakapi kte śni.

14 Jehowa niyepi on kize kta, qa niś inina dukanpi kta.

15 Unkan Jehowa Mowis heciya, Tokeca miye hoyemayalkiya he? Israel cinca kin ihdag wicaśi wo.

16 Qa niś cansakadan yuwankan ikikcu, qa ninape kin mde kin iwankan ye kiya wo; qa he yuakipam iyeya wo, hecen Israel cinca kin mde cokaya maka puza ohna manipi kta.

17 Unkan miś Egupton cantepi kin mdusuta, kta, hecen wicapasipi kta, qa Paro on, qa ozuye tawa ocowasin, canpahmihma qa śuktanka akan yotankapi on mayutanpi kta.

18 Qa Paro on, canpahmihma tawa on, qa suktanka akan yotankapi on, wowitan waton kinhan hehan Jehowa he miye, Egupton sdonyapi kta, eya.

19 Unkan Wakantanka ohnihde kin Israel ihdakapi wicitokam mani qon śkanśkan, qa wicihektam u, qa mahpiya bosdata wicitokapatanhan iyaya, qa wicihakam najin.

20 Qa Egupton owanka kin, qa Israel owanka kin otahedan $u$, qa mahpiya śapa qa otpaza heca, tuka dena hanyen iyoyamya, hecen hanyetn osan icikiyedan upi śni.

21 Unkan Mowis mde kin iwankam riape hdugata, unkan J̀ehowa hanyetu osan wiyohiyanpatanhan tateyanpa waśaka on mde kin yutokan, mini kin kicaśpe ca mde kin puza kaga.

22 Unkan Israel cinca kin mde cokaya ipi, puze cin ohna, qa etapa tanhan catka tanhan ko mini kin aconkaśke wicaya.

23 Unkan Egupton kuwa awicayapi, qa Paro śuktanka tawa owasin, canpahmihma, śuktanka akan yotankapi koya, mde kin cokaya wicinakam ipi.

24 Unkan hanhanna iwaktapi hehan, Jehowa Egupton ihdakapi ekta etonwan, peta bosdata qa mahpiya śapa ohna, qa Egupton ihdakapi kin yuśinye wioraya.

25 Qa canpahmihma huha kin yuśdoka hecen tketkeya tokśupi ; unkan Jehowa Israel on Egupton wicakiza, heon etanhan Israel etanhan naunjicapi kta, Egupton eyapi.

26 Hehan Jehowa Mowis heciya, Mde kin ektakiya ninape kiyugata wo, hecen mini kin ecen hdiwanke kta Egupton akan, canpahmihma tawapi, qa śuktanka tawapi akan.

27 Unkan Mowis mde kin iwankam nape yekiya; unkan hanhanna hehan mde kin token un qon he iyecen hdiwanka; unkan ligupton najicapi kin he itkokipapi, hecen Jehowa Egupton kin mde cokaya elipe wicaya.

28 Unkan mini hdiwanka qa canpahmihnia, śuktanka akan yotankapi ko awicakahpa, Paro ozuye tawa owasin, tona wicihakam mde kin en hipi wanjidan kaś ni śni.

29 Unkan Israel cinca kin mde cokaya puze cin amanipi, qa etapa tanhan catka tanhan ko mini kin aconkaśke wicaya.

30 Unkan Jehowa anpetu kin he en Israel niwicaya, Egupton napepi etanhan. Unkan IsraeI 


\section{HDINANPAPI,}

Egupton tapi wanwicayaka, mde kin hutata ekta.

$31 \mathrm{Qa}$ Israel wicohan tanka Jehowa Egupton ecawicakicon kin he wanyakapi, qa oyate kin Jehowa kokipapi, qa Jehowa wacinyanpi, taokiye Mowis nakun.

\section{WICOWOYAKE 15.}

1 Hehan Mowis Israel cinca ko odowan kin de Jehowa kahiyayapi, qa heyapi.

Jehowa iwadowan kta, wowitan tanka icicaga.

Suktanka qa tuwe akan iyotanke cin mde kin en ehpe wicaya.

2 Ja mitowaśake qa mitadowan kin hee, qa nakaha nimayan.

Taku wakan wada kin hee, heon mdatan kta.

Ate taku wakanda, heon, mdawankantu ye kta.

3 Jehowa wicaśta kicizapi itancan kin heca, caje tawa kin Jehowa ee.

4 Paro tacanpahmihma, ozuye tawa ko, mde en ehpe wicaya.

Unkan taakicita kahnigapi mde śa ohna minin țapi.

5 Wośbe kin awicakahpa; mini śbe kin ohna kun iyayapi; inyan wan iyecen.

6 Jehowa ninape etapa kin wowaśake on yutanpi ce.

Ninape etapa, Jehowa, toka kin wicakawanka.

7 Nitowitan tanka on tona nicipajinpi kin ihang wicayaya.

Nitocanniye kin yeyakiye cin he peji.śeca iyecen hulinaliwicaya.

8 Nipoge oniye kin on mini kin ki witayapi.

Minitan kin paha iyecen bosdan najin. icu.

Mde cokaya wośbe kin tasag
9 Toka kin heya, Wicawakuwa kta ewicawehdege ktá, woyuha wapamni kta, hena on minagi imnayanpi kta, isan wahduśdoke kta, minape ihang wicaye kta.

10 Tate nitawa ipoh yakiya,

Mde kin awicakahpa.

Mini waśaka aohdute wicaya, maza su iyecen.

11 Jehowa taku wakan ehna tuwe iyeniceca?

Tuwe iyeniceca wowakan on yutanpi kta?

Yatanpi kin nicinihanpi kta, wowapetokeca ecannon.

12 Ninape etapa kin yeyakiya, maka kin nawicapca.

13 Oyate kin de opewicayakiton, nitocantekiye on awicada.

Nitowaśake on oyanke wakan nitawa kin en hiyuwicayaye kta.

14 Oyate nahonpi qa kokipapi kta, Palestina ounyanpi kin wokokipe wicayuze kta.

15 Hehan Edom itancanpi kin wicayuśinyayapi kta.

Moab wicaśta waśaka wocancan wicayuze kta.

Kanan ounyanpi iyuhpa skanpi kta.

16 Nihinciyapi, wokokipe ko awicahinlipaye kta.

Niisto tanka kin on tasag țapi kta, inyan iyecen.

Oyate nitawa iyoopta iyaye kte cin hehanyan, Jehowa;

Oyate kin de opeyakiton iyoopta iyaye kte cin hehanyan.

17 He nitawa kin he ekta hiyu wicayaye ça ohna hu hde wicayaye kta.

Oyanke ohna yakidotanke kta e wiyeya yakaga, Jehowa.

Tipi wakan, Itancan, ninape nicicage kte cin he ekta.

18 Jehowa owihanke wanin wicaśta yatapi kta. 
19 Hecen Paro śuktanka tawa, canpahmihma qa śuktanka akan yotankapi kin rnde kin en hipi, unkan Jehowa mde mini kin hena akan awicahdi; tuka Israel cinca kin mde cokaya taku puze cin amanipi.

20 Unkan Miriam, winyan wokcan, Aaron tankeku cancega wan nape ohna icu, unkan winohinca owasin cancega yuha opapi, qa wacipi.

21 Unkan Miriam awicayupta, qa heya, Jehowa idowanpo, wowitan tanka icicaga, śuktanka qa akan yotanka kin he mde en ehpe wicaya.

22 Unkan Mowis Israel Mdeśa etanhan ihdag wicaya, unkan Śur hopuze krin ekta ipi, qa anpetu yamni Hopuza ohna manipi, qa mini iyeyapi śni.

23 Qa Mara en hipi qa Mara mini yatkanpi okihipi śni, ecin pa ce, heon he Mara (pa hee) eciyapi.

24. Unkan oyate kin Mowis kipajinpi qa taku unyatkanpi kta hwo? eyapi.

25 Unkan Jehowa hoyekiya, unkan Jehowa he can wan sdonyekiya; he mini kin en elipe ye cin hehan mini waśte icu. Hen wokage wan qa woyaco wan wicaqu, qa hen iyutan wicaya.

26 Qa heya, Jehowa wakan yada ho kin ohinniyan anayagoptan, qa taku iye iśta kin ohna ecetu kin hecannon, qa woahope tawa kin owasin nayahon, qa wokage tawa owasin duhe cinhan, wowayazan tona Egupton awicawahnaka wanjidan acihnake kte śni, nakaś Jehowa asniniye cin he miye.

27 Unkan Elim en hipi, hen miniyowe ake nonpa, qa tamar can wikcemna sakowin, qa hen etipi mini icahda.
WICOWOYAKE 16.

1 Unkan Elim etanhan ihdakapi, qa Egupta makoce etanhan iyayapi, wi inonpa anpetu iake zaptan hehan Israel cinca omniciye owasin Sin. Hopuze cin ekta hipi; he Elim qa Sina otahedan.

2 Qa Israel cinca omniciye ocowasin Hopuze cin ohna Mowis qa Aaron en kipajinpi.

$3 \mathrm{Qa}$ Israel cinca kin hewicakiyapi, Tokin Egupta makoce ohna Jehowa nape on unțapin, cehpi cega icahda iyotankehan aguyapi immahan untapi qehan; omniciye kin de ocowasin akihan te unyayapi kta e Hopuze cin de ekta hiyu unyayapi.

4 Unkan Jehowa Mowis heciya, Inyun, mahpiya etanhan aguyapi amagaju ciciyapi kta, qa oyate kin tankan yapi, qa anpetu otoiyohi taku anpetu wan iyohiye cin he mnayanpi kta; hecen iyutan wicawaye kta, mitoope omanipi kta, qaiś omanipi kte śni.

5 Qa anpetu iśakpe hehan taku anpetu otoiyohi mnayanpi kin he nonpa akihde ahdipi kta, qa he śpanyanpi kta.

6 Unkan Mowis Aaron kici Israel cinca kin owasin hewicakiya, Htayetu kinhan Egupta makoce etanhan hdinanpe niyanpi kin Jehowa hee sdonyayapi kta.

7 Qa hanhanna eca Jehowa towitan kin wandakapi kta; Jehowa en wiyahnupi kin he nahon, tuka unkiyepi untakupi hwo? on wiunyahnupi he?

8 Qa Mowis heya, Htayetu eca Jehowa cehpi yatapi kta e niçupi, qa hanhanna ca aguyapi inimnapi kta, heon etanhan Jehowa wiyahnupi kin iś iye en wiya103 


\section{HDINANPAPI,}

hnupi kin lie nation sdonyayapi kta; tuka unkiś untakupi he? unkiyepi en wiunyahnupi śni, tuka Jehowa he en.

9 Unkan Mowis Aaron heciya, Israel cinca omniciye ocowasin hewicakiya wo; Jehowa wiyahnupi kin nahon, heon ikiyedan upo.

10 Unkan Aaron Israel omniciye ocowasin ewicakiye cin he icunhan, Hopuze cin ekta ihduhomnipi, qa inyun, Jehowa towitan kin mahpiya śoka kin ohna wanyakapi

11 Unkan Jehowa ie cea Mowis heciya ;

12 Israel cinca wihnupi kin nawahon, hecen ewicakiya wo, Ḣtayetu eca cehpi yatapi ece kta, qa hanhanna eca aguyapi inimnapi kta, qa Jehorva wakan yadapi kin he miye sdonyayapi kta.

13 Unkan hitayetu śiyo en hipi qa owanke kin akahpapi, qa hanhanna eca owanke ihdukśan cu kin makata wanka ece.

14 Qa cu makata wanke cin akan hiyu qehan, inyun hopuze ite akan taku cistinna wa suta iyecen, hewanke iyecen cistinna maka akan wanka.

15 Unkan Israel cinca kin he wanyakapi, qa wicaśta otoiyohi hunkawanjitku kin hekiciyapi, Man hu (de taku hee:) eya; nakaś he taku sdonyapi śni. Unkan Mowis hewicakiya, Aguyapi yutapi kte Jehowa niçupi kin dee.

16 Taku Jehowa econ niśipi kin dee, Hetanhan mnayanpo, wicaśta otoiyohi token yute kta iyacinyan wicaśta iyohi, wicanagi tona wakeya tawa ohna yakonpi, pahu otoiyohi on omer iyutapi wanjidan icu kta.

17 Unkan Israel cinca hin ecen econpi, qa hunl ota mnayanpi, qa hunh aoptetu mnayanpi.

18 Qa omer ohna iyutapi qehan tuwe ota mnaye ein he taku iyakicuya yuhe śni, qa tuwe cistinna mnaye cin he aokpani yuhe śni; otoiyohi token yute lita iyececa hecen mnayan.

19 Unkan Mowis hewicakiya; Ihnuhan tuwe hetanhan ihanhanna hehanyan onge oyapte cinhan.

20 Unkan Mowis nahonpi śni, qa wicaśta wanjikśi ihantianna kin hehanyan onge oyaptapi; unkan he śicamna qa ohna wamdudan icagapi; unkan Mowis canniye wicaya.

21 He hanhanna otoiyohi mnayanpi, wicaśta otoiyohi token yute kta iyececa; tuka anpetu wi kin kate cin hehan skan.

22 Unkan anpetu iśakpe hehan aguyapi nonpa akihde mnayanpi, otoiyohi on omer iyutapi nonpa; unkan omniciye itancan kin owasin en hipi, qa Mowis okiyakapi. 23 Unkan hewicakiya, Jehowa eye ciqon dee, Heyakecinhan Sabaton Jehowa okithapi wakan tawa kin hee. Taku aguyayapi kte cin he aguyapo, qa taku cega en oyahanpi kte cin he ohanpo, qa taku ihe cin owasin kihnakapo ; heyakecinhan héhanyan he yahduhapi kta.

24 Unkan hanhanna hehanyan kihnakapi, Mowis econ wicaśi kin he iyecen ; tuka śicamna śni, qa ohna wamdudan yuke śni.

25 Unkan Mowis heya, Nakaha he yutapo, anpetr kin de Jehowa okilipapi tawa kin ee. Ecin tinta ekta he iyeyayapi kte śni.

26 Anpetu sakpe he mnayayapi kta, qa anpetu iśakowin kin he okilhpapi, he icunhan wanice kta. 
27 Unkan anpetu iśakowin kin hehan oyate etanhan warijikśi mnayanpi kta tankan ipi, tuka takudan iyeyapi śni.

28 Unkan Jehowa Mowis heciya, Tohanyan mitawoahope, qa mitoope oyapapi tawațen yayapi kte śni he.

29 Wanyakapo, Jehowa okihpapi niçupi kin, heon anpetu iśakpe kin he en nonpa can on woyute niçupi, owanji yankapo, otoiyohi tohe kin ohna. Anpetu iśakowin icunhan tuwedan oyanke tawa etanhan tankan iyaye kte śni, eya.

30 Unkan oyate kin anpetu iśakowin kin he en okihpapi.

31 Qa Israel ti kin he Manna eya caje yatapi, he taku su kin iyececa ska, qa he utapi kin he aguyapi zibzipedan canhanpi tiktica icicahiyapi iyececa.

32 Unkan Mowis heya, Taku Jehowa econ niśipi kin dee, hetanhan omer wanjidan ojuyapo he inicagapi yeye cin yuha yaunpi kta; hecen Egupta makoce etanhan hdinanpe ciyapi qehan, Hopuze cin ohna aguyapi yun ciyapi kin he wanyakapi kta.

33 Unkan Mowis Aaron heciya, Cega wan icu qa he ohna manna omer iyutapi wan yeya wo, qa he Jehowa itokam kihnaka wo, Inicagapi yeye cin he yuha unpi kta.

34. Unkan Aaron he woyaatanin kin itokam, he yuhapi kta e kilnaka, Jehowa Mowis econ śi qon he iyecen.

35 Unkan Israel cinca kin manna yutapi, waniyetu wikcemna tom hehanyan, makoce ohna woju tipi wan en ipi kin hehanyan, Kanan makoce ihanke kin en ipi kin hehanyan manna kin yutapi.

36 Unkan omer iyutapi wikcemna ca epah wanji ojunyanpi.

\section{WICOWOYAKE 17.}

1 Unkan Israel cinca kin omni. ciye owasin Jehowa oie kin eciyatanhan ihdakapi kin hena Sin hopuze etanhan ihdakapi, qa Repidim en etipi tuka oyate yatkanpi kta e mini wanica.

2 Unkan oyate kin Mowis iyope yapi qa, Mini unqupo, unyatkanpi kta eyapi ; unkan, Tokeca miś iyope mayayapi? Tokeca Jehowa iyutan yayapi? Mowis ewicakiya.

3 Unkan hen oyate kin mini on ipuzapi, qa oyate kin Mowis i en hiyeyapi, qa, De tokeca hwo? Egupta etanhan inape unyayapi qa ipuza te mayaye kta, qa micinca, qa mitawanuyanpi kin, eyapi.

4 Unkan Mowis Jehowa hoyekiya, qa, Oyate kin de taku ecawicawecon kta he? unhanketa e inyan on makininpi kta, eya.

5 Unkan Jehowa Mowis heciya, Oyate kin itokam ya wo, qa Israel hunkayapi etanhan ope wicayaśi kta, qa cansakadan on wakpa ayape ciqon ninape ohna ikikcu, qa iyaya wo.

6 Inyun miś Ḣoreb heciya imnija kin akan nitokam iyawahe kta, qa imnija kin ayape kta, qa hetanhan mini hiyu kta; hecen oyate kin mini yatkanpi kta. Unkan Israel hunkayapi kin wanyakapi, Mowis hecen econ.

7 Unkan oyanke kin he Masa (Iyutanyanpi) qa Meriba (Iyopeyapi) cajeyata, Israel cinca kin iyopeyapi qa Jehowa iyutan yanpi, qa Jehowa unkiyopeya un, qaiś un śni he? eyapi kin heon etanhan.

8 Hehan Amaleqi en hipi, qa Repidim ohna Israel azuya.

9 Unkan Mowis Jośuwa heciya, 


\section{HDINANPAPI,}

Wicaśta unkicicaliniga wo, qa Amaleqi wicakiza wo. Heyakecinhan Wakantanka cansakadan tawa nape ohna yuha paha iyawahe kta.

10 Unkan Jośuwa Amaleqi wicakiza, token Mowis eciye cin he iyecen econ. Unkan Mowis, Aaron qa Hur paha akan itanwankanhdeya iyayapi.

11 Unkan tohan Mowis nape kin wankantuya hdugate hehanyan Israel ohiya, qa tohan nape ozikiya ca Amaleqi ohiya.

12 Unkan Mowis nape kin tke heon inyan wan icupi, qa ihukuya ehnakapi; unkan he akan iyotanka; hehan Aaron Hur kici nape en yuzapi, unman etapa tanhan, qa unman catka tanhan; hecen nape kin patin anpetu wi kin iyaya, hehanyan.

13 Unkan Jośuwa tacanhipi hi kin on Amaleqi, qa taoyate wicakawanka.

14 Unkan Jehowa Mowis heciya; Wokiksuye kin de wowapi wan en kage ça Jośuwa noge kin en kihnaka wo. Amaleqi kiksuyapi kin mahpiya ihukuya tanhan wapajuju kta.

15 Unkan Mowis wahna wośnapi wan kage ca, Jehowa Nisi (Mitawiyokihedan) eya caje yata.

16 Qa heya, Nape kin Ja toiyotanke kin akan heon wicoicage yeye cin ohinniyan Jehowa Amaleqi kize kta.

\section{WICOWOYAKE 18.}

1 Unkan Jetro Mowis tunkanku, Midian wawayuśna kin, Wakantanka taoyate Israel, qa Mowis token ecawicakicon owasin nahon, Jehowa Israel Egupta etanhan hdinanpe wicaye cin he.

2 Hehan Jetro Mowis tunkanku kin Zipora Mowis tawicu kin icu, he kihdeye ciqon iyohakam.

3 Qa cinhintku nonpa, tokapa Gerśom (Hen ounwaya) eciyapi, Makoce tokeca ohna ounwaya, eya, heon etanhan.

4. Qa unman Eliezer (Taku wakan wada ornakiya) eciyapi ; Ate Taku Wakanda kin omakiye ça Paro tacanhipi kin etanhan emahdaku, eya, heon etanhan.

5 Unkan Wakantanka he tawa kin icahda, hopuze ohna Mowis ti kin he elita Jetro Mowis tunkanku hi, qa cinhintku qa tawicu nakun.

6 Qa Mowis heciya, Nitunkan Jetro he miye, niye en wahi, nakun nitawin, qa nicinca nonpa opapi.

7 Unkan Mowis, iye tunkanku itkokipe kta tankan iyaye ca pakicapsan, qa i iputaka, qa Zaniyan unpi hecinhan ikiciwangapi, qa wakeya kin en hipi.

8 Unkan Jehowa taku Paro qa Egupton ecawicakicon, Israel on etanhan owasin Mowis iye tunkanku okiyaka, taku tehika canku ohna awicakipa owasin, qa Jehowa ewicahdaku kin nakun, Mowis iye tunkanku okiyaka.

9 Unkan Jehowa Egupton napepi etanhan Israel ehdaku, qa taku waśte ecawicakicon owa.sin on Jetro iyuśkin.

$10 \mathrm{Qa}$ Jetro heya, Jehowa Egupton napepi etanhan, qa Paro nape etanhan enihdakupi kin he yawaśtepi nunwe. He Egupton napepi ihukuya tanhan taoyate kin ewicahdaku.

11 Wanna Jehowa taku wakan kin owasin isanpa tanka ee sdonwaya, taku en wahan icidaya śkanpi kin he en ohiwicaya ce.

12 Unkan Mowis tunkanku Jetro wośnapi, qa wohulinali yapi Wakantanka wakiciyuśna. Un-

106 


\section{WICOWOYAKE 19.}

kan Aaron qa Israel hunkayapi, Wakantanka itokam, Mowis tunkanku kici aguyapi yutapi kta en hipi.

13 Unkan ihanhanna Mowis oyate kin wicayaco kta e iyotankahan yanka. Unkan oyate kin Mowis ihdukśan najinpi, hanhanna etanhan ecen litayetu.

14 Unkan Mowis tunkanku ta$k u$ iye taoyate kin ecawicakicon owasin wanyake ça heya, De taku oyate kin ecawicayecon hwo? Tokeca niś nana yakidotanka, qa oyate kin owasin hanhanna etanhan ecen htayetu nihdukśan najinpi he?

15 Unkan Mow is iye tunkanku heciya, Oyate kin Wakantanka iwangapi kta en mahipi ece.

16 Nakaś taku akinicapi eca en mahipi ece, qa wicaśta wiciyotahedan mdaco, qa Wakantanka tokage, toope, ko sdonye wicawakiya ece.

17 Unkan Mowis tunkanku kin heya, Taku ecannon kin de waśte śni.

18 Hanyaye kta, niś qa oyate kin de onipapi owasin nakun; Taku kin de tke heon niś nana hecon oyakihi śni nakaś.

19 Wanna maho kin nahon, wahokon ciciya, qa Wakantanka nici un kta. Oyate kin ie ska niyanpi kta, Wakantanka ekta, qa oiepi kin Wakantanka oyakidake kta.

20 Qa wokage, woope ko onspe wicayakiye kta, qa canku ohna omanipi kta, qa woecon econpi kte cin hena sdonye wicayakiye kta.

$21 \mathrm{Qa}$ niye oyate kin owasin etanhan wicaśta waditaka yakahnige kta, wicaśta wicakapi, Wakantanka kokipapi qa basminyanpi kin śice dakapi kin hecapi, ya kektopawingege itancanpi, opawingege itancanpi, qa wikcemna zaptanptan itancanpi, qa wikcemnamna itancanpi kin hena wicayecage kta.

22 Unkan hena ohinniyan oyate kin yacopi kta, qa taku tanka kin owasin en anihipi kta ; hecen iyepi nicicinpi kta qa kapojedan nicicagapi kta.

23 Taku kin de ecannon, qa Wakantanka hecon niśi kinhan, najinhan oyakihi kta, unkan oyate kin dc owasin oyanke tawapi kin en zaniyan kipi kta.

24 Unkan Mowis iye tunkanku ho kin anagoptan, qa token eye cin owasin ecen econ.

$25 \mathrm{Qa}$ Mowis Israel owasin etanhan wicaśta waditaka wicakahnige ca oyate pa wicayapi kta, kektopawingege itancanpi, opawingege itancanpi, wikcemna zaptanptan itancanpi, qa wikcemnamna itancanpi wicakaga.

26 Unkan hena ohinniyan oyate kin yacopi, taku tehike cin he Mowis en ahipi, qa taku cistinna akinicapi kin he iye yacopi.

27 Unkan Mowis iye tunkanku kihde ya; unkan iye tamakoce kin ekta kihda.

\section{WICOWOYAKE 19.}

1 Israel cinca Egupta makoce etanhan inanpapi kin ctanhan, wi iyamni, wi tanin kin anpetu kin en Sina ho puze cin en hipi. 2 Nakaś Repidim etanhan ihdakapi qon, qa Hopuze en hipi, qa Hopuze ohna e tipi, qa Israel hen wankapi he itokam.

3 Unkan Mowis itanwankanhdeya Wakantanka ekta i, unkan .Jehowa paha kin etanhan hoyekiye ca heya, Jakob tiyohnaka hecen eyakiye ca Israel cinca kin owicayakidake kta; 


\section{HDINANPAPI,}

4. Taku Egupton ecawicawecon niś wandakapi, qa Wamdi hupahu akan ciyuhapi, qa miye ell cicahipi.

5 Qa wanna maho kin katinyan nayahonpi, qa wicotakuye mitawa yapatanpi kinhan, maka kin ocowasin mitawa, tuka oyate owasin isanpa miśs tawa ciyapi kta.

6 Unkan niye oyate wakan, qa wicaśta yatapi wawayuśnapi ciyuhapi kta. Wicoie kin hena Israel cinca kin owicayakidake kta.

7 Unkan Mowis en hi, qa oyate hunkayapi kin wicakico, qa wicoie kin hena owasin wicitokam ehde, Jehowa econ śi kin iyecen.

8 Unkan oyate kin owasin okonwanjidan ayuptapi qa heyapi, Token Jehowa eye cin owasin ecen econkupi kta. Unkan Mowis itkom oyate oiepi kin Jehowa okiyaka.

9 Unkan Jehowa Mowis heciya, Inyun mahpiya śoka wan ohna en cihi kta, hecen ociciye cin he oyate kin nahonpi kta, qa owihanke wanin wicanidapi kta. Unkan Mowis oyate oiepi kin Jehowa okiyaka.

10 Unkan Jehowa Mowis lieciya, Oyate kin ekta hda, qa wicayuwakan wo, ecin qa nakun heyakecinhan, qa wokoyake hdujajapi kta.

11 Unkan anpetu iyamni on wiyeya icihnakapi kte, anpetu iyamni kin hehan Jehowa kun u, qa Sina paha akan iyahe kte cin he oyate owasin wanyakapi kta.

12 Unkan ihdukśan oyate kin iwicayecago kta, qa hehe kta, Ihnuhan paha akan idadapi kin, qa ihanke kin eśta odutanpi kin; tuwe kaśta he yutan kinhan ktepi kta.
13 Ihnuhan wicanape wanjidan he yutan kin, tuka inyan on kininpi kta qa iś wanhinkpe on ipahdan iheyapi kte, woteca wicaśta unman tukte kaśta ni kte śni. Maza yahotonpi tehan ho ton kinhan iyepi paha en itanwankanhdeya yapi kte.

14. Unkan Mowis paha kin etanhan apamahdedan $\mathrm{ku}$, oyate kin ekta, qa oyate kin wicayuwakan, unkan wokoyake kin hdujajapi.

15 Unkan oyate kin hewicakiya, Anpetu iyamni on wiyeya un po. Ihnuhan winohinca odu tanpi kin. 16 Unkan anpetu iyamni hanhanna hehan wakinyan hotonpi, qa wakanhdi, qa paha akan mahpiya wan śoka hinca, qa maza yahotonpi nina hoton, unkan oyate kin owanka ohna owasin cancanpi.

17 Unkan Mowis oyate kin Wakantanka itkokipapi kta owanke etanhan inanpe wicaya; unkan paha ihukuya inajinpi.

18 Unkan Jehowa peta ohna Sina paha akan kun hiyu, heon paha kin owancaya śotoju, qa śota wankan hiyaya, maza śdoyapi oceti sota kin iyececa, qa paha kin owancaya nina cancan.

19 Unkan maza yahotonpi kin tehan nina hoton qehan, Mowis ia, unkan Wakantanka ho wan on ayupta.

20 Unkan Jehowa Sina paha kin akan kun hiyu, he paha kin akan, qa Jehowa Mowis kipan he paha kin ekta, qa Mowis itanwankanhdeya ekta i.

21 Unkan Jehowa Mowis heciya, kun hda oyate kin wicakiyaotanin, okini wanyakapi kta e Jehowa ekta iyoptapi kta, qa etanhan wicota ihpayapi kta.

$22 \mathrm{Qa}$ wawayuśnapi Jehowa ikiyedan hipi ece kin, iś eya 
ihduwakanpi kte, okini Jehowa wicakaohpe kta.

23 Unkan $\dot{H}$ e kin yuwakan, qa ihdukśan icago wo, unyakidaotanin, qa eha, heon oyate kin Sina he kin ekta ipi okitpanipi ce, Mowis Jehowa eciya.

24 Unkan, Hunktiya kun hdà, qa itanwankanhdeya yau kta niś qa Aaron yecica kta, tuka wawayuśnapi kin, qa oyate kin ihnunhan Jehowa ekta yapi kta e naoksapi, okini wicakaolipe kte, Jehowa eciya.

25 'Unkan Mowis oyate ekta kun hde ca owawicakiye.

\section{WICOWOYAKE 20.}

1 Unkan Wakantanka ie ça oie kin dena owasin eya.

2 Jehowa wakanyada, qa Egupta makoce etanhan, wayaka tipi etanhan, inanpe niye cin he miye ce.

3 Mitokam Taku Wakan tokeca duhe kte śni.

4 Ihnunhan wakagapi pagopi nicicage cin, qa mahpija wankan taku ohnaka, qa ihukuya taku maka kin ohnaka, qa mini maka ihukuya taku ohnaka kin hena owasin taku iyececa niçicage cin.

5 Hena ohoyada kte śni, qa itokam yapatuje kte śni. Nakaś Jehowa wakanyada, Taku Wakan winawizi he miye, tona śice madapi wicoicage iyamni, qa itopa kin hehanyan ateyapi walitanipi iye cincapi kin en awicawai ece.

$6 \mathrm{Qa}$ tona waśte madapi qa mitawoahope patanpi kin hena wicoicage kektopawinge hehanyan cantewicawakiya ece.

7 Jehowa wakan yada kin he ikcekceya caje date kte śni, Jehowa tuwe ikcekceya caje yate cinhan yaowotanna kte śni.
8 Anpetu iśakowin wakan yada kta e kiksuya wo,

9 Anpetu śakpe litayani, qa nitohtani kin owasin ecannon kta. 10 T'uka anpetu iśakowin kin Jehowa Wakan yada kin he tawa, he en wolitani takudan ecannon kte śni; niye qa nicinkśi, qa nicunkśi, nitahokśidan, qa wiciyanna nitawa, qa wanuyanpi nitawa, qa tuwe oyate to keca otonwe nitawa ohna un kin. 11 Nakaś anpetu śakpe en Jehowa, mahpiya kin, qa maka kin, miniwanca, qa taku hena ohna. un kin owasin kage ca anpetu iśakowin kin en okilipa, heon Jehowa anpetu iśakowin kin he hdawaśte qa hdawakan.

12 Niyate qa nihun wicahduonihan wo, hecen Jehowa wakan yada kin makoce niçu kin he en tehan yani kta.

13 Tin wicayakte kte śni.

14 Wawicilialiapi ecannon kte śni.

15 Wamayanon kte śni.

16 Nitakoda on woyaotanin iton śniyan odake kte śni.

17 Nitakoda ti kin cantiheyaye kte śni. Nitakoda tawicu, qa hokśidan tawa, qa wiciyanua tawa, qa tatanka tawa, qa śuktanka tawa, qa taku kaśta nitakoda tawa cantiheyaye kte śni.

18 Unkan oyate owasin taku hotonpi kin qa taku ide kin qa mazayahotonpi kin hoton, qa he śotoju kin he wanyakapi qehan, oyate kin lrokipapi, qa cancanpi, qa itehan kinajinpi.

19 Qa, Niś unkokiyapo, hecen naunhonpi kta, tuka Wakantanka unkokiyapi kte śni, okini untapi kta, Mowis eciyapi.

20 Unkan Mowis oyate kin hewicakiya, Inihanpiśnipo ; iyutanniyanpi kta on Wakantanka hi, qa tokokipe niitepi itokam un 109 


\section{HDINANPAPI,}

kta, hecen wayahtanipi kte śni, heon etanhan.

21 Unkan oyate kin itehan najinpi, tuka Mowis otpaza śoka ohna Wakantanka yanke cin he ikiyedan $\mathrm{i}$.

22 Unkan Jchowa Mowis heciya, Israel cinca kin hecen ewicayakiye kta, Mah̉piya etanhan, ociciyapi kin he niś wandakapi.

23 Mitokam mazaska taku wakan, qa mazaskazi taku wakan nicicagapi kte śni.

24 Maka owayuśna miyecage kta, qa he alkan peta wośnapi, qa wopida wośnapi nitawa kin, tahinca nitawa qa pte nitawa kin wayaduśna kta; tuktee kaśta micaje kiksuye ciyapì kin he en cihi qa ciyawaśte kta.

25 Qa inyan owayuśna miyecage cinhan, wokakanpi on yakage kte śni, maziyape nitawa kin he ekta yeyakiye cinhan duśape kta. 26 Qa owayuśna mitawa kin ekta itanwankanhdeya idada eca, woiyadipi akan mayani kte śni ece, okini tanconikadan tanin kta.

\section{WICOWOYAKE 21.}

1 Unkan woyaco wicitokam eyahde kta dena ee.

2 Heberi ookiye wan opeyaton kinhan waniyetu śakpe wowidag yaye kta, tuka iśakowin hehan iyuwin codan ikceya tankan iyaye kta.

3 Tanśnana en hi kinhan tanśnana tankan ye kta, tawicu ton kinhan, tawicu kici tankan ye kta.

4 Yuhe cin he winohinca wan qu kinhan, qa cinca wica qa iś winyan kiciton kinhan, tawicu cinca ko yuhe cin tawaye kta, qa iye taśnana inape kta.

5 Tuka, Mayuhe cin waśte wa- daka, mitawin, micinca nakun, ikceya inawape kte śni, ookiye kin he katinyan eye cinhan,

6 Yuhe cin he wayaco ekta aye kta, qa tiyopa, qa iś tiyopa icahda tośu kin ekta, qa tahinśpa wan on noge kin pahdoke kta, hecen owihanke wanin he okiye kta.

7 Unkan wicaśta wan iye cunwintku wiciyanna on wiyope kiye cinhan, he hokśipidan tankan yapi kin he iyecen tankan inape kte śni.

8 Yuhe cin he wokilipe śni, qa śicedake cinhan he opekiton wicakiye kta, wanna he hnayan, heon wiyopekiye ça oyate tokeca qu kta okihi śni.

9 Qa iye cinhintku on he wokihpe cinhan, cunwintku yapi woyaco kin he iyecen ecakicon kta. 10 Winoliinca tokeca yuza eśta tado tawa, qa wokoyake tawa qa kici un kin he ekiciyaku kte śni.

11 Qa hena yamni ecakicon śni kinhan, mazaska wanica ikceya inape kta.

12 Tuwe wicaśta wan apa, unkan te cinhan, awicakehan te yapi kta.

13 Unkan tuwe he kuwa sni unkanś, tuka nape ekta Taku Wakan hiyukiye cinhan, oyanke wan ociciyake kta hen inape kta 14 Tuka tuwe takodaku kte kta e hnayan kicah kuwa kinban, owayuśna mitawa eśta etanhan ktepi kta e iyacu kta.

15 Unkan tuwe iye atkuku qaiś hunku ape cinhan awicakehan te yapi kta.

16 Unkan tuwe wicaśta wan manun qa wiyope ye .cinhan, qaiś yuha iyeyapi kinhan țe yapi kta.

17 Unkan tuwe atkuku qaiś hunku ihakta śni kinhan awicakehan te yapi kta. 


\section{WICOWOYAKE 22.}

18 Unkan wicaśta nom akinicapi qa wanji tawaśiłku inyan on, qaiś nape hdupśunka on ape cinhan, unkan te śni tuka hinhpaya makan wanka.

19 Najin, qa sagye kiton tankan nuani kinhan, tuwc he ape cin he te kte śni ; tuka okizi yapi kajuju kta, qa nakun makan wanke cin on.

20 Unkan wicaśta wan tahokśidan, qaiś wiciyanna tawa cansakadan on ape cinhan, qa nape kin ihukuya te cinhan, katinyan tokiconpi kta.

21 Tuka anpetu wanji, qaiś nonpa can najin kinhan, tokiçonpi kte śni, he mazaska tawa nakaś.

22 Unkan wicaśta nom akicipapi qa winohinca ihduśaka wan kiuniyanpi kinhan, unkan cinca hiyu tuka taku śica sanpa ope śni kinhan, mazaska on kajuju kiyapi kta, token winohinca hihnaku eye ca wayaco konzapi kin he qu kta.

23 Tuka taku śica ope cinhan wiconi on wiconi yaqu kta,

24 Iśta on iśta, hi on hi, nape on nape, siha on siha,

25 Guyapi on guyapi kta, capapi on capapi kta, apapi on apapi kta.

26 Unkan wicaśta wan tahokśidan iśta kin, qaiś tawiciyanna iśta kin apa, unkan kpe cinhan, iśta kin on ikceya kiyuśke kta.

27 Qa tahokśidan hi wan qaiś tawiciyanna hi wan kapśun kinhan, hi kin on ikceya kiyuśke kta.

28 Unkan tatanka wan wicaśta qaiś winohinca capa, unkan te cinhan, tatanka inyan on kininpi kta, qa celipi kin yutapi kte śni ; tuka yuhe cin takudan ecakiconpi kte śni.

29 Tuka he itokam tatanka kin he wacapa, qa yuhe cin okiya- kapi eśta, he hdaśke śni kinhan, tatanka wicaśta qaiś winohinca te kiye cinhan, inyan on kininpi kta, qa yuhe cin nakun te yapi kta.

30 Mazaska on kajuju śipi kinhan token nagi kin on kajuju śipi kin owasin qu kta.

31 Cinca wica qaiś winyan cape cinhan, woyaco kin de iyecen ecakiconpi kta.

32 Tatanka kin hokśidan, qaiś wiciyanna cape cinhan, wicayuhe cin mazaska wikcemna yamni kicu kta, qa tatanka inyan on ktepi kta.

33 Unkan wicaśta wan woha wan yuhdoke cinhan, qaiśs woha wan qe ca akalipe kiton śni kinhan, unkan tatanka wan, qaiś śuktanka śonśonna wan he oiyolipaye cinhan,

34 Wolia tawa kin kajuju kta, qa yuhe cin mazaska qu kta, qa taku te cin he tawa kta.

35 Ünkan wicaśta wan tatanka tawa tawaśitku tatanka tawa kiunni on te cinhan, tatanka ni kin he wiyope kiyapi kta, qa mazaska kin yuakipam icupi kta, qa te cin nakun cokaya kibaśpapi kta.

36 Tuka tatanka kin wacapa he itokam sdonyapi eśta, yuhe cin he hdaśke śni kınhan, yuhe cin tatanka te cin on tatanka wan qu kte ça te cin he tawaye $\mathrm{kta}$.

\section{WICOWOYAKE 22.}

1 Wicaśta wan tatanka qaiś tahinca manun kinhan, qa he pata qaiś wiyope ye cinhan, tatanka zaptan, tatanka wanjidan on kicu kta, qa tahinca topa tahinca wanjidan on.

2 Wamanun wan tipi kalidokahan iyeyapi, qa apapi on ța eśta he on weyapi wanice kta. 


\section{HDINANPAPI,}

3 Wi kin iyoyam ye cinhan wokajuju on kajuju kiyapi kte, takudan yuhe śni eśta, womanun kin on wiyope kiyapi kta tuka, heon tuwe he kte kinhan we yapi kta. 4. Taku manun kin he niyake nape kin ohna iyeyapi kinhan, tatanka, śuktanka śonśonna, tahinca eśta, wanjidan on rionpa hdajuju kta.

5 Wicaśta wan taku wilian ye kte cin tokan tamaga, qaiś tahastanhanka iyuwi oju kin en iyaye ye ca maga qaiś hastanhanka iyuwi oju kin temye cinhan, iye tamaga waśte qa hastanhanka iyuwi waśte kin on hdajuju kta.

6 Cetipi qa tinta ideyapi, qa peji paha, qaiś aguyapi baśdapi śni, qaiś maga wan hulinage cinhan he hdajuju kta.

7 Wicaśta wan tawaśitku kin mazaska qaiś wakśica kicihnake kta e qu kinhan qa tipi tawa etanhan manunpi kinhan wamanun iyeya kinhan nonpa akihde hdajuju kta.

8 Wamanun kin iyeyapi śni kinhan, tipi yuhe cin he tawaśitku woynha tawa ekta nape yekiye śni taku wakan ekta ohdag kiyapi kta.

9 Taku akinicapi owasin on, tatanka on, śuktanka śonśonna on, talinca on, wokoyake on, taku kaśta tuwe tawa tanin śni akinicapi kinhan, napin taku wakan kin ekta ohdag wicakiyapi kta, qa tuwe taku wakan kin yaśicapi kinhan tawaśitku nonpa akibde kicu kta.

10 Wicaśta wan tawaśitku śuktanka śonśonna, qaiś tatanka, qaiś talinca wanuyanpi, taku kaśta awanyake kta e qu kinhan, unkan țe cinhan, qaiś tuwedan wanyake śni kiunniyanpi, qaiś tokan kahapapi kinhan; 112
11 Tawaśitku taku tawa kin ekta nape kin yekiye śni, Jehowa namahon keya ohdake kta, hecen tawa qon he iyowin kiye kta, unkan kajuju kte śni.

12 Tuka manunpi kinhan tawa qon taku iyehantu kicu kta.

13 Yahidecapi kinhan onśpa yahidecapi yuotanin kta e ahi kta, qa hecen yahdecapi on takudan kicu kte śni.

14. Unkan wicaśta wan takodaku etanhan taku odote, qa tawa kin kici un śni icunhan kiunniyanpi, qaiś te cinhan wokajuju kicu kta.

15 Tawa kin kici un kinhan kajuju kte śni, opeton odote cinhan iyuwin kin he on u ce.

16 Wicaśta wan holsśiwinna wan wahoye kuns okiye ça kici wanke cinhan tawicu kta e awicakehan wicakicida kta.

17 Tuka wikośka atkuku kin kicu kta e katinyan tehinda kinhan, wikośka wohpapi kin he iyecen mazaska qu lite.

18 Wicahmugesa niyakiye kte śni.

19 Tuwe woteca wan kici wanke cinhan katinyan ktepi kta.

20 Jehowa heceedan wakiyuśnapi kta, qa tuwe taku wakan tokeca wan wakiyuśna kinhan ocowasin ihangyapi kte.

21 Tuwe oyate tokeca nici ounye cinhan iyokiśin yaye kte śni, qa yakiduśe kte śni, nakaś niś Egupta makoce kin ohna oyate tokeca ounyayapi.

22 Wiwazica qa wamdenica wanjidan duśicapi kte śni.

23 He duśice unkan hoye makiye cinhan ho kin nalion manke kta ce.

$24 \mathrm{Qa}$ mitocanniye ideye $\mathrm{kta}$, qa canhipi on ciktepi kta, hecen nitawinpi wiwazicapi kta, qa nicinca wamdenicapi kta. 


\section{WICOWOYAKE 23.}

25 Oyate mitawa tuwe onśika nici un kin mazaska oyaqu kinhan, wayahtakesa iyecen ecayecon kte śni, woyahtake yakidake kte śni.

26 Nitakoda taku oyaqu nicicajuju kta e taśina iyacu kinhan tohan wi iyaye cinhan yecu kta.

27 Taśina uka kin hee, taku hdowin kta heceedan kinhan, taku ohna iśtinbe kta he? hecen hoye makiye cinhan nawahon kta; wacantkiya waun ce.

28 Taku wakan duśice kte śni, qa oyate nitawa itancan kin ihnuhan wahte yada śni kinhan.

29 Nicinkśi tokapa kin mayaqu kte; ça taku icah yaye tokaheya suton kin woyute woyatke ko mayaqu dutehan kte śni.

30 He iyecen pte nitawa qa tahinca nitawa kin ecayecon kte ; anpetu śakowin hunku kici yanke kte ça iśahdogan can hehan mayaqu kta.

31 Wicaśta wakan mitawa kin yaunpi kta, heon taku tinta ekta yahdecapi kin he yatapi kte śni, he śunka ekta ehpe yayapi kta.

\section{WICOWOYAKE 23.}

1 Taku ecinkta oyakapi kin iyacu kte śni, qa itonśniyan wadaatanin kta e wicaśta śica nape duze kte śni.

2 Wicota taku sica econpi owicayape kte śni, qa taku akinicapi en wicota yaśkopapi eśta yaśkope kta e awicadupte kte śni.

3 Nakun wicaśta wahpanica toakinice kin en duonihan kte śni.

4 Tuwe niciyuśe tatanka tawa, qaiśs taśunke śonśonna nuni kin ayakipe cinhan, he ekta hdiyakiye kta.

5 Tuwe śice nidake taśsuka śonśonna tawaqin ibukuya ma- kata wanka wandake cinhan duśke kta yakapin eśta kici duśke kta.

6 Wicaśta wahpanica nıci un kin toakinice kin en woyaco dapemni kte śni.

7 Wicoie itonśni etanhan ihdutehan wo, ihnuhan wicaśta owotanna qa tuwe taku śica econ śni yakte kinhan nakaś tuwe śice cin he mdaowotanna kte śni.

8 Taku ituhanpi kin iyacu kte śni; Nakaś taku ituhanpi tona iśta mdezapi kin hena iśta gonge wicaye ça ohan owotanpidan eśta oiepi kin wicakiyupemni.

9 Egupta makoce kin ohna ounyayapi qon, heon wicaśta oyate tokeca ohna ounyanpi cantepi kin sdonyayapi, qa tuwe oyate tokeca yakiduśe kte śni.

10 Waniyetu śakpe makoce nitawa woyaju kte ça taku aicage cin mnayaye kta.

11 Tuka iśakowin kin he aduśtan kte ça ehpe yaye kta, hecen oyate nitawa tona onśika he yutapi kta, unkan taku ihe cin tinta wamanica kin yutapi kta; hastanhanka iyuwi nitawa qa wihdi can nitawa kin nakun he iyecen ecayecon kta ce.

12 Anpetu śakpe nitohts.ni ecannon kte ca anpetu iśakowin kin en oziniçiye kta ce, hecen tatanka nitawa qa nitaśunke śonśonna okihpe kta; qa nitawiciyanna cinca, qa tuwe oyate tokeca nakun magaga iciye kta.

13 Taku eciciyapi kin owasin en ikpatanpo, qa taku wakan tokeca caje kin he kiksuye yakiye kte śni nii kin etanhan tuwedan he nahon kte śni.

14 Mdoketu eca yamnı akihde womiyecihe ece kta.

15 Aguyapi napoliye codan wohanpi yapatanpi kta, Abib wi 113 


\section{HDINANPAPI,}

kin (aguyapi itka hinanpe cin wi kin) he en Egupta etanhan yahdinape, heon etanhan iyehantu eca anpetu śakowin aguyapi napoliye codan yatapi ece kta, econ ciśipi kin he iyecen, qa wośna codan tuwedan mitokam wanyakapi kte śni.

16 Nakun baśdapi wohanpi kin nitohtani taku maga ohna oyaju tokaheya icage cin hee, qa wamnayanpi wohanpi kin omaka owihanketa, nitohtani kin maga etanhan mnayaye cin iyehantu eca.

17 Mdoketu eca, yamni akihde tona wica owasin Jehowa itancan kin itokam nihdutaninpi ece kta.

18 Taku wamayakiduśna we kin aguyapi napohyapi kici mayaqu kte śni, qa wohanpi mitawa waśin kin ihantianna kin hehanyan ihe kte śni.

19 Maga nitawa taku tokaheya aicage cin he Jehowa wakanyada ti kin en ayahi ece kta. 'Tatokada cinca kin he hunku asanpi kin ohna oyahe kte śni.

20 Inyuı miś olnilide wan nitokam ye waśi he canku ohna awanniyake ca oyanke wiyeya cicihnake cin he ekta aniye kta.

21 Ite kin awacin wo, qa ho kin nahon wo, ihnuhan yakipajin kin, wayahtanipi kin tokan aniyanpi kte śni, nakaś he cokaya micaje yanka.

22 Tuka awicakehan ho kin anayagoptan, qa taku eciciye cin owasin ecen ecannon kinhan tona toka niyanpi kin owasin toka waye kta, qa tona nicipajinpi kin hena wicawakipajin kta.

23 Mitaohnihde nitokam ye kta, qa Amori kin, qa Hiti kin, qa Perazi kin, qa Kanani kin, qa Hiwi kin, qa Jebuśi kin ekta aniye kta, qa awihnuni wicawaye kta ce.
24 Hena taku wakan dapi kin ekta yapatuje kte śni, qa ohoyada kte śni, qa token econpi kin he iyecen ecannon kte śni ; tuka tawakagapi kin yakawanke kta, qa ocowasin yakamdemdece kte ce.

25 Tuka Jehowa wakan yadapi kin he oyecipapi kte, hecen aguyapi nitawapi kin he yawaśte kta qa mini nitawa kin nakun, qa nicokayatanhan wowayazan mdutokan kta.

26 Qa makoce nitawa kin ohna takudan okaśkan ton kte śni, qa cinca nica yuke kte śni, anpetu nitawa oyawa kin ojuwaye kta.

27 Qa wokokipe mitawa kin nitokam yewaye ca oyate ekta wicaya $i$ kte cin owasin yuśinye wicawaye kta, qa tona toka niyanpi kin owasin tahupi kin ciçu kta.

28 Unkan tuhmaga nitokam yewaye kta, unkan hena Ḧiwi kin, Kanani kin, qa Hiti kin nitokapa tanhan wicakahapapi kta.

29 Waniyetu wanjidan en ham wicawaye kte śni, okini makoce kin hewoskantu kta, qa wamanica ota kta niyepi ehna.

30 Tonana qa hehan tonana nitokapatanhan ham wicawaye kta, ecen nihduota, qa makoce kin tawayaye kta.

$31 \mathrm{Qa}$ Mde-śa etanhan Pilistim tamde kin aiyahdeya, qa Hopuze cin etanhan wakpa kin ekta, hehanyan makoce kin cicu kta, nakaś makoce kin he tona ounyanpi kin hena ninape en waqu kta; unkan nitokapatanhan ham wicayaye kta.

32 Hena om, qa taku wakandapi om wicotakuye yakage kte śni.

33 Makoce nitawa kin en ounyanpi kte śni, okini miye en wahtani niyanpi kta. Taku wa- 


\section{WICOWOYAKE 24.}

kandapi kin oyakiye cinhan he nihmunke kta.

\section{WICOWOYAKE 24.}

1 Unkan Mowis heciya, Jehowa ekta itanwankanhdeya u wo, niś qa Aaron, Nadab qa Abihu, qa Israel hunkayapi kin wikcemna śakowin, qa itehanyan yapatujapi kte.

2 Qa Mowis iś nana Jehowa ikiyedan hi kta, tuka hena ikiyedan hipi kte śni ; nakun iye kici oyate kin itanwankanhdeya upi kte śni.

3 Unkan Mowis ekta hda, qa Jehowa oie kin owasin, qa woyaco kin owasin oyate kin owicakiyaka; unkan oyate kin owasin ayuptapi, qa ho wanjidan heyapi; wicoie owasin Jehowa eye cin ecen econkupi kte ce.

4 Unkan Mowis Jehowa oie kın owasin owa, qa hanhanna hin kikta, qa wahna wośnapi wan paha ihukuya ehde, qa inyan wokiksuye wikcemna sanpa nonpa Israel wicoun akenonpa on:

5 Qa Israel cinca kin etanhan kośka ye wicaśi, unkan wohuhnaliyapi huhnahyapi, qa tatanka wopida wośna Jehowa wa kiyuśnapi.

6 Unkan Mowis we kin hanke maza wakśica ohna icu, qa we kin hanke, wahna wośnapi akan ehpeya.

7 Qa wicotakuye wowapi kin icu, qa yawa oyate nogepi kin ohna; unkan, Taku Jehowa eye cin owasin ohinniyan ecen econkupi kta, eyapi.

8 Unkan Mowis we kin icu qa oyate kin awicamnimni, qa, Inyun wicoie kin dena on Jehowa wicotakuye nicicagapi we kin dee ce, eya.

9 Hehan Mowis qa Aaron, Na- kin ohna yanka. dab qa Abihu, qa Israel hunkayapi kin etanhan wikcemna śakowin itanwankanhdeya yapi.

10 Qa Israel Taku Wakan dapi kin wanyakapi, unkan siha kin ihukuya Sapir inyan kamdayapi qa owanka kagapi kin iyecen, qa mahpiya hinca kamdeza kin he iyecen.

$11 \mathrm{Qa}$ Israel cinca otancanke kin Wakantanka wanyakapi, qa wotapi qa wayatkanpi, tuka nape kin awicahnake śni.

12 Unkan Jehowa Mowis heciya, Itanwankanhdeya kuwa, he kin ekta, miye en, qa hen yanka wo, qa onspe wicayakiye kta e inyan mdaska qa woope woahope akan owawa kin hena cicu kta ce.

13 Unkan Mowis najin, taokiye Jośuwa kici, qa Mowis Wakantanka he tawa kin ekta itanwankanhdeya iyaya.

14 Qa hunkayapi kin hewicakiya, Deciya unkapepo, niyepi en unhdipi kte kin hehanyan, qa ihopo Aaron qa Ḣur niyepi om unpi, qa tuwe taku akinice cinhan hena en hi kte ce.

15 Qa Mowis itanwankanhdeya paha akan i, qa mahpiya śoka kin paha kin akahpa.

16 Unkan Jehowa towitan kin Sina paha akan owanji yanka, qa anpetu śakpe kin heharyan mahpiya śoka kin paha akahipa, qa anpetu iśakowin kin hehan mahpiya śoka cokayatanhan Mowis kipan.

17 Unkan Israel cinca kin Jehowa towitan kin peta wahuhnahye cin he iyecen he ipa akan wanyakapi.

18 Unkan Mowis mahpiya śoka cokaya i, qa he kin akan i, qa Mowis anpetu wikcemna topa, qa hanyetu wikcemna topa he 


\section{HDINANPAPI,}

WICOWOYAKE 25.

1 Unkan Jehowa Mowis okiye ca heya;

2 Taku itulianpi kte cin he makahipi kta e Israel cinca kin hewicakiya wo, wicaśta tona cante kin iyopaśtake cin hena owasin taku itumakihanpi kin he iyacupi kta.

3 Qa hena etanhan taku ituhanpi iyacupi kte cin dee; mazaskazi, qa mazaska, qa mazaśa;

4 Qa tahinca hin to, qa stan, qa duta, qa minihuha ska, qa tatokadan hin,

5 Qa tamdokia ha śayapi, qa hoka ha, qa śitim can;

6 Wihdi petijanjan on, qa taku waśtemna wihdi sdawicayapi on kagapi kin heon, qa izin yapi kin on.

7 Inyan wicaśake iyececa, qa inyan amdo akahpe, qa maku akahpe otaśpuyapi.

8 Unkan tipi wakan wan micagapi kta, hecen wicacokaya ounwaye kta.

9 Wakeya okagapi kin, qa taku wo winyunyanpi owasin okagapi kin hena wanyag ciciye cin owasin, he iyecen yakage kta.

10 Qa can wohnaka wan micagapi kta, śitim can kin on, wiciśpa nom sanpa hanke ohanske cin, qa wiciśpa sanpa hanke ohdakinyan kin, qa obosdatu kin wiciśpa sanpa hanke.

11 Qa mazaskazi ecedan on ayapawinte kta, mahentanhan, akapatanhan koya ayapawinte kta, qa mazaskazi wateśdake wan he akan ihdukśan yakage kte.

12 Qa mazaskazi napcupe topa oyecicaśte kta, qa hena oise topa ekta ikoyag yaye kta, cuwi tokaheya ekta napcupe nonpa, qa cuwi inonpa ekta napcupe nonpa.
13 Unkan śitim can tośu nonpa yakage kte ca hena mazaskazi on ayapawinte kte.

14 Qa canwohnake akiyuhapi kta e tośu kin napcupe canwohnake cuwi ekta ikoyakapi kin hena ohna iyeyaye kta.

15 Qa tośu kin canwohnaka napcupe kin ohna yakonpi kta, hetanhan icupi kte śni.

16 Unkan woyaatanin cicu kte cin he canwohnaka kin en yehnake kta.

17 Qa wokajuju iha wan mazaskazi ecedan on yakage kta, wiciśpa nonpa sanpa hanke ohanske cin, qa wiciśpa wan sanpa hanke ohdakinyan kin.

18 Qa Kerubi nonpa mazaskazi pagopi on yakage kta, wokajuju iha ihanke nonpa etanhan hen: yakage kta.

19 Hecen Kerubi wanji wokajuju iha ihanke deciyatanhan kaga wo, qa Kerubi unman ihanke unman eciyatanhan wokajuju iha kin hetanhan, ihanke anokatanhan akan Kerubi kin yakage kta.

20 Qa Kerubi hupahu wankan kamdah yakonpi kte, hupahupi kin wokajuju iha kin akahpa unpi kta, qa itepi kin napin unman ektakiya kta; Kerubi itepi kin wokajaju iha kin ektakiya tonwanpi kta.

$21 \mathrm{Qa}$ woyaatanin ciç kte cin he canwohnake mahen oyakihnake kta, qa he iwankam canwohnaka akan wokajuju iha kin eyahnake kte.

$22 \mathrm{Qa}$ hen itkocicipe kte ça wokajuju iha kin iwanka-patanhan Kerubi nonpa woyaatanin canwohnaka akan unpi kin hena cokayatanhan ociciye kte, taku Israel cinca kin owicakiyag ciśi kte cin owasin.

$23 \mathrm{Qa}$ śitim can wahna wotapi 


\section{WICOWOYAKE 26.}

wan yakage kta, wiciśpa nom ohanske cin, qa wiciśpa wanjidan ohdakinyan kin, qa obosdatu kin wiciśpa sanpa hanke.

24 Qa he mazaskazi ecedan on ayapawinte kte, qa ihdukśan mazaskazi wateśdake wan yecage kta.

$25 \mathrm{Qa}$ he ihdukśan iyuskite nape hdakinyan yecage kta, qa iyuskite kin ihdukśan mazaskazi ecedan wateśdake wan yecage kta.

$26 \mathrm{Qa}$ mazaskazi napcupe topa he yecage kta qa siha topa kin itepi topa kin akan napcupe kin ikoyag yaye kta.

27 Wahna wotapi akiyuhapi kta e mazanapcupe kin tośu icupi kta on iyuskite iyotakons unpi kta.

28 Qa tośu kin śitim can on yakage kte ca mazaskazi on ayapawinte kta, hena on wahna wotapi kin akiyuhapi kte.

29 Qa wahna wotapi kin wakśica, qa tukiha, ya wiyatke, qa cega, hena owasin yecage kta, on wakanyan okaśtanpi, qa mazaskazi ecedan on hena yakage kta. 30 Qa wahna wotapi kin akan aguyapi itokam hnakapi eyahnake kta, mitokam ohinniyan un kte.

31 Unkan mazaskazi ecedan petijanjan ihupa wan yakage kta, pagopi he yakage kta, ceca kin, qa adetka kin, qa tawakśica kin, qa pśonka kin, qa walica kin.

$32 \mathrm{Qa}$ petijanjan ihupa cuwi etanhan adetka śakpe inanpe lita, adetka yamni cuwi wanji etanhan, qa adetka yamni petijanjan cuwi unman kin eciyatanhan.

33 Wakśica yamni uma iyececa, pśonka wan, qa wahca wan kicica adetka wanjidan en, qa wakśica yamni uma iyececa, qa pśonka wan qa wahica wan adetka unman en, adetka śakpe petijanjan ihupa etanhan inanpe cin owasin hececa kta.

34 Qa petijanjan ihupa kin en wakśica topa uma iyececa, otoiyohi pśonka wan qa wahica wan kicica kta.

35 Qa pśonka wan adetka nonpa ihukuya, qa ake pśonka wan adetka nonpa ihu kuya, qa pśonka wan adetka nonpa ihukuya, adetka śakpe petijanjan ihupa etanhan inanpe cin owasin hececa kta.

36 Petijanjan ihupa pśonka tawa, qa adetka tawa kin, okonwanjidan kta, mazaskazi ecedan onśpa wanjidan pagopi on owasin kagapi kta.

37 Unkan petijanjan śakowin yecage kta, qa akan petijanjan ehnakapi kta, qa he itolsapatanhan iyoyam ye kta.

38 Qa petijanjan iyukse, qa ohna cahota icupi mazaskazi ecedan.

$39 \mathrm{He}$ qa on kicanyanpi kin hena owasin mazaskazi ecedan woqin wanjidan on kagapi kta.

40 Qa waktaya wo owasin okagapi paha en wandake cin he iyecen kaga wo.

\section{WICOWOYAKE 26.}

1 Unkan tipi kin ozanpi wikcemna miniliuha ska nonpa kahmupi, to, qa stan, qa duta Kerubi kazuntapi hecen yakage kte.

2 Ozanpi wanji ohanske cin wiciśpa wikcemna nonpa sanpa śahdogan, qa ohdakinyan kin wiciśpa topa, ozanpi owasin otoiyohi hinskokeca kta.

3 Ozanpi zaptan icikoyag yapi kte, qa ozanpi zaptan icikoyag yapi kta, 


\section{HDINANPAPI,}

4 Qa icikoyag yapi kta e ozanpi tokaheya opapun kin en śunjoyake to yakage kta, apahdate ekta, qa ozanpi inonpa ihanke opapun icikoyag yapi en hecen yakage kta.

5 Śunjoyake wikcemna zaptan ozanpi tokaheya en yakage kta, qa icikoyag yapi kin ekta śunjoyake wikcemna zaptan ozanpi inonpa opapun en yakage kta, śunjoyake iyotakonzapi kta, wanji unman ekta.

6 Unkan mazaskazi taśpu wikcemna zaptan yakage kta, qa maza taśpu kin on ozanpi kin icikoyag yaye kte, hecen wakeya wanjidan kte.

7 Unkan tatokadan hin ozanpi wakeya kin yecage kte, tipi kin iwankam; ozanpi kin ake wanji yakage kte.

8 Ozanpi wanji ohanske cin wiciśpa wikcemna yamni, qa ohdakinyan kin wiciśpa topa ; ozanpi akewanji owasin 'iakedececa hinskokeca kte.

9 Qa ozanpi zaptan yuwitaya icikoyag yaye kte, qa ozanpi śakpe icikoyag yaye kta, qa ozanpi iśakpo kin wakeya tiyopa kin iwankam yape han kte.

10 Qa icikoyag yapi kta e ozanpi opapun ihanke kin en sunjoyake wikcemna zaptan yakage kte, qa ozanpi inonpa opapun en ikoyagyapi kta e śunjoyake wikcemna zaptan.

11 Qa mazaśa taśpu wikcemna zaptan yakage kte, qa mazataśpu kin śunjoyake ohna yeyaye kte, hecen wakeya kin icikoyag yaye kte, qa wanjidan kte.

12 Qa wakeya ozanpi etanhan taku ihe cin he ozanpi wan hanke i.yaye cin he tipi kin ihektam okazeze he kta.

$13 \mathrm{Qa}$ wakeya anokatanhan ozanpi ohanske cin wiciśpa wanji iyaye cin he tipi cuwi anokatanhan okazeze he kta.

14. Unkan tarndoka wanunyanpi ha śayapi woakahpe wakeya kin yecage kta, qa akapatanhan ho-. ka ha woakahpe wan.

15 Unkan śitim can canmdaska bosdan unpi kta tipi kin yecage kta.

16 Canmdaska otoiyohi ohanske cin wiciśpa wikcemna, qa ohdakinyan kin wiciśpa sanpa hanke.

17 Qa canmdaska wanji nape nonpa yecage kta, on icikoyag yapi kte; tipi canmdaska kin owasin hecen yecage kta.

18 Qa tipi on canmdaska kin hecen yecage kta, canındaska wikcemna nonpa itokaga cuwi kin on, wiyotanhan ektakiya.

19 Qa mazaska sicu wikcemna tom canmdaska wikcemna nonpa ihukuya yakage kta, canmdaska wanji nape nonpa kin on maza sicu nonpa, canmdaska wanji ihukuya, canmdaska otoiyohi on hecen maza sicu nonpa kta.

20 Qa tipi cuwi inonpa on waziyatakiya canmdaska wikcemna nonpa kta,

$21 \mathrm{Qa}$ mazaska sicu wilkcemna topa ; canmdaska wanji ihukuya sicu nonpa, qa canmdaska iyokihe ihukuya sicu nonpa kta.

22 Qa tipi catku wiyohpeyata ektakiya canmdaska śakpe yecage kta.

23 Qa tipi catku kahmin nonpa kin on canmdaska nonpa yecage kta.

24. Qa napin iakedececapi kta, ihukuyatanhan, qa napin otoiyohi pa kin ekta maza napcupe tokaheya en ikoyag yapi kte kahmin nonpa kin on hena nonpa okonwanjidan kta.

25 Hecen canmdaska kin śahdogan kta, qa maza sicu kin ake śak- 


\section{WICOWOYAKE $2 \%$}

ne, maza sicu nonpa canındaska wanjidan ihukuya, qa maza sicu nonpa canmdaska wanjtdan ihukuya.

26 Qa śitim canhdakinyan yakage kta, zaptan tipi onnaptan tokaheya canmdaska kin on.

27 Qa canhdakinyan zaptan tipi onnaptan inonpa canmdaska on, qa canhdakinyan zaptan tipi ihanke wiyolipeyata ektakiya catkuta canmdaska on.

$28 \mathrm{Qa}$ canhdakinyar cokaya kin canmdaska cokaya ohna iyaye kta, ihanke wanji etanhan ihanke unman ekta iyohi ye kta. 29 Qa canmdaska kin mazaskazi ayapawinte kta, qa mazaskazi napcupe yecage kta, qa hena ohna canhdakinyan iyaye kta, qa canhdakinyan kin mazaskazi ayapawinte kta.

30 Qa tipi kin eyahde kta, he en okagapi kin wanyag niyanpi kin he iyecen.

31 Unkan cokaya ozanpi wan yakage kte, miniliuha ska nonpa kahmupi, qa to qa stan, qa duta kazuntapi, Kerubi akan kazuntapi kte.

32 Unkan mazaska sicu topa akan sitim can ipatan tom mazaskazi apawintapi qa mazaskazi yukśanpi tom akan cokaya ozanpi otkeyaye kte.

33 Qa cokaya ozanpi kin maza yukśanpi kin ihukuya otkeyaye kta, qa cokaya ozanpi kin he mahen woyaatanin can wohnake kin ade kta, qa niyepi on cokaya ozanpi kin tipi wakan qa wakan hinca otahedan yukinukan kta.

34 Qa wokajuju iha kin woyaatanin can wohnake akan eyahnake kta, tipi wakanhinca mahen.

35 Qa wahna wotapi kin he cokaya ozanpi kin itankan eyahde kta, qa petijanjan ihupa kin wahna wotapi iyotakons, tipi cuwi itokaga ekta, qa wahna wotapi kin cuwi waziyata kin ekta eyahnake kta.

36 Qa wakeya tiyopa woakahpe wan yecage kta, miniliuha ska nonpa kahmupi, to qa stan qa duta hdehdega ipatapi.

37 Unkan śitim can ipatan zaptan woakahpe kin yecage kta, qa hena mazaskazi ayapawinte kta, qa yukśanpi kin mazaskazi kta; qa hena on mazaśa sicu zaptan śdoyakiye kte.

\section{WICOWOYAKE $2 \%$.}

1 Unkan owayuśna wan śitim can on yakage kte, ohanske cin wiciśpa zaptan, qa ohdakinyan kin wiciśpa zaptan; owayuśna topa omdoton kta; qa obosdata kin wiciśpa yamni kta.

2 Qa oise topa kin akan he yakage kta, he kin owayuśna en ikoyakapi kta, qa owayuśna ocowasin mazaśa ayapawinte kte.

$3 \mathrm{Qa}$ cahota wakśica yecage kta, qa maza mdaska qa wakśica on amnimnipi, qa mazajata, qa. mazaoceti kin hena owasin mazaśa on yakage kta.

4 Qa mazaśa oceti wan ho kagapi iyececa, owayuśna kin yecage kta, qa oceti kin akan mazaśa napcupe topa oise topa kin akan.

5 Qa owayuśna opapun kin ihukuya oceti kin otkeyaye kta, qa owayuśna cokaya kin iyohi kta.

6 Qa śitim can tośu nonpa owayuśna kin yecage kta, qa tośu kin mazaśa ayapawinte kte.

7 Qa tośu kin mazanapcupe ohna yeyaye kta, qa tośu kin owayuśna cuwi napin akan unpi kta, hena on akiyuhapi kta.

8 Canmdaska on yakage kta 119 


\section{HDINANPAPI,}

hdogeca, paha akan okagapi kin wanyag niyanpi kin he iyecen he kagapi kte.

9 Unkan tipi tahocoka kin yakage kta, cuwi itokaga wiyotanhan ektakiya hocoka cuwi wanjidan on ozanpi wan minitiuha ska nonpa kahmupi ohanske cin wiciśpa opawinge kta.

10 Qa mazaśa ipatan kin wikcemna norpa, qa mazaśa sicu kin wikcemna nonpa, qa ipatan yukśanpi kin, qa içikoyag yapi kin hena mazaska on kagapi kita.

11 He iyecen waziyata cuwi on ozanpi ohanske cin wiciśpa opawinge, qa mazaśa ipatan kin wikcemna nonpa, qa mazaśa sicu kin wilkemna nonpa, ipatan maza yukśanpi kin, qa icikoyag yapi kin hena maza ska kta.

12 Qa hocoka hdakinyan wiyohpeyata ihanke on ozanpi kin wiciśpa wikcemna zaptan, ipatan wikcemna, qa sicu wikcemna.

13 Qa ihanke wihinanpe ektakiya tiyopata hocoka hdakinyan kin wiciśpa wikcemna zaptan kta.

$14 \mathrm{Qa}$ hiyete wanji on ozanpi kin wiciśpa akezaptan, ipatan kin yamni qa sicu kin yamni.

15 Qa hiyete unman kin on ozanpi akezaptan, ipatan kin yamni, qa sicu kin yamni kta.

16 Qa lıocoka tiyopa akahpe kin minihuba ska nonpa kahmupi, to qa stan, qa duta ipatapi, wiciśpa wikcemna nonpa, qa ipatan topa, qa sicu topa.

17 Ipatan owasin hocoka ihdukśan mazaska on ikoyag yapi kta, qa yukśanpi kin hena mazaska kta, qa tasicu kin mazaśa kta.

18 Hocoka ohanske cın wiciśpa opawinge, qa anog ihanke ohdakinyan kin wiciśpa wikcemna 120 zaptan, qa obosdatu kin wiciśpa zaptan, anog ihanke ozanpi kin miniliuha ska nonpa kahmupi, qa sicu kin mazaśa kta.

19 Tipi wakśica kin owasin on kicanyanpi, qa wihutipaspe kin owásin, qa hocoka wihutipaspe kin owasin mazaśa kta.

20 Unkan Israel cinca kin can ihdi bopanpi heceedan nicahi wicayaśi kta, petijanjan on, hecen ohinniyan ideye kta.

21 Aaron qa iye cinca kin itkokipapi wakeya kin ohna, cokaya ozanpi kin woyaatanin itokam yanke cin, he itankan petijanjan kin kicanyanpi kta ece, htayetu etanhan ihanhanna aiyalıdeya Jehowa itokam, Israel cinca kin wicoicage yeye cin, wicoope kin de ohinniyan yuhapi kta.

\section{WICOWOYAKE 28.}

1 Unkan niś Israel cinca cokayatanhan nicinye Aaron iye cinca om nikiyedan hiyu wicayakiye kte, wayuśnapi ece omakiyapi kte, Aaron qa iye cinca Nadab qa Abihu, Eleazer qa Itamar.

2 Qa wokoyake wakan wowitan on owanyag waśte hinca nicinye Aaron yecage kte.

3 Qa tona cante ksapapi woniya ksapa ojun wicawaye cin owasin Aaron yuwakanpi kte on wamiciyuśna kta e wokoyake kicagapi kta, ewicayakiye kte.

4 Qa wokoyake kagapi kta dena ee; maku akahpe, qa amdo akahpe, qa nitośke, qa mahen unpi hdeśkaślka, paipahte, qa ipiyaka, hecen wokoyake wakan n1cinye Aaron, qa iye cinca wicakicagapi kte; unkan wayuśnapi ece omakiyapi kte.

5 Unkan mazaskazi kin, qa minihuha ska kin, qa to kin, qa stan 
kin, qa, duta kin hena icupi qa ohdakinyan kin napapaśdecakta.

6 Qa amdo akalipe kin kagapi kta, mazaskazi qa minihuha ska nonpa kahrumpi to qa stan qa duta kazuntapi kin he kagapi kta.

7 Hiye te icaślie nonpa yuke $\mathrm{k}$ ta, ihanke nonpa kin ekta hecen ikoyag yapi kta.

8 Qa amdo akahpe ipiyaka kin he akan un kin he iyecen mazaskazi qa miniluha ska qa to qa stan qa duta on kagapi kte.

9 Unkan inyan wicaśake iyececa nonpa iyacu kta, qa hena akan Israel cinca cajepi kin yapago kta.

10 Cajepi kin śakpe inyan tokaheya kin akan, qa cajepi unman śakpe inyan inonpa kin akan, token icagapi kin he iyecen.

11 Inyan apagopi iyecên ipuspe akan owapi he iyecen, Israel cinhintku cajepi kin inyan nonpa kin akan apago kta, mazaskazi ozapi en taśpuyapi kta e hena yaliage kta.

12 Qn inyan nonpa kin amdo akalipe hiyete akan eyahnake kta, wokiksuye inyan Israel cinca on, qa wicakiksuye kta e Aaron iye hiyete anokatanhan akan cajepı Jehowa itokam yuha kta.

13 Qa mazaskazi ozapi yakage kta.

14 Qa mazaskazi hecedan maza icicahilia yuhmunpi nonpa yakaæ̌e kta, kazuntapi qa maza icicahiha yuhmunpi kin ozapi kin ekta ikoyag yaye lita.

15 Unkan woyaco maku akahpe kin yakage kta, amdo aliahpe kagapi kin he iyecen, mazaskazi qa miniliuha ska nonpa kahmupi, to qa stan qa duta kazuntapi kin he yakage lite.

16 Topa omdoton kta, icitakihna, ohanske cin napapaśdecapi, pi kta.

17 Qa inyan taśpuyapi cankuye topa he ohna ojuyaye kta, sardius qa topaz qa petaga canku tokaheya kin hee kta.

18 Qa cankuye inonpa kin he smaragdos, qa sapiros, qa inyan paksa ;

19 Qa canku iyamni kin he ligurion, agate, qa ametustos ;

20 Qa cankuye itopa kin krusolitos qa inyan wicaśake iyececa, qa iyaspis, qa mazaskazi ozapi ohna hena taśpuyapi kta.

21 Qa inyan kin hena Israel cinca akenonpa cajepi kin hena iyececa ipuspa pagopi kin he iyecen wicoun akenonpa cajepi kin otoiyohi akan pagopi kta.

$22 \mathrm{Qa}$ maku akahpe kin akan mazaskazi ecedan ikan maza icicahiha yuhmunpi yakage kta.

23 Qa maku akahpe kin mazaskazi napcupe nonpa yecage kta, qa maza napcupe nonpa kin hena naku akahipe ihanke nonpa en koyag yaye kta.

24 Qa mazaskazi ikan nonpa kin maza napcupe nonpa maku akahpe oise nonpa akan unpi kin hena ohna iyeyaye kta.

25 Qa ikan nonpa ihanke nonpa ozanpi nonpa kin en koyag yaye kta, qa amdo akahpe hiyete kin akan itankan eyahnake lkta.

26 Qa mazaskazi napcupe nonpa yakage kta, qa hena maku akahipe oise nonpa opapun en ikoyag yaye kta, amdo akalipe mahentuya iyotakonza.

27 Qa mazaskazi napcure nonpa yakage kte amdo akahpe opapun nonpa kin ihukuya tanhan itokam en ikoyag yaye kta, icikoyag yapi lyotakons, maku akahpe ipiyaka kin iwankapatanhan. 28 Qa maku akahpe kin maza 121 


\section{HDINANPAPI,}

napcupe tawa kin on amdo akahpe napcupe kin en iyakaśkapi kte, hahonta to wan on, hecen amdo akahpe ipiyaka kin akan yanke $\mathrm{kta}$, qa maku akahpe kin amdo akahpe kin etanhan yukinukan kte śni.

29 Unkan Aaron Israel cinhintku cajepi kin iye cante kin akan yuha kta, woyaco malku akalipe ohna, tipi wakan en ya eca, Jehowa itokam ohinniyan wokiksuye kte.

30 Unkan iyoyamwicaye cin qa yuśtanwicaliye cin hena woyaco maku akahpe kin ekta ikoyag yaye kta, qa Aaron Jehowa itokam u eca hena cante kin akan yanke kta, hecen Aaron Israel cinca woyacopi kin iye cante kin akan ohinniyan Jehowa itokam yuha kta.

31 Unkan amdo akahpe nitośke kin ocowasin to yakage kta.

32 Qa he cokaya pa $\mathrm{i}$ kin yuke kta, qa i kin ihdukśan apalidate kazuntapi maku akahpe i kin iyececa $\mathrm{kta}$, hecen natidece kte śni.

33 Unkan upi akan taspan tanka seca, to qa stan qa duta yakage kta, opapun ihdukśan, qa mazaskazi lidalida hena otahedan.

34 Mazaskazi hdahda wan, qa taspan tanka seca wan, mazaskazi hdalida wan, qa taspantanka seca wan, nitośke opapun akan ihdukśan.

$35 \mathrm{Qa}$ Aaron omakiye kta e he koyake kta, qa Jehowa itokam, tipi wakan en u eca, qa tankan inanpa eca he sna kin nahonpi kta, hecen te kte śni.

36 Qa mazaskazi ecedan mdaska wan yakage kta, qa 1puspe pagopi kin he iyecen, he akan Johowa wakan da wo, yapago kta.
$37 \mathrm{Qa}$ ikan to wan ikoyag yaye kta, hecen pa iyuskite akan un kta, iyuskite itokapatanhan kta.

38 Qa Aaron ite kin akan un $\mathrm{kta}_{\mathrm{H}}$ Israel cinca taku yuwakanpi, woqupi yuwakanpi kin hena owasin woahitani kin yuha kta, qa Jehowa iyokipi yapi kta e he ite kin akan ohinniyan yanke kta.

39 Unkan mahenunpi miniliuha hdehdega yakazonte kta, qa miniliuha ska pa iyuskite yakage kta, qa ipiyaka ipatapi yakage kta.

40 Unkan Aaron cinca kin mahenunpi wicayecage kta, qa ipiyaka wicayecage kta, qa wapaha, owanyag waśte qa wowitan on yakage kta.

$41 \mathrm{Qa}$ hena nicinye Aaron i.ye cinca kiçi koyag wicayaye kta, qa napepi kin ojudan wicayakiye kta, hecen wamiciyuśnapi kta e wicayaduwakan kta.

42 Qa miniliuha onzeoge wicayecage kta, on celipi iśtecapi akahpapi kta, wicapakśin etanhan wicaceca ekta iyohiye kta.

43 Qa Aaron qa iye cinca kin hena koyakapi kta, itkokipapi wakeya ekta upi eca, qa tipi wakan ohna omakiyapi kta "e owayuśna ikiyedan upi eca, hecen woalitani yuhapi kte śni, qa tapi kte śni ; iye, qa tona iye etanhan icagapi kte, wicoope kin he owihanke wanin yuhapi kte.

\section{WICOW OYAKE 29.}

1 Unkan wamiciyuśnapi kta wicaduwakan kta e taku ecawicayecon kte cin dee, tatarka wan, pte wanunyanpi cinca, qa tamdoka wanunyanpi nonpa owasin waśte icu wo.

$2 \mathrm{Qa}$ aguyapi napoliye codan, qa aguyapi hmiyanyanna ona- 
pohye codan, wihdi icicahiyapi, qa aguyapi ceguguyapi napohyapi śni, wihdi on sdayapi; hena owasin aguyapi mdu on yakage kta.

3 Qa makanopiye wanjidan en oyahnake kta, qa hena makan opiyedan ohna, qa tatanka kin, qa tamdoka nonpa kin ikiyedan awicayahi kta.

$4 \mathrm{Qa}$ itkokipapi wakeya tiyopa ikiyedan, Aaron qa iye cinca awicayahi kta, qa mini on wicadujaja kta.

5 Qa wokoyake kin iyacu kta, qa maher unpi kin, qa amdo akahpe nitośke kin, qa amdo akahpe kin, qa maku akahpe kin, hena owasin Aaron koyag yaye kta, qa amdo akahpe ipiyaka lin ipiyag yaye kta.

6 Qa pa iyuskite cin pa akan payahte kta, qa wateśdake wakan kin pa iyuskite akan.

7 Qa wihdi on sdayapi kin he iyacu kta, qa pa akan yakaśtan kta, hecen he sda yaye lita.

$8 \mathrm{Qa}$ cinhintku kin ikiyedan awicayahi kta, qa mahenunpi kin koyag wicayaye kta.

9 Qa ipiyake on ipiyag wicayaye kta, Aaron qa cinhintku, qa wapaha kin iyawicayakicaśke kta, hec $\_$wawayuśna hecapi kta, wicoope owihanke wanin, hecen Aaron iye cinca ko napepi ojudan wicayaye kte.

10 Qa tatanka qon itkokipapi wakeya kin itokam ikiyedan ayahi kta, qa Aaron iye cinca koya napepi kin tatanka pa kin akan aputakapi kta;

11 Qa tatanka qon yakte kta, Jehowa itokam, itkokipapi wakeya tiyopa ekta.

12 Qa tatanka we kin onge iyacu kta, qa owayuśna he kin akan ehpe yaye kta, ninapsukaza on, qa we kin ocowasin owa- yuśna sicu kin ekta oyakaśtan kta.

13 Qa watejikśija kin ocowasin, qa pizi pi kin ikoyake cin he, qa pakśin nonpa kin waśin ikoyake cin iyahna, qa owayuśna izin yaye kta.

14 Tuka tatanka qon cehpi km, qa ha kin, qa tacesdi kin owanka iheyata peta on huhnah yaye kta, woalitani wośna hee.

15 Unkan tamdoka tokaheya kin he iyacu kta, unkan Aaron qa iye cinca kin napepi kin tamdoka pa aputakapi kta.

16 Unkan niye tarndoka kin yakte kta, qa we kin iyacu kta, qa owayuśna akan ihdukśan ehpeyaye kta.

17 Qa tamdoka kin yapate kta wobaśpe iyececa, qa śupe kin huha kin ko dujaja kta, qa hena wobaśpe kin qa pa kin ekta eyahnake kta.

$18 \mathrm{Qa}$ tamdoka kin ocowasin on owayuśna izin yaye kta. Jehowa wokiciliuhnagapi wan hee; woomna wiciyokipi wan Jehowa kicagapi hee.

19 Unkan tamdoka inonpa kin iyacu kta, qa Aaron, qa iye cinca kin napepi kin tamdoka pa kin aputakapi kta.

20 Qa niś tamdoka kin yakte kta, qa we kin etanhan iyacu kta, qa Aaron noge inkpa akan, qa cinhintku nogepi inkpa akan eyahnake kta, etapa kin eciyatanhan, qa napepi Etapa hunka akan qa sipahunkepi etapa akan, qa we kin owayuśna akan ihdukśan ehpe yaye kta.

$21 \mathrm{Qa}$ we owayuśna akan un kin he etanhan iyacu kta, qa wihdi on sdawicayapi kin he e. tanhan, qa hena Aaron iyakiun kta, tawokoyake ko, qa cinhintku tawokoyakepi koya, hecen Aaron duwakan kta, qa tawokoyake, 
qa cinhintku tawokoyakepi koya.

22 Qa tamdoka etanhan waśin kin iyacu kta, qa sinte, qa watejikśija kin he, qa pi pizi kin, qa pakśin napin, qa waśin hena akan un kin, qa hiyete etapa kin, tamdoka wicayuśtan kin hee.

23 Qa aguyapi wanji, qa aguyapi hmiyanyanna wihdi icicahiyapi wanjidan, qa aguyapi ceguguyapi wanji aguyapi napohye codan makan opiye kin Jehowa itokam yanke cin hetanhan.

24 Qa hena owasin Aaron nape kin en eyahnake kta, qa cinhiritku napepi kin en, qa Jehowa itokam hena yakoze kta, wokozapi wan hee.

25 Qa napepi kin etanhan hena iyacu kta, qa owayuśna kin izin yaye kta, wohuhnahyapi woomna wiciyokipi Jehowa itokam, peta wośnapi wan Jehowa kicagapi hee.

26 Qa tamdoka Aaron on yuśtanpi kin he maku kin iyacu kta, qa Jehowa itokam he yakoze kta, qa obaśpe kin he nitawa kta.

27 Hecen tamdoka on Aaron ojunyapi, qa iye cinca nakun ojun wicayapi kin he maku kozapi qa hiyete yuwintapi, taku kozapi, qa taku yuwintapi kin he duwakan kta.

$28 \mathrm{Qa}$ he Aaron qa cinhintku tawapi kta, Israel cinca kin etanhan wicoope owihanke wanice kta, he yuwintapi heon Israel cınca wopida wośnapi etanhan he yuwintapi kta, Jehowa ekta yuwintapi kta.

29 Unkan wokoyake wakan Aaron tawa kin he cinhintku, iye iyohakam tawapi kta, hena ohna sdawicayapi kta, qa napepi kin ojun wicayapi kta.

30 Cinhintku etanhan tuwe heekiya wawayuśna kta, qa tipi wa- kan ohna omaliiye kta e itkokipapi wakeya ekta hi kinhan, anpetu śakowin hena koyake kta.

31 Unkan tamdoka ojunwicaye cin he iyacu kta, qa celipi kin oyanke wakan kin ohna oyahe kta.

32 Unkan Aaron qa cinhintku tamdoka celipi kin yutapi kte, aguyapi makan opiye ohna un kin he nakun, itkokipapi wakeya tiyopa kin ekta.

33 Taku on woakahpe kagapi napepi ojun wicayapi, wicayuwakarpi kte cin, hena yutapi kta, tuka tuwe tokeca hena yute kte śni, nakaeś hena wakan.

34 Unkan ojun wicayapi celipi kin onge oyaptapi kinhan qaiś aguyapi kin onge ihanlianna hehanyan, taku oyaptapi kin he luhinali yaye kta hee wakan heon yutapi kte śni.

35 Unkan Aaron qa cinhintku hecen ecawicayecon kta, token econ ciśi kin owasin iyecen, anpetu śakowin napepi kin ojun wicayaye kta.

$36 \mathrm{Qa}$ woakalipapi on anpetu otoiyohi tatanka woalitani wośnapi yapate kta, hecen owayuśna kin duteca kta, woakahpe akan yakage cin on, qa duwakan kta e sdayaye kta.

37 Anpetu śakowin owayuśna on woakahpe yakage kta, qa he duwakan kta, hecen owayuśna kin wakan hinca kta, taku kaśta he yutan kinhan wakan kta.

38 Unkan uwayuśna akan taku waduśna kte cin dee; amnos (tahin wanuyanpi) waniyetu wanjidan, nonpa anpetu o toiyohi ohinniyan.

39 Hanhanna eca amnos tokaheya yapate kta, qa amnos inonpa kin olitayetu otahedan yapate kta.

40 Qa amnos wanjı kici aguya- 


\section{WICOWOYAKE 30.}

pi mdu iyutapi iwikcemna (wiyatke ohnaka śakpe) qa wihdi bopanpi hin itopa kin (wiyatke ohnaka nonpa) icicahiyapi qa woakaśtan qupi miniśa hin itopa kin.

41 Unkan tahinca inonpa kin ohtayetu otahedan yapate kta hanhanna minha kin qa woakaśtan kin he iyecen ecayecon kta peta wośnapi woomna Jehowa iyokipi ye kta.

42 Jehowa itokam itkokipapi wakeya tiyopa kin ekta wicoicage nitawapi kin yeye cin he peta wośna wan ohinniyan un kte; hen ociciye kta e heciya itkocicipapi kta.

43 Qa hen Israel cinca kin itkowicawakipe kta, qa mitowitan kin he yuwakanpi kta.

$44 \mathrm{Qa}$ itkokipapi wakeya kin, qa owayuśna kin mduwakan kta, qa wamiciyuśnapi kta e Aaron cinhintku ko wicamduwakan kta.

45 Qa Israel cinca kin wicehna ounwaye kta, qa taku wakan dapi kin he miye kta.

$46 \mathrm{Qa}$ Jehowa wakandapi $\mathbf{E}-$ gupta makoce etanhan hdinanpe wicaye cin he miye sdonyapi kta, wicehna ounwaye heon etanhan; Jehowa Wakandapi kin he miye.

\section{WICOWOYAKE 30.}

1 Unkan taku waśtemna izin yapi kta e wizinya owayuśna wan yakage kta, śitim can on yakage kta.

2 Ohanske cin he wiciśpa warljidan kta, qa ohdakinyan kin wiciśpa wanjidan, topa omdoton kta, qa obosdatu wiciśpa nonpa, he kiyuke kta.

3 Qa mazaskazi ecedan on ayapawinte $\mathrm{kta}$, toakahpe kin, qa cuwi kin ihduksan, qa he kin; qa ihdukśan mazaskazi wateśdake wan yecage kta.

4 Qa mazaskazi napcupe nonpa yecage $\mathrm{kta}$, wateśdake ihukuya cuwi nonpa akan anokatanhan hena yakage kta, qa hena tośu on akiyuhapi icupi kta e yuke kta.

5 Qa śitim can tośu kin yakage kta, qa mazaskazi ayapawinte kta.

6 Qa cokaya ozanpi kin itokam woyaatanin can ohnaka iyotakons, tukten itkocicipe kta, wokajuju iha woyaatanin can wohnake kin akan yanke cin he itokam eyahde kta.

$7 \mathrm{Qa}$ he akan Aaron pejuta waśtemna izinye kta, hanhanna otoiyohi petijanjan pikiya eca he izinye kta.

8 Qa Aaron petijanjan wankan ehnaka eca olitayetu otahedan taku waśtemna he akan izinye kta, ohinniyan Jehowa itokam nitoicagepi yeye cin.

9 He akan wizinyapi tokeca, qa wohulinaliyapi, qa minlia huhnali yaye kte śni, qa woakaśtan ayakaśtan kte śni.

10 Tuka he kin akan ptanyetu otoiyohi wancadan Aaron woakahpe kage kta; nitoicagepi yeye cin ptanyetu eca wancadan woaltani kajujupi we on he akan waakahpe kta. He. Jehowa tawa wakan hinca.

11 Unkan Jehowa ie ca Mowis heciya,

12 Tohan Israel cinca kin wicadawa eca, wicayawapi kta e wicaśta otoiyohi nagi kin on woakahpe Jehowa qu kta, wicayawapi icunhan, hecen wicayawapi icunhan makośice awicakipe kte śni.

13 Hecen qupi kta, tona wicayawapi kin iyoopta ya otoiyohi 


\section{HDINANPAPI,}

śeqel hanke tipi wakan śeqel iyececa (omnica wikcemna nonpa śeqel ee ce) śeqel hanke Jehowa qu kta.

14. Tona wicayawapi iyoopta ya wica waniyetu wikcemna nonpa qa iwankam owasin woahi Jehowa qupi kta.

15 Tuwe wijica eśta śeqel hanke yuota kte śni, qa tuwe onśika eśta yuoptetu kte śni, ninagipi on hdajujupi kta woahi wan Jehowa qupi eca.

16 Qa woakahpe mazaska kin Israel cinca etanhan iyacu kta, qa. itkokipapi wakeya kicanyanpi on yaqu kta, qa Israel cinca wokiksuye yapi kte, Jehowa itokam ninagipi kin on wokajuju kta.

17 Unkan Jehowa ie ca Mowis heriya ;

18 Nakun mazaśa koka wan yakage $\mathrm{kta}$, qa mazaśa cetetahe kin, ekta ihdujajapi kta, qa itkokipapi wakeya qa owayuśna otahedan eyahde kta, qa he ohna mini oyakaśtan kta.

19 Unkan Aaron iye cinca koya hetanhan napepi sihapi ko ihdujajapi kta.

20 Itkokipapi wakeya kin en yapi eca mini on ihdujajapi kta ece, hecen tapi kte śni, qa tohan Jehowa ókiyapi owayuśna ikiyedan upi, peta wośna izin kiyapi ece kta.

21 Napepi sihapi ko ihdujajapi kta, hecen țapi kte śni; he wokage owihanke wanice kta, iye qa cinca kin wicoicagepi ecen econ kta.

22 Unkan Jehowa ie ça Mowis heciya,

23 Nakun niś pejuta waśtemna itancan icu wo, mur śbuśbu śeqel opawinge zaptan, qa canhaśa waśtemna he hanke, opawinge nonpa sanpa wikcemna zaptan, 126 qa sinkpe tawote waśtemna opawinge nonpa sanpa hanke,

24 Qa kasia opawinge zaptan, tipi wakan śeqel ohna iyutapi kta, qa can ihdi hina wanjidan.

25 Qa hena sdayapi wakan wihdi yakage kta, pejuta wicaśta taku waśtemna kagapi kin he iyecen, sdayapi wakan wihdi waśtemna hee kta.

$26 \mathrm{Qa}$ he on itkokipapi wakeya kin sdayaye kta, qa woyaatanin canwohnaka kin,

$27 \mathrm{Qa}$ wahna wotapi kin, qa wakśica tawa kin owasin, qa petijanjan ihupa, qa on kicanyanpi kin, qa izin yapi owayuśna kin.

28 Qa woliuhinahyapi owayuśna kin, qa taku on kicanyanpi owasin, qa koka kin qa tacetetahe koya.

29 Hecen hena duwakan kta, qa wakanhincapi kta, taku kaśta hena yutan kinhan wakan kta.

30 Unkan Aaron qa iye cinca kin sdawicayaye kta, qa wamiciyuśnapi kta e wicaduwakan kta. 31 Qa Israel cinca kin hecen ewicayakiye kta, wakan sdayapi wihdi mitawa kin dee kta, nitoicagepi yeye cin ohna.

32 Wicaśta cehpi kin akan he akaśtanpi kte śni qa he icicahiyapi kin, qa taku on kagapi iyecen yakagapi kte śni, hee wakan, qa wakanyan yadapi kte.

33 Tuwe he iyecen wihdi waśtemna ye cin, qa tuwe wicaśta tokeca akan he akaśtan kinhan, oyate tawa kin etanhan kaśpapi kta.

34. Unkan Jehowa Mowis heciya, Taku waśtemna icu wo, canśin qa tukiha waśternna, qa galbanum oomna suta, qa canśin ska, otoiyohi iakedenakeca.

$35 \mathrm{Qa}$ hena wizinyapi yakage kta, pejuta wicaśta taku icicahiyapi kin he iyecen yakage kta 


\section{WICOWOYAKE 31.}

miniskuya ecedan icicahiyapi wakan kta.

$36 \mathrm{Qa}$ hetanhan boyapan kta, mduhinca yakage kta, qa onge woyaatanin itokam itkokipapi wakeya ohna tukten itkocicipe kta eyahnake kta, he wakanhinca dawapi kta.

37 Qa taku waśtemna kin de yakage cin he iyecen takudan niçicagapi kte śni; he Jehowa tawa, he wakan dawa kta.

38 Tuwe omna kta e taku he iyecen kage cinhan, oyatc tawa kin etanhan kaśpapi kta.

\section{WICOWOYAKE 31.}

1 Unkan Jehowa ie ça Mowis heciya,

2 Tho wo Betzalel Uri cinhintku, Hur cinhintku, Juda wicoun etanhan caje kin on weco.

3 Qa taku wakan toniya on ojuwaya woksape qa wookahnige, qa wosdonye on, qa wohtani owasin en.

4 Taku wayupiya kagapi iyukcan kta, mazaskazi, qa mazaska, qa mazaśa on kage kta.

5 Qa inyan ojuyapi kin pago kta, qa can pago kta, qa taku kagapi owasin kage kta.

6 Qa he kici miś miye Aholiab Ahisamak cinhintku, Dan wicoun kin etanhan waqu, qa tona cante ksapapi cantepi ohna woksape wicawaqu, hecen taku kah ciśi kin owasin kagapi kta.

7 Itkokipapi wakeya kin, qa canwohnake woyaatanin on, qa he akahpe cin, wokajuju iha kin, qa taku wakeya kicanyanpi owasin.

8 Qa wahna wotapi wakśica tawa iyahna, qa petijanjan ihupa ecedan kin, qa taku on kicanyanpi owasin, qa wizinyapi owayuśna kin.
9 Qa wohuhnahyapi owayuśna kin, qa taku on kicanyanpi owasin, qa maza koka kin, qa tacetetahe kin.

10 Qa śina ozanpi kin, qa Aaron wawayuśna tawokoyake wakan kin, qa cinhintku tawokoyakepi ohna wayuśnapi kte.

11 Qa wihdi on sdayapi kin, qa wizinyapi waśtemna kin tipi wakan kin on; token econ ciśi kin owasin iyecen econpi kta.

12 Unkan Jehowa ie ca Mowis heciya,

13 Niś Israel cinca kin hecen ewicakiya wo, Tokcśta anpetu wakan mitawa kin yapatanpi kta, nakaś nitoicagepi yeye cin niyepi qa miye unkiotahedan, he wowapetokeca on ciyuwakanpi ; Jehowa he miye sdonyapi kta.

14 Qa anpetu okihpapi kin he yapatanpi kta, nakaś niyepi on he wakan, tuwe he yuśape cinhan he ktepi kta, heon tuwe he icunhan wohtani taku kaśta econ kin he taoyate kin cokayatanhan kaśpapi kta.

15 Anpetu śakpe wohtani econpi kta, tuka anpetu iśakowin kin he anpetu wakan, okilipapi wakan Jehowa tawa, tuwe kaśta anpetu okihpapi en wolitani econ kinhan he awicakehan ktepi kta.

16 Heon Israel cinca kin anpetu okihpapi kin he patanpi kta, wicoicagepi yeye cin wicotakuye owihanke wanica, arpetu okihpapi kin kagapi kta.

17 Miye qa Israel cinca unkiotahcdan he wowapetokeca owihanke wanice kta, nakaś anpetu śakpe en Jehowa malipiya kin qa maka kin kage ça anpetu iśakowin kin en okihpe ca oziiciye.

18 Unkan Sina he kin ohna Mowis kici okiye enakiye cehan inyan mdaska woyaatanin qu, in127 
yan mdaska nonpa Jehowa napsukaza on owapi.

\section{WICOWOYAKE 32.}

1 Unkan oyate kin Mowis he kin etanhan apamahdeya hiyu hdutehan kin he wanyakapi qehan, oyate kin Aaron en mniciyapi, qa heciyapi, Najin wo, taku wakan unkiyepi itokam yapi kta unkicicagapo. Ecah Mowis wicaśta Egupta makoce etanhan hinanpe unyanpi kin he toki un kin sdonunyanpi śni ce.

2 Unkan Aaron hewicakiya, Mazaskazi oinpi kin nitawinpi qa nicincapi wica winyan ka, nogepi ikoyakapi kin hena yuksapi qa en makahipo.

3 Unkan oyate kin owasin mazaskazi oinpi kin nogepi kin etanhan hduksapi, qa Aaron en kahipi.

4 Unkan Aaron hena napepi kin etanhan icu, qa ojuha wan en pahta qa ptejicadan śdoyapi wan kaga. Unkan, Israel taku wakan nitawa Egupta makoce etanhan hinanpe niyanpi kin dena ee ce, eyapi.

5 Unkan Aaron wanyake ça he itokam owayuśna wan kage ca, Heyakecinhan Jehowa wakan wokicihanpi kta, Aaron ieyanpaha, eya.

6 Unkan ihanhanna hin kiktapi, qa wohuhnaliyapi hulinahyapi, qa wopida wośnapi ahipi, qa oyate kin wotapi qa wayatkanpi kta e iyotankapi, qa śkatapi kta e najinpi.

7 Unkan Jehowa Mowis heciya, Kun hda, oyate nitawa Egupta makoce etanhan hinanpe yaye cin wanna ihduhowinpi ce.

8 Canku wan ope wicawaśi qon he etanhan kohanna ihdutokanpi, ptejicadan śdoyapi wan içi128 cagapi, qa ekta pakicapsanpi, qa wakiciyuśnapi, qa Israel taku wakan yada, Egupta rnakoce etanhan hdinanpe niye cin dena ee ce, eyapi.

9 Unkan Jehowa Mowis heciya, Oyate kin de wanmdake ca inyun oyate tahu patin hecapi.

10 Qa wanna micuni wo, hecen mitocanniye kin awicakate kta, qa ihang wicawaye kta, qa niś oyate tanka cicage kta ce.

11 Unkan Mowis Jehowa taku iye wakan da kin cin kiye ca heya, Jehowa, tokeca oyate nitawa kin canniye yaya he? hena Egupta makoce etanhan hdinanpe wicayaya, wowaśake tanka on, qa nape waśaka on.

12 Tokeca Egupton heyapi kta, Taku sica on inanpe wicaya, he kin ohna wicakte kta, qa maka ite kin etanhan awihnuni wicaye kta heon etanhan, eyapi kta; nitocanniye kate cin etanhan ihduhomni, qa oyate nitawa en taku śice cin de on iyope içiya ye.

13 Nitaokiye Aberaham, qa Izak, qa Israel wicakiksuya ye, token caje nihdate ca konze hewicayakiya, Nicincapi kin mduota kta, mahpiya wicanhpi kin iyenakecapi kta, qa makoce kin de cajemdate cin ocowasin nicincapi lkin wicawaqu kta, qa owihanke wanin tawayapi kta.

14 Unkan Jehowa taku śica taoyate kin ecawicakicon kta, eye ciqon on iyope iciya.

15 Unkan Mowis ihdamna, qa he kin etanhan apamahdeya hda, qa woyaatanin inyan mdaska nompa qon nape kin ohna hdohda, inyan mdaska kin hena anokatanhan owapi, deciyatanhan qa unman eciyatanhan nakun, inyan mdaska owapi ce.

16 Inyan mdaska kin hena Wakantanka kaga, qa owapi kin he 


\section{WICOWOYAKE 32.}

Wakantanka owa ce, inyan mdaska kin akan pago.

17 Unkan Jośuwa oyate oqoyapi kin nation qa, Owanka ohna kicizapi iyecen oqoyapi ce, Mowis eciya.

18 Unkan, Wicaśta ohiyapi, qa panpanpi ho kin hee śni, qa wicaśta wicaktepidan howayapi kin hee śnì ce, tuka wicaśta dowanpi ho kin nawalion, eya.

19 Qa owanka kin ikiyedan $u$ qehan, qa ptejicadan, qa wacipi kin wanyake cehan, Mowis śinhda, qa inyan mdaska qon nape etanhan ehpeya, qa kamdeca, he kin ihukuya.

20 Qa ptejicadan kagapi qon he icu qa peta on hulinaga, qa yukpan, hecen mdu kage ça mini kin akada; qa Israel cinca kin yatke wicaliya.

21 Unkan Mowis Aaron heciya, Oyate kin de taku ecannionpi kin on woahtani tanka kin de awicayakahi he?

22 Unkan Aaron heya, Itancan, ihnuhan śinyahda kin. Niś oyate kin de śicapi ce, sdonwicayaya. 23 Qa hemakiyapi; Taku wakan unkitokam yapi kta unkicicagapo, Mowis wicaśta kin he Egupta makoce kin etanhan, itanwankanhde mani unyanpi kin, tuktee hesdonunyanpi śnice. 24 Unkan, Tuwe mazaskazi onge yuhe cinhan hdukse kta, ewicawakiya, unkan he maqupi, unkan petan ehpewaya, qa ptejicadan kin de inanpa ce.

25 Hehan oyate kin śdokahanpi e Mowis wanyaka, nakaś tokawicayapi iwicahahapi kta Aaron wicay uśdoka ;

26 Qa owanka tiyopa kin ohna Mowis najin qa, 'Tuwe Jehowa ope cin en mahi wo, eya. Unkan Lewi cinca kin owasin en kawitavapi.

Ex.
27 Unkan hewicakiya, Wicaśta otoiyohi tamazasagye kihnake kta, ceca akan qa owanka ohna tiyopa iyaza ye kta, qa wicaśta otoiyohi iye sunkaku qa takodaku, qa tuwe iye ikiyedan ti kin wicakik te kta, Jehowa Israel wakandapi kin he eya ce.

28 Unkan Lewi cinca kin Mowis eye. cin he iyecen econpi; unkan anpetu kin he oyate kin etanhan wicaśta kektopawinge yamni ecetu ihpayapi.

29 Nakaś Mowis hewicakiye ciqon, Jehowa on anpetu kin de ninapepi kin ojunkiyapo, wicaśta iye cinhintku qaiś sunkaku kin on, hecen anpetu kin de woyawaśte wan niçupi kta ce.

30 Unkan ihanlianna Mowis oyate kin hewicakiya, Woahtani tanka wan wayahtanipi, heon wanna itanwankanhdeya mde kta, Jehowa ekta, okini wayahtanipi kin akahpe waye kta ce.

$31 \mathrm{Qa}$ Mowis icicawin Jehowa elsta ye ca heya, Hehe, oyate kin de woahtani tanka wahtanipi, qa mazaskazi taku wakan içicagapi ;

32 Qa wanna tokin wahtanipi kin wicakiciyutokan, qa hecetu śni kinhan wowapi wan oyakiwa kin hetanhan mapajujuye, ceciciya.

33 Unkan Jehowa Mowis heciya, Tuwe amawahtani kin he wowapi mitawa kin etanhan wapajuju kta ce.

34 Qa wanna ekta hda, tokiya caje mdata qon heciya oyate kin awicaya wo, ito ohnihde wakiye cin he nitokam ye kta, tuka, tohan en wahi eca wahtanipi kin awicawahi ece kta.

35 Unkan Jehowa ptejicadan kagapi on, Aaron kage cin hee, on etanhan oyate kin wicakaśtaka. 


\section{HDINANPAPI,}

\section{WICOWOYAKE 33.}

1 Wanna Jehowa Mowis hecen eciye ciqon, Hunktiya detanhan itanwankanhdeya ya wo, niś qa oyate Egupta makoce etanhan hdinanpe wicayaye cin, makoce wan nicinca kin he waqu kta ce, Aberaham, qa Izak, qa Jakob iwicawakonze ciqon he ekta.

2 Qa ohnihde wakiye cin he nitokam ye waśi kta, qa nitokapatanhan Kanani kin, qa Amori kin, qa Hiti kin, qa Perazi kin, qa Hiwi kin, qa Jebusi kin, ham wicawaye kta;

3 Makoce wan asanpi qa canhanpi tik tica kaduze cin lie ekta; oyate tahu patin henicapi heon niyepi cokaya mde kte śni, okini tahepi tem ciyapi kta.

4 Unkan oyate kin wicoie sice cin he uahonpi, qa iyokiśin içiyapi, qa tuwedan oinpi kin ikoyag kiye śni.

5 Nakaś Jehowa Mowis heciye ciqon, Niś oyate tahu patin henicapi, ihnuhanna niyepi cokaya inawape kte ca ihang ciyapi kta ; heon wanna oinpi nitawa kin niye etanhan makata elipe kiya wo, hecen taku ecacicon kta sdonwakiye kta, Israel cinca kin ewicakiya wo.

6 Hecen Israel cinca kin oinpi kin hduśdokapi, Horeb he kin ihukuya.

7 Unkan Mowis wakeya kin icu, qa owanka kin itankan ehde, owanka kin itehan, qa itkokipapi wakeya kin, eya cajeyata. Unkan tona Jehowa akitapi kin hena owasin itkokipapi wakeya kin ekta owanka kin itankan inanpapi.

8 Unkan Mowis wakeya kin ektakiya inanpa eca oyate kin owasin najinpi ece, otoiyohi ta- wakeya tiyopa kin ekta qa Mowis ihakam etonwanpi wakeya kin ekta i kin hehanyan:

9 Unkan Mowis wakeya kin ekta i eca mahipiya śoka bosdata kin kun hiyu, wakeya tiyopa kin ekta, qa Mowis okiya ece.

10 Unkan oyate kin owasin mahpiya bosdata qon, wakeya tiyopa kin ekta najin e wanyakapi, qa oyate kin owasin najinpi qa cekiyapi, otoiyohi tawakeya tiyopa ekta.

11 Unkan Jehowa Mowis kici wohdaka, kaicitkokim, wicaśta wan takodaku kici wohdaka he iyececa, unkan owanka kin elkta kihda, qa taokiye Jośuwa Nun cinhintku kośka kin, tuka mahpiya bosdata wakeya cokayatanhan tokan ye śni.

12 Unkan Mowis Jehowa heciya, Tho oyate kin de itanwankanhdeya awicaya wo, eha tuka tuwe mici ye yaśi kta sdonye mayakiye śni, tuka nicaje on sdon ciya, qa nakun miiśta kin iyokipi yaya ce, eha.

13 Qa wanna niiśta kin iyokipi waye cinhan nitacanku kin sdonye makiya ye; hecen niiśta kin ohna woiyokipi iyewaye cin he sdotciye kta, qa oyate kin de oyate nitawa kin ee, awacin wo. 14 Unkan, Miite kin ye kta qa oziciciye kta ce, eya.

15 Unkan heciya, Niite kin ye śni kinhan, detanhan itan wankanhdeya unkayapi śni ye.

$16 \mathrm{Qa}$ wanma niiśta kin ohna woiy okipi iyewaye, miye qa oyate nitawa kin tokiyatanhan sdonyapi kta he? unkicipi idade cin hee śni he? hecen miye qa oyate nitawa kin oyate maka itohnake akan unpi kin owasin etanhan unyukinukanpi kta.

17 Unkan Jehowa Mowis hec1ya, Taku ehe cin he nakun eca- 


\section{WICOWOYAKE 34.}

mon kta, nakaś miiśta kin ohna woiyokipi iyeyaya, qa nicaje kin on sdonciya.

18 Unkan, Tokin nitowitan he wanyag makiya ye, eya.

19 Unkan, Mitowaśte kin owasin niite kin itokam iyaye wakiye kta, qa Jehowa caje kin eyan wapaha kta, nitokam, qa tuwe cante wakiye cin he cante wakiye kta, qa tuwe onśiwada kin he onśiwalkidake kta ce.

20 Tuka miite kin wandaka oyakihi śni, nakaś wicaśta tuwe wanmayake cinhan ni kte śni ce, eya.

21 Nakun Jehowa heya, Inyun oyanke wan mikiyedan, qa imnija kin akan ayahe kta.

$22 \mathrm{Qa}$ mitowitan kin ahiyaye cin hehan imnija olidoka wan ohdateya ecihde kta, qa awahimdamde cin icunhan minape on akahpe ciye kta.

23 Qa minape kin mihdutokan kta, hecen mitapete tanhan wandake kta, tuka miite (wicaśta) wanyakapi kte śni.

\section{WICOWOYAKE 34.}

1 Unkan Jehowa Mowis heciya, Inyan mdaska nonpa kakan wo, tokaheya qon he iyececa, qa inyan mdaska tokaheya ya kamdeca, oie akan un qon, hena inyan mdaska kin akan owawa kta.

2 Qa hanhanna on ihduwiyeya wo, qa hanhanna Sina he kin ekta itanwankanhideya yau kta, qa heciya he paha kin akan iyamiyecihe kta.

3 Qa wicaśta tuwedan niciu kte śni, qa nakun he kin owancaya wicaśta tuwedan ihdutanin kte śni; nakun tahinca qa pte kin he kin he icahda wihanpi kte śni.
4 Unkan inyan mdaska nonpa kakan, tokaheya qon hena iyececa, qa Mowis hanhannahin kikta, qa Sina he kin ek ta itanwankanhdeya i, Jehowa econśi qon he iyecen, qa inyan mdaska nonpa kin nape kin ohna yuha.

5 Unkan Jehowa mahpiya śoka ohña kun hiyu, qa kici hen iyahan, qa Jehowa caje kin ieyanpaha.

6 Qa Jehowa he itokam ahiyaye ça ieyanpaha, Jehowa, Jehowa, "Taku Wakan waonśida, qa wacantkiya, tehan śihda śui, tocantekiye, towicake ko ota.

7 Wicoicage yeye kektopawinge cantewicakiya ece, wicohan śica qa wokipajin qa woahtani kajuju ece, tuka ohinniyan kajuju kte śni, ateyapi wicolian śicapi cincapi qa sanpa cincapi kin en awicahi ece, wicoicage iyamni qa itopa kin hehanyan.

8 Unkan Mowis inahni, qa makata pakicapsan, qa cekiya.

9 Qa heya, Itancan wanna niista kin ohna woiyokipi iyewaye cinhan, Itancan kin unkiyepi cokaya ye kta ceciciya, qa wicohan śica unkitawapi, qa waunhtanipi kin unkicicajuju miye, qa tawa unkiya miye,nakaś oyate kin tahu patin hecapi.

10 Unkan heya, Inyun miye wicotakuye wakaga, oyate nitawa kin owasin itokam, wicohan wowinihan ecamon kta, hena iyececa maka kin owancaya ikcewicaśta owasin ehna tuwedan tohini econ śni, qa oyate wicehna yaun kin he owasin Jehowa ohan kin wanyakapi kta nakaś taku wokokipe hinca nici ecamon kta.

11 Taku nakaha econ ciśi kin awacin wo. Ito nitokapa tanhan Amori kin, qa Kanani kin qa Hiti kin qa Perazi kin, qa 
H̉iwi kin, qa Jebusi kin nape wicawaye kta.

12 Waktaya wo. Ihnuhan oyate makoce ekta idade cin he ounyanpi kin om wicotakuye yakage cinhan okini he niyepi cokaya wihmunke kta.

13 Tuka owayuśnapi tawapi kin ihang ya yapi kta, qa wakagapi tawapi kin yakamdecapi kta, qa can pasdatapi kin hena yakawankapi kta.

14 Taku wakan tokeca ekta payecapsan kte śni; Jehowa winawizi eciyapi kin he Taku Wakan winawizi kin ee.

15 Okini makoce en ounyanpi kin om wicotakuye yakage cinhan, qa taku wakandapi kin ókiyapi, qa taku wakandapi kin walkiyuśnapi, qa nicopi qa taku wośnapi kin he yate kta.

16 Qa nicinkśi kin cunwintkupi kin etanhan yus yakiya, qa cunwintkupi kin taku wakandapi ókiyapi qa nakun nicinkśi taku wakandapi kin ókiye yapi kta.

17 Taku wakan śdoyapi kin niçicage kte śni.

18 Aguyapi napohyapi śni wohanpi kin yapatan kta. Anpetu śakowin aguyapi napolyapi śni yate kta, econ ciśi kin he iyecen. Aguyapi itka hinanpa wi kin iyehantu kin hehan, nakaś aguyapi itka hinanpe cin wi kin he en Egupta etanhan yahdinanpa ce.

19 Winyan cinca tokaheya ton kin hena owasin mitawa, qa wanunyanpi nitawa, pte, qa tahinca cinca tokapa ow asin mdoka kinhan.

20 Tuka śuktanka śonśonna cinca tokapa kin he opeyakiton kta ; tahinca cinca kin iyope yakiye kta, qa opeyakiton kte śni kinhan tahu kin bayakse kta.
Qa nicinca tokapa kin opeyakiton kta. Qa tuwedan mitokam cokadan ihdutanin kte śni.

21 Anpetu śakpe htayani kta, qa anpetu iśakowin en oziniçiye kta, maga yumdupi, qa woksapi iyehantu eśta oziniçiye kta.

22 Anpetu wakan iśakowin wohanpi kin nakun miyecagapi kta, aguyapi baksapi tokaheya ahipi kin hee, qa womnayanpi wohanpi kin, omaka ihuniyanpi kinhan.

23 Waniyetu otahedan yamni akihde nicinca wica kin owasin Itancan Jehowa Israel Taku Wakan dapi kin he itokam ihdutaninpi kta.

24 Nitokapa tanhan Ikcewicaśta kin tokan ye wicawaye kta ; qa nitamakoce kin mdutanka kta, qa waniyetu otahedan Jehowa itokam nihdutanin kta, yamni akihde, itanwankanhdeya idade cinhan tuwedan nitamakoce kin cin kte śni.

25 Taku wamayakiduśna we kin onapohye ayakaśtan kte śni. Qa acakśin wohanpi wośna kin ihanhanna kin en yanke kte śni. 26 Maga nitawa taku tokaheya icahya tokapa kin Jehowa wakan yada ti kin ekta ayahi kta. Tatokadan cincadan hunku asanpi kin en oyahe kte śni.

27 Unkan Jehowa Mowis heciya, Wicoie kin dena owa wo; nakaś wicoie kin dena i kin iyececa wicotakuye cicicaga, Israel kici nakun.

28 Unkan Jehowa kici hen yanke anpetu wikcemna tom, qa hanyetu wikcemna tom, aguyapi yute śni, qa mini yatke śni: Unkan wicotakuye oie kin inyan mdaya kin akan owa wicoie wikcemna kin.

29 Unkan Mowis woyaatanin inyan mdaska nonpa napohila yuha apamahdeya $\mathrm{u}$, qa Mowis $\mathrm{Si}$ - 
na he kin etanhan apamahdeya u qehan, he kici wohdaka icunhan ite uka kin iyege cin he sdotkiye śni.

30 Unkan Aaron qa Israel cinca kin owasin Mowis ite kin wanyakapi ; unkan inyun ite uka kin iyega, unkan ikiyedan upi kin ilkopapi.

31 Unkan Mowis wicakipan, unkan Aaron qa omniciye itancan owasin en hdipi, unkan hena om Mowis wohdaka.

32 Unkan he iyohakam Israel cinca kin owasin ikiyedan hipi, unkan Jehowa Sina paha ohna taku eciye cin owasin econ wicaśi.

33 Qa Mowis owicakiye hdaśtan kin hehanyan ite akahpe wan ite kin akan ehnaka.

34 Qa Mowis Jehowa kici wohdaka en i qehan, ite akahpe kin hdutokan, tankan i kin heharıyan, qa tankan inanpe ca taku econ śipi kin owicakiyaka.

35 Unkan Israel cinca kin Mowis ite kin wanyakapi, Mowis ite uka kin iyega; heon Mowis ite akahpe kin ake ite akan hiyuya, kici wohdake kta en i kte cin hehanyan.

\section{WICOWOYAKE 35.}

1 Unkan Mowis Israel cinca omniciye ocowasin yuwitaya u wicakiye, ca hewicakiya, Wicoie Jehowa econ niśipi dena ee.

2 Anpetu śakpe wohtani ecannon kta, tuka anpetu iśakowin kin he wakan yada kta, anpetu okihpapi wakan Jehowa tawa, he icunhan tuwe kaśta wohtani econ kinhan te yapi kta.

3 Ounyayapi kin owasin ohna anpetu okihpapi icunhan ceyatipi kte śni.
4 Unkan Mowis ie ca Israel cinca omniciye ocowasin hewicakiya, Taku Jehowa econ niśipi kin dee, qa heya;

5 Taku Jehowa ituyakihanpi kta he icupo. Tuwe cante kin iyopaśtaka, taku Jehowa itukihan kte cin he ahi kta, mazaskazi, qa mazaska; qa mazaśa ;

6 Qa tahinca hin to, qa stan, qa duta, qa minihuha ska, qa tatokadan hin ;

7 Qa tamdoka ha śayapi, qa hoka ha, qa śitim can;

$8 \mathrm{Qa}$ wihdi petijanjan on, qa taku waśtemna wihdi sdayapi kin on, qa wizin yapi waśtemna on ;

$9 \mathrm{Qa}$ inyan wicaśake iyececa, qa inyan ojuyapi kta, amdo akahpe ohna, qa maku akahpe ohna.

10 Qa niyepi ehna tona cante ksapapi kin owasin upi kta, qa taku Jehowa kah śi kin owasin kagapi kta;

11 Tipi kin, tawakeya, qa toakahpe kin nakun, tamaza taśpu kin, qa canmdaska kin, canhdakinyan kin, can bosdata tawa qa sicu tawa kin ;

12 Can wohnake kin, ya tatośu kin, wokajuju iha kin, qa oakalipe ozanpi kin ;

13 Wahna wotapi, qa tatośu kin, qa taku on kicanyanpi kin owasin, qa aguyapi itokam hnakapi kin;

14 Qa petijanjan ihupa kin, qa taku on kicanyanpi kin, qa wihdi on iyoyam yapi kin ;

$15 \mathrm{Qa}$ wizin yapi owayuśna kin, qa tośu on akiyuhapi kin, qa wihdi on sdawicayapi kin, qa taku waśtemna on wizin yapi kin ; qa ozanpi tipi tiyopa akahpe cin he.

16 Qa peta wośnapi owayuśna kin, qa mazaśa oceti tawa; qa 133 
tośu on akiyuhapi kin, qa taku on kicanyanpi kin, qa koka kin, tacetetahe iyahna;

17 Hocoka ozanpi kin, ipatan kin, qa sicu kin, qa hocoka tiyopa akahpe kin ;

18 Tipi wihutipaspe kin qa hocoka wihutipaspe, qa ikan kin owasin ;

19 Qà tipi wakan ohna taku wakan ohodapi kta e ohodapi wokoyake, wokoyake wakan, Aaron wawayuśna kin on, qa cinhintku tawokoyakepi ohna wayuśnapi kta.

20 Unkan Mowis itokapa tanhan Israel cinca omniciye ocowasin inanpapi.

21 Unkan tuwe cante kin iyopaśtaka, qa tuwe taniya kin iyokipi kin hena owasin upi ; qa taku Jehowa itukihanpi ahipi, itkokipapi wakeya kin kagapi kta e, qa taku kicanyanpi on, qa wokoyake wakan on.

22 Unkan wicaśta qa winohinca upi, tona cantepi iyokipipi owasin maza taśpudan, qa oinpi, qa mazanapcupe, qa maza śipto, mazaskazi oinpi owasin hiyuyapi ; qa wicaśta tona taku kosyapi kin hena owasin Jehowa mazaskazi kos yapi.

$23 \mathrm{Qa}$ wicaśta tona hin to, qa stan, qa duta, qa ninihuha ska, qa tatokadan hin, qa tamdoka ha śayapi, qa hoka ha yuha iyewicayapi kin hena ahipi.

$24 \mathrm{Qa}$ tona mazaska qa mazaśa wankan hiyuyapi kin hena Jehowa taku itukihanpi kin he kahipi, qa tuwe sitim can on taku kah wicaśi kagapica he kahipi.

$25 \mathrm{Qa}$ winohinca tona cante ksapapi owasin hin to, qa stan, qa duta, qa miniliuha ska napepi on kahmupi, qa taku kahmupi kin he kahipi.
$26 \mathrm{Qa}$ winohinca tona cantepi kin iyowicapaśtakapi wolksape en, tatokadan hin kahmupi.

27 Unkan wicaśta itancanpi kin inyan wicaśake iyececa ahipi, qa inyan ojuyapi kta ahipi, amdo akahpe kin en, qa maku akahpe kin en.

28 Qa taku waśtenına, qa wihdi petijanjan on, qa wihdi sdawicayapi on, qa wizin yapi waśtemna on.

29 Wicaśta qa winohinca owasin tona cantepi kin taku kahipi kta iyowicapaśtake, taku kagapi Jehowa Mowis nape on kah wicaśi kin hena owasin on, Israel cinca kin iyokipiya Jehowa itukihanpi.

30 Unkan Mowis Israel cinca kin hewicakiya, Jehowa Betzaleel Uri cinhintku Hur cinhintku Juda wicoun etanhan he caje kin on kipan.

$31 \mathrm{Qa}$ Taku Wakan woniya ojunya, woksape, qa wookahnige en, qa wosdonye, qa wohtani ocaje owasin en.

32 Taku wayupiya kagapi iyukcan kta, mazaskazi, qa mazaska, qa mazaśa kage ktı.

33 Qa inyan ojuyapi kta e pago kta, qa can pago kta, taku wayupiya kagapi kin owasin kage kta:

34 Qa waonspe kiye kta e 1ye cante en qu, iye qa Aholiyab Ahisamak cinhintku Dan wicoun etanhan.

35 Hena cante woksape kin ojun wicaya, wapagopi wicohan, qa taku wayupiya kagapi owasin econpi kta, qa to qa stan, qa duta, qa minihuha ska on wipatapi kta. qa kazuntapi kte, taku kagapi owasin, qa taku wayupiya econpi iyukcanpi kta. 


\section{WICOWOYAKE 36.}

WICOWOYAKE 36.

1 Unkan Betzaleel qa Aholiyab htanipi, nakun wicaśta tona cante ksapapi, tona tipi wakan token Jehowa kah wicaśi, taku kagapi owasin sdonyapi kta, qa kagapi kta e Jehowa woksape qa wookahnige yuhe wicakiya.

2 Nakaś Mowis Betzaleel qa Aholiyab wicakipan qon, nakun tona cante ksapapi, tona cante mahen Jehowa woksape yuhe wicakiya, tona taku kagapi kage kta e cante htani kta e iyowicapaśtaka owasin ikiyedan hiyu wicakiya.

3 Unkan Mowis itokapa tanhan taku ituhanpi kin icupi, tipi wakan kagapi kta, qa kicanyanpi kta e taku Israel cinca kin ahipi kin, nakun nahanhin halianna otoiyohi taku iyokipiya ahipi.

4 Unkan tona ksapapi tipi wakan wohtani econpi kin owasin wohtani econpi etanhan en hipi ;

5 Qa Mowis heciyapi, Taku kagapi kta, Jehowa kah unśipi kin iyehantu, qa iyakicuya oyate kin ahipi ce, eyapi.

6 Hehan Mowis wicoti ohna ieyanpaha wicaśi, Wicaśta winolinca unmanna tipi wakan kagapi itukihanpi kta e tokata taku kage kte śni, eya, hecen oyate taku ahipi kin ayuśtan wicalkiya.

7 Taku kah wicaśi owasin kagapi kta iyoliya qa nakun ihan.

8 Unkan tipi wakan kin hitanipi wicehna tona cante ksapapi kin hena ozanpi wikcemna kagapi, minihuha ska nonpa kahmupi, qa to, qa stan, qa duta, kerubi kazuntapi hena kagapi.

9 Ozanpi wanji ohanske cin wiciśpa wikcemna nonpa sanpa śa- hdogan, qa ozanpi wanji ohdakinyan kin wiciśpa topa, ozanpi owasin hinskoskocecapi.

10 Unkan ozanpi zaptan icikoyag ya, qa ozanpi zaptan icikoyagya.

11 Hahonta to śunjoyake ozanpi wanji opapun ekta kaga, apalidate etanhan icikoyag yapi en, he iyecen ozanpi unman icikoyag yapi kta e opapun apalidate ekta kaga.

12 Śunjoyake wikcemna zaptan ozanpi tokaheya en kage ça śunjoyake wikcemna zaptan ozanpi inonpa opapun ekta, tokalıeya kici ikoyag yapi kta e śunjoyake kin iciyotakonzapi.

13 Unkan mazaskazi taśpu wikcemna zaptan kaga, qa maza taśpu kin on ozanpi wanji unman ekta ikoyag ya; hecen wakeya wanjidan.

14 Unkan tatokadan hin ozanpi wakeya tipi akapatanhan un kin kicaga, hena ozanpi ake wanji kaga.

15 Ozanpi wanji ohanske cin, wiciśpa wikcemna yamni, qa ozanpi ohdakinyan kin wiciśpa tom, ozanpi ake wanji kin owasin iyakehinskokeca.

16 Unkan ozanpi zaptan icikoyag ya, qa ozanpi śakpe icikoyag ya.

17 Unkan icikoyag yapi kta e śunjoyake wikcemna zaptan ozanpi tokaheya opapun akan kaga, qa śunjoyake wikcemna zaptan ozanpi inonpa opapun ekta ikoyag yapi kta e kaga.

18 Qa mazaśa taśpu wikcemna zaptan wakeya icikoyag ye kta e kaga, hecen wanjidan kta.

19 Unkan tamdoka ha śayapi woakahpe wan wakeya kin kicaga, qa he akapatanhan kta hoka ha woakahpe wan kaga. 


\section{HDINANPAPI,}

20 Unkan tipi kin śitim can can mdaska bosdan unpi kta e kicaga.

21 Can mdaska wan ohanske cin wiciśpa wikcemna, qa ohdakinyan kin wiciśpa wan sanpa wiciśpa hanke.

22 Can mdaska ekiciyuzapi kta e otoiyohi nape nonpa kicaga, tipi can mdaska owasin hecen kicaga.

23 Unkan tipi can mdaska kin ti onnaptan itokaga wiyotanhan ektakiya can mdaska wikcemna nonpa tipi kin kicaga.

24 Qa mazaska sicu wikcemna tom kaga, can mdaska wikcemna noupa ihukuya, sicu nonpa, canmdaska wanji nape nonpa yuke cin on he ihukuya un kta, canmdaska otoiyohi nape nonpa kiyuke cin on, he ihukuya sicu nonpa kta.

25 Qa tipi onnaptan inonpa waziyata ekta-kiya canmdaska wikcemna nonpa kicaga.

26 Qa mazaska sicu wikcemna topa, canmdaska otoiyohi ihukuya maza sicu nonpa.

27 Qa tipi catku kin wiyolipeyata ektakiya kin he canmdaska śakpe kicaga.

28 Qa canmdaska nonpa tipi kahmi catkutanhan kin hena kicaga.

29 Unkan napin iyakedececapi ihukuya tanhan, qa napin otoiyohi pa kin ekta mazaska napcupe tokaheya en ikoyagyapi, kahmi nonpa on hena nonpa okonwanjidan.

30 Hecen canmdaska kin śahdogan, qa mazaska sicu kin ake śakpe, canmdaska otoiyohi ihukuya sicu nonpa.

31 Qa tipi onnaptan tokaheya canmdaska kin on sitim can hdakinyan zaptan kicaga.

32 Qa tipi onnaptan inonpa can136 mdaska kin on canhdakinyan zaptan, qa tipi catku kin wiyohpeyata ekta-kiya canmdaska kin canhdakinyan zaptan kicaga.

33 Qa canhdakinyan wanji cokaya un kin he canmdaska cokaya ohna iyopte kta e kaga, ihanke wanji etanhan ihanke unman ekta kiya.

34 Qa canmdaska kin mazaskazi on apawinta, qa maza napcupe ohna canhdakinyan yakonpi kin hena mazaskazi on kaga, qa canhdakinyan kin mazastrazi apawinta.

35 Qa cokaya ozanpi kin minihuha ska, qa to, qa stan, qa duta kerubi kazuntapi he kaga.

$36 \mathrm{Qa}$ śitim can bosdata tom he kicage ça hena mazaskazi apawinta, qa mazaskazi yukśanpi hena kicage ca mazaska sicu tom śdoyapi kicaga.

$37 \mathrm{Qa}$ wakeya tiyopa kin oakahpe wan, miniliuha ska, qa to qa stan, qa duta wipatapi kin he kicaga.

$38 \mathrm{Qa}$ he on can bosdata zaptan mazayukśanpi iyahna, qa hena pa kin, qa can icikoyagyapi kin hena mazaskazi apawinta, tuka sicu zaptan kin hena mazaśa.

\section{WICOWOYAKE $3 \%$.}

I Unkan Betzaleel canwohnake kin śitim can on kaga, wiciśpa nonpa sanpa hanke ohanske cin, qa wiciśpa sanpa hanke ohdakinyan kin, qa wiciśpa sanpa hanke obosdatu kin.

2 Qa he mazaskazi ecedan on apawinta, mahentuya, qa akapatanhan, qa ihdukśan mazaskazi wateśdake wan kicaga.

3 Qa mazaskrzi śdoye ca maza napcupe tom he kicaga, siha topa kin akan, maza napcupe nonpa onnaptan wanji akan, qa 


\section{WICOWOYAKE $3 \%$.}

maza napcupe nonpa onnaptan unman akan.

4 Qa śitim can tośu kageça mazaskazi on apawinta.

$5 \mathrm{Qa}$ canwohnake kin akiyuhapi kta e maza napcupe canwohnake anokatanhan onnaptan ikoyag yapi kin hena ohna tośu kin iyopte ya.

6 Unkan woahtani kajuju iha kin mazaskazi ecedan on kaga, ohanske cin wiciśpa nonpa sanpa hanke qa ohdakinyan kin wiciśpa sanpa hanke.

7 Qa kerubi nonpa kaga wanji wokajuju iha ihanke anokatanhan akan ; mazaskazi pagopi hena kaga.

8 Kerubi wanji ihanke deciyatanhan qa kerubi unman kin ihanke kakiya tanhan, woahtani kajuju iha kin etanhan kerubi kin kaga; ihanke nonpa kin etanhan.

9 Unkan kerubi kin wankantuya hupahu kamdah yakonpi, hupahupi on woahtani kajuju iha kin ahanzipi, qa itepi kin otoiyohi unman ekta kiya, kerubi itepi kin wokajuju iha ekta kiya yakonpi.

10 Unkan wahna wotapi śitim can on kaga, ohanske cin wiciśpa nonpa, qa ohdakinyan kin wiciśpa, qa obosdatu kin wiciśpa sanpa hanke.

11 Qa he mazaskazi ecedan on apawinta, qa ihdukśan mazaskazi wateśdake wan kicaga.

12 Nakun ihdukśan iyuskite wan nape mdaska hinskokeca kicaga; qa iyuskite akan mazaskazi wateśdake wan kicaga.

13 Qa mazaskazi śdoye ça maza napcupe topa kicage cà oise topa siha topa yuke cin hena ekta maza napcupe kin ikoyag ya.

14 Wahna wotapi akiyuhapi kta e maza napcupe iyuskite iyotakons kagapi, qa hena ohna tośu kin iyeyapi.

15 Unkan śitim can tośu kin kage ça mazaskazi apawinta hena on wahna wotapi kin akiyuhapi.

16 Qa taku wahna wotapi akan un taku on kicanyanpi kin, tawakśica, qa maza tukiha tawa, qa wiyatke on waakaśtanpi kin hena owasin mazaskazi ecedan on kaga.

17 Unkan petijanjan ihupa kin he kaga, mazaskazi ecedan pagopi petijanjan ceca kin, taadetka kin, tawakśica kin, tapśonka kin qa tawahca kin, hena owasin he etanhan kaga.

18 Qa adetka śakpe petijanjan ihupa cuwi kin etanhan inanpapi, petijanjan ihupa cuwi wanji etanhan adetka yamni, qa petijanjan cuwi unman kin etanhan adetka yamni.

19 Adetka wanjidan en wakśica yamni hma iyececa, otoiyohi pśonka wan, qa wahca wan kicica adetka wanjidan en, qa ake wakśica yamni otoiyohi hma iyececa pśonka wan qa wahca wan kicica adetka wanjidan en, adetka śakpe petijanjan ihupa etanhan inanpapi, owasin hececapi.

$20 \mathrm{Qa}$ petijanjan ihupa en wakśica topa hma iyececa, otoiyohi pśonka wan qa wahca wan kicica.

21 Hecen petijanjan adetka nonpa ihukuya pśon'ka wanji, qa adetka nonpa ihukuya pśonka wanji, qa adetka nonpa ihu kuya pśonka wanji petijanjan ihupa etanhan adetka śakpe inanpapi owasin hececapi.

22 Petijanjan ihupa tapśonka, qa taadetka okonwanjidan, mazaskazi ecedan onśpadan pagopi on owasin kagapi. 
23 Qa mazaskazi ecedan petijanjan śakowin petijanjan ihupa kin kicaga, nakun petijanjan iyukse qa ohna cahota icupi kin.

24 Mazaskazi ecedan woqin wanjidan on he kage ça tawakśica owasin.

25 Unkan wizinya owayuśna kin śitim can on kaga; ohanske cin wiciśpa, qa ohdakinyan wiciśpa, topa omdoton, qa obosdatu kin wiciśpa nonpa; he kicagapi.

26 Qa mazaskazi ecedan, on apawinta iwankam qa onnaptanyan kin ihdukśan, qa he kin; qa ihdukśan mazaskazi ecedan wateśdake wan kicaga.

27 Qa mazaskazi napcupe nonpa he kicaga, wateśdake kin ihukuya onnaptan nonpa akan, tośu on akiyuhapi kin icupi kta e hena owayuśna cuwi nonpa akan kaga.

28 Qa tośu kin śitim can on kage, ça mazaskazi on apawinta.

29 Unkan wihdi wakan on sdawicayapi kaga, nakun taku waśtemna on wizinyapi ecedan kin, pejuta wicaśta kagapi kin iyececa.

\section{WICOWOYAKE 38.}

1 Unkan śitim can peta wośnapi owayuśna kin kaga, ohanske cin wiciśpa zaptan, qa ohdakinyan kin wiciśpa zaptan, topa omdoton, qa obosdatu kin wiciśpa yamni.

2 Qa oise topa kin akan he kicaga, owayuśna on he kin kaga, qa mazaśa on apawinta.

3 Unkan owayuśna taku on kicanyanpi kin owasin kaga ; cega kin, qa maza mdaska kin, qa wakśica kin, qa mazajanjata kin, qa petaga wakśica kin, owayuśna taku on kicanyanpi kin owasin mazaśa on kaga.

4 Qa mazaśa oceti wan ho kagapi iyececa owayuśna kin kicaga, opapun ihukuya, oldateya cokaya ekta.

5 Qa oceti oise topa kin en mazaśa śdoyapi napcupe tom kaga, hena ohna tośu iyeyapi kta.

6 Unkan śitim can tośu kin kage, ca mazaśa on apawinta.

7 Q́a owayuśna akiyuhapi kta e maza napcupe kin owayuśna onnaptan en unpi kin ohna tośu kin iyeya ; owayuśna canmdaska on kaga, hdogeca.

8 Unkan mazaśa koka kin he kaga, tacetetahe mazaśa on kaga, winolinca itkokipapi wakeya tiyopa ekta obe itokto yuwitaya celkiyapi taihdiyomdasinpi on hena kaga.

9 Unkan hocoka kin kaga, itokah onnaptan wiyotanhan ektakiya on miniliuha ska nonpa kahmupi ozanpi wan wiciśpa opawinge.

10 Ipatan wikcemna nonpa, qa sicupi wikcemna nonpa, mazaśa on kicaga, tuka ipatan yukśanpi kin qa satapi kin hena mazaska on kaga.

11 Unkan waziyata onnaptan ozanpi kin wiciśpa opawinge, ipatan kin wikcemna nonpa, qa sicu wikcemna nonpa, mazaśa on lraga, tuka ipatan yukśanpi kin, qa satapi kin hena mazaska.

12 Unkan ihanke wiyohpeyata ektakiya ozanpi kin wiciśpa wikcemna zaptan, ipatan wikcemna, qa sicu kin wikcemna, tuka ipatan yukśanpi kin qa satapi kin hena mazaska.

$13 \mathrm{Qa}$ ihanke wihinanpe ektakiya wiciśpa wikcemna zaptan.

14 Hiyete tokaheya ozanpi kin wiciśpa wikcemna sanpa zaptan, ipatan yamni, qa sicu yamni. 


\section{WICOWOYAKE 39.}

15 Qa hiyete inonpa ozanpi kin wiciśpa wikcemna sanpa zaptan, ipatan yamni, qa sicu yamni, hocoka tiyopa kin anokatanhan hececa.

16 Hocoka ihdukśan ozanpi kin owasin minihuha ska nonpa kahmupi.

17 Ipatan sicupi kin hena mazaśa, qa ipatan yukśanpi kin, qa satapi kin mazaska, qa ipatan pahapi kin mazaska on apawinta; qa hocoka ipatan kin owasin mazaska on icikoyag yapi.

$18 \mathrm{Qa}$ hocoka tiyopa toakahpe kin he miniliuha ska nonpa kahmupi, qa to, qa stan qa duta ipatapi ; qa ohanske cin wiciśpa wikcemna nonpa, qa obosdatu ohdakinyan kin hee wiciśpa zaptan hocoka ozanpi kin iyececa.

19 Qąipatan topa, qa sicupi topa mazaśa; qa yukśanpi kin mazaska; qa pahapi qa satapi kin mazaska on apawintapi.

20 Qa tipi wihutipaspe, qa hocoka ihdukśan wihutipaspe kin owasin mazaśa.

21 Tipi wakan woyakapi kin hee, woyaatanin tipi kin, Mowis i kin oyaka, Lewi kin kicanyanpi kta Aaron wawayuśna cinhintku Itamar ihukuya.

22 Unkan Betzaleel Uri cinhintku, Hur cinhintku, Juda wicoun etanhan, taku Jehowa Mowis kah śi kin owasin kaga.

$23 \mathrm{Qa}$ he kici Aholiyab, Ahisamak cinhintku, Dan wicoun etanhan, he wayupiya wapago, qa wapazunta, qa wipata, miniliuha ska, qa to, qa stan, qa duta on.

24 Taku kagapi owasin tipi wakan kin on kagapi, mazaskazi ocowasin mazaskazi ituhanpi kin he woqin wikcemna nonpa sanpa napciwanka, qa śeqel opawinge śakowin, qa wikcemna yamni, tipi wakan śeqel he iyececa.
$25 \mathrm{Qa}$ omniciye wicayawapi kin etanhan mazaska kin woqin opawinge, qa seqel kektopa winge sanpa opawinge śakowin, sanpa wikcemna śakowin sanpa zaptan tipi wakan śeqel iyececa.

26 Kibaśpapi wan wicapa otoiyohi on śeqel hanke kin hee, tipi wakan śeqel iyececa, tona wicayawapi kta ahiyayapi, waniyetu wikcemna nonpa qa iwankam, kektopawinge opawinge śakpe qa kektopawinge yamni, qa opawinge zaptan qa wikcemna zaptan.

27 Unkan maza ska woqin opawinge kin hena śdoyapi qa tipi wakan sicu kin, qa cokaya ozanpi sicu kin kaga, woqin opawinge on sicu opawinge, woqin wan on sicu wanjidan.

$28 \mathrm{Qa}$ śeqel kektopawinge sanpa opawinge śakowin sanpa wikcemna śakowin sanpa zaptan on ipatan papi kin, qa satapi kin apawintapi qa ipatan yukśanpi kin kaga.

29 Qa mazaśa ituhanpi kin woqin wikcemna śakowin, qa śeqel kektopawinge nonpa qa opawinge topa.

30 Qa he etanhan itkokipapi wakeya tiyopa sicu kin kage ça mazaśa owayuśna kin, qa mazaśa oceti kin, qa owayuśna tawakśica kin owasin.

31 Qa hocoka ihdukśan sicu kin, qa hocoka tiyopa sicu kin, qa tipi wihutipaspe owasin, qa hocoka ihdukśan wihutipaspe owasin.

\section{WICOWOYAKE 39.}

1 Unkan hahonta to, qa stan, qa duta on ohodapi wokoyake kin tipi wakan ohna wohtani econpi kin hena heyake wicakicagapi qa wokoyake wakan 139 


\section{HDINANPAPI,}

Aaron on kagapi, Jehowa Mowis econ śi qon he iyececa.

2 Unkan amdo akahpe kin kaga mazaskazi, qa hahonta to qa stan qa duta, qa minihuha ska.

3 Qa mazaskazi kin zibzipedan kamdayapi qa basosopi, hecen hahonta to qa stan qa duta, qa minihuha ska icicahiya kazontapi kta.

$4 \mathrm{Qa}$ amdo akahpe kin, icikoyag yapi kta e hiyete ikan kin kicagapi, ihanke napin ekta icikoyag yapi.

5 Qa amdo ipiyake kin he akapatanhan un kin he iyecèn kagapi, mazaskazi qa hahonta to, qa stan qa duta, qa minihuha ska, nonpa kahmupi on kagapi, Jehowa Mowis econśi kin he iyecen.

6 Unkan inyan wicaśake iyecen hena kicanyanpi Israel cinhintku cajepi kin hena akan apagopi, ipuspe pagopi kin he iyecen, qa mazaskazi ozepi ohna iyeyapi.

7 Qa amdo akahpe hiyete akan hena ahnaka, wokiksuye Israel cinca kin on, Jehowa Mowis econ śi kin he iyecen.

8 Unkan maku akahpe kin kaga, mazaskazi, hahonta to, qa stan, qa duta, qa minihuha ska nonpa kahmupi kin hena kazuntapi, arndo akahpe kin he iyecen.

9 He topa omdoton, icitakihna he kagapi, ohanske cin napapaśdecapi qa ohdakinyan kin napapaśdecapi, icitakihna.

- 10 Qa he ohna inyan ocankuye topa ojuyapi, ocankuye wan, sardius, qa topaz qa petaga, ocankuye tokaheya kin hee.

11 Qa ocankuye inonpa kin he, smaragdos, qa sapiron, qa diamon :

12 Qa ocankuye iyamni kin he ligurion, qa agate, qa ametuston;

13 Qa ocankuye itopa kin he krusolitos, (mazaskazi inyan) qa inyan wicaśake iyececa, qa iyaspis; hena ihdukśan mazaskazi ozepi en ojuyapi.

14 Qa inyan kin hena Israel cinca ake nonpa cajepi kin iyececa, ipuspe pagopi kin he iyecen, wicoun ake nonpa cajepi kin otoiyohi inyan wanji akan apagopi.

15 Qa maku akahpe kin ihanke anog ekta mazaskazi ecedan icicahilia yuhmupi kagapi.

$16 \mathrm{Qa}$ mazaskazi ozepi nonpa kagapi, qa mazaskazi napcupe nonpa, qa maku akahpe oise nonpa kin en, maza napcupe nonpa ikoyag yapi.

17 Qa maza napcupe nonpa maku akahpe oise en unpi kin hena ohna mazaskazi ikan nonpa kin iyeyapi.

18 Qa ikan nonpa ihanke nonpa maza ozepi nonpa en iyakaśkapi qa amdo akahpe hiyete akan ite ekta-kiya iyakaśkapi.

19 Qa mazaskazi napcupe nonpa kagapi, qa maku akahpe oise nonpa en iyakaśkapi, mahentuya amdo akahpe ek takiya opapun en. 20 Unkan mazaskazi napcupe nonpa kagapi, qa amdo akahpe hiyete nonpa en ikoyag yapi, ihukuya ite ekta kiya, icikoyag yapi iyotakons, amdo akahpe, ipiyaka iwankam.

21 Qa hahonta to wan on maku akahpe maza napcupe ekta iyakaśkapi, hecen amdo akahpe piyaka akan yanke kta, qa maku akahpe kin amdo akahpe kin etanhan yukinukan lite śni.

22 Unkan amdo akahpe nitośke kin ocowasin to kazuntapi kin he kaga.

23 Qa nitośke i kin he nitośke cokaya, minihuha maku akahpe i kin he iyececa, i kin ihdukśan apahdan tonpi, nahdece kte śni heon etanhan. 


\section{WICOWOYAKE 40.}

24 Unkan nitośke upi akan taspantanka seca to, qa stan qa duta nonpa kahmupi on kagapi.

25 Unkan mazaskazi ecedan hdahda kicagapi, qa mazahdahda kin taspan tanka seca ehna kaśkapi, nitośke upi akan ihdukśan taspantanka seca otahedan.

26 Mazahdahda qa taspantanka seca, mazahdahida qa taspantanka seca, nitośke ohna ohoda kin upi kin ihdukśan akan, Jehowa Mowis econ śi kin he iyecen.

27 Unkan mahen unpi Aaron on, qa iye cinhintku, wicakicagapi, minihuha ska kazuntapi.

28 Unkan minihuha pa ipahte kin qa miniliuha wapaha waśte, qa miniliuha onzeoge minitiuha ska nonpa kahmupi.

29 Qa ipiyaka miniliuha ska nonpa kahmupi, qa to, qa stan, qa duta, ipatapi he kagapi, Jehowa Mowis econśi qon he iyecen.

30 Unkan mazaskazi ecedan mdaska wateśdake wakan kin kagapi, qa Jehowa wakandapo, akan owapi, ipuspe pagopi kin he iyecen owapi.

31 Qa hahonta to wan ek ta iyakaśkapi, he on pa ipalite kin akan akapatanhan iyakaśkapi ; Jehowa Mowis econśi gon he iyecen.

32 Hecen itkokipapi wakeya tipi kagapi kin ocowasin yuśtanpi, token Jehowa Mowis econśi kin owasin he iyecen Israel cinca kin yuśtanpi.

33 Unkan tipi kin Mowis ekta kahipi ; wakeya kin, qa taku on kicanyanpi kin owasin, tamaza taśpu, tacanmdaska, tacanhdakinyan, qa taipatan, qa tasicu kin ;

34 Qa tamdoka ha sayapi on akahpe kin, qa hoka ha on akahpe kin, qa cokaya ozanpi kin ; $35 \mathrm{Qa}$ woyaatanin canwohnaka kin, qa tośu kin, qa wokajuju iha kin ;

36 Wahna wotapi tawakśica koya owasin, qa aguyapi itokam hnakapi kin;

37 Petijanjan ihupa ecedan kin, petijanjan kin koya, petijanjan kicanyanpi kin hena, qa taku on kicanyanpi kin owasin, qa wihdi on iyoyam yapi kin;

38 Qa mazaskazi owayuśna kin qa sdawicayapi wihdi kin, qa taku waśtemna on wizin yapi kin, qa wakeya tiyopa akahpe kin ;

39 Mazaśa owayuśna kin, qa mazaśa oceti tawa kin, qa tatośu kin qa taku on kicanyanpi kin .owasin; mazaśa koka kin, tacete tahe koya.

40 Hocoka ozanpi kin, can bosdata kin qa sicu kin, qa hocoka tiyopa oakahpe kin, taikan kin, qa tawihutipaspe kin qa itkokipapi wakeya ohna ohodapi kin, tawakśica koya owasin ;

41 Ohodapi wokoyake kin on tipi wakan ohna ohodapi, Aaron wawayuśna tawokoyake wakan kin, qa cinhintku wokoyake unpi wawayuśnapi ece kta.

42 Taku Jehowa Mowis econ śi kin owasin, he iyecen Israel cinca kin taku owasin kagapi.

43 Unkan Mowis taku kagapi kin owasin wanyaka; unkan inyun taku Jehowa kah wicaśi kin owasin he iyecen kagapi, unkan Mowis wicayawaśte.

\section{WICOWOYAKE 40.}

1 Unkan Jehowa ie ca Mowis heciya,

2 Wi tokaheya, anpetu tokahe141 


\section{HDINANPAPI,}

ya en itkokipapi wakeya tipi kin eyahde kta.

$3 \mathrm{Qa}$ he ohna woyaatanin can wohnaka kin eyahnake kta, qa can wohnaka kin akapatanhan cokaya ozanpi kin otkeyaye kta.

4 Qa wahna wotapi kin he en hiyuyaye kta, qa taku akan hnakapi kin hena akan eyahnake kta, qa petijanjan ihupa kin yakahi kta, qa petijanjan kin ideyaye kta.

5 Qa mazaskazi owayuśna kin wizinyapi kta e woyaatanin can wohnaka itokam eyahnake kta, qa tipi tiyopa oakahipe otkeyaye kta.

6 Qa peta wośnapi owayuśna kin itkokipapi wakeya tipi tiyopa itokam eyahde kta.

7 Qa koka kin he itkokipapi wakeya kin, qa owayuśna kin o tahedan eyahde kta, qa he ohna mini oyakaśtan kta.

$8 \mathrm{Qa}$ he ihdukśan hocoka kin eyahde kta, qa hocoka tiyopa oakahpe kin otkeyaye kta.

9 Qa sdawicayapi wihdi kin he iyacu kte ca tipi kin, qa taku ohna un kin, owasin sdayaye kta, hecen he qa taku on kicanyanpi kin owasin duwakan kta, unkan wakan kta.

10 Qa peta wośnapi owayuśna kin he sda yaye kta, taku on kicanyanpi nakun owasin; hecen owayuśna kin duwakan kta; qa owayuśna kin wakan hinca kta.

11 Qa koka kin he sdayaye kta, tacetetahe nakun, hecen he duwakan kta.

12 Unkan Aaron, iye cinhintku om, itkokipapi wakeya tiyopa kin ikiyedan hiyu wicayaye kta, qa mini on wicadujaja kta.

13 Qa wokoyake wakan kin he Aaron koyag yaye kta, qa sda yaye kta, hecen wamiciyuśna kta e duwakan kta.
14 Unkan cinhintku kin ikiyedan hiyu wicayaye kta, qa mahen unpi kin hena koyagg wicayaye kta.

15 Qa atkukupi kin sda yaye ciqon he iyecen sda wicayaye kta, hecen wamiciyuśnapi kta, qa sdawicayapi kin on owihanke wanin wawayuśna hecapi $\mathrm{kta}$, wicoicagepi yeye cin ohna.

16 Unkan token Jehowa Mowis econśi kin owasin he iyecen econ.

17 Unkan kaketu wetu inonpa wi tokaheya, an petu tokaheya kin he ehan tipi wakan kin ehdepi.

18 Qa Mowis tipi kin ehde qehan tasicu kin eju, qa tacanmdaska kin en iyeya, qa tacanhdakinyan ohna iyoopte iyeya, qa taipatan kin ehde.

19 Qa tipi 1 wankapatanhan wakeya kin yumdaya, qa wakeya oakahpe kin he wakeya akapatanhan iwankam yumdaya, Jehowa Mowis econśi qon he iyecent.

20 Unkan woyaatanin kin he icu, qa canwohnaka mahen ehnaka, qa tośu kin canwohnaka ekta iyeya, qa wokajuju iha kin canwohnaka akan ehnaka iwankapatanhan.

21 Qa canwohnake kin tipi kin mahen hiyuye ca cokaya ozanpi kin otkeya, hecen woyaatanin canwohnaka kin akahpa, Jehowa Mowis econ śi kin he iyecen.

22 Qa wahna wotapi kin he itkokipapi wakeya ohna ehde, tipi cuwi waziyata ekta kiya, cokaya ozanpi itankan.

$23 \mathrm{Qa}$ he akan aguyapi itokam hnakapi kin heca tanyan ehnaka, Jehowa itokam, Jehowa Mowis econ śi kin he iyecen.

$24^{\circ} \mathrm{Qa}$ petijanjan ihupa kin itkokipapi wakeya mahen ehde, wahna wotapi kin iyotakons, tipi cuwi itokaga ekta kiya.

25 Qa petijanjan kin hena ide- 
WICOWOYAKE 40.

ya, Jehowa itokam, Jehowa Mowis econ śi kin he iyecen.

26 Unkan mazaskazi owayuśna kin he itkokipapi wakeya mahen ehde, cokaya ozanpi kin itokam.

$27 \mathrm{Qa}$ he akan taku waśtemna wizinyapi kin izin ya, Jehowa Mowis econ śi kin he iyecen.

28 Qa tipi tiyopa akahpe kin he otkeya.

29 Qa wahuhnah yapi owayuśna kin he itkokipapi wakeya tipi tiyopa kin ikiyedan ehde, qa he akan woluhinahyapi qa minha kin hulinahya.

30 Qa koka kin itkokipapi wakeya kin, qa owayuśna kin otahedan ehde qa mini on yujajapi kte hen okaśtan.

31 Unkan hetanhan Mowis qa Aaron iye cinhintku om napepi sihapi ko ihdujajapi.

32 Itkokipapi wakeya en ipi eca: qa owayuśna ikiyedan ipi eca ihdujajapi ece, Jehowa Mowis econ sil kin he iyecen.

33 Unkan tipi kin owayuśna kin koya ihdukśan hocoka kin ehde, qa hocoka tiyopa akahpe 'kin otkeya, hecen Mowis wohtani kin hduśtan.

34 Hehan mahpiya soksa qon itlokipapi wakeya kin akahipa, qa Jehowa towitan kin tipi kin ojunya.

35 Unkan Mowis itkokipapi wakeya en i kta okihi śni, mahpiya qon he akan ounyan qa Jehowa towitan kin tipi kin oju ya nakaś.

36 Unkan mahpiya kin wankan iyaya eca, Israel cinca kin ihdakapi ece, unhdakapi kin owasin en hececa.

37 Tuka mahipiya kin wankan iyaye śni kinhan, ihdakapi śni ece, wankan iyaye śni lkin hehanyan.

38 Jehowa mahipiya śoka kin tipi kin akan yanka, anposkantu eca, tuka hanyetu ca he ohna peta icaga, Israel cinca tipi kin owasin unhdakapi owasin en he wanyasapi. 



\section{LEWI TOOPE.}

\section{WICOWOYAKE 1.}

1 Unkan Jehowa Mowis kipan, qa itkokipapi wakeya etanhan heciya,

2 Israel cinca kin hecen ewicakiya wo, Niyepi etanhan wicaśta tuwe woahi wan Jehowa kahi kte cinhan, woteca etanhan woahi nitawapi yakahipi kta, pte wanunyanpi etanhan, qaiś tahinca wanunyanpi etanhan.

3 Pte wanunyanpi etanhan .woliuhnahyapi on toahi kinhan, mdoka zanika ahi kte, iyokipiye kta e Jehowa itokam, itkokipapi wakeya tiyopa ekta kahi kta.

4 Hehan wohuhnahyapi pa akan nape kin aputake $\mathrm{kta}$, hecen iye wahtani kin akahpe kta e iyokipi ye kta.

5 Unkan Jehowa itokam tatankadan kin patapi kta; unkan Aaron cinca wawayuśnapi kin we kin ahipi kta, qa wahna wośnapi kin itkokipapi wakeya tiyopa ekta yanke cin akan we kin aihpe yapi kta.

6 Unkan wohuhinahyapi ha kin yuze kta, qa wobaśpe kin baśpuśpu kta.

${ }_{7}$ Unkan wawayuśna Aaron cinca kin wahna wośnapi akan peta ehnakapi kta, qa peta akan can aonpapi kta.

8 Unkan Aaron cinca wawayuśnapi kin wobaśpe kin, pa kin, qa waśin kin, can akan peta wahna wośnapi akan yanke cin ahnakapi kta.

9 Unkan śupe kin, qa huha kin mini on yujaja kta, qa ahi kta, Levit. unkan wawayuśna kin he ocowasin izin ye kta, peta on wohuhnahyapi wan waśtemna Jehowa iyokipi kin hee.

10 Unkan tahinca etanhan wolinhahyapi taku ahi kinhan, tahin wanunyanpi etanhan qa iś tatokadan etanhan mdoka zanika wan ahi kta.

11 Unkan Jehowa itokam wahna wośnapi icahda, iwaziya tanhan he pate kta. Unkan Aaron cinca wawayuśnapi kin we kin amnimnipi kta, wahna wośnapi aihdukśan.

12 Unkan wobaśpe kin baśpuśpu kta, qa pa kin, qa waśin kin, unkan wawayuśna kin hena can akan ehnake kta, peta wahna wośnapi akan yanke cin he akan. 13 Unkan śupe kin qa huha kin mini en yujaja kta. Unkan hena owasin wawayuśna kin ahi kta, qa wahna wośnapi izin ye kta. Peta on wohuhnahyapi wan waśtemna Jehowa iyokipi kin hee.

14 Unkan taku kinye cin etanhan wohulinaliyapi wan Jehowa kahi kte cinhan, wakiyedan cinca qaiś tinwakiyedan etanhan toahi kin ahi kta.

15 Unkan wawayuśna kin he wahna wośnapi ikiyedan kahi kta, qa pa kin cape kta; qa wahna wośnapi kin izin ye kta; tuka we kin yuśkice kta, wahna wośnapi cuwi kin ekta.

16 Qa śupe kin, cesdi ohna yuke cin koya icu kta, qa wahna wośnapi icahda iwiyohinyanpatanhan cahota yanke cin ekta elipe ye kta. 


\section{LEWI TOOPE.}

17 Unkan maku bamdaze lita, hupahu en, tuka kibaśpe kte śni, qa wawayuśna kin he on wahna wośnapi kin izin ye kta, can akan peta wahna wośnapi akan yanke cin he akan. Peta on wohuhnahyapi wan waśtemna Jehowa iyokipi hee.

\section{WICOWOYAKE 2.}

1 Unkan wicanagi wan minka woahi Jehowa kahi kte cinhan, aguyapi mdu kin kahi kta, qa wihdi he akaśtan kta, qa canśin waśtemna akan ehnake kta.

2 Qa he Aaron cinca wawayuśnapi kin wicakahi kta, qa he etanhan aguyapi mdu qa wihdi nape ohnaka wanjidan, qa canśin ocowasin icu kta; unkan wawayuśna kin wokiksuye kin he on wahna wośnapi kin izin ye kta, peta wośnapi waśtemna wan Jehowa iyokipi kin hee.

3 Unkan minha kin he etanhan taku okapte cin he Aaron qa iye cinca kin tawapi, Jehowa peta wośnapi tawa wakan hinca hee.

4 Unkan taku makacega ohna śpanyanpi minha woahi wan yakahi kte cinhan, he aguyapi onnapoliye codan wihdi icicahiyapi, qaiś aguyapi zipzibedan onapohye codan wihdi on sdayapi kin heca kta.

5 Unkan minha woahi nitawa mazawiceonpe akan śpanyanpi linhan, he aguyapi onapohye codan wihdi on sdayapi heca kta.

6 He duśpaśpa kta qa onśpaśpa akan wihdi ayakaśtan kta, minha wan hee.

7 Unkan minha woahi nitawa kin be cega ihupa tonna ohna spanyanpi kinhan, he aguyapi on wihdi en yakage kta.

8 Qa minha hena etanhan kagapi kin he Jehowa ekta hiyu146 yaye kta, unkan wawayuśna en kahipi kinhan iye he wahna wośnapi ekta kahi kta.

9 Unkan wawayuśna kin minhia kin etanhan wokiksuye wan icu kta, qa heon wahna wośnapi kin izin ye kta, he peta wośnapi waśtemna Jehowa iyokipi kin heca. 10 Unkan minha etanhan taku okaptapi kin he Aaron qa iye cinhintku tawapi kta, taku peta on Jehowa wakiyuśnapi wakan hinca hee.

11 Minhia Jehowa yecicahipi kin wanjidan onnapoliye on yakage kte śni. Onnapohye qa canhanpi tiktica etanhan peta on Jehowa izinyaye kte śni.

12 Taku tokaheya suton kin woahi kin hena Jehowa yakahi kta, tuka wahna wośnapi akan waśtemnayanpi iyokipi kte śni.

$13 \mathrm{Qa}$ minlia woahi kin hena owasin mmiskuya kici icicahiyaye kta, qa taku wakan yada miniskuya on takuyayapi kin he minha kin he etanhan miniskuya teyahinda kte śni. Woahi nitawa kin owasin akan miniskuya yakahi kta.

14 Unkan taku tokaheya suton etanhan minha wan Jehowa yakahi kte cinhan, aguyapi itka śtonkadan petan ceonpapi, bopanpi kin heca taku tokaheya suton minha nitawa yakahi kta.

$15 \mathrm{Qa}$ he akan wihdi ayakaśtan kta, qa canśin waśtemna ayakakada kta, minhia wan hee.

16 Unkan wawayuśna kin taku bopanpi etanhan, qa wihdi etanhan onge canśin ocowasin iyahna wokiksuye on izin ye kta. Peta on. Jehowa wakiyuśnapi wan hee.

WICOWOYAKE 3.

1 Unkan wopidå wośnapi wan kahi kte cinhan, pte wanunyanpi 


\section{WICOWOYAKE 4.}

etanhan mdoka qaiś wiye unman tukte kaśta wanji zanika, Jehowa kahi kta.

- 2 Qa taku kahi kin pa akan nape kin aputake kta. Hehan itkokipapi wakeya tiyopa ekta he pate kta ; unkan Aaron cinca wawayuśnapı kin we kin amnimnipi kta, wahna wośnapi aihdukśan.

3 Unkan wopida wośnapi etanhan peta wośnapi wan Jehowa kahi kta tejikśije qa śupe śin kin owaśin.

4 Qa pakśin kin napin, qa pakśin śin kin, mica en yarlke cin he, nakun pizi pi ikoyake cin he icu kta.

5 Unkan Aaron cinca kin he on wahna wośnapi kin izin yapi kta, wohuhnahyapi kin iyahna, he can peta akan yanke cin he akan, peta wośnapi waśtemna Jehowa iyokipi wan hee.

6 Unkan tahinca etanhan wopida wośnapi Jehowa kahi kte cinhan, mdoka qaiś wiye unman tukte kaśta zanika kahi kta.

7 Woahi tawa amnos wan kahi kinhan, he Jehowa itokam kahi kta.

8 Qa woahi tawa pa kin akan iye nape kin aputake kta, qa itkokipapi wakeya tiyopa kin ekta pate ktá, unkan Aaron cinca kin we kin amnimnipi kta, wahna wośnapi aihdukśan.

9 Unkan wopida wośnapi etanhan peta wośnapi wan Jehowa kahi kte, waśin kin, sinte ocowasin nite kin ekta baśpe kta, qa watejikśije, qa śupe śin kin owa$\sin$,

$10 \mathrm{Qa}$ pakśin napin, qa pakśin śin kin mica en yanke cin he, qa pizi kin pi ikoyake cin he icn kta.

11 Unkan wawayuśna kin he on wahna wośnapi izinye kta, peta wośnapi Jehowa tawote kin hee.
12 Unkan tatokadan wan kahi kinhan, he Jehowa itokam kahi kta.

13 Qa pa kin akan iye nape kin aputake kta, qa itkokipapi wakeya tiyopa kin ekta he pate kta, unkan Aaron cinca kin we kin amnimnipi kta, wahna wośnapi aihdukśan.

14 Unkan he etanhan toahi peta wośnapi wan Jehowa kahi kte, watejikśije kin he, qa śupe śin kin owasin ;

15 Qa pakśin kin napin, qa pakśin śin kin mica en yanke cin he, qa pizi kin pi ikoyake cin pakśin iyahna icu kta.

16 Unkan wawayuśna kin hena on wahna wośnapi kin izin ye kta, woyute peta wośnapi waśtemna wiciyokipi, waśin kin owasin he Jehowa tawa.

17 Nitoicagepi yeye cin tukte e kaeś yatipi kin owasin ohna waśin qaiś we takudan yatapi kte śni, he wokage owihanke wanice $k$ ta.

\section{WICOWOYAKE 4.}

1 Unkan Jehowa ie ca Mowis heciya,

2 Israel cinca kin hecen ewicakiya wo; Wicanagi wan ecinśni wahtani kinhan, qa Jehowa tawoahope wan taku econ śni wicaśi kin hena wanji econ kinhan : 3 Wawayuśna sdayapi kin he wahtani, qa oyate kin wahtani wicaye cinhan, woahtani wahtani kin on tatankadan pte cinca wan zanika Jehowa kahi kta, woahtani wośnapi kin on.

$4 \mathrm{Qa}$ tatankadan itkokipapi wakeya tiyopa kin ekta hiyuye kta, Jehowa itokam, qa tatankadan pa kin nape kin aputake kta, qa tatankadan kin pate kta, Jehowa itokam. 


\section{LEWI TOOPE.}

5 Qa wawayuśna sdayapi kin he tatankadan we kin onge icu kta, qa itkokipapi wakeya tiyopa kin ekta hiyuye kta.

6 Qa wawayuśna kin napsukaza wan we en oputkan qa śakowin akihde we onge ehpeye kta, Jehowa itokam, tipi wakan cokaya ozanpi kin ektakiya.

7. Unkan wawayuśna kin we kin etanhan onge wahna wośnapi izinyapi waśtemna he kin akan iun kta; he itkolkipapi wakeya ohna yanke cin, Jehowa itokam, qa tatankadan we-kin ocowasin wohuhnahyapi wahna wośnapi sicu ekta akaśtan kta, he itkokipapi wakeya tiyopa ekta yanka.

8 Qa woahtani wośnapi tatanka etanhan waśin kin owasin icu kta, watejikśije kin qa śupe śin kin owasin.

9 Qa pakśin kin napin qa pakśin śin mica en yanke cin he, qa pizi pi kin ikoyake cin mica en yanke cin he icu kta.

10 Wopida wośnapi tatanka etanhan icupi qon he iyecen, qa wawayuśna kin hena wohuhnahyapi wahna wośnapi akan izin ye kta.

11 Tuka tatanka ha kin qa cehpi kin ocowasin, pa kici, qa huha kici, qa śupe kin qa tacesdi kin.

12 Tatanka kin ocowasin hewoskantuya ayapi kta, tukten taku śica wanica ekta, cahota okadapi kin heciya, qa can akan peta on huhnahyapi kta, cahota okadapi kin he akan huhnahyapi kta.

13 Unkan Israel omniciye ocowasin ecinśniyan wahtanipi kinhan, qa Jehowa tawoahope taku econśni wicaśi kin wanji econpi, tuka okodakiciye kin he sdonye śni ecorıpi qa wahtanipi kinhan,
14 Tolian woahtani woahope awahtanipi kin he sdotkiyapi kinhan, okodakiciye kin wahtanipi kin or tatankadan wan ahipi kta, qa itkokipapi wakeya itokam hiyuyapi kta.

15 Unkan omniciye honkayapi kin tatanka pa kin akan napepi kin aputakapi kta, Jehowa itokam, qa tatankadan kin patapi kta, Jehowa itokam.

16 Unkan wawayuśna sdayapi kin tatanka we kin etanhan onge itkokipapi wakeya ekta hiyuye kta;

17 Qa wawayuśna kin napsukaza wan we oputkan kta, qa he etanhan śakowin akihde ehpeye kta, Jehowa itokam - cokaya ozanpi ekta kiya.

$18 \mathrm{Qa}$ we kin onge wahna wośnapi he kin hena akan iun kta, he Jehowa itokam itkokipapi wakeya ohna yanka, qa we kin owasin wohuhnahyapi wahna wośnapi kin itkokipapi wakeya tiyopa ekta yanke cin he ceteta kin ekta okaśtan kta.

19 Qa waśin kin owasin he etanhan icu kta, qa on wahna wośnapi kin izin ye kta.

20 Qa woahtani wośnapi tatankadan ecakicon qon he iyecen tatanka kin he ecakicon kta, hecen wawayuśna kin wahtanipi kin akahpe wicakiye kta ; unkan wicakicicajujupi kta.

21 Unkan tatankadan kin hewoskantuya ayapi $\mathrm{kta}$, qa tatankadan tokaheya huhnahyapi qon he iyecen de huhnahyapi kta. Okodakiciye woahtani wośnapi kin hee.

22 Wicaśtayatapi kin wahtani kinhan, qa taku iye wakanda Jehowa tawoahope tehinda kin wanji ecinśni econ kinhan qa ihduśica, 


\section{WICOWOYAKE 5.}

23 Tohan woahtani kin hena en wahtani kin sdotkiye cinhan toahi kin tatokadan mdoka zanika wan hiyuye kta.

24 Qa tamdoka pa akan iye nape kin aputake kta, qa Jehowa itokam tukten wohuhnahyapi patapi kin hen he pate kta; woahtani wośnapi wan hee.

2 Unkan wawayuśna kin woahtani wośnapi we kin etanhan napsukaza wan on icu kta, qa woliulinaliyapi wahna wośnapi he kin hena akan iun kta, qa we kin wohubnahyapi wahna wośnapi sicu ekta okaśtan kta ;

$26 \mathrm{Qa}$ waśin kin owasin on wahna wośnapi jzinye kta, wopida wośnapi waśin kin he iyecen, hecen wahtani kin wawayuśna kin akahipe kiciye kta, unkan kicicajujupi kta.

27 Unkan oyate tokecinyan unpi etanhan wicanagi wanji wahitani, qa Jehowa tawoahope taku econśni wicaśi wan ecinśniyan econ, qa ihduśice cinlian ;

28 Tohan woahtani wahtani kin he sdotkiye cinhan, woahtani wahtani kin on toahi tatokadan wiye wan zanika hiyuye kta.

29 Qa woahtani wuśnapi pa akan iye nape kin aputake kta, qa wohluhnalyapi tukten patapi kin hen woahttani wośnapi kin pate kta.

30 Unkan wawayuśna kin he we kin onge napsukaza wan on icu kta, qa wohuhnahyapi wahna wośnapi he kin hena akan iun kta, qa we kin owasin wahna wośnapi sicu ekta okaśtan kta.

31 Qa wopida wośnapi waśin kin icupi qon, he iyecen waśin kin owasin icu kta, qa wawayuśna kin wahna wośnapi kin izinye kta; waśtemnayanpi Je- howa iyokipi, hecen wawayuśna kin akalipe kiciye kta, unkan kicicajujupi kta.

32 Unkan woahtani wośnapi on amnos wan toahi hiyuye cinhan, wiyedan zanika wan hiyuye kta. 33 Qa woahtani wośnapi pa akan iye nape kin aputake kta, unkan tukte wohuhnaliyapi patapi ece kin hen woalitani wośnapi kin patapi kte.

34 Unkan wawayuśna kin woahtani wośnapi we onge napsukaza wan on icu kta, qa wohuhnahyapi wahna wośnapi he kin hena akan iun kta, qa we kin ocowasin wahna wośnapi sicu. ekta akaśtan kta.

$35 \mathrm{Qa}$ wopida wośnapi amnos waśin kin icupi qon he iyecen waśin kin owasin icu kta; unkan wawayuśna kin heon wahna wośnapi kin izin ye kta, Jehowa peta on wakiyuśnapi he iyecen, hecen wawayuśna kin akahpe kiciye kta, woalitani wahtani kin on, unkan kicicajujupi kta.

\section{WICOWOYAKE 5.}

1 Unkan wicanagi wan wahtani, qa tuwe Taku wakan cajeyata nahon, qa wayaatanin śipi, taku nalion qaiś sdonya kin he, tuka oyake śni kinhan, wahtani kin kiçin kta.

$2 \mathrm{Qa}$ iś wicanagi tuwe taku śapa wan icahtake cinhan, wamanica te śapa, qa woteca țe śapa, qa watutka țe śapa unman tukte kaśta sdotkiye śni econ eśta, hee śape kta, qa hdajuju kte.

3 Qa is tuwe wicaśta śapa wan icalitake cinhan, woaśape taku kaśta on wicaśta wan ihduśape cinhan, he sdonye śni econ eśta, tohan sdonye cinhan hdajuju $k$ ta.

4 Qaiś: wicanagi tuwe Taku 


\section{LEWI TOOPE.}

wakan cajeyate ca awacinśniyan iha on taku eye cinhan, taku śica econ kta, qaiś taku waśte econ kta wicaśta kin awacinśniyan eye cinhan, iyukcan śniyan econ eśta, tohan he sdonyê cinhan hena wanji on hdajuju k ta.

5 Unkan tohan hena wanji on hdajuju kte cinhan, taku en wahtani kin he ohdake kta.

6 Qa woahtani wahtani kin on taku on hdajuju kta Jehowa ekta hiyu ye kta, wahtani kin on tahinca etanhan wiyedan wan tahinca ska, qaiś tatokadan etanhan, unkan wawayuśna kin he on akahpe kiciye kta.

7 Unkan nape kin tacincadan wan iyohiye kte śni kinhan, wahtani kin hdajuju kta e tinwakiyedan nonpa, qaiś wakiyedan cinca nonpa, Jehowa kahi kta, wanji woahtani wośnapi on, qa unman wohuhnahyapi on.

$8 \mathrm{Qa}$ hena wawayuślla kin ekta hiyuye kta, unkan woahtani wośnapi kin he tokaheya ahi kta, qa pa olidateya dote cape kta, tuka baśpe kte śni.

9 Qa woahtani wośnapi kin we onge wahna wośnapi cuwi akan elipe ye kta, qa we okapte cin owasin wahna wośnapi sicu ekta yuśkice kta woahtani wośnapi wan hee.

10 Unkan inonpa kin woliuhnahyapi wan kage kta, econ wicaśipi kin iyecen, hecen wawayuśna kin woahtani wahtani qon akalipe kiciye kta, unkan kicicajujupi kta.

11 Tuka nape kin tinwakiyedan nonpa, qaiś wakiyedan cinca nonpa iyohiye kte śni kinhan, wahtani kin on toahi kin aguyapi mdu can wakśica ohnaka wanjidan woahtani wośnapi on hiyuye kta. He akan wihdi akaśtan kte śni, qa canśin waśtemna aehnake kte śni, woalitani wośnapi wan hee nakaeś.

$12 \mathrm{Qa}$ he wawayuśna ekta hiyuye kta. Unkan wawayuśna kin he etanhan napohnaka wanji icu kta, he wokiksuye ee, qa on wahna wośnapi kin izin ye kta, peta on Jehowa wakiyuśna iyecen, woahtani wośnapi wan hee.

13 Hecen hena on woahtani wan walitani kin on wawayuśna kin akahpe kiciye kta, unkan kicicajujupi kta. Unkan taku okapte cin he wawayuśna tawa kta, minha wan iyecen.

14. Unkan Jehowa ie ca Mowis heciya;

15 Wicanagi wan śicaya ohanyan, qa Jehowa taku wakanyan tawa en ecinśniyan wahtani kinhan, tohdajuju kin Jehowa ekta hiyuye kta, tamdoka wan tahinca etanhan mazaska śeqel tona idacin, tipi wakan śeqel iyececa kici on hdajuju kta.

16 Hecen taku wakanyanpi kin manon qon kicu kta, qa izaptan kin he kici aopekiciciye kta, qa wawayuśna kin he qu kta, unkan wawayuśna kin on hdajujupi tamdoka on akahpe kiciye kta, unkan kicicajujupi kta.

17 Unkan wicanagi wan wahtani kinhan, qa taku wanji Jehowa econ śni wicaśi econ kinhan, he sdonye śni eśta he walitani, qa on hdajuju kta.

$18 \mathrm{Qa}$ hdajuju kta e wawayuśna ekta tahinca etanhan tamdoka wan, taku idacin kici hiyuye kta, unkan taku ecinśniyan walitani, qa iyukcanśniyan nuni kin heon wawayuśna kin akahpe kiciye kta, unkan kicicajujupi kta.

19 On hdajujupi wan hee; Jehowa en wahtani kin on hdajuju kta. 


\section{WICOWOYAKE 6 .}

20 Unkan Jehowa ie ca Mowis heciya ;

21 Wicanagi wan wahtani qa taku Jehowa tawa wan manon kinhan, qaiś tuwe ikiyedan ti en itonśni, taku yuhe śipi qaiś taku wicakicihnaka on, qaiś taku wicaki kin on qaiśs tuwe ikiyedan ti kiyuśe kinhan;

22 Qaiś taku wicakitaninpi śni iyeye ca on itonśni, qa taku kaśta wicaśta econpi kin hena wanji en wahtani, qa itonśniyan on taku wakan caje yate cinhan;

23 Hehan kaketu ktá, wahtani kin on hdajuju kta e taku wicaki qon kicu kta, qa iś taku wicahnayan on yuha, qa iś taku kicihnakapi qon, qaiś taku wicakitanin śni iyeye ciqon.

24 Qa taku kaśta on taku wakan cajeyate ca itonśni kin, he ocowasin kicu kta, qa anpetu tohan hdajuju kin hehan izaptan wan aopekiciciye kta, qa tuwe tawa kin kicu kta.

25 Nakun on hdajuju kta Jehowa wakiyuśnapi wan talinca etanhan, tamdoka wan zanika, taku idacin kici hdajuju kta e wawayuśna elta hiyuye kta.

26 Unkan wawayuśna kin Jehowa itokam akahpe kiciye kta, unkan taku kaśta on hdajuju kta econ qon, iyuhi kicicajujupi kta.

\section{WICOWOYAKE 6.}

1 Unkan Jehowa ie ca Mowis heciya,

2 Aaron qa iye cinca hecon wicaśi, qa hewicakiya wo; Wohulnahyapi wośnapi woope kin dee: Hanyetu osan wahna wośnapi akan itkonyan un kta, ihanhanna kin hehanyan, qa wahna wośnapi akan peta kin itkonye cin heon wohuhnahyapi kin eciyapi.

3 Unkan wawayuśna kin mini- huha ska mahen unpi kin kicun qa minihuha ska onze oge koyake kta, iye cehpi akan, qa wohulinahyapi wośnapi cahota peta wahna .wośnapi akan huhnage cin he icu kta, qa wahna wośnapi kin icahda ehnake kta.

4 Hehan wokoyake kin hduśdoke kta, qa wokoyake tokeca kiçun kta, qa cahota kin hewoskantuya aye kta; tukten taku śica wanica ekta.

5 Unkan peta wahna wośnapi akan yanke cin he ohinniyan itkon yapi kta, he kasnipi kte śni. Unkan he akan hanhanna otoiyohi wawayuśna kin can ideye kta, qa he akan wohulinahyapi kin aehnake kta, qa he akan wopida wośnapi waśin kin izin ye kta.

6 Peta kin ohinniyan wahna wośnapi akan itkon yapi kta, tohinni sni kte śni.

7 Unkan minlia woope kin dee, Aaron cinhintku wanji he Jehowa itokam wahna wośnapi ekta kahi kta.

$8 \mathrm{Qa}$ minha aguyapi mdu qa wihdi etanhan napohnaka wan icu kta, qa canśin minha akan un lin he ocowasin, qa wahna wośnapi kin izin ye kta, he wokiksuye waśtemna Jehowa iyokipi.

9 Unkan taku minha etanhan okapte cin he Aaron qa iye cinca kin aguyapi onapohye codan yutapi kta, oyanke wakan kin ohna, he yutapi kta, itkokipapi wakeya hocoka kin ohna he yutapi kta.

10 Onnapohye on śpanyanpi kte śni, tuka peta on wamiciyuśnapi etanhan wopamni kin he wicawaqu. He wakan hinca, woahtani wośnapi kin iyecen, qa wokajuju wośnapi kin iyecen.

11 Aaron cinca kin tona wica kin hena owasin he yutapi kta. 


\section{LEWI TOOPE.}

Nitoicagepi yeye cin wokage kin de owihanke wanice kta, tona wakanpi kin henana taku peta on Jehowa wakiyuśnapi kin yutanpi kta.

12 Unkan Jehowa ie ca Mowis heciya,

13 Aaron qa iye cinca anpetu. en wanji sdayapi kinhan, woahi kin de kahipi kta, aguyapi mdu can wakśica ohnaka wanji, minha ohinniyan wan, hanke hanlianna eca, qa hanke hitayetu eca.

14 Maza wiceonpa akan wihdi en cegugu yaye kta, śpan hehan hiyu yaye kta, minlia yuśpuśpupi waśtemna Jehowa iyokipi yakahi kta.

15 Qa tuwe iye cinca etanhan hee kiya wawayuśna sdayapi kin he kage kta, he ocowasin Jehowa tawa izinyapi kta, wokage kin de owihanke wanice kta.

16 Hecen wawayuśna minha tawa kin he ocowasin hulinahyapi kta, tuwedan he etanhan yute kte śni.

17 Unkan Jelowa ie ça Mowis heciya,

18 Aaron qa iye cinca kin hecen ewicakiya wo: Woahtani wośnapi woope kin dee, tukten wohulinaliyapi patapi kin he en woahtani wośnapi kin patapi kta, Jehowa itokam he wakan hinca.

19 Wawayuśna tuwe heon wokajuju kage cin he yute kta, oyanke wakan kin itkokipapi wakeya hocoka kin en he yutapi kta.

20 Taku kaśta he cehpi kin icahtake cinhan wakan kta, qa wokoyake taku kaśta he we kin akan ehpeyapi kin, he akan hinhpaye cin on, oyanke wakan en yujajapi kta.

21 Qa maka cega ohna he śpanyanpi kin he kamdecapi kta, qa mazaśa cega ohna he śpanyanpi kinhan, he payezapi qa mini on yujajapi kta.

22 Wawayuśna tona wicapi kin hena owasin yutapi kta, he wakan hinca.

$23 \mathrm{Qa}$ woahtani wośnapi tona we kin on akahpapi kta e tipi wakan ohna itkokipapi wakeya en hiyuyapi hena yutapi kte sni, peta on hulinaliyapi kta.

\section{WICOWOYAKE $\%$}

1 Unkan on hdajuju wośnapi woope kin dee, he wakan hinca.

2 Tukte wohuhnaliyapi wośnapi ktepi kin he en on hdajujupi ktepi kta, qa we kin he wahna wośnapi akan ihdukśan elipeyapi kta.

$3 \mathrm{He}$ etanhan waśin owasin ahi kta, sinte kin qa waśin śupe akahipe cin he;

4 Qa pakśin kin napin, qa pakśin śin mica en yanke cin he, qa pizi pi ikoyake cin, pakśin icahda he yutokan kte;

5 Qa hena on wawayuśna kin wahna wośnapi kin izin ye $\mathrm{ktr}$, peta on Jehowa wakiyuśnapi, on hdajujupi kin hee.

6 Wawayuśna wica kin hena owasin he yutapi kta, oyanke wakan ohna yutapi kta, he wakan hinca.

7 Woahtani wośnapi kin, qa on hdajuju wośnapi kin hena woope kin okonwanjidan; wawayuśna kin tuwe hena on woakah̉pe kage cin he tawa kta.

8 Qa wawayuśna tuwe wicaśta wan wohuhnahyapi kicicahi kinhan, wohuhinahyapi ha kin he wawayuśna ahi kin he tawa kta.

$9 \mathrm{Qa}$ minha kin oceti akar. śpanyanpi kin he owasin, qa cega ohna qa cega ihupatonna akan kagapi kin he owasin wawayuś-

152 


\section{WICOWOYAKE $\%$}

na kin tuwe he ahi kin he tawa kta.

10 Tuka minha wihdi icicahiyapi, qa aguyapi mdu kin hena iyuhpa Aaron cinca kin owasin otoiyohi hunkawanjitku iyececa tawapi kta.

11 Unkan wopida wośnapi Jehowa kahipi kta woope kin dee.

12 Tuwe he woyatan on ahi kinhan, woyatan wośnapi kici aguyapi napoliyapi śni wihdi icicahiyapi, qa aguyapi zibzibedan napoliyapi śni, wihdi on sdayapi, qa aguyapi ceguguyapi wihdi akaśtanpi ;

13 Aguyapi napohyapi śni kici aguyapi napohyapi ahi kta, toahi wopida woyatan wośnapi tawa on.

14 Qa woahi kin ocaje owasin etanhan aguyapi wanjidan wokosyapi Jehowa tawa, wawayuśna wopida we kin amnimni kin he ektakiya kahi kta, he tawa kta.

15 Qa woyatan wopida wośnapi celipi kin he yutapi kta, ampetu en ahipi kin en, hetanhan ongedan ihanhanna hehanyan okaptapi kte śni.

16 Tuka toahi kin woyakapi wośnapi qaiś, itukihanpi wośnapi kinhan, anpetu en taku wośna ahi kin hen yutapi kta, qa taku okapte cin he ihanlianna nakun yutapi kta.

17. Qa tado wośnapi anpetu iyamni kin hehanyan okapte cin he peta on huhnahyapi kta.

18 Qa wopida wośnapi tado onge anpetu iyamni en yutapi kinhan, iyokipi kte śni, qa tuwe ahi kin kiciyawapi kte śni, taku śicamna iyecece kta, wicanagi kin tuwe hetanhan yute cinhan wośice cin hduhe kta.

19 Cehpi taku śapa wan icahitake cin he yutapi kte śni, he pe- tan huhnahyapi kta. Unkan celipi kin tona ecepidan kin hena owasin cehpi yutapi kta.

20 Tuka wicanagi tuwe toaśape ikoyake cin, wopida wośnapi cehpi kin Jehowa wakiyuśnapi kin he yute cinhan, wicanagi kin he taoyate kin etanhan kaśpapi kta.

21 Qa wicanagi tuwe taku śapa yutan kinhan, wicaśta towa aśape qaiś woteca towaaśape, qaiś watutka śapa wan, qa wopida wośnapi । Jehowa wakiyuśnapi cehpi etanhan yute cinhan wicanagi kin he taoyate etanhan kaśpapi kta.

22 Unkan Jehowa ie ca Mowis heciya,

23 Israel cinca kin hecen ewicakiya wo; Pte waśin kin, qa tahinca ska waśin kin, qa tatokadan wanunyanpi waśin kin ongedan yatapi k te śni.

24 Taku wayazanka te cin waśin kin, qa taku wamanica yațapi kin waśin kin he wowiyunyanpi kta, tuka he yutapi kte śni.

25 Tuwe kaśta woteca peta on Jehowa wakiyuśnapi kin he etanhan waśin onge yute cinhan wicanagi kin he iye taoyate etanhan kaśpapi kta.

26 Nakun yatipi owasin ohna we ongedan yatapi kte śni, wahupakoza we kin, qa woteca we kin unman tukte kaśta.

27 Wicanagi tuwe kaśta we ongedan yute cinhan wicanagi kin he taoyate kin etanhan kaśpapi kta.

28 Unkan Jehowa ie ça Mowis heciya;

29 Israel cinca kin hecen ewicakiya wo, Tuwe kaśta wopida wośnapi wan Jehowa kahi kte cinhan, he wopida wośnapi toahi kin Jehowa ekta hiyuye kta. 
30 Iye nape kin Jehowa peta wośnapi tawa hiyuye kta, waśin maku iyahna, maku yuwintapi, Jehowa itokam he yuwintapi kta e hiyuye kta.

31 Unkan wawayuśna kin waśin kin on wahna wośnapi kin izinye kta, tuka maku kin he Aaron qa iye cinca kin he tawapi kta.

32 Qa hiyete etapa kin he wopida wośnapi nitawapi etanhan wokozapi wan wawayuśna kin yaqupi kta.

33 Aaron cinca etanhan tuwe wopida wośnapi we kin, qa wa sin kin ahi kinhan, hiyete etapa kin wobaśpe tawa kta.

34 Israel cinca wopida wośnapi tawapi etanhan, maku yuwintapi, qa hiyete kozapi kin hena iwicawacu, qa Aaron qa iye cinca wicawaqu, Israel cinca etanhan, wokage owihanke wanica.

35 Taku peta on Jehowa wakiyuśnapi etanhan Aaron wiyutapi tawa, qa iye cinca wiyutapi tawapi kin hee: Jehowa wawakiyuśnapi kta e en awicahi anpetu kin he en.

$36 \mathrm{He}$ Jehowa wicaqu śi kin anpetu en sdawicaye cin he ehan, Israel cinca etanhan wicoicagepi yeye cin, wokage owihanke wanica.

37 Wohuhnahyapi on woope kin hee, qa nakun minha on, qa woahtani wośnapi on, qa wokajuju wośnapi on, qa wojunyapi on, qa wopida wośnapi on.

38 Jehowa Mowis hecon śi, Sina he ohna anpetu wan Israel cinca toahipi Sina hopuze cin en, Jehowa ekta ahi wicaśi qehan.

WICOWOYAKE 8.

1 Unkan Jehowa ie ca Mowis heciya,
2 Aaron qa iye cinca om iwicacu wo, nakun wokoyake kin, qa wihdi on sdawicayapi kin, qa woahtani tatanka kin, qa tamdoka nonpa kin, qa aguyapi napohyapi śni wakiśkotpa kin.

3 Qa omniciye owasin itkokipapi wakeya tiyopa ekta wicakico wo.

4. Unkan token Jehowa econ śi kin he iyecen Mowis econ; unkan omniciye owasin itkokipapi wakeya tiyopa ekta mniciyapi.

5 Unkan Mowis omniciye kin hewicakiya, Taku Jehowa econ unśipi kin dee.

6 Hehan Mowis Aaron qa iye cinca kin awicahi, qa mini on wicayujaja.

7 Qa mahenunpi kin koyag ya, qa ipiyake on ipiyag kiciton, qa nitośke kin koyag ya, qa amdo akahpe kin alsihnake ca amdo akahpe ipiyake kazuntapi kin on ipiyag kiya, hecen amdo kin akahpe kiya.

8 Qa maku akahpe kin akihnake ça iyoyam wicaye ca ecetu wicaye cin maku akahpe kin en iyeya.

9 Qa pa akan pa ipalite kin pahta, qa pa ipahte akan ite ektakiya mazaskazi mdaska wateśdake wakan pahta; Jehowa hecon si kin he iyecen.

10 Unkan Mowis wihdi on sdawicayapi kin icu, qa tipi kin sdaya, nakun taku ohna un kin owasin; hecen hena yuwakan.

$11 \mathrm{Qa}$ he etanhan śakowin akihde wahnawośnapi akan ehpeya, qa wahnawośnapi kin sdaya, nakun taku on kicanyanpi owasin, nakun maza koka kin, qa taceteta kin; hecen hena yuwakan.

$12 \mathrm{Qa}$ wihdi on sdayapi onge Aaron pa kin akaśtan, qa he yuwakan lita e sdaya.

13 Unkan Mowis Aaron cinca 
kin awicahi, qa mahen ùni kin ikoyag wicaya, qa ipiyake on ipiyag wicakiciton, Jehowa Mowis hecon si kin he iyecen.

14 Qa woahtani tatanka kin ikiyedan hiyuya; unkan Aaron qa iye cinca kin tatanka pa akan napepi aputakapi.

15 Unkan pata, qa Mowis we kin icu qa napsulaza wan on wahna wośnapi he kin aihdukśan iun, hecen wahna wośnapi kin wakiyuśna, qa we kin wahna wośnapi sicu ekta kaśtan, hecen he akan akahpapi kta e he yuwakan.

16 Unkan watejikśija kin he owaśin icu, qa pi pizi kin, qa pakśin napin, qa pakśin śin, qa Mowis hena on wahna wośnapi kin izinya.

17 Tuka tatanka pa kin, qa cehpi kin peta on huhnahya, otipi kin itankan, Jehowa Mowis hecon śi kin he iyecen.

18 Hehan wohuhnahyapi tamdoka kin ahi, unkan Aaron qa iye cinca kin napepi tamdoka pa kin aputakapi.

19 Unkan he pata, qa Mowis he we kin wahna wośnapi aihdukśan akaśtan.

20 Unkan tamdoka kin token baśpapi kta iyececa baśpaśpa; unkan Mowis tamdoka pa kin, qa obaśpe kin, qa waśin kin izinya. 21 Unkan śupe kin qa huha kin mini on yujaja, unkan Mowis tamdoka ocowasin on wahna wośnapi kin izinya, peta on Jehowa wakiyuśnapi wan wohuhnahyapi waśtemna wiciyokipi wan hee, Jehowa Mowis hecon śi kin he iyecen.

22 Unkan tamdoka inonpa kin he ahi, ojunyapi tamdoka kin hee; unkan Äaron qa iye cinca kin napepi kin tamdoka pa kin aputakapi.
23 Unkan he pata, qa Mowis he we kin etanhan icu, qa Aaron noge etapa inkpa akan ikiciun, nakun napahunka etapa akan, qa sipahunka etapa akan.

24 Qa Aaron cinca kin awicahi, qa Mowis nogepi etapa inkpapi akan we kin onge iwicakiciun, nakun napahunkepi, qa sipahunkepi etapa akan, qa we ihe cin wahna wośnapi aihdukśan alkaśtan.

25 Qa waśin kin icu, nakur sinte kin, qa watejikśija ocowasin, qa pi pizi kin, qa pakśin napin, qa pakśin śin kin qa hiyete etapa kin ;

26 Nakun aguyapi napoliyapi śni wakiślkotpa Jehowa itokam yanke cin etanhan aguyapi napohyapi śni hmiyanyan wanjidan, qa wihdi aguyapi hmiyanyan wanjidan, qa aguyapi zibzibedan wanjidan, qa hena waśin akan, qa hiyete etapa akan ehnaka.

27 Qa hena owasin Aaron nape en qu, nakun cinhintku napepi en ; unkan hena kozapi, Jehowa itokam; wolkozapi wan hee.

28 Unkan napepi etanhan Mowis hena icu, qa on wahna wośnapi kin izinya, wohuhinahyapi akan, wojunyapi kin hena eepi, woomna wiciyokipi peta wakiyuśnapi wan hee.

29 Unkan Mowis maku kin icu, qa Jehowa itokam koza, wokosyapi ojunyapi tamdoka etanhan obaśpe kin he Mowis tawa, Jehowa Mowis hecon śi kin he iyecen.

30 Unkan Mowis sdayapi wihdi etanhan icu, qa we wahna wośnapi akan un kin etanhan, qa Aaron akan elipeya, nakun wokoyake tawa akan, qa cinhintku akan, qa cinhintku tawokoyakepi akan, hecen Aaron yuwa155 


\section{LEWI TOOPE.}

han, qa tawokoyake, qa cinhintku, qa nakun cinhintku tawokoyakepi.

31 Unkan Mowis Aaron qa iye cinhintku hewicakiya, Itkokipapi wakeya tiyopa kin ekta tado kin ohanpo, qa heciya he yatapi kta, qa aguyapi ojunyapi kin wakiślkotpa ohna un kin he nakun, hecon ciśipi kin he iyecen, Aaron qa iye cinca'kin he yutapi kta, epa.

32 Qa taku okaptapi tado kin etanhan, qa aguyapi kin etanhan, petan ehpeyayapi kta.

33. Qa śakowin can itkokipapi wakeya tiyopa etanhan inayapapi kte śni, anpetu ojunniyanpi kin henakecapi kte cin hehanyan, anpetu śakowin ninapepi ojunniyanpi kta nakaś.

34 Nakaha econ ciśipi kin he iyecen Jehowa econ unśipi; alkahpe niciyapi kta heon.

35 Qa anpetu śakowin, anpetu hanyetu koya, itkokipapi wakeya tiyopa ekta nankapi kta, qa Jehowa topatan kin yapatanpi $\mathrm{kta}$, hecen nițapi kte śni, hecen econ ciśipi heon etanhan.

36 Unkan Aaron, qa iye cinca kin taku Jehowa Mowis nape on econ. wicaśi kin owasin econpi.

\section{WICOWOYAKE 9.}

1 Unkan anpetu iśahdogan hehan Mowis Aaron qa iye cinca kin wicakico, nakun Israel hunkawicayapi.

2 Qa Aaron heciya, Ptejicadan wan pte wanunyanpi cinca woahtani wośnapi on icu, qa tamdoka wan wohulinahyapi on, napin zanipi, qa Jehowa itokam awicahi wo.

3 Qa Israel cinca kin hecen ewicayakiye kta, Tatokadan mdoka wan woahtani wośnapi 156 on icupo, qa wohuhnahyapi on ptejicadan wan, qa amnos wan, napin waniyetu wanjidan zanipi. 4 Qa tatanka wan, qa tamdoka wan wopida wośnapi on, Jehowa itokam wakiyuśnapi kta; nakun minlia wihdi icicahiyapi ; anpetu kin de Jehowa niyepi en ihdutanin kta, heon etanhan.

5 Unkan taku Mowis itkokipapi wakeya tiyopa ekta au wicaśi kin he aupi, qa omniciye kin ocowasin ikiy edan hiyupi qa Jehowa itokam najinpi.

6 Unkan Mowis heya, Taku Jehowa hecon niśipi kin dee, hecen Jehowa towitankin niyepi en ihdutanin kta.

7 Unkan Mowis Aaron heciya, Wahna wośnapi kin ikiyedan $u$, qa woahtani wośnapi nitawa, qa wohuhnahyapi nitawa kin kaga wo, hecen niye on, qa oyate kin on akahpe yakiye kta, nakun oyate toahi kin kaga wo, hecen hena on akahpe yakiye kta, Jehowa econ niśi kin he iyecen.

8 Unkan Aaron wahna wośnapi kin ikiyedan hiyu, qa ptejicadan woahtani wośnapi tawa kin pata.

9 Unkan Aaron cinca kin we kin kahipi, unkan napsukaza wan we kin en oputkan, qa wahna wośnapi he akan iun, qa we kin wahna wośnapi sicu ekta kaśtan.

10 Unkan woalitani wośnapi etanhan waśin kin, qa pakśin kin, qa pi etanhan pizi on wahna wośnapi kin izinya, Mowis econ śi kin he iyecen.

11 Unkan tado kin, qa ha kin huhnahya, owanka itankan.

12 Hehan wohuhnahyapi kin pata ; unkan Aaron cinca kin we kin kahipi, unkan he wahna wośnapi aihdukśan akaśtan.

13 Unkan wohuhnahyapi kin kahipi, obaśpe kin, qa pa kin, unkan izinya wahna wośnapi akan. 


\section{WICOWOYAKE 10.}

14 Qa supe kin, qa huha kin: yujaja, qa wohulinahy api wahna wośnapi akan izinya.

15 Qa oyate toahi kin he ahi, qa tatokadan mdoka woahtani wośnapi oyate tawapi kin he icu, qa pate ça wayuśna, tokaheya qon he iyecen.

$16 \mathrm{Qa}$ wohuhnahyapi kin ahi, qa woyaco kin he iyecen ecakicon.

17 Qa minha kin he ahi, qa hetanhan napohnaka wan icu, qa hanlianna wohuhnahyapi iyahna wahna wośnapi akan izinya.

18 Qa tatanka qa tamdoka oyate wopida wakiyuśnapi kin hena pata; unkan Aaron cinca kin we kin kahipi, unkan he wahna wośnapi aihdukśan akaśtan.

19. Unkan tatanka etanhan, qa tamdoka etanhan waśin kin, sinte kin, qa watejikśija, qa pakśin kin, qa pi pizi kin kahipi.

20 Qa waśin kin maku kin akan ehnakapi, qa waśin kin on wahna wośnapi kin izinya.

21 Qa maku, qa hiyete etapa kin Aaron kosyu, Jehowa itokam wokosyapi, Mowis econ śi kin he iyecen.

22 Qa Aaron oyate ektakiya nape kin hduwinta, qa wicayawaśte; hehan woalitani wośnapi, qa wohuhnaliyapi, qa wopida wośnapi kage cin etanhan hdicu.

23 Unkan Mowis Aaron kici itkokipapi wakeya en ipi, qa tankan inanpapi, qa oyate kin wicayawaśtepi : unkan Jehowa towitan kin oyate kin owasin en ihdutanin.

24 Unkan Jehowa itokapatanhan peta inanpe ca wohulinahyapi kin, qa waśin kin wahna wośnapi akan huhnahya. Unkan oyate kin owasin he wanyakapi, qa panpanpi, qa makipusdiya ihpayapi.
WICOWOYAKE 10.

1 Unkan Aaron cinca kin $\mathrm{Na}$ dab qa Abihu iyohi tamaza mdaska icu, qa hena akan peta ehnakapi, qa he akan wizinyapi kadapi, qa peta tokeca Jehowa itokam kahipi, hecon wicaśi śni tuka.

2 Unkan Jehowa itokapa tanhan peta inanpe ca hulinah wicaya.

3 Unkan Mowis Aaron heciya, Jehowa heye ciqon he dee, Tona mikiyedan hipi kin, mayawakanpi kta, qa oyate owasin itokam mayutanpi kta, eya, Unkan Aaron inina yanka.

4 Unkan Mowis Aaron ateye Uziel cinca kin Miśael qa Elitzapan wicakipan, qa hewicakiya, Ikiyedan upo, qa nihunkawanjipi kin tipi wakan itokapa tanhan awicayapo, hewoskantuya.

5 Unkan en hipi, qa mahen unpi ohna owanka itankan awicayapi, Mowis eye cin he iyecen.

6 Unkan Mowis Aaron qa iye cinca kin Eleazar qa Itamar hewicakiya, $\mathrm{Pa}$ bakiśdapi śni po, qa wokoyake hdutokecapi śni po: hecanonpi kinhan okini nițapi kta, qa omniciye ocowasin en wocanteptanye u kta; tuka nihunkawanjipi, Israel cinca tipi ocowasin wogu kin Jehowa guye cin he aceyapi kta.

7 Unkan Jehowa tosdaye wihdi aniunpi, heon itkokipapi wakeya tiyopa etanhan inayapapi kte śni, okini ni țapi kta, eya. Unkan Mowis eye cin ecen econpi.

8 Unkan Jehowa ie ça Aaron heciya,

9 Itkokipapi wakeya ekta yahipi eca miniśa, qa miniwakan datke kte śni, niye qa nakun nicinca, hecen nițapi kte śni. Woka157 


\section{LEWI TOOPE.}

ge kin de owihanke wanica nitoicagepi yeye cin.

10 Qa hecen taku wakan qa taku wakan śni otahedan dukinukanpi kta, qa taku śapa qa taku ecedan otahedan:

11 Qa hecen wokage Jehowa Mowis nape eciyatanhan eniciyapi kin, hena owasin Tsrael cinca kin onspe wicayakiyapi kta.

12 Unkan Mowis Aaron qa iye cinca kin nahanhin en unpi, Eleazar qa Itamar hewicakiya, Minha Jehowa tapeta wośnapi etanhan taku okaptapi kin he icu, qa napohyapi śni yutapo, wahna wośnapi icahda, he wakan hinca.

13 Qa he oyanke wakan ohna yutapi kta; taku peta on Jehowa wakiyuśnapi etanhan wopamni nitawa, qa nicinca wopamni tawapi kin hee, heon hecen econ ciśipi nakaś.

14 Qa maku kosyapi, qa hiyete yuwintapi kin, hena oyanke wakaśote śni ohna yatapi kta, niye qa nicinkśi qa nicunkśi opapi kta, wopamni nitawa, qa nicinca wopamni tawapi Israel cinca wopida wośnapi kin etanhan niçupi nakaś.

15 Hiyete yuwintapi kin qa maku kosyapi kin waśin iyahna hiyuyapi kta, wokosyapi Jehowa itokam kosyapi kta heon, qa he nitawa kta, qa nicinca nakun tawapi kta, wokage owihanke wanica, Jehowa econ unśipi kin he iyecen.

16 Unkan Mowis tatokadan woahtani wośnapi kin he nina akita, tuka huhnahyapi; heon Eleazar qa Itamar Aaron cinca nahahin en unpi canniye wicaye ça heya,

17 Tokeca woahtani wośnapi kin he yatapi śni, oyanke wakan ohna, he wakan hinca, qa omni- ciye śicaya ohanyanpi kin duhapi kta e he nicupi, qa akahipe wicayayapi kta e Jehowa itokam.

18 Ito he we kin tipi wakan mahen hiyuyapi sni heon tipi wakan ohna he yatapi kta iyececa, econ ciśipi kin he iyecen.

19 Unkan Aaron Mowis heciya, Ito nakaha woahtani wośnapi tawapi qa tohuhnahyapi kin hena Jehowa itokam ahipi, unkan taku hececa amakipapi, unkan anpetu kin de woahtani wośnapi wate kte cin he Jehowa iyokipi ye kta he?

20 Unkan Mowis he nahon qehan he iyokipi.

\section{WICOWOYAKE 11.}

1 Unkan Jehowa ie ça Mowis Aaron kici hewicakiya,

2 Israel cinca kin hecen ewicakiyapo. Taku maka akan ni un kin owasin etanhan woteca kin dena yatapi kta.

3. Woteca tona wayatakonza śake jate śake ocowasin kinaśpe cin hena owasin yatapi kta.

4 Tuka dena wayatakonzapi qaiś śake jatapi eśta yatapi kte śni ; camo kin he wayatakonza eśta śake kin kinaśpe śni, he śapa yadakapi kta.

5 Qa śapan kin he wayatakonza eśta śake kin kinaśpe śni heon he śapa yadakapi kta.

6 Qa maśtinca kin he wayatakonza eśta śake kinaśpe śni heon he śapa yadakapi kta.

7 Qa kukuśe kin he śake jata, qa śake ocowaśin kinaśpe eśta wayatakonze śni heon he śapa yadakapi kta.

8 Hena cehpi kin ongedan yatapi kte śni, qa tapi tancan dutanpi kte śni, hena śapa yadakapi kta.

9 Unkan taku mini oicage cin 
owasin etanhan dena yatapi kta, Taku hoape, qa hoceśpu yukan, mini oicage, mde ohna, qa wakpa ohna, hena owasin yatapi kta.

10 Qa taku mde ohna qa wakpa ohna hoape qa hoceśpu wanice cimhan, taku mini oniwan, qa taku nagi ni un kin, hena owasin etanhan yatapi kte śni, hena wowahteśni yadapi kta.

11 Hena wowahteśni yadapi kta, heon cehpipi etanhan yatapi kte śni, qa țapi tancan wahiteśni yadapi kta.

12 Taku mini ohna hoape, qa hoceśpu wanice cin hena owasin wowahteśni yadapi kta.

13 Unkan wahupakoza dena wahteśni yadapi kta, liuya, qa wamdi, qa anog paska; hena yatapi kte śni, hena wowahte śni.

14 Qa daa, qa canśka wanmdidan ocaje owasin ;

15 Qa kangi ocaje owasin;

16 Qa hinhanska, qa heca, qa canśka, qa cetan ocaje owasin;

17 Qa hinhan kaga, qa huntkan, qa yaneśupa,

$18 \mathrm{Qa}$ tinśemet, qa mdega, qa moloza ;

19 Qa hoka, qa pehan, qa upupa, qa hupawakihdaka.

20 Taku kinyan sdohan, siha topa awinta lkin hena owasin wowahteśni yadapi kta.

21 Tuka taku kinyan sdohan siha topa awinta etanhan dena yatapi kta, tona siha iwankam hu nonpa yúkanpi on maka aipsicapi kin hena.

22 Hena elanhan dena yatapi kta, psipsicadan qa, hehakacanteyuśniśnija ocaje owasin.

23 Tuka taku kinyan sdohan siha topa yuke śni kin hella owasin wowahiteśni yadakapi kta.

24 Qa dena on niyuśapapi kta, tuwe kaśta dena wanji țe cin yutan kinhan hitayetu aiyahdeya śape kta.

25 Qa tuwe hena wanji te cin qin kinhan wokoyake hdujaja kta, qa hitayetu aiyahdeya śape kta.

26 Woteca tona śake gangata eśta śake ocowasin kinaśpe śni, qa wayatakonze śni kin hena owasin śapa yadakapi kta, tuwe kaśta hena wanji țe cin yutan kinhan śape kta.

27 Qa wamanica tona nape amani, hu topa amani kin hena owasin śapa yadapi kta, tuwe kaśta hena tapi wanji yutan kinhan $h^{\dagger}$ ayetiu aiyahdeya śape kta,

$28 \mathrm{Qa}$ tuwe hena tapi qin kinhan wokoyake hdujaja kta, qa hitay etu aiyahdeya śape kta, hena śapa yadapi kta nakaś.

29 Unkan taku maka asdohan ehna dena śapa yadapi kta, napeheyatahdedan kin, qa hitun ka, qa kezunta ocaje owasin.

30 Qa ahdeśkadan, qa kolia, qa mini wamnuliadan, qa liomat, qa tinśamet,

31 Taku sdohan ehna hena śapa yadapi kta, tuwe kaśta hena tapi wanji yutan kinhan litayetu aiyahdeya śape kta.

32 Taku raśta hena etanhan wanji te cin ahinhpaye cinhan śape kta, canwakśica, qa ogepi; qa wakihdaka, qa wojuha, taku kaśta on wohtani econpi kin hena owasin minin iyeyapi kta, qa litayetu aiyahdeya śape kta, hehan ska kta.

33 Qa maka wakśica tona ohna hena wauji ohinlipaye cin taku ohna un kin owasin śape kta, qa wakśica kin kamdecapi kta.

34 Taku yutapi tona hena etanhan mini atpapsonpi kin hena owasin śape kta, qa woyatke wakśsica kin hena ohna yatkanpi kin śape kta. 
35 Qa taku kaśta hena țe onśpa ahinkpaye cin he śape kta, maka cega qa maka oceti kinhan kamdecapi kta, hena śapapi, qa śapa yadakapi kta.

36 Tuka wakoniya, qa miniowe mini ota kiwitaye cin he śape kte śni ; tuka taku tancanpi te wan icahtake cinhan śape kta,

37 Unkan tancanpi te etanhan su wojupi ahinlipaye cinhan wojupi kin śape kte śni.

38 Tuka wojupi minin hpanyanpi qa tancanpi te etanhan onśpa ahinhpaye cinhan śapa yadakapi kta.

39 Unkan woteca yatapi kin wanji te cinhan tuwe tancan țe yutan kinhan htayetu aiyahdeya śape kta.

$40 \mathrm{Qa}$ tuwe hena tancan te onśpa yute cinhan wokoyake kin hdujaja kta, qa hitayetu aiyahdeya śape kta, qa tuwe tancan te cin onśpa qin kinhan wokoyake hdujaja kta, qa htayetu aiyahdeya śape kta.

41 Qa watutka maka asdohan kin hena owasin wowahte śni, hena yutapi kte śni.

42 Taku itpi asdohan, qa siha topa eśta sdohan, qa siha ota nakun taku kaśta maka asdohan kin hena yatapi kte śni, hena wowahte śni nakaś.

43 Ihnuhan watutka sdohan kin on ninagipi wowahteśni nicicagapi kin, qa ihnuhan hena on nihduśapapi kin, qa hecen hena on niśapapi kta.

44 Jehowa Wakanyadapi kin he miye heon nihduwakanpi kta, qa miś mawakan heon wakanyan yaunpi kta; qa ihnuhan watutka wan taku kaśta maka asdohan on ninagipi kin nihduśapapi kin.

45 Jehowa he miye qa wakanmayadapi kta e heon Egupta makoce etanhan hdinanpe ciya- pi, qa miś nıawakan heon wakanyan yaunpi kta.

46 Woteca on, qa wahupakoza on, qa nagi niyake mini ośkanśkan owasin on, qa nagi maka asdohan owasin on woope kin hee.

47 Taku śapa qa taku ecedan otahedan yukinukan kta, qa taku niya yutapi kta, qa taku niya yutapi kte śni otahedan.

\section{WICOWOYAKE 12.}

1 Unkan Jehowa ie ca Mowis heciya,

2 Israel cinca kin hecen ewicakiya wo, Winohinca wan ihduśake ca cinea wica wan ton kinhan, anpetu śakowin śape kta anpetu iśnati ececa kin hehanyan śape kta.

3 Unkan anpetu iśahdogan en cinhintku ce inkpaha kin bakihdayapi kt́a.

4 Unkan winohinca kin anpetu wikcemna yamni sanpa yamni we yuskapi kin en yanke kta, taku kaśta yuwakanpi kin icahtake kte śni, qa tipi wakan kin en i kte śni, anpetu yuskapi henakeca kte cin hehanyan.

5 Unkan cinca ton kin he winyan kinhan anpetu aketopa śape k ta iśnati kin iyececa, qa anpetu wikcemna śakpe sanpa śakpe we yuskapi en yanke kta.

6 Unkan anpetu yuskapi cinhintku on, qaiś cunwintku on henakeca kinhan, wohuhnahyapi on amnos wan waniyetu wanjidan, qa woahtani wośnapi on wakiyedan cinca wan, qaiś tin wakiyedan wanji itkokipapi wakeya tiyopa ekta wawayuśna ekta kahi kta.

7 Unkan hena Jehowa itokam ahi kta qa winohinca on akalipe kta, unkan we kaduze cin etan- 
han ska kta. Winohinca cinca wica qaiś winyan ton kin on woope kin hee.

8 Qa nape kin taku tahinca wan iyohi iyeye śni kinhan tinwakiyedan nonpa qaiś wakiyedan cinca nonpa icu kta, wanji wohuhnahyapi on qa wanji woahtani wośnapi on, unkan wawayuśna akahpe kiciye kta, hecen ska kta.

\section{WICOWOYAKE 13.}

1 Unkan Jehowa ie ca Mowis Aaron kici hewicakiya,

2 Wicaśta wan celipi uka ohna oyuhi wan, qaiś han wan, qaiś wiyega wan tanin, qa he cehpi uka ohna leprosi makośica iyececa kinhan, Aaron wawayuśna qaiś iye cinca wawayuśnapi wan en hiyuyapi kta.

3 Unkan wawayuśna kin makośica cehpi uka ohna wanyake kta; unkan makośica ohna hin kin hota aye cinhan qa makośica kin cehpi uka sanpa mahen iyaya tanin kinhan, leprosi makośica hee: heon wawayuśna kin he wanyake ça yaśape kta.

- 4 Tuka wiyege celipi uka ohna kin he hota qa uka sanpa mahen iyaye śni taniı kinhan, qa hin kin hota aye śni kinhan, wawayuśna kin makośica ececa kin anpetu śakowin kaśkahnake kta.

5 Unkan anpetu iśakowin en wawayuśna kin wanyake $\mathrm{kta}$; unkan makośica kin ecen yanke ça uka ohna sanpa iyaye śni wanyake cinhan, wa yuśna kin he anpetu śakowin inonpa kaśka hnake kta.

6 Unkan anpetu iśakowin inonpa en ake wawayuśna kin wanyake kta, unkan awicakehan makośica kin san, qa uka ohna makośica kin kahtanye śni kinLev. han, wawayuśna kin yaska kta, ceśpu wan hee, heon wokoyake hdujaja kta qa ska kta.

y 'I'uka wawayuśna yuska kta e wanyake cin he iyohakam, ceśpu kin uka ohna kahtan aye cinhan ake wawayuśna kin en ihdutanin kta.

8 Unkan wawayuśna kin wanyake kta, unkan awicakehan ceśpu kin uka en kahtan aye cinhan, wawayuśna kin he yaśape kta; leprosi hee.

9 Tohan leprosi makośica wicaśta wan en un kinhan, he wawayuśna kin en hiyuyapi kta.

10 Unkan wawayuśna kin atonwan kta, unkan inyun ha ohna oyulii hota wan, qa hin kin hota aya, qa oyuhi ohna cehpi ni tanin kinhan,

11 Leprosi tanina cehpi uka ohna hee, unkan wawayuśna kin he yaśape kta, hee śapa heon kaśka hnake kte śni.

12 Unkan leprosi ha ohna nina ahinape ça leprosi kin makośica ececa ha kin ocowasin pa etanhan siha aiyahdeya wawayuśna taku wanyake cin iyuhpa akahpe cinhan,

$13 \mathrm{Qa}$ inyun leprosi cehpi iyuhipa akahpe cin he wawayuśna kin wanyake cinhan, makośica ececa kin he yaska kta, ocowasin hota icu, hee ska.

14 Tuka tohan he ohna celipi niyake tanin kinhan śape kta.

$15 \mathrm{Qa}$ wawayuśna cehpi niyake cin he wanyake ca yaśape kta, cehpi niyake cin hee śapa, leprosi hee.

16 Tuka cehpi niyake ihdutokeca, qa hota icu kinhan, ake wawayuśna en hi kta.

17 Unkan wawayuśna wanyake kta, unkan makośica kin hota icu kinhan, wawayuśna kin ma161 


\section{LEWI TOOPE.}

kośica ececa kin yaska kta, hee ska.

18 Unkan celipi uka hin ohna siyakao qon okiziyapi,

19 Qa śiyakao yanke ciqon ohna oyuhi hota wan, qaiś wiyega hota kitanna śa kinhan, wawayuśna kin wanyag yapi kta.

20 Unkan wawayuśna kin he wanyake ca inyun uka kin sanpa mahen iyaye ca hin kin hota icu kinhan, wawayuśna kin he yaśape kta, leprosi makośica śiyakao qon ohna ahinape cin hee.

21 Tuka wawayuśna kin he wanyaka unkan ohna hin hota wanice ca uka sam mahen iyayc śni qa hee san kinhan, wawayuśna kin he kaśkahnake kta anpetu śakowin.

22 Unkan uka olına kahtan aye cinhan yaśape kta, makośica wan hee.

23 Tuka wiyege cin ohna yanke ciqon ecen han, qa kahitanye śni kinhan, śiyakao osnaze wan hee, heon wawayuśna kin yaska kta.

24 Unkan tohan cehpi uka kin ohna peta ogu yuke ca ogu orve kin wiyega hota kitanna śa qaiś ocowasin hota kinhan,

25 Wawayuśna kin wanyake kta, unkan wiyega kin uka sanpa mahen iyaya tanin, qa he ohna hin kin liota aye cinhan, leprosi osnaze ohna ahinanpe cin hee, unkan wawayuśna kin he yaśape kta; leprosi makośica hee.

26 Tuka wawayuśna he wan"yaka, unkan awicakehan wiyega ohna hin hota wanice ca uka kin sanpa mahen iyaye śni, tuka hee san kinhan, wawayuśna kin śakowin can kaśka hnake kta.

27 Qa anpetu iśakowin en wawayuśna kin he wanyake kta, uka ohna kahtan aye cinhan wawayuśna kin he yaśape kta, leprosi makośica hee.

28 Tuka wiyega kin ohna yanke ciqon ecen han, ha ohna kalitan śni tuka hee san kinhan, ogu kin oyuhi wan hee, heon wawayuśna kin he yaska kta, ogu osnaze wan hee.

29 Unkan wicaśta qaiś winohinca paha ohna, qaiśs putinhin ohna makośica yuke cinhan,

30 Waẃayuśna kin makośica kin wanyake, kta, unkan uka sanpa mahen iyaya tanin kinhan, qa ohna hin zi zibripedan yuke cinhan, wawayuśna kin he yaśape kta, netaq hee paha qaiś putinhin leprosi hee.

31 Unkan wawayuśna kin netaq makośica wanyaka, uka ihukuya tanin śni kinhan, qa ohna hill sapa wanice cinhan, wawayuśna kin netaq makośica ececa kin anpetu śakowin kaśka hnake kta.

32 Unkan anpetu iśakowin en wawayuśna kin makośica kin wanyake kta, unkan netaq kin awicakehan kahtan iyaye śni, qa ohna hin zi wanice cinhan, qa netaq uka ihukuya iyaye śni . tanin kinhan,

33 Ihdasan kta, tuka netaq kin hdasan kte śni, unkan ake wawayuśna kin netaq ececa kin anpetu śakowin inonpa kin kaśka hnake kta.

34 Qa anpetu iśakowin en wawayuśna kin netaq ececa kin wanyake kta, unkan awicakehan netaq uka ohna sanpa kahtan śni, qa uka ihukuya tanin śni kinhan, wawayuśna kin yaska kta; unkan wokoyake hdujaja kta, qa ska kta.

35 Tuka yaskapi kin iyohakam netaq uka ohna kahtan aye cinhan, 


\section{WICOWOYAKE 13.}

36 Wawayuśna kin wanyake kta, unkan netaq kin uka okahtan aye cinhan, wawayuśna kin hin zizi kin akite kte śni, hee śapa.

37 'Tuka netaq ecen han wanyake cinhan, qa ohna hin sapa inape cinhan netaq wanna okizi yapi, hee ska, unkan wawayuśna kin he yaska kta.

38 Unkan wicaśta wan qaiś winohinea wan celipi uka ohna wiyegaga hota yuke cinhan,

39 Wawayuśna kin wanyake kta; unkan celipi uka hin ohna wiyega kin san kitanna hota kinhan, bohaq uka ohna ahinape wan hee, hee ska.

40 Unkan wicaśta wan pesdete śda kinhan, he pesdete śda eśta hee ska.

41 Unkan ite ektakiya śda kinhan pa śda eśta hee ska.

42 'Tuka paśda ohna makośica hota kitanna śa yuke cinhan, leprosi paśda ohna ahinape cin hee.

43 Unkan wawayuśna kin he wanyake kta, unkan awicakehan paśda ohna makośica oyuhi kin hota kitanna śa leprosi cehpi uka ohna tanin kin iyececa kinhan,

44 Wicaśta kin he leprosi ececa, hee śapa; pa kin akan mako. śica yukan, wawayuśna kin he yaśape kta.

45 Unkan wicaśta tuwe leprosi makośica ececa kin be tawokoyake hdehdecahe kta, qa pa codan kta, qa pute akahipe ton kta, qa, Śapa śapa, pan kta.

46 Tohan makośica ececa hehanyan śape kta, śapa kin heon iśnana ti kta, otonwe itankan ounye kta.

47 Unkan taku koyakapi ohna leprosi makośica yuke cinhan, wokoyake tahinca hin on kagapi qaiś miniliuha unman tukte kaśta ohna;

48 Kazuntapi qaiś kahmupi, hahonta on kagapi qaiś tahinca hin etanhan, qaiś wakihdaka, qaiś taku kaśta taha on kagapi ohna. 49 Qa wokoyake kin ohna makośica kin san, qaiś kitanna śa kinhan, wakihdaka ohna, qaiś taku kazuntapi ohna, qaiś taku kahmupi ohna, qaiś taku kaśta taha on kagapi ohna, leprosi makośica kin hee; unkan wawayuśna kin wanyake kta.

50 Qa wawayuśna kin makośica kin wanyake cinhan, anpetu śakowin taku makośica ohna un kin kaśka hnake kta.

51 Qa anpetu iśakowin en wokoyake ohna makośica kahtan aya wanyake cinhan, taku kazuntapi ohna, qaiś taku kahmupi ohna, qa taha ohna, qaiś taku kaśta unpi kta e taha on kagapi ohna, leprosi pahinca makośica hee, hee śapa.

52 Unkan wokoyake kin he huhnahyapi kta kazuntapi qaiś kahmupi, tahinca hin qaiś hahonta onl kagapi ohna, qaiś taku kaśta taha on kagapi ohna, leprosi pahinca hee nakaś peta ohna huhnahyapi kta.

53 Tuka wawayuśna kin wanyaka, unkan awicakehan makośica kin wokoyake kazuntapi ohna, qaiś kahmupi ohna, qaiś taha ohna, qaiś taku kaśta taha on kagapi ohna kahtan aye śni kinhan;

54. Wawayuśna kin taku ohna makośica yuke cin yujaja wicaśi kta, qa ake anpetu śakowin kaśka hnake kta.

55 Qa makośica yujajapi iyohakam wawayuśna kin wanyake kta, unkan awicakehan makośica otanin kin ihdutokeca śni, qa makośica kin sanpa kahtan śni 163 


\section{LEWI TOOPE.}

eśta hee śapa, wayaśdoka hee, mahentanhan śda qaiś akapatanhan śda.

56 Unkan yujajapi iyohakam makośica kin hee san, wawayuśna wanyake cinhan, he wokoyake etanhan baśpe kta, kazuntapi etanhan, qaiś kahmupi etanhan, qaiś taha etanhan;

57 Unkan ake wokoyake ohna ihdutanin kinhan, taku kazuntapi ohna, qaiś taku kahmupi ohna, qaiś taku taha on kagapi ohna, makośica icaga wan hee, taku ohna un kin he huhnal ye kta.

58 Tuka wokoyake kahmupi, qaiś kazuntapi, qaiś taku kaśta taha on kagapi kin yujajapi iyohakam makośica kin ayuśtan kinhan, ake yujajapi kta qa ska kta. 59 Leprosi makośica woope kin hee, wokoyake tahinca hin, qaiś hahonta on kagapi, kazuntapi qaiś kahmupi, qaiś taku kaśta taha on kagapi on yaskapi kta qaiś yaśapapi kta.

\section{WICOWOYAKE 14.}

1 Unkan Jehowa ie ça Mowis heciya;

2 Leprosi ececa on woope kin dee, anpetu yuskapi kin en wawayuśna kin en hiyuyapi kta.

3 Unkan wawayuśna kin tonwanyanpi itankan inape $\mathrm{kta}$, qa leprosi makośica ececa qon leprosi etanhan awicakehan akisni kinhan;

4 Yuskapi kta e wawayuśna zitkadain nonpa zanika, ska icu wicaśi kta, nakun liante śa can, qa hin duta, qa pejihota.

5 Qa wawayuśna kin zitkadan wanji maka wakśica ohna mini kaduze cin iwankam tuwe kte śi kta.

6 Qa zitkadan ni kin he icu kta, nakun hante śa can, qa hin duta kin, qa pejihota kin, qa hena owasin zitkadan ni un kin iyahna zitkadan ktepi we en oputkan kta, mini kaduza iwankam. 7 Qa tuwe leprosi etanhan yuskapi kin he śakowin akihde amnimni kta, hecen yuska kta, hehan zitkadan ni kin tinta ektakiya ehpeye kta.

8 Unkan tuwe yuskapi kin wokoyake hdujaja kta, qa hin owasin hdasan kta, qa mini en niwe kta, hecen ska kta, hehan otonwe en hi kta; tuka anpetu śakowin wakeya tawa itankan yanke kta.

9 Qa anpetu iśakowin en hin owasin hdasan kta, paha hin qa putinhin, qa iśtahe hin, qa tancan hin owasin hdasan kta, qa wokoyake hdujaja kta, qa tancan mini en niwe kta hehan ska kta.

10 Unkan anpetu iśahdogan en amnos mdoka zanika nonpa, qa amnos wiyedan wanjidan, waniyetu wanjidan, zanika icu kta, nakun minha on aguyapi mdu can wakśica ohnaka nonpa wihdi icicahiyapi, qa wihdi wiyathe ohnaka wanjidan.

11 Unkan wawayuśna wayaska kin wicaśta yuskapi kte cin he, qa hena owasin Jehowa itokam ehde kta, itkokipapi wakeya tiyopa ekta.

12 Qa wawayuśna kin amnos mdoka wanji icu qa wohdajuju on ahi kta, nakun wihdi wiyatke ohnaka kin, qa hena koze kta, wokosyapi Jehowa itokam.

13 Qa amnos kin pate kta, tukte woahtani wośnapi, qa wohulinahyapi kin patapi, oyanke wakan ohna; wohdajuju kin woahtani wośnapi kin he iyececa, wawayuśna kin he tawa, he wakan hinca.

14 Unkan wawayuśna kin wohdajuju we kin etanhan icu kta, 


\section{WICOWOYAKE 14.}

qa tuwe yaska kta noge etapa inkpa akan ikiciun $\mathrm{kta}$, qa nape etapa hunka akan, qa sipa hunka etapa akan.

$15 \mathrm{Qa}$ wawayuśna kin wihdi wiyatke ohnaka etanhan icu kta, qa wawayuśna nape coka catka kin okaśtan kta.

16 Unkan wawayuśna kin nape apazo etapa kin wihdi nape catka ohna un kin okputkan kta, qa nape apazo on we kin śakowin akihde ehpe ye kta, Jehowa itokam.

17 Qa nape kin ohna wihdi ihe cin he etanhan wawayuśna kin tuwe yaska kta noge etapa inkpa akan ikiciun kta, nakun nape hunka etapa akan, qa sipahunka etapa akan, wohdajuju we akan.

18 Qa wihdi okapte cin wawayuśna nape coka ohna kin he tuwe yuska kte cin he pa akan ikiciun kta, qa wawayuśna kin akalipekiciye kta, Jehowa itokam.

19 Qa wawayuśna kin woahtani wośnapi kin kage kta, qa tuwe yaska kte cin toaśape etanhan akahpe kiciye kta, qa he iyohakam wohuhnahyapi kin pate kta. 20 Qa wawayuśna kin wohuhnahyapi kin qa minlia kin wahna wośnapi akan hulinahye kta, hecen wawayuśna kin akalipe kiciye kta, unkan ska kta.

21 Tuka wahpanica on nape kin hena iyohi śni kinhan, akahpe kiciye kta e amnos wanjidan icu kta, wohdajuju wokosyapi on, nakun aguyapi mdu can wakśica ohnaka wanjidan wihdi icicahiyapi minha on, qa wihdi wiyatke ohnaka wanjidan.

22 Qa tin wakiyedan nonpa qaiś wakiyedan cinca nonpa, unman tukte nape kin iyohiye kta, wanji woahtani wośnapi on, qa unma woliuhnahyapi on.
23 Qa yuskapi kta e anpetu iśahdogan hehan hena wawayuśna kin ekta hiyuye kta, Jehowa itokam itkokipapi wakeya tiyopa ekta.

24 Unkan wawayuśna kin amnos wohdajuju kin icu kta, qa wihdi wiyatke ohnaka kin, qa hena koze kta, wokosyapi Jehowa itokam.

$25 \mathrm{Qa}$ amnos wohdajuju kin pate kta, qa wawayuśna kin wohdajuju we etanhan icu kta, qa noge inkpa etapa akan, qa nape hunka etapa akan, qa sipa hunka etapa akan ikiciun kta.

26 Qa wawayuśna kin wihdi etanhan wawayuśna napcoka catka kin oihdæśtan kta.

27 Qa wawayuśna kin napsukaza etapa on wihdi napcoka catka ohna un kin etanhan śakowin akihde ehpeye kta, Jehowa itokam.

$28 \mathrm{Qa}$ wawayuśna kin wihdi napcoka ohnaka un kin etanhan, tuwe yuskapi kte cin noge inkpa etapa akan ikiciun kta, qa napahunka etapa akan, qa sipa hunka etapa akan tukten wohdajuju we ikiciun he akan.

29 Qa wihdi wawayuśna napcoka ohna okapte cin he tuwe yuskapi kte cin he pa akan ikiciun kta, Jehowa itokam akahpe kiciye kta heon etanhan.

$30 \mathrm{Qa}$ tin wakiyedan etanhan wanji qaiś wakiyedan cinca etanhan taku nape kin hiyohiya etanhan.

31 Taku nape kin hiyohiye cin wanji woalitani wośnapi kta, qa unman wohuhnahyapi kta, minha iyahna hecen wawayuśna kin tuwe yuskapi kte cin he on akalipe kiciye kta, Jehowa ito$\mathrm{kam}$.

32 Tuwe leprosi makośice ececa, qa taku yuskapi kta iyececa 


\section{LEWI TOOPE.}

nape kin hiyohi śni woope kin hee.

33 Unkan Jehowa ie ca Mowis Aaron kici hewicakiya;

34. Kanan makoce tawayayapi kta e ciçupi kin he en yakipi kinhan, qa makoce tawayayapi kin he ohna leprosi makośice tipi wan iyohpewakiye cinhan ;

35 Tipi tawa kin wawayuśna kin en hi kta, qa oyake qa heciye kta, tipi ohna makośice wan iyececa makitanin epca.

36 Unkan wawayuśna kin makośice wanyag en i śni itokam tipi kin yucokaka wicaśi kta, hecen taku tipi kin ohna owasin yuśapapi kte śni, hehan wawayuśna kin wanyake kta en i kta. 37 Qa makośice kin wanyake kta, qa inyun tipi conkaśke ohna makośice kin toto, qaiś śaśa śkopa, qa cuwi kin mahen iyaye tanin kinhan ;

38 Wawayuśna kin tipi etanhan inanpe kta, tiyopa ekta, qa tipi kin anpetu śakowin natake kta.

39 Qa wawayuśna kin anpetu iśakowin ake en hi kta, qa wanyake kta, unkan inyun tipi conkaśke en makośice kin sanpa iyaye cinhan,

40 Wawayuśna kin inyan tona makośice en un kin hena icu wicaśi kta, qa otonwe itankau tukten taku śapa ehpeyapi heciya hena ehpeyapi kta.

41 Qa ihdukśan tipi kin ti mahen paticapi kta, qa maka paticapi kin he otonwe itankan oyanke sapa wan ekta okadapi kta.

42 Qa inyan tokeca icupi kta, qa inyan qon hena ee kiya ehnakapi kta, qa maka tokeca icupi qa tipi apawintapi kta.

43 Unkan inyan elipeyapi iyohakam, qa tipi paticapi iyoha- kam, qa apawintapi iyohakam makośice ake en hi, qa tipi ohna ahinanpe cinhan,

44 Wawayuśna kin hi kta, qa wanyake kta, unkan inyun makośice kin tipi ohna iyaye cinhan, leprosi iyokiśin wicaye cin tipi ohna hee, he yaśape kta.

45 Unkan tipi kin yujujupi kta, qa tipi inyan kin, qa can kin qa maka kin owasin otonwe itankan ayapi kta, oyanke śapa wan ekta. 46 Qa natakapi icunhan tuwe tipi kin he en i kinhan litayetu aiyahdeya śape kta.

47 Qa tuwe tipi kin ohna makan wanke cin he wokoyake hdujaja lita, qa tuwe tipi ohna wote cin he wokoyake hdujaja kta.

48 Tuka wawayuśna kin en i qa wanyaka, unkan inyun tipi apawintapi iyohakam makośice kin tipi en ahinanpe śni kinhan, wawayuśna kin tipi yaska kta, makośice kin he wanna okizi nakaś.

49 Qa tipi woahtani wośnapi on zitkadan nonpa icu $\mathrm{kta}$, nakun hanteśa can, qa tahin duta qa peji hota.

50 Qa zitkadan wan cape kta, makawakśica wan ohna, mini ni iwankam.

51 Qa hianteśa can kin, qa peji lota kin, qa tahin duta kin, qa zitkadan niyake kin hena icu kta, hena owasin zitkadan ktepi qon we en oputkan kta, qa mini ni un kin nakun en qa śakowin akihde tipi kin ekta ehpeye kta.

52 Hecen tipi toaśape kin akahpe kiciye kta, zitkadan we kin on, qa mini ni un kin on qa zitkadan niyake on, qa hante śa can on, qa tahinduta on.

53 Tuka zitkadan ni kin he otonwe itankan tinta ekta iyaye ye kta, hecen tipi kin akalipe kiciye kta, unkan ska kta. 


\section{WICOWOYAKE 15.}

54 Leprosi makośice owasin on woope kin hee.

55 Qa leprosi wokoyake en, qa tipi en.

56 Qa kapo kin on, qa ceśpu kin on, qa wiyega on:

57 Leprosi woope kin hee, tohan śapa qa tohan ska onspewicakiye kta.

\section{WICOWOYAKE 15.}

1 Unkan Jehowa ie ca Mowis qa Aaron hewicakiya;

2 Israel cinca kin hecen ewicakiya po; Wicaśta tuwe kaśta cehpi kin taku kaduze cinhan wokaduze cin he on hee śapa.

3 Qa tokaduze cin en toihduśape cin dee kta. Cehpi kaduze cin kajo, qaiś celpi kaduze cin anapte cinhan unman tukte kaśta hee śapa.

4 Tuwe wakaduze cin owinja tona akan iwanke cin hena owasin śape kta, qa taku kaśta akan iyotanke cin hee śape kta.

5 Qa tuwe towinja kin yutan kinhan wokoyake hdujaja.kta, qa minin niwan kta, qa hitayetu kin hehanyan śape kta.

6 Qa wakaduze cin taku akan iyotanke cin tuwe he akan iyotanke cinhan htayetu aiyahdeya śape kta.

7 Unkan tuwe kaśta wakaduze cehpi kin yutan kinhan wokoyake hdujaja kta, qa minin niwan kta, qa litayetu hehanyan śape kta.

8 Unkan wakaduze cill tuwe śape śni atagośe cinhan he wokoyake hdujaja kta, qa minin niwan kta, qa hitayetu hehanyan śape $\mathrm{kta.}$

9 Unkan śuktanka aqin tona wakaduze cin akan iyotanke cin hena owasin śape kta.

$10 \mathrm{Qa}$ taku kaśta he ihukuya yanke cin tuwe he yutan kinhan htayetu hehanyan śape kta, qa taku hececa tuwe qin kinhan wokoyake hdujaja kta, qa minin niwan kta, qa litayetu hehanyan śape kta.

11 Qa tuwe kaśta wakaduze cin nape minin hdujaja śbi yutan kinhan, wokoyake hdujaja kta, minin niwan kta, qa hitayetu hehanyan śape kta.

12 Qa maka wakśica tona wakaduze cin yutan kin hena owasin kamdecapi kta, qa can wakśica kin hena owasin minin y ujajapi kta.

13 Unkan wakaduze cin he tokaduze cin etanhan akisni kinhan, hehan ihduska kta e anpetu śakowin hdawa kta, qa wokoyake hdujaja kta, qa mini ni kin en niwan kta, qa hehan ska kta.

14 Unkan anpetu iśahdogan tin wakiyedan nonpa, qaiś wakiyedan cinca nonpa icu kte ca itkokipapi wakeya tiyopa ekta Jehowa itokam hi kte ca hena wawayuśna qu kta.

15 Unkan wawayuśna kin hena wakiyuśna kta, wanji woalitani on qa unman wohuhnahyapi on, hecen wawàyuśna kin Jehowa itokam akahpe kiciye kta, tokaduze etanhan.

16 Unkan wicaśta wan wankapi su inanpe cinhan cehpi kin owasin minin hdujaja kta, qa litayetu hehanyan śape kta.

17 Unkan wokoyake, qa owinja tona wankapi su ahinlpaye cin hella owasin minin yujajapi kta, qa litayetu hehanyan śape kta.

18 Unkan winohinca wan wicaśta wan wankapi su on kici wanke cinhan niwan kte ca htayetu hehanyan śape kta.

19 Unkan winohinca wan we kaduza, qa cehpi ohna kaduze cinhan, anpetu śakowin iśnana 


\section{LEWI TOOPE.}

ti kta, qa taku kaśta icahtake cinhan owasin hitayetu hehanyau śape $\mathrm{kta}$.

$20 \mathrm{Qa}$ tohanyàn iśna ti kin hehanyan taku akan wanke cin owasin śape kta, qa taku akan iyotanke cin owasin śape kta.

21 Nakun tuwe taku akan iwanke cin he yutan kinhan wokoyake kin hdujaja kta, qa minin niwan kte, ca hitayetu hehanyan śape kta.

22 Qa taku kaśta akan iyotanke cin he tuwe yutan kinhan wokoyake kin hdujaja kta, qa minin niwan kte ca hitayetu hehanyan śape kta.

23 Nakun towinje qaiś taku akan iyotanke cin tuwe he yutan kinhan htayetu hehanyan śape kta.

24 Unkan wicaśta wan iśna ti kin icunhan kici iwanke cinhan he anpetu śakowin śape kta, qa owinja tona akan iwanke cin hena owasin śape kta.

25 Unkan winohinca wan iśna ti kta iyehantu śni anpetu ota we kaduze cinhan, qaiś iśna ti kta iyohakam wakaduze cinhan, tona can toaśape kaduze cin hena owasin śape kta, iśna ti kin anpetu kin iyececa.

26 Anpetu tona wakaduze cin owasin owinja akan iwanke cin hena owasin iśna ti towinja kin iyececa kta, qa taku kaśta akan iyotanke cin śape kta, iśna ti toaśape kin iyececá.

27 Qa tuwe kaśta hena yutan kinhan śape kta, wokoyake hdujaja qa minin niwan qa litayetu hehanyan śape kta.

28 Qa tokaduze cin etanhan akisni kinhan anpetu śakowin ihdawa kte ca iyohakam ska kta.

29 Qa anpetu iśahdogan tin wakiyedan nonpa, qaiś wakiyedan cinca nonpa icu $\mathrm{kta}$, qa hena wa- way uśna ekta hiyuye kta, itkokipapi wakeya tiyopa ekta.

30 Unkan wawayuśna kin wanji woahtani on wośna kta, qa unman wohuhnahyapi on, hecen wawayuśna kin wakaduze toaśape on akahpe kiciye kta, Jehowa itokam.

31 Hecen Israel cinca kin toaśapapi kin etanhan wicadukinunkan kta, qa wati kin hena cokaya un kin toaśapapi on yuśapapi kte śni, qa țapi kte śni.

32 Tuwe wakaduze cin on, qa tuwe wankapi su inanpe cin on, ihduśape cin on woope kin hee.

33 Qa nakun tuwe iśna ti wayazanke cin on, qa tuwe wakaduze kaduza, wica qaiśs winyan on, qa wicaśta winohinca śapa wan kici wanke cin he on.

\section{WICOWOYAKE 16.}

1 Unkan Aaron cinca nonpa Jehowa itokam ikiyedan hipi qa tapi kin hena tapi kin iyohakam Jehowa Mowis kici wohdaka.

2 Qa Jehowa Mowis heciya; Nicinye Aaron tipi wakan cokaya ozanpi mahen wokajuju iha can wohnake akan un kin he ekta anpetu owasin hi kte śni, hecen te kte. śni, keciya wo; mahpiya ohna wokajuju iha kin iwankam mihdutanin kta nakaś. 3 Kaken Aaron tipi wakan en hi kta, tatankadan pte wanunyanpi cinca wan woahtani on, qa tamdoka wan wohuhnahyapi on.

4 Miniliuha mahenunpi wakan kin koyake kta, qa minihuha onze oge cehpi akan un kta, qa miniliuha ipiyake on ipihdake kta, qa miniliuha pa iyuskite kin pahte kta, wokoyake wakan hena ee, heon cehpi minin hdujaja kta, qa hena koyake kta. 


\section{WICOWOYAKE 16.}

5 Unkan Israel cinca omniciye etanhan tatokadan mdoka nonpa icu kta, woahtani wośnapi on; qa tahinca wanunyanpi midoka wanjidan wohuhnaliyapi on.

6 Unkan Aaron woahtani wośnapi tatanka tawa kahi kta, qa akahpe iciye $\mathrm{kta}$, qa iye ti kin akahpe kiciye kta.

7 Qa tatokadan nonpa kin icu kta, qa Jehowa itokam ewicahde kta, itkokipapi wakeya tiyopa ekta.

8 Qa tatokadan nonpa on Aaron veconna econ kta, oeconna on wanji Jehowa tawa kta, qa oeconna un unman Azazel tawa kta.

9 Qa Aaron tatokadan oeconna eciyatanhan Jehowa tawa kin ahi kta, qa woahttani on wośna kage kta.

10 Qa tatokadan oeconna eciyatanhan Azazel tawa kin niyake Jehowa itokam ehde kta, he on woakahpekiciye kta, qa hewoskantuya ekta iyaye ye lita.

11 Hehan Aaron woahtani tatanka tawa kin ahi kta, qa akahpe içiye kta, qa ti kin akahpe kiciye kta, qa woahtani tatanka tawa kpate kta.

12 Qa oizinye wan petaga ojudan owayuśna etanhan Jehowa itokapatanhan icu $\mathrm{kta}$, qa nape sakim wizinyapi waśtemna bomdupi on ojudan, qa cokaya ozanpi mahen hiyuye kta.

13 Qa Jehowa itokam wizinyapi kin peta akada kta, unkan wizinyapi śta kin wokajuju iha kin woyaatanin akan yanke cin akahpe kta hecen te kte śni.

14 Qa tatankadan we kin icu kta qa nape apazo on wokajuju iha itokam wiyohiyanpata ektakiya ehpeye kta, hecen śakowin akihde nape apazo on we kin onge wokajuju iha itokam ehpeye kta.
15 Hehan woahtani tatokadan oyate tawapi kin pate kta, qa we kin cokaya ozanpi ti mahen hiyuye kta, qa token tatankadan we kin ecakicon qon he iyecen we kin he ecakicon kta, qa wokajuju iha kin akan qa wokajuju iha ektakiya ehpeye kta.

16 Hecen tipi wakan kin akahpe kiciye kta, Israel cinca toaśapapi etanhan qa wahtanipi etanhan, śicaya ohanyanpi owasin on, qa itkokipapi wakeya hena om yanka toaśapapi ehna hecen ecakicon kta.

17 Unkan tipi wakan akahpe kiciye kta, en hi kin etanhan tankan iyaye cin hehanyan tuwedan itkolkipapi wakeya ti mahen un kte śni; hecen akalipe içiye k.ta qa iye ti kin on, qa Israel omniciye owasin on akahpe wicakiciye kta.

18 Hehan owayuśna Jehowa itokam yanke cin ekta hinanpe kta, qa he akahpe kiciye kta qa tatankadan we etanhan icu kta, nakun tatokadan we etanhan, qa owayuśna he kin aihdukśan aiun kta.

19 Qa he ektakiya nape apazo on we kin śakowin akihde ehpeye kta; hecen Israel cinca toaśapapi etanhan he yuska kta, qa yuwakan kta.

20 Unkan tipi wakan kin, qa itkokipapi wakeya kin, qa owayuśna kin hena akahpe kiciya yuśtan kinhan, hehan tatokadan niyake kahi kta.

$21 \mathrm{Qa}$ Aaron nape napin tatokadan niyake pa kin aputake kta, qa akan Israel cinca śicaya ohanyanpi kin owasin ohdake kta; nakun wokipajinpi owasin, token wahtanipi kin owasin, qa hena tatokadan pa akan ehnake kta; hehan wicaśta wan wiyeya un kin iyaye śi kta. 


\section{LEWI TOOPE.}

26 Unkan tatokadan qon sicaya ohanyanpi kin owasin makoce tuwedan oti śni ekta yuha kta. Unkan tatokadan hewoskan yuśke kta.

23 Unkan Aaron itkokipapi wakeya ekta hi kta, qa tipi wakan ekta hi qehan minihuha wokoyake koyake ciqon hena hduśdoke kta, qa hen kihnake kta.

24 Qa oyanke wakan ohna cehpi kin hdujaja kta, hehan tawokoyake kohdake kta, qa tawohuhnahyapi, qa oyate tawohuhnahyapi kin wakiyuśna kta, hecen akahpe ic̣iye kta, qa oyate kin akahipe wicakiciye kta.

25 Qa woahtani wośnapi waśin kin owayuśna kin aizinye kta.

26 Unkan tuwe tatokadan Azazel tawa kin kiyuśke cin he wokoyake hdujaje ça minin niwe kta, qa ohakam owanka en hi kte.

27 Unkan woahtani tatankadan kin, qa woahtani tatokadan kin hena wepi kin akalipe kiciyapi kta e tipi wakan en hiyuyapi qon, owanka itankan ayapi kta, qa hapi kin, qa cehpipi kin, qa cesdipi kin, peta on huhnahyapi kta.

28 Unkan tuwe hena hulinahye cin he wokoyake hdujaje ca minin niwe kta, qa ohakam owanka en hdi kta.

$29 \mathrm{Qa}$ wokage kin de owihanke wanin duhapi kta, wi iśakowin wi anpetu iwikcemna kin en ninagipi iyokiśin niciyapi kta; wicaśta makoce tawapi qaiś oyate tokeca. niyepi ehna ounye cin unman tukte kaśta wohtani takudan econ kte śni.

30 Anpetu kin he en akahpe niciyapi $k$ ta, niyuskapi kta heon etanhan, hecen wayahtanipi owasin etanhan Jehowa itokam niyuskapi kta.
31 Anpetu okihpapi wakan hinca he niciyukanpi kta, qa ninagipi iyokiśin niciyapi kte, wokage owihanke wanica.

32 Unkan wawayuśna tuwe atkuku heekiya wawayuśna kta e sdayapi, qa nape kin ojunyapi kin he waakahpe kta, qa minihuha wokoyake kin, wokoyake wakan kin koyake kta.

33 Qa tipi wakan hinca alkahpe kiciye kta, nakun itkokipapi wakeya kin, qa owayuśna kin akahpe kiciye kta, qa wawayuśnapi kin, qa oyate omniciye owasin akahpe wicakiciye kta.

34 Wokage owihanke wanica he duhapi kta, Israel cinca wahtanipi owasin etanhan akahpe wicakiciyapi kta, waniyetu otoiyohi wancadan. Unkan token Jehowa Mowis econ śi he iyecen econ.

\section{WICOWOYAKE 17.}

\section{Unkan Jehowa ie ca Mowis} heciya,

2 Ie ça Aaron qa iye cinca qa Israel cinca owasin hewicakiya wo; Taku Jehowa econ unśípi kin dee.

3 Wicaśta Israel ti kin etanhan tuwe kaśta tatanka wan pata, qaiś tahinca, qaiś tatokadan owanka ohna, qaiś owanka itankan pata;

4 Qa Jehowa ti itokam woahi Jehowa kahi kta e itkokipapi wakeya tiyopa ekta hiyuye śni kinhan, wicaśta kin he tin wicakte wan iyecen yawapi kta, wicaśta kin he weye cin heon oyate tawa wicehna tanhan he kaśpapi kta.

5 Hecen Iśraej cinca kin taku wośnapi, tinta akan wośnapi qon hena Jehowa ekta hiyuyapi kta, qa hena itkokipapi wakeya tiyo- 


\section{WICOWOYAKE 18.}

pa ekta hiyuyapi kta, wawayuśna ekta, qa hena wopida wośnapi Jehowa wawicakiciyuśnapi kta.

6 Unkan wawayuśna kin we kin Jehowa owayuśna tawa akan ehpe ye kta, itkokipapi wakeya tiyopa ekta, qa waśin kin izinye kta, woomna Jehowa iyokipi ye kta.

7 Hecen icimanna wośnapi tawapi wamanica wakiciyuśnapi kta, hena okiyapi iyecen wokage kin he owihanke wanica wicoicagepi yeye cin yuhapi kta.

8 Unkan hecen ewicayakiye kta, Wicaśta tuwe kaśta Israel ti kin etanhan, qaiś oyate tokeca niyepi ehna ounye cin etanhan, tuwe kaśta woh̆uhnahyapi wan, qaiś wośnapi wan wośna kinhan; 9 Qa Jehowa wakiyuśna kta e itkokipapi wakeya tiyopa ekta hiyuye śni kinhan, wicaśta kin he oyate tawa etanhan kaśpapi kta.

$10 \mathrm{Qa}$ wicaśta Israel ti etanhan, qaiś oyate tokeca niyepi ehna ounye cin etanhan, tuwe kaśta we onge yute cinhan, wicanagi we yute cin miite awehnake kta, qa oyate tawa etanhan wakaśpe kta.

11 Cehpi nagi kin we kin ohna yanka heon ninagipi akalipe niciyapi kta e owayuśna akan we kin cicupi, wicanagi akahpe kiciye cin we kin hee nakaś.

12 Heon Israel cinca kin hewicawakiya, Niyepi etanhan tuwedan we yute kte śni, qa oyate tokeca niyepi ehna ounye etanhan tuwedan we yute kte śni.

13 Qa wicaśta Israel cinca etanhan, qa oyate tokeca niyepi ehna ounye cin etanhan, tuwe kaśta wotihni, qa woteca, qaiś wah̀upakoza wanji yutapi kta iyececa kte kinhan, we kin papson kta, qa maka on akahpe kta.
14 Cehpi owasin nagi kin we kin hee, nagi kin he ohna yanka, heon Israel cinca kin hewicawakiya, Cehpi owasin etanhan we ongedan yutapi kte śni, celipi owasin nagi kin we kin hee nakaś; tuwe he yute cinhan kaśpapi kta.

15 'Tuwe kaśta makoce en icaga, qaiś oyate tokeca taku wayazánka te, qaiś taku yațapi ongedan yute cinhan wokoyake hdujaja kta qa minin niwe kta, qa hitayetu aiyahdeya śape kta.

16 Tuka wahdujaja śni qa niwe śni kinhan, tohan śica hduha kta.

\section{WICOWOYAKE 18.}

1 Unkan Jehowa ie ça Mowis heciya,

2 Israel cinca hecen kewicakiya wo, Jehowa taku wakan yadapi kin he miye;

3 Egupta makoce ohna ounyayapi qon, token ohanyanpi kin he iyecen oyahiandapi kte śni, qa Kanan makoce ekta ye ciyapi ohanyanpi kin he iyecen oyahandapi kte śni, qa tawokagepi omayanipi kte śni.

4 Woyaco mitawa ecen econpo, qa wokage mitawa patanpo, qa hena omanipo, Jehowa taku wakan yadapi kin he miye.

5 Qa wokage mitawa kin yapatanpi kta, woyaco mitawa nakun; wicaśta tuwe hena iyecen econ kinhan hena on ni kta, Jehowa he miye.

6 Tuwedan iye cehpi takuye hinca tancodan yuzamni kta e ikiyedan hi kte śni, Jehowa he miye.

7 Niyate tancodan kin, qa nihun tancodan kin duzamni kte śni, ni hun kin hee heon tancodan kin duzamni kte śni.

8 Niyate tawicu tancodan kin 171 


\section{LEWI TOOPE.}

duzamni kte śni, niyate tancodan kin hee.

9 Nitawinohitin niyate cunwintku, qaiś nihun cunwintku wohpapi qaiś nahmana yuzapi en tonpi unman tukte kaśta tancodan kin duzamni kte śni.

10 Nicinkśi cunwintku qa nicunkśi cunwintku tancodan kin duzamni kte śni, niye tanconikadan kin hee.

11 Niyate tawicu cunwintku niyate cinca kin tancodan kin duzamni kte śni, nitawinohtin kin hee, heon tancodan kin duzamni kte śni.

12 Niyate tawinohtin tancodan kin duzamni kte śni, niyate celipi kin bee.

13 Nihun tankaku tancodan kin duzamni kte śni, nihun cehpi kin hee.

14 Niyate sunkaku tancodan kin duzamni kte śni, tawicu ikiye dan yai kte śni, nihun kin hee.

15 Nitakoś tancodan kin duzamni kte śni, nicinkśi tawicu kin hee, tancodan kin duzamni kte śni.

16 Nicinye tawicu, qa nisunka tawicu tancodan kin duzamni kte śni, nisunka tancodan kin hee.

17 Winohinca wan qa iye cunwintku tancodan kin duzamni kte śni, iye cinhintku cunwintku qaiś cunwintku cunwintku tancodan kin duzamni kta e duze kte śni, he wowicaśta śni, hena celipi tawa hecapi nakaś.

18 Nakun winohinca wan cunku kici duze kte śni, hecannon kinhan tancodan duzamni, qa tohanyan ni kin iyokiśin yaye kta.

19 Unkan winohinca tohan toaśape on iśna ti kin hehanyan tancodan duzamni kta e ikiyedan yai kte śni.
20 Nakun tuwe nikiyedan ti tawicu kin kici inonke kte śni. Hecannon kinhan kici nihduśape kta.

21 Nakun nicinca etanhan wanjidan Molok ekta iyopta yaye kte śni, qa taku wakan yada caje kin duśape kte śni ; Jehowa he miye. 22 Nakun winyan kici wankapi kin he iyecen wica kici inonke kte śni, wowahte śni hee.

23 Nakun woteca taku kaśta kici inonke kte śni, hecannon kinhan kici nihduśape kta, nakun winohinca wan woteca kici kiyuhe kta e he itokam wanke kte śni, worśape hee.

24 Ihnuhan hena on nihduśapapi kin, oyate nitokapa tanhan ye wicawaye cin hena owasin on ihduśapapi.

25 Unkan makoce kin he śapa, heon tohan śice cin he akan hiyu waye kta, unkan makoce kin wicaśta en ounyanpi kin hena hdem wicaya.

26 Tuka niyepi wokage mitawa, qa woyaco mitawa kin yapatanpi kta, qa wowahte śni kin hena ecannonpi kte śni, niye makoce tawayayapi qa wicaśta oyate tokeca niyepi ehna ounye cin unmanna.

27 Wicaśta niyepi itokam makoce kin hen tipi kin wowahte śni kin hena owasin econpi, qa makoce yuśapapi.

28 Hecen makoce kin duśapapi kte śni, qa oyate nitokapa tanhan wicahdepe cin he iyecen nihdepapi kte śni.

29 Wicanagi tona wowahte śni kin hena wanjidan econpi kin, hena owasin taoyatepi etanhan kaśpapi kta.

30 Heon wopatan mitawa yapatanpi kta, qa wowahte śni wokage nitokam econpi kin hena ecannon pi kte śni, hecen hena 
on nihduśapapi kte śni, Jehowa wakan yadapi kin he miye.

\section{WICOWOYAKE 19.}

1 Unkan Jehowa ie ca Mowis heciya,

2 Israel cinca omniciye ocowasin ieyanpaha hewicakiya wo, Jehowa wakan yadapi kin he miye, mawakan, heon wakan yaunpi kta.

3 Otoiyohi hunku kin yakinihan kta, nakun atkuku, qa anpetu okihpapi mitawa kin yapatanpi kta, Jehowa wakan yadapi kin he miye.

4 Ihnuhan takuśniśni ekta nihduhomnipi kin, qa ihnuhan taku wakan śdoyapi niçicagapi kin, Jehowa wakan yadapi kin he miye.

5 Unkan wopida wośnapi wan Jehowa wayakidúśnapi kte cinhan token iyokipi yayapi kte cin hecen wayakiduśnapi kte.

6 Anpetu en waduśnapi qa ihanhanna hena en he yatapi kta, tuka taku anpetu iyamni hehanyan oyapte cin, he petan liuhnaliyapi kta.

7 Unkan anpetu iyamni en onge yutapi kinhan he wośicamna kta, iyokipi kte śni.

8 Qa tuwe he yute cin he taku Jehowa on yuwakanpi kin yuśape cin heon tohan śice cin hduha kta, qa wicanagi kin he taoyate etanhan kaśpapi kta.

9 Unkan nitamakoce woksapi bayaksapi eca nitamaga kalimin owasin bayakse kte śni, qa baksapi icunhan taku hinhpaye cin he mnayaye kte śni.

$10 \mathrm{Qa}$ hastanhanka iyuwi nitawa akta duśpi lite śni, qa hastanhanka makata ihpayapi kin hena mna yaye kte śni, hena wicaśta onśika, qa oyate tokeca ekta elipe wicaya kiye kta, Jehowa wakanyadapi kin he miye. 11 Jhnuhan wamayanunpi, qa ihnuhan iyatonpi śni, qa ihnuhan otoiyohi yecihnayanpi kin.

12 Qa ihnuhan micaje itonśniyan cajedatapi qa taku wakan yada caje kin daśapapi kin, Jehowa he miye.

13 Ihnuhan nitakoda yakiduśe kin, qa taku tawa yaki kinhan. Ihnuhan tuwe tohtani opeyaton iyuwin tawa ihanhanna hehanyan niciyanke cin.

14 Tuwe nogetpa daśice kte śni, qa tuwe iśtagonge cin itokam taku iboto kta yecihnake kte śni, tuka taku wakan yada kin he ikoyape kta, Jehowa he miye.

15 Wayacopi en wopemni ecannon kte śni; wicaśta wahpanica ite kin ihayakta kte śni, qa wicaśta tanka ite kin yakinihan kte śni. Tuwe nikiyedan ti kin ecetuya daco kta.

16 Ihnuhan oyate nitawa tipi iyaza waiesa mayani kin, qa ihnuhan nitakoda we kin anayajin kin, Jehowa he miye.

17 Nihunka wanji nicante mahen śice yada kte śni ; tuwe niciti kin atayedan iyope yakiye kta, hecen iye on etanhan woahitani duha kte śni.

18 Toyeçon kte śni, qa oyate nitawa cincapi kin canniye wicayaya eśta ecadan enayakiye kta, qa token waśte niçida kin he iyecen tuwe nikiyedan ti kin waśte yadake kta.

19 Wokage mitawa yapatanpi kta. Wanunyanpi nitawa kin ocaje tokeca kici kiyulia yaki ye kte śni. Maga nitawa su ocaje nonpa icicahiya oju yakiye kte śni, qa wokoyake tahinca hin qa hahonta onkagapi icicahiya kazuntapi kodake kte śni. 


\section{LEWI TOOPE.}

20 Unkan wikośka wan wayaka heca wicaśta wan he wahoya tuka nahanhin wohpe śni qa kiyuśkapi śni, wicaśta tokeca wan winohinca kin he kici wanke cinhan napin wicakapsinpsintapi kta, wikośka kin ihduhe śni, heon te wicayapi kte śni.

21 Unkan wicaśta kin wohdajuju Jehowa kahi kte itkokipapi wakeya tiyopa ekta, tamdoka wan on hdajuju kta.

22 Unkan woahtani wahtani kin on wawayuśna kin akahpe kiciye kta wohdajuju tamdoka on, Jehowa itokam, hecen woahtani wahtani kin he kicicajujupi kta.

23 Unkan makoce kin en yakipi, qa waskuyeca can hu yahdepi kinhan, waskuyeca kin mdoketu yamni taku śapa iyecen ehpe yayapi kta, śapa yadapi kta, tuwedan he yute kte śni.

24 Unkan mdoketu itopa kinhan waskuyeca kin owasin Jehowa yatanpi kta e wakan kta.

25 Tuka mdoketu izaptan kin waskuyeca kin yatapi kta, hecen waskuyeca ota icah niciyapi kta, Jehowa wakan yadapi kin he miye.

26 Taku we akan un kin yatapi kte śni. Wamduśka etanhan waadatapi kte śni, qa mahpiya etanhan waadatapi kte śni.

$27 \mathrm{~Pa}$ nitawapi ihdukśan ihanke kin yahduśdapi kte śni, qa putinhin nitawa ihanke kin ihang yakiyapi kte śni.

28 Tuwe nagi ye cin on niçicagopi kte śni nicehpipi en, qa akito niçiyapi kte śni; Jehowa he miye

29 Ihnuhan nicunkśi duśape ça wihomni win yakage cin, hecen makoce en witkowin ota kte śni, qa makoce kin wowicaśta śni on ojudan kte śni.
30 Okihpapi mitawa yapatanpi kta, qa tipi wakan mitawa yakinihanpi kta; Jehowa he miye.

31 Ihnuhan wapiyesa ekta nihduhomnipi, qa ihnuhan wakan icidapi kin awicayakite cin, hecannoll kinhan hena on nihduśape kta; Jehowa wakan yada kin he miye.

32 Tuwe paska kin he itokam nayajin kta, qa wicahinca ite kin duonihan kta, qa taku wakan yada kin yakinihan kta, Jehowa he miye.

33 Unkan wicaśta oyate tokeca nici ounye cinhan he yakiduśe kte śni.

34 Tuwe oyate tokeca nici ounye cin he wicaśta makoce tawa yapi kin iyecen nicipi un kta, qa waśte nicida kin he iyecen waśte yadake $\mathrm{kta}$, oyate tokeca Egupta makoce en ounyayapi qon nakaś; Jehowa wakan yadapi kin he miye.

35 Ihnuhan wayacopi en taku owotanna śni ecannopi kin, ohanske iyutapi en, qa aspe yetonpi en, qa taku kaśta ohna iyutapi en.

36 Taku on aspeyapi ecetu qa epah ecetu, qa hina ecetu duhapi kta; Jehowa wakanyadapi Egupta makoce etanhan hdinanpe niyanpi kin he miye.

37 Heon wokage mitawa owasin, qa woyaco mitawa owasin yapatanpi kta, qa hena ecanonpi kta; Jehowa he miye.

\section{WICOWOYAKE 20.}

\section{Unkan Jehowa ie ca Mowis} heciya;

2 Hecen Israel cinca kin ewicayakiye kta, Wicaśta tuwe kaśta Israel cinca etanhan, qaiś oyate tokeca Israel om ounye cin etanhan, iye cinca wan Mo- 


\section{WICOWOYAKE 20.}

lok qu kinhan, awicakehan te yapi kta; makoce oyate kin inyan on ktepi kta.

3 Unkan miś wicaśta kin he ekta. ite ye wakiye kta, qa cinhintku Molok qu kin heon oyate tawa etanhan wakaśpe kta, tipi wakan mitawa yuśape ça micaje wakan yuzamni heon etanhan.

4 Unkan makoce oyate kin wicaśta tuwe iye cinhintku Molok qu kin wanyakapi kte śni e iśtapi katinyan hduohmuzapi, qa hecen ktepi śni kinhan,

5 Miś wicaśta kin he miiśta awehnake kta, nakun tona taku wicaya, qa oyate tawapi etanhan wicawakaśpe kta, iye qa tona Molok kici wankapi kta iye opeya okiyapi owasin.

6 Unkan wicanagi tuwe wapiyesapi, qa wicaśta wakan, içidapi kin hena opeya okiyapi kta e ekta ihduhonıni kinhan, miś miite wicanagi kin he ekta ye wakiye ça taoyate kin wicehna tanhan wakaśpe lita.

7 Unkan Jehowa wakan yadapi kin he miye, heon ihduwakan po, hecen niwakanpi kta.

8 Qa wokage mitawa yapatanpi kta, qa hecanonpi kta; Jehowa niyuwakanpi kin he miye.

9 Hecen tuwe kaśta atkuku qaiś hunku yaśice cinhan awicakehan țe yapi kta, atkuku qaiś hunku yaśica, hecen we içiya.

10 Unkan wicaśta tuwe wicaśta tokeca tawicu kici wawicihahapi econ, takodaku tawicu eśta kici wawicihahapi econ kinhan, awicakehan țe yapi kta, wicaśta qa winolinea wawiciliahapi econpi napin.

11 Unkan wicaśta wan atkuku tawicu kici wanke cinhan atkuku tancodan kin yuzamni tokeśta napin te wicayapi kta, iye we içyapi.
12 Unkan wicaśta wan iye takoślku kici wanke cinhan tokeśta sakim te wicayapi kta, wowicaśtaśni ohanyapi iye we içiyapi.

13 Unkan wicaśta wan winohinca kici wankapi kin he iyecen wica wan kici wanke cinhan, sakim.wowahte śni econpi tokeśta te wicayapi kta, iye we içiyapi.

14 Unkan wicaśta wan winohinca wan hunku kici wicayuze cinhan wicaśtapiśniyan ohanyan, iye qa hena nakun, peta ohna huhnali wicayapi kta, hecen niyepi ehna wowicaśtaśni wanice kta.

15 Unkan wicaśta wan woteca wan kici wanke cinhan tokeśta te kta qa woteca kin nakun yalitepi kta.

16 Unkan winohinca wan woteca wan kici wanke kta e ikiyedan i kinhan, winohinca kin woteca kin kici wicayakte kta, tokeśta țapi kta, iye we içiyapi.

17 Unkan wicaśta wan iye tawinohtin yuze cinhan, atkuku cunwintku qaiś hunku cunwintku tancodan wanyake cinhan, unkan winyan kin wicaśta tancodan kin wanyake cinhan hee wowiśteca wicakaśpapi kta, oyate tawapi cincapi iśtapi itokam, tawinohtin tancodan kin yuzamni woahtani kin hduha kta.

18 Unkan wicaśta wan winohinca iśna ti kici. wanke cinhan, qa tancodan kin yuzamni kinhan, tawakoniya yutanin ; unkan winyan kin we wakoniya kin hduzamni, heon napin oyate tawapi wicehna tunhan wicakaśpapi kta.

19 Nakun nihun tawinolitin, qa niyate tawinohtin tancodan kin duzamni kłe śni, tuwe hecon kin he iye cehpi kin hdutanin woahtani hduhapi kta.

20 Unkan wicaśta wan iye tun- 


\section{LEWI TOOPE.}

wineu kici wanke cinhan, tunwincu tancodan kin yuramni, wahtanipi kin hduhapi kta, cinca nica ewicakiyapi țapi kta.

21 Unkan wicaśta wan iye sunkaku tawicu yuze cinhan, wowahte śni hee, sunkaku tancodan kin yuzamni cinca nica ewicakiyapi kta.

22 Hecen wokage mitawa owasin qa woyaco mitawa owasin yapatanpi kta, qa ecanonpi kta, unkan makoce ohna ounyayapi kta e ekta yeciyapi kin he inihdepapi kte śni.

23 Unkan oyate nitokapa tanhan iyaye wicawaye cin hena wokagepi omayanipi kte śni. Iye hena owasin econpi heon hiti wicawahda.

24 Unkan heciciyapi, Maka tawapi kin tawayayapi lita, qa makoce kin he pteasanpi qa canhanpi tiktica kaduze cin he tawayayapi kta e ciçupi kta; Jehowa wakanyadapi oyate tokeca etauhan yukinukan ciyapi kin he miye.

25 Heon woteca ska, qa tona śapapi yukinukan yayapi kta, nakun wahupakoza sapa qa ska dukinukanpi kta. ihnuhan ninagipi nihduwahtepi śni woteca on, qaiś taku kinyan on, qaiś taku kaśta maka asdohan on. Hena śapa yadapi kta e niyepi etanhan mdukinukan.

26 Unkan tawa ciyapi k ta e miye oyate tokeca etanhan ciyukinukanpi, Jehowa mawakan heon miyeci wakanyan yaunpi kta.

27 Unkan wicaśta wan, qaiś winohinca wan niyepi ehna wapiyesa, qaiś wicaśta wakan içidake cinhan, awicakehan te kta, tona hecapi inyan on wicayaktepi kta, iye we içiyapi.
WICOWOYAKE 21.

1 Unkan Jehowa Mowis heciya, Aaron cinca wawayuśnapi kin hecen kewicayakiye kta; "Tuwe nagi ye cin on ihduśapapi kte śni, oyate tawapi ehna.

2 Tuka iye celipi takuye hinca hunku on, qa atkuku on, qa cinhintku on, qa cunwintku on, qa sunkaku on,

3 Qa iye ta winohtin linca wikośka tuwedan yuze śni, henana on ihduśape kta.

4 Winohinca oyate tawa ehna yuhe cin on ihduśape kte śni, qa ihduikceka lite śni.

5 Papi tuktedan paśda icicagapi kte śni, qa putinhinpi oise kin baśdapi kte śni qa cehpi içicagopi kte śni.

6 Tuwe wakandapi on wakanyan unpi kta, qa tuwe wakandapi caje kin yuikcekapi kte śni, Jehowa tapeta wośnapi, tuwe wakandapi taaguyapi kin kahipi nakaś, heon wakanyan unpi kta.

7 Witkowin qaiś wakikśanpi wan yuzapi kte śni, nakun winohinca hihnaku elipe kiye cin he yuzapi kte śni ; tuwe wakandapi on wakanpi nakaś.

8 Tuwe wakan yadapi taaguyapi kahipi heon wicaduwakan kta; Jehowa niyuwakanpi kin he miye mawakan heon hena niye om wakanpi kta.

9 Unkan wawayuśna cunwintku wan witkowin ohanyan on ihduśape cinhan, he atkuku yuśapa, petan huhnahyapi kta.

10 Unkan wawayuśna sunka wicaye cin ehna itancan tawokoyake kin koyake kta e sdawicayapi wihdi kin pa akaśtanpi, qa nape ojun yapi kin he pa kin hduśda kte śni, qa wokoyake hdulidece kte śni.

$11 \mathrm{Qa}$ tuwedan nagiye tancan 


\section{WICOWOYAKE 22.}

te cin ekta i kte śni, atkulku on, qa hunku on ihduśape $k$ te śni.

12 Qa tipi wakan etanhan inanpe kte śni, qa taku wakanda toti wakan kin yuikceka kte śni. Tuwe wakanda wateśdake wihdi sdayapi tawa kin he akaśtanpi nakaś, Jehowa he miye.

13 Qa wikośka wan tuwedan kici wanke śni heca yuze kta.

14. Wiwazica qa tuwe ehpe kiyapi qa wakikśanpi, qa witkowin, tona hecapi etanhan winohinca yuze kte śni; tuka iye taoyate etanhan wikośka wan yuze kta.

15 Qa tona iye etanhan icagapi kin wica hduilkceka kte śni taoyate ehna; Jehowa he yuwakan kin he miye.

16 Unkan Jehowa ie ça Mowis heciya,

17 Aaron hecen eciya wo. Nicinca wicoicage yeye cin tuwe ośteka, Taku wakanda taaguyapi kahi kta e ikiyedan hi kte śni.

18 Nakun tuwe kaśta ośteke cin he ikiyedan hi kte śni, wicaśta iśta gonge, qaiś huśte, qaiś poge mdaśka, qaiś huha unman tukte kaśta iyotan hanska,

19 Qaiś siha ksa, qaiś nape ksa, 20 Qaiś cankahu pawegapi, qaiś tanyan icage śni, qaiś iśta aska, qaiś tuwe ayaśpuya, qaiś halidi, qaiś susu kapopapi.

21 Aaron wawayuśna cinca etanhan wicaśta ośteka tuwedan Jehowa peta wośnapi tawa kahi kta e ikiyedan hi kte śni, he ośteka heon tuwe wakanda taaguyapi kin kahi kta e ikiyedan hi lite śni.

22 Tuwe wakan da tagguyapi wakan, qa nakun wakan hinca etanhan yute kta ;

23 Tuka cokaya ozanpi kin ekta i kte śni, ośteka nakaś, heon taku miciyuwakanpi kin he yuikceke kte śni; Jehowa niyuwaLev, kanpi kin he miye heon etanhan.

:24 Unkan Mowis Aaron qa iye cinca kin, qa Israel cinca owasin owicakiyaka

\section{WICOWOYAKE 22.}

1 Unkan Jehowa ie ça Mowis heciya,

2 Aaron qa iye cinca kewicakiya wo, Israel cinca kin taku hduwakanpi kin on waktaya unpi kta, hecen taku miciyuwakanpi on micaje wakan kin yuikcekapi kte śni, Jehowa he miye.

3 Hecen ewicakiya wo, Nitoicagepi yeye cin nicincapi owasin etanhan wicaśta tuwe toaśape hduhe cin icunhan, taku yuwakanpi Israel cinca taku Jehowa kicihduwakanpi kin ikiyedan hi kinhan, wicanagi kin he rniite itokapa tanhan kaśpapi kta ; Jehowa he miye.

4. Aaron cinca etanhan wicaśta leprosi ececa, qaiś wakaduze cin, tohanyan yuskapi śni taku yuwakanpi kin ongedan yute kte śni; nakun tuwe taku nagiye cin on śapa icahtake cinhan, qaiś wicaśta tuwe wanke cin su hiyuye cin.

5 Qaiś tuwe watutlza on wicaśta śape kta wan icalitake cinhan, qaiś wicaśta wan taku hececa on śapa, talzu kaśta on ihduśape kta icahtake cinhan,

6 Wicanagi tuwe taku hececa icahtake cin htayetu aiyahdeya sape kta, qa mini on celipi hdujaja śni kinhan, taku yuwakanpi kin yute kte śni.

7 Qa wi kin tohan iyaye cinhan ska kta, qa he iyohakam taku yuwakanpi kin yute kta, aguyapi tawa kin hee nakaś.

8 Taku wayazanka te qa taku yapotapi kin yute kte śni, qa 


\section{LEWI TOOPE.}

hena on ihduśape kte śni ; Jehowa he miye.

9 Qa taku patan wicawaśi kin he patanpi kta, hecen hena on ihduikcekapi kte śni, qa woahtani hduhapi kte śni; Jehowa wicayuwakan kin he miye.

10 'Tuwe tokeca taku yuwakan pi kin yute kte śni, wawayuśna kici ti, qaiś wohtani opeton kin, he taku yuwakanpi kin yute kte śni.

11 Tuka wawáyuśna kin wicanagi wan opeton, mazaska tawa on opetonpi kin he etanhan yute lkta; nakun tuwe ti ohna tonpi lkin he, hena aguyapi tawa etanhan yutapi kta.

12 Unkan wawayuśna cunwintku wan wicaśta tokeca he yuze cimhan, taku ikce qupi yuwakanpi kin etanhan yute kte śni.

13 Tuka wawayuśna cunwintku wan wiwarica, qaiś elpe kiyapi kinhan, qa cinca nice ça atkuku ti en hdi kinhan, atkuku taaguyapi etanhan yute kta, wikośka qon iyececa, tuka tuwe tokeca hetanhan yute kte śni.

14 Unkan wicaśta wan taku yuwakanpi onuniyan yute cinhan, he izaptan aokijuye kta, qa taku yuwakanpi kici wawayuśna kin qu kta.

15 Hecen taku Israel cinca yuwakanpi taku Jehowa ektakiya yuwintapi kin hena yuikcekapi lite śni.

16 'Tuka taku yuwakanpi kin hena yutapi kinhan, oicazopi woahtani kin he wicakiciyuhapi kta; Jehowa wicayuwakan kin he miye, nakaś.

17 Unkan Jehowa ie ca Mowis heciya,

18 Aaron qa iye cinca, qa Israel cinca owasin hecen ewicakiya wo, Wicaśta tuwe kaśta Israel tiohnaka etanhan, qaiś oyate to- keca etanhan, Israel om ounye cin woahi wan makahi kte cinhan, taku içiconzapi on, qaiś taku ikce qupi kin owasin on, wohuhnahyapi wan makahi kte cinhan;

19 Iyokipi yayapi kta heon mdoka zanika, pte etanhan qaiś tahinca etanhan, qaiś tatokadan etanhan kahi kta.

20 Tona ośteka wanjidan yakahi kte śni, hena on iyokipi yayapi kte śni.

21 Unkan wicaśta wan taku içconze hduecetu kta e wopida wośnapi wan Jehowa kahi kte cinhan, qaiś taku ikceya qu kta, pte wanunyanpi, qaiś tahinca etanhan iyokipi ye kta e he zanike kta, tuktedan ośteke kte śni.

22 Iśta gonga, qaiś huha wan kaśujapi, qaiś kaśpapi, qaiś ceśpu yukan, qaiś ayaśpuya, qaiś lidihidi, taku hececa Jehowa yakahipi kte śni qa hena etanhan peta wośnapi wan owayuśna akan Jehowa yaqupi kte śni.

23 Tatanka qa tahinca huha iyakicuya, qaiś huha aokpani kin he ikceya yaqu kta, tuka woyakapi wośnapi on iyokipi ye kte śni.

24 Nakun taku kaśujapi, qa kawegapi, qa nahdecapi, qa baspapi kin Jehowa yakahipi kte śni, qa nitamakocepi ohna taku hececa ecannonpi kte śni.

25 Nakun taku hececa owasin oyate tokeca cinca nape etanhan taku wakanyadapi taaguyapi kin yakahipi kte śni, taku on howinpi hena mahen un nakaś, ośtekapi, niyepi on iyokipi yapi kte śni.

26 Unkan Jehowa ie ça Mowis heciya,

27 Tatanka qaiś tahinca qaiś tatokadan wanji tonpi ehantanhan śakowin can hunku kici un kta, 


\section{WICOWOYAKE 23.}

tuka anpetu iśahdogan qa ohakam Jehowa wakiyuśnapi woahi on iyokipi kta.

28 Unkan pte qaiś tawiyedan wan iye cinca kici anpetu wanjidan en yapatapi kte śni.

29 Unkan wopida wośnapi wan Jehowa wayakiduśnapi kinhan, iyokipi yayapi kta e wayakiduśnapi kta.

30 Anpetu kin he en temyayapi $k t a$, ihanhanna hehanyan ongedan oyahdaptapi kte śni; Jehowa he miye.

31 Qa woahope mitawa yapatanpi kta, qa ecen ecanonpi kta, Jehowa he miye.

32 Qa micaje wakan kin duikcekapi kte śni, tuka Israel cinca wicehna mayawakanpi kta, Jehowa niyuwakanpi kin he miye.

33 Wakanmayadapi kta heon Egupta makoce etanhan hdinanpe ciyapi, Jehowa he miye.

\section{WICOWOYAKE 23.}

1 Unkan Jehowa ie ca Mowis heciya,

2 Israel cinca kin hecen ewicakiya wo, Jehowa omniciye tawa ieyanyapahapi kta, omniciye wakan ieyanpahapi mitawa kin dena ee.

3 Anpetu śakpe wohtani ecannon kta, tuka anpetu iśakowin kin he anpetù okihpapi wakan, ieyanpahapi wakan, ounyayapi owasin ohna, wohtani takudan econpi kte śni; Jehowa taokilipapi kin hee nakaś

4 Jehowa ta omniciye ieyanpahapi wakan iyehantu eca ieyanyapahapi kta dena ee.

5 Wi tokaheya anpetu iake topa en litayetu otahedan Jehowa toacakśin kin hee.

6 Qa wi kin he anpetu iake zaptan en aguyapi napohyapi śni wohanpi Jehowa tawa, anpetu śakowin aguyapi napoliyapi śni yatapi kta.

7 Anpetu tokaheya ieyanpahapi wakan duhapi kta, wayaka wohitani ecannonpi kte śni.

$8 \mathrm{Qa}$ anpetu śakowin peta wośnapi Jehowa yakahipi kta, anpetu iśakowin ieyanpahapi wakan kta, wayaka wohtani takudan ecannonpi kte śni,

9 Unkan Jehowa ie ca Mowis heciya,

10 Tsrael cinca kin hecen ewicakiya wo, Makoce cicupi kin he ekta yaipi, qa woksapi bayaksapi kinhan, tokaheya bayaksapi etanhan opahte wan wawayuśna ekta hiyuyayapi kta.

11 Unkan iyokipi yayapi kta e Jehowa itokam wopahte kin he koze kta ; anpetu okihpapi ihanhanna hehan wawayuśna kin he koze kta.

12 Unkan anpetu wopahte yakozapi kin en, amnos wan zanika, waniyetu wanjidan, wohulinahyapi Jehowa yecicagapi kta.

13 Unkan minha tawa aguyapi mdu can wakśica ohnaka nonpa wihdi icicahiyapi, peta wośnapi waśtemna Jehowa iyokipi ye kta, qa woakaśtan kin mini śa wiyatke ohnaka nonpa.

14 Tuwe wakan yadapi kin ekta woahi hiyuyapi śni anpetu kin hehanyan, aguyapi, qa wamnaheza ceunpapi, qa paśdayapi unmana yatapi kte śni ; ounyayapi owasin ohna nitoicagepi yeye cin wokage kin he owihanke wanica.

15 Unkan wopahte kosiyapi yakahipi anpetu wakan ihanlianna etanhan anpetu wakan śakowin dawapi kta, anpetu wakan ocowasin dawapi kta.

16 Anpetu wakan iśakowin ihanhanna etu dawapi kta, anpetu wikcemna zaptan hehanyan, 


\section{LEWI TOOPE.}

qa minha teca wan Jehowa yakahi kta.

17 Ounyayapi etanhan aguyapi kozapi nonpa, aguyapi mdu can wakśica ohnaka nonpa, napoliyapi śpanyanpi, taku tokaheya suton kin Jehowa ekta hiyuyayapi kta.

18 Qa aguyapi kici amnos śakowin zanika waniyetu wanjidan, qa tatankadan pte wanuyanpi cinca wanjidan, qa tamdoka nonpa yakahipi kta, Jehowa huhnahkiciyapi kta, qa minha tawapi, qa woakaśtan tawapi, peta wośnapi - waśtemna Jehowa iyokipi.

19 Hehan tatokadan mdoka wan woahtani wośnapi on, qa amnos nonpa waniyetu wanjidan wopida wośnapi on, wayakiduśnapi kta.

20 Unkan wawayuśna kin hena koze kta aguyapi tokaheya suton kin ahna, nakun amnos nonpa qon, Jehowa itokam wokosyapi wan, hena Jehowa on wakanpi kta, wawayuśna tawa kta.

21 Unkan anpetu kin he en niy epi on omniciye wakan ieyanpahapi kta, wayaka wohtani takudav ecannonpi kte śni, ounyayapi owasin ohna nitoicagepi yeye cin, he wokage owihanke wanice kta.

22 Unkan makoce nitawapi woksapi kin bayaksapi kinhan, maga nitawapi kahmin owasin bayakse kte śni, qa woksapi nitawa taku okapte cin mnayaye kte śni, wicaśta onśika, qa oyate tokeca on' he elipe wicayeciye kta ; Jehowa wakan yadapi kin he miye.

23 Unkan Jehowa ie ça Mowis heciya,

24. Israel cinca kin hecen ewicakiya wo, $\mathrm{Wi}$ iśakowin anpetu tokaheya kin wookilipe duhapi kta, mazayahotonpi on kiksuyapi, ieyanpahapi wakan,

25 Wayaka wohtani takudan ecannonpi kté śni, qa peta wośnapi wan Jehowa yakahipi kta. 26 Unkan Jehowa ie ça Mowis heciya,

27 Awicakehan wi iśakowin anpetu iwikcemna kin waakahpapi anpetu kin hee, eyanpahapi wakan duhapi kta, qa ninagipi iyokiśin nic̣iyapi kta, qa peta wośnapi wan Jehowa yakahipi kta.

28 Anpetu kin he en wohtani takudan ecannonpi kte śni, waakalipapi anpetu kin hee. Jehowa wakan yadapi itokam akahpe niçiyapi kta e hee nakaś.

29 Wicanagi tuwe kaśta anpetu kin he en iyokiśin içiye śni kinhan taoyate etanhan kaśpapi kta. 30 Unkan wicanagi tona anpetu kin he en wohtani econpi wicanagi kin hena owasin taoyatepi etanhan ihang wicawaye kta.

31 Ounyayapi owasin ohna wohitani takudan ecannonpi kte śni, nitoicagepi yeyecin wokage owihanke wanica.

32 Anpetu okihpapi wakan he duhapi kta, qa ninagipi iyokiśin niciyapi kta, wi anpetu inapcinwanka htayetu etanhan ake htayetu kte cin hehanyan wookilipe nitawapi kin okihpe yayapi kta.

33 Unkan Jehowa ie ca Mowis heciya,

34 Israel cinca kin hecen ewicakiya wo, Wi iśakowin anpetu iake zaptan kin en ohanzi hdepi wohanpi kin hee, anpetu śakowin Jehowa tawa.

35 Anpetu tokaheya ieyanpahapi wakan, he en wayaka wohtani takudan ecannonpi kte śni.

36 Anpetu śakowin peta wośnapi Jehowa yakahipi kta, anpetu iśahdogan eyanpahapi wakan du-

180 
hapi kta, qa peta wośnapi Jehowa yakahipi kta, witaya iheyapi wan hee, wayaka wolitani ecannonpi kte sni.

37 Jehowa taomniciye ieyanyapahapi lita anpetu kin hena ee, eyanpahapi wakan on wohulinahyapi, qa minha wośnapi, qa woakaśtanpi Jehowa yakahipi kta, anpetu iyohi taku tawa kin iyececa.

38 Nakun Jehowa taokiłipapi, qa nakun taku yaqupi, qa nakun taku niciconzapi kin, nakun taku ikce yaqupi kin Jehowa yaqupi kin owasin isanpa.

39 A wicakehan wi iśakowin anpetu iakezaptan makoce taku aicage cin mnayayapi kinhan, anpetu śakowin Jehowa tawohanpi oyakihanpi kta, anpetu tokaheya wookihpe, qa anpetu iśahdogan wookilipe kta.

40 Unkan anpetu tokaheya can wiciyokipi waskuyeca iyacupi kta, tamar can adetka, qa canhahaka adetka, qa wakpa cohwanjica nakun, qa anpetu śakowin Jehowa wakan yadapi kin itokam widuśkinpi kta.

41 Qa wohanpi Jehowa oyakicihanpi kta, anpetu śakowin ptanyetu otoiyohi nitoicagepi yeye cin, wokage owihanke wanica, wi iśakowin en he woyakihanpi kta. 42 Anpetu śakowin can adetka ohanzi hdepi oyatipi kta, tona Israel tamakoce en tonpi kin hena owasin can adetka ohanzi hdepi ohna tipi kta.

43 Hecen Israel cinca Egupta makoce etanhan hdinanpe wicawaye cehan ohanzi hdepi ohna tipi wicawaya, nitoicagepi sdonyapi kta; Jehowa wakan yadapi kin he miye.

44 Unkan Mowis Jehowa wokicihanpi toketu Iśrael cinca owicakiyaka.

\section{WICOWOYAKE 24.}

1 Unkan Jehowa ie ca Mowis heciya ;

2 Petijanjan on can ihdi ecedan bopanpi nicahipi kta, Israel cinca icu wicaśi wo, hecen ide kin ohinniyan wankan ye kta.

3 Woyaatanin cokaya ozanpi itankan, itkokipapi wakeya ohna, htayetu etanhan ihanh̉anna kta eca Aaron he ideye kta, ohinniyan nitoicagepi yeye cin wokage owihanke wanica.

4 Petijanjan ihupa ecedan akan petijanjan ideye kta, Jehowa itokam ohinniyan.

5 Unkan aguyapi mdu iyacu lita, qa he śpan yaye kta, aguyapi wikcemna sanpa nonpa, aguyapi otoiyohi ohna can wakśica ohnaka nonpa kta.

6 Unkan hena Jehowa itokam wahna wotapi ecedan akan eyahnake kta, ocankuye nonpa ocankuye iyohi ohna śalspe.

7 Unkan ocankuye akan canśin ska kohdi eyahnake kta, unkan he aguyapi on wokiksuye kta; peta on Jehowa wakiciyuśnapi kta.

8 Anpetu okilipapi otoiyohi Israel cinca etanhan hena Jehowa itokam ehnakapi kta, ohinniyan wicotakuye owihanke wanica.

$9 \mathrm{Qa}$ Aaron qa iye cinca kin he tawapi kta, qa he yutapi kta, oyanke wakan ohna, Jehowa peta wośnapi tawa etanhan, iye on he wakan hinca nakaś; wokage owihanke wanica.

10 Unkan Israel winohinca wan cinhintku, qa he Egupta wicaśta wan cinhintku, Israel cinca wicehna inanpa, qa Israel winohinca cinhintku, qa Israel wicaśta wan owanka ohna kicizapi.

$11 \mathrm{Qa}$ Israel winohinca cinhintku caje kin atayedan ie ça ya181 


\section{LEWI TOOPE.}

śica, unkan Mowis ekta hiyuyapi he hunku Selomit eciyapi; Dibri cunwintku, Dan wicoun etanhan.

12 Unkan kaśka hnakapi Jehowa i kin etanhan owicakiyakapi kte cin hehanyan.

13 Unkan Jehowa ie ça Mowis heciya,

14 Wicaśta yaśice cin he owanka etanhan inanpe ya wo, unkan tona nahonpi kin owasin pa kin nape aputakapi kta, unkan omniciye owasin inyan on ktepi kta.

15 Unkan Israel cinca kin hecen ewicayakiye kta, wicaśta tuwe kaśta taku iye wakanda yaśice cinhan, iye wahtani kin hduha kta.

16 Jehowa caje kin yaśice cinhan tokeśta te yapi kta, omniciye owasin inyan on aohduteyapi kta, wicaśta oyate tokeca, qaiś makoce en tonpi caje kin yaśice cinhan te kta.

17 Unkan tuwe kaśta wicaśta nagi kaśtake cinhan he ktepi kta.

18 Unkan tuwe woteca wan nagi kaśtake cinhan hdajuju kta, nagi on nagi.

19 Unkan wicaśta wan tuwe iye ikiyedan ti kin kiunniye cinhan token econ kin he iyecen ecakiconpi kta.

20 Kawegapi on kawegapi kta, iśta on iśta, hi on hi token wicaśta wan kiunniye cin he iyecen kiunniyanpı kta.

21 Unkan tuwe woteca wan kte kinhan he on hdajuju kta, qa tuwe wicaśta wan kte kin he ktepi kta.

22 Wicaśta oyate tokeca on, qa tuwe makoce en tonpi on, woyaco wanjidan duhapi kta; Jehowa wakan yadapi kin he miye.

23 Unkan Mowis Israel cinca kin owicakiyaka, unkan wicaśta wayaśice cin he owanka itankan inanpe yapi, qa inyan on ktepi hecen Israel token Jehowa Mowis econ śi kin he iyecen econpi.

\section{WICOWOYAKE 25.}

1 Unkan Jehowa Sina he kin akan ie ça Mowis heciya,

2 Israel cinca kin ekta i qa hecen ewicakiya wo. Makoce wan ciçupi kin he ekta yaipi kinhan, makoce kin wookilipapi wan Jehowa on oziiciye kta.

3 Waniyetu śakpe maga nitawa oyaju kta, qa waniyetu śakpe hastanhanka iyuwi nitawa adetka bayaśpe kta, qa taku aicage cin mnayaye kta;

4 Tuka waniyetu iśakowin kin he makoce tookihpe wakan kta, Jehowa tookihpe, maga nitawa oyaju kte śni, qa hastanhanka iyuwi nitawa adetka kin bayaśpe kte śni.

5 Bayakse ciqon etanhan taku icage cin he bayakse kte śni, qa hastanhanka iyuwi nitawa adetka baśpapi śni hastanhanka aicage cin duśpi kte śni, makoce kin tookilipe omaka kin hee nakaś.

6 Qa waniyetu okihpapi kin he woyute yayapi kta, niye, qa nitahokśidan qa nitawicinyanna, qa tuwe tohtani opeyaton, qa tona oyate tokeca nici ounyanpi kin.

7 Qa woteca nitawa, qa wamanica makoce nitawa en unpi taku icage cin owasin woyute yapi kta.

8 Unkan waniyetu okihpapi śakowin yahdawa kta, śakowin akihde waniyetu śakowin, hecen waniyetu okilipapi śakowin, waniyetu wikcemna tom sanpa napcinwanka anpetu iyenakeca kta.

9 Hehan wi iśakowin wi anpetu iwikcemna mazayahotonpi 


\section{WICOWOYAKE 25.}

hoton yakiye kta, woakahpapi anpetu en, makoce nitawa owancaya mazayahotonpi hoton yayapi kta.

$10 \mathrm{Qa}$ waniyetu iwikcemna zaptan waniyetu kin he duwakanpi lkta, qa makoce ohna tona en ounyanpi owasin iye ihduhapi kta, eyanpaha yayapi kta, he Jubele yayapi kta, qa yahdapi kta, otoiyohi tamaga ekta, qa takuwicaye cin ekta.

11 Qa waniyetu iwikcemna zaptan waniyetu kin he Jubele yayapi kta, woyajupi kte śni, qa taku baksapi qon etanhan icage cin he bayaksapi kte śni, qa hastanhanka iyuwi baśpapi śni taku aicage cin duśpi kte śni.

12 Jubele hee nakaś, wakan yayapi kta, maka kicanyanpi śni, taku aicage cin he yatapi kta.

13 Jubele waniyetu kinhan yahdapi kta, otoiyohi iye tamaga ekta.

14 Unkan tuwe nikiyedan ti kin ekta taku wiyopeyapi iyope yakiye cinhan, qaiś tuwe nikiyedan ti nape etanhan taku opeyaton kinhan, ihnuhan nihunkawanji duhukuye cinhan.

15 Jubele etanhan waniyetu yawapi kin eciyatanhan opeyaton kta, tuwe nikiyedan ti etanhan, qa waniyetu taku aicage kte cin iyenaka eciyatanhan iyopeniciye kta.

16 W aniyetu ota on iyuwin kin duota kta, qa waniyetu tonana on iyuwin kin duoptetu kta, nakaś tona taku aicage cin yawapi eciyatanhan he iyopeye nicaton.

17 Unkan wicaśta wan tuwe ikiyedan ti kin yakiduśe kte śni, tuka tuwe wakan yada kin koyakipe kta; Jehowa wakan yadapi kin he miye nakaś.

18 Heon wokage mitawa kin ecen ecanonpi kta, qa mitawoyaco yapatanpi kta, qa ecen ecanonpi kta, hecen okope wanin makoce kin ounyayapi kta.

19 Hecen maka kin waskuyeca tawa nicu kte ca imnahan wayatapi kta, qa okope wanin he ounyayapi kta.

20 Unkan, Inyun unkojupi kte śni, qa taku icałunkiciyapi mnaunkiyapi kte śni, taku untapi kta hwo, ehapi kinhan.

21 Woyawaśte mitawa ciçupi kta, waniyetu iśakpe en, hecen waniyetu yamni on woicaliye icahniciyapi kta.

22 Unkan waniyetu iśahdogan woyajupi kta, qa woicahye tannina etanhan yatapi kta, waniyetu inapcinwanka kin hehanyan taku aicage cin mnayanpi kin hehanyan tannina yatapi kta.

23 Makoce kin owihanke wanica iyope yapi kte śni, makoce kin he mitawa nakaś, wicaśta ihdakapi, qa mici tipi henicapi heon etanhan.

24 Unkan makoce tawayayapi kin owasin en wopekitonpi yaqupi kta.

25 Nihunkavanji wahpanice ça makoce tawa etanhan iyope kiye cinhan taku wicaya wan opekiciton cin kinhan, taku hunkawanjitku wiyopekiye cin he opekiciton kta.

26 Unkan wicaśta wan tuwedan opekiciton śni kinhan, qa iye nape waśaka on taku iyohiya iyeye cinhan, iye opekiton kta.

27 Qa wiyopekiye ciqon ehantanhan omaka yawa kta, qa taku iyaye tuwe he opeton qu kte ca maga tawa kin en hdi kta.

28 Tuka taku kicupi kta iyohiya nape kin iyeye śni kinhan, taku iyopekiye cin tuwe he opeton kin nape ohna yanke kta, Jubele waniyetu kin hehantu kta; un183 


\section{LEWI TOOPE.}

kan Jubele waniyetu hehan inape kta; unkan maga tawa qon en hdi kta.

29 Unkan wicaśta wan otonwe aconkaśkayapi ohna tipi ounyanpi wan iyope kiye cin he opekiton kinhan iyopekiyapi ehantanhan waniyetu wanjidan mdoketu iyahna anpetu kin hehanyan wopekitonpi kta.

30 Tuka waniyetu mdolietu iyahna ihunniyan hehanyan opekitonpi śni kinhan, tipi otonwe conkaśkayapi ohna tuwe he opeton, qa toicage yeye cin owihanke wanica tawa kta, Jubele en inanpe kte śni.

31 Tuka tipi otonwe cistinna tona ihduksan conkaśke wanice cin ohna hena owasin makoce maga kin iyecen yawapi kta, hena opekitonpi kta, qa Jubele en inanpe kta.

32 Unkan Lewi otonwe tawapi tipi otonwe tawayapi, Lewi kin tohantu kaśta opekitonpi kta.

33 Unkan tuwe Lewi kin etanhan opeton kinhan, tipi opeton etanhan, qa otonwe tawaye cin etanhan Jubele en inanpe kta, Lewi otonwe tawapi tipi kin Hena taku tawayapi ee; Israel cinca ehna nakaś.

34 Tuka otonwe tawapi ihdukśan tinta maga kin hena wiyopeyapi kte śni, he tawayapi owihanke wanica nakaś.

35 Unkan nihunkawanji nici wahpanica aye ca nape hdugate cinhan, he waśagyakiye kta, he oyate tokeca eśta, en ounye cinhan, hecen nici ni kta.

36 Thnuhan he etanhan woyahtake qa oicage iyacu kinhan, tuwe wakan yada kin iknyape kta, hecen nihunkawanji ni kta niyepi kici.

37 Mazaska nitawa woyahtake on yaqu kte śni, qa woyute 184 nitawa oicage cin on yaqu kte śni.

38 Jehowa wakanyadapi Kanan makoce niçupi kta e Egupta makoce etanhan hdinanpe niyanpi kin he miye, hecen taku wakan yadapi kin he miye kta.

39 Nihunkawanji wahpanica, qa niye en wiyopeiçiye cinhan, wayaka wohtani on wowidag yakiye kte śni.

40 Wicaśta wohtani opekitonpi iyecece kta. Tuwe makoce ounye cin iyecen nici un kta, Jubele omaka kin hehanyan nici hitani kta.

41 Hehan niye etanhan inanpe kta, qa iye cinca nakun opapi kta, qa takuwicaye cin ekta hde $\mathrm{kta}$, qa atewicaye cin makoce tawapi kin en hde kta.

42 Mitaokiye Egupta etanhan hdinanpe wicawaye cin hena eepi, heon wayaka iyope wicayapi kin he iyecen iyope wicayapi kte śni.

43 Wacinkoya wowidagwicayaye kte śni, tuka tuwe wakan yada kin koyakipe kta.

44 Oyate nihdukśan yakonpi kin hena etanhan hokśidan wicinyamna koya duhe kta, ookiye wica qa winyan hena etanhan opeyaton kta.

45 Nakun wicaśta oyate tokeca niye om ounyanpi kin cincapi kin opewicayaton kta, qa takuwicayapi nitamakoce en tonpi, qa niyepi ehna unpi kin hena etanhan, qa hena tawawicayayapi kta.

$46 \mathrm{Qa}$ nicincapi niyepi iyohakam icagapi kin hena tawawicayapi kta e iwicayacupi kta, owihanke wanin hena wowidag wicayayapi kta, tuka nihunkawanjipi kin Israel cinca kin wacinkoya wowidag wicayeciyapi kte śni. 


\section{WICOWOYAKE 26.}

$4^{17}$ Unkan tuwe oyate tokeca, qa nici ounye cin wijice cinhan, qa nihunkawanji niciwahpanica wicaśta oyate tokeca nici ounye cin ekta wiyopeiciye cinhan, qaiś oyate tokeca takuwicaye cin wan elita.

48 Wiyopeyapi iyohakam wopekitonpi kta; iye hunkawanjitku wan opekiton kta.

49 Dekśitku qaiś tahanśitku he opekiton kta, qaiś iye cehipi etanhan tuwe takuye cin he opekiton kta, qaiś iye nape waśake cinhan, opeiciton kta.

50 Unkan tuwe he opeton kici waniyetu yawa kta iyopeiciye cin ehantanhan, Jubele waniyetu kin iyehantu kta, qa mazaska iyopeiçiye cin etanhan waniyetu yawapi kta, wicaśta wohtani opetonpi kin he iyecen anpetu yawapi kta.

51 Nahanhin waniyetu ota kinhan hena eciyatanhan mazaska on opetonpi qon iyecen kicu kta.

52 Qa waniyetu tonana okaptapi Jubele iyehantu kinhan, waniyetu iyenakeca yawapi eeiyatanhan wopekitonpi kicu kta.

53 Tuwe wolitani waniyetu wanjidan opetonpi kin he iyecen, he kici yanke kta, niista itokam wacinkoya wowindag ye kte śni.

$54 \mathrm{Qa}$ hena on opekitonpi śni kinhan Jubele waniyetu kinhan inanpe kta, iye qa cinca kin opapi kta.

55 Israel cinca kin ookiye wicamduha nakaś, mita ookiye Egupta makoce etanhan hdinanpewicawaye cin hena eepi; Jehowa Wakan yadapi kin he miye.

\section{WICOWOYAKE 26.}

1 Wakan taku śniśni, qa wakagapi pagopi nicicagapi kte śni, qa wakagapi bosdata eniçihdepi kte śni, qa inyan śayapi wan itokam patujapi kta e nitamakoce ohna duhapi kte śni, Jehowa wakan yadapi kin he miye nakaś.

2 Okihpapi mitawa kin yapatanpi kta, qa tipi wakan mitawa yakinihanpi kta.

3 Wokage mitawa omayanipi, qa mitawoahope yapatanpi qa ecen ecanonpi kinhan,

4 Iyehantu eca amagaju ciciyapi kta, unkan maka kin taku aicage kta iyececa qu kta, qa waskuyeea can kin tawaskuyeca kin qu kta.

5 Hecen wonapanpi nitawa kin hastanhanka yuśpipi kin iyohi kta, qa hastanhanka yuśpipi kin wojupi kte cin iyohi kta, qa aguyapi imnahan yahdutapi kta, qa nitamakocepi ohna okope wanin ounyayapi kta.

6 Unkan makoce ohna wookiye waqu kta, hecen makan inonkapi eca yuśinye niyanpi wanice kta, qa makoce nitawa etanhan wamanica śica enawakiye kta, qa ozuye nitamakoce kin omanipi kte śni.

7 Únkan toka niyanpi kin wicayakuwapi kta, unkan nitokam canlipi on hieahanpi kta.

8 Unkan niyepi etanhan wicaśta zaptan wicaśta opawinge tawicapapi kta, qa niyepi etanhan opawinge wanjidan kekto pawinge wikcemna wicapasipi kta, qa tokaniyanpi nitokam canhipi on hicahanpi kta.

9 Unkanacitonwanpi kta, qa ieaheiyapi, qa ciyuotapi kta, qa wicotakuye nicipi wahdusuta kta.

10 Hecen tannina śeca kin yatapi kta, qa teca on tannina kin tankan hiyuyayapi kta.

11 Unkan niyepi ehna tipi mitawa ewahde kte, qa minagi hitinihodapi kte śni. 


\section{LEWI TOOPE.}

12 Qa niyepi ehna mawani kta, qa taku wakan yadapi kin he miye kta, qa oyate mitawa kin he niyepi kta;

13 Jehowa wakan yadapi, Egupta makoce etanhan hdinanpe niyanpi kin he miye, qa wowidag niyanpi kte śni, heon wiçin icaśke nitawapi kin wapaksa, qa bosdan maniciyapi.

14 Tuka namayalionpi śni, qa mitawoahope kin dena owasin ecen ecanonpi śni kinhan;

15 Qa wokage mitawa ihayaktapi śni kinhan, qa ninagipi woyaco mitawa hitihdapi on mitawoahope owasin ecen ecanonpi śni, hecen wicotakuye mitawa duksapi kinhan,

16 Miś eya hecen ecaciconpi kta, woyuśinye, qa waśinkte, qa tancan kata yuhe niyanpi waśi kta, hena niiśtapi kin sotapi, qa ninagipi kin skan niyanpi kta, hecen wojupi nitawapi taku śni on oyajupi kta, qa toka niyanpi kin he yutapi kta.

$17 \mathrm{Qa}$ miite acihnakapi kta, qa toka niyanpi kin nicaśtakapi kta, qa wicaśta śice nidapi kin hena wowidag niyanpi kta, qa tuwedan nipasipi śni eśta nayajicapi kta.

18 Unkan hena on etanhan nayahonpi śni kinhan, sanpa śakowin akihde wayahtanipi on iyopeciyapi kta.

19 Qa nitowaśakapi on wahaniçidapi kin wakakse kta, qa mahpiya nitawapi maza sapa iyececa, qa maka nitawapi kin mazaśa iyececa wakage kta.

20 Qa nitowaśakapi kin taku śni on sote kta, qa nitamakoce kin takudan aicage kte śni, qa makoce can kin tawaskuyeca kin icahyapi kte śni.

21 Unkan makipajinyan mayanipi, qa namahon tawațen yayapi śni kinhan, ake śakowin akihde cicaśtakapi kta, wayahtanipi kin iyececa.

22 Qa tinta wamanica kin nitatpe yewaye kta, unkan nicincapi yasotapi kta, qa nitawanunyanpi kin yațapi kta, hecen niyatonanapi kta, qa canku nitawapi kin tuwedan omani kte śni.

23 Unkan hena on miye en nihduecetupi śni, qa makipajinyan mayanipi kinhan;

24 Hehan miś eya cicipajinpi kta, qa nakun miś wayahtanipi kin on śakowin akilıde cicaśtakapi kta.

25 Qa canhipi wan anihiyu waye kta, he wicotakuye mitawa oyapapi śni tokicon kta, hecen otonwe tanka nitawapi en kataiheyayapi kta, unkan niyepi ehna makośice yewaye kta, qa toka niyanpi kin napepi en cicupi kta. 26 Unkan aguyapi sagye cicaksapi kinhan winohinca wikcemna makacega wanjidan ohna aguyapi nitawapi kin śpanyanpi kta, qa aguyapi nitawapi tkeutapi eciyatanhan nicupi kta, unkan wayatapi $\mathrm{kta}$, tuka inimnapi kte śni.

27 Unkan he on namayahonpi śni, qa mayakipajiripi kinhan,

28 Hehan wocanksiya cicipajinpi kta, qa ake miś eya śakowin akihde wayahtanipi on cicaśtakapi kta.

29 Unkan nicinkśipi ceh̉pipi kin yatapi kta, qa nicunkśipi celipipi kin yatapi kta.

30 Unkan paha tehanwankantuya nitawapi kin wapajuju kta, qa anperu wi kagapi nitawa wakawanke kta, qa nitancan tapi kin wakagapi nitawapi tapi akan wehnake kta, qa minagi kin wahtenidapi kte śni.

31 Qa otonwe nitawapi hewoskan wakage kta, qa tipi wakan

186 
nitawapi otiwota wakage kta, qa izinyapi waśtemna nitawapi owamna kte śni.

$32 \mathrm{Qa}$ miś makoce kin hewoskan wakage kta, hecen toka niyanpi kin he en ounyanpi kin yuśinyayapi kta.

33 Qa niyepi ikcewicaśta ehna enanakiya iyaye ciyapi kta, qa nihakam isan wahduśdoke kta, qa makoce nitawapi kin liewoskantu kta, qa otonwe nitawapi kin tuwedan oti kte śni.

34. Hecen makoce kin tookihpapi kin iyokipi kta, tona can liewoskan, qa niyepi toka niyanpi tamakocepi en dukanpi hehanyan makoce okilipe kta, qa tookihpapi kin iyskipi kta.

35 Akan ounyayapi qehan okihipapi tawa icunhan okilipe śni, he on anpetu tona hewoskan okilipe kta.

36 Unkan niyepi etanhan tona iyahanpi nicantepi wankapidan wakage kta, tokaniyanpi tamakocepi kin ohna; canwapa hapa hoton nicahapapi kta, qa canlipi etanhan najicapi iyecen nayajicapi kta, qa nilicahanpi kta, tuwedan nicuwapi śni eśta.

37 Qa iyahdaskin nihinhipayapi kta, canhipi etanhan najicapi iyecen tuwedan nipasipi śni eśta, qa toka niyaupi itokam najin oyakihipi kte śni.

$38 \mathrm{Qa}$ Ikcewicaśta ehna aniwi hnunipi kta, qa toka niyanpi tamakocepi kin niyasotapi kta.

39 Qa niyepi etanhan tona ihanpi kin hena śicaya olianyanpi kin en skanpi kta, toka niyanpi tamakocepi ohna, qa nakun hunkake wicayapi śicaya ohanyanpi en skanpi kta.

40 Hehan iye śicaya ohanyanpi kin, qa hunkakepi śicaya ohanyanpi kịn ohdakapi kta, woki- pajin on makipajinpi, qa nakun token makiza manipi;

4.1 Nakun miś wicakipajinyan mawani, qa toka wicayapi tamakocepi en awicamda, hehan cantepi bakilidayapi śni ihduhukuyapi kinhan, qa śicaya ohanyanpi on sitkihdayapi iyowin kiyapi kinhan;

42 Hehan wicotakuye mitawa Jakob kici weksuye kta, qa wicotakuye mitawa Izak kici qa wicotakuye mitawa Abereham kici weksuye kta, qa makoce kin weksuye kta.

43 Unkan makoce kin ehpeyapi kin, qa tookihpapi on iyuśkin kta, hena en unpi śni icunhan, unkan iye wahtanipi śitkihdayapi kin iyowinkiyapi kta, woyaco mitawa ihaktapi śni, qa nagipi kin wokage mitawa wahtedapi śni kin he on etanhan.

44. Takomni tokawicayapi tamakocepi ohna yakonpi eśta ehpe wicawakiye kte śni, qa ihangwicaye kta, qa wicotakuye wicawecicage cin wahdujuju kta e hitiwicawahda kte śni, Jehowa wakandapi kin he miye. 45 Tuka iyepi on wicotakuye hunkakewicayapi Egupta makoce etanhan wakanmadapi kta e inanpe wicawaye cin he ikcewicaśta wanyakapi hena om wicotakuye weksuye kta, Jehowa he miye.

46 Wokage, qa woyaco, qa woope Jehowa Sina he ekta, Mowis nape eciyatanhan, iye qa Israel cinca otahedan wicaqu kin hena ee.

\section{WICOWOYAKE 27.}

1 Unkan Jehowa ie ça Mowis heciya ;

2 Israel cinca kin hecen ewicakiya wo; Wicaśta wan tuwe hdu187 


\section{LEWI TOOPE.}

kinukan kta iciconze cinhan, token nagi niyawapi kin Jehowa qu kta.

3 Unkan hecen niyawapi kta, wica wan waniyetu wikcemna nonpa etanhan wikcemna śakpe aiyahdeya mazaska seqel wikcemna zaptan niyawapi kta, tipi wakan śeqel iyececa.

4 Tuka he winyan hecinhan śeqel wikcemna yamni niyawapi kta.

5 Unlran waniyetu zaptan etanhan waniyetu wikcemna nonpa aiyahdeya, wica kinhan śeqel wikcemna nonpa niyawapi kta, qa winyan eqe śeqel wikcemnana.

6 Unkan wi wanjidan etanhan waniyetu zaptan aiyahdeya niyawapi kinhan wica kin mazaska śeqel zaptan, qa winyan eqe mazaska śeqel yamni niyawapi kta.

7 Unkan waniyetu wikcemna śakpe etanhan, qa iwankapatanhan, wica kinhan śeqel wikcemna sanpa zaptan niyawapi kta, qa winyan eqe śeqel wikcemna.

8 Tuka taku niyawapi kin iyohiye śni kinhan, wawayuśna kin itokam inajin kta, unkan wawayuśna kin he yawa kta, tuwe iciconze taku nape kin iyohiye cin he wawayuśna kin iyukcan kta.

9 Unkan wanunyanpi etanhan woahi Jehowa kahipi kin hena etanhan taku qu kin owasin Jehowa on wakan kta.

10 He yutokeca kte śni, qa waśte śica on tokiyopeye kte śni, qa nakun śica waśte on, qa wanunyanpi wan wanunyanpi tokeca on tokiyopeye kte cinhan sakim wakan kta.

11 Unkan wanunyanpi śapa etanhan woahi Jehowa kahipi śni hena owasin etanhan kinhan, wanunyanpi kin he wawayuśna kin itokam najin kiye kta.

12 Unkan wawayuśna kin he niciyawa kta, waśte qa śica unman tukte kaśta, token wawayusna kin he niciyawa kinhan, hecetu kta.

13 Unkan he opekiton kte cinhan, token niciyawapi, qa nakun sanpa izaptan qu kta.

14 Unkan wicaśta wan Jehowa on wakan kta tipi kin hduwakan kte cinhan, wawayuśna kin he waș́te qaiś śica iyawa kta, qa token wawayuśna niciyawa kinhan, hecetu kta.

15 Unkan tuwe tipi hduwakan kin he opekiton kte cinhan, token kiciyawapi, qa nakun sanpa izaptan qu kta, hehan hduhe kta.

16 Unkan wicaśta wan maga tawaye cin etanhan onśpa Jehowa on hduwakan kte cinhan, su on wojupi kin eciyatanhan niciyawapi kta, Barle Homer wan woju iyohiye kte cin he mazaska śeqel wikcemna zaptan niciyawapi kta.

17 Unkan Jubele waniyetu etanhan maga hduwakan, token niciyawapi kin hecetu kta.

18 Unkan Jubele iyohakam maga hduwakan kinhan niciyawapi qon etanhan yuaoptetu kta, qa wawayuśna kin waniyetu tona Jubele waniyetu iyehantu eciyatanhan mazaska kiciyawa kta.

19 Unkan tuwe maga hduwakan kin he opekiton kte cinhan, mazaska niciyawapi qa nakun he kici izaptan qu kta, hecen ekicetupi kta.

20 Unkan maga kin opekiton kte śni, ecen wicaśta tolkeca maga kin he opeton kinhan, icimanna opekiton kte śni.

21 Qa maga kin he wakan kta, Jubele kinhan tankan ye kte śni, Jehowa tawa kta, maga yuwa-

188 


\section{WICOWOYAKE . $2 \%$.}

kanpi hinca iyececa, wawayuśna kin he tawaye kta.

22 Unkan maga wan opetonpi, qa hunkakewicaye cin etanhan maga kin he tawaye śni, he yuwakan kta, qa Jehowa qu kte cinhan;

23 Wawayuśna niciyawapi kin eciyatanhan. Jubele waniyetu iyehantu kin taku iyehantu kiciyawa kta, unkan anpetu kin he en token niciyawapi qu kta, he wakan Jehowa tawa.

24 Jubele waniyetu kinhan maga tuwe etanhan opetonpi kin he ekta hdi kta, wicaśta makoce tawaye ciqon he ekta.

25 Taku niciyawapi kin owasin tipi wakan śeqel eciyatanhan, omnica wikcemna nonpa śeqel wanjidan kta.

26 Tokeśta woteca tokaheya wicatonpi kin he Jehowa tawa, heon tokaheya wicatonpi kin he tuwedan yuwakan kte śni, he pte qaiś tahinca unman tukte kaśta Jehowa tawa.

27 Unkan woteca śapa heca opekiton kte cinhan niciyawapi iyecen he izaptan kici qu kta, qa opekiton kte śni kinhan wiyopeyapi kta, niciyawapi kin iyecen.

28 'Tokeśta taku yuwakanpi hinca, taku wicaśta wan Jehowa ekta yuwakan hinca kin, taku tawaye cin owasin etanhan wicaśta, qa wanunyanpi etanhan, qa maga tawaye cin etanhan he wiyopeyapi kte śni, qa opekitonpi kte śni, taku yuwakanpi hinca kin he owasin Jehowa tawa, wakan hinca.

29 Wicaśta tona wicayuwakan. pi hinca kin hena opewicakitonpi kte śni, tuwe yuwakanpi hinca kin he te kta.

30 Unkan maka taku aicage cin iwikcemna kin maka ojupi etanhan, qa can waskuyeca etanhan, he owasin Jehowa tawa, he Jehowa on wakan.

31 Unkan wicaśta wan iwikcemna kin etanhan taku opekiton kte cinhan, iyehantu, qa nakun kici izaptan kin qu kta.

32 Unkan, pte qa tahinca iwikcemna kin owasin tona cansakadan ihukuya iyoptapi kin hena owasin iwikcemna kin Jehowa on wakan kta:

33 Waśte qaiś śica unmanna on kah̉nige kte śni qa he yutokeca kte śni, qa tokiyopekiya eśta he, qa wanji on tokiyopekiyapi koya wakan kta, opekiton kte śni.

34 Sina he ohna Israel cinca on Jehowa Mowis woahope qu kin hena ee. 


\section{WICA Y A W A I.}

\section{WICOWOYAKE 1 .}

1 Unkan Egupta makoce etanhan hdinapapi kin waniyetu inonpa wi inonpa anpetu tokaheya en, Sina hopuze cin ohna, itkokipapi wakeya ohna, Jehowa ie, ca Mowis heciya.

2 Israel cinca omniciye ocowasin pa kin wicayawapo, wicowazipi iyeccn, ateyapi tipi kin iyecen wicapa kin owasin cajepi yawapi iyecen.

3 Waniyetu wikcemna nonpa etanhan qa aktonpi, Israel ohna wica tona ozuye yapi, niye, qa Aaron wicadawapi lita, obe tawapi kin iyecen,

4 Unkan wicoun otoiyohi etanhan wicaśta wan niyepi om un kta, wicaśta ateyapi tipi itancan heca.

5 Unkan wicaśta niyepi om najinpi kta, wicasta cajcpi kin dcna eepi, Ruben etanhan Elitzur Śedeur cinhintku.

6 Simeon etanhan Śclumiel Tzuriśada cinhintku.

7 Juda etanhan Nahśon Aminadab cinhintku.

8 Isakar etanhan Netaneel Tzuar cinhintku.

9 Zubulun etanhan Eliab Helon cinhintku.

10 Josep cinca etanhan, Epraim etanhan, Eliśama Amihud cinhintku, Manaśe etanhan Gamaliel Pedatzur cinhintku.

11 Benjamin etanhan Abidan Gideoni cinhintku.

12 Dan etanhan Ahiezer Amiśada cinhintku.

Num.
13 Aśer etanhan Pagiel Okran cinhintku.

14 Gad etanhan Eleasap Deuel cinhintku.

15 Neptali etanhan Ahira Enan cinhintku.

16 Omniciye etanhan hena wicakicopi, ateyapi wicoun wicaśta yatapi kin, Israel kektopawinge itancan hecapi.

17 Unkan Mowis qa Aaron wicaśta caje wicayatapi qon hena icupi.

$18 \mathrm{Qa}$ wi inonpa anpetu tokaheya en, omniciye owasin yuwitaya hiyu wicayapi, unkan tuwewe etanhan tonpi kin ohdakapi, wicowazipi iyecen, ateyapi tipi on, waniyetu wikcemna nonpa aktonpi caje wicayawapi, wicapa owasin.

19 Qa Sina hopuze ohna wicayawapi, Jehowa Mowis hecon śi kin he iyecen.

20 Unkan Israel cinhintku tokapa Ruben cinca kin token wicatonpi wicowazipi iyecen, qa ateyapi tipi kin iyecen caje wicayawapi wicapa kin iyecen, wica waniyetu wikcemna nonpa aktonpi owasin, tona ozuye yapi owasin ;

21 Ruben wicoun etanhan kektopawinge wikcemna topa sanpa opawinge zaptan wicayawapi. 22 Unkan Simeon cinca etanhan token wicatonpi, wicowazipi iyecen, qa ateyapi tipi kin iyecen, caje wicayawapi wicapa iyecen, wica waniyctu wikcemna nonpa aktonpi owasin, tona ozuye yapi owasin. 


\section{WICAYAWAPI,}

23 Simeon wicoun etanhan kektopawinge wikcemna zaptan sanpa kektopawinge napcinwanka.sanpa opawinge yamni wicayawapi.

24 Unkan Gad cinca etanhan token wicatonpi, wicowazipi iyecen, ateyapi tipi kin iyecen, caje wicayawapi wica waniyetu wikcemna nonpa aktonpi, tona ozuye yapi owasin;

25 Gad wicoun etanhan kektopawinge wikcemna topa sanpa kektopawinge zaptan sanpa opawinge sakpe sanpa wikcemna zaptan wicayawapi.

26 Juda cinca etanhan token wicatonpi wicowazipi iyecen, ateyapi tipi kin iyecen, caje wicayawapi waniyetu wikcemna nonpa aktonpi, tona ozuye yapi owasin ;

27 Juda wicoun etanhan kektopawinge wikcemna śakowin sanpa kektopawinge topa sanpa opawinge śakpe wicayawapi.

28 Isakar cinca etanhan token wicatonpi. wicowazipi iyecen, ateyapi tipi kin iyecen, waniyetu wikcemna nonpa aktonpi caje wicayawapi, tona ozuye yapi owasin ;

29 Isakar wicoun etanhan kektopawinge wikcemna zaptan sanpa kektopawinge topa sanpa opawinge topa wicayawapi.

30 Zebulur cinca etanhan token wicatonpi wicowazipi iyecen, ateyapi tipi kin iyecen waniyetu wikcemna nonpa aktonpi caje wicayawapi, tona ozuye yapi owasin;

31 Zebulun wicoun etanhan - kektopawinge wikcemna zaptan sanpa kektopawinge śakowin sanpa opawinge topa wicayawapi.

32 Josep cinca etanhan Epraim cinca etanhan token wicatonpi 192 wicowazipi iyecen, ateyapi tipi kin iyecen, waniyetu wikcemna nonpa aktonpi, caje wicayawapi, tona ozuye yapi owasin;

33 Epraim wicoun etanhan kektopawinge wikcemna topa sanpa opawinge zaptan wicayawapi.

34 Manaśe cinca etanhan, token wicatonpi wicowazipi iyecen, ateyapi tipi kin iyecen, waniyetu wikcemna nonpa aktonpi caje wicayawapi, tona ozuye yapi owasin ;

35 Manaśe wicoun etanhan kektopawinge wikcemna yamni sanpa kektopawinge nonpa, sanpa opawinge nonpa wicayawapi. 36 Benjamin cinca etanhan token wicatonpi, wicowazipi iyecen, ateyapi tipi kin iyecen, waniyetu wikcemna nonpa aktonpi caje wicayawapi, tona ozuye yapi owasin :

37 Benjamin wicoun etanhan kektopawinge wikcemna yamni sanpa kektopawinge zaptan sanpa opawinge topa wicayawapi.

38 Dan cinca etanhan token wicatonpi, wicowazipi iyecen, ateyapi tipi kin iyecen, waniyetu wikcemna nonpa aktonpi caje wicayawapi, tona ozuye yapi owasin ;

39 Dan wicoun etanhan kektopawinge wikcemna śakpe sanpa kektopawinge nonpa sanpa opawinge śakowin wicaya wapi.

40 Aśer cinca etanhan token wicatonpi wicowazipi iyecen, ateyapi tipi kin iyecen, waniyetu wikcemna nonpa aktonpi caje wicayawapi, tona ozuye yapi owasin ;

41 Aśer wicoun etanhan kektopawinge wikcemna topa sanpa kektopawinge wanjidan sanpa opawinge zaptan wicayawapi.

42 Neptali cinca etanhan token 


\section{WICOWOYAKE 2.}

wicatonpi wicowazipi iyecen, ateyapi tipi kin iyecen, waniyetu wikcemna nonpa aktonpi caje wicayawapi, tona ozuye yapi owasin ;

43 Neptali wicoun etanhan kektopawinge wikcemna zaptan sanpa kektopawinge yamni sanpa opawinge topa wicayawapi.

44. Mowis qa Aaron qa Israel itancan wikcemna sanpa nonpa ateyapi tipi otoiyohi etanhan wicaśta wanjidan, hena wicayawapi.

45 Hecen Israel cinca kin ateyapi tipi kin iyecen, tona wicayawapi, waniyetu wikcemna nonpa aktonpi, Israel ohna tona ozuye yapi kin owasin ;

46 Tona wicayawapi owasin kektopawinge opawinge śakpe sanpa kektopawinge yamni sanpa opawinge zaptan sanpa wikcemna zaptan eepi.

47 Tuka Lewi kin ateyapi wicoun iyecen hena om wicayawapi śni.

48 Nakaś Jehowa Mowis hecen eciye ciqon;

49 Ihnunhan Lewi wicoun kin wicadawa kin, qa hena oyawa kin Israel cinca kin wicehna aokiju yaye kte śni.

50 Tuka niye Lewi kin wayaatanin tipi kin, qa tawakśica owasin, qa taku ohna un kin owasin yuhe wicayakiye kta. Hena tipi kin he, qa wakśica tawa owasin qinpi kta, qa he kicanyanpi kta, qa tipi kin he ihdukśan etipi kta.

51 Ihdakapi eca Lewi kin tipi kin yujujupi kta, qa etipi eca Lewi kin tipi kin piya iticagapi kta. Unkan tuwe tokeca ikiyedan hi kinhan te yapi kta.

52 Unkan Israel cinca kin otoiyohi wicobe iyecen wicoti tawa, qa wiyokiye tawa ekta ti kta.
53 Tuka Lewi kin wayaatanin tipi kin ihdukśan etipi kta, hecen Israel cinca omniciye kin wocanniye awicahinhpaye kte śni, Lewi kin woyaatanin tipi awanyag wicaśipi kin he iyecen awanyakapi kinhan.

54 Unkan Israel cinca kin token Jehowa Mowis econpi kta eciye cin he iyecen taku owasin econpi.

\section{WICOWOYAKE 2.}

1 Unkan Jehowa ie ca Mowis, qa Aaron hewicakiya.

2 Israel cinca kin otoiyohi wiyokiye tawa ekta, ateyapi tipi wiyokiyedan kin icahda wakeya iticage kta, itkokipapi wakeya ihduksan owasin wakeya iticagapi kta.

3 Unkan he itokam wi hinape ektakiya Juda wicoti wiyokihe kin obe tawapi kin iyecen wakeya iticagapi kta. Unkan Nahśon Aminadab cinhintku kin Juda cinca itancan kin hee.

4. Qa obe tawa kektopawinge wikcemna śakowin sanpa kektopawinge topa sanpa opawinge śakpe wicayawapi.

5 Unkan he icahda Isakar wicoun tipi kta, qa Isakar cinca itancan kin Netanael Tzuar cinhintku kin hee.

6 Qa obetawa kektopawinge wikcemnazaptan sanpa kektopawinge topa sanpa opawinge topa wicayawapi.

7 Hehan Zebulun wicoun, qa Zebulun cinca itancan kin Eliab Helon cinhintku kin hee.

$8 \mathrm{Qa}$ obe tawa kektopawinge wikcemna zaptan sanpa kektopawinge śakowin sanpa opawinge topa wicayawapi.

9 Juda wicoti wicayawapi owasin kektopawinge opawinge san193 


\section{WICAYAWAPI,}

pa kektopawinge wikcemna śahdogan sanpa kektopawinge śakpe sanpa opawinge topa wicayawapi.

10 Ruben wicoti wiyokiye kin wiy otanhan ektakiya tipi kta, obe tawapi kin iyecen, qa Ruben cinca itancan kin Elitzur Śdeur cinhintku kin hee.

11 Qa obe tawa kektopawinge wikcemna topa sanpa kektopawinge śakpe sanpa opawinge zaptan wicayawapi.

12 Unkan he icahda Simeon wicoun tipi kta, qa Simeon cinca itancan kin Ślumiel Tzuriśada cinhintku kin hee.

13 Qa obe tawa kektopawinge wikcemna zaptan sanpa kektopawinge napcinwanka sanpa opawinge yamni wicayawapi.

14. Hehan Gad wicoun, qa Gad cinca itancan kin Eliasap Reuel cinhintku kin hee.

15 Qa obe tawa kektopawinge wikcemna topa sanpa kektopawinge zaptan sanpa opawinge śakpe sanpa wikcemna zaptan wicayawapi.

16 Ruben om tipi wicayawapi owasin kektopawinge opawinge sanpa kektopawinge wikcemna zaptan sanpa kektopawinge wanjidan, sanpa opawinge topa sanpa wikcemna zaptan, obe tawapi kin iyecen, qa hena inonpa ihdakapi kta.

17 Hehan itkokipapi wakeya kin ihdake $\mathrm{kta}$, Lewi wicoti om wicoti cokaya, token tipi kin he iyecen ihdakapi kte, otoiyohi oyanke tawa ohna wiyokiyepi om.

18 Epraim wiyokiye obe tawapi kin iyecen wiyolipeyata ektakiya tipi kta, qa Epraim cinea itancan kin Eliśama Amihud cinhintku kin hee.

19 Qa obe tawa kektopawinge 194 wikcemna topa sanpa opawinge zaptan wicayawapi.

20 Qa he icahda Manaśe wicoun, qa Manaśe cinca itancan kin Gamaliel Pedatzur cinhintku kin hee.

21 Qa obe tawa kektopawinge wikcemna yamni sanpa kektopawinge nonpa sanpa opawinge nonpa wicayawapi.

22 Hehan Benjamin wicoun etipi kta, qa Benjamin cinca itancan kin Abidan Gideoni cinhintku kin hee.

23 Qa obe tawa kektopawinge wikcemna yamni sanpa kektopawinge zaptan sanpa opawinge tapa wicayawapi.

24 Epraim wicoti om wicayawapi owasin kektopawinge opawinge sanpa kektopawinge śahdogan sanpa opawinge wanjidan, obe tawapi kin iyecen, qa hena iyamni ihdakapi kta.

25 Dan wiyokiye waziyata ektakiya tipi kta obe tawapi kin iyecen, qa Dan cinca itancan kin Ahiezer Amiśada cinhintku kin hee.

26 Qa obe tawa kektopawinge wikcemna śakpe sanpa kektopawinge nonpa sanpa opawinge śakowin wicayawapi.

27 Unkan he icahda tipi kin dena eepi; Aśer wicoun, qa Aśer cinca itancan kin Pagiel Okran cinhintku kin hee.

28 Obe tawa kektopawinge wikcemna topa sanpa kektopawinge wanjidan sanpa opawinge zaptan wicayawapi.

29 Qa Naptali wicoun kin, qa Naptali cinca itancan kin Ahira Enan cinhintku kin hee.

30 Qa obe tawa kektopawinge wikcemna zaptan sanpa kektopawinge yamni sanpa opawinge topa wicayawapi.

31 Dan wicoti wicayawapi owa- 


\section{WICOWOYAKE 3.}

sin kektopawinge opawinge sanpa kektopawinge wikcemna zaptan sanpa kektopawinge śakowin sanpa opawinge śakpe hena ehake ihdakapi kta, wiyokiye tawapi kin iyahna.

32 Israel cinca ate wicayapi tipi ecekcen hena wicayawapi, obe tawapi kin ohnahna, wicoti owancaya denakeca wicayawapi, kektopawinge opawinge śakpe sanpa kektopawinge yamni sanpa opawinge zaptan sanpa wikcemna zaptan.

33 Tuka Lewi kin hena Israel cinca wicehna wicayawapi śni, Jehowa Mowis hecen econ śi nakaeś.

34 Unkan token Jehowa Mowis econ śi kin owasin he iyecen Israel cinca kin econpi, hecen wiyokiye tawapi kin icahda iticagapi, qa hecen otoiyohi wicotakuye tawa kin iyecen atewicaya tipi kin om ihdakapi.

\section{WICOWOYAKE 3.}

1 Unkan Aaron, qa Mowis wicoicage kin dee, Sina he kin ohna Jehowa Mowis kici wohdake cehan.

2 Äaron cinca kin cajepi kin dena eepi, Cinhintku tokapa Nadab, hehan Abihu, Eleazar, qa Itamar.

3 Aaron cinca sda wicayapi cajepi kin hena eepi, hena wośna kagapi kta e nape ojun wicayapi.

4 Tuka Nadab, qa Abihu Jehowa itokam tapi Sina hopuze cin ohna, peta tokeca Jehowa itokam hiyuyapi qehan, qa cinca nicapi. Unkan Eleazar qa Itamar wawayuśnapi ateyapi Aaron itokam.

5 Unkan Jehowa ie ça Mowis heciya,
6 Lewi wicoun kin awicahi wo, qa Aaron wawayuśna kin itokam najin wicayakiye kta, hecen okiyapi kta.

7 Qa iye taku awanyake kte cin, qa omniciye owasin taku awanyakapi kte cin he awanyakapi kta, itkokipapi wakeya itokam, qa tipi tohtani kin econpi kta.

8 Qa itkokipapi wakeya wakśica kin owasin awanyakapi kta, nakun Israel cinca kin toawanyake kin owasin, hecen tipi tohtani kin econpi kta.

9 Qa Lewi kin taku qupl wan iyecen Aaron qa iye cinca kin wicayaqu kta, Israel cinca kin wicehna tanhan hena iye wicakicupi kta.

10 Unkan Aaron qa iye cinca kin hena yuhe wicayaśi kta, unkan wowayuśnapi kin awanyakapi kta, unkan tuwe tokeca ikiyedan hi kinhan teyapi kta.

11 Unkan Jehowa ie ca Mowis heciya.

12 Iho miś Israel cinca wicehna tanhan Lewi kin iwicawacu, Israel cinca tokapapi, tona winyan tamni nahdoke cin owasin hena eekiya, hecen Lewi kin wicamoluhe kta.

13 Tona tokapa kin owasin mitawa, Egupta makoce ohna tona caske owasin awicawape cin anpetu kin he en Israel wicehna wicaśta, qa woteca tona caske owasin mici wahduwakan, hena mitawa kta, Jehowa he miye.

14 Unkan Sina hopuze cin ohna Jehowa ie ca Mowis heciya.

15 Lewi cinca ateyapi tipi kin iyecen, wicowazipi iyecen, tona wica owasin wicayawa wo, wi wanjidan aktonpi wicadawa ktá.

16 Unkan Jehowa i kin eciya195 


\section{WICAYAWAPI,}

tanhan token econ sii kin he iyecen Mowis wicayawa.

17 Unkan Lewi cinca cajepi kin dena eepi, Gerśon, qa Qohat, qa Merari.

18 Qa Gerśon cinca cajepi kin wicowazipi iyecen, dena eepi Libni, qa Śimei.

19 Unkan Qohat cinca kin wicowazipi iyecen, Amram qa Itzar, Hebron qa Uziel.

20 Unkan Merari cinca kin wicowazipi iyecen, Mahli qa Muśi, Lewi ateyapi tipi wicowazipi kin dena eepi.

21 Gerśon etanhan Libni wicowazi, qa Śimei wicowazi ; Gerśoni wicowazi hena eepi.

22 Hena wicayawapi tona wica waniyetu wanjidan aktonpi owasin kektopawinge śakowin sanpa opawinge zaptan.

23 Gerśoni wicowazi tipi catku tanhan wiyohpeya ektakiya etipi kta.

24. Qa Gerśoni ateyapi tipi itancan kin Eleasap Lael cinhintku kin hee.

$25 \mathrm{Qa}$ itkokipapi wakeya etanhan Gerśoni cinca taku awanyakapi kte cin dee, tipi kin, qa wakeya kin, qa toakalipe kin, qa itkokipapi wakeya tiyopa akahpe cin.

26 Qa hocoka ozanpi kin, qa hocoka tiyopa akahpe cin, he tipi kin qa wahna wośnapi ihdukśan yanka, nakun ikanyanpi kin owasin.

27 Unkan Qohat etanhan Amrami wicowazi, qa Itzar wicowazi, Hebroni wicowazi, qa Uzieli yicowazi; Qohati wicowazi kin hena eepi.

$28 \mathrm{Wi}$ wanjidan aktonpi kin wica owasin, kektopawinge śahdogan sanpa opa winge sakpe, tipi wakan wokicanye kin awanyakapi.
29 Qohat cinca wicowazi kin tipi icahda, wiyotanhan ektakiya etipi kta.

30 Qa Qohati wicowazi ateyapi tipi itancan kin Elitzapan Uziel cinhintku kin hee.

31 Qa hena can wohnaka kin, qa wahna wotapi kin, qa petijanjan ihupa kin, qa wahna wośnapi kin, qa tipi wakan tawakśica kin hena on tohtani econpi kin, qa taku on kicanyanpi owasin, qa tiyopa akahpe kin.

32 Unkan Lewi itancan itancanpi kin Aaron wawayuśna cinhintku kin Eleazar hee kta, iye tipi wakan awanyakapi kin hena awanwicayake kta.

33 Meræri etanhan Malili wicowazi kin qa Muśi wicowazi kin; Merari wicowazi kin hena eepi.

34 Wica owasin wi wanjidan aktonpi kektopawinge śakpe sanpa opawinge nonpa.

35 Qa Merari ateyapi tipi wicowazipi itancan kin Tzuriel Abihael cinhintku kin hee; hena waziyata ekta kiya tipi kta.

36 Unkan Merari cinca kin tipi canmdaska kin, qa can hdakinyan kin, qa can bosdata kin, qa sicu kin, qa tawakśica kin owasin, qa taku on kicanyanpi kin owasin awanyag wicayaśi kta.

37 Nakun hocoka ihdukśan can bosdata kin, qa sicupi kin qa wihutipaspepi kin, qa ikanpi kin owasin.

38 Unkan Mowis qa Aaron qa iye cinca kin tipi itokam wiyohiyanpa ektakiya, itkokipapi wakeya itokam wi hinanpa ektakiya etipi kta, Israel cinca kin tipi wakan awanyakapi kin hena awanyakapi kta, qa tuwe tokeca ikiyedan hi kinhan te yapi kta.

39 Lewi kin Jehowa i eciyatanhan Mowis qa Aaron wicayawa- 


\section{WICOWOYAKE 4.}

pi owasin wicowazipi iyecen, wica wi wanjidan aktonpi wicayawapi owasin kektopawinge wikcemna nonpa sanpa kektopawinge nonpa.

40 Unkan Jehowa Mowis heciya, Israel cinca caskepi owasin wicayawa wo, wi wanjidan aktonpi kin hena, qa cajepi oyawa icu wo.

$41 \mathrm{Qa}$ Jehowa he miye, heon Israel cinca caskepi owasin hee kiya Lewi kin imicicu wo, qa Israel cinca tawanunyanpi caskepi owasin hee kiya Lewi tawanunyanpi kin ;

42 Unkan Mowis Israel cinca caskepi owasin wicayawa, Jehowa hecon śi kin he iyecen.

43 Unkan caskepi owasin wi wanjidan aktonpi, cajepi wicayawapi iyecen, kektopawinge wikcemna nonpa sanpa kektopawinge nonpa sanpa opawinge nonpa sanpa wikcemna śakowin sanpa yamni wicayawapi.

44 Unkan Jehowa ie ça Mowis heciya,

45 Lewi kin iwicacu wo, qa Lewi tawanunyanpi Israel cinca caskepi, qa tawanunyanpi hee kiya, hecen Lewi kin mitawa kta.

46 Qa Israel cinca caskepi opawinge nonpa sanpa wikcemna śakowin sanpa yamni Lewi kin isanpa hena ope wicakitonpi kta.

47 Hena otoiyohi etanhan pa wicayawapi kin iyecen śeqel zaptan, tipi wakan śeqel iyecen iyacu kta. Śsel wanjidan omnica wikcemna nonpa hee.

48 Qa wicayawapi iyaye cin mazaska on ope wicatonpi kin he Aaron qa iye cinca kin wicayaqu kta.

49 Unkan Mowis Lewi ope wicakitonpi sanpa iyayapi kin hena etanhan mazaska on opeicitonpi kin he icu.

50 Israel cinca caskepi etanhan mazaska kin icu, śeqel kektopawinge wanjidan sanpa opawinge yamni sanpa wikcemna śakpe sanpa zaptan tipi wakan śeqel iyececa.

51 Qa Mowis mazaska on ope wicakitonpi kin he Aaron qa iye cinca kin wicaqu; Jehowa i kin eciyatanhan Jehowa Mowiseconśi kin he iyecen.

\section{WICOWOYAKE 4.}

1 Unkan Jehowa ie ça Mowis qa Aaron hewicakiya.

2 Lewi cinca wicehna tanhan Qohat cinca kin tonaka wicayawa wo, wicowazipi iyecen, ateyapi tipi kin iyecen.

3 Waniyetu wikcemna yamni aktonpi, qa waniyetu wikcemna zaptan aiyahdeya, tona itkokipapi wakeya wohtani econpi kta e obe en opapi owasin.

4 Qa Qohat cinca wohtani econpi kta dee, itkokipapi wakeya ohna taku wakan hinca.

5 Wicoti ihdakapi kte cinhan Aaron qa iye cinca kin en hipi. kta, qa cokaya ozanpi woakahpe kin kun icupi kta, qa he on woyaatanin can wohnake kin akahpapi kta.

$6 \mathrm{Qa}$ he iwankam hoka ha woakahpe wan ehnakapi kta, qa he iwankam sina wan ocowaśin to ayumdayapi kta, qa tośu kin en iyeyapi kta.

7 Qa wahna wotapi itokam hnakapi akan śina to wan ayumdayapi kta, qa he akan wakśica kin, qa maza tukiha kin, qa wiyatke kin, qa cega etanhan wakanyan kaśtanpi kin ehnakapi kta, qa aguyapi ohinniyan kin he akan yanke kta. 


\section{WICAYAWAPI,}

8 Qa hena akan śina duta wan ayumdayapi kta, qa hoka ha woakalipe wan on akahpapi kta, qa can akiyuhapi kin wiyeya kagapi kta.

9 Qa śina to wan icupi kta, qa petijanjan ihupa kin, qa petijanjan kin, qa petijanjan iyukse kin, qa ohna cahota icupi kin, qa wihdi wakśica on he kicanyanpi owasin akahpapi kta.

$10 \mathrm{Qa}$ he qa tawaśica owasin hoka ha ojuha wan en ohnakapi kta, qa can akiyuhapi wan akan ikoyag yapi kta.

11 Qa mazaskazi wahna wośnapi akan śina to wan ayumdayapi kta, qa hoka ha woakahpe wan on akahpapi kta, qa can akiyuhapi kin he ikoyag yapi kta.

12 Qa wakśica kicanyanpi, tipi wakan ohna taku econpi kin hena owasin icupi kta, qa śina to wall akan ehnakapi kta, qa hoka ha ojuha wan en iyeyapi kta, qa can akiyuhapi wan akan ikoyag yapi kta.

13 Qa wahna wośnapi etanhan cahota pakintapi kta, qa akan śina stan wan ayumdayapi kta.

14 Qa he akan taku on kicanyanpi owasin, petaga wakśica kin, qa mazajanjata kin, qa mazamdaska kin, qa waksica kin, taku on wahna wośnapi kicanyanpi owasin ehnakapi kta, qa akan lioka ha woakalipe wan ayumdayapi kta, qa can akiyuhapi kin ekta ikoyag yapi kta.

15 Unkan tipi ihdakapi eca Aaron qa iye cinca tipi wakan qa taku on kicanyanpi kin owasin akahpapi yuśtanpi kinhan, hena qinpi kta e Qohat cinca kin en hipi kta, tuka taku wakan seca yutanpi kte śni, heconpi kinhan okini tapi kta. Itkokipapi wa- keya ohna $Q$ shat cinca tawaqinpi kin hena eepi.

16 Unkan Eleazar Aaron wawayuśna cinhintku kin wihdi iyoyam yapi kin, qa pejuta izinyapi waśtemna, qa anpetu iyohi minha kin, qa wihdi on sdawicayapi kin hena awanyake kta; tipi wakan ocowasin, qa taku ohna un kin owasin, tipi wakan ohna, qa tawakśica ohna taku un kin awanyake kta.

17 Unkan Jehowa ie ca Mowis qa Aaron hewicaliya,

18 Ihnuhan Lewi kin wicehna tanhan Qohati wicoun wicowazi kin wicayakaśpapi kin.

19. Qa hecen ecawicayeconpi kta, hecen nipi kta, qa taku wakan, qa taku wakan hinca ikiyedan hipi eśta tapi kte śni; Aaron qa iye cinca kin en ipi, qa otoiyohi taku econ, qa taku qin kta okiyakapi kta.

20 Tuka taku tipi wakan ohna akahpapi eca wanyakapi kta e en hipi kte śni, okini țapi kta.

21 Unkan Jehowa ie ca Mowis heciyà.

22 Gerśon cinca nakun wicayawa wo, ateyapi tipi kin iyecen, qa wicowazipi kin iyecen ;

23 Waniyetu wikcemna yamni aktonpi etanhan waniyetu wikcemna zaptan aiyahdeya wicadawa kta, obe itkokipapi wakeya ohna wohtani econpi kta e en yapi kin owasin.

24 Gerśoni wicowazi kin wohtani econpi kta, qa taku qinpi kte cin dee.

25 Tipi ozanpi kin qa itkokipapi wakeya he akalipe cin, qa hoka ha woakahpe kin he iwankam akapa tanhan yanke cin, qa itkokipapi wakeya tiyopa ozanpi kin hena qinpi kta.

26 Nakun hocoka ozanpi kin, hocoka tipi ihdukśan, qa wahna

198 


\section{WICOWOYAKE 4.}

wośnapi ihdukśan yanke cin tiyopa ozanpi kin, qa ikan kin qa tawakśica kin owasin, qa taku on hena kicanyanpi kin owasin.

27 Gerśonï cinca taku qinpi, qa taku kicanyanpi kin owasin Aaron qa iye cinca oiepi eciyatanhan econpi kta, qa taku qinpi kta owasin awanyag wicayaśipi kta.

28 Gerśoni cinca wicowazipi itkokipapi wakeya ohna wohtanipi kin hee, qa hena taku awanyakapi kte cin he Itamar Aaron wawayuśna cinhintku nape ihukuya un kta.

29 Merari cinca kin wicowazipi iyecen, ateyapi tipi kin iy.ecen wicadawa kta ;

30 Waniyetu wikcemna yamni aktonpi waniyetu wikcemna zaptan aiyahdeya, obe itkokipapi wakeya wohtani econpi kta e en upi kin owasin wicadawapi kta. 31 Qa itkokipapi wakeya on wohtanipi kin tawaqinpi awanyakapi kte cin dee; tipi canmdaska kin, qa can hdakinyan kin qa can ipatan kin, qa maza sicu kin.

32 Qa hocoka ihdukśan maza ipatan kin, qa sicupi kin, qa wihutipaspepi, qa ikanpi kin; nakun taku on hena kicanyanpi, qa yuhapi kin owasin, qa waqinpi awanyakapi kin cajepi on wicayecidawapi kta.

33 Merari cinca wicowazi wohtani owasin itkokipapi wakeya ohna htanipi kte cin hee, Itamar Aaron wawayuśna kin cinhintku nape kin ikukuya.

34 Unkan Mowis qa Aaron qa omniciye itancanpikin Qohat cinca wicowazipi iyecen, qa ateyapi tipi kin iyecen wicayawapi,

35 Waniyetu wikcemna yamni aktonpi qa waniyetu wikcemna zaptan aiyahdeya tona itko- kipapi wakeya wohtani econpi kta obe en hipi kin owasin.

36 Kektopawinge nonpa sanpa opawinge śakowin sanpa wikcemna zaptan wicayawapi wicowazipi iyecen qa atcyapi tipi kin iyecen.

37 Qohati wicowazipi etanhan tona itkokipapi wakeya en litanipi owasin wicayawapi kin hena eepi ; hena Mowis qa Aaron wicayawapi Jehowa i kin eciyatanhan Mowis nape kin on.

38 Unkan Gerśon cinca kin wicowazipi iyecen qa ateyapi tipi kin iyecen wicayawapi.

39 Waniyetu wikcemna yamni aktonpi qa waniyetu wikcemna zaptan wicatonpi aiyahdeya, tona itkokipapi wakeya en hitanipi kta e obe en hipi kin owasin.

40 Kektopawinge nonpa sanpa opawinge śakpe sanpa wikcemna yamni wicayawapi, wicowazipi iyecen, qa ateyapi tipi kin iyecen.

41 Gerśon cinca wicowazipı etanhan wicayawapi kin hena eepi, tora itkokipapi wakeya ohna htanipi owasin hena Mowis qa Aaron wicayawapi Jehowa i eciyatanhan.

45 Unkan Merari cinca wicowazi wicayawapi wicowazipi kin iyecen, qa ateyapi tipi kin iyecen.

43 Waniyetu wikcemna yamni aktonpi qa waniyetu wikcemna zaptan aiyahdeya, tona itkokipapi wakeya ohna litanipi kta e obe en opapi kin owasin.

14 Kektopawinge yamni sanpa opawinge nonpa, wicowazipi iyecen wicayawapi.

45 Merari cinca wicowazipi etanhan wicayawapi hena Mowis qa Aaron wicayawapi Jeho- 
wa $\mathrm{i}$ eciyatanhan Mowis nape kin on.

46 Mowis qa Aaron qa Israel itancanpi kin Lewi kin wicowazipi iyecen, qa ateyapi tipi kin iyecen, wicayawapi owasin,

47 Waniyetu wikcemna yamni aktonpi, qa waniyetu wikcemna zaptan aiyahdeya, tona wolitani econpi kta, qa waqinpi econpi kta e itkokipapi wakeya en hipi kin owasin.

48 Kektopawinge sahdogan sanpa opawinge zaptan sanpa wikcemna śahdog an wicayawapi.

49 Jehowa i eciyatanhan Mowis wicayawa otoiyohi taku econ kta, qa taku qin kta owicakiyaka, Jehowa Mowis econ śi kin he iyecen.

\section{WICOWOYAKE 5.}

1 Unkan Jehowa ie ca Mowis heciya.

2 Israel cinca kin tona leprosi ececa, qa tona ton kaduze cin, qa tona taku nagi iyaye cin on sape cin, hena owasin wicoti etanhan tokan iyaye wicayapi wicaśi wo.

3 Wica, winyan urman tukte kaśta ye wicayaśipi kta, wicoti, etanhan iyaye wicayayapi kta, hecen wicoti cokaya wati kin he yuśapapi kte śni.

4 Unkan Israel cinca kin ecen econpi, qa hena wicoti itankan iyaye wicayapi, token Jehowa Mowis eciye cin hecen Israel cinca kin econpi.

5 Unkan Jehowa ie ca Mowis heciya,

6 Israel cinca kin hewicakiya wo. Wicaśta qaiś winolinca wicaśta wan en woahtani econ kinhan, qa itonśniyan Jehowa caje yate qa wicanagi kin he hdajuju kta sdotkiye cinhan,
7 Woahtani econ qon ohdake kta, qa wokajuju ocowasin hdajuju kta, qa he izaptan aope kiciye ça tuwe en wahtani kin kicu kta.

8 Tuka wicaśta takuye wohdajuju kicupi kta wanice cinhan, wohdajuju kin Jehowa kicupi kta, wawayuśna akahipe kiciye cin he ekta woakahpe tamdoka iyahna.

9 Urikan Israel cinca taku wośnapi etanhan wokosyapi owasin wawayuśna elita kahipi kin he tawa kta.

10 Qa wicaśta tuwe kaśta taku wośna kin he wawayuśna he kahi kinhan he tawa kta.

11 Unkan Jehowa ie ça Mowis heciya.

12 Israel cinca kin hecen ewicakiya wo. Wicaśta tuwe kasta tawicu ihduhomni, qa iye en nalimana awahtani kinhan;

13 Qa wicaśta tokeca wan kici iwanke cinban, he nahmana econ, qa hihnaku iśta kin wanyake śni, qa ihduśape tuka wayaatanin wanica, hecon icunhan iyeyapi śni nakaś ;

14 Unkan wowinawizi woniya wall en iyopte ca tawicu kin inakiwizi, unkan he ihduśapa; qaiś wowinawizi woniya wan en iyopte ça tawicu inakiwizi, tuka he ihduśape śni kinhan;

15 Wicaśta kin he tawicu kin wawayuśna kin ekta u kiye kta, nakun tawicu toahi kin hiyuye kta, barle mdu can wakśsica ohnaka wanjidan, wihdi akaśtan kte śni, qa canśin waśtemna aehnake late śni, wowinawizi minlia hee nakaś, wokiksuye minlia on wicohan śica kiksuyapi kta.

16 Unkan wawayuśna kin he ikiyedan hiyuye ca Jehowa itokam najin kiye kta. 


\section{WICOWOYAKE 6.}

17 Qa wawayuśna kin mini y uwakanpi maka wakśica wan ohna icu kta, qa tipi wakan owanka etanhan maka molu nakun wawayuśna icu kta, qa mini kin akada kta.

18 Unkan wawayuśna kin winohinca kin Jehowa itokam najin kiye kta, qa pa yugan iyeye kta, qa nape kin akan wokiksuye minha, wowinawizi minha kin hee aehnake kta ; tuka mini pa taku tehika icahye cin he wawayuśna kin nape ohna yuhe kta.

19 Qa wawayuśna kin winohinca kin taku wakan cajeyan kiye kta, qa winohinca heciye kta, Nihduśape śni kinhan, qa nihihna etanhan nihduhomni śni, qa wicaśta tokeca kici inonke śni kinhan, mini pa taku tehika icahiye cin de kiunni niye kte śni.

20 Tuka nihihna etanhan nihduhomni, qa nihduśape ca nihihna hee kiya wicaśta tokeca kici inonke cinhan;

21 Hecen wawayuśna kin winohinca kin taku wakan cajeyan wowicake ohdag śi kta, qa wawayuśna kin winohinca kin heciye kta, Jehowa oyate nitawa wicehna woyaśice nicage kta, Jehowa niceca kin hidi niye ca nitezi po niye cinhan;

22 Qa mini taku telike icaliye cin de niśupe en ye cinhan tezi nipo kta, qa ceca nihdi kta, eye kta: Unkan hecetu nunwe amen, winohinca kin eye kta.

23 Unkan wawayuśna kin woyaśice kin he wowapi wan akan owa kta, qa mini pa kin on pajaja kta.

$24 \mathrm{Qa}$ winohinca kin mini pa taku tehika icaliye cin he yatke kiye kta: Unkan mini taku tehilka icahye cin he tan mahen iyaye ça pa kta.
25 Hehan wawayuśna kin wowinawizi minha kin winohinca nape etanhan icu kta, qa Jehowa itokam yuwinte kta, qa wahna wośnapi ekta kahi kta.

26 Qa warvayuśna kin minha etanhan nape ohnaka wan wokiksuye on icu kta, qa wahna wośnapi izinye kta, hehan winolinca kin mini yathe kiye kta. 27 Unkan mini yatke kiye cin iyohakam kaketu kta, he ihduśape ça hihnaku nalimana awahtani unkanś, mini taku tehika icahye cin tan mahen iyaye ça pa kta, heon tezi kin po kta, qa ceca kin hdi kta, unkan winolinca kin he oyate tawa ehna woyaśice kta.

28 Tuka winohinca kin ihduśape śni, qa ska kinhan he kiunniye kte śni. tuka cinca ton kta.

29 Wowinawizi woope kin hee, winohinca wan hihnaku etanhan ihduhomni qa ihduśape cinhan.

30 Nakun wowinawizi woniya wan wicaśta wan en iyaye cinhan, qa tawicu kin inakiwizi, qa Jehowa itokam najin kiye lsta; unkan wawayuśna kin woope kin de owasin iyecen ecakicon kta.

31 Hecen wicaśta kin woahtani kiciyawapi kite śni, tuka winohinca iye wahtani kin hduhe kta.

\section{WICOWOYAKE 6.}

1 Unkan Jehowa ie ca Mowis heciya.

2 Israel cinca kin hecen ewicakiya wo: Wicaśta wan qaiś winohinca wan Jehowa ekta ihdukinunkan, Nazari wohdakapi on, Nazari heca lita e içiconze cinhan.

3 Miniśa qa mini wakan etanhan ihdukinunkan kta, minisku201 


\section{WICAYAWAPI,}

mna miniśa etanhan, qa mini wakan etanhan miniskumna yathe kte śni, qa taku kaśta hastanhanka en lipanyanpi kin yatke kte śni, qa hastanhanka do, qaiś puza unmanna yute kte śni.

4 Tohanyan Nazari heca anpetu owasin hastanhanka iyuwi taku aicage cin ha etanhan qaiśs su etanhan kagapi ongedan yute kte śni

5 Tohanyan Nazari iciconze cin icasan wan pa akan ye kte śni, Jehowa on ihdukinunkan ohdake cin anpetu henakeca kin hehanyan paha kin hanska icage kta.

6 Jehowa en Nazari içicu anpetu kin hena icunhan tuwe nagi ye cin en i kte śni.

7 Atkuku on, qaiś hunku on, qaiś sunkaku on, qaiś tawinohitin on, hena țapi on ihduśape kte śni. Tuwe wakan da Nazari kin iye pa akan un nakaś.

8 Tohan Nazari heca hehanyan Jehowa on wakan kta.

9 Unkan tukten yanke cin tuwe ihnuhanna en te cinhan, $\mathrm{Na}$ zari pa kin śape kta; unkan anpetu en yuskapi kinhan, pa hdaśda kta, anpetu iśakowin hehan ihdaśda kta.

10 Qa anpetu iśahdogan tinwakiyedan nonpa, qaiśs wakiyedan cinca nonpa wawayuśna kin ekta kahi kta, itkokipapi wakeya tiyopa ekta.

11 Unkan wawayuśna kin wanji woahtani wośnapi kage kta, qa unman wohihnahyapi kta, hecen wicaśta nagiye cin en wahtani kin akalipe kiciye kta, qa piya pa kin yuwakan kta, anpetu kin he en.

12 Unkan Nazari anpetu kin Jehowa on hdukinunkan kta, nakun wohdajuju on amnosi wan waniyetu wanjidan kahi kta, qa 202
Nazari kin hduśape cin on anpetu tokaheya kin yawa kte śni.

13 Unkan Nazari woope kin dee tohan Nazari anpetu henakeca kinhan, anpetu kin he en itkokipapi wakeya tiyopa ekta ihdohi kta.

14 Qa toahi kin Jehowa kahi kte, wohulinaliyapi on arnnos mdoka wan zanika, waniyetu wanjidan, qa woahtani wośnapi on ammos wiyedan waniyetu wanjidan zanika, qa wopida wośnapi on tamdoka wanjidan zanika.

15 Qa minlia tawapi qa woakaśtan tawapi, qa aguyapi napoliyapi śni, aguyapi mdu hinca on kagapi, wakiśkotpa ohnaka wan aguyapi hmiyanyan wihdi icicahiyapi, qa aguyapi napoliyapi śni wihdi on sdayapi.

16 Unkan wawayuśna kin hena Jehowa itokam kahi kta, qa woahtani wośnapi, qa wohuhnahyapi kin wośna kta.

17 Qa tamdoka kin wopida wośnapi kin Jehowa wakiyuśna kta, aguyapi napohyapi śni wakiśkotpa kin iyahna, qa wawayuśna kin minla kin, qa woakaśtan kin kage kta.

18 Unkan Nazari kin pa kin hdaśda kta, itkokipapi wakeya tiyopa ekta, qa Nazari heca paha kin peta wopida wośnapi ihukuya un kin he akan ehpe kiye kta.

19 Hehan wawayuśna kin tamdoka isto śpanyanpi kin icu kta, nakun wakiślkotpa etanhan aguyapi napohyapi śni wanjidan, qa Nazari nape akan ehnake kta, Nazari heca kaśdapi iyohakam.

20 Qa wawayuśna kin hena Jehowa itokam yuwinte kta; woyuwintapi wakan hee, wawayuśna tawa kta, maku yuwinta- 


\section{WICOWOYAKE $\%$}

pi kici, qa hiyete kozapi kici. Unkan he iyohakam Nazari kin miniśa yatke kta okihi.

21 Nazari woope kin hee; tuwe Jehowa ekta ihdukinunkan kta oyaka, woahi kahi kte cin taku nape kin iyohiye cin iyahna, token oyake cin he iyecen kahi kta, Nazari woope kin he kici.

22 Unkan Jehowa ie ça Mowis heciya.

23 Aaron qa iye cinca kin hecen ewicakiya wo. Israel cinca kin hecen wicadawaśtepi kta, qa hewicayakiyapi kta.

24 Jehowa niyawaśte, qa nipa$\tan :$

25 Jehowa ite kin iyoyam niciya, qa onśinida kta;

26 Jehowa ite kin anitonwe ça wookiye niçu nunwe.

27 Hecen micaje kin Israel cinca kin awicahnakapi kta, unkan miye wicamdawaśte kta.

\section{WICOWOYAKE $\%$}

1 Unkan kaketu, Mowis tipi kin ehde yuśtan qehan, qa sdaye ca yuwakan, nakun taku on kicanyanpi owasin; qa wahna wośnapi, qa taku on kicanyanpi owasin, nakun hena sdaye ça yuwakan.

2 Hehan Israel itancan kin ateyapi tipi pa kin hena wakahipi, wicoun itancanpi wicayawapi icunhan en najinpi kin hena eepi.

3 Toahipi kin Jehowa itokam hiyuyapi ; canpahmihma akahpetonpi śakpe, qa tatanka akenonpa, itancan nonpa on canpahmihma wanjidan, qa otoiyohi on tatanka wanjidan, qa hena tipi kin itokam ahipi.

4 Unkan Jehowa ie ça Mowis heciya.
5 Hena icu wo, hecen itkokipapi wakeya wohtani econpi lita e hena unpi kta, qa hena Lewi kin wicayaqu kta, otoiyohi wohtani econ kin iyecen.

6 Unkan Mowis canpahmihma qa tatanka kin hena icu, qa Lewi kin wicaqu.

7 Canpahmihma nonpa, qa tatanka topa Gerśon cinca kin wicaqu, wohtani econpi kin on.

8 Qa canpahmihma topa, qa tatanka śahdogan Merari cinca kin wicaqu, wohtani econpi kin on ; Aaron wawayuśna kin cinhintku Itamar nape kin ihukuya.

9 Tuka Qohat cinca kin takudan wicaqu śni, hena tipi wakan tawohtanipi hiyetepi akan qinpi nakaś.

10 Unkan wahna wośnapi sdayapi anpetu kin he en, itancanpi kin wahna wośnapi kin yuwakanpi kta e toahipi kin hdoipi, qa itancanpikin toahipi wahna wośnapi itokam hdoipi.

11 Unkan Jehowa Mowis beciya, Wahna wośnapi yuwakanpi kta e itancan otoiyohi anpetu wan tawakiya en toahi kin hdoi kta.

12 Unkan Nahśon Aminadab cinhintku Juda wicoun itancan kin anpetu tokaheya kin toahi kin hdoi.

13 Qa toahi kin mazaska wakśica wan śeqel opawinge sanpa wikcemna yamni aspeyapi, qa mazaska wakśica on amnimnipi wan śeqel wikcemna śakowin tipi wakan śeqel iyececa, napin aguyapi mdu hinca wihdi icicahiyapi on ojudan minha kin hee.

14 Mazaskazi tukiha wan śeqel wikcemna wizinyapi on ojudan;

15 Tatanka wanji ptewanunyanpi cinca, tamdoka wanji, a203 
mnos wan waniyetu wanjidan wohuhnahyapi hee;

16 Woahtani wośnapi on tatokadan wanunyanpi mdoka wan ;

17 Qa wopida wośnapi on tatanka nonpa, tahincaska mdoka zaptan, tatokadan mdoka zaptan, amnos waniyetu wanjidan zaptan; Nahison Aminadab cinhintku toaki kin hee.

18 Unkan anpetu inonpa kin Natanael Zuhar cinhintku Isakar itancan kin hdoi,

19 Qa toahi kin dee, mazaska wakśica wan śeqel opawinge sanpa wikcemna yamni aspeyapi, qa mazaska wakśica on amnimnipi wan śeqel wikcemna śakowin, tipi wakan śeqel iyececa, napin aguyapi mdu hinca wihdi icicahiyapi on ojudan, minha kin hee;

20 Mazaskari tukiha wan śeqel wikcemna wizinyapi on ojudan ; 21 Tatanka wanji ptewanunyanpi cinca, tamdoka wanji, amnos wanji waniyetu wanji, wohuhnahyapi hee ;

22 Tatokadan wanunyanpi mdoka wan woahtani wośnapi on ;

$23 \mathrm{Qa}$ wopida wośnapi on tatanka nonpa, taliincaska mdoka zaptan, tatokadan mdoka zaptan, amnos waniyetu wanjidan zaptan, Natanael Zuhar cinhintku toahi kin hee.

24 Anpetu iyamni Zebulun cinca itancan kin Eliab Helon cinhintku hdoi,

25 Toahi kin mazaska wakśica wan śeqel opawinge sanpa wiIrcemna yamni aspeyapi, mazaska wakśica on amnimnipi śeqel wikcemna śakowin, tipi wakan śeqel iyececa, napin aguyapi mdu hinca wihdi icicahiyapi on ojudan, minha kin hee;

26 Mazaskazi tukiha wan śeqel wikcemna wizinyapi on ojudan.

27 Tatanka wanji ptewanunyanpi cinca, tamdola wanji, amnos waniyetu wanjidan wanji, wohuhahyapi kin hee;

28 Tatokadan wanunyanpi mdoka wanji, woahtani wośnapi on; 29 Qa wopida wośnapi on tatanka nonpa, tahincaska mdoka zaptan, tatokadan indoka zaptan, amnos waniyetu wanjidan zaptan; Eliab Helon cinhintku toahi lin hee.

30 Anpetu itopa kin Ruben cinca itancan kin Elitzur Śedeur cinhintku hdoi ;

31 Toahi kin mazaska wakśica wanji śeqel opawinge sanpa wikcemna yamni aspeyapi, mazaska wakśsica on amnimnipi wan śeqel wikcemna śakowin, tipi wakan śeqel iyececa, napin aguyapi mdu hinca wihdi icicahiyapi on ojudan, minlia/kin hee;

32 Mazaskazi tukiha wanji śeqel wikcemna wizinyapi on ojudan ;

33 Tatanka wanji pte wanunyanpi cinca, tamdoka wanji, amnos wanji waniyetu wanjidan, wohuhnahyapi hee;

34. Tatokadan mdoka wanji woahtani wośnapi on.

35 Qa wopida wośnapi on tatanka nonpa, tahinca ska mdoka zaptan, tatokadan mdoka zaptan, amnos waniyetu wanjidan zaptan, Elitzur Sedeur cinhintku toahi kin hee.

36 Anpetu izaptan kin Simeon cinca itancan kin Śelumiel Tzu riśada cinhintku kin hdoi,

37 'Toahi kin mazaska wakśica wan śeqel opawinge sanpa wikcemna yamni aspeyapi, qa mazaska wakśica on amnimnipi śeqel wikcemna śakowin, tipi wakan śeqel iyececa, napin agu- 


\section{WICOWOYAKE $\%$}

yapi mdu hinca wihdi icicahiyapi on ojudan, minha kin hee.

38 Mazaskazi tukiha wanji śeqel wikcemna wizinyapi on ojudan ;

39 Tatanka wanji pte wanunyanpi cinca, tamdoka wanji, amnos wanji waniyetu wanjidan, wohuhnahyapi kin hee;

40 Tatokadan wanunyanpi mdoka wanji, woalitani wośnapi on :

41 Qa wopida wośnapi on tatanka nonpa, tahincaska mdoka zaptan, tatokadan mdoka zaptan, amnos waniyetu wanjidan zaptan, Śelumiel Tzuriśada cinhintku toahi kin hee.

42 Anpetu iśakpe en Gad cinca itancan kin Eleasap Duel cinhintku kin hdoi.

43 Toahi mazaska wakśica wan śeqel opawinge sanpa wikcemna yamni aspeyapi, mazaska wakśica on amnimnipi wanji śeqel wikcemna śakowin, tipi wakan śeqel iyececa, napin aguyapi mdu hinca wihdi icicahiyapi ojudan, minlia kin hee.

44 Mazaskazi tukiha wan śeqel wikcemna wizinyapi on 0judan ;

45 Tatanka wanji pte wanunyanpi cinca, tamdoka wanji, amnos wanji waniyetu wanjidan, wohulinaliyapi kin hee.

46 Tatokadan mdoka wanji waohtani wośnapi on ;

$47 \mathrm{Qa}$ wopida wośnapi on tatanka nonpa, tahincaska mdoka zaptan, tatokadan mdoka zaptan, amnos waniyetu wanjidan zaptan, Eleasap Duel cinhintku toahi kin hee.

48 Anpetu iśakowin en Epraim cinca itancan kin Eliśama Amihud cinhintku hdoi,

49 Toahi kin mazaska wakśica wan śeqel opawinge sanpa wikcemna yamni aspeyapi, ma- zaska waksica on amnimnipi wanji śeqel wikcemna śakowin, tipi wakan śeqel iyececa, napin aguyapi mdu linca windi icicahiyapi on ojudan, minlia kin hee.

50 Mazaskazi tukiha wanji seqel wikcemna wizinyapi on ojudan.

51 Tatanka wanji pte wanunyanpi cinca, tamdoka wanji, amnos wanji waniyetu wanjidan, wohulinaliyapi kin hee ;

52 Tatokadan mdoka wanji woahitani wośnapi on ;

53 Qa wopida wośnapi on tatanka nonpa, tahinca ska mdoka zaptan, tatokadan mdoka zaptan amnos waniyetu wanjidan zaptan, Eliśama Amihud cinhintku toahi kin hee.

54 Anpetu iśahdogan Manaśe cinca itancan kin Gamaliel Pedatzur cinhintku hdoi,

55 Toahi mazaska wakśica wan śeqel opawinge sanpa wikcemna yainni aspeyapi, mazaska wakśica on amnimnipi wan śeqel wikcemna śakowin, tipi wakan śeqel iyececa, napin aguyapi mdu hinca wihdi icicahiyapi on ojudan, minha kin hee.

56 Mazaskazi tukiha wan śeqel wikcemna wizinyapi on ojudan;

57 'Tatanka wanji pte wanunyanpi cinca, tamdoka wanji, amnos wanji waniyetu wanjidan, wohuhnahyapi kin hee.

58 Tatokadan mdoka wanji woalitani wośnapi on;

$59 \mathrm{Qa}$ wopida wośnapi on tatanka nonpa, tamdoka zaptan, tatokadan mdoka zaptan, amnos waniyetu wanjidan zaptan, Gamaliel Pedatzur cinhintku taohi kin hee.

$60^{\circ}$ Anpetu inapcinwanka en Benjamin cinca itancan kin Abidan Gideoni cinhintku hdoi,

61 Toahi kin mazaska wakśica 205 
wan śeqel opawinge sanpa wikcemna yamni aspeyapi, mazaska wakśica on amnimnipi wanji śeqel wikcemna śakowin, tipi wakan śeqel iyececa, napin aguyapi mdu hinca wibdi icicahiyapi on ojudan minlia kin hee.

62 Mazaskazi tukiha wan śeqel wikcemna wizinyapi on ojudan ;

63 Tatanka wanji pte wanunyanpi cinca, tamdoka wanji, amnos wanji waniyetu wanjidan, wohulinahyapi kin hee.

64 Tatokadan mdoka wanji woahtani wośnapi on ;

65 Qa wopida wośnapi on tatanka nonpa, tamdoka zaptan, tatokadan mdoka zaptan, amnos waniyetu wanjidan zaptan; Abidan Gideoni cinhintku toahi kin hee.

66 Anpetu iwikcemna en Dan cinca itancan kin Ahiezer Amiśada cinhintku kin hdoi. .

67 Toahi kin mazaska wakśica wan śeqel opawinge sanpa wi. kcemna yamni aspeyapi, mazaska wakśica on amnimnipi wanji śeqel wikcemna śakowin tipi wakan śeqel iyececa, napin aguyapi mdu hinca wihdi icicahiyapi on ojudan minha kin hee ;

68 Mazaskazi tukiha wanji śeqel wikcemna wizinyapi on ojudan;

69 Tatanka wanji pte wanunyanpi cinca, tamdoka wanji, amnos wanji waniyetu wanjidan, wohuhinaliyapi kin hee;

70 Tatokadan mdoka wanji woahtani wośnapi on ;

71 Qa wopida wośnapi on tatanka nonpa, tahinca ska mdoka zaptan, ta tokadan mdoka zaptan, amnos waniyetu wanjidan zaptan, Ahiezer Amiśada cinhintku toahi kin hee.

72 Anpetu iakewanji Aśer cin206 ca itancan kin Pagiel Okran cinhintku kin hdoi.

73 'Toahi kin mazaska wakśica wan śeqel opawinge sanpa wikcemna yamni aspeyapi, mazaska wakśica on amnimnipi śeqel wikcemna śakowin tipi wakan śeqel iyececa, napin aguyapi mdu hinca wihdi icicahiyapi on ojudan, minlia kin hee.

74 Mazaskazi tukiha wanji śeqel wikcemna wizinyapi on ojudan ;

75 Tatanka wanji pte wanun. yanpi cinca, tamdoka wanji, amnos wanji waniyetu wanjidan, wohuhnahyapi kin hee;

76 Tatokadan mdoka wanji woalitani wośnapi on;

77 Qa wopida wośnapi on tatanka nonpa, tamdoka zaptan, tatokadan mdoka zaptan, amnos waniyetu wanjidan zaptan $\mathrm{Pa}$ giel Okran cinhintku toahi kin hee.

78 Anpetu iake nonpa Naptali cinca itancan kin Ahira Enan cinhintku'kin hdoi.

79 Toahi kin mazaska wakśica wan śeqel opawinge sanpa wikcemna yamni aspeyapi, mazaska wakśica on amnimnipi wanji śeqel wikcemna śakowin, tipi wakan śeqel iyececa, napin aguyapi mdu hinca wihdi icicahiyapi on ojudan, minha kin hee.

80 Mazaskazi tukina wan śeqel wikcemna wizinyapi on ojudan ;

81 Tatanka wanji pte wanunyanpi cinca, tamdoka wanji, amnos wanji waniyetu wanjidan, wohulinaliyapi kin hee.

82 Tatokadan mdoka wanji woahtani wośnapi on ;

$83 \mathrm{Qa}$ wopida wośnapi on tatanka nonpa. tamdoka zaptan, tatokadan mdoka zaptan, amnos waniyetu wanjidan zaptan, Ahi- 


\section{WICOWOYAKE 8.}

ra Enan cinhintku toahi kin hee.

84 Wahna wośnapi sdayapi qehan Israel itancanpi etanhan yuwakanpi kin dee, mazaska wakśica akenonpa, mazaska wakśica on amnimnipi akenonpa mazaskazi tukiha akenonpa,

85 Wakśica tanka otoiyohi śeqel opawinge sanpa wikcemna yamni, qa wakśica on amnimnipi otoiyohi wikcemna śakowin, wakśica owasin mazaska kin the utapi kin śeqel kektopawinge nonpa sanpa.opawinge topa, tipi wakan śeqel iyececa.

86 Mazaskazi tukiha wikcemna sanpa nonpa wizinyapi on ojudan, otoiyohi śeqel wilkcemna, tipi wakan śeqel iyececa, tukiha owasin mazaskazi śeqel opawinge sanpa wikcemna nonpa ;

87 Wohuhnahyapi on tatanka wanunyanpi owasin wikcemna sanpa nonpa, tamdoka wikcemna sanpa nonpa, amnos waniyetu wanjidan wikcemna sanpa nonpa, minha tawapi iyahna, qa woałitani wośnapi on tatokadan mdoka wikcemna sanpa nonpa;

$88 \mathrm{Qa}$ wopida wośnapi on tatanka wikcemna nonpa sanpa topa, tamdoka wikcemna śakpe, tatokadan mdoka wikcemna śakpe, amnos waniyetu wanjidan wikcemna śakpe ; wahna wośnapi sdayapi iyohakam on yuwakanpi kin hee.

89 Unkan kici wohdake kta e Mowis itkokipapi wakeya ekta i eca, ho kin nahon, woyaatanin can wohnaka iwankapa tanhan taku eciya, kerubi nonpa otahedan etanhan taku eciya.

\section{WICOWOYAKE 8.}

1 Unkan Jehowa ie ca Mowis heciya,
2 Ie ça Aaron hecen eciya wo, Petijanjan yuwankan yeyaya eca, petijanjan śakowin kil petijanjan ihupa itokapa tanhan iyoyamyapi kta.

3 Unkan Aaron hecen econ petijanjan oide kin petijanjan ihupa itokapa tanhan wankan ye kiya: Jehowa Mowis hecon śi kin he iyecen.

4. Unkan petijanjan ihupa kin kaken kagapi, mazaskazi pagopi, ceca kin, qa adetka kin nakun pagopi: token Jehowa Mowis wanyagkiye ciqon he iyecen petijanjan ihupa kagapi.

5 Unkan Jehowa ie ca Mowi heciya,

6 Lewi kin Israel cinca wicehna tanhan iwicacu, qa wicayuska wo.

7 Qa wicayuskapi kta e hecen ecawicayecon kta, Mini on wicayuskapi kin heakan elipeya wo ; unkan ukapi kin owancaya hdasanpi kta, qa wokoyake hdujajapi kta, hecen skapi kta.

8 Unkan tatankadan pte wanunyanpi cinca wan icupi kta, qa minlia tawa aguyapi mdu wihdi icicaliiyapi, unkan tatanka inonpa pte wanunyanpi cinca kin iyacu kta woahtani wośnapi on.

9 Qa itkokipapi wakeya itokam Lewi kin ikiyedan awicayahi kta, qa Israel cinca omniciye owasin yuwitaya hiyu wicayaye kta.

10 Qa Lewi kin Jehowa itokam awicayahi kta; unkan Israel cinca napepi kin Lewi kin awicaputakapi kta.

11 Unkan Aaron Lewi kin wicayuwinte kta, Jehowa itokam, wolkosyapi wan Israel cinca etanhan, hecen Jehowa okiyapi kta e wiyeya unpi kta.

12 Unkan Lewi kin napepi ta207 
tanka pa akan awicatputakapi kta, unkan wanji woahtani wośnapi, qa unman wohuhnahyapi Jehowa kicaga wo; hecen Lewi akahpe wicakiciyapi kta.

13 Unkan Aaron itokam, qa iye cinca itokam, Lewi kin najin wicayaye kta, qa wicaduwaśte kta, Jehowa tawokosyapi.

14 Israel cinca wicehna tanhan Lewi kin wicadukinunkan kta, hecen Lewi kin mitawa kta.

15 Unkan he iyohakam Lewi kin itkokipapi wakeya wohtani econpi kta e en upi kta; wicaduska, qa wokosyapi on wicaduwinte cinhan.

16 Hena ocowasin maqupi nakaś, Israel cinca wicehna tanhan winyan owasin cinca tokapa hee kiya, Israel cinca caskepi owasin hee kiya, hena mitawa kta e iwicawacu.

17 Israel cinca ehna wicaśta woteca koya, tona caskepi owasin mitawa, Egupta makoce ohna caskepi owasin wicawakaśtaka, anpetu kin he en hena miciwahduwakan nakaś.

18 Unkan Lewi kin wanna iwicawacu, Israel cinca caskepi owasin hee kiya.

19 Qa Asron, qa iye cinca hena yuhapi kta e Israel cinca wicehna tanhan Lewi kin wicawaqu, itkokipapi wakeya ohna Israel cinca tohtanipi econpi kta, qa Israel cinca akahpe wicakiciyapi kta, hecen Israel cinca kin tipi wakan ikiyedan hipi kte śni qa wicehna makośice wanice kta, ikiyedan hipi unkanś makośice yuke kta tuka.

20 Unkan Mowis, qa Aaron, qa Israel cinca omniciye owasin, token Jehowa Mowis Lewi kin ecawicakicon wicaśi kin owasin, he iyecen Israel cinca Lewi kin esawicakiconpi.
21. Unkan Lewi kin ihduskapi, qa wokoyake hdujajapi, unkan Aaron wicayuwinta, Jehowa itokam, wokosyapi wan, qa wicayuska kta e Aaron akahpe wicakiciya.

22 Unkan he iyohakam, Lewi kin itkokipapi wakeya ohna wohtani econpi kta e Aaron itokam, qa iye cinca itokam hipi. Token Jehowa Mowis Lewi kin ecawicakicon ši kin he iyecen ecawicakiconpi.

23 Unkan Jehowa ie ça Mowis heciya.

24 Lewi kin kaken econpi kta, waniyetu wikcemna nonpa sanpa zaptan aktonpi kin hena itkokipapi wakeya en htanipi kin obe en opapi kta.

25 Qa waniyetu wikcemna zaptan aktonpi kin hena wohtani obe kin ayuśtanpi kta, qa icimanna en htanipi kte śni,

26 Tuka sunka wicayapi om taku awanyakapi kin awanyakapi kta e itkokipapi wakeya ohna apeya unpi kta, qa wolitani takudan econpi kte śni, Lewi kin taku awanyakapi kin icalitaka hecen ecawicayecon kta.

\section{WICOWOYAKE 9.}

1 Unkan Israel cinca Egupta makoce etanhan hdinanpapi, waniyetu inonpa wi tokaheya en, Sina hopuza ohna, Jehowa ie ça Mowis heciya.

2 Iyehantu eca Israel cinca woacakśin econpi kta.

$3 \mathrm{Wi}$ kin de anpetu iake topa en hitayetu otahedan he yakagapi kta, iyehantu kinhan tokage owasin, qa tawoyaco owasin iyecen he ecanonpi kta.

4 Unkan Mowiś Israel cinca kin woacakśin kagapi kta kewicakiya. 


\section{WICOWOYAKE 9.}

5 Unkan wi tokaheya anpetu iake topa en, ohtayetu otahedan, Sina hopuza ohna, woacakśin kin kagapi : token Jehowa Mowis econ śi kin owasin hecen Israel cinca kin econpi.

6 Unkan wicaśta wanjigji, wiicaśta wan nagi ye cin on śapapi, heon anpetu kin he en woacakśin kagapi okihipi śni, heon anpetu kin he en Mowis itokam, qa Aaron itokam hinajinpi.

7 Qa wicaśta kin hena heciyapi, Unkiyepi wicaśta wan nagi ye cin on unśapapi, tokeca heyata iyeunyanpi on iyehantu eca, Israel cinca wicehna Jehowa woalii wan unkahipi kte śni he?

8 Unkan Mowis hewicakiya, Kakiya najinpo, Token Jehowa econ niśipi kte cin he nawahon kta.

9 Unkan Jehowa ie ça Mowis heciya,

10 Israel cinca kin hecen ewicaḱiya wo, Niyepi ehna, qaiś nitoicagepi yeye cin ehna, wicaśta tuwe kaśta wicaśta wan nagiye cin on śapa, qaiś tehan icimani un eśta, woacakśin kin Jehowa kicage kta,

$11 \mathrm{Wi}$ inonpa anpetu iake topa en ohtayetu otahedan he kage kta, aguyapi napohyapi śni kici, qa peji pa kici he yute kta.

12 Ongedan hankanna aiyahdeya ohdaptapi kte śni, qa hetanhan huhu wanjidan kaś kawegapi kte śni, woacakśin wokage owasin iyecen heconpi kta.

13 Unkan wicaśta tuwe ska qa icimani un śni, qa woacakśin kage kapin kinhan, wicanagi kin he iye taoyate etanhan kaśpapi kta, iyehantu Jehowa toahi kin kahi śni, heon wicaśta kin he woahtani kin hduhe kta.

14 Unkan wicaśta wan oyate tokeca niyepi om ounye ca woaNum. cakśin kin Jehowa kicage kte cinhan, woacakśin wokage kin, qa woyaco kin owasin iyecen he kage kta. Wicaśta oyate tokeca on, qa tona makoce en tonpi kin on wokage wanjidan duhapi kta.

15 Unkan tipi kin ehdepi anpetu kin "he en malipiya kin tipi kin akahpa, woyaatanin wakeya kin hee, qa htayetu eca tipi iwankam peta iyececa tanin, ihankianna hehanyan.

16 Ohinniyan liececa mahpiya kin he akahpe ca hanyen peta iyececa tanin.

17 Unkan tohan mahpiya kin wakeya iwankapa tanhan warıkan iyaya, hehan Israel cinca ihdakapi, qa tukten mahpiya kin owanji najin kin, heciya Israel cinca kin etipi.

18 Jehowa i kin eciyatanhan Israel cinca kin ihdakapi, qa Jehowa i kin eciyatanhan tipi ehdepi ; tona can malipiya kin tipi kin iwankam yanka hehanyan ihdakapi śni.

19 Qa mahpiya kin tipi iwankam yanka anpetu ota kinhan, Israel cinca taku Jehowa aiwacin wicaśi kin he awacinpi, qa ihdakapi śni.

20 Unkan he iyecen mahipiya kin anpetu tonana tipi iwankam yanke cinhan, Jehowa i kin eciyatanhan owanji unpi, qa Jehowa i eciyatanhan ihdakapi.

21 Unkan mahpiya kin hitayetu etanhan ihanhanna hehanyan owanji yanke ca hanhanna yuwankan iyaye cinhan ihdakapi, anposkan qa hanyen unman tukte kaśta mahpiya kin wankan iyaye cinhan ihdakapi.

22 Anpetu nonpa, qaiś wi wanjidan, qaiś sanpa anpetu ota eśta, mahpiya tipi kin iwankam yanke cinhan, hehanyan 209 


\section{WICAYAWAPI,}

Israel cinca kin wakeya ohna owanji unpi, qa ihdakapi śni ; tuka tohan yuwankan iyaya hehan ihdakapi.

23 Jehowa i kin eciyatanhan wakeya iticagapi, qa Jehowa i eciyatanhan ihdakapi, Jehowa taku awacin wicaśi kin he awacinpi, token Mowis nape on Jehowa econśi kin he iyecen.

\section{WICOWOYAKE 10.}

1 Unkan Jehowa ie ça Mowis heciya,

2 Mazaska yahotonpi nonpa icicaga wo, pagopi hena yakage kta, qa omniciye eyanwicayapaha kta, qa oyate ihdag wicayakiye kta e hena duhe kta.

3 Unkan napin on yahotonpi kinhan omniciye ocowasin niye en yuwitaya hipi kta, itkokipapi wakeya tiyopa ekta.

4 Qa wanjidan on yahotonpi kinhan, itancanpi İsrael kektopawinge en tokapapi kin niye en mniciyapi kta,

5 Qa panyanhanhan dahotonpi kinhan, oyate iwiyohiyanpata tipi kin ihdakapi kta.

6 Qa ake panyanhanhan dahotompi kinhan, oyate itokaga tipi kin ihdakapi kta; ihdakapi lkta e panyanhanhan yahotonpi kta.

7 Qa oyate kin yuwitaya mniciyapi kte cinhan dahotonpi kta, tuka panyanhanhanpi kte śni.

8 Unkan Aaron cinca wawayuśnapi, kin maza yahotonpi kin yahotonpi kta, nitoicagepi yeye cin wokage kin owihanke wanica duhapi kta.

9 Unkan toka niyanpi niciyuśepi kin nitamakocepi ohna azu wicayayapi kinhan, mazayahotonpi kin panyanhanhan ho dahotonpi kta; unkan Jehowa wakan ya210 dapi kin itokam niksuyapi kta, qa toka niyanpi etanhan enihdakupi lita.

10 Unkan anpetu widuśkinpi, qa mniniciyapi kin en, qa wi nitawapi anpetu tokaheya en mazayahotonpi kin hoton yayapi kta, wohuhnahyapi nitawapi iwankam, qa wopida wośnapi nitawapi iwankam, qa hena on tuwe wakan yadapi itokam niksuyapi kta, Jehowa wakan yadapi kin he miye.

11 Unkan waniyetu inonpa wi inonpa wi anpetu wikcemna nonpa en, malipiya kin wayaatanin tipi iwankapa tanhan wankan iyaya.

12 Unkan Israel cinca kin unhdakapi iyecen Sina hopuze kin etanhan ihdakapi ; unkan mahpiya kin Paran hopuze kin en iyotanka.

13 Hehan tokaheya Mowis nape eciyatanhan Jehowa ie cin iyecen ihdakapi.

14. Unkan Juda cinca wicoti obe wiyokiye kin tokaheya ihdakapi, qa obe tawa mdetanhunka kin Natison Aminadab cinhintku kin hee.

15 Unkan Isalkar cinca wicoun mdetanhunka kin Netaneel Tzuhar cinhintku kin hee.

16 Unkan Zebulun cinca wicoun mdetanhunka kin Eliyab Helon cinhintku kin hee.

17 Hehan tipi wakan kin yujujupi qa Gerśon cinca kin, qa Merari cinca kin tipi kin yuha ihdakapi.

18 Hehan Ruben wicoti obe wiyokiye ihdakapi, qa obe tawa mdetanhunka kin Elitzur Śedeur cinhintku kin hee.

19 Unkan Simeon cinca wicoun mdetanhunka kin śelumiel Tzuriśada cinhintku kin hee.

20 Qa Gad cinca wicoun mde- 


\section{WICOWOYAKE 11.}

tanhunka kin Eleasap Duel cinhintku kin hee.

21. Hehan Qohati kin taku yuwakanpi kin yuha ihdakapi, qa nahanh̉in ekta kipi śni unmanpi tipi kin ehdepi.

22 Hehan Epraim cinca wicoti wiyokiye kin ihdaka obe tawapi kin iyecen, qa obe tawa mdetanhunka kin Amihud cinhintku Eliśama hee.

23 Unkan Manaśe cinca wicoun obe mdetanhunka kin Gamaliel Pedatzur cinhintku kin hee.

24. Unkan Benjamin cinca wicoun obe mdetanhunka kin Abidan Gideoni cinhintku kin hee.

25 Hehan wicoti owasin hakam Dan cinca wicoti wiyokiye ihdaka, obe tawa kin iyecen, qa obe tawa mdetanhunka kin Ahiezer Amiśada cinhintku kin hee.

26 Unkan Aśer cinca wicoun obe mdetanhunka kin Pagiel Okran cinhintku kin hee.

27 Unkan Naptali cinca wicoun obe mdetanhunka kin Ahira Enan cinhintku kin hee.

28 Israel cinca obepi ihdakapi eca hecen ihdakapi.

29 Unkan Nowis Hobab Raguel cinhintku Midiani kin, Mowis tahanku kin heciya, Unkiyepi oyanke wan Jehowa cajeyate ça he cicupi kta unkekiyapi heciya unkihdakapi, Iho opa wo, kinhan taku waśte ecaunniconpi kta, Jehowa Israel taku waśte icaje wicayate nakaś.

30 Unkan, Mde kte śni, tuka makoce mitawa, qa wicowazi mitawa ekta wahde kta, eciya.

31 Unkan tokin ehpe unyayapi śnin. Niye hopuze kin sdonyaya tukten euntipi kta, hecen iśta unniyanpi kta.

32 Qa unkiyepi om idade cinhan kaketu kta, token Jehowa taku waśte ecaunkiconpi, he iyecen taku waśte ecaunniconpi kwa,eya.

33 Unkan Jehowa lie tawa etanhan ihdakapi, anpetu yamni canku yeyapi, unkan Jehowa wicotakuye can wohnake kin wicitokam iyaya anpetu yamni canku yapi kin, tukten etipi kta iwanwicakiciyake kta heon etanhan.

34 Qa wicotipi etanhan ihdakapi eca, Jehowa tamahpiya kin anposkan wiciwankan un.

35 Unkan kaketu can wohnaka kin iyaya eca Mowis heya, Jehowa najin ye, qa toka niyanpi kin enanakiya iyayapi kta, qa tona śicenidapi kin nitokapa tanhan najicapi kte.

36 Unkan tipi ehdepi eca, Jehowa hdi ye Israel kektopawinge ota kin ekta, eya.

\section{WICOWOYAKE 11.}

1 Unkan oyate kin Jehowa noge ohna śicaya śicahowayapi Jehowa nation qehan canniyan, qa Jehowa tapeta aide wicaye ça wicoti ihanke en luhinah wicaya.

2 Unkan oyate kin Mowis hoye kiyapi; unkan Mowis Jehowa cekiya, hecen peta kin anapta.

3 Unkan oyanke kin he Tabera (Wohuhnaga) eya caje yata; hen Jehowa tapeta huhnah wicaya nakaś.

4 Wanna wicota yuwitaya hipi, qa owicapapi kin hena nina wakonpi ; unkan Israel cinca kin nakun ake ceyapi qa heyapi, Tuwe tado yun unkiyapi kta hwo.

5 Egupta ohna hogan imnahan untapi kin he unkiksuyapi ; nakun saka yutapi ocaje nonpa, qa pśin ocaje yamni. 


\section{WICAY AW API,}

6 Tuka wanna unnagipi śeca aya, takudan wanunyakapi śni, manna kin de heceedan.

7 Unkan manna kin korianna su kin hinskokeca, qa wanyakapi kin inyan wicaśake iyececa tanin.

8 Unkan oyate kin enanakiya iyayapi, qa he mnayanpi, qa wiyukpan ohna yukpanpi, qaiś wibope en bopanpi, qa cega ohna śpanyanpi, qaiś aguyapi hmiyanyanna cahota ohna śpanyanpi, qa utapi kin aguyapi skuya wihdi icicayapi utapi kin he iyececa.

9 Unkan cu kin hanyen wicoti ahinhpaye çehan manna kin he akan hiyu.

10 Unkan Mowis oyate kin wicowazipi kin ecekcen ceyapi nawicahon, wicaśta otoiyohi tawakeya tiyopa ohna, unkan Jehowa nina śihda nalrun Mowis he śicedaka.

11 Unkan Mowis Jehowa heciya, Tokeca nitaokiye śicaya icayecon, qa tokeca nitokam woiyokipi iyewaye śni he ? oyate kin de iyuhpa wicaqin mayakiya he?

12 Miye oyate kin de iyuhpa cinca wicawaton he? qaiś miye cinca wicawakaga on, Itpi ohna wicayuha wo, wicaśta wan iye cinhintku azin hduhe cin he iyecen emayakiya, hecen makoce wan hunkake wicayapi wicayaqu kta yakonze cin heciya awicamde kta.

13 Tokiya tanhan tado mduhe ca oyate kin de iyuhpa wicawaqu kta he? wanna amaceyapi, qa, Tado unqu po, hecen untapi kta, eyapi.

14. Oyate kin de miśnana mduha kta owakihi śni, waqin kta isanpa tke nakaś.

15 Hecen ecamiyecon kinhan, 212 tokin te mayayen, woiyokipi nitokam iyewaye cinhan, hecen mitoiyokiśice cin wanwahdake kte śni.

16 Unkan Jehowa Mowis heciya, Oyate hunkayapi etanhan wicaśta wikcemna śakowin mniciye wicakiya wo, miye ekta, wicaśta oyate kin hunka wicayapi heca sdonwicayaya, qa itancan hecapi, qa itkokipapi wakeya ekta hiyu wicayaye kta; unkan niye kici hen najinpi kta.

17 Unkan miś kun wau, qa hen nici wowahdake kta, qa woniya niye en un kin etanhan emdaku kta, qa hena en ye waye kta; unkan niśnana oyate kin wicaduha kte śni, hena nici wicayuhapi kta.

18 Unkan oyate kin hewicayakiye kta, Heyake cinhan on ihduwakan po; hecen tado yatapi kta; yaceyapi, qa Tuwe tado yun unkiyapi kta he? Egupta ohna tanyan unyakonpi ehapi kin he Jehowa noge kin iyohipaya, heon Jehowa tado niçupi kta, qa yatapi kta.

19 Anpetu wanjidan yatapi kte śni, qa anpetu nonpa kte śni, qa anpetu zaptan kte śni, qa anpetu wikcemna kte śni, qa anpetu wikcmna nonpa kte śni ;

20 Tuka wi wanji anpetu owasin hehanyan, nipogepi etanhan inanpe ca hitiyahdapi kte cin hehanyan; Jehowa niyepi ehna un kin he ihayaktapi śni, qa yaceyapi qa, Tokeca Egupta etanhan inanunpapi he? ehapi, heon etanhan.

21 Unkan Mowis heya, Oyate ehna waun kin de kektopawinge opawinge śakpe ozuye huiyunpi ; unkan tado wicawaqu kta, qa wi wanji ihunniyan yutapi kta, eha.

22 Tahinca qa pte wicakipa- 


\section{WICOWOYAKE 12.}

tapi kta, qa hecen lyowicahi kta? qaiśs miniyowancaya hogan owasin mnawicakiciyapi kta, qa hecen iyowicahi kta he?

23 Unkan Jehowa Mowis heciya, Jehowa nape kin kaksapi he? Dehan mioie ecetu niciye kta, qaiś ecetu niciye kte śni hecinhan wandake kta.

24. Unkan Mowis tankan inanpe ca Jehowa oie kin oyate kin owicakiyaka, qa oyate hunkawicayapi etanhan wicasta wik cemna śakowin mnawicaya, qa wakeya qon ihdukśan najin wicakiya.

25 Unkan Jehowa mahipiya śapa wan ohna kun hiyu, qa kici wohdake ca woniya iye en un kin hetanhan icu, qa hunkayapi wicaśta wikcemna sakowin qon akan awicahnaka; unkan woniya kin aozi wicaye çehan waayatapi, tuka icimana econpi śni.

26 Tuka wicaśta nonpa wicoti ohna owanji yakonpi, wanji Eldad eciyapi, qa unman Medad eciyapi, qa woniya kin iyawicahan, qa hena owicawapi qon en opapi, tuka wakeya qon ekta ipi śni, qa hena wicoti ohna waayatapi.

27 Unkan kośka wan inyanke ca Mowis okiyake ça, Eldad qa Medad wicoti ohna waayatapi ce, eya.

28 Unkan Nun cinlintku Jośuwa; Mowis taokiye, kośka kahinigapi heca wan ayupte ça heya, Itancan Mowis wicakiśica wo.

29 Unkan Mowis heciya. Miye on etanhan winayawizi he? Tokin Jehowa taoyate kin iyulipa waay atapin, qa Jehowa toniya kin owasin wicaqun.

30 Unkan Mowis wicoti kin ekta kihda, iye qa Israel hunkawicayapi.
31 Unkan tateyanpa wan Jehowa eciyatanhan iyaye ca mde kin akotanhan śiy o icu, qa wicoti akan, qa wicoti ihdukśan anoka tanhan, anpetu wan imanipi kin hehanyan ahinhe wicaya, wiciśpa nonpa maka akan.

32 Unkan oyate kin najinpi, anpetu kin he osan, qa hanyetu osan, qa ihanhianna anpetu osan, qa ślyo kin mnayanpi; tuwe aopten mnayan eśta opaha wikcemna muayan, qa hduhapi kta e wicoti ihdukśan hena pceyapi.

33 Unkan conica nahanhin hipi ohna yanka, yasotapi śni itokam Jehowa tocanniye oyate kin aide wicaya, qa Jehowa makośice teliike hinca on oyate kin a wicapa.

34 Unkan oyanke kin he Qiberot Hatawa (Akaskapi kin wicahnakapi,) eya cajeyatapi ; oyate akaskapi kin hen wicahnakapi nakaś.

35 Unkan Qiberot Hatawa etanhan ihdakapi, Hazerot ekta, qa Hazerot en yakonpi.

\section{WICOWOYAKE 12.}

1 Hehan Miriam qa Aaron Mowis kigepi, Kuśi winohinca yuze cin heon etanhan, Kuśi winohinca wan yuza nakaś.

2 Qa heyapi, Awicakehan Jehowa Mowis iśnana ie kiya he? Unkiś nakun ie unkiyapi śni he? unkan Jehowa he nałion.

3 Wanna wicaśta maka akan hiyeye cin owasin Mowis iśnana wicaśta wahibadan.

4 Unkan ihnuhanna Jehowa Mowis, Aaron, qa Miriam hewicakiya; Upo niyamnipi itkokipapi wakeya ekta, Unkan hena yamni ekta ipi.

5 Unkan Jehowa mahipiya bo213 


\section{WICAYAWAPI,}

sdata ohna kun hiyu, qa itkokipapi wakeya tiyopa ekta yanke ca Aaron qa Miriam wicakipan; unkan napin ekta inanpapi.

6 Unkan heya, Mioie kin nalonpo, Niyepi ehna waayate wan yuke cinhan, iye en Jehowa mihdutanin kta wowanyake en, qa wowihamde en taku ewakiye kta.

7 Tuka mitaokiye Mowis iś hecece śni, wati ocowasin ohna iye wacinye pica.

$8 \mathrm{He}$ i i kici wowahdake taninyan, qa hanmdohdake śniyan, qa Jehowa ouncage kin he atonwan, heon tokeca mitaokiye Mowis ayaiapi kin koyakipapi śni he?

9 Qa Jehowa canniye wicaye ca kihda.

10 Qa mahpiya kin wakeya kin etanhan wankan iyaya; unkan inyun Miriam leprosi ececa, wa iyececa, unkan Aaron Miriam ekta etonwan, unkam leprosi ececa.

11 Hehan Aaron Mowis heciya, Itancan ceciya, tokin woahtani kin de ecinśniyan waunhtanipi kin aunkihnakapi śni miyen.

12 Tokin taku hunku tezi kin etanhan ta inanpe ca celipi hanke sote cin iyecece kte śnin.

13 Unkan Mowis Jehowa hoyekiye ca heya, Iyotan waśaka ceciciye, wanna okiziya ye.

14 Unkan Jehowa Mowis heciya, Atkuku kin he ite kin atagośa unkanś anpetu śakowin iśtece kte śni he? anpetu śakowin wicoti itankan natakapi kta, qa ohakam en hdi kta.

15 Unkan anpetu śakowin hehanyan Miriam wicoti itankan natakapi, qa Miriam en hdi śni kin hehanyan oyate kin ihdakapi śni.
16 Unkan ohakam oyate kin ihdakapi, Hazerot etanhan, qa Paran hopuza en etipi.

\section{WICOWOYAKE 13.}

1 Unkan Jehowa ie ca Mowis heciya,

2 Kanan makoce Israel cinca wicawaqu kin he iwanniciyakapi kta e wicaśta ye wicaśi wo. Ate wicayapi wicoun otoiyohi etanhan wicaśta wan ye yaśi kta, hena wicehna owasin itancanpi hecapi.

3 Unkan Mowis Jehowa i kin eciyatanhan Paran hopuze kin etanhan ye wicaśi, wicaśta kin hena owasin. Israel cinca mdetanhunka hecapi.

4 Qa cajepi kin dena eepi, $R u$ ben wicoun etanhan Śamuha Jakur cinhintku.

5 Simeon wicoun etanhan Śapat Hori cinhintku.

6 Juda wicoun etanhan Kaleb Jepune cinhintku.

7 Isakar wicoun etanhan Igal Josep cinhintku.

8 Epraim wicoun etanhan Hośeya Nun cinhintku.

9 Benjamin wicoun etanhan Patti Rapu cinhintku.

10 Zebulun wicoun etanhan Gadiel Sodi cinhintku.

11 Josep wicoun on Manaśe wicoun etanhan Gadi Susi cinhintku.

12 Dan wicoun etanhan Ammiel Gemali cinhintku.

13 Aśer wicoun etanhan Setur Mikael cinhintku.

14. Naptali wicoun etanhan Nalibi Wapsi cinhintku.

15 Gad wicoun etanhan Guel Maki cinhintku.

16 Wicaśta Mowis makoce kin iwanyag ye wicaśi cajepi kin hena eepi. Qa Mowis Hośeya 


\section{WICOWOYAKE 14.}

Nun cinhintku kin Jehośuwa eya cajeyata.

17 Unkan Mowis Kanan makoce kin iwanyag ye wicaśi, qa hewicakiya, Deciya itokaga en yapo, qa he kin itan wankanhde yapi.

$18 \mathrm{Qa}$ makoce kin he toketu wandakapi kta, nakun oyate en ounyanpi kin, waśakapi, qaiś wankapidan unman tukte hecinhan, nakun tonana, qaiś otapi.

19 Qa makoce ounyanpi kin he waśte qaiś śica, qa otonwe otipi kin hena, wakeya otipi, qaiś conkaślke otipi.

$20 \mathrm{Qa}$ makoce kin cepa qaiś tamaheca unman tukte, ohna can yukan qaiś can wanica. Waditakapo, qa makoce waskuyeca kin etanhan icupo, eya. Unkan he ehan hastanhanka toka suton.

21 Unkan iyayapi qa makoce kin iwanyakapi, Tzin hopuza etanhan Hamat ektakiya yapi, Rehob ekta hehanyan.

$22 \mathrm{Qa}$ itokaga en ipi, qa Ḣebron ekta hipi. Unkan Anaq cinca Ahiman, Śśa, qa Talma hen yakonpi. Unkan Tzohan Egupta ohna kagapi he itokam waniyetu śakowin Hebron kagapi. 23 Unkan Eślkol kaksiza kin en hipi, qa hetanhan adetka wan kaksapi, qa hastanhanka iyage wanjidan, qa cansagye wan akan akiyuhapi, nakun taspantanka su ota, qa witanśnan etanhan akiyuhapi.

24 Oyanke kin he Eśkol (Iyage) kaksiza eciyapi, Israel cinca kin hastanhanka iyage wan hetanhan kaksapi heon etanhan.

25 Unkan anpetu wikcemna topa hehan makoce iwanyakapi kin etanhan hdipi.

26 Hecen iyayapi qa Mowis ekta, qa Aaron, qa Israel cinca omniciye ocowasin ekta hdipi,
Qadeś, Paran hopuza ohna un kin ekta, qa hośi wicakahdipi, qa makoce waskuyeca wicakipazopi.

27 Qa okiyakapi qa heyapi, Makoce wan ekta ye unyaśipi kin he ekta unkipi, qa awicakehan pteasanpi qa canhanpi tiktica ohna kaduza, qa waskuyeca aicage cin dee.

28 Hececa eśta oyate makoce ounyanpi kin waśakapi, qa otonwe tawapi kin aconkaśkapi, qa nina tankinyanyan. Nakun Anaq cinca kin heciya wanwicunyakapi.

29 Amaleqi makoce itokahi ounyanpi, qa Heti kin qa Jebusi kin qa Amori kin $\dot{H} e$ kin en ounyanpi, qa Kanani miniwanca icahda, qa Jordan omdaye kin ouny anpi.

30 Unkan Kaleb Mowis itokam oyate inina yanke wicasi, qa heya, Itanwankanhde unyanpi, qa unhduhapi kta iyececa, ohiunyanpi kta waunśakapi.

31 Tuka wicaśta iye kici iyayapi qon heyapi, Oyate kin he ekta itanwankanhde unyanpi unkokihipi śni; hena unkiyepi isanpa waśakapi nakaś.

32 Qa makoce iwanyag ipi qon Israel cinca itokam aiapi, qa heyapi, makoce ohna iyaunyuptapi, qa iwanunyakapi kin tona ounyanpi kin wicayasota, qa oyate ohna wanunyakapi kin owasin wicaśta hanskaskapi.

$33 \mathrm{Qa}$ hen waziya wanwicunyakapi Anaq cinca kin, hena waziya etanhan icagapi qa wicitokam psipsicadan iyeuncecapi.

\section{WICOWOYAKE 14.}

1 Unkan omniciye ocowasin hoyeyapi, qa oyate kin hanyetu kin he ceyapi. 


\section{WICAYAWAPI,}

2 Qa Israel cinca owasin Mowis qa Aaron aiwicahnupi, qa omniciye owasin hena hewicakiyapi, Tokin Egupta makoce ohna untapin, qaiś hopuza kin de ohna unțapin.

3 Qa tokeca Jehowa makoce kin de elkta hiyu unyanpi, hecen canhipi on unhinhpayapi kta, unkitawinpi, qa unkicincapi nakun wayaka unpi kta? Egupta ekta unhdapi kinhanl waśte kta naceca.

4 Unkan hekiciyapi, Mdetanhunka wan unkagapi, qa Egupta ekta unhdapi kta.

5 Unkan Mowis qa Aaron makipusdiya hinhpeiciyapi, Israel cinca omniciye owasin wicitokam.

6 Unkan Jośuwa Nun cinhintku, qa Kaleb Jepune cinhintku makoce iwanyakapi etanhanpi wokoyake hduhdehdecapi.

7 Qa Israel cinca omniciye owasin hewicakiyapi, makoce iwanyakapi kta e iyaunyuptapi kin he makoce wan nina waśte hinca.

8 Jehowa iyounkipipi kinhan, makoce kin he ekta ye unkiyapi kta, qa makoce pte asanpi qa canhanpi tiktica kaduze cin he unqupi kta.

9 Takomni ihnuhan yakipajinpi kin, qa makoce oyate kin ihnuhan ikowicayapapi kin aguyapi unkitawapi iyececapi kta, taku wacinyanpi kin he elipewicaya; tuka Jehowa unkicipi un. Ihnuhan ikowicayapapi kin.

10 Unkan omniciye owasin inyan on wicaktepi kta keyapi qehan, Jehowa towitan kin itkokipapi wakeya akan Israel cinca owasin ekta ihdutanin.

11 Unkan Jehowa Mowiś heciya, Tohanyan oyate kin de ihamaktapi kte śni he? qa to216 hanyan wowapetokeca wicehna ecamon on wicamadapi kte śni he?

12 Makośice on awicawape ca ihang wicawaye kta, qa niye etanhan oyate wan tanka, qa hena isanpa waśaka wakage kta.

13 Unkan Mowis Jehowa heciya, Kinhan Egupton he nahonpi kta, hena wicehna tanhan nitowaśake tanka on oyate kin de hiyu wicayaya.

14. Qa makoce kin de ounyanpi kin hewicakiyapi, Niye Jehowa oyate kin de wicehna yaun, qa niye Jehowa iśta kin iśtapi en nihdutanin, mahpiya bosdata wiciwankan, qa anposkan malipiye bosdata ohna wicitokam idade, qa hanyetu eca peta bosdata ohna, he wanna nahonpi.

15 Unkan oyate kin de wicaśta wanjidan iyecen te wicayaye cinhan, oyate niye on wotanin nahompi kin hecen eyapi kta.

16 Jehowa makoce wakicons owicakiyake ciqon, he ekta hiyu wicaye kta olihi śni, heon hopuza ohna wicakte.

17 Tolkin, itancan towaśake kir tanka kten, kehe ciqon he iyecen.

18 Jehowa tehan śihda śni, tocantekiye tanka; wicohan śca, qa wokipajin kajuju ece, tuka ohinniyan kajuju kte śni, ateyapi wicolian śicapi kin wicoicage iyamni, qa itopa kin hehanyan awicahi ece.

19 Tokin oyate kin de wahtanipi kin wicakicajujun, nitowacantkiye tanka kin iyecen, qa Egupta etanhan dehanyan oyate kin de wicayecicajuju kin he iyecen.

20 Unkan Jehəwa heya, wicawecicajuju, ehe cin he iyecen. 
21 Qa hececa eśta wani kin iyecen Jehowa towitan kin maka owancaya ojudan ye kta.

22 Takomni wicaśta kin tona mitowitan wanyakapi, nakun wowapetokeca ecamon Egupta ohna, qa Hopuza ohna, qa wikcemna akihde iyutan mayanpi, qa maho kin nalionpi śni kin hena owasin,

23 Makoce hunkake wicayapi kin wakicons owicawakiye cin he wanyakapi kte śni ; ihamaktapi śni kin hena etanhan wanjidan he wanyakapi kte śni.

24. Tuka mitaokiye Kaleb woniya tokeca yuhe cin heon, qa ohinniyan mihakam $u$, heon makoce ekta i qon he ekta hiyu waye kta, qa iye cinca kin he tawayapi kta.

25 Wanna Amaleqi qa Kanani kaksiza ohna yakonpi, heon heyakecinhan ihdamnapi, qa Mdeśa ekta-kiya, Hopuza ohna ihdaka po.

26 Unkan Jehowa ie ca Mowis, qa Aaron hewicakiya;

27 Tohanyan omniciye śice kin de imahnupi kin wicawecicajuju kta he? Israel cinca wihnupi imahnupi kin he nawahon ce.

.28 Hecen ewicakiya wo. Jehowa heya, Wani kin hecen token ehapi nawaron kin he iyecen ecaciconpi kta.

29 Ḧopuza kin de ohna nitancanpi kin hinhpayapi kta, tona niyawapi, oniwapi qon iyecen waniyetu wikcemna nonpa aktonpi, tona imahnupi owasin etanhan ;

30 Ohna ounyayapi kta nape hduwankan iwacu qon awicakehan makoce kin he en yaipi kte śni; tuka Kaleb Jepune cinhintku qa Jośuwa Nun cinhintku kin henana en ipi kta.

31 Nakun nitaśicecapi kin wa- yaka unpi kta kehapi qon, hena ekta awicamde kta, unkan makoce ihayaktapi śni kin he sdonyapi kta.

32 Tuka niyepi nitancanpi kin hopuze kin den hinhpayapi kta.

33 Tuka nicincapi hopuza ohna wiliankiya unpi kta, waniyetu wikcemna topa, qa wawiciliahapi ecanonpi kin hdajujupi kta, nitancanpi kin owasin hopuza ohna sotapi kte cin hehanyan.

34 Tona can makoce iwanyakapi kin anpetu wikcemna topa anpetu otoiyolii on waniyetu wan yawapi kta, waniyetu wikcemna tom, hehanyan way ahitanipi kin yahdajujupi kta, qa mitocanniye kin sdonyayapi kita.

35 Jehowa miye hepa, omniciye sice cin de miye en amamniciyapi kin awicakehan hecawicawecon kta, hopuza kin de ohna sotapi, qa tapi kta.

36 Unkan wicaśta Mowis makoce iwanyag ye wicaśi, qa makoce śicaya cajeyan hdipi kin heon omniciye ocowasin aihnu wicayapi.

37 Wicaśta makoce śicaya cajeyatapi kin hena makośice on Jehowa itokam tapi.

38 Unkan makoce iwanyag ipi qon hena etanhan Jośuwa Nun cinhintku, qa Kaleb Jepune cinhintku henana nipi.

39 Unkan Mowis wicoie kin hena Israel cinca omniciye owasin owicakiyaka; unkan oyate kin nina liin iyokiśín iciyapi. 40 Unkan hanhanna hin kiktapi qa heyapi, Hopo, oyanke Jehowa cajeyate kin he ekta itanwankanhde unyanpi kte, waunlitanipi nakaś. Qa lie paha kin ekta itanwankanhde ipi.

41 Tuka Mowis hewicakiya, Tokeca decen Jehowa oie kin 217 


\section{WICAYAWAPI,}

acayaksinpi he? He ohna tanyan iyahunipi kte śni.

42 Itanwankanhde yapi śni po, Jehowa niyepi ehna un śni heon, hecen toka niyanpi kin wicitokam anipapi kte śni.

43 Amaleqi qa Kanani kin heciya nitokam yakonpi, unkan canhipi on nihinhpayapi lita. Jehowa etanhan nihdamnapi, heon Jehowa nicipi un śni.

44 Unkan he paha ekta-kiya ihaktapi śniyan itanwankanhde yapi, tuka Jehowa wicotakuye can-wohnaka kin, qa Mowis wicoti cokaya tanhan tokidan ipi śni.

45 Unkan Amaleqi qa Kanani he kin he ounyanpi kin apamahdedan upi qa wicakaśtakapi, qa wicaktepi fHorma ekta hehanyan.

\section{WICOWOYAKE 15.}

1 Unkan Jehowa ie ca Mowis heciya.

2 Ie ca Israel cinca kin hecen ewicalkiya wo, makoce ounyayapi kta e cicupi kin he ekta yaipi kinhan.

3 Qa peta wośnapi wan Jehowa yecagapi, wohuhinahyapi, qaiś woyakapi hdajujupi wośnapi, qaiś taku ikce qupi on, qaiś mniniciyapi on, woomna Jehowa iyokipi yecagapi kinhan, pte etanhan qaiś tahinca etanhan.

4 'Tuwe woahi Jehowa kahi kinhan, minha wan aguyapr mdu can wakśica ohnaka wan wihdi wiyatke ohnaka wan icicahiyapi ahi kta;

5 Qa woakaśtan on miniśa wiyatke ohnaka wan wohuhnahyapi kin, qaiś wośnapi kin ayakaśtan kta e amnos otoiyohi on;

$6 \mathrm{Qa}$ tamdoka wanjidan on aguyapi mdu can wakśica ohna218 ka nonpa, wihdi wiyatke ohnaka wanji sanpa hanke icicahiyapi minha yecage kta.

7 Qa miniśa wiyatke ohnaka wanji sanpa hanke woakaśtan yakahi kta, woomna Jehowa iyokipi.

8 Qa pte wanunyanpi cinca wohuhnahyapi qaiśs woyakapi hdajuju wośnapi, qaiś wopida wośnapi Jehowa yecage kte cinhan ;

9 Pte cinca wan on aguyapi mdu can wakśsica ohnaka yamni, wihdi wiyatke ohnaka nonpa icicahiyapi minha kahi kta.

10 Qa woakaśtan on miniśa wiyatke ohnaka nonpa yakahi kta, peta wośnapi woomna Jehowa iyokipi.

11 Hecen econpi kta tatanka otoiyohi on, qa tamdoka otoiyohi on, qa tacincadan on, tahinca ska qaiś tatokadan cincadan on.

12 Tona waduśnapi kin iyenaka yawapi iyecen otoiyohi on hecen ecanonpi kta.

13 Tona makoce en tompi kin hena owasin hecen econpi kta, peta wośnapi woomna Jehowa iyokipi kahipi eca.

14 Unkan tuwe oyate tokeca niyepi ehna ihdaka, qaiś niyepi ehna ounye cinhan nitoicagepi yeye cin, qa peta wośnapi waśtemna Jehowa iyokipi kage cinhan token niye ecanonpi kin he iyecen econ kta.

15 Omniciye, wokage wanjidan kta, niyepi on, qa tuwe oyate tokeca niyepi ehna yanke cin on ; wokage owihanke wanica nitoicagepi yeye cin, Jehowa itokam token yaunpi kin he iyecen tuwe oyate tokeca kin un lita.

16 Niyepi on, qa tuwe oyate tokeca niyepi ehna ounye cin on woope wanjidan, qa woyaco wanjidan kta. 


\section{WICOWOYAKE 15.}

17 Unkan Jehowa ie ca Mowis heciya,

18 Ie ca Israel cinca kin hecen ewicakiya wo, Makoce wan ekta ye ciyapi kin he ekta yaipi kinhan;

19 Qa maknce taku aicage cin yatapi kinhan, wokosyapi wan Jehowa yaqupi kta.

20 Taku tokaheya boyapanpi kin etanhan aguyapi hmiyanyanna wokosyapi wan yaqupi kta, aguyapi su kapanpi wokosyapi kin he iyecen, he yakozapi kta.

21 Tokaheya boyapanpi etanhan wokosyapi wan Jehowa yaqupi kta, nitoicagepi yeye cin.

22 Unkan ecinśniyan wayahtanipi, qa woahope kin dena Jehowa Mowis eciye cin owasin ecanonpi śni kinhan;

23 Taku Jehowa Mowis nape on econ niśipi owasin, anpetu wan Jehowa Mowis taku econ śi kin hetanhan, qa tokata nitoicagepi yeye cin ohna ecanonpi śni kinhan ;

24 Qa omniciye sdotkiyapi śni taku ecinśniyan econpi kinhan, omniciye ocowasin tatanka wan pte wanunyanpi cinca wohuhnahyapi kage kta, woomna waśte Jehowa iyokipi, minlia kin iyahna, qa nakun woakaśtan kin woyaco kin iyecen, nakun tatokadan mdoka wan woahtani wośnapi on.

25 Unkan wawayuśna kin Israel omniciye ocowasin akahpe wicakiciye $\mathbf{k t a}$, unkan wicakicicajujupi kta, ecinśniyan econpi nakaś, qa toahipi petá wośnapi kin Jehowa kahipi, qa ecinśniyan econpi Jehowa itokam on woałtani wośnapi nakun,

26 Hecen oyate iyuhpa sdonye śni econpi heon Israel cinca, qa tuwe oyate tokeca wicehna ti kin omniciye ocowasin wicakicicajujupi kta.

27 Unkan wicanagi wan ecinśniyan wahtani kinhan, tatokadan wiyedan waniyetu wanjidan wahtani kin on ahi kta.

28 Unkan wawayuśna kin wicanagi ecinśniyan wahtani kin akahpe kiciye kta, ecinśniyan wahitani wośnapi Jehowa itokam akahpe kiciye kta on, unkan kicicajujupi kta.

29 Tona ecinśniyan wahtanipi on woope wanjidan duhapi kta Israel cinca makoce tawayapi on, qa tuwe oyate tokeca niyepi ehna ti kin on.

30 Unkan wicanagi tuwe wahan-içidaya taku śic:a econ kin he makoce tawayapi etanhan, qaiś oyate tokeca etanhan, wicanagi kin he Jehowa kipajin, heon oyate tawa etanhan kaśpapi kta. 31 Jehowa oie kin ihakta śni, qa tawoahope kin iśtenya, heon wicanagi kin he tohan śica hduha taoyate kin ctanhan kaśpapi kta.

32 Unkan Israel cinca Ḣopuza en yakonpi qehan, wicaśta wan anpetu wakan icunhan, cande kin iyeyapi.

33 Qa he cande iyeyapi kin hena Mowis ekta, qa Aaron ekta, qa omniciye ocowasin ekta kahipi.

34 Qa kaśka hnakapi, token ecakiconpi kta, nahahin owicakiyakapi śni nakaś.

35 Unkan Jehowa Mowis heciya, Wicaśta kin awicakehan te kta, omniciye ocowasin, wicoti itankan, inyan on kininpi kta.

36 Unkan omniciye ocowasin wicoti itankan inanpe yapi, qa inyan on kininpi, Jehowa Mowis econ śi kin he iyecen, unkan ta. 37 Unkan Jehowa ie ca Mowis heciya. 


\section{WICAYAWAPI,}

38 Israel cinca owawicakiye ça wicoicagepi yeye cin tawokoyakepi opapun ekta olicilici icicagapi kta, qa opapun olicilici akan hahonta to wan pahtapi kta, kewicakiya wo.

39 Qa he wowapetogton duhapikta, qa wandakapi kta, qa Jehowa tawoahope owasin yeksuyapi qa ecanonpi kta, hecen nicantepi opeya, qa miiśtapi opeya yanunipi kte śni, hena opeya wiyacinpi ece qon iyecen.

40 Hecen mitawoahope owasin yeksuyapi qa oyapapi kta, qa tuwe wakanyadapi taoyate wakan yaunpi kta.

41 Jehowa Wakan yadapi kin he miye, qa Wakan mayadapi kta e Egupta makoce etanhan hdinanpe ciyapi, Jehowa Wakanyadapi kin he miye.

\section{WICOWOYAKE 16.}

1 Unkan Qora Itzar cinhintku Qohat cinhintku Lewi cinhintku, qa Datan qa Abiram Eliab cinca kin, qa On Pelet cinhintku Ruben cinca etanhan wohdakapi.

$2 \mathrm{Qa}$ Mowis anajinpi, nakun Israel cinca etanhan wicaśta opawinge nonpa sanpa wikcemna zaptan omniciye itancanpi, wicaśta okinihanpi, omniciye ekta wicakicopi hecapi.

3 Qa Mowis Aaron kici amniciyapi, qa hewicakiyapi, Omniciye ocowasin wicasta otoiyohi owasin wakanpi, qa Jehowa wicacokaya un; heon tokeca Jehowa taomniciye iwankam ye niciyapi, qa niyepi on taku ota yacinpi he?

4 Unkan Mowis he nation qehan makipusdiya ehpe iciya.

5 Qa Qora, qa okodakiciye tawa owasin hewicakiya, Hanhanna kinhan Jehowa tuwe tawa kin, qa tuwe wakan, qa tuwe iye ikiyedan hiyuye cin hdutanin kta, ya tuwe katinige cin he iye ekta ikiyedan hiyuye kta.

6 Decen econ po, Qora qa okodakiciye tawa owasin oizinye icupo.

7 Qa hena ohna peta ehnaka po, qa akan wizinyapi akada po. Jehowa itokam heyakecinhan, hehan wicaśta tuwe Jehowa kahnige cin hee wakan kta; Lewi cinca niyepi on taku ota yacinpi.

8 Nakun Mowis Qora heciya, Lewi cinca kin namahonpo.

9 Taku Israel wakandapi kin Israel omniciye etanhan niyepi niyukinunkanpi, iye ikiyedan hiyu niyanpi, Jehowa ti wolitani kin ecanonpi kta, qa omniciye itokam nayajinpi qa owicayakiyapi kta, he taku śni yadapi he?

10 Nakun niye qa nihunkawanji Lewi cinca owasin niye kici ikiyedan hiyuniyanpi: -unkan nakun wawayuśnapi henicapi kta e ayakitapi he?

11 Hecen niye qa okodakiciye nitawa owasin Jehowa en amniniciyapi, tuka Aaron taku econ hwo on he iyahnupi.

12 Unkan Mowis tuwe Datan qa Abiram Eliab cinca wicakico ye śi qon, unkan, Ekta unyanpi kte śni eyapi.

13 Hopuza ohna te unyayapi kta, makoce wan pte asanpi qa canhanpi tiktica ohna kaduze cin etanhan inanpe unyayapi kin he taku śni yada, heon unkiyepi iwankam wicaśta yatapi itancan nicicage kte he?

14 Hiya makoce pte asanpi qa canhanpi tiktica ekta hiyu unyayapi śni qa maga qa hastanhanka iyuwi ojupi tawa un- 


\section{WICOWOYAKE 16.}

yanpì kta e unyaqupi śni, Wicaśta kin dena iśtapi kin duśdoke kta he? Ekta unyanpi kte śni ce.

15 Unkan Mowis nina canteptanyan, qa Jehowa heciya, Minha tawapi kin ihakta śni ye. Hena etanhan śuktanka śonśonna wanjidan iwacu śni, qa iyepi wanjidan wakimduśe śni.

16 Unkan Mowis Qora heciya, Heyakecinhan niye qa okodakiciye nitawa owasin Jehowa itokam u po, niye qa iyepi qa Aaron.

17 Qa niyepi otoiyohi oizin e ikikcupo, qa hena akan wizinyapi akada po, qa wicaśta opawinge nonpa sanpa wikcemna zaptan oizinyapi ayahipi kta, Jehowa itokam; nakun niye qa Aaron otoiyohi oizinya tawa hduha po.

18 Unkan otoiyohi oizinye ikikcupi, qa peta aehnakapi, qa wizinye akadapi, qa itkokipapi wakeya tiyopa ekta najinpi, nakun Mowis qa Aaron.

19 Unkan Qora okodakiye tawa iyuhpa mnawicaya, itkokipapi wakeya tiyopa ekta; unkan Jehowa towitan kin ornniciye ocowasin en ihdutanin.

20 Unkan Jehowa ie ça Mowis Aaron kici hewicakiya,

21 Omniciye kin de etanhan ihdukinunkanpo, kinhan ihnuhanna wicamdusote kta.

22 Tuka makipusdiya ehpeiciyapi, qa heyapi, Iyotan Waśaka wicacehpi owasin toniyapi wakan nidapi, wicaśta wanjidan wahtani kin heon omniciye iyuhpa canniye wicayaye kta he?

23 Unkan Jehowa ie ca Mowis heciya.

24 Ie ça oyate kin Qora qa Datan qa Abiram totipi ihdukśan tanhan tokan iyaya po, ewicakiya wo.

25 Unkan Mowis najin qa Datan qa Abiram yakonpi kin ekta i, qa Israel hunkayapi kin ihakam ipi.

$26 \mathrm{Qa}$ ie ca oyate kin hewicakiya, Ihopo, wicaśta śice kin dena tawakeyapi etanhan tokan iyaya po; qa ihnuhan taku tawapi kin wanji dutanpi kin. Hecanonpi kinhan okini hena wahtanipi owasin ohna ihang niyanpi kta.

27 Unkan Qora Datan qa Abiram tipi kin ihdukśan tanhan tokan iyayapi; Unkan Datan qa Abiram inanpapi qa tawakeyapi tiyopa ekta najinpi, tawicupi qa cinhintkupi qa cunwintkupi nakun.

28 Unkan Mowis heya, wicohan kin dena owasin ecamon kta Jehowa u maśi, qa miye cinka eciyatanhan śni, detanhan sdonyayapi kta.

29 Wicaśta owasin token tapi kin he iyecen wicaśta kin dena tapi kinhan, qa wicaśta owasin taku akipapi kin dena akipapi kinhan Jehowa u maśi śni.

30 Tuka Jehowa taku teca wan kage ça maka kin i hdukawa, qa nawicapca, nakun taku tawapi kin iyuhpa hecen niyake Hades ekta kun yapi kinhan, wicaśta kin dena Jehowa walitedapi śni sdonyayapi kta.

31 Unkan wicoie kin hena owasin eya hdaśtan qehan, maka kin wicihukuya naptuja;

32 Qa maka kin i.kin hdukawa, qa nawicapca, qa tipi kin nakun, qa Qora wicaśta tawa owasin, nakun taku tawapi kin owasin.

33 Hecen iyepi qa taku tawapi owasin Hades ekta niyake ipi, qa maka kin okahpe wicaya, he221 


\section{WICAYAWAPI,}

cen omniciye etanhan awihnunipi.

34 Unkan Israel wicihdukśan yakonpi kin owasin hena śicahowayapi etanhan najicapi, qa heyapi, Okini maka kin naunpcapi kta.

35 Unkan peta Jehowa etanhan inanpe ca wicaśta opawinge nonpa sanpa wikcemna zaptan wizinyapi ahipi qon hena hulinah wicaya.

36 Unkan Jehowa ic ca Mowis heciya,

37 Eleazar Aaron wawayuśna cinhintku kin heciya wo. $\dot{H} u-$ hnali wicayapi wicehna tanhan oizinyapi icu, qa peta kin kakiya ehpeya wo; hena wakan nakaś. 38 Qa wicaśta iye nagipi kin en walitanipi kin hena oizinyapi tawapi kin kamdayapi kta, qa on wahna wośnapi kin akalipapi kta, héna Jehowa itokam ahipi, heon hena wakan; hecen Israel cinca kin hena wowapetogton yuhapi kta.

39 Unkan Eleazar wawayuśna kin mazaśa oizinyapi kin wicaśta huhnah wicayapi ahipi qon icu, unkan wahna wośnapi akalipapi kta kamdayapi.

40 Israel cinca kin he wokiksuye yapi, hecen wicaśta tokeca Aaron cinca hetanhan śni wizinyapi izinye kta e Jehowa itokam ikiyedan hi kte śni, qa Qora qa okodakiciye tawa iyecece kte śni ; Jehowa Mowis nape eciyatankan eciye ciqon he iyecen.

41 Unkan ihanhanna Israel cinca omniciye ocowasin Mowis qa Aaron iwicahnupi qa heyapi, Niyepi Jehowa taoyate te wicayayapi.

42 Unkan omniciye kin Mowis qa Aaron amniciyapi qehan, Itkokipapi wakeya ektakiya etonwanpi; unkan inyun, ma222 lipiya qon he akahipa qa Jehowa towitan kin ihdutanin.

43 Unkan Mowis qa Aaron itkokipapi wakeya itokam hipi.

44 Unkan Jehowa ie ca Mowis heciya.

45 Oyate kin wicehna tanhan ihdukinunkan po, kinhan ihnuhanna wicamdasote kta. Unkan makipusdiya ilipayapi.

46 Unkan Mowis Aaron heciya, Oizinye ikikcu q̃a wahna wośnapi akan tanhan peta aonpa wo, qa wizinyapi akada wo, qa oyate ekta, kohanna aya wo, qa akahpe wicakiciya wo. Jehowa etanhan wocanniye iyaya, makośice wanna en wicahi.

47 Unkan Mowis eye cin he iyecen Aaron icu, qa omniciye wicacokaya inyanka; unkan inyun makośice wanna en wicahi. Unkan wizinyapi akada qa akalipe wicakiciya.

48 Unkan tapi qa nipi kin otahedan inajin qehan makośice kin anapta.

49 Wicaśta kektopawinge wikcemna sanpa kektopawinge topa sanpa opawinge śakowin makośica on țapi, Qora oie on țapi qon isanpa.

50 Unkan makośice anapte cin ohakam Aaron Mowis en hdi itkokipapi wakeya tiyopa ekta.

\section{WICOWOYAKE 17.}

1 Unkan Jehowa ie ca Mowis heciya,

2 Israel cinca kin kewicakiya, qa hena etanhan cansakadan icu wo, ateyapi tipi otoiyohi on cansakadan, ateyapi itancanpi owasin on, cansakadan wikcemna sanpa nonpa, wicaśta otoiyohi caje kin cansakadan tawa akan oyawa kta.

3 Qa Lewi cansakadan tawa 
akan Aaron caje kin oyawa kta, ateyapi tipi mdetanhunka iyohi on cansakadan wanjidan kta.

$4 \mathrm{Qa}$ hena itkokipapi wakeya ohna, woyaatanin itokam, tukten itkocicipapi eca, hen eyahnake kta.

5 Unkan wicaśta tuwe wakahnige cin he cansakadan tawa kin hea lata, hecen Israel cinca imahnupi kin anawapte kta, niyepi inihnupi kin hena.

6 Unkan Mowis Israel cinca kin ccen cwicakiya ; unkan itancanpi owasin cansakadan qupi itancan otoiyohi on cansakadan wanjidan, ateyapi tipi itancan iyohi cansakadan wan, cansakadan akenonpa, qa Aaron cansakadan tawa cansakadan tawapi ehna.

7 Unkan Mowis cansakadan kin hena ehnake Jehowa itokam itkokipapi wakeya ohna.

8 Unkan ihanhanna Mowis wayaatanin wakeya ekta hi, unkan inyun Aaroll cansakadan tawa Lewi ti kin on camni uye ca wahca inanpe ye ça hmaska suton.

9 Unkan Mowis cansakadan kin owasin hiyuya, Jehowa itokapa tanhan Israel cinca owasin ekta, unkan wanyakapi, qa otoiyohi cansakadan ikikcupi.

10 Unkan Jehowa Mowis heciya, Aaron cansakadan tawa woyaatanin itokam ake kihnaką wo, qa he yapatan kta; wowapetokeca wokipajin cinca kin on, hecen imahnupi ayaśtan wicayakiye kta, qa țapi kte śni.

11 Unkan token Jehowa econ śi kin he iyecen Mowis econ.

12 Unkan Israel cinca kin iapi qa Mowis heciyapi, untapi untakunipi śni owasin untakunipi śni.

13 Tona Jehowa ti kin ikiye- dan hipi kin owasin tapi ; unțapi on unsotapi kta he?

\section{WICOWOYAKE 18.}

1 Unkan Jehowa Aaron heciya, niye qa nicinca, qa niyate tiwale kin nakun tipi wakan woahtani kin duhapi kta, qa niye qa nicinca kin wawaduśnapi woahtani kin duhapi kta.

2 Nakun nihunkawanjipi kin Lewi wicoun, ateyaya wicoun kin nici hiyuwicaya wo. Hecen onicipapi kta, qa oniciyapi kta; tuka niye qa nicinca kin woyaatanin tiyopa ikiyedan yaunpi kta.

3 Qa wakeya kin ocowasin patampi kin, qa taku patan wicayaśi kin patanpi kta; tuka tipi wakan wakśsica kin, qa wahna wośnapi kin yutanpi kte śni, hecen tapi kte śni, iyepi, qa niyepi nakun.

4 Unkan onicipapi kta, qa itkokipapi wakeya kin wopatanpi kin patanpi kta, wakeya wohtani kin owasin, tuka tuwe tokeca nicipi ikiyedan hi kte śni.

5 Unkan niyepi tipi wakan awanyakapi kin duhapi kta, nakun wahna wośnapi wopatan kin, hecen wocanniye Israel cinca kin icimanna awicahi kte śni.

6 Unkan ito miye nihunkawanji Lewi kin Israel cinca wicehnatanhan iwicawacu, qa taku ikcequpi wan he iyecen hena nicupi, Jehowa on itkokipapi wakeya wolitani kin econpi kta, heon etanhan.

7 Tuka niye qa nicinca om wowayuśnapi kin yakpatanpi kta, taku wahna wośnapi ekta econpi owasin, qa taku cokaya ozanpi mahen econpi, qa wohtani kin ecanonpi kta; taku ikce qupi wan iyecen wowayuśnapi wo223 


\section{WICAYAWAPI,}

htani kin cicupi, qa tuwe tokeca ikiyedan hi kinhan teyapi kta.

8 Unkan Jehowa Aaron heciya, Tho miye wokosyapi patanpi kin ciçu, Israel cinca taku yuwakanpi owasin etanhan cicu, wiyutapi nitawa, qa nicinca kin tawapi kta, wokage owihanke wanica.

9 Taku wakan hinca peta etanhan okaptapi kin de niye nitawa kta, woahi tawapi owasin, minha tawapi owasin, qa woahtani wośnapi kin owasin, qa tohdajujupi makahipi kin owasin, wakan liinca hee, niye on, qa nicinca on.

10 Tipi wakan hinca mahen hena yatapi kta, tona wica owasin hetanhan yutapi kta; niye on he wakan kta.

11 De nakun nitawa kța, wokosyapi, Israel cinca taku yuwintapi owasin etanhan, taku qupi kin, he cic̣u, qa nicinkśi, qa nicunkśi nakun opapi kta; wokage owihanke wanica on, oyate ohna tona skapi owasin hetanhan yutapi kta.

12 Taku iyotan waśte wihdi etanhan, qa miniśa etanhan, qa aguyapi etanhan taku iyotan waśte, taku tokaheya suton Jehowa qupi kin hena ciçu.

13 Tamakocepi ohna taku tokaheya suton Jehowa kahipi kin nitawa kta; tona skapi yati ohna hetanhan yutapi kta.

14 Israel ohna taku yuwakanpi hinca owasin nitawa kta.

15 Tona caske celipi owasin etanhan Jehowa kahipi, wicaśta qaiś woteca unman tukte kaśta niye nitawa kta. Tuka wicaśta caske kin opekiton wicayakiye kta, nakun wanunyanpi śapa cinca tokapa kin opeton wicayakiye kta. 16 Unkan opekitonpi kta wi hna. wanji tonpi ehantanhan opeyeton kta, dawa kin he iyecen, mazaska śeqel zaptan tipi wakan śeqel iyececa, omnica wikcemıa nonpa śeqel wanjidan.

17 Tuka pte tokapa, qa tahincaska tokapa, qa tatokadan tokapa kin opekitonpi kte śni; hena wakanpi, wepi kin wahna wośnapi akan ayakaśtan kta, qa waśinpi kin izinyaye kta, peta wośnapi waśtemina Jehowa iyokipi.

18 Tuka celipipi kin he nitawa kta, maku kosyapi kin, qa hiyete etapa kin he iyecen nitawa kta.

19 Israel cinca taku yuwakanpi kin owasin etanhan, taku Jehowa ekta kozapi wokosyapi owasin ciçu, niye, qa nicinkśi, qa nicunkśi nakun, wokage kin de owihanke wanica miniskuya wicotakuye ohinniyan Jehowa itokam, he niye nitawa kta, qa nakun tona niye e tanhan icagapi he tawapi kta.

20 Unkan Jehowa Aaron heciya, Makoce tawapi ohna maga tawayaye kte śni, qa wicehna makoce onśpa duhe kte śni; Israel cinca wicehna wopamni nitawa, qa taku tawa yaye kte cin he miye.

21 Unkan ito Lewi cinca Israel ehna iwikcemna kin owasin tawayapi kta e wicawaqu, wohtani econpi kin on, iyuwin itkokipapi wakeya wolitani kin on.

22 Hecen Israel cinca kin icimana itkokipapi wakeya ekta hipi kte śni, okini woahtani hduhapi kta, qa țapi kta.

23 Tuka Lewi kin itkokipapi wakeya wohtani kin econpi kta, qa iyepi wahtanipi hduhapi kta, wokage kin de owihanke wanica, nitoicagepi yeye cin maga tawayapi kte śni, İsrael cinca wice- 


\section{WICOWOYAKE 19.}

24 Tuka Israel cinca taku icahyapi etanhan iwikcemna kin Jehowa kahipi wokosyapi kin he Lewi kin wicawaqu, he tawa yapi kta, heon hewicawakiya Israel cinca wicehna maga tawayapi kte śni.

25 Unkan Jehowa ie ça Mowis heciya,

26 Ie ça Lewi kin hecen ewicayakiye kta, Israel cinca etanhan iwikcemna maga heekiya ciçupi kin hena iyacupi eca hena etanhan Jehowa tawokosyapi kin yakahipi $\mathrm{kta}$; iwikcemna etanhan iwikcemna kin.

$27 \mathrm{Qa}$ wokosyapi nitawapi aguyapi su kapanpi oyanke etanhan icupi he iyecen, qa miniśa hastanhanka yuśkica etanhan he iyecen niciyawapi kta.

28 Hecen niyepi nakun Jehowa tawokosyapi yakahipi kta; iwikcemna Israel cinca niçupi kin owasin etanhan Jehowa wokosyapi kin Aaron wawayuśna kin yaqupi kta,

29 Taku nicupi kin owasin etanhan Jehowa wokosyapi iyohi yakahipi kta, taku iyotan waśte taku yuwakanpi etanhan.

30 Unkan hewicayakiye kta, Taku iyotan waśte yakahipi eca he Lewi wicakiciyawapi kta, maga taku aicage cin, qa hastanhanka iyuwi taku aicage cin he iyecen.

31 Unkan he yatapi kta tukte en yaunpi $\mathrm{kta}$, niyepi qa tona yatipi ohna unpi kta itkokipapi wakeya ohna wohtani ecanonpi on iyuwin niçupi kin hee.

32 Qa he etanhan taku iyotan waśte yakahipi kinhan woahtani yahduhapi kte śni, qa Israel cinca taku, yuwakanpi kin duikcekapi kte śni, qa nițapi kte śni. Num.
WICOWOYAKE 19.

1 Unkan Jehowa ie ca Mowis qa Aaron hewicakiya,

2 Wokage woope Jehowa econ niśipi kin dee, qa heya, Israel cinca kin kewicayakiye kta, Pte he-yuktanna hinśa wan zanika tuktedan ośteke śni, cannapinpi tohinni un kiyapi śni, heca icupi qa nicahipi kta, kehe kta.

3 Qa Eleazar he yaqupi kta, qa wicoti itankan ayapi kta, qa iye itokam patapi kta.

4 Unkan Eleazar wawayuśna kin napsukaza on we kin etanhan icu kta, qa itkokipapi wakeya tiyopa ektakiya we kin etanhan śakowin akihde ehpeye kta.

5 Unkan iye iśta kin itokam pte-heyuktanna kin hulinahyapi kta; ha kin, qa tado kin, qa we kin, qa cesdi kin huhnahyapi kta. 6 Unkan wawayuśna kin hanteśadan can, pejiliota, qa tahincaska hin duta icu kta, qa pteheyuktanna liulinage cin akan ehpeye kta.

7 Qa wawayuśna kin woloyake hdujaja kta, qa cehpi minin iyeiçiye $\mathrm{kta}$, qa ohakam wicoti en hi kta, qa hitayetu kte cin hehanyan śape kta.

8 Qa tuwe he hulinaliye cin he wokoyake hdujaja kta, qa cehpi kin minin niwe kta, qa ilitayetu hehanyan śape kta.

9 Unkan wicaśta śape śni wan pte heyuktanna cahota kin mnaye kta, qa wicoti itankan kihnake kta, oyanke wan śape śni en, qa he patanpi kta mini awicamnimui kin on, Israel cinca oyate on woahtani ipakinte cin hee.

10 Unkan tuwe pte-heyuktanna cahota mnaye cin he woko225 


\section{WICAYAWAPI,}

yake hdujaja kta qa hitayetu kte cin hehanyan sape kta; qa he Israel cinca on qa tuwe oyate tokeca wicehna ounye cin on en yanke kta, wokage kin de owihanke wanice kta.

11 Tuwe wicaśta nagiye cin cehpi yutan kinhan, anpetu śakowin śape kta.

$12 \mathrm{Qa}$ he on ikpakinte kta, anpetu iyamni en, hecen anpetu iśakowin en ska kta, tuka anpetu iyamni en ikpakinte śni kinhan, anpetu iśakowin en ska kte śni.

13 Tuwe taku te cin, wicaśta nagiye ca te cin icalitake cinhan, qa ikpakinte śni kinhan, Jehowa toti kin yuśapa, qa wicanagi kin he Israel etanhan kaśpapi kta, wipakintapi mini kin he amnimnipi śni heon hee śapa, toaśape nahanhin askapa.

14 Wicaśta wan wakeya ohna te cin woope kin dee, tona wakeya ohna unpi kin owasin, nakun tona wakeya en hiyupi kin hena owasin anpetu śakowin śapapi kta.

15 Qa wakśica iha ton śni owasin, qa iha akahpapi śni kin hena śape kta.

16 Unkan tuwe wicaśta wan makoskan canhipi on ktepi, qaiś wayazanka ța, qaiś wicahu wan, qaiś ohna wicahnakapi wan icahitake cinhan anpetu śakowin hehanyan śape kta.

17 Qa tuwe śape cin on wipakintapi kta e pte huhnahyapi qon caliota etanhan icupi kta, qa wakśica wan ohna mini kaduze cin akaśtanpi kta.

18 Unkan wicaśta wan śape śni pejihota icu kta, qa mini kin he en oputkan kta, qa wakeya kin qa wakśica owasin, qa wicanagi hen yakonpi kin owasin awicamnimni kta, nakun tuwe wicahu wan icalitake qaiś tuwe ktepi, qaiś wayazanka țe, qaiś ohnahnakapi wan icahtake cinhan.

19 Unkan wicaśta śape śni kin he tuwe śape cin he amnimni kta, anpetu iyamni en, qa anpetu iśakowin en, unkan ànpetu iśakowin en ihdkusa kta, wokoyake hdujaja kta, qa minin niwe kta, hecen hitayetu en ska kta.

$20 \mathrm{Qa}$ wicaśta tuwe śape ca ihduska śni kinhan, wicanagi kin he omniciye etanhan kaśpapi kta, Jehowa tipi wakan tawa kin yuśape cin heon etanhan, wipakintapi mini kin amnimnipi śni heon hee śapa.

21 Unkan woope kin de owihanke wanin yuhapi kta, tuwe wipakintapi mini amnimni kin wokoyake hdujaja kta; qa tuwe wipakintapi mini kin icahtake cinhan ifitayetu hehanyan śape kta.

22 Qa taku kaśta tuwe śapa yutan kinhan śape kta, qa wicanagi tuwe he icahtake cin htayetu kta hehanyan śape kta.

\section{WICOWOYAKE 20.}

1 Unkan wi tokaheya en Israel cinca oyate kin owasin Tzin liopuze cin en hipi, qa oyate kin Qadeś en iyotankapi, qa hen Miriam ta, unkan hen hnakapi.

2 Unkan mini yatkanpi kta wanica, heon oyate Mowis qa Aaron amniciyapi.

3 Qa oyate kin Mowis kigepi, qa heyapi, Tokin unki hunkawanjipi Jehowa itokam țapi qehan unkiś eya unțapin.

$4 \mathrm{Qa}$ tokeca unkiye unțapi kta e, qa nakun wanunyanpi unkitawapi, hopuze cin de ekta Jehowa taomniciye hiyuwicayayapi he? 
5 Qa tokeca Egupta etanhan itanwankanhde mani unyayapi, qa makoce sice kin den liyu unyayapi he? tukten wojupi iyecece śni, nakun witanśna hu wanica, qa hastanhanka iyuwi wanica, qa taspantanka su ota wanica, qa mini yatkanpi lita wanica.

6 Unkan Mowis qa Aaron omniciye etanhan upi, qa itkokipapi wakeya tiyopa ekta hipi, qa makipusdiya ehpe ic̣iyapi, qa Jehowa towitan kin wanyakapi.

7 Unkan Jehowa ie ca Mowis heciya,

8 Cansakadan qon icu, qa niye qa Aaron nicinye oyate kin mniciye wicayayapi kta, qa wanyakapi icunhan imnija kin eyakiyapi kta, unkan mini tawa wicakicu kta; hecen imnija etanhan mini hinanpe wicayeciye kta, qa oyate kin, qa tawanunyanpi kin yatke wicayakiye kta.

9 Unkan Mowis Jehowa itokapa tanhan cansakadan icu, econ śi kin he iyecen.

10 Unkan Mowis, qa Aaron omniciye kin mniciye wicayapi, imnija itokam, qa hewicakiya. Wawakipajinpi sa anagoptan po. Imnija kin de etanhan mini inanpe unniciyapi kta he?

11 Unkan Mowis nape yuwankan ikikcu, qa cansakadan on imnija kin apa ; unkan mini ota inanpa ; unkan oyate kin yatkanpi, tawanunyanpi nakun.

12 Unkan Jehowa ie ca Mowis qa Aaron hewicakiya. Wicamayadapi śni, qa Israel cinca wicitokam mayaduwakanpi śni, heon omniciye kin de makoce wicawaqu kin ekta hiyuwicayayapi kte śni.

13 Meriba (Kigepi) mini kin hee; hen Israel cinca kin Jehowa kigepi, unkan hen ihduwakan.
14 Unkan Qadeś etanhan Mowis Edom wicaśtayatapi ekta wicaśta ye wicaśi, qa heciya. Nisunka Israel hecen eya, Niye woiyokiśice unkakipapi kin owasin sdonyaya.

15 Token hunkake wicunyanpi Egupta ekta ipi, qa Egupta ohna unyakonpi anpetu ota, qa token Egupton unkiyuśepi, unkiyepi, qa nakun hunkake wicunyampi.

16 Unkan Jehowa hoye unkiyapi, unkan ho naunkihonpi, qa ohnihde wan ye śi, qa Egupta etanhan hdinanpe unyanpi, unkan iho wanna Qadeś en unyakonpi, otonwe wan makoce nitawa ihanke ekta.

17 Tokin nitamakoce ohna unkiyayapi kten. Maga nitawa ohna, qa hastanhanka iyuwi ojupi ohna unyanpi kte śni, qa miniyowe nitawapi etanhan unyatkanpi kte śni, wicaśtayatapi tacanku ohna maunnipi kta, hetanhan etapa tanhan qa catka tanhan unmanna unyanpi kte śni, nitamakoce isanpa unkiyayapi śni kin hehanyan.

18 Unkan Edom heciya. Miye ohna idade kte śni okini canhipi hduha itkocicipe kta.

19 Unkan Israel cinca kin heciyapi, canku tanka ohna unyanpi kta, qa mini nitawa unyatkanpi kinhan miye qa wanunyanpi mi.. tawa on iyuwin cicu kta. 'Takudan econ śni siha ecedan weçon opta mde kta.

20 Unkan heya, Iyoopta idade kte śni, qa Edom wicota om qa nape waśaka on inanpe ca itkokim u.

21 Hecen Edom iye tamakoce ohna Israel ye kta iyoki śni ;

22 Qa Qadeś etanhan ihdakapi, qa Israel cinca omniciye owasin Hor he ekta hipi.

23 Unkan Jehowa ie ca Edom 
makoce ilianke ekta, Hor he ohna Mowis qa Aaron hewicakiya.

24 Aaron iye taoyate ekta okipe yapi kta, makoce Israel cinca wicawaqu kin he ekta i kte śni, nakaś, Kigepi mini kill ekta mioie yakipajinpi heon etanhan.

25 Aaron qa iye cinhintku Eleazar iwicacu, qa Hor he akan hiyuwicaya wo.

$26 \mathrm{Qa}$ Aaron tawokoyake kin duśdoke kta, qa cinhintku Eleazar he koyag yaye kta, qa hen Aaron te kta, qa okipe yapi kta.

27 Unkan token Jehowa econ śi kin he iyecen Mowis econ, qa Hor he akan ipi kin he oyate owasin wanyakapi.

28 Unkan Mowis Aaron tawokoyake kin kiciyuśdoke ca cinhintku Eleazar he koyag kiya; unkan Aaron hen ta, Hor he paha akan : unkan Mowis qa Eleazar he kin etanhan kun hdicupi.

29 Unkan omniciye owasin Aaron te cin sdonyapi, heon Israel cinca tiyohnaka ocowasin Aaron aceyapi, anpetu wikcemna yamni hehanyan.

\section{WICOWOYAKE 21.}

1 Unkan Arad wicaśtayatapi Kanani kin itokah makoce ounye cin he Israel Atarim canku ohna u nahon qehan azuwicaya, qa etanhan wayaka iwicacu.

2 Unkan Israel wokonze wan Jehowa en iciconzapi, qa heyapi, Oyate kin de minape en katinyan mayaqu kinhan, otonwe tawapi ocowasin ihang waye kta.

3 Unkan Jehowa Israel ho kin nahon, qa Kanani kin wicaqu: unkan ocowasin ihang wicayapi, otonwe tawapi nakun, heon makoce kin he Horma (Woihangye) eciyapi.
4 Unkan Hor he kin etanhan ihdakapi, qa Edom makoce ihdukśan yapi kta, heon Mde śa canku ohna yapi, qa oyate nagipi kin hanyan, canku kin on etanhan.

5 Qa oyate kin Wakantanka aiapi, qa Mowis aiapi, Tokeca Hopuze cin ohna untapi kta e Egupta etanhan hdinanpe unyayapi he? aguyapi wanica, qa mini wanica, qa unnagipi woyute kapojedan kin de hitihda, eyapi. 6 Heon Jehowa wamduśka wahuhnahya, oyate kin en hiyu wicaya, unkan wicayahtakapi, hecen Israel oyate etanhan wicota tapi.

7 Hehan oyate kin Mowis ekta hipi, qa heyapi, Waunhtanipi, Jehowa unkaiapi, qa niś nakun; Jelıowa wamduśka yutokan iyeunkiciciyapi kta e iceliya wo ; unkan Mowis oyate on cewicakiciya.

8 Unkan Jehowa Mowis heciya, Wamduśka wahiuhnahya wan icicaga wo, qa can pasdatapi wan akan ikoyag ya wo, unkan tona wicayahtakapi qa he wanyakapi kinhan hena owasin nipi kta.

9 Unkan Mowis mazaśa wamduśka wan kage ca can pasdatapi wan akan ikoyag ya; unkan kaketu wamduśka wicaśta wan yahtake cinhan, mazaśa wamduśka kin atonwan eca ni ece.

10 Unkan Israel cinca kin ihdakapi, qa Obot (Miniiyokaśtan) en etipi.

11 Unkan Obot etanhan ihdakapi, qa Ije-A barim (Abarim Otiwota) en etipi, he hopuza ohna Moab itokam wihinanpe ektakiya yanka.

12 Unkan hetanhan ihdakapi, qa Zered kaksiza ohna etipi.

13 Hetanhan ihdakapi qa Arnon akasanpa etipi, he hopuza 


\section{WICOWOYAKE 21.}

ohna un, Amori tamakoce ihanke ekta, Arnon Moab ihanke kin hee, Moab qa Amori kin otahedan.

14. Heon Jehowa azuye wicaya oyakapi wowapi kin en heyapi, Waheb ekta Supa en, qa Aruon wakpadan ekta.

$15 \mathrm{Qa}$ wakpadan omdaye kin he Ar tipi kin iyohiya, qa Moab makoce ihanke kin icahitaka.

16 Unkan Beer (Miniyowe) ekta hipi, Miniyowe kin he Jehowa ke ca Mowis heciya, Oyate kin yuwitaya u wicakiya wo, kinhan mini wicawaqu kta.

17 Hehan Israel odowan kin de ahiyayapi, Miniyowe inanpa wo. He kahiyayapo.

18 Itancan miniyowe qapi kin hee, oyate akicita yapi kin tasagyepi on, Wicoope kage cin eye cin iyecen. Unkan hopuze cin etanhan Matana en hipi.

19 Unkan Matana etanhan $\mathrm{Na}-$ haliel (Kaksiza wakan) en hipi, Nahaliel etanhan Bamot (Pahaota) ekta.

20 Qa Bamot etanhan Makomdaye ekta, he Moab tatinta ohna yanka, Pisga paha ihukuya, qa he etanhan hewoskan kin wanyaliapi.

21 Hehan Israel Sihon Amori wicaśtayatapi kin ekta ohnihde ye wicaśi, qa heciya,

22 Nitamakoce kin iyopta mde kta; maga nitawa en unyanpi kte śni, qa hastanhanka iyuwi ojupi nitawa ohna unyanpi kte śni ; qa miniyowe nitawa etanhan mini unyatkanpi kte śni; nitamakoce iyoopta unyanpi kin hehanyan, wicaśtayatapi tacanku kin omaunnipi kta.

23 Tuka Sihon iye tamakoce Israel opta yapi kta iyowinwicakiye śni, qa Sihon taoyate kin iyuhpa yuwitaya $u$ wicakiye ça
Israel itkokim hiyu, hopuza ektakiya, qa Jahatz (Anatanpi) ekta $\dot{i}$, qa Israel azu wicaya. 24 Unkan Israel tacanlipi hi on kaśtakapi, qa tamakoce kin tawa yapi, Arnon etanhan, Jaboq hehanyan, Amon cinca kin ekta; Amon cinca tamokoce ihanke kin he aconkaśkayapi, nakaś.

25 Unkan Israel otonwe kin hena owasin icupi, qa Israel Amori totonwépi owasin en iyotankapi, Heśbon qa otonwe cunkśi wicaya owasin.

26 Ḣeśbon Silion Amori wicaśtayatapi totonwe kin hee. Iye he itokam Moab wicaśta yatapi kin azuye ça tamakoce Amon ekta owasin nape kin etanhan icu.

27 Heon dowanpi qa heyapi, Ḧeśbon otonwe ekta u po. Silion totonwe kagapi qa aconkaśkaya po.

28 Heśbon etanhan peta wan inanpa, Sihion totonwe etanhan ide wan. Ar Moab hulinaliya, Arnon paha itancan nakun.

29 Moab hehehe, Kemoś taoyate nitakuni śni, cinhintku tona najicapi cunwintku nakun Amori wicaśtayatapi Sihon wowidag wicaye kta e wicaqu.

30 Unkan wicunkutepi, Ḧesbon ihang yapi. Dibon ekta, qa Nopa elita liewoskan kagapi, he Medeba ekta iyohiya.

31 Hecen Israel Amori tamakocepi kin en iyotankapi.

32 Unkan Mowis wicaśta Jazer ekta tonwe ye wicaśi, unkan totonwe kin icupi, qa Amori hen unpi kin nape wicayapi.

33 Hehan ihduhomnipi, qa Baśan canku ohna itanwankanhde yapi; unkan Og Baśan wicaśtayatapi kin itkowicakipe kta inanpa, iye qa taoyate owasin Edrei okicize ekta. 


\section{WICAYAWAPI,}

34 Unkan Jehowa Mowis heciya, Ihnuhan he ikoyape cir, ninape en he waqu kta, qa taoyate owasin, qa makoce tawa nakun; unkan token Silion Amori wicaśtayapi Ḣeśbon en yanke cigon ecayecon, he iyecen he ecayecon kta.

35 Unkan kaśtakapi iye qa cinca kin, qa taoyate owasin, hecen wanjidan niyake okapte śni.

\section{WICOWOYAKE 22.}

1 Unkan Israel cinca -kin ihdakapi, qa Moab makomdaya ohna Jordan icahda Jeriko itakasam etipi.

2 Unkan Balaq Tzipor cinhintku taku Israel Amori kin ecawicakicon owasin wanyaka.

3 Unkan Moab nina kokipa, oyate wicitokam, wicotapi nakaś, qa Israel cinca kin on Moab lianyan.

4 Unkan Moab Midiyani hunkawicayapi kin hewicakiya, Wanna obe kin de taku unkihdukśan un kin owasin sdipapi kta, tatanka wan tinta wato kin sdipa he iyecen. Unkan hehan Moab wicaśtayatapi kin Balaq Zipor cinhintku kin hee.

5 Qa ohnihde Balam Beyor cinhintku ekta ye wicaśi, Petori ekta, he iye tamakoce wakpa kin icahda yanka; kico kta, qa heciya, Tho oyate wan Fgupta etanhan inanpa; qa inyun maka ite kin akahpe ca micahda iyotankapi.

6 Heon wanna ceciciya, u qa oyate kin de wicamiciyaśica wo; wamaśaka eśta hena sanpa waśakapi, okini wicawakaśtaka, qa makoce etanhan nape wicawaya owakihi kta. Tuwe dawaśte kin he yawaśtepi, qa tuwe daśice cin hee yaśicapi e sdon waya nakaś.
7 Unkan Moab hunkayapi, qa Midiyani hunkayapi woayate iyunwin nape ohua yuha iyayapi, qa Balam ekta ipi, qa Balaq oie lin eciyapi.

8 Unkan hewicakiya, Hanyetu kin de den yanka po, qa token Jehowa emakiye cin he iyecen wicoie kin aciyuptapi kta. Unkan Moab itancan kin Balam kici wankapi.

9 Unkan Wakantanka Balam. ekta hi, qa heciya, Wicaśta kin dena nici unpi kin tuwepi hwo?

10 Unkan Balam Wakantanka heciya, Balaq Beyor cinhintku, Moab wicaśtayatapi wahomayan,

11 Inyun, oyate wan Egupta etanhan inanpe ca maka ite kin akahipa. Wanna $u$, qa miciwicayaśica wo, hecen azu wicawaye ca nape wicawaya owakihi kta.

12 Unkan Wakantanka Balam heciya, Ihnuhan om idade cin, innuhan oyate kin daśice cin, yawaśtepi nakaś.

13 Unkan Balam hanhanna kikta, qa Balaq ohnihde wicaya, hewicakiya, Nitamakoce ekta hdapo. Niyepi om mde kta Jehowa iyowin makiye śni.

14 Unkan Moab itancan kin najinpi, qa Balaq ekta hdapi, qa heciyapi, Balam unkicipi u kte śni, keya.

15 Unkan Balaq ake wicaśta sanpa wicakinihanpi, qa sanpa ota ye wicaśi.

16 Unkan Balam ekta hipi, qa heciyapi, Balaq Tzipor cinhintku kin hecen eya, Ceciciya, ihnuhan ekta mau yakapin kin.

17 Wowitan tanka hinca cicu, qa taku emayakiye cin owasin ecamon kta. U wo, ceciciya, oyate kin de wicamiciyaśica wo. 


\section{WICOWOYAKE 22.}

18 Unkan Balam ayupte ca Balaq taokiye hewicakiya, Balaq iye ti kin mazaska qa mazaskazi ojudan maqu eśta, Taku wakan oie kin kawape ca taku cistinna qaiś taku tanka unmanna econ owakihi kte śni.

19 Heon ceciyapi hanyetu kin de nakun den wankajo, hecen taku Jehowa ake emakiye kta sdon waye kta.

20 Unkan Wakantanka hanyen Balam elita hi, qa heciya, Wicaśta kin nico hipi hecinhan, najin, qa om ya wo; tuka wicoie eciciye cin heceedan ecanon kta.

21 Unkan Balam hanlianna kikta, qa śonśonna aqin kiton, qa Moab itancan om iyaya.

92 Unkan iyaye cin heon Wakantanka canniyan, qa kize kta e Jehowa ohnihde kin canku ohna najin. Unkan śonśonna akan iyotanka, qa tahokśidan nonpa opapi.

23 Unkan śonśonna kin Jehowa ohnihde kin canku ohna najin, qa isan hduśdoka nape ohna wanyaka, heon śonśonna kin canku etanhan ihdutokan, qa tinta omani. Unkan Balam śonsonna kin apa, canku ohna iyaye ye kta heon etanhan.

24 Unkan Jehowa ohnilude kin hastanhanka iyuwi ojupi ehna canku qapi wan ohna najin anonkatanhan acankaśkayapi.

25 Unkan śonśonna kin Jehowa ohnihde kin wanyake ca conkaśke ipuskica, qa Balam siha kin conkaśke elkta inatan; unkan ake he apa.

26 Hehan Jehowa ohnihde kin ake ako iyaye ca tukten ocistiyedan ohna inajin: hen canku etanhan tokan iyaye pica śni, etapa tanhan qaiś catka tanhan. 27 Unkan śonśonna kin Jehowa ohnihde kin wanyake ca makipusdi elipe ic̣iye, Balam ihukuya. Unkan Balam canniye ca sagye on śonśonna kin apa.

28 Hehan Jehowa śonśonna i kin yukawa; unkan Balam heciya, Taku ecacicon hwo on etanhan wanna yamni akihde amayapa he?

29 Unkan Balam śonśonna kin heciya, Iyokiśin mayaya heon hecamon, Tokin isan wall minape ohna yukan, unkanś cikte kta tuka.

30 Unkan sonśonma kin Balam heciya, śonśonna nitawa totanhan mayaduhe cin ecen anpe dehanyan akan dotanke śni he? Qa ijehan hecen hecacicon he? Unkan, Hiya, eya.

31 Hehan Jehowa Balam iśta kin yuzamni, unkan Jehowa ohnihde nape kin ohna isan yuśdog hduha, canku onajin wanyake ça makipusdiya ehpe ic̣iya.

32 Unkan Jehowa ohnihde kin heciya, Tokeca wanna yamni akihde śonśonna ayapa he? Niohan nitokam pemni ce, heon miś cicize kta e wahinawapa.

$33 \mathrm{Qa}$ śonśonna wanmayake ca yamni akihde mitokapa tanhan ihdutokan śni unkanś he niwaye kta, qa wanna awicakehan ci kte kta tuka.

34 Unkan Balam Jehowa ohnihde kin heciya, Wawalitani, canku ohna amayakipe kta nayajin kin sdon waye śni nakaś, qa wanna hecen iyonicipi śni kinhan wahde kta.

35 Unkan Jehowa ohnihde kin Balam heciya. Wicaśta qon om ya wo. Tuka wicoie eciciye cin heceedan ehe kta. Unkan Balam Balaq ohnihde wicaya owicapa.

36 Unkan Balam u kin he Ba231 
laq nahon, qa itkokipe kta e iyaya, Moab otonwe ekta, he Arnon icahda .makoce ihanke kin hee.

37 Unkan Balaq Balam heciya, Cico kta e hoye ciciye śni he? qa tokeca ekta mayahi śni he? Awicakehan nina ciyutan owakihi śni he?

38 Unkan Balam Balaq heciya, Inyun wanna en cihi, taku iwae kta owakihi he? wicoie Jehowa mii en maqu kin heceedan iwae kta.

39 Unkan Balam Balaq kici iyaya, qa Hutzot otonwe ekta ipi.

40 Unkan Balaq tatanka, qa tahinca ska wayuśna, qa Balam qa itancan opapi kin tuwe wicakico yeśi.

41 Unkan ihanhanna Balaq Balam icu qa Baal paha kin ekta $i$, qa hetanhan oyate wicoti ihanke wan wanyaka.

\section{WICOW OYAKE 23.}

1 Unkan Balam Balaq heciya, Wahna wośnapi śakowin den micicaga wo; qa den tatanka śakowin, qa tahiin wanunyanpi śakowin wiyeya micicaga wo.

2 Unkan token Balam eye cin hecen econ, qa Balaq qa Balam tatanka wan, qa tamdoka wan wahna wośnapi otoiyohi akan huhnaliya.

3 Unkan Balam Balaq heciya, Wohuhnali yaye cin icahda den yanka wo. Miś kakiya mda, okini Jehowa itko makipe u kta, qa wicoie wanyag makiye cin owasin ociciyake kta, eye ça paha śdayehna ekta iyaya.

4 Unkan Wakantanka Balam itkokipa, unkan heciya, Wahna wośnapi śakowin ewahde, qa wahna wośnapi iyohi akan ta- tanka wan, qa tamdoka wan huhinah waya.

5 Unkan Jehowa wicoie wan Balam i en yekiye ca heciya, Balaq ekta hde, qa heyakiye kta. 6 Unkan ekta hda, unkan inyun wohulinah ye cin icahda yanka, iye qa Moab itancan owasin.

7 Unkan Balam wicoie wakan kin ohdake ça heya, Balaq Moab wicaśtayatapi kin Aram etanhan, Wiyohiyanpa lie kin etanhan u makiye ca heya, Iho Jakob miciyaśica wo, qa kuwa Israel mici canniye ya wo.

8 Iyotan waśake cin he canniye ye śni, miś token canniye waye lata he? Jehowa wicayaśice śni, token wicamdaśice kta he?

9 Inyan paha etanhan wanmdaka, pajodan etanhan aowakasin, Inyun oyate kin de iśnana ounye kta, qa oyate tokeca om wicayawapi kte śni.

10 Jakob maka mdu sukaza kin, qa Israel ośpaye itopa kin, tuwe yawa okihi he? Tokin wicaśta ecetu tapi kiniyecen minagi te kten qa owihanketa hena iyemacece kten.

11 Unkan Balaq Balam heciya, Taku ecamiyecon hwo? Toka wicawaye cin daśice kta e cico, unkan inyun nina wicadawaśte.

12 Unkan ayupte ca heya, Taku Jehowa mii en ye kiya he patanyan iwae kte śni he?

13 Unkan Balaq heciya, Oyanke tokeca wan ekta mici u wo, qa hetanhan wanwicadake kta, ihanke hinca wan heceedan wandake kta, owasin wanwicadake kte śni, qa hetanhan wicamiciyaśica wo.

14 Qa Tzopim (Iwanyakapi) tinta en Pisga paha ekta hiyuye ca wahna wośnapi śakowin kage ca tatanka wan, qa tamdoka 


\section{WICOWOYAKE 24.}

wan wahna wośnapi iyohi akan huhnahya.

15 Qa Balaq heciya, Den yanka wo, wohuhnah yaye cin icahda, tuka miś kakiya itkowakipe kta.

16 Unkan Jehowa Balam itkokipe ca wicoie wan i kin en ye kiye ça heciya, Balaq ekta hde ca hecen eya wo.

17 Unkan en hdi; unkan inyun wohuhnah ye cin icahda yanka, nakun Moab itancan kin opapi, qa Balaq heciya, Jehowa taku eya he?

18 Unkan wicoie wakan kin ohdake ça heya, Balaq najin qa nahon wo. Tzipor cinhintku kin anoh makiciya wo.

19 Iyotan waśake cin wicaśta heea śni, tohini itonśni, qa Adam cinca śni iyope içiye śni. Iś eye cinhan ecen econ kte śni he ? Ie cinhan hduwicake kte śni he?

20 Inyun iye yawaśte qa yawaśte maśi, unkan mdatokeca owakihi śni.

21 Jakob en wicohan śica atonwe kte śni, qa I'srael en woiyokiśice wanyake kte śni, Jehowa wakan dapi kin wica kici un, wicaśta yatapi iyaśapi kin.

22 Iyotan waśake cin Egupta etanhan hdinanpa ya, tinta tatanka iyecen waśaka ce.

23 Jakob en wapiyapi wanica ce, qa Israel en wakan kagapi wanica. Iyotan waśaka Jakob on, qa Israel on, taku econ he? detanhan eyapi kta.

24 Inyun oyate kin mnaja wiyedan iyecen najin hiyaye kta, qa mnaja mdoka wan iyecen yuwankan iye ic̣iye kta. Taku yahtake cin we kin yatke, ca taku yapota yute śni kin hehanyan makan iwanke kte śni.

25 Hehan Balaq Balam heciya,
Ilmuhan wicadaśice cin, qa nakun ihnuhan wicadawaśte kin.

26 Unkan Balam, ayupte ca Balaq heciya, Taku Jehowa emakiye cin owasin ecamon kta eciciye śni he?

27 Unkan Balaq Balam heciya, Wanna kuwa, oyanke tokeca ekta unye kta, okini hetanhan miyeciwicadaśice kta e Wakantanka iśta kin en ecetu kta.

28 Qa Balaq Balam iyaye ya, Peyor paha kin ekta, hetanhan Jeśimon (Hewoskan) wanyakapi.

29 Unkan Balam Balaq heciya, Wahna wośnapi śakowin den micicaga wo, qa den tatanka śakowin, qa tamdoka śakowin, wiyeya micicaga wo.

30 Unkan token Balam eye cin he iyeeen Balaq econ; unkan wahna wośnapi otoiyohi akan tatanka wan, qa tamdoka wan huhnah̀ ya.

\section{WICOWOYAKE 24.}

1 Unkan Israel wicayawaśte kin he Jehowa iśta kin en waśte Balam wanyaka, heon woayate akin iyaye śni, econ qon iyecen, tuka liopuze cin ektakiya etonwan.

2 Qa Balam iśta yuwankan ikikcu, qa Israel wicoun iyecen tipi kin wanwicayaka, unkan Wakantanka toniya kin he alkan un.

3 Hehan wicoie wakan ohdake ca heya, Balanı Beyor cinhintku heya, wicaśta iśta yuhdokapi kin heya;

4 Tuwe El oie kin nahon qa Iyotan waśaka towanyake kin wanyaka, he licahan eśta iśta yuzamni hduhe cin he heya;

5 Israel yatipi kin qa Jakob nitawakeya kin hena waśte hinca. 
6 Wakpadan kin iyecen yeye cin, taśkoju wakpa icahda iyecen, hanteśa Jehowa oju kin iyecen, wazi can mini icahda iyececapi.

7 Koka tawa etanhan mini kaduze kta, qa taku iye etanhan icage cin mini ota akan un kia, qa wicaśtayatapi tawa Agag iwankam yanke kta, qa tokiconze kin pajodan kta.

8 Taku wakan waśaka Egupta etanhan inanpe wicaya; Oyate tona tokayapi kin hena temwicaye kta, huhupi kin wicakiyukse kta ; tawahinkpe kin ipahdan ihewicaye kta.

9 Patuja mnaja iyecen, qa makan iwanka mnaja wiyedan iyecen, tuwe pahice kta he? Tuwe niyawaśte kin yawaśtepi kta, qa tuwe niyaśice cin yaśicapi kta.

10 Hehan Balaq Balam nina canniye ya, qa nape hdaskape ca Balaq Balam heciya, Toka wicawaye wicadaśice kta e cico, unkan inyun yamni akihde katinyan wicadawaśte ce.

11 Heon wanna najica ekta hda, wowitan tanka cicu kta epa, tuka inyun niyutanpi kta Jehowa iyoki śni.

12 Unkan Balam Balaq heciya, ohnihde wicayaya mico ye wicayaśi qon hecen ewicawakiye śni he?

13 Balaq iye ti kin mazaska, qa mazaskazi ojudan maqu eśta, Jehowa i kin kawape, qa taku waśte qaiś taku śica econ owakihi śni, tuka taku Jehowa ie cin heceedan iwae kta.

14 Unkan ito wanna oyate mitawa ekta wahde kta, Kuwa wo, taku oyate kin de oyate nitawa ecawicakiconpi kta, tokata anpetu ota iyohakam, he ociciyake kta.
15 Qa Balam wicoie wakan ohdake ca heya, Balaq Beyor cinhintku kin heya, wicaśta iśta yuliuokapi kin he heya :

16 'Tuwe El oie kin nahon, qa Otancanke tosdonye kin okahniga, Iyotan waśaka towanyake kin wanyaka, makipusdiya hinhpaya eśta iśta yuzamni hduhe cin he heya ;

17 He wanmdake kta tuka dehantu śni, awatonwe kta tuka ikiyedan kte śni, wicanhipi wan Jakob etanhan u kta, mazasagye wan Israel etanhan najin kta, qa Moab ihanke kin owasin kaśtake kta, qa Śt (Owodutaton) cinca kin owasin ihang ye kta.

18 Qa Edom tawaye kta, qa Seyir tokayapi kin he tawaye kta, qa Israel waditagya econ kta.

19 Qa tuwe idake ye kta Jakob etanhan kta, qa tona otonwe etanhan okaptapi ihang wicaye kta.

20 Hehan Amaleq wanyake ca heya, Amaleq oyate tokaheya kin hee, tuka tokata iś eya awihnuni kta.

21. Hehan Qeni kin wanwicayake ca wicoie wakan ohdake ca heya, yatipi kin sutaya aconkaśkayapi, qa inyan ehna hohpi nicicaga.

22 Hececa eśta Qeni kin tokan awicayapi kta; Tohantu kta he? Aśur wayaka aniye kta.

23 Unkan wicoie wakan kin ohdake ça heya, Hehehe, E1 hena econ kin tuwe hehanyan ni kta he?

24 Unkan witawata Kitim huta kin etanhan upi kta, qa Aśur iyokiśin yapi kta, qa Eber iyokiśin yapi kta: unkan iś eya owihanketa awihnuni kta.

25 Hehan Balam najin qa 


\section{WICOWOYAKE 26.}

ekta kihda, qa Balaq iś eya ekta hda.

WICOWOYAKE 25.

1 Unkan Israel Śitim en ounyanpi, qa oyate kin Moab cunwintkupi inawicahmanpi on ihduśapapi.

2 Unkan winyan kin hena taku wakandapi wakiyuśnapi ekta oyate wicakicopi, unkan oyate kin yutapi, qa winyan kin taku wakandapi kin ohodapi.

3 Hecen Israel Baal Peyor (Peyor Itancan kin) en ikoyag içiyapi; unkan Jehowa Israel canniye wicaya.

4 Qa Jehowa Mowis heciya, Oyate itancanpi kin owasin wicakico wo, unkan hena Jehowa on anpetu wi itokam otke wicayapi kta, hecen Jehowa Israel nina canniye wicaya anapte kta.

5 Unkan Mowis Israel wayacopi kin hewicakiya, Otoiyohi wicaśta tawa tona Baal Peyor en ikoyag içiyapi kin hena wicaktepo.

6 Unkan Inyun Mowis qa Israel cinca oyate kin itkokipapi wakeya tiyopa ekta ceyapi icunhan, Israel cinca etanhan wicaśta wan ku, qa Midiyani winohinca wan sunka wicaye cin ekta hiyuya, Mowis qa oyate kin wanyakapi.

7 Unkan Aaron wawayuśna cinhintku Eleazar cinhintku Pinehas he wanyake cehan oyate cokaya tanhan najin iyaye ca nape ohna wahukeza wan icu;

8 Qa Israel wicaśta kin ihakam iyaya, wakeya catkuta ekta, qa napin, cawicapa, wicaśta lin, qa winolinca nakun tezi kin ohna, hecen makośice kin Israel cinca etanhan anapta.

9 Warına makośice on tapi kin hena wicaśta ketkopawinge wikcemna nonpa sanpa kektopawinge topa.

10 Unkan Jehowa ie ca Mowis heciya,

11 Pinehas Eleazar cinhintku Aaron wawayuśna cinhintku kin, Israel cinca etanhan mitocanniye yutokan, inawawizi iyecen iye wicehna inawizi, qa hecen inawawizi kin en ihang wicawaye śni.

12 Heon hecen eciya wo. Ito wookiye wicotakuye waqu ;

13 Qa wicotakuye wawayuśna wicohan owihanke wanica yuhe kta, iye qa cinkśi wicaye cin iye iyohakam, Wakantanka on inawizi kin Israel cinca akahpe wicaya heon etanhan.

14 Wanna Israel wicaśta ktepi kin Midiyani winohinca kici ktepi kin he Zimri eciyapi, Salu cinhintku, Simeon ateyapi tipi wan en itancan wan hee.

I5 Qa Midiyani winohinca ktepi kin he Kozbi eciyapi, Tzur cunwintku Midiyani ateyapi tipi wan en itancan wan hee.

16 Unkan Jehowa ie ça Mowis heciya,

17 Midiyani toka wicaye ca wicakaśtaka wo.

18 Iyepi toka niyanpi qa nihnayanpi ecinśniyan ohanyanpi on, Peyor wicoie icahtaka, qa tawinohtinpi Kozbi Midiyani itancan wan cunwintku, Peyor on etanhan, makośice anpetu kin en ktepi heon etanhan.

\section{WICOWOYAKE 26.}

1 Unkan makośice iyohakam Jehowa ie ca Mowis qa Eleazar Aaron wawayuśna cinhintku kin hewicakiya.

2 Israel cinca oyate kin owasin wicayawa wo, wica waniye235 
tu wikcemna nonpa aktonpi, ateyapi tipi kin iyecen, Israel ohna tona ozuye yapi kin owasin.

3 Unkan Mowis qa Eleazar wawayuśna kin wicoie kin hewicakiyapi, Moab makomdaye ohna, Jordan icahda Jerilio iyotakons.

4 Waniyetu wikcernna nonpa aktonpi wicayawapo, token Jehowa Mowis qa Israel cinca econ wicaśi qon, Egupta etanhan inanpapi qehan, he iyecen.

5 Ruben Israel cinhintku tokapa, Ruben cinca Ḣanok etanhan Hanoki wicowazi kin, Palu etanhan Palui wicowazi kin,

6 Hetzron etanhan Hetzroni wicowazi kin, Karmi etanhan Karmi wicowazi kin.

7 Rubeni wicowazi kin hena eepi, Kektopawinge wikcemua topa sanpa kektopawinge yamni sanpa opawinge śakowin sanpa wikcemna yamni wicayawapi.

8 Unkan Palu cinhintku Eliab hee.

9 Qa Eliab cinca kin Nemuel, qa Datan qa Abiram. Datan qa Abiram obe wicakicopi kin hena eepi, hena Mowis qa Aaron wicakipajinpi. Qora taomniciye en Jehowa kipajinpi qehan.

10 Qa maka kin i hdukawa, qa nawicapca, qa Qora taobe kin tapi qehan, peta kin wicaśta opawinge nonpa sanpa wikcemua zaptan wicahuhnage çehan; unkan hena wowapetokeca hecapi.

11 Tuka Qora cinca kin tapi śni.

12 Simeon cinca kin wicowazipi kin iyecen, Nemuel etanhan Nemueli wicowazi, Jamin etanhan Jamini wicowazi kin, qa Jakin etanhan Jakini wicowazi kin.

13 Zerah etanhan Zerahi wico236 wazi kin, Śaul etanhan Śauli wicowazi kin.

14 Simeoni wicowazipi kin hena eepi; kektopawinge wikcemna nonpa sanpa kektopawinge nonpa sanpa opawinge nonpa.

15 Gad cinca kin wicowazipi kin iyecen, Tzepon etanhan Tzeponi wicowazi kin, Hagi etanhan Ḣagi wicowazi kin, Śuni etanhan Śuni wicowazi kin,

16 Ozni etanhan Ozni wicowazi kin, Eri etanhall Eri wicowazi kin,

17 Arod etanhan Arodi wicowazi kin, Areli etanhan Areli wicowazi kin.

18 Gad cinca wicowazipi kin hena eepi wicayawapi iyecen, kektopawinge wikcemna topa sanpa opawinge zaptan.

19 Juda cinca kin Er qa Onan, tuka Fr qa Onan Kanan makoce ohna tapi.

20 Unkan Juda cinca kin wicowazipi kin iyecen dena eepi, Śla etanhan Ślani wicowazi kin, Perets etanhan Peretzi wicowazi kin, Zerali etanhan Zerehi wicowazi kin

21 Unkan Peretz cinca kin Hetzon etanhan Hetzoni wicowazi kin, Hamul etanhan Ḣamuli wicowazi kin.

22 Juda wicowazipi kin hena eepi wicayawapi iyecen kektopawinge wikcemna śakowin sanpa kektopawinge śakpe sanpa opawinge zaptan wicayawapi.

23 Unkan Isakar cinca kin wicowazipi kin iyecen, Tola etanhan Tolai wicowazi kin, Puwa etanhan Puwani wicowazi yin, 24 Jaśub etanhan Jaśubi wicowazi kin, Śsimron etanhan Śțroni wicowazi kin.

25 Isakar wicowazipi kin hena eepi wicayawapi kin iyecen kektopawinge wikcemna śakpe 
sanpa kektopawinge topa sanpa opawinge yamni, wicayawapi.

26 Zebulun cinca wicowazipi kin iyecen, Sered etanhan Saredi wicowazi kin, Elon etanhan Eloni wicowazi kin, Jahleel etanhan Jahleeli wicowazi kin.

27 Zebulun wicowazipi kin hena eepi kektopawinge wikcemna śakpe sanpa opawinge zaptan wicayawapi.

28 Josep cinca wicowazipi kin iyecen Manaśe qa Epraim.

2.9 Manaśe cinca Makir etanhan Makiri wicowazi kin, qa Makir Gilead kicitonpi, Gilead etanhan Gileadi wicowazi kin.

30 Gilead cinca kin dena eepi, Jezer Jezeri wicowazi, Heleq etanhan Heleqi wicowazi kin,

31 Qa Asriel Asrieli wicowazi kin; qa Śekem Śkemi wicowazi kin,

$32 \mathrm{Qa}$ Śemida Śemidai wicowazi kin, qa Ḧeper etanhan Ḣeperi wicowazi kin.

33 Qa Tzelopehad Heper cinhintku cinca wica nica cunwintku hecedan, qa Tzelopehad cunwintkn cajepi kin dena eepi $\mathrm{Ma}$ hla, qa Noya, Hogla Milka, qa Tirtza.

34 Manaśe wicowazipi kin hena eepi kektopawinge wikcemna zaptan sanpa kektopawinge nonpa, sanpa opawinge śakowin wicayawapi.

35 Epraim cinca kin dena eepi wicowazipi kin iyecen, Sutelah etanhan Śutelahi wicowazi kin, Beker etanhan Belkiri wicowazi kin, Tahan etanhan Tahani wicowazi lin.

36 Qa Śtelałi cinca kin dena eepi, Enan etanhan Enani wicowazi kin.

37 Epraim cinca wicowazipi kin hena eepi, wicayawapi kin iyecen kektopawinge wikcemna yamni sanpa kektopawinge nonpa sanpa opawinge zaptan; Josep cinca wicowazipi kin hena eepi.

38 Benjamin cinca wicowazipi kin iyecen, Bela etanhan Belayi wicowazi kin, Aśbel etanhan Aśbeli wicowazi kin, Aliram etanhan Ahirami wicowazi kin. 39 Śupam etanhan Śupami wicowazi kin, İupam etanhan İupami wicowazi kin.

40 Qa Bela cinca kin Ard, qa Naaman, Ardi wicowazi kin, Naaman etanhan Naamani wicowari kin.

4.1 Benjamin cinca hena eepi wicowazipi kin iyecen, qa kektopawinge wikcemna topa sanpa kektopawinge zaptan sanpa opawinge śakpe wicayawapi.

42 Dan cinca kin wicowazipi kin iyecen dena eepi ; Śuham etanhan Śuhami wicowazi kin, Dan wicowazi kin hee wicowazipi kin iyecen.

43 Suhami wicowazi kin owasin wicayawapi kin iyecen kektopawinge wikcemna śakpe sanpa kektopawinge topa sanpa opawinge topa.

44 Aśer cinca wicowazipi kin iyecen, Jimna etanhan Jimnahi wicowazi kin, Jiśui etanhan Jiśuwi wicowazi kin, Beriya etanhan Beriyi wicowazi kin.

45 Beriya cinca etanhan, $\dot{H e}$ ber etanhan Heberi wicowazi kin, Malkiel etanhan Malkieli wicowazi kin.

46 Qa Aśer cunwintku Sarah eciyapi.

4\%ั Aśer cinca wicowazipi kin hena eepi, wicayawapi kin iyecen kektopawinge wilkcemna zaptan sanpa kektopawinge yamni sanpa opawinge topa.

48 Naptali cinca wicowazipi kin iyecen Jalitzel etanhan Jah237 


\section{WICAYAWAPI,}

tzeli wicowazi kin, Guni etanhan Guni wicowazi kin.

49 Jetzer etanhan Jetzeri wicowazi kin, Ślem etanhan Śilemi wicowazi kin.

50 Naptali wicowazipi kin hena eepi wicowazipi kin iyecen: kektopawinge wikcemna topa sanpa kektopawinge zaptan sanpa opawinge topa wicayawapi.

51 Israel cinca wicayawapi kin hena eepi, kektopawinge opawinge śakpe sanpa kektopawinge wanjidan sanpa opawinge śakowin sanpa wikcemna yamni.

52 Unkan Jehowa ie ça Mowis heciya,

53 Makoce tawayayapi kta e hena wicakicipamnipi kta, cajepi wicayawapi kin iyecen.

54 Wicota kin tankaya tawayapi kta wicayaqu kta, qa tonana on tawayapi cistiyedan wicayecage kta; otoiyohi tona yawapi kin eciyatanhan tawaye lita e qupi kta.

55 Hececa eśta oeconna eciyatanhan makoce pamnipi kta, ateyapi wicoun cajepi eciyatanhan tawayapi kta.

56 Oeconna i kin eciyatanhan makoce tawapi wicakicipamnipi kta, wicota qa tonana otahe dan.

57 Lewi kin wicayawapi kin dena eepi, wicowazipi kin iyecen, Gerśon etanhan Gerśoni wicowazi kin, qa Qohat etanhan Qohati wicowazi kin, qa Merari etanhan Merari wicowazi kin.

58 Lewi wicowazipi kin dena eepi, Libni wicowazi kin, $\dot{H} e-$ broni wicowazi kin, Mahli wicowazi kin Muśi wicowazi kin ; Qorahi wicowazi kin. Unkan Qohat Amram kicitonpi.

59 Unkan Amram tawicu Jokebed eciyapi, Lewi cunwintku,
Egupta ohna he Lewi kicitonpi, unkan he Aaron qa Mowis qa tawinohtinpi Miriam Amram kiciton.

60 Unkan Aaron cinca kin Nadab, qa Abihu, Eleazar qa Itamar.

61 Tuka Nadab qa Abihu peta tokeca Jehowa itokam ahipi qehan tapi.

62 Unkan kektopawinge wikcemna nonpa sanpa kektopawinge yamni wicayawapi, wica wi wanjidan aktonpi owasin. Tuka Israel cinca wicehna makoce tawayapi wicaqupi śni, heon Israel cinca wicehna wicayawapi śni.

63 Mowis qa Eleazar wawayuśna kin hena wicayawapi, Israel cinca wicayawapi qehan, Moab makomdaye ohna Jordan icahda Jeriko iyotakonza.

64 Qa wicehna wicaśta Mowis qa Aaron wawayuśna kin Israel cinca Sina hopuza ohna wicayawapi qon wanjidan ope śni.

65 Hena liopuza ohna tapi kta Jehowa kewicakiya nakaś, hecen hena etanhan wanjidan okapte śni, Caleb Jepune cinhintku, qa Jośuwa Nun cinhintku henana.

\section{WICOWOYAKE $2 \%$.}

1 Hehan Josep cinhintku Manaśe wicowazi kin etanhan Manaśe cinhintku Makir cinhintku Gilead cinhintku Heper cinhintku Tzelopehad cunwintku hipi, qa Tzlopehad cunwintku cajepi kin dena eepi : Mahla qa Noya Ḧogla Milka qa Tirza.

2 Qa Mowis itokam qa Eleazar wawayuśna itokam, qa omniciye owasin qa itancanpi itokam itkokipapi wakeya tiyopa ekta najinpi qa heyapi ;

3 Ate unyanpi hopuza ohna ta 
tuka omniciye Jehowa amniciyapi kin ope śni, Qora obe kin he; tuka iye wahtani kin on ța, qa cinca wica nica.

4 Tokeca ate unyanpi cinhintku nica heon caje kin wicowazi tawa etanhan kajujupi kta he? Ate sunka wicaye cin wicehna makoce onśpa unqumiye.

5 Unkan token ecawicakiconpi kta Mowis Jehowa iwanga.

6 Unkan Jehowa ie ca Mowis heciya,

7 Tzelopehad cunwintku kin ecetuya eyapi. A te yapi tamaga kin hena ekta iyopta yaye kta.

8 Unkan Israel cinca kin hecen ewicayakiye kta, Wicaśta wan cinca wica nica țe cinhan, maga tawa kin cunwintku ekta iyopte yayapi kta.

$9 \mathrm{Qa}$ cunwintku nice cinhan cincu qa sunkaku maga tawa yaqupi kta.

10 Qa hunkawanjitku nice cinhan, atkuku hunkawanjitku kin maga tawa yaqupi kta.

$11 \mathrm{Qa}$ atkuku hunkawanjitku nice cinhan, tuwe wicowazi tawa etanhan iye celipi takuye hinca kin maga tawa yaqupi kta ; unkan iye he tawaye kta. Woyaco kin de Israel cinca owihanke wanin yuhapi kta, Jehowa Mowis econ śi kin he iyecen.

12 Unkan Jehowa Mowis heciya, Abarim lie kin de itanwankanhde ye ca makoce Israel cinca kin wicawaqu kin he wanyaka wo.

$13 \mathrm{He}$ wandake kta, hehan niś eya oyate nitawa ekta okipe niyanpi kta, Aaron nicinye okipe yapi kin he iyecen.

14 Tzin liopuza ohna mii kin yakipajinpi oyate kin kigepi qehan, iśtapi en mayaduwakanpi śni, mini ekta, Kigepi mini kin hee, Qadeś ekta, Tzin hopuza ohna.
15 Unkan Mowis ie ça Jehowa heciya,

16 Tokin Jehowa taku wakan wicacehpi toniyapi owasin wicayuhe cin wicaśta wan oyate kin wicayuhe śi kten.

17 He wicitokam inanpe kta, qa wicitokam ku kta, qa inanpe wicaye kta, qa hdi wicaye kta, hecen Jehowa taomniciye kin tahin wanunyanpi waawanyake nica iyececapi kte śni.

18 Unkan Jehowa Mowis heciya, Jośuwa Nun cinhintku icu wo, wicaśta kin he woniya ohna yanka qa nape aputaka wo.

19 Qa Eleazar wawayuśna itokam, qa omniciye ocowasin itokam, najin yakiye kta, qa token econ yaśi kin hena wanyakapi kta.

20 Qa wowitan nitawa etanhan he yaqu kta, hecen Israel cinca omniciye owasin he nalionpi kta.

21 Unkan Eleazar wawayuśna kin itokam najin kta; unkan he Jehowa ikiciwange kta, iyoyam wicaya woyaco eciyatanhan, Iye i kin eciyatanhan inanpapi kta, qa iye $i$ eciyatanhan hdipi kta, iye qa nakun Israel cinca owasin omniciye ocowasin.

22 Unkan token Jehowa Mowis econ śi he iyecen econ, qa Jośuwa icu qa Eleazar wawayuśna itokam, qa omniciye ocowasin itokam najin kiya.

23 Qa akan nape aputaka, Jehowa Mowis eciye ciqon he iyecen.

WICOWOYAKE 28.

1 Unkan Jehowa ie ca Mowis heciya,

2 Israel cinca kin wahokon wicakiye ça hewicakiya wo. Waktaya unpo, iyehantu eca woahi mitawa, woyute mitawa peta 239 


\section{WICAYAWAPI,}

wośnapi waśtemna wiciyokipi makahipi kta.

3 Qa hewicayakiye kta. Peta wośnapi Jehowa yakahipi kte cin dee, amnos nonpa, napin zanika, waniyetu wanjidan wohuhinaliyapi ohinniyan anpetu otoiyohi.

4 Amnos wanji hanlianna eca waduśnapi kta, qa amnos inonpa kin ohtayetu otahedan ecanonpi kta.

5 Qa minlia on aguyapi mdu can wakśica ohmaka wanjidan, wihdi bopanpi wivatke ohnaka wanjidan icicahiyapi.

6 Wolibinahyapi ohinniyan Sina lie en kagapi, peta wośnapi waśtemna Jehowa iyokipi.

7 Qa toakaśtan kin ammos wanjidan on wiyatke ohnaka wanjidan, tipi wakan ohna miniśa kin Jehowa okicicaśtan wo.

8 Qa amnos inonpa kin ohtayetu otahedan waduśna kta, hanhanna minha kin qa woakaśtan kin kici yakage kta, peta wośnapi waśtemna Jehowa iyokipi.

9 Unkan anpetu okilipapi en amnos nonpa waniyetu wanjidan zanika, qa aguyapi mdu can wakśica ohnaka nonpa wihdi icicahiyapi, minlia hee, nakun toakaśtan kin.

10 Anpetu okilhapi wohulinahyapi kin hee, anpetu okihpapi otoiyohi on ohinniyan wohuhnahyapi, qa toakaśtan kici.

11 Qa wi anpetu tokaheya kin en wohulinaliyapi Jehowa yakahipi kta, tatanka pte wanunyanpi cinca nonpa, tamdoka wanjidan, qa amnos śakowin zanika.

$12 \mathrm{Qa}$ minha kin aguyapi mdu can wakśica ohnaka yamni, wihdi icicahiyapi, tatanka otoiyohi on, qa tamdoka on minha aguyapi mdu can wakśica ohnaka nonpa, wihdi icicahiyapi. 240
13 Qa minlia amnos otoiyohi on aguyapi mdu can wakśica ohnaka wanjidan, wihdi icicahiyapi, peta wośnapi waśtemna Jehowa iyokipi.

$14 \mathrm{Qa}$ toakaśtanpi kin miniśa wiyatke ohnaka nonpa, tatanka wan on, qa wiyatke ohnaka wanji sanpa hanke tamdoka kin on, qa wiyatke ohnaka wanjidan amnos otoiyohi on; omaka wi otoiyohi on wi toka tanin eca wohuhnalyapi kin hee,

15 Nakun tatokadan mdoka wan woahtani wośnapi Jehowa wakiyuśnapi kta, ohinniyan wośnapi kici, qa toakaśtan kici. 16 Unkan wi tokaheya anpetu iake topa en woacakśin Jehowa kicagapi kta.

17 Unkan wi kin he anpetu iake zaptan en Jehowa wokicihanpi kta, Anpetu śakowin aguyapi napohyapi śni yutapi kta.

18 Anpetu tokaheya en wicakicopi wakan, wayaka wolitani takudan econpi kte śni.

19 Qa peta wośnapi wohuhinahyapi wan Jehowa yakahipi kta, tatanka pte wanunyanpi cinca nonpa, tamdoka wanjidan, qa amnos waniyetu wanjidan śakowin, niyepi on zanipike kta.

20 Qa minhapi aguyapi mdu wihdi icicahiyapi can wakśica ohnaka yamni tatanka otoiyohi on, qa tamdoka on can wakśica ohnaka nonpa yecagapi kta.

21 Qa amnos śakowin on can wakśica ohnaka śakowin, amnos otoiyohi on can wakśica ohnaka wanjidan, wicayecagapi kta. 22 Qa tatokadan wanjidan woahtani wośnapi akahpe niçiyapi kta.

23 Hena wośnapi yakagapi kta, hanhanna woliulinaliyapi kici, wohulinahyapi ohinniyan kin hee. 24 Anpetu śakowin kin anpetu 


\section{WICOWOYAKE 29.}

otoiyohi peta tawote waśtemna Jehowa iyokipi yakagapi kta, wohuhnahyapi ohinniyan toakaśtan kici nakun kagapi kta.

25 Unkan anpetu iśakowin en wicakicopi wakan duhapi kta, wayaka. wohtani takudan ecanonpi kte śni.

26 Nakun taku tokaheya suton anpetu en minha teca Jehowa yakahipi eca, anpetu wakan śakowin owihanketa wicakicopi wakan duhapi kta, wayaka wohtani takudan ecanonpi kte śni.

27 Qa woliuhnahyapi waśtemna Jehowa iyokipi yakahipi kta, tatanka pte wanunyanpi cinca nonpa, tamdoka wanjidan, qa amnos waniyetu wanjidan śakowin.

$28 \mathrm{Qa}$ minhapi aguyapi mdu wihdi icicahiyapi can wakśica ohnaka yamni tatanka otoiyohi on, qa can wakśica ohnaka nonpa tamdoka wan on.

29 Qa can wakśica ohnaka śakowin amnos śakowin on, amnos otoiyohi on can wakśica ohnaka wanjidan.

30 Tatokadan mdoka wanjidan akahpe niciyapi kta heon.

31 Woluhlinahyapi ohinniyan, qa taminlia kici, hena yakagapi kta, woakaśtanpi kin nakun niyepi on hena zanipike kta.

\section{WICOWOYAKE 29.}

1 Unkan wi iśakowin, wi anpetu, tokaheya en wicakicopi wakan duhapi kta, wayaka wolitani takudan ecanonpi kte śni, anpetu mazayahotonpi wiyuśkinyan hotonpi kin duhapi kta. 2 Qa wohuhnahyapi waśtemna Jehowa iyokipi yakagapi kta, tatanka wanji ptewanunyanpi cinca, tamdoka wanji, amnos Num. waniyetu wanjidan śakowin zanika.

3 Qa taminhapi kin aguyapi mdu wihdi icicahiyapi, can wakśica ohnaka yamni tatanka kin on, qa ohnaka nonpa tamdoka on,

4 Qa amnos śakowin on otoiyohi on can wakśica ohnaka wanjidan.

5 Qa tatokadan mdoka wanjidan woahtani wośnapi hee akahpe niciyapi kta.

6 Nakun wi wohuhnahyapi kin taminha kici, qa ohinniyan wohuhnahyapi kin taminha kici, qa toakaśtanpi kin woyaco iyecen, peta wośnapi waśtemna Jehowa iyokipi.

7 Unkan wi iśakowin kin he anpetu iwikcemna en wicakico. pi wakan duhapi kta, qa ninagipi iyokiśin niciyapi kta, he en wayaka wohtani takudan ecanonpi kte śni.

8 Qa wohuhnahyapi wan Jehowa yecahipi kta, waśtemna wiciyokipi, tatanka ptewanunyanpi cinca wanji, tamdoka wanji, amnos waniyetu wanjidan śakowin zanika niyepi on.

9 Qa minhapi kin aguyapi mdu wihdi icicahiyapi can wakśica ohnaka yamni tatanka wan on, qa can wakśica ohnaka nonpa tamdoka wanjidan kin on.

$10 \mathrm{Qa}$ amnos śakowin on, amnos otoiyohi on can wakśica ohnaka wanjidan.

11 Tatokadan mdoka wanjidan woalitani wośnapi on, nakun akahpe wicakiyapi woahtani wośnapi, qa ohinniyan wohuhnahyapi kin, qa minha kin, qa toakaśtanpi kin.

12 Unkan wi iśakowin anpetu iake zaptan en wicakicopi wakan duhapi kta, wayaka wohtani takudan ecanonpi kte śni, qa 241 
anpetu śakowin wohanpi Jehowa oyecihanpi kta.

$13 \mathrm{Qa}$ wohuhnahyapi wan Jehowa yakahipi kta, peta wośnapi waśtemna wiciyokipi, tatanka ptewanunyanpi cinca wikcemna sanpa yamni, taindoka nonpa, amnos waniyetu wanjidan aketom zanipike kta.

14 Qa taminhapi aguyapi mdu wihdi icicahiyapi can wakśica ohnaka yamni tatanka otoiyohi on, tatanka iakeyamni on, qa tamdoka nonpa on, otoiyohi on can wakśica ohnaka nonpa.

$15 \mathrm{Qa}$ amnos aketopa on, amnos otoiyohi on can wakśica ohnaka wanjidan.

16 Qa tatokadan mdoka wanjidan woalitani wośnapi, nakun ohinniyan wohuhnahyapi kin, taminha kin qa toakaśtan kici.

17 Qa anpetu inonpa en tatanka ptewanunyanpi cinca wikcemna sanpa nonpa, tamdoka nonpa, amnos waniyetu wanjidan aketopa zanipika.

18 Qa taminhapi kin, qa toakaśtanpi kin, tatanka on, qa tamdoka on, qa amnos on, woyaco eciyatanhan iyenakecapi iyecen.

19 Qa tatokadan mdoka wanjidan woalitani wośnapi, nakun wohuhnahyapi ohinniyan, qa minha tawa, qa toakaśtanpi kin.

$20 \mathrm{Qa}$ anpetu iyamni en tatanka akewanji, tamdoka nonpa, amnos waniyetu wanjidan aketopa zanika.

21 Qa taminhapi, kin qa toakaśtanpi kin, tatanka on, qa tamdoka on, qa amnos on, woyaco eciyatanhan iyenakecapi iyecen.

22 Qa tatokadan mdoka wanjidan woahtani wośnapi, nakun wohuhnahyapi ohinniyan, qa minha tawa, qa toakaśtan kin.

$23 \mathrm{Qa}$ anpetu itopa en tatanka wikcemna, tamdoka nonpa, a242 mnos waniyetu wanjidan aketopa zanika.

24 Tạtanka on, qa tarndoka on, qa amnos on iyenakecapi, taminhapi, qa toakaśtanpi kin woyaco iyecen.

25 Qa tatokadan mdoka wanjidan woaktani wośnapi, nakun wohuhnahyapi ohinniyan, taminha kin, qa toakaśtan kici.

26 Qa anpetu izaptan en tatanka napcinwanka, tamdoka nonpa, amnos waniyetu wanjidan aketopa zanika.

27 Qa tatanka, qa tamdoka, qa amnos iyenakecapi on taminhiapi, qa toakaśtanpi, woyaco eciyatanhan.

$28 \mathrm{Qa}$ tatokadan mdoka woahtani wośnapi wanjidan, nakun wohuhnahyapi ohinniyan, qa taminha, qa toakaśtan kici.

$29 \mathrm{Qa}$ anpetu iśakpe en, tatanka śahdugan, tamdoka nonpa, amnos waniyetu wanjidan aketopa zanika.

30 Qa taminhapi, qa toakaśtanpi kin, tatanka on, qa tamdoka on, qa amnos iyenakecapi on, woyaco eciyatanhan.

$31 \mathrm{Qa}$ tatokadan mdoka woahtani wośnapi wanjidan, nakun wohuhnahyapi ohimniyan kin, taminlia qa toakaśtan kici.

$32 \mathrm{Qa}$ anpetu iśakowin en tatanka sakowin, tamdoka nonpa, amnos waniyetu wanjidan aketopa zanika.

33 Qa taminhapi, qa toakaśtanpi kin tatanka iyenaka on, qa tamdoka iyenaka on, qa amnos iyenaka on, woyaco eciyatanhan.

34 Qa tatokadan mdoka woahtani wośnapi wanjidan, nakun wohuhnahyapi ohinniyan, taminha kin qa toakaśtan kici.

35 Anpetu iśahdogan en omniciye wakan duhapi kta, wayaka 
wohtani takudan ecanonpi kte śni.

36 Qa wohuhnahyapi peta wośnapi waśtemna wiciyokipi Jehowa yakahipi kta, tatanka wanji, tamdoka wanji, amnos waniyetu wanjidan śakowin zani$\mathrm{ka}$.

37 Tamilliapi qa toakaśtanpi kin tatanka on, qa tamdoka on, qa amnos iyenakecapi on, woyaco eciyatanhan.

$38 \mathrm{Qa}$ tatokadan modoka woahitani wośnapi wanjidan, nakun wohuhnahyapi ohinniyan kin, qa taminha kin toakaśtan kici.

39 Taku odakapi kin qa taku ikceya waduśnapi kin, wohuhnahyapi nitawapi on, qa minha nitawapi on, qa woakaśtanpi nitawapi on, qa wopida wośnapi nitawapi on, isanpa wohanpi iyehantu eca hena Jehowa yecagapi kta.

40 Unkan token Jehowa Mowis econ śi he iyecen Mowis Israel cinca kin owicakiyaka.

\section{WICOWOYAKE 30 .}

1 Unkan Mowis Israel cinca wicoun itancanpi kin hewicakiya, Wicoie Jehowa econ niśipi kin dee.

2 Wicaśta wan woyake wan Jehowa okiyake cinhan qaiś taku wakan cajeyate on nagi ihdaśke cinhan, oie kin ihduikceke kte śni, tuka taku i kin eciyatanhan inanpe cin owasin iyecen econ kta.

3 Unkan winohinca wan woyake wan Jehowa okiyake cinhan, qa nahanhin wikośka atkuku ti ohna wicaśke on ihdaśke cinhan,

$4 \mathrm{Qa}$ atkuku woyake kin qa wicaśke on nagi ihdaśke cin he nahon, ga atkuku inina yanke cinhan taku oyake cin owasin suta kta, qa wicaśke on nagi kin ihdaśke cin owasin ecetu kta.

5 Tuka tohan atkuku woyake kin, qa wicaśke on nagi ihdaśke cin nahon, anpetu kin he en tehinda kinhan, ecetu kte śni, qa atkuku he tehinda kin heon Jehowa kicicajuju kta.

6 Unkan woyake on ihdaśka, qaiś iha on ecinśniyan nagi ihdaśke cehan wicaśta wan he yuhe cinhan;

$7 \mathrm{Qa}$ hihnaku he nation, qa anpetu en nation inina yanke cinhan, woyake kin ecetu kta, qa wicaśke on nagi kin ihdaśke cin suta kta.

8 Tuka hibnaku tohan nahon anpetu kin he en tehinda kinhan, woyake kin qa taku iha ecinśniyan nagi kin ihdaśke cin he yujuju kta, unkan Jehowa he kicicajuju kta.

9 Unkan woyake qa taku on wiwazica qaiś winohinca elpekiyapi nagi ihdaśke cin owasin suta kta.

10 Unkan hihnaku ti kin ohna oyake, qaiś taku wakan caje yate ça wicaśke on nagi kin ihdaśka :

11 Qa hihnaku nahion eśta inina yanke ça tehinda śni kinhan, woyake kin ecetu kta, qa wicaśke on nagi kin ihdaśke cin owasin sutakta.

12 Tuka hihnaku tohan nation taku iha kin etanhan inanpe cin owasin katinyan yujuju kinhan, woyake kin, qa wicaśke on nagi ihdaśke cin he suta kte śni, hihnaku he yujuju he on Jehowa kicicajuju kta.

13 Woyake owasin, qa nagi iyokiśinye kta e taku wakan caje yate, wicaśke owasin hihnaku yasuta okihi, qa yajuju okihi. 14 Tuka hihnaku anpetu wan243 
ji qa anpetu iyokihe katinyan inina yanka cinhan, taku oyake owasin, qa wicaśke on ihdaśke cin owasin hena yasuta, hena nahon qehan anpetu kin he en inina yanka nakaś.

15 'Tuka nahon kin iyohakam hena katinyan yajuju kinhan winyan wahtani kin hihnaku yuhe kta.

16 Wokage wicaśta wan, qa tawicu otahedan, qa wicaśta ateyapi qa cunwintku wikośka atkuku ti ohna yanke cin otahedan, Jehowa Mowis eciye cin hena eepi.

\section{WICOWOYAKE 31.}

1 Unkan Jehowa ie ça Mowis heciya,

2 Israel cinca on Midiyani tokiçon wicaya wo, ohakam oyate nitawa ekta okipe niyanpi kta.

3 Unkan Mowis ie ca oyate kin hewicakiya, Niyepi etanhan ozuye yapi kta e wicaśta wipe kiton wicaya po, unkan Midiyani azu wicayapi kta, hecen Jehowa on Midiyani en watoyeconpi kta.

4 Israel wicoun owasin etanhan wicoun otoiyohi etanhan kelitopawinge wanjidan ozuye ye wicayaśipi kta.

5 Unkan Israel kektopawinge etanhan wicoun iyohi etanhan kektopawinge wan, kahnigapi, kektopawinge akenonpå ozuye on wipe kitonpi.

6 Unkan Mowis wicoun iyohi etanhan kektopawinge wan ozuye ye wicaśi nakun Pinehas Eleazar wawayuśna cinhintku kin ozuye yeśi, qa taku on tipi wakan kicanyanpi, qa mazayahotonpi on panyanhanhan yahotonpi kin nape kin ohna.
7 Unkan Midiyani kin azu wicayapi, Jehowa Mowis econ śi kin he iyecen, qa tona wica owasin wicaktepi.

8 Qa wicaktepi iyahna Midiyani wicaśtayatapi kin wicaktepi, Ewi, qa Reqem, qa 'Tzur, qa Hur, qa Reba Midiyani wicaśtayatapi zaptan, nakun Balam Beyor cinhintku canhpi on ktepi.

9 Unkan Israel cinca kin Midiyani winohinca kin, qa śicecapi kin, wayaka iwicacupi, nakun tawanunyanpi pte tahinca ko owasin, qa taku yuhapi kin owasin kipi.

10 Qa otonwe ohna ounyanpi qon owasin, qa taconkaśkepi owasin peta on hulnahyapi.

11 Unkan taku kipi kin owasin icupi, wicaśta woteca koya. 12 Qa wayaka qa taku icupi, qa taku kipi owasin hdohdapi, Mowis elkta, qa Eleazar wawayuśna ekta, qa Israel cinca omniciye ocowasin ekta, wicoti kin ekta; he Moab makomdaya ohna un, Jordan icahda Jerilio iyotakonza.

13 Unkan Mowis qa Eleazar wawayuśna kin, qa omniciye itancan wicaye cin owasin itkowicakipe kta wicoti itankan inanpapi.

14 Unkan Mowis ozuye 'mdetanhunkapi kektopawinge itancanpi, qa opawinge itancanpi obe ozuye etanhan hdipi kin canniye wicaya.

$15 \mathrm{Qa}$ Mowis hewicakiya, Winyanpi kin owasin ni wicayayapi he?

16 Inyun hena Balam oie eciyatanhan Israel cinca kin Jehowa kipajin wicakiyapi, Peyor wicoie en, heon Jehowa taomniciye en makośice yukan.

17 Heon wanna śiceca ehna 
tona wica owasin wicatke po, qa winohinca tona wicaśta kici wankapi on wicaśta sdonyapi owasin wicakte po.

18 Tuka śiceca winyanpi wicaśta sdonyapi śni, qa wica kici wankapi śni hena niyepi on ni wicayapo.

19 Qa niyepi anpetu śakowin wicoti itankan yankapo, qa tona wicanagi wan ktepi owasin, qa tona wicatancan ta icahtakapi owasin anpetu iyamri en, qa anpetu iśakowin en ihduskapo, qa wayaka duhapi kin hena wicayuska po.

20 Qa heyake owasin, qa taku kaśta taha on kagapi, qa tatokadan hin on kagapi, qa can on kagapi hduska po.

21 Unkan Eleazar wawayuśna kin ozuye wicaśta wokicize etanhan hdipi kin hewicakiya, Woope wokage Jehowa Mowis eciye cin dee.

22 Awicakehan mazaskazi, qa mazaska, qa mazaśa, qa mazasapa, qa mazaskaśdoyapi kin, qa mazasu,

23 Taku kaśta peta ohna opta ya okihi he peta iyopte yayapi kta; nakun wipakintapi mini on pakintapi kta, hecen ska kta, qa taku peta en ye kta okihi śni kin he owasin minin iyopte yayapi kta.

$24 \mathrm{Qa}$ anpetu iśakowin en heyake kin hdujajapo, qa ihduskapo, qa ohakam wicoti en yahipi kta.

25 Unkan Jehowa ie ça Mowis heciya,

26 Ozuye ipi taku icupi kin wicaśta wanunyanpi koya yawa wo, niye qa Eleazar, qa omniciye ateyapi otokapapi kin.

$27 \mathrm{Qa}$ taku icupi kin yapamni kta, obe kizapi kta ozuye ipi kin hena hanke wicayaqu kta, qa omniciye ocowasin hanke wicayaqu kta.

28 Qa ozuye obe wicaśta kizapi kta iyayapi kin hena etanhan Jehowa on onśpa kosyaye kta, opawinge zaptan etanhan wicanagi wanjidan iyacu kta, wicaśta etanhan, nakun pte etanhan, qa śonśonna etanhan, qa tahinca etanhan.

29 Hanke tawapi etanhan Jehowa tawokosyapi kin iyacu kta, qa Eleazar wawayuśna .kin yaqu kta.

30 Unkan Israel cinca hanke tawapi etanhan wikcemna zaptan etanhan wanjidan iyacu kta, wicaśta etanhan, qa pte etanhan, qa śonśonna etanhan, qa tahinca etanhan, wanunyanpi owasin etanhan, qa hena Lewi Jehowa toti kin awanyakapi kin wicayaqu kta.

31 Unkan token Jehowa Mowis econ si hecen Mowis qa Eleazar econpi.

32 Unkan taku icupi ihe cin oyate ozuye ipi taku kipi kin he tahinca kektopawinge opawinge śakpe sanpa kektopawinge wikcemna śakowin, sanpa kektopawinge zaptan.

$33 \mathrm{Qa}$ pte kektopawinge wikcemna śakowin sanpa kektopawinge nonpa.

34. Qa śonśonna kektopawinge wikcemna śakpe sanpa kektopawinge wanjidan.

35 Qa wicanagi wicinyanpidan wica kici wankapi eciyatanhan wicaśta sdonyapi śni, winyan wicanagi owasin kektopawinge wikcemna yamni sampa kektopawinge nonpa.

$36 \mathrm{Qa}$ he hanke obe ozuye ipi wopamni tawapi kin tahinca yawapi kin etanhan kektopawinge opawinge yamni sanpa kektopawinge wikcemna yamni san- 


\section{WICAYAWAPI,}

pa kektopawinge śakowin sanpa opawinge zaptan'.

37 Qa tahinca etanhan Jehowa onśpa tawa kin opawinge -śakpe sanpa wikcemna śakowin sanpa zaptan.

$38 \mathrm{Qa}$ pte kektopawinge wikcemna yamni sanpa kektopawinge sakpe, qa Jehowa onśpa tawa wikcemna śakowin sanpa nonpa.

39 Qa śonśonna kektopawinge wikcemna yamni sanpa opawinge zaptan, qa Jehowa onśpa tawa wikcemna śakpe sanpa wanjidan.

40 Qa wicanagi kektopawinge wikcemna sanpa kektopawinge śakpe, qa hena etanhan Jehowa onśpa tawa wicanagi wikcemna yamni sanpa nonpa.

41 Unkan Mowis Jehowa onśpa tawa wokosyapi kin Eleazar wawayuśna kin qu, Jehowa Mowis econ sil kin he iyecen.

42 Unkan Israel cinca hanke tawapi wicaśta ozuye ipi kin etanhan Mowis icu qon etanhan:

43 Wanna omniciye hanke tawapi kin tahinca etanhan kektopawinge opawinge yamni sanpa kektopawinge wikcemna yamni sanpa kektopawinge śakowin sanpa opawinge zaptan.

44 Qa pte kektopawinge wikcemna yamni sanpa kektopawinge śakpe.

$45 \mathrm{Qa}$ śonśonna kektopawinge wikcemna yamni sanpa opawinge zaptan.

$46 \mathrm{Qa}$ wicanagi kektopawinge wikcemna sanpa kektopawinge śakpe.

47 Unkan Mowis Israel cinca hanke tawapi kin etanhan taku icu wikcemna zaptan etanhan wanjidan icu, wicaśta etanhan, qa wanunyanpi etanhan, qa he246 na Lewi Jehowa toti awanyakapi kin wicaqu, Jehowa Mowis econ śi kin he iyecen.

48 Unkan ozuye kektopawinge mdetanhunkapi, kektopawinge itancanpi, qa opawinge itancanpi kin Mowis ek ta hipi :

49 Qa Mowis heciyapi, Nitaokiye wicaśta unnapepi ihukuya okicize ekta ipi kin hena wicunyawapi, qa unkiyepi etanhan wicaśta wanjidan aokpani.

50 Heon woahi wan Jehowa unkahipi wicaśta otoiyohi mazaskazi oinpi iyeye cin, mazaicicahilia, qa mazahuhu, mazanapcupe, oinpi, qa maza śipto, nagi akahpe unkiciyapi kta Jehowa itokam.

51 Unkan Mowis qa Eleazar taku mazaskazi on kagapi owasin bena etanhan icupi.

52 Mazaskazi wokosyapi Jehowa ekta kosyapi kin he seqel kektopawinge akeśakpe sanpa opawinge śakowin sanpa wikcemna zaptan henakeca, kektopawinge itancanpi qa opawinge itancanpi etanhan.

53 Obe wicaśta kin otoiyohi iye on taku ki.

54 Unkan Mowis qa Eleazar wawayuśna kin mazaskazi kin icupi kektopawinge, qa opawinge itancanpi etanlian, qa itkokipapi wakeya en ahipi, Israel cinca on wokiksuye Jehowa itokam.

\section{WICOWOYAKE 32.}

1 Unkan Ruben cinca qa Gad cinca kin wanunyanpi ota yuhapi, ota hinca, qa Jazer nlakoce kin, qa Gilead makoce kin wanyakapi, qa inyun makoce kin he wallunyanpi makoce heca.

2 Qa Gad cinca qa Ruben cinca upi, qa Mowis qa Eleazar 


\section{WICOWOYAKE 32.}

wawayuśna kin, qa omniciye itancanpi kin hewicakiyapi ;

3 Atarot, qa Dibon, qa Jazer qa Nimra, qa Heśbon, qa Eleale, qa Śbam, qa Nebo, qa Beon.

4 Makoce Jehowa Israel omniciye itokam kaśtake cin, he wanunyanpi on makoce waśte hinca, qa nitaokiye wanunyanpi yuhapi.

5 Niiśta kin en woiyokipi iyeunyanpi kinhan, makoce kin he nitaokiye unqumiye, tawa unyanpi, kta, qa Jordan akasanpa unyanpi k te śni, eyapi.

6 Unkan Mowis Gad cinca, qa Ruben cinca kin hewicakiya, Nilıunkawanjipi wokicize ekta yapi, qa niyepi den yakidotankapi kta he?

7 Tokeca Israel cinca cantepi kin wankadan yakagapi? hecen makoce Jehowa.wicaqu kin en iyoptapi kte śni.

8 Niyatepi Qadeś Barneya etanhan makoce iwanyag ye wicawaśi qehan hecen econpi.

9 Hehan Eśkol kaksiza ekta ipi, qa Israel cinca canwankapidan wicakagapi, heon makoce Jehowa wicaqu kin he ekta ipi śni.

10 Unkan anpetu kin he en Jehowa canniye ça caje ihdate konze ca heya,

11 Wicaśta waniyetu wikcemna nonpa aktonpi.Egupta etanhan itanwankanhde upi kin hena makoce Aberaham qa Izak qa Jakob konza ewicawakiye ciqon he wanyakapi kte śni, ocowasin omapapi śni nakaś.

12 Kaleb Jepune Qenizi kin, qa Jośuwa Nun cinhintku henana, hena Jehowa iyohakam yuśtanpi nakaś.

13 Unkan Jehowa Israel canniye wicaya, unkan hopuza ohna waniyetu wikcemna topa ihdakapi, wicoicage Jehowa iśta kin en taku śica econpi kin hena sotapi kin hehanyan.

14 Unkan inyun niyatepi heekiya wicaśta wahtanipisa wicoicage nayajinpi, qa Jehowa Israel canniye wicaye cin he sanpa tanka yakagapi kta.

15 Tuka iye etanhan nihdamnapi kinhan, ake hopuza en yanke wicaye kta, qa oyate kin de owasin awihnuni wicayayapi kta.

16 Unkan ikiyedan hipi qa heciyapi, Deciya tahinca wanunyanpi tipi wicunkicagapi kta, qa unkicincapi otonwe wicunkicagapi kta.

17 Qa unkiyepi wipe kiton waditagya Israel cinca wicitokam unyanpi kta, tukten yakonpi kta ekta hiyuwicunyanpi kin hehanyan, tuka śiceca unkitawapi otonwe aconkaśkayapi ohna iyotankapi kta, oyate makoce kin den unpi kin heon etanhan.

18 Israel cinca otoiyohi maga tawa tawaye śni kin hehanyan untipi en unhdipi kte śni.

19 Qa hena om Jordan akasanpa takudan tawa unyanpi kte śni, Jordan itato wiyohiyanpata ektakiya maga unkitawapi yanke nakaś.

20 Unkan Mowis hewicakiya, Token ehapi hecen ecanonpi kinhan, Jehowa itokam wipe kiton ozuye dapi kinhan,

21 Qa otoiyohi wipe kiton Jehowa itokam Jordan akasanpa idadapi, iye itokapa tanhan toka wicaye cin nape wicaye cin hehanyan.

22 Qa makoce Jehowa itokam ktepidan, qa ohakam yahdipi kinhan, Jehowa itokam, qa Israel itokam iyaonpepicaśni yaunpi kta, qa Jehowa itokam makoce kin de tawa yayapi kta. 


\section{WICAYAWAPI,}

23 Tuka hecen ecanonpi śni kinhan, inyun Jehowa awayahtanipi, qa wayahtanipi kin iyeniyanpi kta sdonyapo.

24 Śceca nitawapi on otonwe icicagapo, qa talinca nitawapi tipi wicakicagapo, qa taku niihapi etanhan inanpe cin econpo.

25 Unkan Gàd cinca, qa Ruben cinca iapi, qa Mowis heciyapi, Token Itancan unyanpi eye cin ecen econkunpi kta.

26 Unkicincapi unkitawicupi, tahinca unkitawapi, qa wanunyanpi unkitawapi owasin, heciya Gileyad otonwe en yakonpi kta.

27 Tuka nitaokiye wipe kiton obe owasin Jehowa itokam wokicize ekta iyounptapi kta, itancan unyanpi eye cin iyecen.

28 Unkan Mowis hena on Eleazar wawayuśna kin qa Jośuwa Nun cinhintku kin, qa Israel cinca wicoun ateyapi itancanpi kin wahokonwicakiya.

29 Qa Mowis hewicakiya, Gad cinca, qa Ruben cinca wipe kitonpi owasin niyepi om Jehowa itokam wokicize ekta iyoptapi, qa nitokam makoce ktepidan kinhan, Gileyad makoce kin tawayapi kta, e wicayaqupi kta.

30 Tuka wipe kiton niyepi om iyoptapi śni kinhan, niyepi ehna Kanan makoce onśpa tawayapi kta.

31 Unkan Gad cinca, qa Ruben cinca ayuptapi, qa heyapi, Taku Jehowa nitaokiye unkekiyapi he econkunpi kta.

32 Unkiyepi wipe kiton Jehowa itokam Kanan makoce ekta iyounptapi kta, hecen Jordan itato makoce kin tawa unyanpi kta.

33 Unkan Mowis Gad cinca, qa Ruben cinca, qa Josep cinhintku Manaśe wicoun hanke, Si248 lion Amori wicaśtayatapi kin makoce idake cin he, qa $\mathrm{Og}$ Baśan wicaśtayapi makoce idake cin, makoce otonwe kin, qa otonwe ihdukśan makoce wanke cin wicaqu.

34 Unkan Gad cinca kin otonwe kagapi Dibon, qa Atarot, qa Aroyer,

$35 \mathrm{Qa}$ Aterot-Ś́opan, qa Jazer, qa Jogbeha.

36 Qa Bet-Nimra, qa Bet-Haran, otonwc conkaśkeyapi, nakun tahinca tipi kagapi.

37 Unkan Ruben cinca kin Heśbon, qa Eleale, qa Qireyataim kagapi,

38 Nakun Nebo, qa Bayal Meyon, caje yatokecapi, qa Sibma, qa otonwe kagapi cajepi kin cajehdatapi.

39 Unkan Manaśe cinhintku Makir cinca kin Gileyad ekta ipi, qa he icupi, qa Amori hen tipi kin nape wicayapi.

40 Unkan Mowis Gileyad makoce Manaśe cinhintku Makir cinca kin wicaqu, unkan hen iyotankapi.

41 Unkan Manaśe cinhintku Jair, wicotipi kin ekta i qa hena icu, qa hena Hawot-Jair (Jair totonwe) eya caje yata.

42 Unkan Noba Qenat ekta i qa icu, nakun otonwe ciqadan cunkśi wicaya, qa he Noba eya cajeyata iye caje eciyatanhan.

\section{WICOWOYAKE 33.}

1 Israel cinca obe tawapi iyecen Egupta makoce etanhan inanpapi, Mowis qa Aaron nape kin ihukuya, oihdakapi kin dena eepi.

2 Unkan inanpapi kin ihdakapi iyecen, Jehowa i kin eciyatanhan Mowis owa, qa ihdakapi inanpapi eciyatanhan dena eepi. 


\section{WICOWOYAKE 33.}

3 Unkan wi tokaheya en wi anpetu iakezaptan en Rameses etanhan ihdakapi, woacakśin ihanhanna, Israel cinca nape yuwankan icupi inanpapi, Egupton owasin wanyakapi.

4 Unkan Egupton tona iyepi etanhan Jehowa wicakaśtaka, caskepi ow asin wicahnakapi, nakun taku wakan dapi kin Jehowa woyaco ecawicakicon.

5 Unkan Israel cinca Rameses etanhan ihdakapi, qa Sukot (ohanzihdepi) ekta etipi.

6 Unkan Sukot etanhan ihdakapi, qa Etam ekta etipi, he hopuza ihanke ekta yanka.

7 Unkan $\mathbb{E}$ tam etanhan ihdakapi qa ihdamnapi Pi-Hahirot ektakiya, he Bayal Tzepon itokam yanka, qa Migdol (Conkaślke) itokam etipi.

8 Unkan Hahirot itokapa tanhan ihdakapi, qa mde cokaya iyoptapi, hopuza ekta, qa Etam hopuza ohna anpetu yamni ihdakapi; qa Mara en etipi.

9 Unkan Mara etanhan ihdakapi, qa Elim en etipi, qa Elim ohna miniyowe akenonpa, qa tamar can wikcemna śakowin, qa hen ticagapi.

10 Unkan Elim etanhan ihdakapi qa Mde śa icahda etipi.

11 Unkan Mde śa etanhan ihdakapi qa Sin hopuza ohna etipi.

12 Unkan Sin hopuza etanhan ihdakupi qa Dopqa ohna etipi.

13 Unkan Dopqa etanhan ihdakapi qa Aluś ohna etipi.

14 Unkan Aluś etanhan ihdakapi qa Repidim ohna etipi, qa hen mini yatkanpi kta wanica.

15 Unkan Repidim etanhan ihdakapi qa Sina hopuza ohna etipi.

16 Unkan Sina hopuza etanhan ihdakapi qa Qibrot-Hatawa ohna etipi.
$17 \mathrm{Qa}$ Qibrot-Hatawa etanhan ihdakapi qa Ḣatzerot ohna etipi. $18 \mathrm{Qa}$ Hatzerot etanhan ihdakapi qa Ritma ohna etipi.

19 Unkan Ritma etanhan ihdakapi qa Rimmon-Parets ohna etipi.

20 Unkan Rimmon-Parets etanhan ihdakapi qa Libna ohna etipi.

21 Unkan Libna etanhan ihdakapi qa Risa ohna etipi.

22 Unkan Risa etanhan ihdakapi qa Qehelata ohna etipi.

23 Unkan Qehelata etanhan ihdakapi, qa Śaper he kin ekta etipi.

24 Unkan Śaper he etanhan ihdakapi qa Harada ohna etipi.

25 Unkan Ḧarada etanhan ihdakapi qa Maqhelot ohna etipi. 26 Unkan Maqhelot etanhan ihdakapi qa Tahat ohna etipi.

27 Unkan Tahat etanhan ihdakapi qa Tarah ohna etipi.

28 Unkan Tarah etanhan ihdakapi qa Mitqa ohna etipi.

29 Unkan Mitqa etanhan ihdakapi qa Ḣaśmona ohna etipi.

30 Unkan Haśmona etanhan ihdakapi, qa Moserot ohna etipi.

31 Unkan Moserot etanhan ihdakapi qa Bene-Jaaqan ohna etipi.

32 Unkan Bene-Jaayan etanhan ihdakapi qa Hor-Hagidgad (wakinyan ti kin) ekta etipi.

33 Unkan Hor-Hagidgad etanhan ihdakapi qa Jotbata ohna etipi.

34 Unkan Jotbata etanhan ihdakapi qa Abrona ohna etipi.

35 Unkan Abrona etanhan ihdakapi qa Etzion-Gaber (wicaśta cankahu) ekta etipi.

36 Unkan Etzion-Gaber etanhan ihdakapi qa Tzin, Qadeś liee, hopuza ohna etipi.

37 Unkan Qadeś etanhan ihda249 


\section{WICAYAWAPI,}

kapi, qa Hor he kin ekta etipi, Edom makoce ihanke ekta.

38 Unkan Jehowa i eciyatanhan Aaron wawayuśna kin Hor he kin akan itanwankanhde $i$, qa hen ța, Israel cinca Egupta makoce etanhan hdinanpapi waniyetu wikcemna topa wi izaptan anpetu tokaheya en.

$39 \mathrm{Qa}$ Aaron waniyetu opawinge sanpa wikcemna nonpa sanpa yamni tonpi ehantanhan Hor lie kin en ta.

40 Hehan Arad wicaśtayatapi Kanani kin Kanan makoce itokaga en ounye cin Israel cinca upi kin nahon.

41 Unkan Hor he kin etanhan ihdakapi qa Tzalmona ohna etipi.

42 Unkan. 'Tzalmona etanhan ihdakapi, qa Punon ohna etipi.

43 Unkan Punon etanhan ihdakapi qa Obot ekta etipi.

44 Unkan Obot etanhan ihdakapi qa Ije-Abarim Moab makoce ihanke ekta etipi.

45 Unkan Ije-Abarim etanhan ihdakapi qa Dibon-Gad ohna etipi.

46 Unkan Dibon-Gad etanhan ihdakapi qa Almon ohna Diblataim ektakiya etipi.

47 Unkan Almon Diblataim ektakiya tanhan ihdakapi qa Abarim he ohna, Nebo itokam etipi.

48 Unkan Abarim lie etanhan ihdakapi qa Moab makomdaye Jordan icahda Jeriho iyotakons etipi.

49 Unkan Jordan icahda Bet Jeśimot etanhan Abel (Woiyokiśica) Śitim ekta Moab makomdaya ohna etipi.

50 Unkan Moab makomdaya ohna Jordan icahda Jeriho iyotakons Jehowa ie ca Mowis heciya,

51 Ie ca Israel cinca kin hewica250 kiya wo, Kanan makoce ekta Jordan iduwegapi kinhall ; 52 Makoce ounyanpi owasin nitokapa tanhan nape wicayayapi kta, qa wakagapi owapi tawapi kin owasin awihnuni yayapi kta, qa wakagapi śdoyapi tawapi kin owasin ihang yayapi kta, qa tawahnawośnapi kin owasin dujujupi kta.

53 Hecen nape wicayayapi kta makoce etanhan, qa ohna yakidotankapi kta, makoce kin he tawayayapi kta e ciçupi nakaś.

54 Unkan oeconna eciyatanhan makoce yapamnipi kta, wicowazipi nitawa iyecen, wicotapi kinhan makoce tarkaya wicayaqupi kta, qa tonanapi kinhan makoce aoptetu wicayaqupi kta, otoiyohi taku oeconna eciyatanhan icu kin he tawa ye kta, ate wicayayapi wicowazipi kin iyecen tawa yayapi kta.

55 Tuka makoce ounyanpi kin nitokapa tanhan nape wicayayapi śni kinhan, kaketu kta : tona owicayakaptapi kin hena, wapepeka niiśtapi ohna iyececapi kta, qa taku pepe nicuwipi en, qa makoce ohna yakidotankapi akan toka niyanpi kta.

56 Unkan token ecawicawecon kta kepce cin hecen ecaciconpi kta.

\section{WICOWOYAKE 34.}

1 Unkan Jehowa ie ca Mowis heciya,

2 Israel cinca wahokon wicakiye ça hecen ewicayakiye kta, Kanan makoce en yaipi kinhan makoce tawayayapi kta nicupi kta dee, Kanan makoce ihanke owasin ekta.

$3 \mathrm{Qa}$ itokaga ihanke kin Tzin hopuza etanhan Edom icahda duhapi kta, qa wihinanpe ektakiya miniskuya mde ihanke ito- 


\section{WICOWOYAKE 34.}

kaga etanhan ihanke duhapi kta.

4 Qa makoce nitawa ihanke kin Aqrabim iyakaptapi itokaga tanhan. iyaye kta, Trin ekta i kta; qa Qadeś-Barnea itokaga tanhan iyaye kta Hadar ti ekta, qa Atzmon ekta iyopte kta.

5 Qa Atzmon etanhan ihanke kin yuktanyan ye kta, Egupta wakpa ekta, qa miniowanca ekta ihunni kta.

6 Unkan ihanke wiyohipeyata ekta miniowanca huta kin hee duhapi kta, qa he huta kin wiyolipeyata ektakiya ihanke duhapi kta.

7 Unkan waziyata elatakiya ihanke kin de duhapi kta, miniowanca etanhan Hor lie kin ekta iyecagopi kta.

$8 \mathrm{Qa}$ Hor lie kin etanhan Hamat ocanku ektakiya iyakagopi kta, qa makoce ihanke kin Tzedad ekta iyohi kta.

9 Qa makoce ihanke kin Zipron iyohi kta, qa Hatzar-Enan (Miniyowe Otonwe) hehanyan ye kta, waziyata ektakiya ihanke duhapi kta hee.

10 Qa wiyohiyanpata ektakiya ihanke iyecagopi kta ḦatzarEnan etanhan Sepam ekta.

11 Qa ihanke Śepam etanhan Ribla ekta Ain (Miniyowe) iwiyohiyanpa tanhan qa opapun kin itokaga ye kta, qa Kiniret mde huta kin icalitake kta wi hinanpe ektakiya ;

12 Qa opapun kin Jordan iyokaga ye kta, makoce hecen ihdukśan icagopi duhapi kta hee.

13 Unkan Mowis Israel cinca wahokon wicakiye ça heya, Makoce oeconna eciyatanhan tawayayapi kte cin hee, Jehowa wicoun napcinwanka qa wicoun wan hanke wicaqu maśi hee.
14 Ruben cinca wicoun kin ateyapi tipi kin iyecen, qa Gad cinca wicoun ateyapi tipi kin iyecen wanna icupi qa Manaśe wicoun hanke makoce tawa yapi kte cin he wanna icupi.

15 Wicoun nonpa qa wicoun wan hanke makoce tawayapi kte cin he wanna icupi, Jordan itato Jerilio iwiyohiyanpa tanhan wi hinanpe ektakiya.

16 Unkan Jehowa ie ca Mowis heciya,

17 Wicaśta makoce nicipamnipi kta cajepi kin dena eepi, Eleazar wawayuśna kin, qa Jośuwa, Nun cinhintku.

$18 \mathrm{Qa}$ wicoun otoiyohi etanhan itancan wan makoce pamnipi kta e iyacupi kta.

19 Qa wicaśta cajepi kin dena eepi, Juda wicoun etanhan $\mathrm{Ka}$ leb Jepune cinhintku,

$20 \mathrm{Qa}$ Simeon cinca wicoun etanhan Śsemuel Amihud cinhintku,

21 Benjamin wicoun etanhan Elidad Kiselon cinhintku,

22 Dan cinca wicoun etanhan itancan kin Buqi Jogeli cinhintku,

23 Josep cinca etanhan, Manaśe cinca wicoun etanhan itancan kin Haniyel Epod cinhintku, 24 Qa Epraim cinca wicoun etanhan itancan kin Qemuel Śiptan cinhintku.

$25 \mathrm{Qa}$ Zebulun cinca wicoun etanhan itancan kin, Elitzapan Parenak cinhintku,

$26 \mathrm{Qa}$ Isakar cinca wicoun etanhan itancan kin, Paltiel Azan cinhintku,

27 Qa Aśer cinca wicoun etanhan itancan kin Ahihud Śelomi cinhintku.

28 Qa Naptali cinca wicoun etanhan itancan kin Pedahel Amihud cinhintku, 


\section{WTCAYAWAPI,}

29 Hena Jehowa Kanan makoce Israel cinca wicakicipamni wicaśi.

\section{WICOWOYAKE 35.}

1 Unkan Moab makomdaye ohna Jordan icahda Jerilio iyotakons Jehowa ie ca Mowis heciya.

2 Israel cinca wahokon wicakiye ca makoce oeconna eciyatanhan tawayapi kta etanhan Lewi otonwe ohna iyotankapi kta e wicaqupi kta kewicakiya wo; qa tonwanyanpi kin ihdukśan tinta onśpa wicayaqupi kta ehe kta.

3 Qa otonwe ounyanpi kta e yuhapi kta, qa tinta kin tawotecapi on, qa tawanunyanpi, qa taku yuhapi owasin on yuhapi kta.

4. Qa otonwe tinta kin, otonwe conkaśke anokatanhan ihdukśan wiciśpa kektopawinge iyohi ye kta.

5 Unkan otonwe itankapa tanhan wiyohiyanpata ihanke kin wiciśpa kektopawinge nonpa idutapi kta, qa itokaga ihanke kin wiciśpa kektopawinge nonpa, qa wiyohpeyata ihanke kin wiciśpa- kektopawinge nonpa, qa waziyata ihanke kin wiciśpa kektopawinge nonpa, cokaya tonwanyanpi kta otonwe tinta heca yuhapi kta.

6 Unkan otonwe Lewi wicayaqupi śakpe wowinape otonwe heca wicayaqupi kta, on tuwe wicaśta wan kte kinhan ekta inyanke kta, qa nakun otonwe wikcemna topa sanpa nonpa wicayaqupi kta.

7 Otonwe Lewi wicayaqupi kta owasin otonwe wikcemna topa sanpa śahdogan, hena qa tinta ihdukśan koya. 252
$8 \mathrm{Qa}$ Israel cinca taku tawayapi etanhan otonwe wicayaqupi kta, otoiyohi otonwe tawa etanhan, Lewi wicaqu kta, makoce oeconna eciyatanhan tawaye cin iyecen, ota etanhan ota yaqupi kta, qa tonana etanhan tonana yaqupi kta.

9 Unkan Jehowa ie ça Mowis heciya,

10 Ie ça Israel cinca kin hecen ewicakiya wo, Kanan makoce ek ta Jordan iduwegapi kinluan,

11 Wowinape otollwe nicicagapi kta, qa tuwe wanun wicaśta wanji kte kinhan hena wanji ekta inyanke kta e hena duhapi kta.

12 Qa hena watokicon etanhan wowinape otonwe duhapi kta; hecen tuwe wicaśta wan kte kinhan, yacopi kta e omniciye itokanı najin śni kin hehanyan țe kte śni.

13 Otonwe wicayaqupi etanhan wowinape otonwe śakpe duhapi kta.

14 Otonwe yamni Jordan itato yaqupi kta, qa Kanan makoce en otonwe yamni yaqupi kta, wowinape otonwe hecapi kta.

15 Otonwe śakpe kin hena wowinape hecapi kta, Israel cinca on, qa tuwe oyate tokeca, qa niye ehna ounye cin on, tuwe wir canagi wan wanun kaśtake cinhan heciya nape kta.

16 Tuka maza śapa wipe wan on kaśtaka on țe cinhan tin kte, qa tinwicakte awicakehan țe lita.

17 Unkan inyan on wicaśta te kta iyececa on apa, unkan ta, tuwe he ape cinhan te kta, tinwicakte heca, tuwe tinwicalste awicakehan te kta.

18 Qaiś can wanji on wicaśta apapi te lita iyececa on ape ca te cinhan tinwicakte heca, qa 
tuwe tinwicakte heca awicakehan te kta.

19 Tuwe we tokiçon kin tinwicakte kin kte kta, tohan he akipe cinhan kte kta.

$20 \mathrm{Qa}$ he śicedaka on taku patan, qaiś ehpeye cinhan, qa hiecon kte hinca on te cinhan ;

21 Qaiś tokaye cin on nape on ape ca on te cinhan, tuwe he ape cin awicakehan te kta, he tinkte; tuwe tokicon kin tohan tinwicakte cin akipe cinhan he kte kta.

22 Tuka he śicedake śni qa ihnunhanna wipe taku kaśta patan, qaiś ehpeye cinhan, qa econ kte hince śni.

23 Qaiś he wanyake śni, qa inyan wan taku kaśta on wicaśta te kta iyececa elipeye ca akan ilipaye ca on te cinhan, tuka he tokaye śni, qa akite śni kinhan,

24 Omniciye kin tuwe ape cin qa we tokiçon kin otahedan yacopi kta, woyaco kin hena eciyatanhan.

$25 \mathrm{Qa}$ omniciye kin tuwe wicakte kin we tokicon nape kin etanhan eyakupi kta, qa omniciye kin wowinape otonwe ekta nape ciqon ake ekta ayapi kta, qa hen yanke kta, wawayuśna tanka wihdi wakan on sdayapi te kte cin hehanyan.

26 'Tuka tuwe wicakte wowinape otonwe ekta nape ciqon ihanke itankan inanpe cinhan,

27 Unkan we tokicon kin he wowinape otonwe ihanke itankan iyeye cinhan, qa we tokiçon kin wicakte kin kte kinhan, he on tuwedan we yapi kte śni.

28 Wowinape otonwe tawa en yanke kta iyececa, wawayuśna tanka te kte cin hehanyan, qa wawayuśna tanka te cin iyohakam wicakte kin makoce tawaye cin en hdi kta.
$2 y$ Wokage woope kin hena duhapi kta, nitoicagepi yeye cin tonwanyayapi kin owasin ohna. 30 Tuwe wicanagi wan ape cinhan wayaatanin nonpa ipieciyatanhan ktepi kta, tuka wayaatanin wanjidan wicanagi ktepi kta ayuptapi kte śni.

31 Tuwe tinwicakte yacopi nagi kin akahpe kta e woakahpe iyacupi kte śni, tuka awicakehan te kta.

32 Nakun woakahpe iyacupi kte śni on tuwe wowinape otonwe ekta nape cin wawayusna te śni itokam makoce ounye kta ekta hde kta.

33 Qa makoce en dukanpi kta duśapapi kte śni, maka kin yuśape cin we kin hee, qa we makoce ohna papsonpi taku tokeca akahipe kta okihi śni tuwe he papson we tawa on hecedan.

34 Qa makoce ohna ounyayapi kin he duśapapi kte śni, he ohna miye ounwaya, miye Jehowa Iśrael cinca wicehna ounwaye nakaś.

\section{WICOWOYAKE 36.}

1 Unkan Manaśe cinhintku Makir cinhintku Gileyad cinca wicowazi ateyapi itancanpi Josep cinca wicowazipi etanhan ikiyedan hipi qa Mowis itokam qa Israel cinca ateyapi watokapapi itancanpi itokam iapi.

2 Qa heyapi, Makoce tawayapi kta e Israel cinca oeconna eciyatanhan Jehowa itancan mitawa wicaqu śi, qa Tzelopehad maga tawa iye cunwintku Jehowa itancan mitawa wicaqu śi.

3 Unkan Israel cinca wicoun wan cinca etanhan wicaśta wan wicayuze cinhan, maga tawapi ate unyanpi makoce tawapi etanhan yuśpapi kta, qa tuwe wica253 


\section{WICAYAWAPI.}

yuze cin tawicoun tamakoce ekta okijuyapi kta, hecen makoce oeconna eciyatanhan tawa unyanpi kin he cistinna kagapi kta.

4 Israel cinca Jubele yuhapi kinhan, winyanpi tamakocepi tuwe wicayuze wicoun tamakoce ekta okijuyapi kta, qa maga tawapi ate unyanpi wicoun tamakoce etanhan yuśpapi kta.

5 Unkàn Mowis Israel cinca Jehowa i eciyatanhan wahokon wicakiye ca heya, Josep cinca oiepi kin iyececapi.

6 Wicoie Jehowa Tzelopehad cunwintku econ wicaśi kin dee, heya, Ateyapi wicoun wicowazi etanhan heceedan tuwe wicayuze kta, tuka hena etanhan tuwe iśtapi en waśte wicayuze kta.

7 Israel cinca makoce oeconna eciyatanhan tawayapi kin wicoun wanji etanhan wicoun tokeca ekta yutokanpi kte śni ; tuka Israel cinca otoiyohi ate wicaye wicoun tamakoce kin ekta ihdaśke kta.

8 Unkan Israel cinca wicoun 254 etanhan tuwe kaśta cunwintk maga tawa ye kta, wicaśta wan ateye wicoun wicowazi etanhan he tawicu kta hecen Israel cinca otoiyohi ate wicaya tamakocepi kin tawaye kta.

9 Qa makoce kin wicoun wanji etanhan wicoun tokeca ekta yutokanpi kte śni, tuka Israel cinca wicoun etanhan wicaśta otoiyohi makoce oeconna etanhan tawaye cin he en ihdaśke kta.

10 Token Jehowa Mowis eciye cin hecen 'T'zelopeliad cunwintku econpi,

11 Unkan Makla Tirtza qa Hoglaqa Milka qa Noya Tzelopehad cunwintku ate wicayapi cinca wicayuzapi.

12 Josep cinhintku Manaśe cinca wicowazipi etanhan wicayuzapi qa maga tawapi ateyapi wicowazi wicoun en yanka:

13 Wokrage qa woyaco Jehowa Mowis nape on Israel cinca econ wicaśi, Moab makomdaya ohna, Jordan icahda, Jeriho iyotakons dena eepi. 


\section{W00PE ITAKIHN}

\section{WICOWOYAKE 1.}

1 Jordan oiyuwege ekta, hewoskan en, omdaye puza ohna, Mdeśa iyotakonza, Paran qa 'Topel qa Iaban qa Hatzerot qa Dizaba otahedan, wicoie Mowis Israel owasin ewicakiya dena ee. 2 Horeb qa Qadeś Barneya otahedan, Seyir he kin canku oiyahde kin, anpetu akewanji omani.

3 Unkan waniyetu iwikcemna topa kin en, wi iakewanji en, wi anpetu tokaheya kin en, he ehan, Mowis token Jehowa eye śi kin owasin iyecen ewicakiya.

4 Silion Amori tawicaśta yatapi Ḣeśbon en ounye ciqon, qa Oğ Baśan en wicaśta yatapi Aśterot en Edreyi ohna ounye ciqon; hena wicakaśtaka iyohakam

5 Moab makoce en, Jordan oiyuwege ekta, Mowis woope kin de tokaheya owicakiye ça heya;

6 Ḧoreb he kin en Jehowa Wakan undapi kin unkokiyakapi, qa heunkiciyapi, Ḣe kin de en ounyayapi kin wanna henakeca.

7 Ihdamnapi, qa Amori tahe kin heciya ihdakapo, qa makoce kin he en ikiyedan owancaya, Araba (Omdaye puza) kin, qa he kin, qa makoce hukuya kin, qa Itokaga kin, qa miniwanca huta kin, Karsani tamakocepi kin, qa Lebanon he kin, wakpa tanka Yuperat Wakpa kin hehanyan.

8 Wanyakapo, makoce kin nitokam ewahde kin he en ipi, qa tawayapo; makoce kin he nihunkakepi Abereham, qa Izak, Deut. qa Jakob Jehowa wicaqu kta kewicakiye ciyon; qa cincapi kin hena iyohakam koya.

9 He ehan heciciyapi, Miśnana owasin ciyuhapi owakitpani ce.

10 Jehowa Wakan yadapi kin he wanna niyuotapi, qa anpetr kin de wicanhipi iyenakeca winicotapi.

11 Jehowa nihunkakepi Wakan dapi kin kektopawinge akihde nakun sam iyeya niyuotapi, qa niyawaśtepi nunwe; iwationiyanpi qon he iyecen.

12 Nitohtanipi, qa nitawaqinpi, qa waayakinicapi kin, hena tokiya tanhan miśnana mduha k ta owakihi kta he?

13 Wicaśta ksapa, qa wokahniga, qa okitaninpi, wicoun nitawapi on kahnigapo, unkan hena itancan cicagapi kta.

14. Unkan amayaduptapi qa, Taku ehe cin hecen econpi waśte ehapi ;

15 Hecen nitawicoun itancanpi wicaśta ksapa, qa okitaninpi iwicawacu qa hena wicaśta yatapi cicagapi ; kektopawingege itancan, qa opawingege itancan, qa wikcemna zaptanptan itancan, qa wikcemuamna itancan, qa nitawicounpi on wowapi kagapi.

16 Qa he ehan wicaśta wayaco nitawapi kin wahokonwicawakiye ca hewicawakiya, Nihunkawanjipi wakinicapi kin nahonpi, qa owotanna wayacopo, wicaśta sunkaku kici, qa tuwe tokeca kici un koya.

17 Wicaśta owanyakapi eciya3 


\section{WOOPE ITAKIHNA,}

tanhan iciyapi śni po; wayacopi en cikcistinpidan tankinkinyanpi ko akidecen anawicagoptanpo. Thnuhan wicaśta ite on wakoyakipapi kin; woyaco kin he Wakantanka tawa. Qa woakinice tona teliike yadapi kin hena mitokam ayau pi kta, kinhan anagoptan manke kta ce.

18 He ehan taku owasin token ecanonpi kta eciciyapi.

19 Hehan Horeb etanhan unkihdakapi, qa hopuza tanka, qa wikopapi kin he ohna maunnipi, Amori tahe canku iyahde kin he ohna, Jehowa Wakantanka unkitawapi hecon unśipi kin he iyecen, qa Qadeś Barneya heci unkipi.

20 Unkan heciciyapi, Amori tahe Jehowa Wakan undapi kin unqupi kin he wanna ekta yakipi ce.

21 Wanyaka wo, Jehowa Wakan yada kin makoce kin de nitokam ehnaka. Iyadi qa tawa ya wo, Jehowa hunkake wicayaye cin Wakan dapi eniciye cin he iyecen. Ihnuhan koyakipe ca ininihan kin.

22 Hehan niyepi owasin mikiyedan yahipi qa hehapi;. Wicaśta unkitokam ye wicunśipi kta, unkan makoce kin iwanyakapi kta, qa canku tukte ohna itanwankahde unyanpi kte cin he hośi unkahdipi kta, otonwe en unyanpi kte cin he nakun.

23 Unkan wicoie kin he iyomakipi, he etanhan wicaśta akenonpa enitanhanpi iwicawacu, wicoun otoiyohi wanjikśi iwicawacu.

24 Unkan iyayapi, qa he kin itanwankahde yapi, qa Eśkol kaksiza kin en ipi, qa he iwanyakapi.

25 Qa makoce kin he etanhan waskuyeca napepi ohna icupi, qa unkahdipi, qa wahośi unkahdipi qa, Makoce Jehowa wakan undapi unqupi kin he waśte ce eyapi.

26 Tuka itanwankahde yapi kta tawațenyayapi śni, qa Jehowa wakan yadapi kin i kin yakipajinpi.

27 Qa tuwe wakan yadapi kin iyahnupi, qa nitawakeyapi ohna hehapi, Jehowa śice undakapi heon Egupta makoce etanhan deci inanpe unyanpi, qa Amori napepi kin en unqupi kta, qa ihang unyanpi kta.

28 Tukte en itanwankahde unyanpi kta he? Oyate kin he wicota, qa unkikapeya tankapi. Otonwe tankinyanyan, qa ihdukśan conkaśke tehanwankatuya mahpiya ekta aiyahdeya, qa nakun Anaqim cincapi kin hen wanwicunyakapi, hunkawanjin unyanpi eya hdipi, qa cante skan unyanpi ce, ehapi.

29 Unkan heciciyapi, Ihnuhan ininihanpi, qa kowicayakipapi kin.

30 Jehowa Wakan yadapi kin, qa tokanicihan mani kin he iye niyepi on kize kta ; Egupta ohna niśtapi itokam ecaniconpi qon owasin he iyecen.

31 Qa hopuza ohna wicaśta cinca kicin kin he iyecen Jehowa wakan yada kin nicin, canku omayanipi kin owasin ecen deciya yahipi kin he wandaka.

32 Tuka taku kin de en Jehowa Wakan yadapi kin cețunyahdapi. 33 Iye qe oweti anicicitapi kta, qa canku nicipazopi kta, hanyetu eca peta ohna nitokam mani, qa anposkan eca mahpiya ohna.

34 Hehan Jehowa nioiepi ho kin nahion, qa caute ptanyeiciye, qa wakonze ca heya;

3 Jihunkakepi makoce waśte kin wicawaqu kta konza kewica- 


\section{WICOWOYAKE 2.}

kiye ciqon wicoicage śice cin de etanhan tuwedan wanyake kte śni.

36 Kaleb Jepune cinhintku kin heceedan wanyake kta, qa iye cinca om makoce omani qon he wicawaqu kta. Iye ohinniyan Jehowa ihakam mani nakaś.

37 Nakun niyepi on Jehowa canniyemaye ça, Niś eya he en idade kte śni emakiya.

38 Tuka Jośuwa Nun cinhintku kin nitokam najin kin he heei i kta; iyopaśtaka wo, makoce kin he iye Israel wicakipamni kta nakaś.

39 Nakun śiceca nitawapi kin, hena wayaka unpi kta kehapi, qa nicincapi anpetu kin de en taku waśte qa taku śica ko sdonyapi śni heci ipi kta, qa he wicawaqu kta, qa hena tawa yapi kta.

40 Tuka niyepi ihdamnapi, qa hewoskantuya Mdeśa canku kin ohna ihdakapo.

41 Hehan aduptapi qa hemayakiyapi; Jehowa en waunlitanipi. Itanwankabde unyanpi, qa token Jehowa wakan undapi econ unśipi kin owasin iyecen unkizapi kta, qa otoiyohi wipe ipiyag yakitonpi, qa he akan yaipi kta tuka.

42 Unkan Jehowa hemakiya, Ihnuhan itariwankahde dapi qa yakizapi kin; hecen toka niyanpi itokam nicațapi kte śni, ewicakiya wo.

43 Unkan hecen eciciyapi, tuka nayahonpi śni, qa Jehowa i kin yakipajinpi, qa wahan niçidapi, qa he kin he akan yaipi.

44. Unkan Amori he kin he en yakonpi kin nitkokim hinanpapi, qa nicuwapi, tuhmaga econpi kin iyecen, qa Sehir ohna nicakaśtakapi Horma ekta hehanyan.

45 Hehan yahdipi qa Jehowa itokam yaceyapi, tuka Jehowa nihopi nanilionpi, śni, qa anohniciyapi śni.

46 Unkan Qadeś en anpetu ota ounyayapi anpetu en yaunpi kin iyenakeca kin.

\section{WICOWOYAKE 2.}

1 Hehan unkihdamnapi, qa hopuze cin en, Mdeśa canku kin ohna unkihdakapi, Jehowa emakiye cin iyecen, qa Sehir he kin ihdukśan maunnipi anpetu ota

2 Tinkan Jehowa omákiye ça heya,

3 Ḣe kin de ihdukśan yaunpi kin wanna tehan; Waziyatakiya hdapo.

4 Qa oyate kin wahokonwicakiye ça heya wo, Esa cinca hunkawanjin wicayayapi Sehir en yakonpi kin tamakocepi icahda idadapi kta, qa konicipapi kta, heon nina awanihdakapo.

5 Ihnuhan wicayakizapi kin, Sehir he kin he Esa tawaye kta waqu; makoce kin he etanhan napapaśdecapi wanjidan ciçupi kte śni.

6 Woyute tawapi kin mazaska iyopeyayapi qa yatapi kta, qa nakun mini mazaska iyopewicayakiyapi qa datkanpi kta ce.

7 Ninape on niohan kin owasin Jehowa Wakan yada kin niciyawaśte, hopuza tanka kin de omayani kin he sdonya; Jehowa Wakan yada kin waniyetu wikcemna topa nici un kin hena en takudan inicakije śni.

8 Unkan Esa cinca hunkawanjin unyanpi Sehir en yakonpi etanhan unkiyayapi, Araba (omdaye puze cin) canku kin etanhan Elat qa Etzeon Geber ko etanhan, hehan unkihdamnapi qa Moab makomdaye canku kin ohna unkupi.

9 Hehan Jehowa hemakiya, 


\section{WOOPE ITAKIHNA,}

Ihnuhan Moabi iyokiśin wicayaye cin, qa ihnuhan wokicize on wicayakize cin, makoce tawapi etanhan tawayaye kta e onśpadan cicu kte śni nakaś, Lot cinca kin tawayapi kta wanna wicawaqu heon etanhan.

10 Hena itokam Emim hen ounyanpi, oyate wall wicotapi, qa tanka, qa hanskapi Anaqim iyewicacecapi.

11 Hena Anaqim iyecekcecapi waziya wicayawapi, tuka Moabi kin Emim (Wayuśinyeya) ewicakiyapi.

12 Unkan ehanna Ḧori kin Sehir en yakonpi, tuka Esa cinca kin nape wicayapi, qa wicakasotapi, qa iś ito en yalionpi ; Israel makoce tawayapi kta Jehowa wicaqu ecakiconpi kin he iyecen.

13 Wanna najinpo, qa Zered wakpadan kin iyuwegapo, eya, unkan $Z$ ered wakpadan kin unkiyuw egapi.

14 Unkan Qadeś Barneya etanhan maunnipi, qa ecen Zered wakpa unkiyuwegapi anpetu kin waniyetu wikcemna yamni sanpa śałdoyan hehanyan unyakonpi, wicoicage kin he wicaśta zuyapi qon wicoti cokaya tanhan owasin sotapi, Jehowa wicakonze ca ewicakiye ciqon he iyecen.

15 Unkan heon Jehowa nape kin iyahdaskin wicaye ca ihang wicaya, wicoti cokavatanhan ecen wicakasota.

16 Unkan oyate kin hetanhal: ozuye wicaśta qon owasin țapi, qa sotapi kin wanna hiyohi.

17 Hehan Jehowa omakiye ca heya.

18 Anpetu kin de Ar (Conkaśke) kin Moabi makoce ihanke kin opta idade kta.

19 Nakun Amon cinca makoce ihanke ikiyedan idade kta. Ihnuhan toka wicayaye cin, qa ihnu- han wicayakize cin; Amon cinca tamakocepi etanhan tawa yaye kta takudan ciçu kte śni, Lot cinca kin he tawayapi kta wicawaqu nakaś.

20 Eya itokam makoce kin he Waziya tamakocepi kin eciyapi, ehanna Waziya he en ounyanpi, qa Amoni kin Zamzumim caje wicayatapi.

21 Oyate kin he tanka, qa wicota, Anaqim iyecekcecapi; tuka Jehowa wicitokam ihang wicaya, qa hecen he tawayapi, qa hena eekiya en ounyanpi ece. 22 Hecen Esa cinca Sehir en ounyanpi ecawicakicon, wicitokam Ḧori kin ihang wicaya, qa tawayapi kta wicaqu qon, qa iś ito hehantanhan anpetu kin de dehanyan ounyanpi.

23 Nakun Awim kin Hatzarim (otonwe) en ounyanpi qon, Gaza etu; tuka Kaptorim Kaptor etanhan upi, qa ihang wicayapi, qa iś ito hen ounyanpi.

24. Najinpi ihdakapo, qa Amon wakpa kin iyuwegapo. Wan Heśbon en wicaśtayatapi Silion Amori kin tamakoce kin koya ninape en iyohpe ciciya. 'Tawayaye kta inahini wo, azuya qa kiciza wo.

25 Anpetu kin detanhan nicaje kin wowinihan, qa wokokipe oyate mahpiya owancaya ihukuya yakonpi ahinhpaye wicawaye kta, hena caje niyatapi nahonpi eca cancanpi kta, qa niye on hanyanpi kta.

26 Unkan Qedemot hopuza kin etanhan wahośi Silion Heśbon en wicaśtaya tapi ekta ye wicawaśi, qa wokiyapi wicoie hewakiya.

27 Nitamakoce kin opta mde kte, cankuku ohna mawani lita, etapa tanhan qa catka tanhan, unmanna eaiyatanhan mde kte śni, iyowin makiya wo. 


\section{WICOWOYARE 3.}

28 Woyute mazaska on mayaqu kin he wate kta, qa nakun mini mazaska on mayaqu kta unkan mdatke kta. Opta mawani kta ecedan iyowin makiya wo.

29 Esa cinca Sehir en ounyanpi, qa Moabi Ar en ounyanpi kin ecamiconpi kin he iyecen, ecen Jordan imduwege kta, qa Jehowa wakan undapi makoce wan unqupi kin he en mde kta ce.

30 Tuka he unkiyoptapi Silion Ḣeśbon en wicaśtayatapi kin iyowin unkiyapi śni; Jehowa wakan yada kin he ninape en onihnake kta, anpetu kin de iyecen, heon toksape kin kiyusuta, qa cante kin kipatin nakaś.

31 Unkan Jehowa hemakiya. Wan, detanhan Sihon tamakoce koya ciçu ce; tamakoce tawayaye kta e inahini wo.

32 Unkan Sihon, taoyate owasin om hinanpe cea unkizapi kta Jahatz en itkounkipapi.

33 Tuka Jehowa Wakan undapi kin he unqupi, unkan iye qa, cinca kin, qa taoyate kin owasin wicunkaśtakapi.

$34 \mathrm{Qa}$ hehan otonwe tawa owasin unkicupi, qa otonwe owasin, wicaśta qa winohinca qa śiceca ocowasin ihang wicunyan$\mathrm{pi}$, tuwedan niyake unkokaptapi śni.

35 Tuka wanunyanpi kin unhapi kta e unkicupi, qa nakun otonwe unkicupi, woyuha kin hen.

36 Aroer Arnon wakpa, qa otonwe wakpa ohna he cin he. tanhan.Gileyad aiyahdeya, otonwe unkiyepi etanhan niiçiye wanica, Jehowa Wakan undapi kin hena owasin unqupi.

37 Tuka Amon cinca tamakocepi kin ekta yai śni; Jaboq wakpa icahtake cin he ocowasin, qa he akan otonwe kin, qa otonwe tona Jehowa wakan undapi kin tehinda owaśin.

\section{WICOWOYAKE 3.}

1 Hehan unkihdamnapi, qa Baśan canku kin ohna itanwankanhde unyanpi. Unkan $\mathrm{Og} \mathrm{Ba-}$ śan en wicaśtayatapi inanpa, iye qa taoyate owasin om, Edreyi ekta unkicizapi kta takpe unkupi.

2 Tuka Jehowa hemakiya, Ihnuhan he koyakipe cin. Iye qa taoyate owasin tamakoce koya ninape en iyohpe ciciye, Sihon Heśbon en wicaśtayatapi token ecayecon kin he iyecen ecawicanon kta.

3 Unkan Jehowa wakan undapi kin Og Baśan en wicaśtayatapi, nakun taoyate owasin om unnapepi en unqupi, unkan wicunkaśtakapi ecen etanhan tuwedan okaptapi śni.

4 Unkan he ehan otonwe tawa owasin unkicupi, Og Baśan en wicaśtayatapi, Argob makoce wowidag yecin ntonwe wikcemna śakpe; conkaśke unkicupi śni wanica.

5 Otonwe kin hena ow่asin conkaśke tehanwankantuya, qa tiyopa kin inatagtonpi, qa nakun otonwe conkaśke codan ota hinca.

6 Hece" ocowasin ihang wicunyanpi, Ḣeśbon en wicaśtayatapi Sihon ecaunkiconpi qon iyecen, otonwe owasin wicaśta winohinca śiceca koya ocowasin ihang wicunyanpi.

7 Tuka wanunyanpi owasin, qa otonwe woyuha kin unhapi kta e unkicupi.

$8 \mathrm{Qa}$ he ehan Amori wicaśtayatapi nonpa, Jordan itato yakonpi qon, napepi etanhan makoce kin unkicupi, Arnon wakpa- 


\section{WOOPE ITAKIHNA,}

dan etanhan Hiermon he kin aiyahdeya.

9 Ḣermon he kin Tzidoni Siriyon tuku Amori kin Sinir eciyapi.

10 Makomdaye otonwe owasin, qa Gileyad ocowasin, qa Baśan Salka, qa Edreyi aiyahdeya.; Og Baśan en otonwe wowidag wicaye cin hena.

11 Baśan wicaśtayatapi $\mathrm{Og}$ iśnana waziya etanhan ni, tohe kin mazașapa ohehdepi kin heca dehanyan wanyakapi, Amon cinca otonwe tawapi Raba ohna, ohanske cin wiciśpa napcinwanka, qa hdakinyan wiciśpa topa, wicawiciśpa.

$12 \mathrm{He}$ ehan makoce kin he tawaunyanpi, Aroyer Arnon wakpa icahda he cin hetanhan, qa Gileyad hanke, qa otonwe kin koya Rubeni Gadi kici wicawaqu.

- 13 Qa Gileyad okaptapi kin he, qa Baśan ocowasin, Og wowidag ye ciqon Manaśe wicoun hanke wicawaqu; Argob makoce ocowasin, Gileyad makoce ocowasin kici Waziya tamakocepi eciyapi.

14 Manaśe cinhintku Jair Argob makoce kin ocowasin icu, Griśuri kin qa Maakati tamakocepi kin ekta, qa iye caje kin on Baśan Jair totonwe caśkiton, anpetu kin de hehanyan.

15 Qa Makir iś Gileyad waqu.

16 Qa Rubeni qa Gadi kin Gileyad etanhan Arnon wakpa kin hehanyan, wakpa cokaya, qa makoce kin, qa ecen Jaboq wakpa kin, Amon cinca tamakocepi ihanke kin hehanyan.

17 Qa omdaye puza, qa Jordan qa makoce Kinneret etanhan omdaye puza mde, Miniskuya mde kin hee, Aśdot (Kaduzyapi) Pisga he kin ihukuya, hehanyan.
18 Unkan he ehan wahokon ciciyapi, qa hepa, Jehowa. Wakan yadapi kin makoce kin de nicupi, tona waniśakapi owasin wipe kiton Israel cinca hunkawanjinwicayayapi wicitokam idadapi kinhan tawayayapi kta.

19 Tuka nitawinpi qa śiceca nitawapi, qa nitawannnyanpi, (wanunyanpi ota duhapi sdonwaya,) otonwe nitawapi cicupi kin hena ohna yakonpi kta.

20 Jehowa oziniyanpi kin he iyecen nihunkawanjipi oziwicaye cin hehanyan; qa iś eya makoce Jordan akasanpa, Jehowa wakan yadapi kin wicaqu kin he tawayapi $\mathrm{kta}$ hehanyan, qa hehan niś tawayayapi kta ciçu kin en otoiyohi yahdipi kta.

21 Unkan hehan Jośuwa wahokonwakiye ca hepa, Wicaśta yatapi kin henaos Jehowa wakan yada kin token ecawicakicon kin he niista kin on wandaka, wokiconze ekta yai kte cin hena owasin he iyecen ecawicakicon kta.

22 Kowicakipe śni wo, Jehowa wakan yada kin he niyepi on wicakize kta.

23 Unkan he ehan Jehowa cewakiye ca hepa;

24 Itancan Jehowa nitanka qa ninape waśaka kin he wowidag mayaya wanna onśpa mayalkidutanin, Mahpiya ekta qa maka akan tuwe wakan waśaka, nitowaśake iyecen, qa woecon ecanon kin iyecen econ okihi he?

25 Tokin akasanpa mde kten, qa makoce waśte Jordan akasanpa yanke cin, qa he waśte kin he, qa Libanon wanmdake kten.

26 Tuka niyepi on Jehowa canniye mayan, qa anamagoptan śni, qa Jehowa hemakiya, Henakeca kta, Ihnuhan wicoie kin he iyececa emayakiye cin. 


\section{WICOWOYAKE 4.}

27 Pisga paha kin adi wo, qa niiśta wankan ikikcu, Wiyohpe yatakiya, Waziyata kiya. Itokaga kiya, qa Wiyohiyanpatakiya, henakiya niiśta kin on wanyaka wo; Jordan wakpa kin de iduwege kte śni ce.

28 Tuka Jośuwa hee wahokonkiya wo, qa yasuta, qa iyopaśtaka wo; Iye oyate kin de wicito- kam akasanpa ye kta, qa makoce wandake kte cin he tawa wicakiye kta.

29 Unkan Gia (Osmaka) ohna Bet Peyor (Peyor ti kin) iyotakons unkiyotankapi.

\section{WICOWOYAKE 4.}

1 Heon nakaha Israel wokage qa woyaco onspeciciyapi kin nahonpo, qa econpo : hecen yanipi kta, qa makoce Jehowa niyatepi Wakan dapi kin he wicaqupi en yaipi qa tawayayapi kta.

2 Wicoie ociciyakapi kin de takudan ayakagapi kte śni, qa nakun aopten yakagapi kte śni, tuka wokage Jehowa Wakan yadapi tawa kin ope ciśipi kin hena oyapapi kta.

3 Jehowa Bayal Peyor (Peyor Itancan) on token econ kin he niiśtapi wanyakapi, Jehowa Wakan yada kin wicaśta tona Bayal Peyor opapi qon owasin niyepi ehna tanhan awihnuni wicaya.

4 Tuka niyepi tona Jehowa Wakan yadapi kin sutaya duzapi kin owasin, anpetu kin de nahanhin yanipi.

5 Wanyaka wo, makoce wan tawayayapi kta en yaipi kinhan, token ecanonpi, wokage qa woyaco onspeciciyapi, Jehowa Wakan wada econ maśi kin he iyecen,

6 Hena duhapi, qa ecen eca- nonpi kta, hecen yaksapapi qa widukcanpi kta, ovate tona wokage kin dena owasin nahonpi kin hena wanniyakapi qa, oyate tanka kin de iśnana ksapapi qa wiyukcanpi eniciyapi ktá.

7 Jehowa Wakan undapi taku hoyeunkiyapi owasin on unkikiyedan icihnake cin he iyecen oyate tanka wan tuktee he, taku wakan dapi kin wicikiyedan un he?

8 Qa woope kin de nakaha nitokam ecicihdepi kin owasin iyecen, oyate tanka tukte wanji he iyecen wokage qa woyaco yuhapi he?

9 Tuka niye itonicipa wo, qa ninagi nina itonkipa wo, okini wicoie niiśta wanyake cin ayektunja nunce. Nakun he nicinca qa nicinca cincapi kin sdonye wicayakiye kta, he ihnuhan nicante ehpeye cin tohan yani kin hehanyan.

10 Horeb ekta Jehowa Wakan yada itokam nayajil qon, anpetu kin he en Jehowa hemakiya, Oyate mitokam mnawicaya wo, mioie nahon wicawaye kta, hecen tohanyan maka akan nipi kin hehanyan komakipapi onspe içciyapi kta, qa cincapi onspe wicakiyapi kta.

11 Unkan kiyadan yahipi, qa he kin ihukuya nayajinpi, qa he kin peta on itkon, mahpiya cante kin ekta, otpaza mahpiya qa iyowotanin śni.

12 Unkan peta kin cokaya tanhan Jehowa oniciyapi, wicoie ho kin nayahonpi, tuka ouncage takudan wandakapi śni, ho kin heceedan nayahonpi.

13 Qa wicotakuye econ niśipi kin oniciyakapi, wicoie wikcemna kin hena, qa inyan mdaska nom akan okiwa.

14 Qa makoce wan tawa yaya- 


\section{WOOPE ITAKIHNA,}

pi kta en yaipi kinhan, wokage, qa woyaco ecanollpi kte cin hena he ehan onspe niciyapi maśi.

15 Ḧoreb ekía peta cokaya tanhan Jehowa Wakan yadapi kin oniciyapi qon, he ehan, ouncage takudan wandakapi śni heon ninagipi nina ikpatan po.

16 Okini nihduśicapi qa wakagapi taku iyacinyan wan niçicagapi kta, ouncage mdoka wiye unman tukte kaśta iyececa.

17 Maka akan woteca ouncage, qa zitkadan hupahu tonna mahpiya onawin un kin ouncage,

$18 \mathrm{Qa}$ watutka maka asdohan ouncage, qa maka ihukuya mini ekta hogan un kin ouncage, hena takudan oyakage kte śni.

19 Qa mahpiya ekta eyatonwe ça anpetu wi, qa hanyetu wi, qa wicanhpi mahpiya obe owasin wandake cinhan, ihnuhan yanuni, qa hena ektakiya patuś niçiye ca en wowidag niciye cin, mahpiya owancaya ihukuya oyate owasin hena yuhapi kta e Jehowa wakan yada kin wicaqu.

20 Tuka niyepi Jehowa inicupi, qa anpetu kin de iyecen taoyate niyanpi, qa tawa niyanpikta, e Egupta makoce etanhan, maza śdoyapi oceti etanhan hinanpe niyanpi.

21 Qa nioiepi on Jehowa canniye maye ca Jordan imduwege kte śni, qa makoce waśte tawa yaye kta Jehowa Wakan yada niçu kin he en wai kte śni konza.

22 Miś makoce kin den mate kta. Jordan imduwege kte śni, tuka niyepi iduwegapi, qa makoce waśte kin he tawayayapi kta.

23. Awanihdaka po, ihnuhan wicotakuye Jehowa Wakan yadapi niçicagapi kin ayektonjapi, qa wakagapi wanji yapagopi kin, taku kaśta ouncage iyececa Jehowa Wakan yada kin tehinda qon.

24 Jehowa Wakan yada kin he peta wahuhnahye cin taku Wakan waśake ca winawizi nakaś.

25 Makoce kin he en tehan yaunpi, qa cinca nicitoripi, qa rincapi cinca, hehan nihduśicapi, qa wakagapi wan niçipagopi ; taku kaśta ouncage iyececa, qa Jehowa Wakan yada kin itokam, taku śica ecanonpi, qa canniye niyanpi yakagapi kinhan;

26 Mahpiya maka kici nakaha wicaweco, qa niyaotaninpi kta ; Inakoce wan tawa yayapi kta e Jordan iduwegapi kin he etanhan ecadan ocowasin nisotapi kta, he akan anpetu nitawapi yahdutehanpi kte śni, tuka ecaca awihnuni niyanpi kta.

27 Qa oyate ota ehna Jehowa oniyumdecapi kta, qa toki Jehowa aniyanpi kin ikce wicaśta opeya tonagnana onicaptapi kta.

$28, \mathrm{Qa}$ heciya can qa inyan, taku wakan wicanape on kagapi kin hena wowidag niyanpi kta, hena tonwanpi kte śni, qa wanahonpi kte śni, qa wotapi kte śni, qa takudan omnapi kte śni.

29 Tuka heciya tanhan Jehowa Wakan yada ayakitapi kinhan iyeyakiye kta, nicante ocowasin on, qa ninagi ocowasin on ayakite cinhan.

30 Tohan wicoie kin hena owasin nihiyahde, qa iyoniciśice cinhan, anpetu hakakta kin en, Jehowa Wakan yada kin en nihduhomni, qa ho kin nayalion kinhan,

31 Jehowa Wakan yada kin waśake ca waonśida, elipeniye kte śni, qa awihnuni niye kte śni, qa wicotakuye nihunkakepi wicakicage akiktunje kte śni.

32 Ito hekta anpetu tokaheya 


\section{WICOWOYAKE 4.}

inicage śni qehan, Wakantanka wicaśta maka akan icali wicaye cin ehantanhan, qa mahpiya owihanke anog wawiwanga wo, Taku he iyecen tanka yukan hecinhan? qa taku he iyecen nahonpi hecinhan?

33 Peta wan cokaya tanhan Wakantanka ie cin ho kin tukte oyate wan nalion qa ni, nayalion qon he iyececa.

34. Wakantanka oyate cokaya tanhan oyate tokeca wan iwicacu konza, iyutanyanpi kin on, qa wapetokeca on, qa wicohall wakan on, qa okicize on, qa nape waśaka qa isto hdukatin on, qa woyuśinyaye tanka on, Jehowa Wakan yada Egupta en niiśta itokam onicihanyanpi kin he iyecen.

35 Jehowa iśnana taku Wakan, qa iye icunonpa tanhan wanica sdonyaye kta, heon hena wandaka.

36 Mahpiya eciyatanhan ho kin nahon riciye, taku onspe niciye $\mathrm{kta}$ heon, qa peta tanka tawa maka akan wanyag niyan, qa peta kin he cokaya tanhan iye oie kin nayahon.

37 Nihunkakepi waśte wicakida heon ohakam cincapi wicakahniga, qa towaśake tanka on, qa nici un kin on, Egupta etanhan hdinanpe niye.

38 Ilkce wicaśta nikapeya tanka, qa waśakapi nitokapa tanhan napewicaya, qa tamakocepi en aniipi, qa tawayaye kta e nicupi anpetu kin dehan iyececa.

39 Heon etanhan anpetu kin de en sdonya wo, Jehowa wankan mahpiya kin ekta, qa ihukuya maka kin owancaya taku Wakan kin hee, qa tuwedan iyecece śni.

40 Qa tawokage, qa tawoahope nakaha econ ciśi kin hena patan wo, hecen tanyan yaun kta, qa nihakam nicinca iś nakun, qa hecen Jehowa Wakan yada kin makoce nicu lin he akan anpetu yahduhanske kta, anpetu owasin.

$41 \mathrm{He}$ ehan Mowis otonwe yamni yukinukan, Jordan ita to wi hinanpe cin elsta kiya.

42 Hena ekta inanpapi kta, tuwe takodaku helrtam śicekidake śni, tuka wanun ktc kinhan, hen onape kta, otonwe kin he wanji en $i$ kinhan niiciye kta.

43 Betzer tinta ohna makoce mdaye Rubeni tawapi ohna, qa Ramot Gileyad ohna Gadi tawapi, qa Golan Baśan ohna Manaśe tawapi.

44 Unkan Mowis woope Israel cinca wicitokam ehnake cin he dee.

45 Israel cinca Egupta etanhan hdinanpapi qehan, woyaatanin, qa wokage, qa woyaco Mowis ewicakiye cin he dena ee. 46 Jordan wakpa kin itato Bet Peyor (Peyor ti) iyotakons, omdaye wanke cin en, Silion Amori tawicaśtayatapi Hesbón en ounye ciqon, Mowis Israel cinca om Egupta etanhan hiyupi qehan ktepi qon, makoce tawa qon he ohna.

47 Makoce kin he, qa $\mathrm{Og} \mathrm{Ba}-$ śan en wicrśtayatapi tamakoce nakun, Amori wicaśtayatapi nonpa Jordan itato wi hinanpe cin ektakiya unpi qon.

48 Aroer otonwe Arnon wakpa icahda wanke cin hetanhan Sion he kin Ḣermon hee hehanyan.

49 Qa Jordan itato iwiyohiyanpa tanhan omdaye puza ocowasin, omdaye puza mde kin Aśdot Pisga he kin ihukuya wanke cin hehanyan. 


\section{WOOPE ITAKIHNA,}

\section{WICOWOYAKE 5.}

1 Unkan Israel owasin Mowis wicakico, qa hecen ewicakiya, Wokage qa woyaco nakaha ninogepi ohna eciciyapi Israel nahonpo, qa hena onspe niçiciyapi kta, qa ecen ecanonpi kta yuha unpo.

2 Jehowa Wakan undapi kin Horeb he ekta wicotakuye unkicicagapi.

3 Jehowa hunkake wicunyanpi om wicotakuye kin he wicakicage śni, tuka unkiyepi hecen unkicicagapi nakaha owasin den ni unyakonpi.

$4 \dot{\mathrm{H}}$ e akan peta cokaya tanhan itohnake icitkokim Jehowa oniciyapi.

5 He ehan Jehowa oie kin ociciyakapi kta e Jehowa qa niyepi okitahedan nawajin, peta lin he koyakipapi, qa he kin akan yaipi śni nakaś, unkan heya;

6 Jehowa Wakan yadapi, qa Egupta makoce etanhan, wayaka tipi kin hetanhan hdinanpe niyanpi kin he miye.

7 Mitoye kin itokam Taku Wakan tokeca duhe kte śni.

8 Wakagapi yakpago kte śni, wankan mahpiya ekta, qa kuya maka kin akan, qa maka ihukuya mini mahen taku henakiya ohna ouncage iyecen.

9 Hena itokam patuś niçiye kte śni, qa en wowidag niciye kte śni; Jehowa Wakan yada taku Wakan winawizi kin he miye, tona śice madapi wahtanipi kin cincapi qa wicoicage iyamni qa itopa kin hehanyan kiba wicawakiya ece.

$10 \mathrm{Qa}$ tona waśte madapi, qa mitawoahope tanyan yuhapi kin hena wicoicage kektopawinge hehanyan cante wicawakiya ece. 11 Jehowa Wakan yada kin ituya caje date kte śni, tuwe he caje kin ituya eye cinhan Jehowa iyopeye kta.

12 Anpetu okihpapi duwakan kta e patan wo, Jehowa Wakan yada econ niśi kin he iyecen.

13 Anpetu śakpe litayani, qa taku yakincanye cin owasin ecanon kta.

14 Tuka anpetu iśakowin kin he Jehowa Wakan yada tookihpe kin hee; he en wohtani takudan ecanon kte śni, niye, qa nicinkśi, qa nicunkśi, qa nitahokśidan, qa wikoślka nitawa, qa tatanka nitawa, qa nitaśonśonna, qa nita wanunyanpi, qa tuwe tokeca otonwe nitawa ohna un kin, hecen hokśi dannitawa qa wicinyanna nitawa niye iyecen oziiciyapi kta.

$15^{\mathrm{Qa}}$ Egupta makoce ohna wayaka yaun qon, tuka Jehowa Wakan yada kin he etanhan nape waśake ca isto katinkiye cin on hdinanpe niye, heon Jehowa Wakan yada kin anpetu kin de okihipe niśi he yeksuye kta.

16 Niyate nihon kici wicahduonihan wo, Jehowa Wakan yada kin econ niśi kin he iyecen; hecen anpetu nitawa hanske kta, qa makoce Jehowa Wakan yada niçu kin he akan tanyan yaun kta.

17 Tuwedan yakte kte śni.

18 Wawicihahapi ecanon kte śni.

19 Wamayanu kte śni.

20 Nitakoda kin en itonśniyan wodake kte śni.

21 Qa Nitakoda tawicu yacin kte śni, qa nitakoda ti kin, qa tamaga, qa tahokśidan, qa wicinyanna tawa, qa tatanka tawa, qa taśunke qa taku kaśta nitakoda tawa yakon kte śni.

22 Ḣe akan mahpiya śapa otpa- 


\section{WICOWOYAKE 6 .}

za hinca, qa peta cokaya tanhan, Jehowa niyepi owasin mniniciyapi kin en, wicoie kin hena owasin ho tanka kiya oniciyakapi, qa taku sanpa eye śni,qa hehan inyan mdaska nom akan owa qa maqu.

23 Unkan otpaza cokaya tanhan ho kin nayalionpi qehan, qa he kin peta on itkon, hehan niyepi wicoun otoiyohi etanhan wicaśta tankapi, qa hunkayapi kin ow?sin mikiyedan yahipi ;

24 Qa hehapi, Inyun Jehowa Wakan undapi token tanka qa towitan kin wanyag unyanpi, qa ho kin naunlionpi, peta cokaya tanhan Wakantanka wicaśta kici wohdaka eśta wicaśta kin ni, nakaha wanunyakapi.

$25 \mathrm{Qa}$ nakaha tokeca untapi kta he? Ake Jehowa Wakan undapi ho kin naunhonpi kinhan, peta tanka kin de huhnahunyanpi kta, qa unțapi kta.

26 Petal cokaya tanhan Takn Wakan wiconi hduhe cin ho kin ie cin naunhonpi, tuwe wicaśta akantu he iyecen nation qa nahanhin ni un he?

27 Niye Jehowa Wakan undapi ikiyedan ya, qa nahon wo, Jehowa Wakan undapi taku eniciye cin owasin, qa hehan Jehowa Wakan undapi taku eniciye cin owasin unkoyakidakapi kta, kinhan naunhonpi qa ecen econkupi kta.

28 Unkan omayakiyapi kin he icunhan Jehowa nioiepi ho kin nahon, qa Jehowa hemakiya, Oyate kin de oie ho kin nawahon, taku eniciyapi owasin, taku eyapi kin owasin tanyan eyapi.

29 Tokin ohinniyan komakipapin, qa mitawoahope owasin opapin, hecen cante yuhapi kten, hecen tany an unpi kta, qa cincapi nakun, owihanke wanica.
30 Hde ça, Icicawin nitawakeyapi ekta hda po, ewicakiya wo

31 Tuka niye den miyeci nayajin kta, qa woahope, qa wokage, qa woyaco onspe wicayakiye kte cin owasin ociciyake kta, qa makoce tawayapi kta wicawaqu kin he en hena econpi kta.

32 Heon token Jehowa econ niśipi ecen ecanonpi kta waktaya unpo, enitapa tanhan canitkà tanhan unmanna ekta itoheya nihduhomnipi kte śni.

33 Jehowa Wakan yada canku openiśipi kin owasin omani po ; hecen makoce tawayayapi kte cin en yanipi kta, qa tehan en tanyan yaunpi kta.

\section{WICOWOYAKE 6.}

Unkan woahope, wokage, qa woyaco Jehowa Wakan yadapi onspe ciciyapi maśi kin dena ee ; makoce tawayayapi kta en yaipi kinhan he en ecen ecanonpi kta. 2 Heon Jehowa Wakan yada kin koyakipe kta; qa wokage qa woahope tawa ociciyake cin owasin duhe kta, niye qa nicinkśi qa nicinca cinhintku, anpetu owasin, tohan yani kin, qa hecen anpetu nitawa niciyuotapi kta.

$3 \mathrm{E}$, Israel nalion wo qa ecen ecanon kta wakta iciya wo, hecen tanyan yaun kta, qa hecen makoce pte asanpi qa canhanpi tiktica kaduze cin ohna nina nihduotapi kta; Jehowa nihunkakepi Wakandapi eniciye cin he iyecen.

4 Israel nahon wo, Jehowa Wakan undapi kin iśnana Jehowa.

5 Heon nicante ocowasin, qa ninagi ocowasin, qa waniśake cin ocowasin, hena on Jehowa Wakan yada kin waśte yadake kta. 


\section{WOOPE ITAKIHNA,}

6 Qa wicoie nakaha eciciye cin he nicante akan yanke kta.

7 Qa he nicinca amnihenyan onspe wicayakiye kta, qa yati kin ohna idotanka ca cajedate kta, nakun canku omayani eca, qa makan inonke ca yekta eca.

8 Qa ninape en wapetogton he payahte kta, qa niiśta otahedan itohnakapi nun kta.

9 Qa yati tośu kin akan oyawa kta, qa nitatiyopa nakun akan.

10 Unkan kaketu kta, Jehowa Wakan yada makoce wan nicupi kta e niyate Abereham, Izak, qa Jakob konza ewicakiye ciqon, otonwe tankinyanyan, qa waśteśte; hena niye yakage śni en aniye cinhan;

11 Qa tipi taku waśte owasin ojugjudan, hena niye oyaju śni, qa mini hidoka ota herra olidog yaye śni, hastanhanka iyuwi, qa wihdi can hena niye hu yahde śni, en yai, qa wayate, qa inimnan kinhan ;

12 Jehowa Egupta makoce etanhan, wayaka tipi kin etanhan hdinanpe niye ciqon he ihnuhan ayektonje cin.

13 Jehowa Wakan yada kin he koyakipe ca htayecini kta, qa iśnana cajeyan wodake kta.

14 Nitan okśan oyate yakonpi taku wakan dapi etanhan taku wakan tokeca oyapapi kte śni.

15 Jehowa Wakan yada kin he taku wakan winawizi niyepi ehna un, heon okini Jehowa Wakan yada tocanniye kin aide niye ca maka itohnake kin etanhan ihang niye kta.

16 Masa en Jehowa Wakan yadapi kin iyutan yayapi qon, he iyecen ihnuhan iyutan yayapi kin.

17 Woahope, qa woyaatanin, qa wokage Jehowa Wakan yadapi kin ope niśipi itonpeyahan oyapapi kta.

$18 \mathrm{Qa}$ taku Jehowa iśta kin itokam waśte qa ecetu ecanon kta; hecen tanyan yaun kta, qa makoce waśte Jehowa nihunkakepi iwahowicaye ciqon, he en yai, qa tawa yaye kta.

19 Qa hecen toka niyanpi kin owasin nape wicaye kta, Jehowa ie ciqon he ecetu kta.

20 Tokata yeye cin Jehowa Wakan undapi kin woyaatanin, qa wokage, qa woahope econ niśipi kin he token ka he? nicinca eye ca iniwange cinhan ;

21 Egupta en Paro wayaka unyuhapi qon, tuka Jehowa nape waśake cin on Egupta etanhan hdinanpe unyanpi, nicinkśi eyakiye kta.

$22 \mathrm{Qa}$ wowapetokeca, qa ohan wakan tanka, qa tehika, Egupta en Paro, qa iye tiohnaka owasin en unkiśtapi itokam Jehowa econ ;

23 Qa hetanhan tankan hdinanpe unyanpi, qa makoce hunkake wicunyanpi konza ewicakiye ciqon he unqupi, qa en iyaye unyanpi kta e hecon.

24 Qa Jehowa wokage kin hena owasin econ unśipi, qa Jehowa Wakan undapi kin kounkipapi kta, hecen nakaha tanyan unyakonpi kin he iyecen tohan unnipi kin ohinniyan tanyan unyakonpi kta:

25 Qa Jehowa Wakan undapi woahope kin dena owasin econ unśipi kin he iyecen itonpeyahan econkupi kinhan, woowotanna unkitawapi kin hee kta.

\section{WICOWOYAKE $\%$}

1 Makoce wan tawayaye kta e ekta de cin he en Jehowa Wakan yada anii kinhan, qa ikce 


\section{WICOWOYAKE $\%$.}

wicaśta ota nitokapa tanhan tankan iyaye wicaye cinlıan, Heti kin, qa Girgaśi kin, qa Amori kin, qa Kanani kin, pa Perazi, kin, qa Hiwi kin, qa Jebusi kini hena oyate śakowin nikapeya otapi qa waśakapi.

$2 \mathrm{Qa}$ hena Jehowa Wakan yada nicu kinhan, hehan awicayape kta, ecaca wicayakasote kta ; wicotakuye on wicayecage kte śni, qa onśiwicayada kte śni.

3 Qa okiciyuze otakuye hena om yakage kte śni, nicunkśi cinhintkupi kin wicayaqu kte śni, qaiśs cunwintkupi wan nicinkśi yus yakiye kte śni.

4 Hecanon kinhan nicinkśi omape cin etanhan wicayutokanpi kta, qa taku wakan tokeca owicapapi kta, hecen Jehowa tocanniye kîn aide niyanpi, qa ecahankeya ihang niye kta.

5 Tuka hecen ecawicayeconpi kta, wahna wośnapi tawapi dujujupi kta, qa wakagapi tawapi yakamdecapi kta, qa can bosdata tawapi yakawankapi kta, qa wapagopi tawapi petan huhnahyayapi kta.

6 Niye oyate niwakan, Jehowa Wakan yada kin tawa, oyate hiyeye cin maka owancaya akan unpi owasin etanhan Jehowa Wakan yada kin niye nicahniga, oyate tehindapi yeci yaun kta, e hecon.

7 Jehowa nicahnige ca niyuze cin, oyate hiyeye cin niye iyotan niotapi e hecon śni, niśnana oyate hiyeye nitonana nakaś.

8 Tuka Jehowa waśte nidapi, qa taku nihunkakepi konza ewicakiye ciqon, ecetu kiye kta, heon Jehowa wayaka tipi etanhall, Fgupta wicaśta yatapi nape etanhan, nape waśaka on openicitonpi, qa hdinanpe niyanpi.

9 Jehowa Wakan yada kin iśnana taku Wakan waśake ca wacinyepica, tona waśte dakapi qa tawaohope opapi kin hena wicoicage kektopawinge hehanyan wicotakuye qa wocantekiye wicakiciyuha ece, he sdonya wo.

10 Qa tona śice dapike cin hena itohnakapi en iyecen ecawicakicon kta, qa ibang wicaye kta. Tuwe śice dake cinhan itołnake kin en iyuwin qu kte ça yutehan kte śni.

11 Heon woahope, qa wokage, qa woyaco nakaha econ ciśi kin hena duhe kta, qa ecen ecanon kta.

12 Hecen woyaco kin dena nayahonpi, qa duhapi, qa ecen ecanonpi kinhan, Jelıowa Wakan yadapi kin wotakuye, qa wocantekiye nihunkakepi konza ewicakiye ciqon niciyuhe kta.

13 Qa waśte nidake ca niyuwaśte kta, qa niyuota kta, qa nicinca, qa maga nitawa taku oicage cin, aguyapi su nitawa, qa hastanhanka nitawa, qa can wihdi nitawa, qa pte nitawa cinca, qa tahinca nitawa cinca kin hena wicayawaśte kta, nakoce wan nicu.kta nihunkakepi iwahowicaye ciqon he en.

14 Oyate hiyeye cin owasin isanpa niyawaśtepi kta, wica, qa winyan, qa woteca nitawa, koya en takudan hokśi codan kte śni.

15 Qa Jehowa wowayazan owasin niciyutokan kta, qa wośikotin śica Egupta en wandake ciqon wanjidan en aniu kte śni, qa tona śice nidakapi kin owasin en awicaye kta.

16 Jehowa Wakan yada oyate tona nicu kinhan hena owasin wicayakasote kta, niiśta itonwicape kte śni, qa taku Wakan dapi kin owicayape kte śni, hecanon kinhan he nihmonkapi kta. 


\section{WOOPE ITAKIHNA,}

17 Ikce wicaśta kin hena iye mikapeya otapi, token hena tawawicawaye kta he? nicante en ehe cinhan.

18 Ihnuhan kowicayakipe cin, Jehowa Wakan yada Paro qa Fgupta oyate owasin token ecawicakicon qon he kiksuya un wo.

19 Wowiyutan tankinyanyan niiśta wanyaka wapetogtogya, qa wicohan wakan, qa nape waśaka, qa hupahu katinkiya on Jehowa Wakan yada Egupta etanhan tankan hinanpe niye ciqon ; he iyecen oyate tona itepi kowicayakipe cin owasin Jehowa Wakan yada ecawicaon kta.

20 Nakun Jehowa Wakan yada kin hena ehna tuhmaga yewicaśi kta, qa tona okaptapi, qa nitokapa tanhan inahmanpi kin hena owasin sotapi kta.

21 Jehowa Wakan yada kin he taku Wakan tanka qa ohitike cin, he nicokaya un kin heon kowicayakipe kte śni.

22 Nitokam Jehowa Wakan yada kin ikce wicaśta kin hena apapadan nape wicaye kta, wancake owasin ihangya oyakihi kte śni, hecanon kinhan okini hewoskan wamanica niye en ilsduotapi kta.

23 Jehowa Wakan yada wowinihan tanka on nitokam skan wicaye kta, qa ecen ihang wicaye kta.

24 Qa wicaśta yatapi tawapi ninape en iyolipe wicaye kta, qa mahpiya ihukuya tanhan cajepi kin awihnuni wicayaye kta. Nitokam wicaśta wanjidan najin han kte śni, ecen owasin ihang wicayaye kta.

25 Taku pagopi wakan dapi kin petan huhnah wicayaye $\mathrm{kta}$, mazaska qa mazaskazi hena akan yanke cill he yakon kte śni, qa iyacu kte śni; okini heon nihmonkapi nonce, Jehowa Wakan yada he wahteda śni nakaś. 26 Hecen wowalite śni kin he yati kin ekta ade kte śni, okini he iyecen walite nidapi kte śni, he wahte dapi śni kin, heon wahte yada kte śni qa hitiyahda kta.

\section{WICOWUYAKE 8.}

1 Woahope nakaha econ ciśipi kin dena owasin ecen ecanonpi kta e yapatanpi kta, heon yanipi, qa nihduotapi, qa Jehowa nihunkakepi makoce iwahowicaye ciqon he en yaipi qa tawa yayapi kta.

2 Qa onśiniçida niye kta, qa iniyute kta; taku nicante en un, tawoahope oyape kta, qa oyape kte śni kin tuktee kta sdonye kta, heon waniyetu wikcemna topa kin dena hewoskan omani niye cin canku kin he owasin yeksuye kta.

3 Qa iyokiśin niye ca wotektehda niciye, qa wicaśta aguyapi hecedan on ni kte śni, tuka taku owasin Jehowa i kin etanhan inanpe cin heon wicaśta ni kte, sdonye niye kta; he manna kin yun niye cin, he nihunkakepi sdonyapi śni, qa. niye sdonyaye śni qon.

4. Waniyetu wikcemna topa kin dehanyan nitawokoyake nicikuke śni, qa nisiha kin nicapo śni.

5 Qa wicaśta wan cinhintku iyopekiye $\operatorname{cin}$ he iyecen Jehowa Wakan yada iyopeniciye cin, he nicante en sdonyaya.

6 Heon Jehowa Wakan yada koyakipe ca tacanku tanyan omayani kta e tawoahope kin yapatan kta.

7 Jehowa Wakan yada kin makoce waśte en iyaye niye kta; 


\section{WICOWOYAKE 9.}

makoce wakpa, mde, qa wakoniya, mini omdaye ohna, qa nakun he ohna inanpa.

8 Aguyapi su makoce, qa nakun barle, qa hastanhanka iyuwi, qa witanśna hu, qa taspan tanka su ota, makoce canhanpi tiktica, qa can wihdi yukan.

9 Makoce kin he en aguyapi icakije śni yan yate kta, qa he en takudan inicakije kte śni, makoce kin he en inyan kin hena mazasapa, qa lie kin etanhan mazaśa yaqe kta.

10 Hecen wayate ca inimna kta, qa Jehowa Wakan yada makoce waśte nicu kin heon dawaśte kta.

11 Awanihdaka wo, okini Jehowa Wakan yada kin ayektonje cin on tawoahope, tawoyaco, qa tawokage nakaha ope ciśi kin yapatan kte śni.

12 Okini wayate ca winipi, qa tipi waśteśte yakage ca oyati ;

13 Qa pte nitawa, qa tahinca nitawa ihduotapi, qa mazaska nitawa, qa mazaskazi nitawa ota aye ça taku duhe cin owasin ota kinhan ;

14 Nicante kin ihduwankantuya, qa Jehowa Wakan yada Egupta makoce wayaka tipi kin etanhan hdinanpe niye ciqon ayektonje cin.

15 He hopuza tanka qa okopa, wamduśka wahuhnahya, qa wamduśka sinte wipekiya ko yukan, qa puze hinca omani niyan kin, mini wanica tuka wanhi inyan etanhan mini inanpe niciya.

16 Onśiniçida niciye ça iniyute kta, qa oniwihanketa taku waśte nicicage kta; heon hopuza kin he en manna woyute nicu kin, he nihunkakepi sdonyapi śni.

17 Maminiheca, qa minape waśaka kin woyuha kin de owasin micicaga, ehe kte śni.

18 Tuka Jehowa Wakan yada kin yeksuye kta, he iye woyuha kin he yakage kta e wowaśake nicu, qa hecen nihunkakepi orn wicotakuye iwahowicaye ciqon hduśtan anpetu kin de iyececa. 19 Jehowa Wakan yada ayektonje ca taku wakan tokeca owicayape, ca en wowidag niçiye ca wicitokam canpeślka makehde inayajin kinhan, awicakehan nitakunipi kte śni, anpetu kin de en sdonye ciciyapi.

20 Jehowa Wakan yada ho kin anayagoptanpi śni, heon anitakunipi kte śni, ikce wicaśta Jehowa nitokam atakuni śni wicaye cin he iyecen.

\section{WICOWOYAKE 9.}

1 Israel anagoptan wo, nakaha Jordan wakpa kin iduwege ça oyate nikapeya wicokcota, qa waśakśaka en wicayai kta, otonwe tankinkinyan qa mahpiya ekta conkaśkeyapi kin hena tawa wicayaye kta.

2 Anaqi cinca, oyate tanka qa hanskaska sdonwicayaye ca hecen eyapi nayalion, Anaq cinca kin tuwe wicitokam najin okihi he?

3 Anpetu kin de en sdonya wo; Jehowa Wakan yada kin peta wahuhnahye cin heca, nitokam iyopte kta, qa ihang wicaye kta, qa nitokam wicakawanke kta; hecen nape wicayaye kta, qa ecadan awihnuni wicayaye kta, Jehowa eniciye cin he iyecen. 4 Jehowa Wakan yada nitokam hena nape wicaye cin iyohakam, ihnuhan nicante kin en hecen eha, omaowotanna heon makoce kin de tawa waye kta e Jehowa he en hiyu mayan. Hiya oyate kin hena sicaya olianyanpi kin heon Jehowa nitokam nape wicaya ce. 
5 Jehowa Wakan yada nihunkakepi Abereham, Izak, qa Jakob wahowicaye ciqon hduśtan kta, qa oyate kin hena śicaya olianyanpi kin heon etanhan Jehowa nape wicaye nitokapa tanhan, qa makoce tawapi en yai, qa tawa yaye kta, tuka, oniwotanna, qa nicante oze ecetu kin heon etanhan śni.

6 Oyate tahu patin henica, qa makoce waśte kin de tawayaye kta e Jehowa Wakan yada nicu kin he oniwotanna heon etanhan śni kin he sdotkiya wo.

7 Hewoskan Jehowa Wakan yada token cantiyahde yaye cin he kiksuye ca akiktunje śni wo. Egupta makoce etanhan anpetu wan en yahinanpe ciqon hetanhan, makoce kin den yahipi kin ecen, ohinniyan Jehowa yakipajinpi ecee.

8 Eya Ḣoreb en Jehowa cantiyahde yaye cin, he etanhan Jehowa canniye niyanpi, qa heon ihang niyanpi kta tuka.

9 Inyan mdaska wicotakuye Jehowa nicicaga, inyan mdaska akan owapi kin hena iwacu kta e he kin akan wai, qa anpetu wikcemna tom, qa hanyetu wikcemna tom lie en manka, he icunhan aguyapi wate śni qa mini mdatke śni.

10 Unkan Jehowa inyan mdaska nonpa kin maqu, Wakantanka napsukaza on owapi ; anpetu wan en imniciye ciqon ehar Jehowa he akan peta cokaya tanhan token oniciyapi qon he iyecen.

11 Unkan anpetu wikcemna tom, qa hanyetu wikcemna tom ihanketa, Jehowa wicotakuye inyan mdaska nonpa kin hena maqu.

12. Qa Jehowa hecen emakiya, Najin qa inaliniyan apamahde hda wo. Oyate nitawa Egupta makoce kin etanhan hdinanpe wicayaye cin ihdutakunipi śni ce, canku omani wicawaśi qon oliankoya etanhan ihdutokanpi, maza śdoyapi wakagapi wan ic̣icagapi.

13 Qa Jehowa hemakiya, Oyate kin de wanmdaka, unkan inyun oyate tahu patinpi hecapi ce.

14 Amayuśtan wo, unkan malipiya ihukuya tanhan ihang wicawaye kta, qa cajepi kin wakajuju kta, qa niye oyate hena isanpa waśake ca otapi icahciciye kta ce, eya.

15 Unkan mihduhomni, qa he ow ancaya peta on itkonyan etanhan apamahdedan waku, qu wicotakuye inyan mdaska napin minape napin ohna mduha.

16 Unkan wanmdaka, unkan inyun Jehowa Wakan yadapi kin en wayahtanipi, qa canku wan Jehowa ope niśipi qon, he etanhan ohankoya nihduhomnipi, ptejincadan śdoyapi niçicagapi.

I7 Hehan inyan mdaska kin napin minape napin on mduza nitokam elipewaye ça wakamdeca.

18 Hehan Jehowa cantiyahdeyayapi, qa wayahtanipi iśta kin itokam taku śica ecanonpi kin owasin on makata elipemiçiye, Jehowa itokam, ecamon qon iyecen, anpetu wikcemna tom, qa hanyetu wikcemna tom aguyapi wate śni, qa mini mdatke śni.

19 Jehowa tocanteptanye kata on, canniye niyanpi on ihang niyanpi kte cin kowakipa nakaś; unkan he ehan nakun Jehowa anamagoptan.

20 Jehowa Aaron iś eya nina canniye on te ye kta, tuka he ehan Aaron nakun on cewakiya. 21 Qa wayahtanipi kin ptejin- 


\section{WICOWOYAKE 10.}

cadan yakagapi qon he iwacu, qa petan hulinahwaya, qa wakaindeca, tanyan mdukpan, watuśekśeca iyecen cistinna, qa mdu kin lie etanhan wakpadan uye cin he en elipewaya.

22 Unkan Tabera (Woliulinahye,) qa Masa (Iyutanyanpi,', qa Qibrot Hatawa (Wakonpi wicahnakapi) hena owasin en, Jehowa iyutan yayapi.

23 Qa Qadeś Barneya etanhan Jehowa ye niśipi, qa hecen eniciyapi, Makoce wan ciçupi kin he ekta itanwankanhde yapi, qa tawa ya po ; tuka Jehowa Wakan yadapi kin i en iyeyapi, qa oie kin wicayadapi śni, qa ho kin ecen ecanonpi śni.

24 Anpetu totanhan sdonciyapi hehantanhan ohinniyan Jehowa yakipajinpi ecee.

25 Qa Jehowa ihang niyanpi kta, keya, heon Jehowa itokam makata elipemiciye ciqon anpetu wikcemna tom, qa hanyetu wikcemna tom ake hehanyan makata elipemiçiya.

26 Qa Jehowa cewakiye ca kaken epa, 1tancan Jehowa nitaoyate ihang wicaye śni ye, tawa wicayaya, qa nitanka kin on opewicayakiton, qa nape waśaka on Egupta etanhan hinanpe wicayaya.

27 Abereham, qa Izak, qa Jakob wowidag wicayaye ciqon wicakiksuya ye, oyate kin de wawakipajinpi qa śicaya ohanyanpi, qa wahtanipi hena ekta etonwe śni ye.

28 Okini makoce wan etanhan hinanpe unyayapi qon, en kaken eyapi kta, Jehowa makoce wan en awicaye kta kewicakiye ciqon, tuka okihi śni kin heon, qa śice wicadake cin heon etanhan Egupta etanhan awicaye ca hewoskan țewicaya, eyapi kta.
29 Tuka hena oyate nitawa, qa hena tawa wicayaya, qa nitowaśake tanka on, qa nilupahu yahdukatin, qa hdinanpe wicayaya.

\section{WICOWOYAKE 10.}

$1 \mathrm{He}$ elian Jehowa hemakiya, Inyan mdaska nom kakan wo, eya tokaheya qon he iyecen, qa yuha he kin akan mitankiyedan yau kta. Nakun can wohnaka wan nicicage kta.

2 Eya inyan mdaska nom yakamdece ciqon akan wicoie wakage ciqon, ake inyan mdaska akan owawa kta, qa can wopiye ohna eyahnake kta.

3 Unkan Śsitim can on wopiye wakage ca inyan mdaska nom wakakan, tokaheya qon iyecen, qa inyan mdaska kin napin nape ohna mduhe ca lie kin akan wai. 4. Unlan wicoie wikcemna he kin en peta cokaya tanhan Jehowa eniciyapi, anpetu omniciye en wowapi tokaheya iyecen owa, qa Jehowa hena maqu.

5 Hehan mihdamna qa he etanhan apamahde waku, qa inyan mdaska kin hena wopiye wakage ciqon he mahen owehnaka. Unkan mahen yanka, Jehowa emakiye cin iyecen.

6 Unkan Jaaqan cinca miniyowe tawapi etanhan Israel cinca ihdakapi, Mosera ekta, Aaron hen ta, qa opazuntapi, qa cinhintku Eleazar tohe qon ohna wawayuśna.

7 Hetanhan ihdakapi Gudgoda ekta, qa Gudgoda etanhan Jotba ekta, makoce kin he mini wakpadan.

8 He ehan Jehowa Lewi wicoun Jehowa wicotakuye tawa wopiye akiyuhapi kta wicayukinunke ciqon; Jehowa itokam najinpi kta, qa wowidag ic̣iyapi kta, 
qa iye caje kin on wayawaśtepi kta, anpetu kin dehan aiyahdeya.

9 Heon etanhan Lewi kin hunka wanjin wicayapi kin makoce wicakipamnipi, qa tawayapi kte cin en opapi kte śni ; tuka wotawayapi kin Jehowa hee ce, Jehowa Wakan yada wahowicaye ciqon iyecen.

10 Eya tokaheya anpetu wikcemna tom, qa hanyetu wikcemna topa hehanyan he kin akan manke ciqon ake iyena ecen waun. Unkan ake Jehowa anamagoptan, heon Jehowa ihang niyanpi kta cin śni.

11 Unkan Jehowa hemakiya, Najin, ekta hda. oyate kin wicitokam mani wo, hunkake wicayapi makoce wan wicawagu kta, eya wakonza qon, he tawa yapi kta e ekta awicaya wo.

12 Wanna Israel Jehowa Wakan yada taku econ niśi kin dee śni he? Jehowa Wakan yada koyakipe kta, tacanku owasin omayani kta, qa Jehowa Wakan yada nicante ocowasin on, qa ninagi ocowasin on, waśte yadake kta, qa wowidag niciye kita.

13 Qa Jehowa tawoahope oya. pe kta, nakun tawokage nakaha ope ciśi, hecen tanyan yaun kta. 14 Wan mahpiya kin, qa mahpiya mahpiya kin Jehowa Wakan yada kin he tawa, qa nakun maka kin taku ohnaka koya owasin.

15 Hececa tuka Jehowa nihunkakepi waśte wicadake kta e wicayuza, qa wicihakam cincapi, niyepi oyate hiyeye cin owasin e tanhan nicalinigapi, nakaha iyecen.

16 Heon etanhan nicantogepi kin bakihdayapo; qa icimiana tahu botin kiyapi śni po.

17 Jehowa Wakan yadapi kin Taku wakan Wakan dapi ee, qa itancanpi itancan kin ; Taku wakan tanka waśake ça wohitika, qa owanyake eciyatanhan tuwedan itonpe śni, qa taku nahmana qupi icu śni.

18 Wamdenica wiwazica ko iwicakiya, qa tona oyate tokeca ehna unpi cante wicakiye ca aguyapi wokoyake ko wicaqu.

19 Heon wicaśta tokeca kin cante wicayakiye kta, Egupta en tokeca niye yaun qon nakaeś. 20 Jehowa Wakan yada kin koyakipe ca tawowidake yaun kta, qa iye en iyanihdaślke kta, qa iśnana cajeyan ceyakiye kta.

21 Taku datan kte cin hee, qa Taku wakan yada kin hee, wicohan tanka, qa ohitika niiśta on wandake cin hena ecanicon.

22 Nihunkakepi wicanagi wikcemna śakowinpidan Egupta ekta ipi qon, qa wanna Jehowa Wakan yadapi kin mahipiya wicanhpi hiyeye cin iyenakeca niyuotapi ce.

\section{WICOWOYAKE 11.}

1 Heon Jehowa Wakan yada kin waśte yadake kta, qa taku yuhe niśi kin tawokage, tawoyaco, qa tawoahope kin hena. anpetu owasin oyape kta.

$2 \mathrm{Qa}$ anpetu kin de en wasdotkiya po; nicincapi heepi śni hena Jehowa Wakan yadapi kin wawiyopeye ciqon wanyakapi śni qa sdonyapi śni, token tanka, qa nape kin waśake ça hupahu katinkiya.

3 Qa Egupta cokaya, Egupta wicaśta yatapi Paro, qa tamakoce owasin wowapetokeca, qa woecon ecawicakicon.

4 Qa Egupta ozuye kin śung akan yotankapi, canpahmihma ko Mde śa en kuwa aniupi tuka mini wiciwankam hiyuya; hecen 


\section{WICOWOYAKE 11.}

Jehowa owasin ihang wicaya, anpetu kin de hehanyan.

5 Nakun liewoskan taku ecaniconpi ecen dehan yahipi,

$6 \mathrm{Qa}$ nakun Datan qa Abiram Eliab cinca he Ruben cinkśiya, token ecawicakicon, Israel owasin wicacokaya maka kin i hdukawa, qa nawicapca, iyepi, qa tiyohnakapi, qa wakeya tawapi, qa taku yuhapi owasin.

7 'Tuka niś niyepi wicohan tanka Jehowa econ qon niiśtapi wanyakapi.

8 Heon nakaha woahope ope ciśipi kin owasin duhapi kta, hecen niyuwaśakapi kta, qa makoce wan tawa yayapi kta e ekta dapi kin he en yaipi,qa tawa yayapi kta.

$9 \mathrm{Qa}$ hecen makoce wan he en asanpi canhanpi tiktica ko kaduze cin, he Jehowa nihunkakepi iwahowicaya, iye cincapi wicaqu kta kewicakiya, he akan anpetu kin yahduhanskapi kta.

10 Makoce wan tawa yaye kta e ekta yai kin he Egupta makoce etanhan yahidu kin iyecece śni ; makoce kin he en taku kaśta oyaju ca mahicistinna wan iyecen nisiha on nayalpanyan ecee.

11 Tuka makoce tawa yayapi kta e ekta dapi kin he makoce he qa kaksiza ko yukan, hecen mahpiya eciyatanhan magaju kin yatkan.

12 Makoce kin he Jehowa Wakan yada kin awanyaka, omaka tokaheya ecen omaka owihanke kte cin hehanyan, ohinniyan Jehowa Wakan yada iśta kin on atonwan yanka.

13 Unkan kaketu kte, anpetu kin de en woahope ope ciśipi kin tanyan nayahonpi, qa Jehowa Wakan yadapi nicantepi kin on, qa ninagipi ocowasin on, waśte yadapike ca wowidake niyanpi yeciunpi kinhan;
14. Makoncage iyenantu eca nitamakocepi kin amagaju waqu kta, magaju tokaheya, qa magaju ehakedan, hecen aguyapi su nitawa, qa miniśa nitawa, qa can ihdi nitawa, yatpahi kta

$15 \mathrm{Qa}$ tinta nitawa kin en woteca nitawa on peji icali wicaweciye kta, heren wayate ça winipi kta.

16 Itoniçipa po, okini nicantepi kin içihnayanpi, qa nihduhomnipi, qa taku wakan tokeca itokam canpeśka makehde nic̣ihnakapi, qa wowidag niyanpi nonce.

17 Kinhan Jehowa tocanniye itkon kiye ça mahpiya kin anakipte kta, hecen magaju wanice kta, qa maka kin aicage kte śni, qa makoce waśte Jehowa niçupi kin hetanhan kohanna ihang niyanpi kta.

18 Heon mioie kin dena nicantepi kin ninagipi ko akan ehnaka po, qa ninapepi kin on wapetogtonyan iyakaśka po, qa niitepi en niiśtapi otahedan ohinniyan duhapi kta.

19 Qa nicincapi kin hena onspe wicyakiyapi kta, tohan yati kin ohna idotanke ca canku ohna mayani, qa makan inonke kte cin, qa ye kta eca hena caje date kta.

20 Qa yati tiyopa tośu, qa nitatiyopapi henakiya akan oyawa kta.

21 Hecen maka kin .Jehowa nihunkakepi wicaqu kta konza ewicakiye ciqon, he akan anpetu nitawapi, qa nicincapi anpetu tawapi koya yuotapi kta, maka akan mahpiya anpetu kin iyececa.

22 Woahope kin de ope ciśipi kin ocowasin tanyan duhapi, qa Jehowa Wakan yadapi kin waśte yadakapi, qa tacanku owasin 21 


\section{WOOPE ITAKIHNA,}

omayanipi, qa iye en iyanihdaśkapi kinhan ;

23 Jehowa ikce wicasta kin hena owasin nitokam nape wicaye kta, qa hecen oyate nikapeya tankinyanyan, qa waśakapi tawa wicayayapi kta.

24 Makoce tonakiya ayahanpi kin hena nitawapi kta; hopuze cin etanhan Lebanon lie kin ekta hehanyan, qa wakpa kin, Yuperat wakpa ktn etanhan wiyolipeyata miniwanca kin hehanyan makoce nitawapi kta.

25 Tuwedan nitokam najinhan najin kte śni. Makoce tinskoya ayahe cin owasin Jehowa Wakan yadapi kin konicipapi, qa ikonipapi wicakiye kta, eniciyapi qon iyecen.

26 Nakaha woyawaśte ociciyakapi, qa wotehi kin de nakun wanyaka po.

27 Jehowa Wakan yadapi kin tawoahope nakaha ope ciśipi kin he anayagoptanpi kinhan, woyawaśte kin ee kta.

$28 \mathrm{Qa}$ Jehowa Wakan yadapi tawoahope nayalionpi śni, qa canku nakaha omani ciśipi kin hetanhan nihduhomnipi, qa taku wakan tokeca sdonwicayayapi śni kïn hena owicayapapi kinhan taku tehika kin hee kta.

$29 \mathrm{Qa}$ hecen ecanon kta, makoce wan tawa yaye kta e ekta de cin he tohan Jehowa Wakan yada en iyaye niye cinhan, Gerizim he kin akan woyawaśte kin datanin kta, qa Ebul lie kin en wotehi kin datanin kta.

30 Paha kin hena Jordan akasanpa wanka, wi aisinyan iyaye cin canku iyade kin icahda, More utuhu kin ikiyedan, Kanani Araba (Omdaye puza) kin Gilgal icunom ounyanpi makoce tawapi kin en.

31 Makoce wan tawayayapi kta e Jehowa Wakan yadapi kin nicupi kin he en dapi kta e Jordan iduwegapi, qa he tawayayapi kta, qa en ounyayapi kta;

32 Heon wokage, qa woyaco owasin nakaha ociciyakapi kin hena ecen ecanonpi kta, awanihdaka po.

\section{WICOWOYAKE 12.}

1 Makoce wan Jehowa nihunkakepi wakan dapi kin tawa yayapi k ta e niçupi, tohanyan maka akan yanipi he ohna anpetu owasin, wokage, qa woyaco ecen ecanonpi kta e waktaya yaunpi kta, dena eepi.

2 Ikce wicaśta tawa wicayayapi kte cin taku kaśta on taku wakan dapi kin ohodapi, he tehanwankantuya akan, qa paha akan, qa can ape yukan owasin ihukuya, hena dujujupi kta.

3 Wahna wośnapi tawapi ihang yayapi kta, qa wakagapi tawapi iyakapanpi kta, qa can wakan tawapi petan huhnali yayapi kta, qa taku wakan pagopi tawapi yakawankapi kta, qa cajepi oyanke kin he etanhan ihang yayapi kta.

4 Jehowa Wakan yadapi kin hecen ecayeconpi kte śni.

5 Tuka oyanke wan wicoun nitawapi owasin etanhan, ohna ti kta, qa caje kin hen ohnake kta e kahnige cin he ayakitapi kta, qa ekta yaipi kta.

$6 \mathrm{Qa}$ he ekta wolulinahyapi nitawapi. qa wośnapi nitawapi, qa taku icaliyayapi iwikcemnamna kin, qa ninapepi taku qupi kin, qa woyakapi wośnapi nitawapi, qa taku ikceya yaqupi, qa wanullyanpi nitawapi, pte tahinca koya cinca tokapapi kin owasin hiyuyayapi kta.

7 Qa hen wayatapi kta Jehowa 


\section{WICOWOYAKE 12.}

Wakan yadapi kin itokam tiyohnaka nitawa om, Jehowa Wakall yada kin niyawaśte kin on, taku ninapepi ekta yeyakiyapi owasin en widuśkinpi kta.

8 Token nakaha deciya econkupi, wicaśta otoiyohi iś taku owotanna kecin, he iyecen ecanonpi kte śni.

9 Makoce tawa yayapi kta e Jehowa Wakan yada niçu kin he ekta, qa wookihpe kin ekta nahanhin yakipi śni nakaś.

10 Qa Jordan iduwegapi makoce tawa yayapi kta Jehowa Wakan yadapi niçupi kin hen ounyayapi kta, qa toka niyanpi nihdukśan unpi owasin etanhan iyoziniyanpi kta, hecen okope wanin ounyayapi kta.

11 Unkan oyanke wan yuke kta, Jehowa caje kin ohna yanke kta, tukten hdahnige kte cin hentu; he ekta wohuhnahyayapi, qa taku waduśnapi kin, qa taku icahyayapi etanhan iwikcemnamna kin, qa wodakapi, taku Jehowa iwahoyayapi etanhan taku iyotan waśte owasin, taku au ciśipi owasin ayahipi kta.

12 Qa hen Jehowa Wakan yadapi kin itoham widuśkinpi kta, niyepi, qa nicincapi, qa nicunkśipi ; hokśipidan, qa wicinyanpidan wicaduhapi koya, qa nakun Lewi kin tona otonwe nitawapi ohna unpi; niyepi ehna iye makoce onśpa yuhapi śni nakaś.

13 Awanihdaka wo, oyanke tona wandake cin owasin ohna wohuhnahyapi nitawa huhnah yakiye kte śni.

14. Tuka wicoun nitawapi wanji ohna, oyanke wan Jehowa kalinige kte cin, hen taku huhnayaye cin hulinaliyakiye $\mathrm{kta}$, qa hen taku econ ciśi kin owasin ecanon kta.

15 Takomni woyawaśte Jeho- wa Wakan yada niçu kin iyecen otonwe nitawa owasin ohna wayapate ca tado yate kta, tuwe śapa, qa tuwe ska he yute kta, tatokadan qa tahinca ikce iyecece kta.

16 Tuka we kin yate kte śni, he mini iyecen maka kin ayakaśtan kta.

17 Otonwe nitawa ohna dena owasin etanhan ongedan yuta oyakihi kte śni, aguyapi su nitawa iwikcemna kin, qa miniśa nitawa, qa can ihdi nitawa iwikcemna kin, pte, qa tahinca wanunyanpi nitawa cinca tokapa kin, qa taku wodaka yakonze cin owasin, qa taku ninape koze cin.

18 Tuka hena oyanke wan Jehowa Wakan yada kahnige kte cin he ohna, Jehowa Wakan yada kin itokam hena yate kta, niye, qa nicinkśi, qa nakun nicunkśi, hokśidan qa wicinyanna wicaduhe cin, qa Lewi kin otonwe ohna ti kin, qa tuku ninape iyohiye cin owasin on Jehowa Wakan yada itokam iduśkin kta.

19 Awanihdaka wo, anpetu nitawa owasin maka nitawa akan nanke cin ihnuhan Lewi kin aduśtan kin.

20 Tohan Jehowa Wakan yada kin makoce ni tawa kin yutanka, eniciye cin iyecen, qa ninagi tado yute kta kon kinkan, heon tado wate kta ehe kta, hehan token ninagi cin kinhan, iyecen tado yate kta.

21 Oyanke Jehowa Wakan yada kin caje ohna ehnake kta e kahnige kte cin he nitantanhan tehan kinhan, pte nitawa qa tahin wanunyanpi nitawa Jehowa niçu kin, hena etànhan yapate kta, econ ciśi kin iyecen, qa otonwe nitawa ohna yate kta, taku ninagi cin kin owasin. 


\section{WOOPE ITAKIHNA,}

22 Token ikce tatokadan qa ikce tahinca yutapi kin he iyecen he yatapi kta, tona sapa qa tona ska sakim he yutapi kta.

23 Tuka we kin yate kte śni, waditaka wo, we kin nagi kin hee, qa tado kin iyahna nagi kin yate kte śni.

24 Ihnuhan he yate cin, he maka akan ayakaśtan kta, mini iyecen.

25 Taku Jehowa iśta kin en ecetu eca:ıon kinhan, niye tanyan yaun kta, qa nihakam nicinca nakun, heon he yate kte śni.

26 Tuka taku yuwakanpi niciyuke cin owasin, qa taku odake cin oyanke Jehowa kahnige kte cin he ekta yuha yahi kta.

27 Qa wahnhnahyaye cin, tado kin, qa we kin Jehowa tawahna wośnapi akan hulinah yaye kta, tuka wopida wośnapi nitawa we kin Jehowa Wakan yada tawahna wośnapi akan kaśtanpi kta, qa tado kin yate kta.

28 Wakta wo, qa wicoie kin dena nakaha eciciyapi owasin nahon wo, hecen tanyan yaun kta, nakun nicinca nihakam owihanke wanica, Jelıowa $\mathrm{Wa}$ kan yada iśta kin en taku waśte qa ecetu ecanon kinhan.

29 Tohan ikce wicaśta tawa wicayaye kta e ekta de cin Jehowa Wakan yada nitokapa tanlian wicakaśpe einhan, tawa wicayaye cinhan qa makoce tawapi en yakido tanke cinhan;

30 Awanihdaka wo, okini nitokapa tanhan ihang wicayapi iyohakam nihmunkapi, qa econpi qon iyecen ecanon; qa okini taku wakan dapi kin ayakite ca Ikce wicaśta kin hena token ohodapi kin he iyecen ecamon kta, ehe kta.

31 Jehowa Wakan yada kin 24 hecen ecayecon kte śni. Hena wowahte śni Jehowa śice dake cin.hena owasin taku wakan dapi kin ecawicakiconpi nakaś, qa nakun cincapi wica winyan koya taku wakan dapi on petan hulinakwicayapi.

32 Wicoie econ ciśipi kin owasin ecen ecanonpi kta e patan po; he ekta takudan ayakage kte śni, qa etanhan ongedan bayaśpe kte śni.

\section{WICOWOYAKE 13.}

1 Niyepi ehna waayata wan, qaiśs tuwe wowihanmna ihannna wan najin, qa wowapetokeca qaiś ohan wakan wan eniciye cinhan ;

2 Qa wowapetokeca, qa ohan wakan eniciye cin ecetu eśta, Taku wakan tokeca (sdonwicayaye śni kin hena) Tho unkopapi qa ohoundapi kta eye cinhan;

3 Waayate kin he, qaiś wowihanmna ihanmna kin he oie kin anayagoptan kte śni. Jehowa Wakan yadapi kin he nicantepi ocowasin on, qa ninagipi ocowasin on waśte yadakapi kta, hecinhan sdonye kta e Jehowa Wakan yodapi iyuteniyanpi.

4 Jelowa Wakan yadapi kin oyapapi kta, qa he koyakipapi kta, qa tawoahope yapatanpi kta, qa ho kin nayahonpi kta, qa hee wowidake niyanpi kta, qa en iyanihdaśkapi kta.

5 Qa waayate kin he, qaiś wowihanmna ihanmde cin he te yapi kta, he Jehowa Wakan yadapi Egupta makoce etanhan hdinanpe niyanpi, qa woyaka tipi kin etanhan openicitonpi kin he ayuśtanpi keniciyapi, hecen canku Jehowa Wakan yada omani niśi kin etanhan tokan iyaye niye kta; hecen niyepi 


\section{WICOWOYAKE 14.}

ehna tanhan taku śica yakasotapi kta.

6 Tohan nihunkawanji nihun cinhintku, qaiś nicinkśi, qaiś nicunkśi, qaiś nitawin niitpi ohna wanke cin, qaiś nitakoda ninagi iyecen teyahinda $\mathrm{kin}$, hena unman tukte, cimniciye ça Taku wakan tokeca ekta unyanpi, qa ohowicundapi kte, nahmana eniciye cinhan, sdonwicayaye śni nihunkakepi nakun.

7 Oyate nihdukśan unpi nikiyedan yakonpi, qaiś itehanyan maka anog owihanketa yakonpi taku wakandapi kin hena,

8 Adupte kte śni, qa anayagoptan k te śni, qa niiśta itonkipe kte śni onśiyakida kte śni, qa akahpe yakiye kte śni.

9 Tuka awicakehan te yaye kta, ktepi kta e ninape tokaheya ape kta, qa ohakam oyate owasin napepi.

10 Inyan on yakinin kta, qa te $k$ ta, Jehowa Wakan yada wayaka tipi etanhan, Egupta makoce e tanhan inanpe niye cin oyape cin etan han nape niye kta aki ta nakaś.

11 Unkan Israel owasin nahonpi kta, qa kokipapi kta, qa ake taku śice kin de iyecen niyepi ehna econpi kte śni.

12 Tohan otonwe ohna ounyayapi kta e Jehowa Wakan yada niçu kin, hena wanji ohna heyapi nayation kinhan,

13 Wicaśta Beliyal (Wowahte śni) cinca niyepi ehna tanhan inanpapi, qa otonwe tawapi wicaśta ounyanpi kin cin wicakiyapi, qa, Ihopo taku wakan tokeca ohoundapi kta eyapi, hena sdonwicayayapi śni.

14 Hehan oyade kta, qa ayakite ca tanyan inonge kta, wowahte śni kin de niyepi ehna un, wicoie nayahon kin he wicake ça ecetu hecinhan.
15 Otonwe kin he ounyanpi kin canhipi hi kin on wicayakaśtake kta, ocowasin ihang yaye kta, qa taku ohna un kin owasin tawanunyanpi nakun canhpi hi on.

$16 \mathrm{Qa}$ wahpaya kin owasin ocanku kin cokaya mnayaye kta, qa peta on huhnahyaye kta, Jehowa Wakan yada kin on otonwe qa tawahpaya owasin ocowasin, hecen owihanke wanin otiwota kta icimana ticagapi kte śni.

17 Qa he ocowasin ihang yapi kin etanhan takudan ninape askape kte śni, hecen Jehowa tocanniye kate cin ahduśtan kte ca wowaonśida niẹu, qa cante niciye kta, qa niyuotapi kta, nihunkakepi iwahowicaye ciqon iyecen.

18 Jehowa Wakan yada iśta kin en taku ecetu ecanon kta, tawoahope nakaha ope ciśi owasin yapatan kta e Jehowa Wakan yada ho kin anayagoptan eca.

\section{WICOWOYAKE 14.}

1 Jehowa Wakan yadapi cinkśi niyanpi, heon tuwe lasáta te cin on caniçipapi kte śni, qa niiśtapi otahedan śda yakasanpi kte śni.

2 Jehowa Wakan yada taoyate wakan he niyepi, qa oyate owasin maka ite akan yakonpi etanhan oyate tawahinca niyanpi kta e Jehowa nicalinigapi.

3 Taku wahte śni wanjidan yate kte śni.

4 Woteca yatapi kta dena eepi. Tatanka qa tahin wanunyanpi ska, qa tahin wanunyanpi tatokadan.

5 'Tahinca, qa tatokadan, qa hehaka, qa tatoka, qa ta, qa tinta tatanka, qa Zemer.

6 Qa woteca tona wayata konza śake jata, śake ocowasin ki- 


\section{WOOPE ITAKIHNA,}

naśpe cin, woteca kin hena yatapi kta.

7 Tuka wayata konzapi etanhan, qa śake kinaśpapi etanhan dena yatapi kte śni, camo, qa maśtinca, qa śapan kin, hena wayata konzapi eśta śake kinaśpapi śni hena śapa yadakapi kta.

8 Qa kukuśe kin siha kinaśpa eśta wayata konze śni heon śapa yadakapi kta, cehpipi etanhan yatapi kte śni, qa tancan tapi kin dutanpi kte śni.

9 Qa taku mini ohna yanke cin owasin etanhan dena yatapi kta, taku hoape qa hoceśpu napin yukan hena owasin yatapi kta.

$10 \mathrm{Qa}$ taku hoape qa hoceśpu nice cin hena owasin yatapi kte śni, hena niyepi on śapapi.

11 Zitkadan tona śape śni kin hena owasin yatapi kta.

li Tuka wahupakoza etanhan dena yatapi kte śni, huya, qa wanmdi, qa anog paska,

13 Qa raa, qa canśka wanmdidan, qa daya ocaje owasin,

14 Qa kangi ocaje owasin,

15 Qa hinhan ska, qu heca, qa canśka, qa cetan ocaje owasin,

16 Qa hinhan kaga, qa yaneśu$\mathrm{pa}$, qa tinsemet,

17 Qa mdega, qa mdoza, qa huntka,

18 Qa hoka, qa pehan, ocaje owasin, qa upupa, qa hupawakihdaka.

19 Qa nakun taku kinyan kin sdohan owasin niyepi on śape kta, he yatapi kte śni.

20 Wahupakoza śapa śni owasin yatapi kte.

21 Taku iyecinka te cin yatapi kte śni. Tuwe oyate tokeca otonwe nitawa ohna yanke cin he yaqu kta, qa he yute kta, qaiś oyate tokeca kin ekta wiyopeyaye kta, Jehowa wakan yada taoyate yuwakanpi niyepi. Ta- tokadan cinca he hunku taasanpi en oyahe kte śni.

22 Taku oyaju etanhan taku icage cin maga taku aicage cin owasin mdoketa otoiyohi iwikcernna kin dukinunkan kta.

$23 \mathrm{Qa}$ Jehowa Wakan yada itokain tukten caje kin ounye kta e kahnige kte cin, oyanke kin he ohna aguyapi su nitawa, qa miniśa nitawa, qa can ihdi nitawa iwikcemnamna kin qa pte nitawa qa tahinca nitawa cinca tokapapi wiyedan kin yate kta; hecen Jehowa Wakan yada kin koyakipe kta anpetu owasin onspe niciciye kta.

$24 \mathrm{Qa}$ tohan oyanke Jehowa Wakan yada caje ohna ehnake kta e kalinige cin he tehantu on canku nicihanska, qa duha oyakitpani kinhan, tohan Jehowa Wakan yada niyawaśte kinhan.

$25 \mathrm{He}$ mazaska on tokiyopeyaye kta, qa mazaska kin he ninape on payahte kta, qa oyanke Jehowa Wakan yada kahnige kte cin he ekta yai kta.

26 Qa taku kaśta ninagi cin kin on mazaska kin yaqu kta, pte on, qa tahinca on, qa mini śa on, qa mini wakan on, qa taku ninape cin kin owasin on, qa hen Jehowa Wakan yada kin itokam yate kta, qa iduśkin kta niye qa yati ohnaka owasin.

27 Nakun Lewi kin otonwe nitawa ohna ti kin he ehpeyaye kte śni, niyepi ehna makoce qa maga yuhe śni nakaś.

28 Mdoketu iyamini ihanketa taku. omaka kin he icah yaye cin iwikcemna kin owasin tankan hiyuyaye kta, qa otonwe nitawa ohna eyahnake kta.

29 Unkan Lewi kin he niyepi om makoce onśpa qa maga tawaye śni en hi kta, nakun tuwe oyate tokeca, qa wamdenica kin 


\section{WICOW OYAKE 15.}

qa wiwazica otonwe nitawa ohna tipi kin hena owasin en hipi kta, qa yutapi qa wipipi kta, hecen Jehowa Wakan yada niyawaśtc kta taku ninape kage ca taku ecanon owaśin en.

\section{WICOWOYAKE 15.}

1 Waniyetu śakowin ihanketa woyuśke yakage kta.

2 Qa woyuśke wicoie kin dee; Jehowa tawoyuśke eciyapi, heon tuwe takodaku qaiś hunkawanjitku taku oqu, qaiś icazo qu kin he kida kte śni, ga takodaku etanhan nape kin kiyuśke kta.

3 Tuwe oyate tokeca etanhan yakida kta, tuka taku nitawa nihunkawanji yuhe cin ninape yuśke lita.

4 Hececa eśta niyepi ehna wicaśta onśika wanice kta, Jehowa Wakan yada makoce tawayayapi kta, qa duhapi kta nicu ǩ kin he en Jehowa nina niyawaśte kta nakaś ;

5 Woahope kin de nakaha ope ciśi owasin yapatan qa ecen ecanon, qa. Jehowa Wakan yada ho kin tanyan anayagoptan kinhan.

6 Jehowa Wakan yada niyawaśte kta, eniciya iyecetu kinhan, ikcewicaśia ota owicayaqu kta, tuka niye oyadote kte śni, qaikcewicaśta ota wowidag yaye lita, tuka niye wowidag niyanpi kte sni.

7 Makoce Jehowa Wakan yada nicu kin ohna, otonwe nitawa ehna nihunkawanji etanhan wanji wahpanica aye cinhan, nicante kin yahdutehike kte śni, qa nihunkawanji wahpanica etanhan ninape kin yahdutehan kte śni.

8 Tuka he ekta ninape tankaya yakidugate kta, qa taku icakije cin tokakije cin on ohinniyan oyaqu kta.

9 Awanihdaka wo okini nicante kici wicoie wowahte śni wan yuke ça waniyetu iśakowin woyuśke waniyetu kin he ikiyedan u ce, eha, qa nihunkawanji wahpanica ekta niiśta kin śice kta, qa taku yaqu kte śni; unkan niye on Jehowa hoyekiya, qa woahtani niciyawapi kta.

10 Ohinniyan yaqu kta, qa yaqu kin on cante niśice kte śni ; hecen wicohan kin he on Jehowa Wakan yada kin niyawaśte kta, taku ecanon owasin en, qa taku ekta ninape yeyakiye cin owasin en.

11 Makoce ohna wicaśta wahpanica tohini wanice kte śni, heon miye heciciya, Nitamakoce ohna nihunkawanji onśika, qa wahpanica kin ekta ohinniyan ninape yakidugate kta.

12 Nihunkawanji Heberi wica winyan unman tukte kaśta opeyaton, qa waniyetu śakpe wowidag yaye cinhan, qa waniyetu iśako win en enitanhan ikce iyaye yaye kta.

13 Qa ikce nitantanhan yeyaye cinhan, cokadan ye yaye kte śni.

14 Taku on Jehowa Wakan yada niyawaśte kin yaqu kta, qa tahinwanunyanpi nitawa etanhan, qa aguyapi su wopiye nitawa etanhan, qa miniśa qa wihdi nitawa etanhan qin yaye kta.

15 Qa Egupta makoce ohpa wowidake yaun qon, tuka Jehowa Wakan yada openiciton kin he yeksuye kta; heon wicoie kin de nakaha ope ciśi.

16 Unkan waśte nidake ça yati nakun waśtedaka, qa tanyan nici un kin on, Nitan tanhan toki mde kte śni, eniciye cinhan ; 


\section{WOOPE ITAKIHNA,}

17 Tahinspa wan iyacu kta, qa noge tawa yapahdoke kta, tiyopa kin ekta, unkan ohinniyan oniciye kta. Wicinyanna nitawa nakun hecen ecayecon kta.

18 Wanna waniyetu śakpe wowidag yaya, qa ookiye wohtani opetonpi nonpa akihde oniciye, lieon yati etanhan ikce yeyaye cin he niista kin en tehilke kte śni; unkan Jehowa Wakan yada kin taku ecanon owasin en niyawaśte kta.

19 Pte nitawa ehna, qa tahinca nitawa ehna tona caskepi owasin Jehowa Wakan yada kin on duwakan kta; tatanka nitawa caske kinhan hỉani yakiye kte śni, qa tahinea nitawa caske hin kin duśda kte śni.

20 Omaka otoiyohi Jehowa Wakan yada itokam oyanke iye kahnige kte cin ohna, he yate kta, niye tiyohnaka nitawa om.

21 'Tuka he ośteke cinhan, huśte qaiś iśtagonga, tuktee kaśta śicaya ośteke cinhan, Jehowa Wakan yada on wayakiduśna kte śni.

22 Otonwe nitawa ohna he oyate kta, tuwe śapa qa tuwe ska sakim yutapi kta, ikce tatokadan, qa hehaka iyececa.

23 Tuka we kin yate kte śni, maka akan yakaśtan kta mini iyecen.

\section{WICOWOYAKE 16.}

1 Abib (aguyapi itka) wi kin patan wo. Jehowa Wakan yada kin Abib wi kin en Egupta etanhan, hanyen hdinanpe niye cin, heon woacakśin yakage kta.

$2 \mathrm{Qa}$ woacakśin kin Jehowa Wakan yada wayakiduśna kta, tahinca, qa tatanka wanunyanpi nakun, tukte Jehowa caje kin en ounye kta e kahnige kte cin, oyanke kin he en.
3 He kici aguyapi napohyapi yate kte śni, anpetu śakowin icunhan aguyapi napoliyapi śni yate kta, aguyapi iyokiśinyapi; Egupta makoce etanhan inahiniyan yahdinanpe nakaś; hecen anpetu Egupta makoce etanhan yahdinanpe cin he yeksuye kta, tohan yani anpetu owasin.

4 Makoce nitawa owancaya ohna onapohye niciyuke wanyakapi kte śni; anpetu śakowin hehanyan, qa anpetu tokaheya htayetu taku waduśna etanhan, tado ongedan ihanhanna kin hehanyan en yanke kte śni.

5 Otonwe Jehowa Wakan yada nicu kin otoiyohi ohna woacakśin waduśna oyakitpani kta.

6 Tuka oyanke wan Jehowa Wakan yada caje kin en yanke kta e hdahnige kte cin, hen woacakśin waduśna kte, hitayetu wiiyaye cin hehan, Egupta etanhan yahdinanpe ciqon oniciyakapi qun iyehantu.

7 He ceyaonpe ca yate kte cinhan oyanke Jehowa Wakan yada hdahnige kte cin he ohna, qa ihanhanna nihdamna, qa nitawakeya ekta yahde kta.

8 Anpetu śakpe aguyapi napohyapi śni yate kta, qa anpetu iśakowill en omniciye wakan $\mathrm{kta}$, Jehowa Wakan yada kin on; woh̆tani ecanon kte śni.

9 Anpetu wakan śakowin nicidawa kta, isan skopa aguyapi hu kin ekta toka yekiyapi etanhan, anpetu wakan śakowin dawa kta.

10 Hehan anpetu wakan yawapi wohanpi Jehowa Wakan yada kin yecage kta, token Jehowa Wakan yada niyawaśte, taku ninape iyokipiya okihi yaqu kta. 11 Qa Jehowa Wakan yada kin itokam widuśkin kta, niye, qa nicinkśi, nicunkśi, qa nitaho- 


\section{WICOWOYAKE $1 \%$.}

kśidan, qa wicinyanna nitawa, qa Lewi kin otonwe nitawa ohna ti kin, qa tuwe tokeca, qa wamdenica, qa wiwazica, niyepi ehna unpi kin nakun; oyanke Jehowa Wakan yada kin caje ohna yank kta e hdahnige kte cin hen.

12 Qa Egupta ohna wowidag niyanpi yeksuye kta, qa wokage kin dena yapatan, qa ecanon kta.

13 Ohanzi hdepi wohanpi nicicage kta, anpetu śakowin, aguyapi su nitawa qa miniśa qa wihdi nitawa mnanyan yahduśtan kinhan.

$14 \mathrm{Qa}$ wohanpi wakan nitawa en widuśkin kta, niye, qa nicinkśi, qa nicunkśi, qa nitahokśidan, qa wicinyanna nitawa, qa Lewi kin, qa tuwe oyate tokeca, qa wamdenica, qa wiwazica otonwe nitawa en tipi kin owasin.

15 Taku icahyaye cin owasin en, qa wohtani ninape econ kin owasin en Jehowa Wakan yada kin niyawaśte kta, qa nina widuśkin kta, heon oyanke Jehowa kahnige kte cin ohna anpetu śakowin Jehowa Wakan yada wohanpi yecage lkta.

16 Mdoketu otoiyohi tona wica owasin Jehowa Wakan yada kin itokam yamni akihde nihdutanimpi kta, oyanke kahnige kte cin en, aguyapi napohyapi śni, wohanpi en, qa anpetu wakan yawapi kin wohanpi en, qa ohanzi hdepi wohanpi en; qa Jehowa itokam tuwedan cokadan ihdutanin k te śni.

17 Jehowa Wakan yada niyawaśte kin, taku nicu kin etanhan otoiyohi token nape kin qu okihi, he iyecen ahi kta.

18 Wicoun nitawa on, otonwe Jehowa Wakan yada niçu kin owasin ohna wicaśta wayacopi, qa wowapi kagapi niçicagapi kta; unkan woyaco owotanna on oyate kin wicayacopi kta.

19 Woyaco duktan kte śni, qa wicite ihayakta kte śni, qa taku nahmana qupi iyacu kte śni, taku nahmana qupi kin wicaśta ksapa iśta gonge wicaya, qa tona owotanna oiepi, wicayupemni ecee.

20 Woowotanna ohinniyan opa wo, hecen yani kta, qa makoce Jehowa Wakan yada niçu kin he tawa yaye kta.

21 Taku kaśta can Aśere (Wakagapi) huyahde kte śni, Jehowa Wakan yada tawahna wośnapi nicicage cin ikiyedan.

22 Qa wakagapi wan eyahde kte śni, Jehowa Wakan yada he śicedaka.

\section{WICOWOYAKE $1 \%$.}

1 Tratanka, qaiś tahinca ośteka, taku kaśta en śice cin he Jehowa Wakan yada kin wayakiduśna kte śni, he Jehowa Wakan yada wahteda śni nakaś.

2 Tohan niyepi ehna otonwe Jehowa Wakan yada niçu kin wanji ohna wicaśta, qaiś winohinca wan Jehowa Wakan yada iśta kin en taku śica econ, qa otakuye tawa kin acakśin iyeyapi ;

3 Qa ekta ye ca taku wakan tokeca ohoda, qa wicitokam patuja, anpetu wi, qaiś hanyetu wi, qaiś mahpiya obe wanji unmantukte kaśta miś hecon waśi śni.

$4 \mathrm{He}$ oniciyakapi, qa nayahon, qa tanyan inonge, qa iny un wicakapi, qa wicoie ecetu, wowahiteda śni kin he Israel ohna econpi kinhan ;

5 Wicaśta kin he, qaiś winohinca kin he, wicoie śice cin he econpi kin otonwe tiyopa ekta hinanpe yaye kta, qa wicaśta kin he, qaiś winohinca kin he inyan 29 


\section{WOOPE ITAKIHNA,}

on wicayakinin $\mathrm{kta}$, hecen tapi kta.

6 Wayaotanin nonpa, qaiś wayaotanin yamni ipi kin on tuwe te kta iyececa țe yapi kta, wayaotanin wanjidan i kin on tuwedan te yapi kte śni.

7 T'e yapi kta e wayaotaninpi napepi tokaheya aompapi kta, qa ohakam oyate iyuhpa; hecen wośice kin he niyepi etanhan dutokan kta.

8 Tohan otonwe nitawa ohna wicoie akinicapi, wicawe wicawe kici, taku yuhapi tuwe tawa, kaśtakapi tuwe econ he? qa wicoie yacopi tehika on iyohi yaye śni kinhan, nayajin kta, qa oyanke Jehowa Wakan yada hdahinige kte cin he ekta yai kta.

9 Qa wawayuśnapi Lewi kin ekta yai kta, nakun tuwe anpetu kin hena en wayaco heca ekta, qa odake kta, unkan woyaco wicoie kin oniciyakapi kta.

10 Qa oyanke Jehowa hdahnige kte cin wicaśta etanhanpi i on wicoie oniciyakapi ecekcen ecanon kta; qa taku onspeniciyapi owasin iyecen aiciciya ecanon kta.

11 Woope i hin onspeniciyapi, qa woyaco oniciyakapi iyecen ecanon kta, wicoie oniciyakapi etanhan icunom etapa, qa catka unmantukte kaśta ektakiya idade kte śni.

$12 \mathrm{Qa}$ wicaśta tuwe walianhan içidaya ohanyan, qa wawayuśna hen najin, qa Jehowa Wakan yada okiye cin anagoptan śni, qaiś wayaco kin nation śni, wicaśta kin he te kta; hecen śica kin he Israel etanhan dutokan kta.

13 Unkan oyate kin owasin nahonpi, qa wakokipapi kta, qa icimana wahaniçidapi kte śni.

14 Tohan makoce Jehowa Wa- kan yada niçu kin ekta yai, qa tawa yay e ca en idotanke cinhan, qa, Wicaśtayatapi wan micicage kta, ikce wicaśta nihdukśan unpi owasin econpi he iyecen, ehe cinhan;

15 Tuwe Jehowa Wakan yada hdahinige kte cin hee wicaśta yatapi nicicage kta, nibunkawanjipi etanhan wicaśta yatapi nicicage kta Nibunkawanjipi etanhan śni wicaśta oyate tokeca wicaśta yatapi nicicage kte sni.

16 Tuka śunktanka hduota kte śni, qa śunktanka hduota kta e oyate kin Egupta ekta kihdewicaye kte śni. Jehowa canku kin de ohna icimana idadapi kte śni eniciyapi qon nakaś.

17 Winohinca nakun hduota kte śni, hecen cante kin yuhomnipi kte śni, Nakun mazaska ota hinca maiciye kte śni.

18 Unkan tokiconze oiyotanke kin akan kiyotanke cinhan, woope kin de wowapi wan oiçiwa kta wawayuśnapi Lewi kin wicitokam wowapi yanke cin iyececa :

19 Qa he kici un kta, qa tohanyan ni kin anpetu owaśin he en yawa kta; hecen Jehowa iye Wakan da kokipe kta onspe kta qa woope kin de oie kin owasin patan kta, qa wokage kin dena econ kta.

$20 \mathrm{Qa}$ hunkawanjitku wiciwankam cante kin ihduwankantuya kte śni, qa woahope etanhan ihduhomni kte śni, etapa catká mnman tukte ekta kiya.

\section{WICOWOYAKE 18.}

'1 Waway uśnapi Lewi kin, Lewi wicoun ocowasin wopamni, qa maga takudan yuhapi kte śni. Israel om, Jehowa tapeta wośna-

30 
pi, qa taku tawa kin he yutapi kta.

2 Tuka hunkawanji wicayapi ehna makoce yuhapi kte śni, Jehowa hee tawa yapi, ewicakiye cin iyecen.

3 Qa oyate etanhan, tona wośnapi wan patapi etanhan wawayuśnapi tawoyacopi kin dee; tatanka, qaiś tahinca etanhan isto, qa tapon napin qa tezi kin wawayuśna qupi kta.

4 Aguyapi su, qa hastanhanka, qa can ihdi hena etanhan taku toka suton, nakun talinca nitawa hin tokaheya yuśdapi kin wicayaqu kta.

5 Jehowa Wakan yada kin nitawicoun owasin etanhan Jehowa caje kin on wowidake najinpi kta e hena wicakahniga, qa cincapi nakun anpetu owasin.

6 Unkan Lewi wan otonwe nitawa wan etanhan Israel ohna tukten yanke ciqon etanhan $u$, qa nagi kin iyokipikiye kta e oyanke Jehowa hdalinige kte cin ekta hi kinhan.

7 Qa hunkawanji wicaye cin Lewi kin owasin Jehowa itokam hen najinpi kin iyecen, Jehowa caje, iye Wakan da caje kin on wowidake un kte cinhan ;

8 'Taku pamnipi etanhan unman yutapi iyecen yute kta, tuka taku ateyapi etanhan tawayapi kin iyopeyapi kin hecece kte śni.

9 Tohan makoce Jehowa Wakan yada niçu kin he ekta yai kinhan, ikcewicaśta kin hena wowahte śni econpi kin iyecen onspe niçiciye kte śni.

10 Wicaśta tuwe iye cinhintku, qaiś cunwintku peta iyopte kiye kta wanjidan iyeyapi kte śni, nakun waayate mahpiya etanhan, qaiś wamduśka etanhan, qaiś hmungapi etanhan waayatapi kin;
11 Qa waajijisa, qa wapiyesa, qa wasdonyapi ihdawapi, qa wicanagi i yayapi kin awicakitapi.

12 Tona taku hececa econpi kin owasin Jehowa wahte wicada śni nakaś, qa wowahte śni kin hena on etanhan Jehowa Wakan yada nitokapa tanhan hena nape wicaya.

13 Jehowa Wakan yada kici ecetu hinca yaun kta.

14 Ilkce wicaśta tawa wicayaye kte cin hena wahmungapi, qa malipiya etanhan waayatapi, kin hena anawicágoptanpi, tuka niye hecen ecanon kta Jehowa Wakan yada iyowin niciye śni.

15 Jehowa Wakan yada kin nihunkawanjipi etanhan niyepi ehna waayate iyemaceca icali niciyapi kta; hee anayagoptan kta.

16 Ḧoreb ekta omniciye anpetu kin en, Jehowa Wakan yada etanhan taku yakida kin owasin iyecen, Tokin icimana Jehowa Wakan wada ho kin nawahon kte śni, qa peta tanka kin de icimana wanmdake kte sni, hecen mațe kte śni, eha.

17 Unkan Jehowa hemakiya, 'Taku eyapi kin he waśte.

18 Hunka wanjinpi wicehna tanhan waayate wan icah wicawakiye kta, niye iyeniceca, qa mioie iye en yewakiye kta, qa taku eye waśi kin owasin ewicakiye kta.

19 Qa mioie micajeyan eye kte cin wicaśta tuwe nahon śni kinhan, miś toweçon kta.

20 Tuka wayyate.tuwe taku eye waśi śni wahanicidaya ie cinhan, qa tuwe taku Wakan tokeca cajeyan ie cinhan, waayate kin he te yapi kta.

21 Unkan, Token wicoie Jehowa eye śni sdonyapi kta? nicante mahen ehe cinhan. 


\section{WOOPE I'TAKIHNA,}

22 Wicoie wayate Jehowa cajeyan eye cin he ecetu śni, qa wicoie kin he hi śni kinhan, wicoie kin he Jehowa eye śni, waayate kin he wahaniçidaya ia, heon koyakipe kte śni.

\section{WICOWOYAKE 19.}

1 Tohan Jehowa Wakan yada ikce wicaśta makoce tawapi nicu kin hena Jehowa Wakan yada wicakaśpe, qa he tawa yaye, qa otonwe tawapi, qa tipi tawapi ohna yakidotanke cinhan.

2 Makoce Jehowa Wakan yada tawa yaye kta e niçu kin he ohna otonwe yamni nicidukinukan kta.

3 Qa canku tanyall nicicage kta, qa makoce tawayaye kta e Jehowa Wakan yada nicu kin he yamni kiya iyakago kta, hecen tuwe wicaśta wan kte kinhan hen nape kta.

$4 \mathrm{Qa}$ tuwe wicaśta wan kte kin on wicoie kin dee. Tuwe takodaku wanun kte, qa hektam he śice dake śni kin hen onape kta, qa ni kta.

5 Qa takodaku kici taśknju ekta can kakse kta e i, qa can wan kakse kta e onspe yuha nape ye kiya, unkan onspe kin ihupa kin etanhan ihduśdoke ça takodaku ape cin on te cinhan, he otonwe kin hena wanji ekta nape kta, qa ni kta.

6 Heconpi śni kinhan, okini tuwe we tokiçon kin cante kata icunhan tin kte kin kuwa eyaya, qa canku kin hanska on kihdege kta, qa kte kta tuka, wicanagi kin he woyaco on te kte śni, he itokam śice dake śni nakaś.

7 Heon woope wakage ca otonwe yamni nicidukinukan kta eciciya.

8 Unkan Jehowa Wakan yada nitamakoce niciyutanka kinhan, nihunkakepi konza ewicakiye cin iyecen, qa makoce nihunkakepi wicaqu kta kewicakiye sin owasin nicu kinhan;

9 Qa woahope kin de nakaha ope ciśi owasin yapatan kinhan, qa Jehowa Wakan yada kin waśte yadake ça anpetu owasin tacanku omayani kinhan, otonwe yamni kin dena isanpa otonwe yamni nakun dukinukan kta.

10 Hecen makoce nitawa tawayaye kta Jehowa Wakan yada niçu kin ohna wicawe taku iyaonpepicaśni papsonpi kte śni, qa wicawe niciyawapi kte śni.

11 Tuka tohan wicaśta wan takodaku śice kidake ca hmunke ca anajin, qa nagi kin ape cin on te cinhan, qa otonwe kin hena ekta wanji nape cinhan ;

12 Otonwe tawa hunkayapi kin akicita ekta yewicaśipi kta, qa hetanhan he icupi kta, qa we tokicon nape en qupi kta; hecen te kta.

13 Niiśta kin onśikidake kte śni, tuka wicawe iyaonpepicaśni papsonpi Israel etanhan dutokan kta, qa tanyan yaun kta.

14. Makoce Jehowa Wakan yada tawa yaye kta e niçu kin en, makoce onśpa tawayaye kte cin en wicaśta ehanna makoce icago nicicagopi, nitakoda tamaga icago kin dutokan kte śni.

15 Wicohan taku kaśta on, qa woahtani taku kaśta on wayaatanin wanjidar wicaśta anajin kte śni, woahtani wicaśta wahtani kin owasin en wicoie kin wayaatanin nonpa ipi on, qaiś wayaatanin yamni ipi on yasutapi kta.

16 Wayaatanin wai:iunniyan wicaśta wan anajin, qa wicolian śica wan econ, eya yaatanin kinhan, 
17 Wicaśta waakinicapi napin Jehowa itokam najinpi kta, waway uśnapi, qa anpetu kin hena en wicaśta wayaco hecapi itokam,

18 Unkan wayaco liin tanyeh iwangapi kta, qa wayaatanin itonśni, hunkawanjitku en itonśniyan woyaatanin oyake cinhan ;

19 Taku śice cin hunkawanjitku ecakic on kta konze cin, he iyecen ecakiconpi kta; hecen niye cokaya tanhan wicolian sica dutokanpi kta.

20 Unkan unman nahonpi qa kokipapi kta; qa niyepi ehna icimana wicoie śica kin he iyecen econpi kte śni.

21 Niiśta kin he onśikidake kte śni, tuka wicanagi on wicanagi, wiciśta kin on wiciśta, hi wan on hi, nape on nape, siha on silı.

\section{WICOWOYAKE 20.}

1 Toka niyanpi azu wicayaye kta e tankan idade ca suktanka, qa canpahmihma, qa oyate nikapeya ota wandake cinhan, ihnuhan kowicayakipe cin; Jehowa Wakan yada Egupta makoce etanhan hdinanpe niye cin nici un nakaś.

2 Qa wokicize ikiyedan idadapi kinhan, wawayuśna kin en najin kta, qa oyate kin wahokon wicakiye kta.

$3 \mathrm{Qa}$ hewicakiye $\mathrm{kta}$; Israel nahonpo. Toka niyanpi wicayakizapi kta anpetu kin de ikiyedan yaunpi; ihnuhan canniwankapidan kin. Thnuhan koyakipapi, qa nayajicapi, qa wicitokam niyuśinyayapi kin.

4. Jehowa Wakan yadapi kin tóka niyanpi wicakize kta, qa niyepi ni niyanpi kta e nicipi ya ce.
5 Unkan wowapi kagapi kin iapi, qa oyate kin hewicakiyapi kta. Wicaśta tuwe kaśta tipi teca wan icicage ça nahanbin he yawakan śni kin, he hdicu qa ti kin ekta kihde kta; okini wokicize en te kta, unkan wicaśta tokeca he yawakan kta.

$6 \mathrm{Qa}$ wicaśta tuwe hastanhanka iyuwi ojupi wan hu hde, qa nahanhin he yaikceke śni kinhan, iyaye ca ti kin ekta kihde kta; okini wokicize en țe kta, unkan tuwe tokeca he yaikceka kta.

$7 \mathrm{Qa}$ wicaśta tuwe winohinca wan wayuhpe ca nahanhin yuze śni kinhan, hdicu qa ti kin ekta kihde kta; okini wokicize en țe kta qa wicaśta tokeca he yuze kta.

$8 \mathrm{Qa}$ Wowapi kagapi nakun iapi qa oyate kin hewicakiyapi kta; Wicaśta tuwe kolkipe ça canwankadan kinhan, hdicu qa kihde kta; hecen hunkawanjin wicaye cin cantepi skan kte sni, iye cante kin iyecen.

9 Qa wowapi kagapi oyate wahokon wicakiyapi ayaśtanpi kinhan oyate wiciwankam mdetanhunka wicakicagapi kta.

10 Unkan tohantu kaśta otonwe wan azuyaye kta e ikiyedan idade cinhan, wookiye waho yaye kta.

11 Unkan wookiye aniyuptapi, qa niciyuhdokapi kinhan, oyate en iyeyapi kin owasin tawa wicayaye kta, qa wowidag wicayaye kta.

12 Tulזa wookiye nicicage śni, qa wokicize nicicage cinhan onayatake kta.

13 Qa Jehowa Wakan yada kin he ninape en qu kinhan, tona wica owasin cantipi hi on wicayakte kta.

14 Tuka winohinca, qa śiceca, 33 
WOOPE ITAKIHNA,

qa wanunyanpi, qa taku otonwe ohna un kin owasin, woyuha iyulpa kin niye on iyacu kta, qa tóka niyanpi tawoyuha Jehowa Wakan yada niçu kin he yate kta.

15 Otonwe tona ilkce wicaśta kin dena etanhan śni, tuka nitantanhan tehan unpi kin, hena owasin hecen ecawicayeconpi kta.

16 'Tuka oyate kin dena makoce tawayayapi kta Jehowa Wakan yada niçu kin, otonwe tawapi etanhan tona niyapi owasin etanhan wanjidan niyaye $k$ te śni.

17 Hiti kin qa Amori kin, qa Kanani kin, qa Perazi kin, qa Hiwi kin, qa Jebusi kin ocowasin ihang wicayaye kta, Jehowa Wakan yada econ niśi kin iyecen.

18 Hecen wowahteśni, taku iye wakan dapi ecawicakiconpi owasin iyecen econ onspe niciyapi kte śni, qa Jehowa Wakan yadapi awayahtanipi kte śni.

19 Qa otonwe wan anpetu ota onayatakapi, qa he iyacupi.kta e yakizapi kinhan, can kin ihang yaye kta e onspe ekta ye yakiye kte śni, can kin he etanhan yate kta nakaś: heon yakakse kte śni, onatakapi kin on nun kta heon etanhan; maga can lin he wicaśta on icaga nakaś.

20 Tuka can tona etanhan woyute wanica sdonyaya hena ihang yaye kta, hena yakakse kta, qa otonwe wokicize nicicage cin ohiyaye kte cin hehanyan can kin hena on conkaśke nicicage kta.

\section{WICOWOYAKE 21.}

1 Tohan makoce Jehowa Wakan yada tawayaye kta e nicu kin ohna wicatancan wan ktepi manin ryeyapi, qa tuwe he kte kin sdonyápi śni kinhan;

2 Hunkayapi kin, qa wayacopi kin hiyupi, qa wicatancan ktepi kin etanhan otonwe ihdukśan unpi ekta iyutapi kta.

3 Unkan otonwe wicatancan ktepi ikiyedan, otonwe hunkayapi kin pte wanunyanpi pte he yuktanna tohinni hitanikiyapi śni, qa can wanapin en tokśu śni icupi kta.

$4 \mathrm{Qa}$ otonwe kin he hunkayapi kin pte he yuktanna kin kaksiza wan ohinniyan mini kaduza ca yumdupi śni, qa ojupi śni ekta apamahdedan ayapi kta, qa hen kaksiza ohna pte he yuktanna pa baksapi kta.

5 Unkan wawayuśnapi Lewi cinca kin ikiyedan hipi kta; Jehowa okiyapi kta, qa caje kin on yawaśtepi kta, qa woakinice, qa kiunniyapi owasin ipi on anaptapi kta e Jehowa Wakan yada wicakahniga.

6 Unkan otonwe kin he hunkayapi owasin wicatancan ktepi kin ikiyedan hipi kta, qa pte he yuktanna kaksiza ohna pa baksapi qon iwankam nape hdujajapi kta.

7 Qa iapi qa heyapi kta, unnapepi we kin de papsonpi śni, qa unkiśtapi tuwe hecon wanyakapi śni.

8 Jehowa Israel oyate nitawa opewicayakiton akahpe wicakiciya ye, qa wicawe tin wicaktepi oyate nitawa Israel wicakiciyawa śni ye; unkan wicawe kin akahpe wicakiciyapi kta.

9 Hecen till wicaktepi we kin niyepi ehna tanhan dutokan kta, taku Jehowa iśta kin en ecetu e ecanon kinhan.

10 Tohan tokaniyanpi wicayakize kta e tankan inayapa, qa Jehowa Wakan yada ninape en 


\section{WICOWOYAKE 22.}

wicaqu, qa wayaka iwicayacu kinhan;

$11 \mathrm{Qa}$ wayaka ehna winohinca owanyag waśte wan wandake ca nina iyonicipi, qa nitawin on duze kta yacin kinhan;

12 Yati mahen hiyuyaye kta, qa pa hduśda kta, qa śake icahkiye kta.

13 Qa wokoyake wayaka icupi un kin hduśdoke kta, qa yati kin ohna yanke kta; qa atkuku hunku ko wi wanjidan anpetu iyenaka awicaceye kta; unkan he iyohakam ekta yai kta, qa hihna niye kta, qa nitawin hee kta.

$14 \mathrm{Qa}$ ohakam iyonicipi śni kinhan, toki cin kin ekta yeyaye kta, tuka mazaska on iyope yrye kte śni, qa wowidag yaye kte śni, onśika yakaga nakas.

15 Wicaśta wan winohinca nonpa yuhe ca wanji waśte dakapi, qa unman śice dakapi, qa waśte dakapi kin, qa śice dakapi kin napin cinca kicitonpi, qa śice dakapi cinca kin he cinca tokapa kinhan.

16 Tohan taku yuhe cin he cinhintku yuhe wicakiye cinhan, śice dakapi caske cinhintku tokapa hinca itokam waśte dakapi cinhintku caske kage kte śni.

17 Tuka śicedakapi cinhintku kin caske yawa kta, qa taku tawa iyeyapi kin owasin nonpa akihde qu kta, hee tookihi otokahe, caske wayaco kin he tawa nakaś.

18 Tohan wicaśta wan cinhintku wan śica, qa wawakipajin yuha, he atkuku ho kin qa hunku ho kin nahon śni, qa iyopekiyapi eśta nawicahon śni kinhan ;

19 Atkuku hunku ko he yuzapi, qa oyanke tawapi tiyopa ekta totonwe tawapi hunkayapi ekta hiyuyapi lita.

20 Qa taotonwepi hunkayapi kin hewicakiyapi kta; Unkicin- capi kin de śice ça wawakipajin, unhopi kin nahon śni, wicaśtaśni, qa witkosa ce.

21 Unkan totonwepi wicaśta owasin inyan on kininpi kta, hecen te kta. Hecen taku śica niyepi cokaya tanhan dutokan kta. Unkan Israel owasin nalonpi qa kokipapi kta.

22 Tohan wicaśta wan wahtani on te kta yacopi, unkan te yayapi, qa can wan akan otke yayapi kinhan;

23 Tancan te cin hanyetu osan can kin akan yanke kte śni, tuka anpetu kin he en maka mahen oyahnake kta ; wicaśta otke yapi kin Wakantanka wowahite da śni, qa maka tawa yaya Jehowa Wakan yada niçu kin he duśape kte śni.

\section{WICOW OYAKE 22.}

1 Nihunkawanji tatanka, qaiś talinca tawa nuni wandake cinhan, nanicilibe kte śni, tuka hena nihunkawanji ekta hdi wicayakiye kta.

2 Unkan nihunkawanji nikiyedan ti śni, qa tuwe kin sdonyaye śni kinhan, yati kin ekta hiyuyaye kta, qa nici yanke kta, nihunkawanji he akite kte cin hehanyan, qa hehan yecu kta.

3 Nakun taśonśonna iyecen ecayecon kta, qa he iyecen tawokoyake ecayecon kta, qa taku nihunkawanji tawa owasin kitanin śni qa iyeyaye cinhan; hecen ecayecon kta, he etanhan nanicihibe oyakitpani kta.

4 Nihunkawanji taśonśonna qaiś tatanka tawa canku ohna ihpaya wandake cinhan naniçilibe kte śni, tuka kici najin yaye kta.

5 Winohinca wan wicaśta tawokoyake kin koyake-kte śni, qa 
wicaśta wan winyan tawokoyake kin koyake kte śni; Jehowa Wakan yada tona heconpi owasin wah̉te wicada śni nakaś.

6 Canku omavani eca zitkadan hohpi wan can wanji akan qaiś maka akan iyeyaye cinhan, cinca qaiś witka ohna unpi, qa hunkupi cinca akan qaiś witka akan man kinhan, cinca kici hunkupi kin iyacu kte śni.

7 Cinca kin iyacu kta, qa hunkupi niyake yeyaye kta, hecen tanyan yaun kta, qa anpetu nici yahduota kta.

8 Tipi teca wan nicicage cinhan, akeyapi ihdukśan canokaśke yaye kta; hecen tuwedan hetanhan ihpaye kte śni, qa yati kin awe yaye kte śni.

9 Hastanhanka iyuwi oju nitawa ohna su tokeca oyaju kte śni ; hecanon kinhan, su tokeca oyaju qa hastanhanka iyuwi, taku oicage cin koya duwakan kta.

10 Tatanka wan qa śonśonna wan akicaśkapi on maga dumdukte śni.

11 Wokoyake tahinca hin qa hahonta on kagapi icicahiya kazuntapi kodake kte śni.

12 Woakahpe on akahpe niciye opapun topa kin akan soso yaye kta ce.

13 Wicaśta wan winohinca yuze ca kici wanke ca śicekidake cinhan;

$14 \mathrm{Qa}$ wicohan śica oie on aonpe ca caje śica kicage ca, winohinca kin de mduze ca ikiyedan wai qehan witanśna heca śni iyewaya, eye cinhan;

15 Wikośka kin atkuku hunku ko witanśna awewe kin icupi kta, qa tankan hiyuyapi kta, otonwe tiyopa ekta, hunkayapi ekta ;

16 Qa wikośka atkuku kin hunkayapi kin hewicakiye kta, Mi- cunkśi wicaśta kin de tawicu kta e waqu, unkan he śicedaka.

$17 \mathrm{Qa}$ inyun oie on wicolian śica aonpe ca, Nicunkśi witanśna heca śni iyewaya ce eya: tuka micunkśi witanśna awewe kin dee eye kta, qa minihuha śina kin, otonwe hunkayapi kin wicitokam kamdaye kta.

18 Unkan otonwe kin he hunkayapi kin wicaśta qon, icupi kta, qa iyope kiyapi kta.

19 Qa Israel witanśna wan en caje śica inanpe ye cin on mazaska opawinge on hdajuju kiyapi kta, qa wikoślka atkuku kin hena qupi kta, qa he tarvicu kta, tohanyan ni kin hehanyan ehpe kiya okihi kte śni.

20 Tuka wicoie kin he wicake ca, wikośka qon witanśna awewe kin iyeyapi śni kinhan;

21 Wikośka qon atkuku ti tiyopa ekta inanpe yapi kta, qa otonwe wicaśta kin inyan on kininpi kta; hecen te kta Israel ohna witkotkoya ohanyan, qa atkuku ti ohna witkowin ic̣icage nakaeś ; hecen niyepi cokaya tanhan taku śica dutokan kta.

22 Wicaśta wan winohinca wicaśta tokeca tawicu heca kici wanke ça iyeyapi kinhan, napin tapi kta, wicaśta winohinca kici wanke cin, qa winohinca nakun; hecen Israel etanhan taku śica dutokan kta.

23 Wicaśta wan wikośka witanśna wayuhpapi heca, otonwe ohna iyeye ça kici wanke cinhan,

24 Napin otonwe kin tiyopa kin ekta tankan inanpewicayapi kta, qa inyan on wicakininpi kta ; hecen napin țapi kta, wikośka otonwe ohna śica howaye śni he on etanhan, qa wicaśta kin takodaku tawicu kin kiyuśe kin heon etanhan: hecen niyepi 


\section{WICOWOYAKE 23.}

cokaya tanhan taku śica dutokan kta.

25 Tuka manin wicaśta wan wikośka wayuhipapi iyeye ça iyahpaye ça kici wanke cinhan, wicaśta he kici wanke cin, iś nana te kta.

26 Qa wikośka takudan ecayecon kte śni, wikośka te kta e wahitani śni, tuka wicohan kin he wicaśta wan takodaku anajin, qa nagi kin kte kin he iyececa:

27 Wikośka wayuhpapi kin manin iyeyapi śicahowaya, tuka tuwedan he nahion śni.

28 Wicaśta wan wikośka witanśna wayulipapi śni iyeye ça iyahpaye ca kici wanke, qa iyewicayapi kinhan;

29 Wicaśta he kici wanke cin wikośka atkuku kin mazaska wikcemna zaptan qu kta, qa he onśika kage cin heon he tawicu kta, tohan ni kin hehanyan he ehpekiya okihi kte śni.

\section{WICOWOYAKE 23.}

1 Wicaśta wan atkuku tawicu qon yuze kte śni, qa atkuku towinje kin yuzamni kte śni.

2 Tuwe susu kaślujapi qaiś ce baśpapi kin Jehowa taomniciye en ope kte śni.

3 Wicaśta tuwe ateye tanin śni Jehowa taomniciye en ope kte sni; nakun cinhintku wicoicage wikcemna hehanyan Jehowa taomniciye en ope kte śni.

4 Amoni kin qa Moabi kin Jehowa taomniciye en ope kte śni. Tuwe hena etanhan icage tohini Jehowa taomniciye en ope kte śni, wicoicage wikcemna hehanyan.

5 Egupta etanhan yahdinapapi qehan, aguyapi qa mini yuha canku ohna nitkokim upi śni, heon etanhan, nakun Balam Be- yor cinhintkl1, Aram Naharaim (Mdamdata wakpa otahedan) makoce, Petor otonwe etanhan niyaśicapi kta e opetonpi, heon etanhan.

6 'Tuka Jehowa Wakan yada kin Balam nalion tawațen ye śni, qa Jehowa Wakan yada waśte nidake cin, heon Jehowa Wakan yada kin niyaśicapi kte cin yuhomni, qa niyawaśtepi.

7 Wokiyapi kta, qa tanyan unpi kta icimana ayakite kite śni, anpetu nitawa owasin.

8 Edomi nihunkawanji hee, heon ihnuhan wahteyada śni kin. Egupton tainakoce ohna yati qon, heon ihnuhan he wahte yada kte śni.

9 Cincapi wicakicitonpi wicoicage iyamni Jehowa taomniciye en opapi kta.

10 Toka niyanpi azu wicaya idade cinhan, taku śica owasin. etanhan nikpatan kta.

11 Niyepi ehna wicaśta wan hanyen kaduze cin on śape cinhan, wicoti itankan inanpe kta, qa wicoti mahen hi kte śni.

12 Tuka htayetu kte cinhan, minin ihdujaja kta, qa wi iyaye cinhan, wicoti mahen hdi kta.

$13 \mathrm{Qa}$ wicoti itankan oyanke wan duhe kta, qa he ekta tankan idade kta.

14. Qa wipe nitawa kici wamnahecadan duhe kta, qa tankan idotanke cinhan, he on maka yaqe kta, qa idotanka ca enitanhan taku inanpe cin akahpe yakiye kta.

15 Jehowa Wakan yada kin ni niyanpi kta e, qa toka niyanpi kin nitokam wicaqu kta e wicoti nitawa ohna mani kin; heon wicoti nitarva wakan kta, qa niye en taku śape wanyake kte śni; hecen niye etanhan hde kte śni. 


\section{WOOPE ITAKIHNA,}

16 Onkiye wan yuhe cin etanhan niye ekta najice cinhan, yuhe cin yecu kte śni ;

17 Nici ounye kta, niyepi ehna oyanke kahnige kta ohna, otonwe nitawa wan iyokipi he en; iyokiśin yaye kte śni.

18 Israel cunwintku wanjidan witkowin kte śni, qa Israel cinhintku wanjidan winyan içida kte śni.

19 Witkowin taku qupi, qa śunka taku iyope yapi kin, Jehowa Wakan yada ti kin ekta yakahi kte śni ; takil kaśta woyake on hena napin Jehowa Wakan yada wahte da śni nalkaś.

20 Nihunkawanji dahtake kte śni, mazaska woyahtake on qa woyute woyahtake on, qa taku owasin woyahtake on.

21 Tuwe oyate tokeca woyalitake on oqu oyakihi kta, tuka nihunkawanji woyahtake on oyaqu kte śni, hecen Jehowa Wakan yada kin taku ninape ekta yeyakiye cin owasin en, makoce tawa yaye kta e ekta idade cin he akan niyawaśte kta.

22 Woyake Jehowa Wakan yada odake cin yecu kta e dutehan kte śni, hecanon kinhan woahtani nici yawapi kta, qa Jehowa Wakan yada kin nicida kta.

23 Wodake yakapin kinhan woahtani niciyawapi kte śni.

24 Awanihdake ça taku niiha etanhan inanpe cín econ wo; token Jehowa Wakan yada oyakidake, woyake nii kin on ehe cin.

25 Nitakoda hastanhanka iyuwi kin en yai kinhan, hastanhanka imnahan token ninagi cin wayate kta, tuka wojuha nitawa en takudan iyeyaye kte śni.

26 Nitakoda aguyapi oju tawa en yai kinhan, itka ninape on duksa oyakihi, tuka nitakoda aguyapi su icage cin ekta isan yeyaye kte śni.

\section{WICOWOYAKE 24.}

1 Wicaśta wan winohinca yuze ça hihnaku ee, qa ohakam he en taku śapa iyeye cin on iśta kin en iyokipi śni kinhan, ehpekiyapi wowapi wan kicage kta, qa nape kin en qu kta, qa iye ti kin etanhan iyaye ye kta.

2 Unkan iye ti kin etanhan inanpe ca toki iyaye ca wicaśta tokeca he yuze cinhan;

3 Unkan wicaśta ehake yuze cin he śicedake ca elipekiyapi wowapi wan kicage ca ti kin etanhan iyaye ye cinhan, qaiś wicaśta tawicu kta e ehake he yuze cin te cinhan;

4 Hihnaku tokaheya ehpekiya gon, yuśapapi iyohakam, tawicu kta e ake yuze kta okihi śni, Jehowa Wakan yada kin he itokam wowahte śni kin hee, qa makoce Jehowa Wakan yada tawa yaye kta e niçu kin he wahtani yaye kte śni.

5 Wicaśta tuwe aśkatudan winohinca wan yuze cinhan, ozuye obe en ope kte śni, qa on takudan aonpapi kte śni, tuka waniyetu wanjidan ti kin ohna ikce yanke kta, qa tawicu yuze cin iyuśkin kiye kta.

6 'Tuwe taku odote hdajuju kiyapi kta e wiyukpanpi inyan sakim qaiś unmana tuwedan icu kte śni, he wicanagi icupi kin he iyececa nakaś.

r Tuwe hunkawanjin wicaye cin etanhan, Israel cinca etanhan wicanagi wan iyahpaye ça manun, qa wiyopeya, iyeyapi kinhan, wamanun kin he te kta, hecen taku śica niyepi cokaya tanhan dutokan kta.

8 Leprosi makośice on waktaya 


\section{WICOWOYAKE 25.}

un wo, qa nina awanihdake ca Lewi kin wawayuśnapi kin taku onspe niciyapi owasin iyecen econ wo; token econ wicawaśi kin iyecen ecanonpi kta awandakapi kta.

9 Egupta etanhan yahdinanpapi canku ohna token Jehowa Wakan yada Miriam ecakicon kin he kiksuya wo.

10 Tohan nitakoda taku oyaqu kinhan, taku odote cin on taku hdajuju kiyapi kin iyacu kte e tipi tawa en yai kte śni.

11 Tankan inayajin kta, qa wicaśta tuwe taku oyaqu, taku on hdajuju kiyapi kin niye ekta tankan hiyuye kta.

12 Qa wicaśta kin onśika hecinhan, taku on hdajuju kiyapi yuha niśtinbe kte śni.

13 Tohan wi iyaye cin taku on hdajuju kiyapi yecu kta; hecen tawokoyake hdowin iśtinbe kta, qa niyawaśte kta, qa Jehowa wakan yada woowotanna niciyawa kta ;

14 Tuwe wahpanice ca onśike wohtani ope yaton kin yakiduśe kte śni; he nihunkawanji qaiś, oyate tokeca nitamakoce en otonwe nitawa ohna un kin unman tukte kaśta.

15 Tuka anpetu tawa en wi iyaye śni iyuwin yecu kta, he wahpanica, qa nagi kin ekta yeiciya nakaś, hecen niba Jehowa hoyekiye kte śni, qa woahtani niciyawapi kte śni.

16 Hunkayapi iye cinhintkupi on te wicayapi kte śni, qa cinca hunkayapi on te wicayapi kte śni, otoiyohi iye wahtani kin on te kiyapi kta.

17 Tuwe oyate tokeca, qa wamdenica tawoyaco dapemni kte śni; qa wiwąica taku nicicajuju sni kin on tawokoyake iyacu kte śni.
18 Qa Egupta ohna wayaka yaun qon, he yeksuye kta, qa hetanhan Jehowa Wakan yada openiciton heon miye wicoie kin de econ ciśi.

19 Nitamaga ohna woksapi bayaksa eca, qa nitamaga ohna wopahte ayektonje cinhan; he iyacu kta e ake ekta yai kte śni; tuwe oyate tokeca, wamdenica, ga wiwazica he yuhapi kta; hecen Jehowa Wakan yada niyawaśte kta, wohtani ninape econ kin owasin en.

20 Wihdi can nitawa yakahna eca akta duśpi kte śni, tuwe oyate tokeca, wamdenica, qa wiwazica he yuhapi kta.

21 Hastanhanka iyuwi nitawa duśpi eca okaptapi kin ake duśpi kte śni, hena tuwe oyate tokeca, wamdenica, qa wiwazica vuhapi kta.

22 Unkan Egupta makoce ohna wayaka nanke cin he yeksuye kta, heon wicoie kin de econ ciśi.

\section{WICOWOYAKE 25.}

1 Wicaśta woakinicapi, qa wayaco ekta hipi kinhan wayacopi kin tuwe owotanna kin he yaowotanpi kta, qa tuwe śica śicaya econ eciyapi kta.

2 Qa śicaya econ kin apapi kta iyecece cinhan, wayaco kin he makipusdiya ehpe kiyapi wicaśi kta, qa iye itokam, śicaya econ kin on woape iyenaka apapi kta.

3 Wikcemna topa akihde apapi okihipi, tuka sanpa apapi kte śni ; hena isanpa apapi kinhan ota apapi kta, qa nihunka wanji nitokam wahte śni yawapi kta.

4 Tatanka aguyapi su napan kiyapi i kin yuohmuzapi kte śni. 5 Wicaśta hunka wanjin kiciyapi icikiyedan tipi, qa wanji cinca nica țe cinhan, wicaśta 


\section{WOOPE ITAKIHNA,}

tokeca tokan tanhan te cin tawicu kin yuze kte śni, śiçeku kin he ekta i kta, qa tawicu kta e yuze kta, qa śiceku taku ecakicon kta iyececa ecakicon kta.

6 Unkan cinca ton tokapa kin hunkåwanjitku te ciqon caje kin yuhe kta, hecen caje kin Israel etanhan pajujupi kte śni.

7 Unkan wicaśta kin hankaku yuze kta tawaten ye śni kinhan, hankaku hunkayapi ekta, otonwe tiyopa ekta ye kta, qa heye kta. Sice waya iye cincu caje kin Israel ohna icahye kta wicada śni, qa mayuze kta cin śni.

8 Hehan otonwe hunkayapi kin he kicopi kta, qa kici wohdakapi kta, unkan ekta najin, qa he mduze kta tawațen waye śni, eye kta.

9 Hehan hankaku ikiyedan i kta, qa hanpa siha kin etanhan kiciyuśdoke kta, hunkayapi itokam, qa ite kin en tagośa kta, qa tuwe cincu ti kin icah ye kta tawaten ye śni hecen ecakiconpi kta, eye kta.

10 Unkan Israel ohna, Hanpa kiciyuśdokapi toti kin he, eciyapi kta.

11 Wicaśta wan hunka wanjitku kici akicipapi, qa wanji tawicu kin tuwe ape cin nape kin etanhan hihnaku ehdaku kta e ikiyedan hi, qa nape kin yekiye ca wowiśtece ekta yuze cinhan,

12 Nape kin bayaśpe kta, niiśta kin onśikidake kte śni.

13 Wanspeya ojuha ohna inyan toktokeca, tanka qa ciśtinna duhe kte śni ;

14 Wiyutapi toktokeca tanka qa cistinna yati kin ohna duhe kte śni.

15 On aspeyapi ecetu qa owotanna duhe kta, qa wiyutapi ecetu qa owotanna duhe kta; hecen. anpetu nitawa hanske kta, ma- koce Jehowa Wakan yada niçu kin akan.

16 Jehowa Wakan yada wicohan hena owasin wicohan sica owasin wahite da śni nakaś.

17 Egupta etanhan yahdinanpe ciqon tahepi Amaleq token ecannicon kin kiksuya wo.

18 He tahepi anicipe ca tona śihtinpi nihakam upi owasin wicakaśpe, qa taku Wakan kokipe śni, niye hanyaya qa mdoyakițe cehan.

19 Heon tohan Jehowa Wakan yada iyozi niciye, makoce tawa yaye kta, qa yecipamnipi kta e Jehowa Wakan yada niçu kin ohna, toka niyanpi ihdukśan unpi owaśin etanhan, Amaleq kiksuyapi kin mahpiya ihukuya tanhan yapajuju kta, ihnuhan ayektonje cin.

\section{WICOWOYAKE 26.}

1 Unkan tohan makoce yecipamnipi kta Jehowa Wakan yada nicu kin ekta yaki, qa tawa yaye ca ohna yakidotanke cinhan,

- 2 Maga nitawa taku toka suton owasin, makoce Jehowa Wakan yada niçu kin etanhan taku icage cin etanhan iyacu kte ca wakiśkotpa wan en iyeyaye kta, qa oyanke ohna caje kin yanke kta e Jehowa Wakan yada hdahnige cin he ekta yai kta.

3 Qa wawayuśna anpetu kin hena en yuke kte cin he ekta yai kta, qa heyakiye kta, Makoce wan unqupi kta Jehowa hunkake wicunyanpi konza ewicakiya, he ekta wahi, Jehowa Wakan yada kin nakaha ewakiya.

4 Unkan wawayuśna kin wakiśkotpa kin ninape etanhan icu, qa wahna wośnapi Jehowa Wakan yada tawa kin icahda ehde kta. 


\section{WICOWOYAKE $2 \%$}

5 Hehan Jehowa Wakan yada itokam iyae ça ehe kta, Aram wicaśta hanyan ate waya, Egupta ekta apamahdeya $i$, qa hen yan$\mathrm{ka}$, wicaśta tonana om, qa hen oyate tanka, waśaka, qa wicota icaga.

6 Unkan Egupton unkiyuśepi, qa iyokiśin unyanpi, qa tehiya wowidag unyanpi.

7 Unkan Jehowa hunkake wicunyanpi Wakandapi kin hoyeunkiyapi ; unkan Jehowa ho naunkiłonpi, qa iyokiśin unyanpi, qa hitani unkiyapi, qa unkiyuśepi kin wanyaka.

8 Qa Jehowa Figupta etanhan hdinanpe unyanpi nape waśaka on, qa isto katinkiya on, qa wowanyanke tanka on, qa wo wapetokeca on, qa tohan okitanin on ;

$9 \mathrm{Qa}$ oyanke kin de ekta hiyu unyanpi, qa makoce kin de unqupi, makoce pte asanpi qa canhanpi tiktica on kaduza.

10 Heon wanna wanyaka wo, maga mitawa Jehowa maqu kin taku aicage toka suton wakahi, ehe kta, qa Jehowa Wakan yada kin itokam eyaju kta, qa Jehowa Wakan yada ohoyada kta.

11 Qa taku waśte Jehowa Wakan yada niçu, qa yati taku qu kin hena owasin on iduśkin $\mathrm{kta}$; niye, qa Lewi kin, qa tuwe tokeca niyepi ehna un.

12 Omaka iyamni en iwikcemna mnayanpi omaka hee, taku ical yaye cin iwikcemna yukinukan yahduśtan kinhan, Lewi kin, qa tuwe tokeca, qa wamdenica, qa wiwazica wicayaqu kta ; unkan otonwe nitawa ohna yutapi qa imnapi kta.

$13 \mathrm{Qa}$ Jehowa Wakan yada itokam hehe kta. Taku yuwakanpi iyuhpa wati etanhan hiyu waya; qa nakun Lewi kin, qa tuwe oyate tokeca, wamdenica, qa wiwazica he wicawaqu, woahope nitawa ope mayaśi kin owasin iyecen, woahope nitawa kawape śni, qa awektonje śni.

14 Hetanhan waśiwahda icunhan ongedan wate śni, qa taku śapa un ongedan mun śni, qa tuwe te cin on he etanhan ongedan wicawaqu śni, Jehowa Wakan wada ho kin nawahon, qa token econ maśi kin owasin iyecen ecamon.

15 Nitohe wakan etanhan, Mahpiya etanhan ahitonwan, qa oyate nitawa yawaśte ye, Israel hee; nakun makoce unyaqupi kin he makoce pte asanpi qa canhanpi tiktica on kaduza, hunkake wicunyanpi konza ewicayakiye ciqon iyecen.

16 Anpetu kin de Jehowa Wakan yada wokage qa woyaco kin dena econ niśi, heon waktaya un, qa nicante ocowasin on, qa ninagi ocowasin on hena ecanon kta.

17 Jehowa taku Wakan yada kin hee, qa tacanku omayani kta, qa tokage, qa "tawoahope, qa tawoyaco yapantan kta, qa ho kin nayahon kta, nakaha eyakiya. 18 Unkan nakaha Jehowa heniciya, oyate tehindapi miyeciun kta, eniciya qon iyecen, qa tawoahope owasin yapatan kta.

$19 \mathrm{Qa}$ oyate owasin wicakaga woyatan on, qa caje kin on, qa wokitanin on, wiciwankam enihdepi kta, qa Jehowa Wakan yada tao yate wakan yaunpi kta, eye ciqon iyecen.

\section{WICOWOYAKE $2 \%$.}

1 Hehan Mowis qa Israel hunkayapi kin oyate wahokonwicakiyapi, qa heyapi, Woahope nakaha ope çiśipi kin owasin patanpo. 


\section{WOOPE ITAKIHNA,}

2 Unkan tohan Jordan iduwega, makoce Jehowa Wakan yada ekta, inyan tankinyanyan eyahnake kta, qa makasan upśija on hena ayapawinte kta.

$3 \mathrm{Qa}$ hena akan woope wicoie kin owasin oyawa kta, makoce Jehowa Wakan yada nicu kin en yaki kta e iduwegapi iyohakam, maknce pte asanpi ga canhanpi tiktica on kaduza, Jehowa nihunkakepi Wakan dapi kin eniciye iyecen.

4 Qa Jordan iduwegapi ohakam Ebal paha kin en inyan kin hena eyahnakapi kta, nakaha econ ciśipi iyecen, qa makasan upśija on hena ayapawinte kta.

5 Qa hen wahna wośnapi wan Jehowa Wakan yada kin yecage kta, wahna wośnapi inyan kin hena akan mazasapa yakoze kte śni.

6 Inyan ocowasin kakanpi śni on Jehowa Wakan yada owayuśna kin yecage kta; qa he akan Jehowa Wakan yada tawohuhnahyapi huhnah yakiye kta.

7 Qa hen wopida wośnapi yapate ca yate kta, qa Jehowa Wakan yada kin itokam widuśkin kta.

8 Qa woope kin de oie kin owasin inyan akan taninyanhin oyawa kta.

9 Unkan Mowis qa wawayuśnapi kin Lewi kin iapi, qa heyapi, Israel inina un, qa anagoptan wo. Nakaha Jehowa Wakan yadapi kin taoyate kin he niyepi.

10 Heon Jehowa Wakan yada ho kin nalion, qa tawoahope qa tokage nakaha eciciye cin econ wo.

11 Unkan anpetu kin he en Mowis oyate wahokon wicakiye ca heya,

12 Jordan iduwegapi ohakam oyate wicayawaśtepi kte e Geri- zim paha akan inajinpi kta dena eepi, Simeyon, qa Lewi, qa Juda, qa Isakar, qa Josep, qa Benjamin. 13 Qa yaśicapi kta e Ebal paha akan najinpi kta dena eepi, Ruben, Gad qa Aśer, Zebulun, Dan qa Naptali.

14 Unkan Lewi kin ayuptapi kta, qa ho tankakiya Israel wicaśta owasin hewicakiyapi kta; 15 Tuwe wakagapi kakanpi, wan qaiś śdoyapi wan, wapago wan nape on kagapi, be Jehowa wahteda śni, kage ça nahmana ehde, wicaśta kin he yaśicapi nunwe. Unkan oyate owasin ayuptapi, qa Amen (Hecetu nunwe,) eyapi kta.

16. Tuwe atkuku, qaiś hunku ihakta śni kin he yaśicapi nunwe; unkan oyate kin owasin Amen, eyapi kta.

17 Tuwe wicaśta tokeca tamaga icago yutokan yaśicapi nunwe; unkan oyate kin owasin Amen, eyapi kta.

18 Tuwe wicaśta iśta gonge cin canku etanhan nuni kiye cin, yaśicapi nunwe; unkan oyate kin owasin, Amen, eyapi kta.

19 Tuwe wamdenica, wiwazica, qaiś tuwe tokeca tawoyaco yapemni kin he yaśicapi nunwe; unkan oyate kin owasin, Amen, eyapi kta.

20 Tuwe atkuku tawicu kici wanke cin, atkuku towinje kin yuzamni, heon he yaśicapi nunwe; unkan oyate kin owasin, Amen, eyapi kta.

21 Tuwe woteca wan kici wanke cin he yaśicapi nunwe; unkan oyate kin owasin, Amen, eyapi kta.

22 'Tuwe tawinolitin kin atkuku cunwintku, qaiś hunku cunwintkı kici wanke cinhan yaśicapi nunwe; unkan oyate kin owasin, Amen, eyapi kta. 


\section{WICOWOYAKE 28.}

23 Tuwe konku, qaiś takośku kici wanke cin yaśicapi nunwe; unkan oyate kin owasin, Amen eyapi kta.

24 Tuwe wicaśta tokeca wan nalimana kaśtake cinhan yaśicapi nunwe; unkan oyate kin owasin, Amen eyapi kta.

25 Tuwe wicanagi taku śica econ śni we ye kta e taku nahmana qupi icu kinhan, yaśicapi nunwe; unkan oyate kin owasin Amen, eyapi kta.

26 Tuwe woope kin de oie kin owasin yasuta śni, qa ecen econ śni kin yaśicapı nunwe; unkau oyate kin owasin Amen, eyaps kta.

\section{WICOWOYAKE 28.}

1 Unkan kaketu kta, Jehowa Wakan yada ho kin nayation, qa tawoahope nakaha ope ciśi kin owasin yapatan, qa ecen ecanon kinhan, Jehowa Wakan yada oyate maka akan iyeye cin owasin iwankam enihde lita.

¿ Qa woyawaśte kin dena owasin en niupi, qa iyonihipi kta; Jehowa Wakan yada ho kin nayahon kinhan,

3 Otonwe ohna niyawaśtepi kta, qa maga ohna niyawaśtepi kta.

4 Tamni nitawa taku icah ye cin yawaśtepi kta, nakun maka nitawa taku icah ye cin, qa nitawanunyanpi taku icah yapi, pte nitawa, qa tahin wanunyanpi wiyedan cincapi kin yawaśtepi lita.

5 Waskuyeca opiye nitawa yawaśtepi kta.

6 Tin hidu eca niyawaśtepi kta, qa tankan inanyapa eca niyawastepi kta.

7 Tóka niyanpi aninajinpi kin wicayakaśtaka okihi niye kta; canku wanjidan ohna anihinanpapi kta, qa canku śakowin ohna nitokapa tanhar najicapi kta.

8 Woha nitawa en Jehowa wowaśte niçu kta, nakun taku ekta ninape yeyakiya owasin en; qa Jehowa Wakan yada maka niçu kin en niyawaśte kta.

$9 \mathrm{Qa}$ Jehowa taoyate wakan yaun kta, sutaya najin niyanpi kta konza eniciye cin iyecen; Jehowa Wakan yada tawoahope oyape ca tacanku omayani kinhan.

10 Qa oyate maka akan hiyeye cin owasin Jehowa caje on caje niyatapi kin wanyakapi qa konicipapi kta.

11 Qa Jehowa taku waśte niciyuota kta, taku tamni nitawa icah ye cin en, qa nitawanunyanpi taku icah yapi en, qa makoce Jehowa nicu kta, nihunkakepi konza ewicakiye ciqon ohna maga nitawa taku icah ye cin en.

12 Qa Jehowa wopiye tawa niciyuhdoke kta, mahpiya kin, qa hecen iyehantu eca makoce nitawa amagaju ye kta, qa ninape tohtani owasin niciyawaśte kta; hecen oyate ota owicayaqu kta, tuka niye oyadote kte śni.

13 Qa pa yaun kta e Jehowa enihde kta, qa sinte henica kte śni; qa wankan heceedan yaun kta, qa ihukuya yaun kte śni ; Jehowa Wakan yada tawoahope nakaha miye patan qa econ ciśi nayahon kinhan.

$14 \mathrm{Qa}$ wicoic owasin nakaha ope ciśi kin etanhan nihduhomni śni, etapa qa catka unman tukte ekta kiya, qa taku wakan tokeca owicayape śni, qa olowicayada śni kinhan;

15 Tuka tawoahope, qa tawokage owasin nakaha ope cisipi yapatan kta, qa ecanon kta e Jehowa Wakan yada ho kin na43 


\section{WOOPE ITAKIHNA,}

yahon śni kinhan, woyaśice kin dena owasin en niupi qa nicihdegapi kta.

16 Otonwe ohna niyaśicapi kta, qa maga ohna niyaśicapi kta.

17 Waskuyeca opiye nitawa en, qa aguyapi su opiye nitawa en niyaśicapi kta.

18 Tamni nitawa oicage cin, qa maga nitawa taku oicage cin, taliin wanunyanpi wiyedan nitawa, qa pte nitawa taku tonpi yaśicapi kta.

19 Tin hidu eca niyaśicapi kta, qa tankan inanyapa eca niyaśicapi kta.

20 Unkan Jehowa woyaśice kin niye ekta ye kiye kta, wowinihan kin, qa woiyopeye kin; taku yakage kta e ninape ekta yeyakiye cin owasin en; ecen ihang niyanpi, qa kohanna nisotapi kta, niokan wośice kin, qa amayaduśtan kin on etanhan.

21 Qa Jehowa makośice ikoyag niye kta, ecen makoce tawayaye kta e ekta idade cin hetanhan nisotapi kta.

22 Qa Jehowa waśinkte, qa tancan kata, qa śiyakao, qa śaśa anihinanpe on, anipe kta, nakun canhipi on, qa aguyapi hu śnija qa gigi kin on, hena nipasipi ecen nisotapi kta.

23 Qa mahpiya nitawa nipa iwankam mazaśa kta, qa maka kin nihukuya kin mazasapa kta.

24. Qa Jehowa watuśekśeca maka nitawa ahinhe ye $\mathrm{kta}$, qa wiyaka mahpiya etanhan ahinhe niye kta, ecen ihang niyanpi kta.

25 Qa tóka niyanpi itokam nayajicapi kta Jehowa kage kta, canku wanjidan ohna wicatatpe inanyape kta, qa canku śakowin ohna wicitokam nayajice kta, qa maka wokiconze owasin ekta nape niyanpi kta.

26 Qa mahpiya wahupakoza, qa maka wamanica owasin, nitancanpi woyute yapi kta, qa tuwedan ham wicaye kte śni.

27 Qa Jehowa Egupton tancan hdi on anipe kta, nakun nitepo, qa wicayaspuya, qa hahidi on, tuwedan okizi niye kta okihi kte śni.

28 Qa Jehowa woyuhnaśkinyan on, qa iśtagonga on, qa cante hnuni on anipe kta.

29 Qa tuwe iśtagonga otpaza en yutantan un kin iyecen, wiyotanhan en yutantan yaunpi kta; qa niohan tanyan ihuni yakiye kte śni, qa ohinniyan niciyuśepi, qa taku nitawa nicipi kta, qa tuwedan eniyaku kte śni. 30 Winohinca waduhpe kta, qa wicaśta tokeca he kici wanke kta; tipi yakage kta, tuka ohna yati kte śni. Hastanhanka iyuwi huyahde kta, tuka tohini waskuyeca kin duśpi kte śni.

31 Tatanka nitawa nitokàm patapi kta, tuka etanhan onśpadan yate kte śni. Śonśonna nitawa nitokapatanhan nicipi kta, qa en nihdi kte śni. Toka niyanpi tahinca nitawa icupi kta, qa tuwedan óniciye kte śni.

32 Oyate tokeca nicinkśi qa nicunkśsi iwicacupi kin niiśta wanyakapi, qa hena on etanhan anpetu owasin hanyanpi kta; tuka ninape wowaśake nice kta.

33 Oyate tokeca sdon wicayaye śni taku maka nitawa aicage ca taku on htayani owasin tem yapi kta ; qa niye anpetu owasin niciyuśepi, qa nicaśujapi ece yaun kta.

34. Qa wowanyake niiśta on wandake cin on nihnaśkinyan kta.

35 Unkan Jehowa hupahu akan, qa iśkahu akan nipo śica wan, okiziyepica śni on anipe kta, nisiha etanhan nipesdete aiyahdeya. 


\section{WICOWOYAKE 28.}

36 Unkan Jehowa niye, qa wicaśta yatapi niwankam nicicage kte cin oyate tokeca wan ekta ye niyanpi kta, he sdonyaye śni, qa nihunkakepi sdonyapi śni, qa hen taku wakan tokeca, can qa inyan ohowicayada kta.

37 Qa oyate tona ekta Jehowa yeniyanpi owasin woyuśinyeye, qa wiyacinpi, qa oweśtepi niyuhapi kta.

38 Wojupi ota nitamaga ekta ade kta, tuka tonana mnayaye kta; psipsicadan temyapi kta nakaś.

39 Hastanhanka huyahde, qa yakicanye kta ; tuka miniśa datke kte śni, qa duśpi kte śni ; wamdudan yutapi kta nakaś.

40 Wihdi can makoce nitawa owancaya yuke kta, tuka wihdi on sdaniçiye kte śni ; wihdi waskuyeca śtonkadan ilipaye kta nakaś.

41 Cinca wica winyan ko yakage kta, tuka nici unpi kte śni; wayaka awicayapi kta nakaś.

42 Can nitawa owasin, qa maga nitawa taku aicage cin psipsicadan icupi kta.

43 Tuwe tokeca niyepi ehna ounye cin ohiniyan niwankam sanpa, qa sanpa wankan ye kta, qa niye apamahdedan kuya qa kuya idade kta.

44. Tye oniçu kta, tuka oyaqu $k$ te śni. Iye pa kin heca kta, qa niye sinte henica kta.

$45 \mathrm{Qa}$ Jehowa Wakan yada ho kin nayahon śni, qa tawoahope, qa tokage ope niśi oyape śni, heon woyaśice kin dena owasin nipasipi, qa en niupi, qa nicihdegapi kta, ihang niyanpi kte cin hehanyan.

46 Qa niye en, qa tona niye etanhan icagapi kte cin en, hena wowapetokeca, qa wowanyake unpi kta, owihanke wanica.
47 Taku iyuhpa ota niçu kin on Jehowa Wakan yada kin wiyuśkinyan, qa eante waśte on oyakiye śni, heon,

48 Toka niyanpi niye en Jeho. wa ye wicaśi kin wowidag niye kta, wotektayahda en, qa taku iyulipa inicakija en, Mazasapa tawanapin nitahu ikoyag niye kta, ecen ihang niyanpi kta.

49 Qa Jehowa oyate wan tehantanhan maka ihanke etanhan ananitan wicaye kta, wanmdi kinyan iyececa, oyate wan iapi kin nahon oyakihi kte śni.

50 Oyate ite sutapi, wicahinca ite ihaktapi kte śni, qa tona aśkatupidan onśiwicadapi kte śni.

51 Qa wanunyanpi nitawa cincapi kin, qa maga nitawa taku aicage cin tem yapi kta, ecen ihang niyanpi kta; qa aguyapi su, miniśa, qa wihdi onicaptapi kte śni, nakun pte nitawa, qa tahinca wiyedan nitawa cinca kin, ecen awihunni niyanpi kta.

52 Qa makoce owancaya, otonwe nitawa owasin ohna onanitakapi kta, ecen conkaśke nitawa tehanwankan, qa suta, wacinyaye kte cin hena owasin hinhpayapi kta. Jehowa Wakan yada makoce nicu kin owancaya, otonwe nitawa owasin ohna onanitakapi kta.

53 Qa onanitakapi en, qa iyoniciśice cin, toka niyanpi iyokiśin niyanpi kin en, tamni nitawa taku oicage cin, nicinca wica winyan koya Jehowa Wakan yada nicu cehpipi kin yate kta.

54 Q̇a wicaśta wahiba, qa wiyuśkinyan, nina wota qon niyepi ehna iśta kin hduśice kta, sunkaku ekta, qa tawicu itpi ohna wanke cin ekta, qa iye cinca nahahin nipi ekta ;

55 Hecen otonwe nitawa owaśin ohna toka niyanpi onanita- 


\section{WOOPE ITAKIHNA,}

kapi, qa iyokiśin niyanpi en takudan, ihe śni on, iyokiśice cin en iye cinca cehpi hdute cin hetanhan unmanna onśpadan qu kte śni.

56 Niyepi ehna winohinca wahba, qa tancan wankadan tanyehin un qon, wankadan on siha makahde ute śni qon, he iśta kin hduśice kta, itpi hihnaku kin en, qa iye cinhintku qa cunwintku kin en ;

57 Qa otonwe nitawa ohna toka niyanpi iyokiśin niyanpi onanitakapi, qa iyokiśin niyanpi kin en taku iyuhpa icakije kin on, cinca nakaha tonpi iye siha otahedan etanhan hiyu kin, qa cinca wicaton qon hena nahmana hdute kta.

58 Wowitan qa wowinihan caje kin de Jehowa Wakan yada kin koyakipe kta, qa wowapi kin de woope wicoie owapi owasin ecanon kta waktaya yaun śni kinhan.

59 Wokaśtake tanka, qa wowinihan on anipe kta, qa nicinca awicape kta, wowayazan śica, qa suta on.

60 Qa Egupton wośihtin ikoyape ciqon owasin niye en ahinlipa ye kta, qa hena ikoyag niye kta.

61 Nakun wowayazan owasin, qa wokaśtake woope kin de wowapi en owapi śni owasin, Jehowa niye akan ehnake kta, ecen ihang niyanpi kta.

62 Qa wicota linca yaunpi qon mahpiya wicanhipi iyenakeca heekiya Jehowa Wakan yada ho kin nayahon śni, heon wicaśta tonana onicaptapi kta.

63 Unkan token tanyan ecanicon kta, qa niyuota kta e Jehowa iyuśkin qon, he iyecen awihnuni niye kta, qa ihang niye kta e Jehowa iyuśkin kta; qa makoce tawa yaye kta e ekta idade cin he etanhan nicahintapi kta.

64 Qa Jehowa oyate owasin ehna enanakiya iyaye niyanpi kta, maka anog ihanke ekta, qa heciya taku wakan tokeca can qa inyan ohoyada kta, hena sdon wicayaye śni, qa nihunkake nakun.

65 Qa ikce wicaśta kin hena ehna owanji nanke kte śni, qa nisiha on iyozi wanice kta, qa heciya cante cancan, qa iśta sota, qa nagi skan niyanpi kta.

$66 \mathrm{Qa}$ wiconi nitawa nitokam kaozeze un lita, qa hanyetu anpetu koya wakoyakipe kta, qa wiconi nitawa wacin yaye kte śni.

67 Nicante wokokipe ikoyape cin on, qa niiśta wowanyake wandake cin on hahanna eca, Tokin htayetu kten, ehe kta, qa htayetu eca, Tokin hahanna kten, ehe kta.

68 Qa Jehowa wita wata ohna Egupta elrta hde niye kta, ocanku kin he icimana wandake kte śni, eciciya, qa hen wiyope niyanpi kta ; toka niyanpi kin, hokśipidan on qa wicinyanpidan on wowidag niyanpi kta, qa ecen tuwedan ope niton kte śni.

\section{WICOWOYAKE 29.}

1 Horeb en Jehowa wicotakuye wan Israel cinca om kage cin ohakam, Moab makoce ohna wicotakuye hena om Mowis kah śi kin wicoie kin dena ee.

2 Unkan Mowis Israel owasin wicakico, qa hewicakiya, Taku Jehowa Egupta makoce ohna niiśtapi itokam Paro, qa tamakoce ocowasin, qa taokiye owasin ecawicakicon owasin wandakapi.

3 Wowiyutanyan tanka kin

46 


\section{WICOWOYAKE 29.}

niiśta wanyaka, wowapetokeca kin, qa wicohan tanka kin hena.

4 'Tuka cante sdonye kta, qa iśta wanyake kta, qa noge nahon kta e anpetu kin de nahahin Jehowa nicupi śni.

5 Waniyetu wikcemna topa hewoskan mani ciyapi, nitancanpi etanhan wokoyake nitawapi sote śni, qa hanpa nitawa nisiha etanhan napote śni.

6 Jehowa Wakan yada kin he miye sdon yaye kta, heon aguyapi yatapi śni, qa miniśa, qa mini wakan datkanpi śni.

7 Oyanke kin den yahipi, unkan Silion Ḣesbon wicaśta yatapi, qa Og Baśan wicaśta yatapi itkounkipapi kta, qa unkizapi kta e inanpapi; unkan wicunkaśtakapi.

$8 \mathrm{Qa}$ makoce tawapi unkicupi, Rubeni, qa Gadi, qa Manase wi coun hanke he tawayapi kta e wicunqupi.

9 Heon wicotakuye kin de oie kin patanpi qa ecen econpo; hecen taku ecanonpi kta owasin idukcanpi kta.

10 Niyepi owasin nakaha Jehowa Wäkan yadapi itokam nayajimpi, wicoun nitawapi itancanpi, qa hunkayapi, qa wowapi kagapi kin ; Israel wicaśta owasin ;

11 Śiceca nitawapi, qa nitawin. pi, qa tuwe tokeca tonwanyayapi en un, tuwe cande qa mini tokśu aiyahdeya.

12 Jehowa Wakan yada wicotakuye kin en yaipi kta, qa tawokonze Jehowa Wakan yada nakaha nicicagapi en.

13 Heon taoyate henicapi kta e, qa iye wakan yadapi kta e nakaha enihde, eniciye cin iyecen, qa nihunkakepi Abereham, qa Izak, qa Jakob konza ewicakiye cin iyecen,

14 Qa wicotakuye kin de, qa wokonze kin de niyepi niśnanapidan om wakage śni.

15 Tuka tona nakaha Jehowa Wakan undapi itokam najinpi owasin om, qa nakun tona nakaha unkiyepi om un śni.

16 Token Egupta makoce en unyakonpi sdon yayapi, qa nakun oyate ehna unkupi kin token hena iyoopta unkupi.

17 Qa wowahte śni tawapi, qa toaśapapi wandakapi, can qa inyan mazaska, qa mazaskasi ohodapi kin.

18 Okini niyepi ehna wicaśta, qaiś winohinca, qaiś wicowazi, qaiś wicoun wan yukan, qa cante kin Jehowa Wakan undapi etanhan nakaha ihduhomni, qa ikcewicaśta kin hena taku wakandapi kin ekta ye ça ohowicada, okini niyepi ehna hutkan wan etanhan pijihuta śica, qa pejihota icage kta.

19 Qa woyaśice kin de oie kin nahon kinhan, cante kin ohna ihdawaśte kta, qa heye kta ; Micante ihdusuta en mawani, qa imnahan mdatke cin on imapuza anamicipte kta eśta, tanyan waun kta.

20 Jehowa wicaśta kin he kicicajuju kta tawaten ye kte śni ; tuka wicaśta kin he en Jehowa tocanniye kin, qa towinawizi kin ideye kta, qa woyaśice wowapi kin de en owapi ocowasin he akan yanke kta, qa caje kin mahpiya ihukuya tanhan Jehowa pajuju kta.

21 Qa Jehowa taku śica on Israel wicoun owasin etanhan he yukinukan kta, wicotakuye woope wowapi de en owapi woyaśice owasin iyecen.

22 Unkan nicincapi niyepi iyohakam yukanpi kta, wicoicage haka kta, qa wicaśta tokeca makoce itehan tanhan upi, qa ma- 


\section{WOOPE ITAKIHNA,}

koce kin he wokaśtake kin, qa wowayazan on Jehowa he kaśtake cin wanyakapi kta, qa heyapi kta ;

23 Maka kin owancaya inyanzi, qa miniskuya, gugu he wojupi śni, qa camni uye śni, qa wato takudan aicage śni, Sodom qa Gomora, Adma qa Tzeboim Jehowa tocanniye, qa tośihda en wicakaśtake cin qon, he iyecen kaśtakapi.

$24 \mathrm{Qa}$ Ikcewicaśta owasin heyapi kta; Tokeca Jehowa makoce kin de hecen ecakicon he? Wocanniye tanka kin de token nina itkon he?

25 Unkan ayuptapi, qa heyapi kta, Jehowa hunkake wicayapi Wakan dapi wicotakuye wicakicaga, Egupta malkoce etanhan hdinanpe wicaye ciqon he ehan wicakicage cin he ayuśtanpi heon etanhan.

26 Qa taku wakan tokeca ekta ipi, qa ohodapi, qa hena itokam patujapi, taku wakan kin hena sdon wicayapi śni, qa wicakicipamni śni.

27 Heon Jehowa tocanniye kin makoce kin he aitkon, qa woyasice wowapi kin de en owapi owasin akan hiyuya.

28 Jehowa wocanniye en, qa wocanteptanyan en qa wośihda tanka en maka kin etanhan wicayujun, qa makoce tokeca ekta ye wicaya, nakaha iyececa.

29 Taku nahmanpi kin he Jehowa Wakan undapi kin he tawa tuka taku yuzamnipi kin he unkitawapi, qa unkicincapi tawapi, owihanke wanica woope kin de oie owasin ecen econkupi kta heon etanhan.

WICOWOYAKE 30.

1 Unkan kaketu kta, wicoie kin dena owasin, woyawaśte qa woyaśice nitokam ewahde nihiyohipi kinhan, qa ikcewicaśta ekta Jehowa Wakan yadapi nape niyanpi kin owasin wicehna, hena akan nicante ahdi yaye cinhan.

$2 \mathrm{Qa}$ Jehowa Wakan yada kin en yahdi, qa ho kin anayagoptan, taku nakaha eciciye cin owasin iyecen, niye qa nicinca nicante ocowasin on, qa ninagi on hecanon kinhan,

3 Jehowa Wakan yada kin wayaka yaunpi kin hdi niyanpi kta, qa onśinidapi kta, qa oyate owasin ekta Jehowa Wakan yada enanakiya iyaye niyanpi qon etanhan ake niyawaśtepi kta.

4 Mahpiya ihanketa ekta nape niyanpi eśta, hetanhan Jehowa Wakan yada inicu kta, qa mniciye niye kta.

5 Qa Jehowa Wakan yada kin makoce nihunkakepi tawa yapi qon he ekta hiyu niyanpi kta, unkan tawa yayapi kta; unkan tanyan ecanionpi kta, qa nihunkakepi sam iyeya niyuotapi kta.

6 Qa Jehowa Wakan yada nicante kin banicihdaye kta, qa nicinca cante kin nakun, hecen nicante ocowasin on, qa ninagi ocowasin on Jehowa Wakan yada kin waśte yadake kta, wiconi nitawa hee nakaś.

7 Unkan Jehowa Wakan yada kin woyaśice kin dena owasin toka niyanpi akan, qa tona śicenidapi, qa śicaya nicuwapi akan awicahnake kta.

8 Hecen niye yahdi, qa Jehowa ho kin nayahon, qa tawoahope nakaha ope ciśi kin owasin ecanon kinhan;

9 Jehowa Wakan yada kin taku ninape econ kin owasin en niciyuota kta, nitamni taku icahye cin en, qa nitawanunyanpi taku icali yapi en, qa tanyan ecani- 
con kta, Jehowa nihunkakepi on iyuśkin qon, iyecen, ake taku niciwaśte kin en iniyuśkin kta. nakaś.

10 Tohan Jehowa Wakan yada ho kin nayation, qa tawoahope, qa tokage, woope kin de wowapi en owapi kin hena yapatan, qa ni cante ocowasin on, qa ninagi ocowasin on, Jehowa Wakan yada en yahdi kinhan;

11 Woahope kin de nakaha ope ciśi kin inanicihmapi śni qa initehan śni ;

12 Mahpiya en un sni. hen un unkanś, 'Tuwe unkiyepi on malipiya kin adi $k t a$, qa hetanhan unkicicupi kta he? kinhan naunhonpi kta, qa ecen econkupi kta, ehe kta naceca.

13 Qa miniowanca akasanpa un śni. He akasanpa yanka unkanś, Tuwe unkiyepi on miniowanca akasanpa ye kta, qa unkicicupi kta he? hecen naunhionpi kta, qa ecen econkupi kta, ehe kta naceca.

14 Tuka wicoie kin ecen ecanon kta e nikiyedan linca nii kin ohna, qa nicante kin ohna.

15 Wanyaka wo, nakaha, wiconi qa taku waśte ecicihnaka, nakun wiconte qa taku śica.

16 Token nakaha econ ciśi, Jehowa Wakan yada kin waśte yadake ca tacanku omayani, qa tawoahope, tokage, qa tawoyaco yapatan kinhan yani kta; unkan Jehowa Wakan yada kin makoce tawa yaye kta e ekta de cin en niyuota kta, qa niyawaśte kta.

17 Tuka nicante kin ihduhomni, qa wanayahon śni, qa nihnayanpi, qa taku wakan tokeca ohoyada, qa óyakiye cinhan,

18 Nakaha hecen eciciyapi. Awicakehan ihang niyanpi kta, maka tawa yaye kta e Jordan iduwege ca ekta yai kta, he akan anpetu yahduota kte śni.

19 Wiconi qa wiconte, woyawaśte qa woyaśice nitokam ewahde, niyepi on, Mahpiya qa maka namalionpi kta nakaha epa. Heon wiconi kahniga wo, hecen yani kta, niye qa nicinca nakun.

20 Hecen Jehowa Wakan yada kin waśte yadake $\mathrm{kta}$, ho kin nayation kta, qa he ekta ikoyag niciye kta, on yani kin hee nakaeś; qa Jehowa makoce nihun. kakepi Abereham Izak qa Jakob wicaqu kta, konza ewicakiya, he akan anpetu ota ounyaye kta.

\section{WICOWOYAKE 31.}

1 Unkan Mowis ekta i qa wicoie kin de Israel owasin owicakiyaka.

$2 \mathrm{Qa}$ hewicakiya, Matonpi ehantanhan anpetu kin de wanitu opawinge sanpa wikcemna nonpa. Tankan inawapa, qa en wahihbu wanna owakihi śni ; nakun, Jordan wakpa kin de akasanpa de kte śni, Jehowa emakiya.

3 Jehowa Wakan yada kin iye nitokam akasanpa ye kta, iye nitokam ikcewicaśta kin hena ihang wicaye kta, qa tawa wicayaye kta, Jośuwa iye nitokam. akasanpa ye kta, Jehowa eye cin iye cen.

4 Unkan token Jehowa Sihon, qa Og Amori wicastayatapi ihang wicaya, qa makoce tawapi kin nakun, he iyecen hena ecawicakicon kta.

5 Qa Jehowa niyepi itokam hena ewicahde kta, hecen woahope nakaha econ ciśipi owasin iyecen ecawicayeconpi kta.

6 Waditakapo, qa waśakapo. Ihnuhan bena kowicayakipapi, qa niyuśinyayapi. Jehowa Wa49 


\section{WOOPE ITAKIHNA,}

kan yada kin hee, nici ye kta; aniyuśtan kte śni, qa elipe niye kte śni.

7 Unkan Mowis Jośuwa kico, qa Israel owasin wanyakapi heciya, Waditaka, qa wakiśaka wo; niye oyate kin de makoce wan Jehowa hunkake wicayapi wicaqu kta konza ewicakiya, he ekta awicade kta, qa niye he tawa yapi kta e yakage kta.

8 Qa Jehowa iye nitokam ye kta, iye niciun kta; aniyuśtan kte śni, qa elipe niye kte śni. Ihnuhan kopeyahda kin qa niyuśinyaye cin.

9 Unkan Mowis woope kin de owa, qa he wawayuśnapi Lewi kin, Jehowa wicotakuye can wohnaka yuhapi kin hena wicaqu, qa nakun Israel hunkayapi owasin.

$10 \mathrm{Qa}$ Mowis wahokonwicakiye ça hewicakiya, Waniyetu śakowin ihanketa, woyuśka waniyetu ohanzi hdepi wohanpi iyehantu hehan.

11 Israel owasin Jehowa Wakan yada oyanke kahnige kte cin ekta, itokam ihdutaninpi kta e hipi kinhan, Israel owasin nahonpi wicitokam woope kin de dawa kta.

12 Oyate mniciye wicakiya wo, wicaśta, qa winohinca, qa śiceca, qa oyate tokeca otonwe nitawa en unpi, hecen nahonpi kta, qa Jehowa Wakan yadapi kokipapi kta e onspepi kta, qa woope kin de oie kin owasin ecen econpi kta e onspepi kta.

13 Hecen cincapi takudan sdon yapi śni nahonpi kta, qa makoce wan ekta yaipi kta e Jordan iduwegapi kin he akan tohanyan yaunpi kta, anpetu owasin Jehowa Wakan yadapi kokipapi kta e onspepi kta.

14 Unkan Jehowa Mowis heci- ya, Ito anpetu en nite k ta wanna ikiyedan, Jośuwa kico, qa itkokipapi wakeya en najinpo, hecen wahokon wakiye kta. Unkan Mowis Jośuwa kici ekta ipi, qa itkokipapi wakeya en najinpi.

15 Unkan Jehowa itkokipapi wakeya en ihdutanin, malipiya bosdata ohna; unkan malipiya bosdata kin he wakeya tiyopa kin akan han.

16 Unkan Jehowa Mowis heciya, Ito nihunkake om niśtinbe kte; unkan oyate kin de najinpi kta, qa makoce ekta yapi ohna wicaśta tokeca taku wakan dapi om wiinahmapi kta; hecen amayuśtanpi kta, qa wicotakuye mitawa wicawecage yuksapi kta.

17 Unkan anpetu kin he en mitocanniye awicaide $\mathrm{kta}$, qa awicamduśtan kta, qa miite kin inawicawakiliman kta; hecen yason unpi kta; qa wokakije, qa wośice ota akipapi kta, qa anpetu kin he en heyapi kta, Unkiyepi ehna taku wakan wanice naceca, heon wośice kin dena unkakipapi.

18 Unkan miś anpetu kin he en miite kin ocowasin inawakihman kta, taku śica econpi owasin on, taku wakan tokeca ekta ihduhomnipi nakaś.

19 Heon odowan kin de niyepi on owapo, qa Israel cinca kin onspe wicakiyapo, hena ipi kin en he ejupo, hecen odowan kin de wayaatanin mduhe $\mathrm{kta}$, Israel cinca kin en.

20 Makoce wan pte asanpi qa wihdi on kaduze cin, hunkake wicayapi konza wahowicawakiya qon, he ekta awicamda; unkan tohan wotapi, qa imnapi, qa cepapi kinhan, taku wakan tokeca ekta ihduhomnipi kta, qa ohowicadapi kta, qa imahahapi kta, qa wicotakuye mitawa yuksapi lita. 


\section{WICOWOYAKE 32.}

21 Unkan kaketu kta, wokakije qa woiyokiśice ota akipapi kinhan, odowan kin de wayaatanin awicayatanin kta, cincapi ipi etanhan he akitkonjapi kte śni, nakaś. Miś nahaulhin makoce konza caje mdate cin ekta awicamde śni, token nakaha awacinpi kin sdonwaya.

22. Unkan anpetu kin he en Mowis odowan kin de owa, qa Israel cinca onspewicakiya.

23 Qa Jośuwa Nun cinhintku wahokon kiye ca heya, Waditaka, qa waśaka wo; Niye Israel makoce konza wahowicawaya ekta awicade kta nakaś, qa miś nici waun .kta.

24 Unkan Mowis woope kin de oie kin wowapi wan en kaga, ocowasin yuśtan qehan,

25 Mowis Lewi kin Jehowa otakuye can wohnaka yuhapi kin wahokonwicakiye ca heya.

26 Woope kin de wowapi kin icupo, qa Jehowa Wakan yadapi otakuye can wohnaka icahda ehnakapo; hecen niyepi en wayaatanin hen yanke kta.

27 Miye ayakinicapi kin sdonwaya, nakun nitahu patin. Inyun nakaha nahanhin niyepi om wani Jehowa en yakipajinpi, mate cin iyohakam awicakehan sanpa hecece kta.

28 Miye ekta nitawicoun hunkayapi owasin, qa wowapi kagapi nitawapi mniciye wicayapo, qa nogepi en wicoie kin dena epe kta, qa mahpiya qa maka kin hena nahonpo, epe kta.

29 Mate cin iyohakam nihdutakunipi kte śni sdonwaya, qa canku ope ciśipi etanhan nihduhomnipi kta; qa anpetu ehake kin en taku śica ayakipapi kta, taku Jehowa iśta kin en śice cin ecanonpi kta; qa taku ninape econpi kin on śihdayayapi kta.

30 Unkan Mowis odowan kin de oie kin owasinhin Israel omniciye ocowasin nogepi en oya$\mathrm{ka}$.

\section{WICOWOYAKE 32.}

1 Mahpiya anagoptanpo, hecen iwae kta; Qa maka mii oie kin nahon wo.

2 Woonspe mitawa magaju iyecen hinhe kta, Mioie kin cu kin iyecen kaduze kta; Wato akan magaju kin iyececa kta, Magajuju peji akan iyecece kta.

3 Jehowa caje kin eyanwapaha kta, Taku Wakan undapi kin yatankapo.

4 Wakage cin hee, taku econ kin ecetu; Tolian kin owasin woyaco, Taku wakan wicaka wohnaye wanica; Iśnana ohan owotanna qa ecetu.

5 Ihduśapapi, iye cinca hecapi śni, śapapi ce ; Wicoicage pemni qa śkopa.

6 Jehowa decen ecayeconpi kta he? Oyate witkotko, qa ksape śni ?

Niyate qa tuwe openiciton hee śni he? Iye nicage ca niyusuta.

7 Anpetu wanakaja kiksuya wo; 


\section{WOOPE ITAKIHNA,}

Wicoicage otoiyohi taomaka awacin wo.

Niyate iwanga wo, kinhan niciyaotanin kta,

Hunkayapi nitawa, unkan eniciyapi kta.

8 Otancanke oyate maka wicálicipamni, Adam cinca enanakiya iyaye wicaye cehan;

Israel cinca iyenakecapi kin iyecen, Oyate kin makoce iwicakicago.

9 Jehowa taku tawaye cin taoyate kin hee; Qa maga yuhe cin Jakob hee.

10 Hewoskan makoce wan en iyewicaya.

Makoskan takudan ohnaka śni, śicahowayapi ohna. Aconkaśke wicaya; onspewicakiya ;

Iśtasu tawa kin iyecen awanwicayaka.

11 Token wanmdi wan hohipi kin coskiya.

Qa cinca kin aman;

Hupahu kamdage ca iwicacu ;

Taśun akan wicahduha.

12 He iyecen Jehowa isnana nape yus awicaya.

Qa taku wakan tokeca owicape śni.

13 Maka paha akan iyotang wicaya;

Hecen maga waskuyeca kin yutapi ;

Qa canlıanpi tiktica imnija etanhan yazokapi;

Qa wihdi inyan suta hinca etanhan.

14 Pte asanpi nini, qa tahinca asanpi kin,

Qa waśin tacincadan etanhan;

Nakun tamdoka Baśan en icagapi etanhan, qa tatokadan etanhan ;

Aguyapi mdu iyotan waśte linca kici,

Qa hastanhanka we miniśa datkan.

15 Unkan ecetudapi kin cepa ayapi, qa nalitakapi.

Nicepapi, waśin niśokapi ;

Qa taku Wakan icahwicaye cin he ihaktapi śni;

Qa imnija niwicaye cin taku dapi śni.

16 Taku tokeca wakan dapi on inawizi yapi,

Taku wahteśni on śihdayapi.

17 Wanagi wakan śni wakiciyuśnapi,

Taku wakan sdonyapi śni qon,

Taku wakan teca aśkatudan en upi,

Hunkakepi hena sdonwicayapi śni.

18 Imnija icaliniye cin he elpeyaya,

Qa Taku Wakan nicage cin ay ektonja.

19 Unkan Jehowa wanyake ça waliteda śni,

Iye cinca wica winyan koya śibdayapi nakaś.

20 Qa heya, Miite inawicawakilibe kta.

Token ihunnipi kta wanmdake kta;

Wicoicage pemni hecapi nakaś.

Cinca wowicake nicapi.

21 Iyepi taku wakan śni on winawizi mayanpi.

Tawakagapi on śihda mayanpi. 


\section{WICOWOYAKE 32.}

Heon miś oyate heca śni on winawizi wicawaye kta, Ikcewicaśta witkotkoka on śinhda wicawaye kta.

22 Mitocanniye on peta wan ideya;

Hades temahentu ekta itkon kta;

Maka kin taku aicage cin ko yasote kta;

He taku ahanpi kin liuhinaliye kta.

23 Wiciwankam taku śica mnawaye kta.

Hena en wahinkpe mitawa bowakisote kta.

24 Wicaakihan on yasotapi kta,

Qa makośice on temyapi kta,

Qa woihangye tehika on.

Qa wicayahitake kta e wamanica hipi kin en yewaye kta,

Nakun watuśekśeca osdohanpi tagepi kin.

25 Tankan canhipi kin wicakte kta,

Timahen woyuśinyaye cin,

Kośka kahnigapi, wikośka koya ;

Hokśiyoqopa waazin, wicahinca pa ska kici.

26 Wicawakaśpe kta, epa,

Wicaśta ehna tanhan kiksuyapi kin ihangwaye kta.

27 Tuka tokayapi tocanniye on itonwapa,

Okini tona wicakiyuśepi okahnigapi kte śni,

Okini heyapi kta, Unnapepi wankantuya ;

Taku kin de owasin Jehowa econ śni.

28 Oyate wokcan nicapi nakaś,

Hena ohna wookahnige wanica.

29 Tokin ksapapin, taku kin de awacinpin,

Owihanketa token unpi kta awacinpi unkanś;

30 Hehan wanjidan kektopawinge pasi kta,

Qa nonpa kektopawinge wikcemna hamyapi kta tuka;

Imnija tawapi wiyope wicaye śni unkanś ;

Qa Jehowa awicayuśtan śni unkanś.

31 Imnija tawapi Imnija unkitawapi kin iyececa śni nakaś.

Qa toka unyanpi kin he iyukcanpi.

32 Hastanhanka iyuwi tawapi kin Sodom iyuwi kin iyececa,

Qa Gomora tamaga etanhan,

Hastanhanka, icaliyapi kin pizi hastanhanka heca ;

Qa iyage yuhapi kin pahinica.

33 Miniśa tawapi wamduśka tage kin heca;

Sintelida tage śica tehika hinca.

34 De mici kihnakapi śni he?

- Wowapi opiye mitawa en ipuspapi.

35 Tokiçonpi kin he mitawa, wokajuju nakun.

Tohan sihapi naśdute cinhan,

Anpetu en atakunipi kte śni kin he wanna ikiyedan.

Qa taku wiyeya wicakicagapi kin ecadan hi kta.

36 Jehowa iye taoyate kin wicayaco kta nakaś; 


\section{WOOPE ITAKIHNA,}

Qa taokiye on iyope iciye kta ;

Tohan napepi waśake śni unpi wanyake cinhan;

Nakun natakapi qa okaptapi wanica.

37 Qa heye kta, Taku wakan dapi qon tukteepi he?

Imnija wacinyanpi qon?

38 Hena wopida wośnapi śin kin yutapi qon ;

Qa miniśa kaśtanpi kin yatkanpi qon;

Hena najinpi qa óniciyapi nunwe.

Wowinape nicupi nunwe.

39 Wanyakapo miye miśnana hemaca;

Qa taku wakan iyemaceca wanica.

Miś watewaya qa waniwaya,

Kiunniwaya qa okizi waye kta.

Qa tuwedan minape etanhan ehdaku okihi śni.

40 Wanna ninape mahpiya ekta kiya ye wakiya,

Qa hepa, Owihanke wanin wani ;

41 Kinhan wakanhdi isan wahdube kta.

Qa minape wayaco yuze kta.

Toka manyanpi wotokicon wicawecu kta;

Qa tona śice madakapi kin hdajuju wica waye kta.

42 Wahinkpe mitawa we on witko wakiye kta.

Qa isan mitawa wicacehpi yute kta;

Wicaopi qa wayaka unpi etanhan.

Toka itancarpi pa tawapi kin on.

43 Ikce wicaśta taoyate kin om idowanpo.

Iye taokiye wepi kin he tokicon kta;

Toka wicayapi kin wotokiçon wicakicu kta;

Taoyate tamakocepi kin akahpe kiciye kta.

44 Unkan Mowis ekta hi, qa odowan kin de oie kin owasin oyate nogepi en ia, iye, qa Nun cinhintku Jośuwa.

45 Unkan Mowis Israel owasin wicoie kin hena owasin ewicakiye cehan,

46 Hewicakiya, Wicoie nakaha ciciyataninpi kin owasin ekta nicantepi kin yekiyapo, Hecen woope kin de oie kin owasin nicincapi patan qa econ wicayaśipi kta.

47 Wicoie kin de on yanipi kta nakaś; heon ihnuhan he takuśni yadapi, qa wicoie kin de on anpetu niciyuotapi kta, maka ekta yaipi kta e Jordan iduwegapi kin he akan.

48 Unkan anpetu kin he en Jehowa ie ca Mowis heciya,
49 Abarim he kin de, Nebo paha kin, Moab makoce ohna yanke cin, Jeriho iyotakons he itanwankanhde adi wo, qa Kanan makoce Israel cinca icupi kta e wicawaqu kin he wanyaka wo.

50 Qa he ayadi kte cin he akan nite kta, qa oyate nitawa ekta okipe niyanpi kta, Nicinye Aaron Hor he akan te ca taoyate ekta okipe yapi qon he iyecen.

51 Wamiyecilitanipi Israel cinca ehna, Meriba Qades (Kigepi Wakan) mini ekta, Tzin hewoskan ohna, qa Israel cinca ehna mayadawakanpi śni.

52 Heon nitokam makoce kin wandake kta, tuka makoce wan Israel cinca kin wicawaqu kin heciya yai kte śni. 


\section{WI COWOYAKE 33.}

WICOWOYAKE 33.

1 Unkan Mowis Wakantankal waśte kin dee.

2 Unkan heya,

Jehowa Sina etanhan u, qa Sehir etanhan awicahinanpe ;

Qa Paran he kin etanhan iyega;

Qa taokiye wakan oyawa tanka etanhan;

Iye etapa tawa etanhan peta woope wan en wicahi.

3 Nakun oyate cante wicakiya;

Wicaśta wakan tawa owasin nape ohna wicahduha;

Qa siha ekta wankapi,

Otoiyohi nioie icu kta.

4 Mowis woope wan onspe unkiyapi, Jakob omniciye taku tawayapi kte cin hee.

5 He Jeśurun (Hicetudanpi) en wicaśtayatapi,

Israel wicoun, oyate itancanpi kin yuwitayapi hiyeyapi qehan.

6 Ruben ni kta, qa țe kte śni,

Qa wicaśta tawa tonana kte śni nunwe.

7 Qa Juda on heya,

Jehowa Juda ho kin nalion qa taoyate kin elita hdicuya ye.

Iye on nape kin iyakicu ye kta, qa toka yapi etanhan iciya ye.

8 Qa Lewi on heya,

Wiyuśtan wicakiye nitawa qa iyoyam wicaye nitawa kin wicaśta wacantkiye nitawa yuhe kta.

He Masa (Iyutanyapi) ekta iyutan yaya,

Qa Meriba (Iyopeyapi) mini kin ekta iyope yaya.

9 Iye atkuku hunku ko on wanmdake śni eya,

Sunkaku iyekiye sni,

Qa iye cinca kin sdonwicaye śni ;

Tuka nioie yuhapi, qa wicotakuye nitawa patanpi.

10 Jakob woyaco nitawa onspe kiyapi kta;

Woizinye nipoge ekta yekiyapi kta,

Qa wohuhnahyapi wahna wośnapi nitawa akan.

11 Taku yuhe cin Jehowa yawaśte ye,

Qa taku iye nape kin econ iyuśkin kiya ye ;

Tona kipajinpi nitepi wicakiyuśuja,

Nakun tona śicedakapi, hecen ake najinpi kte śni.

12 Qa Benjamin on heya,

Tuwe Jehowa waśte dake cin he wakokipe śniyan iye ikiyedan ti kta.

Anpetu osan he akahpe kta, qa hiyete otahedan ounye kta.

$13 \mathrm{Qa}$ Josep on heya,

Makoce tawa Jehowa yawaśte nunwe, taku iyotan waśte on, 


\section{WOOPE ITAKIHNA,}

Mahpiya etanhan, cu etanhan, qa wośbe ihukuya wanke cin etanhan.

14 Nakun taku iyotan waśte anpetu wi icahye cin on, Qa taku iyotan waśte hanyetu wi inanpe ye cin on ;

15 Qa he wanakaja pajodan etanhan, Qa paha owihanke wanica etanhan taku iyotan waśte on.

16 Qa maka taojudan koya etanhan taku iyotan waśte on; Tuwe otehi ounye cin toiyokipi kin Josep paha akan, Qa-tuwe iye cincu etanhan yukinukanpi pesdete akan u nunwe.

17 'Tatanka tawa tokaheya tompi towitan kin hee, Hehe tawa tinta tatanka wan tahe kin iyececa, Hena on maka ihanke ekta oyate kin yuwitaya wicapatan kta;

Epraim oyawawa tanka qa Manase kektopawingege kin hena eepi.

18 Qa Zebulun on heya,

Zebulun inanpe yaye cin en iyuśkin wo;

Qa Issakar wakeya nitawa ohna.

19 He kin ekta oyate wicakicopi kta, Hen woowotanna wośnapi patapi kta ;

Taku wiyaka ohna nahmanpi,

Qa miniwanca toicewin kin yazokapi kta, nakaś.

20 Qa Gad on heya,

Tuwe Gad yutanka yawaśtepi nunwe,

Mnaja iyecen iwanke ca isto pa kici yahideca.

21 Makoce tokaheya kin he tawa ye kta, iwanyaka;

Woope kage cin taku yuhe kiya kin he aconkaślkayapi nakaś ;

Qa oyate itancanpi om hi,

Qa Jehowa toowotanna qa tawoyaco Israel om econ.

22 Qa Dan on heya.

Dan mnaja cinca wan heca,

Baśan etanhan ipsice kta.

23 Qa Naptali on heya,

Naptali wocantkiye on wipi, qa Jehowa toyawaśte ojudan ;

Mde kin qa wiyotanhan kin tawaya wo.

24 Qa Aśer on heya,

Aśer cinca on yawaśtepi kta,

Hunkawanjin wicaye cin iyokipi wicaye kta ;

Qa siha wihdi en oputkan kta.

25 Tiyopa inatake nitawa mazasapa qa mazaśa hecapi kta, Qa anpetu nitawa iyecen iyozi nitawa kta.

26 Jeśurun (Ecetudanpi) taku wakan yada kin tuwedan iyecece śni, he óniciye kta ;

Mahpiya akan iyotanke ça towitan tanka en mahpiya 56 śapa akan u ce, 


\section{WOOPE ITAKIHNA.}

27 Taku wakan otokahe wanica wowinape yaya,

Qa isto owihanke wanica nihukuya un ce.

Nitokapa tanhan tóka kin nape wicaye kta qa, Ihang wicaya wo eye kta.

28 Unkan Israel wikopeśniyan kinukankiya ounye kta;

Jakob iśta kin aguyapi su, qa miniśa makoce wan akan un kta;

Qa mahpiya tawa cu śbu kta.

29 Israel wowiyuśkin tanka duha;

Tukte oyate wan niye iyecen Jehowa niwicaya he?

Wahacanka akahpe niye qa,

'Lacanlipi wowitan nitawa kin hee.

Qa toka niyanpi nitokam iśtenya hecapi kta,

Qa oyanke pajodan tawapi amayani kta.

\section{WICUWOYAKE 34.}

1 Unkan Mowis Moab makomdaye etanhan, Nebo he kin, Pisga paha kin, Jeriho iyotakonza, itanwankanhde adi. Unkan Jehowa Gileyad makoce kin ocowasin, Dan aiyahdeya wanyag kiya.

2 Nakun Naptali tamakoce kin ocowasin, qa Epraim qa Manaśe tamakocepi kin, qa Juda tamakoce kin ocowasin, wiyolipeyata mde kin hehanyan;

3 Qa itokaga kin, qa omdaye Tamar can otonwe Jeritio kaksiza etanhan, 'Tzohar hehantu.

4 Unkan Jehowa heciya, Makoce Abereham, qa Izak, qa Jakob nicinca kin he wicawaqu kta konza ewicawakiye ciqon he dee; niista on he wanyag ciciya, tuka he ekta iduwege kte śni.

5 Unkan Jehowa taokiye Mowis hen ta; Moab makoce ohna Jehowa eye cin iyecen.

6 Unkan hen hnakapi Moab makoce kaksiza wan ohna, Bet Peyor (Peyor ti) iyotakonza, tuka ohna hnakapi anpetu kin de hehanyan wicaśta wanjidan sdonye śni.

7 Wanna Mowis waniyetu opawinge sanpa wikcemna nonpa hehan te ; iśta mdeza, qa-toolihi silitin śni.

8 Unkan Israel cinca anpetu wikcemna yamni Mowis aceyapi ; Moab makomdaye ohna; hehan Mowis on iyokiśicapi aceyapi anpetu kin henakecapi.

9 Unkan Jośuwa Nun cinhintku woksape woniya ojudan, Mowis nape kin atputaka nakaś; unkan Israel cinca lin he anagoptanpi, qa token Jehowa Mowis eciye cin iyecen econpi.

10 Unkan wicaśta wokcan Mowis iyecen Jehowa itkokim sdonya icimana najin śni.

11 Wowapetokeca, qa ohan wakan Jehowa Egupta makoce ohna Paro, qa taobe owasin ecawicakicon kta yeśi qon, owasin en iyecen.

12 Nakun nape waśake cin owasin iyecen, qa ohan tanka, qa woyuśinyaye Mowis Israel owasin iśtapi itokam econ kin iyecen. 
$\checkmark$ 


\section{JOŚUWA TAWOWAPI.}

\section{WICOWOYAKE 1.}

1 Unkan Jehowa taokiye Mowis te cin iyohakam, Jehowa ie ca Jośuwa Nun cinhintku, Mowis tawaśitku kin heciya,

2 Mitaokiye Mowis wanna te heon niye najin wo, wakpa kin de Jordan iyuwega wo; niye qa oyate kin de owasin, makoce wan miye Israel cinca kin wicawaqu kin he ekta.

3 Oyanke tona nisiha acankuye kte cin hena owasin ciçupi, Mowis ewakiye cin he iyecen,

4 ḦHopuze cin qa Lebanon he kin de etanhan, wakpa tanka kin ekta Yuperat wakpa kin hehanyan. Hiti tamakocepi kin ocowasin, mini owanca wi iyaye cin ektakiya, hehanyan makoce nitawapi kta.

5 Yani kin anpetu owasin, hehanyan wicaśta tuwedan nitkokim najin kte śni. Token Mowis kici waun qon he iyecen nici waun kta; tohinni aciyuśtan kte śni, qa ehipeciye kte śni.

6 Wakiśaka wo, qa miniheca wo; oyate kin de makoce wan wicawaqu kta, hunkake wicayapi kin konza ewicawakiye ciqon, he wicayakipamni kta nakaś.

T Tuka woope wan mitaokiye Mowis ope niśi kin ocowasin iyecen waktaya ecanon kta; Wakiśaka qa nina miniheca wo, Ihnuhan hetanhan nihduhomni kin, etapa ektakiya, qaiś catka ektakiya, hecen toki de cin owasin en tanyan iyahuni kta.

8 Woope kin de wowapi kin nii etanhan tokan iyaye kte śni, tuka he awacanni kta, anpetu qa hanyetu owasin; hecen taku he en owapi owasin waktaya ecanon kinhan, niolian owasin tanyan ihuniyakiye kta, qa yaksape kta. 9 Miye hecon ciśi śni he? wakiśaka qa miniheca wo. Ihnuhan niyuśinyaye cin, qa ihnuhan waknyakipe cin; toki de cin owancaya en Jehowa Wakanyada nici un nakaś.

10 Unkan Jośuwa oyate wowapi kagapi kin wahokon wicakiye ca hewicakiya;

11 Wicoti ehna manipo, qa oyate wahokon wicakiye ca hewicakiyapo, Tokata ampetu yamni, makoce tawayayapi kta e Jehowa Wakan yadapi niçupi kin he ekta yaipi kta, on Jordan wakpa kin de iduwegapi kta, heon waneya icicagapo.

12 Ưnkan Jośuwa ie ca Rubeni kin, qa Gadi kin, qa M̉anaśe wicoun hanke kin hewicakiya,

13 Mowis Jehowa taokiye wicoie econ niśipi, qa Jehowa Wakanyadapi makoce kin de niçupi, qa oziniyanpi eye cin he kiksuyapo.

14 Nitawinpi, qa śiceca nitawapi, qa wanunyanpi nitawapi makoce Mowis niçupi kin, Jordan itato en yakonpi kta, tuka niyepi tona waśakapi, qa waditakapi owasin wipekitonpi nihunkawanjinpi wicitokam idadapi, qa owicayakiyapi kta.

15 Jehowa Wakan yadapi nihunkawanjipi ozi wicayapi kte cin, niyepi iyecen, qa iś eya makoce Jehowa Wakanyadapi wicaqu kte cin, he tawa yapi kta 


\section{JOŚUWA TAWOWAPI,}

hehanyan; qa hehan yahdipi kta, makoce nitawapi ekta, Jordan itato, wihinanpe cin ektakiya, Mowis Jehowa taokiye niçupi kin he ekta, qa he tawayayapi kta.

16 Unkan ayuptapi, qa Jośuwa heciyapi, Taku econ unyaśipi kin owasin econkupi kta, qa toki ye unyaśipi kin he ekta unyanpi kta ;

17 Jehowa Wakan yada Mowis kici un qon, he iyecen nici un kinhan, token Mowis naunhonpi qon, he iyecen naunnihonpi kta.

18. Tuwe kaśta nii kin kipajin, qa nioie taku econ unyaśipi kin owasin nahon śni kinhan he te yapi kte; wakiśake ca miniheca wo.

\section{WICOWOYAKE 2.}

1 Wanna Jośuwa Nun cinhintku Śitim etanhan wicaśta nonpa tonweyapi kta, nahmana ye wicaśi, qa hewicakiya, Yapo, qa makoce qa Jeriho iwanyakapo. Unkan iyayapi, qa wihomni win wan ti kin en ipi, winohinca Rahab eciyapi, qa hen wankapi.

2 Unkan he Jeriho wicaśta yatapi okiyakapi qa, Inyun, hanyetu kin de Israel cinca etanhan, wicaśta makoce iwanyakapi kta e den hipi ce, eyapi.

3 Unkan Jeriho wicaśta ya tapi kin Rahab wahoya, qa heciya, Wicaśta niye ekta hipi, yati en ipi kin, tankan hiyu wicaya wo ; makoce owancaya iwanyakapi kta e hipi ce nakaś.

4 Tuka winohinca kin wicaśta nonpa qon iwicacu, qa nawicahma, qa heya, Hecetu wicaśta kin en mahipi ce, tuka tokiya tanhan upi kin sdonwaye śni ye.

5 Unkan otonwe tiyopa natakapi qehan, otpaza en wicaśta qon tankan iyayapi. Wicaśta kin toki iyayapi sdon waye śni ye. Inahniya owicadepe, hecen wicayehdegapi kta.

6 Tuka winohinca kin tipi tuwa akan adi wicaye ca tipi tawa akan, halionta on kagapi hu kin kihnake ciqon ohna nawicahma.

7 Unkan wicaśta kin owicadepi, canku Jordan iyahde ohna, oiyuwegapi ekta. Unkan wicaśta owicadepi kin iyayapi hehan otonwe tiyopa natakapi.

8 Unkan iśtimapi itokam, winohinca qon tipi tawa akan, ekta wicai ;

9 Qa wicaśta qon hewicakiya, Jehowa makoce kin de niçupi kin sdon waya ye; konicipapi kin he unkahinhpayapi ye, qa makoce ounyanpi kin owasin niyepi on skanpi nakaś.

10 Egupta etanhan yahdinanpapi qehan, token Jehowa Mdeśa mini kin oyahe ya, nakun token Amori wicaśta yatapi nonpa Jordan akotanhan yakonpi qon, Sihon, qa Og ecawicayeconpi, qa ocowasin ihang wicayayapi naunhonpi ye.

11 He naunhonpi heon uncantepi skan, qa yaupi on tuwedan toniya najin śni ye; Jehowa Wakan yadapi kin wankan Mahpiya en, qa nakun ihukuya maka akan Wakantanka ee nakaś.

12 Heon ceciciyapi wacantkiya ecaciconpi kin' he iyecen ate tiyohnaka wacantkiya ecawicayeconpi kta, Jehowa cajeyan konza kemakiyapi qa wowakta wacinyepica wan maqupe.

13 Hecen ate, qa ina, qa cincapi wica winyan koya, qa taku tawapi owasin niwicayayapi kta, qa urnagipi kin wiconte etanhan eundakupi kta ye.

14 Unkan wicaśta kin heciyapi. Unnagipi kin, nitawapi kin on 


\section{WICOWOYAKE 3.}

tapi kta, Unkohanpi kin de daotaninpi śni "kinhan, tohan Jehowa makoce kin de unqupi kinhan, wowacanthiya ecaunniconpi, qa wicaunkapi kta.

15 Unkan hahonta kahmupi wan on ojanjan hdepi ohna kun iyaye wicaya; iye ti kin otonwe conkaśke akan kagapi nakaś, qa otonwe conkaśke akan ounyan.

16 Qa hewicakiya, He ekta yape, okini onide iyayapi kin anicipapi kta, qa yamni can hen inahmanpe; onide iyayapi hdipi kin hehanyan, qa ohakam toki dapi kin ekta idadapi kta ye.

17 Unkan wicaśta qon heciyapi, Wokonze kin de on icicons unyakiyapi kin de etanhan unkihduśpapi kta;

18 Tho makoce kin en unhipi kinhan, ojanjanhdepi ohna kun hiyu unyayapi kin he en, halionta duta kin de iyayakaśke kta, qa niyate, qa nihun, qa nihunkawanji niyate tiyohnaka owasin tipi kin den niye ekta wicaduwitaye cinhan ;

19 Tuwe kaśta yati tiyopa etanhan inanpe cinhan iye we kin pa kici un kta, qa unkiye iyaonpe pica śni unyakonpi kta; tuka tona tipi ohna nici unpi kinhan, tuwe iyahpe wicaye cinhan, we tawapi unpapi akan yanke kta.

20 Nakun taku on unhipi kin de odake cinhan, wokonze on icicons unyakiyapi kin de etanhan unkihduśpapi kta.

21 Unkan, Token ehapi ecetu kta ye eye ca kihde wicaśi. Unkan iyayapi. Unkan hahonta duta kin ojanjan hdepi en iyakaśka.

22 Unkan iyayapi qa he ekta ipi, qa anpetu yamni hen yakonpi, owicadepi kin hena hdipi kin hehanyan. Unkan owicadepi kin canku owasin ohna awicakitapi, tuka iyewicayapi śni.

23 Unkan wicaśta nonpa qon kihdapi, he etanhan inaliniya apamahde kupi, qa iyuwegapi, qa Jośuwa Nun cinbintku kin en hdipi, qa taku akipapi owasin okiyakapi.

$24 \mathrm{Qa}$ Jośuwa heciyapi, Jehowa makoce kin ocowasin unnapepi en unqupi ce, qa makoce ounyanpi kin owasin unkiyepi on skanpi ce.

\section{WICOWOYAKE 3.}

1 Unkan Jośuwa hanhanna hin kikta, qa iye qa Israel cinca owasin Śsitim etanhan ihdakapi, qa Jordan ekta ipi, qa iyuwegapi kta itokam hen wankapi.

2 Unkan anpetu yamni hehan wowapi kagapi kin wicoti cokaya iyayapi ;

3 Qa oyate kin wahokon wicakiyapi, qa heyapi, Jehowa.Wakanyadapi wicotakuye can wohnaka tawa, qa wawayuśnapi Lewi kin lıe akiyuhapi wandakapi kinhan, niyepi dukanpi kin etanhan iyahdakapi, qa he ihakam idadapi kta.

4 Tuka he etanhan itehan dukanipi kta, wiciśpa kektopawinge nonpa iyutapi ece kin hehanyan, he ikiyedan idadapi kte śni, hecen canku ohna idadapi kta sdonyayapi kta. Hektam canku kin he ohna idadapi śni nakaś.

5 Unkan Jośuwa oyate kin hewicakiya, Ihduwakanpo, heyakecinhan Jehowa niyepi ehna woyuśinyaye wan econ kta.

6 Nakun Jośuwa ie ca wawayuśnapi hewicakiya, Wicotakuye can wohnaka kin akiyuhapi, qa oyate wicitokam iyayapo; unkan wicotakuye can wohnaka kin 


\section{JOŚUWA TAWOWAPI,}

akiyuhapi, qa oyate kin itokam iya yapi.

7 Unkan Jehowa Jośuwa heciya, Anpetu kin de tokaheya ciyutan $\mathrm{kta}$, Israel owasin iśtapi en, token Mowis kici waun qon, he iyecen niye kici waun kin he sdonyapi kta, heon etanhan.

8 Heon wawayuśnapi wicotakuye can wohnaka akiyuhapi kin wahokon wicakiye ca hewicakiya wo, Tohan Jordan mini tokaheya ekta yaipi kinhan Jordan en nayajinpi kta.

9 Unkan Jośuwa Israel cinca kin hewicakıya, Den ikiyedan kuwapo, qa Jehowa Wakanyadapi oie kin nahompo.

$10 \mathrm{Qa}$ Jośuwa heya, Taku kin de etanhan, Taku wakan ni un kin niyepi ehna yanka, qa nitokapa tanhan Kanani kin, qa Hiti kin, qa Hiwi kin, qa Perazi kin, qa Girgaśi kin, qa Amori kin, qa Jebusi kin ohinniyan nape wicaye kte cin sdonyayapi kta.

11 Inyun maka owancaya itancan kin wicotakuye can wohnaka tawa kin nitokam Jordan en iyaye kta ce.

12 Heon wanna Israel wicoun etanhan wicaśta wikcemna sanpa nonpa ikikcupo, wicoun iyohi wicaśta wanjikśi.

13 Unkan kaketu kta, wawayuśnapi Jehowa maka owancaya itancan can wohnaka tawa akiyuhapi sihapi kin Jordan mini en iyozipi kinhan, Jordan mini kin kiyuśpapi kta, Jordan mini kin tatowapa tanhan kun u kin he, qa bosdan paha wan iyecen wanke kta.

14 Unkan oyate kin Jordan iyuwegapi kta e tawakeyapi etanhan ihdakapi qehan, wawayuśnapi kin wicotakuye can wohnaka akiyuhapi kin hena oyate itokam manipi.
15 Qa can wohnaka kin ahiyuhapi kin Jordan ekta ipi, qa wawayuśnapi can wohnaka akiyuhapi sihapi kin mini hutata en oputkanpi qehan, (aguyapi baksapi ece icunhan anpetu owasin Jordan maya owasin iyujiminayan wanka,)

$16 \mathrm{Qa}$ Jordan mini kin tatowapa tanhan u kin he anaptapi, qa bosdan han, paha wan heca nina hanska, Adam otonwe Tzaretan icahda yanke cin hehanyan; tuka Araba mde, miniskuya mde kin hee ekta kaduze cin he oyahe, ocowasin skepa. Unkan oyate kin Jeriho iyotakons opta iyayapi.

17 Unkan wawayuśnapi Jehowa otakuye can wohnaka akiyuhapi kin Jordan cokaya maka puza seca akan owanjin najinpi, ecen Israel owasin maka puza akan opta iyayapi, oyate kin owasin Jordan akasam iyayapi yuśtanpi kin hehanyan.

\section{WICOWOYAKE 4.}

1 Hecen oyate kin owasin Jordan iyuwegapi yuśtanpi. Unkan Jehowa ie ca Jośuwa heciya,

2 Oyate kin etanhan wicaśta wikcemna sanpa nonpa ikikcu wo, wicoun otoiyohi etanhan wicaśta wanjidan.

3 Qa wahokon wicakiye ca hewi cakiya, Detanhan Jordan cokaya tanhan, oyanke wawayuśnapi sihapi kin sutaya ahanpi kin hetanhan inyan wikcemna sanpa nonpa icupo, qa hena yuha dapi, qa tukten hanyetu kin de inonkapi kte cin hena eyajupi kta.

4 Unkan Jośuwa Israel cinca etanhan wicaśta wikcemna sanpa nonpa wiyeya wicakage ciqon wicoun iyohi etanhan wicaśta wanjidan wicakipan. 


\section{WICOWOYAKE 4.}

5 Qa Jośuwa hewicakiya, Jehowa Wakan yadapi can wohnaka tawa ikiyedan yapo, Jordan cokaya ekta, qa otoiyohi inyan wan yurwankan icupo, nitahpapi akan. Israel cinca wicoun iyenaka;

6 Hecen de wapetokeca duhapi $k t a$, tokata nicincapi iniwangapi qa, Inyan kin dena token kapi he? eniciyapi kinhan?

7 'Token Jordan mini kiyuśpapi kin Jehowa otakuye can wohnaka itokam, Jordan iyuwegapi qehan, Jordan mini kin kiyuśpapi owicayakidakapi $k$ ta; hecen Israel cinca kin inyan kin dena wokiksuye owihanke wanin yuhapi kta.

8 Hehan Israel cinca token Jośuwa econ wicaśi iyecen econpi, qa Jordan cokaya tanhan inyan akenonpa icupi, Israel cinca wicoun iyenaka, Jehowa Jośuwa eciye ciqon iyecen, qa hena yuha yapi ewankapi kin ekta, qa hen ejupi ;

9 Qa nakun inyan akenonpa Jośuwa ehde Jordan cokaya, wawayuśnapi wotakuye can wohnaka akiyuhapi sihapi ahanpi kin he akan; qa hena hen yakonpi anpetu kin dehanyan.

10 Unkan wawayuśnapi can wohmaka akiyuhapi kin Jordan cokaya najinpi, taku Jośuwa oyate kin ewicakiya Jehowa eye śi qon owasin yuśtanpi, qa oyate kin inaliniya opta yapi kin hehanyan, Mowis Jośuwa econ śi qon he iyecen.

11 Unkan oyate kin owasin iyuwegapi yuśtanpi qehan, Jehowa can wohnaka tawa, qa wawayuśnapi kin oyate itokam iyayapi.

12 Wanna Ruben cinca, qa Gad cinca, qa Manaśe wicoun hanke wipe yuhapi Israel cinca itokam iyayapi, Mowis ewicakiye ciqon he iyecen,

13 Wicaśta kektopawinge wikcema topa, kicizapi obe zuya iyayapi, Jehowa itokam, Jerilio makomdaya kin ekta.

14. Anpetu kin he en Jehowa Jośuwa yutanka, Israel owasin iśtapi en. Unkan tohanyan ni kin anpetu owasin kokipapi, Mowis lrokipapi qon he iyecen.

15 Unkan Jehowa ie ça Jośuwa heciya,

16 Wawayuśnapi kin woyaatanin can wohnaka akiyuhapi kin Jordan etanhan itanwankanhde ye wicaśi wo.

17 Unkan Jośuwa wawayuśnapi hewicakiya, Jordan etanhan itanwankanhde yapo.

18 Unkan wawayuśnapi Jehowa otakuye can wohnaka akiyuhapi kin Jordan cokaya tanhan iyayapi qehan; wawayuśnapi sihapi kin maka puza ekta hdutitanpi qehan, Jordan mini kin owanka tawa ekta hdi, qa maya tawa owasin iwankam iyaya, htanihan, qa sanpa econ qon he iyecen.

19 Wanna wi tokaheya anpetu wikcemna en oyate kin Jordan etanhan iyayapi, qa Jerilio iwiyohiyanpa tanhan Gilgal ohna etipi.

20 Unkan inyan wikcemna sanpa nonpa, Jordan etanhan icupi qon hena Jośuwa Gilgal ohna ehde.

$21 \mathrm{Qa}$ Israel cinca kin hewicakiya, Tokata nicincapi kin hunkayapi kin iwangapi, qa, Inyan kin dena taku he? eyapi kinhan,

22 Nicincapi sdonye wicayakiyapi kta, qa Israel maka puza amani Jordan kin de ohiyupi, ehapi kta:

23 Token Jehowa Wakan ya- 


\section{JOŚUWA TAWOWAPT,}

dapi kin niyepi itokam Jordan mini kin oyahe ya, iduwegapi icunhan, he iyecen Jehowa Wakan yadapi unkiyepi itokam Mdeśa mini kin ecakicon, qa oyahe ya, unkiyuwegapi icunhan.

24 Heon oyate owasin maka owancaya Jehowa nape kin hee waśaka sdonyapi $\mathrm{kta}$, qa heon Jehowa Wakan yadapi kin koyakipapi kta anpetu owasin.

\section{WICOWOYAKE 5.}

1 Unkan Amori wicaśta yatapi kin Jordan itato, wiyohpeyata ektakiya owasin, qa Kanani wicaśta yatapi miniwanca icahda yakonpi owasin, Jehowa Israel cinca kin Jordan iyuw egapi icunhan, wicitokam token mini kin oyalie ye cin he nalionpi qehan, cantepi kin skanpi, qa woniya nicapi, Israel cinca itokam.

2 He ehan Jehowa Jośuwa heciya, Inyan isan icicaga, qa ake Israel cinca inonpa bawicalidaya wo.

3 Unkan Jośuwa inyan isan icicaga, qa Ce inkpa paha kin ekta Israel cinca kin bawicahdaya,

$4 \mathrm{Qa}$ taku on Jośuwa bawicahidaye cin dee, oy ate Egupta etanhan hdinanpapi wica owasin, wicaśta ozuye okihipi owasin hewoskan tapi ; Fgupta etanhan hdinanpapi canku ohna.

5 Oyate hdinanpapi qon hena owasin bawicahdayapi; tuka oyate hewoskan tonpi Egupta etanhan hdinanpapi canku ohna, hena owasin bawicahdayapi śni.

6 Israel cinca waniyetu wikcemna topa hewoskan manipi, oyate wicaśta ozuye okihipi, Egupta etanhan inanpapi kin hena owasin sotapi kin hehanyan. Hena Jehowa ho, kin anagoptanpi śni nakaś, heon makoce ptea- sanpi, qa canhanpi tiktica kaduze cin he unqupi kta hunkake wicayapi konza ewicakiye ciqon, he wanyag wicakiye kte śni konza ewicakiya.

7 Tuka hena eekiya cincapi icagapi kin hena bahidayapi śni unpi, tahepi tuwedan bawicahdaye śni nakaś, heon Jośuwa hena bawicalidaya.

8 Unkan oyate kin owasin bawicahdayapi yuśtanpi qehan wicoti ohna owanji yukanpi akisnipi kin hehanyan.

y Unkan Jehowa Jośuwa heciya, Nakaha Egupta woaie kin niyepi etanhan paptan iyewaya, heon oyanke kin he anpetu kin dehanyan (Gilgal) Paptanyanpi eciyapi.

10 Unkan Israel cinca Gilgal ekta tipi, qa woacakśin kagapi, wi anpetu wikcemna sanpa topa en htayetu ehan, Jerilio makomdaye ohna.

11 Unkan woacakśin ihanhanna hetanhan maka' taku icaliye cin he yutapi, aguyapi napoliyapi śni, qa papahyapi, anpetu kin he en.

12 Unkan makoce taku icahye cin he yutapi ihanlianna hetanhan manna kin anaptapi, qa Israel cinca kin icimana manna yutapi śni, qa waniyetu kin he Kanan makoce taku icahye cin he yutapi.

13 Unkan Jośuwa Jeriho ikiyedản un kin icunhan iśta kin yuwankan ikikcu, qa etonwan ; unkan inyun iye itokam wicaśta wan najin, qa nape ohna isan wan yuśdokapi yuha, unkan-Jośuwa ikiyedan i qa heciya, Niye unkiyepi kici yatidan, qaiś toka unyanpi kici unman tukte he?

14 Unkan heya, Hiya tuka Jehowa taobe mdetanhunka heca wahi ce. Unkan itokam Jośuwa 


\section{WICOWOYAKE 6 .}

makipusdiya ehpe ic̣iye ca ohoda, qa heciya. Itancan taku nitaokiye eyakiye kta he?

15 Unkan Jehowa taobe mdetanhunka kin Jośuwa heciya, Siha etanhan hanpa hduśdoka wo. Oyanke akan nayajin kin he wakan ce. Unkan Jośuwa ecen econ.

\section{WICOWOYAKE 6.}

1 Wanna Jeriho tiyopa kin ecen icupi, qa Israel cinca on sutaya natakapi, tuwedan hinanpe śni, qa tuwedan en i śni.

2 Unkan Jehowa Jośuwa heciya, Ito ninape en Jeriho ciçu, nakun tawicaśta yatapi, qa wicaśta waśakapi.

3 Heon ozuye wicasta owasin otonwe ihdukśan mayanipi kta; wancadan ohomni dapi kta, anpetu śakpe hecen ecanonpi kta.

4 Qa wawayuśnapi śakowin can wohnaka kin itokam Jubele (woiwakta) mazayahotonpi kin ayapi kta, qa anpetu iśakowin en otonwe ihdukśan śakowin akihde mayanipi kta, qa wawayuśnapi kin maza yahotonpi kin yahotonpi kta.

5 Qa Jubele (woiwakta) he kin tehan yahotonpi kinhan, yahotonpi ho kin nayahonpi kinhan, oyate owasin iyaśapi tanka iyakiśapi kta, unkan otonwe conkaśke kin hukuyata hinhipaye kta, unkan oyate wicaśta iyohi iye iyotakonza en yapi kta.

6 Unkan Jośuwa Nun cinhintku kin wawayuśnapi wicakipan, qa hewicakiya, Wicotakuye can wohnaka kin akiyuhapo. Unkan wawayuśnapi śakowin Jubele mazayahotonpi śakowin Jehowa canwohnaka kin itokam ayapi kta.

7 Qa oyate kin hewicakiya, Iya- yapi qa otonwe kin ihdukśan yapo. Tona wipe kitonpi otoiyohi Jehowa canwohnaka tawa itokam mani kta.

8 Unkan Jośuwa ewicakiya yaśtan qehan, wawayuśna śakowin Jubele rnazayahotonpi śakowin yuhapi Jehowa itokam iyayapi, qa maza yahotonpi kin yahotonpi, qa Jehowa otakuye can wohnaka kin wicihakam ku.

9 Qa tona wipe yuhapi kin hena wawayuśnapi mazayahotonpi kin yahotonpi itokam iyayapi, qa oyate kin can wohnaka ihakam manipi, yapi eca maza yahotonpi yahotonpi ece.

10 Wanna Jośuwa oyate taku ewicakiye ciqon he dee, Yapanpanpi kte śni, qa nihopi kin nalionpi kte śni, qa, Panpanpo eciciyapi anpetu kin hehanyan niipi etanhan ho wanjidan inanpe kte śni, tuka hehan yapanpanpi kta.

11 Unkan Jehowa can wohnaka tawa kin otonwe ihdukśan wancadan iyaya, hehan wicoti en hdipi, qa wicoti ohna wankapi.

12 Unkan ihanhanna Jośuwa hanhannahin kikta, qa wawayuśnapi kin Jehowa canwohnaka tawa kin ayapi.

$13 \mathrm{Qa}$ wawayuśna sakowin Jubele mazayahotonpi śakowin yuhapi, Jehowa canwohnaka kin itokam manipi ; manipi eca mazayahotonpi kin yahotonpi ece; qa wicitokam tona wipe yuhapi kin manipi, qa oyate unman kin Jehowa can wohnaka kin ihakam manipi, qa maza yahotonpi kin yahoton manipi.

$14 \mathrm{Qa}$ anpetu inonpa wancadan otonwe ohomni yapi, qa wicoti en hdipi. Anpetu śakpe hecen econpi.

15 Qa anpetu iśakowin anpao hinanpe cehan kiktapi, qa woyaco kin he iyecen śakowin aki- 


\section{JOŚUWA TAWOWAPI,}

hde otonwe ohomni yapi; tuka anpetu kin heceedan otonwe kin śakowin akihde ohomni yapi.

16 Unkan iśakowin hehan wawayuśnapi kin mazayahotonpi kin yahotonpi qehan, Panpanpo, Jehowa otonwe kin niçupi ce, Jośuwa oyate kin ewicakiya.

17 Qa otonwe kin he Jehowa on yuwakanpi kte hinca, nakun taku ohna un kin owasin, Rahab witkowin kin iś nana ni kta, iye qa tona iye ti kin ohna yakonpi kin owasin; ohnihde ye wicunśipi kin hena nawicalima nakaś.

18 Tuka ihnuhan taku yuwakanpi kin he iyacupi kin, okini niyaśicapi kta; taku yawakanpi kin ongedan iyacupi kinhan, Israel obe kin woyaśice yakagapi kta, qa he iyoyag yayapi kta.

19 Tuka mazaska, qa mazaskazi owasin, nakun taku mazaśa qa maza sapa on kagapi owasin Jehowa on wakan kta; he Jehowa tawopiye en hiyuyapi kta.

20 Unkan oyate kin iyaśapi, qa mazayahotonpi kin yahotonpi, qa oyate maza yahotonpi ho kin nahonpi, qa oyate iyaśapi tanka on panpanpi qehan conkaśke hukuya ekta hinhpaya; unkan oyate kin otonwe en ipi, otoiyohi iye iyotakonza, qa otonwe kin icupi.

$21 \mathrm{Qa}$ otonwe ohna taku un kin iyulipa yuwakanpi, wicaśta qa winohinca, kośka qa wicahinca, pte, qa taliinca, qa śonśonna owasin canhipi hi on ihang yapi.

22 Unkan Jośuwa wicaśta nonpa makoce iwanyag ipi qon, itokam hewicakiya, Witkowinna ti en yapo, qa hetanhan winohinca hiyu yapo, nakun taku tawa iyuhpa kin, konza eyakiyapi qon iyecen.

23 Unkan kośka tonwe ipi qon en ipi, qa Rahab hinanpe yapi; nakun atkuku, qa hunku, qa hunka wanjin wicaye cin, qa taku tawa iyuhpa, qa wicowazi tawa owasin hinanpe wicayapi, qa Israel owanka itankan ewicahnakapi.

24 Unkan otonwe kin peta on huhnahyapi, taku ohnaka ko owasin; tuka mazaska kin, qa mazaskazi kin, qa taku mazaśa on, qa mazasapa on kagapi kin he Jehowa ti wopiye en ehnakapi.

25 Tuka Rahab witkowin kin, qa atkuku tiyohnaka, qa taku yuhe cin iyuhpa Jośuwa niwicaya: Unkan anpetu kin dehanyan Israel ehna ti, ohnihde Jośuwa Jerilio iwanyag ye wicaśi qon hena nawicalima nakaś.

26 Unkan he ehan Jośuwa wakonza, qa heya, Tuwe najin qa otonwe kin de conkaśke kage cin, Jehowa itokam yaśicapi nunwe; caske tawa en oahehde ejukta, qa cinhintku hakakta en otonwe tiyopa kin bosdan ehde kte.

27 Hecen Jehowa Jośuwa kici un, qa makoce kin owancaya he caje yatapi.

\section{WICOWOYAKE $\%$}

1 Tuka Israel cinca kin taku yuwakanpi en woahtani wahtanipi, qa Akan Karmi cinhintku, Zabdi cinhintku, Zerah cinhintku, Juda wicowazi etanhan taku yaśicapi kin etanhan icu, heon Jehowa Israel cinca canniye wicaya.

2 Unkan Jośuwa Jeriho etanhan Hai ekta wicaśta ye wicaśi, he Bet Awen (Takuśni ti) icahda, Bet-Fl (Wakanti) iwiyohiyanpa tanhan wanka; qa hewicakiya, Itanwankanhde yapo, qa makoce kin iwanyakapo. Un- 


\section{WICOWOYAKE $\%$}

kan wicaśta kin itanwankanhde yapi, qa Hai iwanyakapi ;

3 Qa Jośuwa en hdipi, qa heciyapi, Oyate kin owasin itanwankanhde ye wicaye śni ye. Wicaśta kektopawinge nonpa, qaiś wicaśta kektopawinge yamni itanwankanhde yapi kta, qa $\mathrm{Hai}$ kaśtakapi kte. Wicaśta kin tonanapidan heon etanhan oyate kin owasin heciya mdokite wicaye śni wo.

4 Unkan oyate etanhan wicaśta kektopawinge yamni cetu itanwankanhde yapi, qa Hai wicaśta itokam najicapi.

5 Unkan Hai wicaśta kin oyate etanhán wicaśta wikcemna yamni sanpa śakpe wicaktepi, qa otonwe tiyopa etanhan wicakuwapi, Śbarim (Otiwota) hehanyan, qa apamahde yapi en wicaktepi, heon oyate cantepi skan, qa mini iyececa.

6 Heon Jośuwa tawokoyake kin hduhdehdeca, qa Jehowa canwohnaka tawa itokam makipusdiya elipe içiye htayetu kin hehanyan, iye nakun Israel hunkayapi, qa pesdetepi akan watuśekseca ejupi.

7 Unkan Jośuwa heya, Hehehe, Itancan Jehowa tokeca oyate kin de Jordan hiyuweli wicayaya, qa Amori napepi en unyaqupi kta, qa awihnuni unyanpi kta he? Tokin Jordan akasanpa unyakonpi kta tawațen unyanpin.

8 Hehehe Itancan wanna Israel tapete tokayapi ekta ihduhomnipi, qa taku epe kta he?

9 Qa Kanani, qa makoce ounyanpi kin owasin he nahonpi kta, qa unkiyepi ihdukśan kupi kta, qa uncajepi kin maka kin etanhan kaśpapi kta; unkan nicaje tanka on taku ecannon kta he?
10 Unkan Jehowa Jośuwa heciya, Najin wo. Tokeca decen makipusdiya elipe niciya he?

11 Israel wahtanipi, qa nakun wicotakuye mitawa ope wicawaśi kin he acakśinpi, qa nakun taku yawakanpi qon etanhan icupi, qa manunpi, qa itonpi śui, qa nakun wahpaya tawapi ehna ejupi.

12 Heon Israel cinca toka wicayapi itukam najinpi okihipi śni, woyaśica hecapi nakaś; heon toka wicayapi ekta tapetepi ihduhomnipi. Woyuśice kin he enitanhanpi ihang yayapi śni kinhan icimana ocipapi kte śni.

13 Najin, oyate kin wicayuwakan wo; qa hehe kta, Heyakecinhan on ihduwakanpo, Jehowa Israel Wakan dapi kin hecen eya nakaś, Israel niyepi ehna taku yaśicapi yukan, heon taku yaśicapi niyepi ehna tanhan dutokanpi śni hehanyan toka niyanpi itokam najin oyakihipi kte śni.

14 Heon hanlianna wicoun nitawapi ecekcen ikiyedan yahipi $\mathrm{kta}$, qa wicoun Jehowa icu kte cin he wicowazi kin ecekcen ikiyedan hi kte, qa wicowazi Jehowa icu kte cin he tiyohnaka kin ecekcen ikiyedan hi kta, qa tiyohnaka Jehowa icu kte cin wicaśta otoiyohi ikiyedan hi kte. $15 \mathrm{Qa}$ tuwe woyaśice en iyeyapi kin he petan huhinaliyapi kta, nakun taku yuhe cin owasin; Jehowa tawicotakuye acakśin, qa Israel ohna witkotkoya ohanyan heon etanhan.

16 Unkan Jośuwa hanhannahin kikta qa Israel wicoun ecekcen ikiyedan hiyu wicaya; unkan Juda wicoun kin icupi.

17 Qa Juda wicowazi ikiyedan hiyuwicaya. Unkan Zerahi wicowazi kin icupi. Unkan Zera11 


\section{JOŚUWA TAWOWAPI,}

hi wicowazi wicaśta kin ikiyedan hiyuwicaya, qa Zabdi icupi.

18 Unkan iye tiyohnaka kin ikiyedan hiyu wicaya, wicaśta iyohi, qa Akan Karmi cinhintku. Zabdi cinhintku, Zerah cinhintku, Juda wicowazi etanhan ic upi.

19 Unkan Jośuwa A kan heciya, Micinkśi ito Jebowa Israel Wakandapi kin wowitan kiçu wo, qa he en ohdaka wo, qa taku ecanon kin omakiyaka wo, Ihnuhan miye etankian nayakihman.

20 Unkan Akan Jośuwa ayupte ca heciya, Awicakehan Tehowa Ísrael Wakandapi kin he awawahtani, qa decen, qa decen ecamon.

21 Woyuha ehna Śinar śina wan waśte wanmdaka, nakun mazaska śeqel opawinge nonpa, qa mazaskazi ceji wan śeqel wikcemna zaptan aspeyapi, hena wanmdake cehan cantihewaye ca iwacu, qa inyun hena wakeya mitawa ohna, maka mahen nahmanpi, qa mazaska kin hukuya wanka.

22 Iinkan Jośuwa ohnihde ye wicaśi; unkan ti ekta inyankąpi, qa inyun he ti ohna nahmanpi, qa mazaska kin he ihukuya wanka.

23 Unkan wakeya cokaya tanhan hena icupi, qa Jośuwa ekta, qa Israel cinca owasin ekta kahipi, qa Jehowa itokam hena ejupi.

24 Unkan Jośuwa Akan Zerah cinhintku kin icu, qa mazaska kin qa śina kin, qa mazaskazi ceji kin, qa cinca wica winyan koya owasin, nakun tatanka tawa qa taśonśonna, qa tahinca tawa, qa tawakeya, qa taku yuhe cin owasin, qa Jośuwa qa Israel owasin Akor (Woiyokiśi12 ca) kaksiza kin ekta hiyu wicayapi.

25 Unkan Jośuwa heya, Tokeca iyokiśin unyayapi he? Nakaha Jehowa iyokiśin niye kta. Unkan Israel owasin inyan on kininpi, qa peta ohna hulinah wicayapi, inyan on wicakininpi ohakam.

$26 \mathrm{Qa}$ akan inyan paha tanka wan ejupi, anpetu kin dehanyan ; heon oyanke kin he Akor kaksiza kin eciyapi anpetu kin dehanyan. Unkan Jehowa tocanniye kin etanhan ihduhomni.

\section{W1COWOYAKE 8.}

1 Unkan Jehowa Jośuwa heciya, Ihnuhan wakoyakipe ca ihnuhan yuśinye niye cin. Oyate ozuye yapi kin owasin nici iwicacu, qa najin Hai ekta itanwankanhde ya wo. Inyun Hai wicaśta yatapi kin ninape en waqu, nakun taoyate, qa totonwe, qa tamakoce.

$2 \mathrm{Qa}$ token Jerilio qa wicaśta yatapi tawa ecayecon he iyecen Hai qa tawicaśta yatapi kin ecayecon kta, tuka tawahpaya, qa tawanunyanpi niyepi on yakipi kta. Otonwe ilieyata wicaśta anahbeya iyape wicaya wo.

3 Unkan Jośuwa hanhiannahin kikta Hai ekta ye kta, iye, qa wicaśta ozuye yapi owasin. Qa Jośuwa wicaśta waśaka qa waditaka kektopawinge wikcemna yamni wicakahiniga, qa hanyen ye wicaśi.

4 Unkan hecen econ wicaśi qa heya, Wanyakapo, niyepi otonwe iheyata analibeya dukanpi kta. Ihnuhan otonwe etanhan nina itehanyan dukanpi kin, tuka owasin wiyeya yaunpi kta.

5 Unkan miye qa oyate mici unpi kin owasin otonwe kin iki- 


\section{WICOWOYAKE 8.}

yedan unyanpi kta; unkan unkitkokim tankan inanpapi kinhan, tokaheya econpi qon iyecen wicitokam naunjicapi kta.

6 Qa unkiyepi ihakam inanpapi $k t a$, hecen otonwe etanhan hiyu wicunyanpi kta, wicitokam naunjicapi kta nakaś, heon, Unkitokam najicapi, otokahe ekta iyecen eyapi kta.

7 Hehan niyepi nayajinpi kta, anahbeya dukanpi etanhan, qa otonwe kin iyayalipa dapi kta, qa Jehowa Wakan yadapi kin he ninapepi en qu kta.

8 Qa tohan otonwe kin iyacupi kinhan, otonwe kin peta on ideyayapi kta, Jehowa oie kin iyecen ecanonpi kta; wanyakapo, miye hecon ciśipi.

9 Hecen Jośuwa yewicaśi, unkan anahbeya unpi kta e iyayapi, qa Hai qa Betel otahedan wankapi, Hai iwiyolipeyatanhan, unkan Jośuwa hanyetu kin he oyate om wanka.

10 Unkan Jośuwa hanhannahin kikta, qa oyate kin wicayawa, qa itanwankanhde ya; oyate kin itokam, Hai ekta, iye qa Israel hunkayapi kin.

11. Unkan oyate ozuye yapi iye om unpi kin owasin itanwankanhde ipi, qa otonwe itokam ikiyedan ipi, qa Hai iwaziya tanhan etipi, qa iyepi qa Hai otahedan kaksiza wan yanka.

12 Unkan wicaśta kektopawinge zaptan cetu iwicacu, qa hena anahbeya yukanpi kta, otonwe kin iwiyolipeya tanhan, Betel qa Hai otahedan yanke wicasi.

13 Unkan oyate obe kin ocowasin otonwe iwaziya tanhan etipi, qa waiyapepi kin otonwe iwiyohpeya tanhan, qa Jośuwa hanyetu kin he en kaksiza kin mahen $\mathrm{i}$.

14 Unkan Hai wicaśta yatapi kin he wanyake cehan, otonwe oyate kin inahnipi, qa hanhanna kiktapi, qa iyehantu kinhan iye qa oyate tawa owasin kizapi kta e Israel awicakipapi kta e omdaye puza ekta kiya inanpapi, tuka otonwe ilheyata iye on waiyapepi yukanpi kin he sdonye śni.

15 Unkan Jośuwa, qa Israel owasin awicapapi seca konzapi, qa hewoskan canku kin ohna najicapi.

16 Unkan oyate otonwe ohna yukanpi kin owasin wicakuwapi kta e wicakipanpi, qa Jośuwa kuwa iyayapi, hecen otonwe kin etanhan hiyu wicayapi.

17 Hecen Hai ohna, qa Betel ohna wicaśta wanjidan okaptapi śni owasin Israel helitam inanpapi, qa otonwe yuhdog elipeyapi, qa Israel kuwa iyayapi.

18 Unkan Jehowa Jośuwa heciya, nape, qa wahukeza he ohna duhe cin Hai ektakiya hdugata wo, he ninape en waqu kta nakaś. Unkan Jośuwa wahukeza nape ohna Hai ektakiya hdugata.

19 Unkan nape kin hdugate cehan analibeya unpi kin hena tukten yukanpi kin etanhan inahiniyan najinpi, qa inyankapi, qa otonwe en ipi, qa otonwe kin peta on ideyapi.

20 Unkan Hai wicaśta kin ihdamnapi, qa hekta etonwanpi, qa inyun otonwe śota kin wankan iyaya mahpiya ektakiya, qa tokidan najica okihipi śni, oyate hewoskan najicapi qon hena wicakuwapi ektakiya ihdamnapi nakaś.

21 Anahbeya yukanpi qon wanna otonwe kin icupi, qa otonwe śota kin wankan iyaye cin Jośuwa qa Israel owasin wanyakapi qehan, ihdamnapi, qa Hai wicaśta kin wicakaśtakapi. 


\section{JOŚUWA TAWOWAPI,}

22 Unkan unman itkokim otonwe etanhan inanpapi, hecen Israel cokaya unpi, hunh itato, qa hunh ako, heon wicaktepi ecen inahmanpi qa napapi etanhan tuwedan niyanpi śni.

23 Tuka Hai wicaśta yatapi kin niyake yuzapi, qa Jośuwa ekta aipi.

24 Unkan Israel Hai ounyanpi kin wicakuwa iyayapi qon owasin maga en, qa hewoskan wicaktepi yuśtanpi qehan, owasin canhipi hi on ihpayapi ecen sotapi qehan, Israel owasin ihdamnapi Hai ekta, qa he cantipi hi on kaśtakapi.

25 Hecen anpetu kin he en wicaśta winohinca koya hinhpayapi owasin keptopawinge ake nonpa, Hai wicaśta kin owasin.

26 Jośuwa Hai ounyanpi kin owasin ihang wicaye śni kin hehanyan nape kin on wahukeza hdugata qon ehdakn śni.

27 Tuka wanunyanpi kin, qa otonwe wahpaya kin he Israel yuhapi kta e icupi, wicoie Jehowa Jośuwa econ śi kin he iyecen.

28 Unkan Jośuwa Hai peta on hulnahya, qa otiwota paha heca kaga, qa anpetu kin dehanyan tuwedan oti śni.

$29 \mathrm{Qu}$ Hai wicaśta yatapi kin can wan akan otkeya, htayetu kte cin hehanyan, qa wi iyaye cehan tancan te cin can kin etanhan icupi, qa otonwe tiyopa ekta ehpeyapi, qa akan inyan paha tanka wan ejupi, Jośuwa econ wicaśi kin iyecen anpetu kin dehanyan.

30 Hehan Jośuwa Ebal paha akan wahna wośnapi wan Jehowa Israel Wakandapi kin kicaga.

31 Inyan ocowasin hena iwankan tuwedan mazasapa wan koze 14 śni on wahna wośnapi kin he kagapi, Jehowa taokiye Mowis econ wicaśi kin he iyecen, Mowis toope wowapi en owapi kin he iyecen: qa he akan wohuhnalyapi huhnahyapi, qa wopida wośniapi wayuśnapi.

32 Unkan hen inyan kin akan Mowis toope itakihna Israel cinca kin itokam owa qon he owa.

33 Unkan Israel owasin hunkayapi, qa wowapi kagapi, qa wayaco hecapi, can wohnaka anokatanhan najinpi, Israel oyate cinca, qa tuwe tokeca wicehna ounye cin wawayuśnapi Lewi kin Jehowa canwohnaka akiyuhapi wicikiyedan, hanke Gerizim paha ikiyedan, qa hanke unman Ebal paha ikiyedan, Israel oyate kin wicayawaśtepi kta heon etanhan, Mowis Jehowa taokiye tokaheya hecon wicaśi qon he iyecen.

$34 \mathrm{Qa}$ he iyohakam woope oie kin owasin yawa, woyawaśte, qa woyaśice woope wowapi en owapi kin owasin iyecen.

35 Taku Mowis yawaśi owasin Jośuwa yawa, yawa śni oie wanica, Israel omniciye owasin itokam winohinca, qa śiceca, qa tuwe tokeca wicéhna mani.

\section{WICOWOYAKE 9.}

1 Unkan wicaśta yatapi Jordan itato yakonpi kin he ohna, qa Sepela (makoce hukuya) kin ohna, qa miniwanca huta kin ocowasin ohna, Lebanon ikiyedan. Hiti kin, qa Amori kin, qa Kanani kin, qa Perazi kin, qa Hiwi kin, qa Jebusi kin onaȟonpi qehan,

2 Okowanjidan Jośuwa kici, qa Israel kici kicizapi kta e witaya mniciyapi.

3 Unkan Gibeyon ounyanpi kin 


\section{WICOWOYAKE 9.}

Jośuwa Jeriho qa Hai taku ecakicon nahonpi;

4 Qa hena nakun ksamya ohanyanpi, qa manipi, qa waneya ic̣icagapi, qa śonśonna tawapi akan wojutonpi tanni, qa miniśaapahite tanni, qa nahdecapi qa akagegepi icupi.

5 Qa hanpa tanni qa akihdag tonpi ohanpi, qa wokoyake tanni koyakapi, qa waneya aguyapi yuhapi kin owasin śeca, qa aa.

6 Qa Jośuwa ekta hipi, Gilgal wicoti en, qa heciyapi, iye qa Israel wicaśta nakun, Makoce tehantanhan unkupi, heon wanna wicotakuye unkicicagapo.

7 Unkan Israel wicaśta kin Hiwi kin hewicakiyapi, Okini unkiyepi ehna yatipi, token wicotakuye unnicicagapi kta he?

8 Unkan Jośuwa heciyapi, Nitaokiye heuncapi. Unkan Jośuwa hewicakiya, Nituwepi, qa tokiya tanhan yaupi he?

9 Unkan heciyapi, Nitaokiye makoce nina tehantanhan unkupi, Jehowa Wakan yada caje kin on, iye otanin, qa taku Egupta en econ kin owasin naunhonpi.

10 Nakun Amori wicaśta yatapi nonpa Jordan akasanpa yaKonpi qon, Śition Ḣeśbon wicaśta yatapi qá $\mathrm{Og}$ Baśan wicaśta yatapi Aśtarot en un qon, taku ecawicakicon.

11 Heon hunkayapi unkitawapi, qa makoce unkitawapi ounyanpi kin owasin heunkiyapi, Ninapepi ohna waneya ikikcupo, qa wicitkokim yapo, qa hewicakiyapo, Nitaokiyepi heuncapi, heon iho, wicotakuye unkicicagapo.

12 Aguyapi kin de waneya on untipi etanhan kata unkikcupi, niyepi ekta unkupi kta anpetu kin he en, tuka inyun wanna śeca qa aa.
13 Qa miniśa apalite kin dena teca oju untonpi, tuka wanna nahdecapi, qa canku kin nina tehan on wokoyake unkitawapi wanna kuka.

14. Unkan wicaśta kin waneya ahipi kin icupi, tuka Jehowa i kin iwangapi śni.

$15 \mathrm{Qa}$ Jośuwa wookiye wicakicaga, qa ni wicaye kta e wotakuye wicakicaga, qa omniciye itancan kin Wakantanka naunhonpi ce, ewicakiyapi.

16 Unkan wicotakuye wicakicagapi kin iyohakam anpetu yamni, hehan wicehna unpi qa wicehna tipi kin he nationpi.

17 Qa Israel cinca kin ihdakapi, qa anpetu iyamni tonwanyanpi kin ekta ipi, qa otonwe tawapi kin Gibeyon, qa Kiepira, qa Beerot, qa Qirejat Jeyarim (Taskoju Otonwe.)

18 Qa omniciye itancan kin Jehowa Israel Wakandapi kin cajeyan ewicakiyapi qon heon Israel cinca kin wicakaśtakapi śni. Unkan omniciye ocowasin itancanpi kin i en iyewicayapi.

19 Unkan itancanpi kin owasin omniciye ocowasin hewicakiyapi, Jehowa Israel Wakandapi lin cajeyan konza ewicunkiyapi, heon awicunpapi unkokihipi śni.

20-Decen ecawicunkiconpi kta, qa niwicunkiyapi kta, hecen wokonze ewicunkiyapi kin on wośihda unkiyepi en unkupi kte śni.

21 Qa itancanpi kin kewicakiyapi, nipi kta; tuka omniciye ocowasin on can depi qa mini tokśupi kin hecapi kta, itaincanpi kin kewicakiyapi iyecen.

22 Unkan Jośuwa wicakico, qa om wohdaka, qa hewicakiya. Tokeca unyahnayanpi, qa hehapi, Niyepi etanhan nina tehan 15 


\section{JOŚUWA TAWOWAPI,}

unyakonpi; tuka unkiyepi ehna yatipi.

23 Heon wanna niyaśicapi, qa wowidagniyanpi niyepi etanhan tuwedan yuśkapi kte śni, qa tuwe Wakan wada ti kin on can depi qa mini tokśupi henicapi kta.

24 Unkan Jośuwa ayuptapi qa heyapi, Taku Jehowa Wakan yada kin iye taokiye Mowis econ śi, qa makoce kin owasin niçupi kta, qa makoce ounyanpi kin owasin nitokapa tanhan awihnuni wicaye kta, he nitawowidake nina unkokiyakapi, heon nina ikounnipapi, unnagipi on, qa decen econkupi.

$25 \mathrm{Qa}$ wanna ninape en unyakonpi, token ecaunyeconpi kta, niiśta kin en ecetu, qa waśte kta hecen econ wo.

26 Unkan Jośuwa hecen econ, qa Israel cinca napepi etanhan ewicayaku, hecen wicaktepi śni. 27 Hecen anpetu-kin he en omniciye on, qa Jehowa tawahna wośnapi on candepi, qa mini tokśupi hecapi wicakaga, tukte kahnige kta he ekta anpetu kin dehanyan.

\section{WICOWOYAKE 10.}

1 Unkan Adonitzedeq (Itancan owotanna) JerusaIem wicaśta yatapi kin Jośuwa Hai icu qa ihangya, token Jerilio qa tawicaśta yatapi ecakicon, he iyecen Hai qa tawicaśta yatapi kin ecakicon; qa nakun Gibevon ounyanpi kin Israel om wokiyapi qa wicehna unpi kin, he nation qehan ;

2 Nina kopehda, Gibeyon he otonwe tanka, otonwe wicaśta yatapi tanka yuhapi wan he iyececa, qa Hai isanpa tanka, qa wicaśta ounyanpi kin owasin wicaśta waśakapi nakaś :
3 Heon Adonitzedeq Jerusalem wicaśta yatapi kin Hoham Hebron (Dakota) wicaśta yatapi kin, qa Piram Jarmut wicaśta yatapi kin, qa Japiya (Wiyega) Lakiś wicaśta yatapi kin, qa Debir Eglon tawicaśta yatapi kin hena wahowicaye ca hewicakiya.

4 En Maupo, qa omakiyapo, hecen Gibeyon unkaśtakapi kta, Jośuwa kici, qa Israel om wanna wookiye kngapi nakaś.

5 Hecen Amori wicaśta yatapi zaptan witaya iheyapi, Jerusalem wicaśta yatapi, qa Hebron wicaśta yatapi, qa Jarmut wicaśta yatapi, qa Lakiś wicaśta yatapi, qa Eglon wicaśta yatapi, iyepi qa obe tawapi owasin, qa Gibeyon kizapi kta e iyotakonza etipi.

6 Unkan Gibeyon wicaśta kin Jośuwa wahoyapi Gilgal owankapi ekta, qa heciyapi, Ihnuhan wowidake nitawa on ninape kuje cin. Inahniya unkiyepi ekta kuwa wo, qa niunkiyapi, qa ounkiyapo; Amori he kin ounyanpi wicaśta yatapi owasin unkiyepi ek ta kawitaya iheyapi nakaś.

7 Unkan Jośuwa Gilgal etanhan itanwankanhde ya, iye qa oyate ozuyapi owasin, wicaśta waśaka waditaka owasin.

8 Unkan Jehowa Jośuwa heciya, Ihnuhan kowicayakipe cin, ninape en owasin wicawaqu, hena etanhan wicaśta wanjidan nitokam najin kte śni.

9 Unkan Jośuwa hanyetu osan Gilgal etanhan itanwankanhde ye ca ibnuhanna anawicatan.

$10^{\circ}$ Unkan Jehowa Israel itokam yuśinye wicaya, qa wokaśtake tanka on wicakaśtaka Gibeyon ekta, qa canku Bethoron ekta iyadipi ohna wicakuwapi, qa Ázeqa, qa Makeda hehanyan wicakaśtakapi. 


\section{WICOW OYAKE 10.}

11 Unkan Israel itokam napapi Bethoron apamahde yapi icunhan Jehowa inyan tankinkinyan ahinhe wicaya mahpiya etanhan Azeqa ekta ipi kin hehanyan, unkan wasu inyan on țapi kin hena otapi, qa Israel cinca canhipi on wicaktepi kin hena tonananpidan.

12 Unkan Jehowa. Tsrael cinca itokam Amori wicaqu, anpetu kin he ehan Jośuwa ie ça Israel owasin itokam Jehowa heciya, Anpetu wi Gibeyon en owanji yanka wo, qa hanyetu wi Ajalon iwankam.

13 Unkan anpetuwi kin owanji yanka, qa hanyetuwi nakun sanpa i śni, oyate tóka yapi kin tokiconpi kin hehanyan, Jaśer (Ecetu) wowapi en he owapi. Unkan anpetuwi kin mahpiya cokaya owanji yanka, qa iyaye kte inalini śni, anpetu wan ocowasin hehanyan.

14 Unkan he itokam, qa iyohakam anpetu kin he iyececa wanica, Jehowa wicaśta ho kin nahon, Jehowa Israel on kiza nakaś.

15 Unkan Jośuwa qa Israel owasin Gilgal owanka ekta kihdapi.

16 Unkan wicaśta yatapi zaptan kin hena napapi qa Maqeda en makohdoka wan ohna inalimanpi.

17 Unkan, Wicaśta yatapi zaptan Maqeda en makohdoka ohna inahmanpi, wanna iyewicayapi ce, eya Jośuwa okiyakapi.

18 Unkan Jośuwa heya, Inyan tankinkinyan makohioha i kin ekta paptan iyeyapo, qa he ekta wicaśta awanyag wicaśipo.

19 Tuka niyepi ihnuhan owanji nayajinpi kin, toka wicayayapi wicakuwapo, qa ehake yakonpi kin wicaktepo. Ihnuhan ton- wanyanpi kin en kipi kta iyowin wicayayapi kin ; Jehowa Wakan yadapi kin ninapepi en wicaqu nakaś.

20 Unkan Jośuwa, qa Israel cinca wopate tanka kin on wicaktepi, yuśtanpi ecen ihang wicayapi, tona okaptapi najicapi, qa otonwe conkaśke en ipi.

21 Hehan oyate kin owasin Jośuwa ekta Maqeda owanka kin en zaniyan hdapi, tuwedan Israel cinca kin ektakiya ceji. kin hdaśkan śni.

22 Unkan Jośuwa heya, Makohdoka $\mathrm{i}$ kin yuhdokapi, qa wicaśta yatapi zaptan kin hena makohdoka etanhan miye ekta hinanpe wicayapo.

23 Unkan hecen econpi, qa iye ekta wicaśta yatapi zaptan kin hena hinanpe wicayapi ; Jerusalem wicaśta yatapi kin, qa Hebron wicaśta yatapi kin, qa Jarmut wicaśta yatapi kin, qa Lakiś wicaśta yatapi kin, qa Eglon wicaśta yatapi kin.

24 Unkan wicaśta yatapi kin hena Jośu wa ekta hiyu wicayapi qehan, Jośuwa Israel wicaśta owasin wicakipan, qa wicaśta iye kici ozuye ipi mdetanhunkapi kin hewicakiya, Kuwapo, qa wicaśta yatapi kin deria tahupi akan nisihapi kin aputakapo. Unkan ikiyedan hipi, qa tahu kin akan siha atputakapi.

25 Unkan Jośuwa hewicakiya, Ihnuhan koyakipapi, qa yuśinyeniyanpi kin, Wakiśakapo, qa waditakapo. Jehowa toka yayapi azuwicayayapi kin hena owasin hecen ecawicakicon kta nakaś.

26 Urkan hehan Jośuwa awicapa, qa wicakte, qa can zaptan akan otkewicaya, unkan htayetu kin hehanyan can akan okazeze unpi. 


\section{JOŚUWA TAWOWAPI,}

27 Unkan wi iyaye kte cehan Jośuwa can kin etanhan icu wicaśi, qa makohdoka ohna inahmanpi qon en ehpewicayapi, qa makohdoka i akan inyan tankinkinyan ejupi, anpetu kin dehanyan hen yankapi.

28 Unkan anpetu kin he en Iośuwa Maqeda icu, qa canhipi hi on kaśtaka, tawicaśta yatapi nakun, wicanagi ohna unpi owasin ihang wicaya, okaptapi wanjidan nikiye śni, qa token Jerilio wicaśta yatapi ecakicon qon, lie iyecen Maqeda wicaśta yatapi kin ecakicon.

29 Unkan Jośuwa qa Israel owasin Maqeda etanhan iyoptapi, Libna ekta, qa Libna azuyapi.

30 Unkan Jehowa he nakun Israel nape en qu, nakun tawicaśta yatapi, unkan canhipi hi on kaśtaka, qa wicanagi ohna unpi kin owasin, okaptapi kin tuwedan nikiye śni, qa Jerilio wicaśta yatapi ecakicon qon he iyecen tawicaśtayatapi kin ecakicon.

31 Unkan Jośuwa Israel owasin om Libna etanhan Lakiś ekta i qa ikiyedan eti, qa kiciza.

32 Unkan Jehowa Lakiś Israel nape en qu; unkan anpetu inonpa en icupi, qa canl’pi hi on kaśtakapi, nakun wicanagi ohna yakonpi kin owasin Libna ecakiconpi qon owasin iyecen.

33 Hehan Îloram Gezer wicaśta yatapi Lakiś okiye kta e itanwankanhde u, unkan Jośuwa he kaśtaka, nakun taoyate owasin ecen tuwedan okicicapte śni.

34 Unkan Jośuwa Lakiś etanhan Figlon ekta i qa Israel owasin opapi, qa he elsta etipi qa azuyapi.

35 Qa anpetu kin he en icupi, qa canhipi hi on kaśtakapi, qa anpetu kin he en wicanagi ohna unpi kin owasin awihnuni wica- yapi, Lakiś ecakicon qon owasin iyecen.

36 Unkan Jośuwa Eglon etanhan Ḧebron ekta itanwankanhde $i$, qa Israel owasin opapi, qa he azuyapi,

37 Qa icupi, qa canhpi hi on kaśtakapi nakun tawicaśta yatapi, qa totonwe kin owasin, qa wicanagi ohna unpi kin owasin, tuwedan niyake okaptapi śni; Eglon ecakicon qon owasin iyecen he ihang ya, qa wicanagi ohna unpi kin owasin nakun.

38 Unkan Jośuwa ihdamna Debir ekta, qa Israel owasin opapi, qa he azuyapi.

39 Qa icupi, qa tawicaśta yatapi, qa totonwe kin owasin; qa cantipi hi on wicakaśtakapi, qa wicanagi ohna unpi kin owasin awihnuni wicayapi, tuwedan niyake okaptapi śni. Hebron ecakicon qon, qa Libna qa tawicaśta yatapi ecakicon qon, he iyecen Debir qa tawicaśta yatapi ecakicon.

40 Hecen Jośuwa he kin, qa hukuya makomdaya, qa Negeb (Itokaga) kin, qa kaksiza kin owasin, makoce kin ocowasin kaśtaka, qa wicaśta yatapi owasin, tuwedan niyake okapte śni, tona woniya yukan owasin awihnuni wicaya, Jehowa Israel Wakandapi kin econ śi kin owasin iyecen.

41 Hecen Jośuwa Qadeś Barneya etanhan Gaza hehanyan wicakaśtaka, qa Gośen makoce owasin, Gibeyon hehanyan.

$42 \mathrm{He}$ ehan Jośuwa wicaśta yatapi kin hena owasin icu, 11akun tamakocepi, Jehowa Israel Wakandapi kin Israel on kiza nakaś.

43 Hehan Josuwa Gilgal owanka ekta kihda, qa Israel owasin opapi. 


\section{WICOWOYAKE 11.}

\section{WICOWOYAKE 11.}

1 Unkan Jabin H̊tatzor wicaśta yatapi kin onahon qehan Jobab Madon wicaśta yatapi kin, qa Simron wicaśta yatapi kin, qa Aksap wicaśta yatapi kin, wahowicaya.

2 Nakun wicaśta yatapi. Waziyatakiya he kin ohna, qa Kinnerot ikiyedan Araba ohna, qa Śsela (huta) kin ohna, qa Napot Dor ohna wiyoheya tanhan.

3 Kanani kin wiyohiyanpe cin etanhan, qa wiyohpeya tanhan, qa Amori kin, qa Hiti kin, qa Perazi kin, qa Jebusi kin he ohna, qa Hiwi kin Hermon ihukuya Mitzpa makoce ohna.

4 Unkan hena inanpapi, nakun obe tawapi owasin oyate otahinca, wiyaka miniwanca liutata yanke cin iyecen wicota, qa śuktanka, qa canpahmihma nina ota.

5 Unkan wicaśta yatapi kin hena owasin mniciyapi, qa upi, qa Merom (Tatowapa) mini ekta Waya etipi, Israel kizapi kta heon etanhan.

6 Unkan Jehowa Jośuwa heciyå, Ihnuhan hena on koyakipe cin; heyake cinhan wi dehantu hena owasin capapi Israel itokam wicawaqu kta. Śuktanka tawapi kin kan wicayecakse kta, qa canpahmihma tawapi kin peta on huhnah yaye kta.

7 Unkan Jośuwa oyate ozuye yapi owasin om, Merom mini ekta ihnuhanna en wicahi, qa anawicatan.

8 Unkan Jehowa Israel napepi en wicaqu; Unkan wicakaśtakapi, qa wicakuwapi, Tzidon tanlia ekta, qa Misrepat maim (Mini kata) ekta, qa wihinanpa ekta kiya Mitzpa Kaksiza ekta; qa wicakaśtakapi ecen hena etanhan tuwedan niyake okapte śni.

9 Qa Jośuwa token Jehowa eciye cin iyecen ecawicakicon, Śuktanka tawapi kan wicakicakse, qa canpahmihma tawapi peta on huhnaliya.

$10 \mathrm{Qa}$ he ehan Jośuwa ihdamna, qa Hatzor (Conkaśke) icu, tawicaśta yatapi nakun, qa canhipi hi on kaśtaka; itokam wicośkanśkan kin hena owasin Hatzor pa kin ee yawapi.

11 Qa wicanagi he ohna unpi kin owasin canhyi hi on wica kaśtakapi, ocowasin ihang wica: yapi, niyanpi kin wanjidan okapte śni, qa Hatzor peta on liuhinah ya.

12 Qa wicaśta yatapi kin hena totonwepi owasin, qa wicaśta yatapi kin Jośuwa icu, qa canhpi hi on wicakaśtaka awilnuni wicaya Jehowa taokiye Mowis econśi kin he iyecen.

13 Tuka otonwe paha akan ecen iharipi kin hena Israel hulinahye śni; Hatzor heceedan he Jośuwa hulinaliya.

14 Qa otonwe kin hena wahpaya, qa tawanunyanpi kin Israel cinca yuhapi kta e kipi, tuka wicaśta kin owasin canhipi hi on, wicakaśtakapi, ecen ihang wicayapi, niyanpi wanjidan okaptapi śni.

15 Token Jehowa iye taokiye Mowis econśi kin, he iyecen Mowis Jośuwa econśi, qa Jośuwa hecen econ, taku Jehowa Mowis econśi kin wicoie ecetu śni wanica.

16 Hecen Jośuwa makoce kin he ocowasin icu, he kin, qa $\mathrm{Ne}$ geb (Itokaga) kin, ocowasin qa Sepela, qa Gośen makoce acowasin, qa Araba kin, qa Israel tahe kin qa tahuta kin.

17 He Halaq (Śduśduta) Seyir 


\section{JOŚUWA TAWOWAPI,}

itanwankanhde yapi etanhan, Bayal Gad (Gad itancan) ekta, Lebanon osmaka ohna Hermon he kin ihukuya hehantu, qa wicaśta yatapi en yakonpi kin owasin iwicacu, qa wicakaśtake ca wicakte.

18 Jośuwa anpetu ota wicaśta yatapi kin hena azuwicaya.

19 Otonwe wanjidan Israel cin. ca om wokiye śni; Hiwi kin Gibeyon ounyaupi kin lıenana, tokankan owasin wokicize on icupi.

20 Jehowa hecen konza, heon cantepi ihdusutapi, qa Israel itkokim kicizapi, hecen onśiwicadapi śni, qa ocowasin awihnuni wicayapi, qa heon ihang wicayapi, Jehowa Mowis econ śi qon he iyecen.

21 Unkan he ehan Jośuwa Anaqim (tahu hanska) talie kin ekta $i$, qa hetanhan wicakaśpe, ஷ̈ebron etanhan, Debir etanhan, Anab etanhan, qa Juda he kin owancaya etanhan, qa Israel he kin owancays etanhan Jośuwa ocowasin ihang wicaya, otonwe tawapi nakun.

22 Israel cinca kin tamakocepi ohna Anaqim okaptapi wanica, tuka Gaza olına, qa Gat ohna, qa Aśdod ohna okapta yakonpi.

23 Hecen Jośuwa makoce kin ocowasin icu, Jehowa Mowis eciye ciqon owasin iyecen, qa Jośuwa he tawa yapi kta e wica$q u$, Israel token pamnipi wicoun tawapi kin iyecen. Unkan makoce kin kicizapi etanhan iyoziya.

\section{WICOWOYAKE 12.}

1 Israel cinca kin wicaśta yatapi wicakaśtakapi, qa tamakocepi tawayapi, Jordan akotanhan wihinanpe cin ektakiya, Arnon wak- pa etanhan Ḣermon he kin hehanyan, qa Araba wihinanpa ektakiya ocowasin dena eepi.

2 Sihon Amori kin tawicaśta yatapi, Heśbon ounye ciqon, qa Aroer Arnon wakpa huta akan yanka, qa wakpa cokaya tanhan, qa Gileyad hanke, Jaboq wakpa iyohiya, Amon cinca tamakocepi ihanke kin hehanyan idaka.

3 Nakun makomdaya Kinerot mde iyohiya wihinanpa ektakiya qa makomdaya mde kin Minisliuya mde kin hee, wihinanpe cin ektakiya, Bet Jeśimot (otiwotati) canku kin ekta, qa Itokaga Pisga huta kin ekta hehanyan.

4 Nakun Og Baśan wicaśta yatapi kin he Repaim etanhan okaptapi, qa Aśterot qa Edreyi (waśaka) en ounye cin tamakoce kin ;

5 Qa Ḣermon he kin, qa Salka, qa Baśan ocowasin idaka, Geśuri kin, qa Mayakati kin tamakocepi kin ekta, qa Gileyad hanke Sihon Heśbon wicaśta yatapi tamakoce kin iyohiya.

6 Mowis Jehowa taokiye, qa Israel cinca wicakaśtakapi. Qa Mowis Jehowa taokiye he tawa yapi kta e Rubeni kin, qa Gadi kin, qa Manaśe wicoun hanke kin wicaqu.

7 Unkan makoce wicaśta yatapi kin Jośuwa qa Israel cinca kaśtakapi, Jordan itato wiyohpeyata ektaliya, Bayal Gad Lebanon osmaka ohna yanke cin etanhan, Halaq he kin Sehir ekta itanwankanhde yapi hehanyan, qa Israel wicoun pamnipi iyecen tawayapi kta e Jośuwa wicaqu.

8 He kill ohna, qa Śsepela (huta) kin, qa Araba (makomdaye) kin; qa Aśdot (kaksizaota) kin, qa Hopuzakin, qa Itokaga kin hena owasin ohna, Ḧiti kin, Amori 


\section{WICOWOYAKE 13.}

kin, qa Kanani kin, Perazi kin, Hiwi kin, qa Jebusi kin ounyanpi.

9 Jeriho wicaśta yatapi kin wanji ; Hai Betel ikiyedan wanka tałwicaśta yatapi kin wanji ;

10 Jerusalem wicaśta yatapi kin wanji; Hebron wicaśta yatapi kin wanji ;

11 Jarmut wicaśta yatapi kin wanji ; Lakiś wicaśta yatapi kin wanji ;

12 Eglon wicaśta yatapi kin wanji ; Gezer wicaśta yatapi kin wanji ;

13 Debir wicaśta yatapi kin wanji; Geder wicaśta yatapi kin wanji ;

14 Horma wicaśta yatapi kin wanji; Arad wicaśta yatapi kin wanji ;

15 Libna wicaśta yatapi kin wanji; Adullam wicaśta yatapi kin wanji :

16 Maqeda wicaśta yatapi kin wanji; Betel wicaśta yatapi kin wanji ;

17 Tapuha wicaśta yatapi kin wanji ; Heper wicaśta yatapi kin wanji ;

18 Apeq wicaśta yatapi kin wanji ; Śaron wicaśta yatapi kin wanji ;

19 Madon wicaśta yatapi kin wanji; Hatzor wicaśta yatapi kin wanji ;

20 Śimron Meron wicaśta yatapi kin wanji : Aksapi wicaśta yatapi kin wanji ;

21 Tayanak wicaśta yatapi kin wanji; Megido wicaśta yatapi kin wanji ;

22 Qedeś wicaśta yatapi kin wanji; Jokneyam Karmel ekta wicaśta yatapi kin wanji ;

23 Dor Nopat (ipasotka) Dor wicaśta yatapi kin wanji ;

24 Tiretza wicaśta yatapi kin wanji; Wicaśta yatapi kin owa- sin wikcemna yamni sanpa wanjidan.

\section{WICOWOYAKE 13.}

1 Unkan Jośuwa wanna wicahinca, anpetu ota qehan Jehowa heciya, Wanna winicahinca anpetu ota iyahuni, qa makoce tankaya hin nahanhin tawayapi śni.

2 Makoce kin de nahanhin ecen han, Pilistim tamakocepi kin ocowasin, nakun Geśuri tamakocepi ocowasin.

3 Sihor wakpa kin he Egupta iwiyohiyanpa tanhan waziyatakiya Eqron makoce hehanyan, Kanani kin he tawapi kecinpi, Pilistim wicośkanśkan zaptan kin, Gazati kin, qa Aśdodi kin, qa Aśqeloni kin, Giti kin, qa Eqroni kin nakun Awim kin.

4 Itokaga tanhan Kanani tamakocepi ocowasin, qa Meyara (Makohdoka) Tzidoni kin he tawapi, Apeqa ekta Amori tamakocepi ihanke kin hehanyan.

5 Qa Gibeli tamakocepi kin; qa Lebanon wi hinanpe cin ekta kiya ocowasin, Bayal Gad, ஷ̇ermon he kin ihukuya yanke cin etanhan Ḣamat ekta cankuyapi kin hehanyan.

6 İe kin ounyanpi kin owasin. Lebanon etanhan Misrepat Maim (mini kata) ekta, Tzidoni kin owasin Israel cinca itokapa tanhan, nape wicawaye kta, tuka tawayapi kta e 1 srael niye wicakicipamni wo, econ ciśi kin he iyecen.

7 Heon wanna makoce kin de oeconna on wicoun napcinwanka qa Manaśe wicoun hanke tawayapi kta e wicakipamni wo.

8 He kici Rubeni qa Gadi kin makoce tawayapi kta e wanna icupi, he Mowis Jordan akasan- 


\section{JOŚUWA TAWOWAPI,}

pa wicaqu, hena Mowis Jehowa taokiye wicaqu kin he iyecen.

9 Aroyer Arnon huta akan un qa otonwe wakpa cokaya wanke cin etanhan, Medeba mdamdata kin ocowasin Dibon hehanyan.

10 Nakun Silion Amori wicaśta yatapi kin, Ḣeśbon en wicaśta yatapi totonwe owasin, Amon cinca tamakocepi kin hehanyan.

11 Nakun Gileyad, qa Geśuri kin, qa. Mayakati tamakocepi kin, qa Hermon he kin ocowasin, qa Baśan owasin Salka iyohiya.

12 Og Aśterot qa Edreyi idake cin tośkanśkan owasin, Baśan ohna iye iś nana Repaim etanhan okaptapi, hena Mowis wicakaśtake ça nape wicaya.

13 Tuka Israel cinca kin, Geśuri kin, qa Mayakati kin nape wicayapi śni, tuka Geśuri kin, qa Mayakati kin anpetu kin dehanyan Israel ehna ounyanpi.

14 Tuka Lewi wicoun kin makoce tawayapi kta takudan wica qu śni, Jehowa Israel Wakan dapi kin he petawośnapi tawa kin taku tawayapi kin hee kewicakiye ciqon he iyecen.

$15 \mathrm{Qa}$ Mowis Ruben cinca kin wicowazipi kin iyohiya wawicaqu ;

16. Qa tamakocepi kin Aroyer Arnon wakpa huta akan yanke cin etanhan, qa otonwe wakpa ohna yanka hetanhan mdamdata kin owasin, Medeba hehanyan.

17 Heśbon, qa totonwe mdamdata ohna wanke cin owasin, Dibon, qa Bamot Bayal, qa Bet Bayal Meyon;

18 Qa Jahatza, qa Qedemot, qa Mepayat;

19 Qa Qirataim, qa Sibma, qa Tzerat Sahar (Anpao iyega) kin, he Ḣe kaksiza ohna yanka.

20 Qa Betpeyon, qa A.śdot Pisga, qa Bet Jeśimot;
21 Qa mdamdata kin otonwe owasin, Sihion Amori wicaśta yatapi kin Ḣeśbon en ounye cin tośkanśkan ocowasin, Mow is he kaśtaka; nakun Midian itancan kin Ewi, qa Reqem, qa Tzur, qa Ḧur, qa Reba Silion tamdetanhunka makoce ounyanpi kin.

22 Israel cinca kin nakun $\mathrm{Ba}$ lam Beyor cinhintku waayate kin canhipi hi on ktepi, unman wicaktepi opeya.

23 Qa Ruben cinca kin tamakocepi ihanke kin Jordan ee, qa makóce kin he Ruben cinca taku tawayapi kin hee, otonwe kin hena, qa totonwe cikcistina.

24 Nakun Mowis Gad wicoun Gad cinca kin wawicaqu, wicowazipi lin iyecen.

25 Qa makoce tawapi kin he Jazer, qa Gileyad otonwe owasin, qa Amon cinca tamakocepi hanke, Aroyer Raba itokam yanke cin hehanyan.

26 Qa Heśbon etanhan Ramot Mitzepa (Iwanyakapi paha) kin ekta, qa Betonim, qa Mahanaim (Wicobe) etanhan Deber tamakoce ihanke kin hehanyan.

27 Qa Osmaka kin ohna Bet Haram (Teharwankantipi,) qa Betnimra, qa Sukot (ohanzihdepi,) qa 'Trapon; Silion Heśbon wicaśta yatapi kin tośkanśkan okaptapi, Jordan qa makoce Kineret mde ihanke ekta, Jordan akasanpa wihinanpe cin ektakiya.

$28 \mathrm{Gad}$ cinca kin makoce tawayapi kin hee, totonwepi, qa otonwe cikcistinna tawapi, wicowazipi kin iyecen.

29 Unkan Mowis Manaśe wicoun hanke wawicaqu; unkan Manaśe wicoun hanke kin wicowazipi kin iyecen he yuhapi.

30 Qa makoce tawapi kin dee: Mahanaim etanhan Baśan oco- 


\section{WICOWOYARE 14.}

wasin, Og Baśan wicaśta yatapi tośkanśkan ocowasin, Haw ot Jair (Jair totonwe) Baśan ohna otonwe wikcemna śakpe.

$31 \mathrm{Qa}$ Gileyad hanke, qa Aśtarot, qa Edreyi otonwe Baśan ohna, Og idake cin Manaśe cinhintku Makir cinca hanke kin wicowazipi kin iyecen yuhapi.

32 Makoce kin hena Mowis Moab makomdaya ohna, Jordan akasanpa, Jerilio iwiyohiyanpa tanhan tawayapi kta e wicaqu.

33 Tuka Lewi wicoun kin tawayapi kta Mowis wawicaqu śni. Jehowa Israel Wakandapi kin taku tawayapi kin hee; ewicakiye ciqon he iyecen.

\section{WICOW OYAKE 14.}

1 Unkan Kanan makoce ohna Eleyazar wawayuśna kin, qa Jośuwa Nun cinhintku, qa Israel cinca wicoun hunkayapi tokapapi kin Israel cinca taku tawayapi kta wicaqupi kin dee.

2 Oeconna eciya tanhan wicoun napcinwanka, qa wicoun hanke kin wawicaqupi; Mowis nape on Jehowa econ wicaśi kin he iyecen.

3 Mowis Jordan akasanpa wicoun nonpa, qa wicoun wan hanke taku tawayapi wicaqu nakaś, qa Lewi kin hena ehna taku tawayapi kta wicaqu śni.

4 Josep cinca kin wicoun nonpa, Manaśe qa Epraim, qa Lewi kin makoce ohna onśpa wicaqupi śni, tuka otonwe otipi kta, qa tinta otonwepi ilkiyedan tawotecapi on, qa tawanunyanpi on.

5 Token Jehowa Mowis econ śi kin he iyecen Israel cinca kin econpi, qa makoce kin pamnipi.

6 Unkan Juda cinca kin Jośuwa ikiyedan hipi Gilgal en, qa Kaleb Jepune cinhintku Qenizi kin he- ciya, Jehowa wicoie wan miye on, qa niye on Mowis Wakantanka wicaśta tawa eciye cin he sdonyaya.

7 Waniyetu wilkcemna matopa qehan Mowis Jehowa taokiye kin Qadeś Barneya etanhan makoce iwanyake kta u maśi, qa micante kin iyecen hośi wakaki. 8 Tuka misunka micihipi kin hena oyate cante kin skan kiyapi, qa miye Jehowa. Wakan wada kin ocowasin owapa.

9 Qa he ehan Mowis konza emakiya, Awicakehan makoce nisiha amani kin he niye, qa nicinca owihanke wanica tawa yapi kta e duhe kta, Jehowa Wakanyada kin ohinniyan oyapa heon etanhan.

10 Unkan inyun ehantanhan wanna waniyetu wikcemma topa sanpa zaptan, dehanyan Jehowa ni mayan, Jehowa wicoie kin he Mowis eciye cin hehantanhan Israel hewoskan manipi ; qa inyun nakaha anpetu kin de waniyetu wikcemna śahdogan sanpa mazaptan.

11 Qa anpetu kin dehantu, anpetu Mowis yemaśi kin he en wamaśaka, kizapi on qa inanpapi qa en hdipi on, token he ehan wamaśaka he iyecen dehan wamaśaka ce.

12 Heon wanna he kin de maqu wo, Jehowa anpetu kin he en eye cin he iyecen; niye anpetu kin he en, Anaqim hen yakonpi, qa tonwanyanpi kin tankinkinyan, qa aconkaślke yapi ce, eyapi nayation; Jehowa mici un kinhan nape wicawa ye kta, Jehowa eye cin he iyecen.

13 Unkan Jośuwa Kaleb. Jepune cinhintku yawaśte qa tawaye kta Ḧebron qu.

14 Heon Kaleb Jepune cinhintku Qenizi kin anpetu kin dehan- 


\section{JOŚUWA TAWOWAPI,}

yan Hebron tawaya, Jehowa Israel Wakandapi kin ohinniyan opa heon etanhan.

15 Wanakaja Ḧebron Qirjat Arba (Arba totonwe) eciyapi $A r b a$ he wicaśta iyotan tanka Anaqim ehna. Unkan makoce kin kicizapi etanhan iyoziya.

\section{WICOWOYAKE 15.}

^ Unkan Juda cinca wicoun, wicowazipi kin iyecen, oeconna eciya tanhan makoce tawayapi kin dee; Edom tamakoce ekta kiya Tzin tinta kin wiyotahan ekta kiya itokah ihanke ekta.

2 Qa makoce itokah ihanke kin dee; Miniskuya mde ihanke etanhan, ceji kin itokah kiya iyaye cin etanhan,

3 Qa Aqrabim (wamduśka) iyadipi itokah kiya iyaya 'Tzin ekta, qa Qadeś Barneya iyokaga tanhan tatowapa iyaya, qa Hetzron ahiyaya, qa tatowapa Adar ekta ya, qa Qarqaya ekta ihduhomni.

4 Qa Atzmon ekta ya, qa Egupta kaksiza ekta inanpa, hecen makoce ihanke kin de miniwanca ekta ihuni ; wiyotanhan ektakiya makoce ihanke kin he duhapi kta.

5 Qa wihinanpe cin ekta kiya makoce ihanke kin Miniskuya mde kin hee, Jordan mdote kin hehanyan. Qa waziyatakiya ihanke kin mde kahmi etanhan Jordan mdote etanhan,

6 Makoce ihanke kin tatowapa iyaya, Bet Ḣogla (śiyoti) ekta, qa Bet Araba iwaziyatanhan ya, qa icagopi kin Bohan Ruben cinhintku inyan tawa kin ekta, tatowapa ya ;

7 Qa Akor osmaka etanhan Debir ekta itanwankanhde icagopi, qa ihduhomni wazi yatakiya Gilgal ekta, he Adunmim itanwan- kanhdeyapi iyotakonza, kaksiza iyokaga tanhan, qa icagopi En śemeś (Anpetuwi wakoniya) mini ekta ye ça En Rogel (Iwanyakapi wakoniya) ekta ihuniya;

$8 \mathrm{Qa} \mathrm{Hinnom} \mathrm{cinhintku} \mathrm{kak-}$ siza ohna tatowapa ihanke icagopi, Jebusi heunnaptan (Jerusalem hee itokaga tanhan, qa tatowam icagopi he paha wan Hinnom kaksiza itokam yanke cin he ekta, wiyohpeyata kiya, he Repaim (Waziya) osmaka ihanke ekta yanka waziyatakiya.

9 Qa he paha etanhan Nepetowa mini wakoniya ekta icagopi, qa Epron he oconwe ekta ya, qa Bayala ekta ihanke kin icagopi, Qirejat Jeyarim (taskoju otonwe) kin hee;

10 Qa ihanke icagopi Bayala etanhan wiyohpeyata kiya ohomni yapi Seyir he kin ekta, qa Jeyarim (Taskoju) he unnaptan ekta iyaya, waziyatakiya Kesalon her, qa Betśemeś (Anpetuwiti) ekta apamahde ya, qa Timena ekta iyaya.

11 Qa Eqron icahda iwaziyata kiya ihanke icagopi, qa Śikeron ekta icagopi, qa Bayala he kin ekta iyaya, qa Jabenat ekta i, qa ihanke kin miniwanca ekta ihuni.

$12 \mathrm{Qa}$ miniwanca huta kin wiyohpeyeta kiya ihanke kin hee, Juda cinca wicowazipi kin iyecen ihdukśan ihanke icagopi kin hee.

13 Unkan Jośuwa token Jehowa econ śi kin he iyecen, Juda cinca ehna Kaleb Jepune cinhintku makoce onśpa qu, Anaq atkuku Arba totonwe Hebron hee.

14 Unkan Kaleb Anaq cinhintku yamni kin Śiśai, qa Ahiman, qa Talmai Anaq kicitonpi kin hena hetanhan nape wicaya.

15 Qa hetanhan itanwankanhde 


\section{WICOWOYAKE 15.}

iyaya, Debir ounyanpi kin ekta, qa he itokam Debir Qerejat Seper (Wowapi otonwe) eciyapi.

16 Unkan Kaleb heya, Tuwe Qerejat Seper kaśtake ca icu kin he micunkśi Aksa tawicu kta e waqu kta.

17 Unkan Kaleb sunkaku Qenaz cinhintku Otniyel he icu. Unkan cunwintku Aksa tawicu kta e qu.

18 Unkan ekta i qehan atkuku etanhan maga wan kida kta e iyopaśtaka, qa śonśonna etanhan makata iyahan; unkan Kaleb heciya, Taku yacin he?

19 Unkan heciya, Woyawaśte wan maqu ye. Makoce puza wanna maya qu, nakun minihidoka maqu ye. Unkan minihdoka tatowapa kin, qa minilidoka hukuya kin qu.

20) Iuda cinca wicoun wicowazipi iyecen makoce tawayapi kin dee.

$21 \mathrm{Qa}$ Juda cinca wicoun tonwanyanpi itokaga ihanke ekta Edom tamakoce ikiyedan dena ee, Qabetzel, qa Eder, qa Jagur,

22 Qa Qina, qa Dimona, qa Adada,

23 Qa Qedeś, qa Ḣatzor, qa Jitnan,

24 Zip, qa Telem, qa Beyalot,

$25 \mathrm{Qa}$ Hatzor teca kin, qa Qerejat Hetzron (Ḧetzron otonwe) Hatzor hee.

26 Aman, qa Śema, qa Molada. 27 Qa Hatzor gada (Wicotati) qa Heśemon, qa Bet Palet,

28 Ḣatzor śuyal (Sungidan otonwe) qa Berśeba (Wokonze minihdoka,) qa Bozejoteha,

29 Qa Bayala, qa Iyim, qa Yatzem,

30 Qa Ettolad, qa Kesel, qa Ḣorma,

31 Qa Tziqlag, qa Medmanna, qa Sansanna.
32 Qa Lebaot, qa Ślehim, qa Ayin, qa Rinmon; otonwe tankinkinyan owasin wikcemna nonpa sanpa napcinwanka, nakun otonwe cikcistinna tawapi.

$33 \mathrm{Qa}$ Śsepela (makoce hukuya) ohna dena ee, Eśtaol qa Tzora qa Aśena,

34 Qa Zanoha, qa En Gannim (carıojupi wakoniya,) Tapuha, qa Henam,

35 Qa Jarmut, qa Adullam, Soko, qa Azeqa,

36 Qa Śayaraim, qa Aditaim, qa Gedera (conkaśke) kin, qa Gederotairn, otonwe tankinkinyàn wikcemna sanpa topa nakun tontonwepi cikcistinna.

37 Tzenan, qa Ḣadaśa, qa Migdolgad,

38 Qa Dilan, qa Mitzepa, qa Jagtel,

39 Lakiś, qa Botzegat, qa Eglon,

40 Qa Kabon, qa Lahmas, qa Kitliś,

41 Qa Gederot (Conkaśke,) Betdagon, qa Nayama, qa Maqeda; Otonwe akeśakpe, qa totonwepi cikcistinna.

42 Libna qa Eter, qa Aśan, 43 Qa Jipta, qa Aśna, qa Net. zib,

44 Qa Qeyila, qa Akzib, qa Mareśa; otonwe napcinwanka, qa tatonwepi cikcistinna;

45 Eqron, qa cunwintku tawa, qa totonwe cikcistinna;

46 Eqron etanhan Miniwanca ekta Aśdod icahda hehanyan owasin, qa totonwepi cikcistinna.

47 Aśdod cunwintliu, qa totonwe cikcistinna, Gaza cunwintku, qa totonwe cikcistinna, Egupta kaksiza kin hehanyan, qa miniwanca ihanke kin hehanyan.

$48 \mathrm{Qa}$ he kin ohna Śamir, qa Jatir qa Sokn, 


\section{JOŚUWA 'TAWOWAPI,}

49 Qa Danna, qa Qirejat Sanna Debir hee.

50 Qa Anab, qa Estemo, qa Anim,

51 Qa Gośen, qa Ḧolon, qa Gila; otonwe akewanji, qa totonwepi cikcistinna.

52 Arab, qa Duma, qa Eśeyan, 53 Qa Janim, qa Bettapuha, qa Apeqa,

54 Qa Hirneta, qa Qirejat Arba Hiebron hee, qa 'Tziyor otonwe napcinwanka, qa totonwepi cikcistinna.

55 Mayon, Karmel, qa Zip, qa Juta,

$56 \mathrm{Qa}$ Jezrel, qa Joqdeyam, qa Zenoha.

57 Haqin, Gibeya, qa Timna; otonwe wikcemna, qa totonwepi cikcistinna.

58 Ḧalhul, Bet Tzur, qa Gedor, 59 Qa Mayarat, qa Bet Anot, qa Elteqon; otonwe śakpe, qa totonwepi cikcistinna ;

60 Qirejat Bayal, Qirejat.Jeyarim hee, qa Harabba (tanka kin) otonwe nonpa qa totonwepi cikcistinna.

61 Hewoskan Bet Araba (Makomdaya ti kin) Midin, qa Sekaka, 62 Qa Hanibśan, qa Yir Hamelah (Miniskuya otonwe,) qa Fin Gedi(tatokadan wakoniya,) Otonwe śakpe, qa totonwepi cikcistinna.

63 Tuka Juda cinca kin Jebusi Jerusalem ounyanpi kin nape wicayapi okitpanipi; heon Jebusi kin Juda cinca kin wicehna Jerusalem ounyanpi anpetu kin dehanyan.

\section{WICOWOYAKE 16.}

1 Unkan Josep cinca on oeconna eciya tanhan taku tawayapi kin dee, Jordan etanhan Jeriho iyotakonza, Jordan mini kin ekta wihinanpe cin etanhan hewoskan tatowapa he ohna Betel ekta.

2 Qa Betel etanhan inanpa Luz ekta qa Arki Atarot tamakoce ekta iyaya;

3 Qa wiyohpeyatakiya apamahde ya, Japleti tamakoce ekta, Bethoron hukuya kin tamakoce ekta, qa Gezer ekta qa oihuni kin miniwanca ekta.

4. Hecen Josep cinca Manaśe qa Epraim makoce tawayapi ;

5 Qa Epraim cinca kin wicowazipi kin iyecen makoce yuhapi, qa makoce tawayapi icagopi wihinanpe cin etanhan Atarot Adar Bethoron tatowapa kin ekta.

6 Qa miniwanca ekta icagopi Mikmeta iwaziya tanhan, qa wihinanpe cin elitakiya ohomni icagopi Taanat Śilo ekta, qa he opta iyaya Janoha iwiyohi yanpa tanhan.

7 Qa Janolia etanhan apamahde ya Atarot qa Nayarot ekta, qa Jeriho icahtaka, qa Jordan ekta ihuni.

$8 \mathrm{Qa}$ Tapulia etanhan wiyohipeyata kiya icagopi Qana kaksiza ekta, qa oihuni kin miniwanca lzin ekta. Epraim cinca wicoun makoce tawayapi kin hee wicowazipi kin iyecen.

9 Nakun Manaśe cinca makoce tawayapi ohna Epraim cinca on otonwe yukinukanpi, otonwe iyohi totonwe cikcistinna iyahna.

10 Tuka Kanani Gezer ounyanpi kin hena nape wicayapi śni, tuka Kanani kin Epraim ehna ounyanpi anpetu kin dehanyan, qa wowidake wolitani econpi.

\section{WICOWOYAKE 17.}

1 Unkan Manaśe wicoun makoce oeconna on tawaya, Josep cinhintku tokapa kin hee nakaś; 


\section{WICOW OYAKE $1 \%$.}

Makir Manaśe cinhintku tokapa kin Gileyad atkuku kin he wicaśta ozuyesa heca heon iye Gileyad qa Baśan yuha.

2 Qa Manaśe cinca unman kin wicowazipi kin iyecen Abiyezer cinca, qa Ḣeleq, cinca, qa Asriel cinca kin, qa Śekem cinca, qa Ḧeper cinca, qa Śsemida cinca, Josep cinhintku Manaśe cinca wica kin hena eepi, wicowazipi kin iyecen taku yuhapi.

3 Tuka Tzelopehad Heper cinhintku, Gileyad cinhintku, Makir cinhintku, Manaśe cinhintku, cinca wica nica, cunwintku eceedan, qa cunwintku cajepi kin dena eepi Mahla, qa Noya, Hogla, Milka, qa Tirtza.

4 Qa Eleyazar wawayuśna kin itokam qa Jośuwa Nun cinhintku itokam, qa itancanpi kin wicitokam ikiyedan hipi, qa heyapi, Jehowa sunka unyanpi wicehna makoce onśpa Mowis unqupi śi. Unkan Jchowa eye ciqon iyccen ateyapi hunka wanji wicaye cin wicehna tawayapi kta makoce onśpa wicaqu.

5 Unkan Manaśe oeconna on onśpa wikcemna tawayapi, qa nakun Jordan akasanpa Gileyad qa Baśan makoce kin.

6 Manaśe cunwintku iye cinca wica wicehna makoce onśpa tawayapi nakaś, qa Manaśe cinca unman kin Gileyad makoce tawayapi.

7 Qa Manaśe makoce kin Aśer etanhan icagopi, Mikmeta Śekem iyotakonza hee ekta, qa etapakiya yapi En Tapulia ounyanpi kin ektakiya,

8 Tapuha makoce kin he Manaśe tawaya, tuka Tapulia otonwe Manaśe makoce icahda un kin he Epraim yuha.

9 Qa hetanhan apamahde icagopi Qana (Cedi) kaksiza ohna, itokaga kaksiza otonwe kin hena Epraim tawa, Manaśe totonwe kin ehna, qa kaksiza iwaziya tanhan makoce kin he Manaśe tawa, qa icagopi kin miniwanca ekta ihuni.

10 Wiyntanhan ekta kiya Epraim tawa, qa tamakocepi kin miniwanca iyohi qa waziyatanhan Aśer icahtaka qa wihinanpa tanhan Isakar iyohi.

11. Qa Isakar ohna, qa Aśer ohna, Manaśe dena tawaya, Betśean qa otonwe cunkśiye cin, qa Jibleyam qa otonwe cunkśiwicaye cin, qa Dor ounyanpi kin qa cunkśiwicaye cin, qa En Dor qa cunkśiwicaye cin ounyanpi kin, qa Tayanak qa cunkśiwicaye cin ounyanpi kin, qa Mogiddo qa cunkśi wicaya ounyanpi kin, Napot (makoce pajodan) yamni.

12 Tuka Kanani kin makoce kin he ounyan kitanpi, heon Manaśe cinca kin otonwe kin hena etanhan nape wicayapi okitpanipi.

13 Tuka Israel cinca kin waśaka ayapi. qehan Kanani kin wowidake wolitani econ wicakiyapi, tuka ocowasin nape wicayapi śni.

14 Unkan Josep cinca kin iapi, qa Jośuwa heciyapi, Tolscea makoce tawayapi en oeconna wanjidan, qa onśpa wanjidan mayaqu he? Miye Jehowa dehanyan mayawaśte, qa dehan oyate matanka.

15 Unkan Jośuwa hewicakiya, Oyate nitanka hecinhan contanka ekta itanwan kanhde ya wo ; qa Perazi, qa Repaim tamakocepi ohna oyanke wan nicicakse kta, Epraim lie kin he nitawa nakaś.

16 Unkan Josep cinca kin heyapi, Ḣe kin iyounhipi śni, qa Kanani kin osmaka makoce ounyanpi kin hena owasin mazasapa canpahmihma yuhapi, Betśean 27 


\section{JOŚSUWA TAWOWAPI,}

qa cunkśiwicaye cin ounyanpi kin, qa Jezereel osmaka ounyanpi kin hena.

17 Unkan Jośuwa ie ca Josep tiyohnaka Epraim qa Manaśe hewicakiya, Oyate nitanka qa wowaśake nitawa kin he tanka. Oeconna wanjidan duhe kte śni.

18 Tulsa he kin he nitawa kta, contanka kin hee, qa he yakawanke kta, qa he oihuni kin nitawa kta, qa Kanani kin mazasapa canpahmihma yuhapi eśta, qa waśakapi eśta nape wicayaye kta.

\section{WICOWOYAKE 18.}

1 Unkan Israel cinca omniciye owasin witaya hiyupi, Śilo ekta, qa hen itkokipapi wakeya kin ehdepi ; wanna wicitokam makoce kin ohiyapi.

2 Tuka wicoun śakowin Israel cinca etanhan makoce tawayapi kta nahanhin icupi śni.

3 Unkan Jośuwa Israel cinca kin hewicakiya, Tohanyan nikujapi on makoce Jehowa nihunkakepi Wakan dapi kin nicupi kin he elta yaipi śni, qa iyacupi kte śni he?

4. Wicoun iyohi etanhan wicaśta yamni nicihdahnigapo. Unkan ye wicawaśi kta; hecen najinpi qa makoce kin omanipi $k$ ta, qa tawayayapi kta iyecen owapi, qa makahipi kta.

$5 \mathrm{Qa}$ he en onśpa sakowin icagopi kta; Juda wiyotanhan ektakiya malioce tawa ohna yakonpi lita, qa Josep tjyohnaka makoce tawa ohna yakonpi kta waziya takiya.

6 Tuka niyepi makoce kin owapo, okaśpa śakowin, qa den makahipo; qa den Jehowa itokam niyepi on oeconna ecamon kta.
7 Niyepi ehna Lewi kin okaśpa. yuhapi śni ; Jehowa wakiciyu. śnapi kin taku tawayapi kin hee nakaś; qa Gad, qa Ruben, qa Manaśe wicoun hanke kin taku tawa yapi kta wanna icupi, Jordan akasanpa wihinanpe cin ekta kiya, he Jehowa taokiye Mowis wicaqu.

8 Unkan wicaśta kin najinpi, qa iyayapi. Wanna Jośuwa, makoce owa iyayapi kin hena wahokon wicakiye ciqon, qa heya, Hopo, makoce iyaza ómanipi qa owapo, qa miye en hdipo; kinhan den Śilo ohna Jehowa ito.. kam, niyepi on oeconna ecamon kta.

9 Unkan wicaśta qon iyayapi, qa makoce kin iyaza omanipi, qa wowapi wan en otonwewe kin iyecen okaśpa śakowin owapi, qa Jośuwa en ahdipi, Silo wicoti ekta.

10 Unkan Jośuwa Śilo ohna, Jehowa itokam hena on oeconna econ; hecen Jośuwa hen makoce kin Israel cinca kin token yuhapikta wicakipamni.

11 Unkan Benjamin cinca wicoun kin on oeconna hiyu, qa oeconna on makoce icupi kin he Juda cinca kin qa Josep cinca kin otahedan.

$12 \mathrm{Qa}$ makoce tawapi waziyata ihanke kin Jordan etanhan tatowapa icagopi Jerilio icahda iwaziya tanhan, qa he ohna wiyohpeyata kiya itanwankan hdeya icagopi, qa Betawan (Takuśniti) hopuza ekta ihuni.

13 Qa hetanhan Luz ekta icagopi, Luz Betel hee itokah kiya icahda, qa okah kiya icagopi ; Yatarot Adar ekta, he wan Bethoron hukuya kin itokaga tanhan yanke cin ikiyedan.

$14 \mathrm{Qa}$ hetanhan wiyohpeyata ihanke on icagopi, qa itokah kiya 
yuhomnipi, qa Bethoron itokam he wanke cin etanhan itokahikiya icagopi, qa Qirejat Bayal Qirejat Jeyarim (Taśkoju otonwe) hee, Juda cinca totonwe wan hee elta ihuni; wiyohpeyata ihanke kin hee.

15 Qa itokaga ihanke kin Qirejat Jeyarim ihanke tanhan wiyolipeya tanhan iyaye ca Nepetolia mini wakoniya ekta ihuni.

$16 \mathrm{Qa}$ okali icagopi Hinnom cinhintku takaksiza iyotakonza he wanke cin he ihanke ckta, he Repaim osmaka ohna yanka waziyata kiya, qa. Hinnom takaksiza ohna okafi iyaya, Jebusi icahda itokali kiya, qa okah iyaya En Rogel (Iwanyakapi wakoniya) ekta.

17 Qa waziya tanhan icagopi, qa En Śemeś ekta ihuni, qa Gelilot he Adunmim itanwankanhde yapi kin iyotakonza wanke cin ekta ibuni, qa okah iyaya Ruben cinhintku Bohan inyan tawa ekta.

$18 \mathrm{Qa}$ Araba heonnaptan icahda wiziyata kiya iyaya, qa Araba ekta okah iyaya.

19 Qa variyata kiya icagopi Bet Ḧogla icahda, Jordan mdote kin ekta; itokaga ihanke kin hee. 20 Qa wihinanpe ektakiya ihanke kin Jordan hee. Benjamin cinca makoce tawa yapi kin ihdukśan icagopi kin hena ee, wicowazipi kin iyecen.

$21 \mathrm{Qa}$ Benjamin cinca wicoun, wicowazipi kin iyecen, otonwe kin dena yuhapi, Jeriho, qa Bet Hogla, qa Yemek, Qetzitze (osinaka śda.)

22 Qa Bet Araba, qa Tzemaraim, qa Betel.

23 Qa Hayawim, qa Hapara, qa Yopera.

24 Qa Amoni otonwe kin, qa Yopeni kin, qa Gaba; otonwe 22 wikcemna sanpa nonpa, qa totonwepi cikcistinna.

25 Gibeyon, qa Rama, qa Berot. 26 Qa Mitzpa, qa Kepira, qa Motzepa.

27 Qa Reqem, qa Jirpel qa Tarala.

28 Qa Tzela, Halep (Tatanka kin) qa Jebusi kin Jerusalem hee, Gebeyat, Qirejat: otonwe wikeemna sanpa topa, qa totonwepi cikcistinna; Benjamin cinca wi cowazipi kin iyecen makoce tawayapi kin hee.

\section{WICOWOYAKE 19.}

1 Unkan oeconna inonpa kin Simeon on hiyu Simeon cinca wicoun kin on, wicowazipi kin iyecen, qa makoce oeconna on tawayapi kin he Juda cinca tamakocepi ohna wanka.

2 Qa tamakocepi ohna otonwe kin dena yuhapi, Berśeba qa Śeba qa Molada.

3 Qa Ḣatzar śuyal (Śungidan otonwe, qa Bala, qa Atzem,

4. Qa Eltolad, qa Betul qa Ḧorma,

5 Qa Tziqlag, qa Bet markabot, qa Hatzar susa (Śuktanka otonwe.)

6 Qa Betlebaot (Mnajati,) Śarulien, otonwe wikcemna sanpa yจmni, qa to tonwepi cikcistinna. 7 Yain, Rinmon, Yeter, qa Yaśan, otonwe topa qa totonwepi cikcistina.

$8 \mathrm{Qa}$ otonwe kin hena ihdukśan otonwe cistinna owasin, Bayalatber ekta Ramot Negeb (Itokaga) hehanyan; Simeon cinca wicoun wicowazipi kin iyecen makoce tawayapi kin hee.

9 Juda cinca okaśpa tawapi kin he nina tanka, heon Juda cinca iwicakicagopi ohna Simeon cinca kin tawayapi. 


\section{JoŚUWA TAWOWAPI,}

10 Unkan oeconna iyamni kin Zebulun cinca kin on hiyu, wicowazipi kin iyecen, qa makoce tawayapi kin Sarid iyohiya.

11 Qa waziyata kiya icagopi mini wanca ekta, qa Marala ekta, qa Dabaśet icahtaka, qa kaksiza wan Jokneyam icahda wanke cin he iyohiya;

12 Qa ake Sarid etanhan wiyohiyanpa wihinanpe cin ekta kiya Kiselot Tabor makoce kin ekta ya, Daberat iyohi, qa tatowapa Japiya ekta ya.

13 Qa hetanhan wihinanpa ekta kiya iyaya Git Hீeper iwiyohiyanpa tanhan Yet Qatzin ekta, qa Rinmon ekta ihuni, qa icagopi winhya Neya ekta ya.

14 Qa icagopi kin hetanhan winh iyaya Hannatón iwaziya tanhan, qa oihuni Jepetael kaksiza kin ekta yanka.

15 Qa Qatat, qa Nahalal, qa Śi meron, qa Jedala, qa Betlehem, otonwe wikcemna sanpa nonpa, qa totonwepi cikcistinna.

16 Otonwe kin hena, qa totonwepi cikcistinna Zebulun cinca wicowazipi kin iyecen makoce tawayapi kin hee.

17 Qa oeconna itopa kin Isakar on hiyu, Isakar cinca kin on, wicowazipi kin iyecen.

18 Qa makoce tawapi kin otonwe dena iyohiya, Jezereel, qa Kesulot, qa Śnem,

19 Haparim, qa Sion, qa Anaharat,

20 Qa Rabit, qa Qiśeon, qa Abetze,

$21 \mathrm{Qa}$ Remet, qa Engannim, qa Enhada, qa Betpatzetze.

22 Qa makoce tawapi icagopi kin Tabor icahtaka, qa Śahotzim iyohi, qa Betśemeś; qa makoce tawapi kin Jordan iyohiya ; otonwe wikcemna sanpa śakpe qa totonwepi cikcistinna.
23 Isakar cinca wicoun wicowazipi kin iyecen makoce tawayapi kin hee, otonwe, qa totonwepi cikcistinna.

24. Unkan oeconna izaptan kin Aśer cinca wicoun on hiyu, wicowazipi kin iyecen.

25 Qa makoce tawapi icagopi krin otonwe kin dena iyohiya, Helgat, qa H̊ali, qa Beten qa Aksap,

26 Qa Alanmelek, qa Amad, qa Miśal, qa Karmel mini wanca icahda iyohi, qa Libenat (Janjan) wakpa kin.

27 Qa wihinanpe cin ekta kiya winh iyaya, Bet Dagon ekta, qa Zebulun ekta iyohi, qa Jiptahel osmaka kin waziyata kiya Bet Emeq (Osmaka ti) kin, qa Niyel, qa hehan Kabul catkatanhan iyaya;

28 Qa Yebron, qa Rehob, qa Ḧamon, qa Qana Zidon tanka kin iyohi.

29 Qa yuwinhya icagopi Rama ekta, qa otonwe conkaśke kin Tzur ekta, qa yuwinhya icagopi Hosa ekta, qa miniwanca ekta ihuni Akzib makoce ekta ;

30 Qa Unma, qa Apeq, qa Reliob, otonwe wikcemna sanpa nonpa, qa totonwepi cikcistinna. 31 Otonwe kin hena, qa totonwepi cikcistinna kin makoce Aśer cinca wicoun tawayapi kin hee.

32 Oeconna iśakpe kin Naptali cinca on hiyu, Naptali cinca on wicowazipi kin iyecen.

33 Qa makoce ta wapi kin Ḧelep etanhan, qa Tzayananim utuhu oju etanhan, qa Adami Neqeb. (Imnija ohdoka kin,) qa Jabenet, Lequm ekta hehanyan, qa Jordan ekta iyohiya,

34 Qa ihdamna icagopi wiyohpeyata kiya, Azenot Tabor ekta, qa hetanhan Ḧuqoq ekta iya- 


\section{WICOWOYAKE 20.}

ya, qa itokaga ektakiya Zebulun iyohi, qa wiyohpeya tanhan Aśer iyohi, qa wihinanpa ekta Jordan Juda en.

35 Qa otonwe conkaśke kin dena Tridim, 'Tzer, qa Hamat, qa Raqet, qa Kinneret,

36 Qa Adama, qa Rama, qa Hatzor,

37 Qa Qedeś, qa Edreyi, qa En Ḧatzor,

$38 \mathrm{Qa}$ Jireon, qa Magdolel, Ḣoram, qa Bet Anat, qa Bet Śemeś ; otonwe wikcemna sanpa napcinwanka, qa totonwepi cikcistinna.

39 Naptali cinca wicoun wicowazipi kin iyecen makoce tawayapi kin hee; otonwepi, qa totonwepi cikcistinna.

40 Oeconna iśakowin kin Dan cinca wicoun on hiyu, wicowazipi kin iyecen.

$41 \mathrm{Qa}$ makoce tawayapi kin dee, 'Yzora, qa Eśtaol, qa Yirśemeś (Anpetuwi otonwe.)

42 Qa Sayalbim, qa Ajalon, qa Jitela,

43 Qa Elon, qa Timenat, qa Eqron:

44 Qa Elteqa, qa Gibbeton, qa Bayalat,

45 Qa Jehud, qa Beneberaq, qa Gat Rinmon.

46 Qa Me Jarqon (Minizi,) qa Raqon, makoce Jopa iyotakonza kin iyahna.

47 Qa Dan cinca makoce tawapi iyowicahi śni, heon Dan cinca kin itanwankanhde ipi, qa Leśem azuyapi, qa icupi, qa canhipi hi on kaśtakapi, qa tawayapi, qa hen iyotankapi, qa Leśem Dan eciyapi, Dan ateyapi caje kin on:

48 Dan cinca wicoun wicowazipi kin iyecen makoce tawayapi kin hee.

49 Unkan makoce icagopi kin iyecen kicipamnipi yuśtanpi ; qa Israel cinca iyepi ehna Jośuwa
Nun cinhintku makoce onśpa qupi.

50 Jehowa eye cin iyecen, otonwe wan da kin he qupi; Timnat Seral hee Epraim he kin ohna. Unkan otonwe kin he kaga, qa he ohna ti.

51 Eleazar wawaynśna kin, qa Jośuwa Nun cinhintku, qa Israel cinca wicoun ateyapi tokapapi kin Śsilo ohna Jehowa itokam, itkokipapi wakeya tiyopa ekta, oeconna on makoce pamnipi kin hena ee, hecen makoce kin pamnipi kin yuśtanpi.

\section{WICUWOYAKE 20.}

1 Unkan Jehowa ie ça Jośuwa heciya.

2 Wowinape otonwe ihdahnigapo, Mowis nape on ociciyakapi qon he iyecen, Israel cinca kin ewicakiya wo.

3 Hecen tuwe iyukcan śniyan wicanagi wan wanun ape ca kte kinhan, heciya najice kta; qa we tokicon kin etanhan hena wowinape duhapi kta.

4. Qa tuwe otonwe kin hena wanji ekta nape, ca otonwe tiyopa ekta najin, qa otonwe kin hunkayapi nogepi kin ohna ie ca toketu owicakiyake cinhan, iyepi ehna otonwe kin en hiyuyapi kta; qa oyanke wan qupi kta, unkan hen yanke kta.

5 Unkan we tokicon kin he kuwa kinhan; he nape en wicaśta tin kte kin hiyuyapi kte śni; takodaku itokam śicedake śni, tuka sdon ye śni he ape nakaś.

6 Unkan otonwe kin he en yanke kta, omniciye wayaco kin itokam najin kte cin, qa wawayuśna itancan anpetu kin hena en ni kin, he te kte cin hehanyan; hehan wicaśta tin kte kin kihde kta, qa otonwe etanhan najica 


\section{JOŚUWA TAWOWAPI,}

qon, iye totonwe, qa toti kin ekta ki kta.

7 Unkan Qedeś Galile ohna Naptali he kin en, qa Śekem Epraim he kin en, qa Qirijat Arba, Ḣebron hee, Juda lie kin ohna yuwakanpi.

8 Qa Jordan akotahan Jeriho iwiyohiyanpa tanhan Ruben wicoun etanhan, Betzer, he tinta ohna yanka, makoce mdaye ohna ; qa Gad wicoun etanhan Ramot, he Gileyad ohna yanka ; qa Manaśe wicoun etanhan Golan, Baśan ohna.

9 Otonwe kin hena wowinape on qupi, Israel cinca owasin on, qa tuwe tokeca wicehna ounye cin on, tuwe kaśta wicanagi wan wanun ape cinhan hena wanji en nape kta, qa omniciye itokam najin śni kin hehanyan we tokicon nape kin on țe kte śni.

\section{WICOWOYAKE 21.}

1 Unkan Lewi ateyapi tokapapi kin Eleazar wawayuśna kin ekta, qa Jośuwa Nun cinhintku ekta, qa Israel wicoun ateyapi tokapapi ekta ikiyedan hiyupi.

-2 Qa Silo ohna Kanan makoce ohna iapi, qa hewicakiyapi, Jehowa Mowis nape on otonwe olma untipi kta, qa hena ihdukśan tinta wanunyanpi unkitawapi on unqupi niśi.

3 Unkan Israel cinca kin makoce tawayapi etanhan Jehowa eye ciqon iyecen otonwe kin dena, qa tinta kin hena ikiyedan Lewi kin wicaqupi.

4 Unkan Qohati wicowazipi on oeconna kin hiyu, qa Lewi Aȧron wawayuśna cinca kin oeconna on Juda wicoun etanhan, qa Benjamin wicoun etanhan qa Simeon wicoun etanhan otonwe ake yamini yuhapi.
5 Qa Qohat cinca unmanpi kin Epraim wicoun etarıhan, qa Dan wicoun etanhan, qa Manaśe wicoun hanke kin etanhan wicowazipi kin etanhan oeconna on otonwe wikcemna ynhapi.

6 Unkan Gerśon cinca kin Isakar wicoun etanhan, qa Aśer wicoun etanhan, qa Naptali wicoun etanhan, qa Manaśe wicoun hanke Baśan en, wicowazipi kin etanhan otonwe wikcemna sanpa yamni yuhapi.

$7 \mathrm{Qa}$ Merari cinca kin wicowazipi kin iyecen Ruben wicoun etanhan, qa Gad wicoun etanhan, qa Zebulun wicoun etanhan otonwe wikcemna sanpa nonpa yuhapi.

8 Unkan Israel cinca kin otonwe kin dena, qa hena ihdukśan tinta ikiyedan Lewi kin wicaqupi, oeconna on Jehowa Mowis nape on econ wicaśi kin he iyecen.

$9 \mathrm{Qa}$ Juda cinca wicoun etanhan, qa Simeon cinca wicoun etanhan otonwe cajeyatapi kin dena qupi.

10 Qa Lewi cinca etanhan Qolati wicowazipi etanhan Aaron cinca kin hena yuhapi; oeconna tokaheya kin he tawapi nakaś.

11 Unkản Arba Anaq atkuku totonwe Hiebron hee Juda be kin ohna, qa tinta ihdukśan ikiyedan wicaqupi.

12 Tuka otonwe tamaga kin, qa totonwe cikcistinna kin Kaleb Jepunne cinhintku tawaye kta e qupi.

13 Unkan Aaron wawayuśna kin cinca kin Æ̈ebron qa tinta ihdukśan kin wowinape otonwe, tinwicakte kin on, wicaqupi, nakun Libna qa tinta ibdukśan;

14. Qa Jatur, qa tinta ihdukśan qa Estemoya qa tinta ihdukśan; 


\section{WICOWOYAKE 21.}

15 Qa Holon qa tinta ihdukśan, qa Debir qa tinta ihdukśan,

16 Qa Ayin qa tinta ihdukśan, qa Juta, qa tinta ihdukśan, qa Betśemeś qa tinta ihdukśan, o tonwe napcinwanka wicoun nonpa kin hena etanhan.

$17 \mathrm{Qa}$ Benjamin wicoun etanhan Gibeyon qa tinta ihdukśan; qa Geba, qa tinta ihdukśan :

$18 \mathrm{Qa}$ Anatot, qa tinta indukśan, qa Almon qa tinta ihdukśan, otonwe topa.

19 Otonwe Aaron cinca wawayuśnapi kin yuhapi owasin otonwe wikcemna sanpa yamni; qa tinta hena ihdukśan.

$20 \mathrm{Qa}$ Qohat cinca unmanpi, Qohat cinca Lewi wicowazipi etanhan, oeconna on Epraim wicoun etanhan otonwe yuhapi :

21 Qa Epraim he kin ohna Śekem qa tinta ihdukśan, wowinape otonwe tin wicakte kin on wicaqupi, qa Gezer qa tinta ihdukśan ;

22 Qa Qebetzaim qa tinta ihdukśan, qa Bethoron (Woha tipi) qa tinta ihdukśan, otonwe topa.

$23 \mathrm{Qa}$ Dan wicoun etanhan Elteqa qa tinta ihdukśan, qa Gibbeton qa tin ta ihdukśan;

24 Qa Aijalon, qa tinta ihdukśan, qa Gatrinmon qa tinta ihdukśan, otonwe topa.

25 Qa Manaśe wicoun hanke etanhan Tayanak qa tinta ihdukśan, qa Gat Rinmon qa tinta ihdukśan, otonwe nonpa.

26 Qohat cinca wicowazipi unman on otonwe owasin wikcemna, qa tinta hena ihdukśan.

27 Unkan Lewi wicowazi Grelśon cinca kin Manaśe wicoun hanke etanhan, Baśan ohna Golon wowinape otonwe tin wicaktc kin on, qa tinta ihdukśan, qa Bayeśterat qa tinta ihdukśan, otonwe nonpa wicaqupi.
$28 \mathrm{Qa}$ Isakar wicoun etanhan Qiśeon qa tinta ihdukśan, qa Daberet qa tinta ihdukśan,

29 Qa Jarmut, qa tinta ihdukśan, qa Engannim qa tinta ihdukśan, otonwe topa.

30 Qa Aśer wicoun etanhan Miśal qa tinta ihdukśan qa $\mathrm{Ab}$ don qa tinta ihdukśan;

31 Qa Ḣelgat qa tinta ihdukśan, qa Rehob qa tinta ihdukśan, otonwe topa.

32 Qa Naptaii wicoun etanhan Qedeś qa tinta ihdukśan, Galile ohna wowinape otonwe tin wicakte kin on, qa Hamat Dor qa tinta ihdukśan, qa Qaretan qa tinta ihdukśan, otonwe yamni.

33 Gerśoni totonwepi owasin wicowazipi kin iyecen otonwe wikcemna sanpa yamni, qa tinta hena ihdukśan.

34 Unkan Lewi unmanpi kin Merari cinca wicowazipi kin Zebulun wicoun etanhan Joqneyam qa tinta ihdukśan, qa Qareta qa tinta ihdukśan,

35 Dimna qa tinta ihdukśan, qa Nahalal qa tinta ihdukśan otonwe topa.

$36 \mathrm{Qa}$ Ruben wicoun etanhan Betzer qa tinta ihdukśan, qa Jahatza qa tinta ihdukśan,

37 Qedemot qa tinta ihdukśan, qa Mepayat qa tinta ihdukśan otonwe topa.

38 Qa Gad wicoun etanhan Gileyad ohna Ramot wowinape otonwe tinwicakte on, qa tinta ihdukśan, qa Mahanaim qa tinta ihdukśan ;

39 Ḣesbon qa tinta ihdukśan, Jazer qa tinta ihdukśan otonwe topa.

40 Lewi wicowazipi okaptapi Merari cinca wicowazipi kin on otonwe oeconna on wicaqupi owasin otonwe wikcemna sanpa nonpa. 


\section{JOŚUWA TAWOWAPI,}

41 Lewi totonwepi owasin Israel cinca makoce yuhapi ohna, otonwe wikcemna topa sanpa śahdogan, qa tinta kin hena ihdukśan.

42 Otonwe hena owasin otonwe iyohi tinta ihdukśan kicica, otonwe owasin hececa.

43 Hecen Jehowa, Israel makoce hunkake wicayapi wicaqupi lita konza ewicakiye ciqon, he owasin wicaqu, unkan tawayapi, qa en iy otankapi.

44 Qa Jehowa hunkake wicayapi konza ewicakiye ciqon iyecen wicihdukśan iyozi wicaqu; hecen toka wicayapi owasin etanhan tuwedan wicitokam najin śni, Jchowa napcpi en tokawicayapi owasin wicaqu.

45 Wicoie waśte Jchowa Israel tiyohnaka kewicakiya owasin ecetu, wicoie ecetuśni wanica.

\section{WICOWOYAKE 22.}

1 Hehan Jośuwa Rubeni kin, qa Gadi kin, qa Manaśe wicoun hanke kin wicakico;

2 Qa hewicakiye; Taku Mowis Jehowa taokiye econ niśipi kin owasin yapatanpi, qa taku miye econ ciśipi owasin maho kin nayahonpi ce.

3 Anpetu ota lín dena, anpetu kin dehany an nihunkawanjipi kin awicaduśtanpi śni, qa Jehowa Wakanyadapi tawoahope patan niśipi kin hena yapatanpi.

4 Unkan warna Jehowa Wakan yadapi kin nihunka wanjipi oziwicaya, ewicakiya qon he iyecen; heon wanna kihdapo, qa makoce tawa yayapi Mowis Jehowa taokiye niçupi kin Jordan akasanpa, nitawakeyapi kin ekta hdapo.

5 Tuka woahope, qa woope Mowis Jehowa taokiye ope niśi- pi kin ecen ecanompi kta, qa Jehowa Wakan yadapi kin waśte yadakapi kta, qa tacanku kin owasin omayanipi kta, qa tawoahope oyapapi kta, qa iye kin en ikoyag niyanpi kta, qa nicantepi ocowasin on, qa ninagipi ocowasin on oyapapi kta e nina waktaya unpo.

6 Unkan Jośuwa wicayawaśte, qa kihde wicaśi ; unkan tawakeyapi ekta kihdapi.

7. Wanna Mowis Manaśe wicoun hanke Baśan ohna taku wicàqu, qa hanke kin Jośuwa Jordan itato wiyohpeyata kiya taku wicaqu, hunkawanji wicayapi wicehna, qa tawakeyapi ekta kihde wicaya, qa wicayawaśte qehan,

8 Hewicakiya, Wowijice ota yuha nitawakeyapi ekta hdapo: nakun wanuny anpi nina ota hin, qa mazaska, qa mazaskazi, qa maza sapa, qa mazaśa, qa wokoyake otahinca, nihunkawanjipi om wayuha tokawicayayapi kin ctanhan wicayakipi kin yuakipam ahdapo.

9 Unkan Ruben cinca, qa Gad cinca, qa Manaśe wicoun hanke kin kihdapi ; qa Israel cinca etanhan, Śsilo Kanan makoce ohna wanke cin etanhan iyayapi, qa Gileyad makocc ekta makose tawayapi kin, Jehowa eciya tanhan Mowis nape on yuhe wicakiyapi kin le ekta yapi.

10 Qa Jordan Gelilot (huta) kin ekta ipi, he Kanan makoce ohna un, qa Ruben cinca, qa Gad cinca, qa Manaśe wicoun hanke kin hen, Jordan icahda wahna wośnapi wan kagapi, wahna wośnapi tanka, atonwanpi kta heon.

11 Unkan Israel cinca kin hecen eya nahonpi, Inyun Ruben cinca, qa Gad cinca kin, qa $\mathrm{Ma}$ naśe wicoun hanke kin wahna 


\section{WICOWOYAKE 22.}

wośnapi wan kagapi, Kanan makoce icahda; Jordan huta akan, Israel cinca kin akasanpa tanhan.

12 Israel cinca kin he nahonpi, qa Israel cinca ornniciye owasin witaya hiyupi, Ślo ekta, qa wicakizapi kta ekta yapi kta.

13 Unkan Israel cinca kin Ruben cinca kin, qa Gad cinca kin, qu Manaśe wicoun hanke ekta Pinehas Eleazar wa wayuśna cinhintku kin yeśipi, Gileyad ekta.

14 Qa he kici wicaśta itancan wikcemna, Israel wicoun owasin ehna atewicayapi tiyohnaka iyohi on itancan wanjidan, Israel kektopawingege ehna ateyapi tiyohnakapi wicaśta tokapa hecapi.

15 Unkan Gileyad makoce ekta, Ruben cinca, qa Gad cinca, qa Manaśe wicoun hanke ekta ipi, qa iapi, qa hewicakiyapi;

16 Jehowa taomniciye owasin hecen eyapi, Tokeca wokipajin kin de on Israel taku Wakandapi kin yakipajinpi, qa nakaha Jehowa etanhan nihduhomnipi, qa anpetu kin de Jehowa yakıpajinpi en wahna wośnapi wan niçicagapi kin.

17 Peyor ekta waunhtanipi, qa Jehowa taomniciye en makośice yukan, qa anpetu kin dehanyan etanhan unyuskapi śni he cistinna kecannipi he?

18 Qa heon nakaha Jehowa etanhan nihduhomnipi he? Nakaha Jehowa yakipajinpi, heon heyakecinhan Israel omniciye owasin canniye wicaye kta.

19 Hiya makoce tawayayapi kin he śape cinhan, Jehowa makoce tawa ye cin, qa Jehowa ti kin olma yanke cin he ekta hiyuwegapo, qa unkiyepi ehna tawayapo ; tuka ihnuhan Jehowa yakipajinpi kin, qa ihnuhan unkiyepi en yakipajinpi, qa wahna wośnapi, Jehowa Wakan undapi tawa kin isanpa wahná wośnapi wan nicicagapi kin.

20 Akan Zerah cinhintku kin taku yawakanpi kin en wahtani, qa heon Israel omniciye owasin en wocanniye yuke śni he? hecen wicaśta kin he tolian śica on iś nana te śni.

21 Unkan Ruben cinca kin, qa Gad cinca kin, qa Manaśe wicoun hanke kin ayuptapi, qa Israel kektopawinge itancanpi kin hewicakiyapi ;

23 Jehowa taku wakan iyotan waśaka, Jehowa taku wakan iyotan waśaka sdonya, qa Israel sdonye kta, wokipajin on econkupi kinhan, qa Jehowa en waunhtanipi kta heconkupi kinhan, nakaha niunkiyapi śnipo.

23 Jehowa etanhan unkihduhomnipi kta e wahna wośnapi wan unkiçicagapi kinhan, qa akan wohulinaliyapi, qa minha huhnahunyanpi kta, qa akan wopida wośnapi waunkiyuśnapi kta e unkagapi kinhan, Jehowa he iwanga nun we.

24 Tuka taku kin de ikounkipapi, heon heconkupi, qa unkeyapi, okini tokata nicincapi unkicincapi hewicakiyapi kta, Jehowa Israel Wakandapi kin en taku iyoniwajapi he?

25 Ruben cinca, qa Gad cinca, niyepi qa unkiyepi otahedan Jehowa Jordan oicago unqupi, Jehowa en niyepi takudan tawayayapi śni; hecen nicincapi kin unkicincapi wicayuhomnipi kta on Jehowa kokipapi kte śni.

$26 \mathrm{Qa}$ unkeyapi. Ito wahna wośnapi wan unkiçicagapi, akan wohulinahyapi, qa wośnapi liuhnah unyanpi kta heon etanhan śni ;

27 'Tuka unkiyepi, qa niyepi 35. 


\section{JOŚUWA TAWOWAPI,}

otahedan, qa wicoicage unkitawapi unkihakam he wayaatanin un kta; wohuhnahyapi, qa wośnapi, qa wopida wośnapi unkitawapi on Jehowa ohoundapi kta, iye itokam, qa tokata, Jehowa en takudan tawa yayapi śni nicin-. capi unkicincapi ewicakiyapi kte śni.

28 Heon unkeyapi, Tokata tohan heunkiyapi, qa unkicincapi hewicakiyapi kinhan unkeyapi kta, Iho Jehowa tawahna wośnapi ouncage kin he wanyakapo; hunkake wicunyanpi kin wohuhnahyapi on, etanhan śni, tuka unkiyepi, qa niyepi otahedan woyaatanin yanke kta e he kagapi.

29 Jehowa unkipajinpi iyounkipipi śni nunwe; qa nakaha Jehowa etanhan unkihduhomnipi, qa Jehowa Wakan undapi tawahna wośnapi toti kin itokam yanke cin icunonpa tanhan wahna wośnapi wan wohulinahyapi on, qa minha on, qa wośnapi on unkagapi kta iyececaśni.

30 Unkan Pinehas wawayuśna kin, qa omniciye itancanpi kin Israel kektopawinge en wicaśta tokapapi iye opapi. kin wicoie Ruben cinca, qa Gad cinca, qa Manaśe cinca eyapi kin nahonpi qehan he iyowicakipi.

$31 \mathrm{Qa}$ Pinehas Eleazar wawayuśna cinhintku kin Ruben cinca, qa Gad cinca, qa Manaśe cinca kin hewicakiya, Nakaha Jehowa unkiyepi ehna un kin sdonunyanpi, qa woecon kin de en yakipajinpi śni ; hecen Israel cinca kin Jehowa nape kin etanhan ewicayahdakupi.

$32 \mathrm{Qa}$ Pinehas Fleazar wawayuśna cinhintku, qa wicaśta itancan qon Ruben cinca, qa Gad cinca etanhan kihdapi; Gileyad makoce etanhan Kanan makoce ekta, Israel cinca ekta, qa hośi wicakahipi.

33 Unkan wicoie kin Israel cinca kin iyokipipi, qa Israel cinca kin Wakantanka yawaśtepi, qa Ruben cinca, qa Gad cinca kin, azuwicayapi kta, qa makoce en ounyanpi kin ihang yapi kta eyapi śni.

34 Unkan Ruben cinca kin, qa Gad cinca kin wahna wośnapi kin Ed (Wayaatanin) eciyapi; Jehowa Wakantanka ee unkiyepi otahedan he wayaatanin kta, eyapi nakaś.

\section{WICOWOYAKE 23.}

1 Unkan Jehowa Israel wicihdukśan toka wicayapi owasin etanhan iyozi wicaya ohakam tehantu, qa Jośuwa anpetu ota wicahinca qehan ;

2 Jośuwa Israel owasin wicakico, wicahincapi, qa itancanpi, qa wayacopi, qa wowapi kagapi, qa hewicakiya, Miś wanna wicamahinca, anpetu maota.

3 Qa niyepi on Jehowa Wakanyadapi kin ikce wicaśta kin dena owasin taku ecawicakicon owasin wandakapi; Jehowa Wakan yadapi kin he niyepi on kiza nakaś.

4 Wanyakapo, oyate okaptapi kin hena owasin, oyate wicawakaśpe kin owasin om, wicoun nitawapi tawa yayapi kta e cicipamnipi. Jordan etanhan miniwanca wi iyaye cin ekta kiya hehanyan.

$5 \mathrm{Qa}$ Jehowa Wakan yadapi kin iye hena nitokapa tanhan nape wica ye kta, qa nitokam wicakahape kta, qa makoce tawapi kin, tawa yayapi kta, Jehowa Wakan yadapi eniciyapi qon iyecen.

6 Heon Mowis toope wowapi 


\section{WICOWOYAKE 24.}

en taku owapi kin owasin yapatanpi kta, qa ecen ecanonpi kta e wakiśakapo, hetanhan nihduhomnipi kte śni, etapa qa catka unman tukte kaśta ekta kiya.

7 Hecen ikce wicaśta kin hena niyepi ehna okaptapi kin en yaipi kte śni, qa taku wakandapi caje kin yeksuyapi kte śni, qa Namahon ehapi kte śni, qa ohowicayadapi kte śni, qa wicitokam yapatujapi kte śni.

8 Tuka Jehowa Wakan yadapi en ikoyag niyanpi kta, anpetu kin dehanyan ecanonpi iyecen.

9 Qa Jehowa nitokapa tanhan oyate tanka, qa waśaka nape wicaya, qa niyepi itokam anpetu kin dehanyan, tuwedan najinhan okihi śni.

10 Niyepi etanhan wicaśta wanjidan opawinge wicakuwa kta, Jehowa Wakan yadapi kin iye niyepi on kize kta nakaś, eniciyapi qon iyecen.

11 Heon Jehowa Wakan yadapi kin waśte yadakapi kta e ninagipi nina yapatanpi kta.

12 Tuka nihduhomnipi, qa ikce wicaśta okaptapi kin dena ekta ikoyag niyanpi, niyepi om okaptapi kin dena cunwintkupi duzapi, qa nicunkśipi wicayaqupi kinhan; hena elsta yaipi, qa iyepi en nihipi kinhan;

13 Jehowa Wakan yadapi kin oyate kin dena nitokapa tanhan sanpa nape wicaye kte śni, tuka mazahtakiyapi, qa wihmuke iyecen nici unpi kta, qa nicuwipi ekta icapsinte hecapi kta, qa niiśtapi en wapepeka hecapi kta, maka waśte kin de Jehowa Wakan yadapi nicupi kin hetanhan ihang niyanpi kta hehanyan, he tanyan sdonyapo.

$14 \mathrm{Qa}$ nakun iny un miye wicaśta maka owancaya yapi kin heciya nakaha mde kta; qa wicoie wa- śte Jehowa Wakan yadapi eniciyapi kin owasin etanhan wanjidan ihpaye śni, nicantepi owasin en, qa ninagipi owasin en sdonyayapi; owasin niyepi en iyonihipi, hetanhan wicoie wanjidan ihpaye śni.

$15 \mathrm{Qa}$ token wicoie waśte Jehowa Wakan yadapi eniciyapi qon owasin iyonihipi kin, he iyecen Jehowa wicoie śice cin hena iyohi niyanpi kta; ecen maka waśte kin de, Jehowa Wakan yadapi niçupi kin etanhan ihang niyanpi kta.

16 Wicotakuye Jehowa Wakan yadapi ope niśipi kin he acayakśinpi kinhan, qa toki dapi, qa taku wakan tokeca ohoyadapi, qa hena ekta patuś niçiyapi kinhan, Jehowa tocanniye kin aide niyanpi kta, qa ecadan makoce waśte kin detanhan ihang niyanpi kta.

\section{WICOWOYAKE 24.}

1 Unkan Jośuwa Israel wicoun owasin Śsekem ekta mniciye wicaśi, qa Israel hunkayapi, qa wicaśta tokapapi, qa wayacopi, qa wowapi kagapi wicakico ; unkan Jehowa itokam ahinajinpi.

2 Unkan Jośuwa oyate owasin hewicakiya, Jehowa Israel Wakan dapi kin hecen eya, Nihunka kepi ehanna wakpa kin akasanpa tipi, Terah Abereham atkuku, qa Nahor atkuku, qa taku wakan tokeca ohodapi.

3 Qa Abereham ateyayapi kin wakpa kin akasanpa tanhan iwacu, qa Kanan makoce owancaya omani wakiya, qa iye cinca kin mduota qa Izak waqu.

4 Unkan Izak Jakob qa Esa waqu; qa Esa Seyir lie kin tawa ye kta e waqu; tuka Jakob, qa iye cinca kin Egupta ekta apamahde ipi. 


\section{JOŚUWA TAWOWAPI,}

5 Unkan Mowis qa Aaron yewicawaśi, qa Egupton awicawapa, taku ecawicawecon kin iyecen; qa ohakam hetanhan hdinanpe ciyapi.

6 Qa ate yayapi Egupta etanhan inanpe wicawaye ca mde kin ekta yahipi. Unkan Egupton niyatepi wicakuwapi, canpahmihma, qa śuktanka on Mdeśa en.

7 Unkan Jehowa ho yekiyapi qehan, niyepi qa Egupton otahedan otpaza hiyuya qa mde kin hena wiciwankam hiyuya, qa akahpe wicaya, qa niiśtapi taku Egupton ecawicawecon kin wanyakapi, qa hewoskan anpetu ota yatipi.

8 Unkan Amori Jordan akasanpa tipi qon tamakocepi ek ta hiyu ciyapi. Unkan nicizapi; unkan ninapepi en wicawa qu. Unkan makoce tawapi kin he iyacupi; unkan niyepi itokam ihang wicawaya.

9 Unkan Balaq Tzipor cinhintku kin Moab wicaśta yatapi kin najin, qa Israel azuya, qa Balam Bezor cinhintku kin ekta ye wicaśi qa niyaśicapi kta e kico.

10 'Tuka Balam nawahon tawațen waye śni. Unkan nina niyawaśtepi, hecen nape kin etanhan ecihdakupi.

11 Unkan Jordan iduwegapi, qa Jerilio ekta yahipi. Unkan Jeriho itancan, kin qa Amori kin; qa Perizi kin, qa Kanani kin, qa Ḧiti kin, qa Girgaśi kin, qa Hiwi kin, qa Jebusi kin nicizapi, qa ninapepi en wicawaqu.

12 Unkan niyepi itokam tulimaga ye waya; unkan niyepi itokapa tanhan Amori wicaśta yatapi nonpa kin nape wicaya, niyepi caulipi nitawa, qa nitinazipe on hecanonpi śni.

13 Unkan makoce wan ciçupi 38 kin heon hitayanipi śni, qa nakun otonwe yakagapi śni; unkan hena ohna yatipi, hastahanka iyuwi qa wihdican ojupi hu yahdepi śni kin, hena etanhan yatapi.

14 Heon Jehowa ho kin kokipapo, qa ecetuyahin, qa wowicake en ohodapo, qa taku wakan nihunkakepi wakpa akasanpa, qa Egupta ohna ohodapi kin hena etanhan ihduhomnipo, qa Jehowa ohodapo.

15 Tuka Jehowa ohodapi kin he niiśtapi en śice cinhan, tuwe ohoyadapi kta nakaha kahinigapo, taku wakan nibunkakepi wakpa kin akasanpa ohodapi qon hena, qaiś Amori kin tamakocepi ohna yatipi taku wakandapi kin, unman tukte kaśta; tuka miye, qa watiyohnaka kin Jehowa ohoundapi kta.

16 Unkan oyate kin ayuptapi, qa heyapi; Hiya, Jehowa unkayuśtanpi qa taku wakan tokeca ohoundapi kin iyounkipi śni nunwe.

17 Tuka taku wakan undapi kin Jehowa hee. Iye unkiyepi, qa hunkake wicunyanpi Egupta makocé etanhan, wayaka tipi etanhan itanwankanhde hiyu unyanpi, qa unkiśtapi itokam wowape tokeca tanka kin hena econ, qa canku omaunnipi kin owasin ohna awan unyákapi, nakun oyate wicehna iyounptapi kin owasin ehna.

18 Qa Jehowa Amori, qa oyate makoce ounyanpi kin owasin unkiyjepi itokapa tanhan nape wicaya, heon unkiyepi Jehowa ohoundapi kta, taku Wakan undapi kin he iye nakaś.

19 Unkan Jośuwa oyate kin hewicakiya, Jehowa ohoyadapi kin oyakihipi śni. Taku wakan wakanhinca, Iyotan waśaka, winawizi kill hee nakaś; wayaki- 
WICOWOYAKE 24.

pajinpi kin, qa wayahtanipi kin nicicajujupi kte śni.

20 Tanyan ecaniconpi iyohakam Jehowa aduśtanpi, qa taku wakan tokeca ohoyadapi kinhan, iye ihduliomni kta, qa śicaya ecaniconpi, qa niyusotapi kta.

21 Unkan oyate kin Jośuwa heciyapi, Hiya Jehowa hee ohoundapi kta.

22 Unkan Jośuwa oyate kin hewicakiya, Jehowa ohoyadapi kta e wanna yakahnigapi wayaatanin henicapi ce. Unkan, Wayaatanin heuncapi ce, eyapi.

23 Unkan, Wanna taku wakan tokeca niyepi ehna unpi kin hena yutokan iyewicayapo, qa Jehowa Israel Wakan dapi kin elta nicantepi kin yeyapo.

24 Unkan oyate kin Jośuwa heciyapi, Jehowa Wakan undapi kin he ohoundapi kta, qa ho kin naunhonpi kta.

25 Unkan anpetu kin he en $\mathrm{J}_{0}$ śluwa oyate kin wicotakuye wan wicalicage ca wokage, qa woyaco wicitokam ehde Škem ohna. 26 Qa Jośuwa Wakantanka toope wowapi en wicoie kin hena owa, qa inyan tanka wan icu, qa hen ehde, utuhu can wanji Jehowa toti wakan icahda he cin he ihukuya.

27 Qa Jośuwa oyate kin owasin hewicakiya, Wan inyan kin de unkiyepi otahedan wayaatanin kta, Wicoie Jehowa unkekiyapi owasin he nahou, qa niyepi on wayaatanin kta; Ihnuhan Jehowa en iyatonpi śni kin.

28 Unkan Jośuwa oyate kin otoiyohi maga tawa ekta kihde wicaya.

29 Unkan takú kin hena iyohalam Jośuwa Nun cinhintlu, Jehowa taokiye ta, waniyetu opawinge sanpa wikcemna wanjidan ni.

30 Unkan Timnat Serah ohna, iye tamaga ikanke elita, he Epraim lie kin ohna, Gayaś paha iwaziyata yanke cin hen, hnakapi.

31 Unkan Israel Jośuwa taanpetu owasin Jehowa ohodapi; nakun hunkayapi woecon Jehowa Israel ecawicakicon owasin sdonyapi, qa Jośuwa iyohakam nipi anpetu tawapi owasin.

32 Unkan Josep huhu kin Israel cinca kin Egupta etanhan aupi kin hena Seliem ohna hnakapi maga wan tawa ye kta e Jakob Śkem atkuku Ḣamor etanhan maza ska tke utapi opawinge iyope kiya, qa Josep cinca kin he tawayapi he ohna.

33 Nakun Eleazar Aaron cinhintku kin te, qa iye cinlintku Pinehas paha tawa Epraim he kin ohna qupi kin hee ohna hnakapi. 


\section{WA YACOPI WOWAPI KIN.}

WICOWOYAKE 1 .

1 Unkan .Jośuwa te cin iyohakam Israel cinca kin Jehowa iwangapi qa heyapi, Unkiyepi on tuwe Kanani azuwicaye kta e tokaheya ye kta he?

2 Unkan Jehowa heya, Juda hee tokaheya azuwicaye kta. Tho iye nape kin en makoce kin waqu ce.

3 Unkan Juda iye cincu Simeyon heciya, Makoce mitawa en mici ya wo; hecen Kánani kin azuye wicunye kta, kinhan miś eya nitamakoce en nici mde kta. Unkan Simeyon he kici i.

4 Unkan Juda Kanani kin, qa Perazi kin azuwicaya. Unkan nape kin en Jehowa wicaqu; unkan Bezeq ohna wicaśta kektopawinge wikcemna wicakaśtakapi.

5 Qa Bezeq ohna Adoni Bezeq (Bezeq Itancan kin) iyeyapi, qa kizapi; qa Kanani kin, qa Perazi kin wicakaśtakapi.

6 'Tuka Adoni Bezeq najica, hecen kuwa eyayapi qa icupi, qa napahunka, qa sipahunka bakiciksapi.

7 Unkan Adoni Bezeq heya, Wicaśta yatapi wikcemna śakowin napahunka, qa sipa hunka bawicaksapi wahna wotapi mitawa ihukuya woyute pahi yakonpi ece. Token ecamon qon he iyecen taku wakan ecamicon. Unkan. Jerusalem ekta aipi, unkan hen ta.

8 Wanna Juda cinca kin Jerusalem azuyapi, qa icupi, qa canJudg. hpi hi on kaśtakapi, qa otonwe kin ideyapi.

9 Unkan he iyohakam Juda cinca kin kun hdapi, qa Kanani he kin, qa Negeb (Itokah makoce), qa Sepela (Huta kin) otipi kin azu wicayapi.

10 Nakun Juda Kanani Hebron otipi kin ekta i, (qa he itokam Hebron Arba otonwe kin eciyapi), qa Śseśi, qa Ahiman, qa Talma wicakaśtakapi.

11 Qa hetanhan Debir otipi ekta i, qa he itokam Debir Qirjat Seper (Otonwe Wowapi) eciyapi.

12 Wanna Kaleb heya, Tuwe Qirjat Seper kaśtake ça icu kinhan micunksi Yaksa tawicu kta e waqu kta.

13 Unkan Otniel, Kaleb sunkaku Qenaz cinhintku kin he icu; unkan cunwintku Yalisa tawicu kta e qu.

14 Unkan ekta i qehan, atkuku etanhan maga wan kida kta e iyopaśtaka, qa śonśonna etanhan makata iyahan. Unkan Kaleb heciya, Taku yacin he?

15 Unkan heciya, Woyawaśte wan maqu ye; makoce puza wanna mayaqu, mini owe nakun maqu ye. Unkan Kaleb miniyowe wankantuya, qa miniyowe hukuya kin qu.

16 Unkan Mowis tunkanku Qeni cinca kin Tamar can otonwe etanhan, Juda cinca om itanwankanhde ipi, Juda tinta ekta, he Arad itokaga tanhan wanka, qa oyate kin om ipi qa om iyotankapi. 


\section{WAYACOPI WOWAPI KIN,}

17 Unkan Juda iye cincu Simeon kici i, qa Kanani Tzepat, otipi kin wicakaśtakapi, qa ihang wicayapi; heon otonwe kin he Horma (Ihangyapi) eciyapi.

18 Nakun Juda Gaza ekta i, qa tamakoce kin, qa A.śquelon qa tamakoce kin, qa Yekron qa tamakoce kin, qa hena icu.

19 Unkan Jehowa Juda kici un, hecen $\dot{H}$ e otipi kin nape wicaya, tuka osmaka otipi kin napewicaya okitpani; hena mazasapa canpahmihma yuhapi nakaś. 20 Unkan Kaleb İebron qupi, Mowis eye ciqon he iyecen. Unkan Yanaq cinhintku yamni hetanhan nape wicaya.

21 Unkan Benjamin cinca kin Jebusi Jerusalem otipi kin nape wicayapi śni, tuka Jebusi kin Benjamin cinca om Jerusalem otipi anpetu kin dehanyan.

22 Nakun Josep tiyohnaka kin Betel ekta yapi, qa Jehowa owicapa.

23 Qa Josep tiyohnaka kin Betel iwanyakapi, qa he itokam otonwe kin he Luz eciyapi.

24 Unkan tonweyapi kin wicaśta wan otonwe etanhan inanpa wanyakapi, qa heciyapi, Token otonwe kin en unyanpi kta wanyag unkiyapo, kinhan tanyan ecaunniconpi kta.

25 Unkan token otonwe kin en yapi kta wanyag wicaya; unkan otonwe kin canhipi hi on kaśtakapi; tuka wicaśta qon, qa wicowazi tawa owasin tokan ye wicaśipi.

26 Unkan wicaśta qon Hiti kin tamakocepi ekta $i$, qa otonwe wan kage ça Luz eya caje yata; he anpetu kin dehanyan hecen eciyapi.

27 Unkan Manaśe BetŚan (Iyozi $\mathrm{Ti}$,) qa otonwe cunkśiwicaya ounyanpi kin nape wicaye śni, nakun, Tayanak qa cunkśiwicaya, qa Dor qa cunkśiwicaya, ounyanpi kin, qa Jibleyam qa cunkśiwicaya ounyanpi kin, qa Megido qa cunkśiwicaya ounyanpi kin, tuka Kanani kin makoce kin he ounyanpi kta e iyowin wicayapi.

28 Tuka Israel waśake aye cehan Kanani kin wowidag wicayapi, eśta nape wicayapi śni.

29 Unkan Epraim Kanani Gezer ounyanpi kin nape wicayapi śni, tuka iyepi ehna Kanani kin Gezer en tipi.

30 Unkan Zebulun Qiteron ounyanpi kin nape wicaye śni, nakun Nahalol ounyanpi kin, tuka Kanani iye ehna ounyanpi, qa wowidake unpi.

31 Aśer Ako ounyanpi kin nape wicaye śni, nakun Tzidon ounyanpi kin, qa Ahelab, qa Akzib, qa Ḣeleba, qa Apiq, qa Rehob ounyanpi kin :

32 Tuka Aśeri kin Kanani kin maknce ounyanpi kin wicehna tipi, nape wicayapi śni nakaś.

33 Naptalj Bet Śemeś (Anpetu wi ti) ounyanpi kin nape wicaye śni, nakun Bet Yanat ounyanpi kin; tuka Kanani makoce ounyanpi kin wicehna tipi, qa Bet Śemeś qa Bet Yanat ounyanpi kin hena wowidake wicayuhapi. 34 Unkan Amori kin Dan cinca kin he kin en otins wicayapi, qa Osmaka ekta kun upi iyowin wicakiyapi śni.

35 Unkan Amori kin Har Ḣeres (Anpetu wi talie) ohna, qa Ajalon ohna, qa Śayalbim ohna ounyanpi kta kitanpi ; hececa eśta Josep tiyohnaka nape kin waśaka aye cehan wowidag wicaya.

36. Unkan Amori tamakocepi kin Yakrabim itanwankanhde yapi kin hetanhan imnija kin etanhan qa he iwankam. 


\section{WICOWOYAKE 2.}

1 Unkan Jehowa ohnihde kin Gilgal etanhan, Bokim (Oceyapi) ekta i, qa heya, Egupta etanhan itanwankanhde hiyu ciyapi, qa makoce nihunkakepi konza wahowicawaye ciqon he en hiyu ciyapi, qa hepa, otakuye cicicagapi kin icimana wahdukse kte śni.

2 Qa niyepi oyate makoce otipi kin om otakuye yakagapi kte śni ; tawahna wośllapi kin dujujupi kta. Tuka maho kin nayahonpi śni. Tokeca hecannonpi he?

3 Heon hepa, Niyepi itokapa tanhan nape wicawaye kte śni, tuka hena toka wicaduhapi kta, qa taku Wakan dapi kin hena nihmunkapi kta.

4 Unkan Jehowa ohnihde kin wicoie kin hena Israel cinca owasin ewicakiye cehan, oyate kin ho yeyapi qa ceyapi.

5 Unkan oyanke kin he Bokim (Oceyapi) eciyapi, qa hen Jehowa wakiy uśnapi.

6 Wanna Jośuwa oyate kihde wicaye cehan, Israel cinca kin otoiyohi makoce onśpa tawa ye cin hduhe kta e ekta i.

7 Qa oyate kin Jehowa ohodapi, Jośuwa taanpetu owasin, nakun hunkayapi tona Jehowa ohan tanka, Israel ecawicakicon owasin wanyakapi qon, Jośuwa iyohakam anpetu hdutehanpi kin owasin.

8 Unkan Jośuwa Nun cinhintku Jehowa taokiye kin ța, waniyetu opawinge sanpa wikcemnana ni.

9 Unkan makoce tawa ye cin Timnat Heres ohna hnakapi, Epraim he kin ohna, Gayaś paha iwaziya tanhan.

10 Nakun wicoicage kin he owasin ate wicayapi ekta okipe wicayapi. Unkan ohakam wicoicage tokeca wan icaga, Jehowa sdonyapi śni, qa wicohan Israel ecawicakicon nakun.

11 Unkan Israel cinca kin Jehowa iśta kin en taku śica econpi, qa Bayalim ohodapi.

12 Qa hunkake wicayapi kin Jehowa ohodapi qon, qa Egupta makoce etanhan hinanpe wicaye ciqon he ayuśtanpi, qa taku wakan tokeca oyate wicihdukśan yakonpi taku wakan dapi etanhan opapi, qa hena itokam patujapi; hecen Jehowa siihda yapi.

13 Hecen Jehowa ayuśtanpi, qa Aśterot, qa Bayal ohodapi.

14 Heon Jehowa Israel canniye wicaye ca tona wicakipi kin hena napepi en wicaqu, unkan wicakipi kin, qa toka wicayapi wicihdukśan yakonpi napepi kin en iyope wicaya; unkan toka wicayapi wicitokam sanpa najin okihipi śni.

15 Toki yapi eśta Jehowa nape kin taku śica on awicapaha, Jehowa eye ciqon he iyecen, qa Jehowa konza wahowicaye ciqon he iyecen, hecen nina iyokiśicapi.

16 Unkan Jehowa wayaco wicaśta icah wicakiciya; unkan hena tona wicakipi napepi etanhan niwicayapï.

17 Unkan nakun wayacopi kin nawicahonpi śni, tuka taku wakan tokeca om nahmana wankapi, qa wicitokam patujapi; qa hunkake wicayapi kin canku omanipi kin, qa Jehowa nahonpi kin hetanhan kohanna ihdutokanpi, qa he iyecen econpi śni.

18 Unkan Jehowa wayaco wan icahwicakiciya eca, Jehowa wayaco kici un ece, qa toka wicayapi napepi kin etanhan $n$ wicaya; wayaco tarpetu kin owa- 


\section{WAYACOPI WOWAPI KIN,}

sin; qa tona iyokiśin wicayapi, qa śicaya wicakuwapi on śicahowayapi, heon Jehowa tawacin hdutokeca nakaś.

19 Unkan wayaco kin te cehan ihdamnapi, qa ate wicayapi isanpa ihduśicapi, qa taku wakan tokeca ihakam manipi, qa ohodapi, qa ekta patujapi. Sicaya ohanyanpi, qa carnu telika tawapi kin ayuśtanpi śni.

20 Unkan Jehowa Israel canniye wicaye ca heya, Oyate kin de wotakuye mitawa ate wicayapi opewicawaśi kin acakśinpi, qa maho kin nahonpi śni;

21 Heon miś eya tokata ikce wicaśta Jośuwa te cehan owicakapte cin, hena etanhan tuwedan nape waye kte śni.

22 Hecen hena on Israel iwicamdute kta, Jehowa tacanku kin patanpi kta, qa omanipi kta, ate wicayapi econpi qon he iyecen, qaiś heconpi kte śni.

23 Heon Jehowa oyate kin hena iyozi wicaya, qa kohanna Josuwa nape kin en wicaqu śni.

\section{WICOWOYAKE 3.}

1 Unkan Israel etanhan tona Kanani wokicize owasin sdon yapi śni, iyutan wicaye kta on Ikce wicaśta iyozi wicaye cin dena eepi ;

2 Hecen Israel cinca wicoicage taku hektam econpi kin sdonyapi śni kin hena wokicize onspe wicakiyapi kin on etanhan he sdon. yapi kta.

3 Pilistim wicaśta yatapi zaptan; qa Kanani kin, qa Tzidoni kin, qa Hiwi kin Lebanon he otipi kin owasin, Bayal ظ̇ermon he etanhan Hiamat en yapi kin hehanyan ;

4 Hena on Israel iyutan wicaye kta, heon hen yakonpi, qa Jeho- wa tawoahope Mowis nape on ate wicayapi ope wicaśi qon hena nahonpi kta, he cinhan sdonye kta heon etanhan.

5 Unkan Israel cinca kin Kanani kin, qa Hiti kin, qa Amori kin, qa Perazi kin, Hiwi kin, qa Jebusi kin, wicehna tipi :

6 Qa tawicu yapi kta e cunwintkupi kin wicayuzapi, qa iye cunwintkupi Kranani cinhintkupi kin wicaqupi, qa taku wakandapi kin hena ohowicadapi ece.

7 Unkan Israel cinca kin Jehowa iśta kin en takuśice cin he econpi, qa Jehowa Wakan dapi qon akiktunjapi, qa Bayalim qa Aśterot ohodapi.

8 Unkan Jehowa Israel canniye wicaye ca A ram Wakpa otahedan wicaśta yatapi kin Kuśan Riśataim nape kin en wiyope wicaya; unkan Kuśan Riśataim Israel cinca kin waniyetu śahdogan wowidag wicaya.

9 Hehan Tsrael cinca kin Jehowa hoyekiyapi, unkan Jehowa Israel cinca kin wanikiya wan icah wicakiciya; unkan Otniel Kaleb sunkaku Qenaz cinhintku kin niwicaya.

10 Unkan Jehowa toniya kin he akan un, hecen Israel wicayaco, qa ozuye kaga, unkan nape kin en Jehowa Kuśan Riśataim Aram wicaśta yatapi kin qu, qa Kuśan Riśataim itkom nape kin waśag kiya.

11 Unkan makoce kin waniyetu wikcemna topa oziya, hehan $\mathrm{O}$ tniel Qenaz cinhintku ta.

12 Unkan Israel cinca kin ake Jehowa iśta kin en taku śica econpi, heon Jehowa Moab wicaśta yatapi Yeglon Israel itkom waśag ya; Jehowa iśta kin en taku śica econpi heon etanhan.

13 Unkan Amon cinca kin, qa Amaleq iye ekta mnawicaya, qa 


\section{WICOWOYAKE 4.}

Israel ekta i, qa wicakaśtake ça Tamar can otonwe kin tawaya.

14 Qa Yeglon Moab wicaśta yatapi kin Israel cinca kin waniyetu wikcemna sanpa śahdogan wowidag wicaya.

15 Unkan Israel cinca kin Jehowa ho yekiyapi ; unkan Jehowa wanikiya wanji icaliwicakiciya Ehud Gera cinhintku Benjami heca, qa nape anog etapa; unkan iye nape kin on Israel cinca kin Yeglon Moab wicaśta yatapi kin taku qupi.

16 Unkan Ehud isan wan icicaga, anog ope, ohanske wiçiśpa wanjidan, qa tawokoyake ihukuya ceca etapa akan iya kaśka.

17 Unkan taku qupi kin he Yeglon Moab wicaśta yatapi kin kahi. Unkan Yeglon wicaśta cepa hinca.

18 Unkan taku qupi kin owasin kahi qehan, wicaśta taku qupi kin qinpi qon kihde wicaya.

19 Tuka iye inyan kakanpi Gilgal ikiyedan etanhan ihdamna, qa heya, Wicaśta yatapi wicoie wan nahmana eciciye kta mduha ce. Unkan inina un wo, eya. Unkan tona iye itokam najinpi owasin iye etanhan tankan iyayapi.

20 Unkan Fhud ekta i. Unkan mdoketu wankan tipi tawa ohna iś nana iyotankahan yanka. Unkan Ehud heciya, Wakantanka oie wan niye ekta mduha ce. Unkan oiyotanke etanhan najin.

21 Unkan Ehud nape catka kin yekiye ca isan ceca etapa etanhan ikikcu, qa tezi kin ohna capa.

22 Unkan ihupa kin hi iyahna mahen iyaya, qa waśin kin hi kin askapa, hecen tezi etanhan ikikcu śni, qa cesdi kin tankan hiyu.

23 Unkan Ehud 'ohanzi hdepi ohna tankan iyaye ça wankan 28 tipi tiyopa kin ecen icu, qa sutaya nataka.

24 Hecen iye kihda. Unkan taokiye kin en hipi, qa wanyakapi qehan; iny.un wankan tipi tiyopa kin ecen icupi, qa natakapi, heon heyapi, Ecaeś mdoketu tipi ohna siha kin ahdahipa yanka.

25 Qa akipe unpi ecen iśtecapi ; unkan wankan tipi tiyopa kin hduhdoke śni, heon tiyopa iyuhdoka wan icupi, qa yulidokapi, qa inyun itancan tawapi makata hinhpaya wanka, qa te.

26 Unkan iyokiśn içiyapi icunhan Ehud najica, qa inyan kakanpi kin sam iyaye ça Seỵira ekta ki.

27 Qa ekta ki qehan, Epraim tahe kin ohna cotanka yalioton, unkan lie kin etanhan Israel cinca kin om apamahde upi, unkan wicitokam mani.

28. Qa hewicakiya Mihakam upo, Jehowa Moab toka niyanpi kin ninapepi en niçupi. Unkan ihakam iyayapi qa Jordan oiyuwegapi kin icupi, Moab itokam, hecen tuwedan iyuwega kta iyowin kiyapi śni.

29 Unkan he ehan Moab kaśtakapi, wicaśta kektopawinge wikcemna cetu, owasin cepapi qa owasin wicaśta waśakapi, qa wicaśta wanjidan niyanpi śni.

30 Hecen anpetu kin he en Moab yuhukun yapi Israel nape kin ihukuya, unkan waniyetu wikcemna śahdogan makoce kin iyozi ya.

31 Unkan he iyohakam Śamgar Yanat cinhintku tatanka icape on Pilistim wicaśta opawinge śakpe wicakaśtaka hecen Israel ni wicaya.

\section{WICOWOYAKE 4.}

1 Unkan Ehud țe cin iyohakam 45 


\section{VAYACOPI WOWAPI KIN,}

ake Israel cinca kin Jehowa iśta kin en taku śica econpi.

2 Unkan Jehowa wiyope wicaya Jabin Kanan wicaśta yatapi nape kin en, iye Hatzor ohna wicaśta yatapi, qa taobe mdetanhunka kin Sisera hee; qa iye Harośet Ilkcewicaśta tawapi ohna ounyan.

3 Qa canpahmihma opawinge napcinwanka yuha, qa waniyetu wikcemna nonpa Israel cinca kin tehiya kakiśs wicaya; heon Israel cinca kin Jehowa ho yekiyapi.

4 Unkan he ehan Debora waayatewin wan Lapidot tawicu kin he Israel wicayaco.

5 Unkan Debora tamar can tawa kin ihukuya ti, Rama qa Betel otahedan, Epraim tahe lin ohna, qa Israel cinca kin wicayaco kta e ekta ipi ece.

6 Qa Baraq Abinoam cinhintku kin wohoya, qa kico, Qedeś Naptali etanhan, qa heciya, Awicakehan Jehowa Israel Wakandapi kin hecon niśi ; oyate Tabor he kin ekta hiyu wicayaye lita, qa Naptali cinca etanhan, qa Zebulun cinca etanhan wicaśta kektopawinge wikcemna iyacu kta.

7 Qa miye Qiśon wakpa kin ekta, Sisera Jabin taobe mdetanhunka kin, qa canpahmihma tawa, qa taozuye hiyu wicawaye kta, qa ninape en waqu kta.

8 Unkan Baraq heciya, Mici de cinhan mde kta, qa mici de śni kinhan mde kte śni ce.

9 Unkan heya, Awicakehan nici mde kta ye. Takomni canku ohna de kte cin on wowitan kin nitawa kte śni ye, Jehowa Sisera winohinca wan rape kin en wiyope ye kta nakaś. Qa Debora inajin, qa Baraq kici iyaya Qedeś ekta.

10 Unkan Baraq Zebulun, qa
Naptali Qedeś ekta wicakico; unkan wicaśta kektopawinge wikcemna caehde hakam hipi, qa Debora iye kici iyaya.

11 Unkan Ḣeber Qeni kin wanna ihdukinukan Hobab Mowis tahanku Qeni cinca etanhan, qa tawakeya Tayanaim ohna utuhu kin ekta ehde, he Qedeś ikiyedan.

12 Unkan Baraq Abinoyam cinhintku kin Tabor he akan iyaye cin he Sisera okiyakapi.

13 Unkan Sisera canpahmihma tawa owasin, maza sapa canpahmihma opawinge napcinwanka witaya hiyu wicaya, qa oyate iye opapi owasin Ḣarośet ikcewicaśta tawapi etanhan Qiśon wakpa kin ekta.

14 Unkan Debora Baraq heciya; Najin ye, nakaha Jehowa Sisera ninape en qu kta ye. Awicakehan Jehowa nitokam iyaya ce. Unkan Baraq' Tabor he etanlan apamahde iyaya, qa wicaśta kektopawinge wikcemna ihakam yapi.

15 Unkan Jehowa Sisera, qa canpahmihma owasin, qa taozuye ocowasin canlipi hi on yuśinye wicaya, Baraq itokam, hecen Sisera canpahmihma etanhan ipsice ca hu inyun najica.

16 Unkan Baraq canpahmihma ihakam, qa ozuye kin ihakam kuwa eyaya. Harośet Ikce wicaśta tawapi kin hehanyan; Unkan Sisera taozuye kin owasin canhipi hi on hinhpaya; wanjidan okaptapi śni.

17 Unkan Sisera hu inyun najica, Heber Qeni kin tawicu Jayel tawakeya ekta, Hatzor wicaśta yatapi Jabin qa Hieber Qeni kin tiyohnaka kin wokiyapi nakaś.

18 Unkan Jayel Sisera itkokim iyaye ça heciya, Kuwa ye, itan- 


\section{WICOWOYAKE 5.}

can kuwa ye. Thnuhan wakoyakipe cin, Unkan ihdamna tipi tawa ekta; unkan śina wan on akahipa.

19 Unkan heciya, Imapuza, tokin mini onge yatke mayakiyen. Unkan pte asanpi apalite wan hduhdoke ca yatkekiye ça akahpa.

20 Unkan heciya, Wakeya tiyopa ekta najinhan inajin, qa wicaśta wan u qa iniwange ça, Wicaśta wan den un he? eye cinhan, Hiya ehe kta.

21 Unkan Jayel Ḧeber tawicu kin maza wihutipaspe wan icu, qa nape ohna maziyape kin yuze ca nahmana en hi, qa nawate ohna wibutipaspe kin maziyape on kahuga, qa he maka mahen iheya. Unkan iye ta; nina iśtima, mdokița nakaś.

22 Unkan iho Baraq Sisera kuwa eyaya; unkan itkokipe kta Jayel inanpe ca heciya, Kuwa ye; wicaśta ayakite cin he wanyag ciciye kta ye. Unkan en hi qehan Sisera ța makata wanke ça wihutipaspe nawate ikoyag yanka.

23 Hecen anpetu kin he en Wakantanka Jabin Kanani wicaśta yatapi kin yuhukuya, Israel cinca wicitokam.

24 Unkan hetanhan Israel cinca nape kin waśaka aya sanpa qa sanpa, Jabin Kanani wicaśta yatapi en, ecen Jabin Kanan wicaśta yatapi kin ihang yapi.

\section{WICOWOYAKE 5 .}

1 Unkan anpetu kin he en Debora, qa Baraq Abinoyam cinhintku dowanpi qa heyapi,

2 Israel ohna mdetanhunka tokata iyayapi on, oyate iyokipiya icicupi kin heon, Jehowa ahiyayape.

3 Wicaśta yatapi nalonpe, Itancan dukanpi anagoptanpe. Miś miye Jehowa iwadowan kta, Jehowa Israel wakan dapi kin awahimdamde kta ye.

4 Jehowa Seyir etanhan inanpe cehan,

Edom tatinta etanhan mayani qehan,

Maka kin śkanśkan; nakun mahipiya kin iheya.

Nakun mahpiya śapa kin mini śbu.

5 Ḣe kin śkanśkan Jehowa itokam;

Sina kin de Jehowa Israel Wakan dapi kin itokam.

6 Śamgar Yanat cinhintku taanpetu kin en;

Jayel taanpetu en canku tankinkinyan kin ayuśtanpi.

Icimanipi kin canku kakśankśan ohna yapi.

7 Mdetanhunka ayuśtanpi, Israel ohna wanica ayapi ye. Ecen miye Debora nawajin ye,

Israel ehna inamayanpi nawajin.

8 Taku wakan teca kalinigapi,

Qehan otonwe tiyopa elkta kicizapi.

Wahacanka, qa wahukeza wanyakapi śni ye ;

Israel kektopawinge wikcemna topa ohna.

9 Micante kin Israel wowapi kagapi kici i ye.

Oyate ohna iyokipiya içiçupi kin kici, Jehowa yatanpe.

10 Tona śonśonna wiye skaska akan idotankapi,

Wayaco oiyotanke akan yakidotankapi kin,

Qa canku ohna dapi kin dowanpe. 


\section{WAYACOPI WOWAPI KIN,}

11 Wanunyanpi mini oyatkanpi ekta wapamnipi kin hotonpi kin heon.

Hen Jehowa toowotanna kin yatanpi,

Toowotanna kin Israel mdetanhunka kin ekta.

Hehan Jehowa taoyate kin otonwe tiyopa ekta ipi.

12 Kikta ye. Debora kikta ye.

Kikta ye; odowan oie kin kikta ye.

Baraq najin ye, qa Abinoyam cinhintku wayaka nitawa hiyu wicaya ye.

13 Hehan okaptapi kin waśakapi kin anawicatanpi ye.

Jehowa taoyate miye kici wohitipika anawicatan.

14 Epraim etanhan tona Amaleq ohna hutkan ican̉ yapi kin kun hiyupi.

Niye nihakam Benjamin oyate nitawa ehna.

Makir etanhan mdetanhunka hipi ye.

Qa Zebulun etanhan wowapi icage yuzapi kin hena.

15 Nakun Isakar mdetanhunka Debora opapi ye.

Qa Isakar Baraq iyececa;

Caehde tawa ohna omdaye en natanpi.

Ruben taobe kin on cante ode tankinkinyan.

16 Tokeca tahin wanunyanpi yajopi nayahion kta e,

Tahinca tipi otahedan owanji nanka he?

Ruben taobe kin on cante ode tankinkinyan yukan ye.

17 Gileyad Jordan akasanpa yanka.

Qa tokeca Dan wita wata ohna ti he?

18 Zebulun oyate țapi kta nagipi ihaktapi śni ye.

Naptali nakun tinta pajodan ohna.

19 Wicaśta yatapi kin hiyupi qa kizapi ye.

Hehan Kanan wicaśta yatapi, kin hiyupi, qa kizapi ye.

'Tayanak ohna Megiddo mini icahda;

Mazaska kaśpapidan icupi śni.

20 Mahipiya etanhan kizapi ;

Wicanhipi kin ocankuyapi kin etanhan Sisera kizapi ye.

21 Wakpa Qiśon ewicayaya ye,

Wakpa wanakaja Qiśon wakpa kin.

Minagi waśakapi kin amayani ye.

22 Hehan śuktanka śakepi kin nahugapi ye;

Wohitiya śkanpi, śuktanka waśaka tawa wohitiya śkanpi kin.heon.

23 Meroz yaśicapo, Jehowa ohnihde kin eya.

En ounyanpi kin nina wicayaśicapo.

Jehowa okiyapi kta e hipi śni ;

Wicaśta waditakapi en Jehowa okiyapi kta e hipi śni, heon etanhan.

24 Winohinca isanpa Jayel yawaśtepi kta ye ;

Heber Qeni tawicu kin.

Wakeya ohna winohinca isanpa yawaśtepi kta ye.

25 Mini da, unkan pte asanpi qu; 


\section{WICOWOYAKF 6.}

Wicaśta yatapi tawakśica ohna płe asanpi nini hiyu kiciya.

26 Wihutipaspe wan ekta catka ye kiya;

Ftapa kin cankajipa tamaziyape ekta.

Qa Sisera ape ca pa kin kahuga,

Qa nawate kin cape ca kahdoka.

27 Winyan siha ekta patuś hinhpaya, makata wanka ye.

Winohinca siha kin ekta patuja hinhpaya ye.

Tukten patuja hen hinhipaya ta.

28 Owanye ohna eokasin qa eya niyan,

Sisera honku owanye akahpa ohna;

Tokeca canpahmihma tawa kin, tehan hi śni he?

Tokeca ozuye canpahmihma tawa upi kin hunkapi śni he?

29 Winohinca ksapa wicayuhe cin ayuptapi ;

Iye aihdupte ca heya,

30 Woyuha jyeyapi qa pamnipi śni he ye?

Wikośka wan, qaiś wikośka nonpa wicaśta iyohiya ye.

Wokoyake dun yapi Sisera on,

Wakoyake ipatapi.

Wayaka iyohi tahu kin wanapin ipatapi nonpa ye.

31 Jehowa tona toka niyanpi owasin he iyecen ihang yapi nunwe ye.

Qa tona waśte nidapi kin hena anpetu wi towaśake en hinanpe cin iyececapi kta ye.

Unkan makoce kin waniyetu wikcemna topa iyozi ya.

\section{WICOWOYAKE 6.}

1 Unkan Israel cinca kin Jehowa iśta kin en taku śica econpi. Unkan Jehowa Midian nape en wicaqu waniyetu śakowin.

2 Unkan Midian nape kin Israel akan waśaka, Midian on etanhan Israel cinca kin he kin akan makohdoka kın, qa woha kin, qa inyan conkaśke ic̣icagapi.

3 Unkan Israel wojupi eca Midian en hiyu, nakun Amaleq, qa Wihinanpe cinca kin he akan hiyupi.

4 Qa akan awicahitipi, qa taku maka aicage cin ihang yapi, Gaza ekta de cin hehanyan; hecen Israel ohna takudan on nipi kta okaptapi śni, nakun tahinca, qa pte, qa śonśonna wanica.

5 'Tawanunyanpi, qa tawakeyapi hduha ihdakapi, psipsicadan iyecen wicota hinca nakaś, qa iyepi qa camo tawapi yawapica śni, qa makoce awihnuni yapi kta heon en hipi.

6 Hecen Israel Midian on etanhan nina wahpanicapi, qa Israel cinca kin Jehowa hoyekiyapi.

7 Unkan Israel cinca kin Midian on etanhan Jehowa hoyekiyapi qehan,

8 Jehowa Israel ekta waayate wan yeśi; unkan hewicakiya, Jehowa Israel Wakandapi kin hecen eya ce, Miye Egupta etanhan itanwarkanhde hiyu ciyapi, qa wayaka tipi kin etanhan hinanpe ciyapi.

9 Nakun Egupton napepi kin etanhan ecihdakupi, qa tona iyokiśin niyanpi kin owasin napepi etanhan, qa niyepi itokapa tan- 


\section{WAYACOPI WOWAPI KIN,}

han nape wicawaya, qa makoce tawapi kin ciçupi.

10 Qa heciciyapi, Tohowa Wakan yadapi kin he miye, Amori tamakocepi en yakidotankapi taku wakan dapi kin kowicayakipapi kte śni, qa hopi kin nawicayalionpi kte śni.

11 Unkan Jehowa ohnihde kin u, qa utuhu wan Yopra ohma he cin, Joaś Abiyezeri tawa kin he ihukuya hiyotanka; Unkan cinhintku Gideyon hastanhanka iyuskica ohna aguyapi su kapa yanka, Midian etanhan naliman kta heon etanhan.

12 Unkan Jehowa ohnihde kin en ihdutanin, qa heciya, Wicaśta waśaka waditaka Jehowa nici un ce.

13 Unkan Gideyon heciya. Itancan ceciciya, Jehowa unkicipi un kinhan tokeca taku kin de owasin unkakipapi he? Qa tolian wakan ate wicunyanpi kin cajeyatapi, qa Jehowa Egupta etanhan itanwankanhde hiyu unyanpi ce, eyapi kin toki un he? Tuka Jehowa wanna paha iyeunyanpi, qa Midian nape en unqupi ce.

14 Unkan Jehowa ekta ihduhomni qa heciya, Nitowaśake kin de hduha ya wo, qa Israel Midian nape kin etanhan ni yaye kta. Miye ye ciśi śni he?

15 Unkan heciya, Itancan ceciciya, tokiya tanhan miye Israel ni waye kta he? Manaśe ohna kektopawinge mitawa kin he onśika, qa ate ti kin ohna miye mahakakta ce.

16 Unkan Jehowa heciya, Tokeśta miye cici waun kta, qa Midian wicaśta wanjidan iyecen yakaśtake kta.

17 Unkan heciya, Niiśta en woiyokipi iyewaye cinhan, wowapetokeca ecamiyecon kten, on mici wohdake cin he niye tanin kta.

18 Tokin ake en eihj kte cin hehanyan detanhan tokidan de kte śnin, hecen wailipeyapi mitawa awahi, qa nitokam ewehnake kta. Unkan ake en yahi kte cin hehanyan owanji manke kta, eya. 19 Unkan Gideyon kihde ça tatokadan wanunyanpi cincadàn śpankiya, nakun aguyapi mdu epa (wiyutapi) wan onnapoliye codan, qa tado kin wakiśkotpa en iyeya, qa wahanpi kin cega en, qa utuhu ihukuya yanke cin ekta iyaye, ça ikiyedan hiyuya.

20 Unkan Wakantanka ohnihde kin heciya, Tado kin, qa aguyapi onnapoliye codan kin icu, qa inyan kin de akan eju, qa wahanpi kin akaśtan. Unkan hecen econ. 21 Unkan Jehowa ohnihde kin cansagye nape ohna hduhe cin inkpa kin tado kin, qa aguyapi ek ta yekiye ça icalitaka. Unkan inyan kin etanhan peta hinanpe ca tado kin, qa aguyapi kin hulinali ya. Unkan iśta kin etanhan Jehowa ohnihde kin aisinyan iyaya:

22 Unkan Gideyon Jehowa ohnihde kin hee wanyake ca Gideyon heya, Hehehe, Jehowa itancan, icitkokim Jehowa ohnihde kin wanmdaka nakaś.

23 Unikan Jehowa heciya, Wookiye duhe kta. Ihnuhan walroyakipe cin; nite kte śni.

24 Unkan Gideyon-hen wahna wośnapi wan Jehowa kicage ça Jehowa Śalom (Wookiye) eya cajeyata: he anpetu kin dehanyan Abiyezeri Yopra ohna yanka. 25 Unikan hanyetu kin he en Jehowa heciya, Niyate tatanka wayumdu tawa kin icu, qa tatanka iyokihe waniyetu śakowin, qa Bayal tawalına wośnapi niyate yuhe cin pajuju wo, qa Áseri 


\section{WICOWOYAKE \%}

(canhuhde) he icahda he cin he yapawanke kta.

26 Qa Jehowa Wakan yada kin wahna wośnapi wan imnija kin de paha akan yakage kta, tukten econpi kta iyececa; qa tatanka iyokihe kin iyacu kte ça Aśeri yapawanke kte cin can kin on wohuhnahyapi huhnah yaye kta.

27. Unkan Gideyon iye atkuku taokiye etanhan wicaśta wikcemna iwicacu, qa Jehowa eciye ciqon he iyecen econ, qa atkulku tiyohnaka, qa otonwe wicaśta kin on anposkan econ kte cin kokipa, heon hanyen hecon.

28 Unkan otonwe wicaśta kin ihanhanna kiktapi qehan, inyun Bayal tawahna wośnapi kin pajujupi, qa Aśeri kin he icahda he ciqon kawankapi, qa tatanka iyokihe kin wahna wośnapi kagapi kin he akan huhnahyapi.

29 Unkan, Tuwe taku kin de econ hwo, eya ikiciwangapi, qa akitapi. Unkan Gideyon Joaś cinhintku taku kin de econ eyapi.

30 Qa otonwe wicaśta kin Joaś heciyapi, Nicinkśi Bayal tawahna wośnapi kin pajuju, qa Aśeri kin he icahda he cigon kawanke cin, heon te kta e hinanpe ya wo.

31 Unkan Joaś tona ahinajinpi owasin hewicakiya, Bayal on yakizapi kta he? He ni yayapi kta hecinhan tuwe he ikiye kta e kize cinhan hanhanna kin de te kta. Iye taku wakan heca kinhan tawahna wośnapi pajujupi kin heon iye kize kta.

32 Unkan anpetu kin he en Jerub Bayal (Bayal kize kta) eya caje yata, qa tawahna wośnapi kin pajuju kin heon Bayal kize kta, eya.

33 Unkan Midiani kin owasin, qa Amaleq, qa Wihinanpe cinca - witaya mniciyapi, qa hiyuwe- gapi, qa Jezreyel osmaka ohna ahitipi.

34 Unkan Jehowa toniya kin Gideyon koyag ya, unkan maza yahoton wan yahoton, qa Abiyezer iye en wicakico.

35 Unkan Manaśe ocowasin ehna wahośi ye wicaśi, qa iye en wicakico, nakun Aśer ekta, qa Zebulun ekta, qa Naptali ekta ye wicaśi; unkan itrokipapi kta e hiyupi.

36 Unkan Gideyon Wakantanka heciya, Minape on Israel niwicayaye kta hecinhan ehe ciqon he iyecen;

37 Ito tahin wanunyanpi hin yuśdapi wan aguyapi napanpi ohna ewahnake kta, qa hin yuśdapi heceedan akan cu yuke kta, qa maka kin owancaya puze cinhan, minape on Israel niyaye kte cin ehe ciqon iyecen he sdonwaye kita.

38 Unkan iyecetu; hecen ihanlianna kikta, qa tahinca hin kin yuwitaya icu, qa tahinca hin yuśdapi etanhan cu kin yuśkica, can wakśica wan mini ojudan.

39 Qa ake Gideyon Wakantanka heciya, Canniye maye śni ye, hecinhan ake wancadan iwae kta. Tokin ake wancadan tahinca hin on imdute kten, Ceciciya tahinca hin kin hecedan puze kta, qa maka kin owancaya akan cu yuke kta.

40 Unkan hanyetu kin he en Jehowa iyecen econ. Talinca hin kin he puza, qa maka kin owancaya akan cu yukan.

\section{WICOWOYAKE $\%$}

1 Unkan Jerub Bayal Gideyon hee hanhannahin kikta nakun oyate iye opapi kin owasin, qa Harod wakoniya ekta etipi ; unkan Midian ozuye kin More paha 


\section{WAYACOPI WOWAPI KIN,}

iwaziya tanhan iye itokam osmaka ohna yakonpi.

2 Unkan Jehowa Gideyon heciya, Oyate wicaduhe cin otahin; napepi kin en Midian waqu kinhan okini Israel mitokam ihdatan kta qa, Minape kin he ni mayan ce eye kta.

3 Heon wanna oyate nogepi ohna ieyanpaha qa, Tuwe kokipe ca cancan kinhan kihde kta, qa Gileyad he kin etarhan najice kta, eya wo. Unkan oyate etanhan kektopawinge wikcemna nonpa sanpa kektopawinge nonpa kihdapi, qa kektopawinge wikcemna okaptapi.

4. Unkan Jehowa Gideyon heciya Oyate kin nahahin ota ce. Apamahde mini ekta iyaye wicaya wo. Heciya niye on iwicamdute kta, ya tuwe nici ye kta eciciye cinhan hee nici ye kta; qa tona nici yapi kte śni eciciye cin hena niciyapi kte śni.

5 Unkan mini ekta apamahde iyaye wicaya. Unkan Jehowa Gideyon heciya, Tona cejipi on mini sdipapi, śunka wan sdipa iyecen kinukan najin wicayakiye kta; tona yatkanpi kta hupahupi akan patujapi kin etanhan.

6 Unkan tona napepi on ipi ekta sdipapi kin hena oyawa kin wicaśta opawinge yamni, qa oyate unman owasin mini yatkanpi kta e hupahupi akan patujapi.

7 Unkan Jehowa Gideyon heciya, Wicaśta opawinge yamni sdipapi kin hena on niciyapi kta, qa Midian ninape en cicu kta, qa oyate kin owasin kihdapi kta.

8 Unkan oyate etanhan napepi ohna waneya icupi, nakun he yahotonpi kin; hehan Israel wicaśta kin owasin tawakeyapi ekta kihde wicaya, qa wicaśta opawinge yamni wicahduha yanka.
Unkan Midian ozuye kin iye ihukuya osmaka ohna yakonpi.

9 Unkan hanyetu kin he en Jehowa heciya, Najin ozuye ekta apamahde ya wo, he ninape en cicu naḳaś.

10 Qa apamahde de kta ikoyape cinhan, niye hokśidan nitawa Purakiciśnana ozuye ekta apamahde ya wo.

11 Qa taku eyapi kin he nayahon kta, qa ohakam nirape waśake kta, qa ozuye ekta ya i kta. Unkan iye tahokśidan Pura kici apamahde ipi, ozuye wicaśta wipe kitonpi wankapi ihanke elsta.

12 Unkan Midian, qa Amaleq, qa wiyohiyanpa cinca kin owasin osmaka ohna makata wankapi, wicota hinca psipsicadan iyececapi, qa camo tawapi yawa pica śni, wiyaka miniwanca huta ekta yanke cin iyecen otahin.

13 Unkan Gideyon ekta i, unkan inyun wicaśta wan wowihanmna wan takodaku okiyake ça heya, Inyun wowihanmna wan iwahanmde ca, inyun barle aguyapi hmiyanyanna wan ihduptanptan Midian ozuye kin en, qa wakeya kin ekta hi, qa ape cin on hinlipaya: qa wankan tanhan naptanyan hecen wakeya kin hinhpaya.

14 Unkan takodaku ayupte ca heya Israel wicaśta wan Joaś cinhintku Gideyon tacanhipi kin dee, qa takudan tokeca śni; iye nape en Wakantanka Midian qa ozuye kin owasin qu ce.

15 Unkan Gideyon wowihanmna oyakapi, qa wowiyukcan kin nahon qehan cekiye ça Israel obe kin ekta kihde ça heya, Najinpo, Jehowa Midian ozuye kin ninapepi en qu ce.

16 Unkan wicaśta opawinge yamni wicayaśpe, ośpaye yamni, qa owasin napepi en heyahoton 


\section{WICOWOYAKE 8.}

wicaqu, nakun makacega mini codan, tuka petijanjan maka cega ohna:

$17 \mathrm{Qa}$ hewicakiya, wanmayakapi, qa iyecen econpo. Inyun ozuye wankapi ihanke ekta wai kinhan, token ecamon kin he iyecen ecanonpi kte.

18 Miye, qa tona mici unpi heyahotonpi on unyahotonpi kinhan, niyepi nakun ozuye ihdukśan owancaya he yahotonpi hoton yayapi kta; qa Jehowa qa Gidey on tacanhipi kin, ehapi kta.

19 Unkan Gideyon, qa wicaśta opawinge iye opapi kin, colkaya iwaktapi otokahe ekta, akicita najin wicakiyapi yuśtanpi qehan, ozuye wankapi ihanke kin ekta ipi, qa heyahotonpi kin yahotonpi, qa maka cega napepi en yuhapi kin hena namdemdecapi.

$20 \mathrm{Qa}$ obe yamni kin heyahotonpi kin hoton yapi, qa makacega kin kamdemdecapi, qa nape catka ohna petijanjan yuzapi, qa nape etapa en hoton yapi kta e heyahotonpi kin; qa Jehowa qa Gideyon tacanhipi kin, eya eyanpahapi.

21 Qa ozuye wankapi ihdukśan otoiyohi tohe kin anajin; tuka ozuye kin owasin napapi, qa śicahowayapi, qa najicapi.

22 Unkan wicaśta opawinge yamni kin heyahotonpi kin hoton yapi; unkan Jehowa wicaśta otoiyohi tacanhipi takodaku ekta kiya ye kiye ça ozuye owasin ektakiya; unkan ozuye kin Bet Sitta ekta napapi, Tzarera ektakiya, Sepat Abel Mehola ekta 'Tabat ikiyedan.

23 Unkan Isracl wicaśta $\mathrm{Na}$ ptali etanhan, qa Aśer etanhan, Manaśe owancaya etanhan, wicakipan, unkan kuwa eyayapi.

24 Unkan Gideyon Epraim he kin owancaya wahośi ye wicaśi qa heya, Midian itkowicayakipapi kta kun yapo, qa wicitokam mini kin Jordan hee icupo, Bet Bara hehanyan. Unkan Epraim wicaśta kin owasin witaya mniciyapi qa Jordan mini iyuwegapi kin icupi, BetBara hehanyan.

$25 \mathrm{Qa}$ Midian itancan nonpa iwicacupi, Oreb (Kangi) qa Zeb (Śunktokeca), qa Oreb Kangi immija kin ekta ktepi, qa Zeb. Śunktokeca wolia kin ekta ktepi, qa Midian kuwa eyayapi, qa Oreb pa kin qa Zeb pa kin Jordan akasanpa Gideyon ekta kahipi.

\section{WICOWOYAKE 8.}

1 Qa Epraim wicaśta kin heciyapi, Tokeca hecen ecaunyeconpi, qa Midian azuyaye kta iwaho unyayapi śni he? qa nination i en iy eyapi.

2 Unkan hewicakiya, Niyepi iyecen dehan taku ecamon he? Epraim akta yuśpipi kin he Abiyezer toka yuśpipi kin isanpa waśte śni he?

3 Taku walsan Midian itancan nonpa Oreb qa Zeb, ninapepi en wicaqu qa niyepi ecanonpi iyecen taku owakihi he? Unkan wicoie kin he ewicakiye cehan tocanniyepi kin akisni.

4 Unkan Gideyon Jordan ekta $i$, qa iyuwega, qa iye qa wicaśta opawinge yamni opapi kin watukapi, tuka wicakuwapi.

5 Unkan Sukot wicaśta kin hewicakiya, Wicaśta mibakam upi kin aguyapi wanjikśi wicaqupo; hena watukapi ce, qa miye Midian wicaśta yatapi kin Zeba qa Tzalmuna wicawakuwa.

6 Unkan Sukot itancan kin heyapi, Zeba qa Tzalmuna napepi kin ninape en wanna duha nace, qa heon obe nitawa aguyapi wicunqupi kta. 


\section{WAYACOPI WOWAPI KIN,}

7 Unkan Gideyon hewicaliya, Heon Jehowa Zeba qa Tzalmuna minape en wicaqu kinhan nicehpipi kin hopuza wapepelsa on, qa takanheca hu on wakaśtake lita.

$8 \mathrm{Qa}$ hetanhan Pénuel ekta itanwankanhde i, qa iyecen ewicakiya. Unkan Sukot wicaśta ayuptapi qon, he iyecen Penuel wicaśta kin ayuptapi.

9 Unkan iś eya Penuel wicaśta kin hewicakiya, Zaniyan waku kinhan conkaśke kin de wapajuju kta ce.

10 Unkan Zeba qa Tzalmuna Qarqor en yakonpi, ozuye tawapi om wicaśta kektopawinge ake zaptan cetu, Wihinanpe cinca ozuye etanhan henana okaptapi, qa wicaśta canhipi kitonpi kektopawinge opawinge sanpa kektopawinge wikcemna nonpa wanna hinhpayapi.

11 Unkan Gideyon wakeya otipi tacankupi ohna itanwankanlide i, Nobahi qa Jogbeha iwiyohiyanpa tanhan, qa ozuye wilkope śniyan unpi icunhan ozuye kin kaśtaka.

12 Unkan Zeba qa Tzalmuna najicapi; unkan Zeba qa TzaImuna wicakuwa, qa Midian wicaśta ya tapi nonpa kîn wicayuza; qa ozuye kin owasin yuśinye wicaya.

13 Hehan Gideyon Joaś cinhintku kin wokicize etanhan Ḧeres itawankanhde yapi etanlıan ku.

14 Qa Sukot wicaśta etanhan kośka wan iyahpayc ca iwanga ; unkan Sukot itancan kin, qa hunkayapi kin wicaśta wikcemna śakowin sanpa śakowin okiciwa.

15 Unkan Sukot wicaśta kin $€ n$ wicahi, qa heya, Wanyakapo ; Zeba qa Tzalmuna, dena on i en iyemayayapi qa hehapi, Zeba qa Tzalmuna napepi kin wanna ninape en duha nace, heon wicaśta nitawa watukapi aguyapi wicunqupi kta.

16 Unkan otonwe hunkayapi kin wicayuza, qa hopuza wapepeka, aa takanhcèa hu icu, qa hena on Sukot wicaśta kin kiksuye wicaya.

17 Qa Penuel conkaśke kin he pajuju, qa otonwe wicaśta kin wicakte.

18 Unkan Zeba qa Tzalmuna hewicakiya; Wicaśta Tabor en wicayaktepi kin hena tokecapi he? Unkan heyapi, Niye iyenicccapi, otoiyohi wicaśta yatapi wan cinca kin iyececapi.

19 Unkan heya, Hena cinye waya, ina cinca hecapi, Jehowa ni kinhan hena ni wicayayapi unkanś ciktepi kte śni tulka.

20 Qa cinhintku tokapa Jeter heciya. Najin wicakte wo. Tuka hokśidan nahanhin hokśika, heon kokipe ca canhipi yuwankan ikikcu śni.

21 Unkan Zeba qa Tzalmuna heciyapi, Niye najin qa unkaśtakapo, wicaśta kin towaśake kin iyececa nakaś. Unkan Gideyon najin, qa Zeba qa Tzalmuna wicakte, qa camo tawapi taku napin wicakiyapi kin icu.

22 Unkan Israel wicaśta kin Gideyon heciyapi, Wowidag unyanpo, niye qa nicinkśi, qa nicinkśi cinhintku, Midian nape kin etanhan niunyayapi heon etanhan.

23 Unkan Gideyon hewicakiya, Miye wowidag ciyapi kte śni, qa micinkśi wowidag niyanpi kte śni. Jehowa hee wowidag niyanpi kte.

24 'Tuka Gideyon hewicakiya, Taku wanji cicidapi, wicaśta otoiyohi oinpi yakipi kin wanjikśi maya qupi kte; Ismayeli hecapi nakaś, heon mazaskazi oinpi yuhapi. 


\section{WICOWOYAKE 9.}

25 Unkan heyapi, Awicakehan he unniçupi kta, qa śina wan yumdaya ehnakapi, qa he akan otoiyohi oinpi wicakipi qon ehpeyapi.

26 Unkan maraskazi oinpi wicakida kin śeqel kektopawinge sanpa opawinge, mazaskazi aspekiyapi ; tuka mazaska mibe, qa maza śipto, qa wokoyake stan Midian wicaśta yatapi koyakapi kin ope śni; nakun wanapin camo tawapi napinpi kin hena yawapi en ope śni.

27 Unkan he etanhan Gideyon amdo akahpe wan kage ca totonwe en ehna ka Opra ohna; unkan, Israel owasin heciya he kici wawicihaliapi econpi; hecen he Gideyon, qa tiyohnaka tawa wicahmuka.

28 Hecen Midian ktepidan Israel cinca itokarn, qa icimana pa yuwankan ikikcu okihi śni. Unkan taanpetu icunhan makoce kin waniyetu wikcemna topa ozi ya. 29 Unkan Jerub Bayal Joaś cinhintku kihde ça iye ti ohna yanka.

30 Qa Gideyon cinca wica wikcemna śakowin yuha, iye ceca etanhan inanpapi, winohinca ota yuza nakaś.

31. Unkan tawicu tokeca Śekem en ounye cin he nakun cinca wan kiciton, qa Abimelek (Ate wicaśta yatapi) caje qu.

32 Unkan Gideyon Joaś cinhintku paska waśte en te, qa Joaś taohnahnakapi kin ohna hnakapi, Yopra Abiyezer ohna.

33 Unkan Gideyon te cin ohakam Israel cinca kin ihduhomnipi, qa Bayalim kici warvicihaliapi econpi, qa Bayal berit wakandapi kta e ehdepi.

34 Hecen Israel cinca kin Jehowa Wakan dapi qon, qa toka wicayapi wicihdukśan owașin etan- han ewicāhdaku kin he kiksuyapi śni.

35 Qa Jerub Bayal Gideyon wowaśte owasin Israel ecawicakicon kin iyecen tiyohnaka tawa wowaeantkiye ecakiconpi śni.

\section{WICOWOYAKE 9.}

\section{Unkan Abimelek Jerub Bayal} cinhintku Śekem ekta i, hunku sunkawicaye cin owasin ekta, qa hena, qa hunku atkuku tiyohnaka owasin hewicakiya,

2 Ihopo, Śekem itancan owasin nogepi ohna heyapo, Jerub Bayal cinca owasin wicaśta wikcemna śakowin wowidag niyanpi kin he waśte he? qaiś wicaśta wanjidan wowidag niyanpi unman tukte waśte he? Qa nihuhu kin, qa nicehpi kin he rniye kiksuyapo.

3 Unlsan hunku sunka wicaye cin iye eciya tanhan Śekem itancan owasin nogepi ohna wocoie kin hena eyapi; unkan Abimelek opapi kta cantepi yeyapi. He sunka unyanpi eyapi nakaś.

4. Unkan Bayal berit (Wicotakuye itancan) ti kin etanhan mazaska wikcemıa śakowin qupi. Unkan Abimelek hena on wicaśta wicaśtapiśni, qa wahan icidapi heca opewicaton, qa hena ihakam yapi.

5 Unkan atkuku ti kin ekta i, Opra ekta, qa iye cincu Jerub Bayal cinca wicaśta wikcemna śakowin inyan wanjidan akan wicakte, tuka Jotam Jerub Bayal cinhintku hakakta kin ope śni, iye inahina nakaśs.

6 Unkan Ślkem itancan kin owasin, qa conkaśke ohna tipi kin owasin mniciyapi, qa Abimelek wicaśta yatapi kagapi, wokiksuye utuhu Śsem ohna yanke cin he elita.

7 Unkan Jotam okiyakapi qe55 


\section{WAYACOPI WOWAPI KIN,}

han, Gerizim he kin akan i, qa iyahan, qa ho yeya, qa eyanpaha, qa hewicakiya, Śkem itancan kin namahonpo, kinhan taku wakan nanihonpi kta.

8 Ehanna can kin wicaśta yatapi sda ic̣iyapi kta konzapi, qa wihdi can kin heciyapi, I to niye ate unniyanpi kta.

9 Unkan wihdican kin hewicakiya, can iwankam waun kta heon wihdi mitawa on taku wakan wicaśta ko yuonihanpi kin he amduśtan lita he?

10 Unkan can kin witanśna hu kin heciyapi, Ito niye ate unniyanpi kta.

11 Unkan witanśna hu kin hewicakiya, Can iwankam waun kta e woskuye mitawa, qa taku waśte icali wakiye cin he amduśtan kta he?

12 Unkan can kin hastanhanka hu kin heciyapi, Ito niye ate unniyanpi kta.

13 Tuka hastanhanka hu kin. hewicakiya, Can iwankam waun kta e heon miniśa skuye cin taku wakan wicaśta koya iyuśkin wicaye cin he amduśtan kta he?

14 Unkan can kin owasin wapepeka hu kin heciyapi, Ito niye. ate unniyanpi $\mathrm{kta}$.

15 Unkan wapepeka hu kin can kin hewicakiya, Wowicake en wicaśta yatapi sdamayakiyapi kinhan, ihopo ohanzi mitawa wacinyanpo, tuka hecetu śni kinhan wapepeka hu etanhan peta inanpe ca Lebanon hante śa kin huhnahya nunwe.

16 Heon wanna wowicake en, qa woecetu en ecanonpi, qa Abimelek wicaśta yatapi yakagapi kinhan; qa Jerub Bayal qa tiyohnaka tawa tanyan ecawicaye conpi hecinhan, qa nape kin iyuwin iyecetu yaqupi kinhan;

17 Ate niyepi on kiza, qa nagi 56 kin ehpekiya, qa Midian nape etanhan enihdakupi ;

18 Tuka niyepi nakaha ate tiyohnaka kin iyawicayahpadapi, qa iye cinca wicaśta wikcemna śakowin inyan wanjidan akan yaktepi, qa tawicinyanna cinhintku Abimelek, sunkayayapi kin heon. Śekem itancanpi iwankam wicaśta yatapi heca yakagapi.

19 Hecen Jerub Bayal qa tiyohnaka tawa kici nakaha wowicake en, qa woecetu en ecawicayeconpi kinhan, Abimelek en iyuśkinpo, qa niyepi en Abimelek iyuśkin nunwe.

20 Tuka hecetu śni kinhan, Abimelek etanhan peta wan inanpe ça Śekem itancan kin, qa Conkaśke otipi kin huhnah wicaye kte; qa Śekem itancan kin, qa Conkaślse otipi kin etanhan peta inanpe ca Abimelek hulinah ya nunwe.

21 Hehan Jotam najice ca cincu Abimelek itokapa tankan nape ca Beer ekta i, qa hen ti.

22 Unkan Abimelek waniyetu yamni Israel iwankam itancan yanka.

23 Unkan Wakantanka woniya śica wan yekiya, Abimelek qa Ślkem wicaśta tokapapi kin otahedan; unkan Śekem wicaśta tokapaji kin nahmana Abimelek kipajinpi.

24 Hecen Jerub Bayal cinca wikcemna śakowin tehiya ecawicakiconpi, weyapi kin he sunkakupi Abimelek wicakte akan hnakapi kta, qa Śsekem wicaśta tokapapi kin cincu wicakte kta e nape waśag yapi kin hena akan u kte.

25 Unkan Śekem itancan kin wicaśta Abimelek nahmana iyapepi kta e he paha akan yanke wicayapi. Unkan tona wicikiyedan canku omanipi kin owasin makicinunpi. 


\section{WICOWOYAKE 9.}

26 Unkan Gayal Eibed cinhintku kin hunkawanjitku kin om u, qa Śekem en hipi. Unkan Śekem wicaśta tokapapi kin he wacinyanpi.

27 Qa maga ekta ipi, qa hastanhanka yuśpipi, qa naśujapi, qa witkotkoya econpi, qa taku wakan dapi ti kin en ipi, qa wotapi qa wayatkanpi, qa Abimelek yaśicapi.

28 Unkan Gayal Ebed cinhintku heya, Śekem he tuwe? qa Abimelek he tuwe on wowidag unyanpi kta he? Jerub Bayal cinhintku kin hee śni he? qa tawowapi kaga Zebul hee śni he? Tokeca he wowidag unyanpi kta he? Hamor Śekem atkuku tawicaśta kin ówicakiyapo.

29 Tokin oyate kin de minape en unpin, Unkanś Abimelek mdutokan kta tuka, qa Abimelek on heya, Obe nitawa tanka kage ça inanpa wo.

30 Unkan Zebul otonwe itancan kin Gayal Ebed cinhintku oie kin nahon qa nina sihda.

31 Qa wahośi, Abimelek ekta nahmana ye wicaśi, qa heciya, Inyun Gayal Ebed cinhintku hunkawanjitku om Śekem en hipi, qa otonwe toka niyanpi kagapi ;

32 Heon wanna hanyen najin wo, niye qa oyate onipapi, qa tinta ohna nahmana iyawicape wo.

33 Qa hanhanna wihinanpe cinhan yektapi, qa otonwe kin anayatanpi kta, qa iho iye qa oyate opapi kin hena nitkokim inanpapi kinhan, token ninape okihi ecawicayecon kta.

34 Unkan Abimelek, qa oyate iye opapi owasin hanyen kiktapi, qa obe topa Śsemem nahmana iyapepi.

35 Unkan Gayal Ebed cinhin- tku inanpe ca otonwe tiyopa ekta inajin; unkan 'Abimelek, qa oyate iye opapi kin inalimanpi qon etanhan najinpi.

36 Unkan Gayal oyate kin wanwicayake ca Zebul heciya, Inyun oyate lie paha etanhan apamahde upi ce. Unkan Zebul heciya, He ohanzi kin wandaka, wicaśta iyececa.

37 Unkan Gayal ake ie ça heya, Inyun makoce pajodan etanhan oyate upi, qa wapiyesa utuhu canku kin ohna obe wanji u ce.

38 Unkan Zebul heciya, Nii on Abimelek he tuwe on wowidag unyanpi kta he? ehe cin wanna tuktee he? Oyate ihawicayakta śni kin dee śni he? Tokin wanna inanpe ca wicakiza wo.

39 Unkan Gayal inanpa Śekem itancan kin wicitokam, qa Abimelek kiza.

40 Unkan Abimelek he anatan. Unkan najica iye itokapa tanhan, qa wicota capapi hinhpayapi, otonwe tiyopa ekta hehanyan.

41. Unkan Abimelek Aruma en iyotanka. Unkan Zebul Gayal qa hunkawanjitku Śekem en tipi kte śni napewicaya.

42 Unkan ihanhianna oyate kin maga ekta ipi. Unkan Abimelek okiciyakapi.

4.3 Unkan oyate tawa ikikcu, qa obe yamni kage ça nahmana iyawicape maga ohna, qa oyate otonwe etanhan inanpapi wanwicayake cehan anawicatan, qa wicakaśtaka.

$44 \mathrm{Qa}$ Abimelek, qa obe iye opapi kin anatanpi, qa otonwe tiyopa ekta najinpi; qa obe nonpa tona maga ohna unpi kin owasin anawicatanpi, wicakuwapi qa wicaktepi.

45 Unkan Abimelek anpetu kin he ihuniyan otonwe kin azuye ça 
otonwe kin icu, qa oyate ohna unpi kin wicakte, qa otonwe kin pajuju, qa miniskuya akada.

46 Unkan Śekem conkaśke itancan owasin nahonpi qehan, El Berit (Wakan Otakuye) ti ipasotka kin en ipi.

47 Unkan Śekem conkaśke wicaśta owasin witaya yakonpi, Abimelek okiyakapi.

48 Unkan Abimelek Tzalmon he kin ekta i, iye qa oyate iye opapi kin owasin, qa Abimelek nape kin ohna onspe wan icu, qa can adetka kakse ca yuwankan icu, qa tapete akan ehnaka, qa oyate opapi kin hewicakiya, Token ecamon kin wandakapi kin he iyecen kohanna econpo.

49 Unkan oyate owasin nakun, otoiyohi adetka kaksapi, qa Abimelek ihakam yapi, qa ipasotka ekta ejupi, qa peta on ipasotka kin ideyapi; hecen wicaśta conkaśke ohna yakonpi kin iś eya owasin tapi, wicaśta qa winolinca owasin kektopawinge cetu.

50 Unkan Abimelek Tebetz ekta i, qa Tebetz itkom iyotanka, qa he icu.

51 Tuka conkaśke wan suta otonwe ohna yukan. Unkan wicaśta qa winohinca owasin, qa otonwe wicaśta itancan owasin heciya napapi, qa wicihakam sutaya natakapi, qa conkaśke awakeyapi akan adipi.

52 Unkan Abimelek conkaślke ekta i, qa azuya, qa conkaśke tiyopa huhnali ye kta e ikiyedan i.

53 Unkan winohinca wan wokpan inyan wan onśpa kin Abimelek pa akan ehpeya, qa nasuhu kin kahuga.

54 Unkan kośka tawipe kicicin kin he kohanna kipan, qa heciya, Nitacanhipi ikikcu, qa makte wo ; hecen Winohinca wan makte ke- yapi kte śni. Unkan kośka kin cape ca kte.

55 Únkan Israel wicaśta kin Abimelek te cin wanyakapi, qa otoiyohi kihdapi.

56 Hecen Wakantanka Abimelek tohan śica iye atkuku ecakicon, qa cinca wikcemna śakowin wicakte iye en hdikiya.

57 Qa Śkem wicaśta tolianpi śica kin owasin iye papi akan hdikiya, qa Jerub Bayal cinhintku Jotam woyaśice kin iyowicahi.

\section{WICOWOYAKE 10.}

1 Unkan Abimelek iyohakam, Tola Pua cinhin tku Dodo cinhintku Issakar wicaśta Israel ni wicaye kta najin, qa iye Epraim he ohna Samir en ounyan.

2 Qa Israel waniyetu wikcemna nonpa sanpa yamni wicayaco, hehan țe ça Śamir en hnakapi.

3 Unkan iye iyohakam Jair Gileyadi najin qa waniyetu wikcemna nonpa sanpa nonpa Israel wicayaco.

4 Qa cinca wica wikcemna yamni yuha, hena śonśonna mdoka wilkcemna yamni akan yotankapi, qa otonwe wikcemna yamni yuhapi, hena Hawot Jair (Jair totonwe) eciyapi, anpetu kin dehanyan Gileyad makoce ohna.

5 Qa Jair țe ça Qamon en hnakapi.

6 Unkan Israel cinca kin ake Jehowa iśta kin en taku śica econpi, qa Bayalim, qa Aśterot ohodapi; nakun Aram taku wakanda, qa Tzidon taku wakanda, qa Moab taku wakanda, qa Amon cinca taku wakandapi, qa Pilistim taku wakandapi kin hena ohodapi; hecen Jehowa ayuśtanpi qa ohodapi śni. 


\section{WICOWOYAKE 11.}

7 Unkan Jehowa Israel canniye wicaye ça Pilistim napepi en, qa Amon cinca napepi en wiyope wicaya.

8 Unkan waniyetu kin he etanhan Israel cinca tona Jordan akasanpa Amori tamakocepi ohna Gileyad ohna yakonpi kin hena owasin śicaya wicakuwapi, qa iyokiśin wicayapi.

9 Qa Amon cinca Jordan iyuwegapi, qa Juda nakun azu wicayapi, nakun Benjamin, qa Epraim tiyohnaka, hecen Israel nina iyokiśin wicayapi.

10 Unkan Israel cinca kin Jehowa hoyekiyapi, qa heciyapi, 'Taku Wakan undapi unkayuśtanpi, qa Bayalim ohoundapi kin en awaunnilitanipi.

11 Unkan Jehowa Israel cinca kin hewicakiya, Egupton etanhan, qa Amori etanhan qa Amon cinca etanhan, qa Pilistim etanhan ecihdakupi śni he?

12 Nakun Tzidoni, qa Amaleq, qa Mayon iyokiśin niyanpi qehan hoyemayakiyapi, unkan ecihdakupi ;

13 Tuka niyepi amayaduśtanpi, qa taku wakan tokeca ohoyadapi, heon ake niciyapi kte śni.

14. Thopo taku wakan iyonicipipi kin hena ho yewicalkiyápo; dehan tehiya yaunpi heon hena niniyanpi nunwe.

15 Unkan Israel cinca kin Jehowa heciyapi, Waunhtanipi, niye taku niiśta en waśte kin ecaunkiconpo, anpetu kin de en eunyahdakupi kinhan.

16 Hehan taku wakan tokeca iyepi etanhan yutokan iyeyapi, qa Jehowa ohodapi. Unkan Israel wicakiyuśepi on nagi kin iyokiśica.

17 Hehan Amon cinca kin witaya iheyapi, qa Gileyad en ahi wankapi. Unkan Israel cinca kin mniciyapi, qa Mitzpa en ewankapi.

18 Unkan oyate kin Gileyad itancanpi kin hekiciyapi, Tuwe Amon cinca kin tokaheya azu. wicaye kta wicaśta kin he Gileyad ounyanpi kin owasin pa yuhapi kta.

\section{WICOWOYAKE 11.}

1 Unkan Jeptali Gileyadi wicaśta waśaka waditaka heca tuka hunku witkowin heca, qa Jeptali Gileyad cinhintku kin hee.

2 Unkan Gileyad tawicu kin he cinca kiciton; unkan tawicu cinca kin tanka icagapi qehan, Jeptah nape yapi, qa heciyapi, Ate unyanpi ti kin ohna takudan tawa yaye kte śni, witkowin cinca henica nakaś.

3 Unkan Jeptah atkuku cinca itokapa tanhan najice ca Tob makoce en iyotanka. Unkan wicaśta takudan yuhapi śni Jeptah en mniciyapi, qa kici iyayapi.

4 Unkan anpetu ota iyohakam Amon cinca kin Israel azuwicayapi.

5 Unkan Amon cinca kin Israel azuyapi qehan Gileyad hunkayapi Tob makoce kin ekta, Jeptah huweyapi.

6 Qa heciyapi, Kuwa mdetanhunka unniyuhapi kta, qa Amon cinca wicunkizapi kte.

7 Unkan Jeptah Gileyad hunkayapi hewicakiya, Śicemayadakapi śni he?.qa ate ti kin etanhan nape mayayapi, qa tokeca nakaha tehiya dukanpi qehan en mayahipi he?

8 Unkan Gileyad hunkayapi kin Jeptah heciyapi, Unkicipi de kta, qa Amon cinca kin wicunkizapi kta, qa Gileyad otipi kin owasin itancan unniyuhapi kta, heon en unnihipi. 


\section{WAYACOPI WOWAPI KIN,}

9 Unkan Jeptah Gileyad hunkayapi kin hewicakiya, Amon cinca wicawakize kta e hde mayayapi kinhan, qa Jehowa mitokam wicaqu kinhan miye itancan mayaduhapi kta he?

10 Unkan Gileyad hunkayapi Jeptah heciyapi, Unkiyepi otahedan Jehowa wanahon yanka, token ehe cin iyecen econkupi śni kinhan.

11 Unkan Jeptah Gileyad hunkayapi kin om iyaya: unkan oyate kin wiciwankam he pa kagapi, qa mdetanhunka. Unkan Jeptah iye oie kin owasin Jehowa itokam Mitzpa he en ia.

12 Unkan Jeptali Amon cinca wicaśta yatapi ekta ohnihde ye wicaśi, qa heciya, Taku ecaunkicicon on mitamakoce en azumayaye kta yahi he?

13 Unkan Amon cinca wicaśta yatapi kin Jeptali ohnihde wicaye cin hewicakiya, Israel Egupta etanhan itanwankanhde upi qehan, makoce mitawa icupi, A.rnon etanhan Jaboq, qa Jordan hehanyan, heon hecamon. Hecen wanna makoce kin he wokicize codan micu 'wo.

14 Unkan Jeptali ake ohnihde Amon cinca wicaśta yatapi ekta ye wicaśi,

15 Qa heciya, Jeptah hecen eya, Israel Moab tamakoce, qa Amon cinca tamakocepi kin icu śni.

16 Egupta etanhan itanwankanhde upi qehan, Israel hopuza omanipi, Mdeśa ekta, qa Qadeś ekta hipi.

17 Qa Israel ohnihde Edom wicaśta yatapi ekta ye wiçśi, qa heciyapi, Tokin nita makoce kin opta mde kten; tuka Edom wicaśta yatapi kin nation śni. Nakun Moab wicaśta yatapi ekta ye wicaśi, tuka wicada śni, heon Israel Qadeś en ounyanpi.
18 Hehan hopuza kin omanipi, qa Edom tamakoce, qa Moab tamakoce ohomni yapi, qa Moab tamakoce kin wihinanpe cin eciya tanhan, ahitipi, Arnon akasanpa tanhan qa Moab tamakoce en ipi śni, Armon Moab tamakoce ihanke kin hee nakaś.

19 Unkan Israel Silion Amori wicaśta yatapi kin Ḣeśbon wicaśta yatapi kin hee, ekta ohnihde ye wicaśi, qa heciyapi, Tokin oyanke mitawa ekta nitamakoce kin itoopta unyanpin.

20 Tuka Silion iye tamakoce ohna Israel opta ye kta, wicada śni, qa Silion oyate tawa owasin mnawicaya, qa Jahatze ohna ahitipi, qa Israel om kicizapi.

21 Unkan Jehowa Israel Wakandapi kin Silion qa taoyate owasin Israel nape en wicaqu. Unkan Israel wicakaśtaka, qa Amori makoce kin he en ounyanpi kin tamakocepi kin ocowasin tawayapi.

22 Hecen Amori tamakocepi kin ocowasin Arnon etanhan Ja. boq ekta hehanyan, qa Hopuza etanhan Jordan ekta tawayapi.

$23 \mathrm{Qa}$ wanna Jehowa Israel Wakan dapi kin Amori kin napewicaya, iye taoyate Israel itokapa tanhan, qa niye he tawayaye kta he?

24. Kemoś wakan yada taku nicu kin he tawa yaye kte śni he? Hecen taku Jehowa Wakan undapi, tawa unyanpi kta unqupi kin he owasin tawa unyanpi kta.

25 Unkan ecah Balaq Tzipor cinhintku Moab wicaśta yatapi kin isanpa niwaśte he? Iye Israel om akinica qaiś azuwicaya he?

26 Israel Ḣeśbon qa otonwe cunkśi wicaya, qa Aroyer qa cunkśi wicaya, qa otonwe Arnon icahda yakonpi owasin waniyetu 


\section{WICOWOYAKE 12.}

opawinge yamni hehanyan ounyanpi, tokeca he icunhan iyacupi śni he?

2) Hecen miye awacilitani śni, tuka niye śicaya ecamiyecon, qa azumayaya; Jehowa wayaco kin nakaha miye qa niye otahedan wayaco kta, qa Israel qa Amon cinca kin otahedan.

28 Tuka Amon cinca wicaśta yatapi kin Jeptah oie wahoyekiye cin he anagoptan śni.

29 Unkan Jehowa taniya kin Jeptah akan hiyu, qa Gileyad opta iyaya, nakun Manaśe, qa Mitzpa Gileyad ekta, qa Mitzpa Gileyad etanhan Amon cinca kin itkom i.

30 Qa wokonze wan Jeptah Jehowa okiyake ca heya, Amon cinca kin minape en wicayaqu kinhan,

$31 \mathrm{Qa}$ Amon cinca kin etanhan zaniyan waku kinhan, taku kaśta wati tiyopa kin etanhan itkomakipe kta inanpe cinhan Jehowa yuhe kta qa wohuhnahyapi on huhnahwaye kta.

32 Qa Jeptah azuwicaye kta e Amon ekta iyaya, qa iye nape en Jehowa wicaqu;

33 Qa wicakaśtaka, Aroyer etanhan Minnit ekta yaki kin hehanyan, otonwe wikcemna nonpa, qa Abel hastanhanka iyuwi oju ekta, wopate tanka hinca, hecen Amon cinca patujapi Israel cinca itokam.

34 Unkan Jeptah iye ti ekta hdi, Mitzpa en; unkan inyun itkokipe kta e cunwintku cancega qa wacipi yuha inanpa; unkan heceedan iśnana icaga cinca tokeca wica winyan unmana yuhe śni.

35 Unkan he wanhdake cehan wokoyake hdulidehdece ca heya, Cunś nina yuhukun mayaya, qa niye iyokiśin mayaya.
Jehowa ekta i wahdukawa, qa mihdamna owakihi śni.

36 Unkan heciya, Ate nii Jehowa ekta yahdukawa. Token nii etanhan inanpe cin he iyecen ecamicon ye. Jehowa toka niyanpi Amon cinca kin toniciçon nakaś.

37 Unkan atkuku heciya, Taku kin de ecamicon ye; wi nonpa iyowin makiya ye, hecen imdamde ca he kin amawani lita, qa witanśna waun kta awakiceye kta ye, miye qa mitawaśi kin hena.

38 Unkan heya, Ya wo. Hecen wi nonpa hehanyan ye śi. Unkan iyaya, iye qa koda wicaye cin, qa witanśna un kta on lie akan akiceya.

39 Unkan wi nonpa hehan atkuku en hdi. Unkan wokonze oyake ciqon he iyecen ecakicon. Unkan wicaśta sdonye śni yanka.

40 Unkan Israel ohna wokage wan dee, iyehantu eca Israel cunwintku waniyetu otoiyohi Jeptah Gileyadi cunwintku anpetu topa aceyapi kta e ekta ipi ece.

\section{WICOWOYAKE 12.}

1 Unkan Epraim wicaśta kin mnaiciyapi, qa waziyata kiya yapi, qa Jeptah heciyapi, Tokzca Amon cinca azuwicayaye $\mathrm{kta}$ idade cehan nici unyanpi kta unyecopi śni he? Yati kin niwankam peta on hulinah unyanpi kta.

2 Unkan Jeptah hewicakiya, Miye, qa oyate mitawa Amon cinca om woakinice tanka unhapi, qa cicopi tuka nimayayapi śni.

3 Unkan niye waniyakiyapi śni wanmdake cehan, minagi minape 


\section{WAYACOPI WOWAPI KIN,}

en ye wakiye ça Amon cinca kin ekta wai. Unkan Jehowa minape en wicaqu; heon tokeca mayakizapi kta e nakaha anamayatanpi he?

4 Qa Jeptah Gileyad wicaśta owasin mna wicaye ça Epraim kiza. Unkan Gileyad wicaśta kin Epraim wicakaśtakapi, Niyepi Gileyadi kin Epraim etanhan nayajicapi Epraim qa Manaśe otahedan, eyapi kin heon etanhan.

5 Unkan Gileyadi Jordan oiyuwega kin icupi, Epraim itokam. Unkan Epraim najicapi kin, Imduwege kta eyapi qehan, Epraim wicaśta henica he? Gileyad wicaśta kin heciyapi. Unkan Hiya, eye cinhan,

6 Śibolet, (Wakpa) eya wo, eč yapi. Unkan Sibolet, eya, qa iyecetuya ie śni; hehan iyahpayapi, qa Jordan oiyuwega ekta ktepi; hecen he ehan Epraim etarhan wicaśta kektopawinge wikcemna topa sanpa kektopawinge nonpa hinhpayapi.

7 Unkan Jeptah waniyetu śakpe Israel wicayaco, hehan Jeptali Gileyadi kin ța, qa Gileyad otonwe wan en hnakapi.

8 Unkan iye iyohakam Ibetzan Betlehem etanhan Israel wicayaco.

9 Qa cinca wikcemna yamni yuha, qa cunwintku wikcemna yamni titokan ekta ye wicaya, qa titokan etanhan iye cinhintku on winyan takoś wicaye kta e wikcemna yamini hiyu wicaya qa waniyetu śakowin Israel wicayaco.

10 Unkan Ibetzan te ca Betlehem en hnakapi.

11 Unkan iye iyohakam Elon Zebuluni kin Israel wicayaco, qa waniyetu wikcemna Israel wicayaco.
12 Unkan Elon Zebuluni kin te, qa Aijalon en, Zebulun tamakoce ohna hnakapi.

13 Unkan iye iyohakam Abedon Hillel cinhintku Piratori kin Israel wicayaco.

14 Qa iye cinca wikcemna topa yuha, qa takojatpaku wikcemna yamni, hena śonśonna wikcemna śakowin akan iyotankapi; qa iye waniyetu śałdogan Israel wicayaco.

$15 \mathrm{Qa}$ Abedon Hillel cinhintku Piratoni kin te ca Amaleqi he kin en Epraim makoce ohna Piraton en hnakapi.

\section{WICOWOYAKE 13.}

1 Unkan ake Israel cinca kin Jehowa iśta kin en taku sica econpi; heon Jehowa Pilistim napepi en wicaqu waniyetu wikcemna topa.

2 Unkan Dani wicowazi etanhan wicaśta wan icage ca Manoah eciyapi, qa tawicu kin cinca ton śni, qa ihduśake śni.

3 Unkan Jehowa ohnihde kin winohinca kin en ihdutanin, qa heciya, Inyun dehan cinca yatonśni, qa nihduśake śni eśta, nihduśake ça cinca wica wan yaton kta.

4 Heon detanhan waktaya un wo. Ihnuhan miniśa qaiś miniwakan datke cin, qa taku śapa ongedan yate kte śni.

5 Inyun nihduśake ca cinca wica wan yaton kta, qa pa kin akan iyuśda hi kte śni, hokśidan kin, tamni kin etanhan Wakantanka Nazir (yukinukanpi) heca kta, qa iye tokaheya Pilistim etanhan Israel ni wicaye kta.

6 Unkan winyan kin hihnaku ekta i qa heciya, Wakantanka wicaśta wan ekta mahi; qa wanyakapi kin Wakantanka ohnihde 
wan wanyakapi kin iyececa, wohitika hinca, heon tokiya tanhan u kin imonge śni, qa caje kin omakiyake śni.

7 Tuka hemakiya, Inyun inihduśake ca cinca wica wan yaton kta; heon wanna innuhau miniśa, qa mini wakan unmana datke cinhán, qa taku śapa ongedan yate kte śni, tamni etanhau inanpe cin ehantanhan anpetu en te kte cin hehanyan hokśidan kin Wakantanka Nazir heca kta.

8 Unkan Manoah cekiye ca heya, Itancan tokin, Wakantanka tawicaśta u yaśi qon, ake unkiyepi en hi kte ca hokśidan tonpi kte $\operatorname{cin}$ he token ecaunkiconpi kta onspe unkiyapi kten.

9 Unkan Wakaritanka Manoah ho kin nahon; unkan Wakantanka ohnihde kin ake winohinca kin en hi, maga ohna iyotankehan yanka he icunhan; tuka hihnaku Manoali kici un śni.

10 Unkan winohinea kin inahni, qa inyanke ça hihnaku okiyake ca heciya, Inyun wicaśta anpetu wan en mahi qon ake miye en ihdutanin.

11 Unkan Manaoh uajin, qa tawicu ihakam iyaye ca wicaśta qon ekta i, qa heciya, Winohinca taku eciye ciqon wicaśta kin he - niye he? Unkan, He miye ce, eya.

12 Unkan Manoąi heciya, Nioie ecetu kinhan hokśidan tawoyaco kin toketu, qa token ecaunkiconpi kta he?

13 Unkan Jehowa ohnihde kin Manoah heciya, Winohinca taku ewakiye ciqon owasin on waktaya un kte,

14 Hastanhanka iyuwi taku aicage cin ongedan yute kte śni, qa miniśa, qa miniwakan ongedan yatke kte śni, qa taku śapa ongedan yute kte śni; token econ waśi qon owasin iyecen econ kte.

15 Unkan Manoab. Jehowa ohnihde kin heciya, Tokin den unniyuhapin, ecen tatokadan cinca wan nitokam unpatapi kte.

16 Unkan.Jehowa ohnihde kin Manoah heciya, Den mayaduhapi eśta aguyapi nitawa ongedan wate kte śni, qu wopate wan yakage cinhan Jehowa on yapate kta. Jehowa ohnihde kin hee Manoah sdon ye śni nakaś.

17 Unkan Manoah Jehowa ohnihde kin heciya, Token eniciyapi he? hecen nioie kin ecetu kinhan unniyuonihanpi kta.

18 Unkan Jehowa ohnihde kin heciya, Tokeca de micaje imayanonga? qa Wawinihan hee.

19 Unkan Manoah tatokadan cinca kin ikikcu, minha kin iyahna, qa inyan kin akan Jehowa ekicihnaka. Unkan taku wowinihan econ kin Manoah tawicu kici wanyakapi.

20 Wahna wośnapi etanhan woide kin malipiya ektakiya wankan iyaye cehan, Jehowa ohnihde kin wahna wośnapi oide ohna wankan iyaya. Unkan Manoah tawicu kici he wanyakapi qehan makipusdiya hinhipayapi.

21 Unkan Jehowa ohnihde kin icimana Manoah qa tawicu en ihdutanin śni. Hehan Jehowa ohnihde kin hee Manoah sdonya.

22 Qa Manoah tawicu kin heciya, Tokeśta unte kta, Taku wakan wan wanunyaka nakaś.

23 Unkan tawicu kin heciya, Jehowa te unkiya iyokipi unkanś wohuhnahyapi wan qa minhia wan unnape etanhan icu kte śni tuka, qa taku kin dena owasin wanyag unkiye kte śni, qa nation unkiye kte śni econ kin iyecen. 24 Unkan winohinca kin cinca 63 


\section{WAYACOPI WOWAPI KIN,}

wica wan ton; qa Samson eya cajeyata. Unkan hokśidan kin tanka icaga; unkan Jehowa he yawaśte.

25 Qa Jehowa ohnihde kin Dan taakicita ti ohna tokaheya iyopaśtaka, Tzora qa Eśtaol otahedan.

\section{WICOWOYAKE 14.}

1 Unkan Samson Timnata ekta kun iyaye ca Timnata ohna Pilistim cunwintku winohinca wan wanyaka.

2 Qa hdi, qa atkuku hunku kici owicakiyake ca hewicakiya, Timnata ohna Pilistim cunwintkupi wan wanmdaka. Ito mduze kta e wanna imicicupo.

3 Unkan atkuku hunku kici heciyapi, Nihunkawanji cunwintkupi ehna, qa oyate nitawa owasin wicehna winohinca wanica nace, heon Pilistim bawicakilidayapi śni ekta de ca etanhan winohinca wan duze kta he? Unkan Samson atkuku heciya, He imicicu wo; miiśta kin ohna he ecetu ce.

4 Tuka atkuku qa hunku Pilistim taku ecawicakicon kta akite cin he Jehowa kage cin sdon yapi śni. Unkan he ehan Pilistim Israel wowidag yapi.

5 Unkan Samson qa atkuku hunku kici Timnata ekta kun iyayapi; qa Timnata hastanhanka iyuwi ojupi ekta ipi qehan, mnaja kośka wan iye itkokim hoton yanka.

6 Unkan Jehowa toniya kin ahinhpaye ca nape ohna takudan yuke śni eśta kiyulideca tatokadan cinca wan kiyuhdecapi he iyecen; tuka taku econ kin atkuku qa hunku owicakiyake śni.

7 Qa ekta i, qa winohinca kici 64 wohdaka, unkan Samson iśta kin erı ecetu.

8 Unkan iyohakam anpetu ota he yuze kta e ake ekta iyaye ca mnaja tancan kin wanyake kta icunom iyaya, unkan inyun tuhmaga optaye wan mnaja tancan kin ohna yanka; nakun tuhmaga canhanpi.

9 Qa nape en onge icu, qa yun iyaye ca atkuku hunku kici ekta i, qa wicaqu ; unkan yutapi, tuka ninaja tancan etanhan tulimaga canhanpi kin icu owicakiyake śni.

10 Unkan atkuku winohinca kin ekta i; unkan Samson wohanpi wan hen kaga, koślka hecen econpi ece nakaś.

11 Unkan wanyakapi qehan, kośka wikcemna yamni koda wicaye kta e kahnigapi qa hena opapi.

12 Unkan Samson hewicakiya, Wowiyukcan wan ociciyakapi kta. Wohanpi anpetu śakowin icunhan he iyeyayapi, qa awicakehan omayakidakapi kinhan; mahen unpi wikcemna yamni, qa wokoyake tokeca iyuhpa wilecemna yamni cicupi lita.

13 Qa omayakidakapi oyakitpanipi kinhan, mahen unpi wikcemna yamni, qa wokoyake ocaje tokeca iyuhipa wikcemna yamni niyepi mayaqupi kta. Unkan, Wowiyukcan nitawa ohdaka wo, naunhonpi kta, eyapi.

14 Unkan hewicakiya, Wotesa etanhan woyute inanpa, qa waśake cin etanhan taku skuya inanpa. Unkan anpetu yamni wowiyukcan kin oyakapi okitpanipi.

15 Unkan anpetu iśakowin Samson tawicu kin heciyapi, Nihihna, wowiyukcan unkokiyakapi oniciyake kta, cin kiya wo. Hecanon śni kinhan, niye qa 


\section{WICOWOYAKE 15.}

niyate ti kin peta on hulinah unyanpi kta? Taku unkitawapi kin tawa yayapi kta heon unyecopi śni he?

16 Unkan Samson tawicu kin ceye ca heciya, Waśte mayadake śni, tuka śice mayadaka ecee. Wowiyukcan wan oyate mitawa cinca kin iyukcan wicayaśi, tuka token ke cin omayakidake śni. Unkan heciya, Inyun ate qa ina owicawakimdake śni; qa niye ociciyake $\mathrm{k}$ ta he?

17 Unkan anpetu śakowin wohanpi kagapi kin hena icunhan itokam ceya yanka, qa nina iyahdaskica, heon anpetu iśakowin en he okiyaka. Unkan troyate cinca kin owicakiyaka.

18 Unkan otonwe wicaśta kin anpetu iśakowin en wi iyaye śri itokam heciyapi, Taku tuhmaga canhanpi sanpa skuye cin tuktee he? Qa mnaja isanpa waśaka tuktee he? Unkan Pte mitawa on maka iyakagopi śńi unkanś, wowiyukcan mitawa idukcanpi kte śni tuka.

19 Unkan Jehowa toniya kin iyopaśtaka, heon Aśkelon ekta kun iyaye ca hetanhan wicaśta wikcemna yamni kte, qa heyakepi kin wicakiciyuśdoka, qa wowiyukcan kin okiyakapi kin wokoyake wicaqu, qa canniye atkuku ti ekta hda.

20 Unkan Samson tawicu kin takodaku koda ye ciqon he yuza.

\section{WICOWOYAKE 15.}

1 Unkan ohakam aguyapi su baksapi kin he eban Samson tatokadan cinca wan tawicu kahi qa, Mitawin ekta mde kta winohinca tipi en, eya, tuka winyan atkuku kin en ye kta iyowinkiye sni.

$2 \mathrm{Qa}$, Atkuku heciya, $\mathrm{He}$ śice Dak. yadaka epapa, qa nitakoda waqu. Tankaku he isanpa waśte śni he? Tokin heekiya he nitawa kten.

3 Unkan Samson hewicakiya Pilistim taku śica ecawicawecon eśta nakaha iyaonpepica śni waun kta.

4 Unkan Samson iyaye ça sungidan opawinge yamni yuza, qa petuspe icu, qa sinte icikoyag wicaya, qa nomnom otahedan sintepi en petuspe ikoyag ya.

5 Qa petuspe ideya, qa Pilistim aguyapi baksapi śni en iyaye wicaya, hecen aguyapi paha, qa aguyapi baksapi śni, qa hastanhanka iyuwi, qa wihdi can liuhonah ya.

6 Unkan, Tuwe decon hwo? Pilistim eyapi. Unkan Samson Timnati takośku, tawicu icupi, qa takodaku qupi nakaś. Unkan Pilistim ekta ipi, qa winyan qon, qa atkuku peta on huhnah yapi.

7 Unkan Samson hewicakiya, Hecen ecannonpi kinhan tokeśta niyepi en toweçon kta, qa hehan amduśtan kta.

8 Unkan cankpe ceca akan wicakaśtaka wicota wicakte, hehan iyaye ca Yetam (Wamanicati) inyan nasdecapi kin ohna ti.

9 Unkan Pilistim itanwankan hde ipi, qa Juda en e tipi, qa Lehi (Cehupa) en enanakiya iyayapi.

10 Unkan Juda wicaśta kin heyapi, Tokeca tatpe unyahipi he? Unkan heyapi Samson unkaśkapi kta e urhipi, qa token iye ecaunkiconpi, he iyecen unkiye ecaunkiconpi kta, heon unhipi ce.

11 Unkan Juda etanhan wicaśta kektopawinge yamni Yetam inyan nasdecapi kin ekta kun iyayapi, qa Samson heciyapi Pilistim wowidag unyanpi sdonyaye 65 


\section{WAYACOPI WOWAPI KIN,}

śni he? taku ecaunyeconpi he? Unkan, Token ecamiconpi he iyecen ecawicawecoll, ewicakiya.

12 Unkan nicaśkapi, qa Pilistim napepi en unnicupi kta, heon unhipi ce, eciyapi. Unkan Niyepi mayakaśtakapi kte śni, taku wakan cajeyan emakiyapo, eya.

13 Unkan heciyapi, Hiya, tuka unnicaśkapi kta, qa napepi en unnicupi kta, qa unkiyepi unniktepi kte śni. Hehan hakahmonpi teca nonpa on kaśkapi, qa iny an qon, etanhan itanwankanhde hiyaye yapi.

14 Lehi ekta i, unkan Pilistim itkokim iyakiśapi. Unkan Jehowa toniya iyopaśtaka, unkan hakahmonpi isto on kaśkapi kin hena hahonta hu peta on gu kin iyececapi, qa taku on kaśkapi nape etanhan śkanpi.

15 Unkan śonśonna cehupa do wan iyeye cea nape elsta ye kiye ca icu, qa heon wicaśta kektopawinge wicakte.

$16 \mathrm{Qa}$ Samson heya, Śonśonna cehupa on opahi opahihi, Śonśonna cehupa on wicaśta kektopawinge wicawakte.

17 Unkan ia ayaśtan qehan cehupa qon nape kin etanhan ehpeya. Unkan oyanke kin he Ramot Lehi (Cehupa Paha) eciyapi.

18 Unkan nina ipuza, heon Jehowa hoye kiye ca heya, Niye nitaokiye nape kin on woohiye tanka kin de yaqu; unkan wanna ipuza mate ca wicaśta bakihdayapi śni napepi mayuzapi kta.

19 Unkan Wakantanka wibope wan Lehi ohna yanke cin he yuptuja. Unkan hetanhan mini hinanpa; unkan yatkan, qa toniya kin ake en hdi. Unkan heon miniowe kin he, En haqora, (Mi- ni owe hoyeya,) eciyapi, qa anpetu kin dehanyan Lehi en yanka.

20 Unkan Pilistim taanpetu icunhan waniyetu wilkcemna nonpa Israel wicayaco.

\section{WICOWOYAKE 16.}

1 Unkan Samson Gaza ekta i, qa hen winohinca witkowin wan wanyake ca ekta i.

2 Unkan Samson den hi ce, eyapi Gaza wicaśta kin nahonpi*; unkan aohomnipi, qa hanyetu osan otonwe tiyopa ekta iyapepi, ga inina unpi, qa hanhanna anpa kinhan un ktepi kta, eyapi.

3 Unkan Samson hanye cokaya hehanyan makan wanka, qa hanyetu cokaya qehan, najin hiyaya, qa otonwe tiyopa kin yuza, qa tiyopa tośu napin yujon icu, tiyopa inatake iyahna, qa amdo akan ehnaka, qa he paha Hiebron itokam yanke cin ekta aya.

4 Unkan he iyohakam Sorea kaksiza ohna winohinea wan waśte daka, Delila eciyapi.

5 Unkan Pilistim itancanpi kin winohinca kin elsta ipi, qa heciyapi, Cinkiya wo; qa towaśake tanka kin taku en un kin, qa tokiya tanhan kakiś unyanpi kta e unkaśkapi unkokihipi amdesya wo; kinhan unkiyepi otoiyohi mazaska kektopawinge sanpa opawinge unnicupi kta.

6 Unkan Delila Samson heciya, 'Tokin nitowaśake tanka kin he taku en un, qa iyokiśin niyanpi kta e token nicaśkapi kta omayakiyaken.

7 Unkan Samson heciya, Telimiso do, tohinni pusyapi śni śakowin on makaśkapi kinhan, wicaśta wan iyemaceca kta.

8 Unkan Pilistim itancanpi kin tehmiso do śakowin, tohinni pus- 
yapi śni ekta ahipi, unkan hena on kaśka.

9 Unkan wankanti ohna iyapepi. Unkan winyan qon heciya, Samson Pilistim iyanihpayapi ye ; unkan tehmiso papsaka, hahonta penmna kinhan papsakapi he iyecen; hecen towaśake kin tuktee kin sdonyapi śni.

10 Unkan Delila Samson heciya, Inyun mayahnayæn, qa oitonśni emayakiya ye. Tokin wanna tokiya tanhan nicaśkapi kta omayakiya ken.

11 Unkan heciya, Hakahmonpi teca, on tohinni wohtani takudan econpi śni heca on makaśkapi kinhan, wamaśake kte śli, qa wicaśta wan iyemaceca $\mathrm{kta}$.

12 Unkan Delila hakahmonpi teca icu, qa hena on kaśka, qa heciya, Pilistim iyanihpayapi ye Samson. Unkan hena isto kin etanhan papsaka, hahontadan wan iyecen.

13 Unkan Delila Samson heciya, Dehanyan mayahnayan, qa oitonśni emayakiya ye. 'Taku on nicaśkapi kta omakiyaka ye. Unkan heciya, Mapasonpi śakowin hahonta kici yakazonte cinhan.

14 Unkan canicazonte en kaśke ca heciya, Pilistim iyanilipnyapi ye Samson. Unkan woiśtiman etanhan kikta, qa canicazonte hahon ta iyshna yuha iyaya.

15 Unkan heciya, Nicante mici un śni ye; qa token waśte cidaka emayakiya he? De iyamni mayahnayan ye, qa nitowaśake tanka taku en un kin omayakidake śni ye.

16 Unkan anpetu owasin oie on iyahdaskice ça iyokiśin ya ; unkan nagi te cakiśya qehan;

17 Cante kin ocowasin okiyake ça heciya, Wiyuśda mapa akan tohinni unpi śni. Ina tamni etahan Nazir wakan hemaca. Mayuśdapi kinhan mitowaśake amayuśtan kta, qa maśiłtin, qa wicaśta owasin iyemaceca kta.

18 Unkan cante ocowasin ohda. ke cin he Delila wanyaka; qa Pilistim itancan kin wahowicaye ca hewicakiya, Wanna umiye, cante kin ocowasin omakiyaka ye nakaś. Unkan Pilistim itancanpi kin itanwankanhde ekta ipi, qa mazaska qon napepi ohna ekta kahipi.

19 Uinkan śiyoto akan iśtima kiye ça wicaśta wan kico, qa paha sonpi śakowin yuśda kiye ca kakiś ya. Unkan towaśake kin enakiya.

20 Unkan heciya, Samson Pilistim iyanihpayapi ye. Unkan iśtibe cin etanhan kikta, qa heya, Inanwape kta, ohinniyan ecamon qon he iyecen, qa mihduśke kta, tuka Jehowa wanna ayuśtan kin sdotkiye śni.

21 Unkan Pilistim iyahpayapi, qa iśta su kin yuśdokapi, qa Gaza ekta apamahde iyaye yapi, qa mazaśa icaślke on kaśkapi, unkan wicakaśka tipi ohna wayukpan yanka.

2:2 Unkan yuśdapi iyohakam paha lin ake icaga.

23 Unkan Pilistim itancanpi kin Taku wakandapi kin Dagon wośnapi tanka wan wakiyuśnapi kta, qa wiyuśkinpi kta e mniciyapi, qa heyapi, Taku wakan undapi kin Samson toka unyanpi qon unnapepi en unqupi ce.

24 Unkan oyate wanyakapi qehan taku wakan dapi idowanpi, qa, Taku wakan undapi kin he tuwe toka unyanpi, qa makoce unkitawapi kin ihang ye ça, unkiyepi ota țe unyanpi kin he unnapepi è unqupi ce, eyapi nakaś.

25 Qa cante waśtepi qehan heyapi, Samson uśipo unkiyepi on 67 


\section{WAYACOPI WOWAPI KIN,}

śkate kta. Unkan wicakaśka tipi etanhan u śipi. Unkan wicitokam śkata. : Unkan ipatan hdepi nonpa kin otahedan najinkiyapi.

26 Unkan Samson hokśidan wan napata yuze cin heciya, Ozi miçiye kta e ipatan hdepi nonpa tipi akan he cin hena mdutan kta iyowin makiya ye, kinhan hena akan mikpatan kte.

27 Unkan tipi kin wicaśta qa winohinca ojudan, qa Pilistim itancanpi kin owasin hen unpi, qa ohanzi hdepi ohna wicaśta qa winohinca kektopawinge yamni cetı yakonpi, Samson śkata wanyakapi kta heon.

28 Unkan Samson Jehowa hoyekiye ca heciya, Itancan Jehowa wanna miksuya ye, qa Wakantanka nakaha deceedan waśag makiya ye; hecen miiśta napin on nakaha Pilistim en watowecon kta.

29 Ủnkan Samson ipatan hdepi cokaya nonpa, tipi akan he cin yuza, wanji nape etapa, qa unman catka kin on icu.

30 Qa Samson heya, Minagi Pilistim orn te kte, hehan towaśake on patuja; unkan tipi qon itancanpi akan, qa oyate ohna yakonpi owasin akan hinhpaya; hecen wicaśta tapi iye te cin en te wicaye cin hena tona ni icunhan te wicaya isanpa otapi.

31 Unkan hunkawanji wicaye cin, qa atkuku tiyohnaka owasin apamahde ipi, qa icupi, qa itanwankanhde ahdipi, qa Tzora qa Estaol otahedan hnakapi, atkuku Manoali ohna hnakapi tawa ohna. Wanna waniyetu wikcemna non$\mathrm{pa}$ Israel wicayaco.

\section{WICOWOYAKE 17.}

1 Unkan wicaśta wan Epraim lie kin etanhan Mika eciyapi, 68
2 Qa hunku kin heciya, Mazaska kektopawinge sanpa opawinge inicicupi, qa on wadaśice ca minonge en iyae ciqon, inyun mazaska kin he mici un, miye he iwacu. Unkan hunku kin heciya, Micinkśi Jehowa niyawaśte ye.

3 Unkan Mazaska kektopawinge sanpa opawinge kin hunku. kin kicu; Unkan hunku heya, Mazaska kin he minape etanhan Jehowa ekta mdawakan micinkśi on hetauhan wakagapi śdoyapi qa pagopi on kagapi kta, heon ake he cicu kta.

4. Tuka iye mazaska kin hunku íicu. Unkan hunku mazaska opawinge nonpa icu, qa waśdoya wan qu; Unkan hetanhan wakagapi pagopi qa śdoyapi wan kaga. Unkan he Mika ti ohna yanka.

5 Unkan Mika wicaśta kin tipi wakan wan yuha, qa amdo akahe wan, qa terapim kage ca iye cinhintku wan nape kin ojukiya hecen he wawayuśna yuha.

6 Anpetu kin hena icunhan Israel ohna wicaśta yatapi wanica wicaśta otoiyohi taku iye iśta kin en owotanna kin he econ.

7 Unkan Betlehem Juda etanhan Juda wicowazi etanhan kośka wan Lewi wicaśta heca tuka hen un.

8 Unkan wicaśta kin he Juda otonwe Betlehem etanhan icimani iyaya, tukten oyanke iyeye cinhan ohna yanke kta, heon, qa oicimani kage cehan Mika ti kin en hi.

9 Unkan Mika heciya, Tokiya tanhan yau he? Unkan heciya, Betlehem Juda etanhan, Isewi. wicaśta hemaca, qa tukten oyanke wan iyewaye cinhan ohna manke kta e icimawani.

10 Unkan Mika heciya, Miciti 
wo, kinhan ate ciye kta ; qa wawayuśna ciyuhe kta, qa mazaska wikcemna ciçu kta, waniyetu iyohi; nakun wokroyake iyecetu kin, qa taku yate kta. Unkan Lewi kin kici i.

11. Unkan hehantanhan Lewi kin wicaśta qon kici ti, qa kośka kin iye cinhintku wanji iyececa.

12 Unkan Mika Lewi nape kin ojukiya, qa kośka qon wawayuśna yuha; unkan Mika ti kin ohna yanka.

13 Unkan Mika heya, Lewi wan wawayuśna mduha, heon Jehowa tanyan ecamicon kta wanna sdonwaya.

\section{WICOWOYAKE 18.}

1 Anpetu, kin hena icunhan Israel ohna wicaśta yatapi wanica, qa anpetu kin hena en Dani wicoun kin makoce tawa yapi kta, qa en tipi kta e akitapi, anpetu kin hehanyan Israel wicoun ehna makoce tawa yapi kte cin he yuhapi śni.

2 Unkan Dan cinca kin wicowazi tawapi etanhan tonwanyanpi kin etanhan wicaśta waditaka zaptan Tzora etanhan, qa Eśtaol etanhan makoce omanipi, qa iwanyakapi kta ye wicaśipi qa hewicakiyapi, Hopo makoce kin iwanyakapo. Unkan Epraim he kin ekta ipi, Mika ti kin ekta, qa heciya wankapi.

3 Unkan Mika ti ikiyedan yakonpi qehan, kośka Lewi ho kin iyekiyapi, qa ekta ipi, qa heciyapi, Tuwe deciya hiyu niyan, qa taku den ecanon he? qa taku duha he?

4 Unkan hewicakiya, Mika deccn qa decen ecamicon, qa wawayuśna mayuhe kta e iyuwin maqu ce.

5 Unkan heciyapi, Wakantanka iwanga wo, canku ohna unyanpi kin he tanyan unkihunipi kta hecinhan sdon unyanpi kta.

6 Unkan wawayuśna kin hewicakiya, Zaniyan yapo, canku ohna dapi kin Jehowa atonwan.

7 Unkan wicaśta zaptan qon iyayapi, qa Laiś ekta ipi, qa oyate hen yakonpi kin hena wanwicayakapi wikope śniyan yakonpi, Tzidoni iyecen waditagya oziiçiyapi; unkan kiunniwicaya, qaiś wicakaśke kta makoce kin he ohna wicaśta yatapi wanica; qa Tridoni etanhan tehan yakonpi, qa wicaśta tokeca om takudan econpi śni.

8 Unkan hunkawapji wicayapi en hdipi, Tzora qa Eśtaol ekta. Unkan hunkawanji wicayapi kin hewicakiyapi, Taku wandakapi he?

9 Unkan heyapi, Najinpo ekta unyanpi kta. Makoce wanunyakapi kin he inyun waśte hinca, qa niyepi inina dukanpi, makoce kin ekta yaipi qa tawayayapi kta e ihnuhan nikujapi kin.

10 Ekta yaipi kinhan, oyate wan takudan ikopapi śni ece; qa makoce anoka tanhan tankaya ekta yaipi kta. Oyanke wan Wakantanka nicupi kin he ohna taku maka akan un kin owasin etanhan takudan icakijapi śni.

11 Unkan hehan Dani wicowazipi etanhan, Tzora qa Eśtaol etanhan wicaśta opawinge śakpe ihdakapi, otoiyohi wipe kitonpi.

12 Qa iyayapi, qa Qirejat Jeyarim (otonwe contanka) en, Juda ohna etipi, heon oyanke kin he Mehane Dan (Dan tipi) eciyapi anpetu kin dehanyan, he Qirejat Jeyarim iheyata yanka.

13 Unkan hetanhall Epraim he kin iyakaptapi, qa Mika ti ekta ipi.

14 Unkan wicaśta zaptan Laiś 


\section{WAYACOPI WOWAPI KIN,}

makoce iwanyag ipi qon iapi, qa hunka wanjin wicayapi kin hewicakiyapi, T'ipi kin dena ohna amdo akahpe wan, qa terapim, qa wankagapi pagopi, qa śdoyapi wan, yukan sdonyayapi he? heon token ecanonpi kta iyukcanpo.

15 Unkan icuom iyayapi, qa Lewi kośka ti ekta ipi, Mika ti kin qa zaniyan un kinhan iwangapi.

$16 \mathrm{Qa}$ wicaśta opawinge śakpe Dan cinca etanhan wipe kitonpi tiyopa itankan najinpi.

17 Unkan wicaśta zaptan makoce iwanyag ipi qehan hen ipi qon, wankan ipi qa wakagapi, pagopi, qa amdo akahpe, qa terapim, qa wakagapi śdoyapi kin icupi. Unkan wawayuśna kin tiyopa kin en najin, wicaśta opawinge śakpe ozuye wipe kitonpi kin hena itokam.

18 Unkan Mika ti en ipi kin hena wakagapi pagopi kin, qa amdo akahpe kin, qa terapim, qa wakagapi śdoyapi kin icupi qehan, wawayuśna kin, Taku ecanonpi he? ewicakiya.

19 Unkan heciyapi, Inina un wo, ninape kin,i atpuka wo, qaunkicipi ya wo; hecén wawayuśna, qa ate unniyanpi kta, Tipi wanjidan on wawayuśna yaun kta, qaiś Israel ohna wicoun qa wicowazi wan on wawayuśna yaun kta, unman tukte waśte he ?

20 Unkan wawayuśna kin cante waśte, qa amdo akahpe kin, qa terapim kin, qa wakagapi pagopi kin icu, qa oyate kin cokaya iyaya.

21 Hehan ihduhomnipi qa iyayapi, qa śiceca, qa wanunyanpi kin, qa wahpayapi kin owasin wicitokam ye yapi.

22 Mika ti kin etanhan tehan iyayapi qehan, wicaśta tona Mika ti kin ikiyedan tipi kin hena mni70 ciyapi, qa Dan cinca kin kihdegapi.

23 Qa Dan cinca kin hoyewicakiyapi. Unkan itkom ihdamnapi, qa Mika heciyapi, 'l'aku yaka heon decen anaunyatanpi?

24 Unkan hewicakiya, Taku wakan micicage cin hena iyacupi, wawayuśna kin nakun, qa sanpa taku mduha he? qa token, Taku yaka he, emayakiyapi he?

25 Unkan Dan cinca kin heciyapi, Ihnuhan niho kin unkiyepi ehna nahonpi kin. Okini wicaśta nagi wacinko ananitanpi, qa ninagi, qa tiyohnaka nitawa nagipi kin toki ehpeyakiye kta.

26 Qa Dan cinca kin toki yapi canku kin ohna iyayapi. Unkan Mika iye isanpa hena waśakapi wanwicayake cehan ihdamna, qa kihda.

27 Unkan hena taku Mika kage ciqon, qa wawayuśna yuhe ciqon nakun icupi, qa Laiś elsta ipi, oyate owanji unpi, qa wikopapi śni ekta, qa canhipi hi on wicakaśtakapi, qa otonwe kin peta on hulinaliyapi.

28 Tzidon etanhan tehan yakonpi; qa tuwedan kici wotakuye yuhapi śni, heon wanikiye nicapi, qa Bet Rehob osmaka ohna yanka. Unkan otonwe kin kagapi, qa hen iyotankapi.

29 Qa otonwe kin Dan caje yatapi ; ateyapi Dan, Israel kicitonpi caje kin iyecen; tuka otonwe kin he otokahe ekta Laiś eciyapi. 30 Unkan Dan cinca kin wakagapi kin iyepi on ehdepi, qa Dan wicoun kin Jonatan Gerśom cinhintku Manaśe cinh.intku, iye qa iye cinca kin wawayuśna wicayuhapi, makoce etanhan tokan ayapi śni kin hehanyan.

31 Qa wakagapi Mika kage cin ekicihdepi, tohan Wakantaka ti kin Śilo ohna un kin hehanyan. 


\section{WICOWOYAKE 19.}

WICOWOYAKE 19.

1 Unkan Israel ohna wicaśta yatapi wanica qehan, anpetu kin hena icunhan, Lewi wicaśta wan Epraim he onnaptanyan ohna ti, qa Betlehem Juda etanhan winohinca wan yuza, tuka wakan yuze śni.

2 Unkan winohinca kin he ihduhomni, qa ehpekiye ca atkuku ti kin ekta kihda, Betlehem Juda ekta, qa wi topa anpetu kin hen yanka.

3 Unkan hihnaku najin, qa cante iyokipi ye kta, qa hdicu kiye kta, heon okide iyaya. Unkan tahokśidan qa śonśonna nonpa opapi. Unkan winyan qon atkuku timahen hiyuya. Unkan wikośka atkuku kin he wanyake cehan itkokipe cin on iyuśkin.

4 Unkan tunkanku wikośka atkuku kin adoksohan yuza. Unkan anpetu yamni kici iyotanka, qa wotapi, qa wayatkanpi, qa hen wankapi.

5 Unkàn anpetu itopa hanhanna kiktapi qehan iyaye kta e najin. Unkan wikośka atkuku kin takośku heciya, Aguyapi onśpa on nicante kin waśag kiya wo, qa hehan idade kta.

6 Unkan iyotankapi, qa sakim wotapi qa wayatkanpi, qa wikośka a tkuku kin wicaśta qon heciya, Tokin den inonke kta iyonicipin, qa cante ni waśte $k$ ta.

7 Unkan wicaśta kin iyaye kta e najin qehan tunkanku nina cinkiya; unkan iyotanke ca hen wanka.

8 Q a anpetu izaptan iyaye kta e hanhanna hin kikta. Unkan wikośka atkuku heya, Ceciciya cante kin waśagkiya wo. Unkan wiyotanhan inaśdoke cin hehanyan yutehanpi, qa sakim wotapi. 9 Hehan wicaśta qon iyaye kta e najin, iye qa tawicu, qa tahokśidan. Unkan tunkanku wikośka atkuku kin heciya, Ḣtayetu kta e anpetu wanna inaśdoka, den wanka wo, hecen cante niwaśte kta, qa heyakecinhan hanhanna hin yektapi qa icimayanipi lita, qa wakeya nitawa ekta yahde kta.

10 Tuka wicaśta qon hen wanke lkta wicada śni; heon najin iyaya kihda, qa Jebus (Jerusalem hee) iyotakons ki, qa śonśonna nonpa aqin kitonpi opapi ; qa tawicu nakun kici un.

11 Jebus ikiyedan unpi qehan anpetu wanna iyaye kta hinca; unkan hokśidan kin yuhe cin heciya, Ito icuom unyanpi Jebusi otonwe kin de ekta, qa ohna unwankapi kte.

12 Unkan yuhe cin heciya, Otonwe oyate tolseca, Israel cinca etanhan hecapi śni ekta unyaupi kte śni; tuka Gibea ekta iyoopta unyanpi kta.

13 Nakun tahokśidan kin heciya, Ito otonwe kin dena Gibea qaiś Rama, unman tukte wanji ikiyedan unyanpi, qa ohna unwankapi kte.

14 Unkan iyooptapi, qa manipi, qa Gibea Benjamin tawa ikiyedan yakonpi qehan anpetu wi km aisinyan iyaya.

15 Unkan Gibea ohna wankapi kta e heciya icuom iyayapi, qa en ipi, qa otonwe canku kin ohna iyotankapi. Unkan wankapi kta e tuwedan tin hiyu wicaye śni.

16 Unkan inyun htayen wicahinca wan tohtani etanhan maga etanhan hdi, wicaśta kin he Epraim he kin etanhan, qa Gibea ohna ti, tuka wicaśta hen yakonpi kin hena Benjamin cinca hecapi.

17 Qa iśta yuwankan ikikcu, qa wicaśta icimani kin otonwe can- 


\section{WAYACOPI WOWAPI KIN,}

ku kin ohna wanyake ca wicahinca kin heciya, Toki da, qa tokiya tanhan yau he?

18 Unkan heciya, Unkiyepi Betlehem Juda etanhan, Epraim he onnaptanyan ekta unkiyayapi. Miye hematanhan, qa Betlehem Juda ekta wai qa Jehowa ti kin ekta mda, qa tuwedan tin hiyu makiye śni.

19 Tuka peji śeca, qa woyute śonśonna unkitawapi on yukan, nakun aguyapi, qa miniśa miye on, qa wikośka nitawa, qa hokśidan nitawa unkicipapi on yukan ce ; takudan unkicakijapi śni.

20 Unkan wicahinca kin heya, Tanyan yaunpi nunwe; miye taku nun kta iyececa owasin wacinmayaye kta, tuka ihnuhan otonwe canku ohna inonke cin.

21 Unkan iye ti mahen hiyu wicaye ca śonśonna wowicaqu; unkan siha ihdujajapi, qa wotapi qa wayatkanpi.

22 Qa cante waśte iciyapi. Unkan otonwe wicaśta kin wowalite śni cinca hecapi; tipi kin ihdukśan najinpi, qa tiyopa kin kabubupi, qa wicaśta tipi yuhe cin wicahinca qon heciyapi, Wicaśta yati ekta hi qon tankan hiyuya wo; sdon unyanpi kta ce.

23 Unkan wicaśta tipi yuhe cin ekta wicai, qa hewicakiya, Hiya. Mihunkawanji ceciciyapi, ihnuhan taku śica ecanonpi. Wicaśta kin de wati en hi ehantanhan, ihnuhan taku witkotkoya kin de ecannonpi kin.

24 Ito micunkśi witanśna, qa iye tawicu kin hena niyepi ekta tankan hiyu wicawaye kta, hena yuhukuya wicayayapi, qa token niiśtapi iyokipi ecawicayeconpi kta, tuka ihnuhan wicaśta kin de taku wowalite śni kin he ecayeconpi kin.
25 Tuka wicaśta kin he nahonpi kta wicadapi śni. Unkan wicaśta kin tawicu napata yuza, qa hena ekta tankan hiyuya. Unkan sdonyapi, qa hanyetu osan kakiś yapi, ihantianna hehanyan, qa anpao hinanpe cehan ayuśtanpi.

26 Unkan winohinca kin anpao qehan u, qa tipi ohna hihnaku yanke cin tiyopa ekta hinhpaya, anpa kta hehanyan.

27 Unkan hihnaku kin hanlianna kikta, qa tipi tiyopa kin yulidoka, qa canku ohna iyaye kta e inanpa; unkan inyun tawicu tipi tiyopa kin ekta makata wanka, qa nape kin tiyopa ahdehe cin akan yanka.

28 Unkan heciya, Najin wanna unye kta; tuka takudan ayupte śni. Hehan wicaśta kin najin qa śonśonna kin akan ehnaka qa kihda.

29 Qa ti kin ekta ki qehan, isan wan icu, qa tawieu te cin iyahpaya, qa huhu iyahna baśpa, obaśpe akenonpa, qa Israel makoce kin owancaya yekiya.

30 Unkan tuwe wanyaka eca heya, Israel cinca Egupta makoce etanhan itanwankanhde upi ehantanhan taku dececa econpi śni, qa wanyakapi śni; cante ekta ye kiyapo, qa nitawacin ohdakapo, eya ece.

\section{WICOWO YAKE 20.}

1 Unkan Israel cinca owasin inanpapi, Dan etanhan Berśeba ekta hehanyan, qa Gileyad makoce nakun, omniciye wicaśta wanjidan iyecen Jehowa itokam Mitzpa ekta yuwitaya hiyupi

2 Qa Israel wicoun owasin oyate wicaśta tokapa kin owasin Wakantanka troyate omniciye en najinpi, wicaśta huiyun canlipi 


\section{WICOWOYAKE 20.}

yuhapi kektopawinge opawinge topa.

3 Unkan Benjamin cinca kin Israel cinca kin Mitzpa ekta hipi kin nahonpi. Unkan Israel cinca kin heyapi, Taku śica kin de token econpi kin oyakapo.

4 Unkan Lewi wicaśta, winohinca baśpapi qon hihnaku kin ayupte ça heya, Gibea Benjamin tawa en wai, miye qa mitawin ohna unwankapi kta.

5 Unkan Gibea itancanpi kin anamatanpi, qa hanyen tipi ohna manke cin ihduksan najinpi, qa maktepi kta kecinpi, qa mitawin yuhukuyapi on țe.

6 Heon mitawin iwekcu, qa bawakiśpa, qa Israel makoce tawayapi owancaya yewakiya; taku wowahte śni, qa witkotkoya Israel ohna econpi nakaś.

7 Thopo niyepi Israel cinca owasin nioiepi, qa token idukcanpi den eyapo.

8 Unkan oyate owasin wicaśta wanjidan iyecen najinpi qa heyapi, Unkiyepi tuwedan tipi tawa en kihde kte śni.

9 Qa wanna taku econkupi kte cin dee, woecon eciya tanhan Gibea azu unyanpi kta.

10 Israel wicoun owasin etanhan wicaśta opa winge on wikcemna unkicupi kta, qa kektopawinge etanhan opawinge, qa kektopawinge wikcemna etanhan kektopawinge wanjidan, hena oyate on woyute huweyapi kta, hecen Gibea Benjamin ekta unyanpi kta, qa taku walite śni econ kin owasin iyecen ecaunkiconpi kte.

11 Hecen Israel wicaśta owasin wicaśta wanjidan iyecen imniciyapi, otonwe kin ekta.

12 Unkan Israel wicoun kin Benjamin wicowazi owasin ekta wicaśta ye wicaśipi, qa heyapi,
Wicolian śica kin de niyepi ehna. econpi kin taku hwo?

13 Heon wanna wicaśta wowalite śni cinca Gibea ohna yakonpi kin hiyu wicayapo; unkan wicunktepi kta, qa taku sica Israel etanhan unyutokanpi kta. Tuka Benjamin cinca kin, hunkawanji wicayapi Israel cinca kin nawicahonpi wicadapi śni.

14. Heon Benjamin cinca kin tonwanyanpi kin owasin etanhan Gibea ekta mniciyapi, qa Israel cinca om kicizapi kta.

$15 \mathrm{Qa}$ anpetu kin he en Benjamin cinca tonwanyanpi etanhan wicayawapi wicaśta kektopawinge wikcemna nonpa sanpa kektopawinge śakpe canhipi kitonpi, qa nakun Gibea ohna tipi kin etanhan wicaśta kahnigapi heca opawinge sakowin.

16 Oyate kin de owasin etanhan wicaśta opawinge śakowin etapa unpi śni, wicaśta kahnigapi hecapi, hena hahonta icistinna ekta inyan kaho iyeyapi eśta yuśnapi śni.

17 Unkan Israel wicaśta Benjamin codan wicayawapi wicaśta kektopawinge opawinge topa canlipi kitonpi, hena owasin wicaśta zuyapi hecapi.

18 Qa najinpi, qa Betel ekta ipi, qa Wakan tanka irvangapi, qa Israel cinca kin heyapi, Tuwe unkiyepi etanhan tokaheya Benjamin cinca kin azuwicaye kta he? Unkan Jehowa heya, Juda hee tokaheya ye kte.

19 Unkan Israel cinca kin hanhanna kiktapi, qa Gibea itkom etipi.

20 Unkan Israel wicaśta kin Benjamin om kicizapi kta e inanpapi, qa Israel wicaśta kin ocimdagehan iyayapi, Gibea ekta kizapi kta heon.

21 Unkan Benjamin cinca kin 


\section{WAYACOPI WOWAPI KIN,}

Gibea etanhan inanpapi, qa anpetu kin he en Israel wicaśta kektopawinge wikcemna nonpa sanpa kektopawinge nonpa, makata ihang wicayapi.

22 Unkan Israel wicaśta oyate kin wakiśag içiyapi, qa tukten anpetu tokaheya ocimdah najinpi qon, he ekta ake kicizapi kta e ocimdagehan iyayapi.

$23 \mathrm{~W}$ anna Israel cinca kin itanwankanhde iyayapi; qa Jehowa itokam ceyapi, hitayetu kte hehanyan, qa Jehowa iwangapi, qa heyapi, Ake misunka Benjamin cinca wecizekta e ekta mde kta he? Unkan ekta yawo, Jehowa eya.

24 Unkan anpetu iyokihe en Israel cinca kin Benjamin cinca kin anawicatan ipi.

25 Unkan itkowicakipe kta e Benjamin Gibea etanhan inarnpa, anpetu inonpa en, qa Israel cinca etanhan wicaśta kektopawinge ake śahdogan makata wicaktepi, hena owasin canhipi kitonpi.

26 Hehan Israel cinca kin owasin itanwankanhde yapi, qa oyate kin owasin Betel ekta ipi, qa ceyapi, qa hen Jehowa itokam iyotankapi, qa anpetu kin he en hitayetu hehanyan wotapi śni; qa Jehowa itokam wohulinah yapi qa wopida wośnapi liulinahi yapi.

27 Qa Israel cinca kin Jehowa wiwangapi, Wakantanka otakuye can wohnaka kin he ehan hen yanka nakaś.

28 Unkan anpetu kin hena en Pinehas Eleyazar cinhintku Aaron cinhintku he itokam najin, qa heyapi, Ake misunka Benjamin cinca kin wicawecize kta e ekta mde kta, qaiś amduśtan kta he? Unkan Jehowa heya. Ya wo, heyakecinhan ninape en waqu kita nakaś.

29 Unkan Israel Gibea ihdu74 kśan wicaśta nalimanna iyapepi kta iwanke wicayapi.

$30 \mathrm{Qa}$ Israel cinca kin anpetu iyamni en Benjamin cinca ekta iyayapi, qa Gibea ekta ocimdagehan ipi, nonpa akihde econpi qon he iyecen.

31 Unkan Benjamin cinca kin oyate itkowicakipapi kta inanpapi, qa wicahnayanpi on otonwe etanhan iyayapi, qa canku nonpa tanka, wanji Betel iyahde, qa unman Gibea tinta ohna iyahde, hena ohna Israel etanhan wicaśta wikcemna yamni cetu cawicapapi wicakaśtakapi ; wanna nonpa akihde econpi qon he iyecen.

32 Qa Benjamin cinca kin heyapi, Unkitokam hinlipayapi otokahe ekta he iyecen. Ecin Israel cinca kin heyapi, naunjicapi, qa otonwe etanhan cankuku ekta hiyu wicunyanpi kta.

33 Qa Israel wicaśta owasin tukten wankapi kin etanhan najinpi, qa Bayal Tamar ohna ocimdagehan inajinpi : nakun Israel waiyapepi kin wankapi etanhan Gibea tinta kin etanhan inanpapi.

34 Qa Gibea itokapa tanhan upi, wicaśta kektopawinge wikcemna, Israel owasin etanhan wicakahinigapi ; qa nina kicizapi, tuka taku sica iwicakicihan sdotkiyapi śni.

35 Unkan Jehowa Benjamin kaśtaka Israel itokam; unkan anpetu kin he en Israel cinca kin Benjamin wicaśta kektopawinge wikcemna nonpa sanpa kektopawinge zaptan sanpa opawinge wanjidan ihangwicayapi, hena owasin canlipi kitonpi.

36 Unkan Benjamin cinca kin iye ktepidan wanhdakapi. Ecin Israel wicaśta kin wicaśta Gibea nahmana iyape wicaśipi 
qon hena wacinwicayapi, heon Benjamin etanhan najicapi.

37 Unkan waiyapepi kin hena inahnipi, qa Gibea anatanpi, qa waiyapepi kin obe iyayapi, qa otonwe ocowasin canlipi hi on kaśtakapi.

38 Unkan Israel cinca kin waiyapepi kin wowapetokeca kin de econ wicaśipi, śota tanka hinca otonwe etanhan wankan iyayeyapi kta.

39) Heon Israel cinca kicizapi en ihdamnapi. Unkan Benjamin otokahe ekta Israel wicaśta etanhan wicaśta wikcemna yamni cetu maka ta wicakaśtakapi. Unkiyepi awicakehan wanna wicunkaśtakapi, wokicize tokaheyạ en iyecen, eyapi nakaś.

40 Unkan ide otonwe etanhan tokaheya wánkan iyaye, çehan, śota bosdata seca, Benjamin ihdamna, ga inyun otonwe ocowasin ide kin mahpiya ektakiya wankan iyaya.

41 Unkan Israel wicaśta kin ihdamnapi qehan Benjamin yuśnyayapi, taku śica wicayuśkica kin wanyakapi nakaś.

42 Qa Israel itokapa tanhan ihdamnapi, canku hopuza iyahde ekta, qa wokicize wicakihdega, qa hen wicaktepi.

43 Tona Benjamin kuwa ayapi kin hena wicihdukśan iyayapi, Nuha (iyozi) ekta anawicatanpi, Gibea iyotakonza wihinanpe cin ektakiya hehanyan.

$44 \mathrm{Qa}$ Benjamin etanhan wicaśta kektopawinge ake śahdogan hinhpayapi, hena owasin wicaśta waśakapi.

45 Hehan ihdamnapi, qa hewoskantuya napapi, Rimmon imnija ektakiya. Unkan cankuku ohna wicaśta kektopawinge zaptan enanakiya wicaktepi; qa Gidom ekta wicakuwapi qa wica- śt่a kektopawinge nonpa wicaktepi.

46 Hecen anpetu kin he en Benjamin etanhan hinhpayapi kin owasin wicaśta kektopawinge wikcemna nonpa sanpa kektopawinge zaptan, canhipi kitonpi, hena owasin wicaśta waśakapi.

47 Tuka wicaśta opawinge śakpe ihdamnapi, qa hewoskantu napapi Rinmor imnija ekta, qa wi topa Rinmon imnija ohna tipi.

48 Unkan Israel wicaśta kin ihdamnapi, Benjamin cinca ekta, qa tonwanyanpi ohna canhipi hi on wicaktepi, wicaśta qa woteca qa taku iyeyapi owasin. Nakun otonwe tona iyeyapi kin owasin peta on ideyapi.

\section{WICOWOYAKE 21.}

1 Wanna Israel wicaśta Mitzpa ohna taku wakan caje yatapi, qa heyapi, Unkiyepi etanhan tuwedan iye cunwintku Benjamin yuze kta e qu kte śni.

2 Unkan oyate kin Betel ekta ipi, qa hen Wakantanka itokam iyotankapi litayetu kin hehanyan, qa hotanka kiya, nina ceyapi.

3 Qa heyapi, Jehowa Israel Wakandapi kin hehehe de toketu hwo, Israel ohna nakaha wicoun wanji Israel etanhan kitanin śni. 4 Unkan ihanlianna oyate kin najinpi, qa wahna wośnapi wan hen kagapi, qa wohulinahyapi, qa wopida wośnapi wayuśnapi.

5 Unkan Israel cinca kin heyapi, Israel wicoun owasin etanhan ozuye kin Jehowa ekta tuwe hi śni he? Ecin wokonze tanka kagapi qa heyapi, Tuwe Jehowa ekta hi śni awicakehan țe kta.

6 Unkan Israel cinca kin Benjamin sunkayapi on iyope içiya- 


\section{WAYACOPI WOWAPI KIN.}

pi qa heyapi, Nakaha Israel etanhan wicoun wan kaśpapi ce. 7 Tona okaptapi on token econkupi kta he? Cunkśi unyanpi etanhan winohinea wicun qupi kte śni, Jehowa cajeyan unkonzapi nakaś.

8 Heon heyapi, Israel wicoun etanhan Jehowa ekta Mitzpa ekta tuwe hi śni he? Unkan Jabeś Gileyad etanhan omniciye wicoti ekta tuwedan hi śni.

9 Qa oyate kin ihdawapi, qa Jabeś Gileyad ounyanpi kin etanhan wicaśta wanjidan hen un śni.

10 Unkan omniciye kin wicaśta kektopawinge ake nonpa wicaśta waditakapi heciya ye wicaśipi, qa wahokon wicakiyapi, qa hewicakiyapi, Yapo Jabeś Gileyad ounyanpi kin wicakaśtakapo, canhipi hi on; nakun winohinca qa śiceca.

Il Qa taku ecanonpi kte cin dee; tona wica owasin, qa winolinca wica kici wankapi on wicaśta sdonyapi kin owasin wicayaktepi kta.

12 Unkan Jabeś Gileyad ounyanpi kin etanhan wikośka tanśna unpi, wica kici wankapi on wicaśta sdonyapi śni opawinge topa iyewicayapi, qa hena yuha wicoti Śilo ekta hipi, he Kanan makoce ohna wanka.

13 Unkan omnicive ocowasin Benjamin cinca Rinmon ohna yakonpi ekta wahośi ye wicaśipi, qa wokiyapi wicakicopi.

14 Unkan he ehan Benjamin hdi. Unkan Jabeś Gileyad winolinca qon etanhan winohinca wicaqupi, tuka owasin iyowicahipi śni.

$15 \mathrm{Qa}$ Jehowa Israel wicoun ohna woihang ye wan kage cin heon oyate kin Benjamin on iyope içiyapi.
16 Unkan omniciye hunkayapi kin heyapi, Benjamin winohinca ihang wicunyaripi heon wica unman nipi kin winohinca wicunqupi kta e token econkupi kta he?

17 Nakun heyapi, Benjamin etanhan nipi kin hena makoce tawayapi, qa Israel etanhan wicoun wanjidan kahintapi kte śni.

18 Tuka unkiyepi cunkśi unyanpi etanhan winohinca wicunqupi kta unkokihipi śni. Tuwe winohinca wan Benjamin qu kinhan yaśicapi kta, Israel cinca eyapi qon nakaś.

19 Unkan heyapi, Thopo mdoketu otoiyohi-wohanpi wan Jehowa kicagapi, Ślo ekta, BeteI iwaziya tanhan, canku tanka Betel etanhan Śekem iyahde kin he iwiyohiyanpa tanhan, Lebona itokaga tanhan.

20 Qa Benjamin cinca kin wahokon wicakiyapi, qa heyapi, Ihopo ekta yapi qa hastanhanka iyuwi ojupi ohna inahmanpo.

$21 \mathrm{Qa}$ inyun Silo cunwintkupi wacipi en ślkatapi kta inanpapi kinhan wandakapi $k$ ta, qa nayajinpi kta, hastanhanka iyuwi ojupi etanhan, qa iyawicayahpa dapi kta, niyepi on wicaśta otoiyohi tawicu kin Ślo cunwintkupi etanhan, qa Benjamin makoce ekta yuha yahdapi kta.

22 Unkan ate wicayapi qaiś timdo wicayapi kin kizapi kta en unhipi kinhan hewicunkiyapi kta, Hena wicayaqupi śni, heon dehan nibapi ktc śni; qa wokicize en winohinca wicaśta iyohi unkicupi śni, heon hena ionśiundamiye.

23 Unkan Benjamin cinca kin hecen econpi, qa iyc iyenaka winohinca icupi, wacipi kin en iyawicalipayapi qa hena yuha 


\section{RUTE TAWO'NAPI.}

makoce tawapi kin ekta hdapi, | wazi tawa ekta, qa hetanhan qa otonwe tawapi piya kagapi, qa hena en iyotankapi.

24 Unkan he ehan Israel cinca kin hetanhan kihdapi, wicaśta otoiyohi iye tawicoun, qa wico-l econ. otoiyohi tamaga ekta kihda.

$25 \mathrm{He}$ ehan Israel ohna wicaśta yatapi wanica, wicaśta otoiyohi iye iśta kin en taku ecetu kin he

\section{RUTE TAWOWAPI.}

\section{WICOWOYAKE 1.}

1 Unkan wayaco wicaśta kin wicaśta yatapi hecapi qehan, makoce kin ohna wicaakilian; unkan wicaśta wan, Betlehem Juda etanhan, Moab makoce ohna yanke kta e ekta i, iye qa tawicu, qa cinhintku nonpa.

2 Qa wicaśta kin he Elimelek (Wakan wicaśtayatapi) eciyapi, qa tawicu Nayomi (Iyomakipiwin) e ciyapi, qa cinhintku nonpa kin Mabilon qa Kileon ewicalsiyapi. Fprati hecapi, Betlehem Juda etanhan; qa Moab makoce ekta ipi, qa hen yakonpi.

3 Unkan Elimelek Nayomi hihnaku ta, hecen iś nana ni, cinhintku nonpa om.

4 Unkan napin Moab winohinca yuzapi, wanji Orpa eciyapi, qa unman Rute eciyapi, qa hen yakonpi waniyetu wikcemna cetu.

5 Unkan Mahilon qa Kileon napin nakun țapi ; hecen cinhintku napin, qa hihnaku willohinca ehpeya iyayapi.

6 Unkan Moab makoce etanhan kihde kta e' najin, takoś wicaya onl; Jehowa taoyate en wicai qa aguyapi wicaqu kin he Moab makoce ohna nation nakaś.

7 Qa ohna yanke ciqon etanhan hinanpa, takoświcaya napin om, qa Juda makoce ekta kihdapi kta, canku ohna iyayapi.

$8 \mathrm{Qa}$ Nayomi takoś wicaye cin napin hewicakiya, Hope, otoiyohi hunku ti kin ekta yahdapi kta ye, Jehowa cante niciyapi nunwe, niyepi tapi kin cante wicayakiyapi, qa miś eya cante mayakiyapi kin he iyecen.

9 Iyohi hihnaku ti kin ohna iyozi iyeyayapi kta e Jehowa ionśinidapi ye; eye ca i iwicaputaka. Unkan hoyeyapi qa ceyapi.

10 Qa heciyapi, Hiya, niye kici oyate nitawa ekta unhdapi kta ye. 11 Tuka Nayomi heya, Micunkśi kihdape. Tokeca micidapi kta he? Nahanhin mitezi ohna cinca mayukan, qa hena niyuzapi kta he?

12 Micunkśi kihdape; wamakanka.hinca, heon tuwedan mayuze kte śni ye. Nakun, Wowacinye mayukan qa hanyetu kin de wicaśta wan mayuze kta, q̣a hokśidan waton kta ye, epa eśta,

13 Heon ayapepi kta, tanka icagapi kta, hehanyan, wicaśta niyuzapi kte śni e onanitakapi tawaten yayapi kta he? Hiya micunkśi, niyepi isanpa tehiya ecamiconpi, Jehowa nape kin amapa ye nakaś. 


\section{RUTE TAWOWAPI,}

14 Hehan hoyeyapi qa ake ce. yapi, qa Orpa kunku i kin itputaka; tuka Rute en ikoyag içiya. 15 Unkan Nayomi Rute heciya, Iny un nitanka oyate tawa, qa taku iye wakan da kin ekta kihda ye. Nitanka okipa kihda ye.

16 Tuka Rute heya, Ihnuhan mayakiśica ye, on aciyuśtan, qa nihakapa tanhan wahde kte cin. Awicakehan toki de cin heciya miśs mde kta ye, qa tu. kten nanke kte cin hen manke kta ye; oyate nitawa kin he oyate mitawa kte, qa taku wakan yada kin he miś wakan wada kta ye.

17 Tukten nite cin hen mate kta qa hen mahnakapi kta ye. Wiconte heceedan niye qa miye unyukinunkan kta ye ; taku tokeca hecon kinhan Jehowa hecen qa isanpa ecamicon ye.

18 Unkan kici ye kta wakiśag içiye cin he wanyake ceehan heciye kta ayaśtan.

19 Unkan BetLehem (Aguyapi Ti) ekta ipi kin hehanyan sakim manipi, qa Betlehem ekta hipi qehan otonwe kin ocowasin hena on yuśinyayapi, qa Nayomi dee, eyapi.

20 Unkan hewicakiya, Ihnuhan Nayomi (Iyomakipiwin) emayakiyapi kin, Mara (Iyokiśica) hemakiyape, Iyotan waśake cin he nina iyokiśin mayan ye.

21 Omajudan imdamda, unkan comakadan Jehowa hdicu mayan. Tokeca Nayomi emayakiyapi he? Jehowa amayatanin, qa Iyotan waśake cin iyokiśin mayan ye.

22 Hecen Nayomi takośku Rute Moabiwin kin kici hdi, he Moab makoce etanhan hiyu, qa barle tokaheya baksapi iyehantu, he. han Betlehem ekta hipi.

\section{WICOWOYAKE 2.}

1 Unkan wicaśta wan Nayomi takuya, hihnaku qon Elimelek tawicowazi etanhan, wicaśta waśaka waditaka, qa Boyaz eciyapi.

2 Unkan Rute Moabiwin kin Nayomi heciya, Ceciciye mag: ekta mde kta ye, qa tuwe iśta kin en woiyokipi iyewaye cin he ihakam aguyapi su itka kin mnawaye kta ye. Unkan, Micunkśi ya ye, eciya.

3 Unkan iyaye ca ekta i, qa wa baksapi ihakam maga ohna wamnayan, hecen Boyaz Elimelek wicowazi etanhan tamaga en wamnayan.

4 Unkan inyun Boyaz Betlehem etanhan hiyu, qa Jehowa niyepi kici un nunwe, wabaksapi kin ewicakiya. Unkan Jehowa niyawaśte ye eciyapi.

5 Unkan Boyaz tahokśidan wabaksapi awanwicayake cin heciya, Wikośka kin de tuwe tawa he?

6 Unkan hokśidan wabaksapi awanwicayake cin he ayupte ca heya, Moabi wikośka kin dee. Moab makoce etanhan Nayomi kicí hdi kin hee.

$7 \mathrm{Qa}$ heya, ceciciya waitka mnawaye kta iyowin makiyaye, kinhan wopahte ehna wamnawaye kta, baksapi kin ihakam, qa en hi, qa hecen śkan hanhanna ehantanhan dehantu, Tipi kin de ohna iyotanka aśkatudan.

8 Unkan Boyaz Rute heciya, Micunkśi namahon wo. Ihnuhan wamnaye kta e maga tokeca ekta de cin; qa nakun detanhan iyaye śni wo ; tuka den wiciyanna mitawa wicikiyedan un wo.

9 Qa maga baksapi kin he atonwan, qa wicinyanpidan owicapa wo. Hokśipidan niyutanpi kte śni 


\section{WICOWOYAKE 3.}

wicawaśi ce, qa inipuza eca cega tawapi kin ekta de kta, qa hokśipidan taku huweyapi hin hetanhan datke kta.

10 Unkan patuja, qa makipusdiya elipe iciya, qa heciya, Tokeca niiśta en woiyokipi iyewaya he? qa oyate matokeca eśta en amayatonwan ye.

11 Unkan Boyaz ayupte ca heciya, Nihihna te cin iyohakam taku nikun ecayecon kin, qa niyate, qa nihun, qa makoce en nitonpi kin elipe wicayakiye cin tanyan omakiyakapi, qa oyate wan itokam sdonyaye śni kin ekta yahi ce.

12 Jehowa niohan kin nicicajuju kta, qa Jehowa Israel Wakandapi hupahu ihukuya inayape kta e yahi kin hetanhan iyuwin iyakicuya duhe kta.

13 Unkan Itancan niiśta en woiyokipi iyewaya nunwe. Cantomayahnake ca nitawicinyanna cante ekta iyae, tuka miye wicinyanpidan nitawa wanji iyemaceca śni ye.

14 Unkan wotapi iyehantu qehan Boyaz heciya, Deci ikiyedan kuwa wo, qa aguyapi onśpa yuta, qa onśpa nitawa miniskuya kin en oputkan wo. Unkan wabaksapi kin icahda hiyotanka. Unkan ceonpapi kin onge kicu. Unkan wota qa wipi qa onge okapta.

15 Unkan wamnaye kta najin iyaye cehan, Boyaz tahokśipidan wahokon wicakiye ca hewicakiya, Wopahte ehna wamnaye kta, qa ihnuhan iśteı yayapi kin.

16 Qa nakun mnaye kta e napohnaka kin etanhan ongege yuśnapo, qa hena mnaye kta e ehpeyapo, qa iyopekiyapi śnipo.

$1 \%$ Unkan btayetu kin hehanyan maga ohna wamnayan, qa taku mnayan kapa barle epa wanji cetu.
18 Qa qin qa otonwe ekta hdohda. Unkan kunku taku mnaye cin wanyaka. Unkan wipi gon etanhan taku okapte cin kipazo.

19 Unkan kunku kin heciya Nakaha tukten wamna yaya he? qa tukten htayani he? Tuwe en anitonwe cin yawaśtepi nunwe. Unkan tuwe kici wakage cin kunku okiyake ca, Wicaśta kici nakaha wawakage cin Boyaz eciyapi ye, eya.

20 Unkan Nayomi takośku heciya, Jehowa he yawaśte nunwe ye. He tocantkiye nipi kin qa tapi kin unmanna ek takiya ahduśtan śni. Nakun Nayomi heciya, Wicaśta kin he taku unyanpi, qa ope unkitonpi heca wanji ee ye.

21 Unkan Rute Moabiwin kin heya, Nakun hemakiya ye, Hokśipidan wicamduha taku mitawa owasin yuśtanpi śni hehanyan wicikiyedan un wo.

22 Unkan Micunkśi tawikośka om idade ca maga tokeca en anicipapi śni hee waśte ye, Nayomi iye takośku eciya.

23 Unkan barle baksapi, qa àguyapi su baksapi lin yuśtanpi śni kin hehanyan Boyaz tawikośka opeya un, qa hehan kunku kici kiyotanka.

\section{WICOWOYAKE 3.}

1 Unkan kunku Nayomi heciya, Micunkśi iyozi acicite kte śni he? Niye on he waśte kta ye.

2 Qa Boyaz wiciyanna wicayuhe cin om, yaun qon he awicakehan taku unyanpi, qa ito hanyetu kin de wakapanpi kin ohna barle kaduga ye.

3 Heon ihdujaja, qa sdaiçiyaye, qa wokoyake waste kicun ye, qa wakapanpi ekta apamahde ya ye, wotapi qa wayatkanpi kin hduśtanpi śni kin hehanyan ihnu- 


\section{RUTE TAWOWAPI,}

han wicaśta kin en nihdutanin kin.

4 Unkan iwarke cinhan, tukten wankekte cin oyanke kin tanyan wanyaka ye, qa ekta de kta, qa siha kin duzamni kta, qa ekta inonke kta. Unkan iye taku ecanon kte cin oniciyake kta ye.

5 Unkan heciya, Taku emayakiye cin owasin ecamon kta ye.

6 Unkan apamahde iyaya wa kapanpi ekta, qa token kunku econśi kin owasin ecen econ.

7 Unkan Boyaz wota qa wayatkan, qa cante waśte qehan barle hu paha ihanke kin ekta iwanka. Unkan winyan kin nahmana ekta $i$, qa siha kin yuzamni, qa ekta wanka.

8 Unkan hanye cokaya qehan wicaśta kin yuśinyaye ca ihduptanyan qa inyun siha kin yanke cin ekta winohinca wan yanka.

$9 \mathrm{Qa}, \mathrm{Ni}$ tuwe he? eya, Unkan Rute wicinyanna nitawa kin he miye ye, qa wopekiton he niye, heon wicinyanna nitáwa niliupahu amakahipa ye, eya.

10 Unkan heya, Micunkśi Jehowa on niyawaśtepi, Wocante duza ehake kin de tokaheya kin kapa, qa kośka wahpanica qa wijica unmanna oyape śni.

11 Qa micunkśi wanna ihnuhan wikoyape cin. Taku emayakiye cin owasin ecacicon kta; otonwe mitawa oyate owasin winohinca ksapa henica sdonyapi nakaś.

12 Qa wanna wicayaka, wopekiton wan hemaca, tuka wopekiton wan miye isanpa ikiyedan yukan.

13 Hanyetu kin de den wanka wo; qa hanhanna iye openiciton kinhan waśte kta, openiciton kta. Tuka openiciton kte tawaten ye śni kinhan, miye ope ciciton kta,
Jehowa ni kinhan. Hanhanna kte cin hehanyan wanka wo.

14 Unkan ihanhanna hehanyan siha kin yakonpi ekta wanka. Unkan, Ihnuhan winohinca wan kapanpi owanka en hi kin sdonyapi kte cin, eya, heon wicaśta wan takodaku iyekiye kta okihi itokam winyan kin kikta.

15 Unkan heya, Śina hinni kin hduza wo. Unkan hduza. Unkan barle iyutapi śakpe ikiciyuta, qa winyan qon akan ehnaka, qa otonwe ekta kihda.

16 Unkan winyan kin. kunku ekta ki. Unkan Nituwe he ye micunkśi? eya. Unkan wicaśta qon taku ecakicon owasin okiciyaka.

17 Nakun heya, Barle śakpe kin dena maqu, qa heya, Ihnuhan nikun ekta cokadan yaki ce.

18 Unkan, Micunkśi iyotanka ye, toketu kte cin sdon yaye kte cin hehanyân. Wicaśta kin he nakaha taku owasin hduśtan kte cin hehanyan owanjin yanke kte śni ye, eya.

\section{WICOWOYAKE 4.}

1 Unkan Boyaz otonwe tiyopa ekta i qa hen iyotanka; unkan wopekiton kin Boyaz ke ciqon ahiyaya. Unkan he caje yate ca heciya, Iho ihduhomni qa den iyotanka wo. Unkan ihduhomni, qa hiyotanka.

2 Unkan otonwe hunkayapi etanhan Boyaz wicaśta wikcemna iwicacu, qa den iyotankapo, ewicakiya ; unkan iyotankapi.

$3 \mathrm{Qa}$ wopekiton qon heciya, Nayomi Moab makoce etanhan hdi kin he maga onśpa Elimelek hunkawanji unyanpi tawa qon wiyopekiye kta cin.

$4 \mathrm{Qa}$ miye he nalion ciye kta, qa den iyotankapi itokam, qa 


\section{WICOWOYAKE 4.}

oyate mitawa hunkayapi itokam opeton wo, epe kta, epca. Opeyakiton kta yacin kinhan opekiton wo. Qa opeyakiton kte śni kinhan omakiyaka wo, hecen sdonwaye kta. Wopekiton kta niś nana, qa nihakam he miye. Unkan, Miye opewakiton kta, eya.

5 Unkan Boyaz heya, Tohan Nayomi nape etanhan maga opeyakiton kinhan, nakun Rute Moabiwin, te cin tawicu kin etanhan opeyakiton kta, hecen țe cin caje kin maga tawaye cin akan eyahde kta.

6 Unkan wopekiton kin heya, Miye opewakiton owakihi śni. Hecamon kinhan taku tawa waye cin mảuśice kta, Niye on opekiton wo, he opekiton maśipi, tuka, miye opewakiton kta owakihi śni, nakaś.

7 Unkan ehanna Israel ohna wopekitonpi, qa wiyopeyapi en decen econpi, hecen taku owasin yusutapi, wicaśta kin hanpa hduśdoka, qa takodaku qu, qa Israel ohna woyaatanin kin hee.

8 Heon wopekiton kin Boyaz heciya, Niye on opekiton wo, qa hanpa kin hduśdoka.

9 Unkan Boyaz hunkayapi, qa oyate kin owasin hewicakiya, Taku Elimelek tawa owasin, qa taku Kileon tawa, qa Mahilon tawa owasin, nakaba Nayomi nape etanhan opewaton wayaatanin he niyepi.

10 Qa nakun Rute Moabiwin kin mduze kta e opewaton; Mahlon tawicu qon, te cin tamaga akan caje kin ewahde kta heon etanhan; hecen te cin caje kin hunkawanji wicaye cin etanhan, qa otonwe tawa tiyopa etanhan yuśpapi kte śni, nakaha wayaataninpi he niyepi.

11 Unkan oyate otonwe tiyopa Dak. ohna yakonpi kin owasin heyapi, Wayaatanin heuncapi, Jehowa winohinca yati en hi kin Rahel qa Leha iyececa $k$ te ionśinicida kte; hena napin Israel tiyohnaka kagapi. Niye Eprata ohna wowijice kaga wo, qa Betlehem ohna caje niyatapi nunwe ye.

12 Qa yaüi kin Parez Tamar Juda kiciton ti kin iyececa kte, nicinca Jehowa wikośka kin de etanhan niçu kte cin etanhan ye.

13 Unkan Boyaz Rute yuza, hecen tawicu kin hee, qa ekta i, unkan ihduśake kta e Jehowa okihi ya, heon cinca wica, wan ton.

14 Unkan winohinea Nayomi heciyapi, Jehowa yawaśtepi nunwe; he nakaha wopekiton codan aniciyuśtan śni, qa he Israel ohna nina caje yatapi kta ye.

15 Qa nagi ekicetu niciye kta, qa pa niska hehan wonieu kta, nitakoś cante niciye cin he cinca śakowin isanpa niye ekta waśte ye, he ton nakaś.

16 Unkan Nayomi hokśidan kin icu, qa maku ohnaka, qa kic̣in ece.

17 Unkan winohinca hen tipi kin caje wan qupi, qa heyapi, Nayomi cinca wan kicitonpi, qa Obed (Ookiye) eya caje yatapi, He Jesse atkuku Dawid atkuku, kin hee.

18 Unkan Parez wicoicage kin dena eepi ; Parez Hezron cinca kaga.

19 Unkan Ḧezron Ram cinca kaga, qa Rain Aminadab cinca kaga.

20 Qa Aminadab Nahison cinca kaga, qa Nahison Salmon cinca kaga.

21 Qa Salmon Boyaz cinca kaga, qa Boyaz Obed cinca kaga.

22 Qa Obed Jesse cinca kaga, qa Jesse Dawid cinca kaga. 



\section{SAMUEL TOKAHEYA.}

\section{WICOWOXAKE 1.}

1 Unkan wicaśta wan Ramataim 'I'zopim etanhan, Epraim he kin etanhan, Elqana eciyapi, Jeroham cinhintku, Elihu cinhintku, Tohu cinhintku, Tzup cinhintku Eprati heca.

$2 \mathrm{Qa}$ tawicu nonpa, tokaheya kin Hanna eciyapi, qa inonpa kin Peninna eciyapi, qa Peninna cinca yuha, tuka Hanna cinca nica.

' 3 Unkan wicaśta kin he omaka iyohi Jehowa obe yuhe cin cekiye kta, qa wakiy,uśna kta e totonwe etanhan Silo ekta i; unkan Eli cinhintku nonpa kin Hopni qa Pinehas hen Jehowa wawakiyuśnapi.

4 Unkan Elqqana wayuśna eca, anpetu kin he en tawicu Peninna, qa iye cinca wica.winyan koya owasin, woparnni wicaqu e.ce.

5 Tuka Hanna wopamni nonpa qu ece, Hanna waśte kida nakaś; tuka Jehowa he tamni kin nataka.

6 Unkan teyaku kin he yaśinlida, qa nina cante okiçuninya, Jehowa he tamni kin natake cin heon etanhan.

7 Unkan omaka iyohi hecen econ ece, Jehowa ti kin ekta itanwankanhde ya eca yaśinhda ece; unkan ceya, qa wote śni.

8 Unkan hihnaku Elqqana heciya, Hanna tokeca yaceya he? qa tokeca wayate śni, qa tokeca cante niśica he? Niye on miye cinca wikcemna isanpa mawaśte sni he?

I. Samuel.
9 Unkan Śilo ohna wotapi, qa wayatkanpi ohakam, Hanna najin. Unkan Eli wawayuśna kin Jehowa ti kin ipatan wan icahda oiyotanke wan akan iyotankahan wanka.

10 Unkan winyan naği kin iyokiśica, Jehowa cekiye ça nina ceya.

11 Qa wokonze wan iciconze ca heya, Jehowa obe yuhe cin nitawicinyanna toiyokiśice cin ayatonwe cinhan, qa miyeksuye ça nitawicinyanna ayektunje śni, qa nitawicinyanna cinca wica wan yaqu kinhan: he Jehowa waqu kta ye, tohanyan ni kin anpetu owasin, qa iyuśda tohinni pa akan ye kte śni ye.

12 Unkan Jehowa itokam tehan cekiya yanke çehan, Eli he iha kin wanyag yanka.

13 Unkan Hanna cante mahen ia, iha kin hecedan śkanśkan, tuka ho kin enapeye śni; heon witko, Eli hecin.

14 Unkan Eli winyan kin heciya, Tohanyan winitko kta he? Iho, miniśa kin hdutokan iyeya wo.

15 Unkan Hanna ayupte ça heya, Hiya itancan, winohinca woniya iyokiśica hemaca ye; qa miniśa qa mini wakan unmanna mdatke śni ye; tuka Jehowa itokam nagi watpapson ye.

16 Wicinyanna nitawa wicaśtapi śni cunwintku heca kecin śni ye. Nina iyomakiśica, qa tehiya waun heon dehanyan iwaa ye.

17 Unkan Eli ayupte ça heya, Zaniyan hda wo; hecen Israel 391 


\section{SAMUEL TOKAHEYA,}

taku Wakandapi kin taku cekiya yakida kin ecetu niciye kta.

18 Unkan heya, Wicinyanna nitawa iyonicipi ye. Hehan winohinca kin najin hiyaye ca wota, qa ite kin icimana ecece śni.

19 Unkan hanhanna hin kiktapi, qa Jehowa itokam cekiyapi, qa kibdapi, qa Rama ekta kipi. Unkan Elqana tawicu Hanna sdotkiya. Unkan Jehowa winyan kin kiksuya.

20 Unkan omaka iyehantu qehan, Hanna ihduśake ca cinca wica wan ton, qa Samuel eya caśkiton, Jehowa etanhan wakida, eya nakaś.

21 Unkan Elqana wicaśta kin, qa tiyohnaka tawa owasin omaka wośnapi kin, qa taku konze cin Jehowa wakiyuśna kta e itanwankanhde i.

22 Tuka Hanna ekta iyaye śni, qa hihnaku heciya, Hokśidan kin azin ehpekiya hehan ekta amde $\mathrm{kta}$, "qa Jehowa itokam íhdutanin kta, qa ohinniyan hen yanke kta.

23 Unkan hihnaku Elqana heciya, 'Token niiśta kin en waśte kin iyecen econ wo. Azin ayaśtan yakiye cin hehanyan owanji yanka wo.

24 Unkan azin ayaśtan kiye çehan, hduha ekta i, nakun tatankadan yamni, qa aguyapi mdu epa wanjidan, qa miniśa apahte wan, qa Ślo Jehowa ti kin ekta kahi: unkan hokśidan kin aśkatudan.

25 Unkan tatankadan wan patapi, qa hokśidan kin Eli ekta kahipi.

26 Unkan heya, Itancan ceciciya ye, ninaği ni kinhan itancan winohinca den nici najin, qa Jehowa cekiya yanka he miye ye.

27 Hokśidan kin de Jehowa 392 cekiya wakida, unkan taku cekiya wakida kin ecetu makiya ye.

28 Heon Jehowa he owaqu ye; tohanyan ni kin hehanyan Jehowa oqupi kta ye, eya. Unkan hen Jehowa cekiyapi.

\section{WICOWOYAKE 2.}

1 Unkan Hanna cekiye ca heya. Micante kin Jehowa en iyuśkin ye, mahe kin Jehowa on wankan iyaya; toka mayanpi ekta i mayukawapi; ni mayakiye cin on imduśkin ye.

2 Jehowa iyecen tuwedan wakan śni ye; niś nana heniceca nakaś, qa Taku wakan undapi kin iyecen wowinape wanica. 3 Ihnuhan wahanicidaya wicoie yahduotapi kin. Jehowa taku wakan wasdonya, qa wicacanteoze kin tkeuta ye; heon ihnuhan taku wiśtenya niipi etanhan inanpe cinhan.

4 Wicaśta waśaka tinazipepi kin yuwegapi; tuka hanyanpi kin hena wowaśake ipiyag kitonpi.

5 TTona wipipi qon wanna ağ uyapi on wowidake içiçupi; qa wicaakilianpi qon wanna oziiçiyapi.

Winyan cinca ton śni qon cinca śakowin ton, qa winyan cinca ota ton kin wanna śilitin ye.

6 Jehowa te wicaya, qa ni wicakiya. Hades ekta ye wicaya, qa hetanhan hdicu wicakiya ye.

7 Jehowa wicayuwahpanica, qa wijica wicakaga.

Wicayuhukuya, qa wicayuwankantuya ye.

8 Onśika kin upśija etanhan eyaku, wahpanica kin tacesdi. paha etanhan yuwankan icu. Wicaśta tokapapi om iyotang 


\section{WICOWOYAKE 2.}

wicakiye kta; qa wowitan oiyotanke kin tawa wicakiye kta. Maka ipatan kin hena Jehowa tawa, qa hena akan woicagge kin ahekiya ye.

9 Wacantkiyapi tawa sihapi kin awanwicakiciyake kta.

Tuka wicaśta śica otpaza ohna inina unpi kta.

Wicaśta towaśake on tuwedan wawokihi kte śni ye.

10 Jehowa kipajinpi kin hena yuśinyeyapi kta ;

Hena iwankam mahpiya ohna wakinyan hoton kiye kta.

Jehowa maka ihanke kin wicayaco kta.

Wicaśta yatapi tawa kin wowaśake qu kta ye;

Qa tuwe sdakiye cin he yuwankantu ye kta ye.

11 Unkan Elqana kihda, Rama ekta; tuka hokśidan kin Jehowa ókiya yanka; Eli wawayuśna kin itokam.

12 Unkan Eli cinca kin wicaśtapi śni, Jehowa sdonyapi śni.

13 Unkan oyate kin en wawayuśna tawoyaco kin kaketu, tuwe kaśta woteca wan wayuśna kinhan tado kin śpanyanpi icunhan, wawayuśna tahokśidan kin ekta i, qa mazicape hiyamni nape ohna yuha.

14. Qa ceğa en, qaiś wakśica en, qaiś taku kaśta ohna śpanyaripi en capa, qa taku mazicape kin yuwankan icu kin owasin wawayuśna kin iye on icu; Israel heciya Silo ekta ipi kin hena owasin hecen ecawicakiconpi.

15 Nakun waśin kin nahanhin zinyapi śni wawayuśna tahokśidan kin ekta i, qa wicaśta wayuśna kin heciya, Tado ceonpe kta e wawayuśna qu wo. Tado śpan niye etanhan icu kte śni tuka saka.

16 Unkan, Tokaheya waśin kin zinyapi kta, ohinniyan econpi kta iyececa, qa hehan taku ninagi cin kin owasin icu wo, wicaśta wayuśna eye cinhan, Hiya, wanna maqu wo; hecanon śni kinhan iyalipaya iwacu kta, eya.

17 Hecen kośka qon Jehowa itokam wahtanipi; heon Jehowa taminha kin wicaśta walitedapi śni.

18 Unkan Samuel Jehowa itokam waokiya; hokśidan kin miniliuha amdo akahpe wan ipiyag kiton.

19 Unkan hunku kin śina cistinna wan kicage ca omaka iyohi kahi; hihnaku omaka wośnapi wakiyuśna kta e kici hi eca.

20 Unkan Eli Elqana, qa tawicu wicayawaśte, qa heya, Jehowa winohinca kin de etanhan cinca nicu kta, de Jehowa oqu kin heekiya; unkan ekta hdapi.

21 Unkan Jelowa Hanna ekta i; hecen ihduśake ca cinca wica yamni, qa winyan nonpa wicaton. Unkan hokśidàn Samuel Jehowa itokam tanka icağa.

22 Unkan Eli nina wicahinca, qa cinhintku Israel owasin token ecawicakiconpi kin he nalion, qa token winohinca itkokipapi wakeya tiyopa kin ekta hipi kin hena om wankapi kin nakun.

$23 \mathrm{Qa}$ hewicakiya, Tokeca wicolian dena ecanonpi he? Oyate kin de owasin etanhan niohanpi śica onawalion ece.

24. Hiya micinkśi taku oyakapi nawahon kin he waśte śni. Jehowa taoyate kin śicaya econwicayakiyapi ece.

25 Nicaśta wan wicaśta tokeca awahtani kinhan, Taku wakan yuecetu kta ; tuka wicaśta wan Jehowa awalitani kinhan tuwe iciye kta he? Unkan atkukupi ho kin anakigroptanpi śni ; Jehowa te wicaye kta iyokipi nakaś. 


\section{SAMUEL TOKAHEYA,}

26 Unkan hokśidan kin Samuel icağa, qa tanka qa waśte Jehowa itokam, qa nakun wicaśta wicitokam.

27 Unkan Wakantanka tawicaśta wan Eli ekta i qa heciya, Jehowa hecen eya; Niyate tiyohnaka kin en mihdutanin, Egupta ohna, Paro ti kin ekta yakonpi qehan.

28 Qa he wakahnigia, Israel wicoun owasin etanhan, wamakiyuśna $\mathrm{kta}$, wahna wośnapi mitawa akan wahulinahye kta, wizite izinye kta, qa mitokam amdo akahpe yuha kta; qa niyate tiyohnaka kin Israel cinca peta wośnapi kin owasin wicawaqu.

29 Tokeca wośnapi, qa minha tipi wakan ohna wamiciyuśna wicawaśi kin hena nayahtakapi he? qa niye nicinca kin miye isanpa wicadutan, qa oyate mitawa Israel minlia makahipi kin owasin etanhan taku iyotan waśte kin on cemniciyapi he?

30 Heon Jehowa Israel Wakan dapi kin hecen eya, Tiyohnaka nitawa, qa niyate tiyohnaka tawa kin owihanke wanin mitokam manipi kta, epapa; tuka he ecetu waye kte śni; tuwe mayutan kin he mdutan kta, qa tuwe ihamakta śni kinhan ihaktapi kte śni, Jehowa nakaha eya.

31 Inyun tokata anpetu kin en niisto, qa niyate tiyohnaka istopi kin wakaśpe kta, hecen yati ohna wicahinca wanice kta.

$32 \mathrm{Qa}$ taku waśte owasin Israe? iyowicahi kin en, tipi wakan ohna toka wan wandake kta, qa icimana wicahinca wan yati kin ohina yuke kte śni.

33 Qa wicaśta nitawa kin tona wahna wośnapi mitawa etanhan wicawakaśpe śni kin hena on niiśta kin niciyazan $\mathrm{kta}$, qa nag̉i 394. śihtin niciyapi kta, qa yati oicag̉e kin owasin nahanhin kanpi śni tapi kta.

34 Unkan wowapetokeca kin de duhe kta, taku nicinca napin awicakipe kta, Hopni qa Pinehas napin anpetio wanjidan en tapi kta.

35 Unkan wawayuśna wacinyepica wan icalimiçiye kta, iye token micante, qa minagi iyokipi kin econ kta, qa tipi wacinyepica wecagie kta, qa tuwe sdawakiye cin itokam ohinniyan mani kta.

36 Unkan tona yati etanhan okaptapi kin he en ipi kta, qa mazaska kaśpapidan on, qa aguyapi hmiyanyanna on ekta patujapi kta, qa Wawayuśna wohtani wan ecamon kta e amakaśtan ye, hecen ağuyapi onśpadan wate kta ce, eye kta.

\section{WICOWOYAKE 3.}

1 Unkan hokśidan kin Samuel Eli itokam Jehowa ókiya. Unkan anpetu kin hena en Jehowa oie kin telika, wow anyake taninyan un wanica.

2 Unkan he ehan Eli iśta mdeze śni, hecen wawanyaka okihi śni, qa oyanke tawa ohna makata iwanka.

3 Unkan tipi wakan Jehowa tawa, Wakantanka can wohnaka tawa ohna yanke cin, he ohna Samuel makata wanka, qa taku wakan tapetijanjan nahanhin ideya yanka.

4 Unkan Jehowa Samuel kipan; unkan, He miye ce, eya,

5 Qa Eli ekta inyanke ça heya, De miye mayakipan nakaś. Unkan wapan śni ; ekta hda kiwanka wo. Unkan hda iwanka.

6 Unkan Jehowa ake Samuel kipan. Unkan Samuel najin, qqa 
Eli ekta i, qa heya, Mayakipan heon de miye ce. Unkan wapan śni micinkśi, hda kiwanka wo, eya.

7 Unkan Samuel nahanlin Jehowa sdonye śni, qa en Jehowa oie kin nahanhin ihdutanin śni.

8 Unkan ake iyamni Jehowa Samuel kipan. Unkan najin qa Eli ekta i qa heya, Mayakipan, heon de miye ce. Unkan hokśidan kipan kin he Jehowa ee Eli iyukcan.

$9 \mathrm{Qa}$ Eli Samuel heciya; Hda kiwanka wo, qa ake nicipan kinhan, Jehowa ia ye, nitaokiye nation yanka ce, ehe kta. Unkan Samuel hda qa toyanke en wanka.

10 Unkan Jehowa ake en hi qa najin, qa hecon qun iyecen Samuel, Samuel kipan. Ũnkan Samuel heya, Ia ye, nitaokiye wanation yanka ce.

11 Unkan Jehowa Samuel heciya, Inyun Israel ohna taku wanji ecamon kta, qa tuwe kaśta he nahon kinhan nog̉e napin snasna kta.

12 Anpetu kin he en, taku Eli tiyohnaka on epe ciqon otokahe qa ehake kin owasin Eli ecawecon lita.

13 Iye tiyohnaka kin taku śica econpi kin sdonya, heon owihanke wanin wicamdaco kta, ewakiya, cinhintku walite śni içicağapi, qa iye wicakiśice śni nakaśs.

14 Qa heon Eli tiyohnaka kin on wakonze ca hepa, Eli tiyohnaka kin wah̆tanipi kin wośnapi on qa mintia on tohinni wakajuju kte śni.

15 Unkan Samuel ihanhanna kin hehanyan makata wanka, qa hehan Jehowa ti tiyopa kin yulidoka, qa Samuel wowanyake kin Eli okiyake kte cin kokipa.
16 Unkan Eli Samuel kipan, qa Micinkśi Samuel, eya. Unkan De miye ce, eya.

17 Unkan, Wicoie eniciye cin he taku? Ihnuhan miye etanhan he nayahbe cin ; wicoie eniciye cin owasin miye etanhan wicoie wanjidan nayahbe cinhan, taku wakan hecen ecanicon kta qa nakun isanpa.

18 Unkan Samuel wicoie kin owasin okiyaka, qa takudan analibe śni, iye etanhan. Unkan, Jehowa hee; taku iye iśta kin en waśte kin hee econ kte, eya.

19 Unkan Samuel tanka aya, qa Jehowa kici un, qa oie eye cin wanjidan makata elipe kiye śni.

20 Unkan Israel owasin Dan etanhan Berśeba ekta hehanyan, Samuel awicakehan Jehowa tawaayate heca e sdonyapi.

$21 \mathrm{Qa}$ ake Jehowa Śilo ohna ihdutanin, Silo ohna Jehowa Samuel en ihdutanin, Jehowa oie on nakaś.

\section{WICOWOYAKE 4.}

1 Unkan Samuel oie kin Israel owasin ekta i. Unkan Israel Pilistim itkowicakipe kta wokicize ekta inanpa, qa Eben-ezer (Inyan waokiye kin) ekta etipi; unkan Pilistim Apeq en wankapi.

$2 \mathrm{Qa}$ Pilistim Israel itkowicakipapi kta e ocimdahi najinpi, qa kicizapi qehan Israel napapi, Pilistim itokapa tanhan. Unkan wokicize en tinta ohna wicaśta kektopawinge topa cetu wicaktepi.

3 Unkan oyate kin owanka en hdipi qehan, Israel hunkayapi kin heyapi. Tokeca Jehowa Pilistim itokam nakaha unkaśtakapi he? Jehowa otakuye can 395 
wohnaka kin Śilo etanhan unkicupi kta, qa unkiyepi cokaya iyaye kta, qa Pilistim napepi etanhan ni unkiyapi kta.

4. Unkan oyate kin Śilo ekta wicaśta yewicaśipi, qa Jehowa obe yuha, Kerubim en ounye cin otakuye canwohnaka tawa kin hetanhan yuwankan icupi. Unkan Eli cinhintku napin Ḣopni qa Pinehas Wakantanka otakuye can wohnaka kici hen unpi.

5 Unkan Jehowa otakuye can wohnaka kin owankapi en hi qehan, oyate kin owasin iyaśapi tanka on iyaśapi; hecen maka kin snasna.

6 Unkan Pilistim kin iyaśapi ho kin nahonpi, qa heyapi, Heberi owankapi ohna iyaśapi tanka ho kin de taku hwo? qa Jehowa can wohnaka kin Israel owankapi en hi kin nalionpi.

7 Qa Taku wakan owankapi en hi eyapi qehan, Pilistim kokipapi, qa heyapi, Hehehe de itokam tohini hececa śni.

8 Hehehe tehiya unyakonpi kta. Taku wakan waśaka kin dena etanhan tuwe eunyakupi kta he? Fgupton wokaśtake owasin on hewoskan wicakaśtakapi taku wakan kin dena eepi.

9 Pilistim wakiśag içiyapi, qa wicaśta ihdutaninpo. Okini Heberi kin wowidag niyanpi kta, niyepi wowidag wicayayapi kin iyecen, heon wicaśta ihdutaninpo, qa wakizapo.

10 Unkan Pilistim wakizapi, qa Israel kaśtakapi. Unkan Israel napapi wicaśta iyohi ti kin ekta; qa nina wicakaśtakapi hecen Israel wicaśta huiyun kektopawinge wikcemna yamni hinlipayapi.

11. Unkan Wakantanka can wohnaka tawa kin icupi, qa, Eli cin. hintku Hopni qa Pinelias napin wicaktepi.
12 Unkan Benjamin wicaśta wan wokicize etanhan inyanke ca anpetu kin he ell Ślilo en hi, taheyake hidehdecahan, qa pa kin maka akadapi.

13 Unkan hdi qehan, Eli canku kin icahda, oiyotanke wan akan iyotanka yanka; qa Wakantanka can wohnaka tawa kin on cante kin cancan, heon waktaya un. Unkan wicaśta.qon oyake kta en hi qehan, otonwe ocowasin ceyapi.

14. Unkan Eli ceyapi ho kin nahon qa heya, Wicota hotonpi kin de taku hwo? Unkan wicaśta qon inalini, qa Eli en hi, qa okiyaka.

15 Wanna Eli tonpi ehantanhan waniyetu wikcemna napcinwanka sanpa śahdoġan, qa iśta kin mdeze śni, wawanyaka okihi śni.

16 Unkan wicaśta qon Eli heciya, Wokicize etanhan u kin he miye, qa miye nakaha wokicize etanhan nawajica. Unkan, Micinkśi wicoie kin toketu he? eya.

17 Unkan wotanin ahi kin ayupte ca heya, Israel Pilistim itokam napapi, qa oyate kin wicotahin tapi, qa nakun nicinkśi Hopni qa Pinehas napin tapi, qa Wakantanka canwohnaka tawa kin icupi.

18 Unkan Wakantanka canwohnaka tawa kiksuye kiye cehan, itunkam ilipaya, oiyotanke etanhan, otonwe tiyopa kin icahda, qa tahu kin nawegge ça te. He wicahinca nakaś qa tike; qa Israel waniyetu wikcemna topa wicayaco.

19 Unkan takośku Pinehas tawicu kin ihduśake cinca ton kta iyehantu; qa Wakantanka canwohnaka tawa kin icupi, qa tunkanku, qa hihnaku kin țapi, wo. 


\section{WICOWOYAKE 5 .}

tanin nalion qehan patuja, qa cinca ton, hokśiksuya yazan hda nakaś.

20 Unkan te kte cehan ihdukśan najinpi kin heciyapi, Wakokipe śni ye; hokśidan wan yaton heon etanhan. Unkan waayupte śni, qa cante kin ekta yekiye śni.

21 Tuka hokśiyoqopa kin, Ikabod (Wowitan toki un he) caśkiton, Wowitan Israel etanhan tokan iyaya ce eya; Wakantanka canwolnaka tawa icupi he on, qa tunkanku qa hihnaku on.

22 Qa Wakantanka canwohnaka tawa kin icupi kin, heon Israel etanhan wowitan kin toki iyaya ye, eya.

\section{WICOWOYAKE 5.}

1 Unkan Pilistim Wakantanka canwohnaka tawa kin icupi, qa Ebenezer etanhan Aśdod ekta ayapi.

2 Qa Pilistim Wakantanka tacanwohnaka kin icupi qehan, Dagon ti kin en kaipi, qa Dagon icahda ehdepi.

3 Unkan Aśdodi ihanhannahin kiktapi qehan, inyun Dagon makipusdiya ilipaya, Jehowa canwohnaka tawa kin itokam. Unkan Dagon yuwankan icupi, qa ake yanke ciqon en ehdepi.

4 Unkan ihanlianna hanhannahin kiktapi qehan, inyun Daǵon makipusdiya ilipaya, Jehowa canwohnaka tawa itokam, qa Dagon pa kin, qa nape kin napin naksa tiyopa oahehde akan, qa Dagon huha codan okapta.

5 Heon Dagon wawayuśnapi kin, qa tona Dagon ti kin en yapi owasin, anpetu kin dehanyan Aśdod ohna Dagon tiyopa oalıde kin amanipi śni.
6 Unkan Jehowa nape kin Aśdodi akan tke, qa ihang wicaya, qa Aśdod qa makoce kin ohna onzepo on wicakaśtaka.

7 Unkan Aśdod wicaśta kin he hecetu iwanhdakapi qehan heyapi, Israel taku wakandapi kin can wohnaka tawa kin unkiyepi om yanke kte śni; iyc nape kin tehika, unkiyepi akan, qa Dagon wakanundapi kin akan nakaś.

8 Unkan tuwe ye sipi, qa Pilistim itancanpi kin owasin iyepi en mniciye wicayapi, qa heyapi, Israel taku wakandapi canwohnaka tawa kin on token econkupi kta he? Unkan, Israel taku wakandapi canwohnaka kin Gat ekta ayapi kta, eyapi. Unkan Israel taku wakan dapi canwohnaka kin Gat ekta ayapi.

9 Unkan heciya ayapi ohakam, Jehowa nape kin otonwe akan yanka, woyuśinye nina tanka on, qa otonwe wicaśta kin cistinna tanka 'koya awicapa, qa onzepo awicahinanpa.

10 Unkan Wakantanka canwohnaka tawa kin Eqron ekta ayapi. Unkan Fqroni kin heyaniyanpi, Israel taku wakandapi tacanwohnaka kin miye en makahipi, he miye makte kta, qa mitaoyate kin nakun.

11 Qa tuwe ye śipi, qa Pilistim itancanpi kin owasin witaya hiyu wicayapi, qa heyapi, Israel taku wakandapi canwohnaka tawa kin oyanke tawa ekta kihde yapo, hecen miye te maye kte śni, qa oyate mitawa te wicaye kte śni. Taku wakan nape kin hen tehika, qa otonwe ocowasin akan wiconțe woyuśinyan nakaś.

12 Unkan wicaśta tona țapi śni onzepo ececapi; heon śicahowayapi kin mahipiya ektakiya iyaya. 


\section{SAMUEL 'TOKAHEYA,}

\section{WICOWOYAKE .6.}

1 Unkan Jehowa canwohnaka tawa kin PiIistim tamakocepi ohna wi śakowin yanka.

2 Unkan Pilistim kin wawayuśnapi kin, qa wapiyesapi kin wi. cakicopi qa heyapi, Canwohnaka Jehowa tawa kin taku ecaunkiconpi kta he? Token kihde unyanpi kta sdonye unkiyapo.

3. Uukan heyapi, Israel taku wakan dapi canwohnaka tawa kihde yayapi kte cinhan, cokadan kihde yayapi kte śni; tuka hdajuju wośnapi wan kici kihde yayapi kta: hecen anisnipi kta, qaiś tokeca niyepi etanhan nape kin ehdaku śni sdonye niciyapi kta.

4 Unkan, Hdajuju wośnapi unqupi kte cin he taku? eyapi. Unkan heyapi, Pilistim wicaśta yatapi iyenaka mazaskazi onzepo seca zaptan, qa mazaskazi hitunkadan zaptan, makośice kin okonwanjidan niyepi akan, qa wicaśta yatapi nitawapi akan yanka nakaś.

5 Heon onzepo ouncagie, qa hitunkadan makoce nitawa ihang yapi kin ouncage kin yakagiapi kta, qa Israel taku wakandapi kin wowitan yaqupi kta; hecen okini nape kin niyepi akan yanka, qa taku wakan yadapi akan, qa nitamakocepi kin akan un kin, he hdukapojedan kta.

$6 \mathrm{Qa}$ tokeca cante kin tins niciyapi? Egupton qa Paro cantepi kin tins içiyapi kin iyecen, yuśinye wicaye cin ohakam kihdewicaye śni, unkan iyayapi śni he?

7 Heon wanna canpahmilima teca kagapo, qa pte cinca yukan nonpa, canwanapin tohini napin wicakiyapi śni icupo, qa pte kin canpahmihma kin ekta iko- yag wicayayapi kta, qa cincapi kin ti mahen wicayahdohdipi kta. 8 Qa canwohnaka Jehowa tawa kin iyacupi, qa canpahmihma kin akan eyahnakapi kta, qa mazaskazi kagaapi kin on yahdajujupi kin hena wojuha wan ohma eyahnakapi kta, canwohnaka kin icahda, qa kihde yayapi kta, hecen iyaye kta.

9 Qa ekta eyatonwanpi kta makoce tawa canku kin ohna Betśemeś (Anpetuwi ti kin) ohna iyaye cinhan, iye taku śica tanka kin de ecaunkiconpi, tuka kihde śni kinhan nape unkaśtakapi kin he tawa śni, tuka de wanun unkakipapi.

10 Unkan wicaśta qon hecen econpi, qa pte asanpi yukan nonpa icupi, qa cincapi kin tipi en onatakapi.

11 Qa Jehowa can wohnaka tawa kin canpahmihma kin akan ehnakapi, nakun wojuha kin, qa mazaskazi hitunkadan kin, onzepo ouncage kin.

12 Unkan pte kin Betśemeś canku kin ohna owotanna cankuyapi, canku tanka kin katinyan omanipi, hotonton manipi; qa etapa qaiś catka unnanna ektakiya yuwinh manipi śni. Unkan Pilistim wicaśta yatapi kin wicihakam yapi, Betśemeś makoce kin hehanyan.

13 Unkan Betśemeś wicaśta kin osmaka ohna ag̉uyapi su kin baksapi, qa iśtapi kin yuwankan ikikcupi, qa canwohnaka kin wanyakapi qa wanyakapi on iyuśkinpi.

14 Unkan canpahmihma kin Jośuwa Betśemeś wicaśta tamağa en hi, qa hen owanji yanka, qa heciya inyan tanka wan yukan. Unkan canpahmihma can kin kaksapi, qa pte kin wohuhnahyapi Jehowa wakiyuśnapi. 
15 Wanna Lewi kin Jehowa canwohnaka tawa, nakun wojuhadan kici un, qa mazaskazi wakagapi en un kin, hena kun icupi, qa inyan tanka kin he akan ehdepi. Unkan anpetu kin he en Betśemeś wicaśta kin wohuhnahyapi hulinahyapi; qa woteca Jehowa wakiyuśnapi.

16 Unkan Pilistim wicaśta yatapi zaptan kin wanyakapi qehan, anpetu kin he en Eqron ekta kihdapi.

17 Unkan mazaskazi onzepo wokajuju on Pilistim hdajujupi kta e Jehowa qupi dena ee, Aśdod on wanjidan, qa Gaza on wanjidan, qa Aśqelon on wanjidan, qa Gat on wanjidan, qa Eqron on wanjidan.

18 Unkan mazaskazi hitunkadan Pilistim otonwe owasin iyenaka, wicaśta yatapi zaptan yuhapi kin hena otonwe aconkaślkayapi, qa otonwe ikceka koya. Unkan inyan tanka wan akan Jehowa canwohnaka tawa ehnakapi kin, he Jośuwa Betśemeś wicaśta wan tamag̉a ohna dehanyan yarika.

19 Unkan Betśemeś wicaśta kin Jehowa tacanwohnaka kin mahen etonwanpi, heon wicakaśtaka, oyate kin wicaśta kektopawinge wikcemna zaptan sanpa wikcemna śakowin wicakaśtaka. Unkan Jehowa wokaśtake tanka on wicakaśtake cin heon oyate kin ceyapi.

20 Unkan Betśemeś wicaśta kin heyapi,-Jehowa wakan undapi kin de wakan ce. Tuwe itokam najin okihi he? qa unkiyepi etanhan tuwe ekta itanwankanhde ye kta he?

21 Qa Qerejat Jeyarim ekta ohnihde ye wicaśipi qa heyapi, Pilistim Jehowa tacanwohnaka kin ake ahipi ce. Kun upo, qa niyepi ekta ayapo.

\section{WICOWOYAKE \%.}

1 Unkan Qerejat Jeyarim wicaśtá kin elata ipi qa, Jehowa canwohnaka tawa kin itanwankanhde aupi, qa Abinadab ti kin paha akan ekta kahipi, qa cinhinthu Eleazar Jehowa canwohnaka tawa awanyake kta heon - yuwakanpi.

2 Unkan canwohnaka kin Qerejat Jeyarim en yanke cin ehantanhan wanna tehan, waniyetu wikcemna nonpa qehan, Israel tiyohnaka kin ocowasin Jehowa cantokpani.

3 Unkan Samuel Israel tiyohnaka kin ocowasin hewicakiya, Nicantepi ocowasin on Jehowa en yahdipi kinhan, taku wakan tokeca, qa Aśterot niyepi etanhan yutokan iyeyapo; qa Jehowa on nicantepi kin pikiyapo, qa iśnana ohodapo, kinhan Pilistim napepi etanhan enihdakupi kta.

4. Unkan Israel cinca kin Bayalim, qa Aśtarot yutokan iyeyapi, qa Jehowa iśnana ohodapi.

5 Unkan Samuel heya, Israel owasin Mitzpa ekta mnawicayapo ; kinhan niyepi on .Jehowa cewakiye kta.

6 Unkan Israel owasin Mitzpa ekta mniciyapi, qa mini huweyapi, qa Jehowa itokam kaśtanpi; qa anpetu kin he en wotapi śni, qa, Jehowa awaunhtanipi ce, eya ohodapi. Unkan Samuel Mitzpa ohna Israel wicayaco.

7 Unkan Israel Mitzpa ekta mniciyapi kin Pilistim nahonpi, qa Pilistim wicaśta yatapi kin Israel anatan upi. Unkan Israel cinca kin he nahonpi qehan, $\mathrm{Pi}$ listim kowicakipapi.

$8 \mathrm{Qa}$ Israel cinca kin Samuel 399 


\section{SAMUEL TOKAHEYA,}

heciyapi, Jehowa wakan undapi kin Pilistim napepi etanhan niunkiyapi kta e hoyekiya wo, qa inina yanke śni wo.

9 Unkan Samuel tacincadan waazin wan icu, qa ocowasin wohuhnahyapi Jehowa wakiyuśna, qa Samuel Israel on Jelıowa hoyekiya. Unkan Jehowa ayupta.

10 Unkan Samuel wohulinahyapi huhnahye cin icunhan, Pilistim Israel kizapi kta e ikiyedan hipi. Unkan anpetu kin he en Jehowa ho tanka on Pilistim iwankam wakinyan hoton kiya, qa yuśinye wicaya. Unkan Israel itokam najicapi.

11 Unkan Israel wicaśta kin Mitzpa etanhan inanpapi, qa $\mathrm{Pi}$ listim kuwa eyayapi, qa wicakaśtakapi, Betkar ihukuya ipi kin hehanyan.

12 Unkan Samuel inyan wan icu, qa Mitzpa qa Śen otahedan ehde, qa Eben-ezer (Inyan waokiye) eya cajeyata qa, Dehanyan Jehowa ounkiyapi ce eya.

13 Unkan Pilistim wicaktepidan, qa ake Israel makoce en hipi śni, qa anpetu Samuel ni kin owasin Jehowa nape kin Pilistim. iwankam un.

14 Unkan otonwe tona Pilistim Israel etanhan icupi qon, hena Israel ake hduhapi ; Eqron etanhan Gat ekta hehanyan, qa makoce kin Israel Pilistim napepi etanhan ehdakupi. Unkan Israel Amori kin om wokiyapi.

15 Unkan Samuel tohanyan ni kin hehanyan Israel wicayaco.

16 Unkan omaka iyohi Betel, qa Gilgal, qa Mitzpa iyohi ekta $i$, qa otonwe kin hena owasin ohna Israel wirayaco.

17 Qa Rama ekta hda, tipi tawa kin hen yanka nakaś, qa heciya Israel wicayaco, qa heci400 ya wahna wośnapi wan Jehowa kicaga.

WICOWOYAKE 8.

1. Unkan Samuel wicahinca qehan, iye cinhintku Israel wicayaco wicaśi.

2 Unkan cinhintku tokapa kin Joel eciyapi, qa inonpa kin Abia eciyapi, Hena Berśeba en wayacopi ece.

3 Unkan cinhintku iye tacanku omanipi śni, tuka wokamna ekta ihduhomnipi, qa taku nahmana qupi kin icupi, qa woyaco yaśkiśkapi.

4 Unkan Israel hunkayapi kin owasin witaya hiyupi; qa Samuel ekta Rama en hipi.

5 Qa heciyapi, Tho wanna wicanihinca, qa nicinca kin nitacanku omanipi śni; heon wanna wicaśta yatapi wan unkicicaġapo ; ikcewicaśta owasin yuhapi kin iyececa.

6 Unkan, Wicaśta yatapi wan unyacopi kta e unqupo, eyapi kin wicoie kin he Samuel iśta kin en śica: heon Samuel Jehowa cekiya.

7 Unkan Jehowa Samuel heciya, Oyate ho kin taku eniciyapi kin owasin nahon wo. Niye qe heyata iyeniyanpi śni; tuka miye atemayanpi kte śni e heyata iyemayanpi ce.

8 Woecon, Egupta etanhan itanwankanhde hdinanpe wicawaya, anpetu kin ehantanhan econpi kin owasin iyecen, anpetu kin dehanyan elipemayanpi, qa taku wakan tokeca ohodapi kin he iyecen, niś eya ecaniconpi.

9 Heon wanna hopi kin nahon wo. Hececa eśta woyaatanin wicakiyaatanin wo; qa wicaśta yatapi wowidag wicaye kte cin woyaco kin toketu kte cin owicakiyaka wo. 


\section{WICOWOYAKE 9.}

10 Unkan S'amuel Jehowa oie kin owasin oyate wicaśta yatapi dapi kin owicakiyaka;

11 Qa heya, Wicaśta yatapi wowidag niyanpi kta tawoyaco kin kaketu kta. Nicinkśipi iwicacu qa canpahniluma tawa en, qa śuktanka tawa akan iyotang wicakiye kta, qa canpahmihma tawa itokam inyankapi kta.

$12 \mathrm{Qa}$ kektopawinge itancan, qa wikcemna zaptan itancan wicakage kta, qa tamaga kin yumdu wicakiye kta, qa woksapi tawa bakse wicakiye kta, qa tawipe owasin, qa canpahmihma tawa aqin kin owasin kahwicakiye kta.

13 Qa nicunkśipi kin iwicacu kta, qa pejuta waśtemna kahwicakiye, ca wohe wicakiye ca ag̉uyapi śpanye wicakiye kta.

$14 \mathrm{Qa}$ nıaga nitawapi, qa hastanhanka iyuwi ojupi nitawapi, qa wihdican ojupi nitawapi iyotan waśteśte kin icu kta, qa taokiye hena wicaqu kta.

15 Qa taku oyajupi kin, qa hastanhanka nitawapi iwikcemna kin icu kte ca taakicita, qa taokiye wicaqu kta.

16 Qa nitaholsśipidan, qa nitawicinyanpidan, qa kośka nitawapi iyotan waśtepi kin, qa śonśonna nitawapi iwicacu, qa wohtani tawa econ wicakiye kta.

17 Nakun tahinca nitawapi iwikcemna icu kta, qa wowidake niyanpi kta.

18 Qa anpetu kin he en ateyapi nicicahniğapi on śicahowadapi kta eśta, Jehowa hehan nanilionpi kte śni.

19 Unkan oyate kin Samuel ho kin nahon wicadapi śni, qa heyapi, Hiya wicaśta yatapi wản unhapi kta.

20 Nakun unkiyepi ikce oyate kin owasin iyewicuncecapi kta, 26 qa wicaśta yatapi unkitawapi unyacopi $\mathrm{kta}$, qa unkiyepi itokam zuya ye kta, qa unkiyepi on kize kta.

21 Unkan Samuel oyate oiepi kin owasin nahon, qa Jehowa okiyaka.

22 Unkan Jehowa Samuel heciya, Hopi kin nahon wo, qa wicaśta yatapi wan wicakicağa wo. Unkan Samuel Israel wicaśta kin hewicakiya, Kihdapo, wicaśta iyohi totonwe kin ekta.

\section{WICOWOYAKE 9.}

1 Unkan Benjamini wicaśta wan Qiś eciyapi Abiel cinhintku, Tzeror cinhintku, Bekoret cinhintku, Apiah cinhintku Benjamin wicaśta wan cinhintku, wicaśta waśaka waditaka.

2 Unkan cinhintku wan Saul eciyapi kośka wiciyokipi, qa owanyag waśte, Israel cinca wicehna iye isanpa owanyag waśte wicaśta wanica; amdo kin, qa he iwankapa tanhan oyate owasin wiciwankam najin. 3 Unkan Saul atkuku Qiś taśonśonna kin kitaninpi śni, qa Qiś iye cinhintku Saul heciya, Kośka wanji ikikcu wo, qa najin, qa śonśonna owicade ya wo.

4 Unkan Epraim he kin opta iyayapi, qa Saliśa iyoopta iyayapi, qa iyewicayapi śni, qa Sayalim makoce kin opta iyayapi, tuka hen unpi śni, qa Benjamin makoce kin opta iyayapi tuka iyewicayapi śni.

5 Tzup makoce en ipi qehan, Saul iye tahokśidan kici un kin heciya, Ito unhde kta, okini ate sonśonna kin ayuśtan, qa unkiyepi on iyokiśin içiye kta.

6 Unkan heciya, Wan otonwe kin de ohna wicaśta wakan wan yanka. Wicaśta kinihanpi taku 401 


\section{SAMUEL TOKAHEYA,}

eye kte cinhan owasin ecetu kta hinca. Wanna en unye kta. Okini canku ohna unye kta iyececa unkokiyakapi kta.

7 Unkan Saul tahokśidan kin heciya, Ekta unye cinhan wicaśta kin taku unqu kta he? Wojuha unkitawapi ohna aguyapi wanica. Wicaśta wakan ekta unkaye kta takudan unkokapte śni. Taku unqu kta he?

8 Unkan hokśsidan kin ake Saul ayupte ça heya, Ito minape ohna mazaska śeqe? ośpa itopa kin wahduha, he wicaśta wakan waqu kta, unkan canku unye kte cin unkokiyakapi kta.

9 Ehanna Israel ohna wicaśta wan taku wakan wawiwanli ya ca decen eya ece. Iho wawanyake kin ekta unye kta. 'Tuwe nakaha waayate eciyapi kin he ehanna wawanyake eciyapi.

10 Unkan iye takokśidan heciya, Wicoie ehe cin he waśte ce. Iho ekta unye kta. Unkan otonwe ohna wicaśta wakan yanke cin ekta ipi.

11 Otonwe ekta itanwankanhde yapi qehan, wikośka mini huweyapi kin awicakipapi, qa hewicakiyapi, Wawanyake kin deciya un he?

12 Unkan awicayuptapi qa heyapi, Toś iho nitokam un ye. Nakaha oyate kin paha akan wawicakiciyuśna, qa heon dehan otonwe en hi ye, hecen inahnipe.

13 Hecen otonwe en yaipi kinhan nahanhin wote kta e pahata iyaye śni iyeyayapi kta. Ekta i śni kin hehanyan oyate kin wotapi kte śni. Iye wośnapi kin yawaśte kta; ohakam tona wicakicopi wotapi kta ye nakaś.

14 Unkan itanwankanhde otonwe en ipi qehan, inyun Samuel 402 wicitkokim inanpe ça paha kin ekta iyaye kta.

15 Unkan Jehowa Samuel nog̀e kin yuzamni, qa Saul hi śni itokam anpetu wan heciya,

16 Heyakecinhan wi kin dehantu Benjamin makoce etanhan wicaśta wan niye en hiyu waye kta, he qe Israel oyate mitawa mdetanhunka kta e sda yaye kta, qa iye oyate mitawa Pilistim napepi kin etanhan niwicaye kta, oyate mitawa wanwicamdake ca śicahowayapi kin en mahi nakaś.

17 Qa Samuel Saul wanyake cehan Jehowa heciya, Wanyaka wo, wicaśta wan oyate mitawa ewicahdaku kte cin, eciciye ciqon he dee ce.

18 Unkan Saul otonwe tiyopa kin ohna Samuel ikiyedan hi qa heya, Tokin wawanyake ti kin tuktee omayakidaken.

19 Unkan Samuel Saul ayupte ca heciya, Wawanyake kin he miye ce. Pahata mici ya wo, qa nakaha miciwayatapi kta, qa hanhanna kinhan kihde ciye kta, qa taku nicante en un kin owasin ociciyake kta.

20 Qa śonśonna htanihan sanpa nicitaninpi śni kin hena ekta nicante kin yekiye śni wo; wanna iyewicayapi nakaś. Nakun Israel tuwe iyotan cantiheyapi he? He niye, qa niyate tiyohnaka owasin.

21 Unkan Saul ayupte ca heciya, Miye Benjamin wicaśta hemaca śni he? Israel etanhan wicoun iyotan cistinna, qa wicowazi mitawa Benjamin wicoun kin wicowazipi owasin aoptetu; lieon tokeca wicoie kin de iyecen emayakiya he?

22 Unkan Samuel Saul, qa tahokśidan iwicacu, qa wohan tipi kin ekta hiyu wicaya, qa wicaśta 


\section{WICOWOYAKE 10.}

wikcemna yamni cetu wicakicopi wicehna oiyotanke iyotan waśte wicaqu.

23 Qa Samuel wohekiyapi kin heciya, Wopamni cicu qa nici kihnaka wo, eciciye cin he hiyuya wo.

24 Unkan wohekiyapi kin ceca kin, qa taku ikoyake cin he yuwankan icu, qa Saul itokam ehnaka. Unkan, Ho wo, taku kihnakapi kin nitokam ehde wo, qa yuta wo. Oyate kin wicakico wo, epe ciqon ehantankan, he nicihnakapi nakaś, eya. Unkan anpetu kin he en Saul Samuel kici wota.

25 Unkan paha etanhan otonwe kin ekta hdipi, qa tipi awakeyapi kin akan Samuel Saul kici wohdaka.

26 Qa hantiannahin kiktapi, qa Samuel anpao hinanpe cehan Saul tipi awakeyapi ekta kipan, qa heciya, Kikta wo; hecen kihde ciye kta. Unkan Saul kikta qa Samuel kici tankan iyaya.

27 Sakim otonwe ihanke ekta ipi qehan, Samuel Saul heciya, Kośka kin unkitokam ye śiwo; hecen iyaye kta; tuka niye den owanji najin wo; kinhan Wakantanka oie kin nation ciye kta.

\section{WICOWOYAKE 10.}

1 Hehan Samuel wihdi opiye wan icu, qa pa kin akaśtan, qa i kin iputake ca heciya, Awicakehan Jehowa sda niyan, iye taoyate mdetanhunk a yaun kta heon etanhan.

2 Mitanhan ecin idade cinhan, "Tzeltzah ohna, Benjamin makoce ihanke ikiyedan, Rałel ohnahnakapi ikiyedan, wicaśta nonpa awicayakipe kta, unkan Śonśonna akin idade cin wanna iyewi- cayapi ce, qa niyate wanna śonśonna kin awacin ayuśtan, qa niyepi on iyokiśin içiya; qa heya, Micinkśi on taku ecamon kta he? eniciyapi kta.

3 Unkan hetanhan ako idade cinhan, Tabor utuhu' kin ekta, wicaśta yamni Wakantanka kin Betel ekta yapi, itkonicipapi kta, wanji tatokadan cinca yamni hduha, qa wanji ag̉uyapi span yamni hduha, qa unman minisa apahte wanji.

4. Qa, Tanyan yaun he? eya iniwangiapi kta, qa ag̉uyapi nonpa niçupi kta, hena napepi etanhan iyacu kta.

5 Qa iyohakam Paha wakan Pilistim akicita akan yakonpi kin ekta yai kta, qa hcciya otonwe kin en yai kinhan, waayate optaye wan ayakipe kta, hena pajodan etanhan kun upi, qa wicitokam candowankiyapi wan, qa cancega wan, qa cotanka wan, qa caupakinzapi wan, qa hena waayata dowanpi.

6 Unkan Jehowa taniya kin akan nihi kta, qa hena om niye waadate kta, qa wicaśta nitokeca kta.

7 Unkan wowapetokeca kin hcna owasin anicipapi kinhan, taku ninape iycye cin he econ wo; Jehowa nici un nakaś.

8 Qa mitokam Gilgal ekta apamahde idade kta, qa iho miye woliuhnaliyapi hulinah ye kta, qa wopida wośnapi wotcca wakiyuśna kta, niye ekta apamahde mde kta; qa anpetn śakowin amape nanke kta, niye ekta wai kte cin hehanyan, unkan token ecanon kta ociciyake kta.

9 Unkan Samuel etanhan iyaye kta ihdamna, hehan cante kin Wakantanka yutokeca, qa wowapetokeca kin hena owasin anpetu kin he en iyecetupi. 
10 Paha kin ekta ipi qehan inyun waayate optaye wan itkokipapi; unkan Wakantanka taniya kin en hi, heon iye wicehna waayata.

11 Unkan tona itokam sdonyapi qon, inyun waayatapi om iye waayate kin wanyakapi qehan, oyate kin hekiciyapi, Qiś cinhintku kin toketu hwo. Saul iś eya waayatapi kin owicapa he? eyapi.

12 Unkan wicaśta wan hetanhan awicayupte ca heya, Tuka tuwe ate yapi he? heon, Saul iś eya waayatapi kin owicapa he? wicoie wakan on yuhapi.

13 Unkan waayate ayaśtan, qa pajodan kin ekta i.

14. Unkan Saul dekśitku kin jye, qa tahokśidan kin hewicakiya, Toki yaipi he? Unkan Sonśonna ode unkiyayapi, qa tuktedan wanwicunyakapi śni qehan, Samuel ekta unkipi eya.

15 Unkan Saul dekśitku kin heya, Tokin Samuel taku eniciye cin omayakidaken.

16 Unkan Śonśonna wanna iyewicayapi kin tanyan unkokiyakapi, Saul iye deksitku eciya. 'Tuka wokiconze wicoie kin Samuel eciye cin he okiyake śni.

17 Unkan Samuel oyate kin Jehowa itokam, Mitzpa ekta mniciye wicaśi.

18 Qa Israel cinca kin hewicakiya, Jehowa Israel wakan dapi kin hecen eya, Miye Israel Egupta etanhan itanwankanhde hiyu wicawaye ca Egupton napepi etanhan, qa wokiconze tona kakiś niyanpi kin owasin etanhan ecihdakupi.

19 Tuka niyepi nakaha, Taku wakan yadapi kin, he taku kiunni niyanpi, qa iyokiśin niyanpi kin owasin etanhan ni niyanpi kin, he yakipajinpi, qa heyakiyapi,
Tokeśta wicaśta yatapi wan unkicicagapo. Heon ecin wicoun nitawapi kin, qa kektopawinge nitawapi kin iyecen Jehowa itokam inajinpo.

20 Unkan Samuel Israel wicoun owasin ikiyedan hiyu wicaya; unkan Benjamin wicoun kin he icupi.

21 Unkan Benjamin wicoun kin wicowazipi kin iyecen hiyuwicaya; unkan Matri wicowazi kin icupi; hehan Saul Qiś cịnhintku kin icupi. Unkan akitapi qehan iyeyapi śni.

22 Hehan sanpa Jehowa iwangapi, Wicaśta kin nahanhin deciya hi śni he? Unkan Jehowa heya, Iho wahpayeca ehna inahima ce.

23 Unkan inyankapi qa hetanhan akupi. Unkan oyate wicehna najin qehan, oyate kin owasin hiyete kin hehanyan okihanpi.

24 Unkan Samuel oyate kin owasin hewicakiya, Tuwe Jehowa kahinige cin he wandakapi. Oyate kin owasin ehna tuwedan he iyececa śni. Unkan oyate kin owasin iyaśapi, qa heyapi, Wicaśta yatapi kin zaniyan un nunwe.

25 Unkan Samuel oyate kin wokiconze woope kin owicakiyaka, qa wowapi wan en kagga, qa Jehowa itokam ehnaka, qa Samuel oyate kin owasin kihde wicaśi, iyohi iye ti kin ekta.

26 Unkan Saul iś eya kihda, Gibeya ekta. Unkan wicaśta waditaka tona Jehowa' cantepi kin wicayutan kin hena kici ipi.

27 Tuka wowahte śni cinca kin, Wicaśta kin de token niunkiyapi kta he? eyapi, qa ihaktapi śni, qa takudan qupi śni. Tuka nahon śni iyececa inina yanka. 
WICOWOYAKE 11.

1 Unkan Nahaś Amoni kin Jabeś Gileyad tatpe hi, qa en ahi ti. Unkan Jabeś wicaśta kin owasin Nahaś heciyapi, Wotakıye unkicicagapo, hecen wowidag inyayapi kta.

2 Unkan Nahaś Amoni kin hewicakiya, Wotakuye cicicagapi lite cin dee. Iśta etapa kin owasin ciciyuśdokapi kta, qa Israel owasin he ośtehda wicawakiye kta.

3 Unkan Jabeś hunkayapi kin heciyapi, Anpetu śakowin unkayuśtanpo; hecen Israel makoce kin owancaya wahośiye yewicunśipi kta: unkan tuwedan niunkiyapi śni kinhan, niye ekta unkipi kta.

4 Unkan wahośiye kin Gibeya Saul ekta hipi, qa wicoie kin oyate nogepi en oyakapi. Unkan oyate kin owasin ho yeyapi, qa ceyapi.

5 Unkan inyun Saul mag̣a etanhan tatanka kaham u, qa Saul heya, Oyate kin toketupi on ceyapi he? Unkan Jabeś wicaśta oiepi kin okiyakapi.

6 Unkán wicoie lin hena nalon qehan, Wakantanka toniya kin Saul iyahpaya, unkan nina śihda.

7 Qa tatanka akicaśkapi wan ikikeu, qa kaśpaśpa, qa wahośiye nape kin on Israel makoce kin owancaya iyaye ya, qa heya, Tuwe Saul qa Samuel opa hinanpe 'śni kinhan tatanka tawa kin hecen ecakiconpi kta. Unkan Jehowa tokokipe kin oyate kin awicahinhpaya; heon wicaśta wanjidan iyecen hinanpapi.

8 Unkan Bezeq ohna wicayawa. Unkan Israel cinca kin kektopawinge opawinge yamni, qa Juda wicaśta kin kektopawing̀e wikcemna yamni.
9 Qa wahośi hipi qon hewicakiyapi, Jabeś Gileyad wicaśta kin hecen ewicayakiyapi kta, Heyaliecinhan, anpetu wi kin kata aye cinhan, ounniciyapi kta ce. Unkan wahośiye qon ekta kipi, qa Jabeś wicaśta kin owicakiyakapi ; unkan iyuśkinpi.

10 Qa Jabeś wicaśta kin heyapi, Heyakecinlıan niyepi ekta inaunpapi $\mathrm{kta}$, qa token iyonicipipi kin owasin ecaunyeconpi lita.

11 Unkan Saul oyate kin obe yamni wicakagia; unkan heyake cinhan akicita hanhanna iwakta wicayapi kin en, wicoti kin anatanpi, qa anpetu kin kate śni hehanyan Anmon oyate kin wicakaśtakapi. Unkan tona okaptapi kin hena enanakiya iyayapi, hecen wicaśta nonpa witaya owicakaptapi śni.

12 Unkan oyate kin Samuel heciyapi, Saul ate unyanpi kta he? eyapi hena tuwepi he?. Wicaśta kin hena hiyu wicayapo, hecen wicunktepi lita.

13 Unkan Saul heya, Nakaha Jehowa Israel niwicaya; heon anpetu kin de wicaśta wanjidan teyapi kte śni.

14 Unkan Samuel oyate kin hewicakiya. Hopo Gilgal ekta unyanpi, qa hen wokiconze kin piya unkağapi kta.

15 Unkan oyate kin owasin Gilgal ekta ipi, qa hen Gilgal ohna, Jehowa itokam Saul wicaśta yatapi kagapi, qa hen wopida wakiyuśnapi Jehowa itokam, qa Saul, qa Israel wicaśta kin owasin heciya nina wiyuśkinpi.

\section{WICUWOYAKE 12.}

1 Unkan Samuel Israel owasin hewicakiya, Ihopo taku emayakiyapi owasin en nihopi kin ana405 


\section{SAMUEL TOKAHEYA,}

wağoptan, qa niyepi wicaśta yatapi wan cicicağapi.

2 Qa ihopo, dehan wicaśtayatapi kin nitokam mani, qa miye wicamahinca, qa pamaska, qa micinca niyepi om unpi, qa miye homakśidan ehantanhan anpetu kin dehanyan niyepi itokam mawani ce.

3 Iho miye Jehowa itokam, qa tuwe sdakiye cin itokam mayaotaninpo. Tuwe tatanka tawa iwacu he? qa tuwe śonśonna tawa iwacu he? Tuwe wahnayan, qa tuwe wakimduśe, qa iśtawahmuze kta taku qupi kin iwacu kinhan yaotaninpo, hecen cicicajujupi kta.

4 Unkan, Unyahnayanpi śni, qa unyakiduśepi śni, qa wicaśta nape etanhan takudan iyacu śni, eyapi.

5 Unkan hewicakiya, Minape ohna takudan iyeyayapi śni nakaha niyepi en Jehowa wayatanin kin hee; qa tuwe sdakiye cin hee waayatanin. Unkan, Hee wayatanin, eyapi.

6 Unkan Samuel oyate kin hewicakiya, Tuwe Mowis, qa Aaron icaliwicaye ça niyatepi kin Egupta makoce kin etanhan hdinanpe wicaye cin Jehowa hee.

$7 \mathrm{Qa}$ nakaha owanji najinpo, hecen Jehowa toowotanna niye ecaniconpi, qa niyatepi ecawicakicon kin owasin Jehowa itokam ociciyakapi kta.

8 Jakob Egupta en i kin ohakam, niyatepi Jehowa ho yekiyapi. Unkan Jehowa Mowis, qa Aaron ekta ye wicaśi, qa niyatepi hdinanpe wicaya, Egupta etanhan, qa oyanke kin den ounye wicaya.

9 Unkan Jehowa wakandapi kin akiktunjapi, heon Hatzor ozuye mdetanhunke Sisera nape kin en iyope wicaya; nakun Pi406 listim napepi en, qa Moab wicaśta yatapi nape en; unkan azuwicayapi.

10 Unkan Jehowa ho yekiyapi, qa heyapi, Waunhtanipi, qa Jehowa unkayuśtanpi, qa Bayalim, qa Aśterot ohoundapi, tuka nakaha toka unyanpi napepi kin etanhan eunhdaku miye, kinhan niye ohounnidapi kte.

11 Unkan Jehowa Jerubbayal, qa Bedan, qa Jeptah, qa Samuel u wicaśi, qa toka niyanpi nihdukśan yakonpi napepi etanhan enihdakupi, heon wikopeśniyan ounyayapi.

12 T'Tuka Nahaś Amon cinca wicaśta yatapi kin tatpe niupi lin wandakapi qehan, hemayakiyapi, Hiya wicaśtayatapi wan wowidag unyanpi kta uncinpi ce; Jehowa wakanyadapi kin he wicaśta yatapi nitawapi tuka qon.

13 Unkan wanna ito wicaśtayatapi yakahinigapi, qa yadapi kin, he niwankam Jehowa wicaśta yatari nicupi ce.

14. Jehowa koyakipapi, qa ohoyadapi, qa ho kin neyahonpi kte, qa Jehowa i kin yakipajinpi kte śni kinhan, niyepi qa nakun wicaśta yatapi inidakapi kin Jehowa opeya yaunpi kta.

15 Tuka Jehowa ho kin anayagoptanpi śni, qa Jehowa i kin yakipajinpi kinhan; Jehowa nape kin apaha niyanpi $k t a$, niyatepi qon iyecen.

16 Nakun owanji najinpo, qa wicoie tanka kin de niyepi itokam Jehowa econ kte cin he wanyakapo.

17 Dehan aguyapi su baksapi iyehantu śni he? Jehowa ho yewakiye kta, unkan wakinyan hoton qa magaju kiye kta; hecen niyepi wicaśta yatapi yadapi kin he Jehowa iśta kin en 


\section{WICOW OYAKE 13.}

nina śicaya ecanonpi sdonyayapi qa wandakapi kta.

18 Unkan Samuel Jehowa ho yekiya; unkan Jehowa anpetu kin he en wakinyan hoton qa magaju kiya. Unkan oyate kin owasin Jehowa, qa Samuel nina kowicakipapi.

19 Qa oyate kin owasin Samuel heciyapi, Waunhtanipi kiı owasin isanpa taku śica econkupi, qa unkiyepi on wicaśta yatapi wan unkicidapi; heon nitaokiye on Jehowa wakanyada kin cekiya wo, hecen untapi kte śni.

20 Unkan Samuel oyate kin hewicakiya, Ihnuhan wakoyakipapi kin. Taku śica kin de owasin ecanonpi eśta, Jehowa oyapapi etanhan ihduhomnipi śni po; tuka nicantepi ocowasin on ohodapo:

21 Qa ihduhomnipi śnipo. Tona takuśni, qa ta!su owicakiyapi okihipi śni kin opapi kin, hena nipi kte śni, hena taku śni nakaś.

22 Jehowa niyepi iye taoyate nicağapi kta iyokipi, heon iye caje tanka on, Jehowa iye taoyate paha iyewicaye kte śni.

23 Nakun miye canku waśte qa ecetu kin onspe ciciyapi kta, hecen niyepi on cewakiya amdustan, qa Jehowa awawahtani kta iyomaki śni nunwe.

24 Tuka niyepi, Jehowa kokipapo, qa wowicake en, qa nicantepi ocowasin on ohodapo, tohan tanka ecaniconpi kin wandakapi naknś.

25 Tuka śicaya ecanonpi yakitanpi kinhan, ihang niyanpi kta, niyepi, qa nakun wicaśtayatapi nitawapi.

\section{WICOWOYAKE 13.}

1 Saul Israel iwicadaka, qa waniyetu tokaheya, qa waniyetu. inonpa wicaśta yatapi un kin en,

2 Saul Israel etanhan wicaśta kektopawinge yamni wicakahniga, qa hena kektopawing no non Mikmaś ohna, qa Betel he kin ohna Saul kici unpi, qa kektopawinge wanjidan Gibeya ohna Jonatan kici unpi ; Unkan wicaśta unmanpi kin owasin kihde wicaya.

3 Unkan Jonatan Pilistim akicita Gibeya ohna yakonpi kin wicakaśtaka, unkan Pilistim he nabonpi. Unkan Saul makoce kin owancaya mazayahotonpi yahoton wicakiya, qa heya, Heberi kin nahonpi kte.

4 Unkan, wul Pilistim taakicita wicakaśtaka, eyapi kin Israel owasin nahonpi, qa nakun Pilistim Israel wahte wicadapi śni ; heon oyate kin Saul opapi kta e Gilgal ekta wicakipanpi.

5 Unkan Pilistim Israel kizapi kta e kiwitayapi canpahmihma kektopawinge wilkcemna yamni, qa śung akan yotankapi kektopawinge śakpe, qa wicaśta wiyaka mini wanca hutata wanke cin iyenaka wicota, qa itanwankanhde hipi, qa Betawen wiyohiyanpa tanhan Mikmaś en ahitipi.

6 Unkan Israel wicaśta kin tehiya unpi e wanhdakapi nagiye wicayapi nakaś, hehan oyate kin inahmanpi makohdoka ohna, qa otehi ohna, qa imnija ohna, qa conkaśke ohna, qa woha ohna.

7 Qa Heberi kin Jordan iyuwegapi, Gad makoce kin elita, qa Gileyar ekta. Unkan Saul nahanhin Gilgal ohna yanke cehan oyate iye opapi kin owasin cancanpi.

8 Unkan Saul anpetu śakowin Samuel eye riqon hehanyan ape yanka, tuka Samuel Gilgal ekta. $40 \%$ 


\section{SAMUEL TOKAHEYA,}

hi sni; unkan oyate lin Saul etanhan enanakiya iyayapi.

9 Unkan Saul heya, Wohuhinahyapi wan, qa wopida wośnapi hiya makiyapo, qa wohuhnahyapi kin hulinahya.

10 Unkan wohuhnahyapi kin hulinahya hduśtan qehan, inyuı Samuel ekta hi. Unkan nape kin yuze kta Saul itkokim iyaya. 11 Unkan, Taku ecanon he? Samuel eya. Unkan Saul heya, Oyate kin miye tanhan enanakiya iyayapi qa niye anpetu cajedate ciqon en yahi śni, qa Pilistim Mikmaś en witaya ahitipi kin wanmdake cehan.

12 Hepa, Ecadan Pilistim Gilgal ekta anamatanpi kta, qa Jehowa ocinyope waye śni, heon tius miciye ca wohuhnahyapi wan hulinali waya.

13 Unkan Samuel Saul heciya, Witkotkoya ecanon, qa Jehowa wakan yada tawoahope ope niśi kin oyape śni; hecanon unkanś nitokiconze Israel owihanke wanin iwicayakidake kta e dehan niciyusuta kta tuka.

14 Tuka wanna wokiconze kin niciyusuta kte śni, Jehowa taku econ niśi kin yapatan śni, heon Jehowa wicaśta wan iye cante kin iyecen cante yuze cin, he akita, qa iye taoyate kin wicitokam mani śi kta.

15 Helıan Samuel najin iyaya, Gilgal etanhan Gibeya Benjamin ekta i. Unkan Saul oyate iye kici iyeyapi kin wicayawa, wicaśta opawinge śakpe cetu.

$16 \mathrm{Qa}$ Saul qa cinhintku Jonatan, qa oyate iye opapi kin Gibeya Benjamin otipi, qa Pilistim Mikmaś en ahitipi.

17 Qa Pilistim owankapi kin etanhan ozuye yamni wamanun iyayapi ; wanji Yopra canku kin ohna Suyal makoce ekta $i$. 408
18 Qa ozuye wanji Bethoron canku kin ohna iyaya, qa unman hopuze cin ektakiya Gi-Tzeboin (Sungidan Kaksiza kin) iwankam makoce wanke cin canku kin ohna.

19 Unkan Pilistim heyapi qon, Okini Heberi kin isan qa wahukeza içicagapi kta, heon Israel makoce owancaya mazakağa wanjidan iyeyapi śni.

20 Hecen Israel owasin Pilistim ekta apamahde ipi, otoiyohi mahiyumdu, qa magicamna tawa, qa onspe tawa piyapi kta heon :

21 Tuka mazipabe yuhapi mahiyumdu, qa' magicamna hi pe śni eca, nakun peji icape hi yamni kin on, qa onspe tawapi on, qa tatanka icape pe kagapi kta. on.

22 Heon wokicize anpetu kin en oyate Saul qa Jonatan owicapapi owasin napepi ohna isan, qa wahukeza wanjidan iyeyapi śni ; tuka Saul qa cinhintku Jonatan heca yuhapi.

23 Unkan Pilistim akicita kin Mikmaś oiyuwege ek̀ta e tipi.

\section{WICOWOYAKE 14 .}

1 Unkan anpetu wan Jonatan Saul cinhintku kin kośka iye tawipe kicicin kin heciya, Iho Pilistim akicita akasanpa yakonpi kin ekta unye kta. Tuka atkuku kin okiyake śni.

2 Unkan Saul paha ihanke kin ekta taspantanka suota hu wan Miqron ohna wanke cin ihukuya ti, qa oyate iye kici unpi kin wi= caśta opawing śakpe cetu.

3 Qa Ahija Ahitub cinhintku, Ikabod cincu, Pinehas cinhintku Eli cinhintku, Ślo ohna Jehowa wawakiyuśna kin he amdo akahipa kin yuha. Unkan Jonatan 
iyaye cin oyate kin sdonyapi śni.

4 Unkan oiyuweg̉e wan ohna Jonatan Pilistim akicita tipi ekta iyaye kta cin kin he icahda anokatanhan inyan bosdata; qa inyan bosdata kin hena wanji Botzetz (Iyega) eciyapi qa unman kin Śne (Taspanhu) eciyapi.

5 Qa inyan kin hena wanji waziya tanhan wanke cin he Mikmaś iyotakonza, qa unman itokaga tanhan kin he Gibeya iyotakonza.

6 Unkan Jonatan kośka iye tawipe kicicin kin heciya, Iho wicaśta bakihdayapi śni kin dena akicita tipi kin ekta unye kta; okini Jehowa unkiyepi on econ kta; Jehowa wanikiye kta okitpani wanica, wicota qaiś tonana unmanna on.

7 Unkan tawipe kicicin kin heciya, Token nicante en un kin owasin econ wo. Tokata ya wo, iho ocipe ktid, nicante kin iyecen.

8 Unkan Jonatan heya, Iho wo, akasanpa unye kta, wicaśta kin ektakiya, qa hena en taninunkiciye kta.

9 Owanji najinpo, niyepi ekta unkipi kte cin hehanyan, unkekiyapi kinhan, tukten unyakon kte cin hen naunjin kta, qa tatpe wicunye kte śni.

10 Tuka unkiyepi ekta upo, eyapi kinhan, ekta unye kta, qa unnape en Jehowa wicaqu kta, qa de wowapetokeca unhe kta.

11 Unkan napin Pilistim akicita tipi kin en ihdutaninpi. Unkan, Inyun Heberi kin makohdoka ohna inahmanpi kin hetanhan inanpapi, Pilistim eyapi.

12 Unkan akicita tipi wicaśta kin Jonatan, qa tuwe tawipe kicicin kin hoye wicakiyapi, qa heyapi, Unkiyepi en upo; kinhan wicoie wan sdonye unniciyapi kta. Unkan Jonatan tawipe kiciçin kin heciya, Omapa wo ; Jehowa hena Israel nape en wicaqu nakaś.

13 Unkan Jonatan nape siha ko iyunadi, qa tawipe kiciçin kin ihakam u. Unkan Jonatan itokam hinhpayapi, qa ihakam tawipe kicicin kin wicakte.

14 Unkan wokaśtake tokaheya kin de; Jonatan, qa tawipe kiciçin kin wicakaśtake cin he wicaśta wikcemna nonpa cetu ; maka onśpa tatanka akicaśkapi wanjidan yumdupi ece hanke kin hinskokeca ohna.

15 Unkan wicoti ohna wicacancan tanka yukall, tankan yakonpi, qa akicita tipi ohna oyate unpi owasin ehna, wamanun iyayapi qon iś eya cancanpi; qa maka kin śkanśkan, hecen' cancanpi wakan yukan.

16 Unkan Saul wicaśta tonweya najin wicaśi, Gibeya Benjamin ohna wanyakapi ; unkan inyun wicota kin skanpi, qa akicipapi iyayapi.

17 Unkan Saul oyate iye opapi kin hewicakiya. Hopo, ihdawapo, qa tuwe unkiyepi etanhan iyaye cin iyeyapo. Unkan ihdawapi, qa Jonatan qa tawipe kiciçin kin en unpi śni.

18 Unkan Saul Ahija heciya, Wakantanka canwohnaka tawa kiyedan au wo, he ehan Wakantanka tacanwohnaka kin Israel cinca kin om yanka.

19 Unkan Saul nahanhin wawa, yuśna kin okiye cin icunhan, Pilistim owanka kin ohna owodutaton icagge ca sanpa tanka aya, heon Saul wawayuśna kin heciya, Ninape kin ehdaku wo.

20 Unkan Saul, qa oyate iye kici unpi kin owasin iyaiçiśapi, qa wokicize ekta ipi. Unkan ita 409 


\section{SAMUEL TOKAHEYA,}

ninahin yuśinyeyapi qa canhipi on akicipapi.

21 Unkan Heberi tona he itokam Pilistim opapi, qa owankapi qa ihdukśan en om hipi kin, hena nakun Saul qa Jonatan om unpi kin owicapapi.

22 Unkan Israel Epraim he ohna inahmanpi qon owasin Pilistim najicapi kin nahonpi qehan, iś eya wokicize en wicakuwapi.

23. Unkan anpetu kin he en Jehowa Israel niwicaya. Unkan wokicize Betawen iyopta iyaya.

24 Unkan, Toka mayanpi towicawecon kta, heon htayetu itokam tuwe woyute onge yute cinhan yaśicapi kta Sauleya, qa taku wakan cajeyan wicaya ; heon anpetu kin he en Israel wicaśta kin nina mdokitapi, oyate owasin woyute ong̨ęan yutapi śni nakaś.

25 Unkan makoce wicaśta kin owasin taśkoju wanji en ipi, unkan maka akan tuhmaga canhanpi yukan.

26 Unkan oyate kin taśkoju en ipi qehan, inyun tuhmaga canhanpi kaduza, tuka oyate kin wokonze kin kokipapi, heon tuwedan nape kin i kin ekta ikikcu śni.

27 Tuka Jonatan iye atkuku oyate konza ewicakiye cehan nahon śni, qa sagye nape ohna hduhe cin inkpa kin yekiye ca canhanpi kaduze cin en oputkan, qa nape kin i kin ekta ehdaku, heon iśta kin mdeza aya.

28 Unkan oyate etanhan wicaśta wan ie ça heya, Niyate Oyate wokonze on nina konze wicaye ca heya, Tuwe nakaha woyute onge yute cinhan yaśicapi kta. Unkan oyate kin mdokitapi.

29 Unkan Jonatan heya, Ate makoce kin kiunniyan. Wanna wanyakapo, canhanpi kin de onge uwate cin on iśta mamdeza.
30 Tokin oyate kin toka wicayapi taku elipeyapi iyeyapi kin he etanhan nakaha imnahan yutapin. Unkanś dehan awicakehan Pilistim sanpa ota wicakaśtakapi kta tuka.

31 Unkan anpetu kin he en Mikmaś etanhan Ajalon ekta hehanyan Pilistim wicakaśtakapi ; tuka oyate kin nina hustakapi ;

32 Heon oyate kịn taku kipi kin iyahpayapi qa tahinca, qa tatanlia, qa ptejicadan icupi, qa maka akan patapi, qa oyate tado we koya yutapi.

33 Unkan, Inyun oyate kin Jehowa awahtanipi, qa we koya yutapi ce, Saul okiyakapi. Unkan. Wayahtanipi do. Nakaha inyan tanka wan miye akan amapaptanyanpo, eya.

34 Nakun Saul heya, Oyate wicehna enanakiya iyayapo, qa hewicakiyapo, Wicaśta otoiyohi tatanka tawa, qa talinca tawa mikiyedan hiyuyapo, qa wakiyuśnapi qa yutapo; tuka ihnuhan Jehowa awayahtanipi, qa we koya yatapi kin. Hehan oyate kin owasin iyohi tatanka tawa hanyetu kin he en hiyuyapi, qa hen wakiyuśnapi.

35 Unkan Saul wahna wośnapi -wan Jehowa kicağa, wahnawośnapi Jehowa kicağe cin he tokaheya.

36 Unkan Saul heya, Hopo, hanyetu kin de Pilistim anawicuntanpi, qa hantianna anpa kte cin hehanyan ihang wicunyanpi kte, hecen wanjidan owicunkaptapi kte śli. Unkan, Token iyonicipi kin iyecen econ wo, eyapi. Tuka wawayuśna kin heya, Ito deciya Wakantanka ikiyedan unyanpi kte.

37 Unkan Saul Wakantanka iwange ca heya Pilistim anawicawatan kta, Israel napepi en 


\section{WICOWOYAKE 15.}

wicayaqu kta he? Unkan anpetu kin he en ayupte śni.

38 Unkan Saul heya, Oyate tokapapi kin owasin deciya upo, qa woahtani kin de nakaha tuwe en un kin sdonyapo, qa wanyakapo.

39 Jehowa Israel ni wicaye cin ni kinhan Jonatan micinkśi kaeś en un kinhan hee te kta. Tuka oyate kin owasin tuwedan ayupte śni.

40 Unkan Israel owasin hewicakiya, Niyepi owasin itato dukanpi kta, qa miye qa micinkśi Jonatan ako unyakonpi kta. Unkan, Taku niiśta kin en waśte kin econ wo, oyate kin Saul eciyapi.

4.1 Unkan Saul Jehowa Israel Wakandapi kin heciya, Ecetuya hiyuya ye. Unkan Jonatan qa Saul iwicacupi tuka oyate kin wicayuślkapi .

42 Unkan Saul heya, Miye qa Jonatan on ehpeyapo. Unkan Jonatan icupi.

43 Unkan Saul Jonatan heciya, Taku ecanon omakiyaka wo. Unkan Jonatan okiyake ca heya, Sagye nape ohna wahduhe cin inkpa kin on tulimaga canhanpi ongedan uwata, qa inyun mate kta.

44. Unkan Saul heya, Wakantanka he iyecen qa isanpa econ nunwe, Jonatan awicakehan nite kta ce.

45 Unkan oyate kin Saul heciyapi, Jonatan wowanikiye tanka kin de Israel on nakaha econ kin hee te kta he? Hiya hecetu śni; Jehowa ni kinhan nakaha paha tawa sukaza wanjidan makata hinhpaye kte śni. He nakaha Wakantanka kici htani nakaś. Hecen oyate kin Jonatan yuśkapi ; unkan te śni.

46 Hehan Saul Pilistim wicakuwa etanhan itanwankarhde kihda. Unkan Pilistim tamakocepi ekta hdapi.

47 Hecen Saul Israel iwankam wokiconze kin icu, qa tokawicaye cin ihdukśan yakonpi kin owasin azuwicaya; Moab, qa Amon cinca kin, qa Edom, qa Tzoba wicaśta yatapi kin, qa Pilistim azuwicaya, qa tona ektakiya ihduhomni kin owasin iyokiśñ wicaya.

$48 \mathrm{Qa}$ ozuye tanka wan kagje ca Amaleq kaśtaka, hecen Israel tona taku tawapi kipi qon napepi etanhan niwicaya.

49 Unkan Saul cinca kin dena eepi, Jonatan, qa Jiśuwi qa Malekiśua, qa cunwintku nonpa kin, tokapa kin Merab èciyapi, qa hakakta Mikal eciyapi.

50 Qa Saul tawicu kin Ahinoyam eciyapi he Ahimayatz cunwintku; qa taozuye mdetanhunka kin Abner Saul atkuku sunkaku cinhintku.

51 Qa Qiś Savl atkuku, qa Ner Abner atkuku kin Abiel cinca hecapi.

52 Unkan Saul taanpetu owasin Pilistim om nina kicizapi, heon Saul wicaśta waśaka, qa wica śta waditaka tona wanwicayaka owasin iye elsta yuwitaya hiyuwicakiya.

\section{W1COWOYAKE 15.}

1 Unkan Samuel Saul heciya, Jehowa iye taoyate Israel ate niyanpi kta e sdaciye kta on niye ekta ye maśi, heon nakaha Jehowa oie ho kin nation wo.

2 Jehowa obe yuhe cin hecen eya, Israel Egupta etanhan itanwanhde kupi qehan, Amaleqi taku ecawicakicon, qa canku kin ohna awicakipe kin he weksuya.

3 Wanna ekta ye ca Amaleqi kaśtaka wo, qa taku tawa kin 


\section{SAMUEL TOKAHEYA,}

iyuhpa ihangya wo, qa wicapatan śni wo; tuka wicakte wo, wicaśta qa winohinca qa śiceca azin unpi keś, nakun tatanka, qa talinca, qa camo, qa śonśonna.

4 Unkan Saul oyate kin nakion wicaya, qa Telaim ohna wicayawa, wicaśta huiyun kektopawinge opawing ge nonpa, ga Juda etanhan wicaśta kektopawinġe wikcemna.

5 Unkan Saul Amaleqi tonwanyanpi ekta i, qa kaksiza ohna iyawicape.

6 Qa Saul Qeni kin hewicakiya, Hopo Amaleqi wicehna tanhan ihdutokanpi, qa hunktiyapo. Hecanonpi śni kinhan okini hena om ihang ciyapi kta. Niyepi Israel cinca kin owasin cante wicayakiyapi, Egupta etanhan itanwankanhde kupi qehan. Unkan Qeni kin Amaleqi kin wicehna tanhan iyayapi.

7 Unkan Saul Amaleqi wicakaśtaka Hawila etanhan Sur Egupta itokam wanke cin ekta yapi kin hehanyan.

8 Qa Agag Amaleqi wicaśta yatapi kin niyake icu; tuka oyate kin owasin cantipi hi on ihang wicaya.

9 Tuka Saul, qa oyate kin Agag, qa talinca, qa pte wanunyanpi iyotan waśtepi, qa tatankadan, qa tahinca cinca tona iyotan waśte niyanpi, qa ihang wicayapi wicadapi śni; tuka wanunyanpi śica, qa walite śni kin hena owasin ihang yapi.

10 Unkan Jehowa oie kin Samuel heciya.

11 Saul wicaśta yatapi wakag̉e cin he on iyope miciye, omape cin etanhan ihdamna, qa mioie kin ecen econ śni nakaś. Unkan Samuel iyokiśice ca hanyetu osan Jehowa hoyekiya:

12 Unkan ihanlianna Samuel hanliannaliin kikta, Saul itkokipe kta. Unkan tuwe Samuel okiyake ça heciya, Saul Karmel ekta hi, qa wokiksuye wan ekicihde, qa yuwinh iyaya, qa Gilgal ekta apamahde iyaya.

13 Unkan Samuel Saul ekta i. Unkan Saul heciya, Jehowa niyawaśte, Jehowa oie kin ecen ecamon ce.

14 Unkan Samuel heya, Hecinhan talinca ho kin de, qa pte ho kin noge iyomalipaye cin de nawation kin he taku hwo.

15 Unkan Saul heya, Hena Ameleqi etanhan ahdipi. Oyate kin Jehowa Wakanyada wakiyuśnapi kta, heon tahinca, qa pte waśte kin etanhan hena niyanpi, qa unman owasin ihang unyanpi.

16 Unkan Samuel Saul heciya, Inina yanka wo; hecen Jehowa oie, hinhan emakiye cin ociciyake kta. Unkan, Eya wo, eciya.

17 Unkan Samuel heya, Niiśta en nicistinna qehan, Israel wicoun pa kin henica kta, qa Israel ate niyanpi kta e Jehowa sdaniye śni he?

$18 \mathrm{Qa}$ canku ohna Jehowa ye niśi qa heniciya, Ekta ya, qa wahtanipi sa Amaleqi ocowasin wicakte wo, qa wicadusote kte cin hehanyan azuwicaya wo.

19 Heon tokeca Jehowa ho kin nayalion śni, qa woyuha kin iyayahpada, qa Jehowa iśta kin en taku śica ecanon?

20 Unkan Saul Samuel heciya, He en Jehowa ho kin nawahon, qa canku ohna Jehowa ye maśi kin omawani qa Agag Amaleqi wicaśta yatapi kin awahdi, qa Amaleqi kin ocowasin ihang wicawaya.

21 Tuka oyate kin woyuha etanhan icupi, tahinca, qa pte, taku ihang yapi kta etanhan taku iyo.

412 


\section{WICOWOYAKE 16.}

tan waśte, Gilgal ohna Jehowa wakiyuśnapi kta e icupi.

22 Unkan Samuel heya, wohihnahyapi, qa wośnapi Jehowa ho kin nahonpi kin iyecen Jehowa iyolkipi he? Hiya, wanahonpi kin Wośnapi kin isanpa waśte, qa waanagoptanpi kin tamdoka śin kin isanpa.

23 Wokipajin kin hanmdepi woahtani kin iyececa, qa wanahonpi śni kin wakagapi ohodapi kin iyececa; Jehowa oie kin heyata iyeyaya, heon Jehowa niye wicaśta yatapi henica kte śni e heyata iyeniyan ce.

24 Unkan Saul Samuel heciya, Wawahtani, oyate kin kowicawakipa, qa hopi kin anawaggoptan; heon Jehowa i kin acawakśin qa nioie kin nakun.

25 Heon dehan wawahtani micicajuju wo, qa mici hda wo, ceciciya, hecen Jehowa obowada kta.

26 Unkan Samuel Saul heciya, Nici mde kte sni; Jehowa oie kin lieyata iyeyaya, heon Jehowa heyata iyeniyan; qa Israel iwankam wicaśta yatapi yaun kte śni.

$27 \mathrm{Qa}$ Samuel kihde kta ihdamna ; unkan taśina opapun yuza, qa yuhdeca.

28 Unkan Samuel heciya, Nakaha Jehowa Israel tokiconze kin niye etanhan yubdeca, qa nitakoda wan niye isanpa waśte lin he qu.

29 Nakun tuwe Israel waśagye cin itonśni wanica, qa iyope içiye kte śni ; iyopeiçiye kta e wicaśta heca śni.

30 Unkan heya, Wawalitani eśta ceciciya, nakaha oyate mitawa hunkayapi itokam mayuonihan wo, qa Israel itokam; qa micihda wo, hecen Jehowa Wakan yada kin ohowada kta.
31 Unkan Samuel ihdamna, Saul ihakam. Unkan Saul Jehowa ohoda.

32 Unkan Samuel heya, Agag Amaleqi wicaśta yatapi kin mikiyedan hiyuyapo. Unkan Agag iyokipiya elsta hi; qa, Awicakeha wiconțe oiyokiśice kin wanna. henakeca, Agag eya.

33 Unkan Samuel heya, Canhpi nitawa winohinca cinca wanica wicakage cin iyecen nihun winolinca ehna cinca nice kta; qa Samuel Agag kaśpaśpa, Jehowa itokam, Gilgal ohna.

34. Unkan Samuel Rama ekta hda, qa Saul Gibeya ekta hda.

35 Unkan Samuel te śni kin hehanyan icimana Saul wanyag i śni ; tuka Samuel Saul on iyokiśin içiya. Unkan Jehowa Saul wicaśta yatapi Israel wicakicage cin heon iyope içiya.

\section{WICOWOYAKE 16.}

1 Unkan Jehowa Samuel heciya, Tohanyan niye Saul on iyokisin niçiye kta he? Israel iwankam wicaśta yatapi kte śni wakonza, heon etanhan. Tahe duhe cin wihdi ojuya wo, qa ito Jesse Betlehemi kin ekta ye ciśi kta, iye cinca kin etanhan wicaśta yatapi wan wahdahniga nakaś.

2 Unkan Samuel heya, Token mde kta he? Saul he nahon kinhan makte kta. Unkan Jeho. wa heya, Pte heyuktanna wan nape on iyacu kta qa, Jehowa wawakiyuśna kta e wahi ce ehe kta.

3 Qa wośnapi ekta. Jesse yeco kta, qa token ecanon kta miye sdonye ciciye kta, qa tuwe eciciye cin he sda miyeciciye kta.

4. Unkan Samuel token Jehowa eye cin iyecen econ, qa Betle- 


\section{SAMUEL TOKAHEYA,}

hem ekta i. Unkan otonwe hunkayapi kin cancanyan itkokipapi, qa, Wookiye en yahi he? eyapi.

5 Unkan heya, Wookiye en Jehowa wawakiyuśna $\mathrm{kta}$ e wahi ce. Ihduwakanpo, qa wośnapi ekta mici yapo. Qa Jesse, qa iye cinca kin wicayuwakan, qa wośnapi ekta wicakico.

6 Unkan hiyupi qehan, Eliab wanyake ca heya, Jehowa sda kiye cin he itokam najin ce.

7 Tuka Jehowa Samuel heciya, Ihnuhan itohnake, qa tancan hanske cin ekta eyatonwe cin. He ihawaktaśni nakaś, wicaśta wiciśta kin en etonwanpi, tuka Jehowa wicacante kin atonwan, hecen wicaśta wanyakapi kin iyecen wanmdake śni.

8 Unkan Jesse Abinadab kipan, qa Samuel itokam hiyaye ya. Unkan he nakun Jehowa kahnige śni, eya.

9 Unkan Jesse Śanma hiyayeya. Unkan, he nakun Jehowa kahnig̉e śni, eya.

10 Hecen Jesse iye cinhintku śakowin Samuel itokam hiyaye wicaya. Unkan Samuel Jesse heciya, Hena Jehowa wicakahniğe śni.

11 Unkan Samuel Jesse heciya, Kośka denanapi he? Unkan, Hakakta nahanhin hi śni; tuka ito tahinca kin wihanwicaya, eya. Unkan Samuel Jesse heciya, Tuwe huweye si wo. Tohanyan den hi śni, wotapi unkiyotankapi kte śni ce.

12 Unkan huweyapi, qa en hiyuyapi. Unkan ite kin śa, qa iśta wiciyokipi, qa owanyag waśte. Unkan Jehowa heya, $\mathrm{Na}$ jin, qa sdaya.wo, dee nakaś.

13 Unkan Samuel tahe wihdi ojutonpi kin icu, qa cinye wicaye cin wicehna sdaya. Unkan anpetu kin he ehantanhan Jeho414 wa toniya kin Dawid ahinhe. Unkan Samuel najin iyaye ca Rama ekta kihda.

14 Unkan Jehowa toniya kin Saul ayuśtan iyaya; unkan woniya śica wan Jehowa etanhan yuśinyeya.

15 Unkan Saul taokiye kin heciyapi, Inyun yuśinye niye cin woniya wakan śice ee.

16 Ito itancan unyanpi becon wicayaśi kinhan, nitaokiye nitokam najinpi kin wicaśta wan candowankiyapi econ wayupika akitapi kta; unkan woniya wakan śice cin anihinheya ca nape on dowan kiye kta, hecen niye on waśte kta.

17 Unkan Saul taokiye hewicakiya, Wicaśta wan candowankiya wayupika amicicitapo, qa en hiyu makiya po.

18 Unkan kośkapi etanhan wanji ie ca heya, Tho Jesse Betlehemi kin cinhintku wan candowankiya wayupika wanmdaka, wicaśta waśaka, waditaka, ozuye wicaśta, qa ie ksapa, qa owanyag waśte, qa Jehowa he kici un ece.

19 Unkan Saul Jesse ekta ohnihde ye wicaśi, qa heciya, Nicinkśi Dawid tahinca awanyake cin he miye ekta u śi wo.

20 Unkan Jcsse śonśonna wan ag̉uyapi qin kiye ca miniśa opahte wan, nakun tatokadan wanunyanpi cinca wan icu, qa iye cinhintku Dawid, hena yuha, Saul ekta yeśi.

21 Unkan Dawid Saul ekta i, qa itokam najin. Unkan nina waśtedaka, unkan tawipe kiciçin ece.

22 Unkan Saul Jesse wahoye ca heciya, Tokin Dawid mici yanke kten; miiśta en woiyokipi iyeya nakaś.

23 Unkan woniya taku wakan 


\section{WICOWOYAKE $1 \%$.}

etanhan Saul iyahpaya eca, Dawid candowankiyapi kin icu, qa nape on dowankiya, qa Saul a sni kiya, hecen tanyan un, qa woniya śice cin he ayuśtan iyaya ece.

\section{WICOWOYAKE 17.}

1 Unkan Pilistim wokicize on obe mnaiciyapi, qa Soko Juda tawapi en ihduwitayapi, qa Soko qa Azeka otahedan Epesdanmim ohna ahitipi.

2 Unkan Saul qa Israel wicaśta kin ihduwitayapi, qa Ela (utuhu) osmaka en tipi, qa kicizapi kta Pilistim wicitkokim ocimdagehan najinpi.

3 Unkan Pilistim he wan akan najinpi, qa Israel he tokeca wan akan najinpi, qa hena otahedan kalsiza wan wanka.

4 Unkan Pilistim owanka etanhan wicaśta waśaka wan inanpa, Golia eciyapi, Gat etanhan, ohanske cin wiciśpa śakpe, qa napapasdecapi wanjidan.

5 Qa pa kin akan mazaśa wapaha wan un, qa maku akahpe mazaceśpu seca koyag ya, qa maku akahpe mazaśa kin tkeutapi kin Śseqel kektopawinge zaptan.

6 Qa huha kin akan mazaśa akahpa, qa mazaśa wahacanka wan tahpa akan yuha.

7 Qa tawahukeza ihupa kin wakazuntapi ihupa wan iyececa, qa tawahukeza hi kin mazasapa Śseqel opawinge śakpe, qa wicasta wan wahacanka yuha he itokam mani.

$8 \mathrm{Qa}$ owanji najin, qa Israel ocimdali najinpi kin wicakipan, qa hewicakiya, Tokeca ocimdah wakizapi kta yahipi he? Miye Pilistim wicaśta hemaca śni he? qa niyepi Saul wowidag niyanpi.
Wicaśta wan miye ekta hi kte cin hdahinigapo;

9 Makize ça makaśtake kta okihi kinhan wowidake unyaduhapi kta; tuka miye he ohiwaye ca wakaśtake cinhan, wowidake unniyuhapi kta.

10 Unkan Pilistim wicaśta kin heya, Nakaha Tsrael obe ocimdah okicize eciciyapi, Wicaśta wan maqupo, hecen unkicizapi kta.

11 Unkan Saul, qa Israel owasin Pilisti oie kin hena nalionpi qehan, yuśinyayapi, qa nina kokipapi.

12 Unkan Eprati wicaśta qon Jesse eciyapi, Betlehem Juda etanhan, Dawid cinkśiya. Qa cinhintku śahdoġan qa wicaśta kin he Saul wicaśta yatapi qehan, wicaśta ehna wicalínca yawapi ece.

13 Qa Jesse cinhintku tokapa yamni iyayapi, qa wokicize ekta Saul opapi; qa cinhintku yamni wokicize ekta ipi kin dena cajepi, caske kin Eliab, qa iyokihe Abinadab, qa iyamni Śanma eciyapi.

14 Unkan Dawid hakakta, tuka yamni tokapa kin hena Saul opapi.

15 Wanna Dawid הaul etanhan iyaye ça atkuku tahinca tawa withan wicakiye kta Betlehem ekta ki.

16 Unkan Pilistim.wicaśta qon hanhanna litayetu koya anpetu wikcemna topa wicikiyedan hinajin.

17 Unkan Jesse iye cinhintku Dawid heciya, ceonpapi kin de etanhan epa wanji nicinye on icu wo; nakun agguyapi wikcemna kin dena, qa owanka ekta nicinye ekta inyang ya wo.

$18 \mathrm{Qa}$ pte asanpi suta wikcemna kin dena akicita kektopawinge itancan kin yakai kta; qa 


\section{SAMUEL TOKAHEYA,}

nicinye tanyan unpi kinhan iwanwicadake kta, qa taku icazo icupi kin wicayecicajuju kta.

19 Hehan Saul, qa hena, qa. Israel owasin Ela (utuhu) osmaka ekta Pilistim wicakizapi.

20 Unkan Dawid hanhannaliin kikta, qa waawanyake wan tahinca kin awanyag si, qa hena yuha iyaya, Jesse econ śi qon he iyecen, qa wahpaya hnakapi ekta i, ozuye ocimdah iyayapi, qa wicakizapi kta iyaśapi iyehan.

21 Unkan Israel ocimdali iyayapi ; unkan Pilistim wicitkokim ocimdah hinajinpi.

22 Unkan Dawid taku ahi kin wahpaya awarıyake cin nape ohna ehpeya, qa iyaye ça kicizapi kin ocimdati najinpi kin ekta $\dot{i}$ qa cincu tanyan unpi hecinhan iwicawanga.

$23 \mathrm{Qa}$ om wohdaka icunhan, Inyun wicaśta waśaka qon, Golia Pilisti kin eciyapi, Gat etanhan, Pilistim ocimdaggehan najinpi kin etanhan inanpa, qa oie eye ciqon iyecen ia; unkan Dawid nahon.

24 Unkan Israel wicaśta owasin wicáśta qon wanyakapi qehan, etanhan najicapi qa nina kokipapi.

25 Unkan Israel wicaśta kin heyapi, Wicaśta itanwankanhde $u$ kin de wandaka he? Israel iśten wicaye kta e hiyu ce. Heon tuwe he kaśtake cinhan wicaśtayatapi kin wicaśta kin he wijica kage kta, wowijice tanka on, qa iye cunwintku qu kta, qa atkuku tiyohnaka Israel ohna ihduhapi heca wicakagie kta.

26 Unkan Dawid wicaśła iye ikiyedan najinpi kin hewicakiya, Tuwe Pilisti wicaśta kin kaśtake ca Israel iśten wicaye cin yutokan kin, wicaśta kin he token ecakiconpi kta he? Pilisti baki- hidayapi sni kin he tuwe on nakaha, Taku Wakan ni un taozuye kin iśtenya he?

27 Unkan oyate kin wicoie qon iyecen eyapi, qa heciyapi; Tuwe wicaśta kin he kaśtake cinhan hecen ecakiconpi kta.

28 Unkan cincu tokapa kin Eliab wicaśta om wohdaka kin nahon, qa Eliab Dawid canniyeya, qa heya, Tokeca den yahi he? qa tahinca tonana kin hena tuwe yuha liewoskan elipe wicayaya he? Wahannicida, qa taku śica nicante en un kin sdonwaya; wokicize wanyag yahi nakaś.

29 Unkan Dawid heya, Nakaha taku ecamon he? qa hecamon kta iyecece śni he?

30 Qa cincu tantanhan wicaśta tokeca wan ekta ihduhomni, qa wicoie qon ake heya. Unkan wicoic tokaheya qon iyecen ake eyapi.

31 Unkan wicoie Dawid eye cin nahonpi, qa Saul okiyakapi; unkan he wahoya.

32 Unkan Dawid Saul heciya, Ihnuhan wicaśta tuwe cante kin hanye cin. Nitaokiye ekta i kte ca Pilisti kin de kize kta.

33 Unkan Saul Dawid heciya, Pilisti kin de ekta de ca yakize kta oyakihi śni; honikśidan, qa iye hokśidan ehantanhan, wicaśta zuye sa.

34 UUnkan Dawid Saul heciya, Nitaokiye iye atkuku tahinca awarkiciyaka yanka ca mnaja wan en hi, qa wahanksica wan nakun, qa optaye etanhan tahinca wan icupi.

35 Unkan ihakam kuwa imdamde ca wakaśtake ca i kin etanhan iwekcu, qa anamajin qehan putinhin muduze ça wakaśtake ça wakte.

36 Nitaokiye mnaja, qa walianksica napin wicakte, qa Pilisti 


\section{WICOWOYAKE $1 \%$}

bakilidayapi śri kin de hena wanji iyececa kta. Taku wakan ni un kin taozuye kin iśten ya nakaś.

37 Nakun Dawid heya, Jehowa mnaja nape kin etanhan, qa wahanksica nape etanhan emahdaku kin he Pilisti kin de nape kin etanhan emahdaku kta ce. Unkan Saul Dawid heciya, Ekta ya wo, qa Jehowa nici un nunwe.

38 Unkan Saul iye tawokoyake kin Dawid koyag kiye ça muzaśa wapaha wan pa akan ehnake ca mazasapa maku akahpe wan koyag ya.

39 Unkan Dawid heyake kin akapa tanhan mazasagye kin ipiyag kiton, qa nahanfiin ute śni heon mani kta uta. Qa Dawid Saul heciya, Dena nahanliin imdute śni, heon yuha mde kta owakitpani, qa Dawid hena hduśdoka.

40 Qa cansagye nape en ikikcu, qa wakpadan etanhan inyan śduśduta zaptan kahnige ca wihankiyapi wipe hduhe ehna wojuha en iyeye ca iyulimun nape ohna iki$\mathrm{kcu}$, qa Pilisti kin ikiyedan ya.

41 Unkan. Pilisti kin mani, qa Dawid ikiyedan hiyu, qa wicaśta wahacanka kiciyuhe cin he itokam mani.

42 Qa Pilisti kin etonwe ca Dawid wanyake ça ihakta śni, he hokśidan, ite kin śa, qa owanyag waśte nakaś.

43 Unkan Pilisti kin Dawid heciya, Sunka hemaca kecanni heon cansagye kiton tatpe mayahi he? Qa Pilistim taku iye wakan da on Dawid yaśica.

$44 \mathrm{Qa}$ Pilisti kin Dawid heciya, Kuwa wo, hecen nicehpi kin mahpiya okinyanpi kin, qa tinta wamanica kin wicawaqu kta.

45 Unkan Dawid Pilisti kin heciya, Niye maza sagye, qa wahukeza, qa canhipi hduha tatpe mayahi, tuka miye Jehowa obe yuha Israel ozuye wakandapi kin iśten yaye cin he cajeyan niye ekta wau ce.

46 Qa nakaha Jehowa minape en niçu kta, qa cicaśtake kta, qa nipa lin bacikse kta, qa Pilistim obepi cehpi kin mahpiya okinyanpi kin, qa maka wamanica kin wicawaqu kta, hecen Israel en taku wakan yukan maka owancaya sdonyapi kta.

47 Qa Jehowa mazasagye, qa wahukeza on ni wicaye śni omniciye kin de ocowasin sdonyapi kta. Wokicize kin de Jehowa tawa ce, qa unnapepi en unnicupi kta nakaś.

48 Unkan Pilisti kin najin qa mani, qa Dawid itkokipe kta ikiyedan u qehan, Dawid inahini, qa Pilisti kin itkokipe kta wokicize ekta inyanka.

49 Qa Dawid tawojuhadan ekta nape yekiye ca hetanhan inyan wan icu, qa kaho iyeya, qa Pilisti ite en iheya, unkan inyan kin ite kin mahen iyaya, heon ipusdiya makata hinhpaya.

50 Hecen Dawid iyuhmun, qa inyan wan on Pilisti kin ohiye ca Pilisti kin kaśtake ca tekiya, tuka Dawid nape ohna isan nica.

51 Heon Dawid inyanke ca Pilisti tancan kin akan iyahan, qa isan tawa kin yuśdoka, ojuha etanhan, qa te kiya, qa on pabaksa. Unkan Pilistim kin wicaśta waśaka tawapi kin wanna ta wanyakapi hehan najicapi.

52 Unkan Israel qa Juda wicaśta kin najinpi, qa iyaśapi, qa Pilistim kuwa ewicayayapi, osmaka ekta de cin, qa Yeqron tiyopa ekta hehanyan. Unkan Pilistim capapi kin hena hinhpayapi canku otonwe tiyopa kin iyahde ohna Gat ekta, qa Yeqron ekta hehanyan. 


\section{SAMUEL TOKAHEYA,}

53 Unkan Israel cinca kin Pilistim wicakuwapi etanhan ihdamnapi, qa owanka qon ohna walipaya kin icupi.

54 Unkan Dawid Pilisti qon pa kin icu, qa he yuha Jerusalem ekta i, tuka tawipe kin wakeya tawa en kihnaka.

55 Unkan Saul Dawid Pilisti kin itkokipe kta iyaye cin wanyake cehan taozuye itancan kin Abner heciyá, Abner kośka kin de tuwe cinhintku he? Unkan Abner heya, Wicaśta yatapi ninaği ni kin sdonwaye śni.

56 Unkan wicaśta yatapi kin heya, Niye iwanga wo, kośka kin tuwe cinhintlku he?

57 Unkan Dawid Pilisti kin kaśtake cin etanhan ku qehan, Abner he icu, qa Saul itokam hiyuya, Pilisti pa kin nape ohna yuha un.

58 Unkan Saul heciya, Kośka tuwe cinhintku kin he niye he? Unkan, Nitaokiye Jesse Betlehemi cinhintku kin he miye, Dawid eya.

\section{WICOWOYAKE 18.}

1 Unkan Saul kici wohdaka ayaśtan qehan, Jonatan nagi kin Dawid naggi en iya-ihdaśke ça Jonatan he waśte daka iye nagi kin iyecen.

2 Unkan anpetu kin he en Saul he icu, qa atkuku ti en hde lita icimana iyowinkiye śni.

3 Unkan Jonatan iye naği kin iyecen Dawid waśtedaka, heon otakuye kicicağa.

$4 \mathrm{Qa}$ Jonatan śina in kin hduśdoke, ca Dawid qu, nakun taheyake, qa isan tawa, qa tinazipe, qa ipiyaka tawa.

5 Unkan Dawid tokiya kaśta Saul yeśi kin owasin ekta i, qa wayupiya econ. Unkan Saul taakicita tancan kagja. Unkan oyate kin owasin iyowicakipi ; nakun Saul taokiye owasin iyowicakipi.

6 Wanna Dawid Pilisti kin Kaśtake cin etanhan hdicupi qehan, winohinca Israel otonwe owasin etanhan inanpapi, cancega, qa candowankiyapi yuha, wiyuśkinyan dowanpi, qa wacipi Saul wicaśta yatapi itkokipapi.

7 Qa winohinca ślkatapi alkiciyuptapi qa heyapi, Saul kektopawinge ota kte, qa Dawid kektopawinge wikcenma ota.

8 Heon Saul nina śihda, qa wicoie lzin he śicedaka qa heya, Ecah Dawid kektopawinge wikcemna qupi, qa miye keptopawinge walljidan maqupi. Ehaeś tokata iye wicaśta yatapi kta.

9 Unkan anpetu kin he etanhan, Saul Dawid inakiwizi.

10 Unkan ihanhianna etanhan taku wakan etanhan woniya śica kin Saul iyahpaya, heon tipi ohna waayate. Unkan Dawid nape kin on dowankiya, anpetu iyohi hecon ece kin iyecen. Unkan Saul nape kin ohna wahulseza yuha.?

11 Unkan Saul wahukeza kin yuwankan icu, qa, Dawid tiunnaptan icam ihewaye kta ecin. Tuka itokapa tanhan Dawid ihdutokan, nonpa akihde.

12. Unkan Saul Dawid kokipa, Jehowa he kici un, qa Saul ayuśtan heon etanhan.

13 Heon Saul iye etanhan tokan iyaye ya, qa akicita kektopawingुe itancan kaga. Unkan oyate itokam inanpa, qa hdi.

14 Qa Dawid ohanye cin owasin en ksapa, qa Jehowa kici un.

15 Qa nina ksape cin he Saul wanyaka, heon itokam inihan.

16 Unkan Israel, qa Juda owasin Dawid waśte dakapi, wicitokam inanpe ça en hdi nakaś. 
17 Unkan Saul Dawid heciya, Howo micinkśi, wadinitake ca Jehowa tokicize yakize cinhan, micunkśi tokapa Merab he duze kta e cicu kte. Minape he ape kte śni, tuka Pilistim napepi kin heconpi Ita Saul ecin nakaś.

18 Unkan Dawid Saul heciya, Miye matuwe he? qa wani kin, ate wicowazi tawa Israel ohna he taku on, wicaśta yatapi kin takoś maye kta he?

19 Unkan Saul cunwintku Merab Dawid qupi kta iyehantu qehan; Adriel Meholati tawicu kta e qupi.

20 Unkan Mikal Saul cunwintku kin Dawid waśte daka. Unkan Saul okiyakapi. Unkan wicoie kin he iye iśta kin en waśte.

21 Unkan, He waqu kita, hecen he hmunke kta, qa Pilistim apapi kta, Saul eya qa, Nonpapi on nakaha takoś ciye kta Saul Dawid eciya.

22 Howo wicaśta yatapi kin waśte nidaka, qa taokiye owasin waśte nidakapi, heon wicaśta yatapi kin tunkan ya wo, Saul taokiye owasin Dawid nahmana eciye wicaśi.

23 Unkan Saul taokiye wicoie kin hena Dawid noge ohna eyapi. Unkan Dawid heya, Wicaśta yatapi kin tunkan yanpi kte cin taku śni yadapi he? Miye mawahpanica, qa mataku śni tuka.

24 Unkan Saul taokiye kin okiyakapi, qa Wicoie kin dena iyecen Dawid ia, eyapi.

25 Unkan Saul heya, Decen Dawid eciyapo, Wicaśta yatapi kin wohpe takudan cin śni, Pilistim ceinkpaha kin opawinge wanji heceedan, hecen wicaśta yatapi kin tokayapi towicakiçon kta. Hecen Saul Dawid Pilistim napepi on țe ye kta kecin.

26 Unkan taokiye Dawid wicoie kin hena okiyakapi. Unkan wicaśta yatapi tunkan ye kta wicoie kin Dawid iyokipi, qa anpetu cajeyatapi kin nahanhin henakeca śni ;

27 Qehan Dawid iyaya, iye qa wicaśta wicayuhe cin qa Pilistim wicaśta opawinge nonpa wicakaśtakapi, qa ceinkpaha tawapi kin, Dawid yuha hi, qa wicaśta yatapi takośye kta e owasin kiciyawa. Unkan Saul iye cunwintku Mikal tawicu kta e qu.

28 Qa Jehowa Dawid kici un kin, qa Mikal Saul cunwirtku Dawid waśte dake cin Saul wanyake ca sdonya.

29 Uீnkan ake Saul Dawid on sanpa kokipe ça Saul anpetu owasin Dawid toka ya.

30 Unkan ake Pilistim itancanpi kin zuya hipi, qa zuya hipi eca Dawid Saul taokiye owasin isanpa ksapa ihdutanin, qa caje kin nina kinihanpi.

\section{WICOWOYAKE 19.}

1 Unkan Saul iye cinhintku Jonatan, qa taokiye owasin Dawid ktepi kta kewicakiya, tuka Tonatan Saul cinhintku kin Dawid nina waśte daka.

2 Heon Jonatan Dawid okiyake ca heya, Ate nikte kta akin un, heon waktaya un wo, hanhanna kte cin hehanyan, qa inahma, qa nalimanna iwanka wo.

3 Qa miye inawape kta, qa tinta ohna ate kici nawajin $k$ ta, nanke kte cin ikiyedan, qa niye on ate kici iwae kta, qa taku wanmdake kte cin he ociciyake kta.

4 Unkan Jonatan iye atkukn Saul kici Dawid on taku waśte ie ca heciya, Ihnuhan wicaśta yatapi kin taokiye Dawid en wahtani kin, iye wanicihtani śni, 
tuka taku ecanicen kin owasin waśte hinca.

5 Qa naği kin nape en ikikcu, qa Pilisti kin kaśtaka, qa woehdaku tanka Jehowa Israel owasin on econ kin wandake ca nina widuśkin. Heon nakaha tokeca taku śni on Dawid te yaye kta, qa tuwe takudan śica econ śni we kin awayahtani kta he?

6 Unkan Saul Jonatan ho kin nahon, qa wakonze ca Jehowa ni kinhan teyapi kte śni, eya.

7. Unkan Jonatan Dawid kipan, qa Jonatan wicoie kin hena owasin okiyaka, qa Jonatan Dawid kici Saul elkta ipi, qa he itokam kici un qon ake iyecen kici un.

8 Unkan ake zuya upi, unkan Dawid inanpe ca Pilistim wicakiza, qa wopate tanka on wicakaśtaka, heon itokapa tanhan napapi.

9 Unkan woniya śica qon Jehowa etanhan Saul akan un qehan, ti kin ohna iyotankehan, nape ohna, wahukeza hduha; unkan Dawid nape on dowankiya.

10 Unkan Saul wahukeza on tiunnaptan ekta Dawid cape kta kecin, tuka Saul itokapa tanhan inaśdoka; unkan wahukeza on tiunnaptan kin capa. Unkan Dawid najica, qa hanyetu kin he en niiciya.

11 Unkan Saul Dawid ti kin ekta ohnihde ye wicaśi, awanyakapi kta, qa ihanhanna kinhan ktepi kta, heon etanhan. Unkan Mikal Dawid tawicu kin okiyake ça heya, Ninaggi hanyetu kin de niniciye śni kinhan, heyakecinhan nițe kta ye.

12 Qa Mikal owanyeye wan ohna Dawid kun iyaye ya. Unkan iyaye ça najice ca niiçiya.

13 Unkan Mikal wakagapi wan icu, qa towinja akan ehnake ca tatokadan hin ipahin pa kin ihu- kuya yeya, qa śina wan on akalipa.

14 Unkan Saul ohnihde Dawid huweye rvicaśi; unkan, Wayazanka ye, eya.

15 Unkan Saul ohnihde wanyakapi kta ye wicaśi, qa, Wakte kta e owinja akan miye en aupo, eya.

16 Unkan ohnihde wicaye cin ekta ipi, qa inyun wakagapi wan owinja akan yanke ca pa kin ekta tatokadan hin ipahin yapi.

17 Unkan Saul Mikal heciya, Tokeca decen mayahnayan, qa tokawaye cin iyaye yaya he? hecen wanna niiçiya. Unkan Mikal Saul heciya, Iye hecen emakiya ye, Ye mayan wo, tokeca cikte kta he?

18 Unkan Dawid najice ca niiciye ca Samuel ekta i, Rama ekta, qa taku Saul ecakicon owasin okiyaka, qa Samuel kici iyaya, qa Naiot (Waayate tipi) en tini.

19 Unkan, Ito Dawid Naiot en, Rama ohna yanka ce, Saul okiyakapi.

20 Unkan Dawid yuzapi kta, Saul ohnihde ekta ye wicaśi. Unkan waayate optaye woyakapi kin, qa Samuel wiciwankam najin wanyakapi qehan taku wakan toniya kin Saul ohnihde wicaya awicahinhpaya, qa iś eya woyakapi.

21 Unkan Saul okiyakapi qehan, ohnihde tokeca yewicaśi, unkan iś eya woyakapi. Unkan ake iyamni Saul ohnihde yewicaśi ; unkan iś eya woyakapi.

22 Hehan iś eya Rama ekta i, qa minilidoka tanka Seku en yanke cin ehan i qehan, wawiwange ca Samuel qa Dawid tukten unpi he? eya. Unkan waayate tipi en, Rama ohna yakonpi ce, eyapi. 
23 Unkan wayate tipi Rama ohna un kin ekta i. Unkan taku wakan toniya kin iś eya akan un, qa waayate tipi ekta, Rama en i kin hehanyan mani, qa waayata.

24 Unkan iś eya, wokoyake hduśdoka, qa iś eya Samuel itokam woyaka, qa anpetu kin he osan, qa hanyetu osan tancodan makata wanka; heon Saul iś eya waayatapi om yanka he? eyapi.

\section{WICOWOYAKE 20.}

1 Unkan Dawid waayate tipi, Rama ohna yanke cin hetanhan najice ça Jonatan ekta $\vec{i}$, qa heciya, Taku ecamon he? qa miohan śica tukte e he? qa niyate itokam wawahtani tukte e he on minaği kin akita?

2 Unkan heciya, Hiya hecetu śni nițe kte śni. Ate taku tanka qaiś taku cistinna unmanna econ śni ece, minoge yazamni śni itokam, qa token wicoie kin de miye etanhan nahman kta he? hecetu śni ce.

3 Unkan Dawid taku wakan cajeyate ca ake heya, Niiśta en woiyokipi iyewaye cin niyate awicakehan sdonya, heon heya, Ihnunhan Jonatan de sdonye cinhan, okini icante śice kta. Awicakehan Jehowa ni qa ninagi ni kinhan, miye qa wiconte otahedan caehde wanjidan.

4 Unkan Jonatan Dawid heciya, Ninaği taku cin emayakiye cinhan ecacicon kta.

5 Unkan Dawid Jonatan heciya, Ito heyakecinhan wi teca kin hee kta, qa miye wicaśta yatapi kin kici imdotanke ca wawate kta iyececa. Tuka iyaye makiya wo, hecen anpetu iyamni htayetu kte cin hehanyan magata inawalibe kta ce.
6 Niyate cajemayate cinhan, Dawid cin makiya, qa imawanga, iye totonwe Betlehem ekta inyanke kta; heciya wicowazi owasin on anpetu wanjikśi wo. śnapi wicakicag̉api ce, ehe kta.

7 Unkan Hecetu ce, eye cinhan nitaokiye wookiye yuhe kta. Tuka śihda kinhan, iye wanna wocanniye on ojudan sdonya wo. 8 Heon nitaokiye wocantkiye ecayecon kta; Jehowa wotakuye nitaokiye qa niye otahedan hiyuyaya nakaś : miohan śice cinhan niye makte wo, qa tokeca niyate ekta hiyu mayaye kta he?

9 Unkan Jonatan heya, Hiya niye on hecetu śni nunwe. Ate taku sica hiyu niciye kta konza e awicakehan sdonwaya unkanś ociciyake kta tuka.

10 Unkan Dawid Jonatan heciya, Niyate icanksiya aniyupte cinhan tuwe omakiyake kta he?

11 Unkan Jonatan Dawid heciya, I to maga ekta unye kta. Unkan sakim magga ekta ipi.

12 Unkan Jonatan Dawid heciya, Jehowa Israel Wakandapi kin namahon tohan ate imdute, heyakecinhan, qaiś heyakecinhan icima wi kin dehantu, Dawid on waśte kinhan, tuwe niye ekta ye waśi śni, qa ninoğe mduzamni śni kinhan,

13 Jehowa Jonatan hecen qa nakun isanpa ecakicon nunwe. Tuka taku śica ecanicon kta ate iyokipi kinhan, ninog̉e ohna ociciyake kta, qa toki ye ciśi kta, hecen zaniyan yahde $k$ ta, qa Jehowa nici un kta, ate kici un qon he iyecen.

$14 \mathrm{Qa}$ tohan wani kin hehanyan ecedan śni, tuka mațe kte cin ohakam nakun Jehowa tawocantkiye ecamiyecon kta.

$15 \mathrm{Qa}$ nitawocantekiye watiohnaka etanhan icimana duśpe 421 


\section{SAMUEL TOKAHEYA,}

kte śni; Jehowa Dawid tokayapi kin owasin maka etanhan wicakaśpa eśta.

16 Hecen Jonatan Dawid ti kici otakuye kaga, qa heya, Jehowa Dawid tokayapi kin kajuju wicakiye kta.

17 Unkan Jonatan ake, Taku wakan namalion Dawid eya śi, nina waśte daka heon etanhan; iye naggi kin waśte kidake cin he iyecen he waśte daka nakaś.

18 Qa Jonatan heciya, Heyakecinhan wi teca kta, qa niye on wawiwangapi kta, oiyotanke nitawa kin cokadan kta nakaś.

19 Qa anpetu iyamni kohanna kun yau kta, qa anpetu taku econkupi qon tukten inayahbe cin he en yai kta, qa Ezel (iyayapi) inyan kin icahda yakidotanke kta.

20 Unkan unnaptan kin ekta wanhinkpe yamni ye waye kta, canwakute kte cin iyecen.

21 Qa ito hokśidan kin ye waśi kta, Wanhinkpe huwe ya wo, qa, Wanhinkpe niye itato yanka icu wo hokśina ewakiye cinhan, kuwa wo; wookiye duhe kia, Jehowa ni kinhan taku sica wanice kta.

22 Tuka, Ito wanhinkpe ako yakonpi, hokśina ervakiye cinhan, hunktiya wo, Jehowa hee ye niśi ce.

23 Qa wicoie miye, qa niye unkeye cin. Jehowa miye qa niye unkiyotahedan wayaatanin kta, owihanke wanica.

24 Unkan Dawid maġa ohna inahma. Unkan wi teca qehan, wicaśta yatapi kin aguyapi yute kta iyotanka.

25 Qa wicaśta yatapi kin toiyotanke akan, ohinniyan econ qon he iyecen, iyotanka, tipi unnaptan icahda, oiyotanke he cin he akan, qa Jonatan najin qa Abner qa Saul icahda iyotankapi, tuka Dawid oiyotanke tawa cokadan han, wanyakapi.

26 Unkan Sául anpetu kin he en takudan eye śni. Taku akipa on ska śni, qa nahanhin yuskapi śni kecin nakaś.

27 Unkan ihanhanna wi anpetu inonpa qehan, Dawid oyanke tawa cokadau han wanyakapi. Unkan Saul iye cinhintku Jonatan heciya, Tokeca Jesse cinhintku wotapi en hi śni? hitanihan, qa nakun nakaha.

28 Unkan Jonatan Saul ayupta, Dawid Betlehem ekta hde kta nina cinmakiya.

29 Qa heya, Tokin Betlehem ekta mde kta iyowin mayakiyen; otonwe ohna wicowazi wośnapi wan unhapi, qa cinye ekta u maśipi, heon wanna niiśta en woiyokipi iyewaye cinhan nawajice ca cinye wanwicamdake kta. Qa heon wicaśta yatapi tawahna wotapi ekta hi śni.

30 Unkan Saul Jonatan nina canniye ye ca heciya, Witkowin wakipajin cinhintku kin henica. A wicakehar iśten niçiye $\mathrm{kta}$, qa nihun tancodan iśten yaye kta e Jesse cinhintku kin yakahigiga he sdonwaya.

31 Tohanyan Jesse cinhintku maka akan ni kin hehanyan wokiconze kin niciyusutapi kte śni, heon huwe ye wicaśi, qa miye ekta aupo, te kta iyececa nakaś.

32 Unkan Jonatan iye atkuku Saul ayupte ca heciya, Taku on te kta taku hecon hwo.

33 Unkan cape kta e Saul wahukeza yuwankan ikikcu, hecen Dawid ktepi kta wanna atkuku Saul konza hduśtan kin Jonatan sdonya.

34 Heon Jonatan nina śinhda wahna wotapi etanhan najin iyaya, qa wi kin anpetu inonpa ağuya- 


\section{WICOWOYAKE 21.}

pi onśpadan yute śni; Dawid on iyokiśica atkuku nina iśten kiya nakaś.

35 Unkan ihanhanna. Jonatan Dawid itkokipe kta maga ekta inanpa; unkan hokśidan cistinna wan kicica.

36 Qa hokśidan kin heciya, Ekta inyanka, wanhinkpe ye waye cin akita wo. Unkan hokśidan inyang iyaye cin icunhan iye wanhinkpe wan ako iheya.

37 Unkan wanhinkpe Jonatan kute yanke cin ekta hokśidan i kte çehan, Jonatan hokśidan kin kipan, qa heciya, Wanhinkpe niye akotanhan yanke śni he?

38 Nakun Jonatan hokśidan kin hoyekiye ca heya, Inahni wo, kohanna, ihnuhan owanji nayajin kin. Unkan hokśidan kin Jonatan wanhinkpe mnakiciye ça itancan tawa en hdi.

39 Qa hokśidan kin takudan sdonye śni, Jonatan qa Dawid henana wicoie kin sdonyapi.

40 Unkan Jonatan tawipe kin hokśidan tawa qu; qa heciya, Icu qa otonwe ekta ahda wo.

41 Unkan hokśidan iyaye cehan, Dawid itokagin tanhan najin, qa itokam makata ehpe iciye ca yamni akihde patuja, qa i ikiciputakapi, qa napin ceyapi, tuka Dawid iyotan.

42 Unkan Jonatan Dawid heciya, Wookiye en hda wo. Wanna sakim unkiciconza, Jehowa cajeyan, Jehowa miye qa niye otahedan yanke kta, qa micinca qa nicinca kin otahedan owihanke wanica. Unkan najin, qa toki iyaya; unkan Jonatan otonwe ekta kihda.

\section{WICOWOYAKE 21.}

1 Unkan Samuel Dawid Nobe en i, Ahimelek wawayuśna ekta.
Unkan Ahimelek Dawid wanyake cehan kokipa qa heciya, Tokeca niye niśnana yau, qa wicaśta tuwedan nici un śni.

2 Unkan Dawid Ahimelek wawayuśna kin heciya, Wicaśta yatapi kin taku econ maśi qa heya, Taku econ ciśi, qa toki yeciśi tuwedan sdon ye kte śni. Unkan hokśipidan wanji kakiya qa wanji deciya ye wicawaśi.

3 Qa wanna taku ninape ihukuya un kin aguyapi zaptan, qaiś tona iyeyapi minape en maqu ye. 4 Unkan wawayuśna kin Dawid ayupte ca heciya, Minape ihukuya aguyapi ikceka wanica, tuka aguyapi wakan yukan; hokśipidan awicakehan winohinca etanhan awanihdakapi hecinhan.

5 Unkan Dawid wawayuśna kin ayupte ca heciya, Awicakehan wau, htanihan icima ehantanhan, unkiyepi etanhan winohinca natakapi ce; qa hokśipidan wakśica tawapi kin wakan ce, qa ohan kin de ikceka ce, wakśica ohna nakaha yuwakanpi eśta.

6 Unkan wawayuśna kin ağuyapi wakan kin qu, hen agु uyapi wanica, agjuyapi itokam hnakapi kin hecedan, Jehowa itokapa tanhan icupi qehan, heekiya aguyapi kata ehnakapi kta on icupi kin he.

7 Inkan anpetu kin he en Saul taokiye wan hen yanka, Jehowa itokam natakapi, Doeg eciyapi, Edomi heca, wilianwicakiya Saul wicayuhe cin itancan kin.

8 Unkan Dawid Ahimelek heciya, Nakun den ninape ihukuya wahukeza, qa isan hanska wanica he? Isan, qa wipe nakun minape ohna iwekcu śni, wicaśta yatapi oie kin inahini mayan nakaś.

9 Unkan wawayuśna kin heya, 423 


\section{SAMUEL TOKAHEYA,}

Goliat Pilisti Ela osmaka ohna yakastake cin isan hanska tawa kin, iho den śina wan en opemni, amdo akahpe iheyata yanka; he iyacu kta yacin kinhan icu wo; heceedan den yanka, tokeca wanica ce. Unkan Dawid heya, He iyececa wanica; he maqu wo.

10 Unkan Dawid najin, qa anpetu kin he en Saul itokapa tanhan najica, qa Gat wicaśta yatam pi kin Akiś ekta i.

11 Unkan Akiś taokiye kin heciyapi, Dawid makoce wicaśta yatapi kin dee śni he? qa iwakicipi en ahiyayapi, qa Saul kektopawinge ota kaśtaka, qa Dawid kektopawinge wikcemna ota kaśtaka, eciyapi kin dee śni he?

12 Unkan Dawid wicoie kin dena cante kin en kihnake ca nina kopehda, Akiś Gat wicaśta yatapi kin itokam.

13 Qa iśtapi itokam tawacin ihdutokeca, qa napepi ohna withotkoya konza, qa tiyopa kin yutantan, qa tağośa iku hin kin akadus kiya.

14. Unkan Akiś taokiye hewicakiya, Inyun wicaśta kin wacin hnuni wandakapi. Tokeca he miye en ayahipi he?

15 Wacinhnunipi kin imakakija kecannipi kin, heon de witkotkoya mitokam śkan kta en hiyuyayapi he? De wati en hiyu kta he?

\section{WICOWOYAKE 22.}

1 Unkan Dawid hetanhan iyaye ca niiciya, Adullam makohidoka ekta. Unkan cincu, qa atkuku tiyohnaka owasin nalionpi qehan, heciya iye ekta ipi.

2 Unkan wicaśta tona kakijapi, ga tona icazo hdajujupi okihipi śni, qa tona nag̣i iyokiśicapi kin hena owasin en ihduwitayapi; 424 qa itancan yuhapi; hecen wicaśta opawinge topa cetu opapi.

3 Unkan Dawid hetanhan iyaya, Mitzpa Moab ekta, qa Moab wicaśta yatapi kin heciya, Tokin ate qa ina den hipi, qa taku wakan token ecamicon kte sdonwaye śni, hehanyan nici yakonpi kten.

4 Qa Moab wicaśta yatapi kin itokam hiyu wicaya. Unkan hen yakonyi tohanyan Dawid conkaśke en un kin anpetu owasin.

5 Unkan Gad waayate kin Dawid heciya, Conkaśke ohna nanke kte śni. Hunktiya, qa Juda makoce kin ekta hda wo. Unkan Dawid iyaye ça Ḣaret taśkoju en ki.

6 Unkan Dawid, qa wicaśta opapi kin tukten yakonpi kin wanna sdonyapi Saul nalion, qa Saul Gibeya ohna ti contanka Rama en yanke cin he ihukuya, qa wahukeza nape ohna hduha, qa taokiye owasin ihdukśan najinpi.

7 Hehan Saul iye taokiye ihdukśan najinpi kin hewicakiya, Hopo Benjamini namahonpo, Jesse cinhintku kin owasin mağa nicupi kta he? qa owasin hastanlhanka hu ojupi nakun, qa kektopawinge itancan, qa opawinġe itancan nicagapi kta he?

8 Heon owasin mayakipajinpi, qa micinkśi Jesse cinhintku kici wotakuye kagge cin tuwedan minog̉e en iyolipe makiye śni, qa nakaha hokśidan mitawa wan kiei micinkśi makipajin kin on niyepi wanjidan iyokiśice śni, qa omakiyake śni.

9 Hehan Doeg Edomi kin, Saul taokiye om najin kin he ayupte ca heya, Jesse cinhintku kin Nobe en Ahimelek Ahitub cinhintku ekta i kin wanmdaka. $10 \mathrm{Qa}$ iye on Jehowa iwange 


\section{WICOWOYAKE 23.}

ça waneya qu, qa nakun Goliat Pilisti isan hanska tawa qon qu. 11 Unkan wicaśta yatapi kin Ahimelek Ahitub cinhintku wawayuśna kin, qa atkuku tiyohnaka kin owasin wawayuśnapi, Nobe ohna yakonpi kin tuwe wicakico yeśi. Unkan owasin wicaśta yatapi ekta hipi.

12 Unkan Saul heya, Ahitub cinhintku namahon wo. Unkan, De miye ce, eya.

13 Unkan Saul heciya, Tokeca niye qa Jesse cinhintku mayakipajinpi, qa niye ağuyapi yaqu, qa i:an hanska: qa Wakantanka iyecinunga, hecen iyape mayan dusuta, nakaha iyececa.

14 Unkan Ahimelek wicaśta yatapi kin ayupte ça heciya, Qa nitaokiye owasin ehna, tuwe Dawid iyececa, wacinyepica, qa wicaśta yatapi takośku, qa nanihompi itancan kin, qa yati ohna kinihanpi?

15 Anpetu kin he en tokaheya iye on Wakantanka imonga he? Hiya hecetu śni. Ihnuhan wicaśta yatapi kin iye taokiye akan taku aonpe cin, qa nakun ate tiyohnaka owasin akan. $\mathrm{Ni}$ taokiye wicoie kin de owasin taku cistinna, qa taku tanka unmanna sdonye śni.

16 Unkan wicaśta yatapi kin heya, Ahimelek awicakehan nițe kta, niye qa niyate tiyohnaka kin owasin.

17 Unkan wicaśta yatapi kin akicita tawa ihdukśan najinpi kin hewicakiya, Ohomni yapi, qa Jehowa wawakiyuśnapi kin te wicayapo. Iś eya napepi kin Däwid kicicapi, qa najica sdonyapi qehan minonge ohna omakiyakapi sśni. Tuka wicaśta yatapi taokiye Jehowa wakiciyuśnapi kin awicapapi kta napepi yekiyapi tawațen yapi śni.
18 Unkan wicaśta yatapi kin Doeg heciya, Ihduhomri, qa wawayuśnapi kin wicakaśtaka wo. Unkan Doeg Edomi kin ihduhomni, qa iye wawayuśnapi kin wicakaśtake ca anpetu kin he en wicaśta wikcemna śahdoğan san-. pa zaptan miniliuha amdo akahpe koyakapi ece kin țe wicaya.

19 Qa Nobe wawayuśnapi totonwepi canlipi hi on kaśtaka, wicaśta, qa winohinca, qa śiceca azinpi koya; nakun pte, qa śonśonna, qa tahinca canlipi hi on te wicaya.

20 'Tuka Ahimelek Alitub cinhintku kin he cinhintku wanjidan niiçiya, Abiatar eciyapi, qa najica Dawid ekta.

21 Qa Saul Jehowa wawakiciyuśnapi kin wicakte Abiatar Dawid okiyaka.

22 Unkan Dawid Abiatar heciya, Doeg Edomi kin hen yanke ciqon anpetu kin he en Saul okiyake kta sdonwaya. Miye niyate tiyohnaka owasin naği wicayapi wakaga.

23 Mici ti wo, Ihnuhan wakoyakipe cin; tuwe minagi akite cin nillagi akita; heon miye kici awanniyakapi kta.

\section{WICOWOYAKE 23.}

1 Unkan, Inyụn Pilistim Qeila azuyapi, qa ağuyapi napanpi manunpi kin Dawid okiyakapi.

2 Unkan Dawid Jehowa iwanga qa, Ekta mde ça Pilistim kin dena wicawakaśtake kta he? eya. Unkan Jehowa Dawid heciya, Ya wo kinhan Pilistim wicayakaśtake kta.

3 Unkan Dawid, wicaśta tawa kin heciyapi, Inyun den Juda ohna kopeunhdapi, qa token Qeila en Pilistim ozuye ekta unyanpi kta he? 


\section{SAMUEL TOKAHEYA,}

4 Unkan ake Dawid Jehowa iwanga. Unkan Jehowa ayupta qa, Najin Qeila ekta ya wo, miye Pilistim ninape en wicawaqu kta ce, eya.

5 Unkan Dawid qa wicaśta tawa Qeila ekta ipi, qa Pilistim azuwicayapi, qa tawanunyanpi kin icupi, qa wokaśtake tanka on wicakaśtakapi. Hecen Dawid Qeila ounyanpi kin niwicaya.

6 Wanna Abiatar Ahimelek cinhintku Dawid ekta najice çehan amdo akahpe wan nape ohna yuha, qa Qeila ekta i.

7 Unkan Dawid Qeila en hi ce, Saul okiyakapi. Unkan Saul heya, Wakantanka he minape en qu, otonwe wan tiyopa, qa tiyopa inatake yukan en $i$, hecen natakapi nakaś.

8 Qa Saul Dawid, qa wicaśta: tawa wicakaśke kta e oyate owasin, Qeila ekta, apamahde natan wicaśi.

9 Unkan Saul taku śica ecakicon kta konze cin Dawid sdonye cehan, Abiatar wawayuśna kin heciya, Amdo akahpe kin hduha ikiyedan u wo.

10 Unkan Dawid heya, Jehowa Israel Wakandapi kin Saul miye on otonwe ihang ye kta konze cin nitaokiye wanna nahon.

11 Nitaokiye nahon kin iyecen Saul den hi kte cinhan, qa Qeila wicaśta kin nape kin en kaśka maqupi kte cinhan, Jehowa Israel Wakandapi nitaokiye oyakidake kta, ceciciya. Unkan, $\mathbb{E}$ hi kta, Jehowa eya.

12 Unkan Qeila wicaśta kin Saul nape kin en miye, qa wicaśta mitawa kaśka unqupi kta he? Dawid eya. Unkan. kaśka nicupi kta, Jehowa eya.

13 Unkan Dawid qa wicaśta tawa, wicaśta opawinge śakpe ce- tu najinpi, qa Qeila etanhan iyayapi, qa toki yapi okihipi iyayapi. Unkan Dawid Qeila etanhan ihduśke kin Saul okiyakapi; heon ekta ye kta enakiya.

14 Unkan Dawid hewoskan conkaśke ohna ounye ca Zip tinta kin ohna he kin en ti. Unkan Saul anpetu owasin he akita, tuka nape kin en Jehowa hiyuye śni.

15 Unkan naği kin akite kta e Saul inanpe cin Dawid wanyaka, qa Dawid Zip hewoskan taśkoju kin ohna yanka.

16 Unkan Jonatan Saul cinhintku najin, qa Dawid ekta i, taśkoju en, qa nape kin waśagya, Wakantanka en.

17 Qa heciya, Ihnuhan wakoyakipe cin; ate Saul nape kin iyeniye kite śni nakaś. Qa Israel wicaśta yatapi kin henica kta, qa miye ciyokihe waun kta; qa ate Saul hecetu kta sdonya.

18 Unkan wotakuye kicicağapi, Jehowa itokam, qa Dawid taśkoju ehna yanka, qa Jonatan kihda.

19 Unkan Zipim Saul ekta ipi, Gibeya en, qa heciyapi, Dawid unkiyepi ehna inahbe śni he? Conkaśke ohna, qa taśkoju ehna, Hakila paha kin en, he Jeśimon itokagia tanhan yanka.

20 Qa wanna ninaġi kun u kta cin kin iyecen wicaśta yatapi kun u ye; hecen unkiyepi wicaśta yatapi nape en nauntakapi kta iyececa.

21 Unkan Sauil heya, Onśimayadapi kin heon Jehowa niyawaśtepi.

22 Wanna ekta hdapo, qa sanpa iyukcanpo, qa wanyakapo, qa tukten siha kin mani sdonyapo, nakun hen wanyakapi tuwepi he? Iye ksamya ohanyan ce, omakiyakapi.

23 Qa wanyakapo, qa toinalibe 


\section{WICOWOYAKE 24.}

ohna inahma kin owasin sdonyapo, qa iyecetu kinhan ake en maupo, qa niyepi om mde kta, qa makoce en un kinhan Juda kektopawing g owasin ohna iyewaye kta.

24 Unkan Zipim najinpi, qa Saul itokam elsta ipi. Unkan Dawid, qa wicaśta tawa Mayon tinta kin en unpi, makomdaya ohna, Jeśimon itokagia ektakiya.

25 Unkan Saul, qa wicaśta tawa akin iyayapi. Unkan Dawid okiyakapi heon imnija ekta apamahde i, qa Mayon tinta ohna ti. Unkan Saul nahon, qa Mayon tinta en Dawid kuwa iyaya. 26 Qa Saul he kin itato iyaya, qa Dawid, qa wicaśta tawa kin lie kin akotanhan, qa Dawid Saul kokipe cin on etanhan najice kta inalini qehan, Saul qa wicaśta tawa Dawid qa wicaśta tawa ihdukśan iyayapi, qa wicayuzapi kta tuka;

27 Wahośi wan Saul ekta hi qa, Inahni, qa kuwa wo, Pilistim makoce kin enanakiya iyayapi nakaś, eya.

28 Unkan Saul Dawid kuwa etanhan ihdamna, qa Pilistim itkowicakipe kta iyaya. Heon oyanke kin he Sela Hamalilekot (Ihduśka imnija) eciyapi.

29 Unkan Dawid hetanhan iyaye ça Engedi (Tatokadan minihdoka) oinahbe kin ohna iyotanka.

\section{WICOWOYAKE 24.}

1 Unkan Saul Pilistim wicakuwa etanhan hdi qehan, wahoyapi qa, Iho Dawid Engedi tinta ohna yanka ce, okiyakapi.

2 Unkan Saul Israel owasin etanhan wicaśta kektopawing e yamni wicakahniga, qa hena om Dawid, qa wicaśta tawa awica-. kita iyaya, tatokadan inyan he kin akan.

$3 \mathrm{Qa}$ tahinca tipi kin canku icabda ekta i, qa makohdoka wan hen yukan, qa Saul siha ahdahpe kta hen i. Unkan Dawid qa wicaśta tawa makohidoka okahmin ohna iyotankahan yukanpi. 4 Unkan Dawid wicaśta tawa kin heciyapi, Iho Jehowa heniciye ciqon, Inyun toka niye cin ninape en waqu kte ça token niiśta en waśte iyecen écayecon kta, anpetu kin dee ce. Unkan Dawid najin, qa Saul taśina opapun kin nalimana baśpa.

5 Unkan ohakam Saul taśina opapun baśpe cin on etanhan Dawid cante kin iyope iciya.

6 Qa wicaśta tawa kin hewicakiya, Hiya mayuhe cin Jehowa sdakiye cin ekta nape yewakiye ca wicoie kin de ecawecon $\mathrm{kta}$, Jehowa makiśica nunwe. Jehowa he sdakiya nakaś.

7 Hecen Dawid wicoie on wicaśta tawa iyope wicaya, qa Saul iyahpayapi kta iyowicaki śni. Unkan Saul najin. qa makohdoka etanhan canku ohna iyaya.

8 Unkan ohakam Dawid najin, qa makolidoka etanhan inanpe ca Saul kipan qa, Itancan wicaśta yatapi eya. Unkan Saul hakikta. Unkan Dawid patuja, ite kin maka ektakiya qa ohoda.

9 Qa Dawid Saul heciya, Tokeca Dawid śicaya ecanicon kta cin wicaśta eniciyapi kin anawicayagoptan he?

10 Inyun nakaha makolidoka ohna minape en Jehowa niçu kin anpetu kin de niiśta wanyakapi, qa cikte kta kemakiyapi; tuka itoncipa, qa, Mayuhe cin elrta nape yewakiye kte sni, Jehowa he sdakiya nakaś, epa.

11 Qa iho ate minape ohna sina nitawa opapun kin wanyaka wo. 


\section{SAMUEL TOKAHEXA,}

Śina nitawa opapun kin bawaśpa, qa cikte śni, he etanhan minape ohna taku śica, qa woahtani wanica, wanyaka qa sdonya wo, qa awacihtani śni, tuka minagi iyacu kta e yakuwa.

12 Jehowa miye qa niye otahedan wayaco kta, qa niye en tomicicon $\mathrm{kta}$, tuka minape anipe kte śni.

13 Taku śica wicaśta śica etanhan inanpa ce, wicoie wakan ehanna kin eye cin iyececa; heon minape anipe kte śni.

14 Israel wicaśta yatapi kin tuwe ode inanpa he? qa tuwe yakuwa he? Śnka ta wan, ha wan oyade.

15 Jehowa hee iyukcan kta, qa miye qa niye otahedan wayaco kta, qa wanyake kta, qa waakinice kta, qa ninape etanhan emahdaku kta.

16 Unkan Dawid wicoie kin dena ayaśtan qehan, Saul heya, Micinkśi Dawid niho kin dee he? qa Saul ho yekiye ca ceya.

17 Qa Dawid her:iya, Niye oniwotanna, qa miś hemaca śni, Niye wowaśte ecamiyecon, qa miye śicaya ecacicon.

$18 \mathrm{Qa}$ odake cin iyecen nakaha wowaśte ecamiyecon, Jehowa ninape en kaśka maqu qehan mayakte śni.

19 Wicaśta wan tuwe toka ye cin iyeye cinhan canku waśte ohna hde kiye lita he? Taku nakaha ecamiyecon kin on Jehowa iyuwin waśte wan niçu kta.

$20 \mathrm{Qa}$ wanna ito awicakehan wicaśta niyatapi kta, qa Israel iwicayadake kta e ninape suta kta sdonwaya.

21 Heon wanna, Mihakam micinca wicayakaśpe kte śni, qa ate ti kin etanhan micaje kin yakaśpe kte śni. Jehowa cajeyan kemakiya wo.
22 Unkan Dawid taku wakan cajeyan Saul heciya. Unkan Saul kihda. Unkan Dawid qa wicaśta tawa conkaślke ekta itanwankahde ipi.

\section{WICOWOYAKE 25.}

1 Unkan Samuel ta; heon Israel owasin mniciyapi, qa aceyapi, qa iye ti ekta Rama ohna hnakapi. Unkan Dawid najin, qa Paran tinta kin elta iyaya.

2 Unkan Mayon ohna wicaśta wan ti, qa tawanunyanpi kin Karmel ohna yakonpi, qa wicaśta kin he tanka hinca, qa tahinca kektopawinge yamni yuha, qa tatokadan kektopawinge wanjidan, qa he ehan Karmel ohna tahinca hduśda.

3 Qa wicaśta kin he Nabal (Witkotko) eciyapi, qa tawicu Abigail (Ate iyuśkin) eciyapi, winohinca waśte, ksape ca owanyag waśte; tuka hihnaku lkin wacinko, qa ohan śica, qa taśunka iyececa.

4 Unkan Nabal tahinca hduśda yanka ce, eyapi kin Dawid tinta olina nation.

5 Unkan Dawid kośka wikcemna yewicaśi, qa Dawid kośka kin hewicakiya, Karmel ekta yapo, qa Nabal ekta yaipi kinhan, Zaniyan un hecinhan, micajeyan inongapi kta.

6 Qa tuwe ni un kin hecen eyakiyapi kta. Zaniyan yaun, qa yati kin Zaniyan un, qa taku duhe cin owasin Zaniyan un.

$7 \mathrm{Qa}$ nakaha wayuśdapi duha nawahon, qa iho wihanwicakiya wicaduhe cin om Karmel ohna unyakonpi qehan, nagigiye wicunyanpi śni, qa takudan tokakilionpi śni.

8 Kośka nitawa iwicawanga wo; hecen oniciyakapi kta; qa 


\section{WICOW OYAKE 25.}

kosklkapi kin niiśta en woiyokipi iyeyapi kta. Anpetu waśte wan en unhipi. Tokin taku ninape iyeye cin hokśipidan nitawa, qa nicinkśi Dawid wicayaqu kten.

9 Unkan Dawid kośka tawa ekta ipi, qa wicoie kin hena owasin iyecen Nabal eciyapi, Dawid cajeyan, qa enakiyapi.

10 Unkan Nabal Dawid tahokśipidan awicayupte ca heya, Dawid he tuwe, qa Jesse cinhintku kin he tuwe? Dehan hopśipidan ota otoiyohi yuhe cin etanhan najicapi ce.

11 Ag guyapi mitawa, qa mini mitawa, qa tado wayuśdapi wicamduha on wapate cin hena iwekcu, qa wicaśta tokiya tanhan unpi kin sdonwaye śni wicawaqu kta he?

12 Unkan Dawid kośka tawa kin nakimnipi, canku kin ohna, qa wicoie kin hena owasin iyecen okiyakapi.

13 Unkan Dawid wicaśta tawa hewicakiya, Owasin isan hanska mikihnakapo. Unkan otoiyohi isan hanska mikihnakapi, qa Dawid iś eya isan hanska mikihnaka. Qa wicaśta opawinge topa cetu Dawid opapi, qa opawing nonpa tawahpayeca kin awanyag yakonpi.

14 Unkan kośkapi etanhan kośka wan Nabal tawicu Abigail okiyake ca heya, Inyun Dawid tinta kin etanhan wahosi unyuhapi kin yawaśtepi kta hiyu wicaśi ; unkan i en iyewicaya ;

15 Tuka wicaśta kin hena nina tanyan ecaunkiconpi, qa nag்iye unyanpi śni, qa anpetu unkiyepi om yakonpi, tinta ohna, hehanyan takudan tokaunkilionpi śni.

16 Anpetu tona hena om tahinca wihanunkiyapi kin owasin, hanyen anposkan koya aconkaśke unyanpi.
17 Heon wanna taku ecanon kta iwanyaka qa sdonya wo; unyuhapi, qa tiohnaka tawa owasir on taku śica wanna konza ce. He nina wicaśta śni, hecen tuwe kici wohdake kta okihi śni.

18 Unkan Abigail inahni, qa ag̉uyapi opawinge nonpa, qa miniśa apalita nonpa, qa tahinca patapi zaptan, qa ağuyapisu ceonpapi iyutapi zaptan, qa hastanhanka pusyapi iyage opawinge wanji, qa suken waskuyeca mibe paskicapi opawinge nonpa, hena iyuhpa icu, qa śonśonna qin wicakiya.

19 Qa tahokśidan kin hewicakiya, Mitokam yape, qa miye cihakam wau ce. Tuka hihnaku Nabal okiyake śni.

20. Qa śonśonna akan iyotanke ca he kaksiza kin ekta i qehan, inyun Dawid qa wicaśta tawa itkokim upi, qa awicakipa.

21 Qa Dawid heya, Awicakehan ituh wicaśta kin de taku tinta ohna yuhe cin iyulipa wapatan, qa taku tawa iyuhpa etanhan takudan tokakihon śni. Qa taku waśte on taku śica ecamicon.

22 Wakantanka Dawiu tokayapi kin hecen, qa isanpa ecawicakicon kte, taku tawa owasin etanhan wicawanjidan anpa kamdeze kte cin hehanyan owakapte cinhan.

23 Unkan Abigail Dawid wanyake cehan inalini, qa sonśonna etanhan makata najin, qa Dawid itokam makipusdiya ehpeiçiye ça ohoda.

$24 \mathrm{Qa}$ siha kin ekta ehpe iciye cehan heya, Itancan taku śice cin de amahinhpaya ye, tuka tokin wicinyanna nitawa ninogie ohna ie kten, qa wicinyanna nitawa oie kin nahon ye.

25 Ceciciye, ihnuhan itancan 429 


\section{SAMUEL TOKAHEYA,}

mitawa wicaśta wicaśtaśni kin de, Nabal ekta cante kin yekiye cin ; iye caje kin iyececa ye. Nabal (Witkotkoka) eciyapi, qa wowitkotko kicica. Tuka miye wicinyanna nitawa mayuhe cin tahokśipidan, ye wicaśi kin wanwicamdake śni ye.

$26 \mathrm{Qa}$ wanna itancan Jehowa ni, qa ninagi ni, Jehowa we yapapson kte śni e nipatan, qa ninape nicipatan. Heon wanna tona tolianiyanpi, qa itancan mitawa śicaya ecakiconpi kin hena owasin Nabal iyececapi kta ye.

27 Qa wanna woyuwaśte kin de wicinyanna nitawa mayuhe cin kahi kin de icu ye, qa hokśipidan mayuhe cin cahde kin omanipi wicaqupi kta ye.

28 Wicinyanna nitawa wahtani kin kicicajuju ye, Jehowa tipi wacinyepica awicakehan mayuhe kicagie kta; mayuhe cin Jehowa tokicize kiciciza ye, qa taku śica icimana niye ohna iyeyapi kte śni ye.

$29 \mathrm{Qa}$ wicaśta wan śicaya nicuwa kta, qa ninagi akite kta najin ; tuka Jehowa wakanyada ninaġi kin wiconi opahte en pahta kta ye, qa toka niyanpi nağipi kin iyulimun cokaya tanhan kaho iyewicaye kta ye.

30 Qa tohan Jehowa taku waśte niye on eye cin owasin iyecen econ kinhan, qa Israel mdetanhunka nicagge cinhan,

31 We ituh yapapson kin de, qa mayuhe cin tokicicicon kin de ibonito kte śni, qa cante śilitin niye kite śni. Qa tohan Jehowa mayuhe cin taku waśte ecakicon kinhan wicinyanna nitawa kiksuya ye.

32 Unkan Dawid Abigail heciya, Tehowa Israel wakandapi kin nakaha itkomakipe kta hiyuniye cin yawaśtepi nunwe.
33 Qa nitoksape kin yawaśtepi, qa nakaha we wapapson kta, qa minape on tomicicon kta etanhan anamayapte cin heon niyawaśtepi ce.

34 Jehowa Israel wakandapi, qa śicaya ecacicon makiśice cin he ni kinhan, nakaha itkomayakipe inahniyan yahi śni unkanś, hanhanna anpa kte cin hehanyan Nabal taku tawa etanhan wica wanjidan okaptapi kte śni tuka.

35 Qa taku kahi kin nape kin etanhan Dawid icu qa heciya, Wookiye yuha ekta hda, qa wanyaka wo, niho kin nawahon qa niite kin ihawa kta.

36 Unkan Abigail Nabal ekta hdi, unkan inyun ti kin ohna wohanpi tanka yuha, wicaśta yatapi wohanpi tawa kin iyececa, qa Nabal cante kin waśte, qa witkohinca. Unkan winyaul kin ihanhanna anpa kin hehanyan wicoie cistinna, qa tanka unmanna okiyake śni.

37 Qa ihanhanna miniśa Nabal etanhan iyaye ceehan tawicu kin wicoie kin hena okiyaka. Unkan iye mahen cante kin kițe, qa inyan wan iyececa.

38 Unkan ohakam anpetu wikcemna cetu Jehowa Nabal kaśtaka: unkan ta,

39 Unkan Nabal te cin he Dawid nahon, qa heya, Jehowa yawaśtepi nunwe; i en iyemayanpi woakinice iye Nabal kici akinica, qa taokiye taku śica etanhan anapta, qa Jehowa Nabal tohan śice cin pa kin en hdi kiya. Unkan Dawid Abigail wahoya, tawicu kta e yuze kta.

40 Unkan Dawid taokiye kin Kiarmel heciya Abigail ekta ipi, qa okiyakapi qa heyapi, Dawid tawicu on niyuze kta e niye ekta unkuśipi ce. 
41 Unkan najin qa patuja, ite kin maka ekta kiya, qa heya, Wicinyanna nitawa kin he miye, mayuha taokiye sihapi kin wicakiciyujuja kta e wiyeya manka ce.

42 Qa Abigail inahniyan najin, qa śonśonna akan iyotanka, qa Dawid ohnihde wicaye cin wicihakam ya, hecen tawicu kin hee.

43 Unkan Dawid Ahinoam Jezreel etanhan nakun yuza, qa napin tawicu wicayuha.

44 Unkan Saul iye cunwintku Mikal Dawid tawicu kin Paleti Laiś cinhintku kin qu, iye Gal. lim etanhan $u$.

\section{WICOW OYAKE 26.}

1 Unkan Zipim Saul ekta ipi, Gibeya ekta qa heyapi, David Ḧakila hośkiśki ehna Jeśimon (ن̈ervoskan) wihinanpe cin ektakiya inahbe śni he?

2 Unkan Saul najin qa Zip tinta ekta i, qa Israel wicaśta kahinigapi kektopawinge yamni opapi, qa Zip tinta ohna Dawid akitapi.

3 Qa Saul Hakila hośkiśki ehna ahiti, he Jeśimon iwihinanpe cin ektakiya, canku kin icahda; qa Dawid tinta ohna yanka, qa Saul iye ode u kin iyukcan.

4. Unkan Dawid tonweyapi ye wicaśi, qa Saul awicakehan wanna hi sdonya.

5 Qa Dawid najin, qa Saul ahiti oyanke kin ekta i, qa Saul qa taozuye mdetanhunka Abner. Ner cinhintku kin tukten wankapi kin Dawid wanyaka. Saul wahpayeca ehna wanka, qa ihdukśan oyate kin wankapi.

6 Unkan Dawid ie ca Ahimelek Ḧiti kin, qa Abiśai 'I'zeruja cinhintku Joab cincu kin hewicakiya, Saul ekta ahitipi en tuwe mici ye kta he? Unkan Abiśai heya, Miye nici mde kta ce.

7 Unkan Dawid qa Abiśai hanyen oyate kin ekta ipi. Unkan inyun Saul walipayeca ehna makata iśtima wanka, qa wahukeza tawa maka en pasdan han, pa kin ikiyedan, qa oyate kin ihdukśan wankapi.

8 Unkan Abiśai Dawid heciya, Nakaha Wakantanka tuwe tokaniye cin ninape en niçu, heon dehan tokin wancadan wahukeza on maka ekta cawape kten, qa inonpa awape kte śni.

9 Unkan Dawid Abiśai heciya, Ihnuhan yakte kin, Jehowa sdakiye cin tuwe nape kin apaha kinhan iyaonpe pica śni un kta he?

10 Nakun Dawid heya, Jehowa ni kinhan Jehowa he kaśtake kta, qa anpetu en te k te cin iyohi kta, qaiś wokicize en ye kta qa ihangyapi kta.

11 Tuka Jehowa sdakiye cin ekta nape yewakiye kte cin Jehowa iyomaki śni nunwe. Tuka iho wahukeza pa kin icalıda yanke cin, qa minikoka kin icu wo, qa unhde kta.

12 Hecen Dawid wahukeza, qa minikoka kin Saul pa kin etanhan icu, qa toki iyayapi. Unkan tuwedan wanyake śni; qa sdonye śni, qa kikta śni ; tuka owasin iśtimapi; woiśtima tanka Jelıowa ahinhpe wicaya nakaś.

13 Unkan Dawid hetanhan iyaye ca itehanyan he paha wan iyahan, wiciyotahedan makoce ota;

14 Qa Dawid oyate kin, qa Abner Ner cinhintku wicakipan, qa heya, Abner Ner cinhintku amayadupte śni he? Unkan Abner ay,upte ça, Wicaśta yatapi yakipan kin nituwe he? eya.

15 Unkan Dawid Abner heciya, Wicaśta henica śni he? qa Israel 


\section{SAMUEL TOKAHEYA,}

ohna tuwedan iyeniceca śni, qa tokeca wicaśta yatapi niyuhe cin awandake śni he? Oyate etanhan wicaśta wan wicaśta yatapi itancan nitawa kte kta e ekta i.

16 Taku ecanonpi kin de waśte śni. Niyuhapi kin Jehowa sdakiye cin awandakapi śni; heon Jehowa ni kinhan nițapi kta iyececa, qa wanna wicaśta yatapi wahukeza tawa, qa minikoka pa kin ekta yanke ciqon iwanyaka wo.

17 Unkan Saul Dawid ho kin iyekiye ca heya, Dawid micinkśi niho kin hee he? Unkan, Wicaśta yatapi mayuha maho kin hee ce, Dawid eya.

$18 \mathrm{Qa}$ itancan tokeca nitaokiye decen yakuwa he? Taku ecamon he? qa minape ohna taku śica tukte e he?

19 Qa wanna itancan ceciciya wicaśta yatapi kin taokiye oie kin nahon ye. Jehowa mayakuwa kta iyonipaśtake cinhan minha izite wan orma kte. Tuka Adam cinca kin heconpi kinhan, Jehowa itokam hena yaśicapi ce, nakaha Jehowa tamakoce kin owati kta etanhan nape mayanpi qa, Hunktiya taku wakan tokeca ohoda wo, eyapi kin heon etanhan.

20 Qa wanna Jehowa itokapa tanhan mawe kin makata hinhpaye kte śni nunwe. Israel wicaśta yatapi kin ha wanji akin u ce, he kin ohna śiyo wanjidan kuwa he iyececa,

21 Unkan Saul heya, Wawalitani ce. Micinkśi Dawid en hdi wo. Icimana taku sica ecacicon kte śni; nakaha niiśta en minagoi tehika nakaś. Inyun witkotkoya owahianmda, qa ecinśniyan hinca ecamon.

22 Unkan Dawid ayupte ça heya, Wanyaka wo, wicaśta yatapi tawahukeza hokśipidan wanji deciya hiyu, qa he icu kte.

23 Qa Jehowa otoiyohi toowòtanna," qa towicake kin iyecen ecakicon kte. Jehowa nakaha minape en nicu, tuka tuwe Jehowa sdakiye cin nape awapaha kta tawatenwaye śni.

$24 \mathrm{Qa}$ ito miiśta en ninag̉i kin tanka, he iyecen Jehowa iśta en minaği tanka kte, qa iye minaġi kin woiyokiśice owasin etanhan yuśke kta.

25 Unkan Saul Dawid heciya, Micinkśi Dawid niyawaśtepi ce, woecon tanka ecanon kta, qa ohinniyan ohiyaye kta. Unkan Dawid canku kin ohna iyaya, qa Saul oyanke tawa ekta hda.

\section{WICOWOYAKE 27.}

1 Unkan Dawid cante mahen heya, Tohantu kaśta anpetu wanji en Saul nape kin on ihang mayanpi kta; Pilistim makoce ekta nawajice ca nimiçiye cin he waśte śni he? Hecen Saul icimana Israel makoce kin owancaya amakite kte śni, qa nape kin etanhan nimiciye kta.

2 Qa Dawid najin, qa wicaśta opawing่e śakpe opápi kin hena om, Akiś Mayok cinhintku, Gat wicaśta yatapi kin ekta i.

3 Qa Dawid qa wicaśta tawa nakun Gat ohna iyotankapi, wicaśta iyohi tatiohnaka kici; qa Dawid qa tawicu napin, Alinoyam Jezrelitiwin, qa Abigail Karmeliti Nabal tawicu qon.

4 Unkan Dawid Gat ekta najice cin Saul okiyakapi, heon icimana akite śni.

5 Unkan Dawid Akiś heciya, Tokin niiśta en woiyokipi iyewaye cinhan, tinta otonwe cistinna wan ohna oyanke maqupi kten, qa hen imdotanke kten. Tokeca 
wicaśta yatapi totonwe ohna nitackiye nici yanke kta he?

6 Unkan anpetu kin lie en Akiś Tziqlag qu, heon Juda wicaśta yatapi kin anpetu kin dehanyan "Tziqlag yuhapi.

7 Unkan anpetu Dawid Pilistim makoce ohna yanke cin yawapi kin omaka nonpa qa wi topa anpetu iyenaka.

8 Unkan Dawid qa wicaśta tawa iyayapi, qa Geśuri kin, qa Gerezi kin, qa Amaleqi kin anawicatanpi. Hena ehanna makoce Sur ekta de cin, Egupta ma. koce kin hehanyan ounyanpi.

9 Qa Dawid makoce ounyanpi kin kaśtaka, qa wicaśta qa winohinca unmanna nikiye śni, qa tahinca, qa pte, qa śonśonna, qa camo, qa wokoyake kin Dawid icu, qa hdicu, qa Akiś ekta hdi.

10 Unkan Akiś heya, Nakaha toki omayani he? Unkan Dawid heya, Juda itokaga kin, qa Jerahmeli itokaga kin, qa Qeni kin itokagia kin ekta.

11 Qa Dawid wica, qa winyan unmana niyake Gat ekta hiyuye śni, tuka heya, Okini unkiyepi caje unyatapi $\mathrm{kta}$, qa Dawid decen econ, qa tohan Pilistim tamakocepi kin en ounye cin hehanyan he iyecen econ kta.

12 Unkan Akiś Dawid wicada, qa heya, Oyate tawa Israel nina iśten wicaya, heon ookiye owihanke wanin mduhe kta.

\section{WICOWOYAKE 28.}

1 Unkan anpetu kin hena en Pilistim ozuye kagapi, qa Israel kizapi kta e obe hduwitayapi, qa Akiś Dawid heciya, Niye sdonya wo, wokicize ekta mici de kta, niye qa wicaśta nitawa nakun.

2 Unkan Dawid Akiś heciya, Hecen nitaokiye taku econ kta sdonyaye kta. Unkan Akiš Dawid heciya, Hecen mapa ohinniyan awanmiyecida kte cin ciyuhe kta.

3 Wanna. Samuel te, qa Israel owasin aceyapi, qa otonwe tawa Rama ohna hnakapi qon. Unkan Saul tona wapiyapi, qa tona hanmdepi kin owasin, makoce kin etanhan, tokan iyaye wicaya.

4. Unkan Pilistim mniciyapi, qa upi, qa Śnnem en ahitipi; qa Saul Israel owasin mniciye wicaya, qa Gilboya en etipi.

5 Qa Saul Pilistim obe kin wanwicayake ca kokipa, qa cante kin nina cancan.

6 Qa Saul Jehowa iwanga tuka Jehowa wihanmnanpi kin, qa iyoyam wicaye cin, qa wa yatapi kin unmanna eciya tanhan ayupte śni.

$7 \mathrm{Qa}$ Saul taokiye hewicakiya, Winohinca hanmdohdag ia okihi wan amicicitapo; kinhan ekta mde qa he eciya tanhan imonge kta. Unkan taokiye heciyapi, Inyun winohinca wan hanmdohdag ia Endor ohna yanka.

8 Unkan Saul ibdutokeca, qa wokoyake tokeca koyay ye ça iyaya, qa wicaśta nonpa opapi, qa hanyen winohinca kin ekta ipi, qa heciya, Tokin miye on hanmdohdag iyae ça tuwe cajemdate'wankan hiyu miyeciciye kten.

9 Unkan winohinca kin heciya, Inyun niye taku Saul econ kin sdonyaya, token tona hanmdepi kin, ga wapiyapi kin wicakaśpe makoce kin etanhan, heon tokeca niye te mayaupi kta $e$ minagi kin yahmunka he?

10 Unkan Saul Jehowa cajeyan konze ca heya, Jehowa ni kinhan wicoie kin de-on taku śica anicipe kte śni.

11 Unkan winohinca kin heci433 
ya, Tuwe wankan hiyu ciciye kta he? Unkan Samuel wankan hiyu miciciya wo, eya.

12 Unkan winohinca kin Samuel wanyake ça hotanka on śicahowaya, qa Tokeca mayahnayan he? Saul he niye ye, eya.

13 Unkan wicaśta yatapi kin heciya, Ihnuhan wakoyakipe cin, taku wandaka he? Unkan winohinca kin Saul heciya, Taku wakan, maka etanhan hinanpa wanmidaka ye.

14. Unkan heciya, Owanyake kin toketu he? Unkan Wicahinca wan wankan hiyu, qa śina hdowin ye eya. Unkan Saul Samuel hee, sdonya, qa ite kin maka ektakiya patuja, qa ohoda.

15 Unkan Samuel Saul heciya, Tokeca wankan wahihbu kta e mayaduhica he? Unkan Taku iyotan tehika amakipa, Pilistim makizapi, qa Wakantanka amayuśtan, qa waayatapi qa wihanmnapi unmana on amayupte śni; heon cicipan, taku ecamon kta sdonye mayakiye kta, heon etanhan.

16 Unkan Samuel heya. Jehowa aniyuśtan, qa toka niye cinhan, tokeca miye imayanongia he?

17 Jehowa, token minape on eye ciqon iyecell, ecanicon $\mathrm{kta}$, wokiconze $\mathrm{kin}$, ninape etanhan yuśpe kta, qa nitawaśi kin Dawid he qu kta.

18 Jehowa ho kin nayahon śni, qa tośinhda kin Ameleq en ecayecon śni, heon wicoie kin de ecanicon.

19 Qa Jehowa niye kici Israel Pilistim napepi en wicaqu kta, qa heyakecinhan niye qa nicinca rakun miciunpi kta, nakun Jehowa Israel owanka kin Pilistim napepi en qu kta.

20 Unkan Saul ihnuhanna makata hinhpaya, tohanske cin oco- wasin, qa Samuel oie kin nina kokipe ça wowaśake nica ; anpetu osan, qa hanyetu osan woyute takudan yute śni nakaś.

21 Unkan winolinca kin Saul ekta i, qa nina yuśinyaye cin wanyaka, qa heciya, Tho nitaokiyewin niho kin anaggoptan, qa minagi minape en iwekcu, qa nioie emayakiye cin nawalion ye. 22 Heon wanna niye nakun nitaokiye win ho kin nahon ye; hecen ag̉uyapi onśpa nitokam ewehnake kta, qa yuta ye, hecen wowaśake duhe kta, on toki de cin idade kta ye.

23 Tuka wicada śni, qa, Wawate kte śni eya. Tuka taokiye, qa winohinca koya iyopaśtakapi ; unkan hopi kin nahon, qa maka kin etanhan najin, qa owinja akan iy otanka.

24. Unkan winohinca kin ptejicadan cepa wan, tipi ohna hduha, qa inahni, qa pata. Nakun aguyapi mdu icu qa paținza, qa ağuyapi hmiyanyanna śpan kiciya ;

$25 \mathrm{Qa}$ Saul qa taokiye itokam ehnaka. Unkan yutapi, qa najinpi, qa hanyetu kin he en iyayapi.

\section{WICOWOYAKE 29.}

1 Unkan Pilistim obe kin owasin hduwitayapi, Apeq ekta, qa Israel wakoniya Jezreel ohna yanke cin ekta ahitipi.

2. Unkan Pilistim itancanpi kin opawingege om, qa kektopawingege om iyayapi ; Unkan Dawid qa wicaśta tawa wicihakam iyayapi, Akiś kici.

3 Unkan Pilistim itancanpi kin heyapi, Heberi kin dena tuwepi he? Unkan Akiś Pilistim itancanpi kin hewicakiya, Dawid Saul Israel wicaśta yatapi taokiye dee. śni he? anpetu ota qaiś 


\section{WICOWOYAKE 30.}

omaka kin dena mici un, qa en mahi kin ehantanhan anpetu kin dehanyan, śicaya econ kin takudan iyewaye śni.

4 Unkan Pilistim itancanpi kin canniyeyapi, qa Pilistim itancanpi kin heciyapi. Wicaśta kin de kihde śi wo; oyanke yaqu kin ekta hde kta, qa unkiyepi kici wokicize ekta ye kte śni, qa wokicize en toka unyanpi kte śni. Taki on itancan tawa iyokipiye kta he? Wicaśta kin dena papi kin on hee śni he?

5 Iwakicipi en dowanpi, qa Saul kektopawinge ota kin kaśtaka, qa Dawid kektopawinge wikcemna ota kin, ekiciyapi kin Dawid kin dee śni he?

6 Unkan Akiś Dawid kipan qa heciya, Jehowa namakion ohan oniwotanna, qa wicoti ohna tankan idade cin, qa yahdi kin niwaśte miiśta en. Ekta mayahi kin ehantanhan, anpetu kin dehanyan niye en taku śica iyewaye śni ; tuka itancanpi iśtapi kin en niwaśte śni.

7 Heon wanna wookiye yuha iyaye ça ekta hda wo; qa Pilistim itancanpi iśtapi kin en taku sica econ śni wo.

8 Unkan Dawid Akis heciya, Tuka taku ecamon he? qa anpetu nici waun kin ehantanhan, dehanyan nitaokiye en taku iyeyaya on mayuhe cin wicaśta yatapi tolrayapi wicawakize kta e ekta mde kte śni he?

9 Unkan Akiś ayupte ca Dawid heciya, Miiśta en niwaśte, Wakantanka ohnihdeye cin iyeniceca sdonwaya. Hececa eśta Pilistim itancanpi kin heyapi, Wokicize ekta unkiyepi om ye kte śni.

10 Heon hanhannahin kikta wo, qa niyuha taokiye nicihipi kin hena wicaduhica kta, heyakecinhan anpao kinhan kihdapo.
11 Unkan Dawid qa wicaśta tawa Pilistim tamakocepi kin ekta hdapi kta e hanhanna hin kiktapi. Unkan Pilistim Jezreel ek ta ipi.

\section{WICOWOYAKE 30.}

1 Unkan anpetu iyamni en Dawid, qa wicaśta tawa Tziqlag ekta kipi qehan, Amaleqi kin itokaga makoce kin, qa Tziqlag anatanpi ; qa Tziqlag apapi, qa peta on hulnahyapi.

2 Qa winohinca ohna yakonpi kin wayaka iwicacupi, tuwedan țe yapi śni, cistinna, qa tanka unmana tuka wayaka iwicacupi, qa akiyahdapi.

3 Unkan Dawid, qa wicaśta tawa otonwe ekta hdipi qehan, inyun peta on wanna huhnahyapi, qa tawicupi, qa cincapi wica winyan koya wayaka eyayapi.

4. Unkan Dawid qa oyate iye opapi kin ho yeyapi, qa ceyapi, ecen ceyapi kta wowaśake nicapi.

5 Nakun Dawid tawicu napin Ahinoyam Jezreelitiwin, qa Abigail Nabal Karmeliti kin tawicu qon wayaka eyayapi.

6 Qa Dawid iyotanhan iyekiya un, oyate inyan on kininpi kta keyapi; Oyate kin owasin nina canteśicapi, otoiyohi cinca wica winyan koya on, nakaś. Tuka Dawid taku wakanda Jehowa en waśag içiya.

7 Unkan Dawid Abiatar wawayuśna kin Ahimelek cinhintku kin heciya. Amdo akahpe kin hduha deciya kuwa wo. Unkan Abiatar amdo akahpe kin hduha Dawid ekta hi.

8 Unkan Dawid Jehowa iwanga, qa heya, Ozuye kin de kuwa mde kta he? wakihdege kta he? Unkan heciya, Kuwa ya wo, kin435 


\section{SAMUEL TOKAHEYA,}

han awicakehan yákihdeg̀e kta, qa taku kipi kin eyahdaku kta.

9 Unkan Dawid qa wicaśta opawinge śakpe, iye opapi kin, iyayapi, qa Besor wakpa kin ekta ipi, qa tona elipeya iyayapi kin hen yankapi.

10 Tuka Dawid, qa wicaśta opawinge topa kuwa iyayapi, qa wicaśta opawing go nonpa hustakapi, on Besor walkpa kin iyuwegapi olsitpanipi kin hen yakonpi.

11 Unkan Egupta wicaśta wan tinta ohna iyeyapi, qa Dawid ekta aupi, qa ağuyapi qupi, unkan yuta, qa mini yatke kiyapi.

12 Nakun suken pasutapi on'śpa, qa hastanhanka pusyapi iyage nonpa qupi. Unkan yuta, qa toniya kin hdi; wanna anpetu yamni, qa hanyetu yamni ağuyapi yute śni, qa mini onġedan yatke śni.

13 Unkan Dawid heciya; Tuwe tawa niyan he? qa tokiya tanhan yau he? Unkan, Egupton hokśidan hemaca, qa Amaleqi wicaśta wan wowidag mayan, qa hitanihan sanpa wayazan wahda kin, heon mayuha ehpemayan.

14 Kereti itokagga kin, qa Juda taku tawa kin, qa Kaleb itokaga kin, azuunyanpi, qa 'Tziqlag peta on hulina'h unyanpi, eya.

15 Unkan Dawid heciya, Ozuye kin de ekta amayade kta oyakihi he? Unkan Taku wakan cajeyan maya kte kte śni, qa mayuhe cin nape kin en mayaqu kte śni, hemayakiye cinhan, ozuye kin de ekta aciye kta.

16 Unkan ekta ai qehan, inyun maka ite akan enanakiya wankapi, wotapi qa wayatkanpi, qa woyuha tanka Pilistim tamakocepi etanhan, qa Juda tamakoce etanhan icupi kin on. Wohanpi kağapi.
17 Unkan Dawid wicakaśtaka, anpao etanhan ecen ihanlianna htayetu kin hehänyan. Unkan tuwedan niiciye śni; kośka opawinge topa camo akan iyotankapi, qa najicapi henana.

18 Unkan taku Amaleqi kipi kin owasin Dawid ehdaku, nakun Dawid tawicu napin ewicahdaku.

19 Unkan takudan tokawicakihon śni, cistinna, qa tanka, qa cinca wica, qa winyan, qa woyuha; hecen taku Amaleqi icupi qon owasin Dawid hdohda.

20 Qa tahinca, qa pte kin wanunyanpi tawapi itokam kahapapi kin hena owasin Dawid icu, qa Dawid tawahpayeca kin deo eyapi.

21 Unkan wicaśta opawinğe nonpa hustakapi on Dawid opapi śni, qa Besor wakpa ekta yanke wicaśi kin, hena ekta Dawid hdi. Unkan Dawid qa oyate opapi kin itkowicaki papi kta inanpapi. Unkan Dawid oyate wicikiyedan hi qehan, tanyan unpi hecinhan iwicawanga.

22. Hehan wicaśta śica, qa wicaśtapi śni Dawid opapi kin owasin heyapi, Unkiyepi om ipi śni, heon woyuha unkicupi kin etanhan wicunqupi kte śni, tuka wicaśta otoiyohi tawicu kin, qa cinhintku kin, hena icupi kinhan toki cinpi yapi kta.

23 Unkan Dawid heya, Mihunkawanji hecen ecanonpi kte śni. Jehowa taku kin de uriqupi, qa niunyanpi, qa ozuye anauntanpi kin unnapepi en unqupi.

24 Heon wicoie kin de tuwe nanilionpi kta he? Tuwe, wokicize ekta i tawopamni kin, he iyecen, tuwe wahpayeca kin kici yanke cin tawopamni kta, iyakidecen olinipi kta.

25 Unkan anpetu kin he etanhan, qa ohakam dehanyan, Is- 
rael wokagie qa woyaco kin he yuhapi.

26 Unkan Dawid Triqlag ekta hdi, qa taku kipi kin etanhan Juda hunkayapi koda wicaye cin ekta aye wicaśi, qa hewicakiya. Hopo Jehowa tokayapi etanhan woyuha icupi kin woyawaśte kin de nicupi.

27 Tona. Betel obna yakonpi, qa Ramot (Hośkiśki) itokag̉a en unpi, qa Jatir: en unpi,

28. Qa Aroyer en yakonpi, qa Sipmot en yalronpi, qa Eśtemoya en yakonpi,

29 Qa Rakal en yakonpi, qa Jerahmeli tonwanyanpi en yakonpi, qa Qeni tonwanyanpi en yakonpi, 30 Qa Ḧorma en yakonpi, qa Korasan en yakonpi kin,

$31 \mathrm{Qa}$ Ḣebron en yakonpi kin; Oyanke tona Dawid qa wicaśta tawa ekta ipisa, hena owasin taku wicaqu.

\section{WICOWOYAKE 31.}

1 Wanna Pilistim Israel kizapi; unkan Israel wicaśta kin napapi, Pilistim itokapa tanhan, qa Gilboya he akan capapi hinhpayapi. 2 Unkan Pilistim Saul, qa iye cinca kin wicakihdegapi, qa Pilistim Saul cinca kin Jonatan, qa Abinadab qa Melekiśuya wicaktepi.

3. Qa Saul nina kizapi, qa itazipa yuhapi kin iyeyapi; unkan itazipa wicaśta on nina cancan.

4 Qa Saul tawipe kiciçin kin heciya, Isan hduśdoka, qa camapa wo. Okini wicaśta bakiñdayapi śni kin dena en mahipi, qa camapapi, qa makiyuśepi kta. Tuka tawipe kicicin kin wicada śnj, nina kokipa nakaś, heon Saul isan kin icu qa ahinhpaya.

5 Unkan tawipe kicicin kin Saul wanna te cin wanyaka, heon iś eya taisan kin ahinhpaya, hecen sakim țapi.

6 Hecen Saul, qa cinhintku yamni, qa tawipe kicicin kin țapi; nakun wicaśta tawa owasin anpetu kin he en witaya tapi.

7 Unkan Israel wicaśta osmaka akasanpa yakonpi, qa Jordan akasanpa yakonpi kin Israel wicaśta napapi kin wanyakapi, qa nakun Saul, qa iye cinca tapi kin, heon tonwanyanpi kin ayuśtarıpi, qa napapi. Unkan Pilistim en hipi qa hena ohna iyotankapi.

8 Unkan ihanhanna Pilistim tapi kin heyakepi yuśdokapi k̇ta hipi qehan, Saul qa cinhintku yamni Gilboya he akan tapi iyewicayapi.

9 Qa pa kin baksapi, qa tawipe icupi, qa Pilistim makoce ekta yeyapi, qa tawakagiapi tipi ekta, qa oyate ehna yuotaninpi kta e tipi iyaza ayapi.

10 Qa tawipe kin Aśtarot ti kin ohna ehnakapi, qa tancan kin Betśan otonwe conkaśke akan okatanpi.

11 Unkan Jabeś Gileyad otipi kin Pilistim Saul taku ecakiconpi kin nahonpi qehan.

12 Wicaśta waditaka owasin najinpi, qa hanyetu osan manipi; qa Saul tancan kin, qa cinhintku tancanpi kin Betśan conkaśke etanhan icupi, qa Jabeś ekta ahdapi, qa hen huhnahyapi.

13 Qa huhupi kin icupi, qa contanka Jabeś ohna wanke cin ihukuya hnakapi, qa anpetu śakowin wote śni unpi. 


\section{SAMUEL WOWAPI INONPA KIN.}

WICOWOYAKE 1.

1 Unkan Saul te cin iyohakam Dawid Amaleq kaśtake cin etanhan hdi qehan, anpetu nonpa Tziqlag ohna yanka.

2 Unkan anpetu iyamni qeban inyun wicaśta wan ozuye kin Saul etanhan hiyu qa taheyake yuhdehdecapi, qa pa kin akan maka ahdada yukan, qa Dawid ekta hi qehan patuja, qa makipusdiya ehpeiciya.

3 Unkan Dawid heciya; Tokiya tanhan yau he? Unkan heciya, Israel ozuye kin etanhan nawajica ce.

4 Unkan Dawid heciya, He toketu? tokin omayakidaken. Unkan heya; Oyate kin wokicize etanhan napapi, qa nakun oyate etanhan wicota hinhpayapi, qa țapi, qa nakun Saul, qa cinhintku Jonatan tapi ce.

5 Unkan Dawid kośka okiyake cin heciya, Saul qa cinhintku Jonatan țapi kin token sdonyaya he?

6 Unkan koślka okiyake cin heya, Wanun Gilboa he akan omawani, qa inyun Saul wahukeza akan kpatuja, qa inyun canpahmihma, qa suktanka akanyotankapi indetanhunkapi kin kuwapi.

7 Unkan ihdamna qa. wanmayake ça, makipan, unkan he miye epa.

8 Unkan nituwe he, emakiya. Unkan Amaleqi hemaca, ewakiya.

9 Uunkan hemakiya, Anamajin, qa makte wo; itomahomni, qa minagi kin ocowasin nahanhin en maun; heon etanhan.

10 Unkan anawajin, qa tewaya. Hinhpaye cin ohakam ni kte śni sdonwaya, heon hecamon, qa wateśdake pa kin akan un kin, qa maza huhu isto akan un kin iwacu, qa hena deciya itancan cicahi.

11 Unkan Dawid wokoyake hduze ca hdulidelideca, qa wicaśta kici unpi kin owasin nakun heconpi.

12 Qa aicipapi qa ceyapi, Saul qa cinhintku Jonatan on, qa Jehowa taoyate, qa Israel tiyohnaka owasin canhipi on wicaktepi heon, qa hitayetu kin hehanyan wotapi śni.

13 Unkan Dawid kośka okiyake cin heciya, Nitokiya tanhan he? Unkan heya, Oyate tokeca cinca Amaleqi wicaśta hemaca.

14 Unkan Dawid heciya, Tokeca tuwe Jehowa sdakiye cin ihangye kta e nape ye yakiye kta koyakipe śni he?

15 Qa Dawid kośka wanji kipan qa heciya, Ikiyedan ya, qa kaśtaka wo. Unkan he kaśtake : Inkan te.

16 Wanna Dawid heciya, Niwe kin nipa akan un nunwe, Jehowa sdakiye cin he wakte ce, ni i kin eye ca aniyatanin.

17 Hehan Dawid Saul qa cinhintku Jonatan woceye_odowan kin de on awicakiceya.

18 Qa heya, Juda cinca kin itazipa odowan onspewicakiyapi kta : ito Jaśar (Ecetu) wowapi kin en owapi ce:

\section{Sam. 438}




\section{WICOWOYARE 2.}

19 Israel tatokadan nitawa pajodan nitawa akan ktepi ce. Hehehe wicaśta waśaka hinhpayapi ce.

20 Ihnuhan Gat ohna odakapi kin. Ihnuhan Aśqelon canku ohna wootanin odakapi kin; Okini Pilistim cunwintkupi kin iyuśkinpi kta. Okini bakihdayapi śni cunwintkupi pidaya dowanpi lita.

21 Gilboa he kin anicu śni qa animağaju śni nunwe. Qa mag̣a wośnapi wanica nunwe. Heciya wicaśta waśaka wahacanka ehpekiyapi. Saul wahacanka tawa kin wihdi on sdayapi śni iyececa. 22 Wicaktepi we kin etanhan, waśakśakapi śin kin etanhan Jonatan tinazipe kin hektam hiyu śni, qa Saul taisan cokadan hdi śni.

23 Saul qa Jonatan nipi qehan waśte wicadakapi, qa wiciyokipipi, qa tapi kin en yukinukanpi śni. Wanmdi isanpa duzahanpi, mnaja isanpa waśakapi.

24 Israel cunwintkupi kin Saul akiceyapo. Iye wokoyake duta taku wiciyolkipi kici ikoyag niyanpi. Heyake nitawapi akan mazaskazi oinpi ikoyag niyanpi.

25 Hehehe, wicaśta waśaka wokicize cokaya hinhpayapi ce. Jonatan pajodan nitawa akan niktepi ce.

26 Cinye Jonatan niye on iyomakiśica. Ninahin iyokipi mayaya. Winohinca waśte wicadakapi isanpa nina waśte maya. daka.

27 Hehehe wicaśta waśaka hinhpayapi. Qa wokicize wipe kin atakunipi śni.

\section{WICOWOYAKE 2.}

1 Unkan hena iyohakam Dawid Jehowa iwanğe ça heya, Juda otonwe wan ekta itanwankanhde wahde kta he? Unkan Jehowa heciya; Itanwankanhde hda wo. Unkan Dawid heya; Tukten itanwankanhde wahde kta. Unkan, Ḧebron ekta, eya.

2 Unkan Dawid heciya i, nakun tawicu napin, Ahinoyam Jezreeliwin kin, qa Abigail Nabal Karmeli kin tawicu qon.

$3 \mathrm{Qa}$ Dawid wicaśta iye opapi kin hena ope wicaśi, otoiyohi tiyohnaka om, qa Hebron otonwe ohna iyotankapi.

4 Unkan Juda wicaśta kin ekta hipi, qa hen Dawid sdayapi, Juda tiyohnaka iwankam wicaśtayatapi kta. Unkan Dawid okiyakapi qa heyapi, Jabeś Gileyad. wicaśta kin Saul hnaliapi kin heepi.

5 Unkan Dawid Jabeś Gileyad wicaśta kin ekta ohnihde ye wicaśi, qa hewicakiya, Saul itancan nitawapi wowacantkiya ecayeconpi, qa yahnakapi kin heon Jehowa niyawaśtepi ce.

6 Heon wanna Jehowa wowacantkiye, qa wowicake ecaniconpi kta, qa miśs eya taku kin de ecanonpi kin heon taku waśte ecaciconpi kta.

7 Heon wanna ninapepi wakiśakapo, qa waditakapi cincapi kin iyecen econpo. Saul itancan nitawapi kin wanna te, qa miye Juda tiyohnaka kin wanna atemayanpi kta e sdamayanpi co.

8 Unkan Abner Ner cinhintkn kin Saul ozuye tawa mdetanhunka kin Iśbośet Saul cinhintku kin icu, qa Mahanaim ekta iyuwehya.

3 Qa Gileyad on wicaśtayatapi kağa, qa nakun Aśuri kin on, qa Jezreyel on, qa Epraim on, qa Benjamin on, qa Israel owasin on. 10 Iśbośet Saul cinhintku kin waniyetu wikcemna topa qehan 


\section{SAMUEL WOWAPI INONPA KIN,}

Israel wicaśtayatapi kagapi, qa waniyetu nonpa hehanyan wicaśtayatapi. Tuka Juda tiyohnaka kin Dawid opapi.

11 Unkan Dawid Ḧebron ohna, Juda tiyohnaka iwankam wicaśtayatapi heca, anpetu yawapi kin waniyetu śakowin sanpa wi śakpe.

12 Unkan Abner Ner cinhintku, qa Saul cinhintku Iśbośet trokiye Mahanaim etanhan iyayapi Gibeyon ekta.

13 Unkan Joab Tzeruja cinhintku, qa Dawid taokiye iyayapi, qa Gibeyon mdedan ekta itkowicakipapi, qa hen iyotankapi, dena indedan kin itato, qa unman mdedan akotanhan.

14 Unkan Abner Joab heciya. to hokśipidan najinpi, qa unkiyepi itokam śkatapi kte. Unkan, Najinpi kta, Joab eya.

15 Unkan Benjamin on, Iśbośet Saul cinhintku on wicaśta wikcemna sanpa nonpa wicayawapi najinpi, qa iyayapi; Unkan Dawid taokiye etanhan. wikcemna sanpa nonpa.

16 Qa otoiyohì tuwe itkokim u kin pa kin yuze ca cuwi kin en isan capa; hecen sakim hinhpayapi. Unkan oyanke kin he Helqat Hatzurim (Isan Tamaga) eciyapi, he Gibeyon ohna yanka.

17 Unkan anpetu kin he wokicize nina tehika, qa Abner, qa Israel wicaśta kin Dawid taokiye kin nakicipapi.

18 Unkan Tzeruja cinca yamni Joab, qa Abiśai, qa Yasahel heciya unpi, qa Yasahel siba kin kapoja, tatokadan tinta ohna yakonpi kin iyecen duzahan.

19 Unkan Yasahel Abner kuwa, qa Abner ihakam ye cin etanhan etapa qa catka unmana ekta ihduwinge śni.

20 Unkan Abner ihdamna, ga, 440
Yasahel he niye he? eya. Unkan, He miye eya.

21 Unkan Abner heciya, Ihduwinga etapa tanhan, qaiś catka tanhan, qa kośkapi etanhan wanji iyahpaya, qa tawipe icu. Tuka Yasahel he kuwa etanhan induwinġa wicada śni.

22 Unkan Abner ake Yasahel heciya : Miye etanhan ihduwing்a wo. Tokeca makata cicaśtake kta he? Hecinhan token nicinye Joab ekta ewatonwe kta he?

23 Tuka ihduwinga wicada śni, heon Abner hektam wahukeza on tezj ekta capa, on wahukeza iyoopta inanpa. Unkan hen hinhipaye ça yanke cin ekta ta. Unkan tona Yasahel hinhpaye ca te cin ekta hipi kin, hena owasin en najinpi.

24. Unkan Joab, qa Abiśai, Abner kuwapi ; qa wi iyaya, Anma paha ekta ipi qehan, he Giah iyotakonza, Gibeyon tinta canku iyahde icahda.

25 Unkan Benjamin cinca kin ihduwitayapi; Abner ihakam, optaye wanjidan, qa paha wanjidan akan owanji najinpi.

26 Unkan Abner Joab kipan qa heciya, Isan kin ohinniyan wayusote kta he? Ohakam pa hince kta sdonyaye śni he? 'Tohanyan oyate kin hunkawanji wicayapi kuwapi kin. etanhan ihdamna wicayaśi kte śni he?

27 Unkan Joab heya, Wakantanka ni kinhan, niye iyae śni unkanś nakaha hanhanna oyate kin hunkawanji wicayapi kuwapi etanhan kihdapi kte ciqon tukia.

28 Unkan Joab heyahoton wan yahoton; unkan oyate kin owasin enakiyapi, qa sampa Israel kuwapi śni, qa sanpa wicakizapi śni.

29 Unkan Abner qa wicaśta 


\section{WICOWOYAKE 3.}

tawa hanyetu osan manipi, Araba ohna, qa Jordan iyuw eğapi, qa maya kaksiza kin ihunnipi qa Mahanaim ekta kipi.

30 Unkan Joab A bner kuwa kin etanhan kihda, qa oyate owasin wicayuwitaya; unkan Dawid taokiye etanhan Yasahel, qa wicaśta wikcemna sanpa napcinwanka en unpi śni.

31 Unkan Dawid taokiye Benjamin etanhan, qa. Abner tawicaśta etanhan wicaśta opawinge yamni sanpa wikcemna śakpe apapi qa wicaktepi.

32 Qa Yasahel akiyıhapi, qa atkuku ohnahnakapi tawa kin Betlehem en yanke cin he ohna hnakapi. Unkan Joab qa wicasta tawa hanyetu osan manipi, qa anpao hehan $\dot{H}$ ebron en hdipi.

\section{WICOWOYAKE 3 .}

1 Unkan Saul tiyohnaka kin, qa Dawid tiyohnaka otahedan tehan wokicize yukan, tuka Dawid ohinniyan waśaka aya, qa Saul riyohnaka kin ohinniyan wasake śni aya ece.

2 Unkan Hebron ohna Dawid cinca kicitonpi, qa tokapa kin Amnon ee, Ahinoyam Jezreyeliwin cinhintku.

3 Qa inonpa kin Kileab Abigail Nabal Karmeli kin tawicu qon cinhintku, qa iyamni kin Abiśalom, Geśur wicaśtayatapi kin Talma cunwintku Mayaka he cinhintku.

4 Itopa kin Adonija: Hagit cinhintku, qa izaptan kin Śsepatija, Abital cinhintku.

5 Qa iśakpe hin Jitreyam Egla Dawid tawicu kin he cinhintku. Hena Hebron ohna Dawid kicitonpi.

6 Unkan Saul tiyohnaka kin, qa Dawid tiyolnaka kin kicizapi qehan, Saul tiyohnaka waśagye cin; Abner hee.

7 Unkan Saul tawicu wan Ritzpa eciyapi, Aja cunwintku. Unkan Iśbośct Abner heciya, Tokeca ate tawicu kin ekta yai he?

8 Unkan lśbośet oie kin on Abner nina śinhda, qa heya; Śunka wan pa kin hemaca, Juda ektakiya, kecanni he? Miye niyate Saul tiyohnaka kin nakaha cante wakiya, nakun sunka wicaya, qa koda wicaya, qa Dawid nape kin en ye ciye śni, eśta, nakaha winohinca kin de on $\mathrm{i}$ en iyemayaya.

9 Jehowa Dawid eciye cin he iyecen ecawecon śni kinhan, Wakantanka hecen qa nakun de isanpa Abner ecakicon nunwe.

10 Saul tiyohnaka etanhan wokiconze kin tokan ayapi kta; qa Dawid Israel, qa Juda iwankam, Dan etanhan Berśeba ekta hehanyan, wicaśtayatapi sutaya iyotanke kta.

11 Unkan Abner kokipe cin heon wicoie wanjidan eciye kta okihi śni.

12 Unkan Abner wahośi Dawid ekta ye wicaśi iye on, qa heya, Makoce kin tuwe tawa he? wotakuye micicaga wo, kinhan Israel owasin nihukuya upi kta on minape óniciye kta, eya.

13 Unkan heya; Hecen waśte $\mathrm{kta}$, wotakuye cicicage $\mathrm{kta}$; tuka taku wanji cicida. Wanmayag yau kinhan Saul cunwintku Mikal mayakahi kta, hecanon śni kinhan miite kin wandake kte śni.

14 Unkan Dawid wahośi Saul cinhintku Iśbośet ekta ye wicaśi, qa heciya; Mitawin Mikal maqu wo. He Pilistim ceinkpaha opawinge on opewaton.

15 Unkan Iśbośet akicita ye 441 


\section{SAMUEL WOWAPI INONPA KIN,}

wicaśi, qa hihnaku Laiś cinhintku Paltiel etanhan he icu.

16 Unkan hihnaku kin he kici $\mathrm{u}$, Bahurim hehanyan ihakam mani, qa ceya. Unkan Abner heciya, Kihda wo; unkan kihda.

17 Unkan Abner ie ca Israel hunkayapi kin hewicakiya ; Ehanna Dawid ate yayapi kta e yacinpi.

18 Heon wanna hecen econ po. Jehowa Dawid heciya, qa heya; Mitaokiye Dawid nape kin on oyate mitawa Israel niwaye kta, Pilistim napepi kin etanhan, qa toka wicayapi owasin napepi etanhan.

19 Unkan, Abner Benjamin noge nakun ohna ia, qa Abner nakun Hebron ekta ya, taku Israel iśtapi en, qa Benjamin tiyohnaka owaśin iśtapi en waśte kin, he owasin Dawid noge en ie kta heon.

20 Qa Abner Hebron en Dawid ekta hi, qa wicaśta wikcemna nonpa opapi. Unkan Dawid Abner, qa wicaśta iye opapi kin wohanpi wan wicakicağá.

21 Unkan Abner Dawid heciya; Nawajin, qa Israel owasin itancan mitawa wicaśtayatapi kin ekta mniciye wicawaye kta e mde kta, qa wotakuye nicicagapi kta, qa tona ninagi cin kin wiciwawankan wicaśtaniyatapi kta. Unkan Dawid Abner ye śi ; unkan wookiye en kihda.

22 Unkan hehan Dawid tahokśidan qa Joab ozuye wan etanhan woyuha ota hdohdipi. Unkan Dawid kici Hebron ohrı Abner yanke śni, he kihde śi ; unkan wookiye en kihda nakaś.

23 Unkan Joab, qa obe iye opapi owasin hdipi. Unkan Joab okiyakapi qa, Abner Ner cinhintku wicaśtayatapi kin en hi ; un- kan kihde śi; unkan wookiye en kibda, eyapi.

24. Unkan Joab wicaśtayatapi kin ekta i qa heciya, Taku ecanon he? Inyun Abner en nihi, tokeca kihde yaśi, qa wanna iyaya.

25 Abner Ner cinhintku sdonyaya. Nihnaye kta, qa token timahen yahdi, qa tankan idade cin sdonye kta, qa taku ecanon owasin sdonye kta heon hi.

26 Unkan Joab-Dawid etanhan tankan iyaye ça wahośi Abner ihakam ye wicaśi : unkan Sira wakoniya etanhan icicawin akupi ; tuka Dawid sdonye śni.

27 Unkan Abner Hebron en hi qehan Joab otonwe tiyopa mahen hiyuya ; iśnana kici wohdake kta seca; qa hen tezi kin en capa, sunkaku Yasahel we kin on; unkan ta.

28 Unkan ohakam Dawid he nahon qehall heya; Miye, qa wokiconze mitawa Jehowa itokam Abner "Ner cinbintku we kin on iyaonpe pica śni unyakonpi kta, orvihanke wanica.

$29 \mathrm{He}$ Joab pa kin akan, qa atkuku tiyohnaka kin owasin akan yanke kta. Iye ti kin ohna ohinniyan wicaśta wan ba hdi yuke kta, qaiś leprosi ececa, qaiś tuwe sagye ikpatan, qaiś isan ahirhpaya, qaiś aguyapi icakija. 30 Unkan hecen Joab, qa sunkaku Abiśai Abner ktepi. Sunkakupi Yasahel Gibeyon wokicize en te kiye, heon etanhan.

31 Unkan Dawid Joab, qa oyate iye opapi kin owasin hewicakiya; Wokoyake hduhdehdecapo, qa wakihdaka ipiyag kiton po, qa Abner akiceya po; qa wicaśtayatapi kin Dawid akiyuhapi kin ihakam mani.

32 Unkan Hebron ohna Abner hnakapi, qa wicaśtayatapi kin 


\section{WICOWOYAKE 4.}

hoyeye ça Abner hnakapi ekta ceya, qa oyate owasin ceyapi.

33 Unkan wicaśtayatapi kin Abner aceye ça heya; Wicaśta witkotkoka te cin he iyecen Abner ța.

34 Nape panicihtapi śni, qa siha mazaśa icaśke en iyeniciyapi śni. 'Token wicaśta śica itokam wicaśta wan hinhpaye cin, he iyecen nihinhpaya. Unkan oyate owasin ake aceyapi.

35 Unkan nahanhin anpa oyate kin owasin Dawid ağuyapi yunkiyapi kta e ekta ipi. Unkan Dawid wakonze ca heya; Wi iyaye śni itokam aguyapi, qaiś taku tokeca uwate cinhan, Wakantanka decen, qa nakun de isanpa ecamicon kta.

36 Unkan oyate kin owasin $h 2$ sdonyapi, qa iyowicakipi, taku wicaśtayatapi kin econ kin owasin oyate kin owasin iśtapi kin en waśtc kin he iyecen.

37 Unkan anpetu kin he en Abner Ner cinhintku ktepi kin, he wicaśtayatapi kin eciyatanhan śni kin he oyate kin owasin, qa Israel owasin sdonyapi.

38 Unkan wicaśtayatapi kin taokiye hewicakiya; Wicaśta itancan, qa tanka. wan Israel ohna nakaha hinhpaya sdonyayapi śni he?

39 Qa miye wicaśtayatapi sdámayanpi eśta nakaha wamaśake śni, qa wicaśta kin dena Tzeruja cinca miye isanpa waśakapi ce, Jehowa tuwe taku sica econ kin, tośice cin iyecen iyuwin qu kta.

\section{WICOWOYAKE 4.}

1 Unkan Abner H́ebron ohna te cin Saul cinhintku kirl nahon, heon nape kin staka, qa Israel owasin yuśinyayapi.

$2 \mathrm{Qa}$ Saul cinhintku wicaśta nonpa mdetanhunka heca wicayuha, wanji Bayana eciyapi, qa unman Rekab eciyapi, Rimmon Beroti kin cinca, Berijamin cinca etanhan; Berot he Benjamin kici yawapi nakaś ;

3 Tuka Bcroti kin Gitaim ekta najicapi, qa anpetu kin hehanyan hen yakonpi.

4 Unkan Jonatan Saul cinhintku kin cinhintku wanji yuha, siha huśte, iye waniyetu zaptan behan Saul, qa Jonatan tapi kin Jezrejel etanhan otanin; unkan winyan iye icahye cin he icu, qa napa; qa najice kta, inahni kin, heon hokśidan kin hicahan qa huśtc icaga; unkan Mepibośet eciyapi.

5 Unkan Rimmon Beroti kin cinca Rekab qa Bayana manipi, qa anpetu kate cehan Iśbośet ti kin elsta ipi. Unkan iye wiyotanhan iśtinbe cin on makan wanka.

6 Unkan tipi cokaya en ipi, ağuyapi su icupi kta iyecen; qa tezi kin ekta capapi, qa Rekab qa sunkaku Bayana najicapi.

7 Tipi en ipi qehan iye iśtima, tipi ohna towinja akan makan wanka; unkan capapi, qa ktepi, qa pa kin baksapi, qa pa kin icupi, qa hanyetu osan Araba canku kin omanipi;

$8 \mathrm{Qa}$. Iśboset pa kin Dawid ekta, Hebron ekta kaipi, qa wicaśtayatapi kin heciyapi, Inyun Saul toka niyan, qa ninagi akite ciqon cinhintku Iśbośet pa kin dee; Jchowa rakaha wicaśtayatapi itancan unyanpi kin Saul, qa cinhintku etanhan wokajuju nicu.

9 Unkan Rimmon Beroti cinca Rekab qa sunkaku Bayana Dawid awicayupte ça hewicakiya, Jehowa minaği woiyokiśice owasin etanhan kiyuśke cin he ni, 10 Kinhan wicaśta wan, Inyun 


\section{SAMUEL WOWAPI INONPA KIN,}

Saul wanna ța ce, emakiye ça wotanin on iyuśkin maye kta kecin kin, he iyawahpamde ca wakte, Tziklag ohna; wotanin makahi on iyuwin waqu kta kecin tuka:

11 Hecen iyotan wicaśta śica wicaśta ohan owotanna wan, towinja akan tinktepi kin we kin ninapepi etanhan awakite kte śni he? Maka etanhan ihangciyapi kta.

12 Qa Dawid taakicita wicakte wicaśi ; unkan heconpi, qa napepi sihapi koya wicakicicaksapi, qa miniśkokpa wan Hebron ohna yanke cin, he icahda otkeyapi ; qa Iśbośet pa kin icupi, qa Abner ohnahnakapi kin Hebron ohna hnakapi.

\section{WICOWOYAKE 5.}

1. Unkan Israel wicoun owasin Dawid ekta Ḧebron en hipi, qa wohdakapi, qa heyapi, Nihuhu, qa nicehpi kin heuncapi.

2 Nakun ehanna Saul ateunyanpi qehan, Israel inanpe wicaye ca hdicu wicaye cin he niye. Qa Jehowa heniciya; Niye oyate mitawa Israel wonwicayaye $\mathrm{kta}$, qa Israel on mdetanhunka henica kta.

3 Unkan Israel hunkayapi owasin wicaśtayatapi ekta Hebron en hipi; unkan wicaśtayatapi kin kin Dawid wicotakuye wicakicag’a, Ḣebron ohna, Jehowa itokam. Unkan Israel wiciwark kan wicaśtayatapi Dawid sdayapi.

4 Dawid waniyetu wikcemna yamni wicaśtayatapi kag̉api qehan, qa waniyetu wikcemna topa wicaśtayatapi heca.

5 Ḧebron ohna waniyetu śakowin sanpa wi śakpe Juda ateyapi, qa Jerusalem ohna waniyetu wikcemna yamni sanpa yamni Juda, qa Israel owasin ateyapi.

6 Unkan wicaśtayatapi kin qa wicaśta tawa Jerusalem ek ta ipi, Jebusi maknce ounyanpi kin azuwicaye kta. Unkan Dawid heciyapi, Iśtağongapi, qa huśtepi kin wicadutokan śni kinhan, den hidu kte śni, Dawid hen ye kta okihi śni kapi.

7 Tuka Dawid Zion conkaśke kin icu, Dawid totonwe kin hee. 8 Unkan anpetu kin he en Dawid heya; 'Tuwe kaksiza kin iyohiya, qa Jebusi huśtepi qa iśtagongapi wicakaśtake cinhan, iye mdetanhunka kta: hena Dawid nagi kin śice wicadaka. Iśtağonge cin qa huśte kin tipi kin en hiyu kte śni, eyapi nakaś. 9 Unkan Dawid conkaśke mahen iyotanka, qa Dawid totonwe kin eciya, qa ihdukśan tipi kag̉a Millo ekta hehanyan.

10 Unkan Dawid ohinniyan tanka aya, qa Jehowa taku wakan ozuye yuhe cin he kici un.

11 Unkan Hiram Tzur wicaśtayatapi kin Dawid ekta ohnihde ye wicaśi, nakun hanteśa can, qa cankajipa heca, qa ticagjapi kta wicaśta inyan kakanpi wayupika; unkan Dawid tipi wan kicagapi.

12 Unkan Jehowa Dawid tokiconze-kin Israel iwankam yusuta, qa taoyate Israel on tokiconze kin icaliye cin he Dawid sdonya. 13 Unkan Dawid Hebron etanhan hi kin iyohakam, Jerusalem etanhan winohinca tokeca wicayuza. Unkan ake cinca wica winyan koya kicitonpi.

14 Unkan cinca wica Jerusalem ohna kicitonpi cajepi kin dena eepi ; Śammuwa, qa Śobab, qa Natan, qa Solomon,

15 Qa Jiblier, qa Eliśua, qa $\mathrm{Ne}-$ peg, qa Japiya, 


\section{WICOWOXAKE 6 .}

16 Qa Eliśama, qa Eljada, qa "Elipelet.

17 Unkan Pilistim Dawid Israel wicaśtayatapi kta sdayapi kin nahonpi, heon Pilistim owasin Dawid akin itanwankanhde upi. Unkan Dawid nahon, qa conka- \$ke kin ektakiya iyaya.

18 Unkan Pilistim upi, qa Repaim (Waziya) osmaka kin en enanakiya hiyotankapi.

19 Unkan Dawid Jehowa iwange ca heya, Pilistim anawicawatan kta he? minape en wicamayaqu kta he? Unkan Jehowa Dawid heciya, Anawicatan wo. A.wicakehan Pilistim ninape en wicawaqu kta.

20 Unkan Dawid Bayal Peratzim ekta i, qa hen Dawid wica. kaśtaka, qa heya, Jehowa mitokam toka mayanpi enanakiya ehpewicaya, mini enanakiya iyaye cin he iyecen, heon oyanke kin he Bayal Peratzirn, (enanakiya ehpewicaya oyanke,) eciyapi.

21 Unkan wakag̉api wakan kin hen ehpewicakiyapi, unkan $\mathrm{Da}$ wid qa wicaśta tawa hena icupi.

22 Unkan ake Pilistim itanwan. kanhde upi, qa Repaim usmaka ohna enanakiya hiyotankapi.

23 Unkan Dawid Jehowa iwanga. Unkan heya, Anawicayatan kte śni; Wicikeyata ohomni ya wo, qa canśin can kin eciyatanhan wicikiyedan hidu kta.

24 Qa canśín can inkpa ohna taku hiyaya ho kin nayalion kinhan inahni wo, Jehowa Pilistim ozuye kaśtake kita nitokam iyaya nakaś.

25 Unkan Dawid token Jehowa econ śi kin he iyecen econ, qa Pilistim wicakaśtaka, Geba etanhan Gezer ekta yai kin hehanyan.
WICOWOYAKE 6 .

I Unkan ake Dawid Israel wicaśta kahnigapi kin owasin kektopawinge wikcemna yamni mniciye wicaya.

2 Unkan Dawid, qa oyate iye opapi kin owasin najinpi, qa Bayali Juda ekta iyayapi, hetanhan Taku wakan, Jehowa ozuye yuhe cin, Kerubirn otahedan yanke cin eciyapi, tacanwohnaka kin huweyapi kta.

3 Qa Wakantanka tacanwohnahnaka kin Abinadab ti kin paha akan yanke cin etanhan icupi, qa canpahmihma teca wan akan tokśupi, qa Abinadab cinca kin Uzzia, qa Ahio canpahmihma teca kin kahapapi.

4 Qa Wakantanka tacanwohnaka Abinadab ti kin paha akan yanke cin etanhan icupi qehan, iye opa, qa Ahio canwohnaka kin itokam mani.

5 Qa Dawid, qa Israel tiyohnaka kin owasin Jehowa itokam śkatapi, wazi can dowankiyapi ocaje owasin on, candowankiyapi, qa canpakinzapi, qa cancega, qa wamnuha, qa maza icakokapi hena owasin on.

6 Unkan Nakon tahocoka kin ekta ipi qehan, tatanka kin canwohnaka kin nahpapi kte seca, heon Uzza yuze lkta nape kin ekta ye kiya.

7 Unkan Jehowa Uzza canniyeya, qa taku ecinśniyan econ kin on Wakantanka hen kaśtaka; unkan hen ta, Wakantanka tam canwohnaka kin ikiyedan.

8 Unkan wokastake Jehowa Uzza kaśtake cin on Dawid canteptanyan; unkan oyanke kin he anpetu kin dehanyan Uzza Ka. śtakapi eciyapi.

9 Unkan anpetu kin he en Dawid Jehowa kokipe ca, Token 445 


\section{SAMUEL WOWAPI INONPA KIN,}

Jehowa tacanwohnaka kin miye ekta hi kta he? eya.

10 Heon Dawid Jehowa tacanwohnaka kin iye ekta, Dawid totonwe en hiyuye kta tawatenye śni: tuka Dawid he icunom aya, Obed Edom Giti kin ti kin ekta.

11 Unkan Jehowa tacanwohnaka kin wi yamni Obed Edom ti kin ohna yanka. Unkan Jehowa Obed Edom, qa tiyohnaka tawa owasin wicayawaśte.

12 Unkan Dawid wicaśtayatapi kin okiyakapi qa heyapi, Wakantanka tacanwohnaka on Jehowa Obed Edom tiyohnaka kin, qa taku yuhe cin owasin yuwaśte; heon Dawid iyaya, Wakantanka tacanwohnaka kin Obed Edom ti kin etanhan, Dawid totonwe ekta wiyuśkinyan ahdiyaku kta.

13 Unkan wicaśta Jehowa tacanwohnaka kin akiyuhapi kin caehdepi śakpe hiyupi, hehan tatanka, qa ptejicadan wakiyuśna.

14 Unkan Dawid towaśake ocowasin on Jehowa itokam waci, qa Dawid minihuha amdo akahpe wan ipiyag kiton.

15 Unkan Dawid, qa Israel tiyohnaka owasin. Jehowa tacanwohnaka kin iyaśapi on, qa mazayahotonpi yahotonpi on itanwankanhde aupi.

16 Unkan Jehowa tacanwohnaka kin Dawid totonwe en hi qehan, Mikal Saul cunwintku owanyeye ohna eyokasin, qa wicaśtayatapi kin Dawid ipsipsica, qa waci yanka, Jehowa itokam wanyake cehan, cante mahen wahteda śni.

17 Unkan Jehowa tacanwoohnaka kin hiyuyapi, qa oyanke tawa en okihnakapi, wakeya wan Dawid ekicihde kin cokaya; qa Dawid Jehowa itokam wohu- hnahyapi qa wopida wośnapi wakiyuśna.

18 Unkan Dawid wohulinahyapi, qa wopida wośnapi huhnahya yuśtan qehan, oyate kin Jehowa obe yuhe cin cajeyan wicayawaśte.

19 Qa oyate kin owasin, Israel wicota kin owasin, wicaśta qa winohinca koya, otoiyohi aguyapi hmiyanyanna wan, qa tado onśpa wan, qa miniśa oyatke ohnaka wanji wicakipamni. Unkan oyate owasin kihdapi.

20 Unkan Dawid tiyohnaka tawa kin yawaśte kta kihda. Unkan Mikal Saul cunwintku Dawid itkokipe kta hiyu, qa heya, Israel wicaśtayatapi kin nakaha taokiye wicinyanpidan iśtapi kin itokam tancodan un, kośka ikcekapi wan tancodan mani kin iyecen, he ehan towitan kin ihdutanin naceca.

21 Unkan Dawid Mikal heciya, Jehowa niyate, qa tiyohnaka tawa owasin isanpa makahinge ca Jehowa taoyate Israel on mdetanhunka makagia, heon Jehowa itokam waśkate kta.

22 Qa nakun de isanpa mawahte kte śni, qa miiśta kin en hukuya waun kta, tuka wicinyanpidan cajedate cin hena mayuonihanpi kta.

23 Unkan Mikal Saul cunwintku kin hetanhan cincaton śni, anpetu en te cin hehanyan.

\section{WICOWOYAKE 7.}

1 Unkan wicaśtayatapi kin toti kin en iyotanka, qa tokayapi owasin ihdukśan yakonpi kin etanhan Jehowa woozi qu qehan, 2 Wicaśtayatapi kin. Natan waayate kin heciya; Wan, miye wanna hanteśa can tipi wan ohna wati, tuka Wakantanka tacan- 


\section{WICOWOYAKE \%}

wohnaka kin ozanpi tipi wan ohma yanka ce.

3 Unkan Natan wicaśtayatapi kin heciya; Iho, taku nicante en un kin owasin econ wo; Jehowa nici un nakaś.

4 Unkan hanyetu kin he en, Jehowa oie kin Natan en u qa heciya,

5 Mitaokiye Dawid ekta ye ca heciya wo; Jehowa becen eya; Ohna wati kta e tipi wran miyecağe kta he?

6 Israel cinca kin Egupta etanhan itanwankanhde hiyu wicawaye cin ehantanhan, an petu kin dehanyan, can tipi wan ohna wati śni ; tuka wakeya ohna, qa ozanpi tipi ohna ihdaka waun.

7 Israel cinca owasin wicelina mawani kin owasin en, Israel wayaco, oyate mitawa Israel won wicawaśi kin tuwe wicoie wan ewakiya, qa, Tokeca hanteśa tipi wanji miyecage śni ewakiya he?

8 Qa wanna mitaokiye Dawid hecen eyakiye kta; Jehowa obe yuhe cin hecen eya"; Tahinca wihan wicakiyapi etanhan icicu, oyate mitawa itokam mayani kta heon etanhan.

9 Qa toki yai kin owancaya nici waun, qa toka niyanpi kin owasin nitokapa tanhan wicawakaśpe, ca wicaśta maka akan tankapi cajepi kin, he iyecen caje tanka cicagia.

$10 \mathrm{Qa}$ oyate mitawa Israel on oyanke wan wiyeya wicawecage kta, qa hu wicawecihde kta, qa he ohna tipi kta, qa icimana cancanpi kte śni, qa otokahe ekta woahtani cinca kin wicayuhukuyapi kin icimana heconpi kte śni ;

11. Wayaco, oyate mitawa wicawaqu ehantanhan heconpi kin iyecen; nakun niye toka niyanpi owasin etanhan oziciciya, qa tipi wan Jehowa nieicage kta, Jehowa eniciya.

12 Qa anpetu nitawa henakeca lkinhan, qa ate wicayaye cin om inonke cinhan, nicinca nitezi etanhan inanpe kte cin he icahwaye kta, qa tokiconze kin mdusuta kta.

13 Iye tipi wan micaje on kagge kta; qa tokiconze oiyotanke kin mdusuta kta, owihanke wanica.

14 Iye ate maye kta, qa miye he cinkśi waye kta. Iye śicaya econ kinhan wicaśta cansakadan on wakaśtake kta, wicaśta cincapi awicapapi kin iyecen.

15 Tuka mitocantekiye ewecihdaku kte śni, Saul nitokapa tanhan mdutokan kin etanhan ewecihdaku qon he iyecen.

$16 \mathrm{Qa}$ yati kin, qa nitokiconze kin owilianke wanin nitokam wacinyepica kta; oiyotanke nitawa owihanke wanin suta kta.

17 Wicoie kin hena owasin iyecen, qa wowanyake kin de ocowasin iyecen, Natan Dawid eciya.

18 Unkan Dawid wicaśtayatapi kin ekta i, qa Jehowa itokam iyotanke ça heya, Itancan Jehowa, miye matuwe he? qa wati kin he taku on dehanyan hiyumayaya he?

19 Qa Itancan Jehowa dehantu cistinna niiśta kin en, heon nitaokiye ti kin tokata tehan on iyaa; Itancan Jehowa wieaśta akantu woope kin de tawapi he?

$20 \mathrm{Qa}$ taku sanpa Dawid eniciye kta he? Itancan Jehowa niye nitaokiye sdonyaya.

21 Nioie kin on, qa nicante kin iyecen taku tanka kin dena owasin ecanon, qa nitaokiye kin sdonye yakiya.

22 Jehowa Wakantanka niye nitanka nakaś, qa tuwedan iyenicece śni, niye niśnana, qa taku 


\section{SAMUEL WOWAPI INONPA KIN,}

wakan tokeca wanica; unnog̉epi on taku naunhonpi kin owasin iyecen.

23 Qa tukte maka akan oyate wanji oyate nitawa Israel iyececa, he opekiton k.ta, qa oyate tawaye kta, qa caje wan icicage kta e Taku wakan ekta i, qa oyate wan Figuton oyate, qa taku wakan dapi kin etanhan openiciton kin, he itokam stakoce nitawa en taku tanka qa wowinihan ecanon.

24: Qa oyate nitawa Israel owihanke wanin oyate nitawa kta $e$ niciyahdusuta, qa taku wakan dapi kin Jehow a he niye.

$25 \mathrm{Qa}$ wanna Jehowa Wakantanka nitaokiye, qa tipi tawa on wicoie ehe cin ohinniyan yeucetu, qa token ehe cin iyecen econ wo.

26 Hecen nicaje kin owihanke wanin yatanpi kta; Jehowa obe yuhe cin Israel on Wakantanka kta, qa nitaokiye Dawid ti kin nitokam yusuta kte.

27 Jehowa obe duhe cin Israel wakan nidapi, niye nitaokiye nogge kin duhdoke ca heyakiye; Tipi wan cicicage kta, heon nitaokiye wocekiye kin de eniciye kta e cante kin en iyekiya.

$28 \mathrm{Qa}$ wanna Itancan Jehowa Wakantanka he niye; qa nioie kin wicake kta, qa wowaśte kin de nitaokiye eyakiya.

29 Heon wanna nitaokiye ti kin dawaśte kta iyonicipi "nunwe; hecen ohinniyan nitokam yankekta: Itancan Jehowa niye heha; qa nitaokiye ti kin nitoyawaśte kin on owihanke wanin dawaśte kta.

\section{WICOWOYAKE 8.}

1 Unkan hena iyohakam Dawid Piliśtim wicakaśtake ca wi- caktedan; qa Dawid Meteg-anma (otonwe tokapa iyuwi kin) Pilistim napepi kin etanhan icu.

2 Nakun Moab kaśtaka, qa makata iwanke wicaye, ca hahonta on iwicayuta, qa te wicaye kta e hahonta nonpa on iwicayuta, qa niwicaye kta on hahonta wanjidan ocowasin, qa Dawid Moabi wowidag wicaya; Unkan taku itukihanpi.

3 Unkan Dawid Hadadezer, Rehob cinhintku, Tzoba wicaśtayatapi kin kaśtaka, makoce tawa ekicetukiye kta e Yuperate wakpa kin ekta i qehan.

$4 \mathrm{Qa}$ Dawid he etanhan suktanka akanyotankapi kektopawinge wanji sanpa opawinge śakowin icu, qa huiyun wicaśta kektopawinge wikcemna nompa, qa Dawid suktanka owasin kan wicakicakśe, tuka canpahmihma opawinge wanjidan on okapta.

5 Nakun Aram Damaskos Hadadezer Tzoba wicaśtaya tapi óliye kta hi, qa Dawid Aram wicaśta kektopawinge wikcemna nonpa sanpa kektopawinge nonpa wicakaśtaka.

6 Qa Dawid Aram Damaskos ohna taakicita ti wicakiya, qa Arami kin Dawid ókiyapi, qa taku itukihanpi. Unkan Jehowa Dawid nikiya, tuktetu kaśta i eca.

7 Unkan Dawid mazaskazi wahacanka kin Hadadezer taokiye yuhapi kin hena icu, qa hena Jerusalem ekta hdohdi.

8 Qa Betah qa Berotai, Hadadezer totonwe kin, etanhan wicaśtayatapi kin Dawid mazaśa ota hin icu.

9 Unkan Toyi, Hamat wicaśtayatapi kin, Dawid Hadadezer taozuye owasin kaśtake cin nahon qehan,

10 Toyi iye cinhintku Joram 


\section{WICOWOYAKE 9.}

wicaśtayatapi Dawid ekta yesi, wookiye kida kta, qa Hadadezer kize ça kaśtake cin on yawaśte kta, qa mazaska wakśica, qa mazaskazi wakśica, qa mazaśa wakśica kahi. Toyi qa Hadadezer ohinniyan kicizapi qon nakas.

11 Qa hena wicaśtayatapi Dawid yuwakan, Jehowa on, mazaska, qa mazaskazi oyate wicaktedan kin hena owasin etanhan yuwakan kin iyahna.

12 Aram etanhan, qa Moab etanhan, qa Anmoni cinca etanhan, qa Pilistim etanhan, qa Amaleq etanhan, qa Hadadezer Rehob cinhintku Tzoba wicaśtayatapi kin etanhan taku ki kin.

13 Qa Aram kaśtake cin etanhan Dawid hdi qehan, caje wan icicağa. Miniskuya osmaka ohna wicaśta kektopawinge wikcemma sanpa kektopawinge śahdogian wicakte.

14 Qa Edom ohna taakicita ti wicaśi, Edom owancaya ohıa taakicita yanke wicaśi, qa Edomi owasin Dawid wowidag wicaya. Unkan Jehowa Dawid toki ekta i kin owancaya nikiya.

15 Unkan Israel owasin Dawid ateyapi; unkan Dawid taoyate owasin woyaco qa woowotanna ecawicakicon.

16 Unkan Joab Treruja cinhintku kin obe akicita tancan heca, qa Jehośapat Ahilud wakiksuye cin hee

17 Qa Tradok Ahitub cinhintku, qa Ahimelek Abiatar cinhintku wawayuśnapi hecapi, qa Seraja wowapi kage cin hee.

18 Qa Benaja, Jehojada cinhintku, Kereti (Pabaksapi kin) qa Peleti (Inyankapi,) kin akicita tancan kin hee, qa Dawid cinca kin wawayuśnapi hecapi.

\section{WICOWOYAKE 9.}

1 Unkan Dawid heya, Suul tiyohnaka etanhan wicaśta wan okaptapi he? Kinhan Jonatan on etanhan wowacantkiye ecawecon kta.

2 Unkan Saul tiyohnaka kin ookiye wan yuha, he Tziba eciyapi ; unkan he Dawid elsta kicopi ; unkan wicaśtayatapi kin heciya, Tziba he niye he? Unkan, Nitaokiye kin hee, eya.

3 Unkan wicaśtayatapi kin heya; Saul ti kin etamhan wicaśta wan nahanhin ni he? hecinhan wowacantkiye wakan ecawecon kta. Unkan Tziba wicaśtayatapi kin heciya, Jonatan cinhintku wan nahanhin ni, siha napin ksahan.

4 Unkan wicaśtayatapi kin heciya, Tukte e he? Unkan Tziba wicaśtayatapi kin heciya, Tho Makir Anmiel cinhintku ti kin en, Lodebar ohna yanka ce.

5 Unkan wicastayatapi kin tuwe ekta yesi, qa Makir Anmiel cinhintku ti kin etanhan Lodebar etanhan icu.

6 Unkan Mepibośet Jonatan cinhintku Saul cinhintku kin Dawid ekta hi, qa makipusdiya elipeiciye ca ohoda. Unkan Dawid, Mepibośet eya. Unkan, Nitaokiye he miye, eya.

\% Unkan Dawid heciya, Ihnuhan wakoyakipe cin; Jonatan niyate on etanhan wowacantkiye ohinniyan ecacicon kta, qa Saul. ate yaye cin tamaga kin owasin ake yuhe ciciye kta, qa niye ohinniyan wahna wotapi mitawa ekta ağuyapi yate kta.

8 Unkan patuja qa heya; $\mathrm{Ni}$ taokiye kin he tuwe, śunka ta wan iyemaceca, on ayatonwan he?

9 Unkan wicaśtayatapi kin Tziba Saul tahokśidan kin kipan qa 449 


\section{SAMUEL WOWAPI INONPA KIN,}

heciya, Saul qa tiyohnaka tawa owasin, taku tawapi owasin, itancan nitawa cinhintku kin waqu ce.

10 Heon maka kin yecicicanye kta, niye, qa nicinca, qa nitaokiye, qa taku aicage cin yakahi kta; hecen itancan nitawa cinhintku kin aǵuyapi yuhe ça yute kta, qa Mepibośet, itancan nitawa cinhintku, ohinniyan wahna wotapi mitawa ekta aguyapi yute kta. Unkan Tziba cinca wica wikcemna sanpa zaptan yuha, qa ookiye wikcemna nonpa.

11 Unkan Tziba wicaśtayatapi kin heciya; Token itancan mitawa taokiye econśi kin owasin, he iyecen nitaokiye econ kta. Unkan Mepibośet wicaśtayatapi kin cinhintku wan iyecen wahna wotapi mitawa ekta wote kta, Dawid eya.

12 Wanna Mepibośet cinhintkn cistinna wan yuha, he Mika eciyapi. Unkan tona Tziba ti kin ohna tipi kin owasin Mepibośet ookiye wicayuha.

13 Qa Mepibośet wicaśtayatapi tawahna wotapi ekta ohinniyan wota, heon Jerusalem ohna ti, qa siha napin huśte.

\section{WICOWOYAKE 10.}

1 Unkan hena iyohakam Anmon cinca wicaśtayatapi kin te ça cinhintku Hanun heekiya wicaśtayatapi un.

2 Unkan Dawid heya, Hanun Nahiaś cinhintkn wowacantkiye ecawecon kta, atkuku wowacantkiye ecamicon kin he iyecen; qa atkuku on kicanpte kta Dawid taokiye ekta ye wicaśi ; Unkan Dawid taokiye Anmon cinca tamakocepi kin ekta ipi.

3 Unkan Anmon cinca wicaśta tokapapi kin Hanun itancan ta450 wapi heciyapi, Niyate yuonihan kta e Dawid wakicanptapi niye ekta u wicaśi kecanni he? Hiya otonwe kin iwanyake kta, qa tonweye kta, qa pajuju kta e Dawid taokiye niye ekta u wicaśi śni he?

4 Unkan Hanun Dawid taokiye iwicaru, qa putinhimpi hanke kasan, qa tawokoyakepi kin hanke, cecapi ekta bawicalsa, qa kihde wicaya.

5 Unkan wicaśta kin nina iśtecapi Dawid okiyakapi, heon wahośi itkowicakipe yeśi, qa wicaśtayatapi kin hewicakiya, Putinhin uniyanpi kte cin hehanyan Jeriho en yanka po qa, hehan yahdipi kta.

6 Unkan Anmon cinca kin Dawid en śicamnapi kin wanhdakapi, heon Anmon cinca kin Aram Rehob otipi, qa Aram Tzoba wahowicayapi, qa hena etanhan wicaśta huinyun kektopawing ge wikcemna nonpa ope tonpi, qa Mayaka etanhan wicaśta kektopawing̀e wanji, qa Iśtob etanhan wicaśta kektopawinge wikcemna sanpa kektopawinge nonpa.

y Unkan Dawid onation, heon Joab, qa wicaśta waśaka obe owasin ekta ye wicaśi.

8 Unkan Aumon cinca kin inanpapi, qa kizapi kta otonwe tiyopa ikiyedan ocimdah najinpi, tuka Aram Tzoba, qa Rehob, qa Iśtob, qa Mayaka icunom tinta ohna najinpi.

9 Unkan Joab wokicize anokatanhan iye tatpe upi kin wanyake cehan, Israel ohna wicaśta kahnigapi owasin etanhan wicaśta kahnige ca Aram itkokipe kta ocimdah iyaye wicaya.

10 Qa oyate unmanpi kin owasin iye cincu Abiśai nape en wicaqu, qa Anmon cinca kin wicitkokim ocimdah yeyaya. 
11 Qa heciya, Aram miye isanpa waśake cinhan, niye ni mayaye kta, qa. Anmon cinca kin niye isanpa waśakapi kinhan ni ciye kta e ekta mde kta.

12 Waditaka wo. Oyate unkitawapi on, qa taku wakan undapi totonwe kin on wadiuntakapi kta, qa Jehowa token iśta kin en waśte kin econ kta.

13 Unkan .Joab qa oyate iye opapi kin Aram kize kta ikiyedan ipi qehan, wicitokapa tanhan najicapi.

14 Unkan Aram najica kin Anmon cinca wanyakapi qehan, iś eya Abiśai itokapa tanhan najicapi, qa otonwe en ipi. Unkan Joab Anmon cinca wicakize cin etanhan kihda, qa Jerusalem ekta hdi.

15 Unkan Israel itokam wicaktepi Arami kin wanhdakapi qehan witaya miniciyapi.

16 Qa Hadarezer Arami, wakpa kin akasanpa yakonpi kin, wahowicaye ca hiyu wicaya; unkan Helam ekta hipi ; unkan Hadarezer ozuye mdetanhunka kin śobak wicitokam mani.

17 Unkan Dawid okiyakapi, heon Israel owasin mniciye wicaya; qa Jordan iyuweğa, qa Ḣelam ekta i. Unkan Arami ocimdah Dawid tatpe upi, qa kicizapi.

18 Qa Arami kin Israel itokapa tanhan napapi. Unkan Dawid Aram etanhan canpahmihma opawing̉e śakowin wicakte, qa śuktanka akanyotankapi kektopawinge wikcemna topa, qa Śobak ozuye mdetanhunka kin kaśtaka, unkan hen ta.

19 Unkan Hadarezer taokiye wicaśtayatapi kin owasin Israel itokam iyepi ktepidan kin wanhdakapi qehan, Israel om wookiye kagapi; qa owicakiyapi. He- cen Aram Anmon cinca kin sanpa ni wicaye kta ikopa.

\section{WICOWOYAKE 11.}

1 Unkan omaka kin ihuniyanpi, hehan wicaśtayatapi zuya yapi ece ake iyehantu, Dawid Joab, qa taokiye owasin om, qa. Israel orasin ye wicaśi. Unkan Anmon cinca kin ihang wicayapi, qa Rabba en onawicatakapi. Tuka Dawid Jerusalem ohna yanka.

2 Qa litayetu Dawid towinja etanhan najin, qa wicáśtayatapi ti awakeyapi kin akall mani, qa awakeyapi kin etanhan winohinca wan ihdujaja wanyaka. Unkan winolinca kin owanyag waśte hinca.

3 Unkan Dawid winohinca on iwange ye śi. Unkan, Batśeba, Eliyam cunwintku kin Urija Ḧiti kin tawicu kin hee śni he? eciyapi.

4 Unkan Dawid wahośi ekta ye wicaśi, qa icu, unkan ekta hi ; unkan kiciwanka, (tośape kin etanhan wanna yuskapi nakaś ;) unkan kihda.

5 Unkan winohinea kin ihduśake ça Dawid wahoye ca; Ihdumaśaka ce, eciya.

6 Unkar Dawid Joab wahoya, Urija Hiti kin miye ekta uśi wo. Unkan Joab Urija Dawid ekta yeśi.

7 Unkan Urija ekta hi. Unkan Dawid iwanğa Joab tanyan un he? qa oyate kin zaniyan unpi he? qa wokicize kin toketu he? 8 Unkan Dawid Urija heciya, Yati kin ekta hda, qa siha hdujaja. Unkan Urija wicaśtayatapi ti kin etanhan inanpa. Unkan woyute wicaśtayatapi kin qu kin he ihakam kayapi.

9 Tuka Urija wicaśtayatapi ti 451 


\section{SAMUEL WOWAPI INONPA KIN,}

tiyopa ekta makan wanka, itancan tawa taokiye owasin om, qa toti kin ekta hde śni.

10 Unkan Dawid okiyakapi qa, Urija iye ti kin ekta hde śni, eyapi. Unkan Dawid Urija heciya, Icimayani etanhan yaku śni he? tokeca yati ekta yahde śni he?

11 Unkan Urija Dawid heciya, canwohnaka kin, qa Israel, qa Juda wakeya otipi, qa itancan mitawa Joab, qa itancan mitawa taokiye tinta akan wankapi, icunhan, miye wawate kta, qa wamdatke kta, qa mitawin kici imonke kta e wati en wahde kta he? Yani kinhan, qa ninaği ni kinhan taku kin de ecamon kte śni.

12 Unkan Dawid Urija heciya, Anpetu kin de nakun den yanka wo, kinhan heyakecinhan ye ciśi kta. Unkan Urija anpetu kin he, qa nakun ihanhanna'Jerusalem en yanka.

13 Unkan Dawid he kico; unkan itokam wota, qa wayatkan; unkan witkoya, tuka htayetu itancan tawa taokiye om wanke ciqon om iwanke kta ake ekta inanpa, tuka ti kin ekta hde śni.

14. Unkan ihanhanna Dawid Joab wowapi wan kicage ca Urija iye nape kin ohna kaye śi.

$15 \mathrm{Qa}$ wowapi en owa, qa heya; Tukten iyotan kicizapi ekta Urija ye śi wo, qa kaśtakapi qa te kta on iye etanhan hdicu po.

16 Unkan Joab otonwe kin iwanyake ca tukten wicaśta waditaka yukan sdonye cin heci Urija ye śi.

17 Unkan otonwe wicaśta kin inanpapi, qa Joab kizapi : unkan oyate kin Dawid taokiye etanhan wanjikśi hinhpayapi, qa Urija Hiti kin nakun ta.

18 Unkan Joab Dawid wahoye ça wokicize owasin toketu okiyaka.

19 Qa wahośi kin heciya. Wokicize owasin toketu wicaśtayatapi oyakidake cin adasstan kinhan,

20 Wicaśtayatapi kin śihda kinhan, qa heniciya; Tokeca kizapi kta otonwe ikiyedan yaipi he? Conkaśke etanhan taku ehpeyapi kta sdonyayapi śni he?

21 Tuwe Abimelek Jerubeśet cinhintku kaśtaka he? winohinca wan conkaśke etanhan wokpan inyan wan elipeye śni hc? unkan 'Tebetz ekta ta. Tokeca conkaśke ekta yaipi he? eye cinhan. Nitaokiye Urija Hiti kin iś eya ța ce, ehe kta.

22 Unkan wahośiye iyaye ca Dawid ekta i, qa taku Joab iwahoye cin owasin okiyaka.

23 Qa wahośiye kin Dawid heciya; Wicaśta kin unkiyepi isanpa waśakapi, qa unkizapi kta tinta ekta inanpapi. Unkan otonwe tiyopa kin ekta wicunkuwapi.

24 Unkan itazipe yuhapi kin conkaśke etanhan nitaokiye wicakutepi; unkan wicaśtayatapi taokiye wanjikśi țapi, qa nitaokiye Urija Hiti iś eya ta ce.

25 Unkan Dawid wahośiye kin heciya, Joab hecen eyakiye kta ; Ihnuhan wicoie kin de on iyokiśin niciye cin. Isan kin tuwe kaśta temya ece. Wokicize otonwe ekta hdusuta wo, qa he ihang ya wo, qa niye he waditaka kağa wo.

26 Unkan Urija tawicu kin he hihnaku Urija te cin nahon, qa hihnaku on ceya.

27 Unkan waśihda enakiye ceehan, Dawid he wahoye ca iye ti kin ekta hiyuya; unkan tawicu kta yuza. Unkan cinca wan kiciton. Tuka wicoie Da- 


\section{WICOWOYAKE 12.}

wid econ kin he Jehowa iśta kin en śica.

\section{WICOWOYAKE 12.}

1 Unkan Jehowa Natan Dawid ekta yeśi ; unkan ekta i qa heciya; Otonwe wan ohna wicaśta nonpa, wanji wijica, qa unman wahipanica.

2 Wijica kin tahinca, qa pte wanunyanpi otahin yuha.

3 Tuka wahpanica kin takudan yuhe śni, tawiyedan wan heceedan; he opeton, qa ti kin ohna icahya, iye cinca wicehna, onśpa tawa etanhan yute ca wiyatke tawa etanhan yatkan, qa itpi kin ohna wanka, qa cunwintku wan iyecen hduha.

4 Unkan wicaśta icimani wan wicaśta wijica kin ekta hi; unkan wicaśta icimani en hi kin wohanpi kicagre kta tahinca tawa, qu pte tawa etanhan ikikcu kapin, qa wicaśta wahpanica tahinca tawa kin icu, qa wicaśta en hi kin on pata.

5 Unkan Dawid tocanniye kin wicaśta kin aideye ca Natan heciya, Jehowa ni wicaśta decon kin te kta.

6 Qa wannśida śni, qa taku kin de econ kin heon tawiyedan on topa kajujn kta.

7 Unkan Natan Dawid heciya; Wicaśta kin he niye ce, Jehowa Israel wakan dapi kin hecen eya, Miye Israel wicaśtayatapi on sdaciya, qa miye Saul nape kin etanhan ecihdaku.

$8 \mathrm{Qa}$ itancan nitawa ti kin cicu, qa itancan nitawa tawicu kin niitpi en wicawaqu, qa Israel qa Juda tiyohnakapi kin cicu, qa hena cistinna unkanś isanpa decen qa decen ciçu kta tuka.

9 'Tokeca Jehowa oie kin ilayakta śni, qa taku iye iśta kin en śica ecanon. Urija Hiti kin isan on cayapa, qa Anmon cinca tawipe on yakte, qa tawicu nitawin kta on iyacu.

10 Qa ihamayakta śni, qa Urija Hiti kin tawicu nitawin kta e duze cin, heon detanhan wipe yati anipaha icimana aniyuśtan kte śni.

11 Jehowa hecen eya, Inyun tiyohnaka nitawa etanhan taku śica najin waye kta, qa niiśta itokam nitawin iwicawacu, qa nitakoda kin wicawaqu kta, qa iye anpetu wi kin de itokam nitawin om wanke kta.

12 Niye natimana hecanon, tuka miye wicoie kin de Israel owasin itokam, qa anpetu wi kin itokam ecamon kta.

13 Unkan Dawid Natan heciya; Jehowa awawahtani ce. Unkan Natan Dawid heciya, Nakun Jehowa wayahtani kin niciyutokan ; nițe kte śni.

14 Hececaśta wicoie kin de on, Jehowa tokayapi kin nina iliaha wicayaye cin, he on cinca nakaha nicitonpi kin he awicakehan te kta.

15 Unkan Natan kihda. Unkan Jehowa hokśíyopa Urija tawicu Dawid kiciton kin he apa; unkan hanyan.

16 Unkan hokśiyopa on Dawid Wakantanka cekiya, qa takudan yute śni, qa tankan iyaye ca makan wanka.

17 Unkan iye tiyohnaka hunkayapi kin maka etanhan najinkiyapi kta on ihdukśan najinpi. Unkan wicada śni, qa om ağuyapi yute śni.

18 Unkan anpetu iśakowin hokśiyopa te cehan Dawid taokiye hokśiyopa țe cin okiyakapi kta ikopapi, qa, Iny un hokśiyopa nahanhin ni qehan taku unkeyapi unhopi kin nahon wicada śni, 453 


\section{SAMUEL WOWAPI INONPA KIN,}

hokśiyopa kin wanna ta ce, unkeyapi kinhan sanpa nina iyokiśin içiye kte śni he? eyapi nakaś.

19 Unkan taokiye iyakitedan jijipi kin Dawid wanyake cehan, hokśidan kin wanna ta Dawid iyukcan, heon: Hokśiyopa ta he? Dawid taokiye ewicakiya. Unkan wanna ta, eyapi.

20 Unkan Dawid maka etanhan najin, qa ihdujaja, qa sda-iciye ca wokoyake tokeca kicun, qa Jehowa ti kin ekta i, qa cekiye ca hdi ca ağuyapi da; unkan itokam ehnakapi ; unkan wota.

21 Unkan taokiye heciyapi, Wicoie kin de ecanon kin toketu he? Hokśiyopa ni qehan wote śni yaun, qa yaceya; tuka wanna hokśiyopa ța, unkan nayajin qa ağuyapi yata.

22 Unkan Tohanyan hokśiyopa ni kin hehanyan wawate śni, qa waceya, Jehowa onśimada, qa hokśiyopa niye kta hecinhan tuwe sdonya he? epa nakaś.

23 Tuka wanna te. Tokeca wote śni waun kta he? Ake hdi wakiya owakihi he? Miye he ekta mde kta, tuka iye en mahi kte śni.

24. Unkan Dawid iye tawicu Batśeba kicanpte ca ekta i, qa kici wanka. Unkan cinca wica wan ton. Unkan Dawid he Solomon eya caje yata. Unkan Jehowa he kici un.

25 Qa Natan waayate kin ekta yeśi, qa Jedidija (Ja waśtedaka) eya cajeyata, Jehowa on etanhan.

26 Unkan Joab Anmon cinca kin totonwe Rabba azuye ca wicaśtaya tapi totonwe kin icu.

$27 \mathrm{Qa}$ Joab wahośiye Dawid ekta ye wicaśi, qa heya, Rabba azuwaya, qa mini otonwe kin wanna iwacu.

28 Heon niye oyate unman kin 454 mniciye wicaya, qa otonwe kin tatpe ahi ti, qa icu wo; hecanon śni kinhan okini miye otonwe kin iwacu kta, qa micaje kin he akan yanke kta.

29 Unkan Dawid oyate kin owasin witaya hiyuwicaye ca Rabba ekta i, qa azuye ca he icu.

30 Unkan wicaśtayatapi tawateśdake pa kin etanhan Dawid icu. He inyan tehilika iyahna mazaskazi woqin wan aspeyetonpi, qa Dawid pa akan ehnakapi, qa Dawid otonwe kin etanhan. woyuha ota hin ahda.

31 Qa oyate he ohna unpi kin inanpe wicaya, qa canibakse on wicakuwa, qa mazasapa on ağuyapi su kapanpi kin hena on, qa mazasapa onspe on, qa maka omdoton śpanyanpi ohna iyaye wicaya. Unkan Anmoa cinca tonwanyanpi kin owasin hecen Dawid ecawicakicon, hehan Dawid Jerusalem ekta hdi, qa oyate kin owasin nakun.

\section{WICUWOYAKE 13.}

1 Unkan hena iyohakam Amnon Dawid cinhintku kin Abiśalom Dawid cinhintku tawinohtin wastedaka; unkan he owanyag waśte, qa Tamar eciyapi.

2 Unkan Amnon tawinohtin Tamar cantiheye cin on wayazanka, he witanśna heon taku ecakicon kta Anmnon iśta kin en tehika nakaś.

3 Qa Amnon koda wanji yuha, Jonadab eciyapi, Dawid cincu Śimeya he cinhintku. Unkan Jonadab he wicaśta nina ksapa.

$4 \mathrm{Qa}$ he heciya, Wicaśtayatapi cinhintku kin he niye: tokeca anpetu otoiyohi sanpa tamaheca aniyan he? omayakidake kte śni he? Unkan heciya; Misunka 
Abiśalom tankśitku Tamar waśte wadaka.

5 Unkan Jonadab heciya, Nitowinja akan iwanka wo, qa waniyazanka konza wo; qa niyate wanniyag hi kinhan heyaliye kta. Tokin mitankśi Tamar u, qa ag̉uyapi wonmaye kta, miiśta itokam woyute micicage kta; hecen wanmdake kta, qa nape kin etanhan wate kten.

6 Unkan Amnon makata wanka, qa wayazanka konza. Unkan wicaśtayatapi kin he wanyake kta hi. Unkan Amnon wicaśtayatapi kin heciya; Tokin mitankśi. Tamar u, qa ag̉uyapi hmiyanyan micicağa, miista itokam, hecen iye nape kin etanhan wate kten.

; Unkan Dawid Tamar wahoya, iye ti kin ekta, qa heciya; Ito nitimdo Amnon ti kin ekta ya wo, qa woyute kicagia wo.

8 Unkan Tamar iye timdoliu ti ekta i; unkan makata wanka. Unkan aǵuyapi mdu icu, qa patinza, qa iśta kin itokam ağguapi hmiyanyan kaģe ça śpanyan.

9 Qa cega ihupa tonna kin icu, qa itokam kada. Unkan wota wicada śni, qa Amnon heya; Wicaśta owasin mitan tanhan tankan ya po. Unkan wicaśta owasin iye tan tanhan inanpapi.

10 Unkan Amnon Tamar heciya; Woyute kin oiśtima tipi mahen hiyuya wo; unkan ninape etanhan wate kta. Unkan Tamar aǵuyapi hmiyanyan kag̉e ciqon icu, qa timdoku Amnon kahi oiśtima tipi mahen.

11 Qa yute kta ikiyedan kahi. Unkan iyahpaye ça heciya; Kuwa mitankśi mici wanka wo.

12 Unkan heciya; Hiya, timdo ihnuhan iśten mayaye cin, Israel ohna hecen econpi śni ye. Ihnulian taku kin de ecanon kin.
13 Qa miye imaśtece cin toki amde kta he? qa niye Israel ohna witkotkopika wanji iyenicece kta. Ceciciya, wicaśtayatapi okiyaken, kinhan niye etanhan amanica kte śni ye.

14. Tuka ho kin nation wicada śni, qa he isanpa waśaka; qa iśtenya, qa kici wanka.

15 Qa Amnon he nina śiceda. ka; hecen waśte dake ciqon isanpa nakaha he śice daka, qa Amnon heciya; Najin hunktiya wo.

16 Unkan heciya, He tokeca he? Nakaha kihde mayaye cin tokaheya śicaya ecamiyecon isanpa śica ye. Unkan he nation wica-. da śni.

17 Unkan tahokśidan ookiye kin he kipan qa heya; De mitan tanhan tankan iyaye ya wo, qa inakam tiyopa kin rataka wo.

18 Unkan onhidolida hanska wan kicun, wicaśtayatapi cunwintku witanśna unpi hecer koyakapi nakaś. Unkan taokiye kin tankan iyaye ya, qa ihakam tiyopa kin nataka.

19 Unkan Tamar caliota pa kin ahdada, qa onhdohda hanske cin yuhidehdeca, qa nape kin pa atputaka, qa ceya hda.

20 Unkan timdoku Abiśalom heciya, Amnon nitimdo nici wanka he? qa mitankśi dehan inina un wo; nitimdo hee. Wicoie kin de ekta nicante kin yekiye śni wo. Unkan Tamar ehpeyapi heca timdoku ti liin olma yanka.

21 Unkan wicaśtayatapi Dawid wicoie kin dena owasin nation, qa nina śihda.

22 Unkan Abiśalom Amnon kici wicoie śica, qa wicoie waśte unmanna eye śni ; tankśitku Tamar iśtenye cin heon Abiśalom Amnon śice daka nakaś.

23 Unkan waniyetu nonpa anpe455 


\section{SAMUEL WOWAPI INONPA KIN,}

tu kin ihanketa Abiśalom tahinca yuśdapi heca wicayuha, Bayal liatzor ohna, he Ephraim ikiyedan, qa Abiśalom wicaśtayatapi cinhintku kin owasin wicakico.

24 Unkan Abiśalom wicaśtayatapi kin ekta $\dot{1}$, qa heya; Iho wanna tahinca yuśdapi nitaokiye yuha ce; ceciciya, wicaśtayatapi kin, qa taokiye, nitaokiye kici yapi kte.

25 Unkan wicaśtayatapi kin Abiśalom heciya, Hiya micinkśi, tokin owasin nici unyanpi kte śnin, hecen kagi unniyanpi kte śni. Unkan nina kitan, tuka Krici ye kta wicada śni, qa yawaśte.

26 Unkan Abiśalom heya; De śni kinhan ceciciya, cinye Amnon mici ye kta. Unkan wicaśtayatapi kin heciya; Tokeca iye nici ye kta he?

27 Unkan Abiśalom nina kitan, heon Amnon, qa wicaśtayatapi cinhintku owasin kici ye wicaśi.

28 Unkan Abiśalom tahokśidan wahokonwicakiye ca hewicakiya; Ana̧̧optan po, Ämnon cante kin miniśa on waśte kinhan, qa, Amnon kaśtaka po, qa kte po, eciciyapi kinhan ihnuhan koyakipapi kin, miye hecon ciśipi śni he? waśaka po, qa wowaditake cinca kin lieca po.

29 Unkan Abiśalom taholssidan token Abiśalom econ wicaśi kin iyecen Amnon ecakiconpi: Unkan wicaśtayatapi cinhintku owasin najinpi qa taśunke śonśonna akan iyotankapi, qa najicapi.

30 Unkan nahanhin canku ohna kupi icunhan, wotanin Dawid okiyakapi; qa Abiśalom wicaśtayatapi cinca kin owasin wicakte, qa wanjidan owicakaptapi śni, eyapi.
31 Unkan wicaśtayatapi kin najin iyaye ça tawokoyake kin hduhdelideca, qa maka akan wanka, qa taokiye owasin wokoyake hduhdehdecapi ihdukśan najinpi.

32 Unkan Jonadab, Śimeya Dawid cincu kin he cinhintku lin ie ca; Ihnuhan wicaśtayatapi cinca kośkapi kin owasin wicaktepi kin itancan mitawa eye cin. Amnon iśnana ta ce. Abiśalom tankśitku iśtenye cin ehantanhan he konza, qa $i$ kin on econpi.

33 Heon wanna ihnuhan itancan mitawa wicaśtayatapi kin wicaśtayatapi cinca kin owasin tapi ce, wicoie eyapi kin cante kin ekta, kecin kin ; Amnon iśnana ta nakaś.

$34^{\circ}$ Unkan Abiśalom najica. Unkan kośka tonwan yanke cin iśta kin hduwankan ikikcu, qa inyun wicota iheyata hunnaptan canku kin ohna kupi kin wanwicayaka.

35 Unkan Jonadab wicaśtayatapi kin heciya, Iho, wicaśtayatapi cinca kin kupi ce, nitaokiye eye ciqon ecetu.

36 Unkan ie cin ayaśtan qehan, inyun wicaśtayatapi cinhintku kin hdipi, qa hoyeyapi, qa ceyapi ; qa nakun wicaśtayatapi kin, qa taokiye owasin nina lin ceyapi.

37 Unkan Abiśalom najica, qa Talmai Amihud cinhintku Geśur wicaśtayatapi kin ekta i. Unkan Dawid anpetu owasin cinhintku kin on iyokiśica.

38 Unkan Abis̉alom najice ça Geśur ekta i, qa waniyetu yamni hen yanka.

39 Hehan Dawid wicaśtayatapi nagi kin Abiśalom cantiheya, wanna Amnon te cin on kicanptapi nakaś. 


\section{WICOWOYAKE 14.}

WICOWOYAKE 14.

1 Unkan Joab, Tzeruja cinhintku, wicaśtayatapi kin Abiśalom cantiheye cin sdonya.

2 Unkan Joab Teqoya ekta yewicaśi, qa hetanhan winohinca ksapa wan kico, qa heciya; Ceciciye, iyokiśica konza w.o, qa waśihda kiçun, qa wihdi on sdaiciye śni, qa tuwe kite cin on anpetu ota waśihda kin iyececa wo.

3 Qa wicaśtayatapi kin en yai kta, qa wicoie kin de iyecen ehe kta; qa Joab wicoie kin winyan i kin en qu.

4 Unkan Teqoya winohinca kin wicaśtayatapi kin kici ie cehan makipusdiya ehpeiçiye ça ohoda, qa wicaśtayatapi ni mayan ye, eya.

5 Unkan wicaśtayatapi kin heciya; Taku yaika he?. Unkan heya; Awicakehan wiwazica herraca, qa mihihna te ye.

$6 \mathrm{Qa}$ wicinyanna nitawa cinca wica nomnana icah wicaye cin hena tinta ekta waakinicapi, qa wicayukinukan kta tuwedan en un śni ye; unkan wanji unman kaśtake ça țe kiye ye.

7 Unkan inyun wicowazi kin ocowasin wicinyanna nitawa. anajinpi, qa heyapi ye, Sunkaku kikte kin unqu po; hecen sunkaku kikte kin nagi kin on unktepi kte ça nakun mağa tawaye kte cin he ihang unyanpi kta; qa petaga mitawa olapte $\operatorname{cin}$ he kasnipi kta, hecen mihihna on caje kin, qa takudan maka akan okicaptapi kte śni ye.

8 Unkan wicaśtayatapi kin winohinca kin heciya; Ekta hda, kinhan miye niye on waecon econ wicawaśi kta.

9 Unkan Teqoya win kin wicaśtayatapi kin heciya, Itancan wicaśtayatapi, miye qa ate tiyohnaka kin de on iyope unyanpi lita ye, qa wicaśtayatapi qa toiyotanke kin bapi kte śni ye.

10 Unkan wicaśtayatapi kin heya, Tuwe aniie cinhan miye en hiyuya wo, kinhan icimana inicahtake kte śni.

11 Unkan heya, Ceciciye wicaśtayatapi Jehowa Wakanyada kiksuya ye, on we tokiçonpi kin sanpa ihangyapi kte śni, hecen micinkśi ktepi kte śni ye. Unkan heya, Jehowa ni kimhan nicinkśi pa hin kin sukaza wanjidan makata ihpaye kte śni.

12 Unkan winohinca kin heya, Ceciciye, Wicinyanna nitawa wicaśtayatapi itancan mitawa wicoie wanjidan eciciye kte ye. Unkan, Fya wo, eya.

13 Unkan winohinca kin heya, Tokeca Wakantanka taoyate on decen yakonza lie? qa wicaśtayatapi kin tuwe bapi kta iyecen wicoie kin de eya ye, qa wicaśtayatapi cinhintku napeyapi kin hdicuye śni ye.

14. Unkiyepi awicakehan unțapi kta, mini maka apapsonpi, qa mnayanpi kte śni iyeuncecapi; Wakantanka wicanagi kin ki śni tuka, tuwe napeyapi un kin iye etanhan napeyapi kte śni wayupiya iyukcan.

15 Qa wanna oyate kin kope mayanpi, heon wicoie kin de wicaśtayatapi kin itancan mitawa ociciyag wahi ye, qa wicinyanna nitawa kin Wicaśtayatapi ewakiye kta, okini wicaśtayatapi kin tawiciny anna oie kin iyecen econ kta ye, epa.

16 Qa wanna wicaśta wan miye, qa micinkśi sakim Wakantanka tamakoce etanhan ihang unyanpi kte cin, he nape kin etanhan tawicinyanna ehdaku kta, wicaśtayatapi kin namakon ye. 


\section{SAMUEL WOWAPI INONPA KIN,}

17 Qa wicinyanna nitawa heya, Itancan mitawa wicaśtayatapi oie kin iyozimaye kte ye, itancan mitawa wicaśtayatapi kin Wakantanka ohnihdeya wan iyececa nakaś; qa itancan mitawa wicaśtayatapi kin taku waśte qa taku śica sdonya, qa Jehowa wakanyada kin nici un kte ye.

18 Unkan wicaśtayatapi kin ayupte ca winohinca kin heciya, Wicoie wan iciwange kte cin, he ihnuhan namiyecilibe cin. Unkan winohinca kin heya, Cecicim ye, itancan mitawa wicaśtayatapi, eya ye.

19 Unkan wicaśtayatapi kin heya, Taku kin de owasin en Joab nape kin nici un śni he? Unkan winohinca kin ayupte ca heya, Itancan mitawa wicaśtayatapi ninagi ni, taku itancan mitawa wicaśtayatapi ie cin owasin etanhan etapa qa catka unmanna ekta kiya yuwinh yepica śni ye. Nitaokiye Joab hecon maśi, qa iye wicoie kin hena owasin nitnwicinyanna $i$ kin en iyaye ya.

20 Wicoie kin de yahomniye kta heon nitaokiye Joab wicoie kin de kage ye, qa itancan mitawa ksapa Wakantanka ohnihde wicaye cin ksapapi kin iyeniceca, qa taku maka akan econpi kin owasin sdonyaya.

21 Unkan -wicaśtayatapi kin Joab heciya; Ito wanna wicoie kin de ecamon. Ekta ya, qa kośka kin Abiśalom hdikiya wo.

22 Unkan Joab makipusdiya ehpeiciye ca wicaśtayatapi kin yawaśte, qa ohoda, qa Joab heya, Itancan mitawa wicaśtayatapi iśta kin iyokipi waye cin nakaha nitaokiye sdonya; wicaśtayatapi kin taokiye oie kin iyecen econ nakaś.

23 Unkan Joab najin, qa Geśur ekta i, qa Abiśalom hetanhan Jerusalem ekta hdikiya.

24 Unkan wicaśtayatapi kin heya; Iye ti kin ekta yuwini hde, kta, qa miite kin wanyake kte śni. Unkan Abiśalom iye ti kin ekta hda, qa wicaśtayatapi ite kin wanyake śni.

25 Unkan Israel owasin wicehna tuwedan owanyag waśte śni, Abiśalom iyececa, on nina yatanpi, siha etanhan pesdete aiyahdeya oyuhi wanica.

26 Unkan pa kin hduśda qehan, tke kin on waniyetu iyohi ihanketa hduśda ecá, pa hin hduśda kin he the uta śeqel opawinge nonpa, wicaśtayatapi taonaspeyapi iyecen.

27 Unkan Abiśalom cinca wica yamni, qa winyan wanjidan kicitonpi, qa winyan kin Tamar eciyapi, he winohinca owanyag waśte hinca.

$28 \mathrm{Qa}$ Abiśalom waniyetu nonpa anpetu iyenakeca hehanyan Jerusalem ohna yanke ca wicaśtayatapi ite kin wanyake śni.

29 Qa Abiśalom Joab wicaśtayatapi ekta yeśi kta on wahoya. Unkan en hi kta wicada śni. Unkan ake inonpa wahoya, Unkan en hi kta tawatenye śni.

30 Unkan taokiye hewicakiya; Wanyaka po, Joab tamaga kin mitawa kin ikiyedan, qa hen barle oju, ekta ya po, qa he ideya po. Unkan Abiśalom taokiye kin maga kin ideyapi.

3 I Unkan Joab najin qa Abiśa-

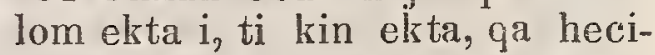
ya; Tokeca nitaokiye maga mitawa peta on ideyapi he?

32 Unkan Abiśalom Joab heciya; 1to wahociye ca deci kuwa wo; Wicaśtayatapi ekta yeciśi kta, qa hewakiye kta, Tokeca Geśur etanhan wahdi he? Dehanyan hen manka unkans waśte 
tuka. Heon wanna wicaśtayatapi ite kin wanmdake kta, qa miohan kin śice cinhan țe maye kta.

33 Unkan Joab wicaśtayatapi kin ekta $i$, qa okiyaka. Unkan Abis̉alom kico. Unkan wicaśtayatapi en hi, qa wicaśtayatapi itokan makipusdiya ohoda. Unkan wicaśtayatapi kin Abiśalom i itputaka.

\section{WICOWOYAKE 15.}

1 Unkan hena iyohakam Abiśalom canpahmihma, qa śuktanka, qa wicaśta wikcemna zaptan, iye itokam inyankapi kta, wiyeya icihnaka.

2 Qa Abiśalom hahanna hin kikta, qa otonwe tiyopa canku kin icahda najinhan inajin, qa tuwe kaśta, woakinice yuhe ça yaco kta e wicaśtayatapi en hiyu kinhan, Abiśalom he kico, qa heciya: Niye otonwe tukte enitanhan he? Unkan Nitaokiye Israel wicoun wanji etanhan ce, eya.

3 Unkan Abiśalom heciya; Nioie kin he waśte, qa ecetu, tuka nanition kta wicaśtayatapi kin tuwedan hecon śi śni.

4 Unkan Abiśalom heya, Tokia makoce ohna wayaco makagapin hecinhan tona woakinice, qaiś woyaco yuhapi kin hena owasin miye ekta hipi kta, qa wicamdaowotanna kte.

5 Unkan tuwe kaśta he ohoda kta ikiyedan i kinhan, nape kin ekta yekiye ca yuze ca i iputaka. 6 Qa Israel wicaśta tona wicaśtayatapi wicayaco kta e ekta hipi kin, hena owasin Abiśalom hecen ecawicakicon, qa Israel wicaśta kin cantepi kin mawicanun.

7 Unkan waniyetu wikcemna topa ihanketa, Abiśalom wicaśtaya tapi kin heciya; Ito Ḣebron ekta mde ça woyake wan Jehowa owakimdake cin hen wahdajuju kta.

8 Nitaokiye Geśur Aram ohna yanke ciqon woyake wan omdake ca hepa, Jehowa Jerusalem en hdimakiye cinhan Jehowa ówakiye kta.

9 Unkan wicaśtayatapi kin heciya; Wookiye en ya wo. Unkan najin, qa ífebron ekta i.

10 Wanna Abiśalom nahmana Israel wicoun owasin ehna wicaśta ye wicaśi, qa hewicakiya. Mazayahotonpi kin yahotonpi kin nayahonpi kinhan, Abiśalom Ḣebron ohna wanna wicaśtayatapi heca ce, ehapi kta.

11 Unkan Jerusalem etanhan wicaśta opawing nonpa Abiśalom opapi, wicakico nakaś, hena ecetupi ipi, takudan sdonyapi śni.

12 Unkan Ahitopel (Cinye witkotko) Giloni kin, Dawid tawiyukcan kin, totonwe Gilo etanhan tawoyuśna patapi kin ekta A biśalom kico. Unkan odakota kin waśaka aya, oyate 'Abiśalom opapi kin ohimniyan sanpa ota aya nakaś.

13 Unkan wahośiye wan Dawid en hi, qa heciya, Israel wicaśta cantepi kin wanna Abiśalom opa yanka.

14 Unkan Dawid iye taokiye owasin iye kici Jerusalem ohna yakonpi kin hewicakiya; Najinpo, naunjicapi kte, Ábiśalom itokam unnipi kte śni. Dapi inahnipo. Okini iye inahni, qa unkihdegapi, qa śicaya ecaunkiconpi kta, qa otonwe kin canhipi hi on kaśtake kta.

15 Unkan wicaśtayatapi taokiye kin wicaśtayatapi kin heciyapi ; Tho token itancan wicaśtaya459 


\section{SAMUEL WOWAPI INONPA KIN,}

tapi econ unśipi kin owasin iyecen econkupi kta.

16 Unkan wicaśtayatapi kin tankan inanpa, qa tiyohnaka tawa owasin opapi, tuka wicaśtayatapi kin winohinca wikcemna wakanyan wicayuze śni tipi awanyakapi kta ehpewicaya.

17 Unkan wicaśtayatapi kin inanpa, nakun oyate opapi kin owasin, qa tipi itehan inajinpi.

$18 \mathrm{Qa}$ taokiye owasin iye icahda manipi, qa Kereti (Pa baksapi), qa Peleti (Inyankapi) kin, qa Giti kin wicaśta opawinge śakpe Gat etanhan opapi qon, hena owasin wicaśtayatapi kin i tokam manipi.

19 Unkan wicaśtayatapi kin Ittai Giti kin heciya; Tokeca niś eya mici de cin; ekta hda, qa wicaśtayatapi kici yanka wo. Oyate nitokeca, qa nakun oyanke nitawa etanhan nayajica.

20 Ḧtanihan yahi, qa nakaha mici enanakiya yeciye kta he? Qa miye toki owakihi mawani kta. Ekta hda, qa wowacantkiye, qa wowicake en nihunkawanji wicahdohda wo.

21 Unkan Ittai wicaśtayatapi kin ayupte ca heciya, Jehowa ni, qa itancan mitawa wicaśtayatapi kin ni kinhan, tukten itancan mitawa wicaśtayatapi kin un kinhan, wiconte qaiś wiconi unman tukte kaśta, oyanke kin he en nitaokiye nici un kta.

22 Unkan Dawid Ittai heciya; Ho wo: Tokata ya wo. Unkan Ittai Giti kin tokata iyaya, iye, qa wicaśta tawa owasin, qa śiceca iye opapi kin owasin.

23 Únkan makoce kin owancaya hotankakiya ceyapi, qa oyate kin iyayapi, qa wicaśtayatapi kin Qedron kaksiza kin akasanpa iyaya, qa oyate kin owasin hopuze kin canku kin ohna iyayapi.
21 Qa inyun Tzadoq, qa iye kici Lewi kin owasin Wakantanka wotakuye canwohnaka kin akiyuhapi, qa Wakantanka tacanwohnaka kin kihnakapi, qa Abiatar, oyate owasin otonwe etanhan iyayapi icunhan, wośnapi kag̉a yanka.

25 Unkan wicaśtayatapi kin Tradoq heciya; Wakantanka tacanwohnaka kin otonwe ekta ahda wo. Jehowa iśta kin iyokipi waye cinhan, ake hdimaye kta, qa he, qa tipi tawa wanyag maye kta.

26 Tuka miye ke ca, Iyomakipi śni eye cinhan, ito token iye iśta kin en waśte kin he iyecen econ kta.

27 Qa wicaśtayatapi kin Tzadoq wawayuśna kin heciya, Wawanyaka henica, wookiye en otonwe kin ekta hda, qa Ahimayatz nicinkśi, qa Jonatan Abiatar cinhintku napin nicincapi onipapi.

28 Ito niyepi etanhan tuwe wahośi makahi kte cin hehanyan tinta omdaye ohna manke kta.

29 Heon Tzadoq qa Abiatar Wakantanka tacanwohnaka kin Jerusalem ekta ahdapi, qa hen yakonpi.

30 Unkan Dawid Wihdican paha itanwankanhde yapi kin ohna itanwankanhde iyaya, pa kin ahdahpe ton, sicodan ceya mani, qa oyate opapi kin owasin otoiyohi pa ahdahpe tonpi, qa ceyapi, itanwankanhde yapi.

31 Unkan Dawid okiyakapi, qa, Ahitopel Abiśalom odakotapi kin en opa, eyapi. Unkan Dawid heya, Jehowa ceciciye Ahitopel wowahokonkiye kin yuwitkotkoka ye.

$32 \mathrm{Qa}$ Dawid paha kin iyohi qehan, hen Wakantanka cekiya. Tnkan inyun Ḧuśai Arki kin wo- 
koyake hduhdehdece, qa pa kin maka ahdata itokam najin.

33 Unkan Dawid heciya; Mici de cinhan mayaduśake kata.

34 Tuka otonwe ekta yahde cinhan, qa, Wicaśtayatapi nitaokiye he miye, wanakaja tanhan niyate taokiye hemaca, qa detanhan nitaokiye hemaca kta, Abisalom eyakiye cinhan, Ahitopel wowahokonkiye kin miyeciduśice kta.

35 Qa Tzadoq, qa Abiatar wawayuśnapi kin nici hen unpi śni he? qa wicaśtayatapi ti kin etanhan wicoie nayalion kinhan, owasin 'Tzadoq qa Abiatar wawayuśnapi kin owicayakidake kta.

$36 \mathrm{Qa}$ ito hena om cincapi nonpa Ahimayatz Tzadoq cinhintku, qa Jonatan Abiatar cinhintku, qa hena napepi on wicoie nayahonpi kin owasin iwaho mayayapi kta.

37 Unkan Hośai Dawid takodaku otonwe en hdi, qa Abiśalom Jerusalem ekta hi.

\section{WICOWOYAKE 16.}

1 Unkan Dawid paha kin kitanna ako iyaye cehan inyun Tziba, Mepibośet tahokśidan kin he akipe kta $\mathrm{u}$, qa śonśonna nonpa aqin kitonpi, qa hena akan aġuyapi opawinge nonpa, qa hastanhanka iyag̉e opawinge wanji, qa waskuyeca pusyapi opawinge, qa miniśa opalite wanjidan.

2 Unkan wicaśtayatapi kin Tziba heciya. Taku on dena duha he? Unkan Tziba heya, Wicaśtaya tapi tiyohnaka kin śonśonna akan iyotankapi kta, qa hokśipidan ağuyapi kirı, qa waskuyeca kin yutapi kta, qa tuwe hewoskan mdokite cinhan miniśa kin yatke kta.
3 Unkan wicaśtayatapi kin heya. Niyuhe cin cinhintku kin toki un he? Unkan Tziba wicaśtayatapi kin heciya, Inyun Jerusalem ekta kihde, ca, Ate wicaśtayatapi kin heon nakaha Israel tiyohnaka kin tohe kin maqupi kta, eya.

4 Unkan wicaśtayatapi kin Tziba heciya, Taku Mepiboset tawa qon owasin nitawa kta. Unkan Tziba heya, Ohocida itancan mitawa wicaśtayatapi, niiśta kin iyokipi ciye kta.

5 Unkan wicaśtayatapi kin Dawid Bahurim (Kośka totonwepi) hehanyan i qehan, inyun wicaśta wan, Saul ti kin wicowazi etanhan, Simeyi Gera cinhintku eciyapi, hetanhan inanpe ca wayaśica mani.

$6 \mathrm{Qa}$ Dawid, qa wicaśtayatapi Dawid taokiye owasin, qa oyate kin owasin; qa wicaśta waśaka Dawid etapata qa catkata manipi kin owasin inyan on wicakinin.

7 Qa Śsimeyi wayaśice ça, hecen eya; Hunktiya, Hunktiya wo, wicaśta weyesa wicaśta śni cinhintku.

8 Saul tiyohnalka we kin owasin Jehowa anihdikiya : heekiya wicaśtayatapi yaun, tuka Jehowa Abiśalom nicinkśi wicaśtayatapi 'kag̉a, qa niye wicaśta weyesa henica, heon ito taku sica iyahde yaye cin he iyonihi ce.

9 Unkan Abiśai Tzeruja cinhintku kin wicaśtayatapi kin heciya, Tokeca śunka te cin de itancan mitawa wicaśtayatapi kin yasica he? Ceciciye, ekta mde ça pa kin bawakiśpe kta.

10 Unkan wicaśtayatapi kin heya, Tzeruja cinca kin niyepi taku iwamayatokiyapi he? Wayaśice kte, Jehowa he Dawid 461 


\section{SAMUEL WOWAPI INONPA KIN,}

yaśiceśi kin heon, Tokeca hecanon, tuwe eciye kta he?

11 Unkan Dawid Abiśai, qa taokiye owasin hewicakiya, Inyun micinksi mitezi etanhan inanpe cin he minagi akita, hecinhan isanpa Bejamini kin de hecon kta iyececa. Mayaśice kta iyowinkiya po; Jehowa hecon śi nakaś.

12 Okini Jehowa iyomakiśice cin wanyake kta, qa nakaha mayaśice cin de on wowaśte maqu kta.

13 Unkan Dawid qa wicaśta tawa kin canku kin omanipi, qa Simeyi iyotakonza hunnaptan omani, wayaśica, qa inyan kaho iyeye ça watuśekśeca kadada mani.

14 Unkan wicaśtayatapi kin, qa oyate opapi kin owasin Yaipim (Mdokitapi) ekta ipi; qa hen mdesiciyapi.

15 Unkan Abiśalom, qa Israel wicaśta oyate kin owasin, Jerŭsalem en hipi, qa Ahitopel opa.

16 Unkan Huśai Arki kin, Dawid takodaku, Abiśalom ekta ki qehan Ḣuśai Abiśalom heciya. Wicaśtayatapi kin ni kte. Wicaśtayatapi,kin zaniyan un nunwe.

17 Unkan Abiśalom H̊uśai heciya, Nitakoda canteyakiye cin dee he? Tokeca nitakoda kici idade śni he?

18 Unkan Ḣuśai Abiśalom heciya, Hiya eeś tuwe Jehowa kaliniga, qa oyate kin de nakun Israel wicaśta owasin kahinigapi kin he tawa maye kta, qa kici manke kta.

19 Qa nakun tuwe ówakiye kta he? Cinhintku kin hee śni he? Nitokam waun kta, niyate itokam ówakiye cin he iyecen.

20 Unkan Abiśalom Ahitopel heciya, Iho unkiciyukcan po. Token econkupi kta he? 462
21 Unkan Ahitopel Abiśalom heciya, Niyate tawicu tipi kin awanyakapi kta owanji yanke wicaśi kin hena en ya wo; hecen Israel owasin niyate wahtenidaśni nahionpi kta, qa Israel owasin napepi kin niciyusutapi kta.

22 Unkan tipi akapatanhan wakeya wan Abiśalom on ehdepi ; Unkan Abiśalom Israel owasin iśtapi itokam, atkuku tawicu kin en wicai.

23 Unkan he ehan Ahitopel oie kin, wahokonwicakiye cin he, taku wakan iwangapi kin oie kin iyececa, Ahitopel oie kin owasin Dawid ekta, qa Abiśalom ekta hececa.

\section{WICOWOYAKE $1 \%$.}

1 Unkan Ahitopel Abiśalom heciya, Ito wicaśta kektopawinge wikcemna sanpa kektopawinge nonpa wakahniğe kta, qa nawajin, qa hanyetu kin de Dawid kuwa amde kta.

2 Iye mdokițe ca nape kin hustaka, hecen yuśinye waye kta, qa oyate opapi kin owasin napapi kta, qa wicaśtayatapi kin iśnana wakaśtake kta,

3 Qa niye ekta oyate kin owasin hdicu wicawaye kta, owasin hdipi kinhan, wicaśta ayakite cin he oyate kin owasin wokiyapi kta.

4 Unkan wicoie kin he Abiśalom iśta kin en, qa Israel hunkayapi owasin iśtapi en ecetu.

5 Unkan Abiśalom heya; Ito, H̃uśai Arki kin nakun kico, iye i kin ohna taku un kin lie nakun naunhonpi kta.

6 Unkan ḦIuśai Abiśalom ekta hi qehan, Abiśalom heciya, Wicoie kin de iyecen Ahitopel econ unśipi ce. Eye cin iyecen econ- 
kupi kta, qaiś econkupi kte śni, niś, eya wo:

7 Unkan Hínsai Abiśalom heciya, Wicoie Ahitopel iyukcan kin he nakaha waśte śni.

8 Qa Ḣuśai heya, Niye niyate, qa wicaśta tawa sdonwicayaya, wicaśta waśaka hecapi, qa nakaha nagipi canteptanyanpi, tinta wahankśica wan cinca kin kipi kin iyececapi, qa niyate wicaśta zuyesa heca, qa hanyen oyate om wanke kte śni.

9 Qa inyun wanna woha wan en, qaiś tuktetu kaśta inalima, qa otokahe ekta oyate kin wanjikśi hinhpayapi kinhan, oyakapi kta, qa oyate Abiśalom opapi kin hena wicaktepi eyapi kin nahonpi kinhan ;

10 Tuwe waditake ca cante mnaja cante kin iyececa eśta skan kta; niyate kin wicaśta waśaka, qa tona opapi kin wicaśta waditakapi kin lsrael owasin śdonyapi nakaś.

11 Miye hecen wahokonciciye, Israel owasin, Dan etanhan Berśeba hinskoya mnayanpi kta, wiyaka miniwanca huta kin iyecen wicota, qa niye hinca wokicize en de kta.

$12 \mathrm{Qa}$ tukten iyeyapi kte cin oyanke kin he en anauntanpi kta, qa cu kin maka kin ahinhpaye cin iyecen akan iyaunhanpi kta, qa wicaśta iye opapi kin owasin wanjidan unkokaptapi lite śni.

13 Unkan otonwe conkaśke yapi wan en nape cinhan, Israel owasin otonwe kin he conkaśke ekta hakahmunpi ikoyag yapi, qa yusdohanpi kta, kaksiza kin ekta, ecen inyan sukaza wanjidan hen iyeyapi kte śni.

14. Unkan Abiśalom, qa Israel wicaśta kin owasin heyapi, $\dot{H} u-$ śai Arki kin wahokonkiye cin he Ahitopel wahokonkiye cin isanpa waśte ce. Jehowa Alitopel wowahokonkiye Abiśalom on waśte kin he yujuju kta konza, Jehowa Abiśalom ekta taku śica hiyuye kta heon etanhan.

15 Unkan Ḧuśai Tzadoq, qa Abiatar wawayuśnapi kin hewicakiya, Ahitopel hecen, qa hecen Abiśalom, qa Israel hunkayapi kin wahokonwicakiya; qa miye hecen wahokonwicawakiya.

16 Heon wanna kohanna Dawid wahoyapi, qa okiyaka po; qa heciya po, Ihnuhan wicaśtayatpi kin hanyetu kin de hewoskan makomdaya ohna wanke cin, hecon kinhan okini wicaśtayatapi, qa oyate opapi kin owasin ihang wicayapi kta; heon katinyan akasanpa idade kta.

17 Unkan Jonatan qa Ahimayatz Enrogel (Tonweyapi wakoniya) kin ekta yakonpi. Otonwe en hiyupi wanwicayakapi ikopapi nakaś, heon wicinyanna wan ekta i, qa owicakiyaka; unkan wicaśtayatapi kin Dawid okiyakapi kta iyayapi.

18 Unkan kośka wan wanwicayaka, qa Abiśalom okiyaka. Unkan napin inahniyan Bahurim. ohna wicaśta wan ti kin en ipi. Unkan iye tahocoka ohna minihdoka wan yuha, unkan hen kun ipi .

19 Unkan winohinca kin minihdoka i kir akakpe ton, ga wokpanpi akada; unkan iyukcanpi śni.

20 Abiśalom taokiye kin winolinca hen ti kin ekta hipi, qa heciyapi, Ahimayatz qa Jonatan tukteepi he? Unkan winohinca kin hewicakiya; Mini wakpadan kin akasanpa iyayapi ce. Unkan owicadepi, qa iyewicayapi śni, qa Jerusalem en hdapi.

21 Unkan kihdapi ohakam minihdoka etanhan inanpapi, qa iya463 


\section{SAMUEL WOWAPI INONPA. KIN,}

yapi, qa Dawid wicaśtayatapi kin okiyakapi, qa Dawid heciyapi, Abitopel decen niyepi on wahokonwicakiya, heon najin po, qa inaliniyan mini kin akasanpa iyaya po.

22 Unkan Dawid, qa oyate iye opapi kin owasin najinpi, qa Jordan iyuwegapi ; hanlianna anpa kin Jordan iyuweg̉e śni wanjidan okapte śni.

23 Unkan Alitopel, iye wahokonwicakiye cin iyecen econpi śni wanyake cehan, śonśonna. aqin kiton, qa akan iyotanke ca toti kin ekta kihda, totonwe kin en, qa ti kin hduwiyeya, qa poskin içikte-qa atkuku ohnahnakapi tawa kin ohna hnakapi.

24 Unkan Dawid Mahanaim ekta i, qa Abiśalom Jordan iyuweğa, qa Israel wicaśta kin owasin opapi.

25 Unkan Abiśalom Yamasa mdetanhunka kagia, Joab hee kiya. Unkan Yamasa atkuku Jitra eciyapi, Iśmaeli wicaśta heca, qa Abigail Naliaś cunwintku yuza, he Tzeruja Joab hunku tawinohitin heca.

26 Unkan Israel qa Abiśalom Gileyad makoce ohna etipi.

27 Unkan Dawid Mahanaim ekta hi qehan Śobi Nahiaś cinhintku Anmon cinca tonwanyanpi Rabba etanhan, qa Makir Yanmiel cinhintku Lodebar etanhan, qa Barzillai Gileyadi kin Rogelim etanhan,

28 Hena owinja, qa maza wakśica, qa maka wakśica, qa ag̉uyapi su, qa barle, qa aguyapi mdu, qa papaliyapi, qa omnica, qa omnica hmiyanyanna, qa papahyapi.

29 Qa canhanpi tiktica, qa asanpi ihdi, qa tahinca, qa pte asanpi suta, Dawid qa oyate opapi kin yutapi kta e wicakahipi. Oyate kin tinta ohna wotektehdapi, qa mdokițapi, qa ipuzapi, eyapi nakaś.

\section{WICOWOYAKE 18.}

1 Unkan Dawid oyate iye opapi kin wicayawa, qa akicita kektopawingege itancan, qa akicita opawingege itancan yuhe wicakiya.

2 Qa Dawid oyate kin obe yamni ye wicasi, obe wanji Joab napc kin en, qa wanji Abiśai Joab cincu Tzeruja cinhintku nape kin en, qa unman Ittai Giti kin nape kin en. Unkan wicaśtayatapi kin oyate kin liewicakiya, Miś eya niyepi om mde kta ce.

3 Unkan oyate kin heyapi, Hiya de kte śni ce. Unkiyepi naunjicapi kinhan unkiyepi ekta cante ye kiyapi kte śni, qa unkiyepi hanke unțapi kinhan unkiyepi ekta cante ye kiyapi kte śni. Unkiyepi kektopawinge wikcemna iyecen niyawapi, heon otonwe etanhan óunyakiyapi kin he waśte.

4 Unkan wicastayatapi kin hewicakiya; Taku niiśtapi en waśte kin hee ecamon kta. Qa wicaśtayatapi kin otonwe tiyopa icahda najin, qa oyate kin opawing g.ge qa kektopawingege inanpapi.

5 Unkan wicaśtayatapi kin Joab, qa Abiśai qa Ittai wahokonwicakiye ça heya, Miye on Abiśalom kośka kin wahbayedan ecakicon po. Unkan wicaśtayatapi kin Abiśalom on mdetanhunka owasin wahokonwicakiye cin oyate kin owasin nahonpi.

6 Qa oyate kin Israel itkokim iyayapi, qa Epraim taśkoju ohna kicizapi.

7 Unkan Israel oyate kin hen ktepi, Dawid taokiye itokam, qa 


\section{WICOWOYAKE 18.}

wokaśtake hen anpetu kin he tanka, wicaśta kektopawing e wikcemna nonpa.

8 Unkan anpetu kin he en makoce kin owancaya kicizapi, qa oyate taśkoju wicakasote cin hena ota, isan wicakasote cin isanpa.

9 Unkan Abiśalom Dawid taokiye awicakipa, qa Abiśalom śonśonna wan akan iyotanka, qa śonśonna kin utuhu tanka wan yuhaha ihukuya iyaya, qa Abiśalom pa kin utuhu en ikoyag ya, qa śunka śonśonna kin iye ihukuya tanhan iyaye ça mahpiya qa maka kin otahedan elpeya.

10 Unkan wicaśta wan he wanyake ca Joab okiyake ca heya, Inyun Abiśalom utuhu wan en okazeze warmdaka.

11 Unkan Joab wicaśta okiyake cin heciya. Inyun he wandake cinhan tokeca lien makata yakaśtake śni he? hecanon unkanśs miye mazaska wikcemna, qa ipiyaka wan cicu kta tuka.

12 Unkan wicaśta kin Juab heciya, Miye qe mazaska kektopawinge minape en aspe miciyapi eśta, wicaśtayatapi cinhintku minape on kiunniwaye kte śni. Wicaśtayatapi kin niye, qa Abisai, qa Ittai wahokonniciyapi, qa, Miye on Abiśalom kośka kin patan po, eniciyapi kin minoge on nawahion.

13 Naği kin kiunniwaya unkanś, wicoie wanjidan wicaśtayatapj kin etanhan nahmanpi śni, qa niye qe anamayajin kta.

14 Unkan Joab heya, Den nici manke kta iyecece śni; qa wahinkpe yamni icu, nape kin ohna, qa Abiśalom cante kin en hena iyeya, nahanhin niyake utuhu cokaya yanke cin icunhan.

15 Hehan kośka wikcemna Joab wipe kin kiciçinpi kin hena Abi- śalom ikiyedan ipi, qa capapi qa ktepi.

16 Hehan Joab mazayahotonpi wan yahoton; unkan oyate kin Israel kuwapi etanhan hdicupi, Joab oyate kin kicunni wicaya nakaś.

17 Unkan Abiśalom icupi, qa taśkoju ohna wolia tanka kin en ehipeyapi, qa inyan paha tanka wan akan ejupi. Unkan Israel owasin najicapi, otoiyohi tawakeya ekta.

18 Abiśalom nahanhin ni qehan wokilssuye wan icu, qa ekicihde, he wicaśtayatapi osmaka ohna yanka, cinca wica on micaje kiksuyapi kta manica, eya nakaś ; qa wokiksuye kin iye caje on cajeyata; unkan anpetu kin dehanyan he Abiśalom nape kin eciyapi.

19 Unkan Ahimayatz Tzadoq cinhintku kin heya; Tokin waimnanke ca wicaśtayatapi kin wotanin kin omdake kten, tokayapi kin Jehowa woyaco ecawicakicon nakaś.

20 Unkan Joab heciya, Wotanin oyake kta wicaśta kin nakaha henica śni, qa anpetu tokeca wan wotanin odake kta; tuka nakaha wicaśtayatapi cinhintku te cin on wotanin odake kte śni.

21 Unkan Joab Kuśi heciya, Inyanka, taku wandake cin wicaśtayatapi kin okiyaka wo. Unkan Kuśi Joab ektakiya pakapsan, qa inyang iyaya.

22 Unkan Ahimayatz Tzadoq cinhintku kin alie Joab heciya, Hececaśta ceciciya, miś eya Kuśi ihakam waimnanke kta. Unkan Joab heya; Micinkśi taku on yainanke kta he? Wotanin odake kta takudan niciyanke śni.

23 Unkan, Hececaśta waimnanke kta, eya. Unkan heciya, Inyanka wo. Unkan Ahimayatz 465 


\section{SAMUEL WOWAPI INONPA KIN,}

omdaye canku kin ohna inyanke ca Kúsi kapeya.

24. Unkan Dawid otonwe tiyopa nonpa kin otahedan iyotanka yanka. Unkan waawanyake cin tiyopa iwankam conkaśke akan i, qa wankan etonwe ca wicaśta wanjidan inyang $\mathrm{ku}$ kin wanyaka.

25 Qa waawanyake kin pan qa wicaśtayatapi kin okiyaka. Unkan wicaśtayatapi kin heya, Wanjidan u kinhan i kin ohna wotanin yukan. Unkan katinyan inyanke ca ikiyedan ku.

$26^{\circ}$ Unkan waawanyake kin wicaśta tokeca wan inyanke cin wanyake ca tiyopa awanyake cin kipan qa heya, Inyun wicaśta wan iśnana inyang ku. Unkan wicaśtayatapi kin heya, $\mathrm{He}$ nakun wotanin yuha ce.

27 Unkan waawanyake kin heya, Tokaheya inyanke cin Ahimayatz Tzadoq cinhintku kin inyanke cin he iyececa wadaka. Unkan wicaśtayatapi kin heya; He wicaśta waśte, qa wotanin waśte au ce.

28 Unkan Ahimayatz hoyeye ça, Wookiye ; wicaśtayatapi kin, eciya, hehan wicaśtayatapi itokam makipusdiya ehpeiçiye ça ohoda, qa heya, Jehowa Wakan yada kin yawaśtepi nunwe. Iye wicaśta tona itancan mitawa, wicaśtayatapi kin, napepi kin apaha kiyapi kin hena wicakaśka.

29 Unkan wicaśtayatapi kin heya, Kośka kin Abiśalom zaniyan un he? Unkan Ahimayatz heya, Joab wicaśtayatapi taokiye, qa miye nitaokiye inyang uśipi qehan, owodutaton tanka wanmdaka, tuka toketu kin sdonwaye śni.

30 Unkan wicaśtayatapi kin heya, Thduhomni, qa den yanka wo. Unkan ihduhomni qa en yanka.

31 Unkan hehan Kuśi hi, qa Kuśi heya, Wotanin, itancan mitawa, wicaśtayalapi, Jehowa nakaha niyaco, qa tona aninajinpi kin owa. sin etanhan enihdaku.

32 Unkan wicaśtayatapi kin $\mathrm{Ku}$. śi heciya; Kośka kin Abiśalorn zaniyan un he? Unkan Kuśi heya. Tona itancan mitawa wicaśtayatapi tokayapi, qa śicaya ecanionpi kta e aninajinpi kin, hena owasin kośka kin he iyececapi kta nunwe.

33 Unkan wicastayatapi kin nina iyokiśice ca tiyopa iwankam tipi ekta i, qa ceye ca heya, ceye cin icunhan; Micinkśi Abiśalom, micinkśi, micinkśi Abiśalom. Tokin niye eekiya miye mața unkanś, Abiśalom micinkśi, micinkśi.

\section{WICOWOYAKE 19.}

1 Unkan wicastayatapi kin Abisalom on ceye ca iyokiśin ic̣iya, Joab okiyakapi.

2 Unkan anpetu kin he en ohiyapi kin oyate kin owasin iyokiśin wicaya, Wicaśtayatapi kin cinhintku kin on iyokiśica eyapi kin anpetu kin be en oyate kin nahonpi nakaś.

3 Unkan oyate kin nahmana otonwe kin en hdicupi, oyate wan okicize etanhan iśteca najica inahmapi kin iyecen.

4 Wanna wicaśtayatapi kin ite ahdahpa, qa ho tankakiya ceye ça heya, Micinkśi Abiśalorn, Abiśalom micinkśi, micinkśi.

5 Unkan Joab wicaśtayatapi ekta ti mahen hi, qa heya. Nitaokiye nakaha ninagi kin niyanpi, ga nicinca wica winyan ko nağipi kin, qa nitawin nag̉ipi kin, qa wicinyanna nitawa naggipi kin niwicayapi, kin hena owasin nakaha itepi kin iśten wicayaya.

6 Tona sicenidakapi kin hena 


\section{WICOWOYAKE 19.}

waśte wicayadake ça waśte nidakapi kin śice wicayadaka; nakahe akicita tancan, qa ookiye ihawicayakikta śni dáotanin, qa anpetu kin de Abiśalom ni. unkanś qa unkiyepi owasin unțapi mnkanś niiśta kin en ecetu kta tuka, nakaha sdonwaya.

7 Heon wamna najin iyaye ca nitaokiye om wacantkiya wohdaka wo. Jehowa cajeyan ociciyaka tankan inayape śni kinhan, wicaśta wanjidan hanyetu kin de nici yanke kte śni, qa he niye on śice kta, koniśka ehantanhan taku śica ayakipe cin hena owasin isanpa.

8 Unkan wicaśtayatapi kin najin, qa otonwe tiyopa en iyotanka. Unkan oyate kin owasin owicakiyakapi qa, Inyun wicaśtayatapi kin tiyopa kin en iyotanka eyapi. Unkan oyate kin owasin wicaśtayatapi itokam hipi, qa Israel owasin wakeyapi ekta najica hdapi.

9 Unkan hehan oyate owasin Israel wicoun owasin ehna akinicapi, qa heyapi, Wicaśtayatapi kin toka unyanpi napepi etanhan eunhdakupi, qa iye Pilistim napepi etanhan niunkiyapi, tuka wanna Abiśalom on makoce kin etanhan nakipa.

10 Qa Abiśalom unhapi kta e sda unkiyapi kin he wokicize en te; heon wanna tokeca wicaśtayatapi kin hdicuyapi kin on inina dukanpi he?

11 Unkan wicaśtayatapi kin Dawid Tzadoq qa Abiatar wawayuśnapi kin wahowicaye ca heya, Juda hunkayapi kin wahokonwicakiye ça heya po; Tokeca wicaśtayatapi kin ti kin en hdikiyapi kin niyepi nihektapapi he? wanna Israel owasin oiepi kin wicaśtayatapi kin ekta ti kin en hi ce.
12. Mihunkawanji he niyepi, mihuhu, qa micehpi kin he niyepi. Tokeca wicaśtayatapi kin hdikiyapi kta nihektapapi kta he?

13 Qa Yamasa heclya po, Mihuhu qa micehpi henica śni he? Wakantanka hecen qa nakun isanpa ecamicon nunwe, Joab heekiya mitokam tokata ohinniyan mdetanhunka henica kte śni kinhan.

14 Unkan Juda wicaśta owasin cantepi kin yuptanyan, wicaśta wanjidan iyecen; unkan wicaśtayatapi kin wahoyapi, qa, Hdi po, niye qa nitaokiye owasin, eyapi.

15 Unkan wicaśtayatapi kin ku, qa Jordan ekta hi. Unkan Juda wicaśtayatapi kin Jordan hiyuweliyapi kta e wicaśtayatapi kin itkokipapi kta iyayapi, qa Gilgal ekta ipi.

16 Unkan Śsimeyi Gera cinhintku Benjamini kin Bahurim ohna yanke cin inahni, qa wicaśtayatapi Dawid itkokipe kta, Juda wicaśta kin om apamahde iyaya.

17 Unkan Benjamin etanhan wicaśta kektopawinge opapi, nakun Saul tiyohnaka ookiye wan Tziba, qa iye cinca wikcemna sanpa zaptan, qa taokiye wikcemna nonpa opapi, qa wicaśtayatapi kin itkokim Jordan iyuwegapi.

18 Qa wicaśtayatapi tiyohnaka hiyuyapi kta, qa iye iśta kin en taku waśte kin econpi kta wata wan akasanpa watom yapi. Qa Śimeyi Gera cinhintku wicastayatapi kin itokam makata ehpeiçiye, Jordan iyuw egapi en.

19 Qa wicaśtayatapi kin heciya, Ihnuhan itancan mitawa miohan śice cin miciyawa kin, qa ihnuhan taku pemniyan nitaokiye econ kin yeksuye cin; itancan mitawa wicaśtayatapi Jerusalem 467 


\section{SAMUEL WOWAPI INONPA KIN,}

etanhan iyaye cin anpetu kin he can mitawa wicaśtayatapi itoen, ihnuhan wicaśtayatapi kin cante kin ekta yekiye cin.

20 Wawahtani nitaokiye sdonya, heon itancan mitawa wicaśtayatapi kin itkokim apamahde nakaha wau, Josep tiyohnaka kin owasin wicitokam.

21 Unkan Abiśai Tzeruja cinhintku ie ca heya, Simeyi de on te kiyapi kte śni he? Tuwe Jehowa sdakiye cin yaśice cin heon etanhan.

22 Unkan Dawid heya Tzeruja cinca kin taku iwamayatokiyapi he? Nakaha mayakipajinpi, Israel ohna nakaha tuwedan te yapi kte śni. Israel wicaśtayatapi kin hemaca nakaha sdonwakiye śni he?

23 Unkan wicaśtayatapi kin, Te niyanpi kte śni, Śimeyi eciya; nakun wicaśtayatapi kîn, Taku wakan namahon eciya.

24 Unkan Mepibośet Saul cinhintku wicaśtayatapi kin itkokim apamahde hi, qa wicaśtayatapi kin iyaye cin anpetu kin he ehantanhan wookiye en hdi anpetu kin hehanyan, siha, qa putinhin kin unmanna pikiye sni, qa wolroyake hdujaja śni.

25 Qa Jerusalem en wicaśtayatapi kin itkokipe cehan, wicaśtayatapi kin heciya, Mepibośet tokeca mici de śni he?

26 Unkan heciya, Wicaśtayatapi itancan mitawa, mitaokiye mahnayan. Nitaokiye kin huśte ecee, heon nitaokiye śonśonna kin aqin miciton, qa akan imdotanke ca wicaśtaya tapi kici mde kta,epa. 27 Nakun itancan mitawa wicaśtayatapi kin itokam nitaokiye itonśniyan aia. Tuka itancan mitawa, wicaśtayatapi kin, Wakantanka ohnihdeye cin iyececa ; heon taku niiśta kin en waśte kin hecon ye. 28 Ate tiyohnaka owasin; itan- l kta he? kam, wicaśta țapi iyeuncecapi ; tuka itancan mitawa wicaśtayatapi kin, nitaokiye tona wahna wotapi nitawa ekta wotapi kin wicehna iyotang kiya, qa token wanna wicaśtayatapi kin sanpa hoyewakiya owakihi kta?

99 Unkan wicaśtayatapi kin heciya, Tokeca nioie kin emayakiya he? Niye qa Tziba maga kin kihduśpa po, wanna epa.

30 Unkan Mepibośet wicaśtayatapi kin heciya, Itancan mitawa zaniyan hdi kin heon iye eśta ocowasin icu kta.

31 Unkan Barzillai Gileadi kin wicaśtayatapi kin Jordan opta ye kiye kta heon Rogelim etanhan apamahdedan u, qa wicaśtayatapi kici Jordan opta iyaya.

32 Barzillai wanna wicahinca waniyetu wikcemna śahdoġan, qa wicaśta nina tanka, heon wicaśtayatapi kin woqu, Matianaim en ti kin hehanyan.

33 Unkan wicaśtaya tapi kin Barzillai heciya. Niye miciu wo, kinhan wocicu kta, Jerusalem ohna, miye kici.

34 Unkan Barzillai wicaśtayatápi kin heciya. Waniyetu tona wani kta on wicaśtayatapi kici Jerusalem ekta itanwankanhde mde kta he?

35 Nakaha waniyetu wikcemna. maśahdogan; Nitaokiye taku yute ca yatke cin ute cinhan, qa wicaśta qa winoliinca dowanpi ho kin! nation kinhan, tuktee waśte, qa tuktee sica sdonya he? Heon tokeca nitaokiye sanpa itancan mitawa wicaśtayatapi kin yuśagye kta he?

36 Nitaokiye Jordan kitanna akasanpa wicaśtayatapi kici ye kta. Qa tokeca wicaśtayatapi kin iyuwin kin de on micicajuju 


\section{WICOWOYAKE 20.}

$3^{17}$ Ceciciye nitaokiye wanna kihde kta, qa otonwe mitawa en mate kta, ate qa ina wicahnakapi kin ikiyedan. Tuka iho nitaokiye Kimham itancan mitawa wicaśtayatapi kin kici ye kta, qa token niiśta kin en waśte kin hecakicon wo.

38 Unkan wicaśtayatapi kin heya, Kimham mici ye kta. Taku niiśta en waśte kin hecawecon kta, qa taku econ mayaśi kin owasin ecacicon kta.

39 Unkan oyate owasin Jordan iyuweǵapi. Unkan wicaśtayatapi kin Jordan akasanpa i qehan, Barzillai i itputaka, qa yawaste. Unkan toyanke kin ekta kihda.

40 Unkan wicaśtayatapi kin Gilgal ekta iyaya, qa Kimham he kici ya; nakun Juda oyate owasin, qa Israel oyate hanke kin wicaśtayatapi kin hdikiyapi.

41 Unkan Israel wicaśta owasin wicaśtayatapi kin en hipi, qa, wicaśtayatapi kin heciyapi, Tokeca hunkawanjin unyanpi Juda wicaśta kin maninonpi, qa wicaśtaya tapi kin, qa tiyohnaka tawa, qa iye kici Dawid wicaśta tawa owasin Jordan itato hiyuwicayapi he?

42 Unkan Juda wicaśta kin owasin Israel wicaśta kin awicayuptapi, Wicaśtayatapi kin mikiyedan ce, heon etanhan; qa tokeca de on śinyahda he? Wicaśtayatapi taku tawa wauntapi he? qaiś iye taku unqupi he?

43 Unkan Israel wicaśta kin Juda wicaśta kin awicayuptapi qa heyapi, Wicaśtayatapi en nape wikcemna mduha, qa Dawid nitawa eśta isanpa mitawa. Qa tokeca ihamayakta śni, qa wicaśtayatapi kin hdiyakiyapi itokam omayakidake śni he? Unkan Juda wicaśta oiepi kin Israel wicaśta oiepi kin isanpa wohitika.
WICOWOYAKE 20.

1 Uukan he ehan wicaśta wahite śni wan hen yanka, Śba Bikri cinhintku eciyapi, Benjamini wicaśta; qa mazayahoton qa heya, Dawid en onśpadan unhapi śni, qa Jesse cinhintku en takudan tawa unyanpi kte śni; Israel owasin tawakayapi ekta hda po. 2 Unkan Israel wicaśta owasin Dawid etanhan ihduhomnipi, qa Seba Bikri cinhintku ihakam iyayapi. Tuka Juda wicaśta kin wicaśta ateyapi kin en ikoyag iciyapi, Jordan etanhan Jerusalem ekta hehanyan.

3 Unkan Dawid Jerusalem en hdi, qa wicaśtayatapi kin wicinyanpidan wikcemna wicayuza, qa tipi awanyag owanji yanke wicaśi qon iwicacu, qa wicakaśka tipi wan en ye wicaya, qa wowicaqu, tuka wicikiyedan ye śni. Unkan wiwazica hecapi, qa anpetu en țapi kin hehanyan kaśka yakonpi.

4. Unkan wicaśtayatapi kin Yamasa heciya, Anpetu yamni en Juda wicaśta kin mniciye wicaya, miye ekta, ga niye den najin wo.

5 Unkan Yamasa Juda nmiciye wicaya iyaya, tuka, mniciye śi qon iyehan hdi śni.

6 Unkan Dawid A biśai heciya, Wanna Śba Bikri cinhintku śicaya ecaunkiconpi kta, Abiśalom isanpa ; niye itancan nitawa taokiye iwicacu, qa he kuwa iyaya wo. Okini otonwe conkaśke iyeya, qa unkiśtapi etanhan ihduśke kta.

7 Unkan Joab tawicaśta, qa $\mathrm{Pa}$ baksapi kin, qa Inyankapi kin, qa wicaśta waśaka owasin kici iyayapi, qa Śeba Bikri cinhintku kuwapi kta Jerusalem etanhan inanpapi. 


\section{SAMUEL WOWAPI INONPA KIN,}

8 Inyan tanka wan Gibeyon ohna yanke cin he ikiyedan yapi gehan, Yamasa wicitokam mani. Unkan Joab śina in kin ipiyag kiton, qa ipiyaka kin akapa tanhan isan wan ojuha kin ohna nite akan mihnaka, qa he hinlipaya, iye iyaye icunhan.

9 Unkan Joab Yamasa heciya, Zaniyan yaun he misunka? qa Toab Yamasa i itputake kta putinhin kin nape etapa on yuza.

10 Unkan Yamasa isan Joab nape en un kin iwakta śni. Unkan he on tezi kin en capa, qa śupe kin makata hiyuya, qa inonpa ape śni, unkan ta. Unkan Joab, qa cincu Abiśai Śeba Bikri cinhintku kuwa iyayapi.

11 Unkan kośka Joab wicayuhe cin wanji he ikiyedan najin, qa heya niyan, Tuwe Joab iyokipi kin, qa tuwe Dawid tawaye cinhan Joab ihakam ya po.

12 Unkan Yamasa we kin en ihduptanptan, canku kin ohna. Unkan wicaśta qon oyate kin owasin en hinajinpi kin wanyaka, heon Yamasa yutokan canku kin etanhan maga ékta, qa sina wan akahpa, tona ekta hipi kin owasin hen najinpi wanyake cehan.

13 Canku kin etanhan tokan ayapi qehan, wicaśta kin owasin Seba Bikri cinhintku kuwapi kta, Joab ihakam iyayapi.

14 Unkan Israel wicoun owasin opta iyaya, qa Abel ekta i. Unkan Bet-mayaka qa Berim kin owasin ihduwitayapi, qa nakun ihakam yapi.

15 Qa Abel Bet-mayaka ekta ipi, qa ohna anaptapi, qa otonwe ihdukśan maka paha kag̉api, hecen aohduteyapi, qa oyate Joab opapi kin owasin otonwe conkaśke kin pajujupi kta apapi.

16 Unkan winohinca ksapa wan 470 otonwe etanhan heya niyan; Nahonpe, nahonpe: Ceciciyapi ye: Den ikiyedan hinajin taku eciciye kta ye, Joab okiyakape.

17 Unkan he ikiyedan hi. Unkan winohinca kin heciya, Joab he niye he? Unkan he miye, Joab eya. Unkan heciya, Wicinyanna ritawa oie kin nalion ye. Unkan nahon manka, eya.

18 Unkan winyan kin heya, Wicoie eyapi ca tokaheya iwangapi ece eyapi; heon Abel iwangapi kta, qa hehan yuśtanpi.

19 Israel ohna mawahbadan, qa wacinmayanpi. Niye otonwe wan Israel inayanpi heca ihang yaye kta ayakita. Tokeca Jehowa taku tawaye cin nayapce kta he?

20 Unkan Joab ayupte ca heya, Hiya hecetu śni, nawapca qa ihang waye kta taku wakan iyomaki śni nunwe.

21 Wicoie kin hecetu śni. Tuka wicaśta wan Epraim he kin etanhan Śeba Bikri cinhintku eciyapi, wicaśtayatapi Dawid. nape apaha. Iśnana hiyuya po, hecinhan otonwe kin amdustan kta. Unkan winohinca kin Joab heciya, Ito iye pa kin conkaślke etanhan elipeniciyapi kta.

22 Unkan winohinca kin tolisape en oyate kin owasin ckta wicai ; unkan Śeba Bikri cinhintku pa kin baksapi, qa Joab ekta elipeyapi. Unkan mazayahoton. Unkan otonwe kin etanhan wicaśta enanakiya tawakeyapi ekta hdapi; qa Joab Jerusalem ekta hdi, wicaśtayatapi kin ekta.

$23 \mathrm{Qa}$ Israel obe kin owasin Joab mdetanhunka heca, qa Benaja Jehojada cinhintku kin $\mathrm{Pa}$ baksapi kin qa Inyankapi kin wicayuha.

24 Qa Adoram mazaska mnayanpi kin itancan, qa Jehośapat 


\section{WICOWOYAKE 21.}

Ahilud cinhintku wokiksuye wowapi kagga.

25 Q: Sewa he wowapi kağa, qa Tzadoq qa Abiatar wawayusnapi ;

$26 \mathrm{Qa}$ Yira Jairi kin nakun wawayuśna heca Dawid yuha.

\section{WTCOWOYAKE 21.}

1 Unkan Dawid wicaśtayatapi anpetu kirı en waniyetu yamni, waniyetu otoiyohi wicaakilian. Unkan Dawid Jehowa ite kin iwanga. Unkan Jehowa heya, Saul, qa tiyohnaka weyesa, qa Gibeyoni kin te wicaya heon hececa.

2 Unkan wicaśtayatapi kin Gibeyoni kin wicakico, qa om wohdaka; ecin Gibeyoni kin Israel cinca hecapi śni, tuka Amori okaptapi hecapi, qa nipi kta Israel cinca kin taku wakan cajeyan ewicakiyapi. Unkan Saul inawizi wicaya, Israel cinca, qa Juda on, qa iharg wicaya akita.

3 Unkan Dawid Gibeyoni kin hewicakiya, Taku ecaciconpi kta, qa Jehowa makoce tawa dawaśtepi kta e taku on akahpe ciciciyapi kta he?

4 Unkan Gibeyoni kin heciyapi, Saul kici, qa tiyohnaka tawa kici mazaska, qa mazaskazi on awakinice śni, qa unkiyepi on Israel ohna tuwedan te yaye kte śni. Unkan, Token ehapi kin he iyecen ecaciconpi kta, eya.

5 Unkan wicaśtayatapi kin heciyapi, Wicaśta wan unyusotapi, qa Israel makoce ohna tuktedan unkanpi kte śni on ihang unyanpi kta kecin kin,

6 Iye cinca kin etanhan wicaśta śakowin unqupi kta, qa hena atkewicunyanpi kta, Saul Jehowa kahnige cin he paha tawa akan. Unkan ciçupi kta, wicaśtaya tapi kin eya.

7 Unkan wicaśtayatapi kin Saul cinhintku Jonatan cinhintku Mepibośet itonpa, Dawid qa Saul cinhintku Jonatan Jehowa cajeyan ekiciyapi kin heon etanhan. 8 Unkan wicaśtayatapi kin Aja cunwintku Ritzpa cinhintku nonpa Armoni qa Mepibośet Saul kiciton kin hena iwicacu, qa Saul cunwintku Mikal cinhintku zaptan Yadriel Barzillai Meholati cinhintku kiciton kin hena nakun iwicacu :

9 Qa Gibeyoni napepi en wicaqu; unkan he akan otke wicayapi, Jehowa itokam. Unkan hena śakowin witaya hinhpayapi, woksapi anpetu en te wicayapi, barle toka baksapi kin he ehan.

10 Unkan Aja cunwintku Ritzpa wakihdaka ikikeu, qa inyan akan owinś kiya, toka wabaksapi etanhan mahipiya mini awicahinhe kin hehanyan, qa mahpiya okinyanpi anposkan awicahiyahan iyowinwicakiye śni, nakun hanyen tinta wamanica kin.

11 Unkan Aja cunwintku Ritzpa Saul tawicinyanna taku econ kin Dawid okiyakapi.

12 Unkan Dawid iyaye ça Saul huhu kin, qa cinhintku Jonatan huhu kin Jabeś Gileyad wicaśta kin etanhan icu ; Pilistim Gilboa akan Israel kaśtakapi qehan, Betśan canku kin en otke wicayapi, unkan hetanhan mawicanonpi qon.

13 Unkan Saul huhu kin, qa cinhintku Jonatan huhu kin hetanhan hiyuya. Unkan otke wicayapi huhu kin nakun mnayanpi.

14 Qa. Saul qa cinhintku Jona$\tan$ huhu kin kicihnakapi, Benjamin makoce ohna, Tzila ekta, 


\section{SAMUEL WOWAPI INONPA KIN,}

atkuku Qiś ohnahnakapi tawa kin ohna, qa taku wicaśtayatapi kin econ wicaśi owasin econpi. Unkan he iyohakam makoce on cekiyapi' Wakantanka nawicahon.

15 Unkan ake Pilistim Israel kizapi. Unkan Dawid qa taokiye apamahde ipi, qa Pilistim kizapi, qa Dawid hustaka,

16 Unkan Iśbibenob, Rapa (Waziya kin) cinca etanhan, tawahunkeza aspeyapi kin mazaśa śeqel opawinge yamni, qa isan teca ipiyagkiton, qa Dawid kaśtake kta keya.

17 Unkan Abiśai Tzeruja cinhintku anakicijin, qa Pilisti kin kaśtake ça țeya. Hehan Dawid wicaśta tawa taku Wakan cajeyatapi, qa heciyapi, Icimana unkiyepi kici wokicize ekta de kte śni; hecen Israel petijanjan kin sni yaye kte śni.

18 Unkan he iyohakarn Gob ekta Pilistim om kicizapi qehan, Sibbekai Ḣuśati kin Sap Waziya cinca wan kaśtaka.

2 Qa heya,

Jehowa imnija mitawa, qa conkaśke mitawa, qa emahdaku kin hee.

3 Taku Wakan wada, inyan paha mitawa en nawape kta.

Wahacanka mitawa qa nimaya he kin;

Paha tehanwankan mitawa, qa wowinape mitawa;

Wanikiya mitawa, wakiunniyanpi etanhan emahdaku.

4 Jehowa yatanpi kta iyecece cin he hoyewakiye kta;

Unkan iye toka mayanpi kin etanhan emahdaku kta.

5 Wiconte taja kin aohdute mayanpi ;

Wicaśtapi śni minitan kin yuśinye mayanpi qehan;

6 Hades icaśke kin mihdukśan iyamapehanpi,

Wiconte ihmunke kin mayuzapi.

7 Iyotanhan iyewakiye cehan Jehowa hoyewakiya;

Qa tuwe wakan wada kin wakipan.

Unkan tipi wakan tawa en maho kin nahon.

Qa wocekiye mitawa anohkiciya.

8 Hehan maka kin cancan, qa śkanśkan.

Mahpiya oahehde kin cancan,

Qa nahuhuza; śinhda nakaś.

9 Sota pogie kin etanhan inanpa, $4 \% 2$ 


\section{WICOWOYAKE 22.}

Qa iye i kin etanhan peta wahulinaliya,

Iye etanhan petaga itkonyan. .

10 Unkan mahpiya kin yuhukuye ça kun hiyu;

Qa siha ihuknya otpaza hinca.

11 Nakun Kerub wan akan iyotanke ça kinyan $u$.

Qa tate liupahu kin akan ihdutanin.

12 Iye ihdukśan otpaza wakeya hduha:

Mini mnayanpi mahpiya śoka kin.

13 Iyoyanpa iye itokam u kin petag̉a ideya.

14. Qa mahpiya etanhan Jehowa wakinyan hotonkiya;

Qa Iyotan Wankan kin ho hdatanin.

15 Qa tunwanhinkpe kihiyeye ça wicakamdeca;

Wakanhdi kin, qa yuśinye wicaya.

16 Unkan miniwanca cete kin wanyakapi :

Qa maka oahehde kin yuzamnipi ;

Jehowa iyope wicaye cin on etanhan.

Poge ohdoka oniya ipogan kin heon etanhan.

17 Wankantanhan wahomaye ça imacu.

Mini ota etanhan mayutitan.

18 Toka mayan waśake cin etanhan mayuśka ;

Tona śce madakapi kin etanhan;

Hena mikapeya waśakapi nakaś.

19 Iyomakiśica anpetu kin en iyamalipayapi;

Tuka ipatan waye cin Jehowa hee.

20 Qa canku tanka wan en hinanpe mayan; Qa mayuśka, iyokipi waya nakaś.

21 Omawotanna kin iyecen Jehowa iyuwin maqu.

Minape ska kin iyecen ecamicon.

22 Jehowa tacanku kin owapa;

Qa Taku wakan wada śicaya amaduśtan śni.

23 Tawoyaco kin owasin mitokam un;

Qa tawokage kin elipewaye śni.

24. Qa iye itokam ecetu waun.

Qa miohan śice cin etanhan țins miçiya;

25 Heon Jehowa mitoowotanna iyecen ecamicon;

Tye iśta kin en maska kin iyecen.

26 Tuwe wacantkiye cin he kici wacantkiya nihdutanin kta.

Wicaśta ecetu kin kici ecetuya ecanon kta.

27 Tuwe écedan un kin he kici écedan nihdutanin kta; Qa tuwe pemni kin he iyuwin kin yecu kta.

28 Qa oyate onśika kin he niyaye kta ;

Qa tona ihduwankantuyapi kin wicaduhukuya kta niiśta awicatonwan.

29 Iyoyam maye cin Jehowa he niye;

Qa otpas maye cin he Jehowa miciyutokan kta.

30 Niye waśag mayaye cin on ozuye wan anawatan kita.

Tuwe Wakan wada kin on conkaśke acawalsśin kta.

31 Iyotan Waśaka olian kin yuśtanpi; 


\section{SAMUEI WOWAPI INONPA KIN,}

Jehowa oie kin peta on iyutanyanpi ce.

Tona wacinyanpi kin hena owasin wahacanka yapi.

32 Tuwe Iyotan Waśaka he? Jehowa iśnana.

Qa tuwe imnija he? Taku Wakanundapi kin heceedan.

33 Iyotan waśake cin wowaśake on waśag mayan.

Qa tacanku kin ecetuya omani mayan;

34 Misiha tatokadan tawa kin iyececa micaga;

Qa pajòdan mitawa akan najin makiya.

35 Minape wicakize kta onspemakiya;

Hecen miisto kin mazazi itazipa yuwinja.

36 Qa wahacanka on niwicayaye cin mayaqu;

Qa nitowahbadan kin mayutanka.

37 Mihukuya caewahde mayadutanka;

Hecen miiśkahu nakśankśan śni.

38 Toka mayanpi kin wicawakuwa, qa ihang wicawaya:

Qa wicamdusote śni hehanyan wahdicu śni.

39 Wicamdusota, qa cawicawapa; unkan icimana najinpi śni :

Qa misiha ihukuya hinlipayapi.

40 Wokicize on wowaśake ipiyag mayakiton :

Anamajinpi kin hena mihukuya patuś wicayaya;

41 Qa toka mayanpi kin tahupi kin mayaqu.

Nakun tona śicemadapi kin, unkan ihang wicawaya.

42 Howayapi tuka wanikiya wanica;

Jehowa hoyekiyapi tuka anawicaggoptan śni.

43 Unkan makamdu kin iyecen wicawakamdumdu;

Ocanku upśjja kin iyecen nawicawaskica qa nawicawamdaya.

44 Unkan oyate mitawa makizapi etanhan emayahdaku;

Ikcewicaśta pa mayanpi kta on mayapatan.

Oyate wan sdonwaye śni qon wowidag waye kta;

45 Oyate tokeca cinca kin makihnapi kta.

Nog̉e on nahonpi kinhan anumagoptanpi kta;

46 Oyate tokeca cinca kin skanpi kta;

Qa conkaśke tawapi on aohdute iciyapi kta..

47 Jehowa ni un, qa imnija mitawa yawaśtepi ce ;

Heon imnija nimaye cin he, Wakan wada kin he yawankantuyapi kta.

48 Iyotan waśake watomiciçon ece kin hee;

Qa mihukuya oyate ota yuhukun wicaya ece.

4.9 Qa toka mayanpi etanhan hinanpe mayan;

Qa tona anamajinpi kin hena wiciwankam emayahde.

Wicaśta woihangye cin etanhan emayahdaku;

50 Heon ikcewicaśta wicehna Jehowa ciyatan kta;

Qa nicaje kin iwadowan kta.

51 Wicaśta yatapi nitawa woehdaku yecidutanka;

Qa tuwe sdayakiye cin wowacantkiye ecayecon ece:

Dawid qa iye cinca kin owihanke wanica. 


\section{WICOWOYAKE 23.}

1 Dawid oi ehake kin dena ee. Dawid Jesse cinhintku kin heya, Wicaśta wan Jakob Wrkanda kin sdaye cin on najin kiya kin, qa Israel tadowan wiciyokipi kage cin he hecen eya.

2 Jehowa taniya kin ie makiya, qa oie kin miceji aehnaka.

3 Tuwe Israel Wakanda kin heya, Israel imnija kin hemakiya, Tuwe wicasta iwicadake cin Jehowa kokipeyahan wowidag wicaye cinhan,

4 Hanhanna anpa kin iyececa, hanlianna inahpiya śapa wanica anpetu wi hinanpa; Wato kin magiaju ohakam maka etanhan inanpe cin iyececá.

5 Wati ohnaka kin Iyotan waśake cin kici hecece śni eśta, wotakuye owihanke wanice kta micicage cin he taku owasin en tanyan kicanyanpi, qa awanyakapi; nimaye cin ocowasin, qa iyomakipi binca hee, he icaliye śni eśta.

6 Tuka wicaśtapiśni kin hena owasin wapepeka ehpeyapi kin iyececapi kta, nape on yuzapi 'śni.

7 Tuka tuwe hena yuze kte cinhan nape ohna mazasapa yuha, qaiś wahunkeza ihupa kin, qa tukten yakonpi kin ohna peta on ocowasin hutinahyapi kta.

8 Dawid wicaśta waśaka tawa cajepi kin dena ee. Yadino yamni itancan kin wicaśta ksapa iyotankapi ohna kiyotanke cin, Iye tawahunkeza wikeemna śahdogan awicapaha, qa wancadan wicakte.

9 Qa he iyokihe Eleazar Dodo cinhintku Ahohi cinhintku, wicaśta waśaka yamni Dawid opapi kin he wanji, Pilistim ośtehda wicayapi, qa hen witaya iheyapi wolkicize on, qa Israel wicaśta kin napapi.

10 Hehan iye najin qa Pilistim wicakaśtaka nape kin watuka, qa tacanlipi kin ikoyake cin hehanyan. Unkan Jehowa anpetu kin he en woehdaku tanka kagge cin on iye ihakam oyate kin wahpaya mnayanpi kta hecedan on ake hipi ce.

11 He iyokihe Śanma Age Arori kin cinhintku, Pilistim ozuye wan mnayanpi qehan maga onśpa omnica ojupi hetu, qa oyate kin Pilistim wicitokam napapi.

12 Tuka iye maga kin cokaya najin, qa he anica, qa Pilistim wicakaśtaka; unkan anpetu kin he en Jehowa woehdaku tanka wan kaga.

13 Unkan wikeemna yamni kin woksapi hentu, Dawid ekta Yadullam makolidoka en ipi kin etanhan yamni itancanpi kin $\mathrm{Pi}$ listim ozuye kin Repaim osmaka kin ohna wankapi qehan apamahde ipi.

14 Unkan hehan Dawid conkaśke wan ohna yanka; unkan Pilistim akicita kin Betlehem otipi.

15 Unkan Dawid wacantiheye ca heya, Tokin Betlehem minihdoka kin otonwe tiyopa icahda wanke cin he mini kin tuwe yatke makiye kten.

16 Unkan wicaśta waśaka yamni qon Pilistim owanka lin kaoksapi, qa Betlehem minihdoka tiyopa icahda wanke cin etanhan mini icupi, qa yuha Dawid en hipi ; Unkan yatke kta wicada śni, tuka Jehowa kicicaśtan.

17 Qa, Taku kin de ecamon kta Jehowa iyomaki śni nunwe; wicaśta naği ehpekiya ipi kin hena wepi kin hee śni he? eya; heon yatke kta cin śni. Wicaśta waśaka yamni kin hena heconpi.

18 Ưnkan Abiśai Joab cincu kin 475 


\section{SAMUEL WOWAPI INONPA KIN,}

Tzeruja cinhintku kin he yamni ehna itancan kin hee; Iye tawahunkeza on wicaśta opawing e yamni cawicapa, qa wicakte; heon yamni kin wicehna caje yuha.

19 Yamni kin he ehna iye towitan kin iyotan, heon mdetanhunka yuhapi, tuka yamni tokaheya kin iyowicahi śni.

20 Unkan Benaja Jehojada cinhintku, wicaśta waśaka wan Qabetzel etanhan wicolian tanka ota econ kin he cinhintku. Iye Moab wicaśta nonpa mnaja iyececapi wicakte. Nakun waniyetu qehan makohdoka wanji en i, qa mnaja ohna yanke cin kte.

21 Nakun iye Egupton wicaśta wan kte, qa Egupton kin wicaśta owanyag waśte, qa nape kin ohna wahunke za wan hduha. Unkan cansagye hduha tatpe i, qa wahunkeza kin Egupton nape etanhan ekiciyaku, qa tawahunkeza on te kiya.

22 Benaja Jehojada cinhintku hena econ, qa wicaśta waśaka yamni ehna caje yuha.

23 Wikcemna yamni kin isanpa yutanpi; tuka yamni tokaheya kin iyowicahi śni. Unkan Dawid iye ti kin awanyakapi kin he itancan lrağa.

24 Wikcemna yamni ehna Yasahel Joab sunkaku yawapi, Elhanan Dodo cinhintku, Betlehemi.

25 Sanma Harodi kin, Eliqa Ḣarodi kin.

26 Ḣeletz Paleti, Yira Yeqeś cinhintku Teqoyi kin.

2) Abiyezer Yanatoti kin, Mebuni Ḧuśati kin.

28 Tzalmon Ahohi kin, Mahari Netopati kin,

29 Heleb Bayana cinhintku Netopati kin, Ittai Riba cinhin-, Joab, qa akicita itancanpi kin 476 tku Benjamin cinca Gibeya tawapi etanhan.

30 Benaja Peratoni kin, Hidda Gayaś wakpadan kin etanhan,

31 Abiyalbon Yarebati kin, Yazemawet Barhumi kin.

32 Elitiaba Śayalboni kin, Jaśen cinca kin Jonatan.

33 Śanma Harari kin, Ahiam Sarar cinhintku Arari kin.

34 Elipelet Ahasbai cinhintku Mayakati kin, Eliam Aliitopel Giloni kin cinhintku.

35 H̉etzera Karmeli kin, Payara Arebi kin.

36 Igal Natan Tzoba etanhan cinhintku, Bani Gadi kin,

37 .Tzeleq Amoni kin, Nahara Beroti kin, iye Joab Tzeruja cinhintku tawipe kin kiciçin ecee.

38 Yira Jiteri kin, Gareb Jiteri kin,

39 Urija Hiti kin: owasin wikcemna yamni sanpa śąkowin.

\section{WICOW OYAKE 24.}

1 Unkan ake Jehowa Israel canniye wicaya, qa Dawid iyopaśtaka on heya, Ito Israel qa Juda wicayawa wo.

2 Unkan wicaśtayatapi kin akicita iye kici unpi itancan kin Joab heciya, Ito Israel wicoun owasin wicehna omani; Dan etanhan Berśeba aiyahdeya, qa oyate kin wicayawa wo; hecen oyate kin tonaka sdonwaye kta.

3 Unkan Joab wicaśtayatapi kin heciya, Jehowa Wakan yada kin he oyate kin tonaka yukan opawinge akihde iyenaka wicayuota kte cin he itancan mitawa wicaśtayatapi iśta kin wanyake kte; tuka tokeca wicoie kin de itancan mitawa wicaśtayatapi kin iyokipi he?

4 Unkan wicaśtayatapi oie kin 
ohiwicaya. Unkan Joab, qa akicita itancanpi kin wicaśtayatapi itokam oyate kin Israel wicayawapi $k$ ta iyayapi.

5 Unkan Jordan iyuwegapi, qa Aroyer ohna etipi, otonwe Gad kaksiza ohna wanke cin etapa tanhan, qa Jazer ekta.

6 Qa Gileyad ekta ipi, qa Hodśi ihukuya yakonpi tamakocepi ekta, qa Dan Jayan ekta ipi, qa yuwinh Tzidon ekta.

$7 \mathrm{Qa}$ Tzur conkaśke etanhan, qa Ḧiwi qa Kànani tonwanyanpi kin owasin, qa Juda itokagia kin, Berśeba ekta ipi.

8 Hecen makoce kin owancaya opta ipi, qa wi napcinwanka sanpa anpetu wikcemna nonpa hehan Jerusalem en hdipi.

9 Qa Joab oyate wicayawapi woyawa kin wicaśtayatapi kin qu : Israel wicaśta waśaka canlipi yuzapi kektopawinge opawinġe śahdoġan, qa Juda wicaśta kin kektopawinge opawinge zaptan.

10 Unkan oyate kin hecen wicayawa iyohakam Dawid cante kin aicipa, qa Dawid Jehowa heciya. Taku kin decamon nina wawahtani, qa wanna Jehowa ceciciya, nitaokiye wahtani kin micicajuju ye, witkotkoya hinca ecamon nakaś.

11 Unkan hankanna, Dawid kikta qehan, Jehowa oie kin Gad waayate kin Dawid tawa wawanyake kin en hi, qa heciya:

12 Ekta ye ca Dawid heciya wo, Jehowa hecen eya, Taku yamni nitokam ewahde, hena etanhan wanjidan kahniga wo, qa hecacicon kta.

13 Unkan Gad Dawid ekta hi, qa okiyake ca heciya, Nitamakoce ohna waniyetu śakowin wicaakihian kta, qaiś wi yamni toka niyanpi nicuwapi itokam nayape kta, qaiś anpetu yamni makośice nitamakoce ohna yuke kta he? Wanna awacin qa wanyaka wo. Wicoie tuktee tuwe u maśi kin he wakai kta he?

14 Unkan Dawid Gad heciya, Taku kin de nina amaskica. Tokin Jehowa nape kin unkohinhpayapin, tawocantkiye kin he tanka ce; tuka wicaśta nape en mahinhipaye śnin.

15 Unkan Jehowa makośice wan Iśrael akan hiyuya, hankanna etanhan cajeyate ciqon iyehan. Unkan oyate kin Dan etanhan Berśeba ekta hehanyàn wicaśta kektopawinge wikcemna śakowin tapi.

16 Unkan ohnihde kin Jerusalem ihang ye kta, nape kin yekiya qehan, Jehowa wośice cin on iyopeiçiya, qa ohnihde oyate ihang wicrye cin heciya, Henakeca, wanna ninape ehdaku wo. Unkan Jehowa ohnibde kin Arana Jebuśi tahocoka kin icahda yanka.

17 Wanna Dawid ohnihde oyate. wicakaśtake cin wanyake çehan ie ca Jehowa heciya, Iho miye wawahtani, qa śicaya ecamon, tuka tahinwanunyanpi kin dena taku ecompi kin tuktee he? Ceciciya miye qa ate tiyohnaka kin ninape kaśtake kten.

18 Unkan anpetu kin he en Gad Dawid ekta hi qa heciya. Itanwankanhde ya, qa Arana Jebusi tahocoka kin ohna wahna wośnapi wan Jehowa kicicağa wo. 19 Unkar Dawid Gad oie kin Jehowa econ śi kin iyecen itanwankanhde i.

20 Unkan Arana etonwan, qa wicaśtayatapi kin, qa taokiye kin iye ektakiya upi kin wanwicayaka, qa Arana inanpe ça wicaśtayatapi ekta ite kin maka ektakiya patuja. 


\section{SAMUEL WOWAPI INONPA KIN.}

- 21 Qa Arana heya, Tokeca itancan mitawa wicaśtayatapi kin taokiye ekta hi he? Unkan Dawid heya, Hocoka kin opecicaton kta, qa wahna wośnapi Jehowa wecağe kta, qa hecen makośice kin oyate etanhan anapte kta, heon etanhan.

22 Unkan Arana Dawid heciya, Ito itancan mitawa wicaśtayatapi icu, qa token iyokipi wośna kte. Wanyaka wo, tatanka kin wohuhnahyapi on, qa canpahmihma qa tatanka tawanapinpi kin can on icu.

23 Arana wicaśtayatapi wan iyecen hena iyuhpa wicaśtayatapi kin qu, qa Arana wicaśtayata- pi kin heciya, Jehowa Wakan yada kin iyokipi yaye kte.

24 Unkan Wicaśtayatapi kin Arana heciya, Hiya, tuka iyuwin on opecicaton kta, qa taku itumakihanpi etanhan wohuhnaliyapi Jehowa Wakan wada kin wakiyuśna kte śni; heon Dawid. hocoka kin, qa tatanka kin opeton, mazaska śeqel wikcemna zaptan iyopeya.

25 Qa Dawid hen wahna wośnapi wan Jehowa kicage ca wohuhnahyapi, qa wopida wośnapi hulinahya. Unkan Jehowa makoce on anohkiciya, qa Israel etanhan makośice kin anapta.

478 


\section{WICASTAYATAPI}

\section{WOWAPI TOKAHEYA KIN.}

\section{WICOWOYAKE 1.}

1 Unkan wicaśtayatapi kin Dawid wicalinca, anpetu ota. qehan, śina akahpapi eśta coze sni.

2 Unkan taokiye heciyapi : Wicaśtayatapi itancan mitawa on wikośka witanśna un okicidepi kta, iye wicaśtayatapi kici yanke kta, qa winyan tawaśitku kta, qa maku nitawa ekta wanke kta, hecen itancan mitawa wicaśtayatapi kin coze kta.

3 Hecen Israel makoce kin owancaya wikośka wanji owanyag waśte akitapi, qa Abiśag Sunamiwin iyeyapi, qa wicaśtayatapi ekta ahipi.

4 Unkan wikośka kin owanyag waśte hinca, qa wicaśtayatapi winyan tawaśitku kin qa taokiye yuha; tuka wicaśtayatapi kin he sdonye śni.

5 Unkan Adonija Hagit cinhintku ihduwankantuya qa heya; Miye wicaśtayatapi hemaca kta, qa canpahmihma, qa śuktanka akanyotankapi, qa wicaśta wikcemna zaptan iye itokam inyankapi kta e wiyeya icicağa.

6 Atkuku he qe tohinni iyokiśinye śni, qa tokeca hecen ecanon eciye śni ; nakun iye owanyag waśte hinca, qa Abiśalom ohakam tonpi.

7 Unkan Joab Tzeruja cinhintku, qa Abiatar wawayuśna kin om wohdaka; unkan hena Adonija opapi qa ókiyapi.

\section{Kin.}

8 Tuka Tzadoq wawayuśna kin, qa Benaja Jehojada cinhintku, qa Natan waayate kin, qa Simeyi, qa Reyi, qa wicaśta waśaka Dawid wicayuhe cin hena Adonija opapi śni.

9 Unkan Zahelet inyan kin, Rogel wakoniya icahda wanke cin heciya Adonija tahinca, qa pte, qa ptejincadan cepa pata, qa sunka wicaya wicaśtayatapi cinca kin owasin wicakico, qa Juda wicaśta, wicaśtayatapi ókiyapi kill owasin wicakico.

10 Tuka Natan waayate kin, qa Benaja, qa wicaśta waśaka hecapi, qa sunkaku Solomon hena wicakico śni.

11 Unkan Natan Batśeba Solomon hunku kin heciya, Adonija Hagit cinhintku kin wanna wicaśtayatapi ee nayahon śni he? tuka itancan unyanpi Dawid he sdonye śni.

12 Heon dehan ceciciya, wahokonciciye cin namahon wo ; hecell ninagi kin niyakiye kta, qa nicinkśi Solomon naği kin nakun.

13 Ito wicaśtayatapi kin Dawid ekta ya wo, qa heciya wo: Nicinkśi Solomon miye iyohakam wicaśtayatapi kta, qa iye oiyotanke mitawa akan iyotanke kta, nitaokiye win eyakiya. qa taku wakan cajedate śni he? hecen tokeca Adonija wicaśtayatapi ee he?

14 Tho niye wicaśtayatapi kici woyahdake cin icunhan miye ni479 


\section{WICAŚTAYATAPI,}

hakam hen wai kta, qa nioie kin mdasuta kta.

15 Unkan Batśeba wicaśtayatapi kin ekta $i$, owanka tipi kin en, wanna wicaśtayatapi kin wicahinca, qa Abiśag Śunamiwin kin wicaśtayatapi kin ókiya ecee.

16 Unkan Batśeba pakapsan, qa wicaśtayatapi kin ohoda. Unkan wicaśtayatapi kin heciya; Taku yacin he?

17 Unkan heciya, Itancan mitawa Jehowa wakan yada kin cajeyan yakonze ca nitaokiye win heyakiya, Solomon nicinkśi miyohakam wicaśtayatapi kta, qa iye oiyotanke mitawa akan. iyotanke lita.

18 Tuka wanna inyun Adonija wicaśtayatapi ee, qa niye wicaśtayatapi itancan mitawa he sdonyaye śni.

19 Qa pte, qa ptejincadan cepa, qa tahinca ota pata, qa wicaśtayatapi cinhintku owasin wicakico, nakun Abiatar wawayuśna kin, qa Joab ozuye mdetanhunka kin; tuka nitaokiye Solomon he kico śni.

20 Qa niye itancan mitawa wicaśtayatapi kin Israel owasin ahinitonwanpi, tuwe wicaśtayatapi iyohakam oiyotanke tawa akan iy otanke lita he owicayakidake kita'heon.

21 Hecanon śni kinhan wicaśtayatapi itancan mitawa kin hunkake wicaye cin on iśtibe cinhan, miye qa micinkśi Solomon wahtanipisa unyawapi kta.

22 Unkan inyun nahanhin wicaśtayatapi kici wohdaka icunhan, Natan waayate kin en hi.

23 Unkan wicaśtayatapi kin okiyakapi, qa heyapi, Tho Natan waayate kin dee. Unkan wicaśtayatapi kin itokam hi, qa maka ektakiya patuja, wicaśtayatapi itokam.
24 Qa Natan heya, Itancan mitawa wicaśta yatapi, Miyohakam Adonija wicaśtayatapi kta, qa iye oiyotanke mitawa akan iyotanke kta niye eha he?

25 Hecen nakaha apamahde iyaye ca tatanka, qa ptejincadan cepa, qa tahinca ota pata, qa wicaśtayatapi cinhintku owasin wicakico, nakun obe itancanpi kin, qa Abiatar wawayuśna kin: unkan inyun iye itokam wotapi, qa wayatkanpi, qa Adonija wicaśtayatapi kin ni nunwe eyapi.

26 Tuka nitaokiye miye qe, qa Tzadoq wawayuśna kin, qa Benaja Jehojada cinhintku qa nitaokiye Solomon unkicopi śni.

27 Wicoie kin de itancan mitawa wicaśtayatapi kin etanhan he? Qa tuwe wicaśtayatapi itancan mitawa ohakam toiyotanke akan iyotanke kta nitaokiye oyakidake śni he?

28 Unkan Dawid wicaśtayatapi kin ayupte ca heya, Miye ekta Batśeba uśipo. Unkan wicaśtayatapi kin itokam hinajin.

29 Unkan wicaśtayatapi kin taku wakan cajeyate ça heya, Jehowa minaği kin woiyokiśice owasin etanhan opekiton kin ni ce.

30 Hecen token heciciye, Jehowa Israel wakandapi kin namahon, Solomon nicinkśi miye iyohakam wicaśtayatapi kta; qa miye eekiya oiyotanke mitawa akan iyotanke kta, epe cin he iyecen nakaha ecamon kta.

31 Unkan Batśeba iye ite kin maka ektakiya patuja, qa wicaśtayatapi kin ohoda, qa; Itancan mitawa Dawid wicaśtayatapi kin owihanke wanin ni nunwe, eya.

32 Unkan Dawid wicaśtayatapi kin heya, Tzadoq wawayuśna kin, qa Natan waayate kin, qa Benaja Jehojada cinhintku miye 
ekta $u$ wicas̉i po. Unkan wicaśtayatapi kin itokam hinajinpi.

33 Unkan wicaśtayatapi kin hewicakiya, Itancan nitawapi taokiye niyepi om $u$ wicayaśipi $k t a$, qa micinksíi Solomon śonśonna mitawa akan iyotang yayapi kta, qa Gihon (Wakpadan) ekta apamahde iyaye yayapi kta.

$34 \mathrm{Qa}$ heciya Tzadoq wawayuśna kin, qa Natan waayate kin Israel wicaśtayatapi on sdayapi kta, qa mazáyahotonpi kin dahotonpi kta, qa Solomon wicaśtayatapi kin ni nunwe ehapi kta.

35 Hehan iye ihakam itanwankanhde yaupi kta; hecen iye den hiyu, qa oiyotanke mitawa akan iyotanke kta, qa miye eekiya iye wicaśtayatapi kta, iye Israel qa Juda iwicadake kta wakonza nakaś.

36 Unkan Benaja Jehojada cinhintku kin wicaśtayatapi kin ayupte ca heya, Hecetı nunwe. Jehowa itancan mitawa wicaśtayatapi kin Wakanda kin hecen eya nunwe.

37 Token Jehowa wicaśtayatapi kin kici un kin, he iyecen Solomon kici un kte ca toiyotanke kin itancan mitawa Dawid wicaśtaya tapi toiyotanke kin isanpa tauka nunwe.

38 Unkan Tzadoq wawayuśna kin, qa Nátan waayate kin, qa Benaja Jehojada cinhintku, qa Pabaksapi kin, qa Wainyankapi kin apamahde iyayapi, qa Solomon Dawid wicaśtayatapi taśunke śonsonna akan iyotang kiyapi, qa he kici Gihon ekta ipi.

39 Unkan Tzadoq tahe wan wihdi ojudan Wakeya kin etanhan icu, qa Solomon sdaya, qa mazayahotonpi wan yahotonpi, qa oyate kin owasin heyapi, Solomon wicaśtayatapi kin ni nunwe.
$40 \mathrm{Qa}$ ihakam oyate kin owasin itanwankanhde kupi, qa oyate kin cotanka yajopi, qa wowiyuśkin tanka on iyuśkinpi, qe hopi kin on maka kin bubu.

4.1 Unkan Adonija, qa tona wicakico iye opapi wotapi ayaśtanpi qehan mahompi, qa Joab mazayahotonpi ho kin nation qehan: Tokeca otonwe owodutaton ho kin de, eya.

$42 \mathrm{Ie}$ cin icunban inyun Jonatan Abiatar wawayuśna cinhintku kin u; unkan Adonija heciya, Kuwa; wicaśta wadinitaka, qa wotanin waśte ayahi nakaś.

43 Unkan Jonatan ayupte ca, Adonija heciya, Hiya, awicakehan itancan unkitawapi Dawid wicaśtayatapi kin Solomon wicaśtayatapi kag̉a.

44. Qa wicaśtayatapi kin Tzadoq wawayuśna kin, qa Natan waayate kin, qa Benaja Jehojada cinhintku, qa Pabaksapi kin qa Wainyankapi kin he kici ye wicaśi, qa wicaśtayatapi taśunke śonśonna akan iyotang kiyapi.

$45 \mathrm{Qa}$ Tzadoq wawayuśna kin, qa Natan waayate kin he wicaśtayatapi on sdayapi, Gihon ekta, qa hetanhan wiyuśkinyan itanwankanhde kupi, hecen otonwe kin bubu, qa ho nayahonpi kin hee.

46 Qa nakun Solomon wicaśtayatapi kin toiyotanke kin akan iyotanka.

47 Qa nakun wicaśtayatapi taokiye en hipi, qa itancan unyanpi wicaśtayatapi kin Dawid yawaśtepi, qa, Tuwe wakan yada kin Solomon caje kin nicaje isanpa waśte kage kta, qa toiyotanke oiyotanke nitawa isanpa yutanka kta, eyapi ; qa wicaśtayatapi kin towinja akan ohoda.

$48 \mathrm{Qa}$ nakun wicaśtayatapi kin. hecen eya, Jehowa Israel wakan. 481 


\section{WICAŚSTAYATAPI,}

dapi nakaha tuwe oiyotanke mitawa akan iyotanke kte cin maqu, qa miiśta kin wanyake cin he yawaśtepi nunwe.

49 Unkan tona Adonija wicakico, qa opapi kin kokipapi, qa enanakiya iyayapi.

50 Unkan Adonija Solomon ikopa, qa inajin, qa ekta ya, qa wahna wośnapi he kin yuza.

51 Unkan Solomon okiyakapi, qa heyapi, Inyun Adonija Solomon wicaśtayatapi kin kokipe ca, inyun wahna wośnapi he kin yus yanka, qa, Ito nakaha Solomon wicaśtayatapi kin iye taokiye isan on țekiye kte śni, taku wakan cajeyan emakiye kta, eya.

52 Unkan Solomon heya, Wicaśta ksapa ihdutanin kinhan pa hin tawa wanjidan makata hinhpaye kte śni. Tuka taku śica econ iyeyapi kinhan țe kta.

53 Hehan wicaśtayatapi kin Solomon ye wicaśi, qa wahna wośnapi etanhan kun hiyuyapi. Unkan en hinajin, qa wicaśtayatapi kin ekta patuja. Unkan Solomon heciya, "Tiyata hda wo.

\section{WICOWOYAKE 2.}

1 Unkan Dawid te kte cin anpetu kin wanna ikiyedan qehan, iye cinhintku Solomon wahokonkiye ça heciya;

2 Miye wicaśta akantu owasin toki yapi kin ekta mde kta ce, heon waśagiçiye ça winicaśta ihdutanin wo.

3 Qa taku Jehowa wakan yada patan niśi kin yapatan kta, qa tokage, tawoahope, qa tawoyaco owasil oyape kta, qa token Mowis wowapi tawa en owapi kin iyecen oyakiye kta, hecen taku ecanon owasin, qa tokiya kaśta idade cin owasin tanyan ihuniyaye kta.
4 Hecen Jehowa oie emakiya, Nicinkśi canku tawapi awanhdakapi, q̇a cantepi ocowasin, qa nagipi ocowasin on wowicake en mitokam manipi kinhan; Israel wicaśtayatapi oiyotanke kin etanhan wicaśta nitawa tohinni kaśpapi kte śni, eya.

5 Qa nakun Joab Tzeruja cinhintku token ecamicon niye sdonyaya, token Israel ozuye mdetanhunka nonpa, Abner Ner cinhintku, qa Yamasa Jeter cinhintku hena wicakte, qa wookiye en zuyapi iyecen we papson, qa wokicize we kin ipiyaka on nite ipiyag kiton kin he akan icu, qa hanpa siha kin ohan akan nakun. 6 Heon nitoksape kin iyecen ecayecoli kta, qa pa ska tawa kin ohna hnakapi kin ekta wooliye en ye kta iyowinyaye kte śni.

7 Tuka Barzillai Gileyadi cinhintku kin wocantkiye ecawicayecon kta, qa wahna wotapi nitawa etanhan yutapi kin wicehna ohinniyan unpi kta, Abiśalom nicinye etanhan nawajice cehan iyepi hecen en mahipi nakaś.

8 Qa iho Simeyi Gera cinhintku Benjamini kin nici yanka, iye Bahurim etanhan Mahanaim ekta wai, anpetu kin he en woyaśice tehika on mayaśica, tuka itkomakipe kta Jordan ekta apamahde i, heon Jehowa caje mdate ca wipe on çikte kte śni, ewakiya.

9 Heon dehan ihnuhan iye iyaonpepica śni kecanni, niye wicaśta yaksapa, qa token ecayecon kta on pa ska kin ohna hnakapi ekta weyapi on apamahde yeyaye kta iyececa sdonyaya.

10 Hehan Dawid hunkake wicaye cin om iśtima, qa Dawid totonwe ohna hnakapi. 


\section{WICOWOYAKE 2.}

11 Qa anpetu Dawid Israel tawicaśtayatapi un kin waniyetu wikcemna topa; Hebron ohna waniyetu śakowin wicaśtayatapi, qa Jerusalem ohna waniyetu wikcemna yamni sanpa yamni wicaśtayatapi.

12 Hehan Solomon iye atkuku Dawid oiyotanke tawa akan iyotanka, qa wokiconze tawa kin nina yusutapi.

13 Unkan A donija Ḣagit cinhintku kin Batśeba Solomon hurku ekta i. Unkan wookiye en yahi he, eciya; unkan, Wookiye en, eya.

$14 \mathrm{Qa}$ taku eciciye kta wacin eya. Unkan, eya ye, eya.

15 Unkan wukiconze kin he mitawa, qa Israel owasin wicaśta mayatapi kta e miye ekta etonwanpi sdonyaya; tuka wokiconze kin yutokanpi, qa misunka he yuha, Jehowa he yube kta konza nakaś.

16 Qa nakaha taku wanji cicida, ihnuhan, Hiya emayakiye cin. Unkan, Eya ye, eciya.

17 Unkan ceciciya, Solomon wicaśtayatapi, Hiya eniciye kte śni, heon Abiśag Sunamiwin mduze kta e maqu kta eciya wo.

18 Unkan Batśeba heya, Han niye on wicaśtayatapi kin ewakiye kte ye.

19 Unkan Batśeba wicaśtayatapi kin Solomon ekta i, Adonija on ie kta heon etanhan. Unkan wicaśtayatapi kin itkokipe kta najin, qa ektakiya pakapsan, qa toiyotanke akan iyotanke ça wicaśtayatapi hunku on oiyotanke ehde wicaśi: unkan etapa kin ekta iyotanka.

20 Qa heya, Taku cistinna wan cicida. Ihnuhan; Hiya emayakiye cin. Unkan wicaśtayatapi pi kin heciya, Ina eya wo, hiya eciciye kte śni.
21 Unkan winyan kin heya, Abiśag Śnamiwin kin nicinye Adonija yuze kta e qupi kte ye. 22 Unkan Solomon wicaśtayatapi kin ayupte ca hunku kin heciya, Qa tokeca Adonija on Abiśag Sunamiwin kin yada he? He cinye waya, hecen wicaśtayatapi kta e da wo; iye on qa Abiatar wawayuśna kin, qa Joab Tzerrija cinhintku on.

23 Qa wicaśtayatapi kin Solo. mon Jehowa cajeyate ca heya, Wakantanka hecen qa nakun isanpa ecamicon kte, Adonija wicoie kin de iye nag̣i on eye śni kinlıan.

24 Qa nakaha Jehowa eye ciqon iyecen tipi micicage ca ate Dawid oiyotanke tawa akan iyotang makiye ça miciyusuta kin he ni kinhan, anpetu kin de Adonija te kta.

25 Unkan wicaśtayatapi kin Solomon Benaja Jehojada cinhintku ye si, qa nape kill on kaśtake ca te kiya.

26 Únkan wicaśtayatapi kin Abiatar wawayuśna kin heciya; Yanatot maga nitawa elata hda wo; wicaśta ktepi kta henica nakaś, tuka ate Dawid itokam Jehowa canwobnaka tawa duha, qa ate toiyokiśice cin owasin en iyoniciśica, heon nakaha cikte kte śni.

27 Unkan Solomon Abiatar yutokan, on Jehowa wawayuśna heca kte śni, hecen Jehowa oie kin Eli tiyohnaka on Śsilo en eye ciqon yuecetu.

28 Unkan Joab nahon (Joab Adonija opa, Abiśalom ope śni eśta,) heon Joab najica, Jehowa tawakeya ekta, qa wahna wośnapi he kin yuza.

29 Unkan wicaśtayatapi kin Solomon okiyakapi, Joab Jehowa tawakeya ekta najica, qa in483 


\section{WICAŚTAYATAPI,}

yun wahna wośnapi icahda yanka. Unkan Solomon Benaja Jehojada cinhintku heya ye śi, Ekta ya, qa kaśtaka wo.

30 Unkan Benaja Jehowa tawakeya ekta i, qa heciya, Wicaśtayatapi kin hecen eya, Inanpa wo. Unkan, Hiya den mate kta eya. Unkan Benaja wicrśtayatapi kin okiyaka, Joab hecen eya, qa hecen amayupta.

31 Unkan wicaśtayatapi kin heciya, Token eye cin iyecen econ, qa kaśtaka, qa hnaka wo; hecen we Joab ituh papson kin miye on, qa ate tiyohnaka on akahpe miyeciton kta.

32 Iye wicaśta nonpa, Abner Ner cinhintku Israel ozuye mdetanhunka, qa Yamasa Jeter cinhintku Juda ozuye mdetanhunka iye isanpa olian owotanna qa waśte, ate .Dawid sdonye 'śni, wicakaśtake ca isan on wicakte; heon we tawa iye pa kin akan Jehowa hdikiye kta.

33 Hecen hena wepi kin Joab pa akan, qa tona iye etanhan icagapi papi akan owihanke wanica hdi kta; qa Dawid qa tona iye etanhan icagapi, qa iye tiyohnaka, qa oiyotanke tawa Jehowa kici wokiyapi kta owihanke wanica.

34 Unkan Benaja Jehojada cinhintku ekta i, qa kaśtake ça țekiya, qa tinta en ti kin ohna hnakapi.

35 Unkan wicaśtayatapi kin heekiya Benaja Jehojada cinhintku ozuye mdetanhunka kagá, qa wicaśtayatapi kin Abiatar heekiya 'Tzadoq wawayuśna kaga.

36 Unkan wicaśtayatapi kin Śimeyi wahoye ca kico, qa heciya, Jerusalem ohna ticağa, qa hen yanka wo, qa hetanhan tokidan inayape kte śni.
37 Tohan hetanhan inayape ca Qidron kaksiza akasanpa idade cinhan, awicakehan nite kta sdonya wo; niwe kin nipa akan yanke kta.

38 Unkan Śsimeyi wicaśtayatapi kin heciya, Wicoie kin de waśte ce, token itancan mitawa wicaśtayatapi kin eye cin he iyecen nitaokiye econ kta. Unkan Śimeyi anpetu ota Jerusalem ohna yanka.

39 Unkan waniyetu yamni hehan Śimeyi taokiye nonpa Akiś Mayaka cinhintku Gat wicaśtayatapi kin ekta najicapi ; unkan Śimeyi okiyakapi qa heyapi, Iho nitaokiye. Gat en yakonpi.

40 Unkan Śimeyi najin, qa taśonśonna aqin kiton, qa taokiye owicade Gat ekta iyaya, Akiś ekta; hecen Śimeyi ekta i, qa taokiye Gat etanhan wicahdohdi. 41 Unkan Śsimeyi Jerusalem etanhan Gat ekta i qa hdi, Solomon okiyakapi.

42 Unkan wicaśtayatapi kin Śimeyi wahoye ça kico, qa heciya, Jehowa cajeyan konze ciye ca ciyaotanin, qa, Tohan inayape ca toki idade cinhan hehan awicakehan nițe kta sdonya wo, eciciye śni he? qa, Wicoie nawation kin he waśte ce, ehe sni he?

43 Qa tokeca woahope Jehowa cajeyan ope ciśi kin oyape śni he?

44 Nakun wicaśtayatapi kin Śimeyi heciya, Niye wicohan śica nicante sdotkiya ate ecayecon owasin sdonyaya; heon niohan śice cin nipa akan Jehowa hdikiye kta.

45 Qa Solomon wicaśtayatapi kin yawaśtepi kta, qa Dawid toiyotanke kin yusutapi kta owihanke wanica.

46 Unkan wicaśtayatapi kin 
Benaja Jehojada cinhintku hecon śi, unkan inanpe ça kaśtake ca tekiya. Unkan wokiconze kin Solomon nape kin en yusutapi.

\section{WICOWOYAKE 3.}

1 Unkan Solomon Paro Egupton wicaśtayatapi kin kici wotakuye kage ca Paro cunwintku kin yuze ca Dawid totonwe en ahdi, tohan tipi tawa qa Jehowa ti kin, qa Jerusalem ihdukśan conkaśke kag̉e cin hduśtan śni kin hehanyan.

2 Hececa eśta oyate kin pajodan akan wośnapi ece, anpetu kin dena hehanyan Jehowa caje on nahanhin tipi kağapi śni nakaś.

3 Qa Solomon Jehowa waśtedake ca atkuku Dawid tokage cin omani, tuka pajodan akan wayuśna, qa wizịnya ece.

4. Qa wicaśtayatapi kin Gibeyon ekta i, heciya wayuśna kta heon; pajodan iyotan kin hee nakaś; wohuhnahyapi kektopawinğe wahna wośnapi kin he akan Solomon huhnaliya.

5 Gibeyon en Jehowa Solomon en ildutanin hanyen wowihanmde en, qa Wakantanka heciya, Taku cicu kta yacin da wo.

6 Unkan Solomon heya, Nitaokiye Dawid ate wowicake en, qa woowotanna en, qa cante ecetu kin en nici mani kin iyecen wocantekiye tanka ecayecon; qa wocan tekiye tanka kin de yecipatan, cinca wan oiyotanke tawa akan iyotanke kta yaqu, anpetu kin de iyececa.

7 Heon Jehowa Wakan cida wanna ate Dawid heekiya nitaokiye wicaśtayatapi yakagia, qa miye hokśiyopa 'hemaca, token tankan inawape ca en wahdi kte cin sdonwaye śni.
$8 \mathrm{Qa}$ nitaokiye oyate nitawa yakahnige cin ehna un, oyate tanka, ota hin on wicayawapi, qa owicawapi okihipica śni.

9 Heon nitaokiye cante wanalion qu ye, oyate nitarva wicayaco kta, qa taku waśte qa.taku śica iyukcan kta heon; ecin tuwe oyate nitawa kin de hinskotanka wicayaco kta okihi.

10 Unkan taku kin de Solomon da kin wicoie kin Itancan iśta kin en waśte.

11 Unkan Wakantanka heciya; Wicoie kin de yada kin, qa niye on anpetu ota yada śni, qa niye on wowijice yada śni, toka niyanpi nagipi kin niye on yada śni, tuka woyaco nayahion kta e wowiyukcan niye on yada.

12 Iho nioie kin iyecen ecamon, iho cante ksape ca wiyukcan cicu, hecen nitokam tuwedan iyenicece śni, qa niyohakam tuwedan niye iyecen najin kte śni.

13 Qa nakun taku yada śni kin ciçu, wowijice, qa wowitan koya, hecen tohanyan yani kin hehanyan wicaśtayatapi wicehna tuwedan iyenicece kte śni.

14 Qa mita canku ohna mayani kinhan, qa wokage mitawa, qa woahope mitawa oyape cinhan, Dawid niyate mani kin iyecen, anpetu nitawa mduota kta.

15 Unkan Solomon kikta; unkan iny un he wowihanmna. Unkan Jerusalem en hdi, qa Jehowa otakuye can-wohnaka kin itokam najin, qa woliuhnah̉yapi hulinahya, qa wopida wośnapi kag̉e ça taokiye owasin wohanpi wicakicag̉a.

16 Hehan winohinca nonpa witkowin hecapi wicaśtaya tapi ekta hipi, qa itokam najinpi.

17 Qa winohinca wanji heya, Ecake, Itancan mitawa, miye qa 485 


\section{WICAŚTAYA'TAPI,}

winohinca kin de tipi wanjidan ohna untipi, qa he kici tipi kin ohna cinca waton ye.

18 Unkan cinca waton kin ohakam anpetu iyamni winohinca kin de nakun cinca ton, qa okonwanjidan unyakonpi, tipi kin ohna tuwedan tokeca yanke śni, unkiś nanapidan ye.

19 Unkan winolinca kin de cinhintku kin hanyen te, ahdaskin iwanka nakaś.

20 Unkan hanyecokaya inajin, qa micinkśi micahda tanhan icu, nitaokiyewin iśtima icunhan, qa maku tawa ohna iwankeya, qa iye cinhintku te cin maku mitawa ohna ehnake ye.

21 Unkan hanhanna micinkśi azin wakiye kta wekta qehan, iny un he te ; tuka anpa en iwanmdake cehan inyun micinkśi waton qon hee śni ye.

22 Tuka winohinca unman kin heya, Hiya ni kin micinkśi kin hee, qa nicinkśi kin he țe. Unkan tokaheya kin heya; Hiya nicinkśi he te, qa micinkśi ni kin hee ye. Hecen wicaśtayatapi itokam wohdakapi.

23 Unkan wicaśtayatapi kin heya, Wanji iś, ni kin de micinkśi ee, qa nicinkśi he te ye, eya; qa unman heya, Hiya nicinkśi kin țe qa micinkśi kin ni ye.

24 Nakun wicaśtayatapi kin heya,'Isan micicau po. Unkan isan wan wicaśtayatapi kin itokam hiyuyapi.

25 Unkan wicaștayatapi kin heya, Hokśidan ni kin kibaśpa po, qa wanji iś lianke qu po, qa unman iś hanke qu po.

26 Hehan winohinca cinhintku ni kin iye cinhintki on tezi kata aya, heon wicaśtayatapi kin heciya, Itancan ceciciya, hokśidan ni kin he qu ye, qa ihnuhan he te yaye cin. Unkan unman he486 ya, He mitawa kte śni, qa nakun iye tawa kte śni, kibaśpa pe.

27 Hehan wicaśtayatapi kin ayupte ca heya, Hokśidan ni kin tokaheya kin he qu po, qa ihnuhan te yayapi kin, hunku kin hee nakaś.

28 Unkan Israel owasin woyaco wicaśtayatapi yaco kin nahonpi, qa wicaśtayatapi kin itokam kokipapi, woecetu econ kta e woksape wakan iye en un kin wanyakapi nakaś.

\section{WICOWOYAKE 4.}

1 Unkan wicaśtayatapi Solomon Israel owasin iwicadaka.

2 Qa wicaśta itancan wicayuhe cin dena eepi, Azarija Tzadoq wawayuśna kin cinhintiku.

3 Qa Eliliorep qa Ahija Śisa cinhintku kin hena wowapi kaga hecapi; Jehośapat Ahilur cinhintku kin wokiksuye wowapi kin kaga.

4. Qa Benaja Jehojada cinhintkn ozuye mdetanhunka, qa Tzadoq qa Abiatar wawayuśnapi.

5 Qa Azarija Natan cinhintku akicita kin wicayuha, qa Zebud Natan wawayuśna cinhintku kin wicaśtayatapi kin takodaku.

$6 \mathrm{Qa}$ Ahiśar tipi kin awanyaka, qa Adoniram Yabeda cinhintku wamnayanpi itancarı.

7 Unkan Solomon akicita wikcemna sanpa nonpa wicayuha, Israel owasin iwankam unpi, qa hena onıaka wi kin wicaśtayatapi qa iye tiyohnaka on woyute mnayanpi, otoiyohi wi wanjidan on woyute mnayan.

8 Qa cajepi kin dena eepi, Ḣur cinhintku Epraim he kin ohna.

9 Deqer cinhintku Meqatz ohna, qa Śaalbim, qa Betśemeś, qa Elon, qa Bethanan ohna.

10 Hesed cinhintku Arubbot 


\section{WICOWOYAKE 4.}

ohna, iye Soko, qa Heper makoce kin ocowasin yuha.

11 Abinadab cinhintku Dor paha owasin, iye Tapat Solomon cunwintku kin yuza.

12 Bayana Ahilud cinhintku Tayanak, qa Megiddo, qa Betśan Tzaretan ikiyedan wanke cin Tezreyel ihukuya, Betśan etanhan Abelmehola ekta, qa Joqmeyam akotanhan ocowasin yuha.

13 Geber cinhintku Rannot Gileyad (Gileyad paha) kin ohna, iye Jair Manaśe cirhintku totonwe Gileyad ohna, qa Argob makoce kin Baśan ohna otonwe tankinkinyan wikcemna śakpe conkaśke qa mazaśa inatake yuhapi kin hena owasin yuha.

14 Alinadab Yido cinhintku Mahanaim yuha.

15 Ahimayatz Naptali ohna, iś eya Solomon cunwintku Basmat yuza.

16 Bayana Huśai cinhintku Aśer ohna, qa Yalot ohna.

17 Jehośapat Paroha cinhintku Issakar ohna.

18 Ś́timeyi Ela cinhintku Benjamin ohna.

19 Geber Uri cinhintku Gileyad Silion Anıori wicaśtayatapi, qa Yog Baśan wicaśtayatapi tamakocepi kin ohna; qa makoce kin he ohna iśnana akicita.

20 Unkan Juda qa Israel wicota, wiyaka miniwanca hutata wandse cin ota hin iyenaka, wotapi, qa wayatkanpi, qa wiyuśkinpi.

21 Unkan Solomon wokiconze owasin iwicadaka, wakpa kin etanhan Pilistim tamakocepi kin, qa Egupta makoce ihanke hehanyan, womnaye kahipi qa Solomon anpetu ni kin owasin ókiyapi.

$22 \mathrm{Qa}$ Solomon anpetu wanjidan on woyute yuhe cin dee, ag̣uyapi mdu waśte hinca koka tanka wikcemna yamni, qa wokpanpi koka tanka wikcemna śakpe.

23 Tatanka cemyapi wikcemna, qa tatanka wilianpi wikcemna nonpa, tahinca wanuyanpi opawinge, makun tatoka qa tahinca ikceka, qa tatokadan qa mağa cemyapi.

24 Wakpa kin itato owasin iwicadaka, Tipsah etanhan Gaza ekta, wicaśtayatapi wakpa itato owasin, qa ihdukśan yakonpi kin owasin om wookiye yuha.

$25 \mathrm{Qa}$ Solomon anpetu tawa owasin, Juda, qa Israel, Dan etanhan Berśeba ekta hehanyan wikopeśniyan yakonpi, wicaśta otoiyohi hastanhanka iyuwi tawa ihukuya, qa suken can tawa ihukuya.

26 Nakun Solomon tacanpahmihma on śuktanka oinajin kektopawinge wikcemna topa yuha, qa śuktanka akan iyotankapi kektopawinge wikcemna sanpa kektopawinge nonpa.

27 Unkan akicita qon woyute Sulomon wicaśtayatapi on mnayanpi, qa tona wicaśtayatapi Solomon wahna wotapi tawa ikiyedan hipi orvasin on, otoiyohi wi tawa en hecen takudan icakijapi śni.

28 Nakun barle, qa peji śeca śuktanka on, qa śonśonna on tukten yakonpi kin ekta ahipi, otoiyohi econ wicaśipi kin iyecen.

29 Unkan Wakantanka Solomon woksape qa wowiyukcan tanka hinca qu, qa cante ohdakinyan tanka, wiyaka miniwanca hutata ekta wanke cin he iyecen. 30 Hecen Solomon toksape kin wiyohiyanpa cinca kin owasin toksapepi kapeya, qa Egupton toksapepi owasin nakun.

31 Qa wicaśta owasin isanpa 487 


\section{WICAŚTAYATAPI,}

ksapa, Etan Ezrahi kin, qa Heman, qa Kalkol, qa Darda Mahol cinca kin hena owasin isanpa, qa oyate ihdukśan yakonpi kin owasin cajeyatapi.

$32 \mathrm{Qa}$ wicoie wakan kektopawinge yamni ia, qa odowan kektopawinge sanpa zaptan.

$33 \mathrm{Qa}$ can kin cajeyata, hanteśa Lebanon aicage cin etanhan pejihota conkaślke aicage cin hehanyan on ia, qa nakun woteca on ia, qa taku kinyan on, qa watutka on, qa hogan on.

34 Unkan oyate owasin etanhan Solomon toksape nahonpi kta hipi, maka wicaśtayatapi kin tona ekta toksape otanin kin owasin etanhan.

\section{WICOWOYAKE 5.}

1 Unkan Hiram 'Tzur wicaśtayatapi kin Solomon elsta iye taokiye ye wicaśi, he atkuku eekiya wicaśtayatapi sdayapi kin nalion nakaś, qa Hiram Dawid waśtedaka anpetu tawa owasin.

2 Unkan Solomon Hiram wahoye ça heya,

3 Ate Dawid ozuye iye ihdukśan unpi siha kin ihukuya Jehowa ye wicaye śni kin hehanyan, Jehowa iye wakanda caje kin on tipi wan kagga okihi śni lie sdonyaya.

4 Tuka wanna Jehowa wakanwada kin woozi maqu, mihdukśan toka wanica, qa taku śica awakipe śni.

5 Qa ito Jehowa wakan wada caje on tipi wan wakagie kta epa, Jehowa ie ca ate Dawid heciye ciqon iyecen, Nicinkśi niye heekiya oiyotanke nitawa akan ciçu kte cin iye micaje on tipi wan kage kta.

6 Heon dehan Lebanon etanhan lianteśa can micicakse wi488 caśi wo; qa nitaokiye mitaokiye om unpi kta. Qa nitaokiye on iyuwin ciç kta, taku ehe kte cin owasin iyeden, Tridoni kin iyecen unkiyepi ehna tuwedan can kakanpi wayupike śni sdonyaya.

7 Unkan Hirram Solomon oie kin naton qehan nina iyuśkin, ya heya, Jehowa nakaha yawaśtepi. Iye Dawid oyate tanka kin de iwankam cinca ksapa wan qu.

8 Unkan Hiram Solomon wahoye ca heya, Wahomayaye cin he nawahon. Taku iyonicipi owasin, hanteśa can qa wazi can en miye ecamon kta.

9 Mitaokiye Lebanon etanhan miniwanca ekta hiyuyapi kta; qa tukten wahomayaye lite cin, heciya, cankaga miniwanca olna amde kta, qa niye heciya can kin iyacu kta, nakun token iyomakipi niye ecanon kta, qa tiyohnaka mitawa on woyute mayaqu kta.

10 Unkan İiram hanteśa can, qa wazi can Solomon qu, token iyokipi.

11 Unkan Solomon aguyapi su koka tanka kektopawinge wikcemna nonpa, qa can ihdi waśte koka tanka wikcemna nonpa, tiyohnalia tawa yutapi kta on, Solomon waniyetu otoiyohi Ḧiram hecen qu ece.

12 Unkan Jehowa Solomon woksape $q u$, eciye ciqon he iyecen. Unkan Hiram qa Solomon wokiyapi, qa otakuye kicicagapi.

13 Unkan Solomon Israel owasin etanhan wowidake mnayan, wicaśta kektopawinge wikcemna yamni wowidake mnawicaya.

14 Qa Lebanon ekta ye wicaśi kektopawing itokto wi iyohi, wi wanjidan Le- 


\section{WICOWOYARE 6.}

banon ohna yakonpi, qa wi nonpa tipi tawapi en. Unkan Adoniram wowidake mnayanpi kin awanyaka.

15 Nakun Solomon wicaśta kektopawinğe wikcemna śaknwin watokśupi heca wicayuha, qa he kin ohna wakakanpi kektopawinge wikcemna śahdogan.

16 Nakun akicita itancanpi kin Solomon wicayuha kektopawinge yamni sanpa opawinge yamni, wohtani econ wicakiyapi, hena oyate wolitani econpi kin awanwicayakapi.

$17 \mathrm{Qa}$ Solomon hecon wicaśi heon inyan tankinkinyan qapi, inyan tehika, inyan kakanpi tipi oahde kin on.

18 Hecen Solomon ticaga tawa, qa Hiram ticaga tawa kin, qa tona inyan kaksapi kin hena kakanpi, qa tipi kin kagapi kta can qa inyan wiyeya kagapi.

\section{WICOWOYAKE 6.}

1 Unkan Israel Egupta makoce kin etanhan hinanpapi ehantanhan waniyetu opawinge topa sanpa wikcemna iśahdogan en, Solomon Israel itancanyaui waniyetu itopa kin en wi inonpa, Zip eciyapi he en, tokaheya Jehowa on tipi kaga.

2 Qa wicaśtayatapi kin Solomon tipi Jehowa kicage cin he ohanske cin wiciśpa wikcemna śakpe, qa ohdakinyan kin wikcema nonpa, qa obosdatu kin wiciśpa wikcemna yamni.

3 Unkan tipi wakan tipi kin wihinanpe cin ektakiya tiyopa awakeyapi kin he ohanske cin wiciśpa wikcemna nonpa, tipi ohdakinyan kin iyenakeca, qa ohdakinyan kin wiciśpa wikcemnana tipi wihinanpe cin ektakiya.
4 Qa owanyeye tipi kicage cin bena cansbudan kazuntapi.

5 Qa tipi tiobosdata ihdukśan owanka kaga, tipi wakan qa tipi wakan hinca itankan tiobosdata akan, qa ilidukśan tiobosdata akan tipidan kağa.

6 Tipidan kuya kin ohdakinyan kin wiciśpa zaptan, qa inonpa kin ohdakinyan kin wiciśpa śakpe, qa iyamni ohdakinyan kin wiciśpa śakowin, tipi ihdukśan itankan oahehde kag̣a nakaś, hecen tipi tiobosdata kin en ikoyag ye kte śni.

$\gamma$ Unkan tipi kagapi qehan inyan oqapi ekta yuśtanpi heca on kagapi, hecen tipi kagapi icunhan hen maziyape, qa onspe, qa mazasapa ikicanye unmanna nalionpi śni.

8 Qa tipidan inonpa tiyopa kin tiunnaptan itokaga ektakiya qa caniyadipi kin aohomniyan tipidan inonpa kin ekta adipi, qa inonpa kin etanhan iyamni kin ekta.

9 Hecen tipi kin kagge ca yuśtan, qa lianteśa can cutuliu qa canmdaska on awakeya.

10 Nakun tipidan obosdata kin wiciśpa zaptan, tipi owancaya ihdukśan kaga, qa hena hanteśa can on tipi kin akan ahekiya.

11 Unkan Jehowa oie kin Solomon en hi qa heciya,

12 Tipi kin de yakage cin hecen wokage mitawa omayani, qa woyaco mitawa ecanon, qa woahope mitawa owasin oyape ca omayani kinhan, mioie Dawid niyate ewakiye ciqon niye en mdusuta kta.

13 Qa Israel cinca wicehna ounwaye kta, qa oyate mitawa a'mduśtan kte śni.

14 Hecen Solomon tipi kin kagge ca hduśtan.

15 Nakun tipi tiobosdata kin 489 


\section{WICAŚ́TAYATAPI,}

mahentu hanteśa canmdaska on kagga, tipi owanka kin hetanhan tice canmdaska aiyahdeya, mahentu can aokatan, qa tipi owanka kin wazi canmdaska aokatan.

16 Qa owohdake kin tipi wakan linca tipi on, tipi ohanske etanhan catkuta wiciśpa wikcemna nonpa, hanteśa canmdaska on kaga, owanka etanhan awakeyapi kin aiyahdeya.

17 Qa wiciśpa wikcemna topa wihinanpe ektakiya tipi wakan kin hee.

18 Qa timahen hanteśa can kin pağopi, pśonkaka qa wahcahica: timahen owancaya hianteśa can, inyan kin aisinyan wanka.

$19 \mathrm{Qa}$ timahen catkuta owohdake tipi kin wiyeya kağa, hen Jehowa wotakuye can wohnaka ehnake kta heon etanhan.

$20 \mathrm{Qa}$ owohdake tipi kin ohanske cin wiciśpa wikcemna nonpa, qa ohdakinyan kin wiciśpa wikcemna nonpa, qa obosdatu kin wiciśpa wikcemna nonpa, qa he mazaskazi ecedan apawinta; qa hanteśa wahna wośnapi kin nakun he apawinta.

21 Hecen Solomon tipi kin timahen mazaskazi ecedan on apawinta qa owohdake tipi itokam ozanpi mazaskazi icicahilia on otkeya, qa mazaskazi apawinta.

22 Qa tipi kin owancaya mazaskazi apawinta ecen tipi kin yuśtanpi. Nakun wahna wośnapi kin owohdake tipi tawa kin he, owancaya mazaskazi apawinta.

$23 \mathrm{Qa}$ owohdake tipi kin ohna Kerubim nonpa wihdi can on kağa, hena obosdatu wiciśpa wikcemna.

$24 \mathrm{Qa}$ kerub hupahu wanji wiciśpa zaptan, hupahı wanji ihanke kin etanhan hupahu unman ihanke ekta wiciśpa wikcemna.
$25 \mathrm{Qa}$ kerub unman wiciśpa wikcemna: Kerub napin iyutapi kin, qa okagisi kin iyakidehankeca, qa iyakidececa.

26 Kerub wanji obosdatu kin wiciśpa wikcemna, qa kerub unman kin hehankeca.

27 Unkan kerub napin tipi kin mahen ehde; qa kerub napin hupahu hdamdagapi, qa kerub wanji hupahu kin tiobosdatu kin iyohi, qa kerub unman hupahu kin tiobosdatu nnman kin iyohi, qa hupahupi kin tipi kin cokaya en iyokicihipi.

28 Unkan kerub napin mazaskazi apawinta.

29 Qa tipi kin ihdukśan tiobosdata kin owancaya mahen, qa tankan kerub qa tamar can, qa wahcahca namdaga okagapi pağo.

30 Qa tipi owanka kin mazaskazi apawinta owohdake tipi kin mahen qa itankan.

31 Qa owohdake tipi tiyopa kin wihdi can on kaga, canbosdata ipatan kin zaptan.

32 Nakun tiyopa nonpa wihdi can heca, qa hena akan kerub, qa tamar can, qa walicalica namdaga opagopi paggo, qa mazaskazi apawinta, qa mazaskazi kin kerub kin, qa tamar can kin apawinsya.

33 Qa hecen tipi kin mahen tiyopa kin on can bosdata topa kag̉a.

34 Qa tiyopa nonpa wazi can on kaga, canm daska nonpa yukśijapi tiyopa wanji on, qa canmdaska nonpa yukśijapi tiyopa unman on.

35 Qa kerub, qa tamar can, qa wahcahca namdağa pağo, qa pagopi kin akan waympiya mazaskazi apawinta.

36 Nakun hocoka mahentu conkaśke kin kag̣a, inyan kakanpi 


\section{WICOWOYAKE $\%$.}

yamni itakihna, qa akan hanteśa can kakanpi ocanku wanji.

37 Waniyetu itopa Zip wi kin en Jehowa ti oahehde kagapi.

38 Qa waniyetu wikcemna iake wanji Bul wi kin, wi iśahdogan kin hee en, taku owasin woyaco owasin iyecen yuśtanpi, hecen waniyetu śakowin he kağapi.

\section{WICOWOYAKE $\%$.}

1 Unkan Solomon tipi tawa waniyetu wikcemna sanpa yamni hehanyan kag̉e ça tipi tawa kin ocowasin hduśtan.

2 Nakun Lebanon contanka, tipi kin kagg, ohanske kin wiciśpa opawinge, qa ohdakinyan kin wiciśpa wikcemna zaptan, qa obosdatu kin wiciśpa wikcemna yamni, hanteśa can pasdatapi cankuye topa akan, qa canpasdatapi akan lianteśa can kakanpi ehnakapi.

3 Qa can bosdan ehdepi wilicemna topa sanpa zaptan cankuye iyohi ake zaptan hena akan tipi cutuhu kin qa lianteśa can on akahpapi.

4 Qa owanyeye cankuye yamni, qa owanyeye wán owanyeye unman iyotakonza yamni akihde.

5 Qa tiyopa kin, qa can ipatan kin owasin topa omdoton kagapi, qa cankuye yamni kin en owanyeye iyotakonza.

6 Qa tiyopa awakeyapi can pasdatapi on kagga, ohanske cin wiciśpa wikcemna zaptan, qa ohdakinyan kin wiciśpa wikcema yamni; qa hena itokam tiyopa awakeyapi wanji, qa canpasdatapi, qa iyadipi wan hena itokam kaga.

7 Nakun wayaco ohanzi hdepi wan kaga, he ohna wayaco oiyotake kin han; qa owanka etanhan wankan owanka kin hehan- yan hanteśa canmdaska on akahipa.

8 Qa tipi tawa ohna ti kin he en tihocoka wan, awakeyapi kin de iheyata, wokage kin de iyececa. Nakun Paro cunwintku Solomon yuze cin tipi wan kicagga tiyopa awakeyapi kin de iyecen.

9 Hena owasin inyan tehika on kagapi, wiyutapi kin iyecen kakanpi, qa canibakse on baksapi, anokatanhan, oahehde etanhan tipi tete kin helianyan, qa tankan ahocoka tanka kin hehanyan.

$10 \mathrm{Qa}$ oahehde kin he inyan telika, inyan tanka, inyan wiciśpa wikcemna, qa inyan wiciśpa śahdogian.

11 Qa iwankam inyan tehika wiyutapi kin iyecen kakanpi, qa hanteśa can.

12 Qa ihdukśan hocoka tanka kin inyan kakanpi yamni icitakibna, qa hena akan hanteśa can kalsanpi cankuye wanjidan, qa Jehowa ti hocoka mahentu kin, qa tiyopa awakeyapi kin he nakun hececa.

13 Unkan Solomon Hiram wahoya, qa Tzur etanhan ukiya.

14 Iye wiwazica wan Naptali wicoun etanhan inaya, qa atkulsu Tzur wicaśta heca, mazazi kagia; unkan he wolssape, qa wowiyukcan ojudan, qa mazazi okagapi wayupiya kaga. Unkan wicaśtayatapi Solomon ekta hiyu, qa wohtani econ śi kin owasin kağa.

15 Qa mazazi ipatan nonpa kaga, ipatan wanji bosdatu kin wiciśpa wikcemna sanpa śahdoğan, qa hahonta wiciśpa wikcemna sanpa nonpa ipatan iyohi ohomni iyaya.

16 Qa ipatan nonpa papi kin akan ehde kta e wateśdake non. pa mazazi śdoyapi on kagga, wa491 


\section{WICAŚT'TAYATAPI,}

teśdake wanji obosdatu kin wiciśpa zaptan, qa wateśdake inonpa obosdatu kin wicispa zaptan.

17 Maza yankapi ho kagapi iyecen mazaicicahilia kahmupi wateśdake, ipatan akan yakonpi kin hena kicagga, wateśdake wanji on śakowin, qa wateśdake inonpa on śakowin.

18 Hecell ipatan kagia, qa hena ihdukśan taspantanka su ota cankuye nonpa maza yankapi wateśdakapi wanji pa akahpe cin on, qa wateśdake inonpa on nakun hecen lagig.

19 Wateśdake ipatan nonpa papi kin akan tiyopa awakeyapi ohna yakonpi hena, mnahcahca kag̣api, wiciśpa topa.

20 Nakun wateśdake ipıtan nonpa akan, taspantanka su ota opawinge nonpa, maza yankapi icunom tezi kin ikiyedan iwankam: wateśdake inonpa akan ihdukśan cankuye nonpa.

21 Qa tipi wakan tiyopa awakeyapi ipatan kin bosdan ehde, qa ipatan etapa kin bosdan ehde qehan Jakin (Jehowa yasuta) cajeyata, qa ipatan catka kin bosdan ehde, qa Boaz (miniheca) cajeyata.

22 Qa ipatan papi akan mnahcahca kagapi : hecen ipatan kagapi kin yuśtanpi.

23 Qa ceğa śdoyapi tanka kin kaga, mima, qa tete etanhan tete unmaı ekta wiciśpa wikcemna; qa obosdatu kin wiciśpa zaptan, qa hałonta wiciśpa wikcemna yamni ihdukśan iyaya.

24 Qa ihdukśan owancaya tete kin ihukuya can paha pagopi, wiciśpa iyohi wikcemna, cankuye nonpa, cegga tanka ihdukśan; he śdoyapi qehan can paha kin nakun śdoyapi.

25 Qa tatanka wikcemna nonpa akan ehdepi, yamni itepi kin wa- ziyata kiya, qa yamni itepi kin wiyohpeyata kiya, qa yamni itepi kin itokahikiya, qa yamni itepi kin wihinanpe cin ektakiya cega tanka kin hena tapetepi akan wanka, qa owasin nitepi kin mahentuya unpi.

26 Qa ośoke cin nape hdakinyan, qa tete wiyatke tete lkin iyececa, mnahicalica namdaya akan kagapi, qa bat (koka iyutapi) kektoparvinge nonpa kipi.

27 Nakun mazazi oahe topa kaga, oahe otoiyohi ohanske cin wiciśpa topa, qa ohdakinyan kin wiciśpa topa, qa obosdatu kin wiciśpa yamni.

28 Qa oahe kin decen kagapi, opapun yuhapi, qa opapun kin oise otahedan.

$29 \mathrm{Qa}$ oise otahedan opapun akan mnaja, qa tatanka, qa Kerub kagapi. Qa oise akan hute kin iwankam; qa mnaja kin, qa tatanka kin ihukuya, oyuskite okazeze kagapi.

30 Qa oahe iyohi ihukuya mazazi canhdeśka topa, qa canhdeśka huhdakinyan kin mazazi, qa cega kin ihukuya siha kin hiyete yuhapi. Hiyete kin śdoyapi, otoiyohi oyuskite iyotakonza.

31 Qa oiyuhdoke cin wateśdake kin mahentuya obosdatu kin wiciśpa wanji; qa oiyuhdoke cin mima, wakśica kagapi iyecen, wiciśpa wanjidan sanpa wiciśpa hanke; qa oiyuhdoke akan wapagiopi, qa opapun topa omdoton, mibe śni.

32 Qa opapun kin ihukuya canhdeśka topa, qa canhdeśka hu hdakinyan oahe en ikoyakapi, qa canhdeśka otoiyohi obosdatu kin wiciśpa wanji sanpa hanke. 33 Qa canhdeśka kağapi kin canpahmihma canhdeśka kag̣api iyececa, huhdakinyanpi kin, qa

492 


\section{WICOWOYAKE $\%$}

cancokaya kin, qa mazacanhdeśka kin, qa canheśkda hu kin hena owasin śdoyapi.

$34 \mathrm{Qa}$ oahe otoiyohi oise topa kin akan hiyete topa, hiyete kịn oahe kin etanhan.

35 Qa oahe pa kin mima, obosdatu kin wiciśpa hanke, qa oahe pa kin, qa nape kin, qa opapun kin he etanhanpi.

36 Qa huhdakinyan omdasta kin akan, qa opapun kin akan Kerub, qa mnaja, qa tamar can bagopi, vtoiyohi okan kin iyececa, qa nakun oyuskite kin ihdukśan.

37 Oahe wikcemna kin hecen kag̣api; owasin iyecen śdoyapi, iyutapi kin wanjidan, obagopi wanjidan.

38 Qa mazazi wakśica wikcemna kag̣a; wakśica kin iyohi bat wikcemna topa kipi; wakśica otoiyohi wicispa topa; qa oahe wikcemna otoiyohi akan wakśica wanjidan.

$39 \mathrm{Qa}$ oahe zaptan tipi etapa kin eciyatanhan, qa oahe zaptan tipi kin catka tanhan ehde; qa cega tanka kin tipi kin etapa tanhan itokaga tanhan wi hinanpe ekta kiya.

40 Unkan Hiram wakśica kin kağa, nakun mazamdaska kin, qa ceğa kin. Hecen Jehowa ti kin on wicaśtayatapi Solomon wohtani kahi śi kin owasin yuśtan.

41 Maza ipatan nonpa kin, qa maza ipatan nonpa papi akan wateśdake mima nonpa kin, qa maza yankapi nonpa on maza ipatan nonpa papi akan wateśdake nonpa akahpapi;

42 Qa taspantanka su ota opawinge topa, maza yankapi nonpa kin on, taspantanka su ota cankuye nonpa, maza yankapi otoiyohi on, hena wateśdake waksica maza ipatan akan unpi kin akahipapi ;

$43 \mathrm{Qa}$ oahe wilkcemna, qa wakśica wikcemna oahe akan yakonpi ;

44 Qa ceğa tanka wanjidan, qa tatanka wikcemna sanpa nonpa ceọa tanka ihukuya;

45 Qa cega kin, qa maza mdaska kin, qa wakśica kin: qa Hiram Jehowa tipi taku ikicanye cin wicaśtayatapi Solomon kicage cin hena owasin mazazi wiyatpa on kaga.

46 Jordan osmaka kin ohna, wicaśtaya tapi kin hena śdoya, maka śka kin ohna Sukot qa Tzaretan otahedan.

47 Hehan Solomon oziiçiya, wakśica kage cin nina ota liinca, maza tkeutapi kin aspeye pica śni.

48 Unkan Solomon Jehowa tipi ikicanye cin owasin kagga, mazaskazi wahna wośnapi kin, qa mazaskazi wahna wotapi kin, he akan ağuyapi itokamhnakapi.

49 Qa petijanjan ihupa owohdake tipi itokam, etapa eciyatanhan zaptan, qa catka eciyatanhan zaptan kin, mazaskazi ecedan on kagapi, qa walica kin, qa petijanjan kin, qa petijanjan iyukse, owasin mazaskazi.

50 Qa wakśica kin, qa isan kin, qa wiyatke kin, qa mazatukiha kin, qa oizinye kin, mazaskazi ecedan, nakun tipi mahentuya tipi wakan hinca tiyopa on, qa tipi wakan tiyopa kin on, tiyopa okihe kin hena mazaskazi.

51 Hecen wicaśtayatapi Solomon wokicanye Jehowa ti kin kicagge cin owasin yuśtanpi. Unkan Sólomon taku atkuku Dawid yuwakan kin, mazaska kin, qa mazaskazi kin, qa wakśica kin ahi, qa Jehowa ti wopiye kin en ehnaka. 


\section{WICAŚTTAYATAPI,}

WIOOWOYAKE 8.

1 Hehan Solomon Israel hunkayapi kin wicoun itancanpi kin owasin Israel cinca ateyapi tokapapi kin mniciye wicaya, wicaśtayatapi Solomon ekta Jerusalem en, Jehowa otakuye canwohnaka kin Dawid totonwe kin Zion etanhan itanwankanhde aupi kta.

2 Unkan Israel wicaśta kin owasin wicaśtayatapi kin Solomon ekta mniciyapi, Etanim wi kin en, wi iśakowin kin hee. wohanpi wakan kagiapi qehan.

3 Qa Israel hunkayapi owasin hipi; unkan wawayuśnapi kin canwohnaka kin akiyuha ayapi.

4 Qa Jehowa tacanwohnaka kin, qa itkokipapi wakeya kin, qa wakśica wakan wakeya ohna yakonpi kin owasin ahipi, hena owasin wawayuśnapi kin, qa-Jewi kin akiyuhapi.

5 Qa wicaśtayatapi Solomon, qa Israel ormiciye iye en mniciyapi ocowasin canwohnaka kin itokam, tahinca qa tatanka, nina ota on owapi śni, qa yawapi śni wayuśnapi ecee.

6 Unkan wawayuśnapi kin Jehowa otakuye canwohnaka kin toyanke en ahipi, kertib hupahupi kin ihukuya, oyanke. wakan hinca owohdake tipi en.

7 Kerub nonpa hupahupi kin hdumdayapi canwohnaka oyanke kin iwankam, hecen kerub nonpa kin canwohnaka kin, qa tośu tawa kin iwankam akahpa.

8 Qa tośu kin yujunpi hecen tośu inkpapi kin tipi wakan owohdaka tipi itokam un kin etanhan taninyan yakonpi, qa itankan aisinyan unpi, qa anpetu kin dehanyan hen yakonpi.

9 Canwohnaka kin ohna takudan yankę śni, inyan mdaska 494 nomnana, otakuye Jehowa Israel cinca wicakicağa, Egupta etanhan hdinanpapi qehan, $\dot{H}$ oreb ekta hena Mowis hen ohnaka.

10 Unkan wawayuśnapi kin tipi wakan etanhan hdinanpapi qehan, mahpiya śoka wan Jehowa ti lin ojuya.

11 Hecen wawayuśnapi kin mahpiya śoka on wokiyapi kta e hen yakonpi kta okitpanipi, Jehowa towitan kin Jehowa ti kin ojuya nakaś.

12 Hehan Solomon heya, Jehowa otpaza śoka en ounye kta keya.

13 Awicakehan tipi en ounyaye kta wan cicicaga, oyanke suta wan ohna yahidotanke kta, owihanke wanin.

14 Hehan wicaśtayatapi kin ite kin ihduhomni, qa Israel omniciye owasin yawaśte ; unkan lsrael omniciye ocowasin bosdan najinpi.

15 Unkan heya, Jehowa Israel Wakandapi kin yawaśtepi nunwe, Iye ate Dawid i kin on ie ca nape kin on yuecetu, qa heya,

16 Oyate mitawa Israel Egupta etanhan hdinanpe wicawaye cin anpetu kin he ehantanhan, Israel wicoun owasin etanhan otonwe wanji ohna tipi micicagapi kta e wakahinige śni, he ohna micaje yanke kta, tuka oyate mitawa iwankam un kta Dawid wakahinig̉a.

17 Unkan Jehowa Israel wakandapi kin tipi kicagge $k$ ta e ate Dawid cante kin en un.

18 Unkan Jehowa ate Dawid heciya, Micaje on tipi wan yakage kta nicante en un kin he tanyan ecanon, nicante en un kin he.

19 Tuka niye tipi kin yakagie kte śni, tuka nicinkśi ninite etan- 
han inanpe kte cin he micaje on tipi kin kagge kta.

20 Unkan Jehowa iye oie eye ciqon ecetu kiya, hecen Dawid ate eekiya nawajin, qa Israel oiyotanke kin akan imdotanka, Jehowa eye ciqon iyecen, qa Jehowa Israel wakandapi caje kin on tipi kin wakaġà.

21 Qa hunkake wicunyanpi Egupta etanhan hdinanpe wicaye cehan otakuye wicakicaga canwohnaka en yanke cin on oyanke wan wecağa.

22 Unkan Solomon wahna wośnapi Jehowa tawa iwiyohiyanpa tanhan, Israel omniciye owasin itokam najin, qa mahpiya ektakiya nape kin hdugiata ;

$23 \mathrm{Qa}$ heya, Jehowa Israel Wakandapi kin wankan malipiya ekta, qa kuya maka kin akan taku wakan iyececa wanica; nitaokiye cantepi ocowasin on nitokam manipi kin om wotakuye kin, qa wowacantkiye kin wicayecipatan.

24. Niye taku nitaokiye Dawid ate eyakiye cin he yapatan, nii kin on eha, qa ninape on yahduecetu nakaha iyececa.

25 Heon dehan Jehowa Israel Wakandapi kin nitaokiye Dawid ate taku eyakiye cin he kici patan ye; Mitokam mayani kin iyecen nicinca kin mitokam manipi, qa olianyanpi kin awanhdakapi kinhan, Israel oiyotanke kin akan iyotanke kte śni wicaśta tohinni nicicaśpe kte śni, eha.

26 Heon nakaha Israel Wakandapi kin ceciciya, nioie nitaokiye Dawid ate eyakiye cin he hduwicaka wo.

27 Hececa eśta Jehowa awicakehan maka akan ounye kta he? Inyun mahpiya kin, qa mahipiya mahpiya kin nicipi okihipi śni; iyotan tipi wakagge cin de okihi śni.

28 Hececa eśta wocekiye nitaokiye eniciye cin ekta ihduhomni, qa taku nicida kin, Jehowa Wakan cida, nitaokiye hoyeye cin, qa wocekiye nakaha nitokam cekiye cin he nalion ye.

29 Hecen niiśta kin tipi kin de ektakiya anpetu hanyetu koya yuzamni hanpi kta, Oyanke micaje ohna yanke kta, ehe ciqon he ekta, hecen wocekiye nitaokiye oyanke kin de ektakiya ceniciye cin nayalion kta.

30 Qa nitaokiye, qa Israel oyate nitawa wocekiye oyanke kin den ceniciyapi ca nayahon $\mathrm{kta}$, niye mahpiya en yakidotanke cin anagoptan ye, qa nayalion eca wahtanipi kin wicakicicajuju ye.

31 Wicaśta wan takodaku wakilitani kinhan, qa taku wakan cajeyan wohdag śipi, qa wahna wośnapi nitawa tipi kin de ohna yanke cin he itokam taku wakan cajeyate cinhan;

32 Niye małpiya ekta nahon ye, qa ecen econ, qa nitaokiye wicayaco, qa tuwe śice tolian śica iyecen qu, qa śitkihda ye, qa tuwe owotanna yaowotanna, qa tohan owotanna kin iyecen qu ye.

33 Oyate nitawa Israel wanicihtanipi kin on toka wicayapi kin itokam wicakaśtakapi kinhan, niye en ihdamnapi, qa nicaje oyakapi, qa tipi kin de ohna cekiyapi, qa niciyugatapi kinhan, 34 Niye malipiya en nalion ye, qa oyate nitawa Israel wahtanipi kin wicakicicajuju ye, qa makoce hunkake wicayapi wicayaqu qon ake en hdicu wicaya ye.

35 Tohan wanicihitanipi kin on mahipiya kin natakapi, qa magaju wanica, hecen kakiś wicayaya, 495 


\section{WICAŚSTAYATAPI,}

qa walitanipi etanhan ihduhomnipi, qa nicaje oyakapi, qa oyanke kin de ektakiya celiyapi kinhan,

36 Niye mahpiya en naton ye, qa nitaokiye, qa nitaoyate Israel wahtanipi kin wicakicicajuju ye, canku waśte nitawa onspe wicayakiye cin he omanipi hehan, qa makoce nitawa oyate nitawa tawayapi kta e wicayaqu qon akan mağaju qu ye.

37 'Tohan makoce en wicaakihan, makośica, qaiś watośnija, aa, psipsicadan, wamduśkadan yuke cinhan; toka wicayapi kin makoce tonwanyanpi kin en onawicatakapi kinhan; wokaśtake, - woyazan taku kaśta yuke cin:

38 Wicaśta tuwe kaśta on, qaiś oyate nitawa Israel owasin, tuwe iye cante kaśtakapi kin sdonye cin on nape kin tipi kin de ek takiya kiyugate, wokiyugate qa wocekiye kin,

39 Niye malipiya ekta oyanke ohna yakidotanke cin ohna nahon ye, qa wahtari kin kicicajuju ye, qa iyecen econ, qa otoiyohi ohanyan owasin iyecen qu ye, cante kin sdonyaye cin iyecen, niye niśnana Adam cinca owasin cantepi kin sdonyaya nakaś.

40 Hecen anpetu tona makoce hunkake wicayapi yaqu qon akan nipi kin owasin konicipapi kta.

41 Nakun tuwe oyate tokeca, oyate nitawa Israel etanhan śni, tuka makoce tehan tanhan nicaje on hiyu kta,

42 Nicaje tanka, qa ninape waśaka, qa isto yahdugata on nahonpi kta, qa wanji hi, qa tipi kin de ekta cekiye cinhan,

43 Niye malipiya oyanke ohna idotanke cin en nahon ye, qa econ ye, wicaśta oyate tokeca hoyeniciye cin owasin iyecen, hecen oyate maka ohnaka owasin nicaje kin sdonyapi kta, qa oyate nitawa Israel iyecen konicipapi kta, qa tipi kin de wakage cin nicaje on cajeyatapi kin sdonyapi kta.

44 Tohan oyate nitawa canku ohna ye wicayaśi, tokayapi azuwicayapi, wokicize ekta yapi kinkan, qa otonwe yakahinige cin, qa tipi nicaje on wakage cin ektakiya Jehowa cekiyapi kinhan:

45 Kiyugatapi qa cekiyapi kin mahpiya ekta nahon ye, qa woyaco ecawicakicon ye.

46 Tohan wanicihtanipi, (ecin wicaśta wahtani śni wanica nakaś,) qa canniye wicayaya, qa toka yapi itokam nape wicayaya, hecen wayaka i wicacupi, qa tokayapi tamakocepi tehan qaiś ikiyedan ekta wayaka awicayapi kinhan;

47 Cantepi en hdipi, makoce ekta wayaka awicayapi ohna, qa ihdamnapi, qa wayaka awicayapi tamakocepi kin ohna ceniciyapi, qa, Waunhtanipi, ecinśniyan unkohanyanpi, śicaya econkupi ce, eyapi kinhan;

48 Qa toka wicayapi kin, wayaka awicayapi kin tamakocepi kin ohna cantepi ocowasin on, qa nagipi ocowasin on niye en hdipi kinhan, qa ceniciyapi, tamakocepi hunkake wicayapi kin wicayaqu kin, otonwe yakahnige cin, qa tipi nicaje on wakagie cin ektakiya kinhan;

49 Mahipiya oyanke ohna idotanke cin en niciyugiatapi, qa ceniciyapi kin nalion ye qa woyaco ecawicakicon ye ;

50 Qa oyate nitawa wanicilitanipi kin, qa wokipajin nicipajinpi kin owasin wicakicicajuju ye, qa tona wayaka awicayapi kin onśiwicadakapi kta kağa, hecen cante wicakiyapi kta:

51 Tawa wicayaya, qa oyate nitawa Egupta makoce, maza

496 


\section{WICOWOYAKE 9.}

oceti cokaya tanhan hdinanpe wicayaye cin hena eepi nakaś :

52 Heon nitaokiye niciyug gate cin ekta, qa oyate nitawa Israel niciyugutapi kin ekta niiśta hduzamni ye, qa taku hoyeniciyapi kin owasin nawication ye.

53 Nive Itancan Jehowa maka oyate kin owasin etanhan tawa wicayaye kta e dena wicadukinukan, nitaokiye Mowis nape on, ehe ciqon iyecen, hunkake wicunyanpi Fgupta etanhan hdinanpe wicayaye cehan.

54. Unkan Solomon wokiyugate, qa wocekiye kin de owasin cekiya yaśtan qehan, Jehowa wahna wośnapi tawa itokam carıpeślka makehde wanke ciqon etanhan, siha akan najin, qa nape kin mahipiya ektakiya hdugata:

55 Qa najin, qa ho tankakiya Israel omniciye ocowasin yawaśte, qa heya,

56 Jehowa yawaśtepi nunwe. Iye taoyate kin Israel iyozi wicaya, eye ciqon iyecen, wicoie waśte taokiye Mowis nape on eye ciqon, wicoie wanjidan hinhpaye śni.

57 Jehowa Wakan undapi kin hunkake wicunyanpi om un qon, he iyecen unkicipi un nunwe, unkayuśtanpi kte śni, qa elipeunyanpi kte śni.

58 Uncantepi kin iye ekta yuptanyan ye, hecen tacanku owasin omaunnipi kta, nakun tawoahope, qa tokage, qa tawoyaco hunkake wicunyanpi econ wicaśi kin.

$59 \mathrm{Qa}$ mioie Jehowa itokam cewakiye cin dena, anpetu, qa hanyerú Jehowa ikiyedan un nunwe, hecen taokiye kin woyaco ecakicon kta, qa taoyate Israel woyaco ecawicakicon kte, anpetu iyohi wicoie kin iyececa.

60 Hecen maka oyate kin owa:B2 sin Jehowa taku wakan kin hee, qa tokeca wanica e sdonyapi kta. 61 Qa nicantepi Jehowa Wakan undapi ekta zanipi kta, qa tokage omaunnipi kta, qa tawoahope unpatanpi kta, nakaha iyececa.

62 Unkan wicaśtayatapi kin, qa Israel owasin opapi, Jehowa itokam wośnapi patapi.

63 Hecen wopida wośnapi, Solomon Jehowa wakiyuśna kin tatanka kektopawinge wikcemna nonpa sanpa kektopawinge nonpa, qa tahinca kektopa winge opawinge sanpa kektopawinge wikcemna nonpa. Hecen wicaśtayatapi kin, qa Israel cinca owasin Jehowa ti kin yuwakanpi.

64. Anpetu kin he en wicaśtayatapi kin Jehowa ti kin itokam hocoka kin cokaya kin yuwakan, hen wohuhnahyapi, qa minlia, qa wopida wośnapi śn kin huh̉naliya, mazaśa wahna wośnapi Jehowa itokam wanke cin he cistinna on wohuhnahyapi kin, qa minha, qa wopida wośnapi śin kin ki. pi śni nakaś.

$65 \mathrm{Qa}$ he ehan Solomon, qa Israel owasin nakun wohanpi wakan kaggapi, omniciye tanka Hamat ekta yapi kin etanhan Egupta kaksiza ekta hehanyan Jehowa itokam anpetu śakowin, qa anpetu śakowin, anpetu wikcemna sanpa topa.

66 Anpetu iśahdoğan kin en oyate kin kihde wicaya. Unkan wicaśtayatapi kin yawaśtepi, qa wiyuśkinyan tawakeyapi ekta kihdapi, taku waśte Jehowa iye taokiye Dawid, qa taoyate Israel ecawicakicon owasin on cante waśtepi.

\section{WICOWOYAKE 9.}

1 Ullkan Solomon Jehowa ti kin, qa wicaśtayatapi ti kin. kağa, qa toiyokipi taku Solomon 497 


\section{WICAŚTAYA'TAPI,}

econ kta cin kin owasin yuśtan qehan :

2. Jehowa inonpa taniniciye Solomon en, Gibeyon en taniniçiye ciqon he iyecen.

$3 \mathrm{Qa}$ Jehowa heciya, Wokiyugate mitokam yakidugate cin, qa wocekiye nitawa nawahon, tipi kin de micaje owihanke wanin en yanke kta, yakagge cin he mdawakan, qa misšta kin, qa micante anpetu owasin hen un kta.

4 Qa niyate mitokam mani kin iyecen niye cante ocowasin, qa woecetu en mayani, qa taku econ ciśi kin owasin iyecen ecanon, wokage qa woyaco mitawa ya- patan kinhan;

5 Nitokiconze oiyotanke kin Israel iwankam owihanke wanin mdusutakta; niyate Dawid̀ ewa. kiye cin iyecen, Israel oiyotanke akapa tanhan wicaśta tohini niciyuśpapi kte śni, epa.

6 Tuka niyepi qa nicincapi mihakapa tanhan ocowasin nihdamnapi kinhan, qa mitawoahope, qa mitokage, niyepi itokam cicupi kin oyapapi śni kinhan, qa idadapi qa taku wakan tokeca ohoyadapi, qa itokam pamahdedan dukanpi kinhan;

7 Israel makoce wicawaqu kin ite etanhan wicawakimduśpe kata; qa tipi micaje on mdawakan kin miite kin etanhan ehpewaye kta, qa oyate owasin ehna Israel wiyacinpi, qa oweśtepi heca kta.

8 Qa tipi kin de pajodan śta, tona ikiyedan iyayapi owasin yuśinyeyapi kta, qa jojopi kta, qa, Tokeca Jehowa makoce kin de, qa tipi kin de hecen ecakicon, eyapi kta.

9 Qa heyapi kta, Jehowa Wakan dapi qon, qa hunkake. wicayapi Egupta etanhan hdinanpe wicaye cin he ayuśtanpi, qa ta498 lu wakan tokeca yuzapi, qa itokam patujapi, qa ohowicadapi, heon Jehowa taku śice cin de owasin iyahde wicaya.

10 Unkan waniyetu wikcemna nonpa icunhan Solomon Jehowa ti kin, qa wicaśtayatapi tipi tawa napin kage cin hera owihanketa,

11 Hiram 'T'zur wicaśtayatapi kin lianteśa can, qa wazi can, qa mazaskazi, taku cin kin owasin kicicahi kin, heon hehan wicaśtayatapi kin Solomon Galile makoce kin ohna otonwe wikcemna nom Hiiram qu.

12 Unkan Hiram otonwe Solomon qu kin wanyake kta inanpa, tuka iśta kin en ecetupi śni.

13 Qa, Mihunkawanji otonwe kin della mayaqu kin taku hwo, qa Kabul (opapun) makoce eya caje wicayata, anpetu kin dehanyan.

14 Tuka Hiram mazaskazi woqin opawinge sanpa wikcemna nonpa wicaśtayatapi kin ekta yekiya.

15 Unkan wicaśtayatapi Solomon wowidake mnayan on econ kin dee, Jehowa ti kin kage kta, qa iye ti kin, qa Millo, qa Jerusalem aconkaśkeye $\mathrm{kta}$, nakun Hatzor, qa Megiddo, qa Gezer on.

16 Paro Egupta wicaśtayatapi kin itanwankanhde hiyu, qa Gezer icu, qa peta on liuhnahya, qa Kanani otonwe ounyanpi kin wicakte, qa iye cunwintku Solomon tawicu kin aihpeye.

17 Unkan Solomon Gezer, qa Bet Horon hukuya kin kagia.

18 Nakun Bayalat, qa Tadmor tinta makoce kin ohna.

19 Qa wopiye otonwe Solomon yule cin owasin, qa canpahmihma otonwe, qa śuktanka akan- 


\section{WICOWOYAKE 10.}

yotankapi ntonwe kin, qa Solomon toiyokipi taku Jerusalem. ohna, qa Lebanon ohna, makoce idake cin owanyaca ohna, taḱn kag̉e kta iyokipi on.

20 Oyate owasin tona Amori etanhan Hiti, Perizzi, Hiwi, qa Jebusi etanhan okaptapi, Israel cinca kin etanhanpi śni,

21 Hena cincapi wicihakam makoce en okaptapi kin, Israel cinca ocowasin ihang wicayapi śni kin hena, Solomon anpetu kin dehanyan wayaka wohtani econ wicakiya;

22 Tuka Israel cinca kin etanhan Solomon wayaka wicayuhe śni; tuka hena ozuye wicaśta, qa taokiye wicaya, qa taakicita; qa tacanpahmihma akicita kin, qa canpahmihma qa śuktanka akanyotankapi itancanpi kin.

23 Solomon wolitani econ wicakiya itancanpi kin dena eepi, opawinge zaptan sanpa wikcemna zaptan, hena oyate wohtani econpi kin awanwicayakapi,

24 Unkan Paro cunwintku Dawid totonwe etanhan iyaya, iye ti kin ekta, Sulomon kicagge cin he ; hehan Millo kagga.

25 Unkan Solomon wahna wośnapi iye Jehowa kicağe cin akan, mdoketu iyohi yamni akihde, wohuhnahyapi, qa wopida wośnapi hulinahya; qa nakun Jehowa itokam wanke cin he izinya; hecen tipi kin yuśtan.

$26 \mathrm{Qa}$ wicaśtayatapi Solomon Yetzion Geber, Elot ikiyedan, Mdeśa huta akan, Edom makoce ohna wita wata kagia.

27 Unkan Hiram iye taokiye, wita wata wicaśta miniwanca sdonyapi kin Solomon taokiye om wita wata kin ohna ye wicaśi.

28 Unkan Opir ekta ipi, qa hetanhan mazaskazi woqin opawin- ge topa sanpa wikcemna nonpa icupi, qa wicaśtayatapi Solomon ekta kahipi.

\section{WICOWOYAKE 10.}

1 Unkan Śeba wicaśtayatapiwin kin Solomon woyakapi kin Jehowa caje kin on, nahon qehan qa wowiyukcan on iyute kta en hiyu.

2 Qa wicota hinca om Jerusalem ekta hi, Kamel taku waśtemna, qa mazaskazi nina ota hin qinpi, nakun inyan tehika, qa Solomon ekta hi qehan taku cante en un kin owasin okiyaka.

3 Unkan Solomon taku iwange cin owasin tanyan ayupta, wicoie wicaśtayatapi olkahnigge śni wanica, owasin okiyaka.

4 Unkan Śeba wicaśtayatapiwin kin Solomon toksape kin, qa tipi kagie cin wanyake cehan, 5 Qa tawahna wotapi woyute kin, qa taokiye token iyotankapi, qa taakicita wowaśi kin, qa tawokoyakepi kin, qa tawoyatkekiya, qa wohulinahapi Jehowa ti kin en huhnahye cin, hena owasin wanyake celian woniya sanpa en un śni.

6 Qa wicaśtayatapi heciya, Makoce mitarva ohna nioie on, qa nitoksape on wicoie nawation kin wicake ye.

7 Tuka en wahi, qa miiśta on wanmdake śni, hehanyan wicoie kin cețonwahda ; tuka iny un hanke kin omakiyakapi śni, nitoksape, qa nitowijice wotanin nawahon kin isanpa ye.

8 Wicaśta nitawa tanyan unpi ye, qa nitaokiye nitokam najinpi, qa ohinniyan nitoksape nahonpi kin tanyan unpi ye.

9 Jehowa Wakan yada kin yawaśtepi ye, he waśte nidake ça Israel oiyotanke kin akan nihna499 


\section{WICAŚTAYATAPI,}

ke cin heon etanhan, Jehowa wanakaja tanhan Israel waśtedaka; heon woyaco qa woowotanna ecanon kta e wicaśtayatapi nicage ye, eya.

10 Qa mazaskazi woqin opawinge sanpa wikcemna nonpa qu, qa taku waśtemna nina ota hinca, nakun inyan tehika. Taku waśtemna ota hin Ś Seba wicaśtayatapiwin kin wicaśtayatapi Solomon qu kin iyecen icimana ahipi śni.

11 Nakun Hiram tawita wata Opir etanhian mazaskazi ahipi kin hena almug can ota, qa inyan tehika Opir etanhan ahipi.

12 Unkan·wicaśtayatapi kin Jehowa ti kin on, qa wicaśtayatapi ti kin on, ipatan kaga, nakun candowankiyapi, qa canpakinza wadowanpi kin. Almug can kin he iyecen icimana ahipi śni, qa wanyakapi śni, anpetu kin dehanyan.

$13 \mathrm{Qa}$ wicaśtayatapi Solomon Śeba wicaśtayatapiwin kin taku cin, qa da kin owasin qu, nakun taku Solomon wicaśtayatapi towaśake kin iyecen ikce qu. UTnkan. iye, qa taokiye ihdamnapi, qa tamakoce kin ekta kihdapi.

14 Unkan mazaskazi waniyetu wanjidan icunhan Solomon en ahipi kin tkeutapi kin woqin opawinğe śakpe sanpa wikcemna śakpe sanpa śakpe.

15 Wopeton tanka, qa wopeton cistinna taku kahipi, qa Arab wicaśtayatapi kin owasin, qa makoce itancan kin owasin, taku kahipi kin akton.

16 Unkan wicaśtayatapi Solomon mazaskazi kamdayapi wahacanka tanka opawinġe nonpa kaga, wahacanka iyohi mazaskazi śeqel ópawing̀e śakpe.

17 Nakun mazaskazi kamdayapi wahacanka opawinge yamni, 500 mazaskazi tkeutapi yamni wahacanka wanji iyohi, qa wicaśtayatapi kin Lebanon contanka tipi kin en hena kihnaka.

18 Qa wicaśtayatapi kin oi yotanke tanka wan putehanska hi on kaga, qa mazaskazi ecedan on apawinta.

19 Oiyotanke kin iyadipi śakpe, qa oiyotanke pa kin ihektam mima qa tukten iyotankapi anokatanhan nape, qa nape kin icahda mnaja nom najinpi.

20 Qa iyadipi kin akan mnaja wikcemna sanpa nonpa najinpi, wokiconze owasin ehna taku hececa kagapi śni.

21 Qa wicaśtayatapi Solomon wakśica iyatke tawa kin owasin mazaskazi, qa Lebanon contanka tipi wakśica kin owasin mazaskazi ecedan; mazaska wanica: Solomon taanpetu kin en mazaska ecaca ihaktapi śni.

22 Wicaśtayatapi kin miniwanca ohna Tarśiś wita wata yuha, Hiram wita wata tawa om, waniyetu yamni ca 'Tarśiś wita wata kin wanca hdipi ; qa mazaskazi, qa mazaska, qa putehanska hi, qa kepi, (waonca,) qa zicatanka upi waśte kahdipi.

¿3 Hecen wicaśtayatapi Solomon tanka wowijice on, qa woksape on, maka wicaśtayatapi kin owasin kawicape.

24 Unkan maka kin owancaya; Solomon ite kin akitapi, cante kin en woksape Wakantanka qu kin he nahonpi kta.

$25 \mathrm{Qa}$ otoiyohi taku qupi kin ahipi, mazaska wakśica, qa mazaskazi wakśica, qa wokoyake, qa wipe, qa taku waśtemna, qa śuktanka, qa śonśonna, waniyetu otoiyohi.

26 Unkan Solomon eanpahmihma, qa śuktanka mnayan, qa canpahmihma kektopawinge san- 


\section{WICOWOYAKE 11.}

pa opawinge topa yuha; qa śuktanka akanyotankapi kektopawinge wikcemna sanpa nonpa, qa hena canpalimihma otonwe ohna yanke wicakiya, qa Jerusalem ohna wicaśtayatapi kin kici.

27 Qa wicaśtayatapi kin Jerusalem ohna mazaska inyan iyececa kağa, qa hanteśa can nina ota kage cin on sukamin can Sepele ohna icagapi iyecen kagia.

$28 \mathrm{Qa}$ Solomon śuktanka tawa Egupta etanhan, qa Qowa etanhan hiyuyapi, wicaśtayatapi wopeton tawa, Qowa etanhan iyuwin on hena opetonpi.

29 Qa canpahmihma wanji mazaska opawinge śapke on opetonpi, qa Egupta etanhan hiyuyapi, qa śuk tanka wanji opawinge wanji sanpa wikcemna zaptan on; nakun hena napepi on Hiti wicastayatapi owasin on, qa Aram wicaśtayatapi on hecen wicakahipi.

\section{WICOWOYAKE 11.}

1 Tuka wicaśtayatapi kin Solomon Paro cunwintku isakim winohinca oyate tokeca ota waśte wicadaka; Moabi, Amoni, Edomi, Tzidoni, qa Hiti winohinca.

2 Ikcewicaśta etanhan hena on Jehowa Israel cinca kin hewicakiya, Taku wakandapi oyapapi kta e awicakehan nicantepi yatitanpi kta, heon hena en yaipi kte śni, qa hena niyepi en hipi kte śni; Solomon hena waśte wicadake kta en ikoyag iciya.

3 Qa winohinca itancan hecapi opawinge śakowin yuha, qa winobinca tokeca opawinge yamni, qa cante kin tawicu kin yuptanyanpi.

4 Hecen Solomon wicahinca qehan tawicu kin taku wakan tokeca ope kta cante kin yuptan- yanpi, hecen cante kin, Jehowa iye wakanda atkuku cante kin iyecen, zaniyan ope śni.

5 Qa Solomon Aśtoret Tzidoni wakandapi kin opa iyaya, qa Amoni wowalite śni kin Milkom opa.

6 Hecen Solomon taku Jehowa iśta kin en śica econ, qa atkuku Dawid iyecen cante kin ocowasin Jehowa ope śni.

7 Hehan Solomon he Jerusalem iwihinanpe cin ekta wanke cin akan paha wanji Kemoś, Moab wowahte śni kin kicaga, qa Molek Amon cinca wowahite śni kin on.

$8 \mathrm{Qa}$ tawicu oyate tokeca winyanpi kin owasin on hecen econ, hena taku wakandapi kin izinkiyapi, qa wakiyuśnapi ece.

9 Unkan Jehowa Solomon canniyeya; nonpa akihde en ihdutanin eśta Jehowa Israel Wakandapi kin ope cin etanhan cante kin.ihduptanyan nakaś.

10 Taku wakan tokeca ope kte śni oie kin de on wahokonkiya, tuka Jehowa taku econ śi kin ahope śni.

11 Unkan Jehowa Solomon heciya, Taku kin de nici un, qa wotakuye mitawa, qa wokage mitawa ope ciśi kin hena ahoyape śni, heon awicakehan wokiconze kin niye etanhan mduhdece kta, qa nitaokiye wan waqu kta.

12 Tuka anpetu nitawa en ecamon kte śni, niyate Dawid he on etanhan, tuka nicinkśi nape kin etanhan mduhdece kta.

13 Tuka wokiconze ocowasin waki kte śni, mitaokiye Dawid on, qa Jerusalem wakahnige cin on, wicoun wanjidan nicinkśi waqu kta.

14 Unkan Jehowa toka wan Solomon anajin kiya, Hadad 501 


\section{WICAŚSAYATAPI,}

Edomi kin, Edom wicaśtayatapi cinca kin etanhan.

15 Dawid Ldom makoce en un qehan, qa Joab ozuye mdetanhunka kin tona ktepi kin wicahnake kta itanwankahde i, qa Edom ohna tona wica kin owasin wicakte qehan;

$16 \mathrm{Wi}$ śakpe Joab hen yanka, qa Israel owasin om, Edom olna wica kin owasin wicakte kin hehanyan.

17 He icunhan Hadad najica, qa Edomi wicaśta wanjikśi atkuku taokiye wicaya opapi, qa Hadad nahanhin hokśidan cistinna Egंupta ekta iyaya.

18 Qa najinpi, qa Midian etanhan, Paran ekta ipi, qa hetanhan Paran wicaśta om iyayapi, qa Egupta ekta ipi ; Egupta wicaśtayatapi kin Paro ekta. Unkan tipi qu, qa woyute qupi kta keya, qa magia qu.

19 Unkan Hadad Paro nina iyokipi. Unkan tawicu tankaku qu, Talipenes wicaśtayatapiwin tankaku.

20 Unkan Tahpenes tankaku cinhintku Genubat kiciton, Tahpenes he azin ayaśtan kiya, Paro ti kin ohna; unkan Genubat Paro cinca kin wicehna Paro ti kin ohna yanka.

21 Unkan Dawid hunkake wicaya om iśtima, qa Joab ozuye mdetanhunka te cin Hadad nalion qehan, Kihde maśi, hecen makoce mitawa ekta wahde kta ce, Hadad Paro eciya.

22 Unkan Paro heciya, Tuka taku inicakija he? on inyun niye makoce nitawa ekta yahde kta yacin. Unkan takudan śni, tuka, Hecaśta kihde mayan wo, eya.

23 Nakun toka ye kta Wakantanka Rezon Eliada cinhintku anajin kiya. Iye itancan tawa
Hadadezer Tzoba wicaśtayatapi kin etanhan najica.

24 Dawid wicakte qehan, iye wicaśta mnawicaya, iye ekta, qa ozuye nidetanhunka ic̣icaga, qa Damaskos ekta i, qa hen iyotankapi, qa iye Damaskos ohna wicaśtayatapi un.

25 Qa Solomon taanpetu owasin Israel toka ya, qa Israel waliteda śni, qa Aram idaka; Hadad taku śica econ iyahna.

26 Nakun Jeroboyam Nebat cinhintku, Eprati, 'Tzereda etanhan, qa hunku wiwazica Tzeruya eciyapi, Solomon taokiye; tuka wicaśtayatapi en nape apaha.

27 Qa wicoie on wicaśtayatapi en nape apaha kin dee, Solomon atkuku Dawid totonwe aconkaśkeye kta e Millo kage cehan, 28 Jeroboyam wicașta kin waśaka, wicaśta waditaka, qa Solomon kośka kin wolitani econ kin wanyaka, heon Josep tiyohnaka woqinpi kin owasin awanyag kiya.

29 Unkan hehan Jeroboyam Jerusalem etanhan inanpa ca Ahija Śloni kin waayate kin he akipa, canku kin ohna, qa śina teca wan hdowin, qa hena osnana sakim tinta olina yakonpi.

30 Unkan Ahija śina teca hdowin kin hduza, qa hduhdelideca, onśpa wikcemna sanpa nonpa.

31 Qa Jeroboyam heciya, Niye on onśpa wikcemna icu wo; Jehowa Israel Wakandapi kin hecen eya, Inyun miye wokiconze kin Solomon nape kin etanhan mduhdece kta, qa wicoun wikcemna cicu kta.

32 'Tuka mitaokiye Dawid on, qa. Jerusalem otonwe Israel wicoun owasin etanhan wakahnige cill on, iye wicoun wanji yuhe kta.

33 Miye amayuśtanpi, qa Aśto- 
ret Tzidoni wakandapi kin, $\mathrm{Ke}$ moś Moab wakanda kin, qa Milkom Amon cinca wakandapi kin, hena ohodapi, qa taku miiśta kin en ecetu kin, qa wokage mitawa, qa woyaco mitawa econpi śni, atkuku Dawid econ qon iyecen heon etanhan.

34 Tuka mitaokiye Dawid wakahnige cin on, qa iye woahope mitawa, qa wokage mitawa ope cin heon wokiconze ocowasin iye nape kin etanhan iwacu kte śni, qa tohanyan ni kin anpetu owasin itancan wakag.a.

35 Tuka cinhintku nape etan. han wokiconze kin iwacu kta, qa wicoun wikcemna cicu kta.

36 Qa wicoun wanji iye cinhintku waqu kta, hecen mitaokiye Dawid anpetu owasin mitokam petijanjan yuhe kta, Jerusalem otonwe micaje hen yanke kte wakahinige cin he ohna.

37 Qa niye wawiyadake kta e cicahniga, ninaggi cin kin owasin iyecen, qa wicaśtayatapi henica kta, Israel iwankam.

38 Qa taku econ ciśi kin owasin nayahon kinhan, qa mitacanku kin omayani, qa taku miiśta en ecetu ecanon, qá wokage mitawa, qa woahope mitawa oyape cinhan, mitaokiye Dawid econ qon he iyecen, miye cici waun kta, qa tipi suta wan cicicage kta, Dawid werage cin iyecen, qa Israel cicu kta.

$39 \mathrm{Qa}$ taku lin de on Dawid cinca kin kakiś waye kta, tuka anpetu owasin kte śni.

40 Unkan Solomon Jeroboyam teye kta akita; unkan najica Egupta ekta, Śiśaq Egupta wicaśtayatapi kin ekta, qa Solomon te śni kin helanyan Eigupta ohna yanka.

41 Unkan Solomon oie tolkeca kin, qa taku econ kin owasin, qa toksape kin hena owasin Solomon wicoie wowapi en owapi śni he?

- 42 Unkan Solomon Jerusalem ohna Israel owasin iwankam wicaśtayatapi un kin waniyetu wikcemna topa anpetu kin hehanyan.

43 Hehan Solomon hunkake wicaye cin om iśtima; qa atkuku Dawid totonwe kin ohna hnakapi ; unkan iye heekiya cinhintku Rehoboyam wicaśtayatapi un.

\section{WICOWOYAKE 12.}

1 Unkan Rehoboyam Śekem ckta i, Israel owasin wicaśtayatapi kagapi kta e Śsekem en mniciyapi nakaś.

2 Unkan Jeroboyam Nebat cinhintku ralion, iye nahanhin $\mathbb{E} \dot{g} u-$ pta ohna un, heciya wicaśtayatapi Solomon itokapa tanhan najica qon heon Jeroboyam Eigupta en yanka.

3 Unkan wahoyapi qa kicopi. Unkan Jeroboyam, qa Israel omniciye ocowasin hiyupi, qa iapi, qa Rehoboyam heciyapi;

4 Niyate wicin tehika unkicagapi, heon niye wanna wohtani tehilka, qa woqin tke niyate qin unkiyapi kin unkiciyukapojepidan po; kinhan wowidag unyayapi kta.

5 Unkan hewicakiya, Kihda po, anpetu yamni hehanyan, qa ake en mau po. Unkan oyate kin kihdapi.

6 Unkan wicaśtayatapi kin Rehoboyam wicahinea iye atkuku ni qehan itokam najinpi qon hena om iyukcan, qa heya, Oyate kin de wicoie wicunqupi kta token idukcanpi he?

7 Unkan iapi qa heciyapi, Nakaha oyate kin de taokiye nicicaga, qa owicayakiye ça awica503 


\section{WICAŚTAYATAPI,}

dupte ca wicoie skuya ewicayakiye cinhan, anpetu owasin ookiye wicaduhe kta.

8 Tuka wicahinca wowiyukcan iyukcanpi kin he ayuśtan, qa kośka iye kici icağapi, qa itokam najinpi iyukcan wicaśi.

9 Qa hewicakiya; Oyate kin de hemakiyapi, Canwanapin niyate napinunkiyapi kin yukapojedan unkiya po, eyapi, token awicunyuptapi kta unkiciyukcan po.

10 Unkan kośka iye kici icagapi iapi, qa heciyapi; Oyate kin de iapi qa, Niyate canwanapin tke unkicicagapi kin he yukapojedan unkiya po, eniciyapi kin hecen ewicayakiye kta; Miśaśte ate nite kin isanpa śoke kta.

$11 \mathrm{Qa}$ ate canwanapin tke wanna yuhe niciyapi kin miye canwanapin isanpa tke cicicagapi kta. Ate cansakadan on nicapsintapi, qa miye tehmiso okaśkeśke on cicapsintapi kta.

12 Unkan anpetu iyamni en Jeroboyam, qa oyate owasin Rehoboyam en hipi, wicaśtayatapi kin ie ciqon iyecen. Anpetu iyamni ake en mau po, eye cin.

13 Unkan wicaśtayatapi kin tehiya oyate kin awicayupta, wicahinca wowiyukcan iyukcanpi kin ayuśtan.

14. Qa kośka iyukcanpi lin iyecen ie ca hervicakiya; Ate nitawaqinpi yutke, qa miye nitawaqinpi sanpa tke wakage kta : ate cansakadan on nicapsintapi, qa miye tehmiso okaśkeśke on cicapsintapi kta.

15 Hecen wicaśtayatapi kin oyate kin nawication śni; woyuhomni kin de Jehowa etanhan, oie kin Jehowa Ahija Śiloni kin nape on Jeroboyam Nebat cinhintku eciye ciqon hduecetu kta heon.
16 Unkan wicaśtayatapi kin nawicahon śni, Israel owasin wanyakapi; heon oyate kin wicaśtayatapi ahoyeyapi, qa heyapi, Dawid en wopamni unhapi kin tuktee he? qa Jesse cinhintku en takudan tawaunyanpi śni, Israel nitawakeyapi ekta hda po. Dawid yati kin awanyaka wo. Unkan Israel tawakeyapi ekta hdapi.

17 Unkan Israel cinca tona Juda tonwanyanpi kin en tipi kin hena Rehoboyam iwicadaka.

18 Unkan wicaśtayatapi kin Relioboyam Adoram womnaye itancan kin ye śi ; unkan Israel inyan on kinimpi, hecen ta, heon wicaśtayatapi kin Rehoboyam Jerusalem ekła najice kta inaliniyan tacanpahmihma akan iyotanka.

19 Unkan Israel Dawid tiyohnaka kin kipajinpi, anpetu kin dehanyan.

20 Qa Israel owasin Jeroboyam hdi nahonpi qehan, wahoyapi, qa omniciye ekta kicopi; qa Israel owasin iwankam wicastayatapi kağapi; tuwedan Dawid ti kin opapi śni, Juda wicoun kin heceedan.

21 Unkan Rehoboyam Jerusalem en hdi, ya Juda tiyohnaka kin ocowasin, qa Benjamin wicoun kin, wicaśta kahnig̉api kektopawinge opawinge sanpa kektopawinge wikcemna śahdoġan mniciye wicaya, ozuye kagge kta, wokiconze kin Relioboyam Solomon cinhintku en hdikiye kta on, Israel azuwicaye kta.

22 Unkan Wakantanka oie kin Śemaja wicaśta wakan kin en hi qa heciya,

23 Rehoboyam Solomon cinhintku Juda wicaśtayatapi kin, nakun Benjamin, qa Juda tiyohnaka owasin, qa ayate okaptapi 
kin wahokon wicakiye ca heya wo,

24. Jehowa hecen eya, Nihunkawanjipi Israel cinca kin ekta dapi kte śni; qa wicayakizapi kte śni. Otoiyohikihda po. Wicoie kin de miye etanhan. Unkan Jehowa oie kin nahonpi, qa yapi kin etanhan kihdapi, Jehowa ie cin iyecen.

25 Unkan Jeroboyam Śekem kagga, Epraim he kin ohna, qa he ohna iyotanka, qa hetanhan iyaye ca Penuel kağa.

26 Unkan Jeroboyam cante mahen heya, Nakaha wokiconze kin Dawid tiyohnaka en hde kta.

27 Oyate kin de wośnapi kagapi kta Jehowa ti kin ekta, Jerusalem en yapi kinhan, oyate kin de cantepi kin itancan tawapi kin Rehoboyam Juda wicaśtayatapi kin ekta hde kta; hecen maktepi kta, qa Rehoboyam Juda wicaśtayatapi kin en hdapi kta.

28 Heon wicaśtayatapi kin wiyukcan, qa mazaskazi ptejicadan nom kaga, qa hewicakiya, Jerusalem ekta dapi kin he tehan. Tho Israel taku wakan yadapi Egupta makoce etanhan hdinanpe niy anpi dena ee.

29 Unkan wanji Betel en ehde, qa unman Dan en ehde.

30 Unkan wicoie kin de wahtani wicaya, qa oyate kin wanji ohodapi kta e Dan hehanyan ipi.

31 Unkan paha akan tipi kagga, qa oyate ikceka etanhan wawayuśna kağa, Lewi cinca etanhanpi śni.

32 Qa Jeroboyam wi iśahdagian wi anpetu iake zaptan kin en omniciye wak an kaga ece ; omniciye wakan Juda ohna he iyececa, qa wahna wośnapi akan wayuśna, Betel ohna hecen econ, qa ptejicadan kagge ciqon wawicakiyuśna, nakun paha kag̉e cin on warvayuśna kin Betel ohna yanke wicaśi.

33 Qa wahna wośnapi Betel ohna kag̉e ciqon akan wayuśna, wi iśahdogian anpetu wikcemna sanpa zaptan kin en, wi iye cinka kalinige cin en, hecen omniciye wakan Israel cinca kin wicakicagga, qa wahna wośnapi kin akan wizice izinya.

\section{WICOW OYAKE· 13.}

1 Unkan inyun wicaśta wakan wan Jehowa oie on Juda etanhan Betel ekta hi ; unkan Jeroboyam wizinye kta wahna wośnapi icahda najin.

2 Unkan wahna wośnapi kin Jehowa oie kin on hoyekiye ça heya, Wahna wośnapi, wahna wośnapi, Jehowa hecen eya, Cinca wan Dawid tiyohnaka kicitonpi kta, Josija eciyapi kta, qa iye qe niye akan paha wawayuśnapi wizinyapi kin wayuśna kta, qa wicaśta huhn kin niye akan huhnağapi kta.

3 Unkan anpetu kin he en wowapetokeca wan qu, qa heya, Wowapetokeca Jehowa cajeyate cin dee, inyun wahna wośnapi kin namdece kta qa cahota akan wanke cin kadadapi kta.

4 Unkan wicaśtayatapi kin wicaśta wakan oie kin wahna wośnapi Betel ohna yanke cin hoyekiye cin he nahon qehan, Jeroboyam nape hdugate, wahna wośnapi kin etanhan, qa heya, Iyahpaya po. Unkan nape kin ekta hdugate cin śnija, hecen ehdaku kta okitpani.

5 Unkan wahna wośnapi kin namdeca, qa cahota wahna wośnapi kin etanhan kadapi, wowapetokeca wicaśta wakan Jehowa oie on qu qon he iyecen.

6 Unkan wicaśtayatapi kin ayu505 


\section{WICAŚTAYATAPI,}

pta, qa wicaśta wakan kin heciya, Tokin Jehowa wakan yada ite lin ohoda, qa miye on wocekiye eya wo, minape kin miye en hdi kten. Unkan wicaśta wakan kin Jehowa ite kin cekiya. Unkan wicaśtayatapi nape kin ekicetu otokahe elata iyececa.

7 Unkan wicaśtayatapi kin wicaśta wakan kin heciya, Wati kin ekta unhde kta, hecen wayate kta, qa iyuwin ciẹu kta.

8 Unkan wicaśta wakan kin wicaśtayatapi kin heciya, Yati hanke mayaqu eśta, nici mde kte śni, qa oyanke kin den aǵuyapi wate kte śni, qa mini mdatke kte śni.

9 Jehowa oie kin on wahokonmakiye ça heya, Agruyapi yate kte śni, qa mini datke kte śni, qa canku ohna idade cin he ohna yaku kté śni.

10 Hecen canku tokeca wan ohna iyaya, qa canku ohna Betel ekta hiyu kin ohna kihde śni.

11 Unkan waayate tokeca wicahinca wan Betel ohna ti. Unkan iye cinca kin en hipi, qa woecon anpetu lin he en wicaśta wakan Betel ohna econ kin owasin, qa wicoie wicaśtayatapi kin eciye cin atkukupi kin okiyakapi.

12 Unkan ateyapi kin hewicakiya; Canku tukte ohna iyaya he? Unkan cinhintku wicaśta wakan Juda etanhan u qon canku ohna iyaye cin kipazopi.

13 Unkan cinca kin hewicakiya ; Śnśonna aqin micicaton po. Unkan śonśonna kin aqin kicitompi. Unkan akan iyotanka.

14. Unkan wicaśta wakan kin ihakam iyaye ca utuhu wan ihukuya iyotankahan iyeye ca heciya, Wicaśta wakan Juda etanhan $\mathrm{u}$ kin he niye he? Unkan, He miye, eya.
15 Unkan heciya, Mici lida, qa aguyapi yuta wo.

16 Inkan heya, Icicawin mde ça yati kin en wai kta owakihi śni, qa oyanke kin de en nici agguyapi wate kte śni, qa mini mdatke kte śni.

1\% Jehowa oie en hemakiya, Heciya agjuyapi yate kte śni, qa mini datke kte śni, qa canku ohna idade cin he ohna yaku kte śni.

18 Unkan heciya, Miś eya waayate hemaca, niye iyemaceca, qa wahośiye wan Jehowa oie en mici wohdaka, qa heya, Hdicuya wo, yati kin ekta, hecen aguyapi yute kta, qa mini yatke kta, itonśni eciya.

19 Unkan icicawin kici i, qa ti kin ohna aguyapi yuta, qa mini yatkan.

20 Unkan wahna wotapi ekta iyotankapi icunhan, Jehowa oie kin waayate hdicukiye cin ekta hi.

21 Qa wicaśta wakan Juda etanhan u qon hoyekiye ca heya, Jehowa hecen eya, Jehowa i kin yakipajin, qa Jehowa Wakantanka tawoahope ope niśi kin oyape śni ;

$22 \mathrm{Qa}$ icicawin yau, qa ag்yapi yata, qa mini datkan, oyanke ohna, Ihnuhan hen ag̉uyapi yate ca ihnuhan mini datke cin, eniciye ciqon, heon nitancan nihunkaképi ohna hnakapi kin ohna hnakapi kte śni.

23 Unkan aguyapi yute cin qa wayatke cin ohakam, śonśonna aqin kiciton waayate icicawin u kiye cin on.

24. Unkan iyaya, tuka mnaja wan canku kin ohna akipe ca te kiya, qa tancan canku ohna ihpaya, qa śonśonna ikiyedan najin, qa mnaja kin tancan țe cin icahda najin. 


\section{WICOWOYAKE 14.}

25 Unkan inyun wicaśta hiyayapi, qa tancan te cin canku ohna ihpaya wanyakapi, nakun mnaja kin tancan kin icahda najin, qa en hipi, qa otonwe waayate wicahinca kin ohna ti kin hen oyakapi.

26 Unkan waayate kin canku etanhan hdicu ye ciqon he nahon, qa heya; Wicaśta wakan Jehowa $\mathrm{i}$ kin kipajin kin he e, heon Jehowa he mnaja qu ; unkan yahideca, qa kte, Jehowa oie eciye cin iyecen.

27 Qa ie ca iye cinhintku hewicakiya, Śonśonna aqin miciton po. Unkan aqin kicitonpi.

28 Unkan iyaye ca tancan kin canku ohna ihpaye cin iyeya, nakun śonśonna kin, qa mnaja kin tancan kin ikiyedan najinpi, mnaja kin tancan kin yute śni, qa śonśonna kin yahdece śni.

29 Qa waayate kin wicaśta wakan tancan kin yuwankan icu, qa śonśonna akan ehnaka, qa yuha kihda, qa wayate wicahinca kin aceye kta, qa he kta e otonwe en hdi.

$30 \mathrm{Qa}$ iye ohnahnakapi tawa en tancan kin kihnaka, qa, Hehehe, misunka! eya aceya.

31 Qa he hnakapi ohakam iye cinca kin hewicakiya, Tohan mațe qa mayahnakapi kinhan, ohna hnakapi kin wicaśta wakan ohna hnakapi kin he ohna, huhu tawa icahda, luhu mitawa hnalia po.

32 Wiroie Jehowa oie en wahna wośnapi Betel en yanke cin hoyekiye cin, qa paha tipi Samaria tonwanyanpi ohna yakonpi kin hoyewicakiye cin awicakehan ecetu kta.

33 Tuka hena ohakam Jeroboyam tacanku śica etanhan ihdamna śni ; tuka oyate ikceka etanhan paha tipi kin wawayuśna ka- ga, tuwe cin kinhan nape ojuya, hecen paha wawayuśna heca.

34 Qa wicoie kin de on Jeroboyam tiyohnaka tawa wahtani kiya, qa hecen kaśpe-kiya, qa ihangkiyd maka ite kin etanhan.

\section{WICOWOYAKE 14.}

1 Hehan Abija Jeroboyam cinhintku wayazanka.

2 Unkan Jeroboyam iye tawicu kin heciya; Nakaha najin, qa togye ihduza, hecen Jeroboyam tawicu kin he niye sdonniyanpi kte śni, qa Śilo ekta de kta, ito Ahija waayate kin hen yanka. Iye oyate kin de iwicawadalke kta kemakiya.

3 Qa ninape ohna ağuyapi wikcemna iyacu kta, nakun aguyapi hmihmiyanna, qa maka cega canhanpi tiktica ojudan, qa ekta yai kta, kośka ni kte cinhan iye oniciyake kta.

4 Unkan Jeroboyam tawicu kin ecen econ, najin qa Silo ekta i, qa Ahija ti en i. Unkan Ahija wawanyaka okihi śni, nina wicahinca on iśta kin śkan śni nakaś.

5 Unkan Jehowa A hija heciya; Ito Jeroboyam tawicu cinhintku on wicoie iniwange kta $u$, he wayazanka nakaś: decen qa decen eyakiye kta; he qe en hi kinhan togye ihduze kta.

6 Unkan tiyopa en hi siha kin bubu kin Ahija nahon qehan heya, Jeroboyam tawicu tin u wo. Tokeca togye nihduza he? Miye wicoie tehika nicahi maśi.

7 Ekta hda Jeroboyam heciya wo, Jehowa Israel Wakan dapi kin hecen eya, Oyate wicehna tanhan yuwankan icicu, qa oyate mitawa Israel mdetanhunka cicağa.

8 Qa Dawid tiyohnaka etanhan wokiconze kin mduhdeca, qa ci507 


\section{WICAŚTAYATAPI,}

cu; tuka mitaokiye Dawid mitawoahope yuha, qa cante kin ocowasin omapa, qa taku miiśta kin en ecetu heceedan econ kin iyenicece śni.

9 Tuka tona nitokam unpi owasin isanpa śicaya ecanon, qa idada, qa taku wakan tokeca nicicaga, qa śihdamayaye kta, waliagapi śdoyapi nakun, qa nitapete ihektam elipemayaya.

10 Heon inyun miye Jeroboyam tiyohnaka kin ekta taku śica hiyuwaya, qa Jeroboyam wica tawa owasin onatakapi, qa okaptapi Israel ohna wakaśpe kta, qa Jeroboyam tiyohnaka kin okapte cin wakahinte kta, unkce kahintapi kin iyecen, ecen sote kta.

11 Jeroboyam tawa tuwe otonwe ohna te cin śunka yutapi kta, qa tuwe tinta ohna te cin mahpiya okinyanpi kin yutapi kta, Jehowa eya ce.

12 Heon niye najin ekta hda, nisiha otonwe kin en kipi kinhan, hoksidan kin te kta.

13 Unkan Israel owasin aceyapi kta, qa hnakapi kta, Jeroboyam tawa de iśnana ohna linakapi en ye kta, Jeroboyam tiyohnaka ohna deceedan Jehowa Israel wakandapi kin taku waśte en iyeya.

14 Nakun Jehowa Israel iwankam wicaśtayatapi wan iye on kagge kta; iye qe Jeroboyam tiyohnaka kin kaśpe kta, anpetu kin he en: qa taku epa he? dehantu.

$15 \mathrm{Qa}$ Jehowa Israel kaśtake kta cedi hu wan mini ohna huhuzahe kin iyecen, qa Israel yujun kta, makoce waśte kin de hunkakewicayapi wicawaqu kin etanhan, qa wakpa kin akasanpa enanakiya iyaye wicaye kta, Jehowa śihdayapi Aśeri kagapi on nakaś.

16 Qa Jeroboyam woahtani kin 508 iye wahtani, qa Israel wahtani wicaye cin on Israel unkce wicakage kta.

17 Unkan Jeroboyam tawicu kin najin, qá kihda, qa 'Tirtza elita ki, qa tipi tiyopa oahde ekta ki qehan hokśidan kin te.

18 Unkan hnakapi, qa Israel owasin aceyapi, Jehowa oie iye taokiye Ahija waayate kin nape on eye cin iyecen.

19 Unkan Jeroboyam ohan unman kin, token zuya, qa token widake kin, ito hena Israel wicaśtaya tapi taanpetu oyakapi wowapi en owapi ce.

20 Qa Jeroboyam waniyetu wikcemna nonpa sanpa nonpa anpetu kin hehanyan iwicadaka, qa hunkake wicaya om iśtima. Unkan heekiya cinhintku Nadab itancanyapi.

21 Unkan Rehoboyam Solomon cinhintku Juda iwicadaka; Rehoboyam waniyetu wikcemna topa sanpa wanjidan qehan, tokaheya itancanyapi, qa waniyetu wikcemna sanpa śakowin Jerusalem en itancanyapi; otonwe kin he Israel wicoun owasin etanhan Jehowa kahniga, caje kin ohna yankekiye kta heon etanhan. Unkan hunku caje kin Nayama Anmoniwin.

22 Unkan Juda taku Jehowa iśta kin en śica econ, qa winawizi yapi, hunkake wicayapi econpi qon owasin isanpa, woalitani walitanipi on.

23 Qa nakun paha içicagiapi, qa wakaggapi, qa Aśeri paha pajodan owasin akan, qa can ape to yukan owasin ihukuya.

24 Qa nakun makoce kin ohna winyan icidapi yukan. Ikcewicaśta Jehowa İsrael cinca kin itokapa tanhan nape wicaya wowahtepi śni kin owasin iyecen econpi. 
25 Unkan Relioboyam itancanyapi waniyetu izaptan kin en, Siśaq Egupton wicaśtayatapi kin Jerusalem azuye hi.

$26 \mathrm{Qa}$ Jehowa tipi tawa mazaskazi kin icu, qa wicaśtayatapi tipi tawa mazaskazi kin icu ; nakun mazaskazi wahacanka Solomon kage cin owasin icu. .

27 Unkan Rehoboyam hena eekiya mazazi wahacanka kag̉a, qa akicita wicaśtayatapi tipi tiyopa awanyakapi itancanpi napepi en hena qu.

28 Unkan wicaśtayatapi kin Jehowa ti kin ekta i ca akicita hena yuhapi, qa ake akicita mazopiye tawapi en hena kihnakapi.

29 Unkan Rehoboyam ohan unman, qa taku econ kin owasin, Juda wicaśtayatapi anpetu oyakapi wowapi en owapi śni he?

30 Unkan Relioboyam, qa Jeroboyam ohinniyan kicizapi.

31 Unkan Rehoboyam hunkake wicaya om iśtima, qa Dawid totonwe ohna hnakapi, hunkake wicaya om, qa hunku Nayama Anmoniwin eciyapi. Qa cinhintku Abijam wawidaka iye eekiya.

\section{WICOWOYAKE* 15.}

1 Unkan Jeroboyam Nebat cinhintku wawidaka, waniyetu wi.kcemna sanpa iśahdogian en, Abijam Juda iwicadaka.

2 Iye waniyetu yamni Jerusalem ohna wawidaka, qa hunku caje kin Mayaka Abiśalom cunwintku.

3 Qa atkuku iye itokam woahtani econ qon hena owasin en omani, qa cante kin iye Wakanda Jehowa kici zaniyan un śni, atkuku Dawid cante kin iyecen.

4 Hececa śta Dawid on etanhan iye Wakanda Jehowa petijanjan wan qu, Jerusalem ohna, qa iye ohakam cinhintku yusuta, qa Jerusalem patan.

5 Dawid taku Jehowa iśta kin en ecetu econ, qa tohanyan ni lin taku econ śi kin wanjidan etanhan yuwinh ye śni, Urija H̊eti kin wicoie kin en heceedan.

6 Unkan Rehoboyam tohanyan ni kin Jeroboyam kici wokicize yukan.

7 Unkan Abijam ohan unman, qa taku econ kin owasin Juda wicaśtayatapi kin anpetu oyakapi wowapi kin en owapi śni he? Nakun Abijam Jeroboyam kici kiciza ecee.

8 Unkan Abijam hunkake wicaya om iśtima, qa Jerusalem en hnakapi, qa eckiya iye cinhintku Asa wawidaka.

9 Jeroboyam Israel iwicadaka waniyetu iwikcemna nonpa en Juda Asa itancanyapi.

$10 \mathrm{Qa}$ waniyetu wikcemna topa sanpa wanjidan Jerusalem ohna wawidaka, qa hunku caje kin Mayaka Abiśalom cunwintku.

11 Qa Asa taku Jehowa iśta en ecetu econ, atkuku Dawid iyecen.

12 Qa winyan içidapi kin makoce etanhan iyaye wicaya, qa wakagapi a te wicaya kagapi kin yutokan iyeya.

13 Qa hunku Mayaka winyan itancan kte śni yutokan iyeya, he qe Aśeri wakagapi wan kicaga, qa Asa wakagapi kin kawanka, qa Qedron kaksiza kin ohna hulinaliya:

14. Tuka paha kin yujujupi śni. Hececa śta Asa cante kin Jehowa kici zaniyan un anpetu tawa owasin.

15 Qa taku atkuku yuwakan, qa taku iye yuwakan kin hena Jehowa ti kin en hiyuya, mazaska, qa mazaskazi, qa wakśica. 16 Unkan Asa Bayaśa Israel 


\section{WICAŚTAYATAPI,}

wicaśtayatapi kici wokicize yukan, anpetu tawapi kin ece owa$\sin$.

17 Unkan Bayaśa Israel wicaśtayatapi kin Juda azuya, qa Rama (Conkaślse) kag̣a, hecen tuwedan Asa Juda wicaśtayatapi kin ekta ye kta, qa hdicu kta iyowinkiye kte śni.

18 Unkan Asa mazaska, qa mazaskazi Jehowa ti wopiye ohna, qa wicaśtayatapi ti kin wopiye ohna okaptapi kin owasin icu, qa taokiye napepi en qu: qa wicaśtayatapi kin Asa Benhadad Tabrinmon cinhintku Hezion cinhintku Aram wicaśtayatapi, Damaskos ohna ounye cin elita ye wicaśi, qa heya,

19 Wotakuye yukan miye qa niye kici, qa ate niyate kici; iho mazaska qa mazaskazi niye ekta yewaye cin he cicu. Ho wo wotakuye nitawa Bayaśa Israel wicaśtayatapi kici yujuju, hecen miye etanhan kihde kta.

20 Unkan Benhadad wicaśtayatapi kin Asa anagoptan, qa ozuye mdetanbunka wirayuhe cin Israel o tonwe azuye wicaśi. Unkan Yijon, qa Dan, qa Abel Betmayaka, qa Kinnerot otonwe kin owasin, Naptali makoce koya kaśtaka.

21 Unkan Bayaśa nahon qehan Rama kag̉e cin ayuśtan, qa Tirtza ohna iyotanka.

2:2 Unkan wicaśtayatapi kin Asa Juda owasin wahowicaya; iyuhpa ope wicaśi ; unkan inyan, qa can kin on Bayaśa Rama kage cin icupi, qa hena on wicaśtayatapi kin Asa Geba Benjamin ohna, qa Mitzpa kağa.

23 Qa Asa ohan unman owasin, qa towaśake owasin, qa taku econ kin owasin, qa otonwe kage cin hena Juda wicaśtayatapi anpetu oyakapi wowapi kin en 510 owapi śni he? Hececa śta wicahinca qehan siba yazan.

24 Qa Asa hunkake wicaya om iśtima, qa atkuku Dawid totonwe ohna hunkake wicaya om hnakapi. Unkan cinhintku Jehośapat eekiya itancanyanpi.

25 Unkan Asa Juda itancanyanpi 'kir waniyetu inonpa. en, Nadab Jeroboyam cinhintku Israel iwicadaka, qa waniyetu nonpa Israel idaka.

26 Unkan taku Jehowa iśta kin en śica econ, qa atkuku tacanku ohna mani, qa woahtani Israel wahtani wicaye cin ohna.

27 Unkan Bayaśa Aliija cinhintku Issakar ti kin etanhan he kipajin, qa Bayaśa Gibbeton Pilistim tawapi ekta he kaśtaka; Nadab, qa Israel owasin Gibbeton azuyapi qehan.

28 'Hecen Juda Asa itancanyanpi waniyetu iyamni en, Bayaśa tekiya, qa eekiya iwicadaka.

29 Qa wawidake cehan, Jeroboyam tiyohnaka owasin wicakaśtaka, Jeroboyam tawa ihangwicaya, ecen tuwedan niya okapte śni; Jehowa oie kin iye taokiye Ahija Śloni kin nape on eye ciqon iyecen.

30 Woahitani Jeroboyam wahtani kin on, qa Israel wahtani. wicaye cin wośihda Jehowa Israel Wakandapi śihda ye cin on.

31 Unkan Nadab ohan unman kin, qa taku econ kin owasin, Israel itancan yapi anpetu oyakapi wowapi en owapi śni he?

32 Unkan Asa qa Bayaśa Israel itancanyapi kin waniyetu tawapi owasin kicizapi ecee.

33 Asa Juda idake cin waniyetu iyamni etanhan, waniyetu wikcemna nonpa sanpa topa Tirtza ohna Bayaśa Aliija cinhintku Israel owasin iwicadaka. 


\section{WICOWOYAKE 16.}

34 Unkan taku śica Jehowa iśta kin en econ, qa Jeroboyam tacanku omani, qa woahtani Israel wahtani wicaye cin ohna.

\section{WICOWOYAKE 16.}

1 Unkan Jehowa oie kin Jehu Ḣanani cinhintku en hi, Bayaśa on, qa heciya,

2 Watuśekśeca etanhan yuwankan icicu, qa oyate mitawa Israel itancan cicaga, tuka Jeroboyam tacanku omayani, qa oyate mitawa Israel wahtanipi on śihdamayanpi kta wahitari wicayaya heon,

3 Inyun miye tona Bayaśa etanhan icag̉api, qa tiyohnaka tawa etanhan icagapi kin ihang wicawaye kta; qa tiyohnaka tawa Jeroboyam Nebat cinhintku tiyohnaka tawa iyecen wakage kta.

4. Bayaśa tawa tuwe otonwe ohna te cin śunka yutapi kta, qa tuwe tawa tinta ohna te cin mahipiya okinyanpi kin yutapi kta.

5 Unkan Bayaśa ohan unman, qa taku econ kin, qa towaśake kin hena Israel wicaśtayatapi anpetu oyakapi wowapi kin en owapi śni he?

6 Unkan Bayaśa hunkake wicaya om iśtima, qa Tirtza en hnakapi, qa eekiya cinhintku Ela wawidaka.

7 Unkan Jehu Ḣanani cinhintku waayate kin nape kin on, Jehowa oie kin Bayaśa ekta hi, qa tiyohnaka tawa ekta, Jehowa śihda yapi kta e taku śica Jehowa iśta kin en econ, iye nape wohtani kin on, Jeroboyam tiyohnaka iyececa, qa nakun he kte $\mathrm{kin}$ on.

8 Asa Juda idake cin waniyetu wikcemna nonpa sanpa iśakpe etanhan Ela Bayaśa cinhintku
Tirtza ohna Israel iwicadaka, waniyetu nonpa behanyan.

9 Unkan iye taokiye Zimri canpahmihma tawa hanke itancan kin he kipajin, Tirtza ohna Artza tipi awanyake cin tipi tawa ohna witkoicive wayatkan icunhan.

10 Qa Zimri ekta i, qa kaśtake ca kte, Asa Juda idake cin waniyetu wikcemna nonpa sanpa iśakowin en, qa heekiya he wawidaka.

11 Unkan wawidaka ca oiyotanke akan iyotanke cehan, Bayaśa tiyohnaka kin owasin wicakaśtaka, takuwicaya, qa koda wicaya owasin etanhan wica wanjidan okicapte śni.

12 Hecen Zimri Bayaśa tiyohnaka owasin ihang wicaya, Jehowa oie Jehu waayate kin nape kin on Bayaśa eciye ciqon iyecen. 13 Bayaśa wah̉tani kin owasin on, qa cinhintku Ela woahtani wahtani kin, qa Israel wahtani wicayapi on, qa taku śni wakandapi on Jehowa Israel wakandapi kin śihda yapi kin on.

14. Unkan Ela ohan unman, qa taku econ kin owasin, Israel wicaśtayatapi anpetu oyakapi wowapi kin en owapi śni he?

15 Asa Juda idake cin waniyetu wikcemna nonpa sanpa iśakowin en, Zimri anpetu śakowin Tirtza ohna wawidaka: Unkan oyate kin Gibbeton Pilistim tawapi kin azuye iwankapi.

16. Unkan Zimri wicaśtayatapi kipajin, qa kte eyapi kin oyate wankapi kin en nahonpi; heon Israel owasin anpetu kin he en owanka ohna Omri obe itancan kin Israel wicaśtayatapi kin kagapi.

17 Unkan Omri, qa Israel owasin opapi, Gibbeton etanhan itanwankanhde hdipi, qa Tirtza aonatakapi. 


\section{WICAŚSTYYATAPI,}

18 Unkan Zimri otonwe kin icupi wanyake cehan wicaśtayatapi conkaśke tipi kin en i, qa wicaśtayatapi tipi kin peta on hulinahya, iye akan, hecen ta.

19 Woalitani iye wahtani kin, qa taku śica Jehowa iśta en econ, qa Jeroboyam tacanku omani, qa woahtani Israel wahtani wicaye kta econ kin ohna heon.

20 Unkan Zimri ohan unman, qa wokipajin kipajin kin, hena Israel wicaśtayatapi anpetu oyakapi wowapi en owapi śni he?

21 Hehan Israel ihdukinukanpi obe nonpa, oyate hanke kin Tibni Ginat cinhintku opapi, he wicaśtayatapi kag̣api kta, qa hante Omri opapi.

22 Unkan oyate Omri opapi kin oyate Tibni Ginat cinhintku opapi kin ohiwicayapi, hecen Tibni ta qa Omri iwicadaka.

23 A.sa Juda idake cin waniyetu wikcemna yamni sanpa tokaheya etanhan, Omri Israel iwicadaka, waniyetu wikcemna sanpa nonpa ; 'T'irtza ohna waniyetu śakpe wawidaka.

24 Hehan Śemer etanhan Samaria lie kin opeton, mazaska woqin nonpa qu, qa he kin otonwe kağa, qa otonwe kagge cin Semer he yube ciqon caje kin on Samaria cajeyata.

25 Qa Omri taku Jehowa iśta kin en śica econ, qa tona iye itokam unpi kin owasin isanpa śicaya econ.

26 Qa Jeroboyam Nebat cinhintku tacanku owasin omani, qa woahtani Israel wahtani wicaye cin ohna, hecen taku śni on Jehowa Israel wakandapi kin śihdayapi ece.

27 Qa Omri olian econ unman, qa wicohan tanka econ kin hena Israel wicaśtayatapi anpetu oyakapi wowapi en owapi śni he?
28 Qu Omri hunkake wicaya om iśtima, qa Samaria ohna hnakapi, qa heekiya cinhintku Aliab wawidaka.

29 Unkan Asa Juda idake cin waniyetu wikcemna yamni sanpa iśahdogan etanhan Aliab Omri cinhintku Israel iwicadaka, qa Ahab Omri cinhintku Samaria ohna waniyetu wikcemna nonpa sanpa nonpa Israel iwicadaka.

30 Qa Ahab Omri cinhintku taku Jehowa iśta kin en śica econ, tona itokam unpi kin owasin isanpa.

31 Qa Jeroboyam Nebat cinhintku tacanku kin omani kin taku śni kecin, qa Jezebel Etbayal Tzidoni wicaśtayatapi kin cunwintku yuza, qa Bayal okiya, qa itokam patuja.

32 Qa Samaria ohna Bayal tipi kicagge cin ohna wahna wośnapi wan Bayal ekicihde.

33 Qa Ahab Aśera kag̉a, qa Israel wicaśtayatapi iye itokam yakonpi kin owasin Jehowa Israel wakandapi kin śihdaye kta-e isanpa Aliab econ ece.

34 Anpetu tawa en Hiel Beteli kin Jerilio conkaślke kaga, caske tawa Abiram en oahe kin ehde, qa cinhintku hakakta Segub en tiyopa oyugan kin ehde, Jehowa oie Jośuwa Nun cinhintku nape on eye ciqun he iyecen.

\section{WICOWOYAKE $1 \%$}

1 Unkan Elija Tiśbi kin Gileyad ounyanpi kin etanhan Aliab heciya, Jehowa Israel wakandapi kin itokam nawajin ni kin, waniyetu kin dena cu qa magaju unmanna yuke kte śni ; mil oie kin eciyatanhan eceedan.

2 Unkan Jehowa oie kin en hi, qa heciya,

3 Detanhan iyaye ça wihinanpe 


\section{WICOWOYAKE 17.}

cin ektakiya yuwinh iyaye ca Kerit kaksiza ohna inahma, lie Jordan iwiyohiyanpata wanka.

$4 \mathrm{Qa}$ wakpadan kin etanhan datke kta; unkan kangi kin heciya woyute nicahi wicawaśi.

5 Unkan iyaye ca Jehowa oie kin iyecen econ, hecen iyaye ca Kerit kaksiza ohna iyotanka, he Jordan iwiyohiyanpata yanka.

6 Unkan kanği kin ağuyapi qa tado hanhanna eca kahipi, qa ağuyapi qa tado htayetu eca kahipi ece, qa wakpadan etanhan wayatkan ece.

7 Unkan anpetu ota ihanketa wakpadan kin puza; makoce kin ohna mag̉aju śni nakaś.

8 Unkan Jehowa oie kin en hi qa heciya,

9 Najin, qa Trarepta Tzidon tawa kin ekta ya wo, qa heciya nanke kta; iho winohinca wan wiwazica heciya woyute nicu waśi.

10 Unkan najin, qa 'Tzarepta ekta iyaye ca otonwe tiyopa kin ekta i, qa inyun, winohinca wiwazica wan hen cande. Unkan kipan qa heciya, Tokin wakśica nitawa ohna mini onge hiyumayakiyen hecen mdatke kta ce.

11 Unkan huwe iyaye cehan, kipan, qa heciya, Ceciciya, aguyapi onśpa ninape ohna makau wo.

12 Unkan heya, Jehowa wakanyada ni kinhan, aǵuyapi hmiyanyanna eśta manice ye ; tuka aguyapi mdu koka ohna nape ohnaka wan, qa wihdi tonana maka cega ohna, qa ito can oksahe nonpa owade; heon śpan wakiye kta, miye on, qa micinkśi on, hecen untapi, qa ủţapi kte ye.

13 Unkan Elija heciya, Ihnuhan niyuśinyaya, ekta hda, qa token ehe cin iyecen econ wo. Tuka tokaheya hetanhan ag̉uyapi hmi渵: yanna cistinna micicağe ça hiyumakiya wo, qa olakam niye on, qa nicinkśi on yakage kta.

14 Jehowa Israel wakandapi kin hecen eya, Aguyapi mdu koka ohlla osote kte śni, qa wihdi maka cega ohna wanice kte śni, anpetu Jehowa maka ite kin akan magaju qu kte cin hehanyan.

15 Unkan winyan kin hde ca Elija oie kin iyecen econ, qa anpetu ota hduta, qa tiyohnaka tawa, qa Mlija nakun yuta.

16 Aguyapi mdu koka kin osote śni, qa maka cega wihdi kin wanica aye śni; Jehowa oie kin Elija nape on eye cin he iyecen.

17 Unkan taku kin dena iyohakam winohiruca tipi yuhe cin cinhintku wayazanka, towayazan nina tehika on ecaca niya śni.

18 Unkan winyan kin Elija heciya, Taku iyociwaja he? wicaśta wakan miohan śica kiksuye mayaye kta, qa micinkśi țe "ye kta on en mayahi lie?

19 Unkan nicinkśi maqu wo, eciye ça maku kin etanhan icu, qa wankan tipi, iye yanke cin ekta aye ça iye towinja akan ehnaka.

$20 \mathrm{Qa}$ Jehowa hoyekiye ça heya, Jehowa wakan cida wiwazica kici wati kin iyokiśin yaye ca cinhintku te yaya he?

21 Unkan yamni akihde hokśidan kin akan ihdugate ca Jeho. wa hoyekiye ca heya, Jehowa wakan cida, hokśidan kin de nagi kin tan mahen hdi kta ye.

22 Unkan Jehowa Elija ho kin nakon. Unkan hokśidan nagi kin tan mahen hdi; hecen ni.

23 Unkan Elija hokśidan kin icu, qa wankan tipi etanhan kuya tipi kin ekta aye ca hunku kin kicu, qa Elija heja, Wanyaka wo; nicinkśi ni ce. 


\section{WICAŚsTAYATAPI,}

24 Unkan winohinca kin Elija heciya, Wanna Wakan wicaśta henica, qa Jehowa oie kin nii kin ohna he wowicake ee ce sdonwaya.

\section{WICOWOYAKE 18.}

1 Unkan anpetu ota hehan Jehowa oie kin Elija en hi, waniyetu iyamni en, heciya, Ekta ya, qa Ahab en ihdutanin wo; unkan maka ite kin akan amagaju waye kta.

2 Unkan Elija Ahab en ihdutanin kta iyaya; unkan Samaria ohna nina wicaakihan.

3 Unkan Ahab Obedija (Jehowa taokiye) kipan, he qe tipi kin awanyake cin ee. Unkan Obedija Jehowa nina kokipa ece.

4 Jezebel Jehowa tawaayate kin ihang wicaye cehan, Obedija waayate opawinge iwicacu, qa inahma wicaya, wikcemna zaptan makohdoka wanji en, qa wikcemua zaptan makohdoka tokeca en, qa wowicaqu ece; aguyapi, qa mini.

5 Unkan Ahab Obedija heciya, Makoce kin ohna miniowe, qa wakpadan kin owasin ekta ya wo. Okini wato iyeunye kta, hecen śuktanka qa śonśonna ni wicunkiye kta, qa wanunyanpi iyuhpa ihang yapi kte śni.

6) Unkan makoce kin kicipamnipi, ohna iyayapi kta on, Ahab canku wanji ohna iyaya, qa Obedija canku tokeca ohna, kinukankiya iyayapi.

7 Unkan Obedija canku kin ohna inyun Elija akipa. Unkan iyekiye ca makipusdiya elipeiciye ca heya, Itancan mitawa Elija de niye he?

8 Unkan heciya, De miye. Ye ca itancan nitawa heciya wo, Elija deciya un ce.

\section{4}

9 Unkan heya, Wawahitani kin tuktee on Ahab te maye kta $e$ nape kin en nitaokiye ye yaye kta he?

10 Jehowa Wakan yada ni kinhan, oyate qa wokiconze owasin ekta itancan mitawa tuwe onide yeśi. Unkan, Den un śni eyapi qehan wokiconze, qa oyate kin iyeniyanpi śni, taku wakan cajeyan keye wicaśi.

11 Unkan wanna, Ekta ya, qa Elija den un ce, itancan nitawa eciya wo, niye eha.

12 Unkan nitan tanhan imdamde hakam Jeliowa toki sdonwaye śni aniye kta. Unkan Ahab owakimdake kta mda ; unkan iyeniye kte śni on makte kta: tuka nitaokiye homakśidan ehantanhan Jehowa kowakipa.

13 Jezebel Jehowa waayate tawa wicakte qehan, taku ecamon itancan mitawa onciyakapi śni he? Jehowa waayate tawa etanhan wicaśta opawinge inahma wicawaya; wikcemna zaptan makohdoka wanji ohna, qa wikcemna zaptan makohdoka tokeca ohna: qa wowicawaqu ece, aguyapi qa mini.

14 Unkan wanna hemayakiya, Ékta ya, qa Elija den un ce, itancan nitawa eciya wo. Unkan makte kta.

15 Unkan Elija heya, Jehowa obe yuhe cin itokam nawajin ni ce, anpetu kin de en mihdutanin kta.

16 Unkan Obedija Ahab akipa iyaya, qa okiyaka. Unkan Ahab Elija akipa iyaya.

17 Qa Ahab Elija wanyake ceehan Aliab he heciya, Israel iyokiśin ye cin he niye he?

18 Unkan heya; Hiya miye . Israel iyokiśin waye śni, tukঞ niye, qa niyate tiyohnaka tawa kin, Jehowa tawoahope aduśtan- 
pi, qa Bayalim owicayapapi kin on.

19 Unkan wanna tuwe ye si, qa miye ekta, Karmel he kin ekta, Israel owasin mniciye wicaya, nakun Bayal waayate tawa opawinge topa sanpa wikcemna zaptan, qa Aśeri waayate tawa opawinge topa, hena Jezebel tawahna wotapi ekta wotapi ece.

20 Unkan Aliab Israel owasin wahowicaya, qa wayate kin Karmel he kin ekta mniciye wicaya.

21 Unkan Eiija oyate owasin wicikiyedan i qa heya; Tohanyan wicotawacin nonpa otahedan kaktihanhan mayanipi kta, Jehowa Wakantanka kin hee hecinhan he opa po. Tuka Bayal hee kinhan he opa po. Unkar oyate kin wicoie wanjidan ayuptapi śni.

22 Unkan Elija oyate kin hewicakiya, Jehowa waayate tawa miśnana omakaptapi, tuka Bayal waayate tawa opawinge topa sanpa wikcemna zaptarı.

23 Hecen tatanka nonpa unqupi kta, hehan iyepi tatanka wanji kahnigapi kta, qa baśpaśpapi, qa can akan ehnakapi kta, tuka peta ekta hnakapi kte śni: qa miye tatanka unman wapate kta, qa can akan ewahnake kita, tuka peta ekta ye waye kte śni.

24 Unkan iyepi taku Wakandapi caje kin hoyekiyapi kta, qa miye Jehowa caje kin hoyewakiye kta. Unkan taku wakan unman tukte peta on ayupte cinhan, hee Wakantarka kta. Unkan oyate kin owasin ayuptapi, qa heyapi, Wicoie kin he waśte ce.

25 Unkan Elija Bayal waayate tawa hewicaliya, Niyepi on tatankadan wanji kahniga po: qa niyepi tokaheya pata po, niyepi niotapi nakaś; qa taku wakan yadapi kin hoyekiya po, tuka peta elsta yeyapi śni po.

26 Unkan tatankadan wicaqupi kin he icupi, qa patapi, qa Bayal caje kin hoyekiyapi hanhanna etanhan ecen wiyotanhan, qa heyapi, Bayal naunlion po. Truka wicaho wanica, qa tuwedan awicayupte śni, heon wahna wosnapi kagapi kin he akan ipsicapi. 27 Unkan wiyotanhe cin hehan Elija iwicahaha, qa heya, Hotankakiya kipan po, taku wakan kin hee nakaś, okini wohdaka yanka, qaiś oziic̣iya, qaiś icimạni ; okini iśtima hecinhan yahicapi kta.

28 Unkan panyanhan hoyeyapi, qa caicipapi isan on, qa wanhi on, iye wayacopi kin iyecen, ecen we awicaliaduza.

29 Qa wiyotanhan sanpa hehan. yan wayatapi, minha liuhnahyapi ecee kta, hehanyan, tuka wicaho wanica, qa waayupte wanica, qa ihawicakta wanica.

30 Hehan Elija oyate kin owasin hewicakiya, Mikiyedan u po. Unkan oyate kin owasin ikiyedan hipi, hehan Jehowa wahna wośnapi tawa pajujupi qon piya kagia.

31 Qa Elija inyan wikcemna sanpa nonpa icu, Jakob Jehowa oie kin en hi, qa, Nicaje kin Israel hee kta, eciye ciqon cinca wicoun yawapi iyenaka.

$32 \mathrm{Qa}$ inyan kin hena on wahna wośnapi Jehowa caje on kaga, qa wahna wośnapi kin ihdukśan osmaka wan kaga, he wojupi wiyutapi nonpa kipi ece hinskokeca.

33 Qa can kin akan ehnaka, qa tatankadan baśpaśpa, qa can akan ehnaka, qa, Wakiśkokpa topa mini ojuyapi, qa wohuhnahyapi kin, qa can kin akaśtan po, eya. 34 Qa, Ake econ po, eya. 


\section{WICAŚSTYYATAPI,}

kan inonpa econpi. Unkan, Iyamui, eya; unkan iyamni econpi.

35 Unkan nini kin wahna wośnapi ihdukśan kaduza, iyaya qa osmaka kin mini ojudan.

36 Unkan minha huhnahyapi ece iyehantu, Elija waayate kin ikiyedan i, qa heya, Jehowa Abraham, qa lzak, qa Israel Wakandapi kin nakaha. Israel ohna Wakannitanka, qa nitaokiye hemaca, qa nioie kin eciyatanlıan taku kin dena owasin ecamon hdutanin ye.

37 Amayupta ye, Jehowa amay upta ye, hecen oyate kin de Jehowa Wakantanka he niye, qa cantepi kin hekta ihdamna wicakiye kin he niye sdonyapi kta.

38 Hehan Jehowa tapeta kin hinhpaye ça wohulinaliyapi kin, qa can kin, qa inyan kin, qa maka mdu kin hulnahya, qa mini osmaka ohna wanke cin sdipa.

39 Unkan oyate kin owasin wanyakapi, qa makipusdiya ehpeiçiyapi, qa heyapi, Jehowa Wakantanka kin hee, Jeliowa Wakantanka kin hee ce.

40 Unkan Elija hewicakiya, Bayal waayate tawa iyawicahpaya po; hena etanhan wanjidan najice kte śni. Unkan wicayuzapi, hehan Elija Qiśon wakpa ekta apamalıde iyaye wicaya, qa heciya wicakte.

41 Hehan Elija Ahab heciya, Itanwankanhde ya, wota, qa wayatkan wo, nina magaju kta hoton nakaś.

42 Unkan wote kta, qa wayatke kta Aliab itanwankanhde iyaya ; tuka Elija Karmel paha kin ekta itanwankanlıde i, qa maka ektakiya patuja, qa hupahu otahedan ite kin hduza.

43 Hehan tahokśidan heciya, Ito itanwankanhde ya, ga miniwanca ekta etonwan wo. Un- kan itanwankanhde i, qa etonwan qa, Tokeca śni ce, eya. Unkan śakowin akihde econ wo, eya.

44 Unkan iśakowin kin hehan heya, Inyun mahpiya śapa cistinna wan, wicanape hinskokeca miniwanca etanhan inanpa ce. Unkan ekta ya, qa Aliab heciya wo, Aqin kiton, qa kun ya wo; hecen magaju kin kagi niye kte śni.

45 Unkan ekta i, qa hdi kin icunhan, mahipiya kin ihduśapa, mahpiya śapa, qa tate, qa nina magaju. Unkan Aliab tacanpahmihma ohna Jezreyel ekta hda. 46 Unkan Jehowa nape kin Elija en hi, unkan nite ipiyag kiton, qa Alab itokam inyanka, Jezreyel ekta ki kin hehanyan.

\section{WICOWOYAKE 19.}

1 Unkan taku Elija econ kin owasin, qa token waayate owasin isan on wicakte, Alab Jezebel okiyaka.

2 Unkan Jezebel wahośiye wan Elija ekta yeśi, qa heciya, Heyakecinhan wi dehantu iyehan, hena wanji nagi kin iyecen ninagi wakage śni kinhan taku wakan kin hena hecen ecamiconpi kte, qa naku isanpa.

3 Unkan kokipe ca najin, qa nagi kin on iyaye ca Berśeba Juda tawa kin ekta $\dot{i}$, qa heciya tahokśidan kin elipekiya.

4 Tuka iye hewoskan iyaya, anpetu wanji oicimani, qa hanteśadan wanji ekta i, qa ihukuya iyotanka, qa nagi kin on te kta icekiya, qa heya; Wanna henakeca, Jehowa minagi icu wo, mihunkake isanpa mawaśte śni ce.

5 Hehan makan iwanke ca iśtima, hanteśadan wanji ihukuya, unkan inyun hen wahośiye wan 


\section{WICOWOYAKE 19.}

yuhica, qa heciya, Najin wota wo.

6 Unkan etonwan, qa inyun pa kin eciyatanhan ag̉uyapi wan pe. tag̉a akan śpanyanpi, qa mini wakiśkokpa ohna. Unkan wote ça wayatkan, qa ake makan iwanka.

7 Unkan wahosilye Jehowa ake inonpa en hi, qa yulice ca heyà, Najin wota wo: oicimani kin oyakihi isanpa nakaś.

8 Unkan najin, qa wota, qa wayatkan; qa woyute kin he waśagye cin on icimani, anpetu wikcemna topa, qa hanyetu wikcemna topa, he wakan kin, Horeb ekta.

9 Qa heciya makolidoka wan ekta i, qa hen yanka. Unkan Jehowa oie en hi, qa heciya, Elija taku den ecanon he?

10 Unkan, Jehowa taku Wakan obe yuhe cin on nina nawawizi, Israel cinca kin wotakuye nitawa elipeyapi, qa wahna wośnapi nitawa yujujupi, qa waayate nitawa isan on wicaktepi : qa miśnana omakaptapi, qa minagi icupi kta e akitapi.

11 Unkan heya, Inanpe ca he akan Jehowa itokam najin wo. Unkan Jehowa ahiyaya, qa tate tanka wohitika he kin kaptuja, qa imnija kamdeca, Jehowa itokam; tuka Jehowa tate kin ohna un śni. Unkan tate kin iyohakam maka cancan, tuka Jehowa maka cancan kin ohna un śni.

12 Unkan maka cancan iyohakam peta, tuka Jehowa peta ohna un śni, qa peta kin iyohakam ho jijiya iwaśtedan.

13 Unkan Elija nahion qehan ite kin śina ahdahpa, qa inanpe ca makohidoka tiyopa kin ekta najin. Unkan inyun wicaho wan en hi, qa heya, Elija taku den ecanon he?
14 Unkan heya, Jehowa taku Wakan obe yuhe cin on nina nawawizi, Israel cinca kin wotakuye nitawa ehpeyapi, qa wahna wośnapi nitawa yujujupi, qa waayate nitawa isan on wicaktepi ; hecen miśnana omakaptapi, qa minagi icupi kta akitapi.

15 Unkan Jehowa heciya, Icimani kihda, iyaya wo, tinta ohna Damaskos ekta, qa en yai kinhan, Hazael Aram wicaśtayatapi on sdaya wo.

16 Qa Jehu Nimśi cinhintku Israel on wicaśtayatapi, qa Eliśa Śapat cinhintku, Abel Mehola etanhan, niye eekiya waayate sdaya wo.

17 Unkan tuwe Hazael taisan etanhan niiciye cinhan Jehu teye kta, qa tuwe Jehu taisan etanhan najice cinhan Eliśa țeye kta.

18 Tuka Israel ohna wicaśta kektopawing๋e śakowin wapatan, hena owasin hupahu naśijapi śni, Bayal itokam, qa hena owasin iye i kin iputakapi śni.

19 Unkan hetanhan iyaya, qa Eliśa Sapat cinhintku iyeya. Unkan mağa hdumdu, tatanka akicaśka ake nonpa iye itokam manipi, qa iye iake nonpa kin ohakam. Unkan Elija ikiyedan ye ça taśina akan ehpekiya.

20 Unkan tatanka kin ahduśtan, qa Elija ihakam inyanke ca heya, Ate qa ina i iwicawaputake kta iyowin makiya ye, hehan ocipe kta. Unkan heciya, Ekta hda; taku ecacicon he?

21 Unkan ope cin etanhan kihda, qa tatanka tawanjidan ikikcu, qa pata, qa tatanka tawanapin on tado kin śpankiye ca oyate kin wicaqu, unkan yutapi. Hehan iye najin, qa Elija ihakam iyaye ca ókiya. 


\section{WICAŚTAYATAPI,}

WICOWOYAKE 20.

1 Hehan Ben Hadad (Hadad cinhintku) Aram wicaśtayatapi kin taozuye kin owasin mniciye wicaya, qa wicaśtayatapi wikcemna yamini sanpa nonpa iye opapi ; nakun śuktanka akanyotankapi, qa canpahmihma, qa Samaria ekta hi, qa onatake ca kiza.

2 Qa wahośiye Alab Israel wicaśtayatapi ekta ye wicaśi, otonwe kin ekta,

3 Qa heciya, Ben Hadad hecen eya, Mazaska duhe ein, qa mazaskazi duhe cin hena mitawa; nakun nitawin, qa nicinca waśte kin hena mitawa.

4 Unkan Israel wicaśtayatapi kin ayupte ca heya, Itancan mitawa wicaśtayatapi kin nioie kin iyecen, miye, qa taku mduhe cin hena iyuhpa nitawa ce.

5 Unkan wahośiye ake en hipi, qa heyapi, Benhadad ie ca hecen eya, Wahociye ciqon, Mazaska nitawa, qa mazaskazi nitawa, qa nitawin, qa nicinca mayaqu kta, epa.

6 Awicakehan heyakecinhan, wi dehantu mitaokiye niye ekta ye wicawaśi kta, qa yati kin yuzamnipi kta, nakun nitaokiye tipi tawapi, qa taku niiśta iyokipi iyuhpa iyahpayapi, qa icupi kta.

7 Unkan Israel wicaśtayatapi kin makoce hunkayapi owasin wicakico, qa hewicakiya; Iye taku sice cin he akita, wanna awacinpi qa wanyaka po. Mitawin, qa micinca, qa mazaska mitawa, qa mazaskazi mitawa makida qehan iye etanhan takudan tewahinda śni.

8 Unkan hunkayapi owasin, qa oyate owasin heciyapi, Ihnuhan he nayahon kin, qa tawațenyaye cin.
9 Unkan Benhadad tawahosiye kin hewicakiya, Itancan mitawa wicaśtayatapi kin heciya po, Nitaokiye taku tokaheya iwahoyaye cin owasin ecamon kta, tuka wicoie kin de ecamon owakihi śni. Unkan wahośiye qon kihdapi, qa hośi kahdipi.

10 Unkan Benhadad wahoyekiye ca heya, Samaria maka mdu oyate omapapi owasin napohnaka iyohiwicaye cinhan, taku wakan kin decen qa nakun isanpa ecamiconpi nunwe.

11 Unkan Israel wicaśtayatapi kin ayupte ca heya, Ihnuhan tuwe ipiyaka iyakaśke cin hduśdoke cin iyecen ihdatan kin, eciya po.

12. Unkan wicoie kin he nahon qehan wayatkan yanka, ohanzihdepi ohna, iye qa wicaśtayatapi kin owasin, qa taokiye hewicakiya, Anatan po. Unikan otonwe kin anatanpi.

13 Unkan inyun waayate wan Aliab Israel wicaśtayatapi ekta hi, qa heya, Jehowa hecen eya, Obe tanka kin de owasin wandaka he? Inyun miye nakaha owasin ninape en wicawaqu kta, hecen Jehowa he mive sdonyaye kta.

14 Unkan Aliab heya, Tuwe on? Unkan heya, Ośpaye itancanpi tahokśipidan kin on, Jehowa eya. Unkan tuwe wokicize mdetanhunke kta he? eya. Unkan, Niye, eya.

15 Unkan ośpaye itancanpi kin tahokśipidan kin wicayawapi, opawing go nonpa sanpa wikcemna yamni sanpa nompa henana, qa hena iyohakam oyate kin Israel cinca owasin wicayawapi, kektopawinge śakowin.

16 Unkan wiyotanhan hehan inanpapi. Unkan Benhadad witko ic̣iya wayatkan ohanzihdepi 
ohna, iye qa wicaśtayatapi wikcemna yamni sanpa nonpa, okiye hipi qon hena om.

17 Unkan ośpaye itancanpi tahokśipidan kin tokaheya inanpapi. Unkan Benhadad wahoyapi, qa okiyakapi, qa heyapi, Wicaśta Samaria etanhan inanpapi ce.

18 Unkan, Wokiyapi upi kinhan niyake iyawicahpaya po, qaiś kizapi kta upi kinhan niyake iyawicahpaya po, eya.

19 Unkan ośpaye itancanpi tahokśipidan kin hena otonwe kin etanhan inanpapi, qa obe kin owicapapi kin.

20 Unkan otoiyohi wicaśta itkokim u kin kaśtaka. Unkan Arami napapi; unkan Israel wicakuwa eyaya. Unkan Benhadad Aram wicaśtayatapi kin śuktanka wan akan najica, qa śuktanka akanyotankapi nakun.

21 Hecen Israel wicaśtayatapi kin inanpa, qa suktanka, qa canpahmihma kuśtaka, qa Aram wopate tanka on kaśtaka.

22 Unkan waayate kin Israel wicaśtayatapi ekta hi, qa heciya, $\mathrm{Hda}$, waśag içiya wo, qa taku ecanon kta awacin, qa iwanyaka wo. Omaka iyehantu kinhan Aram wicaśtayatapi kin ake ananitan kta nakaś.

23 Unkan Aram wicaśtayatapi taokiye kin heciyapi, Iyepi taku wakan dapi kin taku wakan he ounyanpi kin hecapi, heon ohiunyanpi; omdaye ohna wicunkizapi kinhan okini ohiwicunyanpi kta.

24 Heon wicoie kin de econ wo, wicaśtayatapi kin otoiyohi oyanke tawa etanhan yutokan wo, qa hena eekiya akicita tancan en ye wicaya wo.

25 Qa obe nicihinhpaye kin iyecen obe wan mnayan wo, qa śuktanka qon iyecen śuktanka, qa canpahmihma qon canpahmihma iyenaka; qa omdaye ohna wicunkizapi kinhan ohiwicunyanpi kta. Unkan hopi kin anawicağoptan, qa iyecen econ. 26 Unkan omaka ake iyehantu hehan, Benhadad Arami kin wicayawa, qa Apeq ekta i, Israel wicakize kta heon etanlian.

27 Unkan Israel cinca kin ihdawapi, qa waneya icupi, qa wicitkokim eyaya; qa Israel cinca wicitokam etipi, tatokadan cinca optaye cistinna nonpa iyececapi, tuka Arami kin makoce kin ojudanyapi.

28 Unkan Wakantanka tawicaśta qon en hi, qa Israel wicaśtayatapi kin heciye cehan heya, Jehowa hecen eya; Taku wakan lie yuhe cin Jehowa hee, tuka taku wakan osmaka yuhe śni, Arami eyapi kin heon obe tanka kin de ocowasin ninape en waqu; hecen Jehowa he miye sdonyayapi kta.

29 Unkarı dena icitkokim anpetu śakowin owanji yakonpi, tuka anpetu iśakowin en kiza, anatanpi, qa anpetu wanjidan en Israel cinca kin Arami wicaśta huiyun kektopawinge opawinge wicaktepi.

30 Unkan tona okaptapi Apeq otonwe kin ekta napapi, qa conkaśke kin wicaśta okaptapi kektopawinge wikcemna nonpa sanpa kektopawinge śakowin akan hinlipaya. Unkan Benhadad najica, otonwe ekta owanka tipi wan mahentu.

31 Unkan taokiye heciyapi, Iho Israel ti wicaśtayatapi kin wicaśtayatapi waonśida hecapi naunlionpi ce. Iho nite wakihdaka ikounhdakapi kta, qa pa akan hakahmupi, qa Israel wicaśtayatapi kin ekta unyanpi kta; okini naği niniciye kta. 


\section{WICAŚSTAYATAPI,}

32 Unkan nitepi akan wakihdaka kaśkapi, qa hakahmupi papi akan, qa Israel wicaśtayatapi kin ekta hipi, qa heyapi, Nitaokiye Benhadad heya, 'Tokin minagi ni kten. Unkan heya, Mihunkawanji hee, nahanhin ni he?

33 Unkan wicaśta kin waiyukcanpi, kohanna taku iye etanhan innupe ca inahniyan heyapi, Nihunkawanji Benhadad. Unkan heya; Hdapi, huweya'po. Unkan Berhadad ekta inanpa. Unkan canpahmihma tawa akan iyotang kiya.

34. Unkan heciya; Otonwe ate niyate etanhan icu kin hena cicu kta, qa Damaskos ohna oyanke niçicage kta, Eamaria ohna ate kağe cin iyecen. Unkan, Miye wotakuye en kihde ciye kta, eya, 'qa wotakuye kağe ça kihdeya.

35 Unkan wayate cinca etanhan wicaśta wan takodaku heciya, Jehowa oie kin en, Makaśtaka wo, ceciciya. Tuka kaśtake kta wicaśta kin wicada śni.

36 Unkan heciya, Jehowa ho kin nayahon śni kin, heon mitan tanhan de cinhan mnaja wan nikte kta. Unkan iye tan tanhan iyaye cehan mnaja wan akipa, qa kte.

37 Unkan wicaśta tokeca wan akipa, qa heciya, Makaśtaka wo, ceciciya. Unkan nina kaśtake ca kahideca.

38 Unkan waayate kin iyaye ça wicaśtayatapi kin itokam canku icahda najin, qa mnihuha iśta ihduskite on ihdutokeca.

39 Unkan wicaśtayatapi kin hiyaye cehan iye wicaśtayatapi kin hoyekiye ça heya, Nitaokiye wokicize cokaya i, unkan inyun wicaśta wan ihduhomni, qa wicaśta wan miye ekta hiyuye ca heya, Wicaśta kin de awanyalka wo. Iye najice cinhan ninaġi iye naği kin heekiye kta, qaiś mazaska woqin on yakajuju kta. 40 Unkan nitaokiye deciya qa kakiya, waecon icunhan, wicaśta qon en yanke śni. Unkan Israel wicaśtayatapi kin heciya, Woyaco nitawa niye odake cin iyececa.

41 Unkan inahiniyan minibuha kin iśta kin etanhan hduśdoka; unkan Israel wicaśtayatapi kin wicaśta qon waayatapi etanhan hee iyekiya.

42 Unkan heciya, Jehowa hecen eya, Wicaśta ihang waye kta wakonze cin ninape etanhan kihde yaye cin, heon ninaği kin iye naggi kin eekiye kta, qa oyate nitawa oyate tawa eekiye kta.

43 Unkan Israel wicaśtayatapi kin cante tke qa iyokiśica tiyata hda, qa Samaria ekta hdi.

\section{WICOWOYAKE 21.}

1 Unkan wicoie kin hena iyohakam Nabot Jezreyeli kin hastanhanka ojupi wan yuha. Jezreyel ohna, A hab Samaria wicaśtayatapi tipi tawa ikiyedan.

2 Unkan Ahab Nabot okiyaka, qa heya; Hastanhanka iyuwi ojupi nitawa maqu wo; unkan wato ojupi on mduhe kta, he wati kin ikiyedan nakaś, hecen hastanhanka iyuwi ojupi wan he isanpa waśte on ciçu kta, qaiś niiśta en waśte kinhan mazaska iyohiye cin ciçu kte.

3 Unkan Nabot Ahab heciya, Mihunkake maġa tawapi qon ciçu kta Jehowa iyomaki śni nunwe. 4 Unkan Ahab cante śica, qa śihda hdi, Mihunkake tamágapi kin ciç kte śni, wicoie Nabot Jezreyeli eye ciqon, heon etanhan; qa towinja akan iwanka, qa ite hdutokeca, qa ağuyapi yute śni. 


\section{WICOWOYAKE 21.}

5 Unkan Jezebel iye tawicu kin en hi, qa heciya, De taku he? nitaniya hdutokeca, qa ağuyapi yate śni ye.

6 Ujnkan heciya, Nabot Jezreyeli kin kici wowahdaka, qa hewakiya, Hastanhanka iyuwi ojupi nitawa mazaska on maqu wo; qaiś iyonicipi kinhan, heekiya hastanhanka iyuwi ojupi tokeca cicu kta. Unkan, Hastanhanka iyuwi ojupi mitawa ciçu kte śni, eya.

7 Unkan tawicu Jezebel heciya, Niye nakaha Israel iwankam wokiconze ecanon, najin ağuyapi yuta ye, qa cante waśte un ye. Miye Nabot Jezreyeli kin hastanhanka iyuwi ojupi tawa kin cicu kte ye.

8 Unkan Ahab cajeyan wowapi owa, qa tawipuspe on apuspa, qa otonwe tawa ohna hunkayapi ekta, qa wicaśta ihduhapi kin ekta Nabot ikiyedan yakonpi kin wowapi wicaqu.

$9 \mathrm{Qa}$ wowapi kage cin en hecen eya owa; Wote śni unpi kta ieyanpaha pe, qa Nabot oyate wiciwankam iyotang kiya pe.

10 Qa wicaśta nonpa wowahte śni cinca kin he itokam najin wicakiya pe, qa hena, Taku wakan, qa wicaśtayatapi niye daśica, eya yaotaninpi kta; hehan tankan aya pe, qa, țe kta kinin pe.

11 Unkan otonwe wicaśta hunkayapi kin, qa wicaśta ihduhapi iye kici otonwe ounyanpi kin, Jezebel wahowicaya iyecen, wowapi wicaqu en owapi kin iyecen econpi.

12 Wote śni unpi kte ieyanpahapi, qa Nabot oyate kin wiciwankam iyotang kiyapi.

13 Unkan wowahte śni cinca wicaśta nonpa en hipi, qa itokam iyotankapi, qa wowahte śni wicaśta kin Nabot ayaotaninpi, qa oyate itokam heyapi, Nabot taku wakan, qa wicaśtayatapi kin wicayaśica. Unkan otonwe itankan yeyapi, qa inyan on kininpi ; unkan ta.

14 Unkan Jezebel wahoyapi, qa Nabot wanna kininpi, unkan ța ce, eyapi.

15 Unkan Nabot kininpi unkan te, eyapi kin Jezebel nahon qehan, Jezebel Aliab heciya, Najin Nabot Jezreyeli kin hastanhanka iyuwi ojupi kin tawaya ye, Nabot ni śni, tuka wanna țe nakaś.

16 Unkan Nabot wanna ta A liab nahon qehan, Aliab Nabot Jezereyeli hastanhanka iyuiwi ojupi tawa kin ekta ye kta, qa tawaye kta e najin.

17 Unkan Jehowa oie kin Elija Tiśbi kin en hi qa, heya,

18 Najin, qa Aliab Israel wicaśtayatapi kin Samaria ohna ounye cin itkokim ya wo. Inyun Nabot hastanhanka iyuwi ojupi kin tawaye kta e ekta iyaya.

19 Heon ekta de kta, qa heyakiye kta, Jehowa hecen eya ; Yakte qa tawayaya he? Nakun iyae kta, qa heyakiye kta, Jehowa hecen eya, Tukten sunka Nabot we kin sdipapi oyanke kin he en niwe kin nakun śunka sdipapi kta.

20 Unkan Ahab Elija heciya, Toka, iyemayaya he? Unkan, Taku śica Jehowa iśta kin en ecanon kta e wiyopeniciye cin heon iyeciciya ce.

21 Inyun taku śica hiyu siciye. kta, qa enitanhan icağapi kin ihang wicawaye kta, qa Aliab tawa wica owasin, tona onatakapi, qa kiyuśkapi koya, Israel ohna wakaśpe kta.

$22 \mathrm{Qa}$ yati kin Jeroboyam $\mathrm{Ne}$ bat cinhintku ti kin iyecen wakag̉e kta, qa Bayaśa Ahija cin521 


\section{WICASTAYATAPI,}

hintku ti kin iyecen; wośihda on sihda mayaye cin on, qa Israel wahtani wicayaya on

23 Nakun Jezebel on Jehowa heya, Jezreyel conkaślze icahda śnnka Jezebel yutapi kta.

24 Ahab tawa tona otonwe ohna tapi kin hena sunka yutapi kta, qa tona tinta ohna tapi kin malipiya okinyanpi kin wicayutapi kta.

25 Hececa eśta tuwedan Aliab iyecece śni, taku Jehowa iśta kin en śice cin econ kta wiyopeiciya, hecon kta e tawicu Jezebel iyopaśtaka nakaś.

26 Qa nina ihduwahte śni, qa cankagga ohoda, Amori kin Jehowa Israel cinca kin itokapa tanhan nape wicaya, econpi qon owasin iyecen.

27 Tuka Ahab wicoie kin hena nakon qehan, taheyake hduhdehideca, qa cehpi akan wakihdaka koyagya, qa wote śni un, qa makan wanke ca wakihdaka ai hdahpa, qa wahbayedan mani.

28 Unkan Jehowa oie kin Elija Tiśbi kin en hi, qa heya,

29 Token Aliab mitokam ihduhukuya wandaka he? Mitokam heccn ihduhukuye cin heon anpetu tawa en taku śica hiyu waye kte śni, iye cinhintku taanpetu kin en taku śica tipi tawa akan hiyu waye kta.

\section{WICOWOYAKE 22.}

1 Unkan waniyetu yamni owanji unpi, Arami qa lsrael kicizapi śni.

2 'Tuka mdoketu iyamni qehan, Jehośapat Juda wicaśtaya tapi kin Israel wicaśtayatapi kin ekta i.

3 Unkan Israel wicaśtayatapi kin taokiye hewicakiya, Ramot Gileyad he unkitawapi sdonyayapi he? Tuka unkiyepi owanji unyakonpi, qa Aram wicaśtayatapi nape kin etanhan unkikcupi sni.

4 Qa Jehośapat heciya, Ramot Gileyad unkizapi kta mici de k ta he? Unkan Jelıośapat Israel wicaśtayatapi kin heciya, Miye niye iyemaceca, qa oyate mitawa, oyate nitawa iyececapi, qa śuktanka mitawa śuktanka nitawa iyececapi.

5 Nakun Jehośapat Israel wicaśtayatapi kin heciya, tho nakaha Jehowa oie kin iwanga wo. 6 Unkan Israel wicaśtayatapi kin waayate wicaśta opawinge topa cetu mniciye wicaya, qa hewicakiya, Ramot Gileyad wakize kta ekta mde kta, qaiś enawakiye kta he? Unkan, Ekta ya wo; unkan, Itancan kin wicaśtayatapi nape kin en qu kta, eyapi.

7 Unkan Jehośapat heya, Jehowa waayate tawa etanhan unkiwangapi kta, dehanyan deciya wanjidan yuke śni he?

8 Unkan Israel wicaśtayatapi kin Jehośapat heciya, Jehowa unkiwangapi kta on nahanhin wicaśta wanjidan en un; tuka hc śice wadaka, miye on taku .waśte ayate śni, tuka takı śica; Mikaja Imla cinhintku kin hee. Unkan Jehośapat heya, Ihruhan wicaśtayatapi kin hecen eye cin.

9 Hehan Israel wicaśtayatapi kin yunokos wanji kipan,-qa heya, Mikaja Imla cinhintku kohanna deciya hiyuya wo.

10 Unkan Israel wicaśtayatapi kin, qa Jehośapat .Juda wicaśtayatapi kin otoiyohi oiyotanke tawa akan iyotankapi, qa śina hdowinpi, Samaria conkaśke tiyopa hocoka kin ohna, qa wicitokam waayate owasin waayatapi.

11 Unkan Tzedeqija Kenayana cinhintku mazasapa he içicağa, 


\section{WICOWOYAKE 22.}

qa heya, Jehowa hecen eya, Dena on Arami patan iyeyaye kta, ecen wicadusote kta.

12 Unkan waayate owasin iyecen wayatapi, qa heyapi, Ramot Gileyad ekta ya wo, qa ohiya wo, unkan Jehowa wicaśtaya tapi nape kin en qu kta.

13 Unkan wahośiye Mikaja kico iyaye cin ie ca heciya, Iho wanna waayate $\dot{i}$ wanjidan on wicaśtayatapi kin taku waśte eciyapi, ceciciya, nioie hena wanji oie kin iyecece kta, qa taku waśte ia wo.

14 Unkan Mikaja beya, Jehowa ni ce, hecen taku Jehowa emakiye cin, hee epe kta.

15 Qa wicaśtayatapi kin ekta hi. Unkan wicaśtayatapi kin heciya, Mikaja Ramot Gileyad unkizapi kta ekta unyanpi kta, qaiś enaunkiyapi kta he? Unkan, Ya wo, qa ohiya wo; hecen Jehowa wicaśtayatapi nape kin en qu kta.

16 Unkan wicaśtayatapi kin heciya, Jehowa cajeyan taku iewicaka heceedan emayakiye kta, tona akihde wokonze on eciciye kta he?

17 Unkan heya, Israel owasin he akan enanakiya iyayapi, tahinca wanunyanpi waawanyake nicapi iyecen, wanwicamdaka; unkan Jehowa heya, Dena itancan nicapi, wookiye en kihdapi kte, otoiyohi tipi tawa ekta.

18 Unkan Israel wicaśtayatapi Jehośapat heciya, Miye on taku waśte ayate kte śni, tuka taku śice cin, he eciciye śni he?

19 Unkan heya, Heon Jehowa oie kin nation wo. Jehowa toiyotanke akan kiyotanka, qa mahipiyu obe kin owasin etapa tanhan, qa catka tanhan najinpi kin wanwicamdaka.

20 Unkan Jehowa heya, Ahab
Ramot Gileyad ekta ye kta, qa heciya hinlipaye kta, tuwe cinkiye kta he? Unkan wanji he. cen eya, qa unman kaken eya.

21 Hehan woniya wan en indutanin, qa Jehowa itokam najin, qa heya, Riye cinwakiye lita.

22 Unkan, Token ecanon kta he? Jehowa eciya. Unkan heya, Ekta mde ca waayate tawa owasin ipi kin ohna woniya itonśni hemaca kta. Unkan heya, Cinyakiye kta, qa nakun ohiyaye kta. Ekta ya qa hecen econ wo.

23 Hecen wanna inyun, Jehowa woniya itonśni waayate nitawa kin dena owasin ipi en hiyuya, qa Jehowa niye on taku śiєa ia.

24. Hehan Tzedeqija Kenayana cinhintku kin ikiyedan hinajin, qa Mikaja iyolia kin apa, qa heya, Jehowa toniya kin mitan tanhan niye kici wohdake kta toki iyaya he?

25 Unkan Mikaja heya; Tohan tipi timahentu wan mahen inayalibe kta idade cinhan anpetu kin he en iho niye wandake kta.

26 Unkan Israel wicaśtayatapi kin heya, Mikaja icu wo, qa otonwe itancan kin Amon, qa wicaśtayatapi cinhintku Joaś ekta ake aya wo.

27 Qa hecen ehe kta, De wicakaśka tipi kin mahen iyeya wo, qa zaniyan en wahdi śni kin hehanyan woiyokiśica ag̉uyapi kin yunkiya po, qa woiyokiśica mini kin yatke kiya po; wicaśtayatapi kin eya ce.

28 Unkan Mikaja heya, Zaniyan en yahdi kinhan Jehowa miye on ie śni do. Nakun heya, Oyate owasin nation po.

29 Unkan Israel wicaśtayatapi, qa Juda wicaśtayatapi Jehośapat Ramot Gileyad ekta iyayapi. 


\section{WICASTAYATAPI,}

30 TJnkan Israel wicaśtayatapi kin Jehośapat heciya, Mihdutokeca, qa okicize en mde kta, tuka niye śina hdowin wo. Unkan Israel wicaśtayatapi kin togye ihduza, qa okicize en i.

31 Unkan Aram wicaśtayatapi kin tacanpahmihma itancanpi kin wikcemna yamni sanpa nonpa wahokonwicakiye ca heya, Tuwe cistinna qa tuwe tanka unmanna yakizapi kte śni; tuka Israel wicaśtayatapi kin heceedan kiza po.

32 Unkan canpahmihma itancanpi kin Jehośapat wanyakapi qehan, Awicakehan Israel wicaśtayatapi kin hee eyapi, qa he kuwa eyaya kizapi. Unkan Jehośapat śicahowaya.

33 Unkan canpahmihma itancanpi kin he Israel wicaśtayatapi kin ee śni wanyakapi qehan, he ihektapa tanhan ihdamnapi.

34. 'Tuka wicaśta wan ituye cin tinazipe ecate, qa Israel wicaśtayatapi kin maza heyake okihe ohna icam iheya. Unkan canpahmihma kahape cin heciya, Ninape hduwinga, qa obe kin etanhan hdicu mayan wo, maopi nakaś.

35 Unkan anpetu kin he en okicize tehika aya, qa wicaśtayatapi kin Aram iyotakons bosdan iyotanka, qa litayetu hehan ta; qa opi kin etanhan we kin canpahmihma koka kin en kaduza.

36 Unkan wi iyaye cehan obe ohna ieyanpahapi qa heyapi, Otoiyohi totonwe, qa tamagia kin ekta kihde kta.

37 Hecen wicaśtayatapi kin te ; unkan Samaria ekta hdohdapi, qa Samaria ohna wicaśtayatapi kin hnakapi.

38 Unkan canpahmihma kin Samaria mini owe kin ekta yujajapi, qa śunka. we kin sdipapi, 524 qa witkowinpi kin yujajapi, Jehow a oie eye ciqon iyecen.

39 Unkan Ahab ohan unman kin, qa taku econ kin owasin, qa putehanska hi tipi kage cin, qa otonwe kagie cin owasin Israel wicaśtayatapi anpetu oie wowapi kin en owapi śni he?

40 Hecen Aliab hunkake wicaya om iśtima, unkan cinhintku Ahazija eekiya wicaśtayatapi un. 41 Unkan Jehośapat Asa cinhintku Aliab Israel iwicadake cin waniyetu itopa kin en Juda iwicadaka.

42 Jehośapat waniyetu wikcemna yamni sanpa zaptan hehan wawidaka, qa waniyetu wikcemna nonpa sanpa zaptan hehanyan Jerusalem ohna wicaśtayatapi, qa hunku caje kin Yazuba Silbi cunwintku.

43 Unkan atkuku Asa tacanku kin owasin omani, taku Jehowa iśta kin en ecetu econ kin etanhan yuwinh iyaye śni. Tuka pajodan kin yutokanpi śni, nahanhin oyate kin pajodan akan wayuśnapi ece, qa wizinyapi ece.

44 Nakun Jehośapat Israel wicaśtayatapi kin kici wokiya.

45 Unkan Jehośapat ohan unman, qa towaśake, qa taku econ, qa token kicize cin, hena Juda wicaśtayatapi anpetu oyakapi wowapi kin en owapi śni he?

46 Unkan waibupi kin atkuku Asa taanpetu kin etanhan okaptapi kin hena makoce kin etanhan iyaye wicaya.

47 Unkan Edom ohna wicaśtayatapi wanica, tuwe wicayuheśipi kin iwicadaka.

48 Unkan Jehośapat Tarśiś wita wata kaga, Opir heci yapi kta, mazaskazi on; tuka wita wata kin Yetzion Gaber ohna kawegapi, heon ekta ipi śni. 


\section{WICOWOYARE 22.}

49 Hehan Ahazija Ahab cin- Jehośapat Juda wicaśtayatapi tahintku Jehośapat heciya, Mitao- waniyetu wikcemna sanpa iśakiye nitaokiye om yapi kta, wi- kowin etanhan, qa waniyetu nonta wata ohna; tuka Jehośapat pa Israel iwicadaka.

tawatenye śni.

50 Unkan Jehośapat hunkake, wicaya om iśtima, qa hunkake wicaya om hnakapi; atkuku Dawid totonwe ohna. Unkan cinhintku Joram heekiya wicaśtayatapi. 51 Ahazija Ahab cinhintku Sa- Sihdaya, a
maria ohna Israel iwicadaka,
sin iyecen.
52 Qa taku Jehowa iśta kin en śica econ, qa atkuku tacanku, qa hunku tacanku, qa Jeroboyam Nebat cinhintku Israel wahtani wicaye cin tacanku omani.

53 Qa Bayal okiye ca ohoda, qa Jehowa Israel Wakandapi sihdaya, atkuku econ qon owa525 


\section{WIC ASTAYATAPI}

I N O N P A.

\section{WICOWOYAKE 1.}

1 Unkan Aliab te cin iyohakam Moab Israel kipajin.

2 Unkan Aliazija wankan tipi Samaria ohna yuhe cin en, canyankapi kin ohna hinhpaya, qa wayazanka, qa taohnihde yewicaśi, qa hewicakiya, Bayal Zebub (Honagidan itancan,) Yekron wakandapi kin ekta yapi, iwanga po, wowayazan kin de etanhan amasni kta hecinhan?

3 Unkan Jehowa taohnihde kin Elija Tiśbi kin heciya, Najin Samaria wicaśtayatapi kin ohnihdewicaye cin awicakipe ya wo; qa hewicakiya wo, Israel ohna taku wakan wanica naceca, heon niyepi Bayal Zebub, Yekron wakandapi kin inongapi kta e ekta dapi. 4 Heon Jehowa hecen eya, Owanka akan inonke cin hetanhan nayajin kte śni, tuka awicakehan nițe kta. Unkan Elija iyaya.

5 Unkan ohnihdewicaye cin, hdipi ; unkan hewicakiya, 'Tokeca yahdipi he?

6 Unkan heciyapi, Wicaśta wan unkitkokim lii, qa heunkiciyapi, Wicaśtaya tapi yeniśipi kin ekta kihdapi, qa heciya po, Jehowa hecen eya, Israel ohna taku wakan wanica naceca; heon Bayal Zebub, Yekron wakandapi kin inonge kta yewicayaśi naceca. Heon owanka akan inonke cin hetanhan nayajin kte śni, tuka awicakehan nițe kta.

II. Kings. 526
7 Unkan hewicakiya, Wicaśta itkonicipapi hi, qa wicoie kin hena eniciyapi kin oihduze kin toketu he?

8 Unkan heciyapi, Wicaśta kin śina hinśma hdowin, qa telmiso wan ipiyagkiton. Unkan, Elija Tiśbi kin hee, eya.

9 Unkan akicita tancan wicaśta wikcemna zaptan wicayuhe cin om Elija ekta yeśi. Unkan ekta i. Unkan inyun he paha akan iyotankehan yanka. Unkan heciya, Wakantanka tawicaśta kin apamahde kuwa wo, wicaśtayatapi kin eya ce.

10 Unkan Elija ayupte ca akicita tancan kin heciya, Miye Wakantanka tawicaśta hemaca hecinhan, mahpiya etanhan peta hiyu, qa niye, qa akicita wikcemna zaptan nitawa huhnahniyanpi kta. Unkan peta mahpiya etanhan kun hiyu, qa iye, qa wikcemna zaptan tawa liulinaliwicaya.

11 Unkan ake akicita tancan tokeca wan wicaśta wikcemna zaptan tawa om ekta yeśi. Unkan ie ca heciya, Wakantanka tawicaśta, wicaśtayatapi kin hecen eya, Inalini apamahde kuwa wo.

12 Unkan Elija ayupte ça hewicakiya, Miye Wakantanka tawicaśta hemaca kinhan peta mahipiya etanhan kun hiyu, qa niye, qa wikcemna zaptan nitawa liuhnahniyanpi kta. Unkan Wakantanka tapeta kin mahpiya etan- 


\section{WICOWOYAKE 2.}

han kun hiyu, qa iye, qa wilicemna zaptan tawa huhnaliwicaya. 13 Unkan ake akicita tancan iyamni wilicemna zaptan tawa om yeśi. Unkan akicita tancan iyamni kin itanwankanhde ekta i, qa canpeśka makehde Eilija itokam inajin, qa cekiya, qa heciya, Wakantanka tawicaśta ceciciya, minagi kin, qa nitaokiye wikcemna zaptan kin dena nagipi kin niiśta lkin én tehikapi nunwe.

14 Inyun peta malipiya etanhan kutkiya u, qa akicita itancan nonpa tokaheya upi, wikcemna zaptanptan tawapi om, wicayasota, heon tokin minagi kin niiśta kin en tehike kten.

15 Unkan Jehowa ohnihde kin Elija heciya, Kici ya wo. Ihnuhan he ikoyape cin. Unkan najin, qa kici $i$, wicaśtayatapi kin eikta.

16 Qa heciya, Jehowa hecen eya, Israel ohna taku wakan oie kin inonge kta wanica naceca, heon Bayal Zebub, Yekron wakandapi kin inonge kta ohnihde yewicayaśi; heon owanka akan inonke cin etanhan nayajin kte śni, tuka awicakehan nite kta.

17 Hecen Jehowa oie Elija eye cin iyecen ța. Unkan cinca nica heon heekiya Joram wawidaka, Juda wicaśtayatapi Jehośapat cinhintku Joram wawidaka waniyetu inonpa en.

18 Unkan Ahazija ohan unman econ kin hena Israel wicaśtayatapi anpetu oyakapi wowapi kin en owapi śni he?

\section{WICOWOYAKE 2.}

1 Unkan .Tehowa tateiyumni ohna Elija mahpiya ekta yuwankan icu kte çehan, Elija qa Eliśa Gilgal etanhan iyayapi.
2 Unkan Elija Eliśa heciya, Ceciciya den yanka wo, Jehowa Betel ekta yemaśi ce. Unkan Elliśa heya, Jehowa ni, qa ninagi ni kinhan, aciyuśtan lkte śni. Hecen Betel ekta ipi.

3 Unkan waayate cinca, Betel. ohna yukanpi kin, Eliśa ekta inanpapi, qa heciyapi, Jehowa nakaha itancan nitawa nipa iwankapatanhan inicicu kta sdonyaya he? Unkan miś eya he sdonwaya, inina unpo, eya.

4 Unkan Elija heciya, Eliśa ceciciya den yanka wo, Jehowa Jeriho ek ta yemaśi. Unkan, Jehowa ni, qa ninagi ni kinhan aciyuśtan kte śni, eya. Hecen Jeriho ekta ipi.

5 Unkan waayate cinca Jerilio ohna yakonpi kin Eliśa ikiyedan hipi, qa heciyapi, Jehowa nakaha itancan nitawa nipa iwankapatanhan inicicu kta, sdonyaya he? Unkan, miś eya sdonwaya ce. Inina unpo, eya.

6 Unkan Flija heciya, Ceciciye den yanka wo; Jehowa Jordan ekta yemaśi ce. Unkan Jehowa ni, qa ninagii ni kinhan aciyuśtan kte śni ce, eya. Hecen sakim iyayapi.

r Unkan waayate cinca etanhan wicaśta wikcemna zaptan iyayapi, qa wiciheyata tehan najinpi. Unkan napin Jordan ekta najinpi.

8 Unkan Elija śina ikikcu qa hdupehan, qa mini kin apa. Unkan yukinukan iyaya, deciya, qa kakiya. Hecen sakim opta iyayapi, puza akan.

9 Unkan akasanpa ipi qehan, Elija Eliśa heciya, Taku ecacicon kta da wo, nitan tanhan emahdakupi śni itokam. Unkan Eliśa heya, Tokin nitaniya nonpa akihde akan maun kten.

10 Unkan, Taku telika yada, 


\section{WICAŚ'TAYATAPI,}

nitan tanhan emahdakupi wanmayadake cinhan ecetu niciye kta, qa wanmayadake śni kinhan ecetu kte śni.

11 Unkan sakim iyayapi, wohdaka manipi qehan, inyun peta canpahmihma, qa peta śuktanka wicayukinukan; Unkan Elija tate iyumni ohna wankan iyaya mahpiya ekta.

12 Unkan Eliśa wanyake ca hoyeya, Ate, ate, Israel canpahmihma tawa, qa śungakanyotankapi tawa; qa icimana wanyake śni. Hehan heyake ikikcu, qa hduhdehdeca onśpa nom.

13 Qa Elija taśina ihpaye cin yuwankan icu, qa kihda, qa Jordan huta kin anajin.

14 Qa śina Elija etanhan ilipaye cin icu, qa mini kin ape ca heya, Jehowa Elija wakanda kin tukte e he? Unkan mini kaśtake cin deciya qa kakiya yukinukan iyaya, unkan Eliśa opta iyaya.

15 Unkan waayate cinca Jerilio iwiyohiyanpa tanhan yakonpi kin he wanyakapi qehan, Elija taniya kin Wliśa akan un ce, eyapi; qa itkokim upi, qa itokam maka ekta patujapi.

$16 \mathrm{Qa}$ heciyapi, Tho nitaokiye wicaśta waśaka wikcemna zaptan yukan, tokin hena yapi, qa itancan nitawa akitapi kten. Okini Jehowa taniya kin be yuwankan icu, qa he wan akan, qaiś osmaka wanji en elipeya. Unkan, $\mathrm{Ye}$ wicaśipi śni po, eya.

17 Unkan nina kitanpi ecen iye iśteca. Unkan, Yewicaśípo, eya. Unkan wicaśta wikcemna zaptan yewicaśipi. Unkan yamni can akitapi, tuka iyeyapi śni.

18 Qa iye Jeriho ohna yanka en hdipi. Unkan hewicakiya, Yapi śni po, eciciyapi śni he?

19 Unkan otonwe wicaśta kin 528
Eliśa heciyapi, Iho otonwe kin de oyanke kin waśte, unyuhapi kin wanyake cin iyecen; tuka mini kin śica, qa maka kin cinca nica wicakagia ece.

20 Unkan wakśica teca wan hiyu makiyapo, qa miniskuya ohnaka po; eya. Unkan kahipi.

21 Unkan inanpa minihinape cin ekta, qa heya, Jehowa hecen eya, Mini kin de okiziwaya; icimana hetanhan wiconțe, qa itkotpeyapi yuke kte śni.

22 Hecen mini kin okiziyapi, anpetu kin dehanyan, wicoie Eliśa eye cin iyecen.

23 Unkan hetanhan itanwankanhde Betel ekta i, qa itanwankanhde canku ohna mani icunhan, kośka cistinna otonwe etanhan inanpapi, qa heciyapi, Paśda wankan ya wo; wankan ya wo.

24 Unkan ihdamna, qa awicatonwan, qa Jehowa cajeyan wicayaśica. Unkan wahanksica wiye nonpa taśkoju etanhan inanpapi, qa hena etanhan hokśidan wikcemna topa sanpa nonpa wicayahdecapi.

25 Unkan hetanhan Karmel he kin ekta i, qa hetanhan Samaria en hdi.

\section{WICOWOYAKE 3.}

1 Unkan Jehośapat Juda idake cin waniyetu wikcemna sanpa iśahdoġan kin en, Joram Ahab cinhintku toka Israel idaka, Samaria ohna, qa waniyetu wikcemna sanpa nonpa wawidaka.

2 Unkan taku Jehowa iśta kin en śica econ, tuka atkuku, qa hunku iyececa śni; qa Bayal wakagaapi atkuku kagge cin he yutokan.

3 Tuka woahtani Jeroboyam Nebat cinhintku Israel wahtaniwicaye cin he kitan, qa hetanhan ihduhomni śni. 
4 Unkan Meśa Moab wicaśtayatapi kin tahinwanunyanpi y11ha heca, qa tacincadan kektopawinge opawinge, qa tamdoka kektopawinge opawinge hin kin iyahna Israel wicaśtayatapi kin qu ece.

5. Tuka Ahab te cehan Moab wicaśtayatapi kin Israel wicaśtayatapi kin kipajin.

6 Unkan hehan wicaśtayatapi kin Joram Samaria etanhan inanpa, qa Israel owasin wicayawa.

7 Qa nakun Juda wicaśtayatapi kin Jehośapat wahoye ça heciya, Moab wicaśtayatapi kin makipajin, Moab unkize kita mici de kta he? Unkan heya, Mde kta ce. Niye iyemaceca, qa oyate mitawa oyate nitawa iyececa, qa śuktanka mitawa śuktanka nitawa iyececapi.

8 Qa heya, Canku tuktee ohna unye kta he? Unkan Edom tinta kin canku kin ohna, eya.

9 Hecen Israel wicaśtayatapi kin, qa Juda wicaśtayatapi kin, qa Edom wicaśtayatapi kin iyayapi, qa anpetu śakowin yuwinh yapi, tuka mini wanica, ozuye kin on, qa wanunyanpi opapi kin on.

10 Unkan Israel wicaśtayatapi kin heya, Hehehe Jehowa wicaśtayatapi yamni kin dena yuwitaya hiyu unyanpi, Moab nape en unqupi kta e.

11 Unkan Jehośapat heya, Jehowa unkiwangapi kta e Jehowa waayate tawa deciya wanica he? Unkan Israel wicaśtaya tapi taokiye wanji ayupte ça heya, Eliśa Sapat cinhintku Elija nape kin mini akaśtan kin he den un ce.

12 Unkan Jehośapat heya, Jehowa oie kin iye kici un. Unkan Israel wicaśtayatapi kin, qa
Jehośapat, qa Edom wicaśtayatapi kin iye ekta apamahde ipi.

13 Unkan Eliśa lsrael wicaśtayatapi kin heciya, Taku iyociwaja he? Niyate waayate tawa, qa niluu waayate tawa kin hena ekta ya wo. Unkan Israel wicaśtayatapi kin heciya, Hiya Jehowa hee wicaśtayatapi yamni kin dena mniciye wicaya, Moab nape en wicaqu kta heon etanhan.

14. Unkan Eliśa heya, Jehowa obe yuhe cin itokam nawajin kin, he ni kin iyecen, Jehośapat Juda wicaśtayatapi kin ite kin ihawakta, hecetu śni unkanś ilıacikta kte śni, qa acitonwe kte śni.

15 Tuka wanna candowankiyesa wan miye ekta hiyuya po. Unkan candowankiyesa itokam candowankiye ceehan Jehowa nape kin iye akan un.

16 Unkan heya, Jehowa hecen eya, Kaksiza kin den makohdoka ota kaga wo.

17 Jehowa hecen eya nakaś, Tate wandakapi kte sni, qa magaju wandakapi kte śni, tuka kaksiza kin de mini ojudan kta, qa datkanpi kta, niyepi, qa nakun tahinca nitawapi, qa wanunyanpi nitawapi.

$18 \mathrm{Qa}$ he qe Jehowa iśta kin en taku cistinna; nakun Moab ninapepi en qu kta.

19 Unkan otonwe cankaślkapi owasin yakaśtakapi kta; nakun otonwe wiciyokipi owasin, qa can waśte owasin yakawankapi $k t a$ qa miniyowe owasin aohduteyayapi kta, qa magga waśte owasin inyan on yuśag yayapi kta.

20 Unkan hanhanna minha huhnahyapi ece iyehantu, mini Edom canku kin etanhan kaduza, qa maka kin mini ojudan. 


\section{WICAŚTAYATAPI,}

21 Unkan Moab owasin wicaśtayatapi azuwicaya upi e nahonpi qehan, tona wipekiton okihi owasin wicakipanpi, qa ivayapi, qa makoce ihanke ekta najinpi.

22 Qa ihanhanna kiktapi, qa mini akan wi kin himanpe cehan Moab iye itokam mini kin wanyakapi, śa we iyececa.

23 Unkan heyapi, We hee. Wicaśtayatapi kin cakicipapi, qa kiciktepi, heon Moab wahpaya kin iyahpaya po.

24 Unkan Israel owanka en hipi qehan, Israel najinpi, qa Moab kaśtakapi. Unkan wicitokam napapi. Unkan Moab en wicakaśtaka ipi.

25 Qa otonwepi yujujupi, qa mag̉a waśte owasin akan inyan ehpeyapi, wicaśta otoiyohi, hecen ojuyapi, qa miniyowe owasin aohduteyapi, qa can waśte owasin kawankapi, ecen Hereśet conkaśke inyan heceedan okaptapi, qa he ilidukśan ipi, qa inyan yuhmun on he kaśtakapi.

26 Unkan Moab wicaśtayatapi kin ozuye kin iye isanpa waśaka wanyake cehan, wicaśta opawinge śakowin isan hduślokapi om Edom wicaśtayatapi kin kte kta iyaya, tuka okihipi śni.

27 Hehan iye cinhintku tokapa, iye ohakam wicaśtayatapi kte cin icu, qa wohuhnahyapi on conkaśke akan huhnahya. Hehan wośilida tanka Israel ekta kiya. Unkan ayuśtanpi qa makoce ekta kihdapi.

\section{WICOWOYAKE 4.}

1 Unkan waayate cincapi tawicupi etanhan winohinca wan Eliśa hoyekiye ca heya, Nitaokiye mihihna kin wanna te, qa nitaokiye qon Jehowa nina kinihan 530 sdonyaya. Unkan ikicazo qon micinca napin wowidake on iwicacu kta wanna hi ye.

2 Unkan Eliśa heciya, Taku ecacicon kta omakiyaka wo. Yati kin ohna taku duha he? Unkan heya, Nitaokiyewin ti kin ohna takudan yuhe śni ye, wihdi cegia wan ohna heceedan.

3 Unkan heya, Hda ceğ́a odota wo; titokan nikiyedan tipi kin owasin etanhan, cega takudan ohnaka śni ota hin.

4. Qa yahdi, qa niye nicinca kiciśnana mahen tiyopa onataka, qa cega kin hena owasin okastan wo, qa ojudan kin tokan ehde wo.

5 Hecen iye etanhan iyaya, qa cinca kiciśnana mahen tiyopa onataka, hena ceğa hiyuyapi, qa iye okaśtan.

6 Qa cega owasin ojupi qehan, cinhintku wan heciya, Ake ceġa wan makau ye. Unkan heciya, Wanna cega henana. Unkan wihdi kin anapta.

7 Unkan winyan kin iyaye ca Wakantanka tawicaśta kin okiyaka. Unkan heya, Hda, qa wihdi kin wiyopekiye ca iyakazo kin hdajuju, qa tona oyakapte cin on niye qa nicinca yanipi kta.

8 Unkan anpetu wanji Eliśa Sunem ekta iyaya. Unkan winohinca tanka wan hen yanka, qa aguyapi yute kta iyopaśtaka. Unkan heci iyaya eca, aguyapi yute kta e hen yuwinh i ece.

9 Unkan winyan kin hihnaku heciya, Tho ye wicaśta unkiyepi en ijehan hiyaye cin he Wakantanka tawicaśta wakan heca sdonwaya ye.

10 Ceciciye owanka tipi wan conkaśke akan unkicage kte, qa owinja wan, qa wahna wotapi wan, qa oiyotanke wan, qa petijanjan wan hen unkicihnake 


\section{WICOWOYAKE 4.}

kta; hecen unkiyepi en hi eca hen yanka ecee kta ye.

11 Unkan anpetu wan heciya i qehan, owanka tipi kin en i, qa hen iwanka.

12 Qa tahokśidan Gehazi heciya, Sunamiwin kin de kico wo. Unkan kico qehan itokam win. yan kin hinajin.

13 Unkan heciya, Winyan kin heciya wo, Inyun ihaunyaktapi, qa taku lkin dena owasin tanyan ecaunycconpi; taku ecauniconpi kta he? Niye on wicaśtayatapi taku unkekiyapi kta, qaiś akicita tancan tokapa? Unkan, Oyate mitawa ehna ounwaye ye, eya.

14. Unkan heya, Hehan taku ecakiconpi kta he? Unkan Gehazi heya, Awicakehan cinca nica, qa hihnaku kin wicahinca.

15 Unkan kico wo, eya. Unkan kico. Unkan winyan kin tiyopa en hinajin.

16 Unkan heya, Tokata omaka kin de iyehan wicani kin iyecen cinca wica wan adoksohan yahduze kta. Unkan winyan kin heya, Hiya, itancan mitawa, Wakantanka tawicaśta, ihnuhan nitaokiyewin yahnaye cin.

17 Unkan winohinca kin ihduśake ca hokśidan wan ton, wicani kin iyehan omaka kin he en, Eliśa eciye ciqon iyecen.

18 Unkan hokśidan tanka qehan, anpetu wan atkuku ekta iyaya ağuyapi baksapi kin ekta.

$19 \mathrm{Qa}$ atkuku heciya, Mapa, mapa. Unkan, Hunku ekta kaya wo, kośka wan eciya.

20 Unkan qin, qa hunku ekta kahi. Unkan śiyoto akan iyotanke ca wiyotanhan hehan ta.

21 Unkan wankan iyaye ca Wakantanka tawicaśta towinja akan ehnaka, qa tiyopa kin ecen icu, qa tankan iyaya.
22 Qa hihnaku kipan, qa heciya, Hokśidan wanji miye ekta uśi ye ; nakun śonśonna wiyedan, hecen Wakantanka tawicaśta ekta dus mde kta, qa wahdi kta ye.

23 Unkan heya, Tokeca niye nakaha ekta de kta he? Wi teca śni, qa anpetu okihpapi śni. Unkan winyan heya, Tanyan kte ye.

24 Unkan śonśonna kin aqinkiton, qa hokśidan kin heciya, Kahapa qa tokata ya ye. Ihnuhan kahapa enayakiye cin, econ ciśi śni kinhan.

25 Hecen iyaye ca Wakantanka tawicaśta kin ekta i, Karmel he kin ekta. Unkan Wakantanka tawicaśta kin tehantanhan wanyake cehan tahokśidan kin Gehazi heciya, Inyun ŚSunamiwin kin hee.

26 Wanna itkokipe kta inyang ya wo, qa heciya wo, Zaniyan yaun he? qa nihihna zaniyan un he? qa hokśidan kin zaniyan un he? unkan, Zaniyan eya.

27 Unkan Wakantanka tawicaśta kin ekta hi, he kin ekta, qa siha kin yuza. Unkan Geliazi yutokan kta ikiyedan hi. Unkan Wakantanka tawicaśta kin heya, Iyowinkiya wo, nagi kin iyokiśica, tuka Jehowa miye etanhan nahma, qa omakiyake śni.

28 Unkan winyan kin heya, Itancan mitawa etanhan cinca wakida he? Ihnuhan mayahnayan epe śni he?

29 Unkan Gehazi heciya, Nite iyahdaśka, qa sagye mitawa ninape on icu wo; qa ya wo. Wicaśta wan ayakipe cinhan dawaśte kte śni; qa tuwe niyawaśte kinhan adupte kte śni; qa sagye mitawa hokśidan ite kin akan ehnaka wo. 


\section{WICAŚTAYATAPI,}

30 Unkan hokśidan hunku kin beya, Jehowa ni, qa ninagii ni kin iyecen, aciyuśtan kte śni. Unkan najin, qa ihakam iyaya.

31 Unkan Gehazi wicitokam iyaye ca sagye kin hokśidan ite akan ehnaka; tuka ho wanica, qa ekta ewacin wanica, heon wicitkokim ihdamna, qa okiyake ca, Hokśidan kin kikta śni, eya.

32 Unkan Eliśa tipi kin ekta i, qa inyun hokśidan kin ta, iye towinja akan wanka.

33 Unkan timahen i, qa kiciśnana en un, tiyopa ecen icu, qa Jehowa cekiya.

$34 \mathrm{Qa}$ hokśidan kin akan iwanka, qa iye i kin i tawa akan, qa iye iśta kin iśta tawa akan, qa iye nape kin nape tawa akan yekiya, hecen akan ihdugata. Unkan hokśidan celpi kin kata aya.

35 Unkan ake najin, qa tipi ohna icipaśya mani, qa ake akan ihdugata. Unkan hokśidan kin pśa. śakowin akihde, qa hokśidan kin iśta hdukawa.

36 Unkan Gehazi kipan, qa heciya, Śnamiwin kin de kipan wo. Unkan kipan; unkan en hi. Unkan, Nicinkśi ikikcu wo, eya.

37 Unkan winyan kin ikiyedan $i$, qa siha kin ekta elipeiciye ca makata patuja, hehan cinhintku ikikcu, qa tankan iyaya.

38 Unkan Eliśa Gilgal ekta hda. Unkan makoce ohna wicaakitian. Unkan waayate cincapi kin iye itokam iyotankapi. Unkan tahokśidan heciya, Ceğa tanka kin otkeya, qa waayate cincapi wahanpi wicakicagga wo.

39 Unkan wanji wato mnaye kta maǵata iyaya, qa hen ikce wiyuwi wan iyeye ca etanhan wamnon pa yuśpi taśina ojudan, qa iyekiye śni, heon cega wahanpi kin en baśpaśpa ehpeya.
40 Unkan wicaśta yutapi kte okaśtanpi, qa wahanpi yutapi icunhan hoyeyapi, qa heyapi, Wakantanka tawicaśta cega ohna wiconțe yukan, qa yutapi okitpanipi.

41 Unkan heya, Ag guyapi mdu hiyumakiya po, qa cega en kada iyeya; hehan heya, Oyate on okaśtan po. Unkan yutapi, qa ceğa ohna taku śica wanica.

42 Unkan Bayal Śaliśa etanhan wicaśta wan hiyu, qa taku tokaheya suton etanhan Wakantanka tawicaśta kin woyute kahi, barle aguyapi wikcemna nonpa, qa aguyapi śtonkadan itka bopanpi sni. Unkan, Oyate kin yutapi kta e wicaqu wo, eya.

43 Unkan taokiye heya, Wicasta opawinge wicitokam de ewehde lkta he? Unkan heya, Oyate kin wicaqu wo, hecen wotapi kta. Hetanhan yutapi, qa okaptapi kta, Jehowa eya nakaś.

44 Unkan wicitokam ehde. Unkan yutapi qa okaptapi, Jehowa eye ciqon iyecen.

\section{WICOWOYAKE 5.}

1 Unkan Nayaman Aram wicaśtayatapi taobe itancan kin, itancan tawa kin itokam wicaśta tanka, qa kinihanpi, iye on Jehowa Aram nikiya nakaś, wicaśta waśaka, waditaka, tuka leprosi ececa.

2 Ehanna Aram ozuye iyayapi, qa Israel makoce kin etanhan wicinyanna cistinna wan wayaka yuha hdipi. Unkan Nayaman tawicu itokam najin ece.

3 Qa yuhe cin heciya, Tokin Itancan mitawa wayate Samaria ohna yanke cin he itokam najin kten, hecen leprosi asniye kte ye.

4 Unkan tuwe ekta i, qa itan- 


\section{WICOWOYAKE 5.}

can tawa okiyake ca heya, Wicinyanna Israel makoce etanhan kin, decen qa decen eya ce.

5 Unkan Aram wicaśtayatapi kin heya, Iho, ya wo, qa Israel wicaśtayatapi kin wowapi wan waqu kta. Unkan mazaska woqin wikcemna, qa mazaskazi kektopawinge śakpe, qa wokoyake ocaje iyuhipa wikcemna icu, qa iyaya.

6 Qa wowapi Israel wicaśtayatapi kin kahi lin heya, Wowapi lin de nicahipi kinhan, iho nitaokiye Nayaman niye ekta ye waśi, lcprosi ececa asni yaye kta heon.

7 Unkan Israel wicaśtayatapi kin wowapi kin yawa qehan, heyake kin hduhdehdeca, qa heya, Tewaye kta, qa niwaye kte e taku wakan hemaca he? on wicaśta leprosi ececa asniye kta hc miye ekta uśi? Wanna wanyaka po, qa sdonya po, awicakehan makize kta kuwa ce.

8 Unkan Eliśa wakan wicaśta kin Israel wicaśtayatapi taheyake hduhdchdeca nahon qehan, wicaśtayatapi kin wahoye ca heya, Tokeca heyake yahduhdehdeca? Ito miye ekta hi kta, hecen Israel ohna waayate wan yanka sdonye kta.

9 Unkan Nayaman śuktanka, qa canpalımihma hduha, u, qa Eliśa ti tiyopa kin ekta hinajin.

10 Unkan Eliśa wahośi wan elta ycśi, qa heciya, Ya wo, qa Jordan en śakowin akihde ihdujaja wo, hecen nicehpi ake ecetu kta, qa niska kta.

11 Unkan Nayaman śihda, qa kihda, qa heya, Inyun miye ekta - hinanpe kta, qa najin, Jehowa iye wakanda caje kin hoyekiye kta, qa tukten mayazan nape hduwinte kta, hecen leprosi asniye kta, awicakehan ecanmi.
12 Abana qa Parpar Damaskos tawakpa kin Israel mini kin owasin isanpa waśtepi śni he? Hena en mihdujaja kinhan maska kte śni he? eye ca ihdamna, qa canniyan kihda.

13 Unkan taokiye ikiyedan hipi, qa iapi, qa heciyapi, Ate taku tanka waayate kin eniciya unkanś ecanon kte śni he? 'Tuka eeś, Ihdujaja, qa niska kta eniciya.

14 Hehan apamahde i, qa Jordan en spaye içiye, śakowin akilide, wakan wicaśta ie ciqon iyecen, qa cehpi kin ekicetu hokśidan cistinna cehpi kin iyececa, qa iye ska.

15 Unkan ake wakan wicaśta kin ekta i, iye qa obe tawa owasin, qa itokam kinajin, qa heya, Inyun maka owancaya taku wakan wanica, Israel olma heceedan wanna sdonwaya; heon ceciciye woyawaśte wan nitaokiye kin etanhan icu wo.

16 Unkan Jchowa itokain nawajin ni kinhan iwacu ktc śni, eya. Unkan cinkiya tuka wicada śni.

17 Unkan Nayaman heya, Ceciciya maka kin de śonśonna woqin nonpa nitaokiye qupi kta. Detanhan nitaokiye icimana wohuhnahyapi, qa wośnapi taku wakan tokeca wakiyuśna kte śni, Jehowa heceedan hecakicon kta.

18 Taku kin de Jehowa nitaokiye kicicajuju kte, Itancan mitawa Rinmon ti en ohoda kta ya eca, minape akan oziiciya ecee kta, qa Rinmon ti kin ohna wapatuja, Rinmon ti kin ohna wapatuja kin taku kin de on tokin Jelowa nitaokiye kicicajuju kten.

19 Unkan heciya, Zaniyan hda wo. Unkan canku iyutapi wan iye etanhan iyaya. 


\section{WICAŚTAYATAPI,}

20 Unkan Gehazi Eliśa wakan wicaśta tahokśidan kiı heya, Inyun itancan mitawa Arami kin de Nayaman taku ahi kin nape kin etanhan icu kapin; Jehowa ni kin iyecen ihakam waimnanke kta, qa iye etanhan taku iwacu kta.

21 Qa Gehazi Nayaman knwa iyaya. Unkan Nayaman he inyang $u$ wanyaka, qa itkokipe kta canpahmihma etanhan ipsice ca, Wookiye he? eya.

22 Unkan heya, Wookiye ; itancan mitawa umaśi, qa heya, Iho nakaha kośka nonpa waayate cincapi, Epraim he kin etanhan en mahipi, ceciciya, mazaska woqin wan, qa wokoyake ocaje iyuhpa nonpa wicaqu ye.

23 Unkan Nayaman heya, Cante waśteya woqin nonpa icu wo, becen cinkiya, qa mazaska woqin noupa ojuha nonpa en patita; nakun wokoyake ocaje iyuhpa tahokśidan nonpa qin wicakiya, unkan itokam qinpi.

24 Qa paha kin ekta hi qehan, napepi kin etanhan icu, qa timahen kihnake ca wicaśta qon kihde wicaśi ; unkan iyayapi.

25 Unkan iye $u$, qa itancan tawa itokam hinajin. Unkan Eliśa heciya, Gehazi tokiya tanhan yau he? Unkan, Nitaokiye tokidan i śni, eya.

26 Unkall heciya, Wicaśta kin itkonicipe kta canpahmihma tawa etanhan ihdamna qehan, micante nici i śni he? Nakaha mazaska icupi kte, qa wokoyake, qa wihdi can ojupi, qa hastanhanka iyuwi ojupi, qa talinca, qa pte, qa ookiye wica qa winyan opetonpi kta iyehantu he?

37 Heon Nayaman leprosi tawa niye, qa nicinca aniskapapi kta, owihanke wanica. Unkan iye itokapatanhan inanpa leprosi ececa, wa iyececa.

\section{WICOWOYAKE 6 .}

1 Unkan waayate cincapi kin Filiśa heciyapi, Inyun oyanke ohna niciunyakonpi kin unkokanpi śni ce.

2 Iho Jordan ekta unyanpi, qa hetanhan otoiyohi can wanji unkicupi kte, qa heciya oyanke wan ohna untipi kta unkicicagapi kta. Unkan, Ya po, eya.

3 Unkan wanji heya, Tokin nitaokiye om de kta iyonicipi kten. Unkan, Miye mde kta ce, eya.

4 Unkan om iyaya. Unkan Jordan ekta jpi, qa cankaksapi.

5 Unkan wauji can wan kawanke celıan, maza kin minin ihpaya. Unkan hoyeya qa heya, Hehehe, itancan mitawa, he odotapi ce.

6 Unkan wakan wicaśta kin beya, Tukten ihpaya he? Unkan oyanke kiıl kipazo. Unkan can wan kakse ca hen ehpeya. Unkan maza kin okapota.

7 Unkan heya, Yuwankan ikikeu wo. Unkan nape kin hdugate cea icu.

8 Unkan Aram wicaśtayatapi kin Israel azuya, qa taokiye om iyukcan, qa heya, Oyanke kin he en ewati kta.

9 Unkan wakan wicaśta kin Israel wicaśtayatapi kin wahoye ca heciy a, Awanihdaka wo, oyanke kin he iyoopta de kte śni; Aram hen nahmana wankapi nakaś.

10 Unkan Israel wicaśtayatapi kin oyauke kin wakan wicaśta cajeyate ca on iwaktaye cin he ekta tuwe yeśi, qa hecen niiciya wancadan śni, qa nonpa śni.

11 Unkan wicoie kin de on Aram wicaśtayatapi cante kin inihan; qa taokiye wicakico, qa hewicakiya, Unkiyepi etanhan tuwe Israel wicaśtayatapi kin 


\section{WICOWOYAKE 6 .}

wahoye cin omayakidakapi kte śni he?

12 Unkan taokiye wanji heya, Tuwedan śni, itancan mitawa, wicaśtayatapi : Tuka Eliśa waayate Israel en yanke cin wicoie oiśtinma tipi nitawa ohna iyae cin hena Israel wicaśtayatapi kin okiyaka ece.

13 Unkan heya, Ho po tukten yanka iwanyaka po, hecen yewicawayc ca mduze kta. Unkan okiyakapi, qa, Dotan en yanka, eyapi.

14 Unkan śuktanka, qa canpahmihma, qa ozuye tanka yewicaśi. Unkan hanyen ipi, qa otonwe kin aohduteyapi.

15 Unkan wakan wicaśta taokiye najin kta hankikta, qa inanpa: Unkan inyun ozuye wan otonwe kin ihduksan wanka; nakun śuktanka, qa canpahmihma. Unkan tahokśidan heciya, He he he, itancan, token econkupi kta he?

16 Unkan heya, Thnuhan wakoyakipe cin: Unkiye om unpi kin hena, iye om unpi isanpa otapi ce.

17 Unkan Eliśa cekiye ca heya, Jehowa ceciciya, iśta kin yuzamni ye, hecen wanyake ista. Unkan Jehowa hokśidan iśta kin yuzamni ; unkan wawanyaka, qa inyun he kin Eliśa ihdukśan peta canpahmihma, qa śuktanka on ojudan.

18 Unkan apámahde Eliśa ekta hipi. Unkan Jehowa cekiye ca heya, Ceciciya, oyate kin de iśtagonga wicaya ye. Unkan Eliśa oie kin iyecen iśtagonge wicaya.

19 Unkan Eliśa hewicakiya, Canku kin dee śni, qa otonwe kin dee śni. Mihakam upo, hecen wicaśta ayakitapi kin ekta aciyapi kta. Unkan Samaria ekta awicaya.
20 Unkan Samaria en ipi qehan, Eliśa heya, Jehowa dena iśtapi kin wanna wicakiciyumdaya ye, hecen wanyakapi kta. Unkan Jehowa iśtapi kin wicakiciyumdaya, unkan wanyalkapi, qa inyun Samaria cokaya unpi.

21 Unkan Israel wicaśtayatapi kin hena wanwicayake cehan Eliśa heciya, Wicawakaśtake kta he? Ate wicawakaśtake kta he?

22 Unkan heya, Wicayakaśtake kte śni. Tuwe isan nitawa on, qa itazipa nitawa on wayaka iyacu kin he yakaśtake kia he? Aguyapi qa mini wicitokam ehde wo, hecen wotapi qa wayatkanpi kta, qa itancan tawapi ekta hdapi kta.

23 Unkan wohanpi tanka wicakicaga. Unkan wotapi, qa wayatkanpi, unkan kihde wicaśi ; unkan itancan tawapi ekta hdapi. Unkan Aram ozuye kin Israel makoce en hipi enakiyapi.

24. Unkan hena iyohakam Benhadad Aram wicastayatapi kin obe tawa owasin mniciye wicaya, qa Samaria anatan, qa aonataka.

25 Unkan Samaria ohna nina wicaakihan, inyun aonawicatakapi ecen śonóonna pa wan mazaska wikcemna śahdogan iyohi, qa wakiyedan cesdi miniyatkan ohnaka wanjidan mazaska zaptan on wiyopeyapi.

26 Unkan Israel wicaśtayatapi kin conkaśke amani qehan, winohinca wan hoyekiye ca heya, Nimayan ye, itancan wicaśtayatapi.

27 Unkan heya, Jehowa niniye śni, tokiya tanhan miye niciye kta he? wakapanpi kin etanhan, qaiś hastanhanka iyuśkice kin etanhan.

28 Nakun wicaśtayatapi kin 535 


\section{WICAŚTAYA'TAPI,}

heciya, Taku yaka he? Unkan winyan qon heya, Winohinca kin de hemakiya, Nicinkśi kpagan ye, hecen nakaha unhdute kte, qa heyakecinhan micinkśi unhdute kte ye.

29 Hecen micinkśi unkohanpi, qa untapi ye. Unkan anpetu ihanhanna hewakiya, Nicinkśi kpagian ye, he unte kte ye, tuka iye cinlintku nahma ye.

30 Unkan wicaśtayatapi kin winohinca oie kin nation qehan, taheyake hduhdehdeca, qa conkaśke kin amani; unkan oyate kiı wanyakapi, qa iny un mahen cehpi akan wakihdaka un.

31 Unkan heya, Wakantanka hecen ecamicon, qa nakun de isanpa, Eliśa Sapat cinhintku pa kin anpetu kin de iye akan yanke kte cinhan.

32 Unkan Eliśa iye ti kin ohna yanka, qa hunkayapi kin kici iyotankapi. Unkan vicastayatapi kin itokapatanhan wicaśta wan ohnihde yeśi kin nahanhin ekta hi śni, Eliiśa hunkayapi kin hewicakiya, Tin wicakte cinhintku kin de mapa icu kta tuwe uśi wandakapi he? Wanyakapo, ohnihde hi kinhan tiyopa kin ecen icupo; qa tiyopa ekta sutaya yuzapo. Itancan tawa siha kin iye ihakam bubu śni he?

33 Hena om wohdaka icunhan, inyun wahośi kin, qa wicastayatapi kin iye ekta hi, qa heya, Inyun taku sica kin de Jehowa etanhan u ce. Tokeca Jehowa sanpa awape kta he?

\section{WICOWOYAKE $\%$}

1 Unkăn Eỉśa heya, Jehowa oie kin nation po, Jehowa hecen eya, Heyakecinhan wi kin dehantu Samaria tiyopa ekta ağu- yapi mdu iyutapi wan ŚeqeI wanji wiyopeyani kta, qa barle wiyutapi nonpa Śeqel wan wiyopeyapi kta.

2 Unkan akicitatancan wan nape kin akan wicaśtayatapi kin oziiciye cin he ayupte ca Wakantanka tawicaśta kin heciya, Inyun Jehowa mahpiya en owanyeye kağa unkanś wicoie kin de ecetu kta tuka. Unkan heya, Inyun niye niiśta on wandake kta, tuka hetanhan yate kte śni.

3 Unkan wicaśta topa leprosi ececapi otonwe tiyopa ekta yakonpi, qa hekiciyapi, Tokeca unțapi kte cin hehanyan den unyakonpi he?

4 Otonwe en unyanpi kta unkeyapi kinhan, otonwe mahen wicaakihan, qa hen unțapi kta, qa den unkiyotankapi kinhan unțapi kta; heon wanna ho po, Aram owankapi ekta unyanpi kta, niunyanpi kinhan unnipi kta, qa teunyanpi kinhan untapi kta.

5 Unkan otpaza en najinpi, qa Aram owankapi ekta yapi, qa Aram owankapi ihanke ekta ipi, qa inyun tuwedan hen un śni.

6 Wanna Itancan kin Aram obe kin canpahmihma bu, qa śuktanka hoton ozuye tanka nahon wicaya; heon hekiciyapi, Inyun Israel wicaśtayatapi kin Heti wicaśtayatapi kin, qa Egupton wicaśtayatapi, azuunyanpi kta opewicaton.

7 Heon najinpi, qa anpa śni napapi ; qa tawakeyapi, qa śuktanka tawapi, qa śonśonna tawapi elipekiyapi, owanka ecehna, qa nağipi kin on najicapi.

8 Unkan leprosi ececapi kin wakeya kin ekta ipi, qa owanka ihanke ekta wakeya wanji en ipi, qa wotapi, qa wayatkanpi, qa hetanhan mazaska, qa mazaskazi, 
qa wokoyake icupi, qa iyayapi, qa nahmapi, qa icicawin upi, qa wakeya tokeca wanji en ipi, qa hetanhan icupi, qa yuha iyayapi, qa nahmanpi.

9 Unkan otoiyohi takodaku hekiciyapi, Unkiyepi taku ecetu śni econkupi ; anpetu kin de wotanin waśte anpetu heca, qa unkiyepi inina unyakonpi, qa anpa kamdeza unkapepi kinhan taku śica unkakipapi kta; ho po unyanpi, qa wicaśtayatapi ti lin unkokiyakapi kta.

10 Unkan kupi, qa otonwe tiyopa ekta panpi, qa owicakiyakapi, qa lieyapi, Aram owankapi kin ekta unkipi, qa inyun tuwedan en un śni, qa wicaśta ho kin wanica, tuka śuktanka iyakaśkapi, qa śonśonna iyakaśkapi, qa wakeyapi kin ecehna wanka.

11 Unkan tiyopa awanyakapi kin panpi, qa wicaśtayatapi lin ti kin mahen okiyakapi.

12 Inkan wicaśtayatapi kin hanyen najin, qa taokiye hewicakiya, Wanna Aram token ecaunkiconpi kin ociciyalapi kta. Unkakihanpi kin sdonyapi, heon owanka kin etanhan maǵa ekta inahmanpi kta e iyayapi, qa heyapi, Otonwe etanhan inanpapi kinhan, niyake iyawicunlipayapi, qa otonwe en unyanpi kta.

13 Unkan taokiye wan ayupte ça heya, Tokin śuktanka okaptapi etanhan zaptan icupi kta henana okaptapi, Israel wicota owasin iyecen henana okaptapi, Israel wicota owasin iyecen sotapi, qa hena iwanyag yewicunśipi kten.

14 Unkan canpahmihma śuktanka nonpa icupi, qa wicaśtayatapi kin Aram ozuye kin ihakam yewicaśi, qa heya, Tonwe ya po.

15 Unkan wicihakam iyayapi, Jordan ekta hehanyan. Unkan, iho canku kin ihunniyan wokoyake, qa wakśsica ojudan; hena Aram najicapi en ehpekiyapi. Unkan wahośiye hdipi, qà wicaśtayatapi kin okiyakapi.

16 Unkan oyate kin tankan iyayapi, qa Aram owankapi qon iyalipayapi, hecen aguyapi mdu wiyutapi wan śeqel iyohi, qa Barle wiyutapi nonpa śeqel wanji iyopeyapi, Jehowa eye ciqon iyecen.

17 Unkan wicaśtayatapi kin akicitatancan nape akan oziiciye ciqon, he otonwe tiyopa kin awanyag śi. Uंnkan oyate kin tiyopa kin en amanipi; hecen ta, Wakantanka tawicaśta eye ciqon iyecen, wicaśtayatapi kin iye ekta hi qehan.

18 Wakantanka tawicaśta kin wicaśtayatapi kin eciye ciqon, qa heya, Barle wiyutapi nonpa śeqel wanji iyohi kta, qa ağuyapi mdu wiyutapi wan śeqel wanji iyohi kta, heyakecinhan wi kin dehantu Samaria tiyopa kin ohna, eye ciqon he ecetu.

19 Unkan akicita tancan qon Wakantanka tawicaśta kin ayupte ca heciya, Jehowa mahpiya cn owanyeye kagga unkanś wicoie kin de ecetu kta tuka. Unkan heya, Ito niye niiśta on wandake kta, tuka hetanhan yate kte śni.

20 Unkan iyecen iye akipa, oyate kin tiyopa en amanipi, unkan ta.

\section{WICOWOYAKE 8 .}

1 Unkan Eliśa winohinca cinhintku niye ciqon kici wohdake ca heya, Najin, niye qa tiohnaka nitawa, qa tukten oyakihi hen yanka wo, Jehowa wicaakihan wan uśi, qa hi kta, makoce akan, waniyetu śakowin. 


\section{WICAŚSTAYATAPI,}

2 Unkan winohinca qon najin, qa Wakantanka tawicaśta kin eye cin iyecen econ, qa iye, qa tiyohnaka tawa kin iyayapi, qa Pilistim tamakocepi kin ohna waniyetu śakowin yankapi.

3 Unkan waniyetu śakowin ihanketa winohinca kin Pilistim tamakocepi kin etanhan hdi, qa tipi tawa, qa mağa tawa on wicaśtayatapi kin hoyekiye kta e ekta $\dot{i}$.

4 Unkan wicaśtayatapi kin Wakantanka wicaśta tawa tahokśidan qon Gehazi kici wohdaka, qa heya, Iho wicohan tanka Eliśa econ kin owasin omakiyaka wo.

5 Unkan token hokśidan te cin nikiye cin wicaśtayatapi kin okiyake cin icunhan, inyun winohinca cinlnintku nikiye cin he iye ti kin on, qa tamaga on wicaśtayatapi kin hoyekiya. Unkan Gehazi heya, Itancan wicaśtayatapi winohinca kin dee, qa cinhintku Eliśa niye cin dee.

6 Unkan wicaśtayatapi kin winohinca iwanġa ; unkan okiyaka. Unkan wicaśtayatapi kin alkicita wan winolinca kici yeśi, qa heciya, Taku tawa kin owasin kicu wo, nakun tamagia taku aicage cin owasin anpetu ehpekiye ciqon ehantanhan ecen dehanyan.

7 Unkan Eliśa Damaskos ekta i. Unkan Benhadad Aram wicaśtayatapi kin wayazanka. Unkan okiyakapi qa heyapi, Wakantanka tawicaśta kin den hi ce.

8 Unkan wicaśtayatapi kin Hazael heciya, Taku yaqu kta ninape en icu wo, qa Wakantanka tawicaśta akipe kta ya wo, qa iye on Jehowa iwanga wo, wowayazan kin de etanhan amakisni kta hecinhan.

9 Unkan Ḣazel akipe kta iyaya, qa taku qu kta nape en icu, taku waśte Damaskos ohna un kin iyuhpa, camo wikcemna topa tawaqinpi, qa ekta i qa itokam najin, qa heya, Nicinkśi Benhadad Aram wicaśtayatapi niye elita umaśi, qa, Wowayazan kin de etanhan amasni kta he? eya.

10 Unkan Eliśa heciya, Hda qa heciya wo, Arvicakehan yani kta; tuka awicakehan te kta Jehowa wanyag makiya.

11 Unkan ite kin opahta najin ecen iśteca. Unkan Wakantanka tawicaśta kin ceya.

12 Unkan Hazael heya, Tokeca itancan mitawa ceya he? Unkan heya, Taku śica I rael cinca kin ecawicayecon kta sdonwaya. Conkaśke tawapi kin ide yaye kta, qa kośka kahnigapi kin isan on wicayakte kta, qa śicecapi kin wicayakaśtake kta, qa winohinca ihduśaka tawapi bawicayasdece kta.

13 Unkan Hazael heya, Tuka tokeca nitaokiye taku tanka kin de econ kta, sunka heca he? Unkan Eliśa heya, Niye Aram iwicayadake kta Jehowa sdonye makiya ce.

14 Unkan iyaya, Eliśa etanhan, qa itancan tawa ekta i. Unkan heciya, Eliśa taku eniciya he? Unkan heya, Awicakehan yani kta, emakiya ce.

15 Unkan ihanhanna śina śoka onśpa icu, qa minin oputkan, qa ite akan kamdaya. Unkan ta. Unkan heekiya Hazael wawidaka.

16 Joram Ahab cinhintku Israel iwicadake cin waniyetu izaptan kin en, Jehośapat Juda idake cin icunhan Joram Jehośapat cinhintku Juda iwicadaka.

17 Iye waniyetu wikcemna yamni sanpa nonpa hehan tokaheya wawidaka, qa waniyetu śahdogan Jerusalem ohna wawidaka. 


\section{WICOWOYAKE 9 .}

18 Qa Israel wicaśtayatapi kin tacankupi kin omani, Aliab tiyohnaka econpi kin iyecen, Ahab cunwintku kin yuza nakaś, qa taku śica Jehowa iśta kin en econ.

19 Tuka Jehowa iye taokiye Dawid on, Juda ihangya wicada śni, iye qa cinca kin petijanjan wicaqu kta anpetu owasin eciye ciqon iyecen.

20 Iye taanpetu icunhan Edom Juda nape kin kipajin, qa wicaśtayatapi wan icicagapi.

21 Unkan Joram Tzayir ekta iyaya, canpahmihma kin owasin om, qa hankikta qehan Edom iye. ihdukśan yakonpi kin wicakaśtaka, nakun canpahmihma itancanpi kin; tuka oyate kin tawakeyapi kin ekta najicapi.

22 Hecen Edom Juda nape kin etanhan ihduśka, anpetu kin dehanyan; hehan Libna nakun kipajin.

23 Unkan Joram ohan unman, qa taku econ kin owasin Juda wicaśtayatapi anpetu oie wowapi kin en owapi śni he?

24 Unkan Joram hunkakewicaya om iśtima, qa hunkakewicaya om hnakapi, Dawid totonwe ohna; unkan heekiya cinhintku Ahazia wawidaka.

25 Joram Ahab cinhintku Israel idake cin, waniyetu wikcemna sanpa inonpa kin en, Ahazia Joram cinhintku Juda idaka.

26 Ahazia waniyetu wilkcemna nonpa sanpa nonpa qehan toka wawidaka, qa waniyetu wanjidan Jerusalem en wawidaka, qa hunku caje kin Atalia Omri Israel wicaśtayatapi cunwintku kin.

27 Qa Ahab tiyohnaka canku kin ohna omani, qa Jehowa iśta kin en taku sica econ Aliab ti lin iyecen. Ahab wicowazi kin tahan wicaya nakaeś.
28 Unkan Joram Ahab cinhintku Hazael Aram wicaśtayatapi kin kize kta Gileyad Paha kin ekta zuya iyaya. Unkan Arami kin Joram opi.

29 Unkån wicaśtayatapi kin Joram Aram wicaśtayatapi kici Paha kin ek ta kicizapi Aram opi kin okiziyapi kte Jezreel en hdi. Unkan Ahazia Joram cinhintku, Juda wicaśtayatapi kin, Joram Ahab cinhintku wayazanka on Jezreel en wanyake kta e apamahde i.

\section{WICOWOYAKE 9.}

1 Unkan Eliśa waayate kin waayate cincapi kin wanji kico, qa heciya; Nite ipiyag kiton, qa ninape ohna wihdi janjan kin de icu, qa Gileyad paha ekta ya wo.

2 Qa hen yai, qa Nimśi cinhintku Jehośapat cinhintku Jehu hen wandake cinhan, ekta yai kta, qa hunkawanji wicaye cin wicehna tanhan najin yaye ca owanka tipi mahetuya wan en yeyaye kta.

3 Hehan wihdi janjan kin icu, qa pa kin akaśtan wo; qa heciya wo, Jehowa hecen eya, Israel idake kta e sdaciya ce; hehan tiyopa kin yuhdoka qa najica wo. Ihnuhan owanji nayajin kin.

4. Unkan kośka kin waayate tahokśidan kin Gileyad paha kin elita iyaya.

5 Unkan ekta i qehan, akicita tancanpi kin hen iyotankapi. Unkan heya, Akicita tancan wicoie wan eciciye kta. Unkan Jehu heya, Unkiyepi owasin etanhan tukte $e$ he? Unkan, Niye, itancan, eya.

6 Unkan najin, qa tipi mahen i. Unkan wihdi kin pa kin akaśtan, qa heciya, Jehowa Israel wa539 


\section{WICAŚSTAYATAPI,}

kandapi kin hecen eya, Jehowa taoyate Israel iwicayadake kta, sdaciya ce.

7 Qa Aliab itancan nitawa tiyohnaka kin yakaśtake kta, hecen mitaokiye waayatapi wepi kin, qa Jehowa taokiye owasin wepi kin Jezebel nape kin etanhan towecon kta.

8 Hecen Ahab tiyohnaka kin owasin atakuni kte śni. Unkan tona Ahab tawa wica owasin, nakun tona onatakapi, qa Israel ohna okaptapi kin hena ihang wicawaye kta.

9 Qa Alab tiyohnaka Jeroboyam Nebat cinhintku tiyohnaka kin iyecen wakağe kta, qa Bayaśa Ahija cinhintku tiyohnaka kin iyecen.

10 Qa śunka Jezebel yutapi kta, Jezreyel makoce kin ohna, tuwedan hnake kte śni; eye ca tiyopa yukdoke ca najica.

11 Unkan Jehu itancan tawa taokiye ekta inanpa ; unkan wanji heciya, Wookiye he? 'Tokeca wacinhnuni kin he en nihi he? Unkan hewicakiya, Niyepi wicaśta kin sdonyayapi, oie kin nakun.

12 Unkan heyapi, Hecetu śni. Tho unkokiyaka po. Unkan heya, Decen qa decen emakiya, qa heya, Jehowa hecen eya, Israel iwicayadake kta sdaciya ce.

13 Ünkan inahinipi, qa otoiyohi śina ehdaku, qa ihukuya yumdaya ekihnakapi, caniyadipi akan, qa he yahotonpi, qa heyapi, Wicaśtayatapi kin Jehu hee.

14 Hecen Jehu Jehośapat cinhintku he Nimśi cinhintku kin Joram kipajin. Unkan Joram, qa Israel owasin Gileyad paha kin awanyakapi, Hazael Aram wicaśtayatapi kin on etanhan.

15 Qa Joran wicaśtayatapi kin Hazael Aram wicaśtayatapi kin kici kicizapi en, Arami opi kin okiziyapi kta e Jezreyel en hdi wanka. Unkan Jehu heya, Niye hecen wacinduzapi kinhan, Jezreyel ekta okiyake kta tuwedan otonwe kin etanhan najice kte śni.

16 Unkan Jehu canpahmihma en iyotanke ca Jezreyel ekta iyaya, Joram hen yanka nakaeś. Unkan Ahazia Juda wicaśtayatapi kin Joram wanyake kta e heci hi.

17 Unkan waawanyake wan tipi ipasotka akan najin, Jezreyel ohna, qa Jehu taobe kin wanyaka, upi icunhan, qa, Obe wan wanmdaka ce, eya. Unkan Joram heya, Śuktanka akan iyotanka wan itkowicakipe yeśi po; qa, Wookiye he? eye kta.

18 Uinkan śuktanka akan iyotanke kin itkokipa iyaya, qa heya, Wookiye he? wicaśtayatapi kin eya. Unkan Jehu heya, Wookiye en taku iyoniwaja he? Mihektam ihduhomni wo. Unkan waawanyake kin oyaka, qa heya, Wahośi ekta wicai, tuka ku śni.

19 Unkan śuktanka akan yotanka inonpa yeśi. Unkan ekta wicai qa heya, Wookiye he? wicaśtayapi kin eya ce. Unkan Jehu, Wookiye en taku iyoniwaja he? Mihektam ihduhomni wo, eya.

20 Unkan waawanyake kin oyaka, qa, Wahośi ekta wicai tuka ku śni ce. Qa kahapapi kin Jehu Nimśi cinhintku kahape cin iyececa, witkotkoya kahapa nakaeś.

21 Unkan Joram heya, Canpahmihma koyagya wo. Unkan ikoyagyapi. Unkan Joram Israel wicaśtayapi kin, qa Aliazia Juda wicaśtayatapi kin otoiyohi canpahmihma tawa en iyayapi, .Tehu itkokipapi kta, qa Nabot 


\section{WICOWOYAKE 10.}

Jezreyeli kin tamagia qon ekta akipapi:

22 Unkan Joram Jehu wanyake cehan heya, Wookiye he? Jehu? Unkan heya, Nihun Jezebel wiinahmapi kin, qa wapiyapi kin nina ihduota kin hehanyan taku wookiye he?

23 Unkan Joram nape kin hduhomni qa napa, qa Aliazia heciya, Ahazia wokipajin dee.

24 Unkan Jehu token okihi itazipa ecate ca Joram tahpa ekta o, qa wahinkpe kin cante kin kakpaiyeya. Unkan canpahmihma ohna ihpaya.

25 Unkan taakicita itancan Bidqar heciya, Yuwankan icu, qa Nabot Jezreyeli tamagia en ehpeya wo. Miye qa niye sakim atkuku A hab canpahmihma ohna ihakam unkiyaya qehan, Jehowa woyake cin de okiyaka, kiksuya wo. 26 Jehowa heya; Awicakehan Nabot we kin, qa cinhintku wepi kin htanihan wanmdaka, qa magga kin de ekta niye en towecon kta, Jehowa eya, heon yuwankan icu, qa maǵa kin den elipeya wo; Jehowa oie kin iyecen.

27 Unkan Ahazia Juda wicaśtayatapi kin wanyake çehan maġa ti canku kin ohna napa. Unkan Jehu kuwa iyaya, qa heya, $\mathrm{He}$ nakun. Unkan canpahmihma akan opi, Gur itanwankahde yapi ekta, he Jibleyam ikiyadan. Unkan Megiddo ekta najica, qa hen ta.

28 Unkan taokiye Jerusalem ekta canpahmihma olına ayapi, qa ohnahnakapi tawa en hnakapi, hunkakewicaya om, Dawid totonwe ohna.

29 Unkan Joram Alab cinhintku waniyetu wikcemna sanpa, tokaheya wawidake cin en, Ahazia Juda idaka.
30 Unkan Jehu Jerreyel ekta ki; unkan Jezebel he nalion; qa iśta kin śaya, qa pa kin pikiya, qa. owanyeye etanhan eyokasin.

31 Qa Jehu otonwe tiyopa mahen hi qehan heciya, Zimri itancan kikte kin wookiye yuha he? 32 Unkan owanyeye kin ekta wankan etonwan, qa heya, Miciti kin tuwe he? Unkan yunukos nonpa qaiś yamni ahiyokasinpi.

33 Unkan heya, Kun ehpeya po. Unkan kun ehpeyapi; hecen we kin tipi conkaśke kin akastaka, śunktanka nakun. Unkan winyan kin akan ahanpi.

34 Unkan iyaya, qa wota qa wayatkan, hehan heya, Ho po, winohinca yaśicapi kin he ode, qa hnaka po, he wicaśtayatapi wan cunwintku nakaeś.

35 Unkan hnakapi kta iyayapi, tuka nasuhu, qa siha, qa napcoka heceedan iyeyapi.

36 Unkan hdipi, qa okiyakapi. Unkan heya, Jehowa oic, taokiye Elija Tiśbi nape on eye cin dee, Jezreyel makoce kin ohna śunka kin Jezebel cehpi kin yutapi kta.

37 Qa Jezebel tancan te cin Jezreyel makoce ohna tacesdi magia akan iyecece kta; hecen Jezebel dee eyapi kte śni.

\section{WICOWOY:AKE 10.}

1 Unkan Ahab cinca kin wikcemna śakowin Samaria ohna yakonpi, unkan Jehu wowapi kag̉a, qa Israel itancanpi kin hunkayapi kin, qa Aliab cinca icaliwicayapi kin Samaria ekta wahowicaye ca heya,

2 Wowapi kin de nicahipi kinhan, itancan nitawa cinhintku niyepi om unpi, qa canpahmihma, qa śuktanka duhapi, nakun otonwe aconkaśkeyapi, qa wipe. 


\section{WICAŚTAYATAPI,}

3 Itancan nitawapi cinca wicehna tuwe waśte qa ecetu iwanyakapo, qa atkuku toiyotanke akan iyotarng kiyapo, qa itancan nitawapi ti kin on kizapo.

4 Tuka ninahin kokipapi, qa heyapi, Inyun wicaśtayatapi nonpa itokam najinpi śni, token unkiyepi naunjinpi kta?

5 Unkan tipi kin itancan kin, qa otonwe itancan kin, qa hunkayapi kin Jehu wahoyapi, qa heciyapi, Unkiyepi nitaokiye heuncapi, qa taku unkeyeciyapi kin owasin econkupi kta. Tuwedan wicaśtayatapi unkagapi kte śni, taku niiśta kin en waśte econ wo.

6 Unkan inoupa wowapi wicakicağa qa heya, Mici yatipi, qa maho nayahonpi kte cinhan, itancan nitawapi cinca wica papi kin icupo, qa heyakecinhan wi kin dehantu Jezreyel ekta en maupo. Wanna wicaśtayatapi cinca kin wicaśta wikcemna śakowin otonwe wicaśta tanka icahwicayapi om yakonpi.

7 Unkan wowapi wicakahipi qehan wicaśtayatapi cinca kin iwicacupi, qa wicaśta wikcemna śakowin wicaktepi, qa papi kin mankanopiye en iyeyapi, qa ekta yeyapi, Jezreyel ekta.

8 Unkan wahośi wan en hi, qa okiyaka qa heya, Wicaśtayatapi cinca papi kin wanna ahipi ce; unkan heya, Ihanhanna hehanyan otonwe tiyopa ekta hena paha nonpa ehdepo.

$9 \mathrm{Qa}$ ihanlianna inampa, qa ekta najin, qa oyate kin hewicakiya, Niyepi ohan oniwotannapi. Inyun miye itancan mitawa wakipajin qa wakte, tuka tuwe dena owasin wicakte he?

10 Dehan sdonyapo, Jehowa oie, Jehowa Aliab ti kin aie cin, wanjidan makata hinhpaye kte 542 śni, qa Jehowa taku taokiye Elija nape on eye ciqon he econ ce, eya.

$11 \mathrm{Qa}$ Jehu Ahab tiyohnaka Jezreyel ohna okaptapi kin hena owasin wicakaśtaka; nakun wicaśta tanka tawa owasin, qa koda wicaya, qa wawayuśna tawa owasin, ecen tuwedan okicicap̉e śni.

12 Hehan najin Samaria ekta iyaya, qa tahepi tahinca yuśdapi tipi ekta i.

13 Hehan Ahazia Juda wicaśtayatapi kin sunka wicaya awicakipe ca, Nituwepi he, eya. Unkan, Áliazia sunkaku heuncapi, qa wicaśtayatapi cinca kin, qa wicaśtayatapiwin cinca kin wookiye ewicunkiyapi kta on apamanhde unyanpi, eyapi.

14 Unkan, Niyake iyawicalipayapo, eya; unkan niyake wicayuzapi, qa wicaśta wikcemna topa sanpa nonpa wicaktepi, wayuśdapi tipi miniowe kin ekta, hena etanhan wanjidan okapte śni.

15 Unkan hetanhan iyaye ca Jonadab Rekab cinhintku itkokim akipa, qa yawaśte qa heciya, Micante nicante kici un kin iyecen, nicante kin ecetu he? Unkan Jonadab, Han hecetu, heon ninape maqu wo, eya. Unkan nape kin qu, qa icahda canpahmihma akan iyotang kiya.

$16 \mathrm{Qa}$, Mici u wo, qa Jehowa on mamniheca wanyaka wo, eye ca canpahmihma tawa en iyotangkiya.

17 Unkan Samaria ekta ipi, qa Samaria ohna tona Aliab tawa Samaria en okaptapi owasin wicakaśtaka ecen ihang wicaya; Jehowa oie Elija eciye ciqon iyecen.

18 Unkan Jehu oyate owasin mniciye wicaya qa hewicakiya, 
Ahab Bayal kitanna ókiya, tuka Jehu nina ókiye kta.

19 Heon wanna Bayal wayate kin owasin, qa taokiye owasin, qa wawayuśna tawa owasin miye ekta wicakicopo. Ihnuhan wanjidan en hi śni. Wośnapi tanka wan Bayal wecağa, tuwe hi śni kin ni kte śni. Tuka Jehu wohnaye on hecon; Bayal taokiye ihang wicaye kta heon.

20 Unkan omniciye wakan Bayal kicaggapo, Jehu eya; unkan eyanpahapi.

21 Unkan Jehu Israel owancaya wahowicaya, hecen Bayal taokiye owasin hipi, wicaśta hi śni wanjidan okapte śni. Unkan Bayal tipi tawa en hipi, qa Bayal tipi tawa kin ojudan ihanke wanji etanhan ihanke unman ekta.

22 Unkan wokoyake kin yuhe cin heciya, Bayal taokiye owa$\sin$ on wokoyake wicaqu wo. Unkan wokoyake wicaqu.

23 Unkan Jehu, qa Jonadab Rekab cinhintku Bayal ti kin en ipi, qa Bayal taokiye hewicakiya, Akitapi qa iwanyakapo, Bayal taokiye heceedan den dukanpi, okini Jehowa taokiye wanji niyepi om den yanka.

24. Unkan wośnapi, qa wahulinahyapi kag̉api kta en ipi. Unkan Jehu wicaśta wikcemna śahdoğan hen tankan najin wicaśi, qa heya, Wicaśta ninapepi en hiyuwicawaye cin tuwe hena etanhan wanji nikiye cinhan, iye nagi unman naği on kajuju kta.

25 Unkan wohulinaliyapi kin hulnaliya yuśtanpi qehan, Jehu wainyankapi kin, qa akicita kin hewicakiya, En yapi, qa wicakaśtakapo, wicaśta wanjidan tankan lii kte śni. Unkan wainyankapi kin, qa akicita kin isan hi on wicakaśtakapi, qa tankan ehpewicayapi, hehan Bayal tipi otonwe kin ekta ipi.

26 Qa Bayal tipi kin wakagapi kin tankan hiyuyapi, qa hulinaliyapi.

27 Unkan Bayal wakaggapi kin pajujupi, qa Bayal ti kin pajujupi, qa he unkce tipi kagapi, anpetu kin dehanyan.

28 Hecen Jehu Israel etanhan Bayal ihangya.

29 Tuka Jeroboyam Nebat cinhintku woahtani on Israel wahtani wicaye cin hena etanhan Jehu ihduwinge śni, mazaskazi ptejicadan Betel ohna, qa Dan ohna owicape cin etanhan.

30 Unkan Jehowa Jehu heciya, Tanyan ecanon, qa taku miiśta en ecetu ecanon, micante owasin iyecen Ahab tiyolinaka kin ecawicayecon, heon nicinca kin Israel oiyotanke kin akan iyotankapi kta, wicoicagge topa.

31 T'uka Jehu Jehowa Israel Wakandapi toope kin omani kta cante ocowasin on waktaya un śni, tuka Jeroboyam woahtani kin, Israel wahitani wicaye cin, etanhan ihduwinge śni.

32 Anpetu kin hena en Jehowa tokaheya Israel ihanke kin wicakicicaśpa, qa Hazael Israel makoce ihanke owasin en wicakaśtaka.

33 Jordan etanhan wihinanpe cin ektakiya, Gileyad makoce kin ocowasin, Gadi kin, qa Rubeni kin, qa Manaśi kin Aroyer, Arnon wakpa kin ekta yanke cin etanhan Gileyad qa Baśan ek ta hehanyan.

34 Unkan Jehu oie unman, qa taku econ kin owasin, qa towaśake owasin Israel wicaśtayatapi anpetu oyakapi wowapi kin en owapi sni he?

35 Hehan Jehu hunkakewicaya om iśtiman, qa Samaria ohna 


\section{WICAŚTAYATAPI,}

hnakapi, qa heekiya cinhintku Jehoahaz wicaśtayatapi un.

36 Qa anpetu Jehu Samaria ohna Israel iwicadakc cin.waniyetu wikcemna nonpa sanpa śahdogian.

\section{WICOWOYAKE 11.}

1 Unkan Atalja Ahazia hunku kin iye cinlintku te cin wanyake cehan, najin, qa wicaśtayatapi cinca kin owasin wicakte.

2 Tuka Jehośeba Joram wicaśtayatapi cunwintku Aliazia tawinohtin Joaś Aliazia cinhintku kin wicaśtayatapi cinca wicehna tanhan wicaktepi qehan nahmana icu, iye qa azinkiye cin, qa owanka tipi ohna nawicahma, Atalja etanhan, hecen he ktepi śni.

3 Qa winyan kin kici Jehowa ti kin ohna inahma waniyetu śakpe, unkan Atalja makoce kin idaka.

4 Unkan waniyetu iśakowin Jehojada akicitatancanpi kin pabaksapi kin, qa wainyankapi kin iyahna wahowicaye ca wicakico, qa Jehowa ti kin mahen liyuwicaya, qa wotakuye wicakicaga, qa Jehowa ti kin ohna Taku Wakan namation eye wicakiya, qa wicaśtayatapi cinhintku wicakipazo.

5 Qa wahokonwicakiye ca heya, T'aku ecanonpi kte cin dee. Aupetu okihpapi eca tona en yaupi ecee yamni kiyuśpeya yaupi kta, ośpaye wanji wicaśtayatapi ti kin awandakapi kta.

$6 \mathrm{Qa}$ wanji Sur (inanpapi) tiyopa kin ekta, qa wanji tiyopa wainyankapi kin ihektam yanke cin ekta, sutaya tipi kin awandakapi kta.

7 Qa anpetu okihpapi en inanpapi kin owasin, ośpaye nonpa Jehowa tipi tawa wicaśtayatapi kin on awanyakapo.
8 Qa wicaśtayatapi kin ihdukśan nayajinpi kta, wicaśta otoiyohi tawipe nape kin ohna hduhe kta, qa tuwc kaśta ocimdagahan najinpi imahen hiyu kinhan ktepi kta. Qa wicaśtayatapi kin tankan ya, qa en hdi eca oyapapi kta.

9 Unkan akicita itancan kin Jehojada wawayuśna kin taku econwicaśi owasin econpi, qa otoiyohi wicaśta tawa yuha hipi, anpetu okilipapi on hipi kin hena, qa anpetu okihpapi en inanpapi kin sakim, qa Jehojada wawayuśna kin elk ta hipi.

10 Unkan wawayuśna kin akicita itancan kin wahuleza, qa wahacanka wicaqu, hena wicaśtayatapi Dawid tawa gon, qa Jehowa tipi tawa ohna yanka.

11 Unkan wainyankapi kin otoiyoli nape ohna wipe hduha wicaśtayatapi kin ihdukśan najinpi, tionaptan etapatanhan, tionaptan catka aiyahdeya, wahnawośnapi qa tipi ihdukśan.

12 Unkan wicaśtayatapi cinhintku kin tankan hiyuya, qa wateśdake kin pa akan ehnake ca wayaatanin qu, qa wicaśtayatapi kağa, qa sdaya; unkan nape hdaskapapi, qa, Wicaśtayatapi kin ni nunwc, eyapi.

13 Unkan Atalja oyate panpi ho kin nakon qehan, oyate kin ekta Jehowa ti kin en hi.

14 Unkan etonwe ca inyun wicaśtayatapi kin wayaco owanka akan najin, token econpi kin iyecen, qa akicitatancan, qa mazayahotonpi wicaśtayatapi kin ikiycdan, qa maknce oyate kin wiyuśkinpi, qa mazayahotonpi on yahotonpi kin wanyake cehan, Atalja taheyake hdulidehideca, qa, Wokipajin, wokipajin, eya.

15 Unkan Jehojada wawayuśna kin akicitatancan obe yuhapi 
kin wahokonwicaye ça hewicakiya, Ocimdagiahan najinpi kin itankan iyayeyapo, qa tuwe ihakam ye cinlian isan on ktepo, Jehowa ti kin ohna teyapi kte śni, wawayuśna kin eya. nakaeś.

16 Unkan oyanke kicağapi, unkan winyan hin śuktanka wicaśtayatapi ti kin ekta yapi, canku kin en $\mathrm{i}$, qa hen ktepi.

17 Unkan Jehojada wotakuye wan Jehowa, qa wicaśtayatapi kin, qa oyate kin wicakicaga. Oyate kin Jehowa taoyatepi kta, qa wicaśtayatapi kin oyate kin kicica.

18 Unkan makoce oyate kin owasin Bayal ti kin ekta ipi, qa y ujujupi wahnawośnapi tawa, qa wakagapi tawa kamdecapi ocowasin, qa Mattan Bayal wawayuśna tawa kin ktepi wahnawośnapi tawa icahda. IInkan wawayuśna kin Jehowa ti kin on waa wanyake ewicahde.

19 Qa akicitatancanpi kin, qa pabaksapi kin, qa wainyankapi kin, qa makoce oyate kin owasin iwicacu. Unkan wicaśtayatapi kin Jehowa ti kin etanhan wainyankapi tatiyopa canku kin ohna wicaśtayatapi ti kin ekta apamahde hiyayapi. Unkan wicaśtayatapi toiyotanke akan kiyotanka.

20 Unkan makoce oyate owasin wiyuśkinpi, qa otonwe kin iyozi, qa Atalja isan on ktepi wicaśtayatapi ti kin en.

21 Joaś waniyetu śakowin hehan toka wawidaka.

\section{WICOWOYAKE 12.}

1 Jehu wawidake cin waniyetu iśakowin en, Joaś wawidaka, qa waniyetu wikcemna topa Jerusalem ohna wicaśtayatapi un, qa hunku Ziba eciyapi, Berśeba etanhan.

2 Qa Joaś Jehowa iśta kin en taku ecetu econ, tohanyan Jehojada wawayuśna kin onspe kiya anpetu owasin.

3 Tuka paha kin yujujupi śni, oyate kin nahanhin paha akan wayuśnapi qa wizinyapi ece.

4 Unkan Joaś wawayuśnapi kin hewicakiya, Mazaska wakanyapi kin Jehowa ti kin en ahipi kin, wicayawapi nagipi kin on mazaska kin, qa oyakapi mazaska kin, owasin cante iyokipiya wicaśta otoiyohi Jehowa ti en ahi kin,

5 Wawayuśnapi icupi kta, otoiyohi tuwe iyekiye cin etanhan, qa tipi kin onśpaśpa yujujupi kin piyapi kta, tuktee kaśta oyujuju wan iyeyapi kinhan.

6 Tuka Joaś wawidake cin waniyetu wikcemna nonpa sanpa yamni hehanyan tipi kin oyujuju kin piyapi śni.

z Unkan wicaśtaya tapi kin Joaś Jehojada wawayuśna kin, qa wawayuśna unmanpi kin wicakico, qa hewicakiya, Tokeca tipi kin oyujuju kin niyepi piyayapi śni he? Heon detanhan ihnuhan tona sdonwicayayapi kin etanhan mazaska iyacupi kin; he tipi kin piyapi kta e yaqupi lita.

8 Unkan wawayuśnapi oyate etanhan icupi kte śni, qa tipi oyujuju kin iye piyapi kte śni wicadapi.

9 Unkan Jehojada wawayuśna kin can koka wan icu, qa iha kin en ohdoka wan kaga, qa wabnawośnapi kin icahda ehnaka, wicaśta tuwe Jehowa ti kin en ye cin etapa ekta ; unkan wawayuśna tiyopa awanyakapi kin mazaska Jehowa ti en ahipi kin owasin hen iyeyapi. 


\section{WICAŚTAYATAPI,}

10 Qa can koka kin ohna mazaska ota wanyakapi qehan, wicaśtayatapi wowapikaga tawa kin, qa wawayuśna itancan kin kici ekta i, qa mazaska Jehowa ti en iyeyapi kin yawapi, qa pahitapi.

11 Qa mazaska yawapi kin wicaśta wohtani econpi kin napepi kin en qupi, Jehowa ti kin awanyakapi kin hena, cankajipa, qa ticagapi, Jehowa ti kin piya kagapi kin hena ekta he yeyapi.

12 Qa Jehowa ti kin, tukten kamdecapi qon piya kagapi kta e, can qa inyan kakanpi opetonpi kta e wicaśta inyan kakanpi qa inyan ehnakapi kin wicaqupi.

13 Tuka Jehowa tipi tawa on mazaska wakśica, qa petijanjan iyukse, amnimnipi wakśica, mazayahotonpi, mazaskazi wikicanye, qa mazaska wikicanye kagapi śni, mazaska Jehowa tipi tawa en hiyuyapi on.

14 Tuka he Jehowa tipi tawa piyapi kta e wohtani econpi kin he wicaqupi.

15 Qa wicaśta mazaska pamnipi, qa wohtani wicakicicajujupi kin hena ecetuya olianyanpi, heon awanwicayakapi śni.

16 Onhdajuju mazaska kin, qa woahtani wośnapi mazaska kin he wawayuśnapi kin tawapi, heon he Jehowa tipi tawa kin en hiyuyapi śni.

17 Hehan Aram wicaśtayatapi kin Hazael Gat anatan, qa kiza, qa icu, qa Hazael ite kin Jerusalem ektakiya hduhomni, anatan kta e.

18 Unkan Joaś Juda wicaśtayatapi kin taku wakanyapi, hunkake wicaya Jehośapat, qa Joram, qa Ahazia Juda wicaśtayatapi kin wakanyapi kin owasin, qa taku iye yuwakan, qa mazaska Jehowa ti mazopiye en, na546 kun wicaśtayatapi ti kin en iyeyapi kin owasin icu, qa Hazael Aram wicaśtayatapi kin, qu; unkan Jerusalem etanhan kihda.

19 Unkan Jouś ohan uman, qa taku econ kin owasin, hena Juda wicaśtaya tapi anpetu oyakapi wowapi kin en owapi śni he?

20 Unkan taokiye najinpi, qa kipajinpi qa Sila ekta apamanhde yapi kin Millo ti ekta kaśtakapi.

21 Hecen taokiye Jozakar Śímat cinhintku, qa Jozabad Śomer cinhintku kaśtakapi, qa ktepi, qa hunkakewicaya om hnakapi; Dawid totonwe ohna. Unkan heekiya cinhintku Amatzia wawidaka.

\section{WICOWOYAKE 13.}

1 .Joaś Ahazia cinhintku Juda wicaśtayatapi kin waniyetu wikcemna nonpa sanpa yamni en, Johoahaz Jehu cinhintku Samaria ohna toka Israel iwicadaka, qa waniyetu wikcemna sanpa śakowin wawidaka.

2 Qa Jehowa iśta kin en taku śica econ, Jeroboyam Nebat cinhintku woalitani kin Israel wahitani wicaye cin opa, hena etanhan ihduwinge śni.

3 Unkan Jehowa tocanniye kin Israel aide, heon Ḣazael Aram wicaśtayatapi nape kin en, qa Benhadad Hazael cinhintku nape kin en, anpetu tawapi kin owasin wicaqu.

4 Unkan Jehoahaz Jehowa ite kin cekiya, unkan Jehowa Israel toiyokiśice Aran wicaśtayatapi iyọkiśin wicaye cin wanyaka, heon nakithon.

5 Qa Jehowa Israel wanikiya wan wicaqu, qa Aram nape etanhan ewicahdaku. Unkan Israel tawakeyapi ohna ounyanpi, tannina gon iyecen. 
6 Tuka Jeroboyam ti woahtani kin Israel wahtani wicaye cin etanhan ihduhomni śni, tuka en omanipi, qa Aśeri Samaria ohna yanka.

7 Hecen śuktanka akanyotankapi wikcemna zaptan qa canpahmihma wikcemna qa wicaśta huinyun kektopawinge wikcemna henana Jehoaliaz okicaptapi ; Aram wicaśtayatapi kin ihang wicaya, qa watuśekśeca amanipi kin iyecen wicakaga nakaeś.

8 Unkan Jehoahaz ohan unman, qa taku econ kin owasin, qa towaśake kin, hena Israel wicaśtayatapi anpetu oyakapi wowapi kin en owapi śni he?

9 Unkan Jehoahaz hunkake wicaya om iśtima, qa Samaria ohna hnakapi, qa eekiya cinhintku Joaś wawidaka.

10 Joaś Juda iwicadaka waniyetu wikcemna yamni sanpa iśakowin en, Joaś Jehoahaz cinhintku Israel iwicadaka, Samaria ohna, qa waniyetu wikcemna sanpa sakpe wawidaka.

11 Qa Jehowa iśta kin en taku śica econ, Jeroboyam Nebat cinhintku woahtani Israel wahtaniwicaye cin wanjidan etanhan ihduhomni śni, hena omani.

12 Joaś ohan unman, qa taku econ owasin, qa towaśake on Amatzia Juda wicaśtayatapi kin kize cin, hena Israel wicaśtayatapi anpetu oyakapi wowapi kin en owapi śni he?

13 Unkan Joaś hunkakewicaya om iśtima, qa Samaria ohna hnakapi; Israel wicaśtayatapi_om; unkan toiyotanke akan Jeroboyam iyotanka.

14. Unkan Eliśa wowayazan on țe cin wayazankả, unkan Joaś Israel wicaśtayatapi kin ekta i, qa ite akan ceye ça heya, Ate, ate, Israel tacanpahmihma, qa śuktanka akan iyotankapi tawa.

15 Unkan Eliśa heciya, I tazipa qa wanhinkpe icu wo. Unkan itazipa qa wanhinkpe ikikcu.

16 Unkan Eliśa wicaśtayatapi kin heciya, Ninape on itazipa ecata wo. Unkan nape kin on ecata. Unkan Eliśa iye nape on wicaśtayatapi nape kin akan aputaka.

17 Qa.heya, Wi hinape cin ektakiya owanyeye kin yuhdoka wo. Unkan yulidoka. Unkan Eliśa heya, Kute wo. Unkan kute. Unkan Jehowa towanikiye wahinkpe kin hee, qa Aram etanhan wanhinkpe niwicaye cin, qa Apeq ohna. Aram yakaśtake kta ecen dusote kta.

18 Qa wanhinkpe icu, eya, unkan icu, unkan Israel wicaśtayatapi kin heciya, Makata kaśtaka wo; unkan yamni akihde kaśtake ca enakiya.

1y Unkan Wakantanka tawicaśta kin canniyeya, qa heya, Zaptan qaiś śakpe akihde yakaśtake kta tuka, unkanś Aram yakaśtake kta ecen dusote kta tuka. Tokata yamnina akihde Aram yakaśtake kta.

20 Unkan Eiliśa ta, unkan hnakapi. Unkan waniyetu ihanketa Moab ozuye kin makoce en hipi.

21 Unkan wicaśta wan hnakapi icunhan inyun ozuye kin wanyakapi, qa wicaśta kin Fliśa ohnahnakapi kin en ehpeyapi. Unkan iyohi, qa wicaśta Eliśa huhu kin icahtake cehan kini, qa siha akan najin.

22 Unkan Hazael Aram wicaśtayatapi kin Israel iyokiśin wicaya, Jehoahaz anpetu tawa owasin.

23 Unkan Jehowa onśiwicakida, qa wotakuye Abraham, qa 


\section{WICAŚSTAYATAPI,}

lzak, qa Jakob om heon ihduhomni, qa cantewicakiya, qa ihang wicaya wicada śni, qa dehanyan ite kin etanhan elipewicaye śni.

24 Unkan Hazael Aram wicaśtayatapi kin ta, qa eekiya cinhintku Benhadad wawidaka.

25 Unkan Joaś Jehoahaz cinhintku otonwe iye atkuku Jehoahaz nape kin etanhan wokicize en icupi qon, hena ake ikikcu, Hazael cinhintku Benhadad nape etanhan, yamni akihde Joaś ohiye ca Israel otonwe ehdaku.

\section{WICOWOYAKE 14.}

1 Joaś Jehoahaz cinhintku Israel iwicadaka waniyetu inonpa kin en Amatzia Joaś cinhintku Juda iwicadaka.

2 Waniyetu wikcemna nonpa sanpa zaptan qehan toka wawidaka, qa waniyetu wikcemna nonpa sanpa napcinwanka Jerusalem en wawidaka, qa hunku Joadan eciyapi, Jerusalem etanhan.

3 Qa taku ecetu Jehowa iśta kin en econ, tuka atkuku Dawid iyecece śni, atkuku Joaś econ kin owasin iyecen econ.

4 Tuka paha kin yutokanpi śni, oyate kin nahanhin paha akan wayuśnapi, qa wizinyapi ecee.

5 Unkan towidake sutaya yuze cehan taokiye, atkuku wicaśtayatapi kin kaśtakapi kin hena, wicakaśtaka, tuka kaśtakapi cincapi hena wicakte śni.

6 Mowis toope wowapi en owapi kin Jehowa econśi qa, Ateyapi kin cincapi on te wicayapi kte śni, qa cincapi kin iye ateyapi on te wicayapi kte śni. Tuwe țe yapi kinhan iye walitani kin on țe yapi kta, eye cin iyecen.

7 Iye miniskuya osmaka en 548
Edom kaśtaka kektopawinge wikcemna, qa wokicize on Selah (Imnija kin) icu, qa Joktel (Jehowa ohiya) eciya, anpetu kin dehanyan.

8 Hehan Amatzia wahośi Joaś Jehoahaz cinhintku Jehu cinhintku Israel wicaśtaya tapi kin ekta ye wicaśi, qa heya, Iho wicitkokim wanunkiciyake kta.

9 Unkan Joaś Israel wicaśtayatapi kin, Amatzia Juda wicaśtayatapi kin waḷoye ça heciya, Wapepeka Lebanon ohna icage cin hanteśa Lebanon ohna wahoye ça heya, Nicunkśi micinkśi yuze kta qu wo. Unkan contanka wamanica wan Lebanon en yanke cin hiyuye ça wapepeka kin amani.

10 Awicakehan Edom yakaśtaka, qa nicante niyuwankantuya. Ihdatan, qa yati kin en yanka wo. Tokeca taku śica en iyoniçipaśtake kta, qa nilicahe kta, niye, qa Juda nicica?

11 Tuka Amatzia nahon śni. Unkan Joaś Israel wicaśtaya tapi kin itanwankahde i, qa iye qa Amatzia Juda wicaśtayatapi kin Betśemeś Juda tawa kin ohna itkokim wankiciyakapi.

12 Unkan Israel itokam Juda kaśtakapi, qa najicapi, otoiyohi tawakeya ekta.

13 Unkan Joaś Israel wicaśtayatapi kin Amatzia Joaś cinhintku Alazia cinhintku Juda wicaśtayatapi kin wayaka icu Betśemeś ohna, hehan Jerusalem ekta i, qa Jerusalem conkaśke yujuju, wiciśpa opawinge topa, Epraim tiyopa kin etanhan kahmin tiyopa kin aiyahdeya.

14 Qa mazaskazi, qa mazaska owasin, qa wakśica Jehowa ti kin en iyeyapi owasin icu, nakun wicaśtayatapi tipi tawa mazopiye en, qa wicaśta kaśka wicaqupi 


\section{WICOWOYAKE 15.}

kin iwicacu, qa Samaria ekta hda.

15 Qa Joaś ohan unman econ kin, qa towaśake, qa token Amatzia Juda wicaśtayatapi kizé cin, hena Israel wicaśtaya tapi anpetu oyakapi wowapi kin en owapi śni he?

16 Unkan Joaś hunkake wicaya om iśtima, qa Israel wicaśtayatapi om Samaria ohna hnakapi, qa heekiya cinhintku Jeroboyam wawidaka.

17 Unkan Joaś Jehoahaz cinhintku Israel wicaśtayatapi kin te cin iyohakam, Amatzia Joaś Juda wicaśtayatapi cinhintku waniyetu wikcemna sanpa zaptan ni.

$18 \mathrm{Qa}$ Amatzia ohan unman Juda wicaśtayatapi anpetu oyakapi wowapi kin en owapi śni he?

19 Unkan Jerusalem ohna kipajinpi ; unkan Lakiś ek ta najica. Unkan Lakiś ekta kuwa ipi, qa hen ktepi.

$20 \mathrm{Qa}$ śuktanka qin kiyapi, Jerusalem ekta, qa hunkakewicaya om hnakapi, Dawid totonwe ohna.

21 Unkan Juda wicaśta owasin Azaria icupi, iye waniyetu wikcemna sanpa śakpe, qa atkuku Amatzia eekiya wicaśtayatapi kağapi.

22 Iye, wicaśtayatapi kin hunkake wicaya om iśtima iyohakam, Elat kaga, qa ake Juda he yuhe kiya.

23 Amatzia Joaś cinhintku Juda idake cin waniyetu wikcemna sanpa zaptan kin en, Jeroboyam Joaś Israel wicaśtayatapi cinhintku Samaria ohna wawidaka, waniyetu wikcemna topa.

$24 \mathrm{Qa}$ taku śica Jehowa iśta kin en econ, Jeroboyam Nebat cinhintliu woahtani Israel wa- hitani wicaye cin wanjidan etanhan ihduwinge śni.

25 Iye Israel makoce kin ekicetu, Hamat ekta yapi canku kin aiyahdeya; Jehowa Israel wakandapi oie kin iyecen, he Jona Amittai cinhintku wayate Gat Heper etanhan nape on eye cin iyecen.

26 Jehowa Israel toiyokiśica pa hinca e wanyaka, aconkaśkayapi wanica, qa ihduhapi wanjidan okaptapi śni, qa tuwedarn Israel ókiye śni.

27 Tuka Jehowa Israel caje kin mahpiya ihukuya tanhan pajuju kta eye śni, heon Jeroboyam Joaś cinhintku nape kin on niwicaya.

28 Unkan Jeroboyam olian unman, qa taku econ kin owasin, qa towaśake on ozuye kaga, qa Damaskos, qa Hamat Israel on Juda etanhan ekicetu, hena Israel wicaśtayatapi anpetu oyakapi wowapi kin en owapi śni he?

29 Qa Jeroboyam hunkake wicaya om iśtima, Israel wicaśtayatapi kin om, qa eekiya cinhintku Zakaria wawidaka.

\section{WICOWOYAKE 15.}

1 Jeroboyam Israel idake cin waniyetu wikcemna nonpa sanpa śakowin en, Azaria Amatzia cinhintku Juda idaka.

2 Waniyetu wikcemna sanpa śakpe hehan toka wawidaka, qa waniyetu wikcemna zaptan sanpa nonpa Jerusalem ohna wawidaka, qa hunku Jekolija (Jehowa okihiya) eciyapi, Jerusalem etanhan.

3 Qa taku Jehowa iśta kin en ecetu econ, atkuku Amatzia econ qon owasin iyecen.

4 Tuka paha kin yutokanpi śni, 


\section{WICAŚTAYATAPI,}

oyate kin nahanhin paha akan wayuśnapi, qa wizinyapi ece.

5 Unkan Jehowa wicaśtayatapi kin apa, heon leprosi ececa, anpetu en te cin hehanyan, qa wayazankapi tipi kin ohna yar$\mathrm{ka}$, qa wicaśtayatapi cinhintku Jotam makoce oyate kin wicayaco, qa tipi kin itancan un.

6 Unkan Azarija (Jehowa okiya) olian unman, qa taku econ kin owasin, Juda wicaśtayatapi anpetu oyaliapi wowapi en owapi śni hel?

7 Unkan Azarija hunkake wicaya on iśtima, qa hunkake wicaya om hnakapi, Dawid totonwe ohna, qa eekiya cinhintku Jotam (Jehowa owotanna) wawidaka.

8 Azarija Juda idake cin waniyetu iwikcemna yamni sanpa śahdogan en Jeroboyam cinhintku Zakarija, (Jehowa kiksuye cin) toka Israel idaka, Samaria ohna wi śakpe.

9 Qa taku śica Jehowa iśta kin en econ, hunkake wicaya econpi qon iyecen, Jeroboyam Nebat cinhintku woahtani Israel walitani wicaye cin etanhan ihdamna śni.

10 Unkan Śallum Jabeś cinhintku he kipajin, qa oyate wicitokam kaśtake ca țe kiya, qa eekiya wawidaka.

11 Unkan Zakarija ohan unman hena Israel wicaśtayatapi anpetu oyakapi wowapi kin en owapi śni he?

12 Jehowa oie Jehu eciye ciqon dee; Nicinca wicoicage icitopa kin Israel oiyotanke kin akan iyotankapi lita, eya; unkan ecetu.

13 Uzzija (Jehowa towaśake) Juda idake cin waniyetu wikcemna yamni sanpa napcinwanka en Śllum Jabeś cinhintku toka wawidaka, qa wi wanji anpetu iyenaka Samaria en wawidaka.

14 Unkan Menahem Gadi cinhintku Tirtza etanhan Samaria ekta itanwankahde i, qa Śallum Jabeś cinhintku kaśtaka Samaria ohna, qa te kiya, qa eekiya wawidaka.

15 Qa Śallum ohan unman, qa wokipajin on kipajin kin, hena Israel wicaśtayatapi anpetu oyakapi wowapi luin en owapi ce.

16 Hehan Menahem Tipsa kaśtaka, qa tona ohna yakonpi, qa nakun tamakoce ohna Tirtza aiyahdeya, tiyopa kiciyuhdokapi śni, heon winohinca ihduśaka ohna unpi kin owasin wicakaśtake ca bawicasdeca.

17 Azarija Juda idake cin wanIyetu wikcemna yamni sanpa uapcinwanka en Menahem Gadi cinhintku toka Israel idaka, Samaria ohna, qa waniyetu wikcemna sanpa nonpa wawidaka.

$18 \mathrm{Qa}$ taku śica Jehowa iśta kin en econ; tohanyan ni kin Jeroboyam Nebat cinhintku woahtani Israel wahtani wicaye cin etanhan ihduhomni śri.

19 Pul Aśur wicaśtayatapi kin makoce kin azuya ; unkan Menahem Pul mazaska woqin kektopawinge qu, ókiye kta, qa iye nape kin en wokiconze yusuta kta heon.

20 Qa Menahem Israel mazaska kin mnaye wicakiya, Aśur wicaśtayatapi qu kta e, wicaśta waśaka wijica otoiyohi mazaska śeqel wikcemna zaptan hiyuye kiya. Hecen Aśur wicaśtayatapi kin kilada, qa makoce kin en yanke śni.

21 Unkan Menahem ohan unman, qa taku econ kin owasin, hena Israel wicaśtayatapi anpetu oyakapi wowapi kin en owapi śni he? 


\section{WICOWOYAKE 16.}

$22 \mathrm{Qa}$ Menahem hunkake wicaya om iśtima, qa eekiya cinhintku Peqahja wawidaka.

23 Azarija Juda idake cin waniyetu wikcemna zaptan kin en, Peqahja Menahem cirhintku toka Israel idake ca Samaria olna waniyetu noupa wawidaka.

24 Qa taku śica Jehowa iśta kin en econ, Jeroboyam woahtani Israel wahtani wicaye cin etanhan ihduhomni śni.

25 Unkan Peqah Remalija cinhintku akicitatancan tawa kin kipajin, qa Argob, Arje, qa Gileyad cinca wicaśta wikcemna zaptan om, Samaria ohna kaśtakapi wicaśtayatapi tipi tawa conkaśke kin ohna, qa te kiya, qa heekiya wawidaka.

26 Unkan Peqahja ohan unman, qa taku econ kin owasin hena Israel wicaśtayatapi anpetu oyakapi wowapi kin en owapi ce.

27 A zarija Juda idake cin waniyetu iwikcemna zaptan sanpa nonpa kin en, Peqah Remalija cinhintku Israel toka idaka, Samaria ohna, qa waniyetu wikcemna nonpa wawidaka.

28 Qa taku śica Jehowa iśta kin en econ, woahtani Jeroboyam Israel walitani wicaye cin etanhan ihduhomni śni.

29 Peqah Israel idake cehan Tiglat Pileser Aśur wicaśtayatapi hiyu, qa Yijon, qa Abelbetmayaka, qa Janoah, qa Qedeś, qa Hatzor, qa Gileyad, qa Galile Naptali makoce kin ocowasin icu, qa Aśur ekta wayaka awicaya.

30 Unkan Hośeya Ela cinhintku kin Peqah Remalija cinhintku kipajin, qa kaśtake ca te kiya, qa eekiya- wawidaka, Uzzija cinhintku Jotam waniyetu rvikcemna nonpa wawidake cin en.

31 Unkan Peqah ohan unman, qa taku econ kin owasin hena Israel wicaśtayatapi anpetu oyakapi wowapi en owapi ce.

32 Peqah Remalija cinhintku Israel idake cin waniyetu inonpa kin en, Jotam Uzzija cinhintku toka Juda idaka.

33 Waniyetu wikcemna nonpa sanpa zaptan qehan toka wawidaka, qa waniyetu wikcemna sanpa śakpe Jerusalem ohna wawidaka, qa hunku Jeruśa Zadok cunwintku eciyapi.

34 Qa taku ecetu Jehowa iśta kin en econ, atkuku Uzzija econ qon owasin iyecen.

35 Tuka paha kin yutokanpi śni. Oyate kin nahanhin paha akan wayuśnapi ece, qa wizinyapi ece. Tye Jehowa ti tiyopa wankantu kin he kagia.

36 Unkan Jotam ohan unman, qa taku econ kin owasin, hena Juda wicaśtayatapi anpetu oyakapi wowapi kin en owapi śni he?

37 Anpetu kin hena en Jehorva Rezin Aram wicaśtayatapi, qa Pegah Remalija cinhintku Juda anatan wicaya.

38 Unkan Jotam hunkakewicaya om iśtima, qa hunkakewicaya om hnakapi, atkuku Dawid totonwe ohna, qa heekiya cinhintku Aliaz (wiyuha) wawidaka.

\section{WICOW OYAKE 16.}

1 Peqah Remalija cinhintku wawidake cin waniyetu wikcemna sanpa śakowin kin en, Alaz Jotam cinhintku wawidaka.

2 Aliaz waniyetu wikcemna nonpa qehan toka wawidaka, qa waniyetu wikcemina sanpa śakpe Jerusalem ohna wawidaka, qa taku ecetu iye wakanda Jehowa iśta kin en econ śni, atkuku Dawid econ qon iyecen. 


\section{WICAŚTAYYTAPI,}

3 Tuka Israel wicaśtayatapi tacankupi kin omani qa nakun cinhintku peta ehna iyayekiya, Ikcewicaśta Jehowa Israel cinca itokapa tanhan hamwicaya, wowalite śni econpi qon iyecen.

4 Qa paha akan wayuśna, qa wizinya ece, nakun pajodan owasin akan, qa can wapatoto yukan owasin ihnkuya.

5 Hehan Rezin Aram wicaśtayatapi, qa Peqah Remalija cinhintku Isiael wicaśtayatapi kin Jerusalem azuyapi, qa Ahaz a onatakapi, tuka ihangyapi okitpanipi.

6 Hehan Rezin Aram wicaśtayatapi kin Elat Aram on eyaku, qa Juda Elat etanhan nape wicaya; unkan Arani kin Elat ekta ipi, qa anpetu kin dehanyan hen iyotankapi.

7 Unkan Ahaz wahośi Tiglat Pileser Aśur wicaśtayatapi kin ekta ye wicaśi, qa heciya, Nitaokiye, qa nicinkśi hemaca, kuwa qa nimayan wo, Aram wicaśtayatapi nape kin etanhan, qa Israel nape kin etanhan, hena anamajinpi nakaeś.

8 Unkan Ahaz mazaska, qa mazaskazi Jehowa ti kin en iyeyapi kin, qa wicaśtayatapi ti mazopiye en iyeyapi kin icu, qa Aśur wicaśtayatapi kin ekta yekiya qa qu. 9 Unkan Aśur wicaśtayatapi kin anagoptan, qa Aśur wicaśtayatapi kin Damaskos azuya, qa icu, qa Qir ekta wayaka aya, qa Rezin te kiya.

10 Unkan wicaśtayatapi Aliaz Tiglat Pileser Aśur wicaśtayatapi kin nape yuze kta Damaskos ekta i, qa wahnawośnapi Damaskos ohna yanke cin wanyaka, qa wicaśtayatapi Ahaz wahnawośnapi ouncage kin Urija wawayuśna kin ekta yeya, qa token kagapi kin owasin.
11 Unkan wawayuśna kin Urija wahnawośnapi wan kaga; wicaśtayatapi kin Aliaz Damaskos etanhan wahoye cin owasin iyecen, Urija wawayuśna kin kağa, wicaśtayatapi kin Ahaz Damaskos etanhan hdi śni itokam.

12 Unkan wicaśtayatapi kin Damaskos etanhan hdì, qa wicaśtayatapi kin wahnawośnapi kin wanyaka, qa wicaśtayatapi kin wahnawośnapi kin ikiyedan i, qa akan wośna.

13 Qa woliulinahyapi tawa, qa minha tawa on izinya, qa wokaśtan tawa kaśtan, qa wopida wośnapi yuhe cin we kin wahnawośnapi kin akan amnimni.

$14 \mathrm{Qa}$ mazazi wahnawośnapi kin Jehowa itokam yanke cin tipi kin itokapatanhan icu, wahnawośnapi kin, qa Jehowa ti kin otahedan etanhan, qa wahnawośnapi icahrla ehde, waziyata ekta kiya.

$15 \mathrm{Qa}$ wicaśtayatapi kin Alaz Urija wawayuśna kin wahokonkiye ca heciya, Wahnawośnapi tanka kin akan hanhanna wohuhnahyapi kin, qa minha kin, qa htayetu wohulinahyapi kin, qa wicaśtayatapi wohuhnahyapi tawa, minha tawa, qa makoce oyate owasin wohuhnaliyapi tawapi, qa minha tawapi, qa wokaśtan tawapi izinyaye kta, qa wohuhnahyapi we kin owasin, qa wośnapi we kin owasin amnimniyaye kta, qa mazazi wahnawaśnapi kin wimong $\mathrm{kta}$ e mduhe kta.

16 Unkan Urija wawayuśna kin token wicaśtayatapi Ahaz econ śi kin owasin iyecen econ.

17 Unkan wicaśtayatapi kin Ahaz oahe iyuskite kin hena baśpa, qa hena akapatanhan wakśica kin icu, qa cegga tanka kin mazaśa tatanka kin akan yanke 


\section{WICOWOYAKE $1 \%$.}

cin hena etanhan kun icu, qa inyan owanka wan akan ehde.

$18 \mathrm{Qa}$ anpetu okihpapi omani awakeyapi kin tipi kin kicagapi qon, qa wicaśtayatapi tankan omani kin Jehowa ti kin ekta yuhdogya, Aśur wicaśtayatapi kin on etanhan.

19 Unkan Ahaz ohan unman econ kin hena Juda wicaśtayatapi anpetu oyakapi wowapi kin en owapi śni he?

20 Unkan Ahaz hunkake wicaya om iśtima, qa hunkakewicaya om hnakapi, Dawid totonwe ohna, qqa cinhintku Hezekiya (Jehowa waśagya) heekiya wawidaka.

\section{WICOWOYAKE 17.}

1 Aliaz Juda idake cin, waniyetu wikcemna sanpa nonpa kin en, Hośeya Ela cinhintku Samaria ohna Israel idaka, qa waniyetu napcinwanka wawidaka.

2 Qa taku śica Jehowa iśta kin en econ, tuka Israel wicaśtayatapi iye itokam unpi qon iyececa śni.

3 Śalmanezer Aśur wicaśtayatapi kin he anatan; unkan Hoseya wowidake içiçu, qa taku qu.

4 Tuka Aśur wicaśtayatapi kin Hośeya ell wokipajin iyeya, he wahośiye Figupta wicaśtayatapi kin, So ekta yewicaśi, qa Aśur wicaśtayatapi takudan kai śni nakaeś, waniyetu otoiyohi econ kta iyececa; heon Aśur wicaśtayatapi kin aonataka, qa wicakaśka tipi en kaśka hnaka.

5 Aśur wicaśtayatapi kin makoce kin owancaya azuya, qa Samaria ekta lii, qa waniyetu yamni aonataka!

6 Hośeya wawidake cin waniyetu inapcinwanka en Aśur wicaśtayatapi kin Samaria icu, qa
Israel wayaka awicaya, Aśur ekta, qa Halah, qa Ḧabor wakpa icahda Gozan en iyotang wicakiya, qa Madai otonwe kin hena ohna.

7 Takomni Israel cinca Jehowa iye wakandapi kin, qa Egupta makoce kin etanhan itanwankahde uwicaye cin, Paro Egupta wicaśtayatapi nape kin ihukuya tanhan, awahtanipi, qa taku wakan tokeca ohodapi.

8 Qa Ikcewicaśta Jehowa Israel cinca kin wicitokapatanhan napewicaye cin hena wokage tawapi omanipi, qa nakun Israel wica-. śtayatapi wokage tawapi en.

9 Qa Israel cinca kin Jehowa wakandapi kin taku ecetu śni nahmana ecakiconpi, qa otonwe tawapi owasin en paha içicaggapi, waawanyake tacowahe etanhan otonwe conkaśkayapi aiyahdeya. 10 Qa wakagapi, qa Aśerim icicagapi, paha pajodan owasin akan, qa can ape toto owasin ihukuya.

11 Qa hen paha owasin akan wizinyapi, Ikcewicaśta wicitokapatanhan Jehowa hamwicaye ciqon iyecen, qa wicoie śica econpi on Jehowa śihdayapi.

12 Qa wakagapi ohodapi; Wicoie kin de ecanonpi kte śni, Jehowa ewicakiya tuka.

13 Tuka Jehowa waayate qa wawanyakapi owasin napepi kin on Israel, qa Juda wicakiyatanin, qa heya, Niohanpi śica etanhan ihduhomnipo, qa woahope mitawa, qa wokage mitawa opapo, woope nihunkakepi ope wicawaśi kin ocowasin iyecen, qa mitaokiye waayate napepi on wahociyapi kin iyecen.

14. Tuka nahonpi śni, qa tahu patinpi ; hunkake wicayapi Jehowa wakandapi kin wicadapi śni qon tahupi kin iyecen. 


\section{WICAŚTAYATAPI,}

15 Qa wokagie tawa, qa wotakuye hunkakepi om kage ciqon, qa woyaatanin wicayaatanin kin hera ihaktapi śni, qa taku śni opapi, qa ihdutakupi śni, qa Ikcewicaśta wicihdukśan yakonpi kin opapi. Hena iyecen econpi kte śni Jehowa kewicakiya tuka.

$16 \mathrm{Qa}$ Jehowa wakandapi kin tawoahope owasin ayuśtanpi, qa wakağapi śdoyapi içicağapi, ptejicadan nonpa, qa Áśeri kag̣api, qa makpiya obe kin owasin ektakiya patujapi qa Bayal ohodapi.

17 Qa iye cinhintkupi, qa cunwintkupi peta ehna iyayewicayapi, qa wapiyapi on wokcanpi, qa waajijipi, qa taku śica Jehowa iśta kin en econpi kta, qa śihdayapi kta e wiyopeiciyapi.

18 Unkan Jehowa Israel nina canniye wicaya, qa ite kin etanhan iyaye wicaya, Juda wicoun heceedan okapta.

19 Juda nakun .Jehowa Wakandapi kin tawoahope kin opapi śni, tuka Israel wokagge yuhapi kin omanipi.

20 Heon Jehowa Israel cinca kin ow asin ehpewicaya, qa iyokiśin wicaya, qa wawicakipisa napepi en wicaqu, ecen iye ite etanhan iyaye wicaya.

21 Israel Dawid tiyohnaka etanhan ihduśpapi nakaeś, qa Jeroboyam Nebat cinhintku wicaśtayatapi kagapi. Unkan Jeroboyam Israel Jehowa opapi kin etanhan yewicaye ca woahtani tanka wahtani wicaya.

22 Unkan Israel cinca kin Jeroboyam woahtani econ kin owasin omanipi he etanhan ihduhomnipi śni.

23 Ecen Jehowa iye ite itokapa tanhan wicayutokan, ta okiye waayate owasin napepi on eye ciqon iyecen. Hecen Israel tamakocepi etanhan Aśur ekta waya- ka awicayapi, anpetu kin dehanyan.

24 Unkan Aśur wicaśtayatapi kin Babel etanhan, qa Kuta etanhan, qa A wa etanhan, qa Ḣamat etanhan, qa Separwaim etanhan, wicaśta hiyuwicaya, qa Israel cinca eekiya Samaria otonwe ohna iyotang wicaya, unkan Samaria tawayapi, qa otonwe tawa en yakonpi.

25 Unkan tokaheya en iyotankapi qehan Jehowa kokipapi śni, heon Jehowa hena wicehna mnaja hiyuwicaya; unkan hunh wicaktepi.

26 Unkan Aśur wicaśtayatapi okiyakapi qa heyapi; Jkcewicaśta wayaka Samaria otonwe tawa ohna iyotang wicayaya, taku wakan makoce yuthe cin tawoyaco kin sdonyapi śni; heon hena wicchna mnaja hiyuwicaya, qa inyun te wicayapi, taku wakan makoce yuhe cin tawoyaco kin. sdonyapi śni heon etanhan.

27 Unkan Aśur wicaśtayatapi kin ie ca heya; Wawayuśna hetanhan wayaka ayakupi qon wanji heciya ayapo; hecen en kipi, qa iyotankapi kta, qa taku wakan. makoce yuhe cin tawoyaco onspe wicakiyapi kta.

28 Hehan wawayuśna Samaria etanhan awicayapi qon wanji ku, qa Betel en ounyan, qa token Jehowa kokipapi onspe wicakiya ece.

29 Tuka oyate otoiyohi taku wakan icicağapi, qa paha tipi Samaria oyate kin kagapi qon ohna ewicahdepi, oyate otoiyohi otonwe ohna iyotankapi kin ohna. 30 Hecen Babel wicaśta kin Sukkot Benot (cunkśi ohanzihdepi tawapi) kagiapi, qa Kuta wicaśta kin Nergal kagapi, Hamat wicaśta kin Aśima kaggapi.

31 Qa Awi kin Niblaz qa Tar- 


\section{WICOWOYAKE 18.}

tak kag̉api, qa Separwi kin Adra. melek qa Yanamelek Separwi wakandapi kin on, iye cincapi peta en guwicayapi.

32 Hecekcen Jehowa kokipapi ece, qa tuwe taninśni kin etanhan paha wawayuśnapi icicaggapi, hena wośnapi wicakicağapi ece, paha tipi kin ohna.

33 Jehowa kokipapi ece, qa taku iye wakandapi kin ókiyapi ece, Ikcewicaśta etanhan hiyuwicayapi woyaco tawapi iyecen.

34 Anpetu kin dehanyan wanakaja wayacopi kin iyecen econpi ece, Jehowa kokipapi śni, qa wokagie, qa woyaco, qa woope, qa woahope Jehowa Jakob Israel cajeyate cin cinca kin econ wicaśi kin iyecen econpi śni.

35 Hena Jehowa wotakuye wicakicage ca hewicakiya, Taku wakan tolkeca kowicayakipapi kte śni, qa wicitokam yapatujapi kte śni, qa ówicayakiyapi kte śni, qa wośnapi wicayecağapi kte śni. 36 Tuka Jehowa Egupta makoce etanhan inanpe niyanpi kin wowaśake tanka, qa isto katin kin on, hee koyakipapi kta, qa ekta yapatujapi kta, qa wośnapi yecagapi kta.

37 Qa wokagie, qa woyaco, qa woope, qa woahope oniciwapi kin iyecen ecanonpi kta e anpetu owasin yapatanpi kta, qa taku wakan tokeca kowicayakipapi kte śni.

$38 \mathrm{Qa}$ wotakuye cicicagapi kin ayektunjapi kte śni, qa taku wakan tokeca kowicayakipapi kte śni.

39 Jehowa wakanyadapi kin koyakipapi kinhan, iye toka niyanpi kin o'vasin etanhan enihdakupi kta.

40 Hecaeśta nahonpi śni, tuka woyaco wanakaja kin iyecen econpi.
41 Unkan oyate kin hena Jehowa kokipapi ece, qa wakagapi ókiyapi ece ; nakun iye cincapi, qa sanpa cincapi kin hunkake wicayapi econpi qon iyecen iye econpi, anpetu kin dehanyan.

\section{WICOWOYAKE 18.}

1 Unkan Hośeya Ela cinlintku Israel iwicadake cin waniyetu iyamni en, Hezekiya Juda idaka. 2 Waniyetu wikcemna nonpa sanpa zaptan qehan toka idaka, qa waniyetu wikcemna nonpa sanpa napcinwanka 'Jerusalem ohna wawidaka, qa hunku Abi Zakarija cunwintku eciyapi.

3 Unkan taku ecetu Jehowa iśta kin en econ, atkuku Dawid taku econ qon owasin iyecen.

4 Iye paha kin yutokan, qa wakagapi kin kamdeca, qa Aśeri kin kawanka, qa mazaśa wamduśka Mowis kagoge ciqon kaksaksa, qa Nehuśtan, (Mazaśadan,) eciya; anpetu kin hehanyan Israel cinca kin he izinyapi ece nakaeś.

5 Iye Jehowa Israel wakandapi kin wacinyan, hecen Juda wicaśtryatapi kin owasin iye ihakam tuwedan iyecece śni, qa nakun iye itokam.

6 Qa Jehowa en ikoyag içiya, qa iye ope cin etanhan ihduhomni śni; tuka tawoahope Jehowa Mowis econśi kin hena patan.

7 Unkan Jehowa he kici un, tokiyakaśta i eca tanyan ilıunni kiya ece. Unkan Aśur wicaśtayatapi kin kipajin, qa ókiye śni.

8 Iye Pilistim wicakaśtaka, Gaza ekta, qa makoce tawapi waawanyake tacowahe, qa otonwe aconkaśkeyapi koya.

9 Unkan Hezekiya wawidake waniyetu itopa kin en, Hośeya Ela cinhintku Israel iwicadaka, waniyetu iśakowin kin hee, Śal- 


\section{IJ. WICAŚSTAYATAPI,}

maneser Aśur wicaśtayatapi kin Samaria anatan qa aonataka.

$10 \mathrm{Qa}$ waniyetu yamni ihanketa he icu; Hezekiya waniyetu iśakpe kin en, he Hośeya lsrael idake cin waniyetu inapcinwanka kin en, Samaria icupi.

$11 \mathrm{Qa}$ Aśur wicaśtayatapi kin Israel wayaka awicaya, Aśur ekta, qa Ḧalah ohna, qa Ḧabor wakpa ikiyedan Gozan ohna, qa Madai otonwe tawapi ohna iyotangwicakiya.

12 Jehowa wakandapi ho kin nahonpi śni, qa wotakuye tawa acakśinpi, Jehowa taokiye Mowis taku econ wicaśi kin owasin nahonpi śni, qa econpi śni, heon etanhan.

13 Unkan Hezekiya wawidake cin waniyetu wikcemna sanpa topa kin en, Sennaherib Aśur wicaśtayatapi kin Juda totonwe cankaśliaynpi kin owasin anatan, qa icu.

14 Unkan Hezekiya Juda wicaśtayatapi kin, Aśur wicaśtayatapi kin Lakiś ekta wahoye ça heciya, Wawahtani, miye etanhan kihda wo. Taku qu mayaśi kin ciçu kta. Unkan Aśur wicaśtayatapi kin mazaska woqin opawinge yamni; qa mazaskazi woqin wikcemna yamni Hezekiya Juda wicaśtayatapi kin quśi.

15 Unkan Hezekiya mazaska Jehowa tipi tawa ohna iyeyapi kin owasin, qa wicaśtayatapi ti mazopiye en iyeyapi kin nakun qu.

$16 \mathrm{He}$ ehan Hezekiya Jehowa ti tiyopa kin, qa ipatan kin etanhan mazaskazi Hezekiya Juda wicaśtayatapi kin apawinta qon baśpaśpa, qa Aśur wicaśtayatapi kin qu.

17 Hehan Aśur wicaśtayatapi kin Tartan, qa Rabsaris, qa Rab- śaqe Lakiś etanhan ozuye tanka om Hezekiya Jerusalem ekta ye wicaśi. Unkan iyayapi qa Jerusalem ekta hipi, qa ikiyedan lipi qehan, mde kagapi wankanwapa kin en hinajinpi, wakpadan iyahde icahda, he canku tanka wayujaja tamaga en un.

$18 \mathrm{Qa}$ wicaśtayatapi kin kipanpi. Unkan Eliakim Ḧilkiya cinhintku tipi kin awanyake cin, qa Śsbna wowapi kagge cin, qa Joah Asap cinhintku wakiksuye cin hena ekta wicaipi.

19 Unkan Rabśaqe hewicakiya, Hezekiya Juda wicaśtayatapi kin heciyapo, Wicaśtayatapi tanka kin Aśur wicaśtayatapi kin hecen eya, "Wowacinye wacinyaye cin de taku hwo?

20 Awicakehan wicaiha oie eha; Kicizapi on wowiyukcan, qa wowaśake yukan. Dehan tuwe wacinyaya on mayakipajin he?

21 Wanna ito cedi wegiahan sagye kin de; Egupton wacinyaya, he wicaśta wan apatan kinhan nape kin en iyaye ca palidoke kta, Paro Egupta wicaśtayatapi kin hececa tona wacinyanpi kin owasin en.

22 Qa Jehowa wakan undapi kin he wacinunyanpi emayakiyapi kinhan; tuwe paha tawa, qa wahnawośnapi tawa Hezekiya yutokan, qa, Wahnawośnapi kin de itokam Jerusalem en ohoyadapi kta, Juda qa Jerusalem ewicakiye cin hee śli he.

$23 \mathrm{Qa}$ wanna itancan mitawa Aśur wicaśtayatapi kin taku on ake yecu kta qu wo, hecanon kinhan śuktanka kektopawinge nonpa ciçu kta, wicaśta hena akan iyotang wicayakiya oyakihi hecinhan.

24 Hecaeśta itancan mitawa, taokiye itancanpi kin iyotan 


\section{WICOWOYAKE 19.}

cistinna wanji ite kin ihdamna yaye kta he? Tuka niye canpahmihma on qa suktanka akan yotankapi on Egupton wacinyaya.

25 Qa nakaha Jehowa codan oyanke kin de pajuju wahi he? Makoce kin deltakpeya, qa ihangya wo; Jehowa emakiya ce. 26 Hehan Eliakim Hilkiya cinhintku, qa Śbna, qa Joah Rabśaqe heciyapi, Ceunniciyapi, Aram iapi en nitaokiye unkokiyapi, he unkiyepi naunhonpi ce. Qa ihnuhan Juda iapi on oyate conkaśke akan yakonpi kin he nahonpi iyae cin.

27 Tuka Rabśaqe hewicakiya, Mayuhe cin niyuhapi, qa niyepi wicoie kin dena eciciyapi kta umaśi he? qa wicaśta conkaśke akan iyotankapi, iye niyepi om cesdi hdutapi kta, qa deje cin hdatkanpi kte cin hena ekta umaśi śni he?

28 Hehan Rabśaqe najinhan najin, qa Juda iapi en hotankakiya hoyeye ca heya, Wicaśtayatapi tanka, Aśur wicaśtayatapi kin oie kin nahonpo.

29 Wicaśtayatapi kin hecen eya ce; Ihnuhan Hezekiya nihnayanpi kin, minape etanhan enihdakupi kta okihi śni nakaeś.

30 Qa ihnuhản Hezekiya Jehowa wacinye niyanpi kin, Awicakehan Jehowa eunhdakupi kta, qa otorıwe kin de Aśur wicaśtayatapi nape kin en qupi kte śni, eya qeyaś.

31 Ihnuhan Hezekiya anayagoptanpi kin. Aśur wicaśtayatapi kin hecen eya ce; Wotakuye micicagapo, qa en maupo, qa otoiyohi hastanhanka iyuwi tawa etanhan, qu suken can tawa etanhan hdute kta, qa mniyowe tawà etanhan otoiyohi hdatke kta.
32 Ecen wahihbu, qa makoce wan aguyapi su, qa hastanhanka iyuwi makoce, can ihdi qa canhanpi tiktica, nitamakocepi kin iyececa ekta aciyapi kta; hecen yanipi kta, qa nițapi kte śni. Tuka ihnuhan Hezekiya anayagoptanpi kin, Jehowa eunhdakupi kta eniciyapi, qa nihnayanpi.

33 Ikcewicaśta taku wakandapi iyohi iye tamakoce kin Aśur wicaśtayatapi nape kin etanhan ehdaku he?

34 Hamat qa Arpad taku wakandapi tokiya unpi he? Separwaim, Hena, qa Iwa, taku wakandapi tokiya unpi he? Minape etanhan Samaria eyakupi he?

35 Makoce kin owasin taku wakandapi kin tukte wanji iye tamakoce kin minape etanhan ehdakupi he, qa token Jehowa Jerusalem minape etanhạ ehdaku $\mathrm{kta}$ ?

36 Unkan oyate kin inina unpi, qa oie wanjidan ayuptapi śni. Wicaśtayatapi kin hecen econwicaśi, qa, Ayuptapi śni po, eye ciqon.

37 Hehan Eliakim Hilkiya cinhintku tipi awanyake cin he, qa Śbna wowapi kağe cin, qa Joah Asap cinhintku wakiksuye cin wokoyake hduhdehdecapi, Hezeliya en hdipi, qa Rabśaqe oie kin okiyakapi.

\section{WICOWOYAKE 19.}

1 Unkan wicaśtayatapi kin Hezekiya nahon qehan wokoyake hduhdeldeca, qa wakihdaka hdowin, qa Jehowa ti kin ekta i.

2 Qa Eliakim tipi awanyake cin, qa Śbna wowapi kage cin, qa wawayuśna hunkayapi kin wakilıdaka hdowin Isaya Amotz 


\section{WICAŚTAYATAPI,}

cinhintku wayate ekta yewicaśi.

3 Unkan heciyapi, Hezekiya hecen eya ce; Nakaha woiyokiśica, qa wośitkihda, qa woiyopeye anpetu kin heca. Hokśiyopa toupi kta wanna iyehantu, tuka inanpe wicayapi kta e wowaśake wanica.

4 Okini Jehowa wakanyada kin Rabśaqe itancan tawa Aśur wicaśtayatapi kin taku wakan ni un kin yaśice kta uśi kin oie owasin nahon kta, qa wicoie Jehowa wakanyada nalion kin on iyopeye kta; heon tona okaptapi en unpi kin on wocekiye hdawankan ewicayeciye kta.

5 Unkan wicaśtayatapi Hezekiya taokiye Isa ya ekta ipi.

6 Unkan Isaya hewicakiya, $\mathrm{Ni}$ yuhapi kin hecen eyakiyapi kta, Jehowa hecen eya, Ihnuhan koyakipe cin, wicoie Aśur wicaśtayatapi tahokśipidan mayaśicapi kin hena nayation kin on.

7 Inyun woniya wan en ye waye kta, qa woyake wan nahon kta, qa tamakoce en hde kta, qa isan on te waye lita, iye tamakoce ohna.

8 Unkan Rabśaqe kihda, qa Aśur wicaśtayatapi kin Libna kize cin ekta ki. Lakiś etanhan iyaye cin he nahon nakaeś.

9 Unkan Tirhaqe Kuś wicaśtayatapi kin, Ito nicize kta u ce, oyakapi kin nakon, heon kihda, tuka wahośi Hezekiya ekta ye wicaśi, qa heya;

10 Hezekiya Juda wicaśtayatapi kin hecen eyakiyapi kta, Ihnuhan taku wakanyada wacinyakiye cin nihnaye cin, qa Jerusalern Aśur wicaśtayatapi nape kin en qupi kte śni, ehe cin.

11 Iho Aśur wicaśtayatapi kin makoce owasin token ecawicakiconpi kin he niye nayahon, hena ocowasin ihangyapi, qa niye enihdakupi kta he.

12 Oyate hunkake wicawaye cin ihangyapi kin hena taku wakandapi ewicahdakupi he? Gozarr, qa Haran, qa Retzep, qa Eden cinca Telasar en unpi qon.

13 Hamat wicaśtayatapi kin tokiya un he? qa Arpad wicaśtayatapi kin, qa Separwaim otonwe, Hena, qa Iwa wicaśtayatapi kin tokiya un he? eya.

14 Unkan Hezekiya wowapi kin wahośiye napepi kin etanhan icu, qa yawa, qa Jehowa ti kin ekta i, qa Hezekiya he Jehowa itoka m yumdaya.

15 Qa Hezekiya Jehowa itokam cekiye ca heya, Jehowa Israel wakandapi, Kerubim oti kin he niye, qa taku wakan tokeca wanica, maka wokiconze owasin en. Niye mahpiya kin, qa maka kin yakaga.

16 Jehowa anolikiye ca nation wo. Jehowa iśta hdukawa, qa wanyaka ye. Senahierib oie kin taku wakan ni un kin yaśice kta e wahoye cin he nation ye.

17 Jehowa awicakehan Aśur wicaśtayatapi kin ikcewicaśta, qa tamakocepi kin hewoskan kagapi.

18 Qa taku waksandapi kin hena peta en ehpeyapi. Hena taku,wakan hecapi śni nakaeś; tuka can, qa inyan wicaśta napepi on kagapi henn hena ihangyapi ce.

19 Heon Jehowa wakan unnidapi nakaha ceciciye, iye nape kin etanhan niunkiya miye. Hecen niye niśnana Wakannitanka maka wokiconze kin owasin sdonyapi kta.

20 Hehan Isaya Amotz cinhintku Hezekiya wahoye ca heya, Jehowa Israel wakandapi kin hecen eya, Wocekiye Senahe- 
rib Aśur wicaśtayatapi kin on emayakiye cin he nawahon.

21. Wicoie iye on Jehowa eye cin dee; Zion cunwintku wiliośka kin walitenida śni, niye nina iniliaha. Jerusalem cunwintku kin niye on pomnamna ce.

22 Daśice ca ośteyahda kin tuwe he? Tuwe itokam ho yawankan iyeyaya, qa iśta yalıduwankantu he? Israel towakan kin hee.

23 Wahośiye nitawa napepi on Itancan kin ośteyahda, qa heha, Canpahmihma ota mitawa en lie paha ekta wahihbu, Lebanon hunaptan kin ekta, qa hanteśa hanska, wazi can kahnigapi kin wakawanke kta. Ihanke tipi kin, Karmel contanka kin ekta mde kta.

24 Miye waqe ca mini tokeca mdatkan; qa misiha sicu kin on otonwe aconkaśkeyapi wakpadan kin owasin oyahe waya, eha.

25 Taku ecamon, qa anpetu ehanna wakagie cin tehantanhan nayahon sni he? Nakaha ecetu wakiya hecen otonwe aconkaśkapi kin hena yujujupi qa otiwota paha hecapi.

26 Heon en ounyanpi kin nape ksahanpi, nihinciyapi, qa wacinhnunipi, tinta peji kin iyececapi, peji tipi awakeyapi akan icagre ça hu kin icağe śni itokam śnija he iyececapi.

27 Tuka miye tukten yati, qa tankan inayapa, qa en yahdi ece kin sdonwaya; nakun token canniyemayaya.

28 Canniyemayaye cin, qa nihdatanka kin hena minoge en iyohpaye cin, heon mazayukśan mitawa nipoge en iyewaye kta, qa iiyuwi mitawa niiha kin en, qa canku ohna hidu qon he ohna hdicuciye kta.

29 Unkan niye wowapetokeca kin de duhe kta. Omaka kin de baksapi qon etanhan taku icage cin yuta wo, qa waniyetin inonpa taku iyecinka icage cin, tuka waniyetu iyamni en wojupi, qa baksapo, qa hastanhanka iyuwi huhde po, qa taku aicage cin yutapo.

30 Qa Juda tiyohnaka etanhan tona nipi, okaptapi kin hena ake hutkan kuya yeyapi kta, qa akapatanhan waskuyeca aicagapi kta.

31 Jerusalem etanhan wookapte wan inanpe kta, Zion he kin etanhan nipi qon hena, Jehowa obe yuhe cin towinawizi kin hecon kta.

32 Heon Jehowa Aśur wicaśtayatapi kin on hecen eya, Otonwe kin de en hi kte śni, qa wanhinkpe wan en yeye kte śni, qa wahacanka apaha najin kte śni, qa maka paha kag̣e kte śni.

33 Canku ohna hiyu qon he ohna ake hde kta; qa otonwe kin de ekta hi kte śni, Jehowa eya ce.

34 Tuka miye on, qa mitaokiye Dawid on otonwe kin de niwaye kta e anawekśin kta.

35 Unkan hanyetu kin he en, Jehowa ohnihde kin iyaye ca Aśur owanka kin ohna wicaśta kektopawinge opawinge qa kektopawinge wikcemna śahdoğan sanpa kcktopawing zaptan wicakaśtaka. Unkan hanlianna kiktapi qehan hena owasin tancan ta wankapi.

36 Hehan Senalierib Aśur wicaśtayatapi kin iyaye ca kihda, qa Ninewe ekta ki.

37 Unkan taku iye wakanda Nisrok ti kin ohna cekiya icunhan, iye cinhintku Adramelek qa Saretzer isan on capapi, qa Ararat makoce kin ekta najicapi, unkan cinhintku Esarhadon eekiya wawidaka. 


\section{WICASTAYATAPI,}

WICOWOYAKE 20.

1 Anpetu kin hena en Hezekiya wayazanka, on te kta. Unkan Isaya Amotz cinhintku waayate kin en hi, qa heciya, Jehowa hecen eya, Yati kin hduwiyeya wo, nițe kta, qa yani kte śni nakaeś.

2 Unkan ite kin tionnaptan ektakiya ihduhomni, qa Jehowa cekiye ça heya,

3 Jehowa ceciciya, token wowicake en, qa cante ecetu hduha nitoka mawani, qa niiśta kin en taku waśte ecamon ece kin he kiksuya ye, eya. Hehan $\mathrm{He}$ zekiya ninahin ceya.

4 Unkan Isaya nahanhin otonwe cokaya inanpe śni qehan, Jehowa oie kin en hi qa heciya;

5 Icicawin ya, qa Hezekiya oyate mitawa mdetanhunka kin heciya wo, Jehowa Dawid ateyaya wakanda kin hecen eya ce; Ceyakiye cin nawahon, qa iśtamnihanpe nitawa wanmdaka. Tho miye okiziciya ce, anpetu iyamni kin en Jehowa ti kin ekta itanwankanhde de kta.

$6 \mathrm{Qa}$ anpetu nitawa kin en waniyetu alkezaptan ecicihnake kta, qa Aśur wicaśtayatapi nape kin e tanhan ecihdaku kta, qa otonwe kin de nakun; qa otonwe kin de anaweksin kta, miye on, qa nuitaokiye Dawid on.

7 Unkan Isaya heya, Suken waskuyeca kaśujapi icupo. Unkan icupi, qa śiyakao akan ehnakapi, heon ni.

8 Wanna Hezekiya Isaya heciye ciqon, Jehowa okizimaye kta, qa anpetu iyamni en Jehowa ti kin ekta itanwankahde mde kta, wowapetokeca tuktee he.

9 Unkan Isaya heciye ciqon, Wicoie kin de Jehowa eye cin iyecen econ kta e Jehowa wo- wapetokeca kin de nicu. Ohanzi kin iyadipi wikcemna tokata ye kta, qaiś iyadipi wikcemna hektam hdicu kta he?

10 Unkan Hezekiya heya, Ohanzi kin iyadipi wikcemna tokata ye kte cin he taku śni: Hiya ohanzi kin iyadipi wikcemna hektam hdicu kte.

11 Unkan Isaya waayate kin Jehowa hoyekiya. Unkan ohanzi kin Aliaz iyadipi tawa akan iyaye cin hektam iyadipi wikcemna hdicuya.

12 Hehan Berodak Baladan, Baladan cinhintku, Babel wicaśtayatapi kin wowapi qa taku qu kin Hezekiya kaye wicaśi, Hezekiya wayazanke ciquon he nahon nakaś.

13 Unkan Hezekiya hena on iyuśkin, qa tipi waśtemna tawa ocowasin wanyag wicakiya, mazaska kin, qa mazaskazi kin, qa taku waśtemna, qa wihdi waśte, qa tawipe tipi kin ocowasin, qa taku mazopiye tawa en iyeyapi kin iyulipa; iye ti kin ohna, qa tośkanśkan owancaya ohna $\mathrm{He}$ zekiya taku wanyag wicakiye .śni wanica.

14 Hehan Isaya waayate kin wicaśtayatapi kin Hezekiya en hi qa heciya, Wicaśta kin hena tokiya tanhan hiyupi, qa taku eniciyapi he? Unkan Hezekiya heya, Makoce tehan tanhan Babel hee etanhan.

15 Unkan, Yati kin ohna taku wanyakapi he, eya. Unkan Hezekiya heya, Wati kin ohna taku owasin wanyakapi mazopiye mitawa ohna taku wanyakapi śni wanica ce.

16 Unkan Isaya Hezekiya heciya, Jehowa oie kin nation wo.

17 Inyun anpetu u kte cin en taku yati ohna iyuhpa taku nihunkakepi anpetu kin dehanyan 


\section{WICOWOYAKE 21.}

kihnakapi kin hena owasin Babel ekta ayapi kta ; takudan okaptapi kte sni.

18 Nakun nicinca wicayecağe ca niye etanhan inanpapi kte cin hena wanjikśi iwicacupi kta, qa Babel wicaśtayatapi ti kin ohna yunukos hecapi kta.

19 Unkan Hezekija Isaya heciya, Jehowa oie ehe cin he waśte ce, wani kin hehanyan wookiye qa wowacinye yuke kte cinhan.

20 Unkan Hezekiya ohan un. man, qa towaśake owasin, qa token mdedan kin, qa wakpadan he iyahde kin hena kag̉e ca mini otonwe en hiyuye cin, hena Ju. da wicaśtaya tapi anpetu oyakapi wowapi kin en owapi śni he?

21 Unkan Hezekiya hunkakewicaya om iśtima, qa heekiya cinhintku Manaśe wawidaka.

\section{WICOWOYAKE 21.}

1 Manaśe waniyetu wikcemna sanpa nonpa qehan toka wawidaka, qa waniyetu wikcemna zaptan sanpa zaptan Jerusalem olna wawidaka, qa hunku Ḧepetziba eciyapi.

2 Qa taku śica Jehowa iśta kin en econ, ikcewicaśta Israel cinca itokapatanhan Jehowa napewicaye cin wowahte śni econpi qon iyecen.

3 Qa paha atkuku Hezekiya pajuju qon, hena iye piya kağa, qa nakun wahnawosnapi wan Bayal ekicihde, qa Aśeri kag̉a, Aliab Israel wicaśtayatapi kage ciqon iyecen, qa mahpiya obe kin owasin ohowicada, qa owicakiya ece.

4 Qa wahnawośnapi Jehowa ti kin ohna kaga; Jehowa he ka qa, Jerusalem ohna micaje kin ewehde kta, eye ciqon.
5 Tuka iye Jehowa ti hocoka nonpa kin ohna mahpiya obe kin owasin wahnawośnapi wicakicag̣a.

6 Qa iye cinhintku peta opta iyaye ya, qa mahpiya on waryata, ya wamduśka on waayata, qa wapiyesa kaga, qa wicahmungesa nakun, hecen Jehowa sinhdaye kta issta kin en taku śica econ nina hduota.

7 Qa Aśsera wakagapi wan iye kagge cin Jehowa ti kin ohna ehde, Jehowa he cajeyate ca Dawid, qa iye cinhin tku Solomon hewicakiye ciqon; Tipi kin den qa Jerusalem Israel wicoun owasin etanhan wakahinige cin, ohna micaje ewehnake kta owihanke wanin.

$8 \mathrm{Qa}$ Israel token econ wicawași kin owasin iyecen, qa woope mitaokiye Mowis ope wicaśi kin ocowasin iyecen econpi kta, waktaya unpi kinhan, maka hunkake wicayapi kin wicawaqu kin etanhari sihapi kin icimana yewaye kte śni.

9 Tuka wanalionpi śni, qa Manaśe nuni wicaya; hecen śicaya econpi, ikcewicaśta Jehowa Israel cinca itokapa tanhan ihang wicaye cin isanpa.

10 Unkan Jehowa taokiye wạayate owasin napepi on ie ca heya;

11 Manaśe Juda wicaśtayatapi kin wowahte śni kin de econ, qa Amori iye itokam taku śica econpi kin owasin iye isanpa econ, heon; qa nakun wakagiapi tawa on Juda wahtani ye cin.

12 Heon Jehowa Tsrael wakanda kin hecen eya, Inyun Jerusalem en taku śica hiyu waye cin on tuwe he nahon kinhan nogie napin snasna kta.

$13 \mathrm{Qa}$ Jerusalem akan Samaria hahonta kin mdutitan kta; na561 


\section{WICAŚTAYATAPI,}

kun Aliab tiyohraka mazasu kin, qa Jerusalem wapakinte kta, wakśica wan pakintapi, qa yuahdapśin iyeyapi kin iyecen.

14 Nakun tawa wicawaya okaptapi kin awicamduśtan kta, qa tokawicayapi napepi en wicawaqu kta, qa tokawicayapi kin wayaka qa wakipi wicayuhapi kta.

15 Taku śica miiśta kin en econpi, qa hunkake wicayapi kin Egupta etanhan hdinanpapi ehantanhan anpetu kin dehanyan śihdamayanpi heon etanhan.

16 Qa nakun Manaśe wicawe taku iyaonpepicaśni nina ota papson ecen Jerusalem owancaya ojudanya iyahna woahtani Juda wahtaniwicaya on, qa Jehowa iśta kin én śicaya econ wicakiya, heon etanhan.

17 Unkan Manaśe ohan unman, qa taku econ kin owasin, qa woahtani wahtani kin, hena Juda wicaśtayatapi anpetu oyakapi wowapi en owapi ślli he?

18 Qa Manaśe hunkake wicaya om iśtima, qa tipi tawa mag̉a kin en hnakapi, Uzza tamaga en; unkan cinhintku Amon eekiya wawidaka.

19 Amon waniyetu wikcemna nonpa sanpa nonpa qehan toka wawidaka qa waniyetu nonpa Jerusalem ohna wawidaka, qa hunku Miśullamet Marutz cunwintku eciyapi he Joteba etanhan.

20 Unkan taku śica Jehowa iśta kin en econ, atkuku Manaśe econ qon iyecen.

21 Qa atkuku tacanku kin owasin omani, qa wakagapi atkuku ówicakiya qon hena iye ówicakiya, qa wicitokam patuja.

22 Hecen Jehowa hunkake wicaya wakandapi kin ayuśtan, qa Jehowa tacanku kin omani śni. kipajinpi, qa wicaśtayatapi kin tipi tawa ohna ktepi.

24 Unkan niakoce oyate kin tona wicaśtayatapi Amon kipajinpi kin owasin wicakaśtakapi, qa makoce oyate kin heekiya iye cinhintku Josija wicaśtayatapi kagjapi.

25 Unkan ohan unman Amon econ kin hena Juda wicaśtayatapi anpetu oyakapi wowapi en owapi śni he?

26 Unkan ohnahnakapi tawa ohna hnakapi, Uzza tamagia en, qa lieekiya iye cinhintku Josija wawidaka.

\section{WICOWOYAKE 22.}

1 Josija waniyetu śahdoğan qehan toka wawidaka, qa waniyetu. wikcemna yamni sanpa wanjidan Jerusalem ohna wawidaka, qa hunku Jedida Yadaja cunwintku eciyapi, Botzeqat etanhan.

2 Qa taku ecetu Jehowa iśta kin en econ, qa atkuku Dawid tacanku owasin omani, qa hetanhan etapa, qa catka unmanna ektakiya yuwinh iyaye śni.

3 Qa Josija wawidaka waniyetu wikcemna sanpa śahdogan kin en wicaśtayatapi kin Śapan Atzelija cinhintku he Meśullam cinhintku kin Jehowa ti kin ekta yeśi qa heya,

4 Hilqija wawayuśna tanka kin ekta ya, Mazaska Jehowa ti kin en hiyuyapi kin, tiyopa awanyakapi kin oyate kin etanhan mnayanpi kin he yawa kta, keciya wo.

5 Qa Jehowa ti kin awanyakapi kin wohtani econpi kin napepi en qupi kta, Jehowa ti kin ohna wolitani econpi kin tipi oko kin piyapi kta e wicaqupi kta.

6 Cankajipapi kin, qa can qa 23 Unkan Amon taokiye kin / inyan on ticagapi kin wicaqupi 


\section{WICOWOYAKE 23.}

kta; nakun can, qa inyan kakanpi opetonpi kte, on tipi kin piyayapi kta.

7 Tuka mazaska wicaqupi kin he yawapi śni, owotanna ohanyanpi nakaś.

8 Unkan Hilqija wawayuśna tanka kin Śapan wowapi kage cin heciya, Jehowa ti kin ohna woope wowapi kin iyewaya ce, qa Hilqija Śapan wowapi kin qu, unkan he yawa.

9 Qa Śapan wowapi kağe cin wicaśtayatapi kin ekta hi, qa wicaśtayatapi kin hośikahi, qa heya, Nitaokiye tipi kin ohna mazaska iyeyapi kin he mnayanpi, qa Jehowa ti kin awanyakapi kin wohtani econpi napepi en qupi.

10 Qa Śapan wowapi kage cin wicaśtayatapi kin okiyake ca heya, Hilqija wawayuśna kin wowapi wan maqu: heban Śapan he wicaśtayatapi kin itokam yawa.

11 Unkan wicaśtayatapi kin woope wowapi oie kin nahon qehan wokoyake kin hduhdehdeca.

12 Qa wicaśtayatapi kin Hilqija wawayuśna kin qa Aliqam Sapan cinhintku, qa Yakbor Mikaja cinhintku, qa Sapan wowapi kag̉e cin, qa Yasaja wicaśtayatapi taokiye kin wahokonwicakiye ca heya ;

13 Hopo Jehowa iwangapo, miye on, qa oyate kin on, qa Juda owasin on, wowapi iy eyapi kin de oie kin on, Jehowa tocanniye aide unyanpi kin he tanka nakaś; hunkake wicunyanpi wanahonpi śni, qa wowapi kin de oie owasin unkokiciwapi kin iyecen econpi śni, heon etanhan.

14 Unkan Hilquija wawayuśna kin, qa Ahiqam, qa Yakbor, qa Śapan, qa Yasaja hena Harhas cinhintku Tiqwa cinhintku Śallum, heyake awanyake cin tawicu kin, Hulda waaya te win kin ekta ipi ; (iye qe Jerusalem inonpa kin ohna ti), qa kici wohdakapi.

15 Unkan hewicakiya, Jehowa Israel wakandapi kin hecen eya ye, Wicaśta miye ekta u niśipi lin heciyape,

16 Jehowa hecen eya, Inyun oyanke kin de, qa tona en tipi kin hena akan taku śica hiyuya manka; Juda wicaśtayatapi kin wowapi yawa oie kin owasin.

17 Amayuśtanpi, qa taku wakan tokeca ota en wizinyapi, hecen napepi wohtani econpi kin owasin on śihda mayanpi, heon mitocanniye oyanke kin de aide, qa bosnipi kte śni.

18 Tuka Juda wicaśtayatapi kin Jehowa iwanga uniśipi kin he hecen eyakiyapi kta, Jehowa Israel wakandapi kin wicoie nayahon kin on hecen eya;

19 Nicante wankadan, qa, Oyanke kin de otiwota kta, qa en ounyanpi kin woyaśice hecapi kta, epe cin nayahon qehan, Jehowa itokam nihduhukuye ca wokoyake duhdehdece ça mitokam yaceye cin, heon miye nacihon, Jehowa eya.

$20 \mathrm{Qa}$ heon miye nihunkakepi om ope ciye kta, qa ohna hnakapi nitawa en zaniyan nihnakapi kta, qa niiśta kin taku śica oyanke kin de akan hiyuwaye kte cin wanyake kte śni, eya. Unkan wicaśtayatapi kin hośi kahipi.

\section{WICOWOYAKE 23.}

1 Unkan wicaśtayatapi kin wahowicaya, hecen Juda qa Jerusalem hunkayapi owasin iye en mniciyapi.

2 Unkan wicaśtayatapi kin Je-

563 


\section{WICAŚTAYATAPI,}

howa ti kin ekta i, qa Juda wicaśta kin owasin, qa Jerusalem ounyanpi kin owasin opapi, nakun wawayuśnapi kin, qa waayatapi kin, qa oyate tona cistinna tanka koya owasin; qa woope wowapi Jehowa ti kin ohna iyeyapi oie kin owasin nogepi en yawa.

3 Wicaśtayatapi kin cowahe kin akan najin, qa Jehowa itokam wotakuye kaga, Jehowa opapi kta, qa tawoahope, qa tawoyatanin, qa tokage patanpi kta ; cantepi ocowasin on, qa nagipi ocowasin on wotakuye kin de oie worvapi kin he en owapi kin yuecetupi kta; unkan oyate kin owasin wotakuye kin en najinpi.

4 Hehan wicaśtayatapi kin Hilqija wawayuśna tanka kin, qa wawayuśna iyokihepi kin, qa tiyopa awanyakapi kin hena wakśica Bayal kicagapi qa Aśera kicagapi, qa malipiya obe owasin kicagapi qon Jehowa ti kin etanhan hiynya wicaśi ; qa Jerusalem itankan Qidron mağa kin ohna hena huhnahya qa cahota kin Betel ekta ai.

5 Qa wakaġapi wakiyuśnapi kin wicayutokan, hena Juda wicaśtayatapi kin Jerusalem ihdukśan, qa Juda otonwe ohna paha akan wizinya wicakiyapi qon; nakun tona Bayal, qa anpetu wi, qa hanyetu wi qa wicanhpi, qa mahpiya obe owasin izinyapi.

6 Qa Aśera Jehowa ti kin etanhan hiynya, Jerusalem itankan, Qidron kaksiza ekta, qa Qidron kaksiza ohna luhnahya, qa kamdu, qa cahota kin wicaśta cinca ohnahnakapi kin akan kadada.

$7 \mathrm{Qa}$ winyaniçidapi tipi tawapi, Jehowa ti kin ohna yakonpi kin, hena pajuju, hena ohna winohinca kin Aśera tipi kicicazuntapi qon.

$8 \mathrm{Qa}$ Juda otonwe owasin etanhan wawayuśnapi kin u wicaśi, qa Geba etanhan Berśeba aiyahdeya paha kin yuśapa; hena akan wawayuśnapi kin wizinyapi qon; nakun tiyopa paha kin yujuju, he Jośuwa otonwe itancan kin tatiyopa kin ekta yanka, otonwe tiyopa kin catka tanhan. 9 Hecaśta paha wawayuśnapi kin Jehowa wahnawośnapi tawa Jerusalem ohna yanke cin he ekta ipi śni, tıka hunkawanjiwicayapi om aguyapi onapohye codan yutapi ece.

10 Nakun Topet Hinnom cinca taosmaka ohna yanke cin he yuśapa, hecen tuwedan cinhintku qaiś cunwintku Molek ekta peta en yekiye kte śni.

$11 \mathrm{Qa}$ śuktanka Juda wicaśtayatapi kin anpetuwi qupi kin hena yutokan, Jehowa ti tiyopa kin icahda etanhan, Natan melek yunukos owankati ikiyedan tiyopa kin itankan; qa anpetuwi canpahmihma kin petan hukinaliya.

12 Qa wahnawośnapi Juda wicaśtayatapi kin Ahaz wankanti oakalipe akan kaggapi qon, qa wahnawośnapi Manaśe Jehowa ti hocoka napin ohna kagga hella wicaśtayatapi kin pajuju qa hetanhan kohanna yutokan, qa caliota kin Qidron kaksiza ekta elipeya.

13 Nakun paha Solomon Israel wicaśtayatapi kin Aśterot Tzidoni wowalite śni kin kicağe cin, qa Kemoś Moab wowahite śni kin, qa Milkom Anmon cinca wowahíte śni kin kicage cin, Jerusalem wihinanpa ektakiya $\mathrm{Wi}$ hdi paha itokaga tanhan, hena wicaśtayatapi kin yuśapa.

14 Qa wakagapi kin kamdeca, 


\section{WICOWOYAKE 23.}

qa Aśeri kin kaksaksa, qa tukten yakonpi qon wicaśta huhu on ojuya.

15 Qa nakun wahnawośnapi wan Betel ekta yanke cin, paha Jeroboyam Nebat cinhintku Israel wahtani wicaye cin kage cin, wahnawośnapi, qa paha kin napin pajuju, qa ideya, paha kin watuśekśeca ecen kamdemdeca, qa Aśera kin hulinahya.

16 Hehan Josija ihdamna, qa ohnahnakapi hen, he kin akan yakonpi kin wanyaka, qa tuwe yeśi, qa ohnahnakapi etanhan huhu kin icu, qa wahnawośnapi kin akan hulinaliya, hecen yuśapa; Jehowa oie, Wakantanka tawicaśta eyanpaha gon iyecen, wicoie kin dena ieyanpaha qehan.

17 Unkan, Inyan bosdata wanmdake cin he taku hwo, eya. Unkan otonwe wicaśta kin heciyapi, Wakantanka tawicaśta Juda etanhan $u$, qa wicoie kin dena Betel wahnawośnapi kin ecayecon kin ieyanpaha qon ohnahnakapi tawa kin hee.

18 Unkan, Owanji yanke kta, tuweden huhu tawa yutokan kte śni, eya. Heon huhu tawa okaptapi, nakun waayate Samaria etanhan hiyu qon huhu tawa.

19 Unkan paha tipi kin owasin Samaria otonwe tawa ohna $J e-$ howa śihdayapi kta e Israel wicaśtayatapi kin kag̣api qon, hena Josija yutokan, qa Betel en woecon econ qon owasin iyecen hena ecakicon.

20 Nakun paha wawayuśnapi hen yakonpi kin owasin wahnawośnapi kin akan wawicayuśna, qa hena akan wicaśta huhu kin liuhnahya; hehan Jerusalem ek ta hdi.

21 Qa wicaśtayatapi kin oyate kin owasin wahokonwicakiye ca heya, Jehowa wakanyadapi kin woacakśin kicicağapo, wicotakuye kin de wowapi en owapi kin owasin iyecen.

22 Wayacopi Israel wicayacopi kin anpetu tawapi ehantanhan, Israel wicaśtayatapi, qa Juda wicaśtayatapi anpetu tawapi owasin en woacakśin wan de iyececa kag̉api śni.

23 Tuka Josija wawidake cin waniyetu wikcemna sanpa iśahdogan kin en woacakśin kin de Jerusalem ohna Jehowa kicagapi.

24 Qa nakun wapiyesa kin, qa wakanicidapi kin, qa terapim, qa wakagapi kin, qa wowahte śni Juda makoce ohna," qa Jerusalem ohna wanyakapi kin owasin Josija ihangya, hecen wowapi Hilqija Jehowa ti kin ohna iyeya woope oie en owapi kin yuecetu. 25 Qa wicaśtayatapi Mowis toope iyecen cante ocowasin on, qa nagi kin ocowasin on, qa towaśake ocowasin on Jehowa en ihduhomni, iye econ kin iyecen, itokam wanica, qa iye iyohakam iye iyececa wanjidan icage śni.

26 Hececa śta Jehowa tocanniye kata tanka Manaśe ohan śica śihdaya on Juda aideye cin he etanhan ihduhomni śni.

27 Qa Jehowa heya, Juda nakun miite itokapa tanhan mdutokankta, Israel mdutokan kin iyecen, qa otonwe wakahnige cin de Jerusalem, he ihawakta kte śni, nakun tipi ohna micaje hen yanke kta, epe ciqon.

28 Unkan Josija ohan unman, qa taku econ kin owasin, hena Juda wicaśtayatapi anpetu oyakapi wowapi en owapi śni he?

29 Anpetu tawa kin en Paro Neko, Egupta wicaśtayatapi kin u, Aśur wicaśtayatapi kin anatan kta Yuprate wakpa kin ekta. 


\section{WICAŚ'TAYATAPI,}

Unkan wicaśtayatapi Josija itkokipe kta iyaya. Unkan wanyake cehan Megiddo en kte.

$30^{\circ}$ Unkan taokiye iye te cin canpahmihma ohna Megiddo etanhan Jerusalem ekta ahdapi, qa ohnahnakapi tawa en hnakapi. Unkan makoce oyate kin Jehoahaz Josija cinhintku icupi, qa sdayapi, qa atkuku eekiya wicaśtayatapi kagapi.

31. Jehoaliaz waniyetu wikcemna nonpa sanpa yamni qehan toka wawidaka, qa wi yamni Jerusalem ohna wawidaka, qa hunku Hamutal eciyapi, Jeremiya cunwintku Libna etanhan.

32 Qa taku śica Jehowa iśta kin en econ, hunkake wicaya econpi qon owasin iyecen.

33 Unkan Paro Neko Hamat makoce ohna, Ribla ekta kaślka, on Jerusalem en wawidake kte śni, qa makoce kin on mazaska woqin opawinge, qa mazaskazi woqin wanjidan mnakiciciye wicaśi.

34. Qa Paro Neko Josija cinhintku Eliaqim (Taku wakan ehcie) wicaśtayatapi kagga, atkuku Josija eekiya, qa caje yatokeca Jehoaqim, (Jehowa ehde) qa Jehoahaz, (Jehowa yusuta), icu, qa Egupta ekta yuha hda. Unkan hen ta.

35 Unkan Jehoaqim mazaska kin, qa mazaskazi kin Paro qu, tuka makoce kin yawa, mazaska kin qu kta e Paro econśi kin iyecen, makoce oyate kin wicaśta otoiyohi Paro Neko qu kta e mazaska, qa mazaskazi mnaye wicakiya wicayawapi kin iyecen.

36 Jehnaqim waniyetu wikcemna nonpa sanpa zaptan qehan toka wawidaka, qa waniyetu wikcemna sanpa wanjidan Jerusalem ohna wawidaka, qa hun- ku Zebuda Pedaja cunwintku eciyapi, Ruma etanhan.

37 Qa taku śica Jehowa iśta kin en econ, hunkakewicaya econpi qon owasin iyecen.

\section{WICOWOYAKE 24.}

1 Anpetu tawa kin en Nebukadnezar Babel wicaśtayatapi kin anatan hi., Unkan Jehoaqim wowidake icicu; waniyetu yamni ókiya ; hehan tawacin hdutokeca qa kipajin.

2 Unkan Jehowa Kasdim ozuye kin, qa Aram ozuye kin, qa Moab ozuye kin, qa Anmon cinca ozuye kin Jehoaqim anatan wicaya. Hena Juda ihangyapi kta anatan wicaya, Jebowa oie taokiye waayatepi napepi on eye ciqon iyecen.

3 Awicakehan Manaśe wahtani kin, taku econ kin owasin iyecen, Jehowa $i$ kin on hecen iye itokapa tanhan Juda yutokan kta anatanpi.

$4 \mathrm{Qa}$ nakun wicaśta takudan iyaonpepicaśni wepi kin papsonpi kin on, qa wicawe taku iyaonpepicaśni on Jerusalem ojuya ; heon .Tehowa he kajuju kta cin śni.

5 Unkan Jehoaqim ohan unman, qa taku econ kin owasin, hena Juda wicaśtayatapi anpetu oyakapi wowapi en owapi śni he?

6 Unkan Jehoaqim hunkake wicaya om iśtima; unkan eekiya cinhintku Jehoakin wawidaka.

\% Unkan Egupton wicaśtayatapi kin iye tamakoce etanhan inarpa ayuśtan, Babel wicaśtayatapi kin Egupta kaksiza etanhan, Euprate wakpa kin aiyahdeya taku Égupta wicaśtayatapi tawa qon owasin icu nakaś.

8 Jehoakin waniyetu wikcemna sanpa śahdoğan qehan toka wa- 


\section{WICOWOYAKE 25.}

widaka, qa wi yamni Jerusalem ohna wawidaka, qa hunku Nehuśta Elnatan cunwintku eciyapi Jerusalem etanhan.

9 Unkan taku śica Jehowa iśta kin en econ, hunkakewicaya econpi qọ owasin iyecen.

$10 \mathrm{He}$ ehan Nebukadnezar Babel wicaśtayatapi taokiye kin Jerusalem ekta hipi, qa otonwe kin aonatakapi.

11 Nakun Nebukadnezar Babel wicaśtayatapi kin otonwe ekta hi taokiye aonatakapi icunhan.

12 Unkan Jehoakin Juda wicaśtayatapi kin Babel wicaśtayatapi kin ekta inanpa, iye, qa hunku, qa taokiye, qa akicita tawa, qa yunukos tawa; unkan Babel wicaśtayatapi kin wawidake cin waniyetu iśahdoğan kin en wayaka icu.

13 Qa taku Jehowa ti kin ohna kihnakapi qon, qa wicaśtayatapi ti kin ohna kihnakapi qon hetanhan icu, qa mazaskazi wokicanye Jehowa ti kin ohna Solomon Issrael wicaśtayatapi kag̉e ciqon, hena kaksaksa, Jehowa eye ciqon iyecen.

14 Qa Jerusalem ocowasin wayaka icu, akicita owasin, qa wicaśta waśaka waditaka owasin, wayaka kektopawinge wikcemna, nakun cankajipapi qa mazakagapi kin owasin; makoce oyate wahpanica kin henana okaptapi.

15 Hecen Jehoakin Babel ekta wayaka akiyahda, nakun wicaśtayatapi hunku, qa wicaśtayatapi tawicu, qa yunukos tawa, qa makoce wicaśta waśaka owasin wayaka Jerusalem etanhan Babel ekta awicaya.

16 Ozuye wicaśta kektopawing e śakowin, qa cankajipa qa mazakaga kektopawinge wanji, qa wicaśta waśaka ozuye kagapi kin owasin, hena Babel wicaśtayatapi kin Babel ekta wayaka awicaya.

17 Unkan Babel wicaśtayatapi kin heekiya ateya Mattenija, (Jehowa qu kin,) wicaśtayatapi kag̉e ca caje kin yatokeca, qa Zediqija (Jehowa owotanna tawa) eciya.

18 Zedeqija waniyetu wikcemna nonpa sanpa wanjidan qehan toka wawidaka, qa waniyetu wikcemna sanpa wanjidan Jerusalem ohna wawidaka, qa hunku Hamutal Jeremiya cunwintku eciyapi, Libna etanhan.

19 Qa taku śica Jehowa iśta kin en econ, Jehoaqim econ qon owasin iyecen.

20 Jehowa Jerusalem, ga Juda canniye wicaya, heon iye ite itokapa tanhan iyaye wicaya ecen, Zediqija Babel wicaśtayatapi kin kipajin.

\section{WICOWOYAKE 25.}

1. Qa wawidake cin waniyetu inapcinwanka wi iwikcemna anpetu iwikcemna kin en, Nébukadnezar Babel wicaśta yatapi kin hi, iye qa ozuye tawa owasin Jerusalem en ahitipi, qa ihdukśan conkaśke kaggapi.

2 Unkan otonwe kin conkaśke on natakapi, Zedeqija wawidake cin waniyetu iake wanji kin hehanyan.

3 Qa wi itopa anpetu inapcinwanka en wicakkihan otonwe kin ohiya, makoce oyate kin on woyute wanica nakaś.

4. Hehan otonwe kin yulidokapi, qa ozuye wicaśta kin owasin hanyen najicapi, conkaśke nonpa otahedan, tiyopa wicaśtayatapi tamagga icahda canku kin ohna; qa Araba canku kin ohna iyayapi, Kasdim otonwe ihdukśan yakonpi nakaś. 


\section{WICAŚTAYATAPI,}

5 Unkan Kasdim ozuye kin owasin wicaśtayatapi kin kuwa eyaya, qa Jordan makomdaye ohna kihdegapi ; tuka akicita tawa owasin iye etanhan enanakiya iyayapi.

6 Hecen wicaśtayatapi kin yuzapi, qa Babel wicaśtayatapi kin ekta aipi, Ribla ekta, qa hen yacopi.

$7 \mathrm{Qa}$ Zedegija cinca wica kin iye iśta kin itokam wicaktepi, qa Zedeqija iśta kin pahdokapi, hehan mazazi wicaśke on kaśkapi, qa Babei ekta ayapi.

8 Unkan wi izaptan anpetu iśakowin Nebukadnezar Babel wicaśtayatapi wawidake cin waniyetu wikcemna sanpa inapcinwanka kin en, Nebuzaradan wicakte itancan kin Babel wicaśtayatapi taokiye kin Jerusalem en hi.

9 Qa Jehowa ti kin huhnahya, qa wicaśta yatapi ti kin, qa Jerusalem tipi kin iyuhpa, tipi tanka kin owasin peta on liubnaliya. 10 Qa Kasdim ozuye kin wicakte itancan kin wicayuhe cin conkaśke Jerusalem ihdukś:ın owancaya yujujupi.

11 Unkan oyate unman otonwe ohna okaptapi kin, qa najicapi kin tona Babel wicaśtayatapi kin ekta iyayapi kin, Nebuzaradan wicakte itancan kin oyate unman kin wayaka awicaya.

12 T'uka wicakte itancan kin makoce en wahpanicapi kin hena wanjikśi hastanhanka iyuwi, qa magga kicanyanpi kta owicakapta.

13 Unkan Jehowa ti mazazi ipatanhdepi kin hena, qa oahehde kin, qa mazazi eega tanka Jehowa ti ohna yanke cin hena iyuhpa Kasdim kaksaksapi, qa mazazi kin Babel ekta ayapi.

14 Qa cega kin, qa mazamda568 ska kin, qa petijanjan iyukse kin, qa wiyatke kin, mazazi wikicanye on kicanyanpi kin hena owasin icupi.

15 Nakun wicakte itancan kin oizinye kin, qa amnimni wakśica, tona mazaskazi qa mazaska koye icu.

16 Mazazi ipatanhdepi. nonpa, qa cega tanka wanji, qa oahehdepi Solomon Jehowa ti kicage cin, wikicanye kin hena owasin mazazi kin tkeutapi śni.

17 Ipatanhdepi wanji bosdata ohanske cin wiciśpa wikcemna sanpa śahdoğan, qa he iwankam mazazi wateśdake wan, qa wateśdake bosdata kin wiciśpa yamni; qa mazayankapi, qa taspantankasuota wateśdake ihdukśan unpi kin, hena owasin mazazi; qa hena iyecen ipatanhdepi unman akan mazayankapi yanka.

18 Qa wicakte itancan kin Seraja wawayuśna tokaheya kin, qa Zepanija wawayusna inonpa kin, qa tiyopa awanyakapi yamni;

19 Qa yunukos wan ozuye wicaśta wicayawa kin, qa wicaśta zaptan wicaștayatapi ite kin wanyakapi ece kin, hena otonwe ohna iyewicayapi, qa obe kin wowapikaga itancan kin, makoce oyate kin iwicadake cin, qa makoce oyate kin wicaśta wilkcemna śakpe hena iwicacu.

20 Nebuzaradan wicakte itancan kin hena icu, ga Babel wicaśtayatapi kin ekta Ribla ekta awicai.

21 Unkan Babel wicaśtayatapi kin wicakaśtake ca wicakte, Ribla en, Hamat mákoce ohna, hecen Juda makoce tawapi etanhan wayaka awicayapi.

22 Qa oyate Juda makoce en okaptapi, Nebukadnezar Babel wicaśtayatapi kin owicakapte cin, hena iwankam Śapan cin- 


\section{WICOWOYAKE 25.}

hintku, he Ahiqam cinhintku, Gedalija itancan kaga.

23 Unkan ozuye mdetanhunkapi kin, qa wicaśta tawapi Babel wicaśtayatapi kin Gedalija he itancan kaga nahonpi qehan, Iśmael Netanija cinhintku, qa Johanan Qareha cinhintku, qa Seraja Tanhumet Netopati kin cinhintku, qa Jazanija Mayakati kin cinhintku, hena qa wicaśta tawapi Gedalija ekta Miitzpa en hipi.

24 Unkan Gedalija hena, qa wicaśta tawapi hewicakiya, Taku wakan namahon, Ihnuhan Kasdim óyakiyapi kta ikoyapapi kin. Makoce kin en owanji yankapo, hecen tanyan yaunpi kta.

25 Unkan wi iśakowin en Iśmael Netanija cinhintku Eliśama cinhintku, wicaśtayatapi cinca kin etanhan en hi, qa wicaśta wikcemna opapi, qa Gedalija kaśtakapi qa ktepi; nakun Juda wicaśta, qa Kasdim Mitzpa ohna iye kici unpi kin hena.
26 Hehan oyate kin owasin, tona cistinna qa tona tanka koya, najinpi, nakun ozuye mdetanhunkapi kin, qa Kasdim ikopapi on Egupta ekta iyayapi.

27 Unkan Jehoakin Juda wicaśtaytapi wayaka un kir. waniyetu wikcemna yamni sanpa iśakowin en, wi iakenonpa kin anpetu wikcemna nonpa sanpa iśakowin en, Ewil Merodak Babel wicaśtayatapi kin waniyetu toka wawidake cin en, Jehoakin Juda wicaśtayatapi pa kin yuwankan icu wicakaśka tipi etanhan.

$28 \mathrm{Qa}$ taku waśte eciya, qa toiyotanke kin wicaśtayatapi unman, iye kici Babel ohna yakonpi toiyotankapi iwankam ehde.

29 Qa wicakaśkapi taheyake kin yutokeca, unkan iye itokam aguyapi yuta tohanyan ni kin anpetu owasin.

30 Qa wopamni wicaśtayatapi kin etanhan qupi, wopamni ohinniyan tohanyan ni kin anpetu. otoiyohi. 


\section{ANPETU OYAKAPI,}

WOWAPI TOKAHEYA KIN.

\section{WICOWOYAKE 1.}

1 Adam, Śt, Enoś,

2 Qenan, Mahalalel, Jared,

3 Henok, Metuśela, Lamek,

4 Nowa, Śem, Ham, Japet.

5 Japet cinca kin Gomer, qa Magog, qa Madai, qa Jawan, qa Tubal, qa Meśek, qa Tiras.

6 Qa Gomer cinca kin, Askenaz, qa Ripat, qa Togarma.

7 Qa Jawan cinca kin, Eliśa, qa 'Tarśis, Kittim, qa Dodanim.

8 Ham cinca kin, Kuś, qa Mizraim, (Egupton,) qa Put, qa Kanan.

9 Qa Kuś cinca kin, Seba, qa Hawila, qa Sabta, qa Rayema, qa Sabteka; qa Rayema cinca kin, Śeba, qa Dedan.

10 Kuś nakun Nimrod kicitonpi. Iye tukaheya maka akan waśaka aya.

11 Unkan Mitzraim cinca kicitonpi kin dena eepi, Ludim, qa Yanamim, qa Lehabim, qa Naptuhim,

12 Qa Patrusim, qa Kaslulim, hetanlaan Pilistim, qa Kaptorim inanpapi.

13 Unkan Kanan cinca kicitonpi Zidon he tokapa, qa Ḣet;

14 Qa Jebusi kin, qa Amori kin, qa Girgaśi kin,

15 Qa Hiwi kin, qa Yarqi kin, qa Sini kin,

16 Qa Arwadi kin, qa Zemari kin, qa Hamati kin.

17 Sem cinca kin Elam, qa Aśur, qa Arpakśad, qa Lud, qa
Aram, qa Uz, qa Hul, qa Geter, qa Miśek.

18 Unkan Arpakśad Śla kicitonpi, qa Śela Heber kicitonpi.

19 Unkan Heber cinca wica nonpa kicitonpi; wanji Peleg, (Yuśpa) eciyapi, anpetu tawa en maka kin yuśpapi nakaś. Qa sunkaku Joqtan eciyapi.

20 Unkan Joqtan cinksiwicaye cin dena eepi, Almodad, qa Selep, qä Hatzarmawet, qa Jerah,

21 Qa Hadoram, qa Uzal, qa Diqla,

22 Qa Yebal, qa Abimael, qa Seba;

23 Qa Opir, qa Ḧawila, qa Jobab; hena owasin Joqtan cinkśiwicaya.

24 Śem, Arpakśad, Śela,

25 Teber, Peleg, Reyu,

26 Serug, Nalior, Terah,

27 Abram he Abraham ee.

28 Abraham cinca kin Izak, qa

Iśmayel; (Taku Wakan nahon.)

29 Wicoicagepi dena ee. Iśmayel ; cinhintku tokapa kin Nebajot, qa Qedar, qa Adbel, qa Mibśam,

30 Qa Miśma, qa Duma, qa Masa, Hadad, qa 'I'ema,

31 Jetur, Napiś, qa Qedma; Iśmayel cinkśiwicaye cin hena eepi.

32 Unkan Qetura Abraham tawicu tokeca cinca ton kin dena eepi, Zimran, qa Jokśan, qa Medan, qa Midian, qa Iśbaq, qa Sulia; qa Jokśan cinca kin, Seba, qa Dedan.

I. Chron. $\quad 5 \% 0$ 


\section{WICOW OYAKE 2.}

33 Qa Midian cinca kin Yepa, qa Yeper, qa Hanok, qa Abida, qa Eldaha; hena owasin Qetura cinkśi wicaya.

34 Nakun Abraham Tzak kicitonpi. Izak cinca kin Esa, qa Israel.

35 Esa cinca kin Elipaz, Ruhel; qa Jeyuś, qa Jalam, qa Qorali.

36 Elipaz cinca lin Teman, qa Omar, Zepi, qa Gatam, Qenaz, qa Timna, qa Amaleq.

37 Ruhel cinca kin Nahat, Zerah̆, Śanma, qa Miza.

38 Seyir cinca kin Lotan, qa Śobal, qa Zibeon, qa Ana, qa Diśon, qa Etzer, qa Diśan.

39 Lotan cinca kin, Hori, qa Homan; qa Lotan tawinohtin kin Timna.

40 Śbbal cinca kin, Yalan, qa Manahat, qa Yebal, Śepi, qa Unan. Qa Zibeon cinca kin, Aya, qa Ana.

41 Ana cinhintku Diśon; qa Diśon cinca kin Hamran, qa Eśban, qa Jitran, qa Keran.

42 Etzer cinca kin Bilhan, qa Zayan, qa Aqan. Diśon cinca kin Uz, qa Aram.

40 Unkan wicaśtayatapi kin dena Edom makoce kin ohna wawidakapi ; wicaśtayatapi wanjidan Israel cinca iwicadake śni ehan; Bela, he Beyor cinhintku, qa otonwe tawa Dinhaba eciyapi.

44 Unkan Bela ța; qa heekiya Zerah cinhintku Jobab, Botzra etanhan wawidaka.

45 Unkan Jobab ta, qa heekiya Ḧuśam, Timna maḱoce kin etanhan wawidaka.

46 Qa Iniśam ta; unkan heekiya Bedad cinhintku Hadad wawidaka; iye Midian kaśtaka Moab tatinta ohna; qa otonwe tawa Awit eciyapi.

47 Qa Hadad ța, qa heekiya
Samla, Masreqa etanhan, wawidaka.

48 Qa Samla țe; unkan heekiya Śaul, Rehobot wakpa icahda wanke cin etanhan, wawidaka.

$49 \mathrm{Qa}$ Śaul ta, unkan heekiya Bayalhanan Yakbor cinhintku wawidaka.

$50 \mathrm{Qa}$ Bayalhanan ta; unkan heekiya Hadad wawidaka, qa otonwe tawa Payi eciyapi, qa tawicu Mehetabel Matred cunwintlu eciyapi, he Mezahab cunwintku.

51 Qa Hadad ta, Hehan Edom dena itancan wicaya, itancan 'Timna, itancan Alwa, itancan Jetet,

52 Itancan Aholibama, itancan Ela, itancan Pinon,

53 Itancan Qenaz, itancan Teman, itancan Mibzar,

54 Itancan Magdijel, itancan Yiram. Edom itancan wicaya hena eepi.

\section{WICOWOYAKE 2.}

1 Israel cinca kin dena eepi; Ruben, Simeon, Lewi, Juda, Issakar, Zebulun,

2 Dan, Josep, qa Benjamin, Naptali, Gad, qa Aśer.

3 Juda cinca kin Er, qa Onàn, qa Śla; hena yamni Śuya cunwintku Kananiwin kiciton; tuka Er Juda cinhintku tokapa kin he śica, Jehowa iśta kin en; unkan teya.

4 Unkan iye takośkn Tamar Perez, qa Zarali kiciton. Juda cinca kin owasin zaptanpi.

5 Perez cinca kin Hezron, qa Hamul.

6 Unkan Zarah cinca kin Zimri, qa Etan, qa Heman, qa Kalkol, qa Dara, owasin zaptanpi.

7 Unkan Karmi cinca kin Akar (Iyokiśinya), Israel iyokiśinye 571 


\section{ANPETU OYAKAPI,}

cin hee, taku yuwakanpi en walitani nakaś.

8 Unkan Etan cinhintku Azarija.

9 Unkan Ḣezron cinca kiciton-

pi kin Jeralimeel, qa Ram, qa Kelubi.

10 Unkan Ram Aminadab cinkśiya, qa Aminadab Nahison Juda cinca itancan kin cinkśiya.

11 Qa Nalison Salma cinkśiya, qa Salma Boyaz cinkśiya.

12 Qa Broyaz Obed cinkśiya, qa Obed Jesse cinkśiya.

13 Qa Jesse kicitonpi kin tokapa Eliab, qa inonpa kin Abinadab, qa iyamni kin Șimeya,

14. Itopa kin Netaneel, izaptan kin Raddi,

15 Iśakpe kin Otzem, iśakowin kin Dawid.

16 Unkan tawinohtinpi lin Tzeruja, qa A.bigail. Qa Tzeruja cinca kin Abiśai, qa Joab, qa Yasahel, yamnipi.

17 Unkan Abigail Yamasa ton, qa Yamasa atkuku kin Jeter Ismaeli kin.

18 Unkan Kaleb Ḧezron cinhintku tawicu Azuba, iye Jereyot cinca kiciton, qa iye cinca kin dena eepi, Jeśer, qa Śobab, qa Ardon.

19 Unkan Azuba ța, hehan Kaleb Eprat yuza: unkan Hur kiciton.

20 Unkan Hur Uri kicitonpi; qa Uri Betzaleel kicitonpi.

21 Qa ohakam Hezron Makir Gileyad atkuku cunwintku elita i qa yuza; waniyetu wikcemna śakpe qehan; unkan Segub kiciton.

22 Unkan Segub Jair cinkśiya, iye otonwe wikcemna nonpa sanpa yamni Gileyad makoce ohna yuha.

23 Qa Jair otonwe Geśur, qa Aram etanhan icu, Qenat qa 572 cunkśi wicaye cin otonwe wikcemna śakpe, hena owasin Makir Gileyad atkuku cinkśi wicaya.

24 Unkan Hezron, Kaleb Eprata ohna te cin iyohakam Hezron tawicu Ábia Aśliur Teqoa atkuku kiciton.

25 Unkan Hezron cinhintiku tokapa Jerahmeel dena cinkśiwicaya, Ram tokapa kin, qa Buna, qa Oran, qa Otzem Aliija etanhan.

26 Qa Jerahmeel tawicu tokeca wan yuha, Yatara eciyapi, Onam hunku hee.

27 Qa Jerahmeel cinbintku tokapa Rarn dena cinkśi wicaya, Mayatz, qa Jamin, qa Yeqir.

28 Unkan Onam cinca kin Śanmá, qa Jada; qa Śanma cinca kin Nadab, qa Abiśur.

29 Qa Abiśur tawicu kin Abihail eciyapi. Unkan Ahban qa Molid kiciton.

30 Unkan Nadab cinca kin Seled, qa Appaim; unkan Seled cinca nica te.

31 Unkan Appaim cinca kin Jiśyi ; qa Jiśyi cinca kin Śeśan. Unkan Seśan cinca kin Ahlai.

32 Unkan Jada Śanma sunkaku cinca kin, Jeter, qa Jonatan. Unkan Jeter cinca nica ta.

33 Unkan Jonatan cinca kin Pelet, qa Zaza. Hena Jerahmeel cinkśiwicaya.

34 Unkan Śeśan cinca wica nica, tuka cinca winyan. Unkan Śeśan Egupton holśidan wan yuha he Jarha eciyapi.

35 Qa Śśan tahokśidan Jarha yuze kta iye cunwintku qu ; Unkan Yattai kiciton.

36 Unkan Yattai Natan cinkśiya, qa Natan Zabad cinkśiya.

37 Unkan Zabad Eplal cinkśiya ; qa Eplal Obed cinkśiya.

38 Qa Obed Jehu cinkśíya, qa Jehu Azarija cinkśiya. 


\section{WICOWOYAKE - 3.}

39. Qa Azarija Heletz cinkśiya, qa Heletz Eleyasa cinkśíya.

40 Unkan Eleyasa Sisama cinkśiya, qa Sisama Sallum cinkśiya.

41 Qa Śallum Jeqamja cinkśiya, qa Jeqamja Eliśama cinkśiya.

42. Unkan Jerahmeel sunkaku Kaleb cinhintru Meśa he tokapa, Zip atkuku kin hee; nakun Hebron atkuku Mareśa cinca kin. 43 Qa Hebron cinca kin Qorah, qa Tappuha, qa Reqem, qa Samya.

44 Unkan Śamya Raham cinkśiya, Jorqam atkuku hee. Unkan Reqem Sanma cinkśiya;

45 Qa Śnma cinhintku kin Mayon, qa Mayon Betzur atkuku kin hee.

46 Unkan Kaleb tawicu tokeca Yepa he Haran, qa Motza, qa Gazez ton; unkan Haran Gazez cinkśiya.

47 Unkan Jada cinca kin Regem, qa Jotam, qa Geśan, qa Pelet, qa Yepa, qa Sayap.

48 Kaleb tawicu tokeca Mayaka he Śseber, qa Tirhana ton.

49 Nakun Sayap Madmanna atkuku ton, qa Sewa Makbena atkuku, qa, Gibeya atkuku, qa Kaleb cunwintku Yaksa.

50 Kaleb cinca kin dena eepi; fifur Eprata cinhintku tokapa, Sobal Qirjat-Jeyarim atkuku,

51. Salma Bet Lehem atkuku, qa Harep Bet Gader atkuku.

52 Qa Sobal Qirjat-Jeyarim atkuku cinca wicayuha, Haroe, Hatzi, Heminuliot.

$53 \mathrm{Qa}$ Qirjat-Jeyarim wicowazi kin Itri kin, qa Puti kin, qa Śumati lrin, qa Miśrai kin; hena etanhan 'T'zorati kin, qa Eśtaoli kin icağapi.

54 Salma cinca kin Bet-Lehem, qa Netopati kin, Yaterot Bet
Joab, qa Manaheti hanke kin, qa Tzarayi kin,

55 Qa wowapikağa wicowazipi kin Jabez ounyanpi kin, Tireyatim, Simeyatim, Sukatim. Hena Qinim hecapi, Hamat etanhan upi, qa Rekab tiyohnaka ateyapi.

\section{WICOWOYAKE 3.}

1. Unkan Dawid cinca Hebron ohna tonpi kin dena eepi; tokapa kin Amnon, Ahinoyam Jezreeli win kin ton; inonpa Daniel, Abigail Tamali win kin he tawa;

2 Iyamni kin Abiśalom, Talma Geśur wicaśtayatapi cunwintku Mayaka cinhintku; itopa kin Adonija, Hagit cinhintku;

3 Izaptan kin Śepatija, Abital he tawa; iśakpe kin Jitreyam, he tawicu Egla tawa.

4 Hena sakpe Hebron ohna kicitonpi, qa hen waniyetu \$akowin, qa wi sakpe wawidaka; hehan waniyetu wikcemna yamni sanpa yamni Jerusalem ohna wawidaka.

5 Unkan dena Jerusalem ohna kicitonpi, Śsimeya, qa Śobab, qa Natan, qa Solomon topapi; Anmiel cunwintku Batśewa kiciton.

6 Qa Jibhar, qa Eliśama, qa Elipalet,

7 Qa Noga, qa Nepeg, qa Japiya,

8 Qa Eliśama, qa Eljada, qa Elipelet, napcinwanka.

9 Hena owasin Dawid cinca, qa nakun winohinca wakanyan wicayuze śni cincapi kin, qa tawinohtinpi 'Tamar.

10 Unkan Solomon cinhintku Rehoboyam hee, iye cinhintku Abija hee; iye cinhintku Asa hee; iye cinhintku Jehośapat hee;

11 Jye cinhintku Joram hee; 573 


\section{ANPETU OYAKAPI,}

iye cinhintku Aliazija hee; iye cinhintku Joaś hee;

12 Iye cinhintku Amatzija hee; iye cinhintku Yazarija hee; iye cinhintku Jotam hee ;

13 Iye cinhintku Ahaz hee; iye cinhintku Hezekija hee; iye cinhintku Manaśe hee;

14 Iye cinhintku Amon hee; iye cinhintku Josija hee.

15 Unkan Josija cinca tokapa kin Johanan, inonpa kin Jehojaqim, iyamni Zedeqija, itopa kin Śallum.

16 Unkan Jehojaqim cinca kin Jekonija, he Zedeqija cinkśiya.

17 Unkan Jekonija cinca kin Assir, he Salatiel cinkśiya.

18 Qa Malkiram, qa Pedaja, qa Śnazar, Jeqamja, Hośama, qa Nedabja.

19 Qa Pedaja cinca kin Zerubabel, qa Śsimeyi; qa Zerubabel cinca kin Meśullam, qa H̊ananija, qa tawinolitinpi kin Selomit.

20 Nakun Haśuba, qa Oliel, qa Berekija, qa Hasadja, qa Jośabhesed zaptanpi.

21 Unkan Hananija cinca kin Pelateja, qa Jeśaja ; Repaja cinca, Arnan cinca, Obadja cinca Śekaneja cinca.

22 Qa Śkaneja cinca kin Śemayeja; qa Śemayeja cinca kin Hattuś, qa Igal, qa Bariha, qa Neyarja, qa Śapat, śakpepi.

23 Qa Neyarja cinca kin Elijoyena, qa Ḧezeqija, qa Yazriqam, yamnipi.

24 Qa Elijoyena cinca kin Hodaja, qa Eliaśib, qa Pelaja, qa Aqub, qa Johannan, qa Delaja, qa Yanani, śakowinpi.

\section{WICOWOYAKE 4.}

1 Juda cinkśiwicaya Parez, Ḣezron, qa Karmi, qa Hur, qa Śobal.

2 Qa Reaja Śobal cinhintku Jalat kicitonpi; qa Jahat Aliuma cinkśiya, qa Lahad; Tzorati wicowazipi kin hena eepi.

3 Qa hena Yetam, qa Jezreyel, qa Jiśma, qa Jidbaś ateyapi ; qa tawinohtinpi kin Hatzelelponi eciyapi.

4. Qa Penuel Gedor atkuku, qa Ezer Huśa atkuku; hena Ḧur Eprata cinhintku tokapa Betlehem ateye cin cinca kin eepi.

5 Unkan Aślur Teqoya ateye cin tawicu nonpa, Helea, qa Nayara.

6 Unkan Nayara dena kiciton, Ahuzam, qa Heper, qa Temeni, qa Ahaśtari kin, hena Nayara cinca kin eepi.

7 Qa Helea cinua kin Tzeret, qa Jitzohar, qa Etenan.

8 Qa Qotz cinca kin dena eepi, Anub, qa Tzobeba, qa Harum cinhintku Aharahel wicowazi kin.

9 Unkan Jabez hunkawanji wicaye cin isanpa kinihanpi, qa hunku, Wamayazan on waton, eya, heon Jabez, (Wayazan eciya.)

10 Unkan Jabez Israel Wakandapi kin hoyekiye ca heya, Tokin mayadawaśte kta, qa makoce mitawa dutanke kten, qa ninape mici un kten, qa taku śica iyokiśin maye kteśni on micidutehan kten, eya. Unkan Wakantanka taku da kin qu.

11 Unkan Kelub Ślia sunkaku Mehir cinkśiya, Eśton atkuku kin hee.

12 Unkan Eśton he Betrapa, qa Paseha, qa Tehinna Nahaś otonwe ateye cin, hena cinkśiwicaya. Hena Reka wicaśta kin eepi.

13 Unkan Qenaz cinca kin Otniel, qa Seraja. Qa Otniel cinca kin Hatat.

14 Qa Meyonatai he Opra cin. 
kśiya; qa Seraja Joab cinkśiya, he Harasim (cankajipapi) osmaka kin ateyapi, hena cankajipa hecapi nakaś.

15 Unkan Kaleb Jepunne cinhintku cinca kin dena eepi. Yiru, Ela, qa Nayam. Qa Ela cinca kin, Qenaz.

16 Unkan Jehaleleel cinca kin, Zip, qa Zipa, Tirja qa Asriel.

17 Unkan Ezra cinca kin dena .eepi Jeter, qa Mered, qa Yeper, qa Jalon. Unkan Bitia Paro cunwintku Mered yuze cin ihduśake ca Miriam, qa Śanma, qa Iśbali Eśtemoa atkuku hena kiciton.

18 Qa tawicu Judawin kin Jered Gedor atkuku, qa ḦHeber Soko atkuku, qa Jequtiel Zanohia atkuku hena kiciton.

19 Nakun Hodja tawicu, he Naliam tankśitku cinca kin Qeila atkuku Garmi, qa Eśtemoya Mayakati kin.

20 Unkan Śimon cinca kin Amnon qa Rinna, Benhanan, qa Tilon. Unkan Jiśeyi cinca kin Zoliet, qa Benzoliet.

21 Unkan Śela Juda cinhintku cinca kin, Er he Lika atkuku, qa Layeda Mareśa atkuku, qa Aśbeya tiyohnaka wicowazi miniliuha śka kağapi tiyohnaka kin.

22 Nakun Joqim, qa Kozeba wicaśta kin, qa Joaś, qa Sarap, he Moab itancan, qa Leliem ounyanpi kin; tuka wicoie kin hena wanakaja.

23 Hena makawakśica kag̣a hecapi, qa Netayim, qa Gedera ounyanpi, wicaśtayatapi on htanipi kta heon hen yakonpi.

24 Unkan Simeyon cinca kin Nemuel, qa Jamin, Jarib, Zerah, Śaul.

25 Iye cinhintku Śallum, iye cinhintku Mibsam, iye cinhintku Miśma ;
26 Qa Miśma cinhintku Hamuel, iye cinhintku Zakur, iye cinhintku Simeyi.

27 Unkan Śimeyi cinca wicaya wikcemna sanpa śakpe, qa winyan śakpe; tuka hunkawanji wicaya cinca otapi śni, qa wicowazipi kin owasin Juda cinca kin iyecen ihduotapi śni.

28 Qa otonwe ounyanpi kin dena eepi, Berśeba, qa Molada, qa Hatzar-Suyal,

29 Qa Bilha, qa Yetzem, qa Tolad,

30 Qa Betuel, qa Horma, qa Ziqlağ,

31 Qa Betmarkabot, qa Ḣatzarsusim, qa Betbirei, qa Śayarajim. Hena otonwe tawapi Dawid wicaśtayatapi aiyahdeya. 32 Qa otonwe cistinna tawapi Yetam, qa Yain, Rinmon, Token, qa Yaśan, otonwe zaptan.

$33 \mathrm{Qa}$ otonwe cistinna owasin otonwe tanka kin hena ihdukśan, Bayal aiyahdeya. Makoce ounyanpi, qa wicowazi tawapi wowapi kin hee.

34 Unkan Meśobad, qa Jamelek qa Jośa, Amatzija cinhintku,

35 Qa Joel, qa Jehu Jośibija cinhintku, Seraja cinhintku, Yasiel cinhintku,

36 Qa Elejoyena, qa Jayakoba, qa Jeśohaja, qa Yasaja, qa Yadiel, qa Jisimiel, qa Benaja,

37 Qa Ziza Sipeyi cinhintku, Allon cinhintku, Jedaja cinhintku, Śimri cinhintku, Śemayeja cinhintku.

38 Hena cajewicayatapi wicowazipi, qa ateyapi tipi itancanpi nina ihdrotapi.

$39 \mathrm{Qa}$ tukten tahinca tawapi wihanpi kta akin iyayapi, Gedor ektakiya, osmaka wiyohiyanpa ekta.

40 Unkan wihanpi icepapi, qa waśte iyeyapi, qa makoce tan- 


\section{ANPETU OYAKAPI,}

kaya, qa owanji, qa wookiye unpi, Ham cinca kin wanakaja hen ounyanpi nakaś.

41 Qa cajeyatapi kin hena Hezekia Juda idake cehan heciya ipi, qa wakeyapi, qa ounyanpi hen iyeyapi kin kaśtalsapi, qa anpetu kin dehanyan ihang wicayapi, qa hena eekiya en yakonpi, tahinca tawapi on wihanpi hen yukan nakaś.

42 Qa hena etanhan Simeyon cinca etanhan, wicaśta opawing ge zaptan Seyir he kin ekta ipi; hena Pelateja, qa Nayarja, qa Repaja, qa Uziel Jiśyi cinca itancan yapi.

43 Qa Amaleqi najicapi qon, tona okaptapi kin wicakaśtakapi, qa anpetu kin dehanyan hen yakonpi.

\section{WICOWOYAKE 5.}

1 Unkan Israel cinhintku tokapa Ruben cinca kin, (Iye tokapa, tuka atkuku towinja yuśapa, heon watokapa kin Israel cinhintku Josep cinca kin wicaqupi, hecen wicowazipi kin watokapa kin iyecen yawapi śni.

2 Unkan Juda hunkawanji wicaya wicehna iyotan waśaka, qa iye etanhan wicaśta itancanyapi ; tuka watokapa kin he Josep tawa.

3 Israel cinhintku tokapa kin Ruben cinca kin Hanok, qa Pallu, Ḧetzron, qa Karmi.

4 Joel cinca kin, iye cinhintku Śemaja, iye cinhintku Gog, iye cinhintku Simyi.

5 Iye cinhintku Mika, iye cinhintku Reaja, iye cinhintku Bayal.

6 Iye cinhintku Beera, he Tilgat Pilneser Aśur wicaśtayatapi kin wayaka aya; he Rubeni itancan yapi.

7 Tuka hunkawanji wicaya wi$5 \% 6$ cowazipi kin iyecen, wicoicağe wowapi kin en owapi qehan, wicowazi itancanpi kin Jiyel, qa Zekareja.

8 Unkan Bela Yazaz cinhintku, Śma cinhintku, Joel cinhintku, iye Aroer Nebo aiyahdeya en ounyan, nakun Bayal-Meyon en. 9 Qa wiyohiyanpa ektakiya ounyan, Yuprate wakpa etanhan tintoskan en yapi kin hehanyan, tawanunyanpi kin Gileyad makoce kin ohna ihduotapi nakaś.

$10 \mathrm{Qa}$ Saul anpetu tawa en Hagari kin azuwicayapi; unkan napepi on ihpayapi; unkan tawakeyapi en tipi, makoce Gileyad iwiyohiyanpata kin owancaya.

11. Unkan Gad cinca kin wicikiyedan tipi, Baśan makoce ohna, Salka aiyahdeya.

12 Joel he itancan, qa Śapam he inonpa kin, hehan Jayeni, qa Sapat Baśan ohna.

13 Unkan sunkawicayapi ateyapi tipi kin iyecen Mikael, Meśullam, qa Śba, qa Jorai, qa Jayekan, qa Ziya, qa Yeber śakowinpi.

14 Abihail Huri cinhintku, Jaroha cinhintku, Gileyad cinhintku, Mikael cinhintku, Jeśiśi cinhintku, Jalido cinhintku, Buz cinhintku, cinca kin dena eepi ;

15 Alii Yabdiel cinhintku, Guni cinhintku ateyapi ti kin pa kin hee.

16 Unkan Gileyad, qa Baśan, qa otonwe tawa en, qa Śaron tinta ihdukśan owancaya maknce tawapi ounyanpi.

17 Hena owasin Jotam Juda wicaśtayatapi taanpetu en, qa Jeroboyam Israel wicaśtayatapi taanpetu en, wicayawapi.

18 Ruben cinca kin, qa Gad, qa Manaśe wicoun hanke wicaśta waśaka, wahacanka qa isan 
yuhapi, qa itazipa nawinjapi wokicize onspepi, wicaśta kektopawinge wikcemna topa, sanpa kektopawinge topa, sanpa opawinge śakowin sanpa wikcemna sakpe ozuye yapi.

19 Qa Hagari kin azuyapi, nakun Jetur: qa Napeś, qa Nodab. 20 Unkan hena on ówicakiyapi hecen Hagari kin, qa tona owicapapi kin owasin iye napepi kin en wicaqupi, wokicize en Wakantanka hoyekiyapi, qa wacinyanpi kin on cekiyapi kin nawicalion nakaś.

$21 \mathrm{Qa}$ tawanunyanpi icupi kamel kektopawinge wikcemna zaptan, qa tahinca kektopawinge opawinge nonpa sanpa kektopawinğe wikcemna zaptan, qa sonśonna kektopawinge nonpa, qa wicanagi wayaka kektopawinge opawinge.

22 Wicota capapi hinhpayapi, wokicize kin Wakantanka etanhan nakaś. Ijnkan hena eekiyapi en iyotankapi, wayaka awicayapi kin heharyan.

23 Unkan Manaśe wicoun hanke makoce kin ounyanpi Baśan etanhan Bayal Hermon ekta, qa Senir, qa Hermon he kin, bena ihduotapi.

24 Qa hunkake wicayapi tipi itancanpi kin dena eepi ; Yeper qa Jiścyi, qa Eliel, qa Yazriel, qa Jeremia, qa Hodawija, qa Jahidiel, wicaśta waśaka, waditaka, wicaśta kinihanpi hunkakewicayapi tipi kin itancanpi.

25 Tuka hunkake wicayapi taku wakandapi kin awahtanipi, qa makoce oyate kin taku wakandapi kin ihakam wiinahmanpi, oyate kin hena Wakantanka iyepi itokapa tanhan ihang wicaya.

26 Heon Israel taku wakandapi kin Pul Aśur wicaśtayatapi to- niya kin, qa Tilgatpilneser As̉ur wicaśtayatapi toniya kin iyopaśtaka, unkan Rubeni kin, qa Gadi kin, qa Manaśe wicoun hanke kin wayaka iwicacu, qa Halah ekta, qa Ḧabor qa Ḧara, qa Gozan wakpa kin ekta awicayapi, anpetu kin dehanyan.

\section{WICOWOYAKE 6.}

1 Lewi cinca kin Gerśon, qa Qohat qa Merari.

2 Unkan Qohat cinca kin Amram, qa Itzhar, qa Ḣebron, qa Uzziel.

3 Qa Amram cinca kin Aaron, qa Mowis, qa Miriam; qa Aaron cinca kin Nadab, qa Abihu, Eleazar, qa Itamar.

4 Eleazar Pinelias cinkśiya, $q a$ Pinelias Abiśuya cinkśiya,

5 Qa Abiśuya Buqi cinkśiya, qa Buqi Uzzi cinkśiya,

6 Qa Uzzi Zerahja cinkśiya, qa Zerahja Merajot cinkśiya,

7 Qa Merajot Amarja cinkśiva, qa Amarja Ahitub cinkśiya,

8 Qa Ảitub Zadoq cinkśiya, qa Zadoq Ahimayatz cinkśiya,

9 Qa Alimayatz Azarija cinkśiya, qa Azarija Johianan cinkśiya,

10 Qa Jolianan Azarija cinkśiya; iye tipi Solomon Jerusalem ohna kage cin he ohna wawayu. śna ece.

11 Unkan Azarija Amareja cinkśiya, qa Amareja Ahitub cinkśiya,

12 Qa Ahitub Zadoq cinkśiya, qa Zadoq Śallum cinkśiya,

13 Qa Śallum Hilqija, cinkśiya, qa Ḧilquja Azareja cinkśiya,

14 Qa Azareja Seraja cinkśiya, qa Seraja Jehotzadaq cinkśiya,

15 Qa Jehotzadaq Jehowa Juda qa Jerusalem Nebukadnezar nape on wayaka awicaye cehan opa. 


\section{ANPETU OYAKAPI,}

16 Lewi cinca kin Gerśom, Qohat, qa Merari.

$1 \%$ Unkan Gerśom cinca cajepi kin dena ee, Libni, qa Śimeyi.

18 Qohat cinca kin, Amram, qa Itzhar, qa Ḧebron, qa Uzziel.

19 Merari cinca kin, Malili qa Muśi. Hena Lewi kin ateyapi wicowazipi kin eepi.

20 Gerśom etanhan, iye cinhintku Libni, iye cinhintku Jahat, iye cinhintku Zinma,

21 Iye cinhintku Joha, iye cinhintku Jiddo, iye cinhintku Zerah, iye cinhintku Jateri.

22 Qohat cinca kin, iye cinhintku Aminadab, iye cinhintku Qorah, iye cinhintku Assir,

23 Iye cinhintku Elqana, iye cinhintku Ebijasap, iye cinhintku Assir,

24 Iye cinhintku Tahat, iye cinhintku Uriel, iye, cinhintku Uzija, iye cinhintku Śaul.

25 Qa Elqana cinca kin Amasai, qa Ahimot.

26 Iye cinhintku Elqana. Elqana cinhintku Tzopi, qa iye cinhintk u Nahai ;

27 Iye cinhintku Eliab, qa iye cinhintku Jeroham, iye cinhintku Elqana,

28 Qa iye cinhintku Samuel cinca kin tokapa kin Joel qa inonpa kin Abija.

29 Merari cinca kin Mahli, iye cinhintku Libni, iye cinhintku Simeyi, iye cinhintku Uzza,

30 Iye cinhintku Śsimeya, iye cinhintku Hagija, iye cinhintku Asaja.

31 Unkan canwohnaka kin owanji yanke cin iyohakam Jehowa ti kin ohna Dawid dowanpi itancan najin wicakiya dena eepi.

$32 \mathrm{Qa}$ itkokipapi wakeya tipi kin itokam ókiyapi ece, Solomon Jehowa ti kin Jerusalem ohna 578 kag̉e cin hehanyan; qa wohtanipi econpi kta e wayacopi kin iyecen najinpi.

33 Qa dena, qa iye cincapi en yakonpi ece; Qohati cinca kin etanhan Heman dowanpi itancan kin he Joel cinhintku, Samuel cinhintku,

34 Elqana cinhintku, Jeroham cinhintku, Eliel cinhintku, Toha cinhintku,

35 Tzop cinhintku, Elqana cinhintku, Mahat cinhintku, Yamasi cinhintku,

36 Elqana cinhintku, Joel cinhintku, Azarija cinhintku, Tzepanja cinhintku,

37 'Tahat cinhintku, Assir cinhintku, Ebijasap cinhintku, Qorah cinhintku,

38 Itzhar cinhintku, Qohat cinhintku, Lewi cinhintku, Israel cinhintku.

39 Unkan hunkawanjitku Asap iye etapa ekta najin; Asap Berekeja cinhintku, Śimeya cinhintku,

40 Mikael cinhintku, Bayaseja cinhintku, Malkija cinhintku,

41 Etni cinhintku, Zerah cinhintku, Yadja cinhintku,

42 Etan cinhintku, Zinma cinhintku, Śsimayi cinhintku,

43 Jahat cinhintku, Gerśom cinhintku, Lewi cinhintku.

44 Unkan hunkawanji wicayapi Merari cinca kin iye catka tanhan najinpi; Etan Qiśi cinhintku, Yabdi cinhintku, Malluk cinhintku,

45 Ḣaśabja cinhintku, Amatzeja cinlintku, Hilqija cinhintku,

46 Amzi cinhintku, Bani cinhintku, Śemer cinhintliu,

47 Mahli cinhintku, Muśi cinhintku, Merari cinhintku, Lewi cinhintku.

48 Unkan hunkawanji wicayapi kin Lewi kin Wakantanka ti wa- 


\section{WICOWOYAKE 6.}

keya wohtani kin owasin tawayekiyapi.

49 Unkan Aaron, qa iye cinca kin woliuhnaliyapi owayuśna akan, qa wizinyapi owayuśna. akan wizinyapi kin hena tipi iyotan wakan wohtani kin owasin econpi, qa Israel akahpe wicakiyapi; Mowis Wakantanka taokiye econ wicaśi kin owasin iyecen.

50 Qa Aaron cinca kin dena eepi; iye cinhintku Eleazar, iye cinhintku Pinehas, iye cinhintku Abiśua,

51. Iye cinhintku Buqi, iye cinhintku Uzzi, iye cinhintku Zerahja,

52 Iye cinhintku Merajot, iye cinhintku Amarja, iye cinbintku Ahitub,

53 Iye cinhintku Zadoq, iye cinhintku Ahimayatz.

54. Qa oyanke tawapi kin dena ee, makoce tawapi ohna, conkaśke tawapi kin iyecen, Aaron cinca Qohati wicowazipi kin wopamni wicaqupi qehan.

55 Qa Juda makoce ohna H̉ebron, qa ihdukśan tinta ohna wanunyanpi wihanpi kta.

56 'T'uka otonwe mag̉a kin, qa totonwe ciśtinna kin hena Kaleb Jepunne cinhintku kin qupi.

57 Tuka Aaron cinca kin Ḧebron wowinape otonwe on qupi; nakun Libna qa tinta ihdukśan kin, qa Jattir, qa Eśtemoya, qa hena ihdukśan, tinta kin.

58 Qa Hilen qa tatinta kin, qa Debir qa tatinta kin,

59 Qa Yaśan qa tatinta kin, qa Betśemeś qa tatinta kin.

60 Unkan Benjamin wicoun etanhan Geba qa tatinta kin, qa Yalemet qa tatinta kin, qa Anatot qa tatinta kin; otonwe tawapi owasin otonwe wikcemna sanpa yamni tinta tawapi iyahna.
61 Unkan Qohat cinca unman kin otonwe wikcemna wicaqupi, oeconna eciya tanhan, Epraim wicoun, qa Dan wicoun, qa Manaśe wicoun hanke wicowazipi kin etanhan.

62 Unkan Gerśom cinca wicowazipi kin Issakar wicoun etanhan, qa Aśer wicoun etanhan, qa Naptali wicoun etanhan, qa Manaśe wicoun Baśan ounyanpi kin etanhan; otonwe wikcemna sanpa yamni wicaqupi.

63 Merari cinca wicowazipi kin Ruben wicoun etanhan, qa Gad wicoun etanhan, qa Zebulun wicoun etanhan, oeconna eciyatanhan, otonwe wikcemna sanpa nonpa.

64 Hecen Israel cinca kin otonwe kin hena, qa tinta ihdukśan kin Lewi kin wicaqupi.

65 Qa oeconna eciyatanhan Juda cinca wicoun etanhan, qa Simeyon cinca wicoun etanhan, qa Benjamin cinca wicoun etanhan, otonwe kin hena cajeyatapi qon wicaqupi.

66 Unkan Qohat cinca wicowazipi unman kin otonwe iwicakicagapi kin Epraim wicoun ohna; 67 Qa Śekem wowinape otonwe wicaqupi, qa tinta tawa, Epraim he kin ohna, qa Gezer, qa tinta tawa,

68 Qa Joqmeyam qa tatinta, qa Bethoron qa tatinta,

$69 \mathrm{Qa}$ Ajalon qa tinta tawa, qa Gatrinmon, qa tinta tawa;

$70 \mathrm{Qa}$ Manaśe wicoun hanke etanhan Aner, qa tinta tawa, Bileyam qa tinta tawa. Qohat cinca wicowazi unman otonwe kin hena wicaqupi.

71 Unkan Gerśom cinca kin Manaśe wicoun wicowazipi kin etanhan, Golan Baśan ohna, qa tinta tawa wicaqupi, qa Aśtarot qa tinta tawa, 


\section{ANPETU OYAKAPI,}

72 Qa Issakar wicoun etanhan Qedeś, qa tinta tawa, qa Daberat qa tinta tawa,

73 Qa Ramot qa tinta tawa, qa Anem qa tinta tawa;

74. Qa Aśer wicoun etanhan Maśal qa tinta tawa, qa Abdon qa tinta tawa,

75 Qa Ḣuqoq qa tinta tawa, qa Reliob qa tinta tawa;

$76 \mathrm{Qa}$ Naptali wicoun etanhan Qedeś Galil ohna, qa tinta tawa, qa Ḣamon qa tinta tawa, qa Qirataim qa tinta tawa.

77 Unkan umanpi kin Merari cinca kin Zebulun wicoun etanhan Rinmon qa tinta tawa, qa Tabor qa tinta tawa;

$78 \mathrm{Qa}$ Jordan akasanpa Jeriho etanhan, Jordan wihinapa ektakiya Ruben wicoun etanhan $\mathrm{Be}$ tzer tinta ohna qa tinta tawa, qa Jahatza qa tinta tawa,

79 Qa Qedemot qa tinta tawa, qa Mepayat qa tinta tawa;

80 Qa Gad wicoun etanhan Ramot Gileyad ohna, qa tinta tawa, qa Mahanaim qa tinta tawa,

81 Qa Heśbon qa tinta tawa, qa Jazer qa tinta tawa.

\section{WICOWOYAKE 7.}

1 Unkan Issakar cinca kin Tola, qa Puwa, Jaśub, qa Śimron, topapi.

2 Qa Tola cinca kin, Uzzi, qa Repaja, qa Jeriel, qa Jahmai, qa Jibsam, qa Samuel; ateyapi Tola ti kin itancanpi kin, wicoicagepi en wicaśta waśaka waditaka; Dawid taanpetu en wicayawapi kektopawinge wikcemna nonpa sanpa kektopawinge nonpa sanpa opawinge śakpe.

3 Unkan Uzzi cinca kin; Jizrahja; qa Jizrahja cinca kin Mikael, qa Obadja, qa Joel, qa Jiśija, zaptan; owasin itancan hecapi.
$4 \mathrm{Qa}$ hena om wicoicagiepi hunkakewicayapi tipi kin etanhan, obe ozuye yapi wicaśta kektopawinge wikcemna yamni sanpa kek topawinge śakpe; winohinca qa cinca hduotapi nakaś.

$5 \mathrm{Qa}$ hunkawanji wicayapi Issakar wicowazipi kin owasin kektopawinge wikcemna śahdoġan sanpa kektopawinġe śakowin; owasin wicoicage wowapi kin iyecen.

6 Unkan Benjamin cinca kin Bela, qa Beker, qa Jedayel, yamnipi.

7 Qa Bela cinca kin, Etzbon, qa Uzzi, qa Uzziel, qa Jerimot, qa Yeri zaptanpi, hunkakepi tipi itancanpi kin, wicaśta waśaka waditaka, wicoicage wowapi kin iyecen wicayawapi, kek topawinge wikcemna nonpa sanpa kektopawinge nonpa sanpa wikcemna yamni sanpa topa.

8 Unkan Beker cinca kin Zemira, qa Joyaś, qa Eliyezer, qa Elijoyena, qa Yomri, qa Jerimot, qa Abija, Anatot, qa Yamelet, hena owasin Beker cinca.

9 Qa atewicayapi tipi jtancanpi kin, wicoicage wowapi kin iyecen wicayawapi, wicaśta waśaka waditaka kektopawinge wikcemna nonpa sanpa opawinge nonpa.

10 Unkan Jedayel cinca kin Bilhan; qa Bilhan cinca kin Jeyuś, qa Benjamin, qa Ehud, qa Kenayana, qa Zetan, qa Tarśiś, qa Ahisíahar.

11 Hena owasin Jedayel cinca, atewicayapi tipi itancanpi kin iyecen, wicaśta waśaka waditaka kektopawing ${ }^{2}$ wikcemna sanpa kektopawinge śakowin sanpa opawinge nonpa obe zuyapi.

12 Nakun Suppim qa Huppim Yir cinca kin, qa Huśim Ałier cinhintku. 


\section{WICOWOYAKE 7.}

13 Naptali cinca kin Jahtziel, qa Guni, qa Jezer, qa Śallum, hena Bilha cinca.

14 Manaśe cinca kin Asriel he tawicu ton; tawicu tokeca Arami win kin Gileyad atkuku Makir ton.

15 Qa Makir Ḧuppim qa Śuppim tawinohtinpi yuza, he Mayaka eciyapi; qa inonpa kin Tzelopehad; qa Tzelopehad cinca winyan ecédan yuha.

16 Unkan Mayaka Makir tawicu cinca wan ton, qa Pereś eya caśkiton, qa sunkaku Śsereś eciyapi, qa iye cinca kin Ulam qa Raqem.

17 Qa Ulam cinca kin Bedan. Hena Gileyad Makir cinhintku Manaśe cinhintku cinca kin.

18 Qa tawinohitin wicaśtayatapi win kin Iśhod, qa Abiyezer, qa Mahla ton.

19 Unkan Śemida cinca kin Ahiian, qa Śsekem, qa Leqli, qa Aniyam.

20 Unkan Epraim cinca kin, Śutelah, iye cinhintku Bered, iye cinhintku Tahat, iye cinhintku Eleyada, iye cinhintku Taliat;

21 Qa iye cinhintku Zabad, qa iye cinhintku Śtelah. Nakun Ezer qa Eleyad; unkan Gat wicaśta makoce kin en tonpi kin hena wicaktepi, tawanuyanpi kipi kta apamahde ipi qehan.

22 Unkan ateyapi Epraim anpetu ota iyokiśin içiya. Unkan hunkawanji wicaya kicanptapi en hipi.

23 Unkan tawicu ekta i. Unkan ihduśake ca cinca wica ton; unkan Beriya, (Woiyokiśice,) eya caśkiton, tipi tawa taku śica akipa nakaś.

24. Qa cunwintku Śeera he Bet Horon hukuya kin qa wankantu kin kagga; nakun Uzzen Śera.
25 Unkan iye cinhintku Repah, qa Reśep; qa iye cintintku Telah, qa iye cinbintku Tahan;

26 Iye cinhintku Layadan, iye cinhintku Amihud, iye cinhintku Eliśama;

27 Iye cinhintku Nun, iye cinhintku Jośuwa.

$28 \mathrm{Qa}$ makoce yuhapi qa ounyanpi kin Betel, qa otonwe cunkśi wicaya, qa wiyohiyanpa ektakiya Nayaran, qa wiyohpeyata Gezer, qa cunkśi rvicaya, qa Śskem, qa cunkśiwicaya, Gaza qa cunkśiwicaya hehanyan.

29 Qa Manaśe cinca kin icahda, Betśan qa cunkśiwicaya, qa Tayanak qa cunkśiwicaya, qa Megiddo qa cunkśiwicaya, Dor qa cunkśi wicaya; hena ohna Israel cinhintku Josep cinca kin ounyanpi.

30 Aśer cinca kin Jimna, qa Jiśwa, qa Jiświ, qa Beriya; qa tawinohtinpi kin Serah̉.

31 Qa Beriya cinca kin, Ḧeber, qa Malkiel, iye Birzawit atkuku. 32 Unkan Heber cinca kin Japlet, qa Śsomer, qa Ḧotam, qa tawinolitinpi Śuya.

33 Qa Japlet cinca kin Pasak, qa Bimhal, qa Yaśwat; Japlet cinca kin hena eepi.

34 Qa Somer cinca kin Ahi, qa Rohega, Jehubba, qa Aram.

35 Qa sunkaku Helen cinca kin Tzopah, qa Jimna, q̨a Śseleś, qa Yamal.

36. Qa Tzopah cinca kin Suha, qa Harneper, qa Śuyal, qa Beri, qa Jimra,

37. Betzer, qa Hod, qa Śanma, qa Silśa qa Jitran, qa Bera.

38 Qa .Jeter cinca kin, Jepunne, qa Pispa, qa Ara.

39. Qa Yula cinca kin; Arah, qa Hanniel, qa Ritzja.

40 Hena owasin $\Lambda$ śer cinkśiwicaya, hunkawicayapi tipi itan581 


\section{ANPETU OYAKAPI,}

canpi, wicaśta waśaka, waditaka, kahnigapi, pa wicayawapi, qa itancan hecapi; wicoicagge wowapi kin iyecen, obe zuyapi wicaya wapi, wicaśta kektopawinge wikcemna nonpa, sanpa kektopawinge śakpe.

\section{WICOWOYAKE 8.}

1 Unkan Benjæmin kicitonpi kin dena ee, Bela he tokapa, Aśbel inonpa, Aharah iyamui kin,

2 Noha itopa kin, Rapa izaptan kin.

3 Unkan Bela cinca kin, Addar, qa Gera, qa Abihud,

4 Qa Abiśuya, qa Nayaman, qa Ahoha,

5 Qa Gera, qa Śepupan, qa Ḧuram.

6 Unkan dena Ehud cinca kin eepi, Geba ounyanpi ateyapi itancan hecapi, qa Manahat ekta awicayapi ;

7 Nayaman, qa Ahija, qa Gera, iye awicaya; qa Uzza, qa Alilud cinkśiwicaya.

8 Unkan Śaharaim tawicu Ḣuśim qa Bayara wicayutokan ohakam Moab makoce ell cinca kicitonpi.

9 Qa tawicu Hodeś dena kiciton, Jobab, qa Tzibia, qa Meśa, qa Malkam.

10 Qa Jeyutz, qa Śabija qa Mirma. Iye cinca kin hena ateyapi tipi itancanpi kin.

11 Unkan Ḣuśim Abitub, qa Elpayal cinkśiwicaya.

12 Qa Flpayal cinca kin, Eber, qa Miśryam, qa Śamed; iye Ono, qa Lod otonwe, qa cunkśíwicaya kagia.

13 Qa Beriya qa Simyi, hena Ajalon ounyanpi ateyapi itancanpi kin. Iyepi Gat ounyanpi kin nape wicayapi.
14. Unkan Ahio, qa Śaśak, qঞ Jerimot,

15 Qa Zebadeja, qa Yarad, qa Yadar,

16 Qa Mikael, qa Iśpa, qa Joha, hena Beriya cinca kin.

17 Unkan Zebadeja, qa Meśullarn, qa Ḣezeqi, qa Ḧeber,

18 Qa Jismerai, qa Jizelia, qa Jobab, Elpayal cinkśiwicaya.

19 Unkan Jaqim, qa Zikri, qa Zabdi.

20 Qa Eliyena, qa Ziletai, qa Eliel,

21 Qa Adaja, qa Beraja, qa Simrat, hena Simyi cinkśiwicaya.

22 Ullkan Jiśpan, qa Eber, qa Eliel,

23 Qa Abdon, qa Zikri, qa Ḧanan,

24 Qa Ḣananija, qa Elam, qa Anatotja,

25 Qa Jipedeja, qa Penuel, hena Śaśaq cinkśiwicaya,

26 Qa Śamśerai, qa Śeharja, qa Atalija,

27 Qa Jayareśja, qa Elija, qa Zikri, hena Jeroham cinkśi wicaya.

28 Hena atewicayapi tipi itancanpi kin, wicoicage itancanpi kin. Hena Jerusalem en ounyanpi.

29 Unkan Gibeyom en ounyanpi kin Gibeyon atkuku, qa tawicu Mayaka eciyapi ;

30 Qa cinca kin, tokapa kin Abdon, qa Tzur, qa Qiś, qa Bayal, qa Nadab,

31 Qa Gedor, qa Ahjo, qa Zaker,

32 Qa Miqlot, iye Śimea cinkśiya. Tyepi hunkawanjiwicayapi om ounyanpi, hunkawanjiwicayapi Jerusalem ohna iyotakonza.

33 Unkan Ner Qiś cinkśiya, qa Qiś Saul cinkśiya, qa Saul Jona- 


\section{WICOWOYAKE 9.}

tan cinkśiya; nakun Malkiśuya, qa Abinadab, qa Eśbayal.

$34 \mathrm{Qa}$ Jonatan cinhintku Meribbayal, qa-Meribbayal cinlintku Mika.

35 Qa Mika cinca kin Piton, qa Melek, qa Tareya, qa Ahaz.

36 Unkan Ahaz Jehoyada cinkśiya, qa Jelıoyada Alemet cinkśiya; nakun Azmawet, qa Zimri. Unkan Zimri Motza cinkśiya,

37 Qa Motza Bineya cinkśiya; iye cinhintku Rapa, iye cinhintku Eliyasa, iye cinhintku A.zel.

38 Qa Azel cinca śakpe, qa cajepi kin dena ee, Azriqum, Bokeru, qa Iśmayel, qa Śeyarja, qa Obedja, qa Hanan. Hena owasin Azel cinca.

39 Unkan sunkaku Yeśeq cinca kin Ulam; he tokapa, qa Jeyuś he inonpa, qa Elipelet iyamni kin.

40 Qa Ulam cinca kin wicaśta waśaka waditaka itazipa nawinjapi, cinca, qa sanpa cinca otapi, opawinge sanpa wikcemna zaptan; hena owasin Benjamin cinca.

\section{WICOWOYAKE 9.}

1 Hecen Israel owasin wicoicage wowapi en ihdawapi, qa hena Israel wicaśtayatapi tawowapi kin en owapi. Unkan Juda wahtanipi kin on wayaka awicayapi, Babulon ekta.

2 Qa tamakocepi otonwe tawapi en toka ounyanpi kin dena eepi ; Israel, wawayuśnapi kin, Lewi kin, qa Netinim (Waqupi) kin.

3 Qa Jerusalem en Juda cinca kin hunh, qa Benjamin cinca kin etanhan, qa Epraim qa Manaśe cinca kin etanhan.

4 Yutai Amihnd cinhintku, Om- ri cinhintku, Imri cinhintku, Bani cinhintku, Parez Juda cinhintku cinca kin etanhan.

5 Unkan Ślani kin etanhan, Yasaja, he tokapa, qa iye cinca kin.

$6 \mathrm{Qa}$ Zerah cinca kin etanhan Joel: hena qa lıunkawanji wicayapi opawinge śakpe sanpa wikcemna napcinwanka.

\% Unkan Benjamin cinca kin etanhan Sallu, Meśullam cinhintku, Hodawija cinhintku, Hasenua cinhintku.

8 Qa Jibneja, Jeroham cinhintku, qa Ela Uzzi cinhintku, Mikri cinhintku; qa Meśullam Śpateja cinhintku, Ruel cinhintku, Jibnija cinhintku.

9 Qa hunkawanjiwicayapi wicoicaggepi kin iyecen, opawinge napcinwanka sanpa wikcemna zaptan sanpa śakpe; liena owasin ateyapi tipi kin wicaśta ateyapi pa wicayawapi.

10 Unkan wawayuśnapi etanhan Jedaja, qa Jehojarib, qa Jakin,

11 Qa Azarija Ḣilquija cinhintku, Meśullam cinhintku, Zadoq cinhintku, Merajot cinhintku, Alitub cinhintku, Wakantarka ti itancan kin.

12 Qạ Adaja, he Jeroham cinhintku, he Pashur cinhintku, he Malekeja cinhintku; qa Mayasai, he Adiel cinhintku, he Jahzera cinhintku, he Meśullam cirnhintku, he Meśillemit cinhintku, he Inmer cinhintku.

13 Qa sunkawicayapi atewicayapi tipi pa wicayawapi kektopawinge wanjidan sanpa opawinge śakowin sanpa wikcemna śakpe; Wakantanka ti kicanyanpi wohtani kin on wicaśta waśaka waditakapi.

14 Qa Lewi kin etanhan Śemaja H́aśub cinhintku, Yazriqam 583 


\section{ANPETU OYAKAPI,}

cinhintku, Hัośebeja cinhintku, Merari cinca kin etanhan.

15 Qa Baqbaqa, Ḣereś, qa Galal, qa Mattanja Mika cinhintku, Zikri cinhintku, Asap cinhintku.

16 Qa Obadija Semaja cinhintku, Galal cinhintku, Jedutun cinhintku; qa Berekeja Asa cinhintku, Elqana cinhintku; iye $\mathrm{Ne}-$ topati hocoka en ounyan.

I7 Unkan tiyopa awanyakapi kin, Śallum qa Yakub, qa Talmon, qa Aliman, qa hunkawanji wicayapi Śallum pa yawapi.

18 lye wicaśtayatapi tatiyopa wihinanpe ektakiya dehanyan awanyaka; hena tiyopa awanyaka hecapi, Lewi cinca obepi etanhan.

19 Uukan Śallum Qore cinhintku, Ebjasap cinhintku, Qorah cinlintku, qa hunkawanji wicaya atkuku ti kin etanhan Qorahi kin wokicanye wohtani kin awanyakapi, qa wakeya wakśica kin, qa hunkake wicayapi kin Jehowa towanka tiyopa kin awanyakapi.

20 Qa Pinehas Eleazar cinhintku otokahe ekta itancan yuhapi. Jehowa iye kici un.

21 Unkan Zuekarja Miśelemja cinhintku itkokipapi wakeya tiyopa kin awanyaka.

22 Tiyopa awanyakapi kta kahnigapi kin owasin opawinge nonpa sanpa wikcemna sanpa nonpa; hena hocoka tawapi ohna wicoicagepi kin owapi. Hena Dawid, qa Samuel wawanyake kin woawanyakapi kin yuhewicakiyapi.

23 Iy epi, qa cincapi Jehowa ti kin wakeya tipi kin tiyopa ekta waawanyakapi kta e najinpi.

24 Unkan tateyanpa topa ektakiya wiyohiyanpa, wiyohpeya, waziyata, qa okaga tiyopa awanyaka yukan.

$25 \mathrm{Q}$ a hunkawanjiwicayapi oton- we tawapi en tipi kin, hena iyehantu eca anpetu śakowin on en hipi ece.

26 Tiyopa waawanyaka itancan topa yukan, ecetuya yuhapi kta on nakaś, hena Lewi wicaśta he. capi, qa hena Wakantanka ti mazopiye, qa wankantipi awanyakapi ecee.

27 Qa Wakantanka ti kin ihclukśan wankapi; hena awanyag wicaśipi; qa hanhanna iyohi tiyopa yuhdokapi ece, nakaś.

28 Qa hena etanhan wanjikśsi wokicanye wakśica kin yuhapi, hecen woyawa on en aupi, qa woyawa on ahdapi ece.

29 Qa wanjikśi wokicanye yuhe wicaśipi, tipi wakan wokicanye owasin; nakun aguyapi mdu kin, qa miniśa kin, qa wihdi kin, qa canśin waśtemna kin, qa taku omnanpi waśte kin.

30 Unkan wawayuśna cincapi wanjikśi wihdi waśtemna kag̉a hecapi.

31 Unkan Lewi kin etanhan Mattiteja ŚSallum cinhintku tokapa kin, Qoralii heca taku ceguguyapi kin owasin awanyag śipi.

32 Unkan hunkawanji wicayapi etanhan Qohati cinca kin wanjikśi ağuyapi taninyan ehnakapi awanyakapi, anpetu okilipapi otoiyohi on wiyeya kagapi kta.

$33 \mathrm{Qa}$ dowanpi itancanpi kin hena Lewi ateyapi tipi kin pa wicayawapi, qa anposkan hanyen koya wohtani econwicakiyapi, heon owankatipidan ohna ihduhapi ecee.

34 Hena Lewi ateyapi pawicayawapi, wicoicagepi itancanpi kin, iyepi Jerusalem ohna tipi.

35 Unkan Gibeyon ohna Gibeyon ateyapi Jehiel ounyan, qa tawicu Mayaka eciyapi. 


\section{WICOWOYARE 10.}

36 Qa cinhintku tokapa Abdon; hehan 'Tzur, qa Qiś, qa Bayal, qa Ner, qa Nadab.

37 Qa Gedor, qa Arjo, qa Zekarja, qa Miqlot,

38 Qa Miqlot Śimea cinkśiya, qa hena sunkawicayapi om hunkawanji wicayapi Jerusalem en tipi kin iyotakons tipi.

39 Lnkan Ner Qiśs cinkśiya, qa Qiś Saul cinkśiya, qa Saul Jonatan, qa Malkisua, qa Abinadab, qa Eśbayal cinkśiwicaya.

40 Qa Jollatan cinhintku kin he Meribbayal, qa Meribayal Mika cinkśiya.

41 Qa Mika cinca kin Piton, qa Melek, qa Tahreya,

$42 \mathrm{Qa}$ Ahaz; iye Jayera cinkśiya, qa Jayera Alemet cinkśiya, nakun Azmawet, qa Zimri; qa Zimri Motza cinkśiya.

43 Qa Motza Bineya cinkśiya, iye cinhintku Repaja, iye cinhintku Eliyasa, iye cinhintku Azel.

44 Qa Azel cinca śakpe yuha, qa cajepi kin dena eepi; Azriqam, Bokeru, qa Ismael, qa Śeraja, qa Obedja, qa Ḧanan; Azel cinca kin hena eepi.

\section{WICOWOYAKE 10.}

1 Unkan Pilistim Israel azuyapi: unkan Israel wicaśta kin Pilistim itokapa tanhan napapi, qa Gilboya he akan capapi hinhipayapi.

2 Unkan Pilistim Saul, qa iye cinca kin ikiyedan wicakuwapi, qa Pilistim Jonatan, qa Abinadab, qa Malkiśua Saul cinca kin wicaktepi.

3 Qa wokicize Saul yuśag ya, qa itazipa ekatapi kin iyeyapi, qa wanhinkpe on opi.

4 Unkan Saul wicaśta tawipe kicic̣in kin heciya, Isan hduśduka, qa on camapa wo ; okini baki- hdayapiśni kin hena en mahipi, qa ośtemahdapi kta. Tuka tawipe kicicin kin tawatenye śni, nina kokipa nakaś. Heon Saul isan ikikcu, qa akan ehpeiçiya.

5 Unkan tawipe kicicin kin Saul wanna te wanyaka, hieon iś eya iśan akan elipeiciye ca ta.

6 Hecen Saul ța nakur iye cinca yamni, qa tiwahe tawa owasin yuwitaya tapi.

7 Unkan Israel wicaśta osmaka en tipi kin owasin, napapi kin, qa Saul, qa iye cinca kin țapi kin wanyakapi; lieon otonwe tawapi kin elpekiyapi, qa najicapi. Unkan Pilistim en hipi, qa hena ohna tipi.

8 Unkan ihanlianna Pilistim tona capapi qon taheyakepi yuśdokapi kta en hipi qehan, Gilboya he akan Saul, qa iye cinca kin hinhpayapi iyewicayapi.

9 Qa Saul yuśdokapi, qa pa kin, qa tawipe kin icupi, qa Pilistim tamakocepi ek ta ahdapi ; taku wakandapi kagapi, qa oyate tawa ihdukśan wootanin sdonyewicakiyapi kta heon etanhan.

$10 \mathrm{Qa}$ tawipe kin taku wakandapi tipi kin en ehnakapi; qa pa kin Dagon ti kin aokatanpi.

11 Unkan Jabeś Gileyad wicasta owasin taku Pilistim Saul ecakiconpi owasin nahonpi.

12 Qa wicaśta waditaka owasin najinpi, qa Saul tancan kin, qa cinca kin tancanpi kin icupi, qa Jabeś ekta ahdipi, qa huhupi kin utuhu Jabeś en yanke cin he ihukuya hnakapi, qa anpetu śakowin akihaniçiyapi.

13 Hecen Saul te, woahtani Jehowa awahtani kin on, Jehowa oie kin nahon śni kin, henn, qa nakun hanmdohdagia wan iwanh akite cin heon etanhan.

14 Qa Jehowa akite śni, heon Jehowa tekiya, qa wawidake kin 585 


\section{ANPETU OYAKAPI,}

Dawid Jesse cinhintku ekta yuwinhya.

\section{WICOWOYAKE 11.}

1 Unkan Israel owasin Dawid ekta mniciyapi, Hebron en, qa heciyapi, Huhu nitawa, qa cehpi nitawa heuncapi.

2 Nakun litanihan qa sanpa, Saul wicaśtayatapi unhapi qehan, Israel tankan awicaye ca hdicuwicaye cin he niye. Qंa Jehowa Wakanyada kin heniciya, Niye oyate mitawa Israel wonwicayaye kta, qa niye Israel oyate mitawa mdetanhunka niyuhapi kta.

3 Hecen Israel hunkayapi owasin wicaśtayatapi kin ekta Ḣebron en hipi. Unkan Dawid wotakuye wicakicagga, Hebron ohna, Jehowa itokam. Unkan Dawid sdayapi, Israel iwicadake kta, Jehowa Samuel nape on eye ciqon he iyecen.

4 Unkan Dawid, qa Israel owasin Jerusalem, Jebus hee, ekta ipi, qa he ehan Jebusi makoce ounyanpi kin hen yakonpi.

5 Unkan Jebus ounyanpi kin Dawid heciyapi. Den yahi kte śni. Tuka Dawid Zion conkaśke kin icu, otonwe Dawid tawa kin hee.

6 Tuwe Jebusi tokaheya wicakaśtake cinhan he pa, qa mdetanhunka heca kta, Dawid eye ciqon, heon Joab Tzeruja cinhintku kin tokaheya en i, qa iye pa yawapi.

7 Unkan Dawid conkaśke kin en iyotanka, heon he Dawid totonwe eciyapi.

$8 \mathrm{Qa}$ Millo etanhan ihdukśan otonwe kin kaga, ihanke kin ekta. Unkan Joab otonwe okapte cin nikiya.

9 Unkan Dawid ohinniyan san586 pa tanka aya, Jehowa obe yuhe cin kici un nakaś.

10 Unkan wicaśta waśaka Dawid wicayuhe cin itancanpi kin dena wakiśag iciyapi, qa tokiconze en ókiyapi, Israel owasin on wicaśtayatapi kaǵapi kta, Jehowa Israel on eye ciqon iyecen.

11 Qa wicaśta waśaka yawapi Dawid wicayuhe cin etanhan dena eepi ; Jaśobeyam he H্Hakmoni cinhintku, wikcemna yamni kin itancan kin, iye wahukeza on opawinge yamni cawicape kta hduwankan icu, qa wancadan wicakte.

12 Unkan iye ohakam Eleazar he Dodo cinhintku Ahohi kin, wicaśta waśaka yamni kin wanji hee.

13 Qa iye Pasdamin (Wepapsonpi) ohna Dawid kici un. Unkan Pilistim kizapi kta hen mniciyapi, qa hen tinta onśpa barle ojudan, qa oyate kin Pilistim wicitokapa tanhan napapi.

14 Tuka iyepi maga kin cokaya najinpi, qa ohiyapi, qa Pilistim wicakaśtakapi; unkan Jehowa niwicaya, wowanikiya tanka on.

15 Unkan itancan wikcemna yamni etanhan yamni imnija en Dawid ekta ipi, Adullam makohdoka en. Unkan Pilistim Repaim osmaka en wankapi.

16 Unkan hehan Dawid conkaśke kin en yanka, qa Pilistim Betlehem en najinpi.

17 Qa Dawid kon, qa heya, "Tokin minihdoka Betlehem tiyopa en yanke cin etanhan tuwe miri yatke makiye kten.

18 Unkan yamni kin hena Pilistim owankapi kin kaoksapi; qa minilidoka Betlehem tiyopa en yanke cin etanhan mini yuwankan icupi, qa yuhapi, qa Dawid ekta kahipi. Unkan Dawid ya- 


\section{WICOWOYAKE 11.}

tke kta wicada śni, qa Jehowa on kaśtan.

19 Qa heya, Taku kin de ecamon kta Wakantanka iyowin makiye śni nunwe. Wicaśta kin dena nagiipi on ahipi hecen wepi kin hee, qa wepi kin he mdatke $\mathrm{kta}$ he? hecen yatke kta wicada śni. Wicaśta waśaka yamni, kin hena heconpi.

20 Qa Abiśai Joab cincu kin yamni itancanyapi kin hee, qa iye wicaśta opawinge yamni wahukeza wicakipazo, qa cawicapa; heon yamni kin ehna caje yuha.

21 Yamni ehna nonpa isanpa kinihanpi, heon mdetanhunka yuhapi. Tuka yamni kin iyowicahi śni.

22 Benaja Tehojada cinhintku kin, he wicaśta waditaka, Qabetzel etanhan, woecontanka ota econ; he cinhintku. Iye Moab wicaśta nonpa mnaja iyacecapi wicakte; nakun iye mnaja wan woha mahen yanka ekta i, qa kte, anpetu wa yukan he ehan.

23 Nakun iye Egupton wicaśta wan kte, wicaśta hanska, wiciśpa zaptan, qa Egupton nape ohna wahukeza yuha, wakazunta ihupa hinskokeca; tuka cansakadan yuha ekta i, qa $\mathrm{Egu-}$ pton nape kin etanhan wahukeza ki, qa wahukeza tawa on kte.

24 Benaja Jehojada cinhintku hena econ, qa wicaśta waśaka yamni kin ehna caje yuha.

25 Wikcemna yamni kin isanpa kinihanpi, tuka yamni kin iyowicahi śni. Unkan Dawid tona iye ti awanyakapi kin itancan kaga. 26 Unkan wicaśta waditaka iyotan waśakapi dena eepi. Yasahel Joab sunkaku, Elhanan he Dodo cinhintku, Betlehem etanhan;
27 Śanmot Harori kin, Heletz Peloni kin:

28 Yira Yeqeś cinhintku kin, Abiyezer Anatoti kin;

29 Sibbeka Huśati kin, Yilai Ahohi kin,

30 Maharai Netopati kin, íteled he Bayana cinhintku Netopati kin;

31 Itai he Ribai cinhintku Gibeya Benjamin cinca tawapi etanhan, Benaja Piratoni kin,

32 Ḣurai Gayaś kaksiza kin etanhan, Abiel Yarbati kin;

33 Yazmawet Baharumi kin, Eljahba Śayalboni kin;

34 Haśam Gizoni kin cinca kin, Jonatan Śage cinhintku Harari kin;

35 Ahijam Sakar cinhintku Harari kin, Elipal Ur cinhintku kin, 36 Heper Mekerati kin, Ahija Peloni kin,

37 Hetzro Karmeli kin, Nayarai Ezbai cinhintku,

38 Joel Natan sunkaku, Mibhar Hageri cinhintku,

39 Tzeleq Amoni kin, Nahari Beroti kin he Joab Tzeruja cinhintku tawipe kiciçin kin;

40 Yira Jitri kin, Gareb Jitri kin,

41 Urija Hitti kin, Zabad Ahlai cinhintku ;

42 Yadina Śiza cinhintku Rubeni kin, Rubeni itancan, qa iye kici wikcemna yamni;

43 Ḧanan Mayaka cinhintku, qa Jośapat Mitni kin,

44 Uzzia Yaśterati kin, Śama qa Jeyiel Ḣotam Yaroyeri kin cinca kin.

45 Jediyael he Śimri cinhintku, qa sunkakn Joha Titzi kin,

46 Eliel Mahawi kin, qa Jeriba qa Josaja hena Elnayam cinca, qa Jitma Moabi kin,

47 Eliel, qa Yobed, qa Jasiel he Metzobaja etanhan. 


\section{ANPETU OYAKAPI,}

\section{WICOWOYAKE 12.}

1 Unkan dena Dawid ekta 'Tziqlag en hipi, nahanhin Saul Qiś cinhintku on etanhan natakapi qehan, qa hena waśakapi, qa wokicize en ókiyapi.

2 Itazipa yuhapi, qa inyan, qa wanhinkpe itazipa on yeya okihipi, etapapi qa catkapi kin unman tukte kaśta on; Saul hunkawanji wicaye cin Benjamin etanhan.

3 Ahiyezer he itancan, qa Joaś Simaya cinhintku Gibeyati kin, qa Jeziel, qa Pelet Yazmawet cinca, qa Beraka, qa Jehu Amatoti kin.

4. Qa Jiśmaja Gibeyoni kin, wicaśta waśaka wikcemna yamni kin chna, qa wikcemna yamni kin isanpa; nakun Jeremija, qa Jahaziel, qa Johanan, qa Jozabad (rederoti kin.

5 Elyuzai, qa Jerimot, qa Beyalja, qa Semarja, qa Sepatja Haropi kin.

6 Eilqana, qa Jiśija, qa Yazariel, ya Joyezer, qa Jaśobeyam, Qorahim kin.

7 Qa Joyela, qa Zebadja Jeroham cinca, Gedor etanhan hena eepi.

8 Qa.Gadi kin etanhan Dawid, tinta conkaśke kin en yanke cehan, ekta wicaśta waśaka waditaka inanpapi, wicaśta ozuye kaga wayupika, wahacanka, qa wahukeza yuhapi, itepi kin mnaja itepi kin iyececapi, qa ta tokadan he akan yakonpi kin iyecen duzahanpi ;

9 Yezer he itancan kin, Obadja inonpa kin, Eliab iyamni kin.

10 Miśmanna itopa kin, Jeremija izaptan kin,

11 Yattai iśakpe kin, Eliel iśakowin kin,
12 Johanan iśahdoğan kin, Elzabad inapcinwanka kin,

13 Jeremija iwikcemna kin, Makbunnai iakewanji kin.

14 Hena Gad cinca kin akicita tancanpi, wanji cistinna opawinge yuha, qa tanka kin kektopawinge.

15 Hena wi tokaheya en, Jordan minitan ece, maya kin owasin iwankam, he ehan iyuwegapi, qa osmaka ounyanp $i$ kin owasin nape wicayapi, wiyohiyanpata, qa wiyoheyata nakun.

16 Unkan Juda qa Benjamin cincapi kin etanhan Dawid ekta, conkaśke ekta hipi.

17 Unkan Dawid wicitkokim inanpe ça ia, qa hewicakiya, Wookiye on ómayakiyapi kta e yahipi kinhan micante kin nicantepi om okowanjidan kta; tuka minape ohna ohan śica wanica eśta mayahnayanpi, qa toka mayanpi nape en mayaqupi kte cinhan, tuwe hunkake wicunyanpi wakandapi kin he wanyake kte, qa yaco kte.

18 Unkan woniya kin Amasai wikcemna yamni itancan kin koyaka; unkan heya, Dawid tawa unyayapi, qa Jesse cinhintku unnicapi. Wookiye, niye ekta wookiye, qa tona óniciyapi kin wookiye yuhapi nunwe; Tuwe wakanyada óniciya nakaś. Unkan Dawid iyowin wicakiya, qa mde tanhunka wicakagga.

19 Unkan Pilistim Saul azuyapi Dawid owicape cehan; (tuka owicakiye śni ; Pilistim itancanpi kin iwohdakapi, qa heyapi, Unpapi on iye yuhe cin Saul ekta hde kta qa on kihde śipi nakaś ;) hehan Manaśe etanhan wanjikśsi en hipi.

30 Tziglag en hdi qehan Manaśe etanhan Yadna, qa Jozabad, qa Jidayel, qa Mikael, qa Joza- 
bad, qa Elihu, qa Tzilletai, Manaśe kektopawinge itancanpi kin en hipi.

21 Hella Dawid ókiyapi, ozuye anatanpi qehan, hena owasin wicaśta waśaka waditakapi nakaś, qa obe itancan hecapi.

22 He ehan anpetu otoiyohi Dawid ókiyapi kta wicaśta en hipi, ecen obe tanka Wakantanka taobe kin iyececa.

23 Unkan wokicize on wiyeya unpi, itancanpi kin Ḧelmron en Dawid ekta hipi, Saul towidake kin Dawid ekta yuhomnipi kta on, Jehowa eye ciqon iyecen, wicayawapi kin dena eepi.

24 Juda cinca kin, wahacanka wahukeza ko kiçunpi, kektopawinge śakpe sanpa opawinge śahdogan, ozuye on wipe kitonpi.

25 Simeon cinca etanhan, wicaśta waḱaka, ozuye waditakapi kektopawing śe śkowin sanpa opawinge wanjidan.

26 Lewi cinca kin etanhan kektopawinge topa sanpa opawinge śakpe.

27 Nakun Jehojada Aaron cin$c a$ kin itancan kin, qa kektopawinge yamni sanpa opawinge śakowin kici unpi.

28 Nakun Zadok kośka waśaka waditaka, qa atkuku ti kin etanhan wicaśta itancan hecapi wikcemna nonpa sanpa nonpa.

29 Qa Benjamin cinca kin etanhan, Saul sunka wicaye cin etanhan kektopawinge yamni; hena wicota nahanhin Saul ti towanyake kin awanyakapi.

30 Qa Epraim cincakin etanhan kektopawinge wikcemna nonpa sanpa opawinge śahdoġan wicaśta waśaka waditaka hunkake wicayapi ti kin en caje wicayatapi.

31 Manaśe wicoun hanke kin etanhan kektopawinge wikcemna sanpa kektopawinġe śahdog̉an, hena Dawid wicaśtayatapi kagapi kta caje wicayatapi.

32 Qa Issakar cinca kin etanhan wicaśta anpetu kin sdonyapi, on iyehantu wosdonye on taku Israel econpi lita iyececa iyukcanpi, pa wicayawapi opawinge nonpa, qa hunkawanjinwicayapi owasin owicapapi.

33 Qa Zebulun etanhar zuyeyapi, wokicize wipe owasin yuhapi kektopawinge wikcemna zaptan, cante okonwanjidan ocimdag̉ehan najinpi.

34 Qa Naptali etanhan akicita tancan kektopawinge, qa wahacanka qa wahukeza yuhapi kektopawinge wikcemna yamni sanpa kektopawinge śakowin owicapapi.

35 Qa Dani kin etanhan ozuye wiyeya unpi kektopa winge wikcemna nonpa sanpa kektopawinge śahdogan qa opawing̉e sakpe.

36 Qa Aśer etanhan zuye yapi, wokicize wipe yuhapi kektopawinge wikcemna topa.

37 Qa Jordan akasanpa tanhan Rubeni kin, qa Gadi kin, qa Manaśe wicoun hanke kin etanhan obe wokicize wipe owasin yuhapi kektopawinge opawing sanpa kektopawinge wikcemna nonpa.

38 Hena owasin ozuye wicaśta ocimdagehan manipi cante ocowasin on, Dawid wicaśtayatapi kağapi kta, Hebron ekta hipi, Israel owasin iwankam, qa nakun Israel unmanpi kin owasin cante okonwanjidan Dawid wicaśta yatapi kaggapi kta cinpi.

39 Qa hen anpetu yamni Dawid kici yakonpi, wotapi, qa wayatkanpi, hunkawanjiwicayapi kin taku wiyeya wicakicağapi nakaś.

40 Qa nakun Israel ohna wowiyuśkin yukan; heon tona wicikiyedan unpi kin, Issakar, qa Ze- 


\section{ANPETU OYAKAPI,}

bulun, qa Naptali ekta hehanyan woyute wicakahipi, śonśonna, qa Kamel, qa śunkaśonśonna akan, qa woyute ağuyapi mdu, qa suken waskuyeca paskicapi, qa hastanhanka pusyapi, qa miniśa, qa wihdi, nakun tatanka, qa tahinca, nina ota kahipi.

\section{WICOWOYAKE 13.}

1 Unkan Dawid kektopawing̈e itancanpi kin, qa opawinge itancanpi kin, qa mdetanhunka owasin om wohdaka.

2 Qa Dawid Israel omniciye owasin hewicakiya, Iyonicipipi kinhan, qa Jehowa Wakanundapi kin etanhan kinhan, hunkawanji wicunyanpi Israel makoce owancaya okaptapi kin, iwahowicunyanpi kta, qa wawayuśnapi kin, qa Lewi kin otonwe ta- wayapi ohna yakonpi kin om, unkiyepi en mniciye wicunyanpi kta.

3 Qa taku Wakanundapi canwohnaka tawa unkiyepi en unhdohdipi kta; Saul anpetu tawa icunhan he unkakitapi śni nakaś.

4 Unkan ommiciye owasin heconpi kta keyapi; wicoie kin ecetu oyate owasin iśtapi kin en nakaś.

5 Unkan Dawid Israel owasin mniciye wicaya, Egupton wakpa kin etanlıan, Hamat ekta yapi kin hehanyan; Wakantanka canwohnaka tawa Qirjat Jeyarim ekta huweyapi kte heon etanhan.

6 Unkan Dawid, qa Israel owasin Qirjat Jeyarim otonwe kin ekta ipi, hetanhan, Wakantanka, Jehowa kerubim ounye cin eciyapi, canwohnaka tawa huweyapi kte.

7 Unkan Abinadab ti kin etanhan canpahmihma teca wan akan hdokupi. Unkan Uzza qa Ahio canpahmihma kin kahapapi.

8 Unkan Dawid, qa Israel owasin, towaśakapi ocowasin on, Jehowa itokam śkatapi, qa dowanpi, can dowankiyapi on, qa cotanka on, qa cancega on, qa mazaicicasnapi on, qa maza yahotonpi on.

9 Unkan Kidon wakapanpi owanka ekta hipi qehan, Uzza canwohnaka yuze kta nape kin yekiya, tatanka kin nahuhuzapi nakaś.

10 Unkan Jehowa tocanniye kin Uzza aide, qa canwohnaka kin ekta nape kin yekiye cin heon kaśtaka ; unkan hen ța, Wakantanka itokam.

11. Unkan Dawid śihda, Jehowa Uzza kaśtake cin heon etanhan. Unkan oyanke kin he anpetu kin dehanyan Peretz Uzza (Uzza kaśtakapi) eciyapi.

12 Unkan anpetu kin he en Dawid Wakantanka kokipa, qa heya, Token Jehowa canwohnaka tawa miye ekta hiyu waye kta he?

13 Heon Dawid iye ti ekta, Dawid totonwe kin en canwohnaka kin hiyuye śni; tuka icuorn aya, Obededom Gitti ti kin ekta.

14 Unkan Wakantanka canwohnaka tawa Obededom tiyohnaka om, iye ti kin ohna wi yamni yanka. Unkan Jehowa Obededom tiyohnaka kin, qa taku yuhe cin owasin yawaśte.

\section{WICOWOYAKE 14.}

1 Unkan Ḣuram Tzur wicaśtayatapi kin wahośiye Dawid ekta u wicaśi ; nakun lianteśa can, qa inyantipiliaga, qa cankajipa, tipi kicicagapi kta heon etanhan.

2 Unkan Dawid iye tawowidake kin tehanwankan aya, heon Israel 
iwicadake kta e Jehowa iye yusuta oyate tawa Israel on etanhan sdotkiya.

3 Unkan Jerusalem ohna Dawid winohinca sanpa wicayuza, qa cinca wica winyan ko Dawid kicitonpi.

4 Qa cinca Jerusalem ohna kicitonpi cajepi kin dena ee; Śanmuya, qa Śbab, Natan, qa Solomon,

5 Qa Jibhar, qa Éliśua, qa Ëpalet,

6 Qa Noga, qa Nepeg, qa Japiyя.

7 Qa Eliśama, qa Beyeljada, qa Elipalet.

8 Unkan Pilistim Israel ocowasin idake kta e Dawid sdayapi nahonpi qehan, Pilistim owasin Dawid akin itanwankanhde upi. Unkan Dawid nalion, qa wicitkokim inanpa.

9 Unkan Pilistim hipi, qa Repaim osmaka ohna enanakiya iyayapi.

10 Unkan Dawid Wakantanka iwange ca heya, Pilistim anawicawatan kta, qa minape en wicayaqu kta he? Unkan Jehowa heciya, Anatan wo, hecen ninape en wicawaqu kta.

11 Unkan Bayal Peratzim ekta hipi. Unkan hen Dawid wicakaśtaka, qa heya, Jehowa tokamayanpi minape on kadus wicaya, mini caduze cin iyecen: heon oyanke kin he Bayal Peratzim, (Iyotan kaduzapi,) eya caje yatapi.

12 Unkan hen taku wakandapi ehpekiyapi. Unkan peta on huhnahyapi; Dawid hecon wicaśi nakaś.

13 Unkan ake Pilistim osmakạ qon ohna enanakiya iyayapi.

14 Unkan Dawid ake Wakantanka iwanga. Unkan Wakantanka heciya, Wicihakam de kte śni, ewicatanhan ihduhomni, qa Baka can kin itokapa tanhan wicikiyedan ya wo.

15 Qa Baka can inkpa ohna taku iyaya ho kin nayahon kinhan, hehan wokicize ekta inanpa wo; Wakantanka Pilistim wicakaśtake kte e nitokam inanpa nakaś.

16 Unkan Dawid, token Wakantanka econśi kin, he iyecen econ, qa Gibeyon etanhan Gazer ekta, hehanyan Pilistim obe kin kaśtakapi.

17 Hecen makoce kin owasin ohna cajeyatapi, qa ikcewicaśta owasin kokipapi, Jehowa kaga.

\section{WICOWOYAKE 15.}

1 Unkan Dawid totonwe ohna tipi kaga, qa Wakantanka canwohnaka tawa on oyanke wan wiyeya kagaa, qa on wakeya wan ekicihde.

2 Hehan Dawid heya, Lewi kin iśnanapi Wakantanka canwohnaka tawa yuhapi kta iyececa. Hena Jehowa wicakahniga, Wakantanka can wohnaka tawa akiyuhapi kta, qa kicanyanpi kta, owihanke wanica.

3 Unkan Dawid Israel owasin Jerusalem ekta mniciye wicaya, Jehowa canwohnaka tawa hdoupi kta, oyanke tawa iye kicicage cin he en.

4 Qa Dawid Aaron cinca kin, qa Lewi kin wicayuwitaya.

5 Qohat cinca kin etanhan Uriel itancan kin, qa sunka wicaya opawinge sanpa wikcemna nonpa.

6 Merari cinca etanhan Yasaja itancan kin, qa sunkawicaya opawinge nonpa sanpa wilkcemona nonpa.

7 Gerśom cinca kin etanhan Joel itancan kin, qa sunka wi5.91 


\section{ANPETU}

caya opawinge sanpa wikcemna yami.

8 Elitzapan cinca etanhan Śmaja itancan kin, qa sunka wicaya opawinge nonpa.

9 Hebron cinca etanhan Eliel itancan kin, qa sunka wicaya wikcemna śahdogan.

10 Uziel cinca etanhan Anminadab itancan kin, qa sunka wicaya opawinge sanpa wikcenına sanpa nonpa.

11 Unkan Dawid wawayuśna kin 'Ladoq, qa Abiatar; qa Lerwi kin Uriel, Yasaja, qa Jocl, Semaja, qa Eliel, qa Anminadab wicakipan ;

12 Qa hewicakiya, Lewi ate wicayapi itancanpi kin henicapi, ihduwakanpo, niyepi, qa sunka wicayayapi; qa Jehowa Israel wakandapi canwohnaka tawa oyanke wiyeya wecage rin ekta hiyuyapo.

13 'Tokaheya qon hecanonpi śni, heon Jehowa Wakanundapi kin unkaśtakapi, woyaco kin iyecen unkakitapi śni nakaś.

14. Unkan wawayuśnapi kin, qa Lewi kin Jehowa Israel wakandapi canwohnaka tawa huweyapi kta ihduwakanpi.

15 Qa Lewi cincapi kin Wakantanka canwohnaka tawa tośu on hiyetepi akan akiyuhapi, Mowis Jehowa oie kin eciyatanhan, econwicaśi kin iyecen.

16 Unkan Dawid Lewi itancanpi kin sunkawicayapi wanjịkśi dowan wokicanye on dowan najin wicakiyapi kta kewicakiya, candowankiyapi on, qa cotanka on, qa maza icicasnapi on; hecen wiyuśkinyan ho kin wankan yeyapi kta.

17 Unkan Lewi kin, Heman Joel cinhintku, qa hunkawanji wicaye cin etanhan Asap Berekeja cinhintku, qa hunkawanjiwicaye
OYAKAPI,

cin Merari cinca kin etanhan Etan Quśaja cinhintku najin wicayapi.

$18 \mathrm{Qa}$ hena om hunkawanji wicayapi iyokihepi Zekareja, Ben, qa Jayaziel, qa Śsemiramot, qa Jehiel, qa Y uni, qa Eliab, qa Benaja, qa Mayasija, qa Matiteja, qa Elipelu, qa Miqneja, qa Obededom, qa Jeyiel tiyopa awanyakapi.

19 Qa Heman, Asap, qa Etan wadowanpi, mazaicicasnapi on hotaninpi ece.

$20 \mathrm{Qa}$ Zekarija, qa Yaziel, qa Semiramot, qa Jehiel, qa Yuni, qa Eliab, qa Mayaseja, qa Benaja, candowankiyapi wikośka ho on,

21 Qa Matiteja, qa Elipelu, qa Miqneja, qa Obededom, qa Jeyiel, qa Yazazija candowankiyapi iśahdogian kin on ahiyayeyapi.

$22 \mathrm{Qa}$ Kenanaja Lewi itancanpi ahiyayapi kin onspewicakiya, iye ahiyaya wayupika nakaś.

23 Qa Berekeja, qa Elqana canwohnaka kin awanyakapi.

24 Qa Śebaneja, qa Jośapat, qa Netaneel, qa Yamasa, qa Zekareja, qa Benaja, qa Eliezer wawayuśnapi kin Wakantanka canwohnake tawa itokam mazayahotonpi on yahotonpi. Qa Obededom, qa Jehija canwohnaka kin awanyakapi.

25 Unkan Dawid, qa Israel hunkayapi kin, qa kektopawinge itancanpi kin Jehowa wotakuye canwohnaka kin, Obededom ti kin ekta, wiyuśkinyan huwe ipi. 26 Unkan Wakantanka Lewi kin Jehowa wicotakuye canwohnaka akiyuhapi kin ówicakiye cehan tatanka śakowin, qa tamoka śakowin wakiyuśnapi.

27 Unkan Dawid miniliuha onhidohda wan ipiyag kiton; nakun Lewi canwohnaka akiyuha- 


\section{WICOWOYAKE 16.}

pi kin owasin, qa wadowanpi, kin, qa Kenaneja akiyuhapi itancan kin wadowanpi om, qa Dawid minihuha amdo akahpe wan koyagya.

28 Unkan Israel owasin Jehowa otakuye canwohnaka kin iyaśapi, qa heyahotonpi on, qa mazayahotonpi, qa mazaicicasnapi hena owasin ho kin on, qa candowankiyapi qa cotanka dowankiyapi on akupi.

29 Unkan Jehowa wotakuye canwohnaka kin Dawid totonwe kin en hi qehan, Mikal Saul cunwintku owanyeye ohna eokasin, qa wicaśtayatapi kin Dawid śkata, qa waci wanyake cehan cante mahen wahtedaśni.

\section{WICOWOYAKE 16.}

1 Unkan Wakantanka canwohnaka tawa ahipi, qa ehdepi, wakeya wan Dawid ekicihde kin ohna, qa woliulinahyapi, qa wopida wośnapi Wakantanka itokam ahipi.

2 Unkan Dawid wohuhnahyapi, qa wopida wośnapi huhnahya

8 Jehowa yatanmiye,

Iye caje kin hoyekiya miye.

Oyate ehna iye ohan tanka oyakapo.

9 lye idowanpo; kahiyayapo.

Iye tawowapetokeca owasin awacinpo.

10 Caje wakan tawa yatanpo.

Tona Jehowa akitapi cantepi wiyuśkinpi kta.

11 Jehowa odemiye, qa iye towaśake kin.

Iye ite kin ohinniyan akitapo.

12 Taku wowinihan econ kin kiksuyapo.

Iye wowapetokeca tawa.

Qa woyaco iye i kin etanhan.

13 Iye taokiye, Israel etanhan inicagapi;

Jakob cinca nicahnigapi.

14 Jehowa Wakanundapi kin he iye. Tawoyaco kin maka kin owancaya.

15 Wotakuye tawa owihanke wanin kiksuyapo.

Wicoie econ wicaśi kin wicoicag̉e kektopawing̉e hehanyan. 


\section{ANPE'TU OYAKAPI,}

16 Abraham kicicage cin he;

Qa wokonze tawa Izak en.

17 He Jakob kici hdasuta wokage on, Israel kici wotakuye owihanke wanica.

18 Qa heya, Niye Kanan makoce kin ciçu kta, Tawayaye kta e he iniciyutapi.

19 Hinahin tonana wicayawapi, Qa ohna unhdaka unpi.

20 Ikcewicaśta wicehna ihdaka yapi; Wokiconze wan etanhan oyate tokeca ekta.

21 Tuwedan wicakiyuśe iyowinkiye śni. Qa iyepi on wicaśta yatapi iyopewicaya.

22 Sdawicawakiye cin ihnuhan iwicayakahtake cin. Qa ihnuhan waayate mitawa śicaya ecawicayeconpi kin.

23 Maka kin ocowasin Jehowa idowanpo. Anpetu otoiyohi waniwicakiye cin he yaotaninpo.

24 Ikcewicaśta wicehna towitan kin oyakapo. Oyate owasin wicehna iye ohan wakan kin.

25. Jehowa tanka ce, qa nina yatanpi kta.

Taku wakan owusin isanpa kokipapi kta iyececa.

26 Oyate taku wakandapi owasin takuśniśni. Tuka Jehowa mahpiya kin kaga.

27 Iye itokam wotanka, qa wowitan, Oyanke tawa ohna wowaśake qa wowiyuśkin yukản ce.

28 Oyate wicowazipi kin Jehowa qupo; Wowitan, qa wowaśake, Jehowa qupo.

29 Iye caje towitan kin Jehowa qupo; Minha icupi, qa itokam hiyuyapo.

Wowakan wiciyokipi kin en Jehowa ohodapo.

30 Maka ounyanpi kin owasin iye ite kin on inihanpo. Maka kin sutaya ehdepi ce, hohodan kte śni.

31 Mahpiya kin iyuśkinpo, qa maka kin pida wo. Ikcewicaśta wicehna, Jehowa wicaśtayatapi ce, eyapo.

32 Miniwanca, qa toojudan kin śa kta.

Tinta kin, qa taku aicagge cin iyuhpa iyuśkinpi kte.

33 Hehan contanka can kin owasin Jehowa ite kin on dowanpi kta;

Maka kin yaco kta e hiyu nakaś.

34 Jehowa yatanpo, iye waśte ce; Towacantkiye owihanke wanica nakaś.

$35 \mathrm{Qa}$ heyapo, Taku wakan niunkiyapi ece kin, niunkiyamiye.

Qa ilkcewicaśta etanhan eunhdakupi, qa mnaunkiyamiye. Hecen nicaje wakan kin unyatanpi kta.

Qa niyatanpi odowan en unkihdatanpi kta.

36 Jehowa Israel wakandapi kin yawaśtepi nunwe;

Otokahe wanica ehantanhan ecen owihanke wanin.

Unkan oyate kin owasin, Amen, eyapi, qa Jehowa yatanpi.

594 


\section{WICOWOYAKE $1 \%$.}

37 Unkan hen Jehowa otakuye canwohnaka kin itokam Asap, qa sunka wicaya yanke wicaya, ohinniyan canwohnaka kin itokam ókiyapi kta, anpetu otoiyohi wicoie kin iyecen.

38 Nakun Obededom, qa sunka wicayapi wikcemna śakpe sanpa śahdogan, qa Obededom Jedutun cinhintku, qa Hosa tiyopa awanyakapi kta.

39 Unkan Zadoq wawayuśna kin, qa sunkawicaya wawayuśnapi kin Jehowa ti kin paha wan Gibeyon ohnu yanke cin akan he cin, he itokam yakonpi.

40 Wohuhnahyapi owayuśna akan Jehowa liulinalikiciyapi kta, ohinniyan, hanhanna otoiyohi, qa htayetu otoiyohi Jehowa toope, Israel ope wicaśi kin iyecen.

41 Qa hena om Heman, qa Jedutun, qa unmanpi tona Jehowa, iye towaonśida on, owihanke wanica yatanpi kta e wicakahnigapi, qa cajepi owapi.

42 Qa hena wicehna Heman, qa Jedutun mazayahotonpi, qa mazaicicasnapi on hotanin wicakiyapi kta, nakun Wakantanka tadowan kiyapi on yatanpi ; tuka Jedutun cinca kin tiyopa awanyakapi ece.

43 Unkan oyate kin owasin kihdapi, otoiyohi tipi tawa ekta. Qa Dawid iye ti yawaśte kta e kihda.

\section{WICOWOYAKE 17.}

1 Unkan Dawid iye ti kin ohna iyotanka yanka qehan, Dawid Natan wayate kin heciya, Inyún miye lianteśa can tipi ohna wati, tuka Jehowa otakuye canwohnaka kin ozanpi ihukuya yanka.

2 Unkan Natan Dawid heciya, Taku nicante en un kin owasin. econ wo; Wakantanka nici un nakaś.

3 Unkan hanyetu kin he en Wakantanka oie kin Natan en hi qa heciya,

4 Dawid mitaokiye ekta ye ca heciya wo, Jehowa hecen eya, Niye tipi ohna wati kta miyecağe kte śni.

5 Israel hdinanpe wicawaye cin ehantanhan dehanyan cantipi ohna wati śni; tuka wakeya wan etanhan wakeya tokeca ekta, qa oyanke etanhan oyanke tokeca ekta waun.

6 Israel owasin wicehna tuktentu kaśta mawani Israel wayacopi kin, oyate mitawa wonwicaya wicawaśi kin; tukte wanji wicoie wan ewakiye ca, Tokeca lianteśa can tipi wan miyecag̉api śni epa he?

7 Heon nakaha mitaokiye Dawid hecen eyakiye kta, Jehowa obe yuhe cin hecen eya, Miye oyate mitawa Israel itokam mayani kta on, tahinca wicihakam yaun kin, owankapi kin etanhan icicu.

8 Qa tokiya kaśta idada ca nici wai, qa nitokapa tanhan tokaniyanpi kin owasin wicawakaśpa, qa caje cicicaga, maka akan wicaśta tanka cajepi kin iyececa.

9 Qa oyate mitawa Israel oyanke wan wicawaqu kta, qa huwicawehde kta, qa hen yakonpi kta, qa wośica cinca kin icimana wicayusote kte śni, otokahe ekta econpi qon iyecen;

$10 \mathrm{Qa}$ wayacopi oyate mitawa Israel yuhe wicawaśi kin icunhan. Nakun tókaniyanpi kin owasin wicamduhukuya, qa Jehowa tipi nicicagre kta, eciciya.

11 Nakun nihunkakepi ekta de kta, anpetu nitawa ihuniyaye cinhan, hehan nicinca, niye etanhan icagapi etanhan wanji niha595 


\section{ANPETU OYAKAPI,}

kam najin wakiye kta, qa tokiconze mdusuta kta.

12 Iye tipi wan micicağe kta, qa toiyotanke kin mdusuta kta, owihanke wanin.

13 Iye atemaye kta, qa miye he cinkśíwaye kta, qa iye etanhan mitowacantkiye ewehdaku kte śni; tuwe nitokam un etanhan ewehdaku qon iyecen.

14. $\mathrm{Qa}$ wati kin ohna, qa mitokiconze ohna owihanke wanin he najin wakiye kta, qa toiyotanke kin owihanke wanin sutaya he kta.

15 Wicoie lin dena owasin iyecen, qa wowanyake kin de iyecen Natan Dawid eciya.

16 Unkan Dawid ekta i, qa Jehowa itokam iyotanke ça heya, Jehowa Wakantanka, matuwe he? qa wati kin taku he? on dehanyan hiyumayaya.

17 Qa niiśta kin en hena owasin cistinna, Wakantanka, heon nitaokiye tokata tehan on iyae ca wicaśta wankan yapi okitanin kin iyecen wanyag mayaya, Jehowa Wakantanka.

$18 \mathrm{Qa}$ token Dawid, wowitan nitaokiye ecayecon kin on, taku sanpa eniciye kta he? Niye nitaokiye sdonyaya nakaś.

19 Jehowa nicante iyecen wotanka kin de owasin nitaokiye ecayecon, niohan tanka owasin yahdutanin kta, heon etanhan.

20 Jehowa tuwedan iyeniceca śni, qa taku, nogge on naunhonpi owasin en, taku wakan niśnana.

21 Qa maka akan tukte ikce oyate wan oyate nitawa Israel iyececa he? oyate tawaye kta e Wakantanka ekta wicai; hecen caje tanka, qa wowinihan nic̣icaga, oyate nitawa Egupton etanhan opeyakiton kin itokapa tanhan ikcewicaśta nape wicayaye cehan.

$22 \mathrm{Qa}$ cyate nitawa Israel owihanke wanin oyate nitawa kta, qa niye Jehowa wakannidapi kta yakonza.

$23 \mathrm{Qa}$ Jehowa wicoie nitaokiye on, qa tipi tawa on ehe cin, he owilanke wanin wicaka nunwe ; qa token ehe cin iyecen econye. 24 Qa nicaje owihanke wanin wacinyanpi kta, qa yatankapi kta, qa heyapi kta, Israel wakandapi kin Jehowa obe yuhe cin be Israel wakandapi nunwe ; qa Dawid nitaokiye ti kin nitokam yusutapi nunwe.

25 Niye wakan cida nitaokiye tipi yecagie kta, nitaokiye nahon yaya, heon nitaokiye nitokam cekiye kta tawatenya.

$26 \mathrm{Qa}$ wanna Jehowa niye Wakannitanka, qa wowaśte kin de nitaokiye on eha.

27 Heon wanna nitaokiye ti kin owihanke wanin nitokam he kta e dawaśte iyonicipi nunwe. Niye Jehowa taku dawaśte kin he owihanke wanin yawaśtepi kta.

\section{WICOW OYAKE 18.}

1 Unkan hena iyohakam Dawid Pilistim wicakaśtaka, qa wicaktedan, qa Gat, qa otonwe cunkśiwicaya, Pilistim napepi kin etanhan icu.

2 Nakun Moab kaśtaka hecen Moabi kin Dawid wowidag wicaya. Unkan taku qupi kin kahipi.

3 Nakun Dawid Hadarezer Tzoba wicaśtayatapi kaśtaka, Hamat ekta tamakoce Yuprate wakpa ekta yutanke kta i qehan. 4 Qa Dawid iye etanhan canpahmihma kektopawinge icu, qa śuktanka akanyotankapi kektopawinğe śakowin, qa huiyun wicaśta kektopawinge wikcemna nonpa. Qa Dawid canpahmi- 


\section{WICOWOYAKE 19.}

hma opawinge wanjidan on śuktanka patan, qa canpahmihma unman śuktanka kin owasin kan wicakapsaka.

5 Unkan Aram Damaskos Hadarezer Tzoba wicaśtayatapi kin ókiye kta hi ; unkan Dawid Aram wicaśta kin kektopawinge wikcemna nonpa sanpa kektopawinge nonpa wicakaśtaka.

ti Qa Dawid Aram Damaskos ohna akicita yanke wicakiya; hecen Dawid Arami wowidag wicaya. Unkan taku qupi kahipi. Unkan Jehowa Dawid tokiya kaśta i eca, owancaya nikiya ecee.

7 Unkan Dawid mazaskazi wahacanka Hadarezer taokiye yuhapi kin icu, qa Jerusalem ekta ahdi.

8 Nakun Dawid Tibehat, qa Kun, Hadarezer totonwe etanhan mazazi nina ota icu, qa hetanhan Solomon mazazi cega tanka, qa mazazi ipatan nonpa kin, qa mazazi wakśica kin hena kagia.

9 Unkan Dawid Hadarezer Tzobá wicaśtayatapi kin taozuye owasin kaśtake cin "Toyu Ḧamat wicaśtayatapi kin nahon qehan,

10 Iye cinhintku Hadoram wicaśtayatapi kin Dawid ekta ye śi; Tanyan un kinhan iwange kta, qa Hadarezer azuye ça kaśtake cin on yawaśte kta ; Toyu qa Hadarezer kicizapi ece nakaś, qa mazaskazi wakśica, qa mazaska wakśica, qa mazazi wakśica ocaje owasin kai.

11 Hena nakun wicaśtayatapi kin Dawid Jehowa kiciyuwakan, mazaska, qa mazasiazi ikce wicaśta owasin etarihan ahdi kici; Edom etanhan, qa Moab etanhan, qa Anmon cinca etanhan, qa Pilistim etanhan, qa Amaleq e tanhan.
12 Unkan Abiśai Tzeruja cinhintku Miniskuya osmaka ohna Edom kaśtaka, wicaśta kektopawinge wikcemna sanpa kektopawinğe śahdogian.

13 Unkan Edom ohna akicita yanke wicakiya, hecen Dawid Edom owasin wowidag wicaya. Unkan Jehowa Dawid tokiya kaśta i eca nikiya ece.

14 Unkan Dawid Israel owasin wowidag wicaya, qa oyate tawa owasin woyaco, qa woowotanna ecawicakicon ece.

15 Qa Joab Tzeruja cinhintku kin obe kin yuha, qa Jehośapat Ahilud cinhintku wakiksuya ece.

16 Qa Zadoq A.hitub cinhintku, qa Ahimelek Abiatar cinhintku wawayuśna hecapi; qa Śaweśa wowapikağa kin hee.

17 Qa Benaja Jehojada cinhintku Wabaksapi, qa Wainyankapi itancan kin hee, qa Dawid cinca kin wicaśtayatapi kin icahda itancan hecapi.

\section{WICOWOYAKE 19.}

1 Unkan hena iyohakam Nahaś Anmon cinca wicaśtayatapi kín ța, qa heekiya cinhintku wawidaka.

2 Unkan Dawid heya, Hanun Nahaś cinhintku kin wowacanthiye ecawecon kta, atkuku wowacantkiye ecamicon nakaś; qa Dawid wahośiye atkuku on kicanptapi kta ekta ye wicaśi. Unkan Dawid taokiye Hanun kicanptapi kta e Anmon cinca tamakocepi kin ekta ipi.

3 Unkan Anmon cinca itancanpi kin Hanun heciyapj, Niiśta kin en niyate kinihanpi kta on, wakicanpta Dawid niye en u wicaśi he? Tonwanyanpi, qa ihangyapi, qa makoce kin iwanyakapi kta on en hipi śni he? 


\section{ANPETU OYAKAPI,}

4 Unkan Hanun Dawid taokiye iwicacu, qa putinhin wicakasan, qa taheyake cokaya bawicakicaśpe cana ekta, qa kihde wicaya. 5 Unkan tuwe Dawid ekta i, qa wicaśta qon toketu, qa nina iśtecapi okiyaka; heon tuwe itkowicakipa yeśi, qa wicaśta yatapi kin heya, Jerilio en yankapo, putinhin inicicagapi kte cin hehanyan, qa hehan hdipo.

6 Unkan Anmon cinca kin Dawid itokam śicamna içyapi wanhdakapi qehan, Ḣanun, qa Anmon cinca kin mazaska woqin kektopawinge wan yeyapi, on canpahmihma, qa śuktanka akan yotankapi opetonpi kta, Aram wakpa otahedan etanhan, qa Aram Mayaka etanhan, qa Tzoba etanhan.

z Unkan canpahmihma kektopawinge wikcemna yamni sanpa kektopawinge nonpa, nakun Mayaka wicaśtayatapi kin, qa oyate tawa opewicatonpi. Unkan upi qa Medeba itokam hiwankapi. Unkan Anmon cinca kin otonwe tawapi etanhan ihduwitayapi, qa wokicize en hipi.

8 Uukan Dawid nakon qehan, Joab qa wicaśta waśaka obe kin owasin ekta yewicaśi.

9 Unkan Anmon cinca kin inanpapi, qa kizapi kta otonwe tiyopa itankan ocimdagehan najinpi, qa wicaśta yatapi hipi qon hena itankan kinukan tinta ekta yakonpi.

10 Unkan Joab ozuye iye tatpe u, iye itokam hektam koya wanyake cehar, Israel kahnigapi kin owasin etanhan wicaśta wicakaliniga, qa Aram itkokim ocimdah yewicaya.

11 Qa oyate unman kin iye cincu Abiśai nape en wicaqu; unkan ocimdah Ammon cinca kin tatpe iwicayayapi.
12 Unkan heya, Aram miye isanpa waśake cinhan nimayaye kta en hidu kta, qa Anmon cinca kin niye isanpa waśakapi kinhan miye niciye kta.

13 Waśaka wo, qa wadiuntakapi kta, oyate unkitawapi on, qa turve wakanundapi totonwe kin on. Unkan Jehowa taku iye iśta kin en waśte kin econ kte.

14 Unkan Joab, qa oyate iye opapi kin Aram wicakizapi wicikiyedan ipi. Unkan nakicipapi.

15 Unkan Anmon cinca kin Aram napapi kin wanyakapi qehan iś eya napapi, cincu Abiśai itokapa tanhan, qa otonwe en ipi. Unkan Joab Jerusalem en hdi.

16 Unkan Aram iyepi Israel itokam ktepidan kin wanhdakapi qehan, wahośiye yewicaśipi, qa Aram wakpa kin akasanpa yakonpi kin, hena hinanpe wicayapi. Unkan Śopak Hadarezer taobe itancan kin mdetanhunka yuhapi.

17 Unkan Dawid okiyakapi; unkan Israel owasin mnawicaya, qa Jordan iyuwega, qa en wicai, qa ocimdah tatpe wicai; hecen Dawid Aram itkokim ozuye en tatpe wicai, qehan kicizapi.

18 Unkan Aram Israel itokapa tanhan napapi. Unkan Dawid, Aram etanhan, canpahmihma wicasta kektopawinge śakowin wicakte, qa huiyun wicaśta kektopawinge wikcemna topa; nakun Sopak ozuye mdetanhunka te kiya.

19 Unkan Hadarezer taokiye, iyepi Israel itokam ktepidan kin wanhdakapi qehan, Dawid om wokiyapi, qa wowidag ic̣iyapi. Hecen Aram Anmon cinca kin sanpa ówicakiyapi kta tawațenyapi śni. 


\section{WICOWOYAKE 21.}

WICOWOYAKE 20.

1 Unkan waniyetu ihunniyapi qehan, wicaśtayatapi inanpapi iyehantu, Joab obe wowaśake mnayan, qa Aram cinca tamakocepi kin ihang ya, qa Rabba ekta i, qa aonataka; tuka Dawid Jerusalem ohna yanka. Qa Joab Rabba kaśtake ca pajuju.

2 Unkan Dawid wicaśtayatapi wateśdake tawa kin pa kin etanhan icu, qa he mazaskazi aspeyapi, woqin wanji iyehantu iyeya, qa ohna inyan tehika yukan; unkan Dawid pa kin akan ehnakapi. Unkan otonwe etanhan woyuha nina ota icu.

3 Qa oyate ohna yakonpi kin hinanpe wicaya, qa canibaksa on iwicadaka, qa mazasapa mahiyuhinte on, qa onspe on. Nakun Dawid Anmon cinca tonwanyanpi kin owasin he iyecen ècawicakicon; hehan Dawid, qa oyate kin owasin Jerusalem en hdipi.

4 Unkan hena iyohakam wokicize yukan Pilistim om, Gezer ekta qehan Sibbekai Huśati kin Sipai he Rapa cinca etanhan kaśtaka; hecen wicaktepidan.

5 Unkan ake Pilistim om wokicize en Elhanan he Jayir cinhintku Lahmi Golia Gati sunkaku kaśtaka, iye tawahukeza ihupa kin wakazuntapi ihupa kin iyececa.

6 Unkan ake Gat ekta wokicize yukan. Unkan wicaśta wan hanska napsukaza śakpekpe, qa siyukaza śakpekpe wikcemna nonpa sanpa topa; qa iś eya Rapa kin etanhan icaga.

7 Qa Israel iśten wicaya. Unkan Jonatan he Dawid cincu Śimeya cinhintku kin, he kaśtaka.

8 Hena Gat ohna Rapa kin kicitonpi. Unkan Dawid nape on, qa taokiye napepi kin on hinhpayapi.

\section{WICOWOYAKE 21.}

1. Unkan Satan Israel anajin, qa. Israel wicayawa kta Dawid iyopaśtaka.

2 Unkan Dawid Joab, qa oyate itancanpi kin hewicakiya, Hopo, Israel wicayawapo, Berśeba etanhan Dan aiyahdeya, qa uyawa kin miye makaupo.

3 Unkan Joab heya, Jehowa iye taoyate tonaka unpi opawinge akihde wicayuota nunwe. Itancall mitawa wicaśtayatapi, hena owasin itancan mitawa taokiye hecapi śni he? Tokeca itancan mitawa taku kin de cin, qa Israel woahtani wicakiciyawapi kta?

4 'Tuka wicaśtayatapi oie kin Joab ohiya; hecen Joab iyaye ca Israel owancaya omani, qa Jerusalem en hdi.

5 Qa Joab oyate oyawa kin Dawid qu. Unkan Israel owasin kektopawinge kektopawinge sanpa kektopawinge opawinge isan hdusdutapi, qa Juda kektopawinge opawing topa sanpa kektopawinge wikcemna śakowin wicaśta isan hdusdutapi.

6 Tuka Lewi, qa Benjamin elita wicai śni; wicaśtayatapi oie kin Joab wahteda śni nakaś.

7 Unkan wicoie kin de Wakantanka iśta kin en śica; heon Israel wicakaśtalia.

8 Unkan Dawid Wakantanka heciya, Wicoie kin de ecamon miye nina wawahtani, qa wanna ceciciye nitaokiye ohan śica kin kicicajuju ye, witkotkoya ecamon nakaś.

9 Unkan Jehowa Dawid wawanyaka tawa Gad, wahokonkiye ca heya,

10 Ḣo wo, Dawid wahokonkiye 


\section{ANPETU OYAKAPI,}

ca heciya wo; Jehowa hecen eya, 'Taku yamni miye nitokam mduzamni. Hena etanhan wanji kahniga wo, qa he ecacicon kta.

11 Unkan Gad Dawid en hi qa heciya, Jehowa hecen eya, Niye on kahniga wo.

12 Waniyetu yamni wicakkihan kta; qa iś wi yamni tokaniyanpi itokam ihangyapi, qa tokaniyanpi isan tawapi iyonihipi kta; qaiś anpetu yamni Jehowa taisan, qa makośice kin makoce ohna, qa Jehowa ohnihde kin Israel makoce kin owancaya waihang ye kta; unman tukte $k a$ hniga wo, eya. Qa wanna iyukcan wo, taku wicoie tuwe umaśi wakai kta.

13 Unkan Dawid Gad heciya, Taku nina amaskica. Tokin Jehowa nape kin en mahinlipayen, towaonśida kin nina tanka nakaś; qa wicaśta nape en mahinhpaye śni nunwe.

14 Unkan Jehowa makośice Israel ehna yekiya. Unkan Israel wicaśta lrektopawing g wikcemna śakowin hinhpayapi.

15 Unkan Wakantanka ohnihde wan Jerusalem ihangye kta e ekta yeśi, qa waihangye cehan, Jehowa wanyake ca taku śice cin on iyopeiciya; qa ohnibde waihangye cin heciya, Henakeca, wanna nape ehdaku wo. Unkan Jehowa ohnihde tawa kin Ornan Jebusi ag̉uyapi napanpi tawa kin ikiyedan hinajin.

16 Unkan Dawid wankan etonwe ca Jehowa ohnihde tawa maka qa mahpiya otahedan najin kin wanyaka, qa isan hdusduta nape kin ohna Jerusalem ektakiya hdugata; hehan Dawid, qa hunkayapi kin wakihdaka koyakapi kin makipusdiya hinhpayapi.

$17 \mathrm{Qa}$ Dawid Wakantanka he600 ciya, Oyate wicayawa wo, eye ciqon he miye śni he? ga miyehin wawahtani, qa taku śica śicaya ecamon; tuka tahinca kin dena taku econpi tukte he? Jehowa Wakancida ceciciye, ninape kin miye akan, qa ate ti kin akan un nunwe; tuka oyate nitawa ihang wicayaye śni nunwe.

18 Unkan Jehowa ohnihde kin Gad heciya, Dawid itanwankanhde ye kta, qa Ornan Jebusi ohrra aguyapi napanpi tawa kin ohna owayuśna Jehowa kicagge kta, keciya wo.

19 Unkan Dawid Gad oie Jehowa cajeyan eye cin iyecen itanwankanhde $\mathrm{i}$.

20 Unkan Ornan ihduhomni, qa ohnihde kin wanyaka, qa cinhinthu topa kici unpi inahmanpi; hehan Ornan aǵuyapi kapan yanka.

21 Unkan Dawid Ornan ekta iyaya. Unkan Ornan tonwe ca Dawid wanyaka, qa wakapanpi kin etanhan inanpe ça makipusdiya Dawid ohoda.

22 Unkan Dawid Ornan heciya, Wakapanpi oyanke kin de maqu ye, kinhan ohna owayuśna wan Jehowa wecagie kta, mazaska iyohiye cin on mayaqu kte; hecen makośice kin oyate etanhan anapte kta.

23 Unkan Ornan Dawid heciya, Niye on icu wo, qa itancan mitawa wicaśtayatapi kin taku iśta kin en waśte econ nunwe. Iho ciçu, tatanka kin wohuhnahyapi on, qa canwinapan kin can on, qa ağuyapi su kin minha on, hena owasin cicu.

24 Unkan wicaśtayatapi kin Dawid Ornan heciya, Hiya, mazaska iyohiye cin on awicakehan opewaton kta. 'Taku nitawa iwacu kte śni, qa taku ituya maqu- 
pi kin Jehowa wawakiyuśna kte śni.

25 Unkan Dawid oyanke kin on Ornan mazaskazi śeqel opawinge śakpe tkeuta qu.

26 Unkan hen Dawid owayuśna wan Jehowa kicagge ça wohuhnahyapi, qa wopida wośnapi wayuśna, qa Jehowa hoyekiya. Unkan Jehowa ayupta peta on, mahpiya etanhan, wohulinahyapi owayuśna akan.

27 Unkan Jehowa ohnihde kin eciye ciqon on isan kin ojuha mahen hdicukiya.

28 Hehan Dawid Jehowa Ornan Jebusi kin wakapanpi oyanke kin ohna ayupte cin wanyaka heon, hen wayuśna.

29 Tuka he ehan Jehowa tawakeya Mowis hewoskan kicagie ciqon, qa wohitinahyapi owayuśna kin Gibeyon paha kin ohna yanka.

30 Unkan Dawid Wakantanka akite kta he itokam ye kta okihi śni. Jehowa ohnihde kin isan tawa kokipe cin heon etanhan.

\section{WICOWOYAKE 22.}

1 Qa Dawid heya, Jehowa Wakantanka ti kin dee, qa Jehowa wohuhnaliyapi on owayuśna kin dee.

2 Qa Dawid wicaśta oyate tokeca Israel makoce ohna yakonpi kin hena mniciye wicayaśi, qa wakakanpi wicakaga, Wakantanka ti kin on inyan orndoton kakanpi kta heon.

3 Qa mazasapa ota tankan tiyopa okatkugge on, qa okihe kin on Dawid wiyeya kaga, qa mazaśa ota nakaś aspeyapi śni.

4 Nakun hanteśa can yawapica śni; Tzidoni, qa Tzuri, kin hanteśa can ota Dawid Kahipi nakaś.
5 Qa Dawid heya, Solomon micinkśi he hokśidan, qa wankadan, qa tipi Jehowa kicage kte cin he tanka kte, qa tehanwankan, qa makoce owasin ohna caje yatapi qa yutanpi kta: heon dehan wiyeya wecage kta. Qa Dawid te cin itokam taku ota wiyeya kagia.

$6 \mathrm{Qa}$ cinhintku Solomon kico, qa Jehowa Israel wakandapi kin tipi kicag̉e śi.

7 Qa Dawid Solomon heciya, Micinkśi Jehowa wakanwada caje on tipi wecage kta e cantihewaya.

8 Tuka Jehowa oie kin en mahi, qa hemakiya, We ota yapapson, qa ozuye tanka yakaga; heon micaje on tipi yecage kte śni; mitokam maka akan we ota yapapson nakaś.

9 Iho cinca wan nicitonpi kta, iye iyozi wicaśta heca kta, qa tokayapi ihdukśan owasin etanhan oziwaye kta, qa caje kin Solomon, (Wookiye,) eciyapi kta, qa anpetu tawa en Israel wookiye, qa woozi wicawaqu kta.

$10 \mathrm{Qa}$ iye micaje on tipi wan kagge kta, qa iye cinkśiwaye kta, qa miye ate maye kta, qa wicaśtayatapi oiyotanke tawa on Israel iwankam mdusuta kta, owihanke wanica.

11 Heon micinkśi dehan Jehowa nici un kte, qa iyohiyaye kta, qa Jehowa wakanyada ti kin yakagie kta, niye on eye ciqon iyecen.

12 Tokin Jehowa woksape, qa wowiyulican nicu kten, qa Israel iyadake kta, qa Jehowa wakanyada toope oyape kta onspeniciye liten.

13 Wokage, qa woyaco Israel on Jehowa Mowis econśi kin hena waktaya ecanon kinhan awicakehan tanyan ihunniyaye kta. 


\section{ANPETU OYAKAPI,}

Waśaka wo, qa miniheca wo. Ihmuhan kopeyahda kin, qa ihnuhan niyuśinyaye cin.

14. Qa inyun makakija kin en mazaskazi woqin kektopawinge opawinge, qa mazaska woqin kektopawinge kektopawinge, qa mazaśa, qa mazasapa otahin on tkeutapi śni wiyeya wakaġa; nakun can, qa inyan wiyeya wakağa; qa niye sanpa mnayaye kta.

15 Qa wokicanye econpi ota niciunpi ; inyan qa can kakanpi, qa kajipapi, qa wokicanye owasin on wicaśta ksapa ota.

16 Mazaskazi, qa mazaska, qa mazaśa, qa mazasapa otahin on yawapi śni yukan; najin, qa kağa wo, qa Jehowa nici un nunwe.

17 Nakun Dawid Israel itancan kin owasin iye cinhintku Solomon ókiya wicaśi, qa heya,

18 Jehowa niyepi om un śni he? qa ihdukśan iyozi niyanpi śni he? Ninapepi en makoce ounyanpi kin wicaqu nakaś; hecen Jehowa itokam, qa oyate tawa itokam makoce kin ohiyapi.

19 Tokin Jehowa wakanyadapi kin ayakitapi kta nicantepi kin, qa ninagipi qupo; qa najinpo, qa tipi wakan Jehowa wakanyadapi kin kicagiapo. Hecen Jehowa otakuye canwohnaka kin, qa Wakantanka wakśica wakan tawa Jehowa caje on tipi kicagapi kte cin en ahipi kta.

\section{WICOWOYAKE 23.}

1. Unkan Dawid wicahinea, qa anpetu on inma qehan, iye cinhintku Solomon Israel on wicaśtayatapi kag̉a.

2 Qa Israel itancanpi kin owasin, qa waway uśnapi kin, qa Lewi kin mniciye wicaya.

3 Qa Lewi kin wicayawapi, 602 waniyetu wikcemna yamni, qa isanpa, qa wicaśta waśaka papi kin yawapi kin kektopawinge wikcemna yamni sanpa kektopawinge śahdogan iyewicayapi; 4 Qa heya, Hena etanhan kektopawinge wikcemna nonpa sanpa kektopawinge topa Jehowa ti wokicanye econ wicakiyapi ecee kta ; qa kektopawinge śakpe wowapikaga, qa wayaco hecapi ecee kta;

5 Qa kektopawinge topa tiyopa awanyakapi kta, qa kektopawinge topa dowan ikicanye wakage cin on Jehowa idowanpi kta.

6 Unkan Dawid Lewi cinca Gerśon Qohat, qa Merari obepi kin etanhan wicapamni.

7 Gerśoni kin etanhan Layadan, qa Śsimeyi ;

8 Layadan cinca kin Jehijel he itancan, qa Zetam qa Joel, yamnipi.

9 Śsimeyi cinca kin Ślomit, qa Ḣazijel qa Ḣaran, yamnipi, hena Layadan ateyapi itancanpi kin eepi.

10 Simeyi cinca kin Jahat, qa Zina, qa Jeyuś, qa Beriya; hena topa Śśmeyi cinca.

11 Jahat he itancan, qa Zina he inonpa; tuka Jeyuś qa Beriya cinca hduotapi śni, heon ateyapi ti en wopamni wanjidan wicayawapi.

12 Qohat cinca kin Amram, Itzhar, Ḣebron, qa Uziel, topapi.

13 Amram cinca kin Aaron, qa Moses; qa Aaron kahnigapi, taku iyotan wakan kin yuwakan kta, iye, qa iye cinca kin owihanke wanin Jehowa itokam wizinyapi kta, qa waokiyapi kta, qa iye caje kin on wayawaśtepi kta, owihanke wanica.

14 Tuka Moses Wakantanka tawicaśta kin cinca kin Lewi wicoun om wicayawapi. 


\section{WICOWOYAKE 24.}

15 Moses cinca kin Gerśom, qa Eliyezer.

16 Gerśom cinca kin Śebuel, lie itancan.

17 Qa Eliyezer cinhintku Rehabeja itancan; qa Eliyezer cinca tokeca nica; tuka Rehabeja cinca kin, nina ilıduotapi.

18 Itzhar cinca kin, Ślomet he itancan.

19 Hebron cinca kin Jerija itancan, Amarija inonpa, Jehaziel iyamni, Jeqameyam itopa.

20 Uziel cinca kin Mika he itancan, qa Jiśija he inonpa.

21 Merari cinca kin Mahli qa Muśi. Mahli cinca kin Eleazar, qa Qiś.

22 Qa Eleazar cinca wica nica ta; tuka cunwintku yukan, qa timdo wicayapi Qiś cinca kin wicayuzapi.

23 Muśi cinca kin Mahli, qa Yeder, qa Jeremot, yamnipi.

24 Lewi cinca ateyapi tipi kin hena eepi ; atcyapi itancanpi kin wicapa tonakeca caje owicawapi wokicanye econpi kta waniyetu wikcemna nonpa qa akton, Jehowa ti kin wohtani kin econpi kta.

25 Dawid hecen eya nakaś, Jehowa Israel wakandapi kin iye taoyate oziwicaya, qa Jerusalem en ounyanpi kta owihanke wanica.

26 Qa Lewi kin wakeya kin, qa tawakśica owasin akiyuhapi wolitani kin he icimana yuhapi kte sni.

27 Hecen Dawid oie ehake kin eciyatanhan Lewi cinca kin wicayawapi, waniyetu wilkcemna nonpa qa akton.

28 Hena Aaron cinca kin napepi ekta najinpi, Jehowa ti kin wohtani kin on; hocoka, qa owanka tipi kin awanyakapi kta; qa wokicanye wakan owasin yuhapi kta, qa Wakantanka ti kin wohtani owasin econpi kta.

29 Aguyapi ocimdaggehan ehdepi, qa ağuyapi mdu minka kin on qa ağuyapi zipzipedan onnapohyapi codan on, qa aguyapi mazawiceonpa akan śpanyanpi on, qa ceguguyapi on, nakun taku owasin aspekiyapi, qa iyutapi on.

30 Qa hanlianna owasin Jehowa yatanpi, qa ahiyayapi kta e najinpi ece, qa htayetu nakun iyecen najinpi ece.

31 Wohuhnahyapi owasin Jehowa huhnalikiciyapi kta, anpetu okilipapi en, qa witeca kin en, qa omniciye wakan en, woyaco econ wicaśipi kin iyecen, ohinniyan Jehowa itokam iyenaka ahipi ece e kta.

32 Qa itkokipapi wakeya kin awanyakapi kta, qa tipi wakan kin nakun cinye wicayapi Aaron cinca kin Jehowa ti wohtani kin taku awanyag wicaśipi kin owa$\sin$.

\section{WICOWOYAKE 24.}

1 Unkan Aaron cinca ośpaye kag̉api kin dena eepi. Aaron cinca kin Nadab qa Abihu, Eleazar qa Itamar;

2 Tuka Nadab qa Abihu ateyapi kin itokam tapi qa cinca nicapi; qa Eleazar, qa Itamar wawayuśnapi ece e.

3 Unkan Dawid, qa Zadoq Eleazar cinca kin etanhan, qa Ahimelek Itamar cinca kin etanhan wicapamnipi, wohtanipi kin awanyakupi kta.

4 Qa Eleazar cinca wicaśta waśaka itancan ota iyewicayapi ; Itamar cinca kin isanpa; heon Eleazar cinca kin ateyapi tipi itancanpi kin wikcemna sanpa śakpe wicapamnipi, qa Itamar 603 


\section{ANPETU OYAKAPI,}

cinca ateyapi tipi itancanpi śahdogian.

5 Qa napin oeconna on wicapamnipi, tipi wakan itancan, qa taku wakan itancan on, Eleazar cinca etanhan, qa Itamar cinca etanhan.

6 Qa Semaja Netaneel Lewi lsin etanhan wowapikagia kin owicawa, wicaśtayatapi kin itokam, qa itancanpi kin, qa Zadoq wawayuśna, qa Abiatar cinhintku Ahimelek qa wawayuśnapi kin qa Lewi kin ateyapi itancanpi kin itokam tipi ateyapi icupi, Eleazar etanhan, qa Itamar etanhan, unman itokto icupi.

7 Unkan oeconna tokaheya inanpe cin Jehojarib on, inonpa kin Jedaja on,

8 Iyamni kin Harim on, itopa kin Seyarim on,

9 Izaptan kin Malkija on, iśakpe Mejamin on,

10 Iśakowin kin Haqotz on, iśahdogian kin Abija on,

11 Inapcinwanka kin Jeśuya on, iwikcemna kin Sekanija on,

12 Iakewanji kin Eleaśib on, iakenonpa kin Jaqirn on,

13 Iakeyamni kin Ḧupa on, iaketopa kin Jeśebab on,

14 Iakezaptan kin Bilya on, iakeśakpe kin Inmer on,

15 Iakeśakowin kin Hezir on, iakeśahdoġan kin Hepitzetz on,

16 Iakenapcinwanka kin Petaheja on, iwikcemna nonpa kin Jehezeqel on,

17 Iwikcemna nonpa sanpa wanji kin Jakin on, iwikcemna nonpa sanpa nonpa kin Gamul on,

18 Iwikcemna nonpa sanpa yamni kin Delaja on, iwikcemna nonpa sanpa topa kin Mayazija on.

19 Hecen wicayawapi wohtanipi kin on, Jehowa ti kin en hipi kta, ateyapi Aaron woyaco econ wicaśi kin iyecen, Jehowa Israel wakandapi kin econ śi qon iyecen.

20 Lewi unmanpi kin etanhan, Anram cinca kin etanhan Śubael, qa Subael cinca etanhan Jehedija.

21 Rehabeja etanhan, Rehabeja cinca etanhan Jeśija he tokaheya. 22 Itzhari etanhan Śelomut, qa Śelomut cinca etanhan Jahat.

23 Hebron cinca kin Jerija he tokaheya, Amarija he inonpa, Jahaziel he iyamni, Jeqameyan he itopa.

24 Uziel cinca kin Mika, qa Mika cinca etanhan Samir.

25 Mika sunkaku Jiśija, qa Jiśija cinhintku Zekarija.

26 Merari cinca kin Mahli qa Muśi, Jayazija cinca kin Beno.

27 Merari cinca kin Jayazija etanhan Beno, qa ŚSoham, ga Zakur qa Yibri.

28 Mahli etanhan Eleazar tuka iye cinca wica nica.

29 Qiś etanhan, Qiś cinhintku Jerahmeel.

30 Qa Muśi cinca kin Mahili, qa Yeder, qa Jeremot. Lewi cinca ateyapi tipi kin hena eepi.

31 Qa hena iś eya on hunkawanji wicayapi Aaron cinca kin iyecen oeconna econpi, wicaśtayatapi kin Dawid itokam, qa Zadoq, qa Ahimelek, qa wawayuśnapi, qa Lewi ateyapi tipi itancanpi kin itokam, ateyapi tipi tokapapi qa sunkawicayapi hakakta kin iake dececa oeconna on wicapamnipi.

\section{WICOWOYAKF 25.}

1 Unkan Dawid, qa obe mdetanhunkapi kin, Asap cinca etanhan, qa Heman qa Jedutun cincapi etanhan waayatapi wicayukinukanpi, candowankiyapi, 


\section{WICOWOYAKE 25.}

qa cotanka, qa mazaicicasnapi wohtani kin on; qa wicaśta miniheca wohtani kin on dena wicayaw api.

2 Asap cinca kin etanhan Zakur, qa Josep, qa Netaneja, qa Aśarela ; Asap cinca, Asap waayate kin nape ek ta wicaśtayatapi kin konze cin iyecen.

3 Jedutun etanhan Jedutun cinca śakpe Gedaleja, qa Tzeri, qa Jeśayeja, qa Ḣaśabeja, qa Matiteja, qa Simeyi Jehowa yatanpi, qa idowanpi candowankiyapi on Jedutun waayate nape kin ihukuya.

4 Heman etanhan Heman cinca kin Buqeja, Mataneja, Uziel, Śebuel, qa Jerimot, Hananeja, Ḣanani, Elijata, Gedalti, Romantiezer, Jośbeqaśa, Malloti, Hotir, Mahaziot;

5 Hena owasin Heman wicaśtayatapi wawanyake tawa kin cinca kin, Wakantanka oie en wowaśake wankan yeyapi kta. Wakantanka Heman cinca wica wikcemna sanpa topa, qa winyan yamni qu nakaś.

6 Hena owasin ateyapi napepi kin ihukuya, Jehowa ti kin dowanpi en mazaicicasnapi, qa cotanka, qa candowankiyapi on Wakantanka ti wohtani kin econpi, wicaśtayatapi kin, qa Asap, qa Jedutun, qa Heman napepi kin ihukuya.

$7 \mathrm{Qa}$ hena sunka wicayapi Jehowa dowan onspepi kin om wicayawapi, tona wayupikapi owasin opawinge nonpa sanpa wikcemna śahdog̣an sanpa śahdog̣an.

$8 \mathrm{Qa}$ tohantu waktaya unpi kta on oeconna econpi, hakakta qa tokapa, wayupika qa onspe śni iakedececa.

9 Qa oeconna tokaheya kin Asap etanhan Josep on inanpa, inonpa kin Gedaleja on, iye qa sunka wicaya qa cinkśi wicaya wikcemna sanpa nonpapi.

10 Iyamni Zakur on, iye $q a$, cinkśiwicaya, qa sunkawicaya wikcemna sanpa nonpapi ;

11 Itopa kin Jitzir on, iye qa cinkśiwicaya, qa sunkawicaya wikcemna sanpa nonpapi,

12 Izaptan kin Netaneja on, iye qa cinkśiwicaya qa sunkawicaya wikcemna sanpa nonpapi ;

13 Iśakpe kin Buqeja on, iye qa cinkśiwicaya, qa sunkawicaya wikcemna sanpa nonpapi.

14 Iśakowin kin Jesarela on, cinkśiwicaya, qa sunkawicaya wikcemna sanpa nonpapi.

15 Iśahdoğan kin Jeśayeja cinkśiwicaya, qa sunkawicaya wikcemna sanpa nonpapi.

16 Inapcinwanka kin Mattaneja cinkśiwicaya, qa sunkawicaya wikcemna sanpa nonpapi ;

17 Iwikcemna kin Śimeyi cinkśiwicaya, qa sunkawicaya wikcemna sanpa nonpapi ;

18 Iakewanji Azariel cinkśiwicaya, qa sunkawicaya wikcemna sanpa nonpapi ;

19 Iakenonpa kin. Ḣaśabeja on, iye qa cinkśiwicaya, qa sunkawicaya wikcemna sanpa nonpapi ; 20 Takeyamni kin, Subael cinkśiwicaya, qa sunkawicaya wikcemna sanpa nonpapi ;

21 Iaketopa kin Matiteja cinkśiwicaya, qa sunkawicaya wikcemna sanpa nonpapi ;

22 Iakezaptan kin Jeremot on, iye qa cinkśiwicaya qa sunkawicaya wikcemna sanpa nonpapi; 23 Iakeśakpe kin Ḣananeja on, iye qa cinkśiwicaya qa sunkawicaya wikcemna sanpa norıpapi ;

24. Iakeśakowin kin Jośbeqaśa on, iye qa cinkśiwicaya, qa sunkawicaya wikcemna sanpa nonpapi ; 


\section{ANPETU OYAKAPI,}

25 Iakeśahdoğan kin Hanani on, iye qa cinkśiwicaya, qa sunkawicaya wikcemna sanpa nonpapi ;

26 Takenapcinwanka kin Malloti on, iye qa cinkśiwicrya qa sunkawicaya wikcemna sanpa nonpapi ;

27 Iwikcemna nonpa kin Elijata on, iye qa cinkśi wicaya qa sunkawicaya wikcemna sanpa nonpapi ;

28 Iwikcemna nonpa sanpa wanji Hotir on, iye qa cinkśi wicaya qa sunkawicaya wikcemna sanpa nonpapi ;

29 Iwikcemna nonpa sanpa nonpa kin Gedalti on, iye qa cinkśiwicaya qa sunkawicaya wikcemna sanpa nonpapi ;

30 Iwikcemna nonpa sanpa yamni kin Maliaziot on, iye qa cinkśíwicaya qa sunkawicaya wikcemna sanpa nonpapi ;

31 Iwikcemna nonpa sanpa topa kin Romanti-ezer on, iye qa cinkśiwicaya qa sunkawicaya wikcemna sanpa nonpapi.

\section{WICOWOYAKE 26.}

1 Tiyopa awanyakapi obepi kin Qorahi etanhan, Meśelemija he Qore cinhintku, Asap cinca kin etanhan.

2 Qa Miśelemija cinca kin etanhan Zekaraja he tokapa, Jediyel he inonpa, Zebadeja he iyamni, Jatniel he itopa,

3 Elam he izaptan, Johanan he iśakpe, Elihoyenai he iśakowin.

4 Obed-Edom cinca kin etanhan Śmayeja he tokapa, Jehozabad he inonpa, Joah he iyamni, Sakar he itopa, Netaneel he izaptan,

5 Anmiel he iśakpe, Issakar he iśakowin, Peyulti he iśahdoğan; Wakantanka he yawaśte nakaś.

6 Nakun iye cinhintku Śmayeja einca kicitonpi kin hena ateya- pi ti kin idakapi ece, hena wicaśta waśaka waditakapi nakaś.

7 Śemayeja cinca kin Otni, qa Repael, qa Obed, qa Elzahad, he sunkaku Elihu qa Semakeja wicaśta waditakapi.

8 Hena owasin Obed-Elom cinca etanhan heepi qa cincapi qa sunkakupi kin wicaśta waditaka, wohtani on waśaka, wikcemna śakpe sanpa nonpa, ObedFdom etanhan.

9 Nakun Meśelemeja etanhan cinca qa sunka wicaya wicaśta waditaka wikcemna sanpa śahdogan.

10 Nakun Ḣosa Merari cinca etanhan cinca kin Śsimri he itan. can, iye tokapa heca śni, tuka atkuku he itancan kag̉a.

11 Halqija he inonpa, Tebaleja he iyamni, Zekareja he itopa ; Hosa cinca qa sunka wicaya owasin wikcemna sanpa yamnipi.

12 Hena ehna tiyopa awanyakapi kin pamnipi, wicaśta waśaka awanyakapi itancanpi kin ehna, sunkawicayapi om, Jehowa ti kin ohna waokiyapi kta.

$13 \mathrm{Qa}$ tona cistinna tona tanka om ateyapi tipi kin tiyopa otoiyohi on oeconna econpi.

14 Qa wihinanpe cin ektakiya kin Śelemeja oeconna on icupi. Heban iye cinhintku Zekareja, waiyukcan ksapa on oeconna econpi, qa iye oeconna on waziyata kin inanpa.

15 Obed-Edom on okagia kin; qa iye cinca kin womnaye tipi kin.

16 Śupim; qa Ḣosa on wiyohpeyata kin oehpeyapi tiyopa kin iyahna itanwankanhde canku kin ohna waawanyake waawanyake iyotakonza.

17 Wihinanpe cin ektakiya Lewi śakpe, waziyata anpetu 
on topa, itokagia anpetu on topa, womnayanpi on nonpa, qa nonpa.

18 Parbar (awakeyapi) wiyohpeyata canku kin on topa, qa Parbar on nonpa.

19. Tiyopa awanyakaji obepi kin hena eepi, Qorahi cinca kin etanhan, qa Merari cinca etanhan.

20 Unkan hunkawanji wicayapi Lewi kin Wakantanka ti mazopiye kin, qa taku yuwakanpi mazopiye kin awanyakapi.

21 Layadan cinca kin, Gerśoni cinca kin Layadan etanhan, Gerśoni Layadan ateyapi tipi itancanpi kin Jehieli.

22 Jehieli cinca kin Zetam, qa sunkaku Joel Jehowa ti mazopiye kin awanyakapi.

23 Amrami etanhan, Itzhari etanhan, Ḣebroni etanlıan, qa Uzieli etanhan;

24 Moses cinhintku Gersom cinhintku Śebuel mazopiye awanyakapi kin owasin itancan.

$25 \mathrm{Qa}$ sunka wicaya Eliezer etanhan, he cinhintku Reliabeja, qa he cinhintku Jeśayeja, he cinhintku Joram, qa he cinhintku Zikri, qa he cinhintku Ślomit.

26 Selomit iye qa sunka wicaya Dawid wicaśtayatapi kin/ taku yuwakan, qa ateyapi tipi itancanpi kin, qa kektopawinge itancanpi kin, qa opawinge itancanpi kin, qa ozuye mdetanhunkapi kin taku yuwakanpi mazopiye owasin awanyakapi.

27 Ozuye en woyuha kipi etanhan Jehowa ti kin pikiyapi kta e hena yuwakanpi.

28 Nakun Samuel wáwanyaka kin, qa Eaul Qiś cinhintkı, qa Abner Ner cinhintku, qa Joab Tzeruja cinhintku, taku yuwakanpi kin owasin Selomit, qa sunkawicaya napepi kin ihuku- ya, taku yuwakanpi kin owasin yuhapi.

29 Itzhari etanhan Kenaneja, qa iye cinca kin wolitani tankan, Israel on econpi, wowapi kağapi, qa wayacopi ece.

30 Hebroni etanhan Ḣaśabeja, qa sunkawicaya, wicaśta waditaka, kektopawinge sanpa opawing̀e śakowin, Israel Jordan itato wiyohpey atakiya iwicadakapi, Jehowa wokicanye kin, qa wicaśtayatapi wohtani kin owasin on.

31 Hebroni etanhan Jerija he itancan, Ḣebroni etanhan wicoicagiepi ateyapi kin etanhan. Jayezer Gileyad ohna wicaśta waśaka waditaka iyewicayapi, Dawid iwicadake cin waniyetu iwikcemna topa en akitapi qehan. 32 Qa sunkawicaya wicaśta waditaka kektopawinge nonpa sanpa opawinge śakowin ateyapi tipi itancanpi. Unkan wicaśtayatapi kin Dawid hena Rubeni kin, qa Gadi kin, qa Manaśe wicoun hanke kin awanwicayag wicaśi, wicaśtayatapi taku tawa on, qa Wakantanka taku tawa owasin on.

\section{WICOWOYAKE $2 \%$.}

1 Unkan Israel cinca ateyapi tipi itancanpi kin iyecen wicayawapi; qa kektopawinge mdetanhunkapi, qa opawinge mdetanhunkapi kin, qa wowapi kagapi obe tawapi en taku owasin on wicaśtayatapi kin ókiyapi, qa omaka ihumniyan wi otoiyohi ośpaye wanji wicaśta kektopawinge wikcemana nonpa sanpa kektopawinge topa en hiyupi, qa obe wanji inanpa.

2 Obe tokaheya wi tokaheya on Jaśobeyani Zabdiel cinhintku yuha, qa obe tawa kin en wicasta 607 


\section{ANPETU}

kektopawinge wilkcemna nonpa sanpa kektopawinge topa.

3 Parez cinca kin etanhan wi tokaheya ozuye mdetanhunka kin owasin iye itancan.

4. Qa wi inonpa on Doda Ahohi kin obe kin yuha, obe tawa itancan kin he Miqlot, qa obe tawa ohna kektopawinge wikcemna nonpa sanpa kektopawinge topa.

5 Benaja Jehojada wawayuśna kin cinhintku wi iyamni on obe iyamni mdetanhunka, iye itancan, qa obe tawa ohna kektopawinge wikcemna nonpa sanpa kektopawinge topa.

6 Benaja kin he wikcemna yamni ehna waśaka, qa wikcemna yamni kin iwankam, qa iye cinhintku Ammizabad obe tawa he itancan.

7 Yasahel Joab sunkaku itopa kin wi itopa on, qa iye iyohakam iye cinhintku Zebadeja, qa obe tawa ohna kektopawinge wikcemna nonpa sanpa kektopawinge topa.

8 Mdetanhunka izaptan wi izaptan on, Samehut Izrahi kin, qa obe tawa kin ohna kektopawinge wikcemna nonpa sanpa kektopawinge topa.

9 Iśakpe wi iśakpe on Yira Yiqeś cinhintku Teqoyi kin, qa obe tawa ohna kektopawinge wikcemna nonpa, sanpa kektopawing topa.

$10 \mathrm{Qa}$ iśakowin kin, wi iśakowin on Heletz Peloni kin Epraim cinca kin etanhan, qa obe tawa ohna kektopawinge wikcemna nonpa sanpa kektopawinge topa.

11 Iśahdog̣an wi iśahdogan kin on, Sibbeka Huśati kin Zerahi kin etanhan, qa obe tawa ohna kektopawinge wikcemna nonpa sanpa kektopawinge topa.

12 Inapcinwanka wi inapcinwanka kin on, Abiyezer Anatoti 608
OYAKAPI,

kin Benjamini kin etanhan, qa obe tawa ohna kektopawinge wikcemna nonpa sanpa kektopawinge topa.

13 Iwikcemna hin wi iwikcemna on, Mahara Netopati kin, Zeranii kin etanhan, qa obe tawa ohna kektopawinge wikcemna nonpa sanpa kektopawinge topa.

14 Iakewanji wi iakewanji on, Benaja Pereyatoni kin, Epraim cinca kin etanhan, qa obe tawa ohna kektopawinge wikcemna nonpa sanpa kektopawinge topa.

15 Iake nonpa wi iake nonpa on, Heled Netopati kin, Otniel etanhan, qa obe tawa ohna kektopawinge wikcemna nonpa sanpa kektopawinge topa.

16 Unkan Israel wicoun iwankam, Rubeni itancan kin Eliyezer Zikri cinhintku hee. Simeoni on itancan kin Śsepateja Mayaka cinhintku.

17 Qa Lewi kin Ḣaśabeja Qemuel cinhintku; Aaroni kin $\mathrm{Za}$ doq.

18 Juda on Elihu Dawid cincu; Issakar on Omri Mikael cinhintku ;

19 Zebulon on Iśmayeja Obadeja cinhintku; Naptali on Jerimot Azriel cinhintku;

20 Epraim cinca kin on Hośeya Yazazeja cinhintku ; Manaśe wicoun hanke kin on Joel Pedaja cinhintku ;

21 Manaśe wicoun hanke Gileyad ohna yanke cin on Iddo Zakareja cinhintku; Benjamin on Jayaśiel Abner cinhintku;

22 Dan on Yazariel Jeroham cinhintku; Israel wicoun mdetanhunkapi kin hena eepi.

23 Unkan Jehowa Israel yuota kta, mahpiya wicanhpi kin iyenaka keye ciqon; heon tona waniyetu wikcemna nonpa ihukuya oyawa kin Dawid icu śni. 


\section{WICOWOYYARE 28.}

24 Joab Zeruja cinhintku wicasta wicayawa iyuta tuka hecon kin on wocanniye Israel ahinlipaya, heon yuśtan śni, qa wicaśtayatapi kin Dawid anpetu oyakapi wowapi akan oyawa kin owapi śni.

25 Unkan wicaśtayatapi mazopiye tawa awanyake cin Azmawet he Yadiel cinhintku, qa Jonatan Yuzija cinhintku mazopiye tinta ohma, qa otonwe tanka qa cistinna ohna, qa conkaśke ohna awanyaka ece.

26 Qa Ezri Kelub cinhintku mag̣a wohtani econpi kin, qa maka kicanyanpi kin awanwicayaka.

27 Qa Śsimeyi Ramati kin hastanhanka iyuwi kin yuha. Qa hastanhanka iyuwi etanhan miniśa mazopiye kin Zabdi Śsipmi kin yuha.

28 Qa wihdican, qa Sukamin can kin Śsepela ohna Bayalhanan Gederi kin awanyaka; qa wihdi mazopiye kin Joaś awanyaka.

29 Qa pte wanunyanpi Śaron ohna wihanpi kin Śitri Śaroni kin awanyaka. Qa Śapat Adila cinhintku pte osmaka ohna yakonpi kin awanyaka.

$30 \mathrm{Qa}$ Obil Iśmaeli kin kamel kin yuha. Qa Jehedeja Meronoti kin śonśonna kin yuha.

31 Qa Jaziz Hagari kin tahinca wanunyanpi kin awanyaka. Hena owasin wicaśtayatapi kin $\mathrm{Da}$ wid woyuha tawa awanyakapi.

32 Unkan Dawid cinkśiye cin Jonatan he wicaśta ksapa, qa wowapikagga heca, waiyukcan ece. Qa Jehiel Ḣakmoni cinhintku wicaśtayatapi cinca kin om un.

33 Qa wicaśtaya tapi waiyukcan yuhe cin Ahitopel hee. Qa Huśai Arki kin wicaśtayatapi kin takodaku.
34 Qa Ahitopel iyohakam Jehojada Benaja cinhintku, qa Abiatar. Qa wicaśtayatapi taozuye mdetanhunka kin Joab hee.

\section{WICOWOYAKE 28.}

1 Unkan Dawid Israel itancanpi kin owasin mniciye wicaya, wicoun itancanpi kin, qa wicaśtayatapi ókiyapi ośpaye itancanpi kin, qa kektopawinge itancanpi kin, qa opawinge itancanpi kin, qa wicaśtayatapi, qa iye cinhintku woyuha tawapi; qa tawanunyanpi kin yuhapi kin; nakun owinja awanyakapi, qa wicaśta tanka qa wowijice yuhapi kin owasin Jerusalem ekta.

2 Qa wicaśtayatapi kin Dawid siha akan najin, qa heya, Mihunkawanji, qa oyate mitawa namahonpo. Tuwe Wakanundapi siha ahehde on, qa Jehowa wotakuye canwohnaka iyozi kin on tipi wakage kta micante en un, qa kagapi kta on wiyeya wehnaka ece.

3 Tuka Wakantanka hemakiya, Ozuye wicaśta henica, qa we ota yapapson; heon micaje on tipi yakağe kte śni.

4 Tuka Jehowa Israel wakandapi kin miye makahniga, ate tiwahe kin owasin etanhan, Israel iwicadake kta owihanke wanin; he qe Juda mdetanhunka kta e kahnigia, qa Juda ohna ate ti kin, qa ate ti kin ohna miye Israel owasin iwicawadake kta e iyokipi.

5 Qa Jehowa cinca ota maqu, qa micinca owasin etánhan Solomon micinkśi kahniğa, Jehowa tokiconze oiyotanke kin akan iyotanke kta, Israel iwankam.

6 Qa hemakiya, Nicinkśi Solomon, iye tipi mitawa, qa hocoka mitawa kag̣e kte. Iye micinkśi 609 


\section{ANPETU OYAKAPI,}

on wakahniga, qa iye atemaye kta.

7 Qa woahope mitawa, qa woyaco mitawa econ lita waśagiciye cinhan, nakaha iyecen, wokiconze tawa mdusuta kta, owihanke wanica.

8 Qa nakaha Israel owasin Jehowa taomniciye wanmayakapi, qa tuwe wakan undapi kin namation en, Waktaya nnpo, qa Jehowa wakanundapi tawoahope owasin akitapo; hecen makoce waśte kin de tawayayapi kta, qa niyepi ohakam nicinca kin yuhe wicayakiyapi kta owihanke wanica.

9 Qa micinkśi Solomon, niye tuwe niyate wakanda kin sdonya wo, qa cante ecedan on ókiya wo, qa nagii iyokipiya on ; Jehowa wicacante owasin iwanyaka, qa tawacinpi okage kin owasin okahnig̣a nakaś; heon ayakite cinhan iyeyaye kta, tuka aduśtan kinhan owihanke wanin ehpeniye $\mathrm{k}$ ta.

10 Aiciciya wo, dehan Jehowa towakan kin on tipi yecage kta e nicabnig̣a. Waśagic̣iya, qa kaga wo.

11 Hehan Dawid iye cinhintku Solomon tiyopa awakeyapi okaga kin, qa tipi okaga kin, qa mazopiye kin, qa wankan tipi kin, qa tipi mahentuya, qa wokajuju iha tipi kin hena owasin okağa kin qu.

12 Nakun taku woniye iye kici un kin sdonyekiya owasin, Jehowa ti hocoka kin, qa mazopiye tipi owasin, Wakantanka ti hocoka ihdukśan yakonpi kin, qa taku yuwakanpi mazopiye okaga kin.

13 Nakun wawayuśnapi obepi kin, qa Lewi obepi kin, qa Jehowa ti wokicanye wakśica kin toketu.
14 Nakun mazaskazi on mazaskazi tkeutapi tonaka wokicanye waliśica kin owasin on, qa mazaska. wakśica, wokicanye owasin on, qa wokicanye iyuhipa, wakśica iyuhipa toketu oyaka.

15 Qa mazaskazi petijanjan ihupa kin, qa mazaskazi petijanjan kin tkeutapi kin, petijanjan ihupa kin, qa petijaujan on mazaskazi tkeutapi tonaka, qa mazaska petijanjan tkeutapi kin, petijanjan ihupa otoiyohi, qa petijanjan otoiyohi kaggapi kin iyecen.

16 Qa wahna wotapi akan ağuyapi taninyan ehnakapi on mazaskazi tkeutapi kin, wahnawotapi otoiyohi on, qa mazaska mazaska wahna wotapi kin on.

17 Qa wicape, qa wakśica, qa wiyatke mazaskazi ecedan kin, qa mazaskazi cega ihaton tkeutapi kin, cega otoiyohi on.

18 Qa wizinya owayuśna on mazaskazi ecedan tkeutapi kin iyenaka, qa canpahmihma kin, mazaskazi Kcrubim, Jehowa wotakuye canwohnaka iwankam ihdumdayapi, qa akahpapi okağa lin.

19 Hena iyuhipa Jehowa nape kin omiciwa, wolicanye iyuhpa okaga kin sdonye makiya, eya.

20 Nakun Dawid iye cinhintku Solomon heciya, Wakiśaka, qa miniheca wo; qa kagia wo. Ihnuhan niyuśinyaye cin, qa ihnuhan wakoyakipe cin. Jehowa Wakantanka wakanwada kin niciun nakaś; aniyuśtan kte śni, qa elipeniye kte śni, ecen Jehowa ti wolitani wokicanye kin iyuhpa yahduśtan $\mathrm{k}$ te cin.

21 Qa iho wawayuśnapi, qa Lewi obepi kin wicaduha, Wakantanka ti wohtani kin owasin on, qa nakun wokicanye owasin on, tona wohtani owasin on ksapapi wiyeya unpi; qa mdetanhunka- 


\section{WICOWOYAKE 29.}

pi, qa oyate owasin nii kin ekta unpi.

\section{WICOWOYAKE 29.}

1 Nakun wicaśtayatapi kin Dawid omniciye owasin hewicakiya, Micinkśi Solomon iśnana Wakantanka kahnige cin he hokśidan, qa wankadan, qa wohtani kin he tanka, tipi kin he wicaśta akantu tawapi kte śni, tuka Jehowa Wakantanka tawa kta.

2 Qa miye mitowaśake ocowasin on, tuwe wakan wada ti kin on mazaskazi mnawaya, taku mazaskazi on kaģapi on, qa mazaska taku mazaska on, qa mazaśa taku mazaśa on, qa mazasapa taku mazasapa on, qa can taku can on, inyan wicaśake iyececa, qa ojupi kta inyan sapa, qa inyan hdeśkaśka, qa inyan tehika ocaje owasin; qa inyan ska ota.

3 Qa akton tuwe wakan wada ti kin cantihewaye cin on mazaskazi, qa mazaska mitawa hinca etanhan taku tipi wakan kin on wiyeya mnawaye cin isanpa tuwe wakanwada ti kin on dena waqu.

4 Mazaskazi woqin kektopawinge yamni, Opir mazaskazi kin etanhan, qa mazaska śdoyapi woqin kektopawinge śakowin on tiobosdata kin apawintapi kta.

5 Mazaskazi taku mazaskazi on kagjapi on, qa mazaska kin taku mazaska on kaggapi on, qa wikicanye mazakaga napepi on kagapi kin owasin on, qa tuwe nakaha Jehowa on nape kin iyokipiya ojudan kiye kta he?

6 Unkan ateyapi itancanpi kin, qa Israel wicoun itancanpi kin, qa kektopawinge qa opawinge mdetanhunkapi kin, qa wicaśtayatapi wakicanye itancanpi kin iyokipiya qupi.

7 Qa Wakantanka ti wohtani kin on mazaskazi woqin kektopawinge zaptan, qa Darekon kektopawinge wikcemna, qa mazaska woqin kektopawinge wikcemna, qa mazaśa woqin kektopawinge wikcemna sanpa kektopawinge śahdogan, qa mazasapa woqin kektopawinge opawinge qupi.

8 Nakun tona inyan tehika yuha iyeyapi otoiyohi Jehowa ti wopiye on qupi, Jehiel Gerśoni nape kin en.

9 Qa iyokipiya qupi kin on oyate kin iyuśkinpi, cante ecedan on Jehowa itukihánpi nakaś; qa Dawid wicaśtayatapi kin iś eya iyuśkin wowiyuśkin tanka.

10 Unkan Dawid Jehowa yawaśte, omniciye owasin iśtapi itokam, qa Dawid heya, Jehowa Israel ateunyanpi. wakanda kin otokahe wanica ehantanhan owihanke wanica ekta niyawaśtepi.

11 Wotanka kin, qa wowaśake kin, qa wowitan kin, qa wowiyega kin, qa wowiyatpa kin hena owasin nitawa; taku mahpiya ekta, qa maka akan owasin $n i$ tawa nakaś; wokiconze kin niye nitawa, Jehowa, qa taku owasin hduwankan, qa pa kin he niye.

12 Wowijice kin, qa wowitan kin niye etanhan, qa niye taku owasin iyadaka ece; wookihi, qa wowaśake ninape ohna yanka qa ninape taku owasin yutanka, qa waśag ya okihi.

13 Heon wanna Wakan unnidapi unkiyepi unniyatanpi, qa wowitan nitawa caje kin unkidowanpi.

14 Qa miye matuwe he? qa oyate mitawa tuwepi he? on hecen iyokipiya itukihan wookihi unhapi; taku owasin niye etanhan nakaś, qa taku ninape kin etanhan $\mathrm{u}$ kin he unnicupi ce.

15 Unkiyepi niye itokam oyate 611 


\section{ANPETU OYAKAPI.}

tokeca, qa unhdaka unpi iyeuncecapi, ate unyanpi owasin hececapi. Anpetu unkitawapi maka akan ohanzi wan iyececa, qa wacinye picaśni.

16 Jehowa Wakanunnidapi woyuha ota kin de tipi nicagapi kta nicaje wakan kin on unyuwiyeyapi kin he ninape etanhan, qa owasin nitawa.

17 Wakancida wicacante iduta, qa ohan ecetu kin iyonicipi sdonwaya. Micante ecetu on miye dena iyuhpa mduwiyeya, qa wanna oyate nitawa den hiyeye cin iyokipiya itunicihanpi kin wowiyuśkin on wanmdaka.

18 Jehowa hunkake wicunyanpi Abralıam, qa Izak, qa Israel wakandapi kin oyate nitawa cante ozepi okaga kin awanyaka, qa niye ekta cantepi kin yuecetu ye.

$19 \mathrm{Qa}$ micinkśi Solomon cante ecetu qu ye; hecen nitawaohope, woyaco nitawa, qa wokage nitawa ope kta, qa iyuhpa ecen econ kta, qa tipi on wiyeya wahnake cin he kagge kta.

20 Hehan Dawid omniciye owasin hewicakiya, Wanna Jehowa Wakanyadapi kin yawaśtepo. Unkan omniciye kin owasin Jehowa hunkake wicayapi wakandapi kin yawaśtepi, qa patujapi, qa makata ehpeiçiyapi, Jehowa ekta qa wicaśta yatapi kin ekta.

21 Qa wośnapi Jehowa wakiyuśnapi, qa anpetu kin he ihanlianna wohuhnahyapi huhnahyapi, tatanka kektopawinge, qa tamdoka kektopawinge, qa tacinca kektopawinge, woakaśtanpi iyahna, qa wośnapi nina ota Israel owasin on.

22 Qa anpetu kin he en wowiyuśkin tanka on Jehowa itokam 612 wotapi, qa wayatkanpi ; qa inonpa akihde Solomon Dawid cinhintku wicaśtayatapi kagiapi, qa Jehowa on mdetanhunka kta e sdayapi, qa Zadoq wawayuśna kta.

23 Unkan Solomon iye Dawid eekiya wicaśtayatapi kta, Jehowa toiyotanke akan iyotanka, qa taku econ kin tanyan ihunni, qa Israel owasin oie kin nahonpi.

24 Unkan itancanpi kin owasin, qa wicaśta waśaka owasin, qa nakun wicaśta yatapi Dawid cinca kin owasin Solomon wicaśtayatapi kta e napepi kin qupi.

25 Unkan Jehowa Solomon nina yutanka, Israel owasin iśtapi en, qa wicaśtayatapi wowitan kin qu, iye itokam Israel ohna tuwedan he iyececa yuke śni.

26 Wanna Dawid Jesse cinhintku Israel owasin iwicadaka.

27 Israel idake cin waniyetu wikcemna topa, anpetu hehanyan, Hebron ohna waniyetu śakowin wawidaka, qa Jerusalem ohna waniyetu wikcemna yamni sanpa yamni wawidaka.

28 Hehan paska waśte en tạ, anpetu, qa wowijice, qa wowitan on wipi. Unkan heekiya iye cinhintku Solomon wawidaka.

29 Unkan Dawid wicaśtayatapi oie tokaheya, qa ehake kin hena owapi ce, Samuel wawanyaka tawowapi kin en, qa Natan waayate tawowapi kin en, qa Gad wawanyaka tawowapi kin en.

30 Nakun tawowidake, qa 'towaśake owasin, qa anpetu iye iwankam hiyaye cin, qa Israel iwankam, qa makoce wicaśtayatapi kin iwankam. 


\section{ANPETU OYAKAPI,}

\section{WOWAPI INONPA.}

\section{WICOWOYAKE 1.}

1 Unkan Solomon Dawid cinhintku tawowidake en nina ihdusuta, unkan Jehowa iye wakanda kin kici un, qa nina hin yutanka. 2 Unkan Solumon Israel owasin wahowicaya, kektopawinge qa opawing me metanhunkapi kin, qa wayacopi kin, qa itancanpi kin owasin, Israel ateyapi tipi papi kin owasin.

$3 \mathrm{Qa}$ Solomon omniciye ocowasin kici pajodan Gibeyon ohna yanke cin ekta ipi; itkokipapi wakeya Wakantanka tawa, Moses Jehowa taokiye hopuza kin en kag̉e cin hen yanka nakaś.

4 Tuka Wakantanka canwohnaka tawa kin Qiryat Jeyarim etanhan Dawid wiyeya ekicihnake cin ekta itanwankanhde hiyuya; Dawid Jerusalem ohna he wakeya kicicaġe ciqon nakaś.

5 Tuka mazaśa wahnawośnapi kin Betzaleel Uri cinhintku Hur cinhintku kin kage cin, Jehowa ti kin itokam hen yanka, qa Solımon, qa omniciye kin he ihakta hipi ece.

6 Qa Solomon heciya mazaśa wahnawośnapi kin ekta $i$, he Jehowa itokam wakeya icahda wanka: qa wohuhnahyapi kektopawinge he akan huhnahya.

7 Hanyetu kin he en Wakantanka Solomon en ihdutanin, qa heciya, Taku ciçu kta yacin da wo.

8 Unkan Solomon Wakantanka II. Chron. heciya, Niye ate Dawid wocanthiye tanka ecayecon, qa heekiya wicaśtayatapi mayakaga.

9 Heon, Jehowa Wakantanka, nioie ate Dawid eyakiye cin hduwicaka ye. Niye oyate wan wicota, maka watuśekśeca iyenaka, iwankam wicaśtayatapi mayakağa nakaś.

10 Heon woksape qa wosdonye maqu ye, hecen oyate kin de itokam inawape ca en wahdi kta; ecin tuwe oyate tanka nitawa kin de wicayaco kta okihi he?

11 Unkan Wakantanka Solomon heciya, Hecen cante duze ca wowijice, woyuha qa wowitan unmanna yada śni; nakun tókaniyanpi nagipi kin, qa anpetu ota yada śni ; tuka woksape, qa wo. sdonye on oyate mitawa iwankam wicaśtayatapi cicagge cin wicadaco kta yada, heon;

12 Woksape, qa wosdonye wanna niçpi ; nakun wowijice, qa woyuha, qa wowitan ciçu kta, hecen wicaśtayatapi nitokam unpi kin tuwedan iyeniceca śni, qa niyohakam tuwedan iyeniceca kte śni.

13 Unkan Solomon pajodan Gibeyon ohna wanke cin etanhan, itkokipapi wakeya itokapa tanhan, Jerusalem en hdi, qa Israel owasin iwicadaka.

14 Qa Solomon canpahmihma, qa śuktanka akanyotankapi mnayain, qa canpahmihma kektopawinge sarpa opawinge topa yu613 


\section{ANPETU OYAKAPI,}

ha, qa sung akanyotankapi kektopawinge ake nonpa; qa hena canpahmihina otonwe kin ohna, qa wicaśtayatapi kici Jerusalem ohna yanke wicakiya.

15 Qa wicaśtayatapi kin mazaska, qa mazaskazi Jerusalem ohna inyan iyececa kaga, qa hanteśa can kin sukamin can Śepela ohna iyececa nina ota.

16 Qa Solomon śuktanka tawa Egupta etanhan, qa Qowa etanhan inanpapi, wicaśtayatapi wopeton tawa wiyopeya on hena Qowa etanhan icupi.

17 Qa canpahmihma wan mazaska opawinge śakpe on $\mathrm{Egu}$ pta etanhan itanwankanhde hiyuyapi, qa śuktanka wan opawinge sanpa wikcemna zaptan on, qa hecen Hiti wicaśtayatapi, qa Aram wicaśtayatapi kin owasin on hena napepi on hinanpe wicayapi.

\section{WICOWOYAKE 2.}

1 Unkan Solomon Jehowa caje on tipi wan kicage kta, qa nakun tipi wan iye tawowidake on, keya.

2 Qa Solomon watokśupi on wicaśta kektopawinge wikcemna śakowin mnawicaya, qa he akan wakakanpi on kektopawinge wikcemna śahdogran, qa econ wicakiyapi kta e kektopawinge yamni sanpa opawinge śakpe.

3 Qa Solomon Ḧuram Tzur wicaśtayatapi kin wahoye ça heciya, Token ate Dawid ecayecon, qa tipi ohna iye ti kta, ticage kta e lianteśa can hiyuyakiye cin he iyecen ecamicon wo.

4. Ito miye Jehowa wakanwada caje on tipi wan wecaga, he yuwakan kta, qa wizinye waśtemna iye itokam izin yapi kta, qa ağuyapi ohinniyan ehnakapi on, qa anpetu okihpapi, qa witeca, qa Jehowa wakanundapi tomniciye wakan wohuhnaliyapi on; ohinniyan econ wicaśi kin iyecen.

5 Qa tipi wakage cin he tanka, Jehowa wakan undapi lin he taku wakan owasin isanpa tanka nakaś.

6 Hecen tuwe he tipi kicagge kta okihi he? Mahpiya, qa mahpiya malipiya kin he kipi kta okitpani, hecen mive matuwe on tipi wecage kta? Iye itokam wizinye kta heceedan on owakihi.

7 Heon wanna wicaśta ksapa wan miye ekta uśsi wo, mazaskazi kagga, qa mazaska, qa mazaśa, qa mazasapa, qa stan, qa duta, qa to kagja ; qa taku pagopi pagio kta wayupika; hecen iye wicaśta ksapa Juda qa Jerusalem ohna, ate Dawid wiyeya wicakagia, qa miye om unpi lin, iye liena om un kta.

8 Nakun Lebanon etanhan hanteśa can, qa wazi can, qa algumin can makahi wicaśi wo, nitaokiye Lebanon can kaksapi wayupikapi e sdonwaya nakaś; qa nitaokiye mitrokiye om unpi kta.

9 Hecen can ota wiyeya micihnakapi kta, tipi wakage cin he tanka, qa wowinihan nakaś.

10 Qil ito wakakanpi can kaksapi kin on nitaokiye aguyapi su kor kektopawinge wikcemna nonpa, qa barle kor kektopawinge wikcernna nonpa, qa miniśa bat kektopawinge wikeemna nonpa, qa wihdi bat kektopawinge wikcemna nonpa ciçu kta.

11 Unkan Ḧuram Tzur wicaśtayatapi kin Solomon wowapi kicage cin en heya, Jehowa iye taoyate waśte wicadake cin on wiciwankam niye wicaśtayatapi nicağa.

12 Huram nakun heya, Jehowa 


\section{WICOWOYAKE 3.}

Israel wakandapi kin mahpiya maka ko kagge cin he yawaśtepi nunwe; iye wicaśtayatapi $\mathrm{Da}$ wid cinca wan ksapa, qa wasdonya, wayupika, qa wiyukcan $q u, q a$ iye Jehowa ti kin kicag̉e lkta; nakun tipi wan tawowidake on.

13 Qa nakaha wicaśta wan ksapa, wasdonya, qa wiyukcan, $\mathbf{H u}$ ram ate tawa niye ekta yewaśi.

14 Winohinca wan Dan cunwintkupi kin etanhan he cinhintku, qa atkuku Trur wicaśta heca; iye mazaskazi on taku kaģa wayupika, qa mazaska on, qa mazaśa on, qa mazasapa on, qa inyan on, qa can on, qa stan on, qa to on, qa minihuha ska on, duta on, nakun taku pagopi owasin pago kta wayupika; qa taku iyukcan yaśi kin iyukcan kte; wicaśta ksapa nitawa, qa itancan mitawa Dawid niyate wicaśta ksapa tawa om.

I5 Heon kohanna aǵuyapi su kin, qa barle kin, qa wihdi kin, qa miniśa kin itancan mitawa cajeyate ciqon taokiye ekta auwicakiya wo.

16 Unkan unkiyepi Lebanon etanhan can tona yacin kin owasin unnicicaksapi kta, qa cankaga miniwanca akan, Joppa ekta unnicicahipi kta, qa hetanhan niye hena Jerusalem ekta ade Lta.

17 Unkan Solomon wicaśta oyate tokeca Israel makoce ohna yakonpi kin owasin wicayawa, atkuku Dawid wicayawa qon ohakam, qa liektopawinge opawinge sanpa kektopawinge wikcemna zaptan sanpa kektopawinge yamni sanpa opawinge śakpe iyewicaya.

18 Qa hena etanhan kektopawinge wikcemna śakowin watokśupi, qa kektopawinge wikce- mna śahdogian he akan wakakanpi wicakaga, qa kektopawinge yamni sanpa opawinge śakpe oyate kin wohtani econ wicakiyapi.

\section{WICOWOYAKE 3.}

1 Unkan Eolomon Jehowa ti kin Jerusalem ohna kagia, Moria lie alan, tukten iye atkuku $\mathrm{Da}$ wid en Jehowa ihdutanin qon, ya oyanke Dawid wiyeya kage cin akan Ornan Jebusi ạguyapi su okapan tawa akan.

2 Qa waniyetu widake cin itopa, wi inonpa kin en tokaheya kaga. 3 Qa Wakantanka ti Solomon kage cin oahe iyutapi tokaheya kin dee, ohanske cin wiciśpa wikcemna śakpe, qa ohdakinyan kin wiciśpa wilkcemna nonpa.

4 Qa tiyopa awakeyapi tipi kin itokam ohanske kin he tipi ohdakinyan kin iyecen wiciśpa wikcemna nonpa, qa obosdatu kin wiciśpa opawinge sanpa wikcemna nonpa, qa mahen mazaskazi ecedan on apawinta.

5 Qa tipi tanka kin wazi can aokatan, qa mazaskazi waśte on apawinta, qa akan tamar can, qa mazaicicahilia yuhmupi apago.

6 Qa wowitan on inyan tehika tipi kin ikoyagya, qa mazaskazi hin Parwaim mazaskazi heca.

7 Qa tipi can hdakinyan kin, qa ipatan kin, qa ti unnaptan kin, qa tiyopa kin mazaskazi apawinta, qa ti unnaptan akan kerubim apaġo.

8 Qa tipi iyotan wakan kin ohanske cill wiciśpa wikcemna nonpa kaga, tipi kin ohdakinyan kin iyenaka, qa ohdakinyan kin wiciśpa wikcemna nonpa, ca mazaskazi waśte oqin opawinge śakpe on apawinta.

9 Qa maza okatkugapi tkeutapi kin mazaskazi śeqel wikcemna 615 


\section{ANPETU OYAKAPI,}

zaptan; qa wankantipi kin mazaskazi on apawinta.

10 Qa tipi iyotan wakan kin mahen kerubim pagiopi nonpa kag̉a, qa hena mazaskazi apawinta.

11 Qa kerubim hupahupi kin owasin ohaske kin wiciśpa wikcemna nonpa, hupahu wanji wiciśpa zaptan tipi unnaptan kin iyohi, qa hupahu unman kin wiciśpa zaptan, kerub unman hupahu tawa kin iyohi.

12 Qa kerub unman hupahu tawa wiciśpa zaptan tipi unnaptan kin iyohi, qa hupahu unman wiciśpa zaptan kerub tokaheya hupahu kin ikoyaka.

13 Kcrubim kin hena hupahupi kamdaġapi kin wiciśpa wikcemna nonpa, qa sihapi akan najinpi, qa itepi kin tipi kin ektakiya.

14 Qa cokaya ozanpi kin hahonta to, qa stan, qa duta, qa ska on kagia, akan kerubim kaga.

15 Qa tipi kin wiyohiyanpata ipatan nonpa kaga, ohanska wiciśpa wikcernna yamni sanpa zaptan, qa otoiyohi pa akan wateśdake wanke cin he wiciśpa zaptan.

16 Qa mazaicicahilia owohdaka tipi kin ohna iyececa kagga, qa ipatan papi akan ehnaka, qa taspantankasuota opawinge kaga, qa mazaicicaliha ckta ikoyagya.

17 Qa ipatan nonpa kin bosdan ehde, tipi kin iwiyohiyanpata wanji etapa tanhan, qa unman catka tanhan, qa ctapa kin Jakin, (Jehowa yasuta.) qa catka kin Boaz (Miniheca) eya cajeyata.

\section{WICOWOYAKE 4.}

1 Qa mazaśa owayuśna wan kagia, ohanske kin wiciśpa wikcemna nonpa, qa ohdakinyan kin wikcemna nonpa, qa obosdatu kin wiciśpa wikcemna.

2 Qa ceğa śdoyapi tanka kin kağa, mima, tete wanji ctanhan tete unman ekta hdakinyan wiciśpa wikcemna; qa bosdatu kin wiciśpa zaptan, qa ihdukśan hahonta wiciśpa wikcemna yamni iyohiya.

3 Qa ihukuya ihdukśan owancaya ta tanka okagapi yukan, wikcemna wiciśpa otoiyohi en, cega tanka ihdukśan owancaya tatanka ocankuye nonpa, śdoyapi, cegga tanka kin śdoyapi qehan.

4 Qa tatanka ake nonpa akan han, yamni itepi hin waziyatakiya, qa yamni itepi kin wiyohpeyata kiya, qa yamni itepi kin itokalikiya, qa yamni itepi kin wihinanpa ektakiya; qa cega tanka kin hena tapetepi akan wanka, qa nitepi kin mahentuya unpi.

5 Qa ośoke kin nape topa, qa tete kin wiyatke tetc kin iyececa, mnahicahica namdaya akan kagiapi, ojudan ca bat liektopawinge yamni kipi.

$6 \mathrm{Qa}$ wakśica wikcemna kagge ca zaptan etapa tanhan, qa zaptan catka tanhan ehde, hena ohna taku hulinaliyapi kta yujajapi, qa pakintapi ece; tuka wawayuśnapi kin cega tanka kin ohna ihdujajapi ece.

7 Qa mazaskazi petijanjan ihupa wikcemna kaga, woyaco qon iyecen, qa tipi kin ohna hena chde, zaptan etapa tanhan, qa zaptan catka tanhan.

$8 \mathrm{Qa}$ wahnawotapi wikcemna kagga, qa tipi kin en hena ehnaka, zaptan etapa tanhan, qa zaptan catka tanhan; nakun mazaska'zi wakśica on amnimnipi opawinge kaģa.

9 Qa wawayuśnapi tahocoka

616 
kağa, qa hocoka tanka kin; qa hocoka tiyopa kin, qa hocoka napin tiyopapi kin mazaskazi apawinta.

10 Qa cega tanka kin, wihinanpe cin etonwanpi etapa tanhan, itokah kiya ehde.

11 Nakun Ḧuram ceğa hin, qa maza mdaska kin, qa wakśica kin kagja. Hecen Huram wikicanye wicaśtayatapi Solomon kicag'e cin Wakantanka ti kin on hena yuśtan.

12 Ipatan tanka nonpa kin, qa papi kin, qa wateśdake ipatan nonpa papi akan, qa maza yankapi nonpa on wateśdake tapa nonpa ipatan papi akan yankapi kin hena akahpapi kta.

$13 \mathrm{Qa}$ taspantanka suota ópawinge topa mazayankapi nonpa kin on, taspantanka suota cankuye nonpa mazayankapi otoiyohi on, wateśdake tapa nonpa kin akalípe kita.

14. Qa oahe wikcemna kin kagja, qa oahe akan wakśica kin kaga.

15 Qa cegg tanka kin kagga, qa tatanka wikcemna sanpa nonpa kin he ihukuya.

16 Nakun cegga kin, qa maza mdaska kin, qa wicape kin, qa wikicanye Jehowa ti kin on $\dot{H} u$ ram ateye cin Solomon kicage cin owasin mazazi wiyatpa.

17 Jordan osmaka ohna, maka śoka en Sukot qa Tzareda otahedan, wicaśtayatapi kin hena śdoya.

18 Hecen Solomon wakśica kin hena owasin kagra, nina ota, qa mazazi tkeutapi kin iyeyapi śni.

19 Qa Solomon Wakantanka ti kin wakśica kin owasin kaga, qa mazaskazi owayuśna kin, qa wahnawotapi kin, qa hena akan ağuyapi itokam ehnakapi kin,

20 Qa petijanjan ihupa kin, qa petijanjan tawa, mazaskazi ece- dan on, owohdaka tipi kin itokam itkonpi kta, woyaco kin iyecen.

21 Qa wahica kin, qa petijanjan kin, qa petijanjan iyukse mazaskazi, hena owasin mazaskazi ecedan.

22 Qa isan kin, qa wakśica on amnimnipi, qa wiyatke kin, qa oizinye kin mazaskazi ecedan. Nakun tipi tiyopa kin, tiyopa mahentuya, tipi wakanhinca tiyopa, owohdaka tipi tiyopa kin hena mazaskazi.

\section{WICOWOYAKE 5 .}

1 Hecen wokicanye Jehowa ti kin on Solomon kage cin owasin yuśtanpi; qa Solomon taku atkuku Dawid yuwakan kin, mazaska kin qa mazaskazi kin, qa wakśica kin owasin hiyuya, qa Wakantanka mazopiye en ehnaka.

2 Hehan Jehowa otakuye can wohnaka kin Dawid totonwe, Zion hee, etanhan aliyuha aupi kta e Solomon Israel hunkayapi owasin, qa Israel cinca atewicayapi itancanpi kin, qa wicoun papi kin owasin Jerusalem ekta mniciye wicaya.

3 Unkan wi iśakowin wohanpi wakan qehan, Israel wicaśta kin owasin wicaśtayatapi ekta mniciyapi.

4 Qa Israel hunkayapi kin owasin en hipi, qa Lewi kin can wo. hnaka kin yuwankan icupi.

5 Qa can wohnaka kin akiyuha anpi; nakun itkokipapi wakeya kin, qa wakśica wakeya ohna yakonpi kin owasin hena wawayuśnapi kin, Lewi kin akiyuha aupi.

6 Qa wicaśtayatapi kin; qa Israel omniciye iye en mniciyapi kin owasin canwohnaka kin itokam tahinca, qa tatanka wayu617 


\section{ANPETU OYAKAPI,}

śnapi, hena yawapi śni, nina ota heon yawapi śni.

7 Unkan wawayuśnapi kin Jehowa otakuye can wohnaka kin oyanke tawa en ahipi orwohdaka tipi iyotan wakan kin en, kerubim hupahupi kin ihukuya.

8 Unkan kerubim hupahupi kin kamdali yakonpi can wohnaka oyanke kin iwankam, qa kerubim kin can wohnaka kin, qa tośu tawa iwankam akahpapi.

9 Qa tośu kin yujunpi hecen tośu inkpapi can wohnaka etanhan owohdaka tipi itokam taninyan yakonpi, tuka tankan tanhan aisinyan yakonpi, qa anpetu kin dehanyan hen yankapi.

10 Can wohnaka kin ohna takudan yanke śni, inyan mdaşa nonpa heceedan, hena Moses Horeb ekta ohnaka, Jehowa wotakuye Israel rvicakicagge cin Egupta etanhan hdinanpapi qehan.

11 Unkan wawayuśnapi kin tipi wakan etanhan hdinanpapi qehan, wawayuśnapi hen hiyeyapi kin owasin wanna ihduwakanpi, hehan obepi iyehanhan awanyakapi śni nakaś.

12 Qa Lewi kin, wadowanpi kin owasin Asap, qa Heman qa Jedutun, qa cincapi, qa sunkawicayapi minihuha ska koyakapi, mazaicasnasna qa candowankiyapi, qa cotanka yuha wahna wośnapi kin iwiyohiyanpa tanhan najinpi, qa hena om wawayuśnapi opawinge sanpa wikcemna nonpa mazayahotonpi kin yahotonpi.

13 Qa Jehowa yatanpi kta, qa wopida eciyapi kta e wicaśta wanjidan iyecen ho okonwanjidan on yahotonpi, qa dowanpi ho kin nahonpi qehan, mazayahotonpi, qa mazaicasna, qa dowan ikicanye owasin on ho wankan yeyapi, qa Jehowa waśte on to618 wacantkiye owihanke wanica on yatanpi qehan mahpiya śoka wan tipi kin Jehowa ti kin ojuya.

I4 Qa Jehowa towitan kin Wakantanka ti kin ojuya, heon mahipiya śoka kin on etanhan wawayuśnapi kin wakicanyanpi kta hen najin okitpanipi.

\section{WICOW OYAKE 6.}

1 Hehan Solomon heya, Jelowa otpaza śoka ohila ti kta keya.

2 Tuka miye tipi ohna nanke kta e tipi wan cicicaga, oyanke wan ohna owihanke wanin yakidotanke kta.

3 Hehan wicaśtayatapi kin ite ihduhomni, qa Israel omniciye kin ocowasin wicayawaśte; unkan Israel omniciye ocowasin najinpi :

4 Qa heya, Jehowa Israel Wakandapi kin yawaśtepi nunwe; iye ate Dawid i kin on ia, qa iye nape kin on hduecetu qa heya,

5 Oyate mitawa Egupta etanhan hdinanpe wicawaye cin, anpetu kin hehantanhan otonwe Israel wicoun owasin etanhan wanjidan wakahniğe śni, on micaje hen yanke kita e tipi wan micicagapi kta, qa oyate mitarwa Israel wiciwankam itancan kta wicaśta wanjidan wakahnige śni.

6 Tuka naliaha Jerusalem micaje hen yanke kta e wakahniğa, qa Dawid wakahniga, oyate mitawa Israel wiciwankam un kta.

7 Unkan Jehowa Israel wakandapi caje kin on tipi kage kta Dawid ate waya cante kin en un.

8 Tuka Jehowa ate Dawid heciya, Micaje on tipi wan yakage kta cantiheyaye cin, eqe cantiheyaye cin he waśte.

9 Tuka tipi kin he niye yakage kte śni, tuka nicinkśi ninite etan- 


\section{WICOWOYARE 6.}

han inanpe kte cin, he micaje on tipi kin kage kta.

10 Qa Jehowa iye oie eye ciqon hduecetu, hecen Dawid ate eekiya nawajin, qa Israel oiyotanke kin akan imdotanka, Jehowa eye ciqon iyecen, qa Jehowa Israel wakanḑapi caje kin on tipi kin wakaga.

$11 \mathrm{Qa}$ canwohnaka, wotakuye Israel cinca kin Jehowa wicakicag̀e cin he ohna un kin, hen ewahnaka.

12 Hehan Jehowa tawahna wośnapi iwiyohiyanpata Israel omniciye ocowasin wicitokam najin, qa nape hdugata.

13 Wanna Solomon mazazi cowahe wan kage ciqon, ohanske kin wiciśpa zaptan, qa ohdakinyan wiciśpa zaptan, qa obosdatu kin wiciśpa yamni, qa ohocoka kin cokaya ehraka; qa he akan canpeśka makehde najin, Israel omniciye ocowasin itokam, qa malipiya ektakiya nape hdugata ;

14 Qa heya, Jehowa Israel wakandapi kin niye iyececa mahpiya ekta, qa maka akan taku wa"kan wanica, nitaokiye cantepi kin ocowasin on nitokam manipi kin wotakuye, qa wocantkiye wicayecipatan.

15 Nitaokiye ate Dawid wicoie eyakiye cin yecipatan, qa taku n̊ii on eyalsiye cin ninape on yahduecetu, nakaha iyececa.

16. Heon dehan Jehowa Israel wakandapi kin, taku nitaokiye Dawid ate eyakiye cin hduecetu ye. Tho token mitokam mayani kin, he iyecen nicinca mitokam manipi kta tacankupi awanhdakapi kinhan, Israel oiyotanke akan iyotanke kte śni, wicaśta tohinni nicicaśpapi kte śni, eha.

17 Qa Jehowa Israel wakandari kin nioie nitaokiye Dawid eyakiye cin nakaha hduwicaka ye.
18 Ecin, Wakantanka awicakehan wicaśta orn maka akan iyotanke kta he? Inyun mahipiya kin, qa mahpiya malipiya kin nicipi okitpani kinhan, iyotan tipi wakage cin de okitpani.

19 Hececaśta, Jehowa wakancida, nitaokiye hoyeniciye cin, qa ceniciye cin anohkiciya ye; qa howaye cin, qa wocekiye nitaokiye nitokam cekiye cin he nahon ye.

20 Hecen anpetu hanyetu koya, tipi kin de ektakiya niiśta kin kamdaya un kta; oyanke ohna nicaje yanke yakiye kta kehe ciqon he ektakiya; hecen wocekiye oyanke kin de ektakiya nitaokiye ceniciye cin nayalion kita.

21 Qa nitaokiye, qa Israel oyate nitawa wocekiye oyanke kin de ektakiya eyapi kin nahon ye, qa mahpiya oyanke ohna yati kin etanhan nayalion kta, qa nayahon eca wicakicicajuju ye.

22 Wicaśta wan takodaku wakilitani kinhan, qa taku wakan cajeyan wohdag śipi, qa wahnawośnapi nitawa tipi kin de ohna yanke cin itokam $u$ kinhan;

23 Niye malkpiya etanhan nahon ye, qa ecakicon ye, qa nitaokiye wicayaco ye; qa tuwe śica tohan sica iyecen qu ye, pa akan, qa tuwe owotanna yaowotanna, qa toowotanna kin iyecen gu ye.

24 Qa oyate nitawa Israel wanicihtanipi kin on tokawicayapi kin itokam wicakaśtakapi kinlian, niye en ihdamnapi, qa nicaje ohdakapi, qa tipi kin de ohna cekiyapi, qa niciyugatapi kinhan ;

25 Niye mahpiya etanhan nahon ye, qa oyate nitawa wahtanipi kin wicakicicajuju ye, ga makoce wicayaqu, qa hunkake 619 


\section{ANPETU}

wicayapi kin wicayaqu qon, he ekta hdicuwicaya ye.

26 Tohan wanicilitanipi kin on mahpiya kin natakapi, qa maǵaju wanica, qa kakiśs wicayaya on wahtanipi kin etanhan ihdamnapi, qa oyanke kin de ektakiya cekiyapi, qa nicaje ohdakapi kinhan,

27 Niye mahpiya en nahon ye, qa tohan canku waśte nitawa onspe wicayakiye cin omanipi, hehan nitaokiye, qa oyate nitawa Israel wahtanipi kin wicakicicajuju ye, qa makoce nitawa, oyate nitawa tawayapi kta wicayaqu qon maǵaju qu ye.

28 Tohan makoce en wicaakihan yuke cinhan, makośica, qaiś watośnija, aa, psipsicadan, wamduśkadan yuke cinhan; tóka wicayapi kin makoce tonwanyanpi kin en onawicatakapi kinhan, wokaśtake, woyazan taku kaśta yuke cinhan,

29 Oyate nitawa Israel owasin qaiś tuwe kaśta towayazan, qaiś toiyokiśica sdotkiye cin on tipi kin de ektakiya nape hdugate, wokiyugate, qa wocekiye kin,

30 Niye malipiya oyanke ohna yakidotanke cin etanhan nahon ye, qa kicicajuju ye, qa otoiyohi ohanyan kin owasin iyecen qu ye, niye niśnana Adam cinca kin owasin cantepi sdonyaya nakaś.

31 Hecen konicipapi kta, qa nitacanku omanipi kta, makoce hunkake wicayapi kin wicayaqu kin akan nipi kin anpetu owasin.

32 Nakun turve oyate tokeca, oyate nitawa Israel etanhan śni, nicaje tanka on, qa ninape waśa$\mathrm{ka}$, qa niisto yahdugata on, makoce tehan tanhan u, qa hi, qa tipi kin de ektakiya cekiye cinhan ;

\section{OYAKAPI,}

33 Niye mahpiya etanhar, oyanke ohna idotanke cin etanhan nahon ye, qa taku oyate tokeca hoyeniciye cin owasin iyecen econ ye; hecen oyate niaka ohnaka owasin nicaje kin sdonyapi $\mathrm{kta}$, qa oyate nitawa Israel iyecen konicipapi kta; qa tipi kin de wakage cin nicaje on cajeyatapi ce, sdonyapi kta.

34 Tohan oyate nitawa canku ohna yewicayaśi, tokayapi kin azuwicayapi wokicize ekta yapi kinhan, qa otonwe kin de yakahnige cin ektakiya, qa tipi nicaje on wakagee cin ektakiya ccniciyapi kinhan ;

35 Mahpiya etanhan, ceniciyapi, qa niciyugatapi kin nahon ye, qa woyaco ecawicakicon ye.

36 Tohạn wanicihtanipi, (ecin wicaśta wahtani śni wanica,) qa canniye wicayaya, qa tokayapi nape en wicayaqu; hecen iwicacupi, qa makoce tehan qaiś ikiyedan ekta, wayaka awicayapi kinhan,

37 Cantepi en hdipi, makoce ekta awicayapi ohna, qa ihdamnapi, qa wayaka awicayapi tamakocepi kin ohna ceniciyapi, qa, Waunhtanipi, ecinśniyan unkohanyanpi, śicaya econkupi, eyapi kinhan;

$38 \mathrm{Qa}$ makoce ekta wayaka awicayapi, qa wayaka unpi kin he ohna cantepi ocowasin on, qa naggipi ocowasin on niye ell hdipi kinhan; qa tamakocepi hunkake wicayapi kin wicayaqu kin ektakiya ceniciyapi kinhan;

39 Niciyuğatâpi, qa ceniciyapi kin, mahpiya, oyanke ohna idotanke cin etanhan nation ye; qa woyaco ecawicakicon ye, qa oyate nitawa wanicihtanipi kin wicakicicajuju ye.

40 Wakancida nakaha ceciciye, niiśta hduzamni ye, qa oyanke 


\section{WICOWOYAKE 7.}

kin den ceniciyapi kin ninogie kin anoh kiciya ye.

41 Qa Jehowa. Wakantanka, wanna iyozi nitawa en hinajin ye, niye qa nitowaśake canwohnaka kin. Jehowa Wakantanka wawayuśna nitawa wowanikiye koyakapi kte, qa tona cantewicayakiye wowaśte on wiyu śkinpi kta.

42 Jehowa Wakantanka ihnuhan tuwe sdayakiya ite kin yahduhomni kin. Nitaokiye Dawid towacantkiye kiksuya ye.

\section{WICOWOYAKE \%}

1 Unkan Solomon cekiya hduśtan qehan, peta kin mahipiya etanhan kun hiyu, qa woliulinaliyapi, qa wośnapi kin yasota; qa Jehowa towitan kin tipi kin ojuya.

2 Hecen wawayuśnapi kin Jehowa ti kin mahen yapi okihipi śni, Jehowa towitan kin Jehowa ti kin ojuya nakaś.

3 Unkan Israel cinca kin owasin peta kun hiyu kia, qa tipi kin akan Jehowa towitan kin wanyakapi, qa maka kin ektakiya itepi kin patujapi, qa Jehowa ohodapi, qa yatanpi, waśte kin on, towacantkiye kin owihanke wanica on.

4 Wicaśtayatapi kin, qa oyate kin owasin wośnapi Jehowa itokam wayuśnapi.

5 Qa Solomon tatanka kektopawinge wikcemna nonpa sanpa kektopawinge nonpa, qa talinca kektopawinge opawinge sanpa kektopawing e wikcemna nonpa wayuśna; hecen wicaśtayatapi kin, qa oyate kin owasin Wakantanka ti kin yuwakanpi.

6 Qa wawayuśnapi kin toawanyakapi ekta najinpi; qa Lewi kin Jehowa idowanpi, Jehowa towacantkiye owihanke wanica on yatanpi kta e Dawid wicaśtayatapi widowankiyapi kage cin on, hena napepi kin on Dawid yatan qehan; qa wawayuśnapi kin wicitokam mazayahotonpi, qa Israel owasin bosdan najinpi. 7 Unkan Solomon Jehowa ti kin itokam hocoka cokaya kin yuwakan, qa hen woliulinaliyapi kin, qa wopida wośnapi śin kin huhnahya ; mazaśa owayuśna Solomon kagge ciqon wohuhnahyapi kin, qa mintia kin, qa sin kin kipi kta okihi śni nakaś.

$8 \mathrm{He}$ ehan Solomon wohanpi kag̉a, anpetu śakowin; qa Israel owasin opapi, omniciye nina tanka, Hamat en yapi kin etanhan Egupta kaksiza ekta hehanyan.

9 Qa anpetu iśahdog an en omniciye wakan kağa, anpetu śakowin wahnawośnapi kin yuwakanpi, qa anpetu śakowin wohanpi wakan kağapi nakaś.

10 Qa wi iśakowin anpetu iwikcemna nonpa sanpa yamni en, oyate kin tawakeyapi ekta kihde wicaya, wiyuśkinpi, qa cante waśtepi, taku waśte iyulipa Jehowa Dawid, qa Solomon, qa iye taoyate ecawicakicon kin on.

11 Hecen Solomon Jeliowa ti kin yuśtan, qa wicaśtayatapi ti kin, qa taku Jehowa ti kin ohna, qa iye ti kin ohna kagie kta e Solomon cante kin en hiyu kin owasin tanyan ihuni.

12 Unkan hanyen Jehowa Solomon en tanin içiye ça heciya, Wocekiye nitawa nawahon, qa oyanke kin de wamiciyuśnapi tipi on wakaliniğa.

13 Mahpiya kin nawataka on mag̉aju wanice cinhan, qaiś psipicadan makoce yun wicawaśi kinhan; makośice oyate mitawa ekta ye waśi kinhan;

14 Qa oyate mitawa micaje on 621 


\section{II. $\triangle$ NPETU OYAKAPT,}

caje wicayatapi kin ihduhukuyapi, qa cekiyapi, qa miite akitapi, qa tacankupi śica etanhan ihdamnapi kinhan; miye mahpiya etanhan nawahon kta; qa wahtanipi kin wicawecicajuju $\mathrm{kta}$, qa tamakocepi kin asniwaye ktá.

15 Detanhan miiśta kin yumdayapi kta, qa wocekiye oyanke kin den cekiyapi kin minoge kin anolikiciya un kta.

$16 \mathrm{Qa}$ wanna tipi kin de wakahiniga, qa micaje owihanke wanin en yanke kta e mduwakan; qa miiśta, qa micante kin anpetu owasin hen un kta.

17 Qa niye, niyate Dawid mani kin iyecen, mitokam mayani kinhan, qa taku econ ciśi kin owasin ecanon, qa wokağe mitawa, qa woyaco mitawa yapatan kinhan :

18 Wokiconze oiyotanke nitawa kin mdusuta kta, niyate Dawid wahowaye ciqun iyecen; Israel idake kte śni wicaśta tohinni niciyúśpapi kte śni, epa.

19 Tuka nihdamnapi, qa wokage mitawa, qa woahope mitawa niyepi itokam ewahde kin, hena ehpeyayapi kinhan; qa taku wakan tokeca ekta dapi, qa hena ekta yapatujapi kinhan;

20 Makoce mitawa wicawaqu gon etanhan wicamdujun kta; qa tipi kin de micaje on mduwakan kin mitokapa tanhan elipewaye kta, qa wiyacinpi, qa orveśtepi wakag̉e kta, oyate owasin wicehna.

21 Qa tipi kin de pajodan, tona ikiyedan yapi owasin yuśinye yapi kta, qa heyapi kta, Tokeca Jehowa makoce kin de, qa tipi kin de hecen ecakicon he?

22 Unkan heyapi kta, Jehowa hunkake wicayapi wakandapi kin, qa Egupta makoce etanhan hdinanpe wicaye cin he ayuśtanpi, qa taku wakan tokeca yuzapi, qa itokam patujapi, qa ohowicadapi; heon taku śice cin de ocowasin iyahde wicaya.

\section{WICOWOYAKE 8.}

1 Unkan waniyetu wikcemna nonpa icunhan Solomon Jehowa ti kin, qa iye ti kin kage cin ihanketa,

2 Solomon otonwe Ḣuram Solomon kicu qon hena piya kağa, qa hen İsrael iyotang wicaya.

3 Qa Solomon Hamat Troba ekta i, qa ohiya.

4 Qa Tadmor tinta ohna kağa; nakun wopiye otonwe Hamat ohna Solomon kagge cin owasin.

5 Qa Bethoron wankantuya kin, qa Bethoron hukuya kin, otonwe suta conkaśke, qa tiyopa oyuģan, qa tiyopa inatake yukan, hena kagia.

6 Nakun Bayalat, qa wopiye otonwe Solomon yuhe cin owasin, qa canpahmihma otonwe owasin, qa śuktanka akan yotankapi otonwe, qa taku wiciyokipi kage kta e Solomon iyokipi, Jerusalem ohna, qa Lebanon ohna, qa makoce idake cin owancaya ohna;

7 Oyate Hiti kin etanhan, qa Amori kin, qa Perizi kin, qa ந̆iwi kin, qa Jebusi kin etanhan okaptapi kin hena Israel etanhanpi śni ;

8 Qa Israel cinca ocowasin ihangwicayapi śni etanhan cincapi kin iyepi ohakam makoce ohna okaptapi kin, hena Solomon anpetu kin dehanyan wayaka wolitani econ wicakiya.

9 Tuka Israel cinca kin etanhan Solomon wohtani tawa on tuwedan wowidake yuhe śni; tuka hena ozuye wicaśta, qa

622 


\section{WICOWOYAKE 9.}

akicita tancan, qa canpahmihma tawa itancanpi kin, qa suktanka akan yotankapi tawa itancan hecapi.

10 Unkan Solomon wolitani econ wicakiyapi itancan opawinge nonpa sanpa wikcemna zaptan wicayuha; hena oyate kin iwicadakapi.

11 Unkan Solomon Paro cunwintku Dawid totonwe etanhan hiyuya, tipi wan iye kicagge cin ekta; Dawid Israel wicaśtayatapi ti kin he wakan, Jehowa can wohnaka tawa kin hen hiyu nakaś; heon, Mitawin hen yanke kte śni, eya.

12 Hehan Solomon wohulinaliyapi Jehowa wakiyuśna, owayuśna Jehowa kicağe cin akan, tiyopa awakeyapi kin itokam.

13 Anpetu iyohi wicoie kin iyecen wohuhnaliyapi kin, Moses woahope kin iyecen, anpetu wakan kin on, qa witeca kin on, qa omniciye wakan mdoketu otoiyohi yamni akihde; ag่uyapi napohyapi śni wohanpi kin, qa anpetu wakan yawapi wohanpi kin, qa ohanzi hdepi wohanpi kin hena en.

14 Qa wawayuśnapi obepi kin najin wicakiya, atkuku Dawid woyaco tawa kin ivecen, wohtanipi kin on, qa Lewi kin toawanyakapi ekta yatanpi kta, qa wawayuśnapi kin wicitokam najinpi $\mathrm{kta}$, anpetu iyohi wicoie kin iyecen, qa tiyopa awanyakapi obepi kin, tiyopa otoiyohi ekta, Dawid Wakantanka tawicasta hecen econ wicaśi nakaś.

15 Wicaśtayatapi kin wawayuśnapi kin, qa Lewi kin taku econ wicaśi kin takudan ehpe yapi śni, wicoie on, nakun womnaye on.

16 Hecen Jehowa ti oahe hdepi anpetu kin etanhan, ecen Je- howa ti kin tanyan yuśtanpi kin, Solomon tokicanye kin iyuhpa yuśtanpi.

17 Hehan Solomon Etzion gaber ekta i, qa Elot ekta, hena Edom makoce ohna yankapi, niniwanca hutata.

18 Unkan Huram iye taokiye napepi on witawata, qa ookiye mini wanca sdonyapi kin ekta uwicaśi. Unkan hena Solomon taokiye om, Opir ekta ipi, qa hetanlıan mazaskazi woqin opawinge topa sanpa wikcemna zaptan icupi; qa wicaśtayatapi Solomon ekta kahipi.

\section{WICOWOYAKE 9.}

1 Unkan Śeba wicaśtayatapiwin kin Solomon oyakapi kin nahon, qa woiyukcan tehika on iyute kta e Jerusalem en hi, wicota hinca om, qa kamel taku waśtemna, qa mazaskazi nina ota, qa inyan tehika qinpi, qa Solomon ekta hi, qa taku iye cante mahen un kin owasin on kici iwohdaka.

2 Unkan taku iwange cin owasin toketu Solomon okiyaka, qa wicoie Solomon okahnige śni, qa toketu okiyake śni wanica.

3 Unkan Śeba wicaśtaya tapiwin kin Solomon toksape kin qa tipi kage cin wanyaka;

4 Nakun tawahna wotapi kin, qa taokiye token iyotankapi, qa taakicita tawowaśipi kin, qa tawokoyakepi kin; qa tawayatkekiyapi, qa wokoyake tawapi, qa wohuhnahyapi Jehowa ti kin en huhnahye cin, hena iyuhpa wanyake cehan woniya sanpa en un śni.

$5 \mathrm{Qa}$ wicaśtayatapi kin heciya, Maknce mitawa ohna nioie on, qa nitoksape on wicoie nawation kin he wowicake ye. 


\section{ANPETU OYAKAPI,}

6 Tuka en wahi, qa miiśta wanyake śni hehanyan cetonwahda ce; tuka inyun nitoksape otahin hanke kin omakiyakapi śni, wotanin nawation qon kayapa ye.

7 Wicaśta nitawa tanyan unpi ye; qa nitaokiye kin dena ohinniyan nitokam najinpi, qa nitoksape nahonpi kin tanyan unpi ye.

8 Jehowa Wakanyada kin yawaśtepi ye, iye waśte nidake ça toiyotanke akan iyotang niye cin, hecen Jehowa Wakanyada kin on wicaśta niyatapi. Tuwe wakanyada Israel waśte wicadaka, qa owihanke wanin wicayusuta kta e wiciwankam wicaśtayatapi nicaġa; woyaco, qa woowotanna ecanon kta heon etanhan ye, eya. 9 Qa mazaskazi woqin opawinge sanpa wikcemna nonpa qu; nakun taku waśtenma nina ota, qa inyan telika; qa taku waśtemna Śeba wicaśtayatapi win kin wicaśtayatapi Solomon qu kin iyececa wanica.

10 Unkan Ḣuram taokiye, qa Solomon taokiye mazaskazi Opir etanban ahipi kin hena nakun algum can, qa inyan tehika kahipi.

11 Unkan wicaśtayatapi kin algum can kin .Jehowa ti kin on, qa wicaśtayatapi ti kin on caniyadipi kaga; nakun candowankiyapi, qa cotanka wadowanwicakiyapi on; qa hena iyecen itokam tohinni Juda makoce ohna takudan wanyakapi śni.

$12 \mathrm{Qa}$ wicaśtayatapi Solomon Śba wicaśtayatapi win kin taku iyokipi qa da kin iyuhpa qu, taku wicaśtayatapi kin ekta kahi qon isanpa. Unkan ihdamna, qa iye tamakoce ekta kihda; iye, qa ookiye wicrye cin.

13 Unkan mazaskazi Solomon en kahipi waniyetu wanjidan icunhan tkeutapi kin mazaskazi woqin opawinge śakpe sanpa wikcemna śakpe sanpa śakpe.

14 Wopeton cistinna, qa wopeton tanka taku kahipi kin, qa Arab wicaśtayatapi kin owasin, qa makoce itancanpi kin mazaskazi, qa mazaska Solomon kahipi kin owasin akton.

15 Unkan wicaśtayatapi Solomon mazaskazi kamdayapi wahacanka tanka opawinge nonpa kağa, wahacanka iyohi mazaskazi śeqel opawinge śakpe.

16 Nakun mazaskazi kamdayapi wahacanka opawinge yamni, mazáskazi seqel opawinge yamni wahacanka wanjikśi iyohi; qa wicaśtayatapi kin Lebanon contanka tipi kirs en hena kihnaka.

17 Qa wicaśtayatapi kin oiyotanka wan putehanskaki on kaga, qa mazaskazi écedan apawinta.

18 Qa oiyotanke kin iyadipi śakpe, qa siha oahe mazaskazi, qa hena oiyotanke kin ikoyag yapi, qa tukten iyotanke cin anoka tanhan nape yukan, qa mnaja nonpa nape kin icahda najinpi.

19 Qa mnaja wikcemna sanpa nonpa hen najinpi, iyadipi akan, anoka tanhan śakpe; wokiconze owasin ehna taku hececa kagiapi wanica.

20 Qa wicaśtayatapi Solomon wakśica iyatke tawa owasin mazaskazi, qa Lebanon contanka tipi wakśica kin owasin mazaskazi écedan, mazaska wanica, he Solomon taanpetu kin en taku śni yawapi.

21 Wicaśtayatapi tawitawata kin Tarśiś elkta ipi, Huram taokiye om, waniyetu iyamni eca Tarśiś witawata kin wancadan hdipi ece; qa mazaskazi, qa mazaska, qa putehanskahi kin, qa kepe (waonca) qa zicatanka npi waśte kahdipi ece. 
22 Hecen wicaśtayatapi Solomon makoce wicaśtayatapi kin owasin isanpa tanka ece wowijice, qa wolksape on.

23 Qa makr wicaśtayatapi kin owasin Solomon ite kin akitapi ece; woksape Wakantanka iye cante en qu kin nahonpi kta heon.

$24 \mathrm{Qa}$ hena otoiyohi taku qupi kin kahipi ece, mazaska wakśica, qa mazaskazi wakśica, qa wokoyake, wipe, qa taku waśtemna, śuktanka, qa śonśonna, waniyetu otoiyohi wicoie kin iyecen.

$25 \mathrm{Qa}$ Solomon śuktanka tawanji, qa canpahmihma kektopawinge topa yuha, qa śuktanka akan yotankapi kektopawing'e wikcemna sanpa kektopawing.e nonpa; qa hena canpahmihma otonwe kin ohna najin wicakiya, qa wicaśtayatapi kici Jerusalem ohna.

26 Qa wicaśtayatapi kin owasin, wakpa kin etanhan Pilistim tamakocepi ekta, qa Egupta ihanke kin aiyahdeya iwicadaka.

27 Qa wicaśtayatapi kin Jerusalem ohna mazaskazi iny an iyececá kağa, qa hianteśa can kin sukamim can Śepela ohna yakonpi kin iyececa ota.

$28 \mathrm{Qa}$ Solomon on suktanka Egupta etanhan hiyuyapi, qa makoce owasin etanhan.

29 Unkan Solomon wicoie unman tokaheya qa ehake kin, hena Natan waayate oie kin en owapi śni he? qa Aliija Śiloni towaayate kin en, qa Iddo wawanyake towanyake kin Jeroboyam Nebat cinhintku caje yate kin en?

30 Qa Solomon Jerusalem olina Israel owasin waniyetu wikcemna topa iwicadaka.

31 Hehan Solomon hunkake wi(1) caya om iśtima, qa atkuku Dawid totonwe ohna hnakapi. Unkan heekiya cinhintku Rehoboyam wawidaka.

\section{WICOWOYAKE 10.}

1 Unkan Rehoboyam Śsekem ekta i, 1srael owasin wicaśtayatapi kag̣api kta e Śkem elkta hipi nakaś.

2 Wanna Jeroboyam Nebat cinhintku wicaśtayatapi Solomon itokapa tanhan, Egupta ekta najica qun, qa hen yanke cin he nalion qehan, Jeroboyam Egupta etanhan hdi.

3 Unkan tuwe ekta yeśipi, qa kicopi. Unkan en hi, qa Jeroboyam, qa Israel owasin iapi, qa Rehoboyam heciyapi,

4 Niyate woqin tehika qin unkiyapi; heon niye wanna wohitani tehika, qa woqin the niyate qin unkiyapi kin unkiciyukapojepidanpo, kinban wowidag unyayapi kta.

5 Unkan hewicakiya, Tokata anpetu iyamni hehan en maupo ; unkan oyate kin iyayapi.

6 Unkan wicaśtayatapi Rehoboyam wicalinca iye atkuku Solomon ni qehan itokam najinpi ece qon, hena om iyukcan, qa heya, Oyate kin de token awicunyuptapi kta idukcanpi he?

7 Unkan iapi, qa heciyapi, Oyate kin de ekta nakaha nihduwaśte, qa iyokipi wicayaya, qa wicoie skuya wicayaqu kinhan, anpetu owasin ookiye wicaduhe kta.

8 Tuka wicahinca wowiyukcan iyukcanpi kin ayuśtan, qa kośka iye kici icağapi, qa itokam najinpi kin iyukcan wicaśi.

9 Qa hewicakiya, Oyate kin de iapi, qa, Canwanapin niyate napin unkiyapi kin yukapojedan 625 


\section{ANPETU OYAKAPI,}

unkiyapo, enakiyapi, token awicunyuptapi kta unkiciyukcanpo.

10 Unkan kośka iye kici icağapi, kici wohdakapi, qa heyapi, Oyate kin de iapi qa, Niyate canwanapin tke urkkicicagapi kin he yukapojedan unkiyapo eniciyapi kin hecen ewicayakiye kta, Miśaśte kin ate nite kin isanpa śoke kta.

$11 \mathrm{Qa}$ wanna ate can wanapin the qin niciyapi kin he miye canwanapin nitawapi kin isanpa tke cicicagapi kta. Ate cansakadan on nicapsintapi, tuka miye tehmiso okaśkeśke on cicapsintapi kta.

12 Unkan anpetu iyamni en, Jeroboyam, qa oyate owasin $\mathrm{Re}-$ hoboyam ekta hipi, wicaśtayatapi kin wicoie kin de eye ciqon iyecen, Anpetu iyamni kin ake en maupo.

13 Unkan wicaśtayatapi kin tehiyà awicayupta, qa wicaśtayatapi Rehoboyam wicahinca tawiyukcanpi kin ayuśtan;

14. Qa kośka iyukcanpi kin iyecen ie ca hewicakiya, Ate nitawaqinpi kin yutke, qa miye nitawaqinpi sanpa tke wakage kta. Ate cansakadan on nicapsintapi, tuka miye tehmiso okaśkeśke on cicapsintapi kta.

15 Hecen wicaśtayatapi kin oyate kin nawicahon śni, Wa-

- kantanka hena hecen yuhomni uakaś, Jehowa oie kin Ahija Śiloni nape on Jeroboyam Nebat cinhintku eciye ciqon yuecetu kta.

10 Unkan Israel owasin wicaśtaya tapi kin nawicalion śni wanyakapi qehan, oyate kin wicaśtayatapi kin ayuptapi, qa heyapi, Dawid en wopamni unhapi tukte e he? qa Jesse cinhintku en takudan tawaunyanpi śni: Israel wicaśta otoiyohi tawakeya ekta hda wo. Dawid yati kin áwanhdaka wo. Hehan Israel owasin tawakeyapi ekta hdapi.

17 Tuka Israel cinca kin Juda otonwe kin ohna tipi kin hena Rehoboyam iwicadaka.

18 Unkan wicaśtayatapi Rehoboyam Ḣadoram womnaye $\cdot$ itancan kin yeśi. Unkan Israel cinca kin inyan on kininpi, hecen ta. Unkan wicaśtayatapi Rehoboyam minihen iciya, tacanpahmihma akan iyotanke kta, qa Jerusalem ekta najice kta.

19 Unkan Israel Dawid tiwahe kin kipajin anpetu kin dehanyan.

\section{WICOWOYAKE 11.}

1 Unkan Rehoboyam Jerusalem en hdi, qa Juda qa Benjamin tiyohnaka mniciye wicaya, wicaśta kahnigapi kektopawing opawing'e sanpa kektopawinge wikcemna śahdog'an, ozuye kağa hecapi, Israel wicakize kta, qa wokonze kin Rehoboyam en bdikiye kta.

2 Unkan Jehowa oie kin Śemaja Wakantanka wicaśta tawa en hi, qa heciya,

3 Rehoboyam Solomon cinhintku, Juda wicaśtayatapi kin, qa Israel tona .Juda qa Benjamin ohna yakonpi kin owasin hecen ewicakiya wo ;

4 Jehowa hecen eya, Nihunkawanjipi kin ekta yaipi kte śni, qa wicayakizapi kte śni. Otoiyolii tiyata hdapo; wicoie kin de miye etanhan nakaś. Unkan Jehowa oie kin nalionpi, qa Jeroboyam azuyapi kta etanhan kihdapi.

5 Unkan Rehoboyam Jerusalem en yanke ca Juda ohna otonwe conkaśke kag̀a.

6 Hecen Betlehem, qa Yetam, qa Teqoa kağa. 
7 Nakun Betzur, qa Śoko, qa Adullam,

8 Qa Gat, qa Mareśa, qa Zip,

9 Qa Adorajim, qa Lakiś, qa Azeqa,

10 Qa Tzora, qa Ajalon, qa Ḣebron; hena otonwe conkaślkeyapi, Juda qa Benjamin obna.

11 Qa conkaśke kin yusuta, qa hena ohna akicitatancan, qa woyute, qa miniśa, qa wihdi wopiye kağa.

1.2 Qa otonwe otoiyohi ohna wahacanka, qa wahukeza kihnaka; hecen hena nina yusuta, qa Juda qa Benjamin wicayuha.

13 Unkan wawayuśnapi kin, qa Lewi kin Israel owancaya yakonpi qon tonwanyanpi kin owasin etanhan iye en hipi.

14 Hena Jehowa wakiyuśnapi kte śni e Jeroboyam, qa iye cinhintku heyata iyewicayapi, heon Lewi kin otonwe tawapi, qa ihdukśan tinta yuhapi kin ehpekiyapi, qa Juda qa Jerusalem en hdipi.

15 Qa Jeroboyam paha on, qa canotidan on, qa ptejicadan iye kağe cin on, wawayuśnapi eiçihde.

16 Unkan hena iyohakam Israel wicoun owasin etanhan tona Jehowa Israel wakandapi kin akitapi kta cantepi içiçupi kin, hena Jehowa hunkake wicayapi wakandapi kin wakiyuśnapi kta e Jerusalem en hipi ece.

17 Qa waniyetu yamni Juda wokiconze yusutapi, qa Rehoboyam Solomon cinhintku waśag yapi; waniyetu yamni hehanyan Dawid tacanku, qa Solomon tacanku omanipi nakaś,

18 Unkan Rehoboyam Mahala he Dawid cinhintku Jerimot he cunwintku qa Abihail, he Jesse cinhintku Eliab cunwintku yuza.
19 Unkan cinca kiciton, Jeuś, qa Ś Semarja, qa Zaham.

20 Unkan ohakam Mayaka Abiśalom cunwintku yuza. Unkan Abija, qa Yatta, qa Ziza, qa Śelomit kiciton.

21 Unkan Rehoboyam Mayaka Abiśalom cunwintku tawicu unman, qa winohinca wakanyan wicayuze śni, hena owasin isanpa waśte daka; iye winohinca wikcemna sanpa śahdogan wakanyan wicayuza, qa wikcemna śakpe wakan śni wicayuza; qa cinca wica wikcemna nonpa sanpa śahdoġan; qa winyàn wikcemna śakpe kicitonpi.

22 Qa Rehoboyam Abija Mayaka cinhintku wicaśtayatapi kag̉e kta e hunkawanji wicaye cin wicitokam pa kaga.

$23 \mathrm{Qa}$ wiyukcan, qa cinhintku owasin Juda, qa Benjamin tamakocepi kin owancaya enanakiya yanke wicaya, otonwe conkaśkeyapi kin owasin ohna, qa woyute ota wicaqu; qa winohinca ota wicayus wacin.

\section{WICOWOYAKE 12.}

1 Unkan Rehoboyam tośkanśkan yusutapi qehan, qa waśaka aye cehan, Jehowa toope kin ayuśtan, qa Israel owasin nakun. 2 Unkan Rehoboyam wawidake cin waniyetu izaptan kin on Ś́iśaq Egupta wicaśtayatapi kin Jerusalem azuya, Jehowa awahtanipi nakaś.

3 Canpahmihma kektopawing sanpa opawinge nonpa yuha hi, qa śung akan yotankapi kektopawinge wikcemna śakpe, qa oyate kici hipi kin wicayawapi śni, Egupta etanhan, Lubim, Ohanzihdepi otipi kin, qa $\mathrm{Ku}$ śim.

4. Qa otonwe conkaśkeyapi kin 627 


\section{ANPE'TU OYAKAPI,}

Juda tawa kin icu, qa Jerusalem ekta hi.

. 5 Unkan Śemaja waayate kin Rehoboyam, qa Juda itancanpi kin Ś́síaq itokapa tanhan Jerusalem en witaya hipi kin hena ekta wicahi, qa hewicakiya, Jehowa hecen eya, Niyepi amayaduśtanpi heon miye Śiśaq nape en ehpeciyapi ce.

6 Unkan Israel itancanpi kin, qa wicaśtayatapi kin ihduhukuyapi, qa, Jehowa ohan owotanna ce, eyapi.

7 Unkan ihduhukuyapi kin Jehowa wanyake cehan Jehowa oie kin Śmaja en hi, qa heciya, Ihduhukuyapi ce, ihang wicawaye kte śni; tuka woehdaku cistinna wicawaqu kta, qa mitocanniye kin Siśaq nape kin on awakaśtan kte śni.

8 Tuka wowidake wicayuhe kta; hecen wowidag wicawaye cin, qa maka wicaśtayatapi kin wowidag wicayapi kin sdonyapi kta.

9 Unkan Śiśaq Egupta wicaśtayatapi kin Jerusalem azuya, qa Jehowa ti wopiye kin icu, qa wicaśtayatapi ti wopiye kin, hena iyuhpa icu, nakun mazaskazi wahacanka Solomon kagge ciqon.

10 Unkan hena eekiya Rehoboyam mazazi wahacanka kagge ca wainyankapi itancanpi kin wicaśtaya tapi ti tiyopa awanyakapi napepi en hena qu.

11 Unkan wicaśtayatapi kin Jehowa ti kin ekta i ca wainyankapi kin hena yuhapi; qa ake wainyankapi mazopiye tawapi en hena kihnakapi.

12 Unkan ihduhukuyapi qehan Jehowa tocanniye kin etanhan ihduhomni, qa ocowasin ihang wicaye śni. Unkan Juda on wicoie waśte yukan.

13 Hecen Rehoboyam Jerusa628 lem en waśag içiye ca wawidaka. Rehoboyam waniyetu wikcemna topa sanpa waniyetu wanjidan qehan toka wawidaka, qa waniyetu wikcemna sanpa śakowin Jerusalem ohna wawidaka, otonwe kin he Israel wicoun owasin etanhan Jehowa kahnig'a, caje kin ohna yanke kiye kta heon etanhan; qa hunku Nayama eciyapi Anmoniwin.

14 Qa Jehowa iśta kin en taku śica econ, Jehowa akite kta cante kin hduecetu śni nakaś.

15 Qa Rehoboyam ohan unman, tokaheya qa ehake kin, hena Śemaja waayate oie kin en owapi śni he? qa Iddo wawanyake wicoicage oyaka kin en? Unkan Rehoboyam qa Jeroboyam ohinniyan kicizapi.

16 Qa Rehoboyam hunkake wicaya om iśtiman. Unkan Dawid totonwe ohna hnakapi, qa eekiya cinhintku Abija wawidaka.

\section{WICOWOYAKE 13.}

1 Jeroboyam wawidake cin waniyetu iwikcemna sınpa śahdogan kin en, Abija toka wawidaka.

2 Waniyetu yamni Jerusalem ohna wawidaka, qa hunku Mikaja eciyapi, he Uriel Gibeya etanhan cunwintku. Qa Abija, qa Jeroboyam kicizapi ece.

3 Qa Abija wicaśta waśaka waditaka- wicayuha, ozuye kagga wicaśta kahnigapi kektopawinge opawinge topa. Unkan Jeroboyam he kize kta e wicaśta waśaka waditaka kahniğapi hecapi kektopawinge opawinge śahdogan ocimdah najinwicakiya.

4 Unkan Abija Zemaraim he akan inajin, he Epraim he kin en wanka, qa heya, Jeroboyam, qa Israel owasin namahonpo. 


\section{WICOWOYAKE 13.}

5 Jehowa Israel wakandapi kin Dawid, qa iye cinca kin Israel iwankam wokiconze wicaqu, wotakuye owihanke wanica on, he sdonyayapi kta iyececa śni he?

6 Tuka Dawid cinhintku Solomon taokiye Jeroboyam najin, qa itancan tawa kipajin.

7 Unkan wicaśta takudan yuhapi śni, wicaśtapi śni cinca kin iye en witaya hipi, qa Rehoboyam Solomon cinhintku kipajinyan waśag içyapi, he ehan Rehoboyam nahanhin aśkatudan, qa cante wankadan, qa wicitkokim ihdusuta śni.

8 Unkan wanna niyepi Jehowa tokiconze Dawid cinca napepi en un kin itkokim nihdusutapi kta, kehapi ; qa niyepi nina niotapi, qa mazaskazi ptejicadan wakanyadapi kta e Jeroboyam nicicağapi kin hena duhapi.

9 Jehowa wawayuśna tawa Aaron cinca kin, qa Lewi kin hena heyata iyewicayayapi śni he? qa makoce oyatepi kin iyecen wawayuśna nicicaģapi śni he? Tuwe kaśta pte wanuyanpi cincadan, qa tamdoka śakowin on nape oju kiye cinhan iye taku wakan śni wawayuśna içicağa.

10 'Tuka unkiyepi Jehowa wakanundapi, qa he ehpeunyanpi śni, qa Aaron cinca kin wawayuśnapi ece, qa Jehowa ókiyapi, qa Lewi kin wokicanye tawapi lin econpi ece.

11 Qa Jehowa on hanhanna otoiyohi, ga htayetu otoiyohi wohuhnahyapi izinyapi, nakun wizinyapi waśtemna; qa ag̣uyapi cankuyeye kin wahnawotapi écedan akan yanka, qa mazaskazi petijanjan htayetu otoiyohi ideyapi ece, unkiyepi Jehowa Wakanundapi topatan kin unpatanpi nakaś; tuka niyepi he aduśtanpi.
1. Qa inyun Jehowa Wakantanka mdetanhunka on unkicipi un, qa wawayuśna tawa mazayahotonpi on aniyahotonpi kta; Israel cinca ihnuhan Jehowa nihunkakepi wakandapi kin yakizapi kin, ohiyayapi kte śni nakaś.

13 Tuka Jeroboyam wiciheyata wicaśta anahbeya iyaye wicaya, hecen Juda itokam yakonpi, qa anahbeya iyayapi kin wicihakam. 14 Unkan Juda hekta etonwanpi qehan, iny un wokicize kin wicitokam, qa wicihakam un, heon Jehowa hoyekiyapi, qa wawayuśna mazayahotonpi kin yahotonpi.

15 Qa Juda wicaśta kin iyaśapi. Unkan Juda wicaśta kin iyaśapi qehan Wakantanka Jeroboyam qa Israel owasin wicakaśtaka, Abija qa Juda wicitokam.

16 Unkan Israel cinca kin Juda itokam napapi; napepi kin en Wakantanka wicaqu nakaś.

17 Unkan Abija, qa oyate tawa wopate tanka on wicakaśtakapi hecen Israel wicaśta kahnigapi kektopawinge opawinge zaptan capapi hinhpayapi.

18 Hecen anpetu kin he en Israel cinca kin yuhukunwicayapi, qa Juda cinca kin Jehowa hunkake wicayapi wakandapi kin he wacinyanpi kin, heon waśag wicayapi.

19 Unkan Abija Jeroboyam kuwa aya, qa etanhan otonwe icu, Betel qa otonwe cunkśiwicaya, qa Jeśana, qa cunkśiwicaya, qa Epron qa cunksiwicaya.

20 Unkan Jeroboyam wowaśake icimana ekicicetu śni; Abija ni kin hehanyan. Unkan Jehowa he kaśtaka heon ta.

21 Unkan Abija waśag ic̣iye ça winohinca wikcemna sanpa topa wicayuza, qa cinca wica wikee629 


\section{ANPETU OYAKAPI,}

mna nonpa sanpa nonpa, qa winyan wikcemna sanpa śakpe.

22 Unkan Abija ohan unman, qa tacanku, qa oie kin Iddo tawowapi kin en owapi ce.

\section{WICOWOYAKE 14}

1 Hecen Abija hunkake wicaya om iśtima. Unkan Dawid totonwe ohna hnakapi, qa eekiya cirhintku Asa wawidaka. Anpetu tawa en makoce kin waniyetu. wikcema oziya.

2 Qa Asa Jehowa iye wakanda iśta kin en taku waśte qa ecetu econ.

3 Qa owayuśna tokeca, qa pajodan kin yutokan, qa wakagapi kin kandeca, qa Aśere kin kawanka.

4. Qa Juda, Jehowa hunkake wicayapi wakandapi kin akitapi kta, qa toope, qa tawoahope opapi kta, kewicakiya.

5 Qa Juda otonwe kin owasin etanhan pajodan kin, qa anpetuwi okağapi kin yutokan, heon wicośkanśkan kin oziya iye itokam.

6 Qa Jehowa ozikiya, qa iye wokicize nica, makoce woori yuha nakaś, heon Juda ohna otonwe conkaśkeyapi kag̉a.

7 Qa Juda hewicakiya, otonwe kin dena unkagapi kta, qa ihdukśan conkaśke, qa ipasotka, qa tiyopa oyugan, qa inatake on suta unkağapi kta, makoce kin tawaunyanpi icunhan; Jehowa Wakan undapi kin unkakitapi, qa unkakitapi kin on iyozi unqupi, tona unkihdukśan yakonpi kin etanhan; hecen kaggapi, qa tanyan yuśtanpi.

8 Unkan Asa obe yuha Juda etanhan wahacanka, qa wahukeza yuhapi wicasta kektopawinge opawinge yamni, qa Benjamin. etanhan wahacanka qa itazipa yuhapi kelitopawinge opawinge nonpa sanpa wikcemna śahdogan; hena owasin waśaka waditakapi.

9 Unkan Zera Kuśi kin ozuye wicasta kektopawinge kektopawinge om, qa canpahmihma opawinge yamni yuha tatpe wicau, qa Mareśa en ahiti.

10 Unkan Asa itkokim iyaya, qa Tzepata osmaka ohna, Mareśa ikiyedan wokicize kagapi.

11 Unkan Asa iye wakanda kin Jehowa hoyekiye ca heya, Jehowa wicota qaiś tuwe wowaśake nica on waoyakiye kta unman tukte kaśta tokeca śni. Ounkiyamiye Jehowa wakanunnidapi, wacinunniyanpi nakaś; qa nicajeyan ozuye tanka kin de itkom unyanpi, Jehowa wakanunnidapi kin wicaśta ohiniyanpi śni nunwe.

12 Unkan Jehowa Kuśim kin Asa itokam, qa Juda itokam wicakaśtaka, heon Kuśim kin napapi.

13 Unkan Asa, qa oyate iye opapi kuwa awicayapi, Gerar ekta hehanyan. Unkan Kuśim hinhipayapi, ecen wanikiya nicapi, Jehowa itokam, qa taobe kin itokam kamdecapi, nakaś. Unkan walipaya ota kipi.

$14 \mathrm{Qa}$ otonwe Gerar ihdukśan yakonpi kin owasin wicakaśtakapi, Jehowa yuśinye wicaya nakaś, qa otonwe kin hena owasin wawicakipi ; hena ohna walipaya ota nakaś.

15 Nakun wanunyanpi tipi kin yujujupi, qa tahinca ota jcupi, nakun kamel, qa Jerusalem en hdipi.

WICOWOYAKE 15.

1 Unkan Wakantanka toniya kin Azarija Oded cinhintku en hi. 
2 Unkan Asa akipe kta iyaya, qa heciya, Asa, qa Juda, qa Benjamin owasin namakonpo. Tohan Jehowa oyapapi hehanyan Jehowa niyepi om yanke kta, qa ayakitapi kinhan iyeyayapi kta; tuka aduśtanpi kinhan aniyuśtanpi kta.

3 Anpetu ota wanna Israel taku wakan wicaka nicapi, qa wawayuśna waonspekiya nicapi, qa woope nicapi.

4 Tuka tokakijepi en Jehowa Israel wakandapi kin en ihduhomnipi, qa akitapi kte cinhan iyeyapi kta.

5 Qa anpetu kin hena icunhan wookiye nicapi, tankan yapi, qaiś en hdipi unman tukte kaśta; makoce ounyanpi kin owasin en woyuśinyaye tanka wanka nakaś.

$6 \mathrm{Qa}$ oyate oyate kici akicipapi, qa otonwe otonwe kici; Wakantanka yuśinye wicaya wokakije iyulipa on nakaś.

7 Heon niyepi wakiśakapo; ihnuhan nape nistakapi kin, wohtani nitawapi on iyuwin yukan nakaś.

8 Unkan Asa wicoie kin hena, qa Oded waayate kin taku oyake cin nahon gehan, iye waśag içiya, qa wowahte śni yutokan, Juda qa Benjamin makoce owancaya etanhan; nakun otonwe Epraim he kin etanhan icu qon, hena etanhan, qa Jehowa owayuśna tawa kin piya kaga, he Jehowa tiyopa awakeyapi itokam yanka.

9 Qa Juda, qa Benjamin owasin, qa wicaśta tokeca hena om tipi, Epraim, qa Manaśe, qa Simeyon etanhanhan, wicota Israel etanhan, Jehowa iye wakanda kin kici un kin wanyakapi qehan iye en hipi.

10 Qa Asa wawidake cin wani- yetu wikcemna sanpa izaptan wi iyamni en Jerusalem en mniciyapi.

$11 \mathrm{Qa}$ hehan wokipi aupi qon etanhan tatanka opawinge śakowin, qa tahinwanuyanpi kektopawinge śakowin, Jehowa wakiyuśnapi.

12 Qa wotakuye kağapi ; cantepi ocowasin, qa nagipi ocowasin on Jehowa hunkakepi wakandapi kin akitapi kta.

13 Qa tuwe kaśta Jehowa Israel wakandapi kin akite kte śni, cistinna qaiś tanka wicaśta qaiś winohinca he te yapi kta.

14 Nakun Jehowa nahon eyapi lotanka on, qa iyaśapi on, qa he yahotonpi on, qa mazayahotonpi on.

15 Qa Juda owasin wokonze kin on nina wiyuślzinpi, cantepi ocowasin on konzapi nakaś; qa tawacinpi ocowasin on Jehowa akitapi, heon iyeyapi; qa wicihdukśan yakonpi kin owvasin etanhan iyozi wicaya.

16 Nakun Mayaka wicaśtayatapi Asa hunku kin winyan itancan kte śni e yutokan, he wakaģapi wan Aśere kicağe cin heon; qa Asa wakagiapi kin kawanka, qa kamdeca, qa Qidron osmatia ohna huhnatiya.

17 Tuka pajodan kin Israel etanhan yujujupi śni. Hececa śta Asa cante kin Jehowa kici zaniyan un anpetu tawa ihuniyan.

18 Unkan taku iye atkuku yuwakan, qa taku iś iye yuwakan, mazaska, qa mazaskazi, qa wakśica Wakantanka ti kin en hiyuya.

19 Unkan icimana wokicize yuke śni ; Asa wawidake cin waniyetu iwikcemna yamni sanpa zaptan kin hehanyan. 


\section{ANPETU OYAKAPI,}

WICOWOYAKE 16.

1 Asa wawidake cin waniyetu iwikcemna yamni sanpa śakpe en Baaśa lsrael wicaśtayatapi kin Juda azuya, qa Rama aconkaśkeya, hecen tuwedan Asa Juda wicaśtayatapi kin ekta ye kta, qaiś etanhan hdi kta iyowin wicakiye kte śni.

2 Heon Asa mazaska qa mazaskazi kin Jehowa ti wopiye kin, qa wicaśtayatapi ti kin etanhan hiyuya, qa Benhadad Aram wicaśtayatapi Damaskos ohna ti kin ekta yekiye ca heya.

3 Miye qa niye wotakuye unkiciyukan, qa ate niyate kici. Tho mazaska, qa mazaskazi cicu. Howo wotakuye nitarva Bauśa Israel wicaśtayatapi kici kicaksa wo; hecen amayuśtan kta.

4 Unkan Benhadad, wicaśtayatapi Asa nation, qa ozuye mdetanhunka tawa kin Israel totonwe azuye wicaśi. Unkan Yijon, qa Dan, qa Abelmaim, qa Naptali otonwe wopiye kin owasin kaśtakapi.

5 Unkan Baaśa onahon qehan Rama kagie cin ayuśtan, qa wohtani kin enakiya.

6 Unkan wicaśtayatapi Asa Juda owasin mniciye wicaya; unkan inyan, qa can on Baaśa Rama aconkaśkeye cin hena yuwankan icupi, qa hena on Geba, qa Mitzpa conkaśke yapi.

7 Unkan hehan Hanani wawanyake kin Asa Juda wicaśtayatapi kin ekta hi, qa heciya, Aram wicaśtayatapi kin wacinyaye ca Jehowa wakanyada kin wacinyaye śni, heon Aram wicaśtayatapi kin taozuye kin ninapé etanhan niiçiyapi ce.

8. Kuśim kin, qa Lubim kin hena ozuye wicota, qa canpahmihma qa śuktanka akan yo- tankapi nina otapi śni he? Tuka Jehowa wakanyada kin wacinyaya, heon ninape en hena wicaqu.

9 Jelıwa iśta kin maka kin owancaya atowanpi, tona cantepi kin iye zaniyan opapi kin waśag wicaye kta nakaś. Taku kin de en witkoya ecanon, heon detanhan wokicize niciyuke kta. 10 Unkan Asa wawanyake kin canniyeya, qa canicaśrapi tipi kin en yanke kiya, taku kin de on nina śihda nakaś ; qa Asa heehan oyate kin hunh wicakiyuśe.

11 Qa Asa ohan kin tokaheya qa ehahe kin hena Juda, qa Israel wicaśtayatapi tawowapi en owapi ce.

12 Qa Asa wawidake cin waniyetu iwikcemna yamni sanpa napcinwanka en siha yazan, ecen ninahin wayazanka; tuka towayazanke kin en Jehowa akite śni, tuka pejihuta wicaśta kin awicakita.

13 Qa waniyetu wawidake cin iwikcemna topa sanpa tokaheya en ta, hecen Asa liunkake wicaya om iśtima.

14 Qa ohna hnakapi tawa, iye icicakan kin ohna hnakapi, Dawid totonwe ohna, qa owinja taku waśtemna ocaje ota pejihuta wicaśta icicahiyapi ojudan kin he akan ehnakapi, qa iye on nina ota liuhnaliyapi.

\section{WICOWOYAKE $1 \%$}

1 Unkan heekiya iye cinhintku Jehośapat wawidake ca Israel itkom waśag içiya.

2 Qa Juda otonwe conkaśkeyapi kin owasin ohna akicita ota yanke wicakiya. Nakun Epraim otonwe atkuku A.sa icu qon hena ohna.

3 Unkan Jehowa Jehośapat kici 
un, Dawid iye ateye cin tacanku tokaheya omani, qa Bayalim akite śni nakaś.

4 Tuka atkuku taku wakanda kin akita, qa woahope tawa opa, qa Israel token econ kin iyecen econ śni.

5 Heon iye nape kin ohna Jehowa wokiconze kin yusuta. Unkan Juda owasin taku qupi kin Jehośapat kahipi hecen wowijice, qa wowitan ota yuha.

(6) Qa Jehowa tacanku kin en cante kin sanpa ihdutanka, hecen pajodan kin, qa Aśere kin Juda etanhan yutokan.

7 Qa towawidake waniyetu iyamni en wicaśta waśaka wi cayuhe cin Obedija, qa Zekarija, qa Nataneel, qa Mikaja Juda otonwe ohnahna waonśpewicakiya ye wicaśi.

8 Qa hena om Lewi kin Śsemaja, qa Netaneja, qa Zebadija, qa Yasael, qa Ś Semiramot, qa Jehonatan, qa Adonija, qa Tobadonija Lewi kin; qa hena om, Eliśama qa Jehoram wawayuśnapi kin.

9 Unikan hena Juda ohna waonśpekiyapi, qa Jehowa toope wowapi kin yuhapi, qa Juda otonwe owasin ehna iyayapi, qa oyate kin onspewicakiyapi.

10 Unkan makoce Juda ihdukśan yakonpi wicośkanśkan kin owasin Jehowa yuśinye wicaya, heon Jehośapat azuyapi śni.

11 Qa Pilistim hunh taku qupi, qa womnaye mazaska kahipi ece; nakun Arabim tahinca mdoka kektopawinge śakowin sanpa opawinge śakowin qa tatokadan mdoka kektopawinge sakowin sanpa opawinge śakowin kahipi ece.

12 Hecen Jehośapat ohinniyan sanpa tanka icağa, ecen wowitan tanka yuha; qa conkaśke, qa wopiye otonwe Juda ohna kagga.
13 Qa Juda otonwe ohna woyuha ota yuha, qa oznye wicaśta waśaka obe tanka Jerusalem ohna.

14 Unkan ateyapi tipi itancanpi kin dena eepi, Juda kektopawinge itancanpi itancan kin. Yadna, qa iye opapi kin wicaśta waśaka waditaka kektopawinge opawinge yamni.

$15 \mathrm{Qa}$ iye isakim Jehonatan, itancan kin, qa iye opapi kin kektopawinge opawinge nonpa sanpa kektopawinge wikcemna śahdoğan.

16 Qa iye isakim Yamaseja Zikri cinhintku, iye Jehowa en iyokipiya içicu, qa wicaśta waśaka waditaka kektopawinge opawinge nonpa iye opapi.

17 Unkan Benjamin etanhan wicaśta waśaka waditaka wan Elijada, qa wicaśta kektopawinge opawinge nonpa itazipa qa wahacanka hduha iye opapi.

18 Qa iye isakim Jehozabad, qa wicaśta wokicize on wipekitonpi kektopawinge opawinge sanpa kektopawinge wilkcemna śahdogan iye opapi.

19 Wicaśtayatapi ókiyapi ece hena eepi ; nakun tona wicaśtayatapi Juda owancaya otonwe conkaśkeyapi ohna yanke wicakiya.

\section{WICOWOYAKE 18.}

1 Hecen Jehośapat wowijice, qa wowitan tanka yuha, qa wotakuye Alab kicicagga.

2 Qa ohakam waniyetu kitanna ota Ahab ekta i, Samaria en. Unkan Ahab tahinca qa pte ota kicipata; iye on, qa oyate opapi on, qa jye kici Ramot Gileyad ekta ye ape.

3 Qa Aliab Israel wicaśtayatapi kin Jehośapat Juda wicaśtayatapi kin heciya, Ramot Gile- 


\section{ANPETU OYAKAPI,}

yad unkize kta micide kta he? Unkan heciya, Niye iyemaceca, qa oyate mitawa oyate nitawa iyececapi; hecen ozuye en nici unyak onpi.

4 Nakun Jehośapat Israel wicaśtayatapi kin heciya, Tho nakaha Jehowa oie kin iwanga wo.

5 Unkan Israel wicaśtayatapi kin waayate wicaśta opawinge topa mniciye wicaya, qa hewicakiya, Ramot Gileyad kiza mde kta, qaiś enawakiye kta he? Unkan, Ekta ya wo; kinhan Wakantanka wicaśtayatapi nape kin en qu kta, eyapi.

6 Unkan Jehośapat heya, Jehowa tawaayate unkiwange kta deci wanjidan yuke śni he?

7 Unkan Israel wicaśtayatapi kin Jehośapat heciya, Jehowa iwangapi kta on nahanhin wicasta wanjidan en un; tuka miye he śicewadaka, miye on taku waśte ayate śni, tuka taku śica ohinniyan; Mikaja Imla cinhintku kin hee. Unkan Jehośapat heya, Ihnuhan wicaśtayatapi kin hecen eye cin.

8 Unkan Israel wicaśtayatapi kin yunokos wanji kipan, qa heciya, Mikaja Imla cinhintku kin kohanna deci hiyuya wo.

9 Unkan Israel wicaśtayatapi, qa Jehośapat Juda wicaśtayatapi kin, Samaria conkaśke tiyopa hocoka ohna otoiyohi oiyotanke tawa akan śina hdowin iyotantang yakonpi, qa waayatepi kin owasin wicitokam waayatapi.

10 Unkan Tzedekija Kenayana cinhintku mazasapa he icicaga qa heya, Jehowa hecen eya, Dena on Aram patan iyeyaye $k$ ta ecen wicadusote kta.

$11 \mathrm{Qa}$ waayate owasin iyecen wayatapi qa heyapi, Ramot Gileyad ekta ya wo, qa ohiya wo. 634
Jehowa he wicaśtayatapi nape en qu kta nakaś.

12 Unkan wahośiye Mikaja kico iyaye cin ie ca heciya; Tho waayate wicaho wanjidan on iapi waśte wicaśtayatapi eciyapi. Ceciciya nioie hena wanji oie kin iyecece kta, qa taku waśte ehe kta.

13 Unkan Mikaja heya, Jehowa ni ce, hecen tuwe wakanwada taku eye cin he iwae kta.

14 Qa wicaśtayatapi kin ekta hi. Unkan wicaśtayatapi kin heciya, Mikaja Ramot Gileyad kize kta ekta unyanpi kta, qaiś enaunkiyapi kta he? Unkan, Ya wo, qa ohiya wo, hecen ninapepi en wicaqupi kta, eya.

15 Unkan wicaśtayatapi kin heciya, Jehowa cajeyan taku wicaka heceedan emayakiye kta tona akihde taku wakan cajeyan eciciye kta he?

16 Unkan heya, Israel owasin lie akan enanakiya iyayapi, tahinca wanunyanpi waawanyake nicapi iyecen wanwicamdaka. Unkan Jehowa heya, Dena itancan nicapi zaniyan hdapi kte otoiyohi tipi tawa elita.

17 Unkan Israel wicaśtayatapi kin Jehośapat heciya, Miye on taku waśte ayate kte śni tuka taku śice cin, he eciciye śni he? 18 Unkan heya, Heon Jehowa oie kin nahonpo. Jehowa toiyotanke akan iyotanke cin, qa malipiya obe kin owasin etapata qa catkata najinpi kin wanwicamdaka.

19 Unkan Jehowa heya, 'Tuwe Aliab Israel wicaśtayatapi kin cinkiye kta on Ramot Gileyad ekta ye kta, qa hinhpaye kta he? Unkan wanji hecen eya, qa unman kaken eya.

20 Unkan woniya wan inanpe ca Jehowa itokam najin, qa heya, 


\section{WICOWOYAKE 19.}

Miye cinwakiye kta ce. Unkan Jehowa heciya, Token?

21 Unkan imdamde ca wayate tawa owasin ipi kin ohna woniya itonśni hemaca kta. Unkan heciya, Cinyakiye ca ohiyaye kta. Ekta ya qa hecen econ wo.

22 Unkan wanna iho Jehowa woniya itonśni wan waayate nitawa kin dena ipi kin en yekiya, qa Jehowa niye on taku śica ia ce.

23 Hehan Tzedekija Kenayanna cinhintku ikiyedan hi qa iyoha akan Mikaja apa, qa heya, Jehowa toniya kin mitan tanhan nici wohdake kta tukte canku olına iyaya he?

24. Unkan Mikaja heya, Inyun niye wandake $k t a$, tohan tipi timahentu wan mahen inayahbe kta idade ciuhan anpetu kin he en.

25 Unkan Israel wicaśtayatapi kin heya, Mikaja icupo, qa otonwe itancan kin Amon, qa wicaśtayatapi cinhintku Joaś ekta kayapo.

26 Qa hehapi kta, Wicaśtayatapi kin hecen eya, De wicakaśka tipi kin mahen iyeyapo; qa, zaniyan wahdi śni kin hehanyan woiyokiśica ağuyapi kin yun kiyapo, qa wokakije mini kin yatke kiyapo.

27 Unkan Mikaja heya, Zaniyan yahdi kinhan Jehowa miye on ie śni do; nakun heya, Oyate owasin nahoupo.

28 Unkan Israel wicaśtayataṕi kin, qa Jehośapat Juda wicaśtayatapi kin Ramot Gileyad ekta iyayapi.

29 Qa Israel wicaśtayatapi kin Tehośapat heciya, Miye mihdutokeca, qa wokicize en mde kta; tuka niye śina hdowin wo. Unkan Israel wicaśtayatapi kin togye ihduza, qa okicize en ipi.
30 Unkan Aram wicaśtayatapi kin tacanpahmihma itancanpi kin walıokonwicakiye ça heya, Tuwe cistinna, qa tuwe tanka unmanna yakizapi kte śni, tuka Israel wicaśtayatapi kin heceedan kizapo.

31 Unkan canpahmihma itancanpi kin Jehośapat wanyakapi qehan, Israel wicaśtayatapi kin hee, eyapi, qa kizapi kta ihdukśan iyayapi. Unkan Jehośapat hoyeya, unkan Jehowa ókiya, qa Wakantanka wicayutokan.

32 Unkan canpahmihma itancanpi kin he Israel wicaśtayatapi kin ee śni wanyakapi qehan, tokan ihdamnapi.

33 Tuka wicaśta wan ituyaken tinazipe ecate, qa Israel wicaśtayatapi kin mazaheyake okihe olna icam iheya. Unkan canpahmihroa kahape cin heciva, Ninape hduwinga, qa obe kin etanhan hdicumayan wo, maopi nakaś.

34. Unkan anpetu kin he en okicize tehiya aya. Unkan Israel wicaśtayatapi kin Aram iyotakons canpahmihma ohna bosdan iyotanka, litayetu hehanyan, qa wi iyaye cin hehan ța.

\section{WICOWOYAKE 19.}

1 Unkan Jehośapat Juda wicaśtayatapi zaniyan Jerusalem en hdi.

2 Unkan Jehu H̉anani cinhintku wawanyake kin itkokim iyaye ca wicaśtayatapi kin Jehośapat heciya, Wicaśta śica owicayakiye kta iyececa he? qa tona Jehowa śicedakapi waśte wicayadaka he? Hecanon kin on Jehowa canniye niyan.

3 Hececaśta taku waśte nici iyeyapi ce, makoce kin etanhan Aśterot dutokan kin he, nakun 635 


\section{ANPE'TU OYAKAPI,}

nicante Wakantanka akite kta duecetu.

4 Unkan Jehośapat Jerusalem en hdiyotanke cehan, ake oyate kin wicehna iyaya,- Berśeba etanhan Epraim he kin hehanyan, qa Jehowa hunkake wicayapi Wakandapi en hdicuwicaya.

5 Qa makoce en wayaco wicakaga Juda otonwe aconkaśkeyapi owasin ohnahna otonwe otoiyohi on.

6 Qa wayacopi kin hewicakiya, Taku ecanonpi kin waktaya unpo. Wicaśta akantu on wadacopi śni; tuka Jehowa on, qa wayaco oie kin en, iye niyepi om un.

7 Qa wanna Jehowa tokokipe niyepi akan un nunwe. Awanihdakapi, qa econpo, Jehowa wakan undapi kici taku śica wanica, nakun wicite ihaktapi, qa taku nahmana qupi kin icupi kin wanica nakaś.

8 Nakun Jerusalem ohna Jehośapat Lewi kin etanhan, qa wawayuśnapi etanhan, qa Israel ateyapi itancanpi etanhan wayaco wicakagia, Jehowa woyaco tawa on, qa waakinicapi on, Jerusalem en hdi qehan.

9 Qa wahokonwicakiye ça heya, Decen ecanonpi kta Jehowa tokokipe en, qa wowicake en, qa cante zaniyan en.

10 Woakinice owasin en anihipi, nihunkawanjipi otonwe tawapi otipi kin etanhan, we papsonpi kin on, qaiś woope, qa woahope, qa wokage, qa wayacopi kin on, ca iyoyam wicayayapi kta, hecen Jehowa awahtanipi kte śni, qa wośitkihda nihunka wanjipi, qa niyepi anihipi kte śni. Hecen ecanonpi kta, kinhan wayahtanipi kte śni.

$11 \mathrm{Qa}$ iho Ámarija wawayuśna 636 itancan kin, Jehowa taku tawa owasin on niwankam un; qa Zebadeja Iśmayel cinhintku Juda tiyohnaka itancan kin wicaśtayatapi taliu tawa on, qa Lewi wowapi liagapi kin nitokam yakonpi. Waditagya ohanyanpo qa tuwe waśte kinhan Jehowa kici un kta.

\section{WICOW OYAKE 20.}

1 Unkan hena iyohakam Moab cinca kin, qa Anmon cinca kin, qa hena om Mayanim nakun Jehośapat azuya upi.

2 Unkan wicaśta Jehośapat okiyag hipi, qa heyapi; Wicota hinca Mde kin akotanhan, Edom etanhan tatpe niupi, qa inyun Hatzetzontamar, Engedi hee, ohna yakonpi.

3 Unkan Jehośapat kokipa, qa Jehowa akite lita ite kin yekiya, qa Juda owasin wote śni unpi kta ieyanpaha wicaya.

4 Unkan Juda Jehowa etanhan wookiye akitapi kta mniciyapi, nakun Juda otonwe owasin etan. han Jehowa akin hipi.

5 Qa Jehośapat Juda qa Jerusalem omniciye en najin, Jehowa ti kin olına, hocoka teca itokam,

6 Qa heya, Jehowa hunkake wicunyanpi wakannidapi, Mahpiya en taku wakan kin niye śni he? qa ikcewicaśta wokiconze owasin iwicayadaka, qa ninape ohna wookihi, qa wowaśake yuke śni he? hecen tuwedan nicitkokim najin okihi śni.

7 Makoce kin de ounyanpi kin owasin oyate nitawa Israel itokapa tanhan wicayusota tuwe wakan undapi kin niye śni he? qa he nitakuye Abraham cinca kin yaqu, owihanke wanin.

8 Unkan hen tipi, qa hen tipi 
wakan nicicağapi, nicaje on, qa heyapi,

9 Taku śica unkakipapi kinhan isan, woyaco, qaiś makośice, qaiś wicaakiłian, qa tipi kin de itokam naunjinpi niye itokam, nicaje tipi kin de en yanka nakaś ; qa unkakijapi on hoyennniciyapi kinhan nayahon kta, qa niunyayapi kta.

10 Unkan wanna inyun Anmon cinca kin, qa Moab, qa Seyir ounyanpi kin, hena Israel Egupta etanhan kupi qehan, wicehna kupi iyowinwicayakiye śni, hecen icuom hiyupi, qa wicaktepi śni.

11 Qa hena śicaya ecaunkiconpi, qa makoce tawaunyanpi kta e unyaqupi kin etanhan nape unyanpi kta hipi.

12 Wakan unnidapi wicadaco kte śni he? Ozuye tanka kin de tatpe unhipi wicitkokim naunjinpi kta unkiyepi en wookihi wanica, qa taku econkupi kta sdonunyanpi śni; heon unkiśtapi kin anitonwanpi.

13 Hehan Juda owasin Jehowa itokam najinpi, nakun. śicecapi, tawicupi, qa cincapi.

14. Unkan omniciye cokaya Jehowa toniya Jehaziel Zekarija cimhintku he Benaja cinhintku, he Jeyiel cinhintku he Mattaneja cinhintku Lewi kin Asap cinca etanhan, he akan hi.

15 Unkan heya, Anagoptanpo, Juda owasin, qa Jerusalem otipi kin, qa wicaśtayatapi kin Jehośapat, Jehowa hecen eniciyapi, Ihnuhan niyepi yuśinye niyanpi qa ihnuhan ozuye tanka kin de ikowicayapapi kin, wokicize kin niye nitawapi śni, tuka Wakantanka he tawa ce.

16 Heyakecinhan wicitkokim yapo, inyun Tzitz oiyakapte kin itanwankanlıde upi, qa kaksiza ihanke en iyewicayayapi kta ; Jeruel tinta kin wiyohiyanpata.

17 Hen wicayakizapi kte śni, tuka owanji najinpo, en yankapo, qa Jehowa towanikiye niçupi kin wanyakapo. Juda qa Jerusalem ihnuhan yuśinye niyanpi kin, qa ihnuhan wakoyakipapi. Heyakecinhan wicitkokim inanpapo, qa Jehowa nicipi un kta.

18 Hehan Jehośapat ite kin maka ektakiya paíuja, qa Juda qa Jerusalem ounyanpi kin owasin Jehowa ohodapi kta e Jehowa itokam makata ehpeiciyapi.

19 Qa Lewi kin Qohati cincapi kin etanhan, qa Qorahi cinca kin etanhan ho tanka, qa wankantuya on Jehowa yatanpi kta e najinpi.

20 Unkan hanhannahin kiktapi, qa Teqoa tinta kin ekta iyayapi. Unkan yapi kin icunhan Jehośapat najin qa heya, Juda qa Jerusalem ounyanpi kin namahonpo. Jehowa wakanyadapi kin wacinyanpo, hecen niyusutapi kta, Waayate tawa wicawicadapo, hecen ohiyayapi kta.

21 Unkan oyate om wohdake ca Jehowa idowanpi kin najin wicakiya; unkan wipekitonpi wicitokam manipi, qa towitan wakan yatanpi, qa heyapi, Jehowa yatanpo, towacantkiye owihanke wanica ce.

22 Unkan toka panpi kin, qa wayatanpi kin he ehan Jehowa Anmon cinca kin, qa Moab, qa Seyir he ounyanpi kin Juda takpe upi kin waiyapewicakiya hecen wicakaśtakapi.

23 Unkan Anmon cinca kin qa Moab Seyir lie ounyanpi kin anawicatanpi ecen wicak tepi, qa ihang wicayapi; qa Seyir ounyanpi kin wicayusotapi qehan, 


\section{ANPETU}

wa huhnahkiciyapi kta, Moses toope en owapi kin iyecen; wowiyuśkin on, qa odowan Dawid nape kin on.

19 Qa tiyopa awanyakapi kin Jehowa ti tiyopa kin ekta najinwicakiya; hecen tuwe sapa tokadan tin hiyu kte śni.

20 Qa opawinge itancanpi kin, qa wicaśta kinihanpi kin, qa tona wawidakapi kin, qa makoce oyate kin owasin om, wicaśtayatapi kin Jehowa ti kin etanhan apamahde ayapi, qa wicaśtayatapi tipi tawa tiyopa wankantu kin ohna hiyuyari, qa wicaśtayatapi toiyotanke akan wicaśtayatapi kin iyotang kiyapi.

21 Hecen makoce oyate kin owasin wiyuśkinpi, qa otonwe kin oziic̣iya, Atalija țeyapi kin ohakam.

\section{WICOWOYAKE 24.}

1 Joaś waniyetu śakowin, toka wawidake cehan, qá waniyetu wikcemna topa Jerusalem ohna wawidaka, qa hunku Tzibia eciyapi Berśeba etanhan.

2 Qa Joaś taku ecetu Jehowa iśta kin en econ, Jehojada wawayuśna kin anpetu tawa owasin.

3 Unkan Jehojada winohinca nonpa yuskiya. Unkan cinca wica winyan ko kicitonpi.

4 Unkan hena iyohakam Jehowa ti kin pikiye kta e Joaś cante yuza.

5 Qa wawayuśnapi kin, qa Lewi kin mniciye wicaye ca hewicakiya, Juda otonwe kin ektakta yapo, qa Jehowa wakanyadapi tipi tawa kin yusutapi kta e Israel owasin etanhan mazaska mnayanpo, omaka otoiyohi ; qa wicoie kin de niyepi inahniyapo. Tuka Lewi kin inahniyapi śni.

\section{OYAKAPI,}

6 Unkan wicaśtayatapi kia Jehojada itancan kin kico, qa heciya, Tokeca woyaatanin tipi kin on woahi, Moses Jehowa taokiye kin Israel mnaye wicaśi kin he, Lewi kin Juda qa Jerusalem etanhan ahi wicayakiye śni he?

7 Atalija winohinca śica kin he cinca kin iyahna Wakantanka ti kin yujuju, qa Jehowa tipi tawa on taku yuwakanpi kin owasin Bayalim ekta ayapi.

8 Unkan wicaśtayatapi kin eye cin iyecen canwohnaka wan kagrapi, qa Jehowa tipi tawa tiyopa ekta itankan ehnakapi.

9 Hehan woahi, Moses Wakantanka taokiye liopuza kin en Israel ahi wicaśi kin, Juda qa Jerusalem ohna ahipi kta, ieyanpahapi.

10 Unkan itancanpi kin qa oyate kin owasin wiyuśkinpi, qa ahipi, qa en iyeyapi, ecen yuśtanpi.

11 Unkan tohantu kaśta mazaska ota wanyakapi, ca wicaśtayatapi econ wicaśi iyecen, Lewi kin canwohnaka kin ahipi ca wicaśtayatapi tawowapi kaga, qa tuwe wawayuśna itancan kin cajeyate cin ekta ipi; qa canwohnaka yuhidokapi, qa mazaska kin icupi, qa ake canwohnaka kin oyanke tawa kin ekta hnakapi, hecen econpi tohantu kaśta, qa mazaska ota mnayanpi.

12 Unkan wicaśtayatapi kin, qa - Jehojada mazaska kin Jehowa ti kin wokicanye wohtani kin econpi kin wicakipamnipi, qa nakun Jehowa ti kin piyapi kta wakakanpi, qa cankajipapi opewicatonpi, qa nakun mazasapakağa, qa mazaśakagga Jehowa ti kin yusutapi kta on.

13 Hecen wokicanye econpi kin htanipi, qa piyapi wohtani 642 


\section{WICOWOYAKE 22.}

kiconze en najin, qa waśag ic̣iye ca sunkaku owasin isan on wicakte, nakun Israel itancanpi hunli.

5 Joram waniyetu wikcemna yamni sanpa nonpa qehan toka wawidake ça waniyetu śahdog̀an Jerusalem ohna wawidaka.

$6 \mathrm{Qa}$ Israel wicaśtayatapi tacankupi kin ohna mani, Al̉ab tiyohnaka kin econpi kin iyecen, Aliab cunwintku wan yuza nakaś, qa taku śica Jehowa iśta kin en econ ece.

7 Hececa śta Dawid tiyolnaka kin ihangye kta Jehowa iyokipi śni; wotakuye Dawid kicicagge ca iye qa cinca kin petijanjan wicaqu $\mathrm{kta}$, anpetu owasin, keye ciqon, heon etanhan.

8 Anpetu tawa en Edom Juda nape ihukuya unpi qon kipajinpi, qa wicaśtayatapi wan icicağapi.

9 Unkan Joram taakicita tancan orn, qa canpahmihma tawa owasin om tawicakpe iyaya qa hanyen najin, qa Edom iye qa tacanpahmihma itancanpi kin ihdukśan hiyeyepi kin wicakaśtaka:

10 Tuka Edom anpetu kin dehanyan Juda nape kin kipajinpi. He ehan iye Jehowa hunkake wicaya wakandapi kin ayuśtan kin heon Libna nakun iye nape kin kipajin.

11 Iye nakun pajodan kaga, Juda he kin akan; qa Jerusalem otipi kin wawicihahapi econwicakiya, qa Juda cinwicakiya.

12 Unkan wowapi wan Elija waayate kin etanhan kahipi kin he heya, Jehowa niyate Dawid wakanda kin hecen eya, Niyate Jehośapat tacanku, qa Asa Juda wicaśtayatapi tacanku kin ohna mayani śni,

13 Tuka Israel wicaśtayatapi tacankupi kin ohna mayani, qa
Juda, qa Jerusalem otipi kin wawiciliahapi econ wicayakiya; A liab tiwahe wawicihahapi econpi kin iyecen; qa nisunka niyate tiyolnaka niye isanpa waśtepi hena wicayakte;

14 Heon inyun Jehowa wokaśtake tanka on oyate nitawa, qa nicinca, qa nitawinpi, qa taku duhe cin iyuhpa wicakaśtake kta;

15 Qa niye tezi niyazan nina waniyazanke kta ecen anpetu iyohi wowayazan on niśupe kin hiyu kta.

16 Unkan Jehowa Pilistim kin, qe Arabim Kuśim iliyedan yalionpi kin toniyapi kin Joram azuyapi kta e iyopaśtaka.

17 Unkan Juda anatanpi; qa naoksapi, qa wicaśtayatapi tipi tawa ohna woyuha iyeyapi kin iyuhpa icupi, qa nakun iye cinca kin qa tawicu wayaka iwicacupi; hecen cinhintku hakakta Jehoahaz heceedan olicaptapi.

18 Qa hena owasin ohaliam Jehowa he kaśtaka, tezi kin en, wowayazan olkizipica śni on.

19 Unkan anpetu owasin otoiyohi hececa, ecen omaka nonpa ihanketa, towayazanka on śupe kin hiyu, qa wowayazan śica on ța qa hunkake wicaya izinwicayapi kin iyecen iye on woizinye kag̉api śni.

20 Waniyetu wikcemna yamni sanpa nonpa qehan toka wawidaka, qa waniyetu śahdoġan Jerusalem ohna wawidaka, qa iyaye cehan akiceyapi śni, qa Dawid totonwe ohna hnakapi, tuka wicaśtayatapi ohnahnakapi kin hena ohra hnakapi śni.

\section{WICOW OYAKE 22.}

1 Unkan Jerusalem ounyanpi kin heekiya cinhintku hakakta 


\section{ANPETU OYAKAPI,}

Ahazija wicaśtayatapi kağapi, ozuye Arabim om owanka kin en hipi qon, tokapapi kin owasin wicaktepi nakaś. Hecen Joram cinhintku Ahazija Juda idaka.

2 Ahazija waniyetu wikcemna nonpa sanpa nonpa qehan toka wawidaka, qa waniyetu wanjidan Jerusalem ohna wawidaka, qa hunku Atalija Omri cunwintku eciyapi.

3 Nakun iye Ahab tiyohnaka canku kin omani, hunku taku śica econ wahokonkiya nakaś.

4 Hecen Jehowa iśta kin en taku śica econ, Ahab tiyohnaka kin iyecen. Hena atkuku te cin iyohakam wawiyukcan wicayuha, hecen ihangyapi.

5 Nakun hena tawowahokonkiye ohna mani, qa Joram Aliab cinhintku Israel wicaśtayatapi kici Hazael Aram wicaśtayatapi azuya wokicize ekta, Ramot Gileyad en i, qehan Arami kin Joram kaśtakapi.

6 Unkan Ramot ekta Hazael Aram wicaśtayatapi azuya wokicize en opi kin okiziyapi kta, heon Jezreyel en hdi. Unkan Azarija Joram cinhintku Juda wicaśtayatapi. kin Joran Aliab cinhintku wanyake kta apamahde $\mathrm{i}$, he wayazanka nakaś.

7 Qa Ahazija awihnunipi kin he Wakantanka etanhan Joram ekta i kin hee; qa ekta i qehan, Joram kici Jehu Ninsśi cinhintku itkokim iyaya, he Aliab tiyohnaka kin wicakaśpe kta Jehowa sdày.

8 Unkan Jehu Ahab tiyohnaka kin wicayaco qehan; Juda itancanpi kin, qa Ahazija cincu cincapi kin Aliazija okiyapi kin hena iyewicaya, qa wicakte.

9 Qa Ahazija akita, qa icu, he Samaria obna inahma, tuka Jehu ekta kahipi; unkan țe kiya, 640 qa Jehośapat cante kin ocowasin on Jehowa akite cin cinhintku kin hee, eyapi kin, heon hnakapi. Hecen Aliazija tiyohnaka kin wokiconze yuhapi kta wookihi nicapi.

10 Unkan Atalija Aliazija hunku kin iye cinhintku te cin wanyake cehan najin, qa Juda tiyohnaka wicaśtayatapi cinca kin owasin wicakte.

11 Tuka Jehośebeat wicaśtayatapi cunwintku kin Joaś nahmana icu, wicaśtayatapi cinca kin wicehna tanhan, wicaktepi qehan, qa iye, winyan icaliye cin kici, oiśtima tipi mahentu en iyewicaya. Hecen Jehośebeat Juda wicaśtayatapi Joram cunwintku Jehojada wawayuśna tawicu kin he nahma; Atalija ite kin etanhan, unkan ktepi śni; be Ahazija tawinohtin ee nakaś. 12 Unkan iye hena om Wakantanka ti kin ohna nalimana yanka, waniyetu śakpe. Unkan A talija makoce kin idaka.

\section{WICOWOYAKE 23.}

1 Unkan waniyetu iśakowin en Jehojada waśag icciye ça opawinge itancanpi kin wicakico, Azarija Jeroham cinhintku, qa Iśmael Johanan cinhintleu, qa Azarija Obed cinhintku, qa Mayasija Adaja cinhintku, qa Eliśapat Zikri cinhintku, qa hena om wotakuye kaga.

2 Unkan Juda ohna enanakiya iyayapi, qa Juda otonwe owasin etanhan Lewi kin, qa Israel ateyapi itancanpi kin mniciye wicayapi, unkan Jerusalem en hipi.

3 Unkan omniciye kin owasin Wakantanka ti kin ohna wicaśtayatapi kici wotakuye kaggapi. Unkan Jehojada hewicakiya, Inyun wicaśtayatapi cinhintku kin 


\section{WICOWOYAKE 23.}

wicaśtayatapi $\mathrm{kta}$, Jehowa Dawid cinca kin on eye ciqon iyecen.

4. Wicoie kin de ecanonpi kta. Anpetu wakan en yaupi eca, wawayuśnapi, Lewi koya obe yamni yaupi kta, qa wanji hocoka tiyopa en yanke kta.

$5 \mathrm{Qa}$ wanji wicaśtayatapi ti kin en, qa wanji oahehde tiyopa kin ekta, qa oyate kin owasin Jehowa ti hocoka kin ohna yakonpi kta.

6 Qa tuwedan Jehowa ti kin en hi kte śni, wawayuśnapi, qa Lewi owicakiyapi kin henana; hena wakanpi, heon hena en hipi kta, qa oyate kin owasin Jehowa toawanyake kin awanyakapi kta.

7 Unkan Lewi kin wicaśtayatapi kin ihdukśan najinpi kta, otoiyohi wipe kin nape ohna hduze kta, qa tuwe timahen hiyu kinhan teyapi kta, qa wicaśtayatapi kin tin hiyu, qa tankan ya eca kici unpo.

8 Unkan Lewi kin, qa Juda owasin token Jehojada wawayuśna kin econ wicaśi kin ocowasin iyecen econpi, qa otoiyohi wicaśta tawa iwicacupi anpetu wakan en hiyupi kin, nakun anpetu wakan en inanpapi kin; Jehojada wawayuśna kin obe kin kihde wicaye śni nakaś.

9 Unkan Jehojada wawayuśna kin opawinge itancanpi kin wahukeza, qa wahacanka, qa wanju kin wicaqu, hena wicaśtayatapi Dawid tawa qon, qa Wakantaka ti kin ohna yarıapi.

10 Qa oyate kin owasin najin wicakiya, otoiyohi wahukeza nape ohna hduha, tipi hiyete etapa (itokaga) tanhan, tipi hiyete catkata (waziyata) aiyahdeya, owayuśna, qa tipi kin koya, wicaśtayatapi kin ihdukśan.

11 Hehan wicaśtayatapi cin4I hintku kin inanpe yapi, qa wateśdake kin aehnakapi, qa woyaatanin qupi, hecen wicaśtayatapi kağapi; qa Jehojada, qa iye cinca kin sdayapi; qa, Wicaśtayatapi kin ni nunwe eyapi.

12 Unkan Atalija oyate inyankapi, qa wicaśtayatapi yatanpi hopi kin nahon qehan, oyate Jehowa ti en yakonpi kin ekta wicahi.

13 Unkan etonwan, qa inyun wicaśtayatapi kin omanipi ohna cowahe tawa akan najin, qa itancanpi kin, qa mazayahotonpi kin, wicaśtayatapi kin icahda, qa makoce oyate kin owasin wiyuśkinpi, qa mazayahotonpi, qa wadowanpi kin widowanliyapi on wayatan onspewicakiyapi; hehan Atalija taheyake hdulidelideca, qa, Wokipajin, wokipajin, eya.

14 Hehan Jehojada wawayuśna kin opawing'e itancanpi kin obe awanyakapi kin inanpewicaye ca hewicakiya, Ocimdah najinpi kin itankan iyaye yapo, qa tuwe he ope cinhan teyapi kta, Jehowa ti kin ohna teyapi śnipo, wawayuśna kin eya nakaś.

15 Unkan iyahpayapi, unkan wicaśtayatapi tipi śuktanka tiyopa ocanku kin elita i, unkan hen ktepi.

16 Unkan Jehojada wotakuye kağa, iye, qa oyate kin owasin, qa wicaśtayatapi kin om, Jehowa oyate tawapi kta.

17 Hehan oyate kin owasin Bayal ti kin ekta ipi, qa yujujupi, qa owayuśna tawa, qa wakagapi tawa kin kaksaksapi, qa Mattan Bayal wakiciyuśna kin owayuśna tawa itokam ktepi.

18 Unkan Jehojada Jehowa ti kicanyanpi kta on wawayuśnapi kin, qa Lewi kin najin wicakiya, token Jehowa ti kin on Dawid wicapamni, wohulinahyapi Jeho641 


\section{ANPETU OYAKAPI,}

wa huhnahkiciyapi $\mathrm{kta}$, Moses toope en owapi kin iyecen; wowiyuśkin on, qa odowan Dawid nape kin on.

19 Qa tiyopa awanyakapi kin Jehowa ti tiyopa kin ekta najinwicakiya; hecen tuwe śapa tokadan tin hiyu kte śni.

20 Qa opawinge itancanpi kin, qa wicaśta kinihanpi kin, qa tona wawidakapi kin, qa makoce oyate kin owasin om, wicaśtayatapi kin Jehowa ti kin etanhan apamahde ayapi, qa wicaśtayatapi tipi tawa tiyopa wankantu kin ohna hiyuyapi, qa wicaśtayatapi toiyotanke akan wicaśtayatapi kin iyotang kiyapi.

21 Hecen makoce oyate kin owasin wiyuśkinpi, qa otonwe kin oziiçiya, Atalija țeyapi kin ohakam.

\section{WICOWOYAKE 24.}

1 Joaś waniyetu śakowin, toka wawidake cehan, qa waniyetu wikcemna topa Jerusalem ohna wawidaka, qa hunku Tzibia eciyapi Berśeba etanhan.

2 Qa Joaś taku ecetu Jehowa iśta kin en econ, Jehojada wawayuśna kin anpetu tawa owasin.

3 Unkan Jehojada winohinca nonpa yuskiya. Unkan cinca wica winyan ko kicitonpi.

4 Unkan hena iyohakam Jehowa ti kin piliye kta e Joaś cante yuza.

5 Qa wawayuśnapi kin, qa Lewi kin mniciye wicaye ca hewicakiya, Juda otonwe kin ektakta yapo, qa Jehowa wakanyadapi tipi tawa kin yusutapi kta e Israel owasin etanhan mazaska mnayanpo, omaka otoiyolii; qa wicoie kin de niyepi inahniyapo. Tuka Lewi kin inahniyapi śni.
6 Unkan wicaśtayatapi ki.a Jehojada itancan kin kico, qa heciya, Tokeca woyaatanin tipi kin on woahi, Moses Jehowa taokiye kin Israel mnaye wicaśi kin he, Lewi kin Juda qa Jerusalem etanhan ahi wicayakiye śni he?

7 Atalija winohinea śica kin he cinca kin iyahna Wakantanka ti kin yujuju, qa Jehowa tipi tawa on taku yuwakanpi kin owasin Bayalim ekta ayapi.

8 Unkan wicaśtayatapi kin eye cin iyecen canwohnaka wan kagapi, qa Jehowa tipi tawa tiyopa ekta itankan ehnakapi.

9 Hehan woahi, Moses Wákantanka taokiye liopuza kin en Israel ahi wicaśi kin, Juda qa Jerusalem ohna ahipi lita, ieyanpahapi.

10 Unkan itancanpi kin qa oyate kin owasin wiyuśkinpi, qa ahipi, qa en iyeyapi, ecen yuśtanpi.

11 Unkan tohantu kaśta mazaska ota wanyakapi, ca wicaśtayatapi econ wicaśi iyecen, Lewi kin canwohnaka kin ahipi ca wicaśtaya tapi tawowapi kaga, qa tuwe wawayuśna itancan kin cajeyate cin ekta ipi ; qa canwohnaka yuhdokapi, qa mazaska kin icupi, qa ake canwohnaka kin oyanke tawa kin ekta hnakapi, hecen econpi tohantu kaśta, qa mazaska ota mnayanpi.

12 Unkan wicaśtayatapi kin, qa - Jehojada mazaska kin Jehowa ti kin wokicanye wohtani kin econpi kin wicalkipamnipi, qa nakun Jehowa ti lin piyapi kta wakakanpi, qa cankajipapi opewicatonpi, qa nakun mazasapakağa, qa mazaśakağa Jehowa ti kin yusutapi kta on.

13 Hecen wolicanye econpi kin hitanipi, qa piyapi wohtani 


\section{WICOWOYAKE 25.}

kin napepi on yuśtanpi, ecen Wakantanka tipi tawa iyutapi qon iyecen ehdepi, qa yusutapi.

14 Unkan yuśtanpi qehan mazaska okaptapi kin wicaśtayatapi kin, qa Jehojada wicitokam hiyuyapi, qa Jehowa ti kin on wakśica kag̉api, wokicanye wakśica, qa wohihnahyapi on, qa maza tukiha, qa mazaskazi wakśica, qa mazaska wakśica. Unkan Jehowa tipi tawa ohna wohuhnahyapi huhnahyapi, ohinniyan, Jehojada anpetu tawa owasin.

15 Unkan Jehojada wicahinca, qa anpetu imna, qa waniyetu opawinge sanpa wikcemna yamni qehan te.

16 Unkan Israel ohna taku waśte Wakantanka, qa tipi tawa ecakicon, heon Dawid totonwe ohna, wicaśtayatapi om hnakapi.

17 Unkan Jehojada te cin ohakam Juda itancanpi kin wicaśtayatapi kin en hipi, qa itokam makipusdiya ehpeiçiyapi, hehan wicaśtayatapi kin anawicağoptan.

18 Unkan Jehowa hunkake wicayapi wakandapi tipi tawa ayuśtanpi, qa Aśerim, qa wakağapi ókiyapi; qa taku kin de en wahtanipi kin, heon Jehowa Juda qa Jerusalem canniye wicaya.

19 Jehowa en hdicuwicaye kta waayate yewicaśi, qa awicayataninpi eśta anag่optanpi śni.

20 Unkan Wakantanka toniya kin Zekarija Jehojada wawayuśna kin cinhintku kin, koyagya; unkan oyate kin wiciwankam inajin, qa hewicakiya, Wakantanka hecen eya, Tokeca Jehowa tawoahope kin yecaksapi he? Qa tanyan iyahunipi kte śni, Jehowa aduśtanpi kin heon iye aniyuśtanpi.

21 Unkan kipajinpi, qa wicaśta- yatapi kin econ wicaśi kin iyecen Jehowa ti hocoka kin ohna inyan on kininpi.

22 Hecen Joaś wicaśtayatapi lin wowacantkiye atkuku Jehojada iye ecakicon qon, kiksuye śni, tuka cinhintku kte. Unkan te kta qehan, Jehowa wanyaka, qa tokicon ye, eya.

23 Unkan ohakam waniyetu wanjidan Aram ozuye kin iye anatanpi, qa Juda qa Jerusalem ekta hipi, qa oyate itancanpi kin owasin ihang wicayapi, oyate etanhan, qa wokipi kin owasin Damaskos wicaśtayatapi kin ekta yeyapi.

24 Aram ozuye kin wicaśta tonana hipi, unkan napepi kin en Jehowa obe nina tanka wicaqu, Jehowa hunkake wicayapi wakandapi kin he ayuśtanpi nakaś; hecen woyaco Joaś ecakiconpi.

25 Unkan wowayazan ota en ayuśtanpi, qa kihdapi qehan, iye taokiye kipajinpi, qa Jehojada wawayuśna cinca wepi kin on, towinja akan ktepi ; hecen ta, qa Dawid totonwe ohna hnakapi; tuka wicaśtayatapi ohnahnaka tawapi ohna hnakapi śni.

26 Unkan iye kipajinpi kin dena eepi Zabad Śsimeyat Anmoniwin cinhintku kin, qa Jehozabad Śmerit Moabiwin cinhintku kin. 27 Unkan iye cinca kin eciyatanhan, qa woqin tanka aehnakapi kin, qa token Wakantanka tipi tawa kin yusuta kin, inyun hena wicaśtayatapi tawowapi kin en owapi ce. Unkan eekiya iye cinhintku Amatzija wawidaka.

\section{WICOWOYAKE 25.}

1 Amatzija waniyetu wikcemna nonpa sanpa zaptan qehan toka wawidaka, qa waniyetu 643 


\section{ANPETU OYAKAPI,}

wikcemna nonpa sanpa napcinwanka Jerusalem ohna wawidaka; qa hunku kin Jehoyadan eciyapi, Jerusalem etanhan.

2 Qa taku ecetu Jehowa iśta kin en econ, tuka cante zaniyan on econ śni.

3 Qa wokiconze en waśake cehan iye taokiye atkuku wicaśtayatapi kin ktepi kin hena wicakte.

4 Tuka cincapi kin te wicaye śni. Ateyapi iye cincapi kin on te wicayapi kte śni, qa cinca ateyapi on te wicayapi kte śni ; tuka otoiyohi iye wahtani kin on teyapi kta, Moses woope wowapi Jehowa kahisi kin hen eya owapi nakaś.

5 Unkan Amatzija Juda mniciye wicaya, qa ateyapi tipi kin iyecen, Juda qa Benjamin owasin on kektopawinge itancan, qa opawinge itancan wicakicaga; qa waniyetu wikcemna nonpa qa akton wicayawa, qa wicaśta kahinigapi heca kektopawinge opawinge yamni iyewicaya, wahukeza wahacanka koya yuza ozuye eyaya.

6 Nakun mazaska woqin opawing e on, Israel etanhan wicaśta waśaka waditaka kektopawinge opawinge opewicaton.

7 Unkan Wakantanka tawicaśta wan en hi, qa heciya, Wicaśtayatapi, ihnuhan Israel obe kin nici yapi kin; Jehowa Israel Epraim cinca owasin om un śni nakaś.

8 Tuka wokicize on waśag niciya idade cinhan toka kin itokam Wakantanka naśna niye kta. Okiyapi kta, qaiś naśnayanpi kta e Wakantanka en wookihi yukan nakaś.

9 Unkan Amatzija Wakantanka wicaśta tawa heciya, Hecinhan woqin opawinge Israel 644 ozuye kin wicawaqu kin on token econkupi kta he? Unkan Wakantanka wicaśta tawa heya, He isanpa ota Jehowa nicu kta okihi.

10 Hehan Amatzija ozuye kin Epraim etanhan iye en hipi kin kihdapi kta e wicayukinukan. Unkan Juda nina canniyewicayapi, qa wośihda tanka en kihdapi.

11 Unkan Amatzija waśag iciye ça tayate awicaye ca Miniskuya osmaka kin ekta i, qa hen Seyir cinca kin kektopawing wikcemna wicakaśtaka.

12 Nakun kek topawing mna Juda cinca kin niyake wayaka iwicacupi, qa Sela (Imnija) inkpa kin etanhan ehpewicayapi. Unkan owasin naśujapi.

13 Tuka ozuye akicita Amatzija kihde wicaśi qon, hecen wokicize ekta kici ipi śni, hena Juda otonwe kin anatanpi, Samaria etanhan Bethoron aiyahdeya, qa wicaśta kektopawinge yamni wicaktepi, qa woyuha ota kipi.

14 Unkan Amatzija Edom wicakaśtake cin etanhan hdi qehan, Seyir cinca kin taku wakandapi kin ahdi, qa iye wakanda kta ewicahde, qa wicitokam patuja, qa izin wicaya.

15 Unkan Jehowa Amatzija canniyeya, qa waayate wan ekta yeśi qa heciya, 'Taku wakan iye taoyate ninare etanhan ewicahdaku okitpanipi kin, hena owicayape kta he?

16 Unkan okiye cehan wicastayatapi kin heya, Tuwe wicaśtayatapi kin wahokonkiye niśi he. Ayaśtan wo. 'Tokeca niktepi kta he? Unkan waayate kin ayaśtan; tuka, Taku kin de ecanon, qa wahokonciciye cin anayağoptan śni, heon Jehowa 
ihangniyan konza e sdonwaya ce, eya.

17 Unkan Amatzija Juda wicaśtayatapi kin waiyukcan, qa Joaś he Jehoahaz cinhintku he Jehu cinhintku, Israel wicaśtayatapi kin walloye ca heciya, Iho itkokim wanunkiciyake kta.

18 Unkan Joaś Israel wicaśtayatapi kin Amatzija Juda wicaśtayatapi kin wahoye ca heciya, Wapepeka Lebanon akan he cin hanteśa Lebanon akan he cin wahoye ça heciya, Nicunkśsi micinkśi yuze kta e qu wo. Unkan' hewoskan wamanica kin Lebanon ohna un kin ahiyaye ca wapepeka kin naksa.

19 Edom yakaśtaka kecanni, qa nihdatan kta nicante kin ihduwankantuya. Dehan tiyata owanji yanka wo. Tokeca taku sica en iyopaśtag niçiya he? hecen nihicahe kta, qa Juda nakun. 20 Tuka Amatzija nahon śni, Edom taku wakandapi kin hena akita, heon tóka nape en wicaqu kta Jehowa konza.

21 Unkan Joaś Israel wicaśtayatapi kin itanwankanhde $i$, hecen iye qa Amatzija Juda wicaśtayatapi ite wankiciyakapi, Betśemeś Juda tawa kin en.

22 Unkan Juda hinhpayapi, Israel itokam, qa otoiyohi tawakeya ekta najicapi.

23 Tuka Joaś Israel wicaśtayatapi kin Amatzija Juda wicaśtayatapi kin he Joaś cinhintku he Ahazija cinhintku, wayaka icu, Betśemeś ekta, qa Jerusalem ekta ahi, qa Jerusalem conkaśke kin yujuju, Epraim tiyopa etanhan okahmin tiyopa kin ekta hehanyan, wiciśpa opawinge topa.

24. Qa mazaskazi, qa mazaska, qa wakśica Jehowa ti Obededom awanyake cin he ohna iyeyapi kin owasin icu, nakun wicaśta- yatapi wopiye ti kin en, nakun wicakaśka cinca qupi kin, qa Samaria ekta kihda.

25 Unkan Amatzija Joaś cinhintku. Juda wicaśtayatapi kin Joaś Jehoahaz cinhintku IsraeI wicaśtayatapi kin te cin ohakam waniyetu wikcemna sanpa zaptan hehanyan ni.

$26 \mathrm{Qa}$ Amatzija ohan unman tokaheya, qa ehake, Juda qa Israel wicastayatapi tawowapi en owapi śni he?

27 Unkan Amatzija Jehowa ope cin etanhan ihdamna èantanhan Jerusalem ohna kipajinpi. Unkan Lakiś ekta kuwa iyayapi, qa hen ktepi.

28 Qa śuktanka qinkiyapi aupi, qa Juda otonwe ohna hunkake wicaya om hnakapi.

\section{WICOWOYAKE 26.}

1. Unkan Juda oyate kin owasin Uzzija icupi, qa atkuku Amatzija eekiya wicaśtayatapi kagapi ; iye he ehan waniyetu wikcemna sanpa śakpe.

2 Iye, wicaśtayatapi kin hunkake wicaya om iśtima ohakam, Elot conkaske kag̉e ca Juda on ehdaku.

3 Uzzija waniyetu. wikcemna sanpa śakpe qehan toka wawidaka, qa waniyetu wikcemna zaptan sanpa nonpa Jerusalem ohna wawidaka, qa hunku Jekolija eciyapi Jerusalern etanhan.

4 Qa taku ecetu Jehowa iśta kin en econ; atkuku Amátzija econ qon owasin iyecen.

5 Qa Zekarija Wakantanka towanyalke okahnige cin anpetu tawa en Jehowa akita, qa tohan Jehowa akita eca, Wakantanka tanyan waokiya ece.

6 Hecen iyaye ça Pilistim azuwicaya, qa Gat conkaśke kin, qa 645 


\section{ANPETU OYAKAPI,}

Jabne conkaśke kin, qa Aśdod conkaśke kin yujuju; qa Aśdod, qa Pilistim tamakocepi kin en otonwe kagiga.

7 Unkan Wakantanka iye waśagya Pilistim azuwlcaye kta on, nakun Arabi Gurbayal ounyanpi kin, qa Mayunim azuwicaye kta on.

8 Unkan Anmoni kin Uzzija minka qupi, hecen Egupta oenape kin hehanyan cajeyatapi ; nina waśaka aya nakaś.

9 Qa Uzzija tipi ipasotka Jerusalem kicağa, oise tiyopa akan, qa osmaka tiyopa akan, qa okahmin akan, qa hena suta kagia.

10 Qa conkaślke tintoskan kağa, qa minihidoka ota qa, wanunyanpi ota yuha nakaś, Śepela ohna, qa makomdaya ohna; qa maka kicanyanpi, qa hastanhanka iyuwi kicanyanpi he kin akan, qa Karmel akan yuha, wojupi waśtedaka nakaś.

11 Qa Uzzija wokicize on akicita wicayuha, hena Jeyiel wowapikagga, qa Mayaseja akicita tancan wicayawapi kin iyecen obe ozuye iyayapi, wicaśtayatapi mdetanhunka wicayuhe cin wanji Ḧananija nape kin ihukuya.

12 Wicaśta waśaka waditaka ateyapi tipi itancanpi wicayawapi kin owasin kektopawinge nonpa sanpa opawinġe śakpe.

13 Qa hena napepi kin ihukuya ozuye kin wicaśta kektopawing̀e opawing'e yamni sanpa kektopawinge śakowin sanpa opawinge zaptan, wicaśtayatapi toka kin azuwicaye kta okiyapi, qa wookihi on waditagya kizapi.

14 Unkan hena on, obe ihunniyan wahacanka, qa wahukeza, qa mazawapaha, qa mazaheyake, qa itazipa, qa iyuhmun inyan on wiyeya wicakicaga.

$15 \mathrm{Qa}$ Jerusalem ohna wanhin- kpe, qa inyan tanka on kaho iyeyapi lita e taku wicaśta ksapa iyukcanpi kin kahwicaśi, qa he.. na tipi ipasotka en, qa conkaśke okahmin akan ehnaka. Hecen tehan tanhan cajeyatapi, nina ókiyapi ecen waśaka nakaś.

16 Tuka waśake cehan cante kin wahan içida, woihangye ekta; qa Jehowa iye wakanda kin awahtani, qa wizite owayuśna akan wizinye kta e Jehowa tipi wakan tawa mahen iyaya.

17 Unkan iye ihakam Azarija wawayuśna kin, qa Jehowa wawakiyuśnapi waditaka wikcemna śahdoġan opapi, Uzzija ihakam en ipi.

18 Qa wicaśtayatapi kin Uzzija anajinpi, qa heciyapi, Uzzija Jehowa izinye kte cin he niye nitawa śni; tuka wawayuśnapi kin Aaron cinca wizinyapi kta wicayuwakanpi he tawapi. Tipi wakan kin etanhan inanpa wo: wanna wayahtani, qa deon Jehowa etanhan wowitan duhe kte śni.

19 Unkan Uzzija śihda, qa wizinye kta nape ohna oizite yuha, qa wawayuśnapi kin canniye wicaye cehan leprosi ite kin akan ahinanpa, wawayuśnapi wicitokam, Jehowa ti kin ohna wizite owayuśna icahda.

20 Unkan Azarija wawayuśna kin, qa wawayuśnapi kin owasin atonwanpi, qa inyun leprosi ececa ite kin akan; heon hetanhan inahni iyayeyapi, qa iś eya Jehowa kaśtake cin on inanpe kta inalini.

21 Hecen Uzzija wicaśtayatapi kin leprosi ececa, te cin anpetu kin hehanyan, qa leprosi wayazanka tipi kin ohna ti, Jehowa tipi tawa etanhan yukinukanpi nakaś. Unkan cinhintku Jotam wicaśtayatapi ti kin yuha, qa

646 


\section{WICOWOYAKE 28.}

makoce oyate kin wicayaco ece.

22 Unkan, Uzzija hunkake wicaya om iśtima, qa hunkake wicaya om hnakapi, wicaśtayatapi ohnahnakapi magga kin en; Leprosi ececa, eyapi nakaś. Un. kan cinhintku Jotam heekiya wawidaka.

\section{WICOWOYAKE $2 \%$}

1 Jotam waniyetu wikcemna nompa sanpa zaptan qehan toka wawidake ca waniyetu wikcemna sanpa śakpe Jerusalem ohna wawidaka, qa hunku Jeruśa Zadoq cunwintku eciyapi.

2 Unkan taku ecetu Jehowa iśta kin en econ, atkuku Uzzija econ qon owasin iyecen, tuka Jehowa tipi wakan tawa kin en i śni. Hececa eśta oyate kin ihduśicapi.

3 Iye tiyopa tehanwankantu kin Jehowa tipi tawa kicaga. Nakun Opel (Paha kin) conkaśke kin tankaya kag̉a.

4 Nakun otonwe conkaśke Juda he kin akan kaga, qa conkaśke, qa tipi ipasotka taśkoju kin ohna.

$5 \mathrm{Qa}$ Anmon cinca wicaśtayatapi kin azuya, qa ohiwicaya. Unkan Anmon cinca kín mazaska woqin kektopawinge, qa ag̉uyapi. su kor kektopawing'e wikcemna, qa barle kektopawinge wikcemna waniyetu kin he en qupi. Waniyetu inonpa, qa waniyetu iyamni en Anmon cinca kin ake iyenaka qupi.

6 Jotam hecen waśaka aya, Jehowa iye wakanda kin itokam canku kin hduecetu nakaś.

7 Unkan Jotam ohan unman, qa ozuye tawa owasin, qa tacanku, hena Israel qa Juda wicaśtayatapi tawowapi en owapi ce.
8 Iye waniyetu wikcemna nonpa sanpa zaptan qehan toka wawidaka, qa waniyetu wikcemna sanpa śakpe wawidaka Jerusalem ohna.

9 Hehan Jotam hunkake wicaya om iśtima, qa Dawid totonwe ohna hnakapi. Unkan heekiya iye cinhintku Ahaz wawidaka.

\section{WICOWOYAKE 28.}

1 Ahaz waniyetu wikcemna nonpa qehan toka wawidaka, qa waniyetu wikcemna sanpa śakpe Jerusalem ohna wawidaka, tuka taku ecetu Jehowa iśta kin en ateye Dawid iyecen econ śni.

2 Nakun Israel wicaśtayatapi tacankupi kin omani, qa nakun mazaśdoyapi wakagapi Bayalim kicağa.

3 Qa Benhinnom osmaka ohna wizinya, qa iye cinca kin petan huhnahwicaya, Ircewicaśta Jehowa Israel cinca itokapa tanhan nape wicaya wowahte śni econpi kin iyecen.

4 Qa wayuśna, qa wizinya paha akan, qa pajodan akan, qa can ape toto yukan owasin ihukuya.

5 Heon Jehowa iye wakanda kin Aram wicaśtayatapi nape kin en qu. Unkan he kaśtaka, qa etanhan wicota wayaka icupi, qa Damaskos ekta awicahdapi. Nakun Israel wicaśtaya tapi nape en qupi he qe wopate tanka on wicakaśtaka.

6 Peqah Remalija cinhintku Juda wicaśta kektopawinge opawinge sanpa kektopawinge wikcemna nonpa allpetu wanjidan en wicakte, owasin wicasta waditakapi ; Jehowa ateyapi wakandapi kin ayuśtanpi heon etanhan.

7 Qa Zikri Eipraim wicaśta wa647 


\section{ANPETU OYAKAPI,}

śaka wan wicaśtayatapi cinhintku Mayasija, qa Azriqam tipi kin awanyake cin, qa Elqana wicaśtayatapi kin iyokihe kin wicakte.

8 Unkan Israel cinca kin hunkawanji wicayapi etanhan winohinca qa cinca wica qa winyan kektopawinge opawinge nonpa wayaka iwicacupi, qa nakun woyuha ota kipi; qa taku kipi kin Samaria ekta ayapi.

9 Unkan Israel Jehowa waayate tawa wan, Oded eciyapi, hen yanka, qa ozuye kin Samaria ekta hdipi wicitkokim inanpe ca hewicakiya, Inyun Jehowa nihunkakepi wakandapi kin Juda canniyewicaya, heon ninajepi en wicaqu; unkan wośihda mahpiya kin iyahde on wicayaktepi.

10 Qa nakaha Juda qa Jerusalem cincapi kin wicayaktepidan, qa holssipidan on qa wicinyanpidan on wicaduhapi kta kecanipi ; tuka niyepi kaeś Jehowa wakanyadapi kin en taku bapica niciyukanpi śni he?

11 Heon nakaha namałonpo, Jehowa tocanniye aideniyanpi, heon wayaka nihunkawanjinpi etanhan iyacupi kin kihde wicayapo.

12 Hehan Epraim itancanpi kin wanjıkśi Azarija Johanan cinhintku, Berekija Meśillemot cinhintku, qa Jehizeqija Śallum cinhintku, ga Yanıasa Hadlai cinhintku wicaśta ozuye etanhan hdipi kin anawicajinpi;

13 Qa hewicakiyapi, Wayaka kin den hiyuwicayayapi kte śni. Inyun wanna Jehowa etanhan taku śica iyahde unkiciyapi, qa niyepi waunhtanipi, qa taku śica iyahdeunkiciyapi kin duotapi kta kecanipi; wanna Israel wocanniye, qa taku śica ota iyahdeiçiyapi qeyaś.
14 Unkan akicita kin wayaka kin, qa woyuha kin ayuśtanpi, itancanpi, qa omniciye owasin wicitokam.

15 Unkan wicaśta cajewicayatapi qon najinpi, qa wayaka kin iwicacupi, qa tona tancodan unpi kin hena woyuha kipi qon etanhan heyake wicaqupi, qa koyag wicayapi, qa hanpohekiyapi ca woyute qa woyatke wicrqupi, qa sdawicayapi, qa tona manipi śni kin owasin śonśonna akan iyotang wicayapi, qa Jeriho (Tamar can otonwe kin) ekta hunkawanji wicayapi en awicahipi ; hehan Qamaria elita hdapi.

16 Hehan wicaśtayatapi kin Ahaz Aśur wicaśtayatapi kin wahoya, qa, Omakiya ye, eya.

17 Edomi ake hipi, qa Juda kaśtakapi, qa wayaka icupi nakaś.

18 Nakun Pilistim Śepela otonwe kin, qa Juda itokaga kin azuyapi, qa Bet Śsemeś (Anpetuwi ti kin,) qa Ajalon, qa Gederot, qa Soko, qa otonwe cunkśiwicaye cin, qa Timna, qa cunkśiwicaye cin, qa Gimzo, qa cunkśiwicaye cin icupi, qa ohna iyotankapi.

19 Ahaz Israel wicaśtayatapi kin on Jehowa Juda yuhukuya. Iye Juda tancodan wicakiya, qa Jehowa ihakta śni nakaś.

20 Unkan Tilgat Pilneser Aśur wicaśtayatapi kin iyokiśinya, tuka waśagye śni.

21 Ahaz Jehowa tipi tawa etanhan, qa wicaśtayatapi, qa itancanpi tipi tawapi etanhan taku icu, qa Aśur wicaśtayatapi kin qu, tuka ókiye śni.

22 Unkan wicaśtayatapi Aliaz iye toiyokiśice anpetu kin en Jehowa sanpa wakilitani.

23 Qa Damaskos taku wakandapi kin hena wakiyuśna, hena 


\section{WICOWOYAKE 29.}

kaśtakapi, heon heya, Aram wicaśtayatapi taku wakandapi kin hena ówicakiyapi ece; hena miye wawicawakiyuśna kta, hecen miś ómakiyapi kta; tuka hena on iye, qa Israel owasin awihnunipi.

$24 \mathrm{Qa}$ Aliaz Wakantanka tipi tawa wakśica kin mnayan, qa Wakantanka ti kin wakśca kín baśpaśpa, qa Jehowa ti tiyopa kin nataka, qa Jerusalem okahimin owasin en wahnawośnapi içicağa.

25 Nakun Juda otonwe owasin ohna paha kagga; taku wakan tokeca izinwicaye kta, hecen Jehowa iye hunkake wicaya wakandapi kin śihdaya.

26 Unkan iye ohan unman, qa tacanku owasin, tokabeya, qa ehake kin hena Juda qa Israel wicaśtayatapi wowapi kin en owapi ce.

27 Unkan Ahaz ate wicaya om iśtima, qa Jerusalem ohna hnakapi; tuka Israel wicaśtayatapi ohnahnakapi kin ekta ayapi śni. Unkan iye cinhintku Hezekija heekiya wawidaka.

\section{WICOW OYAKE 29.}

1 Hezekija waniyetu wikcemna nonpa sanpa zaptan qehan toka wawidake ca waniyetu wikcemna nonpa sanpa napcinwanka Jerusalem ohna wawidaka, qa hunku Abia Zekarija cunwintku eciyapi.

2 Qa taku ecetu Jehowa iśta kin en econ, ateya Dawid econ qon owasin iyecen.

3 Iye waniyetu tokaheya wawidake cin wi tokaheya en Jehowa ti tiyopa kin yulidoka, qa hena piya.

4 Qa wawayuśnapi kin, qa Lewi kin uwicakiya, qa wiyo- hiyanpata canku kin en mnawicaya ;

5 Qa hewicakiya; Iewi yaunpi kin namahonpo; Ihduwalkanpo, qa Jehowa nihunkakepi wakandapi kin tipi tawa yuwakanpo; qa taku śapa kin tipi wakan etanhan tankan ayapo.

6 Ate wicunyanpi kin wahtanipi, qa taku śica Jchowa wakanundapj iśta kin en econpi, qa iye ay uśtanpi, qa Jehowa tipi tawa etanhan ihdamnapi, qa heyata iyayapi.

7 Nakun tiyopa awakeyapi tiyopa kin natakapi, qa petijanjan kin bosnipi, qa wizite kin izinyapi śni, qa taku Israel wakandapi tipi tawa ohna wohulinaliyapi lin hulinaliyapi śni.

8 Heon Jehowa Juda qa Jerusalem canniye wicaya, qa wonihinciye, woihangye, qa woośtehda en wicaqu, niistapi on wandakapi iyecen.

9 Hecen atewicunyanpi isan on cawicapapi hinhpayapi, qa unkicincapi wica winyan koya, qa unkitawinpi taku kin de on wayaka unpi.

10 Wanna Jehowa Israel wakandapi kin kici wotakuye wecagie kta micante en un; hecen tocanniye kata unkiyepi etanhan hduhomni kta.

11 Micinca nakaha ihnuhan ihayaktapi śni kin, niycpi Jehowa nicahinigapi kin itokam nayajinpi kta, qa óyakiyapi kta, qa ohoda qa waizinya yaunpi kta nakaś.

12 Hehan Lewi kin najinpi Mahat Yamasai cinhintku, qa Joel Azarija cinhintku, Qohati cincapi kin etanhan; qa Merari cinca kin etanhan Qiś Abdi cinhintku, qa Azarija Jehalelel cinhintku; qa Gerśoni kin etanhan Joal Zinma cinhintku.

13 Qa Elizapan cinca kin etan649 


\section{ANPETU OYAKAPI,}

han Śimri, qa Jeyiel; qa Asap cinca kin etanhan Zekarija qa Mattanija.

$14 \mathrm{Qa}$ Heman cinca kin etanhan Jehiel, qa Śimeyi ; qa Jedutun cinca kin etanhan Semayeja, qa Uzziel.

$15 \mathrm{Qa}$ hena hunkawanji wicayapi kin mniciye wicayapi, qa ihduwakanpi; qa wicaśtayatapi kin econ wicaśi qon iyecen, Jehowa oie kin eciyatanhan en hipi, qa Jehowa ti kin yuskapi.

16 Unkan wawayuśnapi kin Jehowa ti kin yuskapi kta ti mahen ipi, qa taku sapa Jehowa tipi wakan tawa mahen iyeyapi kin owasin Jehowa ti hocoka kin ekta hiyuyapi. Unkan Lewi kin he icupi, qa tankan ayapi, Qedron kaksiza kin ekta.

17 Qa wi tokaheya anpetu tokaheya en toka yuskapi, qa wi anpetu iśahdogan kin en Jehowa tiyopa awakeyapi kin ekta hipi ; hehan anpetu śahdogan hehanyan Jehowa ti kin yuwakanpi; hecen wi tokaheya anpetu iake śakpe en yuśtanpi.

18 Hehan wicaśtayatapi kin Hezekija ekta ti mahen ipi, qa heyapi, Jehowa tipi tawa owancaya unyuśtanpi ; nakun wohuhnahyapi owayuśna kin, qa wakśica tawa owasin, qa ağuyapi itokam lnakapi wahna wotapi kin, qa tawakśica kin owasin.

19 Nakun wikicanye tawa wicaśtayatapi Ahaz wawidake ceehan tokipajin en hena yuśape cin, hena owasin piunyanpi ; qa tho hena Jehowa owayuśna tawa kin itokam yankapi.

20 Unkan wicaśtayatapi Hezekija hanlianna hin kikta, qa otonwe itancan mnawicaya, qa Jehowa ti kin ekta itanwankanhde $i$. 21 Unkan tatanka śakowin, qa kage cin on. tamdoka śakowin, qa amnos śakowin, qa tatokadan mdoka śakowin woahtani wośnapi on ahipi, wokiconze kin on, qa tipi. wakan kin on, qa Juda on. Unkan Hezekija wawayuśnapi Aaron cinca kin hena Jebowa owayuśna tawa akan huhnahyapi kta kewicakiya.

22 Unkan tatanka kin patapi, qa wawayuśnapi kin we kin icupi, qa owayuśna kin akaśtanpi, qa tamdoka kin patapi, qa we kin owayuśna kin akaśtanpi, qa amnos kin patapi, qa we kin owayuśna kin akaśtanpi.

23 Hehan tatokadan mdoka woahtani wośnapi on wicaśtayatapi, qa omniciye kin itokam ikiyedan hiyu wicayapi; unkan akan napepi kin aputakapi.

24 Unkan wawayuśnapi kin hena patapi, qa wepi kin on owayuśna akan wookiye kag̉api, Israel owasin on, akahpe wicakiciyapi kta, wicaśtayatapi kin Israel owasin on wohuhnahyapi kin, qa woahtani wośnapi kin kag̣api kta kewicakiya nakaś.

25 Qa Lewi kin Jehowa tipi tawa ohna najin wicakiya, mazicasnasna on ; qa cotanke on, qa candowankiyapi on, Dawid, qa wicaśtayatapi wawanyake tawa Gad, qa Natan waayate kin econ wicaśipi kin iyecen; Jehowa waayate tawa napepi on hecon wicaśi nakaś.

26 Unkan Lewi kin candowankiyapi Dawid kagge cin yuha najinpi; qa wawayuśnapi kin mazayahotonpi kin yuhapi.

27 Unkan wohuhnahyapi kin owayuśna akan hulinahyapi kta Hezekija keya. Unkan toka huhnahyapi qehan Jehowa idowanpi mazayahotonpi on, qa Dawid Israel wicaśtayatapi wikicanye 
28 Unkan omniciye orvasin ohodapi, qa wadowanpi, qa mazayahotonpi owasin dowanpi, ecen wohuhnahyapi kin yuśtanpi.

$29 \mathrm{Qu}$ wohuhinahyapi kin yuśtanpi qehan wicaśtayatapi kin, qa tona kici unpi kin owasin patujapi, qa ohodapi.

30 Hehan wicaśtayatapi Hezekija, qa itancan unpi kin, Lewi kin Jehowa yatanpi kta kewicakiyapi, Dawid qa Asap wawanyaka kin oiepi kin iyecen. Unkan yatanpi ecen wiyuśkinpi qa patujapi, qa ohodapi.

31 Hehan Hezekija ayupte ca heya, Wanna ninapepi Jehowa on ojuyayapi kin ikiyedan upo, qa Jehowa ti kin on wośnapi, qa woyatan hiyuyapo. Unkall omniciye wośnapi, qa woyatan wośnapi hiyuyapi, qa cante iyokipiya owasin wohuhnahyapi ahipi.

32 Unkan wohuhnaliyapi omniciye ahipi kin hena yawapi kin tatanka wikcemna śakowin, qa tamdoka opawinge, qa tacincadan opawinge nonpa, hena owasin Jehowa kihulinahyapi.

33 Nakun pte opawinge śake qa tahinca kektopawinge yamni yuwakanpi.

34 Tuka wawayuśnapi kin tonana hecen wohuhnahyapi kin owasin liay uzapi okitpanipi; heon hunkawanji wicayapi kin Lewi kin ówicakiyapi, wokicanye kin yuśtanpi, qa wawayuśna unman ihduwakanpi kin hehanyan. Lewi kin wawayuśnapi kin isanpa cante ecetupi nakaś.

35 Nakun wopida wośnapi śin kin huhnahyapi kin ota; nakun wohuhnahyapi woakaśtan; hecen Jehowa tipi tawa wohtani kin yuecetupi.

36 Unkan Hezekija, qa oyate kin owasin wiyuśkinpi, Jehowa oyate kin hecen cante yuswicakiya heon. Taku kin de ihnuhanna econpi nakaś.

\section{WICOWOYAKE 30.}

1 Urıan Hezekija Israel qa Juda owasin wahowicaya, qa Epraim, qa Manaśe, wowapi wicakicaga; Jehowa Israel wakandapi woacakśin kicaggapi kta e Jehowa ti kin Jerusalem ohna yanke cin ekta hipi kta.

2 Qa wicaśtayatapi kin, qa itancanpi kin, qa omniciye owasin woacakśin kin wi inonpa en econpi kta aiapi.

3 Iyehantu hin heconpi okitpanipi, heehan wawayuśnapi kin nahanhin ihduwakanpi śni, qa oyate kin Jerusalem en mniciyapi śni nakaś.

4 Qa taku kin de wicaśtayatapi iśta kin en ecetu, qa omniciye owasin iśtapi kin en.

5 Heon wicoie kin yusutapi, Israel owasin Berśeba etanhan Dan aiyahdeya wahowicayapi kta, Jehowa Israel wakandapi toacakśin kin econpi kta e Jerusalem en hipi kta; owapi kin iyecen, ehanna tanhan econpi śni nakaś.

6 Unkan wainyankapi kin wowapi kin wicaśtayatapi, qa itancanpi napepi etanhan yuha iyayapi, Israel qa Juda owancaya ekta, qa wicaśtayatapi kin econ wicaśi kin iyecen heyapi, Israel cinca kin Jehowa Abraham Izak qa Israel wakandapi kin en hdipo ; hecen iye niyepi tona onicaptapi Aśur wicaśtayatapi napepi etanhan nayajicapi kin en nihdipi kta.

7 Ilınuhan ate wicayayapi kin, ga nihunkawanjipi kin Jehowa hunkake wicayapi wakandapi kin wakihtanipi kin iyenicecapi kin, 


\section{ANPETU OYAKAPI,}

hena wonihinciye wicakage, wandakapi kin iyecen.

- 8 Nakaha ihnuhan tahu patinyakiyapi, nihunkakepi kin iyecen. Ninapepi Jehowa kicupo, qa tipi wakan tawa ekta upo; he iyè hduwakan owihanke wanin, qa Jehowa wakanyadapi kin ókiyapo; hecen tocanniye niyepi etanhan hduhomni kta.

y Jehowa en yahdipi kinhan nihunkawanjinpi, qa nicincapi wowaonśida iyeyapi kta ; tona wayaka awicayapi kill wicitokam, qa makoce kin den hdipi kta, Jehowa wakanyadapi kin he wacantkiye ca waonśida nakaś; qa en yahdipi kinhan ite kin niyepi etanhan hduhomni kte śni.

10 Unkan wainyankapi kin otonwe iyaza iyayapi, Epraim makoce, qa Manaśe ohna, qa Zebulun aiyahdeya; tuka iwicahahapi, qa unwicacapi ece.

11 Hececaśta wanjikśi Aśer etanhan, qa Manaśe etanhan, qa Zebulun etanhan ihduhukuyapi, qa Jerusalem en hipi.

12 Nakun Juda ohna Jehowa nape kin cante wanjidan wicaqu, wicaśtayatapi, qa itancanpi kin econ wicaśipi kin iyecen, Jehowa oie kin econpi kta.

13 Hecen oyate wicota Jerusa$1 \mathrm{~cm}$ en ihduwitayapi, omniciye nina tanka, ag'uyapi napolyyapi śni wohanpi econpi kta, wi inonpa kin en.

14 Qa najin liyayapi, qa wahnawośnapi Jerusalem ohna yankapi kin yutokanpi, nakun oizinyapi, qa Qedron kaksiza en hena ehpeyapi.

15 Hehan woacakśin kin patapi wi inonpa anpetu iake topa en; qa wawayuśnapi kin, qa Lewi kin iśtecapi, heon ihduwakanpi, qa wohuhnahyapi kin. Jehowa ti kin en ahipi.
16 Qa tonajinpi kin ohna najinpi woyaco econ wicaśi kin iyecen, Moses Wakantanka tawicaśta toope kin iyecen; wawayuśnapi kin we kin Lewi napepi etanhan icupi qa amnimnipi.

17 Omniciye kin de etanhan wicota ihduwakanpi śni; heon tona skapi śni kin hena owasin on Lewi kin woacakśin kin patapi, Jehowa on wicayuwakanpi kta.

18 Oyate kin etanhan wicota Epraim, qa Manaśe, qa Isakar, qa Zebulun etanhan wicota skapi śni eśta woacakśin kin yutapi, owapi qon iyecen econpi śni; tuka Hezekija wocekiye ewicakiciya, qa heya, Jehowa waśte otoiyohi wicakicicajuju nunwe;

19 Tona Wakantanka Jehowa ate wicayapi wakandapi kin akitapi kta cantepi kin ocowasin yuecetupi kin, tipi wakan yuskapi kin iyecen wicayuskapi śni eśta.

20 Unkan Jehowa Hezekija nahon, qa oyate kin okizi wicaya.

21 Unkan lsrael cinca kin Jerusalem en hiyeya kin ağuyapi napohyapi śni wohanpi kagapi, anpetu śakowin, wowiyuśkin tanka on, qa Lewi kin anpetu otoiyohi Jehowa yatanpi, qa wawayuśnapi kin widowankiyapi on Jehowa towaśake kin idowanpi. 22 Unkan Hezekija Lewi tona wayupiya Jehowa yatanpi kin cantepi ekta ia. Unkan anpetu śakowin hehanyan omniciye wakan kin wotapi wopida wośnapi wayuśnapi, qa Jehowa hunkake wicayapi kin wakandapi kin yatanpi.

23 Unkan omniciye owasin anpetu śakowin tokeca econpi kta iwohdakapi, hecen ake anpetu śakowin wiyuśkinyan econpi. 24. Hezekija Juda wicaśtayatapi 
kin pte kektopawing'e, qa tahinca kektopawinge śakowin omniciye kin ituwicakilian, qa itancanpi kin pte kektopawinge, qa tahinca kektopawinge wikcemna ituwicakihanpi nakaś, qa wawayuśnapi ota ihduwakanpi.

25 Hecen Juda omniciye kin owasin, qa wawayuśnapi kin, qa Lewi kin, qa Israel etanhan upi ornniciye kin, qa oyate tokeca Israel makoce kin etanhan upi qa Juda otipi kin owasin wiyuśkinpi.

26 Hecen Jerusalem ohna wowiyuśkin tanka; Solomon Dawid cinhintku Israel wicaśtayatapi anpetu tawa ehantanhan Jerusalem ohna he iyececa wanica.

27 Hehan wawayuśnapi kin Lewi kin najinpi, qa oyate kin wicayawaśtepi. Unkan lopi kin nahonpi qa wocckiye eyapi kin Jehowa tipi wakan tawa iyohi, mahipiya en.

\section{WICOWOYAKE 31.}

1 Unkan hena owasin yuśtanpi qehan, Israel hen hiyeye cin owasin Juda otonwe kin ektakta iyayapi, qa wakağapi kin kamdccapi, qa Aśeri kin kawankapi, qa paha kin, qa owayuśna kin pajujupi, Juda, qa Benjamin, qa Epraim qa. Manaśe owancaya ecen yuśtanpi, hehan Israel owasin kihdapi otoiyohi otonwe tawayapi kin ekta.

2 Unkan Hezekija wawayuśnapi qa Lewi obepi kin yuecetu, obepi qon iyecen, wawayuśnapi qa Lewi wohtanipi kin iyecen, otoiyohi wohulinahyapi, qa wopida wośnapi on, qa waokiyapi kta, qa Jehowa ounye cin tiyopa ekta yatanpi kta.

3 Nakun wicaśtayatapi kin woyuha tawa etanhan wohulinaliya- pi kin qu, hanhanna, qa htayetu wohuhinaliyapi; qa anpetu okihipapi, qa wi teca, qa omniciye wakan wohulinahyapi kin Jehowa toope kin iyecen.

4 Nakun oyate kin Jerusalem ounyanpi kin wawayuśnapi kin, qa Lewi kin wopamni tawapi wicaqupi kta kewicakiya, hecen Jehowa toope opapi kta e waśag wicayapi kta.

5 Unkan wicoie kin he owancaya iyaye cehan, Israel cinca kin agyapi su tokaheya suton kin ota ahipi ; nakun hastanhanka hanpi, qa wihdi, qa canhanpi tiktica, qa taku mağa aicagge cin iyuhpa iwikcemna kin ota ahipi.

6 Nakun Juda, qa Israel cinca Juda otonwe ounyanpi kin iś eya pte qa tahinca iwikcernna kin ahipi; taku yuwakanpi Jehowa iyepi wakandapi on yuwakanpi kin iwikcemna kin kahipi, qa pahaha kagiapi.

7 W.i iyamni en paha oahe tokaheya kaggapi, qa wi iśakowin kin en yuśtanpi.

8 Hehan Hezekija, qa itancanpi kin ekta ipi, qa pahaha kağapi kin wanyakapi, qa Jehowa, qa oyate tawa wicayawaśtepi.

9 Qa Hezekija wawayuśnapi kin, qa Lewi kin pahaha on iwicawanga.

10 Unkan Azarija Zadoq tiwahe kin wawayuśna itancan kin ayupte ça heciya, Woahi Jehowa ti en toka ahipi kin ehantanhan imna wauntapi, qa ota unkokaptapi; Jehowa iye taoyate kin wicayawaśte nakaś; hecen taku ota kin de okaptapi.

11 Hehan mazopiye tipi Jehowa ti kin ohna kaǵapi kta, Hezekija keya. Unkan wiyeya kagapi.

12 Unkan woahi, qa iwikcemna kin, qa taku yuwakanpi kin ece- 


\section{ANPETU OYAKAPI,}

tuya ahipi, qa Konaneja Lewi kin awanyakapi kin itancan hee, qa sunkaku Ślmeyi he iyokihe.

13 Qa Jehiel, qa Yazazija qa Nahat, qa Yasahel, qa Jerimot, qa Jozabad, qa Eliel, qa Jismakeja, qa Mahat, qa Benaja, waawanyakapi kin Konaneja, qa iye sunkaku Śmeyi napepi kin ihukuya unpi; wi caśtayatapi Hezekija hecon wicaśi kin iyecen; qa Yazareja Wakantanka ti kin awanyaka.

14 Qa Kore Jimna cinhintku Lewi kin tiyopa wihinanpe cin ektakiya awanyake cin he taku Wakantanka itukihanpi kin awanyaka ece, taku Jehowa kahipi, qa taku iyotan wakan kin pamni kta.

15 Qa iye nape kin ekta Eden, qa Minjamin, qa Jeśua qa Śsemayija, Amarija, qa Śskanija wawayuśnapi otonwepi kin ohna ecetuya hunkawanji wicayapi owecinhan taku tawapi wicakipamnipi kta, tona tanka, qa tona cistinna iakcdececa.

16 Nakun tona wica waniyetu yamni qa iwankam wicayawapi, tona Jehowa ti kin en lipi, anpetu otoiyohi wohtani kin econpi kta en hivi ece kin owasin woawanyake tawapi kin wicapamnipi kin iyecen.

17 Qa wawayuśnapi kin ate wicayapi tipi kin iyecen wicayawapi, qa Lewi kin waniyetu wikcemna nonpa qa iwankam, woawanyake tawapi en wicapamnipi iyecen.

18 Qa śiceca, qa winolinca tawapi owasin wicayawapi, qa cincapi wica qa winyan wicayawapi, omniciye ocowasin wicakipamnipi kta wowicake en nina ihduwakanpi nakaś.

19 Qa Aaron cinca kin warvayuśnapi otonwe tawapi ihdukśan tinta kin ohna yakonpi wawayuśna ehna tona wica owasin onśpaśpa tawapi wicaqupi kta e wicaśta cajepi owapi ce en unpi ; qa Lewi tona wicoicage wowapi en owapi nakun qupi.

20 Qa Hezekija Juda owancaya hecen econ, qa taku waśte qa ecetu, qa wicaka econ, Jehowa iye wakanda kin itokam.

21 Qa wohtani Jehowa ti kin kicanye kta konze cin owasin en, qa woope kin en, qa woahope en, cante ocowasin on iye wakanda kin akin econ, qa tanyan ihuniyan.

\section{WICOWOYAKE 32.}

1 Hena iyohakam, qa he yusutapi qehan, Senaherib Aśur wicaśtayatapi u, qa Juda en hi, qa otonwe aconkaśkeyapi kin aonataka, qa iye on ohiwicaye kta keya.

2 Unkan Senahierib u, qa ite kin Jerusalem azuye kta ektakiya etonwe cin Hezekija wanyake cehan,

3 Wicaśta itancan, qa waśaka wicayuhe cin om iwohdaka miniyowe otonwe itankan hiyeye cin natake kta; unkan hecon kta okiyapi.

4 Unkan oyate wicota yuwitaya hiyupi, qa miniyowe kin owasin natakapi, qa wakpadan makoce cokaya kaduze cin akahpapi, Tokeca Aśur wicaśtayatapi kin upi, qa mini ota iyeyapi kta he? eyapi nakaś.

5 Nakun waśag ic̣iye ça conkaśke kawankapi qon owasin piya, qa ipasotka aiyahdeya wankantuya kaga, nakun itankan conkaśke tokeca wan kagaa, qa Millo Dawid totonwe suta kaga ; qa wahukeza, qa wahacanka ota kağa. 


\section{WICOWOYAKE 32.}

6 Qa akicitatancan wokicize on oyate yuhewicakiya, qa otonwe tiyopa hocoka en, iye ekta mnawicaya, qa cantepi ekta ie ca hewicakiya,

7 Wakiśakapo, qa waditakapo. Ihnuhan Aśur wicaśtayatapi kin on, qa obe tanka kin de iye opapi kin on yuśinyeniyanpi kin, unkiyepi om unpi kin iye kici unpi kin isanpa ota ce.

8 Iye kici wicacehpi isto yukan, qa unkiyepi kici Jehowa wakanundapi ounkiyapi kta, qa wokicize unkitawapi kize kta un nakaś. Unkan oyate kin Hezekija Juda wicaśtayatapi oie kin wacinyanpi.

9 He iyohakam Senaherib Aśur wicaśtayatapi kin iye taokiye Jerusalem ekta ye wicaśi, qa iye, qa tokiconze owasin Lakiś azuyapi, qa Juda wicaśtayatapi kin, qa Juda Jerusalem ohna yakonpi kin owasin hewicakiya,

10 Senaherib Aśur wicaśtayatapi kin hecen eya, Taku wacinyayapi, qa Jerusalem kakiśyapi lin en owanji dukanpi he?

11 Jehowa wakanundapi kin Asurur wicaśtayatapi nape kin etanhan niunkiyapi kta, Hezekija eya; qa wicaakihan, qa iwicapuza on țc niyanpi śni he?

12 Tuwe paha tawa, qa wahnawośnapi tawa pajuju, qa wahna wośnapi wanjidan itokam ohoyadapi kta, qa he akan wizinyayapi kta, Juda qa Jerusalem ewicakiya, Hezekija kin de e śni he?

13 Makoce ota oyatepi owasin miye, qa ate wicawaya taku ecawicunkiconpi kin sdonyayapi śni he? Makoce kin hena oyate taku wakandapi kin makoce tawapi minape etanhan ehdakupi he?

14 Ikcewicaśta ate wicawaya ihang wicayapi kin taku wakan- dapi kin owasin tukte wanji oyatc tawa minape etanhan ehdaku okihi, on taku wakanyadapi kin niyepi minape etanhan enihdakupi kta okihi he?

15 Heon etanhan nakaha ihnuhan Hezekija nihnayanpi, qa ihnuhan hecen awacinniyanpi kin; qa ihnuhan wicayadapi kin; Wokiconze oyatepi kin owasin tuwedan minape, qa ate wicawaya napepi etanhan oyate tawa ehdaku okihi śni, qa isarıpa taku wakanyadapi kin minape etanhan enihdakupi kta okihi lste śni.

16 Unkan wahośiye tawa nakun sanpa Jehowa Wakantanka, qa taokiye Hezekija aiapi.

17 Qa Jehowa Israel wakandapi kin $\mathrm{i}$ en iyeyapi kta wowapi wan kağa, qa heya, Makoce ota oyatepi taku wakandapi kin iye taoyatepi minape etanhan ehdakupi okitpanipi kin iyecen Hezekija taku wakanda kin minape etanhan oyate tawa ehdaku kta okitpani.

18 Qa Juda iapi en hotanka ieyanpahapi, Jerusalem oyate conkaśke akan yakonpi kin itokam kopehdawicayapi kta, qa yuśinye wicayapi kta, qa hecen otonwe kin jcupi kta, heon etanhan.

19 Qa Jerusalem taku wakandapi lrin aiapi, makoce oyate taku wakandapi wicanape on kag̉api kin iyecen.

20 Unkan Hezekija wicaśtayatapi kin, qa Isaya Amoz cinhintku waayate kin taku lin de on cekiyapi, qa mahpiya hoyekiyapi.

21 Unkan Jehowa ohnihde wan yeśi, qa Aśur wicaśtayatapi owanka tawa ohna, wicaśta waśaka waditaka owasin, qa itancanpi kin, qa mdetanhunkapi kin owasin ihang wicaya; heon iśte- 


\section{ANPETU OYAKAPI,}

ca makoce tawa elata hda, qa taku iye wakanda ti kin en i, qa iye tezi etanhan inanpapi kin hena isan on ktepi.

22 Hecen Jehowa Hezekija, qa Jerusalem ounyanpi kin Senalierib Aśur wicaśtayatapi nape kin etanhan niwicaya, qa wicihdukśan yakonpi kin owasin napepi kin etanhan ewicahdaku.

23 Unkan wicota Jehowa minha kahipi, Jerusalem ekta, qa Hezekija Juda wicaśtayatapi kin taku tehika ota kahipi; hecen ohakam yuwankan iyeyapi, ikcewicaśta owasin iśtapi en.

24. Anpetu kin hena en Hezekija wayazanka on țe kta, qa Jehowa cekiya. Unkan ayupta, qa wowapetokeca qu.

25 Tuka Hezekija tanyan ecakiconpi kin iyecen kicu śni, qa cante kin wahanicida, heon wośihda iye, qa Juda, qa Jerusalem iyowicahi.

26 Ünkan Hezekija cante kin wahianicida kin on ihdukuya, iye qa Jerusalem ounyanpi kin nakun; heon Jehowa tawośihda kin Hezekija taanpetu en awicahi śni.

27 Unkan Hezekija wowijice, qa wowitan nina tanka yuha, qa mazopiye ic̣icağa, mazaska on, qa mazaskazi on, qa inyan teliika on, qa taku waśtemna on, qa wahacanka on, qa wakśica wiciyokipi owasin on;

28 Qa wopiye aguyapi su on, qa hastanhanka hanpi on, qa wihdi on; qa wanunyanpi iyulipa on oinajin, qa optaye on tipi yuha.

29 Qa otonwe icicaga, tahinca, qa pte ota yuha. Wakantanka woyuha nina ota qu nakaś.

30 Qa Hezekija kin he Gition minilidoka tatowapa kin nataka; qa maka ihukuya Dawid toton- we en wiyohpeya tanhan he owotanna kadusya. Hecen Hezekija taku kage cin owasin tanyan hduśtan.

31 Hececaśta Babel itancanpi kin wahośiye tawapi wowapetokeca niakoce en tanin kin on iwang grapi kta, iye ekta u wicaśipi kin, heon hen iyute kta, qa cante kin en taku un kin owasin sdonye kta Wakantanka ayuśtan.

3. Unkan Hezekija ohan unman, qa towacantkiye kin iho hena Isaya Amoz cinhintku waayate towanyake kin en, qa Juda qa Israel wicaśtayatapi wowapi en owapi ce.

33 Unkan Hezekija hunkakewicaya om iśtima, qa Dawid cinca ohnahnakapi kin iwankam hnakapi; qa te cehan Juda qa Jerusalem ounyanpi kin owasin wowitan ecakiconpi. Unkan heekiya iye cinhintku Manaśe wawidaka.

\section{WICOWOYAKE 33.}

1 Manaśe waniyetu wikcemna sanpa nonpa qehan toka wawidake ca waniyetu wikcenma zaptan sanpa zaptan Jerusalem ohna wawidaka.

2 Qa taku śica Jehowa iśta kin en econ, ikcewicaśta Jehowa Israel cinca itokapa tanhan nape wicaye cin wowahteśni econpi kin owasin iyecen.

3 Qa pahaha atkuku Hezekija yujuju qon owasin piya kaga, qa owayuśna Bayalim tawapi kin ehde, qa Aśerot kağa, qa mahpiya obe owasin ohoda, qa ówicakiya ece.

4 Nakun Jehowa ti kin ohna wahna wośnapi kag̉a, hen Jerusalem ohna micaje owihanke wanin yanke kta Jehowa eye ciqon tuka. 


\section{WICOWOYAKE 33.}

5 Qa Jehowa ti kin hocoka nonpa kin ohna mahipiya obe iyulpa wahnawośnapi wicakicagga.

6 Nakun iye cinca kin Hinnom cinhintku osmaka en peta opta iyaye wicaya, qa hanmde, qa wamduśka on wayyate, qa wahmunga, qa wapiya, qa wakan kağa; hecen Jehowa śilhdaye kta iśta kin en taku śica ota econ.

7 Qa wakagiapi paggopi iye kagie cin Wakantanka ti kin en ehde; he Wakantanka ke ca Dawid, qa iye cinhintku Solomon hewicakiya, Tipi kin den, qa Jerusalem Israel wicoun owasin etanhan wakahinige cin en micaje owihanke wanin yanke wakiye kta.

8 Qa taku econ wicawaśi kin owasin waktaya econpi kinhan, woope, qa wokage, qa woyaco iyuhipa Moses nape on iyecen econpi kinhan icimana Israel sihapi kin makoce hunkake wicayapi akan ewicawahde kin etanhan yewicawaye kte śni.

9 Tuka Manaśe Juda, qa Jerusalem ounyanpi kin nunjwicaya, qa ikcewicaśta Jehowa Israel cinca kin itokapa tanhan ihang wicaye ciqon isanpa taku śica econ wicakiya.

10 Unkan Jehowa Manaśe, qa oyate tawa wahokonwicakiya, tuka anagoptanpi,śni.

11 Heon Jehowa Aśur wicaśtayatapi taozuye mdetanhunkapi kin anawicatan wicaya. Unkan wapepeka hu ehna iyahpayapi, qa mazaśa icaśke nonpa on kaśkapi qa Babel ekta ayapi.

12 Unkan toiyokiśice en Jehowa iye wakanda kin cekiye ca nina ihduhukuya, hunkake wicaya taku wakandapi kin itokam;

13 Qa cekiya: Unkan anohkiciya, qa tawocekiye nalion, qa Jerusalem en hdikiya, tawawi42 dake en. Hehan Jehowa Wakantanka kin hee sdonya.

14. Unkan he iyohakam Dawid totonwe itankan conkaślke wan lagga Gihon wiyohpeya tanhan kaksiza ohna, hogan tiyopa oenape aiyahdeya, qa Opel ihdukśan, qa tehanwankantuya hin kaga; qa Juda otonwe aconkaśkeyapi owasin ohna akicita tancan ewicahde.

15 Qa taku wakan tokeca, qa wakaģapi kin Jehowa ti kin etanhan yutokan, nakun owayuśna Jehowa ti paha kin akan, qa Jerusalem ohna kage ciqon, qa hena iyuhpa otonwe itankau elpeya.

16 Qa Jehowa taowayuśna kin piya kaģa, qa he akan wopida wośnapi, qa woyatan wośnapi wayuśna; qa Jehowa Israel wakandapi kin ókiyapi kta Juda kewicakiya.

17 Hececaśta oyate kin nahanhin pahaha akan wakiyuśnapi ece, tuka Jehowa wakandapi kin heceedan ekta.

18 Unkan Manaśe ohan unman kin, qa tawocekiye iye wakanda kin cekiye cin, qa wawanyake Jehowa Israel wakandapi kin cajeyan okiyapi oiepi kin hena owasin Israel wicaśtayatapi oiepi kin en owapi ce.

19 Nakun tawocekiye, qa token Jehowa anohkiciya. Nakun tawokipajin, qa wahtani kin owa. sin, qa ihduhukuya itokam tukten paha kagia, qa Aśerim, qa wakagapi pagopi ehde, liena wawanyakapi oiepi kin en owapi ce.

20 Hecen Manaśe hunkahe wicaya om iśtima, qa iye ti kin ohna hnakapi, qa eekiya iye cinhintku Amon wawidaka.

21 Amon waniyetu wikcemma nonpa sanpa nonpa qehan toka 657 


\section{ANPETU OYAKAPI,}

wawidaka, qa waniyetu nonpa Jerusalem ohna wawidaka.

22. Qa taku śica Jehowa iśta kin en econ, atkuku Manaśe econ qon iyecen. Amon wakag̉api pağopi iye atkuku Manaśe kagge ciqon owasin wawicakiciyuśna, qa ówicakiya.

23 Tuka Jehowa itokam ihduhukuye śni, atkuku Manaśe ihduhukuya kin iyecen, tuka Amon sanpa śicaya econ.

24 Unkan taokiye kipajinpi, qa iye ti kin ohna te kiyapi.

25 Unkan makoce oyate kin wicaśta kin wicaśtayatapi kin Amon kipajinpi kin owasin wicaktepi, qa heekiya makoce oyate kin iye cinhintku Josija wicaśtaya tapi kagiapi.

\section{WICOWOYAKE 34.}

1 Josija waniyetu śahdoġan qehan toka wawidaka, qa waniyetu wikcemna yamni sanpa wanjidan Jerusalem ohna wawidaka. 2 Qa taku ecetu Jehowa iśta kin en econ, qa ateya Dawid tacanku omani, qa etapa qa catka unmana ektakiya ihduwinge śni.

3 Qa warvidake cin waniyetu iśahdog̣an en nahahin hokśidan iye atkuku Dawid taku wakanda toka akita, qa waniyetu iwikcemna sanpa nonpa kin en Juda, qa Jerusalem toka pakinta, pahaha kin etanhan, qa Aśerim etanhan, qa wakağapi pağopi qa śdoyapi etanhan.

4 Qa iye itokam Bayalim towayuśnapi kin hena pajujupi, qa anpetuwi kagapi kin hena iwankam kaksa, qa Aśerim, qa wakagapi pagopi kin, qa śdoyapi kin kamdeca, ecen kamdu, qa wicaśta hena akan wakiyuśnapi qon ohnahnakapi kin akan mdu kin akada.
5 Qa wawayuśnapi hupi kin huhnaliya, owayuśna tawapi akan; hecen Juda qa Jerusalem pakinta ;

6 Nakun Manaśe, qa Epraim, qa Simeon, qa Naptali otonwe kin hehanyan otiwotapi kin ihdukśan owancaya.

7 Qa owayuśnapi kin, qa Aśerim kawanka, qa wakagapi kin kamdeca ecen mdu kağa, qa Israel makoce kin owancaya anpetuwi kagapi kin owasin kawanka, hehan Jerusalem en hdi.

8 Qa wawidake cin waniyetu iwikcemna sanpa śahdoġan en makoce, qa tipi kin pakintapi qehan, Jehowa iye wakanda ti kin piyapi kta e Śapan Atzaleja cinhintku, qu Mayaseja otonwe itancan kin, qa Joah Joahaz cinhintkı wakiksuye kin ye wicaśi.

9 Unkan Hilkija wawayuśna tanka kin ekta ipi, qa mazaska Wakantanka ti kin en ahipi kin Lewi wakśica awanyakapi kin Manaśe, qa Epraim napepi etanhan, qa Israel okaptapi owasin etanhan, qa Juda qa Benjamin qa Jerusalem ounyanpi kin etanhan mnayanpi qon qupi.

$10 \mathrm{Qa}$ Jehowa ti kin awanyakapi kin wokicanye econpi napepi en qupi, qa Jehowa ti kin ohna htanipi, wohtani econpi kin tipi kin yusutapi kta qa piyapi kta e pamnipi.

11 Qa cankajipapi, qa ticag̉api kin he wicaqupi, inyan kakanpi heca, qa can wiyuskitapi on, qa canmdaska opetonpi kta, Juda wicaśtayatapi kin tipi awihnuniyanpi kin yusutapi, qa piyapi kta, heon etanhan.

12 Unkan wokicanye en wacinyepicaya ohanyanpi, qa awanwicayakapi kin dena eepi Jahat, qa Obedija Lewi kin Merari cinca kin etanhan, qa Zekareja, qa 
Meśullam Qohati cinca kin etanhan iyowicapaśtakapi kta, nakun Lewi tona can dowankiyapi wayupika owasin.

13 Qa Lewi kin etanhan wowapi kagapi, qa mdetanhunkapi, qa tiyopa awanyakapi heca, tona waqinpi, qa wohtani ocaje iyuhpa econwicakiyapi kin hena awan wicayakapi.

14. Unkan mazaska Jehowa ti kin en ahipi qon tankan ahiyupi qehan Ḧilkija wawayuśna kin, Jehowa toope wowapi kin Moses nape on kagapi kin he iyeya.

15 Qa Hilkija wawayuśna kin ie ca Sapan wowapi kag'e cin heciya, Woope wowapi kin Jehowa ti kin ohna iyewaya ce, qa Hilkija wowapi kin Sapan qu. 16 Unkan Śapan wowapi kin wicaśtayatapi kin kahi, qa hośihi, qa heciya, Nitaokiye taku econ wicayaśi kin owasin econpi ce.

17 Qa mazaska Jehowa ti kin en iycyapi kin mnayanpi, qa wolitani econpi napepi en, qa awanwicayakapi napepi en qupi.

18 Qa Sapan wowapi kağe cin wicaśtayatapi kin okiyake ça heya, Hilkija wawayuśna kin wowapi wan maqu; qa Śapan wicaśtayatapi itokam hen yaพล.

19 Unkan wicaśtayatapi kin wowapi oie kin nahon qehan taheyake hdulidelideca.

20 Qa wicaśtayatapi kin Hilkija, qa Ahiqam Śapan cinhintku, qa Abdon Mika cinhintku, qa Sapan wowapi kagge cin, qa Yaśaja wicaśtayatapi taokiye kin hewicakiya,

21 Yapo, qa miye on, qa Israel qa Juda ohna owicakaptapi on, Jehowa iwangapo ; wowapi iyeyapi kin de oie kin on etanhan; hunkake wicunyanpi kin
Jehowa oie kin ihaktapi śni, qa wowapi kin de oiepi kin owasin iyecen econpi śni, heon Jehowa tocanniye unkakaśtanpi kin he tanka ce.

22 Unkan Hilkija, qa wicaśtayatapi tawahośi kin Ḣulda waayatewin Jerusalem ohna Miśene en ti kin he Śalum tawicu, he Toqat cinhintku he Hasra wokoyake awanyake cin cinhintku ekta ipi, qa he iyecen eciyapi.

23 Unkan hewicakiya, Jehowa Israel wakandapi kin hecen eya ye; Wicaśta miye ekta uniśipi kin hecell eciyape,

24 Jehowa hecen eya, Inyun miye taku śica oyanke kin de akan hiyu waye kta, qa ounyanpi kin akan woyaśice tona wowapi Juda wicaśtayatapi itokam yawapi kin en owapi kin owasin.

25 Amayuśtani qa napepi wohtani kin owasin on śihdamayanpi kta, taku wakan tokeca izinyapi; heon mitocanniye oyanke kin de akaśtanpi qa bosnipi kte śni.

26 Tuka Juda wicaśtayatapi Jehowa iwanga u niśipi kin hecen eyakiyapi kta, Jehowa Israel wakandapi kin wicoie nayahon kin eciyatanhan hecen eya ce,

27 Nicante wankadan, qa oyanke kin de qa ounyanpi kin on wicoie nayahon qehan, Wakantanka itokam nihduhukuya, qa. mitokam nihduhukuya ca heyake yahduhdehdeca, qa mitokam yaceya; heon miś eya nacilion, Jehowa eya.

28 Tho, nihunkakepi ekta okipe ciye kta, qa ohnahnakapi nitawa en tanyan aniyanpi kta; qa oyanke kin de akan, qa ounyanpi akan taku śica hiyuwaye 


\section{ANPETU OYAKAPI,}

kte cin orvasin niiśta kin wanyake kte śni. Unkan wicaśtayatapi kin hośi kahdipi.

29 Unkan wicaśtayatapi kin Juda qa Jerusalem hunkayapi kin owasin wahowicaya, qa mniciye wicaya.

30 Qa wicaśtayatapi kin, qa Juda wicaśta, qa Jerusalem ounyanpi kin owasin, qa wawayuśnapi, qa Lewi kin, qa oyate kin owasin, tanka cistinna koya Jehowa ti kin ekta ipi; qa wotakuye worvapi Jehowa ti kin ohna iyeyapi qon oie kin owasin nogepi en wicakiciyawa.

31 Qa wicaśtayatapi kin cowahe tawa akan bosdan najin, qa Jehowa itokam wotakuye kin de kag'a, Jehowa opeya mani kta, qa tawoahope, qa tawoyatanin, qa tawokag'e cante ocowasin, qa nagi ocowasin on patan kta, qa wotakuye oie wowapi kin de akan owapi kin iyecen econ kta.

32 Qa Jerusalem ounyanpi kin Wakantanka hunkake wicayapi wakandapi kin wotakuye tawa iyecen econpi kta, tona Jerusalem, qa Benjamin ohna hiyeye cin najin wicakiya.

33 Qa Josija Israel cinca tamakocepi owancaya wowaliteśni kin owasin yutokan, qa tona Israel ohna iyeyapi kin owasin Jehowa iye wakandapi kin ohoda wicakiya; anpetu tawa ihuniyan Jehorva hunkake wicayapi wakandapi kin opapi etanhan ihduhomnipi śni.

\section{WICOWOYAKE 35.}

1 Unkan Josija Jerusalem ohna woacakśin Jehowa kicağa, qa wi tokaheya anpetu iwikcemna sanpa topa kin en woacakśin kin patapi.
2 Qa wawayuśnapi kin toawanyakapi kin en najin wicakiya, qa Jehowa ti wokicanye kin on iyowicapaśtaka.

3 Qa Lewi kin Israel owasin onspewicakiyapi, qa Jeliowa on wakanpi kin hena hewicakiya, Canwohnaka wakan kin tipi Solomon Dawid cinhintku Israel wicaśtayatapi kin kicağe cin en kihnakapi, niyepi dehan he hiyete akan yaqinpi kte śni, Jehowa wakanyadapi kin, qa taoyate Israel owicakiyapo.

4 Qa hunkake wicayayapi tipi kin iyecen, qa Dawid Israel wicaśtayatapi tawowapi en, qa cinhintku Solomon tawowapi en nipamnipi kin iyecen, wiyeya icihnakapo.

5 Qa oyate cinca nihunkawanjipi ateyapi tipi obepi kin iyecen, qa Lewi ateyapi tipi kin wicapamnipi kin iyecen, tipi wakan kin ohna najinpo.

6 Qa woacakśin kin patapo, qa ihduwakanpo, qa nihunkawanjipi wiyeya wicakicaggapo, hecen Jehowa oie Moses nape kin on he iyecen econpi kta.

7 Unkan Josija talincaska cinca, qa tatokadan cinca oyawa kektopawinge wikcemna yamni hena owasin woacakśin on oyate cincapi hen hiyeye cin wicaqu; nakun pte kektopawinge yamni ; hena owasin wicaśtayatapi tawanunyanpi etanhan.

8 Qa mdetanhunka tawa kin itukihanpi wośnapi, oyate kin, wawayuśnapi kin, qa Lewi kin wicaqupi. Hilkija, qa Zekareja, qa Jehiel Wakantanka ti itancanpi kin wawayuśnapi kin woacakśin on tahinca kektopawinge nonpa qa opawinge śákpe, qa pte opawinge yamni, wicaqupi.

9 Qa Konaneja; qa Śemayeja, qa Netaneel sunkawicaya, qa 


\section{WICOWOYAKE 35.}

Haśabeja, qa Jiyiel, qa Jozabad Lewi itancanpi kin woacakśin on tahinca kektopawinge zaptan, qa pte opawinge zaptan wicaqupi.

10 Hecen wokicanye kin wiyeya kag̉api; qa wawayuśnapi kin oyanke tawapi ohna najinpi, qa Lewi kin wicapamnipi kin iyecen, wicaśtayatapi kin econ wicaśi kin iyecen.

11 Qa woacakśin patapi, qa Lewi ha yuzapi napepi kin etanhan wawayuśnapi kin we kin amnimnipi ce.

12 Qa oyate cincapi ateyapi tipi obepi kin iyecen wicakipamnipi ca taku huhnahyapi kta Jehowa kahipi kta on yukinukanpi, Moses tawowapi en owapi kin iyecen, qa pte on nakun hecen econpi.

13 Qa woacakśin kin pasnupi, peta akan, woyaco kin iyecen; tuka taku yuwakanpi kin he ceg’a ohna, qa wakśica ohna śpanyanpi, qa oyate kin owasin kohanna wicakipamnipi.

14 Qa ohakam iyepi on, qa wawayuśnapi on wiyeya kagapi, wawayuśnapi Aaron cinca kin htayetu hehanyan wohuhnahyapi kin, qa waśin kin huhnahya unpi; heon Lewi kin iyepi on, qa wawayuśnapi Aaron cinca kin on wiyeya kagapi.

$15 \mathrm{Qa}$ wadowanpi kin Asap cinca kin wohtani tawapi ekta najinpi, Dawid, qa Asap, qa Heman, qa Jedutun wicaśtayatapi wawanyake tawa woahope tawapi kin iyecen; nakun tiyopa awanyakapi kin tiyopa otoiyohi elita yakonpi, hena wohtani tawapi etanhan ihdutokanpi kte śni, hunkawanji wicayapi Lewi kin hena on wiyeya wicakicaga pi nakaś.

16 Hecen anpetu kin he en! kan wicaśtayatapi kin taokiye
Jehowa on wohtani kin owasin econpi, woacakśin kağapi kin, qa wohuhnahyapi Jehowa owayuśna tawa akan huhnahyapi, Josija wicaśtayatapi econ wicaśi kin iyecen.

17 Unkan Israel cinca kin hen hiyeye cin he ehan woacakśin kağapi, qa a ġuyapi napohyapiśni wohanpi kin anpetu śakowin.

18 Unkan Israel ohna woacakśin wan he iyecen kaġapi śni, Samuel waayate kin anpetu tawa ehantanhan; qa Josija, qa wawayuśnapi kin, qa Lewi kin, qa Juda qa Israel hen mniciyapi owasin woacakśin kagapi kin iyecen, Israel wicaśtayatapi kin owasin kag̣api śni.

19 Josija wawidake cin waniyetu iwikcemna sanpa śahdogaan kin en woacakśin kin he kaġapi.

20 Hena owasin, qa Josija tipi piya kağa iyohakam, Neko Egupton wicaśtayatapi kin Karkemis-Yuprate ikiyedan wanke cin azuye kta e itanwankanhde u. Unkan Josija itkokipe kta inanpa.

21 Unkan wahośi ekta ye wicaśi, qa heciya, Juda wicaśtayatapi, miye qa niye unkiyotahedan taku un he? Niye tacikpe wau śni, tuka tipi wan wakize cin he, qa taku wakan inahni maśi. Taku wakan mici un ce; itkokim yau enakiya wo, hecen ihangniye kte śni.

22 Tuka Josija iye etanhan ite kin hduhomni śni, qa kize kta ihdutokeca, hecen $\mathrm{Ne}$ ko oie kin taku wakan i kin etanhan anaggoptan śni, qa $\mathrm{Me}$ giddo osmaka en kize kta i. 23 Unkan itazipa yuhapi kin wicaśtayatapi Josija opi. Un661 


\section{ANPETU OYAKAPI,}

hewicakiya, Tokan amayanpo, tehiya maopi ce.

24 Unkan taokiye canpahmihma kin etanhan yutokanpi, canpahmihma inonpa yuhe cin ekta, qa Jerusalem ekta ahdipi. Unkan ta. Unkan hunkake wicaya ohnahnakapi kin en hnakapi; qa Juda, qa Jerusalem owasin Josija aceyapi.

25 Unkan Jeremia aceya, qa wadowanpi wica winyan koya owasin ceyapi en Josija cajeyatapi, anpetu kin dehanyan, qa wokage kin he Israel qupi, qa iho hena Wicaceya kin en owapi ce.

26 Qa Josija ohan unman, qa Jelowa toope en owapi kin iyecen towacankiye;

$27 \mathrm{Qa}$ ohan kin tokaheya qa ehake kin, iho, hena Israel qa Juda wicaśtayatapi kin tawowạpi kin en owapi ce.

\section{WICOWOYAKE 36.}

1 Unkan makoce oyate kin Jehoahaz Josija cinhintku kin icupi, qa atkuku eekiya Jerusalem olina wicaśtayatàpi kagapi.

2 Jehoahaz waniyetu wikcemna nonpa sanpa yamni gehan toka wawidake ca wi yamni Jerusalem ohna wawidaka.

3 Unkan Egupton wicaśtayatapi kin Jerusalem en hi, qa he yutokan, qa mazaska woqin opawinge, qa mazaskazi woqin wanjidan mnaye wicaśi.

$4 \mathrm{Qa}$ Egupton wicaśtayatapi kin cincu Eliaqim, Juda qa Jerusalem on, wicaśtayatapi kage ca caje kin yatokeca, Jehoaqim eciya; qa he sunkaku Jehoahaz Neko icu, qa Egupta ekta ahda.

5 Jehoaqim waniyetu wikcemna nonpa sanpa zaptan qe- han toka wawidaka, qa waniyetu wikcemna sanpa wanjidan Jerusalem ohna wawidake ca taku śica Jehowa iye wakanda iśta kin en econ.

6 Unkan Nebukadnezzar Babel wicaśtayatapi kin iye takpe hi, ga mazaśa icicahilia on kaślka, Babel ekta aye kta.

7 Nebukadnezzar nakun Jehowa ti wakśica kin etanhan hunh Babel ekta aya, qa Babel tipi wakan kin ohna hena kihnaka.

8 Unkan Jehoaqim ohan unman, qa wowahteśni econ, qa en iyeyapi kin, iho hena Israel qa Juda wicaśtayatapi wowapi kin en owapi ce. Unkan iye cinhintku Jehoiakin heekiya wicaśtayatapi. 9 Jehoiakin waniyetu akeśahdogan qehan toka wawidake ca wi yamni, qa anpetu wikcemna Jerusalem obna wawidaka, qa taku śica Jehowa iśta kin en econ.

10 Unkan waniyetu oihuni kin hehan wicaśtayatapi Nebukadnezzar taakicita ekta ye wicaśi, qa Babel ekta ahi, nakun Jehowa ti wakśica wiciyokipi kin. Qa ateye cin Zedekija Juda qa Jerusalem on wicaśtayatapi kaga.

11 Zedekija waniyetu wikcemna nonpa sanpa wanjidan qehan toka wawidake ça waniyetu wikceınna sanpa wanjidan Jerusalem ohna wawidaka.

12 Qa Jehowa iye wakanda iśta kin en taku śica econ, qa Jeremia wayate Jehowa i kin eciyatanhan ie cin itokam ihduhukuye śni.

13 Qa nakun wicaśtayatapi Nebukadnezzar kipajin, he qe taku wakan cajeyan wakonze kiye ciqon; tuka tahu botinkiya, qa cante kin ihdusuta, hecen Jehowa Israel wakandapi kin en ihduhomni śni. 
WICOWOYAKE 36.

14. Nakun wawayuśnapi kin, qa oyate itancanpi kin owasin ikcewicaśta wowahtepiśni kin iyecen sanpa qa sanpa, wahtanipi; qa Jehowa ti kin Jerusalem ohna hduwakan kin yuśapapi.

15 Unkan Jehowa hunkakewicayapi wakandapi kin wahowicaya, wahośi tawa napepi on, bankikta ye wicaśi, tipi tawa, qa oyate tawa wicakpatall nakaś.

16 Tuka Wakantanka tawahośi kin iwicahahapi ecee, qa oie kin ihaktapi śni, qa waayate tawa unwicacapi ece, ecen Jehowa tocanniye kin awicaide ecen wookizi wanica.

17 Heon Kasdim wicaśtayatapi anawicatan $\mathrm{kta}$ itanwankanhde hiyuya, qa taku owasin nape kin en qu, hecen kośkapi kahingapi kin tipi wakandapi kin ohna isan on wicakte, qa kośka qa wikośka, wicahinca qa paskapi unmanna patan śni.

18 Nakun Wakantanka ti wakśica kin owasin tanka cistinna koya; qa Jehowa ti maza kin qa wicaśtayatapi qa iye taokiye mdetanhunkapi maza tawapi iyuhpa Babel ekta ahỏa.

19 Qa Wakantanka ti kin huhioahyapi, qa Jerusalem conkaśke kin yujujupi, qa tipi tehanwankan tawa owasin peta on huhnahyapi, qa taku wiciyokipi en un kin owasin pajujupi.

$20 \mathrm{Qa}$ tona isan owicakapta hena wayaka Babel ekta awicaya, qa iye, qa iye cinca kin wowidake wicayuhapi, Perse wokiconze idake śni hehanyan.

21 Jehowa oie kin Jeremia i kin etanhan makoce kin taokihe on iyokipi kte cin, ecetuye kta; waniyetu wikcemna śakowin henakeca kta, tohan tuwedan oti śni hehanyan okihpa ce. 22 Unkan Kuros Perse wicaśtayatapi waniyetu tokaheya en Jehowa oie kin Jeremia $i$ kin on hduecetu kta e Jehowa Kuros Perse wicaśtayatapi toniya kin iyopaśtaka, heon oyate iwicadake cin owasin wahowicaya, qa nakun wowapi en kage ca heya, 23 Kuros Perse wicaśtayatapi kin hecen eya, Jehowa mahpiya wakandapi kin maka akan wokiconze owasin maqu, qa Jerusalem ohna Iuda makoce en tipi wan wecağe kta kemakiya. Niyepi-ehna tuwe kaśta oyate tawa etanhan yaunpi, ekta hde $\mathrm{kta}$, qa Jehowa iye wakanda kin kici un nunwe. 


\section{EZRA.}

WICOWOYAKE 1.

1 Unkan Kuros Persia wicaśtayatapi tawaniyetu tokaheya en, Jehowa oie Jeremiah i eciyatanhan qon he yuecetupi/kta e, heon Jehowa Kuros Persia wicaśtayatapi taniya kin yukata, hecen iye tokiconze owancaya woyake wan kagia, qa nakun wowapi en heya;

2 Kuros Persia wicaśtayatapi kin hecen eya ce; Maka wokiconze kin iyulipa hena Jehowa Mahipiya Wakantanka maqu; qa iye waeconmaśi, tipi wan wecage kta, Jerusalem en Juda etu.

3 Iye troyate owasin etanhan niyepi tuwe yukan he: Taku Wakan tawa kici un nunwe: kinhan Jerusalem ekta ye kta, he Juda etu, qa Jehowa Israel ta Wakantanka tipi kicage kta; Taku Wakan Jerusalem en un kin hee nakaeś.

$4 \mathrm{Qa}$ tuwe kaśta owanka owasin en okaptapi, he qe tukten ounyan hecinhan, makoce tawa en wicaśta kin najinkiyapi $\mathrm{kta}$, mazaska on, qa mazaskazi on, qa woyuha un, qa woteca on; nakun Jerusalem en Wakantanka ti kin on taku wicaqupi koya.

5 Hehan Juda qa Benjamin ateyapi itancanpi kin najinpi, qa wośna kag̉api qa Levi wicaśta, nakun tona Wakantanka taniyapi wicayukata owasin, Terusalem en Wakantanka tipi tawa kağd aye kta.

6 Qa tona ihdukśan unpi kin hena owasin nape wicayuwaśa- kapi, mazaska walśsica on, mazaskazi on, woyuha on, qa woteca on, qa taku tehika on, taku ituhanpi kin owasin koya.

7 Nakun Jehowa ti tawakśica Nebukadnezzar Jerusalem etanhan ahiyu, qa iye taku wakan tawa tipi kin en ehanke cigon, hena Kuros wicaśtayatapi kin hiyuya :

8 Han, hena Kuros Persia wicaśtayatapi kin Mithredath mazopiye awanyake nape $k$ in on hiyuya, qa Śśbazzar Juda wicaśtayatapi kin en kiciyawa.

9 Unkan yawapi kin dena ee: Mazaskazi waksica wikcemna yamni, mazaska wakśica kektopawinge, isan wikcemna nonpa sanpa napcinwanka;

10 Mazaslsazi wiyatke wikcemna yamni, mazaska wiyatke inonpa kin opawing'e topa sanpa wikcemna, wakśica tokeca kek topawinge.

11 Mazaskazi qa mazaska wakśica iyuhipa kektopawing'e zaptan sanpa opawinge topa. Dena owasin hdicupi kin om Śseśbazzar tokśu, Babel etanhan Jerusalem ekta hdicupi qehan.

\section{WICOWOYAKE 2.}

1 Unkan makoce cincapi wayaka unpi etanhan kihdapi, Nebukadnezzar Babel wicaśtayatapi Babel ekta wayaka awicahdi qon etanhan, dena eepi : unkan Jerusalem qa Juda ekta hdipi, otoiyohi iye totonwe kin en:

2 Zerubabel kici kupi: Jeśua,

Ezra. 664 


\section{WICOWOYAKE 2.}

Nehemiah, .Seraiah, Realiah, Mordekai, Bilśan, Mizpar, Bigvai, Rehum, Baanah. Israel oyate wicaśta wicayawapi :

3 Paroś cincapi kektopawing e nonpa sanpa opawinge, qa wikcema śakowin sanpa nonpa.

4 Sepatiah cinca kin opawinge yamni, qa wikcemna śakow.in sanpa nonpa.

5 Arah cinca kin opawinge śakowin, sanpa wikcemna śakowin såpa zaptan.

6 Pahath-Moab cincapi, JeśuaJoab cinca kin etanhan, kektopawinge nonpa, qa opawing śe śahdogan sanpa akenonpa.

7 Elam cinca kin, kektopawing'e, qa opawing'e nonpa, sanpa wikcemna zaptan sanpa topa.

8 Zattu cinca kin, opawing'e napcinwanka, sanpa wikcemna topa sanpa zaptan.

9 Zakai cinca kin, opawinge śakowin, sanpa wikcemna śakpe.

10 Bani cinca kin, opawing่e śakpe, sanpa wikcemna topa salpa nonpa.

11 Bebai cinca kin, opawing ge śakpe sanpa wikcemna nonpa sanpa yamni.

12 Azgad cinca kin, kektopawinge sanpa opawinge nonpa, sanpa wikcemna nonpa sanpa nonpa.

13 Adonikam cinca kin, opawinge śakpe, qa wikcemna śakpe sanpa śakpe.

14 Bigvai cinca kin, kektopawinge nonpa, qa wikcemna zaptan sanpa śakpe.

15 Adin cinca kin, opawinge topa qa wikcemna zaptan sanpa topa.

16 Ater cinca kin, Hezekiah etanhan, wikcemma napcinwanka sanpa śahdoğan.

17 Bezai cinca kin, opawinge yamni, qa wikcemna nonpa sanpa yamni.

18 Yorah cinca kin, opawing'e sanpa akenonpa.

19 Haśum cinca kin, opawing e nonpa, qa wikcemna nonpa sanpa yamni.

20 Gibar cinca kin, wikcemna napcinwanka sanpa zaptan.

21 Beth-lehem cincapi, opawinge sanpa wikcemna nonpa sanpa yamni.

22 Netopha wicaśta kin etanhan, wikcemna zaptan sanpa śakpe.

23 Anathoth wicaśta etanhan, opawinge qa wikcemna nonpa sanpa śahdoğan.

24 Azmaveth cinca, wikcemna topa sanpa nonpa.

25 Kirjath-arim etanhan, $\mathrm{Ke}$ phira qa Beeroth cincapi, opawinge śakowin qa wikcemna topa sanpa yamni.

26 Ramah qa Gaba cincapi, opawinge śakpe, qa wikcemna nonpa sanpa wanjidan.

27 Mikmas wicaśta kin, opawinge qa wikcemna nonpa sanpa nonpa.

28 Bethel qa Ai wicaśta kin, opawing'e nonpa, qa wikeemna nompa sanpa yamni.

29 Nebo cinca kin, wikcemna zaptan sanpa nonpa.

30 Magbiś cinca kin, opawing ge qa wikcemna zaptan sanpa śakpe.

31 Elam unma qon cincapi, kektopawing'e qa opawinge nonpa sanpa wikcemna zaptan sanpa topa.

32 Harim cinca kin, opawinge yamni sanpa wikcemna nonpa.

33 Lod, Hadid qa Ono cincapi, opawing śakowin, qa wikcemna nonpa sanpa zaptan.

34 Jeriko cinca kin, opawing'e 665 
yamni, qa wikcemna topa sanpa zaptan.

35 Senaah cinca kin, kektopawing yamni, qa opawinge śakpe sanpa wikcemna yamni.

36 Warvayuśnapi kin: Jedaiah cinca kin, Jeśua tipi etanhan, opawinge napcinwanka, qa wiKcemna śakowin sanpa yamni.

3i Immer cinca kin, kektopawinge qa wikcemna zaptan sanpa nonpa.

38 Paśur cinca kin, kektopawinge sanpa opawinge nonpa, qa wikcemna topa sanpa śakowin.

39 Harim cinca kin, kektopawinge sanpa ake śakowin.

40 Levi wicaśta kin: Jeśua qa Kadmiel cincapi, Hodevah cinca etanhan, wikcemna śakowin sanpa topa.

41 Dowanpi kin: A.saph cinca kin, opawinge qa wikcemna nonpa sanpa śahdoğan.

42 Tiyopa awanyakapi cincapi : Sallum cinca, A ter cinca, Talmon cinca, Akkub cinca, Hatita cinca, Śobai cinca, owasin opawinge qa wikcemna yamni sanpa napcinwanka.

43 Nethinim (tipi wakan wowidake): Ziha cinca, Hasupha cinca, 'Tabaoth cinca,

44 Keros cinca, Siaha cinca, Padon cinca,

45 Lebana cinca, Hagaba cinca, Akkub cinca,

46 Hagab cinca, Śalmai cinca, Hanan cinca,

47 Giddel cinca, Gahar cinca, Reaiah cinca,

48 Rezin cinca, Nekoda cinca, Gazzam cinca,

49 Uzza cinca, Paseah cinca, Besai cinca,

50 Asnah cinca, Mehunim cinca, Nephusim cinca,

51 Bakbuk cinca, Hakupha cinca, Harhur cinca,
52 Bazluth cinca, Mehida cinca, Harśa cinca,

53 Barkos cinca, Sisera cinca, Tamah cinca,

54 Neziah cinca, Hatipha cinca.

55 Solomon tawowidake cincapi : Sotai cinca, Sophereth cinca, Peruda cinca,

56 Jaalah cinca, Darkon cinca, Giddel cinca,

57 Sepatiah cinca, Hattil cinca, Zebaim etanhan Pokereth cinca, Ami cinca kin.

58 Nethinim iyulipa qa Solomon tawowidake cincapi koya, opawinge yamni qa wikcemna napcinwanka sanpa nonpa.

59 Unkan tona Tel-mela etanhan, Tel-harsa, Kerub, Addan, Immar etanhanhan hiyupi qon dena eepi: Tuka atkukupi tipi qa wicoicage tawapi, Israel etanhanpi hecinhan, ohdaka okihipi śnj :

60 Delaiah cinca, Tobiah cinca, Nekoda cinca, opawinge śakpe qa wikcemna zaptan sanpa nonpa.

61 Nakun wawayuśnapi cincapi etanhan: Habaiah cinca, $\mathrm{Koz}$ cinca, Barzillai cinca ; heqe Barzillai Gileadi cunwintkupi etanhan tawicuton, qa iye cajepi eciyatanlaan caśtonpi.

62 Hena e wicowazi owicawapi kin en wiciye owicawapi kin okidepi, tuka iyeyapi śni; heor etanhan wawayuśnapi wicohan kin etanhan wicayuśapapi.

63 Unkan Tirśatha kin he, wawayuśna wan Urim qa Thummim yuha hinajin kte cin helıanyan woyute iyotan wakan kin etanhan yutapi kte śni, kewicakiya.

64 Omniciye ocowasin yuwitaya kektopawing ge wikcemna topa sanpa nonpa, qa opawinge yamni sanpa wikcemna śakpe ; 


\section{WICOWOYAKE 3.}

65 Qa wicaśta taokiye, winyan taokiye tawapi koya, hena kektopawinge śakowin, qa opawinge yamni, sanpa wikcemna yamni sanpa śakowin: qa owicapeya wicaśta dowanpi qa winyan dowanpi kin opawinge nonpa.

66 Śsuka wakan tawapi kin opawinge śakowin qa wikcemna yamni sanpa śakpe: Śonśonna tawapi iś opawing go nonpa, qa wikcemna topa sanpa zaptan.

67 Kamel tawapi kin, opawinge topa qa wikcemna yamni sanpa zaptan: Śnsononna hinca kektopawinge śakpe qa opawing ǵe śakowin sanpa wikcemna nonpa.

68 Unkan ateyapi tokapapi etanhanpi, Jerusalem en Jehowa' ti kin ekta hipi qehan, Wakantanka tipi tohe kin en ekihdepi kta on cantewaśteya en wachpeyapi ece.

69 Token okihipi wicohan econpi kta womnaye kin en hiyuyapi, mazaskazi drakma kektopawinge wikcemna śakpe sanpa wanjidan, qa mazaska woqin kektopawinge zaptan, qa wawayusna tawokoyake opawinge.

70 Hecen wawayuśnapi qa Levi wicaśta, qa oyate etanhanhanpi, qa dowanpi kin, qa tiyopa awanyakapi kin, qa Nethinim kin, iye totonwepi ohnahna tipi, qa Israel ocowasin iye totonwepi kin ohna.

\section{WICOWOYAKE 3.}

1 Unkan wi iśakowin kin hiyohi, qa Israel cincapi iye totonwepi kin ohna yakonpi, hehan oyate kin wicaśta wanjidan se Jerusalem ekta ihduwitayapi.

2 Hehan Jeśua Jozadak cinhintku kin inajin, qa iye sunkawicaye wawayuśnapi kin, qa Zerubabel Śealtiel cinhintku, iye sünkawicaye cin nakun, qa Is- rael ta Wakantanka owayuśna tawa qon he piya kaggapi, akan wahuhnahyapi wośnapi wayuśnapi kta, Moses Wakantanka tawicaśta toope kin en owapi kin iyececa.

3 Unkan owayuśna kin tohe qon akan ehdepi, makoce oyate kin hena kowicakipapi nakaeś; qa wohuhinaģe wośnapi Jehowa wakiy uśna pi, wohuhnaģe wośnapi hanhanna hitayetu koya.

4 Qa ohanzihdepi wohanpi kin he kag̣api, wowapi qon iyececa, qa anpetu iyohi woliulinage wośnapi yawapi kin iyecen, wicohan yuhapi qon eciyatanhan, ànpetu iyohi yuśtanpi kta iyececa.

5 Qa he iyohalam wohuhnage ohinniyan kin, wi teca kin en, qa Jehowa tawohe yuwakanpi owasin en, qa taku ituhanpi tuwe Jehowa cante waśteya itukilianpi owasin.

6 Wi yawapi iśakowin anpetu tokaheya hetanhan wohuhnage wośnapi Jehowa wakiyuśnapi ece. Tuka Jehowa ti oahe kin hinyahin kag̣api śni.

7 Nakun wakakanpi qa waeconpi kin hena mazaska wicaqupi ; qa woyute qa woyatke qa wihdi Zidon qa Tyrus wicaśta wicaqupi, Lebanon etanhan hanteśa can aupi kta, Joppa miniwanca kin ekta, Kuros Persia wicaśtayatapi tawowaśi kin eciyatan-. han.

8 Unkan Jerusalem en Wakantanka ti kin ekta hipi waniyetu inonpa, wi inonpa, hehan Zerubabel Śaltiel cinhintku, qa Jeśna Jozadak cinhintku qa hunkawanjitkupi, wawayuśnapi Levi wicaśta koya, tona okaptapi qon, qa tona wayaka unpi etanhan Jerusalem en hdipi iyuhpa econpi : qa Levi wicaśta ewicahdepi, waniyetu wikcemna nonpa qa 667 
sanpa, Jehowa ti wicohan kin en itancanpi kta.

9 Hehan Jeśua iye cinca qa hunkawanjitku kin om inajin, Kadmiel qa iye cinca, Juda cincapi kin om, Wakantanka tipi en wicohan econpi kin iyowicapaśtakapi kta: Henadad cinca, hena cincapi qa hunkawanjitkupi, Levi wicaśta kin hena.

10 Unkan tipi kaggapi kin Jehowa ti oahe ehnakapi qehan wawayuśnapi ihduzapi mazayahotonpi hduha najin wicakiyapi, qa Levi wicaśta Asaph cinca kin hena mazaicasnasnapi yuhapi, on Jehowa yatanpi lita, David Israel wicaśtayatapi toie kin eciyatanhan.

11 Unkan Jehowa yatanpi qa wopida eciyapi on witaya dowanpi; He waśte nakaeś; T'owaonśida kin Israel ekta owihanke wanica nakaeś. Unkan oyate iyuhpa ho tanka on iyaśapi, Jehorva ti oahe hdepi kin heon Jehowa yatanpi ecee.

12 Tuka wawayuśnapi, qa Levi wicaśta, qa ateyapi itancanpi wicahincapi ota, tipi tokaheya wanyakapi qon hena iśtapi itokam tipi kin de oahe hdepi qehan ho tanka on ceyapi : qa wicota wiyuśkinpi on ho tankakiya iyaśapi.

13 Hecen oyate wiyuśkinyan iyaśapi ho kin, qa oyate ceyapi ho kin okicahnigapi śni: oyate kin ho tankakiya iyaśapi nakaeś, qa hopi kin tehan nahonpi.

\section{WICOWOYAKE 4 ,}

l Unkan Juda qa Benjamin tokawicayapi kin hena, wayaka urpi cincapi Jehowa Israel ta Wakantanka tipi wakan kicağapi he nahonpi qehan;

2 Hehan Zerubabel qa ateyapi itancanpi kin en wicahipi qa hewicakiyapi ; Nici unkağapi kta; Taku Wakan nitawapi kin he unkakitapi nakaeś, niyepi iyececa; qa Esarhaddoll Aśur wicaśtayatapi deciya unkahipi qon taanpetu kin hetanhan waunkiyuśnapi ecee.

3 Tuka Zerubabel qa Jeśua qa Israel ateyapi itancanpi unmapi kin hewicakiyapi; Taku Wakan unkitawapi tipi unkicagapi kin en takudan unyecicapi śni; tuka unkiye yuwitaya Jehowa Israel Taku Wakan tawapi kin tipi wan unkicagapi kta, Kuros wicaśtayatapi kin, Persia wicaśtayatapi kin he econunśipi kin eciyatanhan.

4 Hehan makoce oyate kin Juda oyate napepi kin yuwaśakapi śni, qa ticagapi en iyokiśinwicayapi ece:

5 Qa hena on waaiapi opewicatonpi, tawacinpi yuecetupi kte śni, Kuros Persia wicaśtayatapi taanpetu owasin, qa Darius Persia wicaśtayatapi wawidake cin hehanyan.

6 Unkan Ahaśuerus wawidake en, tokaheya warvidake hehantu, Juda qa Jerusalem en ounyanpi kin on woaie wowapi wan kicagapi.

7 Nakun Artahśaśta taanpetu kin en, Biślam, Mithredath, Tabeel qa takodakupi unmapi kin hena Artahíaśta Persia wicaśtayatapi kin wowapi kicag’api ; unkan wowapi kin he Arami oowa on kagapi, qa Arami iapi en oyakapi.

8 Rehum wayaco itancan qa Śimśai wowapi kage cin hena Jerusalem on. Artahíaśca wicaśtayatapi kin tvowapi kicağapi, kaketu:

9 Hehan Rehum wayaco itancan qa Ś́śńai wowapi kag̉e cin, 668 


\section{WICOWOYARE 4.}

qa takodakupi unmapi kin; Dinayi kin, qa Aparsathki kin, Tarpeīi kin, Apharsai kin, Arkewi kin, Babeli kin, Śśáanai kin, Dehawi kin, Elami kin ;

10 Qa oyate toktokeca Asnapper tanka qa kinihanpi qon awicau qa Samaria otonwepi kin ohnahna ewicahnake ciqon, qa unmapi wakpa akasanpatanhan unpi qon, qa decetu :

11 Wowapi ek ta yeyapi, Artahśaśta kicagapi owapi qon he dee; Nitaokiye, wicaśta wakpa akasanpatanhan unpi kin, qa decetu :

12 Wicaśtayatapi kin sdonye kta, Juda wicaśta niye etanhan unkiyepi ekta hiyupi qon hena Jerusalem en hipi, otonwe wawakipajin qa śica qon he kagapi kta, unkan conkaśke kin yuśtanpi, qa oahe kin iyahdekiciyapi.

13 Heon etanhan wicaśtayatapi kin sdonye kta, otonwe kin de kagapi qa conkaślke tawa yuśtanpi kinhan, woicage, woyute qa ocanku kajujupi mazaska kin hiyuyapi kte śni, hecen unhanketa wicaśtayatapi kin owicayakilianśunkeca kta.

14 Iho, heon etanhan, tipi tanka kin etanhan miniskuya untapi nakaeś, qa wicaśtayatapi taku akiciyutakunipi kte śni wanunyakapi kta iyecece śni, heon etanhan yeunyanpi qa wicaśtayatapi kin sdonyeunyanpi.

15 Hecen niyatepi wokiksuye wowapi tawapi kin he ohna odepi kta; kinhan wokiksuye wowapi kin en decehin iyeyaye kta, qa otonwe kin de otonwe wawakipajin kin heca sdonyaye kta, qa wicaśtayatapi qa wayacopi kin wawicakiciyutakuni śni, qa anpetu ehanna he ohna wokipajin kağapi ecee; heon etanhan otonwe kin de ihangyapi ce.
16 Unkiye wicaśtayatapi kin wasdonye unkiyapi, otonwe kin de kagojapi qa conkaśke tawa yuśtanpi kinhan, leciyatanhan wakpa akasanpatanhan takudan nitawa kte śni.

17 Hehan wicaśtayatapi kin woayupte wan yeya, Rehum wayaco qa Śimśai wowapi kag̉e cin qa takodakupi unmapi Samaria en ounyanpi kin, qa wakpa akasanpa unmapi kin hena: Wookiye qa dehantu:

18 Wowapi hiyuunyeciciyapi qon he mitokam taninyan oyakapi ;

19 Unkan econwicawaśi, qa waakitapi, qa anpetu ehanna en otonwe kin de wicaśtayatapi wicitkokim ihdunajin qon he iyeyapi, qa he ohna wokipajin wokicize ko kagapi ecee qon.

20 Nakun Jerusalem en wicaśtayatapi waśakśaka yukan qon hena wakpa akasanpatanhan owasin iwicadakapi, qa woicag'e, woyute qa ocanku kajujupi mazaska kin hena wicaqupi ecee qon.

21 Heon etanhan wokonze wan kagga po, wicaśta kin hena ayuśtanwicakiyapi kta, qa otonwe kin he kaggapi kte śni, miye etanhan wowaśi wan hiyu śni hehanyan.

22 Qa waktaya un po, ihnuhan hecanonpi śni kinhan: Tokeca woyutakuniśni icage $k$ ta he, on wicaśtayatapi taku akicitakunipi kte śni.

23 Unkan wanna Artaliśaśta wicaśtayatapi kin etanhan wowapi owapi qon he Rehum qa Simśai wowapi kage cin, qa takodakupi kin wicitokam yawapi qehan, hehan Juda wicaśta Jerusalem en unpi kin ekta inahniyan yapi qa isto wowaśake $k$ () on ayuśtanwicakiyapi. 


\section{EZRA,}

24 Hehan Wakantanka tipi tawa Jerusalem en wohtani kin ayuśtanpi. Hecen Darius Persia wicaśtayatapi waniyetu inonpa wawidake hehanyan ozikiyapi.

\section{WICOWOYAKE 5.}

1 Hehan wicaśta wokcanpi, Haggai wicaśta wokcan kin hee, qa Zekariah Iddo cinhintku, Juda wicaśta Juda qa Jerusalem en unpi kin hena Israel ta Wakantanka caje akan wicaun kin he eciyatanhan wowicakiyakapi.

2 Hehan Zerubabel Śaltiel cinhintku najin, qa Jeśua Jozadak cinhintku, qa Taku Wakan tipi tawa Jerusalem en kali utapi: Unkan hena owicapeya wicaśta wokcanpi, Wakantanka tawa, owicakiyapi ecee.

3 Unkan hehantu Tatnai wakpa akasanpatanhan wicaśta itancan, qa Śetharboznai qa takodakupi nakun en wicahipi qa kaken ewicakiyapi; Tuwe e wowaśi econniśipi he, hecen tipi kin de yakagapi qa conkaśke kin eyahdepi he.

4 Nakun kaken ewicakiyapi; Wicaśta tona tipi kin de kagapi kin hena tokenken ewicakiyapi he.

5 Tuka Taku Wakan tawapi iśta Juda hunkayapi akan wicaun, hecen ayuśtanwicakiya okihipi śni, ecen wowiyukcan kin he Darius en hi : Unkan he ehan de on wowapi wan ekta yeyapi.

6 Tatnai wicaśta itancan wakpa alkasanpatanhan un, qa Śethar-boznai qa takodakupi A pharsakai kin wakpa akasanpatanhan unpi, wowapi kagapi Darius wicaśtayatapi ekta yeyapi okagapi kin dee :

7 Wowapi wan ekta yekiciyapi qa ohna kaken wowapi : Darius wicaśtayatapi kin wookiye ocowasin kiciun;

8 Wicaśtayatapi kin he de sdonye kta, unkiye Juda makoce kin en unyanpi, Taku Wakan tanka ti kin ekta, heqe inyan tankinkinyan on kag̉api, qa olsśan wanke cin ohna can ehnakapi, unkan wicohan kin de inaliniyan ayapi, qa iye napepi ohna yuśtanpi kta.

9 Hehan hunkayapi kin liena wiwic unwangapi, kaken ewicunkiyapi ; Tuwe e wowaśi econniśipi, hecen tipi kin de yakagapi, qa conkaśke kin bosdan eyahdepi he.

10 Nakun hena cajepi unkiwangapi, on sdonye unniyanpi kta, hecen tona wicaśta itancanpi cajepi kin wowapi en unnicagapi kta.

11 Unkan kaken eya unkayuptapi; Mahpiya qa maka Wakantanka tawa tawowidake kin he unkiyepi, qa tipi ehanna hinca waniyetu ota he ehan kagapi, Israel wicaśtayatapi wan tanka kag̉e ça yuśtan qon hee unkagapi.

12 Tuka atewicunyanpi Mahipiya Wakantanka wacantahdekiyapi iyohakam, hehan Nebukadnezzar Babel wicaśtayatapi, Kas. dim wicaśta kin he nape en wicaqu, heqe tipi kin de ihangya qa oyate kin Babel ekta wayaka awicakiyahda.

13 Hececa eśta Kuros Babel wicaśtayatapi tawaniyetu tokaheya kin en, Kuros wicaśtayatapi kin wokonze wan kağa, Taku Wakan tipi kin de kağapi kta:

14. Qa nakun Wakantanka ti tawakśica mazaskazi qa mazaska, tona Nebukadnezzar'Jerusalem en tipi wakan kin etanhan icu, qa Babel ekta tipi wakan 
wan en ahdi qon hena e Kuros wicaśtayatapi kin Babel tipi wakan kin etanhan eyaku; unkan tuwe Seśbazzar eciyapi wicasta itancan kagge ciqon hee e qupi :

15 Qa heciya; Dena wakśica eyaku qa ya wo, Jerusalem en tipi wakan kin he ekta aya wo, qa Wakantanka ti kin he tohe qon ohna kağapi kta ce.

16 Hehan Seśbazzar heqe Jerusalem en Wakantanka ti oahe kin hena ehnaka: unkan hetanhan qa dehanyan he kagáa śkanpi, tuka yuśtanpi śni.

17 Heon etanhan wanna he wicaśtayatapi kin en waśte kinhan, wicaśtayatapi mazopiye tipi tawa Babel ekta he cin he ohna odepi kta, he wicakapi hecinhan, Kuros wicaśtayatapi kin wokonze wan kaga, on Jerusalem en Wakantanka tipi kin de kagiapi kta; unkan de on wicaśtayatapi kin token iyokipi hecinhan he iwahounyanpi kta.

\section{WICOWOYAKE 6 .}

1 Hehan Darius wicaśtayatapi kin wokonze wan kağa, unkan wowapi tipi Babel en maza ehnakapi ecee qon he ohna odepi ;

2 Qa Akmetha enta, Mede makoce en, tipi tanka kin he ohna wowapi wan iyeyapi, qa he ohna wowapi kin he hecen owapi :

3 Kuros wicaśtayatapi tawaniyetu tokaheya en, Kuros wicaśtayatapi kin wokonze wan kağa, Wakantanka tipi kin on; Tipi kin he kagapi kta, tukten wośnapi wayuśnapi ece; qa oahe kin hena sutaya ehnakapi kta, obosdatu kin he wiciśpa wikcemna śakpe, ohdakinyan kin iś wiciśpa wikcemna śakpe $k$ ta : 4 Inyan tke hinca oehnake ya- kta. mni qa can tekteca kin oehnake wanjidan: qa on kajujupi kin he wicaśtayatapi ti kin etanhan hiyuyapi kta.

5 Qa nakun Wakantanka ti etanhan mazaskazi qa mazaska wakśica, Nebukadnezzar Jerusalem en tipi wakan etanhan eynku qa Babel ekta ahdi qon hena ake wicakicupi kta, qa ake Jerusalem en tipi wakan kin he ekta hde kta, otoiyohi iye tohe qon ekta, qa Wakantanka ti kin en ehnakapi kta ce.

6 Heon etanhan, Tatnai wakpa akasanpatanhan wicaśta itancan, Śthar-boznai qa takodakupi, Apharsakai wakpa akasanpatanhan unpi kin, he itehan yaunpi kta :

7 Wakantanka ticagapi kin de ayuśtan po ; Juda wicaśta itancan qa Juda hunkayapi kin hena Wakantanka tipi tawa kin de tohe ohna kagiapi kta.

$8 \mathrm{Qa}$ nakun miye eciyatanhan wokonze kin de kagipi, Juda hunkayapi Wakantanka tipi tawa kin he kagiapi kta hena kaken ecawicayeconpi kta; hecen wicaśtayatapi tawomnaye wakpa akasanpatanhan mnayanpi kin etanhan, kohanna wokajuju wicaqupi kta, qa hena ayuśtanwicakiyapi kte śni.

9 Qa nakun taku cinpi, tatanka cinca, qa tamdoka qa tacincadan Mahipiya Wakantanka tawośna huhnahyapi kte cin on, ağuyapi, miniskuya, miniśa qa wihdi, Jerusalem en wayuśnapi konzapi kin lie eciyatanhan, anpetu qa anpetu eca yıśna śni wicaqupi kta.

10 Hecen Mahpiya Wakantanka wośna waśtemna kin wakiyuśnapi kta, qa wicaśtayatapi qa iye cinca nipi kta icekiyapi 
I1 Nakun wokonze wan wakaga, wicaśta otoiyohi wicoie kin de yutokeca kinhan, iye ti kin etanlian can yusdun icupi kta, qa iye yuwankan icupi qa akan otkeyapi kta; qa heon etanhan iye ti kin tacesdi paha kagapi kta.

12 Qa Taku Wakan iye caje kin hen ounyekiye cin he, wicaśtayatapi owasin qa oyate ihangwicaya nunwe, de yutokecapi kta, qa Taku Wakan tipi Jerusalem en un kin he ihangya nape yeyapi kinhan. Durius he miye wokonze kin wakaga : kohanna ecen econpi kta.

13 Hehan Tatnai wakpa akasanpatanhan wicaśta itancan, Śethar-boznai qa iye takodakupi kin, Darius wicaśtayatapi taku hiyuye cin he eciyatanhan, kohanna ecen econpi.

14 Unkan Juda hunkayapi kin ticağa pi qa tanyan iyoptapi, Haggai wicaśta wokcan, qa Zekariah Iddo cinhintsu wayatapi icunhan. Han, ticagiapi qa hdustanpi, Israel Taku Wakan tawa wowaśi kin eciyatanhan, qa Kuros qa Darius qa Artahśaśta Persia wicaśtayatapi tawokonze kin eciyatanhan.

15 Unkan tipi kin he yustanpi, Adar wi anpetu iyamni en, he Darius wicaśtayatapi wawidake waniyetu iśakpe entu.

16 Unkan Israel cincapi, wawayuśnapi qa Levi wicaśta qa wayaka ahdipi unmapi kin hena wowiyuśkin on Taku Wakan ti. pi yuwakanpi kağapi ;

17 Qa Taku Wakan tipi tawa de yuwakanpi kin on tatanka opawinge, tamdoka opawinge norpa, tacinca opawinge topa, wayuśnapi: qa Israel ocowasin on woahtani wośnapi kin, tatanka mdoka ake nonpa, Israel wi- coun wicayawapi kin eciyatanhan.

18 Unkan wawayuśnapi kin obepi kin hecen ewicahdepi, qa Levi wicaśta kin owecinhanhanpi, Jerusalem en Wakantanka waokiyapi kta e heon; Moses taworvapi en owapi qon iyececa.

19 Unkan wayaka ahdi cincapi kin, wi tokaheya anpetu iake topa en woacakśin kagapi.

20 Wawayuśnapi qa Levi wicaśta kin hena witaya ihduskapi nakaeś, iyuhpa skapi, hecen wayaka ahdi cincapi kin on woacakśin kin ktepi, qa iye hunkawanjitkupi wawayuśnapi kin hena on, qa iś iyepi nakun on.

21 Unkan Israel cincapi wayaka ahdi kin hena, qa tona makoce en Ikcewicaśta wayuśicapi kin etanhan iyepi ekta ihdoupi, Jehowa Israel Taku Wakan tawa akitapi kta, hena owasin yutapi ;

22 Qa on napoliyapi codan wotapi kin he wowiyuśkin yuha anpetu śakowin econpi: Iye Jehowa wiyuślkinwicakiya nakaeś, qa Aśur vicaśtayatapi cante kin iyepi en yuhomni, Taku Wakan, Israel ta Wakantanka, tipi tawa tawowaśi kin en nape wicayawaśake kta.

\section{WICOWOYAKE $\%$}

1 Unkan wicoie kin dena iyohakam, Artahśaśta Persia wicaśtayatapi wawidake icunhan, Ezra Seraiah cinhintku, Azariah cinhintku, Hilkiah cinhintku,

2 Śallum cinhintku, Zadok cinhintku, Ahitub cinhintku,

3 Amariah cinhintku, Azariah cinhintku, Meraioth cinhintku,

4 Zerahiah cinhintku, Uzzi cinhintku, Bukki cinhintku,

5 Abiśua cinhintku, Phinehas 


\section{WICOWOYAKE $\%$}

cinhintku, Eleazar cinhintku, Aaron wawayuśna itancan qon cinhintku :

6 Ezra heqe Babel etanhan itanwankanhde iyaya: Unkan he wowapi kag'a wayupika, Moses toope Jehowa Israel ta Wakantanka wicaqu qon he en. Unkan taku kida qon ocowasin wicaśtayatapi kin qu, Jehowa iye ta Wakantanka nape akan yanke cin iyececa.

7 Unkan Artahśaśta wicaśtayatapi tawaniyetu iśakowin kin en, Israel cinca kin etanhan, qa wawayuśnapi etanhan, qa Levi wicaśta, qa wadowanpi kin, qa tiyopa awanyakapi kin, qa Nethinim-tipi wakan tawowidakehena Jerusalem ekta iyayapi.

8 Unkan wi izaptan en Jerusalem ekta hi, wicaśtayatapi tawaniyetu iśakowin hehantu.

$9 \mathrm{Wi}$ tokaheya anpetu tokaheya hehan Babel etanhan itawankanhde iyaya, qa wi izaptan anpetu tokaheya hehan Jerusalem ekta hiyohi, iye Taku Wakan tawa nape waśteya akan yanke cin iyececa.

10 Ezra iye cante ihduwiyeya nakaeś, Jehowa toope kin akite kta, qa eceni econ kta, qa Israel en woope qa woyaco onspewicakiye kta.

11 Unkan Artahśaśta wicaśtayatapi kin wowapi, wan Ezra wawayuśna wowapi kağa, Jehowa tawoahope oie, qa Israel taku econ wicaśi wowapi en kaga ecee, qu qon okagapi he dee :

-12 Artahśaśta wicaśtayatapi en wicaśtayatapi kin, Ezra wawayuśna kin Mahpiya Wakantanka toope en wowapi kagga wayupike hinca, qa kaketu ;

13 Miye qe wokonze wakagia, tona wawidake mitawa ohna ihduwiyeyapi, Israel oyate etanhan owasin, qa wawayuśna tawapi, Levi wicaśta koya, Jerusalem ekta yapi kta hecinhan hena niye kici yapi kta.

14 Heon etanhan, niye wicaśtayatapi qa wawiyukcan śakowin tawa kin wicitokapatanhan yeniśipi, Juda qa Jerusalem on wawinunge kta, Taku Wakan nitawa toope ninape ohna yanke cin eciyatanhan:

15 Qa nakun mazaska qa mazaskazi tona wicaśtayatapi kin he, qa wawiyukcan śakowin tawa Israel ta Wakantanka Jerusalem en ti kin ituya qupi kin he ade kta.

16 Nakun mazaska qa mazaskazi iyuhpa Babel makoce ocowasin en iyeyaye cin, oyate qa wawayuśnapi taku ituhanpi koya, taku cante ocowasin on Wakantanka ti Jerusalem en yanke cin qupi hecinhan :

$17 \mathrm{He}$ on inahniyan mazaska kin de on tatanka, tamdoka, tacinca opeyaton kta, nakun minha tawapi, qa tawokaśtan wośnapi kin ahnalina, qa hena Jerusalem en yanke cin Taku Wakan nitawapi tipi owayuśna kin akan wayakiyuśna kta.

18 Qa mazaska mazaskazi ko okaptapi kin, niye qa nihunkawanjipi taku waśteyadakapi he ohnayan ecanon kta, Wakantanka nitawapi tawacin eciyatanhan econ po.

19 Nakun wakśica tona niçupi, Taku Wakan nitawa ti tawowaśi kin.on, hena Jerusalem Wakantanka kin itokam eyahnake kta.

20 Qa taku sanpa Wakantanka nitawa ti kin on cinpica, taku yaqu kta iyececa hecinhan, he wicaśtayatapi mazopiye tawa kin etanhan yaqu kta. 


\section{EZRA,}

21 Qa miye, Artahśaśta wicaśtayatapi kin miye hinca wakpa akasanpatanhan mazaska opiye awanyakapi kin owasin wokonze wan wicawecaga, Ezra wawayuśna kin Mahpiya Wakantanka toope en wowapi kagie cin heca taku nicidapi kin owasin kohanna ecanonpi kta,

22 Mazaska woqin opawinge hehanyan, qa aǵuyapi su kor opawing่e hehanyan, qa miniśa bath opawinge hehanyan, qa wihdi bath opawinge hehanyan, qa miniskuya tohanyan yawapi śni.

23 Mahpiya Wakantanka tawokonze qon ocowasin, Mahpiya Wakantanka tipi tawa kin on cancanse econpi kta: Tokeca ecin wocanniye wicaśtayatapi tawawidake kin en qa cinhintkupi en u kta he.

24 Nakun sdonyeunniyanpi, wawayuśnapi owasin qa Levi wicaśta kin, wadowanpi, tiyopa awanyakapi, Nethinim, qa Wakantanka ti waokiyapi kin hena wiyutapi on, woyute, qa canku on mazaska kajujuwicakiyapi kta iyecece śni.

25 Unkan niye Ezra, nita Wakantanka toksape ninape ohna un kin eciyatanhan, wayaco qa wicaśta itancan kin ewicayahnake $\mathrm{kta}$, hena oyate wakpa akasanpatanhan owasin ehna wayacopi kta, tona Wakantanka nitawa toope kin sdonyapi iyulipa: qa tona onspepi śni kin hena onspewicayakiyapi kta.

26 Qa tuwe kaśta Wakantanka nitawa toope qa wicaśtayatapi toope kin ecen econ kte śni hecinhan cancanse woyaco ecakiconpi kta, he wiconțe hehanyan, qa tokan iyeyapi kta hehanyan, qa tawalipaya kipi hehanyan, qa wicakaśkapi hehanyan.

27 Jehowa atewicunyanpi Wa- kantanka tawapi he yawaśtepi nunwe, he de wicaśtayatapi cante kin ell ehnaka, Jehowa ti .Terusalem en wanke cin yuwaśte kta: $28 \mathrm{Qa}$ wicaśtayatapi kin itokam qa wiyukcanpi tawa, qa wicaśtayatapi wicaśta waśakśaka tawa owasin wicitokam wowaonśida yuhemakiya. Nakun Jehowa Wakantanka mitawa nape akan mayanke cin eciyatanhan mayuwaśakapi, hecen Israel etanhan wicaśta tokapapi wicamduwitaya, mici yapi kta heon etanhan.

\section{WICOWOYAKE 8.}

1. Unkan atewicayapi itancanpi dena eepi, qa tona Artahíaśta wicaśtayatapi wawidake en Babel etanhan mici yapi owicawapi kin dee :

2 Phinehas cinca etanhan, Gerśom: Ithamar cinca etanhan, Daniel: David cinca etanhan Hattuś, Śekaniah cincapi etanhan.

3 Pharoś cinca etanhan, Zekariah : qa he kici owicawapi eciyatanhan wica ece opawinge sanpa wikcemna zaptan wicayawapi.

4. Pahath-Moab cinca etanhan, Elihoenai Zerahiah cinhintku, qa he kici wica ece opawinge nonpa. 5 Śkaniah cinca etanhan, Jahaziel cinhintku, qa kici wica ece opawinge yamni.

6 Nakun Adin cinca etanhan, Ebed Jonathan cinhintku, qa kici wica ece wikcemna zaptan.

7 Qa Elam cinca etanhan, Jeśaiah Athaliah cinhintku, qa he kici wica ece wikcemna śakowin.

8 Qa Sephatiah cinca etanhan, Zebadiah Mikael cinhintku, qa kici wica ece wikcemna śahdoğan. 


\section{WICOWOYAKE 8.}

9 Joab cinca kin etanhan, Obadiah Jehiel cinhintku, qa he kici wica ece opawinge nonpa sanpa ake śahdoġan.

10 Nakun Śelomith cinca etanhan, Josiphiah cinhintku, qa he kici wica ece opawinge sanpa wikcemna śakpe.

11 Qa Bebai cinca etanhan, Zekariah Bebai cinhintku, qa he kici wica.ece wikcemna nonpa sanpa śahdoğan.

12 Qa Azgad cinca etanhan, Johannan Hakkaton cinhintku, qa he kici wica ece opawinge sanpa wikcemna.

13 Qa Adonikam cinca ehake kin etanhan, dena cajepi, Eliphalet, Jeiel qa Śemaiah, qa hena om wica ece wikcemna śakpe.

14 Nakun Bigvai cinca kin etanhan, Uthai qa Zabud, qa bena om wica ece wikcemna śakowin.

15 Unkan hena wakpa wan Ahava iyahde kin he ekta wicamduwitaya, qa hen anpetu yamni eti unyakonpi : Unkan oyate qa wawayuśnapi kin iwanmdaka, qa Levi cinca etanhan tuwedan en iyewaye śni.

16 Hehan Eliezer wahowaya, Semaiah qa Elnathan, qa Jarib, qa Elnathan, qa Nathan, qa Zekariah, qa Meśullam, wicaśta itancanpi; nakun Joarib qa Elnathan wiyukcanpi kin wahowicawaya.

17 Qa hena Iddo, Kasiphia otonwe en, wicaśta itancan kin ekta yewicawaśi, qa hena ipi ohna wicoie owicawecihnaka, Kasiphia otonwe en Iddo qa iye hunkawarjinwicaya Nethinim kin, Wakantanka unkitawapi tipi kin on wowidake unkaupi kta, kewicakiyapi kta.

18 Unkan Wakantanka unkitawapi nape waśteya unkayankapi kin eciyatanhan, wicaśta wiyu- kcan wan unkahipi, Mahli cinca etanhan, he Levi, cinhintku, Israel cinbintku, Śerebiah hee, iye cinca qa hunkawanjitku kin om, ake śahdog̉an:

19 Qa Haśabiah, qa he kici Jeśaiah, Merari cinca etanhan, iye hunkawanjitku qa cincapi om, wikcemna nonpa.

20 Nakun Nethinim etanhan, tona David qa wicaśta itancanpi Levi wicaśta waokiyapi kta on ewicahnakapi qon, Nethinim opawinge nonpa sanpa wikcemna nonpa; hena owasin cajepi on cajewicayatapi.

21 Hehan hen wote śni unpi wan eyanwapaha, Ahava wakpa kin ekta,' Wakantanka unkitawapi itokam iyokiśinunkiçiyapi kta, unkiyepi on canku owotanna wan unkidapi kta, qa hokśiyopa unkitawapi kin on, qa wahpaya unkitawapi owasin on.

22 Canku ohna tokapi kin itokam ounkiyapi kta e akicita obe qa śuktanka akan yotankapi kin wicaśtayatapi kin wakida kta imaśteca; wicaśtayatapi kin kici wounhdakapi qehan, Tona iye akitapi owasin Wakantanka nape kin waśteya akan wicayanka ece, tuka tona ehpeyapi kin iyuhpa iye towaśake qa tocanniye itkowicakipa ece, unkeyapi nakaeś.

23 Heon etanhan wote śni unyakonpi, qa Wakantanka unkitawapi de iceunkiyapi: Unkan Iye unkayuptapi.

24 Hehan wawayuśna itancanpi ake, nonpa wicawakahniga, Serebiah Haśabiah kici, qa om hunkawanjitkupi wikcemna.

25 Qa mazaska kin hena en tkeuwicawecita, nakun mazaskazi, qa wakśica kin, Wakantanka unkitawapi ti kin on jtuhanpi qon, he wicaśtayatapi qa iye 675 


\section{EZRA,}

wawiyukcanpi tawa, qa itancanpi tawa, qa Israel en unpi iyuhpa en elipeyapi qon.

$26 \mathrm{Han}$, hena napepi ohna aspeyewicaweciton, mazaska woqin opawinğe śakpe sanpa wikcemna zaptan, qa mazaska wakśica woqin opawinge, mazaskazi woqin opawinge :

27 Nakun mazaskazi wakśica wikcemna nonpa, hena darik (tkeutapi wan) kektopawinge; qa wakśica nonpa mazáśa pabezapi waśte hinca, mazaskazi iyecen yawapi.

28 Unkan hewicawakiya; $\mathrm{Ni}$ yepi Jehowa elta niwakanpi; nakun wakśica kin hena wakan; qa mazaska qa mazaskazi kin he Jehowa niyatepi Wakantanka tawapi itukihanpi ee.

29 Awanyaka po, qa yuha po, Jerusalem ekta, Jehowa ti kin timahen, wawayuśnapi qa Levi wicaśta itancanpi itokam, qa Israel atewicayapi tokapapi kin wicitokam, hena tkeuyatapi kinhan hehanyan.

30 Hecen wawayuśnapi qa Levi wicaśta kin mazaska qa mazaskazi, qa wakśica tkeutapi kin he icupi, Jerusalem ekta Taku Wakan unkitawapi ti kin en aipi kta.

31 Hehan Ahava wakpa kin etanhan unkiyoptapi, wi tokaheya anpetu iake nonpa en, Jerusalem ekta unyanpi kta. Unkan Taku Wakan unkitawapi nape akan unyankapi, qa iye toka nape kin etanhan eunhdakupi qa tona canku ohna iyaunkipepi etanhan.

32 Hecen Jerusalem ekta hiyounhipi qa anpetu yamni hen unyakonpi.

33 Unkan anpetu itopa hehan, mazaska qa mazaskazi, qa wakśica kin hena, Taku Wakan unkitawapi ti kin ohna, Merimoth Uriah wawayuśna kin cinhintku he nape on tkeutapi; qa Eleazar Phinehas cinhintku kin he kicica; qa hena om Jozabad Jeśua cinhintku, qa Noadiah Binnui cinhintku Levi wicaśta hecapi :

34 Otoiyohi yawapi on tkeutapi: qa tkeutapi ocowasin kin he hehan owapi.

35 Wayaka akiyahdapi cincapi tona wayaka unpi etanhan hdipi kin hena wohuhnaġe wośnapi Israel Taku Wakan tawapi wakiyuśnapi, tatanka ake nonpa Israel ocowasin on, tamdoka wikcemna napcinwanka sanpa śakpe, tacinca wikcemna śakowin sanpa śakowin, tatokadan mdoka akenonpa, woahtani wośnapi : owasin Jehowa en wohuhnage wośnapi.

36 Unkan wicaśtayatapi tawolionze kin hena wicaśtayatapi taakicita tancanpi qa wakpa akasanpa wicaśta ihdawapi kin wicaqupi. Unkan oyate kin iyowinwicakiyapi, qa Taku Wakan tipi tawa.

\section{WICOWOYAKF 9.}

1 Unkan hena yuśtanpi qehan wicaśta itancanpi kin heya en mahipi ; Israel oyate kin, qa wawayuśnapi, qa Levi wicaśta kin hena makoce oyatepi kin etanhan ihduheyapapi śni, wowahte śni tawapi kin on, Kanani kin, Hitti kin, Perizzi kin, Jebusi kin, Ammoni kin, Moabi kin, Egupta oyate kin, qa Amori kin.

2 Hena cunwintkupi kin etanhan wicayuzapi, iyepi qa cinhintkupi kin on: hecen wicoicage wakan kin makoce oyatepi kin kici icicahi içiyapi: lan, wicaśta ihdawapi qa wicaśta itancan- 
pi napepi tokaheya wahtanipi kin de en un.

3 Unkan wicoie kin he nawahon qehan mitaśina qa mita onỉdohda wahduhdeca qa mapa hin putinhin koya wahdujun, qa inihanyan imdotanka.

4. Hehan tona Israel ta Wakantanka oie kin on cancanpi kin hena owasin en mahipi, wayaka unpi qon wahtanipi kin he on etanhan: unkan litayetu wośnapi hehanyan imanihan manka.

5 Unkan hitayetu wośnapi hehan mitoiyokiśice etanhan nawajin, qa mitaśina mitaonhohda ko waliduhdelideca qehan, canpeśka makehde nawajin, qa Jehowa mita Wakantanka nape wakiyugate ;

6 Qa hepa; Wakantanka mitawa, wimaśteca, qa niye ekta miite hduwankan iyewaye kta imaśteca, mita Wakantanka: waunlitanipi kin hena pa iwankam yuotapi nakaeś, qa waunkipajinpi kin hena mahpiya ekta icağa:

7 Atewicunyanpi taanpetu etanhan wowakipajin tanka en unyakonpi, anpetu kin dehanyan: qa waunhtanipi kin on etanhan unkiye, wicaśtayatapi unkitawapi, wawayuśna unkitawapi koya, makoce wicaśtayatapi napepi en hiyuunyanpi, mazasagye ekta, wayaka unpi ekta, qa wawicakipi ekta, qa ite iśtecapi kin ekta, anpetu kin de iyececa.

8 Unkan nakaha cistiyedan Jehowa Wakantanka unkitawapi etanhan wowaonśida unkicipi un, wookapta wan unkokicicaptapi kta, qa iyokatan wan owanka wakan tawa kin ohna unqupi kta; Taku Wakan unkitawapi iśta iyoyamunkiciyapi kta, qa wowidagunyanpi en cistiyedan wiconi unqupi kta.
9 Wowidake unyakonpi nakaeś; tuka 'Taku Wakan unkitawapi wowidagunyanpi kin en ehpeunyanpi śni, tuka Persia wicaśtayatapi wicitokam wowaonśida unkipazopi, wiconi unqupi kta, Wakantanka unkitawapi ti kin bosdan ehdepi kta, qa yujujupi qon piya kaǵapi kta, qa Juda en qa Jerusalem en conkaśke wan unqupi kta.

10 Unkan nakaha Wakantanka unkitawapi, de iyahna taku unkeyapi kta he : nitawoahope unkayuśtanpi nakaeś :

11 Tona nitaokiye wicaśta wokcan napepi on wayakonze ciqon-heha; Makoce tawayayapi kta e ekta dapi kin he makoce. śapa, makoce en ounyanpi wośape tawapi kin on, wowahteśni tawapi on, ihanke etanhan ihanke unma ekta, ojuyapi kin heon.

12 Heon etanhan nicunkśipi kin iye cinhintkupi kin wicaqupi śni po, qa iye cunwintkupi kin nicinkśipi on wicayuzapi śni po, qa wookiye wowaśte ko owicakicidepi śni po owihanke wanica: hecen waniśakapi kta, qa makoce towaśte kin yatapi kta, qa nicinca aihpewicayeciyapi kta, owihanke wanica.

13 'Tuka taku en unkaupi owasin iyohakam, wicohan śica unkitawapi on, qa waunkipajinpi tanka kin on, niye Taku Wakan unkitawapi waunhtanipi ihukuya ipiunyadapi nakaeś, qa wookapte kin de iyececa unyaqupi ;

14 Akeś nitawoahope kin unkaksapi, qa wowahte śni kin dena oyatepi kin takodawicunyanpi kta he : kinhan niye canniyeunyayapi kta, ecen ihangunyayapi kte śni he, hecen wookapte qa wonajice wanice kta tuka.

15 Jehowa Israel ta Wakan677 
tanka, niye oniwotanna: unkiye hinyahin onajice unkokaptapi nakaeś, anpetu de iyececa. Iho, waunkipajinpi en nitokam unyakonpi : de on nitokam inajin unkokihipi kte śni nakaeś.

\section{WICOWOYAKE 10.}

1 Unkan Ezra cekiye cehan, qa ceya wohdaka, qa Wakantanka ti kin itokam makata elipeiçiye cehan, Tsrael etanhan omniciye tanka hinca, wicaśta qa winolinea qa śiceca, iye en rnniciyapi ; woceye tanka hinca on oyate ceyapi nakaeś.

2 Hehan Śkaniah Jehiel cinhintku, Elam cinca kin etanhan, waayupte ca Ezra heciya; Unkiye Taku Wakan unkitawapi kin en waunkilitanipi, qa makoce oyatepi etanhanhan winohinca toktokeca wicunyuzapi : tuka wanna de on Israel en woape yukan.

3 Heon etanhan wanna Taku. Wakan unkitawapi kici wotakuye wan unkag̉api kta, winoliinca iyuhpa hiyuwicunyanpi kta, tona hena etanhan icağapi koya, itancan mitawa tawiynkcan kin eciyatanhan, qa tona Taku Wakan unkitawapi tawoahope on cancanpi kin iyececa: qa he woope kin eciyatanhan econpi nunwe.

4 Najin wo; de taku kin niye nitawa nakaeś; qa unkiye nici unyakonpi : waditaka qa econ wo.

5 Hehan Ezra najin hiyaye ca wawayuśna itancanpi, Levi wicaśta qa Israel ocowasin wicoie kin de ohnayan iciconswicakiya: unkan iciconzapi.

6 Hehan Ezra Taku Wakan tipi kin itokapatanhan najin, qa Johanan Eliaśib cinhintku wan- kan tipi tawa kin mahen iyaya: Unkan en hi qehan aguyapi yute śni qa mini yatke śni ; tona wayaka ewicayayapi qon ihduśicapi kin on iyokiśica nakaeś.

7 Unkan wicaho yaotaninpi, Juda qa Jerusalem en, wayaka unpi cincapi kin owasin Jerusalem en ahi mniciyapi kta:

8 Qa tuwe kaśta anpetu yamni en hi śni kinhan, wicaśta itancanpi qa hunkayapi tawiyukcanpi kin eciyatanhan, he tawalipaya ocowasin ihangyapi kta, qa iye hinca tona wayaka unpi qon omniciye kin etanhan lieyata iyeyapi kta ce.

9 Hehan anpetu yamni en Juda qa Benjamin wicaśta iyuhpa Jerusalem ekta ahi minciyapi. Wi inapcinwanka, wi yawapi anpetu wikcemna nonpa hehantu; unkan oyate iyuhpa Wakantanka ti hocoka kin ohna iyotankapi, wicoie kin de on cancanpi, qa magiaju kin on etanhan.

10 Unkan Ezra wawayuśna kin najinhan najin qa hewicakiya; Niye taku śica ecanonpi qa winohinca toktokeca awicayahdipi, Israel wahtanipi kin yuotapi kta e heon.

11 Heon etanhan wanna Jehor wa niyatepi Taku Wakan tawapi kin woohdake qu po, qa iye toiyokipi kin econ po; qa makoce oyate qa winohinca tokecapi kin etanhan ihduheyapa po.

12 Hehan omniciye ocowasin waayupte qa ho tanka on heyapi ; Niye nioie kin eciyatanhan ecen econkupi kta ce.

13 Tuka oyate kin wicota, qa wanna magaju ota, qa tankan unyakonpi unkokihipi śni ; qa wicohan kin de anpetu wanjidan kte śni, qa anpetu nonpa kte śni : wicoie kin de en woahtani unkihduotapi nakaeś. 


\section{WICOWOYAKE 10.}

14 Heon etanhan omniciye ocowasin on wicaśta itancan unkitawapi hena najinpi kta, qa tona otonwe unkitawapi ohnahna winohinca tokeca wicayuzapi kin hena owasin tohantu eca hipi ecee kta, qa otonwe otoiyohi hunkayapi qa wayaco nakun hena opapi kta; wicoie kin de on Taku Wakan unkitawapi tocanniye ide kin yutokan iyeunkiciciyapi kta hehanyan.

15 Tuka Jonathan Asahel cinhintku qa Jahaziah Tikvah cinhintku kin hena de itkokim inajinpi, qa Meśullam qa Śabbethai Levi wicaśta kin owicakiyapi.

16 Tuka wayaka unpi cincapi kin he ohnayan econpi. Unkan Ezra wawayuśna kin, hunkayapi wicaśta itancanpi atewicayapi tipi kin eciyatanhan, qa tona cajewicayatapi kin owasin hena ihdukinukanpi qa wiroie kin de iyukcanpi kta, wi iwikcemna anpetu tokaheya en iyotankapi. .

17 Qa wi tokaheya anpetu tokaheya hehan wicaśta tona winoliinca tokeca wicayuzapi kin hena iyuhpa wicay uśtanpi.

18 Unkan wawaynśna cincapi etanhan winohinca tokeca wicayuzapi qon dena iyeyapi : Jeśua Jozadak cinhintku kin he cinca qa hunkawanjinwicaye cin etanhan, Marseiah, qa Eliezer, qa Jarib, qa Gedaliah.

19 Unkan winohinca elipewicayapi kta e nape hiyuyapi, qa wahtanipi, hecen woalitani tawapi on optaye etanhan tamdoka wan wayuśnapi.

20 Unkan Immer cinca kin etanhan Hanani qa Zebadiah.

21 Qa Harim cinca kin etanhan, Maaseiah, qa Elijah, qa Śemaiah, qa Jehiel, qa Uzziah.

22. Qa Paśur cinca etanhan,
Elioenai, Maaseiah, Iśmael, $\mathrm{Ne}$ thaneel, Jozabad, qa Elasah. 23 Nakun Levi wicaśta etanhan; Jozabad, qa Śimei, qa Kelaiah-he Kelita ee, Pethahiah, Judah qa Eliezer.

24 Nakun dowanpi kin etanhan, Eliaśib: qa tiyopa awanyakapi kin etanhan, Śallum, qa Telem, qa Uri.

25 Nakun Israel etanhanpi : Paroś cinca etanhan, Ramiah, qa Jeziah, qa Malkiah, qa Miamin, qa Eleazar, qa Malkiyah, qa Benaiah.

26 Qa Elam cinca etanhan, Mattaniah, Zekariah, qa Jehiel, qa Abdi, qa Jeremoth, qa Eliah.

27 Qa Zattu cinca etanhan, Elioenai, Eliaśib, Mattaniah, qa Jeremoth, qa Zabad, qa Aziza. 28 Qa Behai cinca etanhan, Jehohanan, Hananiah, Zabbai, Athlai.

29 Qa Bani cinca etanhan, Meśullam, Malluk, qa Adaiah, Jaśub, qa Śeal, qa Ramoth.

$30 \mathrm{Qa}$ Pahath-moab cinca etanhan, Adnah, qa Kelal, Benaiah, Maaseiah, Mattariah, Bezaleel, qa Binnui, qa Manasseh.

31 Qa Harim cinca kin, Eliezer, Iśiyah, Malkiah, Śmaiah, Śmeon,

32 Benjamin, Malluk, Śemariah.

33 Haśum cinca etanhan, Mattenai, Mattathah, Zabad, Eliphelct, Jeremai, Manasseh, Simei.

34. Bani cinca etanhan, Maadai, Amram qa Uel,

35 Benaiah, Bedeiah, Kelluh,

$36^{\circ}$ Vaniah, Mercmoth, Eliaśib,

37 Mattaniah, Mattenai, qa Jaasan,

38 Qa Bani, qa Binnui, Śsimei, 39 Qa Śelemiah, qa Nathan, qa Adaiah, 


\section{NEHEMIAH,}

40 Maknadebai, Śaśai, Śarai, |Jeiel, Mattathiah, Zabad, Zebina, 41 Azareel qa Śelemiah, Se- Jadua qa Joel, Benaiah. mariah,

42 Śallum, Amariah, Joseph.

43 Nebo cinca kin etanhan, hincâpi hunli cinca wicayuhapi.

\section{NEHEMIAH.}

WICOWOYAKE 1.

1 Nehemiah Hakaliah cinhintku oie kin. Unkan kaketu, Kislu wi kin en waniyetu iwikcemna nonpa, hehan Suśan conkaśke kin ohna waun;

2 Qa Hanani mihunkawanji wan en hi, iye qa Juda wicaśtapi. Unkan wicaśta najicapi, tona wayaka unpi owicakaptapi qon hena on, qa Jerusalem on iwicamunge.

3 Unkan hemakiyapi; Makoce kin he en, wayaka unpi qon owicakaptapi kin hena wokakije tanka qa woaie en unpi : nakun Jerusalem conkaśke kin yujujupi, qa tiyopa kin hena peta on huhnaga ce.

4 Hehan kaketu, wicoie kin hena nawahon qehan imdotanke ca waceya, qa anpetu iyomakiśica, qa wote śni waun, qa Malipiya Wakantanka kin itokam cewakiya; n

5 Qa hepa, Ceciciya, Jehowa Mahpiya Wakantanka, Taku Walkan tanka qa wowinihan, wicotakuye qa wowannśida tona waśtekidapi qa tawoahope ahopapi kin awicakipatan ecee kin:

6 Tokin wanna ninogie anohya yanke ca niiśta hdumdaya, hecen nitaokiye tawocekiye kin nayalion kta, he wanna nitokam cewakiye, anpetu qa hanyetu koya, nitaokiye Israel cinca kin on; qa Israel cinca wahtanipi, niye en waunniciltanipi kin hena owahdaka ece: miye qa ate tiyohnaka koya waunhtanipi nakaeś.

7 Nina pemniyan unkonicihanyanpi, qa wowaśi, qa woope, qa woyaco Moses nitaokiye econ yaśi qon hena unpatanpi śni ece. 8 Ceciciya ce, wicoie Moses nitaokiye econ yaśi qon he kiksuya ye : Wayahtanipi kinhan, oyatepi kin wicennahna ehpeciyapi kta :

9 Tuka miye en ake mayahdipi, qa wowaśi mitawa yapatanpi qa ecen ecanonpi kinhan, niyepi etanhan mahpiya ihanke linca ekta iyaye niyanpi eśta hetanhan mnawicawakiye kta, qa tukte en micaje yanke kta wahdahnige cin hen awicawahdi kta ce, ehe ciqon.

10 Wanna dena nitaokiye qa nitaoyate eepi, nitowaśake tanka qa ninape waśaka on opewicayakiton qon.

11 Jehowa ceciciya, wanna nitaokiye tawocekiye kin en, qa nitaokiyepi nicaje kokipa wacinpi tawocekiyepi kin ekta nino. ge anoliya yanka nunwe: qa anpetu kin de nitaokiye tanyan okihikiya wo, ceciciya, qa wicaśta kin de iśta kin en wowaon. 680 


\section{WICOWOYAKE 2.}

śida yuhekiya ye. Miye wicaśtayatapi tawiyatke mduha ecee nakaeś.

\section{WICOWOYAKE 2.}

1 .Unkan kaketu, Nisan wi kin en, Artahíaśta wicaśtayatapi tawaniyetu iwikcemna nonpa hehan miniśa iye itokam yanka: Unkan miniśa kin iwacu qa wicaśtayatapi kin waqu. Unkan he itokam iyomakiśice śni ecee tuka.

2 Heon etanhan wicaśtayatapi kin hernakiya; Tokeca niite iyokiśica he; tuka waniyazanke śni : wicocante śica ecedan he dee ce. Hehan nina nihinmiciya ;

3 Qa wicaśtayatapi kin hewakiya; Wicaśtayatapi kin ohinniyan ni un nunwe: Tokeca nuite iyokiśice kte śni he, otonwe, atewicawaya wicahapi tipi kin hewoskan wanka, qa tatiyopa kin peta on huhnaga nakaeś.

4 Hehan wicaśtayatapi kin hemakiya; 'Taku e on yada kta he. Hecen Mahipiya Wakantanka kin cewakiya;

5 Qa wicaśtayatapi kin hewakiya; Wicaśtayatapi kin en he waśte kinhan, qa nitaokiye nitokam wowaonśida iyeye cinhan, Juda ekta yemayaśi kta, atewicawaye hnakapi otonwe kin he ekta, hecen piya wakagje kta ce.

6 Hehan wicaśtayatapi kin hemakiya; nakun winohinca tawa iye icahda iyotanka; Oicimani nitawa tohanyan kta he; qa tohan ake yahdi kta he. Hecen wicaśtayatapi kin yemaśi kta iyokipi ; unkan tohanyan kta he owakiyaka.

7 Nakun wicaśtayatapi kin hewakiya; He wicaśtayatapi en waśte kinhan, wakpa akasanpatanhan wicaśta itancanpi wowa- pi wicakicagiapi maqupi kta, hecen Juda ekta wai kta hehanyan amayanpi kta;

8 Qa Asaph wicaśtayatapi contanka tawa awanyake cin he wowapi wan qupi kta, hecen iye can maqu kta, can omdoton tipi conkaśke tiyopa kin on kagapi kta, otonwe conkaśke kin on, qa tipi ohna waun kte cin he on. Unkan mita Wakantanka nape waśte amayanke cin he eciyatanhan wicaśtayatapi kin maqu ece.

9 Hehan wakpa akasanpatanhan wicaśta itancanpi kin en wicawahi, qa wicaśtayatapi tawowapi wicawaqu. Unkan wicaśtayatapi kin ozuye itancanpi qa śuktanka akan yotankapi kin heca mici uwicaśi qon.

10 Unkan Sanballat Horoni kin, qa Tobiah wowidake Ammoni kin hena he nahonpi qehan, wicaśta wan Israel cincapi tanyan unpi kta akita hi kin heon woiyokiśice tanka hinca yuhapi.

11 Hecen Jerusalem en wahi, qa anpetu yamni hen manké.

12 Hehan hanyen nawajin, miye qa wicaśta tonana mici unpi kin: tuka taku Jerusalem ekta ecamon kta. Wakantanka micante en ehnake cin he tuwedan owakiyake śni : nakun woteca wanji mici un śni, miye woteca akan imdotanke cin heceedan.

13 Unkan kaksiza tiyopa kin he ohna hanyen tankan imdamda, wamduśka tamniowe itokam, qa tacesdi tiyopa kin ekta, qa Jerusalem conkaśke yujujupi kin iwarmmake, qa tatiyopa kin hena peta on gipi.

14 Hehan wakoniya tiyopa kin ekta iyoopte mde ca wicaśtayatapi mini ohnaka tawa kin elsta: tuka woteca mihukuya yanke cin he tuktedan hiyaye kte śni. 


\section{NFHEMIAH,}

15 Hehan hanyetu en wakpadan kin ohnayan imdamde, qa conkaśke kin iwanmdake: qa ohomni waku, qa kaksiza tiyopa ohnayan wahdicu qa wahdi.

16 Tuka wicaśta itancanpi kin tukten imdamda qa taku ecamon kin sdonyapi śni; nakun hinyahin Juda wicaśta, qa wawayuśnapi, qa wicaśta ihdawapi, qa wicaśta itancanpi kin owicawakiyake śni, qa tona wohtani econpi kte cin hena.

17 Hehan hewicawakiya; Wośice en unyakonpi kin he niye wandakapi, Jerusalem otiwota wanka, qa tatiyopa kin peta on grupi: U po, qa Jerusalem conkaśke kin unkaggapi kta, hecen sanpa wowiśtece unyakonpi kte śni ce.

18 Hehan Wakantanka nape waśte amayanke cin he owicawakiyaka; qa nakun wicaśtayatapi emakiye ciqon hena. Únkan, Naunjinpi qa unkağapi kta ce, eyapi. Hecen taku waśte on nape ihduwaśakapi.

19 Tuka Sanballat Horoni kin, qa Tobiah wowidake Ammoni kin, qa Geśem Arabi kin, hena he nahompi qehan, wowiliahaunyanpi qa iwahteundapiśni, qa, De taku wicolian ecanonpi he; wicaśtayatapi kin yakipajinpi kta he, eyapi.

20 Hehan wicoie wan itkom wicawaqu, qa hewicawakiya; Mahipiya Wakantanka kin heqe tanyan okihiunyanpi kta; heon etanhan taokiyeunyanpi unkiye naunjinpi qa ti unkagapi kta: tuka niyepi Jerusalem en, woowotanna qa wokiksuye kin, onśpadan nitawapi śni.

WICOWOYAKE 3.

1 Hehan Eliaśib wawayuśna itaacan kin najin qa iye hunka- wanjitku wawayuśnapi kin hena koya, qa tahin wanunyanpi tiyopa kin he kagapi : he yuwakanpi qa tatiyopa kin bosdan ehdepi; han, Meah conkaśke ipasotka hehanyan yuwakanpi, Hananeel conkaśke ipasotka hehanyan.

2 Unkan he nape etanhan Jeriko wicaśta kağapi. Qa iye napepi etanhan Zakur Imri cinhintku kagia.

3 Tuka hogian tiyopa kin he Hassenah cinca kin kagapi, hena cankağa kin ehnakapi, qa tiyopa kin bosdan ehdepi, inatake tawa qa can hdakinyan tawa.

4 Qa hena napepi etanhan Meremoth Urijah cinhintku, $\mathrm{Koz}$ cinhintku kin piya kağa. Qa hena napepi etanhan Meśullam Berekiah cinhintku Meśezabeel cinhintku kin piya kağa. Qa hena napepi etanhan Zadok Baana cinlintku piya kaga.

5 Qa hena napepi eciyatanhan Tekoi wicaśta kin piya kağapi; tuka wicaśta tanka wicayuhapi kin hena Itancan tawapi tawohtani en tahu ekihnakapi śni.

6 Nakun tiyopa tanni qon he Jehoida Paseha cinhintku piya kag̣a, qa Meśullam Besodeiah cinhintku: hena cankaģa ehnakapi qa tatiyopa bosdan ehdepi, qa inatake tawa, can hdakinyan tawa koya.

7 Unkan hena napepi etanhan Melatiah Gibeoni kin, qa Jadon Meronothi kin, Gibeon ga Mizpah wicaśta kin piyapi, wakpa akasanpatanhan wicaśta itancan toiyotanke kin hehanyan.

8 Qa he nape eciyatanhan Uzziel Harhaiah cinhintku, mazaskazi kağapi etanhan, he piya kağa. Qa iye nape eciyatanhan Hananiah pejihuta kaǵapi ecee cinca wan he piya kaga. Unkan con-

682 


\section{WICOWOYAKE 3.}

kaśke hdakinyan tanka kin hehanyan Jerusalem okaptapi.

9 Qa hena napepi eciyatanhan Rephaiah Hur cinhintku Jerusalem hanke en itarican kin he piya kağa.

$10 \mathrm{Qa}$ hena napepi eciyatanhan Jedaiah Harumap cinhintku piya kaga, he qe iye ti kin iyotakonza. Qa he nape eciyatanhan Hattuś Haśabniah cinhintku kin piya kagja.

11 Wiyutapi inonpa kin he Malkiya Harim cinhintku, qa Haśub Pahath-moab cinhintku piya kağapi, qa nakun mazaoceti conkaśke ipasotka kin.

$12 \mathrm{Qa}$ he nape eciyatanhan Sallum Haloheś cinhintku, Jerusalem hanke en itancan kin hee piya kagga, iye qa cunwintkuwicaye cin.

13 Kaksiza tiyopa kin he Hanun piya kağa, qa Zanoah en ounyanpi kin: hena he kağapi, qa tatiyopa kin bosdan ehdepi, inatake tawa qa canhdakinyan tawa; nakun conkaśke en wiciśpa kektopawinge, tacesdi tiyopa kin hehanyan.

14 'Tuka tacesdi tiyopa kin he Malkiya Rekab cinhintku, Bethhakarem hanke en itancan kin he piya kagga; he kage ca tatiyopa kin bosdan ehde, inatake tawa qa canhdakinyan tawa nakun.

15 Tuka miniyorve tiyopa kin he Śllum Kol-hozeh cinhintku, Mizpah hanke en itancan kin he piya kagga; he kage ca akahpa, qa tatiyopa kin bosdan ehde, inatake tawa qa canhdakinyan tawa, nakun Siloah miniyowe conkaśke kin wicaśtayatapi tawoju kin icahda, qa Dawid totonwe etanhan caniyamanipi apamahde iyaye cin hehanyan.
Azbuk cinhintku piya kag'a, Beth-zur hanke en itancan kin hee, wicahnakapi Dawid tawa kin iyotakonza, qa miniyowe kağapi kin hehanyan, qa waśakśakapi tipi kin ekta.

17 He iyohakam Levi wicaśta piyapi, Rehum Bani cinhintku. He nape eciyatanhan Haśabiah, Keilah banke en itancan kin he piya kağa, iye hanke kin on.

$18 \mathrm{He}$ iyohakam iye hunkawanjitkupi piya kaǵapi, Binnui Henadad cinhintku, Keilah hanke en itancan kin hee:

19 Qa iye nape eciyatanhan Ezer Jeśua cinhintku Mizpah en itancan he piya kaģa, onśpa inonpa, oise en wipe opiye kin ekta yapi iyotakonza.

$20 \mathrm{He}$ iyohakam Baruk Zabbai cinhintku onśpa tokeca wan cancanse piya kaga, oyuktan kin hetanhan Eliaśib wawayuśna ifancan ti tiyopa kin hehanyan.

$21 \mathrm{He}$ iyohakam Meremoth Uriyah cinhintku Koz cinhintku nakun onśpa kagoa, Eliaśib ti tatiyupa kin hetanhan, qa Eliaśib ti ihanke kin hehanyan.

$22 \mathrm{Qa}$ he iyohakam wawayuśnapi kin piyapi, makomdaye wicaśta kin hena.

23 He iyohakam Benjamin qa Haśub piya kağapi, iye tipi iyotakonza. He iyohakam Azariah Maaseiah cinhintku Ananiah cinhintku piya kağa, iye ti kin icahda.

24 He iyohakam Binnui Henadad cinhintku onśpa inonpa kaga, Azariah ti kin hetanhan oyuktan kin hehanyan, han, oise kin hehanyan.

25 Palal Uzzai cinhintku kin he oyulitan iyotakons econ, qa conkaśke ipasotka wicaśtayatapi tipi tehanwankantu kin iheyata wanke cin, wicakaśka tipi hoco683 


\section{NEHEMIAH,}

ka kin icahda. He iyohakam Pedaiah Paroś cinhintku econ. 26 Nakun Nethinim Ophel (paha) en tipi qon hena mini tiyopa wiyohiyanpatanhan wanke cin iyotakonza, qa ipasotka tankan wanke cin hehanyan conpi.

27 Hena iyohakam Tekoi kin onśpa tokeca nakun piyapi, ipasotka tanka heyata wanke cin iyotakons, qa Ophel conkaśke kin hehanyan.

28 Śuktanka tiyopa Kin iwankapatanhan wawayuśnapi kin piyapi, otoiyohi iye ti iyotakonza.

29 Hena iyohakam Zadok Immer cinhintku lin piya kagia, iye ti kin iyotakonza. He iyohakam Śmaiah Śekaniah cinhintku wiyohiyanpata tiyopa awanyake cin he piya kaǵa.

30 He iyohakam Hananiah Ślemiah cimhintku qa Hanan Zalaph cinca wiciśakpe kin onśpa tokeca piyapi. He iyohakam Meśullam Berekiah cinhintlu piya kağa, iye ti kin iyotakonza. 31. He iyohakam Malkiah mazaskazi kage cin cinhintku kin piya lagga, Nethinim tipi qa wopctonpi kin hehanyan, Mipkad tiyopa kin iyotakonza, qa oise ekta wankan yapi kin hehanyan.

32 Qa oise elsta yapi qa tahiuca wanunyanpi tiyopa kin otahedan mazaskazi kağapi ecee kin, qa wopetonpi kin hena piya kagapi.

\section{WICOWOYAKE 4.}

1 Tuka kaketu, conkaśke kin he unkag'api he Sanballat nation qehan, canniyan qa nina śihda qa Juda wicaśta iwicahaha.

2 Qa iye hunkawanjiwicaye cin qa Samaria ozuye kin wicitolam ie ça heya; Juda wicaśta lianyanpi kin dena taku econpi he: iye ihduśpapi kta he: wayuśnapi kta he: anpetu wanjidan en hduśtanpi kta he ; maka paha etanhan inyan kin qa tona lukinağe ciqon hena kiniyapi kta he.

3 Unkan Tobiah Ammoni kin he icahda yanka qa heya; Taku kagiapi kin he śungidan wan akan ye cinhan, inyan conkaślze tawapi kin najuju kta ce.

4 Wakantanka unkitawapi, nahon ye; unkiye unkihahapi nakaeś: qa wowihah̉a tawapi kin he iye papi en ihdoyeya wo, qa wayaka unpi makoce en womanon wicakaga wo :

5 Qa taku śica econpi kin akahpe śni wo, qa woahtani tawapi nitokam wanke cin he kajuju śni wo : ticagiapi kin wicitokam wacanniyan econpi nakaeś.

6 Hecen conkaśke kin unkağapi : Unkan conkaśke ocowasin hanke kin kici icikoyagyapi : oyate kin wicohtani ekta canteyuzapi nakaeś.

7 Hehan kaketu, Sanballat qa Tobiah, qa Arabi kin, qa Ammoni kin, qa Aśdodi kin hena Jerusalem conkaśke kin wankan ye cin he nahonpi qehan, ohna yujujupi qon hena piya kagapi, hehan nina śihdapi,

$8 \mathrm{Qa}$ iyuhpa okodakiciye ic̣icagapi, Jerusalem en hipi qa kici kicizapi kta, qa yuśna kiyapi kita.

9. Tuka Taku Wakan unkitawapi ceunkiyapi, qa hena on akicita najinwicunkiyapi, hena iyotakons.

10 Hehan Juda heya; Watokśupi towaśake kin hanyan, qa hinyahin maka ota; hecen unkagiapi unkokihipi śni ce.

11 Qa tokaunyanpi kin heyapi ; Sdonyapi kte śni qa wanyakapi 


\section{WICOWOYAKE 5.}

kte śni, ecen wicacokaya unkupi kta, qa wicunktepi kta, qa wohtani kin ayuśtanunkiyapi kta ce.

12 Unkan kaketu, Juda wicaśta wicikiyedan tipi kin hena hipi, qa wikcemna akihde heunkiyapi; Makoce totanhan yaupi owasin unkiye en yahdipi kta ce; eyapi.

13 Heon etanhan conkaśke iheyata kuya owanka kin en, qa tukten pahaya wanke cin hen ewicawahde; han, miye qe oyate ewicawahnaka, wicowazi eciyatanhan, mazasagye, wahukeza, qa tinazipe hduhapi.

14 Hehan watonwan, qa nawajin, qa wicaśta ihdawapi qa wicaśta itancanpi qa oyate unmapi lin hewicawakiya; Hena ihnuhan kowicayakipapi kinhan; Itancan tanka qa wowinihan kin he kiksuya po, qa nihunkawanjipi on, nicinkśipi, nicunkśipi, nitawinpi, qa yatipi kin on kiza po.

15 Unkan kaketu, he unkiye wanna sdonunyanpi qa iye tawacinpi qon Wakantanka yuecetu śni, he tokaunyanpi kin nahonpi qehan, hehan unkiye iyuhpa conkaśke kin en unhdapi, otoiyohi iye tohtani hin ekta.

16 Unkan kaketu, anpetu kin hetanhan, kośka mitawa hanke wicohtani kin en econpi, qa unma hanke kin iś wahukeza, nakun wahacanka, qa itazipa qa maza wokoyake hduha unpi : qa wicaśta itancanpi kin hena Juda tiyohnaka ocowasin wicilieyata yukanpi.

17 Tona conkaśke en kag̉api, qa tona woqin yuwankan iyeyapi tokśupi ko, otoiyohi nape wanji on wolitani econ, qa nape unma kin ohna wipe hduha un ece.

18 Ticagiapi kin otoiyohi mazasagye sican en iyahdaśkapi na- kaeś, qa hecen kaǵapi ecee. Qa mazayahotonpi yahoton ece kin he micahda yanka.

19 Hehan wicaśta ihdawapi qa wicaśta itancanpi, qa oyate unmapi kin hewicawakiya; Wicohan kin tanka qa tankaya wanke, qa unkiye conkaśke kin akan otoiyohi takodaku kin icitehanyan unyakonpi :

20 Tuktetu kaśta mazayahotonpi ho kin nayahonpi kinhan, hen unkiyepi en nihduwitayapi kta: Taku Wakan unkitawapi kin he okicize ecaunkiconpi kta ce.

21 Unkiye wicohan kin en hecen htaunnipi; qa hena etanhan hanke wahukeza hduhapi, anpao hinanpe etanhan qa wicanhpi taninin hehanyan.

22 Nakun he ehan oyate kin hewicawakiya; Otoiyohi taokiye kici Jerusalem mahen iwankapi kta, hecen hanyetu icunhan akicita unkici najinpi kta qa anposkantu htanipi kta.

23 Hecen miye hinca, qa mihunkawanji, qa mitaokiye, qa wicaśta akicita najinpi miyahna unpi kin, unkiyepi tuwedan wokoyake unhduśdokapi śni-otoiyohi wipe hduha mini ekta yapi ecee.

\section{WICOWOYAKE 5 .}

1 Heharn oyate qa tawicupi kin hoyeyapi tanka yukan, iye hunkawanjitkupi Juda wicaśta kin on.

2 Qa heyapi yukan; Unliyepi, unkicinkśipi, unkicunkśipi, wicota; heon etanhan agguyapi unkicupi ece, hecen wauntapi qa unnipi kta ce.

3 Nakun kaken eyapi yukan; Mağa unkitawapi, qa hastanhanka ojupi unkitawapi, qa untipi 685 


\section{NEHEMIAH,}

kin hena inahniyan wiyopeunyanpi, on aǵuyapi opeuntonpi kta, wicaakilian kin on etanhan.

4 Nakur heyapi yukan; Wicaśtayatapi tawomnaye on mazaska unkodotapi, mağa qa hastanhanka ojupi unkitawapi kin on.

5 Tuka wanna uncelipipi kin hunkawanjinunyanpi celipipi kin iyececa, unkicincapi kin hena iye cincapi iyececapi: Unkan iho, cinkśiwicunyanpi qa cunkśiwicunyanpi kin hena wowidake wicunkagapi; qa cunkśiwicunyanpi wanjikji wanna wowidake unpi; qa unnapepi ohna takudan yanke śni; qa mağa unkitawapi, hastanhanka ojupi unkitawapi ko wicaśta tokeca yuhapi.

6 Hehan hoyeyapi qa wicoie dena nawahion qehan, nina śinwahda.

7 Hehan micante mici wohdaka, qa wicaśta ihdawapi qa wicaśta itancanpi kin iyopewicawaya qa hewicawakiya; Woicage on, otoiyohi iye hunkawanjitku kin, owicayaqupi ecee. Unkan wicitkokim omniciye tanka ewahnaka ;

$8 \mathrm{Qa}$ hewicawakiya; Unkiye unkokihipi eciyatanhan Juda wicaśta hunkawanji wicunyanpi Ikcewicaśta ekta wiyope wicayapi qon hena opewicunkitonpi : unkan niyepi qe nihunkawanjipi wiyopeye wicayayapi kta he; qa unkiye hena opewicuntonpi kta he. Hehan inina unpi, qa wicoie takudan iyeyapi śni.

9 Naliun hepa; 'Taku ecanonpi kin he waśte śni : Wakantanka unkitawapi tokokipe kin ohna mayanipi kta iyecece śni he, Ikcewicaśta tokaunyanpi tawowihaha kin on etanhan.
10 Nakun miś eya, mihunkawanji qa mitaokiye kin, mazaska qa aguyapi owicunqupi ece : ceciciyapi, woicage kin de unkayuśtanpi kta.

11 Ceciciyapi, anpetu kin de wicakicu miye, magga tawapi, hastanhanka ojupi tawapi, wihdi canwojupi tawapi, qa tipi tawapi qon, nakun mazaska iyopawinge kin he, qa aǵtuyapi kin etanhan, miniśa qa wihdi owicayaqupi kin etanhanhan.

12 Hehan heyapi; Unkicupi kta, qa hena etanhan takudan undapi kte śni; hecen niýe ehe cin ohna econkupi kta ce. Hehan wawayuśnapi kin wicaweco, qa wicoie kin de eciyatanhan econpi kta keya iciconswicawakiya.

13 Nakiun śiyoto wahdatata qa hepa; Wicaśta otoiyohi wicoie kin de ohnayan econ śni kinhan, iye ti kin etanhan qa iye tokamna kin etanhan, Taku Wakan kin kadada nunwe : han, decen katatapi qa yucokapi kta. Unkan omniciye ocowasin, Amen, eyapi qa Jehowa yatanpi. Unkan oyate kin wicoie kin he ohnayan econpi.

14 Nakun anpetu totanhan Juda makoce kin en wicaśtayatapi mayuhapi kta makaggapi, Artahśaśta wicaśtayatapi tawaniyetu iwikcemna nonpa hetanhan, qa tawaniyetu wikcemna yamni sanpa inonpa hehanyan, waniyetu akenonpa, miye qa mihunkawanji wicaśtayatapi tawote kin untapi śni.

15 Tuka wicaśtayatapi tokaheyapi, mitokam unpi qon, oyate kin en tkeya yakonpi, qa hena etanhan ağuyapi qa miniśa icupi ecee, nakun mazaska śekel wikcemna topa: han, iye taokiyepi heepi kaeś oyate kin en itancan- 


\section{WICOWOYAKE 6.}

pi ece: tuka miye qe hecen ecamon śni, Wakantanka tokokipe on etanhan.

16 Han, nakun conkaśke wohtani kin de en ecamon ecee, qa mağa takudan opeuntonpi śni: tuka mi taokiye iyuhpa wicohtani kin he en mniciyapi ece.

1; Nakun wahna wotapi mitawa en Juda wicaśta qa wicaśta itancanpi opawing'e sanpa wikcemna zaptan, qa tona Ikcewicaśta ihdukśan hiyeye cin etanhanhan en unhipi ecee.

18 Unkan anpetu iyohi taku kagapi ecee kin, tatanka wanjidan, tahinca waśteśte śakpe, qa nakun wahupakoza micağapi, qa anpetu wikcemna eca miniśa ocaje owasin hnakapi ece. Tuka hececa eśta wicaśtayatapi tawoyute wada śni, oyate kin de en wicohtani tkeya wanka nakàeś.

19 Wakantanka mitawa, taku waśte on miksuya ye, taku oyate kin de ecawicawecon owasin on etanhan.

\section{WICOWOYAKF 6.}

1 Hehan kaketu, Sanballat, qa Tobiah, qa Geśem Arab wicaśta kin, qa tokaunyanpi unmapi kin hena conkaśke wakağa qa en oyujuju takudan okaptapi śni he nahonpi qehan-tuka he ehan oyuganpi en tiyopa kin ewahde śni tuka :

2 Hehan Sanballat qa Geśem heya wahomayanpi : Kuwa, Ono omdaye ohna otonwe kin en unwitayapi kta ce. Tuka taku śíca ecamicon wacinpi.

3 Unkan hena ekta wahośiya heyá yewicawaśi; Wicohan tanka wan ecamon manka, hecen kun wau kta owakihi śni. Tokeca ecin ehpewaye ca en ciupi kta icunhan wicolian kin ayuśtanpi kta he.

4 Tuka wicoie kin de iyecen topa akilhde wahomayanpi ; unkan miye wicoie kin he iyecen awicamdupta ece.

5 Hehan wicoie kin he iyecen, Sanballat iye taokiye kin miye en izaptan uśi, qa nape ohna wowapi yumdayapi wan:

6 Mahen wowapi ; Ikcewicaśta ehna hecen oyakapi, 'qa Geśem heya-niye qa Juda wicaśta wawakipajin wacannipi: heon etanhan conkaśke kin yakagga, hecen niye wicaśtayatapi niyuhapi kta, wicoie kin dena iyececa.

7 Qa nakun niye wicaśta wokcan Jerusalem en eyannicipahapi kta wicayakahinigia; Juda en wicaśtayatapi yanka ce, eyapi. Unkan nakaha wicoie kin dena iyecen wicaśtayatapi kin okiyakapi kta he. Heon etanhan u wo, qa witaya wounhdakapi kta ce.

8 Hehan heya wahowaya; Niye ehe cin ohna wicoie kin takudan econpi śni; tuka nicante etanhan hena ituya yakaga ce.

9 Hena iyuhipa wakokipe unkicaġapi nakaeś: Napepi kin wicohan en yuwaśakapi kte śni, hecen yuśtanpi kte śni ce, eyapi ece. Heon etanhan wanna nape mayuwaśaka wo.

$10 \mathrm{He}$ iyohakam Śsemaiah Delaiah cinhintku, Mehetabeel cinhintku, ti kin en wahi, unkan he ohna natakapi: Hehan heya; Wakantanka ti kin ohna unwitayapi kta, tipi wakan cokahan, qa tipi wakan tiyopa kin nauntakapi kta : hena nicaśtakà hipi kta nakaeś ; han, hanyetu en nicaśtaka hipi lita ce, eya.

11 Tuka hepa; Wicaśta dema- 


\section{NEHEMIAH,}

ceca najice kta iyececa he : qa tuwe e miye iyecen un kinhan tipi wakan timahen niiciya ye kta he. Mahen mde kte śni ce, epa.

12 Hehan iwanmdaka, unkan iho, Wakantanka uśi śni, woyake kin de omakiyake kta, tuka Tobiah qa Sanballat he opetónpi.

13 Heon etanhan opetonpi, hecen wakowakipe kta, qa ohnayan ecamon kta, qa wawahtani kta, qa iye woyake sica yuhapi kta, on iyopemayanpi kta.

14 Wakantanka mitawa, Tobiah qa Sanballat wicakiksuya wo, taku econpi kin dena on, qa nakun Noadiah winyan wokcan kin, qa wicaśta wokcanpi unmapi, hena wakokipe micagapi kta tuka.

15 Hecen conkaśke kin yuśtanpi, Elul wi en, anpetu wikcemna nonpa sanpa izaptarı qehan, anpetu wikcemna zaptan sanpa nonpa en.

16 Unkan kaketu, tokaunyanpi owasin nahonpi, qa Ikcewicaśta unkihdukśan unpi owasin wanyakapi qehan, iye iśtapi en kun iyeiciyapi; qa wicohan kin de Taku Wakan unkitawapi eciyatanhan econpi sdonyapi.

17 Nakun anpetu kin hena en Juda wicaśta ihdawapi wowapi ota Tobiah kicağapi, qa Tobiah tawa hena iś en wicahipi.

18 Juda en wicota he en iciconzapi, he qe Śckaniah Arah cinhintku, he takośku nakaeś: qa iye cinhintku Johanan he Meśullam Berekiah cinhintku he cunwintku kin yuza.

19 Nakun iye tohan waśte kin mitokam oyakapi, qa miye mioie kin hena iye okiyakapi ecee. Wakokipe micagie kta on Tobiah wowapi ukiya ece.

\section{WICOWOYAKE $\%$}

1 Hehan kaketu, conkaśke kin wanna kaǵapi, qa tiyopa kin bosdan ewahde, qa tiyopa awanyakapi, qa dowanpi kin, qa Levi wicaśta kin wicakabnigapi ;

2 Hehan mihunkawanji Hanani qa Hananiah conkaśke tipi itancan kin, hena Jerusalem awanyag wicawaśi; he qe wicaśta iewicaka, qa wicota isanpa Wakantanka kokipa nakaeś:

3 Qa hewicawakiya; Wi kata śni hehanyan Jerusalem tiyopa kin yuhdokapi śni: qa en najinpi icunhan tiyopa ecen iyeyapi qa natakapi kta: qa Jerusalem en ounyanpi etanhan akicita najin wicaśi po, otoiyohi taawanyake kin en, qa otoiyohi iye ti kin iyotakonza.

4 Unkan otonwe kin anokatanhan hanska qa tanka; tuka oyate ohna tonana, qa tipi kin hinyahin kağapi śni.

5 Hehan Taku Wakan mitawa hecen cante yusmakiya, wicaśta ihdawapi qa wicaśta itancanpi qa oyate kin mniciye wicawaśi, hecen owicawapi qon eciyatanhan wicayawapi kta. Unkan owicawapi wowapi wan tona tokaheya hdicupi qon he iyewaya, qa ohna decen owapi iyewaya; 6 Makoce cincapi wayaka unpi etarnan hiyupi, trnna wayaka awicakiyahdapi, Nebukadnezzar Babel wicaśtayatapi awicakiyahde ciqon etanhan dena eepi, unkan Jerusalem qa Juda en hdipi otoiyohi iye totonwe kin ekta.

7 Hena Zerubabel, Jeśua, Nehemiah, Azariah, Rsamiah, Nahamani, Mordekai, Bilśan, Mispereth, Bigvai, Nahum, Baanah om hipi. Israel oyate wicaśta wicayawapi kin: 


\section{WICOWOYAKE 7 .}

8 Paroś cinca kin kektopawing nonpa, qa opawinge sanpa wikcemna śakowin sanpa nonpa.

9 Śephatiah cinca kin opawinge yamni qa wikcemna śakowin sanpa nonpa.

10 Arah cinca kin opawinge s̉akpe qa wikcemna zaptan sanpa nonpa.

11 Pahath-moab cinca kin, Jesua qa Joab cincapi, kektopawinge nonpa, qa opawinge sahdoğan sanpa akeśahdog̣an.

12 Elam cinca kin kektopawinge qa opawinge nonpa sanpa wikcemna zaptan sanpa topa.

13 Zattu cinca kin opawinge śahdoğan qa wikcemna topa sanpa zaptan.

14 Zakai cinca kin opawinge śakowin sanpa wikcemna śakpe.

15 Binnui cinca kin opawinge śakpe qa wikcemna topa sanpa śahdoğan.

16 Bebai cinca kin opawinge śakpe qa wikcemna nonpa sanpa śahdog̣an.

17 Azgad cinca kin kektopawinge nonpa, qa opawinge yamni, sanpa wikcemna nonpa sanpa nonpa.

18 Adonikam cinca kin opa. winge śakpe qa wikcemna śakpe sanpa śakowin.

19 Bigvai cinca kin kektopawinge nonpa qa wikcemna śakpe sanpa śakowin.

20 Adin cinca kin opawinge śakpe qa wikcemna zaptan sanpa zaptan.

21 Ater cinca, Hezekiah etanhan, wikcemna napcinwanka sanpa śahdogan.

22 Haśum cinca kin opawinğe yamni qa wikcemna nonpa sanpa śahdoğan.

23 Bezai cinca kin opawinge yamni qa wikcemná nonpa sanpa topa.
24. Hariph cinca kin opawing sanpa akenonpa.

25 Gibeon cinca kin wikcemna napcinwanka sanpa zaptan.

26 Bethlehem qa Netopha wicaśta kin, opawinge qa wikcemna sahdogan sanpa śahdog'an.

27 Anathoth wicaśta kin opawinge qa wikcemna nonpa sanpa šblohdogian.

28 Beth-azmaveth wicaśta kin wikcemna topa sanpa nonpa.

29 Kirjath-jearim, Kephirah qa Beeroth wicaśta kin opawinge śakowin qa wikcemna topa sanpa yamni.

30 Ramah qa Gaba wicaśta kin opawing śakpe qa wikcemna nonpa sanpa wanjidan.

31 Mikmas wicaśta kin opawinge qa wikcemna nonpa sanpa nonpa.

32 Bethel qa Ai wicaśta kin opawinge qa wikcemna nonpa sanpa yamni.

33 Nebo unma qon wicaśta kin wikcemna zaptan sanpa nonpa.

34. Elam unma kin cinca, kektopawinge qa opawinge nonpa, sanpa wikcemna zaptan sanpa topa.

35 Harim cinca kin opawing yamni sanpa wikcemna nonpa.

36 Jeriko cinca kin opawinge yamni aa wikcemna topa sanpa zaptan.

37 Lod, Hadid, qa Ono cincapi, opawinge śakowin, qa wikcemna nonpa sanpa wanjidan.

38 Senaah cinca kin kektopawinge yamni, qa opawinge napcinwanka sanpa wilkcemna yanini.

39 Wawayuśnapi kin : Jedaiah cinca kin, Jeśua tiyohnaka etanhan, opawinge napcinwanka, qa wikcemna śakowin sanpa yamni. 40 Immer cinca kin kektopa689 


\section{NEHEMIAH,}

winge qa wikcemna zaptan sanpa nonpa.

41 Paśur cinca kin kektopawing'e, qa opawinge nonpa, sanpa wikcemna topa sanpa śakowin.

42 Harim cinca kin kektopawinge qa ake śakowin.

43 Levi wicaśta kin: Jeśua cinca kin, Kadmiel etanhan, Hodevah cinca etanhan, wikcemna sakowin sanpa topa.

44 Dowanpi kin: Asaph cinca kin opawinge, qa wikcemna topa sanpa śahdogian.

45 Tiyopa awanyakapi kin: Sallum cinca, Ater cinca, Talmon cinca, Akkub cinca, Hatita cinca, Śobai cinca, opawinge qa wikcemna yamni sanpa śahdog’an.

46 Nethinim kin: Ziha cinca, Haśupha cinca, Tabbaoth cinca,

47 Keros cinca, Sia cinca, Padon cinca,

48 , Lehana cinca, Hagaba cinca, Ślmai cinca,

49 Hanan cinca, Giddel cinca; Gahar cinca,

50 Reaiah cinca, Rezin cinca, Nekoda cinca,

51 Gazzam cinca, Uzza cinca, Phaseah cinca,

52 Besai cinca, Meyunim cinca, Nephiśesim cinca,

53 Bakbuk cinca, Hakupha cinca, Harhur cinca,

54 Bazlith cinca, Mehida cinca, Harśa cinca,

55 Barkos cinca, Sisera cinca, Tamah cinca,

56 Neziah cinca, Hatipha cinca lin.

57 Solomon wowidake tawa cincapi kin: Sotai cinca kin, Sophereth cinca kin, Perida cinca kin,

58 Jaala cinca kin, Darkon cinca kin, Giddel cinca kin,

690
59 Śephatiah cinca kin, Hattil cinca, Pokereth Zebaim etanhan he cinca, Amon cinca kin.

60 Nethinim iyulipa qa Solomon tawowidake cincapi kin, opawinge yamni, qa wikcemna napcinwanka sanpa nonpa.

61 Unkan tona Tel-melah, Telhareśa, Kerub, Addon qa Immer etanhanhan itanwankanhde yapi kin dena eepi ; tuka atkukupi tipi kin ohdag okihipi śni, qa wicoicagge tawapi, Israel etanhanpi hecinhan:

62 Delaiah cinca, Tobiah cinca, Nekoda cinca, opawinge śakpe qa wikcemna topa sanpa nonpa.

63 Qa wawayuśnapi kin etanhanpi : Habaiah cinca, Koz cinca, Barzillai cinca, he qe Barzillai Gileadi cunwintku etanhan winohinca yuza, qa iye cajepi on cajeyatapi.

64 Dena wicoicage owicawapi kin en tawowapi akitapi, tuka iyeyapi śni : heon etanhan wicayuśapapi iyecen wawayuśnapi etanhan tankan iyewicayapi.

65 Unkan Tirśatha (wicaśta itancan) kin, hena taku iyotan wakan kin etanhan yutapi kte śni, tohan wawayuśna wan $\mathrm{Yu}$ rim qa Thummim (Iyoyanpa qa Wowicake) yuha najin śni hehanyan, kewicakiya.

66 Omniciye ocowasin yuwitaya kektopawinge wikcemna topa sanpa nonpa, qa owawinge yamni sanpa wikcemna śakpe.

67 Wicaśta taokiye qa winyan taokiye wicayuhapi kin opapi śni, hena e kektopawinge śakowin, qa opawinge yamni sanpa wikcemna yamni sanpa śakowin: Nakun wicaśta dowanpi qa winyan dowanpi kin opawinge nonpa qa wikcemna topa sanpa zaptan wicayuhapi. 


\section{WICOWOYAKE 8.}

68 Suktanka tawapi kin opawing e śakowin qa wikcemna yamni saupa śakpe: śonśonna tawapi opawinge nonpa qa wikcemna topá sanpa zaptan :

69 Kamel opawinge topa, qạ wikcemna yamni sanpa zaptan : śonśonna nakpa tanka iś kektopawinge śakpe, qa opawinge śakowill sanpa wikcernna nonpa.

70 Unkan atewicayapi itancanpi kin apa wicohtani kin en waehpeyapi: 'Tirśatha kin iś mazaskazi drakma kektopawinge, wakśica wikcemna zaptan, wawayuśnapi tawokoyake opawinge zaptan sanpa wikcemna yamni mazopiye kin en elipeya.

$71 \mathrm{Qa}$ atewicayapi itancanpi kin etanhan, wicohtani mazopiye kin en chpeyapi, maraskazi drakma kektopawinge wikcemna nonpa, qa mazaska woqin kektopawinge noupa sanpa opawinge nonpa.

72 $\mathrm{Qa}$ oyate unmapi kin iś en ehpeyapi kin, mazaskazi drakma kektopawinge wikcemna nonpa, qa mazaska woqin kektopawinge nonpa, qa wawayuśnapi tawokoyake wikcemna śakpe sanpa śakowin.

73 Hecen wawayuśnapi, qa Levi wicaśta kin, qa tiyopa awanyakapi kin, qa dowanpi kin, qa oyate etanhanpi, qa Nethinim kin, qa Israel ocowasin iye totonwepi kin ohna tipi : Unkan wi iśakowin hiyohi qehan, Israel cincapi kin iye totonwepi kin ohnahna yakonpi.

\section{WICOWOYAKE 8:}

1 Unkan oyate ocowasin kin, wicaśta wanjidan se, witaya mniciyapi, mini tiyopa itokam canku kin he ohna; qa Ezra wowapi kagie cin, Moses toope wowapi kin, Jehowa Israel econwicaśi qon he ahi kta keciyapi.

2 Hehan Ezra wawayuśna kin woope kin ahi, omniciye kin itokam, wica qa winyan, qa tona nakon okahnigapi kin iyuhpa, wi iśakowin anpetu tokaheya en.

3 Qa he etanban yawa, mini tiyopa kin itokam, canku itokam wanke cin hetu, anpa kamdeze hetanhan wicokahan hehanyan, wicaśta qa winohinca, qa tona okahnih okihipi kin wicitokam: Unkan oyate ocowasin noggepi kin woope wowapi kin ekta yanka.

4 Unkan Ezra wowapi kag'e cin can paha wan, on kagapi kin he akan najin, qa isakim Mattithiah, qa Sema, qa Anaiah, qa Uriyah, qa Hilkiah, qa Maaseiah, iye etapa eciyatanhan najinpi; qa iye catkatanhan, Pedaiah, qa Miśael, qa Malkiah, qa Haśum, qa Haśbadana, Zekariah, Meśullam.

5 Unkan oyate ocowasin iśtapi itokam Ezra wowapi kin yumdaya; iye oyatc kin iyulipa wiciwankam un nakaeś: Unkan he yumdaya hehan oyate kin owasin najinhan najinpi.

6 Hehan Ezra Jehowa Taku Wakan tanka kin yawaśte. Qa oyate ocowasin, Amen, Amen, eya ayuptapi, qa nape hdugatapi : qa pamahdedan hiyeya, qa ite makipusdiya Jehowa ohodapi.

7 Nakun Jeśua, qa Bani, qa Śerebiah, Jamin, Akkub, Śabbethai, Hodiyah, Maaseiah, Kelita, Azariah, Jozabad, Hanan, Pelaiah, qa Levi wicaśta kin hena woope kin okahniliwicakiyapi. Unkan oyate kin najin yakonpi.

8 Hecen Wakantanka toope wowapi kin etanhan ieskaya yawapi, qa wookahniğe wicaqupi, qa wayawapi kin okahniliwicakiyapi ece. 


\section{NEHEMIAH,}

9 Unkan Nehemiah Tirśatha kin hee, qa Ezra wawayuśna wowapi kage cin he, qa Levi wicaśta oyate waonspewicakiyapi kin hena oyate kin ocowasin hewicakiyapi; Anpetu kin de Jehowa Taku Wakan nitawapi kin ekta wakan; waśihdapi śni po, qa ceyapi śni po. Oyate kin iyuhpa ceyapi nakaeś, woope oie nahonpi qehan.

10 Hehan hewicakiya; Ya po, wasna tasaka kin yuta po, qa woskuye kin yatkan po, qa tona taku wiyeya ekicihnakapi śni kin hena ong'eg'e wicakaya po. Anpetu kin de Jehowa unkitawapi kin on wakan nakaeś; qa iyokiśicapi śni po, Jehowa towiyuśkin kin nitowaśakepi kin hee nakaeś.

11 Hecen Levi wicaśta kin oyate owasin wicayuininapi : Inina yukan po, anpetu kin wakan nakaeś; qa niye cante śicapi śni po, eyapi.

12 Unkan oyate kin owasin iyayapi, wotapi kta qa wayatkanpi kta, qa wawicaqupi kta, qa wowiyuśkin tanka kagapi kta, wicoie owicakiyakapi kin hena okahnig̣api nakaeś.

13 Nakun anpetu inonpa en oyate owasin etanhan atewicayapi itancanpi kin, wawayuśnapi qa Levi wicaśta kin hena Ezra wowapi kagge cin en witaya mniciyapi, hecen woope oie kin onspeiciciyapi kta.

14 Unkan woope Jehowa Moses nape eciyatanhan econwicaśi kin en wowapi iyeyapi, wi iśakowin wotapi kin icunhan Israel cincapi kin ohanzi hdepi ohna tipi kta ce :

15 Qa iye totonwepi kin owasin en, qa Jerusalem en, woyakapi qa eyanpahapi kta, Ḧe kill ektakta ya po, qa wihdi can adetka, qa wazi can adetka, qa wağa can adetka, qa tamar can adetka, qa can wośma adetka kin aku po, ohanzi hdepi kaġapi kta, wowapi qon iyececa, eyapi.

. 16 Hecen oyate kin iyayapi, qa ahdipi, qa wokeya icicagapi, otoiyohi iye tipi akahpa akankan, qa tahocolapi kin en, qa "Taku Wakan ti tahocoka kin en, qa mini tiyopa canku kin he ohna, qa Ephraim tatiyopa canku kin ohna.

$1 \%$ Unkan tona wayaka unpi etanhan hdipi omniciye kin ocowasin wokeya kaǵapi, qa wokeyapi kin ihukuya iyotankapi. Jośua Nun cinhintku taanpetu kin hetanhan anpetu kin he ekta, Israel cincapi kin heconpi śni nakaeś. Unkan wowiyuśkin kin nina tunka hinca.

18 Nakun anpetu qa anpetu, a npetu tokaheya etanhan anpetu ehake kin ekta, Wakantanka toope wowapi kin en yawa ece. Unkan wohanpi kin anpetu śakowin yuhapi. Unkan anpetu iśahdogian kin en wookilipe omniciye, woyaco kin eciyatanhan.

\section{WICOW OYAKE 9.}

1 Unkan wi kin de anpetu wikcemna nonpa sanpa itopa en, Israel cincapi kin waśihdapi qa wakihdaka unpi qa maka ahdahpapi hecen mniciyapi.

2 Qa Israel wicoicage kin wicaśta tokeca cincapi kin etanhanhan ihduśpapi, qa najinpi qa wahtanipi ohdakapi, atewicayapi taku śica econpi koya.

$3 \mathrm{Qa}$ oyanke tawapi kin ohna inajinpi, qa Taku Wakan tawapi Jehowa toope wowapi kin en yawapi, anpetu eca hanke itopa ; qa hanke itopa icunhan wohda- 


\section{WICOWOYAKE 9.}

kapi qa Jehowa Taku Wakan tawapi kin he ohodapi ecee.

4 Hehan cowahe kin akan najinpi, Levi wicaśta etanhan, Jeśua, qa Bani, Kadmiel, Śebaniah, Bunni, Śerebiah, Bani, Kenani, qa ho tanka on Jehowa Taku Wakan tawapi hoyekiyapi.

5 Hehan Levi wicaśta, Jeśua qa Kadmiel, Bani, Haśabniah, Śerebiah, Hodiyah, Śebaniah, Pethahiah, heyapi; Najin po, Jehowa Taku Wakan nitawapi yawaśte po, otokalıe wanica qa owihanke wanica hehallyan; qa nicaje wakan kin yawaśtepi nunwe, he ge woyawaśte qa woyatan owasin iwankan yanka ece.

6 Niye niśnana Jelıowa hee; Niye malipiya kin yakagga, mahpiya mahpiya kin, qa wicobe tawa iyuhpa, maka kill qa taku olınaka owasin, miniwanca qa taku ohnaka owasin, qa hena iyuhpa niye niyaya ece; qa mahipiya obe kin ohonidapi ecee.

7 Jehowa.Taku Wakan kin he niye, niye Abram yakahiniga, qa Ur Kasdim etanhan hinapeyaya, qa Abraham eya caśyaton qorl :

8 Qa iye cante kin nitokam wicaka e iyeyaya, qa kici wotakuye wan yakaga, Kanani, Hitti, Amori qa Perrizi, qa Jebusi, qa Girgaśi tamakocepi kin yaqu kta, iye wicoicage tawa qupi kta; unkan nioie qon yahduecetu, niye oniwotanna nảkaeś.

9 Nakun atewicunyanpi kakijapi Egupta en wandake ça Mdeśa icahda hoyeyapi qon he nayabon:

10 Qa Pharaoh en, qa taokiye owasin en, qa iye tamakoce oyate iyuhpa akan, wowapetokeca qa woyuśinyaye wicayakipazo; hena wahanhaniçidaya ecawicakiconpi sdonyaya nakaeś. Hecen caje wan niçicağa, anpetu de iyececa.

11 Nakun wicitokam mini kin dukinukan, hecen mini cokahan maka puza akan iyoopta iyayapi : tuka wicihakam kuwa awicaupi kin hena wośbe kin en elipewicayaya, inyan wan mini waśaka kin en iyececa.

12 Nakun anpetu icunhan mahipiya bosdata wan on awicada, qa hanyetu icunhan peta bosdata wan on, canku ohna yapi kte cin en iyoyanpa wicaqupi kta e heon.

13 Nakun Sinai he kin akan kun yahi, qa mahpiya eciyatanhan om woyahdaka, qa woyaco owotanna wicayaqu, qa wowicake woope, wokonze qa woahope waśteśte.

14 Qa wookilipe wakan nitawa sdonyewicayakiya, qa Moses nitaokiye nape eciyatanhan wowaśi, wokonze qa woope econwicayaśi.

15 Qa wotektehdapi on mahpiya etanhan ag̉uyapi wicayaqu, qa ipuzapi. on imnija etanhan mini hinapewicayeciciya, qa makoce wicayaqu kta on nape yahdugate ciqon he tawayapi kin en yapi kta, kewicayakiya.

16 Tuka hena ee, han, atewicunyanpi kin, walianlianiçidapi, qa tahu patin içicagapi, qa wowaśi nitawa kin econpi śni;

17 Qa waanagoptan wicadapi śni, qa iyepi kin ehna taku wowinihan ecanon qon hena kiksuyapi śni; tuka tahu suta içicagapi, qa wawakipajinpi en wokaśke tawapi qon ekta icicawin hdapi kta e wicaśta itancan wan kagapi : Tuka niye wakajuju Wakantanka henica, waśte qa waonśida, tehan canteniptaye 


\section{NEHEMIAH,}

śni, qa nina wacanyakiya ece, hecen ehpewicayaye śni.

$18 \mathrm{Han}$, tohinni ptejicadan śdoyapi wan ic̣icagapi, qa, Taku Wakan Egupta etanhan anihiyupi qon dee ce, eyapi, qa wokipajin tanka econpi qeyaś :

19 Tuka niye nitowaonśida tankinyanyan on makopuza en awicaduśtan śni: anpetu icunhan mahpiya bosdata canku ohna yewicaye kte cin he tokan iwicakiyaye śni, qa peta bosdata hanyetu icunhan, iyoyanpa qa canku ohna yapi kin wicakipazo kta.

20 Nakun Nitaniya waśte waonspewicakiye kta wicayaqu, qa manna nitawa iye ipi ipiwicayakida śni, tuka ipuzapi on mini wicayaqu qon.

$21 \mathrm{Han}$, makopuza en waniyetu wikcemna topa hehanyan wonwicayaya, takudan icakijapi śni : tawokoyakepi kuka aye śni qa siha popi śni.

22 Nakun wokiconze qa oyatepi kin wicayaqu, qa ohomnimni wicayapamni: hecen Sihon tamakoce kin yuhapi, han Heśbon wicaśtayatapi tamakoce, qa $\mathrm{Og}$ Baśan wicaśtayatapi tamakoce kin.

23 Nakun iye cincapi wicaduota, mahpiya wicanhpi kin iyececa, qa makoce on iye hunkakewicayapi wahowicayaye, tawaye kta en yapi kte cin he en awicayahi.

24 Hecen cincapi kin en iyayapi, qa makoce kin tawayapi, unkan wicitokam makoce ounyanpi qon, Kanani kin hena wicaduśihtin, qa iye napepi en wicayaqu, han wicaśtayatapi tawapi, qa makoce oyatepi kin, hecen token cinpi iyecen ecawicakiconpi kta.

25 Unkan otonwe suksuta kin 694 icupi, qa makoce cepa wan, qa tipi taku waśteśte owasin ojudan yuhapi, miniyowe qapi, hastanhanka iyuwi ojupi, wihdi can wojupi, qa waskuyeca can ota hinca: hecen wotapi qa wipipi, qa cepa icagiapi, qa nitowaśte tanka en iyuśkiniciyapi ece.

26 Hececa eśta waanağoptanpi śni, qa niye nicipajinpi, qa nitoope kin wiciheyata ehpeyapi, qa wicaśta wokcan nitawa wicaktepi, hena niye ekta ihduhomnipi kta iwahokonwicakiyapi tuka, qa wowahtedaśni tanka econpi ecee.

27 Heon etanhan iye tokawicayapi nape en wicayaqu, qa hena iyokiśinwicayapi : Hehan tokakijapi anpetu kin en niye hoyeniciyapi qehan, niye mahipiya etanhan nayahon; qa nitowaonśida tankinyanyan eciyatanhan wanikiya heca wicayaqu, unkan tokayapi nape kin etanhan niwicayapi.

28 Tuka woozikiye hduhapi ohakam ihdamnapi, nitokam taku śica econpi kta; heon etanhan tokawicayapi nape en ehpewicayaya, hecen hena wowidakewicayapi: heca eśta ake hdicupi qa hoyeniciyapi hehan mahipiya etanhan niyc nayahon; qa nitowaonśida eciyatanhan ijehan ewicayahdaku ece :

29 Qa iyopewicayaya, nitoope kin ekta hdicuwicayakiye kta: Tuka wahanhaniçidapi qa nitawoahope anagoptanpi śni, tuka nitawoyaco kin en wahtanipihena wicaśta wan econ kinhan on ni kta qeyaś-qa hinyete wawakipajin hiyuyapi, qa tahu ihdusutapi qa wanationpi śni ecee.

30 Tuka omaka ota awicayape, qa wicaśta wokcan nitawa napepi en nitaniya on wahokonwi- 


\section{WICOWOYAKE 10.}

cayakiya: tuka wanalion wicadapi śni, heon etanhan makoce oyatepi nape kin en wicayaqu.

31 Heca eśta nitowaonśida tanka kin on ocowasin ihangwicayaye śni, qa awicaduśtan śni: Taku Wakan wacantkiya qa waonsída kin he niye nakaeś.

32 Heon etanhan nakaha, Taku Wakan unkitawapi, Wakantanka tanka, waśaka qa wawinihan, wotakuye qa wowaonśida yakpatan ece, wokakije owasin en unkupi kin he nitokam cistinna.śni nunwe, wicaśtayatapi unkitawapi en, wicaśta ihdawa unkitawapi, qa wawayuśnapi unkitawapi, qa wicaśta wokcan unkitawapi, qa atewicunyanpi kin en, qa oyate iyulipa en, Aśur wicaśtayatapi taanpetu kin etanhan anpetu kin de hehanyan.

33 Qeyaś taku unkaupi kin owasin en oniwotanna, niye wowicake ccanon, tuka unkiye śicaya econkupi nakaeś :

34 Qa wicaśtayatapi unkitawapi, wicaśta ihdawa unkitawapi, wawayuśnapi unkitawapi, qa atewicunyanpi kin nitoope kpatanpi śni, qa nita woahope qa wadaotanin, on wahokonwicayakiye cin hena anaggoptanpi śni ecee.

$35 \mathrm{Qa}$ hena wokiconze tawapi en, qa nitowaśte tanka wicayaqu kin en, qa makoce tanka qa cepa wicitokam wicayaqu kin en, niye cn wowidagiçiyapi śni, qa wicohan śica tawapi kin etanhan ihduhomnipi śni.

36 Iho, anpetu kin de wowidake unyakonpi, qa makoce hunkakewicunyanpi wicayaqu, ohna waskuyeca qa taku waśte kin yutapi kta, iho, he ohna wowidake unyakonpi :

37 Qa waunhtanipi kin on wicaśtayatapi unkiwankam ewicayahnake cin hena woicage ota icahwicakiciya ece: nakun iye token iyokipipi, untancanpi qa wanunyanpi unkitawapi idakapi ece, hecen wokakije tanka ehna unyakonpi ce.

38 Unkan de owasin on wowicake unkagiapi qa unkowapi ; qa wicaśta ihdawa unkitawapi, Levi wicaśta, wawayuśnapi kin askamyapi kin en unpi.

\section{WICOWOYAKE 10.}

1 Unkan waskamyapi en unpi kin, Nehemiah 'Tirśatha kin Hakaliah cinhintku, qa Zidekiah,

2 Seraiah, Azariah, Jeremiah, 3 Paśur, Amariah, Malkiyah, 4 Hattuś, Śbaniah, Malluk, 5 Harim, Meremoth, Obadiah, 6 Daniel, Ginnethon, Baruk, 7 Meśullam, Abiyah, Miyamin, 8 Maaziah, Bilgai, Ś Semaiah: hena wawayuśnapi.

9 Unkan Levi wicaśta kin: Jeśua Azaniah cinhintku qa Binnui Hanadad cinca etanhan, Kadmiel:

$10 \mathrm{Qa}$ iye hunkawanjitkupi, Ścbaniah, Hodiyah, Kelita, Pelaiah, Hanán,

11 Mika, Rehob, Haśabiah,

12 Zakkur, Śerebiah, Śebaniah,

13 Hodiyah, Bani, Beninu.

14. Oyatc itancanpi kin; Paroś, Pahath-moab, Elam, Zattu, Bani,

15 Bunni, Azgad, Bebai,

16 Adoniyah, Bigvai, Adin,

17 Ater, Hizkiyah, Azzur,

18 Hodiyah, Haśum, Bezai,

19 Harip, Anathoth, Nebai, 20 Magpiaś, Meśullam, Hezir, 21 Meśezabeel, Zadok, Jaddua, 22 Pelatiah, Hanan, Anaiah, 23 Hośca, Hananiah, Haśub, 24 Halloheś, Pileha, Śobek, 25 Rehum, Haśabnah, Maaseiah,

26 Qa Ahiyah, Hanan, Anan, 


\section{NEHEMIAH,}

27 Malluk, Harim, Baanah.

28 Nakun oyate unmapi kin, wawayuśnapi kin, Levi wicaśta kin, tiyopa awanyakapi kin, wadowanpi kin, Nethinim kin, qa tona makoce oyatepi etanhan ihduleyapapi, Wakantanka toope ekta, iye tawicupi, cinbintkupi qa cunwintkupi, owasin waokahnigia sdonyapi :

29 Hena iye hunkawanjitkupi, wicaśta ihdawapi wicayuhapi kin en ikoyagiciyapi, qa woihdaco wokonze ko en ihdokupi, Wakantanka toope, Moses Wakantanka taokiye nape on wicaqu gon he ohnayan manipi kta, qa Jehowa Itancun unkitawapi tawoahope qa tawoyaco qa tawowaśi kin owasin ahopapi qa econpi kta:

30 Qa unkicunkśipi kin makoce oyate kin wicunqupi kte śni, qa iye cunwintkupi kin unkicinkśipi on unkicupi kte śni :

31 Qa makoce oyate kin anpetu okilipapi en maza qa wotpanpi owasin wiyopeya ahipi eśta, wookihpe en qa anpetu wakan icunhan opewicunkicatonpi kte śni; qa waniyetu iśakowin ecee kin, qa wicanape otoiyohi oicazo tawa kpaģanpi kta.

32 Nakun wokonze unkicicağapi, omaka otoiyohi Taku Wakan unkitawapi ti waokiyapi kin on śekel onśpa wiciyamnimini unqupi kta.

33 Ağuyapi ehnakapi ecee kin on, qa ohinniyan woyute wośnapi kin on, qa wohuhnage wośnapi ohinniyan kin on, anpetu okihpapi tawa, wi teca tawa, wohanpi kagiapi tawa, qa taku yuwakanpi kin on, qa woahtani wośnapi lsrael akahpapi kte cin he on, qa Wakantanka unkitawapi tipi tawowaśi owasin on.

34 Unkan wośnapi can kin on oeconna econkupi, wawayuśnapi qa Levi wicaśta qa oyate kin ehnahna, Taku Wakan unkitawapi ti kin en ahipi kta, tohan wakiconzapi eca, omaka qa omaka, Jehowa Wakantanka unkitawapi owayuśna kin akan ide kta, woope en owapi qon iyececa.

35 Nakun mağa unkitawapi oicaǵe tokaheya, qa can owasin waskuyeca tokaheya icage cin hena, omaka qa omaka, Jehowa ti kin en ahipi kta :

36 Nakun unkicincapi qa wanunyanpi unkitawapi tokaheya tonpi kin hena, woope en owapi qon iyececa, qa tatanka unkitawapi qa tahinca unkitawapi tokaheya wicatonpi kin hena Taku Wakan unkitawapi ti kin en unkahipi kta, wawayuśnapi Taku Wakan unkitawapi ti ohna hitanipi kin hena elita.

37 Qa nakun ağuyapi bounpanpi tokaheya, qa wośnapi unkitawapi, qa can ocaje owasin waskuyeca kin, miniśa qa wibdi etanhanhan, wawayuśnapi kin ekta unkahipi kta, Wakantanka unkitawapi ti wopiye kin ekta; qa mağa unkitawapi oicagge iwikcemnamna kin Levi wicaśta kin ekta, hecen Levi wicaśta kin hena woicage unkitawapi otonwe owasin en iwikcemnamna kin yuhapi kta.

38 Unkan wawayuśna, Aaron cinhintku kin Levi wicaśta kin opeya un kta, Levi wicaśta iwikcemnamna kin icupi eca: $\mathrm{Na}$ kun Levi wicaśta kin hena iwikcemnamna kin etanhan iwikcemna kin aupi kta, Taku Wakan unkitawapi ti kin ekta, wopiye ekta, mazopiye tipi kin en.

39 Israel cincapi qa Levi cinca kin ağuyapi su wośnapi kin wopiye en aupi kta, miniśa teca kin etanhan, qa wihdi kin etanhan,

696 


\section{WICOWOYAKE 11.}

hen wakśica wakan iyuhipa hiyeya, qa wawayuśnapi waokiyapi ecee kin, qa tiyopa awanyakapi qa wadowanpi kin: Hecen Taku Wakan unkitawapi ti kin unkayuśtanpi kte śni ce.

\section{WICOW OYAKE 11.}

1 Unkan oyate itancanpi kin hena Jerusalem en tipi: nakun oyate unmapi kin oeconna econpi, wikcemna etanhan warji Jerusalem otonwe wakan kin en ahiti wicakiyapi kta, qa totonwepi kin ohna napcinwanka ounyanpi kta.

2 Unkan oyate kin wicaśta tona Jerusalem en tipi kta iye cinka hiyuiciyapi kin hena owasin wicayawaślepi.

3 Hecen makoce itancanpi kin hema Jerusalem ohna tipi ; tuka Juda totonwepi kin ohna wicaśta otoiyohi iye tamagia totonwepi kin en ounyanpi ece, Israel, wawayuśnapi kin, qa Levi wicaśta, qa Nethinim kin, qa Solomon tawowidake cincapi kin.

4 Unkan Jerusalem ekta Juda cincapi qa Benjamin cincapi kin etanhanhan en tipi. Juda cinca kin etanhan; Athaiah Uzziah cinhintku, Zekariah cinhintku, Amariah cinhintku, Śphatiah cinhintku, Mahalaleel cinhintku, Perez cinca etanhan:

5 Qa Maaseiah Baruk cinhintku, Kolhozeh cinhintku, Hazaiah cinbintku, Adaiah cinhintku, Joiarib cinhintku, Zekariah cinhintku, Śiloni cinhintku.

6 Perez cincapi owasin Jerusalem en tipi, wicaśta waditaka opawinge topa sampa wikcemna śakpe sanpa śahdoğan.

7 Unkan Benjamin cinca kin dena eepi : Sallu Meśullam cinhintku, Joed cinhintku, Pedaiah cinhintku, Kolaiah cinhintku, Maaseiah cinhintku, Ithiel cinhintku, Jesaiah cinhintku.

$8 \mathrm{Qa}$ he iyahna Gabbai, Sallai, opawing'e napcinwanka qa wikcemna nonpa sanpa śahdoğan.

9 Unkan Joel Zikri cinhintku kin hena awanwicayaka: qa Juda Senuah cinhintku kin he otonwe en inonpa ee.

10 Wawayuśnapi kin etanhan: Jedaiah, Joiarib, Jakin.

11 Seraiah Hilkiah cinhintku, Meśullam cinhintku, Zadok cinhintliu, Meraioth cinhintku, Ahitub cinhintku, Wakantanka ti ohna itancan kin hee.

12 Qa iye hunkawanjitkupi tipi kin ohna wicolian econpi kin hena opawing'e śahdogian qa wikcemna nonpa sanpa nonpa: Qa Adaiah Jeroham cinhintku, Pelaliah cinhintku, Amzi cinhintku, Zekariah cinhintku, Paśur cinhintku, Malkiah cinhintku, 13 Qa iye hunkawanjitkupi, atewicayapi itancanpi kin, opawinge nonpa qa wikcemna topa sanpa nonpa: Qa Amaśai Azareel cinhintku, Ahasai cinhintku, Meśillemoth cinhintku, Immer cinhintku,

14 Qa iye hunkawanjitkupi, wicaśta waśaka waditakapi, opawinge qa wikcemna nonpa sanpa śahdogan : Unkan hena awanwicayake cin he Zabdiel hee, wicaśta tarkapi cinca etanhan.

15 Nakun Levi wicaśta etanhan ; Semaiah Haśub cinhintku, Azrikam cinhintku, Haśabiah cinhintku, Bunni cinhintku ;

16 Qa Śabethai Jozabad kici, Levi wicaśta itancanpi kin etanhan, hena Wakantanka ti itankan wicolian kin yuhapi.

17 Qa Mattaniah Mika cinhintku, Zabdi cinhintku, Asaph cinhintku, wocekiye en wiyu697 


\section{NEHEMIAH,}

śkinpi kağa itancan kin hee : Qa Bakbukiah iye hunkawanjiwicaya wicehna inonpa, qa Abda Sammua cinhintku, Galal cinhintku, Jeduthun cinhintku.

18 Levi wicasta otonwe wakan kin ohna yakonpi owasin opawinge nonpa, qa wikcemna śalidogan sanpa topa.

19 Nakun tiyopa awanyakapi kin, Akkub, Talmon qa iye hunkawanjitkupi tiyopa en awanyakapi kin, opawinge qa wikcemna śakowin sanpa nonpa.

20 Unkan Israel unmapi kin, wawayuśnapi, Levi wicaśta, Juda totonwepi owasin ohnahna, otoiyohi iye taku tawa ohna.

21 Tuka Nethinim kin Ophel en tipi : Unkan Ziha Gispa kici Nethinim kin iwankam unpi.

22 Nakun Jerusalem en Levi wicaśta awanwicayake cin he Uzzi Bani cinhintku, Haśabiah cinhintku, Mattaniah cinhintku, Mika cinhintku, Asaph cinca etanhall, dowanpi kin Wakantanka ti ohna wicohan kin he iwankam.

23 Hena on wicaśtayatapi tawokonze hee nakaeś, anpetu qa anpetu dowanpi kin wowicake wopamni wan yuhapi kta.

24 Qa Pethahiah Meśezabeel cinhintku, Zerah Juda cinhintku he cinca etanhan, he oyate kin on etanhan, wicoie owasin on wicaśtayatapi nape elsta yanka.

25 Unkan otonwe cikcistinna en, tamağapi iyahna, Juda cincapi etanhan Kirjath-arba en tipi, qa otonwe cikcistinna tawa kin, qa Dibon qa otonwe cikcistinna tawa kin en, qa Jekabzeel qa otonwe cikcistinna tawa en;

$26 \mathrm{Qa}$ Jeśua en, qa Molada en, qa Bethpelet en ;

27 Qa Hazar-śual en, qa Beer- śeba en, qa otonwe cikcistinna tawa en:

28 Qa Ziklag en, qa Mekonah en, qa otonwe cikcistinna tawa en ;

29 Qa Ayin-rimmon en, qa Zareah en, qa Jarmuth en;

30 Zanoah, Adullam, qa otonwe cikcistinna tawapi en; Lakiś qa tamagia ekta; Azekah ekta qa otonwe cikcistinna tawa en. Unkan Beerśeba etanhan Hinnom kaksiza kin hehanyan tipi.

31 Nakun Benjamin cincapi, Geba etanhan Mikmaś hehanyan, qa Hai qa Bethcl, qa otonwe cikcistinna tawa en;

32 Anathoth, Nob, Ananiah,

33 Hazor, Ramah, Gittaim,

34 Hadid, Zeboim, Neballat,

35 Lod qa Ono wabagopi kaksiza tawa pi kin.

36 Nakun Levi wicaśta etan. hanpi, hena .Iuda qa Benjamin ehna wicapamnipi.

\section{WICOWOYAKE 12.}

1 Unkan wawayuśnapi qa Levi wicaśta, Zerubabel Śsealtiel cinhintku, qa Jeśua om itawankanhde iyayapi qon dena eepi: Seraiah, Jeremiah, Ezra,

2 Amariah, Malluk, Hattuś,

3 Śekaniah, Rehum, Meremoth,

4 Iddo, Ginnetho, Abiyah,

5 Miamin, Mandiah, Bilgah,

6 Śsemaiah qa Joiarib, Jedaiah,

7 Sallu, Amok, Hilkiah, Jedaiah. Jeśua taanpetu kin en wawayuśnapi itancanpi qa hunkawanjitkupi qon dena eepi.

8 Nakun Levi wicaśta kin: Jeśua, Binnui, Kadmiel, Śerebiah, Juda, Mattaniah, wopida odowan en itancan, iye qa hunkawanjiwicaye cin.

9 Nakun hena hunkawanjitku-

698 


\section{WICOWOYAKE 12.}

pi Bakbukiah qa Unni, waawanyakapi iyotakonzapi.

10 Unkan Jcśua Joiakim cincaya, qa Joiakim Eliaśib cincaya, qa Eliaśib Joiada cincaya,

$11 \mathrm{Qa}$ Joiada Jonathan cincaya, qa Jonathan Jeddua cincaya.

12 Unkan Joiakim taanpetu en wawayuśnapi yukan, a tewicayapi itancanpi; Seraiali etanhan Meraiah; Jeremiah etanhan Hananiah ;

13 Ezra etanhan Meśullam; Amariah etanhan Jehohanan;

14 Meliku etanhan Jonathan; Śbaniah etanhan Joseph ;

15 Harim etanhan Adna; Meraioth etanhan Helkai ;

16 Iddo etanhan Zekariah; Ginnethon etanhan Meśullam;

17 Abiyah etanlian Zikri; Miniamin etanhan, Moadiah etanhan Piltai ;

18 Bilgah etanhan Śammua; Śemaial etanhan Jehonathan;

19 Qa Joiarib etanhan Mattenai; Jedaiah etanhan Uzzi ;

20 Sallai etanhan Kallai; Amok etanhan Eber;

21 Hilkiah etanhan Haśabiah; Jedaiah etanhan Nethaneel.

22 Levi wicaśta Eliaśib taanpetu kin en, Joiada, qa Johanan, qa Jaddua, atewicayapi itancanpi owicawapi : Nakun wawayuśnapi kilı Darius Persia wicaśtayatapi un kin hehanyan.

23 Levi cinca kin atewicayapi itancanpi, anpetu iyohi wicoie wowapi en owicawapi, Jolianan Eliaśib cinhintk u taanpetu kin hehanyan.

24 Unkan Levi wicaśta itancanpi : Haśabiah, Śerebiah, qa Jeśua Kadmiel cinhintku, qa iye hunkawanjitkupi iyotakons unpi, yatanpi kta, wopida eyapi kta, David Wakantanka tawicaśta tawowaśi qon eciyatanhan, waa- wanyakapi waawanyakapi kin iyotakonzapi.

25 Mattaniah qa Bakbukiah, Obadiah, Meśullam, Talmon, Akkub, hella waawanyakapi tiyopa icahda waawanyag unpi ecee.

26 Hena e Joiakim Jeśua cinhintku, Jozadak cinhintku taanpetu kin en, qa Nehemiah itancan kin, qa Ezra wawayuśna wowapi kağa ecee taanpetu kin en unpi.

27 Unkan Jerusalem conkaśke yuwakanpi qehan, Levi wicaśta tohepi kin owasin en ewicadepi, Jerusalem en awicahipi kta, yuwakanpi kin en worviyuśkin econpi kta, wopida eyapi kta, qa dowanpi on, mazaicicasnapi, candowankiyapi qa kinskinzapi kin on.

28 Unkan dowanpi cincapi kin hena ihduwitayapi, makohomni Jerusalem ihdukśan wanke cin etanhan, qa Netophathi totonwepi kin etanhan:

29 Nakun Gilgal tipi etanhan, qa Geba qa Azmaveth tamaģapi kin etanhan: Dowanpi kin hena Jerusalem ihdukśan otonwe icicag̣api nakaeś.

30 Unkan wa wayuśnapi qa Levi wicaśta kin ilıduskapi, qa oyate kin wicayuskapi, qa tiyopa kin hena qa conkaśke kin.

31 Hehan miye Juda wicaśta ilıdawapi kin conkaśke akan awicawahi, qa dowanpi obe tankinyanyan nom ewicawahde, unma etapatanhan unkce tiyopa ektakiya conkaśke akan iyayapi:

39 Qa hena wiciyahna Hośaiah qa Juda wicaśta ihdawapi hanke iyayapi ;

33 Qa Azariah, Ezra qa Meśullam,

34 Juda qa Benjamin, qa Ś Semaiah qa Jeremiah;

$35 \mathrm{Qa}$ wawayuśnapi cincapi 699 


\section{NEHEMIAH,}

mazayahotonpi yuhapi; Zekariah Jonathan cinhintku, Semaiah cinhintku, Mattaniah cinhintku, Mikaiah cinhintku, Zakur cinhintku, Asaph cinhintku ;

36 Qa iye hunkawanjiwicaye cin, Semaiah, qa Azarael, Milalai, Gilalai, Maai, Nethaneel qa Juda, Han ni, David Wakantanka tawicaśta candowankiyapi tawa yuhapi, qa Ezra wowapi kage cin he wicitokam un.

37 IJnkan miniyowe tiyopa kin ekta, he iyepi iyotakons wanka, hen David towonwe caniyadipi kin ohna wankan iyayapi, conkaśke itawankanhde ye cin, David ti qon iwankantanhan, qa wiyohiyanpata mini tiyopa kin hehanyan.

38 Unkan wopida eyapi obe unman qon iyotakonza iyayapi, qa wicihakam miye qa oyate hanke kin conkaśke akan, mazaoceti conkaśke tehanwankantu akotanhan qa conkaśke ohdakinyan tanka kin hehanyan.

39 Qa Ephraim tatiyopa kin iwankapatanhan, qa tiyopa tanina qon etanhan, qa hogan tiyopa kin iwankam, qa Hananeel ipasotka tawa, qa Meah ipasotka kin, qa tahinca tiyopa kin hehanyan: Unkan wicakaśkapi tiyopa kin en inajinpi.

40 Hecen wopida eyapi obe nonpa lin hena Wakantanka ti kin ohna najinpi, qa miye qa wicaśta ihdawapi hanke mici unpi. 41 Qa wawayuśnapi kin; Eliakim, Maaseiah, Miniamin, Mikaiah, Elioenai, Zekariah, Hananiah, mazayahotonpi yuhapi ;

42 Qa Maaseiah, qa Semaiah, qa Eleazar, qa Uzzi, qa Jehohanan, qa Malkiyah, qa Iilam, qa Ezer. Unkan dowanpi kin nina hoyeyapi, qa Jezrahiah awanwicayaka.
43 Nakun anpetu kin he en wośnapi tanktanka wayuśnapi qa wiyuśkinpi : wowiyuśkin tanka on Wakantanka wiyuśkinwicakiya nakaeś : nakun winohincapi qa śicecapi kin wiyuśkinpi : hecen Jerusalem tawowiyuśkin kin tehan nahonpi.

44 Unkan anpetu kin he. en wicaśta wopiye tipi awanyagwicaśipi, mazopiye on, wośnapi kin on, woicage tokaheya kin on, qa iwikcemnamna kin on, hena ohna otonwewe tamagiapi kin etanhan mnayanpi kta, woope kin eciyatanhan, wawayuśnapi qa Levi wicaśta kin taku tawapi. Wawayuśnapi qa Levi wicaśta najinpi kin on Juda wiyuśkinpi nakaeś.

45 Unkan wadowanpi qa tiyopa awanyakapi kin hena Wakantanka tawoawanyake yuliapi, qa wicayuskapi tawoawanyake kin, David tawowaśi kin eciyatanhan, qa iye cinhintku Solomon.

46. Ehanna David qa Asaph taanpetu kin en dowanpi itancanpi yukan, qa woyatan odowan, qa Wakantanka wopida eciyapi ecee.

47 Unkan Zerubabel taanpetu kin en, qa Nehemiah taanpetu en, Israel iyulipa wadowanpi kin qa tiyopa awanyakapi kin ongege wicaqupi, anpetu qa anpetu taku tawa: qa Levi wicaśta kin on taku wicakiciyuwakanpi ecee: qa Levi wicaśta kin iś Aaron cinca taku wicakiciyuwakanpi ece.

\section{WICOWOYAKE 13.}

1 Anpetu kin he en oyate nog epi kin ohna Moses tawowapi kin etanhan yawapi; unkan he en kaken owapi iyeyapi, Ammoni kin qa Moabi kin Wakantanka 


\section{WICOWOYAKE 12.}

tomniciye kin en upi kte śni, owihanke wanica:

2 Israel cincapi ag̉uyapi qa mini yuha itkowicakipapi śni nakaeś ; tuka hena on Balaam opetonpi, wicayaśice kta e heon: heca eśta Wakantanka unkitawapi woyaśice qon woyawaśte kaga.

3 Hehan kaketu, woope kin nahonpi qehan, tona icicahiya en unpi kin. owasin Israel etanhan yukinukan iyewicayapi.

4. Unkan de itokam, Eliaśib wawayuśna kin Wakantanka ti kin wankan tipi awanyake cin hee e Tobiah omawahotonya:

5 Qa wankan tipi tanka wan wiyeya ekicihnaka, qa itokam hen minha kin ehnakapi, womna waśtemna qa wakśica kin, qa ağuyapi, qa miniśa teca, qa wihdi kin etanhanhan iwikcemnamna kin, Levi wicaśta tawopamni kin, qa wadowanpi qa tiyopa awanyakapi tawapi ; nakun wawayuśnapi tawośnapi kin.

6 Tuka de ocowasin icunhan miye Jerusalem en waun śni. Artahśaśta Babel wicaśtayatapi tawaniyetu wikcemna yamni sanpa inonpa en, hehan wicaśtayatapi kin ekta wahi, qa anpetu henakeca hehan wicaśtayatapi kin nina cewakiya :

7 Hehan Jerusalem en wahi, unkan 'Tobiah on Eliaśib taku sica econ, Wakantanka ti hocoka ohna wankan tipi wan wiyeya ekicihnake ciqon he owakaliniga.s

8 Hehan nina iyomakiśica; qa Tobiah tawahpaya kin iyuhpa wankan tipi kin etanhan tankan elipewaya.

9 Hehan econwicawaśi, unkan wankan tipi kin hena yuskapi: Unkan Wakantanka tipi tawakśica kin ake en awahi, woyute wośnapi qa canśin waśtemna kin hena koya.

10 Unkan Levi wicasta tawopamni kin wicaqupi śni ecee sdonwaya: Levi wicaśta, qa dowanpi kin wicohan econpi gon hena otoiyohi iye tamaga ekta kihdapi nakaeś.

11 Hehan wicaśta itancanpi kin om awakinica, qa, Tokeca Wakantanka ti kin ayuśtanpi he, epa. Qa hena wicamduwitaya qa oinajinpi qon en ewicawahde. 12 Hehan Juda ocowasin ag்uyapi su iwikcemna kin, qa miniśa teca qa wihdi etanhanhan mazopiye kin en ahipi ece.

13 Unkan mazopiye kin en waawanyag-wicawakiya, Śelemiah wawayuśna kin, qa Zadok wowapi kağe cin, qa Levi wicaśta kin etanhan Pedaiah: qa hena napepi en Hanan Zakkur cinhintku, Mattaniah cinhintku: hena e wacinyepica kecanwicakinpi nakaeś, qa iye hunkawanjitkupi wicakicipamnipi-kta he wicolian tawapi.

14. De on Wakantanka mitawa miksuya wo, qa wowacantkiye mitawa Wakantanka mitawa ti kin on ecamon, qa waawanyakapi tawa on, hena pajuju śni wo.

15 Anpetu kin hena en, Juda ehna, anpetu wakan icunhan wihdi iyuśkice napanpi wanmdaka, qa aǵuyapi pahtapi ahipi, qa śonśonna waqinwicakiyapi; qa nakun miniśa, hastanhanka iyage, qa waskuyeca (suken) qa wogin ocaje owasin, hena anpetu wakan icunhan Jerusalem ekta ahipi ecee. Unkan woyute wiyopeyapi anpetu kin he on om wahdokinica.

16 Nakun Tzur wicaśta en ounyanpi, hena hogan ahipi, qa maza ocaje owasin, qa anpetu wa701 


\section{NEHEMTAH.}

kan icunhan Juda cinca kin wiyopewicakiciyapi, qa Jerusalem entu.

17 Hehan Juda wicaśta ihdawapi kin om wahdokinica qa hewicawakiya; De taku wicoie sica ecanonpi, qa on anpetu okihipapi kin dujujupi he.

18 Niyatepi kin hecen econpi śni he; qa Taku Wakan unkitawapi wośice kin de ocowasin unkiyepi en, qa otonwe kin de en au śni he : tuka niyepi wocanniye sanpa Israel en ayaupi, anpetu okilpapi yujujupi kin on.

19 Unkan kaketu, anpetu okihpapi itokam Jerusalem tiyopa kin aotpasya aya, hehan tiyopa kin ecen iyeyapi kta, kepa, qa anpetu okihpapi ihunniyan yuhdokapi kte śni, kepa: Nakun mitaokiye etanhan tiyopa kin ektakta ewicawahde, anpetu okihpapi icunhan woqin takudan Jerusalem en aupi kte śni.

20 Hecen wicaśta wopeton qa maza ocaje owasin wiyopeyapi ecee qon hena wanca, qa nonpa Jerusalem itankan ahiwanka.

21 Hehan awicawakinica qa hewicawakiya; Tokeca conkaśke kin ikiyedan yahinunkapi he. Ake hecanonpi kinhan miye nape acihnakapi kta ce. Anpetu kin he etanhan icimana anpetu okihpapi kin en hipi śni.

22 Unkan Levi wicaśta kin ihduska wicawaśi, qa tiyopa awanyag hipi kta, anpetu okihpapi kin yuwakanpi kta. Taku Wakan mitawa, de nakun on miksuya wo, qa nitowaonśida ota eciyatanhan mapatan ye.

23 Nakun anpetu kin hena en Juda wicaśta Aśdodi, Ammoni, Moabi winohincapi wicayuzapi wanmdaka.

24 Unkan cincapi kin hena Aśdodi iapi kin hanke unpi ece, qa Juda oie kin ohna ia okihdalinigapi śni, tuka oyate qa oyate iapi kin ohnayan.

25 Unkan hena om awakinica qa wicamdaśica, qa wicaśta wanjikśi awicawapa, qa paha wicamduhmica, qa Wakantanka eciyatanhan wakonze wicawakiya; Nicunkśipi kin iye cinhintkupi wicayaqupi kte śni, qa nicinkśipi on iye cunwintkupi kin wicaduzapi kte śni, qa na. kun niyepi on.

26 Solomon Israel wicaśtayatapi kin he dena on wahtani śni he. Tuka oyate ota ehna wicaśtayatapi kin tuwedan he iyecece śni, qa 'Taku' Wakan tawa on waśtedakapi, nakun Wakantanka Israel ocowasin en wicaśtayatapi kağa: Tuka iye kaeś winohinca toktokeca kin wahtanikiyapi.

27 Hecen unkiye anaunnigoptanpi kta, taku śica tanka kin de econpi kta, winohinca toktokeca wicayuzapi on Taku Wakan unkitawapi waunkiciltanipi $k$ ta he.

28 Unkan Joiada Eliaśib wawayuśna tanka cinhintku kin he cinca Sanballat Horoni kin he tunkanye. Heon etanhan miye etanhan napewaye.

29 Wakantanka mitawa, hena wicakiksuya wo, wawayuśnapi oun kin he yuśicapi nakaeś, qa wawayuśna qa Levi wicaśta tawotakuye kin.

30 Hecen wicaśta tokecapi owasin etanhan wicamduska, qa woawanyake wawayuśna qa Levi wicaśta tawapi wakagga, otoiyohi iye tawowaśi ohna:

31 Nakun wośnapi can kin on, tohan konzapi iyehantu, qa waskuyeca tokaheya icage cin on. Wakantanka mitawa, taku waśte on miksuya wo. 


\section{E S THER.}

\section{WICOWOYAKE 1.}

] Unkan Ahaśuerus taanpetu kin en kaketu: Ahaśuerus India etanhan Kuś hehanyan, makoce opawinge sanpa wikcemna nonpa sanpa śakowin en wicaśtayatapi yanke ciqon he dee:

2 Anpetu kin hena en Ahaśuerus wicaśtayatapi kin iye tokiconze oiyotanke Suśan cornaśke kin en iyotanke ciqon he ehan:

3 Towidake waniyetu iyamni kin en, wicaśta ihdawa qa wowidake tawa iyuhpa wohanpi wan wicakicaga :-Persia qa Media wowaśake kin, makoce en akicita tancan qa wicaśta ihdawa iye itokam unpi kin icunhan :

4 Hehan towidake wowitan wowijice, qa iye tanka wowinihan woyuonihan kin anpetu ota kpazo yanka, anpetu opawing sanpa wikcemna śahdogan hehanyan :

5 Unkan anpetu kin hena henakeca hehan oyate ocowasin Suśan conkaśke ohna yakonpi kin hena wotapi wan wicakicağa, wicatanka qa wicacistinna, anpetu śakorvin hehanyan, wicaśtayatapi tipi waśte canwojupi hocoka kin hentu :

6 Minihuha zipzipedan, skaska qa toto, hahonta ska qa halionta toto on, mazaska canhdeśka qa inyan ska ihupa kin en ikoyagyapi : ohehdepi kin hena rnazaskazi qa mazaska, inyan sapsapa, qa skaska, qa toto, qa śaśa owanka kin akankan.
7 Unkan mazaskazi wiyatke kin ohnahna wayatkewicakiyapi, qa wiyatke kin owasin toktokeca-qa miniśa wicaśtayatapi tawa kin ota hinca, wicaśtayatapi nape kin etanhan.

8 Unkan wayatkanpi kin he woope kin eciyatanhan; tuwedan wanagiyeye śni : wicaśtayatapi iye ti kin ohna wicaśta itancanpi owasin hecen econ wicaśi nakaeś, wicaśta otoiyohi token iyokipi kin hecen ecakiconpi ecee kta.

9 Nakun Vaśti wicaśtayatapi winolinea kin iś eya winohinca wohanpi wan wicakicağa, wicaśtayatapi tipi, Ahaśuerus wicaśtayatapi tawa kin he ohna.

10 Anpetu iśakowin kin en, wicaśtayatapi cante miniśa iwaśte qehan, hehan Mehuman, Biztha, Harbona, Bigtha qa Abagtha, Zethar qa Karkas, ookiye itancan śakowin, Ahaśuerus wicaśtayatapi itokam waokiya unpi ecee kin hena,

11 Vaśti wicaśtayatapi winohinca kin he, wicaśtayatapi tawateśdake un, wicaśtayatapi kin itokam ahipi kta kewicakiya, he owanyag waśte kin oyate qa wicaśta ihdawapi ko wicakipazo kta: he wanyakapi waśte hinca nakaeś.

12 Tuka Vaśti wicaśtayatapi winohinca kin he wicaśtayatapi toie, ookiye itancanpi nape on ahipi kin he on u kta wicada śni : hecen wicaśtayatapi kin nina sihda qa iye tanmahen tocanteptanye ide. 


\section{ESTHER,}

13 Hehan wicaśtayatapi kin wicaśta ksapapi woope sdonyapi ecee kin hena hewicakiya: Tona woope qa woyaco sdonyapi kin hena owasin wicaśtayatapi kin hecen ecawicakicon ecee nakaeś :

14 Unkan iye iyokihe Karśena, Śthar, Admatha, Tarśiś, Meres, Marsena, qa Memukan, Persia qa Media en itancanpi śakowin, wicaśtayatapi ite wanyakapi ece, wokiconze en tokaheya iyotankapi kin hena :

15 Ookiye itancanpi nape eciyatanhan wicaśtayatapi oie kin ecen econ śni kin heon etanhan, woope eciyatanhan, Vaśti wicaśtayatapi winohinca kin taku ecaunkiconpi kta he, eya.

16. Unkan Memukan wicaśtayatapi qa wicaśta ihdawapi kin wicitokam heya ; Vaśti wicaśtayatapi winohinca kin he wicaśtayatapi kin iśnana taku śica ecakicon śni, tuka wicaśta ihdawapi owasin en, qa oyate iyulipa Ahaśuerus wicaśtayatapi makoce tawa owasin en unpi kin liena koya.

17 Wicaśtayatapi winohinca oie kin de winoliinca owasin en u kta nakaeś, hecen iye iśtapi en hihnaku śicewicakidapi kta; Ahaśuerus wicaśtayatapi kin Vaśti wicaśtayatapi winohinca kin he iye itokam aupi kta keya, tuka iye hi śni cee oyakapi kinhan.

18 Persia qa Media winohincapi kin hena wicaśta ihdawapi wicaśtayatapi tawa, anpetu kin de wicaśtayatapi winohinca ohan nahonpi kin iyulipa hecen awicayuptapi ecee kta. Kinhan śicekicidapi qa kicizapi ota kta ce.

19 Wicaśtayatapi kin ekta he waśte kinhan, iye etanhan wicaśtayatapi oie wanji ye kta, qa he
Persia qa Media woope kin en opeya owapi kta, hecen' yutokecapi kte śni, Vaśti icimana Ahaśuerus wicaśtayatapi kin itokam u kte śni: qa wicaśtayatapi tohe tawa kin he tuwe tokeca sanpa waśte kin he wicaśtayatapi kin qu kta ce.

20 Unkan wicaśtayatapi tawokonze kagge cin he wicaśtayatapi toun owancaya nahonpi kinhan--he tanka nakaeś-hehan winohinca owasin, tankapi qa cistinpidan, hihnakupi kin wicahduonihanpi kta ce, eya.

21 Unkan wicoie kin he wicaśtayatapi kin waśtedaka, qa wicaśta ihdawapi kin nakun: hecen wicaśtayatapi kin Memukan oie kin eciyatanhan ecen econ.

22 Unkan wicaśtayatapi makoce ounyanpi tawa kin owasin ektakta wowapi ye śi, ounyanpi otoiyohi kin iye wowapi kin eciyatanhan, qa oyate otoiyohi iye iapi kin ohnahna, wicaśta otoiyohi iye ti kin ohna itancan kta: unkan oyate iapi tawa kin ohnahna oyakapi ecee.

\section{WICOWOYAKE 2.}

1. Wicoie kin dena iyohakam, Ahaśuerus wicaśtayatapi tocanteptanye kin anaptapi qehan, Vaśti kiksuye ça taku econ qon he, qa token wakiconzapi nakun. 2 Hehan wicaśtayatapi tawowidake okiyapi ecec kin hena heyapi; Wikośka aśkatudan owanyag waśteśte kin heca wicaśtayatapi kin kicicalinigapi kta ;

3 Qa wicaśtayatapi kin iye tokiconze en makoce owasin ohnahna wowa wicaśta wicakahinige kta, hecen hena wikośka aśkatudan owanyag waśteśte kin iyuhpa Śsúan conkaśke kin en wino- 


\section{WICOWOYAKE 2.}

hinca tipi kin ekta mnawicayapi $\mathrm{kta}$, Hege wicaśtayatapi taokiye winohinca awanwicayaka ecee kin he nape ihukuya; qa taku on ihduskapi kte cin wicaqupi kta.

4 Qa wikoślka tukte wanji wicaśtayatapi iśta kin en waśte kinhan hee Vaśti eekiya wicaśtayatapi winohinca kta ce. Unkan wicoie kin he wicaśtayatapi iśta kin en waśte: unkan ecen econ.

5 Śuśan conkaśke kin ohna Juda wicaśta wan yanka, qa caje kin he Mordekai ee, Jair cinhintku, Śimei cinhintku, Kiś cinhintku, Benjamin wicaśta:

$6 \mathrm{He}$ qe Jerusalem etanhan wayaka ayapi, Jekoniah Juda wicaśtayatapi wayaka ayapi qon he opeya ayapi, Nebukadnezzar Babel wicaśtayatapi wayaka akiyahde ciqon he en.

7 Unkan he Hadassah icahkiya, Esther hee, iye dekśitku cunwintku; he atkuku qa hunku waniea nakaeś, unkan wi cinyanna kin ouncag̉e waśte qa owanyag waśte: he atkuku qa hunku tapi qehan Mordekai iye cunwintku ye kta on ikikcu.

8 Hecen kaketu, wicaśtayatapi oie qa tawokonze nahionpi qehan, qa wikośka ota Śuśan conkaśke kin ohna, Hege nape ihukuya, wicayuwitayapi qehan, Esther nakun wicaśtayatapi ti kin ekta ahipi; Hege winohinca awanwicayaka ecee kin nape kin en.

9 Unkan iye iśta kin en wikośka kin he waśte, qa iye itokam wowacantkiye iyeya; hecen ta$k u$ on ihduska kte cin hena ohankoya qu iyeya, taku tawa kte cin ahna, qa winyan ookiye śakowin wicaśtayatapi ti kin etanhan qupi kta iyecece cin hena koya: unkan iye qa ookiyewin tawa kin hena winohinca tipi ohna tukten iyotan waśte ekta ewicahnaka.

10 Esther iye taoyate qa takuwicaye cin hinyahin kpazo śni; Mordekai he ohdake śni śi naKaeś.

11 Unkan anpetu otoiyohi Mordekai winohinca tipi hocoka kin itokam mani ece, Esther tanyan un hecinhan, qa taku ecakiconpi kte cin he sdonye kta.

12 Unkan wikośka iyohi eca, Ahaśuerus wicaśtayatapi kin ekta ye kta, wi ake nonpa winohinca ohanpi kin eciyatanban un qehan;-ihduskapi kta anpetu kin hecen hduśtanpi ecee, wi śakpe mur ihdi unpi kin on, qa wi śakpe taku waśtemna kin on, winohinca econpi ecee kin iyececa :

13 Hehan wikośka kin hecen wicaśtayatapi kin en ya ece; iye winohinca tipi etanhan wicaśtayatapi ti kin ekta yuha ye kte cin taku da kin owasin qupi ecee.

14 Htayetu hehan iyaya, qa ihanhanna hehan winohinca tipi inonpa kin ekta hdicu, Śaaśgaz wicaśtaya tapi taokiye winohinca tawa awanwicayake cin he rape kin ekta: ake icimana wicaśtayatapi kin en ku śni, wicaśtayatapi kin waśte dake śni, qa cajeyan kico śni kinhan.

15 Unkan Esther Abihail cunwintku Mordekai dekśitku, eqe cunwintku kta icu qon he wanna wicaśtayatapi kin en ye kta iyehantu qehan, Hege wicaśtayatapi taokiye winohinca awanwicayaka ecee kin he taku cajeyate cin heceedan da. Unkan Esther tona wanyakapi kin owasin iśta kin en wowacantkiye iyeya ece. 


\section{ESTHER,}

16 Hecen Esther wicaśtayatapi ti kin ohna Ahaśuerus wicaśtayatapi kin ekta eyakupi, wi iwikcemna kin en, T'ebeth wi kin hee, iye tokiconze waniyetu iśakowin kin en.

17 Unkan wicaśtayatapi kin winotiinca owasin isanpa Esther waśtekidaka, qa iye iśta kin en wowacantkiye qa woiyokipi iyeya, wikośka iyulpa isanpa: hecen wicaśtayatapi tawapaha kin he iye pa kin alkan ehnaka, qa Vaśti eekiya wicuśta ya tapi winohinca kaga.

18 Hehan wicaśtayatapi kin iye wicaśta ihdawapi qa tawowidake owasin wayatkanpi tanka wan wicakicagia, Esther wayatkanpi tawa; qa makoce ounyanpi kin woozikiye wicaqu, wicaśtayatapi tookihi eciyatanhan wawicaqu ece.

19 Unkan wikośka inonpa mniciyapi hehan Mordekai wicaśtayatapi tatiyopa kin en iyotanka. 20 Esther nahanhin takuwicaye ca taoyate kin kpazo śni, Mordekai econ śi qon iyececa: Esther Mordekai taku eye cin ecen econ nakaeś, kici icağe ciqon he iyececa.

21 Anpetu kin hena en, Mordekai wicaśtayatapi tatiyopa ohna iyo tanka icunhan, Bigthan qa Tereś, wicaśtayatapi taokiye nonpa tiyopa awanyakapi kin hena śihdapi, qa Ahaśueṛus wicaśtayatapi kin nape ahnakapi kta akitapi.

22 Unkan wicoie kin he Mordekai sdonya, qa Esther wicaśtayatapi winohinca kin okiyaka; unkan Esther Mordekai caje eciyatanhan wicaśtayatapi kin okiciyaka.

23 Unkan wicoie kin he akitapi qehan iyeyapi, qa napin can wanji en otkewicayapi. Unkan he anpetu wicoie wowapi kin en owapi, wicaśtayatapi kin itokam.

\section{WICOWOYAKE 3.}

1 Wicoie kin dena iyohakam Ahaśuerus wicaśtayatapi kin Haman, Hamedatha cinhintku, Agagi kin heca, he tanka kaga, qa yuwankan iyeya, qa toiyotanke kin wicaśta ihdawapi om un kin owasin wiciwankam ekicihde.

2 Unkan wicaśtayatapi tawowidake wicaśtayatapi tatiyopa ohna unpi kin owasin canpeśka makehde inajinpi, qa Haman ohodapi ecee; iye on wicaśtayatapi kin hecen econ wicaśi nakaeś. Tuka Mordekai canpeśka makehde inajin śni qa ohoda śni. 3 Hehan wicaśtayatapi tawowidake wicaśtayatapi tatiyopa ohna unpi kin hena Mordekai heciyapi ; Tokeca niye wicaśtayatapi tawowaśi kin acayakśin he.

4. Unkan kaketu, anpetu eca heciyapi ecee, tuka anawicagoptan śni, hehan Haman okiyakapi, Mordekai oie kin ecetu kta hecinhan wanyakapi kta: he qe Juda wicaśta heca wanna owicakiyaka nakaeś.

5 Unkan Mordekai canpeśka makehde inajin śni qa ohoda śni ecee he Haman wanyaka, hehan Haman wocanteptanye ojudan.

6 Tuka Mordekai iśnana nape ahnake kta he iśta en woiyokipi śni ; Mordekai taoyate kin kipazopi nakaeś; heon etanhan Juda wicaśta Ahaśuerus tokiconze owancaya unpi iyuhpa, Mordekai taoyate kin hena ihangye wacin.

7 Wi tokaheya kin en, Nisan wi hee, Ahaśuerus wicaśtayatapi tawaniyetu iake nonpa kin en, anpetu eca Pur, oeconna econpi 
hee, Haman itokam elipeyapi ece, qa wi otoiyohi en, iake nonpa, Adar wi kin hee, hehanyan.

8 Hehan Haman Ahaśuerus wicaśtayatapi kin heciya; Oyate wan enanakiya unpi, qa nitokiconze en makoce owasin ektakta oyate kin opeya yakonpi: unkan iye woope tawapi kin toktokeca, oyate owasin en, qa wicaśtayatapi toope kin ahopapi śni ecee. Heon etanhan wicaśtayatapi kin onśiwicada kta iyecetu śni.

9 Wicaśtayatapi kin en he waśte kinhan, hena ihangyapi kta owapi kta: kinhan tona heconpi kta awanyakapi napepi kin en, miye mazaska woqin kektopawinge wilkemna wicawaqu kta, hecen wicaśtayatapi tawomnayan kin en aupi kta ce.

10 Unkan wicaśtayatapi kin iye nape etanhan mazanapcupe hduśdoka, qa Haman Hamedatha cinhintku Agagi kin, Juda oyate tokawicaye cin he qu.

$11 \mathrm{Qa}$ wicaśtayatapi kin $\mathrm{Ha}$ man heciya; Mazaska kin he niye niçupi, oyate kin he nakun, niiśta en taku waśte kinhan ecawicayecon kta ce.

12 Hehan wicaśtayatapi wowapi kagapi tawa kin wicakicopi, wi tokaheya en anpetu iakeyamni hehantu; unkan Haman econ wicaśi kin owasin iyecen wowapi wicakicagapi, wicaśtaya tapi taakicita tancanpi, qa makoce otoiyohi en wicaśta itancan kin, qa makoce owasin en oyate otoiyohi awanwicayakapi kin hena, iye wowapi kin eciyatanhan, qa oyate otoiyohi iye iapi kin en; Ahaśuerus wicaśtayatapi caje kin on owapi, qa wicaśtayatapi tamazanapcupe kin on apuspapi ece.

13 Unkan wowapi kin hena inyankapi napepi on wicaśtayatapi tamakoce kin owasin ektakta yeyapi, waihangye kta, wicakte kta, qa awihnuniwicaye kta, Juda wicaśta iyuhpa, aślkatudan qa wanakaś wotapi, hokśiyopa qa winohincapi, anpetu wanjidan en, wi iake nonpa, Adar wi kin hee, anpetu iake yamni hehantu; qa tawahpayapi kin icupi kta.

14 Wowaśi wowapi akta owapi makoce otoiyohi en wicaqupi kte cin he oyate owasin wicakiyaotaninpi, anpetu kin he itokam wiyeya unpi kta e heon.

15 Unkan inyankapi kin hena iyayapi, wicaśtayatapi oie kin on yuinahniwicayapi : unkan wokonze kin he Śsúan conkaśke kin ohna kagiapi. Hehan wicaśtayatapi kin hee qa Haman wayatkan iyotankapi ; tuka Śuśan otonwe kin cante sice hinca.

\section{WICOWOYAKE 4.}

1 Hehan Mordekai taku econpi kin owasin sdonye cehan, Mordekai wokoyake hdulidehdeca, qa wakihdaka cahota ko kiçun, qa otonwe kin ocokaya ekta iyaye ca woceye tanka qa pa hinca on śicahowaya :

2 Qa wicaśtayatapi tatiyopa kin hee kaeś itokam hiyu: wakihdaka unpi tuwedan wicaśtayatapi tatiyopa kin ohna tin hiyu kte śni nakaeś.

3 Nakun makoce owasin tukten wicaśtayatapi oie qa tawokonze kin ee hi kin en, Juda oyate ehna wicaceya tanka, qa wote śni unpi, qa ceyapi, qa śicahowayapi, qa wicota wakihdaka caliota ko ohna wankapi ecee.

4 Hecen Esther tawikośka kin iye en hipi, tawowidake kin nakun he okiciyakapi. Hehan wi707 


\section{ESTHER,}

caśtayatapi winyan kin iś nina iyokiśica, qa wokoyake Mordekai koyake kta e kaye wicaśi, qa wakihdaka kin ekiciyakupi kta: tuka iye icu śni.

5 Hehan Esther Hatak, wicaśtayatapi tawowidake wan, itokam najin śi qon he kico, qa Mordekai ekta ye śi, he taku he, qa tokeca hecinhan, he sdonye kta.

6 Hecen Hatak tankan iyaya, Mordekai ekta, otonwe hocoka kin ohna, wicaśtayatapi tatiyopa kin itokam hetu.

7 Unkan Mordekai taku akipe cin owasin he olkiyaka, qa maza- ska oyakapi, tona Haman wicaśtayatapi mazaska opiye tawa kin en, Juda oyate on elipeye kta keye cin, hena ihangyapi kta e heon.

8 Nakun wokonze wowapi owapi wan, ihangwicayapi kta on Suśan ekta wicaqupi qon he qu, Esther kipazo kta, qa okiyake kta, qa wicaśtayatapi kin ekta ye śi kta, cekiye kta, qa iye taoyate on wocekiye ekiciye kta.

9 Unkan Hatak hdicu qa Mordekai oie kin Esther okiyaka.

10 Akeś Esther Hatak kici ie ça Mordekai ekta ye si :

11 Wicaśtayatapi tawowidake owasin, qa makoce wicaśtayatapi tawa en oyate kin he de sdonyapi ecee, tuwe kaśta, wicaśta qa winobinca owasin, kicopi śni kinhan, hocoka mahentu kin en wicaśtayatapi kin ekta tin hiyu kinhan, on tawokonze wanjidan, he ktepi kta; tuwe wicaśtayatapi nikiye kta on mazaskazi sagye kin kipazo śni kinhan. 'Tuka miye qe wanna anpetu wikcemna yamni hehanyan wicaśtayatapi kin ekta u maśipi śni ce.
12 Unkan Esther oie kin Mordekai okiyakapi.

13 Hehan Mordekai Esther decen ayuptapi kta keya: Juda oyate iyulipa isanpa niye wicaśtayatapi ti ohna tanhan nayaśdoke kta ninagi en kecin śni wo: 14 Dehantu hin niye ocowasin inina yaun kinhan, wowanikiye qa woehdaku Juda oyate kin tokantanhan en wicahi kta; tuka niye qa niyate ti kin ihangniyanpi kta; unkan taku dececa on wicaśtayatapi toyanke kin en yahi hecinhan tuwe sdonya he.

15 Hehan Esther Mordekai decen ayuptapi kta keya :

16 Ye ça Juda oyate Śuśan en ounyanpi kin iyuhpa mniciye wicaśi ye, qa miye on wote śni un pe, han, anpetu yamni wotapi śni qa wayatkanpi śni pe, hanyetu qa anpetu : miś eya wikośka mitawa koya wote śni unyakonpi kta: unkan hecen wicaśtayatapi kin en mde kta, he woope kin eciyatanhan śni qeyaś: qa hecen mațe cinhan mațe kta ce.

17 Unkan Mordekai iyaye ça Esther taku econ śi qon owasin ohnayan yuśtan.

\section{WICOWOYAKE 5.}

1 Unkan anpetu iyamni qehan kaketu, Fsther wicaśtayatapi ihduze ca wicaśtayatapi tahocoka mahentu kin ohna inajin, wicaśtayatapi ti kin iyotakonza: unkan wicaśtayatapi kin he wicaśtayatapi ti ohna wicaśtayatapi toiyotanke kin akan kiyotanka yanka.

2 Unkan kaketu, wicaśtayatapi kin Esther wicaśtayatapi winohinca hocoka ohna najin wanhdake cehan, iye iśta en wocantekiye iyeya: unkan wicaśtaya- 
tapi kin mazaskazi sagye nape ohna hduhe cin he Esther kipazo. Hecen Esther kiyedan u qa sagye pa kin yutan.

3 Hehan wicaśtayatapi kin heciya; Esther wicaśtayatapi winohinca, taku yacin he, qa yada kte cin he taku he: wokiconze kin hanke hehanyan kinhan nicupi kta ce.

4 Hehan Esther heya ayupta; Wicaśtayatapi kin en . waśte kinhan, wayatkanpi wan anpetu kin de wicaśtayatapi wecagge cin he en Haman kici u kta ye.

5 Hehan wicaśtayatapi kin heya; Haman inahnikiya po, hecen Esther oie kin ohnayan econ kta. Hecen wicaśtayatapi kin he qa Haman wayatkanpi Esther kage ciqon he en hipi.

6 Unkan miniśa yatkanpi kin en wicaśtayatapi kin Esther heciya; Wocekiye nitawa kin tukte e he, kinban niçupi kta: qa taku yada kte cin tukte e he, wokiconze hanke kin hehanyan ecen ecaniconpi kta ce.

7 Hehan Esther ayupte ca heya ; Mitawocekiye qa taku wada kin;

8 Wicaśtayatapi iśta kin en wocantekiye iyewaye cinhan, qa mitawocekiye ayupte kta wicaśtayatapi waśtedake cinhan, qa taku wada kin ecen econ kta hecinhan, wicaśtayatapi qa Haman wayatkanpi wicawecage kte cin he ekta upi kta, kinlan wicaśtayatapi eye cin he heyakecinhan ecen ecamon kta ye.

9 Hehan anpetu kin he Haman wiyuśkin, qa hetankıan cante waśteya kihda: tuka Mordekai wicaśtayatapi tatiyopa ohna, iye on najin śni qa ihduśkanśkan śni Haman wanyake cehan, hehan Mordekai on Haman nina canteptanyan.

10 Tuka Haman ținsiçiya: un- kan iye ti kin ekta ki qehan yewicaśi, qa iye takuwicaye cin wicakico, qa tawicu Zereś nakun.

11 Qa Haman iye towijice wowitan kin owicakiyaka, qa cinca wicota nakun, qa taku owasin on wicaśtayatapi yuwankan iyeya, qa wicaśtayatapi tawowidake qa wicaśta ihdawapi kin hena wiciwankam ehnake cin.

12 Nakun Haman heya; Han, Esther wicaśtayatapi winohinca kin he wayatkanpi kag'e cin tuwedan wicaśtayatapi kin kici en ya iyowinkiye śni, tuka miśnana; qa heyakecinhan nakun wicaśtayatapi kin kici iye en micopi ;

13 Tuka dena owasin taku śni wadake, tohany an Mordekai Juda wicaśta kin wicaśtayatapi tatiyopa en iyotanka wanmdake cinhan.

14 Hehan tawicu Zereś qa takuwicaye cin owasin heciyapi; Can wan obosdatu wiciśpa wikcemna zaptan kin he kagapi kta, qa heyakecinhan Mordekai he en otkeyapi kta wicaśtayatapi kin keyakiye kta; hehan wayatkanpi kin en wicaśtayatapi kici wiyuśkinyan ya wo. Unkan wicoie kin he Haman waśtedaka: hecen can kin he kah wicaśi.

\section{WICOWOYAKE 6 .}

1 Hanyetu kin he en wicaśtayatapi kin iśtinma okihi śni, qa anpetu wicoie wowapi owapi qon he ahiwicaśi : unkan wicaśtayatapi kin itokam hena yawapi.

2 Unkan Bigthana qa Tereś, wicaśtayatapi tawowidake nonpa, tiyopa awanyakapi ecee qon, hena Ahaśuerus wicaśtayatapi kin nape ahnakapi kta akitapi qon he en owapi iyeyapi, he Mordekai oyake ciqon.

3 Unkan wicaśtayatapi kin he709 


\section{ESTHER,}

ya; De on taku wowitan qa woy uonihan Mordekai ecakiconpi he. Hehan wicaśtayatapi tawowidake en olkiyapi ecee kin hena heciyapi; Takudan ecakiconpi śni ce.

4 Hehan wicaśtayatapi kin heya; Tuwe hocoka kin en un he. Wanna Haman wicaśtayatapi ti hocoka tankantu kin en hi, can wan kicage cin en Mordekai otkeye kta e wicaśtayatapi keciye kta e heon.

5 Unkan wicaśtayatapi tawowidake kin heciyapi; Iho, Haman hocoka kin en najin ce. Unkan, Tin u kta ce, wicaśtayatapi kin eya.

6 Hecen Haman timahen hi. Unkan wicaśtayatapi kin heciya; Tuwe wicaśtayatapi yuonihan lsta iyokipi kin he taku ecakiconpi kta iyececa he. Unkan, Tuwe miye kin isanpa wicaśtayatapi kin yuonihan iyokipi kta he, Haman cante ekta ecin.

7 Hehan Haman wicaśtayatapi kin ayupta; Wicaśta tuwe wicaśtaya tapi yuonihan iyokipi kin,

$8 \mathrm{He}$ on wicaśtayatapi tawokoyake wicaśtayatapi un ecee, qa śuktanka wicaśtayatapi akan iyotanka ecee kin, qa wicaśtayatapi tawapaha iye pa kin akan ehnakapi ecee kin hena aupi kta ;

$9 \mathrm{Qa}$ wokoyake qa śuktanka kin hena wicaśta ihdawa iyotanpi wicaśtayatapi tawa wanji nape en qupi kta, hecen wicaśta kin tuwe wicaśtayatapi kin yuonihan iyokipi kin he koyagyapi kta, qa suktanka akan otonwe canku kin opta hiyuyapi kta, qa itokam, Wicaśta kin tuwe wicaśtayatapi yuonihan iyokipi kin he decen ecakiconpi ecee kta ce, eya eyanpahapi kta ce.

10 Hehan wicaśtayatapi kin 710
Haman heciya; Inahini wo, wokoyake kin he, qa suktanka kin icu wo, ehe cin iyececa, qa Mordekai Juda wicaśta wicaśtayatapi tatiyopa en iyotanke cin he iyecece hinca ecakicon wo: taku tona ehe cin wicoie wanjidan ecetu śni wanice kta.

11 Hehan Haman wokoyake qa śuktanka kin icu, qa Mordekai koyagya, qa otonwe canku kin ohna śuktanka akan iyotangkiya, qa itokam eyanpaha, Wicaśta tuwe wicaśtayatapi yuonihan kta iyokipi kin he decen ecakiconpi kta ce.

12 Unkan Mordekai wicaśtayatapi tatiyopa kin en hdi. Tuka Haman iye ti ekta inahni ceya kihda, qa pa ahdahpa.

13 Unkan Haman iye tawicu Zereś qa takuwicaye cin taku akipe cin owasin owicakiyaka. Hehan wicaśta ksapapi tawa qa tawicu Zereś hena hecen eciyapi ; Mordekai itokam hinhpaye niyanpi kin eqe Juda wicoicage kin etanhan hecinhan, niye ohiyaye kte śni, tuka hinhpayapi on nihinhpaye kta ce.

14 Unkan kici wohidakapi icunhan, wicaśtayatapi tawowidake kin hena hipi, qa Esther wayatkanpi kag'e cin ekta inahni yeyapi.

\section{WICOWOYAKE $\%$.}

1 Hehan wicaśtayatapi qa Haman Esther wayatkanpi kag'e cin en hipi.

2 Unkan miniśa yatkanpi anpetu inonpa kin en wicaśtayatapi kin ake Esther heciva; Esther wicaśtayatapi winohinca, nitawocekiye kin tukte e he : unkan aniyuptapi kta: qa taku yada kin tukte e he; kinhan ecaniconpi kta ce, wokiconze hanke kta hehanyan. 


\section{WICOWOYAKE 8.}

3 Hehan Esther wicaśtayatapi winolinca kin waayupte ca heya; Wicaśtayatapi, niiśta en wowaonśida iyewaye ça wicaśtayatapi kin iyokipi kinhan, wani kte cin he mitawocekiye on maqupi kta, qa wada on mitaoyate kin hena:

4 Wiyopeunkiyapi nakaeś, miye qa mitaoyate, ihangwicayapi kta, wicaktepi kta, qa atakunipi kte śni heon. Tuka wicaśta wowidake qa winyan wowidake kin heca lita wiyopeunkiyapi unkanś inina waun kta tuka; toka kin wicaśtayatapi taku akicitakuni śni kin yuwaśte okihi śni qeyaś.

5 Hehan Ahaśuerus wicaśtayatapi kin waayupte, qa Esther wicaśtayatapi winohinca kin heciya; $\mathrm{He}$ tuwe he, qa tukten un he, cante on hecen econ wacin kta he.

6 Unkan Esther heya; Wicaśta wawakipajin qa toka kin Haman śice cin dee ye, eya. Hehan wicaśtayatapi qa -wicaśtayatapi winohinca kin wicitokam Haman nihinciya.

7 Hehan wicaśtayatapi tośinhda on miniśa yatkanpi kin etanhan najin hiyaya, tipi tanka tawoju kin ekta. Unkan Haman iye nagi on Esther itokam cekiya inajin; wicaśtayatapi kin en wanna taku śica kiciyuśtanpi wanyaka nakaeś.

8 Hehan wicaśtayatapi kin tipi tanka tawoju kin etanhan miniśa yatkanpi owanka kin en hdi; unkan owinja Esther akan wanke cin he Haman ahinlipaya yanka. Hehan wicaśtayatapi kin heya; Nakun tipi ohna mitokam wicaśtayatapi winohinca kin kikśan kta he. Wicoie kin he wicaśtayatapi i kin etanhan enanpe cehan Haman ite akahpapi.
9 Hehan Harbonah, wowidake wanji iś wicaśtayatapi kin itokam beya; Can kin wiciśpa wikcemna zaptan wankantu, Haman Mordekai kicağa, eqe wicastayatapi taku waśte eciya tuka, he Haman ti kin ohna han e wanyaka ye. Hehan wicaśtayatapi kin heya; En otkeya po.

\section{WICOWOYAKE 8.}

1 Anpetu kin he en Ahaśuerus wicaśtayatapi kin Haman Juda oyate tokawicaye cin hee tiyohnaka tawa kin Esther wicaśtayatapi winohinca kin qu. Unkan Mordekai wicaśtayatapi kin itokam hi; token takuye cin he Esther okiyaka nakaeś.

2 Unkan wicaśtaya tapi kin mazanapcupe Haman ekicihdaku qon he hduśdoka qa Mordekai qu. Unkan Esther Haman ti kin en Mordekai itancan kaģa.

3 Unkan Esther akihdeye ca wicaśtayatapi kin itokam ie ça siha kin en makata elipeiciye ca Haman Agag wicaśta kin talu śica kagge ca woawacin Juda oyate kin awicawakicin kin he yutokan iyeye kta e ceya icekiya.

4 Helıan wicaśtayatapi kin mazaskazi sagye kin Esther kipazo. Hecen Esther najin hiyaye ca wicaśtayatapi kin itokam inajin :

5 Qa heya; Wicaśtayatapi kin en he waśte kinhan, qa iye itokan wocantekiye iyewaye cinhan, qa wicoie kin he wicastayatapi kin itokam owotanna kinhan, qa iye iśta en miye mawaśte kinhan, Haman Hamedatha cinhintku, Agag wicaśta kin, Juda oyate wicaśtayatapi tamakoce owasin ohna unpi kin hena ihangye kta on wowapi kagge ciqon;

711 


\section{ESTHER,}

wokonze kin he ecetu śni ye kta e wowapi kagiapi nunwe :

6 Ecin token owakihi kta, qa mitaoyate taku śica awicau kta en ewatonwe kta he; qa token owakihi kta, qa mitakuye ihangyapi kta wanmdake kta he.

7 Hehan Ahaśuerus wicaśtayatapi kin Esther wicaśtayatapi winohinca qa Mordekai Juda wicaśta kin hewicakiya; Wanyaka wo, Haman tiyohnaka kin wanna Esther waqu; unkan iye hinca can wan en otkeyapi, Juda oyate nape awicahnake cin heon etanhan.

8 Nakun niyepi, token iyonicipipi, hecen Juda oyate on wowapi kağa po, wicaśtayatapi caje en, qa wicaśtayatapi mazanapcupe tawa on apuspa po: wowapi kin tukte e wicaśtayatapi caje en kag̉api, qa wicaśtayatapi mazanạpcupe tawa on apuspapi kinhan tuwedan ecetu śni ye kte śni ece. 9 Hehan anpetu kin he en wicaśtayatapi wowapi kağapi tawa kin hena wicakicopi, wi iyamni kin en, Sivan wi kin hee, anpetu wikcemna nonpa sanpa iyamni kin hehantu; unkan wowapi, Mordekai token econwicaśi kin owasin eciyatanhan, Juda oyate, qa wicaśtayatapi, qa wicaśta ihdawapi, qa India etanhan Kuś hehanyan makoce en itancanpi, makoce opawinge sanpa wikcemna nonpa sanpa śakowin, wowapi wicakicagapi; makoce otoiyohi tawowapi kin eciyatanhan, qa oyate otoiyohi iapi tawapi eciyatanhan, qa Juda oyate iye tawowapi qa iapi tawapi kin eciyatanhan.

10 Unkan Ahaśuerus wicaśtayatapi caje kin en wowapi kaga, qa wicastayatapi mazanapcupe tawa kin on apuspa ecee: qa Wowapi kin hena inyankapi napepi on yeya, suktanka akan iyotankapi, śonśonna akan, kamel akan, śunka wakan cincapi akan.

$11 \mathrm{He}$ on wicaśtayatapi kin Juda oyate otonwe otoiyohi en unpi kin hecen wicaqu, witaya mniciyapi kta, qa iye nagipi on najinpi kta, waihangye kta, wicakte kta, qa makoce qa oyate tona takpe wicaupi kin he wowaśake ocowasin yutakuni kte śni, hokśiyopa qa winohinca, qa tawahpaya kin icupi kta;

12 Anpetu wanjidan en, Ahaśuerus wicaśtayatapi tamakoce iyuhpa ohnahna, wi iake nonpa, Adar wi kin hee, anpetu iakeyamni kin en.

13 Wowapi owapi woope on makoce owasin en wicrqupi kin he oyate iyuhpa wicakiyataninpi, qa Juda wicaśta kin hena anpetu kin he en tokawicayapi kin towicakiçonpi kta ihduwitayapi kta.

14 Inyankapi kin hena śonśonna kamel ko akan yanka iyayapi, wicaśtayatapi oie on wicayuduzahanpi, qa inahni wicayapi. Unkan Suśan conkaśke kin en woope kin he wicaqupi.

15 Hehan Mordekai wicaśtayatapi tawokoyake to qa ska, qa mazaskazi wateśdake tanka wan un, qa sina wan ska qa duta in, wicaśtayatapi kin etanhan iyaya. Unkan Suśan otonwe kin wiyuśkin qa cante waśte hinca.

16 Unkan Juda oyate kin iyoyanpa, qa cante waśtepi, qa wowiyuśkin qa woyuonihan yuhapi.

17 Unkan makoce otoiyohi en, qa otonwe otoiyohi en, tukte etu wicaśtaýatapi oie qa toope lin ekta hí eca, Juda wicaśta kin wowiyuśkin qa wicocante waśte, wotapi qa anpetu waśte 
yuhapi ece. Unkan makoce oyate kin ota Juda wicaśta icagapi : Juda oyate tawokokipe kin awicahinlipaya nakaeś.

\section{WICOWOYAKE 9.}

1 Unkan wi iake nonpa kin en, Adar wi kin hee, anpetu iakeyamni kin en, wicaśtayatapi oie qa toope wanna econpi kta kiyedan aye cehan, anpetu kin he en tokawicayapi kin hena Juda wicaśta kin wicaktepidan kta kecinpi tuka qon-eśta he yuecetupi śni, qa Juda oyate kin tona sice wicadakapi qon hena wicaktepidan :

2 Juda wicaśta kin Ahaśuerus wicaśtayatapi tamakoce kin owasin ohnahna, iye totonwepi kin en mniciyapi, tona kiunniwicaye wacinpi tuka qon hena nape awicaputakapi kta: Unkan tuwedan wicitkokim najin okihi śni ; hena kowicakipapi kin oyate owasin awicahinlipaya nakaeś.

3 Unkan makoce kin ohnahna wicaśtayatapi owasin, qa wicaśta ihdawapi, qa wicaśta itancanpi, qa wicaśtayatapi taakicita kin Juda wicaśta owicakiyapi ecee: Mordekai kokipapi kin awicahinhipaya nakaeś.

4 Mordekai wicaśtayatapi ti kin ohna tanka nakaeś, qa tawootanin makoce owasin ektakta iyaya. Mordekai wicaśta kin de icage ca tanka aya ece.

5 Hecen Juda wicaśta tona tokawicayapi kin iyuhpa mazasagye apapi qa wicaktepi, qa ihangwicayapi on awicapapi, qa token tawacinpi tona śicewicadakapi qon ecawicakiconpi ece.

6 Unkan Śuśan conkaśke kin ohna Juda oyate kin wicaśta opawinge zaptan ecetu wicaktepi qa ihangwicayapi.
7 Qa Parśandatha, qa Dalphon, qa Aspatha,

8 Qa Poratha, qa Adalia, qa Aridatha,

9 Qa Parmaśta, qa Arisai, qa Aridai, qa Vajezatha,

10 Haman Hamedatha cinhintku, Juda oyate tokawicaye ciqon he cinca wikcemna kin hena wicaktepi ; tuka tawahpayapi kin nape ahnakapi śni.

11 Anpetu kin he en. tona Śuśan conkaśke kin en wicaktepi wicayawapi kin he wicaśtayatapi kin itokam ahipi.

12 Hehan wicaśtayatapi kin Esther wicaśtayatapi winohinca kin heciya; Śuśan conkaśke kin ohna Juda wicaśta kin wicaśta opawinge zaptan wicaktepi qa ihangwicayapi, qa Haman cinhintku wikcemna kin hena: wicaśtayatapi tamakoce unmapi kin ohnahna taku econpi he: Wanna nitawocekiye tukte e he; unkan aniyuptapi kta: qa taku sanpa yada kin tukte e he; kinhan ecen ecaniciconpi kta ce. 13 Unkan Esther heya; Wicaśtayatapi kin en he waśte kinahan, anpetu kin de wokonze kin he iyecen nakun Juda wicaśta Śuśan en unpi kin heyakecinhan iyecen econpi kta e wakiconzapi nunwe, qa Haman cinhintku wikcemna kin hena can akan otkewicayapi kta ye.

14 Unkan wicaśtayatapi kin hecen econpi kta keya: qa wokonze kin he Śuśan en wicaqupi: unkan Haman cinca wikcemna kin hena otkewicayapi.

15 Hehan Juda wicaśta Śuśan en unpi kin hena Adar wi kin anpetu iake topa kin en nakun witaya iheyapi, qa Śuśan ohna wicaśta opawinge yamni wicaktepi; tuka tawahpaya kin nape ahnakapi śni. 
ESTHER,

16 Tuka Juda wicaśta unmapi wicaśtayatapi tamakoce + kin ohnahna unpi kin hena widwitaya mniciyapi, qa iye nağipi on najinpi, qa tokawicayapi kin etanhan oziiciyapi, qa tokapi kin kektopawinge wikcemna śakowin sanpa kektopawinge zaptan wicaktepi, tuka tawahpayapi kin nape ahnakapi śni;

17 Adar wi kin anpetu iakeyamini kin en; qa anpetu iaketopa kin en oziiciyapi, qa wotapi, qa wiyuśkinpi anpetu kaggapi.

18 Tuka Juda wicaśta Śuśan en unpi qon hena anpetu iakeyamni qa nakun anpetu iaketopa kin en witaya iheyapi; qa anpetu iakezaptan kin en oziiçiyapi, qa he wotapi anpetu qa wiyuśkinpi kağapi.

19 Heon etanhan Juda oyate makomdaye otonwe kin ohna, otonwe acankaśkanpi śni ohnahna tipi kin liena Adar wi anpetu iaketopa kin he wiyuśkinpi qa wotapi qa anpetu waśte kagapi, qa otoiyohi taku kiciçupi ece.

20 Unkan Mordekai wicoie kin dena owa, qa Juda oyate Ahaśuerus wicaśtayatapi tamakoce ohnahna unpi kin owasin wowapi wicakicaga, kiyedan qa tehan unpi kin.

21 Omaka owasin en, Adar wi kin anpetu iaketopa qa nakun anpetu iakezaptan kin ahopapi kta e wicakiciyuśtan kta :

22 Anpetu kin hena en Juda oyate kin tokawicayapi etanhan oziiciyapi, qa wi kin he woiyokiśice etanhan wowiyuśkin iwicakicaga, qa wicaceya anpetu waśte icage ciqon : heon anpetu kin hena wotapi qa wowiyuśkin kagapi kta, qa otoiyohi taku kicicupi kta, qa wahpanica wawicaqupi ecee kta.
23 Unkan Juda wicaśta kin he ohnayan econpi ecee kta icupi, ga Mordekai wowapi wicakicage cin he ohnayan.

24 Haman Hamedatha cinhintku, Agag wicaśta, Juda wicaśta owasin tokawicaye ciqon, Juda oyate kin ihangwicaye kta awacin, qa on Pur ehpeya, oeconna hee, on wicayutakuni kte śni qa ihangwicaye kta e heon.

25 Tuka iye-Esther-wicastayatapi kin itokam hiyu qehan, eqe woawacin śica Juda oyate wicakiconza qon he iye pa kin en hdihpaye kta, qa iye hinca cincarvicaye cin hena koya can en otkewicayapi kta e wowapi on econwicaśi.

26 Heon etanhan anpetu kin dena Purim eya cajeyatapi, Pur caje kin he eciyatanhan. Heon etanhan wowapi kin de wicoie owasin on, qa de on taku wanyakapi, qa taku akipapi kin on etanhan,

27 Juda oyate wakiconzapi, qa iyepi hinca on icupi qa iye cincapi kin on, qa-nakun tona en ihdaśkapi kin hena owasin on, qa ecetu śni wanice kta, hecen anpetu dena oza wowapi iyecen opapi kta, qa waniyetu owasin en omaka iyehantu kin eciyatanhan:

28 Qa anpetu kin dena kiksuyapi kta, qa wicoicage qa wicoicag̀ kin en opapi kta, wicowazi qa wicowazi, makoce qa makoce, otonwe qa otonwe kin en: qa Purim anpetu kin dena Juda oyate kin en ecetu śni wanice kta, qa okiksuye kin iye cincapi kin etanhan atakuni śni wanice kta.

29 Hehan Esther Abihail cunwintku, wicaśtayatapi winohinca kin he, qa Mordekai Juda wicaśta kin wowaśake ocowasin on 


\section{WICOWOYAKE 10.}

wowapi kagapi, Purim wowapi inonpa kin de yusutapi kta.

30 Unkan wowapi kin hena Juda wicaśta owasin ekta yeya, Ahaśuerus tokiconze kin en, makoce opawinge sanpa wikcemna nonpa sanpa śakowin ekta, wookiye qa wowicake oie ;

31 Purim anpetu kin dena yusutapi kta, omaka iyehantu eca, Mordekai Juda wicaśta qa Esther wicaśtayatapi winohinca econ wicaśipi kin iyececa, qa iyepi hinca on qa iye cincapi on içiconzapi qon he eciyatanhan, woteśni unpi qa howayapi wicoie kin hena.

32 Unkan Esther wakiconze cin he Purim oie kin dena yusuta: Unkan wowapi en kagapi.

\section{WICOWOYAKE 10.}

1 Unkan Ahaśuerus wicaśtayatapi kin he wicohtani wan maka kin ahnaka, qa miniwanca wita kin akan.

2 Unkan iye towaśake qa tookihi ohan kin owasin, qa Mordekai tanka oyakapi, on wicaśtayatapi kin yutanka qon hena Media qa Persia wicaśtayatapi anpetu iyohi wicoie wowapi kin en owapi śni he.

3 Mordekai Juda wicaśta kin A haśuerus wicaśtayatapi kin iyokihe yanka, qa Juda oyate kin en tanka, qa iy e hunkawanjitku wicota iyokipipi, iye taoyate towaśte kin akita, qa wicoicağe tawa kin iyuhpa wookiye ewicakiya ece.

\section{JOB.}

WICOWOYAKE 1 .

$1 \mathrm{Uz}$ makoce kin en wicaśta wan Job eciyapi : unkan wicaśta kin he ocowasin qa ecetu, nakun Wakantanka kokipe ca taku śica icunonpa iyaya ecee.

2 Unkan cinhintku śakowin qa cunwintku yamni kicitonpi.

3 Nakun tawanunyanpi kin hena tahin wanunyanpi kektopawinġe śakowin, qa kamel kektopawing gamni, ga tatanka kiciiyakaśkapi kin opawinge zaptan, qa śonśonna wiye opawinge zaptan, qa taokiye ota hinca: hecen wicaśta kin de wiyohiyanpata cinca owasin isanpa tanka.

4 Unkan cinhintku iyayapi, qa otoiyohi iye taanpetu en tipi tawa ohna wotapi ece: qa na- kun tawinohtin yamnipi bena wahowicayapi qa om wotapi kta, qa wayatkanpi kta e wicakicopi.

5 Unkan kaketu, wotapi anpetu kin wanna ohomni iyayapi hehan Job wahowicnya qa wicayuwakan, qa hanhanna hin kikta, qa owasin iyawa iyecen wohuŁnağe wośnapi kin wawicakiciyuśna ecee. Job hecen eya nakaeś ; Okinni micinkśi wahttanipi, qa iye cantepi etanhan Wakantanka ehpeyapi naceca. Anpetu owasin Job hecen econ ece.

6 Unkan anpetu wan Wakantanka cinca kin Jehowa itokam eiçihdepi kta hiyupi; qa Satan iś eya owicapeya hi.

7 Unkan Jehowa Satan heciya; Tokiyatanhan yau he. Hehan Satan Jehowa ayupta, qa, Maka 715 


\section{JOB,}

kin en omawani qa ohna ohnihdeya waun kin hetanhan, eya.

8 Unkan Jehowa Satan heciya; Job mitaokiye kin he nicante on awacanni he, maka akan tuwedan iyecece śni, wicaśta ocowasin qa ecetu, Wakantanka kokipe ça taku śica icunonpa iyaya ecee.

9 Unkan Satan Jehowa ayupte cà heya; Taku śni on Job Wakantanka kokipa he :

10 Iye hinca ihdukśan conkaśke wan yakag̉e śni he, qa iye ti kin ihdukśan, qa taku tawa iyuhpa iyohomni: iye nape ohan kin duwaśte, qa tawanunyanpi kin maka akan yuotapi ecee.

11 Tuka wanna ninape ekta yekiye ça taku tawa owasin yutan wo, kinhan awicakehan niite itokam elipeniye kta.

12 Unkan Jehowa Satan heciya; Iho, taku tawa iyuhpa ninape ohna yanka; tuka iye hinca ihnuhan nape ayahnake cinhan. Hecen Satan Jehowa itokapatanhan tankan iyaya.

13 Unkan anpetu wan, hehan cinhintku qa cunwintku timdoyapi tokapa ti kin ohna wotapi qa miniśa yatkan yukanpi.

14 Unkan wahośi wan Job en hi qa heya; Tatanka kin hena mahyumdupi, qa śonśonna kin iś wicikiyedan wilianpi :

15 Unkan Śseba wicaśta watakpe upi qa ewicayakupi : han, mazasagye hi kin on hokśipidan wicaktepi ; qa miye miśnana nawajica ociciyake kta e wahihbu ce.

16 De iahan icunhan nakun wanji hi, qa heya; Peta Wakantanka tawa kin mahpiya eciyatanhan hinhpaya, qa tahinca wanunyanpi hokśipidan ko huhnahwicaya qa ihangwicaya; qa miye miśnana nawajica ociciyake kta e wahibbu ce.
17 He qe iahan icunhan nakun wanji hi qa heya: Kasdim oyate kin ozuye yamni kagiapi, qa kamel iyawicahpayapi qa akiyahdapi ; han, hokśipidan mazasagye hi on wicaktepi; qa miye miśnana nawajica ociciyake kta e wahihbu ce.

$18 \mathrm{He}$ ge iahan icunhan nakun wanji hi qa heya; Nicinkśi qa nicunkśi timdoyapi tokapa ti kin ohna wotapi qa miniśa yatkan yukanpi :

19 Unkan iho, tate wan tanka linca hewoskan tanhan $u$, qa tipi oise topa kin en iyapa, qa kośka kin awicahinhpaya, hecen hena tapi ; unkan miye miśnana nawajica, ociciyake kta e wahihbu ce, eya.

20 Hehan Job najin hiyaya qa iye taśina hdulidehdeca, qa pa hdasan, qa makata hinhpaya qa cekiya ;

21 Qa heya; Ina itpi kin etanhan tancodan hibu, qa ake tancodan ekta wahde kta: Jehowa wawicaqu ece, qa Jehowa waehdaku; Jehowa caje kin yawaśtepi nunwe.

22 Dena owasin on Job wahtani śni, qa wowitkotkoka Wakantanka qu śni.

\section{WICOWOYAKE 2.}

1 Akeś anpetu wan hehan Wakantanka cinca kin Jehowa itokam eicihdepi kta hiyupi, unkan hena owicapeya Satan iś eya Jehowa itokam eiçihde kta hiyu.

2 Unkan Jehowa Satan heciya; Tokiyatanhan yau he. Unkan Satan Jehowa ayupte ca, Maka kin en omawani qa ohna ohnihdeya waun kin hetanhan, eya.

3 Unkan Jehowa Satan heciya; Job mitaokiye kin nicante on awacanni he, maka akan tuwe- 


\section{WICOWOYAKE 3.}

dan iyecece śni, wicaśta ocowasin qa owotanna, Wakantanka kokipe ca taku śica icunonpa iyaya ece: qa taku on etanhan sni ihangwaye kta icantahdemayaya qeyaś hinyahin toow otanna en waśagiciya ce.

4 Unkan Satan Jehowa ayupte ca heya; Wawaha wawaha on, han, taku wicaśta yuhe cin iyuhpa iye naği on qu $k$ ta.

5 Tuka wanna ninape yekiye ca iye hu qa cehpi kin yutan wo ; kinhan awicakehan niite itokam ehpeniye kta ce.

6 Hehan Jehowa Satan heciya; Iho, ninape ohna yanka; tuka iye naġi kin patan wo.

I Hehan Satan Jehowa itokapatanhan tankan kihda, qa śiyakao śica on Job apa, sicuha etanhan pesdete hehanyan.

8 Unkan maka cegga onśpa icu, on ihdaqog'e kta, qa caliota ehna iyotanka.

9 Hehan tawicu kin heciya; Hinyahin nitoowotanna en nihduwaśaka he; Wakantanka ehpeye ça ța ye.

10 Tuka Job heciya; Winohinca witkotkoka ie cin iyecen iyaa. Wakantanka etanhan taku waśte unkicupi kta he, qa taku śica nakun unkicupi lite śni he. De ocowasin en Job iye iha on wahtani śni.

11 Hehan Job takodaku yamni, taku śice cin de owasin akipa nahonpi qehan, otoiyohi iye tohe kin etanhan hiyupi; Eliphaz Temani, qa Bildad Suhi, qa Zophar Naamathi: hecen wahokiciyapi, ihduwitayapi kta, onśikidapi kta e ekta yapi kta, qa kici ceyapi kta.

12 Unkan itehanyan iśta yuwankan ikikcupi qehan, qa iyekiyapi śni, hehan ho hdawankan iyeyapi qa ceyapi; qa otoiyohi taśina hduhdehdecapi, qa iye pa akan maka ahdadapi, mahipiya ektakiya.

13 Hecen kici makata iyotankapi anpetu śakowin qa hanyetu śakowin; qa tuwedan wicoie wanjidan eciye śni; wayazanke cin he tanka hinca wanyakapi nakaeś.

\section{WICOWOYAKE 3.}

$1 \mathrm{He}$ iyohakam Job taanpetu kin hdaśice kta e i hdukawa. 2 Qa Job wayupte ça heya :

3 Anpetu en matonipi qon he atakuni śni nunwe; Qa hanyetu, Wicacinca wan icagga ce, eye ciqon.

4 Arpetu kin he otpaza icage kta: On Wakantanka wankantanhan wiwange kte śni ; Qa iyoyanpa kin aojanjan śni nunwe.

5 Otpaza qa wiconțe ohanzi opekiton kta: Mahipiya śapa van aunyan nunwe: Anpetu aohanzi kin hena wakokipe kicage kta.

6 Hanyetu kin he, otpaza iyahipaye kta: Owaniyetu anpetu kin ehna kokijuyapi kte śni : Wi yawapi kin en u śni nunwe.

7 Iho, lianyetu kin he wicaton wanice kta: Wowiyuśkin ho kin en $u$ śni nunwe.

8 'Tona anpetu yaśilitinpi ecee kin he yaśicapi kta; Unktehi yuhica wayupikapi kin hena.

9 Anpao wicanhipi tawa kin he aotpasyapi nunwe; Iyoyanpa cantokpani kta, tuka wanice kta: Qa anpao iśtojuha kin wanyake śni nunwe.

10 Ohna imacaga tiyopa kin natake śni nakaeś; Qa woiyokiśce miiśta anakicilibe śni.

11 Tokeca itpi kin etanhan mato śni he: Tamni etanhan hibu qa ta imdamde śni he.

12 Tokeca wicapahu kin itko717 
makipa he; Qa tokeca azepinkpa, hecen awazin kta he.

13 Unkanś wanna imunke ca inina waun kta; Miśtinbe kta: hehan ozimiciye kta tuka;

14 Wicaśtayatapi, qa maka akan waaiapi, otiwota içicağapi kin hena om ;

15 Qa wicaśta ihdawa mazaskazi yuhapi, iye tipi mazaska on ojuyapi kin hena om:

16 Qa iś okaśkan tonpi wan hapi kin iyececa, en waun kte śni ; hokśiyoqopa tohinni iyoyanpa wanyakapi śni iyececa.

17 Heciya śicapi kin wanagiveya ayuśtanpi; Qa hell mdokițapi kin oziic̣iya wankapi ecee.

18 Wicakaśkapi kin opeya ozikiyapi; Wakahape ho kin, nahonpi śni ecee.

19 Wicacistinna qa wicatanka kin hen akiyececapi : Qa wowidake kin yuhe cin etanhan kiyuśkapi.

20 Tokeca kakiśyapi un kin iyoyanpa qupi he: Qa wiconi, wicanaği iyokiśica un kin :

21 Wiconte cantokpanipi, tuka wanica; Qa taku woha en un kin isanpa he odepi ece:

22 Hena nina wiyuśkinpi ecee; Wicaliapi iyeyapi kinhan cante waśtepi hinca ecee.

23 Wicaśta wan tacanku akahpapi, qa tuwe Wakantanka acankaśke cin he.

24 Comniwahdazi kin wawate cin itokam u nakaeś; Qa waśicahowamde cin mini iyecen ikpapson ecee.

25 Wokokipe wan kowakipa, tuka en amau; Qa taku on nihinciya waun kin he en mahi nakaeś.

26 'Tanyan waun śni, qa owanji manke śni, qa ozimiçiye śni, tuka wonihinciye hi.
WICOWOYAKE 4.

1 Hehan Eliphaz Temani kin waayupte ça heya:

2 Tuwe wicole wanji oniciya hecinhan iyokiśinniye kta he : Tuka ie śni un kta tuwe okihi kta he.

3 Tho, wicota waonspewicayakiya; qa nape waśake śni kin hena duwaśaka ecee.

4 Tuwe naśnaśna kin he nioie najinkiya; qa hupahu waśake śni kin niye duwaśaka ece.

5 Tuka wanna niye en nibi, unkan iyoniciśica; niye nicalitaka, unkan nicancan.

6 Wakoyakipe cin nitowaśake, nitowacinye qa nitacanku toowotanna kin hee śni he.

7 Wanna kiksuya wo; tuwewe iyaonpepica śni un atakuni śni he: $\mathrm{Qa}$ tohinni tona owotanpidan kin ihangyapi he!

8 Token wanmdaka eca, tona woahtani ayumdupi, qa woiyokiśice ojupi eca, he qe mnakiyapi ecee.

9 Eloha oniya kin on atakunipi śni: Iye tucanteptanye tateyanpa kin on ihangyapi ecee.

10 Mnaja hoton kin, qa mnaja sapa ho kin, qa mnaja kośka hinske kin yujunpi cee.

11 Tado wanica on mnaja kin omani un ; qa mnaja cincapi enanakiya iyewicayapi ece.

12 Unkan miye en wicoie wanji nalimana hi; qa hetanhan ojijipi minogie nalion:

13 Hanyetu owanyake etanhan awacinpi kin en, woiśtinbe wicaśta ahinhpaya hehan :

14 Wonihinciye wan amakipa, qa wicacancan, qa mahuhu kin iyuhpa cancan makiya :

15 Hehan tate wan miite akan -imayaya; Micehpi hin kin jijiya hiyeya: 


\section{WICOWOYAKE 5.}

16 He owanji najin, tuka owanyake kin iyewakiye śni: Wakagapi wan miiśta itokam yanka: Oinina, unkan wicaho wan nawation:-

17 Wicaśta wan Eloha isanpa owotanna kta he: Qa wicaśta wan Waicaliye tawa kin isanpa ska kta he.

18 Tho, iye taokiye wicaye wacinwicakiye śni, qa tawahośiye kin hena woahtani wicakiciyawa ece.

19 Nakun isanpa tona maka tipi en ounyanpi kin; toicağapi kin maka mdu en un; wamduśkadan itokam námdumdupi ecee kin.

20 Hanhanna tanhan litayetu hehanyan wicakaśuśujapi ; tuwedan awacin śni, hena ohinniyan atakunipi kte śni.

21 Taikanpi kin kipaksapi śni he: Hena țapi, tuka woksape en un śni.

\section{WICOWOYAKE 5.}

1 Wanna pan wo-kinlian tuwe aniyupte kta he; Qa wakanpi kin wanji tukte e elta nihduhomni kta he.

2 Awicakehan wocanniye witkotkoke cin ihangya; qa wowinawizi he ksape śni kin kte ece.

3 Miś miye hinca witkotkoke cin icah aya wanmdaka: 'Tuka ihnuhanna ounye cin he mdaśica.

4 Iye cinca kin wanikiyapi itehan unpi; qa otonwe tiyopa ohna wicakaśujapi, tuka waeyaku wanica.

5 Woksapi tawa kin he wotektelıda temye kta; qa eqe wapepeka ehna tanhan icupi kta; qa tawahpayapi kin he woihangye yapa ece.

6 Wośice watuśekśeca etanhan inanpe śni; qa woiyokiśice maka kin etanhan icağe śni qeyaś:
7 Tuka wicaśta akantu woiyokiśica aicağa ece, wakanhdi cinca wankan kinyan iyayapi iyececa.

8 Hececa eśta miye qe Taku Wakan kin en mde kte hinca; qa wicoie mitawa Wakantanka waqu kta.

9 Iye taku tanka qa okahnihpica śni econ ece; taku wowinihan kin yawapica śni.

10 Maka ite kin akan magaju wicaqu, qa mini kin mağa akan iyayeya ece :

11 Kun unpi kin hena wankan ewicahde kta ; hecen tona kihdapapi kin hena wowanikiye ekta wankan iyewicayapi kta.

$12 \mathrm{He}$ qe wahnayan tawacinpi kin yutakuni śni; hecen iye napepi woecon hduśtanpi śni ece.

13 He qe ksapapi kin wohnaye tawapi en wicayuza ece: Qa wacinśkopa tawowahokonkiye kin he inalini ece.

14 Anposkantu eca otpaza akipapi ece; qa wiyotanhan hehan yutantanpi, hanyetu en iyececa.

15 Tuka mazasagye kin etanhan onśikapi kin ewicahdaku, iye ipi kin etanhan, qa nape waśaka kin etanhan.

16 Hecen waśake śni un kin wowacinye yuha; qa wośice iyohmus hduza ecee.

17 Tho, Eloha wicaśta kaśtake cin he yuwaśtepi ece: Heon Iyotan Waśaka tawowahokonkiye kin he śicedake śni wo.

18 Iye qe wakiunniyan, tuka ake pawicałta : wicakaśtaka,tuka iye nape okiziwicaya ecee.

19 Wokakije śakpe en enihdaku kta: Han, śakowin ei taku śica niyutan kte śni:

20 Wicaakihan en wiconte etanhan openiciton kta; qa kicicapi en, mazasagye nape kin etanhan. 


\section{JOB,}

21 Wicaceji wicayalitake cin etanhan nanilimanpi kta: Qa woihangye $u$ kinhan, he koyakipe kte śni.

22 Woihangye qa wotektehdapi on iyaha kta; Qa maka wamanica kin hena on takudan koyakipe kte śni.

23 Tinta inyan kin hena kici odakonyaya nakaeś: Qa tinta wamanica kin om wookiye duha ecee kta.

24 Nakun nitawakeya kin he wookiye ee sdonyaye kta: Qa wihanpi nitawa wanhdag yai kta, qa wayahitani kte śni.

25 Nakun nitoicage kin he ota sdonyakiye kta: Qa nicinca kin maka wato kin iyecece kta.

26 Tanyan wicahinca wahapi kin en yahi kta, ag่uyapi opahte, tohan iyehantu eca, wankan icaga ecee kin iyececa.

27 Tho, de unkakitapi qon, he hecetu: Anagioptan qa niye hinca sdonya wo.

\section{WOCOWOYAKE 6.}

1 Hehan Job waayupta qa heya: 2 Tokin mitokakije kin tanyan tkeutapi unkanś; qa taku awakipe cin kici on aspeyapi kin en yuwankan icupin :

3 Kinhan he wanna niniwanca wiyaka kin isanpa tke kta: Heon etanhan mioie yaśnaśnapi.

4 Tyotan Waśaka tiwanhinkpe. kin mahen mayanka; hena kata linca mitaniya yahepa: Eloha tokokipe kin takpe maupi ecee.

5 Ikce śonśonna kin he wato ehna hoton kta he: Qa tatanka kin iś woyute icahiyapi kin en hoton kta he.

6 Taku ecamna śni kin he miniskuya codan yunpica lita he: Qa iś witka ska kin ecamna kta'he.
7 Taku minaği yutan kte sni qon, henạ e wamayazanka tawoyute iyecen icaga ece.

8 'Tolsin taku icewakiye cin hiyumakiyapi kten; qa Eloha taku cantowalipani kin he maqu unkzanś :

9 Eloha hecetudake ça ihangmaye kta; iye nape hiyuye ça makaksa unkanś.

10 Hehan cante mawaśte kin ohinniyan kta: Han, woyazan wacantkiye śni kin on imduśkin lita tuka: Taku Wakan oie kin awakalipe śni nakaeś.

11. Mitowaśake kin tukte $\mathbf{e}$, hecen ape waun kta he; qa mitowihanke kin tukte $e$, hecen minagi wacin tanka kta he.

12 Inyan waśake cin mitowaśake kin hee he ; qa iś micehpi kin mazaśa heca he.

13 Mitoiciye en maun kin he taku śni, qa woehdaku kin he ocowasin ehpemayan he.

14 Tuwe onśike cin iye takodaku etanhan wowaonśida en hi kta tuka: Okinni Iyotan Waśáka tokokipe kin ehpeye kta naceca.

15 Mitakuye kin hena wakpadan wan iyecen wahnayanpi ecee; kaksiza wakpadan kin iyecen tanin śni iyayapi:

16 Henake seli caga on sapsapa tuka qon; hena ohna wa anahimanpi tuka :

17 Tohan kadus eyaya eca, hehan tanin śni; kata aya eca tohepi kin etanhan atakunipi śni ecee :

18 Tacankupi omanipi kin hena wicayuhomnipi : Hopuza kin ekta iyayapi qa atakunipi śni.

19 Tema etanhan icimanipi kin hena odepi : Śeba etanhan oicimani kin hena wacinyanpi tuka qon.

20 Wacinyanpi kin on iśtecapi 


\section{WICOWOYARE $\%$}

hinca; dehanyan hiyupi qa ite naśapi hinca.

21 Wanna nitakupi śni: Wonihinciye wandakapi, unkan kopeyahdapi.

22 Tokeca he, Maqu po ; qa wahpaya nitawapi etanhan itumakilian po:

$23 \mathrm{Qa}$ toka nape kin etanhan emahdaku po; qa wohitikapi nape kin etanhan opemakiton po, epa he.

24. Onspemakiya po, kinhan miye inina waun kta: Qa taku en walluni kin he sdonyemakiya po.

25 Wicoie ecetu kin hena waśake hinca: Tuka niyepi etanhan woiyopeye kin taku iyopeye kta he.

26 Wicoie kin iyopeye wacannipi he: Qa tuwe takudan wacinye śni oie kin, tate kin iyececa.

27 Han, wamdenica kin hinhpaye yayapi kta, qa nitakodapi woha yeçapi kta tuka.

28 Unkan nakaha iyonicipipi kta, miye amatonwan po; qa niitepi itokam iwatonśni kinhan.

29 Ceciciyapi, hdicu po; woahtani wanice kte; han, hdicu po. hinyahin mitoowotanna en han.

30 Miceji akan woahtani yukan he: Qa iśs micaka wośice sdonya okihi śni he.

\section{WICOWOYAKE 7.}

1 Maka akan okicize wan wicaśta kiyuke śni he: Qa taanpetu kin wicaśta opetonpi taanpetu kin iyececa.

2 Wowidake wan ohanzi kin cantokpani. hinca, qa wicaśta opetonpi wokajuju ape un kin iyececa :

3 He iyecen wowayazan wi kin yuhemakiyapi, qa wokakije hanyetu kin imiciyawapi ece.
4 Imunka eca hepa ece; Tohan nawajin kta qa hitayetu iyaye kta he: Unkan anpao kta hehanyan mihduśkanśkan on omajudan hinca.

5 Micehpi kin wamduśkadan qa maka onśpaśpa koyaka ece; uka okizi amayan, qa ake tonmayan ecee.

6 Mitaanpetu kin kazontapi yeye cin isanpa dusduzahan, qa wowacinye codan iyayapi ece.

7 Wani kin he tate wan heca e kiksuya ye: Miiśta ake icimana taku waśte atonwe kte śni.

8 Wiciśta wanmayake ciqon he ake amatonwe kte śni: Niye niiśta amayanka, unkan en waun śni.

9 Mahpiya śapa kin he osote qa iyaya ece; he iyecen tuwe Hades ekta iyaye cin he ake ku kte śni.

10 Iye ti kin en icimana hdi kte śni, qa iye tohe qon he ake sdonkiye kte śni.

11 Heon etanhan miye qe mii wakpatan kte śni : Mitaniya iyokiśica en iwae kta: Minagi pa hinca kin en waśicahowamde kta.

12 Miye miniwanca qa iś unktehi wan hemaca he '; hecen akicita amanajin yakiya he.

13 Ohehdepi mitawa cantohnagmaye kta ce, epa keś: Mitowinja kin iapi mitawa miciçin kta ce :

14 Hehan wihamnapi on inihanmayaya, qa wowanyake on kopehda mayakiya ecee.

15 Hecen minagi yuțapi kta kahniğa, wiconțe, huhu mitawa isanpa.

16 Śicewakidaka; ohinniyan wani kta wacin śni: Micunnni wo; mitaanpetu kin oniya wan heca nakaeś.

1\% Wicaśta he taku he, hecen 721 
dutanka kta, qa nicante ekta yeyaye kta he;

$18 \mathrm{Qa}$ hanhanna eca wanyag yai kta; iśta kakpapi eca iduta ecee kta he.

19 Tohanyan amayaduśtan kte śni, qa tag̣e nawalkipce kta e miyecuni kte śni he.

20 Wawahtani; Wicaśta awanwicayaka," taku e ecacicon kta he: Tokeca niye en wotakpe emayahnaka he, hecen woqin micicag̀a.

21 Qa tokeca wowakipajin mitawa miyecicajuju śni; qa wawahtani kin elipemayakiye śni he: Unkanś wanna watuśekśeca en imunke kta; qa omayade kta, tuka en waun kte śni.

\section{WICOWOYAKE 8.}

1 Hehan Bildad Śuhi kin waayupta qa heya:

2 Tohanyan dena odake kta, qa tohanyan nii oie kin tate tanka hinca heca kta he.

3 Wakantanka woyaco yupemni kta he; qu Iyotan Waśake cin he woowotanna yuśkope kta he.

4. Iye en nicinca wakilitanipi kinhan'; qa iye wośice tawapi nape en iyewicaya eśta :

5 Niye qe wanna Wakantanka oyakide kinhan, qa Iyotan $\mathrm{Wa}$ śake cin he ceyakiye cinhan:

6 Niye niska qa oniwotanna yaun kinhan; awicakehan wanna niye on ihduhice $k$ ta, qa nitoowotanna ounye cin he niciyuśtan kta tuka.

7 Nakun otokahe yaun qon he cistinna eśta, oniwihanke kte cin he nina icagie kta.

8 Ceciciya ce, wicoicagge tokaheya kin wiwanga wo, qa iye atewicayapi taku akitapi qon he ekta eicihde wo.
9 Unkiye litanihan unketanhanpi qa wasdonunyanpi śni; anpetu unkitawapi kin maka akan ohanzi heca nakaeś.

10 Hena e waonspeniciyapi kte śni he, woniciyakapi, qa iye cantepi etanhan wicoie aupi kte śni he.

11 Psa hu kin upśija codan icage kta he; sinkpe tawote iś mini codan uye kta okihi he.

12 Hinyahin toya wanka, kaśdapi śni keś, wato owasin itokam śniś aya ece.

13 Tona Wakantanka akiktonjapi owasin tacankupi kin he iyececa; qa tuwe ihduśica tawowacinye kin atakuni kte śni.

14 Toakipe kin he kaksapi 'kta, qa tawowacinye kin he unktomi ti kin heca.

15 Iye ti kin wacinkiye kta, tuka bosdan he kte śni; sutaya hduze kta, tuka en wanke kte śni.

16 Heqe anpetu wi itokam toya wanka, qa taadetka kin iye ta. woju kin ohna icag'a :

17 Taadetka kin inyan paha akan iciyahdaśkapi; inyan tipi kin atonwan yanka ece.

18 Towanke kin etanhan iye ehpekiye cinhan, hehan itonkte śni : Tohinni wanciyake śni ce, eye kta.

19 Iho, tacanku wowiyuśkin kin dee: Nakun toktokeca watuśekśeca kin etanhan icag'e kta.

20 Iho, Wakantanka wicaśta owotanna kin he ehpeye kte śni : Qa wicohan śica econpi kin hena nape wicayuze kte śni.

21 Ecen iliapi on nii ojuniciye kta, qa niiha wowiyuśkin on.

22 Tona śicenidakapi kin hena wowiśtece koyakapi kta: Qa wicohan śica tawakeya kin atakuni kte śni tuka. 


\section{WICOWOYAKE 9.}

\section{WICOWOYAKE 9.}

1 Hehan Job waayupta qa heya:

2 He wicakapi sdonwaya, tuka hehan token Wakantanka kici wicaśta owotanna kta he.

3 He kici wakinica kta akite kta hecinhan; kektopawinge etanhan wanjidan akiciyupte kte śni.

4 Heqe cante ksapa qa wowaśake en wohitika, tuwe he itokam ihdusuta qa wookiye en un he.

5 Iye kin he kin yutokan iyeya, unkan sdonyapi śni; Iye tocanteptanyan en hena yuptanyan eśta:

6 He qe maka kin tohe etanhan yuśkanśkan; unkan oahe tawa kin huhuzahanpi ece.

7 Iye qe anpetu wi kin heciya, unkan hinanpe śni; qa wicantipi kin onakitaka ecee:

8 Iye iśnana mahpiya kin hdumdaya, qa miniwanca wankantu kin amani ece :

9 Iye Aś (wicakiyuhapi), Orion qa Pleiades ('Tawamnipa) kag'a, qa itokah onakitakapi kin hena.

10 Iye hinca taku tanka kaģa, hena akitepica śni, qa taku wowinihan, hena yawapica śni.

11 Tho, Iye en mahiyaya, tuka wanmdake śni; nakun iyoopta iyaya, tuka sdonwaye śni.

12 Iho, iye waehdaku ece, tuwe tehinda kta he: 'Taku yakaga he, tuwe eciye kta he.

13 Eloha tocanteptanye kin anakipte kte śni : Iye ihukuya ookiye wah̉aniçidapi kin patujapi ecee.

14 Hecen token miye kici wowahdake kta he; Iye kici mioie wahdahinige kta he.

15 Miye hinca omawotanna qeyaś amdupte kte śni ; Wayaco mitawa kin cewakiye kta tuka.

16 Miye hoyewakiya qa iye amayupta eśta, miho kin anagoptan kepce kte śni tuka.

17 Iye qe kihanśica on takpe mau kta, qa taku on etanhan śni ksuwemayanpi kin miciyuota kta.

18 Waniya kta e iyowinmakiye kte śni; tuka taku pa hinca on ojudan maye kta.

19 Wowaśake on hecinhan, iho Iye waśaka; qa woyaco hee hecinhan, tuwe wohdag makiye kta he.

20 Miye mihdaowotanna kinhan, mii mahdaśice kta: Miye mihdaecetu keś, Iye pemni mayawa kta.

21 Miye ecetu waun ce, minagi sdonmiçiye śni; mitoni kin śicewakidake kta.

22 De wanjidan, qa heon hepa; Tuwe ecetu qa tuwe śica, napin iye ihangwicaya ece.

23 Ihunhanna makośica wicakte kinhan, wiyaonpe śni unpi iyokiśicapi kin on Iye iha kta.

24 Maka kin wicaśta śica napepi en wicaqupi ; Ohna wayacopi itepi kin iye awicakahpa ecee: Wanna hee śni kinhan, he tuwe he.

25 Wanna mitaanpetu kin wainyanke wan isanpa duzahan; hena kinyan iyaya, taku waśte wanyakapi śni ;

26 Tanpa wata kin iyecen iyoopta iyayapi; wanmdi wan tawote kin iyahpaya ecee kin he iyececa.

27 Mitoiyokiśice awektonje kta, epa eśta ; Miite elipewakiye kta, qa canmawaśte kta ce;

28 Mitokalije owasin on kopewahda ; owotanna nuyadawa kte śni sdonwakiya nakaeś.

29 Miye maśice kta hecinhan, hehan tokeca ituhin hitawani he.

$30 \mathrm{Wa}$ mini on mihdujaja kin723 
han, qa wipajaja on nape wahduska eśta ;

31 Hehan niye woha en iyemayaye kta; qa mitawokoyake kin śicemakidake kta.

32 Iye kin miye iyecen wicaśta akantu heca śni, unkanś .waamdupte kta; napin witaya woyaco ekta unyanpi kta:

33 Unkiyotahedan wicaśta wawiciya wanica; he qe napin nape unkahnakapi kta tuka.

34 Cansakadan tawa kin emiciyaku nunwe: kinhan tokokipe kin wakokipe micağe kte śni.

35 Wowahdake kta qa kowakipe kte śni tuka: Tuka miye qe hecen nawajin śni.

\section{WICOWOYAKE 10.}

1 Wiconi mitawa on minaği śiceicidaka; mitoiyokiśice aihpemiçiye lita ; minaği pa hinca en wowahdake kta:

2 Eloha hewakiye kta; Mayaco śni ye ; taku on mayakiza he sdonyemakiya wo.

3 Wakakiśyaye cinhan he iniwaśte kta he; hecen ninape taku kage cin ehpeyaye kta; qa wicaśta śica tawiyukcan kin aiyoyamyaye kta he.

4 Wicacelipi iśta niciyukan he ; qa wicaśta wawanyake cin iyecen wawandaka he:

5 Nitaanpetu kin wicaśta anpetu tawa iyececa, qa nitawaniyetu kin wicaśta taanpetu iyececa he :

6 Hecen mitośice kin ayakite kta, qa wawahtani kin oyade kta he.

7 Miye maśice śni sdonyaya qeyaś ; qa tuwedan ninape etanhan waeyaku okihi śni ecee.

8 Ninape makaġe ça indukśan ocowasin mayuśtan, tuka ihangmayaye kta he.
9 Wanna kiksuya ye, upśija iyecen may:kaǵa; unkan ake maka mdu mayakage $k$ ta he.

10 Asanpi iyecen mayakaśtan śni he, qa asanpi tasaka iyecen nini mayakağe śni he.

11 Uka qa cehpi on koyagmayaya, qa huhu ikan ko on onamayataka.

12 Wiconi qa wowaonśida ecamiyecon, qa nitoawanyake kin mitaniya awanmiciyaka ece.

13 Dena nicante en nayakilibe: he en niun kin sdonwaye hinca.

14 Wawahtani kinhan, hehan niye wapetogyaton kta, qa mitośice kin miyecicajuju kte śni.

15 Taku śica ecamon kinhan, hehehe, miye; qa omawotanna eśta pa yuwankan iwekcu kte śni ; wowiśtece omajudan qa mitoiyokiśice wanhdag manka.

16 'Tuka ihduwankantu kta; mnaja iyececa omayade kta; ake yahdicu kta, miye en nihdutanka kta :

17 Wayaotanin nitawa piya miyecicage kta, qa nitocanniye kin miyeciduota kta: yutokecapi qa okicize kin en maupi ece.

18 Hecen tokeca tamni kin etanhan hinanpe mayaya he : Niya śni imdarnde kta tuka, qa wiciśta wan wanmayake kte śni ;

19 Tohinni wani śni iyecen waun kta tuka; tamni kin etanhan woha kin ekta amayanpi kta.

20 Mitaanpetu kin tonana śni he : Ayuśtan, micunni wo, hecen kitanna imduśkin kta;

21 Mde śni itokam, qa wahdicu kte śni, otpaza makoce qa wiconte ohanzi kin ekta;

22 Makoce wan otpaza, otpaza śoka iyececa, wiconțe ohanzi qa woyuecetu wanica; qa iyege cin he otpaza śoka iyececa ecee. 


\section{WICOWOYAKE 12.}

WICOWOYAKE 11.

1 Hehan Zophar Naamathi kin waayupta qa heya:

2 Wicoie ota kin hena ayuptapi kte śni, qa wicaśta wohdake sa kin he yaowotanpi kta he.

3 Hitunkankapi nitawa wicaśta wicayuinina kta he ; hecen oweyahanhan eśta tuwedan iśtenniye kte śni.

4 Nakun heha; Wowahokonkiye mitawa kin ecetu, qa niiśta kin en maska hinca ce.

5 Tuka tokin Eloha wicoie hiyuye kta, qa niye on iye iha hdukawa keś ;

6 Qa woksape rwoinahbe kin sdonyeniye kta; heqe wookahnige en yuitakihnapi-: Hecen Eloha wayahtani etanhan akiktonśkiya he sdonya wo.

7 Eloha toinahbe kin okahnih ade kta he; qa Iyotan Waśake cin ocowasin hin hehanyan oyakahnigge kta he.

8 Mahpiya iyecen teharrwankantu, taku ecanon lita he; Hades isanpa temahentu, taku sdonyaye kta he:

9 He iyutapi kin maka kin isanpa hanska, qa ohdakinyan kin miniwanca kin isanpa.

10 Iye waiyahpaye ça kaśka wicahnaka, qa omniciye kage cinhan, hehan tuwe itkokipe kta he.

11 Iye qe wicaśta itonśni kin sdonwicaya, qa woahtani wanyaka ece, unkan okahnige kte śni he.

12 Tuka wicaśta witkotkoke cin he wokahinige kte śni; han, ikce śonśonna cinca kin iyecen wicaśta icağa ece.

13 Hececa eśta niye nicante yahduwiyeya, qa nape yakidugate kte cinhan :-

14 Woañtani ninape ohna yan- ke cinhan, he yutehan iyeya wo; qa wicohan śica nitawakeya ohna ti śni nunwe.

15 Hehan awicakehan woaśape codan ite yuwankan iyekcu kta ; han, sutaya yaun kta, qa kopeyahda kte śni.

16 Nakaeś, woiyokiśice kin he ayektonje $\mathrm{kta}$; mini hiyaye ciqon he iyecen yeksuye kta.

17 Hehan wiyotanhan isanpa wi coni hinanpe kta ; inicage kta, hanhanna iyecen yaun kta.

18 Nakun wacinyan yaun kta, wowacinye yukan nakaeś: Han, waoyade kta, wowacinye en inunke kta.

19 Nakun makan inunke kta, qa tuwedan wakokipe nicagge kte śni: Han, wicota niite yuwintapi kta.

20 Tuka wicaśta śica iśta kin atakuniśni, qa wowinape tokan iwicakiciyaya ece: Qa wowacinye tawapi kin lue naği iyaye cin iyececa.

\section{WICOWOYAKE 12.}

1 Hehan Job waayupta qa heya :

2 Awicakehan oyate kin he niyepi, qa woksape nicipi te kta!

3 Niyepi iyecen miś eya cante mayukan; miye nihektam iwalipamde śni: Han, tuwe kaśta dena sdonye kte śni he.

4. Wanji takodaku ikicilia iyecen waun; Eloha hoyekiya unkan akiciyupta eśta; wicaśta owotanna ecetu kin he wowiliahayapi.

5 Wokakije en wośicedake yukan, tona tanyan unpi awacinpi kin en; tuwe siha hicahe kte cin he iyakipe ece.

6 Waboticapi tawakeyapi kin wookiye en han, qa tona Taku Wakan canniyeyapi kin tanyan 725 


\section{$\mathrm{JOB}$,}

unpi : he nape ohna Eloha aukiya ecee.

7 Tuka wanna woteca kin wiwicawang'a wo, kinhan onspeniciyapi kte; qa mahpiya okinyanpi kin, kinhan hena oniciyakapi kta:

$8 \mathrm{Qa}$ iś maka kin kici wohdaka wo, kinhan he waonspeniciye kta; qa miniwanca hogan kin woniciyakapi kta.

9 Jehowa nape kin he de kagie cin, tuwe dena owasin sdonye kte śni he.

$10 \mathrm{He}$ qe nape ohna taku ni un iyuhpa nagi yukan, qa cehpi wicaśta owasin taniya kin.

11 Wicanoge kin wicoie iyukcan kte śni he, qa wicai kin tawoyute ute kta.

12 Wanakaś unpi kin ehna woksape yukan, qa anpetu hanska kin he wookahinige.

13 Iye kin kici woksape qa wowaśake ; wowiyukcan qa wookahnige kin Iye tawa.

14 Iho, Iye yujuju, unkan ake kağapi kte śni; Iye wicaśta onawicataka, unkan yuhidokapi kte śni.

15 Iho, Iye mini kin anapta, unkan oyalie aya ece; nakun hiyuya, unkan maka kin apaśbog iyaya ecee.

16 Wowaśake qa woawacin Iye kici un; tuwe nuni qa nuniwicakiye cin hena tawa.

17. Waaiapi kin hena heyake yuśdokapi ecen awicaya; qa wayacopi kin witkotkoka wicakağa ecee.

18 Wicaśtayatapi towowidake kin kiyuksa, qa icaśke on nite iyawicakaśka ece:

19 Wawayuśnapi kin heyake codan tokan awicaya, qa waśa. kśake kin ihangwicaya ecee

20 Ieksapapi kin iapi yutokan iyewicakiciya, qa wicahincapi tookahnigapi kin ewicakiciyaku ece.

21 Wowiliaha wicaśta ihdawa awicakaśtan, qa waśaliśaka ipiyake wicakiciyukca ece.

22 'Taku temahentu kin otpaza etanhan yutanin, qa wiconte ohanzi kin iyoyanpa kin ekta hiyuya:

23 Oyate wan yuota, qa hehan ihangwicaya; oyate kin tankaya icaliya, hehan elipewicaya ece.

24 Makoce kin en wicaśta itancanpi kin cante wicayuwanica, qa canku codan hewoskan nuniwicakiya ece ;

25 Hena e otpaza en yutantanpi qa iyoyanpa wanica; unkan wicaśta witko kin iyecen kacekcegya mani wicakiya ece.

\section{WICOWOYAKE 13.}

1 Tho, owasin miiśta wanyaka; minoge nation qa he okabniga:

2 Taku sdonyayapi kin miś eya sdonwaya; miye nilieyapatanhan waun śni cee.

3 Tuka miye qe Iyotan Waśake cin kici iwae kta, qa Wakantanka kici wowahdake kta wacin.

4 Tuka niyepi woitonśni kag̣api sa henicapi; owasin waasniyan okihi śni yaunpi.

5 Tokin ocowasin inina yaunpin, he qe woksape niciyawapi kta tuka.

6 Wanna mitawowahokonkiye kin nation po, qa miiha tawowiyukcan kin anagooptan miye.

7 Wakantanka on taku śica ehapi kta he; qa Iye on wahnayan iyaapi kta he.

8 Iye ite kin Juwankan iyeyayapi kta, qa iś Wakantanka iyakiyapi kta he.

9 Iye iniyukcanpi kinhan he waśte kta he; qa iś wicaśta om 
WICOWOYAKE 14.

owehanhanpi ece kin iyecen Iye kici oweyahanhanpi kta lie.

10 Iye awicakehan iyopeniyanpi kta, nalimana wicaśta ite yuwankan iyeyayapi kinhan.

11 Iye towakan kin he yuśinyeniyanpi kte śni he; qa Iye tokokipe kin anihinhpayapi kta.

12 Taku yeksuyapi kin cahota odowan heca: conkaśke nitawapi kin maka conkaśke kin heca aya.

13 Mitokam inina yukan po, kinhan miye iwae kta; qa taku kaśta en amau kta ce.

14. Tokeca mii ohna micehpi iwekcu kta; qa minape ohna minaği wahduhe kta he.

15 Iho, Iye makte kta qeyaś, wacinwakiye kta; tuka Iye itokam mitacanku wahdaowotanna kta.

16 Nakun Iye hin wowanikiye mitawa ee kta : wicaśta śapa lye itokam hiyu kte śni nakaeś.

17 Nahon miye, mioie kin nahon po, qa wowahdake cin ninogrepi on.

18 Tho, wanna woyaco mduwiyeya; miye mihdaowotanna kta sdonwakiya.

19 Tuwe e wamakinica kta he; kinhan wanna inina waun kta, qa niya sni imdamde kta.

20 Taku nomnana ecamicon śni ye ; kinhan niite etanhan namiçilibe kte śni ye:

21 Miye etanhan ninape ehdaku wo; qa nitokokipe kin wakokipe micag̉e śni nunwe.

22 Hehan pan wo, kinhan miye amdupte kta ; qaiś miye iwae kta qa niye amayadupte $k$ ta.

23 Taku śica mitawa qa wawahitani kin tonaka he: Wawakipajin qa wawahtani kin hena sdonyemakiya wo.

24 Tokeca niite nayakihman he; qa tokaciya kecanmayakin he.
25 Can ape wan kahaya iyeyapi kin he wakokipe yecage kta he ; qa peji puza kin kuwa ade kta he.

26 Taku pa binca kin omiyeciwa ecee nakaeś, qa komaśka tawoahtani kin yuhemayakiya.

27 Nakun misiha oicaślse en eyahnaka; qa mitacanku owasin iwandaka ecee; niye misiha sicu kin ihdukśan imiyecağo.

28 Unkan he qe taku kuka iyecen atakuni śni ; śina wan wamduśka yapotapi kin iyececa.

\section{WICOWOYAKE . 14.}

1 Wicaśta winohinca on tonpi kin he anpetu pteptecedan, qa wokakije ojugjudan ecee;

2 Walica iyecen hinaupa, unkan kaśdapi ; ohanzi wan iyecen kinyan iyaya, qa en yanke śni ecé.

3 Nakun he qe niiśta adumdaya, qa niye kici woyaco en miye amayau kta he.

4 Tuwe taku śapa etanhan taku ska icu okihi kta he: Wanjidan śni.

5 Taanpetu kin wanna kiconzapi ; wi tawa iyawapi kin nici un kinh n; ohomni oicaggo yecağa, qa sam iyaya okihi kte śni:

6 Hecen tokan etonwan qa ayuśtan ye; wicaśta opetonpi iyecen taanpetu ihunikiye kta hehanyan.

7 Can wan on apepica yukan nakaeś: he kaksapi eśta ake icag'e kta, qa camni kin kiwanica kte śni:

8 Hutkan kin maka mahen śenya aya, qa canpaksa watuśekśeca en ța eśta,

9 Mini omua kin on camni uye kta, qa adetka icağe kta, huhdepi wan iyececa.

10 Tuka wicaśta akantu te kta, qa atakuni kte śni; han, wicaśta 
niyaśni iyaye kta, unkan tukten un he.

11 Miniwanca etanhan mini kin tokan iyaya, qa wakpa kin oyahe qa pus aye kta:

12 He iyecen wicaśta iwanke kta, qa najin kte śni; mahpiya kin wanice $k$ ta hehanyan kiktapi kte śni, qa iśtinmapi etanhan wicayuhicapi kte śni.

13 Tokin Hades en namayahibe keś; nitocanniye hdicu kta hehanyan wamayakahipe kta; tohantu kin imiyeconza qa miyeksuya keś.

14 Wicaśta kin țe cinhan ake kini kta he: Mitokicize anpetu kin owasin ape waun kta, tokan amayanpi kte cin hi kin hehanyan.

15 Niye yapan kta, unkan miye aciyupte kta: Ninape taku kağe cin he cantoyakpani kta tuka.

16 Tuka wanna caewahde kin miyeciyawa ece: Wawahtani kin iwanmiyeciyake śni he.

17 Wowakipajin mitawa kin hena wojuha ohna askamtonpi; qa wawahtani kin ayakaggege ecee.

18 Tuka awicakehan he wan hinhpaye cin he atakuni kte śni, qa imnija towanke kin etanhan tokan ayapi kta.

19 Mini kin inyan yuśduśduta ece; minitan kin maka mdu kin tokan eyaya ecee: qa wicaśta tawowacinye kin riye ihangyaya.

20 Ohinniyan yaktedan, unkan tokan iyaya; ite dutokeca qa tokan yeyaśi :

21 Iye cinca kin wicakinihanpi eśta sdonkiye kte śni ; qaiś wahpanicapi eśta iye wanwicayake kte śni.

22 Tuka iye cehpi akan un kin he kakije kta; qa nagi mahen un kin he iyokiśice kta ce.
WICOWOYAKE 15.

1 Hehan Eliphaz Temani kin waayupta qa heya:

2 Tuwe ksape cin he wosdonye takuśni kin oyake kta, qa iye tezi wiyohiyanpata tate kin on ojukiye $k$ ta he.

3 Wicoie waicaliye śni kin on wohdake kta he, qa iapi on wayuwaśte śni ecee.

4 Nakun wokokipe elipeyaya, qa Wakantanka itokam wocekiye anayapta ece.

5 Wayahtani kin he niye nii hdaotanin nakaeś; qa wahnayanpi iapi kin yakahniga ecee.

6 Niye nii nihdaco nakaeś, qa he miye śni; qa niiha bee nihdaotanin ecee.

7 Wicaśta tokaheya icağe ciqon he niye he; qa paha kin itokam nitonpi he.

8 Wakantanka tomniciye kin en wanayationlion, qa niye niśnana woksape duha he.

9 Taku e niye sdonyaya, qa unkiye sdonunyanpi śni; taku oyakahniga, qa he unkicipi un śni he.

10 Nakun tona pa skapi qa wicahincapi kin hena unkicicapi, niyate isanpa anpetu wanakaja.

11 Niye en Wakantanka tocantohnake kin hena cistinna he; qa wicoie iwahnana eniciyapi kin.

12 Tokeca nicante wayaka aniyan he; qa tokeca niiśta kakpankpan he.

13 Hecen nitaniya kin Wakantanka takpeyakiya, qa nii etanhan wicoie inapeyakiya he.

14 Wicaśta akantu he taku, hecen ska kta he; qa tuwo winohinca eciyatanhan tonpi kin he owotanna kta he.

15 Tho, Iye wicaśta wakan tawa kin wacinwicakiye śni; qa 728 


\section{WICOWOYAKE 16.}

mahpiya kin hena iye iśta en ska śni ece:

16 Nakun isanpa wicaśta wahiteśni qa śica, woahtani yahepa, mini iyececa.

17 Wociciyake kta, anamağoptan wo; qa taku miye wanmdake cin he omdake kta.

18 Wicaśta ksapa taku oyakapi qon, qa analimanpi śni, iye ateyapi kin etanhan:

19 Hena ee iśnana makoce kin wicaqupi, qa tuwedan tokeca wicacokaya iyopte śni.

20 Tuwe śice cin he anpetu owasin wayazanhda; qa waniyetu yawapi kin wakakiśye kicihnakapi ecee.

21 Wokokipe ho wan iye noge ohna yanka; wookiye icunhan waihangye cin en u kta.

22 Otpaza etanhan hdicu kta wicada śni; qa mazasagye kin he akicipe yanka.

23 Ağuyapi odede un :-Tokiya yukan he: Otpaza anpetu wan iye nape en wiyeya un he sdonya.

24. Woiyokiśice qa wokakije wakokipe kicagapi kta: Wicaśtayatapi wan okicize on wiyeya yanke cin iyecen iyalipayapi kta.

25 Iye nape Wakantanka itkokim hdug̉ata nakaeś; qa Iyotan Waśake cin en wahanhianicida:

26 Tahu suta on anatan, tawahacanka paha śoka kin on.

27 Iye ite waśin on aihdahpa nakaeś, qa tapakśin en wasna icicag̉a ecee.

28 Hecen otonwe otiwota kin ohna ti kta; tipi ake piya kagapi kte śni; hena otiwota ehpeyapi nakaeś.

29 He qe wijice kte śni, qa tawahpaya kin katinyan un kte śni, qa tawanunyanpi kin makoce en tankaya icağe kte śni.
30 Otpaza etanhan nape kte śni: taadetka kin peta ide kin gu kta; qa Iye i oniya kin on napeyapi kta.

31 Taku śica wacinkiye kte śni-hnayanpi: taku śice cin he tawokamna ee kta nakaeś.

32 Taanpetu kin hinyahinke śni yuśtanpi kta, qa taadetka toya icağe kte śni.

33 Hastanhanka śtunkadan tawa kin kahna kta, wiyuwi wan iyececa ; wahca tawa kin elipekiciye kta, wihdi can iyececa.

34 Wicaśta śica tomniciye kin akihanpi nakaeś; qa wawicaqupi tawakeya kin he peta huhnag'e kta.

35 Hena e woiyokiśice itpihnakapi, qa woahtani hiyuyapi, qa iye tezipi kin wohnaye kaga ecee.

\section{WICOWOYAKE 16.}

1 Hehan Job waayupta qa heya :

2 Taku hececa ota hinca nawahion: wacan tohnagya śica iyuhpa henicapi.

3 Tate wicoie kin wanna henakeca he: qaiś taku e iyonipastaka hecen waadupte kta he.

4 Miś eya niyepi iyecen iwaa owakihi tuka; Ninagipi minaği un kin en unpi unkanś, niyepi on iapi iciyawakaśke kta, qa miye e acipoptanptanpi kta tuka.

5 Hececa eśta mii on ciyawaśakapi kta, qa miiha towacantohnake kin wayuwaśte kta.

6 Miye iwaa eśta mitowayazan kin yuwaśtepi śni ece: qa amdaśtan eśta taku e amahececa kta he.

7 Tuka wanna iye wayazan makaga: Tiyohnaka mitawa ocowasin ihangyaya:

8 Qa piśpija mayakağe, he wa729 
yuotanin kta he; qa matamaheca kin he en mahinajin, miite itokam mahdaotanin ecee.

9 Tocanteptanye kin mayulidehdeca qa śicaya makuwa; iye hi on amahdakinskinza; tokamaye cin he miye en iśta hdupestosto ecee.

10 Hena iye i on imakapapi; wowiliaha on tapon en amapapi ; miye mitkokim mniciyapi ece.

11 Wakantanka wahtani sa kici onamataka, qa śicaya econpi napepi en ehpemayan.

12 Tanyan manka, tuka iye makawehwega; han, tahu en mayuze ca makaweliweğa; qa iye hinca makute kta e bosdan emalide.

13 Iye tiwanhinkpe kin aohdutemayanpi; nite bomahdoka qa itompe śni; pizi mitawa kin maka akan papson.

14 Wopahdoke wopahdoke itakihna on mapalidoka ece: Zuye sa wan iyececa, miye amainyanka.

15. Wakihdaka micehpi awahdagegge; qa he mitawa watuśekśeca en wahduśica.

16 Ceyapi on ite maśica amayan, qa wicunțe ohanzi miiśtojuha akan yanka:

17 Minape ohna taku śica yuke śni qeyaś, qa mitawocekiye kin he hecetu tuka.

18 Maka kin, niye mawe kin akahpe śni wo; qa wahowamde cin tukten wanke śni nunwe.

19 Tuka wanna, iho, mayaotanin kin he mahpiya ekta, qa omayake cin he wankan yanka.

20 Takuwicawaye cin hena aomahanhanpi kin eepi: Tuka Eloha en miiśta ikpapsonpi ecee. 21 Tokin Eloha kici wicaśta iciyepica unkanś, wicaśta cinhintku iye takodaku on iyececa.

22 Omaka iyawapi hiyohi kin- han, canku wan ohna mde kta, ake wahdi kte śni ce.

\section{WICOWOYAKE $1 \%$.}

1 Oniya mitawa kin osota, mitaanpetu kin kasnipi; wicahapi kin hena mitawa.

2 Wawihaha kin hena mici unpi śni he: qa miiśta kin iye toiyokiśice kin en yanka he.

3 Wanna ehnaka wo, niye en wawimakiya wo: ecin tuwe nape mayuze kta he.

4 Niye iye cantepi kin wookahnige analibewicayakiya nakaeś; heon etanhan wankan ewicayahnake kte śni.

5 Tuwe wokamna on takodaku kin wicahnaye cinhan, he qe cinca iśtapi kin ee atakuni kte śni.

6 Nakun iye oyate kin ehna oweśtepi wan makağa; qa miye ite atagośapi kin heca imacaga.

7 Nakun woiyokiśice on miiśta san amayan, qa mihuha kin owasin ohanzi wan iyececa.

8 De on wicaśta owotanna kin yuśinyayapi kta; qa wicaśta waśte kin śice cin on śliniçiye kta. 9 Tuka wicaśta owotanna kin he tacanku kin sutaya hduhe kta; qa tuwe nape kin ska he salpa waśaka icaga ecee.

10 Tuka niyepi owasin hdicu po, qa wanna u po: niyepi ehna wanji ksapa iyewaye śni nakaeś. 11 Mitaanpetu kin hiyaya; mitawacin kin yuksapi, micante oyuze kin hena.

12 Hena e hanyetu anpetu eekiya ehnakapi ece; iyoyanpa kin he aśkadan, otpaza itokam.

13 Ape waun kinhan, Hades wati kin ee kta ; otpaza en mitowinja ewahnake kta.

14 Woha kin hoyewakiya, Ate he niye: Ina qa mitankśi, wamduśkadan ewakiya ece. 


\section{WICOWOYAKE 19.}

15 Heon etanhan wanna wowacinye mitawa kin tukten un he; qa mitawowacinye kin tuwe wanyake kta he.

$16 \mathrm{He}$ qe Hades inatake kin ekta kun ye kta; maka mdu en witaya woozikiye yuke cinhan.

\section{WICOWOYAKE 18.}

1 Hehan Bildad Śuhi kin waayupta, qa heya:

2 Tohanyan kta, wicoie owihanke eyahnakapi kta he: Awacin jo, hehan ohakam unkiapi kta ce.

3 Tokeca woteca iyecen unyawapi he; niiśtapi en unkiye unśapapi ecee.

4 Tocanniye kin en iye naği hdahdehdeca ece: Niye kin on maka kin ehpeyapi kta, qa imnija kin towanke kin etanhan iyaye kta he.

5 Hececa eśta wicaśta śica taiyoyanpa kin kasnipi kta, qa iye tapeta ide kin iyege kte śni.

6 Tawakeya ohna iyoyanpa kin he otpaza icaga, qa petijanjan tawa kin kicisni kta.

7 Iye towaśake cahde kin ptecedan icagia; qa iye toawacin kin kun elipekiye kta.

8 Iye siha on on-hmunkapi wan en iyohpeyapi nakaeś ; qa ihmunke wan amani kta.

9 Mazahtakiyapi kin he siyete en yuze kta; on-hmunkapi kin iye kaśka hde kta.

10 Mazahtakiyapi kin maka mahen ekicionpapi, qa on-hmunkapi wan canku ohna kiciyanka.

11 Ihdukśan wokokipe kin kopehdakiyapi kta, qa iye siha iyahna kuwa ayapi kta.

12 Towaśake kin akihan tekinica kta; qa toihangye kin iye icahda wiyeya yanke lita.

13 Iye uka onśpaśpa kin temki- ciye kta ; wiconte tokaheya ton kin he iye huha kin ternye $\mathrm{k}$ ta.

14 Taku wacinye ciqon he iye tawakeya kin etanhan yujunpi kta; qa wokokipe wicaśtayatapi kin ekta ihdoye kta.

15 Iye tawakeya kin en ounye kta, tawa śni nakaeś; iye ti kin en inyanzi akadapi kta.

16 Kuyatanhan tahntkan kin śen aye kta; qa wankan taadetka kin kaksapi kta.

17 Tokiksuye kin he makoce kin etanhan iyaye kta, qa tinta ite akan caje kiwanice kta.

18 Iyoyanpa etanhan otpaza ekta kahapapi kta; qa maka kin etanhan ehpeyapi kta.

19 Cinca wanice kta, qa iye taoyate kin en oicag'e tawa yuke kte śni; qa iye ounye ciqon en wanjidan okicicaptapi kte śni.

20 Taanpetu kin on tona ihakam icaggapi kin hena yuśinyayapi kta, qa tona itokam icağapi qon hena wonihinciye wicayuze kta.

21 Awicakehan wicaśta śica ounyanpi kin hececa ecee, qa tuwe Wakantanka sdonye śni towanke kin he dee.

\section{WICOWOYAKE 19.}

1 Hehan Job waayupta qa heya :

2 Tohanyan minag̉i iyokiśinyayapi kta, qa wicoie on mayalidehdecapi kta he.

3 Wikcemna akihde iśtenmayayapi: canteśinmayayapi on iniśtecapi śni.

4 Unkan wanuni kin he wicakapi eśta, wanuni kin miye en miciyanka.

5 Awicakehan miye en nihdutankapi kinhan, qa mitowiśtece dawicakapi kta hecinhan; 6 Wanna Eloha miciyupemni, 
qa onhmunkapi tawa kin he amakahpa, he sdonya po.

7 Iho wokakiśye on waśicahowamda, tuka namahọnpi śni; hoyewaya tuka woyaco wanica.

8 Mitacanku kin he iye namicitaka, hecen sanpa imdamde kte śni; qa canku mitawa ohna otpaza ebnaka ece.

9 Mitowitan kin he iye makiyuśdoka, qa mapa wapaha kin he emiciyaku.

10 Ihdukśan tanhan iye ihangmayan, hehan imdamda: qa can wan iyececa, wowacinye mitawa iye miciyujun.

11 lye tocanniye kin aidemakiya, qa iye tokawicaye cin iyecen mayawa.

12 Iye taozuye kin witaya mniciyapi, qa miye en canku pahaya ekihnakapi, qa mitawakeya ihdukśan ewanka ece.

13 Mihunkawanji hena mitehanyan iyewicaya: qa sdonmayanpi qon hena awicakehan tokamayanpi icagapi.

14. Takuwicawaye cin hena ehpemayanpi, qa sdonmayanpi qon hena amiktonjapi.

15 Wati en ounyanpi qa mitawicinyanna hena wicaśta tokeca iyecen mayawapi ; iye iśtapi en wicaśta sdonyapi śni imacaga.

16 Mitawowidake kin wakipan, tuka amayupte śni ; mii on cewakiya tuka.

17 Mitawin ekta oniya mitawa tokeca aya; qa mitawocekiye kin cincawicawaye cin ekta.

18 Nakun hokśsipidan śicemadakapi; nawajin unkan hena amaiapi ece.

19 Mitakodapi owasin walitemadapi śni; qa tona waśtewicawadake cin hena makipajinpi ecee.

20 Uka mitawa qa micehpi kin en huhu mitawa askapa; qa hi mitawa ha kin ecedan hduha nawajica.

21 Onśimada, onśimada po, mitakuye niyepi; Eloha nape kin mayutan nakaeś.

22 Tokeca śicaya mayakuwapi he, Taku Wakan iyececa; qa micehipi on winipipi śni he.

23 Wanna mioie kin owapi kta tuwe maqu kta he; wowapi en tuwe maqu kta, qa icaǵopi keś ;

24 Mazasapa icago wan on, qa mazasu, tokin ohinniyan imnija en bag̀opi keś.

25 Nakun miye sdonwaye kta, Opemakiton kin he ni un; qa iye hinca ehake maka kin akan inajin $\mathrm{kta}$ :

$26 \mathrm{Qa}$ uka mitawa iyohakam de ihangyapi kta, tuka micehpi en Eloha wanmdake kta ;

$27 \mathrm{He}$ ge miye hinca wanmdake kta, qa miiśta wanyakapi kta, qa tokeca kte śni; mapakśin hena tanmahen hanyan amayan eśta.

28 Heon etanhan hehapi kta, Tokeca śicaya unkuwapi kta he: Wicoie hutkan kin miye mahen iyeyapi nakaeś.

29 Heor etanhan mazasagye kin itokam wakokipa po: Wocanniye kin he mazasagye kakiśye kte cin ee nakaeś; heon woyaco yukan e sdonyayapi kta ce.

\section{WICOWOYAKE 20.}

1 Hehan Zophar Naamathi kin waayupta qa heya:

2 Heon etanhan mitoawacin kin waayupte makiyapi ; qa heon miye mahen inahini mayanpi ecee.

3 Mitowiśtece iyopeyapi kin he nawakilion: Tuka mitookahinige taniya kin he wayupte makiya.

4 De wanakaja tanhan un kin 
sdonyaya he; wicaśta maka akan ehnakapi kin ehantanhan:

5 Wicaśta śica wiyuśkinpi kin he ptecedan, qa wicaśta śapa cante waśte kin he iśta kakpanpi seececa.

6 Iye tanka kin he malipiya ekta iyahde, qa iye pa mahpiya śapa iyapațo eśta ;

7 Taunkce kin iyecen ohinniyan atakuni kte śni: Tona wanyakapi qon hena, Tukten un he, eyapi kta.

8 Wowihanmna wan iyecen kinyan iyaye kta, qa tulitedan iyeyapi kte śni; han, hanyetu wowanyake kin iyecen hamyapi kta.

9 Wiciśta kin he he wanyaka, tuka ake econ kte śni; qa iye towanke kin icimana wanhdake kte śni.

10 Iye cinca kin wahpanicapi kin iyokipi wicayapi kta; qa iye nape kin wowijice tawapi wicakicu kta.

11 Huhu tawa kin iye towaśake kin ojudan; tuka he kici maka mahen iwanke kta.

12 Wośice kin iye $\mathrm{i}$ ohna skuye dake cinhan, iye ceji ihukuya inahbekiye kta:

13 Kpatan lita, qa kpagan kte śni; qa iye $\mathrm{i}$ kin mahen hduha un qeyaś;

14. Tezi mahen taag̉uyapi kin yutokecapi, iye tanmahen sintehda pizi kin hee kta ce.

15 Wowijice nakipcs, tuka ihdepe kta; iye tezi etanhan Wakantanka hiyuye kiye kta.

16 Sintehda taǵe śice cin yazoke kta; sintehda ceji kin he kte kta.

17 Wakpa kin hena ell etonwe kte śni, minitan kin, canhanpi tiktica qa asanpi wakpadan kin hena.

18 Tokamna kin he wicakicu kta qa nakipce kte śni; wowi- jice kicupi kta iyececa, qa he iyuśkin kte śni.

19 Kun elipewicaya, wahpanicapi kin awicayuśtan, heon etanhan tipi wan iyahpaya eśta iye piya kagge kte śni.

20 Iye tezi ekta woozikiye sdonye śni nakaeś, talku waśtedake cin etanhan takudan ehdaki kte śni.

21 'Tawoyute kin etanhan takudan okaptapi kte śni; heon etanhan taku waśte tawa kin en yanke kte śni.

22 Toojudan woptecaśni kin en wokakije kiciyanke kta: kakiśyapi napepi iyuhipa en au kta.

23 Kaketu kte; tohan tezi ojukiye kta hecinhan, iye (Wakantanka) tocanniye wohitike cin aihpekiye kta, qa tawoyute kici ahinhekiye lsta.

24 Mazasapa wipe kin etanhan najice kta; mazaśa itazipa wan kakpa iyekiciye kta.

25 Yuśdokapi qa tezi kin etanhan icupi; han mazasagye wiyatpa kin iye pizi etanhan hiyu kta: wokokipe kin akan yanka.

26 Otpaza ocowasin iye tokamna akicihnakapi: peta wan apogianpi śni kin he huhnahye kta: tawakeya ohna tuwe okaptapi kin lie ihangyapi kta.

27 Iye tośice kin mahpiya kin yutanin kta, qa heon maka kin itkokim inajin kta.

28 Iye ti wokamna kin he tanin kte śni, tocanniye anpetu kin en tokan iyaye kta.

29 Wakantanka etanhan wicaśta śica taku tawa kte cin dee, qa Taku Wakan eciyatanhan wokamna cajekiciyatapi kin hee.

\section{WICOWOYAKE 21.}

1 Hehan Job waayupta qa heya: 


\section{JOB,}

2 Nahon po, iwae cin nation po; qa wacantohnagniyanpi kte cin hee kta.

3 Iyowinmakiya po, kinhan miye iwae kta ce; qa womdake cin iyohakam hehan niye waunyaca kta.

4 He miye hinca, oiyokiśinya iwae cin he wicaśta ekta kta he: qa hecetu kinhan, iokeca nitaniya iyokiśice kte śni he.

5 Amatonwan po, qa yuśinyaya po; qa nuipi en nape ekihnaka po.

6 He miye awacanmi eca kowakipa; qa wocancan micehpi en yuza ece.

7 Taku on etanhan wicaśta śica ni unpi he, wicahinca ayapi, han wowijice en waśakapi he.

8 Woicag̉e tawapi kin iye om wicitokam yusutapi ece, qa cincawicayapi kin iye iśtapi itokam.

9 Iye tipi kin wokokipe codan wookiye yuhapi; qa Eloha icapsinte tawa kin akan wicayanke śni.

10 Pte tawa kin ihduśake ca okaśkanton śni; pteheyuktanna tawa cinca ton qa cinca elipekiye śni cee.

11 Optaye wan iyecen hokśiyopa yewicayapi; qa iye cincawicayapi kin wacipi ece.

12 Cancegga qa candowankiyapi on wankan iyeiciyapi, qa cotanka ho kin on wiyuśkinpi ece.

13 Anpetu tawapi wowaśte en hdusotapi ece, qa iśta kakpanpi se Hades ekta iyayapi.

14 Tuka Wakantanka heciyapi ; Unkayuśtan po, qa nitacanku sdonunyanpi kta uncinpi śni ce :

15 Iyotan Waśake cin he taku he; on litaunkicinipi kta he; qa waceunkiyapi kinhan taku unkiwaśteri kta he.
16 Iho, taku waśte tawapi kin iye napepi ohna un śni : wicaśta śica toawacinpi kin mitehanyan yanka nunwe.

17 Tohanhan wicaśta śica toijanjan kin bokicisnipi; qa toihangyapi kin en awicau kta he: Iye tocanniye en woiyokiśice wicakipamni kta.

18 Tateyanpa itokam ag̉uyapi hu kin iyececapi kta, qa aguyapi ha icamna kaha iyeye cin iyececa.

19 Woahtani tawa kin iye cinca Eloha wicakicihnake kta: iye kicicajuju kta, hecen sdonkiye kta.

20 Iye iśta kin toihangye kin wanhdake kta; qa Iyotan Waśaka tocanteptanye kin yaliepe kta.

2 I Taku on iye iyohakam tiyohnaka kin en tawowiyuśkin kta he; wi yawapi tawa kin kiciyuśtanpi nakaeś.

22 Tuwe Wakantanka wosdonye onspekiye kta he: tona wankan unpi kin hena Iye wicayaco kta nakaeś.

23 Wanji ocowasin en un ecen țe kta, ocowasin wikope śni un qa owanji yanka:

24 Wakiślkotpa tawa kin asanpi ojudan; qa iye huluu cupe kin spayeyapi.

25 Qa wanji iś iye nag i iyokiśica en țe kta, qa wowaśte en wote śni ece.

26 Sakim maka mahen iwankapi kta, qa wamduśkadan kin napin awicakahpapi kta.

27 Iho, nitawacinpi kin miye sdonwaya, qa woawacin on kakiśmayayapi kte cin.

28 Niye hehapi nakaeś; Wicaśta itancan tukten ti he, qa wicaśta śica tawakeya ounyanpi kin tukte epi he.

29 Tona canku ohna hiyayapi 
kin wiwicanunģapi śni he; qa owohdake tawapi kin sdonyayapi śni he.

30 Wicaśta śica wokakije anpetu kin apatanpi kta: wocanteptanye anpetu kin en aupi lita.

31 Iye ite kin en tacanku kin tuwe okiciyake kta he; qa taku econ hecinhan tuwe kicicajuju kta he.

32 Tuka iye hapi kte en ahipi kta, qa hnakapi kin he iye awanhdake kta.

33 Kaksiza ohna malia onśpaspa kin hena skuyedaka ece: Qi iye ihakam wicaśta owasin pasipi kta, yawapica śni itokam iyayapi qon iyececa.

34 Hecen token taku śni on cantohnagmayayapi kta he: wohnaye waaduptapi ecee kin en un nakaeśs.

\section{WICOWOYAKE 22.}

1 Hehan Eliphaz Temani kin waayupta qa heya :

2 Wicaśta wan Taku Wakan okiye kta he; tuwe ksape cin oiçiye kta okihi kin iyececa he.

3 Oniwotanna kinhan he Iyotan Waśake cin taku iwaśte kta he; qa nitacanku yahduecetu kinhan he wokamna kta he.

4 Nitokokipe on Iye iyopeniye kta he; woyaco ekta Tye nici ye kta he.

5 Wośice nitawa kin he tanka śni he; qa wayahtani kin owihanke wanica.

6 'Taku on etanhan śni nihunkawanji yahdaśka nakaeś, qa tancodan unpi tawokoyake kin wicayeciyuśloka.

7 'Tuwe ipuze cin he mini yatkeyakiye śni, qa wotektehdapi kin aguyapi ipiwicayada ece.

8 Tuka wicaśta isto yukan- makoce kin he tawa; qa wicaśta wakinihan kin he en ounyan.

9 Wiwazica taku yuhe śni hde wicayaśi ece; qa wamdenica taistopi kawegapi.

10 Heon etanhan mazahitakiyapi nihdukśan hiyeya; qa ihnuhanna wokokipe wakokipe nicaga ecee :

11 Qaiśs otpaza-wandake śni, qa minitan mini kin anicalipa.

12 Eloha wankan yanke śni he, malipiya ekta: qa wicanhipi pa kin wanyaka wo, hena tehanwankantu nakaeś.

13 Hehan, Wakantanka taku sdonya he; Iye malipiya śoka kin ohnayan wayaco kta he, eha. 14. Mahipiya śapa kin akalipa, hecen iye wawanyaka okihi sni ; qa mahipiya ohomni kin he iye omani kta.

15 Canku tanina kin he iwandake kta he, wicaśta śica ohna manipi qon:

16 Hena e sutaya wicayuzapi, qa iyehantu śni, towankapi kin wakpa wan aminitan:

17 Hena Wakantanka heciyapi, Unkayuśtan po; qa Iyotan Waśake cin taku ecawicakicon kta he.

18 Iye tipi tawapi kin taku waśte on ojuwicakiciya tuka qon :-Tuka wicaśta śica toawacin kin mitehanyan un nunwe.

19 Wicaśta owotanna kin he wanyakapi qa wiyuśkinpi; qa tona ecetupi kin hena iwicahahapi ecee.

20 Awicakehan tokawicunyanpi kin ihargyapi; qa tawahpayapi kin peta hulinaǵa ce.

21 Wanna Iye kici takukiciya wo, qa wookiye en un wo; heciyatanhan taku waśte en niu kta: 22 Wanna Iye i kin etanhan woope kin icu wo, qa Iye oie kin nicante en ehnaka wo. 
23 Iyotan Waśake cin en yahdi kinhan, ake icahniyanpi kta ; nitawakeya etanhan woahtani yutokan iyeyaye cinhan.

24. Hehan maka mdu isanpa mazaskazi yahnake kta; qa Ophir mazaskazi kin wakpadan inyan kin iyececa.

25 Han, Iyotan Waśake cin he mazaskazi nitawa ee kta, qa mazaska śtedapi nitawa kta.

26 Hehan Iyotan Waśake cin en widuśkin kta, qa Eloha ekta niite iyekcu kta nakaeś.

27 Niye ceyakiye cinhan, iye nanilion kta: qa taku wahoyaye ciqon yahdajuju kta.

28 Nakun wicoie wanji idukcan kta, unkan niciyuśtanpi kta; qa iyoyanpa ee nitacanku kin aiyojanjan kta.

29 Makata ehpeiciyapi kin hena, Najin po, ewicayakiye kta: unkan iśta kun unpi kin hena iye niwicaye kta.

30 Tuwe ecetu un śni kin he jye eyaku kta; qa ninape ska kin on eyakupi kta ce.

\section{WICOWOYAKE 23.}

1 Hehan Job waayupta qa heya :

2 Nakun anpetu-kin de wowahdake cin sicahowaya; minape comniwahdazi kin en tkeya awanka ece.

3 Tokin tukten iyewaye kta hecinhan sdonwaye ceś ; Iye toyanke kin lietu hinca en wau kta.

4 Mitawoyaco kin Iye itokam ewahnake kta, qa woakinica oie on mii ojuwakiye kta :

5 Wicoie on amayupte kte cin hena sdonwaye kta; qa taku emakiye kte cin owakahinige kta tuka.

6 Wowaśake tanka on amakini- ca kta he: Hiya; tuka Iye en emicihnake kta.

7 Hen tuwe owotanna kin he Iye kici wakinica kta; hecen miye wayaco mitawa ohinniyan nawecipe kta.

8 Iho, wiyohiyanpata mda, tuka hen un śni; qa wiyohpeyata, tuka kenunwaye śni;

9 Waziyata en ohanyan ece, tuka wanyag ihewaye śni; itokagga kin he on ihdahpa, hecen wanmdake śni.

10 Iye qe mitacanku en maun kin he sdonya nakaeś; imayutanpi kinhan mazaskazi iyecen inawape kta tuka.

11 Iye towe kin en misiha sutaya ahan: Iye tacanku kin wapatan qa icunonpa mde śni.

12 Iye iha tawowaśi kin nakun amdaśtan śni; Iye i oie kin miye wawehnake cin isanpa awanmdaka ece.

13 Tuka Iye okonwanjidan, hecen tuwe yuhomni okihi kta he : Qa Iye naggi taku cin kinhan hdliśtan kta.

14 Wamakiconzapi kin he Iye miciyuśtan kta nakaeś: qa taku hececa ota Iye kici yanka ece.

15 Heon etanhan Iye itokam mayuśinyaya ; awacanmi eca kowakipa ece.

16 Wakantanka micante wakokipe kicağa, qa Iyotan Waśake cin he yuśinyemayan nakaeś :

17 Otpaza itokam ihangmayanpi śni nakaeś; qa miite itokam otpaza śoka wakahipa ece kin.

\section{WICOWOYAKE 24.}

1 Tokeca oehnakapi kin Iyotan Waśake cin etanhan nahmanpi śni keś, tona sdonyapi kin Iye taanpetu kin wanyakapi śni he. 2 Mağinatake kin yutokan iye736 


\section{WICOWOYAKE 25.}

yapi : optaye manonpi qa wihanwicakiyapi ece.

3 Wamdenica taśonśonna kin he icupi, wiwazica tatanka tawa kin he kaśkapi ecee.

4 Wahpanicapi kin hena canku etanhan icunonpa iyayewicayapi: Maka akan onśikapi kin hena ptrya inalimanpi kta.

5 Iho, tolianpi kin ekta iyayapi, hewoskan ikce śonśonna kin iyececa; hanhanna hinca wiyahipayapi ece; hopuza kin he iye cincapi kin om woyuteyapi ecee.

6 Mağa kin en wojupi mnakiyapi : qa wicaśta śica hastanhanka tawa yuśpipi.

7 Tancodan wankapi, śina codan, qa osni en woakahpe nicapi.

8 He akan magaju kin on spayapi, qa wowinape codan imnija kin adoksohanpi ece.

9 Wamdenica kin azepi etanhan ewicayakupi kta, qa onśikapi akan un kin he kaśkapi ece.

10 Tancodan iyayapi, wokoyake nicapi, qa wotektehda aǵuyapi pahtapi kin icupi ece.

11 Conkaśke tawapi otahedan wihdi kag̉api ; miniśa iyuśkice kin naśkicapi tuka ipuzapi kta.

12 Otonwe kin etanhan wicaśta comnihdazipi : qa taopi naği kin śicahowaye kta: 'Tuka Eloha wowitkotkoke ewicakicihnake śni.

13 Dena ee iyoyanpa kin tokayapi ecee; tacanku kin okahnigapi śni; qa ocanku tawa kin en ounyanpi kte śni.

14 Tinwicakte kin he anpao hehan najin, wahpanicapi qa onśikapi kin wicakte kta; qa hanyetu en wamanon kin iyecece kta.

15 Nakun wiinahman iśta kin he otpaza akita; Wiciśta wan iyemakiye kte śni ce, eya; qa ite śina pośmi codan hdowin ece.

16 Otpaza hehan tipi ohna qapi ; anposkantu onaiçitakapi ece; iyoyanpa kin sdonyapi śni.

17 Hena en hanlianna kin wiconte ohanzi kin iyahde; wiconțe ohanzi wokokipe kin hena sdonyapi nakaeś.

18 He qe mini ite kin akan kapojedan: taku tawapi kin maka akan yaśicapi ece; hastanhanka iyuwi ojupi canku kin wanyake kte śni.

19 Opuza, nakun okata kin wa mini icu kta: Hades tona wahtanipi kin iyececa.

20 Tamni kin akiktonje kta, wamduśkadan kin yazokapi kta; icimana kiksuyapi kte śni; qa can wan iyecen wośice lin kaksapi kta.

$2 \mathrm{l} \mathrm{He}$ qe cinca yuhe śni cinca tonśni kin he sicaya kuwa ece; qa wiwazica kin taku waśte ecakicon śni :

22 Tuka iye towaśake on wicaśta waśaka ihangwicaya ece : He najin kinhan tuwedan wiconi wacinkiye kte śni.

23 Kokipeśniyan unpi qupi, qa wacinye kta, tuka iye iśta tacankupi kin akan yanka.

24 Cistiyedan yuwankan iyeyapi, hehan en unpi śni; qa kun iyayapi, owasin iyecen ewicayakupi hta; qa wamnaheza inkpa kin iyecen baksapi kta.

$25 \mathrm{Qa}$ he hecetu śni kinhan tuwe itonśni makagge kta, qa mioie kin yutakuni kte śni he.

\section{WICOWOYAKE 25.}

1 Hehan Bildad Śuhi kin waayupta, qa heya :

2 Wokiconze qa wokokipe Iye kici un: Iye wankantu tawa kin en wookiye kag̉a ecee. 
3 Iye taozuye wicayawapi yukan he; qa iyoyanpa tawa kin he tuwe ahinanpe śni he.

4 Hecen taku on wicaśta wan Taku Wakan en owotanna kta he; qa tuwe winolinca eciyatanhan tonpi kin he token ska kta he.

5 Etonwan wo, hanyetu wi ekta, unkan iyojanjan kte śni; han wicanhipi kin hena Iye iśta kin en ska śni ece.

6 Sam iyeya wicaśta kin, wamdudan heca; qa wicaśta cinca kin, wamduśkadan heca kin!

\section{WICOWOYAKE 26.}

1 Hehan Job waayupta qa heya :

2 Tuwe wowaśake nice cin token duwaśaka he; isto waśake śni kin he niyakiya he.

3 Woksape codan un kin he token waonspeyakiya he; qa token wookahnige otakiya odaka he.

4 Tuwe e wicoie oyakidaka he ; qa tuwe taniya kin niye etanhan hiyu kta he.

5 Wanagiipi kin hena ksuweyapi, mini mahentanhan, qa en ounyanpi kin.

6 Iye itokam Hades śdayehna wanka; qa wośbe kin he woakahpe nica.

7 Iye hin waziyata kin takn tanton śni ayutitan; maka kin taku śni akan otkeya.

8 Iye mahipiya śoka tawa kin ohna mini apahta ece; hecen hena ihukuya mahpiya śapa kin nahdece śni.

9 Iye toiyotanke ite kin ahdahpa, mahpiya śapa tawa kin ahdumdaya.

10 Mini ite kin akan iye qe ohomni icağo, iyoyanpa kin otpaza icahtake cin hehanyan.
11 Mahpiya ipatan kin hena cancan, qa, iye iyopeye cin on yuśinyaya ece.

12 Iye towaśake on miniwanca kin wakokipe kicagia, qa iye tookahnigge kin on wahaniçida kin kakpa iyeya ecee.

13 Iye Taniya kin on mahpiya kin hduwaśte: Iye nape wamduśka najice cin he capa.

14 Iho, Iye tacanku opapun kin dena ee: qa Iye on wicoie cistinna hinca naunlionpi: tulia towaśake wakinyan kin, tuwe he okahnigige kta he.

\section{WICOWOYAKE 27.}

1 Nakun Job tadowan katinyan yawankan icu qa heya:

2 Wakantanka ni un, eqe mitawoyaco emiciyaku; qa Iyotan Waśake cin minag̉i nina iyokiśinya :

3 Tohanyan oniya mitawa en maun, qa Eloha Taniya mapogge ohna yanke cinhan ;

4 Hehanyan miiha taku śica ie kte śni, qa miceji kin wohnaye oyake kte śni.

5 Ciyaowotanpi kte cin he mitehanyan un nunwe; tohanyan mate śni hehanyan mitoecetu kin ehpewakiye kte śni.

6 Mitoowotanna en sutaya mihduze kta, qa amduśtan kte śni; mitaanpetu en micante iyopemaye kte śni.

7 Tokamaye cin he śicaya econ kin iyecece kta, qa tuwe mitkokim inajin kin he wahtani sa kin iyecece kta.

8 Wicaśta śica tawowacinye kin tukte e he; kakse kta nakaeś, ţhan nag̉i kin Eloha ekiciyaku kinhan.

9 Hoyeye cin he Wakantanka nahon kta he; wicocante śica akan u kte cinhan. 


\section{WICOWOYAKE 28.}

10 Qaiś Jyotan Waśake cin en wiyuśkin kta he; anpetu owasin Eloha hoyekiye kta he.

II Wakantanka nape kin eciyatanhan waonspeciciyapi kta; taku Iyotan Waśake cin kici un kin hena anawahbe kte śni.

12 Iho, niyepi owasin he wandakapi, hecen tokeca ocowasin winitkotkokapi he.

13 Wakantanka kici wicaśta śica taku tawa kin dee; qa wicaśta wohitika taku aihpekiyapi, Iyotan Waśake cin etanhan icupi ecee kin :

14 Iye cinca yuotapi kinhan, he mazasagye kin on: qa iye icahwicaye cin hena aguyapi imnanpi kte śni.

15 Tona okicaptapi kin hena wiconte en hapi kta; qa wiwazica tawa kin hena ceyapi kte śni.

16 Mazaska maka mdu kin iyecèn kamna eśta, qa upśija iyececa wokoyake içicağa qeyaś;

17 Hena kagge kita, tuka wicaśta owotanna hee koyake kta, qa wicaśta ecetu kin hena mazaska kin kicipamnipi kta.

18 Wamduśkadan iyececa tipi icicagga, qa waawanyake wan ohanzi hdepi wan kagge cin iyececa :

19 Wijice cin he iwanke kta, qa ake econ kte śni: iśta hdumdaya, unkan iye en un śni.

20 Wokokipe yuza, minitan iyececa; hanyetu icunhan icamna wan nahmana eyaya:

21 Wiyohiyanpata tate wan wankan eyaku kta, unkan ye kta; hecen towanke kin etanhan iyaya.

22 Wakantanka en ehpeye kta, qa ayuśtan kte śni; Iye nape kin etanhan nape kta tuka.

23. Eqe nape ahdaskapapi kta, qa tohe kin etanhan ajiji ehpeyapi kta.
WICOWOYAKE 28.

1 Awicakehan mazaska oqapi kin yukan, qa mazaskazi tukten yuecepidan ecee.

2 Maka mdu etanhan mazasapa icupi ece; qa inyan etanhan rnazaśa śdoyapi kta.

3 Otpaza kin owihanke ekicihnaka, qa okahmin owasin en wakita ece; otpaza inyan qa wiconte ohanzi kin.

4 Akan yanke cin etanhan makohdoka wan kahdokapi: hen wicasiha on akiktonjapi; otkeyapi, wicaśta itehan kaozezeiçiyapi ecee.

5 Maka kin hetanhan aguyapi hinanpa ece; qa ihukuya tanhan ayumdupi peta iyececa.

6 Inyan tawa kin ehna sapphiros (inyan toto) yukan ece; qa mazaskazi mdu kin hen yanka.

7 Canku wan, he zitkadan waiyahpaya ece kin sdonye śni; qa hinhankagaa iśta atonwe śni :

8 Wahaniçidapi cincapi kin he cankuyapi śni, qa mnaja kin he tohinni amani śni.

9 Inyan suta kin ekta jye nape yekiya; he kin hutkan kin etanhan yuptanyan ece.

10 Imnija kin en wakpa se kaga ece; qa iye iśta kin taku telike owasin wanyaka.

11 Wakpa kin kuse kte śni on nataka ece; qa taku nahmanpi kin iyoyanpa en au kta.

12 Tuka woksape he tukten iyeyapi kta he; qa wookahnige kin tukten yanka he.

13 Taku iyopeyapi kte cin he wicaśta sdonye śni; qa maka akan ni unpi kin ehna iyeyapi śni :

14 Wośbe kin, En maun śni ce, eya; qa miniwanca kin iś, Mici un śni ce, eya. 


\section{$\mathrm{JOB}$,}

15 Mazáskazi kihnakapi kin he he iyopeyepica śni; qa opetonpi kta on mazaska tkeutapi kte śni.

16 Ophir mazaskazi kin kici tkeutapi kte śni; onyx (wicaśake inyan) tehike, ca sapphiros kicica śni.

17 Mazaskazi qa kohdihdi kin he iyacinpica śni; qa mazaskazi ecedan tehike cin kici iciyopeyepica śni.

18 'Jaku tehika yawapi qa kohdihdi kin hena kiksuyapi kte śni; qa woksape yuhapi kin he inyan teliike cin isanpa ecee.

19 Kuś topaz kin he he iyecece late śni ; mazaskazi ecedan waśte kin kici tkeutapi kte śni.

20 Hecen tokiyatanhan woksape u kta he; qa wookahnige toyanke kin tukten un he.

21 Taku ni un owasin iśtapi etanhan akahpetonpi nakaeś; qa mahpiya okinyanpi kin etanhan nahmanpi ecee.

22 Abadon qa wiconte heyapi ece; Unnogepi on he oyakapi kin naunhonpi :

23 Tacanku kin he Wakantanka okahniga, qa Iye qe oyanke tawa kin sdonya ece.

24. He qe maka ihanke kin ekta etonwan nakaeś; malipiya ihukuya owancaya iye wawanyake lita.

25 Tate tkeutapi kin he kage cehan; qa mini kin iyutapi on aspeyeton ;

26 Mağaju woope wan kicağa qehan; qa wakinyan tawakanhdi canku wan kicaga ;

$27 \mathrm{He}$ ehan Iye he wanyaka qa ohdaka; Iye ehnaka qa nakun iyukcan :

28 Tuka wicaśta kin heciya; Iho, Itancan kokipapi kin he Woksape ee; qa taku śica ehpeyapi kin he wookahnige ee ce.

\section{WICOWOYAKE 29.}

1 Nakun Job katinyan tadowan ikikeu qa heya:

2 Tokin wi wanakaja en iyemacecen; Eloha awanmayaka anpetu qon iyececa :

3 lye qe petijanjan tawa mapa aiyojanjan qehan; Iye taiyoyanpa kin on otpaza omawani ecee qon :

4 Masuton anpetu kin en iyemaceca qon; Eloha tawoinalibe mitawakeya akan yanke cehan;

5 Iyotan Waśake cin he hinyahin mici un; micinca milıdukśan unpi qehan;

6 Miowe kin pteasanpi en yujajapi qehan; qa imnija kin wihdi wakpadan hiyumiciciya ecee qon :

7 Tiyopa olina otonwe en imdamda qehan, canku ohna oiyotanke wan emicihnaka:

8 Kośka kin wanmayakapi qa naicilimanpi; qa wicahincapi kin hena najinhan najinpi.

9 Wicaśta ihdawapi kin ia ayaśtanpi; qa nape on iohmus ehnakapi ecee.

10 Wicaśtayatapi ho kin anahmanpi, qa cejipi kin iye caka en ahdaskape.

11 Hehan wicanoge wanation qa mayawaśte ; wicaiśta kin wawanyaka qa mayaotanin:

12 Wicaśta wahpanica howaya hehan niwakiya nakaeś; nakun wamdenica qa tuwe wawiciye nice cin hena.

13 'Tuwe tekinica tawoyawaśte kin he en mau ece; qa wiwazica cante kin wiyuśkin waya.

14 Woowotanna komdaka, unkan he komayaka; mitawoyaco kin he śina qa wateśdake ee.

15 Iśtag̉ongapi kin hena, iśta mayanpi waun, qa huśtepi kin hena siha mayanpi ecee qon: 


\section{WICOWOYAKE 30.}

16 Onśikapi kin hena atemayanpi waun; qa woakinica sdonwaye śni qon he owade ece.

17 Nakun wicaśta śica hi kin weciyuksaksa, qa iye hi etanhan yaśpaśpapi qon he emdaku.

18 Hehan hepa; Hohpi mitawa ohna mațe kta, qa anpetu wahduota kta, hool iyececa.

19 Hutkan mitawa mini kin ayuhdokapi kta, qa cu kin adetka mitawa akan yanke kta:

20 Mitowitan kin he teca miciyanke kta; qa mitinazipe lin minape ohna yutecapi kta.

21 Hena e namahonpi qa ape unpi; qa mitowiyukcan kin on inina yukanpi :

22 Mioie kin iyohakam iye ake wohdakapi śni; qa iwae cin awicahinhan ece.

23 Nakun amapepi, mag่aju apepi kin iyececa; qa magaju ehake kin on i hdukawapi ecee.

24. Hena iwicawahaha keś wicadapi śni; qa miite iyoyanpa kin he ehpeyapi śni.

25 Canku wicawecicahniga, qa itancan imdotanka, qa ozuye wan ehna wicaśtayatapi iyecen wati; wanji ceyapi kin wacintonhnagwicaye cin iyemaceca tuka qon.

\section{WICOWOYAKE 30.}

1 Tuka wanna tona anpetu en mihakam unpi kin hena imaliahapi; hena atewicayapi qon optaye mitawa taśunke kin om ewicawahnake kta tawațenwaye śni.

2 Han, iye napepi towaśake kin he etanhan imatokeca he, hena en wicahincapi kin atakuni śni ece.

3 Takudan yuhapi śnj, qa wotektehdapi kin on hanyanpi, maka puza kin yaqoǵapi ecee, wi- cotakuni śni hanyetu qa otiwota ehna.

4 Hena otehi etanhan maluha yuśpipi, qa genista hutkan kin he woyute yapi ece.

5 Wicacokaya tanhan hamwicayapi; wamanon sa wan iyececa wicihakam panpi ece gon.

6 Wokokipe osmaka kin en otipi kta, makohdoka qa imnija kin ohna.

7 Can yulialia kin ehna hotonpi kta ; wapepeka ihukuya makata iwankapi kta.

8 Hena witkotkoka cincapi, han, wicaśta śica cincapi; makoce kin etanhan hamwicayapi.

9 Tuka wanna hena worviliahamayanpi waun, qa oweśtepi makagapi ece.

10 Walitemadapi śni, namicijicapi, qa miite atağośapi itonpapi śni.

11 Iye kin ikan mitawa yukca qa kakiśmayan; heon etanhan iyepi kin iiyuwi kin mitokam elipeyapi ece.

12 Wicacinca optaye kin mietapa tanhan inajinpi; misiha naheyam iyeyapi, qa woihangye canku tawapi kin mitokam yuwankan iyeyapi ece.

13 Mitacanku kin yumdu elipeyapi, ihangmayanpi kta śkanpi ; iye wawiciya nicapi tuka.

14. Tankaya bohpapi kin iyecen hiyupi ; kaohpapi kin ihukuya paptanptan iyeiciyapi.

15 Wonihinciye takpe maupi; mitawacin kin he kuwa ayapi, tate iyececa; qa waomakiyapi kin titokan iyaya, malipiya śapa wan iyececa.

16 Unkan wanna minaği amihdapson; wokakije anpetu kin sutaya mayuza ece.

17 Hanyetu kin he mahuhu pahidoka ece; qa kan mitawa oziiçiyapi śni. 
$\mathrm{JOB}$,

18 Wowaśake tanka on mita- cağa; hecen token wikośka wan wokoyake yutokecapi; onhidohda mitawa tahu kin iyecen mayuskiskita ece.

19 Upśija en iyolipemayan; unkan maka mdu qa cahota iyececa imacağa.

20 Hoyeciciya tuka niye amayadupte śni; en nawajin, unkan niye amayatonwe.

21 Wamakipajin nicicağa; ninape wowaśake on tehiya mayakuwa ece.

22 Tate on wankan iyemayaya, akan iyayemayaya, qa wowacinye mitawa dutakuni śni.

23 Tuka de sdonwaya, niye wiconte en amayahdi kta, qa ni unpi iyuhpa tomniciye tipi kin en.

24 Han, iye nape yugate cinhan wocekiye yuke kte śni he; toihangye kin on howayapi eśta. 25 Anpetu tehika on waceye śni he ; wahpanicapi kin on minaği iyokiśica ecee.

26 Taku waśte awakipe, tuka taku śica hi ; iyoyanpa awape waun, tuka otpaza hi ece.

27 Mitezi ipiģa qa ayuśtan śni ; woiyokiśica anpetu kin awakipa ece.

28 Anpetu wi codan śapa omawani ece: nawajin, omniciye kin en waśicahowamda ece.

29 Unktehi sunkamayanpi imacağa; qa hinhankağa tanka kin takodamayanpi.

30 Uka mitawa kin śapa amayan; qa okata on mahuhu hu. hnaga ecee.

31 Nakun candowankiyapi mitawa kin he woiyokiśice icağa; qa cotanke mitawa tona ceyapi ho kin iyececa.

WICOWOYAKE 31.

1 Miiśta kici wicotakuye mici742

opabta manke kta he.

2 Hehan wankantanhan Eloha taku tawa kin tukte e he; qa Iyotan Waśaka tawoaihpeye tehanwankantu kin etanhan tukte $e$ he.

3 Wicaśta śica woihangye akipe kte śni he; qa wicotakuni śni, tona woahtani econpi kin.

4. Iye mitacanku kin wanyake śni be; qa miowe iyuhpa yawa śni he.

5 Woitonśni kici mawani kinhan, qa misiha kin wohnaye iyahna ye cinhan;

6 Iye qe woowotanna on aspeyapi kin ohna tkeumate kta: qa mitoecetu kin Eloha sdonye kta.

7 Miowe kin canku kin etanhan icunonpa iyaya, qa micante miiśta iyahna ye cinhan, qa wośape wan minape askape cinhan; 8 Miye hin wowaju kta, qa tuwe tokeca yute kta; qa taku icalwaye cin hena yujunpi nunwe.

9 Micante winolinca on hnayanpi kinhan; qa mitakoda tatiyopa kin en iyawape hecinhan;

10 Winohinca mitawa wanji tokeca wakiciyukpan kta, qa toktokeca iye akan iwankapi nunwe.

11 He qe wośice hinca tuka; qa he woahtani wayacopi kin ekta.

12 Han, he peta wan Abadon hehanyan huhnaġe kta; qa taku icaliwaye cin owasin yujun kta tuka.

13 Mitaokiye qa mitaokiye win tawoyaco kin ihawakta śni, kici amakinicapi qehan;

14 Hehan Wakantanka inajin kinhan taku ecamon kta he: qa iye waakite cinhan taku amdupte kta he.

15 Tamni mahen tuwe makagge 


\section{WICOWOYAKE 32.}

cin he iś eya he kag̉e śni he; qa tuwe tezi mahen icahunyanpi he Wanjidan śni he.

16 Wahpanicapi taku cantokpanipi kin awicawecinica kinhan, qa wiwazica iśta kin mduwanica hecinhan;

$17 \mathrm{Qa}$ onśpa mitawa kin he miśnana wahdute, qa wamdenica kin mici yutapi śni kinhan :

18 Komaśka ehantanhan ateyapi wan iyececa he mici icağa; qa ina tamni etanhan he waonspewakiya nakaeś.

19 Tuwe wokoyake codan tekinica wanmdake cinhan, qa wahpanica kin woakalipe nica kinhan;

20 Iye nite mayawaśte śni kinhan; qa tahinca mitawa yuśdapi kin on yucozapi śni kinhan:

21 Wamdenica kin nape apaha mduza kinhan, tiyopa ohna waomakiyapi wanmdaka qehan ;

22 Hinyete mitawa okihe etanhan hinhpaya nunwe; qa miisto hu kin etanhan kaksapi kte:

23 Kinhan wokokipe amayanke kta, Wakantanka toihangye kin ; qa Iye tehanwankantu kin on owakihi kte śni.

24. Mazaskazi kin he wowaśake miçicağa, qa mazaskazi hinca, Wowacinye mitawa, ewakiya unkanś :

25 Mitowijice kin tanka on imduśkin kinhan, qa minape taku ota kamna kin on;

26 Anpetu wi iyojanjan wanmdaka, qa hanyetu wi kin wiyatpatpa mani ;

$27 \mathrm{Qa}$ micante nahmana en yutitanpi, qa mïi minape itputaka hecinhan :

$28 \mathrm{He}$ qe nakun woahtani, wayaco ekta; Taku Wakan wankan yanke cin he en iwaton kte śni nakaeś.

29 'Tuwe śicemadake cin ihang- yapi kin on imduśkin, qa taku śica akipa hehan śkinmiçiya kinhan ;

30 Tuka iye naği mdaśice kta e miiha wahtani wakiye śni ece. 31 Mitawakeya taoyate kin, Tokin tado tawa etanhan tuwe unqupin, iunmnanpi śni ce, eyapi śni :

32 Oyate tokeca etanhan tankan iwanke śni ; oicimani kin tiyopa rvakiyuhdoka ece.

33 Wowakipajin mitawa akahpe weciton Adam iyececa, mamaku ohna wawahtani nawakilibe cinhan:

34 Wicota hinca kowakipa heon etanhan, qa oyate śicedakapi kin he wakokipe micağa he ; hecen inina waun, tiyopa etanhan tankan mde śni.

35 Tokin tuwe namahon unkanś : Tho, iwakağo; Tokin Iyotan Waśake cin amayupten, qa wicaśta makipajin wowapi kağa keś :

36 Awicakehan hinyete akan ewehnake kta; he wateśdagweton kta:

37 Miowe iyawapi kin oweciyake kta; wicaśta ihdawa iyecen he ikiyedan wau kta.

38 Magia mitawa amahoton kinhan, qa yumdupi kin ohna witaya ceyapi kinhan;

39 He towaśake kin wiyopeyapi codan temwaye cinhan, qa tona tawapi qon nagipi kin țewaya unkanś :

40 Ağuyapi eekiya toka hu icage kta, qa barle eekiya wato icağa nunwe.

Job oie kin henakeca.

\section{WICOWOYAKE 32.}

1 Hecen wicaśta yamni kin dena Job ayupta ayaśtanpi, iye iśta en owotanna icidaka rakaeś. 


\section{$\mathrm{JOB}$,}

2 Hehan Elihu Barakel cinhintku, Buzi kin, Ram wicoun kin etanhan, he tocanniye kin ide: tocanniye kin Job aide, iye nagi hdaowolanna, Wakantanka isanpa, heon etanhan.

3 Nakun takodaku yamni kin hena tocanniye kin aiwicade; iye woayupte iyeyapi śni qeyaś, Job yacopi.

4 Unkan Elihu wicoie on Job iyakipe un: hena e anpetu en iye itokapapi nakaeś.

5 Unkan Elihu wicaśta yamni kin dena ipi ohna woayupte wanica e wanyaka, hehan tocanniye ide.

6 Hehan Elihu Barakel cinhintku Buzi kin he waayupta qa heya: Miye qe anpetu en amaśkatudan, qa niyepi pa niskapi ; heon etanhan kowakipa, qa wosulonye mitawa cicipazopi kta ikowapa.

7 Anpetu kin wohdake kta iyececa ce, epa; qa waniyetu ota kin he woksape sdonye wicakiye kta ce.

8 Heca eśta, woniya wan wicaśta mahen yanka, qa Iyotan Waśaka toniya kin he wokalinihwicakiya ecee.

9 Wicaśta tankapi woksape yuhapi śni, qa wicahincapi kin woyaco okahinigapi śni cee.

10 Heon etanhan hepa; Anamagoptan po, miś eya wosdonye owahdake kta ce.

11 Tho, nisiepi kin ape waun, nitowiyukcanpi kin awacin manka, woayupte oyadepi icunhan.

12 Han, aciwacinpi manka, tuka iho, niyepi etanhan tuwedan Job yatokeca śni, iye oie kin aduptapi śni cce.

13 Unkanś, Woksape iyeunyanpi ce: Wakantanka napeya, wicaśta hee śni ce, ehapi kta tuka.
14 Unkan miye en iapi ocimdagehan ehnake śni; heon nioiepi kin on miye amdupte kte śni.

15 Hena e yuśinyayapi, ake ayuptapi śni, iapi ayaśtanpi.

16 Ape manka, tuka takudan eyapi śni ; iye owanji najinpi nakaeś, ake ayuptapi śni.

17 Hecen miś eya onśpa mitawa amdupte kta; miś eya wosdonye owahdake kta ce.

18 Wicoie omajudan nakaeś; woniya mahen maun kin he aotinsmayan.

19 Tho, mitezi kin miniśa yuhdokapi śni kin iyececa; nahdece kta seca, wojuha teca kin iyececa.

20 Iwae kta, hecen tanyan waniya kta; miiha mdukawa kta, qa waamdupte kta ce.

21 Tokin wicaśta ite yawankan iyewaye kte śnin; qa wicaśta wanjidan mdawinte ktc śni.

22 Yawintapi kin onmaspe śni nakaeś: Icalimaye cin he ihnuhanna emayaku kta tuka.

\section{WICOWOYAKE 33.}

1 Hececa eśta, Job ceciciya ce, iwae cin hena nation ye: qa mioie owasin tanyan anagoptan wo.

2 Iho, wanna mii wahdukawa; mii ohna miceji wohdaka.

3 Mioie kin hena micante ecetu kin etanhan; qa wosdonye ska kin miiha oyake kta.

4 Wakantanka Taniya kin he miye makagia ; qa Iyotan Waśaka toniya kin he nimayan.

5 Oyakihi kinhan amayupta wo ; mitokam ihduwiyeya wo, najin wo.

6 Iho, iyae cin iyececa, miś eya Taku Wakan etanhan waun; miś eya upśija etanhan maka. gapi. 


\section{WICOWOYARE 34.}

7 Iho, mitokokipe kin wakokipe nicagje kte śni; qa woqin mitawa kin he tkeya akan niyanke kte śni.

8 Awicakehan minogie ohna iyaa, qa nioie ho kin hena nawahon :

9 Miye maska hinca, wokipajin codan, wakaśoteśni waun, qa woahtani manica ce.

10 Iho, miye en wokipajin akita; miye tokawaya kecanmakin ece.

11 Misiha wolsaśke en ehnaka; mitacanku owasin iwanmiciyaka ecee.

12 Iho, de en oniwotanna śni: miye aciyupte kta, Eloha wicaśta isanpa tanka nakaeś.

$13 \mathrm{He}$ tokeca kici ayakinica kta he: Iye oie owasin on waayupte kte śni nakaeś.

14. Tuka Wakantanka wanjidan en ie kta; han, nonpa entuwedan atonwe kte śni.

15 Wowihanmde kin en, hanyetu wowanyake en, woiśtinbe linca wicaśta ahinhpaye cinhan, owinja akan oğungapi kin en :

16 Hehan wicaśta noğepi wicayuldoke kta, qa woonspe aonawicakitake kta.

17 Hecen wicaśta tawowaśi etanhan eyaku kta, qa wahaniçidapi wicaśta anakicilibe kta.

18 Iye naği kin woha kin etanhan ekiciyaku lita, qa toni kin wipe on hinhpaye kta etarihan.

19 Nakun owinja akan woyazan on kakiśyapi, qa huhu ohinniyan akinicapi kin on.

20 Hecen toni kin ağuyapi hitihda ece, qa iye nagi woyute waśtedake ciqon.

21 Wanyakapi etanhan iye cehpi kin atakuni kte śni, qa huhu tawa śdayehna wanke, wanyakepica śni.

22 Hehan iye nagi woha kin ikiyedan u, qa toni kin wicaktepi kin ekta.

23 Wawiciya yeśipi wan kici un kinhan, wanji kektopawinge wicehna, wicaśta toecetu kin okiciyake kta hecinhan;

24 He onśikida qa heye kta; Woha ekta iyaye kta etanhan ehdaku wo, miye woakalpe wan iyewaya ce.

25 Cehpi tawa yutecapi, hokśiyopa isanpa ; kośka taanpetu qon en hdi kta.

26 Eloha cekiye kta, qa iye iyokipiye kta; hecen wowiyuśkin on iye ite kin wanyake kta; wicaśta toowotanna kin hdiyohi kiye lita nakaeś.

27 Wicaśta awicatonwan; unkan, Wawahtani qa woecetu kin mdupemni, tuka iyecen ecamicon śni eye cinhan :

28 Iye qe woha ekta mi naği iyaye kta etanhan eyaku; hecen mitaniya kin iyoyanpa en iyuśkin kta ce.

29 Tho, dena owasin Wakantanka econ kta, nonpa, yamni, wicaśta kici ;

30 Iye nagi woha kin etanhan hdicuye kta, wiconi iyoyanpa kin on iyoyam ye kta e heon.

31 Nalion wo, Job, anamagoptan wo; inina yanka wo, kinhan katinyan iwae kta.

32 Wicoie nici un kinhan amayupta wo, wohdaka wo, miye ciyaowotanna kta wacin nakaeś. 33 Wanica kinhan, niye anamagoptan wo; inina yanka wo, kinhan woksape onspeciciye kta ce.

\section{WICOWOYAKE 34.}

1 Hehan Elihu waayupta qa heya:

2 Wicaśta ksapa, mioie kin nahon miye ; qa wasdonya yaunpi, miye anamagoptan po. 


\section{joB,}

3 Wicanoge kin wicoie iyukcan nakaeś, wicai woyute uta ecee iyececa.

4. Woyaco unkiyukcanpi kta; unkiyotahedan taku waśte kin sdonunyanpi kta.

$5 \mathrm{Job}$ hecen eye ciqon; Miye omawotanna; tuka mitawoyaco kin he Wakantanka heyata iyeya ece.

6 Mitawoyaco kin en iwaton kte śni he : maopi kin he asniyepica śni, wokipajin codan.

7 Tukte en wicaśta wan Job iyececa he; mini iyececa wowihaha yahepa ece.

8 Nakun śicaya econpi kin om takodawicaya, qa wicaśta śica owicapeya mani ecee:

9 Kaken eya nakaeś : Wicaśta wan Wakantanka kici iyokipi içiye cin he takudan iwaśte kte śni ce.

10 Heon etanhan, wicaśta cante yukanpi, miye anamagoptan po: wicohan sica 'Taku Wakan itehan yanka; qa woahtani econ kte cin he Iyotan Waśake cin itehan un nunwe.

11 Wicaśta tohan kin he on kicicajuju kta nakaeś; qa otoiyohi tacanku kin iyecen iyohikiciciye kta.

12 Han, awicakehan Wakantanka śicaya econ kte śni; qa Iyotan Waśake cin woyaco yupemni kte śni.

13 Tuwe e Iye maka kin awanyagkiya he ; qa tuwe maka ocowasin kin ehde he.

14 Iye cante en ehnake cinhan; Tye Taniya qa toniya kin ehdaku kinhan ;

15 Wicacehpi owasin witaya niya śni iyaye kta; qa wicaśta maka mdu kin en hdi lita tuka.

16 Nakun waoyakahniga hecinhan, de nalion wo, mioie ho kin anaġoptan wo.
17 Tuwe woyaco śicedake cin he itancan un kta he; qaiś iyotan owotanna kin he niye daco kta he.

18 Wahteśni ce, wicaśtayatapi kin eciyepica he: Śicaya econ ce, itancanpi kin ewicakiyapi kta iyececa he.

19 Eqe wicaśta itancanpi itepi iyowicalipi śni, qa wijicapi kin wahpanicapi kin isanpa awicatonwe śni ece; owasin iye rape kaģe cin heepi nakaeś.

20 Iśtakakpanpi se hena tapi kta; hanyecokaya hehan oyate kin nihinciyapi qa atakunipi kte śni : qa waśakśakapi kin hena nape codan tokan awicayapi ecee.

21 Iye iśta wicaśta otoiyohi tacanku kin akan un nakaeś ; qa taowe iyulipa wanyake kta.

22 Otpaza wanica, qa wiconțe ohanzi wanica, ohna wicohan śica econpi kin naicilimanpi kta.

23 Iye qeś tuwedan sanpa ahnake kte śni, hecen woyaco en Wakantanka ekta ye kta.

24. Waśakśakapi kin odepica śni wicakamdemdece kta, qa tohepi kin en wicaśta tokeca ewicahnake kta.

25 Heon etanhan wicohan tawapi kin iye okahnigga, qa hanyetu en wicayuptanye kta; hecen ihangyapi kta.

26 Śsicaya econpi sa heon wicakaśtake kta, tukten. wanyakapi ece kin entu.

27 Hena e Iye ihakapa tanhan iyayapi, qa tacanku owasin awacinpi śni nakaeś :

28 Onśikapi howayapi kin Iye en ukiyapi; hecen wahpanica howayapi kin iye nawicalion kta. 29 Tuka Iye qe ozikiye wicaye cinhan hehan tuwe e wicayaśice kta he : qa Iye ite anakihbe cinhan hehan tuwe ecin wanyake 


\section{WICOWOYAKE 36.}

Kita he: qa he oyate kin en, qaiś wicaśta sukaza kicica kta.

30 Hecen wicaśta walite śni kin wicaśtayatapi un kte śni, okinni oyate wicahmunkapi kta.

31 Awicakehan wanji Wakantanka heciye kta; Wanna wawaqin, ake śicaya ecamon kte śni ce :

32 Taku wanmdake śni kin niye wanyagmayan ye; wawahitani kinhan alse icimana ecamon kte śni ce.

33 He niye yacin kin ohnayan kajuju kta he; niye wicayada śni nakaeś: he niye yakahinige kta, qa miye kte śni : hecen taku sdonyaye cin ohdaka wo.

34 Wicaśta cante yuke cin hena hemakiyapi kta; qa wicaśta ksapa anamagoptan kta :

35 Job wosdonye codan ia ece; qa iye oie kin woksape en un śni ce.

36 Job owihanke hehanyan iyukcanpi kta hecen mitawacin; wicaśta wahtanipi kin on waayupta ece kin heon etanhan.

37 Walitani kin en wowakipajin akagge kta nakaeś; unkiyopeyapi nape hdaskaskapa ; qa Wakantanka ekta oie hduota ecee.

\section{WICOWOYAKE 35.}

1 Nakun Elihu waayupta qa heya:

2 De woyaco eciyatanhan idukcan he: Mitoowotanna kin he Taku Wakan tawa kin isanpa ce; ehe ciqon.

3 Taku e iniwaśte kta he, keha nakaeś: Wawalitani kin isanpá token imawaśte kta he, eha.

4 Miye qe wicoie on aciyupte kta, qa nitakodapi nici unpi kin hena.

5 Malipiya kin ekta etonwan qa wanyaka wo; qa mahpiya śapa kin atonwan wo, hena niwankam tehan wankantu.

6 Niye wayahtani kinhan, iye en taku ecayecon kta he: qa wowakipajin yahduota eśta iye en taku yakagge lita he.

7 Oniwotanna kinhan taku e yaqu kta he; qa ninape etanhan iye qe taku icu kta he.

8 Wicaśta wan niye iyjececa kin niohan śica itokeca kta; qa nitoowotanna kin wicaśta cinca iwaśte k ta tuka.

9 Wakakiśyapi ota on etanhan śicahowayapi kta: waśakśakapi isto kin oll howayapi ecee.

10 Tuka tuwedan heye śni; Eloha icalimaye cin tukten un he; he iye hanyetu en dowanpi wicaqu ece.

11 Iye maka woteca kin isanpa waonspeunkiyapi ece, qa mahpiya okinyanpi kin isanpa ksapa unkagapi kta.

-12 Heciya śicahowayapi kta, tuka iye waayupte kte śni, wicaśta śica wahaniçidapi kin on etanhan.

13 Awicakehan Wakantanka taku śni kin nahoon kte śni; qa lyotan Waśake cin lie atonwe kite śni.

14. Niye wandake kte śni, keha eśta, woakinica kin he jye itokam yanka; hecen ape yaun $k$ ta iyececa.

15 Tuka wanna iye tocanniye kin wawiyohi śni qeyaś, wowakipajin elna tanyan wasdonye kte śni he.

16 Tuka Job taku śni on i hdukawa ece; wosdonye codan wicoie hdaota ecee.

\section{WICOWOYAKE 36.}

1 Hehan Elihu ake ie ça heya:

2 Kitanna iyowinmakiya wo, 747 


\section{JOB,}

kinhan wociciyake kta; ehake Eloha on taku oyagpica nakaeś.

3 'Tehantanhan wosdonye mitawa awau kta; qa Icahmaye cin he woowotanna weciyaotanin kta.

4 Awicakehan mioie itonśni wanice kta: tuwe wosdonye en ecetu hince cin he niciyanka.

5 Tho, Wakantanka waśaka, tuka wawahteda śni wanica; - cante wowaśake en iye waśake hinca.

6 Iye kin wicaśta śica niwicakiye kte śni, tuka onśikapi kin woyaco wicaqu kta.

7 Wicaśta owotanna etanhan iye iśta ewicakicihdaku kte śni ; tuka wicaśtayatapi om un, oiyotanke kin akan, qa ohinniyan najin wicakiye kta, unkan wankan ihdoyapi kta.

8 Nakun mazaicicahilia on wicakaśkapi kinhan, wokakije hahonta on wicayuzapi kinhan;

9 Hehan iye ohanpi kin wicakipazo; qa wowakipajin tawapi, hena wahanhaniçidapi nakaeś.

10 Nakun wowahokonkiye ekta noge wicakiyulidoka, qa woahtani etanhan hdicupi kta, kewicakiya ece.

11 Anagoptanpi, qa ecen econpi kta hecinhan, anpetu tawapi kin wowaśte en ihuniyanpi kta, qa waniyetu tawapi kin wowiyuśkin en.

12 Tuka waanağoptanpi śni kinhan, wipe on wicaktepi kta, qa wosdonye codan tapi kta.

13 Tuka tona cante en wahna. yanpi kin hena woranniye mnakiyapi kta; iye wicakaśka eśta ceyapi śni ece.

14 Wicakośka hehan naği tapi kta; qa taniyapi kin wicaśapa om un kta.

15 Iye wicaśta onśika tokakije etanhan eyaku kta, ga ka\%48 kiśyapi en nog̉e wicakiyuhdoke kta.

16 Qa nakun niye qe wokakije i kin etanhan eniyaku kta tuka, makoce tanka ocistiyedan wanica ekta: qa wahna wotapi nitawa tawoyute kin he wasna ojudan kta.

17 Tuka niye qe wicaśta śica yacopi kin onijudan: wayacopi qa woyaco kiciyuzapi kta.

18 Wocanniye yukan nakaeś, okinni kaśtakapi on tokàn aniye kta: hehan wokajuju tanka eniyaku kte śni.

19 Nitowijice kin he iye waśtedake kta he: hiya, mazaskazi oqapi qa wowaśake wokamna ocowasin eśta.

20 Hanyetu kin cantokpani śni wo, en oyate kin tokan awicayapi ece.

21 Waanagioptan wo, taku śice cin ekta nihduhomni kte śni; he qe wokakije isanpa yahdahiniǵa nakaeś.

22 Tho, Wakantanka iye towaśake on yuwankan iyeya ece; tuwe Iye iyececa waonspekiya he.

23 Tuwe tacanku kin okiciyake kta he; qa tuwe; Śicaya ecanon ce, eciye kta he.

24. Iye tolian kin datanka kta kiksuya wo, wicaśta he idowanpi ecee.

25 Wicaśta owasin he wanyakapi kta; itehantanhan wicaśta he atonwe kta ce.

26 Tho, Taku Wakan kin he tanka, qa unkiye sdonunyanpi śni; Iye tawaniyetu iyawapi, he qe okahnilipica śni.

27 Tohan Iye hinca mini ośbu kin yutitan eca, minibozan eciyatanhan magiaju hiyuyapi ece. 28 He mahipiya śapa kin śbuyapi, wicaśta ota awicahinhan ece. 


\section{WICOWOYAKE $3 \%$.}

29 Nakun tuwe malipiya śoka yumdayapi kin okahnige kta he; tawakeya kahdehdecapi kin he.

30 Tho Iye taiyoyanpa kin ahdumdaya, qa miniwanca hutkan kin akahpa ecee.

31 Hena on oyate kin wicayaco nakaeś, woyute ota wicaqu kta.

32 Nape napin iyoyanpa on ahdahpa, qa itkokipe cin en iyayeya ecee.

33 Wakinyan tawa kin oihdaka; nakun wanunyanpi kin, tuwe u kte cin on.

\section{WICOWOYAKE $3 \%$.}

1 Nakun de on micante śkanśkan, qa toyanke kin etanhan tokan iyaya.

2 Nahon miye, Iye ho hoton kin nakon po; qa Iye i etanhan jijiya ho enape cin he.

3 Mahipiya ocowasin ihukuya iyayeya ece, qa wakanhdi tawa maka ihanke kin hehanyan.

4 He iyahna ho wan hoton kta; Iye towitan ho kin on wakinyan hotonkiye kta; qa iye ho nahonpi kinhan, tawakanhdi kin kpatan kte śni.

5 Wakantanka iye ho kin on wowinihanyan wakinyan hotonkiya: taku tanka econ ece, unkiye unkokahniğapi śni.

6 Wa kin, Maka akan yanka wo, eciya nakaeś; qa ikce mag’aju, qa iye towaśake mag̉aju lin he nakun.

7 Wicaśta owasin napepi askamwicakiton ece; hecen wicaśta iyulipa iye tohan kin sdonyapi kita.

8 Hehan wamanica kin waśn mahen kihda ece, qa tipi tawa kin ohna yanka yanke.

9 Iye toyanke kin etanhan tateiyumni kin hiyu ece, qa waziyatanhan tate kin etanhan osni.
10 Wakantanka ipogian kin on cağa wicaqupi, qa mini otanka lin yuciqapidan ece.

11 Nakun mahipiya soka kin mini ojukiya ece; taiyoyanpa mahpiya kin he hdumdaye kta.

12 Unkan dena iye tawiyukcan eciyatanhan ihduhomnimnipi ece; hecen iye taku econ wicaśi kin iyulipa maka sintomni ite akan yuśtanpi kta.

13 Wokakije on hecinhan, qa makoce tawa kin on, qaiś wowaonśida on hecinhan, he hiyukiya ecee.

14 Job, de anagoptan wo ; owanji najin, qa Wakantanka tawowinihan kin awacin wo.

15 Tohinni Eloha liena ehnaka hecinhan niye sdonyaya he; qa tamahipiya iyoyanpa kin iyeliye ciqon.

16 Mahpiya śapa otkeyapi kin he niye oyakahiniga he: Tuwe wosdonye en ecetu hinca taku wowinihan tawa lin hena.

17 Token nitawokoyake coscoza aya hecinhan, iye itokagia tanhan maka kin ozikiye cinhan.

18 Iye kici niś mahipiya to kin dumdaya he; he suta, ihdiyomdasin śdoyapi wan iyececa.

19 'Taku unkekiciyapi kte cin he onspeunkiya po: otpaza ite kin on iapi ehnaka unkokihipi śni ye.

20 Miye womdake cin he iye okiyakapi kta he : Wicaśta wan ie cinhan awicakehan napcapi kta.

21 Unkan nakaha iyoyanpa iyega mahpiya ekta yanke cin he wanyakapi śni; tuka tateyanpa lkin hiyaya qa kaska ecee.

22 Mazaskazi iyege cin he waziyatanhan aupi: Êloha kici wowitan wowinihan hinca.

23 Iyotan Waśaka, he unkoka749 


\section{JOB,}

hniggapi kte śni, wowaśake en oiyokipi hinca, qa woyaco, woowotanna ota nakun; eqe waayupte kte śni.

24 Heon etanhan wicaśta kokipapi kta: Tona cante ksapeiçidapi kin hena owasin awicatonwe kte śni ce.

\section{WOCOWOYAKE 38.}

1 Hehan Jehowa tateiyumni etanhan Job ayupta qa heya:

2 De tuwe wowiyulican aotpasya he, wicoie wosdonye codan on.

3 Wanna wicaśta iyecen ipiyagkiton wo: Miye wiciwange kta, hecen amayadupte kta.

4 Maka kin mdusuta qehan tukten yaun he; wookahnige sdonyaye cinhan, oyaka wo.

5 He iyutapi kin hena tuwe ehnaka he, sdonyaya hecinhan: qa tuwe he hahonta ayutitan he.

6 Taku e akan he cin en oyuśtanpi he: qa oise inyàn tawa kin he tuwe ehnaka he:

7 Anpao wicanhpi kin hena kicidowanpi qehan; qa Wakantanka cinca iyuhpa wiyuśkinyan panpi.

8 Qaiś tuwe tiyopa on miniwanca kin nataka he, nahideca, tamni etanhan hiyu qehan:

9 Wokoyake iyecen mahpiya śapa aopemniwakiya qehan, qa otpaza on yuskiskitapi kin iyececa.

$10 \mathrm{Qa}$ he on wokonze mitawa oweciyaka, qa inatake tiyopa ko ewecihnaka:

11 Qa hepa; Dehanyan yahi kta qa sanpa kte śni; qa den wowitan taja nitawa kin anaptapi nunwe.

12 Nitaanpetu kin en hanhanna kin econ yaśi he; anpao kte cin he toyanke kin sdonyeyakiya he;
13 Hecen maka ihanke kin en yuze kta; qa śicaya econpi kin hena etanhan katatapi kta.

14 Upśija ekta mazanapcupe yuhomnipi kin iyececa; qa wokoyake en iyececa najiniçiyapi ece.

15. Hecen śicaya econpi kin etanhan iyoyanpa yutokan iyekiciciyapi $\mathrm{kta}$; qa isto $\mathrm{yu}$ wankan icupi kin he kaksapi kta.

16 Miniwanca oenape kin ekta yai he; qa ośbe oahe kin hena omayani he.

1\% Wiconte tiyopa kin hena niciyuhdokapi, aa wiconte ohanzi tiyopa kin hena wandaka he.

18 Maka ohdakinyan helianyan oyakalinigga he; hena owasin sdonyaye cinhan, oyaka wo.

19 Iyoyanpa ounye cin ekta canku kin tukte e he ; qa otpaza kin tukten toyanka he.

20 Hecen ihanke tawa kin ekta ade kta; qa hecen tipi tawa tacanku kin oyakahnige kta.

21 He ehan nitonpi kin on sdonyaye kta he; qa nitaanpetu iyawapi kin he tanka hinca!

22 Wa omnayanpi kin mahen yai he; qa wasu ohnakapi kin he wandaka he :

$23 \mathrm{He}$ iś wokakije anpetu kin ewecihnaka; anpetu en watakpepi qa okicize hehanyan.

24 Tukte canku kin ohna iyoyanpa kiyuśpapi he, maka akan wiyohiyanpata tate kin iyayeye cinhan.

25 Magaju mini ohna hiyaye kte cin tuwe e yukinukan he, qa wakinyan wakanhdi kin canku kicaga he.

26 Hecen maka akan tukten wicaśta wanica eśta magaju kta ; hewoskan wicaśta wanica kin hetu.

27 Hewotahedan qa otiwota 
kin he imnaye kta, qa peji wohinśma hinanpeye kta e heon.

28. Magiaju kin he ateyapi yukan he; qa tuwe cu opiye kin icalikiya he.

29 Tuwe tamini etanhar cagia hinanpe kta he: qa mahpiya hewanke kin tuwe icabkiye kta he.

30 Mini kin inyan iyecen nahbeiçiya; qa wośbe ite kin atasaka ece.

31 Tawamnipa (Pleiades) mazaicahilia kin yakaśke kta he: qa Orion ipiyake kin yuśka oyakihi he.

32 Mazaroth (wicanhpi wapaha ake nompa) tohan iyehantu kinhan, niye ayau kta he; qa wahanksica (akiyuhapi kin) iye cinca iyahna yus ade kta he.

33 Mahpiya woope kin sdonyaya he; qaiś maka akan ounye cin he niye yakonza he.

34 Malipiya śapa ekta niho yekiya oyakihi he; hecen mini u tkanna anicalipe kta.

35 Wakanhdi kin hena yewicayaśi, unkan yapi kta he; qa, Den unyakonpi ce, eniciyapi kta he.

36 Tuwe e woksape wicapakśin en ehnaka he; qa tuwe wookahnige wicacante en wicaqu he.

37 Tuwe e woksape on malipiya śapa kin yawa kta he; qa mahpiya ojuha kin tuwe yucoka kta he:

38 Tohan maka mdu kin suksuta aya, qa maka yuśpaśpapi kin askamkiciyapi kinhan.

39 Mnaja kin niye tado iyecihni kta he; qa mnaja cinca toni kin imnayaye kta he.

40 Tohan waśun ohna pustag iwankapi, can wohinśma en waiyape iyotankapi kinhan.

41 Tuwe e kangi woyute ki- camna kta he: tohan cinca kin Wakantanka hoyekiyapi eca, woyute codan omani unpi ecee.

\section{WICOW OYAKE 39.}

1 Tohan imnija tatoka kin cincatonpi eca sdonyaya he; qa tahinca ohomnipi kin he iwandaka he.

$2 \mathrm{Wi}$ tona ihunikiyapi ecee kin yawa oyakihi; qa tohan cinca hiyuyapi ecee kin sdonyaya he.

3 Hena patujapi, cinca hiyuyapi ; woiyokiśice tawapi ehpekiyapi ecee.

4 Cincapi kin icagapi, tintoskan waśaka ayapi ; iyayapi, qa ake en wicahdipi śni.

5 Tuwe e ikce śonśonna kin kaśke śni iyayeya he; qa tuwe ikce śonśonna on kaśkapi kin kiyulkca he :

6 Heqe makopuza tipi tawa wecağa; qa hewoskan makoce kin en ounyan ece.

7 Otonwe en wicota kin wahitewicadaśni ; wakahapa hoyeye cin he nahon kte śni.

$8 \mathrm{He}$ akan taku iyeyepica hen wihan ece; qa taku toto owasin ode kta.

9 Tinta tatanka kin he waoniciye kta he; qa tatanka tipi nitawa ohrua un kta he.

10 Tatanka ikceka kin mahyumdupi en hahonta on yakaśke kta he ; qa nihakarn iye kaksiza kin yuhinhe kta he.

11 Iye towaśake tanka, heon wacinyaye kita he, qa nitohtani kin aihpeyakiye kta he.

12 Wacinyaye kta; woksapi nitawa aku kta, qa wakapanpi nitawa mnaye kta he.

13 Hinhankagia tanka (Ostrich) tahupahu kin wiyuśkin ece; tuka śun qa wiyaka tawa kin wacekiya he. 
14. Maka kin akan witka kada ece; qa maka mdu kin en wabe kta.

15 Qa wicasiha nahuhugga kta naceca he akiktonja; qa tinta woteca kin amani kta.

16 Iye cinca kin teliiya wicakuwa, tawa śni iyececa: tolitani kin he taku sni, wokokipe codan.

17 Eloha he woksape akiktons kiya nakneś, qa wookabnig̉e kin okinikiye śni.

18 Tohan wankan ihdapsinta eca, śuk tanka qa akan iyotanke cin ivicahaha ece.

19 Sunka wakan kin iśs wowaśake niye yaqu he; apeyohin on tahu koyagyaya he.

20 Psipsicadan iyecen psipsinyakiya oyakihi he: Pog̉e on pśa kin he wokokipe hinca.

21 Kaksiza ohna wanaqohqoġa, qa wowaśake on psipsice kta; okicize wipe tonpi kin hena itkokim ye kta.

22 Wokokipe on ihaha qa kokipe kte śni ; qa mazasagye ite etanhan naf́nni kte śni.

23 Iye iwankam wanju. kin kokog hinhda; wahukeza hbehbeza qa wapahaśa kin.

24 Ipsicapi qa wocanniye on maka kin napce kta tuka; qa mazayshotonpi hoton kinhan owanji najin kte śni.

25. Mazayahotonpi hoton eca, Ho, ho, eya ece : qa tehantanhan okicize kin omna, akicita tancan wakinyan hotonkiyapi qa iyaśapi kin.

26 Niye nitoksape kin on canśka kin kinye kta he; itokahkiya hupahu yekiye kta he.

$27 \mathrm{Qa}$ niye nii on wamdi kin wankantkiya kinye kta, qa wankan hohpi kicage kta he.

$28 \mathrm{He}$ qe imnija en ounye kta, qa imnija hi kin akan ticağe kta, qa he ipa kin en.
29 Hetanhan woyute akita ece; iye iśta tehan wawanyakapi kta. 30 Nakun iye cinca kin we yazokapi kta; qa wicaktepi wanke cin hen iś yanka ece.

\section{WICOWOYAKE 40.}

1 Nakun Jehowa Job ayupta qa heya:

2 Wawakipajin kin he Iyotan Waśake cin kici wakinica kta he. 'Tuwe Eloha waonspekiye kte cin he ito ayupte kta.

3 Hehan Job Jehowa ayupta qa heya:

4 Tho, miye mawahte sni, tolken aciyupte kta he : minape mii en ewehnake kta.

5 Wancadan iwaa, tuka waamdupte kte śni: han, nonpa, tuka ake ecamon kte śni ce.

6 Hehan icamna kin etanhan Jehowa Job ayupta qa heya :

$\tau$ Wanna wicaśta iyecen ipiyag kiton wo: Miye wiciwange kta, qa niye amayadupte kta.

8 Nakun mitawoyaco kin he dutaku kte śni; niye oniwotanna lita on mayadaco kta he.

9 Hecen niye, Taku Wakan iyececa, isto niyukan he; qa Iye iyecen ho on wakinyan hoton yakiye kta he.

10 Wanna wowitan qa woiyokipi on ihduza wo; wowaśake qa woyuonihan koyagiçiya wo.

11 Wocanteptanye nitawa woptecaśni kin he kaśtan wo, qa wowahanicida iyulipa wanyake ça kun elipeya wo.

12 Wahanicida otoiyohi wanyaka, kun ehpeya wo; qa taku śica econpi kin iye toyanke ohna awicahan wo.

13 Hena witaya maka mdu en nawicahman wo; woinahbe en ite iyawicakaśka wo.

14. Hehan miś eya wociyake 
kta, nape nietapa kin he waniniciye kta nakaeś.

15 Iho, wanna, behemoth (unktehi) he niye kici wakagia; he peji yuta ece, tatanka iyececa.

16 Iho, wanna, towaśake kin nite ohna un, qa tezi ikan kin ohna toiyokihi yanka!

17 Ḣanteśa can iyecen sinte hdapsanpsan ece; ceca ikan tawa kin iciyuhmunpi.

18 Huhu kin mazazi psonpsonna kin heca; huhu tawa. kin hena mazasapa kamdaskapi kin iyececa.

19 Wakantanka tacanku tokapa kin hee: Tuwe icahye cin he tamazasagye kin hiyukiya.

20 He kin hena iye on woyute icahkiciye kta nakaeś; qa heciya tinta woteca iyulipa śkatapi kta.

21 Can wapośbe kin ihukuya iwanke kta, cedi hu oinahbe qa pteg ga kin en.

22 Can wapośbe kin ahanzikiyapi kta ; wakpa coliwanjica kin aohduteyapi kta.

23 Iho, wakpa kin wahanicida kta, iye kokipe kte śni : kopehda śni un kta, iye i kin en Jordan wan akaduza eśta.

24 Iye iśta on yuze kta; iye poge on hmunkapi kin yahidoke kta ce.

\section{WICOWOYAKE 41.}

1 Hinślijupi wan on leviathan iyacu kta, qa iiyuwi en ceji kin iyeyaye kta he.

2 Psa ikan wan pogie ohna iyeyaye kta, qa wapepeka on cehupa yeciyulidoke kta he.

3 Iye wocekiye niciyuota $\mathrm{kta}$ he; qa iapi skuya eniciye kta he.

4 Niye kici wicotakuye kicagge kta he ; ohinniyan niye wowidake duhe kta he.
5 Kici niye yaśkate kta he, zitkadan wan iyececa; qa wicinca nitawa kin on he yakaśke kta he.

6 Kodakiciya unpi kin hena he hmunkapi lita he: wopetonpi kin om he kiyuśpaśpapi kta he.

7 Iye ha kin wanhinkpe on ojuyaye kta he, qa iye pa kin huhaka on.

8 Ninape hee qaeś akan ehnaka wo-okicize kin kiksuya wo, ake ecanon kte śni.

9 Tho, he wacinyanpi kin wicahnayan; nakun wanyakapi kin on tuwe makata ehpeyapi kte śni he.

10 Hee yuhica kta e tuwedan waditake śni: Hehan tuwe e miye mitokam najin okihi kta he.

11 Tuwe e mitokaheya taku econ, hecen wecicajuju kta he: Taku Mahipiya ocowasin ihukuya kin he mitawa ece.

12 Iye huha on inina manke kte śni ; qa taku on towaśake, qa tawokoyake oiyokipi kin.

13 Tuwe e tawokoyake itohnake kin yuzamni kta he; qa tuwe e cehupa itakihna kin en u kta he.

14 Iye ite tiyopa kin tuwe yuhdoke kta he; ihdukśanyan hi kin hena wokokipe.

15 Wahacanka suksuta tawa kin hena e wowitan; ipuspe sutaya ahnakapi kin iyecen natakapi.

16 Wanji wanji kici iciyaskapa, hecen tate otahedan iyaye śni.

17 Wanji takodaku iakan askamyapi ; icikoyagyapi, hecen yuśdogpica śni.

18 Pśa eca iyoyanpa hiyuya ece; qa iśta kin anpao iśtapehin iyececa. 
19 Iye i etanhan peta ide hiyu; iyc etanhan peśnija hinanpa ece. 20 Iye pogge etanhan śota hiyu ecee, cega ipiga qa mazcega kin iyececa.

21 Taniya kin petagia idekiya, qa iye $i$ kin etanhan ide wan hinanpa ece.

22 'Tahu akan wowaśake yanka, qa iye itokam wonihinciye inyanka ece.

23 Iye cehpi cemcepa kin askamkiciyapi, iakan suksuta, kaśkanśkanpica śni.

24 Cante suta hinca, inyan iyececa; han wiyutpan inyan ihukuya kin iyecen suta hinca.

25 Wankan iyeiciya eca waśakśakapi kin kokipapi; nihinciyapi on naśnapi ecee.

26 Tuwe mazasagye ekta yekiya eśta kahtake kte śni, wahukeza, wanhinkpe, qa huhaka kin.

27 Mazasapa kin he peji puza iyececa daka, mazaśa he can ponpona iyececa.

28 Itazipa cinca kin nape kiye kte śni; inyan yuhmunpi kin ağuyapi hu kin eekiya ece.

29 Canhipi kiń hena peji hu iyececa daka, qa wahukeza koskozapi kin he on iha kta.

30 Wakśica kamdecapi pepe kin ihukuya hiyeya; iyuhinte pepe wan upśija ayumdaya.

31 Wośbe kin ceğa ipigiga iyecen ipilikiya ece; miniwanca kill he pejihuta cega iyececa kagga.

32 Iye ihakam canku wan iyojanjanya ece; wośbe kin wanna pa ska kecinpi kta.

33 Maka akan iye iyececa wanica; wokokipe codan kag'api nakaeś.

34 Taku wankantu owasin ekta etonwe kta; heqe wahaniçidapi cinca iyuhpa elna wicaśtayatapi yanka ce.

\section{WICOWOYAKE 42.}

1 Hehan Job Jehowa ayupta qa heya:

2 Taku owasin niye ecanon oyakihi sdonwaya; qa niye ekta woawacin takudan tehike śni.

3 Hehan tuwe e wosdonye codan wowiyukcan aotpasye kta he: Heon etanhan womdaka, tuka owakahnige śni, taku miye ekta wowinihan, qa sdonwaye śni qon.

4 Ceciciya ce, nakion ye, kinhan miye iwae kta: miye wiciwange kta, qa niye waonspemayakiye kta.

5 Nogge winahonpi kin on niye on nawahon ecee, tuka wanna miiśta wanniyaka:

6 Heon etanhan wahtemicida śni, qa maka mdu cahota ko en iyopemiçiye kta ce.

7 Unkan kaketu, wicoie kin dena Jehowa Job eciye cin iyohakam, hehan Jehowa Eliphaz Temani kin heciya; Niye qa nitakoda nonpa on wocanniye mitawa ide: taku ecetu kin enayakiyapi śni nakaeś, Job mitaokiye kin iyececa.

8 Heon wanna tatanka śakowin qa tamdoka śakowin ikikcu po, qa initaokiye Job ekta ya po, qa niyepi on wośna wan wahduśna po: kinhan Job mitaokiye wocekiye eniciyapi kta; iye ite yuwankan iwacu kta nakaeś; hccen wowitkotkoke eciyatanhan ecaciconpi kte śni: taku ecetu kin emayakiyapi śni nakaeś, mitaokiye Job iyececa.

9 Helıan Eliphaz Temani kin, qa Bildad Suhi kin, Zophar Naamathi kin nakun iyayapi, qa Jehowa ewicakiye ciqon he ohna econpi : Unkan Jehowa Job ite kin ekta etonwan. 


\section{WICOWOYAKE 42.}

10 Hehan Jehowa Job wayaka ayapi kin hdicukiya, takodaku wocekiye ewicakiciye cehan. Unkan Jehowa Job taku tawa qon owasin kiciyuota, nonpa akihide.

11 Hehan sunkawicaye cin owasin, qa tankśiwicaye cin owasin, qa sdonwicaye ciqon iyuhpa en hipi, qa kici ag̉uyapi yutapi, iye ti ohna; qa onśikidapi qa kihnahnapi, taku śica Jehowa en au qon iyuhpa on; qa otoiyohi mazaska oinpi wan. jikji qupi.

12 Unkan Jehowa Job owihanke kin yuwaśte, otokaheya qon isanpa: Hecen tahinca kektopawinge wikcemna ake topa wicayuha, qa kamel kektopawing e śakpe, qa tatanka tawanji kekto- pawinge, qa śonśonna wiye kin kektopawing'e.

13 Nakun cinhintku sakowin qa cunwintku yamni.

14. Unkan winyan tokapa kin he Jemima eya cajeyata, qa inonpa kin Keziya eciyapi, qa iyamni kin Keren-hapuk.

$15 \mathrm{Qa}$ makoce ocowasin en winohinca Job cunwintliu kin iyecen owanyag waśte tuwedan iyeyapi śni. Unkan iye timdowicayapi owicapeya atkukupi woyuha wicaqu.

16 Unkan de iyohakam Job waniyetu opawinge sanpa wikcemna topa ni un, qa iye cinca, qa cinca cincapi, oicage topa hehanyan wanwicahdaka.

17 Hehan Job ța, wicalinca qa anpetu imnahan. 


\section{PSALM WOWAPI.}

\section{PSALM 1.}

1 Wicaśta cante waśte linca;

Tuwe wicaśta śica tawowahokonkiye kin ohna mani śni,

Qa wahtanipi sa tacanku kin en inajin śni,

Qa wauncapi oyanke tawapi kin en iyotanke śni:

2 Tuka Jehowa toope kin wowiyuśkin ya ;

Qa tawoahope kin awacin un kta, anpetu hanyetu koya.

3 Unkan he can wan mini wakpa icahda ojupi,

Qa iyehantu eca waskuyeca icaliya ece kin he iyecece kta;

Nakun ape tawa kin śnije kte śni,

Qa taku econ kte cin owasin tanyan yuśtan kta.

4 Wicaśta śicapi kin hececapi śni ;

Tuka hena aguyapi ha tate kahbog iyeye cin he iyececapi.

5 Heon wicaśta śica woyaco kin en najinpi kte śni;

Qa wahtanipi sa wicaśta owotanna tomniciye kin en unpi kte śni.

6 Jehowa wicaśta owotanpidan tacanku kin he sdonya;

Tuka wicaśta śicapi tacanku kin atakuni kte śni.

\section{PSALM 2.}

1 Tokeca Ikcewicaśta kin oqoyapi, Qa oyatepi takuśni awacinpi kta he.

2 Maka wicaśtayatapi kin odakonkiciyapi, Qa wicaśta itancanpi witaya wohdakapi, Jehowa qa Tuwe Sdakiye cin on:

3 Wicaśke tawapi kin unpapsakapi kta, Qa hakahmonpi tawapi elipeunyanpi kta ce.

4 Mahpiya kin en iyotanke cin he ilia kta; Itancan kin iwicaliaha kta.

5 Hehan tocanniye en wowicakiyake kta ; Qa śinhda hinca en śitkihda wicaye kta.

6 Tuka Zion Paha Wakan mitawa kin akan, Wicaśtayatapi mitawa sdawakiya ce.

7 Wokonze kin owahdake kta ; Jehowa hemakiya, Micinkśi kin he niye, Anpe dehan cinca cicaga ce.

8 Makida wo, kinhan Ikcewicaśta tawa wicayaye kta, Qa maka ihanke kin nitawa kta e ciçu kta.

9 Maza icapsinte wan on wicayakawihnuni kta, Maka wakśica iyecen wicayakamdece kta ce. 
10 Heon etanhan wicaśtayatapi, ksapa po; Maka wayacopi, waonspeiciciya po:

11 Wokokipe yuha Jehowa ohoda po; Qa wonihinciye on iyaśa po.

12 Cinhintku kin i iputaka po, Okinni śinhda kta, qa tocanniye kitanna ide kinhan, Canku kin etanhan nitakunipi kte śni. Tona iye wacinyanpi owasin cante waśtepi ece.

\section{PSALM 3.}

Dawid tadowan, iye cinhintku Absalom ite kin nakicipa, he ehan.

1 Jehowa, toka mayanpi kin hena ota aya; Tona takpe maupi kin hena wicota.

2 Wicota minagi heciyapi;

Wakantanka en nikiyapi wanica ce. Sela.

3 Unkan Jehowa, mihdukśan wahacanka kin he niye ;

Wowitan mitawa qa pa yuwankan imacu kin.

4 Miho kin on Jehowa hoyewakiya;

Uńkan iye Paha Wakan tawa kin etanhan namahon. Sela.

5 Miye imunke ca miśtinbe ;

Ake wekta; Jehowa mayuhe cin heon.

6 Oyate kektopawinge wikcemna kowicawakipe kte śni, Ihdukśan tanhan takpe maupi kin.

7 Jehowa inajin wo;

Wakantanka mitawa nimayan wo ;

Tokamayanpi owasin tapon hu kin en awicayapa;

Wicaśta śica hi kin wicayecamdeca.

8 Woehdaku kin he Jehowa tawa;

Woyawaśte nitawa-nitaoyate kin en un nunwe. Sela.

\section{PSALM 4.}

David tadowan. Candowankiyapi on dowan itancan kin.

1 Wakantanka owotanna mitawa, Houwaye cinhan amayupta wo; Makakija en mayadutanka;

Onśimakida, qa wocekiye mitawa nahon wo.

2 Wicaśta cinca, tohanyan mitowitan wowiśtece yayapi kta he ; Tohanyan takuśni waśteyadapi qa woitonśni ayakitapi kta he. Sela.

3 Tuka Jehowa wicaśta wacantkiye cin iye on eiçihde e sdonya po ;

Hoyewakiya eca Jehowa namakihon ece kta.

4 Kokipa po, qa wahtanipi śni po,

Nitowinjapi akan nicantepi on awaiçicinpi,

Qa inina yukan po. Sela.

5 Wicoowotanna wośnapi kin wośna po, Qa Jehowa wacinyan po. 
6 Tuwe taku waśte unkipazopi kta he, wicota eyapi ece : Jehowa, niye nitohnake iyoyanpa kin unkayuhomni po.

7 Wowiyuśkin micante kin en eyahnaka, Aguyapi qa miniśa wicakiciyuotapi kin he isanpa.

8 Wookiye en imunke ça nakun miśtinbe kta ; Jehowa, niye niśnana wowacinye en ounye mayakiye cin heon.

\section{PSALM 5.}

Dawid tadowan. Cotanka on dowan itancan kin kicagapi.

1 Jehowa mioie kin nahon wo;

Mitawacin kin he iyukcan ye.

2 Mitawocekiye ho kin he nalion wo,

Wicaśtayatapi mitawa, qa Wakantanka mitawa;

Ceciciye kta heon etanhan.

3 Jehowa, hanhanna eca miho. kin nayalion kta;

Hanhianna eca houciciye ca wankan ewatonwe kta.

4 'Taku Wakan woahtani en iyuśkin kin henica śni ;

Taku śice cin he niciti kte śni.

5 Tona witkotkoke cin niiśta itokam najinpi kte śni :

Tona woahtani econpi kin iyuhipa śice wicayadaka ece.

6 Tona itonpiśni kin hena ihangwicayaye kta ;

We wicaśta qa wicahnaye sa kin he Jehowa wahteda kte śni.

7 Tuka miye nitowaonśida ota kin on yati en wau kte;

Kocicipe cin on tipi wakan nitawa etkiya ohowada kta.

8 Jehowa, nitoowotanna on amayan wo, toka mayanpi kin on etanban ;

Miite itokam canku nitawa owotanna kaga wo.

9 I kin obna wowicake wanica:

Mahen tanhan wicośice yukan;

Dotepi kin wicawoha yulidokapi kin heca .

Cejipi on wicahnayanpi ece.

10 Wakantanka, kakiświcaya wo;

Wowahokonkiye tawapi on hinhpayapi nunwe;

Woahtani hduotapi kin on ehpewicaya wo ;

Niye nicipajinpi kin heon etanhan.

11 Tuka wacinniyanpi kin owasin wiyuśkinpi kte ;

Ohinniyan wiyuśkinyan-dowanpi kte;

Niye awanwicayahdake cin heon etanhan:

Nakun tona nicaje waśtedakapi kin hena iniyuśkinpi lite.

12 Wicaśta owotanna kin niye dawaśte kta;

Jehowa, wahacanka iyececa, wowaśte wateśdag yaye kta.

\section{PSALM 6.}

Dawid tadowan. Kuya ahiyayapi en candowankiyapi on dowan itancan kin.

1 Jehowa, nitocanniye en iyopemaye śni ye ;

Qa śinyahda en kakiśmaye śni wo.

2 Jehowa, onśimakida ye, wamaśake śni ; 


\section{PSALM $\%$.}

Jehowa asnimayan ye, mahuhu tehiya kakija.

3 Minagi kin is eya nina kakija;

Tuka niye Jehowa, tohanyan kta he.

4 Jehowa hdicu ye, minagi ehdaku wo; Nitowaonśida kin on nimayan wo.

5 Wiconte en niksuyapi kin wanica; Hades ekta tuwe wopida eniciye kta he.

6 Comniwahdazi on waśake śni amayan ; Hanyetu osan mitowinja amnitan waya; Iśtamnihanpe amau kin on ipahin spaye wakiya ece.

7 Ceyapi on iśta amatakuni śni ; Tokamayanpi owasin on kan amayan.

8 Taku śica ecanonpi kin owasin mitan tanhan ya po; Jehowa woceye mitawa ho mamalion kin heon.

9 Jehowa hoyewakiye cin he namalion; Wocekiye mitawa kin he Jehowa icu kta.

10 Tokamayanpi owasin iśtecapi qa nihinciyapi kte ; Ihnuhanna hdicupi qa iśtecapi nunwe.

\section{PSALM $\%$}

Dawid tadowan. Ku's Benjamite oie kin on Jehowa kahiyaye ciqon.

1 Jehowa Wakantanka mitawa, niye wacinciye; Tehiya makuwapi owasin etanhan nimayan qa emahdaku wo:

2 Okinni mnaja iyecen minagi yaśpaśpa qa yah̉delidece kta ; Unkan waehdaku wanice kta.

3 Jehowa Wakantanka mitawa, hecen ecamon kinhan; Minape ohna taku śica yuke cinhan;

4 Tuwe wookiye en mici un kin itkom taku śica ecawecon kinhan ;

Han, tuwe taku on etanhan śni sicaya makuwa kin he emdaku ece :

5 Hehan toka kin minagi tapa qa ehdege kte; .

Han, mitaniya maka kin en namdu kte;

Qa mitowitan watuśekśeca en ounye kiya nunwe. Sela.

6 Jehowa, canniniye cin en inajin wo;

Tokamayanpi śinhdapi kin on wankan iyeiciya wo ;

Qa miye on woyaco cajedate cin on ihduhica wo.

7 Unkan oyate mniciyapi lin aohduteniyanpi kta;

Heon etanhan hena on wankan ihdoku wo.

8 Jehowa oyatepi kin wicayaco kta;

Jehowa, mitoowotanna qa mitowaśte en maun kin he iyecen mayaco ye.

9 Tokin wicaśta śica tolianpi śica hena owihanke yen ;

Tuka wicaśta owotanna kin he yusuta wo ;

Taku Wakan owotanna wicacante qa wicapakśin iyukcan kin he niye.

10 Wahacanka mitawa kin he Wakantanka etanhan;

Tona cante owotanna niwicaye cin hee. 


\section{P S A L M 9.}

11 Wakantanka wayaco owotanna; Qa Wakantanka anpetu iyohi canniyan un :

12 Ihduhomni śni kinhan isan hdube kta; Tinazipe wanna nawinja qa wiyeya ehnaka:

13 Qa wiconte wipe kin ekta epazo; Tunwanhinkpe kin ide kiye kta.

14 Wanyaka wo, woahtani on tinge;

"Taku śica on ihduśaka, qa woitonśni hiyuya.

15 Woha wan kage ça iye kiça; Qa oqapi iye kage cin en ohinhpaya.

16 Tohtani iye pa kin en hdi kta ; Qa tohan śica iye pesdete ahdihpaye kta.

17 Jehowa toowotanna kin on wakahimdamde kta; Qa Jehowa Tehan wankantu caje kin iwadowan kta.

PSALM 8.

Dawid tadowan. Gittith on dowan itancan kin.

1 Jehowa Itancan unkitawapi, Maka kin owancaya nicaje wolkitanin hinea; Nitowitan mahpiya kin iwankam eyehde.

2 Hokśiyopa qa azin unpi ipi kin etanhan woyatan yakaga; Tona toka niyanpi kin hena on, Toka watokicon ko wicaduinina kta heon.

3 Mahpiya nitawa ninapsukaza kage cin he wanmdaka eca; Hanyetu wi qa wicanhpi eyahnake cin;

4 Wicaśta kin taku, hecen elkta ewacanni he; Qa wicaśta cinhintku kin, on en yahi kta he.

5 Kitan ecinyan Taku Wakan kin ihukuya yakaga; Wowitan qa woyuonihan on wateśdag yecaton;

6 Ninape taku kage cin hena idake yakiya; Taku owasin iye siha ihukuya eyahnaka;

7 Tahinca optaye, tatanka ko owasin; Qa nakun tinta woteca kin;

8 Mahpiya olkinyanpi, qa miniwanca hogan kin, 'Taku miniwanca ohna cankuye cin hena.

9 Jehowa Itancan unkitawapi, Maka kin owancaya nicaje wokitanin hinca.

\section{PSALM 9.}

Dawid tadowan. Muth-laben on dowan itancan kin.

1 Micante ocowasin on Jehowa mdatan kta; Taku wowinihan nitawa owasin mdatanin kta.

2 Cante mawaśte qa.niye on wimduśkin kta; Tehan Wankan yaun nicaje iwadowan kta.

3 Tokamayanpi hekta itoheya hdicuyapi kinhan, Nitokam hicahanpi qa hinhpayapi kte.

4 Woakinica qa woyaco mitawa dusuta; 


\section{P S A L M 10.}

Oiyotanke kin akan owotanna wayaco idotanke.

5 Ikcewicaśta iyopewicayaya, tona śice cin hena ihangwicayaya;

Ohinniyan qa owihanke wanica cajepi yapajuju.

6 Toka woihangye tawapi kin wanna owihanke :

Qa totonwepi kin hena dujuju ;

Ahna wicakiksuyapi kin he atakuni śni.

7 Trka Jehowa owihanke wanica ounye kte;

Woyaco on oiyotanke tawa wiyeya ekihde.

8 Unkan wowaśte on maka kin hdaco kta;

Woowotanna on oyate kin wicayaco kta.

9 Nakun śicaya wicakuwapi kin hena Jehowa wowinape yapi kta ; Wokakije anpetu kin en he wowinape yapi kta.

10 Unkan tona nicaje sdonyapi hena wacinniyanpi kta;

Niye Jehowa, tona anicitapi kin hena ehpewiçayaye-śni ece.

11 Jehowa Zion en ounye cin he idowan po;

Tohan tanka oyate kin en oyaka po.

12. Tohan wicawe akita eca hena kiksuya ece ;

Tona kakija hoyeyapi kin he akiktonje śni.

13 Jehowa onśimakida wo;

Tona śicemadapi token kakiśmayanpi kin he wanyaka wo .

Wiconte tiyopa etanhan imacu kin he niye.

14. Hecen Zion cunwintku tatiyopa kin en nitowitan ocowasin omdake kta;

Wiconi nitawa on imduśkin kta.

15 Tkcewicaśta woha wan kagapi kin he ohna ihpayapi;

Wohmunke wan iye nahmanpi kin he ohna siha icihmunkapi.

16 Woyaco econ kin eciyatanhan Jehowa sdonyapi :

Tuwe śice cin he iye nape ohan kin on hmunkapi ece. Higgaon. Sela.

17 Wicaśta śicapi Hades en hdicuwicayapi kta ;

Oyate Wakantanka akiktonjapi kin iyuhpa.

18 Wahpanicapi kin ohinniyan akiktonjapi kte śni;

Wicaśta onśika wacinyanpi kin he owihanke wanica ihanke kte śni.

19 Jehowa inajin ye, wicaśta akantu waśake śni nunwe;

Nitokam Ilkcewicaśta kin wicayacopi kte.

20 Jehowa, wakokipe wicakicaga wo;

Hecen Ikcewicaśta wicaśta ikceka hecapi e sdoniçiyapi kta. Sela.

\section{PSALM 10.}

1 Jehowa, tokeca itehan nayajin he;

Wokakije anpetu kin en nayakilibe kta he.

2 Wicaśta śica wahanicida on kakije cin tehiya kuwa ece;

Wohnaye awacinpi kin he on içhduzapi nunwe.

3 Wicaśta śica iye nagi taku cantiheye cin on ihdatan;

Qa waicucu kỉnhan ihdawaśte ;

Jehowa he waliteda śni tuka. 


\section{PSA L M 11.}

4 Wicaśta śica, ite walianiçida kin on, Takudan akite kte śni, Wakantanka wanica; Hecen tawacin ece.

5 Tacanku kin ohinniyan suta;

Nitawoyaco kin iwankam un, iśta kin itehan; Tokawicaye cin owasin awicapogan kta.

6 Cante mahen heya; Icimana mayntokanpi kte śni;

Wicoicage qa wicoicage hehanyan woiyokiśice wanice kta ce.

7 Woyaśice, woyahnayan qa woyuśice on i kin ojudan;

Ceji ihukuya woyaśkiśkapi qa woahtani hiyeya.

8 Otonwe en waiyapepi kin hen iyotanke kta;

Woinahbe oyanke kin en wicaśta ow otanna wicakte kta;

Iye iśta wicaśta onśika iyawicape kta.

9 Mnaja wan waśun ohna yanka,

He iyecen, woinahbe oyanke kin ohna waiyape un kta;

Wicaśta onśika yuze kta e iyape kta;

Wohmunke tawa kin en wicaśta onśika au eca yuza ece.

10 Patuś inajin qa makata iwanka,

Hecen wicaśta waśaka wicayuhe cin on wicaśta onśika hinhpayapi kta.

11 Cante mahen heyá; Wakantanka akiktonja;

Ite nakilhman; icimana wanyake kte śni ce.

12 Jehowa, najin ye;

Wakantanka, nape yuwankan ehdaku wo ;

Onśike cin hena akiktonje śni wo.

13 Tokeca wicaśta śica Wakantanka wahteda śni he;

Niye wawinunge kte śni, cante mahen keya he.

14 Niye wandaka; ninape on toyecon kta e

Wicohan śica wocanniye ko ayatonwan ece :

Tuwe onśike cin he wacinniye kta;

Wamdenica kin oyakiya ece.

15 Wahtani sa isto kin kawega wo;

Wicaśta śica tośice cin ayakite kta,

Takudan iyeyaye kte śni hehanyan.

16 Jehowa Wicaśtayatapi ohinniyan qa owihanre wanice kta:

Makoce tawa kin etanhan Ikcewicaśta kin ataliunipi śni.

17 Tona onśika taku icekiyapi kin he; Jehowa niye nayahon;

Cantepi dusuta kta; ninoge anohyakiye kta.

18 Wamdenica qa kakiśyapi kin towicayecicon kta;

Hecen wicaśta maka akan icimana wakokipe wicakicage kte śni.

\section{PSALM 11.}

Dawid tadowan. Dowan itancan kin kicagapi.

1 Jehowa wowinape waye;

Tokeca minagi heyakiyapi he;

He nitawapi onakipa po, zitkadan iyececa.

2 Wan, wicaśta śicapi tinazipe nakiwinjapi ;

Ikan kin ekta tunwanhinkpe wiyeya ehnakapi ; 
Otpaza en wicaśta cante owotanna wicakutepi kta.

3 Woahde kin hena yujujupi kta:

Wicaśta owotanna taku econ okihi kta he.

4 Jehowa tipi wakan tawa kin ohna yanka;

Jehowa oiyotanke tawa mahpiya kin ekta wanka;

Iye iśta kin wanyaka, iye iśtojuha wicaśta cinca wicayukcan. ece.

5 Jehowa wicaśta owotanna kin yukcan kta;

Tuka wicaśta śica qa tona wawicakipi waśtedake cin liena

Iye nagi śicewicadaka ece.

6 Wicaśta śice cin hena wakanhdi awicamagaju kte,

Peta qa inyanzi, tate iyumni wohitike hinca;

Miniyatke ohna wicaqupi kin hee.

7 Jehowa owotanna un, woowotanna waśtedaka ece:

Tona ecetupi kin hena iye ite kin wanyakapi kta.

\section{PSALM 12.}

Iśahdogan on dowankiya itancan kin. Dawid tadowan.

1 Jehowa wanikiya wo; wicaśta wacantkiye cin he owihanke; Wicaśta wicake cin Adam cinca kin etanhan atakunipi śni ce.

2 Otoiyohi iye takodaku kici woitonśni okiciciyapi kta ; Tha śduśduta qa cante nonpa on iapi kta.

3 Jehowa wicaiha śduśduta owasin baśpe kte, Wicaceji watankaicidaya ie cin he nakun.

4 Hena heyapi; Uncejipi on wounhitikapi kta ; Iha unyulianpi; tuwe itancan unyuhapi he.

5 Wicaśta onśika kakijapi kin on, Wicaśta wahpanica ceyapi kin on, Wanna nawajin kta ce, Jehowa eye kta;

Tuwe he cantokpani hinca kinhan, wankan wapa ewahnake kta ce.

6 Jehowa taku eye cin hena wicoie ecedan; Mazaska maka oceti ohna yuecedan, Śakowin akihde śdoyapi.

7 Jehowa, niye hena wicayakpatan kta;

Wicoicage kin de etanhan ohinniyan eyahdaku kta.

8 Wicaśta cinca wahtepi śni kin wankan ehdepi kinhan, Wicaśta śica owancaya manipi kta.

\section{PSALM 13.}

Dowankiya itancan tawa. Dawid tadowan.

1 Jehowa, tohanyan amiyektonje kta he, ohinniyan kta he; Tohanyan niite namayakihbe kta he.

2 Tohanyan minagi on awacin waun kta, Anpetu otoiyohi cante maśice kta he;

Tohanyan tokamaye cin miwankam un kta he.

3 Wanyaka wo, Jehowa Wakantanka mitawa, namahon wo: 
Iśta iyoyammayan wo, okinni wiconte en miśtinbe kta.

4 Okinni tuwe tokamaye cin, Wanna ohiwaya ce, eye kta; Malicahe cinhan śicaya makuwapi kin iyaśapi kta.

5 Tuka miye nitowaonśida wacinwaya;

Micante nitowiconi kin on iyaśa kte.

6 Jehowa iwadowan kta, Tanyan ecamicon heon etanhan.

\section{PSALM 14.}

Dowan itancan kin kicagapi. Dawid tawa.

1 Witkotkoke cin he, Taku Wakan wanica ce, cante mahen eya. Hena ihduśicapi, wicohan walite śni econpi ;

Tuwedan taku waśte econ śni.

2 Jehowa mahpiya eciyatanhan Adam cinca kin ahiwicatonwan; Tuwe wacinksamya ohanyan hecinhan wanyake kta;

Tuwe Wakantanka akita hecinhan.

3 Iyuhpa icunonpa iyayapi ; witaya ihduśicapi ;

Tuwedan taku waśte econ śni; han, wanjidan śni.

4 Taku śica econpi kin owasin takudan sdonyapi śni he;

Mitaoyate aguyapi iyecen wicayutapi,

Qa Jehowa hoyekiyapi śni.

5 Hen wokokipe on kopehdapi;

Wakantanka wicoicage owotanna kin en un, heon.

6 Wicaśta onśika tawowacinye kin iśtenyayapi kta; Jehowa wowinapeye cin heon.

7 Tokin Israel woehdaku tawa kin Zion etanhan u nunwe: Tohan Jehowa taoyate wayaka unpi kin awicahdi kinhan, Jakob iyuśkin kta, Israel pida kta.

\section{PSALM 15.}

Dawid tadowan.

1 Jehowa, tuwe nitawakeya en ounye kta he;

Tuwe paha wakan nitawa kin en ti kta he.

2 Tuwe iyaonpepicaśniyan mani, qa woowotanna econ, Qa cante mahen wowicake ia ece :

3 rTuwe iye ceji on waaie śni, Tuwe ikiyedan un kin taku śica ecakicon śni ; Qa takodaku on woyake śica wan icu śni :

4 Iye iśta en wicaśta wahteśni kin wahtedapi śni : Tuka tona Johowa kokipapi kin hena wicayuonihan kta: Iye içiconza on kiunniic̣iya eśta hdutokeca kte śni :

5 Mazaska tawa ota kamna kta ehnake śni ;

Qa wicaśta iyaonpepica śni un kin on wokajuju icu śni ; Tuwe dena econ kin he ohinniyan pahohopi kte śni. 


\section{PSALM 17.}

PSALM 16.

Dawid tawoinalibe.

1 Wakantanka makpatan wo;

Niye wacinciya, heon etanhan.

2 Jehowa heyakiya; Itancan mitawa kin he niye;

Mitowaśte kin he niye ekta iyahde śni :

3 Makoce kin en wicaśta wacantkiye cin hena ekta, Qa itancanpi kin, hena en ocowasin wimduśkin.

4 Tona wanji tokeca wohpapi kin hena woiyokiśice ota yuhapi kta :

We wośnapi kin hena wapapson kte śni, Qa cajepi kin miiha ohna iwacu kte śni.

5 Jehowa wopamni mitawa qa wiyatke mitawa kin hee;

Woaihpeye mitawa kin he niye dutanka kta.

6 Taku wiciyokipi kin imakiyutapi :

Hán, maga waśte hinca mduha.

7 Jehowa wahokonmakiye cin he mdatan kta;

Nakun hanyetu eca. mitapakśin onspemakiya ece.

8 Mitokam . Tehowa ohinniyan ewahde;

Mietapa ekta un, heon mahohopi kte śni.

9 Heon etanhan micante wiyuśkin,

Qa mitowitan ipsica ece :

Han, micelipi wowacinye en wanke kta.

10 Minagi Hades en amayaduśtan kte śni;

Wanji Wakan nitawa kin he wicahwin wanyagyakiye kte śni.

11 Wiconi canku kin he onspemayakiye kta;

Niite kin he wowiyuśkin ojudan;

Nietapa ekta ohinniyan wiciyokipi.

\section{PSALM $1 \%$.}

Dawid tawocekiye.

1 Jehowa, taku owotanna kin nahon ye;

Sicahowamde cin he anolikiya wo;

Wocekiye mitawa namakilion ye,

Iha wicahnaye śni etanhan u kin he.

2 Mayaowotanpidan kin he nitohnake etanhan u kta;

Niiśśta taku ocitkonza kin hena wanyake kta.

3 Cante imayaduta, hanyetu en mayahi;

Imayadukcan, takudan iyeyaye kte śni ;

Mii kin mitawacin kakipe kte śni.

4 Wicaśta wicohan tawapi ekta, niiha oie kin on,

Waihangye sa ohanpi kin iwanmdaka ece.

5 Mioye kin nitacanku yus un ;

Siha ewahde kin naśdute śni.

6 Wakantanka houciciya; amayadupte kta heon; Anohmakiya wo, taku epe cin namakilion wo. 
7 Tona wacinyanpi niwicayaye nitocantekiye hdutanin wo; Tona najinpi kin etanhan, ninape etapa on.

8 Wiciśta su kin iyecen makpatan wo; Nihupahu ohanzi ihukuya namayahbe kte;

9 Wicaśta śica ihangmayanpi itepi kin etanhan; Minagi tokayapi aohdutemayanpi kin hena.

10 Waśin tawapi kin en aconkaśkapi; Ipi on wah̉aniçidaya iapi ece.

11 Wanna unkowepi kin en aohduteunyanpi; Iśta on wanyag iheyapi, hdatapi kta heon.

12 Mnaja iyececa, wayapota inahini; Qa mnaja kośka woinahbe en iyotanke cin iyececa.

13 Jehowa najin wo, itkokim ya wo, patuśkiya wo; Mazasagye nitawa on wicaśta śica etanhan minagi eyaku wo:

14 Jehowa, ninape on, wicaśta kin etanhan;

Wicoicage wicaśta etanhan, Taku tawapi wiconi kin den un;

Qa taku nalimana yahnake cin on tezi ojuwicayakiye kta: Hena cinca wipipi kta; Qa taku ohdaptapi kin hokśiyoqopa aihpewicakiyapi kta.

15 Tuka miye woowotanna en niite wanmdake kta; Tohan ouncage nitawa yuha wekta kinhan, cante mawaśte kta.

\section{PSALM 18.}

Dowankiya itancan kin. Dawid Jehowa taokiye kin he kaga: Jehowa tokayapi owasin napepi etanhan, qa Saul nape etanhan eyaku qon, anpetr kin he en odowan oie kin dena Jehowa eciya.

1 Unkan heya; Jehowa mitowaśake, nina waśte cidake kta.

2 Jehowa imnija mitawa, qa conkaśke mitawa, qa emahdaku ece kin hee:

Wakantanka mitawa, wowinape mitawa, he wacinwaye kta ; Wahacanka mitawa, qa ni makiya he kin, paha tehanwankantu mitawa kin hee.

3 Jehowa yatanpi kte cin he hoyewakiye kta ;

Unkan tokamayanpi etanhan nimayanpi kta.

4 Wiconte ikan kin on mayuskiskitapi; Qa wicośice wakpa kin mayuśinyaye kta.

5 Hades ikan kin aohdutemayanpi; Wiconte mazalitakiyapi kin mayuzapi.

6 Iyotanhan iyewakiye cin en Jehowa hoyewakiye kta; Qa Wakantanka mitawa cewakiye kta; Tipi wakan tawa kin eciyatanhan miho kin nahon kta; Qa wocekiye mitawa iye itokam u kte, iye noge kin en.

7 Hehan maka kin yuhuhuzapi qa cancan; Ḣe oahde kin yuhuhuzapi qa śkanśkan; Iye śinhda heon etanhan.

8 Canniyan etanhan śota wankan iyaya; 


\section{PSA I M 18.}

Qa i kin etanhan peta waliulinaga;

Heon petaga ideyapi.

9 Nakun mahipiya kin patuśkiye ça kun u;

Qa iye siha ihukuya otpaza.

10 Qa Kerub wan akan iyotanke cea kinyan iyaya:

Han, tate hupahu kin akan kinyan.

11 Woinahibe tawa otpaza kin he kaga;

Ihdukśan tawokeya kin mini otpaza;

Mahpiya en mahpiya śoka kin hee.

12 Itokam iyoyanpa on malipiya śoka tawa kin hiyaya;

Wasu qa petaga.

13 Hehan mahpiya ekta Jehowa wakinyan hotonkiya;

Qa Iyotan Wankan kin lo hdatanin:

Wasu qa petaga.

14 Unkan tunwanhinkpe kihiyeya qa napewicaya;

Nakun wakanhdi hiyuye ça yuśinyewicaya.

15 Hehan mini sicu kin wanyakapi;

Qa maka oahde kin yutaninpi;

Jehowa niye he iyopeyaya;

Nitocanniye oniva ipogan kin heon.

16 Hehan wankantanhan hiyu qa mayuze kta;

Mini ota etanhan imacu kta.

If Tokamaye waśake cin etanhan emayaku kta ;

Qa tona śicemadapi kin etanhan;

Hena mikapeya waśakapi nakaeś.

18 Iyomakiśica anpetu kin en iyamalipayapi kta;

Tuka Jehowa mạyusuta kin hee.

19 Unkan makoce tanka en amahi;

Iyokipiwaye cin heon emayaku kta.

20 Mitoowotanna iyecen Jehowa ecamicon kta;

Minape ska kin iyecen micicajuju kta.

21 Jehowa tacanku kin hena owape; Qa Taku Wakan mitawa śicaya amduśtan śni.

22 Iye tawoyaco kin owasin mitokam un;

Qa toope kin mitantanhan elipewaye kte śni.

23 Nakun iye itokam ecetu waun;

Qa wawahtani kin etanhan ținsmiçiya.

24. Heon mitoowotanna iyecen Jehowa micicajuju; Iye iśta itokam minape ska kin heon.

25 Tuwe wacantkiye cin he kici wacantkiya nihdutanin kta;

Wicaśta owotanna kici oniwotanna kta:

26 'Tuwe ecedan un kin he kici ecedan nihdutanin kta ;

Qa tuwe pemni un kin he kici nihdupemni kta.

27 Niye oyate onślka niwicayaye kte :

Tuka iśta wankantupi kin kun hiyuwicayaye kta.

28 Niye petijanjan mitawa ideyaye lita:

Jehowa mita Wakantanka otpaza iyoyammiciye kte.

29 Niye on ozuye wan awaimnanke kta ;

Wakantanka mitawa on conkaśke wan awapsice kta. 
30 Iyotan Waśaka tacanku kin he yuśtanpi ;

Jehowa oie kin he yuecepidan;

Tona wacinyanpi owasin he wahacanka yapi.

31 Hecen Jehowa icunonpa tanhan Taku Wakan kin tukte e he;

Qa Wakantanka unkitawapi icunonpa tanhan tuwe imnija he.

32 Iyotan Waśake cin wowaśake on ipiyag makiton;

Qa mitacanku miciyuśtan.

33 Misiha tatokadan iyececa micaga;

Qa pajodan mitawa akan najin makiya.

34. Minape kicizapi onspemakiya,

Hecen miisto mazaśa itazipa kin yuwinja.

35 Unkan nitowiconi wahacanka kin mayaqu:

Nakun ninape etapa kin najin makiye kta ;

Qa nitowahibadan tanka makage kta.

36 Mihukuya caewahde kin hena mayadutanka kte;

Hecen miiśkahu naśdute k九te śni.

37 Tokamayanpi tawicawapa qa ewicawehdege kta;

Qa bowicasotapi śni hehanyan wahdicu kte śni.

38 Wicawakahuhuge kita, hecen najin okihipi śni ;

Misiha ihukuya ihpayapi kta.

39 Unkan okicize kta wowaśake on ipiyag mayakiton ;

Tona takpe maupi kin hena milıukuya iyewicayaye kta.

40 Nakun tokamayanpi tahupi kin mayaqu;

Qa tona śice madapi kin hena ihangwicawaye kta.

41 Hena howayapi kta, tuka wanikiya wanica:

Jehowa hoyekiyapi kta, tuka awicayupte śni.

42 Hehan wicawakandumdu kta, tate itokam maka mdu iyececa;

Canku upśija iyecen tankan ehpewicawaye kta.

43 Oyate kicizapi kin etanhan emayahdaku kte;

Ikcewicaśta kin en itancan emayahnake kte ;

Oyate sdonwicawaye śni qon hena wowidagwaye kta.

44. Noge on nahonpi kinhan anamagoptanpi kta;

Wicaśta tokeca cinca kin mayaonihanpi kte.

45 Oyate tokeca cinca kin atakunipi kte śni;

Qa conkaśke tawapi etanhan cancanyan hiyupi kta.

46 Jehowa ni un; qa Imnija mitawa yawaśtepi nunwe; Qa Wakantanka Wanikiya mitawa kin he yatanpi nunwe.

47 Iyotan Waśaka watokic̣onpi maqu ece kin hee; Qa nakun mihukuya oyatepi wicaktedan.

48 'Tokamaye cin etanhan emahdaku ;

Han, tona takpe maupi kin wiciwankam emayahde kta;

Wicaśta waihangye cin etanhan emayahdaku kta.

49 Heon, Jehowa, Ikcewicaśta ehna ciyatan kte ; Qa nicaje iwadowan kta.

50 Wicaśtayatapi tawa kin woehdaku kiciyutanka;

Qa tuwe Sdakiye cin he wowaonsida ecakicon ece;

Dawid qa iye cinca kin, owihanke wanica. 


\section{PSALM 20.}

PSALM 19.

Dowan itancan kin. Dawid tadowan.

1 Mahpiya kin Wakantanka towitan kin oyaka; Qa okotonyan kin iye nape ohan kin yuotanin ece.

2 Anpetu wan anpetu iapi okiciyake kta; Qa hanyetu wan hanyetu wosdonye kiciyuotanin kta.

3 Iapi wanica qa wicoie wanica; Hena ho kin ecaca nahonpi śni.

4 Hena iyutapi ikan kin maka owancaya iyaya; Qa oiepi kin maka ihanke kin ekta. Hena ehna anpetu wi kin wokeya wan kicaga.

5 Unkan he winohinca yuze kte cin wan Wankan tipi etanhan hdinanpe cin iyececa; Wicaśta waśaka iyecen kiinyanka iyuśkin.

6 Mahpiya ihanke kin hetanhan ya ece; Qa unma ihanke kin ekta ki :

Qa iyokate cin etanhan takudan nalimanpi sni.

'7 Jehowa toope kin yuśtanpi, wicanagi kin yuhomni ;

Jehowa tawoyaotanin kin he wowicake,

Witkotkoke cin wicayuksapa ece.

8 Jehowa taku econ wicaśi kin hena ecetu, Wicacante iyuśkinkiya ;

Jehowa tawoahope kin ecedan, wicaiśta iyoyamya ece.

9 Jehowa kokipapi kin he ska, ohinniyan he kta;

Jehowa tawoyaco kin he wowicake, ocowasin owotanna.

10 Hena mazaskazi isanpa waśtedapi k te;

Han, mazaskazi ecedan ota kin isanpa:

Nakun tuhimaga canhanpi isanpa skuya;

Qa tulimaga canhanpi śbu kin.

11 Nakun hena on nitaokiye wahokonkiyapi;

Hena yuhapi kin wokajuju tanka.

12 Tuwe wahtani ohdahniga okihi he;

Nahmanpi kin hena micicajuju wo.

13 Nakun woahtani tanka kin etanhan nitaokiye ehdaku wo;

Hena wowidagmaye śni nunwe; kinhan omaowotanna kta,

Qa woahtani ota iyaonpepica śni waun kta.

14 Jehowa imnija mitawa qa tuwe opemakiton kin,

Mii oie kin qa micante taku awacin kin,

Hena niye iyonicipi nunwe.

PSALM 20.

Dowan itancan kin on. Dawid tadowan.

1 Wicocante śica anpetu kin en Jehowa nanilion kte;

Jakob ta Wakantanka caje kin wankan enihde nunwe.

2 Tipi wakan kin etanhan oniciye kte;

Qa Zion etanhan niyuwaśake kta.

3 Nitawośna owasin kiksuye kte;

Qa peta on waduśna kin hena icu kta. Sela. 
4 Nicante yuze cin eciyatanhan niç kte; Qa nitawacin owasin ecetuniciciye kta.

5 Woehdaku nitawa on unkiyuśkinpi kta; Qa Wakantanka unkitawapi caje kin on Wiyokihedan eunkihdepi lkta. Wocekiye nitawa owasin Jehowa ecetuniciciye kte.

6 Jehowa iye Sdakiye cin he nikiya wanna sdonwaya; Mahipiya wakan tawa eciyatanhan nakilion kta. Nape etapa waniye wowaśake kin he on.

7 Hunli canpahmihma qa hunl suktanka, Tuka unkiye Jehowa Wakantanka unkitawapi caje on unkiwinktapi kta.

8 Hena e patujapi qa hinhpayapi :

Tuka unkiye naunjinpi qa bosdan unyakonpi.

9 Jehowa wanikiya wo :

Hoyeunyanpi anpetu kin en,

Wicaśtayatapi kin naunkilionpi kte.

\section{PSALM 21.}

Dowan itancan kin on. Dawid tadowan.

1 Jehowa, nitowaśake on wicaśtayatapi kin cante waśte kta; Qa woehdaku nitawa on nina iyuśkin kta.

2 Taku cantokpani kin he yaqu;

Qa iye iha taku da kin he teyahinda śni. Sela.

3 Woyawaśte waśte kin yuha itkoyakipe kta ;

Mazaskazi wateśdake wan pa akan eyecihnake kta.

4 Wiconi nicida, he yaqu; Anpetu hanska, ohinniyan qa owihanke wanica.

5 Waniyakiye cin on towitan tanka kte;

Woyuonihan qa wowaśte akan eyahnake kta.

$6 \mathrm{He}$ woyuwaśte owihanke wanica yakage kta ;

Niite etanhan wowiyuśkin on iyuśkinyakiye kta.

7 Wicaśtayatapi kin Jehowa wacinyan un;

Unkan Iyotan Wankan un tawocantekiye en kahuhuzaapi kte śni.

8 Tokaniyanpi owasin ninape iyewicaye kta ;

Tona śicenidapi kin ninape etapa iyewicaye kta.

9 Niite itokam maza śdoyapi oceti ide kin iyecen wicayakage kta;

Jehowa tocanniye on nawicapce kta;

Qa peta kin huhnahwicaye kta.

10 Taku icahyapi kin maka etanhan ihangyaye kta ;

Qa cincapi kin Adam cinca kin etanhan.

11 Taku śica nihiyohi kta cinpi ;

Taku śica konzapi, tuka okihipi kte śni.

12 Heon etanhan wicitokam eyakate cinhan,

Hekta itoheya hdicu wicayaye kta.

13 Jehowa, nitowaśake on nihduwankantuya nunwe,

Unkahiyayapi kta, qa nitowaśake unkidowanpi kta. 


\section{P S A L M 22.}

\section{PSALM 22.}

Dowankiya itancan: Anpao tahinca kin on. Dawid tadowan.

1 Wakantanka mitawa, Wakantanka mitawa,

Tokeca ehpemayaya he:

Waśicahowamde oie kin en tehan omayakiye śni.

2 Wakantanka mitawa, anpetu icunhan hoyewaye kta,

Tuka amayadupte kte śni ;

Nakun hanyetu en, qa inina manke śni.

3 Tuka niye niwakan,

Israel yatanpi kin en ounyaye cin.

4 Atewicunyanpi wacinniyanpi qon;

Wacinniyanpi unkan ewicayahdaku.

5 Hoyeniciyapi unkan ewicahdakupi ;

Wacinniyanpi unkan iśtecapi śni.

6 Tuka miye wamdudan hemaca, qa wicaśta hemaca śni ;

Wicasta ekta wowiśtece mayanpi, qa oyate kin wałtemadapi śni.

7 Tona wanmayakapi owasin wowihaha mayanpi ;

Aikśinmayanpi, apomnamnamakiyapi.

8 Jehowa ihduzeze ce; ehdaku kta;

Waśtedake cin heon nikiye kta ce, eyapi.

9 Tuka wicatamni etanhan imacu qon he niye ;

Ina aze kin akan wowacinye mayaqu.

10 Wicatamni kin etanhan niye en aihpemayanpi ;

Ina tezi kin hetanhan Wakantanka mitawa he niye.

11 Mitehanyan un śni wo, woiyokiśice kiyedan un;

Nakun waokiya wanica, heon etanhan.

12 Tatanka ota aohdutemayanpi;

Baśan etanhan waśakapi kin ohomni takpe maupi.

13 Mnaja ocinśica qa hoton ece kin,

He iyecen aimayukawapi.

14 Mini iyecen mapapsonpi; qa huhu mitawa owasin makap śunpi ;

Micante canśin iyececa, mitezi mahen śdoyapi.

15 Maka cega onśpa iyecen mitowaśake śpan;

Nakun miceji macaka en askapa,

Qa wiconte maka mdu kin en amayade kta.

16 Sunka ohomni imayayapi;

Wicaśta śica omniciye kin aohdutemayanpi;

Minape misiha ko capapi.

17 Huhu mitawa owasin wahdawa;

Ahitonwanpi qa opamahtapi.

18 Wokoyake mitawa kicipamnipi;

Qa mitaśina on kansu kutepi.

19 Tuka Jehowa niye mitehanyan un śni ye;

Mitowaśake he niye, omakiya inahni wo.

20 Mazasagye etanhan minagi ehdaku wo;

Mitawa ecedan kin śunka nape kin etanhan. 
21 Mnaja i kin etanhan nimayan wo:

Unkan tatanka he kin hetanhan amayadupta.

22 Nicaje mihunkawanji owicawakiyake kta; Omniciye kin cokaya tanhan icidowan kta.

23 Jehowa kokipa yaunpi kin, he idowan po;

Jakob cinca owasin, he yuonihan po:

Qa Israel cinca owasin, kokipa po.

24 Tuwe onśika kakije cin he iliaha śni qa śicedake śni;

Nakun ite inakilibe śni ; tuka hoyekiya eca nakition eca.

25 Omniciye tanka kin en niye on wadowan kta;

Tona kokipapi wicitokam wośna mitawa wahdajuju kta.

26 Walibapidan kin hena wotapi qa imnanpi kta;

Tona Jehowa akitapi kin hena idowanpi kte:

Nicantepi owihanke wanin ni kte.

27 Maka ihanke kin owasin kiksuyapi qa Jehowa ekta ihduhomnipi kta;

Qa Ikcewicaśta en wicowazi owasin nitokam ohodapi kta.

28 Wokiconze kin he Jehowa tawa;

Qa iye Ikcewicaśta kin wowidagwicaya ece.

29 Maka akan tona cepapi owasin wotapi qa ohodapi kta ;

Watuśekśeca ekta kun yapi kin iyuhpa he itokam patujapi kta :

Qa tuwe iye nagi nilkiya okihi śni kin.

30 Wicacinca wowidagwicaye kta;

Hena Itancan kin wicoicage wicahdawa kta.

31 Upi qa toowotanna kin oyakapi kta ;

Oyate wan tonpi kte cin en;

Iye hecon kin heon.

\section{PSALM 23.}

Dawid tadowan.

1 Wonmakiye cin Jehowa hee:

Takudan imakakije kte śni.

2 Peji toto en iwanke maye kta;

Wicoozi mini kin icahda yus amaye kta.

3 Minagi yuecetu kte;

Woowotanna canku kin ohna amaye kta;

Iye caje kin on.

4 Han, wiconte ohanzi kaksiza kin en mawani kinhan,

Taku śica kowakipe kte śni, niye mici yaun heon;

Cansakadan nitawa qa cansagye nitawa, hena cantohnagmaye kta.

5 Tokamayanpi wicitokam wahna wotapi wan wiyeya miyecihnake kta;

Wihdi on pa sdamayakiye ;

Wiyatke mitawa iyatahde.

6 Awicakehan wani kta anpetu owasin,

Wowaśte wowaonśida ko miyahna un kta:

Qa Jehowa ti kin en ounwaye kta, anpetu hanskaska. 
PSALM 24.

Dawid tadowan.

1 Maka kin Jehowa tawa, qa woojudan kin;

Makowancaya qa tona ounyanpi kin.

2 He iye miniwanca kin akan ehde;

Qa wakpa kin iwankam sutaya kaga.

3 Jehowa Paha tawa kin tuwe ekta ye kta he;

Qa oyanke wakan tawa ohna tuwe yanke kta he.

4 Tuwe nape kin ska, qa cante kin ecedan;

Tuwe takuśniśni ekta nagi yeiçiye śni ;

Qa wohnaye on iciconze śni kin.

5 He Jehowa etanhan woyawaśte icu kta;

Qa woowotanna, Wakantanka Wanikiya tawa kin etanhan.

6 Wicoicage okide unpi kin he dee:

Niite akitapi kin hena Jakob eepi. Sela.

7 Tiyopa kin, pa yuwankan ehdaku po ;

Qa tiyopa ohinniyan un wankan iyeiciya po:

Unkan Wowitan Wicaśtayatapi kin tin hiyu kta.

8 Wowitan Wicaśtayatapi kin he tuwe he:

Jehowa waśake ça waditake ;

Jehowa kicizapi en mdetahunka.

9 Tiyopa kin, pa yuwankan ehdaku po ;

Qa tiyopa ohinniyan un wankan iyeiciya po :

Unkan Wowitan Wicaśtayatapi kin tin hiyu kta.

10 Wowitan Wicaśtayatapi kin he tuwe he:

Jehowa Sabaoth,

Wowitan Wicaśtayatapi kin hee. Sela.

PSALM 25.

Dawid tawa.

1 Jehowa, niye ekta,

Minagi wankan wahdomde kta.

2 Wakantanka mitawa, niye wacinciya;

Imaśtece śni nunwe;

Tokamayanpi ohimayanpi śni nunwe.

3 Nakun tona anipepi owasin iśtecapi kte śni :

Takuśni on wah̉tanipi kin hena iśtecapi kta.

4 Jehowa, nitacanku kin hena makipazo wo ;

Niohan kin hena onspemakiya ye.

5 Nitowicake en omani makiye ca onspemakiya wo ;

Wakantanka Wanikiya mitawa kin he niye;

Anpetu owasin niye acipe waun.

6 Jehowa, nitowaonśida qa nitocantekiye kiksuya ye;

Hena otokahe wanica heon etanhan.

7 Komaśka ehan wawalitani qa taku śica ecamon qon hena kiksuye śni ye ;

Wawacinkta duza tanka eciyatanhan miksuya wo;

Jehowa, nitowaśte kin heon etanhan. 


\section{P S A L M 26.}

8 Jehowa waśte qa owotanna;

Heon canku kin ohna wahtanipi sa onspewicakiye kta.

9 Tona onśilianpi kin woyaco en yus awicaye kta;

Qa onśihanpi kin iye tacan̂ku onspewicakiye kta.

10 Jehowa tohan kin owasin wowaonśida qa wowicake,

Tona wicotakuye tawa qa woyaatanin tawa opapi kin hena en.

11 Jehowa, nicaje kin on etanhan,

Wawahtani micicajuju ye, he tanka nakaeś.

12 Wicaśta Jehowa kokipe cin tukte e he;

Canku hdalinige kte cin he onspekiye kta.

13 Iye nagi wowaśte en wanke kta;

Qa cinca kin makoce kin tawayapi kte.

14 Tona Jehowa kokipapi kin hena kici wohdakapi ece;

Unkan wicotakuye tawa kin sdonyewicakiye kta.

15 Miiśta ohinniyan Jehowa ekta;

Wohmunke etanhan misiha eyaku kta, heon.

16 Miye ekta ihduhomni qa onśimakida ye;

Miśnana waun qa makakija, heon etanhan.

17 Micante iyotanhan iyekiye cin yutankapi ;

Makakije cin etanhan emayaku wo.

18 Iyomakiśica qa wamayazan kin wanyaka wo;

Qa wawahtani owasin micicajuju ye.

19 Tokamayanpi kin wanwicayaka wo; hena otapi :

Qa wośicedake wohitika on śicemadapi ece.

20 Minagi micipatan qa emayaku wo;

Imaśtece śni nunwe; wacinciya heon.

21 Woyuecetu qa wicoowotanna mapatanpi kta:

Acipe waun kin heon etanhan.

22 Wakantanka, wicokakije owasin etanhan

Israel ewicahdaku wo.

PSALM 26.

Dawid tawa.

1 Jehowa woyaco maqu wo:

Mitoecetu kin ohna mawani, heon:

Nakun Jehowa wacinyan waun;

Mahicahe kte śni.

2 Jehowa mayukcan qa imayutan wo;

Mapakśin micante ko yuecedan ye.

3 Nitowaonśida miiśta itokam un;

Qa wowicake nitawa ohna mawani.

4 Wicaśta itonpiśni om imdotanke śni; Qa wanakilimanpi kin en mde kte śni.

5 Sicaya econpi omniciye kin śice wadaka ;

Qa wahtanipi sa om imdotanke kte śni.

6 Wiyaonpepicaśni ohna nape wahdujaja;

Hecen Jehowa, owayuśna nitawa ohomni mde kta.

7 Wopida ho kin on eyanwapaha kta; 
Qa niohan wakan owasin omdake kta.

8 Jehowa, yati omyanpi kin he waśte wadaka;

Qa nitowitan wokeya oyanke kin he nakun.

9 Wahtanipi sa om minagi mnakiye śni wo;

Qa mitaniya, we wicaśta kin om.

10 Hena napepi ohna wicowicaśta śni;

Qa nape etapapi wiyopeyapi ojudan.

11 Tuka miye qe mitoecetu ohna mawani lita:

Opemakiton qa onśimakida wo.

12 Misiha makomdaya ohna han:

Mniciyapi kin en Jehowa mdawaśte kta.

\section{PSALM 2\%.}

Dawid tawa.

1 Jehowa iyoyanpa mitawa qa Wanikiya mitawa hee, tuwe kowakipe kta he ;

Jehowa wiconi mitawa wowaśake kin hee, tuwe on kopewahda - kta he.

2 Wicaśta śica micehpi yutapi kta e mikiyedan upi qehan, Tokamayanpi qa śicemadapi kin hena eepi hicahanpi qa hinhipayapi.

3 Wicota en ahimawanka eśta, micante kokipe kte śni;

Ozuye wan ahimanajin eśta, de wacinyan waun.

4 Taku wanji Jehowa wakida, he awakita ece kta ;

Anpetu tona wani kin owasin Jehowa ti kin en waun kta;

Jehowa toiyokipi wanmdake kta,

Qa tipi wakan tawa kin ohna wawimunge kte.

5 Anpetu śice cin en tawokeya ohna namalibe kta ; Iye tawakeya onahbe kin en inahibe makiye kta; Imnija wan akan wankan emahnake kte.

6 Unkan nakaha mapa kin toka mihdukśan hiyeya wiciwankam un kte;

Heon iye tawakeya ohna wowiyuśkin wośna kin wawakiyuśna kta;

Wadowan kta, han, Jehowa odowan wakahiyaye kte.

7 Jehowa anagoptan wo, miho on wahowamde;

Hecen onśimakida qa amayupta wo.

8 Miite akita po: Micante heniciya;

Jehowa, niite awakite kta ce.

9 Niite inamakilibe śni wo;

Canniniyan nitaokiye ehpeye śni ye ;

Omakiye cin he niye; amayuśtan śni wo;

Qa ehpemaye śni, Wakantanka Wanikiya mitawa.

10 Tohan ate qa ina ehpemayanpi kinhan,

Hehan Jehowa irracu kte.

11 Jehowa, nitacan'ku kin onspemakiya ye;

Qa ocanku owctanna ohna amayan wo,

Tona iwanmayakapi kin hena on. 


\section{P S A L M 29.}

12 Tokamayanpi tawacinpi kin en wicamaqu šni wo; Wayaatanin itonpi śni lkin irkom mahinajinpi, Qa tona wośitkihda apoganpi kin.

13 Wiconi makoce kin en, Jehowa towaśte opahta wacinwaye śni kinhan.

14 Jehowa wacinyan wo;

Waditaka wo, kinhan cante niyuwaśake kte : Han, Jehowa wacinyan wo.

PSALM 28.

Dawid tawa.

1 Jehowa, niye hoyeciciye kta; Imnija mitawa, miye on inina yanke śni wo; Miye on noge nikpe cinhan, Hehan wicahapi ekta yapi kin iyemacece kta.

2 Houciciya eca wocekiye mitawa ho kin nation wa: Nitawakeya wakan ektakiya nape mdugata eca.

3 Wicaśta śica om ehpemaye ŝni wo; Qa tona woahtani econpi kin om; Hena wicikiyedan unpi kin om wookiye eyapi ; Tuka cantepi en woyuśica yukan.

4 Taku econpi kin iyecen wicaqu wo; Qa śicaya ohanyanpi kin iyececa ; Iye nape ohanpi kin on niye wicaqu wo: Taku econpi kin iyecen wicakicu wo.

5 Jehowa tohan kin hena awacinpi kte śni, Qa iye nape taku kage cin hena, Heon wicakawanke kta, qa icahwicaye kte šni.

6 Jehowa yawaśtepi nunwe ; Wocekiye mitawa ho nation kin heon.

7 Jehowa mitowaśake qa wahacanka mitawa kin hee: Micante wacinyan un, unkan omakiyapi :

Heon micante nina iyuśkin kta; Qa odowan mitawa on mdatan kte.

8 Wowaśake tawapi kin Jehowa hee; Qa wiconi conkaśke wan iye Sdakiye cin tawa.

9 Nitaoyate niwicakiya wo;

Qa taku nitawa kin hdawaśte wo:

Nakun wonwicaya wo,

Qa owihanke wanica hehanyan wicahduha ye.

\section{PSALM 29.}

Dawid tadowan.

1 Waśakapi cinca kin, Jehowa qu po; Jehowa wowitan wowaśake ko qu po.

2 Iye caje towitan kin Jehowa kicu po; Wokoyake wakan un Jehowa ohoda po. 
3 Jehowa ho kin mini kin akan;

Wowitan Wakantanka wakinyan hotonkiya;

Jehowa mini tanka kin akan un.

4 Jehowa ho kin wowaśake en; Jehowa ho kin wowitan en un.

5 Jehowa ho kin hanteśa bowehiwega ;

Han, Jehowa Lebanon hanteśa kin kawehwega:

6 Qa ptejincadan wan iyecen psipsinwicaya;

Lebanon qa Sirion, tatanka cinca iyececa.

7 Jehowa ho kin peta ide kin yapta ece.

8 Jehowa ho contanka kin yahuhuze kta, Qadeś contanka kin Jehowa yuhuhuze kta.

9 Jehowa ho kin tawiyedan hokśiksuye kiya;

Qa can kin kahna okihi kta:

Unkan iye ti kin ohna owasin, Wowitan, eyapi ece.

10 Jehowa mini tanka kin akan iyotanka;

Han, Jehowa Wicaśtayatapi iyotanka, owihanke wanica.

11 Jehowa iye taoyate wowaśake wicaqu kte:

Jehowa iye taoyate wookiye on wicayawaśte kta.

\section{PSALM 30.}

Odowan. Tipi yuwakanpi kin on dowanpi. Dawid tawa.

1 Jehowa, iyotan ciyawa kta, niye wankan emayahde; Qa tokamayanpi miye on iyuśkinwicayaye śni heon.

2 Jehowa Wakantanka mitawa, Hoyeciciya, unkan niye asnimayaya.

3 Jehowa, Hades etanhan minagi iyacu ; Woha ekta yapi kin etarnan nimayaya.

4 Wicaśta wacantkiye tawa, niye Jehowa kahiyaya po; Qa iye towakan kiksuyapi kin on wopida eya po.

5 Tocanniye kin iśta kakpapi hehanyan;

Toiyokipi kin he wiconi :

Htayetu eca wicaceya yuke kta,

Tuka hanhanna dowanpi kta.

6 Unkan miye tanyan waun kin en, Owihanke wanin mapahohopi kte śni ce, epa.

7 Jehowa, nitoiyokipi kin on paha mitawa wowaśake yakaga;

Niite nayakihibe, unkan mayuśinyaya.

8 Jehowa, niye hoy eciciye kta;

Qa Jehowa wocekiye ewakiye kta.

9 Mawe kin en wokamna yukan he,

Woha ekta kun mde cinhan :

Maka mdu kin niyatan kta he;

Nitowicake kin oyake kta he.

10 Jehowa, anagoptan qa onśimakida ye;

Jehowa, omakiye cin he niye nunwe.

11 Waśinwahda kin he wacipi miyecaga;

Heyake s̉ica mayakiduśdoke ça wowiy uśkin on ipiyag mayakiton. 
12 Heon wowitan inidowan kta, qa inina un kte śni :

Jehowa Wakantanka mitawa, owihanke wanin wopida eciciye kta.

PSALM 31.

Dowan itancan kin on. Dawid tadowan.

1 Jehowa niye wacinciya:

Owihanke wanin imaśtece śni nunwe:

Nitoowotanna on emahdaku wo.

2 Anohmakiya ye; emayaku inahni wo:

Wowaśake imnija mitawa kin he niye nunwe;

Qa conkaśke tipi on nimayanpi kte.

3 Imnija mitawa qa conkaśke mitawa kin he niye;

Heon nicaje on napata mayaduze ca yus amayade kta.

4 On hmunkapi natimana emakionpapi kin etanhan mayadusdute kta;

Wowaśake mitawa kin he niye, heon etanhan.

5 Mitaniya ninape en owehnake kta;

Jehowa wowicake Wakantanka, niye opemayakiton.

6 Tona takuśni itonśni awacinpi kin hena śicewicawadaka ;

Tuka Jehowa wacinwaya ece.

7 Nitowaonśida on piwada qa imduśkin kte :

Woiyokiśice mitawa niye wandaka;

Wokakije en minagi sdonyaye ciqon.

8 Nakun toka nape en onamayatake śni ;

Makoce tanka en siha emayahde.

9 Jehowa, onśimada wo, makakija heon:

Woiyokiśica on iśta maśica amayan;

Minagi qa mitezi nakun.

10 Wani kin woiyokiśica on masote;

Qa waniyetu mitawa comnihdazipi on ;

Wawahtani on waśake śni amayan;

Qa mahuhu kin hena śiłtin.

11 Tokamayanpi owasin wowahteda śni mayanpi,

Nakun mikiyedan unpi kin hena iyotan;

Qa tona sdonmayanpi kin wokokipe mayanpi ;

Tona tankan wanmayakapi kin hena namakipapi.

12 Taku ta iyecen cante on amiktonjapi ;

Wakśica kamdecapi wan iyemaceca.

13 Wicota waaiapi kin nawation;

Ihdukśan wokokipe, wiyamaonpapi kin icunhan,

Mitaniya icupi kta akitapi.

14 Tuka Jehowa, niye wacinciya;

Wakantanka mitawa kin he niye ce, epa.

15 Mitaanpetu ninape ohna un;

Tokamayanpi qa śicaya makuwapi napepi etanhan emahdaku wo.

16 Niite nitaokiye aiyehikiya ye;

Nitowaonśida on nimayan wo. 


\section{P S A T.M 32.}

17 Jehowa, imaśtece śni nunwe, hoyeciciye cin heon :

Tona śicapi kin hena iśtecapi nunwe, Hades en inina unpi kte.

18 Woitonśni ihapi kin inina unpi nunwe;

Hena wahanicidaya qa wawośtehdaya

Ikceya wicaśta owotanna aiapi.

19 Tona konicipapi nitowaśte wicayecihnake cin he tanka hinca;

Wicaśta cinca itokam tona wacinniyanpi kin en he wicayakidutanin.

20 Hena nitohnake woinahbe kin en nawicayahbe kta,

Wicaśta miniciyapi kin etanhan;

Wicaceji wakinicapi etanhan wokeya wan ohna wicayakpatan kta.

21 Otonwe suta wan ohna wowinihanyan cantemakiya,

Heon Jehowa yawaśtepi nunwe.

22 Tuka miś imanihan qehan,

Niiśta itokapatanhan makaśpapi ce, epa :

Hececa eśta cewakiya ho kin namayakilion,

Hoyeciciye cehan.

23 Wicaśta wacantkiye tawa kin owasin, Jehowa waśtedaka po:

Tona wicakapi kin hena Jehorva wicakpatan;

Qa tuwe wahanhaniçidaya olianye cin he iyakiçuya kicicajuju ece.

24. Waśaka po, hecen cante niyuṭinzapi kte;

Jehowa wacinyayapi kin owasin.

\section{PSALM 32.}

Wowahokonkiye odowan. Dawid tawa.

1 Tuwe taku śica econ kin kicicajujupi, Qa wahtani akahpapi kin he cante waśte:

2 Wicaśta kin he cante waśte, Tuwe Jehowa woahtani kiciyawa śni, Qa taniya en wohnayan wanice cin he.

3 Inina manke cehan mahuhu śeca aya, Anpetu osan waśicahowamde cehan.

4 Anpetu hanyetu ko ninape amáhdaskin yanka; Mawe kin mdoketu puze cin iyecen aya. Sela.

5 Wawahtani niye ociciyake kta; Qa taku śica ecamon kin anawakihibe śni :

Taku śica ecamon kin hena Jehowa owakiyake kta ce, epe :

Unkan wawalitani śice cin miyecicajuju. Sela.

$6 \mathrm{He}$ on tona wacantkiye cin owasin ceniciyapi kta, Tohan iyeniyanpi kte cinhan :

Awicakehan mini ota apaśboka eśta,

He hiyohipi kte śni.

7 Woinahbe mitawa kin he niye;

Wokakije etanhan emayahdaku kta;

Woehdaku odowan on aohdutemayaye kta. Sela.

8 Wahokonciciye ça canku ohna de kte cin he onspeciciye kta; 


\section{P S A L M 33.}

Miiśta opacilita wahokonciciye kta.

9 Ihnuhan śuktanka qa śonśonna wan iyenicecapi kinhan;

Hena takudan okalinigapi śni ;

Tiyuwi qa ikan oiyokipi on i pawicalitapi ;

Nikiyedan upi śni heon etanhan.

10 'Tona śice cin wokakije ota yuhapi kte:

Tuka tuwe Jehowa wacinye cin he wowaonśida aohduteye kta.

11 Tona owotanna yaunpi, Jehowa on pidapi qa iyuśkin po;

Qa tona cante ecetu yaunpi owasin, wiyuśkinyan iyaśa po.

\section{PSALM 33.}

1 Wicaśta owotanna yaunpi, Jehowa on wiyuśkin po: Yatanpi kin tona ecetupi iyokipipi ece.

2 Candowankiyapi on Jehowa wopida eciya po; Candowankiyapi ikan wikcemna on idowan po.

3 Odowan teca wan kahiyaya miye;

Ho tanka on wayupiya yajo po.

4 Jehowa oie kin he ecetu;

Qa ohan kin owasin wowicake.

5 Woowotanna qa wokonze waśtedaka;

Maka kin Jehowa towaonśida on ojudan.

6 Jehowa oie on mahpiya kin kagapi ;

Qa iye i taniya on hena obe kin owasin.

7 Miniwanca mini kin kawitaya, paha iyececa ;

Ośbe kin mazopiye en ekihnaka.

8 Maka kin ocowasin Jehowa kokipapi kte ;

Maka akan ounyanpi iyuhpa itokam inihanpi nunwe.

9 Iye ia, unkan ecetu;

Iye kaken eya, unkan sutaya han.

10 Ilkcewicaśta tawacinpi kin Jehowa ecetu śni ya;

Oyate token wakiconzapi kin he yujuju ece.

11 Jehowa tawokonze kin ohinniyan he kta;

Iye cante yuze cin wicoicage qa wicoicage hehanyan.

12 Oyate wan Jehowa Taku Wakan yuhapi kin he cante waśtepi ;

Wicaśta iye tawawicaye kta wicahdahnige cin hena.

13 Jehowa mahpiya eciyatanhan ahitonwan;

Adam cinca kin owasin wanwicayaka.

14 Tukten ounye cin hetanhan etonwan,

Maka akan ounyanpi owasin ekta:

15 Cantepi kin owasin wicakaga;

Wicohan tawapi owasin awacin un.

16 Wicaśtayatapi tuwedan ozuye tanka on' niyanpi śni :

Wicaśta waśaka keś wowaśake tanka on ihduśke kte śni.

17 Niwicayapi kta on suktanka kin wacinyepica śni;

Qa iye towaśake tanka on waeyaku kte śni.

18 Tho, Jehowa iśta kin tona kokipapi kin hena awicatonwan;

Tona iye towaonśida apepi kin hena. 


\section{P S A L M 34.}

19 Wiconte etanlıan nagipi ewicahdaku kta;

Qa wicaakilian en niwicaye kta.

20 Unnagipi Jehowa wacinyanpi ;

Ounkiyapi qa wahacanka unkitawapi kin he iye.

21 Iye on uncantepi iyuśkin kte;

Iye caje wakan wacinunyanpi heon.

22 Jehowa, nitowaonśida unkiyepi en un nunwe;

Unkanipepi kin heon etanhan.

\section{PSALM 34.}

Dawid tawa. Abimelek itokam togye ohanyan; unkan hdeǵi hehan kihda, he ehan.

1 Anpetu owasin Jehowa mdawaśte kta;

Iye idowanpi kin ohinniyan mii ohna un lita.

2 Jehowa on minagi itan kta:

Tona onśiłianpi nahonpi k ta qa iyuśkinpi kta.

3 Jehowa mici yatanka miye ;

Qa yuwitaya iye caje kin unyawankantupi kte.

4 Jehowa awakita, unkan amayupta;

Qa wakowakipe cin owasin etanhan emahdaku.

5 Ekta etonwanpi, unkan iyoyamyapi;

Qa ite naśapi śni nunwe.

6 Onśike cin de howaya, unkan Jehowa nalion,

Qa tokakije owasin etanhan ehdaku.

7 Tona kokipapi kin hena wicihdukśan,

Jehowa taohnihde kin iwanka,

Qa ewicayaku ece.

8 Uta miye, qa Jehowa waśte e wanyaka po:

Tuwe wacinye cinhan wicaśta kin he cante waśte.

9 Wacantkiya yaunpi tawaniyanpi, Jehowa kokipa po;

Tona kokipapi kin hena takudan icakijapi kte śni.

10 Mnaja cinca wicakiśs unpi qa wotektehdapi;

Tuka Jehowa akitapi kin hena taku waśte takudan icakijapi kte śni.

11 Iho po, micinca, anamagoptan po;

Jehowa tokokipe kin onspeciciyapi kta.

12 Wicaśta wiconi cin, qa taku waśte

Wanyake kta e anpetu waśtedake cin he tuwe he.

13 Taku śica etanhan niceji ehdaku wo;

Qa niiha wohnayan eyapi kte śni.

14 Taku śica ehpeya wo, qa taku waśte e econ wo:

Wookiye akite ca kuwa aya wo.

15 Jehowa iśta wicaśta owotanna awicatonwan;

Qa howayapi eca anohiwicakiya ece.

16 Tona taku śica econpi Jehowa ite kin itkowicakim un;

Maka kin etanhan wicakiksuyapi kin icu kte.

17 Hoyeyapi, unkan Jehowa nahon,

Qa tokakijepi iyulipa etanhan ewicahdaku. 
18 Jehowa cante kicaksapi kin wicikiyedan un; Qa tona taniya onśike cin hena niwicaya ece.

19 Wicaśta owotanna tokakije kin ota; Tuka owasin etanhan Jehowa eyaku kta.

20 Huhu tawa owasin awankiciyaka; Hecen wanjidan kaeś kawegapi śni.

21 Wośice tona śice cin hena wicakte kta; Qa wicaśta owotanna śice wicadakapi kin hena yacopi kta.

22 Jehowa taokiye nagipi kin opewicakiton; Qa tona iye wacinyanpi kin tuwedan yacopi kte śni.

PSALM 35.

Dawid tawa.

1 Jehowa, tona makigepi kin hena wicakige wo; Tona makizapi kin hena wicakiza wo.

2 Mazamakuakahpe wahacanka ko ikikeu, Qa omakiya inajin wo.

3 Nakun wahukeza ehdaku, Qa tona śicaya makuwapi wicakagi wo ; Wiconi nitawa kin he miye ce, minagi eciya wo.

4 Minagi odepi kin hena inihanpi qa iśtecapi nunwe ; Tehiya amawacinpi kin hena hekta hdicuwicayapi qa iśtenwicayapi nunwe.

5 Aguyapi ha tate itokam hena iyececapi nunwe; Qa Jehowa taohnihde hena wicakaśtake kte.

6 Tacankupi kin otpaza qa śduśduta nunwe; Qa Jehowa taohnihde kin kuwa awicaye kte.

7 Taku on etanhan śni wohmunke wan miye on nahmana eonpapi ;

Taku on etanhan śni minagi on woha wan qapi.

8 Sdonye śni kinhan woihangye kin en u nunwe; Qa wohmunke nalibe cin he iye içihmunka nunwe; Woihangye kin hee en ohinhpaya nunwe.

9 Hehan minagi Jehowa on iyuślkin kta; Wiconi tawa kin idowan kta.

10 Mahuhu owasin heyapi kta; Jehowa, tuwe iyeniceca he;

Tuwe isanpa waśaka etanhan onśike cin eyahdaku; Han, onśike ca wahpanica kin, tuwe wamakinon kin etanhan.

11 Itonśniyan woyakapi kin hinajinpi ; Taku sdonwaye śni kin hena on imawangapi.

12 Taku waśte on taku śica maqupi; On minagi kakiśyapi kta.

13 Tuka miye qe, wayazankapi qehan, wakihdaka komdaka; Akihanmiçiya on minagi kakiśwaye : Unkan wocekiye mitawa mamaku en hdihan.

14. Mitakoda se, misunka hee, he iyecen mawani; Tuwe hunku akiceye cin iyecen waśihda pamahdedan waun. 
P S A L M 36.

15 Tuka nakaha nawaśduta, hehan iyuśkinpi qa witaya mniciyapi; Waaie sa kin hena miye en mniciyapi, unkan sdonwaye śni :

Wayahdehdecapi qa inina unpi śni.

16 Wota ia śicapi kin hena om;

Hi amahdakinskinzapi.

17 Itancan, tohanyan opahta nanke kta he:

Woihangye tawapi etanhan minagi hdohdi wo;

Waśtewakidake cin, mnaja kin etanhan.

18 Omniciye tanka kin en wopida eciciye kta; Oyate waśaka om ciyatan kta.

19 Tokamayanpi itonpiśni kin hena miye on iyuślkinpi śni nunwe: Tona taku on etanhan śni śicemadapi kin hena iśta kakpanpi.

20 Hena wookiye iapi kte śni;

Tuka tona makoce kin en, inina unpi kin

Hena wohnayan wicoie wicakicagapi kta.

21 Han, hena nina i makapapi :

Qa heyapi ; Hoho, hoho,

Iśta on wanunyakapi ce.

22 Jehowa niye wandaka, inina yanke śni wo;

Itancan, mitehanyan un śni wo.

23 Ihduhica ye, qa mayacopi kte cin on kikta wo;

Makiyuśepi kin on,

Wakantanka mitawa, qa Itancan mitawa.

24 Jehowa Wakantanka mitawa,

Nitoowotanna eciyatanhan mayukcan to ;

Qa hena miye on iyuśkinpi śni nunwe.

25 Cante mahen, Hoho, hecen uncinpi ce, eyapi śni nunwe;

Naunkipcapi ce, eyapi śni nunwe.

26 Tona makakija on iyuśkinpi kin hena iśtecapi, Qa witaya ite naśapi nunwe;

Tona miye on ihdatankapi kin hena wowahteda śni,

Qa wowiśtece koyakapi nunwe.

27 Tona mitoowotanna cinpi kin hena iyaśapi,

Qa wiyuśkinpi nunwe;

Han, ohinniyan heyapi kte; Jehowa tanka ce,

Iye taokiye wookiye kicicin kin hee.

28 Unkan miceji nitoowotanna cajeyate kta;

Niyatanpi kin anpetu osan.

\section{PSALM 36.}

Dowan itancan kin on. Jehowa taokiye wan kaga. Dawid tawa.

1 Micante mahen, wicośice wicaśta śica heciya ;

Iye iśta itokam Taku Wakan kokipapi wanica ce.

2 Iye iśta kin en ihdawaśte;

Tuka wahtani kin iyeyapi qa śicedapi kta.

3 Iye i oie kin hena woitonśni qa wohnayan;

Wacinksamya waśteya econ kta he ayuśtan.

4 Towinja akan woitonśni awacin un kta; 


\section{S A L M 37.}

Canku waśte śni wan ohna iyahe kta ;

Taku śica ayuśtan kte śni.

5 Jehowa, nitowaonśida kin he malipiya ekta un;

Nitowicake mahpiya śapa iyahde.

6 Nitoowotanna kin he Iyotan Waśaka ta he kin iyececa:

Wokonze nitawa kin he wośbe tanka:

Jehowa, wicaśta woteca ko ni wicayaya.

7 Wakantanka, nitowaonśida kin he waśte hinca;

Heon Adam cinca niliupahu ohanzi kin en wacinyanpi kta.

8 Yati wasna kin on imnanpi kte;

Qa wowaśte nitawa wakpa kin etanhan yatke wicayaye kta.

9 Wiconi minilidoka wan nici wanke:

Iyoyanpa nitawa en iyoyanpa wanunyakapi kta.

10 'Tona sdonniyanpi kin hena nitowaonśida iyohi wicakiya wo:

Qa nitoowotanna, tona cante ecepidan kin.

11 Wahanicidapi siha kin anamatan śni nunwe;

Qa olian śica nape kin napemaye śni nunwe.

12 Hen wicohan śica econpi kin hinhpayapi ;

Hena makata ehpeyapi, qa najin okihipi kte śni.

\section{PSALM 37.}

\section{Dawid tawa.}

1 Wicohan śica econpi kin hẻna on iyokiśiniçiye śni wo;

Qa woalitani econpi kin on winawizi śni wo.

2 Hena ecadan kaśdapi kta, peji iyececa;

Qa wato iyecen śnijapi kta.

3 Jehowa wacinyan wo, qa taku waśte econ wo:

Makoce kin en ounye ca wowicake akita wo:

4 Nakun Jehowa en iyolipiiciya wo;

Kinhan taku iceyakiye cin hena niçu kta.

5 Nitacanku kin Jehowa yuhekiya wo;

Nakun wacinyan wo; kinhan ecetuye kta:

$6 \mathrm{Qa}$ nitoowotanna iyoyanpa iyecen yutanin $\mathrm{kta}$;

Qa woknonze nitawa lkin wiyotanhan iyececa.

7 Jehowa en inina un, qa wacintankaya ape wo:

Tuwe canku ohna wapiya un kin he on iyokiśiniçiye śni wo;

Tuwe wicotawacin śica hduecetu kin on.

8 Wocanniye ayuśtan qa wośihda elipeya wo;

Taku śica ecanon kta e iyokiśiniciye śni wo.

9 Tona taku śica econpi kin hena ihangwicayapi kta;

Tuka Jehowa wacinyanpi kin hena makoce kin yuhapi kta.

10 Ehake cistiyedan hehan wicaśta śica en un kte śni;

Han, tohe kin opalita yaun kta, tuka en un śni.

11 Tuka tona onśicịidapi kin hena makoce kin tawayapi kta;

Qa woobkiye ota on iyuśkiniçiyapi kta.

12 Wicaśta śica wicaśta owotanna iyape un;

Qa hi ahdakinskinza ece.

13 Itancan kin ihalia kta; 
Taanpetu u kta wanyake cin heon.

14 Wicaśta śicapi mazasagye ehdakupi ; Qa tinazipepi nakiwinjapi ;

Onśika qa wahpanica kin makata ehpewicayapi kta;

Qa tona ohan owotanna kin wicaktepi kta.

15 Mazasagye tawapi kin on iye cante caicipapi kta; Qa tinazipepi kin kawegapi kta.

16 Taku cistinna wicaśta owotanna tawa kin he waśte; Wicaśta śica ota wowijice yuhapi kin isanpa.

17 Wicaśta sica is to kawegapi kta:

Tuka Jehowa wicaśta owotanna najin wicakiya ece.

18 Wicaśta ecetu taanpetu kin hena Jehowa sdonya:

Qa taku yuhapi kin he owihanke wanice kta.

19 Anpetu śica en iśtecapi kte śni;

Qa wicaakihan anpetu kin en imnahan wotapi kta.

20 Tuka wicaśta śice cin hena atakunipi kte śni ;

Qa Jéhowa tokayapi kin;

Tahinca cinca śin kin iyecen hulnagapi;

Śota en taninpi śni.

21. Wicaśta śica wodota keś wicakicu kte śni:

Tuka wicaśta owotanna wacantkiye cea wawicaqu ece.

22 Tona wicayawaśte kin hena makoce kin tawapi kta:

Qa tona wicayaśice cin hena ihangyapi kta.

23 Jehowa eciyatanhan wicaśta caehde kin yuecetupi ;

Qa tacanku kin on iyuśkin kte.

24 Hinhpaye kta, tuka makata ehpeyapi kte śni;

Jehowa nape yuze cin heon etanhan.

25 Homakśidan waun, qa wanna wimacahinca;

Tuka wicaśta owotanna kin ehpeyapi,

Qa cinca woda unpi wanmdake śni.

26 Anpetu osan waonśida qa owicaqu ece :

Unkan cinca kin hena woyawaśte.

27 Taku śica ayuśtan qa taku waśte e econ wo;

Qa owihanke wanin ounyan wo.

28 Jehowa wokonze waśtedaka ece;

Qa wicaśta wacantkiye tawa kin hena ehpewicaye kte śni ;

Hena ohinniyan wicakpatanpi :

Tuka wicaśta śica cinca kin hena ihangwicayapi.

29 Wicaśta owotanna makoce kin tawayapi kta;

Qa owihanke wanin en ounyanpi kte.

30 Wicaśta owotanna i kin woksape ie kta; Qa ceji wokonze iwohdake kte.

31 Iye ta Wakantanka tawoahope kin cante mahen un; Caehde tawa kin kak tihanhan kte śni.

32 Wäcaśta śica wicaśta owotanna iwanyảka; Qa kte kta akita ece.

33 Tuka nape en Jehowa elipeye kte śni ; Qa aiapi kinhan yaco kte śni.

34 Jehowa ape un wo, qa tacanku patan wo ; 


\section{P S A L 38.}

Unkan makoce tawayaye kta e yuwankan inicu kta;

Wicaśta śica ihangyapi kinhan wandake kta.

35 Wicaśta śica wohitika wan wanmdaka; Qa ihdutanka, can teca icage cin iyececa:

36 'Tuka tanin śni iyaya, unkan inyun en un śni ; Han owade, tuka iyeyapi śni.

37 Wicaśta ecetu kin he iyukcan, qa owotanna kin wanyaka wo; Wicaśta kin he owihanke kin wookiye.

38 Tuka wawakipajinpi kin witaya ihangyapi kte;

Wahtanipi sa owihanke kin he baśpa iyeyapi.

39 Tuka wicaśta owotanna niwicayapi kin he Jehowa etanhan:

Wokakije anpetu kin en wowaśake tawapi kin hee.

40 Unkan Jehowa owicakiye ca ewicahdaku :

Wicaśta śica etanhan ewicayaku qa niwicaye kta; Iye wacinyanpi, heon etanhan.

\section{PSALM 38.}

Dawid tadowan. Wokiksuye on.

1 Jehowa, wocanniye nitawa en iyopemaye śni wo;

Qa śinyahda hinca en makapsinpsinte śni wo.

2 Nitunwanhinkpe kin bomahdokapi; Qa ninape sutaya amapaskica.

3 Nitocanniye on micelpi zaniyan un śni ; Wawahtani on mahuhu en woozi wanica.

4. Wawahtani kin.hena pa iwankam imayaya;

Waqin the hinca iyecen on mduśaka ece.

5 Amapapi kin tonyan qa śicamna; Wimatkotkoke cin heon etanhan.

6 Mahnaśkinyan, nina patuś nawajin; Anpetu osan waśihda waun.

7 Wowayazan śica wan on pakśin omajudan; Qa micehpi tuktedan zani śni.

8 Wamaśake śni qa nina makaśuśujapi; Cante mayazan heon waśicahowamda ece.

9 Itancan, token cantowakpani owasin nitokam un; Qa waśicahowamde cin he nanicihmanpi śni.

10 Cante mahniyanyan, waśake śni amayan; Nakun miiśta iyoyanpa kin hee kaeś iyemacetu śni.

11 Tona waśtemadapi qa mitakuye wamayazan kin en najinpi kte śni ; Qa mikiyedan unpi qon itehanyan inajinpi.

12 Unkan minagi akitapi kin hena mahmunkapi ; Qa tona śicaya waun kta cinpi lin hena taku śica eyapi ; Qa anpetu osan wohnayan awacinpi kta.

13 Tuka miye, noge tpa iyececa, nawahon kte śni; Qa ia okitpani i hdukawa kte śni kin iyemaceca.

14 Hecen wicaśta wanahon śni kin iyecen waun; Qa tuwe i ohna iyopeyapi wanice cin. 


\section{PS A L 39.}

15 Jehowa niye acipe waun kin heon, Niye waadupte kte, Itancan Wakantanka mitawa.

16 Unkan hepa; Okinni miye on iyuśkinpi kta; Siha nawaśduta eca miye on ihdatanpi ece.

17 Miye humaśte waun kin heon; Qa iyomakiśice cin ohinniyan mitokam urr.

18 Miohan śice cin owahdake kta; Qa wawahtani kin on iyokiśinmiçiye kta.

19 Tuka tokamayanpi ni unpi kin hena waśakapi ; Qa tona taku on etanhan śni śicemadapi kin hena ota aya.

20 Tona taku waśte on taku śica econpi kin hena, Taku waśte awakite cin on makiyuśepi kta.

21 Jehowa, amayuśtan śni wo: Wakantanka mitawa, mitehanyan un śni ye.

22 Omakiya inahini wo; Itancan, Wanikiya mitawa.

PSALM 39.

Jeduthun dowan itancan kin on. Dawid tadowan.

1 Miohan iwanwahdake kta, epa;

Hecen miceji on wawahtani kte śni :

Ionatake wan mii on mduhe kta;

Wicaśta śica mitokam unpi icunhan.

2 Ia okitpani iyecen inina manka;

Taku waśte ee kaeś ie śni waun;

Qa mitoiyokiśica yuśośapi.

3 Cante mahen makate hinca;

Waawacin waun icunhan peta itkon:

Hehan miceji on iwaa :

4 Jehowa, omawihanke kin sdonye makiya wo ;

Qa mitaanpetu kin tohanyan kta hecinhan;

Tohan en waun kte śni sdonwakiye kte.

5 Wan, mitaanpetu kin nape hdakinyan yakaga;

Qa nitokam wani kin he takuśni iyececa :

Awicakehan wicaśta otoiyohi, sutaya najin eśta, ocowasin takuśni. Sela.

6 Awicakehan wicaśta kin ohanzi wan en omani ;

Awicakehan takuśni on nihinciyapi ece :

Waeju ece, tuka tuwe hena yuhe kta sdonye sni.

7 Unkan nakaha, Itancan, taku e ape waun he:

Niye hinca wacinciya ece.

8 Wawahtani owasin etanhan emayaku wo;

Wicaśta witkotkoka wowihahamayanpi kta makage śni wo.

9 Inina waun, i wahdukawa kte śni;

Niye hecanon kin heon etanhan.

10 Amayape cin he imicicu wo;

Ninape makaśtake cin on atakuni śni amayan.

11 Iyopeyapi on wicaśta wahtani kin on iyopeyaya; 


\section{P S A M 40.}

Qa wayapote sa iyecen taku iyokipi kin dutakuni śni :

Awicakehan wicaśta otoiyohi takuśni. Sela.

1. Jehowa, wocekiye mitawa nalion wo;

Qa houwaye cin anohkiya ye:

Iśtamnihanpe amau kin on inina yanke śni wo ;

Niye kici wicaśta matokeca,

Unhdaka waun, atewicawaye cin owasin iyececa.

13 Makpatan wo, hecen waśagmiçiye kta,

Imdamde śni qa en waun śni itokam.

\section{PSALM 40.}

Dowan itancan kin on. Dawid tadowan.

1 Apepi on Jehowa ape waun;

Unkan anohmakiye ca hoyewaye cin namakihon.

2 Nakun wicotakuniśni woha wan etanhan hiyu makiya, upśija hinca etanhan;

Qa misiha imnija wan ahan makiye; mioye miciyusuta.

3 Qa odowan teca wan mii kin en ohnaka;

Wakantanka unkitawapi yatanpi kin:

Wicota wanyakapi qa kokipapi kta;

Qa Jehowa wacinyanpi kte.

4 Wicaśta wan cante waśte linca, Jehowa wowinape yuhe cin hee;

Qa tona wahanhianiçidapi kin,

Woitonśni opapi kin hena koya ekta etonwe śni.

5 Jehowa mita Wakantanka taku ota ecanon;

Niohan wakan qa unkiyepi on nitawacin kin,

Hena owecinhan niciyawapi kte śni ;

Cajemdate ça omdake kta eśta, hena yawapica śni.

6 Wośnapi qa wawicaqupi kin hena iyonicipi śni ;

Noge mayakidulidoka:

Wahuhnahyapi qa woahtani on wośnapi kin yada śni.

7 Hehan hepa; Wanyaka wo, wau ce;

Wowapi yuhmihmapi kin en hecen omiciwapi :

8. Wakantanka mitawa nitawacin ecen ecamon kta iyomakipi;

Qa nitoope kin micante mahen un.

9 Omniciye tanka kin en woowotanna eyanwapaha:

Wanyaka wo, miiha wakpatan kte śni ;

Jehowa niye sdonyaya.

10 Nitoowotanna micante mahen nawahibe śni ;

Wacinniyepica qa waniyakiya omdaka;

Nitowaonśida qa nitowicake omniciye tanka kin etanhan nawah̉be śni.

11 Jehowa niye,

Nitowaonśida temiyecihida kte śni ;

Nitocantekiye qa nitowicake ohinniyan mapatan kte.

12 Taku śica yawapica śni aohdutemayanpi;

Wawahtani kin hena emihdegapi, 
Qa hecen wawanyaka owakihi śni;

Hena mapa hin isanpa ota ;

Qa on cante mawanica.

13 Jehowa, emahdaku iyonicipi nunwe;

Jehowa, omakiya inahini ye.

14 Tona minagi ihangya akitapi kin

Hena witaya cante toketu taninśni qa iśtecapi kte ;

Tona śicaya waun 'kta cinpi kin

Hena hekta hdicupi qa iśtecapi kte.

15 Tona, Hanhan, hanhan, emakiyapi kin

Hena wowiśtece on atakunipi kte śni.

16 Tona anicitapi kin hena owasin cante waśtepi qa iniciyuśkinpi kte;

Tona wiconi nitawa waśtedapi kin hena, Jehowa yatankapi nunwe, eyapi kte.

I7 Tuka miye onmaśike ça mawahpanica;

Itancan kin amawacin un kta:

Tuwe omakiye ca emahdaku kin he niye;

Wakantanka mitawa yutehan śni ye.

\section{PSALM 41.}

Dowan itancan kin on. Dawid tadowan.

1 Tuwe wicaśta onśika en ewacin kin he cante waśte; Anpetu śice cin en Jehowa ehdaku kte.

2 Jehowa awanhdake ca nikiye lxta;

Maka akan tanyan un kte;

Qa tokayapi tawacin kin en wicayaqu kte śni.

3 Wowayazan ohe akan Jehowa yuwaśake kta; Wayazanka icunhan towinja ocowasin piyaya.

4 Miye hepe; Jehowa onśimalida wo; Minagi asniyan wo; wacicihtani kin heon.

5 Tokamayanpi kin hena taku śica emakiyapi kta;

Tohan te kta qa caje atakuni kte śni he.

6 Qa wanmayag hi kinhan woitonśni oyaka ece kta ; Cante mahen woahtani mnakiya;

Tokiya ye kte ça oyake kta.

7 Tona śicemadapi owasin witaya amajijipi kta ;

Hena śicaya cante makiyuzapi kta.

8 'Taku śice hinca wan aokaśtanpi ce :

Qa tuwe makata wanke cin he ake kinajin kte śni.

9 Han, wicaśta kici wowakiye, wacinwalkiye ciqon, Aguyapi mitawa yute cin he siyete on namahtaka.

10 'Tuka, Jehowa niye, onśimada qa najinmakiya wo; Hecen wicawecicajuju kta.

11 Detanhan waśtemayadaka sdonwakiya; Tokamaye cin maktedan śni kin heon.

12 Unkan miye, mitoecetu kin en mayadusuta; Qa ohinniyan niite itokam najin mayakiya. 
13 Jehowa, Israel ta Wakantanka, yawaśtepi nunwe;

Otokahe wanica qa owihanke wanica.

Amen qa amen.

\section{PSALM 42.}

Dowan itancan kin. Qora cinca wahokonwicakiyapi.

1 Tatokadan mini wakpadan cantokpani,

He iyecen, Wakantanka, minagi cantonikpani ece.

2 Wakantanka on minagi ipuza, Wakantanka ni un kin;

Tohan wau qa Wakantanka ite kin en mihdutanin kta he.

3 Iśtamnihanpe amau kin hena woyute wayẹ, anpetu hanyetu koya;

Nita Wakantanka tukten un he, ohinniyan emakiyapi heon.

4 Dena weksuye ca minagi amihdapson kta;

Wicota om imdamde cinhan;

Hena om Wakantanka ti kin ekta wai;

Wowiyuśkin qa woyatan ho kin yuha;

Wicota anpetu wakan opapi kin hena om.

5 Minagi, tokeca pamahdedan yaun,

Qa tokeca miye mahen iyoniciśica he;

Wakantanka wacinyan wo, ake mdatan kte,

Miite omakiye ça mita Wakantanka kin hee.

6 Mahentanhan minagi iyokiśica un ;

Heon ciksuye kta, Jordan makoce kin etanhan,

Qa Hermon he, paha cistinna kin hetanhan.

7 Mini tanka nitawa ho kin on, mini śma kin mini śma kipan;

Taja nitawa qa mini ihaha nitawa owasin miwankam iyaya.

8 Anpetu icunhan Jehowa towaonśida kin ekihde kta;

Qa hanyetu eca iye tadowan kin mici un;

Wakantanka nimaye cin he cewakiye kte.

9 Wakantanka imnija mitawa hewakiye kta ;

Tokeca aniyektonja he;

Tokeca waśihda imdamda he,

Toka śicaya makuwapi kin on.

10 Tokamayanpi kin iyopemayanpi, mahuhu kaśuśujapi kin iyececa;

Anpetu otoiyohi, Nita Wakantanka toki un he, emakiyapi kinhan.

11 Minagi, tokeca pamahdedan yaun,

Qa tokeca miye mahen iyoniciśica he ;

Wakantanka wacinyan wo, ake mdatan kta,

Miite omakiye ça Wakantanka mitawa kin hee.

\section{PSALIM 43.}

1 Wakantanka mayaco qa imakiya wo;

Oyate wacantkiye śni kin on;

Wohnayan wicaśta qa wahtani sa etanhan emayahdaku kte.

2 Wakantanka conkaśle mitawa kin he niye ; 
Tokeca elipemayaya he;

Tokeca waśsihda imdamde kta he,

Toka śicaya makuwapi kin on.

3 Iyoyanpa nitawa qa wowicake nitawa u kiya wo;

Hena yus amaye kte;

Paha wakan nitawa kin en hi makiye kte;

Qa nakun wokeya nitawa ekta.

4 Hehan Wakantanka owayuśna tawa ekta wau kte;

Taku Wakan mitowiyuślkin tanka ekta.

Unkan candowankiyapi on icidowan kta,

Wakantanka, Wakantanka mitawa.

5 Minagi, tokeca pamahdedan yaun,

Qa tokeca miye mahen iyoniciśica he :

Wakantanka wacinyan wo, ake mdatan kta;

Miite omakiye ça. Wakantanka mitawa kin hee.

\section{PSALM 44.}

Dowan itancan kin on. Qora cinca wahokonwicakiyapi.

1 Wakantanka, noge on naunhonpi,

Atewicunyanpi unkokiyákapi,

Iye taanpetu kin en wicohan ecanon qon,

Wanakaja anpetu kin en.

2 Niye ninape on Tkcewicaśta hamwicayaya,

Qa iyepi en owicayakiju ;

Oyatepi kin ihangwicayaya,

Qa iye icahwicayakiya.

3 Mazasagye tawapi on makoce kin icupi śni ;

Qa iye isto kin he on eiçihdakupi śni ;

Tuka ninape etapa, qa niisto, qa niite iyoyanpa kin;

Niye cantowicayahnake cin heon.

4 Wakantanka, Wicaśtayatapi mitawa kin he niye ;

Jakob woehdaku kiconza wo.

5 Niye on tokaunyanpi kin paha iyewicunyanpi kta;

Nicaje on tona itkounkipapi kin nawicunpanpi kta.

6 Mitinazipe wacinwakiye kte śni;

Qa mazasagye mitawa nimaye kte śni.

7 Tuka niye tokaunyanpi kin etanhan eunyahdakupi ;

Qa tona śiceundapi kin iśtenwicayaya.

8 Anpetu osan Wakantanka unkidowanpi;

Qa nicaje ohinniyan unyatanpi kta. Sela.

9 Hececa eśta, elipeunyayapi qa wowiśtece unyalkagapi ;

Qa ozuye unkitawapi kin om de kte śni.

10 Toka kin itokapatanhan bdicuunyayapi kta:

Qa tona śiceundapi kin hena wakte hdapi.

11 Tahinca wanunyanpi yutapi kte cin iyececa unyakagapi kta:

Qa Ikcewicaśta ehna enanakiya iyeunyayapi.

12 Nitaoyate inyunwin codan wiyopeyakiye kta:

Qa iyopeyapi on takudan yakamna śni. 


\section{P S A L M 45.}

13 Unkikiyepidan unpi kin en wowiśtece unyakagapi kta; Unkihdukśan unpi kin en wowihahaunyanpi qa poptanptanunkiyapi.

14 Ikcewicaśta ekta oweśtepi unyakagapi kta; Oyatepi en pomnamnaunkiyapi kte.

15 Anpetu osan iśtenmayanpi kin mitokam un; Qa miite iśtece cin he amahdalipa:

16 Tuwe wawiyopeye ça wayaśica ho kin on; Toka ite qa waihangye cin on etanhan.

17 Dena owasin unkakipapi, tuka unkaniktonjapi sni; Qa wicotakuye nitawa unhnayanpi śni.

18 Uncantepi hekta hdicu śni ; Qa unkoyepi nitacanku icunonpa ye śni.

19 Unktehi owanka kin en unyakaweliwegapi ; Qa wiconțe on unkayakahpapi.

20 Wakantanka unkitawapi caje unkakiktonjapi, Qa taku wakan tokeca ekta nape unhdugatapi kinhan;

21 Wakantanka he ode kte śni he :

Wicacante woinahbe kin hena iye sdonya nakaeś.

22 Niye on anpetu osan unktepi unyakonpi ;

Tahinca wanunyanpi wicaktepi kte cin iyecen unyawapi.

23 Itancan, ihduhica wo, tokeca niśtinma he ;

Kikta wo, hecehin ehpeunyanpi śni po.

24 Tokeca niite nayakihbe kta he;

Iyounkiśicapi qa śicaya unkuwapi kin ayektonje kta he.

25 Unnagipi watuśekśeca ekta patuś yanka;

- Untancanpi maka kin ahdaskin wanka.

26 Ounyakiyapi kta on inajin wo;

Qa nitowaonśida on opeunkiton po.

\section{PSALM 45.}

Mnahcahca on dowan itancan kin. Qora cinca wahokonwicakiyapi. Wowaște odowan.

1 Micante wicoie waśte on ipiga;

Miohan wicaśtayatapi kin owakimdake;

Wowapi icage wowapi kaga wayupika tawa miceji kin hee.

2 Adam cinca ehna niye iyotan owanyag niwaśte;

Niiha en wowaśte okaśtanpi ;

Heon Wakantanka ohinniyan niyawaśte.

3 Iyotan Waśaka, mazasagye nitawa ceca en iyahdaśka wo;

Nitowitan qa nitoiyokipi ahna:

4 Qa nitowitan hduha śuktanka akan iyoopta ya wo;

Wowicake qa woowotanna onsike cin hena on ;

Unkan nape nietapa taku wowinihan onspeniciye kta.

5 Wanhinkpe nitawa pepe hinca;

Nitokam oyatepi hinhpayapi kta ;

Tona Wicaśtayatapi tokayapi cantepi kin en.

6 Wakantanka, oiyotanke nitawa ohinniyan qa owihanke wanica; 
Nitokiconze sagye kin he woowotanna sagye.

7 Woowotanna waśteyadaka, qa woahtani śiceyadaka;

Heon Wakantanka, nita Wakantanka kin,

Wowiyuśkin wihdi on sdaniciya,

Kodawicayaye cin isanpa.

8 Nitawokoyake owasin canśin, qa canhaśa, qa pejihuta waśtemna ;

Huhu tipi waśte kin etanhan wiyuśkinniyanpi.

9 Wicaśtayatapi cunwintkupi kin winohinca waśteśte nitawa om unpi ;

Wicaśtayatapi tawicu kin nietapa ekta najin,

Mazaskazi Ophir etanhan en.

10 Cunś, anagoptan qa wanyaka qa on anohkiya wo;

Qa nitaoyate niyate ti ko akiktonja wo:

11 Unkan wicaśtayatapi kin nitowaśte waśtedake kte:

He itancan nitawa, hecen itokam patuja wo.

12 Turos cunwintku taku ituhanpi wan on niite akite kta; Oyate kin en wijicapi kin hena.

13 Ti mahen wicaśtayatapi cunwintku kin ocowasịn wowitan; Tawokoyake kin mazaskazi kazontapi.

14 Śina ipatapi in wicaśtayatapi kin en ahipi kta;

Wikośkapi takodawicaye ihakam unpi kin hena niye en awicahipi kta.

15 Wowiyuśkin qa wopida yuha en awicahipi kta;

Wicaśtayatapi ti kin timahen hipi kte.

16 Niyatepi eekiya nicinkśipi yuke kta ;

Hena maka kin owancaya wicaśta itancan ewicayahde kte.

17 Wicoicage qa wicoicage owasin en nicaje kiksuyewicawaye kta: :

Heon oyatepi kin niyatanpi kta, owihanke wanica.

\section{PSALM 46.}

Qora cinca on; dowan itancan kin. Wikośka dowanpi.

1 Wowinape qa wowaśake unkitawapi kin Wakantanka hee; Awicakehan wokakije en waokiye iyeyapi ece.

2 Heon etanhan kopeunhdapi kte śni, maka kin yutokecapi, Qa he kin miniwanca cante en ayapi eśta.

3 Mini kin hotanin qa śkanśkan kte; Taś tanka on he kin yuhuhuzapi kte. Sela.

4 Wakpa wan-adetka kin Wakantanka totonwe kin iyuśkinye kta ;

Tipi wakan kin-lyotan Wankan un ounye cin he.

5 Wakantanka cokaya un, heon pahohopi kte śni ; Anpao hinanpa hehan Wakantanka okiye kta.

6 Ikcewicaśta oqoyapi, wicokiconze kin śkanśkanpi ; Iye ho hdutanin, maka kin skan kta.

7 Jehowa Sabaoth unkicipi un;

Jakob ta Wakantanka wowinape unyanpi. Sela. 


\section{P S A L M 48.}

$8 \mathrm{U}$ miye, Jehowa tohan kin wanyaka po;

Makoce kin en woihangye kaga ece.

9 Maka ihanke hehanyan ozuye ayuśtan kiya; Itazipa kin kawege kta, qa wahukeza kakse kta ;

Canpahmihma kin peta on huhnahye kta.

10 Ayuśtan po, qa Wakantanka kin he miye e sdonya po, Ikcewicaśta ehna mayatanpi kte, maka akan mayatankapi kte.

11 Jehowa Sabaoth unkicipi un :

Jakob ta Wakantanka wowinape unyanpi. Sela.

\section{PSALM $4 \%$.}

Dowan itancan kin on. Odowan; Qora cinca tawapi.

1 Oyate owasin, nape hdaskapa miye;

Wowiyuśkin ho kin on Wakantanka iyaśa po.

2 Jehowa Tehan Wankan kin he wowinihan;

Wicaśtaya tapi tanka, maka kin owancaya.

3 Unkihukun wicaśta kin ewicahnake kta; Qa oyatepi unsihapi ihukuya.

4 Makoce wan unkicicahnigapi kte;

Jakob waśtedake ciqon toiyokipi kin hee. Sela.

5 Tyaśapi yuha Wakantanka wankantkiya ikiyopta; Jehowa mazayahotonpi ho kin hduha.

6 Dowan po, Wakantanka idowan po; Dowan po, Wicaśtayatapi unkitawapi idowan miye.

7 Wakantanka maka kin owancaya Wicaśtayatapi ; Wowahokonkiye wan on dowan miye.

8 Wakantanka Ikcewicaśta kin wowidagwicaya;

Wakantanka oiyotanke wakan kin akan kiyotanka.

9 Oyatepi en itancanpi kin mniciyapi;

Abraham ta Wakantanka taoyate kin :

Makoce wahacanka kin hena Wakantanka tawa:

Jye nina tehanwankan un.

\section{PSALM 48.}

Qora cinca tawapi. Psalm odowan.

1 Jehowa he tanka, qa nina yatanpi kte;

Taku Wakan unkitawapi totonwe, Paha wakan tawa kin en.

2 Oyanke waśte hinca, maka ocowasin wowiyuśkin;

Zion Paha kin, waziyata opapun ekta ;

Wicaśtayatapi tanka totonwe kin.

3 Tipi waśteśte tawa kin ohna,

Wakantanka wowinape yapi kta sdonyapi.

4 Iho, maka wicaśtayatapi kin mniciyapi ;

Witaya en hiyayapi:

5 Hena wanyakapi, unkan inihanpi;

Kopehdapi qa najica iyayapi.

6 Hen cancan hinhdapi ; 
Wayazan hdapi, wihohinca hokśiksuya iyececa.

7 Wiyohiyanpa tanhan tate kin on, Tarśiś wita wata kin yakajuju kta.

8 Naunhonpi qon he iyecen wanunyakapi;

Jehowa Sabaoth totonwe kin en,

Wakantanka unkitawapi totonwe ohna;

He Wakantanka ohinniyan hdusuta kte. Sela.

9 Wakantanka, tipi wakan nitawa ohna,

Nitocantekiye kin awauncinpi.

10 Wakantanka, nicaje iyececa,

Niyatanpi maka ihanke kin hehanyan;

Ninape etapa woowotanna ojudan.

11 Zion Paha kin iyuśkin kte ;

Juda cunwintkupi cante waśtepi kte;

Woyaco nitawa kin on etanhan.

12 Zion ihdulzśan ya miye, ohomni mani po ;

Canpasotka kin hena yawa po:

13 Conkaśke tawa kin elita cante yekiya po;

Tipi waśteśte kin hena awacin miye ;

Hecen wicoicage u kte cin owicayakidakapi kte.

14 Taku Wakan kin de Wakantanka unkitarvapi, owihanke wanica :

Wiconte hehanyan yus unkayapi kte.

\section{PSALII 49.}

Dowan itancan kin. Odowan Qora cinca tawapi.

1 Oyate owasin, de nahon miye;

Maka akan ounyanpi kin owasin, anagoptan po :

2 Adam cinca, nakun wicaśta cinca,

Wijicapi wahpanicapi kin om.

3 Mii woksape oyake kta;

Qa micante taku awacin kin he wookahnige.

4 Wiyacinpi wan ekta minoge yewaye kta;

Candowankiyapi on mitadowan mduotanin kta.

5 Anpetu śica en tokeca kopewahda kta he ;

Tona amahanpi wahtanipi kin aohdutemayan kinhan.

6 Iye towaśakepi kin wacinkiyapi ;

Qa taku ota tonpi kin on ihdatanpi ece:

7 Wicaśta wan iye sunkaku ecaca opekiton kte śni :

On wiyopeyapi Wakantanka qu kta okihi śni.

8 Unkan nagipi opekitonpi kin he teliika;

Qa owihanke wanica okihipica śni :

9 Hecen hinyahin ohinniyan ni un kta ;

Qa wicahwin wanyake kte śni.

10 Wicaśta ksapa tapi kte cin he wanyake kta;

Nakun witkotkoka wacintonśni ko atakunipi kte śni ;

Qa taku tonpi kin toktokeca aihpewicakiyapi kte.

11 Cante mahen, tipi tawapi owihanke wanice kta, kecinpi; 
Ohna yukanpi kin wicoicage qa wicoicage hehanyan;

Makoce tawapi iye cajepi icajeyatapi ece.

12 'Tuka wicaśta woyuonihan en yanke kte śni ;

Woteca iyecen kagapi ; hena atakunipi śni.

13 Hecen ohanyanpi ; hecen witkotkokapi :

Tuka tona ihakam upi kin hena

Token eyapi qon he waśtedakapi kta. Sela.

14 Optaye wan iyecen Hades elita awicayapi;

Wiconte wonwicaye kta;

Qa wicaśta o wotanna, anpao kinhan, wowidagwicayapi kta:

Nakun towaśakepi kin Hades yusote kta;

Iye tipi kin etanhan tawawicaya.

15 Tuka Wakantanka minagi Hades nape etanhan opemakiton kta:

Iye emahdaku kta, heon.

16 Wicaśta wan wijica icage cinhan kopehda śni wo;

Tipi tawa wowitan tanka aye cinhan:

17 Tohan te cinhan takudan hduha ye kte śni;

Towitan ihakam kun ye kte śni.

18 Tuka ni un icunhan nagi hdawaśte kta :

Nakun tanyan niçicuwa kinhan niyatanpi kta.

19 Atewicaye wicoicage kin ekta ye kta:

Hena icimana iyoyanpa wanyakapi kte śni.

20 Wicaśta yuonihanpi, tuka okahnige śni kin

He woteca kin iyacinpi, hena atakunipi kte śni。

PSALM 50.

Asaph tadowan.

1 Jehowa Wakantanka Tyotan Waśake cin ia,

Qa maka kin kipan,

Wihinanpa etanhan wi iyaye cin hehanyan.

2 Zion woiyokipi iyotan hince cin etanhan

Wakantanka iyega.

3 Wakantanka unkitawapi u kta, qa inina un kte śni;

Itokam peta wahuhnahye kta ;

Qa ihdukśan nina icamna kte.

4 Wankan mahipiya kin kipan kta,

Qa nakun maka kin, iye taoyate wicahdaco kta.

5 Wicaśta cante wicawakiye cin miye en awicau po; Tona wośnapi on wicotakuye micagapi kin.

6 Unkan mahpiya kin iye toowotanna kin oyake kta ;

Wakantanka wayaco un kin heon. Sela.

7 Mitaoyate nahon po, kinhan iwae kta;

Qa Israel, wahokonciciye kta;

Wakantanka, Wakantanka nitawa kin he miye.

8 Nitawośnapi kin on iyopeciye kte śni ;

Qa peta on waduśnapi kin ohinniyan mitokam un:

9 Yati etanhan tatanka wan iwacu kte śni;

Optaye nitawa etanhan tamdoka kin: 


\section{PSALM 51.}

10 Contanka en wamanica otoiyohi mitawa;

Qa woteca paha kektopawinge akan unpi kin.

11 He ekta taku kinyan un kin otoiyohi sdonwaya;

Qa makomdaye en woteca owasin miciun.

12 Wotektewahda eśta ociciyale lite śni ;

Maka kin he mitawa qa taku ohnaka kin.

13 Tatanka conica wate kta he;

Qa tamdoka we mdatke kta he.

14 Wakantanka woyatan wakiyuśna wo;

Qa Iyotan Wankan un kin taku iwahoyaya hdajuju wo.

15 Hehan woiyokiśica anpetu kin en, houmakiya wo;

Kinhan ecihdaku kta, hecen imayadowan kta ce.

16 Tuka Wakantanka wicaśta śica heciya;

T'oken on mitoope kin odake kta;

Qa wicotakuye mitawa tokeca cajedate kta he.

17 Wahokonkiyapi kin he sice yadaka;

Qa mioie kin niheyata elipeyaya.

18 Wamanon sa wan wandaka eca takodayaya;

Qa wawicihahapi econpi kin owicayapa ece.

19 Nii taku śica en owicayaqu;

Qa niceji wohnaye kazonte kta.

20 Nisunka akiia idotanke kta;

Nihun cinhintku kin waayape kta.

21 Hena hecen ecanon, tuka inina manke :

Niye yaun kin ocowasin iyemaceca kecanni :

Iyopeciye kta, qa niiśta itokam hena ewahde kta.

22 De awacin po, Wakantanka ayektonjapi kin;

Okinni waehdaku wanin ciyaśpaśpapi kta.

23 Tuwe woyatan wayuśna kinhan, he mayuonihan kta:

Qa tuwe tacanku hduecetu kin

He Wakantanka towiconi kin wakipazo kta.

\section{PSALM 51.}

Dowan itancan kin. Dawid tadowan: Nathan wicaśta wolkcan en hi qehan, iye Bathśeba en hi qon iyececa.

1 Wakantanka, nitocantekiye on onśimada ye ;

Nitowaonśida ota on wawahtani micicajuju wo.

2 Taku śca ecamon kin on ocowasin mayujaja ye ; Qa wawabtani kin hena makipakinta wo.

3 Wawahtani kin hena sdonwakiya;

Qa taku śica ecamon kin ohinniyan mitokam un.

4 Niye niśnana en wacicilitani,

Qa niiśta kin en taku śica ecamon;

Hecen iyae cin en oniwotanna kte;

Wadaco kinhan iyannpepica śni yaun kta.

5 Wanyaka ye, taku śica en matonpi;

Qa woahtani en ina mahduha.

6 Wanyaka ye, tanmahen tanhan wowicake yacin ece: 


\section{P S I M 52.}

Qa woinahbe ekta woksape sdonye mayaye kte.

7 Ceyakata on mayakipakinte kta, unkan ecedan waun kta; Mayadujaja kta, kinhan wa isanpa maska kte.

8 Wicocante waśte wowiyuśkin ko nahon mayaye kte ; Hehan huhu yakaśuje cin hena iyuśkin kta.

9 Wawahtani etanhan niite nakiliman ye;

Qa taku śica ecamon kin owasin micicajuju wo.

10 Wakantanka, cante ska micaga ye;

Qa miye mahen woniya yuśtanpi miciyuteca wo.

11 Niite etanhan ehpemaye śni ye ;

Qa Nitaniya Wakan kin emicihdaku śni wo.

12 Wiconi nitawa wowiyuśkin kin he micu ye;

Qa woniya waśte wan yuhe makiya wo.

13 Hehan śicaya econpi kin nitacanku onspewicawakiye kta; Qa wahtanipi sa niye ekta ihduhomnipi kta.

14 Wakantanka, wicawe etanhan emahdaku wo; Wakantanka, Wanikiya mitawa ;

Miceji nitoowotanna iyuśkinyan idowan kte.

15 Itancan, miiha miyecidukawa kta; Hecen mii woyatan nitawa oyake kte.

16 Wośnapi kin yacin kte śni, he waqu kta tuka; Peta on wośnapi kin iyonicipi śni.

17 Wośnapi Wakantanka tawa woniya kicaksapi kin hena ee; Wicacante kicaksapi qa kaśuśujapi kin,

Wakantanka, śiceyadake kte śni.

18 Nitoiyokipi kin en Zion taku waśte ecakicon wo:

Jerusalem conkaśke kin niye yecage kta.

19 Hehan woowotanna wośnapi kin iyonicipi kta;

Peta on wośnapi qa wośnapi ocowasin hilinaliyapi:

Hehan tatanka owayuśna nitawa adipi kte.

\section{PSALM 52.}

Dowan itancan kin on. Dawid tawowahokonkiye. Doeg Edomi kin en hi qa Saul wokiyaka qa heciya; Dawid Ahimelek ti en hi ce, eye ciqon.

1 Wicaśta waśaka, tokeca taku śica on nihdatan kta he; Iyotan Waśaka towaonśida kin he anpetu osan.

2 Niceji wicohan śica kicanye kta; Wohnayan kaga, putinhin icasan yumanpi iyececa.

3 Taku śica waśteyadaka, taku waśte isanpa; Qa woitonśni, woowotanna oyakapi kin isanpa. Sela.

4 Wicoie waihangye cin owasin waśteyadaka, Wicaceji wicahnayan yaun kin.

5 Heon etanhan Wakantanka owihankeśniyan ihangniye kta; Yutokan iyeniye kta, qa wakeya etanhan inicu kte; Qa wiconi makoce kin etanhan yujun ehpeniye kta. Sela.

6 Unkan wicaśta owotanna wanyakapi qa kokipapi kta ; Qa he on iliapi kta:

7 Wanyaka po, wicaśta kin he 


\section{PS A L M 54.}

Wakantanka wowaśake yuhe kte śni ;

Tuka iye towijice icage cin wacinkiye kta;

Qa tohan śice cin on waśagiciye kte.

8 Tuka miye Oliwe can teca wan iyemaceca,

Wakantanka ti kin ohna;

Wakantanka tocantekiye wacinwaya,

Owihanke wanica hehanyan.

9 Niye hecanon kin heon ohinniyan ciyatan kta;

Qa nicaje wacinwakiye kta;

He wicaśta wacantkiya nitawa itokam waśte kin heon.

\section{PSALM 53.}

Dowan itancan kin on. Wowayazan on Dawid tawowahokonkiye.

1 Taku Wakan wanica ce, witkotkoke cin cante mahen eya:

Ihduśicapi qa wicohian śica walite śni econpi;

Tuwedan taku waśte econ śni.

2 Wakantanka mahipiya eciyatanhan Adam cinca kin ahiwicatonwan ;

Tuwe wacinksamya ohanyan hecinhan,

Tuwe Wakantanka akita hecinhan, he wanyake kta.

3 Iyuhpa nunipi, witaya hwinpi ;

Tuwedan taku waśte econ śni; han, wanjidan śni.

4 Woahtani econpi kin hena takudan sdonyapi śni he: Aguyapi iyecen mitaoyate wicaýutapi ;

Qa Wakantanka hoyekiyapi śni.

5 Wokokipe wanica eśta hen nina wikopapi;

Tuwe en ahiniwanka huhu kin Wakantanka enanakiya elipeya;

Iśtenwicayaya, Wakantanka wahtewicada śni nakaeś.

6 Tokin Israel woehdaku tawa kin Zion etanhan u nunwe:

Tohan Wakantanka taoyate wayaka unpi kin en wicahdi kinhan, Jakob iyuśkin kta, Israel pidapi kte.

\section{PSALM 54.}

Candowankiyapi on dowan itancan kin. Dawid tawowahokonkiye. Ziph oyate upi qa Saul heciyapi ; Dawid unkicipi inabibe śni he, eyapi qon he ehan.

1 Wakantanka, nicaje on nimayan wo: Qa nitowaśake on woyaco ecamiyecon kte.

2 Wakantanka, wocekiye mitawa nahon ye; Mii oie kin hena anohkiya wo.

3 Wicaśta tokeca en ahimanajinpi heon; Qa tehiya wakuwapi kin minagi akitapi : Iye itokam Wakantanka ehdepi śni. Sela.

4 Wanyaka wo, Wakantanka omakiya ece: Itancan kin tona minagi waśagyapi kin hena om un.

5 Wośice kin tokamayanpi en awicahdi kte: Nitowicake en hena ihangwicaya wo.

6 Taku ituhanpi on waciciyuśna kte; 


\section{P S A M 55.}

Jehowa, nicaje waśte heon mdatan kta.

7 Wokakije owasin etanhan emahdaku;

Qa miiśta tokamayanpi kín opawicalita, heon.

PSALM 55.

Dawid tawa. Candowankiyapi on dowan itancan kin. Wowahokonkiye odowan.

1 Wakantanka, mitawocekiye anohkiya wo;

Qa hoyewaye cin on naiçilibe śni ye.

2 Namahon qa amayupta wo;

Awacin waun qa howamde kta:

3 Toka ho kin on, wicaśta śica śicaya kuwapi kin on ;

Hena woahtani aomakawinhyapi kta;

Qa sinhdapi en tokamayanpi kte.

4 Mitan mahen micante śkanśkan;

Qa wiconțe ikopapi kin amahinhpaya.

5 Kopehdapi qa cancanpi kin mahiyohi ;

Qa wonihincive amakahpa.

6 Unkan hepe; Tuwe wakiyedan iyecen hupahu wan maqu kta he :

Kinyan imdamde ça ozimiçiye kta.

$7 \mathrm{Ho}$, tehan wanuni kte;

Hewoskan owati kta. Sela.

8 Wowinape onawakipa inawahni kta;

Tateyanpa hinca etanhan, icamna kin etanhan.

9 Itancan, nawicapca wo, cejipi wicakiyuśkiśka wo:

Otonwe kin en wicokicize qa wicokicige wanmdaka heon.

10 Anpetu hanyetu ko otonwe conkaśke akan ohomni yapi kte;

Qa wicośice wicoiyokiśice ko mahen un.

11 Woahtani cokaya un,

Qa śicaya wicakuwapi wohnayan ko tahocoka kin ayuśtan kte śni.

12 Toka wan iyopemaye kte cin hee śni ;

Kinhan inina manke kta tuka:

Tuwe miye on wahanicida sicemadake cin hee śni ;

He heca unkanś etanhan namicihbe kta tuka.

13 Tuka he niye, wicaśta kici iakinimaskokeca;

Mitakoda qa wacinwaye ciqon hee.

14 Unkiye okonwanjidan wicotawacin skuya unkiçicaga:

Wicota om Wakantanka ti kin en unye ciqon.

15 Woihangye awicakipa nunwe;

Niyake Hades ekta kun yapi kte:

Tipi tawapi ohna wicohan sica yukan,

Iye cantepi kin en.

16 Miye qe Wakantanka hoyewakiye kta ;

Unkan Jehowa nimaye kte.

17 Htayetu qa hanhanna qa wioytanhan, cewakiye ça hoyewaye kta :

Unkan iye miho kin nahon kte. 
18 Makizapi etanhan, wookiye en, nagi opemakiton;

Wicota om ecamon kin heon etanhan.

19 Iyotan Waśake cin he nawicakion qa awicayupte kte;

Qa tuwe wanakajatanhan ounye cin he. Sela.

Tona wicayutokanpi wanin unpi,

Qa Wakantanka kokipapi śni kin hena.

20 Tona om wookiye en un qon hena nape awicahnaka;

Wicotakuye tawa kin he hdaksa.

21 Pteasanpi ihdi iyecen i kin śduśduta;

Tulka cante kin he okicize:

Wihdi isanpa iye oie kin śduśduta;

Tuka hena mazasagye ecedan.

22 Taku nicu kin he Jehowa aihpeya wo;

Unkan iye awanniyake kta:

Wicaśta owotanna wicapahohopi kta tohinni iyowinye kte śni.

23 Tuka niye, Wakantanka, wicotakuniśni woha en kun iyaye wicayaye kta:

Wicawe wicaśta qa wicahnaye sa kin

Hena anpetu tawapi cokaya iyohipi kte śni.

Hececa tuka miye qe wacinciye kte.

\section{PSALM 56.}

Wicakta tokeca om wakiyedan inina un kin on, dowan itancan kin kicagapi. Dawid tawoinahbe. Gath ekta Philistine yuzapi qon he ehan.

1 Wakantanka, onśimakida ye, wicaśta i amahdukawa; Anpetu osan watemya kin he kuwa amau ece.

2 Anpetu osan tona iwanmayakapi kin hena i amahdukawapi; Wahanhanicidapi ota temmakiyapi kta tuka.

3 Anpetu kin en kopewahda kinhan, Hehan wacinciye kta.

4 Wakantanka en iye oie kin mdatan kte;

Wakantanka wacinwaya, kopewahdá kte śni ;

Wicacehpi taku ecamicon kta okihi he.

5 Anpetu otoiyohi mioie yapemnipi ; Amawacinpi kin owasin śica.

6 Witaya mniciyapi, waiyape yukanpi kta; Mioye kin hena awanyakapi kta;

Minagi iyapepi kin iyececa.

7 Woahtani on ihduśkapi kta he ; Wakantanka, wocanniye en oyatepi kun ehpewicaya wo.

8 Wanuni kin hena dawa ece: Iśtamnihanpe mitawa ojuha nitawa en ohnaka wo:

Hena nitawowapi en un śni he.

9 Anpetu en hoyewaye cinhan,' Hehan tokamayanpi kin namnipi kta :

He sdonwaya; Wakantanka miciun kin he.

10 Wakantanka en oie kin mdatan kta; Jehowa en iye oie kin iwadowan kta. 


\section{P S A L M 58.}

11 Wakantanka wacinwaya; kopewahda kte śni;

Wicaśta taku ecamicon kta okihi he.

12 Wakantanka, taku iwahociye cin hena mduha; Woyatan wośnapi kin cic̣u kte.

13 Wiconte etanhan minagi edaku;

Misiha hinhpaye kte śni :

Wakantanka itokam mawani kta;

Wiconi iyoyanpa kin en.

\section{PSALM 57.}

Dowan itancan kin kicagapi. Waihangye śni wo. Dawid tawoinálibe. Makolidoka en Saul ite kin etanhan najice ciqon he ehan.

1 Onśimakida wo, Wakantanka onśimakida wo; Minagi wacinniyan, heon etanhan;

Han, niliupahu ohanzi kin en wowinape awakite kta ;

Wośice kin iyoopte kte cin hehanyan.

2 Wakantanka Iyotan Wankan hoyewakiye kta; Iyotan Waśaka tanyan miciyuśtan kin hee.

3 Mahpiya eciyatanhan u wicaśi qa emahdaku kta;

Tuwe amapogan kin he iyopeye kta. Sela.

Wakantanka iye towaonśida towicake ko hiyuye kta.

4 Minagi mnaja wicehna un;

Ideya unpi kin hena ehna imunke kta;

Wicaśta cincapi hi kin wahukeza qa wanhinkpe;

Qa cejipi kin mazasagye pe linca.

5 Wakantanka, mahpiya kin iwankam niyatanpi nunwe;

Nitowitan maka kin ocowasin iwankam.

6 Wohmunke wan misiha on wiyeya ehnakapi ;

Minagi kin patuś ya;

Mitokam woha wan qapi ;

He en iye ohinhpayapi. Sela.

7 Micante wiyeya, Wakàntanka, micante wiyeya un;

Wadowan kta qa mdatan kta.

8 Mitowitan, kikta wo, cotanke candowankiyapi ko kikta miye :

Miye qe ánpao kin mduhice kta.

9 Itancan, oyate kin ehna ciyatan kte;

Oyatepi wicehna icidowan kta.

10 Nitocantekiye tanka kin malipiya iyapațo;

Qa nitowicake kin mahpiya śapa iyahde.

11 Wakantanka, malipiya kin iwankam niyatanpi nunwe;

Nitowitan maka kin ocowasin iwankam.

\section{PSAIM 58.}

\section{Waihangye śni wo. Dawid tawoinalibe.}

1 Wicaśta cincapi, awicakehan ia oyakitpanipi he;

Hecen taku owotanna odakapi kte śni,

Taku ecetu kin dukcanpi kte śni. 


\section{PSA.L M 59.}

2 Han, cante mahen taku śica ecanonpi kta;

Makoce kin en ninapepi wicowicaśtaśni kin tkeuyatapi kte.

3 Wicaśta śicapi wicatamni etanhan nunipi;

Itonpiśni, tonpi ehantanhan śicaya econpi.

4 Wamduślka tage śica he iyecen tage śica wicakiyukan;

Sintehda noge kpe cin he iyecen noge ohmus hduza:

5 He wajijipi ho nahon kte śni;

Wayupiya wajijipi econ eśta.

6 Wakantanka, hena ipi ohna hi wicakicaksa wo ;

Jehowa, mnaja kośka hi kin kaśuśuja wo.

7 Mini ohinniyan kaduze cin iyecen skan ayapi nunwe;

Tunwanhinkpe nakiwinje kte, kawegapi iyececa.

8 Tusda skan aye cin iyecen tanin kte śni:

Winohinca hinyahinke śni cinca ton kin iyecen, Anpetu wi kin wanyakapi śni.

9 Cega nitawapi wapepeka sdonye śni,

Saka qa iś śpan, ecen kahin iyeye kta.

10 Tokiçonpi kin he wicaśta owotanna wanyake cinhan iyuślkin kte:

Wicaśta śica we kin en siha hdujaja kte.

11 Hecen wicaśta wan heye kta;

Han, wicaśta owotanna waskuyeca ton;

Han, Taku Wakan maka akan wayaco yanka ce.

\section{PSALM 59.}

Dowan itancan kin kicagapi. Waihangye śni wo. Dawid tawoinah̉be. Saul yewicaśi qehan, qa Dawid ti kin awanyaka, kte kta e heon.

1 Wakantanka mitawa, tokamayanpi kin etanhan makiyuśka wo ; Tona takpe maupi kin on wankan emayahde kta.

2 Tona woahtani econpi kin etanhan makiyuśpa wo; Qa we wicaśta kin etanhan nimayan ye.

3 Wan, minagi iyape yukanpi;

Waśakapi kin miye on mniciyapi ;

Jehowa, wawahtani śni qa taku śica ecamon śni ye.

4 Mılian śice śni eśta anamatanpi qa eicihdepi :

Kikta wo, itkomayakipa qa wandake kte.

5 Heon niye, Jehowa, Wakantanka Sabaoth, Israel ta Wakantanka, kikta wo, Oyatepi owasin wanwicadake kte ;

Wicaśta śica wahnayanpi kin owasin wicakpatan śni wo.

6 Ḣtayetu kinhan hdicupi kte; śunka iyecen hdopi kte; Qa otonwe ohomni inyankapi kte.

7 Inyun, ipi kin etanhan hiyuyapi; .

Ihapi kin en mazasagye yukan;

Qa tuwe nahon kta he, eyapi.

8 Tuka Jehowa, niye iwicayahaha kta;

Ikcewicaśta owasin wowihiha wicayaye kte.

9 Towaśake kin on acipe waun kta; 
Conkaśke mitawa Wakantanka heẹ.

10 Mita Wakantanka iye towaonśida on itkomakipe kta; Tokamayanpi kin Wakantanka opawicahta makiye kta.

11 Itancan, wahacanka unkitawapi, Hena wicakte śni wo, okinni mitaoyate akiktonjapi kte: Nitowaśake on onuniwicaye ça kun elipewicaya wo.

12 Ihapi oie kin hena ipi woahtani kin hee :

Hecen wahanicidapi kin on wicayuzapi kte;

Woitonśni qa iapi śica eyapi kte cin hena on.

13 Waihangya wo, wocanniye on wicayusota wo;

Qa en unpi kte śni;

Hecen Jakob en Wakantanka wicaśtayatapi yanka e sdonyapi kte ;

Maka ihanke kin hehanyan. Sela.

14 Unkan htayetu kinhan hdicupi kta;

Sunka iyecen hdopi kte;

Qa otonwe kin ohomni inyankapi kte.

15 Taku yutapi imani unpi kta;

Imnanpi śni eśta hanyetu osan wankapi kta.

16 Tuka miye nitowaśake iwadowan kta ;

Qa hanhanna nitowaonśida mdatan kta:

Conkaśke mitawa kin he niye ;

Qa iyomakiśica anpetu kin en wowinape mitawa.

17 Wowaśake mitawa, niye icidowan kta:

Waliantanka conkaśke mitawa kin hee,

Wowaonśida Wakantanka mitawa.

\section{PSALM 60.}

Dowan itancan kin kicagapi. Woyaotanin Mnahicalica kin on. Dawid tawoinalibe. Waonspekiyapi kta. Aram wakpa nonpa otahedan, qa Aram Zoba ohiwicaya qon, hehan Joab hdicu qa Miniskuya kaksiza en, Edom etanhan kektopawinge akenompa wicakte.

1 Wakantanka, ehpeunyayapi, unyakawehwegapi;

Canniniyan; tuka ake ounyakiyapi kta.

2 Maka kin duśkanśkan qa naptuśyaya,

Naptuptujapi kin yuecetu wo, cancan nakaeś.

3 Nitaoyate taku tehika wanyagwicayakiya;

Miniśa on cekcegyapi kin yatke unyakiyapi.

4 Tona konicipapi kin wiyokihedan wan wicayaqu, Wowicake on yuwankan iyeyapi kta. Sela.

5 Tona cantewicayakiye cin wicayukcapi kta;

Heon ninape etapa on niunkiyapi qa naunhon po.

6 Wakantanka iye towakan kin en ia ;

Wakte wahdi kta;

Śekem wapamni kta;

Qa Sukoth kaksiza kin imdute kta.

7 Gilead he mitawa, qa Manassa he mitawa;

Ephraim nakun mapa wowaśake kin;

Juda woope kaga mitawa kin hee. 
8 Moab cega oyujaja mitawa kin hee; Edom en mitahanpe elipewaye kta;

Philistia, miye on iyaśa wo.

9 Tuwe otonwe aconkaśkapi kin en amaye kta;

Tuwe Edom ekta amai he.

10 Wakantanka, elipeunyayapi qon he niye kte śni he; Qa Wakantanka, ozuye unkitawapi om de kte śni qon.

11 Toka kin on etanhan ounkiya miye:

Qa wicaśta akantu waehdakupi kin he taku śni.

12 Wakantanka en wowaśake unkicicagapi kte:

Unkan iye tona tokaunyanpi kin nawicapan kte.

\section{PSALM 61.}

Dowan itancan kin kicagapi. Candowankiyapi Dawid tawa on.

1 Wakantanka, houwaye cin nahon ye;

Wocekiye mitawa awacin un wo.

2 Micante iyokiśica en, maka ihanke kin etanhan houciciye kta : Imnija wan miwankam tehanwankantu kin he en amayai kte.

3 Wowinape mitawa qon he niye;

Toka kin itokam, conkaśke suta hinca.

4 Ohinniyan nitawakeya ohna wati kta;

Nihupahu ohanzi kin en inawape kta.

5 Wakantanka, niye taku iwahowaye cin he nayahon:

Tona nicaje kokipapi taku tawa kte cin he mayaqu.

6 Wicaśtayatapi taanpetu kin en anpetu yecage kta ;

Waniyetu tawa kin wicoicage qa wicoicage iyececa.

7 Ohinniyan Wakantanka itokam iyotanke kte;

Wowaonśida wowicake ko yuhe yakiye kte;

Hena patanpi kta.

8 Heon ohinniyan nicaje iwadowan kta:

Anpetu eca taku iwahowaye 'cin wakajuju ece kta.

\section{PSALM 62.}

Jeduthun eciyatanhan dowan itancan. Dawid tadowan.

1 Wakantanka ecedan en minagi inina yanka;

Iye eciyatanhan nimayanpi.

2 Iye iśnana imnija mitawa ga Wanikiya mitawa;

Conkaśke suta mitawa kin hee;

Nina mapahohopi kte śni.

3 Tohanyan wicaśta wan inihanyayapi kta he ;

Niyepi owasin nicamdecapi kte;

Conkaśke takinyan yanka,

Mahinatake yujujupi kin iyececa.

4 Wankan yanke cin etanhan iśnana kun ehpeye wacinpi ;

Woitonśni waśtedakapi;

Ipi kin on wayawaśtepi kta,

Qa tanmahentanhan wayaśicapi kta. Sela. 


\section{PSAL M 63.}

5 Wakantanka ecedan en, minagi, inina ua wo; Wowacinye mitawa kin he iye eciyatanhan.

6 Iye iśnana imnija mitawa qa Wanikiya mitawa; Conkaśke mitawa kin hee ; Mapahohopi kte śni.

7 Wiconi mitawa qa wowitan mitawa kin

Wakantanka eciyatanhan;

Imnija suta mitawa qa wowacinye mitawa

Wakantanka en un.

8 Oyate kin, anpetu otoiyohi he wacinyan po;

Itokam nicantepi tpapson po:

Wowacinye unkitawapi kin Wakantanka hee. Sela.

9 Adam cinca kin takuśní ecedan.

Wicaśta cincapi kin hena woitonśni;

On tkeutapi kin en wankan yapi ece;

Heni, witaya takupiśni.

10 Wowidagyapi kin wacinyanpi śni po;

Qa wawicakipi on wahaniçidapi śni po;

Wowijice icage cinhan cantohnakapi śni po.

11 Wakantanka wancadan ia;

Nonpakiya de nawahion;

Wowaśake he Wakantanka tawa:

12 Nakun Itancan, wocantekiye kin he nitawa;

Tuka otoiyohi iye ohan kin eciyatanhan,

Wicayaqu ece kta.

\section{PSALM 63.}

Dawid tadowan-Juda hewoskan en un qehan.

1 Wakantanka, Taku Wakan mitawa kin he niye; Hanhanna hinca ocide kta;

Niye on minagi ipuza, micehpi cantonikpani ;

Makoce puza en, qa mini codan en mdokița.

2 Tipi wakan kin ohna wanciyaka qon iyecen, Nitowaśake qa nitowitan kin wanmdake kta.

3 Nitocantekiye kin wiconi isanpa waśte ;

Heon miiha niyatanpi kta.

4 Hecen wani kin en icidowan kta ;

Nicaje on nape wahdugate kte.

5 Tacupe qa wasna on iyecen minagi imna kte;

Qa iha wiyuśkin on mii niyatan kta.

6 Mitowinja akan ciksuye cinhan,

Hanyetu osan niye awacicin kta.

7 Omakiye cin he niye;

Unkan nihupahu ohanzi kin en imduśkin kta.

\& Minagi kiyedan onicihan un ;

Ninape etapa sutaya mayuza.

9 'Tuka tona minagi ihangya akitapi kin

Hena kun yapi kta, maka cokaya ekta. 


\section{PS A L M 65}

10 Mazasagye nape kin en ehpewicayapi kte;

Hena sungidan taku tawa uupi kta.

11 Tuka wicaśtayatapi kin Wakantanka en iyuśkin kta;

Tona he cajeyatapi owasin ihdatanpi kta ;

Tona itonpiśni kin hena iohmus icupi kta.

\section{PSALM 64.}

Dowan itancan kin kicagapi. Dawid tadowan.

1 Wakantanka, wocekiye mitawa en miho nahon wo; Toka kokipapi kin etanhan wiconi mitawa yapatan kte.

2 Wicaśta śica takodakiciyapi etanhan namayahbe kta ; Ścaya econpi oqoyapi kin etanhan.

3 Hena, mazasagye iyecen, ceji hdumanpi ;

Wanhinkpe iyecen, oie pa kin ekatapi ;

4 Wicaśta ecetu kin nalimana kutepi kte;

Ihnuhanna kutepi kta, qa kokipapi kte śni.

5 Wicoie śice cin en waśagiçiyapi kta ;

Nahmana on hmunkapi eonpapi kin he ohdakapi kta;

Tuwe wanwicayake kta he, eyapi.

6 Wicohan śica nina akitapi ;

Wiyeya unkanpi; tanyan yuśtanpi ce :

Unkan mahen wicaśta tawacin qa cante kin temahentu.

7 Tuka Wakantanka ilınuhanna wanhinkpe on wicakute : Hen taopi wicayukan.

8 Hecen naśna wicalkiyapi ; iye cejipi kin en wicahdi ;

Tona opawicahtapi kin owasin najicapi kta.

9 Heon wicaśta owasin nihinciyapi kta ;

Qa Wakantanka ohan kin he oyakapi kte;

Qa taku econ kin awacinpi kta.

10 Wicaśta owotanna Jehowa en iyuśkin kta, Qa he wacinye kta;

Qa tona cante ecetupi kin owasin witanpi kta.

\section{PSALM 65.}

Dowan itancan kin kicagapi. Psalm odowan. Dawid tawa.

1 Wakantanka, Zion en ainina yatanpi kin he nitawa; Qa taku iwahoyapi kin niçupi kte.

2 Wocekiye nayahon ece kin, Niye ekta wicacehpi owasin $\mathbf{u}$ kte.

3 Woahtani wicoie kin iyakapemayanpi : Taku śica econkupi kin hena niye yakajuju kta.

4 'Tuwe yakahinige ca kiyedan ayau kin he cante waśte; Tihocoka nitawa kin en ounye kta;

Yati wowaśte on iunmnanpi kte ;

Tipi wakan nitawa kin he.

5 Woowotanna en taku wowitonpe on unkayaduptapi kta, Wakantanka Wanikiya unkitawapi ; 


\section{P SALM 66.}

Niye maka ihanke kin owasin wacinniyanpi;

Qa tona miniwanca ekta tehan uripi kin.

6 Towaśake on he kin sutaya ehde;

Wookihi ipiyagkiton kin heon.

7 Miniwanca sa kin yuinina;

Taja sa qa oyate owodutaton kin.

8 Nakun tona ihanke ekta tipi kin

Hena wowapetokeca nitawa kin kokipapi ;

Wiinanpe qa wiiyaya oenape kin hena dowanyakiye kta.

9 Maka kin en yahi qa aminitanyaya:

Waśte hinca yakage kta;

Wakantanka tawakpa kin mini ojudan :

Aguyapi icahwicayeciciye kta;

Wiyeya yakaga nakaeś.

10 Maka yumdupi kin duspaya;

Cankuyetonton kin boyamdaya;

Magaju on panpanna yakaga ;

Taku aicaga ece kin he dawaśte kta.

11 Nitowasste omaka kin wateśdag yecaton;

Qa nitacanku wasna șbuya.

12 Tinta makoskantu kin śbuya;

Qa pajodan kin wowiyuśkin ipiyagkiton.

13 Tahiin optaye kin cincota ogekiton;

Qa omdaye kin aguyapi aihdahpa:

Wowiyuśkin on iyaśapi kta;

Han, dowanpi kta.

PSALM 66.

Dowan itancan; kin kicagapi. Woyatan odawan.

1 Maka kin ocowasin,

Wakantanka on iyaśa po.

2 Iye caje wowitan kin idowan miye;

Iye yatanpi wowitan kin qu po.

3 Wakantanka heciya po;

Niohan wowinihan hinca ce;

Nitowaśake tanka on tokaniyanpi kin

Niye en itonpi Fte śni :

4 Maka kin ocowasin ohonidapi kta,

Qa inidowanpi kta;

Nicaje kin idowanpi kte. Sela.

5 U miye, Wakantanka olian kin wanyaka po;

Wicaśta cinca kin en wowinihanyan ohanyan.

6 Miniwanca kin he puza kaga;

Wakpa kin opta huinyun yapi kta:

Hen iye on unkiyuśkinpi kte.

7 Tawaśake on ohinniyan iye wicaśtayatapi;

Iye iśta Ikcewicaśta kin iwanwicayaka :

Wahanhaniçidapi kin wankan yeiçiyapi kte śni. Sela. 
8 Oyatepi, Wakantanka unkitawapi yawaśte po; Iye yatanpi ho kin nahon wicakiya miye.

9 Unnagipi wiconi en ehnaka; Qa unsihapi hicahe kta iyowinkiye śni.

10 Wakantanka, niye iyutanunyayapi; Mazaska śdoyapi iyecen unyaduecepidan.

11 On hmunkapi kin en unkayaupi ; Pakśin unkitawapi en wokakije eyahnaka.

12 Pa unkitawapi akan wicaśta yanke wicayakiya; Peta qa mini ehna unhiyupi :

Hehan taku utkanna en inanpe unyakiyapi.

13 Peta wośnapi kin yuha yati en hibu kte; Taku iwahociye cin hena cicicajuju kta.

14 Miiha hdaotanin qon hena; Qa makakija en mii taku eye ciqon.

15 Tahinca cepa peta wośnapi waciciyuśna kta, Tamidoka wasna kin iyahna:

Tatanka tatokadan kici wamduśna kta. Sela.

16 U miye, tona Wakantanka koyakipapi kin, nahon po;

Unkan taku minagi ecakicon kin he ociciyakapi kte.

17 Mii on hoyewakiya;

Qa woyatan miceji ihukuya un.

18 Micante en woahtani awacanmi kinhan, Itancan kin nahon kte śni.

19 Tuka awicakehan Wakantanka nahon;

Wocekiye mitawa ho kin he anagoptan.

20 Wakantanka yawaśtepi nunwe, Wocekiye mitawa yutokan iyeye śni, Qa iye tocantekiye kin emicihdaku śni.

\section{PSALM 67.}

Candowankiyapi on dowan itancan kin. Woyatan odowan.

1 Wakantanka onśiunkidapi qa unyawaśtepi kte; Qa iye ite on iyounyanpapi nunwe. Sela.

2 Hecen maka akan nitacanku sdonyapi kte; Wiconi nitawa, oyatepi owasin ehna.

3 Wakantanka, oyatepi kin wopida eniciyapi kta; Oyatepi owasin wopida eniciyapi kte.

4 Oyatepi wiyuśkinpi qa iyaśapi kta; Oyate kin owotanna wicadaco kta heon; Qa maka akan oyatepi yus awicade kta. Sela.

5 Wakantanka, oyatepi kin wopida eniciyapi kte; Oyatepi iyuhpa wopida eniciyapi kta.

6 Maka kin waskuyeca aicage:

Wakantanka, Wakantanka unkitawapi unyawaśtepi kte:

7 Wakantanka unyuwaśtepi kta; Qa maka ihanke owasin iye kokipapi kte. 
PSALM 68.

Dowan itancan kin kicagapi. Woyatan odowan. Dawid tawa.

1 Wakantanka inajin kta;

Tokayapi kin hena enanakiya yapi kta;

Qa tona śicedapi iye itokapatanhan najicapi kta.

2 Sota kahboka he iyecen wicayakahape kta ;

Peta en canśin śdo lin he iyecen,

Wicaśta śica Wakantanka itokam taninpi kte śni.

3 Unkan wicaśta owotanna pidapi kta;

Wakantanka itokam iyaśapi kte ;

Qa wowiyuśkin on iyuśkinpi kte.

4 Wakantanka idowan po, iye caje kin yatan miye ;

Tuwe hewoskan śunka wakan akan ye cin he canku kicaga po;

He Jah eciyapi, heon itokam wiyuśkin po.

5 Wamdenica ateyapi, qa wiwazica wayaco tawapi, Wakantanka hee, wowakan oyanke tawa ohna.

6 Tona tanśnana unpi kin hena Wakantanka tipi en owicahnaka;

Tona kaślka yakonpi kin hena wowaśte en hiyu wicakiya ece :

Tuka toka kin hena makoce puza en ounyanpi kta.

7 Wakantanka, nitaoyate wicitokam idade ciqon;

Hewoskan makoce kin ehna mayani qehan; Sela.

8 Maka kin śkanśkan;

Han, mahpiya kin śbuyapi, Wakantanka itokam;

Sina kin de, Wakantanka itokam,

Israel ta Wakantanka kin.

9 Wakantanka, taku ituhanpi kin magajuyaya:

Nitaoyate qa mdokița kin he niye duwaśaka.

10 Optaye nitawa kin hen ounyanpi ;

Wakantanka, nitowaśte on wicaśta onśika taku wicayecamna kta.

11 Itancan kin wicoie kin wicaqu kta:

Tona eyanpahapi kin wicota hinca.

12 Ozuye wicaśtayatapi kin najieapi kta, najicapi ktı;

Unkan winohinca mdogyanke cin he taku icupi kin pamni kta.

13 'Tohan makoce opapun kin en inunkapi kinhan,

Wakiyedan hipahu mazaska apawintapi kin iyenicecapi kta;

Qa śun kin mazaskazi on wiyatpatpa.

14 Hen Iyotan Waśake cin wicaśtayatapi najice wicaye çehan, Zalmon en wapa iyececa.

15 Baśan paha kin he Wakantanka paha tawa;

Baśan paha kin he imnija lie kin heca.

16 Paha imnija kin, tokeca aikśinya eyatonwanpi he;

Paha ohna Wakantanka ti kta hdahinige cin. hee;

Han, Jehowa ohinniyan en ounye kta.

if Wakantanka canpahmihma tawa kin

Hena woyawa tanka nonpa, kektopawinge yuotapi;

Itancan kin he en owicapa; 


\section{P S A L 68.}

Tawokeya wakan kin Sina en in.

18 Wankan wapa yakiyahda;

Wayaka awicahdapi kin hena ayahdi ;

Wicaśta kin ehna taku wicaqupi kin iyacu;

Han, tokapi kin ehna;

Jehowa Wakantanka en ounye kte.

19 Anpetu qa anpetu Itancan kin yawaśtepi nunwe:

Waqinunkiyapi, tuka Iyotan Waśake cin niunkiyapi kin hee.

Sela.

20 Taku Wakan kin de wiconi Wakantanka unkitawapi kin hee;

Qa wiconte oenape kin hena Jehowa Itancan tawa.

21 Han, Wakantanka tona tokayapi pa wicakahdehdece kta;

Tuwe woahtani en mani un paha kin.

22 Itancan kin heya;

Baśan etanhan awicawaku kte ;

Miniwanca ośbe kin etanhan awicawahdi kta :

23 Hecen nisiha toka we kin en śayapi kta;

Nitaśunke ceji kin he nakun.

24 Wakantanka, iniyopte cin he wanyakapi ;

Nita Wakantanka iyoopte cin ;

Wicaśtayatapi mitawa, owanka wakan kin ohna.

25 Tona dowanpi kin hena tokaheya yapi;

Hektam candowankiyapi kin;

Wicihdukśan wikośka cancega kabupi.

.26 Omniciye kin en Wakantanka yawaśte po;

Itancan kin, Israel minihdoka kin etanhan.

27 Benjamin cistinna kin hen un, ohiwicaya;

Juda itancanpi kin, inyan on wakininpi ;

Zebulon itancanpi ; Naphtali itancanpi kin.

28 Nita Wakantanka nitowaśake kiconza;

Wakantanka, taku unknyecihanyanpi kin he yuwaśaka wo.

29 Jerusalem en tipi wakan nitawa kin on,

Wicaśtayatapi kin taku nicahipi kta.

30 Woteca psa ehna unpi kin hena niye iyopewicaya wo;

Wicota waśakapi kin, oyate ptejicadan om;

Mazaska onśpaśpa yuha ahi patujapi kin ;

Oyate okicize waśtedapi kin wicayuomdeca wo.

31 Egupta etanhan wicaśta cepa upi kta;

Kuś Wakantanka ekta nape hdugate kta.

32 Maka wokiconze kin, Wakantanka yatan po ;

Itancan kin idowan miye: Sela.

33 Tuwe mahpiya kin akan iyotanka,

Mahpiya wanakaja kin ;

Inyun, ho hdaotanin, wowaśake ho kin.

34 Wakantanka yawaśaka miye ;

Iye towitan Israel akan un,

Qa towaśake kin mahpiya kin ekta.

35 Wakantanka, oyanke wakan nitawa etanhan wowinihan yaun; Israel ta Wakantanka; 
Wowaśake qa wookihi kin oyate wicaqu ece.

Wakantanka yawaśtepi nunwe.

PSALM 69.

Mnahcalica kin on dowan itancan kin. Dawid tawa.

1 Wakantanka, nimayan wo;

Mini kin minagi ee kaeś hiyohi, heon.

2 Upśija temahentu mahen imdamde,

Tukten najinpica śni ;

Mini śma kin en wau;

Qa mini kin iwankam imayaya.

3 Waceya on mihduśilitin; dote masaka;

Wakantanka mitawa ape waun kin on iśta mayazan.

4 Tona taku on etanhan śni śicemadapi kin

Hena mapa hin isanpa ota ;

Tona ihangmayanpi kta,

Tokamayanpi itonpiśni kin hena waśakapi ;

Taku iwacu śni kin he wicawecu kta.

5 Wakantanka, wimatkotkoke cin he sdonyaya;

Qa wawahtani kin hena nanicilimanpi śni.

6 'Tona anipepi kin hena miye on iśtecapi śni nunwe;

Itancan Jehowa Sabaoth:

Tona anicitapi kin hena miye on iśtenwicayapi śni nunwe ;

Israel ta Wakantanka kin.

7 Niye on amaiapi waun ;

Wowiśtece ite amakahipa.

8 Mihunkawanji ehna togmahdapi waun;

Qa ina cincawicaye cin hena om wicaśta matokeca.

9 Yati cantokpanipi kin he mayutakuni śni;

Qa tona iyopeniyanpi wawiyopeyapi kin he amahinhpaya.

10 Unkan waceya, minagi woteśni un;

Qa he nakun on amaiapi ece.

1. Unkan wakihdaka ogeweton;

Qa heon oweśtepi makagapi.

12 Otonwe tiyopa en iyotankapi kin hena amaiapi ;

Qa tona woyatke suta yatkanpi kin hena dowanpi.

13 Tuka, Jehowa, miye wocekiye eciciya;

Woiyokipi anpetu kin en,

Wakantanka, nitowaonśida untkana on;

Namahon wo, wiconi nitawa wowicake kin on.

14 Upśija kin etanhan emayaku ye,

Qa mahen imdamde kta iyowinmaye śni ye;

Tona śicemadapi kin etanhan emayakupi nunwe,

Mini śma kin etanhan.

15 Mini tanka kin aomakahpe śni nunwe;

Qa mini śma kin namapce śni nunwe;

Qa wolia i kin aokibe maye śni nunwe.

16 Jehowa, namahon ye, nitowaonśida waśte kin on; 
Wawacinkta duza tanka ota kin on miye ekta ihduhomni ye.

17 Qa niite nitaokiye nakicibibe śni wo:

Makakija he on namahion inahini wo.

18 Minagi ikiyedan u wo, he opekiton ye;

Tokamayanpi kin on etanhan makiyuśka wo.

19 Amaiapi qa iśtenmayanpi qa iyopemayanpi kin, niye sdonyaya;

Tokamayanpi owasin nitokam yakonpi.

20 Waaiapi kin micante kaksa ; heon wamayazan; .

Unkan onśimadapi kta ape waun, tuka wanica ;

Qa cantohnagmayanpi kta, tuka tuwedan ryewaye sni.

21 Nakun wate kta on pizi maqupi ;

Qa imapuza hehan miniskuya yatkemakiyapi.

22 Wicitokam wahna wotapi kin he wohmunke eekiyapi nunwe;

Qa tanyan yukanpi kin he mazahtakiyapi kte.

23 Iśta tawapi aotpasyapi nunwe;

Wawanyakapi kte śni ;

Qa nitepi ohinniyan patuświcakiya wo.

24 Nitocanniye kin awicakaśtan.wo;

Qa wośihda kata nitawa iyahdewicaya nunwe.

25 Hocoka tawapi kin he otiwota elipeyapi kte;

Qa tawakeyapi ohna tuwedan ti śni nunwe.

26 Tuwe yakaśtake cin he śicaya kuwapi ;

Qa wicayapalidoke iyokiśicapi kin he oyakapi ece.

27 Walitanipi on woahtani wicaqu wo ;

Qa nitoowotanna kiń en upi śni nunwe.

28 Wiconi wowapi kin etanhan wicapajujupi nunwe;

Qa wicaśta owotanna om owicawapi kte śni.

29 Tuka miye iyomakiśice ça makakija ;

Wakantanka, wiconi nitawa wankan emahde kte.

30 Odowan wan on Wakantanka caje kin mdatan kta;

Woyatan dowanpi on mdatanka kta.

31 Unkan he Jehowa iyokipi kta,

Tatanka, tatangmdoka he sake ko yuhe cin isanpa.

32 Wicaśta wahbadan he wanyakapi, qa iyuśkinpi kta; Qa Wakantanka ayakitapi kin niye nicantepi ni kte :

33 Tona onsike cin hena Jehowa nawicahon;

Qa wicakaślkapi tawa kin hena śice wicadake śni.

34 Mahpiya qa maka kin he yatanpi nunwe;

Miniwanca qa taku ohna śkanśkan owasin.

35 Wakantanka Zion nikiye kta;

Qa Juda totonwe kin hena piya kage kta :

Hecen en ounyanpi kta qa tawayapi kta.

36 Nakun iye taokiye cinca kin tawapi kta;

Qa tona iye caje waśtedapi kin hena hen tipi kta.

\section{PSALM 70.}

Dowan itancan kin kicagapi. Dawid tawa. Wokiksuye kta.

1 Wakantanka, emahdaku wo: 
Jehowa, omakiya inahini wo.

2 Tona minagi odepi kin hena token cante yuzapi taninśni qa iśtecapi nunwe;

Tona śicaya waun kta cinpi kin hena namnipi qa iśtenwicayapi kte.

3 Iśtecapi on namnipi kta;

Tona, Hanhan, hanhan, eyapi kin.

4 Tona anicitapi kin owasin iyuśkinpi qa pidapi kte;

Qa, Jehowa yatankapi nunwe, ohinniyan eyapi kta;

Tona wiconi nitawa waśtedapi kin hena.

5 Tuka miye makakije ça onmaśsika;

Wakantanka en mahi inahini wo;

Tuwe omakiye ça emahdaku kin he niye;

Jehowa yutehan śni ye.

\section{PSALM 71.}

1 Jehowa niye wacinciya;

Icimana iśtenmayanpi śni nunwe.

2 Nitoowotanna on emayahdaku qa inapemayakiye kta :

Anohmakiye ca nimayan wo.

3 Tokin imnija tipi ciciyuhen, ohinniyan en waku kte;

Nimakiyapi kta econwicayaśi :

Imnija mitawa qa conkaśke mitawa kin he niye.

4 Mita Wakantanka, wicaśta śica nape etanhan emahdaku wo;

Śicaya ohanye ca wahteśni kin napcokaya etanhan.

5 Itancan, wowacinyeciya heon etanhan;

Jehowa, homakśiyopa ehantanhan wacinciya.

6 Wicatamni etanhan niye en imunka;

Ina tezi kin etanhan yus amau kin he niye;

Niye en ohinniyan mitadowan.

7 Wicota wowinihan mayanpi ;

Tuka wowinape suta mitawa kin he niye.

8 Niyatanpi kin on mii ojudan kta;

$\mathrm{Qa}$, anpetu osan, nitowitan kin on.

9 Wimacahinca kinhan ehpemaye śni ye;

Waśake śni amayalı en amayuśtan śni wo.

10 Tokamayanpi kin hena amaiapi ;

Qa tona minagi iyapepi kin hena witaya wohdakapi ;

11 Qa heyapi; Wakantanka ehpeya ce ;

Kuwa aye ça yuza wo, tuwedan eyaku kte śni.

12 Wakantanka, mitehanyan un śni ye ;

Mita Wakantanka omakiya inahini wo.

13 'Tona minagi tokayapi kin,

Hena iśtecapi qa atakunipi śni nunwe;

Tona śicaya waun kta cinpi kin,

Hena waaiapi qa wowiśtece koyakapi nunwe.

14 Tuka miye ohinniyan ape waun kta;

Qa niyatanpi kin owasin mdaota kta. 


$$
\text { PŚALM } \% 2 .
$$

15 Nitoowotanna kin mii oyake kta; Anpetu osan, wiconi nitawa kin ;

Tonakeca sdonwaye śni nakaeś.

16 Jehowa Itancan ohian waśake cin hena en wau kta;

Nitoowotanna omdake kta, nitawa ecedan.

17 Wakantanka, homakśiyopa ehantanhan niye onspemayakiya: Unkan dehanyan niohan wakan kin mdaotanin kta.

18 Nakun wimacahinca qa pa maska hehanyan,

Wakantanka, amayuśtan śni ye;

Hecen niisto kin wicoicage kin de owakiyake kta ;

Nitowaśake, tona u kta owasin en.

19 Nitoowotanna nakun, Wakantanka, tehanwankantu;

Taku tanka hinca ecanon ece ;

Wakantanka, tuwe iyeniceca he.

20 Niye wokakije ota qa tanka wanyag unyakiyapi :

Yahdicu qa niunyakiyapi kta ;

Qa maka ośbe kin etanhan hdicu unyakiyapi kta.

21 Niye mayadutanka kte;

Qa ake cante waśte mayakage kta.

22 Nakun candowankiyapi on ciyatan kta ;

Nitowicake on, Wakantanka mitawa:

Israel Taku Wakan tawa, cotanka on ciciyajo kta.

23 Tohan ciciyajo kinhan miiha iyuśkin kta ;

Qa minagi opeyakiton kin he nakun.

24 Nakun miceji, anpetu osar, nitoowotanna cajeyate kta:

Tona tanyan waun kte śni cinpi qon,

Hena iśtecapi, hena ite naśapi, heon.

\section{PSALM 72.}

\section{Solomon tawa.}

1 Wakantanka, nitawoyaco wicaśtayatapi kin qu wo; Qa nitoowotanna, wicaśtayatapi cinhintku kin.

2 Woowotanna on nitaoyate wicayukcan kta; Qa onśikapi nitawa kin, woyaco on.

3 Hehan he kin oyate wookiye icahwicakiciye kta; Qa paha kin, woowotanna on.

4 Oyate en tona onśikapi kin on wayaco kta ;

Wahpanica cinca kin hena niwicaye kta; Qa tehiya wicakuwa kin he kamdemdece kta.

5 Konicipapi kta, tohanyan anpetu wi, Qa hanyetu wi kin yuke kta, Wicoicage qa wicoicage hehanyan.

6 Maga kaśdapi kin amagaju he iyecen hdihe kta ; Magaju maka bospaya kin he iyececa.

7 Iye taanpetu kin en wicaśta owotanna icage kta; Qa wookiye untkanna, hanyetu wi henakeca kta hehanyan.

8 Unkan iye miniwanca etanhan miniwanca ekta wicaśtayatapi kta; 
PSALM 73.

Qa wakpa kin etanhan maka ihanke kin hehanyan.

9 Iye itokam Ikcewicaśta kin patujapi kta ;

Qa tona tokayapi kin hena maka mdu kin iputakapi kta.

10 Tarśiś wicaśtayatapi qa wita kin

Hena wopida wośna ahiyupi kta ;

Śeba qa Seba wicaśtayatapi kin taku itukihanpi kta.

11 Han, wicaśtayatapi owasin iye itokam makipusdiyapi kta;

Oyatepi owasin wowidagwicaye kta.

12 Wahpanica hoyekiye cin he ehdaku kta;

Qa onśike cin, qa nukun tuwe okiyapi śni.

.13 Wicaśta onśika wahpanica ko wicakpatan kta;

Qa wahpanica nagipi kin niwicaye kta.

14 Wohnayan qa wicokicize etanhan nagi opewicakiton kta;

Qa hena wepi kin tehike kta, iye iśta kin en.

15 Unkan ni kta, qa mazaska Śeba etanhan qu kta;

Nakun ohinniyan wocekiye ekiciye kta;

Anpetu osan yawaśte kta.

16 Makoce kin en wamnaheza napohnaka wanjidan eśta, he ipa kin en ;

Waskuyeca icage cin Lebanon iyecen kahnahnapi kta :

Unkan otonwe etanhanpi kin maka wato iyecen hea aye kta.

17 Iye caje kin owihanke wanice kta;

Anpetu wi itokam iye caje icage kta :

Unkan iye on wicaśta ihdawaśtepi kta;

Oyate owasin iye yawaśtepi kta.

18 Jehowa Wakantanka yawaśtepi nunwe;

Israel ta Wakantanka kin;

Iśnana wowinihan wicohan econ ece.

19 Qa iye caje wakan kin ohinniyan yawaśtepi nunwe;

Qa iye towakan kin on maka kin ocowasin ojudan kte.

Amen qa amen.

20 Dawid Jesse cinhintku tawocekiye kin henakeca.

PSALM 73.

Asaph tadowan.

1 Awicakehan Wakantanka Israel wicakiciwaśte; Tona cante ecepidan kin hena.

2 Tuka miye qe misiha naśdute kta ikeyedan;

Mioye kin kaicucuya hiyeya tuka.

3 Wahanhaniçidapi kin inawawizi ;

Wicaśta śica wookiye en unpi wanmdake çehan.

4 Hena țapi kinhan wicakaślkapi śni;

Qa wowaśake tawapi kin he cepa.

5 Wicaśta iyotanhan iyekiyapi kin en opapi śni ;

Qa wicaśta tokeca om kakijapi śni.

6 Heon etanhan wahanhaniçidapi kin he wanapin kiyapi;

Qa wicokicize wokoyake iyecen awicakahpa.

7 Cepapi on iśta pajoya unpi ; 
Token canteyuzapi ahinanpa ece.

8 Owehanhanpi qa taku śica eyapi ;

Wankantanhan wicokicize cajeyatapi ece.

9 Ipi kin mahpiya iyahdekiyapi ;

Qa cejipi kin maka kin omani un.

10 Heon etanhan iye taoyate dehanyan ahdi;

Qa mini ojudan hdahepapi.

11 Unkan heyapi; Tokiyatanhan Wakantanka sdonye kta he : Qa Iyotan Wankan kin he wookahnige yuha he.

12 Wanyaka po, dena wicaśta śicapi;

'Tuka ohinniyan tanyan unpi,

Sanpa wijica ayapi.

13 Awicakehan ituya micante wahduska; Qa wiyaonpepicaśni en nape wahdujaja.

14 Nakun anpetu otoiyohi makaśtakapi; Qa hanhanna eca iyopemayanpi ece.

15 Hecen omdake kta ce, epe cinhan, Iho, nicinca wicoicage kin iyokiśinwicawaye $\mathrm{kta}$.

16 Unkan de okahnili awacanmi qehan, Miiśta kin en tehike :

17 Tipi wakan Wakantanka tawa kin en hibu kinhan, Hehan owihankepi kin wanmdake kta.

18 Awicakehan canku śduśduta en ewicayahde kta: Woihangye en ohinhpaye wicayaye.

19 Inyun, ihnuhanna wicotakuniśni en iyohpayapi :

Wanna taninpi śni, wonihinciye on atakunipi śni :

20 Wihamnanpi wan ogungapi ekta he iyececa; Itancan, yekta kinhan, touncagepi kin śiceyadake kta.

21 Hecen cante sinmiciya; Qa mapaksin wakpahidoka:

22 Qa wimatkotkoka qa takudan sdonwaye śni; Niye en woteca iyemaceca.

23 Tuka miye hinyahin cici waun ; Minape etapa kin yus mayaun.

24 Nitowahokonkiye on yus amayade kta; Qa iyohakam wowitan iyahdemayaye kta.

25 Mahpiya ekta tuwe mduha he; Qa maka akan niye kici tuwedan wacin śni.

26 Micelipi qa micante atakuni śni; Micante imnija, qa taku ohinniyan mitawa kin Wakantanka hee.

27 Iho, tona nitehanyan unpi kin hena atakunipi kte śni ; Tona ehpeniyan wicin iyayapi kin owasin ihangwicayaya.

28 Tuka miye qe Wakantanka mikiyedan u kin he waśte : Jehowa Itancan kin wacinwaye : Niohan owasin omdake kta. 
PSALM 74.

Waonspekiyapi kta. Asaph tawa.

1 Wakantanka, tokeca ohinniyan waayakta śni he;

Tinta nitawa optaye kin en nitocanniye ide kta he.

2 Omniciye nitawa kiksuya wo,

Wanakajatanhan opeyaton ;

Taku nitawa cansakadan opeyakiton qon;

Zion Paha kin de en ounyaye cin.

3 Ohinniyan ihangyapi kin ekta caehde nitawa hiyuya wo;

Toka taku śica owasin econ, tipi wakan nitawa ohna.

4 Tokaniyanpi nitomniciye kin. en hotonpi ece;

Wiyokihedan tawapi kin wiyokihedan ehdepi.

5 Tuwe contanka en onspe yuwankan ikikcu kin

He sdonyapi tuka qon.

6 Tuka nakaha ayuco pagopi kin witaya

Onspe maziyape ko on kawankapi.

7 Tipi wakan nitawa kin ideyapi ;

Nicaje ohna ti qon he makata ehpeyapi.

8 Witaya ihangunyanpi kta ce, cante mahen eyapi;

Makoce kin owancaya Wakantanka tomniciye kin huhnahyapi.

9 Wowakta wanunhdakapi śni ;

Wicaśta wokcan wanica;

Qa tohanyan kta hecinhan sdonya unkokihipi śni.

10 Wakantanka, tohanyan toka owehanhan kta he;

Toka kin ohinniyan nicaje wahteda kte śni he.

11 Tokeca ninape, han ninape etapa kin, eyahdaku kta he;

Nimaku cokaya tanhan ihangwicaya wo.

12 Tuka Wakantanka wanakajatanhan

Wicaśtayatapi mitawa;

Makoce cokaya wiconi kaga ece.

13 Niye nitowaśake on miniwanca kin duptuja;

Mini akan hogan tankinyanyan pa kin yakaksaksa.

14 Niye unktehi pa kin yakahuhuga;

Oyate yutapi kta wicayaqu kta, makoskan unpi kin.

15 Niye miniyorve qa mini tanka kin dukinukan;

Wakpa ohinniyan minitan kin dupuza.

16 Anpetu kin nitawa, han, hanyetu kin nitawa;

Iyoyanpa qa anpetu wi kin niye yakaga:

17 Niye maka opapun kin owasin eyahnaka;

Mdoketu qa waniyetu, hena niye yakaga.

18 De kiksuya wo; toka wan Jehowa yaśica ;

Qa oyate witkotkoka wan nicaje. wowihahaya.

19 Wakiyedan nitawa optaye wotektehdapi kin en wicaqu śni wo;

Onśika nitawa optaye kin ohinniyan akiktonje śni wo.

20 Wicotakuye kin he atonwan wo;

Maka akan otpaza kin wicakipi ounyanpi kin ojudan.

21 Kiyuśepi kin he iśteca hdicu śni nunwe; 


\section{PSAL L 76.}

Wicaśta onśika wahpanica ko nicaje yatanpi kta.

22 Wakantanka najin wo; oihdaka wo;

Anpetu osan witkotkoka niyaśice cin he kiksuya wo.

23 Tokaniyanpi ho kin he akiktonje śni wo;

Takpe niupi oqoyapi ohinniyan wankan ye cin.

\section{PSALM 75.}

Dowan itancan kin kicagapi. Asaph tadowan. Waihangye śni wo. Woahiyaye wan.

1 Wakantanka, wopida unkeniciyapi;

Unkiye wopida unkeyapi ;

Qa nicaje ikiyedan kin he niohan wakan oyakapi.

2 Tohan mniciyapi kta cajemdate cinhan, Woowotanna on miye wamdaco kta.

3 Maka kin śdo, qa tona akan tipi kin owasin; Can ipatan tawa kin hena tkeuwata. Sela.

4 Tona ihdatanpi kin, Ihdatanpi śni po, ewicawakiya ; Qa wicaśta śica, He hduwankan iyeyapi śni po.

5 He nitawapi hduwankan iyeyapi śni po ; Qa tahu suta hduha iapi śni miye.

6 Wankan yeyapi kin he wiyohiyanpatanhan śni, Qa wiyohpeyatanhan śni ; Qa hewoskan makoce kin eciyatanhan śni.

7 Tuka Wakantanka wayaco yanka;

De kun ehpeye kta, qa he wankan iyeye kta.

8 Jehowa nape ohna wiyatke wan; Qa miniśa ipiga, pejihuta icahiyapi ;

Unkan hetanhan kaśtan ece ;

Ceteta en hiyeye cin henana yahepapi kta; Maka akan wicaśta śica owasin yatkanpi kta.

9 Tuka miye qe ohinniyan womdake kta ; Jakob ta Wakantanka iwadowan kta.

10 Qa wicaśta śica he kin owasin wakaśpe kte:

Tuka wicaśta owotánna he kin wankan icage kta.

\section{PSALM 76.}

Candowankiyapi on dowan itancan kin kicagapi. Asaph tadowan. Woahiyaye wan.

1 Juda en Wakantanka sdonyapi ; Israel en iye caje kin tanka hinca.

2 Nakun tawokeya. Salem en han; Qa Zion en ounyan ece.

3 Hen itazipe wanhinkpe kin kawehwega;

Wahacanka qa mazasagye qa okicize kin. Sela.

4 Niye wiyatpa yaun, wakinihan hinca, Ḣe akan wapatapi ece kin isanpa.

5 Tona cante sutapi kin hena taninpi śni ; Woiśtinma tawa iśtinmapi ;

Qa wicaśta waśakapi tuwedan nape iyekiyapi śni. 


\section{PS A L M 77.}

6 Jakob ta Wakantanka, iyopewicayaye cin on,

Canpahmihma qa nakun śuktanka iśtinma țapi.

7 Niye niśnana konicipapi kta;

Qa tuwe nitokam najin kta he, śinyahda kinhan.

8 Mahpiya eciyatanhan woyaco nahonwicayaya;

Maka kin kokipe ca inina yanka;

9 Wakantanka wicayaco najin qehan :

Maka akan onśike cin owasin niwicaye kta. Sela.

10 Awicakehan wicaśta śinhdapi kin niyatan kta ;

Qa sinhdapi ihe cin he ipiyagyeton kta.

11 Jehowa Wakantanka nitawapi taku iwahoyapi qa hdajuju po;

Tona ihdukśan yaunpi kin owasin ;

Tuwe kokipapi kte cin he taku kahipi kta iyececa.

12 Iye wicaśta itancanpi taniya kin baksa ece:

Maka akan wicaśtayatapi kin kokipapi kta.

PSALM 77.

Dowan itancan Jeduthun etanhan. Asaph tadowan.

1 Miho kin Wakantanka ekta yewaya, qa cewakiye kta ;

Miho kin Wakantanka ekta yewaye kta:

Unkan anamagoptan kte.

2 Makakija anpetu kin en Itancan kin awakita;

Hanyetu hehan minape yugan un, qa tasaka śni ;

Minagi wakihnapi cin śni.

3 Wakantanka weksuya, qa nihinmiciya ;

Awacin manka, unkan mitaniya iyokiśica hinca. Sela.

4 Miiśta iśtojuha sutaya yus yaun;

Makaśtakapi, qa ia owakihi śni.

5 Anpetu wanakaja ekta ewacanmi ;

Wanakaja tanhan waniyetu kin hena.

6 Hanyetu en mitadowan qon he weksuye kta ;

Micante on awacin waun kta;

Qa mitaniya kin nina wiwanga ece.

7 Ohinniyan Itancan kin waakta kte śni he ; Qa ake icimana wacantkiye kte śni he.

8 Towaonśida kin he ohinniyan owihanke he;

Wicoicage qa wicoicage hehanyan, oie kin ayustan he.

9 Iyotan Waśake cin he waonśida akiktonja;

Qa wocanniye on tocantekiye anakipta he. Sela.

10 Unkan hepa; Makakije cin he dee;

Iyotan Wankan un nape etapa waniyetu kin.

11 Jah ohan kin mdaotanin kta;

Wanakaja tanhan niohan wakan kin hena weksuye kta.

12 Nakun niohan owasin awacanmi kta;

Qa taku ecanon kin hena awacin waun kta.

13 Wakantanka, woowotanna en nitacanku:

Wanji waśaka tukte e Wakantanka iyecen tanka he.

14 Iyotan Waśaka wicohan wakan econ kin he niye; 
Oyate kin nitowaśake sdonye wicayakiya.

15 Niisto on nitaoyate opewicayakiton;

Jakob qa Joseph cinca kin. Sela.

16. Wakantanka, mini kin wanniyakapi :

Mini kin wanniyakapi ; śkanśkanpi ;

Han, mini śbe cin cancan.

17 Mahpiya śapa kin mini hdaśtanpi ;

Mahpiya kin hotanin;

Han, nitun wanhinkpe kin kinyan hiyaya.

18 Wakinyan nitawa ho kin tate iyumni en un;

Wakanhdi maka kin iyoyamya;

Maka kin cancan qa śkanśkan.

19 Miniwanca kin en nitacanku;

Qa mini ofa ohna cankuyaye;

Hecen nioye kin sdonyapi śni

20 Optaye wan iyecen nitaoyate yus awicade;

Moses qa Aaron nape kin on.

\section{PSALM 78.}

\section{Asaph tawa. Waonspekiyapi kta.}

1 Mitaoyate, mitoope kin anagoptan po;

Mii oie kin hena anohkiya miye.

2 Wicoie wakan wan on i wahdukawa kta ;

Wanakaja tanhan wiyukcanpi kin omdake kta.

3 Hena unkiye naunlionpi qa sdonunyanpi;

Qa ate wicunyanpi unkokiyakapi qon;

4 Hena iye cinca anawicunkihmanpi kte śni,

Wicoicage u kte cin,

Jehowa yatanpi kin owicunkiyakapi kta ;

Qa iye towaśake, qa wicohan wakan econ qon hena.

5 Unkan Jakob en wayuotanin wan ehde;

Qa Israel ell woope wan kaga;

Hena hunkake wicunyanpi econ wicaśi,

Iye cincapi owicakiyakapi kta.

6 Hecen wicoicage u kte cin sdonyapi kta;

Wicacinca icagapi kte cin,

Hena najinpi qa iye cinca owicakiyakapi kta.

7 Hecen Wakantanka wacinyanpi kta;

Qa Iyotan Waśaka ohan kin akiktonjapi kte śni;

Tuka tawoahope kin opapi kta.

8 Hecen atewicayapi kin iyececapi kte śni ;

He wicoicage tahu suta qa wakize sa;

Wicoicage cante hduwiyeye śni;

Qa taniya kin Wakantanka ekta ówotanna śni.

9 Ephraim cinca, wanhinkpe wotawe yuhapi kin,

Hena namnipi, kicizapi anpetu kin en.

10 Wakantanka wicotakuye tawa yuhapi śni ;

Qa tawoahope eciyatanhan mani wicadapi śni. 
11 Tuka taku econ qon hena akiktonjapi; Qa iye ohan wakan wanyagwicakiye ciqon.

12 Atewicayapi wicitokam wicolian wakan econ; Egupta makoce kin en, Zoan tinta kin etu.

13 Miniwanca kin yukmukan qa ohna iyaye wicaya; Qa mini kin maya iyecen najin kiya.

14 Hehan anpetu icunhan mahpiya śapa wan on awicaya; Qa hanyetu osan peta iyoyanpa kin on.

15 Hewotahedan makoce kin en imnija kin kaptuja; Qa ośbe tanka etanhan iyecen yatkewicakiya.

16 Hecen imnija wan etanhan mini ihaha kiya; Qa wakpa iyecen mini kin hiyuya.

17 Hececa eśta nakun iye en wahtanipi ; Ḧewoskan makoce kin en, Iyotan Wankan kin i en hiyeyapi :

18 Qa.iye cante en Wakantanka iyutanyanpi ; Wipipi kta on woyute kidapi qehan.

19 Han, Wakantanka aiapi, qa heyapi; Iyotan Waśake cin hewoskan makoce kin en, Wahna wotapi wan wiyeya ehde kta okihi he.

20 Iho, imnija kin apa, unkan mini hiyu; Qa etanhan wakpa wan kaduza:

Nakun aguyapi hiyuya okihi, Qa taoyate kin tado wicaqu kta he.

21 Heon Jehowa nation qa sinhda:

Unkan Jakob en peta wan ideyapi ; Qa nakun Israel en wocanniye awicau :

22 Wakantanka wicadapi śni heon etanhan; Qa niwicaye cin he wacinyanpi śni.

23 Unkan wankan mahpiya śapa kin econ śi ; Qa mahpiya tiyopa kin hdulidoka ;

24 Qa manna yutapi kta e ahinhe wicakiya; Qa mahpiya wamnaheza kin wicaqu.

25 Waśakapi taaguyapi kin wicaśta yutapi; Qa waneya imnahan yuhewicakiya.

26 Mahpiya kin ekta wiyohiyanpatanhan tate wan yekiya; Qa iye towaśake on tate itokagatanhan ukiya :

27 Qa maka mdu iyecen conica ahinhewicakiya; Qa taku kinyanpi kin miniwanca wiyaka iyececa.

28 Qa iye tahocoka kin cokaya ahinhpayeya ; Tipi kin ihdukśan hiyeya.

29 Unkan yutapi qa imnanpi hinea ; Taku cinpi qon he wicakahi nakaeś:

30 Hinyanhin taku cinpi qon śicekidapi śni; Woyute nahanhin i ohnakapi ;

31 Unkan Wakantanka tocanniye kin en wicahi; Qa tona cepapi kin etanhan wicakte; Qa Israel kahinigapi kin patuświcakiya.

32 Hececa eśta nakun waȟtanipi ; 


\section{P S A L M 78.}

Qa wakanyan ohanyan eśta wicadapi śni.

33 Unkan anpetu tawapi kin takuśni en wicakiyusota;

Qa waniyetu tawapi, wokakije en.

34 Wicakte qehan, hehan akitapi,

Qa hdicupi, qa hanhanna hinca Wakantanka on wiwangapi.

35 Nakun imnija tawapi qon Wakantanka hee e kiksuyapi;

Qa Iyotan Waśaka, Iyotan Wankan kin opewicakiton kin hee.

36 Hececa eśta iye ipi on hnayanpi ;

Qa cejipi on oitonpi śni.

37 Qa ekta cante ecetu yuzapi śni;

Qa wicotakuye tawa kin en wicakapi śni.

38 Tuka iye, Waonśida kin, woahitani kajuju, qa ihangwicaye sni ;

Nakun ijehan tocanniye anakipta ;

Qa tośinhda ocowasin hduhice śni.

39 Unkan hena wicacelipi heca liiksuya;

Tateyanpa wan iyaye ça ake hdi kte śni.

40 Ḣewoskan makoce lrin ekta i en hiyeyapi;

Qa makoskan ijehan iýokiśinyapi.

41 Nakun namnipi qa Wakantanka iyutanyanpi ;

Qa Israel Taku Wakan tawapi Wanji aowehanhanpi.

42 Iye nape kin kiksuyapi śni, Anpetu en wokakije etanhan ewicahdaku qon.

43 Egupta en wowakta tawa kin ehnaka;

Qa iye ohan wakan kin, Zoan makoce kin en.

44 Nakun wakpa tawapi kin we kaga:

Qa mini wakpadan kin yatkan okihipi śni.

45 Tatawamduśka en hiyuya, unkan wicayajipapi;

Qa hnaśka, unkan ihangwicayapi.

46 Unkan taku icahyapi kin wamıduśkadan wicaqu ;

Qa wicohtani tawapi kin he psipsicadan qu.

47 Hastanyanka iyuwi yuhapi kin wasu on kte;

Qa sakomin can kin, hewanke on.

48 Nakun tawanunyanpi kin wasu en onawicataka;

Qa optaye yuhapi kin, peta ide kin en.

49 Iye tocanniye kata en au wicakiya;

Wośinhda qa wocanniye qa wonihinciye;

Ohnihde śicapi kin hena u wicaśi.

50 Iye tocanniye kin canku wan kiyumdaya;

Hena nagipi wiconte ipiwicada śni ;

Qa taniyapi makośica en wicaqu.

51 Hecen Egupta en tona tokapa kin owasin awicapa;

Hiam tawakeyapi ohna towaśakepi tokaheya lin hena.

52 Hehan tahinca optaye iyecen, iye taoyate kin awicahiyu; Qa liewoskan makoce kin en optaye iyecen yus awicaya.

53 Qa tanyan awicaya, unkan wikopapi śni ;

Tuka tokawicayapi kin hena miniwanca awicakahpa.

54 Hecen opapun wakan tawa kin en awicahi;

Paha kin de en, iye nape etapa ehdaku qon he.

55 Nakun wicitokam oyatepi napewicaya; 


\section{P S A L M 79.}

Qa ounyanpi kte cin iyuta wicaqu;

Qa tawakeyapi ohna Israel wicoun oti wicakiya.

56 Tuka Wakantanka Iyotan Wankan kin

He iyutanyanpi qa śinhdayapi ;

Qa tawoahope kin kiciyuhapi śni.

57 Nakun namnipi, qa hunkake wicayapi iyecen wahnayan ohanyanpi ;

Icunonpa iyayapi, itazipa wahnaye sa iyececa.

58 Qa paha tawapi kin on śinhdayapi ;

Qa wakagapi bagopi kin on nawiziyapi.

59 Wakantanka he nahon, unkan śinhda;

Qa Israel nina śicewicakidake.

60 Hecen Śsilo en ounye cin he ayuśtan;

Wakeya wicaśta ehna ti kicage ciqon:

61 Qa iye towaśuke kin wayaka ahde kiya;

Qa iye towitan kin toka nape kin en wicaqu.

62 Nakun taoyate mazasagye en onawicataka;

Qa taku tawa hince cin he canniyeya.

63 Wicaśta kahnigapi tawa kin hena peta huhinahwicaya;

Qa wikośkapi tawa kin hena wicayatanpi śni.

64 Wawayuśnapi tawa kin mazasagye on hinhpayapi ;

Qa wiwazicapi kin hena ceyapi śni.

65 Hehan, wicaśta iśtinma se iyecen, Itancan kin kikta;

Wicaśta waśaka miniśa on iyaśa kin iyececa.

66 Qa tokayapi kin heyata elipewicaya;

Wowiśtece owihanke kte śni wicaqu.

67 Nakun Joseph tawakeya kin akta śmi;

Qa Ephraim tawicoun kin kahinige śni.

68 Tuka Juda tawicoun kin he hdahiniga;

Zion Paha kin de waśtedake ciqon.

69 Qa tipi wakan tawa kin tewankantuya kaga;

Maka kin iyecen owihankeśniyan ekihde.

70 Nakun iye taokiye Dawid kahiniga;

Qa tahinca tipi kin etanhan ikikcu ;

71 Tawiye azinpi kin wicihektapatanhan ehdaku;

Jakob iye taoyate kin wonwicaye kta;

Qa Israel iye tawa hince cin.

72 Unkan iye cante ecetu kin on wonwicaya;

Nakun iye nape wayupike cin on yus awicaye kta.

\section{PSALM 79.}

Asaph tadowan.

1 Wakantanka, Ikcewicaśta makoce nitawa kin en hipi;

Tipi wakan nituwa kin he yuśapapi ;

Jerusalem paha seksen ehpeyapi.

2 Mahpiya okinyanpi kin yutapi kta e

Nitaokiye tancanpi kin: wicaqupi;

Wicaśta wacantkiye nitawa cehpi kin maka wamanica wicaqupi. 


\section{PSALM 80.}

3 Jerusalem ihdukśan mini iyecen we papsonpi ; Qa tuwedan wicahe śni.

4 'Tona ikiyedan unyakonpi kin hena unkaiapi :

Unkihdukśanpi kin hena pomnamnaunkiyapi qa wowihahaunyanpi.

5 Jehowa, tohanyan kta he;

Ohinniyan canniniye kta he;

Winayawizi kin he peta iyecen ide kta he.

6 Oyatepi sdonniyanpi śni kin

Hena nitocanniye awicakaśtan wo ;

Qa wokiconze nicaje hoyekiyapi śni kin hena.

7 Jakob wanna temyapi ;

Qa tamaga kin ihangyapi.

8 Unkitokam unpi walitanipi qon unkiyepi en kiksuye śni wo;

Inahni wo, wacanyakiye cin he itkounkipapi nunwe;

Nina iyotanhan iyeunkiyapi, heon etanhan.

9 Wakantanka niunkiyapi kin, ounkiya po;

Nicaje wowitan kin heon etanhan;

Nakun unkiyukca po, qa waunhtanipi kin kajuju wo;

Niye nicaje kin on etanhan.

10 Taku Wakan tawapi kin toki un he,

Tokeca Ikcewicaśta eyapi kta he :

Nitaokiye we papsonpi tokiçonpi kin he,

Unkiśtapi itokam, Ikcewicaśta sdonyapi kte.

11 Kaśka unpi comnihdazipi kiı he nitokam u nunwe;

Niisto tanka kin eciya tanhan,

Tona tapi kte cin hena niwicaya wo.

12 Itancan, tona ikiyedan unyakonpi,

Wowihaha on inilialiapi kin he,

Iye maku kin ohna, śakowin akihde wicakicu wo.

13 Hecen unkiye, nitaoyate qa tahinca wonwicayaye cin,

Ohinniyan wopida unkeniciyapi kta ;

Wicoicage qa wicoicage en niyatanpi kin owicunkiyakapi kta.

\section{PSALM 80.}

Asaph tadowan. Mnahicahca on dowan itancan kin kicagapi. Wayaotaninpi kta.

1 Israel wonwicaye cin, anagoptan ye ;

Optaye wan iyecen Joseph yus ade cin;

Kerubim ehna idotanke, iyoyanpa wo.

2 Ephraim qa Benjamin qa Manasse itokam,

Nitowaśake hduhica wo ;

Qa niunkiyapi kta u wo.

3 Wakantanka, piya kiyotang unkiya po;

Qa niite hduwiyakpa, qa niunkiya miye.

4 Jehowa, Wakantanka Sabaoth,

Tohanyan nitaoyate cekiyapi kin izinyaye kta he.

5 Iśtamrihanpe aguyapi yunwicayakiya ;

Qa iśtamnihanpe ota hinca yatke wicayakiya. 
6 Oyate ikiyedan unyakonpi kin en woakinica unyakagapi; Qa tokaunyanpi kin iye iyakitedan iliapi.

7 Wakantanka Sabaoth, Piya kiyotang unkiya po ;

Qa niite hduwiyakpa, qa niunkiya miye.

8 Egupta etanhan hastanyanka iyuwi wan ayahdiyaku:

Ikcewicaśta kin lieyata ehpewicayaye ca he huyahde.

9 Itokam wayakahinta;

Unkan hutkan icage ca makoce ojudan.

10 Ohanzi kin he paha kin akahpa:

Qa adetka, hante śa Wakantanka tawa kin iyececa.

11 Adetka kin miniwanca kin iyahde;

Qa hutkan, wakpa kin ekta.

12 Tokeca conkaśke kin dujuju he:

Hecen tona en hiyayapi owasin yuksaksapi.

13 Taśkoju etanhan kukuśe mdoka kin yatakuni śni; Qa tinta wamanica kin etanhan yutapi ece.

14 Wakantanka Sabaoth, tokin yahdicun; Mahipiya eciyatanhan ahitonwan, qa wanyaka; Qa hastanyanka iyuwi kin de en hdi wo:

15 Qa nape nietapa huhde qon he hdusuta wo; Qa cinca niye icaliyakiye cin he.

16 Peta on huhnaga; kaksapi ;

Niite iyopewicaye cin on atakunipi śni.

17 Nietapa wicaśta kin akan ninape un nunwe; Adam cinhintku niye yahduwaśake cin.

18 Hehan unkiye elipeunniyanpi kte śni :

Niye niunyakiyapi kta,

Unkan nicaje hoyeunkiyapi kta.

19 Jehowa, Wakantanka Sabaoth, Piya kiyotang unkiya po ;

Niite hduwiyakpa, qa niunkiya miye.

\section{PSALM 81.}

Asaph tawa. Gittith on dowan itancan kin kicagapi.

1 Wakantanka wowaśake unkitawapi kin Taninyan idowan miye ;

Jakob ta Wakantanka iyuśkinyan kahiyaya po.

2 Odowan ahiyaya po, qa cancega apa po ; Candowankiyapi waśte cotanka kici.

$3 \mathrm{Wi}$ teca kin en, mazayahotonpi yajo po;

Wi mibe cin en, wounhanpi anpetu kin en.

4 Israel en woahope wanji dee;

Jakob ta Wakantanka toope kin.

5 Joseph en wayuotannin kin de kaga;

Egupta makoce etanhan hinanpe cin he ehan:

Tapi wan owakahnige śni kin he nawahon.

6 Waqinpi kin etanhan tapete eweciyaku; 


\section{PS A L M 82.}

Iye nape wakiśkokpa kin ayuśtanpi.

7 Wokakije en yapan, unkan ecihdaku;

Nakun wakinyan hoton oinahbe etanhan aciyupta:

Woakinica mini kin ekta iyutanciya. Sela.

8 Mitaoyate, nahon wo, kinhan wahokonciciye kta;

Israel, anamayagoptan kta hecinhan :

9 Taku wakan tokeca niyepi en un kte śni;

Qa ihnuhan oyate tokeca taku wakan

Tawa kin en makata ehpeniciye cinhan.

10 Jehowa Taku Wakan nitawa,

Egupta makoce etanhan uniye cin he miye :

Nina i hdukawa wo, kinhan ojuwaye kta ce.

11 Tuka mitaoyate miho kin anagoptan śni ; Qa Israel wicamicida śni.

12 Hecen iye cante hdusutapi kin en ehpewicawaya:

Iye tawacinpi kin en omanipi kta.

13 Tokin mitaoyate anamagoptanpi kinhan;

Qa Israel' mitacanku ohna manipi kta:

14 Ecadan tokawicayapi kin patuś wicawaye kta;

Qa tona śicewicadapi kin minape awicawaknake kta tuka.

15 Jehowa śicedakapi kin hena iye en ihdaśkapi kta:

Tuka iye anpetu tawapi kin owihanke wanice kta.

16 Nakun aguyapi conica kin yunkiye kta:

Qa imnija etanban tuhmaga canhanpi on imnaciye kta.

\section{PSALM 82.}

Asaph tadowan.

1 Iyotan Waśaka tomniciye kin en Wakantanka najin;

Taku wakan kin wicehna wayaco yanka.

2 Tohanyan ecinśniyan wadacopi kta he ;

Qa wicaśta śica itepi kin yakinihanpi kta. Sela.

3 Onśika qa wamdenica kin hena wicakiciyukcan po;

'Tuwe kakije ca wahpanica kin owotanna ecawicakicon miye.

4 Onśika qa wahipanica kin hdinape wicaya po;

Wicaśta śica nape kin etanhan ehdaku miye.

5 Sdonyapi śni qa okahnih wacinpi śni;

Otpaza en manipi kte hinca:

Maka oahde kin owasin yuhohopi.

6 Taku wakan henicapi ce, miye epa;

Owasin Iyotan Wankan un cinca kin niyepi.

7 'Tuka awicakehan wicaśta iyecen nițapi kta ;

Qa wicaśta itancanpi wanji iyecen nihinhipayapi kte.

8 Wakantanka inajin wo, maka kin hdaco wo :

Oyate iyulpa tawawicaye kte cin he niye. 


\section{PSALM 84.}

\section{PSALM 83.}

Psalm odowan. Asaph tawa.

1 Wakantanka, inina yaun śni nunwe:

Iyotan Waśaka, inina yanke śni qa owanji yanke śni wo.

2 Iho, tokaniyanpi kin hena hotonpi;

Qa śicenidapi kin hena pa yuwankan ikikcupi.

3 Nitaoyate kin śicaya awicaiapi;

Qa nawicayakilibe cin hena on wohdakapi ece.

4 Hena heyapi; Upo, oyate kin he ihangwicunyanpi kte;

Qa Israel caje kin icimana kiksuyapi kte śni ce.

5 Cante eciyatanhan witaya awacinpi;

Niye on wicotakuye wan hduśtanpi.

6 Edom tawakeyapi, qa Iśmaeli kin;

Moab, qa Hagari kin hena:

7 Gebal, qa Ammon, qa Amalek;

Philistia, Turos en ounyanpi kin hena om:

8 Nakun Assur hena owicapa:

Hena Lot cinca isto owicaqupi. Sela.

9 Midian en iyecen ecawicakicon wo ;

Sisera iyececa, Jabin iyececa, Kiśon wakpadan en.

10 Endor ekta ihangwicayapi qon :

Maga akan tacesdi iyececa icagapi.

11 Akicita tancanpi kin Oreb qa Zeeb iyecen wicakaga wo; Han, wicaśta itancanpi owasin, Zeba qa Zalmunna iyececapi.

12 Hena heyapi; Wakantanka tamaga kin Hena unkiye tawaunyanpi kta ce.

13 Wakantanka mitawa, Hena tate iyumni iyececa wicakaga wo; Tateyanpa itokam aguyapi ha kin iyececa :

14 Peta contanka wan hulinage cin iyececa; Qa ide wan he aide kin iyececa :

15 Hecen tateyanpa nitawa on kuwa awicade kta; Qa tate iyumni nitawa on nihinciye wicayaye kta ;

16 Itepi kin wowiśtece on ojuwicaya wo: Unkan, Jehowa, nicaje wicaśta akitapi kte.

17 Iśtecapi kta, qa nihinciyapi kta, owihanke wanica; Qa ite naśapi kta, qa atakunipi kte śni.

18 Unkan niye Jehowa eniciyapi kin sdonyapi kta; Niśnana Tyotan Wankan yaun, maka kin owancaya.

\section{PSALM 84.}

Gittith on dowan itancan kin kicagapi. Qora cinca tadowanpi.

1 Jehowa Sabaoth, Nitawakeya kin nina wiciyokipi.

2 Jehowa tahocoka kin on, Minagi cantokpani qa nakun niya śni țe kta seca: 


\section{P S A L M 85.}

Micante qa micehpi Taku Wakan ni un kin hoyekiya ece.

3 Upijate hee kaeś tipi wan iyekiya,

Qa icapśinpśincadan hỏpi wan,

En cinca ekihnake kta;

Jehowa Sabaoth, owayuśna nitawa kin hena,

Wicaśtayatapi mitawa, qa mita Wakantanka.

4 Yati en ounyanpi kin hena cante waśtepi ;

Hena ohinniyan niyatanpi kta. Sela.

5 Wicaśta tuwe towaśake nive en un kin he cante waśte:

Canku tankapi kin iye cantepi ohna wanka.

6 Iśtamnihanpe Kaksiza ohna yapi kinhan,

He miniyowe kagapi;

Nakun magaju kin woyawaśte on akahina.:

7 Wowaśake etanhan wowaśake ek ta yapi kta:

Zion en Wakantanka itokam ihdutanin kta.

8 Jehowa, Wakantanka Sabaoth,

Wocekiye mitawa nahon wo:

Jakob ta Wakantanka, anagoptan ye. Sela.

9 Wakantanka, wahacanka unkitawapi wanyaka wo;

Qa Sdayakiye ite kin atonwan wo.

10 Nitahocoka ohna anpetu wanjidan keś

Kektopawinge isanpa waśte :

Mita Wakantanka ti tiyopa kin en "

Imunke kta wakahniga :

Qa wicowicaśtaśni wakeya kin ohna wati kte śni.

11 Jehowa Wakantanka anpetu wi qa wahacanka kin heca;

Jehowa wowaonśida wowitan ko wicaqu kta ;

Tona ecetuya manipi kin taku waśte ipiwicada kte śni.

12 Jehowa Sabaoth,

Wicaśta wacinniye cin he cante waśte.

\section{PSALM 85.}

Dowan itancan kin kicagapi. Qora cinca tadowanpi.

1 Jehowa, makoce nitawa canteyakiya; Jakob wayaka unpi kin hdicu wicayakiya.

2 Nitaoyate taku śica econpi kin yecicajuju; Wahtanipi kin owasin ayakahpa. 'Sela.

3 Śnyahda kin ocowasin anayecipta; Nitocanniye kin ide śni yakiya.

4 Unkiyepi en hdicu wo, Wakantanka Wanikiya unkitawapi; Qa canniyeunyakiyapi kin anakipta wo.

5 Owihanke wanin canniyeunyayapi $\mathrm{kta}$ he ; Nitocanniye wicoicage qa wicoicage ekta iyahdeyaye kta he.

6 Ake yahdicu qa niunyakiyapi kte śni he:

Kinhan, nitaokiye iniyuśkinpi kta.

7 Jehowa, nitowaonsida wanyagunkiya po: Qa nitowiconi kin unyaqupi kte.

8 Jehowa Iyotan Waśake cin he taku eye cin he nawahon kta; 


\section{P S A L M 86.}

Tye taoyate qa wicaśta wacantkiye tawa kin wookiye on owicakiye kta:

Tuka ihnuhan wowitkotkoke cin ekta ihdoyapi kinhan.

9 Tona kokipapi kin henana wiconi tawa wicikiyedan un;

Hecen makoce unkitawapi ohna wowitan ounye kta.

10 Wowaonśida qa wowicake itkokicipapi :

Woowotanna qa wonkiye i ikiciputakapi.

11 Wowicake maka kin etanhan icaga;

Qa woowotanna mahpiya eciyatanhan kun ahitonwan.

12 Nakun Jehowa taku waśte kin wicaqu kta;

Qa makoce unkitawapi taku icahye kta.

13 Woowotanna iye itokam mani kta;

Qa iye oye kin ohna aunhdepi kte.

\section{PSALM 86.}

Dawid tawocekiye.

1 Jehowa, ninoge ukiye ça amayupta wo;

Makakije ça onmaśika, heon.

2 Minagi awanyaka ye, wacantkiye wanji he miye:

Nitaokiye nikiya wo, Wakantanka mitawa he niye;

Wacinniye cin heon.

3 Itancan, onśimakida wo ;

Anpetu osan hoyeciciye kta heon.

4 Nitaokiye nagi kin iyuśk inkiya wo;

Itancan, niye ekta minagı wahdomda.

5 Niye, Itancan, niwaśte qa wayakajuju ece;

Qa tona hoyeniciyapi kin owasin,

Wocantekiye utkanna wicayeciyuha.

6 Jehowa, wocekiye mitawa nahion ye;

Qa cewakiya ho kin he anagoptan wo.

7 Anpetu en makakije cinhan houciciye kta :

Unkan niye amayadupte kta.

8 Itancan, taku wakan ehna tuwedan-iyenicece śni;

Qa takudan niohan iyecece śni.

9 Itancan, oyate wicayakage cin owasin,

Hena nitokam upi qa ohodapi kta;

Qa nicaje yaonihanpi kta.

10 Niye nitanka qa wowapetokeca ecanon;

Niśnana Wakannitanka.

11 Jehowa, nitacanku onspemakiya ye;

Nitowicake ohna mawani kta ;

Micante nicaje kokipe kta en iyakaśka wo.

12 Itancan, Wakantanka mitawa,

Micante ocowasin on, wopida eciciye kta ;

Qa nicaje mdaonihan kta, owihanke wanica.

13 Miye en nitowaonśida kin tanka;

Qa Hades temahentu kin etanhan minagi edaku.

14 Wakantanka, wahanhaniçidapi kin takpe maupi; 
Qa wicaśta wohitika omniciye hin minagi akitapi ;

Qa wicitokam niye enihdepi śni.

15 Tuka Itancan,

Taku Wakan waonśida qa wacantkiya kin. he niye,

Wawacinkta yuza tanka,

Qa wowaonśida wowicake ko on winijice.

16 En mahdiyaku qa onśimakida wo;

Nitowaśake kin nitaokiye qu wo ;

Qa nitaokiye win cinhintku kin nikiya wo.

17 Wowakta waśte wan makipazo wo;

Hehan tona śicemadapi wanyakapi qa iśtecapi kta :

Jehowa, niye omayakiye ca wacintonhnag mayaye cin heon.

\section{PSALM $8 \%$.}

\section{Qora cinca tawapi. Psalm odowan.}

1 Oahde tawa kin wowakan paha kin en un.

2 Zion tatiyopa kin hena Jehowa waśtekidaka;

Jakob en ounyanpi kin owasin isanpa.

3 Niye en wicoie wakan kin oyakapi,

Wakantanka totonwe kin. Sela.

4 Rahab qa Babel sdonmayanpi kin he omdake kta;

Iho, Philistia qa Turos Kuś kici ;

De hen teca ni en tonpi ce.

5 Qa Zion on heyapi kta ;

Wicaśta kin de qa kae hen tonpi ce:

Unkan iye Iyotan Wankan kin hdusuta kte.

6 Jehowa oyate owicawa kinhan wicayawa kta;

De en teca ni en tonpi ce. Sela.

7 Unkan tona dowanpi, tona yajopi ko;

Minilidoka mitawa owasin niye en un ce, eyapi kta.

\section{PSALM 88.}

Psalm odowan. Qora cinca tawapi. Dowan itancan kin kicagapi. Wowayazan kakiśye cin on. Waonspekiyapi kta. Heman Ezrahi he kaga.

1 Jehowa, Wakantanka Wanikiya mitawa,

Nitokam anpetu hanyetu ko hoyewaye.

2 Wocekiye mitawa nitokam u nunwe;

Hoyewaye cin he anolikiya wo.

3 Wokakije minagi imnahan un;

Qa mitaniyả Hades ikiyedan ayapi.

4 Wohia ek ta iyayapi kin opeya mayawapi ;

Wicaśta wowaśake nice cin he iyemaceca.

5 Tapi kin opeya makiyuśkapi,

Wicaktepi wicahiapi en wankapi kin iyececa,

Hena owihanke wanica wicayeksuye śni :

Qa hena ninape etanhan ehpewicayapi.

6 Woha wan temahentu kin en omayahnaka; 


\section{P S A L M 89.}

Otpaza tipi kin en, ośbe kin en.

7 Nitocanniye tkeya iyamahdaskica;

Qa taja nitawa owasin on kakiśmayaya. Sela.

8 Tona sdonmayanpi kin hena mitehanyan iyeyays;

Hena wahtemadapi śni yakaga;

Onamatakapi, qa tankan waku owakihi śni.

9 Wokakije on miiśta atakuniśni ;

Jehowa, anpetu otoiyohi houciciye ;

Minape ciciyugata ece.

10 Tapi kin hena wicohan wakan ecawicayecon kta he;

Wanagi hdinanpapi qa wopida eniciyapi kta he. Sela.

11 Wicahapi en nitowaonśida oyakapi kta he ;

Nitowicake kin wicotakuniśni en.

12 Wicohan wakan nitawa otpaza en sdonyapi kta he; Qa nitoowotanna, woakiktonje makoce kin en.

13 Tuka miye, Jehowa, hoyeciciya; Qa hanhanna eca mitawocekiye nitokam u kte.

14. Jehowa, tokeca minagi ayakta kte śni ;

Niite anamayakilibe kta he.

15 Homakśiyopa ehantanhan makakije ça mațe kta seca;

Wonihinciye nitawa qin waun;

Token cante mduza tanin śni.

16 Nitocanniye miwankam iyaya;

Wonihinciye nitawa ihangmayaupi :

17 Mini iyececa, anpetu osan, aohdutemayanpi ;

Witaya ohomni imayayapi.

18 Waśtemadake ca mitakuye kin mitehanyan iyewicayaya;

Tona sdonmayarpi qon hena otpaza.

\section{PSALM 89.}

Waonspekiyapi kta. Ethan Ezrahi kin he tawa.

1 Jehowa towaonśida kin ohinniyan iwadowan kta;

Wicoicage qa wicoicage hehanyan,

Mii on nitowicake omdake kta.

2 Wowaonśida ohinniyan icahyapi kta ce, epe ciqon: Mahpiya kin hena en nitowicake eyehde kta.

3 Wanji wakahnige cin he kici wicotakuye wakaga;

Dawid mitaokiye kici iapi weciyasuta:

4 Owihanke wanica hehanyan nicinca sutaya ewahde $k$ ta; Qa wicoicage owasin hehanyan oiyotanke nitawa icaliwaye kta. Sela.

5 Unkan, Jehowa, 'mahpiya kin niohan wakan oyakapi kta; Nakun nitowicake, oyate wakan mniciyapi kin en.

6 Tuwe mahpiya kin ekta Jehowa iyececa he; Waśakapi cinca kin Jehowa iyacinpica he.

7 Oyate wakan onahbeya mniciyapi kin en, 'Taku Wakan nina kokipapi kta iyececa; Qa tona ihdukśan unpi kin isanpa kinihanpi kte. 
8 Jehowa, Wakantanka Sabaoth,

Jah Iyotan Waśaka, tuwe iyeniceca he ;

Qa nitowicake nihdukśan un kin.

9 Miniwanca wankan ye cin he wowidagyaya;

Taja wankan aya eca niye amdakedan yakaga ece.

10 Wicaktepi iyecen Rahab yakaśuśuja;

Niisto waśaka on tokaniyanpi kin wicaduomdeca.

11 Mahpiya kin he niye nitawa,

Nakun maka kin nitawa;

Makoce owasin qa woojudan kin

Hena niye yakaga.

12 Waziyata qa itokaga, hena niye yakaga;

Tabor qa Hermon nicaje on iyuśkinpi kta.

13 Isto waśaka wan niyukan;

Ninape waśaka, nape enitapa kin tehanwankantu.

14 Woowotanna qa woyaco oiyotanke nitawa oyanke kin hee;

Wowaonśida qa wowicake niite itokam yapi kta.

15 Oyate wotanin waśte sdonye cin hena cante waśtepi ;

Jehowa, niite iyoyanpa kin en omanipi kta.

16 Anpetu osan nicaje on iyuśkinpi kta:

Qa nitoowotanna on wankan ihdoyapi kta.

17 Iye towaśakepi wowitan kin he niye,

Qa nitoiyokipi kin en he wankan iyeunyeciciyapi kta.

18 Wahacanka unkitawapi kin he Jehowa tawa;

Qa wicaśtayatapi unkitawapi kin he

Israel Wakandapi kin he tawa.

19 Hehan wanji wacantkiye nitawa woyuotanin en oyakiya, Qa heha; Wanji Waśake cin akan wowaśake ewehnaka;

Wanji oyate etanhan kahnigapi kin wankan ewehde:

20 Dawid"mitaokiye kin iyewaye ;

Wihdi wakan mitawa on sdawakiya:

21 Minape ohinniyan kici un kta;

Nakun miisto yuwaśake kta.

22 Tokapi kin iyokiśinyapi kte śni ;

Qa woahtani cincapi kakiśyapi kte śni.

23 Unkan iye itokam tona tokayapi kin wicawakaśuśuje kta ; Qa tona śicedapi kin awicawape kta.

24 Nakun mitowicake qa mitowaonśida kici un kta; Qa micaje on iye he kin wankan icage kta.

25 Qa iye nape kin miniwanca en ewahnake kta; Qa nape etapa kin mini tanka kin en.

26 Iye hoyemakiye kta; Atewaye cin he niye ; Mita Wakantanka, qa imnija nimaye cin.

27 Unkan miye he micinca tokapa wakiye kta; Maka wicaśtayatapi kin isanpa wankan un kta.

28 Ohinniyan mitowaonśida weciyuhe kta ; Qa wicotakuye mitawa kici wicake kta.

29 Nakun iye cinca owihanke wanica mdusuta kta; Qa oiyotanke tawa kin mahpiya annetu kin iyecece kta. 
30 Tye cinca kin mitoope ehpeyapi kinhan; Qa mita woyaco ohna mani wacinpi śni;

31 Taku omdake cin taku ikceka yawapi ; Qa mitawoahope opapi śni kinhan:

32 Hehan taku sica econpi kin, icapsinte wan on, Qa wahtanipi kin, apapi on iyopewicawaye kta':

33 Tuka mitowaonśida ewecihdaku kte śni ; Qa wowicake mitawa kin en itonśni micicage kte śni.

34 Wicotakuye mitawa taku ikceka wakage kte śni; Qa miiha taku enapeye cin mdatokeca kte śni.

35 Taku wanji mitowakan kin on wakonza ce; Dawid en itonśni owakihi śni :

36 Iye cinca kìn owihanke wanice kta ; Qa niyotanke tawa anpetu wi mitokam iyecece kta.

37 Ohinniyan sutaya yanke $\mathrm{kta}$, hanyetu wi iyececa; Qa mahpiya ekta wayuotanin wicaka. Sela.

38 Hececa eśta niye elipeyaye ça ayakta śni ; Sdayakiye ciqon he canniyeyaya :

39 Nitaokiye wicotakuye tawa yecaksa; Wateśdake tawa kin makata elipeyaya:

40 Inatake tawa owasin dujuju; Conkaśke tawa kin woihangye yakaga :

41 Tona canku ohna hiyayapi owasin he ihangyapi ; Tona ikiyedan unpi kin hena wahtedapi śni :

42 Tona śicedakapi nape etapa kin yuwankan iyeyaya; Tona tokayapi owasin iyuśkinwicayaya.

43 Nakun mazasagye tawa kin pe śni yakaga ; Qa okicize en kici nayajin śni.

44 Toiyege kin ayuśtanyakiya ; Qa oiyotanke tawa kin makata elipeyaya.

45 Kośka taunpetu kin duptecedan; Wowiśtece on akahipeyeton. Sela.

46 Tohanyan kta; Jehowa, ohinniyan nayakihbe kta he; Peta iyecen nitocanniye ide kta he.

47 Miye ptenyedan wani kin he kiksuya wo ; Tokeca Adam cinca owasin itul yakaga he.

48 Wicaśta tuwe ni un qa wiconțe wanyake kte śni ; Hades nape etanhan nagi eihdaku kta he. Sela.

49 Itancan, otokahe ekta nitowaonśida kin tukte e he; Nitowicake en Dawid wahoyaye ciqon

50 Itancan, nitaokiye i en hdepi kin he kiksuya wo; Miikpi ohna oyate ota owasin wicamduha:

51 Jehowa, tokaniyanpi i en iyeyapi qon he; On Sdayakiya oye kin i en iyeyapi qon.

52 Jehowa owihanke wanin yawaśtepi nunwe. Amen qa amen. 


\section{PSALM 90.}

Wocekiye wan. Moses Wakantanka tawicaśta tawa.

1 Itancan, niye otiunniyanpi, Wicoicage qa wicoicage kin en.

2 He kin icage śni he itokam;

Qa maka maga ko yakage śni he ehan;

Utokahe wanica qa owihanke wanica,

Iyotan Waśaka kin he niye.

3 Maka mdu ee kaeś ekta wicaśta hdicuyaya;

Qa, Adam cinca hdicu miye, eha ece.

4 Waniyetu kektopawinge, niiśta kin en, Htanihan wanna henakeca he iyececa; Qa hanyetu en akicita onajin kin iyececa.

5 Okahbog iyewicayaya ;

Woiśtinma wan iyececapi ;

Hanhanna eca, wato iyecen, taninpi śni.

6 Hanhanna eca hica aya, qa hehan tanin śni ;

H́tayetu hehan kaśdapi qa śnija.

7 Nitocanniye kin on unsotapi ;

Qa śinyahda kin on kopeunhdapi ece.

8 Waunhtanipi kin nitokam eyahnaka;

Woanahbe unkitawapi kin niite iyoyanpa kin en.

9 Anpetu unkitawapi owasin nitocanniye en iyaya;

Waniyetu unkitawapi wicotawacin wan iyecen enaunkiyapi.

10 Waniyetu unkitawapi anpetu kin

Hena waniyetu wikcemna śakowin,

Qa wowaśake yuke cinhan, waniyetu wikcemna śahdogan ;

Hececa eśta wowaśake kin he wokakije qa wicośice;

Ihnuhanna atakuni śni, unkan kinyan unkiyayapi.

11 Nitocanniye wowaśake kin tuwe okahniga he ;

Qa sinyahda kin he konicipapi kin iyececa.

12 Hecen anpetu unkitawapi hdawa onspeunkiya po;

Kinhan woksape ekta cante yeunkiyapi kta.

13 Jehowa hdicu wo; tohanyan kta he:

Qa nitaokiyepi on tawacin hdutokeca wo.

14 Hanhanna era nitowaonśida on imnaunyan po ;

Kinhan unkiyuśkinpi qa piundapi kta,

Anpetu unkitawapi owasin en.

15 Anpetu en kakiśunyanpi kin he iyecen wiyuśkinunkiya miye; Waniyetu en taku śica wanunyakapi iyececa.

16 Niohan kin nitaokiye wanyagwicaya wo;

Qa iye cinca kin, nitowitan kin.

17 Qa Jehowa Wakantanka unkitawapi

Towaśte kin unkicipi un nunwe;

Qa unnapepi olian kin unkiciyusuta miye;

Han, unnapepi ohan kin yuecetu wo. 


\section{PSALM 91.}

1 Iyotan Wankan un toinahbe kin en, Tuwe iyotanke cin he,

Iyotan Waśaka ohanzi tawa ihukuya iwanke kta.

2 Jehowa hewakiye kta ;

Wowinape mitawa, qa conkaśke mitawa,

Mita Wakantanka, he wacinwaye kta ce.

3 Wahmung ye cin wohmunke tawa kin

Ftanhan, iye eniyaku kta;

Makośica waihangye cin etanhan.

4 Iye sun kin on akalipenicaton kta ;

Qa tahupahu ihukuya wowinape iyeyaye kta ;

Towicake kin wahacanka qa maza makuakalipe.

5 Hanyetu wokokipe kin he koyakipe kte śni;

Qa anpetu en wanhinkpe kinyan iyaye cin ;

6 Makośica otpaza en omani un ;

Qa wowayazan wiyotanhan eca wayutakuniśni kin.

7 Nicahda kek topawinge hinlipayapi kta ;

Qa nietapa ekta kektopawinge wikcemna;

Tuka niye nikiyedan u kte śni.

8 Niiśta ecedan on ekta eyatonwe kta;

$\mathrm{Qa}$ Wicaśta śica tokiçonpi kin wandake kta.

9 Jehowa, wowinape mitawa kin he niye:

Iyotan Wankan kin he otipi nicicaga:

10 Heon taku śica nihiyahde kte śni;

Qa makośica wan nitawakeya ikiyedan u kte śni.

11 Taohnihde kin niye on wahowicaye kta;

Nitacanku owasin en awanniyakapi kta ;

12 Napepi ohna niyuhapi kta;

Hecen inyan siha ibonito kte śni.

13 Mnaja qa wamduśka si ayahde kta;

Mnaja kośka qa sintehda kin amayani kta.

14 Iye cantomahnaka, unkan ewehdaku kta ;

Micaje sdonye cin on wankan ewehde kta.

15 Hoyemakiye kta, kinhan amdupte kta:

Woiyokiśica en kici waun :

Ewehdaku qa mduonihan $k$ ta :

16 Anpetu hanskaska on imnawaye kta;

Qa wiconi mitawa wanyagwakiye kta.

\section{PSALM 92.}

Anpetu wakan on woyatan odowan.

1 Jehowa yatanpi kin he waśte;

Qa nicaje idowanpi kin, Iyotan Wankan yaun.

2 Hanhanna eca nitowaonśida oyakapi ;

Qa nitowicake, hanyetu kin en.

3 Candowankiyapi ikan wikcemna, qa cancega on; 


\section{P S A L M 94.}

Cotanke on awacinpi kin he nakun.

4 Jehowa, niohan kin on iyuśkinmayaya;

Ninape ohan kin on imduśkin kta.

5 Jehowa, niohan tanka hinca;

Nitawacin kin temahentu hinca.

6 Wicaśta wacintonśni kin he sdonye kte śni ;

Qa witkotkoke cin he de okahnige kte śni.

7 Wicaśta śica peji iyecen icagapi ;

Qa woahtani econpi kin owasin hica ayapi ;

Owihanke wanica yutakunipi kte śni heon.

8 Tuka, Jehowa owihanke wanica, Iyotan Wankan kin he niye.

9 Iho, Jehowa, tokaniyanpi kin,

Iho, tona tokaniyanpi kin atakunipi kte śni :

Woahtani econpi kin owasin enanakiya iyewicayapi kta.

10 Tuka tinta tatanka he kin iyecen,

He mitawa icahyaya:

Wihdi to on sdamayanpi.

11 Nakun tokamayanpi kin miiśta wanwicayake kta;

Tona wicohan śica econpi takpe maupi kin

Hena on minoge nation lita.

12 Wicaśta owotanna kin wazi can iyecen uye kta;

Lebanon hante kin iyecen icage kta.

13 Jehowa ti kin en huhdepi ;

Wakantanka unkitawapi tahocoka ohna hcapi kta:

$14 \mathrm{~Pa}$ skapi hehanyan waskuyeca icahyapi kta;

Cepapi kta, qa toto unpi kta.

15 Jehowa ecetu kin he oyakapi kta;

He imnija mitawa, qa woowotanua śni takudan en un śni.

PSALM 93.

1 Jehowa wicaśtayatapi, wowitan kohdaka;

Jehowa wowaśake kohdaka, ipiyagkiton ;

Nakun maka kin ehdepi, hecen yuhohopi kte śni.

2 Wanakajatanhan oiyotanke nitawa yusutapi ;

Niye otokahe niwanica.

3 Mini tanka kin wankan iyeiciya;

Jehowa, mini tanka kin ho hdawankan iyeya;

Mini tanka kin taja wankan iyeya.

4 Mini ota ho kin isanpa;

Miniwanca taja tanka kin isanpa;

Jehowa wankan un kin he waśaka.

5 Taku odake cin hena wicakapi hinca;

Wowakan yati kin oiyokipi ;

Jehowa, anpetu hanskaska hehanyan.

$$
\text { PSALM } 94 .
$$

1 Jehowa, watokiçon Wakantanka;

Watokicon Wakantanka, iyoyanpa wo. 
2 Maka Wayaco yaun, najin wo; Wahanhanicidapi kin towicakicon wo.

3 Jehowa, wicaśta śica tohanyan kta he ; Tohanyan wicaśta śica iwakicipi kta he.

4 Iwaśicunpi, taku śica eyapi ; Woahtani econpi kin owasin ihdatanpi.

5 Jehowa, nitaoyate wicakapanpi; Qa taku nitawa kakiśyapi ece.

6 Wiwazica qa tuwe oyate tokeca etanhan țewicayapi; Qa wamdenica kin tin wicaktepi.

7 Tuka heyapi ; Jah wanyake kte śni; Qa Jakob ta Wakantanka awacin kte śni ce.

8 Oyate en wacintonśni yaunpi, awacin po; Qa winitkotkokapi, tohan wacinksamya niohanpi kta he.

9 Tuwe wicanoge kage cin he wanahon kte śni he : Qa tuwe wicaiśta kage cin he wawanyake kte śni he.

10 Tuwe oyatepi iyopewicaye cin he wicakaśtake kte śni he; Tuwe wicaśta waonspewicakiye cin.

11 Wicaśta tawacinpi kin Jehowa sdonya ece; Hena taku śni.

12 Jah, wicaśta iyopeyaye cin he cante waśte; Qa nitoope eciyatanhan onspeyakiye cin :

13 Anpetu śice cin etanhan ozikiye yaye kta ; Wicaśta śica woha wan wicakicapi kta hehanyan.

14. Jehowa taoyate kin awicayuśtan kte śni ; Qa taku tawa kilı elipekiye kte śni.

15 Tuka woyaco woowotanna en hdi kta; Qa tona cante ecetu kin owasin he pasipi kta.

16 Sicaya econpi kin on tuwe mici najin kta he; Woahtani econpi kin on tuwe micica kta he.

17 Jehowa omakiye śni unkanś, Ecadan minagi woinina en un kta tuka.

18 Misiha naśduta ce, epe cinhan ; Jehowa, nitowaonśida najin makiye $k$ ta.

19 Miye mahen mitawacin iyokiśica ota icunhan, Wacintonhnake nitawa minagi iyuśkinkiye kta.

20 Woahtani oiyotanke kin he nicica kta he; Wicohan śica woope iyecen konze cin he.

21 Wicaśta owotanna nagi kin takpe hipi ; Qa wicawe taku iyaonpepica śni kin he yacopi.

22 Tuka Jehowa conkaśke mitawa kin hee; Qa mita Wakantanka imnija wowinape waye.

23 Unkan iye wahtanipi kin iyahdewicaya; Qa taku śica econpi kill en ihangwicaye kta ; Jehowa Wakantanka unkitawapi ihangwicaye kta.

PSALM 95.

1 U miye, Jehowa unkahiyayapi kte; Wiconi unkitawapi Imnija kin unkidowanpi kte. 


\section{P S A L M 96.}

2 Wopida yuha iye ite kin en unkupi kte; Wowiyuśkin odowan on unkiyaśapi kta.

3 Jelıowa Taku Wakan Tanka; Qa taku wakan owasin iwankan Wicaśtayatapi tanka.

4 Maka ośbe kin hena iye nape ohna hduha; Qa paha ipa kin hena iye tawa.

5 Miniwanca kin he tawa, qa iye kaga ; Nakun maka puze cin he iye nape kaga.

6 U miye, patuś inaunjinpi qa ohoundapi kte ; Jehowa Waicahye unkitawapi kin itokam, Canpeśka makehde unkanpi kte.

7 Wakantanka unkitawapi kin he iye; Qa makoce tawa oyate kin unkiyepi ; Qa iye nape ohna tahin wanunyanpi kin : Anpetu kin de iye ho kin nayahonpi kta hecinhan;

8 Meribah iyecen cante hdutehipi śni po; Makoskan Massa anpetu kin iyececa.

9 Hunkakewicayayapi imayutanpi qehan ; Imayukcanpi, nakun miohan wanyakapi.

10 Waniyetu wikcemna topa hehanyan wicoicage kin he iyokiśinmayan ;

Unkan hepe; Oyate kin de cante ekta nunipi ; Qa mitacanku sdonyapi śni.

11 Hecen canmaniyan konza kewicawakiya; Woozi mitawa kin en opapi kte śni.

\section{PSALM 96.}

1 Jehowa odowan teca wan kahiyaya po; Maka kin ocowasin, Jehowa idowan po.

2 Jehowa kahiyaya po, iye caje yawaśte po ; Anpetu otoiyohi waniwicakiye cin he yaotanin po.

3 Ikcewicaśta kin ehna iye towitan oyaka po ; Oyate owasin en iye ohan wakan kin.

4 Jehowa tanka, qa nina yatanpi kte; Taku wakan owasin isanpa kokipapi kta iyececa.

5 Ikcewicaśta taku wakan yuhapi kin owasin taku śni; Tuka Jehowa mahpiya kin kaga.

6 Iye itokam woyuonihan qa wowitan; Tipi wakan tawa ohna, wowaśake qa wowaśte.

7 Jehowa qu miye, oyate wicowazipi kin, Wowitan qa wowaśake Jehowa qu miye.

8 Iye caje towitan kin Jehowa kicu po ; Wopida wośna wan icupi qa tahocoka kin en u po.

9 Wowakan oiyokipi kin en Jehowa ohoda po; Iye itokam, maka kin ocowasin, inihan miye.

10 Oyatepi ehna, Jehowa Wicaśtayatapi ce, eya po ; Nakun maka kin ehdepi, yuhohopi kte śni : Oyate kin woecetu eciyatanhán wicayaco kta.

11 Mahpiya kin iyuśkin, qa maka kin pida nunwe; 


\section{PS A. L 98.}

Miniwanca qa woojudan kin hotanin nunwe.

12 Maga kin iyuśkin kte, qa taku ohna un kin owasin; Hehan contanka can owasin wiyuśkinyan dowan kta:

13 Jehowa itokam: He wanna u ;

Maka kin hdaco u ce :

Woowotanna on wicoicage kin yaco kta;

Qa oyate kin, iye towicake eciyatanhan.

\section{PSALM 97.}

1 Jehowa Wicaśtayatapi, maka kin iyuśkin kte;

Wita ota hince cin hena pidapi nunwe.

2 Ihdukśan mahpiya śapa qa otpaza;

Oiyotanke tawa woowotanna qa woyaco akan han.

3 Iye ite kin itokam peta iyaya;

Qa ihdukśan tokayapi kin huhnahwicaye kta.

4 Wakanhdi tawa makoce kin iyoyamya ;

Maka kin wanyaka qa cancan.

5 Jehowa itokam paha kin canśin iyecen śdoyapi ;

Maka ocowasin Itancan tawa kin itokam.

6 Mahpiya kin hena iye toowotanna yuotaninpi; Qa oyate owasin iye towitan wanyakapi.

7 Tona okagapi wan okiyapi kin owasin iśtecapi kte; Tona takuśni on ihdatanpi kin hena:

Iye en patuja po, taku wakan owasin.

8 Zion he nation qa iyuślkin; Qa Juda cunwintku wowiyuśkin on iyaśapi :

Jehowa, nitawoyaco kin hena on.

9 Niye, Jehowa, maka owancaya Iyotan Wankan yaun;

Taku wakan owasin iwankam tehanwankantu.

10 Jehowa waśteyadakapi, taku śica śicedaka po;

Wicaśta wacantkiye tawa nagipi kin awanwicayaka;

Wicaśta śica napepi etanhan wicayukce kta.

11. Wicaśta owotanna kin iyoyanpa owicakicijupi ;

Qa wowiyuśkin, tona cante ecetupi kin on.

12 Owotanna yaunpi kin, Jehowa en iyuśkin po;

$\mathrm{Qa}$ iye towakan kiksuyapi kin he yatan miye.

\section{PSALM 98. \\ Odowan.}

1 Odowan teca wan Jehowa kahiyaya po;

Wicohan wakan kin heca econ ece:

Nape etapa qa isto wakan kin on woohiye içicaga.

2 Jehowa wiconi tawa kin hduotanin;

Ikcewicaśta iśta kin en toowotanna hduzanni.

3 Iye towaonśida qa towicake kin kiksuya,

Israel tiyohnaka kin on ;

Wakantanka unkitawapi waniwicakiye cin, 


\section{PSALM 100.}

Maka ihanke kin owasin wanyakapi.

4 Maka kin ocowasin, Jehowa kahiyaya po; Iyaśapi qa wiyuśkinpi qa dowan po.

5 Candowankiyapi on Jehowa kahiyaya po ; Candowankiyapi qa odowan ho kin on.

6 Mazayahotonpi tanka qa cotanka ho kin on, Jehowạ Wicaśtayatapi kin itokam iyaśa po.

7 Miniwanca kin sa nunwe, qa woojudan kin; Maka kin, qa tona en ounyanpi nakun.

8 Wakpa kin nape hdaskapapi nunwe;

Qa paha kin witaya iyuśkinpi kte;

9 Jehowa itokam :

He maka kin hdaco u ce;

Woowotanna on wicoicage kin hdaco kta;

Qa oyatepi kin, wokonze eciyatanhan.

\section{PSALM 99.}

1 Jehowa Wicaśtayatapi, oyate kin cancanpi ;

Kerubim otahedan iyotanka, maka kin śkanśkan.

2 Zion en Jehowa tanka;

Qa oyate owasin iwankam tehanwankan yanka.

3 Nicaje tanka qa wowinihan kin he yatanpi kte;

He Wakan hinca.

4 Unkan wicaśtayatapi towaśake kin woyaco waśtedaka;

Niye wicoecetu yahdusuta;

Jakob en woyaco qa woowotanna yakaga.

5 Jehowa Wakantanka unkitawapi yatanka po;

Qa iye siha oahe kin en makata ehpeiciya po:

Iye Wakan hinca heon.

6 Moses qa Aaron, wawayuśna tawa kin ehna;

Qa Samuel tona caje hoyekiyapi kin om;

Hena Jehowa hoyekiyapi, unkan iye awicayupta ece.

7 Mahpiya bosdata kin en owawicakiye:

Woyaotanin tawa kin opapi, qa wokage wicaqu kin.

8 Jehowa Wakantanka unkitawapi, niye awicayadupte;

Iyotan Waśaka, niye wicayecicajuju ;

Tuka wahtanipi kin hena towicayeciçon.

9 Jehowa Wakantanka unkitawapi yatanka po;

Qa iye paha wakan tawa kin ohna patuja po;

Jehowa Wakantanka unkitawapi kin he wakan nakaes.

\section{PSALM 100.}

Odowan wan. Wopida eyapi kta.

1 Maka kin ocowasin, Jehowa iyaśa miye.

2 Wowiyuśkin on Jehowa okiya po ;

Itokam dowanwan u miye.

3 Jehowa he Wakantanka e sdonya po: 
Iye unkagapi, qa unkiye unkiçicagapi śni :

Taoyate qa tahinca tinta tawa kin en

Hena unkiyepi.

4 'Tatiyopa kin en wopida eya u po,

Woyatan yuha iye tahocoka ohna u miye;

Wopida eciya miye;

Iye caje kin yawaśte po.

5 Jehowa waśte, towaonśida kin owihanke śni ;

Qa towicake kin he wicoicage qa wicoicage hehanyan.

\section{PSALM 101.}

Dawid tadowan.

1 Wowaonśida qa woyaco on wadowan kta ; Jehowa, niye icidowan kta.

2 Canku yuśtanpi wan ohna wacin waksape kta :

Tohan en mayahi kta he :

Cante ocowasin hduha wati ohna mawani kta.

3 Miiśta itokam wicoie śica ewehnake kte śni ;

Taku śica econpi kin hena śice wadaka;

Miye en amaskape kte śni.

4. Wicacante pemni kin he amayuśtan kta ;

Taku śica sdonwakiye kte śni.

5 Tuwe takodaku nahmana aie cin he ihangwaye kta:

Tuwe iśta tanka qa wahanicida kin iyowin wakiye kte śni.

6 Makoce en tona wicakapi kin miiśta awicatonwan;

Hena mici unpi kta;

Tuwe canku yuśtanpi omani kin he omakiye kta.

7 'Tuwe wohnayan econ kin he wati en ounye kte śni ;

Tuwe itonśni kin he miiśta itokam yanke kte śni.

8 Hanhanna eca, makoce kin en, tona śicapi

Owasin ihangwicawaye kta;

Hecen Jehowa totonwe kin etanhan,

Tona śicaya econpi kin owasin ehpewicawaye kta.

PSALM 102.

Wocekiye wan. Tuwe iyotanhan iyekiye, kakija qa Jehowa itokam waśicahowaye cin he tawa.

1 Jehowa, wocekiye mitawa nahon wo; Qa houwaye cin he en niu nunwe.

2 Niite anamakilibe śni wo; Makakija anpetu kin en anohmakiya wo;

Houwaye anpetu kin en amayupta inatini wo.

3 Mitaanpetu kin sota iyaya;

Qa mahuhu can seca iyecen itkon.

4 Micante peji iyecen śniśyapi qa pus aya: Aguyapi houta awektonja :

5 Waśicahowamda ho kin on, 


\section{P S A L M 102.}

Micehpi kin mahuhu en askapa.

6 'Tinta mdega wan iyemaceca;

Hinhankaga otiwota en iyecen waun.

7 Kiktahan waun, qa zitkadan wan Tice ekta iśnana un kin iyemaceca.

8 Anpetu osan tokamayanpi kin iyopemayanpi ; Tona canniyemayanpi kin hena ośtemahdapi ece.

9 Aguyapi iyecen cahota wata; Qa wamdatke cin he ceyapi kici icahiwaya;

10 Wośinhda qa wocanniye nitawa kin on etanhan: Yuwankan imayacu qa elipemayaye cin heon.

11 Mitaanpetu ohanzi takinyan ye cin iyececa; Qa miye qe peji iyecen maśnija.

12 Tuka niye, Jehowa, owihanke wanin idotanke kta; Qa wokiksuye nitawa kin he wicoicage qa wicoicage hehanyan.

13 Niye nayajin kta, Zion onśiyakida kta ; Tohan okiyapi kta wanna iyehantu, Han, tohan iyehantu hince cinhan:

14 Tohan inyan tawa kin nitaokiye waśtedakapi ; Qa watuśekśeca on iyokipipi kinhan.

15 Unkan Ikcewicaśta Jehowa caje kin kokipapi kta; Qa nitowitan kin, maka wicaśtayatapi owasin.

16 Jehowa Zion kage cin heon; Iye towitan en ihdutanin.

17 Onśike tawocekiye ekta ihduhomni ; Qa wocekiye tawapi kin śicedake śni.

18 Wicoicage $u$ kte cin on de owapi kta; Qa oyate wan icage kte cin he Jah yatanpi kta.

19 Towakan paha kin etanhan eyokasin ; Jehowa mahpiya etanhan maka kin ahitonwan;

20 Kaśka unpi comnihdazipi kin nảion kta; Wiconte cinca kin wicakiyukce kta.

21 Zion en Jehowa caje kin oyakapi kta; Qa iye yatanpi kin, Jerusalem en:

22 Oyatepi witaya mniciyapi kin en ; Qa wokiconze kin, Jehowa ohodapi kta.

23 Canku ohna mitowaśake kin kun ehpeya; Mitaanpetu kin yuptecedan.

24 Mita Wakantanka, mitaanpetu cokaya en, emayaku śni wo, epe kta:

Waniyetu nitáwa wicoicage wicoicage hehanyan.

25 Otokahe ekta maka kin sutaya eyahde :

Qa ninape taku kage cin mahpiya kin hee.

26 Hena awihnuni kta, tuka niye vani kta; Qa hena owasin śina iyecen kuke kta;

Wokoyake iyecen hena dutokeca kta;

Unkan yutokecapi kta.

27 Tuka he niye,

Qa waniyetu nitawa owihanke kte śni. 


\section{P S A L M 103.}

28 Nitaokiye cinca kin ounyanpi kte;

Qa iye cincapi kin nitokam wicayusutapi kte.

\section{PSALM 103.}

\section{Dawid tawa.}

I Minagi, Jehowa yawaśte wo ;

Qa taku mahen maun kin owasin, iye caje wakan kin.

2 Minagi, Jehowa yawaśte wo ;

Qa taku waśte econ kin owasin akiktonje śni wo.

3 He wayahtani owasin nicicajuju ;

Waniyazan kin iyuhipa asniniyan:

4 Wicotakuniśni etanhan nitaniya opekiton;

Wowaonśida qa wocantekiye on wateśdagnicaton.

5 Taku waśte on nitaanpetu ojudan ya ;

Hecen koniśka ihduteca, wamdi iyececa.

6 Jehowa woowotanna ece econ,

Qa woyaco, tona kakiświcayapi owasin on.

7 Iye tacanku kin Moses sdonyekiya;

Qa Israel cinca, iye ohan tanka kin.

8 Jehowa wacantkiye ça waonśida;

Tehan canteptanye śni, qa wawacinkta yuza tanka.

9 Ohinniyan wicakige kte śni ;

Qa owihanke wanin canniye wicaye kte śni.

10 Waunhtanipi kin iyecen ecaunkiconpi śni ;

Qa taku śica unkitawapi iyecen unqupi śni.

11 Mahpiya kin maka iwankam tehanwankantu kin,

He iyecen iye towaonśida tona kokipapi kin iwankam waśake hinca.

12 Wiyohiyanpa etanhan wiyohpeyata hehanyan;

Ihehanyan waunhtanipi kin yutokan ehpeunkiciciyapi

13 Ateyapi wan iye cinca onśiwicakida kin iyececa, Jehowa tona kokipapi kin onśiwicakida ece.

14 Token unkicagapi kin he sdonya;

Maka mdu heuncapi he kiksuya,

15 Wicaśta taanpetu kin hena wato iyececa;

Tinta wahca kin he iyecen hica aya:

16 Tate oniya wan iwankam iyaya,

Unkan en un śni;

Qa tohe kin icimana sdonkiye kte śni.

17 Tuka Jehowa towaonśida otokahe wanica, Qa owihanke wanice kta, tona kokipapi kin on ; Qa toowotanna kin cincapi sanpa cincapi kin en :

18 Tona wicotakuye tawa kiciyuhapi ; Qa tawoahope econpi kta on kik uyapi kin hena.

19 Jehowa malipiya kin en oiyotanke ekihde; Qa tokiconze kin taku owasin wowidagya.

20 Ohnihde wakan tawa, Jehowa yawaśte po; Wowaśake itancanpi, iye oie ecen ecanonpi ; 
Iye oie ho kin anayagoptanpi kta.

21 Taobe kin owasin, Jehowa yawaśte po ;

Taokiyeniyanpi, iye tawacin ecen ecanonpi.

22 Taku kage cin owasin, Jehowa yawaśte wu;

Tokiconze owanka kin owasin ohna :

Minagi, Jehowa yawaśte wo.

\section{PSALM 104.}

1 Minagi, Jehowa yawaśte ye :

Jehowa, mita Wakantanka, niye nitanka linca:

Woyuonihan qa wotanka koyahdaka.

2 Śina wan iyecen iyoyanpa hdoin:

Ozanpi wan iyecen mahpiya kin hdumdaya.

3 Mini tanka on tipi icicaga ;

Mahpiya śapa kin canpahnihma ya;

Tate hupahu kin on icimani ece.

4 Tateyanpa kin hena ohnihde wicakaga;

Peta ide kin taokiye ya ece.

5 Maka kin tohe akan sutaya ehde;

Hecen owihanke wanica yutokanpi kte sni.

6 Miniwanca on wokoyake iyecen ayakahpa;

Mini tanka kin paha iwankarn hiyeya.

7 Yakiśica hehan najicapi ;

Wakinyan nitawa hoton kin on napapi.

8 Paha iyecen wankan yapi;

Kaksiza iyecen kun ipi ;

Owanka kin de yecage cin ekta.

9 Oicago wan yakaga, sanpa yapi kte śni ;

Ake maka kin apaśbog hiyu kte śni.

10 Kaksiza kin en minilidoka inanpe ya;

Hena paha kin otahedan kaduza ece.

11 Tinta wamanica owasin etanhan mini yatkanpi :

Hen śonśonna jtu unpi kin ipuza enakiyapi.

12 Iwankam mahpiya okinyanpi kin otipi ;

Can adetka ehna hotonpi ece.

13 Wankan tipi tawa etanhan he kin amagajuya:

Niolian etanhan taku icage cin on maka kin imnahan

14 Wato kin he woteca icaliwicakiciya;

Qa waskuyeca, wicaśta woju kin on;

Hecen maka kin etanhan aguyapi hinanpe ye kta.

15 Qa miniśa wicaśta cante iyuśkinkiya,

Wihdi isanpa ite kin iyehkiye kta ;

Qa aguyapi wicacante yusuta ece kin he.

16 Jehowa can tawa kin imnahan;

Lebanon liante iye oju kin hena.

17 Hena en zitkadan holipi kagapi ;

Hoka wacantkiye cin he wazi en otipi.

18 He tehanwankantu kin tatokadan tawapi; 


\section{P S A L M 105.}

Qa imnija kin hitunkasan wowinape yapi.

19 Makoncage on hanyetu wi kin kicaga:

Anpetu wi tohan iyaye kte cin he sdonkiya.

20 Otpaza yakaga, unkan ecen hanyetu;

Hehan contanka wamanica owasin hinanpapi.

21 Mnaja cinca taku iyahpayapi kta ahotonpi;

Qa Wakantanka woyute kidapi ece.

22 Wi hinanpa, hehan witaya hdipi;

Qa waśunpi kin en hdiwankapi ece.

23 Hehan wicaśta wicohtani ekta ya;

Qa htayetu hehanyan wicohan econ ece.

24 Jehowa, niohan kin hena ota hinca;

Woksape on hena owasin yakaga:

Wowijice nitawa on maka kin ojudan.

25 Miniwanca kin de tanka qa ohdakinyan hanska;

Hen taku śkanśkan yukan, qa yawapica śni ;

Taku niyake un cikcistinna tankinyanyan koya.

26 He ohna wita wata kin'ohnihdapi :

Unktehi kin de ohna śkate kta yakaga.

27 Hena owasin niye wacinniyanpi :

Tohan iyehantu eca woyute wicayaqu ece kta.

28 Niye wawicayaqu, hena pahipi;

Ninape yahdumdaya, taku waśte on imnanpi ece.

29 Niye niite nayakilibe, hena nihinciyapi :

Woniya ewicayeciyaku, hena țapi ;

Qa maka mdu ekta hdapi.

30 Nitaniya yeyaśi, hena icagapi :

Qa makoce ite kin duteca ece.

31 Jehowa towitan kin owihanke wanice kte:

Jehowa iye ohan kin on ihduśkin nunwe.

32 He maka kin en etonwan, unkan cancan:

Paha kin yutan, unkan hena izitapi.

33 Tohanyan wani kin Jehowa iwadowan kta;

Waun kin hehanyan mita Wakantanka wakahimdamde kta.

34 Iye awacin waun kin he skuye kta:

Jehowa en imduśkin kta.

35 Wahtanipi sa maka kin etanhan owihankepi kta;

Qa wicaśta sica icimana en unpi kte śni.

Minagi, Jehowa yawaśte wo.

Jah yatan miye.

\section{PSALM 105.}

1 Jehowa wopida eciya po,

Iye caje hoyekiya miye ;

Iye ohan tanka oyatepi ehna oyaka po.

2 Iye idowan po, odowan kahiyaya miye;

Iye tawowapetokeca kin owasin awacin po.

3 Iye caje wakan kin itan miye; 


\section{P S A L 105.}

'Iona Jehowa akitapi kin hena cante waśtepi kta.

4 Jehowa ode miye, qa iye towaśake kin;

Ohinniyan ite kin akita miye.

5 Wicohan wakan econ qon hena kiksuya po ;

Iye tawowapetokeca, qa woyaco iye $i$ kin etanhan.

6 Abraham iye taokiye etanhan inicagapi;

Jakob cinca wicakahnige ciqon.

7 Jehowa Wakantanka unkitawapi kin he iye;

Tawoyaco kin maka kin owancaya un.

8 Wicotakuye tawa kin he ohinniyan kiksuya;

Wicoie econ wicaśi qon, wicoicage kektopawinge hehanyan :

9 Abiaham kici hduśtan qon he;

Qa Isaak en wokonze eciya:

10 Nakun Jakob he wokage kiciyusuta;

Israel en wicotakuye owihanke wanica.

11 Niye Kanaan makoce kin cic̣u kta,

Makoce iyutapi nitawapi kta ce, eya.

12 Hinyaliin wicayawapi waśakadan;

Tonana hinca, qa en unhdaka unpi.

13 Qa oyate kin wicehna ihdaka yapi;

Wokiconze wan etanhan oyate tokeca ekta.

14 Tuwedan kakiświcaya iyowinkiye śni ;

Qa iyepi on wicaśtayatapi iyopewicaya :

I5 Sdawicawakiye cin hena owicayutanpi śni po;

Qa waayate mitawa taku śica ecawicakiconpi śni po.

16 Hehan makoce kin he en wicaakihan wan u si ;

Aguyapi sagye kin owasin kaksa.

17 Wicitokam wicaśta wan ye śi ;

Joseph wowidake kta e wiyopeyapi :

18 Wicaśke on siha kiunniyanpi ;

Iye nagi mazasapa kin en u.

19 Oie kin he ecetu hehanyan,

Jehowa taku eye ciqon he iyutanye.

20 Wicaśtayatapi kin he ye wicaśi, qa kiyukca;

Oyatepi itancan kin hee, qa kiciyuhdoka.

21 Iye ti kin ohna itancan kaga;

Qa wowijice tawa kin owasin tawakiya.

22 Tohan iyokipi kinhan akicita tancan wicakaśke kta;

Qa hunkayapi wicayuhe cin ksapa wicakage kta.

23 Hehan Israel Egupta en ahiti;

Qa Jakob Ḣam makoce kin en ounyan.

24 Unkan taoyate kin nina wicahduota;

Qa tokayapi kin isanpa wicayuwaśake.

25 Hehan cante wicayutokeca, taoyate śice wicadakapi kta;

Taokiye wicaye cin hnayan wicakuwapi kta.

26 Moses iye taokiye kin ye śi ;

Qa Aaron kahinige ciqon he.

27 Iye tawowapetokeca oie kin wicakipazopi :

Qa tohan wakan, ப்am makoce kin en. 
28 Otpaza ye śi, qa otpaza kaga;

Unkan iye oie kin kizapi śni.

29 Mini tawapi kin he we kaga;

Qa hogan tawapi kin wicakte.

30 Makoce tawapi hnaśka ota icaliya;

Wicaśtayatapi yuhapi wankan tipi kin ohna.

31 Ecen eya, unkan hoponkadan hiyupi ;

Qa heya, makoce tawapi owancaya.

32 Magaju kte cin he wasu wicaqu ;

Peta ide kin makoce tawapi owancaya.

33 Hastanyanka iyuwi qa suken can tawapi kin hena apa;

Qa tamakocepi ihdukśan can kin kawega.

34 Ecen eya, unkan psipsicadan tanka hiyupi;

Psipsicadan nakun, qa hena yawapica śni :

35 Qa tamakocepi kin en wato owasin yaśdapi ;

Qa tamagapi en taku icage cin temyapi.

36 Nakun tamakocepi en tona tokapapi owasin wicakte; Iye towaśakepi tokaheya icage cin owasin.

37 Hehan mazaska mazaskazi ko yuha hinapewicaya:

Unkan wicowazi tawa kin en wanjidan hustake śni.

38 Iyayapi qehan Egupta iyuśkin :

Nina kowicakipapi, heon etanhan.

39 Woakahpe kta on mahpiya śapa hdumdaya;

Qa peta wan, hanyetu en iyojanjan kta.

40 Kidapi, unkan wakiyedan $u$ wicakiya :

Qa mahpiya aguyapi on imnawicaya.

41 Imnija wan kahdoka, unkan mini hiyu;

Hopuza en wakpa wan hiyaya.

42 Iye oie wakan qon he kiksuya heon;

Taokiye Abraham taku eciye ciqon.

43 Qa iye taoyate iyuśkinyan hinanpe wicaya;

Tona wicakalinige cin hena iyakiśapi.

44 Qa makoce Ikcewicaśta tawapi qon he wicaqu :

Unkan oyatepi litanipi qon he yuhapi.

45 Hecen iye tawoahope kin opapi kta;

Qa toope kin hena yuhapi kta.

Jah yatan miye.

\section{PSALM 106.}

1 Jah yatan miye.

Jehowa wopida eciya po ;

Iye waśte, heon etanhan;

Qa towaonśida kin owihanke wanica.

2 Jehowa tohan tanka kin tuwe oyake kta he; Iye yatanpi ocowasin tuwe nahonwicaye kta he.

3 Tona wokonze opapi kin hena cante waśtepi ;

Tuwe ohinniyan woowotanna econ kin.

4 Jehowa, nitaoyate cantewicayakiye cin iyecen miksuya ye; 
Nitowiconi kin hiyumakiya wo.

5 Tona yakahniga wowaśte yuhapi kin wanmdake kta; Nitaoyate wiyuśkinpi kin on imduśkin kta;

Woaihpeye nitawa kin en wowitan miçiye kta.

6 Hunkakewicunyanpi om waunhtanipi;

Pemniyan unkohanyanpi, śicaya econkupi.

7 Egupta en niohan wakan kin

Hunkakewic unyanpi okahnigapi śni ;

Nitowaonśida untkana kin kiksuyapi śni ;

T'uka wawakipajinpi, mde kin ekta, Mde Śa kin en.

8 Heca eśta iye caje kin on niwicakiya;

Towaśake sdonyewicakiye kta e heon.

9 Nakun Mde Śa kin kiśica, unkan pus aya;

Hecen ośbe kin ehna iyaye wicaya, hopuza iyececa.

$10 \mathrm{Qa}$ waśicedake nape kin etanhan ewicayaku;

Qa toka nape kin etanhan opewicakiton.

11 Unkan tokawicayapi kin mini awicakahpa;

Etanhan wanjidan eśta okaptapi śni.

12 Hehan oie kin wicadapi;

Iye yatanpi kin ahiyayapi.

13 Koyahanna iye ohan kin akiktonjapi ;

Iye tawowahokonkiye kin akipepi śni.

14 Tuka hewotahedan wocantiheye wan cantiheyapi;

Qa hopuza en Wakantanka iyutanpi.

15. Unkan taku kidapi qon he awicayupta;

Tuka wicotamaheca nagipi en ye śi.

16 Nakun otiwita en Moses inakiwizipi; Qa Aaron, Jehowa yuwakan kin he.

17 Hehan maka kin ihduhdoka, qa Dathan napca;

Qa Abiram tona om un ko awicakahpa.

18 Unkan ośpaye kin hena peta wicahuhnaga;

Ide wan śicapi kin hena huhnahwicaya.

19 Horeb en ptejicadan wan kagapi;

Qa taku śdoya kagapi kin itokam patujapi.

20 Hecen iye towitanpi kin hdutokecapi,

Tatanka wato yute cin ouncage iyececa.

21 Wakantanka niwicaye ciqon he akiktonjapi ;

Egupta en wicohan tanka econ qon :

22 Wowapetokeca Ḣam makoce kin en;

Mde Śa ekta taku wowinihan.

23 Hehan ihangwicaye kta, keya ;

Moses iye kahnige cigon he itokam,

Otahedan najin śni unkanś ;

'Tocanniye yutokan iyeye kta, on waihangye kte śni.

24 Qa makoce wiciyokipi kin he aktapi śni ;

Iye oie kin wicadapi śni :

25 Tuka tawakeyapi ohna wihnupi;

Jehowa ho kin he anagoptanpi śni.

26 Hehan hena on nape hdugata ; 
Tintoskan ihpaye wicakiye kta :

27 Qa cincapi oyatepi wicehna hinhpaye wicaye kta;

Qa makoce tokeca ekta iyewicaye kta.

28 Unkan Baal Peor en ikoyagiciyapi ;

Qa țapi taku wakiyuśnapi kin yutapi.

29 Hecen taku śica econpi kin on iyokiśinyapi :

Unkan makośica iyowicalipaya.

30 Hehan Phinehas inajin qa wayaco:

Unkan makośica kin anaptapi.

31 Unkan he woowotanna kiciyawapi ;

Wicoicage qa wicoicage ekta owihanke wanica.

32 Nakun Woakinica mini kin ekta śihdayapi :

Hecen iyepi on Moses taku śica akipa :

33 Iye taniya kin kipajinpi:

Unkan iha on ecinśniyan ia.

34 Oyatepi kin ihangwicayapi śni ;

Jehowa kewicakiye ciqon iyececa.

35 Tuka oyatepi kin om icicahiyapi,

Qa wicohan tawapi onspeiciciyapi :

36 Qa wakagapi tawapi ohodapi ;

Unkan hena e wohmunke yapi kin ee.

37 Han, cinhintkupi qa cunwintkupi kin,

Taku wakan śica wawicakiyuśnapi.

38 Hecen wicawe taku iyaonpepicaśni papsonpi,

Cinhintkupi qa cunwintkupi we kin,

He Kanaan wakagapi kin wawicakiyuśnapi ;

Hecen makoce kin wicawe on yuśapapi.

39 Nakun iye olianpi kin on ihduśicapi ;

Qa śicaya econpi kin on wawicihahapi ic̣icagapi.

40 Unkan Jehowa iye taoyate canniyewicaya;

Qa woaihpeye tawa kin wahtekida śni.

41 Hehan Ilkcewicaśta rapepi kin en wicaquu.

Unkan tona śicewicadapi kin hena wowidake wicayapi:

42 Qa tokawicayapi kin śicaya wicakuwapi :

Hecen napepi kin ihukuya patujapi.

43 Iye ijehan wicakiyukca;

Tuka wakiconzapi on kipajinpi ;

Hecen wahtanipi kin on atakunipi śni.

44 Tuka iyokiśicapi kin he wanyaka,

Śsahowayapi nahon qehan.

45. Qa iyepi on wicotakuye tawa kin he kiksuya;

Qa towaonśida untkanna on tawacin hdutokeca.

46. Qa wayaka wicayuhapi owasin itokam,

Hena onśiwicadapi kta wicaqu.

47 Jehowa Wakantanka unkitawapi, niunkiya po ;

Qa Ikcewicaśta etanhan ake unhduwitaya po:

Nicaje wakan kin unyatanpi kta;

Nitowitan kin en unkihdatanpi kta.

48: Jehowa Israel ta Wakantanka kin yawaśtepi nunwe; 


\section{PSA L M 107.}

Otokahe wanintanhan qa owihanke wanica.

Unkan wicaśta owasin, Amen, eyapi.

Jah yatan miye.

\section{PSALM $10 \%$.}

1 Jehowa wopida eciya po, iye waśte kin heon; "Towaonśida kin he owihanke wanica:

2 Tona Jehowa opewicakiton kin hena eyapi kta; Tona toka nape kin etanhan opewicakiton kin.

3 Qa makoce tokeca etanhan wicahduwitaya; Wiyohiyanpa tanhan qa wiyohpeya tanhan, Waziyatanhan qa miniwanca etanhan.

4 Makoskan onunipi, liewoskan canku ohna; Otonwe en ounyanpi kte cin iyeyapi śni.

5 Wotektehdapi, nakun ipuzapi ; Tanmahen tanhan nagipi hanyanpi.

6 Hehan iyokiśicapi en Jehowa hoyekiyapi :

- Unkan wicokakije etanhan ewicayaku;

7 Qa canku owotanna ohna cankuye wicaya; Otonwe en ounyanpi kta he ekta yapi kta.

8 Jehowa wopida eciyapi kte, Iye towaonśida kin on, Qa wowapetokeca Adam cinca ecawicakicon kin hena on.

9 Wicanagi cantokpani kin he imnaya ece; Qa nagi wotektehda kin he taku waśte on ojuya.

10 Tona otpaza qa wiconțe ohanzi en iyotankapi ; Wokakije mazasapa ko on wicakaśkapi :

11 Hena Iyotan Waśaka oie kin kipajinpi; Qa Iyotan Wankan tawowahokonkiye kin aktapi śni :

12 Hecen wicohtani on cante onśika wicakaga: Hicahanpi qa waokiye wanica.

13 Hehan iyokiśicapi en Jehowa hoyekiyapi : Unkan wicokakije etanhan ewicayaku:

14 Otpaza qa wiconte ohanzi etanhan iwicacu; Qa on wicakaśkapi kin hena yuksa.

15 Jehowa wopida eciyapi kta, towaonśida kin on; Qa wowapetokeca Adam cinca ecawicakicon kin hena on:

16 Mazaśa tiyopa kin kaptuptuja heon; Qa mazasapa inatake kin kaksaksa.

17 Witkotkopi kin, walitanipi canku kin on, Qa taku śica econpi kin on, kakiśiçiyapi.

18 Iye nagipi woyute owasin hitihdapi ; Qa wiconțe tiyopa kin ikiyedan yapi.

19 Hehan iyokiśicapi en Jehowa hoyekiyapi : Unkan wicokakije etanhan ewicayaku:

20 Iye oie kin ukiye ça asniwicaya; Qa wicotakuniśni etanhan hdinanpe wicaya.

21 Jehowa wopida eciyapi kte, towaonśida kin on, 


\section{P S A L M 108.}

Qa wowapetokeca Adam cinca ecawicakicon kin hena on:

22 Qa wopida wośnapi wayuśnapi kte ;

Qa dowanpi on iye ohan kin oyakapi kte.

23 Tona miniwanca ekta wita wata ohna yapi,

Qa mini ota kin ohna wicohan econpi kin;

24 Hena Jehowa ohan kin wanyakapi;

Qa ośbe kin en wowapetokeca econ kin.

25 Hehan ecen eya, unkan tate wohitika wan uye; Qa taja kin wankan icu.

26 Mahpiya ekta wankan yapi ;

Kuya wośbe kin ekta ipi ;

Śicaya unpi kin on nagipi nihinciyapi.

27 Itohomnipi qa kacegya manipi, witkopi iyececa; Qa wacinksapapi qon iyuhpa taninśni iyaya.

28 Hehan iyokiśicapi en Jehowa hoyekiyapi ;

Unkan wokakije etanhan hinanpe wicaya.

29 Tate wohitika qon he amdakedan kaga:

Unkan taja tawapi kin inina hiyeya.

30 Hehan owanji yukanpi on pidapi :

Hecen oihunni cinpi qon en awicahi.

31 Jehowa wopida eciyapi kte, towaonśida kin on; Qa wowapetokeca Adam cinca ecawicakicon kin hena on.

32 Nakun oyate mniciyapi kin en yatankapi kte; Qa hunkayapi omniciye kin en idowanpi kte.

33 Wakpadan kin hena tintoskan ee kiya ; Qa minihdoka kin hopuza kaga:

34 Waskuyeca makoce wan miniskuya icu kıya; Tona en ounyanpi śicaya econpi kin he on.

35 'Tintoskan kin he miniyowe kiya ; Qa hopuza kin he minilidoka eepi kaga:

36 Qa hen wotektehdapi kin ewicahnaka; Unkan otonwe en ounyanpi kte cin he kagapi :

37 Qa maga ojupi, qa hastanyanka iyuwi huhdepi ; Qa woicage waskuyeca icahyapi.

38 Nakun wicayawaśte, hecen nina ihduotapi; Qa tawanuyanpi kin wicayutonna śni.

39 Hena wanistinna ayapi qa patuś unpi tuka qon; Wokakije, wowayazan qa woiyokiśice kin on.

40 Wicaśtayatapi wowahteda śni wicakaga; Qa canku codan makoskan onuniwicaya.

41 Tuka wahpanicapi kin wokakije etanhan ewicayaku; Qa optaye iyececa wicowazi wicakaga.

42 Wicaśta ecetupi wanyakapi qa iyuśkinpi kta; Qa woahtani owasin iohmus icu kta.

43 Tona wacinksapapi qa dena awacinpi kinhan, Hena Jehowa towaonśida kin iyukcanpi kta. 
PSALM 108.

Psalm odowan. David tawa.

1 Wakantanka, micante wiyeya un; Wadowan qa mdatan kta, mitowitan kin he on.

2 Cotanka candowankiyapi ko kik ta miye ; Miye qe anpao kin mduhice kta.

3 Jehowa, oyatepi ehna ciyatan kta; Oyate kin en ciyaonihan kta.

4 Mahpiya iwankapatanhan nitowaonśida kin tanka; Qa nitowicake kin mahpiya śapa iyahde.

5 Wakantanka, mahpiya isanpa niyawankantuyapi nunwe; Qa maka kin ocowasin iwankam nitowitan.

6 Waśtewicayadake cin hena ewicayakupi kta, Heon ninape etapa on niunkiyapi qa unkay upta po.

7 Wakantanka iye towitan en wohdaka; Wimduśkin kta; Śekem wapamni kta ; Sukoth kaksiza kin imdute kta ce.

8 Gilead he mitawa, Manassa mitawa; Ephraim nakun mapa wowaśake kin ; Juda woope kaga mitawa kin hee:

9 Moab woyujaja koka mitawa kin hee; Edom akan mitahanpe elipewaye kta; Philistia on wimduśkin kta.

10 Tuwe otonwe aconkaśkapi kin en amaye kta he; Tuwe Edom en amai kta he.

11 Wakantanka ehpeunyanpi qon hee kte śni he; Qa Wakantanka ozuye unkitawapi om ye śni qon.

12 Toka kin etanhan ounkiya miye : Wicaśta akantu waehdakupi kin he taku śni.

13 Wakantanka eciyatanhan wowaśake unkicagapi kta; Qa iye tokaunyanpi kin nawicapce kta.

PSALM 109.

Dowan itancan kin kicagapi. Dawid tadowan.

1 Wakantanka mdatan ece kin, Inina yanke śni ye.

2 Wicai śica qa wicai wahnayan amahdukawapi ; Wicaceji itonśni on amaiapi.

3 Nakun śicedakapi wicoie on aohdutemayanpi; Qa taku on etanhan śni makizapi.

4. Wacanwakiye cin on toka mayanpi; Tuka miye qe wocekiye en waun.

5 Waśte on taku śica iyamaonpapi; Qa wośicedake, wocantekiye kin on.

6 Wicaśta śica wan iye awanyagkiya wo; Qa etapa eciyatanhan Satan inajin nunwe. 
7 Tohan yacopi kinhan śica yawapi kte; Qa tawocekiye kin he woahtani kte.

8 Anpetu tawa kin tonnana kte; Qa toawanyake kin tuwe tokeca icu kte.

9 Cinca kin wamdenicapi kta; Qa tawicu kin wiwazice kta.

10 Qa cinca kin onuniyan unpi qa wo dapi nunwe; Qa tihulia kin ehna waakitapi kte.

11 Taku tawa kin owasin icazokiye cin he iyahpaye kte; Qa tohtani kin oyate tokeca kipi kte.

12 Tuwedan katinyan onśikida kte śni ; Qa wamdenica tawa kin tuwedan cantewicakiye kte śni.

13 Tona etanhan icage cin hena awihnunipi kte; Wicoicage iyokihe en cajepi pajujupi nunwe.

14 Iye atewicaye wahtanipi kin Jehowa kiksuye kte ; Qa hunku taku śica econ kin he kajujupi śni nunwe.

15 Hena ohinniyan Jehowa itokam wanke kte ; Hecen kiksuyapi kin maka kin etanhan icu kte.

16 Iye wowaonśida econ kta kiksuye śni heon; Nakun wicaśta onśika qa wahpanica kin śicaya kuwa; Qa wanji cante kaśujapi kin kte kta tuka.

17 Tuka wayaśicapi kin he waśtedaka, hecen akipa : Qa wayawaśtepi kin he waśtedake śni, hecen he itehan iyeyapi.

18 Unkan wokoyake iyecen wayaśicapi kohdaka; Hecen mini iyecen tan mahen hiyu; Qa wihdi iyecen huhu kin en hiyohi.

19 Wokoyake un kin he iyecen kohdake kta ; Qa ipiyaka iyececa ohinniyan ipiyagkiton kte.

20 'Tona tokamayanpi Jehowa etanhan wokajuju tawapi kin dee; Qa tona minagi taku śica eciyapi kin hena.

21 Tuka niye, Jehowa, Itancan, Nicaje eciyatanhan ecamicon wo ;

Nitowaonśida waśte, heon makiyuśka wo.

22 Miye makakije ça onmaśika; Qa mahentanhan cante mapalidokapi.

23 Ohanzi wan takinyan ye cin iyecen mataninśni. Qa psipsicadan iyecen kaham iyemayanpi.

24 Akihanpi on hupahu wamaśake śni ; Qa śin manica on micehipi son aya.

25 Nakun miye wowihahamayanpi ;

Wanmayakapi, pomnamnamakiyapi.

26 Jehowa, Wakantanka mitawa, omakiya wo ;

Nitowaonśida eciyatanhan nimayan wo.

27 Unkan ninape kin he dee sdonyapi kta; Jehowa niye hecanon kin.

28 Hena wayaśicapi kta, tuka niye wadawaśte kta:

Hena najinpi qa iśtecapi kta ;

Tuka nitaokiye iyuśkin kta.

29 Tona tokamayanpi wonihinciye koyakapi kta ; 
Qa wowiśtece kin he śina iyecen inpi kta.

30 Mii on Jelıowa nina wopida ewakiye kta;

Qa wicota ehna, mdatan kta.

31 Iye wicaśta onśike cin etapa eciyatanhan najin kta;

Tona nagi yacopi kin etanhan eyaku kta.

\section{PSALM 110.}

Dawid tadowan.

1 Jehowa Itancan mitawa kin heciya;

Mietapa ekta iyotanka wo,

Tona tokaniyanpi siha oahde nilawa wakage kta hehanyan.

2 Nitowaśake icapsinte kin Jehowa Zion etanhan hiyuye kta :

Tokaniyanpi kin cokaya wicaśtayatapi yanka wo.

3 Nitowaśake anpetu kin en, nitaoyate waihduśnapi,

Wowakan wiciyokipi kin on;

Anpao tamni kin etanhan,

Koniśka cu kin he yahduha.

4 Jehowa wakonza, qa tawacin hdutokeca kte śni ;

Niye wawayuśna owihanke wanica henica kta,

Melkizedek touncage kin eciyatanhan.

5 Itancan kin nietapa ekta yanke cin,

Iye tocanniye anpetu kin en,

Wicaśtayatapi katpa iyewicaya.

6 Ikcewicaśta ehna wayaco kta;

Wicaśta tapi on ojuya;

Maka ohdakinyan hehanyan pa wicakahuge.

7 Canku ohna minilidoka kin etanhan yatke kta :

Heon etanhan pa yuwankan icu kta.

\section{PSALM. 111.}

1 Jah yatan miye.

Micante ocowasin on Jehowa mdatan kta,

Wicaśta ecetu takodakiciyapi qa omniciye kin en.

2 Jehowa ohan kin hena tankinyanyan;

Tona iyokipipi owasin hena akitapi ece.

3 Iye ohan kin woyuonihan qa wotanka;

Qa toowotanna kin owihanke wanica.

4 Iye ohan wakan kin wokiksuye kicaga:

Jehowa waonśida qa wacantkiya.

5 Tona kokipapi kin woyute wicaqu ;

Wicotakuye tawa kin ohinniyan kiksuye kta.

6 Iye tohitani wowaśake kin taoyate owicakiyaka; Ilkcewicaśta tamakore kin wicaqu kta.

7 Iye nape taku econ kin hena wowicake qa wokonze :

Tawowahokonkiye kin owasin wicakapi :

8 Owihanke wanica hehanyan yusutapi ;

Wowicake qa woowotanna on econpi. 


\section{P S A L M 113.}

9 Iye taoyate woehdaku wicaqu;

Wicotakuye tawa kin owihankeśniyan hdusuta:

Iye caje kin wakan qa wokokipe.

10 Woksape otokahe Jehowa kokipapi kin hee;

Tona heconpi kin hena owasin wayupikapi:

Iye yatanpi kin he owihanke wanice kta.

\section{PSALM 112.}

1 Jah yatan miye.

Wicaśta Jehowa kokipe cin he cante waśte;

Tawoahope kin on iyuśkin hinca.

2 Iye cinca maka akan waśakapi kta;

Tona ecetupi wicoicage kin he yawaśtepi kta.

3 Woyuha qa wowijice iye ti kin ohna; Qa toowotanna kin owihanke wanice kta.

4 Otpaza en wicaśta ecetu iyoyanpa awicahinanpa;

Waonśida qa wacantkiya qa owotanna.

5 Wicaśta wacantkiye ça wawicaqu kin he waśte;

He wokonze on tohaul kin hdusttan kta.

6 Awicakehan ohinniyan yuhohopi kte śni :

Wicaśta owotanna kin owihankeśniyan kiksuyapi kta.

7 Taku śica nahonpi kin on kopehda kte śni ;

Cante yusutapi, Jehowa wacinyan un.

8 Iye cante kin yusutapi, wakokipe kte śni;

Tokawicaya awicatonwe kte cin hehanyan.

9 Ituwicakilian, wahpanicapi taku wicaqu ;

Toowotanna kin owihanke wanice kta:

Iye he kin wowitan on wankan un kta.

10 Wicaśta śice cin he wanyake ça śinhda kta;

Hi hdakinskinze cea skan kta:

Wicaśta ślca taku cin kin he awihunni kta.

\section{PSALM 113.}

1 Jah yatan miye.

Yatan po, Jehowa taokiye kin; Jehowa caje kin he yatan miye.

2 Jehowa caje kin yawaśtepi nunwe;

Detanhan qa owihanke wanica.

3 Wi hinanpe cin hetanhan, iyaye cin hehanyan, Jehowa caje hin yatanpi nunwe.

4 Jehowa tehan wankan ull, oyate owasin iwankam; Iye towitan mahpiya kin iwankam.

5 Jehowa Wakantanka unkitawapi, Tehanwankantu kiyotanke cin he tuwe iyececa he:

6 Temahentuya etonwe cin hee; Mahpiya en qa maka kin en.

7 Wahpanica kin watuśekśeca etanhan eyaku ; 


\section{P S A L M 115.}

Onśike cin tacesdi paha kin etanhan yuwankan eyaku kta;

8 Wicaśta itancanpi kin om iyotanke kiye kta;

Iye taoyate itancanpi kin om.

9 Winohinca cinca ton śni ti kin

He iyuśkinyan cinca hduha iyotanke kiya.

Jah yatan miye.

\section{PSALM 114.}

1 Israel Egupta etanhan hinanpe cehan:

Jakob ti kin oyate wan śa iapi kin hetanhan;

2 Juda he tipi wakan tawa kin icaga;

Tokiconze kin Israel hee.

3 Mini tanka kin he wanyake ca najica; Jordan he nakun namni :

4 Paha kin hena tamdoka iyecen ipsicapi; Qir pajodan kin tacinca kin iyececapi.

5 Mini tanka, tonikeca on nayajica he; Jordan, tokeca nayamni he.

6 Paha kin, tokeca tamdoka iyecen iyapsicapi he;

Pajodan, tokeca tacinca iyenicecapi he.

7 Maka kin, Itancan kin itokam, cancan wo; Jakob ta Wakantanka kin itokam.

8 He imnija kiu minihdoka kaga ;

Wanhi inyan kin he miniyowe ee kiya.

\section{PSALM 115.}

1 Unkiyepi śni, Jehowa, unkiyepi śni;

Tuka nicaje wowitan qu wo ;

Nitowaonśida on, nitowicake kin on.

2 Tokeca Ikcewicaśta heyapi kta;

Wanna Taku Wakan tawapi tokiya un he.

3 Tuka Wakantanka unkitawapi mahipiya ekta yanka;

Token iyokipi kin owasin econ ece.

4 Wakagapi tawapi kin hena mazaska qa mazaskazi ;

Wicaśta nape taku kage cin hena.

5 Hena i yukanpi, tuka iapi śni; Iśta yukanpi, tuka wawanyakapi śni :

6 Noge yukanpi, tuka winahonpi śni ; Poge yukanpi, tuka taku omnanpi śni :

7 Nape yukanpi, tuka wiyuzapi śni ; Siha yukanpi, tuka manipi śni ;

Nakun dote eciyatanhan ho enapeyapi śni.

8 Tona kagapi kin hena iś iyececapi kta ;

Tona hena wacinyanpi kin owasill.

9 Israel, niye Jehowa wacinyan wo;

Owicakiye ca wahacanka tawapi kin he iye.

10 Aaron ti kin, Jehowa wacinyan wo; 
Owicakiye ça wahacanka tawapi kin he iye.

11 Jehowa koyakipapi kin, Jehowa wacinyan po;

Owicakiye ca wahacanka tawapi kin he iye.

12 Jehowa unkiye unkiksuyapi; wayawaśte kta ;

Israel ti kin wicayawaśte kta;

Aaron ti kin wicayawaśte kta.

13 Tona Jehowa kokipapi kin hena wicayawaśte kta;

Cistinpidan tankinkinyanpi om.

14 Jehowa niyuotapi nunwe;

Niyepi qa nakun nicincapi kin.

15 Jehowa eciyatanhan niyawaśtepi;

Mahpiya qa maka kage cin hee.

16 Mahpiya mahpiya kin he Jehowa tawa;

Tuka maka kin Adam cinca wicaqu.

17 Tona țapi kin hena Jah yatanpi śni;

Tona woinina ekta yapi kin owasin nakun.

18 Tuka unkiye Jah unyawaśtepi kta;

Detanhan qa owihanke wanica.

Jah yatan miye.

\section{PSALM 116.}

1 Jehowa waśtewadaka,

Miho qa mita wocekiye nahon kin heon.

2 Iye anolimakiye cin heon, Mitaanpetu kin en, hoyewakiye kta.

3 Wiconțe icaśke kin aohdutemayan;

Qa Hades wowayazan kin mayuze;

Wokakije woiyokiśica ko iyewaye.

4 Hehan Jehowa caje kin hoyewakiye kta: Jehowa, ceciciya ce, minagi ehdaku wo.

5 Jehowa wacantkiye ca owotanna; Qa Wakantanḱ unkitawapi kin he waonśida.

6 Jehowa ksapapi śni kin hena awanwicayaka: Miye kun ehpemayanpi, unkan nimayan.

7 Minagi, woozi nitawa ekta hdicu wo ; Jehowa tanyan ecanicon kin heon etanhan.

8 Niye wiconțe etanhan minagi edaku;

Miiśta kin ceyapi etanhan, Misiha hicahanpi etanhan edaku.

9 Jehowa itokam mawani kta, Wiconi makoce kin en.

10 Wicawada, heon iwaa:

Nina makakija qon.

11 Nihinmiciye cin en hepa;

Wicaśta owasin itonpi śni ce.

12 Jehowa taku ota maqu kin, Taku on wecicajuju kta he.

13 Wiconi miniyatke kin iwacu kta, 
Qa Jehowa caje kin hoyewakiye kta.

14 Jehowa taku iwahowaye cin wecicajuju kta, Iho, iye taoyate owasin wicitokam.

15 Tona wacantkiye tawa kin hena țapi kin He Jehowa iśta kin en tehika.

16 Tokin, Jehowa, nitaokiye miyen; Nitaokiye, nitaokiyewin cinhintku kin miyen: Makaśkapi kin mayakidukca.

17 Wopida wośna wan waciciyuśna kta; Qa Jehowa caje kin hoyewakiye kta:

18 Jehowa taku iwahowaye cin wecicajuju kta, Iye taoyate owasin wicitokam:

19 Jehowa ti hocoka kin en; Jerusalem, niye cokaya. Jah yatan miye.

\section{PSALM $11 \%$.}

1 Oyate owasin, Jehowa yatan miye; Wicaśta hiyeye cin owasin, he idowan po.

2 Towaonśida kin unkiyepi en tanka hinca; Qa Jehowa towicake kin he owihanke wanica. Jah yatan miye.

\section{PSALM 118.}

1 Jehowa wopida eciya po, iye waśte heon ; Towaonśida kin he owihanke wanica.

2 Tokin Israel heyapin; Iye towaonśida kin he owihanke wanica.

3 Tokin Aaron ti kin heyapin; Iye towaonsida kin he owihanke wanica.

4 Tokin tona Jehowa kokipapi kin heyapin ; Iye towaonśida kin he owihanke wanica ce.

5 Wokaśke etanhan Jah hoyewakiya ; Owanka tanka en Jah amayupta.

6 Jehowa mici un; wakowakipe kte śni; Wicaśta akantu taku ecamicon okihi he.

7 Jehowa mici un, tona omakiyapi kin ehna ; Hecen tona śicemadapi kin awicawatonwe kta.,

8 Jehowa wacinyanpi kin he waśte, Wicaśta wacinwicayapi kin isanpa.

9 Jehowa wacinyanpi kin he waśte; Wicaśtayatapi wacinwicayapi kin isanpa.

10 Ikcewicaśta owasin aohdutemayanpi ; Tuka Jehowa caje kin on bawicawaśpe kta.

11 Aohdutemayanpi, han, aohdutemayanpi; Tuka Jehowa caje kin on bawicawaśpe kta.

12 Tuhmaga iyececa aohdutemayanpi ; 


\section{P S A L M 119.}

Wapepeka ide kin iyececa bowicasnipi ;

Tuka Jehowa caje kin on bawicawaśpe kta.

13 Wacayape, mahinhpaye kta on camayapa; Tuka Jehowa omakiya.

14 Mitowaśake qa mitadowan kin Jah hee; Nakun he wanikiya mitawa.

15 Wiconi qa wowiyuśkin ho kin he Wicaśta owotanna tawakeya kin ohna: Jehowa nape etapa kin he wowaśake kaga.

16 Jehowa nape etapa hduwankan icu; Jehora nape etapa kin he wowaśake kaga.

17 Mate kte śni, tuka wani kta; Qa Jah ohan kin omdake kta.

18 Awicakehan Jah nina iyopemayan; Tuka wiconte ekta yemaye śni.

19 Woowotanna tiyopa kin makiyulidoka ye ; Hena ohna hibu kta, Jah wopida ewakiye kta.

20 Jehowa tatiyopa kin he dee; Ohna wicaśta owotanna tin hiyupi kta.

21 Amayadupta, heon wopida eciciye kta; Qa wiconi mitawa kin he niye.

22 Inyan wan ticagapi aktapi śni qon He oise pa kin icaga ce:

23 He Jehowa eciyatanhan, Qa unkiśtapi kin en taku wowinihan.

24 Jehowa anpetu kage cin he dee; Fn unkiyuśkinpi qa piundapi kta.

25 Ceunniciyapi, Jehowa, dehan niunkiya po: Ceunniciyapi, Jehowa, dehan wapi unyan po.

26 Tuwe Jehowa caje on u kin he yawaśtepi : Jehowa ti kin etanhan unniyawaśtepi.

27 Jehowa Iyotan Waśaka qa iyoyanpa unqupi : Wośnapi kin he hahonta on kaśka po, Owayuśna he kin en.

28 Iyotan Waśaka mitawa kin he niye, Heon ciyatan kta;

Wakantanka mitawa, icidowan kta.

29 Jehowa wopida eciya po;

Iye waśte kin heon etanhan;

Towaonśida kin he owihanke wanica.

\section{PSALIM 119.}

ALEPH.

1 Canku ohna ecetupi kin hena cante waśtepi; Tona Jehowa toope omanipi kin hena.

2 Tawoyaotanin opapi kin hena cante waśtepi ; Tona cante ocowasin on akitapi kin hena:

3 Nakun taku śica econpi śni ; 
Tuka iye tacanku kin ohna manipi.

4 Woonspe nitawa yakonza;

Awicakehan ounpapi kta e heon.

5 Tokin mitacanku yusutapin,

Wokage nitawa owape kta heon.

6 Hehan imaśtece kte śni,

Nitawoahope owasin en ewatonwe cinhan.

7 Cante ecetu kin on wopida eciciye kta ;

Woyaco owotanna nitawa onmaspe kinhan.

8 Wokage nitawa owape kta ;

Tokin ocowasin ehpemayaye śnin.

BETH.

9 Kośka wan taku on tacanku kpakinte kta, Hecen nioie eciyatanhan hduhe kta he.

10 Micante ncowasin on acicita;

Nitawoahope etanhan wanuni śni nunwe.

11 Taku ehe cin he cante mahen nawahman;

Hecen wacicilitani kte śni.

12 Jehowa, niye niyawaśtepi nunwe;

Nitoope kin onspemakiya ye.

13 Nii wayaco kin owasin,

Hena miiha on omdaka.

14 Nitawoyaotanin canku kin ohna imduśkin; Wowijice owasin on iyececa.

15 Wowahokonkiye nitawa awacin waun kta; Qa nitacanku ekta ewatonwe kta.

16 Wokage nitawa en iyuśkin miçiye kta;

Nioie kin awektonje kte śni.

. GIMEL.

17 Nitaokiye miye wani kta maqu wo;

Kinhan nioie awanmdake kta.

18 Iśta mayukawa wo, kinhan ewatonwe kta ;

Nitoope eciyatanhan wicolian wakan.

19 Maka akan unhdaka waun;

Nitawoahope kin anamakibibe śni wo.

20 Ohinniyan minagi nitawoyaco

Cantokpani on kaśuśujapi.

21 Wahanhanicidapi kin hena iyopewicayaya,

Wicayaśicapi kin ;

Hena nitawoahope etanhan nunipi.

22 Waaiapi qa śicedakapi kin yutokan iyemiciciya wo;

Nitawoyaotanin awacanmi kin heon.

23 Wicaśta itancanpi nakun iyotankapi qa amaiapi :

Tuka nitaokiye wokage nitawa awacin yanka.

24 Nakun woyaotanin nitawa wowiyuśkin waye;

Wicaśta waonspemakiye cin hena ee.

DALETH.

25 Minagi maka mdu en askamiçiya : 


\section{P S A L M 119.}

Nioie eciyatanhan nimayan wo.

26 Mitacanku kin owahdaka;

Unkan amayadupta;

Wokage nitawa onspemakiya wo.

27 Nitawoonspe ocanku kin okahnihmayan ye,

Kinhan niohan wakan kin awacanmi kta.

28 Woiyokiśica on minagi ceya un ;

Nioie eciyatanhan najin makiya wo.

29 Woitonśni canku kin yutokan iyemiciciya wo;

Qa nitoope kin he ionśimakida ye.

$3 n$ Wowicake canku kin he wakahniga;

Nitawoyaco kin hena mitokam ewahnaka.

31 Nitawoyaotanin sutaya mduza;

Jehowa, iśtenmaye śni wo.

32 Nitawoahope canku kin ohna waimnanke kta ;

Cante mayakidutanka kta, heon etanhan.

HE.

33 Jehowa, wokage nitawa canku ohna amayan wo;

Ininhan, owihanke hehanyan owape kta.

34 Okahnihmayan wo, kinhan nitoope awacanmi kta;

Qa cante ocowasin on owape kta.

35 Nitawoahope canku ohna mani mayan wo;

He en wimduśkin ece.

36 Nitawoyaotanin ekta cante yemayan ye;

Qa wowijice ekta śni.

37 Takuśni wanyakapi etanhan iśta mayuhomni wo :

Nitacanku ohna nimakiya wo.

38 Nitaokiye nioie kin kiciyusuta wo ;

$\mathrm{He}$ on konicipapi kta.

39 Wowiśtece mitawa kowakipe cin he miciyutokan wo;

Woyaco nitawa kin waśte, heon etanhan.

40 Iho, nitawoonspe kin cantowakpani hinca;

Nitoowotanna kin en nimayan wo.

VAU.

41 Nakun, Jẹhowa, nitocantekiye en mau nunwe;

Nitowiconi, nioie kin eciyatanhan.

42 Hecen tuwe taku iyamaonpe cin amdupte kta;

Nioie wacinwaye cin heon etanhan.

43 Nakun mii etanhan wowicake oie kin

Ocowasin ehdaku śni wo;

Woyaco nitawa ape waun kin heon.

44 Hecen nitoope kin ohinniyan ahowape kta;

Owihanke wanica, qa owihanke wanica.

45 Unkan makoce tanka wan omawani kta;

Nitawowahokonkiye awakite cin heon.

46 Nakun wicaśtayatapi wicitokam

Nitawoyaotanin caje mdate kta;

Qa imaśtece kte śni.

47 Nakun nitawoahope en iyuśkin miçiye kta ; 
Hena waśtewadake hinca.

48 Nitawoahope waśtewadake cin hena on,

Nape wankan yewaye kta ;

Qa wokage nitawa awacin manke kta.

zAIN.

49 Nioie kin nitaokiye kiciksuya wo;

Wacinye mayakiye cin heon.

50 Makakija en wacintonhnagmaye cin he dee;

Qa nioie kin he kinimakiya.

51 Wahanicidapi kin hena nina imahahapi ;

Tuka nitoope amduśtan śni.

52 Jehowa, nitawoyaco wanakaja kin hena weksuya;

Qa cante waśte micicaga.

53 Wicaśta śicapi on nina śinwahda;

Nitoope elipeyapi kin heon.

54. Wokage nitawa odowan mitawa kin hee;

Ounhdaka tipi mitawa ohna.

55 Jehowa, hanyetu icunhan nicaje weksuya;

Qa nitoope ahowapa ece.

56 Nitawoonspe owape cin he on,

De mduha ece qon.

CETH.

57 Jehowa, taku mitawa kin he niye ;

Nioie kin mduhe kta, kepa.

58 Nitocantekiye micante ocowasin on awakita ;

Nioie eciyatanhan onśimakida wo.

59 Mitacanku kin awakicanmi ;

Qa nitawoyaotanin ekta misiha hdicu wakiya.

60 Woonspe nitawa mduhe kta e, Heon inawalini qa mdutehan śni.

61 Wicaśta śica ikan tawapi mihdukśan hiyeya ; Tuka nitoope awektonje śni.

62 Ciyatan kta hanyecokaya imdotanke kta, Nitoowotanna woyaco kin hena on.

63 'Tona konicipapi kin owasin kodawicawaya; Qa tona nitawoonspe opapi kin hena.

64 Jehowa, nitowaonśida on maka kin ojudan; Wokage nitawa kin onspemakiya-wo. TETH.

65 Jehowa, nitaokiye taku waśte ecayecon, Nioie kin eciyatanhan.

66 Wiyukcanpi waśte qa wookahnige onspemakiya wo; Nitawoahope wicawada kin heon.

67 Makakije śni he ehan wanuni ; Tuka nakaha iyae cin he owape.

68 Niye niwaśte qa taku waśte ecanon ece; Wokage nitawa onspemakiya wo.

69 Wahaniçidapi kin hena woitonśni amakagapi ;

Miye qe micante ocowasin on nitawoonspe kin owape kta, 
70 Iye cantepi kin wasna iyecen cepa; Miye qe nitoope on imduśkin.

71 Kakiśmayanpi kin he waśte; He on wokage nitawa onspemiciciye kta.

72 Nii woope kin he miciwaśte, Mazaska qa mazaskazi kektopawinge isanpa.

73 Ninape makage ca icahmayan; Onspemakiya wo, kinhan nitawoahope onmaspe kta.

74. Tona konicipapi kin hena wanmayakapi qa wiyuśkinpi kta ; Nioie wacinwaye cin heon etanhan.

75 Jehowa, nitawoyaco kin hena woowotanna sdonwaya; Qa wowicake on kakiśmayaya.

76 Tokin nitowaonśida wacintonhnagmayen : Nitaokiye taku eyakiye ciqon iyececa.

77 Wacanyakiye cin he mahiyohi kte, hecen wani kta ; Nitoope kin he wowiyuśkinwaye, heon.

78 Wahaniçidapi kin iśtecapi nunwe, Woitonśni on mayapemnipi, heon : Miye qe nitawoonspe awacin manke kta.

79 Tona konicipapi kin hena miye en maupi kte ; Qa tona nitawoyaotanin sdonyapi kin hena.

80 Wokage nitawa en micante zanika un nunwe; Hecen imaśtece kte śni.

KAPH.

81 Wiconi nitawa on minagi niyaśni iyaya; Nioie kin on ape waun.

82 Tyae cin on iśta manaka; Hecen, Tohan cante waśte mayakage kta he, epa.

83 Wojuha wan sota en un kin iy emaceca; Wokage nitawa kin hena awektonje śni.

84 Nitaokiye taanpetu kin tonakeca he ; 'Tona śicaya makuwapi kin tohan wicadaco kta he.

85 Wahaniçidapi kin hena woha miçapi ; Hena nitoope kin eciyatanhan śni.

86 Nitawoahope kin owasin wowicake; Woitonśni on śicaya makuwapi; niye omakiya wo.

87 Iśnikaeś makoce kin etanhan ihangmayanpi śni; Tuka nitawoonspe kin amduśtan śni.

88. Nitowaonśida eciyatanhan nimayan wo: Kinhan nii taku yaotanin kin owape kta. LAMED.

89 Jehowa, nioie owihanke wanica, Mahpiya kin ekta yusutapi.

90 Wowicake nitawa kin he wicoicage qa wicoicage hehanyan: Maka kin dusuta, unkan ecen han.

91 Nitawoyaco on anpetu kin dehan hena ecen un ; Hena owasin wowidagyaye cin heon.

92 Nitoope kin he wowiyuśkinwaye śni unkanś, 
Makakije cin en matakuni kte śni tuka.

93 Nitawoonspe kin ohinniyan awektonje kte śni ;

Hena en kinimayakiya nakảeś.

94 Tawamayaya, nimayan wo ;

Nitawoorspe kin awakite cin heon.

95 Wicaśta śica ihangmayan iyapepi ;

Nitawoyaotanin kin hena owakahnige kta.

96 Woecetu kin owasin ihanke kin wanmdaka;

Nitawoahope ohdakinyan tanka hinca.

MEM.

97 Nitoope waśtewadake linca:

Anpetu osan he awacin manka.

98 Nitawoahope ksapa makaga,

Tokamayanpi kin isanpá;

He ohinniyan mitawa nakaeś.

99 Waonspemakiyapi owasin isanpa,

Wa cinksamya miolian ;

Nitawoyaotanin kin hena awacin waun.

100 Wicahincapi kin isanpa wowakahigiga;

Nitawonnspe wapatan kin heon.

101 Canku śica owasin etanhan misiha ewehdaku;

Nioie mduhe kta heon etanhan.

102 Nitawoyaco kin icunonpa mde śni ;

Niye onspemayakiye cin heon.

103 Micaka en nioie kin skuye hinca;

Tuhmaga canhanpi mii kin ohna he isanpa.

104. Wowahokonkiye nitawa etanhan wookahinga mduha;

Heon woitonśni canku owasin śice wadaka. NUN.

105 Nioie misiha kin en petijanjan hee;

Qa mitacanku ohna iyoyanpa kin.

106 Wakonza, nakun ecen ecamon kta;

Woyaco owotanna nitawa kin ahowape kta.

107 Miye nina hin makakija;

Jehowa, nioie eciyatanhan kinimayan wo.

108 Jehowa ceciciya, mii taku itunicihan kin

Hena iyonicipi nunwe ;

Qa nitawoyaco kin hena onspemakiya wo.

109 Minagi ohinniyan minape ohna yanka;

Tuka nitoope kin he awektonje śni.

110 Wicaśta śica mahmunkapi kta;

Tuka nitawoonspe etanhan wanuni s̉ni.

111 Nitawoyaotanin kin hena ohinniyan mitawa kta;

Micante towiyuśkin kin hena ee.

112 Wokage nitawa ecamon kta e cante ekta yewaye;

Ohinniyan qa owilianketa hehanyan.

SAMEK.

113 Tona cante nonpa kin hena ślcewadaka :

Tuka nitoope kin he waštewadaka. 
114. Wowinape mitawa qa wahacanka mitawa kin he niye; Nioie kin he ape manka.

115 Śsicaya ecanonpi kin, micuni po:

Kinhan mita Wakantanka tawoahope kin wapatan kta.

116 Wahomayaye cin eciyatanhan najin makiya wo;

Kinhan wani kta ;

Qa wacinwaye cin on imaśtece kte śni.

$11 \%$ Sutaya mayuza wo, kinhan tanyan waun kta;

Qa ohinniyan wokage nitawa en ewatonwe kta.

118 Tona wokage nitawa etanhan nunipi kin

Hena owasin wahtewicayada śni ;

Wohnaye tawapi kin he wowiśtece.

119 Ginginca iyececa, maka akan

Wicaśta śica owasin ihangwicayaya ;

Heon nitawoyaotanin kin hena waśtewadaka.

120 Kocicipe cin heon micehpi cancan;

Qa nitawoyaco kin hena kowakipa

AYIN.

121 Woyaco qa woowotanna ecamon ece;

Tehiya makuwapi kin en ehpemaye śni wo.

122 Taku waśte on nitaokiye acakśin wo ;

Wahanicidapi kin hena makiyuśepi śni nunwe.

123 Nitowiconi kin on iśta mamdeze śni;

Qa nakun nitoowotanna oie kin on.

124 Nitocantekiye eciyatanhan nitaokiye ecakicon wo;

Qa wokage nitawa onspemakiya wo.

125 Nitaokiye kin he miye, waokahnihmayan wo;

Qa nitawoyaotanin kin sdonyemakiya wo.

126 Jehowa wanna ohanye kta iyececa;

Nitoope kin kicaksapi heon.

127 Heon etanhan nitawoahope waśtewadaka; Mazaskazi isanpa, han mazaskazi hinca.

128 Heon etanhan nitawoonspe owasin owotanna wadaka; Woitonśni canku otoiyohi śicewadaka

PE.

129 Nitawoyaotanin kin hena wowinihan;

Heon etanhan minagi hena ahopa.

130 Nioie yuzamnipi kin he iyoyamya ece;

Tona wacinton śni kin hena wokahniliwicaya.

131 Mii wahdukawa qa niya śni mața nun seca;

Nitawoahope cantowakpani, heon etanhan.

132 Miye ekta ihduhomni qa cantemakiya wo

Tona nicaje waśtedakapi kin iyececa.

133 Nioie kin on mioye kin yasuta wo;

Qa taku śica takudan wowidagmaye śni nunwe.

134 Wicaśta wakakiśye cin etanhan opemakiton wo;

Hecen nitawoonspe kin ahowape kta.

135 Niite kin nitaokiye aojanjanya wo,

Qa wokage nitawa onspemakiya ye. 


\section{PSA L M 119.}

136 Miiśta etanhan mini wakpadan kaduza; Nitoope opapi śni kin heon etanhan.

TSADI.

137 Jehowa, niye oniwotanna;

Qa nitawoyaco kin hena ecetu.

138 Nitawoyaotanin kin woowotanna eyehde, Qa wowicake hinca.

139 Wacantawahde kin he mahdusota; Tokamayanpi nioie akiktonjapi kin heon.

140 Nioie kin ecedan hinca; Heon nitaokiye he waśtedaka.

141 Miye macistinna qa wahtemadapi śni; Tuka nitawoonspe awektonje śni.

142 Nitoowotanna kin he woowotanna owihanke śni ; Qa nitoope km he wowicake.

143 Wonihinciye qa wokakije mayuzapi; Nitawoahope kin hena wowiyuśkinwaye.

144 Nitawoyaotanin kin ohinniyan owotanna; Okahnilimayan wo, kinhan wani kta. QOPH.

145 Micante ocowasin on hoyeciciya; Jehowa amayupta wo; Wokage nitawa kin hena owape kta.

146 Houciciya ce, nimayan wo; Kinhan nitawoyaotanin awacanmi kta.

147 Anpao kin en nitokam wau qa houciciya: Nioie kin on ape waun.

148 Miiśta hankiktapi kin kawicapa; Nioie kin awacanmi kta heon.

149 Nitocantekiye eciyatanhan ho namakilion wo; Jehowa, nitawoyaco kin on nimayan wo

150 Tona taku śica kuwapı kin hena kiyedan unpi ; Tuka nitoope kin itehanyan unpi.

151 Jehowa, niye kiyedan yaun; Qa nitawoahope kin owasin wowicake.

152 Wanakajatanhan nitoope kin on sdonwaya; Hena otokahe wanin tanhan yahduśtan. REś.

153 Mitokakije wanyake ca emayaku wo; Nitoope awektonje śni, heon etanhan.

154 Woakinica mitawa amicinica qa opemakiton wo ; Nioie kin eciyatanhan nimayan wo.

155 Wanikiyapi kin he wicaśta śica itehan un; Wokage nitawa odepi śni kin heon.

156 Jehowa, wocantekiye nitawa kin hena ota; Nitawoyaco kin on kinimakiya wo.

157 Ścaya makuwapi qa tokamayanpi kin hena otapi ; Tuka nitawoyaotanın kin amduśtan śni.

158 Wahtanipi sa wanwicamdaka qa wamayazan; 


\section{PSA L M 120.}

Hena nioie opapi śni kin heon.

159 Jehowa, nitawoonspe waśtewadake cin he wanyaka ye;

Nitocantekiye eciyatanhan nimayan wo.

160 Nioie otokahe kin he wowicake;

Qa nitoowotanna woyaco kin owasin owihanke wanica. ślN.

161 Ituh wicaśta itancanpi śicaya makuwapi ;

Tuka micante nioie kin kokipa.

162 Taku ehe cin on wimduśkin;

Tuwe woyuha tanka iyeye cin iyececa.

163 Woitonśni śicewadake ça wahtewada śni ;

Nitoope kin he waśtewadaka.

164 Anpetu eca śakowin akihde ciyatan ece ;

Nitoowotanna woyaco kin hena on.

165 Nitoope waśtedakapi kin hena wookiye ota yuhapi ; Qa takudan ibowicato kte śni.

166 Jehowa, nitowiconi kin ape waun ; Qa nitawoahope kin ecamon ece.

167 Minagi nitawoyaotanin kin patan;

Qa hena nina waśtewadaka ece.

168 Nitawoonspe qa nitawoyaotanin kin mduha; Miohan owasin nitokam hiyeye cin heon.

TAU.

169 Jehowa, waceye cin nitokam ikiyedan u nunwe ;

Nioie eciyatanhan okahnihmayan wo.

170 Mitawocekiye nitokam u nunwe;

Nioie kin on makiyuśka wo.

171 Miiha woyatan hiyuye kta;

Wokage nitawa onspemayakiye kta heon.

$1 \% 2$ Miceji iyae cin ayupta nunwe;

Nitawoahope kin owasin owotanna ce.

173 Ninape omakiya un nunwe;

Nitawoonspe kin hena wakahniga heon.

174 Jehowa, waniyakiye cin he cantowakpani ;

Qa nitoope kin he wowiyuśkinwaye.

175 Minagi ni un nunwe, kinhan niyatan kta; Qa nitawoyaco kin omakiya nunwe.

176 'Tahinca wan taninśni iyecen wanuni;

Nitaokiye okide wo;

Nitawoahope awektonje śni, heon etanhan.

PSALM 120.

Oicimani odowan.

1 Makakija en Jehowa hoyewakiya:

Unkan iye amayupta.

2 Jehowa, woitonśni iha etanhan minagi eyaku wo;

Wohnayan ceji kin etanhan.

3 Taku niçu kta he, wohnayan ceji kin ; 


\section{P S A L M 122}

Qa taku sanpa yuheniciye kta he.

4 Wicaśta waśaka tiwanhinkpe pe hinca, Genista petaga koya.

5 Hehehe, miye Meśek en ounwaye; Kedar tawakeyapi kin ohna wati.

6 Tuwe wookiye śicedake cin he Minagi wanna tehan kici ti.

7 Miye wookiye wacin, tuka iwaa eca, Hena e kicizapi kta.

PSALM 121.

Oicimani odowan.

1 Paha kin ekta miiśta wankan yewaya:

Omakiyapi kin he tokiyatanhan $u$ he.

2 Omakiyapi kin he Jehowa eciyatanhan, Mahpiya maka ko kage cin he.

3 Nisiha naśdute kta iyowinkiye kte śni :

Tuwe awarniyake cin he iśtinbe kte śni.

4 Iho, Israel Waawanyake tawa kin He hiba kte śni qa iśtinbe kte śni.

5 Waawanyake nitawa kin Jehowa hee; Nietapa ekta ahanziniye cin Jehowa hee.

6 Anpetu eca anpetu wi kin kiunniniye kte śni ; Qa hanyetu wi kin, hanyetu icunhan.

7 Taku śica owasin etanhan Jehowa awanniyake kta ; Ninagi awanyake kta.

8 Tankan de ça tin yahdi eca, Jehowa awanniyake kta, Detanhan qa owihanke wanica.

\section{PSALM 122. \\ Oicimani odowan. Dawid tawa.}

1 Jehowa ti kin ekta unyanpi kta ce, Emakiyapi kỉ on imduśkin.

2 Jerusalem, nitatiyopa kin en Unsihapi iyahanpi.

3 Otonwe wan icikoyagya he cin He iyececa Jerusalem kagapi.

4. Heciya wicowazipi wankan yapi ece ; Jah tawicowazi kin, Israel yaotaninpi kta; Jehowa caje yatanpi kta heon.

5 Hen woyaco oiyotanke kin hdepi; Dawid tiy ohnaka oiyotanke tawapi.

6 Jerusalem wookiye kin icekiy a po; Tona waśtenidapi kin hena wookiye yuhapi nunwe.

7 Wookiye conkaśke nitawa mahen un nunwe; Qa woozi içiyapi tipi waśteśte nitawa mahen. 


\section{P S A L 125.}

8 Mihunkawanji qa mitakuye on,

Wookiye mahen niun nunwe, epe kta.

9 Jehowa Wakantanka unkitawapi ti kin on,

Tanyan yaun kta awakite kta.

\section{PSALM 123.}

Oicimani odowan.

1 Mahpiya kin en yakidotanke cin

Niye ekta miiśta wankan yewaye.

2 Wan, wicaśta taokiye wicayuhapi napepi kin ekta iśta yeyapi ;

Winyan taokiye yuhe cin nape ekta etonwan ece;

He iyecen unkiśtapi

Jehowa Wakantanka unkitawapi ekta etonwanpi,

Onśiunkidapi kte cin hehanyan:

3 Onśiunkida po, Jehowa onśiunkida po;

Wowahtedaśni on nina iunmnanpi;

4 Tona owanji yukanpi kin hena

Wahtedapiśni on unnagipi imnan hinca;

Wahaniçidapi wowahtedaśni kin he.

\section{PSALIM 124.}

Oicimani odowan. Dawid tawa.

1 Jehowa unkicipi un śni unkanś;

Hecen Israel eyapi kta;

2 Unkicipi un kin Jehowa ee śni unkanś,

Wicaśta akantu anauntanpi qehan ;

3 Hehan niyake naunpcapi kta tuka,

Wocantahdeunyanpi ide qehan :

4 Hehan mini kin unkiwankam iyaye kta, Wakpa wan unnagipi iwankam iyaye kta;

5 Héhan unnagipi iwankam, Mini ipiga kin iyaye kta tuka.

6 Iye hipi kin on unyahtakapi kta unqupi śni. Heon Jehowa yawaśtepi kte.

7 Unnagipi ihduśke, Zitkadan wan wicaśta wahmunke etanhan he iyececa; On hmunkapi kin yulidecapi, Unkan unkiye unkiyukcapi.

8 Ounkiyapi kin he Jehowa caje kin en un ; Mahppiya qa maka kage cin he.

\section{PSALM 125.}

Oicimani odlowan.

1 Jehowa wacinyanpi kin hena,

Zion Paha kin iyececapi ;

Yuhohopi śni, ohinniyan han. 


\section{PSALM 127.}

2 Paha kin Jerusalem ihdukśan hiyeya; Qa Jehowa iye taoyate wicihdukśan un, Detanhan qa owihanke wanica.

3 Wicośice can sagye kin wicaśta uwotanna Tamakoce kiu akan wanke kte śni; Hecen wicaśta owotanna taku śica Ekta nape yeyapi kte śni.

4 Jehowa, tona waśte taku waśte ecakicon wo ; Qa tona cante ecetu kin hena.

5 Tuka tona canku pemni ekta icunom yapi kin, Hena wicolian śica econpi kin om Jehowa iyaye wicaye kta. . Israel wookiye kici un nunwe.

\section{PSALM 126.}

Oicimani odowan.

1 Zion hdicu kin en Jehowa ihdohdi qehan, Wihanmnanpi kin iyeuncecapi.

2 Hehan ihapi on i unkojupidan; Qa uncejipi wowiyuśkin on : Hehan Ikcewicaśta ehna heyapi ; Jehowa taku tanka ecawicakicon ce.

3 Jehowa taku tanka ecaunkiconpi; On unkiye piundapi.

4 Jehowa, unhdicupi kin en ihdoku wo, Itokah wakpadan kin iyececa.

5 Tona ceya wojupi kin Hena wiyuśkinyan wamnayanpi kta.

6 Ceya ye kta, wojupi opahte yuha ye kta; Wiyuśkinyan ku kta, Aguyapi pahtapi hduha ku kta.

PSALM $12 \%$.

Oicimani odowan. Solomon tawa.

1 Tipi kin Jehowa kage śni kinhan, He en tona kagapi kin ituya śkanpi. Jehowa otonwe kin awanyake śni kinhan, Waawanyake kin ituya kiktahan un.

2 Ituh hanhanna hin yektapi ;

Tehan oziniçiyapi śni;

Wicohtani woyute yatapi kta.

Waśtekidake cin hecen woiśtinma qu ece.

3 Iho, wicacinca Jehowa taku wicaqu kin hee;

Wicatamni oicage cin he wokajuju ee.

4. Wanhinkpe wicaśta waśaka nape ohna, Wicakośka cinca kin hena iyececa.

5 Tuwe hena on wanju okikju kinhan, Wicaśta kin he cante waśte hinca: 
Hena iśtecapi kte śni;

Tiyopa kin ohna toka om wohdakapi kta.

PSALM 128.

Oicimani odowan.

1 Jehowa kokipapi kin otoiyohi cante waśte; Iye tacanku ohna manipi kin hena.

2 Ninape ohtani kin he yahdute cinhan, Cante niwaśte hinca, qa tanyan nanke kta.

3. Nitawin hastanyanka iyuwi waicage cin he iyececa, Tipi nitawa mahen;

Nicinca kin hena Oliwe ojupi kin iyececapi, Wahna wotapi nitawa ihdukśan.

4 Wanyaka wo, wicasta Jehowa kokipe cin, He hecen yawaśtepi kta.

5 Jehowa Zion etanhan niyawaśte-kte; Qa Jerusalem towaśte kin wandake kta, Yani kin anpetu owasin.

6 Nakun nicinca cinca kin wanyahdake kta. Israel wookiye kici un nunwe.

PSALM 199.

Oicimani odowan.

1 Komaśka ehantanhan ota kakiśmayanpi ce; Israel eye kta iyececa ;

2 Komaśka ehantanhan ota kakis̉mayanpi, Tuka maktepidan śni.

3 Mahyumdupi kin mitapete ayumdupi ; Cankuyetonton hanskaska kagapi.

4 Jehowa owotanna; Wicaśta śica ikan tawa kin he bapsaka.

5 Tora Zion sicedakapi kin hena Owasin iśtecapi qa hekta hdicuyapi kta.

b. Tipi akan wato icage cin he iyececapi kta ; He yujunpi śni itokam śnija ece.

7 He on aguyapi bakse cin nape okikju s̊ni ; Qa tuwe patite cin he maku en ohnaka śni.

8 Nakun tona en hiyayapi kin heyapi sni ; Jehowa tawoyawaśte en niunpi nunwe; Jehowa caje on unniyawaśtepi ce, eyapi śni.

\section{PSALM 130 .}

Oicimani odowan.

1 Jehowa, wośbe kin etanhan, houciciya ece.

2 Itancan miho kin nation ye; Wocekiye mitawa ho kin anohkiya wa. 
3 Jah, woahtani cajeyakiyate cinhan, Itancan, tuwe en najin okihi kta he.

4 Tuka wokajuju kin he niye duha;

Hecen konicipapi kta.

5 Jehowa ape waun, minagi ape un; Qa iye oie kin wacinwaye.

6 Minagi Itancan kin akipe; Anpao kta ape unpi kin isanpa; Anpao kta ape unpi kin hena.

7 Israel, Jehowa wacinyan wo; Jehowa wowaonśida hduha; Qa wopekitonpi untkanna kici un.

8 Unkan iye Israel opekiton kta, Wahtani owasin etanhan.

\section{PSALM 131. \\ Oicimani odowan. Dawid tawa.}

1 Jehowa, micante wahaniçida śni, Qa miiśta wankantuye śni ; Nakun taku tanka kịn en opimic̣iye śni, Qa taku miwankam hiyeye cin.

2 Awicakehan minagi wahduwalibadan, Qa wahduinina;

Tuwe hunku azin ehpeye cin iyececa; Azin enakiya wanji minagi iyececa.

3 Israel, Jehowa wacinyan wo;

Detanhan qa owihanke wanica.

\section{PSALM 132.}

Oicimani odowan.

1 Jehowa, Dawid on kiksuya wo, Tawokakije kin owasin.

2 He Jehowa ekta iciconza; Awicakehan Wanji Waśaka Jakob tawa kin heciya;

3 Wakeya ohna wati kin en wahde kte śni; Ohehdepi akan manke cin en mde kte śni ;

4 Miiśta woiśtinma waqu kte śni; Qa miiśtojuha, owicagunga ;

5 Jehowa owanka wan iyeweciye śni; Tipi wan Wanji Waśaka Jakob tawa kin on.

6 Iho, Ephrata en he naunhonpi : Can wojupi kin ohna iyeunyanpi ce.

7 Iye ti kin en unkupi kta; Iye siha hde kin en canpeśka makehde inaunjinpi kta.

8 Jehowa najin wo, woozi nitawa kin en; Niye qa nitowaśake can koka kin.

9 Wawayuśnapi nitawa woowotanna koyakapi kte ; 
Qa wicaśta wacantkiya nitawa iyaśapi nunwe.

10 Dawid nitaokiye kin on etanhan, Sdayakiye cin ite kin hduhommi śni wo.

11 Jehowa wowicake eciyatanhan Dawid heciya; Etanhan nanni kte śni ;

Nitancan etanhan icage cin he Oiyotanke nitawa akan iyotangwakiye kta ce.

12 Nicinca wicotakuye mitawa patanpi kinhan; Qa mitawoyatauin unspewicawakiye cin hena; Hehan nakun iye cinca kin ohinniyan Oiyotanke kin akan nici iyotankapi kta.

13 Jehowa Zion hdahniga; Ohna ti kta cin kin heon.

14 Ohinniyan woozi mitawa kin he dee; Den manke kta, wahdahniga heon etanhan.

15 Tawoyute woyawaśte on mdawaśte kta ;

Wahpanicapi tawa kin hena Aguyapi on imnawicawaye kta.

16 Nakun wawayuśnapi tawa kin Hena wiconi koyagwicawaye kta; Qa wicaśta wacantkiya tawa kin Hena iyaśapi, iyaśapi kta.

17 Hen Dawid he wan icaliweciye kta; Petijanjan wan Sdawakiye cin piweciya.

18 Tona tokawicaye cin wowiśtece koyagwicawaye kta. Tuka iye akan tawateśdake kin hica kta.

PSALM 133.

Oicimani odowan. Dawid tawa.

1 Wanyaka wo, hunkawanjinkiciyapi Nakun witaya tipi kin He waśte qa wiciyokipi hinca.

2 He wihdi waśte, kin iyececa, pa akan, Putinhin ekta kaduza, Aaron putinhin tawa; Qa taonhdohda okagege kin ekta iyahde.

3 Hermon cu kin iyececa, Zion paha kin ahinhe cin hee :

Hen Jehowa woyawaśte wan u śi ;

Owihanke wanin wiconi kin hee.

\section{PSALM 134.}

Oicimani odowan.

1 Iho, Jehowa taokiye kin owasin, Jehowa yawaśte miye ;

Hanyetu eca Jehowa ti kin ohna nayajinpi kin.

2 Oyanke wakan kin ekta nape kiyugata po ; Qa Jehowa yawaśte miye. 


\section{P S A L M 135.}

3 Jehowa Zion etanhan niyawaśte kta ; Tuwe mahpiya maka ko kage cin he.

\section{PSALM 135.}

Jah yatan miye.

1 Jehowa caje kin he yatan po ; Jehowa taukiye yaunpi, he idowan po.

2 Tona Jehowa ti kin ohna nayajinpi kin; Wakantanka unkitawapi ti hocoka en yaunpi :

3 Jah yatan miye; Jehowa waśte;

Iye caje kin idowan po, he oiyokipi nakaeś.

4 Jehowa Jakob hdahniga; Israel tawaye kte cin heon.

5 Jehowa tanka hinca he sdonwaya;

Qa Itancan unkitawapi taku wakan owasin isanpa.

6 Jehowa taku cin kin owasin econ ece;

Mahipiya kin ekta qa maka akan;

Miniwanca qa wośbe owasin en.

7 Maka ihanke etanhan opo wankantkiya iyayeya;

Magaju kin wakanhdi kicaga;

Mazopiye tawa etanhan tate kin hiyu kiya.

8 Egupta en tokaheya tonpi kin wicakaśtaka;

Wicaśta qa nakun wanunyanpi kin.

9 Wowapetokeca qa taku wowinihan,

Egupta, niye en ukiye ciqon ;

Pharoh qa taokiye kin owasin en.

10 Oyate ota wicak aśtaka, Qa wicaśtayatapi waśakśaka wicakte:

11 Sihon, Amori wicaśtayatapi kin; Qa Og, Baśan wicaśtayatapi ;

Qa Kanan wokiconze kin owasin :

12 Qa makoce tawapi qon yuhapi kta wicaqu; Irrael iye taoyate yuhapi kta.

13 Jehowa, nicaje kin he owihanke wanica:

Jehowa, niksuyapi kin he

Wicoicage qa wicoicage hehanyan.

14 Jehowa iye taoyate kin hdaco kta ; Qa iye taokiye kin hena on ihduhomni kta.

15 Ikcewicaśta taku wakan tawapi kin

Hena mazaska qa mazaskazi ;

Wicaśta nape on kagapi.

16 I yukanpi, tuka iapi śni ;

Iśta yukanpi, tuka wawanyakapi śni;

17 Noge yukanpi, tuka winahonpi śni ;

Nakun ipi ohna oniya wanica.

18 Tuwe hena kage cin hera iyececapi ;

Nakun tona wacinyanpi kin owasin.

19 Israel tiyohnaka, Jehowa yawaśte po; 
Aaron tiyohnaka, Jehow a yawaśte po.

20 Lewi tiyohnaka, Jehowa yawaśte po; Jehowa koyakipapi kin, Jehowa yawaśte po.

21 Jehowa Zion etanhan yawaśtepi nunwe, Jerusalem en ounye cin. Jah yatan miye.

\section{PSALM 136.}

1 Jehowa waśte, hecen wopida eciya po; -Towaonśida kin he owihanke wanica.

2 Taku wakan ta Wakantanka kin wopida eciya po; Towaonśida kin he owihanke wanica.

3 Itancanpi kin en Itancan kin wopida eciya po; Towaonśida kin he owihanke wanica.

4 Tuwe iśnana taku tanka wowinihan econ kin; Towaonśida kin he owihanke wanica.

5 'Tuwe woksape on mahpiya kage cin; rowaonśida kin he owihanke wanica.

6 'Tuwe maka kin mini akan yumdaya; Towaonsida kin he owihanke wanica.

7 Tuwe iyoyanpa tanka kage cin; Towaonśida kin he owihanke wanica.

8 Anpetu wi anpetu en ounye kte cin; Towaonśida kin he owihanke wanica.

9 Hanyetu wi wicanhpi ko hanyetu en ounyanpi kta ; Towaonśida kin he owihanke wanica.

10 Tuwe Egupta en tokaheya wicatonpi wicakaśtake ciqon; Towaonśida kin he owihanke wanica.

$11 \mathrm{Qa}$ wicacokaya tanhan Israel ewicahdaku; Towaonsida kin he owihanke wanica.

12 Nape waśake cea isto hdugate cin on ; Towaonśida kin he owihanke wanica.

13 Tuwe Mde śa kin yukinukan ehnaka; Towaonsida kin he owihanke wanica.

14 Qa cokaya Israel iyayeye cin; Towaonśida kin he owihanke wanica.

15 Tuka Pharo qa ozuye tawa kin Mde śa kin en ehpewisaya; Towaonsida kin he owihanke wanica.

16 Tuwe iye taoyate hewotahedan yus awicaye cin; Towaonsida kin he owihanke wanica.

17 Tuwe wicaśtayatapi tanka wicakaśtaka; 'Towaonsida kin he owihanke wanica.

18 Qa wicaśtayatapi waśaka wicakte; Towaonśida kin he owihanke wanica.

19 Sihon, Amori wicaśtayatapi kin ; Towaonśida kin he owihanke wanica.

$20 \mathrm{Qa} \mathrm{Og}$, Baśan wicaśtayatapi kin :

Towaonśida kin he owihanke wanica. 
21 Qa tamakocepi kin yuhapi kta wicaqu; Towaonśida kin he owihanke wanica.

22 Iye taokiye Israel yuhe lita; Towaonśida kin he owihanke wanica.

23 Tuwe unwahpanicapi en unkiksuyapi; Towaonśida kin he owihanke wanica.

$24 \mathrm{Qa}$ tokaunyanpi kin etanhan eunhdakupi ; Towaonsida kin he owihanke wanica.

25 Tuwe cehpi ton owasin woyute wicaqu; Towaonśida kin he owihanke wanica.

26 Mahpiya ta Wakantanka kin wopida eciya po; Towaonśida kin he owihanke wanica.

\section{PSALM 137.}

1 Babel tawakpa kin icahda, Hen unkiyotankapi, nakun unceyapi, Zion unkiksuyapi qehan.

2 He cokaya coliwanjica kin en, Candowankiyapi unkitawapi otkeunyanpi.

3 Hen wayaka unyuhapi dowanpi oie kin unkidapi; Qa waunkipi kin hena wowiyuśkin dapi ; Zion tadowan etanhan unkicidowan po, eyapi.

4 Token Jehowa tadowan kin, Makoce tokeca en, unkahiyayapi kta he.

5 Jerusalem aciktonje cinhan, Minape etapa kin akiktonja nunwe:

6 Miceji macaka en askapa nunwe, Ciksuye śni kinhan; Mitowiyuśkin tokapa ekta Jerusalem ewahnake śni kinhan.

7 Jehowa, Edom cinca kin elita, Jerusalem taanpetu kin kiksuya wo: Yujuju po, yujuju po, Taku ahdehe cin hehanyan, eyapi.

8 Babel cunwintku, ihangyapi kte cin, Tuwe ecaunyeconpi kin iyecen

Nicicajuju kinhan he cante waśte kta.

9 Tuwe hokśiyopa nitawa iyawicahpaya, Qa inyan en ehpewicaye cinhan, he cante waśte kta.

\section{PSALIM 138.}

Dawid tawa.

1 Micante ocowasin on wopida eciciye kta; Taku wakan kin wicitokam icidowan kta.

2 Tipi wakan nitawa ekta canpeśka makehde inawajin kta; Qa nicaje mdatan kta, nitowaonśida qa nitowicake on : Nioie kin nicaje ocowasin isanpa tanka yakaga heon. 
3 Anpetu en hoyewaya, hehan amayadupte; Minagi en wowaśake on waditag mayaya.

4 Jehowa, maka wicaśtayatapi owasin niyatanpi kta ; Nii oie kin nahonpi kinhan.

5 Qa Jehowa tacanku ohna dowanpi kta; Jehowa towitan kin he tanka nakaeś.

6 Jehowa tehanwankantu eśta kun unpi kin awicatonwan; Tuka wahaniçidapi kin tehantanhan sdonwicaya.

7 Wokakije cokaya mda eśta nimayaye kta; Tokamayanpi śinhdapi kin ekta nape yahdugate kta; Qa ninape etapa on nimayaye kta.

8 Jehowa taku miciyuśtan kta:

Jehowa, nitowaonśida kin he owihanke wanica:

Ninape taku kage cin ehpeye śni wo.

\section{PSALM 139.}

Dowan itancan kin kicagapi. Dawid tadowan.

1 Jehowa, mayadukcan qa sdonyaya;

2 Imdotanka nawajin ko sdonyaya; Mitawacin tehantanhan oyakahniga.

3 Omawani qa imunke cin wapetogyaton; Qa miohan kin owasin tanyan idukcan.

4 Miceji en wicoie wanjidan eśta, Tho, Jehowa, niye ocowasin sdonyaya.

5 Miheyata qa mitokam aohdutemayaya, Qa ninape amayahnaka.

6 Wosdonye kin he okahnih owakihi śni ; Tehan wankantu, hecen owakihi kte śni.

7 Nitaniya etanhan toki mde kta he; Qa niite etanhan toki nawajin kta he.

8 Wankan mahpiya ekta mde cinhan, hen niye yaun, Qa Hades en owinśwaton kinhan, inyun, niye.

9 Anpao hupahu lin wakamdage kta ; Miniwanca ihanke kin en ounwaye kta :

10 Heciya eśta ninape amayan; Qa nape nietapa kin mayuza.

11 Awicakehan otpaza amahinhipaye kta, epa eśta, Hehan hanyetu kin mihdukśan iyoyanpa.

12 Otpaza hee kaeś aotpasniye śni ; Qa hanyetu kin anpetu iyecen iyojanjan : Otpaza kin he iyoyanpa kin iyececa.

13 Mitapakśin kin niye yakaga; Ina tamni mahen akahpemayaton.

14 Wowinihanyan makagapi heon ciyatan kta;

Niolian kin hena wowinihan; Qa he minagi tanyan sdonya.

15 Woinahbe en makagapi qehan, Mahuhu kin ananicihmanpi śni, 


\section{P S A L M 140.}

Maka ośbe kin en makazontapi qehan.

16 Wiyapemni waun qon niiśta wanmayaka, Qa mitaanpetu icage kte cin, Hinahin wanica ehan,

Owasin nitawowapi kin en owapi.

17 Unkan Iyotan Waśaka nitawacin kin hena nina tewahinda; Hena yuwitayapi kin tanka linca.

18 Hena mdawa kta, tuka wiyaka kin isanpa ota:

Wekta qa hinahin cici waun.

19 Wakantanka, awicakehan wicaśta śica yakte kta:

Heon we wicaśta yaunpi kin, amayuśtan po.

20 Hena taku śica on cajeniyatapi ece :

Tokaniyanpi kin ikcekceya sajeniyatapi.

21 Jehowa, tona śicenidapi kin hena śicewicawada kte śni he;

Qa tona nicipajinpi kin hena wahtewicawada kte śni he.

22 Wośicedake wowicake on śicewicawadaka;

Hena tokawicawaya iyececa.

23 Wakantanka, imayukcan qa micante sdonya wo, Imayute qa micanteoze kin sdonya wo.

24 Qa wokakije canku wan en maun kinhan wanyaka wo: Qa canku owihanke wanice cin en amayan wo.

\section{PSALM 140.}

Dowan itancan kin kicagapi. Dawid tadowan.

1 Jehowa, wicaśta śice cin etanhan emayạku wo;

Wicaśta wohitika etanhan mayakpatan kta.

2 Hena cante mahen wicolian śica awacinpi ;

Anpetu osan wokicize on mniciyapi ece.

3 Ceji hdumanpi, wamduśka iyececa ;

Ihapi mahen sintelida tage yukan. Sela.

4. Jehowa, wicaśta śica nape etanhan emayaku wo;

Wicaśta wawicaki sa etanhan mayakpatan kta;

Hena mioye yutehi wacinpi.

5 Wahianiçidapi kin hena,

On hmunkapi wan emaonpapi, hahonta nakuin;

Canku icahda wohmunke wan ehnakapi ;

Qa mazahitakiyapi emaonpapi. Sela.

6 Wakantanka mitawa kin he niye, Jehowa ewakıya;

Jehowa, wocekiye mitawa ho kin nation wo

7 Jehowa Itancan, wowaśake wanimakiye cin ;

Kicizapi anpetu kin en pa akahpemayaton.

8 Jehowa, wicaśta śica taku cin kin ayupte ślui wo;

Taku awacin kin ecetu śni kiya wo;

Wahanicidapi kta. Sela.

9 Tona mihdukśan hiyeye cin

Hena iha taku wayuśice cin pa ahdahpapi kta.

10 Petaga aihipewicayapi kta ;

Peta en iyewicaye kta, qa mini śma en : 
Hecen ake najinpi kte śni.

11 Wicaśta iwakan kin hena

Makoce kin en yusutapi śni nunwe :

Taku śica wicaśta wawicaki sa ihangya kuwa kta.

12 Jehowa wicaśta onśika woowotanna, Qa wicaśta wahpanica kin woyaco ecakicon kta sdonwaya.

13 Wicaśta owotanna ecedan nicaje yatanpi kta;

Wicaśta ecetupi kin nitokam iyotankapi kta.

\section{PSALM 141.}

Dawid tadowan.

1 Jehowa, houciciya, en mau inahni ye; Ceciciya eca maho kin nahon wo.

2 Wocekiye mitawa azintonpi kin nitokam un nunwe; Minape yugatapi htayetu wośnapi kin iyececa.

3 Jehowa, mii kin en akicita najin wicaśi wo; Miiha tiyopa kin awanyaka ye.

4. Wicoie śica wan ekta micante yekiye śni wo; Wicaśta woahtani econpi kin om, Wicośice en htawani kte śni. Qa woyute waśte yuhapi kin wate kte śni.

5 Wowaonśida on wicaśta owotanna amape; Qa iyopemayan; he ihepi ee kta, Mapa telinda kte śni ;

Tuka nakun iye kakijapi kin en cewakiye kta.

6 Wayaco tawapi kin hena inyan en ehpewicayapi : Unkan mioie nahonpi, hena skuya nakaeś.

7 Tuwe maka yumdu qa yuksaksa iyececa, Huhu unkitawapi Hades i kin en kada ehpeyapi.

8 Jehowa Itancan, miiśta kin niye ek ta yanke ; Wowacinye mitawa kin he niye; Minagi papson śni wo.

9 Mazahtakiyapi emaonpapi kin etanhan imacu wo ; Qa woahtani econpi wohmunke tawapi etanhan.

10 Wicaśta śica wohmunke iye tawapi en elipeiçiyapi nunwe; Tuka miye qe sam imdamde kta.

\section{PSALM 142.}

Dawid tawoonspe, makolidoka en un qehan. Wocekiye wan.

1 Miho kin on Jehowa hoyewakiya; Miho kin on Jehowa cewakiya.

2 Iye itokam taku awacanmi wakpapson; Itokam woiyokiśice mitawa owahdaka.

3 Mahentanhan mitaniya ktepidan; Tuka mitacanku kin niye sdonyaya; Canku ohna mde cin en wohmunke wan emakionpapi.

4 Etapa tanhan etonwe ça wanyaka wo; 
Unkan tuwedan sdonmaye śni ;

Wowinape takudan mduhe śni;

Tuwedan minagi ekta etonwe śni.

5 Jehowa, niye houciciya:

Wiconi makoce kin en taku mitawa,

Wowinape mitawa kin he niye, epa.

6 Waceye cin he nahon wo, nina makakija;

Tona śicaya makuwapi etanhan emayaku wo;

Hena mikapeya waśakapi nakaeś.

7 Wicakaśka tipi kin etanhan minagi icu wo,

Hecen nicaje mdatan kta:

'T'anyan ecamiyecon kinhan,

Wicaśta owotanna mihdukśan hiyeye kta.

\section{PSALM 143.}

Dawid tadowan.

1 Jehowa, wocekiye mitawa nahon wo;

Onśiya hoyewaye cin he anohkiya ye :

Nitoowotanna eciyatanhan nitowicake on amayupta wo.

2 Qa nitaokiye kici woyaco akite śni wo ;

Niye nitokam ni unpi kin tuwedan owotanna śni.

3 Toka kin he minagi śicaya kuwa;

Wiconi mitawa makata elipeya ;

Wanakaś țapi kin iyecen otpaza en ounye makiya.

4 Heon mahentanhan mitaniya aopaskicapi ;

Mahentanhan micante atakuni śni.

5 Anpetu wanakaja kin hena weksuya;

Niohan kin owasin awacanmi ;

Ninape taku kage cin hena awacin waun.

6 Minape ciciyugata;

Maka puze cin iyecen minagi nitokam wanka. Sela,

7 Inalini wo, Jehowa amayupta wo;

Minagi atakuni śni.

Niite inahbe makiye śni wo ;

Okinni wicahapi ekta yapi kin iyemacece kta.

8 Hanhanna eca wocantekiye nitawa nalion mayan wo;

Niye wacinciya, heon :

Canku ohna mde kte cin he sdonye mayan wo;

Niye ekta minagi wahdomda, heon etanhan.

9 Tokamayanpi kin etanhan emayaku.wo;

Jehowa, niye en inawahbe.

10 Nitawacin ecamon kta onspemakiya wo;

Taku Wakan mitawa kin he niye:

Nitaniya kin he waśte;

Makoce omdaya en amayan nunwe.

11 Jehowa, nicaje on etanhan nimayaye kta;

Nitoowotanna on minagi wokakije etanhan inape yaye kta.

12 Nakun nitowaonśida on tokamaye cin ihangyaye kta; 


\section{P S A L 144.}

Qa tona minagi iyokiśinyapi kin owasin atakuniśni iyewicayaye kta ;

Nitaokiye kin he miye, heon etanhan.

PSALM 144.

Dawid tawa.

1 Jehowa, Imnija mitawa, yawaśtepi nunwe;

He minape zuyapi onspeliya ;

Qa minapsukaza, kicizapi kin.

2 Wacanmakiye ca conkaśke mitawa,

Wowinape mitawa qa emahdaku ece ;

Wahacanka mitawa qa tuwe wacinwaye cin,

Mitaoyate mihukuya hiyuye cin he.

3 Jehowa, wicaśta kin taku he, on sdonyaye kta;

Qa wicaśta cinhintku, unkan en yahi kta he.

4 Wicaśta kin taku śni iyececa;

Taanpetu kin ohanzi wan hiyaye cin iyececa.

5 Jehowa, mahpiya nitawa hduhukuye ca kun u wo;

He kin hena yutan wo, kinhan hena izite kta.

6 Wakanhdi hdutanin qa wicakamdeca wo;

Wanhinkpe nitawa hiyuye ça yuśinye wicaya wo.

7 Wankantanhan ninape hiyukiya wo ;

Makiyuśka qa mini ota etanhan imacu wo ;

Toka cinca nape kin etanhan.

8 Hena ipi wohnayan iapi ece;

Qa nape etapa tawapi kin he nape itonśni.

9 Wakantanka, odowan teca wan cicahiyaye kta ;

Candowankiyapi ikan wikcemna on icidowan kta.

$10 \mathrm{He}$ wicaśtayatapi wanikiyapi wicaqu;

Iye taokiye Dawid isan śice cin etanhan icu ece.

11 Makiyuśka qa toka cinca nape kin etanhan imacu wo;

Hena ipi kin wohnayan iapi ece;

Qa nape etapa tawapi kin he nape itonśni.

12 Hecen unkicinkśipi kośkapi ehan

Taku ojupi tanka icage cin iyececapi kta ;

Unkicunkśipi kin tipi wakan oise

Inyan ayuco bagopi kin iyececapi kta.

13 Dotopiye unkitawapi kin ocaje owasin on ojudan kta:

Tahinca unkitawapi kin kektopawinge cinca tonpi kta,

Qa kektopawinge yuotapi canku unkitawapi ohna.

14 Tatanka unkitawapi yuśakapi kta;

Yuksapi wanica qa yujujupi wanica ;

Qa canku unkita wapi ohna ceyapi wanice kta.

15 Oyate wan hecen unpi kin he cante waśtepi :

Oyate Taku Wakan tawapi kin

Jehrwa hee hecinhan he cante waśtepi. 


\section{PSALM 145.}

Dawid tawa. Woyatan.

1 Wakantanka, Wicaśtayatapi mitawa ciyawankantuya kta; Qa nicaje mda waśte kta, ohinniyan qa owihanke śni.

2 Anpetu owasin ciyawaśte kta; Qa nicaje iwadowan kta, Ohinniyan qa owihanke śni.

3 Jehowa tanka qa nina yatanpi kta iyececa; Qa tanka kin he iyukcanpica śni.

4 Wicoicage wicoicage iyahdeya taku ecanon kin yatanpi ; Qa niohan waśaka oyakapi kta.

5 Wotanka nitawa wowitan oiyokipi kin he, Qa wicoie wowinihan nitawa awacanmi kta.

6 Nakun niohan wakan wokokipe kin he oyakapi ; Unkan miye wotanka nitawa mdaotanin kta.

7 Nitowaśte tanka wokiksuye kin he yatanpi ; Qa nitoowotanna kin on iyaśapi ece.

8 Jehowa waonśida qa wacantkiya; Tehan canteptanye śni qa tocantekiye tanka.

9 Owasin ek ta Jehowa waśte ; Qa tocantekiye taku kage cin owasin en un.

10 Jehowa, taku icahyaye cin owasin niyatanpi ; Qa wicaśta wacantkiya nitawa kin hena niyawaśtepi kta.

11 Nitokiconze wowitan kin he oyakapi; Qa nitowaśake kin cajeyatapi ece.

12 Tohan tanka kin wicaśta cinca sdonyewicayapi kta ; Qa tokiconze wotanka wowitan kin.

13 Nitokiconze kin he wokiconze owihanke wanica ocowasin; Qa wicaśta niyatapi kin he wicoicage qa wicoicage en.

14 Tona hicahanpi owasin Jehowa najin wicakiya; Qa patujapi kin hena owasin wicayubosdata.

15 Taku iśta yuke cin owasin niye anipepi ; Unkan iyehantu eca woyute wicayaqu ece.

16 Ninape yahdumdaya, Qa taku ni un kin owasin imna wicayaya.

17 Tacanku owasin en Jehowa owotanna; Qa ohan owasin en wacantkiya.

18 Jehowa tona hoyekiyapi kin owasin wicikiyedan un; Tona wowicake en hoyekiyapi kin owasin.

19 Tona iye kokipapi taku cinpi kin ecetuye kta ; Qa nakun hoyeyapi kin nation, qa niwicaye kta.

20 Tona waśtedapi kin hena owasin Jehowa wicapatan; Tuka śicapi kin hena owasin ihangwicaye kta.

21 Jehowa yatanpi kin he mii cajeyate kta; Qa wicacehpi owasin iye caje wakan kin he yawaśtepi kta; Ohinniyan qa owihanke wanica. 
PSALM 146.

1 Halleluya:

Minagi, Jehowa yatan wo.

2 Tohanyan wani kin hehanyan

Jehowa mdatan kta;

Tohanyan en waun hehanyan

Mita Wakantanka iwadowan kta.

3 Wicaśtayatapi wacinwicayapi śni po ; Adam cinca kin, en wanikiyapi wanica.

4 Taniya kin iyaya, hehan maka ekta hda; Anpetu kin he en tawacin kin atakuni śni.

5 Jakob ta Wakantanka tuwe okiye cin he cante waste ; Ta Wakantanka Jehowa he wacinye cinhan.

6 He mahpiya qa maka kin kaga;

Miniwanca qa taku ohnaka kin owasin :

He wowicake ohinniyan kpatan.

7 Tona śicaya wicakuwapi kin on woyaco econ ece;

Wotektehdapi kin hena aguyapi wicaqu ;

Kaśka unpi kin hena Jehowa wicayukca.

8 Iśtagongapi kin hena Jehowa iśta wicakiyukawa;

Pakopi kin hena Jehowa wicayuowotanna;

Wicaśta owotanna kin hena Jehowa waśte wicadaka.

9 Jehowa tona oyate tokeca kin hena awanwicayaka;

Wamdenica qa wiwazica kin owicakiya ece:

Tuka wicaśta śica tacanku kin yupemni.

10 Jehowa owihanke wanin wicaśtayatapi un kta;

Zion, nita Wakantanka ohinniyan qa ohinniyan kta.

Halleluya.

1 Halleluya.

\section{PSALM $14 \%$.}

Wakantanka unkitawapi idowanpi kin he waśte;

He wiciyokipi, heon yatanpi kin he wicimdeza.

2 Jehowa Jerusalem piya kaga ;

Israel enanakiya iyayapi kin hena mnawicakiya.

3 Tona cante kicaksapi kin okiziwicaya;

Qa capapi kin pawicakilita ece.

4 Wicanhpi kin tonakeca eśta hena yawa;

Owasin cajeyata ece.

5 Itancan unkitawapi kin tanka, qa towaśake kin ota; Qa tookahnige kin he yawapica śni.

6 Wahpanicapi kin hena Jehowa najin wicakiya; Śicapi kin hena makata ehpewicaya ece.

7 Wopida odowan on Jehowa ayupta po:

Candowankiyapi on Wakantanka unkitawapi kahiyaya po.

8 He mahpiya kin mahpiya śapa on akahpa ;

Maka kin magaju kicaga ; 
Qa he kin peji oicahya ece.

9 Woteca kin woyute wicaqu;

Kangi cinca nakun, ceyapi kinhan.

10 Śuktanka towaśake kin he iyokipi śni ;

Wicaśta huha kin hena on iyuśkin śul.

11 Tona kokipapi kin hena Jehowa iyokipi;

Tona iye towaonśida apepi kin hena.

12 Jerusalem, Jehowa yatan wo; Zion, Wakantanka nitawa idowan wo.

13 Nitatiyopa ihupa kin heria yusuta;

Nicokaya nicinca kin wicayawaśte.

14 Nihdukśan wookiye kaga ece ;

Aguyapi śin kin on imnaniyan.

15 Taku eye cin he maka kin ekta ye sii;

Iye oie kin dus inyanka ece.

16 Wa kin he hiyuya, tahinca hin iyececa; Hewanke kin caliota iyecen kada ece,

17 Wasu tawa kin onśpaśpa iyecen ehpeya; Osni tawa itokam tuwe najinhan najin okihi he.

18 Iye oie kin ye śi, qa hena span kiya; Tate tawa ukiya eca mini kaduza ece.

19 Iye oie kin Jakob okiyaka ; Tawoahope qa tawoyaco kin, Israel en.

20 Oyate kin owasin hecen ecawicakicon śni; Qa tawoyaco kin hena sdonyapi śni. Halleluya.

\section{PSALM 148.}

1 Halleluya.

Mahipiya kin etanhan Jehowa yatan po;

Tehanwankantu ekta he yatan miye.

2 Taohnihdewicaye cin owasin, he yatan po; Wicobe tawa iyulipa, he yatan miye.

3 Anpetu wi qa hanyetu wi, he yatan po; Iyoyanpa wicanlipi owasin, he yatan miye.

4 Malipiya malipiya kin, he yatan po; Qa mini, malipiya iwankam un kin nakun.

5 Hena Jehowa caje kin yatanpi kte; Iye ecen eya, unkan kagapi, heon etanhan.

6 Qa hena yusuta, owihanke śni hehanyan; Woope wan wicaqu, unkan he acakśinpi śni.

7 Maka kin etanhan, Jehowa yatan miye; Hogan tankinyanyan qa ośbe kin owasin.

8 Peta qa wasu, wa qa śota; Tateiyumni iye oie econ ece kin :

9 Ḧe kin hena, qa paha owasin; Waskuyeca can, qa liante owasin :

10 Wamanica, qa woteca owasin ; Watutka, qa taku kinyan un kin: 


\section{P S A L M 150.}

11 Maka wicaśtayatapi, qa oyate owasin;

Wicaśta itancanpi, qa maka akan wayaco owasin:

12 Kośka, qa nakun wikośka;

Wicahinca qa hokśiyopa om :

13 Hena Jehowa caje kin yatanpi kte; lye caje kin ecedan yatankapi ece;

Towitan kin maka qa mahpiya kin iwankam.

14 Unkan iye taoyate he wan icahwicakiciya;

Wicaśta wacantkiya tawa owasin on wowitan kin hee;

Israel cinca kin on, oyate wan iye ikiyedan unpi.

Halleluya.

\section{PSALM 149.}

1 Halleluya.

Jehowa odowan teca wan kahiyaya po ;

Towitan kin, wicaśta wacantkiya mniciyapi kin en.

2 Waicahye cin on Israel iyuśkin nunwe ;

Zion cinca Wicaśtayatapi tawapi kin on içidowanpi kte.

3 Wacipi kin on iye caje kin yatanpi nunwe;

Cancega cotanka ko on idowan miye.

4 Jehowa iye taoyate kin on iyuśkin;

Onśiiçidapi kin hena wiconi koyagwicaya ece.

5 Wowitan on wicaśta wacantkiya iyuśkinpi kte;

Towinjapl akan dowanpi nunwe.

6 Iyotan Waśaka yatanpi kin dotepi ohna un;

Qa napepi ohna mazasagye anog ope kin.

7 Hecen Ikcewicaśta ehna watokiconpi kta;

Qa oyatepi kin kakiświcayapi kta.

8 Wicaśtayatapi wicayuhapi mazaicicahilia on wicakaśkapi kta;

Qa tona wicakinicapi kin hena maza icaśke on.

9 Hena en woyaco owapi kin yuśtanpi kta;

Wowitan kin de wicaśta wacantkiya tawa owasin yuhapi.

Halleluya.

PSALM 150.

1 Halleluya.

Tipi wakan tawa ohna Wakantanka yatan po;

Wowaśake mahpiya tawa kin ohna idowan po.

2 Wicohan tanka econ kin on yatan miye;

Iyotan tanka kin iyececa idowan po.

3 Mazayahotonpi on yatan miye;

Cotanka candowankiyapi ko on yatan po.

4 Cancega wacipi ko on he yatan miye ;

Candowankiyapi cotanka ko on yatan po.

5 Mazasnasna hotanka on yatan po;

Mazasnasna wiyuśkin on he yatan miye.

6 Taku niya un kin owasin Jah yatan po.

Halleluya. 


\section{WICOIE WAKAN.}

\section{WICOWOYAKE 1.}

1 Wicoie wakan Israel wicaśta yatapi kin, Dawid cinhintku Salomon he tawa.

2 Woksape woonspe ko sdonye wicakiye kte, wowiyukcan iapi kin okahnih wicakiye kta,

3 Woksape, woonspe, woecetu, woyaco qa wicohian owotanna yuhe wicakiye kta ;

4 Tona waciutonśni ksam wicaye kta; kośka kin woksape wowayupike ko wicaqu kta.

5 Wicaśta ksapa nahon kinhan sanpa ksape kta, qa wicaśta wokcan wokonze okahnige kta.

6 Heon wicoie wakan kin okahnigapi kta, wicaśta ksapa oiepi qa taku okahnigapi tehika eyapi kin koya.

7 .Jehowa kokipapi kin wosdonye otokahe kin hee, tuka wicaśta witkotkopi woksape qa woonspe ihaktapi śni.

8 Micinkśi, niyate taku onspe niciye cin nahon wo, qa nihun taku ope niśi kin elpeye śni wo.

9 He wateśdake waśte nipa kin ihdukśan, qa wanapin nitahu kin en un kta.

10 Micinkśi, wahtanipisa niyutitan cinpi eśta ihnuhan wicayada kin.

11 Ito unyanpi kte, wicaśta ktepi kta e nahmana awicunpepi kta, taku śica econpi śni kin hena ituh wicunhmukapi kte ;

12 Woha en iyohpayapi ocowasin, qa Hades iyecen ni unpi nawicunpcapi kta ;

13 T'aku waśte ota iyeunyanpi Prov. kta, untipi woyuha ojugjudan unhapi kta :

14 Hena owasin en ounyapapi kta, mazaska opiye okonwanjidan unhapi kta, eniciyapi kinhan :

15 Micinkśi ihnuhan canku kin he en owicayape cin; oye tawapi kin etanhan nisiha kin ehdaku wo.

16 Sihapi kin taku śica oinyankapi, qa wicawe papson inahnipi.

17 Taku hupahu ton hiyeye cin owasin wanyakapi icunhan mazahtakiyapi ituh onpapi.

18 Tuka hena iye we kin hmunkapi, iye nagipi kin on inahmanpi.

19 'Iona śicaya taku kamnapi, qa tuwe tawa ktepi kin hena owasin tacankupi kin hececa. 20 Woksape tankan pan, canku kin ohna hoveya ece;

21 Otonwe canku ihanke kin ohna, tiyopa icahda mriciyapi ohna ieyanpaha, qa heya,

22 Wacintonpi śni tohanyan wicawitkotkoke cin he waśte yadakapi kta, qa waoncesapi tohanyan wowaonce kin he iyonicipipi kta, qa witkotkopika wosdonye śiceyadakapi $\mathrm{kta}$ he?

23 Miye ocihanpi heon ihduecetupo ; mitaniya kin acicaśtanpi kta, mioie kin okahnili ciciyapi kta.

24 Hoyeciciyapi tuka ayaktapi śni, minape kin mdumdaya tuka tuwedan en ewacin śni.

25 Wahokonciciyapi kin owasin ehpeyayapi, qa wakta ciyapi kin iyonicipipi śni. 


\section{WICOIE WAKAN.}

26 Miś eya nihnaślkinyanpi kin icihapi kta, tohan nina koyakipapi kinhan oncicapi kta.

27 Woihangye tohan hiyohi qa koyakipapi kinhan, iyoniciśicapi, wamniomni iyececa wocante sica wicokakije ahna nihiyohipi kinhan :

28 Hehan houmakiyapi kta tuka waamdupte kte śni, hankanna omadepi eśta iyemayanpi kte śni.

29 Wosdonye śice dakapi, qa Jehowa kokipapi kin kahnigapi śni.

30 Wahokonwicawakiye cin tawațenyapi śni, iyopewicawaye cin owasin wahtedapi śni ;

31 Heon ohanyanpi waskuyeca kin hdutapi kta, qa iye wahokonkiciyapi kin he imna kiciyapi kta.

32 Oziiciyapi kin witkotkopi kin țe wicaya, qa iyokipiiciyapi kin wacintonpi śni kin ihang wicaya ece.

33 Tuka tuwe anamagoptan kin wikope wanin ounye kta, qa taku śica ikope śni owanji un kta ce.

\section{WICOWOYAKE 2.}

1 Micinkśi, tokin mioie kin iyacu qa wahokonciciye cin nahmana niciyehnaken;

2 Ninoge kin woksape anagoptan qa nicante kin wookahnige ekta ye yakiyen.

3 Han wokcan yakipan, qa wookahnige hoyeyakiye kta;

4 Mazaska iyecen ayakite ca patanyan mazaska wolkihnake iyecen oyade cinhan ;

5 Hehan Jehowa kokipapi kin oyakahnige kta, qa Wakantanka sdonyapi kin iyeyaye kta.

6 Jehowa woksape wicaqu ece, iye i kin etanhan wosdonye wookahnige koya.
7 Tona owotanna kin hena wiconi awicakicihnaka; tona ecetuya ohanyanpi kin Jehowa wahacanka yapi ;

8 Hecen wicoope canku kin ope wicakiye ca, tona waśte wicakida hena canku awanwicakiciyaka ece.

9 Hehan wicoowotanna, wryaco, wokonze, oye waśte owasin oyakahinige kta;

10 Woksape nicante kin en hiyu kinhan, qa wosdonye ninagi kin iyokipi kinhan;

11 Wacintonpi kin awanniciyake kta, wookalinige niyuhe kta.

12 Heon canku śica etanhan enihdaku kta, wicaśta pemniyan ie cin etanhan;

13 Hena canku ow otanna ehpeyapi, qa otpaza.canku kin omanipi ;

14 Taku śica econpi kta e iyuśkinpi, pemniyan ohanyanpi kin wowinktayapi;

15 Oye tawapi kin śkośkopa, qa tacankupi kin pemnimni ece.

16 Wihomniwin kin etanhan enihdaku kta, witkowin i skuya etanhan.

17 He tokaheya yuze cin elpekiye ca, taku wakan tawa tawicoun kin akiktonja.

18 'Tiyohnaka kin wiconte ektakiya atakinyan ya, qa oye tawa kin wanna tapi iyahde.

19 Tona en yapi kin hetanhan wanjidan ku śni, qa wiconi can$\mathrm{ku}$ kin iyahde śni do.

20 Hecen wicaśta waśte tacankupi kin omayani kta, qa wicaśta uwotamna tacankupi kin oyape kta.

21 Wicaśta ecetupi kin hena maka kin otipi kta, wicaśta waste kin hen ounyanpi kta.

22 Tuka wicaśta śica kin maka kin etanhan wicakawankapi 


\section{WICOWOYAKE 3.}

kta, qa tona ścaya ohanyanpi kin hena wicakawihnunipi kta.

\section{WICOWOYAKE 3.}

1 Micinkśi, mitoope kin ihnuhan ayektonje cin, qa mitawoahope kin nicante kin ekta yuha wo.

2 He wookiye anpetu hanskaska qa wiconi omaka ota aokijuniciye kta.

3 lhnuhan wocantkiye qa wowicake aniyuśtan kin, hena nitahu kin en apahta wo, qa nicantojuha kin akan okiwa wo.

4 Hecen yaksape kta, qa Wakantanka wicaśta ko cante niciye kta.

5 Nicante ocowasin on Jehowa wacinyan wo, qa nitawacin kin ikpatan śni wo;

6 Canku nitawa kin owasin ohna he kiksuya wo, kinhan nioye kin owasin awanniciyake kita.

7 Ihnuhan ksape nicida kin, Jehowa kokipeyahan un qa taku śice cin etanhan ihduhomni wo.

$8 \mathrm{He}$ nicehpi zaniyan niniye kta, qa nihuhu acuniciye kta.

9 Woicihde duhe cin un Jehowa ohoda wo, qa taku icahyaye cin otokapa iyahna :

10 Kinhan tipi womnayaye cin woicewinyan on ojudan kta, qa miniśa iyuśkice nitawa kin anapsonpson kta.

11 Cinś Jehowa nicapsinpsinte cin he ihnuhan ihayakta śni; qa iyopeniye cinhan wacin ibośake śni wo.

12 Jehowa tona waśte wicakidake cin hena iyopewicakiya ece, wicaśta wan cinca iyotan kida kin he iyececa.

13 Wicaśta kin woksape iyeye cin, qa wicaśta wookahnige enapeye cin he wopida yuha.
14 He opetonpi kin hee waśte, mazaska opetonpi kin hee śni ce; hetanhan icage cin hee iyotan, qa mazaskazi kapeya.

$15 \mathrm{He}$ inyan tehihika kin he sain iyeya tehika, qa taku iyonicipi iyeye cin owasin hena iyowaja śni.

$16 \mathrm{He}$ etapa kin ohna anpetu hanskaska, qa catka kin ohna woyuha wowitan iyahna un.

17 Owe tawa kin owe wiciyokipi; qa tacanku kin owasin wookiye ;

18 Tona kaskita yuzapi kin he can wiconi yanpi, qa tuwe he patan kinhan he wopida ya.

19 Jehowa woksape on maka kin tinsaya ehnake ca, wookahinige kin on malipiya kin yuśtan.

20 Tosdonye kin on wośbe kin naptujapi, qa mahpiya kin cu kin śbuya.

21 Micinkśi, woksape wicake, wowayupike iyahna awanyaka wo. Ihnuhan hena niiśta kin etanhan nunipi kin ;

22 Kinhan hena nitahu en wanapin waśte kta, qa ninagi wiconi yuhe kta.

23 Hecen okope wanin nitacanku kin ohna mayani kta, qa nisiha kin wanahnaye kte śni.

24. Makan inonke cinhan takudan koyakipe kte śni, makan inonka eca tanyan niśtinbe kta ece.

25 Ihnuhanna yuśinye wicaye cin he koyakipe kte śni, qa wicaśta śica wayutakunipiśni wicahiyohi eśta nakun.

26 Nakaeś Jehowa wacinyaye $k$ ta, qa nisiha icupi kte śni e awanniyake kta ce.

27 Tona onśika ninape taku waśte ecawicakicon okihi kinhan ihnuhan teyahinda kin.

28 Nitrawaśi taku yakiduhe cin- 


\section{WICOIE WAKAN.}

han, Ekta hda qa ake kuwa wo, heyakecinhan cicu kta, ihnuhan eyakiye cinhan.

29 Nitakoda takudan ikopeśniyan nikiyedan ti kinhan takudan śica ecakicon śni wo.

30 Wicaśta taku śica ecanicon śni kinhan ihnuhan kici ayakinica kin.

31 Wicaśta wakisa kin icekin śni wo, qa ohan tawa kin wanjidan kahnige śni wo.

32 Jehowa tona pemniyan ohanyanpi kin wahte wicada śni, tuka wicaśta ecetupi kin om wohdaka.

33 Jehowa wicaśta śica ti kin yaśica, tuka wicaśta owotanna ounye cin hee yawaśte.

34 Waoncapi en Jehowa waonca, eśta onśliç̣idapi kin wowaśte wicaqu ece.

35 Tona ksapapi kin hena wowitan ohiyapi kta, tuka tona witkotkopike cin hena wowiśtece en ihduwankantupi.

\section{WICOWOYAKE 4.}

1 Hokśiyopa niyate wahokonniciyapi kin nahonpo, qa wowiyukcan sdonyapi kin cantotpanipo.

2 Woonspe waśte cicupi ce, mitoope kin ihnuhan elipeyayapi kin.

3 A te cincamayan nahanhin mawankadan, qa miśnana ina icahda waun qehan;

4 Onspemakiya, qa hemakiya; Mioie kin nicante kin yuhe kte, woahope mitawa kin yuha wo, hecen yani kta ce.

5 Woksape kin opeton wo ; wokcan kin opeton wo ; akiktonje śni wo, qa mii kin etanhan mioie kin nakicipe śni wo.

6 Elipeye śni wo, hecen awanniyake kta ; waśte daka wo, hecen nipatan kta.
7 Wicoksape kin he iyotan; wicoksape kin he opeton wo, qa taku mnayaye cin owasin on wowiyukcan kin opeton wo.

8 He iyotan yada kinhan yuwankan inicu kta, kaskita duze cinhan hehan niyuwitan kta.

9 He nipa kin ihdủkśan wowiciyokipi yuwitaye $\mathrm{kta}$; wateśdake okitanin niç kta.

10 Cinś, anagoptan wo, qa mioie kin icu wo, hecen omaka wiconi nitawa kin niciyuotapi kta.

11 Wicoksape canku kin ociciyaka, canku owotanna kin ohna omaniciciya.

12 Ohna mayani kinhan oihe yaye cin aoṭinsyapi kte śni, qa yainanka eśta niliicahe kte śni.

13 Woonspe kaskita yuza wo ; ihnuhan aduśtan kin, awanyaka wo heon yani kta ece.

14 Wicaśta ohan śica tacankupi kin ihnuhan ohua idade cin, qa wicaśta pemni kin tacanku kin ohna mayani kte śni.

$15 \mathrm{He}$ ehpeya wo, ihmuhan ohna de cinhan, he etanhan ihduhomni qa tokan iyaya wo.

16 Taku śica econpi śni kinhan iśtimapi śni ce: Tuwedan wankaheyapi śni kinhan wicohba kin wicakipi ece.

17 Wicohan śica aguyapi kin he yutapi; boticapi miniśa kin he yatkanpi ece.

18 Tuka wicaśta owotanna canku tawapi kin he iyoyanpa iyega ohinniyan sam wiyatpa aya ecen anpetu wiyotanhan he iyececa.

19 Wicaśta śica tacankupi kin he aotpaza; taku en hicahanpi kte cin he sdotkiyapi śni.

20 Micinkśi, mioie kin awacin wo, taku eciciye cin anoh kiciya wo.

21 Ihnuhan he niiśta kin icunom iyeyakiye cin, nicante kin cokaya yuha wo. 


\section{WICOWOYAKE 5.}

29. Tona he iyeyapi kin he wieon: tawapi ee, qa cehpi kin ocowasin okizi wicaya ce.

23 Taku duhe cin owasin isanpa nicante kin awanhdaka wo, hetanhan wiconi owahinanpe kin hee ce.

24 Wicopemni nii kin etanhan yutokan wo, qa wicaśtapi śni niiha etanhan hdutehan wo.

25 Niiśta kin nitokam owotanna etonwan kte, niistojuha kin nitokapa ecetuya tonwanhanpi kte.

26 Nisiha oye kin awacin wo; hecen canku yaye cin owasin tanyan yahduśtan kta.

27 Nietapa nicatka ihnuhan unmanna eciyatanhan nihduhomni kin, taku śice cin etanhan nisiba kin ehdaku wo.

\section{WICOWOYAKE 5.}

1 Micinkśi, mitoksape kin awacin wo, wookahnige mitawa kin anoli kiciya wo;

2 Hecen wowayupike duhe kta, qa nisiha kin wosdonye patan kta.

3 Witkowin iha kin etanhan tuhmaga canhanpi kaduza, qa caka kin wihdi isanpa śduta.

4 Tuka hetanhan taku icage cin peji hota iyecen pa, isan pesto kin iyecen pe hinca.

5 Siha kin apamahdedan wiconte oiyahdeya, oye kin wakanśica ti kin iyohiya.

6 Wiconi canku kin naśna niciye kta e oye kin kpakśikśan, hecen idukcan kte śni.

7 Hokśiyopa detanhan anamagoptanpo, qa wicoie mii kin etanhan inape cin ihnuhan ehpeyayapi kin.

8 Witkowin kin etanhan canku kin hdutehan wo, qa tatiyopa kin ihnuhan kiyadan de cin.
9 Okini nitowaśake tokan wicayaqu kta, qa omaka nitawa kin wicaśta waonśidapi ślli yuhapi kta.

10 Okini toka woyuha nitawa kin on imnapi kta, qa taku on htayani kin witkowin ti kin ohna yanke kta ;

11. Okini oniwihanketa woyute nitawa nicehpi ko sotapi kinhan śicahowade kta;

12 Qa, Hehehe, tokeca woonspe śice wadaka, qa wahokonmakiyapi kin ihawakta śni he.

13 Tona waonspemakiyapi kin nawicawahon śni, qa wahokonmakiyapi ho kin anawagoptan śni ece.

14. Wicota qa ominiciye cokaya taku śica owasin en ye miçiye kta tuka, ehe kta.

15 Minihdoka nitawa kin etanhan hdatkan wo, qa wakpadan mini owe nitawa etanhan kaduze cin nakun etanhan.

16 Hecen wakoniya nitawa kin tankaya kaduze kta; otonwe canku kin ohna mini wakpadan kaduze kta ;

17 Hena niśnana nitawa kte, tokan tuwedan tawa kte śni.

18 Hecen wakoniya nitawa kin yawaśtepi kta, qa honikśidan qehan winohinca duze ciqon he ninduśkin kte;

19 Tawiyedan waśte dakapi, qa tatokadan wiciyokipi iyecece kta, azinpi kin imna niciye kte, anpetu owasin, qa waśte yakidake cin ohinniyan wanipi nunwè.

20 Tokeca micinkśi winohinca tokeca wanipi kta, qa witkowin maku kin adoksohan duze kta he?

21 Jehowa wicaśta canku kin owasin wanyake ca token olian. yanpi kin wicakicitkeuta. 


\section{WICOIE WAKAN.}

22 Iye ecinśniyan olanye cin he wicaśta śice cin kihdege kta, qa iye wahtani ikan kin on hmunkapi kte ;

23 Witkoya olanye cin ota onuni kta, qa onspekiyapi śni on țe lita.

\section{WICOWOYAKE 6.}

1 Micinkśi, nitakoda wanji taku yecicajuju kta kehe cinhan, qa on wicaśta tokeca nape duza hecinhan;

$2 \mathrm{Nii}$ kin etanhan nioie kin he iyanicaśkapi; nii kin on taku ehe cin he niyuzapi ce.

3 Heon micinkśi hecen econ wo, qa ihduśka wo, nitakoda nape kin iyakpade cinhan hunktiya; ihduhukuya qa nitakoda iyopaśtaka wo.

4 Niiśta kin en wicaliba kin qu śni wo, qa niiśtojuha kin on iśtinbe śni wo.

5 Zitkadan tuwe hmunke kta nape kin etanhan ihduśka, qa tatokadan wicanape kin etanhan ihduśke cin he iyecen ihduśka wo.

6 Kuja nanke cin tajuśka kin ekta ya wo, yaksape kta e ohanyanpi kin wanyaka wo.

7 He itancan nica, akicita nica, qa wicaśta yatapi nica;

8 Tuka mdoketu eca taku yutapi kihnaka, qa woksapi eca woyute tawa mnayan ece.

9 Tohantu kinhan makan inonke kta? kuja, niśtinbe cin etanhan tohantu yekta kta he?

10 Niliba onge qa niśtinbe onge, qa makan inonke kta e nape pakśijapi onge ;

1.1 Hecen wowahpanice kin wicaśta icimani wan he iyecen en niu kta, qa wicaśta wipe hduha en nihi kin he iyecen ta$\mathrm{ku}$ owasin inicakije kta.
12. Wicaśta śica wicaśtapi śni i pemni hduha mani;

13 Iśta kin on wiyuta, qa iye siha okiya, qa iye napsukaza on waonspekiya ece;

14 Wacanśinyapi kin cante mahen ohininiyan taku śica kaga, okicize kin he kada ehpeya:

15 He etanhan ihnuhanna ihdutakuni kte śni, ohankoya yukukapi kta, qa wokicizi wanice kta.

16 Taku śakpe Jehowa śice daka, qa śakowin nagi kin wahitedaśni.

17 Wiciśta wankantuya, qa wicaceji itonpi śni, qa wicanape tona taku śica econpi śni wewicayapi ;

18 Wicacante wicohan śica ewacin, wicasiha taku śica econpi kta e inahniyan inyankapi ;

19 Wayaatanin ecinśniyan woitonśni ipohya, qa tuwe hunkawanjin kiciyapi iyakitedan kicikigepi oju kin he nakun.

20 Cinś, niyate wahokonniciye cin tanyan yuha wo, qa nihun toope kin elipeye śni wo.

21 Hena ohinniyan nicante kin en pahta wo, qa nitahu kin en iyakaśka wo.

22 Hecen mayani eca yus aniye kta ece, niśtima eca awanniyake kta, qa tohan yekta eca oniciye kta ece.

23 Woahope kin he petijanjan qa wicoope kin he iyoyanpa, qa iyopewicayapi woonspe kin he wiconi canku kin ee.

24 He winohinca śica etanhan awannihdake kta, winohinca oyate tokeca ceji skuya etanhan.

25 He owanyag waśte eśta nicante kin ekta kon śni wo; qa iśtojuha kin on ihnuhan inicu kin.

26 Witkowin kin wicaśta wan 


\section{WICOWOYAKE 7.}

aguyapi ciqadan ekta aye ktá, qa wawicihahapi econsa kin wicanagi tehika apasi kta.

27 Wicaśta wan peta ikpihnake cinhan tawokoyake kin hułinage kłe śni he?

28 'Tuwe petaga amani kinhan siha kin gu kte śni he?

$29 \mathrm{He}$ iyecen tuwe wicaśta tokeca tawicu kici iwanke cinhan; tuwe kasta he yutan kinhan taku śica iyahdeya.

30 'Tuwe wotektehda on woyute manun qa wipicciya eśta nina śicedakapi śni ;

31 Tuka iyeyapi kinhan śakowin akihde wicakicu kta; ti kin ohna taku yuke cin owasin eśta wicaqu kta.

32 Tuka tuwe wawiciliahapi winohinca wan kici econ kin he cante wanica, tuwe hecon kinhan nagi kin ihang kiya.

33 He apapi kta, qa iśtenyapi kta, qa wowiśtece kin he kajujupi kte śni.

34 Wowinawizi he wicaśta tocanteptanye kin ee, tohan tokiçon kinlıan wawitonpe kte śni.

35 Wokajuju tanka eśta ihakta kte śni, taku ota yaqu eśta iyokipi kte śni.

\section{WICOWOYAKE $\%$}

1 Micinkśi, mioie kin yuha wo, qa mitawoahope kin niye eniçihnaka wo.

2 Mitawoahope niiśta su kin iyecen yuha wo, qa mitoope kin, hecen yani kta;

3 Hena ninapsukaza en apahita wo, qa nicante ojuha kin akan owa wo.

4 Wicoksape kin, Nis tanke ciya eciya wo, qa wookalinige, Mitakuye caje yata wo.

5 Hecen witkowin kin etanhan nipatan kta, wihomniwin i skuya kin etanhan.

6 Wati owanyeye kin hetanhan can ipuskica ohna aowakasin qehan;

7 Wacintonpi f́ni wicehna ewatonwan, cincapi ehna kośkadan cante nica iyewaya;

8 Witkowin oise tawa kin ikiyedan mani, canku wan ti kin iyahde kin he ohna ya;

9 Anpetu owihanketa hitayetu, hanyetu otpaza he ehan;

10 Unkan inyun winohinca kin he itkokipa, witkowin wan iyecen ihduze ca cante kin nakihibe.

11 Owanji yanke śni qa wicakihna, siha kin tipi tawa ohna yakonpi śni.

12 Tuktekten tiyopa ekta, tuktekten canku kin ohna, qa oise owasin ikiyedan wicahmonka.

13 He yuze ca i iputake ca waditagya heciya,

14 Wopida wośnapi mduha, - nakaha hanmdepi wahduśtan:

15 Heon itkocicipe kta e tankan wahinawape ; niite kin wanciyake kte hinca qa wanna iyeciye.

16 Ohewahde kin śina owinś waya; Egupton wipatapi on apahdan waton;

17 Mitowinja kin mura, canśin qa canhaśa okahtan waya.

18 Ito unhde ca iyokipi kiciya imnaunkiçiye kte: Hanyetu osan waśtekicidaya unkiciyuśkin kte ;

19 Wicaśta kin tin yanke śni, tehan icimani iyaya;

20 Mazaska ojutonpi nape ohna icu, wi mibe lin anpetu kin he en hdi kta ce.

21 Wicoie skuya ota on he yahomni, iha skuya on yaptanye ya.

22 Unkan ihnuhanna ihakamya 141 


\section{WICOIE WAKAN.}

mani, tatanka wan tutken patapi kta ekta ye cin he iyecen, qa tahinca hmunkapi kin en inyanke cin he iyecen.

23 Ecen wanhinkpe wan pi kin ipahdan iheyapi; zitkadan wan hmunkapi en kinyan iyopta, qa on țe kta sdotkiye śni he iyecen.

24. Heon micinca anamagoptanpo, qa wicoie mii kin ie cin awacinpo.

25 Ihnuhan nicante kin winohinca kin he oye kin en nihduhomni kinhan, tacanku kin ohna onuniye śni wo.

26 Wicota capapi makata ehpewicaya, wicakte kin hena owasin waśakapi.

27 'Ti kin he Hades canku iyahde kin hee, wiconte temahentuya ohna iyaye wicaya.

\section{WICOWOYAKE 8.}

1 Awicakehan woksape kin waieyanpaha, qa wookahinige kin hoyeya ece.

2 Paha hinca akan najin, canku icipawega ohna.

3 Tiyopa icahda, otonwe tiyopa en, tukten tiyopa ohna hiyupi ek ta wicakipan.

4 Ihopo, wicaśta cicipanpi qa Adam cinca kin hoyeciciyapi ce.

5 Tona wacinnitonpi śni kin wowayupike onspeiciciyapo, qa winitkotkopika cante kiksapapo.

6 Anagoptanpo, qa iha wahdukawa ca taku owotanna epe kta.

7 Micaka kin wowicake eye kta, qa wowicaśta śni miiha kin walite da śni.

8 Mii kin etanhan wicoie kin owasin ecetupi, hena en takudan śkope śni qa pemni śni.

9 Wicaśta wiyukcan kin hena owasin mdeza e iyeya, tuwe wo- sdonye akite cinhan hena owotanna e iyeye kta.

10 Mazaska hee śni, tuka waonspeciciyapi kin he icupo, qa mazaskazi hinca hee śni tuka wosdonye kin he kahinigapo.

11 Woksape kin he inyan teliihika kin sam iyeya tehika, qa taku kaśta iyowicakipi owasin he iyowaja śni.

12 Woksape he miye, qa iyotan wamdupika; taku wayupika sdonyapi kin hena owasin iyewaya ce.

13 Tona Jehowa kokipapi kin hena wicolian śica śicedakapi; wahanicidapi, watanka içidapi, śicaya opiiçiyapi, qa wicai pemni kin hena śice wadaka.

14 Wahokonwicakiyapi wiconi ko hena mitawa, wokcan kin he miye, wowaśake he mitawa.

15 Miye eciyatanhan wicaśta yatapi wawidakapi, qa itancanpi taku owotanna wakiconzapi ece.

16 Miye eciyatanhan itancanpi oyate yuhapi, qa tona maka akan wayacopi itancanyan unpi.

17 Tona waśte madapi kin hena waśte wadaka, qa tona hanhanna hin amakitapi kinhan iyemayanpi kta.

18 Woyuha ota qa wowitan miciyukan, woiçihde suta qa wokiconze.

19 Mazaskazi ecedan hin eśta mitawaskuyeca kin he iyotan, qa mazaska kahnigapi eśta taku icaliwaye cin hee iyotan waśte. 20 Wicoowotanna canku ohna mani wicawaya, wokiconze oye kin cokaya ohna.

21 Hecen tona waśte madapi kin hena taku hohośni tawayapi kta, qa wopiye tawapi ojudan wicawakiye kta.

22 Jehowa tohan tokaheya mayuhe ciqon, takudan icahye śni he itokam kici waun. 
WICOWOYAKE 9.

23 Otokahe wanin ehantanhan sdamayanpi, otokahe ekta maka kin itokam.

24 Ośbe wanica hehan matonpi, wakoniya mini ojudan itokam icahmayanpi ;

25 He imnija kin sutaya ehdepi śni, qa paha kin itokam icahmayanpi ;

26 Maga qa tinta qa maka mdu paha kin kage śni itokam;

27 Mahpiya ehnake cehan en waun; ośbe akan wohmihbe ehde he ehan.

28 Wankantanhan mahpiya śoka otke ya; ośbe kin etanhan wakoniya yuśtan he ehan ;

29 Miniwanca kin toope qu, qa mini kin huta kin sanpa ye kte śni konze cehan, maka kin sicu kin yasuta qehan;

30 He ehan ikiyedan manka, kici icahmayanpi, anpetu otoiyohi toiyokipi kin be miye, qa ohinniyan itokam wimduśkin.

31 Wicaśta cincapi om imduśkin, qa maka ounyanpi kin he iyomakipi.

$32 \mathrm{He}$ etanhan dehan micinca anamagoptanpo. Tona mitacanku opapi kinhan hena pidaiciyapi.

33 Woonspe kin nahonpo, qa ihduksapapo, ihnuhan he ehpeyayapi kin.

34 Wicaśta tuwe anamagoptan anpetu owasin mitatiyópa awanyake ca tiyopa icahda najin kin he wopida.

35 Tuwe iyemaye cin he wiconi iyeya, qa Jehiowa en woiyokipi aihdutan.

36 Tuwe miye en wahtani kin he nagi kin kimnniyan, tona śice madapike cin hena wiconte waśte dakapi ece.

\section{WICOWOYAKE 9.}

1 Woksape tipi tawa wanna kage ça inyan śakowin oahe kin hdakan :

2 Tado wanna kpata, miniśa kin icicahi, qa wahna wotapi kin ekihde.

3 Wikośka tawa kin ye wicaśi, wicote wakan otonwe ohna he ipa kin akan pan yanka.

4 Tuwe wacintonśni deci u wo, cante nicapi kin hewicakiya,

5 Kuwapo, aguyapi mitawa etanhan yutapo, qa miniśa wiyeya ewehde kin etanhan yatkanpo.

6 Wicowitkotko kin elipeyapo, hecen yanipi kta; qa wokcan canku kin ohna manipo.

7 'Tuwe waonca wahokonkiye cin he wowiśtece iyahdeiçiya, qa tuwe wicaśta sica iyopeye cin he ihduśape kta.

8 Wicaśta waonca ihnuhan iyopeyaye cin, śice nidake kta naceca; tuka wicaśta ksapa he iyopeya wo, hecen waśte nidake kta.

9 Wicaśta ksape cin waonspekiya wo, hecen sanpa ksape kta ; wicaśta owotanna wosdonye qu wo, he icu kta.

10 Woksape otokaheya kin he Jehowa kokipapi kin ee, qa taku wakan sdonyapi kin wokcan itancan kin hee.

11 Miye on anpetu nitawa niciyuotapi kta; nakun wiconi omaka yuhe ciciye kta.

12 Yaksape cinhan nitoksape taku aicage cin he nitawa kta, qa waonyace cinban niśnana śitkihda niçiye kta.

13 Winohinea witkotkoka kin he iwakan, wacintonśni qa takudan sdonye śni.

14 Iye ti tiyopa kin icahda iyotanka, otonwe pajodan ohna canakanyotankapi akan.

15 Ahiyayapi kin wicakipan, canku katinyan omanipi kin hena; 


\section{WICOIE WAKAN.}

16 Tuwe wacinton śni kinban, kuwa wo, eciya, qa tona cante nicapi hewicakiya,

17 Mini manonpi kin he skuya ce, qa aguyapi nahmana yutapi kin he wiciyokipi ce, eya.

18 Tuka hen wicanagi yakonpi, tona wicakico Hades osmaka kin ohinhipayapi wicaśta kin sdonye śni.

\section{WICOWOYAKE 10.}

1 Wicoie wakan Salomon tawa. Hokśiyopa ksapa eca atkuku iyuśkin kiya ece; tuka hokśiyopa witkotkoke cin he hunku kin iyokiśinya.

2 Wicohan sica on mazaska mnayanpi kin owicakiyapi śni; truka wicoowotanna wiconte etanhan waehdaku.

3 Jehow wicaśta owotanna nagi kin akilian ye kte śni, tuka wicaśta śica taku cinpi ehpewicaliciya ece.

4 Tuwe nape kuje cinhan ihduwahpanica, tuka wicanape miniheca kin he wijinwicaya ece.

5 Tuwe mdoketr eca wamnayan ece kin he hokśiyopa wayupika, tuka tuwe wamnayanpi icunhan iśtinbe cin he hokśiyopa wawiśtenya ece.

6 Wicaśta owotanna pa kin yawaśtepi, tuka wowiśtece wicaśta śica i kin aohdute ye kta.

7 Wicaśta owotanna kiksuyapi kin yawaśtepi kta, tuka wicaśta śica caje kin kuke kta.

8 Tuwe cante ksape cin he wahokonkiyapi icu kta, tuka tuwe iha witkotkoke cin he wankahe kta.

9 Tuwe wohnaye wanin mani kinhan okope codan mani kia; tuka tuwe canku kin hdupemni kin he sdonyapi kta.

10 Tuwe iśta kin on wiyute 144 cin he woiyokiśice icahya, qa tuwe iha witkotkoke cin he hicahe kta.

11 Wicaśta owotanna i kin wiconi minilidoka kin hee, tuka wicowohitike kin wicaśta śica ipi kin akahpe kta.

12 Wośicedake kin wicakigepi kaga, tuka wowaśtedake kin he woahtani owasin akahpa.

13 Wicaśta wiyukcan iha kin ohna woksape iyeyapi kta, tuka wicaśta cante nice cin nite ekta cansakadan kta.

14 Wicaśta ksape cin hena woksape nakihmanpi, tuka tuwe witkotkoka i kin ecadan inihan kita.

15 Wicaśta wawokihika towijice kin conkaśke suta kin hdawa, tuka wowahpanice wicaśta onśika yuśinye wicaya.

16 Wicaśta owotanna kin wiconi iyuwin yapi, tuka wicaśta śica woahtani icahyapi ece.

17. Tuwe woonspe hduhe cin he canku wiconi iyahde kin he opa; tuka tuwe wahokonkiyapi awakicin śni kinhan nuni.

18 Tuwe iha itonpi śni on wocanniye anakilibe, ca tuwe wowiśtece yaotanin kin iś eya withotkoka.

19 Tuwe wicoie ota ie cin wahtani, tuka tuwe iha nina hduhe cin he ksapa.

20 Wicaśta olian owotanna cante kin he mazaska kahnigapi, wicaśta śica cante kin he taku śni.

21 Wicaśta owotanna iha kin wicaśta won wicaya ece, tuka wicaśta witkotkopi kin cante nicapi on tapi kta.

22 Jehowa toyawaśte kin wawijinya kin hee, qa iyahna woiyokiśica opeye śni.

23 Taku śica econpi kin wicaśta witkotko imagaga içiyapi, 
tuka wicaśta wiyukcan woksape opa.

24. Wicaśta śica taku ikope cin he akipe kta, qa wicaśta owotanna taku cin kin he kiçupi kta. 25 Tate iyumni ahiyaya eca wicaśta śica en un kte śni; tuka wicaśta owotanna oahe kin owihanke wanica.

26 Hastanhanka toto wicahi kiuniyan, qa śota wiciśta kin en he iyecen wicaśta kuja tona yeśipi lkin en.

27 Jehowa kokipapi kin he anpetu wicakiciyuota, tuka wicaśta śica omaka tawapi kin wicakiciyuptecedanpi kta.

28 Wicaśta owotanna wowiyuśkin apepi, tuka wicaśta śica taku apepi awihnuni kta.

29 Jehowa tacanku kin wicaśta waśte waśag wicaya ece, tuka wicaśta śica yuśinyewicaya.

30 Wicaśta owotanna ohinniyan yuhohopi kte śni, tuka wicaśta śica maka kin ounyanpi kte śni.

31 Wicaśta owotanna i kin woksape hinanpe ya, tuka wopemni ceji kin baśpapi kta.

32 Wicaśta owotanna iha kin taku wiciyokipi sdonya, tuka wicaśta śica ipi kin wicośkiśke.

\section{WICOWOYAKE 11.}

1 Wohnayan tke utapi kin he Jehowa wahtedaśni, tuka tke utapi ecetu kin he Jehowa toiyokipi ee.

2 Tohan wahanicidapi hi kinkan wowiśtece he nakun u ece, tuka woksape onśihanpi kin wicayukan.

3 Wicaśta waśte towaśtepi kin awicaye kta, qa wicaśta śica topemnipi kin ihang wicaye kta.

4 Wocanniye anpetu ehan woyuha takudan okihi śni, tuka wicoowotanna wiconte etanhan waehdaku.

5 Wicaśta waśte toowotanna kin canku wicakiciyumdaye kte, qa wicaśta śica tohian śicapi kin on hicahanpi kta.

6 Wicaśta ecetupi kin toowotanpi kin wicakiyuśka ece, tuka wicaśta wakonsa tawohnayanpi kin wicahmunka.

7 Tohan wicaśta śica te cinluan taku cin qon awihnuni kta, qa taku wicaśta ohan śica apepi atakuni śni ece.

8 Wicaśta owotanna woiyokiśice etanhan inapa, qa wicaśta śica wan he en hiyu.

9 Wicaśta wahnayan iye i kin on takodaku ihangya, tuka wicaśta owotanna tosdonyepi kin he ewicahdaku.

10 Wicaśta owotanna tanyan umpi kinhan otonwe kin iyuśkin, qa wicaśta śica awihnunipi eca wiyuśkinyan dowanpi ece.

11 Wicaśta ecetupi yawaśtepi kin he otonwe kin yawankantuya, tuka wicaśta śica ipi kin he yajuju.

12 Tuwe takodaku wahtedaśni kin he cante nica, tuka wookahnige wicaśta kin inina yanka.

13 Waaiesa kin taku nalimana oyakapi kin he yaotanin, tuka tona woniya wacinyepica kin hena wicoie anahmanpi ece.

14 Tukten wahokonkiyapi wanice cin hen oyate wankahe kta, tuka wiyukcanpi ota on etanhan wicani.

15 Tuwe wicaśta tokeca taku icazo kicicajuju kta keye cinhan kiunni kta, tuka tuwe he wecicajuju kta eye kapin kin he wacinyepica.

16 Winohinca waśte wowitan yuhe k ta, qa wicaśta waśaka woyuha patanpi ece.

17 Wicaśta wacantkiya iye na- 
gi tanyan ecakicon; tuka tuwe waonśida śni kin he iye cehpi kin kiunni.

18 Wicaśta śica wohnaye wohtani econpi; tuka tuwe woowotanna oju kin iyuwin wicaka yuhe kta.

$19 \mathrm{He}$ iyecen wicoowotanna on wicani, qa tuwe wicohan śica ope cinhan teiciya.

20 Tona cinte pemniyan unpi kin hena Jehowa wowahtedaśni, tuka tona tacanku ecetupi kin hena iyokipi yapi.

21 Wicanape tokan nape ekta yekiyapi eśta wicaśta śica śitkihdayapi lita; tuka wicaśta owotanna cincupi kin he inape kta.

22 Winohinca owanyag waśte tuka woksape nice cin he mazaska oinna kukuśe pasu kin ohna kin he iyececa.

23 Wicaśta owotanna taku waśte heceedan cinpi, tuka wicaśta śica wocanniye apepi.

24 Wanji wakadada eśta sanpa mnayan, qa wanji taku owotanna isanpa tehinda eśta ihduwahpanica.

25 Wicanagi wayawaśte kin he cepe kta, qa tuwe waamnimni kimhan amnimnipi kta.

26 Tuwe wamnaheza tehinda kin he oyate kin yaśicapi kta, tuka tuwe he iyopeye cinhan woyawaśte pa akan un kta.

27 Tuwe wowaśte nina akite cinhan woiyokipi iyeye kta, qa tuwe taku śica ode kinhan he iyohi kta.

28 Tuwe towijice kin wacinkiye cinhan hicahe kta, tuka wicaśta owotanna canwapa iyecen tanyan icagapi kta.

29 Tuwe iye ti kin iyokiśinye cinhan tateyanpa ekicihnakapi kta, qa tona witkotkokapi kin hena, tuwe ksape cin wowidag wicaye $\mathrm{k}$ ta.
30 Wicaśta owotanra taku icahye cin he can wiconi kin ee, qa tuwe wicanagi ohiwicaye cin he wicaśta ksapa.

31 Wicaśta owotanna maka akan iy uwin yuhe kta, hecinhan wicaśta śica qa wahtanisa isanpa hececapi kta.

\section{WICOWOYAKE 12.}

1 Tuwe wahokonkiyapi waśte dake cinhan wosdonye waśte daka qa tuwe iyopekiyapi kin śice daka he witkotkoka.

2 Jehowa wicaśta waśte cantekiya, tuka tuwe taku śica awacin kin he yaco kta.

3 Wicaśta wicohan śica eciyatanhan sutaya he kte śni, tuka wicaśta owotanna hutkan tawapi kin hohodan kte śni.

4 Tuwe hihnaku iśtenkive sin he huhu owasin kuke kiya iyececa, tuka winohinca ksapa wan hihnaku watcśdake tawa kin hee.

5 Wicaśta owotanna cante ozepi kin hena ecetupi, tuka wicaśta śica wahokonkiyapi kin he wohnaye.

6 Tona śica oiepi on wicawe hmunkapi, tuka wicaśta owotanna i tawapi ewicayakupi kta.

7 Wicaśta śica kawankapi qa en unpi śni, tuka wicaśta owotanna tipi kin sutaya he kta.

8 Wicaśta token ksapa he iyecen yatanpi kta, qa tuwe cante pemni kin woihaktapi śni un kta.

9 'Tuwe ihaktapi śni eśta ookiye wan yuhe cinhan tuwe ibdunnihan qa aguyapi codan un kin he isanpa tanyan un ece.

10 Wicaśta owotanna kin tawoteca ni un kin en ewacin ece, tuka wicaśta śica wawacinkta yuzapi kin he wohitika.

11 Tuwe tamaga kicanye cin 


\section{WICOWOYAKE 13.}

he aguyapi imnaiciye kta, tuka tuwe takuśniśni kuwa kin he cante wanica.

12 Wicaśta śica kin śicapi conkaśke tawapi cin ece, tuka tona owotanna hutkan tawapi kin taku icahya.

13 Tha itonpi śni kin on śicaya wicahmunkapi, tuka wicaśta owotanna wokakije etanhan inanpe kta.

14 Wicaśta i waskuyeca tawa kin he etanhan taku waśte on imnapi kta, qa taku iye nape kage cin he kicupi kta.

15 Wicaśta witkotko canku tawa kin he owotanna kecin, tuka tuwe wahokonkiyapi anagoptan kin he ksapa.

16 Wicaśta witkotko tocanniye hin ecadan hdutanin, tuka wicaśta wayupika iśtenyapi kin ahdahpa.

17 'Tuwe wowicake ie cinhan taku owotanna yaotanin, tuka wayaatanin itonśni kin he wohnaye.

$18^{\circ}$ Wicaśta wan isan cawicape iyecen ia, tuka tona ksapa cejipi kin he wookizi.

19 Wowicake iha kin he ohinniyan suta kta, tuka ceji itonśni kin he aśkayedan.

20 Tona taku śica awacinpi cantepi kin ohna wohnaye yukan, tuka wookiye wahokonkiyapi kin hena wowiyuślkin.

21 Wicaśta owotanna takudan sica iyahde śni unpi kta, tuka tona śicapi kin hena taku sica ojupidan.

22 Wicaiha itonpiśni kin Jehowa wahtedaśni, tuka tona ecetu ohanyanpi kin hena toiyokipi kin ee.

23 Wicaśta ksapa wosdonye ahdahpa, tuka tona witkotkoka cantepi kin wacintonpi śni ieyanpaha.
24 Wicanape miniheca kin he wawidake kta, tuka wicaśta kuje cin he wowidake yapi kta.

25 Woiyokiśice wicaśta cante mahen he patuśya, tuka wicoie waśte wan he iyuśkin ya.

26 Wicaśta owotanna kin tawaśitku kin kapeya, tuka wicaśta śica tacankupi kin wicahnayan.

27 Wicaśta kuja taku ihni kin he pasnu śni, tuka wicaśta miniheca woyuha tawa kin he tehika. 28 Wicoowotanna canku kin ohna wiconi, qa oye canku kin ohna wiconțe wanica.

\section{WICOWOYAKE 13.}

1 Hokśidan ksape cin he atkuku wahokonkiya nahon, tuka waoncesa iyopekiyapi eśta nahon śni.

2 Wicaśta wan i kin taku icaliye cin etanhan taku waśte yute kta, tuka tona pemniyan ohanye cin nagipi kin wicowohitike yutapi kta.

3 Tuwe i kin awanhdake cin he nagi kin kpatan, tuka tuwe iha lkin hdugaga woiyokiśica yuhe kta.

4 Wicaśta kuja nagi kin taku cin tuka wanica ; tuka tona miniheca nagipi cepapi kta.

5 Wicaśta owotanna wicoie wicake śni śice daka, tuka wicaśta śica honwin qa iśtece kta.

6 Wicoowotanna tona ecetupi kin wicapatan, qa wicohan śica kin wahtanipisa nawicahnaye kta.

7 Wanji ihdawijica tuka takudan yuhe śni, qa wanji ihdawahipanica eśta woyuha ota ton.

8 Wicaśta wan toni kin opekiton kta e towijice kin iyopekiya, tuka wicaśta śica iyopeyapi nahon śni. 
9 Wicaśta owotanna toiyoyanpa kin wiyuśkin kiya, tuka wicaśta śica petijanjan tawapi kin bowicakisnipi kta.

10 Wahaniçidapi kin hecedan waakinicapi kaga, tuka tuwe wahokonkiyapi nahon kin he ksapa.

11 Wicahnayanpi kin eciyatanhan woyuha kin he wanistina aye kta, tuka tuwe iye nape kin on kamna kin he hduota kta.

12 Woape kin yutehanpi kin cante kin iyokiśin ya, tuka taku cinpi kin iyohipi kin he wiconi can kin he iyececa.

13 Tuwe wicoie kin ihakta śni kin ihang iciye kta, tuka tuwe woahope kin ikope cin iyuwin yuhe kta.

14 Wicaśta ksapa toope kin he wiconi wakoniya kin heca, on wiconte wihmunke yuiyokapi.

15 Tawacin waśte kin wicoiyokipi icahya, tuka tona wahtedaśniyan ohanyanpi kin canku tawapi kin he tehika.

16 Wicaśta ksapa otoiyuhi wosdonye on taku econ, tuka tuwe wacintonśni towitkotkoke cin hduotanin.

17 Wahośiya śica taku śica ohinhipaya ece, tuka wahośiya wicake cin he wookizi.

18 Tuwe woonspe elipekiye cinhan wowahpanica wowiśtece iyahna içicaga, tuka tuwe iyopekiyapi awacin kin he kinihanpi kta.

19 Taku cinpi kin iyohipi kinhan wicanagi kin iyokipi, tuka wicohan śica ayuśtanpi kin he wicaśta witkotkopi wahtedapi śni.

20 Tuwe wicaśta ksapa om mani kinhan ksape kta, tuka tuwe wicaśta witkotkoke koda wicaye cinhan hee ihang yapi kta.

\section{8}

21 Taku śica wahtanipisa wicapasi, tuka tona owotanna taku waśte wicakicupi kta.

22 Wahtanisa woyuha tawa kin wicaśta owotanna wicakicihnakapi, qa wicaśta waśte cinhintku cincapi kin woyuha tawa wicakiye kta.

23 Wicaśta wahpanica mahkicanyanpi on woyute ota icaga, tuka ow otanna ohanyanpi śni on apa awihnuni.

24 Tuwe wicapsinte tpatan kin he cinhintku śice kidaka, tuka tuwe he waśte kidake cin he kohanna iyopekiya.

25 Wicaśta owotanna nagi kin imnahan wota ece, tuka wicaśta śica tezipi kin akihanpi kta.

\section{WICOWOYAKE 14.}

1 Winohinca ksape cin otoiyohi tipi içicaga ece; tuka witkotkoke cin he iye nape kin on ti kin hdujuju:

2 Tuwe iye toecetu kin omani kin he Jehowa kokipa, tuka tuwe canku kin hdupemni kin he ihakta śni.

3 Wicaśta witkotko ipi kin ohna wahaniçidapi sagye yukan, tuka tona ksapapi ihapi kin wicahduhapi.

4 Tukten tatanka waniea hen aguyapi tipi takudan ohnaka śni, qa oicage ota kin he tatanka waśake cin he eciyatanhan u ce.

5 Wayaatanin wicake cin he itonśni wanice kta, tuka wayaatanin ecinśniyan kin he woitonśni jpohya.

6 Waoncesa woksape akita eśta he iyeye śni, tuka tuwe wookahnige cin he wosdonye waśakadan iyeya.

7 Wicaśta witkotkoka itokapatanhan ya wo, qa nakun tuwe 


\section{WICOWOYAKE 14.}

woksape iha yuhe śni sdonyaye cinhan.

8 Wicaśta wayupika toksape kin he tacanku kin iyukcan, tuka wicaśta witkotko towitkotkopike cin he wohnaye.

9 Wicaśta witkotkopi kin woahtani iliahayapi, tuka tona ecetupi kin ehna wacantkiyapi yukan.

10 Wicacante nagi kin toiyokiśice cin sdotkiya, qa towiyuśkin en tokan icicahiye śni.

11 Wicaśta śica tipi kin kawankapi kta, tuka wicaśta ecetupi tawakeyapi icage kta.

12 Canku wanji ecetu seca wicaśta itokam, tuka he iyohakamya wiconte iyahdeya.

13 Nakun tuktekten ihahapi icunhan cante śicapi, qa wowiyuśkin kin he ihanke kin ekta woiyokisica.

14 Tuwe cante namni kin iye tacanku kin on imna kta, qa wicaśta waśte iye cante oze on ipi kta.

15 Tuwe wacintonśni kin wicoie owasin wicada, tuka wicaśta wayupika caehde kin iwanhdaka.

16 Wicaśta ksapa kokipe ca taku śica etanhan ihduhomni ece, tuka wicaśta witkotkoke cin iyopta iyaye ẹa waciniçiya.

17 'Tuwe wacinko kinhan witkotkoya ohanyan, qa tuwe taku śica cantiheye cin śice dakapi kta.

18 'Tona wacintonpi śni wowitkotko kin tawayapi, tuka wicaśta ksapa wosdonye wateśdag tonpi.

19 Wicaśta śica tona waśtepi wicitokam patujapi, qa tona owotanna tatiyopa itokam.

20 Kodawicaya eśta wicaśta wahpanica kin śicedakapi, tuka wicota wijica wall taku yapi.
21 Tuwe takodaku ihakta śni kin wahtani, tuka tuwe tona onśika onśiwicakida yawaśtepi kta.

22 'Tona taku śica kagapi kin hena nunipi, tuka tona taku waśte kagapi wacantkiyapi wowaonśida ahna tawayapi.

23 Taku kicanyanpi kin owasin on taku mnayanpi ece, tuka wicaiha iapi kin wicayuwahpanica heceedan.

24 Wicaśta ksapa woyuha tawapi kin he wateśdag tonpi, tuka tona wacintonpi śni towitkotkopike cin he wowitkotko.

25 Wayaatanin wicake cin he wicanagi ewicayaku, tuka wayaatanin wahnaye cin woitonśni ipohya.

26 . Jehowa kokipapi kin en wowacinye suta yukan, qa tuwe hecon cinca kin hena wowinape yuhapi kta.

27 Jehowa kokipapi kin he wiconi minihdoka kin hee, on wiconte wihmunke kin etanhan ihduśpapi.

28 Oyate ihduotapi eca wicaśta yatapi kin wowitan yuha ece, tuka oyate kiı wanistina aye cinhan atakuni kte śni e ikopa.

29 Tuwe tehan canteptanye śni kin he wiyukcan tanka, qa tuwe wacinko kin he towitkotkoke cin hdutanin.

30 Cante zanika cehpi nikiya kin hee, tuka winawizipi kin he wicahu kin yukuka kin hee.

31 Tuwe wicaśta onśika wan sanpa yuwahpanice cin he tuwe he icahye cin he iśtenya, tuka tuwe he ohoda kin he wahpanicapi kin cante wicakiya ece.

32 Wicaśta śice cin taku śica en napeyapi kta, tuka wicaśta owotanna ța eśta taku wacinyan un.

33 Woksape kin wicaśta wiyu149 


\section{WICOIE WAKAN.}

kcan cante kin ohna iyozi, qa wicaśta witkotko cokaya kin sdonyapi kta.

34 Wicoowotanna kin he oyate kin wowitan icaliwicakiciye cin ee, tuka woahtani kin he oyate wowiśtece kin ee.

35 Ookiye ksapa kin wicaśta yatapi toiyokipi kin hee, tuka tuwe wowiśtece kage cin he canniye kta.

\section{WICOWOYAKE 15.}

1 Ḧbayedan waayupte cin he wowacinko anapta, tuka wicoie tehike cin he wocanteptanyan kaga.

2 Wicaśta ksapa cejipi kin wosdonye yawaśte, tuka wicaśta witkotko ipi kin wowithotko enapeya.

3 Jehowa iśta kin owancaya wicaśta śica wicaśta waśte ko owasin iyohi wicaya.

4 Wicaceji wawokizi ye cin he can wiconi kin iyececa, tuka wicaceji wayapemni kin wicanagi kin he yawega.

5 Tuwe witkotko kin he atkuku wahokonkiye cin ihakta śni, tuka tuwe iyopeyapi iyowiniciye cin he ksapa.

6 Wicaśta owotanna ti kin ohna woyuha tanka yanka, tuka wicaśta śica taku mnayanpi kin en wośkiśke yulkan.

7 Tona ksapa ihapi kin wosdonye kadadapi, tuka tona witkotko cantepi kin hecetu śni.

8 Wicaśta śica wośnapi kin he Jehowa wowaliteda śni, qa wicaśta ecetupi kin cekiyapi kin he iyokipi.

9 Wicaśta śica tacanku kin he Jehowa wahtedaśni, qa tuwe woowotanna ope cin he waśte daka.

10 Tuwe canku elpeye cin wahokonkiyapi kin iyokipi śni, qa tuwe iyopekiyapi śice dake cin he te kta.

11 Jehowa wicațe cin nagipi kin qa tancan atakunipi śni owasin wanyaka, nakun Adam cinca cante ozepi kin owasin.

12 Waoncesa wahokonkiyapi waśte dake śni, qa wicaśta ksapapi kin ekta ye kte śni.

13 Wicacante rviyuśkin kin he itohnake waśte kagu, tuka cante wicaśice cin on wicoksape kin kawanka.

14 Wicacante ksape cin wosdonye akita, tuka witkotko ipi kin wowitkotkoke woyute yapi.

15 Tona iyokiśica anpetu tawapi owasin śicapi, tuka cante waśte kin wohanpi en ohinniyan opapi kin he iyececa.

16 Jehowa wokokipe yapi taku cistina yuhapi eśta hee waśte, tuka woyuha tanka wicośkiśke iyahna hee waśte śni.

17 Walipe tanka heceedan eśta cante waśteya kiciyus yutapi kin hee waśte, qa tatanka cepa eśta cante śicaya kiciyus yutapi kin hee śica.

18 Wicaśta wacinko kicigepi kaga, qa tuwe tehan canteptanye śni woakinica anapta ece.

19 Wicaśta kujapi tacankupi kin wapepeka mahinatake wan iyececa, tuka wicaśta owotanna tacanku kin he yumdayapi.

20 Hokśidan ksape cin he atkuku wiyuśkin kiya, tuka wicaśta witkotkoke cin he hunku kin ihakta śni.

21 Tuwe cante nice cin he wowitkotkoke cin wiyuśkinyan, tuka wookahiniga wicaśta ecetuya mani.

22 Wiyukcanpi wanice cinhan cante ozepi kin atakuni śni ece, tuka wiyukcanpi ota on yusutapi kta. 


\section{WICOWOYAKE 16.}

23 Wicaśta i kin tanyan waayupte cin on iyuśkin kta, qa wicoie iyehantu kin he waśte hinca.

24 Wiconi canku kin wankantuya wicaśta ksapa opa, hecen Hades ihukuya kin yuiyogya.

25 Jehowa wahanicida ti kin yujuju, tuka wiwazica ti kin yusuta ece.

26 Cante ozepi śikśica kin Jehowa wahtedaśni, tuka wicoie wakaśoteśni kin he iyokipi.

27 Tuwe śikśicaya wakamna kin he iye ti kin iyokiśinya ece, tuka tuwe taku qupi kin śice dake cin hee ni kta.

28 Wicaśta owotanna cantepi token waayupte kta awacin, tuka tona śica ipi kin taku śica enapeya ece.

29 Wicaśta śicapi kin Jehowa itehanyan wicaun, tuka wicaśta owotanna cekiyapi eca nawicahon ece.

30 Wicaśta iyoyanpa kin he wicacante iyuśkin, qa taku waśte nahonpi kin wicahuhu cemya ece.

31 Wicanoge wiconi woiyopeye nahon kin he wicaśta ksapa om wanke kta.

32 Tuwe woonspe aktaśni kin he iye nagi kin ehpekiya, qa tuwe woiyopeye nahon kin he cante ton.

33 Jehowa kokipapi kin woksape woonspe kin ee, qa onśihan içidapi kin he wowitan itokamya u ece.

\section{WICOWOYAKE 16.}

1 Cante ozepi kin wicaśta etanhan, tuka Jehowa ceji woayupte kin he qu.

2 Wicaśta iye tacanku kin owasin ecedan kecin, tuka woniya wicatkeuta Jehowa hee.
3 Nitolitani kin Jehowa en yakizamni wo, hecen nicante ozepi kin yusutapi kta.

4 Taku Jehowa kage cin owasin akiciyuptapi, qa wicaśta śica anpetu śice cin on nakun.

5 Wicacante wahanicida kin otoiyohi Jehowa wowahtedaśni, nape iciyahdeyapi eśta iyopewicayapi kta ce.

6 Wowaonśida wowicake iyahua on woahtani kajujupi, qa Jehowa kokipapi kin on taku śica etanhan inapapi.

7 Tohan wicaśta wan ohan kin Jehowa iyokipi kinhan tona tokayapi qon takuyapi kta e kaga.

8 Woowotanna kici taku cistina eśta hee waśte, qa woyuha tanka ecetu śni mnayanpi kin he sica.

9 Wicaśta cante kin tacanku kin hdukcan, tuka cahde tawa kin Jehowa konza.

10 Wokcan wicoie wan wicaśta yatapi iha kin etanhan, wayaco eca i kin nuni kte.śni.

11 Tke utapi ecetu kin he Jehowa etanhan, ojuhadan ohna inyan un kin hena owasin iye kaga.

12 Wicaśta yatapi kin śicaya ohanyanpi kin wowahtedaśni yanpi kte, nakaeś woowotanna kin oiyotanke kin yusuta.

13 Wiciha owotanna wicaśta yatapi iyowicakipi, qa tuwe ecetuya ie cin he waśte dakapi kta.

14. Wicaśta yatapi tocanniye kin he wiconte wahośiwicaya iyececa, tuka wicaśta ksapa wan he anapte kta.

15 Wicaśta yatapi itohnake kin iyoyanpa kin ohna wiconi yukan, qa cante wicakiye cin he magaju ehake kin he iyececa.

16 Woksape mnayanpi kin hee iyotan, qa mazaskazi hee śni; 


\section{WICOIE WAKAN.}

qa wokcan iyohiyapi kin he mazaska isanpa cinpi kte.

17 Taku śica yuiyokapi kin he wicaśta ecetupi tacanku yumdayapi kin hee, qa tuwe iye ohan kin awanhdake cin he nagi kin kpatan.

18 Wicotakuniśni itokamya watankaiçidapi u, qa wicawankahe kte cin itokam woniya wahanicida ya ece.

19 Onśipika om woniya onśihan icida kin hee waśte, qa wahanicidapi om taku kipi kicipamnipi kin en opapi kin he sica.

20 Tuwe wicoie kin awacin kinhan taku waśte iyeya, qa tuwe Jehowa wacinye cin he yawaśtepi kta.

21 Tuwe cante ksape cinhan wokcan eciyapi kta, qa iha oskuye cin he woonspe icahye kta.

22 Tuwe woksape yuhe cin he wiconi wakoniya wan seca yuha, tuka wicaśta witkotko onspekiyapi kin he wowitkotko.

23 Wicacante ksape cin he i kin wayupikiya, qa iha kin akan woonspe aokijuya ece.

24 Wicoie wiciyokipi tuhmaga canhanpi kin he iyececa, wicanagi woskuye kin, qa, wicahuhu okizi kin hee.

25 Canku wanji ecetu seca wicaśta itokam eśta, iyohakamya wi conțe canku kin iyahdeya.

26 'Tuwe htani kin he iye on litani, i kin iyopaśtaka nakaeś.

27 Wicaśta wicaśtapi śni kin taku śica kicanye ça, iha kin ohna peta ideya seca.

28 Woopemni wicaśta kin he woakinice icaliya, qa wicaśta sin woyag un kin he takodakiciyapi wicayamdece cin hee.

29 Wicaśta wakisa kin takodaku kihnayan, qa canku wan waśte śni kin omanikiya.
30 Woyapemni kin yukcan kta e iśta kin ohmus ikikcu, qa iha kin hdahtaka wicohan sica hduśtan.

31 Wicapa ska woowotanna canku kin ohna iyeyapi kinhan wateśdake owaśtecaka kin hee.

32 Tuwe tehan canteptanye śni kin he wicaśta waśaka kapeya, qa tuwe toniya wowidag kiye cin he wicaśta otonwe icu kin he kapeya.

33 Wicaśta econpidan kansu kin ojuha ohna iyeyapi, tuka token hinanpe kta Jehowa konza.

\section{WICOWOYAKE 17.}

1 Aguyapi onśpadan wapaye codan eśta wokiyapi en hee waśte, qa tipi wan tado akinicapi ojudan kin hee śica.

2 Ookiye ksape cin he cinca iśtenwicakiye cin he wowidag ye kta, qa sunka kiciyapi om taku tawayapi kta en wopamni yuhe kta.

3 Maka wakśica ohna mazaska iyutapi, qa maza oceti ohna mazaskazi, tuka Jehowa wicacantepi kin iwicayuta.

4 Wicaśta śica wiciha ecinśniyan anagoptan, qa tuwe itonśni kin ceji awihnuniyan kin anoh kiciya.

5 Tuwe wicaśta wahpanica kin iha kin he tuwe he kage cin iśtenya, qa tuwe tokan yuśakapi kin on iyuśkin śitkihdayapi kta. 6 Cinca qa sanpa cinca kin hena wicahinca wateśdag yapi, qa hokśipidan atkukupi kin wowitan wicayapi ece.

7 Iapi tanka kin wicaśta witkotkopika iyewicacecapi śni, qa he isanpa iha itonpi śni kin wieaśta tokapapi kin iyowiniẹiyapi kte śni.

8 Taku wicaqupi inyan wici- 
mdeza iyececa tuwe he yuhe cin iśta kin itokam, taku kaśta ektakiya yuhomnipi taku okihi.

9 T'uwe woalitani akahpeton kin he otakuye akita, qa tuwe he oyakesa he kodakiciyapi tanka yujuju.

10 Iyopeyapi kin wicaśta ksapa nina yaskinya, tuka opawinge apapi keś wicaśta witkotko kin awacin śni.

11 Tuwe wakipajin taku śica hecedan akita, heon wahośi wohitika ekta ye śipi kta.

12 Eeś wicaśta wanji wahanksica cinca owasin kitanin śni akipe cin he tehika eśta, wicaśta witkotkoka towitkotkoke cin ohna he isanpa tehika.

13 Tuwe taku waśte on taku śica iyowinye cinhan, taku śica iye ti kin ayuśtan kte śni.

14 Okicigepi otokahe kin he mini okadusyapi kin he iyececa, heon akinicapi kin ihdutaninśni itokam ehpeya wo.

15 Tuwe wicaśta śica yaowotanna, qa tuwe wicaśta owotanna yaśice cin hena napin Jehowa wowahtedaśni.

16 Taku on etanhan woksape opeton kta e witkotkoka nape ohna maza yukan tuka cante wanica?

17 Kodayapi wan ohinniyan takodaku cante kiye kta, qa tehiya unpi eca owicakiye kta ece kin heon sunkayapi wan wicakicitonpi.

18 Wicaśta cante nice cin takodaku itokam icazopi kicicajuju kta keye ca nape yekiya.

19 'Tuwe wokipajin waśte dake cin he akinicapi waśte daka, qa tuwe tatiyopa kin hduwankantuya kin he ihang içiye kta e akita.

20 'Tuwe cante pemni kin he taku waśte iyeye kte śni, qa tu- we ceji kin hdatokeca kin he taku śica ohinhpaye kta.

21 Tuwe cinca witkotko wan kage cin he woiyokiśin iciya, qa hokśidan wicaśtaśni atkuku kin iyuśkin kte śni.

22 Wicacante wiyuśkinyan tanyan okizi wicaya, qa woniya iyokiśice cin he wicahuhu lín naśeca.

23 Taku itpi etanhan qupi kin he wicaśta śica icu, qa woyaco canku kin yapemni.

24 Wokcan wicaśta kin itokamya woksape yukan, tuka wicaśta witkotko iśta kin maka ihankeya kin etonwanpi.

25 Hokśidan witkotko kin he atkuku okiçuninya, qa tuwe ton kin iyokiśinya ece.

26 Wicaśta owotanna iyopewicayapi kin he waśte śni, wicaśta tokapapi kin taku ecetu kin on awicapapi kin he nakun.

27 Tuwe oie kin kpatan kin he wosdonye sdonya, qa woniya inina kin he wookalinige wicaśta.

28 'Tuwe witkotkoka eśta inina un kin hehanyan ksapa kecinpi kta, iohmus un kin he wiyukean.

\section{WICOWOYAKE 18.}

1 Wicaśta wan iyokipi ic̣iye kta e iśnana iyaye ça taku awacinpi kin owasin on wicalkige.

2 Wicaśta witkotko wookahinige iyokipi śni, tuka cante kin toketu ihdutanin kta he iyokipi.

3 Wicaśta śica u kinhan woaktaśni nakun u, qa wicakigepi kin he iwicaśteca opa.

4 Woksape wakoniya kin he wakpa kaduze cin heca, wicaśta i kin etanhan wicoie kin mini śma kiu he iyececa.

5 Wayacopi en wicaśta śica wan ihak tapi on wicaśta owotanna yapemnipi kin he waśte śni. 


\section{WICOIE WAKAN.}

6 Wicaśta witkotko iha kin akinicapi en ye iciya, qa i kin apapi kin kipan.

7 Wicaśta witkotko i kin ihdutakuniśni, qa iha kin iye nagi kin kihmunka ece.

8 Tuwe iwakan kin oie kin woyute skuya kin iyececa, wicatezi kin mahentuya iyaya ece.

9 Nakun tuwe tohtani on kuje cinhan tuwe woyuha ihang ye cin he cinye ya.

10 Jehowa caje kin conkaśke suta wan heca, wicaśta owotanna kin hen onapa qa okope wanin yanke.

11 Wicaśta wijica taku yuhe cin he otonwe suta, qa conkaśke tehanwankantuya iyececa kecin.

12 Nawegapi kin itokam wicacante kin wahanicida, qa wowitan itokam onśihan içidupi kin.

13 'Tuwe taku nahon śni itokam waayupte cin he witkotko içiye ça kiunniiciya.

14 Wicaśta tancan yazan eśtá taniya kin wakiśaka ece, tuka wicaniya naśujapi kinhan tuwe wakiśake kta okihi he?

15 Wicacante wiyukcan kin he wosdonye ton kta, qa wicaśta ksapa nogepi kin wosdonye akite kta.

16 Taku ituhan kin wicaśta kiciyukan kta, qa wicaśta tanka wicitolam hiyuye kta.

17 Waakinicapi en tuwe tokaheya wohdake cin he ihdaowotanna, tuka uman hi qa iwange kta.

18 Oeconna kin akinicapi kin anapte ça wicaśta waśaka wicayukin ukan.

19 Sunkakiciyapi akinicapi kin conkaśke tiyopa onatakapi kin iyececa, qa otonwe suta ohiyapi tehika eśta sunkakiciyapi kicipajinpi kin he sanpa tehika.
20 Wicaśta tezi kin taku i kin icahye cin on imna kta, taku iha kin etanhan inape ein heon imna kta.

21 Wiconte wiconi ko wicaceji nape kin ohna un, qa tuwe he waśte dake cinhan taku icahye cin he etanhan yute kta.

22 Tuwe tawicu iyeye cinhan taku'waśte iyeya, qa Jehowa wicaśta kin he cante kiya.

23 Wieaśta wahpanica wacekiya yanka, tuka tuwe wijice cin he sutaya waayupta.

24 Tuwe wicota kodawicaye cin he kodayapi iyccen ihdutanin kta, qa wanji wacantkiya sunkayapi wicapatan eśta sam iyeya wicapatan.

\section{WICOWOYAKE 19.}

1 Tuwe iha pemni qa witkotkoka hee śni, tuka- tuwe ecetuya mani wahpanica eśta hee waśte.

2 Wicanagi kin wosdonye nice cin he nakun waśte śni, qa tuwe siha kin inahni kin he nuni.

3 Wicaśta towitkotkoke cin canku kin hdupemni; ga cante kin Jehowa canniyeya.

4 Wowijice kodayapi ota icahya, tuka tuwe wahpanica kin he takodaku yukinukan.

5 Wayaatanin itonśni kin he iyopeyapi kta, qa tuwe taku ecinkta enapeye cinhan ihduśpe kte śni.

6 Tuwe nina wo wicaqu kin wicota he ite kin kastostopi kta, qa tuwe ituhansa kin he owasin kodayapi kta.

7 Tuwe onśika eca hunkawanjitku owasin śice dakapi, qa hecen sam iyeya kodawicaya ihdutehanpi, wicoie pasi tuka hena taku śni.

8 Tuwe cante ton kin he nagi 
kin waśte kidaka, tuwe wookahnige patan kin taku waśte iyeye kta.

9 Wayaatanin itonśni kin iyopeyapi kta, qa tuwe taku ecinkta enapeye cinhan awihnuni kta.

10 Wicaśta witkotko taku wiciyokipi yuhe kta he iyecece śni, qa ookiye yuhapi qon wicasta itancan wowidag wicaye kta e sanpa teliika.

11 Wicaśta toksape kin tocanniye kin kihnaka, qa śicaya ecakiconpi kin iwankam iyaye cin towitan kin hee.

12 Wicaśta yatapi tocanniye kin he mnaja hoton kin iyececa, qa toiyokipi kin cu kin wato akan he iyececa.

13 Hokśidan witkotko atkuku toiyokiśice kin ee, qa winolinca kigesa kin śbuyapi ohinniyan kin heca.

14 Tipi qa woyuha hunkake yapi etanhan tawayapi, tuka tawicu ksape cin he Jehowa etanhan.

15 Wokuje kin he hbapi kaga, qa wicanagi econkapin kin he wotektehda un kta.

16 Tuwe woope kin yuhe cinhan nagi kin hduha, qa tuwe tacanku kin iyakikta’śni kin he te kta.

17 Tuwe walipanicapi cante wicakiye cin he Jehowa oqu, qa taku waśte kin he iyecen tanyan kicu kta.

18 Nahanhin taku waśte ape oyakihi nicinca iyopekiya wo, qa te yakiye kta ihnuhan ninagi en inape cin.

19 Tuwe wocanteptanye tanka kin he śitkibdayapi kta, hetanhan edaku eśta ake ecanon kta.

20 Wahokonniciyapi kin awaein wo, hecen iyohakamya yaksape kta.
21 Wicacante ekta taku ota a wacinpi, tuka Jehowa taku konze cin he sutaya he kta.

22 Wicaśta toiyokipi towacantkiye kin hee, qa wicaśta wahpanica kin wicaśta itonśni kin kapeya.

23 Jehowa kokipapi kin on wiconi, qa tuwe hecon kin he imnahan yanke kta, taku śica he iyohi kte śni.

24. Wicaśta kuje cin nape kin wakśica ohna yekiya, ake i kin ekta eśta hiyukiye kte śni.

25 Waoncesa nina ayape cinhan tuwe wacintonśni kin he ksape kta, qa wicaśta wokalinige kin he iyopeya wo, wosdonye okahnige kta.

26 Hokśidan waiśtenya qa waihakta śni kin he atkuku kin hdutakuniśni, qa hunku napekiya.

27 Micinkśi woonspe k̉in wosdonye wicoie kin etanhan nuni wicakiye cin he nalion kta ayuśtan wo.

28 Wayaatanin wicaśta śni kin he woyaco ihaha, qa wicaśta śica ipi kin taku śniśni napcapi.

29 Woyaco wicaśta śica wiyeya wicakicihnakapi, qa wicaśta witkotkopi tapetepi kapsinpsintapi kta.

\section{WICOWOYAKE 20.}

1 Miniśa kin he waihalia qa mini wakan kin he owodutaton wicaya; tuwe unman tukte kaśta on nuni kinhan ksape kte śni.

2 Wicaśta yatapi kin yuśinyewicaye cin he mnaja hoton kin he iyececa, tuwe he canniyeye cinhan iye nagi kin awahtani.

3 Akinicapi anapte cin wicaśta towitan kin ee, tuka wicaśta witkotko otoiyohi wakigepi en yeiçiye kta. 


\section{WICOIE WAKAN.}

4 Wicaśta kuja osni kin on maga hdumdu kte śni, he on woksapi icunhan woda kta, tuka wanice kta.

5 Wicaśta taku konze cin he cante mahen mini śma kin iyececa, tuka wicaśta wookahnige kin he tankan hiyuye kta.

6 Wicaśta ota otoiyohi towacantkiye kin ohdake kta, tuka wicaśta wowicake tuwe iyeye kta he?

7 Tuwe ecetuya mani kin he olian owotanna, cinca iyohakam icagapi iś eya tanyan unpi ece.

8 Wicaśta yatapi woyaco oiyotanke akan yanke cin he iśta kin on taku śica owasin bomden iyaye ya.

9 Micante kin mihduecedan, wawahtani kin etanhan mihduska, tuwe eye kta okihi he?

10 Wiyutapi toktokeca, qa tke utapi toktokeca heniyoza Jehowa wahtedaśni.

11 Kośka eśta ohanye cin etanhan ihdutanin, ohan kin ecedan kinhan qa ecetu kinhan.

12 Noge wanahon kin qa iśta wawanyaka kin heniyoza Jehowa kaga.

13 Thnuhan woiśtima waśte yadake cin, okini nihduwahpanice kta ; iśta hdukawa hecen aguyapi inimna kta.

14 Śica, śica ce, tuwe opeton kta eye ca wanna tawa tankan iyaya hehan ihdatan.

15 Mazaskazi yukan, qa tukihasan śa ota eśta, wosdonye wiciha kin he wojuha telike hinca hee.

16 Tuwe oyate tokeca wicaśta on, wecicajuju kta, eniciye cinhan taśina kin icu wo, qa tuwe wicaśta sdonwicaye śni, wicawecicajuju kta, eye cinhan taku tohanyan kajuju śni duhe kte cin he icu wo.
17 Tokan wicakicicajujupi eyapi kin he aguyapi itonśni, qa iyohakam i kin isbudan oju ye kta.

18 Taku konzapi kin wiyukcanpi kin on yusutapi kta, qa tanyan iyukcanpi kin hehan ozuye kaga wo.

19 Tuwe waaia mani kin he taku nahmana oyakapi kin yaotanin, heon tuwe iha hdakawahan he kici icicahiye śni wo.

20 Tuwe atkuku hunku ko wicayaśice cinhan otpaza cokaya kin petijanjan tawa kin bokicisni kta.

21 Woyuha otokahe ekta inahinina mnayanpi kin he owihanketa yawaśtepi kte śni.

22 Taku śica towecon kta, ihnuhan ehe cin; Jehowa apeya wo, iye niniye kta.

23 Nonpakiya tke utapi kin Jehowa wahteda śni, qa wohnaye aspekiyapi kin he waśte śni.

24 Wicaśta oye kin he Jehowa etanhan, hecen tokiya tanhan wicaśta canku kin hâkcan kta he?

25 Wicaśta tuwe ihnuhanna taku tawa hdawakan kin he hmug içiye, nakun tuwe konze cin iyohakan iwange cinhan.

26 Wicaśta yatapi ksape cin he wicaśta śica wicayamdece ca canpahmihma wiciwankam hiyuya.

27 Jehowa petijanjan tawa kin wicaśta taniya kin ee, taku wicacante mahentuya un kin owasin iwanyaka.

28 Wocantekiye wowicake ahna wicaśta yatapi kin awanyakapi, qa oiyotanke tawa wocantekiye on hdusuta.

29 Kośka towaśakapi kin iwinktapi kin hee, qa wicahinca kin pa skapi kin wowitan yapi.

30 Bahonpi paskitapi kin he 


\section{WICOWOYAKE 21.}

taku śica patehan ya, qa apapi kin tezi cokaya iyohi kin he nakun.

\section{WICOWOYAKE 21.}

1 Jehowa wicaśta yatapi cante kin mini wakpadan iyecen nape kin ohna yuhe ca toki cin kin heciya he yuptanyan.

2 Wicaśta iyohi tacanku kin owasin ecetu kecin, tuka Jehowa wicacante owasin aspe kiya.

3 Wośnapi Jehowa iyokipi eśta taku owotanna qa ecetu econpi kin he isanpa iyokipi.

4 Iśta ihduwankantuyapi qa cante kin ihdatankapi kin hena wicaśta śica petijanjan yapi tuka woahtani.

5 Wicaśta miniheca canteozepi on taku mnayanpi ece, tuka tona inahnipi kin owasin on ihdukakijapi ece.

6 Woyuha ota ceji itonśni on mnayanpi kin hena takuśniśni bomdu iyayapi, qa tona heconpi kin hena wiconte akitapi.

7 Wicaśta śica wakipi kin ihang wicaye kta, nakaś woyaco econ tawatenyapi "śni.

8 Wicaśta canku pemnimni kin he oyate tokeca, tuka tuwe ecedan kin he tancanku kin ecetu.

9 Tice kahmin otipi kin hee waśte, tuka winohinca wakigesa kici tipi tankaya eśta otipi kin he tehika.

10 Wicaśta śica nagi kin taku śica cin ece, iśta kin takodaku eśta wacantkiya yuze śni.

11 Waoncesa aonpapi kinhan tuwe wacintonśni ksape kta, qa wicaśta ksapa onspe kiyapi kinhan wosdonye icu kta.

12 Wicaśta owotanna kin wicaśta śica toti kin iyukcan : Tuwe wicaśta śica taku śica ohna napewicaya.
13 Tuwe tohan wicaśta onśika hoyekiyapi ca noge kin onakitake cinhan iś eya hoyeye kta, tuka tuwedan ayupte kte śni.

14 Taku nalimana qupi kin he wocanniye anapte, ca itpi kin ohna taku ituhanpi kin he canteptanye tanka.

15 Woyaco econpi kin he tona owotanna iyuśkin wicakiya, tuka śicaya ohanyanpi kin wicakahintapi kta.

16 Wicaśta wan wookahinige canku kin etanhan nuni kin he wicaśta țapi yuwitayapi om yanke kta.

17 Tuwe iyokipi iciye kta waśte dake cinhan ihduwahpanica, qa tuwe miniśa wihdi ko waśte dake cin he wijice kte śni.

18 Wicaśta śica tona ow otanna ohanyanpi kin wicakicicajujupi kta, qa wicaśta wakisa kin tona ecetupi on.

19 Tinta hewoskantuya ounyanpi kin he waśte, tuka winohinca wakigesa qa wacanniyesa kici tipi kin he śica.

20 Wicaśta ksapa ounye cin olına woyuha wiciyokipi qa wihdi yukan, tuka wicaśta witkotko kin he napca iyeya.

21 Tuwe woowotanna wocantekiye ohna ope cinhan wiconi woowotanna qa wowitan iyeye kta.

22 Wicaśta ksape cin he waśakapi otonwepi kin ohiye ca, taku suta wacinyanpi kin he yuhukuya ece.

23 'Tuwe i kin qa ceji kin awanhdake cin he nagi kin taku tehika etanhan kpatan.

24 Tuwe wahaniçidaya wocanniye kage cin he wamnaicida, wahanicida waoncesa eciyapi kta.

25 Wicaśta kuja nape kin hitani kapin, heon wocin kin țe kiye. 


\section{WICOIE WAKAN.}

26 Anpetu osan wahduhaha kte cin cantotpani, tuka wicaśta owotanna woqu qa tehinda śni.

27 Wicaśta śica wośnapi kin he wowahtedaśni ece, ecah taku sica awacinyan au kinhan isanpa.

28 Woitonśni wayaatanin kin awihnuni kta, tuka wicaśta token nation kin yatanin kin he ohinniyan ie kta.

29 Wicaśta śice cin itohnake kin hdusuta, tuka wicaśta owotanna kin canku kin hduecetu.

30 Jehowa itkokim wicoksape wanica; qa wookahnige wanice ca wokcan wanica ce.

31 Kicizapi anpetu kin heon śuktanka kin wiyeya kihnakapi, tuka niwicaye cin Jehowa hee.

\section{WICOWOYAKE 22.}

1 Woyuha ota hee śni, tuka tanyan caje niyatapi kin he kahiniga wo; mazaska mazaskazi kici hee śni, tuka tanyan wacin en niyuzapi kin.

2 Wicaśta wijica qa wahpanica itkokicipapi, Jehowa napin wicakaga.

3 Wicaśta ksape cin taku śice cin he wanyake ca inalima, tuka tona wacintonpi śni kin hena iyoptapi qa kakiświcayapi.

4 Jchowa kokipapi qa onśitian icidapi iyuwin kin he wowitan qa wowijice qa wiconi.

5 Wicaśta pemni tacanku kin ohna wapepeka on hmunkapi ko yukan, tuwe nagi kin awanhdake cinhan hena ihdutehan kta.

6 Otokahe etanhan hokśidan tacanku kin ohna kihiya wo, hecen wicahinca eśta elipekiye kte śni.

7 Wicaśta wijica wahpanicapi wowidag wicaya, unkan tuwe waodote cin he waoqu kin he okiya ece.

8 'Tuwe wicohan śica oju kin he wicotaninśni mnaye kta, qa tocanniye sagye kin sote kta.

9 Iśta wacantkiya kin he yawaśtepi kta, nakaś aguyapi tawa kin onśpa wakanheja wicaqu.

10 Waoncesa napeya wo, hecen wakigepi kin tokan ye kta, nakun waakinicapi kicibapi ko enakiyapi kta.

11 Tuwe wicacante ecedan kin he waśte kidake cin he iha wiciyokipi on wicaśta yatapi kin kodaye kta.

12 Jehowa iśta kin wosdonye patan ece, qa wicaśta wahnayesa oie kin yuptanyeya.

13 Mnaja wan tankan yanka, otonwe canku kin ohna makte kta, wicaśta kuje cin eya.

14 Wihomniwin i kin he wolia śbe hinca, tona Jehowa walite wicadaśni kin hena ohinhpayapi kta.

15 Hokśidan cante kin ohna wopemni opahtapi eśta iyopekiyapi icapsinte kin he yutehan yekiciye kta.

16 Tuwe taku tawa hduota kta e wicaśta onśika wicayuwahpanica, qa tuwe watonka wawicaqu kin he awicakehan wahpanice kta.

17 Nogoptan qa wicaśta ksapa oiepi kin nation wo, qa nicante kin mitoksape kin awacin kta.

18 Hena maku mahen yapatan kinhan wiciyokipi; niiha kin akan yuecetupi kta.

19 Niś niye Jehowa wacinyaye kta, heon nakaha hena sdonye ciciya.

20 Wahokonkiciyapi qa wosdonye kin taku itancanyan ociciyake śni he?

21 Hecen wowicake wicoie kin 


\section{WICOWOYAKE 23.}

woecetu kin sdonye ciciye, heon tona ye niśipi kin hena wicoie wicalie cin wicayakahdi kta.

22 Wicaśta onśike cin he onśiya un kin on etanhan ihnuhan taku tawa yaki kinhan, qa wicaśta wahpanice cin he wayácopi en yaśuje śni wo ;

23 Awicanicapi en Jehowa iwicakiye kta, qa tuwe wawicaki kin he nagi kin ki kta.

24 Ihnuhan wicaśta wacinko wan kodayaye cin, qa wicaśta wacanniyesa kin kici ye śni wo ;

25 Okini ohan tawa kin ecewayakta nace, qa ninagi kin nicihmunkapi nun ce.

26 Tokan on taku wicakicicajujupi kta, icazopi kin wicakicicajujupi kta eyapi kin, ihnuhan owicayape cinhan;

27 'Taku on kajujupi oyakihi śni kinhan tokeca owinja nihuhuya tanhan eniciyakupi kta he?

28 Maga wapetokeca wanakaja nihunkakepi chdepi qon he dutokan kte śni.

29 Wicaśta wohtani en miniheca wandaka he? wicaśta yatapi wicitokam najin kta ; wicaśta caje wicayatapi śni kin hena wicitokam najin kte śni.

\section{WICOWOYAKE 23.}

1 Wicaśta yatapi wanji kici wayate kta idotanke cinhan, taku nitokam he cin he en ewacin wo.

2 Wayate cin iyakape niye cinhan isan wan dote kin hdakinyan iniyakiye non ce.

3 Woyute tawa wiciyokipi kin he iyotan da śni wo, he woyute kin wicahnayan.

4 Wijinniciye kta e ihdustute śni wo, wookalinige nitawa kin he ahduśtan wo.

5 Taku en un śni kin he ekta iśta kin yeyakiya he? wanmdi wan mahipiya ektakiya kinyan iyaye cin he iyecen wowijice hupahu icicage ca iyaya ece.

6 Tuwe wolinyesa kin aguyapi tawa kin etanhan yute śni wo, qa woyute skuya tawa kin kon śni wo;

7 Nakaś token nagi mahen ecin kin he iyececa, Wote ça wayatkan wo, eniciya eśta cante kin nici un śni.

8 Onśpa yate cin he hdemyaye kta, qa nioie waśte kin owasin èpeyakiye kta.

9 Wicaśta witkotkoka noge kin ohna ie śni wo, nioie woksape kin ihakta kte śni.

10 Maga wapetokcea wanakaja kin he dutokan kte śni, qa wamdenica maga tawapi kin en ye śni wo.

11 Nakaś tuwe taku wicaye cin he waśaka, iye hinca taku tawapi kin on nici akinice kta.

12. Woonspe ekta nicante kin hiyukiya wo, qa ninoge kin woksape wicoie kin ekta.

13 Hokśidan iyopekiyapi patan śni wo; cansakadan on ayapa eśta te kte śni.

14 Cansakadan on ayape kta, hecen nagi kin Hades etanhan edaku kta.

15 Micinkśi nicante kin ksape cinhan micante kin iyuśkin kta, miye hinca ;

16 Qa pakśin mitawa nina pida kta, niiha taku ecetu eye cinhan.

17 Ihnuhan nicante wahtanisa icewicakin kin, tuka anpetu osan Jehowa kokipeyahan un wo.

18 Nakaś woyuśtan yuke cinhan taku wacinyan ayape kin he nicicaśpe kte śni.

19 Micinkśi niye anagoptan, qa ksapa wo ; qa canku ohna nicante kin hduowotanna wo. 


\section{WICOIE WAKAN.}

20 Miniśa yatkanpisa qa iyokipi içiyapi kta e tado napcapisa owicape sni wo.

21 Witkosa qa wotesa kin hena ihduwahpanicapi, qa ogungapi kin hena wokoyake hielidecahan koyakapi kta.

22 Niyate cinca nicage cin he nakon wo, qa nihun wakanka eśta ihnuhan ihayaktaśni kin.

23 Wowicake kin opeton wo, qa wiyopekiye śni wo, nakun woksape qa woonspe qa wookahnige.

24 Tuwe ohan owotanna kin he atkukı nina iyuśkin kta, qa tuwe hoksidan ksapa wan icahye cinhan he etanhan pida kta;

25 Hecen niyate nihun kici iyuśkinpi kta, qa tuwe niton kin nina pida kta.

26 Cinś nicante kin maqu wo, qa canku mitawa kin he niiśta kin awanyaka nunwe.

27 Witkowin kin he makohidoka temahentuya, qa wihomniwin kin he woha cistiyedan , ee :

28 Awicakehan he wabotica iyecen wawihmunke ca wicaśta ehna wahtanipisa wicayurota.

29 Tuwe, Hehehe, eya he? tuwe ceya he? Tuwe kicikigepi yuha he? tuwe woiyokiśice yuha he? tuwe taku on etanhan taninśni apapi he? iśta samyahan un kin he tuwe?

30 Tona miniśa tehan opapi kin, tona miniśa icicahiyapi kin akin yapi kin hena.

31 Miniśa tohan śaiciye, tohan wiyatke ohna iśta kin hdutanin, wiciyokipiya kaduze cin hehan atonwe śni wo.

$32 \mathrm{He}$ iyohakam wamduśka iyecen wayahtake kta, qa sintehda wan iyecen wakiunniye kta.

33 Hehan niiśta kin winolinca tokeca wanwicayake kta, qa ni- cante kin taku pemnimni kin enapeye kta ;

34 Qa tuwe miniwanca cokaya kin iwanke cin he iyenicece kta, qa tuwe sina watopekiyapi ihupa inkpata wanke cin he iyenicece kta.

35 Makaśtakapi tuka mayazan śni, amapapi tuka weksuye śni, tohan wekta kinhan ake awakite kta, ehe kta.

\section{WICOWOYAKE 24.}

1 Wicaśta śice cin icewicakin śni wo, qa owicayape kta cin śni wo.

2 Cantepi kin waboticapi awacinpi, qa ihapi kin waapatayapi kin ecedan cajeyatapi.

3 Woksape on tipi kagapi ece, qa wookahinge on sutaya he kta.

4 Wosdonye on wopiye owasin woyuha tehike ca wiciyokipi ojudan yapi kta.

5 Wicaśta ksape cin he waśaka, qa wosdonye wicaśta kin he tuwe waśake cin he kapeya.

6 Ozuye yakage cinhan wayupiya econ wo, qa wiyukcanpi ota on ohiyapi ece.

7 Woksape kin he tehanwankantuya un, hecen wicaśta witkotko kin he iyohi śni, otonwe tiy opa kin ohna i kin hdukawa śni. 8 Tuwe taku śica econ wacin kinhan he wicolian sica itancan eciyapi kta.

9 Witkotkoka cante oze kin he woahtani kin ee, qa waoncesa kin he wicaśta wowalitedaśni yapi kta.

10 Iyokiśicapi anpetu kin en cante niwankadan kinhan nitowaśake kin cistinna kta.

11 Tona wiconțe en yusdohan awicayapi, qa wicaktepi kta e kaktihanhanpi kin hena ewicayahdaku kta yakapin kinhan. 


\section{WICOWOYAKE 25.}

$12 \mathrm{He}$ sdonunyanpi śni, eha eśta, tuwe wicacante kin iyukcan kin he iyukcan kte śni he? tuwe ninagi kin awanyake cin he sdonye kta, qa wicaśta otoiyohi token ohanye cin he iyecen yuhekiye kta.

13 Cinś tukmaga canhanpi kin he waśte heon yuta wo, qa canhunpute kin he nicaka ekta skuye kta ;

14. Woksape ninagi kin ekta hecece lita, tohan he iyeyaye cinhan iyuwin yuke kta, qa taku ayape kin heon nicihnaye kte śni he sdonya wo.

15 Wicaśta śica, ihnuhan wicaśta owotanna ounye cin iwandake cin, qa tipi tawa kin awihnuniye śni wo.

16 Wicaśta owotanna śakowin akihde hicahan eśta najin kta, tuka wicohan śice cin he taku śca oilipaye kta.

17 'Toka niye cin hicahe cinhan ihnuhan iduśkin kin, qa naicipson eśta ihnuhan nicante kin iyokipi içiye cin ;

18 Okinni Jehowa he wanyake cinhan iyokipi kte śni, qa tocanniye kin he etanhan niye en aniyuhomni nun ce.

19 Wicaśta śicapi iśta ihnuhan iyoniyake cin, qa wicohan śice cin he icekin śni wo ;

20 Nakaś wicaśta śica iyuwin yuhe kie śni, qa wicohan śicapi kin hena petijanjan wicakiyusnipi kta.

21 Cinś, Jehowa kokipeyahan un wo, wicaśta yatapi nakun; qa tona taku toktokeca akitapi kin hena on opiic̣iye śni wo.

22 Heniyoza tohan kakiś wicayapi kta tuwe sdonya he? woiyokiśicapi ihnuhanna anawicajin kta.

23 Wicaśta ksapa oiepi kin hena nakun eepi: Wayacopi kin Prov. en wicite iyekiyapi kin he waśte śni.

24 'Tuwe wicaśta śice cin, oniwotanna eciye cin he oyate kin yaśicapi kta; han, owasin wowahtedaśni yapi kta.

25 Tuka tona he iyopeyapi taku wiciyokipi iyeyapi kta, qa tuwe waśte kin wicayawaśte kta.

26 Tuwe wicoie ecetu ayupte cinhan iha kin iputakapi kta.

27 Nitolitani tankan iwanhdaka wo, qa nitamaga kin tanyan hduśtan wo, qa hehan tipi yecage kta.

28 Ihnuhan ituli nitakoda on taku śica odake cin; niiha kin on wicayahnaye kta he?

29 Token eeamiconpi kin he iyecen ecawecon kta, wicaśta otoiyohi token ohanye cin he iyecen owakilianye kta, eye śni wo.

30 Wicaśta kuja wan tamaga kin icahda iyamdupta, qa wicaśta cante nica wan wiyuwi tawa ikiyedan;

31. Unkan inyun hena owancaya haśbe aicage ça itolnnake kin osan wapepeka on akahpetonpi, qa inyan on inataktonpi kin he yuwankapi ;

32 Hena awatonwan, qa micante kin ekta ewahnaka; wanmdake ca waonspemiciciye.

33 Ehake cistiyedan niśtibe, cistiyedan makan inunke kta e nape pakśijapi ;

34. Hecen nitowahpanice kin he wicaśta icimani wan he iyecen en nihi kta, qa wicaśta wipe hduhe cin en u kin iyecen taku owasin inicakije kta.

\section{WICOWOYAKE 25.}

1 Wicoie wakan kin dena nakun Salomon tawa, qa Juda o161 


\section{WICOIE WAKAN.}

yate wicaśta yatapi Hizekiya wicaśta tawa kin dena akta owapi.

2 Wakantanka taku anakihbe kta towitan kin ee, tuka taku tanyan iyukcan kta e wicaśta yatapi kin towitan kin hee.

3 Mahpiya tehanwankantuya kin, qa maka temahentuya kin, qa wicaśta yatapi cante kin hena owasin iyukcanpicaśni.

4 Mazaska etanhan gigi kin he yutokan iyeya wo, hecen wakśica wan mazakage cin un kta e hiyu kta.

5 Wicaśta yatapi itokapa tanhan wicohan śicapi kin hena wicayutokan wo, hecen oiyotanke tawa woowotanna on sutaya he kta.

6 Wicaśta yatapi kin itokam ihdutan śni wo, qa wicaśta tokapapi ohe kin ohna najin śni wo.

7 Nakaś, Wankantuya deciya $\mathrm{u}$ wo, eniciyapi kin hee waśte, tuka wicaśta itancan niiśta wanyake cin he itokam niyuhukuyapi kin hee waśte śni.

8 Ihnuhan inahniyan woakinice en yeniciye cin, okini owihanketa tuwe kici ayakinice cin he iśtenniye kta, hehan token ecanon kta he?

9 Tuwe kici ayakinice cin he kiciśnana wohdaka wo, unkan tokan taku nahmana oniciyake cin he yuotanin śni wo.

10 Okini tuwe nanilion kin he iyopeniye kta, qa iśtenniyanpi kin niciyutokanpi kte śni.

11 Wicoie wan tohan iyececa iapi kin he taspan tanka zizi kin mazaska wakiśkotpa ohna he iyececa.

12 Wawiyopeye ksape cin noge wanahon kin ekta he mazaska oinpi kin, qa mazaskazi wanapin kin he iyececa.
13 Wahośi wacinyepica wan tona ye śipi kin iyowicakipi kin he, mdoketu cokaya wa osni kin iyecen, qa itancan tawa nagi kin ekicetu.

14. Tuwe taku wicaqu kta itonśniyan on ihdatan kin he mahpiya sapa qa tate magaju wanica kin he iyececa.

15 Wacintankapi on wicaśta yatapi kin cinkiyapi, qa ceji skuya kin he wicahulu kin yaksa ece.

16 "Tuhmaga canhanpi iyeyaya he? winipi kta e heceedan yuta wo. Okini iyatahdeniciye cinhan yahdepe kta.

17 Ihnuhan nisiha kin anpetu owasin nitakorla ti kin en ye yakiye cin; okini ijehan en de cinhan śice nidake $\mathrm{kta}$.

18 'Tuwe takodaku oitonśniyan wayaatanin kin he wanhinkpe, qa isan qa canhpi wan iyececa.

19 Wohnaye wicaśta wan, anpetu iyokiśicapi en wacinyanpi kin he hi wan ksahan qa siha pśunwahan kin be iyececa ece.

20 Tuwe cante śice cin he ekta wiyuśkinyan odowan ahiyayapi kin he anpetu sni icunhan heyake yuśdokapi kin, qa wipajaja miniskuya akaśtanpi kin he iyececa.

21 Tuwe sice nidake cin he wotek tehda kinhan aguyapi yunkiya wo, qa ipuza kinhan mini yatkekiya wo ;

22 Hecen petaga iye pa kin akan mnayaye kta, unkan Jehowa iyuwin nicu kta.

23 Tate waziya tanhan u kin he magaju kaha iyeya, he iyecen itohnake canksiya wicaceji taku śica nahmana oyake cin.

24 Tice okahmin otipi kin hee waśte, tuka winohinca wakigesa kici tipi tankaya eśta he tehika. 


\section{WICOWOYAKE 26.}

25 Wootanin waśte wan makoce tehantanhan aupi kin he mini sni tuwe ipuza kin ekta he iyececa.

26 Wicaśta owotanna wan wicaśta śica itokam patuje cin he mini owe omanipi kin, qa wakoniya waihang ye cin he iyececa.

27 Tulimaga canlsanpi ota yutapi kin he waśte śni, he iyecen taku tke owasin iyukcanpi kin he telika.

28 Tuwe toniya hduhe kta okihi śni kin he otonwe wan kawankapi, qa conkaśke wanica he iyececa.

\section{WICOWOYAKE 26.}

1 Mdoketu eca wa, qa woksapi icunhan magaju, he iyecen tuwe witkotkoka kinihanpi kin he wiciyokipi śni.

2 Zitkadan kinyanyan, qa icapśinpśincadan anawinyan kin, he iyecen ituli yaśicapi kin he iyowicahi kte śni.

3 Suktanka on wicapsinte, qa śonśonna on iiyuwi kin, qa wicaśta witkotkopi tapetepi kin on cansakadan.

4 Ihnuhan wicaśta witkotko towitkotkoke cin he iyecen adupte cin, okini niś eya he inihdacin kta.

5 Wicaśta witkotko towitkotkoke cin he iyecen ayupta wo ; hecanon śni kinhan okini ksape içida kta.

- 6 Tuwe taku tanka on wicaśta witkotko wahośi ye cin he siha kin kakse ça iye kiunniiciye.

7 Wicoie wakan wan wicaśta witkotko i kin ohna, tuwe huśte sicogan natitantan kin he iyececa.

8 Tuwe wicaśta witkotko wan wowitan qu kin he inyan tehihi- ka opahte wan inyan paha wan en elipeye cin he iyececa.

9 Wicoie wakan witkotkoka ipi kin ohna qa wapepeka wan wicaśta witko nape kin ohna hena iyececa.

10 Tuwe tanka kin he owasin yuśinye wicaya, wicaśta witkotko iyuwin qu, qa tona kapapi nakun iyuwin wicaqu ece.

11 Sunka taku hdepe cin he ake en hdi kin, he iyecen wicasta witkotko towitkotkoke cin ake econ ece.

12 Wicaśta wan ksape içida wandaka he? hee śni tuka wicaśta witkotko kin hee ksape kta kecanni kta.

13 Inmutanka canku icahda yukan, otonwe canku kin ohna mnaja wan yanka ce, wicaśta kuje cin eya.

14 Tiyopa wan iyuze kin akan ihduhomnimni he iyecen wicaśta kujc cin towinja kin akan ihduptanptan.

15 Wicaśta kuja wakśica ohna nape kin ye kiya, ake i kin ekta hiyukiye kapin.

16 Wicaśta kuje cin he wicaśta śakowin wayupiya waayuptapi kin hena isanpa ksape içida.

17 Tuwe taku tawa śni akinicapi ahiyaye ca en ye iciye, he tuwe śunka noge kin yuze cin lie iyececa.

18 Tuwe magaga içiye kta e petuspe wanhinkpe qa wiconte kaho iyeye cin,

19 He iyecen wicaśta takodaku hnaye ca, tokeśta waślkate śni he? eye cinhan.

20 Can wanice cinhan peta kin sni kta, he iyecen woyakesa wanice cinhan kicigepi kin ayuśtanpi ece.

21. Cahidi petaga aonpapi, qa can peta akan, he iyecen wica163 


\section{WICOIE WAKAN}

śta wakigesa woakinice ideya ece.

22 'Tuwe iwakan kin oie kin woyute skuya iyececa, qa wicatezi kin mahentuya iyaya ce.

23 Wiciha kata cante wahnaye kici mazaska icicahiyapi kin maka wakśica apawintapi kin he iyececa.

24 Tuwe śice dake cin he iha kin on ihdatokeca, qa iye mahentuya wohnaye kihnaka;

25 Tohan ho kin wiciyokipi kaga he wacinye śni wo, hehan cante mahen taku wahtedapi śni śakowin yukan.

26 Wocanniye kin wohnaye on akahpe, tolian śice cin he omniciye ohna yazamnipi kta.

27 Tuwe woha wan qe cin he iye ohinhpaye kta, qa tuwe inyan wan paptanye cin he en icicawin hdi kta.

28 Wicaceji itonśni kin he tona wicayaśuje cin śice wicadaka, qa wicai śdute cin wicotakuni śni kaga.

\section{WICOWOYAKE 27.}

1 Ihnuhan heyakecinhan on nihdatan kinhan, anpetu wan taku ton kta he sdonyaye śni.

2 Nii kin hee kte śni, tuka tuwe tolieca niyatan nunwe, wicaśta wan oyate tokeca, tuka niiha kin hee kte śni.

3 Inyan wan tke qa wiyaka kin he yuśagwicaya, tuka wicaśta witkotko tocanniye kin heniyoza isanpa the.

4 Wocanniye he wohitika, qa wocanteptanye kin he minitan wan iyececa, tuka wowinawizi itokam turve najin kta okihi he?

5 Nahmana waśte dakapi kin hee sni, tuka taninyan iyopekiyapi kin hee waśte.

6 Kodayapi iyopewicaye cin he wicaka, tuka tuwe śicedake cin i iwicaputaka eśta wicahnayan.

7 Tuwe wipi kin he tulimaga canhanpi ihakta śni, tuka tuwe wotektehda kin woyute pa eśta owasin skuye daka.

8 Wicaśta oyanke tawa etanhan nuni kin he zitkadan wan hohpi kin etanhan nuni kin he iyececa.

9 Wihdi qa wizinyapi kin wicacante iyuśkin kiya; nakun takodaku nagi kin etanhan wahokonkiye cin oskuya.

10 Nitakoda qa niyate takodaku kin ayuśtan śni wo, qa anpetu winicalije cin hehan nisunka ti kin en ye śni wo; sunkayapi wan tehan yanke cin hee śni, tuka tuwe nikiyedan ti kin hee waste.

11 Micinkśi ksapa wo, hecen micante kin iyuśkin kta, qa tuwe taku śica emakiye cin itkom taku ewakiye kta.

12 Wicaśta ksape cin taku śica wanyake ca inahma, tuka tona wacintonpi śni kin hena iyoptapi qa kakiświcayapi.

13 Tuwe oyate tokeca wicaśta on wecicajuju kta, eniciye cinhan taśina kin icu wo; qa tuwe wicaśta sdonwicaye śni on wicawecicajuju kta, eye cinhan taku tohanyan kajuju śni duhe kte cin he icri wo.

14 Tuwe hanhanna hin kik ta qa takodaku hotankakiya yawaśte kinhan he yaśicapi kiciyawapi kta.

15 Magaju anpetu icumhan ohinniyan ośbuyapi wan, qa winohinca wakigesa wan hena iakedececa ;

16 Tuwe he anakihbe cin he tate kin analima he iyececa, qa nape etapa wihdi waśtemua kin he ihdutanin kta. 


\section{WICOW OYAKE 28.}

17 Mazasapa on mazasapa pekiyapi, qa wicaśta kin takodaku ite kin on pe kiyapi.

18 Tuwe witanśna hu patan kinhan hetanhan waskuyeca yute kta, qa tuwe itancan awanhdake cin he yutanpi kta.

19 Mini ohna ite wan ite kin iyececa, he iyecen wicacante kin wicaśta kin iyececa.

20 Hades qa wiconte kin imnapi śni, he iyecen wiciśta kin imna kte śni.

21 Mazaska maka wakśica on, qa mazaskazi maza oceti on, qa wicaśta kin wicai yatanpi kin on iyutapi.

22 Wicaśta witkotko wan wibope ohna wamnaheza kici wibope ihupa on boyapan eśta, towitkotkoke cin he ayuśtan kte śni.

23 Tahinca nitawa kin token taninpi tanyan sdotkiya wo, qa wanuyanpi kin awakicin wo:

24 Nakaś woyuha kin he ohinniyan en un śni, qa wicaśta yatapi wicowazi wanjidan etanhan ohinniyan un kta he?

25 Peji kin inanpa qa wato kin tanin, qa he peji kin he mnayanpi kta.

26 Talinea ska kin etanhan wokoyake yaton kta, qa tatokadan wanuyanpi on maga wan opeyaton kta ;

27 Hecen tatokadan asanpi imna wayate kta, qa tiyohnaka nitawa nakun, qa he on wikośka nitawa nipi kta.

\section{WICOWOYAKE 28.}

1 Wicaśta śica tuwedan wicakuwa śni eśta najicapi ece, tuka wicaśta owotanna mnaja iyecen waditakapi.

2 Makoce wokipajin kin on wicaśta yatapi ota, tuka wookaO 2 hnige wosdonye wicaśta wan eciyatanhan tehan ecetu kta.

3 Wicaśta wahpanica wan tona onśika wicayuwahpanice cin he magaju wakawankeya wan on woyute wanica he iyececa.

4 Tona woope opapi śni kin hena wicaśta śice cin yatanpi, tuka tona woope opapi kin hena wicakigepi ece.

5 Wicaśta śica woyaco okahnigapi śni, tuka Jehowa akitapi kin hena owasin okahnigapi ece.

6 Wicaśta wahpanica toecetu kin omani kin hee waśte, tuka tuwe canku kin hdupemni wijica eśta hee waśte śni.

7 Tuwe woope patan kin he hokśidan ksapa, tuka tuwe wotapisa kodawicaye cin he atkuku iśtenya.

8 Tuwe woyahtake qa ota wicakida on woyuha kin hduota kin he tuwe wahpanicapi onśiwicada kte cin he on he mnaye kita.

9 Tuwe woope nalion kte śni e noge kin hdutokan kin he wocekiye eye cin he wowahteda śni yapi kta.

10 Tuwe wicaśta ecetu kin canku sica onuni wicakiye cin he woha wan iye qe ein he ohinhpaye kta, tuka tona ecetupi kin hena taku waśte tawayapi kta.

11 Wicaśta watonka kin ksape içida, tuka wicaśta wakahinige cin he iyukcan kta.

12 Wicaśta owotanna iyuśkinpi eca wowitan tanka ece, tuka wicaśta śica wankan ayapi eca wicaśta inalimanpi ece.

13 'Tuwe wahtani kin ahdalipe cin he tanyan ihuni kte śni, tuka tuwe ohdake ça ayuśtan kinhan onśidapi kta.

14. Tuwe ohinniyan kokipe cin he wowaśte wicaśta kin heca, 165 


\section{WICOIE WAKAN}

tuka tuwe cante kin hdusuta kin he taku śica ohinhpaye kta.

15 Wicaśta yatapi śice cin he oyate onsika akan he mnaja hdoya, qa mato waanatan wan he iyececa.

16 Wicaśta yatapi wookahnige nice cin he taoyate kin nina wicayuwahpanica, tuka tuwe wicakipi śice dake cinhan anpetu tawa kin hduota kta.

17 'Tuwe wicaśta we kin on yuśakapi kin he tuwedan yuze kte śni e woha kin ekta inyanka.

18 Tuwe ecetu kiya mani kin he ni kta, tuka tuwe canku ota ohna ihdupemni kin he wanji ohinhpaye kta.

19 Tuwe tamaga kin kicanye cin he woyute imna kta, tuka tuwe tona takuska econpi owicape cin he wowicakakije on imna içiye kta.

20 Wicaśta wicake cin he wowaśte ota, tuka tuwe ihduwijice kta e inahni kin he taku śica akipe kta.

21 Wicite iyekiyapi kin he waśte śni, wicaśta hecon kin he aguyapi onśpadan on wahtani kta.

22 Tuwe ihduwijice kta inahini kin he iśta śica, qa heon wowahpanice akipe kta sdotkiye śni.

23 'Tuwe ceji skuye cin hee śni, tuka wicaśta iyopeye cin hee iyohakam waśte dapi kta.

24 Tuwe atkuku qa hunku eśta taku tawa icu qa, taku śica ecamon śni, eye cin he waihangyesa dakonya.

25 Tuwe nagi tanka icida kin he kicigepi kaga, tuka tuwe Jehowa wacinye cin he cepa aye kta.

26 Cante kin wacinkiye cin he witkotkoka, tuka tuwe woksape omani kin he ihduśke kta.
27 Tuwe onśipike cin hena cante wicakiye cin he wicakije kte śni, tuka tuwe iśta anakilibe cin he wicota yaśicapi kta.

28 Wicaśta śica najinpi eca wicaśta inahimanpi ece, tuka hena atakunipi śni eca wicaśta owotanna ota ayapi ece.

\section{WICOWOYAKE 29.}

1 Wicaśta ijehan iyopeyapi eśta tahu kin ihdusuta kin he ihnuhanna kaśujapi kta, qa woasni wanice kta.

2 Tohan wicaśta ōwotanna ota ayapi eca oyate kin wiyuśkinpi kta, tuka wicaśta śica widakapi eca oyate kin śicahowayapi ece.

3 'Tuwe woksape waśte dake cin he atkuku iyuśkinkiye kta, tuka tuwe witkowin om iyokipi iciye cin tawoyuha kin toki ehpekiye kta.

4 Wicaśta yatapi kin woyaco on makoce tawa kin sutaya he kiye kta, tuka tuwe mazaska qupi waśte dake cin he pawanke kta.

5 Tuwe takodaku on ceji kin hduskuye cin he siha kin on mazahitakiyapi wan eonpa.

6 Wicaśta śica wahtani kin ohna mazhtakiyapi wan yukan, tuka wicaśta owotanna wiyuśkin qa dowan kta.

7 Wicaśta owotanna tona onśika wicayacopi kin sdonya, tuka wicaśta śica he sdonye kta okahnige śni.

8 Wicaśta waoncesa otonwe kin ideyapi, tuka wicaśta ksapa wocanniye anaptapi ece.

9 Wicaśta ksapa wan wicaśta witkotko wahokonkiye cinhan, canksiya ia qa iha eśta iyozi wanice kta.

10 We wicaśta kin hena tuwe 


\section{WICOWOYAKE 30.}

waśte kin šicedakapi, qa wicaśta ecetu nagi kin akitapi.

11 Wicaśta witkotko tawacin kin ocowasin hiyuya, tuka wicaśta ksape cin he tokata ekihnaka.

12 Wicaśta yatapi wicoie itonśni anagoptan kinhan ookiye wicaye cin owasin śicapi kta.

13 Wicaśta wakiyuśe qa wahpanica akicipapi, Jehowa napin iśtapi kin iyoyam wicaya ece.

14 Wicaśta yatapi tona onśika wowicake eciyatanhan wicayaco kinhan oiyotanke tawa kin owihanke wanin sutaya he kta.

15 Hokśidan kiyuśkapi kin he hunku iśtenya, tuka icapsinte iyopekiyapi iyahna he ksapa kaga.

16 Wicaśta śica ihduotapi eca wicohan śica nakun ota kta, tuka wicaśta owotanna hena atakunipi śni kin atonwanpi kta.

17 Nicinkśi kin iyopekiya wo, hecen oziniçiye kte ca ninagi kin iyokipi kta.

18 Tukten Wakantanka oie kin wanice cinhan oyate kin wohitika, tuka woope yuhapi kin he wowaśte oyate.

19 Wowidake wan wicoie on yuecetupi śni, okahniga eśta ayupte kte śni.

20 Wicaśta ia ohanko wandake cinhan hee śni, tuka wicaśta witkotko kin hee etanhan taku waśte ayape kta iyececa.

21 'Tuwe tawowidake kin hokśiyopa ehantanhan kihna kinhan, owihanketa he cinea ye kta.

22 Wicaśta wacinko kicigepi kin icahya, qa wocanniye wicaśta kin woahtani ota.

23 Wicaśta wamnaicida kin on ihdukuye kta, tuka tuwe woniya kucedan kin he wowitan ton kta. 24 Tuwe wamanusa kici wopamni yuhe cin he nagi kin śice kidaka, yaśicapi kin nahon tuka oyake śni.

25 Wicaśta kokipapi kin he wicahmunka, tuka tuwe Jehowa wacinye cinhan okope wanin un kta.

26 Wicota wicaśta yatapi ite kin akitapi, tuka wicaśta wicayaco kin Jehowa hee.

27 Wicaśta owotanna wicaśta śice cin he wowahtedapi śni, qa wicaśta śica tuwe ohan owotanna kin he wowahtedapi śni.

\section{WICOWOYAKE 30.}

1 Agur Jake cinhintku kin wicoie tawa, odowan wan, Itael eciya, Itael Yukal ko ewicakiya. 2 Woteca iyemaceca qa wicaśta iyemacece śni, qa wicaśta towiyukcan kin mayuke śni.

3 Awicakehan woksape kin onmaspe śni qa wicaśta wakan wosdonye kin he sdonwaye śni. 4 Tuwe wankantuya Mahpiya ekta i he? qa tuwe hetanhan kun hdi he? Tuwe nape kin ohna tate kin mnayan he? Tuwe mini kin śina wan ohna opahita he? Tuwe maka ihanke kin ow asin ehde he? Token eciyapi qa cinhintku token eciyapi he? sdonyaye cinhan oyaka wo.

5 Taku wakan oie kin owasin peta on yuecepidan; tona he wacinyanpi kin hena wahacanka yapi.

6 lhnuhan oie tawa kin ekta taku aokijuyaye cinhan, okini iyopeniye kta, qa iyatonśni iyeniyanpi kta.

\% Taku nom cicida, mațe śni ecen hena temicilida śni wo;

8 Wicohan śica qa iapi ecinkta iniciyutehan ye, wowafipanice wowijice unmanna maqu śni, woyute wate kta iyececa wonmayan'ye ; 


\section{WICOIE WAKAN.}

9 Okini wimapi kinhan micihnaye ca, Jehowa he tuwe, epe kta ; qa wimakakije cinhan okini wamawanun, qa iwaton śni eśta taku wakan namalion epe kta.

10 Ihnuhan wowidake wan yuhe cin ekta ayakiia, okini niyaśice kta qa taku śica ayakipe kta.

11 Wicoicage wan atkuku kin yaśice ca hunku kin yawaśte śni.

12 Wicoicage wan wakaśoteśni icidapi, tuka unkce kin wicakiyujajapi śni.

13 Wicoicage wan iśta hduwankanpi linca, qa iśtojuha wankan ayapi ece.

14 Wicoicage wan hipi kin canhipi kin iyececapi, qa hiskepi kin isan iyececapi; hecen tona onśika maka etanhan temwicayapi, qa tona wahipanica wicaśta ehna unpi kte śni.

15 Tusda cunwintku nonpa, napin, Maqu ye, maqu ye, eyapi. Taku yamni imnapi śni, qa taku topa, Henakeca, eyapi śni ;

16 Hades, qa tamni cinca ton śni, qa maka kin mini imna śni, qa peta, Henakeca, eye śni.

17 Wicaśta wan atkuku ihaha, qa hunku kin nahon kta e ihaktaśni kin he kaksiza kangi kin capapi kta, qa wanmdi cinca kin he yutapi kta.

18 Taku yamni yuśinyemayan, qa taku topa owakalinige śni ;

19 Wanmdi canku kin mahpiya ohna, wamduśka canku kin imnija akan, wata canku kin mde cokaya, qa wicaśta canku kin wikośka kici.

20 Winohinca wawiciliahapi econ canku tawa kin he iyececa, wota qa i kin itpakinte ca, Taku śica ecamon śni ce, eya.

21 'Taku yamni on maka kin śkanśkan qa taku topa on oziiciye kta okihi śni.
22 Wowidake on tohall wicaśta yatapi un ece, qa wicaśta witkotko on aguyapi imna wota ece ;

23 Winohinca canniyesa on hihna ton kinhan, qa wayakawin on yuhe ciqon woyuha kin tawaye cinhan.

24 Taku topa maka akan iyotan cistinna tuka ksape hinca;

25 Tajuśka kin oyate waśake śni tuka mdoketu eca woyute kihnakapi ece ;

26 Hitunkasan kin tancan sutapi śni, tuka imnija ohna tipi kicagapi ece ;

27 Arebe (psipsicadan ocaje wan) wicaśta yatapi nicapi tuka obe tawapi owasin yuwitaya icimanipi ;

28 Onktomi napepi on yurapi qa wicaśta yatapi ti kin ohna yakonpi ece.

29 Taku yamni tanyan manipi ece, qa taku topa tanyan yapi ;

30 Mnaja kin he wamanica iyotan waśake ca takudan etanhan ihduhomni śni ;

31 Śnka wakan, nite ipiyag tonpi, qa tatokadan mdoka, qa wicaśta yatapi oyate tawa opapi kin he.

32 Witkotkoya nihduwankantuya kinhan, qa taku śica yakonze cinhan, nii kin akan nape kin atputaka wo.

33 Awicakehan pte asanpi kin icicahiyapi kinhan pte asanpi ihdi kin hiyu kta, qa wicapoge yutitanpi kinhan we hiyu kta, qa wocanniye yutitanpi on kicigepi hiyu kta.

\section{WICOWOYAKE 3L.}

1 Lemuel wicaśta yatapi wicoie tawa, odowan hunku kin he onspekiye cin dee.

2 Cinś taku hwo? mitamni cin- 
ca kin taku eciye kta he? womiciyake ota eciyatanhan citon kin taku hwo?

3 Ihnuhan nitowaśake kin he winohinca yaqu kin, qa canku nitawa taku wicaśta yatapi ihang wicaye cin ekta ye yakiye cin.

4 Wicaśta yatapi, Lemuel, wicaśta yatapi miniśa yatkanpi kta he iyecece śni, qa wicaśta yatapi cincapi kin mini wakan cinpi kta he iyecece śni.

5 Okini he yatke cinhan taku konzapi kin akiktonje kta, qa wicaśta onśika tawoyaco kin yaśkiślke kta.

6 Tuwe wanna te kte cin he mini wakan kin qu wo, qa tona cante śicapi kin hena miniśa wicaqu wo.

7 Hecen yatke kta, qa tokakije cin akiktonje kta, qa toiyokiśice cin icimanna kiksuye kte śni.

8 Iapi okitpani kin he on i kin hdukawa wo, qa wamdenica owasin wicayacopi kinhan;

9 I kin hdukawa qa tona onśika qa wicakijapi owasin iwicakiya owotanna wayaco wo.

10 Tuwe winohinca ksapa wanji iyeye kta he? Tukiha tehihika ee kaeś sam iyeya iyawapi.

11. Hihnaka cante kin he wacinkiya, qa woyuha icakije kte śni yan un kta.

12 Tohan ni kin hehanyan taku waśte ecakicon kta, qa taku sica wanice kta.

13 Tahinca hin halionta on kagapi ko akita, qa nape kin iyokipi ya h̉tani.

14 Wopeton witawata tawapi kin iyececa, tehantanhan woyute tawa kin en ihdoku.

15 Nahanlin anpa śni kikta, qa tiyohnaka tawa owasin woyute wicaqu, qa wikośka taku econpi kta sdonye wicakiya.

16 Maga wan awacin qa ope- ton, taku nape kin kagapi kin on hastanhanka iyuwi wan huhde.

17 Ipiyaka sutaya iyahdaśka qa hupahu kin hduwaśaka.

18 Táku wiyopeye cin he waśte e sdonkiye; hanyetu osan petijanjan hde kin kicisni śni.

19 Wipahmu kin ekta nape yekiya qa napsukaza kin iyuhmu kin yuza.

20 Tona onśika kin hena on nape kin hdugata, qa wicaśta oncikpani owicakiye kta e mape kin ye kiya.

21 Wapa keś tiyohnaka tawa kin on ikope śni; nakaś owasin taku icitakihna ece koyakapi.

22 Owinja icicaga: qa minihuka zibzipedan śinaśa ko koyaka ece.

23 Otonwe tiyopa kin ekta makoce hunkayapi wicehna hihnaku iyotanka eca iyekiyapi ece.

24 Minihuha zibzipedan kage ca wiyopekiye, ipiyaka nakun qa wopeton kin wicaqu.

25 Wowaśake wowitan iyahna ihduze ca tolata anpetu u kte cin ilia.

26 I kin hdukawa eca wicoksape ia, qa ceji lkin wacantkiya woope yuha.

27 Tiyohnaka tawa ohanyanpi kin owasin iwany aka, qa kujahan aguyapi kin hdute śni.

28 Cinca kin najinpi eca hdawaśtepi; hihnaku nakun qa hdatan.

29 Cunwintkupi ota ksamya ohanyanpi, tuka niye owasin kape wicayaya ce, eya.

30 Wowiciyokipi kin he wicahnayan qa wicite waśte kin he ptenyedan, tuka winohinca Jehowa kokipeyahan un kin he yawaśtepi kta.

31 Nape kin taku icahye $\operatorname{cin}$ he qupo, qa otonwe tiyopa kin ohna iye ohan kin hena yatanpinunwe. 


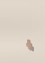




\section{EYANPAHA KIN.}

WICOWOYAKE 1.

1 Eyanpaha kin, Dawid cinhintku Jerusalem en Wicaśtayatapi oie kin dena ee.

2 Takuśni, takuśni, Eyanpaha kin eya, takuśni, takuśni, iyulipa takuśni ce.

3 Anpetu wi ihukuya -wicaśta - wicolitani econ kin owasin on iyunwin taku yuha he.

4 Wicoicage wariji iyaye ca wicoicage wan u ece ; tuka maka kin ohinniyan han.

5 Nakun anpetu wi kin hinanpa, qa anpetu wi kin iyaya, qa totanhan hiyu qon he ekta inahini hda ece.

6 Tate kin itokahkiya iyaye ca waziyatakiya ihduhomni; tate ihduhomnimni, qa totanhan iyaye cin ake en hdi ece.

7 Wakpa iyulipa miniwanca kin en iyaya; tuka miniwanca kin ojudan śni; wakpa kin totanhan hiyupi qon he ake ekta hdapi ece.

8 Wicoie owasin hunkițapi ojudan; wicaśta oyake kta okihi śni: wiciśta kin he wawan.. yaka imnan śni, qa wicanoge kin wanahonpi on imnan śni.

9 Taku un qon he $u$ kte cin hee: qa taku econpi ece kin taku econpi kte cin ee : qa anpetu wi kin jhukuya taku teca wanica.

Eccle.
10 Taku on, Wanyaka wo, de teca ce, eyepica he : wanna tanina un qon hee, unkiye unkitokapatanhan yanke.

11 Taku hekta un qon hena kiksuyapi śni; qa nakun taku tokata kin tona ohakam unpi kte cin hena kiksuyapi kte śni.

12 Eyanpaha kin he miye, Jerusalem en Wicaśtayatapi manka.

13 Unkan taku mahpiya ihukuya econpi kin owasin woksape on awakite kta, qa imdukcan kta e micante ekta yewaya: wicolitani tehike cin de Wakantanka wicaśta cinca wicaqu, on htanipi kta heon.

14 Anpetu wi kin ihukuya wicohan econpi kin owasin wanmdaka, unkan iho, iyulipa takuśni qa woniya iyokiśinyapi kin hee.

15 Taku śkope cin he yuowotanpidan kta okihipica śni; qa taku iyokpani un kin hena yawapica śni.

16 Micante kici wowahdaka qa hepa; Iho, tanka imacaga qa woksape mnawakiya, tona Jerusalem en mitokam unpi qon owasin isanpa: han, micante woksape qa wosdonye ota wanyaka.

17 Nakun woksape sdonwaye kta micante waqu, wicoksape śni qa wowitkotkoke sdonwaye 171 


\section{EYANPAHA KIN,}

kta: De nakun woniya iyokiśinyapi kin hoe indukcan.

18 Woksape ota en woiyokiśice ota yukan; qa tuwe wosdonye hduota kinhan he wicocanteśica hduota ece.

\section{WICOWOYAKE 2.}

1 Micante en hepa; Tho wo, wowiyuśkin on iciyute kta ce; hecen taku wiciyokipi sdonya wo. Unkan iho, he nakun taku śni.

2 Ihapi kin he, Wowitkotkoka, ewakiya: qa wowiyuśkin, $\mathrm{He}$ taku tokon he.

3 Micehpi miniśa on wahdusuta kta micante en awakita, qa micante woksape sdonyewakiye kta; qa wowitkotkoka kin he mduze kta, hecen wicaśta cinca on taku waśte kin tukte e he, anpetu towanakeca nipi kin en, mahpiya ihukuya taku econpi kte cin he wanmdake kta.

4 Taku tanka micicaga; tipi micicaga; hastanhanka iyuwi ojupi kin bu wehde :

5 Maga qa canwojupi kin miçicaga, qa en waskuyeca can ocaje owasin hu wahde:

6 Miniyowe kagapi kin miçicaga, on contanka call icahye cin he spayewaye kta :

7 Wicaśta taokiye qa winyan taokiye opewicawaton, qa wati ohna tonpi wicamduha; nakun tatanka qa tahinca wanunyanpi ota hinca wicawahduha, Jerusalem en mitokam unpi qon owasin isanpa :

8 Nakun mazaska qa mazaskazi mnamiçiye, qa wicaśtayatapi makoce tawapi ko tawokamna kin : wicaśta dowanpi qa winolinca dowanpi heca icahwicawakiya, qa wicaśta cinca tawo- wiyuśkinpi, winohinca qa winohincapi.

9 Hecen matanka, qa tona mi tokam Jerusalem en unpi qon ikapeya taku ota micicaga : nakun woksape mitawa miciun.

10 Qa taku miiśsta da kin takudan ipimic̣ida śni, wowiyuśkin wanjidan keś micante etanhan wakipatan śni ; mitohitani owasin on micante iyuśkin nakaeś : qa mitolitani ocowasin on wokamna mitawa kin hee.

11 Hehan wicohan mirape econ kin owasin en ewakitonwan, qa wicoh̉tani htawani kta ecamon kin hena; unkan iho, ocọwasin takuśni qa woniya iyokisica hee, qa anpetu wi kin ihukuya wokamna wanica.

12 Unkan woksape qa wicoksapeśni qa wowitkotkoke kin iwanmdake kta mihdamna: wicaśta wan wicaśtayatapi ihakam u kin he taku okihi kta he : taku wanna econpi kin heceedan.

13 Hehan woksape en wokamna yukan e wanmdaka, wowitkotkoke kin isanpa, iyoyanpa kin he otpaza isanpa waśte kin he iyececa.

14 Wicaśta ksapa iśta iye pa kin en un; tuka witkotkoke cin he otpaza omani : hececa eśta miye qe taku wanjidan owasin awicakipa ece e wanmdaka.

15 Hehan cante mahen hepa; Witkotkoke cin he taku akipa he iyecen miś eya awakipa ; hecen tokiyatanhan miye qe iyotan waksapa he. Hehan cante mahen, De iś eya takuśni ce, epa.

16 Witkotkoke cin iyececa wi- 
caśta ksapa kin ohinniyan kiksuyapi śni nakaeś; taku nakaha un kin hena tokata anpetu kin en owasin akiktonjapi kta, heon etanhan. Qa wicaśta ksape cin iś token te kta he; witkotkoke cin iyececa.

17 Heon etanhan wicani kinśicewakidaka; anpetu wi kin ihukuya wicohian econpi kin he waciniyowakiśica nakaeś: iyulipa takuśni qa woniya iyokiśsinyapi kin hee.

18 Han, mitolitani anpetu wi ihukuya ecamon kin ocowasin śicewakidake ; wicaśta mihakam u kte cin he aihpewakiye kta, heon etanhan.

19 Qa he wicaśta ksape kta, qa iś witkotkoka kta tuwe sdonya he. Hececa eśta, mitolitani ecamon kin owasin, qa en anpetu. wi ihukuya ksapa mihdutanin kin hena iye tawaye kta. De nakun takuśni.

20 Heon etanhan anpetu wi kin ihukuya wicohtani ecamon kin iyulipa micante kicunniwakiye kta mihdamna.

21 Wicaśta wan tohtani kin woksape en, qa wosdonye en, qa wokonze en un: tuka he wicaśta wan on htani śni kin he tawa kta aihpekiye kta. He nakun takuśni qa taku śica tanka.

22 Wicaśta iye tolitani owasin, qa cante iyokiśica, on anpetu wi ihukuya htani kin etanhan taku hduba he :

23 Taanpetu kin iyulipa wicocanteśica, qa tokakije kin he woiyokiśica nakaeś : han, hanyetu en iye cante oziiçiye śni. He nakun takuśni.

24. Wicaśta wote kta, qa wayatke kta, qa iye nagi tolitani kin on iyuśkinkiye kta, taku sanpa waste wanica. De iś eya Wakan- tanka nape kin etanhan wanmdaka.

25 Tuwe wote kta he, qa miye mikapeya tuwe wiyuśkin kta he.

26 Taku iye itokam waśte kin he Wakantanka wicaśta wicaqu ece, woksape qa wosdonye qa wowiyuśkin : tuka walitani sa kin he wokakije qu, wamnaye kta qa waeju kta, hecen Wakantanka itokam taku waśte kin he qu kta. He naluun takuśni qa woniya iyokiśica.

\section{WICOWOYAKE 3.}

1 Taku iyuhpa iyehantu yukan, qa mahpiy a kin ihukuya woawacin owasin tohantu ktc cin yukan ece.

2 Wicatonpi iyehantu yukan, Qa wicate kta iyehantu ;

Woju econpi iyehantu;

Qa wojupi yujunpi kta iyehantu :

3 Wicaktepi iyehantu yukan, Qa okiziyapi iyehantu;

Wayujujupi iyehantu,

Qa piya kagapi iyehantu yukan :

4 Wicaceya iyehantu yukan,

Qa ihapi kta iyehantu;

Waśihdapi iyehantu, Qa ślkatapi iyehantu yukan:

5 Inyan ehpeyapi iyehantu yukan,

Qa inyan witaya pahipi kta ; Adoksohan wicayuzapi iyehantu yukan,

Qa poskin wicayuzapi ayuśtanpi kta.

6 Waakitapi iyehantu yukan, Qa toki ehpeyapi kta iyehantu; Wapatanpi kta iyehantu, Qa wapaganpi iyehantu yukan :

7 Wayuhdelidecapi iyehantu yukan, 


\section{EYANPAHA KIN,}

Qa wakagegepi iyehantu yukan ;

Inina yukanpi iyehantu,

Qa iapi kta iyehantu yukan:

8 Waśtewicadaka iyehantu yukan,

Qa śicewicadaka iyehantu ;

Okicize iyehantu yukan,

$\mathrm{Qa}$ wookiye kagapi kta iyehantu.

9 Wicaśta hitani kin he iye tohtani eciyatanhan iyunwin taku hduha he.

10 Wicohtani en wicaśta cinca htaniiçiyapi kta Wakantanka wicaqu kin he wanmdaka :

11 Taku owasin iyehantu eca ow nyag waśte kaga : nakun iye cantepi kin en ohinniyan kte cin he ewicakicihnaka, hecen Wakantanka tohtani kage cin otokaheya tanhan qa owihanke ekta wicasta tuwedan okahinige kte śni.

12 Hena en taku waśte wanica sdonwaya; tuka wiyuśkin kta, qa ni un icunhan taku waśte econ kta :

13 Qa nakun wicaśta otoiyohi wote kta, qa wayatke kta, qa tohtani owasin taku waśte en un kin he on ihduśkin kta; Wakantanka taku qu kin hee.

14 Taku Wakantanka econ kin owasin owihanke wanice kta sdonwaya; takudan en akagapi kte śni, qa takudan etanhan icupi kte śni: unkan iye itokam wakokipapi kta e Wakantanka hecon ece.

15 Taku hekta un qon he nakaha un, qa taku tokatam u kte cin he wanna hekta un : qa taku hekta un kin he Wakantanka kin ake hdiyohi kiye kta.

16 Unkan nakun anpetu wi ihukuya woyaco oyanke kin wanmdaka, wośice hen yanka; qa woowotanna oyanke kin, wicośice en yanka.

17 Cante mahen hepa; Owotanna kin he qa śice cin Taku Wakan kin wicayaco kta: han, wicotawacin otoiyohi qa wicohan otoiyohi hen iyehantu yukan.

18 Wicaśta cinca kin on cante mahen hepa; Tokin Wakantanka hena iwicayuten, hecen iye qe woteca hecapi e wanibdakapi kta.

19 Wicaśta cinca kin taku akipapi hecinhan, he woteca akipapi ; han, taku wanjidan awicakipa ece: wanji iś token ta hecinhan, unma kin iś iyecen ta: han, owasin woniya okonwanjidan yuhapi: hecen wicaśta kin iś woteca isanpa takudan iciwaśte śni; iyuhpa takuśni nakaeś.

20 Owasin oyanke wanjidan ekta yapi; iyulipa maka mdu heca, qa iyuhpa ake maka mdu icagapi ece.

21 Wicaśta cinca taniya wankan ye cinhan, qa woteca taniya kin iś maka ekta kun ye cinhan, tuwe sdonya he.

22 Heon etanhan wicaśta iye tohan kin on ihduśkin kta taku sanpa waśte wanica imdukcan; he taku tawa kin ee nakaeś : qa iye iyohakam taku u kte cin he tuwe wanyagkiye kta he.

\section{WICOWOYAKE 4.}

1 Unkan wahdicu qa wokakiśye anpetu wi ihukuya econpi kin hena owasin iwanmdaka : qa iho, kakiśyapi iśtamnihanpe awicau; qa wicakicanpte yuhapi śni : unkan wakakiświcaye nape ohna wowaśake yukan; tuka wicakicanpte yuhapi śni.

2 Heon etanhan tapi kin, tona wanna tapi kin hena wicadma- 


\section{WICOWOYAKE 5.}

waśte, nipi, tona nahanlin ni unpi kin isanpa :

3 Han, tuwe tohinni ni un śni kin he hena napin isanpa waśte, wicohan śica anpetu wi ihukuya econpi kin hena wanyake śni nakaeś.

4 Akeś wicohtani owasin iwanmdaka, qa wicohan yuśtanpi otoiyohi, on wicaśta iye takodaku kici nakiciwizipi kin hee. De iś eya takuśni qa woniya iyokiśica ce.

5 Witkotkoke cin he nape hdukśija qa iye cehpi hduta ece.

6 Napohnaka wanjidan woozi kici hee waśte, nape nonpa ojudan isanpa, wicohtani econpi qa woniya iyokiśica iyahna hecinhan, eya.

7 Hehan wahdiyaku qa anpetu wi ihukuya takuśni kin he wanmdaka.

8 Wanjidan yukan, qa inonpa wanica; han he cinca qa sunkaku takudan hduhe śni ; tuka tohtani owasin ayuśtan śni; nakun iye iśta kin wowijice imna śni; qa, Tuwe on ktawani qa minagi taku waśte icakiśwaya he, eye śni. De nskun taku śni; han, wicohtani tehika.

9 Nonpa kinhan wanjidan isanpa waśtepi ; wicohtani econpi kin on wokajuju waśte yuhapi nakaeś.

10 Hena hinhipayapi kinhan, unma kin iś takodaku najin kiye kta: tuka, hehehe, tuwe iśnana un hinhpaye cinhan; tuwe najinkiye kta yuhe śni nakaeś.

i1 Akeś, nonpa sakim wankapi kinhan cozapi ece ; tuka tokiyatanhan wanjidan iśnana cozakta he.

12 Unkan wanji kici econ ohiye cinhan, nonpa kici inajinpi kta; qa halionta yamni kahmonpi kin he yupsakapi telika.
13 Hokśidan wan walipanica qa ksapa he waśte, wicaśtayatapi wan wicahinca qa witkotlkoka wanna onspekiyapi kta wicada śni kin he isanpa.

$14 \mathrm{He}$ qe wicokaśke tipi kin etanhan wicaśtayatapi kta hiyu; tuka nakun tuwe iye tośkanśkan kin en tonpi kin he wahpanica aya.

15 Wicaśta ni unpi owasin anpetu wi kin ihukuya manipi kin hena, hokśidan inonpa kin eekiya inajin kte cin kici iwanwicamdaka.

16 Oyate kin owasin wopteca śni, tona wicitokam unpi qon owasin : nakun tona ohakam upi kin hena he on iyuśkinpi kte śni. Awicakehan he nakun takuśni qa woniya iyokiśice cin hee.

\section{WICOWOYAKE 5 .}

1 Wakantanka ti kin ekta da eca nisiha awanhdaka wo, qa witkotkoka tawośna yaqu kte śni e wanalion yanka wo; hena eqe taku śica econpi kecinpi śni. 2 Nii on olianko śni wo, qa nicante Wakantanka itokam taku eya inahini kte śni. Wakantanka mahpiya ekta yanka, qa niye maka akan yaun; heon etanhan nioie tonaria kta iyececa.

3 Wicohan ota eciyatanhan wihanmnanpi icaga: ga witkotkoka ho kin wicoie ota en un. 4 Tohan Wakantanka ekta taku on niciconze cinhan, hdajuju dutehan kte śni; iye qe witkotkokapi kin on wiyuśkin śni ; taku on niçiconze cin he hdajuju wo.

5 Niçiconza qa yahdajuju śni kinhan, niciconze śni unkanś hee waśte kta tuka.

6 Ihnuhan nii kin he nicelipi wahtanikiye cinhan; qa Wawa- 


\section{EYANPAHA KIN,}

yuśna kin itokam, He woyaśna ce, ehe kte śni : Taku on etanhan Wakantanka niho on sínhda kta, qa ninape taku econ kin ihangye kta he.

7 Wihanmnanpi ota kin en takuśniśni yukan, qa wicoie ota ; tuka niye Taku Wakan kin kokipa wo.

8 Wicaśta onśika wicakipi kin he, qa makoce tehan yanke cin en woyaco woowotanna ko yupemnipi kin hena wandake cinhan, he taku kin on yuśinyaye śni wo: tuwe waśaka keś isanpa waśake cin he awacin yanka; qa hena isanpa waśakapi yukan.

9 Nakun maka wokamna kin he wicaśta owasin tawapi ; wicaśtayatapi hee kaeś maga kin wowidagya.

10 Tuwe mazaska waśtedake cin he mazaska imnan kte śni; qa tuwe woyuha ota waśtedake cin he oicage on imnan kte śni. He nakun takuśni.

11 Woyuha kin hena ota aye cinhan, tona yutapi kin hena yuotapi; hecen tuwe tawapi kin hena taku iwaśtepi he ; iśta on wanhdakapi heceedan.

12 Tuwe htani iśtinbe cin he skuya, taku tonana qa iś ota yuta eśta: tuka wijice woyuha ota ton kin he iśtinma okihi śni kiya.

13 Anpetu wi kin ihukuya taku śica tehika wan wanmdaka, woyuha tona tawapi iśicapi kte cin on kihnakapi hee.

14 Tuka woyuha kin hena śicaya waakipapi on atakuni śni ece; unkan cinca wan icahkiye ca takudan nape ohna yanke śni.

15 Iye hunku tamni etanhan u qon he iyecen tancodan hde kta, hiyu qon iyecen ye kta, tohtani etanhan taku nape ohna aye kte cin takudan icu kte śni.
16 Unkan de iś eya taku sica tehika, token u qon he iyecehin ake hde kta: hecen tuwe tate htakicini kin wokamna taku yuha he.

17 Nakun taanpetu owasin otpaza en wota, qa wicocante śica ota yuha, qa wayazanka en woiyokiśice.

18 Iho, taku wanmdake cin he dee; taku waśte wan oiyokipi, wote kta qa wayatke kta, qa tohtani anpetu wi ihukuya econ kin owasin, anpetu ni un towanakeca Wakantanka qu kin hehanyan iyuśkin kta; taku tawa kte cin hee nakaeś.

19 Nakun wicaśta otoiyohi Wakantanka woyuha qa wowijice qu kin he etanhan yute kta okihi, qa taku tawa kte cin hduhe kta, qa tohtani on iyuśkin kta: Wakantanka taku qu kin hee.

20 Ota śni qeyaś anpetu ni un kin kiksuye kta ; iye cante wiyuśkin kin en Wakantanka toayupte yanka nakaeś.

\section{WICOWOYAKE 6.}

1 Anpetu wi kin ihukuya taku sica wanji yukan wanmdaka, qa he wicaśta ehna tanka hinca:

2 Wicaśta wanji wowijice, woyuha qa woyuonihan Wakantanka qu, hecen iye nagi taku cin kin iyuhpa takudan kiwanice śni, tuka hetanhan hdute kta Wakantanka okihikiye śni, tuka wicaśta tokeca yuta. De iś eya takuśni qa woyazan tehike.

3 Wicaśta wan opawinge cincaton, qa waniyetu ota ni un, hecen iye tawaniyetu anpetu ota qeyaś, iye nagi taku waśte on imnan śni, qa nakun wicahapi hduhe śni kinhan, okaśkan tonpi wan hee kaeś he isanpa waśte, epa. 


\section{WICOWOYAKE 7.}

4 He qe opo etanhan hiyu, qa otpaza en iyaya, qa iye caje kin otpaza akalipe kta.

5 Nakun anpetu wi wanyake śni qa sdonye śni, eqe woozi yuha, unma qon isanpa.

6. Han, waniyetu kektopawinge nonpa hehanyan ni qeyaś taku waśte takudan wanyake śni: owasin ounyanpi wanjidan ekta yapi śni he.

7 Wicaśta tohtani ocowasin iye i kin on etanhan, hececa eśta iye nagi kin imnan śni.

8 Wicaśta ksapa wicaśta witkotkoka isanpa taku yuha he: wicaśta onśike cin ni unpi wicitokam mani sdonye cin he taku yuha he.

9 Wicaśta wawanyake cin he wicanagi on uni kin isanpa waśte. De nakun takuśni qa woniya iyokiśice cin hee.

10 Taku hekta un qon hena wanna cajeyatapi; qa he taku kin wicaśta ee sdonyapi : nakun tuwe iye isanpa waśake cin he kici econ kta okihi śni.

11 Hecen wicoie ota takuśniśni yuotapi ece, heon wicaśta hena taku iwaśteka he.

12 Wicaśta wan ni un, takuśni ni un taanpetu iyuhpa ohanzi iyecen hiyaye cin he taku waśte yuhe kta tuwe sdonya he: qa anpetu wi kin ihukuya wicaśta wan iyohakam taku u kte cin tuwe he okiyake kta he.

\section{WICOWOYAKE $\%$}

1 Wicacaje waśte kin he w1hdi waśtemna isanpa waśte, qa anpetu en wicate cin he anpetu en tonpi kin isanpa waśte.

2 Wicaceya tipi ekta yapi kin he wayatkanpi tipi ekta yapi kin isanpa waśte; eqe wicaśta owasin owihankepi kin hee,

Ec. qa ni un kin he iye cante en ekihnake kta.

3 Waciniyokiśicapi kin he ihapi kin isanpa waśte; wicite iyokiśice cin on wicacante kin yuwaśtepi nakaeś.

4 Wicaśta ksapapi cante kin he wicaceya tipi kin ohna yanka ; tuka witkotkokapi cante kin iyaśapi tipi kin ohna yanka.

5 Wicaśta ksapa wawiyopeye cin nahonpi kin he waśte, witkotkokapi dowanpi wicaśta nahon kte cin he isanpa.

6 Cega wan ihukuya wapepeka ho kin witkotkokapi iliapi kin iyececa. He nakun taku śni.

7 A wicakehan wokakiśyapi kin he wicaśta ksapa yuwitkotkoka; qa taku wicaqupi kin he wicacante kin yuśica ece.

8 Wicole ihanke kin he otokaheya kin isanpa waśte; qa woniya wacintanka kin he woniya wahaniçida kin isanpa waśte.

9 Ihnuhan nitaniya en canniniyan inayalini kinhan : wocanniye kin he witkotkokapi maku ohna yanka ece.

10 Tokeca anpetu tokaheya qon anpetu kin dena isanpa waśte he, ihnuhan ehe cinhan: woksape eciyatanhan de on winunge śni, heon etanhan.

11 Woksape kin he waśte, woyuha yuhapi kicica; qa tona anpetu wi wanyakapi wokamna tawapi kin hee.

12 Woksape kin he wowinape, qa mazaska he wowinape; tuka wosdonye wokamna kin, woksape tona yuhapi wiconi wicaqu ece kin hee.

13 Wakantanka tohan kin awacin wo: taku śkopa lage cin tuwe owotanna kage kta okihi he.

14 Anpetu waśte kin en cante waśte wo; tıka wośice anpetu kin en waawacin wo: nakun 


\section{EYANPAHA KIN,}

dena icitkokim Wakantanka kaga, wicaśta iye iyohakam takudan iyeye kte śni heon etanhan.

15 Anpetu takuśni mitawa kin icunhan dena iyulipa wanmdaka : wicaśta owotanna iye toowotanna en kaśpapi, qa wicaśta śica iye tohan śice cin en ihdutehan ece e yukan.

16 Ihnuhan owotanna hinca yaun, qa ksape hinca niçicage cinhan: tokeca nihdutakuni kte śni he.

17 Ihnuhan śice hinca nicicage ca winitkotkoke cinhan : tokeca nahahin iyenihantu śni nițe kta he.

18 De duze kte cin he waśte; han, nakun detanhan ninape ehdaku śni wo: tuwe Wakantanka kokipe cin he iyulipa etanhan hdinanpe kta.

19 Woksape he wicaśta ksapa kin yuwaśaka, wicaśta waśaka wikcemna otonwe ohna yukanpi kin isanpa.

20 A wicakehan maka akan wicaśta owotanna, taku waśte ece econ qa wahtani śni kin heca wanica.

21 Nakun wicoie eyapi kin owasin ekta cante yeye śni wo; okinni nitaokiye niyaśica nayahon kta:

22 Niś eya nakun wicaśta tokeca ijehan wicadaśica nicante sdonkiya nakaeś.

23 De ocowasin woksape on imdute: Waksape kta ce, epa; tuka he mitehan un.

24 Taku itehanyan yanke ca temahentu hince cin he tuwe iyukcan okihi kta he.

25 Miye qa micante mihduhomni, sdonwaye kta, qa owade kta, qa woksape wowiyukcan ko awakite kta, qa wowitkotkoke wośice lin sdonwaye kta, han, wowitkotkoke wotakuśni koya.
26 Unkan winohinca tuwe cante kin mazahtakiyapi qa on hmunkapi, nape kin mazaicaśke kin heca he wiconte isanpa pa hinca iyewaye: tuwe Wakantanka itokam waśte kin he etanhan ilıduśpe kta; tuka wahtani sa kin he iye on yuzapi kta.

27 Wanyaka wo, de iyewaya ce, Eyanpaha kin eya; wanjidan wanjidan iyahna wowiyukcan kin iyeye kta;

$28 \mathrm{He}$ hinyahin minagi akita, tuka iyewaye śli ce : kektopawinge ehna wicaśta wanjidan iyewaya; tuka dena owasin ehna winohinca wanjidan iyewaye śni.

29 Wanyaka wo, decedan iyewaya, Wakantanka wicaśta owotanna kaga; tuka iye qe wowiyukcan ota akitapi ece.

\section{WICOWOYAKE 8.}

1 Tuwe wicaśta ksapa iyececa he; qa tuwe e wicoie iyukcan sdonya he : wicaśta toksape kin he iye ite kin iyehkiya, qa ite tosuta kin yutokeca kta.

2 Miye wahokonciciya, wicaśtayatapi tawoahope kin patan wo, qa Wakantanka tawokonze oie kin on etanhan.

3 Iye itokapatanhan de kta inahni śni wo; wicoie śica en inajin śni wo; iye qe taku cin kin owasin econ nakaeś.

4 Wicaśtayatapi oie kin tukten yanke cin hen wowaśake yukan; unkan tuwe, Taku ecanon he, eciye kta he.

5 Tuwe woahope kin patan kinhan he taku śica sdonye kte śni : qa wicaśta ksapa cante kin he tohan iyehantu qa wowiyukean kin sdonye kta.

6 Taku owasin on wiyukcanpi qa tohan iyehantu yukan ece; 
heon etanhan wicaśta wośice tanka kiciyanke :

7 Taku u kte cin he sdonye śni nakaeś: ecin tohantu kte cin tuwe okiyake kta he.

8 Wicaśta tuwedan woniya on waśake śni, iye taniya hduhe kta heon; qa nakun tuwedan wiconte anpetu kin en wowaśake hduhe śni : qa okicize kin de en tuwedan kiyuśkapi śni: nakun taku sica tona en iyohpayapi kin hena wicayuśpe kte śni.

9 De ocowasin wanmdaka, qa taku anpetu wi ihukuya econpi kin owasin ekta micante ewacin wakiya: tohan wicaśta wanji iś wicaśta tokeca wowidagya on taku śica akipa e iyehantu yukan.

10 Unkan hecen wicaśta śica wicahapi wanmdaka, hena upi qa oyanke wakan kin etanhan iyayapi, unkan otonwe en heconpi kin hen awicakiktonjapi. De nakun takuśni.

11 Taku śica econpi yacopi kin kohanna yuśtanpi śni, heon etanhan wicaśta cinca cantepi kin śicaya econ wacinkiyuzapi hinca.

12 Walitani sa wan opawinge akihde taku śica econ qa tehan ni eśta, tona Wakantanka kokipapi, tona iye itokam kokipapi kin hena tanyan unpi kta, awicakehan sdonwaya.

13 Tuka tuwe śice cin he taku waśte yuhe kte śni, qa taanpetu hdutehan kte śni, hena ohanzi iyececa ; Wakantanka itokam kokipe śni, heon etanhan.

14. Takuśni wan maka akan econpi ; wicaśta owotanna wicaśta śica ohanpi kin eciyatanhan iyecen akipapi; akeś wicaśta śica kin iś wicaśta owotanna ohanpi kin eciyatanhan iyecen akipapi. He nakun takuśni ce, epa.
15 Hehan wiyusskinpi kin he mdawaśte, wicaśta anpetu wi ihukuya taku sanpa waśte yuhe śni, wote kta, qa wayatke kta, qa wiyuśkin kta: iye tohtani etanhan, anpetu ni un, anpetu wi ihukuya Wakantanka taku qu kin he hduhe kta nakaeś.

16 Unkan woksape sdonwaye kta e micante awacinwakiya, qa maka akan wicolian econpi kin wanmdake kta : nakun tuwe anpetu icunhan qa hanyetu icunhan iśta on woiśtinma wanyake śni yukan :

17 Hehan Wakantanka tohan owasin wanmdaka; anpetu wi ihukuya wicohan econpi kin owasin wicaśta wan iyeye kta okihi śni: wicaśta wan he iyukcan kta htani qeyaś iyeye kte śni ; han, nakun wicaśta ksapa he sdonye kta keya eśta, iyeya okihi kte śni.

\section{WICOWOYAKE 9.}

1 Dena owasin micante ekta yewaye, qa de ocowasin omdake kta, wicaśta owotanna qa ksapapi, qa wicohan tawapi iyuhpa Wakantanka nape ohna yakonpi : taku wicitokam un qon owasin on wicaśta tuwedan wowaśtedake qa wośicedake unmana sdonye kte śni.

2 Iyuhpa akiyecen owasin en awicau; wicaśta owotanna qa wicaśta sica taku wanjidan awicakipa; tona waśte, qa tona ska qa tona śapapi kin; tuwe wośna qa tuwe wayuśna śni kin : waśte kin he wahtani sa kin iyececa; tuwe Taku wakan cajeyata eciyatanhan taku eye cin he tuwe Taku wakan cajeyata kokipe cin iyececa.

3 Anpetu wi ihukuya taku econpi kin owasin en dee śica, 
owasin taku wanjidan akipapi kin hee: han, nakun wicaśta cinca cantepi taku śica ojúgjudan, nakun tohanyan ni unpi wowitkotkoke cantepi kin en un, qa he iyohakam țapi kill ekta iyayapi.

4 'Tuwe ni unpi kin iyulipa ekta kahinigapi kin he wowacinye yuha; ślunka ni un kin he mnaja te cin isanpa waśte nakaeś.

5 Tona nipi kin hena tapi kta sdonkiyapi ; tuka tapi kin hena takudan sdonyapi śni, qa nakun sanpa iyunwin yuhapi śni ; hena wicakiksuyapi kin hee kaeś akiktonjapi.

6 Nakun wawaśtedakapi qa waśicedakapi qa wawinawizipi qon wanna henakeca ; qa hetanhan anpetu wi ihukuya taku econpi kin takudan tawapi śni owihanke wanica.

7 Ya wo, aguyapi nitawa iyuśkinyan hduta wo, qa cante waśteya miniśa hdatkan wo ; nakaha niolian kin Wakantanka iyokipiya.

8 Nitawokoyake kin ohinniyan ska nunwe; qa nipa kin ihepi codan un śni nunwe.

9 Nitawin waśteyakidake cin he kici wiyuśkinyan ni wo, takuśni wiconi nitawa anpetu kin owasin, anpetu wi ihukuya takuśni anpetu nic̣u kin iyuhpa: wiconi kin de en qa anpetu wi ihukuya wicohan ecanon kin en taku nitawa kte cin hee nakaeś.

10 Ninape taku econ kta iyeye cin he token oyakihi econ wo : Hades ekta de cin heciya wicohan wanica, wicotawacin wanica, wosdonye wanica qa woksape wanica, heon etanhan.

11 Wahdicu qa anpetu wi ihukuya tuwe duzahe cin he oinyanke kin en ohiye śni wanmdaka, qa waśake cin he okicize en ohiye śni, qa nakun ksapapi kin aguyapi yuhapi śni, qa wicaśta wakahniga kin hena wowijice yuhapi śni, qa nakun wicaśta wayupikapi woiyokipi yuhapi śni; tuka tohantu qa toketu kin hena owasin en awicau ece.

12 Nakun tohantu kte cin wicaśta sdonkiye śni : hogan ho śica wan on wicayuzapi kin iyececa, qa zitkadan on hmunkapi wan on wicayuzapi iyececa; he iyecen wicaśta cinca anpetu śica en wicayahtakapi, ihnuhanna awicahinhpaye cinhan.

13 Nakun anpetu wi ihukuya woksape kin de wanmdaka, unkan he tanka wadaka:

14 Otonwe wan cistinna qa ohna wicaśta toliana: unkan wicaśtayatapi tanka wan he takpe u, qa aonataka qa conkaśke tanka en akaga :

15 Unkan he ohna wicaśta ksapa onśika wan iyeyapi, qa iye toksape kin eciyatanhan otonwe kin nikiya: hececa eśta tuwedan wicaśta onśike cin kiksuye śni.

16 Hehan hepa; Woksape he wowaśake isanpa waśte: hececa eśta wicaśta onśike cin he toksape kin dektayapi qa oie kin anagoptanpi śni.

17 Wicaśta ksapa oiepi kin ainina anagoptanpi, tuwe witkotkokapi ehna itancan hoyeye cin he isanpa.

18 Woksape he okicize wipe kin isanpa waśte : tuka wahtani sa wanjidan taku waśte ota ihangya ce.

\section{WICOWOYAKE 10.}

] Honagidan tapi ihepi kaga tawihdi kin śicamna kiya ece : tuwe woksape qa woyuonihan on yatankapi kin he wowitkotko- 


\section{WICOWOYAKE 11.}

ke cistinna hduhe cinhan he iyececa.

2 Wicaśta ksapa cante kin iye etapa eciyatanhan yanka, tuka witkotkoka cante kin he catka tanban yanka.

3 Han, nakun tuwe witkotkoke cin he canku ohna mani eca cante kiwanica, qa iye witkotkoka e owasin owicakiyalka.

4 Tuwe itancan kin he taniya nitkokim inajin kinhan nitohe ayuśtan śni wo; inina unpi kin he woahitani tanka yuwaste ece.

5 Anpetu wi ihukuya taku śica wanji wanmdaka, ecinśniyan econpi wan tuwe itancan kin itokapatanhan hiyu :

6. Wowitkotkoke kin wankan wapa ehnakapi, qa wijicapi kin iś kuya iyotankapi :

7 Wowidake unpi kin hena śuktanka akan iyotankapi wanmdaka, qa wicaśtayatapi makata manipi, wowidake unpi iyececa.

8 Tuwe woha wan qe cinhan en ohinlipaye kta, qa tuwe conkaśke wan yujuju kinhan wamduśka wan yahtake kta.

9 Tuwe inyan qe cinhan hena on kiunniye kta: tuwe can kasdesdece cin he on ksuweiciye kta.

10 Mazasapa kin he pe śni, qa he hdube śni kinhan, nina hin waśagya econ kta : tuka woksape he yukcankiya okihi.

11 Wamduśka kin ajijipi śni kinhan wicayahtake kta; qa tuwe iwakan lain iś he isanpa waśte śni.

12 Wicaśta ksapa i oie kin hena wowaśte; tuka witkotkoka iha kin iye naicipce $k$ ta.

13 Iye i oie tokaheya kin he wowitkotkoke; qa taku eya owihanke kin he iś wowitkotkoke śice hinca.

14 Nakun tuwe witkotkoke cin $\mathbf{P}$ he oie ota: taku kte cin wicaśta wan sdonye śni; qa iye iyohakam taku u kte cin tuwe okiyake kta okihi he.

15 Witkotkokapi htanipi kin mdokițewicaya ece, ecin token otonwe ekta ye kta sdonkiye śni.

16 Hehehe makoce, wicaśtayatapi nitawa hokśiyopa kinhan, qa itancanpi nitawa hanhanna hinca wotapi kinhan.

17 Makoce, niyawaśtepi ce, wicaśtayatapi nitawa wicaśta tanka cinca hecinhan, qa wicasta itancanpi nitawa tohan iyehantu eca wotapi kinhan, waśakapi kta heon qa witkopi kte śni.

18 Wokuje ota on tipi tihuha kin hinhpaya; qa wicanape takudan econ śni kin on tipi kin ohiyu ece.

19 Ihapi kta on aguyapi kagapi, qa miniśa wicani wiyuśkinkiya ece: tuka mazaska taku owasin on waay upte.

20 Nitawacin hee kaeś en wicaśtayatapi kin yaśice śni wo; qa tipi ohna nunke cin mahen tanhan wijice cin yaśice śni wo: mahpiya zitkadan wan wicaho kin aye kta, qa taku hupahu ton kin he wicoie lin oyake kta, heon.

\section{WICOWOYAKE 11.}

1 Aguyapi nitawa mini ite kin akan kada ehpeya wo; anpetu ota kinhan ake iyeyakiye kta.

2 Onge śakowin wicaqu wo, qa nakun śahdogan: taku śica maka akan un kta tukte e sdonyaye śni nakaeś.

3 Mahpiya śapa kin mini ojugjudan kinhan maka akan ihducokapi; qa can wan itokahkiya hinhpaya, qa iś waziyatakiya hinlipaya kinhan, tukte en can 


\section{EYANPAHA KIN,}

wankahan hecinhan hen wanke kta.

4 Tuwc tate kin iwanyake cinhan woju kte śni; qa tuwe mahipiya śapa kin ekta ewacin kinhan aguyapi bakse kte śni.

5 Woniya tacanku kin he, tuwe ihduśaka tamni ohna token huhu icage cin sdonyaye śni, he iyecen Wakantanka taku owasin kage cin he tolian kin sdonyaye śni.

6 Hanhaanna eca nitawoju kin okikju wo, qa htayetu eca ninape ehdaku śni wo: unma tukte icage kta, dee qa hee, qa iś napin akiyecen waśte kta sdonyaye śni.

'7 Awicakehan iyoyanpa kin he oiyokipi linca, qa wicaiśta anpetu wi wanyake cin he waśte:

8 Tuka wicaśta wan waniyetu ota ni, owasin on iyuślkin eśta, otpaza anpetu kin kiksuye lita iyececa; hena iś eya ota kta. Taku u kte cin iyuhpa takuśni.

9 Kośka, honikśiyopa icunhan cante waśte wo; qa koniśka anpetu kin en nicante iyuśkiniciya nunwe; qa nicante tacanku kin ohna mani wo, qa niiśta wawanyake cin en: tuka dena owasin on Wakantanka woyaco en aniu kta, he sdonya wo. 10 Heon etanhan nicante etanhan wicocanteśice hdutokan wo, qa nicehpi etanhan taku śica ehpeya wo: hokśiyopa qa kośka unpi kin napin takuśni nakaeś.

\section{WICOWOYAKE 12.}

1 Wanna konisksa anpetu kin en Wawicahniye cin he kilsuya wo, anpetu śce cin hinyahin ahi śni, qa waniyetu en, Hena ecaca iyomakipi śni ce, ehe kte cin hinyahin kiyadan u śni:

2 Anpetu wi, qa iyoyanpa, qa hanyetu wi, qa wicanhipi kin hinyahin aotpasyapi śni, qa mahpiya śapa magaju iyokakam ake hdiyohi icunhan:

3 Anpetu kin en ti awanhdakapi kin cancanpi kta, qa wicaśta waśaka patuś iciyapi kta, qa hi wiyakpan kin hena ayaśtanpi kta, tonana heon, qa owanyeye eciyatanhan eyokasinpi kin aotpaśapi kta;

4 Qa canku ohna tiyopa kin ecen icupi kta, wotpanpi ho kin ayuśtankiyapi kinhan; qa zitkadan hoton kin on inajin kta, qa dowanpi cunwintkupi iyuhpa lun elipeyapi kta:

5 Nakun taku wankantu kin kokipapi kta, qa canku ohna kopehdapi kta; qa uma kin he aktapi kte śni, qa psipsicadan kin he wośake dapi kta, qa cinpi kin he enakiyapi kta: wicaśta tipi owihanke wanice cin he ekta hde kta nakaeś, qa tona ceyapi kin hena canku ohna yapi ece :

6 Nahanhin mazaska ikan kin yuśkapi śni, qa mazaskazi wiyathe kin yuptujapi śni, qa waksica miniyowe kin elkta kamdecapi śni, qa minilidoka en iyuhmihma kin yuwegapi śni itokam.

7 Hehan maka mdu kin token un qon maka kin ekta hde kta, qa wicaniya kin he Wakantanka qu qon he ekta hde kta.

8 Takuśni takuśni, Fyanpaha kin eya ; owasin takuśni ce.

9 Unkan Eyanpaha kin he sanpa ksapa nakaeś, heon etanhan nakun oyate kin wosdonye onspewicakiya; han, nina awacin qa wicoie wakan ota owotanna kage kta akita.

10 Wicoie oiyokipi Eyanpaha kill iyeye kta akita: unkan taku owapi kin he owotanna, wowicake oie kin heca. 


\section{WICOWOYAKE 1.}

11 Wicaśta ksapa oie kin hena wicahtake kin iyececa, qa wonwicaye wanjidan etanhan qupi mazaiyokatkuge omniciye itancanpi okatanpi kin iyececa.

12 Nakun, micinkśi, dena on onspeiciciya wo: wowapi ota kagapi kin he owihanke yuke śni; qa nina wayawapi kin he wicacehpi nıdokițeya ece
13 Wicoie ocowasin yuśtanpi kin he naunhonpi kte; Wakantanka kokipa wo, qa iye tawoahope kin ahopa wo : wicaśta ocowasin kin hee.

14 Wakantanka wicolian owasin woyaco on au lita nakaeś, taku nahmanpi iyuhipa knya, waśte qa sica unma tukte kasta.

\section{DOWANPI ODOWAN.}

\section{WICOWOYAKE 1.}

1 Dowanpi Odowan Solomon tawa kin he dee.

2 Iye i oiputake tawa on i imaputaka nunwe. Nitowaśtedake kin he miniśa isanpa waśte nakaeś.

3 Ihepi waśtemna nitawa oomna kin on nicaje wihdi okaśtanpi kin iyececa: heon etarihan witanśna unpi kin waśtenidakapi.

4 Mayutitan ye. Nihakam unkinyankapi kta. Wicaśtayatapi kin he iye ti kin timahen amahi. Piundapi kta qa unkiniyuśkinpi kta; nitowaśtedake kin he minisa isanpa unkiksuyapi kta : tona ecetu kin hena waśtenidakapi.

5 Jerusalem cunwintkupi, miye masapa tuka owanyag waśte, Kedar tawakeya iyececa, Solomon ozan hdepi tawa kin iyececa.

6 Masapa heon amatonwanpi śni pe, anpetu wi kin he on maśtimaśpan nakaeś : ina cinca canniyemakiyapi ; hastanhanka iyuwi ojupi kin awanyag emahdepi ; hastanhanka iyuwi ojupi mitawa kin awanwahdake śni.
7 Minagi waśtekidake cin niye, ito, omakiyaka ye, tukten wawihanyakiya, tukten wiyotanhan iwanke wicayakiya hecinhan: tokeca miye, nitawaśi taoptaye kin en, wanji nuni kin iyemacece kta he.

8 Winohinca ehna owanyag niwaśte hinca, he sdonyaye 'śni kinhan, detanhan cankuya ye, optaye owepi ohna, qa wonwicayapi tawakeyapi kin icahda tatokadan cinca nitawa wihanwicakiya ye.

9 Wiwaśte mitawa, Pharaoh tacanpahmihma en śung wiye kin he iciyacin.

10 Nitapon oinpi skaskadan on owanyag waśte, nitahu wanapin on.

11 Maz\&skazi oinpi unnicagapi kta ye, mazaska taśpudan koya.

12 Wicaśtayatapi kin wahna wotapi kin en yanka icunhan nard mitawa oomna hiyuya ece.

13 Waśtewakidake cin he canśin waśtemna opahte wan eewakiya, aze mitawa otahedan hanyetu osan wanke kta.

14 Waśtewakidake cin he kopher iyage wan iyececa wada183 


\section{DOWANPI ODOWAN,}

ka, Engedi hastanhanka iyuwi ojupi kin ehna.

15 Tho, wiwaśte mitawa, owanyag niwaśte; han, owanyag niwaśte, niiśta tinwakiyedan iyececa.

16 Tho we, waśtecicidake, niye owanyag niwaśte, han oiyokipi hinca; nakun owanka unkitawa kin he toto.

17 Untipi canhdakinyan wanke cin hena hanteśa, wankan obagopi unkitawapi kin hena wazi can.

\section{WICOWOYAKE 2.}

1 Śaron onjinjintka, kaksiza en mnahcahca kin he miye.

2 Mnahicahica wapepeka ehna un kin he iyececa, wiwaśte mitawa kin cunwintkuyapi kin owicapeya un.

3 Taspantanka hu taśkoju can kin elına, he iyecen waśtewakidake cin he cinhintkuyapi kin owicapeya un ye. Tye ohanzi tawa kin on imduśkin qa en imdotanka, unkan tawaskuyeca kin micaka en skuye linca.

4 Miniśa tipi kin en amahi; unkan tawiyokihedan miwankan un kin he wocantekiye.

5 Hastanhanka on wacintonhnagmayan ye ; taspantanka on waśagmayan ye, wowaśtedake on wamayazan heon.

6 Tye catka kin mapa kin ihukuya, qa iye nape etapa kin he poskin mahduza ce.

7 Jerusalem cunwintkupi, tinta tatokadan wiye qa tawiyedan on ceciciyapi ce, waśtewakidake cin yapaninipi kte śni qa duhicapi kte śni, tohanyan iyokipi hehanyan.

8 Waśtewakidake ho kin! wan, he kin akan psipsica, paha kin akan psipsin u ye.

9 Waśtewakidake cin he tato184 kadan qa tahinca cinca wan iyececa ye: wan, conkaśke iheyata inajin, owanyeye eciyatanhan ahitonwan, ozanpi ohna taniniciya ye.

10 Waśtewakidake cin he ie ca hemakiya; Wiwaśte mitawa, owanyake waśte mitawa, najin qa kuwa wo.

11 Iho, waniyetu kin wanna henakeca, magaju kin hdapte, wanna sam iyaya ;

12 Maka akan wahca kin taninin; dowanpi kte cin wanna hiyohi: qa makoce unkitawapi ohna tin wakiyedan ho kin nalionpi:

13 Suken can kin waskuyeca toto icahya, qa hastanhanka iyuwi hica aye cin hena omnanpi waśte. Wiwaśte mitawa, owanyag waśte mitawa, najin qa kuwa wo.

14 Tinwakiye dan mitawa, imnija ohdoka ohna, he iyadipi oinahbe kin ohna, tokin niite wanmdaken, niho nawahon kta; niho kin he oiyokipi, qa niite kin owanyag waśte nakaeś.

15 Tokadan, tokadan cikcistinna hastanhanka iyuwi kiunniyanpi kin hena unkiciyuza miye : hastanhanka iyuwi unkitawapi hastanhanka śtunkaka aicaga nakaeś.

16 Waśtewakidake cin he miye mitawa, qa iye tawamayan: mnahcahca kin ehna wawiliankiya ece ye.

17 Anpao hinanpa qa ohanzi kin kinyan iyaye kte cin hehanyan, hdicu ye, waśtecicidake, tatokadan wan iyececa un ye, qa tahinca cinca wan Bether he kin akan iyececa.

\section{WICOWOYAKE ร.}

1 Hanyetu icunhan mitowinja akan tuwe minagi waśtekidake 
cin he owakide; owakide tuka iyewaye śni.

2 Wanna nawajin kta, qa otonwe kin en mde kta, canku kin ohna qa ocanku tanka ohna, tuwe minagi waśtekidake cin he owakide kta ce. Owakide tuka iyewakiye śni ye.

3 Waawanyake otonwe ehnahna yapi ece kin hena iyemayanpi. Minagi waśtekidake cin he wandakapi he, ewicawakiya.

4 Kitan ecinyan hena sanpa imdamda hehan tuwe minagi waśtekidake cin he iyewaya: mduza qa amduśtan kte śni, ecen ina ti kin en awahdi, qa tuwe cinca mayuhe cin ti mahen.

5 Jerusalem cunwintkupi, tinta tatokadan qa tawiyedan kin on ceciciyapi ce, waśtewakidake cin he yapaninipi kte śni qa dulicapi kte śni, tohanyan iyokipi hehanyan.

6 Tuwe śota wankan ye cin iyececa hewoskan tanhan $u$, canśin waśtemna qa wihdi waśtemna wopeton tapejihuta mdu kin owasin koya on aizinyapi kin he tuwe hc.

7 Tho we, on akiyuhapi tawa he Solomon tawa; wicaśta waditaka wikcemna śakpe ihdukśan yakonpi, Israel waditakapi kin etanhan.

8 Hena owasin mazasagye hduhapi, kicizapi en wayupikapi : hanyetu en wokokipe on otoiyohi tamazasagye ceca akan yanka.

9 Solomon wicaśtayatapi kin Lebanon can kin etanhan on akiyukapi wan içicaga ye.

10 Bosdan he cin hena mazaska on kaga, onnaptan kin he mazaskazi on, oakahpe kin he minihuha sa stan on, ocokaya kin he wocantekiye en owinśtonpi, Jerusalem cunwintkupi kin wicakicagapi.
11 Zion cunwintkupi, inanpapiqa Solomon wicaśtayatapi hunku wateśdake teśdag kicaton un kin he wanyaka pe, wakanhduze anpetu kin en, qa iye cante wiyuśkin anpetu kin en.

\section{WICOWOYAKE 4.}

1 Iho wo, wiwaśte mitawa, owanyag niwaśte; iho, owanyag niwaśte ; paha nisonpi otahedan niiśta kin tinwakiyedan iyececa; pa hin nitawa tatokadan optaye wan Gilead paha akan iwankapi kin iyececa.

$2 \mathrm{Hi}$ nitawa optaye wan yuśdapi wicayujajapi etanhan upi kin iyececa, hena otoiyohi cekpa yuhapi, qa etanhan cinca ton śni wanica.

3 Niiha hahonta duta wan iyececa; iyae cin he wiciyokipi hinca ; nawate nitawa taspantanka su ota onśpa iyececa, paha nisonpi otahedan.

4 Nitahu kin he Dawid taconkaśke kin iyececa, wipe on kagapi, wahacanka kektopawinge en otkeyapi, iyulpa wicaśta waśaka wahacanka tawapi.

5 Aze nom nitawa tacinca nom cekpapi, mnalicalica ehna wihanpi kin iyececa.

6 Anpao kta qa ohanzi kinyan iyaye $\mathrm{kta}$, hehan canśin waśternna he kin ekta, qa causín kohdihdi paha kin ekta, mde kte.

7 Wiwaśte mitawa, ocowasin owanyag niwaśte ; tuktedan oniyulii śni.

8 Lebanon etanhan miciu wo, mitawin, Lebanon etanhan miciu wo: Amana ipa kin etanhan etonwan wo, Senir qa Hermon paha pajodan kin etanhan, mnaja otipi kin etanhan, inmutanka he kin etanhan.

9 Cante mayaki, mitawin, mi185 


\section{DOWANPI O'DOWAN,}

tankśi ; niiśta wanjidan on, nitahu tawanapin oboyaya wanjidan on cante mayaki.

10 Mitawin, mitankśi, nitowaśtedake kin he oiyokipi linca: nitowaśtedake kin miniśa isanpa waśte : qa ihepi nitawa omnanpi kin he taku waśtemnạ owasin isanpa.

11 Mitawin, canhanpi tiktica śbu niiha hena ee : niceji ilıkuya tulimaga canhanpi pte asanpi ko yukan: qa nitawokoyake omnanpi Lebanon omnanpi kin iyececa.

12 Mitawin, mitankśi canwojupi natakapi kin hee; minih̉doka natakapi, miniyowe askamtonpi kin heca.

13 'Taku icahyaye cin taspanltanka su ota ojupi kin heca, waskuyeca waśte hinca nakun; canśin oomna waśte nard kicica :

14 Nard qa wiziye kici; sinkpe tawote qa canhaśa, canśin kohdihdi can kin owasin koya; canśin waśtemna qa canśin pa hinca, wizinye waśtemna ocaje owasin koya:

15 Miniyowe canwojupi, minihidoka wakoniya, qa Lebanon etanhan wakpadan kin.

16 Waziyatanhan tate uya, kikta ye; qa itokagatanhan uye cin, $u$ ye : mitawoju kin atateyanpa ye; hecen oomna waśtemna kin hiyu kta. Tokin waśtewakidake iye canwojupi tawa kin en ku, qa waskuyeca waśte kin hduten.

\section{WICOWOYAKE 5.}

I Mitawin, mitankśi, canwojupi mitawa kin en hibu: canśin mitawa taku omna waśtenma ko mnawakiya: canhanpi tiktica mitawa tuhmaga canhanpi 186 mitawa kıci wahdute: miniśa mitawa pte asanpi iyahna wahdatkan. Mitakuye, wota po; wayatkan po, han, waśtecicidapi, wiyuśkinyan wayatkan miye.

2 Miśtinbe, tuka micante kiktahan yanke; Waśtewakidake katoto yanka ho kin hee; Mitankśi, wiwaśte mitawa, tinwakiyedan mitawa, wanji talsu iyaonpepica śni mitawa, makiyulidoka wo; mapa kin cu ojudan, qa mapa hin hanyetu ośbuye kin ojudan nakaeś.

3 Onhdohda wahduśdoka, token ake wecun kta he : siha wahdujaja, token ake śamwakiye lita he.

4 Waśtewakidake cin he owanyeye eciyatanhan nape hiyuye, unkan iye on tanmalien miliduśkanśkan.

5 Waśtewakidake wakiyulidoke lrta najin imdamda, unkan inatake iyuze akan minape etanhan canśin śbuya, qa minapsukaza canśin waśtemna śbuya.

6 Waśtewakidake wakiyulidoka ; tuka waśtewakidake cin he wanna ihdutokan iyaya: ie cehan minagi hiyu tuka: owakide tuka iyewaya owakihi śni: wakipan tuka amayupte śni ye.

7 Waawanyake otonwe ohomni yapi kin hena iyemayanpi, hena amapapi, hena ksuwemayanpi : conkaśke awanyakapi kin hena ite akalipe kin makipi. 8 Jerusalem cunwintkupi, ceciciyapi ce, waśtewakidake cin he iyeyayapi kinhan wowaśtedake on wamayazanka he oyakidakapi kte.

9 Winohinca wicehna owanyag niwaśte hinca, waśteyakidake cin he waśtedakapi tokeca taku on isanpa he; waśteyakidake cin taku on waśtedakapi 


\section{WICOWOYAKE 6.}

tokeca wan isanpa waśte he, on hecen ceunyakiyari he.

10 Waśtewakidake cin he ska qa śamna, kektopawinge wikcemona ehna okitanin hinca.

$11 \mathrm{~Pa}$ kin he mazaskazi ecedall: pa hin kin hena yuliaha qa sapsapa, kangi iyececa :

12 Iśta kin tinwakiyedan mini wakpa icahda kin iyececa, pte asanpi ohna yujajapi, ayuco ośtanpi :

13 Tye tapon taku omna wastemna oicage kin iyececa, wahca rvaśtemna kin iyececa: jha kin mnahcahca iyececa, canśin waśtemna śbuyapi :

14 Iye nape kin mazaskazi napcupe Tarśiś iny an tehilia ośtanpi kin iyececa: tezi kin he huhu wiyatpa inyan toto tehika akahpapi kin iyececa :

15 Iye hu kin inyan skaska ihupa mazaskazi ecedan oyuśtanpi kin en ehdepi iyececa: ite kin Lebanon iyececa, hanteśa kin iyecen oiyokipi hinca.

16 Iye i kin skuye hinca: han, ocowasin waśte hinca. Jerusalem cunwintkupi, waśtewakidake cin he dee, qa mitakuye hinca hee.

\section{WICOWOYAKE 6.}

1 Winohinca ehna owanyag niwaśte hinca, ivaśteyakidake cin lie tokiya iyaya he: waśteyakidake cin he tokiya icunonpa iyaya he; niyeci unkodepi kta ce.

2 Waśtewakidake cin he iye - canwojupi tawa kin ekta iyaya, taku oınna waśtemna oicage ekta: canwojupi kin en wawihanye kta, qa mnalicahica hduśpi kta.

3 Wastewakidake cin he tawamayan, ga waśtewakiduke cin he miye mitawa : mnalicalica kin ehna wawilianyan ece ye.

4 Wiwaśte mitarva, owanyag niwaśte hinca, Tirzeh iyececa, Jerusalem iyecen oiyokipi hinca, ozuye wiyokihedan yuhapi iyecen wokokipe hinca.

5 Miye etanhan niiśta hduho. mni wo, hena maktepidan: pa hin nitawa tatokadan optaye Gilead en iwankapi kin iyececa.

6 Nihi kin hena tahinca wanunyanpi optaye wicayujajapi etanhan iyayuptapi kin iyececa, hena otoiyohi cekpayuhapi, qa hena etanhan cinca ton śni wanica. 7 Paha sonpi otahedan nawate nitawa taspantanka su ota onśpa iyececa.

8 Wicaśtayatapi winohinca wikcemna śakpe, qa winohinca wicayuhapi wikcemna śahdogan, qa witanśna unpi yawapica śni.

9 Tinwakiyedan mitawa, wiyaonpica śni mitawa kin he wanjidan, hunku tawa kin he iśnana, tuwe yuhe ciqun hdahinge cin hee. Cunwintkuyapi kin hena wanyakapi qa yawaśtepi ; wicastayatapi winohinca qa winohinca wicayuhapi kin hena nakun yaonihanpi.

10 Tuwe anpao iyececa etonwan, hanyetu wi iyecen owanyag waśte, anpetu wi kin iyecen wiyatpa, ozuye wiyokihedan yuhapi iyecen wokokipe hinca, he tuwe he.

11 Hma can wojupi ki ekta kun imdamda, kaksiza en waskuyeca kin wanmdake kta, hastanhanka iyuwi icaga hecinhan, taspantanka su ota camni uye wanmdake kta.

12 Sdonwakiye śni, ihnuhanna minagi Amminadib tacanpahmihma iyececa micicaga.

13 Hdicu wo, hdicu wo, Śulamith; hđicu wo, hdicu wo, wan187 


\section{DOWANPI ODOWAN,}

unniyakapikta. Sulamith en taku wandakapi kta he. Ozuye nom owaci kin iyececa ce.

\section{WICOWOYAKE $\%$}

1 Wicaśtayatapi cunwintku, nisiha hanpokiton kin hena owanyag waśte linca : ceca okihe nitawa wamnulia tuwe wayupika nape "on kage cin hena iyececa.

2 Nicekpa kin he wakśica ohmihma miniśa iyujimnana kin hee: nitezi kin he aguyapi su opaha wan mnahcahca ihdukśan hiyeye cin he iyececa.

3 Aze nom nitawa totokadan cinca cekpapi kin iyececa.

4 Nitahu kin he huhu waśte canpasotka kin iyececa : niiśta Heśbon miniyowe kin iyececa, Bath Rabbim tatiyopa kin etu: nipoge Lebanon conkaśke Damasek ektakiya etonwe cin he iyececa.

5 Nipa akan niyanke cin he Karmel iyececa, qa nipa hin boyaya lin śa stan iyececa: sonpi kin on Wicaśtayatapi kin kaśkapi ye.

6 Wiwaśte mitawa, owanyag niwaśte, qa wowiyuślkin on oiyokipi hinca yaun.

- Nihanske cin he tamar can kin iyececa, qa aze nitawa iyage kin iyececa.

8 Tamar can kin en mde kta, adetka kin mduze kta ce, epa: unkan hinnakaha aze nitawa hastanhanka iyage imdacin kta, qa nipoge omnanpi kin taspantanka iyecece kta :

9 Qa nicaka kin miniśa waśte iyececa, he waśtewakidake cin en katinyan ya, tona iśtinmapi iha akan iwaśtedan iwicayaya.

10 Waśtewakidake cin he ta188 wamayan, qa iye tocantekiye kin miye en mau ye.

11 Waśtecicidake, kuwa, maga kin ekta unye kta, otonwe cistixna kin hena ekta hanyetu unyakon kta.

12 Hanlianna hinca hastanhanka iyuwi ojupi kin ekta unye kta; wiyuwi kin icage cinhan wanunyake kta, iyage śtunkaka wanna tanin hecinhan, taspantanka su ota kin wanna camni uye cinhan: heciya mitocantekiye cicu kta.

13 Wocantekiye waskuyeca kin oomna hiyuya, qa tiyopa unkitawapi ohna waskuyeca waśte ocaje owasin, teca qa tanni, waśtecicidake, hena ecicihnaka ce.

\section{WICOWOYAKE 8.}

1 Mitimdo, ina aze hdazoke ciqon, tokin henicecen; unkanś canlsu ohna iyeciciya ehantanhan iiciputake kta: hececa eśta miye wahtemadapi kte śni.

2 Yus aciye kta, ina ti kin en acii kta, he onspemakiye kta: miniśa icicahiyapi taspantanka su ota hanpi mitawa kin he yatheciciye kta tuka ye.

3 Iye nape catka mapa kin ihukuya kta, qa etapa kin poskin mahduze kta tuka.

4 Jerusalem cunwintkupi, ceciciyapi ce, waśtewakidake cin he yapaninipi kte śni, qa duhicapi kte śni, tohanyan iyokipi hehanyan.

5 Tuwe liewoskan tanhan $u$, waśtekidake cin he hdus un kin he tuwe he. Taspantanka hu kin ihukuya najinciciya; nihun hen niton; tuwe niyuhe cin he hen niton.

6 Askape wan iyecen nicante en, ipuspe wan iyececa niisto akan emahnaka ye : wowasteda- 
ke kin wiconte iyecen waśaka: wowinawizi kin he Hades iyecen suta : he pelinige kin peta pelinige ide hinca heca.

7 Mini ota wowaśtedake kasni kte śni, qa mini tanka kin spayeye kte śni : wicaśta wan iye ti tawahpaya kin iyuhpa wowastedake on tokiyopekiya eśta, he ocowasin aktapi kte śni.

8 Tankśiunyanpi kin he cistinna qa aze nica. Anpetu en tankśiunyanpi kin dapi kinhan token ecaunkiconpi kta he.

$9 \mathrm{He}$ conkaśke unkanś akan mazaska tipi wan unkagapi kta; he tiyopa unkanś hante sa canmdaska on onauntakapi kta tuka do.

10 Miye qe conkaślke hemaca, qa aze mitawa pajodan iyececa. Heon iye iśta kin en wanji wo- cantekiye iyekiye cin hemaceca ye.

11 Baal-Hamon en hastanhanka iyuwi ojupi wan Solomon yuha: wiyuwi ojupi kin he waawanyake owicaqu: waskuyeca on o toiyohi mazaska kektopawinge kahi kta.

12 Wiyuwi ojupi mitawa mitokam wanke cin he mitawa. Solomon, niye kektopawinge duhe kta, qa tona waskuyeca awanyakapi kin hena opawinge nonpa yuhapi kta ye.

13 Canwojupi kin en ounyaye cin, olsodakiciye kin hena niho anagoptanpi ece: he iś nahonmakiya wo.

14 Waśtecicidake, najica u ye; qa taku omnanpi waśte paha kin akan tatokadan wiye qa iś tahinca cinca wan iyececa un ye.

\section{ISAYA TAWOYUKCAN KIN.}

\section{WICOWOYAKE 1.}

1 Isayà Amoz cinhintku towanyake kin, Juda qa Jerusalem on wanyake, Juda wicastaytapi Uziya, Jotham, A haz, qa Hezekiya taanpetu kin en.

2 Mahpiya, nahon wo, qa maka, anohya wo: Jehowa ia.; Cinca icahwica wakiye ca tanka wicawakaga, unkan makipajinpi ce.

3 Tatanka ee tuwe tawa kin sdonkiya, qa sonsonna kin he tuwe yuha dotopiye tawa sdonya; tuka Israel wasdonye śni, mitaoyate waawacin sni.

4 Hehehe, oyate wan walitani sa, wicaśta woalitani on hduśakapi, wicoicage wan śicaya econ-

Isaiah. pi, wicacinca wayuśicapi ; Jehowa ayuśtanpi, Israel Wanji Wakan tawa kin he wahtedapi sni, hektam ihdoyapi.

5 Taku on sanpa anipapi kta he; nakun wawakipajinpi ece ecanonpi kta; wicapa ocowasin wayazanka, qa wicacante kin ocowasin hanyeca:

6 Sicu etanhan pa iyahdeya tuktedan zani śni; capapi, kaśuśujapi qa ton awicau; aohduteyapi śni, yuskiskitapi sni qa wihdi on waśte kagapi śni.

7 Makoce nitawapi kin he otiwita, nitotonwepi kin peta on huhnagapi; maga nitawapi wicaśta tokeca nitokam temyapi, qa hewoskan ehpeyapi, wicaśta tokeca awihnunipi iyececa. 189 


\section{ISAYA TAWOYUKCAN KIN,}

8 Zion cunwintku kin hastanyanka ojupi wan en ohanzi hdepi kin he iyecen ehpeyapi, sakayutapi ojupi en wakeya he cin iyececa, otonwe anatanpi kin iyececa.

9 Jehowa ozuye tawa onajice cistinna wan unkokicicaptapi śni unkanśs Sodom iyeuncecapi kta, qa Gomorrah iyecen unkicagapi kta tuka.

10 Sodom wicaśtayatapi, Jehowa oie kin nahon po ; Gomorrah oyate, Wakantanka unkitawapi toope kin awacin po.

11 Tokeca taku ota wamayakidusnapi he, Jehowa eya; tamdoka liuhnagapi qa cemyapi wasna kin on imamna hinca; qa tatanka, tacincadan qa tatokadan mdoka we kin iyomakipi śni.

12 Nakun tohan miye en ihdutanin yahipi kinhan, mitahocoka omayanipi kin, tuwe he ninapepi etanhan icu kta he.

13 Detanhan wośnapi takuśni kin heca e aupi śni po ; wizinyapi kin he wahtewada śni ; wi teca qa wookihpe omniciye kagapi kin hena mduba owakihi śni ; omniciye wakan kin he hee kaeś worlitani.

14. Wi teca nitawapi qa mniniciyapi ece kin hena minagi śicedaka; hena woyuśake mdawa; yuha mdowakita.

15 Unkan nape yahdugatapi kinhan miista anacihmanpi kta ; han, wocekiye daotapi kinhan nawalion kte śni ; nape we onijupidan nakaeś.

16 Ihdujaja po, ihduska po ; miiśta itokapatanhan taka śica ecanonpi kin ehpeya po ; sicaya econpi ayuśtan po :

17 Taku waśte econpi onspeiciciya po: wokonze akita po ; śicaya wicakuwapi kin hena owotanna ecawicakicon po, wa- mdenica kin hena wicayaco po, wiwazica kin he iciya po.

18 tho miye, nakaha wounhdakapi kta, Jehowa eya: wayalitanipi kin hena duta eśta wa iyecen ska kta; hena śa stan iyececa eśta tahinca hin kin iyecece kta ce.

19 Hecen yacinpi qa waanayagoptanpi kinhan, makoce taku waśte aicage cin he yatapi kta :

20 Tuka wicayadapi śni qa wawayakipajinpi kinhan, mazasagye on temniyanpi kta, Jehowa ikin he hecen eya ce.

21 Hehehe, otonwe owotanna qon he witkowinna icaga: wokonze on ojudan, woowotanna ohna ti tnka qon; tuka nakaha tin wicaktepi sa.

22 Mazaska nitawa ginginca icaga; miniśa nitawa mini icahiyapi.

23 Wicaśtayatapi nitawa kin hena wicastapiśni qa wamanonpi sa takodawicayapi : otoiyohi taku wicaqupi waśstedaka qa icajuju akitapi ; wamdenica kin hena on wayacopi śni, qa wiwazica tawoakinica kin he en wicahi śni.

24 Heon etanhan Itancan kin, Jehowa ozuye yuha, Israel Iyotan Waśaka tawa kin he hecen eya; Han, tona makipajinpi kin on iyokipimiçiye kta, qa tokamayanpi kin hena towicawecicon kta ce.

25 Qa minape aciyuhomni kta, qa ginginca nitawa wiśdoye on ciciyuecedan kta, qa maza śdoyapi kin ocowasin ehpeciciye kta.

26 Qa wayaco nitawapi tokaheya ekta iyecen wicamduecetu kta, qa waaiewicakiyapi nitawa otokahe ekta iyececapi kta? hehan iyohakam, otonwe owotan- 


\section{WICOWOYAKE 2.}

na, otonwe wacinyepica, eniciyapi kta

27 Woyaco on Zion opekitonpi kta, qa tona en hdipi kin hena woow otanna on.

28 Unkan śicaya econpi sa qa wahtanipi kin witaya ihangwicayapi kta, qa tona Jehowa ayuśtanpi kin hena yusotapi kta.

29 Qa utuhu can waśteyadakapi qon hena on iśtecapi kta, qa can wojupi yahdahnigapi kin hena on inistecapi kta.

30 Utuhu can wan ape śnije cin he iyenicecapi kta, qa can wojupi wan mini wanice cin he iyececa.

31 Qa tuwe waske cin he hahonta on kagapi kin he iyecece kta, qa iye ohan kin peśnija iyecece kta; unkan napin ptaya ideyapi kta, qa tuwedan kasni kte śni.

\section{WICOWOYAKE 2.}

1 Wicoie Juda qa Jerusalem on, Isaya $A m o z$ cinhintku wanyake cin he dee.

2 Unkan anpetu ehake kin en, Jehowa tipi Paha kin he he ipa kin en ehdepi kta, qa paha kin isanpa wankan kagapi kta; unkan oyate owasin en kawitaya iheye kta.

3 Unkan oyate ota upi qa heyapi kta; U miye, Jehowa Paha tawa kin ekta myanpi kta, Jakob ta Wakantanka ti kin ekta; unkan iye tacanku kin onspeunkiyapi kta, kinhan ocanku tawa ohna maunnipi kta: Zion etanhan woope kin innnpe kta, qa Jehowa oie kin Jerusalem etanhan.

4 Unkan iye Ikcewicaśta ehna wayaco kta, qa oyate ota iyopewicaye.kta; hecen mazasagye yuhapi kin mahiyumdu kagapi kta, qa wahukeza on isan skopa kagapi kta: oyate wan oyate tokeca mazasagye apaha kte śni, qa icimana kicizapi onspeiçiciyapi kte śni.

5 Jacub tiyohnaka, u po, Jehowa iyoyanpa tawa kin en maunnipi kta.

6 Heon nitaoyate, Jakob ti kin he, elpeyakiya; wiyohiyanpata tanhan isanpa ihduotapi, qa hanmdepi, Philistia oyate kin iyececa, qa wicaśta tokeca cinca takodawicayapi, heon etanhan.

ry Nakun makoce tawapi kin mazaska mazaskazi ko ojudan, qa wowijice tawapi kin wopteca śni; nakun makoce tawapi kin śuktanka on ojudan, qa canpahmihma tawapi kin wopteca sni.

8 Makoce tawapi nakun wakagapi on ojudan; iye nape ohan kin hena ohodapi ece, taku iye napsukaza kagapi kin hena:

9 Hecen wicaśta ikceka patuś inajin, qa wicaśta tanka kin he makata ehpeiciya ece; heon wicayecicajuju kte sni.

10 Imnija kin inukuya ya wo, qa maka mdu kin en inaliman wo, Jehowa tokokipe kin itokapa tanhan qa tawootanin wowitan kin heon.

11 Wicaśta wahaniçida iśta kin kun iyeyapi kta, qa wicaśta watankaicidapi kin he kun ehpeyapi kta; qa anpetu kin he en Jehowa iśnana yatankapi kta.

12 Jehowa ozuye tawa taanpetu kin he tona wahanicida qa watankaicida owasin akan un, qa tona yuwankan iyeiçiya owasin akan; unkan yuhukun elipeyapi kta :

13 Nakun Lebanon liante sa tehanwankantu qa wankan iyeyapi owasin akan un, qa Baśan utuhu can kin owasin akan ;

$14 \mathrm{Qa}$ lie tehanwankantu kin 191 


\section{ISAYA TAWOYUKCAN KIN,}

iyulipa akan, qa paha wankan iyeyapi kin owasin akan yanke;

15 Qa tipi tehanwankan otoiyohi, qa conkaśke suta owasin akan;

16 Qa Tarśís wita wata iyuhpa, qa taku owanyag waśte kin owasill akan yanke.

17 Unkan wicaśta walianiçidapi kin kin he kun ehpeyapi kta, qa wicaśta watankaiçidapi kin he patuśyapi kta; qa anpetu kin he en Jehowa iśnana yatankapi kta.

18 Nakun wakagapi kin hena ocowasin tokan aye kta :

19 Qa imnija ohdoka ohna, qa maka ohdoka kin olna yapi kta, Jehowa tokokipe kin itokapatanhan, qa tawootanin wowitan kin heon, tohan maka kin wakokipe kicali inajin kinhan.

20 Anpetu kin he en wicaśta mazaska wakagapi qa mazaskazi wakagapi tawa, iye ohoda kta on kagapi kin hena napeilieyatahedan qa hiupawakihdakedan kin ekta elipeyapi kta :

21 Imnija ohdoka ohna yapikta, han imnija kahdokapi kin ohna, Jehowa tokokipe kin itokapatanhan, ga tawootanin wowitan kin heon, tohan maka kin wakokipe kicah inajin kinhan.

22 Wicaśta, taniya poge ohna un kin, he ayuśtan po: taku on he taku yawapi kta he.

\section{WICOWOYAKE 3.}

1 Wanyaka, Itancan kin Jehowa ozuye tawa Jerusalem qa Juda etanhan ipatan qa sagye kin icu kta, aguyapi sagye kin ocowasin, qa mini sagye kin ocowasin :

2 Wicaśta waśaka qa wicaśta zuye sa, wayaco qa wicaśta wokcan, tuwe hanmdohdaka qa wicalinca kin ;
3 Wikcemna zaptan en itancan qa tuwe ite kinihanpi, qa wawiciye kin, qa wabago wayupika, qa tuwe ie ksapa.

4 Unkan kośka wicaśtayatapi wicawaqu kta, qa hokśsiyoqopa iwicadakapi kta.

5 Qa oyate kin otoiyohi kakiśkiciyapi kta, qa otoiyohi ti kiyedan unpi kin nakun; hokśidan kin he wicahinca en ihdatan kta, qa tuwe wahte śni kin he tuwe kinihanpi kin en.

6 Tohan wicaśta wan iye cinyeku, atkuku ti kin etanhan, he hduze ça, Niye wokoyake niciun, itancan unniyuhapi kta, qa woihangye kin de niye ninape en un kta, eye cinban;

7 Anpetu kin he en nape hdugate heye kta; Wawokiziya hemaca kte śni, wati kin ohna woyute wanica qa wokoyake wanica, heon oyate kin en itancan makagapi śni po.

8 Jerusalem atakuni śni qa Juda hinhpaya ; iye cejipi qa ohanpi kin Jehowa tawowitan iśta kin iyokiśinyapi kin heon etanhan.

9 Iye ite hdutaninpi kin he owicayaka, qa Sodom iyececa iye wahtanipi ohdakapi, nakilimanpi śni. Woiyokiśice i ye nagipi en kiciyankapi nunwe, taku śica ecaiçiconpi nakaeś.

10 Tuwe owotanna kin, Tanyan un kta ce, keciya po; iye ohanpi waskuyeca kin hdutapi ece kta :

11 Hehehe, tuwe śice cin, tehike kta, iye nape ohan kin iyecen ecakiconpi kta nakaeś.

12 Mitaoyate holsśipidan on wowidagyapi, qa winohinea kin itancan wicayuhapi ece. Mitaoyate, tona wahokonniciyapi kin hena nuniniyanpi, qa canku omayanipi kin he awihnuniyapi. 


\section{WICOWOYAKE 5 .}

13 Jehowa wakkinin inajin, qa oyate wicahdaco yanka.

14 Jehowa iye taoyate en hunkayapi kin wicahdaco kta, nakun wicaśtayatapi kin. Niye hastanyanka iyuwi ojupi kin temyayapi ; wowahpanica taku wicakipi kin he yatipi kin ohna yanke.

15 Tokeca mitaoyate wicayakapanpi qa wahipanica itepi kin wicadumanpi he, Jehowa ozuye Itancan kin eya.

16 Nakun Jehowa heya; Zion cunwintku tankaicidapi, qa pa hduwankan icu mánipi, qa token cincin išta yeyapi, manipi qa kaicicuya yapi, qa siha on nasnasnapi ;

17 Heon etanhan Itancan kin Zion cunwintku pesdete oyuhihi on peśda kage kta, qa tancodan unpi kin Jehowa wicayutanin kta.

$18 \mathrm{Qa}$ anpetu kin he en Itancan kin sicogokaśke wowitan kin ewicakiciyaku kta, qa wateśdake mazaska wanapin koya ; 19 Oinpidan, qa napokaśke, qa ite akahpe kin ;

20 Wapaha qa siha icaśke, qa paipaite, qa wojuha wakan, qa oinpi wakan kin;

21 Napcupe qa poge oinpidan;

22 Wokoyake waśte, qa onhdohda, qa śina, qa mazaśka opiye ;

23 Ihdiyomdasin, qa mahen unpi waśte, qa wateśdake, qa ite akahipe.

24 Unkan kaketu kte, taku waśtemna on śicamna yuke kta; qa ipiyake on tehmiso; qa paha sonpi on nasuśda kagapi ; qa śina zipzipedan on wakihdaka ipiyagkitoupi ; owanyag waśte on wicagupi ee yuke kta.

25 Wicaśta nitawapi mazasagye on hinhpayapi kta, qa wicaśta waditaka nitawapi kicizapi en. Is.
26 Hecen iye tatiyopa iyokiśica qa ceye kta, qa iye hinca cokadan makata iyotanke kta.

\section{WICOWOYAKE 4.}

1 Unkan anpetu kin he en winohinca śakowin wicaśta wanjidan en yuzapi qa heyapi kta; Agnyapi unhdutapi kta qa wokoyake kounhdakapi kta, tuka nicaje on cajeunyatapi nunwe, wiyaonpapi eunkiciyakupi kta.

2 Anpetu kin he en Jehowa toicage kin he woyuonihan qa wowitan kta, qa maka waskuyeca kin he wowaśte qa woiyokipi kta, Israel tona okaptapi kin hena on.

3 Unkan kaketu kte, Zion en okaptapi qa Jerusalem en mdogyanke cin hena, Owotanna, ewicakiyapi kta, tona wiconi on Jerusalem en owicawapi kin otoiyohi ;

4 Tohan woyaco oniya qa ide oniya kin on, Itancan kin Zion cunwintku tawośape kicicajuju, qa Jerusalem cokayatanhan we kin pakinte cinhan.

5 Unkan Jehowa Zion Paha oyanke otoiyohi akan, qa tomniciye kin en, anposkan, mahpiya śapa qa śota wan kage kta, qa hanyetu eca, peta ide iyega; wowitan ocowasin iwankam woakahpe kta.

6 Unkan wakeya wan yuke kta, anpetu icunhan waśte kin on ohanzi kta, qa wowinapeyapi kta, qa icamna magaju ko on woinalibe kta.

\section{WICOWOYAKE 5.}

1 Iho, mitakoda wakidowan kta, mitakoda tadowan kin hee, hastanhanka iyuwi ojupi tawa kin on. Mitakoda hastanhanka 193 


\section{ISAYA TAWOYUKCAN KIN,}

iyuwi ojupi wan yuha, pajodan waśte hinca wan en.

2 Unkan he ihdukśan nakitake, qa etanhan inyan pahi, qa hastanhanka iyuwi hu waśteśte kin en oju, qa cokaya cowahe tehanwankantu wan kaga, qa en iyuśkice wanji nakun kicaga. Hehan hastanhanka aicage kta ape yanka, unkan hastanhanka ikceka aicaga.

3 Hecen dehan, Jerusalem en ounyayapi qa Juda wicaśta, tokin miye qa hastanhanka iyuwi ojupi mitawa imiyeciyukcanpin.

4 Hastanhanka iyuwi ojupi mitawa kin en ecamon kin taku sanpa econpica he. Hecen hastanhanka aicage kta ape man$\mathrm{ka}$, tokeca hastanhanka śica aicaga he.

5 Unkan nakaha, iho, hastanhanka iyuwi ojupi mitawa taku ecawecon kta he ociciyakapi kta: Wapepeka inatake kin emdaku kta, unkan temyapi kta; conkaśke kin he mdujuju kta, hecen amanipi kta :

6 Qa hewoskan elipewaye kta; adetka abaśpapi kte śni qa maka akatapi kte śni; tuka wapepeka can pepe ko en icage kta; nakun malipiya śapa kin wahowaye kta, magaju takudan ahinhe kte śni.

7. Jehowa ozuye tawa hastanhanka iyuwi ojupi tawa kin Israel tiyohnaka kin hee, qa Juda wicaśta wojupi waśteśte tawa kin hena ee : unkan wokonze kta e ape yanka, tuka iho, we papsonpi ; woowotanna on ape un, tuka iho, śicahowayapi.

8 Tona tipi en tipi alkagapi, maga en maga ikoyagyapi, hecen oyanke wanica, qa iye iśnana maka cokaya yankapi kta, hena wotehi kiciyankapi nunwe.

9 Minoge en Jehowa ozuye yu194 he cin he hecen eya; Awicakehan tipi ota liewotahedan unpi kta tanka qa waśte tuwedan ohna ti kte śni.

$10 \mathrm{Han}$, hastanhanka iyuwi ojupi maka iyutapi wikcemna bath wanji icaliye kta, qa homer wanji ojupi kin he epha wan icaliye kta.

11 Wotehi kiciyankapi nunwe, tona mini wakan kuwapi kta hankiktapi, litayetu hehanyan econpi, miniśa wicayuwitko kta ;

12 Qa wohanpi kin en candowankiyapi ikan wikcemna qa candowankiyapi ikceka, cancega miniśa ko yukan ; tuka Jehowa tohan kin ekta ewacinpi śni, qa iye nape taku econ kin awacinpi śni.

13 Mitaoyate taku yukcanpi śni heon wayaka ayapi, qa wicaśta kinihanpi kin hena akihan tapi, qa wicota tawa ipuzapi on pus aya.

14 Heon etanhan Hades ihdutanka qa nina hin i hdukawa; unkan wowitan tawa, qa wicota tawa, qa owodutaton kagapi, qa tuwe wiyuśkin nakun en yapi kta.

15 Hecen wicaśta ikceka kin makata iyeyapi kta, qa wicaśta tanka kin yuhuk un ehpeyapi kta, qa wahaniçidapi iśta kin kun icupi kta :

16 Tuka Jehowa ozuye yuhe cin he woyaco en yatankapi kta, qa Wakantanka wakan kin he woowotanna on yawakanpi kta.

17 Hehan tahinca cincapi kin tukten awicayapi hen wihanpi kta, qa makotahedan tona cepapi kin hena wicaśta tokeca temyapi kta.

18 Wotehi kiciyankapi nunwe, tona woahtani tehmiso on wicohan śica hdutitanpi, qa canpahmihma ikan on iyecen walitanipi kin : 


\section{WICOWOYAKE 6 .}

19 Tona heyapi; Ohanko kte, taku econ inahni kte, hecen wanunyakapi kta; qa Israel Taku Wakan tawa kin he ku qa kiyedan $u$ kte, hecen sdonunyanpi kta ce.

20 Tona taku śica waśte éciyapi, qa taku waśte kin he śica ce, eyapi ; tona iyoyanpa otpaza eekiyapi, qa otpaza iyoyanpa eekiyapi; tona taku skuya kin he pa kiyapi qa taku pa skuye kiyapi kin hena wotehi kiciyankapi nunwe.

21 Tona iye iśta kin en ksapapi, qa wayupikeicidapi kin hena wotehi kiciyankapi nunwe.

22 Tona miniśa yatkan ohitikapi, qa mini wakan icahiya wicaśta waśakapi kin hena wotehi kiciyankapi kta;

23 Tona taku wicaqupi on wicaśta śica wicayaowotanpi, qa wicaśta owotanna toowotanna ekiciyakupi kin hena.

24 Heon etanhan, peta ceji aguyapi hu yasota, qa peji ideyapi hinhpaye cin he iyecen, hena hutkan kin can ponpon iyecece kta, qa wahca tawapi kin maka mdu iyecen wankan ye kta; Jehowa ozuye tawa toope kin ehpeyapi, qa Israel 'Taku Wakan tawa oie kin aktapi śni, heon etanhan.

25 Heon Jehowa tocanniye kin iye taoyate aidewicakiya, qa iye nape awicapaha, qa wicakaśtaka : Hecen paha kin cancan aya, qa wicaśta țapi tacesdi iyecen canku cokaya wankapi. Hececa eśta tocanniye enakiye śni, tuka hinyahin nape hdugan un.

26 Unkan oyate tehanhan unpi kin wiyokihedan wan ewicakihde kta, qa maka ihanke tanhan hena wicakijojo kta; unkan iho, hena inahni dus upi kta.

27 Hena etanhan tuwedan mdo- kite śni, qa tuwedan kaktihahan kte śni; hba kte śni qa iśtinbe kte śni; qa nite on ipiyag kitonpi kin he yukcapi kte śni, qa hanpkan tawapi kin yupsakapi kte śni :

28 Hena tiwanbinkpepi kin pepe, qa tinazipepi kin owasin elkatapi ; śunka wakan tawnpi śakepi kin inyan iyecen yawapi kta, qa canhdeśka tawapi kin tateiyumni wan iyecece kta.

29 Hena hotaninpi kin mnaja iyececa, mnaja kośka iyecen hotaninpi kta: han, iyaśapi qa wawiyahpayapi kta, qa tanyan kihnakapi kta; unkan tuwedan ehdaku kte śni.

30 Unkan anpetu kin he en miniwanca sa wanke cin iyecen hena iyawicakiśapi kta; hecen maka kin ekta etonwanpi kinhan, iho, otpaza woiyokiśica, qa mahpiya kin ekta iyoyanpa kin he aotpasyapi.

\section{WICOWOYAKE 6.}

1 Waniyetu Uziya wicaśtayatapi ta he ehan, Itancan kin oiyotanke tehanwankantu qa wakan ehdepi wan akan iyotanka wanmdaka; unkan tawokoyake kin tipi wakan kin ojuya.

2 Hen icahda seraphim inajinpi ; otoiyohi hupahu śakpe yuhapi; nom on ite ahdafipa, qa nom on siha ahdahpa, qa nom on kinyanpi ece.

3 Unkan wanji wanji tokeca kipan qa heciya ; Wakan, wakan, wakan, Jehowa ozuye hduha; towitan kin on maka kin ocowasin ojudan ce.

4. Unkan tuwe pan ho kin on tiyopa taku akan he cin hena śkanśkan, qa tipi kin śota ojudan.

5 Hehan hepa; Hehehe, matakuniśni ce : wicaśta iha śapa he- 


\section{ISAYA TAWOYUKCAN KIN,}

maca, qa oyate wan iha śapapi orn wati ; miiśta Wicaśtayatapi kin Jehowa ozuye yuhe cin he wanyakapi, heon etanhan.

6 Hehan seraphim wanji kinyan en mahi, qa petaga wan peta oicu on owayuśna kin etanhan icu qon he nape ohna yuha :

\% Qa he mii kin icahtagya qa heya; Iho, de niiha kahtaka; qa niohan śice cin eniciyakupi, qa wàahtani kin nicicajujupi ce.

8 Nakun Itancan ho kin heya nawahon; Tuwe yewaśi kta, qa tuwe unkiyepi on ye kta he, eya. Hehan hepa; De miye ce, yemaśi ye.

9 Unkan heya; Ya wo, qa oyate kin de hewicakiya wo ; Wanahompi on nayahonpi, tuka oyakahnigapi śni; qa wanyakapi on wandakapi, tuka sdonyayapi śni ce.

10 Oyate kin de cantepi cemya wo, qa noge kpe wicakaga wo, qa iśtagonge wicakiya wo ; okinni iśta on wanyakapi kta, qa noge on nahonpi kta, qa cante on okahnigapi kta, qa ihduhomnipi kta, kinhan okiziwicawaye kta tuka.

11 Unkan hepa; Itancan, tolianyan kta he. Unkan heya; Otonwe kin ihangyapi kta tuwedan ohna ti śni, qa tipi wicaśta codan, qa makoce kin ocowasin hewoskan ehpeyapi kta;

$12 \mathrm{Qa}$ Jehowa wicaśta kin tehan iyewicaya, qa makoce cokaya yujujupi tanka wanke kta hehanyan.

13 Tuka iwikcemna wanji en un, qa he ake icage kta, qa he woyute yapi kta : wazi can qa utuhu can kin iyececa: kaksapi eśta oicage kin mahen un, he iyecen wicoicage wakan kin he oicage kta ce.

\section{WICOWOYAKE $\%$}

1 Unkan Ahaz, Jotham cinhintku, Uziya cinhintku, Juda wicaśtayatapi taanpetu kin en, Rezin Aram wicaśtayatapi, qa $\mathrm{Pe}$ ka Remaliah cinhintku, Israel wicaśtayatapi kin, hena Jerusalem ekta hipi, azuyapi kta, tuka he ktedan okihipi śni.

2 Hehan, Aram Ephraim takodaya ce, Dawid tiyohnaka kin hecen eya okiyakapi. Unkan iye cante śkanśkan, nakun taoyate cantepi kin, contanka en can tateyanpa on kahuhuzapi iyececa.

3 Unkan Jehowa Isaya heciya; Wanna ekta ya wo, qa Ahaz itkokipa wo, niye qa nicinkśi Sear-Jaśub kici, wankan wapa mde kagapi wakpa iyahde ihanke kin ekta, wayujaja tamaga canku kin ohna:

4 Qa heyakiye kta; Iwanihdake ca inina un wo; kopehda śni qa cante wankadan śni wo; petuspe śonya un sinte kin dena oza on, Rezin Aram kici qa Remaliah cinhintku tocanniye ide kin on :

5 Aram śicaya waniciconza $k$ in heon; nakun Ephraim qa Remaliah cinhintku kin hena heyapi ; 6 Juda ekta unyanpi qa nagiyeunyanpi kta, qa cokaya wicaśtayatapi wan Tabeal cinhintku kin hee, eunhdepi kta ce, eyapi: 7 Heon etanhan Jehowa Itancan kin he hecen eya; He ecen he kte śni, qa ecetu kte śni.

8 Aram pa kin he Damasek, qa Damasek pa kin Rezin hee; nakun waniyetu wikcemna śakpe sanpa zaptan iyotpani Ephraim yuksaksapi kta, hecen oyate kte śni.

9 Nakun Ephraim pa kin Samaria hee; qa Samaria pa kin 


\section{WICOWOYARE 8.}

Remaliah cinhintku kin hee: Wicayadapi śni kinhan niyusutapi kte śni.

10 Nakun Jehowa ie ca Ahaz heciya ;

11 Niye on Jehowa Wakantanka nitawa wowakta wan kida wo; kuyatanhan qa iśs wankantanhan he kida wo.

12 Tuka Ahaz heya; Wakida kte śni, qa nakun Jehowa iyutanwaye kte śni ce.

13 Unkan heya; Dawid tiyohnaka, wanna nahon po; wicaśta akantu ikokiśinyayapi kin he taku cistinna, tuka nakun mita Wakantanka iyokiśinyayapi kta he.

14 Heon etanhan Itancan kin iye hinca wowakta wan nicupi kta: Iho, wikośka wan ihduśake ca cinca ton ; unkan Emmanuel-Wakantanka unkicipi uneya caśkiton kta.

15 Pteasanpi ihdi canhanpi tiktica ko yute kta, taku śica akta śni qa taku waśte kahniga sdonye kta heon.

16 Hokśiyoqopa kin he taku śica akta śni, qa taku waśte kahniga sdonye kta itokam, wicaśtayatapi nom kowicayakipe cin makoce tawapi kin he hewoskan ehpeyapi kta.

17 Jehowa, niye en, qa nitanyate en, qa niyate ti kin en, anpetu tohinni u śni kin heca au kta, anpetu en Ephraim Juda ayuśtan qon hetanhan ; Aśur wicaśtayatapi kin hee kta.

18 Unkan anpetu kin he en kaketu kte, honagidan Egupta wakpa ihanke en un kin he Jehowa kijojo kta, qa tuhmaga Aśur makoce en un kin he nakun.

19 Unkan hena upi kta, qa iyuhpa liewoskan kaksiza kin en ounye kta, qa imnija ohdoka kin ohna, qa wapepeka ojupi owaQ 2 sin en, qa owihankepi iyuhpa akan.

20 Anpetu kin he en, isan pe hinca opetonpi kin, wakpa kin akotanhan kin hena, Aśur wicaśtayatapi kin hee on, Itancan kin pa kasan kta, qa siha kin koya; qa he putinhin nakun eyaku kta.

21 Unkan anpetu kin he en kaketu kte; wicaśta wan pteheyuktanna wanji qa tawiyedan nom icaliwicaye kta :

22 Unkan asanpi ota qupi kin on asanpi ihdi hdute kta; tona makoce cokaya okaptapi kin owasin pteasanpi ihdi canhanpi tiktica ko yutapi ece kta nakaeś.

23 Unkan anpetu kin he en kaketu kte, makocajeyate owasin tukten mazaska kektopawinge on hastanhanka iyuwi he kektopawinge yukan tuka qon, hen wapepeka can pepe ko yuke kta. 24. Wanhinkpe itazipa ko hduha en hipi kta ; makoce owancaya wapepeka can pepe ko yuke kta heon etanhan.

25 Qa paha owasin magicamna on qapi qon hen wapepeka can pepe ko kokipapi on ekta de kte śni : tuka hen tatanka awicayapi kta, qa tahinca wanunyanpi amanipi kta.

\section{WICOWOY.AKE 8.}

1 Unkan Jehowa hemakiya; Tahasaka tanka wan ikikcu wo, qa wowapi icage wicaśta tawa on, Maher-śalal-haśbaz, (Wopate inahnikiya wapata inahni) eya en owa wo.

2 Unkan waayatanin wacinyepica iwicawekcu, Uriah wawayuśna kin he qa Zekariah Jeberakiah cinhintku :

3 Qa winohinca wawiyukcan kin he ikiyedan wai; unkan 197 


\section{ISAYA TAWOYUKCAN KIN,}

ihduśaka qa cinca ton. Hehan Jehowa hemakiya; Maher-śalalhaśbaz, eya caśkiton wo.

4 Hokśiyopa kin he hinahin, Ate qa ina, eya hoyeya onspe śni itokam, Damasek towijice qa Samaria tawahpaya kin hena yutokan icupi kta, Aśur wicaśtayatapi ite kin itokam.

5 Unkan ake Jehowa omakiye ca heya ;

6 Oyate kin de Shiloa mini iwahnana iyaye cin wah̉tedaśni, qa Rezin qa Remaliah cinhintku kin on iyuśkin ;

7 Heon etanhan, iho, Itancan kin wakpa wan mini wașaka qa ota en awicau ; unkan kaksiza owasin ohna hiyu kta, qa maya apaśbog ye kta:

8 Qa Juda ehna ye kta; apaśbog hiyu qa akam iyaye kta, dote kin hehanyan hiyohi kta: qa tahupahu akamdage kta, Fmmanuel, nitamakoce ohdakinyan ojudan kta.

9 Oyate yaunpi, dakonkiciy.a po; unkan nicamdecapi kta : Makoce tehantu owasin, anagoptan po ; ipiyagkiton miye ; kinhan nicamdecapi kta; ipiyagkiton po, unkan nicamdecapi kta ce.

10 Woawacin awacin po, unkan yujujupi kta; wicoie wan eya po, unkan ecen he kte śni : Wakantanka unkicipi un naka'eś.

11 Jehowa nape waśaka wan on decen emakiya, qa oyate kin de tacanku kin ohna mawani kte śni e onspemakiya qa heya ;

12 Oyate kin de tona, odakota eciyapi kin owasin, odakota eyakiyapi kte śni ; qa iye taku kokipapi kin he koyakipapi kte śni, qa kopeyahdapi kte śni.

13 Jehowa ozuye tawa iye hinca daowotanpi kta; qa iye hinca wowitonpe nitawapi kta, qa iye linca wokokipe nitawapi ee kta. 14. Unkan iye wowinape kin heca kta: tuka Israel tiyohnaka napin on inyan ibotopi qa imnija on hicahanpi ee kta, Jerusalem en tipi kin hena on wohmunke qa mazahtakiyapi heca kta.

15 Unkan hena wicota hicahahanpi qa hinhpayapi kta, qa wicakamdecapi kta, qa wicahmunkapi kta, qa wicayuzapi kta.

16 Woyaotanin kin pahta qa woope kin apuspa wo, waonspewicawakiye cin hena en.

17 Unkan Jehowa Jakob tiyohnaka on ite anakihbe cin he miye awakipe kta, qa he ekta ewatonwe kta.

18 Wanyaka wo, miye qa micin. ca Jehowa maqu kin Israel en wowakta qa wowapetokeca unyakonpi, Jehowa ozuye tawa Zion paha en ti kin he eciyatanhan.

19 Unkan tohan, Tona hamdohdag iapi qa tona wahanicidapi jijipi qa wapiya dowanpi kin hena owicade po, eniciyapi kinhan;-oyate wan Taku Wakan tawapi kin akitapi kte śni he; tona nipi on tona tapi kin owicadepi kta he.

20 Woope qa woyaotanin kin akita po; wicoie kin de iyecen iapi śni kinhan, iyoyanpa takudan en wicaun śni heon etanhan. 21 Unkan he ohna iyotanhan iyekiyapi qa wotektehda yapi kta; qa tohan wotehdapi kinhan śinhdaiçiyapi kta, nakun wicaśtayatapi qa Taku Wakan tawapi wicahdaśicapi kta, qa wankan etonwanpi kita.

22 Nakun maka kin ekta etonwanpi kta, unkan, iho, wonihinciye qa otpaza ; otpaza, woiyokiśica; tuka otpaza kin he yutokan iyeyapi kta. 


\section{WICOWOYAKE 9.}

\section{WICOWOYAKE 9.}

1 Hececa eśta iyokiśinyapi kin en tokaheya otpaza qon iyecece śni, Zebulon makoce qa Naphtali makoce iwaśtedan kakiśye ciqon he ehan; tuka iyohakam mde kahda, Jordan akasanpatanhan, Galile Ikcewicaśta ounyanpi en nina iyokiśinya.

2 Oyate otpaza en manipi qon hena iyoyanpa tanka wan wanyakapi; wiconte ohanzi makoce en ouryyanps kin hena iyoyanpa awic thinanpa.

3 Oyate kin dunta; wowiyuśkin kin yeciyutanira; woksapi wowlyuśkin kin chna nitokam wiyuśkinpi; woyuh kicipamnipi on cante waśtepı kin he iyececa.

4. Can napinpi napin kin he, qa iye tapete cansakadan, qa wowidagye cansagye tawa kin hena duksaksa, Midian anpetu kin en iyececa.

5 Zuye cin otoiyohi kicizapi owodutaton, qa wokoyake we en oputkanpi kin en hanpokihan ece ; qa huhnagapi kta, peta tawote kin hee.

6 Hokśiyoqopa wan unkicitonpi, cinca wan unqupi : unkan wokiconze kin he iye tapete akan yanke kta; qa caje kin, Wawinihan, Wawiciya, Taku Wakan Iyotan Waśaka, A teyapi Owihanke Wanica, Wookiye Wicaśtaya tapi kin eciyapi kta.

7 Tokiconze oicage qa wookiye kin he owihanke wanice kta, Dawid oiyotanke tawa akan, qa tokiconze akan, ecen ehde kta, qa woyace woowotanna ko on hdusuta kta, detanhan qa owihanke wanica: Jehowa ozuye hduha he tomniheca kin he de econ kta.

8 Itancan kin wicoie wan Ja- kob en yeśi, unkan he Israel ahinhpaya.

9 Unkan oyate owasin sdonyapi kta, Fphraim qa Samaria en tipi kin heepi kaeś, hena cante wahanicida qa suta kin on heyapi ;

10 Maka śpanyanpi kin hena hinlpayapi, tuka inyan kakanpi on tipi unkagapi kta; sukamin can kin hena kawankapi, tuka hanteśa eeunkiyapi kta ce.

11 Heon etanhan Jehowa tona Rezin śicedakapi kin hena iye itkokim hiyuwicaye kta, qa tokawicaye cin hena wicayuwitaya kta :

12 Aram oyate wiyohiyanpatanhan, qa Philistia oyate wiyohpeyatanhan unpi; qa hena i ocowasin on Israel temyapi kta. Hececa eśta iye tocanniye kin ayuhomnipi śni, tuka hinyahin nape hdugan un.

13 Oyate kin tuwe wicakaśtake cin ekta ihduhomnipi śni, qa Jehowa ozuye yuhe cin he akitapi śni.

14 Heon etanhan, anpetu wanjidan en, Jehowa Israel etanhan pa sinte ko bakse kta, adetka qa psa hu kin nakun.

15 Hunkayapi qa wicaśtayatapi kin he pa kin ee; qa wicaśta wokcan woitonśni oyake cin he sinte kin ee.

16 Tona oyate kin wicayawaśtepi kin hena nuniwicayapi; qa tona hena on yawaśtepi kin he. na napca iyewicayapi.

17 Heon etanhan kośka wicayuhapi kin on Itancan kin wiyuśkin kte śni; qa wamdenica wiwazica ko wicayuhapi kin hena onśiwicada kte śni : otoiyohi wayuśica qa taku śica econpi ; qa wicai otoiyohi witkotkoya ia ece. Hena owasin on iye tocanniye kin etanhan yuhomnipi 199 


\section{ISAYA TAWOYUKCAN KIN,}

śni, tuka hinyahin nape hdugan un.

18 Wicośice peta iyecen itkon; wapepeka canpepe ko huhnage kta, qa contanka otehi kin ohna ide kta, hecen śota wankan ye cin en wankan kahbog yapi kta.

19 Jehowa ozuye yuha tośinhda kin on maka kin aotpasyapi, qa oyate kin peta tawote kin iyecece kta; tuwedan iye sunkaku kin itonkipe kte śni.

20 Unkan etapa eciyatanhan wicaki kta, tuka wotek tehda kta; qa catkatanhan wote kta, tuka hena imnanpi kte śni: wicaśta otoiyohi iye isto conica hdutapi kta:

21 Manassa Ephraim, qa Ephraim Manassa; napin witaya Juda anatanpi. Hececa eśta iye tocanniye kin yuhomnipi śni, tuka hinyahin nape hdugan un.

\section{WICOWOYAKE 10.}

1 Tona woyaco owotanna śni yacopi, qa wowapi kagapi tona wokakiśye owapi kin hena wotehi wicakiciyanka nunwe :

2 Wokonze etanhan wahpanica kin wicayuhomnipi kta, qa mitaoyate onśikapi woowotanna ewicakiciyakupi kta, wiwazica wamawicakinonpi kta, qa wamdenica wawicakipi kta, heon etanhan.

3 Hecen wokakiśye anpetu kin en taku ecanonpi kta he, qa woihangye tehantanhan au kte cinhan, waokiyapi on tuwe ekta nayajicapikta he ; qa nitowitanpi kin tukten eyahnakapi kta he. 4 Miye codan wayaka unpi kin ihukuya canpeśka makehde inajinpi kta, qa wicaktepi kin wicihukuya hinhpayapi kta. Hececa eśta iye tocanniye kin yuho- mnipi śni, tuka hinyahin nape hdugan un.

5 Hehehe, Aśur, mitocanniye icapsinte, qa cansakadan iye napepi ohna wośinhda mitawa kin hee.

6 He oyate wahnayesa wan takpe yewaśi kta, qa oyate canniyewicawaye cin hena on taku econ waśi kta, wawicaki qa tawahpaya icu kta, qa canku upśija iyecen awicamani kta.

7 Hececa eśta iye hecen ke kte śni, qa cante mahen hecen awacin kte śni; tuka waihangyapi iye cante kin en un, qa oyate tonana śni wicakaśpe kta.

8 He kaken eya; Akicita tancan mitawa kin hena ocowasin wicaśtayatapi śni he.

9 Kalno he. Karkemiś iyecece śni he; Hamath Arpad iyecece śni he; Samaria Damasek iyecece śni he:

10 Oyate takuśni śni wakandapi, qa wakagapi tawapi, Jerusalem qa Samaria tawa kapapi qon hena minape iyowicahi kin heon, 11 Samaria qa taku wakan tawa token ecawicawecon he iyecen Jerusalem qa taku wakan tawa kin ecawicawecon kte śni he, eya.

12 Heon etanhan kaketu kte, Itancan kin tohan Zion he kin en, qa Jerusalem en, ocowasin hduśtan kinhan, hehan Aśur wicaśtayatapi cante wahanicida waskuyeca kin he towecicon kta, qa iye iśta wankantu witantan kin.

13 He kaken eya ; Minape waśake cin on hecamon, qa mitoksape on, wamdupika nakaeś: nakun oyate makoce icagopi kin mdutokan, qa towijicepi wicawaki, qa tuwe waśaka iyececa, en ounyanpi kin hena iwicawadaka : 
14 Qa wahohpi wan iyecen minape oyate towijicepi kin iyeya : qa wanji witka okaptapi pahi kin iyecen maka kin ocowasin mnawaye : unkan takudan liupahu hduśkanśkan śni, qa i hdukawa śni, qå hoton śni ce, eya.

15 Onspe kin he tuwe on wakakan kin iwankam wahaniçida kta he; canibakse kin he tuwe kaśkanśkan kin isanpa watankaicida kta he: cansakadan wan tona he yuwankan yuzapi kin wicitokam ihduśkanśkan he iyececa: cansagye kin, taku can śni iyecen bosdan cihde kte cin he iyececa.

16 Heon etanhan Itancan kin, ozuye Itancan kin, tona cepapi wicayuhe cin cn wicotamaheca ye śi kta, qa iye towitan kin ihukuya ide wan ideye kta, peta ide iyececa.

17 Unkan Israel Toiyoyanpa kin he peta heca kta, qa iye Towakan kin he ide kin ee kta; qa tanpetu wanjidan en wapepeka tawa canpepe koya liulinage ca awihnuni kta:

18 Nakun contanka tawa wowitan, qa iye tamaga waśte kin yusote kta, nagi tancan koya: qa wayazanka wan lianye cin he iyecece kta.

19 Qa contanka tawa can okaptapi kin hena tonana kta,hecen hokśiyopawan hena ow o okihikta. 20 Unkan anpetu kin he en kaketu kte, tona Israel etanhan okaptapi, qa Jacob ti kin etanhan tona niyanpi kin hena tuwe wicakaśtake cin he icimana wacinyanpi kte śni; tuka Jehowa Israel Towakan kin he awicakehan wacinyanpi kta.

21 Tona okaptapi, Jakob etanhan owicakaptapi kin hena Taku Wakan lyotan Waśaka en ihdoupi kta.
22 Israel, nitaoyate miniwanca wiyaka kin iyececa qeyaś, tonana okaptapi kin hena hdipi kta: woihangye konzapi qon he woowotanna on iyatahde kita.

23 Woihangye wan, qa taku konzapi kin he, makoce ocowasin cokaya, Itancan Jehowa ozuye yuhe cin he iś econ kta.

24 Heon etanhan Jehowa ozuye Itancan kin kaken eya; Mitaoyate Zion en ounye cin, Aśur kokipe śni wo: cansakadan on anipe kta, qa Egupta ekta econpi qon iyecen niye en cansagye hduwankan icu kta;

25 Tuka ehake cistiyedan hehan wośilida kin henakeca kta, qa mitocanniye tona ihangyapi kin hena en un kta.

26 Unkan Jehowa ozuye yuhe cin he icapsinte wan icahkiciye kta, Midian Oreb imnija ekta wicaktepi qon iyececa; qa cansakadan tawa Mdeśa akan, qa Egupta ekta econ qoul he iyecen hduwankan icu kta.

27 Unkan anpetu kin he en kaketu kte, woqin tawa nitapete etanhan eyakupi kta, qa cannapinpi tawa nitahu etanhan; unkan sdayapi kin on cannapinpi kin yuwegapi kta.

28 Ayath en hi : Migron ekta iyoopte iyaya; Mikmaś en tawahpaya kilinaka;

29 Ḧe hdoka kin ohna iyayapi ; Geba ekta ewankapi : Rama kopehda; Gibeah Saul najica.

30 Gallim cunwintku, ho wankan iyekiya wo: Anathoth onśika, Laśa hehanyan ho hdutanin wo.

31 Madmena najica iyaya: Gebim en ounyanpi kin hena nape kta ihduwiyeyapi.

32 Tuka anpetu kin he Nob en owanji yanke kta; Zion cun201 


\section{ISAYA TAWOYUKCAN KIN,}

wintku he tawa, Jerusalem Paha kin ektakiya nape koze kta.

33 Tho, Itancan Jehowa ozuye yuha wokokipe on adetka kin kaśpe kta : qa tona hanska icagapi kin kaksapi kta, qa wahanicidapi kin hena yuhukun iyeyapi kta.

34. Unkan contanka can kin mazasapa on kawanke kta, qa Lebanon wanji waśaka on hinhipaye kta.

\section{WICOWOYAKE 11.}

1 Unkan Jesse canhute kin etanhan cansakadan wan hinanpe kta, qa tahutkan etanhan adetka wan icage kta;

2 Qa Jehowa Taniya kin iye akan yanke kta, woksape qa wookahnige woniya, wowiyukcan qa wowaśake woniya, wosdonye qa Jehowa kokipapi woniya kin he:

3 Unkan he Jehowa kokipapi kin en wakcanyan wayupika kage kta; iye iśta wanyake cin eciyatanhan wayaco kte śni, qa iye noge nahon kin eciyatanhan wiyukcan kte śni :

4 Tuka woowotanna on wicaśta onśika wicayaco kta, qa wokonze on wakinica kta, maka akan wahpanicapi kin hena on etanhan; qa iye i icapsinte on maka kin ape kta, qa iye iha oniya kin on wicaśta śica wicakte kta.

5 Unkan woowotanna kin iye nite ipiyake kin hee kta, qa wowicake ipiyagkiton kta.

6 Nakun śunktolieca kin he tahinca wanunyanpi cinca kin kici ti kta, qa inmuhdeśka kin he tacinca kin kici iwanke kta; qa tatankadan qa mnaja kośka ptejicadan koya witaya unpi kta ; unkan hokśidan cistinna wan hena yus awicaye kta.
7 Pte kin nakun qa wahanksica kin wihanpi kta; hena cincapi kin witaya makata iwankapi kta; qa mnaja kin he tatanka iyecen aguyapi hu yute kta.

8 Unkan kokśiyoqopa azin kin he sintehda oti kin akan śkate kta, qa hokśiyopa azin enakiye cin he wamduślka sica ti kin akan nape yekiye kta.

9 Ḣe wakan mitawa kin owancaya wakiunniyanpi kte śni qa waihangyapi kte śni : miniwanca mini akahpe cin, he iyecen maka kin Jehowa sdonyapi kin on ojudan kta nakaeś.

10 Unkan anpetu kin he en Jesse hutkan oicrige wan yuke kta, he oyate kin en wiyokihedan he kta; iye ekta Ikcewicaśta kin ode upi kta: unkan iye ozikiye tawa kin he wowitan kta.

11 Nakun anpetu kin he en kaketu kte, Itancan kin ake icinonpa nape yeye kta, tona taoyate okaptapi kin opewicakiton kta, tona owicakaptapi kin hena, Aśur etanhan, qa Egupta etanhan, qa Pathros etanhan, qa Kuś etanhan, qa Elam etanhan, qa Śinar etanhan, qa Hamath etanlian, qa miniwanca wita kin etanhan.

12 Qa Ikcewicaśta iviyokihedan wan ewicakihde $\mathrm{kta}$, qa Israel etanhan heyata iyewicayapi qon hena wicayuwitaya kta, qa Juda etanhan enanakiya iyayapi maka tate ouye topa kin etanhan wicapahi kta.

13 Unkan Ephraim tawowinawizi kin ayuśtan kta, qa Juda tokayapi kin hena wicakaśpapi kta ; Ephraim Juda inakiwizi kte śni, qa Juda Ephraim nagiyeye kte śni.

14 Tuka Philistim hinyetepi akan wiyohpeyatakiya kinyanpi 


\section{WICOW OYAKE 13.}

kta; wiyohiyanpata cinca kin witaya wawicakipi kta; hena Edom qa Moab nape awicahnakapi kta; qa Amon cinca kin anawicagoptanpi kta.

15 Unkan Jehowa Egupta mde ceji kin ocowasin ihangye lita; qa tate waśaka tawa on wakpa kin en nape koza kta, qa adetka śakowin kin en ape kta, qa hanpokiton opta maniwicakiye lita.

16 Unkan iye taoyate okaptapi, Aśur etanlian owicakaptapi kin hena, canku tanka wan yuhapi kta; Israel Egupta makoce etanhan hinanpe cin anpetu qon he iyececa.

\section{WICOW OYAKE 12.}

1 Unkan anpetu kin he en hecen ehe kta; Jehowa, ciyatan kta, canniyemayaya qeyaś nitocanniye yutokan iyeyapi, qa cantohnag mayaya.

2 Iho, Taku Wakan nimakiye cin hee : he wacinwaye kta qa kopewahda kte śni : mitowaśake qa mitadowan kin Jehowa Iyotan Waśake cin hee; nakun iye Wanikiya mitawa kte cin hee.

3 Heon etanhan wowiyuśkin on wanikiyapi miniyowe kin etanhan mini edakupi kta.

4 Nakun anpetu kin he en hecen ehapi kta; Jehowa yatan miye, iye caje kin hoyekiya po, iye ohan kin oyate ehna oyaka po, iye caje kin wankan un ce, eya po:

5 Jehowa idowan miye; taku wiciyokipi econ kin heon; maka kin owancaya de sdonyapi ce.

6 Zion en ounye cin hoyeye ca iyaśa wo ; Wanji Wakan İsrael tawa nicokaya un kin he tanka hinca, heon etanhan.

\section{WICOWOYAKE 13.}

1 Babel tawoyake kin, Isaya Amoz cinhintku wanyake ciqon. $2 \dot{H}$ e tehanwankantu kin akan wiyokihedan wan ehde po, hena hoyewicakiya miye, nape koza po, hecen akicita tancanpi tiyopa tawa kin ohna yapi kta.

3 Wicaśta wakan mitawa wanna econ wicawaśi, nakun mitocanniye on wicaśta waśaka mitawa wicaweco, tona mitawootanin on iyuśkinpi kin hena.

4 Hie kin elita wicota hotaninpi, oyate ota iyececa; oyate wokiconze yuwitaya owodutatonyan hotaninpi : kicizapi kta on Jehowa ozuye tawa ozuye kin owicawa.

5 Makoce tehan tanhan upi, mahpiya ihanke kin etanhan, Jehowa qa iye tocanniye wotawe kin hena, makoce ocowasin ihangye kta heon etanhan.

6 Ceya miye ; Jehowa taanpetu kin kiyedan ihan; Iyotan, Waśake cin etanhan woihangye wan iyecen u kte.

7 Heon etanhan wicanape iyuhpa hinhpayapi kta, qa wicaśta otoiyohi cante skan kta :

8 Qa kokipapi kta; wonihinciye qa woiyokiśice wicayuze kta; wanji cinca ton kte cin iyecen wayazankapi kta: wicaśta iye takodaku kici nihinciyapi kta; iye itepi kin ide ite kin hececapi kta.

9 Iho, Jehowa taanpetu kin u ce, wośinhda qa wocanniye ide kin on wohitika, hecen makoce kin hewoskan kage kta ; qa etanhan wahtanipi sa ihangwicaye kta.

10 Mahpiya wicanhipi qa wicanhpi tankapi kin hena iyoyanpa hiyuyapi kte śni; anpetu wi kin hinanpa eca aotpasyapi kta, 203 


\section{ISAYA TAWOYUKCAN KIN,}

qa hanyetu wi kin iś taiyoyanpa iyehye kte śni.

11 Unkan wośice on etanhan wicoicage kin śitkihdawaye kta, qa wicaśta śica iye walitanipi kin on : nakun wicaśta wahaniçida towohitike kin he ayuśtanwakiye kta, qa wicaśta wohitika towahanicidapi kin he kun elipewaye kta.

12 Wicaśta wan mazaskazi isanpa tehika wakage kta; han, wicaśta wall Ophir mazaskazi tehike cin isanpa kta.

13 Heon etanhan mahpiya kin mduśkanśkan kta, qa maka kin towanke kin etanhan śkanśkan iyaye kta, Jehowa ozuye yuha tocanniye kin on, qa tośinhda ohitika anpetu kin on.

14 Hecen tatokadan wan niya śni kuwapi, qa tahinca wanunyanpi tuwedan wicayuwitaya śni kin he iyecece kta ; wicaśta otoiyohi iye taoyate elsta hde kte, qa iye tamakoce kin ekta wicaśta otoiyohi najice kta.

15 Tuwe iyeyapi kinhan capapi kta, qa tuwe opeya un kin he mazasagye on ktepi kta.

16 Nakun iye iśta itokam iye cinca kin wicakicicahuhugapi kta; tipi tawapi kin yucokapi kta, qa tawicupi wicakikśanpi kta.

17 Iho, Made oyate kin anawicatan wicawakiye kta, hena e mazaska aktapi kte śni, qa mazaskazi on iyuśkinpi kte śni.

18 Unkan tinazipepi kin kośkapi kin makata ehpewicayapi kta, qa wicatamni oicage cin onśidapi kte śni : iye iśtapi wicacinca wicapatanpi kte śni.

19 Hecen Babel wokiconze wiciyokipi, Kasdim wowitan oinpi kin he Wakantanka Sodom qa Gomorrah ihangye ciqon he iyecece kta.
20 He icimana otipi kte śni, qa wicoicage yeye cin hehanyan tuwedan en ounye kte śni : nakun Arabi wicaśta kin hen ticage kte śni; qa tahinca wanunyanpi wonwicayapi kin hen wankapi kte śni.

21 Tuka wamanica kin hena hen wankapi lita; qa wicaśta otipi qon hena hinhankagapi on ojudan kta; qa kangi cinca kin hen tipi kta, qa canotidan kin hena hen wacipi kta.

22 Qa tipi tawapi yujujupi kin ohna wamanica hotonpi kta, qa tipi waśteśte qon ohna unktehi yuke kta. Unkan he tawaniyetu kin kiyedan ihan, qa taanpetu kin yutehanpi kte śni.

\section{WICOWOYAKE 14.}

1 Jehowa Jakob onsiikida kta, qa ehake Israel hdahnige kta, qa iye tamakoce kin ohna ewicahnake kta nakaeś : nakun oyate tokeca kin hena om witayapi kta, qa Jakob ti kin en kokijuyapi kta.

2 Unkan oyate kin iś hena iwicacupi qa tohepi kin en awicahipi kta: qa Israel tiyohnaka kin hena wicaśta taokiye qa winyan taokiye wicayuhapi kta, Jehowa tamakoce kill en: qa tona iye wayaka wicayuhapi qon hena iś wayaka iwicacupi kta ; qa wowidagwicayapi qon hena iś iwicadakapi kta.

3 Unkan anpetu kin he en, nitoiyokiśice etanhan, qa nitokokipe etanhan, qa wowidagyapi tehike en inidakapi qon etanhan Jehowa woozikiye nicu kta:

4 Hehan Babel wicaśtayatapi kin on wicoie kin de iyacu kta, qa hecen ehe kta; Wawicakiśye cin he ayuśtan, wawicakiśyapi kin he ayuśtanpi ce. 


\section{WICOWOYAKE 14.}

5 Jehowa wicaśta śica cansagye tawa kin he yuksaksa, wicastayatapi tasagye kin.

6 Tuwe wośinhda on oyate ayuśtan śni awicape ciqon, tuwe wocanniye on Ikcewicaśta i wicadake cin he śicaya kuwapi, qa tuwedan tehinda śni.

7 Maka kin ocowasin ozikiya un, owanji yanke: hena dowanwan hinhdapi.

8 Han, niye on śinta can iyuśkinpi, Lebanon liante śa kin; Inunka ehantanhan cankaksa tuwedan unkiyepi en unkupi śni ce, eyapi.

9 Kuyatanhan niye on Hades ihduśkanśkan, yau kin itkonicipe kta: niye on wicaśta tapi kin hena wicayulica, maka akan mdetahunkapi owasin : oyate wicaśtayatapi owasin iye tohepi etanhan najin wicakiya.

10 Hena iyuhpa waayuptapi qa heniciyapi kta; Niś eya waunśakapi śni iyecen inicaga he; unyakonpi kin iyeniceca he.

11 Nitowitan kin he Hades ekta kun ahipi, candowankiyapi nitawa ho kin: nihukuya wamdudan owinśyapi, qa woakahpe nitawa wamduśka kin hena ee.

12 Wicanhipi iyega, anpao cinca kin, mahipiya eciyatanhan nihinhpaya ; oyate wicaduwaśake śni qon niye qe makata nicawankapi.

13 Tuka niye nicante en hehe ciqon; Malipiya ekta wankan mde kta ; mitoyanke kin wicanhpi Taku Wakan tawa kin iwankam ewehde kta; nakun omniciye paha kin en waziyata ihanke kin ekta imdotanke kta;

14 Mahpiya śapa wankantu kin isanpa imdamde kta; Iyotan Wankan un kin iyemacece kta ce, eha.
15 Hececa eśta Hades ekta kun elipeniyanpi kta, woha cetete kin ekta.

16 Tona wanniyakapi kin hena opanihtapi kta, iniyukcanpi kta; Wicaśta maka lin yuhuhuza, wokiconze kin yuśkanśkan qon he dee se:

17 Makoce kin hewoskan kage ca otonwe en un kin hena ihangya; kaśkawicahnaka tipi wicakiyulidoke śni he dee he, eyapi kta.

18 Oyate wicaśtayatapi kin owasin, han iyulipa, wowitan ohna wankapi, otoiyohi iye' ti kin ohna.

19 Tuka niye qe nihapi sni tankan ehpeniyanpi, adetka wahte śni wan iyececa, wicaktepi tawokoyake, mazasagye on capapi, inyan wolia kin en elpeyapi kin he iyececa; wicaśta ța wanka amanipi kin iyececa.

20 Hena owicapeya nihapi kte śni; nitamakoce hewoskan yecage nitaoyate wicayekte nakaeś. Sicaya econpi cinca kin tohinni wicayaotaninpi kte śni.

21 Iye cinca hunkakewicayapi wahtanipi on wicaktepi wicakicaga miye: hecen inajinpi kte śni, qa maka kin tawayapi kte śni, qa makoce ite kin otonwe on ojuyapi kte śni.

22 Tuka miye qe hena itkom inawajin kta, Jehowa ozuye yuhe cin he hecen eya; qa Babel etanhan wicacaje, qa wookapte; qa wicacinca, qa wicatakojakpa ko baweciśpe kta, Jehowa eya.

23 Nakun pahin en ounyanpi kta e wakage kta, qa psa mde heca kta: qa wicotakuni śni icahinte kin on wakakinte kta ce, Jehowa ozuye yuhe cin he hecen eya.

24. Jehowa ozuye tawa wakon205 


\section{ISAYA TAWOYUKCAN KIN,}

za on heya; Awicakehan token awacanmi qon he iyecetu kta; qa token wakonze cin he ecetu kta :

25 Makoce mitawa kin ohna Aśr wakamdece $\mathrm{kta}$, qa amawani kta, he mitawa akan : hehan hena etanhan cannapinpi tawa kin tokan iyaye kta, woqin tawa iye tapetepi etanhan tokan ye kta.

26 Wokonze maka kin owancaya wakonzapi kin he dee: qa oyate owasin nape ayukatinpi kin he de $\dot{e}$.

27 Jehowa ozuye tawa he wakonza, unkan tuwe ecetuśniye kta he; qa iye nape hdukatin, unkan tuwe he pakam iyeye kta he.

28 Ahaz wicaśtayatapi ta waniyetu kin he en woyake kin he dee.

29 Palestina ocowasin, tuwe anipe icapsinte tawa kawegapi on iyuśkin śni wo; wamduśka oicage etanhan sintehda wan hinanpe kta, qa he cinca kin peta wamduśka kinyan un kin heca kta e heon.

30 Unkan onśikapi cinca tokapapi kin hena wotapi 'kta, qa wahpanicapi kin wikopeśniyan wankapi kta: tuka miye wicaakihan on hutkan nitawa wakte kta ; qa iye tona onicaptapi kin hena wicakte kta.

31 Tiyopa, śicahowaya wo ; otonwe, hotanin wo ; Palestina ocowasin, niye niskan : waziyatanhan śota uye kta, qa tuwedan ozuye tawa etanhan najice kte śni.

32 Hehan oyate wahośi uwicaśi kin hena token awicayuptapi kta he. Jehowa Zion sutaya ekihde, hecen iye taoyate onśikapi kin hena he wowinape yapi kta.

\section{WICOWOYAKE 15.}

1 Moab tawoyake kin. Hanyetu icunhan Ar-Moab ihangyapi, kaśpapi heon: Hanyetu kin en Kir-Moab ihangyapi, kaśpapi heon etanhan.

2 Dibon tipi, owanka tehanwankantu ekta ceye kta wankan iyayapi: Nebo qa Madeba akan Moab śicahowaye kta; wicapa iyulipa rasuśdapi, qa putinhin otoiyohi baksapi.

3 Iye tacankupi ohna wakihdaka ipiyagkitonpi kta; iye ti akalipapi akan qa tihocoka ohna otoiyohi śicahowaye kta, ceyaya kun kupi kta.

4 Hecen Heśbon ceye kta qa Elealeh; Jahaz hehanyan hohdataninpi kta: heon etanhan Moab taakicita śicahowayapi kta ; iye nagi tehikekida kta.

5 Moab on micante śicahowaye kta: tawonajice kin Zoar iyahdeyapi, pte wan wanna waniyetu yamni: Iuhith ekta wankan yapi kin ohna itanwankanhde ceya yapi kta ; Horonaim canku iyahde ohna woihangye woceye yataninpi kta.

6 Nimrim mini kin hopuza wanke kta; peji kin śnija, wato wanin aya, taku toto wanice liinca.

7 Heon etanhan taku okapta hduhapi, qa taku kihnakapi kin hena cohwanjica kaksiza kin ekta hdoyapi kta.

8 Waśicahowayapi kin he Moab ihanke kin ohomni iyaya; woceye kin he Eglaim ekta, han, woceye kin he Elim minilidoka ekta iyohi.

9 Dimon mini kin we ojudan kta : Dimon en akihdewaye kta; tuwe Moab etanhan najice cinhan mnaja en awau kta, qa tona makoce en okaptapi kin hena. 
WICOWOYAKE 16.

1 Makoce wicaśtayatapi kin tacinca wan kaya po, Sela etanhan hewoskantu hehanyan, Zion cunwintku Paha tawa kin ekta.

2 Unkan kaketu kte, zitkadan wan, hohpi kiyujujupi kinhan, nuni kin he iyecen Moab cunwintkupi Arnon iyuwegapi kin ekta unpi kta.

3 Wiyukcan miye, woowotanna econ po; ohanzi nitawa wiyotanhan cokaya hanyetu iyecen kaga wo; heyata iyewicayapi kin hena nawicahman wo ; tuwe nuni kin he hnaye śni wo.

4 Moab, lieyata iyewicayapi mitawa kin hena niye kici ounyewicakiya wo; waihangya ite kin etanhan niye hena awicakalipa yanka "wo: waśitkihdaye cin he owihanke, waihangye cin he ayuśtan, waanatanpi kin hena makoce kin etanhan atakunipiśni ce.

5 Unkan wowaonśida on oyanke kin sutaya ehdepi kta; qa iye wowicake on akan iyotanke kta, Dawid tawakeya ohna wayaco yanke, wokonze akite ça woowotanna yuinalini kta.

6 Moab towahanicida kin he naunhonpi, nina wahianiçida nakaeś; wotankaicida tawa qa towahanicida qa tośinhda kin hena: tuka woitonśni tawa kin iyecetu kte śni.

7 Heon etanhan Moab Moab on śicahowaye kta, ocowasin waśicahowaye kta : Kirhareś oahde kin on yaceyapi kta, awicakehan kaśtakapi nakaeś.

8 Heśbon tamaga kin śnija aya, qa Sibma hastanhanka iyuwi kin: adetka waśte icage cin hena Ikcewicaśta itancanpi kaksapi ; Yazer hehanyan iyohi, tintoskan onunipi : adetka tawa han- ska icaga mini kin akasanpa iyaya.

9 Heon etanhan Yazer tawoceye on Sibma hastanhanka iyuwi kin awaceye kta: Heśbon, Elealeh kici, iśtamnihanpe mitawa on amagajuciye kta: woceye wan nitawaskuyear qa nitawojupi kin ahinhipaya heon.

10 Nakun maga waśte kin etanhan wowiyuślkin qa wopida eyakupi : hecen hastanhanka ojupi kin en dowanpi wanice kta, nakun iyaśapi yuke kte śni : wanapanpi kin iyuśkice ohna miniśa takudan naślkicapi kte śni : iyaśapi kin ayuśtan wakiya.

11 Heon etanhan mitezi Moab on, candowankiyapi wan iyecen houye $\mathrm{kta}$, qa mitanmahentanhan Kirhareś on.

12 Unkan kaketu kte, tohan Moab oyanke tehanwankantu ohna mdokița ihdutanin kinhan, hehan iye tawakeya wakan kin ekta cekiya hi kta; tuka ohiye kte śni.

13 Tanihan wicoie Jehowa Moab eciye ciqon he dee.

14 Tuka nakaha Jehowa ie ca hecen eya; Waniyetu yamni iyokpani, tuwe opetonpi tawaniyetu iyececa, hehan Moab towitan kin he takudapi kte śni, wicota tanka hince cin he nakun : unkan wookapte kin he tonana hince kta, ota sni.

\section{WICOW.OYAKE 1.7.}

1 Damasek tawoyake kin. Iho, otonwe kin etanhan Damasek ihangyapi; hecen otiwita heca kta.

2 Aroer otonwe kin hena ehpeyapi; hen wanunyanpi optaye yuke kta, en wankapi kta, qa tuwedan wakokipe wicakicage kte śni. 
ISAYA TAWOYUKCAN KIN,

3 Conkaśke kin Ephraim etanhan yutokan iyeyapi kta, qa wokiconze kin Damasek etanhan, qa Aram okaptapi kin etanhan: hena Israel cinca towitan kin iyececapi kta, Jehowa ozuye yuhe cin he hecen eya.

4. Unkan anpetu kin he en Jakob towitan kin waśake śni aye kta, qa iye cehpi cepe cin he tamaheca aye kta.

5 Qa wicaśta wamnayan aguyapi hu mnayan, qa isto on wahuwapa pahi ece kin he iyecece kta; nakun Rephaim kaksiza en wahuwapa mnayanpi kin iyecece kta.

6 Tuka hastanhanka yuśnapi en okaptapi kta, Oliwe can kahnapi iyececa, waskuyeca, nonpa yamni adetka wankan oinkpa ekta, topa zaptan adetka waicahya ece kin en, Jehowa Israel ta Wakantanka hecen eya.

7 Anpetu kin he en, wicaśta wan Waicahye tawa kin ekta ekitonwe kta, qa iye iśta Israel Wanji Wakan tawa kin ihakta kta.

8 Qa owayuśna iye nape kage cin hena ekta ekitonwe kte śni, yุa iye napsukaza taku kage cin wanhdake kte śni, wakagapi qa nakun anpetu wi okagapi kin hena.

9 Anpetu kin he en iye totonwe suksuta kin hena, adetka elipeyapi qa caninkpa tehanwankantu, Israel cinca on okaptapi qon he iyececapi kta: unkan liewoskantu kta.

10 Taku Wakan Wanikiya nitawa kin he ayektonja, qa Imnjja nitowaśake kin he yeksuye śni, heon etanhan wojupi waśteste oyaju kta, qa ehna can tokeca huyahde kta:

11 Anpetu icunhan taku huya208 hde kin he icaliyakiye kta, qa hanhanna eca woyaju kin hcayakiye kta: tuka anpetu tawayapi kte cin en womnayan kin he kinyan iyaye kta, qa woiyokiśice tehike yuke kta.

12 Hehehe, oyate ota wicota kin, miniwanca hoton kin iyecen houyapi: qa oyate owodutatonpi, mini ota ow odutaton iyecen owodutaton kagapi :

13 Mini ota kokijuya iyaye cin iyecen oyate kin owodutatonyan kokijupi kta: tuka iye iyowicaki kte śni, unkan tehan napapi kta, qa he kin akan aguyapi ha tate itokam he iyecen napeyapi kta, qa ohmihma wan tateiyumni itokam he iyececa.

14 Unkan iho, hitayetu eca wonihinciye; hanhanna itokam he en un śni. Tona waunkipi taku tawapi, qa tona unyapotapi taku yuhapi kte cin he dee.

\section{WICOWOYAKF 18.}

1 Hehehe, makoce hupahu on ahanziyapi, Kuś tawakpa kin akotanhan wanke:

2 He wahośiyapi miniwanca akan yewicaśi, han, psa wata ohna mini ite kin akan: Wahośiye dusduzahanpi, oyate wan hanskaska qa śicaya kuwapi ekta ya miye, oyate wan otokaheya tanhan qa dehanyan wohitikapi; oyate waśake hinca qa wanapan ece, wakpa kin makoce tawapi kicaksaksa:

3 Maka kin en ounyayapi qa makoce akan dukanpi kin owasin wanyaka po, tohan he akan wiyokihedan wan ehde kinhan; qa mazayabotonpi wan yahoton kinhan nakon po

4 Jehowa kaken emakiya; $\mathrm{O}$ zimiciye kta, qa mitowanka en awacin manke kta, wato akan 
amdakedan mašte kin iyececa, womnayan maśte kin en amahipiya cu kin iyecece.

5 Wojupi mnayanpi śni itokam, camni wanna icage ca walica ohna hastanhanka skuye cin he suton aye $k t a$, hehan isan śkopa on camni kin baśpe kta, qa nakun adetka kin hena icu qa baksa elipeye kta.

6 Hena witaya ehpeyapi kta, he wakinyanpi qa maka woteca kin hena yuhapi kta: qa wakinyanpi kin hena amdoketupi kta, qa maka woteca iyulipa hena awaniyetupi kta.

7 Hehan woqupi wan Jehowa ozuye yuha kahipi kta, oyate wan hanskaska qa śicaya kuwapi, qa oyate otokaheya tanhan qa dehanyan wohitikapi, oyate waśake hinca qa wanawicapan ece, wakpa kin makoce tawapi kicaksaksa kin hena, Jehowa ozuye yuha caje oyanke kin en, Zion Paha kin ekta.

\section{WICOWOYAKE 19.}

1 Egupta tawoyake kin. Iho, Jehowa malipiya śapa duzahan wan akan iyotanke ca Egupta en u kta. Unkan iye itokam Egupta wakagapi tawa kin hena śkanśkanpi kta, qa cokayatanhan Egupta cante skan kta.

2 Unkan Egupta wicaśta Egupta oyate icitkokim ewicawalide kta; hecen kicizapi kta, wicaśta otoiyohi iye sunkaku kici, qa wicaśta otoiyohi iye takodaku kici ; otonwe otonwe kici, wokiconze wokiconze kici.

3 Unkan tanmahentanhan Egupta toksape kin atakuni kte śni, qa iye tawacin kin ecetuśniwaye kta: hecen wakagapi kin ekta ode yapi kta, qa tona jijipi, qa tona hanmdepi, qa tona wapiya. pi hena awicalkitapi kta.

4 Unkan Egupta oyate kin itancan wan ksizeca nape kin en wicawaqu kta; qa wicaśtayatapi wohitika wan wicayuhe kta ce, Itancan Jehowa ozuye yuha he hecen eya.

5 Unkan miniwanca etanhan mini kin wanica aye kta; qa wakpa kin mini oyahe qa puza aye kta.

6 Qa wakpa. kin hena śicamna kta; Egupta wakpa kin hena honke śni qa puza aye kta ; cedi psa ko śnije kta.

7 Wakpicahda tinta kin, wakpa mdote ekta, qa taku wakpicahda ojupi kin hena iyuhpa śnije kta, kahoya iyeyapi kta, qa en un kte śni.

8 Nakun tona hopsicapi kin hena comnihdazipi kta, qa tona wakpa kin en hoiyupsice ehpeyapi kin hen owasin śicahowayapi kta, qa tona ho minin ehnakapi kin hena hanyanpi kta.

9 Nakun tona hahonta zipzipedan kagapi qa minihuha ska kazontapi kin bena iśtecapi kta.

10 Qa tona en itancanpi kin hena kicaksapi kta, tona taku kamnanpi ece lin hena owasin iyokiśicapi $\mathrm{kta}$.

11 A wicakehan Zoan itancanpi kin witkotkokapi ; wiyukcan ksapapi Pharaoh tawa tawowiyukcan kin he wowitkotkoke icaga. Wicaśta ksapa cinhintku, wana.. kaja wicaśtayatapi cinhintku kin he miye ce, token Pharaoh eyakiyapi kta he.

12 Hena tokiya unpi he: wicaśta ksapa nitawa tokiya unpi he. Tokin wanna oniciyakapin; qa Jehowa ozuye yuha token Egupta on wakonze cin he sdonyapi kte.

13 Zoan itancanpi kin hena 209 


\section{ISAYA TAWOYUKCAN KIN,}

witkotkoka icagapi ; Noph itancanpi kin wicahmayanpi ; nakun Lgupta hnayanpi, tawicoun mdetahunkapi kin hena.

$14 \mathrm{He}$ cokaya Jehowa woakinica woniya wan yuicicahi : hecen wicohan owasin en Egupta nuniyapi, wicaśta witko iye hdepe cin ohna kacegya mani kin he iyececa.

15 Nakun Egupta tohtani wanice kta, taku pa qa sinte, can adetka qa cedi, econ kte cin yuke śni.

16 Anpetu kin he en Egupta winolinea wan iyecece kta ; qa nihinciye kta qa cancan'kta, Jehowa ozuye yula nape koze cin on, iye iwankam hduśkanśkan kin heon etanhan.

17 Unkan Juda makoce kin he Egupta ekta wokokipe ee kta; tuwe kaśta he cajeyate cinhan nihinciye kta, Jehowa ozuye yuha tawokonze he kiconze cin heon etanhan.

18 Anpetu kin he en Egupta makoce kin ohna otonwe zaptan Kanaan iapi on iapi kta, qa Jehowa ozuye yuha en içiconzapi kta. Wanji, Wicotakuniśni otonwe, eciyapi kta.

19 Anpetu kin he en Egupta makoce cokaya owayuśna wan Jehowa kiciyanke kta, qa opapun ihanke ekta obosdatu wan Jehowa kicihe $\mathrm{kta}$.

$20 \mathrm{Qa}$ he wowapetokeca qa woyuotanin Jehowa ozuye yuha tawa kta, Egupta makoce kin en. Tehiya wicakuwapi kin on hena Jehowa hoyekiyapi kta, kinhan he Wanikiya wan, han, wanji waśaka, wicaqu kta, qa iye cwicahdaku kta .

21 Unkan Egupta en Jehowa sdonyapi kta, qa anpetu kin he en Egupta wicaśta kin Jehowa sdonyapi kta, qa wośnapi woqu- pi ko econpi kta; han, Jehowa taku qu iciconzapi kta qa econpi kta.

22 Unkan Iehøwa Eguptz kaśtake kta; hdaśtake ça okiziye kta. Hehan Jehowa en hdipi $\mathrm{kta}_{\text {, unkan iye anokwicakiye kta }}$ qa okiziwicaye kta.

23 Anpetu kin he en canku tanka wan Egupta etanhan Aśur iyahde kta; unkan Aśur wicaśta Egupta en hi kta, qa Egupta wicaśta kin iś Aśur ekta i kta, qa Egupta oyate Aśur oyate kici wowidagiciyapi $\mathrm{kta}$

24 Anpetu kin he en Israel wiciyamni kta, Egupta kici qa Aśur kici, makoce cokaya woyawaśte kta :

$25 \mathrm{He} J$ ehowa ozuye yuhe cin he heya yawaśte kta; Egupta mitaoyate, qa Aśur minape icahye cin he, qa Israel tawa wicawaye cin hena yawaśtcpi nunwe.

\section{WICOWOYAKE 20.}

1 Waniyetu wan Tartan Aśdod ek ta hi, Sargon Aśur wicaśtayatapi u śi, qa Aśdod kici kicize ça icu qehan;

2 He ehan Jehowa oie kin Isaya Amoz cinhintku nape en hi, qa heciya; Ya wo, ka ninite etanhan wakihdaka hduśdoka wo, qa nisiha etanhan nitahanpe hduśdoka wo. Unkan ecen econ, tancodan sicodan ko mani.

3 Unkan Jehowa heya; Isaya mitaokiye Egupta ekta qa Kús ekta wowapetokeca qa woyuśinyaye on waniyetu yamni tancodan sicodan ko mani kin,

4 Hc iyecen Aśur wicaśtayatapi kin Egupia oyate wayaka awicaye kta, qa Kuś oyate wayaka awicaye kta, wicahakakta qa wicatokapa, tancokapidan qa 


\section{WICOWOYAKE 21.}

sicopidan, han, onze taninpi, Egupta iśtece kta heon.

5 Unkan kopehdapi kta, qa Kuś wacinyanpi qa Egupta wowitanyapi qon hena on iśtecapi kta.

6 Unkan wita kin de en ounye cin he anpetu kin he en heye kta; Tho, wowacinye unkitawapi kin dececa, tukten ounkiyapi kta on naunpapi, Aśur wicaśtayatapi nape etanhan eunyakupi kta e heon. Hecen token naunjicapi kta he.

\section{WICOWOYAKE 21.}

1 Miniwanca hewoskantu tawoyake kin. Okaga ekta tate iyumni iyoopte iyaye cin he iyecen makoskan tanhan $u$, makoce okokipe kin etanhan.

2 Wowanyake tehike wan omakiyakapi : Wawicaki sa wawicaki ece, qa waihangye cin he waihangya ece. Elam, itanwankanhde,ya wo; Medea, niś aconkaśka wo: cominihdazipi kin owasin ayuśtan wakiya.

3 Heon etanhan nite wowayazan omajudan, winohinca hokśiksuya yazan kin he iyecen wayazan wabda: he nationpi kin on pamahdedan waun he wanyakapi on mayuśinyaya.

4 Micante nuni, woyuśinyaye mayuśinyeya: hanyetu wimduskin kin he wokokipe micaga.

5 Wahna wotapi kin wiyeya ehnaka wo, owinja owinśkiton wo, wota wo, wayatkan wo: itancan yaunpi, najin po, wahacanka sdakiya miye.

6 Itancan kin kaken emakiya; ya wo, waawanyake wan ehde wo, taku wanyake cinhan ohdake kta.

17 Unkan canpahmihma wan, śuktanka akan iyotankapi nom, śonśonna tacanpahmihma, camo tacanpahmihma ko wanwicayaka: hehan wanalionpi on anolikiya yanka:

8 Qa mnaja wan iyecen houya; Itancan, owanyake tipi ohna anpetu icunhan ohinniyan nawajin, qa oinajin mitawa ohna hanyétu otoiyohi emahdepi ;

9 Unkan iho, hinnakaha canpahmihma wicaśta ohna, śuktanka akan iyotankapi nom upi ce. Hehan waayupte ca heya; Hinhpaya, Babel hinhipaya, qa wakagapi tona wakanda kin hena iyuhpa makata kamden ehpeya ce.

10 Onapanpi mitawa, qa oonapan mitawa cinca kin; Jehowa ozuye yuha Israel ta Wakantanka taku nahonmaye cin he ociciyakapi.

11 Duma tawoyake kin. Sier etanhan houmakiya; Waawanyake, hanyetu kin toketu he: Waawanyake, hanyetu kin toketu he.

12 Waawanyake kin hecen eya; Wihinanpa kin he $u, q a$ nakun nanyetu kin: wawinungapi kta hecinhan wawiwanga po: hdicu po, kuwa miye.

13 Woyake Arab akan un kin. Dedanim etanhan icimayanipi kin, Arab contanka kin en inunkapi kta.

14 'Tema makoce en ounyanpi kin hena tuwe ipuza kin itkokim mini kaupi ; tuwe najice cin he aguyapi yuha itkokipapi.

15 Hena mazasagye ite kin etanhan najicapi, mazasagye yuwankan icupi ite kin etanhan, qa itazipa nawinjapi etanhan qa kicizapi tehike etanhan.

16 Itancan kin kaken emakiya; Waniyetu wanjidan, tuwe wohtani opetonpi tawaniyetu iyececa, hehan Kedar towitan ocowasin tanin kte śni. 


\section{ISAYA TAWOYUKCAN KIN,}

17 Qa itazipa yuhapi qon tona okaptapi, Kedar cinca wicaśta waśakśakapi kin hena wicayutonananpidan kta, Jehowa Israel ta Wakantanka kin he hecen eya nakaeś.

\section{WICOWOYAKE 22.}

1 Wowanyake Kaksiza tawoyake kin. Dehan tonikeca, hecen ocowasin tiakalipe kin ekta idada he.

2 Wicośkanśkan ojudan, owodutaton otonwe, otonwe wiyuśkinyan yaun; tona nicițapi kin hena mazasagye on wicaktepi śni, qa kicizapi en țapi śni.

3 Itancanpi nitawa owasin witaya najicapi, itazipa yuhapi kin eqe hena wicakaśkapi ; tona niye en iyewicayapi kin hena iyuhipa witaya wicakaśkapi, tehan najicapi.

4 Heon etanhan hepa; En ematonwanpi śni po, nina waceye kta; mitaoyate cunwintku wakipi kin on cantohnagmayan akitapi śni po.

5 Anpetu kin he woiyokiśice qa waanatanpi qa wonihinciye, Jehowa Itancan wicobe tawa kin etanhan, wowanyake kaksiza kin en, conkaśke oqapi qa lie kin ekta hoyekiyapi.

6 Unkan Elam wanju hduha u, canpahmihma wicaśta ohnaka, śuktanka akan iyotankapi koya; qa Kir wahacanka hducoka.

7 Unkan kaketu kte, kaksiza kahnigapi nitawa kin hena canpahmihma on ojudan, qa śuktanka akan iyotankapi kin hena tiyopa kin en wiyeya eicihdepi kta.

8 Hehan Juda tawoakahpe kin yuzamni : unkan anpetu kin he en contanka tipi wotawe kin ekta eyakitonwan.

9 Nakun Dawid totonwe olna 212 oyujujupi kin wandakapi, hena ota; qa kuya mini ohnaka mini kin duwitayapi :

10 Qa Jerusalem tipi kin hena dawapi, qa conkaśke piyayapi kta on tipi kin dujujupi.

11 Nakun conkaśke nonpa otahedan tanina mini ohnaka kin on maka ośkotpa wan yakagapi ; tuka Waicahye cin he ekta eyatonwanpi śni, qa tuwe wanakaja he kage cin he ihayaktapi sni.

12 Unkan anpetu kin he en Jehowa Itancan wicobe tawa kin he ceyapi kta iwicakico, qa waśinhdapi, qa pa yuśdapi, qa wakihdaka ogekitonpi kta :

13 Tuka iho, wicocante waśte, qa wowiyuśkin, tatanka wicaktepi, qa taliinca wanunyanpi wicakatapi, tado yutapi, qa miniśa yatkanpi : Wauntapi qa waunyatkanpi kta, heyakecinhan unțapi kta ce.

14 Unkan minoge ohna Jehowa wicobe tawa kin he oihdake : Awicakehan woalitani kin de akahpeniciyapi kte śni ecen nitapi lita, Jehowa Itancan wicobe tawa kin he eya ce.

15 Jehowa Itancan wicobe tawa kin he hecen eya; Hunkatiya, wamnayan kin de ekta ya wo, Shebna tipi awanyake cin hee ekta;

16 Qa heciya wo; Den taku duha, qa tuwe den niciyanka he, hecen den woha wan nihdakan, tuwe wankan woha wan hdakan, imnija ohna tipi wanji ihdakan iyececa.

17 Iho, makata ehpeyapi on Jehowa makipusdiya ehpeniye kta, qa woakahpe on anicahpe kta.

18 Taku pahmihma se awicakehan pahmihma jyeniye kta, tapa wan makoce tanka kin en iyececa : hen nite kta, qa hen 


\section{WICOWOYAKE 23.}

nitowitan canpahmihma kin niyuha ti wowiśtece kin ee kta.

19 Nakun nitoyanke kin etanhan ehpeciye kta, qa nitohe etanhan tuwe kun eniyaku kta.

20 Unkan anpetu kin he en kaketu kte, mitaokiye Eliakim Hilkiah cinhintku kin weco kta:

21 Qa nitawokoyake koyagwakiye kta, qa ipiyake nitawa on waśagwakiye kta, qa wokiconze nitawa iye nape kin ohna ewahnake kta. Unkan Jerusalem en ounyanpi qa Juda tiyohnaka kin hena iye ateyapi kta.

22 Qa Dawid ti tiyopa iyuhdoke kin iye hinyete akan ewahnake kta; hecen yuhdoke kta qa tuwedan ecen icu kte śni; qa iye ecen icu kta qa tuwedan yulidoke kte śni.

$23 \mathrm{Qa}$ he owakatan kta, iyokatkuge owanka wacinyepica kin en iyececa; hecen iye atkuku ti kin en wowitan oyanke heca kta.

24 Unkan atkuku tiyohnaka wowitan ocowasin iye en otkeyapi kta, taku etanhan icage ca inanpe cin, ceganstinna owasin owayujaja wakśica qa cega mini oyuhapi kin iyuhpa.

25 Jehowa wicobe tawa kin he hecen eya; Anpetu kin he en, iyoka tkuge owanka wacinyepica en okatanpi qon he yutokan iyeyapi kta, qa kaksapi kta, qa hinhpaye kta: qa taku en otkeyapi qon he kaśpapi kta: Jehowa hecen eya nakaeś.

\section{WICOWOYAKE 23.}

i Turos tawoyake kin. Tarśiś wita wata tawa, śicahowaya po ; he yujujupi nakae'ś, hecen tipi wanica, mahen yapi kta wanica: Kittim makoce kin etanhan he wicakiyuotanirıpi.

\section{R 2}

2 Wita en ounyayapi, inina un po ; Zidon wopeton tawa miniwanca akasanpa tanhan yapi kin hena ojuniyanpi.

3 Unkan mini tanka lin icahda Sihor tawoju kin, wakpa tawomnayan kin he tawokamna kin ee; qa hen Ikcewicaśta wopetonpi ece.

4 Zidon iśteca wo, miniwanca kin he ia; miniwanca towaśake kin he hecen eya; Mihduśake śni qa cinca waton śni, qa kośka icahwicawakiye śni, wikośla nakun icahwakiye śni ce.

5 Egupta oyakapi kin on, he iyecen Turos oyakapi kin on nina wayazanhdapi kta.

6 Tarśiś ekta akasanpa ya miye ; wita kin en ounyayapi śicahowaya po.

7 Wanji wiyuśkin nitawapi, otokahe ekta icage cin, anpetu wanakaja tanhan, he dee he: ounye kta e iye siha tehan aye kta.

8 Turos wateśdake kiton kin on tuwe hecen wakiconza he; wicaśta wopeton tawa kin hena wicaśtayatapi, qa en wopeton yukanpi kin hena maka akan wicaśta kinihanpi tuka.

9 Jehowa wicobe tawa kin he hecen wakiconza, wowinkta wowitan ocowasin yuśice kta, maka akan wicaśta kinihanpi owasin wahtewicada śni kage kta e heon.

10 'Tarśiśs cunwintku, wakpa wan iyecen nitamakoce opta ya wo ; detanhan ipiyake wanica.

11 Miniwanca kin ekta nape hdukatin; wokiconze kin hena yuśkanśkan : Jehowa wopeton otonwe kin on econwicaśi, towaśake kin ihangyapi kta.

12 Qa heya; Ake icimana widuśkin kte śni, Zidon cunwintku wikośka kakiśyapi kin; najin 213 


\section{ISAYA TAWOYUKCAN KIN,}

wo, Kittim ekta akasam ya wo; heciya nakun oziiciyapi wanin yaun kta.

13 Kasdim makoce kin wanyaka wo ; he oyate śni; Aśur tona tintoskan otipi qon hena he wicakicage; conkaśke kin hena bosdan ehdepi, tipi waśteśte kagapi : tuka iye qe he otiwita kaga.

14 'Tarśiś wita wata, śicahowaya po, nitowaśakepi kin he ihangyapi ce.

15 Unkan anpetu kin he en kaketu kte, Turos akiktonjapi kta, waniyetu wikcemna śakowin, wicaśtayatapi wanjidan taanpetu kin hehanyan. Waniyetu wikcemna śakowin iyohakam hehan witkowinna wan iyececa Turos dowan kta.

16 Witkowinna akiktonjapi qon, niye candowankiyapi wan icu qa otonwe kin ohomni ya wo; wayupiya dowan wo, odowan ota ahiyaya wo; hecen niksuyapi kta.

17 Unkan kaketu kte, waniyetu wikcemna śakowin iyohakam, Jehowa ake 'Turos ekta etonwe kta; unkan iye wokajuju tawa kin en ihdoku kta, qa maka ite lkin owancaya wokiconze maka akan un kin owasin om wawicihahapi econ $\mathrm{kta}$.

18 Tuka tokamna qa wokajuju tawa kin hena Jehowa ekta wakan kta; hena kihnakapi kte śni qa ejupi kte śni; tokamna kin he tona Jehowa itokam ounyanpi kin imnahan wotapi kta, qa wokoyake waśte linca heon.

\section{WICOWOYAKE 24.}

1 Iho, Jehowa makoce kin yucoka, qa hewoskan laga, qa ite yuahdapśinyan ehnaka, qa en ounyanpi kin hena enanakiyaiyewicaye kta.
2 Unkan kaketu kte, oyate unpi kin wawayuśna kin iś iyececa ; wowidake un kin tuwe yuhe cin iyececa; wikośka un kin tuwe yuhe cin iyececa; wopeton un kin wiyopeye cin iyececa; woqu un kin wodota he iyececa; oicage on owicaqu kin tuwe oicage kicicajuju kin he iyecen un kta.

3 Makoce kin ocowasin yucokapi, qa ocowasin wakipi kta; wicoie kin de Jehowa ecen eya nakaeś.

4 Makoce kin ceya un, śniś aye ; wicoicage kin lianyan, śniś aya; makoce kin en oyate tehanwankan unpi kin hena hanyanpi.

5 Nakun makoce kin tona en ounyanpi ihukuya yuśapapi ; hena woope kin ahtanipi, wokonze kin yutokecapi, wicotakuye owihanke śni kin he kicaksapi nakaeś.

6 Heon etanhan woyaśice kin he makoce kin temya iyeya; qa en ounyanpi kin hena śitkihdawicayapi ; heon etanhan makoce en ounyanpi kin wicahulinagapi, qa wicaśta tonana okaptapi.

7 Miniśa teca kin hanyan ; canwiyuwi kin śniś aya; tona cante waśtepi ece kin owasin comnihdazipi.

8 Cancega wiyuśkinpi kin ayuśtan, tona wiyuśkinpi iyaśapi kin he owihanke, candowankiyapi towiyuśkin he ayuśtan.

9 Dowanwan miniśa yatkanpi kte śni; mini wakan tona yatkanpi kin he wicakicipa hince kta.

10 Otonwe cokadan un kin he y ujujupi ; tipi otoiyohi natakapi, hecen tuwedan mahen ye lite śni.

11 Canku ohna miniśa dapi tuka qon; wowiyuśkin ocowasin aotpasyapi, makoce wiyuśkinpi kin he henakeca. 


\section{WICOWOYAKF 25.}

12 Otonwe kin en woyujuju ecedan, qa tiyopa kin ocowasin kamdecapi.

13 Tohan makoce cokaya oyate kin ehna hecetu kinhan, oliwe can yuhnapi iyececa, hastanhanka yuśpi yuśtanpi opahipi kin iyecece kta.

14 Hena ho wankan yeyapi kta, Jehowa towitan on iyaśapi kta, miniwanca etanhan nina houyapi kta.

15 Heon etanhan peta kin en Jehowa yatanka po, miniwanca wita kin ekta Jehowa Israel Taku Wakan tawapi kin.

16 Maka ihanke hinca etanhan dowanpi naunhonpi, wicaśta 0 wotanna wicayatanpi kin he. Tuka hepa; Matakuniśni, matakuniśni, hehehe miye; wahnayan econpi kin hena wahnayanpi ; han wahnayan econpi kin hena nina wahnayanpi.

17 Maka akan ounyaye cin, wokokipe, qa woba, qa wohrnunke kin hena akan niyanka.

18 Unkan kaketu kte, tuwe wokokipe hotanin kin etanhan najice cinhan he woha ohinhpaye kta, qa tuwe wolia cokayatanhan hdicu kinhan wohmunke kin on hmunkapi kta; wankantanhan owanyeye kin hena yuhdokapi, qa maka oahde kin hena śkanśkan nakaeś.

19 Kamdecapi on maka kin kamclecapi, yuksaksapi on maka kin yuksnksapi, maka kin nina śkanśkan.

20 Witkopi iyececa maka kin kacegya un kta, qa cowahe wan iyecen kahuhuzapi kta: unkan woahtani tawa kin on hduśaka; hecen hinhpaye kta qa ake najin kte śni.

21 Unkan anpetu kin he en kaketu kte, tona wankan unpi optaye wahanicidapi kin hena Jeho- wa kakiświcaye kta, qa makata wicaśtayatapi maka akan unpi kin hena.

22 Unkan hena wicayuwitayapi kta, wayaka wokaśke tipi ohna wicayuwitayapi kin om, qa conkaśke en onawicatakapi kta, tuka anpetu ota iyohakam en wicahipi kta.

23 Unkan hanyetu wi kin ite naśa kta, qa anpetu wi kin iśtece kta, tohan Jehowa wicobe tawa kin he Zion Paha akan, qa Jerusalem en Wicaśtayapi yanke kta, qa hunkawicayapi tawa wicitokam wowitanyan un kinhan.

\section{WICOWOYAKE 25.}

1 Jehowa Wakantanka mitawa kin he niye, ciyawankantuya kia, nicaje mdatan kta : taku wowinihan ecanon, nitowiyukcan kin hena wanakajatanhan wowacinye qa wowicake.

2 Otonwe kin he woyujuju pahaha yakaga; otonwe aconkaśkapi kin he ihangyapi; oyate tokeca conkaśke tawa kin he otonwe kte śni ; icimana kagapi kte śni.

3 Heon etanhan oyate waśake cin he niyatan kta, oyate wohitikapi totonwe kin konicipe kta.

4 Tona wahpanica wowaśake tawa kin he niye, onśika kakiśyapi kin wowaśake tawa, icamna etanhan wowinape, omaśte kin en ohanzi wan he niye, oyate wohirike taniya kin he conkaśke aicamna kin iyececa qehan.

5 Toka owodutaton hin he du. hukuya kta, hopuza en maśte kin iyececa ; omaśte en mahpiya śapa ohanzi kin he: oyate wohitikapi tadowanpi kin yuhukuyapi kta.

6 Unkan paha kin de akan Je215 


\section{ISAYA TAWOYUKCAN KIN,}

howa wicobe tawa kin he taku cepa on wohanpi wan oyate owasin wicakicage kta, miniśa koka ohna han oyatke, taku cepa cupe ojudan, miniśa koka etanhan tanyan puskepapi kin.

7 Qa paha kin de en ite akahpe oyate owasin akahpapi kin he yatakuni kte śni, qa woakahpe kazontapi Ikcewicaśta owasin awicakahpapi kin he nakun.

8 Wiconțe ocowasin yatakuni kte śni; qa Jehowa Itancan kin wicite owasin etanhan iśtamnihanpe wicakipakinte kta; qa iye taoyate tawowiśtece kir maka ocowasin etanhan eyaku kta; Jehowa hecen eya nakaeś.

9 Unkan anpetu kin he en heyapi kta; Tho, Wakantanka unkitawapi kin he dee; he unkapepi, unkan iye niunkiyapi kta: Jehowa dee, he unkapepi, cante unwaśtepi kta qa iye towiconi on unkiyuśkinpi kta.

10 Paha kin de en Jehowa nape kin yanke kta; unkan iye ihukuya Moab ahanpi kta, aguyapi hu tacesdi paha kin en amanipi iyececa.

11 Qa hena cokaya nape hdugate kta, tuwe niwan niwe kta nape hdugate cin iyececa: tuka iye nape ośkiśkeya ohanye cin on towahanicidapi kin he kun elpeye kta.

12 Qa conkaśke nitawa ipasotka tehanwankantu kin he yujuju kta, kun ehpeye kta, makata ehnake kta, maka mdu kin en.

\section{WICOWOYAKE 26.}

1 Anpetu kin he en Juda makoce kin ohna odowan kin de ahiyayapi kta :

Otonwe suta wan unhapi ;

Wanikiyapi kin he conkaśke qa maka qapi kin eekiye kta. 216
2 Tiyopa kin yuhdoka miye,

Hecen oyate owotanna wowicake patanpi kin mahen yapi kta.

3 Wicacante wacinyan un kin he wookiye hinca ohna duhe kta,

Iye wacinniyan nakaeś.

4 Ohinniyan Jehowa wacinyan miye;

Wowaśake owihanke wanice cin he Jah Jehowa en un nakaeś.

5 Tona wankantuya tipi kin hena kun iwicacu ;

Otonwe tehanwankantu kin kun ehpeye kta,

Kun ehpeye kta, maka kin ekta ;

Maka mdu kin en icu kta.

6 He wicasiha ahe kta;

Onśika sihapi, wahpanica sicuhapi kin.

- Tuwe owotanna tacanku kin he owotanna:

Owotanna hinca yaun, wicaśta owotanna tacanku kin dumdaye kta.

8 Han, Jehowa, nitawoyaco canku kin ohna unkanipepi;

Unnagipi cantokpani kin he nicaje qa niksuyapi kin ekta.

9 Hanyetu en minagi on cantocikpani ;

Han, tanmahen tanhan mitaniya on nina acicite kta :

Nitawoyaco kin maka akan un kinhan,

Makoce en ounyanpi kin woow otanna onspeiciciyapi kta.

10 Tuwe śica cantekiyapi eśta woowotanna onspeiciciye śni :

Woecetu makoce kin ohna śicaya ohanyan;

Qa Jehowa tokitanin kin wanyake kte śni.

11 Jehowa, ninape yuwankan 


\section{WICOWOYAKE 27.}

icupi eśta hena wanyag wacinpi śni:

Tuka wanyakapi kta, qa oyate inawicayakiwizi kin on iśtecapi kta:

Han, tokawicayaya ide kin he huhnaliwicaye kta.

12 Jehowa, wookiye unyaqupi kta;

Unkiohanpi owasin niye qe unkoyecihanyanpi nakaeś.

13 Jehowa Wakantanka unkitawapi,

Nicunonpa itancanpi wowidagunyanpi ;

Tuka niye niśnana on nicaje cajeunyatapi kta.

14 Takpe wicayai qa ihangwicayaya ;

Qa tokiksuyapi kin ocowasin dutakuni śni :

Heon etanhan tapi, ake kinipi kte śni ;

Nagi iyayapi, hdinanpapi kte śni.

15 Oyate kin duota,

Jehowa, oyate kin duota;

Nihduonihan;

Makoce opapun iyuhpa dutanka.

16 Jehowa, wokakije on en nihipi ;

Kakiświcayaye cin he on

Wocekiye wan hoyeniciyapi.

17 Tuwe ihduśaka wanna ecadan cinca ton kta,

He wayazanhda, hokśiksuya on śicahowaya,

He iyecen, Jehowa, nitokam unyakonpi ce.

18 Unkihduśákapi, waunyazanpi,

Tate hiy uunyanpi seca;

Makoce kin en owicakiyapi econkupi śni ;

Nakun maka ounyanpi kin hena hinhpayapi śni.

19 Tona nicițapi kin hena nipi kta;
Mitancan te cin he kici hdinanpapi kta :

Kikta po, iyaśa miye, tona maka mdu en ounyayapi kin ;

Wato cu kin he cu nitawa;

Qa maka kin wicate cin hiyuye kta.

20 Iho ye, mitaoyate, $t_{1}$ mahen hdicu wo,

Qa tiyopa kin onaiçitag icu wo:

Cistiyedan se anaiciliman wo ;

Wośinhda kin sam iyaye kta hehanyan.

21 Iho, Jehowa iye tohe etanhan hiyu,

Maka ounyanpi kin wahtanipi on kakiświcaye kta:

Nakun maka kin he we hdutanin kta,

Qa tona wicaktepi tawa kin icimana a wicakahpe kte śni.

\section{WICOWOYAKE $2 \%$}

1 Unkan anpetu kin he en, Jehowa, iye tacanhipi tke, tanka qa suta on, Leviathan wanmduśka duzahe cin he kaśtake kta; han, Leviathan wanmduśka pemni kin he; qa unktehi tanka miniyata un kin he kte kta.

2 Anpetu kin he en hastanhanka ojupi wan kahiyaya miye.

3 Jehowa miye he awanwahdaka ; ohinniyan amagajuwaye kta: olkinni kiunniyanpi $\mathrm{kta}$, heon hanyetu anpetu ko awanmdake kta.

4 Wośinhda en maun śni : tuwe okicize en wapepeka canpepe ko mitkokim ehnake lita he: hena takpe mde kta, hena ocowasin huhnahwaye kta tuka.

$5 \mathrm{Qa}$ iś mitowaśake en sutaya yuze kta; miye kici wookiye içicage kta : han, wookiye micicaga nunwe. 


\section{ISAYA TAWOYUKCAN KIN,}

6 Anpetu u kte cin en Jakob hutkan icage kta: Israel paha kta qa hica aye kta, qa waskuyeca on maka ite kin ojuyapi kta.

7 Tuwe ape ciqon apapi kin iyecen apa he; qa wicaktepi on iye wicakte qon iyecen ktepi he.

8 Ehpeyapi kin he kici iyuteya ayakinica kta: wiyohiyanpatanhan tate uye anpetu kin en tate wohitika tawa on yutokan iyeya ece.

9 Heon etanhan de on Jakob tohan śice cin kajujupi kta; qa woahtani tawa yutokan iyeye kta oicage ocowasin he dee. Owayuśna inyan kin iyuhpa inyan acetipi kamdemdecapi kin iyecen ehpeye cinban, wakagapi qa anpetu wi okagapi kin hena bosdan he kte śni.

10 Tuka otonwe aconkaśkapi kin he hewoskan wanke kta : otipi yujujupi qa ehpeyapi, tintoskan iyececa : hen ptejicadan wihan kta, qa hen makan iwanke kta, qa adetka kin temye kta.

11 Tohan adetka śnijapi kinhan yuksapi kta: winohinea kin upi qa hena ideyapi kta: He oyate wiyukcan śni, heon etanhan tuwe icahwicaye cin he onśiwicada kte śni, qa tuwe wicakige cin he cantewicakiye kte śni.

12 Unkan anpetu kin he en wakpa tancan kin etanhan Egupta kaksiza kin hehanyan Jehowa kahna kta; qa, Israel cinca, niyepi wanjigjidan nipahipi kta.

13 Nakun anpetu kin he en mazayahotonpi tanka wan yahotonpi kta; hehan tona Aśur makoce kin en enanakiya unpi, qa Egupta makoce en ehpewicayapi qon hena upi kta, qa Jerusalem ekta, Palia wakan kin akan, Jehowa ohodapi kta. 218

\section{WICOWOYAKE 28}

1 Wateśdake tehanwankantu, Ephraim witkopi kin wotehi wicakiciyanka nunwe; qa wahca śnije kta iye towaśte wakan kin he, miniśa on ohiyapi kaksiza cepa tawapi oinkpa kin ekta yanke cin he.

2 Iho, wanji wawokihi qa waśaka Itancan kin kici un, wasu hinhe, icamma waihangye cin iyececa, mini tanka nina apaśbogye cin iyecen iye nape on makata ehpeye kta.

3 Ephraim witkopi kin tawateśdake tehanwankantu kin he wicasiha ihukuya napanpi kta:

4 Qa towaśte wakan kin, wahea śnije Kta kaksiza cepa oinkpa kin ekta yanke cin he, mdoketu śni suken waskuyeca suton, tuwe ekta etonwe wanyake cinhan, nahahin nape ohna un icunhan temya iyeya he iyecece kta.

5 Anpetu kin he en, iye taoyate okaptapi kin on Jehowa wicobe tawa kin he wowakan wapaha qa wowaśte wateśdake kin ee kta ;

6 Qa tona wayaco lyotankapi kin hena on woyaco woniya kin heca kta, qa tona otonwe tiyopa kin ohna okicize yuhomnipi kin hena on wowaśake kta.

7 Tuka hena eqe nakun miniśa on nunipi, qa mini wakan on icunonpa unpi ; wawayuśna qa wicaśta wokcan kin hena mini wakan on nunipi, hena miniśa on napcapi, mini wakan on icunonpa unpi ; wawanyakapi en nunipi, wiyukcanpi en kaktihanhanpi.

8 Wahna wotapi iyuhpa hdepapi śica on ojugjudan; owanka wanica.

9 Tuwe he wosdonye onspekiye kta he; qa tuwe he woonspe 
okahnihkiye kta he: tona asanpi ayuśtanwicakiyapi, tona aze etarihan ewicayakupi.

10 Woonspe woonspe iyahna, woonspe woonspe iyahna; woope woope iyahna, woope woope iyahna; deciya tonana, heciya tonana ece.

11 Heon etanhan wicaiha yaśkiśkapi qa wicaceji tokeca on oyate kin de om wowahdake kta.

12 Hena hecen ewicakiya; Woozi kin he dee; mdokițapi kin oziwicakiya miye ; qa owanji yankapi kin he dee ce; tuka anagoptan wacinpi śni.

13 Hececa eśta hena en Jehowa oie kin he woonspe woonspe iyahna; woope woope iyahna; deciya tonana, heciya tonana; hecen yapi kta qa itunkam hinhpayapi kta, qa wicakawegapi kta, qa wicahmunkapi kta, qa wicayuzapi kta.

14 Heon etanhan wicaśta wawihaha yaunpi, Jerusalem en oyate kin de iwicayadakapi kin, Jehowa oie kin nation po.

15 Wiconțe kici wicotakuye unkicagapi, qa Hades kici okiciciya unyakonpi; hecen tohan wawiyopeye apaśboka iyopta ye cinhan unkikiyepidan u kte śni ; woitonśni he wowinape unyanpi nakaeś, qa ecinkta eyapi kin en inaunkiçilimanpi ce, ehapi ;

16 Heon etanhan Jehowa Itancan kin he becen eya; Iho, Zion en inyan wan oahehde ewahnaka, inyan iyutapi, oise inyan tehika, oahehde hdepi wan; tuwe wicada kin he inahini kte śni.

17 Nakun woope kin en woyaco ewahnake kta, qa woowotanna, on tkeutapi kin en: unkan wasu kin he woitonśni wowinape kin kahin iyeye kta, qa mini kin woinahbe kin apaśboke kta.

18 Hecen wiconte kici wicota- kuye nitawapi kin he yujujupi kta, qa Hades kici oyeciciyapi kin he ecen he kte śni; qa wawiyopeye apaśboke $\operatorname{cin}$ he iyoopta iy aye cinhan, hehan anihanpi kta.

19 Tohan iyaya eca niyuzapi ece kta : hanlianna qa hanhianna iyaye $\mathrm{kta}$, anpetu qa hanyetu: hecen onahonpi kin he okalinigapi kin he wonihinciye ecedan kta.

20 Owinja kin he tuwe anasonson kta iyehantu śni, qa oakahpe kin he cistinna, hecen on iyaiçipemni kte śni nakaeś.

21 Peråzim paha kin ekta Jehowa iyecen inajin kta; Gibeon kaksiza qon en iyecen śinhda kta; hecen iye tohan kin econ kta, iye tohan tokeca kin he; qa iye tolitani hduśtan kta, tohtani tokeca kin he.

22 Heon etanhan wawilialiapi śni po, okinni on nicaśkapi kin niciyusutapi kta: woyutakuniśni wan, qa he. Itancan Jehowa wicobe tawa kin eciyatanhan nawalion, maka kin owancaya yuśtanpi.

23 Anohya miye, qa miho kin nation po; anagoptan miye, qa iwae cin nalion po.

24 Maliyumdu kin woju kta e on anpetu otoiyohi maga hdumdu he ; tamaga hdupanpan qa hduhinta ece kta he.

25 Tohan maga ite kin yumdaya hehan qetsa kada śni he ; komin he oju, qa aguyapi su kin cankuyetonton ohnaka, qa śuktanka tawote kin tukten hdahnige cin en, qa icage kte cin en wayahota kada elipeya ece.

26 Hecen iye Taku Wakan tawa wowiyukcan onspekiya, wokalinilikiya ce.

27 Qetsa kin he maziyapan on kapanpi śni, qa canpahmihma 219 


\section{ISAYA TAWOYUKCAN KIN,}

wan komin ayuhomnipi śni; tuka qetsa kin he cansagye on kapanpi, qa komin he cansakadan on.

28 Aguyapi icahyapi kin he napanpi ece, tuka ohinniyan kapan kte śni, qa canpahmihma tawa kin ayuhmihma kte śni, qa śuktanka akan iyotankapi tawa kin on namdu kte śni.

29 De nakun Jehowa wicobe tawa kin etanhan u ece; iye towiyukcan kin wakan hinca, tohan kin hdutanka ece.

\section{WICOW OYAKE 29.}

1 Hehehe, Ariel, Ariel otonwe en Dawid ti qon : waniyetu waniyetu en kokijuya po: wośnapi kin ilıunnikiyapi kta.

2 Tuka Ariel tehiya wakuwa kta; qa woiyokiśice woceye ko yuke kta: hececa eśta he Ariel iyececa miciyanke kta.

3 Tuka niye nihdukśan ewati kta, qa ozuye on aonacitake kta, qa niye en conkaśke awakage kta.

4. Hecen kun ehpeniyanpi kta, maka kin etanhan houyaye kta, qa iyae cin he kuya maka mdu etanhan kta, qa niho kin wanagi maka etanhan iyecece lsta, qa iyae cin he maka mdu kin etanhan jiji kta.

5 Nakun oyate tokeca ota wicaduhe cin hena watuśekśeca iyececapi kta, qa wicota waśakśakapi kin hena aguyapi ha kahbog iyaye cin iyececapi kta: unkan he ihnuhanna hince kta.

6 Wakinyan hotonpi, qa maka śkanśkan, qa ho tanka on Jehowa wicobe tawa kin he en nihi kta, magaju qa icamna on, qa peta ide wahuhnahye cin on.

7 Unkan oyate kin owasin wicota hinca, Ariel kici kicizapi, tona iye qa taconkaśke kin kici kicizapi owasin, qa tona iyoki. sinye cin hena hanyetu en wowanyake ihamnanpi kin iyececapi kta.

8 Tuwe wotektehda wihamna, unkan iho wota, tuka kikta, unkan nagi cokadan, he iyecece kta ; qa iś, tuwe ipuza wihamna, unk an iho wayatkan, tuka kikta, unkan iho waśake śni qa nagi ipuza : oyàte ota hinca Zion Paha kin en kicizapi kin owasin iyececapi kta.

9 Owanji yukan po, qa nihinciya po ; iyuśkiniciya po qa iśtagonga po. Hena witkopi, tuka miniśa on etanhan śni ; kacekeegya manipi, tuka mini wakan on etanhan śni.

10 Woiśtinbe hinca oniya wan Jehowa anicaśtanpi, qa iśta niyuoținzapi: wicaśta wokcan qa itancan nitawapi, tona wawanyakapi kin hena wawicakalipa.

11 Hecen wowanyake ocowasin niyepi ekta wowapi oie apuspapi kin iyececa; tuwe wowapi onspe kin he qupi, qa; De yawa wo, ceunniciyapi ce, eyapi: tuka, owakihi śni, he apuspapi ce, eya :

12 Hehan wowapi kin he tuwe wowapi onspe śni kin he qupi, qa; De yawa wo, ceunniciyapi ce, eyapi : tuka, Wowapi onmaspe śni ce, eya.

13 Heon Itancan kin heya; Oyate kin de $\mathrm{i}$ on mikiyedan upi, qa ihapi on mayaonihanpi, tuka cantepi mitehanyan iyeiciyapi, qa komakipapi kin he wicaśta tawoonspe kin eciyatanhan onspewicakiyapi;

14 Heon etanhan iho, oyate kin de ehna wakanyan owalianmde kta, taku wowinihan qa wowapetokeca : tona ksapa wicayuhapi toksapepi kin he atakuni kte 
WICOWOYAKE 30 .

śni, qa tona wiyulkcanpi tookahnigepi kin anahmanpi kta nakaeś.

15 Hehehe, tona towiyukcanpi kin temahentuya Jehowa anakicibman akitapi, qa tohanpi kin otpaza en, qa heyapi, Tuwe wanunyakapi he; qa tuwe sdonunyanpi be.

16 Awicakehan waduptanyanpi kin he maka cega kaga maka tawa kin iyacinpi kta: wicolian wan tuwe econ kin on, $\mathrm{He}$ makage śni ce, eye kta he ; qa taku kagapi kin he tuwe kage cin on, Takudan okahnige śni ce, eye k.ta he.

17 Ehake cistiyedan hin hehan Lebanon maga waśte icage kta, qa maga waśte kin he contanka yawapi kte śni he.

18 Qa anpetu kin he en nogetpapi kin wowapi oie kill hena nahonpi kta, qa iśtagongapi iśtapi kin owotanin śni qa otpaza etanhan wawanyakapi kta.

19 Wicaśta onśiic̣idapi kin nakun Jehowa en sanpa wiyuśkiniciyapi kta, qa wicaśta opeya onśikapi kin hena Israel Taku Wakan tawa kin ikiciyuśkinpi kta.

20 Tuwe wohitike cin he atakuni śni, qa wawihaha kin he ihangyapi, qa tona woahtani iyapepi kin owasin wicakaksapi :

21 Wicoie wanjidan on wicaśta wahtani yawapi, qa tuwe tiyopa ohna wayaco kin he hmung wacinpi, qa takuśni on wicaśta owotanna icunonpa iyayeyapi kin hena.

22 Heon etanhan Jehowa Abraham opekiton qon he Jakob tiyohnaka kin hewicakiya; Dehan Jakob iśtece kte sni, qa dehan iye ite nasan kte śni.

23 Tuka tohan iye cinca, minape taku kage cin hena, iye cokaya wanwicahdake cinhan, mica- je yawakanpi kta, qa Jakob Taku Wakan tawa yawakanpi kta, qa Israel ta Wakantanka kokipapi kta.

24 Qa tona tawiyukcanpi en nunipi qon hena nakun wookahnige sdonyapi kta, qa tona wawakipajinpi qon hena woonspe onspepi kta.

\section{WICOWOYAKE 30.}

1 Hehehe, wawakipajinpi cinca, Jehowa eya; hena wokonze hduśtanpi, tuka miye etanhan śni; qa woyatke wan okaśtanpi, tuka Mitaniya kin eciyatanhan śni, hecen woahtani woahtani en ejupi kta.

2 Hena Egupta ekta apamahde huinyun yapi, tuka mii etanhan wawiwangapi śni; Pharaoh towaśake kin en waśagiçiyapi kta, qa Egupta ohanzi kin wacinyanpi kta.

3 Heon etanhan Pharaoh towaśake kin he wowiśteceyayapi kta, qa Egupta ohanzi wacinyanpi kin he wonihinciye kta.

4 Iye ta wicaśtayatapi kin Zoan en unpi, qa iye uwicaśi qon hena Hanes en hipi.

5 Hena owasin oyate wan owicakiye kta okihi śni kin he on iśtecapi, waanakikśinpi qa waokiyapi okihipi śni, tuka wowiśtece qa nakun wowiliahia ecedan.

6 Itokah woteca tawoyakapi kin. Wonihinciye qa woiyokiśice makoce, etanhan mnaja wiye qa mnaja waśaka, sintehda qa wamduśka kinyan ideya, hena etanhan upi, he ekta towijicepi kin śunka wakan śonśonna amdo akan ayapi kta, qa taku kihnakapi kin camo pśunka kin akan, oyate waokiye kte śni wan ekta. 


\section{ISAYA TAWOYUKCAN KIN,}

7 Egupta wawokiye cin he takuśni, qa takudan okihi śni : heon etanhar decen ewakiye ciqon; Wahaniçidapi owanji yankapi ce.

8 Iho wo, wanna wicitokam wahna wowapi wan en he owa wo, qa wowapi en kaga wo, hecen he anpetu u kte cin hehanyan kta, owihanke wanice :

9 Oyate kin de wawakipajin ece, wicacinca itonpi śni, wicacinca Jehowa toope kin anagoptan wacinpi śni hecapi :

10 Hena, Wawanyakapi śni po, wawanyakapi kin ewicakiyapi ; qa wiyukcanpi kin, Taku ecetu unkiciyukcanpi śni po, iapi śduśduta unkokiyaka po, woitonśni ayata po:

11 Canku kin icunonpa ya po; ocanku icunonpa walitani po: Israel Taku Wakan tawa kin he yutokan iyeunkiciciya po, eyapi.

12 Heon etanhan Israel Towakan kin he hecen eya; Oie kin de ayaktapi śni, qa wohnaye woyupemni ko wacinyayapi qa en enicihnakapi ;

13 Heon etanhan woaktani kin de conkaśke tehanwankantu en okakse wan iyecen he apaha yanka qa hinhpaye kta se, okamdece kin lie iśtakakpapi se ihnuhanna u kte cin he iyecen niciyankapi kta.

14 Qa he maka cega kaga tawakiśḱtpa ocowasin kamdecapi wokamdece kin he iyecen kamdece kta; itonkipe kte śni: hecen okamdece kin he etanhan onśpa oceti etanhan on peta icupi kta, qa on miniyowe etanhan mini eyakupi kta, takudan iyeyapi kte śni.

15 Itancan Jehowa Israel Towakan kin he hecen eya; Hdicupi qa owanji yukanpi kin he on yanipi kta; inina unpi qa wa222 cinyanpi kin on waniśakapi kta tuka : unkan wicayadapi śni.

16 'Tuka hehapi; Hiya, suktanka akan naunjicapi kta ce; heon etanhan nayajicapi kta : qa, Taku duzahan akan unkiyotankapi kta, ehapi; heon etanhan tona tanipapi kin hena duzahanpi kta.

17 Wanjican wawiyopeye on kektopawinge wanji najicapi kta, zaptan wawiyopeyapi on nayajicapi kta: hecen niyuhuhuzapi kta, wiyokihedan he akan ehdepi qa wapahaśa wan paha ekta he cin iyececa.

18 Heca eśta Jehowa ape un kta, onśinidapi kta; qa heon inajin kta, cantonihnakapi kta e heon: Jehowa Taku Wakan kin he wayaco nakaeś: Tona apepi kin owasin cante waśtepi ece.

19 Oyate kin Zion en Jerusalem ohna ounyanpi kta : iśtamnihanpe aniu yaceye kłe śni; tuwe waonsida kin he ho uyaye cin on onśinida kta; he nation kinharl aniyupte kta.

20 Unkan. Itancan kin woiyokiśice aguyapi qa wokakije mini kin niçupi qeyaś, tona waonspeniciyapi kin hena ake icimana naiẹilimanpi kte śni, tuka niiśtapi waonspeniciyapi kin wanwicayakapi kte :

$21 \mathrm{Qa}$ niheyatanhan ninogepi wicoie wanji nahonpi kta, Canku kin he dee ce, ohna mani po, eye kta, tohan etapatanhan dapi kta, qa tohan catkatanhan dapi kta hecinhan.

22 Nakun nita mazaska wakagapi oakahipe kin daśapapi kta, qa nita mazaskazi wakagapi okaśtanpi oakalipe kin ; iśnati mahen unpi tawa iyecen hena elipeyaye kta: Tokan yanka wo, eyakiye kta.

23 Hehan nitawojupi magaju 
kin hiyuye kta, hecen on nitamaga kin oyekju kta; qa maka oicage etanhan aguyapi yuke kta; qa he cepa qa oicah ota kta. Anpetu kin he en nitawoteca tinta tanka en wihanpi kta.

24 Nakun tatanka qa śonśonpidan maga kicanyanpi kin hena woyute skuyeyapi, mazaicu qa icaduge on kadugapi kin he yutapi kta.

25 Unkan he tehanwankan otoiyohi, qa paha pajodan otoiyohi akan wakpadan yuke kta, mini kaduze kta, anpetu kin en tankaya wicaktepi, conkaśke kin hinhpayapi kinhan.

26 Nakun hanyetu wi iyoyanpa kin he anpetu wi iyoyanpa iyecece kta ; qa anpetu wi iyoyanpa kin he śakowin akihde kta, anpetu śakowin iyoyanpa jyecece kta; anpetu kin en Jehowa iye taoyate okamdece tawa pakỉhte ca apapi okaśpe kin okiziye cinhan.

27 Iho, Jehowa caje kin tehantanhan u, tocanniye ide, qaide kin he tehike: iye iha kin wośinhda on ojudan, qa ceji kin he peta wahuhnage cin iyececa.

28 Qa iye taniya wakpa apaśboke wan iyecen tahu cokaya iyahde kta, wicotakuniśni icaduge wan on oyate kin wicakaduge kta: qa nuniwicaye kta e iiyuwi wan oyate ipi kin ohna yanke kta.

29 Odowan wan duhapi kta, hanyetu en omniciye yuwakanpi kin iyececa; qa cante iyuśkinpi, tuwe cotanka wan hduha Jehowa Paha tawa ekta ye kte cin iyececa, Israel ta Imnija kin ekta.

30 Unkan Jehowa towitan ho kin nahon wicakiye kta, qa iye isto kun u kin he hdutanin kta, nakun wocanniye wośinhda, qa peta wahuhnage ide kin, icamna qa magaju, qa wasu hirhan.

31 Jehowa ho kin on, Aśur cansagye on wakaśtaka ece qon he kawankapi kta.

32 Unkan cansakadan kahnigapi kin Jehowa akan ehnake kte cin he tukten hiyaye cin otoiyohi, he cancega qa candowankiyapi kicica kta: qa okicize owodutaton on om kicize kta.

33 Tanihantanhan Tophet wiyeya kagapi ; han, wicaśtayatapi kin on yuwiyeyapi ; tanka, temahentu kaga; peta qa can ota ejupi ; Jehowa taniya kin, canśin wakpa wan iyececa, he ideye kta.

\section{WICOWOYAKE 31.}

1 Hehehe, tona owicakiyapi kta on Egupta ekta apamahde iyayapi; qa śunka wakan wacinwicayapi, qa canpahmihma inapapi, hena.otapi heon; qa śuktanka akan iyotankapi, hena waśakapi hinca nakaeś: tuka Israel Towakan kin he ekta etonwanpi śni, qa Jehowa akitapi śni.

2 Hececa eśta iye nakun ksapa, qa taku śica au kta, qa iye oie kin ehdaku kte śni : tuka wicohan śica econpi tipi kin itkom inajin kta, qa woahtani econpi waokiyapi kin hena itkowicakipe kta.

3 Nakaeś, Egupta oyate kin hena wicaśta, qa Taku Wakan hecapi śni; qa iye taśunkepi kin hena cehipi qa woniya hecapi śni. Tohan Jehowa nape hdugate cinhan hehan tuwe waokiye cin he kacegya mani kta, qa tuwe okiyapi kin he nakun hinhpaye kta, qa owasirı witaya a takunipi kte śni 


\section{ISAYA TAWOYUKCAN KIN,}

4 Jehowa hecen emakiye ciqon; Mnaja qa mnaja kośka taku iyahpaya ahdo, waawanyake wicota takpe upi qeyaś hena hopi on kopehda kte śni, qa hena owodutaton kagapi kin on makata ehpeiciye kte śni; he iyecen Jehowa wicobe tawa kin he $\mathrm{Zi}$ on he kin on, qa paha tawa kin on kicis kun u kta.

5 Zitkadan waakahpapi ece kin he iyecen Jehowa wicobe tawa kin he Jerusalem ahdahpe kta; ahdahpa qa ehdaku kta ; acakśin qa kpatan kta.

6 Israel cinca, tuwe itehan icunonpa idadapi kin he ekta ihdoliu po.

7 Anpetu kin he en wicaśta otoiyohi iye tamazaska wakagapi, qa tamazaskazi wakagapi, niye ninape woahtani on nicicagapi qon hena ehpeyapi kta.

8 Hehan Aśur oyate kin mazasagye on hinhpaye kta, wicaśta tawa śni, qa mazasagye wicaśta akantu tawa śni kin he he temye kta: tuka mazasagye ite kin etanhan nape kta, qa losóka tawa kin hena wayaka unpi kta.

9 Qa iye wokokipe on taconkaśke kin en onajice kta, qa itancan wicayuhe cin hena wiyokihedan kin kokipapi kta ce, Jehowa iye tapeta Zion en un, qa oceti tawa Jerusalem en yanke cin he hecen eya.

\section{WICOWOYAKE 32.}

1 Iho, wicaśtayatapi wan woowotanna on wicaśtayatapi kta, qa itancanpi kin iś woyaco on wakonzapi kta.

2 Hecen wicaśta wan tateyanpa etanhan woinahbe kta, qa icamna etanhan wowinape iyecece kta; hopuza en mini wakpadan iyececa, makoce ohna wicalitate 224 en imnija tanka ohanzi kin iyececa.

3 Qa tona wanyaka iśtośnijapi kte śni, qa tona wanahonpi nogepi anagoptanpi kta.

4. Nakun tona inahnipi cantepi kin wosdonye okahnigapi kta, qa ia yaśkiśkapi cejipi kin tany an ia inalinipi kta.

5 Hehan witkotkoke cin icimana wacantkiya eciyapi kte śni, qa watehinda lin he ohanpi eciyapi kte śni.

6 Witkotkoke cin he wowitkotkoke ecen ie kia, qa iye cante woahtani kage kta, wicośice econ kta, qa Jehowa on woitonśni oyake kta; tuwe wotektehda un nagi kin he yucoka kta, qa tuwe ipuza tawoyatke kin yuwanice kte.

7 Nakun watehinda taku wowinyunye kin hena śica; he woyuśice wakiconza, woitonśni oie kin on wicakiś unpi kin wicayutakuni kte śni, wicaśta onśika ecetuya ia eśta.

8 Tuka wacantkiye cin he taku wocantekiye lkin konza ece; qa wocantekiye on sutaya najin kta.

9 Winohinca wahanicidapi inajin miye; kopehda śni cunwintkupi, maho kin nahon po, iwae cin anagoptan po.

10 Waniyetu anpetu ota ahna nihinniciyapi kta, kopehda śni yaunpi ; hastanhanka oicage yuke kte śni, mnayanpi kin he u kte śni.

11 Wahaniçida yaunpi, cancan po ; kopehda śni yaunpi, nihinciya po, ihduśdoka po, qa tancokapidan po, qa nite en ipiyagkiton po.

12 Maku en aicipapi kta, omdaye waśte hinca on, qa hastanhanka iyuwi waicahye cin on.

13 Mitaoyate tamakoce kin en wapepeka can pepe ko uye kta ; 
han, wowiyuskkin tipi iyulipa akan, otonwe wiyuśkin kin en.

14. Tipi tehanwankantu kin ay uśtanpi, oyate ota tonwanyanpi kin he elipeyapi; paha qa conkaśke kin hena ohinniyan makoh̉deke kta, śonśonna itu unpi on wiyuśkinpi, wanunyanpi en wihanpi kta :

15 Ecen Woniya kin wankantanhan unkakaśtanpi kta, qa tintoskan kin he maga waśte kta, qa maga waśte kin he contanka yawapi kta.

16 Hehan wokonze tintoskan ounye kta, qa woowotanna maga waśte kin ohna yanke kta.

17 Unkan woowotanna ohan kin wookiye hee kta, qa woowotanna yuśtanpi kin he oziiciyapi qa wowacinye owihanke wanice kta.

18 Qa mitaoyate wookiye owanka wan en ounyanpi kta, qa tipi wacinyepica ohna, qa wikope śni ozikiyapi owanke kin en.

19 Unkan wasu contanka kin ahinhe kta, qa otonwe kin omdaye wan en yuhukun ehpeyapi kta.

20 Mini owasin icahda woyajupi cante niwaśtepi, tatanka qa śonśonna siha kin heciya yeyaśipi.

\section{WICOWOYAKE 33.}

1 Hehehe, niye wawicayaki tuka wanicipi śni; qa wawicayahnayan tuka niye nibnayanpi śni : Tohan wawicaki arluśtan kinhan hehan wanicipi kta; tohan wawicahnayan enayakiye cinhan hehan niye nihnayanpi kta.

2 Jehowa onśiunkida miye; unkanipepi. Hanhanna eca hena isto niyuhapi nunwe; nakun wokakije anpetu kin en waniunkiyapi kin he niye kte.

Is.
3 Owodutaton hoyeye cin on oyate kin najicapi ; wankan nihdohda on oyate kin enanakiya iyayapi.

4 Unkan wayakipi kin he mnayanpi kta, psipsicadan mnaiciyapi kin hee kta; psipsica tanka inyankapi kin he iyecen ainyankapi kta.

5 Jehowa wankan hdoyapi; wankan ounyan nakaeś : wokonze qa woowotanna on Zion ojuya.

6 Qa iye nitaanpetu woyusuta kin hee, wanikiyapi wowaśake, woksape qa wosdonye kin hena eepi kta : wokihnaka tawa Jehowa kokipapi kin hee.

7 Iho, mdetahunkapi wicayuhapi kin tankan śicahowayapi kta : wookiye on yewicaśipi qon hena nina ceyapi kta.

8 Canku tanka kin hena hewotahedan ehpeyapi ; oicimani wanica. Wicotakuye kin he kicaksa, otonwe kin wahtewicada śni, wicaśta kin ihawicakta śni.

9 Maka kin hanyan, ceya: Lebanon iśteca, śeca aya: Śaron tintoskan iyececa: qa Baśan Karmel kici kahnapi.

10 Wanna nawajin kta ce, Jehowa eya: wanna wankan mahdoyapi kta; wanna mihduwantu kta ce.

11 Peji śeca on ihduniśakapi kta, aguyapi hu yatonpi kta; nitaniyapi kin petaiyecen hulinahniyanpi kta.

12 Qa oyate kin inyan acetipi kin hecapikta; wapepeka kahin iyeyapi iyecen peta en huhnagapi kta.

13 Tehan yaunpi, taku ecamon kin he nahon miye; qa kiyedan yaunpi, mitowaśake kin he sdonya po.

14 Zion en wahtanipi kin hena kopehdapi ; wicacancan wayuśa225 


\section{ISAYA TAWOYUKCAN KIN,}

papi kin wicayuza. Unkiyepi etanhan tuwe peta wahulinage cin en ounye kta he; unkiyepi etanhan tuwe ide owihanke wanice cin en ounye kta he.

15 Tuwe owotanna mani, qa ecetuya ia ece; tuwe wohnaye wokamna śicedaka, on opetonpi kte cin yuza nape hdatata, weyapi nahon kte śni on noge okihmuze, qa taku sica wanyake kte śni on iśtohmuza icu ;

16 He wankan owanka kin en ounye kta ; imnija conkaśke kin wowinapeye kta; aguyapi qupi ece kta ; mini tawa kin he ohinniyan kta.

17 Niiśta wicaśtayatapi iye toiyokipi kin en wanyakapi kta; makoce tehantu hince cin he wanyakapi kta.

18 Nicante wonihinciye qon he kiksuye kta. Wowapi kage cin he tokiya un he ; tuwe waaspeya ece kin he tokiya un he ; tuwe conkaśke yawa ece qon he tokiva un he.

19 Oyate wan ite wawinihan kin heca wandake kte śni ; oyate wan iapi nayalion kta isanpa tehika; ceji yaśkiśka, taku kapi tanin śni kin heca.

20 Zion otonwe ohna mniunkiciyapi ece kin he wanyaka wo: Jerusalem woozi ounyanpi kin he niiśta wanyakapi kta ; wakeya kahpapi kte śni, canhutipaspe tawa icimana yujun icupi kte śni, qa taikan kin wanjidan yuksapi kte śni.

21 Tuka hen Jehowa waśake hince cin he wakpa qa wakpadan ohdakinyan tankapi kin eeunkiyapi kta; wamnaheca wata takudan he ohna ye kte śni, nakun wita wata waśaka en hiyaye kte śni.

22 Wayaco unkitawapi kin Jeho. wa hee; woope kaga unkitawapi 226
Jehowa hee; Jehowa he Wica. śtaya tapi unkitawapi ; iye niunyanpi kta.

23 Ikan nitawa yukcapi, can ihupa kin en sutaya iyakaśkapi kte śni : śina on watopapi kin hena yumdayapi kte śni. Hehan wawicakipi tanka wan kicipamnipi kta : taku icupi kin tona huśte iyahpayapi.

24 'Tuwe en ounye cin, Wamayazanka ce, eye kte śni ; oyate en tipi kin hena wahtanipi wicakicicajujupi nakaeś.

\section{WICOWOYAKE 34.}

1 Ikcewicaśta, nayahionpi kta e kiyadan u miye, qa oyate yaunpi, anagoptan po: maka kin nahon kte, qa toojudan kin ; maka kin tona etanhan icagapi kin hena koya.

2 Jehowa tocanniye kin Ikcewicaśta owasin akan yanke, qa ozuye tawapi owasin wośinhda awicaun: Hena iye wicakiconza, wicaktepi kta e wicaqu.

3 Unkan wicaktepi tawapi kin hena tankan ehpeyapi kta, qa tancan tapi kin etanhan śicamna au kta, qa hena we kin on he kin lipan kta.

4 Qa mahpiya taobe kin iyuhpa skan kta, qa mahpiya kin hena tahasaka wan iyecen opehanpi kta, qa taobepi owasin hinhpaye $\mathrm{kta}$, hastanhanka iyuwi ape hinhpaya, qa suken can etanhan ape śnije cin iyececa.

5 Han, mazasagye mitawa mahpiya kin en imnan: iho, woyaco on Edom en ahiyu kta, qa oyate wicamdaśice cin en.

6 Jehowa tamazasagye kin he we on ojudan, waśin on cepa, tahin wanunyanpi cinca qa tatokadan we on, tamdoka tapakśin śin on: Bozra en wośna wan Jeho- 
wa kicagapi nakaeś, qa wokte tanka wan Edom makoce kin en. 7 Unkan tinta tatanka hena om apamahde upi kta, qa tatanka tatang mdoka kin om : unkan iye tamakoce kin we on imnan kta, qa maka mdu lin waśin on cepe kta.

8 Jehowa towicakicon anpetu kin dee, Zion toakinica on wokajuju waniyetu kin hee nakaeś.

9 Hecen tawakpa kin hena canśin icage kta, qa maka mdu kin inyanzizi kta, qa makoce kin canśin ide eceh icage kta.

10 Hanyetu qa anpetu he kasnipi kte śni; etanhan śota kin he owihanke wanin wankantkiya ye kta; wicoicage qa wicoicage hehanyan hewoskan wanke kta; tuwedin he opta ye kte śni, owihanke wanica.

11 Tuka modega qa pahin he tawayapi kta; l1akun hoka qa kangi hen unpi kta; qa toketu tanin śni ikan kin he ayutitanpi kta, qa woihangye inyan kin.

12 Wicaśta tankapi kin wicaśtayatapi kta e iwicakicopi kta, tuka wanica; qa akicita tancanpi tawa owasin sotapi kta:

13 Qa tipi waśteśte tawa kin en wapepelka uye kta, haśbe canpepe ko conkaśke tawa kin ohna : qa canotidan kin hena he tipi yapi kta, hinhankaga cinca tahocoka kin bee kta.

$14 \mathrm{Qa}$ tintoskan tanhan woteca kin wita etanhan wamanica kin itkowicakipapi kta, qa holinogeca kin he takodaku kipan kta; nakun wanagi kin he hen yanke kta, qa woozi makoce wan iyeiçiye kta.

15 Hen wanhinkpe wamduśka kin waśun ic̣icage kta, qa witka kada kta, qa man kta, qa taohanzi kin en mnawicaye kta; nakun heciya kangi tanka kin mniciya- pi kta, otoiyohi iye takodaku kici.

16 Jehowa tawowapi kin ohna akita po, qa wanyaka po; dena wanjidan en un śni wanice $\mathrm{kta}$, otoiyohi iye takodaku kicica kta. Mii kin he de econwicaśi, qa iye taniya kin he hena mnawicaya nakaeś.

17 Íś eya hena makoce wicakipamni, qa iye nape ikan on de iwicakiciyute : hena ohinniyan tawayapi kta, wicoicage qa wicoicage hehanyan hen ounyanpi kta.

\section{WICOWOYAKE 35.}

1 Dena on tintoskan qa makoce puze cin iyuśkin kta, qa hopuza kin he wiyuśkin lkta ga onjinjintka iyecen hica kta:

2 Ḧcahca kta qa iyuśkin kta, han, wowiyuśkin qa dowanpi kin on. Lebanon towitan kin qupi kta, Karmel qa Śaron toiyokipi kin : Hena Jehowa towitan wanyakapi kta, Wakantanka unkitawapi toiyokipi kin.

3 Wicanape suta śni kin hena yuwaśaka po, wicahupahu waśake śni kin hena wicayusuta miye.

4 Tona cante inahnipi kin hena hewicakiya po; Ihdutinza po; kopehdapi śni po: Taku Wakan nitawapi wanhdaka po: watokiconpi u kta, Wakantanka tawokajuju kin he; iye hinca u qa niniyanpi kta ce.

5 Hehan iśtagongapi kin iśta wicakiyukawapi kta, qa noge tpapi kin hena noge wicakiyuhokapi kta.

6 Hehan tuwe huśte kin he tamdoka wan iyecen ipsice kta, qa ia okitpani ceji kin dowan kta: hewoskan mini bohdog hiyu nakaeś, qa wakpa hopuza kin en.

7 Qa makoce aśpanśpan kin he mde icage kta, qa maka puze 


\section{ISAYA TAWOYUKCAN KIN,}

cin he minihdoke kta: Canotidan ounyanpi tukten wankapi kin hen cedi psa ko yuke kta.

8 Unkan canku tanka wan hen wanke kta, qa ocanku kta; qa he Woowotanra canku eciyapi kta : tuwe śape cin he omani kte śni : tuka he iye tawapi kta: oicimanipi kin hena witkotkopi qeyaś nunipi kte śni.

9 Hen mnaja wanice kta, qa wamanica wayapote cin he ohna ye kte śni, hen iyayapi kte śni : tuka tona opewicakitonpi kin hena omanipi kta :

10 Qa tona Jehowa opew.cakiton qon hena hdicupi kta, qa iye pa akan dowanpi qa wowiyuśkin owihanke śni hduha Zion en hipi kta: wowiyuśkin wopida ko hduhapi kta, qa woiyokiśice comnihdazipi ko najice kta.

\section{WICOWOYAKE 36.}

1 Unkan Hezekiya waniyetu aketopa wicaśtayatapi he en, Senakerib Aśur wicaśtayatapi kin Juda otonwe aconkaśkapi kin owasin takpe wicau qa iwicacu.

2 Qa Aśur wicaśtayatapi kin Lakiś etanhan Rabśaka, ozuye tanka wan kici, Hezekiya Jerusalem en un kin he ekta ye śi. Unkan wankan miniyowe wakpa kagapi kin icahda hinajin, wayujaja tamaga canku tanka kin he ohina.

3 Hehan Fliakim Hilkiya cinhintku, tipi awanyake cin he, qa Śebna wowapi kaga ece, qa Joah Asaph cinhintku, owicawa ece kin, hena ekta hinanpapi.

4 Unkan Rabśaka hewicakiya ; Ito, Hezekiya heciya po; Wicaśtayatapi tanka, Aśur wicaśtayatapi kin he hecen eya ; Wowacinye kin de wacinyaye cin he tukte e he.
5 Kicizapi on wowiyukcan qa wowaśake, hena e wicoie takuśni ecedan cajemdate. Iho, tu. we e wacinyaya qa on mayaki: pajin he.

6 Tho, cedi yuksapi sagye kin de, Egupta he wacinyaya; he wicaśta wan apatan linhan nape en iyaye ca pahdoke kta. Pharaoh Egupta wicaśtayatapi kin hececa tona wacinyanpi kin owasin en.

7 Tuka, Jehowa Wakantanka unkitawapi kin he wacinunyanpi ce, emayakiye cinhan; tuwe pahata tipi kagapi tawa, qa owayuśna tawa Hezekiya tokan ehpeye ca Juda Jerusalem kici, Owayuśna kin de itokam ohoyadapi kta ce, ewicakiya, he dee śni he.

8 Heon nakaha ceciciya ce, mayuhe cin, Aśur wicaśtayatapi kin, kici ekiciya wo, kinhan śuktanka kektopawinge nonpa ciçu kta; wicaśta akan iyotangwicakiya oyakihi kinhan:

9 Hecen token mayuha taokiye itancan cistinna wanjidan qeyaś ite kin napeyakiye kta, qa canpahmihma śuktanka akan iyotankapi ko Egupta iwacinyaye kta he.

10 Qa nakaha Jehowa codan makoce kin de ihangya wau he. Makoce kin de takpe ya wo, qa ihangya wo, Jehowa emakiya ce.

11 Hehan Eliakim qa Śebna qa Joah Rabśaka heciyapi; Tokin nitaokiye Aram iapi on unkokiyapin; he unkokahnigapi: qa Juda iapi on unkokiyapi śni po, conkaśke akan oyate yukanpi kin nahonpi kta.

12 Tuka Rabśaka heya; Mayuhe cin he niyuhapi qa niyepi wicoie kin dena eciciyapi kta e umaśi he ; qa wicaśta conkaśke 


\section{WICOWOYAKE $3 \%$.}

akan iyotankapi, iye cesdi hdutapi kta qa iye deje cin niyepi om hdatkanpi kte cin hena ekta umaśi śni he.

13 Hehan Rabśaka najin qa Juda iapi en hotankakiya hoyeye ce heya; Wicaśtayatapi tanka, Aśur wicaśtayatapi, oie kin nahon po.

14 Wicaśtayatapi kin he heya ce; Hezekiya nihnayanpi śni nunwe ; iye enihdakupi kta okihi śni.

15 Nakun ihnuhan Hezekiya Jehowa wacinye niyanpi kinhan : Awicakehan Jehowa eunhdakupi kta ; otonwe kin de Aśur wicaśtayatapi nape kin en qupi Inte śni ce, eya geyaś:

16 Hezekiya anagoptanpi sni po: Aśur wicaśtayatapi kin he kaken eya; Wookiye micaga po, qa tankan en mau po; kinhan wicaśta otoiyohi iye hastanhanka iyuwi etanhan, qa suken can tawa kin etanhan hdute kta, qa otoiyohi miniyowe nitawapi etanhan yahdatkanpi kta :

17 Eicen wau qa makoce wan nitamakocepi kin iyececa, wamnaheza miniśa ko makoce, aguyapi qa hastanhanka iyuwi ojupi makoce kin elita aciyapi kta ce.

18 Jehowa eunhdakupi kta ce, Hezekiya eye cin on ihnuhan awacinniyanpi kinhan. Oyate tokeca taku wakan yuhapi kin iye tamakoce Aśur wicaśtayatapi nape kin etanhan ehdaku he.

19 Hamat qa Arpad taku wakan tawapi kin hena tokiya un he: Sepharvaim taku wakan tawa kin tokiya un he : qa Samaria minape etanhan eyakupi he. 20 Makoce kin hena owasin taku wakan tawapi kin tukte wanji iye tamakoce minape etanhan ehdaku he; hecen Jehowa Jeru- salem minape etanhan ehdaku kta, eya.

21 Tuka inina yukanpi qa oie wanjidan ayuptapi śni : wicaśtayatapi kin hecen econ wicaśi, qa, Takudan-ayuptapi śni po, eye ciqon.

22 Hehan Eliakim Hilkiya cinhintku tipi a wanyake cin he, qa Śebna wowapi kage cin, qa Joah Asaph cinhintku owicawa ece kin, hena wokoyake hdupotapi, Hezekiya en hdipi qa Rabśaka oie kin okiyakapi.

\section{WICOWOYAKE 37.}

1 Unkan Hezekiya he nahon qehan, tawokoyake hduldece, ça wakihdaka ogekiton, qa Jehowa ti kin en tin iyaya:

2 Qa Eliakim tipi awanyake cin he, qa Śbna wowapi kage cin, qa wawayuśna itancanpi kin hena wakihdaka ogekitonpi Isaya Amoz cinhintku wicaśta wokcan kin ek ta ye wicaśi.

3 Unkan hena heciyapi; Hezekiya hecen eya ce; Anpetu kin de woiyokśice qa wośitkihda qa woiyopeye anpetu' kin hee : hokśiyoqopa hiyupi kta wanna en hipi, tuka hiyuwicayapi kta e wowaśake yuke śni.

4. Okinni Jehowa Wakantanka nitawa Rabśaka oie kin nation kta, he iye yuhe cin Aśur wicaśtayatapi kin Taku Wakan ni un kin yaśice kta e uśi, qa wicoie Jehowa Wakantanka nitawa nahon kin hena iyopeye kta : heon etanhan tona okaptapi en unpi kin hena on wocekiye hdawankan ewicayeciye kta.

5 Unkan Hezekiya wicaśtayatapi taokiye kin Isaya en hipi.

6 Unkan Isaya hewicakiya; Niyuhapi kin hecen eyakiyapi kta; Jehowa kaken eya ce ; Wi229 


\section{ISAYA TAWOYUKCAN KIN,}

coie nayahon kin on Aśur wicaśtayatapi taokiye wicaye cin mayaśicapi kin hena kokipe śni wo.

7 Iho, woniya wan en yewaśi kta, nakun woyake wan nation kta, qa iye tamakoce kin ekta hde kta: qa iye tamakoce kin en mazasagye on hinhpaye waye $k$ ta ce.

8 Hecen Rabśaka hdicu qa Aśur wicaśtayatapi Libna kici kiciza en hdi: Lakiś etanhan kihda he nahon tuka qon.

9 Unkan iye Tirhaka Kuś wicaśtayatapi on heyapi nahon; Nicize kta e wanna hiyu ce. Qa he nahon qehan Hezekiya ekta wahośi yewicaśi qa heya;

10 Hezekiya Juda wicaśtayatapi kin oyakiyapi qa kaken eyakiyapi kta ; Ihnuhan Taku Wakan nitawa wacinyakiye cin he nihnayan kinhan, on hehe cin, Jerusalem Aśur wicaśtayatapi nape kin en qupi kte śni ce.

11 Iho, Aśur wicaśtayatapi kin makoce owasin token ecawicakiconpi kin he niye nayahon, hella ocowasin ihangyapi; unkan niye enihdakupi kta he.

12 Ikcewicaśta oyate tona atewicaye cin ihangyapi qon hena taku wakan tawapi ewicahdakupi he: Gozan, qa Haran, qa Rezep, qa Eden cincapi Telasar en unpi kin.

13 Hamat wicaśtayatapi kin tokiya un he, qa Arpad wicaśtayatapi, qa Sepharvaim otonwe, Hena qa Ivah en wicaśtayatapi kin tokiya un he.

14 Unkan wahośiyapi napepi etanhan Hezekiya wowapi kin he icu qa yawa. Hehan Hezekiya Jehowa ti kin ekta ye ça he Jehowa itokam yumdaya.

15 Qa Hezekiya Jehowa cekiye ca heya;

16 Jehowa wicobe tawa, Israel 230
Taku Wakan tawa, Kerubim oyati, maka akan wokiconze owasin en niye niśnana Wakannitanka; niye mahpiya qa maka kin yakaga :

17 Jehowa anohye ca nation wo ; Jehowa niiśta hdumday.e ca wanyaka wo; qa Senakerib oie kin, on Wakantanka ni un yaśice kta e u wicaśi kin, hena owasin nahion wo.

18 Jehowa, awicakehan Aśur wicaśtayatapi kin maka ounyanpi owasin qa makoce tawapi kin yu takunipi śni ;

19 Qa taku wakan tawapi kin peta en qupi; hena taku wakan śni nakaeś, tuka wicaśta nape taku kagapi kin heca, can qa inyan, heon etanhan hena ihangyapi.

20 Heon nakaha Jehowa Wakantanka unkitawapi, he nape etanhan niunkiya po; hecen maka wokiconze kin owasin Jehowa he niye, niye niśnana e sdonyapi kta.

21 Hehan Isaya Amoz cinhintku Hezekiya ekta yewicaśi qa heciya; Jehowa Israel ta Wakantanka kin hecen eya; Senakerib Aśur wicaśtayatapi kin on wocekiye emayakiye cin heon etanhan,

22 Jehowa oie wan eciye cin he dee: Wikośka Zion cunwintku kin he wahtenidaśni, nina inihaha: Jerusalem cunwintku kin niye on pomnamna ce.

23 Wawiyopeyaye ça daśice cin he tuwe he: tuwe on ho hdawankan iyeyaye ca niiśta yahduwankan he: Israel Towakan kin hee.

24 Nitaokiye napepi on Itancan kin iyopeyaya, qa heha; Canpahmihma ota mitawa on he paha kin ekta hibu, Lebanon opapun kin ekta ; qa hante śa tankinyan- 


\section{WICOWOYAKE 38.}

yan qa wazi can kahnigapi kin hena wakawanke kta, qa wankan ihanke kin ekta wai kta, qa maga waśteśte contanka kin en.

25 Miye maka waqe ca mini mdatkan; qa misiha sicu kin on otonwe aconkaśkapi wakpadan kin owasin oyahewaya ce, eha.

26 Wanakaja taku ecamon kin he nayahon śni he; ehanna anpetu kin en he wakaga: Dehan nakaha ecetuwakiye, niye otonwe aconkaśkapi kin wicotakuniśni on ihangyaye kta :

27 Heon en ounyanpi kin hena nape ptecedan, nihinciyapi qa wacinhnunipi; hena maga wato kin iyececapi, peji toto, tipi akahpapi kin ekta wato, qa taku icage śni itokam śnija he iyececapi. 28 Tuka tukten inunke cin he miye sdonwaya, qa tankan idada, qa tin hidu ece, qa canniyemayaye cin nakun:

29 Canniyemayaye ca nihdatanka kin hena noge en hiyomalipaya, heon etanhan maziyukśan mitawa nipoge en iyewaye kta, qa iiyuwi mitawa niiha en, qa canku ohna hidu qon he ohna hdicu ciciye kta ce.

30 Unkan de wowakta yaye kta; Omaka kin de taku iye cinka icage cin etanhan yatapi kta; qa omaka inonpa taku he etanhan icage cin hena : tuka mdoketu iyamni hehan woju po, qa wamnayan po, qa hastanhanka iyuwi huhde po, qa waskuyeca etanhan hduta po. 31 Unkan tona najicapi, Juda tiyohnaka etanhan okaptapi kin, hena ake kuyatanhan hutkan icagapi kta, qa wankantanhan waskuyeca icahyapi kta.

32 Jerusalem etanhan wookapte hiyu kta, qa Zion etanhan niiciyapi yuke kta: Jehowa wicobe tawa kin he tocantekiye kin hecon kta ce.
33 Heon etanhan Jehowa Aśur wicaśtayatapi kin on kaken eya ; Otonwe kin de en hi kte śni, qa wanhinkpe wanji en hiyuye kte śni, qa wahacanka hduha itokam u kte śni, qa ihdukśan maka qe k te śni :

34 Canku ohna hiyu qon he ohna ake hde kta, qa otonwe kin de en u kte śni, Jehowa eya.

35 Miye on etanhan qa mitaokiye Dawid on etanhan otonwe kin de niwaye kta e awahdahpe lita ce.

36 Hehan Jehowa tawahośiye wan iyaye ca Aśur oyate wankapi kin en kektopawinge opawinge qa kektopawinge wikcemna śahdogan sanpa kektopawinge zaptan wicakaśtaka. Unkan hanhanna hin kiktapi hehan, inyun, hena owasin ta wankapi.

37 Hecen Senakerib Aśur wicaśtayatapi kin ihdake ca kihde ca hdicu qa Ninewa ekta eti.

38 Qa iye taku wakan tawa Nisrok ti kin ohna cekiya icunhan iye cinhintku Adramelek qa Śarezer mazasagye on hdaśtakapi; qa Ararat makoce kin en nieciyapi. Unkan cinhintku Esar-hadon iye eekiya wicaśtayatapi yanka.

\section{WICOWOYAKE 38.}

1 Anpetu kin hena en Hezekiya te kta wayazanka. Unkan Isaya wicaśta wokcan Amoz cinhintku kin he en hi qa heciya; Jehowa hecen eya ce; Yati kin hduwiyeya wo ; nite kta qa yani kte śni, heon etau han.

2 Hehan Hezekiya tiyonaptan ektakiya ite hduhomni qa Jehowa cekiya,

3 Qa heya; Hehehe, Jehowa ceciciya ce, wowicake en qa cante ecetu hdulia nitokam ma231 


\section{ISAYA TAWOYUKCAN KIN,}

wani, qa niiśta kin en taku waśte ecamon ece kin he dehan kiksuya ye, eya. Unkan Hezekiya woceye tanka on ceya.

4 Hehan Jehowa oie kin Isaya en hi qa heya;

$5 \mathrm{Ya}$ wo qa Hezekiya heciya wo; Jehowa Dawid ateyaya ta Wakantanka kin he hecen eya ce; Nitawocekiye kin he nawahon, iśtamnihanpe nitawa wanmdaka; iho, nitaanpetu kin en waniyetu akezaptan ewaju kta.

6 Qa Aśur wicaśtayatapi nape kin etanhan ecihdaku kta, niye qa otonwe kin de; qa otonwe kin de awahdahpe kta.

7 Qa Jehowa taku cajeyata wicohan kin de econ kta e Jehowa etanhan decen wowakta yaye kta:

8 Iho, iyadipi ohanzi kin hdicuwakiye kta, Ahaz iyadipi tawa en anpetu wi kici iyaye cin, he iyadipi wikcemna hekta hdicu kta, eya. Unkan anpetu wi kin iyadipi wikcemna hdicu, iyadipi kin hena wanna iyaya nakaeś.

9 Hezekiya Juda wicaśtayatapi kin wayazanke ca wayazanke etanhan kini qon he ehan tadowan kin he dee :

10 Miye hepe ciqon;

Mitaanpetu kaksapi en Hades tiyopa ekta mde kta;

Mitawaniyetu okaptapi $\mathrm{k}$ in hena makipi.

11 Jah wanmdake kte śni ce, epa,

Jah wicani makoce kin ohna:

Icimana wicaśta wanmdake kte śni,

Nakun maka akan ounyanpi kin hena.

12 Mitoicage kin he ihdag iyaya, Qa tahinca awanyaka tawakeya iyecen emiciyakupi :

Wakazonta wan iyecen wani kin wahduksa:
Hahonta etanhan iye mayukse kta :

Anpetu etanhan hanyetu ekta owihanke mayaye kta.

13 Hanhanna hehanyan mitokam ewahde;

Mnaja iyecen mahuhu iyuhpa yuwehwege kta;

Anpetu etanhan hanyetu ekta owihanke mayaye kta.

14 Icapśinpśincadan ohomni kinyan he iyecen wahotonton;

Tinwakiyedan iyecen waceya :

Wankan etonwanpi on iśta matke :

Woiyokiśice miciun, Jehowa anamakikśin wo.

15 Token epe kta he;

Iye omakiye ca nakun iśnana he hduśtan;

Minagi iyokiśica on waniyetu mitawa owasin iwaśtedan mde kta.

16 Itancan, dena on wicani ece ; Qa dena owasin on mitaniya ni un :

Hecen asnimayaye ça nimayaye kta.

17 Iho, wookiye on wicocante śice hinca imicicaga;

Qa minagi canteyakiya on wicotakuniśni wolia etanhan edaku:

Wawahtani owasin nilieyata elipeyaya nakaeś.

18 Hades niyatan kte śni, wiconte inidowan kte śni;

Tona woha kin ekta iyayapi hena nitowicake apepi kte śni.

$19 \mathrm{Ni}$ un kin, ni un kin he niyatan kta,

Anpetu kin de ecamon iyececa ;

Ateyapi kin iye cinca nitowicake kin sdonyewicakiye kta.

20 Jehowa nimaye cin hee: 
Hecen candowankiyapi on mitadowan unkahiyayapi kta, Anpetu unnipi kin owasin, Jehowa ti kin ohna.

21 I waskuyeca kapanpi icupi kta qa śiyaka ahnakapi kte, kinhan asni kta ce.

22 Nakun Hezekiya, Jehowa ti ekta mde kta e wowakta tukte e he, eye ciqun.

\section{WICOWOYAKE 39.}

$1 \mathrm{He}$ ehan Merodak Baladan, Baladan cinhintku Babel wicaśtayatapi kin he wowapi qa taku qu kin iyahna Hezekiya kaye wicaśi : he wayazanka qa akisni nahion kin heon.

2 Unkan Hezekiya hena on iyuśkin, qa tipi ohna wakihnake cin he wanyagwicakiya, mazaska, qa mazaskazi, qa taku waśtemna, qa wihdi waśte, qa tawotawe tipi kin ocowasin, taku mazopiye tawa kin en iyeyapi kin iyuhpa koya; taku iye ti kin ohna qa tośkanśkan ocowasin en Hezekiya wanyag wicakiye śni wanica.

3 Hehan Isaya wicaśta wokcan Hezekiya wicaśtayatapi kin en hi qa heciya; Wicaśta kin dena taku eyapi he ; qa tokiyatanhan hipi he. Unkan Hezekiya heya ; Makoce wan tehan tanhan Babel hee etanhan en mahipi.

4 Hehan heya ; Yati ohna taku wanyakapi he. Unkan Hezekiya ayupta; Wati ohna taku owasin wanyakapi; taku wehnake cin taku wanyagwicawakiye śni wanica, eya.

5 Unkan Isaya Hezekiya heciya; Jehowa wicobe tawa he oie kin nahon wo:

6 Iho, anpetu kin u kta, hehan taku yati ohna yanke cin iyuhpa, qa niyatepi taku kihnakapi anpetu kin dehanyan, hena owasin Babel ekta ayapi kta; takudan okaptapi kte śni ce, Jehowa eya.

7 Qa nicinca niye etanhan inanpapi kta, tona cincawicayaye cin etanhan awicayapi kta; qa hena Babel wicaśtayatapi ti kin ohna wowidake unpi kta ce.

8 Hehan Hezekiya Isaya heciya; Jehowa oie odake cin he waśte. Nakun, Wookiye qa wowicake mitaanpetu kin en un kta ce, eya.

\section{WICOWOYAKE 40.}

1 Wacintonhnagya po, mitaoyate wacintonhnagya miye, nita Wakantanka eya.

2 Jerusalem cante kin okiya po qa hoyekiya po, toozuye kin yuśtanpi, taku śica econ qon hena kicicajujupi ; iye wahitani owasin on Jehowa nape kin etanhan nonpa akihde kicupi nakaeś.

3 Wicaho wan hewoskan hoyeya; Jehowa tacanku kin yuwiyeya po; hewoskantu Wakantanka unkitawapi canku tanka wan owotanna kicaga miye.

4 Kaksiza otoiyohi wankan kagapi kta, qa he paha ko otoiyohi kun icupi kta; qa hośkiśki kin makomdaya kta, qa țahtaga kin he yumdayapi kta:

5 Qa Jehowa towitan kin yutaninpi kta, qa he wicacehpi owasin yuwitaya wanyake kta; Jehowa $\mathrm{i}$ kin he hecen eya nakaeś. 6 Wicaho kin he, Hoyeya wo, eya. Unkan, Taku eyanwapaha kta he, eya. Wicacehpi iyuhpa wato, qa towaśte kin ocowasin maga wahica kin iyececa :

7 Wato kin śnija, wahca kin san aya; Jehowa taniya kin atateyanpa nakaeś: awicakehan oyate kin wato heca. 
8 Wato kın śnija, wahica kin san aya: tuka Taku Wakan unkitawapi oie kin he ohinniyan un kta.

9 Zion, wotanin waśte eyanyapaha kin, paha tehanwankantu ekta ihdoya wo ; Jerusalem, wotanin waśte eyanyapaha kin, waśagya niho hdawankan iyeya wo: Hdawankan iyeya kokipe śni wo; Taku Wakan nitawa wanhdaka miye, Juda otonwe kin ewicakiya wo.

10 Iho, Jehowa Itancan kin wowaśake hdula u kta, qa iye isto kin he wawidagye kta: Iho, iyopeyapi hduha un, qa tokajuju kin iye itokam yanka.

11 Wonwicaya wan iyececa iye optaye tawa kin wonwicakiye kta ; isto on tacincadan mnawicakiye kta, qa maku ohna wicahduhe $\mathrm{kta}$ : tona azinwicakiye cin hena iwaśtedan awicaye kta.

12 Tuwe mini kin nape cokaya ohna iyuta he, qa napapaśdecapi on mahpiya kin iyuta : qa maka mdu kin wiyutapi wan en onakitaka, qa lie kin hena on aspeyetonpi en, qa paha kin on tkeutapi on aspeyeton kin he tuwe he.

13 Tuwe Jehowa Taniya kin wahokonkiya he, qa iś wicaśta wiyukcan tawa; hecen waonspekiye kta he.

14 Tuwe he kici wohdaka, qa wokahnihkiya, qa woyaco canku en onspekiya, qa wosdonye onspekiya, qa wookahinige canku kin wanyagkiya he.

15 Tho, Ikcewicaśta kin cega etanhan śbuyapi wan iyececapi qa on aspeyetonpi akan watuśekśeca iyecen yawapi : iho, wita kin hena taku śni se iyecen yuwankan icu kta.

$16 \mathrm{Qa}$ Lebanon ideyapi kta henakeca śni, qa wamanica tawa 234 kin hena woh̉ulinage wośnapi on henakeca śni.

17 Iye itokain Ikcewicaśta iyuhpa takupi śni; qa hena taku wanica qa taku śni hdawa ece.

18 Hecen tuwe e Wakantanka idacinpi kta he; qa wiyacinpi kin tukte e he iyececa yadapi kta he.

19 Wakagapi wan wabago kin kaga, qa mazazikage cin he mazaskazi on akahpa, qa mazaska icicahiha kicaga.

20 Tuwe wośna iwahpanica kin he can wan ponpon kte śni hdahnige kta; wabago wayupika wan akite kta; wakagapi bagopi wan yuhohopi kte śni kin heca ehde kta.

21 Sdonyayapi śni he; nayahonpi śni he ; otokaheya tanhan he oniciyakapi śni he; maka kagapi kin ehantanhan he oyakahnigapi śni he ;

22 He maka mihbe akan iyotanke cin hee, unkan tona ounyanpi kin hena psipsicadan iyececapi: he ozanpi wan iyecen mahpiya kin hdumdaya, qa hena wakeya otipi kta iyecen hdutitan:

$23 \mathrm{He}$ iye wicaśta itancanpi kin wicayutakuni śni ; maka akan wayaco yukanpi kin hena takuśni iyececa wicakaga ce.

$24 \mathrm{Han}$, hena huhdepi śni ; han, hena ojupi śni; han, hena tancanpi maka en hutkan icagapi śni : tuka iye hena awicatateyanpa, unkan śnijapi kta, qa tateiyumni kin hena kahbog iyewicaye kta, aguyapi ha iyececa.

25 Hecen tuwe e imayadacinpi kta qa iyemacece kta he, 'Tuwe Wakan kin he hecen eya.

26 Niiśtapi wankan yeya po, qa wanyaka po, tuwe dena kaga he, wicayawa iyecen obepi kin dena hinanpe wicaye cin he tu- 
we he: tookihi tanka kin on hena owasin cajeyata; wowaśake on waśake hinca he on wanjidan okapte śni.

27 Mitacanku Jehowa anakicihinanpi, qa 'Taku Wakan mitawa mitawoyaco kin acakśin ce, tokeca Jakob, hecen ehe kta he, qa Israel, tokeca hecen iyaa he.

28 Sdonyaye śni he; nayation śni he; Taku Wakan Owihanke wanica, Jehowa, maka ihanke kage cin he hanye kte śni, qa mdokite kte śni : tookahnige kin he iyukcanpica śni.

29 Tona mdokitapi kin hena wookihi wicaqu, qa tona takudan okihipi śni kin hena wowaśake wicakicaga ece.

30 Kośka kin heepi kaeś mdokitapi qa hanyanpi kta! qa wicakahnigapi kin hena waśakapi śni, waśakapi kte śni:

31 Tuka tona Jehowa apepi kin hena sanpa ihduwaśakapi kta, wamdi iyecen liupahu on wankan yapi kta; hena iyankapi kta, tuka mdokițapi kte śni; manipi kta, tuka hustakapi kte śni.

\section{WICOWOYAKE 41.}

1 Wita, mitokam inina yukan po; kinhan oyate kin ihduwaśakapi kte; hena kiyedan upi kte; hehan iapi kte; woyaco oiyotanke kin en witaya kiyedan unkupi kta.

2 Tuwe wiyohiyanpatanhan wicaśta owotanna kin yuhica he, iye siha ekta kico, qa itokam Ikcewicaśta kin qu, qa wicaśtayatapi wowidagyekiya he; watuśekśeca iyecen iye tamazasagye kin en, peji okahbogyapi kin iyecen iye tinazipe kin en wicaqu.

3 Hena kuwa awicaya, tanyan iyopta, iye siba canku wan ohna ye śni kin he ohna.

4 'Tuwe he kage ca hduśtan, otokaheya tanhan wicoicage kin cajewicayata he: Jehowa miye, tokaheya qa ehake un kin he miye ce.

5 Wita kin hena wanyakapi qa kokipapi ; maka ihanke kin hena cancanpi ; kiyedan hiyupi qa hipi.

6 Wicaśta otoiyohi lye takodaku kin okiciyapi kta, qa otoiyohi iye sunkaku, Waśaka wo, ekiciyapi kta.

7 Hecen wabago waśdoya kin waśagye ; tuwe maziyape on kaśduśdute cin he maziyapapi ape cin he waśagya ; qa mazaśdoyapi kin he waśte ce, eya: Unkan iyokatkuge on kasutapi, hecen yuhohopi kte śni.

8 Tuka Israel mitaokiye, Jakob wahdahinige cin, mitakoda Abraham cinca kin he niye :

9 Maka ihanke kin etanhan ecihdaku, qa hunnaptan tanhan cico qa heciciya; Mitaokiye kin he niye; cihdahinige ca elipeciye śni ce.

10 Wakokipe śni wo, cici waun nakaeś; nihinciye śni wo, Wakantanka nitawa kin he miye: ciyuwaśaka; han, ociciya: han, mitonwotanna nape etapa kin on ciyuza.

11 Iho, tona canniyeniyanpi kin hena owasin iśtecapi qa nihinciyapi kta ; hena takuśni iyececapi kta; qa wicaśta nicigépi kin hena a takunipi kte śni.

12 Wicaśta nicigepi qon hena awicayakite kta tuka iyewicayaye kte śni ; wicaśta nicizapi kin hena taku śni qa taku sotapi kin iyececapi kta.

13 Jehowa Taku Wakan nitawa, nape nietapa yus un kin he miye nakaeś: Kokipe śni wo; 235 


\section{ISAYA TAWOYUKCAN KIN,}

ociciya ce, tuwe eniciye cin he miye.

14 Jakob wamdudan, wakokipe śni wo, qa Israel wicaśta kin ; miye ociciye kta ce, Jehowa, qa tuwe openiciton, Israel Towakan kin he hecen eya.

15 Iho, mazicapan pe hinca teca hi yukan heca cicage kta; he kin hena yakapan qa yakamdu kta, qa paha kin hena aguyapi ha iyececa yakage kta.

16 Hena yakaduge kta, unkan tate kin bena yuwankan iwicacu kta, qa tateiyumni kin hena kahoya ehpewicaye kta: Tuka niye Jehowa on iduśkin kta, Israel Towakan kin on nihdatan kta.

17 Onśikapi qa wahpanicapi kin hena mini odepi, unkan wanica, ipuzapi on ceji sakapi ; hehan Jehowa miye nawicawahon kta, Israel Taku Wakan tawa kin miye hena elipewicawaye kte śni.

18 Hopuza en wakpa mdulidoke kta, qa kaksiza cokaya miniyowe kta: tintoskan kin he minihidoka qa makoce puze cin he miniyowe wakage kta.

19 Hante śa, śitta can, qa hedas can, qa wihdi can hena tintoskan owaju kta; wazisaka can utuhu can, qa wazi can hewoskan makoce kin en witaya huwahde kta.

20 Hecen wanyakapi kta, qa sdonyapi kta, qa iyukcanpi kta, qa witaya okahnigapi kta; Jehowa nape kin he de econ qa Israel Towakan kin he kaga.

21 Woakinica nitawapi kin aku po, Jehowa eya: Wicoie waśaka nitawapi hduha kiyedan u po, Jakob ta Wicaśtayatapi kin eya. 22 Hena aupi kta, qa taku u kte cin wanyagunyanpi kte; taku otokahe ekta un qon hena 236 yutaninpi kta, hena taku hecinhan, hecen hena awauncinpi kta, qa hena owihanke kin sdonunyanpi kta; qa iś taku u kte cin hena unkokiyakapi kte.

23 Taku tokata u kte cin hena pazo po, hecen taku wakan henicapi sdonunyanpi kta : han, taku waśte qa iś taku śica econ po, kinliar ekta euntonwanpi kta qa wanunyakapi kta.

24 Tho, takuśni enitanhanpi, qa niolianpi kin taku śni; tuwe nicalinigapi kin he wowahte śni.

25 Waziyatanhan tuwe mduhica, unkan he u kta ; wihinanpatanhan micaje hoyemakiye kta; wicaśtayatapi kin en wicau kta, upśija iyececa, qa wakśica kaga wan maka nacoco kin iyececa.

26 Tuwe otokaheya tanhan oyaka he; hecen sdonunyanpi kta; qa itokamtu, hecen, Owotanna ce, unkeyapi kta: Han, tuwedan wayuotanin śni; han, tuwedan woyake śni; han, tuwedan nioiepi nation śni.

27 Tokaheya kin he Zion heciye kta; Wanyaka, wanwicayaka wo: unkan tuwe wotanin waśte au kin he Jerusalem waqu kta.

28 Unkan ewatonwan, tuka wicaśta wanica; han, hena ekta, tuka wiyukcan wanica; qa hena wiwicamunga, tuka oie wanjidan amayuptapi śni.

29 Tho, hena iyuhipa takupi śni, iye ohanpi kin taku śni; wakagapi śdoyapi yuhapi kin hena tate qa toketu taninśni.

\section{WICOWOYAKE 42.}

1 Iho, mitaokiye sutaya wahduze; wahdahnige cin minagi iyuśkin kin hee; he Mitaniya awahnaka; iye wokonze 


\section{WICOWOXAKE 42.}

Ikcewicaśta kin wicakaye kiye kta.

2 Pan kte śni, qa hdawankan iyeye kte śni, qa canlsu ohna ho hdatanin kte sni.

3 Cedi kaśujapi kin he yukse kte śni, qa halionta kitanna ide kin he bosni kte śni : wowicake ekta wokonze au lita.

4. Iye hanye kte śni qa wacin ibosake kte sni, ecen wokonze maka kin en ekihde kta : qa wita kin hena iye toope kin apepi kta.

5 Jehowa Wakantanka, mahpiya kin kage ca hdumdaya; tuwe maka kin kamdaya qa taku etanhan uye cin; tuwe oyate dkan unpi wiconi wicaqu, qa tona amanipi woniya wicaqu ece kin he hecen eya :

6 Jehowa miye woowotanna en cico, nakun nape cihduze kta, qa cipatan kta, qa oyate wicotakuye tawapi kta, qa Ikcewicaśta ekta iyoyanpa cicage kta.

7 Iśta tonwanpi śni kin wicadumdaye kta, wicakaśkapi kin wicokaśke etanhan hiyuwicayaye kta, tona otpaza en iyotankapi okaśke tipi kin etanhan.

8 Jehowa he miye; micaje kin hee: unkan mitowitan kin he tuwe tokeca waqu kte śni, qa mitoyatan kin taku bagopi kin waqu lite śni.

9 Iho, taku tokaheya qon hena yuecetupi, nakun taku teca omdaka ece; hena icage śni itokam nahonciyapi kta.

10 Odowan teca wan Jehowa kahiyaya po, iye toyatan maka ihanke kin etanhan, tona miniwanca ekta idadapi qa taku on ojudan; wita kin hena, en ounyanpi kin hena koya :

11 Tintoskan qa en tonwanyanpi ho wankan yeyapi kte, Kedar en tonwanyanpi kin hena: imni- ja ounyanpi kin hena dowanpi kte, he ipa kin etanhan iyaśapi nunwe.

12 Wowitan Jehowa qupi nunwe, qa iye toyatan kin he wita kin ekta oyakapi kte.

13 Wicaśta waśaka iyecen Jehowa hinanpe kta: wicaśta zuye cin iyecen wowinawizi hduliice kta: iyaśa kta, han; ho hdatanin kta; tokawicaye cin on ihduwaśake kta.

14 Wanakajatanhan inina manka; ie śni waun; tinsmiciya ce ; tuka nakaha winohinca hokśiksuya iyecen waśicahowamde kta ; wamdapote kta qa wancahna wanawapce kta.

15 Hீe qa paha kin hena hiewoskarl wakage kta, qa wato en un kin iyulipa mduśnije kta; qa wakpa kin hena iliewita wakage kta; qa mdedan kin hena mdupuze kta :

16 Qa canku wan sdonyapi śni kin he ohna iśtagongapi kin maniwicawaye kta; ocankn sdonyapi śni kin ohna yus awicawau kta : wicitokam otpaza kin he iyoyanpa kta, qa taku śkośkopa owotanna wakage kta. Dena taku kin ecawicawecon kta, qa awicamduśtan kte śni.

17 Tona wakagapi bagopi wacinyanpi, tona wakagapi śdoyapi kin, Taka wakan unkitawapi kin he niyepi ce, eyapi kin liena nina iśtecapi kta, hena hokta hdicuwicayapi kta.

18 Noge nitpapi, nalion po; qa iśtanigongapi, etonwan po, hecen wandakapi kta ce.

19 Tuwe mitaokiye iyecen iśtagonga he; qa tuwe wahośiya mitawa yewaśi kte cin iyecen nogetpa he: tuwe koda iyecen iśtagonga, qa tuwe Jehowa taokiye iyecen iśta wanica he.

20 Taku ota wandaka, tuka 237 


\section{ISAYA TAWOYUKCAN KIN,}

awacanni kte śni: noge yulidokapi, tuka wanahon kte śni.

21 Jehowa iye toowotanna on iyuśkin hinca; woope kin he hdutanka qa hduonihan kta.

22 Tuka oyate kin de wicakipi qa waboticapi ; hena owasin makohdoka ohna wicayuzapi, qa wicokaśke tipi ohna nawicahmanpi : hena wayaka awicayapi, qa tuwedan ewicahdaku śni ; wawicakipi qa tuwedan, Wicakicu wo, eye śni.

23 Niyepi etanhan tuwe de awacin kta he; tuwe anolikiye ca tokata anagoptan kta he.

24 Jakob wakipi kta wicaqu, qa Israel wamanonpi en hiyuwicaye cin he tuwe he: Jehowa waunkiciltanipi kin hee śni he. Iye tacanku kin ohna mani wacinpi śni, qa toope kin anagoptanpi śni nakaeś.

25 Heon etanhan iye tocanniye wohitika qa wicokicize wowaśake kin he akaśtan : unkan he ohomni aidekiya, tuka sdonye śni ; qa iye guya tuka cante ekta yus wacin śni.

\section{WICOWOYAKE 43.}

1 Tuka wanna Jakob, tuwe nicage cin he, qa Israel, tuwe icahniye, Jehowa hee hecen eya; Wakokipe śni wo, opeciciton nakaeś; nicaje on cico, tawaciya.

2 Mini kin ehna idada kinhan cici waun lkta; qa wakpa kin opta, he akam iniyaye kte śni; peta ehna mayani kinhan nigu k te śni, nakun ide kin ainide kte śni.

3 Jehowa Wakantanka nitawa kin he miye nakaeś, Israel Towakan, Wanikiya nitawa; opeciciton kta on Egupta waqu, niye on Kuś qa Seba iyopewaya.
4. Miiśta en nitehika heon ni. yuonihanpi, nakun miye waśtecidaka; heon etanhan niye on wicaśta wicawaqu kta, qa oyate ninagi on.

5 Wakokipe śni wo, miye cici waun nakaeś; wicoicage nitawa wiyohiyampatanhan awaku kta, qa wiyohpeyatanhan mnaciye kta:

6 Waziyata kin hewakiye kta ; Hiyuya wo; qa itokaga kin ; $\mathrm{Pa}$ tan śni wo; tehantanhan micinkśi awicau wo, qa micunkśi kin maka ihanke kin etanhan :

7 Tona micaje on caśtonpi qa mitowitan on wakaga owasin; miye wakaga nakaeś, han icahwaya.

8 Oyate iśtagongapi kin hena hiyuwicaya wo, qa tona iśta yulranpi; qa nogetpapi, qa tona noge yukanpi :

9 Ikcewicaśta owasin witaya upi kta, qa oyate kin mniciyapi kta; hena etanhan tuwe he de oyake kta, qa taku otokahe ekta un qon unkipazopi kta he: wayaotanin wicahdoupi kte, hecen ihdaowotanpi kta; qa iś nahonpi qa, He wowicake ce, eyapi lite.

10 Wayaotanin mitawa kin he niyepi, qa mitaokiye wahdahnige ciqon, Jehowa eya; hecen sdonyayapi qa wicamayadapi kta, qa he miye e oyakahnigapi kta : mitokam taku wakan takudan kagapi śni, qa mihakam wanice kta.

11 Jehowa he miś miye: qa micunonpatanhan Wanikiya wanica.

12 Miye womdake ca waniwakiya qa wamdaotanin, wanji tokeca niyepi ehna un śni qehan; heon etarhan wayaotanin mitawa kin niyepi, Wakantanka he miye e, Jehowa eya. 


\section{WICOWOYARE 44.}

$13 \mathrm{Han}$, anpetu kin he itokam he miye; qa tuwedan minape etanhan waeyaku okiti śni : miye taku ecamon kta, qa tuwe anapte kta he.

14. Jehowa Wanikiya nitawapi, Israel Towakan kin he hecen eya; Niyepi on Rabel ekta yewicawaśi, qa wonajice tawa iyuhpa kun ehpewicawaya, nakun Kasdim oyate wita wata ohna iyaśapi kin hena.

15 Jehowa Taku Wakan nitawapi, Israel Icahwicaye cin, Wicaśtayatapi nitawapi kin he miye ce.

16 Tuwe miniwanca ohna canku wan lage ca mini tanka en ocanku wan ;

17 Tuwe canpahmihma qa śuktanka, ozuye qa wowaśake hiyuye cin, Jehowa heehecen eya: Witaya iwankapi kta, ake inajinpi kteśni : hena atakunipi śni, hahonta ide kin iyecen kasnipi ce.

18 Taku tokaheya qon hena kiksuyapi śni po; qa taku tanina un kin hena awacinpi śni po.

19 Tho, taku teca wan ecamon; wanna icage kta; he sdonyayapi kte śni he. Han, tintoskan canku wan wakage kta, hewotahedan wakpa wanke kta.

20 Tinta wamanica kin, unktehi qa hinhankaga cinca hena mayuonihanpi kta; tintaoskan mini hiyuwaye, hewotahedan wakpa wicawaqu, mitaoyate wahdahnige ciqon mini yatkewicawakiye kta heon.

21 Oyate kin de miye micicaga: hena mitoyatan yaotaninpi kta.

22 Tuka Jakob, hoyemayakiye śni ; Israel, miye on mdoyakițe ciqon :

23 Wohulinage nitawa tahinca cinca mayakahi śni ; qa nitawośna on mayaduonihan śni. Wo- śnapi on wowidagciye śni, qa wowizite on iyotanhan iyeciciye śni.

24 Mazaska on sinkpe tawote takudan opemiyeciton śni, qa nitawośna cepa on imnamayaye śni : tuka wayahitani on wowidag mayaya, taku śica ecanon kin on iyotanhan iyemayakiya.

25 Miye, miye hinca on, tuwe taku śica nitawa nicicajuju kin he miye; qa wayahtani kin hena weksuye kte śni.

26 Kiksuyemayan ye ; unkiciyukcan kta : nibdaowotanna kta e on wohdaka wo.

27 Niyate tokaheya qon he wahtani, qa tona waonspeniciyapi kin hena makipajinpi.

28 Heon etanhan tipi wakan itancanpi kin wicamdaśica, qa Jakob woyaśice en iyewaya, qa Israel woiyopeye ekta.

\section{WICOWOYAKE 44.}

1 Tuka nakaha Jakob mitaokiye, nahon wo ; qa Israel wahdahinige cin :

2 Jehowa hecen eya; Tuwe nicage ca wicatamni etanhan icahniye cin he oniciye kta: Jakob mitaokiye, wakokipe śni wo; qa niye Jeśurun wahdahnige cin.

3 T'uwe ipuza kin he mini awakaśtan kta, qa mini tanka maka puza kin akan: nicinca kin Mitaniya awakaśtan kta, qa mitoyawaśte cincawicayaye cin akan:

4 Hecen peji ehna icagapi kta, wakpicahda cohwanjica kin iyececa.

5 De, Jehowa tawamayan ce, eye kta; qa he Jakob caje eya caje ihdate kta; qa wanji iś, Jehowa tawa ce, iye nape en okiwa kta, qa Israel caje eya caje ihdate kta.

6 Jehowa Israel ta Wicaśtaya239 


\section{ISAYA TAWOYUKCAN KIN,}

tapi, qa tuwe opekiton qon, Jehowa wicobe tawa kin he hecen eya; Tokaheya kin he miye, qa chake un kin be miye; qa micunonpatanhan Taku Wakan wanica ce.

7 Qa tuwe, miye iyececa eyanpaha kta, qa he oyake kta, qa wiyeya emicihnake kta, wanakaja oyate ewicawahde hin iyececa he: hecen taku tona $u$, qa taku u kte cin hena owicakiyakapi kta.

8 Cancanpi śni qa wakokipapi śni po: hetanhan miye nahonciyapi śni qa omdake śni he; wayaotanin mitawa kin he niyepi nakaeś: Micunonpatanhan Taku Wakan yukan he. Hiya, Imnija wanica, takudan sdonwaye śni.

9 Tona wakagapi bagopi kagapi kin hena owasin takupi śni ; taku waśtedakapi kin hena takudan okihi kte śni: nakun iye ihdaotaninpi ; hena wawanyakapi kte śni, qa wasdonyapi kte śni; hecen iśtecapi kta tuka.

10 Tuwe taku wakan wan lraga, qa wakagapi wan takudan okihi śni kin heca śdoya he.

11 tho, tawasitku kin iyulipa iśtecapi kta: qa tona kagapi kin hena wicaśta etanhanpi : hena owasin yuwitayapi kta, hena najinpi kte; hena wakokipapi kta, hena witaya iśtecapi kta.

12 Maza kage cin he onspe wan kaga, qa petaga ehna htani, qa nakun maziyape on kicanyan qa iye isto waśake cin on yuśtan kta : han, iye hinca wotektehda, unkan towaśake wanica; mini yatke, śni, unkan hunkița.

13 Cankajipe cin he caniyute wan on iyuta ; icago wan on icagokta ; canicahdoke on kaśpe kta ; qa mazicago wan on kago kta ; qa hehan wicaśta ouncage iyece- ca kage kta, wicaśta towaśte lkin iyececa; heren tipi kin ohna he kita.

14 Hante śa hdaksa, nakun uskuyeea qa utuku can icu, he contanka can kin ehna kiyuwaśake kta ; wazi can wan oju, unkan magaju kin icahye kta.

15 Unkan he wicaśta wan peta en aonpe kta; qa hetanhan iye icu kta, qa on cosiciye kta; han, iceti qa aguyapi śpanyan; han, on taku wakan wan kage ca ohoda; etanhan wakagapi bagopi wan kage ca itokam makata ehpeiceiya.

16 Hanke etanhan peta en huhnaga; hanke on tado yuta; wośpanye ceonpa qa imnan; han, cosiciya, qa, Aha, macoza, peta wanmdaka ce, eya:

17 Qa taku okaptapi kin he taku wakan kaga, wakagapi bagopi iye tawa kin hee; en makata ehpeiciya, qa ohoda, qa cekiya, qa, Emahdaku wo, taku wakan mitawa kin he niye nakaeś, eya.

18 Hena sdonyapi śni, qa okahnigapi śni; iye hena iśta aohdutewicaya, hecen wanyakapi kte śni, cantepi nakun, hecen okahinigapi kte śni.

19 Heon tuwedan cante on awacin śni, nakun wosdonye wanica, qa wookahnige wanica, on heye lita tuka; Hanke peta en huhnahwaye; han, nakun he petaga on aguyapi spanwaye; on tado cowaqin qa wata: unkan taku okaptapi kin he etanhan wowalitedaśni wan wakage kta he; cankaga wan en makata elipemiciye $\mathrm{k}$ ta he.

20 Cahota yuta; cante hnayanpi wan he icunonpa iyayeya, heon iye nagi eihdaku kte śni, qa, Minape etapa ohna woitonśni yuke śni he, eye kte sni.

21 Dena kiksuya wo, Jakob qa 
Israel; mitaokiye kin he niye nakaeś: miye cicaga, mitaokiye kin he niye: Israel, miye aciktonje kte sni.

22 Taku śica ecanon kin, mahipiya śoka iyececa, wakajuju ; qa wayahtani kin mahpiya sapa iyececa: Miye en ihdoku wo, opeciciton kin heon etanhan.

23 Mahpiya, dowan miye, Jehowa hecon nakaeś : maka ihukuya kin, iyaśa po: paha kin niye, contanka qa ohna can o toiyohi, kahiyaya po: Jehowa Jakob opekiton nakaeś; qa Israel en wowitan içicaga.

24 Jehowa openiciton qa wicatamni etanhan icabniye cin he hecen eya; Jehowa taku owasin kaga, iśnana makpiya kin hdumdaya qon he miye : maka kin mıśnana wahdumdaya:

25 Tona itoupi śni wowakta tawapi kin yuecetu śni, qa wapiye sa kin wicayuhnaśkinye kta ; wicaśta ksapa hekta itoheya hdicuwicaya, qa tookahnigepi kin yuwitkotkoke kta:

26 Iye taokiye oie kin yuecetu, qa wahosilya tawa tawowahokonkiye kin ecetukiciciye kta ; tuwe, Ounniyanpi kta ce, Jerusalem eciya; qa Juda otonwe kin, Ake nicagapi kta, qa makoskantuya wanke cin ake piwaye kta ce, eye cin he miye.

27 Tuwe mini śbe cin heciya; Puza wo, qa wakpa nitawa oyaliewaye kta ce :

28 Tuwe Kuros heciya; Wonwicaye mitawa hee, hecen mitoiyokipi ocowasin econ kta; qa Jerusalem heciye kta; Nicagapi kte ; qa tipi wakan kin, Ohehdepi nitawa ehnakapi kta ce, eciye kta.

\section{WICOWOYAKE 45.}

1 Jehowa Kuros sdakiye cin hee, itokam Ikcewicaśta kin awicahanpi kta e nape etapa sutaya mduza; qa wicaśtayatapi ipiyake wicawakiyuśke kta, hecen he itokam tiyopa itakihna kin yuhdokapi kta; qa tiyopa kin hena ecen icupi It te śni, hecen eciya ;

2 Nitokam miye mde kta, qa taku śkopa kin he owotanna wakage kta: mazaśa tiyopa kin mduwehwege kta, qa maza sapa inatake kin wakaksaksa kta.

3 Qa otpaza en womnaye kin cicu kta, qa wowijice onalibe en nahmanpi kin hena; hecen Jehowa miye, tuwe nicaje cajeyate cin, Israel Taku Wakan tawa kin he miye o sdonyaye kta.

4. Jakob mitaokiye qa Israel wahdahnige cin heon nicaje on cico kta: sdonmayaye śni eśta caściton kta.

5 Jehowa he miye, qa tokeca wanica, micunompatanhan Taku Wakan wanica: miye ipiyagciton lita, sdonmayaye śni eśta.

6 Hecen tona wihinanpatanhan qa wiyohpeyatanhan kin hena micunonpatanhan wanica e sdonyapi kta. Jehowa he miye, qa tokeca wanica.

7 Iyoyanpa icaliwaya, qa otpaza wakaga; wookiye mduśtan, qa wośice wakaga; Jehowa miye dena owasin ecamon ece.

8 Mahpiya kin wankantanhan śbuya miye, qa mahpiya śoka kin hena woowotanna hinheya nunwe; maka kin ihduhdoke kte, hecen wowanikiye icahyapi kte, qa woowotanna kici icaga nunwe: Jehowa miye hena wakaga ce.

9 Hehehe, tuwe Waicahye tawa kin kipajin hecinhan ; wakśica onśpa maka wakśica onśpa kicica. Upśija kin he tuwe kage cin, Taku ecanon he, eciye 241 


\section{ISAYA TAWOYUKCAN KIN,}

kta he: qa nitohtani, Nape wanica ce, eye $k$ ta he.

10 Hehehe, tuwe atkuku heciya; Taku icaliyaya he; qa winohinca kin, Taku yaton he, eciye cinhan.

11 Jehowa Israel Towakan qa Waicahye tawa kin he hecen eya; Micinca on taku tokata $u$ kte cir hena imawanga po, qa minape taku kage cin on econ mayaśipi kta.

12 Miye maka kin wakaga, qa wicaśta aicaliwaye. Miye minape kin mahipiya kin yumdayapi, qa obe tawa kin iyuhpa mdusuta.

13 Woowotanna on iye icahwaya, qa tacanku owasin mduowotanna kta: iye mitotonwe kin kage kta, qa wayalia mitawa hdicuwicakiye kta, on opetonpi qa wiyopeyapi wanica, Jehowa wicobe tawa kin he hecen eya.

14. Jehowa hecen eya; Egupta tohtani, qa Kuś tokamna, nakun Sabea wicaśta tanka tokamna kin niye en u kta, qa hena nitawa kta; nitokam upi kta; mazaicicahiha ikoyag ihdoupi kta, qa nitokam makata elipeiciyapi kta: hena ceniciyapi kta; Awicakehan Taku Wakan kin nici un, qa wanji tokeca yuke śni, taku wakan wanica ce, eyapi kta.

15 Israel ta Wakantanka, Wanikiye cin he, awicakehan Taku Wakan anaiciibe cin he niye.

16 Hena owasin witaya iśtecapi qa nakun nihinciyapi; wakagapi kagapi kin hena witaya wonihinciye ekta iyayapi.

17 Jehowa en wowanikiye owihanke wanica on Israel nikiyapi kta: niye iniśtecapi kte śni, qa nihinniciyapi 'kte śni, owihanke wanica.

18 Jehowa malipiya kin kaga; Wakantanka iye hinca maka kin 242 icahye ca kaga; he hdusuta, taku on etanhan śni kage śni, ohna tipikta e icaliye cin he hecen eya; Jehowa he miye, qa tokeca wanica.

19 Woinahibe en, maka otpaza awanke cin ohna iwae śni: Jakob cinca kin, Taku śni on miite akita po, ewicawakiye śni: Jehowa woowotanna ohdake cin he miye, taku ecetu kin hena omdaka ece.

20 Miniciyapi qa u po ; Ikcewicaśta etanhan nayajicapi kin witaya kiyedan ihdou po. Tona wakagapi bagopi can kin ekihdepi qa taku wakan wanikiya okihi śni cekiyapi kin hena takudan sdonyapi śni.

21 Woyaka po qa kiyedan ihdou po: han witaya ikiciyukcanpi kte. Wanakaja tanhan de tuwe oyaka he; hetanhan tuwe yaotanin he: Jehowa miye śni he; qa micunonpatanhan taku wakan wanica; Taku Wakan owotanna qa Wanikiya; micunonpa tanhan wanica.

22 Maka ihanke kin owasin ahimatonwan po, kinhan yanipi kta: Wakantanka he miye, qa tokeca wanica nakaeśs.

23 Miye hinca on wakonza, woowotanna on wicoie kin mii etanhan enapeya, unkan hdicu kte śni: Miye en wicahupahu otoiyohi patuje lita, qa wicaceji otoiyohi wohdake kta:

24 Awicakehan Jehowa en woowotanna qa wowicake mduha ce, eye kta: iye en ahi kta; qa tona canniyeyapi kin owasin iśtecapi kta.

25 Israel cinca kin owasin Jehowa en ihdaowotanpi qa itanpi kta.

WICOWOYAKE 46.

1 Bel canpeśka makehde ina- 


\section{WICOWOYAKE $4 \%$.}

jin, Nebo patuś un: wakagapi tawapi kin hena woteca qa wanunyanpi kin akan hiyeya: waqinpi nitawapi kin iakan ehnakapi; mdokițe cin he yuśaka.

2 Patuś unpi, witaya canpeśka makehde yukanpi; taku qinpi kin anakikśin okihipi śni, tuka iyepi kaeś wayaka iyayapi.

3 Jakob tiyohnaka qa Israel tipi etanhan tona okaptapi, wicatezi etanhan wicayuhapi, wicatamni etanhan wicaqinpi owasin niye anamagoptan po:

4 Wicahinea ehan yaipi kta hehanyan he miye ; qa pa skapi hehanyan cicinpi kta; miye wakaga nakun mduhe kta; miye hinca wawaqin kta, qa ecihdakupi kta.

5 Hecen tuwe e imayadacinpi kta he, qa iyececa mayakagapi kta he, qa kici iwanmayadakapi kta, hecen akiyeuncecapi kta.

6 Mazaska opiye etanhan mazaskazi hiyuyapi, qa onaspeyapi kin on mazaska tkeutapi ; mazaskazi kage cin wan opetonpi kta ; unkan he taku wakan wan kage kta : en makata ehpeiciyapi kta, han ohodapi kta:

7 Hinyete akan ehnakapi kta; qinpi kta, qa tohe kin en ehdepi lsta; unkan en he kta; tohe kin etanhan tokan ye kte śni: han, tuwe hoyekiya eśta ayupta okihi kte śni, qa tokakije etanhan eyaku kte śni.

8 De kiksuya po, qa wicaśta yaunpi hdutanin po: ake cante en yuza miye, wayahtanipi sa.

9 Taku wanakajatanhan un kin hena kiksuya po; Iyotan Waśake cin he miye, qa tokeca wanica; Taku Wakan kin he miye, qa tuwedan iyemacece śni.

10 Otokaheya tanhan owihanke kin omdaka, qa wanakajatanhan taku nahanhin econpi śni kin; Mitowiyukcan kin ecen he kta, qa mitoiyokipi kin iyulipa mduśtan kta ce, epa :

11 Wihinanpatanhan zitkadan wayapote sa wan weco, qa makoce tehan wanke cin etanhan mitowiyukcan wicaśta kin : Han, miye ecen epa, nakun ecetuwakiye kta; wakonza, nakun ecen ecamon kta ce.

12 Tona cante nisutapi, woowotanna itehan yaunji kin, anamagoptan po :

13 Mitoowotanna kin he kiyedan awaku; he itehan yanke kte śni, qa wowanikiye mitawa kin he hanhi kte śni. Tuka Israel mitowitan kin on Zion en wowanikiye ewehnake kta

\section{WICOWOYAKE $4 \%$.}

1 Babel cunwintku witanśna, kun u qa watuśekśeca en iyotanka wo: makata iyotanka wo: Kasdim cunwintku, oiyotanke waśte wanica; detanhan icimana wankadan qa suta śni eniciyapi kte śni.

2 Inyan wiyutpan kin icu qa wotpanpi kaga wo: ite akahpe nitawa eyaku wo, nitośke hduśdoka wo, sican hducoka wo, wakpa kin copa wo.

3 Tanconikadan śdayehna un kta; han, nitowiśtece kin wanyakapi kta: watokiconpi ecamnn kta, qa wicaśta kici oweciye kte śni.

4 Opeunkitonpi kin he Jehowa wicobe tawa eciyapi, Israel Towakan kin hee.

5 Kasdim cunwintku, inina iyotanka wo, qa otpaza ekta ya wo; detanhan icimana, Wokiconze wicaśtayatapi winohinca, eniciyapi kte śni.

6 Mitaoyate canniyewicawakiya, taku mitawa kin he mduśape 


\section{ISAYA TAWOYUKCAN KIN,}

ca ninape en wicawaqu. Ecaca onśiwicayada śni ; wicahincapi kin hena cannapinpi nitawa tkeya a wicayahnaka.

7 Qa heha; Ohinniyan wicaśtayatapi wimanohinca kta ce. Hecen dena en nicante eyahnake śni, owihanke kte cin he yeksuJe śni.

8 Heon etanhan de nahon wo, oiyokipiiciya nanke cin, oziiciya idotanke, nicarite en hehe cin; Miye qa micunonpatanhan tuwedan śni, wiwazica imdotanke kte śni, qa wicacinca taninpi śni kin he sdonwaye kte śni ce, eba.

9 Tuka dena oza ihnuhanna, anpetu wanjidan en aniu kta, wicacinca taninpi śni, qa wiwazica unpi kin : hena ocowasin en ni u kta, wakan yakaga ota qeyaś; nina hin wapiyapi ecanon eśta.

10 Niohan śice cin he wacinyakiya; Tuwedan wanmayake śni $\mathrm{ce}_{2}$ eha. Nitoksape qa nitookahnige kin he nihnayan: hecen nicante en heha; Miye, qa micunonpatanhan tuwedan śni ce.

11 Heon etanhan taku śica en niu kta; tokiyatanhan hinanpa sdonyaye kte śni ; qa wośice anihinhpaye kta; yutokan iyeyaye kta nyakihi kte śni ; qa woihangye sdonyaye kte śni kin he ihnuhanna en niu kta.

12 Wanna wapiyapi nitawa, qa wakan yakaga ota hinca, inicaga ehantanhan ehna yaśkan kin hena hduha inajin wo; okinni iwaśte yaun oyakihi kta, okinni wakokipe wicayecage kta.

13 Wowiyukcan nitawa ota on mdoyakita. Iho, wanna tona ina hpiya iyutapi kin, tona wicanhpi wanyakapi, tona wi kin on waayatapi ece kin hena inajinpi, qa taku en aniupi kte cin etanhan eniyakupi nunwe.
14 Tho, hena aguyapi hu iyececapi ; peta huhnahwicaye kta; ide nape kin etanhan iye nagi eihdakupi kte śni: petaga on cosiçiyapi, qa peta itokam iyotankapi kte cin wanice kta.

15 Tona inicaga ehantanhan om litayani, wicaśta wopeton nitawa kin hena hecen nicuwapi kta; otoiyohi makoce tawa kin ekta hde kta; tuwedan niniye $k$ te śni.

\section{WICOWOYAKE 48.}

1 Jakob tiyohnaka, de nation po, tona Israel caje on cajeniyatapi, qa Juda mini kin etanhan inayapapi, tona Jehowa caje on wakonzapi qa Israel ta Wakantanka cajeyatapi ece, tuka wowicake qa woowotanna eciyatanhan śni.

2 Hena otonwe wakan kin icajeiciyatapi, qa Taku Wakan Israel tawa kin he wacinyanpi nakaeś: He Jehowa wicobe tawa eciyapi.

3 Otokaheya tanhan taku tokaheya qon hena omdaka; unkan hena mii etanhan enape, qa hena mdaotanin: ihnuhanna ecamon, unkan hena ecetu.

4 Nitehika e sdonwaya, qa nitahu maza ikan kin heca, qa niite mazaśa, nakaeś :

5 Heon etanhan otokaheya tanhan hena ociciyaka; hinyahin ecetu śni ehan ciciyaotanin : okinni, Wakagapi mitawa dena econ; qa wakagapi bagopi mitawa, qa wakagapi śdoyapi mitawa kin he hena yuśtan ce, ehe kta nace.

6 Wanna nayahon, dena owasin wanyaka wo; unkan niye odakapi kte śni he. Detanhan taku teca wanyagciciya, taku nahmanpi qon, unkan hena sdonyaye śni. 


\section{WICOWOYAKE 49.}

7 Hena nakaha kagapi, qa otokaheya tanhan śni ; anpetu kin de itokam hena nayahon śni; okinni, Iho, hena sdonwaya ce, ehe kta tuka qon.

8 Han, nayahon śni; hàn, sdonyaye śni ; han, nakun itokam noge niyulidokapi śni. Wahnayan oyahande kta, qa wicatamni etanhan wahtani sa eniciyapi kin he sdonwaya.

9 Micaje on etanhan mitocanniye wahdapte kta, qa mayatanpi kta e niye on anamiçipte kta, hecen cicakse kte śni.

10 Iho, ciyuecedan, tuka mazaska kicica śni ; wokakije oceti kin en cihdahniga.

11 Miye on etanhan, miye hinca on etanhan ecamon kta : tokeca micaje yuaśapapi kta he: qa mitowitan kin he tuwe tokeca waqu kte śni.

12 Jakob anamagoptan wo, qa Israel weco qon; He miye, Tokaheya qa nakun Ehake un kin he miye.

13 Nakun minape maka oahe cin ehnaka; qa minape etapa mahpiya kin. hdumdaya. Hena wicawakipan eca witaya inajinpi ece.

14 Niyepi owasin mniciyapi qa nahon po: hena etanhan wanji tukte dena oyaka he. Jehowa he waśtedaka: iye toiyokipi kin Babel en econ kta, qa iye nape Kasdim akan yanke kta.

15 Miye, miye iwae; han, miye he weco; miye awahi; unkan iye tacanku kin tanyan ihunnikiye kta.

16 Mikiyedan u po, de nahon miye: otokaheya tanhan oinahbe en iwae śni; totanhan un kin hen miś waun. Unkan nakaha Jehowa Itancan kin u maśi, qa iye Taniya kin.

17 Jehowa openiciton kin, IsT 2 rael Towakan kin he hecen eya ; Jehowa Taku Wakan nitawa, token oyakihi kta onspeniciye, canku opeya de kte cin he ohna aniye cin he miye.

18 Tokin mitawoahope kin hena anayagoptan unkanś ; hehan, wookiye nitawa kin wakpa wan iyecece kta, qa nitoowotanna miniwanca taja kin iyecece kta tuka.

19 Nakun nicinca wiyaka kin iyecece kta, qa nitezi etanhan icage cin hena casnu iyececapi kta: iye caje kin kaksapi kte śni, qa mitokapatanhan ihangyapi kte śni tuka.

20 Babel etanhan hdinanpa po, Kasdim etanhan najica po ; dowanpi ho kin on eyanpaha miye, de oyaka po, maka ihanke kin hehanyan yaotanin miye; Jehowa iye taokiye Jakob he opekiton ce, eya po.

21 Unkan hena hewotahedan makoce kin ohna awicaye ciqon hehan ipuzapi śni : imnija kin etanhan mini hiyuwicakiciciya ; nakun imnija kin kahidoka, unkan mini bomdu hiyu.

22 Tona śicapi kin hena wookiye nicapi ce, Jehowa eya.

\section{WICOWOYAKE 49.}

1 Wita kin, niye namahon po; qa oyate tehan yaunpi, anohkiya po: Wicatamni etanhan Jehowa makipan, ina tezi etanhan cajemayata.

2 Qa mii kin he mazasagye pe hinca iyececa kaga; iye nape ohanzi kin en namahbe, qa wanhinkpe pabezapi makaga; iye wanju tawa kin onamahman;

3 Qa hemakiya; Israel, mitaokiye kin he niye, niye on mihduwitan kta ce.

4 Hehan miye hepe; Takuśni 245 


\section{ISAYA TAWOYUKCAN KIN,}

on htawani; etanhan takudan icage śni, qa takuśni on mitowaśake wahdusota; 'Tuka woyaco mitawa kin he Jehowa kici un, qa mitolitani kin mita Wakantanka kici un.

5 Unkan nakaha Jehowa wicatamni etanhan taokiye maye kta makaga, Jakob iye en awaku kta, he kaken eya; Israel mnayanpi śni qeyaś Jehowa iśta kin en wowitanyan waun $\mathrm{kta}$, qa mita Wakantanka wowaśake mitawa kin hee kta.

6 Nakun hecen eya; Mitaokiye he niye, Jakob towicoun najin wicayakiye kta, qa Israel okaptapi kin wicaduecetu kte cin he taku tanka śni : nakun Ikcewicaśta-kin iyoyanpa yaun kta cicu, heon maka ihanke kin hehanyan wowanikiye mitawa kin he niye kta.

7 Jehowa Israel opekiton, qa Towakan kin he, tuwe nina śicedakapi, tuwe Ikcewicaśta wahitedapi śni, wicaśtayatapi tawowidake kin he heciya; Wicaśtayatapi wanyakapi kta, qa wicaśta itancanpi kin inajinpi $\mathrm{kta}$, nakun patujapi kta, Jehowa wacinyepica; Israel Towakan kin on ; unkan iye nicalinigapi kta.

8 Jehowa kaken eya; Tohan oiyokipi kinhan nacilion, qa wowanikiye anpetu kin en ociciya: Unkan awanciyake kta, qa oyate kin en wicotakuye wan ecihde kta, maka kin yusutapi kta, qa ounyanpi hewoskantu kin tawa wicayaye kta:

9 Hecen wicakaśkapi kin, 'Tankan u po, ewicayakiye kta : tona otpaza en unpi kin hena, Thdutanin po, ewicayakiye kta. Canku kin ohna wotapi kta, qa paha sdayehna owasin akan tawilianpi yuke kta.

10 Hena e wotektehdapi kte 246 śni, qa ipuzapi kte śni; qa oma. śte qa anpetu wi kin aśpanwicayapi kte śni: Tuwe onśiwicakida kin he yus awicaye kta nakaesś, qa miniyowe kin en awicai kta.

11 Qa he mitawa owasin canku wakage kta, qa ocanku tanka mitawa kin hena wankan yeyapi kta.

12 Tho, dena tehantanhan hipi kta; qa iho, dena waziyatanhan qa wiyohpeyatanhan; qa dena Sinim makoce kin etanhan.

13 Mahpiya, dowan miye; qa maka, wiyuśkinyan un wo; nakun paha kin, dowan hinhda miye; Jehowa iye taoyate cantohnagwicaya nakaeś, qa kakiświcaye cin hena onśiwicakida kta.

14 Tuka Zion heya; Jehowa amayuśtan, qa Itancan mitawa amiktonja ce.

I5 Winohinca hokśiyoqopa azin kin he akiktonje kta, hecen iye tamni cinca kin onśikida kte śni he: Han, hena wakiktonjapi kta nace; tuka miye qe aciktonje kte śni.

16 Iho, minape cokaya en bacigo ; conkaśke nitawa ohinniyan mitokam wanke.

17 Nicinca inahnipi : tona niyujujupi qa niyutakunipi śni qon hena nitantanhan napapi kta.

18 Ohomni iśta yuwankan ikikcu qa wanyaka wo: dena owasin ihduwitayapi; hena en niupi. Miye wani, Jehowa eya, hecen dena iyulipa koyahdake kta, oinpi wan iyececa, qa winohinca wan hihnaton kte cin iyecen ipiyahdake kta.

19 Tintoskan nitawa, qa hewoskan makoce nitawa. qa makoce en niyutakunipi śni qon he dehan wicota en ounyanpi kin on onikan kte śni, qa nanipcapi qon hena itehan unpi kta. 


\section{WICOWOYAKE 50.}

20 Nakun cinca nicitaninpi śni qon hena ninoge en heyapi kta; Makoce ocikan śni, makiyukan wo, hecen en ounwaye kta ce.

21 Hehan nicante en hehe kta; Dena tuwe icalmiciya be, cinca makitanin śni, qa cinca codan wayaka waun qaunhdaka waun ; unkan dena tuwe icahwicaya he. Iho, miśnana omakaptapi ; dena tokiya unpi tuka he.

22 Jehowa Itancan kin he hecen eya: Iho, Ikcewicaśta ekta nape wahdugate $\mathrm{kta}$, qa oyate kin en wiyokihedan wan ewehde kta: unkan maku ohna nicinkśi awicaupi kta, qa nicunkśipi kin hinyete akan wicaqinpi kta.

$23 \mathrm{Qa}$ ateyayapi wonicupi kte cin wicaśtayatapi eepi kta, qa winohinca tanka tawapi kin hena azinniciyapi kta: hena niye en makipusdiya patuś inajinpi kta, qa nisiha watuśekśeca kin asdipapi kta: unkan Jehowa he miye sdonyaye kta ; tona wacinmayanpi kin hena iśtecapi kte śni nakaeś.

24. Wakipi kin he wicaśta waśaka etanhan icupi lita he, qa owotanna wayaka un kin he ehdakupi kta he.

25 Tuka Jehowa hecen eya; Wicaśta waśaka wayaka wicayuhapi kin hena ewicayakupi kta, qa wakipi kin wicaśta wohitika ewicakicihdakupi kta ce. Tuwe nicize cin he kici wecize Kta nakaeś, qa nicinca niwicawaye kta.

26 Qa tona kakiśniyanpi kin hena iye cehpi hdunwicawakiye kta, qa iye we kin on witkopi $k t a$, miniśa teca on iyececa ; unkan Jehowa Wanikiya nitawa, qa tuwe openiciton, Wanji Waśaka Jakob tawa kin he miye e wicacehpi owasin sdonyapi kta.

\section{WICOWOYAKE 50.}

1 Jehowa hecen eya; Kicipa. ganpi wowapi on nihun elpewa. kiye cin tukte e he: qa icazomakiyapi kin tukte wanji en wiyopeciciyapi he. Iho, wayahtanipi on wiyopeniciyapi, qa taku śica ecanonpi kin on etanhan inayayapi kin kpaganpi.

2 Heon etanhan wahı qehan tokeca wicaśta.wanica he: wapan qehan tokeca tuwedan amayupte śni he. Minape ptecedan, ptecedan, hecen wopekiton okihi śni he; qa waehdaku owakihi śni he. Iho, wawiyopewaye on miniwanca kin mdapuze kta; wakpa kin hena hewotahedan wakage kta; hogan tawapi śicamna kta, mini wanica nakaeś, qa ipuza on țapi kta.

3 Mahpiya kin otpaza koyagwaye kta, qa wakihdaka woakahipe wecage kta ce.

4 Jehowa Itancan kin waonspekiyapi ceji kin maqu, hecen wicoie wanji on tuwe mdokita i wakiya onmaspe kta : hanhanna, hanhanna wayuhice kta, Ininoge wicaśta waonspe iyecen wana. hon kta e yuhice kta.

5 Jehowa Itancan kin noge makiyuhdoka; unkan wawakipajinyan waun śni, qa hekta wahdicu śni.

6 Mitapete waapapi kin wicawaqu, qa hin yujunpi kin iyoha mitawa wicawaqu: miite wowiśtenyapi qa atagośapi kin etanhan nawakihbe śni.

7 Tuka Jehowa Itancan kin omakiye kta, heon etanhan mayuśinyaye kte śni: heon etanhan miite wanhi iyecen wahduza, hecen imaśtece kte śni sdonwakiya.

8 Tuwe mayaowotanna kin he ikiyedan un: tuwe amakinica 247 


\section{ISAYA TAWOYUKCAN KIN,}

kta he; witaya naunjinipi kte: tuwe makipajin kta he; he mikiyedan u nunwe.

9 Iho, Jehowa Itancan kin omakiye kta; tuwe mayaco kta he: iho, hena owasin wokoyake iyecen kuke kta; wayapote sa kin hena wicayapotapi kta.

10 Niyepi etanhan tuwe Jehowa kokipe, tuwe e iye taokiye ho kin anagoptan, tuwe otpaza omani qa iyoyanpa codan un he; he Jehowa caje kin wacinye kta, qa ta Wakantanka en eiçihde nunwe.

11 Tho, niyepi owasin ceyatipi, qa peśnija on aohduteniciyapi; peta nitawa iyoyanpa kin en mani po, qa peśnija ideyayapi kin en. Minape etanhan de nitawapi kta; woiyokiśice en inunkapi kta.

\section{WICOWOYAKE 51.}

1 Tona woowotanna yapasipi, Jehowa ayakitapi, niye anamagoptan po: imnija etanhan nicakanpi kin he ekta ekitonwan po, qa maka ohdoka etanhan niçapi qon he ekta:

2 Abraham ateyayapi kin he ekta etonwan miye, qa Sara niyuhapi kin he ekta: iye ecedan weco, qa mdawaśte qa mduota ce.

3 Jehowa Zion wacintonhnagya; makoce puza tawa ocowasin wacintonhnagya nakaeś : qa tintoskan tawa kin he Eden iyececa kage kta, qa hopuza tawa Jehowa tawoju kin iyececa: wicocante waśte qa wiyuśkinpi hen un kta, wopida eyapi qa dowanpi ho kin hena.

4 Mitaoyate, anamagoptan po; qa oyate mitawa, anolimakiya po: woope kin mitantanlan inanpe kta, qa mitawoyaco oyate kin en iyoyanpa ewehde kta nakaeś.
5 Mitoowotanna kin he kiyedan un; wowanikiye mitawa hinanpa; qa miisto oyate kin wicayaco kta: wita kin hena amapepi kta, qa miisto kin he wacinyanpi kta.

6 Mahpiya kin ekta iśta hduwankan iyeya po, qa kuya maka kin ekta etonwan po. Mahpiya kin śota iyecen tanin śni iyaya, qa maka kin wokoyake iyecen kuka aye kta; qa tona en ounyanpi kin iś eya iyecen tapi kta; tuka wowanikiye mitawa kin he owihanke wanice kta, ga mitoowotanna kin he ihangyapi kte śni.

7 Tona woowotanna sdonyayapi, oyate mitoope nicantepi en un kin, anamagoptan po: wicaśta wawiyopeyapi kin he kolkipapi śni po, qa wayaśicapi kin hena on nihinciyapi śni po.

8 Hena wokoyake iyececa wayapote sa temwicaye kta, qa tahinca hin iyececa wamduśliadan hena wicayapotapi kta: tuka mitoowotanna kin he owihanke wanice kta, qa wowanikiye mitawa kin he wicoicage qa wicoicage hehanyan.

9 Ihduhica, ihduhica wo; Jehowa isto, ihduwaśaka wo ; wanakaja anpetu kin en iyececa, kikta wo, wanakaja wicoicage kin en iyececa. Rahab kaksaksa qa unktehi pahdoke ciqon he niye śni he :

10 Miniwanca, mini tanka kin yupuze ciqon he niye śni he; tuwe miniwanca ośbe kin en canku kaga, hecen tona opewicakitonpi kin ohna yapi kta.

11 Heon etanhan Jehowa opewicakiton kin hena hdicupi kta, qa dowanwan Zion ekta kupi kta; unkan wowiyuśkin owihanke śni kin he iye pa akan yanke kta : wicocante waśte qa wowi-

248 


\section{WICOWOYAKE 52.}

yuśkin icupi kta; woiyokiśice qa comnihdazipi kin hena najice kta.

12 Miye, han tuwe wacinton. hnagniyanpi kin he miye: tuwe niye he, hecen wicaśta te kte cin koyakipe kta he, qa wicaśta cinhintku peji iyececa kagapi kte cin he.

13 Qa Jehowa icaliniye cin, mahipiya kin hdumdaya qa maka oahehde kin ehde kin he ayektonja; qa wawakipajin tocanniye kin on anpetu otoiyohi ohinniyan kopeyahda, waihangya okihi kta iyececa. Unkan wawakipajin tocanniye kin tukte e he.

14 Patuś un kin he kiyuśkapi kta inahni, qa hecen woha kin ohna te kte śni, qa aguyapi kiwanice kte śni.

15 Tuka Jehowa he miye, Taku Wakan nitawa, miniwanca yuśkanśkan, unkan taś tawa hoton; Jehowa wicobe tawa eciyapi.

16 Unkan mioie kin hena nii en owahnaka, qa minape ohanzi kin ohna akalipecicaton: hecen mahpiya kin ti wecage kta, qa maka oahehde kin ewehde kta, qa, Mitaoyate kin niye, Zion ewakiye kta heon.

17 Ihduhica wo, ihduhica wo, Jerusalem, Jehowa nape etanhan iye tocanniye miniyatke dahepe ciqon, inajin wo: witkopi miniyatke cetete hehanyan paskicapi kin dahepa.

18 Cinca wicaton kin owasin etanhan tuwedan yus aye śni; qa cinca icahwicakiye cin iyulipa etanhan wanjidan napata hduze śni.

19 Taku kin dena oza en ni. upi ; tuwe aniceye kta he: wicotakuni śni qa woihangye, qa wicaakihan, qa mazasagye : tokiyatanhan wacintonhnagciye kta he.

20 Nicinca kin hena hustakapi ; canku otoiyohi ipa kin en wankapi, tatokadan wan wohmunke en un kin iyececa. Jehowa tocanniye kin on ojupidan, Taku Wakan nitawa towiyopekiye kin on.

21 Heon etanhan, kakiśniyanpi qa winitko yaun tuka miniśa on etanhan śni, ceciciya, de nahon wo ;

22 Jehowa Itancan nitawa qa Wakantankta nitawa, tuwe taoyate iwicakiye cin he hecen eya; Tho, witkopi miniyatke kin ninape etanhan emdaku, mitocanniye miniyatke hminyanna kin hee; ake icimana datke kte śni.

23 Tuka tona kakiśniyanpi napepi kin en wicawaqu kta ; tona ninagi heciyapi; Patuja wo, kinhan akan unkiyayapi kta ce : unkan iwankam iyayapi kin hena en nitancan maka iyecen eniçihnaka, qa canku kin iyececa.

\section{WICOW OYAKE 52.}

1 Kikta wo, kikta wo; Zion, nitowaśake kohdaka wo: Jerusalem otonwe wakan kin, wokoyake waśteśte kin kohdaka wo ; detanhan cehpi bakihdayapi śni qa aśapapi kin icimana en niupi lite śni.

2 Maka mdu kin etanhan ihdatata wo; Jerusalem, najin, iyotanka wo; nitahu iyakaśkapi kin hduśdoka wo, Zion cunwintku wayaka yaun kin.

3 Jehowa hecen eya; Taku śni on wiyopeniciyapi; unkan mazaska codan openicitonpi kta. 4 Jehowa Itancan kin he hecen eya; Ehanna mitaoyate Egupta en ounyanpi kta e ekta

249 


\section{ISAYA TAWOYUKCAN KIN,}

apamahde iyayapi; unkan taku on etanhan śni Aśur oyate kin kakiświcayapi.

5 Unkan nakaha den taku mici un he, hecen mitaoyate taku śni on ewicayakupi he, Jehowa eya ; tona iwicadakapi kin hena iyaśapi, hecen ohinniyan anpetu osan micaje yaśicapi ce, Jehowa eya.

6 Heon etanhan mitaoyate micaje sdonyapi kta : heon etanhan anpetu kin he en he miye hepa e sdonyapi kta; iho, he miye.

$7 \dot{\mathrm{H} e}$ kin akan tuwe wotanin waśte au, tuwe wookiye eyanpaha, he siha oiyokipi hinca; tuwe wowaśte wotanin au, tuwe wowanikiye eyanpaha; tuwe, Wakantanka nitawa he Wicaśtayatapi ce, Zion eciye cin.

8 Waawanhdake nitawa hopi kin; ho wankan yeyapi ; witaya dowanpi kta ; iśta iśta itkokim wankiciyakapi kta nakaeś, tohan Jehowa Zion ake en hdi kinhan.

9 Jerusalem otiwita kin, wiyuśkin hinhda po, witaya dowan miye; Jehowa iye taoyate wacintonhnagwicaya, Jerusalem opekiton nakaeś.

10 Oyate owasin iśta kin itokam Jehowa iye isto wakan kin hduzamni: unkan maka ihanke kin iyuhpa Wakantanka unkitawapi tawowanikiye kin wanyakapi kta.

11 Hanta po, hanta po, hetanhan tankan ya po, taku śapa yutanpi śni po ; cokaya tanhan tankan u po; Jehowa tawakśica yaqinpi kin niye ihduska miye.

12 Hetanhan inahniyan inayapapi kte śni, qa najica dapi kte śni: Jehowa nitokapatanhan ye kta, qa Israel ta Wakantanka kin he hektapatanhan mnaniyanpi kta.

13 Tho, mitaokiye wacinksam250 ya ohanye kta, ihduwankantu kta, qa yuwankan iyeyapi kta, qa tehan wankan un lita.

14 Token niye on wicota nina yuśinyayapi : iye tookitanin kin nina kaśicapi, wicaśta isanpa, qa itohnake kin Adam cinca isanpa.

$15 \mathrm{He}$ iyecen oyate ota awicamnimni kta: iye on wicaśtayatapi iohmus icupi kta: taku owicakiyakapi śni kin he wanyakapi kta; qa taku nahonpi śni qon he awacinpi kta nakaeś.

\section{WICOWOYAKE 53.}

1 Wounyakapi kin he tuwe wicada he; qa Jehowa isto kin, tuwe ekta yutaninpi he.

2 Unkan iye itokam camni wankadan iyecen uye kta, qa maka puza etanhan hutkan wan iyececa: wookitanin codan un, qa owanyag waśte śni ; hecen wanunyakapi kinhan waśteundakapi kta e owanyake waśte wanica.

3 Wahtedapi śni qa wicaśta on ehpeyapi ; wicaśta cante śica qa woiyokiśice sdonkiya; qa tuwe ite anaunkicihmanpi kin iyececa ; wahtedapi śni, unkan unkiye awauncinpi śni.

4 Awicakehan waunyazanpi kin hena iye yuha, qa wicocante śica unkitawapi kin hena iye qin : tuka kaśtakapi, Wakantanka eciyatanhan apapi qa kakiśyapi ecanunkinpi.

5 Tuka waunhtanipi kin hena on iye pahdokapi, taku śica econkupi kin on kaśujapi : wookiye unkitawapi on wokakiśye iye akan yanke; qa iye apapi kin eciyatanhan woasni unhapi.

6 Unkiye owasin tahinca wanunyanpi iyecen unnunipi ; otoiyohi iye tacanku kin ekta unkihduhomnipi ; unkan Jehowa un- 


\section{WICOWOYAKE 54.}

kiye owasin taku śica econkupi kin hena iye en yuwitaya ehnaka.

7 Nagiyeyapi qa iye hinca kakiśyapi eśta ihdukawa kte śni; tahinca cinca iyecen ktepi kta en ahipi, qa tahinca wanunyanpi hin yuśdapi, wicitokam inina yanke cin he iyecen iye i hdukawa kte śni.

8 Kaśkapi qa yacopi etanhan eyakupi; unkan toicage kin tuwe oyake kta he: wicani makoce kin etanhan kaśpapi nakaeś; mitaoyate taku śica econpi kin on, iyepi on kaśtakapi.

9. Unkan wicaśta śicapi om woha qupi, tuka țe cehan wijicapi kin owicapeya wanka: ecin wośice takudan econ śni, qa iye i ohna wohnaye wanica nakaeś. 10 Tuka kaśuje kta Jehowa iyokipi ; wanna iyokiśinya: 'Tohan iyc nagi woahtani wośna yakage cinhan, hchan cinca wanhdake kta, anpetu hduhanska kta, qa Jehowa toiyokipi kin iye nape ohna ecetu kta.

11 Iye nagi htani kin etanhan wanhdake kta, imnan kta: Iye sdonyapi kin on mitaokiye owotanna wicota wicayuowotanna kta ; qa wahtanipi kin iye wicakicicin kta.

12 Heon etanhan wicaśta tanka om wecipamni kta; qa iye wakipi kin wicaśta waśaka om okini kta ; wiconte hehanyan iye nagi kpapson nakaeś. Unkan śicaya econpi sa om yawapi; qa wicota walitanipi kin hena iye wicakiciçin; hecen śicaya econpi sa kin hena iwicakiye kta.

\section{WICOWOYAKE 54.}

1 Cinca okitpani, cinca yaton sni, dowan wo: kokśinyeksuye śni, dowan hinhda qa iyaśa wo: tuwe iśnana elipeyapi kin he cinca ota nakaeś, winohinca hihnaton cinca kin isanpa, Jchowa eya.

2 Nitawakeya owanka kin hdutanka wo, qa yati ozanpi kin yutitanpi nunwe; kicunni śni wo, ikan hduhanska qa hutipaspe hdusuta wo.

3 Etapatanhan qa catkatanhan nihduota kta; qa nicinca Ikcewicaśta kin tawawicayapi kta, qa otonwe otiwita ehpeyapi kin en ounyanpi kta.

4 Wakokipe śni wo, iniśtece kte śni nakaeś; nakun wiśtece śni wo, iśtenniyanpi kte sni nakaeś: tokaheya inicaga wowiśtece kin he ayektonje kta, qa wiwazica yaun iyopeyapi qon he icimana yeksuye kte śni.

5 Wawicahniye cin he nihihna ee nakaeś; Jehowa wicobe tawa eciyapi; qa tuwe openiciton Israel Towakan kin hee, Taku Wakan maka ocowasin tawa eciyapi kta.

6 Winohinca wan ehpeyapi qa nagi iyokiśica, qa aniktapi śni qehan wikośka yuzapi kin iyececa Jehowa nico ce, Wakantanka nitawa eya.

7 Iśta kakpapi se hehanyan ehpeciya; tuka wowaonśida tanka on cikpahi kta.

8 Wośinhda hiyuyapi kin en iśta kakpapi se hehanyan miite anacihbe; tuka wowaśte owihanke wanica on onśicida kta ce, Jehowa openiciton kin he hecen eya.

9 Miye ekta Nowa mini kin he de iyececa: Nowa mini kin icimana ake maka akahpe ye kte śni, keya wakonze ciqon, he iyecen nakun icimana canniyeciye kte śni, qa iyopeciye kte śni, keya wakonza.

10 Ḣe kin hena tokan aye kta, 251 


\section{ISAYA TAWOYUKCAN KIN,}

qa paha kin yutokan iyeyapi kta; tuka mitowaśte tokan iniciyaye kte śni, qa wookiye mitawa wicotakuye kin he yutokan iyeyapi kte śni, Jehowa canteniciye cin he hecen eya.

11 Kakiśyapi, kahuhuzapi, wacintonhnagyapi śni, iho, miye hinca inyan nitawa waśeśa on ewahnake kta, qa oahehde nitawa inyan tehiliika on.

12 Qa ipasotka nitawa inyan wiyatpatpa on wakage kta, qa nitatiyopa peśniśnija inyan kin on, qa nihdukśan owancaya inyan wiciyokipi kin on.

13 Unkan nicinca owasin Jehowa waonspewicakiye kta ; qa nicinca wookiye tanka yuhapi kta.

14 Woowotanna on niyusutapi kta: wicokakiśyapi kin itehan un wo; koyakipe kte śni nakaeś: qa wonihinciye kin, he nikiyedan u kte śni.

15 Iho, mniciyapi, mniciyapi kta, tuka wapahaśa mitawa ekta śni : tona niye itkokim mniciye cin hena niye on hinhpaye kta.

16 Iho, mazakaga peta en petaga apogan, qa iye tohtani on ikicanye wan hiyuye cin he miye linca icahwaya: qa nakun waihangye ihangye kte cin he miye wakaga ce.

17 Ikicanye otoiyohi niye nicis kagapi kte cin he takudan okihi kte śni; qa wicaceji niye en wayaco inajin kte cinhan otoiyohi niye daco kta. Jehowa taokiye taku yuhapi kte cin he dee, qa iye toowotanpidan kin he miye eciyatanhan, Jehowa eya.

\section{WICOWOYAKE 55.}

1 Ho, ipuzapi kin owasin, mini kin en u po; qa tuwe mazaska codan un eśta; kuwa miye, wo252 petonpi qa wota po ; han, u miye, mazaska codan qa iyunwin codan miniśa qa pteasanpi opeton po.

2 Tokeca aguyapi śni on mazaska yahdusotapi kta he; qa tokeca taku imnawicaye śni kin on htayanipi he: Anagoptanyan anamagoptan po, qa taku waśte kin he yuta po; kinhan ninagipi waśin on iyuśkiniçiyapi kta.

3 Anohmakiyapı qa en mau po; waanagoptan 'miye, kinhan ninagipi ni kta; unkan wicotakuye owihanke wanica wan cicicagapi kta, Dawid towaonśida wowicake kin hee.

4 Tho, iye wayaotanin $\mathrm{kta} \cdot \mathrm{e}$ oyate kin wicawaqu, oyate kin en wicaśtayatapi qa waonșpekiya.

5 Iho, oyate wan sdonyaye śni qon he yeco kta; qa oyate sdonniyanpi śni kin hena niye en inyang upi kta, Jehowa nita Wakantanka kin on, qa Israel Towakan kin on etanhan; iye niyuwakan nakaeś.

6 Jehowa iyeyepica icunhan akita miye, ikiyedan un kin icunhan hoyekiya po :

7 Tuwe sice cin he tacanku. ahduśtan kte, qa wicaśta wah̀tani sa iye tawacin ehpekiye kta ; qa Jehowa en ilıdoku kta, kinhan onśikida kta; qa Wakantanka unkitawapi kin ekta, iye wokajuju hduota kta nakaeś.

8 Niye nitawacinpi kin mitawacin kin ee śni, qa mitacanku kin he nitacankupi kin ee śni, Jehowa eya.

9 Mahpiya kin maka kin isanpa tehanwankantu, he iyecen mitacanku nitacankupi kin isanpa tehanwankan, qa mitawacin nitawacinpi kin isanpa nakaeś.

10 Magaju kin he kun u, qa wa 


\section{WICOWOYAKE 56.}

kin malipiya eciyatanhan, qa ake ekta hnihde śni, tuka maka kin imnakiye ca waicaliyekiye ca camni uyekiya, hecen tuwe woju kin ojupi qu kta, qa wayute cin he woyute qu kta ;

11 He mioie mii etanhan inanpe cin iyecece kta : miye en cokadan ihdoku kte śni; tuka taku iyomakipi kin he yuśtan kta, qa taku on yewaśi kin he ecetukiye kta.

12 Niye wowiyuśkin yuha inayapapi kta, qa wookiye hduha yus aniyanpi kta: nitokapatanhan lie qa paha kin dowan hinhdapi kta, qa maga can kin iyuhpa nape hdaskapapi kta.

- 13 Canpepe kin eekiya wazi can uye kta, qa wapepeka eekiya hanteśa uye kta: unkan he Jehowa en wocajeyatapi ee kta, qa wowakta owihanke wanica kaśpapi kte śni kin heca kta.

\section{WICOWOYAKE 56.}

1 Jehowa hecen eya; Woyaco patan po, qa woowotanna econ miye: wowanikiye mitawa kin he kiyedan u nakaeś, qa mitoowotanna kin he yuotaninpi kta.

2 Wicaśta tuwe de econ kte, ça wicaśta cinhintku de sutaya yus un kte cinhan; tuwe anpetu okihpapi yuśape śni kpatan, qa iye nape taku sica econ śni awanihdake cinhan, he cante waśte.

3 Unkan wicaśta tokeca cinhintku Jehowa en askamiciye cin he ie ca, Jehowa iye taoyate kin etanhan ocowasin heyata iyemayan ce, ihnuhan eye cinhan " nakun, Wanyaka wo, can śeca hemaca ce, ihnuhan yunokos eye cinhan.

4 Jehowa hecen eya; Yunokos tona anpetu okilipapi mitawa patanpi, qa taku iyomakipi kalinigapi, qa wicotakuye mitawa yus unpi kinhan;

5 Hena wati ohna qa conkaśke mitawa mahen owanka wicawaqu lkta, qa wicacaje cinhintkuyapi qa cunwintkuyapi isanpa waśte ; wicacaje owihanke wanica icimana laśpapi kte śni waqu kta.

6 Nakun wicaśta tokeca cinca Jehowa en askamiciyapi, ohodapi kta, qa Jehowa caje kin waśtedapi kta, iye wowidagwicaye kta, wicaśta otoiyohi anpetu ohihipapi yuśape śni patan, qa wicotakuye mitawa sutaya yus un kinhan ;

7 Hena eepi kaeś paha wakan mitawa kin ekta awicawau kta, qa wocekiye tipi mitawa ohna, wiyuśkin wicawaye kta : wohuhnage wayuśnapi qa woślla tawapi kin owayuśna mitawa akan oiyokipi kta; wati kin he oyate owasin on wocekiye tipi eciyapi kta nakaeś.

8 Jehowa Itancan Israel enanakiya iyewicayapi qon mniciye wicakiye cin he hecen eya; Tona iye en mniciyapi lzin isanpa nakun en mniciye wicawakiye kta ce.

9 Tinta wamanica owasin, niye watemya u miye; contanka wamanica.kin iyulipa.

10 Waawanyake tawa kin hena owasin iśtagongapi, wasdonye śni unpi, owasin śunka inina unpi, wapa okihipi śni ; wihamnanpi. iwankapi, iśtinma waśtedakapi.

11. Han, hena śunka wotapi sa, imnanpi sdonkiyapi śni, qa hena iś wonwicaya okahnil okihipi śni ; hena owasin iye tacankupi ekta ekiktonwanpi, otoiyohi iye oyanke tawa kin etanhan tawokamna kta ekta. 


\section{ISAYA TAWOYUKCAN IKIN.}

12 Kuwa miye, miniśa iwacu kta, unkan mini wakan on wipiunkiciyapi kta; qa heyakecinhan anpetu kin de iyecece kta, tanka, wopteca śni, iyotan hinca kta ce, eyapi.

\section{WICOWOYAKE $5 \%$}

1 Wicaśta owotanna taninśni iyaya, tuka tuwedan cante ekta yeye śni : qa wicaśta waonśida ewicayakupi, tuka wicaśta owotanna taku śica etanhan eyakupi tuwedan kecin śni.

2 Wookiye en ye kta ; towankapi kin akan ozikiyapi kta; tuwe ecetuya mani kin.

3 Tuka wapiye sa cinhintkupi, deciya kiyedan $u$ po, wiinahmanpi qa wawiciliahapi econ sa cinca kin.

4 Tuwe on iyahahapi he : tuwe on i yahdukawapi he, ceji hiyuyayapi he: wokipajin cinca, woitonśni ojupi kin henicapi śni he :

5 Uskuyeca can ehna carn teca otoiyohi ihukuya iyokipiiciya yaunpi, hokśiyopapi kin kaksiza ohna wicayaktepi, imnija yuptuptujapi kin ihukuya:

6 Kaksiza en inyan śduśduta ehna taku oyakini qon yanke; hena, hena e taku tawayaye cin ee: nakun hena en woyatke wośna yahdaśtan, wośna wayahduśna. Hena on iyokipimiçiye kta he.

7 Paha pajodan qa tehanwankantu akan nitohe eyehde; han, heciya wahduśna idada.

8 Nakun tiyopa can qa tiyopa kin iheyatanhan wokiksuye eyehde; miye icunonpatanhan nihduzamni, qa wankan idada; ohehdepi nitawa yahdutanka, qa hena om wicotakuye nicicaga; iye ohehdepi tawapi kin waśteyadaka, owanka yahdutanka.
9 Wihdi on wicaśtayatapi kin anihduwiyeya, qa wihdi waśtemna yahduota; qa makoce tehan ekta wahośi yewicayaśi, qa Hades e qeś ekta nihduhukuya.

10 Canku hanska nitawa on mdokițe niçiya; tuka, Wacinye. pica śni ce, ehe śni ; ninape towiconi kin he iyeyakiya; heon etanhan waśake śni nicida śni.

11 Unkan tuwe e on kopeyahda qa koyakipa he, hecen iyatonśni, qa miyeksuye śni, qa en cante duze śni he: wanakajatanhan kaeś inina manke śni he : hecen komayakipe śni,

12 Miye nitoowotanna omdake kta, qa niohan nakun; tuka hena iniwaśte kte śni.

13 Hoyeyaye cinhan hehan nitomniciye kin hena enihdakupi nunwe: tuka tate kin he hena iyulipa kahbog iyewicaye kta, takuśni iwicacu kta. Tuka tuwe wacinmaye cinhan makoce kin yuhe kta, qa paha wakan mitawa kin he tawaye kta:

14 Qa heye kta; Pahaya ehnaka po, pahaya ehnaka po, canku wiyeya kaga miye, can ibotopi kin mitaoyate ewicakiciyaku po.

15 Wanji tehanwankantu qa wankan un, otokahe wanica en ounyan, qa tuwe Wakan eciyapi kin he hecen eya; Tehanwankantu qa owanka wakan kin hen wati kta, nakun tuwe taniya kaśujapi qa onśike cin he kici ; tona onśikapi taniyapi niwicawaye kta, qa cante kaśujapi kin hena kiniwicawakiye kta heon.

16 Owihanke wanica hehanyan wawakize kte śni, qa ohinniyan śinwahda kte śni : mitokam woniya kin hanye kta nakaeś, wicataniya wakage cin nakun.

17 Tokamna śica woalitani kin on śinwahda qa wakaśtaka : namiçihbe qa śinwahda; heca eśta 
iye cante yuze canku kin ohna pemniyan ikiyopta.

18 Tacanku kin wanmdaka, unkan okiziwaye kta; nakun yus amde kta, qa iye akiceyapi qon hena koya om wacintonhnagwaye kta.

19 Wicaiha oicage cin he miye wakaga; Wookiye, wookiye, tuwe itehan un qa tuwe ikiyedan un kin kici, Jehowa ekiciya: unkan miye okiziwaye kta ce.

20 Tuka wicaśta śicapi kin hena miniwanca taś ton kin iyececapi, he owanji yanka okihi śni, mini tawa kin upśija qa maka hiyuya ece.

21 Wicaśta śicapi kin hena wookiye nicapi ce, Jehowa eya.

\section{WICOWOYAKE 58.}

1 Dote eciyatanhan pan wo, ihnuhan inina nanke cinhan, maza yahotonpi wan iyecen niho wankan yeya wo; qa mitaoyate taku śica econpi, qa Jakob tiyohnaka iye wahtanipi kin owicakiciyaka wo.

2 Tuka anpetu otoiyohi omadepi, qa mitacanku sdonya iyokipipi, oyate wan woowotanna econ ece, qa Taku Wakan tawapi tawoahope elipeye sni kin he iyececa: Woowotanna wokonze kin hena makidapi, Taku Wakan ikiyedan upi iyokipipi.

3 Tokeca akihan unkiçiyapi tuka wandake kte sni he: nagi iyokiśinunkiçiyapi tuka sdonye wacanni kte śni he, eyapi. Wanyaka wo, anpetu en akilianniciyapi hehan iyokipi niçiyapi kta, qa wicohtani ecaniconpi kin ocowasin wicayakidapi ece.

4 Wanyaka wo, wicokicige qa woakinica on akilhanniciyapi, qa wośice nape on waayapapi kta heon: Anpetu kin de iyececa nihopi wankantanhan nahonwicayayapi kta e akihanniciyapi kte śni.

5 Akilhaniciyapi wakahnige kte cin he de iyecece kta he: Anpetu wan en wicaśta jyokiśiniçiye kta: hintkan hu iyecen pamahdedan un kta, qa wakihdaka cahota ko owinśkiton kta he. He akihaniciyapi qa anpetu. Jehowa iyckipi kta, eya cajedate kta he.

6 Akilianiciyapi wakahnige kte cin he dee śni he ; wicośice icaśke kin yukcapi kta, canwanapin wiçin kin kiyuśkapi kta, tona kakiśyapi kin .hena wicakiyukcapi kta, qa can napinpi owasin duksapi kta :

7 Wotektehdapi kin aguyapi nitawa wicayakipamni kte cin hee śni he ; qa tona onśika kakiśyapi kin hena yati en awicayaku kta ; tuwe tancodan un wandake cinhan wakalipeyecaton kta, qa wicacehpi nitawa kin etanhan nanicilibe kte śni.

8 Hehan iyoyanpa nitawa anpao iyecen inanpe lita, qa woasni nitawa kohanna hiyu kta; nakun nitoowotanna nitokam ye kta, qa Jehowa towitan kin he hekpatanhan awanniyake kta.

9 Hehan niye hoyeyaye kta, unkan Jehowa waayupte kta; niye yapan kta, unkan iye, Iho, miye ce, eye kta. Nicokayatanhan canwanapin kin elipeyakiye cinhan, napsukaza pazopi qa ecinkta eyapi kin hena:

$10 \mathrm{Qa}$ wotektehdapi kin ekta ninagi hiyuyaye ça wicanagi kakiśyapi kin he imnayaye cinhan, hehan iyoyanpa nitawa kin otpaza en hinanpe kta, qa owotaninśni nitawa kin he wiyotanhan iyecece kta.

11 Unkan Jehowa ohinniyan yus aniye kta, qa iwicapuza en 255 


\section{ISAYA TAWOYUKCAN KIN,}

ninagi imnaye kta, qa nihuhu kin cemniciye kta: hecen niye maga wan mini imna kin he iyenicece kta, qa minilidoka wan mini wicahnaye kte śni kin he iyececa.

12 Unkan niye eciyatanhan otiwita wanakaja kin hena piya kicagapi kta; wicoicage qa wicoicage oahehdepi lin áke yakage kta; qa, Conkaśke kawankapi piya kage cin, Cánku otipi kta yuecetu kin, eniciyapi kta.

13 Anpetu okihpapi kin etanhan siha eyahdaku, anpetu wakan mitawa en nitoiyokipi kin ecen ecanon kte śni ; qa anpetu okilipapi kin he woi yokipi, Jehowa towakan kin he wowitan, keya cajedate cinhan; qa nitacanku ohna oyahande śni, nitoiyokipi oyakide śni, qa niye nioie oyahdake śni, on he duonihan kinhan :

14 Hehan Jehowa en iyokipiniẹiye kta; unkan maka paha kin akan iyotanke ciciye kta, qa Jakob niyate taku tawa qon. etanhan wonciye kta ce, Jehowa i kin he hecen eya nakaeś.

\section{WICOWOYAKE 59.}

1 Iho, Jehowa nape niwicaya okiki kte śni e yuptecedan śni ; qa iye noge wanahon okihi kte śni e kpe śni :

2 Tuka taku śica ecanonpi kin hena niyepi qa Taku Wakan nitawapi yukinukan iyeniyanpi ; qa wayahtanipi kin hena iye ite anahbeniciyapi, hecen nahon kte śni.

3 Ninapepi we on aśapapi nakaeś, qa ninapsukazapi śicaya econpi kin on : niihapi woitonśni iapi, nicejipi wośice ajijipi ece.

4 Tuwedan woowotanna kipan 256 śni, qa tuwedan wowicake eciyatanhan wayaco śni : hena takuśni wacinyanpi, qa woitonśni ohdakapi ; wicolian śica on ihduśakapi qa woahtani hiyuyapi.

5 Wamduśka itka kin manpi, qa unktomi tahokata kazontapi : tuwe witka tawapi yute cinhan te kta, qa wanji pakpipi kinhan sintehda wan hiyu kta.

6 Taku kazontapi kin hena wohoyake kte śni, qa iye ohanpi kin on ihdahpapi kte śni: iye ohanpi kin wośice wicohan kin heca, qa iye napepi ohna wakipi ohanyanpi yukan.

7 Iye siha taku śica ekta inyankapi, qa tona taku iyaonpepica śni unpi we kin he papson inahnipi ; iye tawacinpi śicaya econpi wicotawacin kin heca; woihangye qa wokakse iye tacankupi ohna yanka.

8 Wookiye canku kin sdonyapi śni; qa manipi kin en wokonze wanica : ocanku śkośkopa içicagapi ; tuwe ohna ye cinhan wookiye sdonye kte śni.

9 Heon etanhan wokonze unkitehampi yanka, qa woowotanna unkihdegapi kte śni : iyoyanpa unkapepi, tuka iho, otpaza; iyowotanin unkapepi, tuka owotanin śni unkomanipi.

10 Iśtagongapi iyececa conkaśke yutantan unkakitapi, iśta codan iyecen unyutantanpi: wiyotanhan siha ibountopi, hanyetu en iyececa; maga waśteśte ohna wicaśta tapi iyeuncecapi.

11 Unkiye iyuhpa wahanksica iyececa unlidopi, qa tinwakiyedan ceya iyecen unceyapi : wokonze unkapepi, tuka wanica; wowanikiye unkapepi, tuka unkitehanpi yanka.

12 Taku śica econkupi kin hena nitokam yuotapi, qa waunlitanipi kin hena unkoyakapi 


\section{WICOWOYAKE 60.}

ece : taku śica econkupi kin hena unkicipi hiyeya, qa waunlitanipi kin hena sdonunkiyapi :

13 Sicaya econpi, qa Jehowa en itonpi sni, qa Taku Wakan unkitawapi ayuśtanpi, wokakiśyapi qa okicize cajeyatapi, woitonśni oie awacinpi qa cante eciyatanhan eyapi kin hena on.

14 Hecen woyaco hek ta i toheya iyeyapi, qa woowotanna itehan inajin; hocoka ohna wowicake hinlipaya, qa woecetu kin en $u$ kta okihi śni.

15 Han, wowicake wanica aya; qa tuwe taku śica ayuśtan kin he wakipi ece: Unkan he Jehowa wanyake ca woyaco wanice cin he śicedaka.

16 Qa wicaśta wanica he wanyaka, qa wawiciya wanice cin heon yuśinyaya: heon etanhan iye isto wowanikiye hdamna; qa iye toowotanna kin he ihdusuta.

17 Woowotanna kin he maku akahpe iyecen kicun: qa wowanikiye wateśdake wapaha kiya; qa watokiçonpi wokoyake kin hena kohdaka, qa wowinawizi śina iyecen hdowin nakaeś.

18 Iye ohanyanpi kin eciyatanhan wicakicu kta, tona kipajinpi kin, wocanniye ; tokayapi kin hena wotokicon wicakicu kta; wita kin hena wicolian on towicakicicon kta.

19 Heon wiyolipeyatanhan Jehowa caje kin kokipapi kta, qa iye towitan wihinanpatanhan. Wakiyuśe kin wakpa tanka iyecen hiyu kinhan, Jehowa Taniya kin itkokim wiyokihedan ekihide kta.

20 Hehan Wopekiton kin Zion en u kta, qa Jakob etanhan tona śicaya econpi ayuśtanpi kin hena en, Jehowa eya.

21 Unkan miye, wicotakuye mitawa wirakici un kin he dee, Jehowa eya: Mitaniya en niun, qa mioie nii en owehnake cin hena nii ayuśtan kte śni, qa nicinca ipi kin, qa nicinca sanpa cincapi ipi kin awicayuśtan kte śni, detanhan qa owihanke wanica, Jehowa eya.

\section{WICOWOYAKE 60.}

1 Najin wo, iyojanjan wo; iyoyanpa nitawa wanna $u$, qa Jehowa towitan kin anihinanpa.

2 Iho, otpaza maka kin akahpe kta, qa otpaza śoka oyate kin awicakahpe Kta; tuka Jehowa anihinanpe kta, qa iye towitan kin anitanin kta.

3 Qa Ikcewicaśta kin iyoyanpa nitawa en manipi kta, qa wicaśtayatapi kin hena yahinanpa ojanjan kin en.

4 Ihdukśan iśta hduwankan iyeye ça wanyaka wo; hena owasin witaya mniciyapi, niye en niupi ; nicinkśipi tehantanhan upi kta, qa nicunkśipi adoksohan wicayuhapi kta.

5 Hehan wandake ca widuśkin kta ; qa nicante cancan qa tanka aye kta: miniwanca wicota kin niye en yuhomnipi kta, Ikcewicaśta towijicepi kin niye en niu kta.

6 Camo ota hinca anicalipapi kta, Midian qa Epha etanhan camo kośka kin hena: Śeba etanhan hena owasin upi kta; mazaskazi q̇a canśin waśtemna kin ahipi kta, qa Jehowa yatanpi wotanin waśte oyakapi kta.

7 Kedar optaye kin iyuhpa niye en mniciyapi kta, Nebayoth tamdoka kin hena iwicadake kta ; hena oiyokipiya owayuśna mitawa adipi kta, unkan mitowitan tipi kin he wahduwitan kta. 8 Mahpiya śapa iyececa, qa tin257 


\section{ISAYA TAWOYUKCAN KIN,}

wakiyedan iyecen iye tipi ekta kinyan upi kin dena tuwepi he.

9 Awicakehan wita kin hena amapepi kia; qa Tarśiś tawitawata tokaheya, tehantanhan nicinkśi awicaupi kta, mazaska qa mazaskazi tawapi koya, Jehowa Taku Wakan nitawa caje kin ekta, qa Israel Towakan kin ekta, he iye niyuwitan nakaeś.

10 Unkan wicaśta tokeca cincapi conkaślke nitawa kagapi kta, qa wicaśtayatapi tawapi kin hena oniciyapi kta. ŚSinwahda qehan cicaśtaka, tuka canmawaśte kin en onśicida nakaeś.

11 Unkan nitatiyopa ohinniyan yuldog he kta, hena anpetu hanyetu koya ecen iyeyapi kte śni ; hecen Ikcewicaśta tawowijice kin niye ekta aupi kta, qa wicaśtayatapi tawapi kin hena upi kta.

12 Oyate qa wicośkanśkan tukte wanji oniciye kte śni kinhan he atakuni kte śni; han, Ikcewicaśta kin hena ocowasin ihangyapi kta.

13 Lebanon towitan kin he en niu lta; wazisaka can, wazi can qa hanteśa kicica, tipi wakan mitawa owanka kin yuwaśte kta; unkan tukten siha wahde kin he wahduwitan kta ce.

14 Hehan tona kakiśniyanpi qon hena cinca patuś en niupi kta; qa tona wahitenidapi śni qon owasin siha yahde kin en makata patujapi kta; qa, Jehowa Totonwe, Zion Israel Towakan tawa, eniciyapi kta.

15 Niye elipeniyanpi qa śicenidapi, hecen tuwedan opta ye śni ; heon etanhan wowaśte owihanke wanica, wicoicage yeye cin hehanyan wowiyuśkin cicage kta.

16 Nakun Ikcewicaśta asanpi tawa dazoke kta, qa wicaśtaya258 tapi aze ayazin kta: qa Jehowa Wanikiya nitawa qa Wopekiton nitawa, Wanji Waśaka Jakob tawa kin he miye e sdonyaye kta.

17 Mazaśa on mazaskazi eekiya awaukta, qa mazasapa on mazaska eekiya awau kta, qa can on mazaśa, qa inyan on mazasapa kta: Nakun akicita tancan nitawa wookiye wicawakage kta, qa wicaśtayatapi nitawa woowotanna kta.

18 Wawicakipi kin he nitamakoce ohna icimana nahonpi kte śni, woihangye qa woyutakuniśni nitaopapun mahentanhan ; tuka conkaślke nitawa, Wowanikiye, qa nitatiyopa kin, Woyatan, eya caśyakiton kta.

19 Hetanhan anpetu icunhan anpetu wi kin iyoyanpa nitawa kte śni, qa iyojanjan kta on hanyetu wi kin iyoyamniye kte śni ; tuka niye en iyoyanpa owihanke wanica Jehowa ee kta, qa nita Wakantanka wowitan nitawa ee kta.

20 Anpetu wi nitawa ake icimana isinyan iyaye kte śni, qa hanyetu wi nitawa icimana eihdaku kte śni; iyoyanpa owihanke wanica nitawa Jehowa ee kta, qa anpetu en yaceye cin hena henakeca kta.

21 Nakun nitaoyate iyulipa owotanna kta: makoce kin ohinniyan tawapi kta, adetka huwahde, minape taku kage cin heepi; hecen mayuwitanpi kta.

22 Wanji cistinna kin he kektopawinge icage kta, qa tonana kin he oyate waśake kta. Tohan iyehantu kinhan Jehowa miye he mduinalini kta ce.

\section{WICOWOYAKE 61.}

1 Jehowa Itancan Taniya kin 
akan mayanka; Jehowa sdamakiya, wotanin waśte wicaśta on śihanpi owicawakiyake kta heon etanhan; tona cante kaśujapi wicamduskiskite kta e yemaśi; wayaka unpi wicayukcapi kta owicawakiyake kta, qa kaśka unpi wicokaśke tipi wicakiyuhidokapi kta :

2 Jehowa tawaniyetu oiyokipi kin omdake kta, qa Wakantanka unkitawapi anpetu watokiconpi tawa kin; tona ceyapi owasin wacintonhnagwicawaye $\mathrm{kta}$ :

3 Tona Zion en ceyapi kin hena wakoyagwicayapi kta, cahota eekiya wateśdake wicaqu kta, wicaceya eekiya wowiyuśkin wihdi, cante wankadan eekiya woyatan wokoyake kin wicaqu kta : heon etanhan, Woowotanna uskuyeca can, Jehowa tawoju, ewicakiyapi kta, hecen iye yuwitanpi kta:

4 Unkan otiwita kin hena piya kagapi kta, tanina yujujupi kin hena bosdan ehdepi kta, qa otonwe otiwita wanke cin hena piyapi kta, wicoicage qa wicoicage hewoskantuya wanke ciqon.

5 Hehan oyate tokeca etanhan najinpi qa nitawanunyanpi wonwicayapi kta, qa wicaśta tokeca cinca kin hena maga niciyumdupi qa hastanhanka iyuwi nicipakintapi kta.

6 Tuka niyepi, Wawayuśnapi Jehowa tawa, eniciyapi kta: Wakantanka unkitawapi taokiye, eniciyapi kta. Ikcewicaśta tawowijicepi kin yatapi kta, qa towitanpi kin on nihdatanpi kta.

ry Nitowiśtecepi kin on nonpa akihde kta, qa wonihinciye on taku tawapi kin on wiyuśkinpi kta; heon etanhan tawapi ohna nompa akihde yuhapi kta; wowiyuśkin owihanke wanica wicakiciun $\mathrm{kta}$.
8 Jehowa miye, woyaco waśtewadaka; wahuhnage wośnapi kta on wawicakipi kin śicewadaka: qa iye olianyanpi iyecen wicawaqu kta, wowicake eciyatanhan, qa wicotakuye owihanke wanica wan wicawecage kta.

9 Hehan iye oicage tawa Ikcewicaśta ehna sdonwicayapi kta, qa etanhan icagapi kte cin oyate kin wicehna: 'Tona wanwicayakapi owasin, oicage Jehowa yuwaśte kin hena eepi e sdonwicayapi kta.

10 Miye qe iyuśkinyan Jehowa on imduśkin kta, minagi mita Wakantanka on pida kta: iye wowanikiye wokoyake koyagmayan nakaeś, woowotanna śina kin amakahpa; wicaśta tawicu ton kta wateśdake hduwaśte, qa winohinca hihna ton kta oinpi kiçun kin iyececa.

1i Maka kin camni ukiye ca maga kin taku en ojupi icahikiye cin he iyecen Jehowa Itancan kin woowotanna qa woyatan oyate owasin wicitokam icahye kta.

\section{WICOWOYAKE 62.}

1 Zion on etanhan inina manke kte śni; qa Jerusalem on etanhan oziwakiye kte śni; toowotanna kin woiyege iyececa inanpe kta, qa towanikiye kin petijanjan ide kin iyecece kta hehanyan.

2 Unkan Ikcewicaśta kin nitoowotanna wanyakapi kta, qa wicaśtayatapi owasin nitowitan kin. Qa wicacaje teca, Jehowa i cajeyate kte cin he icajeniyatapi kta.

3 Nakun Jehowa nape ohna wowitan wateśdake kin he niye kta, qa wicaśtayatapi tawapaha Wakantanka nitawa nape kin ohna. 


\section{ISAYA TAWOYUKCAN KIN,}

4 Hetanhan icimana, (Azubah) Ehpeyapi, eniciyapi kte śni; qa nitamakoce icimana, (Śemamah) Hewoskan, eciyapi kte śni ; tuka, (Hephzibah) Mitowiyuśkinen-un, eniciyapi kta, qa makoce nitawa, (Beulah) Wakanyuzapi, eciyapi kta: Jehowa iniyuśkin, qa nitamakoce kin he wakan yuzapi kta nakaeś.

5 Kośka wan wikośka wan wakan yuze cin he iyecen nicinkśipi wakan nihduzapi kta; qa wicaśta winohinca yuze cin on iyuśkin kin he iyecen nita Wakantanka iniyuśkin kta.

6 Jerusalem, conkaśke nitawa akan waawanyake ewicawahnaka, anpetu owasin qa hanyetu owasin ohinniyan inina unpi kte śni : tona Jehowa kiksuyeyayapi, ihnuhan inina dukanpi kinhan ;

7 Qa woozikiye qupi śni po, Jerusalem hdusuta qa maka kin ohna woyatan kage kte cin hehanyan.

8 Jehowa iye nape etapa kin on, qa isto waśake cin on iciconza; Awicakehan icimana wamnaheza nitawa tokaniyanpi yutapi kta wicawaqu kte śni; qa oyate tokeca cincapi kin miniśa nitawa on litayanipi kin he yatkanpi kte śni.

9 Tuka tona mnakiyapi kin he hdutapi kta, qa Jehowa yatanpi kta; qa tona wayuśpipi kin hena mitowakan hocoka kin ohna hdatkanpi kta.

10 Ohna ya po, tiyopa kin ohna ya po; oyate tacanku kin wiyeya kaga po: wankan ehnaka po, canku wankantu kaga po; etanhan inyan pahi po; wiyokihedan wan oyate kin wankan ewicakicihde po.

11 Tho, Jehowa maka ihanke hehanyan nahonwicaya; Zion cunwintku kin heciya po; Tho, wowanikiye nitawa kin u ce; iho, inyunwin hduha un, qa woecon tawa kin he itokam yanke.

12 Unkan hena, Oyate wakan, Jehowa opewicakiton, ewicakiyapi kta: qa niye, Akitapi, otonwe ehpeyapi śni, eniciyapi kta.

\section{WICOWOYAKE 63.}

1 Edom etanhan, Bozra etanhan śina duta in u kin he tuwe he; wokoyake waśte kohdaka, iye towaśake tanka on icimani un kin he tuwe he. Woowotanna eciyatanhan ia, wanikiya wasake cin he miye ce.

2 Tokeca nitawokoyake kin duta, qa nitaśina tuwe miniśa iyuśkice naśkice cin iyececa he.

3 Miniśa iyuśkice cin miśnana nawaśkica; qa oyate kin etanhan tuwedan micica śni: heon mitocanniye on nawicarvaślkice kta, qa mitośinhda on nawicawapan kta ; qa iye hanpi kin mitaśina amnimnipi kta, qa mitawokoyake ocowasin wahdustan kta.

4 Watokiconpi anpetu kin he micante en un, qa opewicawakiton tawaniyetu kin he wanna hiyohi naka eś.

5 Unkan ekta ewatonwe, tuka waokiya wanica; qa tuwedan wayusuta śni heon mayuśinyaya; heon etanhan miye miisto wowanikiye hdamna, qa mitośinhda kin he mahdusuta.

6 Hecen mitocanniye on oyate kin nawicawapan $\mathrm{kta}$, qa mitośinhda on witkowicawakiye lsta, qa iye hanpi kin he maka ta elipewaye lita.

7 Jehowa wawacinkta yuza tanka kin he mdatan kta, Jehowa yatanpi kin, Jehowa taku icantounhnakapi kin owasin eci-

260 


\section{WICOWOYAKE 64.}

yatanhan, qa wowaśte tanka Israel tiyohnaka icantowicahnaka, iye towaonśida eciyatanhan qa iye wawacinkta yuza tanka ota kin eciyatanhan.

8 Unkan iye heya; Awicakehan hena mitaoyate, wicacinca. taku ecinkta eyapi kte śni ce. Hecen Wanikiya tawapi kin he iye.

9 Toiyokiśicapi iyuhpa en iye iyokiśica; qa iye ite Taohnihde kin he niwicakiya: iye towaśtedake qa tocantekiye kin on opewicakiton, qa wicaqin, qa wanakaja anpetu kin owasin iye wicahduha un.

10 Tuka hena eqe wawakipajinpi qa iye Taniya Wakan kin iyokiśinyapi; heon etanhan iye tokawicaye kta ihduhomni, iye hinca wicakiza.

11 Hehan wanakaja anpetu kin hena kiksuya, Moses qa iye taoyate: Tuwe mini tanka etanhan awicau qon he tukten un he, obe tawa wonwicaye ciqon: 'Tuwe iye Taniya Wakan mahen ehnake ciqon he tukten un he.

12 Tuwe Moses nape etapa on yus awicaya, iye isto wakan kin on wicitokam mini kin wicakiyukinukan, caje owihanke wanica wan içicage kta.

13 Tuwe mini śbe kin ehna maniwicakiya, śuktanka wan hopuza en un kin iyececa, hecen kaktihanhanpi kte śni.

14 Woteca wan kaksiza ekta iyaye cin iyecen Jehowa Taniya kin oziyekiya; he iyecen niye nitaoyate yus awicada, wowitan caje niçicage kta heon.

15 Mahpiya kin eciyatanhan kun ahitonwan wo, qa nitoowotanna qa nitowitan tipi kin etanhan wanyaka ye : nitowinawizi qa nitowaśake kin tukte e he; nitowaonśida qa miye en nito. $\mathrm{U} 2$ cantekiye kin hena anakiptapi he.

16 Awicakehan niye ateunniyanpi, Abraham sdonunkiyapi śni qa Israel iyeunkiyapi śni qeyaś : niye, Jehowa, Ateunniyanpi, Wopekiton unkitawapi ; nicaje kin he otokahe wanica.

17 Jehowa, tokeca nitacanku etanhan nuniunyakiyapi he; nitokokipe icunonpa cante unyadusutapi he. Nitaokiyepi on, wicoun tawawicayaye cin on etanhan hdicu ye.

18 Oyate wakan nitawa ptenyedan tawakiyapi : tokaunyanpi kin hena tipi wakan nitawa naśapapi.

19 Unkiye wanakajatanhan unyakonpi : hena e tohinni wowidagwicayaye śni : hena nicaje icajewicaya tapi śni.

\section{WICOWOYAKE 64.}

1 Tokin mahpiya kin yahduhdecen, kun hidu kta; hecen nitohnake on he kin skan aye kta.

2 Peta canhaka ideya, peta mini ipihya ece kin iyececa; tona tokaniyanpi nicaje sdonyewicakiye kta, nitohnake on Ikcewicaśta cancanpi kta heon.

3 Taku wowinihan ecanon qehan, hena unkapepi śni; kun hidu, nitohnake on he kin skan aya.

4 Wakantanka, nicunonpatanhan, tuwe wacinyan un taku kicage kte cin, otokaheyatanhan nalionpi śni, wicanoge kin en iyolipaye śni, wicaiśta wanyake śni.

5 Tuwe wiyuśkin qa woowotanna econ ece kin he itkoyakipa; nitacanku ohna niksuyapi kin hena: Iho, niye śinyahda; unkan waunhtanipi: dena en ohinniyan, tuka niunyanpi kta. 


\section{ISAYA TAWOYUKCAN KIN,}

6 Tuka unkiye owasin taku śapa iyeuncecapi, qa woowotanna unkitawapi iyuhpa wokoyake awepi kin iyececa; qa iyuhpa canwapa iyecen śniś unkayapi; qa taku śica econkupi kin hena, tate iyececa, yutokan unkayapi kta.

7 Hececa eśta tuwedan nicaje hoyekiye śni, tuwedan en niyuze lkta ihduhica śni; niye nïite anaunyecihmanpi nakaeś, qa taku śica econkupi kin on awihnuniunyakiyapi.

8 Tuka nakaha Jehowa, Ateunyanpi kin he niye; maka coco kin he unkiyepi, qa cega kaga unkitawapi kin he niye; qa ninape taku kage cin he unkiyepi iyulipa.

9 Jehowa nina śinhda śni wo, qa ohinniyan woahtani kiksuye śni ye: iho, wanyaka ye, ceunniciyapi, unkiye owasin nitaoyate unyakonpi.

10 Otonwe wakan nitawa kin hena makoskantu; Zion hewoskantu; Jerusalem otiwita.

11 Tipi wakan qa owanyag waśte unkitawapi, ohna atewicunyanpi niyatanpi qon he peta on hulinaga: qa taku oiyokipi unkitawapi iyulipa ihangyapi.

12 Jehowa, dena on ananiçipte kta he ; inina nanke ca nina kakiśunyayapi lita he.

\section{WICOWOYAKE 65.}

1 Tona wimawangapi śni qon hena amakitapi; tona omadepi śni qon hena iyemayanpi : Ikcewicaśta micaje on icajeyatapi śni qon; Wanmayaka ye, wanmayaka ye, ewicawakiya.

2 Oyate wan wawakipajin, canku waśte śni ohna iye tawacinpi eciyatanhan mani kin he anpetu osan nape wicawakiyugate : 262
3 Oyate wan miite itokam ohinniyan śinhdamayanpi, can wojupi ehna wawayuśnapi, qa maka omdoton ohna wizinyapi ece.

4 Hena wicaśta hnakapi ehna yukanpi, qa woinahbe kin en iwankapi ; kukuśe śin yutapi, qa cega ohna tado aśapa hanpi hduhapi.

5 Hena heyapi; Ako inajin wo; mikiyedan u śni wo; niye isanpa miye mawakan nakaeś. Dena mapoge ohna śota heca, peta wan anpetu osan itkon.

6 Iho, mitokam wowapi ; Inina manke kte śni, tuka watokiçon ecamon kta; han, iye maku ohna wicawecu kta;

7 Wayahtanipi qa niyatepi wahtanipi yuwitaya : hena he kin akan wizinyapi, qa paha kin akan iśtenmayanpi : heon etanhan iye ohanyanpi qon hena maku ohna iwicaweciyute kta ce, Jehowa eya.

8 Jehowa kaken eya; Miniśa teca kin hastanhanka iyage kin en un, qa, Ihangye śni wo, woyawaśte wan en un ce, eyapi kin, he iyececa mitaokiye on ecamon kta, hecen iyuhpa ihangwicawaye kte śni.

y Unkan Jakob etanhan oicage wan awau kta, qa Juda etanhan tuwe paha mitawa tawaye kta wan: hecen wicawahdahnige cin hena tawayapi kta; qa mitaokiye kin hena he en ounyanpi kta.

10 Unkan Śaron tahinca optaye otipi kin heca kta, qa Akor kakśiza kin he wanunyanpi owanka kin hee kta, mitaoyate amakitapi kin hena on.

11 Tuka Jehowa ayuśtanpi, paha wakan mitawa akiktonjapi, Gad (wicanhipi tanka) wahna wotapi wan wiyeya ekicihnakapi, qa Meni, (anpao wicanlipi) 
woyatke wan okicaśtanpi kin hena niyepi.

12 Heon etanhan mazasagye ekta ciyawapi kta, qa niyepi owasin wicaktepi en yapatujapi kta : cicipanpi tuka amayaduptapi śni, iwaa tuka nayahonpi śni, tuka miiśta itokam taku śica ecanonpi, qa taku iyomakipi śni kin he yakahnigapi;

13 Heon etanhan Jehowa Itancan kin hecen eya; Iho, mitaokiye wotapi kta, tuka niye wotekteyahdapi kta; iho, mitaokiye wayatkanpi kta, tuka niye inipuzapi kta; iho, mitaokiye wiyuśkinpi kta, tuka niye winiśtecapi kta :

14. Iho, mitaokiye cante waśte on dowanpi kta, tuka niye cante śicapi on yaceyapi kta, qa woniya kaksapi on yaśicahowadapi kta.

15 Qa nicajepi woyaśice icajeyatapi kin he wicawahdahinge cin aihpewicayayapi kta : qa Jehowa Itancan kin nikte kta, qa iye taokiye kin wicacaje tokeca eya icaśkiton kta.

16 Hecen tuwe maka akan ihdawaśte kinhan Taku Wakan wicake cin on ihdawaśte kta ; qa tuwe maka akan taku eya içiconze cinhan, Taku Wakan wicake cin on konze kta; tanina woiyokiśica kin hena akiktonjapi qa miiśta etanhan analimanpi kin heon etanhan.

17 Tho, mahpiya teca qa maka teca wakaga; unkan tanina qon hena kiksuyapi kte śni, qa wicacante kin en u kte śni.

18 Tuka niyepi, taku wakage cin on ohinniyan pidapi qa wiyuśkin po ; iho, Jerusalem he wiyuślkinpi, qa taoyate kin wowiyuśkin wakaga heon etanhan.

19 Hecen Jerusalem on imdu- śkin kta, qa mitaoyate on cante mawaśte kta: unkan he ohna wicaceya ho kin icimana nahonpi kte śni, qa śicahowayapi ho kin nakun.

20 Hetanhan anpetu hokśiyoqopa wan icimana yuke kte śni, qa wicahinca anpetu imna śni wanice kta: hokśiyoqopa kin eqe waniyetu opawinge cinca hehan țe kta nakaeś: tuka wahitanisa kin he waniyetu opawinge kinhan yaśicapi kta.

21 Unkan tipi kagapi kta qa ohna tipi kta; qa hastanhanka hu hdepi kta qa etanhan waskuyeca hdutapi kta.

22 Tipi kagapi kinhan tuwe tokeca ohna ti kte śni; wojupi kinhan tuwe tokeca yute kte śni : mitaoyate taanpetu kin can anpetu kin iyecece kta; qa tona wicawahdahinge cin hena iye nape ohanyanpi kin tehan hdutapi kta.

23 Takuśni on litanipi kte śni, qa woiyokiśica on cinca tonpi kte śni : tona Jehowa wicayawaśte cinca kin hena eepi, qa tona hena etanhan icagapi nakur.

24 Unkan kaketu kte, hena hoyeyapi śni itokam waamdupte kta, qa iahan unpi icunhan nawahon kta.

25 Sunktokeca qa talinca cinca kin akiptan wihanpi kta; qa mnaja kin he tatanka iyececa peji yute kta; qa wamduśka tawoyute maka mdu kin hee kta. Paha Wakan mitawa owancaya wayuśicapi kte śni, qa waihangyapi kte śni, Jehowa eya.

\section{WICOW OYAKE 66.}

1 Jehowa hecen eya; Mahpiya kin he mitoiyotanke kin ee, qa maka kin misiha oahde kin hee. Tipi miyecagapi lite cin tukte 


\section{ISAYA TAWOYUKCAN KIN,}

e he; qa woozikiye mitawa kin tukten yanka he.

2 Dena owasin minape kaga, qa dena owasin ecen un, Jehowa eya: tuka de ekta ewatonwe kta, tuwe onśike ca taniya kaśujapi, qa mioie on cancan kin he.

3 Tuwe tatanka kikte kin he wicaśta kaśtaka iyececa; tuwe tahinca cinca wayuśna kin śunka tahu kakse cin iyececa; tuwe minha wan wayuśna kin he kukuśe we iyececa; tuwe wizinyapi wokiksuye wośna kin he wakagapi wan yawaśte kin iyececa. Han, hena e canku hdahnigapi, qa taku śapa tawapi on nagi ihduśkinpi.

4 Miś eya wicoiyokiśica wicawecicahnige kta, qa taku kokipapi kin hena en awicawau kta. Wicawakipan qehan tuwedan waayupte śni ; iwae cehan nahonpi śni ; tulka miiśta itokam taku śica econpi, qa taku iyomakipi śni kin hena hdahnigapi kin heon etanhan.

5 Tona iye oie on nicancanpi kin, Jehowa oie kin nahon miye : Nihunkawanjipi śicenidapi, qa micaje on etanhan tankan ehpeniyanpi qon hena, Jehowa yuwitanpi nunwe, eyapi : tuka widuśkinpi kta on ihdutanin kta, qa hena eqe iśtecapi kta.

6 Oqoyapi ho wan otonwe kin etanhan; tipi wakan kin etanhan wicaho wan; Jehowa tona tokayapi towicakicicon ho kin hee.

7 Hokśiksuye śni itokam hiyuya, hinyahin wayazanhda śni itokam hokśidan wan ton.

8 'Taku he iyececa tuwe nation he; tuwe talku hececa wanyaka he. Maka kin anpetu wanjidan en waicahye kta he : oyate wan wancahna wicatonpi kta he: 264
Tuka Zion hokśiksuya hehantudan cinca hiyuwicaya.

9 Ihduhdece wakiye kta qa hiyuwakiye kte śni he, Jehowa eya : hiyuwakiya eśta onawatake kta he, nita Wakantanka eya.

10 Jerusalem kici wiyuśkin po, qa tona waśte yadakapi owasin kici cante waśte miye; wowiyuśkin on kici wiyuśkin po, tona ayakiceyapi kin iyuhpa.

11 Hecen ayazinpi kta qa tocantohnake aze on winipipi kta ; hecen dazokapi kta, qa iye towitan aze ojudan kin etanhan wiyuśkinniçiyapi kta.

12 Jehowa kaken eya; Iho, wakpa iyecen wookiye waqu kta, qa Ikcewicaśta towitanpi kin mini kaduze cin iyececa. Hehan ayazinpi kta, maku ohna niyuhapi kta, qa śiyoto alkan niyuhnahnapi kta.

13 Tuwe hunku cantohnagye cin he iyecen cantohnagciyapi kta; qa Jerusalem en wacintohnagniyanpi kta.

14 Tohan wandakapi kinhan nicantepi iyuśkin kta, qa nihuhupi kin wato iyecen icage kta. Unkan Jehowa nape kin he iye taokiye sdonyapi kta, qa tokawicaye cin en iye tośinhda kin tanin kta.

15 Iho, Jehowa peta yuha $u$ kta, qa canpahmihma tawa kin tate iyumni iyececa; hecen tocanniye kin wośinhda kici, qa toiyopeye kin peta ide kici wicaqu kta.

16 Peta on qa iye tamazasagye on Jehowa wicacehpi iyulipa om wohdake kta: unkan Jehowa wicakte kin hena ota kta.

17 Tona ihduwakanpi qa can wojupi ehna ihduskapi, cokata wanji ihakam, kukus̉e sin, qa taku aśapa, hitunkadan ko yutapi 


\section{WICOWOYAKE 66.}

kin hena yuwitaya awihnunipi kta, Jehowa eya.

18 Unkan kaketu kte, iye ohianpi qa tawacinpi kin hena on etanhan Ikcewicaśta qa wicaceji iyuhpa mduwitaya kta : unkan hena upi qa mitowitan kin wanyakapi kta.

19 Unkan hena wicehna wowakta wan ewahnake kta, qa tona etanhan najicapi kin hena Ikcewicaśta kin ekta yewicawaśi kta, Tarśiś, Pul qa Lud, hiena itazipa ekatapi ; Tubal qa Javan, wita tehan unpi kin, tona omayakapi nahonpi śni qa mitowitan wanyakapi śni. Unkan hena iś Ikcewicaśta ehna mitowitan yaotaninpi kta.

20 Qa hena nihunkawanjipi owasin awicaupi kta, Jehowa wakiyuśnapi wan, Ikcewicaśta owasin etanhan, śuktanka akan, qa canpahmihma ohna, qa tatokadan akan, qa sonśonna akan, qa camo cincapi akan, Jerusalem
Paha Wakan mitawa ekta, Israel cinca wośna wan wakśica ska ohna Jehowa ti kin en ahipi kin he iyececa, Jehowa eya.

21 Unkan miś eya hena etanhan wawayuśnapi qa Lewi wicaśta hecapi kta e iwicawacu kta ce, Jehowa eya.

22 Mahpiya teca qa maka teca wakage kte cin hena mitokam wanke kta, he iyecen niye nicincapi qa nicajepi unpi kta ce, Jehowa eya.

23 Unkan kaketu kte, wi teca wan etanhan witeca ekta, qa wookihpe etanhan wookilipe ekta hehanyan, wicacehpi owasin mitokam waohoda au kta, Jehowa eya.

24. $\mathrm{Qa}$ hena yapi kta, qa wicaśta wamicihtanipi tancan țapi kin wanwicayakapi kta. Wamduśka tawapi kin țe kte śni, qa peta tawapi kin kasnipi kte śni: tuka wiracehpi owasin hena wowahiteca śni yawapi kta. 265 


\section{JEREMIAH TAWOYOKCAN KIN.}

\section{WICOWOYAKE 1.}

1 Jeremiah Hilkiah cinhintku oie kin dena; Benjamin makoce kin en wawayuśna Anathoth en ounyanpi kin hetanhan :

2 He qe Jehowa oie kin en hi, Josiah Amon cinhintku Juda wicaśtayatapi taanpetu kin en, waniyetu iakeyamri wicaśtayatapi yanka hehantu.

3 Nakun Jehoiakim Josiah cinhintku Juda wicaśtayatapi taanpetu kin en, Zedekiah Josiah cinhintku Juda wicaśtayatapi tawaniyetu iakewanji ihanke kin hehanyan, wi izaptan en Jerusalem wayaka ayapi kin hehanyan.

4 Unkan Jehowa oie en mahi kin he hecen eya:

5 Wicatezi ohna cicage cin he itokam sdonciya; qa tamni kin etanhan inayape śni he itokam ciyuwakan, oyate kin en wicaśta wokcan cicaga ce.

6 Hehan hepa; Hehehe, Jehowa Itancan, wanyaka ye, iapi onmaspe śni ; homakśidan nakaeś.

7 Tuka Jehowa hemakiya; Homakśidan ce, eye śni wo; tona ekta yeciśi kin owasin ekta de $k$ ta, qa taku eye ciśi kin hecehin odake kta ce.

8 Hena itokam kopehda śni wo ; miye ecihdaku kta on cici waun nakaeś, Jehowa eya.

9 Hehan Jehowa nape hiyukiya qa i mayutan: qa Jehowa hemakiya; Iho, mioie kin nii en owahnaka ce.

10 Wanyaka wo, anpetu kin de oyate kin wiciwankam ecihnaka, qa wokiconze kin iwankam, yujunpi qa yujujupi kin on, qa ihangyapi qa yutakunipi kte śni on, icaliyapi qa ojupi kta on etanhan.

11 Hehan Jehowa oie en mahi kin he hecen eya; Jeremiah, taku wandaka he. Unkan, Waawanyake can adetka wanji wanmdaka ce, epa.

12 Hehan Jehowa hemakiya; Tanyan wandaka: mioie wahduecetu kta on awanwahdake kta nakaeś.

13 Unkan Jehowa oie kin inonpa en mahi; Taku wandaka he, eya. Unkan hepa; Ceg̣a ipiğa wan wanmdaka, qa ite lzin waziyata ektakiya yanka ce.

14 Hehan Jehowa hemakiya; Waziyatanhan wośice wan makoce en ounyanpi kin owasin ahiyu kta ce.

15 Tho, waziyata wokiconze lin wicowazipi kin owasin wicawakipan kta, Jehowa eya: unkan hena upi kta, qa otoiyohi toiyotanke kin Jerusalem tiyopa yuhidokapi kin en ekihdepi kta, qa conkaślke ihdukśan wanke cin owasin akan, qa Juda otonwe Kin owasin ekta.

16 Unkan tona amayuśtanpi qa taku wakan tokeca izinwicakiyapi, qa iye nape ohanyanpi kin en patuśiciyapi kin hena taku śica econpi kin owasin on woyaco mitawa mdaotanin kta ce. 17 Heon etanhan niye najin qa ipiyag kiton wo, qa miye taku eye ciśi kin owasin owicakiyaka wo; hena itepi kin on kopehda 


\section{JEREMIAH TAWOYUKCAN KIN,}

śni wo, okinni wicitokam wakokipe cicagge kta.

18 Unkan miye, iho, anpetu kin de, otonwe acankaśkapi wan iyececa cicag̉a, qa mazasapa bosdan he cin iyececa, qa mazaśa conkaśke kin iyececa, makoce kin owasin on, Juda wicaśtayatapi kin on, wicaśta ihdawapi kin on, wośna kag̣api kin on, qa makoce en oyate kin hena on etanhan.

19 Unkan hena e nicizapi kta tuka ohiniyanpi kte śni; miye ecihdaku kta on cici waun kta nakaeś, Jehowa eya.

\section{WICOWOYAKE 2.}

1 Hehan Jehowa oie en mahi kin he hecen eya:

2 Ya wo, qa Jerusalem nog̀e ohna eyanpaha wo, hecen eya wo ; Jehowa hecen eya ce; Ciksuya, winikośka towaśte kin, wakankiciyuzapi nitawa tocantekiye kin, hopuza en, makoce ojupi śni ohna mihakam yau qehan :

3 Israel wakan, Jehowa en, toicagge tokaheya suton kin hee: tona temyapi kin hena owasin - śicaya econpi kta; wośice en awicau kta ce, Jehowa eya.

4 Jakob tiyohnaka qa Israel tipi wicowazi iyuhpa, Jehowa oie kin nahon miye :

5 Jehowa hecen eya; Taku śica en maun nihunkakepi iyeyapi kin tukte e he, hecen tehan imayayapi, qa takuśni kin ihakam manipi, qa takuśni ic̣icağapi he :

6 Qa, Tuwe Egupta makoce kin etanhan hinanpe unyanpi qon, tuwe hopuza kin en mani unkiyapi, hewotahedan makoce qa woha yuke cin ehná, makoce puza qa wiconte ohanzi kin en, makoce wicaśta tuwedan ohna mani śni, qa wicaśta cinca tuwedan ohna ti śni ece, Jehowa hee tukten un he, eyapi śni.

7 Unkan makoce cepa wan en hiyuciyapi, waskuyeca tawa qa taku waśte oicagge tawa kin yatapi kta heon: Qa en hidupi qa makoce mitawa duśicapi qa taku mitawa' kin wowahteśni yaksgapi tuka qon.

8 Wawayuśna kin hena, Jehowa tukten un he, eyapi śni; qa tona woope awanyakapi kin hena sdonmayanpi śni; nakun wawihanwicakiye cin hena wamakilitanipi, qa wicaśta wokcan kin hena Baal on waayatapi, qa taku waokiye śni imanipi ece.

9 Heon etanhan nakun acicinica kta, Jehowa eya, qa nicinca cincapi kin om wahdokinica kita ce.

10 Hecen Kittim makoce kin ekta ya po, qa wanyaka miye ; qa Kedar ekta ye wicaśi po, qa tanyan awacin po, qa taku hececa yuke cinhan wanyaka po:

11 Oyate wan taku wakan tawa, wakan śni qeyaś, hena hdutokecapi he : tuka mitaoyate iye towitanpi kin taku waokiye śni on tokiyopekiyapi.

12 Mahpiya kin, de on inihan po, qa nihinciya miye; nina tansag ța nunwe, Jehowa eya.

13 Mitaoyate taku śica nom econpi; niiye amayuśtanpi wiconi minilidoka kin he, miniyowe icicapi kta e heon, miniyowe kaohpapi, mini yuhe kta okihi śni heca.

14 Israel wowidake heca he; tipi kin ohna tonpi hecinhan tokeca wakipi he.

15 Mnaja cinca kin hena ahotonpi ; wanna ho hdataninpi, qa makoce tawa hewoskan kicagapi; otonwe tawa kin hena 


\section{WICOWOYAKE 2.}

huhnahyapi, tuwedan en ounye śni.

16 Nakun Noph qa Tahapanes cinca kin hena pesdete nicalidecapi.

17 De niye nicicaǵe śni he; Jehowa Taku Wakan nitawa canku ohna maniniye ciqon he ehpeyaya, heon etanhan.

18 Unkan nakálıa Egupta canku iyahde kin ohna, sihor mini kin datke kta, taku iniwaśte kta he; qa Aśur ekta canku kin ohna taku iniwaśte kta he, wakpa kin etanhan mini datke kta.

19 Niye niohan śice cin he nihdaśtake kta, qa wayakipajin kin he iyopeniye kta : heon etanhan sdonya wo, qa wanyaka wo, Jehowa Taku Wakan nitawa elipeyakiye ca mitokokipe en ni un śni kin he taku śica qa pa hinca, Jehowa ozuye Itancan kin he hecen eya.

20 Wanakaja cannapinpi nitawa mduksaksa, on nicaśkapi kin mdupsapsaka: unkan, Wawakipajin kte śni ce, eha ; tuka paha pajodąn owasin akan, qa can teca otoiyohi ihukuya wawicilia. hapi imayani ece.

21 Heca eśta miye qe hastanhanka iyuwi kalinigapi wan hucihde, ocowasin ojupi waśte hinca heca : unkan tolken hastanhanka tokeca, huhdepi śica kin heca imiyecicağa he.

22 Neter on nihdujaja qa wipajaja ota iyacu qeyaś, wayahtani kin mitokan okağopi yanka ce, Jehowa Itancan kin eya.

23 Mihduśapa śni, Baalim ihakam mawani śni ce, token ehe kta he: kaksiza kin ohna nitacanku wankdaka wo ; taku ecanon kin he sdonkiya wo; śonśonna duzahan canku icipaweliya ece kin henica:

24 Śnśnnna wiye wan mako- skan un ece kin he token iyokipi tate omna eca, tuwe hdicukiya okihi kta he : tona odepi owasin ito mdokiteiciyapi kte śni, wi tohan iyehantu kinhan iyeyapi kta.

25 Sicodan unpi kin etanhan nisiha kpatan wo, qa dote nitawa ipuzapi kin etanhan. Tuka heha; Wacinyepica śni ; hiya, wicaśta tokeca waśtewicawadake ça hena wicihakam mde kta ce, eha.

26 Wicaśta wamanon iyeyapi kinhan iśteca ece, he iyecen Israel tiyohnaka iśteniçiyapi, iyepi, wicaśtayatapi tawapi, wicaśta itancan tawapi, wawayuśna tawapi qa wicaśta wokcan wicayuhapi :

27 Hena e qe, Atewaye cin he niye ce, can kin eciyapi; qa, Niye mayakag̉a ce, inyan kin eciyapi : Tapete makiyuhomnipi qa itepi kin ee śni qeyaś tohan iyokiśicapi eca, Najin qa niunkiya miye, eyapi ece.

28 Tuka taku wakan niçicag̉e cin hena tukte e he : hena eeś najinpi qa iyoniciśica anpetu kin en niniyanpi kta, okihipi kinhan: Juda, nitotonwe tonakeca hecinhan taku wakan nitawa kin henakeca ce.

29 Tokeca kici amayalinicapi kta he: iyulipa mayakipajinpi nakaeś, Jehowa eya.

30 Itulin nicinca wicawakaśtaka: wowaonspekiye ecaca icupi śni: Mazasagye nitawapi kin he wicaśta wokcan nitawapi ihangwicaya, mnaja waihangye cin iyececa.

31 Wicoicage, niye Jehowa oie kin wanyaka po: Israel ekta hewoskan makoce, qa otpaza makoce kin hemaca he. Unkiye wicaśtaunyatapi ; icimana en unnikupi kte śni ce, tokeca mitaoyate eyapi he. 


\section{JEREMIAH TAWOYUKCAN KIN,}

32 Wicinyanna wan oinpi tawa, qa wikośka wan tawanapin akiktonje kta he: tuka mitroyate anpetu yawapica śni amiktonjapi ce.

33 Tokeca waśtedakapi ayakita on nitacanku piyaliya he : hecen nitacanku on niohan sica onspewicayakiya ecc.

34 Nakun nitaśina en walipanica wiyaonpepeca śni nag̣i we kin he iyeyapi. Ohna qapi kin he eciyatanhan iyewaye śni, tuka dena owasin akan.

35 Tuka kaken eha; Wiyaonpepica śni waun, heon awicakehan iye tocanniye kin mitantanhan hduhomni kta: Iho, wawahtani śni ce, ehe cin heon woyaco kin en acicinica kta.

36 Tokeca nitacanku ijehan dutokeca kta on nina imayani he : Aśur on iśtenniyanpi kin he iyecen Egupta on nakun iśtenniyanpi kta.

$37^{-}$Nakun detanhan inayape kta, qa ninape nipa akan yanke kta: tona wacinwicayaye cin hena Jehowa wahtewicada śni nakaeś, qa hena on tanyan yaun kte śni.

\section{WICOWOYAKE 3.}

1 Heyapi ecee; Wicaśta wan tawicu kpagian kinhan, qa hetanhan iyaye ca wicaśta tokeca tawaya hecinhan ake en hde kta he : makoce kin he nina yuśapapi kte śni he. Tuka niye qe waśtewicayadake cin ota om wawiciliahapi ecanon eśta miye en ihdoku wo, Jehowa eya.

2 Paha ipa kin ektakta etonwan qa iwanyaka ye, tukte en niciwankapi śni he: Arab wicaśta makoskan ti kin he iyecen canku ohnahna iyawicape nanka; hecen wawiciliahiapi nitawa qa niolian śice cin on makoce yahduśapa ce.

3 Heon etanhan mağaju kin anaptapi, qa magaju ehake kin he wanica: tuka wihomni win ite heniceca, iniśtece. Inta wicayada śni.

4 Detanhan, Ate, homakśiyopa yus amayan kin he niye ce, eya hoyemayakiye kte śni he.

5 Ohinniyan kpatan kta he; owihanke hehanyan hduhe kta he. Iho, iyae ca token oyakihi hecen taku śica ecanon ece.

6 Hehan Josiah wicaśtayatapi taanpetu kin en Jehowa hemakiya; Israel wawakipajin kin he taku econ kin wandaka he : paha tehanwankantu owasin ekta iyaya, qa can teca otoiyohi ihukuya, qa hen wawiciliahapi econ ece.

7 Unkan hena owasin econ kin iyohakam hepa; Miye en ihdoku wo: Tuka ihdoku śni. Unkan cunku Juda wahnaye sa kin he he wallyaka.

8 Hehan wanmdaka, dena taku owasin on, Israel wawakipajin wawicihahapi econ kin on ehipewakiya, qa kpagianpi wowapi wan waqu; hececa eśta cunku Juda wahnaye sa kin he kokipe śni, tuka iye hinca iyaye ca nakun wawicihahapi econ.

9 Unkan ohankoya witkowinna ohanyan kin on makoce kin hduśapa, qa inyan qa can kici wawiciliahapi econ ece.

10 Tuka nakun dena owasin on etanhan cunku Juda wahnaye sa kin he cante ocowasin on miye en ihdoku śni, tuka itonśni, Jehowa eya.

11 Hehan Jehowa hemakiya ; Juda wahnaye sa isanpa Israel wawakipajin kin nagi ihduowotanna ce.

12 Ya wo, qa waziyatakiya 


\section{WICOWOYAKE 4.}

wicoie kin dena ieyanpaha, qa heya wo; Israel wawakipajin, ihdoku wo, Jehowa eya; mitocanniye kin he anihinhpaye waye kte śni : waonśiwada nakaeś, Jehowa eya, ohinniyan wośinhda wahduhe kte ślui ce.

13 Tuka wayalitani kin he sdonkiya wo ; Jehowa Taku Wakan nitawa kin he yakipajin, qa nitacanku wicaśta tokeca en wicayakipemni, can toto otoiy ohi ihukuya; qa miho kin he anayağoptanpi śni ce, Jehowa eya.

14 Cinca wawakipajinpi, hdicu po, Jehowa eya, cihduzapi nakaeś; kinhan otonwe wan etanhan wanjidan, qa wicowazi etanhanhan nom icicupi, qa Zion ekta hiyuciyapi kta ce.

15 Qa wonwicaye micante eciyatanhan kin heca cicupi kta; unkan bena wosdonye qa wookahinig̉e yunniciyapi kta.

16 Unkan tohan makoce kin ohna nihduotapi qa inicağapi kinhan, anpetu kin hena en, Jehowa tawotakuye canwohnaka kin, tohinni eyapi kte śni, Jehowa eya; qa he cante en yuzapi kte sni, qa kiksuyapi kte śni, qa wanyag yapi kte śni, qa tohinni kağapi kte śni.

17 Hehan Jerusalem Jehowa toiyotanke eciyapi kta; qa en oyate kin owasin mniciyapi kta, Jehowa caje kin on, Jerusalem ekta : qa nakun ake icimana iye cante sicapi wacinyuzapi kin hena eciyatanhan manipi kte śni.

18 Anpetu kin hena en Juda tiyohnaka Israel tiyohnaka kin kici mani kta, qa hena yuwitaya waziyata makoce kin etanhan hiyupi kta, makoce hunkakewicayayapi hduhapi kta wicawaqu qon he ekta.

19 Tuka miye qe hepa; Token cincapi kin en opeciye kta he; qa makoce oiyokipi ciçu kta, oyate wicota yuhapi lita cinpi qon he. Nakun hepa; Niye, Ate emayakiye kta, qa miye etanhan nihduhomni kte śni ce. 20 Awicakehan, winohine? wan hihnaku okilianśunkeca he iyecen Israel tiyohnaka omakitianśunkeca ce, Jehowa eya.

21 Paha pajodan kin etanhan wicaho wan nalionpi, wicaceya, Israel cinca celiyapi kin hee: canku ihduśicapi, Jehowa Taku Wakan tawapi kin he alkiktonjapi, heon etauhan.

22 Hokśiyopa wawakipajinpi, hdicu po, wawayakipajinpi kin he okiziwaye kta ce. Iho, en unnikupi, Jehowa Taku Wakan unkitawapi kin he niye nakaeś.

23 Awicakehan paha kin etanhan taku śni, he ota kin hena: Awicakehan Israel towanikiye kin he Jehowa Taku Wakan unkitawapi kin en un.

24 Nakun wowiśtece hounkśiyopapi ehantanhan atewicunyanpi tohtanipi kin temya; tahinca optaye qa tatanka tawapi, cinhintkupi qa cunwintkupi koya.

25 Unkiśtecapi kin en unkiwankapi, qa wowiśtece unkitawapi unkakahpapi : Jehowa Taku Waka11 unkitawapi awaunkilitanipi nakaeś, unkiye qa atewicunyanpi, hounkśiyoqopapi etanhan, anpetu kin dehanyan; qa Jehowa Taku Wakan unkitawapi ho kin anaungoptanpi śni ce.

\section{WICOWOYAKE 4.}

1 Israel, yahdicu kta hecinhan miye en hdicu wo, Jehowa eya; qa mitokapatanhan wośice nitawa yutokan iyeyaye cinhan onuni yaun kte śni ce.

2 Tohan, Jehowa ni un ce, wowicake en, woyaco en qa woo. 271 


\section{JEREMIAH TAWOYUKCAN KIN,}

wotanna en, eya niçiconza kinhan, hehan Ikcewicaśta kin iye on ihdawaśtepi kta, qa iye on ihduwitanpi kta.

3 Jehowa Juda qa Jerusalem wicaśta kin hecen ewicakiya; Maga yumdupi nitawapi kin akta hdumdu po, qa wapepeka ehna wojupi śni po.

4. Juda wicaśta qa Jerusalem en ounyanpi, Jehowa on ohomni bakilidaya po, nicantepi ha iyotan kin he eyaku po: okinni niohanpi śice cin on mitośinhda peta iyecen hiyu kta, qa ide kin tuwerlan kasni kte śni.

5 Juda en oyaka po, qa Jerusalem en eyanpaha po; qa heya po; Han, makoce kin ohna niazayahotonpi tanka kin yajo po; ihduwitaya hoyeya po, qa heya po; Ihduwitaya miye, otonwe acankaśkapi kin hena en unyanpi kta :

6 Zion ekta wiyokihedan ekihde po: inatini po, owanji yukanpi śni po; waziyatanhan taku sica wan qa wicotakuniśni tanka awau kta nakaeś.

7 Otelii tawa kin etanhan mnaja kin hiyu, qa Ikcewicaśta oyate ihangwicaye kte cin he ihdaka $u$ : makoce nitawa ihangye kta heon. iye tohe kin etanhan hinanpa: nitotonwe kin awihnunipi kta, tuwedan ohna ti kte śni.

$8 \mathrm{He}$ on wakihdaka ipiyag kiton po, waśihdapi qa śicahowaya po; Jehowa tocanteptanye wohitike cin unkiciyuhomnipi śni, heon etanhan.

9 Unkan anpetu kin he en kaketu kta, Jehowa eya: Wicaśtayatapi cante kin atakuni kte śni, qa wicaśta ihdawa cantepi kin; qa wawayusna kin hena nihinciyapi kta, qa wicaśta wokcan kin yuśinyayapi kta ce.
10 Hehan miye hepa; Hehehe Jehowa Itancan, awicakehan oyate kin de qa Jerusalem nina wicayahnayan, Wookiye duhapi kta eyapi kin he on; tuka mazasagye wicanagi kin hiyohiya ce.

11 Hehan oyate kin de qa Jerusalem hewicakiyapi kta ; Hopuza makoce kin etanhan tateyanpa kata wan mitaoyate cunwintku kin en u kta, kadugge kte śni qa kaska kte śni :

12 Tateyanpa suta hinca wan hetanhan miye on $\mathrm{u} k \mathrm{kta}$; hehan miye hinca wicamdaco kta ce.

13 Tho, malipiya śapa kin iyecen wankan u kita, qa canpahmihma tawa kin tateiyumni iyecece kta; śuktanka tawa kin hena wanmdi isanpa duzahanpi. Hehehe unkiyepi ; ihangunyanpi hinca nakaeś.

14 Jerusalem, taku śica etanhan nicante hdujaja wo, hecen niniyanpi kta: tohanyan nitawacin śica mahen niun kta he.

15 Wicaho wan Dan etanhan eyanpaha, qa Ephraim lie kin etanhan wośice oyaka ece :

16 Ikcewicaśta oyate kin owicakiyaka po; Iho, Jerusalem ekta eyanpaha po; Iwanyakapi kin heca makoce tehan etanhan upi, qa Juda otonwe kin iyawicaśapi lita ce.

17 Mag̣a awanyakapi kin he iyecen he ihdukśan hiyeya: iye makipajin, heon etanhan, Jehowa eya.

18 Nitacanku qa niohan kin hena taku dececa nicicaga; wośice kin he niye nitawa,..teliike linca qeyaś nicante kin en iyahde.

19 Mitezi, mitezi! micante og่e ekta mayazan; mahen micante śicahowaya; inina manke kte śni; mazajahotonpi tanka ho 


\section{WICOWOYAKE 5.}

kin minag̉i nahon, kicizapi iyasapi kin hee.

20 Kamdecapi, kamdecapi iyahna oyakapi : makoce ocowasin atakunis̉ni nakaeś; ihnuhanna wakeya mitawa ihangyapi, ozanpi mitawa iśtakakpanpi wan en.

21 Tohanyan wápahaśa kin wanmdake kta he: tohanyan mazayahotonpi tanka ho kin nawahon kta he.

22 Mitanyate kin witkotkoka, miye sdonmayanpi śni: hokśiyopa wacinton śni, qa takudan okahnigapi śni : taku sica econ wayupikapi, tuka taku waśte econpi kta sdonyapi śni.

23 Maka kin ekta ewatonwan, unkan iho, takudan en un śni, qa toketu tanin śni; mahipiya kin ekta, uıkan iyoyanpa wanica.

$24 \dot{\mathrm{He}}$ kin ekta ewatonwan, unkan iho, hena cancan, qa paha kin owasin śkanśkan :

25 Ekta ewatonwan, unkan iho, wicaśta wanica, qa mahpiya okinyanpi kin owasin najicapi.

26 Ekta ewatonwan, unkan iho, Karmel hopuza icaga, qa totonwe owasin ihangyapi hinca, Jehowa itohnake kin on, iye tośinhda wohitike on etanhan.

27 Jehowa hecen eya ce : Makoce kin ocowasin hewoskantu kta, tuka ocowasin owihanke waye kte śni.

28 De on makoce kin ceye kta, qa wankan mahpiya kin sapa icu kta: miye hepa nakaeś, miye hecen wakonza, qa iyopemiçiye kte śni, qa etanhan nawamni kte śni ce.

29 Śuktanka akan iyotankapi qa itazipa yuhapi iyaśapi kin on otonwe kin ocowasin najica: contanka kin mahen iyayapi qa imnija kin adipi ; otonwe owasin elipeyapi qa wicaśta tuwedan ohna ti śni.
30 Unkan ihangniyanpi kinhan niye taku ecanon lita he. Wokoyake duta kodaka eśta; mazaskazi oinpi kin on nihduwaśte eśta ; waśeśa on niiśta yahdutanka qeyaś, taku on etanhan śni owanyag waśte nicicag̉e kta: canteniciyapi kin hena ehpeniyanpi kta, hena ninagi akitapi kta.

31 Wanji hokśiksuya ho kin nawahon, tuwe hokśin tokaheya hiyuya śicahowaya, Zion cunwintku ho kin hee; tehiya niya, nape hdugata; Hehehe miye, tinwicaktepi kin on minagi skan aya ce.

\section{WICOWOYAKE 5.}

\section{Jerusalem canku kin ohnahna} ya po, qa wanna wanyaka po, qa sdonya po ; qa canku tanka kin ohna ode po; wicaśta wanjidan iyeyayapi kinhan; tuwe wokonze econ kinhan, tuwe wowicake akita heca yuke cinhan, wakpatan kta ce.

2 Tuka, Jehowa ni un ce, eyapi eśta, awicakehan itonśniyan içiconzapi kta.

- Jehowa, niiśta worvicake kin ekta yanke śni he : Hena wicayakaśtaka tuka iyokiśicapi śni : hena wicadutakuni śni; woiyopeye icu wacinpi śni : imnija isanpa ite suta icicagapi : ahdiyaku kta wicadapi śni.

4 Hehan hepa; Awicakehan dena onśikapi ; dena witkotko ayapi; Jehowa tacanku, Taku Wakan tawapi tawokonze kin sdonyapi śni nakaeś.

5 Miye hinca wicaśta tankinkinyan ekta mde kta, qa hena om wowahdake kta; hena eqe Jehowa tacanku, Taku Wakan tawapi tawokonze kin sdonyapi naceca: tuka iś eya cannapinpi 273 


\section{JEREMIAH TAWOYUKCAN KIN,}

kin ocowasin hduweg̣api, icaśke kin hduksapi.

6 Heon etanhan mnaja wan contanka kin etanhan wicakte kta; śunktokeca wan tintoskan tanhan ihangwicaye kta; inmu lota tanka wan otonwe tawapi kin awanyake kta: hetanhan tankan yapi kin otoiyohi yahdehdecapi kta: wahtanipi kin hena ota, wawakipajinpi kin ihduotapi nakaeś.

7 De on token cicicajuju kta he. Nicinca amayuśtanpi qa taku wakan śni kin on iciconzapi. Miye qe imnahan wonwicawaya tuka wawicihahapi econpi, qa witkowinpidan tipi kin ohna mniciyapi.

8 Śuktanka hankinna eca wonwicayapi kin iyececapi ; otoiyohi iye takodaku tawicu ahotonpi ecee.

9 Dena on en wicawai kte śni he, Jehowa eya: qa oyate wanji dececa kin en minagi watokiçon kte śni he.

10 Inyan conkaśke tawa kin akan ya po, qa waihangya po: tuka ocowasin owihankeyapi śni po: Adetka tawa kin hena eyaku po; hena Jehowa tawa śni nakaeś.

11 Israel tipi qa Juda tiyohnaka kin hena wohnaye on śicaya ecamiconpi ce, Jehowa eya.

12 Hena Jehowa oitonpiśni, qa, He iye śni; qa taku sica en unkaupi kte śni ; nakun mazasagye qa wicaakiban wanunyakapi kte śni ce, eyapi.

13 Unkan wicaśta wokcan kin tate heca kta; qa wicoie kin en wicaun śni: hecen ecawicakiconpi kta ce.

14 Heon etanhan Jehowa Wakantanka ozuye yuhe cin he hecen eya; Iapi kin de ehapi kin heon, iho, mioie kin he nii 274 ohna peta wakage kta, qa oyate kin de can heca kta, unkan huhnaliwicaye kta ce.

15 Wanyaka wo, Israel tiyohnaka, oyate wan tehantanhan niye en awau kta ce, Jehowa eya: oyate wan waśake hinca, oyate wanakajatanhan un, oyate iapi tawa kin sdonyaye śni, qa taku eyapi kin nayahion kte śni.

16 Wanju tawapi kin woha yuhdokapi kin heca, owasin wicaśta waśakśaka.

17 Unkan wojupi nitawa qa woyute nitawa temniciye kta; qa nicinkśi nicunkśi kici temniciyapi kta; tahinca wanunyanpi nitawa qa tatanka nitawa temye kta; hastanhanka iyuwi nitawa qa witanśna hu nitawa temye kta ; nitotonwe acankaśkapi wacinyaye ciqon hena mazasagye on ocowasin ihangye kta.

18 Tuka hececa eśta anpetu kin hena en ocowasin ihangciyapi kte śni, Jehowa eya.

19 Hehan kaketu kta, tohan, Tokeca e Jehowa Taku Wakan unkitawapi kin dena owasin ecaunkiconpi he, ehapi kinhan, hehan niye awicayadupte kta; Niye amayaduśtanpi qa nitamakoce ohna taku wakan tokeca ohoyadapi kin he iyecen makoce nitawapi śni ohna wicaśta tokeca wowidagniyanpi kta ce.

20 Jakob tiyohnaka en de oyaka po, qa Juda ohna eyanpaha, heya po;

21 Oyate witkotkoka qa wacinton śni unpi, wanna de nahion miye ; iśta yukanpi tuka wawanyakapi śni ; nogge yukanpi tuka wanahonpi śni :

22 Miye komayakipapi kte śni he, Jehowa eya : Miye miniwanca opapun kin wiyaka ewahraka, wokonze owihanke wanica on, unkan acakśin iyaye śni; taja 
WICOWOYAKE 6.

kin ipsipsica eśta okihi śni; qa nina hotonton eśta acakśin iyaye śni, miiśta itokam nicancanpi kte śni he.

23 Tuka oyate kin he wicacante pemni qa wawakipajin ece kin he en un; wawakipajinpi qa iyayapi ce.

24 Nakun cante mahen, Wanna Jehowa Taku Wakan unkitawapi kounkipapi kta, he qe magiaju hiyuya ece, tokaheya qa ehake kin iyehantu kinhan; anpetu wakan tona woksapi kta iyehantu konzapi qon hena unkicipatanpi ce, eyapi śni.

25 Taku śica ecanonpi kin hena dena yutokan iyeyapi, qa wayahtanipi kin hena taku waśte anicinicapi ece.

26 Mitaoyate ehna wicaśta śicapi yukan; waakita unpi, tuwe mazahtakiyapi eonpe cin iyececa; on hmunkapi kin ehnakapi, wicaśta wicayuzapi ece.

27 On hmunkapi wan zitkadan ojudan kin he iyececa tipi tawapi kin wolnaye on ojukiyapi: heon tanka icağapi qa wijica ayapi.

28 Hena cepa aya, hena iyeġapi : han, tona śica oiepi kin kape. yapi ece; woyaco on wayacopi śni, wamdenica tawoyaco kin hee, tuka wápiya unpi ; qa wicaśta onśikapi taku owotanna wicakiciyuśtanpi śni.

29 Dena on en wicawai kite śni he, Jehowa eya: oyate kin dececa on minagi watokicon kte śni he.

30 Taku wowinihan qa wowitonpe hinca makoce lin ohna econpi :

31 Wicaśta wokcan itonśniyan woyakapi, qa hena napepi on wawayuśna kin itancan umpi : unkan mitaoyate kin hecetu da- kapi : hecen he owihanke kin en token ecanonpi lita he.

\section{WICOWOYAKE 6.}

1 Benjamin cinca, Jerusalem cokayatanhan napa inahini po; qa Tekoa en mazayahotonpi tanka kin yajo po; qa Beth-hakerim ohna wiyokihe dan ehde po: waziyatanhan wośice qa woihangye tanka tanin nakaeś.

2 Wanji owanyag waśte qa tanyan icaliyapi kin heca Zion cunwintku kin imdacin.

3 Waawanyake optaye tawapi kin om en hipi kta; hena en ikiyedan iticagapi kta, ihdukśantanhan ; otoiyohi iye tohe kin en wihanpi kta.

4 En okicize yuwankan po; najin po, wiyotanhan hehan anatan unyanpi kta. Hehehe, unkiyepi, anpetu kin wanna henakeca, htayetu ohanzi kin hanskạska aya ce.

5 Najin po, qa hanyen unyanpi kta, qa tipi waśteśte tawa kin ihangunyanpi kta.

6 Jehowa ozuye yuhe cin he hecen eya; Can kaksa po, qa Jerusalem icahda paha wan kaga po: otonwe en hipi kte cin he dee: ocowasin wokakiśye cokaya yanka ce.

7 Miniyowe wan mini hiyuye cin he iyecen wicohan śica tawa kin hiyuya ece : iye ohna wokakiśye qa wicakipi nahonpi ece : ohinniyan kiunniyanpi qa waapapi yukan.

8 Jerusalem, ihduecetu wo, okinni minaği nikpağan kta; okinni hewoskan ehpeciye kta, makoce wan tuwedan en ounye śni kin heca.

9 Jehowa ozuye itancan kin he hecen eya; Hastanhanka iyurvi wan iyecen, akta wośpipi on Is275 


\section{JFREMIAH TAWOYUKCAN KIN,}

rael okaptapi kin wicayuśpipi kta: hastanhanka yuśpi kin iyecen ninape makanopiye kin ekta yekiya wo.

10 Tona e wowicawakiyake kta qa owawicawakiye kta, hecen nahonpi kta he. Iho, noge bakilidaye śni yukanpi, hecen anagoptan okihipi śni : Tho, Jehowa oie kin he wowahteśni dakapi, ecaca en iyuśkinpi śni ce.

11 Tuka Jehowa tocanteptanye kin omajudan hinca : tinsmiçiya mdowakița: tankan śiceca kin awicawakaśtan kta, qa nạkun kośka omniciye kin en: han, wicaśta qa tawicu kin napin wicayuzapi kta: wicahinca qa tuwe anpetu ojudan kici.

12 Unkan tipi tawapi kin wicaśta tokeca yuhewicakiyapi kta, maga qa tawinohincapi koya: makoce en ounyanpi kin hena nape awicawakiyugate kta nakaeś, Jehowa eya.

13 Wicacistinna qa wicatanka hehanyan ocowasin wakipi kamna wacinpi : nakun wicaśta wokean qa wawayuśna kin ocowasin wohnaye econpi ece.

14 Nakun takuśni on mitaoyato cunwintku tokakije kin okiziyapi; Wookiye, wookiye, eyapi; tuka wookiye wanica.

15 Taku wahteśni econpi kin on iśteniçiyapi ; tuka wowiśtece on iśtecapi śni; nakun ite naśapi sdonkiyapi śni; heon etanhan tona hinlipayapi kin om hinhipayapi kta, tohan en wicawahi kinhan, hehan hicahanwicayapi kta, Jehowa eya.

16 Jehowa kaken eya; Canku kin ohna inajin qa etonwan miye; qa tanina canku kin on wiwanga po; canku waśte kin tukte e hecinhan, qa he ohna ya po, kinhan ninaggipi on woozi$276^{\circ}$ kiye iyeyayapi kta ce. Tuka, Unyanpi kte śni ce, eyapi.

17 Nakun niyepi on waawanyake najin wicawakiya: Mazayahotonpi tanka ho kin anagjoptan po: Tuka, Anaungoptanpi kte śni, eyapi.

18 Heon etanhan, oyatepi, nalion miye, qa omniciye, taku wicalici un kin sdonya po.

19 Maka, nation wo; Tho, taku śica wan oyate kin de en miye awau kta, iye tawacinpi oicağe kin hee; mioie anagoptanpi śni, qa mitawoahope aktapi śni, heon etanhan.

20 De taku on etanhan canśin waśtemna Śseba etanhan makahipi he; qa sinkpe tawote makoce tehan tanhan: wohulinage wośnapi nitawapi kin hena icupica śni, qa nitawośnapi kin hena iyomakipi śni.

21 Heon etanhan Jehowa kaken eya; Tho, oyate kin de itokam on hicahanpi kin ewahde kta; unkan hena ahicahanpi kta, ateyapi qa cincapi kin om: tuwe en ounyan qa takodaku kici atakunipi kte śni.

22 Jehowa kaken eya; Iho, oyate wan waziyata makoce kin etanhan u kta, qa oyate tanka wan maka ihanke kin etanhan icağe kta :

23 Itazipa qa wahukeza hduzapi kta: hena wohitikapi, qa waonśidapi śni : hena hopi kin miniwanca iyecen hoton kta, qa śuktanka akan iyotankapi kta; wicaśta zuyapi ece he iyecen, Zion cunwintku, niye on wiyeya eiçihdepi.

$24 \mathrm{He}$ oyakapi kin naunhonpi ; unnapepi waśake śni aya; woiyokisice unyuzapi, woyazan wanji hokśiksuye cin iyececa.

25 Mağa kin ekta tankan ye śni wo; qa canku kin ohna mani 


\section{WICOWOYAKE $\%$}

śni wo: toka tamazasagye, wokokipe ihdukśan tanhan yanka nakaeś.

26 Mitaoyate cunwintku, wakihdaka ipiyag kiton wo, qa cahota en iwanka wo: hokśidan iśnana on iyecen wicaceya içicağa wo, śicahowayapi tehike hinca: wawicaki sa kin ihnuhanna unkiyepi en u kta nakaeś.

27 Mitaoyate en wiwanyake ecihde, conkaśke wan, hecen sdonyaye ça tacankupi kin idukcan kta e heon.

28 Hena owasin wawakipajinpi on wawakipajinpi, waaiapi om manipi : mazaśa qa mazasapa heca ; iyuhpa ihduśicapi.

29 Wipogan kin he peta on giu, mazasu kin he hulinaga; ituhin waśdoye kin śdoya ece; qa śicapi kin ewicayakupi śni.

30 Mazaska ehpeyapi eya cajeyatapi kta ; Jehowa elipewicaya nakaeś.

\section{WICOWOYAKE $\%$}

1 Jehowa etanhan wicoie Jeremiah en hi qon he hecen eya:

2 Jehowa ti tiyopa kin ohna najin qa hen wicoie kin de eyanpaha wo, qa heya wo: Juda owasin tiyopa kin dena ohna Jehowa cekiya mahen idadapi kin, Jehowa oie kin nahon miye.

3 Jehowa ozuye itancan Israel ta Wakantanka he hecen eya; Nitacankupi qa niohanpi kin hduwaśte po, kinhan den cicipi waun kta ce.

4 Tona itonśniyan iapi qa, Jehowa ti kin, Jehowa ti kin, Jehowa ti kin dena ee ce, eyapi kin hena wacinyanpi śni po.

5 Yuwaśtepi on nitacankupi qa niohanpi yahduwaśtepi kinhan; wicaśta qa takodaku otahedan wokonze tanyan ecanonpi kinhan :
6 Wicaśta tokeca, wamdenica qa wiwazica kin hena kakiświcayayapi śni, qa owanka kin de ohna wicawe taku iyaonpepica śni kin yapapsonpi śni, nakun nihduśicapi kta on taku wakan tokeca imayanipi śni kinhan ;

7 Hehan den ounyeciyapi kta, makoce niyatepi wicawaqu qon he ohna, ohinniyan qa owihanke wanica.

8 Iho, wicoie itonśni qa waokiya okihi śni kin hena wacinyayapi :

9 Wamanonpi, tin wicaktepi, qa wawicibahapi econpi, qa itonśni içiconzapi, qa Baal en wizite izinkiyapi, qa taku wakan tokeca sdonyayapi śni qon hena ihakam mayanipi ;

10 Tuka yaupi qa tipi kin de micaje on cajeyatapi kin ohna nayajinpi, qa, Dena wowahte śni kin owasin econunkiyapi ce, ehapi kta he.

11 Tipi kin de micaje on cajeyatapi kin he niiśtapi en wamanon sa tipi heca he. Iho, miye qe hena wanmdaka ce, Jehowa eya.

12 Tuka wanna owanka mitawa Ślo en, otokahe ekta micaje ewahnake ciqon he ekta ya po, qa mitaoyate Israel taku śica econpi kin on taku ecawecon kin he wanyaka po.

13 Unkan nakaha, wicohan kin dena owasin ecanonpi, Jehowa eya; qa wociciyakapi, hanwekta qa iwaa, tuka niye waanayagogptanpi śni, qa cicipanpi tuka amayaduptapi śni ;

14 Heon etanhan nakun tipi micaje on cajeyatapi wacinyayapi kin he, qa owanka niyepi qa niyatepi ko cicupi qon hena en, taku Śilo ecawecon qon he iyecen ecamon kta.

15 Qa miite etanhan ehpeciyapi $2 \% \tilde{c}$ 


\section{JEREMIAH TAWOYUKCAN KIN,}

kta, nihunkawanjipi owasin, Ephraim oicage ocowasin ehpewicawaya iyececa.

16 Heon etanhan niye oyate kin de iwicakiye śni wo, qa hena on hoyeyapi qa wocekiye uyaye kte śni; qa hena on wocekiye emakiye śni wo; nacihon kte śni, heon etanhan.

17 Juda otonwe kin en qa Jerusalem canku kin ohna taku econpi kin he wandake śni he.

18 Hokśipidan can depi, qa atkukupi kin cetipi, qa winohinca kin hena ağuyapi pasutapi, ag̉uyapi hmiyanna mahpiya wicaśtayatapi winohinca kin kicagapi kta, qa wokaśtan wośnapi taku wakan tokeca kicaśtanpi kta, iyokiśinmayanpi kta e heon etanhan.

19 Unkan iyokiśinmayanpi he, Jehowa eya : iye ite iśtecapi kta on ecaiciconpi śni he.

20 Heon etanhan Jehowa Itancan kin hecen eya; Iho, mitocanniye qa mitocanteptanye kin owanka kin de en akaśtanpi kta, wicaśta qa woteca akan, qa maga can kin hena akan, qa makoce oicage kin akan; unkan ide kta, qa kasnipi kte śni ce.

21 Jelıowa ozuye yuhe cin, Israel Taku Wakan tawa kin he hecen eya; Wohuhnagge wośnapi nitawapi nitawośnapi kin en ehnaka po, qa tado hduta po.

22 Niyatepi Egupta makoce etanhan hinanpewicawaye ciqon anpetu kiu he en, wohulinage wośnapi qa wośnapi kin on takudan ewicawakiye sni, qa econ wicawaśi śni.

23 Tuka wicoie kin de econwicawaśi qa hepa; Miho kin anagoptan po, kinhan Taku Wakan nitawapi kin he miye kta, qa mitaoyate kin he niyepi kta; qa taku econ ciśipi kin he ocowasin ohna mani po, hecen tanyan yaunpi kta ce.

24 Tuka anagoptanpi śni qa nog̣e ekta uyapi śni; tuka iye cante śicapi tawacinpi pemni kin he ohnayan manipi, qa lieyatakiya ihdoyapi qa tokatawapa śni ;

- 25 Anpetu en niyatepi Egupta makoce etanhan hinanpapi qon hetanhan anpetu de hehanyan: Unkan mitaokiye wicaśta wokcan owasin niyepi ekta ye wicawaśi, anpetu otoiyohi hanwekta qa ye wicawaśi :

26 Tuka anamağoptanpi śni, qa nog̉e ekta uyapi ślii ; tuka tahu suta içicagapi ; atewicayapi isanpa taku śica econpi ece.

27 Heon etanhan niye wicoie kin dena owasin owicayakidake kta ; tuka ananigoptanpi kte śni : nakun niye wicayakipan kta, tuka aniyuptapi kte śni.

28 Heon hewicayakiye $\mathrm{kta}$; Oyate kin de Jehowa Taku Wakan tawapi oie kin anagoptanpi śni, qa iyopeyapi icupi śni : wowicake kin tanin śni, qa iye ipi kin etanhan kaśpapi ce.

29 Paha hduśda wo, qa ehpeya wo, qa pajodan ektakta woceye wan eyaku wo; Jehowa iye wicoicage canniye cin he elipekiya qa ayuśtan nakaeś.

30 Juda cinca kin miiśta itokam taku śica econpi ece, Jehowa eya: Taku wahteśni tawapi kin liena tipi micaje on cajeyatapi kin he en ahipi, yuśicapi kta e heon.

31 Nakun Tophet paha kin içicagapi, Hinnom cinhintku takaksiza kin ohna, iye cinhintkupi qa cunwintkupi peta en hulinalwicayapi kta e heon; he hecen econ wicawaśi śni, qa micante kin en u śni tuka.

32 Heon etanhan anpetu kin u

$2 \% 8$ 


\section{WICOWOYAKE 8.}

kta, Jehowa eya; hehan, Tophet, qa Hinnom cinhintku takaksiza, icimana eciyapi kte śni, tuka, Wicaktepi kaksiza: Tophet en wicaliapi kta, owanka wanica nakaeś.

33 Unkan oyate kin de wicaśta tapi kin hena mahpiya okinyanpi qa maka wamanica kin woyute yuhapi kta: qa tuwedan wahamye kte śni.

34 Hehan Juda otonwe tawa kin etanhan, qa Jerusalem canku. kin etanhan wowiyuśkin ho kin ayuśtanwakiye kta, qa iyaśapi ho kin, wicaśta tawicu ton kta ho qa winohinca yuzapi kta ho kin hena: makoce kin hewoskantu kta nakaeś.

\section{WICOWOYAKE 8.}

1 Jehowa hecen eya; Anpetu kin he en Juda wicaśtayatapi huhu tawapi kin hena aupi kta, qa wicaśta ihdawa huhu, qa wawayuśna huhu, qa wicaśta wokcan huhu, qa Jerusalem en ounyanpi huhu kin hena, wicahapi kin etanhan :

2 Qa hena anpetu wi kin itokam kadapi kta, qa hanyetu wi kin itokam, qa mahpiya obe kin iyulipa itokam, hena waśtedakapi qa hena anagoptanpi qa hena ihakam manipi, qa hena odepi qa hena en patujapi nakaeś: hecen pahipi kte śni qa wicahapi kte śni; maka ite kin akan tacesdi iyecece kta.

3 Unkan wiconi ee śni, wiconte hee e kahnigapi kta, wookapte ocowasin tona wicowazi śice cin de etanhan okaptapi, makoce tuktekte ekta yewicawaye ciqon tona en unpi kin hena, 'Jehowa ozuye yuhe cin he hecen eya.

4. Nakun decen ewicayakiye kta; Jehowa hecen eya ce:
Hena hinhpayapi kta, qa ake najinpi kte śni he: tuwe ye kta qa ake hdicu kte śni he:

5 Tokeca oyate kin de hdicupi he: Jerusalem ohinniyan hdicucu kta: wohnaye sutaya yuzapi ; hdicu kta wicadapi śni.

6 Anohya manka qa nawahon: Hiya: hecen eyapi: Tuwedan tośice on iyopeiçiye śni; hecen, Taku ecamon he, eye kta. Otoiyohi iye toinyanke kin ekta ihdoyapi, śuktanka olkicize ekta inyang ye cin he iyececa.

7 Nakun malipiya en hoka kin he tohan iyekicihantu sdonkiya ece; qa tin wakiyedan qa pehangidan, qa upijate kin tohan upi kte cin he awacinpi ece : tuka mitanyate Jehowa tawoyaco kin sdonyapi śni.

8 Tokiyatanhan, Unkiye unksapapi, qa Jehowa toope kin unkicipi un ce, ehapi kta he. Nakaeś; iho, wohnaye on kag̣api; wowapi kaga icagge tawapi kin he wohnaye on.

9 Tona ksapapi hena iśtecapi, hena inihanpi qa wicayuzapi : Tho, Jehowa oie kin aktapi śni, hecen woksape tukte e en wicaun he.

$10 \mathrm{Heon}$ etanhan tawicupi kin wicaśta tokeca wicawaqu kta, tamagapi kin tuwe tokeca tawayapi kta: wicacistinna qa wicatanka hehanyan otoiyohi wokamna akita nakaeś; wicaśta wokcan qa wawayuśna kin otoiyohi wohnayan kagapi ece.

11 Qa mitaoyate cunwintku tokakije kin taku śni on okiziyapi: Wookiye, wookiye, eyapi ece; tuka wookiye wanica.

12 Wowahteśni econpi kin heon iśtecapi he : Hiya, wowiśtece on iśtecapi śni, qa ite naśapapi kta onspepi śni : heon etanhan tona hinlipayapi kin hena om hinhpa$2 \% 9$ 


\section{JEREMIAH TAWOYUKCAN KIN,}

yapi kta: tohan en wicahipi kinhan hehan atakunipi kte śni ce, Jehowa eya.

13 Miye woihangye on ihangwicawaye kta ce, Jehowa eya : hastanhanka iyuwi en hastanhanka wanice kta; qa suken can kin en waskuyeca wanice kta; qa canwapa kin śniś aye kta: qa tona ehna yapi kin hena wicawaqu kta ce.

14 Tokeca owanjidan unkiyotankapi he. Ihduwitaya po, kinhan otonwe acankaśkapi kin en unyanpi kta; qa hen inina unkanpi kta: Jehowa Taku Wakan unkitawapi kin he inina yanke unśipi, qa pizi mini kin yatkeunkiyapi, Jehowa waunkihtanipi kin heon etanhan.

15 Wookiye apepi, tuka taku waśte wanica: wokizi iyehantu kta, tuka, iho, wonihinciye.

16 Sunkawakan tawa poğanpi kin Dan etanhan nahonpi ; waśakśaka tawa hotonpi ho kin on makoce kin ocowasin cancan : unkan hena upi kta, qa makoce taku ohna un ko temyapi kta; otonwe qa en ounyanpi kin hena koya.

17 Nakun, iho, wamduśka, wamduśka tanka niyepi ehna yewicawaśi kta, hena iwicadowanpi kte śni, tuka niyahtakapi kta ce, Jehowa eya.

18 Iyuśkinmiçiye en woiyokiśica mici un; micante mahen matakuni śni ce.

19 Tho, tehan unpi makoce kin hetarhan mitaoyate cunwintku hoyeya ho kin : Jehowa Zion en un śni he: en Wicaśtayatapi wanica he: Tokeca wakagapi baǵopi kin on, takuśniśni toktokeca on canteptanyan mayanpi he.

20 Womnaye kin wanna henakeca, mdoketu kin wanna owi- hankeyapi, tuka unkiye niunkiyapi śni ce.

21 Mitaoyate cunwintku tokakije on makakija; masapa amayan: wonihinciye mayuze hinca. 22 Gilead en wiconi pejihuta wanica he; awicakehan wawokiziye cin en un śni he : tokeca mitaoyate cunwintku zaniyan kağapi s̊ni lie.

\section{WICOWOYAKE 9.}

1 Mapa kin mini, qa miiśta iśtamnihanpe owenape kin heca $\mathrm{kta}$ e tuve maqu kta he; hecen mitaoyate cunwintku wicakiktepi kin hena on anpetu qa hanyetu waceye kta tuka.

2 Hewoskan wakeya oicimani en yapi ece kin wan tuwe maqu kta he: hecen mitaoyate ehpewicawakiye ca tokan mde kta; hena owasin ivawicihahapi econpi sa, witaya nahmana ohanyanpi ece kin hecapi nakaeś.

3 Nakun iye cejipi woitonśni itazipa tawapi kin hena nawinjapi ece : tuka makoce ohna wowicake kin on waditakapi śni; taku śica etanhan taku śica ekta iyoopta yapi nakaeś, qa miye e sdonmayanpi śni ce, Jehowa eya. 4 Otoiyohi iye takodaku kin etarıhan ihdonicapi po, qa sunkayayapi wanjidan wacinyakiyapi kte śni: wicasunkaki otoiyohi wiciheyatanhan wicahnaye $\mathrm{kta}$, qa takodayapi otoiyohi waaie mani kta.

5 Unkan otoiyohi iye takodalicu kin wicahnaye kta, qa wowicake eyapi kte śni: woitonśni oie eyapi kta iye cejipi onspekiyapi, walitanipi kta on mdokite iciyapi ece.

6 Wohnaye cokaya ounyaya: wohnaye on miye sclonmayan wicadapi śni ce, Jehowa eya.

280 


\section{WICOWOYAKE 9.}

7 Heon etanhan Jehowa ozuye yuhe cin he hecen eya; Iho, śdowicawaye kta qa iwicamdute kta: Ecin mitaoyate cunwintku kin on token ecamon kta he.

8 Ceji tawapi kin wanhinkpe wao sa kin heca; wahnayan ia ece; wanji takodaku kici i on wookiye cajeyata, tuka cante mahen iyakipe.

9 Dena on en wicawahi kte śni he, Jehowa eya: oyate wanji dececa minaği tokiçon kte śni he.

10 He kin on woceye qa śicahowayapi kin iwacu kta, qa hewoskan owilianpi kin on waceye kta; hena gupi, tuwedan opta ye śni, qa ohna wanuyanpi hotonpi kin nahonpi śni; mahpiya okinyanpi kin hena, qa nakun woteca kin najicapi, tokan iyayapi.

11 Unkan Jerusalem pahaha wakagie kta, wamduśka tanka tipi kin heca; qa .Juda otonwe kin hewoskan wakagge kta, tuwedan en ounye kte śni.

12 Tuwe wicaśta ksapa qa de okahinige kta he ; qa tuwe Jehowa $i$ kin kici wohdaka he, hecen oyake kta; taku on makoce kin ihangyapi, gupi, tinta kin iyececa, hen oicimani wanica.

13 Unkan Jehowa heya; Wicitokam mitoope wahnake cin he ehpeyapi, qa miho kin anagoptanpi śni, qa ohna manipi śni :

14 Tuka iye cante tawacinpi kin eciyatanhan manipi, qa Baalim ihakam, he qe atewicayapi kin onspewicakiyapi.

15 Heon etanhan Jehowa ozuye yuha, Israel Taku Wakan tawapi kin he hecen eya; Iho, oyate kin de peji pa hinca yunwicawakiye kta, qa pizi mini kin yatkewicawakiye $k$ ta ce.

16 Nakun Ikcewicaśta, iye qa atewicayapi sdonwicayapi śni qon̉ hena ehna enanakiya iyewicawaye kta; qa wicihakam mazasagye wan ye waśi kta, ihangwicawaye kta hehanyan.

17 Jehowa ozuye yuhe cin he hecen eya; Awakicin po, qa winohinca accya ece econpi kin hena wicakico po, hecen upi kta, qa tona wayupipi kin hena wahowicaya miye, hecen upi kta:

18 Qa inahinipi kta, qa woceye wan yawankan iyeunkiciciyapi kta; hecen unkiśtapi iśtamnihanpe hiyuye kta, qa iśta ojuha unkitawapi mini śbuye kta.

19 Zion etanhan woceye ho kin nahonpi; Hehehe, ihangunyanpi hinca, nina iśtenunyanpi; makoce ehpeunkiyapi nakaeś, en untipi kin tankan hiyuunyanpi, heon etanhan.

20 Tuka winohincapi, ito Jehowa oie kin nation po, qa iye i oie kin ninogiepi icu kta, qa nicunkśi wicaceya onspewicakiya po, qa otoiyohi iye takodaku woceye odowan onspekiyapi kta.

21 Wiconte owanye unkitawapi kin adi, conkaśke unkitawapi kin ohna hiyu; hokśiyopa tankan unpi kin hena, qa kośka canku ohna yakonpi ihangwicaye kta e heon.

22 Woyaka wo, Jehowa hecen eya ce; Nakun wicaśta ta hinhpayapi kta, tacesdi magia ite kin akan iyececa, qa ağuyapi baśda wanjikji yuśna kin he iyececa, qa tuwedan wapahi kte śni.

23 Jehowa hecen eya; Tuwe ksape cin he toksape on ihdatan kte śni, qa tuwe waśake cin towaśake itan kte śni, qa tuwe wijice cin towijice en witan kte śni.

24 Tuka tuwe witan kta hecinhan de on witan kta, omakahnige qa sdonmaye cin heon: Jehowa maka akan wowaonśida, wokon- 


\section{JEREMIAH TAWOYUKCAN KIN,}

ze qa woowotanna econ ece kin he miye; hena en wimduśkin hinca nakaeś, Jehowa eya.

25 Tho, anpetu kin u kta ce, Jehowa eya; hehan ohomni bahdayapi śni kin om ohomni bahdayapi kin hena en wicawai kta: 26 Egupta, qa Juda, qa Edom, qa Ammon cinca, qa Moab, qa tona putinhin hdasanpi kin owasin hewoskan ounyanpi kin hena: oyate kin hena iyulipa ohomni bahdayapi śni nakaeś ; qa Israel tiyohnaka ocowasin cante en bahdayapi śni.

\section{WICOW OYAKE 10.}

1 Israel tiyohnaka, wicoie Jehowa eniciyapi kin hena nation po.

2 Jehowa hecen eya; Ikcewicaśta tacanku kin onspeiciciyapi śni po; qa mahpiya wowakta kin on nihinciyapi śni po; hena on Ikcewicaśta nihinciyapi nakaeś.

3 Oyate tawokagie kin hena taku śni: contanka kin etanhan can wan kaksapi; tuwe nape on onspe un kin he wicohan tawa nakaeś:

4. Mazaska qa mazaskazi on yuwaśtepi ; mazaiyokatkuge qa maziyape on sutaya kagapi ; hecen pahohopi kte śni.

5 Hena bosdan han, wazi can iyececa, tuka iapi śni; qinpi on yuhapi, mani okihipi śni nakaeś. Hena kowicakipapi śni po; taku śica econ okihipi śni, qa nakun taku waśte econpi kta en wicaun śni, heon etanhan.

6 Jehowa, tuwedan iyenicece śni; niye nitanka, qa nicaje kin tanka, wowaśake en.

7 Oyate en Wicaśtayatapi kin, tuwe e konicipe kte śni he; he niye nitawa nakaeś: oyate en 282 wicaksape iyuhpa ehna, qa iye tokiconzepi kin owasin en tuwedan iyenicece śni, heon etanhan. 8 Tuka hena e ocowasin woteca iyececa, qa witkotkoka : takuśniśni onspewicakiye cin can kin hee.

9 Mazaska kandaskapi kin hena Tarśiś etanhan aupi, qa mazaskazi Upaz etanhan, mazakağa tohan qa tuwe śdoya nape ohan lin hee: wokoyalie tawapi kin to qa stan kin heca, hena owasin wicaśta ksapa tohanpi.

10 T'uka Jehowa wowicake Wakantanka, Taku Wakan ni un kin hee, qa Wicaśtayatapi owihanke wanica: iye tośinhida kin on maka kin cancan kta, qa iye tocanteptanye kin Ikcewicaśta kin okihipi kte śni.

11 Kaken ewicayakiyapi kta ce; Taku wakan mahpiya maka ahna kag̉e śni kin hena maka kin etanhan, qa mahpiya kin dena ihukuya tanhan atakunipi kte śni ce.

12 Tuwe iye towaśake on maka kagge cin he toksape kin on taku maka akan wiyeya ehnaka; qa tookahnige kin on mahpiya kin hdumdaya :

13 Iye ho uya eca malipiya ekta mini ota ece, maka ihanke kin etanhan malipiya śapa au nakaeś : Wakanhdi maģaju kin kicagia, qa mazopiye tawa kin etanhan tate ulxiya ece.

14. Wicaśta owasin wosdonye kin en woteca iyececapi; waśdoye cin otoiyohi wakagapi bagopi kin on iśteca içicağa, wakag̉api śdoye cin he woitonśni; qa woniya takudan en wicaun śni.

15 Hena takuśni, wicahnayanpi wicohan; tohan en wicaipi kinhan atakunipi kte śni.

16 Jakob Tawaye cin he hena 


\section{WICOWOYAKE 11.}

iyecece śni : He qe taku owasin kaga: qa taku tawaye kta wiyute kin Israel hee; Jehowa ozuye yuha, he caje kin ee.

17 Conkaśke ohna yati kin, makoce kin etanhan wopahte nitawa ehdaku wo.

18 Jehowa kaken eya ce; Iho, dehan makoce eli ounyanpi kin hena inyan iyuhmun etanhan kahoya ehpewicawaye kta, qa acanwicawakaśke kta, hecen iyewicayapi kta.

19 Hehehe makaśtakapi on; amapapi kin tehike hinca: Tuka hepe; Awicakehan woiyokiśice he dee; tuka mduha kta ce.

20 Wakeya mitawa kin he ihangyapi, qa ikan mitawa owasin yupsapsakapi; micinca kin hena ehpemayanpi, qa en unpi śni; detanhan tuwedan mitawakeya ticaǵe kte śni, qa ozanpi mitawa otkemiciye kte śni.

21 Wawiliankiye cin hena woteca iyececapi, qa Jehowa akitapi śni; heon etanhan wayupiya hduśtanpi kte śni; qa wilianwicakiyapi kin owasin oyumdecapi kta.

22 Ho wan nahonpi, iho uye do; han, waziyata makoce kin etanhan wośkanśkan tanka; Juda totonwe kin ihangyapi kta; wamduśka tanka otipi kta heca.

23 Jehowa, wicaśta tacanku kin he iye en un śni sdonwaya; nakun tuwe mani kta owe hdusuta kta okihi kte śni.

24 Jehowa iyopemayan wo, tuka woyaco eciyatanhan; nitocanniye kin eciyatanhan śni, okinni mayadutakuni kte śni.

25 Ikcewicaśta oyate sdonniyanpi śni qa wicowazi tona nicaje hoyekiyapi śni kin hena nitocanteptanye kin awicakaśtan wo: hena e Jakob yutapi qa temyapi qa ihangyapi qa toounye kin yutakunipi śni nakaeś.

\section{WICOWOYAKE 11.}

1 Wicoie Jehowa etanhan Jeremiah en hi kin he hecen eya;

2 Wicotakuye kin de oie kin hena nahon po: Unkan Juda wicaśta qa Jerusalem en ounyanpi kin om woyahdake kta;

$3 \mathrm{Qa}$ hecen ewicayakiye lata; Jehowa Israel Taku Wakan tawapi kin he hecen eya ce : Wicaśta tuwe wicotakuye kin de oie kin anağoptan śni kinhan he yaśicapi ce.

4 Niyatepi anpetu wan en Egupta etanhan, mazasapa oceti kin etanhan hiyuwicawakiye ciqon he ehan econ wicawaśi qon hee : Maho kin nahon po, qa taku econ ciśipi kin hena owasin econ po : kinhan mitaoyate $k$ in he niyepi kta, qa Wakantanka nitawapi kin he miye kta ce, epa.

5 Hecen wokonze oie niyatepi konza ewicawakiye ciqon, makoce wan pte asanpi tulimaga canhanpi koya on apaśboka wicawaqu kta he mdusuta kta, anpetu kin de iyececa ce. Hehan waamdupta qa, Jehowa hecetu nunwe, epa.

6 Hehan Jehowa hemakiya : Wicoie kin dena owasin Juda otonwe kin en, qa Jerusalem canku kin ohna eyanpaha wo, qa heya wo; Wicotakuye kin de oie kin nahon po, qa hena econ po :

7 Wasdonyeyapi on niyatepi sdonyewicawaye ciqon, Egupta etanhan hiyuwaye ciqon anpetu kin he en, qa anpetu dehanyan, hanwekta qa wowicawakiyaka; Maho kin anagoptan po, epa.

8 Tnka anagoptanpi śni, qa nogge ekta uyapi śni ; tuka otoi- 


\section{JEREMIAH TAWOYUKCAN KIN,}

yohi iye cante tehike sutapi kin eciyatanhan manipi : heon etanhan wicotakuye kin de oie kin econ wicawaśi tuka econpi śni kin hena owasin en awicawau kta ce.

9 Hehan Jehowa hemakiya: Juda wicaśta qa Jerusalem en ounyanpi kin om woihdaśke wan kag̀api.

10 Iye hunkakewicayapi tokaheya mioie nahon wacinpi śni qon hena wahtanipi kin ekta ihdohdapi ; qa taku wakan tokeca ohodapi kta e ihakam manipi; Israel tiyohnaka qa Juda tiyohnaka kin hena wicotakuye mitawa iye atewicayapi om wakagie ciqon he yujujupi.

11 Heon etanhan Jehowa hecen eya; Iho, taku śica en awicawau kta, he qe etanhan napa okihipi kte śni : hehan nina hoyemakiyapi kta, tuka miye nawicawahon kte śni ce.

12 Hehan Juda otonwe qa Jerusalem en ounyanpi kin hena yapi qa taku wakan izinwicakiyapi kin hena nina hoyewicakiyapi kta: tuka toiyokiśicapi anpetu kin en wiconi on niwicakiyapi kte śni.

13 Juda, nitotonwe kin tonakeca hecinhan taku wakan nitawa kin iyenakeca; qa Jerusalem canku tonakeca kin iś iyenakeca taku wowiśtece kin he wahna wośnapi yecagapi, wahna wośnapi on Baal izinyakiyapi ktá e heon.

14 Heceu niye oyate kin de on wocekiye ewicakiciye śni wo, qa hena on woceye wocekiye ko wankan ukiye śni wo: tohan toiyokiśice on hoyemakiyapi kinhan nawahon kte śni nakaeś.

15 Hecen waśtewakidake ciqon wati ohna taku econ kta he, wicota om wowalite śni econ nakaeś, qa cehpi wakan kin he niye etanhan tokan iyaya: tohan taku śica ecanon eca widuśkin. ece.

16 Oliwe can teca, owanyag waśte, waskuyeca waśte heca, Jehowa cajeniyata: oqoyapi tanka ho kin on peta wan en idekiya, unkan adetka kin boksaksapi ce.

17 Hecen Jehowa ozuye yuha hunihde qon he taku śica eniciya, Israel tiyohnaka qa Juda tiyohnaka taku śica iye ecaiçiconpi kin on, wizite Baal qupi kin on canteptanyan mayanpi kta e heon etanhan.

18 Unkan Jehowa wasdonyemakiya, qa sdonwaya: Hehan wicohan tawapi kin wanyagmayakiya.

19 Tuka miye qe tahin wanunyanpi cinca wahbadan ktepi kta aupi kin iyemaceca; hecen miye on taku śica awacinpi sdonwaye śni: Can kin tawaskuyeca kici ihangunyanpi kta, han wicani makoce kin etanhan unkaksapi kta, qa iye caje tohinni kiksuyapi kte śni ce, eyapi.

20 Tuka Jehowa ozuye yuha, wayaco owo tanna, wicapakśin qa wicacante iyukcan yaun; hena towicayecicon kte cin wanmdake kta, woakinica mitawa kin he niye en wahdomda nakaeś.

21 Heon etanhan, Anathoth wicaśta, ninagi akitapi, Jehowa caje 'kin on wounkiciyakapi śni po, hecen unnapepi on nițe kte śni ce, eyapi kin hena on Jehowa hecen eya:

22 Heon etanhan Jehowa ozuye yuha he hecen eya; Iho, hena wicawakaśtake kta: kośkapi kin hena mazasagye on tapi kta: cinhintkupi qa cunwintkupi kin hena akilian țapi kta.

$23 \mathrm{Qa}$ hena etanhan wookapte wanice kta: Anathoth wicaśta 
kin taku sica en awicawau kta nakaeś, wicakaśtakapi waniyetu kin hee.

\section{WICOWOYAKE 12.}

1 Jehowa niye oniwotanna, heon nici wowahdake kła; tuka woyaco on wociciyake kta: Tokeca wicaśta śica tacanku kin tanyan ihuni he : tona wohnaye on wahnayan kin hena owasin owanji yakonpi.

2 Hena niye huwicayahde, han, hutkan icah aya; sanpa icagapi, han, waskuyeca icahyapi : hena ipi kin en ikiyedan nanka, tuka pakśinpi kin itehan yaun.

3 Tuka niye, Jehowa, sdonmayaya; wanmayadaka, qa micante cante niciyuze cin he idukcan : tahinca wanuyanpi wośnapi kte cin iyecen iwicacu wo, qa anpetu en wicaktepi kte cin on wiyeya ewicahnaka wo.

4. Tohanyan makoce kin cante śin un kta he, qa en ounyanpi taku śica econpi kin on mağa otciyohi oicagge kin śen aye kta he: woteca qa zitkadan nakun kahin iyewicayapi : Unkowilıankepi kte cin he wanyake kte śni ce, eyapi eśta.

5 Huinyun unpi kin om yainanka qa hena mdokite niyanpi hecinhan, hehan suktanka om token nihdutemni kta he: qa wookiye makoce kin en tanyan yaun, tuka Jordan minitan kin en token yahan kta he.

6 Nihunkawanji qa niyate tiyohnaka hena eepi qaeś nihnayanpi, liena ee nihakam nina houyapi; taku waśte eniciyapi eśta wicawicada śni wo.

7 Wati kin he elipewakiya; taku mitawa qon he amduśtan; minag̉i waśtekidake ciqon he tokayapi napepi kin en waqu:
8 Taku mitawa kin he contanka en mnaja kin iyececa imicicagga: ho kin on amahoton, heon etanhan śicewakidake.

9 Taku mitawa qon he miye en zitkadan hdehdezedan kin heca; ihdukśan zitkatanka kin takpe upi: U po, tinta wamanica otoiyohi mniciya po, watemya inahini po.

10 Wawihankiye ota hastanhanka iyuwi ojupi mitawa kin ihangyapi, wopamni mitawa kin siha on ahanpi; wopamni waśte mitawa kin he hewoskan hopuza kağapi :

11 Ocowasin hewoskantu ehpeyapi ; hopuza heon hoyemakiya; makoce. kin ocowasin hewoskantu, tuka tuwedan arvakicin śni.

12 Ḣopuza en pajodøn owasin elktakta waihangye kin hena upi; Jehowa etanhan mazasagye kin watemye kta; makoce ihanke kin etanhan makoce ihanke un. ma kin hehanyan wicacehpi owasin wookiye nicapi.

13 Ag guyapi ojupi, tuka wapepeka mnakiyapi kta ; nina htanipi, tuka on wijicapi kte śni: han, womnaye nitawapi kin on iśtecapi kta, Jehowa tocanteptanyan wohitike cin on etanhan.

14 Mikiyedan unpi śicaya econpi kin owasin, taku tawayapi mitaoyate Israel hduhewicawakiye ciqon tona he yutanpi kin hena on Jehowa hecen eya; Iho, makoce tawapi kin etanhan wicamdujun kta, qa hena wicehna tanhan Juda tiyohnaka kin wahdujun kta ce.

15 Hehan kaketu kta, wicamdujun kin iyohakam wahdicu kta, qa onśiwicawakida kta, qa otoiyohi taku tawaye cin en, qa otoiyohi iye tamakoce kin ekta hdicuwicawakiye kta :

16 Hehan kaketu kte, hena 285 


\section{JEREMTAH TAWOYUKCAN KIN,}

mitaoyate tacankupi kin tanyan onspeiciciyapi kinhan, micaje on konzapi kta, Jehowa ni un ce, eyapi kta; mitaoyate Baal on konza onspewicakiyapi qon iyececa; hehan mitaoyate wicacokaya icahwicayapi kta:

17 Tuka waanagoptanpi śni kinhan hehan oyate kin he wicamdujun kta, mdujun qa ihangwaye kta ce, Jehowa eya.

\section{WICOWOYAKE 13.}

1 Jehowa decen emakiya; Ye ça hahonta ipiyaka wan opeiciton wo, qa ninite en ipiyag kiton wo, qa mini cn oputkan śni wo.

2 Hccen ipiyake wan opewaton qa ipiwahdake, Jehowa oie kin iyececa.

3 Hehan Jehowa oie inonpa en mahi kin he hecen eya:

4 Ipiyaka opeyaton ninite akan yanke cin he icu wo, qa najin qa Euphrates ekta ya wo, qa heciya imnija ohdoka wan ohna inahman wo.

5 Hecen imdamde qa Euphratcs ekta he nawahbe, Jehowa econ maśi kin iyececa.

6 Hehan anpetu ota iyohakam Jehowa hemakiya; Najin qa Euphrates ekta ya wo, qa hetanhan ipiyake en inahbe ciśi qon he ehdaku wo.

17 Unkan Euphrates elita wai, qa en waqe ca ipiyake en nawalibe ciqon he iwekcu: unkan iho ipiyake qon kuke hinca, takudan on waśte śni.

8 Hehan Jehowa oie en mahi kin he hecen eya:

9 Jehowa hecen eya ce; $\mathrm{He}$ iyecen Juda towahaniçida kin mdukuke kta, qa Jerusalem towahaniçida tanka kin.

10 De oyate śica mioie anağoptan wicada śni, iyc cante tawa286 cinpi kin eciyatanhan manipi, qa taku wakan tokeca íhakam yapi, ohodapi kta qa itokam makata elipeiçiyapi kta, hena eqe ipiyake kin de iyececapi kta, takudan on waśte kte śni.

11 Ipiyake wan wicaśta nite en askape cin he iyecen, Israel tiyohnaka ocowasin qa Juda tiyohnaka ocowasin miye en askam mayanpi kta wakago; mitaoyate kin ee kta, qa miye on wicacaje qa woyatan qa wowitan heca kta e heon etanhan: tuka anaggoptan wacinpi śni.

12 Heon etanhan wicoie kin de ewicayakiye kta; Jehowa Israel Taku Wakan tawa kin he hecen eya cc;. Makajanjan otoiyohi miniśa on ojudan kta cc. Unkan, Makajanjan otoiyohi miniśa on ojudan kta, he wosdonye on sdonunyanpi śni he, eniciyapi kta.

13 Hehan hecen ewicayakiye kta; Jehowa hecen eya ce; Ilio, makoce kin de en ounyanpi kin owasin, wicaśtayatapi Dawid toiyotanke kin akan kiciiyotankapi kin heepi kaeś, qa wawayuśnapi kin hena, qa wicaśta wokcanpi, qa Jerusalem en ounyanpi kin iyuhpa witkopi on ojuwicawakiye kta.

14 Qa hena walramdemdece kta, w anji iye sunkaku kici, atkukupi qa iye cinhintkupi kin yuwitayapi: wacanwakiye kte śni, qa wakpatan kte śni, qa onśiwicawada kte śni, tuka ihangwicawaye kta ce, Jehowa eya.

15 Nahon po, qa anaggoptan po: wahaniçidapi śni po; Jehowa ia nakaeś.

16 Jehowa Taku Wakan nitawapi kin he wowitan qu po; otpaza kagge śni itokam ; qa otpaza he kin akan nisihapi hicahanpi śni itokam; qa anpa ayapepi icunhan wiconțe ohanzi kin ee 


\section{WICOWOYARE 14.}

kagge kta, otpaza soka hinca icaliye kta.

17 Tuka anayagogtanpi kte śni hecinhan, hehan minaği onahbe en wahanicidapi kin on ceye kta: han, śicahowayapi on waśicahowamde kta, qa miiśta etanhan iśta minigaga au kta, Jehowa optaye tawa kin wayaka ayapi kin heon etanhan.

18 Wicaśtayatapi qa wicaśtayatapi winohinca kin hena hewicakiya wo; Thduhukuya po, iyotanka po; wowitan wateśdake nitawapi nipapi etanhan hinhpaye kta nakaeś.

19 Itokali otonwe kin hena natakapi, qa tuwedan yulidoke kte śni : Juda ocowasin wayaka ayapi ; wayaka ayapi yuśtanpi hinca.

20 Niiśtapi wankan ehdaku po, qa tona waziyatanhan upi kin wanyaka po: optaye niçupi qon, wowitan optaye nitawa kin tukten un he.

21 Tohan en nihi kinhan taku ehe kta he: mdetahunkapi kin itancan nitawa kta e niye onspewicayakiya nakaeś: winolinca hokśiksuye cin iyececa woiyokisica niyuze lite śni he.

22 Tuka nicante en, Tokeca dena mahiyohi he, ehe cinhan: Wayahtani ota heon etanhan nitośke niciyutaninpi, siyete nitawa śdayehna enicihnakapi.

23 Kuśi wicaśta kin ha hdutokeca kta he, qa inmu hdeśkaślka kin he hdeśkaśka hdutokeca okihi kta he: nakun niye taku śica ecanonpi ece kin taku waśte econ oyakihipi kta.

24 Heon etanhan aǵuyapi ha liopuza tate on kahbog iyeyapi kin he iyecen enanakiya iyewicawaye kta ce.

25 Taku tawayaye kte cin he dee, miye etanhan hinskokeca iniciyutapi qon, Jehowa eya: miye amiyektonja qa woitonśni wacinyaya nakaeś:

26 Heon etanhan miś nakun niite hehanyan nitośke ciciyuśdoke kta, hecen nitowiśtece tanin kta.

27 Wawicihahapi ecanon, qa yadowanwan, qa inalimanpi awacanni, mag̉a ekta paha akan wowahte śni nitawa kin hena wanmdaka. Hehehe Jerusalem, niye ska nicagapi tawatenyaye śni he; ehake tohanyan lita he.

\section{WICOWOYAKE 14.}

1 Wopuza wicoie kin on Jehowa oie Jeremiah en hi qon he dee.

2 Juda waśihda, tatiyopa kin atakunipi śni, makoce kin on hena ceyapi ; qa Jerusalem śicahowrye cin he wankan iyaya.

3 Qa wicaśta itancan wicayuhapi kin hena taśiceca kin mini huwe yewicasipi qehan miniyowe kağapi kin ekta ipi, tuka mini iyeyapi śni; ceğa coka ahdipi; iśtecapi qa nihinciyapi, qa pa ahdahpapi.

4 Makoce kin en mağaju śni nakaeś maka kin nalidelideca, heon etanhan maliyumdu kin hena iśtecapi, pa ahdahpapi.

5 Nakun tawiyedan kin tintata un cinca ton qa ehpekiya, wato wanica heon etanhan.

6 Qa śonśonna itu unpi kin hena pajojo kin alkan najinpi. tate ahotonpi, wamduśka tanka iyececa, iśta akitakunipi śni, peji wanica heon etanhan.

7 Waunhtanipi kin hena unyaotaninpi eśta, Jehowa niye nicaje on ohanyan wo: wawaunkipajinpi kin hena ota aya; niye waunnicihtanipi nakaeś.

8 Israel wacinkiye cin, woiyo$287^{\circ}$ 
kiśica anpetu kin en "Wanikiya tawa, tokeca wanji makoce kin en ti sni lzin iyeniceca he; qa icimani wan hanyetu wanke kta e tin iyaye cin iyececa:

9 Tokeca wicaśta wan nihinciya iyeniccce $\mathrm{kta}$ he; wicaśta waśaka keś wanikiya okihi śni kin iyececa: tuka, Jehowa niye unkicokayapi yaun; qa nicaje icajeunyatapi : ehpeunyanpi śni po.

10 Oyate kin de on Jehowa he cen cya; Hena hecen nunipi waśtedakapi, siha ehdakupi śni: heon etanhan Jehowa cantewicakiye śni; wanna taku śica econpi kin hena kiksuye kta, qa wahtanipi kin on iyopewicayc kta.

11 Hehan Jehowa hemakiya; Oyate kin de on wocekiye ewicakiye śni wo, taku waśte on.

12 Tohan wotektehdaiçiyapi kinhan hoyeyapi kin he miye nawalion kte śni; qa tohan woliulinag̉e wośnapi qa wośnapi wayuśnapi kinhan cantewicawakiye kite śni ; tuka mazasagye on, qa wicaakitian on, qa makośice on atakuni śni iyewicawakiye kta.

13 Hchan hepa; Hehehe Jehowa Itancan; iho, wicaśta wokcan tawapi kin hena, Mazasagye wandakapi kte śni, qa wicaakihan en niunpi kte śni; tuka owanka kin de en awicakehan wookiye ciçupi kta ce, ewicakiyapi ecee.

14 Hehan Jehowa liemakiya; Wicaśta wokcan kin hena micaje on woitonśni oyakapi ece: yewicawaśi śni, qa takudan econwicawaśi śni, qa ecaca owicawakiye śni: woitonśni wowanyake, qa wakan kagiapi, qa wotalruśni qa iye cantepi eciyatanhan wohnaye kin hena e iye cinka oniciyakapi ece. 288
15 Heon etanhan wicaśta wokcan micaje on woyakapi, qa yewicawaśi śni tuka; Mazasagye qa wicaakilian makoce kin de en yule kte śni ce, eyapi kin hcna on Jehowa hecen eya; Mazasagye qa wicaakilian on wicaśta wokcan kin hona atakunipi kte śni.

$16 \mathrm{Qa}$ oyate wowicakiyakapi kin hena wicaakitian qa mazasagye on etanhan Jerusalem canku kin ohna tankan elipewicayapi kta; qa tuwedan wicahe kte śni; iyepi qa tawicupi, qa cinhintkupi qa cunwintkupi : hecen taku sica ecompi kin iyepi en awicawecicaśtan kta.

17 Heon etanhan wicoie hin de ewicayakiye kta cc: Miiśta etanhan iśtaminihanpe kadus au $\mathrm{kta}$, hanyetu qa anpetu, qa hena ayuśtan kte śni: wokakse tanka on mitaoyate cunwintku kin kaksapi ; kaśtakapi kin lie tehilkehinca.

18 Mağa ekta tankan mde cinhan, hehan iho, mazasagye on capapi; qa otonwe kin en mde cinhan, hehan iho, wicaakihan on hanyanpi ; tuka wicaśta wokcan qa nakun wawayuśna kin hena makoce kin en omani unpi. qa wasdonyanpi śni.

19 Elipcyapi on Juda ehpeyaya he; ninagi Zion wahtekida śn he: tokeca unyakaśtakapi qa okiziyapi unnicapi he: wookiye apepi, tuka talku waśte wanica: qa tohan wokiziyapi kta, tuka iho, wonihinciye.

20 Jehowa taku sica unkitawapi kin hena sdonunkiyapi, atewicunyanpi wahtanipi kin; niye en wanunicilitanipi nakaeś.

21 Waśicedake śni wo, nicaje on etanhan; nitowitan oyanke kin hduśice śni wo ; kiksuya wo, wicotakuye nitawa unkicipi un kin he hdakse sni wo. 
22 Ikcewicaśta takuśniśni tawapi kin maǵaju inahinikiya okihi he: qa is mahpiya kin hena mini hinhan wicaqu he: Jehowa Wakantanka unkitawapi kin he niye ee ŝni he: heon etanhan niye ekta eunnitonwanpi kta, dena owasin niye yakag̀a nakaeś.

\section{WICOWOYAKE 15.}

I Hehan Jehowa hemakiva: Moses qa Samuel mitokam najinpi qeyaś minagi oyate kin de ektakiya yanke kte śni: mitokapatanhan elipewicaya wo, tokan yapi kta ce.

2 Unkan kaketu; Tokiya unyanpi kta he, eniciyapi kinhan, hehan hewicayakiye kta; Jehowa hecen eya ce; "Tona wiconte tawa, hena wiconte ekta; qa tona mazasagye tawa kin hena mazasagye kin ekta; qa tona wicaakilian tawa hena wicaakihan ekta ; qa tona wayaka ayapi kte cin hena wayaka ayapi kin ekta.

3 Unkan ocaje topa en wanyag wicahi wakiye kta, Jehowa eya: mazasagye kin wicakte kta; qa śunka wicayahdehdece kta; qa mahpiya okinyanpi qa maka wamanica kin watemyapi qa wayapotpotapi kta.

4 Qa hena wonihinciye on wokiconze maka akan un kin owasin wicawaqu kta, Mannaseh Hezekiah cinhintku Juda wicaśtayatapi kin on etanhan, taku Jerusa lem en econ qou heon.

5 Jerusalem, tuwe e onśinida kta he; tuwe wookiye nitawa on iwangige kta e icunom ye kta he.

6 Niye ehpemayaya ce, Jehowa eya; hekta itoheya mayani : tuka niwankam minape yewakiye kta $\$ 6$ qa ihangciye kta : waonśidapi on wamatuka ce.

7 Unkan wicaduge wan on wicawakaduge kta, makoce tatiyopa owasin ohna; cinca codan ehpewaye kta, mitaoyate kin ihangwakiye kta; iye tacankupi kin etanhan hdicupi śni nakaeś.

8 Wiwazica tawapi kin hena miciyuotapi, miniwanca wiyaka kin isanpa; en awicawau, koślka hunku kin en waihangye wan awau, wiyotanhan hehantu; ihnuhanna ahinhpaye waye, wonihinciye qa woihangye hinca.

9 Tuwe śakowin cinca ton kin he hanyan; iye naği niya śni iyaya; hinyahin anpetu tuka anpetu wi tawa isinyan iyaya ; iśteca qa nihinciya: unkan tona okaptapi kin hena mazasagye en wicawaqu kta, tokawicayapi kin itokam, Jehowa eya.

10 Hehehe, miye, ina, maka ocowasin en wicaśta wakinica qa wicaśta wawakipajin kin heca mayaton. Wodote śni waun qa wicaśta wornakidotapi śni ; tuka iyuhpa mayaśicapi ece.

11 Jehowa heya; Otokahe nitawa kin he waśte śni he ; anpetu śica en qa wokakije anpetu kin en toka kin tanyan ecanicon wakiye śni he.

12 Mazasapa kin he waziyata mazasapa qa nakun mazaśa kin kamdece kta he.

13 Wowijice qa wokamna nitawa kin, wiyopeyapi codan, wokipi wakagie kta, tuka wayahtani owasin on etanhan, qa makoce opapun nitawa owasin en.

14 Qa tokaniyanpi om makoce wan sdonyaye śni qon he ekta iyaye ciye kta: mitocanteptanye en peta wan itkon, niyepi aideniyanpi kta nakaeś.

15 Jehowa, niye wasdonyaya: miksuye ca en mahi wo; qa tona 289 


\section{JEREMIAH TAWOYUKCAN.KIN,}

kuwa amaupi kin en tomicicon wo: nitocanniye kin hdutehan śni wo; emayaku wo: niye on waajapi mduha he sdonya wo.

16 Nioie kin hena iyeyapi, unkan hena temwaya; qa nioie kin hena wopida qa taku on micante iyuśkin kin hee: Jehowa Taku Wakan ozuye yuha, niye nicaje on caśmatonpi nakaeś.

17 Wawihaha unpi kin hena om imdotanke śni ; tuka ninape on etanhan imduśkin: miśnana imdotanke, wocanteptanyan on ojumayaya nakaeś.

18 Tokeca wamayazan kin ohinniyan, qa ksuwemayanpi kin asniyepica śni he; okiziyapi kta wicada śni : mini wacinyepicaśni wohnaye kin iyececa miye en ocowasin yaun kta he.

19 Heon etanhan Jehowa hecen eya; Yahdicu kinhan hehan hdicuciciye kta, mitokam nayajin kta: qa taku śice cin etanhan taku tehika iyacu kinhan, hehan mii kin hee iyenicece kta: hena e niye en ihdokupi kta, tuka hena ekta niye nihdoye kte śni.

$20 \mathrm{Qa}$ oyate kin de en mazaśa conkaśke suta hinca cicaġe kta: unkan nicizapi kta, tuka ohiniyanpi kte śni; miye cici waun kta, niciciye kta, qa ecihdaku kta e heon, Jehowa eya.

21 Han, wicaśta śicapi nape etanhan ecihdaku kta, qa wicaśta wohitikapi nape kin etanhan ciyuśke lsta ce.

\section{WICOWOYAKE 16.}

1 Hehan Jehowa oie en mahi kin he hecen eya :

2 Makoce kin de ohna tawicu yaton kte śni, qa nicinkśi qa nicunkśi niciyuke kte śni.

3 Makoce kin de en cinkśiwicayapi qa cunkśiwicayapi wicaton290 pi, qa hunkupi wicayuhapi qa atkukupi malkoce kin de ohna wicakaggapi kin hena on Jehowa hecen eya:

4 Hena wośilitin wiconte on țapi kta, awicakiceyapi kte śni qa wicaliapi kte śni ; tacesdi iyececa maka ite kin akan hiyeye kta: han, mazasagye qa wicaakihan on atakunipi kte śni, qa tancan tapi kin hena mahpiya zitkadan qa maka wamanica woyute yapi kta.

5 Jehowa hecen eya; Wicaceya tipi kin en ye śni wo; qa awicakiceyapi qa wacintonhnagwicayapi on ye śni wo: Oyate kin de wookiye mitawa eweciyaku nakaeś, Jehowa eya; wowaonśida qa wocantekiye kin hena ee.

6 Wicatanka qa wicacistinna kin makoce kin de en tapi kta; qa wicahapi kte śni qa awicakiceyapi kte śni : qa hena on baiçihonpi kte śni, qa ihduśdapi kte śni.

7 Qa ceyapi on ag̉uyapi wicakiyuśpapi kte śni, tapi on wacintonhnagyapi kta: qa atkukupi on qa hunkupi on wowacintonhnake wiyatke kin yatke wicakiyapi kte śni.

8 Nakun wotapi qa wayatkanpi on om idotanke kta e wohanpi tipi kin en de kte śni.

9 Jehowa ozuye yuha, Israel ta Wakantanka kin he hecen eya: Iho, makoce kin de ohna, niiśtapi itokam qa nitaanpetu kin en wowiyuśkin ho qa iyaśapi ho kin ayuśtan wakiye kta, tuwe winohinca yuze kta qa tuwe hihnaton kta ho kin nakun.

10 Unkan tohan wicoie kin dena owasin oyate kin de owicayakiyake cinhan, qa, Taku on etanhan Jehowa taku śica tanka kin de ocowasin unkekiciyapi he; qa 
waunhtanipi kin tukte e he; qa taku śica Jehowa Wakantanka unkitawapi ecaunkiconpi kin tukte e he, eniciyapi kinhan ;

11 Hehan hewicayakiye kta; Niyatepi elipemayanpi kin heon etanhan, Jehowa eya; qa taku wakan tokeca ihakam manipi, qa hena anağoptanpi, qa itokam makata elipeiciyapi; han, miye elpemayanpi qa mitawoahope yuhapi śni :

12 Unkan niye niyatepi isanpa taku śica ecanonpi ; iho, wicaśta otoiyohi iye cante śica tawacinpi kin eciyatanhan mayanipi ece, hecen anamag̉optanpi kte śni.

13 Heon makoce kin de etanhan tankan iyaye ciyapi kta, makoce wan niyatepi qa niyepi nakun sdonyayapi śni qon he ekta: unkan heciya taku wakan tokeca wowidag niyanpi kta, anpetu qa hanyetu koya; hen wocantekiye ciçupi kte śni.

14 Heon etanhan anpetu kin u kta, Jehowa eya; hehan, Jehowa, Israel cinca Egupta makoce kin etanhan hiyuwicaye ciqon he ni un ce, icimana eyapi kte śni :

15 Tuka, Jehowa Israel cinca waziyata makoce kin etarhan, qa makoce owasin ektakta kaham iyewicaye ciqon hetanhan awicahdiyaku kin he ni un ce, eyapi kta: Unkan miye makoce tawapi, atewicayapi wicawaqu qon he en awicawahdi kta ce.

16 Tho, hopsicapi ota wahowicawaye kta, Jehowa eya ; unkan wicayupsicapi kta: qa iyohakam wotihnipi ota wahowicawaye kta, unkan hena iwicahnipi kta, he kin owasin etanhan, qa paha otoiyohi etanhan, qa imnija ohdoka kin etanhan.

17 Miiśta iye tacankupi kin owasin ekta etonwe kta nakaeś: hena miite etanhan inahbe içiya- pi śni, qa miiśta etanhan walitanipi kin analimanpi śni.

18 Tuka tokaheya, iye wahtanipi qa taku śica econpi kin nonpa akihde kajujuwicawakiye kta; taku wowaliteśni tawapi țapi kin hena on makoce mitawa yuśicapi, qa taku śice hinca yuhapi kin on taku tawawaya ojuyapi, heon etanhan.

19 Jehowa, wowaśake mitawa, qa conkaśke mitawa, qa wokakije anpetu kin en wowinape mitawa, maka ihanke kin etanhanhan Ikcewicaśta oyate kin niye ekta upi kta, qa heyapi kta; Awicakehan atewicunyanpi kin woitonśni yuhapi, taku śni qa taku owicakiye śni cee.

20 Wicaśta wan taku wakan icicagge kta he, qa hena taku wakan heca śni.

21 Heon etanhan, iho, dehan wasd onye wicawaye kta, minape qa mitowaśake sdonyewicawaye kta: unkan micaje kin he Jehowa ee e sdonyapi kta ce.

\section{WICOWOYAKE $1 \%$.}

1 Juda wahtani kin mazasapa icağo kin on owapi qa inyan suta oinkpa kin on: iye cantepi omdaska kin en bagopi, qa owayuśna nitawa he kin akan.

2 Icunhan, iye cinca owayuśna qa wakagapi tawapi kin hena kiksuyapi, can teca icahda, paha tehanwankantu kin akan:

$3 \dot{\mathrm{H}} \mathrm{e}$ nitawa, magia kin ekta, taku nitawa, womnaye nitawa ocowasin wokipi kta wicawaqu kta, paha nitawa kin wahtanipi on, makoce nitawa owancaya.

4 Unkan niye, han niye hinca, makoce tawayaye kta cicu qon he aduśtan kta: qa makoce wan sdonyaye śni qon he olna tokaniyanpi wowidagniyanpi wakage 


\section{JEREMIAH TAWOYUKCAN KIN,}

kta: mitocanteptanye kin en peta wan ideyayapi nakaeś, he ohinniyan ition kta.

5 Jehowa hecen eya; Wicaśta kin wicaśta wacinye cinhan, qa wicacehpi isto içiya, qa cante tawa Jehowa elipeye cin he yaśicapi ce.

6 Qa he hewoskan tancodan un kin iyecece kta, qa tohan taku waśte u kinhan wanyake kte śni ; tuka. hopuza en maka puza oti kta, miniskuya makoce qa tuwedan ti śni kin hetu.

7 Wicaśta tuwe Jehowa wacinye ca wowacinye tawa kin Jehowa ee hecinhan he yawaśtepi ce.

8 Unkan he qe can wan mini icahda ojupi, qa hutkan wakpadan ektakiya yeye cin he iyecece kta; qa tohan kata aye cinhan sdonye kte śni, tuka ape tawa kin toya yanke kta, qa omaka puza kin kokipe kte śni, qa waskuyeca icahya ayuśtan kte śni.

9 Wicacante taku owasin isanpa wicahnaye sa qa olkiziyepica śni ; tuwe sdonya okihi kta he.

10 Jehowa miye hinca wicacante mdukcan, wicapakśin kin imduta, wicaśta otoiyohi iye tacanku kin eciyatanhan, iye ohan icaliye cin on waqu kta heon.

11 Zica wan waman tuka wapakpi śni, tuwe taku owotanna śni on wowijice kamna kin he iyecece kta, taanpetu cokaya hehan elipeliye kta, qa owihanke ekta witkotkoka heca kta.

12 Otokaheya tanhan tipi wakan unkitawapi oyanke kin he wowitan oiyotanke tehanwankantu kin heca.

13 Jehowa Tsrael wacinyanpi kin, tona aniyuśtanpi kin hena owasin iśtecapi kta, tona mitehan iyayapi kin hena maka en owicawapi kta; Jehowa mini wiconi wakoniya kin ayuśtanpi nakaeś.
14 Jehowa, okizimayan wo, kinhan omakizi kta; nimakiya wo, kinhan wani kta: woyatan mitawa kin he niye nakaés.

15 Iho, hemakiyapi; Jehowa oie kin tukte e he: wanna eśta u kte.

16 Tuka miye qe nihakam wonwicawaya waun kta inawahi śni; qa wokalije anpetu kin he awakite śni : miiha etanhan taku inanpe cin hena niye sdonyaya, niite itokamtu nakaeś.

17 Wakokipe micage śni wo; anpetu śica en wowacinye mitawa kin he niye.

18 Tona śicaya makuwapi kin hena iśtecapi kta, tuka miye qe imaśtece kte śni; hena e nihinciyapi kta, tuka miye qe nihinmiciye kte śni: anpetu śiea kin he en awicau wo; qa woihangye itakihna on ihangwicaya wo.

19 Jehowa hecen emakiya; Ya wo, qa nitaoyate cinca tatiyopa kin ohna inajin wo, Juda wicaśtayatapi kin ohns tin hiyupi, qa ohna tankan hdapi ece kin hena, qa Jerusalem tatiyopa owasin ohna.

20 Qa hewicakiya wo; Juda wicaśtayatapi, qa Juda oy ate ocowasin, qa Jerusalem en ounyanpi kin iyuhpa, tiyopa kin dena ohna idadapi ece, Jehowa oie kin naholl po:

21 Jehowa hecen eya ce; Ninagipi iwanihdaka po, qa anpetu wakan icunhan ecaca waqinpi śni po, qa Jerusalem tiyopa ohna tin akiyahdapi śni po.

22 Qa anpetu wakan eca yatipi kin etanhan tankan taku qin ayapi śni po, qa wicohtani takudan econpi śni po: tuka anpetu wakan kin he niye yuwakan po, niyatepi econwicawaśi qon iyececa.

23 Tuka anağoptanpi śni qa 
WICOWOYAKE 18.

noġe ekta yeyapi śni, tuka tahu suta içicagapi, hecen nahionpi kte śni, qa woonspe icupi kte śni.

24 Unkan kaketu kte, Jehowa eya; Wanahonyan anamayagoptanpi kinhan, anpetu wakan icunhan otonwe kin de tiyopa kin ohna woqin takudan ayahdiyakupi śni, qa anpetu wakan en wicohtani econ śni ohoyadapi kinhan;

25 Hehan wicaśtayatapi qa wicaśta itancan Dawid oiyotanke tawa akan yankapi, canpahmihma qa śuktanka akan iyotankapi ecen otonwe kin de tiyopa kin ohna hiyupi kta, iyepi qa wicaśta ihdawa wicayuhapi, Júda wicaśta, qa Jerusalem en ounyanpi kin hena; qa otonwe kin de en ounyanpi kta owihanke wanica.

26 Hehan Juda totonwe kin etanhanhan upi kta, qa Jerusalem ihdukśan wanke cin etanhanhan, qa Benjamin makoce kin etanhan, qa mde huta kin etanhan, qa he kin etanhan, qa itokağa tanhan, wohuhnag̉e wośnapi qa ikce wośnapi, qa waskuyeca wośnapi qa wizite yuha upi kta, qa woyatan wośnapi Jehowa ti kin en aupi kta.

27 Tuka anpetu wakan kin ohoyadapi kta e on anamayagoptanpi śni kinhan, qa anpetu wakan icunhan woqin hduha Jerusalem tiyopa kin ohna hidupi kinhan, hehan tiyopa kin dena ohna peta idewaye kta, qa he Jerusalem en tipi waśteśte kin hena huhnagge kta, unkan kasnipi kte śni.

\section{WICOWOYAKE 18.}

1 Wicoie Jehowa etanhan Jeremiah en hi kin he hecen eya:

2 Najin wo, qa maka wakśica kaġa tipi kin ekta kun ya wo: W 2 unkan hen mioie kin nahonciye kta ce.

3 Hehan maka ceg̉a kag̉a ti kin ekta apamahde imdamda: unkan iho, inyan pahmihma kin akan taku kag̉a yanka.

4 Unkan upśija etanhan wakśica kag̉e cin he maka cegga kağa nape ohna yuśicapi: hecen ake wakśica tokeca kaga, iye maka ceğa kagge cin token iyokipi he iyececa.

5 Hehan Jehowa oie kin en mahi qa heya;

6 Israel tiyohnaka, maka cegia kag̉e cin de iyecen ecaciconpi kta owakihi śni he, Jchowa eya. Wanyaka wo, upśija maka ceg̀a kaġa nape ohna yanke cin he iyecen, Israel tiyohnaka, minape ohna yaunpi ce.

7 Tohan ihnuhanna oyate wan qa wokiconze wan on iwae kta, yujunpi kta qa yujujupi kta qa ihangyapi kta on:

8 Unkan oyate kin he taku śica econpi cajemdate cin he etanhan ihduhomini kinlıan, hehan taku śica ecawecon kta wacanmi qon etanhan mihduhomni kta.

9 Qa akeś ihnuhanna oyate wan qa wokiconze wan on iwae kta, ojupi kta qa icahyapi kta on:

10 Miiśta kin en taku śica econ, on miho anaggoptan śni kinlıan, hehan taku waśte on mduwaśte kta kepe ciqun he etanhan mihduhomni kta ce.

11 Heon etanhan wanna Juda wicaśta qa Jerusalem en ounyanpi kin wowicakiyake ca heya wo: Jehowa kaken eya ce; Tho, wośice wan cicağapi, qa niyepi on woawacin wan awacanri : Wanna otoiyohi tacanku sica etanhan hdicu po; qa nitacankupi niohanpi koya waśte kağa po.

12 Tuka heyapi; Wowacinye wanica; heon unkitawacinpi kin 293 


\section{JEREMIAH TAWOYUKCAN KIN,}

ohna maunnipi kta, qa otoiyohi iye cante śica taku awacin kin he ohnayan econkupi kta ce.

13 Heon etanhan Jehowa hecen eya; Wanna Ikcewicaśta kin ehna wiwanga po, tuwe taku hececa nahon hecinhan; Israel wikośka kin taku wowinihan hinca econ nakaeś.

14 Imnija on tuwe magga wan Lebanon wa kin on spayeyapi kin ehpeye kta he : wakpa snisni kin hena mini tokeca on elipeyapi kta he.

15 Tuka mitaoyate amiktonjapi; takuśni izitekiyapi, qa tacankupi ohna hicahan wicakiyapi, canku wanakaja kin hena; hecen canku cistinna wan ohna manipi kta, canku wiyeya kag̣api śni.

16 Makoce tawapi kin he hewoskan ehpeyapi kta ; taku ohinniyan ajijipi kin heca lita: tona en hiyayapi kin otoiyohi yuśinyaye kta qa pakapsanpsan kta.

$1 \%$ Tate wiyohiyanpatanhan kin on iyecen toka ite kin itokam enanakiya iyewicawaye kta: wokakije anpetu tawapi kin en tahu wicawakipazo kta, qa ite hee kte śni.

18 Hehan heyapi; U miye, Jeremiah on woawacin awauncinpi kta; awicakehan woope kin wawayuśna kin akicitakuni śni wanice kta; qa wowahokonkiye wicaśta ksapa etanhan; qa wicoie kin wicaśta wokcan ayuśtan kte śni. U po, ceji on unyapapi kta, qa wicoie tawa owasin anaungoptanpi kte sni ce.

19 Jehowa, amawacin ye, qa tona makigepi kin hena ho kin nahon wo.

20 Taku śica taku waśte on tokiyopeyapi kta he; woha wan minag̣i kiçapi nakaeś. Hena on taku waśte epe kta heon nitokam nawajin tuka qon he kiksu294. ya wo, nitocanniye wicaweciyuhomni kta e heon.

21 Heon etanhan iye cincapi kin wicaakilian kin en wicaqu wo, qa mazasagye nape en iyewicaya wo; qa tawicupi cinca codan unpi kta, qa wiwazicapi kte: qa wicaśta tawapi kin hena wiconte on wicaktepi kte : kośka tawapi kin hena okicize en mazasagye on wicakaśtakapi nunwe.

22 Tohan ihnuhanna ozuye wan iye en awicayau kinhan. hehan iye tipi kin etanhan śicahowayapi wan nahonpi kta: mayuzapi kta on wolia wan micapi, qa misiha on mazahtakiyapi emakionpapi nakaeś.

23 Tuka Jehowa, maktepi lita on token amawacinpi kin owasin niye sdonyaya: Woahtani tawapi kin akahpe śni wo, qa taku śica econpi kin hena nitokapatanhan kajuju śni wo; tuka nitokam hena ihangyapi kta, nitocanniye anpetu kin en ecawicakicon wo.

\section{WICOWOYAKE 19.}

1 Jehowa hecen eya; $\mathrm{Ya}$ wo, qa maka cega kage cin etanhan maka janjan wan opeton wo, qa oyate hunkayapi qa wawayuśna wicahincapi kin om;

2 Qa Hinnom cinhintku takaksiza kin ek ta inanpa wo, he maka wakśica tiyopa yuhdokapi kin hetu, qa hen wicoie tona ociciyake kte cin owasin eyanpaha wo:

3 Qa hecen ehe kta; Iuda wicaśtayatapi qa Jerusalem en ounyanpi kin, Jehowa oie kin nation po: Jehowa ozuye yuha, Israel Taku Wakan tawa kin he hecen eya ce; lho, otonwe kin de en taku śica wan awau kta, tuwe he nahon kinhan noge snasna kta. 4 Miye elhpemayanpi; qa oyan- 


\section{WICOWOYAKE 20.}

ke kin de yutokecapi, qa ohna taku wakan tokeca izitewicakiyapi, iyepi qa atewicayapi, qa Juda wicaśtayatapi kin sdonyapi śni qon hena, qa oyanke kin de tona wiyaonpepicaśni unpi we kin on ojudanyapi nakaeś:

5 Nakun Baal pajodan kin hena kagapi, iye cinhintkupi kin peta on liuhnahya Baal wakiyuśnapi kta e heon; he qe econwicawaśi śni, qa cajemdate śni, qa tohinni micante en u śni tuka.

6 Heon etanhan iho, anpetu kin u kta, Jehowa eya, oyanke kin de Tophet qa Hinnom cinhintku takaksiza kin icimana eciyapi kte śni, tuka, Wicaktepi kaksiza eciyapi kta.

7 Unkan owanka kin de ohna Juda qa Jerusalem taku awacinpi kin he ecetu śni wakiye kta; qa tokawicayapi wicitokam mazasagye on hinhpaye wicawakiye kta, qa tona naği iyaye wicaya akitapi napepi kin orı: qa tancan tapi kin hena malipiya okinyanpi qa maka wamanica kin woyute yapi kta wicawaqu kta.

$8 \mathrm{Qa}$ otonwe kin de woyuśinyaye qa wowiliaha wan wakage kta; tona en hiyayapi kin otoiyohi yuśinyaye kta qa ihaha kta, wokaśtake tawa kin owasin on etanhan.

9 Unkan iye cinhintkupi cehpi kin yunwicawakiye kta, qa cunwintkupi cehpi kin, qa otoiyohi iye takodaku cehpi kin yutapi kta, onatakapi qa wokakije kin on, tona tokawicayapi qa tona naği wicakuwapi onawicatakapi kte cin he on.

10 Hehan wicaśta om idade cin hena iśta itokam makajanjan qon he yakamdece $\mathrm{kta}$;

11 Qa hewicayakiye kta; Jehowa ozuye yuha he hecen eya ce; He iyecen oyate kin de qa otonwe kin de owakamdece kta, tuwe maka ceg̣a kagga tawakśica wan kamdece cin he iyececa, he ake piya kağapi kta okihipica śni: unkan Tophet en wicahapi kta; tukten wicahiapi kta owanka wanica nakaeś.

12 Oyanke kin de qa en ounyanpi kin hena hecen ecawicawecon kta ce, Jehowa eya: qa otonwe kin de Tophet iyececa icaġe kta: 13 Qa Jerusalem tipi kin hena, qa Juda wicaśtayatapi tipi tawapi kin hena yuśnpapi kta, Tophet owanka kin iyececa; tipi tona akahpe akan mahpiya ozuye kin iyuhpa izitekiyapi kin hena owasin on, qa taku wakan tokeca wokaśtan wośna owicakicicaśtanpi kin heon etanhan.

14 Hehan Jeremiah Tophet en woyake kta Jehowa ekta yeśi qon hetanhan hdicu; qa Jehowa ti tihocoka kin ohna inajin, qa oyate kin ocowasin hewicakiya;

15 Jehowa ozuye yuha Israel Taku Wakan tawa kin he hecen eya ce; Iho, otonwe kin de en, qa otonwe tawa kin iyuhpa en taku sica owakiyake cin ocowasin awau kta; mioie anagroptanpi kte śni e on tahı patin içicağapi kin heon etanhan.

\section{WICOWOYAKE 20.}

1 Unkan Paśur Immer cinhintku wawayuśna kin hee, qa nakun Jehowa ti kin ohna itancan tokapa kin hee, wicoie kin dena Jeremiah oyaka he nahon:

2 Hehan Paśur Jeremiah wicaśta wokcan kin kaśtaka, qa can icaśkapi kin en ehnaka, he Benjamin tiyopa wankantu kin hetu, Jehowa ti kin icahda.

3 Unkan ihanlianna hehan Paśur canicaśkapi kin etanhan Jeremiah eyaku. Hehan Jeremiah 295 


\section{JEREMIAH TAWOYUKCAN KIN,}

heciya; Nicaje Paśur (Itancan waśte) Jehowa eya cajeyate śni, tuka Magor-missabib (Thdukśan wokokipe.)

4 Jehowa kaken eya ce; Iho, niye hinca en qa nitakuye owasin en wokokipe cicage kta : unkan hena e tokawicayapi tamazasagye on hinhpayapi kta, qa niye niiśta wanyake kta. Nakun Juda ocowasin Babel wicaśtayatapi nape kin en wicawaqu kta, unkan iye Babel ekta wayaka awicakiyalıde kta, qa mazasagye on wicakte kta.

5 Nakun otonwe kin de towaśake ocowasin, qa tohtani ocowasin, qa taku tehike tawa kin ocowasin waqu kta; han, Juda wicaśtayatapi wokamna tawapi kin iyuhpa iye tokawicayapi napepi en waqu'kta, qa hena wawicakipi kta, qa wicayuzapi kta, qa Babel ekta awicayapi kta.

6 Qa niye, Paśur, qa yati ohna unpi kin iyuhpa wayaka aniyanpi kta; han, Babel ekta yai kta, qa hen nițe kta, qa hen nihapi lita, niye qa takuwicayaya woitonśni owicayakidake cin hena owasin koya.

7 Jehowa, awacinmayaya unkan awacanmi; sutaya mayaduza qa niye ohiyaya; anpetu otoiyohi wowihahamayanpi waun; ocowasin imahahapi :

8 Tohan iwaa eca wokakiśye mdaotanin qa wawicakipi omdaka ecee: Jehowa oie kin he, anpetu iyohi, miye en wowihaha qa woaie kin heca micagapi nakaeś. 9 Heon etanhan, Ake cajemdate kte śni, qa icimana iye caje on iwae kte śni ce, epa: tuka he micante kin en peta wahuhnagia maluhu kin en onatakapi iyecen icağa; unkan tinsmiçiya owakița qa owakihi śni.

10 Wicota waaiapi nawation nakaeś; anokatanhan wokokipe: Oyaka po, kinhan unkoyakapi kta ce. Wicaśta wookiye en miciunpi kin owasin mitankiyedan iwanmayakapi. Okinni yuśna kta, hehan ohiunyanpi kta, qa tounkiciconpi kta ce, eyapi.

11 Tuka Jehowa miciun wicaśta wohitike cin iyececa; heon etanhan tona śicaya makuwapi kin hena hicahanpí kta, qa ohiye śni unpi kta: wacinksamya econpi kte śni, heon nina iśtecapi kta; he wowiśtece owihanke wanica, icimana akiktonjapi kte śni.

12 Tuka Jehowa ozuye yuha, wicaśta owotanna kin iyukcan, wicapakśin qa wicacante wanyaka ecee kin, watowicayeçon kin he wanyagmayan wo: mitowakinica kin he niye en amda nakaeś.

13 Jehowa kahiyaya po, Jehowa yatan po; tona taku śica econpi napepi etanhan wicaśta onśika naği lkin ehdaku kin heon etanhan. 14 Anpetı en matonpi qon he yaśicapi nunwe; anpetu en ina mayuhe ciq̣on he yawaśtepi śni nunwe :

15 Wicaśta wan ate hośikahi qa, hokśin cinca wan nicitonpi ce, eciya, qa nina iyuśkinkiye ciqon he yaśicapi nunwe:

16 Nakun otonwe Jehow a ihangye hinca qa on iyopeiçiye qon hena wicaśta kin he iy ececa nunwe: qa hanhanna eca iyaśapi nahon kta, qa wiyotanhan kinhan owodutaton kta.

17 Tokeca tamni kin en makte śni he; qa iś ina woha mitawa eekiyapi śni qa tamui ohinniyan ihduśake śni he.

18 Tokeca wicohtani qa woiyokiśice wanmdake kta e on tamni kin etanhan hibu, qa mitaanpetu wowiśtece en sotapi kta he. 


\section{WICOWOYAKE 22.}

\section{WICOW OYAKE 21.}

1 Jehowa etanhan wicoie Jeremiah en hi qon he dee; Zedekiah wicaśtayatapi kin Paśur Melkiah cinhintku qa Zephaniah Maasaiah cinhintku wawayuśna kin hena ekta yewicaśi qehan, hecen eya:

2 .Ceciciya ce, unkiyepi on Jehowa iwanga wo: Nebukadnezzar Babel wicaśtayatapi kin unkizapi nakaeś: okinni Jehowa iye tohan wakan kin owasin eciyatanhan ecaunkiconpi kta, qa unkiyepi etanhan kihdeye kta naceca.

3 Hehan Jeremiah hewicakiya ; Kaken Zedekiah eyakiyapi kta ce :

4 Jehowa Israel ta Wakantanka kin he hecen eya ce; Iho, wipe ninape ohna yahduhapi, on Babel wicaśtayatapi kin kici, qa on Kasdim oyate conkaśke tankantanhan aonanitakapi om yecizapi kin hena hekta mduhomni kta, qa hena e otonwe kin de cokaya wicamduwitaya kta.

5 Qa miye hinca cicizapi kta, nape hdugata qa isto waśaka on ; han, wocanniye en, qa wocanteptanye qa wośinhda tanka en :

6 Qa otonwe kin de en ounyanpi kin hena wicawakaśtake kta, wicaśta qa woteca nakun: makośica tehika on tapi kta.

7 Qa he iyohakam Zedekiah Juda wicaśtayatapi, qa iye taokiye, qa oyate kin, qa tona otonwe kin de ohna makośica qa mazasagye qa wicaakilian etanhan okaptapi kin hena Nebukadnezzar Babel wicaśtayatapi nape kin en wicawaqu kta, qa tokawicayapi napepi kin en, qa tona nagipi akitapi kin hena napepi kin en: Inkan iye qe mazasagye hi kin on awicape kta, iton- wicape kte śni, qa wacantkiye kte śni qa waonśida kte śni, Jehowa eya.

8 Nakun oyate kin de hewicayakiye kta; Jehowa hecen eya ce; Tho, nitokam wiconi canku qa wiconte canku ervahnaka:

9 Tuwe otonwe kin de ohna owanji yanke cinhan mazasagye qa wicaakihan qa makośica on te kta: Tuka tuwe tankan ye ça Kasdim oyate onanitakapi kin en iyohpaye cinhan he ni kta, qa iye nagi kin wokamna iyecen hduhe kta.

10 Miite otonwe kin de itkokim ewehnaka nakaeś, taku śica on, qa taku waśte on etarihan śni, Jehowa eya: Babel wicaśtayatapi nape kin en qupi kta, unkan iye peta on huhnahye $k$ ta ce.

11 Nakun, Juda wicaśtaya tapi ti kin on, Jehowa oie kin nation po: 12 Dawid tiyohnaka, Jehowa hecen eya ce; Hinlianna eca woowotanna econ po, qa tuwe wakipi kin he wakakiśye nape kin etanhan eyaku po; okinni wicolian śica ecanonpi kin on mitocanniye hinanpe kta, peta iyececa, qa ide iyaye kta, qa tuwedan kasni kte śni.

13 Tho, osmaka en ounye cin, imnija mdaya kin akan, nitkokim waun, Jehowa eya; tuwe itkounkipapi u kta, qa tuwe oununyanpi kin en hiya kta he, eyapi ece.

14 Tuka miye qe niolianpi taku icahye cin en aciupi kta, Jehowa eya: qa contanka tawa kin en peta wan wakage kta, qa taku ihdukśan wanke cin owasin hulinahye kta ce.

\section{WICOW OYAKE 22.}

1 Jehowa hecen eya; Juda wicaśtayatapi ti kin ekta kun ya $29 \pi$ 


\section{JEREMIAH TAWOYUKCAN KIN,}

wo, qa heciya wicoie kin de oyaka wo;

$2 \mathrm{Qa}$ heya wo; Juda wicaśtayatapi Dawid oiyotanke tawa akan idotanka, Jehowa oie kin nahon wo, niye qa nitaokiye qa nitaoyate tiyopa kin dena ohna hiy upi ecee :

3 Jehowa hecen eya ce: Woyaco qa woowotanna econ po, qa tuwe wakipi wakakiśye nape kin etanhan eyaku po; qa wicaśta tokeca, wamdenica qa wiwazica śicaya ecakiconpi śni po, qa otonwe kin de ohna wiyaonpepica śni we kin papsonpi śni po.

4. Awicakehan wicoie kin de ecanonpi kinhan, hehan tipi kin de tiyopa kin ohna wicaśtayatapi hiyupi kta, Dawid oiyotanke tawa kin akan kici iyotankapi kta, qa canpahmihma en qa śuktanka akan iyotankapi kta, iye, qa taokiye, qa tanyate kin.

5 Tuka wicoie kin dena nayahonpi śni kinhan, miye miciconza ce, Jehowa eya; tipi kin de otiwota icage kta ce.

6 Jehowa Juda wicaśtayatapi tiyohnaka kin hecen eciya; Niye Gilead Lebanon ipa kin iyececa cidaka eśta, hewoskan makcce, otonwe tuwedan ohna ti śni kin heca cicaje kte śni he.

7 Qa niye on waihangye kin heca wicamduwakan kta, wicaśta qa tawipe kici: unkan hena e haute śa waśteśte nitawa kawankapi kta, qa petan ehpeyapi kta.

8 Unkan oyate ota otonwe kin den hiyayapi kta, qa otoiyohi iye takodaku hekiciyapi kta ; Tokeca Jehowa otonwe tanka kin de hecen ecakicon hwo :

9 Hehan heyapi kta; Jehowa Taku Wakan tawapi toope kin he ehpeyapi, qa taku wakan tokeca en makata ehpeiçiyapi, qa en wowidagiciyapi kin heon etanhan.

10 Tapi kin on ceyapi śni po, qa on pakapsanpi śni po: ceyapi on tuwe titokan iyaye cin akiceya po: he icimana ku kte śni, qa makoce tawa ake wanhdake kte śni nakaeś.

11 Sallum, Josiah Iuda wicaśtayatapi kin he cinhintku, iye'atkuku Josiah eekiya wicaśtayatapi yanka, makoce kin de etanhan iyaye ciqon he on Jehowa hecen eya; Deciya icimana hdi kte śni ;

12 Tuka makoce ekta wayaka ayapi kin hen te lita, qa makoce kin de ake icimana wanhdake kte śni ce.

13 Hehehe, tuwe woowotanna śni on tipi icicage cinhan, qa wankan tipi woyaco śni on; tuwe iyunwin codan takodaku wowidagye cinhan, qa wicohtani econ kin on takudan qu śni kinhan:

14 Tuwe, Tipi tanka qa wankan tipi okadusyapi kin heca micicage kta ce, eye cinhan; hecen ojanjan hdepi tanka kag̉a: unkan hante śa can on akahpapi, qa waśeśa on śayapi.

15 Ḣante śa on iyokipi niçiye cinhan wicaśtayatapi yaun lita he: Niyate wota qa wayatke śni he: tuka woyaco woowotanna ko econ qehan hehan waśteya un.

16 Wayacopi on onśikapi qa wahpanica kin wicakiciyukcan ecee: hehan waśte: sdonmayanpi kin he dee śni he, Jehowa eya.

17 Tuka nuisśta qa nicante wokamna nitawa eceedan akan yanka; qa wiyaonpepica śni we kin papsonpi kta, qa wokakiśye qa wicakipi kin ekta, econpi kta e heon.

18 Heon etanhan Jehoiakim Jo- 


\section{WICOWOYAKE 23.}

siah cinhintku Juda wicaśtaya- /kin heciya: unkan hen nițapi tapi kin on Jehowa hecen eya; kta.

He akiceyapi kte śni; Hehe, cinye; qa, Hehe, micun: He akiceyapi kte śni ; Hehe Itancan; qa, Hehe towitan kin, eyapi kte śni.

19 Śsonśonna hapi ece kin iyecen hapi kta, yusdohanpi qa Jerusalem tiyopa kin itankan ehpeyapi kta.

20 Lebanon ekta wankan ya wo, qa pan wo; Baśan he kin akan ho hduwankan iyeya wo; Abarim etanhan śicahowaya wo: tona waśtenidapi qon hena owasin ihangyapi nakaeś.

21. Oziiciya yaun qehan wociciyaka. Nawalion kte śni ce, eha ece. Hokśiyopa yaun ehantanhan hecen cankuyaya ece: miho anayağoptan śni nakaeś.

22 Tona wonniciyapi kin hena owasin tateyanpa temwicaye kta; qa waśtenidakapi qon hena wayaka awicayapi kta: hehan awicakehan niohan śica owasin on iniśtece kta qa nihinniciye kta.

23 Lebanon en ounyaya, hante śa en hohpi niçicagge ciqon, tohan hokśinyeksuya, cinca tonpi iyecen yazan yahda kinhan, hehan onśike nidapi kta he.

24 Miye wani, Jehowa eya, Koniah Jehoiakim cinhintku Juda wicaśtayatapi kin he ipuspe mazanapcupe nape ematapa akan yanka hee kaeś, hetanhan ciyuśdoke kta tuka ce :

$25 \mathrm{Qa}$ tona ninaggi akitapi kin hena napepi kin en ciçu kta, qa tona ite koyakipa nape kin en, han, Nebukadnezzar nape kin en, qa Kasdim oyate napepi kin en :

36 Qa tankan elpeciye kta, qa inayaya niton kin he nakun, makoce tokeca ekta, en nitonpi śni

$27 \mathrm{Qa}$ makoce cantekiyuzapi kin ekta hdicupi kta, he ekta ihdokupi kte śni.

28 Maka wakśica wahteśni kamdecapi kin heca Koniah wicaśta kin hee he: wakśica wan woiyokipi takudan en un śni kin heca he: Tokeca iye qa cinca kin tankan ehpewicayapi he, qa makoce wan sdonyapi śni qon ekta iyaye wicayapi he.

29 Maka, maka, maka kin, Jehowa oie kin nation wo.

30 Jehowa hecen eya ce; Wicaśta kin de ehpeyapi owa po; wicaśta iye taanpetu kin en tanyan icage kte śni: han, iye oicagge kin etanhan tuwedan tanyan icage kte śni, Dawid oiyotanke tawa kin akan iyotanke kte śni, qa Juda en icimana wicaśtayatapi yanke kte śni.

\section{WICOWOYAKE 23.}

1 Hehehe, wawiliankiya tona owiliankiye mitawa etanhan tahinca kin ihangwicayapi, qa enanakiya iyayewicayapi kin, Jehowa eya.

2 Heon etanhan Jehowa Israel Taku Wakan tawa kin he wawihankiyapi mitaoyate wonwica yapi kin hena hecen ewicakiya; Niye optaye mitawa wicaduomdecapi qa tankan iyewicayayapi, qa awanwicadakapi śni: iho, niohanpi śice cin hena en cicaupi kta ce, Jehowa eya.

3 Qa optaye mitawa okaptapi kin hena makoce ektakta iyayewicawaye ciqon owasin etanhanhan mnawica wakiye kta: unkan icaggapi qa ihduotapi lita.

4 Qa wawihankiya heca wicawaqu kta, unkan wihanwicakiyapi kta: unkan icimana kope299 


\section{JEREMIAH TAWOYUKCAN KIN,}

hdapi kte śni qa nihinciyapi kte śni, qa nakun nunipi kte śni, Jehowa eya.

5 Iho, anpetu kin $\mathrm{u} \mathrm{kta}$, Jehowa eya, hehan Adetka Owotanna wan Dawid icahweciciye kta, qa Wicaśtayatapi wan wicaśtayatapi un kta, qa iye wacinksamya ohanye kta, qa maka akan wokonze qa woowotanna econ kta. 6 Iye taanpetu kin en Juda nikiyapi kta, qa Israel wowacinye en unpi kta; unkan caje on cajeyatapi ece e kta, Jehowa Woowotanna unkitawapi hee.

7 Heon etanhan, iho, anpetu kin u kta, Jehowa eya; hehan, Jehowa Israel cinca Egupta makoce kin etanhan hiyuwicaye ciqon he ni un ce, icimana eyapi kte śni :

8 Tuka, Jehowa Israel tipi wicoicage kin -waziyata makoce kin etanhan hiyuwicaye, ca makoce owasin ektakta iyayewicaye ciqon hetanhan yus awicau kin he ni un'ce: unkan iye tamakoce kin en ounyanpi kta.

9 Wicaśta wokcan kin hena on micante mahen maun kin nina iyokiśinyapi: mahuhu owasin cancan: wicaśta witko kin hemaceca, qa wicaśta wan miniśa ktedan kin iyecfca, Jehowa ite kin on, qa iye towitan oie kin on etanhan.

10 Makoce kin wiinahmanpi on ojudan; itonśni ic̣icag̉api heon makoce ceya ; tinta wilianpi kin śeca aya; hecen iye inyankapi kin he śica aya, qa towaśakepi kin suta śni.

11 Wicaśta wokcan qa nakun wawayuśna kin ihduśicapi : han, wati ohna taku śica econpi kin iyewaya ce, Jehowa eya.

12 Heon etanhan iye tacankupi kin otpaze linca en canku śduśduta linca iyecece kta: he en 300 naśdun yapi kta qa ohna hinhpa-yapi kta : taku śica wan en awicawau kta nakaeś, omaka en wanyag wicaipi kte cin hee ce, Jehowa eya.

13 Nakun Samaria wicaśta wokcan kin hena en wowitkotkoka wanmdaka: hena Baal eciyatanhan waayatapi, qa Israel mitaoyate nuniwicakiyapi ece.

14 Tuka Jerusalem wicaśta wokcan kin hena en taku wonihinciye wan wanmdaka; wawiciliahapi econpi qa woitonśni ohna manipi ece: nakun śicapi kin nape kiyuwaśakapi, hecen iye tośice etanhan otoiyohi ihdubomnipi kte śni : hena owasin Sodom iyececa wicawadaka icagapi, qa en ounyanpi kin Gomorrah iyececapi.

15 Heon etanhan Jehowa ozuye yuhe cin he wicaśta wokcan kin hena hecen ewicakiya; Iho, woyute śica yunwicawakiye kta qa pizi mini kin yatkewicawakiye kta; Jerusalem wicaśta wokcan kin hena etanhan ihduśicapi kin makoce owancaya iyaya nakaeś.

16 Jehowa ozuye yuha he hecen eya; Wicaśta wokcan waniciyulicanpi oiepi kin anaggoptanpi śni po: hena niyawitkotkokapi ; iye cantepi kin en taku wanyakapi kin he ohdakapi, qa Jehowa i kin eciyatanhan śni.

17 Tona wahtemadapi śni kin hena hewicakiyapi ece ; Wookiye duhapi kta, Jehow a eya ce: qa tuwe iye cante tawacin kin eciyatanhan mani otoiyohi, 'Taku śica takudan en niupi kte sni ce, ewicakiyapi ece.

18 Tuka tuwe Jehowa toinalibe kin ohna najin he: qa tuwe iye oie wanyake ca okahniga he ; iye oie kin tuwe e nation qa okahiniga he.

19 Iho, tateiyumni wan, Jehowa 
tocanniye kin iyaya; han, tateiyumni waśake hinca; wicaśta śica pa kin ayulidece kta.

20 Jehowa tocanniye tohanyan hduśtan śni, qa tohanyan iye cante tawacin kin ecen econ śni hehanyan hdicu kte śni : anpetu ehake kin en wookahinge on de oyakalinigapi kta.

21 Wicaśta wokcan kin dena yewicawaśi śni, tuka inyang yapi; wowicawakiyake śni tuka woyakapi ece.

22 Hececa eśta mitawiyukcan ohnayan najinpi unkanś, hehan mitaoyate mioie nakonwicayapi kta, qa canku śica tawapi kin etanhan, qa wicohan śica econpi kin etanhan wicayuhomnipi kta tuka.

23 Taku Wakan ikiyedan un kin hemaca he, Jehowa eya; qa itehan un Taku Wakan hemaca sni he.

24 Wicaśta wan woinahbe en inalibe kta okihi, qa hecen miye wanmdake kte śni he, Jehowa eya'; Mahpiya kin qa maka kin miye ojudan waye śni he, Jehowa eya.

25 Wicaśta wokcan woitonśni on woyakapi ece kin hena taku eyapi ; Wiwahanmna, wiwahamna ce, eyapi kin he nawation ce.

26 Wicaśta wokcan woitonśni oyakapi, qa iye cantepi wohnaye kin ohdakapi ece kin hena tohanyan de iś cantepi en un kta he :

27 Iye wihamnapi otoiyohi takodaku okiciyakapi kin hena on mitaoyate micaje akiktonś kiya wacinpi, iye atewicayapi Baal on micaje akiktonjapi qon iyececa.

28 Wicaśta wokcan kin tuwe wowihanmde wan kici un kinhan wowihanmde ohdake kta: qa tuwe mioie kici un kinhan he awicakehan mioie yaotanin kta; aguyapi ha kin he ağuyapi su kin kici taku kicica kta he, Jehowa eya.

29 Mioie kin he peta iyecece śni he; qa maziyape wan imnija kamdemdece cin he iyecece śni he, Jehowa eya.

30 Heon etanhan, iho, wicaśta wokcan kin hena itkowicawakipa, Jehowa eya; hena otoiyohi mioie kin iye takodakupi etanhanhan makicinonpi.

31 Iho, wicaśta wolrcan kin hena itkowicakim waun, Jehowa eya; hena iye ceji unpi tuka, Iye heya ce, eyapi ece.

32 Iho, tona wowihamna itonśni kin heca ayatapi kin hena wicitkokim waun, Jehowa eya; qa hena ohdakapi qa iye itonpiśni qa wahanhanicidapi kin on mitaoyate nuniwicakiyapi: tuka hena ye wicawaśi śni qa econ wicawaśi śni: heon etanhan. oyate kin de ecaca waowicaliyapi kte śni, Jehowa eya.

33 Unkan tohan oyate kin de, qa iś wicaśta wokcan qa wawayuśna wan iniwangaapi qa, Jehowa tawoqin kin tukte e he, eyapi kinhan, hehan hewicayakiye kta ; Woqin kin he niyepi; unlan cipahpapi kta ce, Jehowa eya.

34 Han, wicaśta wokcan qa wawayuśna qa oyate kin tuwe kaśta, Jehowa tawoqin, eya cajeyate cinhan, hehan wicaśta kin he qa tiyohnaka nakun kakiśwaye kta.

35 Otoiyohi iye takodaku kici, qa otoiyohi iye sunkaku kici kaken eycciyapi kta; Jehowa token wayupta he; qa, Jehowa taku eya he.

36 Tuka Jehowa tawoqin icimana cajedatapi kte śni : wicaśta otoiyohi tawoqin kin iye oie kin hee kata nakaeś: Wakantanka ni un, Taku Wakan unkita301 


\section{JEREMIAH TAWOYUKCAN KIN,}

wapi, Jehowa ozuye yuha he oie kin datolsecapi nakaeś.

37 Wicaśta wokcan kin kaken eyakiye kta; Jehowa token aniyupta he; qa, Jehowa taku eya he.

38 Tuka, Jehowa tawoqin, ehapi ece kin heon etanlian Jehowa hecen eya; Wicoie kin de, Jehowa tawoqin, eya cajedatapi ece, tuka miye wahociyapi qa, Jehowa tawoqin kin ecaca cajedatapi kte śni ce, epa :

39 Heon etanhan, iho, miye, han, miye qin aciyapi kta qa cipahpapi kta; miite etanhan elipeciyapi $\mathrm{kta}$, qa otonwe niyepi qa niyatepi koya ciçupi qon he nakun.

40 Qa woaia owihanke śni wan he niyepi en aciupi kta, qa ohinniyan wowiśtece akiktonjapi kte śni kin heca.

\section{WICOWOYAKE 24.}

I Nebukadnezzar Babel wicaśtaya tapi kin Jekoniah Jehoiakim - cinhintlu Juda wicaśtaya tapi, qa Juda itancanpi, nakun cankajipa qa mazakaga kin hena Jerusalem etanhan wayaka awicaya qa $\mathrm{Ba}$ bel en awicahdi kin he iyohakam, Jehowa wawanyagmakiya, unkan iho, makanopiye nonpa suken waskuyeca ojudan, hena Jehowa ti kin itokam ehnakapi.

2 Makanopiye wanji suken waskuyeca waśte hinca ohnaka, suken waskuyeca tokaheya suton kin iyececa; qa makanopiye unma kin ohna suken waskuyeca śice hinca, yunpica śni, śice hinca nakaeś.

3 Hehan Jehowa hemakiya; Jeremiah, taku wandaka he. Unkan, suken waskuyeca, epa: suken waskuyeca waśte kin hena waśte hinca; qa śice cin hena śice hinca, yunpica śni, śice hinca nakaeś.
4 Hehan Jehowa oie en mahi kin he hecen eya;

5 Jehowa Israel ta Wakantanka kin he hecen eya ce; Suken waskuyeca waśte kin dena iyecen, tona Juda etanhan wayaka awicayapi, otonwe kin de etanhan Kasdim makoce kin ekta taku waśte on yewicawaśi qon hena tawawicawaye kta :

6 Hena taku waśte on awicawatonwe kta, qa ake makoce kin de en awicawahdi kta: qa piya icaliwicawaye $\mathrm{kta}$, qa ake mdujuju kte śni; qa owicawaju kta qa mdujun kte śni ce.

7 Qa wicacante wan on Jehowa he miye e sdonmayanpi kta wicawaqu kta: unkan hena mitaoyate kin eepi kta, qa Wakantanka tawapi kin he rniye kta; cante ocowasin on miye en ihdokupi kta nakaeś.

8 Tuka suken waskuyeca śica, śice hinca heon yunpica śni he iyececa, awicakehan Jehowa hecen eya; Zedekiah Juda wicaśtayatapi, qa wicaśta itancan tawa, qa Jerusalem en owicakaptapi, makoce kin de en yakonpi, qa tona Egupta makoce kin en ounyanpi kin hena iyecen wicawakage kta. 9 Qa wośice on maka akan wokiconze owasin ektalita śicaya wicakuwapi kta on wicawaqu kta, woiyaonpe qa woaie, wośtehda qa woyaśice eepi kta, tukte en kaham iyewicawaye kte cir owasin ekta.

$10 \mathrm{Qa}$ hena ehna mazasagye, wicaakihian qa makośice yewaśi kta, ecen makoce, iyepi qa atewicayapi wicawaqu qon etanhan ihangwicawaye kta ce.

\section{WICOWOYAKE 25.}

1 Jehoiakim Josiah Juda wicaśtayatapi cinhintku tawaniyetu 
itopa en, Nebukadnezzar Babel wicaśtayatapi tawaniyetu tokaheya kin he en, wicoie Juda oyate

- kin owasin on Jeremiah en hi qon he dee:

$2 \mathrm{He}$ Jeremiah wicaśta wokcan kin Juda oyate owasin qa Jerusalem en ounyanpi kin owasin owicakiyaka qa heya;

3 Josiah Amon cinhintku Juda wicaśtayatapi tawaniyetu iakeyamni hetanhan qa anpetu kin dehanyan waniyetu wikcemna nonpa sanpa yamni hehanyan Jehowa oie kin en mahi, unkan ociciyakapi, hanwekta qa epa ecee : tuka anayağoptanpi śni.

4 Nakun Jehowa iye taokiye owasin wicaśta wokcan kin hena niyepi ekta yewicaśi, hankikta qa yewicaśi : tuka anayağoptanpi śni, qa nayahonpi kta e ekta noge yeyayapi śni.

5 Hena hecen eyapi; Wanna ake ihduhomni po, otoiyohi iye tacanku śica etanhan, qa niohanpi śice cin etanhan; kinhan Jehowa makoce nicupi, qa nihunkakepi kin nakun, he en ounyan po, wicoicage qa wicoicage hehanyan.

6 Qa taku wakan tokeca en wowidag niçiyapi kta, qa ohowicayadapi kta e on ihakam yapi śni po; qa ninape ohanpi kin on śinhda mayanpi śni po; kinahan taku śica ecaciconpi kte śni.

7 Tuka anamayagoptanpi śni ce, Jehowa eya; niye śicaya yaunpi kta e ninape taku śica econpi kin on śinhdamayayapi kta nakaeś.

8 Heon etanhan Jehowa ozuye yuha he hecen eya; Mioie anayağoptanpi śni, heon etanhan,

9 Iho, wahowaye kta, qa waziyata wicowazi iyuhpa iwicawacu kta, Jehowa eya; qa mitaokiye Nebukadnezzar Babel wi- caśtayatapi nakun, qa makoce kin de en, qa en ounyanpi kin hena en takpe hiyuwicawaye kta, qa oyate ihdukśan unpi owasin en, qa hena ocowasin ihangwicawaye kta, qa hena wonihinciye qa woajiji, qa ohinniyan woihangye wicawakage kta ce.

10 Nakun hena ekta ihapi ho, qa wiyuśkinpi ho kin ayuśtan wakiye kta; wicaśta tawicu ton kta ho, qa winohinca yuzapi lita ho kin; wiyutpan ho kin, qa petijanjan ijanjan kin nakun.

11 Qa makoce kin de ocowasin hewoskan wanke kta, wonihinciye kta: unkan oyate kin dena Babel wicaśtayatapi kin en wowidagiçiyapi kta, waniyetu wikcemna śakowin hehanyan.

12 Unkan kaketu kte, waniyetu wikcemna śakowin hena yuśtanpi kinhan, hehan Babel wicaśtayatapi qa oyate kin he, taku śica econpi kin on, en wicawahi kta ce, Jehowa eya; qa Kasdim makoce nakun, unkan he owihanke wanin hewoskan wakage k.ta ce.

13 Qa mioie tona awomdaka owasin, wowapi kin de en kagapi owasin, Jeremiah oyate iyuhpa on oyake ciqon, hena makoce kin he en awaukta.

14 Oyate ota qa wicaśtayatapi tankinyanyan dena e qe wowidagwicayapi kta: qa iye ohanpi kin eciyatanhan wicawaqu kta, iye napepi ohanyanpi kin eciyatanhan.

15 Jehowa Israel Taku Wakan tawa kin he hecen emakiya; Wocanteptanye miniśa iyatke kin de minape etanhan icu wo, qa oyate tona ektakta yeciśi kin bena iyulipa etanhan yatkewicakiya wo.

16 Unkan yatkanpi kta, qa witkoiçiyapi kta, qa wicehna mazasagye yewaśi kin he on capapi kta ce. 


\section{JEREMIAH TAWOYUKCAN KIN,}

17 Hehan Jehowa nape etanhan wiyatke kin iwacu, qa oyate tona ektakta Jehowa y emaśi qon hena owasin yatke wicawalkiya :

18 Jerusalem qa Juda otonwe kin hena, qa wicaśtayatapi tawa, qa wicaśta itancan tawa kin hena, hena e woihangye kagapi kta, qa wonihinciye, qa woajiji qa woyuśice ; anpetu dehanyan iyececa.

19 Pharo Egupta wicaśtayatapi, qa taokiye, qa wicaśta itancan tawa, qa taoyate owasin.

20 Qa oyate icicahiyapi owasin, qa Uz makoce kin en wicaśtayatapi owasin, qa Philistia makoce en wicaśtayatapi iyulipa, qa Aśkelon, qa Azzah, qa Ekron, qa Aśdod en okaptapi kin :

21 Edom, qa Moab, qa Ammon cinca :

22 Qa Turos wicaśtayatapi owasin, qa Zidon wicaśtay atapi owasin; han, miniwanca akasanpatanhan wita en wicaștayatapi linin :

23 Dedan, qa Tema, qa Buz, qa tona ihanke ekta yakonpi kin owasin.

24 Qa Arabia en wicaśtayatapi owasin, qa oyate icicahiyapi hopuza en ounyanpi hena wicaśtayatapi tawapi kin iyuhpa:.

25 Qa Zimri wicaśtayatapi owasin, qa Elam wicaśtayatapi owasin, qa Mede wicaśtayatapi owasin :

$26 \mathrm{Qa}$ waziyata wicaśtayatapi kin iyuhpa, tehan qa ikiyedan, wanji qa sunkaku kici, qa oyate wokiconze kin iyuhpa, maka ite akan yakonpi kin; qa hena ihakam Śśak wicaśtayatapi kin wayatke kta ce.

27 Unkan hewicayakiye kta: Jehowa ozuye yuha, Israel Taku Wakan tawa kin he hecen eya ce; Wayatkan po, qa witkoiçi304 ya po, qa lidepa po, qa hinkpaya po, qa mazasagye niyepi en yewaśi kte cin he itokam ake majinhan nayajinpi kte śni.

28 Unkan kaketu kte, ninape etanhan wiyatke yatkanpi kta on icu wicadapi śni kinhan, hehan hewicayakiye kta; Jehowa ozuye yuhe cin he hecen eya ce; Yatkan po, datkanpi kta ce.

29 Tho, otonwe micaje on cajeyatapi kin he en talku śica awau manka; unkan niye kiyuśkapi on niciyuśkapi kta he; Niciyuśkapi lite śni : miye hinca maka kin en ounyanpi kin owasin akan mazasagye wan weco kta nakaeś, Jehowa ozuye yuhe cin eya.

30 Heon etanhan niye wicoie kin dena owasin owicayeciyake kta, qa hewicayakiye kta; Jehowa wankantanhan houye kta, qa tipi wakan tawa kin etanhan ho hdatanin kta: ho hdataninpi on iye ounye tawa kin ahoton kta; hastanhanka naśkicapi iyaśapi kin iyececa, on maka akan ounyanpi kin owasin awicayupte kta.

31 Hotaninpi kin he maka ihanke kin ekta i kta; Jehowa oyate kin hena om woakinica wan yuha; wicacelipi iyulipa wicayaco kta; tona sicapi lin hena mazasagye en wicaqu kta, Jehowa eya. 32 Jehowa ozuye yuhe cin he hecen eya; Iho, wośice wan oyate wan etanhan oyate tokeca ekta ye kta, qa maka ihanke etanhan tateiyumni tanka wan icagie kta.

33 Unkan anpetu kin he en Jehowa wicakte kin hena maka ihanke kin etanhan maka ihanke kin hehanyan wanke kta: hena awicakiceyapi kte sni, qa wicapahipi kte śni, qa wicahapi kte śni; tacesdi iyecen maka ite kin akan hiyeye"kta. 
34 Wilhanwicakiya yaunpi kin, ceya po, qa śicahowaya po; qa optaye en itancan yaunpi, paptanptan iyciciya po: anpetu en niktepi kta qa oyumden elipeniyanpi kte cin wanna.

35 Hehan wihanwicakiya unpi kin hena on wonajicc wanice kta, qa optaye itancanpi kin woehdaku yuhapi kte śni.

36 Wihanwicakiya unpi ho hdataninpi, qa optaye itancanpi śicahowayapi yukan; owilian tawapi kin he Jehowa ihangya nakaeś.

37 Hecen wookiye owilianpi kin atakunipi śni, Jehowa tocanniye ide kin on etanhan.

38 Mnaja wan psa kin ehpekiye cin iyecen wakakiśya towohitike on, qa tocanniye ide kin on etanhan, makoce tawapi kin hewoskan icagga.

\section{WICOWOYAKE 26.}

1 Jehoiakim Josiah cinhintku Juda wicaśtaya tapi kin tokaheya wicastayatapi yanke cin en, wicoie kin de Jehowa etanhan u qa heya:

2 Jehowa hecen eya ce; Jehowa ti hocoka kin en najin wo, qa Juda otonwe owasin etanhan tona Jehowa ti kin en wacekiya hipi kin hena wicoie tona ewicakiye ciśi kin hena iyuhpa owicakiyaka wo: wicoie wanjidan oyapte śni wo.

3 Okinni nahonpi kta, qa otoiyohi iye tacanku śica etanhan thduhomnipi kta; kinhan miś miye, iye ohanpi śica on taku śica cn awicawau kta wakonze ciqon etanhan mihduhomni kta.

4. Unkan hewicayakiye kta; Jehowa hecen eya ce; Mitoope nitokam ewahnake cin ohna maตซ yanipi kta e miye namayahonpi śni kinhan;

5 Mitaokiye wicaśta wokcan oiepi Kin anayagoptanpi ktahena e niyepi ekta jewicawaśi, hanwekta qa yewicawaśi ; tuka waanayagoptanpi śni:

6 Hehan tipi kin de Śloh iyecen wakage latu, qa otonwe kin de maka akan nyate owasin ehnahna woyaśice wakage kta.

7 Hecen wawayuśna kin hena qa wicaśta wolican, qa oyate ocowasin wicoie kin dena Jeremiah Jehowa ti kin ohna oyake cin he nationpi.

8 Unkan kaketu, Jercmiah taku Jehowa oyate ocowasin ewicakiye śi qon oyaka ihunnikiya, hehan wawayuśna kin hena qa wicaśta wokcan qa ayate ocowasin he yuzapi, Wiconțe on nițe kta ce, eyapi :

9 Tokeca Jehowa caje on wodaka; Tipi kin de Śiloh iyecece kta, qa otonwe kin de ihangyapi $\mathrm{kta}$, en ounyanpi wanice kta ce, tokeca eha he. Unkan oyate kin ocowasin Jeremiah en kiwitayapi, Jehowa ti kin ohna.

10 Juda itancanpi kin hena dena wicoie nahonpi qehan, hehan wicaśtayatapi ti kin etanhan Jehowa ti kin ekta itawankanhde iyayapi qa Jehowa ti tiyopa teca en iyotankapi.

11 Hehan wawayuśna kin hena, qa wicaśta wokcan kin hena koya wicaśta itancanpi qa oyate ocowasin wowicakiyakapi; Wicaśta kin de ta iyacopi kta iyececa ce, eyapi; otonwe kin de on woyaka nakaeś, niye ninogepi on nayahonpi kin iyececa ce.

12 Hehan Jeremiah wicaśta itancanpi qa oyate ocowasin wowicakiyaka; Tipi kin de on qa otonwe kin de on, wicoie naya305 


\section{JEREMIAH TAWOYUKCAN KIN,}

honpi kin owasin orndake kta e Jehowa umaśi ce, eya.

13 Heon etanhan nakaha nitacankupi qa niohanpi kin hena waśte kicagga po, qu Jehowa Taku Wakan nitawapi ho kin he anagoptan po; kinhan Jehowa taku śica enjciyapi kin he etanhan ihduhomni kta ce.

14. Tuka miye qe, iho, ninapepi ohna manka; niiśtapi en taku waśte qa owotanna hecen ecamicon po:

15 Hececa eśta, wosdonye on sdonya po, mayaktepi kinhan wicawe taku iyaonpepica śni kin he niyepi akan ayakamnapi kta, qa otonwe kin de en, qa en ounyanpi kin hena en : awicakehan ninogepi en wicoie kin dena owasin omdake kta e Jehowa umaśi ce.

16 Hehan wicaśta itancanpi qa oyate ocowasin wawayuśna qa wicaśta wokcan kin hena hewicakiyapi; Wicaśta kin de ța iyacopi kta iyecece śni; Jehowa Taku Wakan unkitawapi caje on wounkiyakapi kin heon etanhan.

17 Hehan makoce kin en hunkayapi wanjikji najinpi qa oyate inniciyapi kin ocowasin wowicakiyakapi qa heyapi ;

18 Hezekiah Juda wicaśtayatapi taanpetu kin en Mika Morasthi kin he woyake ca Tuda oyate ocowasin wowicakiyaka; Jehowa ozuye yuhe cin he hecen eya ce; Zion yumdupi kta, magia wan iyececa, qa Jerusalem pahaha kta, qa tipi paha kin he otehi pajojodan iyecece kta ce, eye ciqon.

19 Hezekiah Juda wicaśtayatapi qa Juda oyate ocowasin wiconte on he ktepi he. Jehowa kokipe śni he; qa Jehowa cekiya: unkan taku śica ewicakiye ciqon he on Jehowa iyokiśini306 ciya. Hecen unkiye taku śica tanka unnagipi en ecaunkiçiconpi kta tuka.

20 Qa nakun wicaśta wan Jehowa caje on woyaka, Urijah Semaiah cinhintku, Kirjath-jearim etanhan, he qe otonwe kin de qa makoce kin de on woyaka, Jeremiah oie kin owasin iyececa:

21 Qa Jehoiakim wicaśtayatapi, qa wicaśta waśakśaka tawa kin owasin, qa wicaśta itancanpi kin hena iyulipa he nalionpi qehan wicaśtayatapi kin he he kte kta akita; tuka Urijah he nahon qehan kolkipa, qa najica, qa Egupta ekta iyaya:

22 Unkan Jehoiakim wicaśtayatapi kin he Egupta ekta wicaśta yewicaśi, Elnathan Akbor cinhintku qa kici wicaśta toktokeca, Egupta ekta.

23 Unkan hena Egupta etanhan Urijah ahdiyakupi qa Jehoiakim wicaśtayatapi kin en ahdipi; he qe mazasagye on kte, qa tancan te cin he wicaśta ikceka wicahapi kin ohna ehpeya ce.

24 Tuka Ahikam Śaphan cinhintku nape kin Jeremiah kici un, hecen ktepi kta oll oyate napepi kin en wicaqupi kte śni.

\section{WICOWOYAKE $2 \%$}

1 Jehoiakim Jusiah cinhintku Juda wicaśtayatapi kin, wicaśtayatapi yanke cin otokahe ekta, wicoie kin de Jeremiah en hi, Jehowa etanhan, qa heya :

2 Jehowa hecen emakiya ce; lcaśke qa can napinpi içicağa wo, qa nitahu en ekihnaka wo:

3 Qa hena tona Jerusalem ekta Zedekiah Juda wicaśtayatapi kin en hipi hena napepi on, Edom wicaśtayatapi qa Moab wicaśtayatapi, qa Ammon cinca wica- 


\section{WICOWOYAKE $2 \%$}

stayatapi tawapi kin, qa Turos wicaśtayatapi, qa Zidon wicaśtayatapi kin hena wicakaya wo.

4 Qa wicayuhapi kin hena hewicakiye wicaśi wo: Jehowa ozuye yuha Israel Taku Wakan tawa kin he hecen eya ce ; Niyuhapi kin hecen ewicayakiyapi kta;

5 Miye hinca maka kin wakagia, wicaśta kin hena qa woteca kin tona maka ite akan unpi kin, mitowaśake tanka qa nape wahdukatin on; qa miiśta en token iyecetu wadaka hecen wicawaqu ecee.

6 Unkan nakaha miye qe makoce kin dena owasin Nebukadnezzar Babel wicaśtayatapi mitaokiye nape kin en waqu; qa makun mağa woteca kin wowidagwicaye kta e waqu.

7 Hecen oyate kin owasin iye en wowidaggiçiyapi kta, qa cinhintku, qa cinhintku sanpa cinhintku, iye tamakoce taanpetu hinca hi kte cin hehanyan: hehan oyate odota qa wicaśtayatapi waśakapi he wowidagyapi kta.

8 Unkan kaketu kte, oyate wan qa wokiconze wan Nebukadnezzar Babel wicaśtayatapi kin hee en wowidagiciye kte śni hecinhan, qa Babel wicaśtayatapi tawanapin kin ihukuya tahu iyeiciye kte śni kinhan, oyate hin he en wai kta, mazasagye on, qa wicaakihan on, qa makośica on, iye nape kin on ihangwicawaye kte cin hehanyan, Jehowa eya.

9 Heon etanhan niye wicaśta wokcan nitawapi anawicagoptanpi śni po, qa wakanyan econpi wicaduhapi, qa wihanmnanpi nitawapi, qa wicanhpi iwanyakapi nitawapi, qa wakan kağapi wicaduhapi kin hena, hena heniciyapi ece, Babel wicaśtayatapi kin en wowidagniçiyapi kte śni ce, eyapi.

10 Hena itonśniyan woniciyakapi, nitamakoce itehan iyaye niyanpi kta: hecen kaham iyeciyapi kta, qa nitakunipi kte śni. 11 Tuka oyate tona Babel wicaśtayatapi tawanapin ihukuya tahu iyeiciyapi qa en wowidagiciyapi kinhan, hena iye tamakoce kin en owanji yanke wicawakiye kta, Jehowa eya ; unkan kicanyanpi kta qa en omnanpi kta.

12 Nakun Zedekiah Juda wicaśtayatapi kin wowakiyaka, wicoie kin dena owasin eciyatanhan ; Babel wicaśtayatapi tawanapin kin ihukuya tahu iyeiçiya po, qa iye en, qa taoyate en wowidag iciya po, qa ni po, epapa:

13 Tokeca nițapi kta he, niye qa nitaoyate, mazasagye on, wicaakilian on, qa makośica on, oyate wan Babel wicaśtayatapi kin en wowidagiciye kte śni, Jehowa eciye ciqon iyececa.

14 Heon etanhan wicaśta wokcan woniciyakapi qa, Babel wicaśtayatapi kin he wowidagniyanpi kte śni ce, eyapi kin hena anawicağoptanpi śni po: hena woitonśni oniciyakapi nakaeś.

15 Miye yewicawaśi śni, Jehowa eya: tuka micaje en woitonśni wan oniciyakapi : hecen tankan iyeciyapi kta, qa hecen nitakunipi kte śni, niyepi qa wicaśta wokcan woniciyaliapi kin hena koya.

16 Nakun wawayuśna kin hena, qa oyate kin de ocowasin wowicawakiyaka, Jehowa hecen eya ce; Wicaśta wokcan nitawapi woniciyakapi oiepi kin anawicağoptanpi śni po; hena heyapi ; Tho, wanna aśkadan Jehowa ti tawakśica kin hena ake Babel etanhan akupi kta ce, eyapi : he$30 \%$ 


\section{JEREMTAH TAWOYUKCAN KIN,}

na woitonśni oniciyakapi nakaeś epa.

17 Hena anawicagoptanpi śni po: Babel wicaśtayatapi kin en wowidagiciya po, qa ni po; tokeca otonwe kin de ihangyapi kta he.

18 Tuka hena wicaśta wokcan hecapi, qa Jehowa oie kin wicakiciun hecinharl, wanna Jehorva ozuye yuhe cin he cekiyapi kta, hecen wakśica tona Jehowa ti kin en okaptapi kin hena, qa tona Juda wicaśtayatapi ti kin ohna, qa tona Jerusalem en un kin hena Babel ekta ayapi kte śni.

19 Jehowa ozuye yuhe cin he kaken eya, Bosdan he cin hena on, qa mini ohnaka tanka kin he on, qa oahe kin hena on, qa wakśica tona otonwe kin de en okaptapi kin hena on ;

20 Nebukadnezzar Babel wicaśtayatapi Jekoniah Jehoiakim cinhintku Juda wicaśtayatapi, qa Juda qa Jcrusalem wicaśta itancanpi owasin, Jerusalem etanhan Babel ekta wayaka awicakiyahda he ehan hena icu śni;

21 Han, Jehowa ozuye yuha, Israel Taku Wakan tawa kin he, wakśica tona Jehowa ti kin ohna yanke, qa Juda wicaśtayatapi ti kin ohna, qa Jerusalem en yanke cin hena on hecen eya ce ;

22 Hena Babel ekta ayapi kta, qa anpetu en wanyagwicawai kte cin hehanyan hen hiyeye kta, Jehowa eya: hehan hena awahdiyaku kta qa owanka kin de en ake ewehnake kta ce.

\section{WICOWOYAKE 28.}

1 Unkan waniyetu kin he en, Zedekiah Juda wicaśtaya tapi yanke cin otokahe ekta, waniyetu itopa kin en, qa wi izaptan hehan Hananiah Azur cinhintku wicaśta 308 wokcan, Gibeon etanhan, he Jehowa ti kin ohnayan, wicaśta wawayuśna kin hena, qa oyate kin ocowasin wicitokam, womakiyaka, qa hecen eya;

2 Jehowa ozuye yuha Israel Taku Wakan tawa kin he hecen eya ce ; Babel wicaśtayatapi tawanapin kin mduksa ce :

3 Waniyetu nompa ocowasin kinhan Jchowa ti tawakśica tona Nebukadnezzar Babel wicaśtay atapi kin owanka kin de etanhan icu qa Babel ekta akiyahde ciqon hena owasin ake den awahdi kta ce :

4 Qa nakun Jekoniah Jehoiakim cinhintku Juda wicaśtayatapi qon, tona Juda etanhan wayaka awicayapi qa Babel ekta ipi kin hena koya owasin owanka kin de en awicawahdi kta; Babel wicaśtayatapi tawanapin mdukse kta nakaeś, Jehowa eya ce, eya.

5 Hehan Jeremiah wicaśta wokcan kin, wawayuśna kin hena, qa oyate owasin Jehowa ti kin ohna najinpi kin hena wicitokam Hananiah wicaśta wokcan kin heciya;

6 Han, Jeremiah wicaśta wokcan kin hecen eya; Amen: Jehowa hecen econ nunwe: Jehowa ti tawakśica kin hena, qa wayaka ayapi kin ocowasin Babel etanhan owanka kin de en ahdipi kta e nioie odake cin Jehowa yuecetu nunwe.

7 Hececa eśta, wanna wicoie kin de, ninogge en qa oyate ocowasin nogepi kin en, omdake cin he nation wo:

8 Wanakajatanhan wicaśta wokcan miye mitokam unpi qa niye nitokam unpi qon hena makoce ota qa wokiconze tankinyanyan en, okicize, qa taku śica, qa makośica on oyakapi ecee.

9 Wicaśta wokcan kin wookiye 
on woyake cinhan, tohan wicaśta wokcan oie kin yuecetupi kinhan, he qe awicakehan wicaśta wokcan Jehowa uśi kin hee e sdonyapi kta ce.

10 Hehan Hananiah wicaśta wokcan kin he Jeremiah wicaśta wokcan tahu etanhan can napinpi kin icu qa yuksa.

11 Qa Hananiah oyate ocowasin wicitokam woyaka qa hecen eya; Jehowa liecen eya ce; He iyecen Nebukadnezzar Babel wicaśtayatapi tawanapin kin oyate owasin tahupi etanhan wicaweciyukse kta, waniyetu nom ocowasin kinhan. Unkan Jeremiah wicaśta wokean kin kibda.

12 Hehan Hananiah wicaśta wokcan kin Jeremiah wicaśta wokcan tahu etanhan cannapinpi kin yukse cin iyohakam, Jehowa oie Jeremiah en hi kin he hecen eya;

$13 \mathrm{Ya}$ wo, qa Hananiah wokiciyake ca heya wo ; Jehowa hecen eya ce; Can napinpi kin hena duksa; tuka mazasapa wanapin kin wicayecagge kta ce.

14 Jehowa ozuye yuha, Israel Taku Wakan tawa kin he hecen eya ce; Mazasapa napinpi wan oyate kin dena owasin tahupi kin en ewicawecihnaka, Nebukadnezzar Babel wicaśtayatapi kin wowidagwicaye kta e heon: unkan wowidagwicaye kta : Nakun tinta wamanica kin hena koya waqu.

15 Hehan Jeremiah wịcaśta wokean kin he Hananiah wicaśta wokcan kin hecen eciya; Hananiah, wanna nahon wo; Jehowa uniśi śni; tuka oyate kin de woitonśni wan wacinkiye wicayakiya.

16 Heon etanhan Jehowa hecen eya ce; Iho, maka ite kin etanhan ehpeciye kta: omaka kin de en nite kta, Jehowa etanhan icunonpa iyayapi kin he onspewicayakiya nakaeś.

17 Unkan omaka kin he en $\mathrm{Ha}$ naniah wicaśta wokcan kin ta, wi iśakowin kin en.

\section{WICOW OYAKE 29.}

1 Unkan hunkayapi okaptapi tona wayaka awicayapi qon hena, qa wawayuśna unpi kin, wicaśta wokcanpi koya, qa oyate ocowasin Nebukadnezzar Jerusalem etanhan Babel ekta wayaka awicakiyahde ciqon, Jeremiah wicaśta wokcan lín Jerusalem etanhan wowapi wicakicaga wicoie kin dena ee :

2.Jekoniah wicaśtaya tapi, qa wicaśtayatapi winohinca, qa ookiye unpi kin, nakun Juda qa Jerusalem en itancanpi kin, qa cankajipa qa mazakaga kin hena Jerusalem etanhan iyayapi qon he iyohakam :

3 Elasah Śaphan cinhintku qa Gemariah Hilkiah cinbintku napepi kin on; hena Zedekiah Juda wicaśtayatapi kin Babel ekta yewicaśi, Nebukadnezzar Babel wicaśtayatapi kin ekta; unkan heya:

4 Jehowa ozuye yuha Israel Taku Wakan tawa kin he, tona wayaka awicayapi, Jerusalem etanhan Babel ekta iyayewicawakiye ciqon hena owasin hecen ewicakiya ;

5 Tipi içicağa po qa okiti po; canwojupi kin okikju po, qa etanhan waskuyeca kin hduta po:

6 Winohinca wicayuza po, qa cinca wica winyan ko wicakaga po; qa nicinkśipi kin hena tawicu tonwicakiya po, qa nicunkśipi wicaśta wicaqu po, hena iś eya cinhintku qa cunwintku wicayuhapi kta; hecen hen nihduota- 


\section{JEREMIAH TAWOYUKCAN KIN,}

pi kta qa nihdutonananpidan kte śni.

7 Qa otonwe ekta wayaka ayeniciyapi wakagie cin he wookiye ayecitapi kta, qa on Jehowa cekiya po; wookiye tawa hin en niye wookiye duhapi kta nakaeś.

8 Jehowa ozuye yuha, Israel Taku Wakan tawa kin he hecen eya ce; Wicaśta wokcan nitawapi qa wicaśta wakan nitawapi nicokaya unpi kin hena ihnuhan nihnayapi kinhan; qa wowihanmde nitawapi ihamna wicayakiyapi kin hena anakigoptanpi śni po.

9 Hena e micaje on woitonśni oniciyakapi; hena yewicawaśi śni ce, Jehowa eya.

10 Jehowa hecen eya ce; Waniyetu wikcemna śakowin Babel ekta yuśtanpi kinhan, hehan en cihipi kta, qa mioie waśte kin he niyepi on mduecetu kta, owanka kin de en ake hdiyohiniyanpi kta e heon.

11 Miye hinca mitawacin tona niyepi on awacanmi kin hena sdonwakiya ce, Jehowa eya; hena wookiye woawacin, qa wośice ee śni, owihanke kin hee, qa wowacinye wan cicupi lita.

12 Hehan hoyemayakiyapi kta, qa iyoopta dapi qa cemayakiyapi kta, kinhan nacihonpi kta.

13 Unkan omayadepi kta qa iyemayayapi kta, nicantepi ocowasin on omayadepi kta hecinhan:

14 Qa iyemayayapi kta, Jehowa eya: unkan wayaka yaunpi kin he hdicuwakiye kta ; qa oyate owasin etanhan, qa makoce tukte e ekta iyaye ciyapi kin etanhanhan mnaciyapi kta ce, Jehowa eya: qa totanhan wayaka ayeniciyapi wakage ciqon makoce kin he en ake hdiyohiciyapi kta.

15 Jehowa wicaśta wokcan Babel en icahunkiciciyapi ce, ehapi;
16 Heon etanhan Jehowa, wicaśtayatapi Dawid oiyotanke tawa kin akan iyotanke cin he, qa oyate otonwe kin de en ounyanpi kin iyuhpa, hunkawanji wicayayapi, wayaka aniyanpi qon en opapi śni kin hena on hecen eya ce :

17 Jehowa ozuye yuhe cin he hecen eya; Iho, hena en mazasagye, qa wicaakilian qa makośica yewaśi kta, qa suken waskuyeca śikśice cin iyececa wicawakagge kta, hena śikśice linca nakaeś yunpica śni.

18 Qa mazasagye on, wicaakihan on, qa makośica on kuwa awicamde kta, qa maka akan wokiconze owasin ektakta awicayapi kta wicawaqu kta, woyaśice, qa wonihinciye, qa woajiji, qa woaie kin heca kta, oyate owasin ektakta iyayewicawaye kte cin heciya.

19 Mioie kin anağoptanpi śni heon etanhan, Jehowa eya; hena mitaokiye wicaśta wokcan kin on wahowicawaya, hanwekta qa yewicawaśi tuka: tuka anayagoptanpi śni, Jehowa eya.

20 Heon etanhan niye Jehowa oie kin nahon miye, wayaka yaunpi kin owasin, Jerusalem etanhan Babel ekta iyayewicawaye cin:

21 Jehowa ozuye yuha, Israel Taku Wakan tawa kin he, Ahab Kolaiah cinhintku qa Zedekiah Maaseiah cinhintku micaje on woitonśni wan oniciyakapi kin hena on hecen eya ce; Iho, $\mathrm{Ne}$ bukadnezzar Babel wicaśtayatapi nape kin en wicawaqu kta, unkan iye hena wicakte kta niiśtapi itokam.

22 Unkan hena on Juda etanhan Babel en wayaka unpi kin owasin woyaśice wan icupi kta, Zedekiah iyececa qa Ahab iyececa 


\section{WICOWOYARE 30.}

Nebukadnezzar Babel wicaśtayatapi peta en huhnaliwicaye ciqon hena iyecen Jehowa nicaga nunwe, eyapi kta.

23 Israel en wowaliteśni kag̣api, qa iye takodakupi tawicupi kin om wawicilialiapı econpi, qa micaje on woitonśn1 oie oyakapi, hena eye wicawaśi śni tuka: un. lian miye hinca hena sdonwaya qa mdaotanin ce, Jehowa eya.

24 Nakun Śemaiah Nehelemi kin he kaken eyalkiye kta:

25 Jehowa ozuye yuha, Israel Taku Wakan tawa kin he hecen eya ce; Niye nicaje on Jerusalem en oyate ocowasin, qa Zephaniah Maaseiah cinhinthu wawayuśna kin, qa nakun wawayuśnapi kin owasin wowapi wicayecağa ;

26 Jehoiada wawayuśna kin eekiya Jehowa wawayuśna nicaġa ce; hecen Jehowa.ti kin ohna waawanyake yaunpi kta, wicaśta witkotkoka otoiyohi on, qa tuwe waayate ic̣icage cin on, hecen mazaicaśke en, qa wicakaśka tipi kin ohna eyahnake kta ce.

27 Heon etanhan Jeremiah Anathoth etanhan, niyepi en wicaśta wokcan iceicage cin he tokeca iyopeyaye śni he.

28 Iye Babel en unyalronpi kin hecen wahounyanpi, qa, De tehan kta ; tipi içicaga po qa okiti po; qa canwojupi kin okikju po qa waskuyeca etanhan hduta po, eya ce, eha.

29 Unkan Zephaniah wawayuśna kin Jeremiah wicaśta wokcan noge kin ohna wowapi kin he yawa.

30 Hehan Jehowa oie kin Jeremiah en hi kin he hecen eya;

31 Tona wayaka unpi kin owasin wahowicaye ca heya wo; Semaiah Nehelemi kin on Jehowa hecen eya ce; Śmaiah ye- waśi śni tuka woniciyakapi qa woitonśni wan wacinyeniyanpi ;

32 Heon etanhan $\mathfrak{J}$ chowa hecen eya; Iho, Śemaiah Nehelemi kin takpe mde kta, qa oicagje tawa kin nakun: wiraśta tawa wanjidan oyate kin de om ounye kte śni: nakun taku waśte mitaoyate ecawicawecon kte cin he wanyake kte śni, Jehowa eya: Jehowa en wawakipajinpi kin he oyake nakaeś.

\section{WICUWOYAKE 30.}

1 Jehowa etanhan wicoie Jeremiah en hi kin he hecen eya;

2 Jehowa Israel Taku Wakan tawa kin he ie ca hecen eya ce; Wicoie tona ociciyake cin hena owasin wowapi wan en owa wo. 3 Iho, anpetu kin u kta, Jehowa eya; hehan Israel qa Juda mitaoyate wayaka unpi kin ake hdicuwakiye kta, Jehowa eya; qa makoce iye hunkakewicayapi wicatvaqu qon he ekta hdicuwicawakiye kta; unkan tawayapi kta.

4 Unkan Israel on qa Juda on, wicoie tona Jehowa ie cin dena ee :

5 Jehowa hecen eya ce; Wicacancan ho wan naunhonpi, wokokipe hee, qa wookiye śni:

6 Warna wawiwangapi qa wanyaka miye; Wicaśta wan hokśiksuya he: Toketu he. Wicaśta otoiyohi nape nite kin akan yanka wanmdaka, winolinea hokśiksuye cin iyececa; qa wicaite kin owasin san icagga.

7 Hehehe, anpetu kin he tanka kta; wanjidan iyecece śni : han Jakob toiyokiśice anpetu kin hee kta; tuka etanhan ehdakupi kta ce.

8 Unkan anpetu kin he en kaketu lite. Jehowa ozuye yuhe 311 


\section{JEREMIAH TAWOYUKCAN KIN,}

cin eya; cannapinpi tawa kin he nitahu etanhan ciciyukse kta, qa maza icaśke nitawa kin mdupsake kta: qa oyate tokeca icimana ake wowidag yapi kte śni.

9 Tuka Jehowa Taku Wakan tawapi kin en wowidagiçiyapi kta, qa Dawid wicaśtayatapi tawapi kin icahwicaweciciye kte cin he nakun.

10 Heon etanhan niś, Jakob mitaokiye, wikope śni wo, qa Israel niye waciniyokiśice śni wo, Jehowa eya: Iho, tehan tanhan niciye kta, qa woicage nitawa'makoce en wayaka unpi kin etanhan ; Jakob hdicu kta, qa oziiciye kta, qa owanji yanke kta, qa tuwedan wakokipe kicage kte śni ce.

11 Niciye kta on ciciwaun kta ce, Jehowa eya: oyate owasin tukte e en iyayeciye ciqon hena owihanke wicawaya eśta, niye ocowasin ihangciye kte śni ; tuka wiyukcanyan iyopeciye kta, qa ocowasin wiyaonpepica śni ciyawa kte śni ce.

12 Jehowa hecen eya ce; Nicawegapi kin he asniyepica śni, nicaśtakapi kin he tehike nakaeś.

13 Tuwedan wawiniciye śni; pahtapi kta on wokizi waskape cin ninica.

14 Waśtenidakapi qon owasin aniktonjapi; hena onidepi śni : awicakehan toka wicakaśtaka wan on cicaśtaka, iyopewicayapi tehilke hinca on; taku śica ecanon kin ota, wayahtani kin yahdusuta nakaeś.

15 Tokeca nitokakije en yaśicahowada he: nitoiyokiśice kin he asniyepica śni, talku śica ecanon kin hena ota hinca aya nakaeś, wayahitani kin hena waśaka icaga, heon dena ecacicon ce.

16 Heon etanhan tona temniyanpi kin hena owasin temwica- yapi kta; qa tona tokaniyanpi kin iyuhpa, han, otoiyohi, wayaka awicayapi kta: qa tona wanicipi kin hena wawicakipi kta; qa tona wamanicinonpi kin hena owasin womanon wicawakage kta.

17 Hehan wookiziye cicahi kta, qa nicaśtakapi qon olkiziwaye kta, Jehowa eya: T'ankan ehpeyapi, Zion he wicaśta tuwedan okide śni kin dee ce, eniciyapi kin, heon etanhan.

18 Jehowa hecen eya; Iho, Jakob tawakeya wayaka unpi kin hena hdicuwicawakiye kta, qa ounyanpi tawa kin onśiwakida kta: unkan otonwe kin palia tawa qon ohna piya kaģapi kta, qa conkaśke kin iye tohe kin en he kta.

19 Hehan hena etanhan woyatan qa wiyuśkinyan unpi ho kin hinanpe kta: unkan hena wicamduota kta, qa tonana aye kte śni; nakun wicamduonihan kta qa yuhukun iyewicayapi kte śni. 20 Nakun cincawicayapi kin hena otokahe ekta iyececapi kta, qa omniciye tawapi kin he mitokam yusutapi kta; qa tona kakiświcayapi kin hena owasin en wicawai kta.

21 Unkan wicaśta itancan tawapi kin hena iye etanhanpi kta, qa wicaśtayatapi yuhapi kin iyepi cokayatanhan hinanpe kta, qa kiyedan hiyu wakiye kta, hecen mikiyedan u kta: De tuwe he mikiyedan u kta on cante içiconza he, Jehowa eya.

22 Hehan mitaoyate kin he niyepi kta, qa Wakantanka nitawapi kin he miye kta ce.

23 Tho, tateiyumni wan Jehowa towohitike kin hiyaya, tateiyumni wohitike hinca: woyazan on wicaśta śicapi pa kin en hdihpaye kta. 


\section{WICOWOYAKE 31.}

24 Jehowa tocanteptanye wohitike cin he hdicu kte śni, tohanyan econ śni qa tohanyan iye canteyuze cin kiciyuśtan śni hehanyan: anpetu ehake kin en niye awacannipi kta.ce.

\section{WICOWOYAKE 31.}

1 Hehan Israel wicowazi owasin en miye Taku Wakan waun $\mathrm{kta}$, qa mitaoyate kin hena iyepi $k$ ta, Jehowa eya.

2 Jehowa hecen eya; Makoskan oyate tona mazasagye owicakapte cin hena wowaonśida iyeyapi, Israel wicoozi tawa kin ekta iyaya qehan.

3 Wanakaja Jehowa miye en ihdutanin: "Tuka wowaśtedake owihanke śni on waśtecidaka; heon etanhan wocantekiye on ciyutitan ce, eya.

4 Israel wikośka, ake icahciye kta, unkan inicage kta : ake canceğa nitawa yeçun kta, qa tona wiyuśkinyan yapi wacipi kin en owicayape kta.

5 Ake Samaria paha kin en hastanhanka iyuwi hu kin huyahde kta: wojupi kin hena huhdepi kta, qa taku ikceka iyecen yutapi kta ce.

6 Anpetu kin u kta, Ephraim he kin akan waawanyake kin panpi kta; Najin po qa Zion en Jehowa Taku Wakan unkitawapi kin ekta unyanpi kta ce.

7 Jehowa hecen eya ce; Jakob towiyuśkin kin idowan miye; qa oyate itancanpi kin en eyanpalıa po, wayaotanin po, yatan po qa, Jehowa nitaoyate Israel okaptapi kin niwicakiya wo, eya po.

8 Wanyaka wo, waziyata makoce kin etanhan awicawaku kta, qa maka ihanke kin etanhan mnawicawakiye kta, iśtağonga qa huśtepi kin, winohinca ihduśaka qa tuwe cinca yuhe cin hena koya opapi kta: wicota hinca den hdiyohipi kta.

9 Ceyapi qa wocekiye eyapi hduha kupi kta ; awicawaku kta, yus awicawau kta, mini wakpa kin icahda, canku owotanna wan ohna: he ohna hicahanpi kte śni: Israel ateyapi kin he miye, qa Ephraim micinca tokapa kin hee nakaeś.

10 Oyate yaunpi, Jehowa oie kin nation po, qa wita tehan yanke cin ekta eyanpaha po, qa heya po; Tuwe Israel enanakiya iyayewicaye ciqon hee ake mnakiye kta, qa awanhdake kta, wawihankiye wan optaye tawa hduha he iyececa.

11 Jehowa Jakob opekiton $\mathrm{kta}$, qa tuwe iye isanpa waśaka nape kin etanhan ehdaku kta nakaeś.

12 Hehan kupi kta, qa Zion paha kin akan dowanpi kta, qa Jehowa towaśte kin on cantewaśtepi kta, ağuyapi on, qa miniśa teca on, qa wihdi on, qa optaye cinca qa pte kin on; qa iye nagipi kin canwojupi wan spayeyapi kin iyecece kta ; qa ake icimana hanyanpi kte śni.

13 Hehan wikośka kin wacipi kin en wiyuśkin kta, nakun kośkapi wicaśta tanka koya: unkan ceyapi qon he wowiyuśkin wakagge kta; qa cantohnagwicawakiye kta, qa cante śicapi qon isanpa cantewaśte wicawakagge kta ce ;

14 Nakun wawayuśna nag̣ipi kin waśin on imnawicawakiye kta ; qa mitaoyate kin mitowaśte on ipipi kta ce, Jehowa eya.

15 Jehowa hecen eya; Rama en wicaho wan nahonpi, śicahowayapi, ceyapi pa hinca; Rachel cinca awicakiceya, cinca on kihnahnapi kta cin śni, hena en unpi śni nakaeś. 


\section{JEREMIAH TAWOYUKCAN KIN,}

16 Jehowa hecen eya; Ceyapi etanhan niho kin ținsiçiya wo, qa niiśta iśtamnihanpe etanhan: niolianpi kin on iyunwin yuke kta ce, Jehowa eya: unkan hena e toka tamakoce kin etanhan hdicupi kta.

17 Qa oniciwihanke kin ekta wowacinye yuke kta ce, Jehowa eya; han, wicacinca kin hena iye tamakoce kin ake en hdipi kta. 18 Winahonpi on Ephraim iyokiśiniçiya nawahon ce; Iyopemayaya, unkan iyopemay anpi, tatanka kaonspepi śni kin iyececa. Hdicumayan wo, kinhan wahdicu kta; Jehowa niye Taku Wakan mitawa lkin hee nakaeś.

19 Awicakehan hdiyohimayanpi iyohakam iyopenniçiya; qa sdonmiciye cin iyohakam sican en amiçipe: imaśteca, han, nakun nihinmiciya, komaśka wiyamaonpapi kin hduha waun kin heon etanhan.

20 Ephraim micinca tewahinda kin hee he ; hokśincinca wiciyokipi kin heca he: totanhan awakiie cin ehantanhan kiksuyapi on hinyahin weksuya: heon e tanhan iye on mitezi śkanśkan: wacalltkiya onśiwakida kta ce, Jehowa eya.

21 Iwanyakapi kin eicihde wo, inyan bosdata ekihde wo : canku wankantu kin, canku ohna idade cin he elita cante yekiya wo: hdicu wo, Israel wikośka, otonwe nitawa qon dena ekta hdiyohi wo.

22 Wowakipajin cunwintku, tohanyan nihdonica kta he: Jehowa taku teca wan maka akan kag̉e kta; Winohinca wicaśta acakśin kta.

23 Jehowa ozuye yuha, Israel Taku Wakan tawa kin he hecen eya; Tohan wayaka unpi hdicuwicawakiye cinhan ake Juda makoce kin en, qa otonwe tawa kin 314 ohna, wicoie kin de, Woowotanna tipi, Paha wakan kin Jehowa niyawaśte nunwe, eyapi kta.

24 Unkan Juda makoce qa totonwe kin owasin en, woju wicaśta kin heca, qa optaye hduha indaka unpi kin hena witaya tipi kta.

25 Wicanagi ipuza kin he wayatkewakiye kta ; qa wicanagi wotektehdapi kin owasin wipiwicawaye kta nakaeś.

26 Hehan wekta qa iwanmdaka, unkan miśtinbe kin he miciwaśte linca.

27 Tho, anpetu kin u kta, Jehowa eya; hehan Israel tipi qa Juda tipi kin hena wicaśta oicagge qa woteca oicage kin on owelkju kta.

28 Unkan kaketu kta, yujunpi, qa yuksapi, qa yujujupi, qa ihangyapi, qa kakiświcayapi on awanwicamdake ciqon, he iyecen piya kaġapi kta, qa ojupi kta e on awanwicawahdake kta ce, Jehowa eya.

29 Anpetu kin hena en, Atewicayapi kin hastanhanka śtunkaka yu tapi, unkan cincapi kin hi psonpsonna icago ce, icimana eyapi kte śni.

30 Tuka otoiyohi iye wahtani kin on te kta: wicaśta otoiyohi hastanhanka stunkaka yute cinhan he iye hi psonipsonna icagge lita ce.

3 I Iho, anpetu kin u kta, Jehowa eya; hehan Israel tiyohnaka qa Juda tiyohnaka kin om wicotakuye teca wan wicawecicage kta:

32 Atewicayapi Egupta makoce kin etanhan hinanpe wicawaye kta on nape wicamduza, anpetu kin he en wicotakuye wan om wicawecicagia qon he iyecece śni: he qe wicotakuye mitawa yujujupi, miye qe wicawahduza tuka qon, Jehowa eya. 


\section{WICOWOYAKE 32.}

33 Tuka Israel tiyohnaka om wicotakuye wicawecicago kte cin he dee; Anpetu kin hena iyohakam, Jehowa eya; mitoope kin iye tanmahen ewakihnake kta, qa iye cantepi akan owakiwa kta; unkan Taku Wakan tawapi kin he miye kta, qa iś ṇakun mitaoyate ee kta ce.

34 Unkan otoiyohi iye takodaku qa otoiyohi iye sunkaku kin waonspekiciyapi kte śni, qa, Jehowa sdonya miye eyapi kte śni : hena owasin sdonmayanpi kta nakaeś, wicacistinna qa wicatanka koya, Jehowa eya: taku śica econpi kin hena wicawecicajuju kta, qa wahtanipi kin icimana weksuye kte śni, heon etanhan.

35 Jehowa hecen eya; Tuwe anpetu iyoyanpa kta anpetu wi elınaka, hanyetu iyoyanpa kta on hanyetu wi qa wicanlipi wokonze wicaqu, miniwanca taja hoton eca tuwe yuamdakedan ece e, Jehowa ozuye yuha he caje kin ee :

36 Wokonze kin dena mitokapa tanhan hiyaye cinhan, Jehowa eya ; hehan Israel cinca kin mitokam oyate yanke cin he nakun ayuśtan kta, anpetu owasin.

37 Jehowa kaken eya; Wankan mahpiya kin he iyutapi kinhan, qa kuya maka oahe kin hena iyukcanpi kinhan, hehan nakun Israel cinca ocowasin, taku econpi kin owasin on elipewicawaye kta ce, Jehowa eya.

38 Iho, anpetu kin u kta, Jehowa eya; hehan otonwe kin Jehowa kicagiapi kta, Hananeel conkaśke kin etanhan okahmin tiyopa kin hehanyan.

39 Han, hahonta on iyutapi kin he ake ayapi kta, he iyotakonza Gareb paha kin ohna, qa Goath aihdukśan ye kta.

40 Qa kaksiza ocowasin ohna wicața qa cahota wanka, qa maga iyuhpa Kidron wakpadan hehanyan, wiyohiyanpata elsta oliahmin en suktanka tiyopa kin hehanyan, Jehowa on wakan lita: he ake yujujupi kte śni qa ihangyapi kte śni, owihanke wanica.

\section{WICOWOYAKE 32.}

1 Zedekiah Juda wicaśtayatapi tawaniyetu iwikcemna, Nebukadrezzar tawaniyetu iakeśahdogan kin hee en wicoie Jehowa etanhan Jeremiah en hi qon he dee.

2 Hehan Babel wicaśtayatapi taakicita kin Jerusalem aonatakapi nakaeś: Unkan Jeremiah wicaśta wokcan kin wicakaśka tipi hocoka kin ohna natakapi, Juda wicaśtayatapi ti kin hetu.

3 He olna Zedekiah Juda wicaśtayatapi kin onakitaka qa heya; Tokeca e wodake ça heha he; Jehowa hecen eya ce; Iho, otonwe kin de Babel wicaśtayatapi nape kin en waqu kta, unkan icukta;

4 Qa Zedekiah Juda wicaśtayatapi kin Kasdim oyate napepi kin etanhan najice kte śni, tuka awicakehan Babel wicaśtayatapi nape kin en qupi kta, qa iye i kin on kici wohdake kta, qa iye iśta kin iśta tawa wanyake kta.

5 Unkan Zedekiah Babel ekta aye kta, qa hen un kta, en wai kte cin hehanyan, Jehowa eya ce: Kasdim oyate kin om yecizapi eśta oyakihipi kte śni ce.

6 Hehan Jeremiah hecen eya; Jehowa oie en mau kin he hecen eya;

7 Iho, Hanameel Śallum ateyaya he cinhintku kin en nihi lita, qa, Anathoth ekta magga mitawa kin he opeiciton wo: opekitonpi 315 


\section{JEREMIAH TAWOYUKCAN KIN,}

kin he niye nitawa, on opeyaton kta iyececa ce, eye kta ce.

8 Hehan Hanameel ate cinhintku kin wicakaśka tipi hocoka ohna en mahi, Jehowa oie kin iyececa, qa hemakiya; Ceciciya ce, maga mitawa, Anathoth ekta, Benjamin makoce kin en, he opeton wo; tawayapi kta iyececa he niye nitawa, qa opekitonpi kin he nakun nitawa; hecen opeiciton wo. Hehan de Jehowa oie kin hee e sdonwakiya.

9 Hecen Hanameel ate cinhintku tamagia Anathoth ohna wanke cin he opewecaton, qa mazaska aspeye weciton, sekel mazaska akeśakowin.

10 Qa wowapi kin en owawa qa askamwaton, qa wayaotanin iwa$\mathrm{cu}$, qa on-aspeyapi kin on mazaska kin tkeimduta.

11 Qa opetonpi wowapi kin iwacu, askamyapi kin he, woope qa wicohan econpi ece kin eciyatanhan, qa yuhdog un kin he nakun :

12 Qa opetonpi wowapi kin he Baruk Neriah cinhintku, Maaseiah cinhintku kin waqu, Hanameel ate cinhintku iśta kin itokam, qa wayaotanin tona opetonpi wowapi yutanpi kin hena wicitokam, qa Juda wicaśta wicakaśka tipi hocoka kin en iyotankapi kin owasin wicitokam :

13 Qa hena wicitokarn Baruk wahokonwakiya on hepa;

14 Jehowa ozuye yuha Israel Taku Wakan tawa kin he hecen eya ce; Wowapi kin hena icu wo, opetonpi wowapi askamyapi kin he, qa wowapi yumdayapi kin he nakun, qa maka cega wan en ohnaka wo, hecen anpetu ota yanke kta ce.

15 Jehowa ozuye yuha, Israel ta Wakantanka kin he hecen eya; Tipi qa maga qa hastan316 hanka iyuwi ojupi kin makoce kin de ohna ake yuhapi kta ce.

16 Hehan Jehowa cewakiye, opetonpi wowapi kin Baruk Neriah cinhintku waqu qon iyohakam, qa hepa ;

17 Hehehe Jehowa Itancan, iho, nitowaśake tanka qa isto yahdukatin on mahipiya qa maka kin niye yakaga; niye ekta takudan tehike śni :

18 Wowaonśida kektopawing wicayakipazo, qa ateyapi wahtanipi kin hena iye cincapi ihakam unpi maku en wicayecu ecee: Taku Wakan Tanka, Waśaka, Jehowa ozuye yuha, he caje kin ee:

19 Wowiyukcan en tanka, qa wicohan econpi kin en waśake hinca: wicaśta cinca tacankupi kin owasin ekta niiśta opahta yanka, otoiyohi iye tacanku eciyatanhan qa tohan taku icahye cin eciyatanhan yaqu kta:

20 Egupta makoce kin en wo.wapetokeca qa taku wowinihan ecanon, anpetu kin de hehanyan, Israel itokam qa wicaśta kin ehna; qa wicacaje wan nicicaga, anpe dehan iyececa:

21 Qa Israel nitaoyate Egupta makoce kin etanhan hinanpe wicayaya, wowapetokeca on, qa taku wowinihan on, qa nape waśaka on, qa isto hdukatin on, qa wonihinciye tanka on:

$22 \mathrm{Qa}$ makoce kin de atewicayapi konza wahowicayaye ciqon he wicayaqu; makoce wan pteasanpi qa tuhmaga canhanpi on apaśboka :

23 Unkan en hiyupi qa tawayapi ; tuka niho kin anagoptanpi śni qa nitoope kin ohnayan manipi śni ; taku econ wicayaśi qon owasin takudan econpi śni : heon etanhan taku śice cin de ocowa- 


\section{WICOWOYAKE $3 \%$}

sin niye hinca itkokipe wicayakiya :

24 Paha kagiapi kin hena wanyaka wo; otonwe kin icupi kta heon hipi: unkan Kasdim oyate kis unpi kin hena napepi en otonwe kin wicaqupi, mazasagye on, qa wicaakilian on, qa makośica on: hecen taku ehe ciqon he yuecetupi ; unkan iho, niye wandaka.

25 Tuka Jchowa Itancan niye hemayakiya; Magja kin he opeton wo, mazaska on, qa wayuotanin kin icu wo: otonwe kin Kasdim oyate napepi kin en wicaqupi tuka.

26 Hehan Jehowa oie Jeremiah en un kin he hecen eya:

27 Iho, Jelıowa taku cehpi iyuhpa ta Wakantanka kin he miye: taku owasin miye ekta telike kta he.

28 Heon etanhan Jehowa hecen eya ce ; Iho, otonwe kin de Kasdim oyate napepi kin en wicawaqu kta, qa Nebukadrezzar Babel wicaśtayatapi nape kin en; unkan he icu kta :

29 Qa Kasdim oyate otonwe kin de kici kicizapi kin hena en upi kta, qa peta on otonwe kin de ideyapi kta, qa hulinaliyapi kta, tipi akahpe akan Baal izinyapi, qa canteptanye mayanpi kta on taku wakan tokeca woyatke wośnapi wicakicaśtanpi qon hena nakun.

30 Israel cinca qa Juda cinca kin hena tokahi icağapi kin hetanhan mitokam taku śica eceedan econpi ; Israel cinca kin iye nape ohampi kin on canteptanye mayanpi eceedan nakaeś, Jehowa eya.

31 Anpetu kin en kagapi kin ehantanhan anpetu kin dehanyan otonwe kin de wocanteptanye qa wośinhda icahmiciya ece; heon mitokapatanhan tokan iyem waye kta:

32 Israel cinca qa Juda cinca taku śica econpi ocowasin on etanhan, canteptanye mayanpi kta on econpi kin hena; iyepi, wicaśtayatapi tawapi, wicaśta ihdawa wicayuhapi kin, wawayuśna tawapi qa wicaśta wokcan tawapi, qa Juda wicaśta, qa .Jerusalem en ounyanpi kin hena.

33 Unkan miye en ite itoheya śni, tuka tapete itoheya ihduzapi: qa waonspewicawakiya, han. wekta qa onspewicawakiya qeyaś woonspe icupi kta on anağoptanpi śni ecee.

34 Tuka tipi ohna micaje cajeyatapi ecee lrin he en wowalite śni tawapi kin ehdepi, yuśapapi kta e heon etanhan.

35 Qa conkaślke, Hinnom cinhintku takaksiza kin ohna, hena Baal kicagapi, cinhintkupi qa cunwintkupi kin Molek ekta iyaye wicayapi kta; he qe econwicawaśi śni, qa tohinni mitawacin kin en u śni, Juda wicaśta wahtani wicakiyapi kta e on wowahitc śni kin de econpi kta.

36 Unkan nakaha, heon etanhan Jehowa Israel ta Wakantanka kin he, otonwe kin de on, Babel wicaśtayatapi nape en qupi ce, mazasagye qa wicaakilian qa makośica on, niye ehapi ecce kin heon hecen eya ce:

37 Iho, makoce owasin ektakta, mitocanniye en, qa mitośinhda en, qa mitocanteptanye tanka en, iyaye wicawaye ciqon hetanhan miye mnawicawaye kta ; qa makoce kin de en ake awicawahdi kta, qa wikopeśniyan en ounye wicawaye kta.

38 Unkan hena mitaoyate eepi kta, qa Taku Wakan tawapi kin he miye kta ce.

39 Qa wicacante wanjidan qa 


\section{JEREMIAH TAWOYUKCAN KIN,}

canku wanjidan wicawaqu kta, hecen anpetu owasin komakipapi kta, iyepi qa iyohakam iye cincapi kin tanyan unpi kta heon etanhan.

40 Nakun wicotakuye owihanke śni wan wicawecagge kta, taku waśte ecawicawecon kta e wicihekpatsnhan mihduhomni kte śni ; tuka wokokipe mitawa iye cantepi kin en ewahnake kta, hecen elipemayanpi kte śni, heon etanhan.

41 Han, taku waśte ecawicawecon kta on iwicaweciyuśkin kta; qa awicakehan micante on qa minaǵi ocowasin on makoce kin de en owicawakiju ktace.

42 Jehöwa hecen eya nakaeś; Taku śica tanka kin de ocowasin oyate kin de wanna en awicawau kin he iyecen, taku waśte wahowicawaye cin owasin en awicawau kta ce.

43 Unkan ake makoce kin de ohna maǵa opetonpi kta, on, Hewoskan wanka, wicasta wanica, woteca wanica; Kasdim oyate napepi kin en qupi ce, ehapi ecee tuka.

44 Mazaska on maǵa opetonpi kta, qa wowapi en kağapi kta, qa apuspapi kta, qa wayuotanin yutanpi kin icupi kta, Benjamin makoce kin ohna, qa Jerusalem ihdukśan wanke cin, qa Juda totonwe kin en, qa lie akan otonwe kin ohna, qa omdaye otonwe kin en, qa itokah otonwe kin ohnahna; wayaka unpi kin hdicuwicawaye kta nakaeś, Jehowa eya.

\section{WICOWOYAKE 33.}

1 Nakun inonpa Jehowa oie kin Jeremiah en hi, wicakaśka tipi hocoka kin ohna natakapi icunhan, he hecen eya:
2 Jehowa waicaliye kin, Jehowa hdusuta kta on icaliye cin hee; Caje kin Jehowa hee, he hecen eya ce :

3 Makipan wo, kinhan aciyupte kta, qa taku tanka qa taku anahmanpi, sdonyaye śni con hena cicipazo kta ce.

4 Jehowa Israel Taku Wakan tawapi kin be, otonwe kin de ohna tipi kin hens, qa Juda wicaśtayatapi tipi kin hena on hecen eya; Hena paha kaggapi kin on, qa mazasagye on yujujupi ;

5 Kasdim oyate kin zuya upi, qa wicaśta țapi, mitocanniye en qa mitocanteptanye en wicawakaśtaka, hena on tipi ojuyapi kta; taku śica econpi iyulipa on otonwe kin de miite anawecihman kin heon etanhan.

6 Iho, on yuskiskitapi qa okiziyapi kin wakahi kta, qa okiziwicawaye kta, qa wookiye wowicake ko woptecaśni. wicawakiyuzamni kta.

7 Qa Juda wayaka unpi qa Israel wayaka unpi kin he hdicuwakiye kta, qa ake icahwicawakire kta, otokahe ekta iyececa.

8 Qa taku śica econpi kin owasin, tona on wamakihtanipi kin hena etanhan wicawakiyujaja kta; qa taku śica econpi kin owasin, on wahtanipi, qa on śicaya ecamiconpi kin hena wicawecicajuju kta ce.

9 Unkan he qe wowiyuśkin caje mduhe kta, woyatan qa woyuonihan kta, maka akan oyate iyuhipa wicitokam, taku waśte ecawicawecon kin owasin nahompi kta nakaeś : unkan wowaśte qa wookiye yuhewakiye cin owasin on kokipapi kta qa nihinciyapi kta ce.

10 Jehowa hecen eya; Makoce kin de hewoskan wanka kehapi, 


\section{WICOWOYAKE 33.}

wicaśta wanica qa woteca wanica; Juda totonwe kin ohna, qa Jerusalem canku kin ohna, hewoskan wanka, wicaśta wanica, en ounyanpi wanica, qa rvoteca wanica, hena en,

11 Wowiyuśkin ho kin nahonpi kta, qa wicocante waśte ho kin; wicaśta winohinca yuza ho kin, qa winyan yuzapi kin he ho kin; tona, Jehowa ozuye yuhe cin yatan miye; Jehowa waśte qa tawocantekiye kin he owihanke wanica ce, eyapi hopi kin : tona Jehowa ti kin en wowiyuśkin wośnapi ahipi kte cin hena. Makoce wayaka unpi kin he hdicuwakiye kta nakaeś, otokahe ekta iyececa, Jehowa eya.

12 Jehowa ozuye yuhe cin he hecen eya; Ake makoce kin den, hewoskan wanka, wicaśta wanica qa woteca wanica, qa totonwe iyuhipa en wawiliankiya owanka, en optaye kin iwangwicakiyapi kin heca yuke kta.

13 He otonwe lin en, omdaye otonwe kin en, qa itokah otonwe kin en, qa Benjamin makoce kin en, qa Jerusalem ihdukśan wanke cin, qa Juda otonwe kin en, optaye kin ake tuwe wicayawa nape ohna hiyayapi kta ce, Jehowa eya.

14 Tho, anpetu kin u kta, Jehowa eya, hehan wicoie waśte Israel tiyohnaka qa Juda tiyohnaka ervicawakiye ciqon he wahduśtan kta ce.

15 Anpetu kin hena en, qa hehantu hin Woowotanna Adetka kin Dawid icaliweciciye kta: Unkan he qe woyaco qa woowotanna makoce kin ohna econ kta.

16 Anpetu kin hena en Juda nikiyapi kta, qa Jerusalem wikopeśniyan ounye kta: Unkan he, Jehowa Woowotanna unkitawapi, eciyapi kte cin hee.
17 Jehowa hecen eya nakaeś; Wicaśta wan Israel tiyohnaka oiyotanke tawa kin akar iyotanke kta Dawid kiwanice kte śni.

18 Qa wawayuśnapi, Lewi wicaśta, mitokam wohuhnage wośnapi wayuśnapi kta, qa woyute wośna izitekiyapi kta, qa wawayuśnapi kta anpetu owasin yulse kta ce.

19 Hehan Jehowa oie Jeremiah en u kin he hecen eya :

20 Jehowa hecen eya ce; Anpetu wicotakuye mitawa qa hanyetu wicotakuye mitawa kin hena yujuju oyakihipi kinhan, hecen tohan iyehantu eca anpetu qa hanyetu yuke kte śni hecinhan;

21 Nakun Dawid mitaokiye kin lici wicotakuye mitawa kin yujujupi kta, hecen iye oiyotanke tawa kin akan cinhintku wicaśtayatapi yanke kta takudan yuke kte śni; nakun Lewi wicaśta wawayuśna wowidake mitawa kin hena om.

22 Malipiya obe kin hena yawapica śni, qa miniwanca wiyaka kin iyutepica śni, he iyecen Dawid mitaokiye oicage tawa kin wahduota kta, qa Lewi wicaśta mitaokiye kin hena.

23 Nakun Jehowa oie kin Jeremiah en u kin he hecen eya :

24 Oyate kin de iapi qa, Wicowazi nonpa Jehowa hdahnige ciqon hena eqe elipewicaya ce, eyapi kin he wandake śni he: hecen mitaoyate kin wahtewicadapi śni, wicitokam icimana oyate kte śni e heon.

25 Jehowa hecen eya; Wicotakuye mitawa kin he anpetu qa hanyetu kin kici un śni ; mahpiya qa maka woope kin he mdusuta śni kinhan;

26 Hehan Jakob oicagie, qa Dawid mitaokiye kin elipewicawa- 


\section{JHREMIAH TAWOYUKCAN KIN,}

kiye kta; hecen oicagie tawa kin etanhan, Abraham, Isaak qa Jakob oicage tawapi kin en wicaśtayatapi kta on iwacu kte śni : Wayaka unpi kin hdicuwakiye kta qa onśiwicawakida kta nakaeś, Jehowạ eya.

\section{WICOWOYAKE 34.}

1 Nebukadnezzar Babel wicaśtayatapi, qa ozuye tawa kin ocowasin, qa maka akan wokiconze tona iye nape ihukuya unpi kin owasin, qa oyate iyuhipa, Jerusalem qa totonwe owasin nakun azuwicayapi qehan, wicoie Jehowa etanhan Jeremiah en hi kin he hecen eya:

2 Jehowa Israel Taku Wakan tawa kin he hecen eya ce; Ya wo, qa Zedekiah Juda wicaśtayatapi kin kici wohdaka qa heciya wo; Jehowa hecen eya ce; Iho, otonwe kin de Babel wicaśtayatapi nape en waqu kta, unkan iye peta on huhnahye kta:

$3 \mathrm{Qa}$ iye nape etanhan niye nayajice kte śni, tuka awicakehan niyuzapi lsta qa iye nape kin en niçupi lita, qa niiśta Babel wicaśtayatapi iśta kin wanyake kta, qa iitkopatanhan nici wohdake kta, qa Babel ekta de kta ce.

4 Tuka, Zedekiah Juda wicaśtayatapi, Jehowa oie kin nalion wo; Jehowa hecen eniciya; Mazasagye on nițe kte śni ;

5 Wookiye en nite kta, qa atewicayaya, wicaśtayatapi nitokam unpi qon hena huhnahwicakiciyapi kin iyecen huhnahniciyapi kta, qa, Hehehe Itancan, eya aniceyapi kta: miye wicoie kin de omdaka nakaeś, Jehowa eya.

6 Hehan Jeremiah wicaśta wokcan kin, Jerusalein en, Zedekiah
Juda wicaśtayatapi wicoie kin dena owasin okiyaka:

7 Babel wicaśtayatapi taakicita kin Jerusalem qa Juda otonwe okaptapi kin owasin om kicizapi qehan, Lakiś qa Azekáh kici: Juda otonwe acankaśkapi qon hena okaptapi nakaeś.

8 Jehowa etanhan wicoie Jeremiah en hi qon he dee; Zedekiah wicaśtayatapi kin oyate Jerusalem en unpi kin iyulipa om wicotakuye wicakicagia iyohakam, tawaiçiyapi kta owicakiyaka qehan :

9 Wicaśta otoiyohi wicaśta taokiye, qa wicaśta otoiyohi winyan taokiye wicayuśke iyaye wicayapi kta, hena Hebrew wicaśta qa Hebrew winolinca kin heca kinhan; hecen tuwedan iye sunkaku Juda wicaśta kin wowidagwicaye kte śni ecee.

10 Unkan wicaśta ihdawa iyuhpa, qa oyate kin ocowasin, wicotakuye en opapi qon hena, otoiyohi wicaśta taokiye qa otoiyohi winyan taokiye kin tankan iyayewicayapi kta, qa hetanhan tuwedan wowidagwicaye kte śni, nahonpi qehan, hehan waanağo.ptanpi qa iyayewicayapi :

11 Tuka iyohakam ihduhomnipi, qa wicaśta taokiye qa winyan taokiye iyayewicayapi qon hena ake en hdicuwicayapi, qa ake wicaśta taokiye qa winyan taokiye heca wicahduhapi.

12 Heon etanhan Jehowa etanhan Jehowa oie Jeremialı en hi kin he hecen eya;

13 Jehowa Israel Taku Wakan tawa kin he hecen eya ce; Atewicayayəui Egupta makoce kin etanhan, wokaśke tipi kin etanhan hinanpe wicawaye ciqon anpetu kin he en wicotakuye wan wicawecağa ;

14 Waniyetu sakowin ihanke 


\section{WICOWOYAKE 35.}

Kin ekta otoiyohi sunkaku Hebrew wicaśta kin heca kinhan, niye en wiyopeiçiye cinhan, hena wicayakiduśkapi kta; qa wanna waniyetu śakpe wowidagyaye cinhan, hehan niye etanhan tawaiciya iyaye yaye kta ce, epa. Tuka hunkakewicayayapi kin anamağoptanpi śni qa nog̣e ekta uyapi śni.

15 Unkan anpetu kin de nihduLomnipi, qa miiśta en taku owotanna ecanonpi, otoiyohi takodaku tawaiciyapi owicakiciyakapi kin on; nakun miye mitokam tipi kin micaje on cajeyatapi kin he ohna wicotakuye niçicağapi tuka;

16 Tuka nihdamnanpi qa micaje duśicapi, qa otoiyohi wicaśta taokiye qa winyan taokiye nagi ihduhapi kta e iyaye wicaye ciqon hena ake en hdicuwicayakiyapi, qa wowidake wicayakiyapi, wicaśta taokiye qa winyan taokiye wicaduhapi kta e heon.

17 Heon etanhan Jehowa hecen eya; Otoiyohi iye sunkaku qa otoiyohi iye takodaku kin tawaiçiyapi kta owicayeciyakapi qon he en anamayagoptanpi śni : Tho, niyepi on tawaiciyapi kta wan omdake kta, Jehowa eya ; mazasagye en, makośica en, qa wicaakifian kin ekta; unkan wonihinciye kta on maka akan wokiconze owasin ektakta ciçupi kta.

18 Nakun wicaśta tona wicotakuye mitawa awahtanipi kin hena wicawaqu kta, mitokam wicotakuye içicagapi wicoie kin hena hduśtanpi śni, ptejicadan kicaksapi qa onśpaśpa kin ehna hiyayapi qehan;

19 Juda wicaśta ihdawapi, qa Jerusalem wicaśta ihdawapi, akicita tancanpi qa wawayuśnapi kin, qa makoce en oyate iyuhpa ptejicadan onśpaśpa kin ehna iyayapi qon hena;

20 Han, hena ee tokawicayapi napepi kin en wicawaqu kta, qa nağipi akitapi kin hena napepi kin en : unkan hena tancan tapi kin mahpiya zitkadan qa maka wamanica kin hena woyute yapi kta.

21 Qa Zedekiah Juda wicaśtayatapi kin he, qa wicaśta ihdawa wicayula, hena tokawicayapi napepi kin en wicawaqu kta, qa tona nagipi odepi kin hena napepi kin en, qa Babel wicaśtayatapi taakicita niyepi etanhan kihdapi kin hena napepi en.

22 Iho, miye econ wicawaśi lita ce, Jehowa eya; qa otonwe kin de en ake icicawin hiyuwicawakiye kta: unkan kici kicizapi kta, qa icupi kta qa peta on huhnahyapi kta: Hecen Juda otonwe kin hena hewoskan wakage kta, en ounyanpi wanice kta.

\section{WICOWOYAKE 35.}

1 Jehoiakim Josiah cinhintku Juda wicaśtayatapi taanpetu kin en, Jehowa etanhan wicoie Jeremiah en u lin he hecen eya:

2 Rekabi tipi kin ekta ya wo, qa om wohdaka wo, qa Jehowa ti kin ekta awicau wo, wankan tipi kin wanji en, qa miniśa yatke wicakiya wo.

3 Hehan Jaazaniah, Jeremiah cinhintku, Habazaniah cinhintku kin iwacu, qa iye hunkawanjitku qa cinhintku kin iyuhpa, qa $\mathrm{Re}_{\text {- }}$ kabi tiyohnaka kin ocowasin:

4 Qa Jehowa ti kin en awicawahi, wankan tipi wan Hanar cinca tawapi kin he en, he Igdaliah cinhintku, Wakantanka tawicaśta kin heca, wicaśta ihdawapi wankan tipi tawapi kin icahda, Maaseiah Śallum cinhintku 321 


\section{JEREMFAH TAWOYUKCAN KIN,}

tiyopa awanyake kin he wankan tipi tawa kin iwankamtu:

5 Unkan Rekabi tiyohnaka cin. ca kin wicitokam ceg̉a miniśa ojugjudan ewahde, qa wiyatke nakun: qa, Miniśa yatkan po, ewicawakiya.

6 Tuka heyapi; Miniśa unyatkanpi kte śni: Jonadab, Rekab cinhintku, a teunyanpi kin he wahokonunkiyapi nakaeś, qa heya; Miniśa datkanpi kte śni, niyepi qa nicincapi owihanke wanica.

7 Qa tipi niçicag̉api kte śni, qa wojupi oyajupi kte śni, qa hastanhanka iyuwi ojupi yakagapi kte śni, qa duhapi kte śni : tuka anpetu nitawapi owasin wakeya ohna yatipi kta; hecen makoce en oyate tokeca yaunpi kin he ohna anpetu ota yanipi kta ce.

8 Unkan Jonadab Rekab cinhintku ateunyanpi ho kin he anaunkigoptanpi, tona iwahokon. unkiyapi kin ocowasin, anpetu unkitawapi owasin miniśa unyatkanpi kte śni, unkiyepi, unkitawicupi, cinkśi wicunyanpi qa cunkśsi wisunyanpi kin hena:

9 Qa tipi unkotipi kta unkicicag̉api śni; nakun hastanhanka iyuwi ojupi qa magga qa wojupi unhapi śni ce.

10 Tuka wakeya ohna untipi, qa waanagoptan unyakonpi, qa Jonadab ateunyanpi token econ unśipi owasin eciyatanhan econkupi ecee.

11 Tuka Nebukadnezzar Babeĩ wicaśtayatapi kin he makoce kin en hiyu qehan, hehan, U po, qa Jerusalem ekta unyanpi kta, Kasdim oyate ozuye itepi kin etanhan, qa Aram oyate ozuye itepi kin etanhan, unkeyapi ce. Hecen Jerusalem en unyakonpi ece, eyapi.

12 Hehan Jehowa oie Jeremiah en hi lin he hecen eya:

$$
322
$$

13 Jehowa ozuye yuha, Israel Taku Wakan tawa kin he hecen eya ce; Ya wo, qa Juda wicaśta qa Jerusalem en ounyanpi kin hena hecen ewicakiya wo; Mioie anayaggoptanpi kta on wowahokonkiye iyacupi kte śni he, Jehowa eya.

14 Jonadab Rekab cinhintku oie kin, iye cinca iwaholsonwicakiye ciqon, miniśa yatkanpi kte śni, hena e ecen econpi, anpetu dehanyan takudan yatkanpi śni nakaeś, tuka ateyapi ho kin anakjgoptanpi : hececa eśta miye taku eciciyapi, hanw ek ta qa epa ecee ; tuka anamayagooptanpi śni :

15 Nakun mitaokiye wicaśta wokcan kin owasin niyepi ekta yewicawaśi, hanwekta qa yewicawaśi ; Wanna otoiyohi tacanku sica etanhan hdicu po, qa niohanpi kin waśte kagga po, qa taku wakan tokeca wowidagniyanpi kta e ihakam yapi śni po, kinhan makoce miye ciçupi qa hunkakewicayayapi nakun, he en ounyayapi kta, epa ece: tuka ninogepi kin uyayapi śni qa anamayagoptanpi śni.

16 Jonadab Rekab cinhintku cinca kin hena ateyapi tawoahope econwicaśi qon he ecen ecakiconpi ; tuka oyate kin de anamağoptanpi śni :

17 Heon etanhan, Jehowa Taku Wakan ozuye yuba, Israel ta Wakantanka kin hee hecen eya: Iho, Juda qa Jerusalem en ounyanpi kin owasin, taku śica ewicawakiye ciqon iyuhpa en awicawau kta: Wowicawakiyaka tuka nahonpi śni: wicawakipan tuka iye waayuptapi śni, heon etanhan.

18 Hehan Jeremiah Rekabi tipi kin hewicakiya; Jehowa ozuye yuha, Israel Taku Wakan tawa kin he hecen eya ce; Jonadab 
niyatepi tawoahope kin anayakigoptanpi, qa toope kin owasin yeciyuhapi, qa taku econniśipi kin orrasin ecen ecanonpi ecee;

19 Heon etanhan Jehowa ozuye yuha Israel Taku Wakan tawa kin he hecen eya ce; Jonadab Rekab cinhintku wicaśta mitokam najin kte cin nice kte śni, owihanke wanica.

\section{WICOWOYAKE 36.}

1 Unkan kaketu, Jehoiakim Josiah cinhinttzu Juda wicaśtayatapi tawaniyetu itopa kin en, Jehowa etanhan wicoie kin de Jereniah en hi kin he hecen eya:

2 Wowapi pehanpi wan ehdaku wo, qa tokaheya wociciyalke cin ehantanhan, Josiah taanpetu kin hetanhan, anpetu kin dehanyan, Israel on, qa Juda on, qa oyate owasin on, wicoie tona ociciyake cin hena owasin en owa wo.

3 Okinni Juda tiyohnaka kin taku śica ecawicawecon kta wacanmi kin hena owasin nahonpi kta: hecen-wicaśta otoiyohi iye tacanku śica etanhan ihduhomnipi kta; hecen taku śica econpi qa wahtanipi kin wicawecicajuju kta ce.

4 Hehan Jeremiah Baruk Neriah cinhintku kin kico: Unkan Baruk Jeremiah i kin etanhan, Jehowa oie kin owasin, tona eciye ciqon hena, wowapi pehanpi kin en owa.

5 Hehan Jeremiah Baruk wahokonkiya qa heya; Miye iyamanicapi; Jehowa ti kin ekta mde kta owakihi śni :

6 Heon etanhan niye ya wo, qa Jehowa oi mii eciyatanhan wowapi en yakage cin hena, Jehuwa ti kin ohna woteśni unpi anpetu kin he en, oyate nahonpi kin en yawa wo: qa nakun Juda wicaśta owasin iye totonwepi etanhan upi kin hena nalionpi kin en dawa kta.

7 Okinni wocekiye tawapi kin he Jehowa itokam u kta, qa otoiyohi iye tacanku śica etanhan ihduhomnipi kta: wocanniye qa wocanteptanye, oyate kin de on, Jehowa cajeyate cin he tanka hinca nakaeś.

8 Unkan Baruk Neriah cinhintku kin he Jeremiah wicaśta wokcan kin taku econśi kin owasin ecen econ; Jehowa ti kin ohna Jehowa oie kin yawa. 9 Unkan kaketu, Jehoiakim Josiah cinhintku Juda wicaśtayatapi kin tawaniyetu izaptan, wi inapcinwanka kin en Jehowa itokam woteśni unpi wan yaotaninpi, oyate kin ocowasin Jerusalem en unpi, qa Juda otonwe kin etanhanhan oyate Jerusalem en hipi kin hena iyulipa en.

10 Hehan Baruk, Jehowa ti kin ohna, Jeremiah oie kin hena wowapi kin etanhan yawa, Gemariah Saphan cinhintku wowapi kagge cin he wankan tipi tawa kin ohna, wankan hocoka kin he ekta, Jehowa ti tiyopa teca ohna hiyupi ece kin hetu, oyate owasin nahonpi kin en.

11 Unkan Mikaiah Gemariah cinhintku Śaphan cinhintku kin he wowapi kin etanhan Jehowa oie owasin nahon qehan;

12 Hehan wicaśtayatapi ti kin ekta iyaya, wowapi kag̣api tipi kin en: Unkan, iho, wicaśta itancanpi kin owasin hen iyotankapi; Eliśama wowapi kagge cin he, qa Delaiah Śemaiah cimhintku, qa. Elnathan Akbor cinhintku, qa Gemariah Śaphan cinhintku, qa Zedekiah Hananiah cinhintku, qa wicaśta ihdawa iyuhpa.

13 Hehan Mikaiah Baruk oyate 


\section{JEREMIAH TAWOYUKCAN KIN,}

nog̉epi ohna wowapi yawa qchan, wicole tona nahon qon. hena owasin owicakiyaka.

14 Heon etanhan wicaśta itancanpi kin iyulipa Jehudi Nethaniah cinhintku, Śelemial cinhintku, Kuśi cinhintku kin he Baruk ekta ye śipi, qa heyapi, Wowapi pehanpi etanhan oyate noggepi kin en dawa qon he ninape ohna icu qa u wo. Hecen Baruk Neriah cinhintku kin he wowapi qon nape ohna eyaku qa en wicahi.

15 Unkan heciyapi; Wanna iyotanka wo, qa unnogiepi ohna he yawa wo. Hecen Baruk iye nogepi kin ohna yawa.

16 Unkan kaketu, wicoie kin hena owasin nalionpi qchan, otoiyohi takodaku kici kopehdapi, qa Baruk heciyapi; Awicakehan wicoie kin dena owvasin wicaśtayatapi kin unkokiyakapi kta ce.

17 Hehan Baruk wiwangapi ; Token iye i kin eciyatanhan wicoie kin dena owasin oyawa hecinhan, wanna unkokiyaka po, eyapi.

18 Hehan Baruk awicayupta; Iye i kin on wicoie kin dena owasin omakiyaka, unkan minisapa on wowapi kin en wakagra ce.

19 Hehan wicaśta itancanpi kin Baruk heciyapi; Ya wo, inaliman un wo, niye qa Jeremiah nakun; qa tukten yaunpi kin tuwedan sdonye kte śni.

20 Hehan hocoka kin en, wicaśtayatapi kin elkta iyayapi ; tuka wowapi kin he Eliśama wowapi kagie cin wankan tipi tawa kin en ehnakapi, qa wicoie kin hena iyuhpa wicaśtayatapi nog̉e kin en oyakapi.

21 Hecen wicaśtayatapi kin he Jehudi wowapi kin huwe yeśi : Unkan Eliśama wowapi kaga wankan tipi tawa kin etanhan 324 eyaku. Hehan Juhudi wicaśtayatapi noge kin ohna, qa wicaśta itancanpi wicaśtayatapi icahda najinpi kin hena nogepi kin ohna wowapi kin he yawa.

22 Unkan wicaśtayatapi kin he waniyetu tipi kin en iyotanka yanka, wi inapcinwanka kin en; qa itokam oceti kin en cetipi.

23 Unkan kaketu, Jehudi yumdapi yamni, qa iś topa yawa qehan, hehan hena isan on baksa, qa oceti en peta kin en elipeya ecee, ecen wowapi kin oceti peta en ocowasin huhnag.a.

24. Tuka nibinciyapi śni, qa onhdohda kin hdupotapi śni, wicaśtayatapi qa iye taokiye kin owasin, wicoie kin dena nahonpi qehan.

25 Hececa eśta Elnathan qa Delaiah qa Gemariah wicaśtayatapi kin cekiyapi, wowapi kin he hulinaliye kte ślli : tuka anawicag̉optan śni.

26 Tuka wicaśtayatapi kin he Jerameel Hammalek cinhintku, qa Seraiah Azriel cinhintku, qa Selemiah Abdeel cinhintku kin hena Baruk wowapi kage cin he qa Jeremiah wicaśta wokcan kin wicayuze wicaśi. 'Tuka Jehowa inahbe wicakiya.

27 Hehan wowapi qa wicoie Jeremiah i kin etanhan Baruk owa qon hena wicaśtayatapi huhnahye cin iyohakam Jehowa oie Jeremiah en hi kin he hecen eya :

28 Ake wowapi pehanpi tokeca wan icu wo, qa wowapi tokaheya Jehoiakim Juda wicaśtayatapi huhnahye cin wicoie en un qon hena owasin en owa wo.

29 Unkan Jehoiakim Juda wicaśtayatapi kin heyakiye kta; Jehowa hecen eya ce; Wowapi kin he liulinahyaya; Tokeca, A wicakehan Babel wicaśtaya tapi 


\section{WICOWOYAKE $3 \%$}

kin hi kta, qa makoce kin de ihangye kta, qa ohna wicaśta qa woteca wanica kage kta, eha qa wowapi en oyawa he, eha ce.

30 Heon etanhan Jehowa Jehoiakim Juda wicaśtayatapi kin on hecen eya; Dawid oiyotanke tawa kin akan tuwedan kici iyotanke kte śni; qa iye tancan țe cin he anposkan omaśte kin en tankan elipeyapi $k t a$, qa hanyetu osni kin en.

31 Qa iye linca qa oicage tawa qa taokiye kin hena wahtanipi kin en awicawau kta; qa iyepi en qa Jerusalem en ounyanpi kin hena, qa Juda wicaśta kin hena en, taku śica cajewicaweciyate cin owasin en awicawau kta: tuka anağoptanpi śni ce.

32 Hehan Jeremiah wowapi pehanpi tokeca wan icu, qa $\mathrm{Ba}-$ ruk Neriah cinhintku wowapi kage cin he qu: unkan he ohna Jeremiah i kin etanhan wowapi wan Jehoiakim Juda wicaśtayatapi kin peta en huhnahye ciqon wicoie en un qon owasin en owa. Nakun wicoie iyececa ota koya en ehnakapi.

\section{WICOWOYAKE $3 \%$}

1 Unkan Zedekiah Josiah cinhintku wicaśtayatapi kin he Koniah Jehoiakim cinhintku eekiya wicaśtayatapi yanka; he qe Nebukadnezzar Babel wicaśtayatapi kin Juda makoce kin en wicaśtaya tapi kag̉a.

2 Tuka iye, qa taokiye kin hena, qa makoce en oyate kin, Jchowa oie Jeremiah wicaśta wokcan kin oyake cin hena anagoptarpi śni.

3 Hehan Zedekiah wicaśtayatapi kin he Jehukal Ślemiah cinhintku, qa Zephaniah Maaseiah cinhintku wawayuśna kin, hena W 2
Jeremiah wicaśta wokcan kin ekta yewicaśi, qa heya; Wanna Jeliowa Wakantanka.unkitawapi kin wocekiye unkekiciya miye.

4. He icunhan Jeremiah oyate kin ehna tin u qa tankan ya ecee: hinahin kaśka hnakapi śni nakaeś.

5 Unkan Pharaoli taakicita kin Egupta etanhan hinanpapi. Qa Kasdim oyate Jerusalem azuyapi kin hena hecen oyakapi kin nahonpi qehan, hehan Jcrusalem etanhan kihdapi.

6 Hehan Jehowa oie Jeremiah wicaśta wokcan en hi kin he hecen eya:

7 Jehowa Israel Taku Wakan tawa kin he hecen eya; Juda wicaśtayatapi wimayanongapi kta on miye en uniśipi kin he kaken eyakiyapi kta; Iho, Pharaoh taakicita oniciyapi kta hiyupi kin hena Egupta iye tamakoce kin ekta hdapi kta:

8 Qa Kasdim oyate kin ake upi kta, qa otonwe kin de kici kicizapi kta, qa icupi kta, qa peta on hulinaliyapi kta.

9 Jehowa hecen eya; Awicakehan Kasdim oyate kin ehpeya unkakiyahdapi kta ce, eya ninaġipi iyuśkiniçiyapi śni po : hena hdapi kte śni nakaeś.

10 Kasdim akicita nicizapi kin iyulipa wicayakaśtakapi, qa hena en tawicaopi wicaśta eceedan okaptapi qeyaś, otoiyoli iye tawakeya kin etanhan najinpi kta, qa otonwe kin de peta on huhnahyapi kta ce.

11 Unkan kaketu, Kasdim ozuye kin Pharaoh taakicita kin wicitokapatanhan Jerusalem etanhan iyayapi qehar ;

12 Hehan Jeremiah Jerusalem etanhan iyaya, Benjamin maknce kin ekta ye kta, hetanhan taku 325 


\section{JEREMIAH TAWOYUKCAN KIN,}

tawa kin oyate wicacokayatanhan ehdaku kta.

13 Unkan Benjamin tatiyopa kin en un qehan owicawa itancan wanji hen un, Irijah eciyapi, Ślemiah cinhintku, Hananiah cinhintku; unkan he Jeremiah wicaśta wokcan kin yuza, Kasdim oyate kin ekta nayajica ce, eya.

14 Hehan Jeremiah heya; He wicakapi snil, Kasdim oyate kin ekta nawajice śni ce. Tuka anagoptan sni : hecen Irijah Jeremialı yuze ça itancanpi kin en ahi.

15 Heon etanlaan wicaśta itancanpi kin Jeremiah canniyeyapi, qa kaśtakapi, qa kaśka hnakapi, Jonathan wowapi kagja ti kin ohna: he wicakaśka tipi kaggapi nakaeś.

16 Jeremiah woha tipi kin en $i$, qa ohna yakonpi ece kin en, qa Jeremiah ota can hen yanka qehan ;

17 Hehan Zedekiah wicaśtayatapi kin he ekta yewicaśi, qa hetanhan eyaku : qa wicaśtayatapi kin iye ti kin ohna.nahmana wiwanga, qa heya; Jehowa etanhan wicoie yukan he. Unkan Jeremiah, Han, eya; qa nakun heya; Babel wicaśtayatapi nape kin en nicupi kta ce.

18 Nakun Jeremiah Zedekiah wicaśtayatapi kin heciya; 'Taku e on niye en wacicilitani he, qa nitankiye, qa oyate kin de en, hecen mayakaśkapi he.

19 Wanna wicaśta wokcan tona woniciyakapi qa, Babel wicaśtayatapi kin takpe niupi kte śni, qa makoce kin de en u kte śni ce, eyapi qon tukte epi he.

20 Heon etanhan ceciciya, wicaśtayatapi itancan mitawa namahon ye; ceciciya ce, wocekiye mitawa nitokam hiyu nun326 we; hecen Jonathan wowapi kagia ti kin ekta ake iyaye mayaye kte śni, qa hen mațe kte śni.

21 Hehan Zedekiah wicaśtayatapi kin wicakaśka tipi hocoka kin en Jeremiah ehnake wicaśi, qa anpetu otoiyohi aguyapi spanyanpi canku kin etanhan aguyapi hminyanna wan qupi kta, otonwe ohna aguyapi ocowasin yusotapi kta hehanyan. Hecen Jeremiah wicakaśka tipi hocoka kin en yanka.

\section{WICOW OYAKE 38.}

1 Hehan Śephatiah Mattan cinhintku, qa Gedeliah Paśur cinhintku, qa Jukal Ś́elemiah cinhintku, qa Paśur Malkiah cinhintku kin hena wicoie Jeremiah oyate kin owasin owicakiyake cin hena nahionpi ;

2 Jehowa hecen eya ce; Tuwe laśta otonwe kin de ohna yanke cinhan mazasagye qa wicaakihan qa makośice on țe kta; tuka tuwe Kasdim oyate kin ekta ye cinhan he ni kta: iye nagi kin he woehdaku hduhe kta qa ni kta nakaeś.

3 Jehowa hecen eya; Awicakehan otonwe kin de Babel wicaśtayatapi taakicita napepi kin en qupi kta ce, eya ecee.

4 Heon etanhan wicaśta itancanpi kin wicaśtayatapi kin heciyapi ; Ceunniciyapi ce, wicaśta kin de teyapi kta: wicoie kin hena owicaliyake cin on akicita tona otonwe kin de ohna yakonpi qa oyate iyuhipa napepi wicakiyawaśake śni ecee: wicaśta kin de oyate kin de tanyan unpi kta akite śni nakaeś, tuka śicaya unpi kta.

5 Hehan Zedekiah wicaśtayatapi kin heya; Tho, ninapepi kin 


\section{WICOWOYAKE 38.}

ohna yanka; niye icunonpatanhan wicaśtayatapi kin takudan okihi śni nakaeś.

6 Hehan Jeremiah icupi qa Malkiah Hammelek cinhintku woha tawa kin en iyeyapi, he wicakaśka tipi hocoka kin hetu : Unkan hahonta on woha kin ekta Jeremiah kun iyeyapi. Unkan woha kin he en mini wanica, upśija eceedan. Hecen Jeremiah upśija kin en iyotanka.

7 Unkan Wbed-melek, Kuś oyate kin etanhan, wicaśtayatapi ti kin ohna ookiye unpi kin wanji hee, Jeremiah woha kin en iyeyapi he nahon qehan; icunhan wicaśtayatapi kin Benjamin tiyopa kin en iyotanka :

8 Hehan Ebed-melek wicaśtayatapi ti kin etanhan iyaye ca wicaśtayatapi kin kici wohdaka qa heya;

9 Wicaśtayatapi itancan mitawa, wicaśta kin dena Jeremiah wicaśta wokcan taku ecakiconpi kin owasin śicaya econpi, he woha kin en iyohpeyapi: unkan yanke cin en akilian te kta ; otonwe kin en wanna aguyapi wanica nakaeś.

10 Hehan wicaśtayatapi kin Ebed-melek Kuś wicaśta kin waeconśi, qa heciya; Detanhan wicaśta wikcemna yamni ninape en iwicacu wo, qa Jcremiah wicaśta wokcan kin te śni itokam woha kin etanhan eyaku wo.

11 Hehan Ebed-melek wicaśta kin hena iye nape en iwicacu, qa wicaśtayatapi ti kin mazopiye ihukuya ekta iyaya, qa hetanhan wokoyake tanika yulidelidecapi qa heyake kuke hinca hena icu, qa hahonta on woha kin en Jeremiah ekta iyekiciciya.

12 Qa Ebed-melek Kuś wicaśta kin Jeremiah heciya; Wanna wokoyake tanika yulidelidecapi qa heyake kuke hinca kin hena hahonta ohdateya ninape okihe ihukuya ehnaka wo. Unkan Jeremiah ecen econ.

13 Hecen hahonta kin on Jeremiah icupi, qa woha kin etanhan eyakupi. Unkan Jeremiah wokaślie tipi hocoka kin ohna yanka.

14 Hehan Zedekiah wicaśtayatapi kin yewicaśi, qa Jeremiah wicaśta wokcan kin Jchowa ti kin oenape iyamni kin he ohna iye ekta hiyuya. Unkan wicaśtayatapi kin Jeremiah heciya; Miye taku wanji iciwange kta; wicoie wanjidan anamakilibe śni wo.

15 Hehan Jercmiah Zedekiah heciya; Ociciyake cinhan awicakehan mayakte kte śni he; qa wahokonciciye cinhan anamayagoptan kte śni he.

16 Unkan Zedekiah wicaśtayatapi kin Jeremiah en anahbeyahan iciconza, qa heya; Jehowa naği kin de unkicagapi kin he ni un, cikte kte śni, qa wicaśta kin dena ninaggi akitapi kin hena napepi kin en cicu kte śni ce.

17 Hehan Jèremiah Zedekiah heciya; Jehowa Taku Wakan ozuye yuha, Israel Taku Wakan tawa kin he hecen eya; Awicakehan Babel wicaśtayatapi taakicita tancanpi kin hena ekta de cirhan, hehan ninaggi ni kta, qa otonwe kin de peta on huhnahyapi kte śni ; tuka niye yani kta, tiyobnaka nitawa nakun.

18 Tuka Babel wicaśtayatapi taakicita tancanpi kin ekta de kte śni kinhan, hehan otonwe kin de Kasdim oyate napepi kin en qupi kta, unkan peta on huhnahyapi kta, qa niye hena napepi etanhan enihdaku kte śni.

19 Hchan Zedekiah wicaśtayatapi kin Jeremiah heciya; Juda 


\section{JEREMTAH TAWOYUKCAN KIN,}

wicáśta Kasdim oyate kin ekta iyayapi kin hena kowicawakipa, okinni hena napepi kin en maqupi kta, qa imahaliapi kta.

20 Tuka Jeremiah heya; Nicupi kte śni. Ceciciya ce, Jehowa oie ociciyake cin he anagioptan wo; kinhan tanyan yaun kta, qa ninagi ni kta.

21 Tuka de kta tawatenyaye śni kinhan, wicoie Jehowa wanyagmakiye cin he dee :

22 Unkan iho, winohinca owasin tona Juda wicaśtayatapi ti kin en owicakaptapi kin hena Babel wicaśtayatapi taakicita tancanpi kin ekta yapi kta, qa hena heyapi kta; Wookiye wicaśta nitawa kin hena nihnayanpi qa ohiniyanpi : nisiha upśija kin en kadom niyanpi, ehpeya niciyahdapi ce.

23 Hecen nitawinohinca owasin qa nicinca kin hena Kasdim oyate kin en wicakahipi kta; qa niye hena napepi kin etanhan nihduśpe kte śni, tuka Babel wicaśtayatapi nape on niyuzapi kta; qa otonwe kin de peta on huhnahye wicayaye kta ce.

24 Hehan Zedekiah Jeremiah heciya; Wicoie kin dena tuwedan sdonye yaye kte śni, kinhan nite kte śni.

25 Tuka wicaśta itancanpi kin hena wounhdaka he nahonpi, qa en nihipi kinhan, qa heniciyapi, Wicastayatapi kin taku eyakiye cin hena wanna unkokiyaka po, anaunkilimanpi śni po, kinhan țeunniyanpi kte śni: qa nakun wicaśtayatapi kin taku eniciye cin :

26 Hehan hewicayaliye kta; Wicaśtayatapi kin itokam wocekiye epa, Jonathan wowapi kaga ti kin en mațe kta e ake ekta iyaye maye kte śni ce.

27 Hehan wicaśta itancanpi kin 328 owasin Jeremiah en hipi qa wiwangapi: unkan wicaśtayatapi econśi kin wicoie kin dena owasin eciyatanhan owicakiyaka. Hecen kici wohdaka ayaśtanpi: wicoie kin okahnigapi śni nakaeś.

28 Unkan Jeremiah wokaśke tipi hocoka kin hen yanka, Jerusalem icupi anpetu kin hehanyan: Qa Jerusalem icupi qehan hen yanka.

\section{WICOWOYAKE 39.}

1 Zedekiah Juda wicaśtayatapi kin tawaniyetu inapcinwanka en, wi iwikcemna en, hehan Nebukadnezzar Babel wicaśtayatapi kin Jerusalem ekta hi, qa taakicita owasin, qa aonatakapi.

2 Zedekiah tawaniyetu iake wanjidan en, wi itopa, wiyawapi anpetu inapcinwanka kin en otonwe kin kamdecapi.

3 Hehan Babel wicaśtayatapi takicita tancanpi kin owasin en hipi, qa otonwe tiyopa cokaya kin en iyotankapi-Nergal-śarezer, Samgar-nebo, Sar-sekim, Rab-saris, Nergal-śarezer, Rabmag, qa Babel wicaśtayatapi taakicita tancanpi unmapi kin iyuhpa.

4. Unkan kaketu, Zedekiah Juda wicaśtayatapi kin hena qa ozuye wicaśta kin iyuhpa wanwicayaka qehan, hehan najica, qa hanyen otonwe kin etanhan tankan inanpa, wicaśtayatapi tawnju canku kin he eciyatanhan, conkaśke nonpa otahedan tiyopa kin he ohna: qa omdaye canku kin he ohnayan iyaya.

5 Tuka Kasdim akicitapi kin tawicapapi, qa Jeriko omdaye kin en Zedekiah ekihdeğapi : unkan yuzapi qehan Nebukadnezzar Babel wicaśtayatapi kin ekta 


\section{WICOWOYAKE 40.}

ahipi, Riblah en Hamath makoce kin ohna, unkan hen woyaco okiciyaka.

6 Hehan Babel wicaśtayatapi kin Zedekiah cinhintku kin hena wicakte, Riblah en, iye iśta itokam: nakun Babel wicaśtayatapi kin Juda itancanpi kin owasin wicakte.

7 Qa nakun Zedekiah iśta kiyuśdoka, qa mazaicicahilia nom on kaśka, Babel ekta ahde kta.

8 Unkan Kasdim oyate kin wicaśtayatapi ti kin he, qa oyate tipi kin hena peta on huhnaliyapi, qa Jerusalem conkaśke kin yujujupi.

9 Hehan oyate okaptapi, tona otonwe kin ohna yakonpi, qa tona iye ekta najicapi kin, oyate etanhan okaptapi kin hena koya, Nebuzar-adan wicakte itancan kin he Babel ekta wayalka awicakiyahda.

10 Tuka oyate etanhan tona onśikapi, takudan yuhapi śni kin hena Nebuzai-adan wicak te itancan kin Juda makoce kin en owicakapta, qa anpetu kin he en hastanhanka ojupi magga ko wicaqu.

11 Unkan Nebukadnezzar Babel wicaśtayatapi kin Nebuzaradan wicakte itancan nape kin on Jeremiah on econwicaśi, qa heye ciqon:

12 Icu wo, qa niiśta on tanyan awanyaka wo, qa taku śica ecakicon śni wo; tuka taku eniciye cinhan he ohna hinca ecakicon wo.

13 Hecen Nebuzar-adan wicakte itancan kin yewicaśi, qa Nebuśasban, Rab-saris qa Nergalśarezer, Rab-mag qa Babel wicaśtayatapi taakicita tancanpi kin iyuhpa ;

14 Han, hena- yewicaśipi qa Jeremiah wokaśke tipi hocoka kin, etanhan eyakupi, qa Gedeliah Ahikam cinhintku, Śaphan cinhintku kin he ekta kahipi, iye ti kin ekta ahde kta e heon. Hecen oyate kin om ounyan.

15 Tuka Jeremiah linyahin wokaśke tipi hocoka kin en onatakapi qehan Jchowa oie kin en hi, qa hecen eya:

16 Ya wo, qa Ebed-melek Kuś wicaśta kin he wokiciyaka wo, qa heya wo; Jehowa ozuye yuha, Israel Taku Wakan tawa kin he hecen eya ce: Iho, mioie kin otonwe kin de en awau kta, taku śica on, qa taku waśte on etanhan śni, qa anpetu kin he en niiśta itokam ecetu kta.

17 Tuka anpetu kin he en eci. hdaku kta, Jehowa eya; qa wicaśta itepi kowicayakipe cin hena napepi kin en niçupi kte śni!

18 Woehdaku on ecihdaku kta, qa mazasagye on nihinhpaye kte śni, tuka ninag̣i kin he wokamna yahduhe kta; wacinmayaye cin heon etanhan, Jehowa eya.

\section{WICOWOYAKE 40.}

1 Jehowa etanhan wicoie Jeremiah on hi kin he dee, Nebuzaradan wicakte itancan kin Ramah etanhan kiyuśke cin iyohakam; he icu tuka, Jerusalem etanhan qa Juda etanhan wayaka awicayapi, tona Babel ekta awicakiyahdapi qon hena om mazaicicahiha on kaśkapi qehan.

2 Unkan wicakte itancan kin he Jeremiah icu qa heciya; Jehowa Taku Wakan nitawa otonwe kin de taku śice cin de okiciyaka:

3 Nakaha Jehowa hduecetu, qa eye ciqon ohna econ: Jehowa wayecihtanipi nakaeś, qa ho kin anayaggoptanpi śni, heon etanhan wicoie kin de en aniupi. 


\section{JEREMIAH TAWOYUKCAN KIN,}

4 Unkan nakaha, iho, anpetu kin de ninape pahtapi kin ciciyuśka; niiśta kin en waśte kinhan, Babel ekta mici de kta hecinhan, $u$ wo, kinhan tanyan awanciyake kta; tuka Babel ekta mici de kta niiśta kin en śice cinhan, u śni wo. Wanyaka wo, makoce kin ocowasin nitokam wanka, tukte en de kta iyonicipi qa waśteyadake cinhan, en ya wo.

5 Unkan hinyahin hde śni icunhan, hehan, Gedaliah Ahikam cinhintku, Saphan cinhintku, Babel wicaśtayatapi kin Juda otonwe kin en itancan kage cin he ekta hda wo, qa kici un wo, oyate kin wiciyopeya; qa tukten de kta iyonicipi kinhan, hen ya wo, eya. Hehan wicakte itancan kin woyute qa mazaska qu, qa kihdeya.

6 Hehan Jeremiah Gedaliah Ahikam cinhintku kin ekta iyaya, Mizpah ekta; qa kici un, oyate makoce en okaptapi kin hena owicapeya.

7 Unkan akicita tancanpi tona maǵata unpi kin owasin, iyepi qa wicaśta wicayuhapi kin hena, Babel wicaśtayatapi kin Gedaliah Ahikam cinbintku makoce kin en itancan kag̉a, qa wicaśta ya winohinca śiceca koya, qa makoce ohna wah̆panicapi, tona Babel ekta wayaka awicayapi śni kin, hena yuhe kiya, he nahonpi qehan;

8 Hehan Mizpah en, Gedaliah ekta hipi ; han, Iśmael Nethaniah cinhintku, qa Johanan qa Jonathan Kareah cinca, qa Seraiah Tanhumeth cinhintku, qa Ephai Netophath wicaśta wan he cinca, qa Jezaniah Maakath wicaśta wan cinhintku, iyepi qa wicaśta tawapi kin hena.

9 Unkan Gedaliah Ahikam cinhintku, Śaphan cinhintku kin, hena qa wicaśta wicayuhapi kin wokonze on hecen ewicakiya; Kasdim oyate kin en wowidagniçiyapi kta kokipapi śni po: makoce kin en ounyan po, qa Babel wicaśtayatapi kin en wowidagiciya po, kinhan tanyan yaunpi kta ce.

10 Miye hinca, iho, Mizpah en waun kta, Kasdim oyate en unkupi kte cin hena itokam waowakiya ecee kta: Tuka niyepi miniśa mnakiya po, qa mdoketu waskuyeca, qa wihdi, qa cega nitawapi kin en okihnaka po, qa otonwe iyacupi kin hena en ounyan po, eya.

11 Nakun Juda wicaśta owasin Moab en unpi, qa Ammon cinca kin om, qa Edom en, qa makoce owasin ektakta yakonpi kill hena Babel wicaśtayatapi kin Juda onge owicakapta, qa hena Gedaliah Ahikam cinhintku Śaphan cinhintku kin wicayuhekiya he nahonpi qehan :

12 Han, Juda wicaśta owasin tuktekte ekta iyaye wicayapi qon owasin etanhanhan hdicupi, qa Juda makoce kin en hdipi, Gedaliah ekta, Mizpah etu, qa miniśa mdoketu waskuyeca ko ota hinca mnayanpi.

13 Hehan Johanan Kareah cinhintku qa akicita tancanpi magata unpi kin iyuhpa Gedaliah ekta hipi, Mizpah eta;

14 Qa heciyapi, Baalis Ammon cinca wicaśtayatapi kin he Iśmael Nethaniah cinhintku kin ninaği ape kta u śi, he wosdonye on sdonyaya he. Tuka Gedaliah Ahikam cinhintku kin cețunwicahda;

15 Hehan Jolıanan Kareah cinhintku kin Mizpah en Gedaliah kici nahmana wohdaka qa heya; Ceciciya, iyowinmakiya wo, kinhan Iśmael Nethaniah cinhintku 
kin wakaśtake kta, qa tuwedan sdonye kte śni; tokeca ninaggi ape kta he, hecen Juda wicaśta niye en mnayanpi kin owasin enanakiya iyewicayapi kta, qa Juda okaptapi kin atakuni kte śni he.

16 Tuka Gedaliah Ahikam cinhintku kin he Johanan Kareah cinhintku kin heciya; De wicolian kin ecanon kte śni : Iśmael on iewicayake śni nakaeś.

\section{WICOWOYAKE 41.}

1 Hehan kaketu, wi iśakowin kin en, Iśmael Nethaniah cinhintku, Eliśama cinhintku, wicaśtayatapi cinca kin etanhan, qa wicaśta itancanpi wicaśtayatapi tawa qon etanhan wicaśta wikcemna kin hena om Gedaliah Ahikam cinhintku kin en hi, Mizpah ekta; qa her witaya aguyapi yutapi, Mizpah en.

2 Hehan Iśmael Nethaniah cinhintku qa wicaśta wikcernna kici unpi kin hena najinpi, qa Gedaliah Ahikam cinhintku, Śaphan cinhintku kin mazasagye on kaśtakapi qa ktepi, Babel wicaśtayatapi kin makoce kin en itancan kage ciqon.

3 Nakun Juda wicaśta kici unpi kin owasin, Mizpah en, hena Gedaliah kici Iśnıael wicakte, qa Kasdim oyate, akicita unpi hen iyewicayapi kin hena nakun.

4 Unkan he Gedaliah kte kin iyohakam anpetu inonpa, qa tuwedan sdonye śni,

5 Hehan Śsekem etanhan, Ślioh etanhan qa Samaria etanhan, wicaśta en hipi, wicaśta wikcemna śahdoğan, putinhin hdasanpi, qa wokoyake hduhdehdecapi, qa baiçihonhonpi, qa napepi kin ohua minha wośnapi qa wizite kin, Jehowa ti kin en ayapi kta.
6 Unkan Iśmael Nethaniah cinhintku kin he Mizpah etanhan itkowicakipa iyaya, mani, mani qa ceya: Uukan itkowicakipa hehan hewicakiya; Gedaliah Ahikam cinhintku kin ekta u po. 7 Unkan kaketu, wanna otonwe cokaya ehan hipi qehan, hehan Iśmael Nethaniah cinhintku liena wicakte, woha cokaya kin hetu, iye qa wicaśta om un kin hena.

8 Tuka hena owicapeya wicaśta wikcemna, hena Iśmael heciyapi ; Unktepi śni po, wokamua mağata unhapi nakaeś, ag̣uyapi, qa barle, qa wihdi, qa tuhmaga canhanpi. Hecen ayuśtan qa hunkawanjitkupi kin orn wicakte śni.

9 Unkan wolia Iśmael wicaśta owasin tancan tapi, tona Gedaliah kici wicakaśtake cin en ehpewicaye cin he Asa wicaśtayatapi kin Baaśa ite kin on kag̈e ciqon hee. Iśmael Nethaniah cinhintku kin wicaktepi kin on ojuya.

10 Hehan Iśmael oyate okaptapi, Mizpah en unpi kin owasin iwicacu, wicaśtayatapi cunwintku kin hena, qa oyate Mizpah en unpi qon iyuhpa, Nebuzaradan wicakte itancan kin Gedaliah Ahikam cinhintku kin wicayuhekiye cin hena: unkan hena Iśmael Nethaniah cinhintku kin iwicacu, qa Ammon cinca kin ekta ye kta e iyaya.

11 Tuka Johanan Kareah cinhintku, qa akicita tancan tona om un kin hena Iśmael Nethaniah cinhintku taku śica econ kin owasin nahonpi qehan;

12 Hehan wicaśta iyuhpa iwicacupi qa Iśmael Nethaniah cinhintku kin kici kicizapi kta iyayapi, qa Gibeon en mini tanka kin ekta iyeyapi.

13 Unkan kaketu, oyate iyuhpa 331 


\section{JEREMTAH TAWOYUKCAN KIN,}

Iśmael kici unpi kin Johanan Kareah cinhintku qa akicita tancanpi kin owasin.om un kin hena wanwicayakapi qehan wiyuśkinpi :

14 Hecen oyate iyuhpa Iśmael Mizpah etanhan iwicacu qon hena ihduhomnipi, qa hdicupi, qa Johanan Kareah cinhintku kin ekta iyayapi.

15 Tuka Iśmael Nethaniah cinhintku kin, wicaśta śahdoġan om, Johanan ite kin etanhan nakiśdoka, qa Ammon cinca kin ekta iyaya.

16 Hehan Johanan Kareah cinhintku qa akicita tancan opapi kin owasin, oyate okaptapi, Iśmael Nethaniah cinhintku kin etanhan ewicayakupi kin hena owasin iwicacupi, Mizpah etanhan, Gedaliah Ahikam cinhintku kaśtake ciqon he iyohakam-okicize wicaśta waśakśakapi, qa winohinca qa śiceca kin, qa wowidake unpi, Gibeon etanhan awicakupi kin hena;

17 Unkan iyayapi qa Cimham oti qon he en ounyanpi, he Bethlehem ikiyedan, Egupta ekta yapi kta e heon etanhan:

18 Kasdirn oyate itepi kin etanlan; hena kowicakipapi nakaeś, Iśmael Nethaniah cinhintku Gedaliah Ahikam cinhintku, Babel wicaśtayatapi makoce kin en itancan kagge ciqon he kaśtaka heon etanhan.

\section{WICOWOYAKE 42.}

1 Hehan akicita tancanpi kin iyuhpa, qa Johanan Kareah cinhintku, qa Jezaniah Hośeaiah cinhintku, qa oyate iyuhpa, wicaciśtinna qa wicatanka kin hehanyan, ikiyedan upi ;

2 Qa Jeremiah wicaśta wokcan kin heciyapi; Ceunniciyapi, wo332 cekiye unkitawapi kin nitokam u nunwe, qa unkiyepi on Jehowa Taku Wakan nitawa wocekiye unkeyeciyapi kta, okaptapi kin de ocowasin on ; wicota etanhan tonana unkokaptapi rakaeś ; niye niiśta wanunyakapi kin iyececa: 3 Hecen Jehowa Taku Wakan nitawa kin he canku ohna maunnipi kte cin he unkipazopi kta, qa wicoie econkupi kte cin hena. 4 Hehan Jeremiah wicaśta wokcan kin hewicakiya; Nawahon; iho, Jehowa T'aku Wakan nitawapi kin he nioiepi kin eciyatanhan cewakiye kta: unkan Jehowa taku aniyuptapi kinhan, he ociciyakapi kta, takudan anaciciptapi kte śni.

5 Hehan Jeremiah heciyapi; Unkiyotahedan Jehowa wayaotanin wacinyepica qa iewicaka heca nunwe; wicoie on Jehowa Taku Wakan nitawa kin unkiyepi en uniśi kin hena owasin eciyatanhan econkupi śni kinhan.

6 Waśte kinhan, qa śice cinhan, Jehowa Taku Wakan unkitawapi ekta ye unniśipi kin he ho kin anaunkigoptanpi kta; hecen on tanyan unyakonpi kta, Jehowa Taku Wakan unkitawapi ho kin anaunkig̣goptanpi kinhall.

7 Unkan anpetu wikcemna iyohakam, hehan Jehowa oie kin Jeremiah en hi.

8 Hehan Johanan Kareah cinhintku, qa akicita tancanpi om un kin owasin, qa oyate kin ocowasin, wicacistinna qa wicatanka kin hehanyan, hena wicakico;

9 Qa hewicakiya; Jehowa Taku Wakan Israel tawa, wocekiye nitawapi kin itokam amde kta e ekta yemayaśipi qon he hecen eja ce :

10 Makoce kin de en ounyan owanji dukanpi kta hecinhan, hehan icahciyapi kta, qa mduju- 


\section{WICOWOYAKE 43.}

ju kte śni: qa ocijupi kta, qa mdujun kte śni ; taku śica ecaciconpi kin on iyopemiçiya nakaeś.

11 Babel wicaśtayatapi koyalipapi kin he kokipapi śni po; he kokipapi śni po, Jehowa eya: miye niniyanpi kta qa iye nape kin etanhan enihdakupi lita on cicipi waun nakaeś.

12 Nakun wowaonśida ciçupi kta, hecen iye onśinidapi kta, qa nitamakoce kin en ounyeniyanpi kta.

13 Tuka Jehowa Taku Wakan nitawapi ho kin anagoptanśniyan; Makoce kin de en unyakonpi kte śni ce, ehapi kinhan:

14. Hiya; tuka Egupta makoce kin ekta unyanpi kta, heciya okicize wanunyakapi kte śni, qa mazayahotonpi ho kin naunfionpi kte śni, qa ağuyapi iwotekteunhdapi kte śni, qa hen oununyanpi kta ce, ehapi kinhan:

15 Wanna Jehowa oie kin nahon po, Juda etanhan okaptapi yaunpi kin: Jehowa ozuye yuha, Israel Taku. Wakan tawa kin he hecen eya; Egupta ekta dapi kta awicakehan niitepi eyehdepi, qa en ounyayapi kta e elata dapi kinhan ;

16 Hehan kaketu kte, mazasagye koyakipapi kin he Egupta makoce kin en enihdegapi kta, qa wicaakilian on nihinniciyapi kin he Egupta ekta nihakam nipasipi kta; qa heciya nitapi kta.

17 Wicaśta owasin Egupta en ounyampi kta ekta yapi kta ite ekihdepi kin hena hecetu kte; mazasagye on, wicaakilian on, qa makośica on tapi kta : qa hena taku śica en awicawau kte cin etanhan tuwedan okaptapi kte śni, qa tuwedan najice kte śni.

18 Jehowa ozuye yuha, Israel Taku Wakan tawa kin he hecen eya nakaeś; Mitocanniye qa mitocanteptanye Jerusalem en ounyanpi kin hena awicakaśtanpi qon he iyecen mitocanniye anicaśtanpi kta, Egupta en yaipi kinhan; unkan woyaśice, qa wonihinciye, qa iapi śica, qa woienhdepi kin henicapi lsta; qa ake makace kin de icimana wandakapi kte śni.

19 Juda etanhan wokapte yaunpi kin, Jehowa heniciyapi ; Egupta ekta yapi śni po: Anpetu kin de wahokonciciyapi he awicakehan sdonya po.

20 Jehowa Taku Wakan nitawapi kin ekta yemayaśipi, qa, Jehowa Taku Wakan unkitawapi kin wocekiye unkekiciya miye; qa Jehowa Taku Wakan unkitawapi kin taku eye kte cin owasin eciyatanhan unkokiyaka po, kinhan ecen econkupi lita se, ehapi qehan, ninagipi en nicihnayanpi.

21 Unkan anpetu kin de wociciyakapi; tuka Jehowa Taku Wakan nitawapi ho kin anayagoptanpi śni, qa taku on niyepi en umaśi kin hena owasin.

22 Heon etanhan wanna wosdonye on sdonya po, mazasagye on, wicaakitian on, qa makośica on nițapi kta, makoce en ounyayapi kta e ekta dapi yacinpi kin heciya.

\section{WICOWOYAKE 43.}

1 Unkan kaketu, Jehowa Taliu Wakan tawapi oie kin owasin on, Jehowa Taku Wakan tawapi kin ekta wicaiśi, wicoie kin dena owasin, Jeremiah oyate ocowasin owicakiyaka ihunikiya;

2 Hehan Azariah Hośaiah cin. hintku qa Johanan Kareali cinhintku, qa wicaśta walianhanicidapi kin owasin iapi qa Jeremiah 


\section{JEREMIAH TAWOYUKCAN KIN,}

heciyapi ; Iyaton śni ce; Jehowa.Taku Wakan unkitawapi kin he, Egupta en ounyanpi kta e ekta yapi śni po, eya uniśi śni.

3 Tuka Baruk Neriah cinhintku kin hee unkiyepi on iyopaśtagniyan, Kasdim oyate napepi en unqupi kta, hecen unktepi kta, qa Babel ekta wayaka unkayapi kta e heon etanhan.

4 Hecen Johanan Kareah cinhintku, qa akicita tancanpi kin owasin, qa oyate kin ocowasin Jehowa ho kin anağoptanpi śni, Juda makoce kin en ounyanpi kta :

5 Tuka Johanan Kareah cinhintku, qa akicita tancanpi kin owasin, Juda okaptapi kin ocowasin oyate tokeca ektakta iyewicayapi qon etanhan hdicupi, Juda makoce kin en ounyanpi kta, hena iwicacupi.

6 Wicaśta qa winolinca qa śiceca kin, qa wicaśtayatapi cunwintkupi, qa tona Nebuzar-adan wicakte itancan kin Gedaliah Ahikam cinhintku Śaphan cinhintku kin kici iyotanke wicaśi qon, qa Jeremiah wicaśta wokcan kin, qa Baruk Neriah cinhintku kin hena.

7 Qa Fiputa makoce kin en hipi ; Jehowa ho kin anag̉optanpi śni nakaeś. Hecen Taplianes ekta hipi.

8 Hehan Taphanes en Jehowa oie Jeremiah en hi kin he hecen eya :

9 Inyan tankinyanyan ninape ohna icu wo, qa maka omdoton Kag̉api upśija kin en inahman wo, Taphanes en, Pharaoh ti tiyopa kin hetı, Juda wicaśta iśtapi kin itokam :

$10 \mathrm{Qa}$ hewicakiya wo; Jehowa ozuye yuha, Israel Taku Wakan tawa kin he hecen eya ce; Tho, Nebukadnezzar Babel wicaśta334 yatapi mitaokiye kin he wahowaye kta, qa awau kta, qa iye toiyotanke kin inyan nawalibe cin dena akan ewahde kta, unkan iye ohehdepi waśte tawa kin hena akamdaye kta.

11. Unkan hi kinhan hehan Egupta makoce kin kaśtake kta, tona wiconte ekta wiconte on; qa tona wayaka ayapi kta ekta, hena wayaka ayapi kta on; qa tona mazasagye ekta hena mazasagye kin en wicaqu kta.

12 Unkan Egupta taku wakan tawa tipi kin en peta wakaǵe $\mathrm{kta}$, qa hena hulinage kta; qa hena iwicacu kta, qa Egupta inakoce kin he koyake kta, tahinca awanwicayake wan śina hdowin kin iyececa; qa hetanhan wookiye en hde kta.

13 Nakun Beth-śemeś (anpetu wi ti) wakagapi tawa, Egupta makoce kin en un, hena kamdemdece kta; qa Egupta taku wakan tipi kin hena peta on fiblinaliye kta.

\section{WICOWOYAKE 44.}

1 Wicoie Juda wicaśta Egupta makoce kin en ounyanpi kin owasin on. Jeremiah en hi kin he dee, tona Migdol en ounyanpi, qa Taphanes en, qa Noph en, qa Pathros makoce kin en, he hecen eya ;

2 Jehowa ozuye yuha; Israel Taku Wakan tawa kin he hecen eya ce; Taku śica ocowasin Jerusalem qa Juda totonwe kin owasin en awau kin he niye wandakapi: unkan iho, anpetu kin de hena otiwota wanka, qa tuwedan ohna ti śni.

3 Wicohan sica econpi, on śinhdamayanpi kta, hena on etanhan, taku wakan tokeca izitewicakiyapi kta, qa en wowidagiçi- 
yapi kta iyayapi qehan, hena sdonwicayapi śni tuka, iyepi qa niyepi, qa nakun atewicayayapi kin.

4 Tuka wicaśta wokcan mitaokiye kin owasin niyepi ekta yewicawaśi, hanwekta qa yewicawaśi ; Ceciciyapi ce, wowahte śni śicewadake cin he econpi śni po, epapa.

5 Tuka nahonpi śni, qa nog̣e ekta ukiyapi śni, wicolian śica etanhan ihduhomnipi kta, taku wakan tokeca wizite izitekiyapi kte śni.

6 Heon etanhan mitocannive qa mitocanteptanye kin akaśtanpi, qa Juda otonwe kin en, qa Jerusalem canku kin ohna ide: unkan hena liewoskan qo wonihinciye, anpetu kin de iyecece.

7 Heon etanhan wanna Jehowa ozuye en Taku Wakan, Israel Taku Wakan tawa kin he hecen eya ce; Tokeca taku śica tanka kin de ninaggipi en ecayeconpi he, niyepi etanhan wicaśta qa winohinca, śiceca qa hokśiyoqopa Juda etanhan wicakaśpapi kta; hecen tuwedan onicaptapi kte śni.

8 Ninapepi ohanpi kin on śinhdamayayapi, Egupta makoce en ounyayapi kta yaipi kin he ohna taku wakan tokeca izite wicayakiyapi ece kin on, hecen ihangniyanpi kta, qa hecen maka akan oyate owasin ehnahna woyaśice qa woienhdepi kin henicapi kta.

9 Atewicayayapi wicohan śica tawapi, qa Juda wicaśtayatapi wicohan śica, qa tawicupi wicohan śica, qa niye niohanpi śica, qa winohinca nitawapi tolianpi śica, Juda makoce kin en, qa Jerusalem canku kịn ohna econpi qon hena ayektonjapi he.

10 Anpetu kin dehanyan iyoki- śinic̣iyapi śni, qa wakokipapi śni, qa mitoope qa wowaśi mitawa nitokam qa niyatepi wicitokam ewahnake ciqon hena olnayan manipi śni.

11 Heon etanhan Jehowa ozuye yuha, Israel Taku Wakan tawa kin he hecen eya; Iho, taku śica on niite nitkokim ewehnake kta, Juda ocowasin ihangyapi kta e heon.

12 Qa Juda okaptapi kin, tona Egupta makoce kin en ounyanpi kta e ekta yapi kta ite eiçihdepi kin hena wicamduze kta, ça iyuhpa awihnunipi kta, Eigupta makoce kin ohna hinhpayapi kta; mazasagye qa wicaakitian on awihnunipi kta ; wicacistinna qa wicatanka kin hehanyan mazasagye on, qa wicaakihan on tapi kta; qa woyaśice, wonihinciye qa woienhdepi qa woiyopeye kin hecapi kta.

13 Qa tona Egupta makoce kin en ounyanpi kin hena, mazasagye on, wicakkilian on, qa makośica on, en wicawai kta, Jerusalem. en wicawai qon iyececa.

14 Qa Juda okaptapi Egupta makoce kin en ounyanpi kta e ekta hipi, qa Juda makoce kin ekta hdapi kta, en ounyanpi kta e ekta cante yeyapi kin hena wonajice qa wookapte wanice kta: Najicapi śni kinhan ekta hdapi kte śni nakaeś.

15 Hehan wicaśta owasin tona iye tawicupi kin taku wakan tokeca izite kiyapi sdonyapi kin hena, qa winolinca en najinpi kin iyuhipa, omniciye tanka hinca, oyate Egupta makoce kin en ounyanpi kin owasin, Pathros etu, hena Jeremiah ayuptapi qa heciyapi ;

16 Wicoie Jehowa caje on unkoyeciyakapi kin he en anaunnigoptanpi kte śni : 


\section{JEREMIAH TAWOYUKCAN KIN,}

17 Tuka i unkitawapi etanhan taku enanpe cin hena awicalsehan econkupi kta, liecen mahpiya wicaśtayatapi winohinca kin iziteunkiyapi kta, qa woyatke wośnapi kin unkokicicaśtanpi kta, econkonpi ece kin iyecen, unkiyepi, qa atewicunyanpi, wicaśtayatapi unkitawapi, qa wicaśta itancanpi unkitawapi, Juda otonwe kin hena en, qa JerusaIem canku kin ohna: qa agguyapi iunmnanpi, qa taku waśte unhapi, qa taku śica wanunyakapi śni tuka gon.

18 Tuka mahpiya oicagre kin izitekiya qa woyatke wośnapi okicicaśtan unkayuśtanpi ehantanhan taku owasin. unnicapi, qa mazasagye qa wicaakilian on awiunhnunipi :

19 Qa mahpiya oicag̉e kin wizite unkiyapi qa woyatkan wośnapi kin unkokicicaśtanpi qehan, on ohoundapi kta, wicaśta unkitawapi codan ag่uyapi hminyanna unkicag̉api qa woyatkan wośnapi kin unkokicicaśtanpi he.

20 Hehan Jeremiah, oyate kin iyuhpa, wicaśta, qa winohinca, qa oyate ocowasin woayupte kin he qupi kin hena wowicakiyaka qa heya:

21 Wizite Juda otonwe kin hena en, qa Jerusalem canku kin ohna iziteyayapi qon, niyepi qa atewicayayapi, wicaśtayatapi nitawapi qa wicaśta itancanpi nitawapi, qa makoce kin en oyate ocowasin, hena Jehowa kiksuye śni, qa iye cante kin en u śni he.

22 Hecen niohanpi śice cin on, qa wowahteśni ecanonpi kin hena on, Jehowa tinsiçiya okihi śni; heon etanhan makoce nitawapi qon he hewoskantu, qa wonihinciye, qa woyaśice, anpetu kin de iyececa.

23 Wizite iziteyakiyapi kin 336 heon, qa Jehowa wayakihtanipi, qa Jehowa ho kin anayagoptanpi śni, qa toope kin en, qa wowaśi tawa qa tawoyatanin kin ohnayan mayanipi śni kin heon etanhan taku śice cin de en niupi, anpetu kin dehan iyececa.

24 Nakun Jeremiah oyate kin iyuhpa, qa winohinca kin owasin hewicakiya; Juda ocowasin Egupta makoce ohna yaunpi kin, Jehowa oie kin nahon po:

25 Jehowa ozuye yuha. Israel Taku Wakan tawa kin he hecen eya ce; Niyepi qa winohinca nitawapi niipi on taku ehapi, qa ninapepi on yahduśtanpi : Mahpiya oicagge kin wizite iziteunkiyapi kta, qa woyatkan wośnapi kin unkokicicaśtanpi kta e wokonze on unkiciconzapi kin he awicakehan econkupi kta ce, ehapi : wokonze nitawapi awicakehan yahduecetupi kta, qa wokonze nitawapi awicakehan ecanonpi kta ce, eya.

26 Heon etanhan, Juda wicaśta Egupta makoce kin en ounyayapi owasin, Jeliowa oie kin nation po; Tho, miye micaje tanka kin on miciconza, Jehowa eya; Ihnuhan Juda wicaśta wanjidan i on micaje hoyekiye ça, Jehow a Itáncan kin ni un ce, Egupta makoce kin owancaya, eye cinhan.

27 Iho, taku śica on awicatonwan waun kta, qa taku waśte on etanlian śni ; qa Juda wicaśta Egupta makoce en unpi kin hena iyuhpa mazasagye qa wicaakilian on awihnunipi kta, ihangyapi kta hehanyan.

28 Tuka mazasagye etanhan wonajice kin hena Egupta makoce kin etanhan Juda makoce kin ekta hdapi kta: qa Juda okaptapi kin Figupta makoce kin en ounyanpi 'kta ekta hipi kin hena owasin, wicoie, miye mita- 
wa qa iś iye tawapi kin unma tukte ecetu kta hecinhan sdonyapi kta.

29 Unkan makoce kin de en cihipi kta hecen taku śica on mioie kin niyepi en awicakehan sutaya he kta sdonyayapi kta e wowakta kin de duhapi kta:

30 Jehowa hecen eya ce; Tho, Pharaoh Hophra Egupta wicaśtayatapi kin he iye tokayapi napepi kin en waqu kta, qa tona nag̀i akitapi napepi kin en; Zedekiah Juda wicaśtayatapi qon Nebukadnezzar Bábel wicaśtayatapi iye tokaye ça naġi akite ciqon nape kin en waqu qon he iyececa ce.

\section{WICOWOYAKE 45.}

1 Jehoiakim Josiah cinhintku Juda wicaśtayatapi tawaniyetu itopa kin en, Baruk Neriah cinhintku Jeremiah i kin etanhan wicoie kin dena wowapi en kage cehan, hehan Jeremiah wicaśta wokcan taku eciye cin de wicoie ee.

2 Baruk, Jehowa Israel Taku Wakan tawa kin he hecen eniciya :

3 Hehehe, miye nakaha; Jehowa mitoiyokiśice en wolsakije iyahdemayan, comniwahdazi on mdowalitata, qa woozikiye iyewaye śni ce, ehe ciqon.

4 Kaken eyakiye kta; Jehowa hecen eya ce ; tho, taku wakag̉e cin he mdujuju kta, qa taku owaju kin he wahdujun kta, han makoce kin de ocowasin.

5 Nakun taku tanka onicide he : okide śni wo: Iho, wicacehipi owasin en taku śica awicawan kta ce, Jehowa eya; tuka tokiya de cin owasin ektakta ninagi woihdamna yuhe ciciye kta ce.

\section{WICOWOYAKE 46.}

1 Ikcewicaśta oyate kin on Jehowa oie Jeremiah wicaśta wokcan kin en hi qon he dee :

2 Egupta on, Pharaoh Neko Egupta wicaśtayatapi taakicita kin on, hena Karkemiś en Perat wakpa kin icahda Nebukadnezzar Babel wicaśtayatapi kin wicakaśtaka, Jehoiakim Josiah cinhintku Juda wicaśtayatapi tawaniyetu itopa hehantu.

3 Woakahpe qa wahacanka kin hena hduwiyeya po, qa okicize kin en ya po.

4 Śuktanka kin en ikoyagwicaya po, qa, śuktanka akan yotankapi, wankan ya po, qa wapaha kiton eicihde po; wahukeza pabeza po, maza wokoyake kin kicun po.

5 Taku on etanhan nihinciya hekta itoheya hdicupi wanwicamdaka he: qa waditakapi tawapi kin hena wicakaśtakapi, qa najicapi on najicapi, qa hakiktapi śni: Ihdukśan wokokipe yukan, Jehowa eya.

6 Tuwe duzahan kin he nape kte śni, qa tuwe waditake cin he eihdaku kte śni: waziyata ekta Perat wakpa kin icahda hicahanpi qa hinhipayapi $k$ ta.

7 De tuwe mini tanka kin iyecen wankan u he; mini tawa kin śkanśkan, wakpa kin iyececa.

8 Egupta mini tanka kin iye. cen wankan u : qa mini tawa kin śkanśkan, wakpa kin iyececa: unkan heya; Wankan mde kta, maka lin awakahpe kta; otonwe kin he ihangwaye kta, en ounyanpi kin hena koya.

9 Wankan u po, śuktanka; qa canpahmihma, psipsica po; qa wicaśta waditakapi kin hiyupi kta: Kuś qa Put wicaśta wahacanka 337 


\section{JEREMIAH TAWOYUKCAN KIN,}

yuzapi kin; qa Lud wicaśta itazipa hdus nawinjapi kin hena.

10 Anpetu kin de Jehowa ozuye en Itancan kin he tawa; watokiconpi anpetu kin hee, tona tokawicaye cin towicakiçon kta e heon: unkan mazasagye kin he watemye kta, qa hena we on imnahan iciye kta, qa witkoiciye kta: Jehowa ozuye Itancan kin he waziyata ekta Perat wakpa kin icahda wośna wan hduha nakaeś.

11 Wikośka, Egupta cunwintku, Gilead ekta ya wo, qa canśin icu wo: ituhin pejihuta yahduota kta; wookiziye ninice kta.

12 Wowiśtece nitawa kin be oyate kin nalionpi; qa yaśicahowada kin he maka kin ojudan: waditaka kin he waditaka kin kici hicahan, qa napin okonwanjidan hinlipayapi.

13 Nebukadnezzar Babel wicaśtayatapi kin Egupta makoce kin kaśtake kta hi kte cin he on Jehowa oie, Jeremiah wicaśta wokcan kin eciye ciqon he dee :

14 Egupta en woyaka po; qa Migdol en eyanpaha po, qa Noph en, qa Tahpanes en eyanpaha po: Inajin wo, qa ihduwiyeya wo; ihdukśan mazasagye kin waihangye kta nakaeś, eya po.

15 Tokeca waditakapi nitawa kin hena makata ehpewicayapi he: Jehowa kaham iyewicaya, heon inajinpi śni.

16 Wicota hinhpayewicaya; han, wanji takodaku ahinhpaya ece: Unkan heyapi; Najin po, qa oyate unkitawapi kin ekta unhdapi kta, qa makoce en unkicagapi kin ekta, mazasagye waihangye cin itokapatanhan.

17 Heciya panpi; Pharaoh Egupta wicaśtayatapi kin he woihangye; iyehantu kin wanna sam iyaya ce.
18 Miye wani waun ce, Wicaśtaya tapi kin Jehowa ozuye yuha eciyapi kin he hecen eya ce; Awicakehan Tabor he kin ehna wanka he iyececa, qa Karmel miniwanca kin icahda wanke cin he iyecen u kta.

19 Egupta cunwintku en ounyaye cin, unhdaka wakśica icicaga wo: Noph hewoskan wanke kta, qa ihangyapi kta, tuwedan en ounye kte śni nakaeś.

20 Egupta he pte wiye owanyag waśte hinca heca : woihangye waziyatanhan u kte cin he u ce.

21 Nakun wicaśta opewicaton kin hena ptejicadan cemyapi kin iyecen cokaya unpi ; hena hekta lidicupi, witaya napapi; en najinpi śni ; tawoiyokiśice anpetu kin, tohan wanyag wicahipi kte cin he en awicau nakaeś.

$22 \mathrm{He}$ ho kin wamduśka wan iyecen ye kta; ozuye hduha upi lita nakaeś; qa can kaksapi ece kin iyecen onspe hduha takpe upi kta:

23 Qa contanka tawa kawankapi kta, Jehowa eya, he iwanyakepica śni qeyaś ; psipsicadan isanpa ihduotapi qa wicayawapica śni nakaeś.

24. Egupta cunwintku kin iśteca kta: waziyata oyate napepi kin en qupi kta.

25 Jehowa ozuye yuha, Israel Taku Wakan tawa kin he hecen eya; Iho, No wicaśta ota kin hena en, qa Pharaoh en, qa Egupta en, qa taku wakan tawa kin en, qa wicaśtayatapi tawa kin hena en wanyag wicawahi kta; han, Pharaoh qa tona wacinyanpi kin hena.

26 Qa tona nagi akitapi kin hena napepi kin en wicawaqu kta, qa Nebukadnezzar Babel wicaśtayatapi nape kin en, qa 


\section{WICOWOYAKE 48.}

iye taokiye napepi kin en : tuka iyohakam en ounyanpi kta, anpetu wanakaja kin en iyececa, Jehowa eya.

27 Tuka niye, Jakob mitaokiye, wakokipe śni wo, qa Israel, nihinciye śni wo: iho, miye tehantanhan ecihdaku kta, qa oicage nitawa makoce en unhdaka unpi kin hetanhan : unkan Jakob hdicu kta, qa oziiciye kta, qa wikope śni un kta, qa tuwedan wakokipe kicagge kte śni.

28 Niye, Jakob mitaokiye, wakokipe śni wo, Jehowa eya; miye cici waun nakaeś; oyate ektakta iyaye ciye cin hena owasin ocowasin ihangwicawaye kta; tuka ocowasin ihangciye kte śni; hececa eśta wokonze eciyatanhan iyopeciye kta; tuka aktakta cicicajuju kte śni ce.

\section{WICOWOYAKE $4 \%$}

1 Philistia oyate on Jehowa oie Jeremiah wicaśta wokcan en hi kin he dee; Pharaoh Gaza kaśtake cin he itokamtu.

2 Jehowa hecen eya; Iho, waziyatanhan mini au, qa hena wakpa apaśboke cin iyececa kta, qa makoce kin apaśbog iyaye kta, qa taku akan un; otonwe, qa tona en ounyanpi kin hena koya: Hehan wicaśta kin śicahowayapi kta, qa makoce en ounyanpi kin owasin ceyapi kta.

3'Tona waśakapi tawa śake nahotonpi kin on, canpahmihma tawa inyankapi kin on canhdeśka tawa hmunyan kin on, wicaśta ateyapi un kin hena nape waśake śni on cincapi ekta hakiktapi kte śni.

4 Anpetu u kte cin he on, Philistine wicaśta owasin ihangwicaye kta; Tyrus qa Zidon etanhan ookiye okaptapi kin owasin kaśpapi kta.e heon etanhan : Jehowa Philistine oyate kin ihangwicaye kta nakaeś, Kaptor wita okaptapi kin hena.

5 Gaza en nasuśdapi icag̣a : Aśkelon ihangyapi, Anakim okaptapi qon hena: Tohanyan banicihonhon kta he.

6 Hehehe, Jehowa tamazasagye, tohanyan owanji nanke kte śni he: wojuha nitawa kin en ihdoya wo, oziiçiya qa owanji yanka wo.

7 Token owanji yanke kta he, Jehowa Aśkelon ekta ye śi nakaeś, qa miniwanca kahda ekta; heciya wakiciconza.

\section{WICOWOYAKE 48 .}

1 Jehowa ozuye yuha, Israel Taku Wakan tawa kin he Moab on hecen eya; Hehehe, Nebo, ihangyapi nakaeś; Kiriathaim iśtenyapi, icupi ; Misgab iśtenyapi, qa nihinciya.

2 Heśbon en Moab idowanpi wanice kta; he on taku sica awacinpi; U po, qa oyate kin etanhan unkaksapi kta ce : Nakun, Madmen, niś eya ihangniyanpi kta; nihakam mazasagye kin u kta.

3 Horonaim etanhan śicahowayapi ho kin; woihangye qa wokamdeca tanka.

4 Moab kamdecapi; wicacistinna tawa kin hena śicahowayapi hdataninpi.

5 Luhith ekta itanwankanhde yapi, ceyapi ceya ece ya ecee : Horonaim ekta apamahde yapi kin en woihangye on śicahowayapi, wocante sica he nahonpi.

6 Napa po, ninag̉ipi niiciya po, qa Aroer hopuza en wanke cin iyenicecapi kta.

7 Taku yakage cin hena, qa mazopiye nitawa wacinyaliiye 


\section{JEREMIAH TAWOYUKCAN KIN,}

cin heon etanhan nakun niye hinca niyuzapi kta: Nakun Kemoś wayaka ayapi kta, wawayuśna tawa qa wicaśta itancan wicayuhe cin hena koya.

8 Unkan waihangye kin he otonwe owasin en hi kta, qa otonwe wanjidan eihdaku kte śni; nakun osmaka kin awihnuni kte qa omdaye kin ihangyapi kta, Jehuwa eye cin iyececa.

9 Moab hupahu qu po, hecen kinyan iyaye kta; totonwe kin hena ihangyapi kta nakaeś, tuwedan en ounye kte śni.

10 'Tuwe Jehowa tohtani kin ecinśniyan econ kinhan he yaśicapi nunwe ; qa tuwe tamazasagye kin we etanhan kpatan kinhan he yaśicapi kta.

11 Hokśiyopa ehantanhan Moab owanji yanka, qa cetete en hiyeye cin hena akan kiyotanka, qa cega wanji etanhan cega tokeca en okaśtanpi śni, qa unhdaka ye śni : heon etanhan toyate kin en kiciun, qa toomna kin yutokecapi śni.

12 Heon etanhan iho, anpetu kin u kta, Jehowa eya; hehan wayuptanyan kin heca en yewicawaśi kta, unkan yuptanyanpi kta, qa cega tawa kin yucokapi kta, qa maka-janjan wicakicamdecapi kta.

13 Unkan Moab Kemoś on iśtece kta, Israel tiyohnaka Bethel wacinkiyapi qon on iśtecapi kin iyececa.

14. Wicaśta waśaka heuncapi, qa okicize on akicita waditaka heuncapi ce, tokiyatanhan ehapi he.

15 Tuwe Moab qa totonwe kin ihangye kte cin he wankan iyaya ; qa kośka kahnigapi tawa kin hena wicaktepi ekta kun ivayapi ce, Wicaśtayatapi kin tuwe Je- howa ozuye yuha eciyapi kin he hecen eya.

16 Moab toihangye kin kiyedan $u$, qa taku śica tawa kin inalini hinea.

17 Tona ihdukśan yaunpi kin owasin, akiceya po ; qa caje sdonyayapi kin iyulipa, Iye towaśake sagye kin he, wowaśte cansakadan kin he taku on kaksapi he, ehapi kta.

18 Dibon cunwintku en ounyaye cin, wowitan etanhan kun $u$, liopuza en iyotanka wo: Tuwe Moab yutakuniśni, conkaśke suta nitawa ihangye kte cin he takpe niu k ta nakaeś.

19 Aroer en ounye cin, canku kin icahda inajin qa tonwan wo ; tuwe naśdoke ça winyan najice cin hena wiwicawanga wo ; Taku econpi he, eya wo.

20 Moab iśteca; he kawankapi nakaeś : śicahowaya po qa ceya po: Moab ihangyapi kin he Arnon en oyaka po:

21 Qa woyaco omdaye makoce kin en hi ; Holon akan, qa Jahazah akan, qa Mephaath akan;

22 Qa Dibon akan, qa Nebo akan, qa Diblathaim tipi akan;

23 Qa Kiriathaim akan, qa Beth-gamul akan, qa Beth-meon akan;

24 Qa Kirioth akan, qa Bozrah akan, qa Moab makoce kin en otonwe owasin akan, tehan qa ikiyedan kir.

25 Moab he kin he kaksapi, qa isto kawegapi ce, Jehowa eya.

$26^{\circ}$ Witko kaga po; Jehowa itokam ihdutanka nakaeś: Nakun Moab ihdepe cin hiyuye kta, qa iś eya wowihaha içicage kta.

$27 \mathrm{Qa}$ niye, Israel he wowiliaha dawa śni he: Wamanonpi kin om iyeyapi he: Awicakehan taku eyakiye cin ehantanhan niś psipsin idada. 
28 Moab en ounyayapi kin, otonwe kin hena ayuśtan po, qa imnija kin ohna ti po, qa wakiyedan akowapa tehan makohdoka ohna ticagga ece kin iyenicecapi kta.

29 Moab towahanicida kin he on naunhonpi ; nina wahaniçda; qa watankaiçida, qa wahanhaniçida, qa witantan, qa cante en ihdutanka kin.

30 Iye watankaicida kin miye sdonwaya ce, Jehowa eya; tuka iyecetu kte śni ; iye oitonśni kin iyeren econpi kte śni.

3L Heon etanhan Moab on waśicahowamde kta, qa Moab ocowasin on hoyewaye kta: Kir-heres wicaśta kin hena on waceye kta.

32 Jazer aceyapi kin on aciceye kta, Sibmah hastanhanka iyuwi kin ; ojupi nitawa kin hena mini tanka kin akasanpa iyaya; Jazer mini tanka kin iyahde: mdoketu waskuyeca qa hastanhanka nitawa waihangye wan iyabpaya.

33 Hecen mag̉a waśte kin etanhan, qa Moab makoce kin etanhan wowiyuśkin qa wicocante waśte kin eyakupi: Nakun hastanhanka iyuśkice kin en mini śa wanica wakagga: tuwedan iyaśa omani kte śni : iyaśapi kin he iyaśapi kte śni.

34 Heśbon śicahowayapi kin etanhan Eleala ekta, han, Jahaz ekta, ho ukiyapi; Zoar etanhan Horonaim ekta, pte wan waniyetu yamni: Nimrim mini kin he nakun hopuza kta nakaeś.

35 Nakun Moab en tuwe paha akan wawayuśna, qa tuwe taku wakan tawa kin wizite izinwicakiye cin hena ayuśtan wakiye kta ce, Jehowa eya.

36 Heon etanhan Moab on micante howaye kta, cotanka kin iyececa; qa micante cotanka $\mathbf{Z} 2$ iyecen Kir-heres wicaśta kin on ho uye kta: wokamna kage cin hena atakuni śni, heon etanhan.

37 Wicapa owasin nasu śda kta, qa owasin putinhin hdujunpi kta; wicanape owasin en baicihonhonpi yuke kta, qa wakihdaka wicanite owasin akan un kta. 38 Moab tipi akahpe owasin akan, qa canku owasin ohnahna wicaceya yuke kta: wakśica wan oiyokipi śni kin iyecen Moab wakamdeca nakaeś, Jehowa eya. 39 Hehe, kamdecapi; hehe, tahu ihduhomni; Moab iśteca ce, eyaya ceyapi kta: Hecen Moab wowiliaha icage kta, qa wokokipe kta tona ihdukśan unpi kin owasin en.

40 Jehowa hecen eya ce; Iho, wanmdi wan iyecen kinyan u kta, qa tahupahu Moab akamdage kta.

41 Kerioth icupi, qa conkaśke suta kin hena yuzapi; qa anpetu kin he en Moab wicaśta waśaka cante kin winohinca hokśiksuya cante kin iyecece kta.

42 Unkan Moab oyate kin etanhan ihangyapi kta: Jehowa itokam ilıdutanka-nakaeś.

43 Moab en ounyaye cin, wokokipe, qa woha, qa wohmunke en niciyanke kta, Jehowa eya.

44 Tuwe wokokipe kin etanhan nape cinhan woha kin ohinhpaye kta, qa tuwe woha etanhan hdicu kinhan wohmunke kin on yuzapi kta: Waniyetu wanyag wicahipi kte cin he en awau kta, Moab en, Jehowa eya.

45 Tona najicapi kin hena Heśbon ohanzi kin en najinpi, wowaśake codan: tuka Heśbon etanhan peta wan u kta, qa Sihon otahedan tanhan ide wan, qa Moab oise kin hulinaliye $\mathrm{kta}$, qa owodutaton cinca pesdete kin. 


\section{JEREMIAH TAWOYUKCAN KIN,}

46 Hehe' Moab, niye; Kemoś taoyate kin atakunipiśni : nicinkśi wayaka awicayapi, qa nicunkśi unhidaka unpi.

47 Tuka anpetu ehake kin en Moab unhdaka unpi kin hdicuwakiye kta ce, Jehowa eya. Moab yacopi kin he dehanyan.

\section{WICOWOYAKE 49.}

1 Ammon cinca kin on Jehowa hecen eya; Israel cinca nica he: tuwe tawaye kte cin hduhe śni he: 'Tokeca wicaśtayatapi tawapi kin Gad tawaya, qa totonwe kin en taoyate ounyanpi he.

2 Heon etanhan, iho, anpetu kin upi, Jehowa eya; hehan Rabbah Ammon cinca tawapi en kicizapi iyaśapi kin nahonwicawaye kta: unkan he woihangye paha kin heca kta, qa otonwe cunwintkuwicaye cin hena peta on huhnahwicayapi kta: hehan tona Israel yuhapi qon hena iye wicayuhe kta ce, Jehowa eya.

3 Heśbon, śicahowaya wo, Ai ihangyapi nakaeś; Rabbah cunkśiwicaya, ho hdatanin po, wakihdaka ipiyag kiton po; ceya po, qa conkaśke kin ohnahna icicawin inyang ya po: wicaśtayatapi yuhapi kin he unhdaka iyaya nakaeś, wawayuśna tawa qa wicaśta itancan tawa kin hena koya.

4 Wawakipajin cunwintku, tokeca osmaka kin on winitantan he ; osmaka nitawa taninśni iyaya; wokamna wacinkiye cin he, Tuwe en mau kta he, eya.

5 Tho, tona nihdukśan unpi kin owasin etanhan wokokipe wan niye en aciu kta, Jehowa ozuye Itancan kin he hecen eya: Unkan napeniyanpi kta, wicaśta otoiyohi iye ite itoheya; qa nunipi kin tuwedan mnaye kte śni.
6 Hehan iyohakam Ammon cinca unhdaka unpi kin hdicuwakiye kta ce, Jehowa eya.

7 Edom on Jehowa ozuye hduhe cin he hecen eya: Wanna Teman en woksape wanica he: Wacinksapapi etanhan wookahnige atakuni śni : woksape tawapi qon tanin śni.

8 Dedan en ounyanpi, napa po ; hdicu po, tipi temahentu içicağa po: Esau tokakije, tohan en hipi kte cin he en awau kta nakaeś.

9 Hastanhanka yuśpipi kin en nihipi unkanś, hastanhanka wanjikji okaptapi kte śni he; hanyen wamanonpi kinhan, hena tohanyan cinpi ihangyapi kta.

10 Tuka miye Esau tancodan wakagie kta, taku anakilibe cin hena śdayehna ewahnake kta; naiçihbe kta okihi kte śni : ojupi tawa kin ihangyapi, qa hunkawanjitku, takodaku koya, qa iye en un śni.

11 Wamdenica nitawa elipekiya wo, miye niwicawaye kta ce; qa wiwazica nitawa kin hena wacinmayanpi kte.

12. Jehowa kaken eya; Tho, tona tawoyaco miniyatke kin etanhan yatkanpi kte śni kin hena awicakehan yatkanpi kta: unkan niś niye wiyaonpepica śni yaun kta he; wiyaonpepica śni yaun kte śni; tuka awicakehan datke kta ce.

13 Miye on miçiconza nakaeś, Jehowa eya; Bozrah he wonihinciye, woiyopeye, otiwita qa woyaśice icağe kta; qa totonwe iyuhpa hopuza kta owihanke wanica.

14 Wonalion wan Jehowa etanhan nawahon, qa wahośi wan Ikcewicaśta oyate kin ekta yeśipi; Mniciya po, qa takpe u po, qa kicizapi kta on inajin po.

15 Iho, Ikcewicaśta kin ehna 
cistinna cicage kta, wicaśta ehna wahtedapi śni.

16 Imnija olidoka kin en ounyaye, paha ipa kin akan yati kin, wakokipe wicayecage cin he, nicante wahanicida kin hee e nicihnayan. Wanmdi kin iyecen tehanwankan holipi nicicağa eśta, hetanhan kun hiyuciye kta ce, Jehowa eya.

17 Nakun Edom hewoskan wanke kta, en hiyayapi kin otoiyohi nihinciye $\mathrm{kta}$, qa tokakije owasin on ajiji kta.

18 Sodom qa Gomorrah qa ihdukśan wanke cin ihangyapi qon he iyecen, Jehowa eya, wicaśta tuwedan en ounye kte śni, qa wicaśta cinhintku kin en ti kte śni ce.

19 Tho, mnaja wan Jordan minitan kin etanhan iyecen tipi suta kin ekta itanwankanhde u kta: tuka etanhan ihnuhanna najice wakiye kta: qa tuwe kahnigapi kin he en itancan wakagie kta: Tuwe miye iyemaceca he; qa tuwe itkomakipe kta he : qa wawihankiye cin mitokam najin kte cin he tuwe he.

20 Heon etanhan Jehowa toawacin on Edon awakicin kin he, qa tokiconze on Teman en ounyanpi wicakiconze cin he nahon po: Awicakehan optaye etanhan cistinpidan kin hena yusdun iwicacupi kta: awicakehan tipi tawapi kin ihangwicakiciciye kta.

21 Hinhpayapi nahonpi kin on maka kin śkanśkan; śicahowayapi ho kin he Mde śa ekta nahonpi.

22 Iho, wanmdi wan iyecen wankan u kta, qa kinye kta, qa tahupahu Bozrah akamdagc kta ; Unkan anpetu kin he en Edom wicaśta waditake cantepi kin winohinca wan tokakije en cante kin iyecece hta ce.
23 Damasek on etanhan: Hamath iśteca, Arpad nakun : wotanin śica nahonpi nakaeś, owasin skan aya; miniwanca en woiyokiśice; tuwedan owanji yankekiya okihi śni.

24 Damasek waśake śni aya ; nape kta ihduhomni, unkan wokokipe iyalipaya; woiyokiśice qa woyazan yuza, winohinca hokśiksuye cin iyececa.

25 Tokeca woyatan otonwe kin okaptapi śni he, mitowiyuśkin otonwe kin he.

26 Heon etanhan koślka tawa kin hena canku tawa ohnahna hinlipayapi kta, qa anpetu kin he en ozuye wicaśta kin owasin ihangwicayapi kta ce, Jehowa ozuye hduhe cin eya.

27 Unkan Damasek conkaśke kin en peta wakage kta, qa tipi waśteśte Ben-hadad tawa kin hena awihnuniyc kta.

$28 \mathrm{Kedar}$ on, qa Hazor wokiconze, Nebukadnezzar Babel wicaśtayatapi kin wicalisátake kte cin hena on Jchowa hecen eya; Najin po, qa Kedar takpe ya po, qa wiyohiyanpa cinca kin wawicaki po.

29 Tawakeyapi qa optaye tawapi kin hena ewicayakupi kta; ozanzan hdepi qa wakśica tawapi owasin, qa kamel wicayuhapi kin hena tawakiyapi kta; qa, Ihdukśan wokokipe ce, eya hoyewicakiyapi kta.

30 Hazor en ounyayapi, najica po, tehan ya po, temahentuya ti po, Jehowa eya; niyepi on Nebukadnezzar Babel wicaśtayatapi kin woawacin wan awacin, qa niyepi on wokonze wan kiconza nakaeś.

31 Najin po, oyatc wijica wan, wikopeśniyan ounyan, conkaśke tiyopa qa inatake wanica, iśnana un kin he ekta ya po, Jchowa eya. 


\section{JEREMIAH TAWOYUKCAN KIN,}

32 Unkan kamel tawapi kin hena wokipi ee kta, qa wanunyanpi ota yuhapi kin hena womanon ee kta; qa okahmin tehan ekta yakonpi kin hena tate ouye topa kin ektakta iyewicawaye kta ; qa owancaya ihdukśantanhan oihangye tawapi kin awau kta ce, Jehowa eya.

33 Unkan Hazor śunktolseca ece en ounyanpi kin heca kta, ohinniyan otiwota wanke kta: wicaśta tuwedan en ti kte śni, qa wicaśta cinhintku kin en ounye kte śni.

34 Zedekiah Juda wicaśtayatapi tokaheya wicaśtayatapi yanke cin en, Elam on Jehowa oie Jeremiah wicaśta wokcan en hi kin dee, hecen eya;

35 Jehowa ozuye yuhe cin he hecen eya ce; Iho, Elam tinazipe, towaśakepi iyotan kin he mduwegge kta.

$36 \mathrm{Qa}$ mahpiya ouye topa kin etanhan tate topa kin hena Elam en awau kta, qa tate ouye kin hena owasin ektakta iyaye wicawaye kta: qa oyate kin, Elam onajice kin ekta ipi kte śni wanice kta ce.

37 Qa tokawicayapi wicitokam, qa tona naǵi akitapi kin hena wicitokam, Elam nihinciye waye kta: qa taku śica, mitocanteptanye ide kin he en awicawau kta, Jehowa eya: qa mazasagye kin wicihakam yewaśi kta, ihangwicawaye kta hehanyan.

38 Qa miye mitoiyotanke kin Elam en ewehde kta, qa hetanhan wicaśtayatapi, qa wicaśta itancanpi kin ihangwicawaye kta ce, Jehowa eya.

39 Tuka anpetu ehake kin en Elam unhdaka unpi kin he ake hdicuwaye kta ce, Jehowa eya.

\section{WICOWOYAKE 50.}

1 Babel on, Kasdim oyate makoce kin on, Jehowa oie Jeremiah wicaśta wokcan nape kin eciyatanhan ie cin he dee :

2 Oyate kin ehnahna eyanpaha po, qa nation wicaya po; wiyokihedan ehde po; nalion wicaya po; anahmanpi śni po: Babel icupi ce, eya po; Bel iśteca, Merodak kamdecapi, wakagapi bağopi tawa kin hena iśteca, wakagapi tawa kin hena kamdecapi ce.

3 Waziyatanhan oyate wan takpe u kta, makoce tawa kin he hewoskan kag̉e kta nakaeś, hecen tuwedan en ounye kte śni: hena najicapi kta, wicaśta qa nakun woteca tokan yapi kta.

4 Anpetu kin hena en qa hehantu, Jehowa eya; Israel cinca kin kupi kta, iyepi qa Juda cinca kokijuya, manipi qa ceyapi kta : manipi kta qa Jehowa Taku Wakan tawapi kin okidepi kta.

5 Itepi etkiya hduzapi Zion canku kin on wiwangapi kta; U miye, qa wicotakuye wan owihanke śni qa akiktonjapi kte śni kin he on Jehowa en unkihdaśkapi kta ce.

6 Mitaoyate tahinca nuni kin hecapi; wawilianwicakiye cin hena icunonpa iyayewicayapi; he kin akan onuni wicayapi : he kin etanhan paha kin ekta yapi ece, woozikiye tawapi qon be akiktonjapi.

7 Tona iyewicayapi kin hena iyuhpa temwicayapi: qa tona tokawicayapi kin hena heyapi; Unkiye śicaya econkupi śni, hena Jehowa woowotanna otipi kin hee e wakihtanipi nakaeś; han, atewicayapi wacinkiyapi qon Jehowa hee, heon etanhan. 8 Babel cokayatanhan najica 


\section{WTCOWOYAKE 50.}

po, qa Kasdim makoce kin etanhan ya po, qa optaye wicitokam tamdoka kin hena iyewicaceca po.

9 Iho, miye hinca waziyata makoce kin etanhan oyate tankinyanyan ota wicamduhice kta, qa Babel takpe uwicawakiye kta : unkan hena en wiyeya eiçihdepi kta: hecen icupi kta: wanhinkpe tawapi kin hena wicaśta waśaka wayupika tawa iyecece kta; cokadan hdicupi kte śni.

10 Unkan Kasdim makoce kin wokipi kin heca kta, tona wakipi kin owasin imnanpi lita ce, Jehowa eya.

11 Cante niwaśtepi nakaeś, widuśkinpi nakaeś, makoce mitawa ihangyayapi kin; pte wihan kin iyecen nicepapi nakaeś, qa śuktanka waśaka iyecen hoton yaunpi kin heon etanhan ;

12 Inayayapi kin he nina iśtece kta, tuwe niyuhapi qon he nihinciye kta: Iho, oyate en ehake kin hee, makoce hewoskantu, makopuza, qa hopuza kin heca kta.

13 Jehowa tocanteptanye kin on tuwedan en ounye kte śni, tuka ocowasin hewoskan wanke kta: Babel en hiyayapi otoiyohi yuśinyaye kta, qa wokakije tawa kin owasin on jojo kta.

14 Babel ihdukśan itkokim wiyeya eiçihnaka po ; itazipa nayawinjapi kin owasin, he kute po, wanhinkpe kpatanpi śni po: he qe Jehowa wakilitani, heon etanhan.

15 Ihdukśantanhan iyaśa po; wanna nape hiyuya: taku akan he cin hena jujuwahan, conkaśke tawa kin yujujupi: Jehowa watokiçon kin hee nakaeś; tokicicon po; iye econ ece kin he iyecen ecakicon miye.
16 Babel etarihan tuwe woju, qa tuwe woksapi eca ibaksa un ece kin hena awihnuni wicaya po: Mazasagye waihangye itokapatanhan otoiyohi iye taoyate ektakta etonwanpi kta, qa otoiyohi makoce tawa kin ekta najice kta.

17 Israel tahinca nuni kin heca: mnaja kin hena hamyapi : tokaheya Aśur wicaśtayatapi kin temya; hehan ehake de Nebukadnezzar Babel wicaśtayatapi kin he huhu kin yamnumnugga.

18 Heon etanhan Jehowa ozuye yuhe cin he hecen eya; Tho, Babel wicaśtayatapi qa iye tamakoce kin wanyag wai kta, Aśur wicaśtayatapi.kin wanyag wai qon iyececa.

19 Qa ake Israel en ounyanpi qon he ekta hdicuwakiye lita; hehạn Karmel qa Baśan akan wilian kta, qa Ephraim qa Gilead he kin akan iye naği wipiiçiye kta.

20 Anpetu kin hena en qa hehantu, Israel taku śica econpi qon hena odepi kta, tuka wanice kta; qa Juda wahtanipi kin hena, tuka iyeyapi kte śni; tona owicawahdapta kin hena wicawecicajuju kta nakaeś, Jehowa eya.

21 Makoce wawakipajin hinca kin he ekta takpe ya wo, qa $\mathrm{Pe}$ kod en ounyanpi kin hena; wicakte, qa ihakam unpi kin hena ihangwicaya wo, Jehowa eya; qa token econ ciśi kin owasin eciyatanhan econ wo.

22 Makoce kin ohna okicize ho kin, qa woilhangye tanka.

23 Wan, maka ocowasin maziyape tawa kin he kaksapi qa kamdecapi: Wan, oyate kin ehna Babel wonihinciye icagga.

24 Babel, cihmunka, unkan nakun niyuzapi, tuka sdonyakiye 345 


\section{JEREMTAH TAWOYUKCAN KIN,}

śni ; iyeniyanpi qa nakun inicupi, Jehowa kici yeciza nakaeś.

25 Jehowa mazopiye hduhdoka, qa tocanteptanye wipe kin hena ikikcu: Kasdim makoce kin ohna Jehowa ozuye Itancan tohan kin he dee nakaeś.

26 Thanke hince cin etanhan takpe u po, dotopiye tawa kin yuhdoka po; pahaha iyecen kagga po, qa ocowasin ihangya po: takudan ikiciyaye śni nunwe.

27 'Tatanka tawapi kin owasin wicakte po; wokte kin ekta kun yapi kte: Hehehe, iyepi on ; anpetu tawapi kin, tohan wanyag wicahipi kte cin he wanna hiyohi nakaeś.

28 Tona najicapi qa Babel makoce kin etanhan ihduśpapi hena ho kin dee, Zion en Jehowa Taku Wakan unkitawapi watokicon kin he oyakapi kta, tipi wakan tawa watokicon kin hee.

29 Babel elita wicota kin wicakico po: tona itazipa nawinjapi owasin, he ihdukśantanhan eti po: tuwedan etanhan eihdaku kte śni : iye tohan kin eciyatanhan kicu po: talku econ ece owasin iyecen ecakicon po: Jehowa en wahanhanicida nakaeś, Israel Wanji Wakan tawa kin en.

30 Heon etanhan kośka tawa kin hena canku ohnahna hinhpayapi kta, qa okicize wicaśta tawa kin iyulipa anpetu kin he en wicaktepi kta ce, Jehowa eya.

31 Tho, wahanhaniçida, miye itkocicipa ce, Jehowa ozuye Itancan kin eya: Anpetu nitawa, tohan wanyag cihi kte ciqon he wanna hiyohi nakaeś.

32 Hehan wahanhanicida kin he hicahe kta qa hinhpaye kta, qa tuwedan ake najinkiye kte śni : unkan totonwe kin ohna peta wakage kta, qa ihdukśan346 tanhan taku owasin huhnag̉e kta.

33 Jehowa ozuye yuhe cin he hecen eya; Israel cinca qa Juda cinca kin hena witaya kakiświcayapi: unkan tona iwicacupi kin liena sutaya wicayrzapi ; kihdewicayapi kta wicadapi śni.

34 Wopewicakiton kin he waśaka; Jehowa ozuye yuha eciyapi: woakinica on woakinica tawapi kin akinica kta; hecen makoce kin oziiçiye kiye kta, qa Babel en ounyanpi kin wakokipe wicakicage kta.

35 Mazasagye wan Kasdim oyate kin akan yanka, Jehowa eya; qa Babel en ounyanpi kin hena akan, qa itancan wicayuhe cin akan, qa wicaśta ksapapi tawa kin hena akan.

36. Mazasagye wan itonpiśni kin hena akan wanka, unkan witkotkokapi kta; wicaśta waditakapi tawa kin hena akan mazasagye wan yanka, unkan nihinciyapi kta.

37 Mazasagye wan śuktanka tawapi qa canpahmihma tawapi kin akan yanka, qa oyate tokeca etanhan cokaya unpi kin hena owasin akan; unkan hena winyan icagapi kta: tokamna kin akan mazasagye wan wanka, un kan hena manonpi kta.

38 Makopuze wan mini tawa kin akan, unkan hena oyalie aye kta: wakagapi bağopi makoce kin dee nakaeś, qa taku wakan tawapi kin on witantanpi.

39 Heon etanhan hopuza tanhan woteca, qa wita tanhan wamanica kin hena en ounyanpi kta, qa hinhankagapi kin hena en unpi kta: Unkan ake owihanke wanica hen tuwedan ti kte śni; qa wicoicage qa wicoicage hehanyan en ounyanpi kte śni.

40 Wakantanka Sodon qa Go- 
morrah, qa wicikiyedan unpi kin hena ihangwicaye ciqon he iyececa, Jehowa eya ; wicaśta tuwedan en ti kte śni, qa wicaśta cinca kin en ounye kte śni.

41 Iho, oyate wan waziyatanhan u kta, han, oyate tanka qa wicaśtayatapi ota maka ihanke kin etanhan wicayuhicapi kta.

42 Hena itazipa wahukeza ko ikikcupi kta: hena wohitikapi qa waonśidapi kte śni : hena ho kin miniwanca iyecen hotanin kta, qa wicaśta kicizapi kta iyecen ocimdağahan śuktanka akan iyotanka, niye Babel cunwintku, takpe niupi kta.

43 Hena oyakapi kin Babel wicaśtayatapi kin nalion, unkan nape waśake śni aya: wicoiyokiśice yuza, woyazan, winolinea hokśiksuye cin iyececa.

- 44 Iho, mnaja wan Jordan minitan kin etanhan iyecen, tipi suksuta kin ekta itawankanhde u kta: Tuka hetanhan ihnuhanna najice wicawakiye kta: Qa tuwe kahnigapi kin, he en itancan ewahnake kta: Tuwe miye iyemaceca he: Qa tuwe itkomakipe kta he: Qa wawihankiye cin mitokam najin kta okihi kin he tuwe he.

45 Heon etanhan Jehowa toawacin on Babel awakicin kin he, qa tokiconze on Kasdim makoce kiconze cin he nahon po: Awicakehan optaye tona cistinna kin hena wicayusdutapi kta; awicakehan tipi tawapi kin hella om ihangwicakiciciye kta.

46 Babel yuzapi howayapi kin on maka kin śkanśkan ; qa śicahowayapi kin he oyate kin ehnahna nahonpi.

\section{WICOWOYAKE 51.}

1 Jehowa hecen eya; Iho, Babel itkom, qa tona tamakpe ina- jinpi wicacokaya ounyanpi kin hena wicitkokim waihangye tate wan icahwaye kta.

2 Qa wakaduge kin heca Babel ekta yewicawaśi kta, unkan kadugapi kta, qa tamakoce kin yucokapi kta; anpetu śice cin en hena itkokim ihdukśanyan unpi kta nakaeś.

3 Wanawinge kin itkokim wanawinge itazipa nakiwinje $\mathrm{kta}$, qa tuwc mazawokoyake tawa on witantan kin he nakun: Unkan kośka tawa kin hena onśiwicadapi śni po, ozuye tawa kin ocowasin ihangya po.

4. Hehan tona tawicaopi kin hena Kasdim makoce kin ohna hinhpayapi kta, qa tona katpa iyewicayapi kin hena tacanku kin ohnahna.

5 Israel Towakan wakilitanipi kin on makoce tawapi kin ojudan qeyaś, Wakantanka tawa, Jehowa ozuye hduhe cin he Israel qa Juda wiwazica ehipewicakiye śni tuka.

6 Babel cokayatanhan najica po, qa wicaśta otoiyohi nag̊i eihdakupi kte: ihnuhan taku śica econ kin en ihangniyanpi kinhan: Jchowa watokicon anpetu kin he dee nakaeś; woecon tawa kin he kicu kta.

7 Jehowa nape ohna mazaskazi miniyatke Babel heca, maka kin ocowasin witkokiya: miniśa tawa kin he oyate kin yatkanpi : heon etanhan oyate kin witkotkokapi.

8 Ihnuhanna Babel hinhpaya qa ihangyapi : akiceya po; woyazan tawa kin on canśin ikicicu po, hecen okizikiyapi kta naceca.

9 Babel okiziunyanpi kta uncinpi tuka okiziyapi śni : elpeya po, qa otoiyohi iye tamakoce kin ekta unlidapi kta: tawoyaco kin 


\section{JEREMIAH 'TAWOYUKCAN KIN,}

he mahpiya kin icahtake, qa mahipiya śapa kin iyahde nakaeś.

10 Woowotanna unkitawapi kin he Jehowa unkiciyuotaninpi : U po, qa Zion en Jehowa Taku Wakan unkitawapi tohan kin unyaotaninpi kta.

11 Wanhinkpe kin kaqoga po ; wahacanka kiçun po: Mede wicaśtayatapi taniya kin Jehowa wicayubica: Babel ihangyapi kta awacin nakaeś: Jehowa watokicon tawa kin hee, Tipi wakan tawa watokiçon kin hee, heon etanhan.

12 Babel conkaśke kin akan wiyokihedan ekihde po; tonweya unpi kin wicayuwaśaka po; akicita najin wicakiya po; waiyape kin hena wiyeya ewicahnaka po: Jehowa Babel en ounyanpi kin ta$\mathrm{ku}$ ewicakiye ciqon he awacin qa nakun ecen econ nakaeś.

13 Mini ota ehna ounyaye cin, wowijice niota, oniwihanke kin, wawicayaki iyutapi kin he wanna hiyohi.

14 Jehowa ozuye hduhe cin he iye naği on iciconza; Awicakehan wicaśta on ojuciye kta, psipsicadan iyececa: unkan niye on iyaśapi kta.

15 Iye qe towaśake kin on maka kin kagiga; toksape kin on taku owasin hdusuta; qa tookahnige eciyatanhan mahpiya kin hdumdaya.

16 Iye ho kin on mahpiya ekta mini ota hiyuya ece; qa maka ihanke kin hena etanhan po kin wankantkiya yeya ece; qa mazopiye tawa kin etanhan tate kin hiyukiya ecee.

17 Wicaśta otoiyohi wosdonye on witkotkoka: waśdoye kin owasin wakagiapi śdoyapi kin on iśtecapi; wakagapi śdoyapi kin he itonśni; qa woniya en wicaun śni nakaeś.
18 Hena taku śni, wohnaye wicohan : tohan en wicahipi kinhan hehan hena atakuni kte śni.

19 Jakob tawakiyapi kin he hena iyecece śni: He qe taku owasin kaǵa nakaeś; qa taku tawa sagye kin hee; Jehowa ozuye hduha eciyapi.

20 Canhipi mitawa, okicize wipe kin he niye: qa niye on oyate kin wicamduomdemdece kta, qa niye on wokiconze kin ihangwicawaye kta :

21 Qa niye on suktanka qa tuwe akan iyotanke cin wicamduomdemdece kta; qa niye on canpahmihma qa tona en iyotanke cin hena wicamduomdemdece kta :

22 Qa niye on wicaśta qa tawicu kici wicamduomdemdece kta ; qa niye on wicahinca qa hokśiyopa kin hena wicamduomdemdece kta; qa niye on kośka wikośka ko wicamduomdemdece ìta:

23 Qa niye on wawiliankiye qa optaye tawa kin wicamduomdemdece kta; qa niye on mahyumdu qa tatanka wicayuhe cin hena wicamduomdemdece kta; qa niye on akicita tancanpi qa wicaśtayatapi kin wicamduomdemdece kta.

$24 \mathrm{Qa}$ taku śica tawapi Zion en econpi qon hena ocowasin Babel en qa Kasdim makoce en ounyampi kin hena owasin en, niiśtapi itokam hdicuwakiye kta ce, Jehowa eya.

25 Iho, he waihangye, maka kin ocowasin ihangya ece kin, miye itkocicipa ce, Jehowa eya; qa niye akan minape yewaye kta, qa imnija kin etanhan paptanptanyan iyeciye $k t a$, qa he ideyapi cicagge kta ce.

26 Unkan niye etanhan oise inyan wan, qa oahehde inyan kin icupi kte śni: tuka hewoskan 


\section{WICOWOYAKE 51.}

nanke kta, owihanke wanica, Jehowa eya.

27 Makoce kin en wiyokihedan wan ehde po; oyate kin ehnahna mazayahotonpi kin yahoton po; he itkom oyate kin wicayuwiyeya po; itkokim Ararat, Meni qa Aśkenaz wokiconze kin wicakico po; en akicita tancan kagia po ; śuktanka kin hena e uwicakiya po, psipsica tanka kin iyececa.

28 En oyate kin wicayuwohduze miye, Mede wicaśtayatapi kin hena, akicita tancanpi, qa wicaśta itancan kin owasin, qa tokiconze makoce kin ocowasin.

29 Hehan makoce kin śkanśkan kta qa yazanhda kta: Babel on Jehowa toawacin kin owasin yuśtanpi kta nakaeś, Babel makoce kin hewoskan kağapi kta, en ounyanpi kin wanice kta.

30 Babel wicaśta waditakapi kin hena kis ayuśtanpi ; conkaśke kin ohna iyotankapi : wowaditake tawapi qon he skan aya: winyan icağapi : tipi waśteśte tawa kin hena huhnahyapi ; otonwe tiyopa inatake kin kaksapi.

31 Wainyanke wan wanji tokeca itkokipa inyang ye kta; qa wakośiye wanji wanji tokeca itkokipe kta, otonwe ihanke kin ekta icupi kin he Babel wicaśtayatapi kin okiyakapi kta :

32 Qa oiyuwegge kin iyahpayapi, qa cedi ojupi kin peta on ideyapi, qa okicize wicaśta kin hena nihinciyapi ce.

33 Jehowa ozuye hduha, Israel Taku Wakan tawa kin he hecen eya ce; Babel cunwintku kin he onapanpi wan iyececa; napanpi kte cin iyehantu kte; ebake cistiyedan hehan woksapi kin he kicihi kta.

34 Nebukadnezzar Babel wicastayatapi kin he temmayan, ma- yahuhiuga, wakśica cokadan han emahde, ocowasin namapca, miniwanca hogan wan iyececa ; taku waśteśte mitawa on tezi ojuiçiya ; ehpemayan.

35 Mitokakije qa micelipi taku ecakiconpi kin hena Babel akan yanka nunwe, Zion en ounye cin eye kta: qa mawe kin he Kasdim en ounyanpi kin akan yanka nunwe, Jerusalem eye kta :

36 Heon etanhan Jehowa hecen eya; Tho, woakinica nitawa kin miye awakinica kta, qa miye watociciçon kta: Unkan miniwanca tawa kin mdupuza kta, qa minilidoka tawa kin oyahe waye kta ce.

37 Unkan Babel pahaha icagie kta, wamduśka en ounyanpi kin heca kta, wonihinciye qa woajiji kta, tuwedan en ounye kte śni.

38 Witaya hotonpi kta, mnaja kin iyececa; qa mnaja cinca kin iyecen ihduśkanśkanpi kta.

39 Kaniçiyapi kin en woyatke ewicawecihde kta, qa witko wicawakiye kta; hecen wiyuśkinpi kta, qa woiśtinma owihanke śni iśtinmapi kta, qa kiktapi kte śni, Jehowa eya.

40 Wicaktepi kin ekta hiyuwicawaye kta, tacinca kin iyececa, tamdoka kin iyececa, tatokadan nakun.

41 Hehe Śeśek icupi, qa maka ocowasin woyatan kin he iyahpayapi! Hehe oyate kin owasin ehnahna Babel wonihinciye icağa!

42 Babel ekta miniwanca kin hiyu; taja ota tawa kin on akahpapi.

43 Totonwe kin hena wonihinciye aya, makopuza qa hewoskantu, makoce wicaśta owasin tuwedan en ounye kte śni, qa wicaśta cinhintku kin ehna hiyaye kte śni. 


\section{JEREMIAH TAWOYUKCAN KIN,}

44 Nakun Babel en Bel wanyag wai kta, qa taku napce cin hena iye i kin etanhan ake hiyukiye waye kta: Unkan oyate kin hena iye ekta ake kiwitaya iheye kte śni: nakun Babel conkaśke kin hinhpaye kta ce.

45 He cokaya tanhan hda po, mitaoyate; qa Jehowa tocanteptanye wohitike cin etanhan otoiyohi naği niiciya po.

$46 \mathrm{Qa}$ ihnuhan cante niwankapidan, qa makoce kin ohna woyakapi oyakapi kin koyakipapi kinhan: tohan waniyetu wanji en woyakapi wan u kta, qa iyohakam waniyetu kin en woyakapi kta, qa makoce kin ohna wawicakipi yuke kta, wicaśta itancan wan wicaśta itancan kici.

47 Heon etanhan iho, anpetu kin u kta, hehan Babel wakagapi bagopi kin wanyag wai kta; qa makoce kin ocowasin nihinciye kta, qa wicaktepi tawa kin hena iyuhpa iye cokaya hinhpayapi kî.

48 Hehan mahpiya qa maka qa taku ohnaka kin owasin Babel on dowanpi kta: waziyatanhan waihangye lin hena he en hipi kta nakaeś, Jehowa eya.

49 Israel wicaktepi kin hena Babel hinhpaye wicaye ciqon, he iyecen maka ocowasin wicak tepi kin hena Babel ekta hinlipayapi kta ce.

50 Tona mazasagye kin etanhan nayaśdokapi, katinyan ya po, owanji najinpi śni po: itehan tanhan Jehowa kiksuya po, qa Jerusalem nicantepi kin en $\mathrm{u}$ nunwe.

51 Unkiśtecapi, woiyopeye naunhonpi kin heon etanhan; wowiśtece ite unkakahpapi, wicaśta tokeca Jehowa ti tipi wakan kin en upi nakaeś.

52 Heon etanhan, iho, anpetu 350 kin u kta, Jehowa eya, hehan wakagiapi bagopi tawa kin hena wanyag wahi kta; qa tamakoce kin owancaya wicaktepi kin hena śicahowayapi kta.

53 Babel mahpiya ekta iyohi eśta, qa towaśake tehanwankantu kin suta içicagga qeyaś, miye etanhan waihangye kin hena en upi kta, Jehowa eya.

54 Babel etanhan śicahowayapi ho wan, qa oyumdecapi tanka Kasdim makoce kin etanhan.

55 Jehowa Babel yutakuniśni qa ihangya, heon etanhan hetanhan wicaho tanka wan $u$, qa taja kin hena tanin, mini ota iyececa, ho uyapi kin he owodutaton.

56 Waihangye kin he. en hi, Babel en, qa wicaśta waditakapi tawa kin hena wicayuzapi ; tinazipepi kin iyuhpa yuwehwegapi; Jehowa Taku Wakan watokicon ece kin he awicakehan wawicakicu kta.

57 Unkan wicaśta itancan tawa kin hena witko wicawakiye kta, wicaśta ksapa, akicita tancan, wicaśtayatapi qa wicaśta waditaka tawa kin hena; unkan woiśtinma owihanke wanica iśtinmapi kta, qa kiktapi kte śni, Wicaśtayatapi, Jehowa ozuye hduha, eciyapi kin he hecen eya.

58 Jehowa ozuye yuhe cin he hecen eya; Babel conkaślke ohdakinyan tanka kin he ocowasin yujujupi kta, qa tatiyopa tehanwankantu kin peta on gupi kta; hecen oyate kin takuśni on htanipi kta, qa wicaśta kin peta en, qa mdokițe iciyapi kta.

59 Jeremiah wicaśta wokcan kin Seraiah Neriah cinhintku, Maaseiah cinhintku, taku econśi qon wicoie kin dee, Zedekiah Juda wicaśtayatapi tawaniyetu itopa kin en kici Babel ekta ye ciqon he ehan. Unkan Seraiah 


\section{WICOWOYAKE 52.}

wicaśta itancan ozikiya ùn kin heca.

60 Hecen Jeremiah taku śica Babel en u kte cin hena owasin wowapi wan en kaga, Babel on wicoie kagapi qon dena ee.

61 Unkan Jeremiah Seraiah heciya; Babel en yai kinhan, qa wandake cinhan, hehan wicoie kin dena owasin dawa lita;

$62 \mathrm{Qa}$ hehe kta, Jehowa niye otonwe kin de ihangyapi kta, hecen tuwedan en un kte śni, wicaśta qa woteca nakun, tuka hewoskan wanke kta owihanke wanica, keyakiya ce.

63 Unkan kaketu kte, tohan wowapi kin de yawa ihunniyakiye cinhan, hehan inyan wan en iyayakaślke kta, aa Euphrates cokaya kahoya iyeyaye kta:

64 Qa, He iyecen Babel spaya iyaye kta, qa taku śica miye en awau kte cin etanhan hinanpe kte śni ce, ehe kta: unkan mdokițapi kta. Dehanyan Jeremiah oie kin.

\section{WICOWOYAKE 52.}

1 Zedeliah waniyetu wilkcemna nonpa sanpa wanjidan hehan wicaśtayatapi kag̉api ; qa waniyetu ake wanji Jerusalem en wicaśtayatapi yanka. Unkan hunku kin Hamutal eciyapi, Jeremiah Libnah etanhan he cunwintku.

2 Unkan Jehoiakim econ qon owasin eciyatanhan he iyecen Jehowa iśta kin en taku śica econ ece.

3 Heon etanhan Jehowa tocanteptanye kin Jerusalem qa Juda en yanka, hecen iye itokapatanhan ehpewicaye kta: Unkan Zedekiah Babel wicaśtayatapi kin kipajin.

4 Unkan kaketu, wicaśtayatapi yanka waniyetu inapcinwanka, wi iwikcemna, wiyawapi anpetu iwikcemna, hehan Nebukadnezzar Babel wicaśtayatapi kin Jerusalem takpe hi, iye qa ozuye tawa kin iyulipa, qa en etipi, qa ihdukśan acankaślkapi.

5 Hecen otonwe kin onatakapi, Zedekiah wicaśtayatapi tawaniyetu iake wanji hehanyan.

6 Unkan wi itopa kin en, wiyawapi inapcinwanka hehan otonwe kin ohna wicakilian tehike hinca, hecen makoce kin en oyate kin ağuyapi nicapi hinca.

7 Hehan otonwe kin yujujupi, qa ozuye wicaśta kin iyulipa najicapi, qa otonwe kin etanhan hanyen iyayapi, conkaśke nonpa otahedan tiyopa canku kin he ohna, wicaśtayatapi tawoju kin hetu: Kasdim oyate kin otonwe kin ihdukśanyan hiyeya: Unkan makomdaye canku kin he ohna hiyayapi.

8 Tuka Kasdim akicita kin hena wicaśtayatapi kin tapapi qa Jeriko makomdaye kin en Zedekiah ehdegapi : Unkan taakicita kin owasin iye etanhan enanakiya iyayapi.

9 Hehan wicaśtayatapi kin yuzapi, qa Babel wicaśtayatapi, Riblah en, Hamath makocè ohna, he ekta ayapi : Unkan woyaco okiciyaka.

10 Qa Babel wicaśtayatapi kin Zedekiah cinhintku kin hena, iye iśta itokam, wicakte : nakun Juda wicaśta itancanpi kin owasin, Riblah en, wicakte.

11 Hehan Babel wicaśtayatapi kin Zedekiah iśta kiyuśdoka, qa mazaicicaliihia on iyakaśka, qa Babel ekta akiyahda, qa wokakiśye tipi kin en ohnaka, anpetu en te cin hehanyan.

12 Hehan wi izaptan en, wiyawapi anpetu iwikcemna kin en, Nebakadnezzar Babel wicaśta- 


\section{JEREMTAH TAWOYUKCAN KIN.}

yatapi tawaniyetu iunmanapcinwanka kin hee, hehan Nebuzaradan wicakte itancan, Babel wicaśtayatapi itokam najin ecee kin he Jerusalem en hiyu;

13 Qa Jehowa ti kin he hulinahya, qa wicaśtayatapi ti kin nakun; qa Jerusalem ohna tipi kin iyuhipa, han, tipi tankinkinyan owasin, peta on huhinahya.

14. Qa Kasdim akicita tona wicakte itancan kici unpi kin hena owasin Jerusalem conkaśke ihdukśan wanke cin he ocowasin yujujupi.

15 Hehan Nebuzar-adan wicakte itancan kin he, oyate wahpanicapi kin etanhan, qa otonwe o hna oyate etanhan okaptapi qon, qa tona najicapi, Babel wicaśtayatapi kin ekta najicapi qon, qa wicota etanhan okaptapi qon hena etanhanhan wayaka awicakiyahda.

16 Tuka Nebuzar-adan wicakte itancan kin makoce kin en wahpanicapi kin etanhan hastanhanka iyuwi kicanyanpi kta, qa maga yumdupi kta e on en owicakapta.

17 Nakun mazazi ipatan kin, Jehowa ti kin ohna, qa oahe kin, qa mazazi mini ohnaka tanka Jehowa ti kin en yanke ciqon, hena Kíasdim oyate kin kaksaksapi, qa mazazi kin ocowasin Babel ekta akiyahdapi.

18 Qa cega kin hena, qa on cahota icupi, ya wiyatke kin, qa tukiha, qa mazazi wakśica on kicanyanpi ecee qon hena owasin eyakupi :

19 Hecen oyujaja kin, qa oceti kin, qa wiyatke kin, qa cega kin, qa petijanjan kin, qa tukiha kin, qa miniyatke kin; tona mazaskazi ecedan, qa tona ocowasin mazaska, hena wicakte itancan kin akiyahda.
20 Maza ipatan nonpa, mini ohnaka tanka wanjidan, qa mazazi tatanka akenonpa'oahe kin hukuya wanke cin, Solomon wicaśtayatapi kin Jehowa ti kin kicagge ciqon; wakśica kin hena owasin mazazi kin tkeutapi śni.

21 Nakun maza ipatan kin, maza ipatan wanji tehanwankantu kin wiciśpa akeśahdog̉an, qa ihdukśan hahonta wiciśpa akenonpa iyuta; qa śoka kin he napehdakinyan; mahen ohdoka.

22 Qa akan wateśdake kin he mazazi ; qa wateśdake wanji wiciśpa zaptan wankantu ; qa wateśdake kin akan okag̉eg̉e qa taspantanka kagapi kin ihdukśan hiyeya, hena owasin mazazi : Nakun mazaipatan inonpa, qa taspantanka kagapi kin hena iś iyececapi.

23 Qa tate ouye eciyatanhan taspantanka kagapi wikcemna napcinwanka sanpa śakpe. Ihdukśanyan okag̉egge akan taspantanka kagapi kin owasin hena opawinġe tkonsedan.

24. Unkan wicakte itancan kin he Seraiah wawayuśna itancan, qa Zephaniah wawayuśna inonpa, qa tiyopa awanyake yamni kin hena iwicacu:

25 Qa otonwe kin etanhan akicita tancan 'wan, ozuye wicaśta kin en itancan kin he nakun icu; qa wicaśtayatapi ikiyedan unpi qon etanhan wicaśta śakowin otonwe ohna iyewicayapi kin hena; qa ozuye owicawa itancan, makoce kin en oyate wicayawa kin he; qa makoce ohna oyate kin etanhan wicaśta wikcemna śakpe otonwe ohna iyewicayapi kin hena nakun.

26 Hena Nebuzar-adun wicakte itancan kin ewicayaku, qa Riblah en Babel wicaśtayatapi kin ekta awicaki. 


\section{WICOWOYAKE 1 .}

27 Unkan Babel wicaśtayatapi kin he wicakaśtake ca wicakte, Riblah en Hamath makoce kin ohna. Hecen Juda oyate kin iye tamakoce kin etanhan wayaka awicayapi.

28 Oyate kin Nebukadnezzar unhdaka iyayewicakiye cin he dee: waniyetu iśakowin kin en Juda wicaśta kektopawinge yamni, sanpa wilacemna nonpa sanpa yamni.

29 Nebukadnezzar tawaniyetu iake śahdogan hehan Jerusalem etanhan wicaśta opawinge śahdogan sanpa wikcenma yamni sanpa nonpa wayaka awicakiyahda.

30 Nebukadnezzar tawaniyetu wikcemna nonpa sanpa iyamni kin en, Nebuzar-adan wicakte itancan kin he Juda wicaśta opawing่e sakowin sanpa wikcemna topa sanpa zaptan awicakiyahda: wicanagi owasin kektopawinge topa sanpa opawing่e śakpe.
31 Unkan kaketu, Jehoiakin Juda wicaśtayatapi wayaka un waniyetu wikcemna yamni sanpa śakowin, wi iake nonpa qa wiyawapi wikcemna nonpa sanpa zaptan, hehan Evil Merodak Babel wicaśtayatapi kin, waniyetu en wicaśtayatapi kagapi he en, Jehoiakin Juda wicaśtayatapi qon pa yuwankan iyeya, qa wicakaśka tipi etanhan hdinanpe kiya;

$32 \mathrm{Qa}$ taku waśte eciya, qa toiyotanke kin wicaśtayatapi om Babel en un kin hena toiyotankepi kin iwankam ehde.

33 Qa wicakaślka tipi wokoyake kin hena yutokeca: unkan tohanyan ni un kin anpetu owasin itokam ag̉uyapi yuta.

34 Unkan tawoyute kin, Babel wicaśtayatapi kin etanhan anpetu woyute kin ohinniyan qupi, anpetu otoiyohi onge, anpetu en te cin hehanyan, anpetu ni un kin owasin.

\section{W IC A C E Y A.}

\section{WHOWOYAKE 1.}

1 Tokiyatanhan otonwe oyate ojudan qon he iśnana iyotanka he: oyate kin ehna tanka tuka qon he wiwazica iyecen icaga: makoce kin ehna wicaśtayatapi winohinca yanke ciqon he kajujukiyapi ihukuya yanka.

2 Ceya ece, hanyetu kin en ceya yanka; qa tapon akan iśtaminiggag̉a yukan; waśtedakapi qon owasin etanhan maggagaye kte cin wanica : takuwicaye ciqon hena iyulipa hnayanpi, hena toka icaggapi.
3 Wokakiśye qa wowidagyapi ota on etanhan Juda unhdaka iyaya: Ikcewicaśta oyate kin om ounyan, woozikiye iyeye śni : pasi yapi kin owasin okiyute kin en ehdegapi.

4 Zion tacanku kin ceyapi, tomniciye wakan kin elsta tuwedan u śni nakaeś : totonwe tiyopa kin owasin ihangyapi: wawayuśna tawa kin hena comnihdazipi ece, witanśna tawa kin hena kakiśyapi, qa iye hinca wopazeca en un.

5 Wakakiśye cin hena itancan icaggapi, tokayapi kin hena tanyan unpi : walitani ota kin heon 353 


\section{WICACEYA,}

etanhan Jehowa iyokiśinya nakaeś: taśiceca kin wakakiśya ite kin itokam wayaka awicayapi.

$6 \mathrm{Qa}$ Zion cunwintku kin towanyagwaśte qon ocowasin ayuśtan : wicaśta itancan tawa kin hena tawiyedan wihanpi iyeye śni kin iyececapi, qa wicapasi kin itokam wowaśake codan iyayapi.

7 Wokakiśye anpetu tawa qa tokakije kin en, Jerusalem wanakaja anpetu kin en taku waśteśte yuhe ciqon hena kiksuya; tokayapi nape en ohinhpaya qa tuwedan okiye śni, hehan toka kin wanyaka, woihangye tawa kin on ihahapi.

8 Jerusalem wahtani hinca, heon wayaka iyaya; tona yuonihanpi qon owasin sicedakapi, towiśtece kin wanyakapi nakaeś: han, iye hinca comnihdazi qa hektam ihdohda.

9 Tośice kin he taśina en un; owihanke tawa kin kiksuye śni : heon etanhan wowinihanyan hinhpaya; wicakicanpte takudan yuhe śni. Jehowa, kakiśmayanpi kin wanyaka ye; toka kin ihdutanka hinca nakaeś.

10 Taku cinpica tawa qon owasin toka kin nape ayumdaya; iye wanyaka nakaeś; Ikcewicaśta oyate kin tipi wakan tawa kin en yapi qehan; niye ekta omniciye kin en upi kte śni, kewicayakiya tuka qon.

11 Oyate tawa iyuhpa comnihdazipi, aguyapi akitapi ; taku tehike hinca yuhapi kin woyute on tokiyopeyapi, nagi nikiyapi $k$ ta heon: Jehowa wanyaka wo, qa awacin wo, miye waliteśni imacağa nakaeś.

12 Canku ohna idadapi owasin, niye initokecapi śni he: Tonwan po qa wanyaka po, woiyokiśice wan woiyokiśice mitawa en mau kin iyececa yukan hecinhan, on Jehowa tocanteptanye anpetu kin en kakiśmaye ciqon.

13 Wankantanhan mahuhu kin en peta uśi, unkan mahen iyaya; onhmunkapi wan misiha emakionpa; hekta hdicumayan : anpetu ocowasin ataknini śni cante śica emahnaka ece.

14 Miohan śica can napinpi kin he iye nape kin on iyakaślkapi; hena pahmonpi, mitahu akan $u$ : mitowaśake kin arvihnunimakiya: Itancan kin wicanape kin en emahnaka; najin owakihi kte śni.

15 Itancan kin waśakśakapi mitawa kin owasin micokaya awicanajin: mitokam ozuye wan wicalıico, kośka mitawa wicakamdecapi kta: miniśa iyuśkice wan ohna Itancan kin Juda cunwintku wikośka kin naśkica ece. 16 Hena on miye waceya ; miiśta, miiśta etanhan miniğağa au ; wicakicanpte kin tuwe minagi yuecetu kte ciqon he mitehanyan yanka nakaeś; micinkśi awihnunipi, toka kin ohiya nakaeś.

17 Zion nape hdugata; wicakicanpte kiwanica; Jehowa Jakob on hecen wakiconza, ihdukśan unpi kin hena wakakiśyapi kta: hena owicapeya Jerusalem winohinca iśnati kin iyececa.

18 Jehowa iye hinca owotanna; miye $\mathrm{i}$ en iyewaya nakaeś: Ceciciyapi ce, oyate owasin onahon po, qa mitoiyokiśice kin wanyaka miye : wikośka mitawa qa kośka mitarva wayaka iyayapi.

19 Cantemakiyapi qon hena wicawakipan; hena mahnayanpi : Wawayuśna mitawa qa hunkayapi mitarva otonwe kin en tapi, woyute on nagi hduecetuyapi kta e okidepi icunhan. 


\section{WICOWOYAKE 2.}

20 Jehowa wanyaka wo, wokakije en maun nakaeś : mitezi nina śkanśkan; tanmahen micante ihduptanye; miye nina hin wawakipajin nakaeś : tankan mazasagye kin cincodan ehpewicaya, timahen wiconte iyececa.

21 Comniwahdazi kin he nahonpi ; wicakicanpte kin manica: tokamayanpi kin owasin taku śica mitawa onahonpi; niye hecanon kin on iyuśkinpi: Niye anpetu cajedate ciqon he ayahi kta; unkan iye iyemaceca unpi kta.

22 Taku śica tawapi kin ocowasin niye nitokam u nunwe: qa wawahtani owasin on token ecamiyecon kin he iyecen ecawicakicon wo: comniwahdazi kin hena ota, qa micante wankadan nakaeś.

\section{WICOWOYAKE 2.}

1 Tokiyatannan Itancan kin iye tocanteptanye en Zion cunwintku kin mahipiya śapa on akahipa he: Israel toiyokipi kin he mahpiya eciyatanhan makata ehpeya : qa tocanteptanye anpetu kin en siha: oahe tawa kin kiksuye śni.

2 Itancan kin wanapca iyeya, qa Jakob ounye cin iyuhpa onśikida śni : tośinhda en Juda cunwintku taconkaśke suta kin yujuju; hena makata ehpeya: wokiconze kin he qa wicaśta itancan tawa kin wicayuśica.

3 Tocanteptanye wohitike en Israel he kin ocowasin kaksa: toka kin itolkapatanhan nape etapa kin ehdaku; hecen Jakob aide kiya, peta itkon iyececa, ihdukśan huhnahya ece.

4 Tinazipe kin nakiwinja, toka kin iyececa; wawakipajin wan iyecen nape etapa hdus najin; qa tona owanyag waśteśte kin owasin Zion cunwintku tawakeya ohna wicakte: tośinhda hdaśtan, peta iyececa.

5 Itancan kin toka wan iyececa ; Israel ihangya, tipi waśteśte tawa kin iyulipa ihangya: taconkaśke suta kin yujuju, qa Juda cunwintku kin en wicoiyokiśice qa wicaceya nina yuota.

6 Qa mag̀a iyecen ihdukśan canokaśke kin hdujunjun: omniciye tipi kin hena ihangkiya: Zion en omniciye wakan qa anpetu wakan kin hena Jehowa akiktonśyeya, qa tocanteptanye wohitike cin en wicaśtayatapi wawayuśna ko walitewicada śni. 7 Itancan kin he owayuśna tawa ehpekiya: tipi wakan tawa kin walitekida śni : tipi waśteśte tawa conkaśke kin hena toka nape kin en wicaqu: Jehowa ti kin ohna ho hiyuyapi, omniciye anpetu kin en iyececa.

8 Zion cunwintku taconkaśke kin he Jehowa ihangya awacin: ikan wan ayutitan, ihangya etanhan nape chdaku śni : heon etanhan ihdukśan maka qapi qa conkaślke kin hinhpayekiya; ptaya ocowasin atakuni śni.

9 Otonwe tiyopa tawa kin maka mahen iyaya: inatake tawa ihangya qa yuksaksa: wicaśtayatapi tawa qa wicaśta itancan wicayuha qon hena Ikcewicaśta ehna unpi : woope kin wanica: nakun wicaśta wokcan tawa kin hena Jehowa etanhan wowanyake takudan yuhapi śni.

10 Makata iyotankapi, Zion cunwintku hunkayapi tawa kin inina unpi : pa akan maka aihpeiciyapi : wakihdaka ipiyag kitonpi : Jerusalem tawikośka kin makata pamahdedan unpi.

11 Iśtamnihanpe on miiśta atakuni śni, mitezi śkanśkan, mapi 


\section{WICACEYA,}

kin he makata papsonpi, mitaoyate cunwintku ihangyapi kin heon etanhan; śiceca qa hokśiyoqopa otonwe canku kin ohna hanyanpi qehan.

12 Wicaśta taopi iyecen otonwe canku kin ohnahna ihpayapi qehan, Aguyapi qa miniśa tukte e hunkupi ewicakiyapi ; iye inayapi maku kin ohna nagi kpapsonpi qehan.

13 Taku e akta ociciyake kta he; Jerusalem cunwintku, taku iciyacin kta he; taku e iyececa cidake kta, hecen cantohnagciye kta he, wikośka Zion cunwintku: ihangniyanpi kin he tanka, miniwanca kin iyececa nakaeś: tuwe okiziniyan okihi kta he.

14. Wicaśta wokcan nitawa wojtonśni qa wowitkotkoke wanniciyakapi; tuka wayahtanipi kin niciyataninpi śni, wayaka yaunpi kin yahomnipi kta : tuka woitonśni wowiyukcan qa wohnaye wanniciyakapi ece.

15 Tona canku ohna hiyayapi kin owasin niye on nape hdaskaskapapi; jojopi qa pa kapsanpsanpi, Jerusalem cunwintku kin on: Otonwe wan, Iyotan owanyag waśte hinca, Maka ocowasin wowiyuśkin, eciyapi qon he dee he, eyapi.

16 Tokaniy anpi kin owasin niye on i kapapi : jojopi qa hi hdakinskinzapi : Napca iyeunyanpi ce: Awicakehan anpetu unkodepi qon he dee, iyeunyanpi, wanunyalsapi ce, eyapi.

17 Jehowa taku konze ciqon he hduśtan; iye oie anpetu wanakaja tanhan hdasute ciqon he hduecetu: waehpeya qa waonśida śni; tuka niye on toka kin iyuśkinkiya; nicipajinpi he kin he yuwankan iyeya.

18 Iye cantepi Itancan kin hoyekiyapi: Zion cunxintku ta356 conkaśke, anpetu qa hanyeta iśtaminigaga hiyukiya wo, minicaduza iyececa ; oziiciye śni wo; niiśta cunwintku (su) kin ayuśtan kiye śni wo.

19 Najin wo; hanyetu en pan wo: tokaheya awanyakapi kin en, Itancan ite kin itokam, nicante, mini iyecen, hdapson wo: hokśiyopa nitawa canku pa kin owasin en wotektehdapi on hanyanpi hena nagoipi on iye ekta nape hdugata wo.

20 Wanyaka ye, Jehowa, qa tuwe decen ecayecon kin he awacin ye: Winohinca iye cinca hdutapi kta iyececa he, hokśiyoqopa nape ohna wicahduhapi kin: Itancan tipi wakan tawa ohna wicaśta wokcan wawayuśna ko wicaktepi kta iyececa he.

21 Hokśidan qa wicahinca kin canku ohnahna makata wankapi: wikośka mitawa qa kośka mitawa mazasagye on hinhpayapi : nitocanniye anpetu kin en wicayakte; wațeyaya, waonśiyada śni.

22 Anpetu en mniciyapi kin iyecen wonihinciye mitarva ihdukśantanhan yeco, hecen Jehowa tocanniye anpetu kin en najica un qa okaptapi kin wanica : tona wicawahnahna qa icaliwicawaye cin hena tokamaye cin áwihnuniwicaya.

\section{WICOWOYAKE 3.}

I Wicaśta wokakije wanyake cin he miye, iye tocanteptanye cansakadan kin on.

2 Yus amayan, qa otpaza en a mayan, qa iyoyanpa śni.

3 Awicakehan miye en iye ihduhomni ; anpetu osan iye nape hduptanyan ece.

4 Micehpi qa uka kin kuka icahmiciya; mahuhu kin hena kawehwega. 


\section{WICOWOYAKE 3.}

5 Iye acanmakaśka, qa pizi wokakije ko on aohdutemayan.

6 Tukten otpaza kin en ounye mayan, wanakaja țapi kin iyececa.

7 Iye onamataka, hecen tankan mde kte śni ; on makaśkapi kin tke hinca micaǵa.

8 Nakun wapan qa hoyewaya eśta mitawocekiye kin he icagi makiya.

9 Tnyan kakanpi on mitacanku kin aconkaśka; cankuwaye cin he yupemni.

10 Miye en wahanksica wawiyape kin iyececa; mnaja wan woinahbe en iyecen un.

11 Mitacanku miciyupemnimni, qa mayuhdehdeca: wotakuni śni makağa.

12 Itazipa nakiwinja, qa wanhinkpe on makutepi kta emahnaka.

13 Tawanju wanhinkpe kin minite en iyaye kiya.

14. Mitaoyate iyuhipa imahahapi waun; anpetu ihuniyan imadowanpi waun.

15 Taku paza on ojumayan, pizi on witkomayan.

16 Nakun inyan on he mayutemtepa ; cahota on amakahpa.

17 Unkan minagi wookiye itehan iyeyaya; taku waśte awektonja.

18 Hehan hepa; Mitowaśte qa taku Jehowa etanhan ape waun qon he atakuni śni ce.

19 Makakije qa iyomakiśice cin kiksuya wo, taku paza qá pizi kin.

20 Kiksuya, hena kiksuya waun kta, hecen miye mahen minaggi pamahdedan yanke kta.

21 De micante ekta yewaye kta, heon etanhan ape waun kta.

22 Jehowa tocantekiye on awicakehan unyusotapi śni ; towaonśida kin owihanke śni nakaeś.
23 Hanhanna eca hena yutecapi ece; nitowicake kin he tanka hinca.

24 Taku mitawa kte cin Jehowa hee, minagii eya ; heon etanhan wacinwaye kta.

25 Tona alkipe unpi kin hena en Jehowa waśte, wicanagi akite cin he en.

26 Jehowa towanikiye apepi qa inina unpi kin he waśte ece.

27 Wicaśta kośka icunhan cannapinpi kin qin kinhan he waśte ce.

28 Iśnana iyotanke, qa inina yanka; iye akan ehnaka nakaeś.

29 Iye i kin makata eicihnake kta; okinni apepica yuke kta.

30 Iye tapon waapa kin kipazo kta; waaiapi kin on imna hinca.

31 Itancan kin ohinniyan waehpekiye kte śni nakaeś.

32 Tuka wakakiśya eśta towaonśida ota kin eciyatanhan wacanteliye kta.

33 Cante eciyatanhan wakakiśye śni, qa wicaśta cinca iyotanhan iyewicakiye śni nakaeś :

34 Iye siha ihukuya maka akan wicakaśkapi kin iyuhpa nawicaśuśuje kta :

35 Iyotan Wankan un ite itokam wicaśta tawoyaco kin yupemnipi kta :

36 Wicaśta tawoakinica yuhomnipi kin he ekta Jehowa atonwe śni ecee.

37 He tuwe heya unkan ecetu he, Itancan kin econ śi śni kinhan.

38 Iyotan Wankan un i kin etanhan taku śica qa taku waśte koya inanpe kte śni.

39 Tokeca wicaśta ni un kin wawicaba kta he; wicaśta wan tawoahtani kin on?

40 Canku unkokidepi qa unkakitapi kta, qa Jehowa en unkihduhomnipi kta. 


\section{WICACEYA,}

41 Wicanape kici uncantepi kin Wakantanka malipiya ekta wankan iyeunkiyapi kta.

42 Unkiye waunhtanipi qa wawaunkipajinpi ecee : niye wayakajuju śni.

43 Wocanniye on aohduteunyayapi qa kuwa unkayaupi: niye wațeyaya, niye onśiwicayada śni.

44 Mahpiya śapa on aohduteniciya, hecen ohna wocekiye nihiyohi kte śri ye.

45 Oyate wicacokaya watuśekśeca qa taku tankan ehpeyapi ece kin heca unyakagapi.

46 Tona tokaunyanpi kin owasin iunkapapi ece.

47 Wokokipe qa mazahtakiyapi en unkanpi; woihangye qa woyutakuni śni.

48 Mitaoyate cunwintku kin awihnuniyapi kin on etanhan miiśta mini wakpadan hiyuya ece.

49 Miiśta minigaga ya owanji yanke kte śni, ayuśtan wanica:

50 Jehowa malipiya eciyatanhan kun ahitonwan, qa wanyake kte cin hehanyan.

51 Miiśta minag̣i iyokiśinya, mitotonwe cunwintku kin owasin on etanhan.

52 Taku on etanhan śni tokamayanpi kin nina makuwapi ece, zitkadan wan iyececa.

53 Woha kin en mitaniya kawihnunipi, qa inyan wan amapaptanyanpi.

$54 \mathrm{~Pa}$ iwankam mini imayaya: Makaksapi ce, epa.

55 Wolia temahentu kin etanhan, Jehowa, nicaje hoyewakiya.

56 Miho kin nayahon ece; waniya kin en, hoyewakiye cin en, ninoğe kpe içicage s̉ni wo.

57 Anpetu en hoyeciciya he ehan kiyedan yau: Wakokipe śni wo, eha.
58 Itancan, minagi toakinica kin he ayakinica: mitaniya kin opeyakiton.

59 Jehowa, patúśmayanpi kin he wandaka: mitawoyaco kin he niye yaco wo.

60 Watokiconpi tawapi kin iyulpa niye wandaka; amawacinpi kin hena owasin.

61 Woaie tawapi kin, Jehowa, niye nayahon; amawacinpi kin hena iyuhpa:

62 Tona makipajinpi iha kin, qa anpetu osan amajijipi kin hena.

63 Iyotankapi qa najinpi kin hena wanyaka wo: miye imadowanpi waun.

64 Jehowa, iye nape ohanpi kin eciyatanhan wokajuju wicakicu wo:

65 Cante aotpasyapi kin wicaqu wo; woyaśice nitawa wicakiciun nunwe.

66 Wocanniye en wicakuwa qa ihangwicaya wo, Jehowa tamahipiya kin ihukuyatanhan.

\section{WICOWOYAKE 4.}

1 Tokiyatanhan mazaskazi kin san aya he; mazaskazi iyotan waśte kin he yutokecapi : inyan wakan kin hena tankan elipeyapi, canku pa kin owasin ektakta!

2 Zion cinhintku tehilipike cin hena mazaskazi kici tkeuwicatapi iyececa, tokiyatanhan hena makawalsśica, maka wakśica kaga nape on kagapi kin iyececa wicadakapi he.

3 Unktehi heepi kaeś aze kpazopi, cinca azin wicakiyapi ece: mitaoyate cunwintku kin cante tehike icaga, makoskan hinhankagia tanka iyececa.

4 Hokśiyoqopa azin kin he ceji caka en ihdaskapa, ipuza on 


\section{WICOWOYAKE 4 。}

etanhan: śiceca ag̉uyapi dapi, tuwedan wicakipamni śni.

5 Tona taku waśteśte ece yutapi qon hena canku ohnahna hanyanpi : tona taku duta ece un icaǵapi kin hena tacesdi paha kin adoksohanpi ece.

6 Mitaoyate cunwintku taku śica econ kin he Sodom wahtani lin isanpa tanka: he qe ihnuhanna ihangyapi, qa he ekta wicanape ihduhomnipi śni.

7 Iciconzapi tawa kin hena wa isanpa wakaśoteśni unpi; pteasanpi kin isanpa skaskapi; hena tancan inyan śaśa kin isanpa śaśapi ; sapphir (inyan wan) iyecen śduśdutapi :

8 Itohnake tawapi kin otpaza isanpa sapsapa aya; otonwe canku kin ohna sdonwicayapi śni: ha kin huhu en askapa, piśpija, can śeca iyececa.

9 Mazasagye on ktepi kin he akihanțapi kin isanpa waśte : dena e hanyanpi, magga waskuyeca codan on wicaktepi nakaeś.

10 Winohinca waonśida napepi iye cinca kin ohanpi: mitaoyate cunwintku ihangyapi kin on hena e woyuteyapi ece.

11 Jehowa wanna tocanniye kin hduśtan; tocanteptanye wohitike cin he hdaśtan, qa Zion en peta wan itkonya, unkan taku akan he cin hena liulinahya.

12 Maka akan wicaśtayatapi qa maka en ounyanpi kin owasin, wawakipajin qa toka kin hena Jerusalem, tiyopa kin ohna tin iyayapi kta, he wicadapi kte śni tuka.

13 Wicaśta wokcan tawa tawoahtanipi kin on, wawayuśna tawa taku śica econpi kin on etanhan, hena e otonwe cokaya vicaśta owotanna we papsonpi nakaeś :

14 Canku kin ohna nunipi ece, iśtagongapi ; we on ihduśapapi, hecen tawokoyake yutanpi kta okihipi kte śni.

15 Woaśape, napa po, eya hoyewicakiyapi ; Iapa po, napa po, yutanpi śni po: najicapi, han onuni unpi gehan, Ikcewicaśta kin ehna heyapi, Icimana ake en ounyanpi kte śni ce.

.16 Jehowa ite kin yukinukan iyewicaya; ake en arvicatonwe kte śni : wawayuśna tawapi itepi kin ohokidapi śni, hunkayapi wicayuhapi kin onśiwicakidapi śni ece.

17 Hehanyan unkiyepi, waounkiyapi takuśniśni kin on iśta unkitalkunipi śni ; oyate wan wanikiya okihi śni kin he ekta etonwan unyakonpi nakaeś.

18 Unkowepi kin ode unpi; he. cen otonwe canku unkitawapi ohna unyanpi unkokihipi śni ; unkowihankepi kin he kiyedan; anpetu unkitawapi kin henakeca; unkowihankepi kin wanna hiyohi nakaeś.

19 Kuwa unkaupi lkin hena mahpiya wamdi kin isanpa duzahanpi hinca: he akan kuwa unkaupi, makotahedan unkapepi yákonpi.

20 Unpoġepi taniya, Jehowa sdakiye cin hee e woha tawapi kin ohna yuzapi; he qe on, Ikcewicaśta ehna ohanzi tawa kin ihnkuya unnipi kta ce, unkeyapi tuka qon.

21 Edom cunwintku, Uz makoce kin en ounyaye cin, cante waśte qa wiyuślkin wo: nakun wiyatke kin he niye ekta iyoopta iyaye kta: winitko kta qa tancodan nicicage kta.

22 Zion cunwintku, taku śica ecanon kin on wokakiśyapi kin he yuśtanpi ; ake icimana wayaka aniye kte śni: Edom cunwintku, taku śica ecanon kin he 359 


\section{WICACEYA.}

wanyag i kta; wayahitani kin he śdayehna ehnake kta.

\section{WICOWOYAKE 5.}

1 Jehowa, taku unkakipapi kin he kiksuya wo: awacin qa iyaunqonpapi kin he atonwan wo.

2 Taku ailipeunkiyapi qon he toka wicaśta kin ekta iyaya, untipi kin wicaśta tokeca ekta.

3 Wamdenica heuncapi qa ateyapi codan unyakonpi; inawic. unyanpi kin wiwazicapi iyececapi.

4 Mini unkitawapi kin mazaska on unyatkanpi; can unkitawapi kin he opetonpi on u ece.

5 Untahupi akan kuwa unkaupi ece ; htaunnipi, qa woozikiye unhapi śni.

6 Egupta oyate kin nape wicunqupi, Aśur oyate kin, ağuyapi iunnmanpi kta e heon.

7 Atewicunyanpi wahtanipi, qa en anpi śni ; unkan unkiye taku śica econpi kin unkiçinpi ece.

8 Wowidake unpi hena unkidakapi: iye nape kin etanhan tuwedan eunyakupi śni.

9 Unnagipi oțohnaka ag̉uyapi unkicupi ece, hewoskan mazasagye kin on etanhan.

$10 \mathrm{Ha}$ unsapapi mazaoceti wan iyececa, wicaakilian telike hinca on etanhan.

11 Zion en winohinca wicaki- yapi nakaeś.

we kin ohna. ceya icağa. kaeś. ece. yan.
12 Wicaśta itancanpi kin hena nape on otkewicayapi ece; wicalinca itepi ohowicadapi śni.

13 Kośkapi kin hena wotpan wicakiyapi, qa hokśipidan can ihukuya kaktihanhanpi ece.

14. Wicahincapi otonwe tiyopa kin ayuśtanpi, kośka can ceg̉a apapi enakiyapi.

15 Uncantepi wiyuśkin kin henakeca; unyajojopi kin wica-

16 Paha unkitawapi wateśdake kin hinhpaya: wanna woyaśice unkicipi un, waunhtanipi na-

17 Heon etanhan cante unyazanpi : dena on iśta unkatpazapi. 18 Ḧewoskan icaga, heon Zion lie kin akan śungidan amanipi

19 Jehowa, niye owihanke wanica idotanka; nitoiyotanke kin wicoicage qa wicoicagge hehan-

20 Tokeca ohinniyan unkayektonjapi kta he; anpetu ota elipeunyayapi.

21 Jehowa, niye en hdicu unkiya po, kinhan unhdicupi kta; anpetu unkitawapi kin yuteca ye, wanakaja qon iyececa.

22 Tuka ocowasin ehpeunyayapi ; nina hin canniyeunyaki360 


\section{EZEKIEL TAWOWAPI.}

\section{WICOWOYAKE 1.}

1 Unkan waniyetu iwikcemna yamni, wi itopa, wiyawapi anpetu izaptan kin en, Kebar wakpa kin ekta, wayaka unpi kin om waun qehan, mahpiya kin yuhdokapi qa Taku Wakan towanyake kin heca wanmdaka.

2 Wiyawapi anpetu izaptan kin en, Jehoiakim wicaśtayatapi wayaka un kin waniyetu izaptan hehantu.

3 Awicakehan Jehowa oie kin Ezekiel Buzi cinhintku wawayuśna kin he en hi, Kasdim makoce kin en, Kebar wakpa kin hetu: unkan hen Jehowa nape kin akan yanka.

4 Unkan watonwan, qa iho, tate iyumni wan waziyatanhan $\mu$, mahipiya śapa tanka wan, qa peta wan ihdus un, qa ihdukśan wiyatpa hinca, qa ocokaya mazazi pabezapi iśta kin iyececa, peta cokaya tanhan.

5 Unkan he cokaya tanhan taku ni un topa ouncage kin au; unkan decen owanyakapi, wicaśta ouncagge kin yuhapi.

$6 \mathrm{Qa}$ otoiyohi ite topa, qa otoiyohi hupahu tom yuhapi.

1 Unkan sihapi kin hena siha owotanna, qa sihapi sicu kin he ptejicadan sicuha kin iyececa, qa mazazi pabezapi iśta kin iyecen wiyatpatpa.

8 Unkan cuwi topa kin en hipahu ihukuya wicaśta nape yuhapi: Hecen hena topa itepi qa hupahu yukanpi.

9 İupahu tawapi kin kicicaśka-

Ezekiel. pi, wanji takodaku kici ; yapi eca ihduhomnipi śni; otoiyobi iye ite itoheya iyayapi ecee.

10 Unkan itepi ouncage, hena topa wicaśta ite qa mnaja ite kin etapa eciyatanhan yuhapi; qa hena topa catkatanhan tatanka ite yuhapi; nakun hena topa wamdi ite kin yuhapi.

11 Itepi kin hecetu: unkan hupahu kin wankan hduzapi; otoiyohi nomnom kicicaślkapi, qa nom tancan ahdahipapi.

12 Unkan otoiyohi ite etoopteya yapi; woniya kin tukte ekta ye kta hecinhan heciya yapi ece; yapi eca ihduhomnipi śni ecee.

13 Unkan taku ni un ouncage kin owanyakapi kin he peta petağa ide kin iyececa, petijanjan wanyakapi kin iyececa: he qe taku ni un kin hena ehna icimani ece: unkan peta kin ijanjan, qa peta kin etanhan wakanhdi hiyu. 14 Unkan taku ni un kin iyaye ca hdi kin he wakanhdi tanin wanyakapi kin iyececa.

15 Unkan taku ni un kin wanmdaka, hehan iho, taku ni un ite topa yuhe cin he icahda canhdeśka wanji makata han.

16 Canhdeśka owanyakapi qa okag̉api kin Tarśiś iśta kin iyececa: unkan hena topa ouncage wanjidan; qa owanyakapi qa okagapi kin he canhdeśka wan canhdeśka ocokaya iyececa.

17 Yapi eca topa omdotonyan yapi ece ; yapi eca ihduhomnipi śni.

18 Unkan canhdeśka kin hena tehanwankantu, qa wokokipe hin361 
ca: unkan hena topa ihdukśan tanhan canhdeśka kin iśta ojugjudan.

19 Unkan taku ni un kin hena iye yapi eca, eanhdeśka kin hena icahda yapi ecee: qa taku ni un kin hena maka kin etanhan wankan eyakupi eca canhdeśka kin iś wankan eyakupi eeec.

20 Woniya kin tukte elkta ye kta hecinhan heciya yapi ecc; woniya kin hen ye kta nakacś: qa hena kici canhdeśka kin wankan eyakupi ece: taku ni un taniya kin canhdeśka kin mahen un nakaeś.

21 Hena iyayapi eca, dena iś yapi; hena owanji najinpi eca, dena owanji najinpi ; hena wankan cyakupi eca, canhdeśka kin iś eya kici wankan eyakupi ecee: taku ni un taniya kin he canhdcśka kin mahen wicaun nakaeś.

22 Unkan taku ni unpi pa iwankam okotonyan ouncage kin he cag̉a okokipe linca iśta kin iyececa, iye pa. kin iwankam yumdayapi.

23 Unkan okotonyan kin ihukuya tanhan hupahu tawapi kin owotanna, wanji qa tawinolitin ektakiya: otoiyohi nom yuha, deciyatanhan aihdahpa, qa otoiyohi nom tancan unma eciyatanhan aihdahpa.

24 Unkan iyayapi hehan hupahu tawapi limunyanyan kin he nawahon, mini tanka ho kin iyececa, Iyotan Waśaka ho kin iyececa; oqoyapi. ho kin, ozuye ho kin iyeccca: owanji najinpi eca hupahu kpehanpi ece.

25 Unkan hupahu kpehan owanji najinpi qehan, okotonyan iye pa iwankam wanke cin hetanhan wicaho wan hiyu.

26 Unkan iye pa iwankam okotonyan wanke cin he iwankam oiyotanke ouncage wan, saphir inyan owanyakapi kin iyececa: qa oiyotanke ouncage lin akan wicaśta ouncage uwanyakapi wan he iwankam akan yanka.

27 Unkan mazazi pabezapi iśta kin iyececa wanndaka, he imahentu ihdukśan peta owanyakapi kin iyececa, nite kin etanhan wankantanhan owanyakapi, qa nite etanhan kuyatanhan owanyakapi, peta owanyakapi kin iyececa wanmdaka, unkan ihdukśan wiyatpatpa.

28 Magaju anpetu kin en wihmunke mahpiya śapa ohna yanka owanyakapi kin he iyecen ihdukśan wiyatpatpa owanyakapi kin iyececa. Jehowa towitan ouncage owanyakapi kin he dee. Unkan wanmdaka hehan ite makipusdiya elipemiçiya, qa tuwe ie cin he ho kin nawahon.

\section{WICOWOYAKE 2.}

1 Unkan hemakiya; Wicaśta cinhintku, siha ohna najin wo, kinhan wociciyake kta ce.

2 Unkan womakiyaka icunhan Woniya kin en mau, qa siha on najin makiya, unkan tuwe womakiyake cin he nawabon.

3 Hehan hemakiya; Wicaśta cinhintku, Israel cinca, oyate wawakipajin w: makipajin ece kin he ekta ye ciśi : iyepi qa atewicayapi kin wamakilitanipi, anpetu. dehanyan.

4. Hena cinca ite sutapi qa cante tehipike nakaeś. Hcna ekta ye ciśi: Unkan hewicayakiye kta; Jehowa I tancan kin hecen eya ce.

5 Unkan hena e nahonpi kta hecinhan, qa iś econpi kte śni unma tukte keś, tipi wawakipajin heca qeyaś, wicaśta wokcan wan wicacokaya un e sdonyapi kta.

6 Unkan niye, wicaśta cinhintku, hena kowicakipe śni wo, qa 


\section{WICOWOYAKE 3.}

oiepi kin kokipe śni wo, wapepeka can pepe ko nici un eśta, qa wanduśka śica. om yati eśta; hena oiepi kin kokipe śni wo, qa ite owanyakapi kin on nihinciye śni wo, tipi wawakipajin heca qeyaś.

7 Unkan mioie kin hena owicayakidake kta, anagioptanpi kta qa iś econpi kte śni hecinhan, hena wawaliipajinpi hinca nakaeś.

8 Tuka, wicaśta cinhintku, niye taku eciciye cin he nahon wo: Wawakipajin tipi kin he iyecen niye wawakipajin śni wo: nii hdukawa, qa taku ciçu kte cin he yuta wo.

9 Hehan watonwan, unkan iho, wicanape wan en umakiyapi: unkan iho, ohna wowapi pehanpi wan.

10 Hehan mitokam yumdaya; unkan mahen qa akantanhan wowapi: Unkan wicaceya, qa wicanihinciye, qa wicokakije kin hena en owapi.

\section{WICOWOYAKE 3.}

1 Nakun hemakiya; Wicaśta cinhintku, taku iyeyaye cin he yuta wo; opehanpi lin de temya wo, qa ya wo, Israel tiyohnaka kin wowicakiyalka wo:

2 Unkan i wahdukawa, hecen opehanpi kin he yunmakiye kta.

3 Unkan hemakiya; Wicaśta cinhintku, nitezi yunkiya wo, qa opchanpi ciçu kin de on śupe nitawa ojudan kiya wo. Hehan temwaya: unkan mii ohna tuhinaga canhanpi kin iyecen skuya.

4 Hehan hemakiya; Wicaśta cinhintku, ya wo, Israel tiyohnaka kin en $\mathrm{i}$ wo, qa mioie kin on hena om wohdaka wo.

5 Oyate wan śa iapi qa ceji tehike hinca ekta śni, Israel tiyohnal ${ }_{\mathrm{q}}^{\mathrm{a}}$ kin ekta yeniśipi.
6 Oyate ota iapi okahinilipica śni, qa cejipi tehike hinca, oiepi nayahon kte śni kin ekta śni. Awicakehan hena ekta ycciśi unkanś ananiğoptanpi li ta tuka.

7 Tuka Israel tiyohnaka kin ananigoptanpi kte śni; miye qaeś anamag̉optanpi kte śni nakaeś: Israel tiyohnaka ocowasin itohnake sutapi, qa cante tehipike.

8 Iho, iye itepi kin itkokim niite suta wakaga, qa itohnake nitawa suta jye itohnakepi kin itkokipatanhan.

9 Inyan pe hinca iyececa, imnija isanpa suta nitohnake wakaga; kowicakipe śni wo, owanyakapi kin on nihinciye śni wo, tiyohnaka wawakipajin kin hecapi eśta.

10 Nakun hemakiya; Wicaśta cinhintku, mioie kin tona ociciyake kte cin hena owasin nicante en icu wo, qa ninogge on nahon wo.

11 Qa ya wo, tona wayaka unpi kin en i wo, nitaoyate cinca kin ekta, qa om wohdaka wo, qa, Jehowa Itancan kin hecen eya ce, ewicakiya wo ; nahonpi kta hecinhan, qa iś econpi kte śni.

12 Hehan Woniya kin yuwankan imacu, qa mihieyata wośkanśkan tanka lo kin nawalion; Toyanke kin etanhan Jehowa Towitan kin yawaśtepi nunwe, eya.

13 Nakun taku ni unpi tahupahu ho kin, hena kicicahtake, wanji tokodaku kici; qa canhdeśka itkokim yanke cin hena ho kin; qa wośkanśkan tanka ho kin.

14 Hecen Woniya kin yuwan' kan imacu qa emayaya; unkan mitaniya kata en iyokiśica imdamda; tuka Jehowa nape kin sutaya amayanka.

15 Hehan Tel-abib ekta, Kebar wakpa icahda tipi, wayaka unpi kin hena en wicawai, qa iyotan- 


\section{EZEKIEL TAWOWAPI,}

kapi kin om imdotanka, qa anpetu śakowin hena owicapeya yuśinyaya manka.

16 Unkan kaketu, anpetu śako. win ihuniyanpi hehan Jehowa oie en mahi kin he hecen eya;

17 Wicaśta cinhintku, Israel tipi kin en waawanyake cicaga; heon mii etanhan wicoie kin nahon wo, qa miye eciyatanhan wahowicaya wo.

18 Tohan wicaśta śica, Wiconte on nițe kta ce, ewakiye cinhan; hehan wahoyaye śni, qa wicaśta śica iye tacanku śica on iwaktayaye kta e on takudan ehe śni kiuhan, on niiçiye kta tuka; hehan wicaśta śice cin iye wahtani kin en te kta, tuka iye we kin he ninape etanhan awakite kta.

19 Tuka wicaśta śica iwaktayaye cinhan, qa iye tohan śice qa tacanku śica etanhan ihduhomni śni kinhan, he qe wahtani kin ohna țe kta, tuka niye ninaği eyehdaku.

20 Nakun wicaśta owotanna wan iye toowotanna kin ayuśtan qa taku śica econ kinhan, qa itokam inaśna wan ewahnake cinhan, he qe te kta: iwaktayaye śni kin heon iye wahtani kin en te kta, qa toowotanna econ qon hena kiksuyapi kte śni ; tuka iye we kin ninape etanhan awakite kta.

21 Tuka wicaśta owotanna walitani kte śni iwaktayaye cinhan, qa hecen wahtani śni kinhan awicakehan ni kta, waktayapi nakaeś ; nakun niye qe ninaği eyehdaku ce.

22 Unkan hen Jehowa nape kin amayanka; unkan hemakiya; Najin wo, makomdaye kin ekta ya'wo, kinhan heciya wociciyake kta ce.

23 Hehan nawajin qa mako. 364 mdaye kin ekta imdamda ; unkan iho, Jehowa 'Towitan kin hen najin, Kebar wakpa kin en wowitan wanmdake ciqon he iyececa : unkan ite makipusdiya ehpemiciya.

24 Hehan Woniya kin en mau qa siha on najin makiya, qa womakiyaka qa hemakiya; Ya wo, yati kin en onaicitaka wo.

25 'Tuka niye, wicaśta cinhintku, iho, icaśke anihnakapi kta, qa hena on nicaśkapi kta, hecen wicacokaya tankan de kte śni.

26 Unkan niceji kin nicaka en askape wakiye kta, hecen ie śni yaun kta, qa hena en wicaśta wawiyopeya nanke kte śni: tipi wawakipajin kin heca nakaeś.

27 Tuka tohan wociciyake cinhan, hehan nii mduhdoke kta, qa hewicayakiye kta; Jehowa Itancan kin hecen eya ce: Tuwe anagoptan kta hecinhan anago-' ptan kta, qa tuwe econ kte śni hecinhan econ kte śni: tipi wawakipajin kin heca nakaeś.

\section{WICOWOYAKE 4.}

1 Unkan niye, wicaśta cinhintku, maka śpanyanpi wan ikikcu wo, qa niite itokam eyahnake kta, qa he akan Jerusalem otonwe kin bayago kta:

2 Qa en ihdukśan acanyakaśke kta, qa owanyake wan en yakage kta, qa paha wan ayakağe kta : nakun ozuye kin en ewicayahnake kta, qa ihdukśan ibojuju tanka ehnaka wo.

3 Nakun mazacegia ihupa hanska wan niye iyekcu kta, qa niye qa otonwe kin otahedan mazasapa conkaśke hee e eyahnake kta: qa itkokim niite enicihnake kta, hecen azuyapi kta, qa niye azuyaye kta. Israel tiyohnaka kin en wowakta kin hee kta. 


\section{WICOWOYAKE 5.}

4 Nakun niye nicuwi catkatanhan en inunke kta, qa Israel tiyohnaka walitani kin aenicihnake kta; anpetu towanakeca iyawa nunke cin hehanyan walitanipi kin wicayeciyuha kta.

5 Anpetu iyawa towanakeca he iyecen waniyetu wahtanipi kin hena acihnaka, anpetu opawinge yamni sanpa wikcemna napcinwanka hehanyan. Hecen Israel tiyohnaka wahtanipi kin duha kta.

6 Unkan hena ihuniyakiye cinhan, hehan ake nicuwi etapatanhan ecen inunke kta, qa Juda tiyohnaka wahtanipi kin anpetu wikcemna topa hehanyan duha kta, waniyetu on anpetu, waniyetu on anpetu hecen ciçu ce.

7 Unkan Jerusalem azuyapi kin ektakiya niite eyehnake kta, qa niisto ogeton śni un kta, unkan woyeciyake kta.

8 Unkan iho, icaśke kin acihnake kta, hecen cuwi unma eciyatanhan nihduptanye kte śni, azuyapi nitawa anpetu kin ihuniyakiye śni hehanyan.

9 Nakun ağuyapi, qa barle, qa omnica, qa omnica hmiyanyan, qa peji su, qa wayahota, liena niye iyekcu kta, qa cega wanjidan en oyahnake kta, qa on agguyapi nicicage kta, anpetu iyawa towanakeca nicuwi akan nunke kte cin he iyacinyan; anpetu opawinge yamni sanpa wikcemna napcinwanka hehanyan etanhan yate kta.

10 Unkan woyute nitawa tkeuta yata ecee kta, anpetu iyohi śekel wikcemna nonpa kta; tohanhan yata ecee kta.

11 Nakun iyuteyaken mini datran ecee kta, hin ong̉e iśakpe, tohanhan datkan ecee kta.

12 Unkan barle aǵuyapi hminyanyan iyecen yate kta, qa iye wanyakapi kin en, cesdi wicaśta etanhan hiyu kin he on śpanyakiye kta ce.

13 Unkan Jehowa heya; He iyecen Israel cinca Ikcewicaśta kin ehnahna iyayewicawaye kte cin hen ağuyapi śapa hdutapi kta ce.

14 Hehan hepa; Hehehe Jehowa Itancan, iho, minagi tohinni ihduśape śni ; homakśidan ehántanhan qa dehanyan, taku iye cinka ta qa taku yalidelidecapi kin tohinni wate śni, qa nakun tado śica tohinni mii ohna hiyaye śni cee.

15 Hehan iye hemakiya; Wanyaka wo, tacesdi kin hee wicaśta cesdi kin eekiya ciçu; hecen he on ag̉uyapi niçicağe kta ce.

16 Nakun kaken emakiya; Wicaśta cinhintku, iho, Jerusalem en aguyapi sagye kin mdukse kta; unkan aguyapi tkeutapi qa itonpapi on hdutapi kta; qa mini iyuteya qa nihinciya hdatkanpi kta.

17 Hecen ağuyapi qa mini icakijapi kta, qa wanji takodaku kici nihinciyapi kta, qa wahtanipi kin on atakunipi kte śni ce.

\section{WICOWOYAKE 5.}

1 Nakun niye, wicaśta cinhintku, isan pe hinca wan ikikcu wo, putinhin kasanpi ece icasan tawapi wan ikikcu wo, qa nipa qa putinhin nitawa kin en iyayeyakiye kta; hehan aspeyeton kta on tkeutapi kin icu wo, qa kihduśpaśpa wo :

2 Hanke iyamni kin he otonwe cokaya peta on huhnahyaye kta, azuyapi anpetu kin wanna henakeca kinhan: qa hanke iyamni wanji jyacu kta, qa isan on ohomnimni ayape kta: qa hanke iyamni wanji is tate elsta kaho- 


\section{EZEKIEL TAWOWAPI,}

ya ehpeyaye kta; unkan hena ihakam mazasagye mduśdoke kta.

3 Nakun hetanhan tonana iyawa iyacu kta, qa śina nitawa en payalite kta:

4 Hehan hena etanhan ake icu, qa peta cokaya en ehpeya wo, qa peta en hena huhnahya wo: hetanhan Israel tiyohnaka ocowasin en peta wan hiyu kta ce.

5 Jehowa Itancan kin he hecen eya ; De Jerusalem ee: Oyate qa makoce ihdukśan wanke cin hena wicacokaya ewahnaka tuka.

6 Tuka mitawoyaco kin woyusice on tokiyopeyapi, Ikcewicaśta kin isanpa, qa wowaśi mitawa, makoce ihdukśan wanke cin isanpa: mitawoyaco kin hena aktapi śni, qa wowaśi mitawa kin hena ohnayan manipi śni nakaeś.

7 Heon etanhan Jehowa Itancan kin hecen eya; Oyate nihdukśan yakonpi kin isanpa ota inicağapi qeyaś, mitoope kin ohnayan mayanipi śni, qa mitawoyaco kin eciyatanhan ecanonpi śni; qa nakun oyate nihdukśan yakonpi tawoyacopi kin ohna ecanonpi śni ecee :

8 Heon etanhan Jehowa Itancan kin he hecen eya; Iho, miye, han miye itkocicipa waun; qa oyatepi kin wicitokam niye en woyaco cicjyuśtan kta:

9 Qa niye en, taku tohinni ecamon śni, qa taku tohinni ake iyecen ecamon kte śni, kin he ecamon kta, wowahte śni nitawa kin owasin on etanhan.

10 Heon etanhan nicokaya atewicayapi kin iye cinhintkupi wicahdutapi kta, qa cincapi kin iś iye atkukupi kin wicahdutapi kta: unkan niye en woyaco wahduśtan kta, qa tona onicaptapi kin iyuhpa tate ouye owasin ektakta enanakiya iyayewicawaye kta ce.

11 Heon etanhan, miye wani ce, Jehowa Itancan kin eya; Awicakehan tipi wakan mitawa wowahte śni nitawa owasin on, qa taku śica nitawa iyuhpa on duśapa, heon etanhan nakun miś miye hinca elpeciye lita; qa miiśta kpatan kte śni, qa miye ecaca waonśiwada kte śni.

12 Niye etanhan ongie wiciyamni kin makośica on țapi kta, qa wicalikian on nicokaya atakunipi kte śni: qa onġe wiciyamni wanji nihdukśan mazasagye on hinhpayapi kta: qa onge wiciyamni wanji iś tate ouye owasin ektakta yewicawaye kta, qa wicihakam mazasagye yewakiye kta.

13 Hecen mitocanniye kin yuśtanpi kta, unkan mitocanteptanye kin he iyepi en ahinhpaye waye kta, hecen cante waśte micicage kta: Unkan tohan mitocanteptanye kin iyepi en wicaweciyuśtan kinhan, hehan Jehowa miye e cante makata en hecen epa, iye sdonyapi kta ce.

14 Nakun otiwita cicağe kta, qa oyate nihdukśan wanke cin en wowihaha yaun kta, tona en hiyayapi owasin iśtapi kin en.

15 Hecen he wowibaha kta, qa woienhdepi kta, woonspe kta, qa wonihinciye kta, oyate nihdulsśan wanke cin hena en, tohan wocanniye, qa wocanteptanye, qa woiyopeye wohitike on niye en woyaco walıduśtan kinhan; Jehowa miye e hecen epa ce.

16 Tohan wicaakilian tiwanhinkpe sice cin hena en yewakiye cinhan, hena on woihangye kta, hena ihangniyanpi $k$ ta on yewakiye kta: unkan niyepi akan wicaakihan kin mduota kta, qa 


\section{WICOWOYAKE 6.}

ag̉uyapi sagye nitawapi kin he mdukse kta:

17 Hecen wicaakilian qa wamanica śikśice cin hena niyepi kin en yewicawaśi kta, unkan hena wanicipi kta; qa makośica qa wewe kin hena niye en hiyaye kta, qa mazasagye kin he niye en awau kta: Jehowa he miye e hecen epa ce.

\section{W1COWOYAKE 6.}

1 Hehan Jehowa oie en mahi kin he hecen eya :

2 Wicaśta cinhintku, Israel he kin itkokim niite ehnaka wo, qa hena on woyaka wo:

$3 \mathrm{Qa}$, Israel he kin, niye Jehowa Itancan oie kin nakon ye, ehe kta: Jehowa Itancan kin he he qa paha, wakpa qa osmaka kin hena hecen ewicakiya ce: Tho wo, miye, miye hinca, mazasagye en aciupi kta, qa owanka tehanwankuntu nitawapi kin hena ihangwaye kta ce.

4 Unkan oway uśna nitawapi kin hena otiwota kagapi kta, qa wakagapi nitawapi kin kamdemdecapi kta, qa wicaktepi nitawa wakagapi bağopi nitawapi kin itokam makata ehpewicawaye kta.

5 Qa Israel cinca tapi kin hena wakagapi tawapi kin itokam ewicawahnake kta; qa huhu nitawapi kin hena owayuśna nitawapi ihdukśan ehpewaye kta.

6 Tukten ounyayapi kin owasin en otonwe kin hena ihangyapi kta, qa paha tehanwankantu kin hena otiwota kta: hecen owayuśna nitawapi kin ihangyapi kta, qa otiwota kta; qa wakağapi nitawapi kin hena kamdemdecapi kta, qa henakeca kta ; qa wakaġapi bağopi nitawapi kin hena kawankapi kta, qa niohanpi kin hena pajujupi kta.
7 Qa wicaktepi kin hena nicokayapi hinhpayapi kta; unkan Jehowa he miye e sdonyayapi kta ce.

8 Tuka wookapte owakapte kta, hecen makoce ehna enanakiya yaunpi kinhan, Ikcewicaśta kin en mazasagye napapi kta yuke cin hena wicaduhapi kta.

9 Unkan tona onicaptapi kin liena tukten wayaka ayapi, Ikcewicaśta hena ehnahna miksuyapi kta; cantepi wawicihahapi econ ece kin he miye elipemayan, qa iśtapi wakagapi tawapi en inahiman yapi ece kin hena on makamdecapi heon etanhan: Hehan iye iśtapi kin en śiceicidakapi kta, wowahte śni tawapi owasin en talku śica econpi kin hena on etanhan.

10 Unkan Jehowa he miye e sdonyapi kta; taku śice cin de ecawicawecon kta ituhin epe śni.

11 Jehowa Itancan kin he hecen eya; Ninape on waapa wo, qa risiha on wanahtaka wo, qa heya wo; Hehehe, Israel tiyohnaka wowahte śni śica tawapi kin owasin on: mazasagye, qa wicaakilian, qa makośica on hinhpayapi kta nakaeś.

12 Tuwe tehan un kin he makośica on țe kta; qa tuwe ikiyedan un kin he mazasagye on hinhpaye kta; qa tuwe okaptapi qa onatakapi kin he wicaakihan on te kta: hecen mitocanteptanye kin wicaweciyuśtan kta ce.

13 Tohan wicaktepi tawapi kin wakagapi yuhapi kin ehnahna, owayuśna tawapi kin ihdukśan wanke cinhan, paha tehanwankantu owasin akan, lie ipa kin owasin ekta, qa can toto owasin ihukuya, qa utuhu canwapośbe owasin hukuya, tukten wizite waśte wakagapi tawapi kin owa367 


\section{EZEKIEL TAWOWAPI,}

sin wakiyuśnapi ece qon hetu, hehan Jehowa he miye e sdonyayapi kta.

14 Hecen minape awicawakiyugate kta, qa makoce kin otiwota wakage kta, han, Diblath hopuza kin isanpa hewoskantu, iye ounyanpi kin owasin en. Unkan Jehowa he miye e sdonyapi kta.

\section{WICOWOYAKE 7.}

1 Nakun Jehowa oie en mau kin he hecen eya:

2 Nakun, niye wicaśta cinhintku, Jehowa Itancan kin he Israel makoce kin on hecen eya ce : Owihanke, owihanke kin he wanna makoce oise topa kin akan u ce.

3 Wanna owihanke kin en niu; unkan mitocanniye kin he niye en yewaśi kta, qa nitacanku kin eciyatanhan ciyaco kta, qa wowahtteśni nitawa kin iyuhpa niye en cicicau kta.

4. Qa miiśta nikpatan kte śni, qa waonśiwada kte śni: tuka nitacanku kin he niye en cicicau kta, qa wowahteśni nitawa kin hena nicokaya un kta: Unkan Jehowa he miye e sdonyayapi kta.

5 Jehowa Itancan kin hecen eya; Taku śica, taku śica ecedan wan, iho, wanna hiyohi.

6 Owihanke wan $u$, owihanke kin wanna hi ; iś anipe yanka; iloo, wanna hiyohi.

7 Makoce kin en ounyaya, hanhanna kin he wanna nihiyohi : wanna iyehantu, wokakije anpetu kin kiyedan u, qa he tawowiyuśkin kin hee śni.

8 Wanna ecadan mitocanteptanye kin acicaśtan kta, qa mitocanniye kin he niye en wahdiśtan kta: qa nitacanku kin eciyatanhall ciyaco kta, qa wowa368 liteśni nitawa kin iyuhpa niye en cicicahdi kta.

9 Qa miiśta patan kte śni, qa waonśiwada kte śni: nitacanku kin eciyatanhan cicu kta, qa wowahteśni nitawa nicokaya yanke kta: unkan tuwe waapa Jehowa he miye e sdonyayapi kta.

10 Wan, anpetu kin; iho, wanna hiyohi; hanhanna kin wanna hiyaya; adetka kin lica aya, wahanicidapi waskuyeca icaliya.

11 Wakalkiśyapi kin he wośice adetka icağa : hena etanhan śni, qa wicota tawapi etanhan śni, qa taku tawapi kin etanhan wanice kta: qa hena on wicaceya yuke kte śni.

12 Wanna iyehantu, anpetu kin kiyedan $\mathrm{u}$ : wopeton kin he wiyuśkin kte śni, qa wiyopeye cin he cante śin iciye kte śni: wocanteptanye wicota tawa kin ocowasin akan wicaun nakaeś.

13 Wiyopeye cin he taku wiyopeyapi kin en ku kte śni, hena ni unpi opapi eśta: wowanyake kin he wicota kin ocowasin on, hena hdicupi kte śni nakaeś; qa tuwedan iye tośice kin en towiconi hduwaśake kte śni.

14 Taku owasin hduwiyeyapi kta on mazayahotonpi kin yahotonpi ; tuka tuwedan okicize kin ekta ye śni: mitocanteptanye kin he wicota tawa kin owasin akan wicaun nakaeś.

15 Tankan mazasagye, qa timahen makośica qa wicaakilian yukan: tuwe magata un kin he mazasagye on te kta, qa tuwe otonwe mahen un kin he, wicaakihan qa makośica temyapi kta.

16 Tuka liena etanhan tona najicapi kte cin hena najicapi kta, ya he kin akan unpi kta, kaksiza wakiyedan kin iyececa, hena owasin ceyapi kta, otoiyohi iye wahtani kin on. 


\section{WICOWOYAKE 8.}

17 Wicanape owasin waśake kte s̉ni, qa wicahupahu owasin mini iyecen śkanśkan kta.

18 Nakun wakihdaka ipiyag kitonpi kta, qa wonihinciye awicakahpe kta; qa wicaite owasin akan wowiśtece yuke kta, qa hena owasin pa akan nasuśda kta.

19 Mazaska tawapi kin he canku ohna ehpeyapi kta, qa mazaskazi yuhapi kin he woyuśice kta: mazaska tawapi qa mazaskazi hduhapi kin Jehowa tocanteptanye anpetu kin en ewicayaku olsihi kte śni: iye nagipi kin imnaiciyapi kte śni, qa tezi ojuiciyapi kte śni ; iye wahtanipi on hicahanpi kte cin hee nakaeś.

20 Towaśte wowitan kin he woiyokipi en ekihde ; tuka hena e wowahte śni tawapi, taku śice hinca yuhapi okagapi kin he ohna kagapi : heon etanhan he taku elipeyapi on wicawaqu.

21 Unkan he wokipi on oyate tokeca napepi kin en, qa woicupi kta on maka akan tona śicapi kin wicawaqu kta: unkan hena yuśapapi kta.

22 Nakun iyepi etanhan miite wicaweciyuhomni kta, unkan woinahbe mitawa yuśapapi kta: wayujujupi kin hena hipi kta qa yuśapapi kta nakaeś.

23 Mazaicicaliiła wan kag̣a wo: makoce kin weyapi on wicayacopi ojudan, qa otonwe kin wokakiśye on ojudan, heon etanhan.

24. Heon etanhan Ikcewicaśta iyotan śicapi kin hena arvicawau kta, unkan tipi tawapi kin hena tawayapi kta: Nakun waśakapi towahinnicidapi kin he ayuśtan wakiye kta; qa tipi wakan tawapi qon hena yuśapapi kta.

25 Woihangye kin $\mathrm{u}$ : hehan wookiye akitapi kta, tuka wanice kta.
26 Woyuśice woyuśice itakihna u kta, qa woyakapi woyakapi itakihna kta: hehan wicaśta wokcan etanhan wowanyake akitapi kta: tuka woope kin wawayuśna kin kitanin kte śni, qa wowahokonkiye hunkayapi kin ayuśtan kta.

27 Wicaśtayatapi kin he ceye kta, qa wicaśta itancan kin wicotakuni śni koyake kta, qa makoce oyate napepi kin cancanpi kta : iye tacankupi kin eciyatanhan ecawicawecon kta, qa tawoyacopi kin eciyatanhan wicamdaco kta: Unkan Jehowa he miye e sdonyapi kta.

\section{WICOWOYAKE 8.}

1 Unkan kaketu, waniyetu iśakpe, wi iśakpe, wiyawapi arpetu izaptan, wati ohna iyotankehan manka, qa Juda hunkayapi kin mitokam iyotankapi, hehan Jehowa Itancan nape kin hen amahinhipaya.

2 Hehan watonwan, unkan iho, ouncagje wan peta owanyake kin iyececa: nite owanyake kin hetanhan kuntkiya, peta; qa nite etanhan wankantkiya ojanjan owanyake kin iyececa, mazaśa pabezapi iśta kin iyececa.

3 Unkan wicanape ouncage iyececa wan hiyuya, qa mapa hin sonpi kin on mayuza: Unkan Woniya kin yuwankan imacu, maka kin qa mahpiya kin otahedan, qa Wakantanka towanyake kin on Jerusalem ekta amahi, tiyopa mahentu waziyatakiya okahmin ohanzi kin hetu: wowinawizi ouncagie oiyotanke kin hen yanka, he winawizikiyapi ecee. 4 Unkan iho, Israel Taku Wakan tawa towitan kin hen yauka, omdaye kin en wowanyake wanmdake ciqon iyececa. 


\section{EZEKIEL TAWOWAPI,}

5 Hehan iye hemakiya; Wicaśta cinhintku, wrnna waziyatakiya canku kin ekta niiśta yuwankan iyeya wo. Hecen waziyatakiya canku kin ekta miiśta hduwankan iyewaya, unkan iho, waziyatakiya owayuśna tiyopa kin ekta, wowinawizi ouncage kin de, ohna hiyupi kin hetu.

6 Hehan hemakiya; Wicaśta cinhintku, taku econpi kin hena wandaka he; wowaliteśni tankinyanyan Israel tiyohnaka kin den econpi ecee; hecen on tipi wakan mitawa kin etanhan tehan mde kta. Tuka ake ihduhomni wo, wowahteśni sanpa tanka wandake kta ce.

7 Hehan tihocoka tiyopa kin ekta amahi; unkan watonwan, qa iho, conkaśke kin ohna ohdoka yukan.

8 Hehan iye hemakiya; Wicaśta cinhintku, wanna conkaśke kin ohna qa wo. Unkan conkaśke kin owaqa, hehan iho, tiyopa wan.

9 Unkan iye hemakiya; En ya wo, qa wowahteśni śice hinca den econpi kin hena wanyaka wo.

10 Hecen mahen wai qa wanmdaka; unkan iho, wamakaśkan ouncage owasin, qa woteca wahtepi śni, qa Israel tiyohnaka wakagapi tawa iyuhpa conkaśke akan ohomni owapi.

11 Unkan hena itokam Israel tipi hunkayapi kin etanhan wicaśta wikcemna śakowin en najinpi, qa Jaazaniah Saphan cinhintku wicacokaya najin, qa otoiyohi nape ohna oizite wan hduhapi: unkan izite malipiya soka wankan iyaya.

12 Hehan iye hemakiya: Wicaśta cinhintku, Israel tipi hunkayapi kin otpaza en taku econpi wandaka he, otoiyohi iye waka370 gapi tipi tawa kin ohna: Jehowa wanunyakapi śni; Jehowa maka kin ayuśtan ce, eyapi ece kin heon etanhan.

13 Nakun iye hemakiya; Ake ihduhomni wo, wowaliteśni tanka hinca econpi kin hena wandake kta ce.

14 Hehan Jehowa ti tiyopa waziyatakiya wanke cin he ekta amahi: unkan iho, hen winohinca iyotankapi Tammuz akice yapi.

15 Hehan iye hemakiya; Wicaśta cinhintku, wandaka he : ake iliduhomni wo, dena isanpa wowahteśni tanka wandake kta ce. 16 Unkan Jehowa ti. kin en tihocoka mahentu kin ekta amahi; unkan iho, tipi wakan Jehowa tawa tiyopa kin hetu, ohanzi hdepi qa owayuśna kin otahedan, wicaśta wikcemna nonpa sanpa raptan ecetu, tapete tipi wakan Jehowa tawa kin ektakiya yukanpi, qa ite wiyohiyanpatakiya yakonpi, qa ite wiyohiyanpatakiya anpetu wi kin itokam makata ehpeiciyapi.

17 Hehan iye hemakiya; Wicaśta cinhintku, de wandaka he. Juda tiyohnaka kin wowahteśni econpi kin den econpi kin he taku cistinna lie: wnkakiśye on makoce kin ojuyapi, qa miye canteptanye mayanpi kta on en hdicupi nakaeś: Unkan iho, hena can adetka kin pogge en hduzapi ecee.

18 Heon etanhan miś eya wocanteptanye on ecamon kta: miiśta patan kte śni qa waonśiwada kte śni: qa ho tanka on minog̉e en hoyekiyapi eśta nawicawalion kte śni ce.

\section{WICOWOYAKE 9.}

1 Nakun ho tanka on minog̉e en hoyemakiya, qa heya; Oton- 


\section{WICOWOYAKE 10.}

we awanyakapi kin hena kiyedan uwicakiya wo, qa otoiyohi waihangye wipe nape ohna hduhe kta.

2 Unkan iho, wicaśta śakpe tiyopa wankantu waziyatakiya wanke cin canku kin he ohna upi, qa otoiyohi tawipe canhipi kin he nape ohna hduhapi: unkan wicacokaya wicaśta wan minitiuha ogekiton, qa wowapi kag̉a iyokaśtan tawa ipiyake kin en yanka: unkan hena mahen iyayapi qa mazazi owayuśna kin icahda inajinpi.

3 Unkan Israel Taku Wakan tawa towitan kin he Kerub akan yanka ece kin hetanhan iyaya, tipi tiyopa akan he cin ekta. Unkan wicaśta miniliuha kohdake ca wowapi kağa iyokaśtan ipiyake ohna hduhe cin he kipan:

$4 \mathrm{Qa}$ Jehowa heciya; Otonwe kin cokaya ehna ya wo, Jerusalem cokaya, qa wicaśta tona wowahteśni owasin ohna econpi kin hena on comnihdazipi qa ceyapi kin hena itohnake en wowapetokeca wan ehnaka wo.

5 Tuka nation manke cin en unmapi kin hewicakiya; He iyahna otonwe kin ehria ya po, qa wakaśtaka po: niiśtapi wicapatan kte śni, qa waonśiyadapi kte śni.

6 Wicahincapi, kośka qa wikośka, qa hokśiyopa, qa winohincapi, woihangye on wicakte po; qa tipi wakan mitawa kin en tokaheya econ po. Unkan wicahincapi tipi itokam unpi kin hena en tokaheya econpi.

7 Nakun iye hewicakiya; Tipi kin yuśapa po, qa tihocoka kin wicaktepi kin on ojuya po: ya po. Unkan hena iyayapi qa otonwe kin ohna wicaktepi.

8 Unkan kaketu, wicaktepi icunhan, qa miye omakaptapi, hehan ite makipusdiya ehpemiciya, qa wapan, qa hepa; Hehehe, Jehowa Itancan, wocanteptanye nitawa Jerusalem ayakaśtan kin en Israel wookapte ocowasin ihangwicayaye kta he.

9 Hehan iye hemakiya; Israel qa Juda tiyohnaka wahtanipi kin he tanka hinca wopteca śni, qa makoce kin he we ojudan, qa otonwe kin wopemni econpi kin on: Jehowa maka kin elipekiya ; qa, Jehowa wawanyake śni ce, eyapi nakaeś.

10 Heon etanhan miś eya, miiśta wicapatan kte śni, qa waonśiwada kte śni : iye pa kin en tacankupi kin wicawecu kta ce.

11 Unkan iho, wicaśta minihuha ihduze wowapi kagia iyokaśtan ipiyake en hduhe ciqon he hośi hdi, qa heya; Taku econ mayaśi qon he ecen ecamon ce.

\section{WICOWOYAKE 10.}

1 Hehan watonwan, unkan iho, okotonyan iwankam, kerubim pa kin iwankapatanhan, saphir inyan wan iyecen, oiyotanke ouncage owanyake kin iyececa, hena iwankam tanin.

2 Unkan he qe wicaśta miniliuha ihduze cin kici wohdaka qa heciya; Canhdeśka kin iyotahedan, kerub ihukuya, ya wo, qa kerubim otahedan tanhan peta petaga kin nape ojudan eyaku wo, qa otonwe kin iwankamkam ehpeya wo. Unkan en ewatonwan icunhan mahen iyaya.

3 Unkan wicaśta qon ti mahen iyaya hehan kerubim kin tipi kin etapatanhan najinpi; qa mahpiya śapa kin on tihocoka mahentu kin ojudan.

4 Hehan Jehowa towitan kin kerub iwankapatanhan wankan iyaya, tipi tiyopa oahe iwankam 


\section{EZEKIEL 'TAWOWAPI,}

ekta: unkan tipi kin mahpiya śapa on ojuyapi, qa tihocoka kin Jehowa towitan wiyatpa hinca on ojudan.

5 Unkan kerubim taliupahu ho kin tankan tihocoka kin hehanyan nahonpi, Taku Wakan iyotan Waśaka ia eca ho kin iyececa.

6 Unkan kaketu, wicaśta minihuha ihduze cin he econ śi, qa, Canhdeśka kin otahedan, keru. bim iyotahedan tanhan peta icu wo, eciya, hehan mahen iyaya, qa canhdeśka kin icahda inajin.

7 Unkan kerub wanji kerubim otahedan tanhan nape hiyukiya, kerubirn otahedan peta wanke cin ekta, qa etanhan icu, qa minitiuha ihdus uli kin nape napin en ohnaka; unkan he icu qa tankan iyaya.

8 Unkan kerubim taliupahu kin ihukuya wicaśta nape ouncagge kin iyececa wan tanin.

9 Unkan watonwan, qa iho, kerubim icahda canhdeśka topa, kerub wariji isakimtu canhdeśka wanjidan, qa kerub wanji isakim canhdeśka wanjidan : unkan canhdeśka kin hena owanyake kin Tarśiś inyan iśta kin iyececa.

10 Unkan hena topa owanyake kin ouncage wanjidan, canhdeśka wanji canhdeśka wanji cokaya un kin iyececa.

11 Yapi eca topa omdotonyan yapi ece; yapi en oyuktanyan yapi śni, tuka tukte ekta pa itoheya etonwan yanke cin heciya iyahna yapi ece; yapi en oyuktanyan yapi śni.

12 Unkan tancan sintomni, qa tapete ekta, qa napepi, qa liupahu, qa canhdeśka kin hena ișta ojugjudan, canhdeśka hena topa kin ihdukśan.

13 Canhdeśka kin hena wicaki- panpi, minoğe en, $O$, canhdeśka, eyapi.

14 Unkan otoiyohi ite topa; ite tokaheya kin he kerub ite, qa ite inonpa kin he wicaśta ite, ça iyamni kin he rnnaja ite, qa itopa kin he wamdi ite kin heca.

15 Unkan kerubim ixin wankan iyayapi. Taku ni un Kebar wakpa ekta wanmdake ciqon he dee.

16 Unkan kerubim iyoopta yapi eca, canhdeśka kin iś icahda yapi ece : qa tohan kerubim hupa. hu wankan ehdakupi, maka etanhan wankan yapi kta, hehan canhdeśka kin iś hdicupi śni, hena icahda unpi ecee.

17 Hena najinpi eca dena najinpi ; qa hena wankan yapi eca, iś eya wankan ihdoyapi ecee: taku ni un taniya kin he mahen wicaun nakaéś.

18 Hehan Jehowa towitan kin tipi tiyopa oahe kin etanhan iyaye ça kerubim iwankam inajin.

19 Unkan miiśta itokam kerubim liupaha yuwankan ikikcupi qa maka kin etanhan wankan iyayapi: tankan iyayapi hehan canhdeśka kin icahda unpi ; unkan Jehowa ti tiyopa wiyohiyanpatanhan yulidokapi kin hen najinpi: qa Israel Taku Wakan tawa towitan kin hena iwankam yanka.

20 Kebar wakpa kin ekta taku ni un Israel Taku Wakan tawa ihukuya wanmdake ciqon he dee: Unkan kerubim hena ee sdonwaya.

21 Hena otoiyohi ite topa, qa otoiyohi hupahu tom yuhapi; qa wicaśta nape ouncage kin hipahu olidateya wicakiciyanka.

22 Unkan itepi ouncage kin hena Kebar wakpa ekta itepi wanmdake ciqon heepi : towanyake- 
pi qa iyepi: hena otoiyoni iye ite itoheya yapi ecee.

\section{WICOWOYAKE 11.}

1 Hehan Woniya kin yuwankan imacu, qa Jehowa ti wiyohiyanpata tiyopa wiyohiyanpatakiya etonwan kin he ekta amahi : unkan iho, tiyopa yuhdokapi kin ekta wicaśta wikcemna nonpa sanpa zaptan; hena wicacokaya Jaazaniah Azur cinhintku, qa Pelatiah Benaiah cinhintku, oyate en itancanpi kin hena wanwicamdaka.

2 Hehan hemakiya; Wicaśta cinhintku, otonwe kin de ohna wicaśta taku śica awacinpi, qa wowahokonkiye śica wicaqupi ecee kin dena eepi.

3 He ikiyedan śni ; tipi unkiçicagapi kta ce : cegga kin dee, qa tado kin he unkiyepi ce, eyapi ece.

4 Heon etanhan dena en woyaka wo; wicaśta cinhintku, eyanpaha wo.

5 Hehan Jehowa Taniya kin amahinhpaya, qa hemakiya; Heya wo; Jehowa hecen eya ce; Israel tiyohnaka, niye heeen ehapi ece; nitawacinpi taku en u kin hena miye sdonwaya nakaeś.

6 Otonwe kin de ohna wicaktepi nitawapi yahduotapi, qa canku kin hena wicaktepi kin on ojuyayapi.

7 Heon etanhan Jehowa Itancan kin he hecen eya ce; Wicaktepi nitawapi he cokaya ewicayahnakapi kin hena tado eepi, qa otonwe kin de ceğa kin hee : tuka de cokayatanhan tankan iyeciyapi kta ce.

8 Mazasagye kin he koyakipapi ece; unkan mazasagye en aciupi kta ce, Jehowa Itancan kin eya.
9. Hecen de cokayatanhan iyayeciyapi kta, qa wicaśta tokeca napepi kin en hiyuciyapi kta, qa niyepi ehna woyaco ecamon kta ce.

10 Mazasagye kin on nihinhpayapi kta; Ir rael makoce ihanke kin ekta ciyacopi kta : unkan Jehowa he miye e sdonyayapi kta. 11 Cega nitawapi kin he dee kte sni, qa he ocokaya tado kin he niyepi kte śni: Israel makoce ihanke kin ekta ciyacopi kta.

12 Unkan Jehowa he miye e sdonyayapi kta: mitawoahope kin ohnayan mayanipi śni, qa mitawoyaco kin hena ecanonpi śni nakaeś : tuka Ikcewicaśta nihdukśan unpi tawoyacopi kin ohna ecallonpi ecee.

13 Unkan kaketu, womdaka icunhan Pelatiah Benaiah cinhintku kinta: Hehan ite makipusdiya ehpemiçiya, qa hotankakiya hoyewaya qa hepa; Hehehe, Jehowa Itancan, Israel okaptapi kin ocowasin owihanke yaye kta he.

14 Hehan Jehowa oie en mau kin he liecen eya:

15 Wicaśta cinhintku, nihunkawanjipi, nihunkawanjipi, wicaśta takuwicayaye, qa Israel tiyohnaka ocowasin, Jerusalem en ounyanpi kin heepi ; Jehowa itehanyan ya po, makoce kin de tawaunyanpi kta unqupi ce, ewicakiyapi qon hena eepi.

16 Heon etanhan heya wo; Jehowa Itancan kin hecen eya ce; Hena Ikcewicaśta ehna tehan ehpewicawaya eśta, qa makoce kin ohnahna enanakiya iyewicawaya qeyaś, makoce kin tuktekte ekta ipi kinhan, hen tipi wakan cistinna iyececa wicakici waun ecee kta.

17 Heon etanhan heya wo; Jehowa Itancan kin hecen eya ce; 373 


\section{EZEKIEL TAWOWAPI,}

Nakun oyate kin ehnahna tanhan mnaciyapi kta, qa makoce ektakta enanakiya iyaye niyanpi qon hetanhan ciyuwitayapi kta, qa Israel makoce kin cicupi kta.

18 Unkan hena den hdipi kta, wowaliteśni en un kin owasin, qa wakagiapi kin iyuhpa hetanhan yutokanpi kta.

19 Unkan wicacante okonwanjidan wicawaqu kta, qa woniya teca wan tanmahen ecicihnakapi kta; qa iye celipi etanhan inyan cante kin ewicaweciyaku kta, qa wicacehpi cante wicawaqu kta :

20 Hecen mitoope kin ohnayan manipi kta, qa mitawoyaco kin ahopapi kta, qa ecen econpi kta : unkan hena mitaoyate eepi kta, qa Taku Wakan tawapi kin he miye kta ce.

21 Tuka tona cantepi wowahteśni tawapi kin eciyatanhan, qa wakagapi tawapi eciyatanhan mani kinhan, iye tacankupi kin iye pa akan awicawau kta ce, Jehowa Itancan kin eya.

22 Hehan kerubim kin hupahu yuwankan ikikcupi, qa nakun canhdeśka wicicahda unpi kin: qa Jehowa Israel Taku Wakan taw a towitan kin he wiciwankam yanka.

23 Unkan Jehowa towitan kin otonwe cokayatanhan wankan iyaye ca he otonwe iwiyohiyanpatanhan wanke cin he akan han.

24 Hehan Woniya kin yuwankan imacu qa Kasdim makoce kin en amahdi, wowanyake en, wayaka unpi kin ekta, Wakantanka Taniya kin on. Hecen wowanyake wanmdake cin he ehpeya imiciyaya.

25 Hehan wicoie Jehowa wanyagmakiye cin hena owasin wayaka unpi kin owicawakiyaka.

\section{WICOW OYAKE 12.}

1 Nakun Jehowa oie en mahi kin he hecen eya:

2 Wicaśta cinhintku, wawakipajin tipi wan cokaya yati; hena iśta on wanyakapi kta yuhapi, tuka wawanyakapi śni; hena noġe winahonpi kta yuhapi tuka wanalionpi śni ece: tipi wawakipajin kin hena eepi nakaeś.

3 Heon etanhan wicaśta cinhintku, niye wahpaya on ihdakapi ece kin hera wiyeya ehnaka wo, qa iye wanyakapi kin en, anpetu icunhan ihdaka wo: unkan iye iśtapi itoliam nitohe etanhan owanka tokeca ékta iyahdake kta : okini awacinpi kta, tipi wawakipajin kin hecapi qeyaś.

4. Hehan anposkan, iye iśtapi itokam wahpaya nitawa edaku kta, wahpaya on ihdakapi kta iyececa: qa litayetu hehan iye iśtapi itokam idade kta, wayaka unpi ihdakapi kin iyececa.

5 Iye iśtapi itokam conkaśke ohna qa wo, qa ohna qin aya wo. 6 Iye iśtapi itokam tapete akan wayaqin kta, tokali otpaza hehan aya wo: niite ayahdahpe kta, hecen maka kin wandake kte śni: Israel tiyohnaka en wowakta ecihnaka nakaeś.

7 Unkan econ maśipi kin iyecen ecamon; walipaya mitawa anposkan emdaku, wayaka yapi Ir ta wahpaya kin iyececa, qa litayetu hehan minape on conkaśke kin owaqa ; tokali otpaza hehan tankan awau, hinyete akan waqin, iye wanyakapi icunhan.

8 Unkan ihanlianna Jehowa oie en mahi kin hé hecen eya:

9 Wicaśta cinhintku, Israel tiyohnaka, wawakipajin tipi kin he, Taku ecanon he, eniciyapi śni he.

10 Hewicakiya wo; Jehowa 


\section{WICOWOYAKE 12.}

Itancan kin hecen eya ce; Woqin kin de Jerusalem en wicaśta itancan, qa Israel tiyohnaka wicacokaya unpi kin ocowasin heepi.

11 Wowakta nitawapi kin he miye ce, eya wo: token ecamon kin he iyecen ecawicakiconpi kta; ihdakapi, qa wayaka unpi kin en yapi kta.

12 Unkan wicaśta itancan wicacokaya un kin he tokah otpaza hehan hinyete akan qin kta qa inanpe kta : hena conkaśke ohna tanhan waqinpi kta e oqapi kta: iye qe ite ahdahpe kta, becen iśta on maka kin wanyake kte śni.

13 Nakun wohmunke mitawa kin he ewaonpe kta, qa mazahtakiyapi mitarva on yuzapi kta: unkan Babel ekta Kasdim makoce kin en awahi kta; tuka iye qe wanyake kte śni, ohna te kta eśtahan.

14 Unkan tona ihdukśan unpi owasin, taokiye qa ozuye tawa iyulipa tate ouye owasin ektakta yewicawaye kta; qa wicihakam mazasagye wan mduśdoke kta.

15 Hecen tohán oyate kin ehnàhna enanakiya iyewicawaya, qa makoce eltakta iyaye wicawaya, hehan Jehowa he miye e sdonyapi kta.

16 Tuka hena etanhan mazasagye etanhan, qa wicakkihan etanhan, qa makośica etanhan wicaśta tonana owakapte kta; hecen Ilkcewicaśta ektakta ipi kin hena en wowahte śni tawapi kin owasin ohdakapi kta; qa Jehowa he miye sdonyapi kta ce.

17 Hehan Jehowa oic en mahi kin he hecen eya:

18 Wicaśta cinhintku, ağuyapi nitawa cancanse hduta wo, qa mini nitawa cancanyan qa kokipeyahan hdatkan wo:
19 Qa makoce en oyate kin hewicakiya wo; Israel makoce ohna, Jerusalem en ounyanpi kin hena on Jehowa Itancan kin hecen eya ce; Hena ag̉uyapi kokipeyahan hdutapi kta, qa wonihinciye en mini hdatkanpi kta; hecen makoce tawapi kin taku ota tawa kin iyutakunipi kte śni: en ounyanpi owasin wakakiśya ohanyanpi kin he on etanhan. $20 \mathrm{Qa}$ otonwe otipi kin hena ihangyapi Ikta, qa makoce kin otiwota kta: unkan Jehowa he miye e sdonyapi kta.

21 Hehan Jehowa oie en mahi kin he hecen eya;

22 Wicaśta cinhintku, he taku wicoie wakan Israel makoce ohna duhapi he ; Anpetu kin yutehanpi, qa wowanyake owasin ecetu śni ce, eyapi ece.

23 Heon etanhan hewicakiya wo; Jehowa Itancan kin hecen eya ce; Wicoie walsan kin de ayuśtan wakiye kta, qa Israel en icimana hecen wiyacinpi kte śni : Tuka hewicakiya wo; Anpetu kin, qa wowanyake wicoie kin owasin wanna iyehantu ce.

24 Detanhan icimana wowanyake itonśni qa wakan kagapi śduśduta owasin Israel tiyohnaka ohna yuke kte śni.

25 Jehowa he miye e iwae kta nakaeś; wicoie kin epe kta, qa he ecen ecamon kta, icimana yutehampi kte śni; wawakipajin tipi, niye nitaanpetu kin en wicoie kin epe kta qa ecen ecamon kta ce, Jehowa Itancan kin eya. 26 Hehan Jehowa oie en mahi kin hé hecen eya;

27 Wicaśta cinhintku, iho, Israel tiyohnaka kin heyapi; Wowanyake wanyake cin he anpetu ota ekta, qa waniyetu tehan on woyaka ecee.

28 Heon etanhan hewicakiya 375 


\section{EZEKIEL TAWOWAPI,}

wo; Jehowa Itancan kin hecen eya ce; Detanhan mioie owasin icimana yutehanpi kte śni: wicoie kin epe kta, unkan ecen econpi kta ce, Jehowa Itancan kin eya.

\section{WICOWOYAKE 13.}

1 Unkan Jehowa oie en mahi kin he hecen eya:

2 Wicaśta cinhintku, Israel wicaśta wokcan woyakapi ece kin hena wowicakiyaka wo; qa tona iye cantepi eciyatanhan woyakapi ece kin hena hewicakiya wo ; Jehowa oie kin nahon po:

3 Jehowa Itancan kin hecen eya ce; Hehehe, wicaśta wokcan witkotkokapi, tona taniyapi okipapi, qa takudan wanyakapi śni!

4 Israel, wicaśta wokcan nitawapi kin hena liewoskan sungidan kin iyececapi :

5 Oyujujupi kin ekta dapi śni, qa conkaśke piya yakağapi sni, on Isiael tiyohnaka okicize en najinpi kta, Jehowa taanpetu. kin en.

6 Taku śni qa wakan kag̉api woitonśni kin wanyakapi: Jehowa heya ce, eyapi; tuka Jehowa yewicaśi śni: Unkan wicoie hdusutapi kta kecinpi.

7 Wowanyake taku śni kin heca wandakapi śni he; qa wakan kag̣api itonśni wan odakapi śni he: Jehowa heya ce, ehapi nakaeś; tuka miye takudan epe śni.

8 Heon etarhan Jehowa Itancan kin hecen eya ce; Takuśniśni odakapi qa woitonśni wandakapi kin heon etanhan iho, miye itkocicipapi, Jehowa Itancan kin eya.

9 Qa wicaśta wokcan takuśni wanyakapi, qa woitonśni ayatapi ece kin hena minape akan wicaun kta: hena mitaoyate inniciyapi kin en unpi kte śni; qa Israel tipi oiciwapi kin en owicawapi kte śni; nakun Israel makoce kin en yapi kte śni; unkan niye Jehowa Itancan kin he miye e sdonyayapi kta.

10 Heon etanhan, han, mitaoyate wicahnayanpi, Wookiye eyapi, tuka wookiye wanica: unkan tuwe conkaśke ehnaka, qa upśija on apawintapi ece, heon etanhan;

11 Tona upśija apawintapi kin hena hewicakiya wo; $\mathbb{H a n}$, hinhpaye kta; minitan magaju yuke kta, qa caga inyan hiyuwaye Ita, qa tate iyumni wan bomdece kta ce.

12 Unkan iho, conkaśke kin hinhpaye cinhan, hehan, Upśija on ayapawintapi qon he toki un he, eniciyapi kte śni he.

13 Heon etanhan Jehowa Itancan kin hecen eya ce: Mitocanteptanye kin en tate iyumni hinaripe wakiye kta, qa mitocanniye en minitan magaju yuke kta, qa cagia inyan wocanteptanye en, ihangyapi kta e heon.

14 Hecen conkaśle upśija on ayapawintapi kin he nudujuju kta, qa makata elipewaye kta, qa akan he ciqon he tanin kta, unkan hinhpaye kta, qa cokayatanhan niye ihangniyanpi kta: hecen Jehowa he miye e sdonyayapi kta.

15 Hecen conkaśke kin en, qa tona upśija on apawintapi qon hena akan mitocanteptanye waduśtan kta: hehan heciciyapi kta; Conkaśke kin he wanna en un śni, qa tona apawintapi qon hena nakun :

16 Israel wicaśta wokcan tawapi, Jerusalem on woyakapi, qa on wookiye wowanyake wanyakapi ece kin heepi; tuka wookiye 


\section{WICOWOYAKE 14.}

wanica ce, Jehowa Itancan kin eya.

17 Nakun, wicaśta cinhintku, nitaoyate cunwintku iye cantepi eciyatanhan woyakapi ece kin hena wicitkokim niye nuite ekihnaka wo; qa niś wowicakiyaka wo ;

18 Qa heya wo; Jehowa Itancan kin he hecen eya ce; Hehehe, tona nape okihe owasin en ipahin akag்eg̉epi, qa wicaśta ouncage owasin pa kin paogedan kicağapi ece, wicanaği iyapepi kta $e$ heon. Mitaoyate nagipi kin ayapepi kta he; qa ninagipi kin niniciyapi kta he.

19 Qa mitaoyate owicapeya mayaduśapapi kta he, barle napohnaka on, qa ağuyapi onśpaśpa on; hecen wicanaği țapi kte śni kin hena wicaktepi kta, qa wicanag̉i nipi lite śni kin hena niwicayápi kta, mitaoyate woitonśni nahonpi ece kin hena wicayahnayanpi kin heon etanhan.

20 Heon etanhan Jehowa I tancan kin hecen eya; Tho, ipahin nitawapi on wicanagi ayapepi, kinye wicayapi kta, hena itkokim waun, qa hena niistopi etanhan mduldece lita, qa wicanagi kin hena niwicawaye kta, wicanaği kinye wicayapi kta on iyawicayapepi kin hena.

21 Nakun wapaoġedan nitawapi kin hena mduhdehdece kta, qa ninapepi etanhan mitaoyate ewehdaku kta; unkan iyawicapepi $k$ ta on icimana ninapepi en unpi kte śni: hecen Jehowa he miye e sdonyayapi kta.

22 Woitonśni on wicaśta owotanna cante iyokiśinyayapi, tuka miye iyokiśinwaye śni ; qa wicaśta śica nape duwaśakapi, hecen wiconi yuhe kta on iye tacanku śica etanhan ihduhomni kte śni nakaeś ;
23 Heon etanhan icimana woitonśni wandakapi kte śni, qa wakan kagapi ecanonpi kte śni: ninapepi etanhan mitaoyate ewicawehdaku kta nakaeś: unkan Jehowa he miye e sdonyayapi kta.

\section{WICOW OYAKE 14.}

1 Hehan Israel hunkayapi kin etanhan wicaśta wanjikji en mahipi, qa mitokam iyotankapi.

2 Unkan Jehowa oie en mahi kin he hecen eya;

3 Wicaśta cinhintka, wicaśta kin dena wakagapi tawapi iye cante kin en ekihdepi, qa woahtani inaśnapi tawapi iye itepi itokam ehnakapi: wiwangapi on hena wimawangapi kta iyececa he.

4 Heon etanhan wowicakiyake ca hewicakiya wo; Jehowa Itancan kin hecen eya ce; Israel tiyohnaka wicaśta otoiyohi wakagapi iye cante kin en ekihde kinhan, qa woahtani inaśnapi tawa kin iye ite itokam ekihnaka, qa wicaśta wokcan kin en hi kinhan; Jehowa miye hinca, tuwe hi kin he wakagapi tawa ota hinca eciyatanhan amdupte kta ce:

5 Hecen Israel tiyohnaka iye cantepi kin on wicamduze kta, wakag̉api tawapi eci yatanhan hena iyuhipa elipemayanpi nakaeś.

6 Heon etanhan Israel tiyohnaka kin hecen ewicakiya wo; Jehowa Itancan kin hecen eya ce ; Namni po, qa wakagapi nitawapi etanhan ihduhomni po; qa wowahteśni nitawapi owasin etanhan niitepi hduhomni po.

7 Israel tiyohnaka etanhan wicaśta otoiyohi, qa wicaśta tokeca Israel om ounye cin hena etanhan, tuwe elipemaye ca iye cante kin en wakagiapi tawa ekihde, qa 377 
woahtani inaśnapi tawa iye ite itokam ekihnaka, qa miye on wicaśta wokcan wiwange kta en hi kinhan; Jehowa miye hinca atayedan waamdupte kta ce.

8 Qa miite wicaśta kin he itkokim ewehnake kta, qa wowakta qa wocajeyate wakage kta, qa mitaoyate cokaya tanhan wicaśta kin he ihangwaye kta; unkan Jehowa he miye e sdonyayapi kta ce.

9 Unkan wicaśta wokcan wan hnayanpi qa wicoie wan oyake cinhan, Jehowa miye wicaśta wokcan kin he wahnayan : qa minape amdugate kta, qa Israel mitaoyate cokaya tanhan wicaśta kin he ihangwaye kta ce.

10 Unkan iye wahtanipi kin kicinpi kta; tuwe wiwanh hi wahtani kin he wicaśta wokcan wahtani kin iyecece kta.

11 Hecen Israel tiyohnaka ake omapapi etanhan nuni yapi kte śni, qa taku śica ecompi lin on icimana ihduśapapi kte śni : tuka liena mitaoyate eepi kta, qa Taku Wakan tawapi kin he miye kta, Jehowa Itancan kin eya.

12 Hehan Jehowa oie en mahi kin he hecen eya:

13 Wicaśta cinhintku, makoce kin wohnaye tehilke on wamakihtani kinhan, hehan minape amdugate kta, qa aguyapi sagye tawa kin mdukse kta, qa wicaakilian en yewaśi kta, qa etanhan wicaśta woteca ko. ihangwicawaye kta :

$14 \mathrm{Qa}$ dena wicaśta yamni, Noah, Daniel qa Job cokaya unpi eśta, woowotanna tawapi on iye nağipi ecedan eihdakupi kta, Jehowa Itancan kin eya.

15 Wamanica śica makoce kin ehna iyaye wicawaye cinhan, qa hena he ihangyapi hecinhan, hecen liewoskan wanke, qa wama378 nica on etanlian tuwedan opta ye kte śni heciniran;

16 Dena wicaśta yanıni en unpi eśta, miye wani, Jehowa Itancan kin eya ; awicakehan cinhintkupi qa cunwintkupi niwicakiyapi kte śni; iye iśnana eihdakupi kta, tuka makoce kin hewoskan wanke kta.

17 Mazasagye wan makoce kin en awau kinhan, qa, Mazasagye, makoce kin ehna ya wo, epe cinhan; hecen hetanhan wicaśta qa woteca ihangwicawaye cinhan;

$18 \mathrm{Qa}$ dena wicaśta yamni en unpi eśta, miye wani, Jehowa Itancan kin eya; hena cinhintkupi qa cunwintkupi kin niwicakiyapi kte śni, tuka iye iśnana eihdakupi kta ce.

$19 \mathrm{Qa}$ makoce kin he en wiconțe wan yewaśi, qa wewe en mitocanteptanye kin awakaśtan kinhan, etanhan wicaśta qa woteca ihangyapi $k$ ta ;

20 Noah, Daniel qa Job en unpi eśta, miye wani ce, Jehowa I tancan kin eya; hena cinhintku qa cunwintku unmana ehdakupi kte śni; iye woowotanna tawapi on nagói eihdakupi kta.

21. Jehowa Itancan kin hecen eya; Nakun isanpa, woyaco śica topa mitawa, mazasagye, qa wicaakilian, qa wamanica śica, qa makośica kin hena Jerusalem en yewicawaśi, on wicaśta qa woteca ihangwicayapi kta hecinhan :

22 Tuka iho, najicapi en wookapte un hena hinanpe yapi kta, cinhintkupi qa cunwintkupi ; iho hena niyepi ekta hiyupi kta, unkan iye tacankupi qa ohanpi kin niye wandakapi kta: hehan taku śica Jerusalem en awau qon, taku owasin en hiyuwakiye cin hena on niye wacintonhnagniciyapi kta. 


\section{WICOWOYAKE 16.}

23 Unkan hena wacintonlinagniyanpi lita, tohan iye tacankupi qa ohanpi kin wandakapi kinhan: unkan he en taku ecamon kin owasin taku śni on etanhan ecamon śni he sdonyayapi kta ce, Jehowa Itancan kin eya.

\section{WICOWOYAKE 15.}

1 Hehan Jehowa oie en mahi kin he hecen eya:

2 Wicaśta cinhintku, hastanhanka can kin he taku he, can adetka can owasin contanka ehna kin isanpa he.

3 Hetanhan can icupi kta wicohtani on taku kagapi kta he; qa iś hetanhan can kapestodan icupi kta, taku wakśica kin en otkeyapi kta he.

4 Iho, peta tawoyute on petan ehpeyapi ; oinkpa napin peta kin huhnaliya, qa cokaya kin he nakun ǵu: Taku wicohtani kin on okihi kta he.

5 Iho, zaniyan un qehan taku on kahpica śni : hecen tohan peta hulinahya qa ocowasin gu kinhan isanpr taku wicolitani on takudan okihi kte śni.

6 Heon etanhan Jehowa Itancan kin he hecen eya; Hastanhanka can contanka can ehna, peta tawoyute on peta waqu kin he iyecen Jerusalem en ounyanpi kin hena wicawaqu kta:

7 Qa miite wicitkokim ewehnake kta; hena peta wanji etanhan hiyupi kta, qa peta kin huhnahwicaye kta: unkan tohan miite wicitkokim ewehnake cinhan, Jehowa he miye e sdonyayapi kita.

8 Unkan makoce kin he hewoskan wakagge kta, iye wohnaye on wahnayanpi kin heon etanhan, Jehowa Itancan kin eya.

\section{WICOWOYAKE 16.}

1 Hehan Jehowa oie en mahi kin he hecen eva:

2 Wicaśtæa cinhintku, Jerusalem wowahte śni tawa kin sdonkiyeya wo:

3 Qa heya wo; Jel.owa Itancan kin he Jerusalem hecen eciya ce; Icahniyanpi qa nitonpi kin Kanaan makoce kin etanhan, niy ate Amori heca qa nihun Hittiwin heca.

4 Unkan nitonpi kin, anpetu en nitonpi qehan cekpa kan nitawa baksapi śni, qa yuskapi kta on mini en niyujajapi śni; qa miniskuya on skuyeniyanpi śni; qa woy uskite on iyanipemnipi śni.

5 Wicaśta wacantkiye akan niyanke śni, dena taku kin wanjidan ecanicon kta ionśinida kta: tuka tankan mağata ehpeniyanpi, ninaggi wahtedapi kte śni, anpetu en nitonpi qehan.

6 Unkan niye nanke cin en wahimdamda qehan, qa niwe en tankan ehpeniyanpi wanciyaka, hehan niwe kin en heciciya; $\mathrm{Ni}$ wo; han, $\mathrm{Ni}$ wo, niwe kin en eciciya.

7 Maga oicagie kin iyecen ihduota ciciya; unkan nihduota qa tanka inicagia, qa oinpi waśte hinca ekta yahi: aze nitawa hminyana hiyu, qa nipahin hanska icaga; tancodan qa onśika yaun tuka qon.

8 Unkan niye en wahimdamda qa acitonwan, hehan iho, anpetu nitawa kin he waśtedakapi anpetu ee: unkan niye akan mitaśina iyewaya, qa tancodan yaun kin awakahpa: Han, awicakehan wociciyaka qa wokonze wan ci. cicaga, Jehowa Itancan kin eya ; unkan mitawa kta inicaga.

9 Hehan mini on ciyujaja; han, niye etanhan niwe kin ocowasin 379 


\section{EZEKIEL TAWOWAPI,}

yujaja iyewaya, qa wihdi on sdaciciya :

10 Nakun wokoyake hdeśkaśka koyagciciya, qa hokaha hanpa oheciciya, qa minihuha waśte on ipiyagciciton, qa hamhapedan ahdahipe ciciya:

11 Nakun oimpi kin on ciyuwaśte, qa mazahuhu ninape en iyewakiya, qa nitahu en wanapin wan :

12 Qa nipog̉e en taku hminyanna wan ewahnaka, qa oinpi ninoge en, qa wateśdake waśte hinca wan nipa kin akan.

13 Hecen mazaskazi qa mazaska on nihduwaśte; qa nitawokoyake kin minihuha waśte qa liamhapedan qa hdeśkaślka kin heca : ag̉uyapi mdu qa tulimağa canhanpi qa wihdi yata ecee: hecen owanyag niwaśte linca, qa wokiconze ekta tanyan yahinape.

14 Unkan Ikcewicaśta oyate kin ehnahna nicaje yutaninpi, owanyag niwaśte hinca on ; he yuśtanpi hinca, wowaśte mitawa acihnaka heon etanhan, Jehowa I tancan kin eya.

15 Tuka owanyag niwaśte kin he wacinyakiya, qa nicaje tanka on wawicihahapi ecanon, qa wiinahmanpi nitawa tona en hiyaye cin otoiyohi ayakaśtan; he iye tawa kta.

16 Unkan nitawokoyake kin etanhan iyekcu qa wakeya hdeśkaśka niçicaga, qa hena on wawicihahapi ecanon ece: en yai kte śni, nakun iyecetu kte śni tuka.

17 Nakun oinpi waśte nitawa, mazaskazi qa mazaska mitawa etanhan ciçu qon hena iyekcu qa wicaśta ouncage kin niçicaga qa hena on wawicihahapi ecanon ecee.

18 Nakun wokoyake hdeśkaśka 380 nitawa iyekcu, qa on awicayakahpa: qa wihdi mitawa qa wizite mitawa kin hena wicitokam eyahnaka.

19 Nakun woyute mitawa cicu qon, ag̉uyapi mdu, qa wihdi, qa tuhmaga canhanpi yunciye ciqon hena ee womna oiyokipi wicitokam eyahnaka; unkan hecetu ecee, Jehowa Itancan kin eya.

20 Nakun nicinkśi qa nicunkśi miyeciton kin hena ewicayahda$\mathrm{ku}$, qa hena on wicayekte, temyapi kta e heon: Wawiciliahapi ecanon kin de taku cistinná he.

21 Qa micinca kin hena wawicaduśna, qa hena ekta ehna hiyayeyapi kta ewicayahnaka.

22 Tuka wowahteśni nitawa owasin en, qa wawiciliahapi nitawa ehna, winikośka anpetu qon hena yeksuye śni, tancodan qa śdayehna yaun, niwe kin en tankan ehpeniyanpi yaun qehan.

23 Unkan kaketu, taku śica nitawa owasin iyohakam-hehehe, hehehe, niye, Jehowa Itancan kin eya-

24 Nakun wakeya wan nicicaga, qa canku owasin ohnahna paha niçicaga :

25 Canku owasin pa kin en pajodan niçicağa ; hecen nitowaśte kin he wahteśni dakapi yakagga; qa en hiyayapi kin otoiyohi siha yakidujate, qa wawicihahapi nitawa yahduota ece.

26 Nakun nitankiyedan unpi, Mizraim cinca cehpi tankinyanyan hena om wawicihahapi ecanon; qa canteptanye mayanpi kta on wiinahmanpi yahduota ecee.

27 Heon etanhan iho, minape aciyugate, qa taku nitawa kte cin ewehdaku, qa tona śicenidapi cante kin ekta hiyayeciya, 


\section{WICOWOYAKE 16.}

Philistin cunwintkupi nitacanku wahteśni on iśtecapi kin heepi.

28 Nakun Aśur cinca om wawicihahapi ecanon, winipi śni nakaeś : han, hena om wawicihahapi ecanon ece, tuka nakun imnaniciya olkihipica śni.

29 Nakun Kanaan makoce kin en Kasdim makoce hehanyan wawicihahapi nitawa yahduota; tuka nakun imnaniçiye śni.

30 Cante niwankadan hinca, Jehowa Itancan kin eya; dena owasin ecanon ece kin on, winohinca witkowinna wohitika ohan kin iyececa.

31 Canku oinkpa otoiyohi en wakeya nitawa eyehde kin heon, qa canku tanka owasin ohna pajodan nitawa yakag̉a ece; qa wiyopeyapi ayakta śni ece, hecen witkowinna iyenicece śni.

32 Winohinca wan wawicihahapi econ ece kin he iye hihnaku eekiya wicaśta tokeca iyowinwicakiya ecee, he iyececa.

33 Witkowinpidan owasin wiyopeyapi wicaqupi ecee: tuka tona waśtewicayadake cin owasin niye taku wicayaqu, qa opewicayaton ece, hecen ihdukśantanhan en nihipi kta, wiinahmanpi nitawa on etanhan.

34. Unkan winohinca witkowinpidan ece kin iyenicece śni, tuwedan wiinahmanpi on nihakam u śni nakaeś: nakun niye taku wicayaqu ecee, qa takudan nicupi śni, heon etanhan niye nitokeca.

35 Heon etanhan, witkowinna, Jehowa oie kin nation wo:

36 Jehowa Itancan kin hecen eya ce : Mazaśa nitawa kadadapi kin heon, qa waśte wicayadake cin on wawicihahapi ecanon ecee kin on tanconikadan tanin, qa wowalite śni nitawa wakag̉api kin hena owasin om ; qa nicinca wicayaqu kin hena we kin on etanhan.

37 Heon etanhan, iho, tona wa. śtenidakapi kin owasin, tona or iyokipiniçiye ciqon hena, han, tona waśtewicayadake qa tona śicewicayadake cin hena koya wicamduwitaya kta: han, hena niye en nihdukśan wicamduwitaya kta, qa hena ekta tanconikadan kin miye mdutanin kta; unkan hena e tanconikadan kin ocowasin wanyakapi kta.

38 Unkan tona wawicilialiapi econpi qa weyapi econpi ecee tawoyaco kin eciyatanhan ciyaco kta; qa wocanniye wowinawizi en we cicu kta.

39 Nakun iye napepi kin en cicu kta; unkan wakeya nitawa kahpapi kta, qa pajojodan kin hena niciyujujupi kta: nakun wokoyake nitawa kin niciyuśdokapi kta, qa oinpi waśte hinca nitawa kin hena icupi kta, qa tancodan qa śdayehna ehpeniy anpi kta.

40 Nakun niye en ozuye wan aupi kta, qa inyan on nicininpi kta, qa mazasagye on canipapi kita.

41 Qa tipi nitarva peta on huhnahyapi kta, qa winohinca ota iśtapi itokam woyaco ecaniconpi kta: hecen witkowinna yaun kin he ayuśtanciciye kta : qa niśs eya icimana woiyopeye wicayaqu kte śni.

42 Unkan niye ekta mitocanteptanye kin ozikiye wakiye kta, qa wowinawizi mitawa kin aniyuśtan kta; hecen ozimiçiye kta, qa icimana canmaniye kte śni ce.

43 Winikośka anpetu qon hena yeksuye śni, tuka dena owasin on canzemayaya nakaeś; heon etanhan, iho, miś eya nitacanku kin nipa en awau kta, Jehowa Itancan kin eya; qa wowahte- 


\section{EZEKIEL TAWOWAPI,}

śni nitawa kin owasin isanpa taku śice cin de ecanon kte śni.

44 Tho, owasin wiyacinpi kin de on iniyacinpi kta; Cunwintku kin he hunku kin iyececa ce, eyapi kta.

45 Nihun hihnaku qa cinca śicewicakidake ciqon cunwintku kin he niye; qa nicunwicayaye hihnakupi qa cincapi śicewicakidapi qon hena tankayapi kin niye: Inayayapi kin he Hittiwin heca, qa ateyayapi kin he Amori heca.

46 Qa nicunyaye cin Samaria hee, iye qa cunwintku kin nicatkatanhan ounyanpi; qa tankayaye cin, nietapa eciyatanhan ti kin he Sodom qa iye cunwintkupi kin heepi.

47 Tuka hena canku tawapi kin ohnayan mayani śni, qa wowahteśni tawapi kin eciyatanhan ecanon śni-he qe taku cistinna seca-tuka nitacanku owasin ohna hena isanpa nihduśica ece. 48 Miye wani ce, Jehowa Itancan kin eya; niye taku ecanon, niye qa nicunkśi kin hena, nitanka Sodom iyecen econ śni, iye qa cunwintkuwicaye cin.

49 Iho, nitanka Sodom woahtani tawa qon dee, wahaniçidapi, woyute ota, qa ozikiyapi tanka iye qa cunwintkuwicaye cin kici un; tuka wicaśta onśika qa wahpanica kin hena nape wicayuwaśake śni ecc.

50 Unkan hena tankaicidapi, qa mitokam wowahteśni kin econpi ecee: heon etanhan miye wanmdake cin iyecen ewicamdaku.

51 Nakun wayalitani hanke kin hehanyan Samaria wahtani śni ; tuka niye taku wowahte śni kin iye isanpa yahduota, qa taku wowahteśni ecanon kin iyuhpa on nitankawicayaye cin wicaduowotanna ece.
52 Nitanka wicayaya wicadaco, niś niye hinca wowiśtece hduha wo, wayahtani en hena isanpa taku śica ecanon nakaeś: hena e niye isanpa ihduowotanpi: han, nakun nihinciya wo, qa wowiśtece nitawa hduha wo, nitanka wicayaye cin wicayahduowotanna kin heon etanhan.

53 Tohan hena wayaka unpi kin ayuśtanwakiye kta, Sodom qa cunwintku wayaka unpi, qa Samaria qa iye cunwintku wayaka unpi kin, hehan hena wicacokaya wayaka unpi nitawa ayuśtan wakiye kta :

54 Hecen wowiśtece nitawa yahduhe kta, qa taku ecanon kin owasin on nihinniciye kta, hena wacintonhnag wicayaya nakaeś.

55 'Tohan nitankawicayaye, Sodom qa iye cunwintku koya otokaheya qon ekta hdicupi kinhan, qa Samaria iye cunkśiwicaye cin koya otokaheya unpi qon ekta hdicupi kinhan, hehan niye nicunkśi kin om otokahe nitawa qon en yahdipi kta.

56 Wahanhanniçida anpetı qon en nitanka Sodom nii tawoyake kin en un śni ;

57 Taku śica nitawa yuotaninpi śni itokam, Aram cunwintku iśtenniyanpi qon he ehan, qa tona ihdukśan unpi kin owasin, Philistine cunwintku ihdukśantanhan wahtenidapi śni qon hena etanhan.

58 Woihduśica nitawa qa wowahteśni nitawa kin hena yeçin, Jehowa eya.

59 Jehowa Itancan kin hecen eya ce; Taku ecanon kin he eciyatanhan miye ecacicon $k$ ta, wicotakuye kaksapi kta on woiciconze kin wahteyada śni nakaeś.

60 Hececa eśta winikośka anpetu qon en wicotakuye mitawa. 


\section{WICOWOYAKE $1 \%$}

nici un kin he rveksuye kta, qa wicotakuye owihanke wanica wan ciciyusuta kta ce.

61 Hehan nitacanku kin yeksuye kta, qa iniśtece kta, tohan nitanka wicayaye cin, nicun qa nitanka, hena ewicayahdaku kinhan: unkan hena cunkśiwicayaye kta ciẹu kta, tuka wicotakuye nitawa eciyatanhan śni

62 Unkan wicotakuye mitawa kin ciciyusuta kta; qa Jehowa he miye e sdonyaye kta ce :

63 Hecen yeksuye kta, qa on iniśtece kta, qa wowiśtece nitawa on icimana $i$ yahdukawa kte śni, tohan taku ecanon kin owasin on cicicajuju kinhan, Jehowa Itancan kin eya.

\section{WICOWOYAKE $1 \%$.}

1 Unkan Jehowa oie en mahi kin he hecen eya:

2 Wicaśta cinhintku wiyacinpi wan oyaka wo, qa wowiyukcan wan Israel tiyohnake iyukcan wicaśi wo:

$3 \mathrm{Qa}$ heya wo; .Jehowa Itancan kin hecen eya ce; Wamdi tanka wan hupahu tankinyanyan, wiyaka hanskaska, hin ota hinca, hena hdeśkaśka, he Lebanon en hi, qa hante śa oinkpa kin eyaku :

4 Taadetka pa kin he yaksa, qa owopeton makoce wan ekta aya; wopeton otonwe wan en ehde.

5 Nakun makoce ojupi kin etanhan icu qa maga waicahye wan en oju, mini tankinyanyan ekta huhde, coliwanjica can iyecen ehde.

6 Unkan icaga, qa wiyuwi yuhaha kucedan icaga, taade tka kin 1 ye etkiya yulktanyan, qa tahutkan kin hena iye ihukuya yanka: hecen wiyuwi iyecen icaga, qa adetka icahya, qa etanhan ape uya.
7 Hehan nakun wamdi tokeca tanka wan, iś hupahu tankinyanyan, qa hin ota hinca: unkan iho, wiyuwi kin de hutkan kin iye ekta nakiktanyan, qa taadetka kin iye etkiya uyeya, hecen tawoju kin ohna cankuyetonton kin en spayekiciye kta.

$8 \mathrm{He}$ qe maka waśte en mini tanka icalıda ojupi, adetka oicage kta, qa waskuyeca icahye kta, hecen wiy uwi waśte hinca kta.

9 Niś heya wo : Jehowa Itancan kin heeen eya ce; He qe tanyan icagie kta he: tahutkan kin yujun kte śni, qa tawaskuyeca kin kakse kte śni he; hecen śniś aye kta ; taadetka canwapa kin owasin śnije kta; qa hute patanhan yujunpi kta, isto tanka qa oyate ota on etanhan śni.

10 Unkan iho, ojupi eśta tanyan icagge kta lie: wiyohiyanpata tate kin ape cinhan wośnije on śnije kte śni he: cankuyetonton ohna icag̛e cin hen śniś aye kta ce.

11 Nakun Jehowa oie en mahi kin hecen eya:

12 Wanna tiyohnaka wawakipajin kin heciya wo; Dena taku hecinhan sdonyayapi śni he. Heya wo; Iho, Babel wicaśtayatapi kin he Jerusalem en hi, qa wicaśtayatapi tawa kin eyaku, qa wicaśta itancanpi nakun, qa Babel ekta awicakiyahda:

13 Qa wicaśtayatapi toicage kin etanhan icu, qa kici wicotakuye wan kicağa; qa woiçiconze oie kin icu kiya: qa makoce kin en waśakapi lin hena ewicayaku:

14. Hecen wokiconze kucedan kta ; han, icimana ihduwankantuya kte śni; wicotakuye tawa kin ahope kta, hecen ohna najin lita tuka.

15 Tuka iye kipajin, wahośiye tawa Egupta ekta yewicaśi, śu383 


\section{EZEKIEL TAWOWAPT,}

ktanka qa oyate ota qupi kta e heon: Tanyan icaggc kta he: dena econ kin he eihdaku kta he: qa wicotakuye hdakse kta, qa niiciye $\mathrm{kta}$ he.

16 Miye wani, Jehowa Itancan kin eya; awicakehan wicaśtayatapi tuwe he wicaśtayatapi kağa hecinhan, woiciconzc tawa śice kicidaka, qa wicotakuye tawa kicaksa, he toyanke kin ohna, iye kici Babel cokaya hen to kta ce.

17 Nakun Pharaoh ozuye tanka tawa qa oyate ota hinca on, okicize kin en okiye kte śni, wicanaği ota wicaktepi kta on pahaha ehnakapi qa conkaślie kağapi kta e heon.

18 Nakaeś wicotakuye kicakse kta on woiciconze kin walitekida śni, unkan iho nape hiyukiya tuka; hecen dena owasin econ kin on niiciye kte śni.

19 Heon etanhan Jehowa Itancan kin he hecen eya; Miye wani, awicakehan woiçiconze mitawa wahtedaśni kin he, qa wicotakuye mitawa kicakse cin he iye pa kin en hdicu wakiye kta.

20 Qa wohmunke mitawa aihpewakiye kta, unkan mazahtakiyapi mitawa kin on yuzapi kta: liecen Babel en awahi kta, qa hen mdaco kta, woahtani tawa on wamakilitani kin heon etanhan.

$21 \mathrm{Qa}$ onajice tawa iyuhpa, ozuye tawa ocowasin koya, mazasagye on hinhpayapi kta; qa tona okaptapi kin hena tate ouye owasin ektakta iyaye wicayapi kta: Unkan Jehowa he miye e iwae cin he sdonyayapi kta.

22 Jehowa Itancan kin he hecen eya; Nakun hanteśa hanska adetka tehanwankantu etanhan iwacu kta, qa ewahde kta: taa- detka aślkatudan kin etanhan wankadan wan mdukse kta, qa he tehanwankantu qa pajodarn kin akan owaju kta:

23 Israel tehanwankantu he kin en owaju kta: unkan etanhan adetka uye kta, qa waskuyeca icahye lita, qa hanteśa waśte hinca heca kta: nakun zitkadan ocaje owasin hupahu ton iyuhpa he ihukuya unpi kta; taadetka ohanzi kin en otipi kta.

24 Hecen Jehowa miye e can tehanwankantu kin kun elpewaya, qa can kucedan kin he hanska wakag̉a, can teca kin iś śniśwaya, qa can śeca qon he piya icahwaya, he taśkoju can kin owasin sdonyapi kta: Jehowa miye e hecen epa, qa ecen ecamon ece.

\section{WICOWOYAKE 18.}

1 Ake Jehowa oie kin en mahi kin he hecen eya :

2 Etanhan initokecapi he; Israel makoce kin ohna wiyacinpi kin de on widacinpi ece; Ateyapi kin hena hastanhanka hanpi skuya yutapi, hecen cincapi kin hi psonpsonna icaga ece, eyapi.

3 Miye wani, Jehowa Itancan kin eya; Israel en wiyacinpi kin de icimana on widacinpi kte śni. 4 Iho, wicanagi kin iyuha mitawa; atkuku nagi kin he iyecen cinhintku nag்i kin mitawa : wicanaği wahitani kin he țe kta.

5 Tuka wicaśta wan owotanna, qa woyaco woowotanna ko econ kinhan :

6 Ḧe kin akan wote śni, qa Israel tiyohnaka wakaggapi tawa kin ekta iśta yuwankan ikikeu śni kinhan; qa takodaku tawinohinca kin yuśice śni, qa winyan iśnati kin en ye śni kinhan; 7 Qa tuwedan kakiśye śni, iki- 
cazo oicazo kicu kinhan, womanon on tuwedan wamakinon śni, agoyapi tawa tuwe wotektehda kin qu kinhan, qa tancodan un kin śina akahpa hecinhan :

8 Woyahtake on owicaqu śni, qa oicage icu sni kinhan; taku śica econpi kin etanhan nape ehdaku, wicaśta qa wicaśta otahedan awicakehan woyaco econ kinhan ;

9 Mitoope kin ohnayan mani kinhan, qa mitawoyaco kin ahopa, wowicake econ kta e heon; he qe owotanna, nipi on ni kta ce, Jehowa Itancan kin eya.

10 Tuka he qe cinhintku wan yuha, wamanon sa, weya ece, qa dena wanji iyecen econ kinhan;

11 Nakun hena owasin ohnayan econ śni kinhan; tuka he kin akan wota, qa takodaku tawinohinca kin yuśice cinhan;

12 Onśika qa walipanica kin hena kakiświcaya; womanon'on wamakinon ece; oicazo kin wicakicu śni; qa wakagapi kin ekta iśta yuwankan ikikcu, wowahte śni econ kinhan;

13 Woyalitake on owicaqu, qa oicagie icu ece : hecen ni kta he: ni kte śni : wowaliteśni kin dena owasin econ : wiconte on te kta: iye we kin iye hinca akan yanke kta.

14. Unkan iho, he qe cinhintku wan yuhe cin he atkuku woahtani econ kin owasin wanyake ca kokipe ça iyecen takudan econ śni kinhan;

$15 \dot{\mathrm{H}} \mathrm{e}$ kin akan wote śni, qa Israel tiyohnaka wakagapi tawa kin ekta iśta yuwarnkan ikikcu śni kinhan, takodaku tawinohinca kin yuśice śni,

16 Qa tuwedan kakiśye śni, oicazo on wicakaśke śni, qa wokakiśye on wawicaki śni; agguyapi tawa wotektehdapi kin wi- caqu, qa tancodan un hin sina akahipa hecinhan;

17 Onśikapi kin etanhan nape ehdaku, oicage qa wokajuju kin icu śni kinhan; mitawoyaco kin econ, qa mitawoahope kin ohnayan mani kinhan; he qe atkuku walitani kin on țe kte śni, wiconi on ni kta.

18 Atkuku nina wakakiśya sunkaku kin waki ecee; qa iye taoyate ehna taku waśte śni econ ece, iho, he qe iye wahtani kin ohna te kta ce.

19 Tuka, Tokeca, cinhintku kin atkuku tawoahitani qin kte śni he, ehapi ece. Cinhintku kin woyaco qa woowotanna econ kinhan ; mitawoahope owasin ahopa qa hena ecen econ kinhan; he qe wiconi on ni lita.

20 Wicanaưi wahtani kinhan hee te kta: Cinhintku kin atkuku woahtani tawa kin kiçin kte śni; qa atkuku kin he iś cinhintku woalitani tawa kicin kte śni: wicaśta owotanna toowotanna kin iye akan yanke kta, qa wicaśta śica tośice kin iye akan yanke kta ce.

21 Tuka wicaśta śice cin he woahtani econ kin iyuhipa etanhan ihduhomni kinlıan, qa mitawoahope owasin ahope cinhan, qa woyaco woowotanna ko econ kinhan, wiconi on ni kta, te kte śni.

22 Wokipajin tawa econ qon hena owasin icimana cajekiciyatapi kte śni: woowotanna tawa econ kin he ohnayan ni kta.

23 Wicaśta śice cin he te kta e ecaca iyomakipi lita he, Jehowa Itancan kin eya: qa ni kta e tacanku kin etanhan ihduhomni kte śni he.

24 Tuka tuwe owotanna kin iye toowotanna etanhan ihduhomni kinhan, qa taku śica econ 385 


\section{EZEKIEL 'TAWOWAPT,}

kinhan, wicaśta śica wowahteśni econ kin owasin ohnayan econ kinhan, he ni kta he. Woowotanna econ kin owasin cajeyatapi kte śni: wohnayan tawa on wicahnayan, qa woahtani tawa on wahtani kin hena en țe kta.

25 Tuka, Itancan tacanku kin mdaye śni ce, ehapi ecee: Israel tiyohnaka, wanna nahon po; $\mathrm{Mi}$ tacanku kin he mdaye śni he: niye nitacankupi kin hośkiśki śni he.

26 Tohan wicaśta owotanna wan iye toowotanna kin etanhan ihduhomni qa taku sica econ kinhan, qa hena en te cinhan; tohan śica econ kin he on te kta ce.

27 Nakun wicaśta śica wan tośice kage cin he etanhan ihduhomni kinhan, qa woyaco woowotanua ko econ kinhan, he qe iye naği kin niiçiye kta.

28 Ekta etonwan qa wokipajin tawa tona econ qon owasin etanhan ihduhomni, heon etanhan awicakehan ni kta; te kte śni.

29 Tuka Israel tijohnaka kin, Itancan tacanku kin mdaye śni ce, eyapi ece. Israel tiyohnaka, mitacanku kin hena mdaye śni he; niye nitacankupi kin hena hośkiśki śni he.

30 Heon etanhan Israel tiyohnaka, otoiyohi iye tacanku kin eciyatanhan ciyacopi kta ce, Jehowa Itancan kin eya: Hdicu po, qa ihdoku po, wokipajin nitawapi kin owasin etanhan : hecen wośice kin hicahan niyanpi kte śni.

31 Wokipajin nitawapi on wawayakipajinpi kin owasin ehpeya po: qa cante teca qa woniya teca icicag̉a po: Israel tiyohnaka, tokeca nițapi kta he.

32 Tuwe te cinhan wiconte kin he on iyomakipi śni ce, Jehowa
Itancan kin eya : Heon etanhan ihdoku po, qa niiciya po.

\section{WICOWOYAKE 19.}

1 Nakun Israel itancanpi kin on woiyokiśica odowan wan icu wo: 2 Qa heya wo; Tokeca nihun mnaja wiye kin heca he; muaja kin ehna iwanka; mnaj-cinca tawa kin hena mnaja koślka kin ehna icaliwicakiya ece.

3 Unkan mnaj-cinca tawa etanhan wanji icalikiya; he mnaja kośka icaga qa woteca yahidehdeca onspeiçiciya ; wicaśta temwicaya.

4 Hehan he on oyate kin nahonpi; makohdoka tawapi kin ohna yuzapi ; unkan inazaicicahilia on Egupta makoce kin en ahipi.

5 Unkan taku wacinkiye cin, taku ape un kin he atakuni śni wanhdaka, hehan ake mnaj-cinca tawa etanhan wanji icahlkiya, mnaja kośka icage kta.

6 Unkan he qe mnaja kin ehna mani ece; mnaja lośḱa icağa, qa woteca yahdehdeca onspeiciciya, wicaśta temwicaya.

7 Unkan tipi waśteśte tawapi kin hena sdonya, qa totonwepi kin ihangya ece; hecen makoce qa toojudan kin hewoskan elipeyapi, iye ho hoton kin -heon etanhan.

8 Hehan makoce ihdukśan wanke cin hetanhan oyate kin hena takpe upi, qa on hmunkapi tawapi kin akahpapi: unkan makohdoka tawapi kin ohna yuzapi.

9 Unkan wokaślie tipi ohrı mazaicicahilia en ehnakapi, qa Babel wicaśtayatapi kin en ahipi : conkaślke kin en ahipi, hecen ake icimana ho kin Israel he akan nahonpi kte śni.

10 Niye iyeniceca, nihun hastan-

386 
hanka iyuwi mini icahda ojupi kin iyececa; he waicahya qa adetka ojudan, mini ota kin heon etanhan.

11 Unkan adetka suksuta kiyukan, tona itancanpi cansagye yuliapi kta e heon; unkan ohanske kin he adetka yuhaha ehna icaga, qa adetka ota kin on tehanwankantu wanyakapi.

12 Tuka wocanteptanye en yujunpi, makata ehpeyapi ; qa wiyohiyanpata tate kin waskuyeca tawa kin bośnija: can adetka suksuta tawa kin hena yuksaksapi qa śniś aya; peta kin hena hiuhnahya.

13 Unkan he wanna hewoskan ojupi, makoce puza qa mini icalkija kin ohna.

$14 \mathrm{Qa}$ taadetka cansakadan wanji etanhan peta iyaya, waskuyeca tawa hiuhnahya; hecen iye en adetka suta, on itancanyan cansagye yuhapi kta wanica. He qe woiyokiśica odowan, qa woiyokisíica odowan heca kta ce.

\section{WICOWOYAKE 20.}

1 Unkan kaketu, waniyetu iśakowin, wi izaptan, wiyawapi iwikcemna kin en, Israel hunkayapi etanhan Jehowa wiwangapi kta on upi, qa mitokam hiyotankapi.

2 Hehan Jehowa oie en mahi kin he hecen eya;

3 Wicaśta cinhintku, Israel hunkayapi kin wowicakiyaka qa hewicakiya wo; Jehowa Itancan kin hecen eya ce; Wimayanungapi kta yahipi he: Miye wani, wimayanungapi waun kte śni ce, Jehowa Itancan kin eya.

4 Wicadaco kta he : wicaśta cinhintku, niye hena wicadaco kta he: atkukupi wowahteśni tawapi kin hena sdonyewicakiya wo:
$5 \mathrm{Qa}$ hewicakiya wo; Jehowa Itancan kin hecen eya ce; Anpetu en Israel wakahnige ciqon, qa Jakob tiyohnaka oicage kin nape wicawakiyugate, ca Ligupta makoce hin en sdonmaye wicawaye ciqon, he ehan nape wicawaliyugate, Jehowa 'Taku Wakan nitawapi kin he miye ce, epa.

6 Anpetu en nape wicawakiyugate, Egupta makoce kin etanhan hinanpe wicawaye kta, makoce wan iwanwicaweciyake cin he ekta, asanpi qa tuhmaga canhanpi apaśbog wanka, makoce owasin en woiyokipi kin hee:

$7 \mathrm{He}$ ehan hewicawakiye ciqon; Wicaśta otoiyohi iye iśta taku wowahteśni tawa kin hena elipeya po, qa Egupta wakagapi kin hena on ihduśapapi śni po; Jehowa Taku Wakan nitawapi kin he miye ce.

8 Tuka miye wamakipajinpi qa anamagoptan wacinpi śni ; wicaśta otoiyohi iye iśta taku wowaliteśni tawa kin hena elipekiyapi śni, qa Egupta wakagapi kin ayuśtanpi śni : Hehan; Mitocanteptanye wicaweciyuśtan kta on Egupta makoce cokaya mitocanniye awicawakaśtan kta ce, epa. 9 Tuka micaje on ecamon, Ikcewicaśta wicacokaya unpi wicitokam yuśapapi kte śni, iye iśtapi kin en sdonmaye wicawakiye ciqon, Egupta makoce kin etanhan hinanpe wicawaye kta e heon.

10 Heon etanhan Egupta makoce kin etanhan hinanpe wicawaye ça hopuza kin en awicawahi: $11 \mathrm{Qa}$ mitoope wicawaqu, ga mitawoyaco kin wanyagwicawakiya, hena e wicaśta wan ecen econ kinhan, eqe ohnayan ni kta ce.

12 Nakun anpetu okihpapi mitawa kin hena wicawaqu, miye $38 \%$ 
EZEKIEL TAWOWAPI,

qa iyepi otahedan wowakta heca kta, hecen tuwe wicayuwakan kin Jehowa he miye e sdonyapi kta tuka.

13 Tuka Israel tiyohnaka hopuza kin en wamakipajinpi, mitoope kin ohnayan manipi śni, qa mitawoyaco kin hena walitedapi śni : hena e wicaśta wan ecen econ kinhan hena ohna ni kta tuka; qa anpetu okilhpapi mitawa kin hena nina yuśapapi : hehan hopuza en ihangwicawaye kta on mitocanteptanye awicawakaśtan kta, kepa.

14 Tuka micaje kin on litawani, hecen he qe oyate iśtapi kin en hinanpe wicawaye ciqon hena wicitokam yuśapapi kte śni.

15 Tulsa nakun hopuza kin en nape wicawakiyugate, hecen makoce wicawaqu qon, asanpi qa tulimaga canhanpi apaśbog wanka, makoce orvasin en woiyokipi hinca he en awahi kte śni tuka:

16 Mitawoyaco kin hena śicedakapi, qa mitoope kin ohnayan manipi śni, qa anpetu okihpapi mitawa kin yuikcekapi, heon etanhan : iye cantepi wakagapi tawapi kin imanipi nakaeś.

17 Tuka hena e wicayutakunipi kte śni miiśta wicakpatan, qa hena hopuza kin en owihanke wicawaye śni.

18 Tuka hopuza kin en iye cinca kin heepi ; Niyatepi toope kin ohnayan manipi śni po, qa tawoyaco kin hena ahopapi śni po, qa wakagiapi tawapi kin on ihduśapapi śni po;

19 Jehowa Taku Wakan nitawapi kin he miye cc: mitoope kin ohnayan mani po, qa mitawoyaco kin ahopa po, qa ecen econ po, ewicawakiya:

$20 \mathrm{Qa}$ anpetu okilipapi mitawa kin hena yuwakan po; kinhan hena miye qa niyepi otahedan wowakta un kta, hecen Jehowa Taku Wakan nitawapi kin he miye e sdonyayapi kta.

21 Hececa eśta cincapi kin iś eya makipajinpi ; mitoope kin ohnayan manipi śni; qa mitawoyaco kin ecen econpi kta on ahopapi śni; he qe wicaśta wan ecen econ kinhan hena on ni kta tuka; anpetu okihipapi mitawa kin hena yuśapapi ece: Hehan hopuza kin en mitocanniye wicaweciyuśtar kta on mitocanteptanye kin awicawakaśtan kta, kepe.

22 Tuka minápe ewehdaku, qa micaje on htawani, hecen Ikcewicaśta iśtapi kin en hinanpe wicawaye cin hena wicitokam yuśapapi kte śni.

23 Nakun hopuza kin en nape wicawakiyugate, hena Ikcewicaśta kin ehnahna wicamduomdece kta, qa makoce kin ektakta iyaye wicawaye kta e heon:

24 Mitawoyaco kin hena ecen econpi śni, tuka mitoope kin śicedakapi, qa anpetu okilipapi mitawa kin hena yuśapapi, qa iye iśta atkukupi wakag̉api tawapi qon imanipi ecee heon etanhan.

25 Heon nakun woope waśte śni kin heca vicawaqu, qa woyaco on nipi kte śni heca:

26 Qa iye tawośnapi kin en wicamduśapa, tona tamni yuhdokapi kin hena owasin peta ehna iyaye wicakiyapi heon, hecen on ihangwicawaye kta, hecen Jehowa he miye e sclonyapi kta.

27 Heon etanhan, wicaśta cinhintku, Israel tiyohnaka kin wowicakiyake ca hewicakiya wo; Jehowa Itancan kin hecen eya ce ; De on niyatepi mayaśicapi, wohnaye on mahnayanpi kin heon. 
28 Makoce wieawaqu kta on nape wicawakiyugate cin he en awahi qehan, hehan paha tehanwankantu kin owasin, qa can wapośbe owasin wanyakapi, qa hen ece wośna tawapi kin wahduśnapi, qa he en tawośnapi woiyokiśinye kin ahipi : nakun he en wowizite waśtemna kagiapi ece, qa lien woyatke wośnapi kill hdaśtanpi ecee.

29 Hehan hewicawakiya; Tehanwankantu kin ekta dapi ece kin he taku he. Unkan he caje kin anpetu dehanyan. Bamah (tehanwankantu) eciyapi.

30 Heon etanhan Israel tiyohnaka kin hewicakiya wo; Jehowa Itancan kin he hecen eya ce ; Niyatepi tacanku kin ohna nihduśapapi he: qa wowahte śni tawapi kin eciyatanhan wawicihahapi ecanonpi he.

31 Tohan nitawośnapi wayahduśnapi qa nicincapi peta ehna hiyayewicayayapi eca, wakagapi nitawapi iyulipa on nihduśapapi ecee, anpetu kin de iyececa: Unkan, Israel tiyohnaka, wimayanungapi waun kta he. Miye wani, Jehowa Itancan kin eya, wimayanunğapi kte śni ce.

32 Qa taku nitawacinpi kin en hiyu kin he ecaca ecetu kte śni; niye hehapi; Ikcewicaśta oyate kin, makoce wicowazipi kin iyeuncecapi kta, can qa inyan ohoundapi kta ce.

33 Miye wani, Jehowa Itancan kin eya, nape waśake cin on, qa isto wahdukatin on, qa wocanteptanye wahdaśtan kin on, wowidagciyapi kta :

34 Qa oyatepi kin etanhan hinanpe ciyapi kta, qa makoce ektakta iyeniyanpi qon etanhan mnaciyapi kta, nape waśaka on, qa isto hdukatinpi kin on, qa wocanteptanye hdaśtanpi kin on.
$35 \mathrm{Qa}$ oyate hopuza tawa kin en acihipi kta, qa hen ite itkocicipa ciyacopi kta.

36 Egupta makoce hopuza kin en niyatepi wicamdaco qon iyecen ciyacopi kta ce, Jehowa Itancan kin eya.

37 Qa cansagye kin ihukuya iyaye ciyapi kta, qa wicotakuye icaśke kin en uciyapi kta.

38 Qa niyepi etanhan wawakipajinpi kin hena, qa tona wamakihtanipi kin hena wicawapahi kta: Makoce en ounyanpi kin hetanhan hiyuwicawaye kta, qa Israel makoce kin en hdipi kte śni; hecen niye Jehowa he miye e sdonyayapi kta ce.

39 Unkan wanna niyepi, Israel tiyohnaka, Jehowa Itancan kin hecen eya ce; Otoiyohi wakagapi tawa kin ohoda ya po, nakun tokata, anamayagoptanpi kte śni kinlıan : tuka nitawośnapi qa wakağapi nitawapi kin on, micaje wakan kin icimana yuśapapi śni po.

40 Nakaeś he wakan mitawa kin en, Israel tehanwankantu he kin akan, Jehowa Itancan kirt eya, heciya Israel tiyohnalka ocowasin, tona makoce en unpi iyulipa, ohomadapi kta: hen ece iyowicawakipi kta, qa hen nitawośnapi kin owade kta, qa taku mayaqupi tokaheya kin hena, taku tona dawakanpi kin owasin koya.

41. Womna waśtemna nitawapi ohna iyowinciciyapi kta, tohan oyate kin etanhan hinanpe ciyapi kta, qa makoce ektakta enariakiya idadapi qon hena etanhan mnaciyapi kinhan; qa niyepi en Ikcewicaśta itokam mayuwakanpi kta.

42 Qa tohan Israel tamakoce kin en hdiyohiciyapi kinhan, nakoce niyatepi wicawaqu kta e on 389 


\section{EZEKIEL TAWOWAPI,}

nape wahdugate ciqon, hehan Jehowa he miye e sdonyayapi kta.

43 Unkan hen nitacankupi kin yeksuyapi kta, qa niohanpi owasin on nihduśapapi kin hena : qa taku śica ecanonpi kin owasin on etanhan niye niiśtapi én śiceniçidapi kta.

44 Unkan tohan micaje hinca on htacicinipi kinhan, nitacankupi śice cin hena eciyatanhan śni, qa niohanpi waliteśni kin on etanhan śni, hehan, Israel tiyohnaka, Jehowa he miye e sdonyayapi kta ce, Jehowa Itancan kin eya.

45 Nakun Jehowa oie mici un kin he hecen eya;

16 Wicaśta cinhintku, niite itokahikiya canku kin ekta hduza wo, qa itokah makoce kin aśbuya wo, qa itokah tinta contanka kin he on woyaka wo.

$47 \mathrm{Qa}$ itokah contanka kin heciya wo; Jehowa oie kin nalion wo: Jehowa Itancan kin hecen eya ce; Iho, niye en peta wan wakag̉e kta; unkan niye en can teca. otoiyohi qa can śeca otoiyohi huhnahye kta: peta ide kin kasnipi kte śni; unkan he on itokaga tanhan waziyata ekta hehanyan wicaite kin iyulipa giu kta.

48 UTnkan Jehowa he miye e idewaya wicacehipi ocowasin wanyakapi kta; he kasnipi kte śni ce.

49 Hehan hepa; Hehehe Jehowa Itancan, hena, Wiyacinpi kin on wiyacin śni he, emakiyapi ecee:

\section{WICOWOYAKE 21.}

1 Hehan Jehowa oie en mau kin be liecẹn eya;

2 Wicaśta cinhintku, niite Jeru390 salem itkokim hduza wo, qa nioie owanka wakan kin hena aśbuya wo, qa Israel makoce hin on woyaka wo:

$3 \mathrm{Qa}$ Israel makoce kin heciya wo; Jehowa hecen eya ce; Iho, itkocicipa, qa mazasagye mitawa ojuha etanhan wahduśdoke kta, niye etanhan wicaśta owotanna qa śice cin napin bawicawakse kta ce.

4 Heeen niye etanhan tuwe owotanna qa śice cin nakun bawicawakse kta, heon etanhan iye ojuha etanhan mazasagye mitawa kin he itokaga tanhan qa waziyata ekta hehanyan wicacehipi ocowasin takpe wicaye kta:

5 Hecen Jehowa miye mazasagye mitawa ojuha kin etanhan wahduśdoka e wicacehipi ocowasin sdonyapi kta; ake icimana en ihdoku kte śni.

6 Heon etanhan, wicaśta cinhintku, wicanite pawegapi kin iyecen śicahowaya wo; qa iyokiśicapi on iye iśtapi itokam śicahowaya wo.

7 Unkan kaketu kte, tohan, Taku on yaśicahowada he, eniciyapi kinhan, hehan waadupte kta; Taku nahonpi kin on, he u kta nakaeś: Unkan wicaśta cante owasin skan kta, qa wicanape orvasin śilitin kta, qa wicataniya otoiyohi waśake kte śni, qa wicahupahu owasin mini iyecen jcagge kta: iho, u kta, ecetu kta, Jehowa Itancan kin eya.

8 Ake Jehowa oie en mau kin he hecen eya :

9 Wicaśta cinhintku, woyake ca heya wo; Jehowa hecen eya ce; Heya wo, Mazasagye wan, mazasagye wan yumanpi qa pabezapi nakun:

10 Nina wicakte kta heon yumanpi ; wiyakpakpa kta heon pabezapi; hecen unkiyuśkinpi kta 


\section{WICOWOYAKE 21.}

he; micinkśi tasagye kin can owasin takuda śni ece.

11 Unkan he pabezapi kta wicaqu, hecen unpi kta : mazasagye kin de yumanpi qa pabezapi, hecen wicakte sa nape kin en qupi kta.

12 Wicaśta cinhintku, ceya qa sicahowaya wo; he qe mitaoyate kin akan wanke kta, Israel itancanpi kin owasin akan: mazasagye on wonihinciye mitaoyatc kin akan un kta: heon etanhan sican en aicipa wo.

13 He unpi nakaeś; unkan tokeca, sagyc watakuda śni ece kin he en un śni kinhan, Jehowa Itancan kin eya.

14 Heon etanhan, wicaśta cinhintku, niye woyake ça nape hdaskaskapa wo, qa mazasagye kin yamni akihde yukipaś econpi kta, mayasagye wicakte kin; mazasagyc kin he tona tanka wicakte ecee, aohdutewicaye kin hee.

15 Heon cantepi skan kta, qa woyujuju tawapi kin yuotapi kta e heon mazasagye wicakte sa kin tiyopa tawapi owasin en ewahnaka. He wiyakpakpa kta kagapi, wicakte kta on pabezapi.

16 Ilıduwitaya wo, etapa ekta; catka ekta inajin wo; niite ektakiya hdepi hecen ya wo.

17 Nakun miśs eya nape wahdaskaskapa kta, qa mitocanteptanye kin oziwakiyc kta ce: Jehowa miye e hecen epa.

18 Hehan Jehowa oie en mau kin he heccn eya :

19 Qa niś eya, wicaśta cinhintku, canku nonpa ic̣icağa wo, ohna Babel wicaśtayatapi tarnazasagye kin u kta : napin makoce wanjidan etanhan hiyu kta: qa owanka wan kagga wo, otonwe iyahde canku pa kin en kağa wo. 20 Canku wan yakage kta, he- ciyatanhan mazasagye kin Rabbath Ammon cinca tawa kin en hiyu kta, qa Juda en Jerusalem acankaśkapi kin ekta.

21 Babel wicastayatapi kin he canku ojate ekta, canku nonpa ipa kin en inajin, wakanyan econ kta: wanhinkpe kin paśkanśkan, wakagapi kin on wawiwanga, taku pi kin en etonwan.

22 Iye etapa eciyatanhan Jerusalem on wakanyan econpi kta yanka, on akicita ewicahde kta, wicaktepi kta on i hdukawapi kta, iyaśapi on ho hdataninpi kta, tiyopa itkopatanhan ibohtake ehdepi kta, on paha kaggapi kta, conkaślke kagapi kta e heon. 23 Unkan tona woiciconze on içiconzapi kin hena iśtapi kin en wakanyan ecorpi kin he ituya econpi iyecece kta: tuka iye qe taku śica econpi kin kiksuye kta, hccen wicayuzapi kta.

24 Heon etanhan Jehowa Itancan kin hecen eya ce; Taku śica ecanonpi kin kiksuyeyakiyapi, wawayakipajinpi kin hena tanin kta, hecen niohanpi owasin en wayahtanipi wanyakapi nakaeś ; heon etanhan wanna niksuyapi hecen nape on niyuzapi kta ce. $25 \mathrm{Qa}$ niś niyc, Israel wicaśtayatapi, sica ihduśapa kin, woahtani elıake kin on nitaanpetu kin wanna hiyohi ;

26 Jehowa Itancan kin hecen eya; Wateśdake kin eyaku po; qa wicaśtayatapi tawapaha lin yutokan iyeya po: de qe wanna hee kte śni : kuya un kin he yuwankan iyeyapi, qa wankan un gon he yuhukuyapi ecce :

27 Mduptanye kta, mduptanye kta, he mduptanye kta: unkan de qe en un kte śni; tuwe woyaco tawa kin he hi kta hehauyan; unkan he waqu kta ce. 28 Unkan niye, wicaśta cinhin391 
tku, woyake ça heya wo; Ammon cinca kin on qa waośtehdapi tawapi kin on, Jehowa Itancan kin hecen eya ce: Han, heya wo; Mazasagye, mazasagye kin yuśdokapi ; wicaktepi kta on pabezapi; wiyatpatpa on waihangye kta.

29 Niye on woitonśni wanyakapi, niye on wohnaye iyukcanpi icunhan, wicaśta wicak tepi tahupi en aniupi kta, wicaśta śicapi taanpetu kin wanna hiyohi, taku śica econpi kin owihanke kte cin he on.

30 Taojuha kin en iyekiya wo: owanka ohna nicaǵapi, makoce en nitonpi qon he ohna ciyaco kta ce.

31 Qa mitocanteptanye kin acicaśtan kta; mitocanniye peta kin on acipogan kta, qa wicaśta wacintonśni wicakte wayupikapi napepi kin en oiçu kta.

32 Peta tawoyute kin henica kta; niwe kin he makoce cokaya wanke kta; niye niksuyapi kte śni: Jehowa he miye e hecen epa nakaeś.

\section{WICOWOYAKE 22.}

1 Hehan Jehowa oie en mau kin he hecen eya:

2 Unkan niye, wicaśta cinhintku, wadaco kta, otonwe awewe kin daco lsta he: Han, wowaliteśni tawa iyuhpa wanyagyakiye kta ce.

3 Hehan heya wo; Jehowa Itancan kin hecen eya ce; Anpetu tawa hiyohi kiye kta e heon otonwe kin he cokahan weya ecee; qa ihduśape kta on wakagapi içicağa ecee.

4 We yakpapson kin on wahtani niçiya; qa wakağapi niçicağe cin hena on nihduśapa; qa nitaanpetu kin kiyedan hiyuyaki392 ya, qa nitawaniyetu kin wanna yahdiyohi : heon etanhan Ikcewicaśta elna woaie cicaga, qa makoce owasin en waunnicapi ece.

5 Kiyedan unpi qa nitehan unpi kin hena waunnicapi kta, caje niyuśapapi qa nina nihinciya yaun.

6 Iho, niye en Israel itancanpi lkin otoiyohi token okihiya we papsonpi ece.

7 Niye en atkukupi qa hunkupi takuśni wicakidapi; nicokaya wicaśta tokeca kakiśyapi ece : niye ohna wamdenica wiwazica ko iyotanhan iyewicakiyapi ece.

8 Taku kin wakan mitawa kin hena niye ihayakta śni, qa anpetn okihipapi mitawa kin hena duśapa ecee.

9 Wicaśta waaie sa kin hena en niunpi, weyapi kta e heon: qa niye ohna he kin akan wotapi ece: nicokaya wawicihatiapi econpi ece.

10 Niye ohna atkukupi tancodan kin he wanhdakapi : niye ohna tuwe iśnati yanke cin he yuhukuyapi ecee.

$11 \mathrm{Qa}$ wanji iye takodaku tawicu kin kici taku wowalite śni econ; qa wanji iś takośku kin wośice on hduśica; qa niye ohna wanji iś tankśitku, iye atkuku cunwintku kin he hduhukuya ece.

12 Niye ohna we papsonpi kta on wiyopeya icupi ecee: woyalitake qa oicage kin niye iyacu, qa wokakiśye on nitakodapi wawicayaki, qa miye e amiyektonja ce, Jehowa Itancan kin eya.

13 Unkan iho, wamayanon ecanon kin he on, qa nicokaya we nitawa yanke cin he on nape wahduskapa ce.

14. Anpetu en miye ecacicon kinhan, hehan nicante sutaya yanke lkta, ga ninape waśake kta 


\section{WICOWOYAKE 22.}

he: Jehowa miye e hecen epa, qa ecen ecamon kta ce.

15 Unkan Ikcewicaśta ehnahna iyayeciye kta, qa makoce kin ektakta ciyuomdece kta, qa niye etanhan nitawośice kin ihangciciye kta.

16 Unkan Ikcewicaśta iśtapi itokam niye hinca taku nitawa tawayakiye kta, qa Jehowa he miye e sdonyaye kta ce.

17 Hehan Jehowa oie en mau kin he hecen eya:

18 Wicaśta cinhintku, Israel tiyohnaka kin he ginginca imicicag̣a: hena iyulipa mazaśa, qa wiśdoye, qa mazasapa, qa mazasu, peta ośdoye cokaya hiyeya; hena mazaska ginginca kin heca.

19 Heon etanhan Jehowa Itancan kin hecen eya; Niyepi iyulipa ginginca inicağapi nakaeś; iho, heon etanhan Jerusalem cokaya mnaciyapi kta.

20 Mazaska, qa mazaśa, qa mazasapa, qa mazasu, qa wiśdoye kin hena peta ośdoye cokaya mnayanpi ece, on peta ipoganpi $\mathrm{kta}$, he iyecen, mitocanniye qa mitocanteptanye kin en wamnawaye kta, qa en ehpeciyapi kta, qa śdociyapi kta.

21 Han, ciyuwitayapi lita, qa mitocanteptanye ide kin ohna acipoganpi kta: unkan he ocokaya niśdopi kita.

22 Peta ośdoye ohna hinca mazaska śdoyapi ece kin he iyecen he ocokaya śdoniyanpi kta ; unkan Jehowa he miye e mitocanteptanye acicaśtanpi kin he sdonyayapi kta ce.

23 Hehan Jehowa oie en mau kin he hecen eya;

24 Wicaśta cinhintku, kaken eciya wo; Makoce yuhintapi śni, qa wocanteptanye anpetu kin en amagaju śni kin he niye.
25 Cokaya wicaśta wokcan tawa kin hena ihdaśkapi, mnaja hoton wayahdehdeca ece kin he iyececa; hella wicanagi temyapi ; hena womnaye qa taku tehike cin hena icupi; hena he ocokaya wiwazica ota kicagapi ece.

26 Wawayuśna tawa kin hena mitoope kin śicaya yuhap̧i, qa taku mitawa wakan kin hena yuśapapi, taku wakan qa taku ikceka kin yukinukanpi śni, qa taku śapa qa taku ska kin hena wicakipazopi śni, qa anpetu okihpapi mitawa kin etanhan iśta ehdakupi; hecen wicacokaya mayuśapapi.

27 Ocokaya wicaśta itancanpi tawa kin hena sunktokeca wayahidehdeca kin iyececapi, we papsonpi kta, wicanagi ihangyapi kta, ohinniyan wamanonpi kta e heon.

28 Unkan wicaśta wokcan tawa kin hena upśija awicapawintapi, wohnaye hanmdepi, qa woitonśni iwicakiciyukcanpi, Jehowa ie śni qeyaś, Jehowa Itancar kin heya ce, eyapi ece.

29 Makoce oyate kin hena wokakiśye on wakakiśyapi ece, qa womanon kag̉api, qa onśika walipanica ko hena cante śinwicayapi ecee: han, woyaco eciyatanhan śni wicaśta tokeca kakiśyapi ece.

30 Unkan wicaśta wan owade, makoce kin en mitokam conkaśke kin piya kage kta, qa oyujujupi kin ohna inajin kta, hecen ihangwaye kte śni tuka; tuka iyewaye śni.

31 Heon etanhan mitocanteptanye kin awicawakaśtan : mitocanniye peta kin en wicamdutakuni śni : iye tacankupi kin iye pa kin en hdiyohi wakiya ce, Jehowa Itancan kin eya. 


\section{EZEKIEL TAWOWAPI,}

\section{WICOWOYAKE 23.}

1 Hehan Jehowa oie en mau kin he hecen eya:

2 Wicaśta cinhintku, winohinca noupa, hena hunkupi wanjidan cunkśiwicaya.

3 Unkan Eyupta en wawiciliahapi econpi ; hena wikośkapi qehan wawicihahapi econpi : heciya azepi paskicapi; qa heciya witanśna unpi qehan, aze pinkpapi kin yutantanpi.

4 Unkan hena cajepi, Ahola he tokapa, qa tankaku kin iś Aholiba: Unkan hena mitawa, qa hena cinhintkupi q̨a cunwintkupi wicatonpi : Unkan cajepi kin hena, Samaria he Ahola ee, qa Jerusalem he Aholiba ee.

5 Unkan Ahola mitawa qeyaś wawicihahapi econ ece; qa tona waśtedakapi qon hena cantewicakiya, Aśur wicaśta kiyedan unpi kin hena :

6 Sina to inpi, akicita tancan qa wicaśtayatapi, owasin kośka oiyokipipi, śnktanka-wicaśta śunka wakan akan iyotankapi ecee.

7 Hecen hena om wawicihahiapi econ ece, Aśur cinca kahniggapi kin hena owasin om, qa tona cantewicakiye ciqon iyuhpa kici ; wakaǵapi tawapi kin iyuhpa kici ihduśica ece.

8 Qa nakun Egupta etanhan wawicihahapi hduhe ciqon hena ayuśtan śni ; wikośka qehan kici iwankapi, qa witanśna un aze kin yutantanpi, qa wiinahmanpi tawapi kin hena akaśtanpi ecee.

9 Heon etanhan tona waśtedakapi kin napepi kin en waqu, Aśur cinca cantewicakiye ciqon hena napepi kin en.

10 Hena tancodar wanka kiyuzarmipi; cinhintku qa cunwintkupi hena ewicayakupi, qa iye qe mazasagye on ktepi: Unkan 394 winohinca ehna nina cajeyatapi, hena e woyaco ecakiconpi nakaeś.

11 Unkan tankaku Aholiba he wanyaka, hehan iś isanpa cantewicakiye cin om ihduśica, qa iye wawicihahapi tawa kin en cunku wawiciliahapi tawa qon isanpa econ.

12 Aśur cinca kiyedan unpi kin hena cantewicakiya, akicita tancan qa wicaśtayatapi oiyokipiya ihduzapi, śuktanka akicita śunka wakan akan iyotankapi ece.

1.3 Hehan iś eya ihduśica wanmdaka: hena napin canku wanjidan.

14 Unkan de qe wawicihahapi hduota: tiunnaptanyan wicaśta owapi wanyaka qehan, Kasdim oyate ouncagge kin waśeśa on owicawapi ;

15 Nite en ipiyake on ipiyagkitonpi, pa akan wateśdake śtedapi hinca, hena owasin wicaśtayatapi se ececa, Babel cinca Kasdim makoce en wicatonpi ouncage kin iyececa.

16 Unkan hena iśta on wanwicayaka qehan, hehan cantewicakiya, qa Kasdim ekta wahowicaye kta yewicaśi.

17 Unkan Babel cinca kin hena iye en hipi, tocantekiye ohehdepi kin entu, qa wiinahmanpi on yuśicapi; hecen iye qe hena om ihduśapa, hehan-hena etanhan naggi eihdaku.

18 Hecen wawicihahapi hdu tanin qa tancodan wanke cin hdutanin: Hehan iye etanhan miye minaği ewehdaku, cunku etanhan nagi emiçihdaku qon he iyececa.

19 Tuka nakun wawicihahapi hduota, wikośka anpetı qon kiksuyeiciye cin heon, he ehan Egupta makoce kin ohna witkowinna un qon. 


\section{WICOWOYAKE 23.}

20 Qa waśtewicadakapi qon hena cante en wicakiyuza, hena cehpi kin śonśonna celipi iyececa, qa tadeja kin śuktanka deje kin heca.

21 Hecen winikośka tośice qon he kiksuyeniciya, aze nitawa Fgupta wicaśta yutantanpi qehan, winikośka aze pinkpa nitawa kin hena on.

22 Heon etanhan, Aholiba, Jehowa Itancan kin hecen eya ce ; Iho, waśtenidakapi qon, tona ninaǵi śicewicadake cin hena nitkokim najinwicawakiye kta, qa ihdukśantanhan hena takpe niu wicawakiye $\mathrm{kta}$ :

23 Babel cinca qa Kasdim oyute kin ocowasin, akicita tancan, qa wijica, qa wicaśta ihdawa, Aśur cinca kin iyulipa om: owasin kośka oiyokipipi, akicita tancanpi, qa wicaśtayatapi, itancan tankapi qa kinihanpi ; iyuhpa śuktanka akan iyotankapi.

24 Unkan hena takpe niupi kta, wipe kiton, ozuye canpahmihma qa canpahmihma ikceka ohna, qa oyate wicota hinca om; ihdukśan maza-makuakalipe qa wahacanka qa ozuye wapaha nitkokim ehdepi kta: Unkan miye wicitokam woyaco ewahnake kta, hecen iye tawoyaco kin eciyatanhan niyacopi kta.

25 Nakun wowinawizi mitawa nitkokim ewehde kta; hecen hena e wocanniye on nicuwapi kta; nipoge qa ninogge hena eyakupi kta; qa onicaptapi kin hena mazasagye on hinhpayapi kta; hena nicinkśipi qa nicunkśipi iwicacupi kta; qa onicaptapi kin he peta on hulinaliyapi kta.

26 Nakun nitawokoyake kin niciyuśdokapi kta, qa oinpi waśteśte nitawa kin hena icupi kta.

27 Hecen nitośice kin he niye etanhan ayuśtanwakiye kta, qa wawicihahapi nitawa Egupta makoce kin etanhan qon: Heon etanhan hena ekta iśta yuwankan iyekcu kte śni, qa Egupta ake icimana yeksuye kte śni.

28 Jehowa Itancan kin hecen eya nakaeś; Iho, tona śicewicayadake cin nape kin en, qa tona etanhan ninagoi eyehdaku qon hena napepi kin en cicu kta:

29 Unkan hena wośicedake on ecaniconpi kta, qa wokamna nitawa ocowasin eniciyakupi kta, qa tancodan qa śdayehna ehpeniyanpi kta: hecen wawiciliahapi nitawa tancodan kin he yutaninpi kta, nitośice qa wawicihahapi nitawa nakun.

30 Ikcewicaśta wicihakam witkowinna idada heon, qa wakagapi tawapi on nihduśapa kin heon etanhan dena decen ecacicon kta.

31 Nicun tacanku kin ohnayan mayani, heon etanhan iye tawiyatke kin ninape en ewahnake kta ce.

32 Jehowa Itancan kin hecen eya ; Nicun tawiyatke temahentu qa tanka hinca etanhan niye datke kta: wowiliaha niyarpi kta qa waunnicapi kta: he utkanna ohnaka nakaeśs.

33 Witkopi qa woiyokiśice on winipi kta, wonihinciye qa wotakuni śni wiyatke kin on, nicun Samaria tawiyatke kin on.

34 Unkan niye datke kta qa dazoke kta, qa kamdecapi kin hena dahtalitake kta, qa aze bayehonhon kta: he miye e hecen epa nakaeś, Jehowa Itancan kin eya.

35 Heon etanhan Jehowa Itancan kin hecen eya ce; Miye amiyektonja, qa nilieyata ehpemayaya, heon etanhan nitośice qa wawicilahapi nitawa kin hena yecin kta ce. 


\section{EZEKIEL TAWOWAPI,}

36 Nakun Jehowa hemakiya; Wicaśta cinhintku, Ahola qa Aholiba hena niye wicadaco kta he: Han, wowahteśni tawapi kin hena owicakiciyaka wo :

37 Wawicilialiapi econpi ece, qa iye napepi ohna we yukan, qa wakagapi tawapi kin om wawicihahapi econpi, qa nakun iye cinhintkupi micitonpi kin hena iyepi on iyoopta iyayewicayapi, ihangwicayapi kta e heon.

38 Nakun de ecamiconpi ; anpetu wanjidan en tipi wakan mitawa kin he yuśapapi, qa anpetu okihpapi mitawa kin hena yuikcekapi ecee.

39 Tye cinhintkupi wakagiapi tawapi kin en wicakiktepi qehan, anpetu kin he en tipi wakan mitawa yuśapapi kta e en hipi : unkan iho, tipi mitawa cokaya hinca hecen econpi ecee.

40 Qa nakun tehantanhan wicaśta upi kta wahowicayayapi, hena ekta wahośiye wanji yeśipi ; unkan iho, hipi : Hena on nihdujaja, qa iśta yehdapa, qa oinpi on nihduwaśte;

41 Qa owinja waśte hinca akan idotanka, qa itokam wahna wotapi wan wiyeya yanka; unkan he akan wizite mitawa qa wisdaye mitawa kin hena eyahnaka.

42 Unkan wicota ozikiyapi ho kin he kici un; qa wicaśta om, hopuza etanhan wicaśta wakize sa witkopi kin heca awicaupi, qa hena mazahuhu isto en iyekiyapi, qa wateśdake owanyag waśte hinca wapaha kitonpi.

43 Hehan wawicihaliapi kin on ihduśilitin kin hewakiya; He kici wiinahmanpi econpi kta he, qa iye nakun.

44 Tukaś hena en iyayapi, winohinca witkowinna en yapi ece kin he iyececa; hecen Âhola qa 396
Aholiba winolinea witkowinpi kin hena en iyayapi.

. 45 Heon wicaśta owotanna kin hena e wicayacopi kta, witkowinpi tawoyaco kin eciyatanhan, qa winohinca we papsonpi ece kin tawoyaco kin eciyatanhan : hena witkowinpi, qa napepi ohna we yukan nakaeś.

46 Heon etanhan Jehowa Itancan kin hecen eya; Wicota hena takpe wicau wicawakiye kta, qa kakiświcayapi qa wawicakipi kta wicawaqu kta ce.

47 Unkan wicota kin he hena inyan on wicakininpi $\mathrm{kta}$, qa mazasagye tawapi on bawicaśpuśpupi kta; cinhintkupi qa cunwintkupi kin hena wicaktepi kta, qa tipi tawapi kin peta on huhnahyapi kta.

48 Hecen wośice makoce kin etanhan ayuśtanwakiye kta, qa winolinca owasin wośice nitawapi kin ohnayan econpi kte śni e onspewicakiyapi kta.

49 Unkan wośice nitawapi kin niye en aniupi kta, qa wakagapi nitawapi walitanipi kin hena yecinpi kta: qa Jehowa Itancan kin he miye e sdonyayapi kta ce.

\section{WICOW OYAKE 24.}

1 Ake waniyetu inapcinwanka, wi iwikcemna, wiyawapi iwikcemna en, Jehowa oie en mahi kin hecen eya :

2 Wicaśta cinhintku, anpetu caje kin owa wo, anpetu kin dee ; anpetu kin de en Babel wicaśtayatapi kin Jerusalem anatan.

3 Qa wiyacinpi wan tipi wawakipajin kin owicakiyaka wo, qa hewicakiya wo; Tehowa Itancan kin hecen eya ce; Cegga wan akan ehde wo; ehde wo, qa nakun mini en okaśtan wo:

4 Baśpuśpupi kin hena omna- 
yan wo, onśpaśpa waśteśte kin owasin, ceca qa amdo; huhu kahiniğapi kin hena on ojuya wo.

5 Optaye etanhan kahnigapi kin icu wo, qa nakun ilukuya huhu kin hena ohan wo, nilla ipilikiya wo; nakun ołna huhu kin śpanyanpi kta.

6 Heon etanhan Jehowa Itancan kin he hecen eya; Hehehe otonwe awewe kin, cegga tage hinyahin ohna yanka, qa tage kin ehpekiyapi śni: onśpaśpa kin hena yuze icu wo; he akan ihnuhan oeconna econpi kinhan.

7 Iye we kin cokaya yanka nakaeś ; imnija oinkpa kin akan ekihnaka; maka akan kpapson śni, hecen maka on akahpapi kta tuka.

8 Hecen watokiconpi kta on wocanteptanye icahikiye kta: miye qe iye we kin innija pa kin akan ewahnaka, hecen akalipapi kte śni.

9 Heon etanhan Jehowa Itancan kin hecen eya; Hehehe, otonwe awewe kin; nakun miye qe can ejupi tanka wakage kta ce. 10 Can ota aonpa wo, qa ideya wo, tado kin śpanyan wo, qa wapaya en ohnaka wo, nakun huhu kin hena guyapi kta.

11 Hehan cokadan petaga kin akan ehde wo, hecen mazaśa kin kate kta, qa gi kta, qa ohna tośice kin śdoyapi kta, ğgigi kin he hulinahyapi kta.

12 Nina htani kin on mdokite içiya, tuka gọigi kin ayuśtan śni ; gigi kin he peta en un kta.

13 Nitośape kin en wośice yukan: Ciyujaja tuka niyuskapi śni, heon etanhan icimana nitośape etanhan niyuskapi kte śni, mitocanteptanye niye en acicaśtan kta hehanyan.

14 Jehowa miye e hecen epa: ecetu kta, qa ecen ecamon kta; nawamni kte sni, qa wawakpatan kte śni, qa iyopemiçiye kte śni : nitacanku eciyatanhan "qa niohan kin eciyatanhan niyacopi kta, Jehowa Itancan kin eya.

15 Hehan Jehowa oie en mau kin he hecen eya :

16 Wicaśta cinhintku, iho, niiśta waśtekidake cin he makośica on eciciyaku kta: tuka anicipe kte śni qa ayakiceye kte sni, qa iśtamnihanpe aniu kte śni:

17 Comnihdazi, inina yanka, wicate cin on akiceyapi kag̉e śni wo ; wateśdake nitawa kin tekiśdaka wo, qa harpa hanpolihan wo, qa putinhin akahpekiton śni wo, qa wicaśta taaģuyapi kin yute śni wo.

18 Unkan hanhianna hehan oyate kin om wowahdaka; qa litayetu hehan mitawinohinca makița: unkan ihanlianna token econ maśipi kin ecen ecarnon.

19 Hehan oyate kin hemakiyapi ; Decen ecanon kin on, dena itokeca unyakonpi kta hecinhan unkoyakidakapi kte śni he.

20 Hehan awicamdupta; Jehowa oie en mau kin he hecen eya ce :

21 Israel tiyohnaka kin hewicakiya wo; Jehowa Itancan kin hecen eya ce; Iho, tipi wakan mitawa kin he wahduśape kta, nitowaśakepi woiyokipi kin, niiśtapi towaśtedake, qa taku ninagipi kpatan kin hee; qa nicinkśipi qa nicunkśipi ehpewicayayapi kin hena mazasagye on hinhipayapi kta ce.

22 Kinhan miye ecamon kin iyecen ecanonpi kta; putinhin ayahdahpapi kte śni, qa wicaśta tokeca aguyapi tawa kin yatapi kte śni.

23 Tuka wateśdake kiton yaunpi kta, qa nisiha en hanpoyaki$39 \%$ 


\section{EZEKIEL TAWOWAPI,}

hanpi kta ; aniçipapi kte śni, qa yaseyapi kte śni ; tuka wayahtanipi kin on hanyan yaunpi kta, qa wicaśta otoiyohi ayeciceyapi kta.

24 Hecen Ezekiel wowakta duhapi : Iye taku econ kin owasin iyecen niye ecanonpi kta: Unkan de iyecetu kinhan, hehan Jehowa Itancan kin he miye e sdonyayapi kta ce.

25 Nakun niye, wicaśta cinhintku, anpetu kin en tohan iye towaśakepi, iye towitanpi wowiyuśkin, iye iśtapi towaśtedake, qa taku iye nagipi awacinpi, cinhintkupi qa cunwintkupi ewicaweciyaku kinhan;

26 Anpetu kin he en tuwe najice cinhan, noge on nahonniye kta on en niu lite śni he.

27 Anpetu kin he en turve najica hi kin he nii kiyukawapi kta; qa niye iyae kta, qa icimana ia okitpani yaun kte śni: Hecen wowakta wicakici yaun kta; unkan Jehowa he miye e sdonyapi kta ce.

\section{WICOWOYAKE 25.}

1 Hehan Jehowa oie en mau kin he hecen eya:

2 Wicaśta cinhintku, Ammon cinca kin itkowicakim niite ekihde wo, qa hena on woyaka wo:

3 Qa Ammon cinca kin hervicakiya wo; Jehowa Itancan oie kin nahon po; Jehowa Itancan kin he hecen eya ce; Tipi wakan mitawa yuśapapi qehan, qa Israel makoce hewoskan ehpeyapi, qa Juda tiyohnaka wayaka awicayapi qehan, niye, Aha, eha ece: 4 Heon etanhan, iho, wiyohiyanpata cinca kin tawaniyanpi kta on niyuhewicawakiye kta; unkan niye en conkaśke eiçihdepi kta; qa niye en tipi içicağapi 398 kta, nitawaskuyeca kin hena yutapi kta, qa asanpi nitawa he yatkanpi kta.

5 Unkan Rabbah kamel tipi heca wakage kta, qa Ammon cinca kin optaye owanka heca kta: Hecen Jehowa he miye e sdonyayapi kta ce.

6 Jehowa Itancan kin hecen eya ce; Nape yahdaskaskapa, qa siha on nayatantan, qa naği en nitowahanhanicida ocowasin on Israel makoce kin itkom widuśkinśkin ;

7 Heon etanhan, iho, minape niye awahdumdaye kta, qa wokipi on lkcewicaśta oyate kin niyuhe wicawakiye kta; qa oyate etanhan cicalsse kta, qa makoce kin etanhan atakuniśni iyayeciye kta: Ocowasin ihangciye kta; unkan Jehowa he miye e sdonyaye kta ce.

8 Jehorva Itancan kin hecen eya ce; Moab qa Seir, Iho Juda tiyohnaka kin Ikcewicaśta owasin iyececa ce, eyapi ece;

9 Heon etanhan, iho, Moab unnaptanyan kin mdúlidoke $\mathrm{kta}$, otonwe kin itoopteya, iye ihanke otonwe lin en, makoce towitan kin hena ee, Beth-jeśimoth, Baalmeon qa Kiriathaim,

10 Ammon cinca kin hena om, wiyohiyanpata cinca wicawaqu kta; qa hena tawawicayapi kta wicawaqu kta; hecen oyate wicehna Ammon cinca kin wicalkiksuyapi kte śni.

11 Nakun Moab en woyaco ecamon kta; hecen Jehowa he miye e sdonyapi kta.

12 Jehowa Itancan kin hecen eya; Edom watokiçonpi on Israel tiyohnaka kin ecawicakicon, qa woahtani on wahtani, qa iyepi en watoiçiçon nakaeś ;

13 Heon etanhan Jehowa Itancan kin hecen eya ce; Miye qe 


\section{WICOWOYAKE 26.}

nakun minape Edom awahdumdaye kta, qa etanhan wicaśta woteca ko wakaśpe kta; qa Teman hetanhan hewoskan wakagge kta, qa Dedan mazasagye on hinhpayapi kta.

14 Qa mitaoyate Israel nape on, watokiconpi mitawa Edom akan ewahnake kta: unkan hena e mitocanniye eciyatanhan qa mitocanteptanye kin iyecen Edom en econpi kta: qa hena watokiconpi mitawa sdonyapi lita ce, Jehowa Itancan kin eya.

15 Jehowa Itancan kin hecen eya ce ; Philistine oyate kin watokiconpi eciyatanhan econpi, qa naği en wahanhanicidaya watoiciçonpi, tannina wośicedake on waihangyapi kta.:

16 Heon etanhan Jehowa Itancan kin hecen eya ce: Iho, minape Philistine oyate kin awicawahdumdaye kta, qa Kerethim wicawakakse kta, qa mini icahda okaptapi qon hena ihangwicawaye kta.

17 Qa hena en watokiconpi tanka ecamon kta, wocanniye woiyopeye koya: unkan watokiconpi mitawa iyepi aewicawahnake cinhan, hehan Jehowa he miye e sdonyapi kta ce.

\section{WICOWOYAKE 26.}

1 Unkan kaketu, waniyetu iakewanji, wiyawapi tokaheya kin en Jehowa oie en máu kin he hecen eya:

2 Tyrus Jerusalem itkom, Aha, eciya; tuwe oyate tatiyopa hee qon he yujujupi; miye ekta ihdou; iye ihangyapi, miye ojumayanpi kta ce.

3 Heon etanhan Jehowa Itancan kin hecen eya; Tho, Tyrus, miye nitkokim waun, qa oyate ota takpe niu wicawakiye kta, miniwanca kin taja tawa wankan hiyukiya iyececa.

4 Unkan hena e Tyrus conkaśke kin ihangyapi kta, qa conkaśke tehanwankantu kin hena yujujupi kta: Nakun miye hetanhan maka mdu kin wakahinte kta, qa imnija puza kin iyecen wakag̉e kta.

5 Miniwanca cokaya ohna ho yumdayapi ece kin heca kta. Miye qe hecen epa nakaeś, Jchowa Itancan kin eya: Unkan he Ikcewicaśta womanon tawapi ee kta.

6 Unkan cunwintkupi hutata unpi kin hena mazasagye on wicaktepi kta: qa hena e Jehowa he miye e sdonyapi kta.

7 Jehowa Itancan kin kaken eya nakaeś; Tho, Nebukadnezzar Babel wicaśtayatapi kin he Tyrus takpe u wakiye kta; waziyata ekta wicaśtayatapi en wicaśtayatapi heca; suktanka qa canpahmihma koya; qa śuktanka akan yotankapi, qa wicobe, qa oyate ota om.

8 Hutata nicunkśipi kin hena mazasagye on wicakte kta: qa niye en conkaśke wan akağe kta, qa niye en pahaha ehnake kta, qa niye itokam wahacanka yuwankan iyeye kta.

9 Qa ibohtake kin conkaśke nitawa itokam ekihde kta, qa conkaśke tehanwankantu nitawa kin hena taonspe on kawanke kta.

10 Śunka wakan tawa kin ota hinca, heon maka mdu on akahpe niyanpi kta: Śuktanka akan yotankapi, qa canpahmihma, qa ozuye canpahmihma hopi kin on conkaśke nitawa huhuzahe kta, tohan nitatiyopa mahen iyaye cinhan, otonwe wan obomdecapi kin ohna wicaśta tin iyayapi kin iyececa.

11 Śunkawakan tawa sake kin 399 


\section{EZEKIEL TAWOWAPI,}

on nitacanku owasin nasuta kta: nitaoyate kin mazasagye on wicakte kta, qa conkaśke suksuta nitawa kin hena makata iyaye kta.

12 Unkan hena nitowijice kin nicipi kta, qa maza nitawa kin iyahpayapi kta: qa conkaślke nitawa kin hena yujujupi kta, qa tipi waśteśte nitawa kin hena ihangyapi kta: nakun inyan nitawa, qa can nitawa, qa maka mdu njtawa mini cokaya ehnakapi kta.

13 Unkan nitadowan ho kin ayuśtanwakiye kta, qa candowankiyapi nitawa ho kin he icimana nahonpi kte śni.

14. Qa imnija puza kin iyecen cicagge kta: tnkten ho ayumdayapi ece kta henica kta: ake piya nicagiapi kte śni: Jehowa miye hecen epa nakaeś, Jehowa Itancan kin eya.

15 Jehowa Itancan kin he Tyrus heciya; Tohan tawicaopi śicahorvayapi, tohan nicokaya wicaktepi kağapi kinhan, hehan nihinhpaya lo kin on wita kin cancanpi kte śni he.

16 Hehan miniwanca wicaśtayatapi kin owasin iye toiyotankepi kin etanhan kun upi kta, qa taśina ekihnakapi kta, qa wokoyake hdeśkaślka kin hduśdokapi kta: hena wocancan koyakapi ktá: makata iyotankapi kta, qa ihnuhanna cancanpi kta, qa niye on nihinciyapi kta.

17 Unkan hena woceye odowan wan inicicupi kta qa heniciyapi kta; Miniwanca tawicaśta : en ounniyanpi kin, token ihangniyanpi he ; otonwe idowanpi ece, iye qa en ounyanpi kin hena, miniwanca kin ohna. waśakapi qon, ohna tipi kin iyuhpa wakokipe wicakicagapi ecee tuka.

18 Wanna anpetu en nihinlipa- ye cinhan, wita kin hena cancanpi kta; han, miniwanca wita kin hena, taku ayakipe cin on nihinciyapi kta.

19 Jehowa Itancan kin hecen eya nakaeś; 'Tohan otonwe otiwota cicage cinhan, otonwe en ounyanpi śni iyececa; tohan mini śma kin niye en awau kinhan, qa mini tanka kin hena anicalipe cinhan;

20 Hehan kun elipeciye kta, tona woha kin ekta yapi kin hena om, oyate wanakaja kin hena om, qa maka cetete kin ekta ecihnake kta, owanka tvanakaja hewoskantu lin en, tona woha kin ekta iyayapi kin hena om, hecen icimana en ounniyanpi kte śni : tuka wiconi makoce kin ohna wowaśte ewehde kta:

21 Wokokipe cicagge kta, qa en yaun kte śni: han onidepi kta, tuka ake iyeniyanpi kte śni, owihanke wanica, Jehowa Itancan kin eya.

\section{WICOWOYAKE 27.}

1 Hehan Jehowa oie en mau kin he hecen eya:

2 Wanna, wicaśta cinhintku, Tyrus on woceye wan yawankan iyeya wo:

3 Qa Tyrus heciya wo; Miniwanca oiyaye en enihdepi, wita ota taoyate on wopetonna henica, Jehowa Itancan kin hecen eya; Tyrus niye, Owanyake waśte en mayuśtanpi ce, eha ece.

4 Makoce opapun nitawa miniwanca cante ekta yanka; ticagapi nitawa kin hena nitowaśte niciyuśtanpi :

5 Wata akahpe nitawa kin hena owasin Senir wazi can on kagiapi: Lebanon etanhan hante śa icupi, on wita wata ihupa nicicagapi kta: 


\section{WICOWOYAKE $2 \%$.}

6 Baśan utuhu kin hena on wamnaheca nicagapi; Kittim wita etanhan Śserbin hante śa cunwintku, huhu kin he on akan iyotankapi kin nicagapi :

7 Egupta etanhan miniliuha ska hdeśkaśka ko he wiyolihedan nitawa kta dumdaya: Eliśa wita etanhan taku to qa śa stan kin heca on anihdahpa ece.

8 Zidon qa Arrad en ounyanpi watopapi nitawa kin heepi : $\mathrm{Ty}$ rus, tona wacinksapa en niunpi kin hena iyupse yuzapi nitawa eepi.

9 Gebal etanhan wicaśta tanka qa wacinksapa en niumpi kin hena watopuskicapi nitawa: Miniwanca wita wata iyulipa qa tona watopapi kin hena en niunpi, maza nitawa wiyopeyapi kta heon.

10 Pares qa Lud qa Put etanhanpi kin hena ozuye nitawa en unpi, hena akicita nitawa: hena wahacanka qa maku akahpe kin niye en otkeyapi ecee; hena nitowitan kin yutaninpi.

11 Arvad cinca qa nitaakicita kin hena conkaśke nitawa ihdukśan wanke cin akan unpi, qa akicita wohitikapi kin hena conkaśke tehanwankantu nitawa ohna yakonpi ecee: hena ihdukśan conkaślke nitawa en wahacanka tawapi otkeyapi: hena owanyag niwaśte kin yuśtanpi hinca.

12 Tarśiś he wopetonna nitawa ee, wowijice ocaje owasin en ; mazaska, mazasapa, mazaikceka qa mazasu, hena mazopiye nitawa ohna ehnakapi ece.

13 Javan, Tubal qa Meśek, hena wopeton nitawa; hena wicaśta nagiipi qa mazaśa ceg̣a hena wopeton tipi nitawa ohna ehnakapi ecee.

14 Togarma tipi etanhan hena śuktanka qa ozuye śuktanka qa śonśonna kin hena mazopiye nitawa ohna ehnakapi ece.

15 Dedan cinca kin wicaśta wopeton nitawa eepi; wita ota hena ninape wiyopeyapi kin hee; hena taku nicupi, huhu qa inyancan kin nicahipi ece.

16 Taku ikicanye ota hinca yakagie cin heon Aram wopetonna nitawa ee: hena e inyan tehike, witoye, qa taku hdeśkaśka, qa miniliuha ska, qa taku opetonpi telika, qa inyan wiyatpatpa kin hena wopeton tipi nitawa en ehnakapi ecee.

17 Juda qa Israel makoce kin hena wopetonna nitawa eepi : hena ağuyapi su Minnith etanhan, qa ağuyapi skuskuya, qa tuhmaga canhanpi, qa wihdi, qa canśin hena wopeton tipi nitawa kin en ehnakapi ece.

18 Damasek wopetonna nitawa ee, taku ota yakage cin on, wowijice owasin ota hinca on: miniśa Helbon etanhan, qa talinca hin skaska kin hena on.

19 Vedan qa Javan taku pahmonpi kin wopeton tipi nitawa en'ahihnakapi ece: mazasapa kamdaskapi, canhaśa qa sinkpe tawote, hena mazopiye nitawa en un.

20 Dedan wopetonna nitawa ee; canpahmihma ozanpi waśte hinca kin hena on.

21 Arabia qa Kedar itancanpi kin hena owasin tacinca, qa tamdoka, qa tatokadan, hena niye en alihnakapi; hena en wopetomna nitawa kin heepi.

22 Śba qa Raama en wopetonpi kin hena wopetonna nitawa eepi: hena mazopiye nitawa ohna taku iyotan waśtemna kin owasin, qa inyan tehike ocaje owasin, qa mazaskazi hena ahihnakapi ece.

23 Haran, qa Kanne, qa Eden, 401 


\section{EZEKIEL TAWOWAPI,}

Seba, Aśur Kilmad wopeton tawapi kin hena wopetonna nitawa.

24 Dena wopetonna nitawa eepi, maza waśteśte en, śina toto qa hdeśkaśka kin en, qa wokoyake hdehdezedan canwohnaka hahonta on yuskiskitapi qa hanteśa on kag̉api kin hena ohnahna, hena maza nitawa ehna un.

25 Tarśiś wita wata kin hena wopeton tipi nitawa en waoniciyapi: hecen miniwanca cante kin en ojuniyanpi, qa niyuwitanpi hinca.

26 Watopapi nitawa kin hena mini tanka ekta aniyanpi: wiyohiyanpata tate kin he nicamdemdeca, miniwanca cante kin ekta.

27 Nitowijice, qa mazopiye nitawa, maza nitawa, watopapi nitawa, qa iyupse yuzapi nitawa, watopuskicapi nitawa, qa maza iyopeyapi wicaduhe cin hena, qa ozuye wicaśta nitawa en niunpi kin iyuhpa, qa omniciye nitawa ocowasin nicokaya unpi kin hena, miniwanca cokaya iyohpayapi kta, anpetu en ihangniyanpi kinhan.

28 Iyupse yuzapi nitawa śicahowayapi ho kin on tinta ihdukśan wanke cin he rahuhuza kta.

$29 \mathrm{Qa}$ tona wamnaheca unpi owasin, watopapi kin hena; miniwanca en iyupse yuzapi kin iyuhpa wita wata kin etanhan kun hdicupi $\mathrm{kta}$, hena makata hdinajinpi kta :

30 Qa niye on ho hdaotaninpi kta, qa nina śicahowayapi kta, qa maka mdu pa ahdadapi kta; hena caliota ohna paptanptan iyeiciyapi kta :

31 Qa niye on ocowasin nasuśda içcağapi kta, qa wakihdaka ipiyag kitonpi kta, qa nina cante- śicapi on aniceyapi kta, woceye tehike hinca on.

$32 \mathrm{Qa}$ ceyapi en niye on woceye odowan wan yawankan iyeyapi kta, qa niye aniciceyapi kta; Tyrus taku iyececa he; miniwanca cokaya ihangyapi kin he taku iyececa he.

33 Maza nitawa miniwanca kin etanhan hiyaye ciqon, hehan oyate ota ojuwicayaya ecee : nitowijice ota hinca qa taku iyopeyaye ciqon hena on maka wicaśtayatapi kin wijinwicayaya ecee qon.

34 Tohan miniwanca kin on, mini śbe hinca en nicamdemdecapi kinhan, taku iyopeyaya ece kin, qa wicota nitawa iyuhpa nicokaya hinhpayapi kta.

35 Wita en ounyanpi kin hena owasin niye on nilinciyapi kta, qa wicaśtaya tapi tawapi kin hena nina kopehdapi kta; hena itepi en cancanpi kta.

36 Ikcewicaśta ehnahna wicaśta wopeton kin hena anijijipi kta: wokokipe yaun kta, qa ake icimanna en yaun kte śni ce.

\section{WICOWOYAKE 28.}

1 Hehan Jehowa oie en mau kin hecen eya :

2 Wicaśta cinhintku, Tyrus wicaśtayatapi kin heciya wo; Jehowa Itancan kin hecen eya ce; Nicante wankan iyeiciya, qa, Taku Wakan hemaca, 'Taku Wakan toiyotanke kin en imdotanka, miniwanca cante kin en, eha ecee: tuka wicaśta herica, qa taku wakan śni, Taku Wakan cante kin iyecen nicante eniçihnaka eśta.

3 Tho, Daniel isanpa niye yaksapa, woinahbe takudan niye etanhan natakapi śni.

4 Nitoksape qa nitookahing gin 


\section{WICOWOYAKE 28.}

on wowijice niçicag̉a, qa mazaskazi mazaska ko mazopiye nitawa ohna mnayakiya.

5 Nitoksape tanka on, wopeton yaun kin on nitowijice yahduota; qa nitowijice kin on etanhan nicante wankan iyeiçiya ece.

6 Heon etanhan Jehowa Itancan kin he hecen eya ce; Nicante kin Taku Wakan cante kin iyecen eniçihnaka nakaeś ;

7 Heon etanhan, iho, wicaśta tokeca niye en awicawau kta, ovate wohitikapi : Unkan hena nitoksape oiyokipi kin on mazasagye hduśdokapi kta, qa nitowiyatpatpa kin he yuśapapi kta.

8 Hena woha kin en anihipi kta, qa miniwanca cante en wicaktepi wiconte kin he on niye nite kta.

9 Tuwe nikte kte cin itokam, Taku Wakan kin he miye ce, ehe kta he : Tuka wicaśta henica, qa taku wakan śni, tuwe nikte kta nape ohna.

10 Wicaśta tokeca nape on, ohomni bahdayapi śni wiconte kin on nite kta: He miye e hecen epa nakaeś, Jehowa Itancan kin eya.

11 Nakun Jehowa oie en mau kin he hecen eya :

12 Wicaśta cinhintku, Tyrus wicaśtayatapi kin on woceye odowan wan yawankan icu wo, qa heciya wo; Jehowa Itancan kin hecen eya ce; Woksape ojudan, qa wowaśte oiyokipi hinca niye woojudall kin askamyaya.

13 Eden Wakantanka tawoju kin en yaun; inyan tehihike cin owasin woakahpe nitawa ee, inyan śa (sardius) inyan zi (topaz), qa inyan kohdihdi (diamond), inyan tehike (beryl), inyan wicaśake iyececa (onyx), qa inyan śduśduta (jasper), inyan oiyokipi (sapphire), inyan toto (emerald), qa inyan wiykpakpa (carbuncle), qa mazaskazi : oyulidoke qa oyuśtanpi nitawa okagjapi kin he anpetu en nicag̉api qehan, niye en wiyeya ehnakapi qon.

14 Kerub sdayapi waakahpe cin he niye: unkan miye ecihnaka: lie wakan Wakantanka tawa kin he akan yaun; peta inyan kin ehnahna icicawin mayani ecee.

15 Anpetu en nicagogapi kin ehantanhan nitacanku kin ohna niyuśtanpi hinca, wośice en niun iyeyapi śni hehanyan.

16 Wiyopeyapi ota nitawa kin on etanhan nicokaya wośice ojuniyanpi ; hehan wayahtani: Heon etanhan he Wakantanka tawe etanhan taku śapa iyecen kun elipeciye kta: Nakur, kerub waakahpe, peta inyan kin cokaya tanhan ihangciye kta.

17 Owanyag niwaśte on nicante wankan iyeiçiya: nitowiyatpatpa kin on nitoksape kin yahduśica : Miye qe makata ehpeciye kta; wicaśtayatapi wicitokam ecihnake kta, hecen wanniyakapi kta.

18 Wośice ota nitawa kin on, wiyopeyapi nitawa wośice kin on tipi wakan nitawa kin hena ya. hduśapa: heon etanhan nicokaya tanhan peta wan hinanpe waye kta; he qe hulinahniye kta, hecen maka akan cahota cicage $\mathrm{kta}$, tona wanniyakapi owasin iśtapi kin itokam.

19 Tona oyate kin ehma sdonniyanpi kin hena owasin niye on nihinciyapi kta: wokokipe yaun kta; qa ake icimana en yaun kte śni ce.

20 Hehan Jehowa oie en mau kin he hecen eya :

21 Wicaśta cinhintku, niite Zidon itkokim ekihnaka wo, qa he on woyaka wo;

22 Qa heya wo: Jehowa Itancan kin hecen eya ce; Iho, Zi403 


\section{EZEKIEL TAWOWAPT,}

don nitkokim waun : qa nicokaya mihduwitan kta: Unkan tohan he en woyaco ecamon, qa he en mihduwakan kinhan, hehan Jehowa he miye e sdonyapi kta ce. - $23 \mathrm{He}$ en makośica yewaśi kta nakaeś, qa we, iye tacankupi kin ohna: unkan ihdukśan mazasagye kin on iye cokaya tawicaopi kin hena hinhpayapi kta: Unkan Jehowa he miye e sdonyapi kta ce.

24. Unkan ake icimana Israel tiyohnaka kin en wapepeka wacape, qa canpepe iyoliśinwicaye cin wanice kta, tona wicihdukśan wanke ciqon, qa śicewicadakapi qon owasin etanhan. Unkan hena Jehowa Itancan kin he miye e sdonyapi kta ce.

.25 Jehowa Itancan kin he hecen eya; Tohan Israel tiyohnaka kin oyate ehnahna iyaye wicayapi qon hetanhan wicawapahi kinhan, qa Ikcewicaśta iśtapi itokam hena en mayuwakanpi kinban, hehan makoce tawapi, mitaokiye Jakob waqu qon he en ounyanpi kta.

$26 \mathrm{Qa}$ wilkopeśniyan hen unpi kta, qa tipi içicagapi kta, qa hastanhanka iyuwi ojupi kin hena okikjupi kta : han, wikopeśniyan en unpi kta, tohan tona wicihdukśan śicewicadakapi qon hena owasin en woyaco ecamon kinhan. Unkan Jehowa Taku Wakan tawapi kin he miye e sdonyapi lita ce.

\section{WICOWOYAKF 29.}

1 Waniyetu iwikcemna, wi iwikcemna, wiyawapi iakenonpa, hehan Jehowa oie en mau kin he hecen eya:

2 Wicaśta cinhintku, niite Pharaoh Egupta wicaśtayatapi kin itkokim ekihde wo, qa he on 404 woyaka wo, qa Egupta ocowasin on :

3 Ie ca heya wo, Jehowa Itancan kin hecen eya ce ; Tho, Pharaoh Egupta wicaśtayatapi, citkokim waun, wanmduśka śa tanka tawakpa kin cokahan iwanka, Mitawakpa kin he miye mitawa, qa he miye miçicaga ce, eya ecee.

4 'Tuka iyolia nitawa ohna hinśkijupi iyewaye kta, qa nitawakpa hoggan kin hena hoceśpu nitawa en askape wicawakiye ista ; qa wakpa nitawa cokayatanhan ciyupsice kta : unkan nitawakpa hogan kin iyuhipa hoceśpu nitawa en askape kta.

5 Unkan hewostan ehpeciye kta, niye qa nitawakpa hogan kin iyuhpa nakun : tintoskan nihinlipaye kta; niyuwitayapi kte śni qa nipahipi kte śni: maka wamanica qa mahpiya okinyanpi tawoyute cicaga.

6 Hecen Egupta en ounyanpi kin owasin Jehowa he miye e sdonyapi kta: hena e Israel tiyohnaka ekta cedi sagye kin hecapi nakaeś :

7 Nape en niyuzapi qehan nipawegapi, qa amdo ocowasin wicayeciyupśun ; qa sagye niyanpi qehan nipaksaksapi, qa iye nitepi owasin cancanwicayakiya.

8 Heon etanhan Jehowa Itancan kin hecen eya; Iho, mazasagye wan niye en awau kta, qa enitanhan wicaśta woteca ko ihangwaye kta ce.

9 Unkan Egupta makoce kin hewoskan qa hopuza kta: qa hena Jehowa he miye e sdonyapi kta: Wakpa kin he mitawa, qa miye wakagga ce, eye cin heon etanhan.

10 Heon etanhan iho, miye nitkokim waun, qa nitawakpa kin itkokim waun, qa Egupta ma- 
koce kin ocowasin hopuza hewoskan wakage kta, Syenne conkaśke kin hetanhan, qa Kuś ihanke kin hehanyan :

11 Wicaśta siha kin he ehna mani kte śni, qa woteca siha kin ohna ye kte śni, qa waniyetu wikcemna topa hehanyan en ounyanpi kte śni.

$12 \mathrm{Qa}$ inakoee hewoskan wanke cin hena ehna Egupta makoce kin otiwita wakage kta, qa otonwe ihangyapi kin opeya iye totonwe kin otiwita wanke kta, waniyetu wikcemna topa hehanyan : qa Egupta wicaśta kin hena oyate kin ehnahna iyaye wicawaye kta, qa makoce kin elktakta yewicawakiye kta ce.

13 Tuka Jehowa Itancan kin kaken eya; Waniyetu wikcemna topa henakeca kinhan, Egupta oyate kin oyate ehnahna iyayewicayapi qon hetanhan ake mnawicawaye kta :

14 Qa Egupta ounhdaka un qon he awaku kta, qa Pathros makoce kin, makoce en icagapi qon he ekta hdicuwicawakiye kta: Unkan hen wokiconze kun wanke cin hecapi kta :

15 Wokiconzepi kin isanpa he kun un kta; qa ąke icimana oyate kin wiciwankam iyeiciye kte śni; qa wicamdutonana kta, hecen icimana oyate kin wowidagwicayapi kte śni.

16 Unkan hetanhan icimana Israel tiyohnaka wowacinye tawapi, wicihakam etonwanpi eca woahtani kiksuyeyapi ecee kin hee kte śni : Tuka Jehowa Itancan kin he miye esdonyapi kta ce.

17 Unkan kaketu, waniyetu wikcemna nonpa sanpa is̉akowin, wi tokaheya, wiyawapi tokaheya kin he en Jehowa oie en mau kin he hecen eya :

18 Wicaśta cinhintku, Nebukad- nezzar Babel wicaśtayatapi kin he takicita kin Tyrus on woecon tanka econwicawakiya; wicapa owasin nasuśda kag̣api, qa wicahinyete iyuhipa ha paśdolapi : tuka Tyrus on wokajuju takudan yuhe śni, iye qa taakicita kin, wicolitani on econpi qon heon.

19 Heon etanhan Jehowa Itancan kin hecen eya; Iho, Egupta makoce kin Nebukadnezzar waqu lita; unkan wicota tawa kin hena iwicacu kta, qa wokipi tawa wicaki kta, qa womanon tawa kin makinon kta; unkan he taakicita wokajuju tawapi kin ee kita.

20 Iye tolitani, he en hitani qon he on Egupta makoce kin waqu, litamicinipi nakaeś, J ehowa Itancan kin eya.

21 Anpetu kin he en Israel tiyohnaka he kin he icahwakiye kta; qa hena wicacokaya i hdukawapi kte cin he cicu kta: Unkan hena Jehowa he miye e sdonyapi kta cee.

\section{WICOWOYAKE 30.}

1 Hehan Jehowa oie en mau kin he hecen eya:

2 Wicaśta cinhintku, woyaka wo, qa heya wo ; Jehowa Itancan kin hecen eya ce; Śicahowaya po; Hehehe anpetu kin:

3 Anpetu kin kiyedan nakaeś ; han, anpetu kin kiyedan; Jeho. wa taanpetu kin he amahpiya; he qe Ikcewicaśta taanpetu kin hee kta.

4 Hehan mazasagye wan Egupta en hi kta; qa hokśiksuya woyazan kin he Kuś en un kta; wicaktepi Egupta ohna hinhpayapi kinhan; unkan wicota tawa kin hena iwicacupi kta, qa oahehde tawa kin yujujupi kta. 
5 Kuś qa Put qa Lud, qa oyate tokeca owasin, qa Cub, qa makoce odakonyapi cinca lin hena owicapeya mazasagye kin on hinhpayapi kta.

6 Jehowa hecen eya; Nakun tona Egupta okiyapi kin hena hinhpayapi kta: qa towaśake wowitan kin he kun u kta : Syenne conkaśke kin hetanhan, he ohna mazasagye on hinhpayapi kta ce, Jehowa Itancan kin eya.

7 Unkan makoce hewoskan wanke cin wicacokaya hena hewoskan wanke kta; qa totonwe kin hena otonwe ihangyapi kin hena cokaya wanke kta.

8 Unkan Egupta en peta wan wakage cinhan, qa tona okiyapi qon iyuhipa ihangyapi kinhan, hehan Jehowa he miye e sdonyapi kta ce.

9 Anpetu kin he en wita wata ohna wahośiye mitantanhan yapi kta, Kuś oyate wikopeśniyan unpi wakokipe wicakicağapi kta; unkan hokśiksuye woyazan kin en awicau kta, Egupta taanpetu qon iyececa: Iho, wanna u nakaeś.

10 Jehowa Itancan kin hecen eya; Nakun Egupta wicota kin, Nebukadnezzar Babel wicaśtayatapi nape on, yuwanin wicawakiye kta ce.

11 Iye qa taoyate, Ikcewicaśta ehna wohitikapi kin hena, makoce kin ihangyapi kta on uwicakiyapi kta: Unkan mazasagye Egupta ayuśdokapi kta, qa wicaktepi kin on makoce lrin ojuyapi kta.

12 Unkan wakpa kin hena puza wakag̉e kta, qa wicaśta śica napepi en makoce kin wiyopeya waqu kta; qa oyate tokeca napepi on makoce kin hewoskan wakag̉e kta, qa taku en un kin ocowasin : Jehowa miś miye hinca hecen epa.
13 Jehowa Itancan kin hecen eya; Nakun wakagapi kin hena ihangwaye kta, qa takuśniśni kin hena Noph etanhan ayuśtanwakiye kta ; qa Egupta makoce kin etanhan icimana wicaśta itancan yuke kte śni : qa Egupta makoce lkin en wokokipe wan ewahnake kta.

14 Nakun Pathros hewoskan wakag̉e kta, qa Żoan en peta wan wakage kta, qa No en woyaco ecamon kta.

15 Qa Sin Egupta towaśake kin mitocanteptanye awakaśtan kta; qa No wicota tawa kin awihnuniwicawaye kta.

16 Qa Egupta en peta wakage kta; Sin nina yazan hda kta, qa No kicaksapi kta, qa Noph en anpetu iyohi woiyokiśice yuke kta.

17 Aven qa Pi-beseth kośkapi kin hena mazasagye on hinlipayapi kta, qa hena wayaka awicayapi kta.

18 Nakun Tehapnehes en anpetu kin otpaza kta, tohan hen Egupta cannapinpi tawa mduksaksa kte cinhan: unkan he ohna towaśake wahanicida kin he ayuśtan kta: iye qe mahpiya śapa wan akahpe kta, qa cunwintkuwicaye cin hena wayaka yapi kta.

19 Hecen Egupta en woyaco ecamon kta; qa hena Jehowa he miye e sdonyapi kta ce.

20 Hehan kaketu, waniyetu iakewanjidan, wi tokaheya, wiyawapi iśakowin kin en, Jehowa oie en mau kin he hecen eya:

21 Wicaśta cinhintku, Pharaoh Egupta wicaśtayatapi isto kin mduwegga; unkan iho, okiziyapi kta on yuskiskitapi kte śni, ipahte ehnakapi on pahtapi kta, mazasagye yuze kta on yuwaśake kte śni. 


\section{WICOWOYAKE 31.}

22 Heon etanhan Jehowa Itancan kin hecen eya ce; Iho, Pharaoh Egupta wicaśtayatapi kin itkokim waun, qa isto weciyulisaksa kta, waśake cin he, qa yuwegapi qon he nakun; qa iye nape kin etanhan mazasagye kin hinhpaye wayc kta.

:3 Qa Egupta oyate kin Ikcewicaśta kin ehnahna iyayewicawaye kta, qa makoce ektakta enanakiya yewicawakiye kta.

$24 \mathrm{Qa}$ Babel wicaśtayatapi isto kin mduwaśake kta, qa mazasagye mitawa iye nape kin en ewahnake kta: Tuka Pharaoh isto kin mduksaksa kta, unkan wicaśta taopi śicahowaye cin on itokam śicahowaye kta.

$25 \mathrm{Han}$, Babel wicaśtayatapi isto kin mdusuta kta, tuka Pharaoh isto kin hinhpaye kta: Unkan tohan Babel wicaśtayatapi nape kin en mazasagye mitawa cwahnake, ça he Egupta makoce kin ayugate cinhan, hchan Jehowa he miye e sdonyapi kta ce.

26 Unkan Egupta oyate kin Ikcewicaśta ehnahna iyayewicawaye kta, qa makoce ektakta enanakiya yewicawakiye kta; hecen Jehowa he miye e sdonyapi kta ce.

\section{WICOWOYAKE 31.}

1 Hehan kaketu, waniyetu iakewanji, wi iyamni, wiyawapi anpetu tokaheya kin en Jehowa oie en mau kin he hecen eya:

2 Wicaśta cinhintku, Pharaoh Egupta wicaśtayatapi, qa wicota tawa kin hena hewicakiya wo; Tanka yaun kin en tuwe iyeniceca he.

3 Iho, Aśur Lebanon en hante śa adetka waśteśte kin heca, qa contanka ohanzi, qa tehanwan- kan icagia; qa oinkpa kin he canwapośbe hinca:

4. Mini kin hena he tanka kağapi ; mini ośbe kin yuwarlkan ehde, tawakpa kin ojupi tawa ohomni ahiyaya ece kin he on, qa tawakpadan kin omdaye can lin owasin ektakta iyayeya cce.

5 Heon etanhan tohanske lkin omdaye can kin owasin iwankam iyeyapi, qa taadetka kin hena yuotapi, qa adetka tawa icaga qehan mini ota on nina hanska aya :

6 Taadetka kin ohna mahpiya okinyanpi owasin hohpi kağapi, qa adetka tawa ihukuya tinta wamanica kin iyulipa cinca tonpi ece, qa taohanzi kin ihukuya oyate tankinyanyan owasin ounyanpi.

7 Hecen tanka kin en qa taadctka kin hanskaska on nina oiyokipi: hutkan kin he mini tanka icahda nakaeś.

8 Taku Wakan canwojupi tawa ohna hanteśa kin hena aohanzikiya okihipi śni; wazi can kin he taadetka kin iyecece śni, qa adetka tawa wazi saka can kin iyecceapi śni; iye owanyag waśte kin on Taku Wakan tawoju kin ohna can hiyeye cin owasin iyececapi śni.

9 Taadetka ota hinca on woiyokipi wakagga; hecen Eden en can kin owasin, Taku Wakan tawoju ohna un kin iyulipa he inawizipi ecee.

10 Heon etarhan Jehowa Itancan kin hecen eya; Ohanska en nihduwankantu nakaeś, qa canwapośbe kin ehna oinkpa kin wankan icahkiya, qa tehanwankantu kin on cante ihduwankan iyeiçiya:

11 Heon etanhan Ikcewicaśta iyotan waśaka nape kin en waqu ; 


\section{EZEKIEL TAWOWAPI,}

woecon on ecakicon kta: tośice kin on etanhan tankan iyewaya.

12 Unkan wicaśta tokecapi, oyate wohitikapi hena, he kaksapi qa ehpeyapi : he akan qa kaksiza owasin ohnahna taadetka hinhpayapi ; qa adetka tawa kin hena makoce wakpa kin owasin on kaksaksapi ; qa maka akan oyate kin iyulipa taohanzi kin etanhan eyaya, qa ayuśtanpi.

13 Ihangyapi kin en mahpiya okinyanpi kin iyulipa ounyanpi kta, qa taadetka kin ekta tinta wamanica kin owasin hiyeye kta:

14. Hecen can kin owasin mini icahda ohanska on ihduwankantupi kte śni, qa canwapośbe kin ehna oinkpa lin wankan iyeiciyapi kte śni, qa mini yahepapi kin owasin can kin hena olıanska kin on najinpi kte śni: Hena iyulipa wiconte en wicaqupi nakaeś, maka kin ihuliuya ekta, wicaśta cinca kin wicacokaya, tona woha kin ekta iyayapi kin hena om.

15 Jehowa Itancan kin hecen eya; Anpetu en Hades ekta iyaye ciqon he ehan woceye wan wakaga; he on wośbe kin awakahpa, qa tawakpa kin anawapte; unkan mini tanka kin hena anaptapi: Nakun he on Lebanon aceye wakiya, qa kaksiza can kin owasin iye on hanyanpi.

16 Iye hinhpaya ho kin on Ikcewicaśta oyate kin cancanwicawakiya, tona woha en iyayapi kin hena om Hades ekta kun ehpewaye ciqon he ehan: hecen maka ihukuya Eden can kin owasin, Lebanon en kahnigapi qa waśteśte, tona mini yahepapi kin hena iyulipa cantohnagyapi kta.

17 Hena is eya iye kici Hades ekta iyayapi, mazasagye on wi408 caktepi kin ekta; qa iye istoyapi, Ikcewicaśta cokaya iye to hanzi en ounyanpi qon hena.

18 Wowitan qa wotanka en, Eden can kin ehna tuwe iyeniceca he: Tuka Eden can kin hena opeya maka ihukuya ekta kun aniupi kta; bawicalidayapi śni wicacokaya mazasagye ton wicaktepi kin hena om inunke kta. Pharaoh qa wicota tawa ocowasin he dee ce, Jehowa Itáncan kin eya.

\section{WICOWOYAKE 32.}

1 Unkan kaketu, waniyetu iakenonpa, wi iakenonpa, wiyawapi tokaheya kin en, Jehowa oie en mau kin he hecen eya:

2 Wicaśta cinhintku, Pharaoh Egupta wicaśtayatapi kin on woceye odowan yawankan iyeya wo, qa heciya wo; Ikcewicaśta ehna mnaja kośka iyeniceca, qa miniwanca ohna unktehi wan iyecen yaun; qa nitawakpa kin om naśdog hidu, qa nisiha on mini kin nayaśośe, qa tawakpapi kin hena nayacoco ece.

3 Jehowa Itancan lin he hecen eya; Heon ho mitawa kin acicalipe $\mathrm{kta}$, oyate ota hinca kin hena om: unkan hena e ho mitawa ohna wankan hiyu niyanpi kta.

4 Hehan makata acihnake kta, mağa ite kin akan ehpeciye kta, qa mahpiya zitkadan iyutipa niye en iyahan wicawakiye kta, qa niye on maka ocowasin wamanica kin wipi wicawaye ?ta.

5 Qa nicelipi kin he kin akan ewahnake kta, qa wamdudan nitawa kin on kaksiza kin ojuwaye kta.

6 Qa nakun makoce apaśbogyaye cin he niwe kin on lipanwakiye kta, lie kin hehanyan; 


\section{WICOWOYAKE 32.}

qa niye on wakpa kin hena ojudan kta.

7 Unkan nicasnipi kin en mahpiya kin awakahpe kta, qa wicanlipi tawa aotpaswakiye kta ; anpetu wi kin he mahpiya śapa on awalkahpe kta, qa hanyetu wi kin iś janjan kte śni.

8 Niye niwankam malipiya en iyoyanpa hinca kin iyuhpa otpaza wakage $\mathrm{kta}$, qa nitamakoce kin en otpaza ewahde kta ce, Jehowa Itancan kin eya.

9 Nakun oyate ota cante kin iyokiśinwaye kta, tohan Ikcewicaśta ehnahna ihangniyanpi kin makoce sdonyaye śni qon ektakta awau kinhan.

10 Han, niye on oyate ota nihinciye wicawakiye kta, qa wicaśtayatapi tawapi kin hena niye on nina kopehdapi kta, tohan wicitokam mazasagye mitawa hiyuwakiye cinhan: qa ihnuhanna cancanpi kta, wicaśta otoiyohi iye nagi kin on, anpetu en nihinhpaye cinhan.

11 Jehowa Itancan kin he hecen eya nakaeś; Babel wicaśtayatapi tamazasagye kin he en nihi kta ce :

12 Waśakśakapi tamazasagye on wicota nitawa hinhpaye wicawaye kta, hena owasin oyate en wohitikapi kin heepi : unkan hena e-Egupta towahaniçidapi kin yutakunipi kte śni, qa wicota tawa kin iyuhpa ihangyapi kta.

13 Nakun mini tanka kin icahda woteca iyulipa ihangwicawaye kta; qa hetanhan icimana wicaśta siha hena naśośe kte śni, qa woteca śake kin nakun naśośapi kte śni.

14 Hehan mini tawapi kin ahewakiye kta, qa tawakpapi kin wihdi iyecen iyaye waye kta, Jehowa Itancan kin eya.

15 Tohan Egupta makoce kin hewoskan wakagge cinhan, qa makoce taku on ojudan qon owasin ihangyapi kinhan; tohan en ounyanpi kin iytiupa wicawakaśtake cinhan, hehan Jehowa he miye e sdonyapi kta.

16 De woceye kin ee, unkan akiceyapi kta : Ikcewicaśta cunwintkupi kin hena aceyapi lita : Akiceyapi kta, Egupta hee, qa wicota tawa kin owasin on, Jehowa Itancan kin eya.

17 Hehan kaketu, waniyetu iakenonpa, wiyawapi iakezaptan, hehan Jehowa oie en mau kin he hecen eya :

18 Wicaśta cinhintku, Egupta wicota tawa kin on śicahowaya wo, qa hena kun ehpewicaya wo, iye qa Ikcewicaśta waśakśakapi cunwintkupi kin hena, maka ihukuya ekta, tona wolia ekta iyayapi kin hena om.

19 Tuwe isanpa oiyokipi yaun he: kun ya wo, qa tona balkilidayapi śni kin hena om iwanka wo. 20 Tona mazasagye on wicaktepi kin hena wicacokaya hinhpayapi kta: mazasagye en qupi : yutokan iyeya po, iye qa wicota tawa kin iyulipa.

21 Tona okiyapi ecee qon hena om, Hades cokaya tanhan iyotan waśakapi kin hena kici wohdakapi kta : kun iyayapi, bakihidaye śni iwankapi, mazasagye on wicaktepi ce.

22 Aśur hen yanka qa tomniciye kin iyulipa: ohna hnakapi tawa kin owasin ihdukśan wanka: hena iyuhpa wicaktepi, mazasagye on hinhpayapi :

23 Ohna hnakapi tawa kin hena woha unnaptanyan en ehnakapi, qa tomniciye kin hena iye ihdukśan wanka: Hena owasin wicani makoce kin en unpi wokokipe kag̣api qeyaś, wicaktepi. mazasagye on hinhpayapi. 


\section{EZEKIEL TAWOWAPI,}

24. Hen Elam yanka, qa wicota tawa kin ohna hnakapi kin ihdukśan wanka, iyulipa wicaktepi, mazasagye on hinhpayapi; hena wicani makoce kin en wokokipe kağapi qeyaś, maka olidateya bakihdaye śni iyayapi: tuka tona woha ekta iyayapi kin hena om wowiśtece hduhapi ece.

25 Wicaktepi wicacokaya ohehdepi wan akan ehnakapi, wicota tawa kin iyulipa om : ohna hnakapi kin hena ihdukśan wanka : hena iyulipa bakilidayapi śni, mazasagye on wicaktepi : wicani makoce kin ohna wokokipe kağapi qeyaś, tona woha kin ekta iyayapi kin hena om wowiśtece hduhapi: eqe wicaktepi wicacokaya ohnakapi.

26 Meśek hen yanka, Tubal qa wicota tawa kin iyuhpa: ohna hnakapi tawa kin ihdulsśan wanke: hena iyulipa bakilidayapi śni, mazasagye on wicaktepi, wicani makoce ohna wokokipe kagapi qeyaś.

27 Unkan hena, tona waśalkśakapi bakilidaye śni hinhpayapi, ozuye wipe kiton Hades ek ta iyayapi qon, hena om wankapi kte śni he: Unkan hena mazasagye pa ihukuya kihnakapi; tuka wahtanipi kin hena iye huhu tawapi kin akan yanke kta, wicani makoce kin ohna waśakśaka wakokipe wicakicaġapi qeyaś.

$28 \mathrm{Han}$, bakilidayapi śni wicacokaya nicaksaksapi kta, qa tona mazasagye on wicaktepi kin hena om inunke kta ce.

29 Edom hen yanka, wicaśtayatapi tawa, qa wicaśta itancan tawa kin owasin, hena wowaśake hduhapi koya mazasagye on wicaktepi kin om ehnakapi : tona bakilidayapi śni, qa tona woha kin ekta kun iyayapi kin hena om iwankapi kta.
30 Waziyata itancanpi kin hen yakonpi, hena owasin, qa Zidoni kin iyuhpa, hena wicaktepi kin om iyayapi : wokokipe tawapi en towaśakepi kin on iśtecapi: qa bakihdayapi śni mazasagye on wicaktepi kin hena om iwankapi; qa tona woha kin ekta iyayapi kin hena om wowiśtece hduhapi.

31 Pharaoh heria wanwicayake lita, qa iye taobe ocowasin on cantohnagyapi kta; Pharaoh qa iye taakicita iyuhpa mazasagye on wicaktepi kin, Jehowa Itancan kin eya.

\section{WICOWOYAKE 33.}

1 Hehan Jehowa oie en mau kin he hecen eya:

2. Wicaśta cinhintku, nitaoyate cinca kin om wohdake ca hewicakiya wo; Tohan mazasagye kin makoce wan en awau kinhan, qa makoce en oyate kin wiciye etanhan wicaśta wan icupi, qa he waawanyake kicagapi kinhan :

3 Qa iye mazasagye makoce kin en u wanyake cinhan, qa mazayahotonpi kin yahoton, qa oyate kin waktawicaya kinhan:

4 Hehan tuwe kaśta mazayahotonpi ho kin nahon, tuka onspekiyapi śni, qa mazasagye kin u qa eyaku kinhan, iye we kin pa akan kiciyanke kta.

5 Mazayahotonpi ho kin he nahon, tuka iwakta śni; iye we kin iye hinca akan un kta. Tuka tuwe waktaya un kinhan iye naği eihdaku kta.

6 'Tuka waawanyake kin he tohan mazasagye $u$ wanyake cinhan, mazayahotonpi kin yahoton śni, qa oyate kin iwaktayapi śni: qa mazasagye kin $u$, qa hena etanhan wicanagi wan eyaku 


\section{WICOWOYAKE 33.}

kinhan; he qe tośice kin en eyakupi; tuka we kin he waawanyake nape etanhan wakida kta.

7 Hecen niye wicaśta cinhintku, Israel tiyohnaka kin en waawanyake ecihnaka; heon etanhan mii etanhan wicoie kin nayahion kta, qa miye eciyatanhan waonspewicayakiye kta.

8 Tohan, Wicaśta śica, wiconțe on nite $\mathrm{k}$ ta ce, śice cin ewakiye cinhan ; wicaśta śica tacanku on onspeyakiye kta iyae śni kinhan; wicaśta śice cin he iye wahtani kin ohna te kta; tuka we kin he ninape etanhan wakida kta.

9 Tuka niye wicaśta śica tacanku kin ayuśtan kta on onspeyakiye cinhan; iye tacanku kin etanhan ihduhomni śni kinhan, iye wahtani kin ohna te kta; tuka niye qe ninaği eyehdaku.

10 Heon etanhan, niye wicaśta cinhintku, Israel tiyohnaka kin hewicakiya wo; Decen ehapi ; Waunkipajinpi qa waunhtanipi kin hena akan unyankapi, qa hena en unhanyanpi kinhan, token unnipi kta he, ehapi ece.

11 Hewicakiya wo ; Miye wani, Jehowa Itancan kin eya; Wicaśta sice cin he te cinhan iyomakipi śni ; ‘tuka wicaśta śica iye tacanku kin etanhan ihdubomni qa ni kinhan: Ihduhomni po, nitacankupi sica etanhan ihduhomni po ; Israel tiyohnaka, tokeca nitapi kta he.

12 Heon etanhan, niye wicaśta cinhintku, nitaoyate cinca kin hena hewicakiya wo; Wicaśta owotanna toowotanna kin he, anpetu en wawakipajin kinhan, ehdaku kte śni; qa wicaśta sica anpetu kin en tośice kin etanhan ihduhomni kinhan, he on hinhpaye kte śni ; qa nakun wicaśta owotanna anpetu kin en wahtani kinhan toowotanna qon on ni kte śni.

13 Tohan wicaśta owotanna kin wiconi on ni kta kewakiye cinhan, iye toowotanna kin wacinkiye ça taku śica econ kinhan, toowotanna qon ocowasin kilksuyapi kte śni ; tuka taku śica econ kin hee on te kta.

14 Ake tohan wicaśta śice cin, Wiconte on nite kta ce, ewakiye cinhan; hehan iye wahtani qon etanhan ihduhomni, qa woyaco woowotanna ko eciyatanhan ohanye cinlian;

15 Wicaśta śica woicaśke kin wicakicu, taku wicaki qon wicakicu, taku śica econ śni yanka wiconi woope kin ohnayan mani kinhan : he qe wiconi on ni kta, te kte śni.

16 Woahtani tawa qon on wahtani kin hena owasin kiciksuyapi kte śni : woyaco qa woowotanna econ nakaeś; he wiconi on ni kta.

17 Tuka nitaoyate cinca kin, Itancan tacanku kin ocitkonze śni ce, eyapi ece: Tuka iś iyepi tacankupi kin ocitkonzapi śni.

18 Tohan wicaśta owotanna kin he toowotanna kin etanhan ihduhomni, qa taku śica econ kinhan hee on te kta.

19 Tuka wicaśta śice cin he tośice kin etanhan ihduhomni, qa woyaco woowotanna ko econ kinhan, hee on ni kta.

20 Heca eśta, Itancan tacanku kin ocitkonze śni ce, ehapi ece. Israel tiyohnaka otoiyohi iye tacanku kin eciyatanhan ciyacopi kta ce.

21 Hehan kaketu, wayaka unyakonpi waniyetu iakenonpa, wi iwikcemna, wiyawapi anpetu izaptan en, wanji Jerusalem etanhan najica kin he cn mali qa, Otonwe kin kaśtakapi ce, eya. 


\section{EZEKIEL TAWOWAPI,}

22 Unkan hitayetu hehan Jehowa nape kin akan mayanka, najica qon en mahi śni itokamtu, qa i makiyuhdoka, hanhanna en mahi kin hehanyan: unkan i mayuhdokapi, qa hetanhan ia owakitpani wanica.

23 Hehan Jehowa oie en mau kin he hecen eya:

24 Wicaśta cinhintku, tona Israel makoce hewoskan wanke cin dena en ounyanpi kin hena iapi, qa, Abraham he wanjidan, tuka makoce kin tawaya: unkan unkiye wiuncotapi; makoce kin tawaunyanpi kta unqupi tuka qon, eyapi ece.

25 Heon etanhan hewicakiya wo; Jehowa Itancan kin hecen eya ce: We koya yatapi ece, qa wakağapi nitawapi ekta iśta yuwankan iyekcupi, qa we yapapsonpi ecee: unkan niye makoce kin tawayayapi kta he.

26 Mazasagye nitawapi kin en nayajinpi ece, wowahteśni yakagapi; qa otoiyohi takodaku tawicu wicayeciyuśapapi ece: unkan niye makoce kin tawayayapi kta he:

27 Kaken ewicakiya. wo: Jehowa Itancan kin hecen eya ce; Miye wani ce, awicakehan tona hewotahedan unpi hin hena mazasagye on hinhpayapi kta, qa tuwe tintoskan un kin he wamanica temyapi kta wicawaqu kta, qa tona conkaśke qa makohdoka kin ohna yakonpi kin hena makośica on tapi kta.

28 Makoce kin hewoskantu qa hopuza wakag̉e kta nakaeś, qa towaśake wahanicida kin he ayuśtan kta; qa Israel taḩe kin hena hewoskantu kta, hecen tuwedan opta ye kte śni.

29 Unkan tohan wowahteśni econpi kin owasin on etanhan makoce kin hewoskan qa hopuza 412 wakage cinhan, hehan Jehowa he miye e sdonyapi kta ce.

30 Nakun niye, wicaśta cinhintku, nitaoyate cinca kin conkaśke icahda, qa tipi tiyopa kin ohna aniia yukanpi, qa wanjikji wohdahdakapi, otoiyohi sunkaku kici, U po, ceciciyapi, qa Jehowa etanhan wicoie hinanpe kte cin he naunhonpi kta ce, eyapi ecee. .31 Unkan oyate upi kin iyecen en nihipi, qa mitaoyate iyecekcen nitokam hiyotankapi, qa nioie nahonpi, tuka hena ohnayan econpi kte śni : hena ipi kin on woiyokipi odowan kagapi, tuka cantepi wocantahdepi tawapi kin iyahna yapi ece.

32 Unkan iho, niye, tuwe ho waśte tadowan oiyokipi kin iyececa nidakapi, qa candowankiyapi on wayupiya econ kin iyececa; nioie nahompi, tuka hena ohnayan econpi śni ecee.

33 Unkan de ecetu kinhan, iho u kta, hehan wicaśta wokcan wan wicacokaya un kin he sdonyapi kta ce.

\section{WICOWOYAKE 34.}

1 Hehan Jehowa oie en mau kin he hécen eya:

2 Wicaśta cinhintku, Israel wonwicaye cin hena on woyaka wo, woyake ça hewicakiya wo ; Jehowa Itancan kin wonwicaye cin hena hewicakiya; Hehehe, Israel wonwicayapi kin, hena woniciyapi ece: wonwicaye cin hena optaye kin wonwicayapi kta iyecece śni he.

3 Waśin kin he yatapi, qa hin kin kodakapi, qa tona cemyapi kin hena wicayalitepi ece; optaye kin wonwicayayapi śni.

4 Ḧanye cin he waśagyayapi śni, qa wayazanke cin he asniyayapi śni, qa yuweğapi kin pa- 


\section{WICOWOYAKE 34.}

yahtapi śni, qa hamyapi kin he ake ayakupi śni, qa taninśni qon he oyadepi śni : tuka wowaśake qa wokakiśye on wicayakuwapi ece.

5 Hecen okamden iyayapi, wonwicaya wanica hcon etanlian: Unkan hena e tinta wamanica kin owasin woynte yapi kta heca, qa enanakiya iyayapi.

6 Optaye mitawa kin hena lie kin owasin ehnahna nunipi, qa paha tehanwankantu kin owasin ektakta : han, optaye mitawa kin maka ite kin ocowasin akan eyaya: qa tuwedan waode śni qa waakite śni ce.

7 Heon etanhan, wonwicaya yaunpi kin, Jehowa oie kin nahon po:

8 Miye wani, Jehowa Ițancan kin eya; Optaye mitawa wokipi icaga, qa optaye mitawa tinta wamanica woyute yapi kta heca, wonwicaya wanica liakaeś, qa wonwicaya mitawa kin hena optaye mitawa okidepi śni, tuka wonwicaye cin hena.woniciyapi, qa optaye mitawa wonwicayapi śni ece:

9 Heon etanhan, wonwicaya yaunpi kin, Jehowa oie kin nahon po:

10 Jehowa Itancan kin hecen eya ce; Wonwicaye cin hena wicitkokim waun; qa iye napepi kin etanhan optaye mitawa wicawakida kta, qa optaye kin wonwicaya ayuśtanwicawakiye kta; qa wonwicaye cin hena ake icimana woniciyapi kte śni; qa iye ipi etanhan optaye mitawa kin ewehdaku kta, hecen hena woyute yapi kte śni.

11 Jehowa Itancan kin hecen eya ; Tho, miye, miye hinca optaye mitawa kin awakite kta, qa nakun owicawakide kta ce.

12 Wonwicaya wan optaye ta- wa enanakiya unpi anpetu kin he en owicakide kin he iyecen, miśs eya optaye mitawa kin owicawakide kta, qa tuktekten anpetu amalipiya qa otpaza en enanakiya iyewicayapi qon owasin hetanhan ewicawehdaku kta.

13 Qa oyate kin etanhanhan awicawaku kta, qu makocc kin etanhanhan mnawicawakiye kta, qa iye tamakoce kin ekta hdicuwicawakiye k ta, qa Israel lie kin akankan wonwicawaye kta, wakpa kin icahda, qa makoce en ounyanpi ece kin hena owasin en. 14 Owilian waśte kin en wihanwicawakiye kta, qa Israel he tehanwankantu kin ekta optaye tipi kin yanke kta; hen optaye tipi waśte kin ohna.iwankapi kta, qa owitian cepa wan ohna wilianpi kta, Israel take kin akan.

15 Miye hinca optaye mitawa kin wonwicawakiye kta, qa miye hinca hena iwankewicawakiye kta ce, Jehowa Itancan kin eya. 16 Taku taninśni qon he owakide kta, qa taku liamyapi qon he ake awaku kta, taku pawegapi kin pawakilite kta, qa wayazanke cin he mduwaśake kta; tuka taku cepa qa waśake cin he ihangwaye kta; hena woyaco yunwicawakiye kta ce.

17 Qa niś niyepi, optaye mitawa, Jehowa Itancan kin hecen eya; Tho wanunyanpi etanhan wanunyanpi kin otahedan wamdaco kta, talinca ska mdoka, qa tatoka mdokapi kin kici.

18 Owilianpi waśte temyayapi kin he taku cistinna yadakapi; tuka owilian nitawa odaptapi kin he nakun siha on nayawinświnjapi kta he : qa miniśma etanhan datkanpi eśta, nukun oyaptapi kin siha on nayaśośapi kta he.

19 Tuka optaye mitawa taku 413 


\section{EZEKIEL TAWOWAPI,}

siha on nayawinświnjapi kin he yutapi, qa taku siha on nayaśośapi kin he yatkanpi ecee.

20 Heon etanhan Jehowa Itancan kin he hecen ewicakiya; Iho, miye, han miye linca wamdaco kta, wanunyanpi cepa qa wanunyanpi tamaheca kin otahedan.

21 Cuwi qa hinyete on paheyata iyeyayapi, qa he nitawapi on wayazanpi kin owasin cawicayapapi nakaeś, hecen enanakiya iyewicayayapi :

22 Heon etanhan optaye mitawa kin niwicawakiye kta, qa hena icimana womanon yapi kte śni, tuka wanunyanpi wanunyanpi kici wamdaco kta ce.

23 Qa Wonwicaye wanjidan awanwicayagwakiye kta, qa iye wihanwicakiye kta, Dawid mitaokiye kin hee: he qe wilianwicakiye kta, qa wonwicaye tawapi kin hee kta ce.

$24 \mathrm{Qa}$ Jehowa Taku Wakan ta. wapi kin he miye kta, qa Dawid mitaokiye kin he wicacokaya itancan yanke kta; Jehowa miye e hecen epa.

$25 \mathrm{Qa}$ hena om wookiye wicotakuye wicawecage kta, qa wamanica sice cin hena makoce kin ayuśtan wicawakiye kta, qa hena wikopeśniyan hewoskan ounyanpi kta, qa taśkoju ohna iśtinmanpi kta.

26 Qa hena eqe, qa paha mitawa ihdukśan wanke cin wowaśte wakagge kta: qa iyehantu eca magiaju kin ahinhewakiye kta; wowaśte mağaju kin yuke kta.

$2 \%$ Unkan can maggata un kin he waskuyeca icalye kta, qa maka kin oicagge kin hiyuye kta : qa iś iye makoce tawapi ohna wikopeśniyan unpi kta; qa cannapinpi wicawakiyuweğe ca, tona wowidagwicayapi qon napepi 414 etanhan ewicawehdaku kinhan, hehan Jehowa he miye e sdonyapi kta.

28 Unkan hena e ake icimana Ikcewicaśta on womanon yapi kte śni; qa makoce wamanica kin hena temwicayapi kte śni; tuka wowacinye en ounyaupi $\mathrm{kta}$, qa tuwedan wakokipe wicakicağe kte śni.

29 Unkan hena on woicagie wocajeyate wan icaliwicaweciye kta; hecen makoce kin ohna ake icimana akihanpi on iyog iyewicayapi kte śni, qa Ikcewicaśta tawowiśtece kin ake icimana yuhapi kte śni.

30 Heciyatanhan Jehowa miye Taku Wakan tawapi wicakici waun kin he sdonyapi kta, qa iyepi, Israel tiyohnaka kin mitaoyate eepi, Jehowa Itancan kin eya.

31 Qa nakun niye optaye mitawa, owilian mitawa optaye kin, wicaśta henicapi, Taku Wakan nitawapi kin he miye, Jehowa Itancan kin eya.

\section{WICOWOYAKE 35.}

1 Nakun Jehowa sie en mahi kin he hecen eya:

2 Wicaśta cinhintku, Seir he kin itkokim niite ekihde wo, qa he on woyaka wo;

3 Qa heya wo; Jehowa Itancan kin hecen eya ce; Iho, Seir lie kin, nitkokim waun, qa minape aciyugate kta, qa hewoskantu hinca cicag̉e kta.

4 Nitotonwe kin hena liewoskan ehpewaye kta, hecen niye otiwita yaun kta, qa Jehowa he miye e sdonyaye kta.

5 Ohinniyan wośicedake hduha yaun nakaeś, qa Israel cinca tokakijepi anpetu kin en mazasagye nape kin en ye wicaya- 


\section{WICOWOYAKE 36.}

ya, wośice woihangye kin hehantu :

6 Heon etanhan, miye wani, Jehowa Itancan kin eya; Weyapi on cicage kta, qa we kin he kuwa aniye kta; we kin śiceyadake śni, hecen we kin eqe nicuwa ecee kta.

7 Hecen Seir hie kin he otiwita qa otiwita ewahnake kta, qa hetanhan tuwe opta ye ca hdicu kin wakaśpe kta.

$8 \mathrm{Qa}$ he tawa kin wicaktepi on ojuwaye kta: paha nitawa, qa kaksiza nitawa, qa wakpa nitawa owasin ohnahna mazasagye on wicaktepi kin hinhpayapi kta.

9 Owihanke wanica otiwita cicage kta; qa nitotonwe kin hena piya kagapi kte śni: unkan Jehowa he miye e sdonyayapi $k$ ta ce.

10 Oyate kin denaoza, qa makoce kin denaoza mitawa kta ce, qa unkive tawaunyanpi kta ce, eha nakaeś; tuka Jehowa hen yanka:

11 Heon etanhan, miye wani, Jehowa Itancan kin eya; nakun nitocanniye qa nitowinawizi kin on śicewicayadake cin en oyaliande cin he eciyatanhan miye ecacicon $\mathrm{kta}$; qa hena wicehna mihdutanin kta, tohan ciyaco kinhan.

12 Unkan Jehowa he miye e sdonyaye kta; woyaśice nitawa owasin Israel he kin on iyae ciqon, Hena hewoskan kagaapi, qa unkiye unyutakunipi kte śni unqupi re, eha ecee nawahon.

13 Hecen niipi kin on miye en nihdatankapi, qa iapi ota on amayaiapi : miye hinca nawahon ce.

14. Jehowa Itancan kin he hecen eya; Tohan maka kin ocowasin wiyuśkin kinhan, hehan otiwita cicağe kta.
15 Israel tiyohnaka taku tawapi qon otiwita wanke cin on widu'śkin, heon he iyecen ecacicon kta; Seir he kin niye otiwita yaun kta, qa Edorn ocowasin, han ocowasin: unkan hena e Jehowa he miye sdonyapi kta ce.

\section{W1COWOYAKE 36.}

1 Nakun, wicaśta cinhintku, niye Israel he kin on woyake ca heya wo; Israel he kin Jehowa oie kin nation pô:

2 Itancan kin Jehowa hecen eya ce: Hohohe, toka kin eniciyapi, qa, conkaśke wanakaja kin hena tawaunyanpi ce.

3 Heon etanhan woyake ça heya wo; Itancan kin Jehowa hecen eya ce: Hewoskan nicagapi, qa ihdukśan tanhan inicapapi ece, hecen Ikcewicaśta okaptapi kin tawaniyanpi kta, qa waaia ipi kin on inicupi qa oyate aniiapi ecee :

4 Heon etanhan, Israel he kin, Itancan Jehowa oie kin nation po ; $\dot{H} e$ kin, qa paha kin, qa wakpa kin; qa kaksiza kin, hewoskan wanke cin, qa oton we elipeyapi, Ikcewicaśta okaptapi ihdukśan wanke cin on womanon yapi, qa oyate wowihahayapi kin hena Itancan Jehowa kin hecen ewicakiya:

5 Heon etanhan Itancan kin Jehowa hecen eya; Awicakehan mitowinawizi ide kin en Ikcewicaśta okaptapi qa Edom ncowasin on iwaa; iye cante ocowasin wiyuśkin on mitamakoce kin tawayapi kta ic̣iconzapi, cante wahanhaniçidapi on wicakipi kta nakaeś :

6 Heon etanhan Israel makoce kin on woyake, ca he kin, qa paha kin, qa wakpa kin, qa kaksiza kin hewicakiya wo; Jehowa 415 


\section{EZEKIEL TAWOWAPI,}

Itancan kin he hecen eya ce; Tho, mitowinawizi qa mitocanteptanye kin en iwaa, Ikcewicaśta tawowiśtece duhapi kin heon etanhan.

7 Heon etanhan Itancan kin Jehowa hecen eya; Miye minape wahdugate: Awicakehan Ikcewicaśta nihdukśan unpi kin hena wowiśtece hdubapi kta.

8 Tuka Isirael he kin niye adetka wankan icaliyayapi kta, qa Israel mitaoyate waskuyeca icahwicaycciciyapi kta: wanna ecadan kupi kta nakaeś.

9 Iho, miye ocipapi waun nakaeś, qa niyepi ekta mihduhomni kta: unkan niyumdupi kta qa onijupi kta.

$10 \mathrm{Qa}$ niyepi akan wicaśta wicamduota kta, Israel tiyohnaka owasin, ocowasin linca: unkan otontve kin hena en ounyanpi kta, qa otiwota qon hena piya kagiapi kta.

11 Han, niy epi akan wicaśta qa woteca wicamduota kta : unkan hena ihduotapi kta qa cinca icahkiyapi kta: hecen otokahe ekta yaunpi qon iyecen en owanji yankeciyapi kta; qa tokaheya yaunpi qon isanpa waśte ecamon kta; qa Jehowa he miye e sdonyayapi kta.

12 Han, wicasta animani wicawakiye kta, Israel mitaoyate heepi; unkan niye tawaniyanpi kta, qa tawayapi kte cin he niye lita; qa hetanhan icimana cinca codan wicayakag̀e kte śni.

13 Itancan kin Jehowa hecen eya; Niye wicaśta temwicayakiya, qa oyate nitawa cinca codan wicayakaga ce, eniciyapi ecee :

14 Heon etanhan ake icimana wicaśta temwicayakiye kte śni, qa ake icimana nitroyate cinca wanignica wicayakagge kte śni, Jehowa Itancan kin eya.
15 Qa nakun niye en icimana Ikcewicaśta tawowiśtece kin nahonwicawaye kte śni; qa nakun oyate tawiyopeye lin icinana duhe kte śni; qa nitaoyate kin icimana hinlipayeyakiye kte śni, Jehówa Itancan kin eya.

16 Hehan Jehowa oie en mahi kin he hecen eya :

17 Wicaśta cinhintku, Israel tiyohnaka iye tamakoce en ounyanpi qehan, helian iye tacankupi qa ohanpi kin on hduśicapi : tacankupi mitokam wanke cin hena winolinca iśnati tośape kin iyececa.

18 Heon etanhan makoce kin en we papsonpi kin on, qa wakagapi tawapi hduśapapi kin on, mitocanteptanye kin awicawakaśtan:

19 Qa Ikcewicaśta ehnahna iyaye wicawaya, qa makoce kin ektakta enanakiya iyayapi: iye tacankupi kin on, qa iye ohanpi kin on wicamdaco.

20 Unkan Ikcewicaśta ektakta iyayapi qon hena en hipi qehan, micaje wakan kin hc yaśicapi, Jehowa taoyate kin dena eepi, qa iye tamakoce kin etanhan tankan iyayapi ce, ewicakiyapi qehan.

21 Tuka micaje wakan kin on waonśiwada, Israel tiyohnaka tokiya ipi eca, Ikcewicaśta ehnahna yaśicapi ece tuka.

22 Heon etanhan Israel tiyohnaka kin hewicakiya wo; Jehowa Itancan kin hecen eya ce; Israel tiyohnaka, niyepi kin on etanhan decen ecamon śni, tuka micaje wakan, toki yaipi eca, Ikcewicaśta ehnahna datakupi śni ecee kin hee on etanhan.

23 Unkan micaje tanka kin he wahduwakan kta, he qe Ikcewicaśta kin ehnahna yaśicapi, hena wicacokaya niye daśicapi qon: 


\section{WICOWOYAKE $3 \%$.}

unkan tohan iye iśtapi kin itokam, niyepi kin on mihduwakan kinhan, hehan Jehowa he miye e sdonyapi kta ce, Jehowa Itancan kin eya.

24 Ikcewicaśta ehnahna tanhan eciyakupi kta nakaeś, qa makoce owasin etanhanhan mnaciyapi kta, qa makoce nitawapi kin en acihdipi kta ce.

25 Hehan mini ska acimnimnipi kta, unkan niskapi kia: nitośapapi owasin etanhan, qa wakagapi nitawapi owasin etanhan ciyuskapi kta :

26 Nakun wicacante teca cicupi kta, qa woniya teca mahen ecicilınakapi kta: qa nicehpi etanhan inyan cante kin he emdakukta, qa wicacehpi cante wan cicupi kta:

27 Qa Mitaniya kin he nitanmahen ewehnake kta, qa mitoope kin ohnayan maniciyapi kta, unkan mitawoyaco kin hena yapatanpi kta, qa ecen ecanonpi kta.

28. Unkan makoce atewicayayapi wicawaqu qon he en ounyayapi kta; qa mitaoyate kin he niyepi kta, qa Taku Wakan nitawapi kin he miye kta ce.

29 Nakun nitośapapi kin owasin etanhan niciyapi kta: qa aguyapi kin wakipan lita qa mduota kta, qa wicalkilian takudan acihnakapi kte śni.

30 Qa can waskuyeca kin mduota kta, qa magga oicage kin nakun; hecen ake icimana Ikcewicaśta ehna wicaakihan iyanionpapi kta duhapi kte śni.

31 Hehan nitacankúpi śice cin hena yeksuyapi kta, qa niohanpi waśte śni kin hella; qa niiśtapi en wahteśniniçidapi $\mathrm{kta}$, wayalitanipi qa wowahiteśni nitawapi kin on etanhan.

32 Niyepi kin on etanhan decen ecamon śui, Jehowa Itancan kin 7 eya, he sdonya po: Israel tiyohnaka, iśteca po, qa nitacankupi kin on nihinciya po.

33 Jehowa Itancan kin he hecen eya; Anpetu en wayahtanipi owasin etanhan ciyuskapi kinhan, hehan otonwe kin ohnayan ounyewicawakiye kta, qa otiwota kin hena piya kagapi kta.

34 Qa makoce liewoskan wanke ciqon he yumdupi kta, he qe tona hiyayapi owasin iśtapi en hewoskan wanka tuka qon.

35 Unkan heyapi kta, Makoce kin de hewoskan wanke ciqon he Eden tawoju kin iyecen icaga; qa otonwe otiwota, qa hewoskan, qa yujujupi qon hena acankaślkapi kin en ounyanpi ecee.

36 Hehan Ikcewicaśta nihdukśan okaptapi kin hena, tuwe yujujupi kin piya kaga, hewoskan wanke ciqon woju kin he Jehowa miye e sdonyapi kta: Jehowa miye hecen epa, qa miye ecen ecamon kta ce.

37 Jehowa Itancan kin hecen eya ce; Tuka de on Israel tiyohnaka kin wimawangapi kta, ecawicawecon kta e heon: hena optaye iyecen wicaśta wicamduota kta :

38 Optaye wakan kin iyececa, Jerusalem tomniciye kin en optaye kin he iyececa: hecen otonwe otiwota qon hena wicaśta optaye ojugjudan kta: Unkan hena Jehowa he miye e sdonyapi kta ce.

\section{WICOWOYAKE $3 \%$.}

1 Jehowa nape kin akan mayanka, qa Jehowa Taniya kin on hetanhan emayaya, qa omdaye huhu ojudan kin cokahan emahnaka;

2 Qa hena ehna ihdukśan hiyaye rnayan: unkan iho, omdaye 417 


\section{EZEKIEL TAWOWAPI,}

ite akall ota hinca; qa iho, hena śekśeka hinca.

3 Hehan iye hemakiya; Wicaśta cinhintku, huhu kin dena ni okihi kta he. Unkan amdupta; Jehowa Itancan, niye sdonyaya ce.

4 Hehan ake iye hemakiya; Huhu kin dena on woyaka wo, qa hewicakiya wo; Huhu śekśeca, Jehowa oie kin nahon po.

5 Itancan kin Jehowa huhu kin dcna hecen ewicakiya; Tho, miye woniya mahen niupi wakiye kta, unkan yanipi kta.

6 Qa kan kin acicihnakapi kta, qa cehpi icahciciyapi kta, qa uka on akahpeton ciyapi kta, qa oniya mahen ecicihnakapi lita, unkan yanipi kta: hecen Jehowa he miye e sdonyayapi kta ce.

7 Hecen econ maśipi kin iyecen womdaka: unkan womdaka icunhan ho yukan, qa iho, śkanśkanpi, qa huhu kin hena itkokicipa upi, hu wanji hu tawa ekta.

8 Unkan wanmdaka, qa iho, kan qa cehpi kin akan awicau, qa akantanhan uka awicakahpa: tuka oniya en wicaun śni.

9 Hehan iye hemakiya; Tate kin wahoya wo, wicaśta cinhintku, woyake ca tate kin heciya wo; Jehowa itancan kin hecen eya ce; Tate ouye topa kin etanhan woniya u wo, qa dena wicaktepi kin awicaniya wo, hecen nipi ksta ce.

10 Hehan econ maśi kin iyecen womdaka; unkan woniya kin mahen wicau, qa hena kinipi, qa siha on inajinpi, ozuye nina tanka hinca.

11 Hehan iye hemakiya; Wicaśta cinhintku, huhu kin dena Israel tiyohnaka ocowasin heepi : Iho, hena, Huhu unkitawapi kin śekşeca, qa wacinunyanpi qon he 418 taninśni ; unkiyepi unyutakunipi śni ce, eyapi ece.

12 Heon etanhan woyake ca hewicakiya wo; Jehowa Ttancan kin hecen eya,ce; Iho, mitaoyate, woha nitawapi ciciyuhdokapi kta, qa niliapi kin etanhan hdinanpe ciyapi kta, qa lsrael makoce kin en hdiyohiciyapi kta.

13 Hehan mitaoyate, Jehowa he miye e sdonyayapi kta, tohan woha nitawapi ciciyuhdokapi, qa nihapi etanhan hdinanpe ciyapi kinhan ;

14 Qa Mitaniya mahen ecicihnakapi, qa yanipi, qa nitamakoce kin en alıdicihnakapi kinhan : hehan Jehowa miye e hecen epa, qa ecen ecamon kin he sdonyayapi kta ce, Jehowa eya.

15 Hehan Jeknowa oie en mahi kin he hecen eya:

16 Nakun wicaśta cinhintku, niye cansakadan wanji icu wo, qa akan, Juda qa Israel cinca, tawaśitku wicaye cin tawapi, he en owa wo: Hehan cansakadan tokeca wan icu wo, qa akan, Joseph, Ephraim cansakadan tawa, qa Israel tiyohntka tawaśitku wicaye cin owasin tawapi, he en owa wo.

17 Qa wanji unma kin kici icikoyagya wo, cansakadan wanjidan kta: unkan hena ninape ohna okonwanjidan icage lita.

18 Unkan tohan nitaoyate cinca winiwangapi kinhan, Dena taku hecinhan unyakipazopi kte śni he, eniciyapi kinhan;

19 Hewicakiya wo; Itancan kin Jehowa hecen eya ce; Iho, Joseph cansakadan tawa, Fphraim nape en un, qa tawaśitku Jsrael wicowazi kin hena, iwacu kta, qa he kici ewahnake kta, han, Juda cansakadan tawa kici, qa hena cansakadan wanjidan wa- 


\section{WICOWOYAKE 38.}

kağe kta, unkan hena minape ohna wanjidan icage kta ce.

20 Unkan cansakadan akan oyawa kin hena ninape ohna yanke kta, iye iśtapi itokam:

21 Qa hewicakiya wo; Jehowa Itancan kin hecen eya ce; Iho, Israel cinca kin Ikcewicaśta wicehna tanhan, toki iyayapi qon hetanhan miye ewicamdaku kta, qa ihdukśan tanhan mnawicawaye kta, qa iye tamakoce kin en awicawahdi kta:

$22 \mathrm{Qa}$ makoce kin ohna Israel he kin akan hena oyate wanjidan wakag̉e kta; qa wicaśtayatapi wanjidan hena owasin en wicaśtayatapi un kta; qa hetanhan ake oyate nonpapi kte śni, qa ake icimana wokiconze nonpa on kiyuśpapi kte śni.

23 Nakun hetanhan icimana wakağapi tawapi kin on, qa wowahteśni tawapi, qa wawakipajinpi econpi owasin on, ihduśapapi kte śni : tuka en ounyanpi tawapi ohna walitanipi qon hena owasin etanhan niwicawaye kta, qa wicamduska kta: hecen hena mitaoyate kin eepi kta, qa Taku Wakan tawapi kin he miye kta ce. 24 Qa mitaokiye Dawid hena en wicaśtayatapi yanke kta; qa hena owasin wonwicaye wanjidan yuhapi kta: Nakun hena mitawoyaco kin ohnayan manipi kta, qa mitoope kin ahopapi kta qa ecen econpi kta.

25 Unkan hena makoce Jakob mitaokiye waqu qon he en ounyanpi kta, atewicayayapi kin en ounyanpi qon hee, iś eya en ounyanpi kta, iyepi qa cincapi, qa cincapi sanpa cincapi owihanke wanica : unkan Dawid mitaokiye he Itancan hduhapi kta, owihanke wanica.

26 Nakun miye wookiye wicotakuye wan om wicawecage kta, he qe wicotakuye owihanke wanica wicakici un kta: unkan ewicawahnake kta qa wicamduota kta, qa hena wicacokaya tipi wakan mitawa ewehde kta, owihanke wanica.

27 Unkan mitawakeya wakan kin he wicakici yanke kta: Han, Taku Wakan tawapi kin he miye kta, qa hena mitanyate eepi kta. 28 Unkan tipi wakan mitawa kin he owihanke wanin wicacokaya yanke cinhan, hehan Jehowa miye e Israel wicamduwakan he Ikcewicaśta kin sdonyapi kta ce.

\section{WICOWOYAKE 38.}

1 Hehan Jehowa oie en mau kin he hecen eya:

2 Wicaśta cinhintku, Gog itkokim niite ekihde wo, Magog tamakoce, Meśek qa Tubal en wicaśtayatapi itancan kin hee; qa he on wakanyan woyaka wo;

$3 \mathrm{Qa}$ heya wo; Jehowa Itancan kin hecen eya ce; Iho, Gog, $\mathrm{Me}$ śek qa Tubal wicaśtayatapi itancan tawapi kin, miye nitkokim waun :

4 Qa hẻktam hdicuciye kta, qa maza icu cehupa nitawa ohna iyewaye kta, qa/tankan hinanpe ciye kta, niye qa ozuye nitawa ocowasin, śuktanka qa śunka wakan akan yotankapi, hena iyuhpa taku ota koyakapi, omniciye tanka hinca, mazawokoyake qa wahacanka, hena iyulipa mazasagye kiçunpi :

5 Peres, Kuś qa Put owicapapi ; hena iyuhpa wahacanka qa mazawapaha yuhapi :

6 Gomer qa ozuye tawa owasin; Togarmah tipi waziyata ihanke kin etanhan, qa ozuye tawa kin iyuhpa; oyate ota hinca nici unpi. 


\section{EZEKIEL TAWOWAPI,}

7 Wiyeya un wo, qa ihduwiyeya wo, niye qa wicota nitawa niye ekta mniciyapi kin owasin, qa niye hena awanwicayag yaun kta.

8 Anpetu ota iyohakam yahdawa kta: waniyetu ehake kin en makoce kin en yahi kta, mazasagye etanhan ehdakupi, oyate ota etanhanhan mnakiyapi qon, Israel he ohinniyan hewoskan wanke ciqon he etu; tuka he qe oyate kin etanhanhan hinanpe yapi, qa hena iyuhpa wikopeśniyan ounyanpi tuka:

9 Tuka itawankanhde yau kta, magaju hinca wan iyecen yau kta, makoce akahpe kta on malipiya śapa iyecen yaun kta, niye qa ozuye nitawa iyuhpa, qa oyate ota onipapi kin hena.

10 Jehowa Itancan kin hecen eya; Nakun kaketu kta, anpetu kin he en wicoie nicante en upi kta, qa wicotawacin śica wan awacanni kta :

11 Qa hecen ehe kta; Makoce ikce otonwe kin ekta mde kta ; tona oziic̣iyapi wikopeśniyan ounyanpi, iyuhpa acankaśkapi śni unpi, qa tiyopa, inatake ko nicapi kin hena takpe wicamde kta ce :

12 Wokipi wan wicakipi kta, qa womanon wan manonpi kta; hewoskan wanke ciqon en ounyanpi kin hena ekta nape yeyaye kta, oyate wan Ikcewicaśta etanhanhan mnawicayapi, qa woteca walipaya koya kamnanpi, makoce tehanwankantu en ounyanpi kin hena.

13 Śeba qa Dedan qa Tarśiś en wicaśta wopeton kin hena, qa en mnaja kośka kin owasin heniciyapi kta; Wokipi wicaki kta on yau he: womanon wan manon kta on nitomniciye mnayakiya he; mazaska qa mazaskazi aya- hde kta, woteca qa walipaya iyacu kta, wokipi tanka wan wicayaki kta he.

14. Heon etanhan, wicaśta cinhintku, wakanyan woyaka wo, qa Gog heciya wo ; Jehowa Itancan kin hecen eya ce; Anpetu kin en mitaoyate Israel wikopeśniyan okihpapi kinhan, niye sdonyaye kte śni he.

15 Hecen nitohe kin etanhan yau kta, waziyata makoce kin etanhan, niye qa oyate ota nici upi kin, hena owasin śuktanka akan yotakanpi, omniciye tanka qa ozuye ota hinca.

16 Qa mitaoyate Israel takpe wicayau kta, mahpiya śapa iyecen makoce kin akalipapi kta: he.anpetu ehake kin etu, hehan mitamakoce kin takpe uciye kta, hecen Ikcewicaśta kin sdonmayanpi kta, tohan iye iśta itokam, Gog, niye en mihduwakan kinhan.

17 Jehowa Itancan kin hecen eya; Tuwe wanakaja cajemdate ciqon he niye he; Israel en wicaśta wokcan, anpetu waniyetu hena en woyakapi qon hena nape eciyatanhan, hecen takpe wicauciye kta.

18 Unkan kaketu kta, anpetu en Gog Israel makoce kin takpe u kinhan, hehan mitocanteptanye miite akan hiyu kta, Jehowa Itancan kin eya.

19 Mitowinawizi en, mitocanniye ide kin en hecen epa nakaeś; Awicakehan anpetu kin he en Israel makoce kin ohna wicacancan tanka kta :

20 Hecen miniwanca hog̉an kin hena qa mahipiya zitkadan, qa tinta woteca, qa wamakaśkan tona maka asdohan unpi kin owasin, qa wicaśta owasin tona maka ite akan unpi kin hena miite on cancanpi kta, qa he kin 


\section{WICOWOYAKE 39.}

hena pawankapi kta, qa he imnija kin hena hinhpayapi kta, qa inyan conkaśke otoiyohi makata hinhpaye $\mathrm{kta}$.

21 Hehan he on he mitawa owasin ohnayan mazasagye wan weco kta ce, Itancan kin Jehowa eya: wicaśta otoiyohi tamazasagye kin iye sunkaku kin apaha un kta.

22 Qa makośica qa we on he mdaco kta; qa iye kin, ozuye tawa koya, qa oyate ota kici unpi kin hena awicamagjaju waye kta, magaju apaśboke kta, qa wasu tankinkinyan, peta qa cansin.

23 Hecen milıdutanka kta qa mihduwakan kta; unkan oyate ota iśtapi kin en sdonmayanpi waun kita, qa Jehowa he miye e sdonyapi kta ce.

\section{WICOWOYAKE 39.}

1 Heon etanhan, wicaśta cinhintku, Gog on wakanyan woyake ça heya wo; Itancan kin Jeliowa hecen eya ce; Iho, Gog, Meśek qa Tubal wicaśtayatapi itancan, miye itkocicipa ce.

2 Unkan ciyuhomni kta, qa hinanpe ciye kta, qa waziyata ihanke kin etanhan hiyuciye kta, qa Israel he kin akan acihi kta.

3 Qa ninape catka etanhan nitinazipe kin wakaśpe kta, qa ninape etapa etanhan nitawanhinkpe kin hinhpaye waye kta.

4- Israel he kin akan nihinhpaye $k$ ta, niye qa ozuye nitawa iyulipa, qa oyate nici unpi kin hena: zi tkadan wayapote cin ocaje owasin, qa tinta wamanica kin temniyanpi lita e cicu kta.

5 Tinta ite kin akan nihinhipaye kta: miye hecen epa nakaeś, Jehowa Itancan kin eya.

6 Unkan peta wan Magog en E yewaśi kta, qa wita en wikopeśniyan ounyanpi kin hena ehna; hecen .Jehowa he miye e sdonyapi kta ce.

7 Hecen micaje wakan kin Israel mitaoyate cokaya sdonye wicawaye kta, qa ake icimana micaje wakan kin wahduśape kte śni. Unkan Jehowa Israel en Wanji Wakan kin he miye e Ikcewicaśta kin sdonyapi kta.

8 Iho, wanna u qa iyecetu, Jehowa Itancan kin eya: anpetu cajemdate ciqon he dee ce.

9 Unkan Israel otonwe en ounyanpi kin hena tankan yapi kta, qa wipe kin hena ideyapi qa huhnahyapi kta, han, wahacanka qa maku akahpe, itazipa qa wañhinkpe kin, qa nape sagye qa wahukeza, unkan waniyetu śakowin hena peta on hulinaliyapi kta:

10 Hecen taśkoju etanhan can icupi kte śni, qa contanka kin etanhan hdalssapi kte śni; wipe kin hena peta en aonpapi kta nakaeś : hecen tona iye wawicakipi qon hena wicakipi kta, qa tona wamawicakinonpi qon hena mawicakinonpi kta, Itancan kin Jehowa eya.

11 Unkan anpetu kin he en kaketu kta, Israel en tukten wicahapi kin wan Gog waqu lita, kaksiza ohna manipi ece, mini tanka iwiyohiyanpa tanhan; qa he qe icimanipi kin wicaliagi kta: Unkan hen Gog qa wicota tawa qon owasin wicaliapi kta; qa, He Gog-wicota takaksiza, eciyapi kta.

12 Unkan Israel tiyohnaka kin wi śakowin hehanyan wicaha śkanpi lzta, makoce yuskapi lita e heon.

13 Han, makoce en oyate ocowasin wahapi kta: unkan he qe wocajeyate hduhapi kta, anpetu 421 


\section{EZEKIEL TAWOWAPI,}

mihduwakan kte cinhan, Jehowa Itancan kin eya.

14 Unkan wicolian tawapi kta on wicaśta wicakahinigapi kta, hena icimanipi kin om makoce optapta yapi kte, tona maka ite akan okaptapi kin hena wicaliapi kta, hecen yuskapi kta: wi śakowin ohakam hehan ode yapi kta.

15 Unkan icimanipi kin hena maka ohna yapi eca, tohan wanji wicaśta hu wanyake cinhan, hehan bosdatu wan icahda ehde kta, tohanyan wahapi kin Gogwicota takakśiza ohna hapi kta helianyan.

16 Qa nakun otonwe kin he Hamona (wicota) eciyapi kta. Hecen makoce kin hduskapi kta.

17 Unkan niye wicaśta cinhintku, Itancan kin Jehowa hecen eya; Zitkadan hupahu ton owasin qa tinta wamanica kin iyuha hewicakiya wo; Ihduwitaya po qa u po; ihdukśantanhan mnaiçiya po, wośna mitawa niyepi on wawahduśna kin ekta, Israel he kin akan wośnapi tanka hinca, liecen tado yatapi kta qa we datkanpi kta.

18 Waśakśalzapi celipi kin yatapi kta, qa wicaśtayatapi we kin datkanpi kta, wanunyanpi tamdoka tawa, tacincadan tawa, qa tatoka mdoka tawa, tatanka tawa, hena iyuhipa Baśan en cemyapi qon heca.

19 Unkan inimnanpi kta e waśin yatapi kta, qa winitkopi kta hehanyan we datkanpi kta, wośna mitawa niyepi on wawahduśna kin etanhan.

20 Hecen wahna wotapi mitawa en, suktanka qa canpahmihma on, waśakśakapi qa ozuye wicaśta owasin on winipipi kta, Itancan kin Jehowa eya.

21 Unkan mitowitan kin he Ikcewicaśta ehna ewehde kta, qa mitawoyaco ecamon kin he, qa minape akan ewicawahnake cin hena Ircewicaśta. owasin wanyakapi kta.

22 Hecen anpetu kin hetanhan qa sanpa, Israel tiyohnaka kin Jehowa Taku Wakan tawapi kin he miye e sdonyapi kta.

23 Unkan walitanipi kin on Israel tiyohnaka wayaka unpi kin en iyayapi he Ikcewicaśta kin sdonyapi kta: taku śica ecamiconpi kin heon etanhan miye miite anawicawakilibe, qa tokawicayapi napepi en wicawaqu: unkan hena iyuhpa mazasagye on hinhpayapi.

24 Ihduśapapi kin on, qa wawakipajinpi kin eciyatanhan ecawicawecon, qa miite anawicawakitibe.

25 Heon etanhan Jehowa Itancan kin hecen eya; Wanna Jakob unhdaka unpi kin ake hdicuwakiye kta, qa Israel tiyohnaka ocowasin onśiwakida kta, qa micaje wakan kin on winawawizi kta ce.

26 Tohan tawowiśtece kiçinpi kinhan, qa wawakipajinpi tawapi owasin on makipajinpi, makoce en wikopeśniyan owanji yukanpi qa tuwedan wakokipe wicakicage śni qehan.

27 Tohan oyate kin etanhanhan hdicuwicawakiye, ca tokawicayapi tamakoce kin etanhanhan mnawicawakiye, ca iyepi en oyate ota itokam mihduwakan kinhan ;

28 Hehan Ikcewicaśta ehnahna wayaka iyayewicaye ciqon Jehowa Taku Wakan tawapi kin he miye e sdonkiyapi kta : tuka makoce tawapi kin ohna mnawicawakiya, qa hena etanhan tuwedan ake ehpewaye kte śni.

29 Nakun miite ake anawicawakilibe kte śni: Mitaniya kin 
Israel tiyohnaka kin awicawakaśtan kta nakaeś, Jehowa Itancan kin eya.

\section{WICOWOYAKE 40.}

1 Wayaka unyakonpi waniyetu wikcemna nonpa qa sanpa zaptan en, omaka otokahe ekta, wiyawapi anpetu iwikcemna hehantu, otonwe kin kaśtakapi qon iyohakam waniyetu iaketopa kin en, anpetu kin hee linca, hehan Jehowa nape kin akan mayanka, qa ekta amahi :

2 Taku Wakan tawowanyake kin en Israel makoce kin ekta amahi, qa he wan tehanwankantu hinca akan emahnaka, qa hen itokagatanhan otonwe okagapi wan wanka.

3 Hecen he en amahi, unkan iho, wicaśta wan towanyake kin mazazi wanyakapi kin iyececa, hahonta pahmonpi wan nape ohna qa cedi on iyutapi wan: unkan he qe tiyopa kin ohna inajin.

4 Unkan wicaśta kin he hemakiya; Wicaśta cinhintku, niiśta on wawanyaka wo, qa ninoge on wanahon wo, qa taku wanyagciciye cin owasin en nicante yekiya wo: wawanyagciciye kta e heon den anihipi nakaeś : taku wandake kte cin hena owasin Israel tiyohnaka kin owicakiyaka wo.

5 Unkan iho, tipi kin itankan ihdukśan conkaśke wan, qa wicaśta qon nape ohna cedi wan on iyutapi kta, wiciśpa śakpe, wiciśpa qa napehdakinyan eciyatanhan : hecen conkaśke kin iyuta, ohdakinyan cedi wanjidan; qa obosdatu kin cedi wanjidan.

6 Hehan tiyopa wan ite kin wiyohiyanpatakiya wanke cin he en hi, qa caniyadipi kin ohna wankan iyaya, qa tiyopa ihukuya wanke cin he iyuta, okdakinyan cedi wanjidan, qa ihukuya wakke cin unma kin iś ohdakinyan cedi wanjidan.

7 Qa wankan tipi kin iś ohanske cedi wanjidan qa ohdakinyan cedi wanjidan : qa wankan tipi kin otahedan wiciśpa zaptan: qa tiyopa ihukuya wanka, tiyopa ohanzi hdepi icahda wanke cin mahentanhan, cedi wanjidan.

8 Nakun tiyopa ohanzi hdepi kin mahentanhan iyuta, cedi wanjidan.

9 Hehan tiyopa en ohanzi hdepi kin iyuta, wiciśpa śahdoggan, qa can ipatan kin hena wiciśpa nonpa : unkan tiyopa en ohanzi hdepi kin mahenkiya wanka.

10 Unkan tiyopa wiyohiyanpatakiya canku ekta wankan tipi yamni deciyatanhan qa yamni heciyatanhan; hena yamni wiyutapi okonwanjidan: qa can ipatan kin wiyutapi okonwanjidan, deciyatanhan qa heciyatanhan.

11 Unkan tiyopa oenape ohdakinyan kin iyuta, wiciśpa wikcemna; qa tiyopa ohanske kin wiciśpa akeyamni.

12 Nakun wankan tipi itokam opapun kin he wiciśpa wanjidan, qa heciyatanhan opapun kin iś wiciśpa wanjidan: unkan wankan tipi kin deciyatanhan wiciśpa śakpe, qa heciyatanhan wiciśpa śakpe.

13 Hehan tiyopa kin iyuta, wankan tipi akalipe etanhan akalipe ekta; ohdakinyan kin wiciśpa wikcemna nonpa sanpa zaptan, oenape oenape icitkokim.

14 Nakun can ipatan kin hena wiciśpa wikcemna śakpe kag̉a, qa tiyopa ihdukśan hocoka can ipatan kin ekta.

15 Unkan tiyopa nenape ite kin 423 


\section{EZEKIEL TAWOWAPI,}

etanhan tiyopa mahentu ohanzi hdepi ite kin hehanyan wicispa wikcemna zaptan.

16 Unkan wankan tipi kin ohna owanyeye natakapi yukan, qa tiyopa imahentu ihdukśan can ipatan tawapi kin ohna, qa nakun opalite kin en: qa imahentu ihdukśankśan owanyeye yukan, qa can ipatan en tamar can okagapi.

17 Hehan tankan hocoka kin ekta amahi, unkan iho, tipi cistinna yukan, qa hocoka ihdukśan inyan canku wan kicağapi : inyan canku kin ekta tipi cistinna wikcemna yamni yukan.

18 Unkan inyan canku tiyopa icahda wanke cin, tiyopa ohanske iyotakonza kin he kuya inyan canku kin ee.

19 Hehan kuya tiyopa kin itokapa locoka mahentu kin itankan, ohdakinyan kin iyuta, wiciśpa opawinge wiyohiyanpata qa waziyata ekta.

20 Nakun tankan hocoka tiyopa. ite waziyatakiya canku kin ekta he ohanske qa ohdakinyan kin iyuta:

21 Unkan wankan tipi kin deciyatanhan yamni qa heciyatanhan yamni ; qa can ipatan kin, opalite tawa nakun, hena tiyopa tokaheya iyutapi qon iyececa: ohanske wiciśpa wikcemna zaptan qa ohdakinyan kin iś wikcemna nonpa sanpa zaptan.

$22 \mathrm{Qa}$ owanyeye tawapi, qa opahte qa tamar can okaggapi tawapi kin hena tiyopa wiyohiyanpata canku ekta yanka iyutapi qon iyececa: unkan can adipi śakowin on ekta yapi ece; qa opahte kin hena itokam yanke.

23 Unkan mahen hocoka tiyopa kin he tiyopa ite wariyatakiya qa wiyohiyanpatakiya canku kin ekta iyotakons wanke: Unkan tiyopa etanhan tiyopa ekta iyuta, wiciśpa opawinge.

24 Hehan itokah canku kin ekta amahi: unkan iho, tiyopa wan itokahkiya canku kin ohna: unkan he can ipatan tawa kin iyuta, qa opahte kin nakun, wiyutapi qon hena iyececa.

25 Unkan he ohna owanyeye yukan, qa ihdukśan opahte kin hena ohna, owanyeye qon hena iyecekceca: ohanske wiciśpa wikcenina zaptan, qa ohdakinyan kin iś wikcemna nonpa sanpa zaptan.

26 Qa adipi śakowin on ekta yapi ece; qa opahte kin hena itokapatanhan wanke: unkan tamar can okagapi yukan, wanji. deciyatanhan qa wanji heciyatanhan, can ipatan tawa kin akan.

27 Unkan hocoka mahentu kin én, canku itokahkiya wanke cin olna, tiyopa wan yanka: unkan tiyopa etanhan tiyopa ek ta itokahkiya wiyuta, wiciśpa opawing g.

28 Hehan itokah tiyopa kin ohna hocoka mahentu kin ekta amahi: unkan itokah tiyopa kin iyuta, wiyutapi qon hena iyececa. $29 \mathrm{Qa}$ wankan tipi tawa kin hena, qa can ipatan kin hera, qa opahte tawa kin hena, wiyutapi qon hena iyececa: unkan ohna owanyeye yukan, qa ihdukśan opalite tawapi kin ohna: ohanske wiciśpa wikcemna zaptan, qa ohdakinyan kin iś wikcemna nonpa sanpa zaptan.

30 Unkan opahte ihdukśan wanke cin hena ohanske wiciśpa wikcemna nonpa sanpa zaptan, qa ohdakinyan iś wiciśpa zaptan.

31 Unkan opahte tawa kin hena tankan hocoka kin ektakiya; qa can ipatan tawa akan tamar can okag̉api yukan; unkan adipi sahdoğan on ekta yapi ece.

32 Hehan hocoka mahentu kin

424 
en amahii, wiyohiyanpata canku ektakiya wanke cin hetu: Unkan tiyopa kin he iyuta, wiyutapi kin dena iyececa.

$33 \mathrm{Qa}$ wankan tipi tawa kin hena, qa can ipatan, qa opahte tawa kin hena wiyutapi kin dena eciyatanhan: unkan he ohna owanyeye yukan, qa ihdukśan opahte tawa kin ohnahna : ohanske wiciśpa wikeemna zaptan, qa ohdakinyan iś wiciśpa wikcemna nonpa sanpa zaptan.

34 Unkan opahte tawa kin tankan hocoka kin ektakiya wanke; qa can ipatan tawa kin akan tamar can okağapi yukan, deciyatanhan qa heciyatanhan : unkan adipi śahdog̣an on ekta yapi ece.

35 Hehan waziyata tiyopa kin en amahi, qa wiyutapi kin dena iyecen iyuta :

36 Wankan tipi kin, can ipatan kin, qa opahte tawa, qa ihdukśan orvanyeye tawa kin hena: ohanske wiciśpa wikcemna zaptan, qa ohdakinyan kin iś wiciśpa wikcemna nonpa sanpa zaptan.

37 Unkan can ipatan tawa kin hena hocoka tankantu kin ektakiya; qa can ipatan kin akan tamar can okagapi yukan, deciyatanhan qa heciyatanhan: qa adipi śahdoġan on ekta yapi ece.

38 Unkan mazopiye qa oenape kin hena tiyopa can ipatan kin icahda ; hen wohulinagge wośnapi kin yujajapi ece.

39 Unkan tiyopa ohanzi hdepi kin ohna, deciyatanhan wahna hnakapi nonpa, qa heciyatanhan wahna hnakapi nonpa; hena akan wohulinage wośnapi, qa woahtani wośnapi, qa wayuśnapi wośnapi kin wicaktepi kta.

40 Unkan tankan tiunnaptanyan en, waziyata tiyopa oenape ekta yapi ece kin hetu, wahna hnaka- pi nonpa; qa tiunnaptanyan unma eciyatanhan, tiyopa ohanzi hdepi kin icahda, wahna hnakapi nonpa yukan.

41 Deciyatanhan wahna hnakapi topa, qa heciyatanhan wahna hnakapi topa, tiyopa unnaptanyan kin icahda: wahna hnakapi śahdoğan akan wapatapi ece.

42 Nakun wohuhinage wośnapi tawahnahnakapi topa kin hena inyan kakanpi, ohanske wiciśpa wanji sanpa hanke, ya ohdakinyan wiciśpa wanji sanpa hanke, qa obosdatu kin iś wiciśpa wanjidan: unkan hena akan ikicanye on wohuhnage wośnapi qa wośnapi wicaktepi ece kin hena ehnakapi ece.

$43 \mathrm{Qa}$ timahen oyuze nape hdakinyan wanji ihdukśan okatanpi : qa wahna hnakapi kin akan wośnapi conica kin hiyeya.

44 Unkan tiyopa mahentu itankan mazopiye dowanpi tawapi, hocoka mahentu kin hetu, waziyata tiyopa unnaptanyan kin ekta; unkan hena itokah canku kin ektakiya etonwan; wanji wiyohiyanpata tiyopa icahda kin he waziyata canku kin ektakiya yanka.

45 Unkan hemakiya; Mazopiye kin de itokah canku ektakiya yanke cin he wawayuśna tipi tawowaśi awanyakapi kin hena tawapi :

46 Qa mazopiye waziyata canku ekta itoheya yanke cin he wahna wośnapi tawowaśi awanyakapi wawayuśna kin hena tawapi: Hena Zadok cinhintku, Lewi cinca ehnatanhan Jehowa okiyapi kta ikiyedan upi ecce kin eepi ce.

47 Hecen hocoka kin he iyuta, ohanske kin wiciśpa opawinge, qa ohdakinyan wiciśpa opawinge, topa omdotonyan wanka; qa na- 
kun tipi kin itokam wahna wośnapi kin.

48 Hehan tipi ohanzi hdepi kin en amahi, qa ohanzi hdepi can ipatan kin iyuta, deciyatanhan wiciśpa zaptan, qa heciyatanhan wiciśpa zaptan; qa tiyopa ohdakinyan kin he deciyatanhan wiciśpa yamni, qa heciyatanhan wiciśpa yamni.

49 Ohanzi hdepi ohanske kin he wiciśpa wikcemna nonpa, qa ohdakinyan kin iś wiciśpa akewanji; unkan elsta yapi ece kin adipi yukan: unkan can ipatan icahda oinajin yukan, wanji deciyatanhan qa wanji heciyatanhan.

\section{WICOWOYAKE 41.}

1 Hehan tipi wakan kin en amalii, qa can ipatan kin iyuta, deciyatanhan ohdakinyan wiciśpa śakpe, qa heciyatanhan ohdakinyan wiciśpa śakpe; wakeya ohdakinyan kin hee.

2 Qa oenape ohdakinyan kin he wiciśpa wikcemna; qa oenape unnaptanyan kin deciyatanhan wiciśpa zaptan, qa heciyatanhan wiciśpa zaptan: qa ohanske kin iyuta rviciśpa wikcemna topa, qa ohdakinyan kin iś wiciśpa wikcemna nonpa.

3 Hehan mahenkiya iyaya, qa owenape can ipatan kin iyuta, wiciśpa nonpa, qa tiyopa kin wiciśpa śakpe, qa tiyopa ohdakinyan kin iś wiciśpa śakowin.

4 Hecen ohanske kin iyuta, wiciśpa wikcemna nonpa; qa ohdakinyan kin iś wikcemna nonpa, tipi wakan kin itokapatanhan: Unkan iye hemakiya; De iyotan wakan kin hee ce.

5 Hehan tipi unnaptanyan kagapi kin he iyuta, wiciśpa śakpe; qa cuwi tipi kin ohdakin- yan wiciśpa topa, tipi kin anokatanhan ihdukśan hiyeya.

6 Unkan cuwi tipi kin hena yamni, cuwi tipi cuwi tipi iakankan, owancaya wikcemna yamni; unkan tipi kagapi unnaptanyan kin en, cuwi tipi ihdukśan hiyeye cin hena mahen ya, hecen oyuze kta, tuka tipi kağapi kin en yuzapi śni.

7 Unkan yutankapi qa yuktanyanpi yukan, wankan, wankan yapi, cuwi tipi kin ekta: tipi oyuktanyanpi kin he wankan ece ya, tipi ihdukśan nakaeś; hecen tipi ohdakinyan kin he wankantkiya ya, qa hecen cokaya kuyatanhan wankan icah aya ece.

8 Nakun ihdukśan tipi obosdatu kin wanmdaka: cuwi tipi oahe kin hena unnaptanyan kin he cedi wanji ocowasin wiciśpa śakpe.

9 Unkan tankantanhan cuwi tipi kin on conkaśke kag̉api ohdakinyan kin he wiciśpa zaptan; qa okaptapi kin he mahentu, cuwi tipi owanka kin hee.

10 Unkan wankan tipi kin otahedan wiciśpa wikcemna nomnonpa ohdakinyan, tipi kin ihdukśan hiyeya.

11 Unkan cuwi tipi oenape kin hena okaptapi kin ektakiya wanke; tiyopa wanji waziyata canku kin ekta, qa tiyopa wanji iś itokagatanhan yanka: qa owanka okaptapi ohdakinyan lin he wiciśpa zaptan ihdukśan hiyeya.

12 Unkan hocoka okaptapi kin itokam wiyohpeyata ihanke kin ekta, tipi kagapi kin he ohdakinyan wiciśpa wikcemna śakowin, qa tipi conkaśke kin ohdakinyan wiciśpa zaptan ihdukśan hiyeya, qa ohanske kin iś wiciśpa wikcemna napcinwanka.

13 Hecen tipi kin iyuta, ohan- 
ske wicispa opawinge; qa hocoka okaptapi kin he, qa tipi kagapi, conkaśke koya bena ohanske wiciśpa opawinge.

14 Nakun tipi kin itokam ohdakinyan kin he, qa hocoka okaptapi wiyohiyanpatakiya, hena wiciśpa opawinge.

15 Qa tipi kağapi ohanske kin he iyuta, hocoka okaptapi kin itokam, he iheyata nakaeś, qa omanipi kin, deciyatanhan qa heciyatanhan wanke, wiciśpa opawinge, tipi wakan mahentu qa hocoka ohanzi hdepi kin hena iyahna.

16 Tiyopa ipatan kin, qa owanyeye ociqadan kin, qa ihdukśan yamnikiya omanipi kin, tiyopa iyotakonza, ihdukśan can on akahpapi, qa maka etanhan owanyeye kin elkta, qa owanyeye kin hena natakapi.

17 Tiyopa iwankamtu hehanyan, qa nakun tipi kin mahen qa itankan, qa conkaśke ihdukśan hiyeye cin ocowasin ekta, iyutapi.

18 Unkan kerub qa tamar can okagiapi kin on econpi, hecen kerub qa kerub iyotahedan tamar can okagapi wan yanka: qa kerub otoiyohi ite nonpa yuha.

19 Hecen deciyatanhan wicaśta ite kin tamar can okagapi kin ek takiya yanka, qa heciyatanhan mnaja ite kin tamar can okagapi ektakiya yanka; tipi kin ihdukśan owancaya hecen kaġapi.

20 Maka etanhan tiyopa kin iwankamtu hehanyan kerub qa tamar can okaġapi kin kagaapi, qa tipi wakan unnaptanyan kin en.

21 Tipi wakan can ipatan kin hena omdoton kagiapi, qa owanka wakan kin itokam owanyake kin iś owanyakapi kin iyececa.

22 Can wahna wośnapi kin he obosdatu wiciśpa yamni, qa ohanske kin iś wiciśpa nompa; unkan oise kin, qa ohanske, qa unnaptanyan kin hena can: Unkan iye hemakiya; Jehowa itokam wahna hnakapi kin he dee ce.

23 Unkan tipi wakan qa tipi wakan hinca kin hena en tiyopa nonpa.

24 Unkan tiyopa otoiyohi oyugan nonpa, oyuggan yuhdokapi kta nonpa; tiyopa wanji oyugan nonpa, qa unma kin iś oyuggan nonpa.

25 Unkan hena akan, tipi wakan tiyopa kin akan, kerub qa tamar can okagiapi kin iyahna kagapi, unnaptanyan kin en kağapi kin he iyececa : unikan ohanzi hdepi kin tankan tanhan ite kin akan canmdaska oakalipe.

26 Unkan owanyeye ciqadan qa tamar can okagiapi yukan, deciyatanhan qa heciyatanhan, ohanzi hdepi unnaptanyan kin en, qa tipi en cuwi tipi kin akan, qa oakalipe kin.

\section{WICOW OYAKE 42.}

1 Hehan tankan hocoka kin elta irinanpe mayan, canku waziyatakiya yanke cin he ohna: qa tipi cistinna owanka okaptapi iyotakonza kin he cn amahi, qa he qe tipi kagapi kin iwaziyata itokamtu.

2 Ite ohanske wiciśpa opawing ge kin hentu waziyata tiyopa kin yanka, qa ohdakinyan kin iś wiciśpa wikcemna zaptan.

3 Wikcemna nonpa kin iyotakonza, hocoka mahentu kin hee, qa inyan canku kin iyotalionza, tankan hocoka kin hee, hen omanipi omanipi kin iwankam yamni yulran.

4. Unkan tipi cistinna kin hena itokam cankuyapi wan ohdakin- 


\section{EZEKIEL TAWOWAPI,}

yan wiciśpa wikcemna mahentu, ranku kin he wiciśpa wanjidan; qa tiyopa tawapi waziyatakiya yanka.

5 Unkan tipi cistinna wankantu kin hena pteptecedan: omanipi kin he dena etanhan, qa tipi kagapi kin en, kuya qa ocokaya Janke cin nakun etanhan nakaeś. 6 Hena yamnikiya yanka, tuka can ipatan wanica, hocoka can ipatan kin iyececa; heon etanhan yuciqapidan, maka kin etanhan, kuya qa ocokaya kin isanpa.

7 Unkan tankan conkaśke, tipi cistinna kin iyotakonza, tankan hocoka canku kin heciya, tipi cistinna itokam, he ohanske kin wiciśpa wikcemna zaptan.

8 Tankan hocoka kin ohna tipi cistinna kin hena ohanske wiciśpa wikcemna zaptan nakaeś: unkan iho, tipi wakan kin itokamtu he wiciśpa opawinge.

9 Unkan tipi cistinna kin dena ihukuya wiyohiyanpata oenape yanka ; tankan hocoka kin etanhan hena mahen yapi kte cin hee.

10 'Tipi cistinna kin hena hocoka wiyohiyanpata conkaśke kin ohnahna, owanka okaptapi kin iyotakonza, qa tipi kagapi kin iyotakonza.

11 Unkan hena itokam canku kin he tipi cistimna waziyatakiya hiyeye cin owanyakapi kin iyececa; ohanska kici akiyececa, ohdakinyan kin hena kici akiyececa: qa hena oenape owasin okaggapi qon iyececa, qa tiyopa tawapi kin iyececa.

12 Unkan itokali canku ohna tipi cistinna tiyopa kin hena iyecen canku ipa kin en tiyopa wan yanka : conkaśke itokantu linca wiyohiyarpata canku kin hee, en yapi ecee hetu.

13 Hehan iye hemakiya; Waziyata tipi cistinna, itokali tipi 428 cistinna ko, owanka okaptapi kin itokam, hena tipi cistinna wakan, hena ohnahna wawayuśna Jehowa ikiyedan upi ecee kin woyute wakan kin yutapi kta: han, taku wakan hinca kin hena hen ehnakapi kta, woyute wośnapi, qa woahtani wośnapi, qa way uśnapi wośnapi kin hena : owanka kin he wakan nakaeś.

14 Wawayuśna kin hena he mahen yapi eca, hehan tipi wakan kin etanhan tankan hocoka kin en hdapi kte śni ; tuka tawokoyake un kicanyanpi kin hena hen kihnakapi kta; hena wakan nakaeś : qa wokoyake tokeca kiçuni kta, hehan oyate taku tawapi kin ikiyedan yapi kta.

15 Hehan tipi mahentu iyuta hduśtan qehan, hehan wiyohiyanpata canku ohna tiyopa ektakiya etonwe cin he en amahi, qa he ihdukśan iyuta.

16 Cedi iyute kin on wiyohiyanpata wanke cin he iyuta, cedi opawinge zaptan, cedi iyute kin on ihdukśantanhan.

17 Waziyata wanke cin he ohna iyuta, cedi iyute kin on ihdukśan, cedi opawinge zaptan.

18 Itokali wanke cin he iyuta, cedi iyute on cedi opawinge zaptan.

19 Wiyohpeyata wanke cin ekta ihduhomni, qa cedi iyute on," cedi opawinge zaptan iyuta.

20 Topa omdotonyan wanka hecen iyuta : he ihdukśan conkaśke yukan, ohanske cedi opawinge zaptan, qa ohdakinyan opa winge zaptan, hecen tipi wakan qa owanka ikceka kin yukinukan kta.

\section{WICOWOYAKE 43.}

1 Hehan tiyopa kin en amahi, tiyopa wiyohiy anpata canku ek ta oenape kin hee. 


\section{WICOWOYAKE 43.}

2 Unkan iho, Israel Taku Wakan tawa Towitan kin wiyohiyanpata canku kin ohna u : unkan iye ho kin he mini ota lio kin iyececa : qa Towitan kin on maka kin iyoyamyapi.

3 Unkan wowanyake wanmdake ciqon he owanyake kin iyececa, otonwe ihangyapi kta on wahi qon wowanyake kin he iyececa: nakun wowanyake kin he wowanyake Ḱebar wakpa ekta wanmdake ciqon iyececa : unkan makipusdiya elipemiciya.

4 Unkan Jehowa Towitan kin he tiyopa wiyohiyanpata canku ektakiya ite kin, canku kin he ohnayan ti mahen hiyu.

* 5 Hehan Woniya kin imacu qa hocoka mahentu kin en amahi; unkan iho, Jehowa 'J'uwitan tipi kin ojuya.

6 Qa ti mahen tanhan womakiyaka nawahion: unkan wicaśta qoll micahda najin.

7 Hehan iye hemakiya; Wicaśta cinhintku, mitoiyo tanke oyanke, qa misiha oahe oyanke, tukten. Israel cinca wicacokaya ohinniyan wati kte ciqon, qa micaje wakan kin, hena Israel tiyohnaka ake icimana yuśapapi kte śni, iyepi, qa wicaśtayatapi tawapi, wawicihaliapi econpi kin on, qa paha tawapi akan tawicaśtayatapi tancan țapi kin hena on.

8. Tiyopa oahe tawapi tiyopa oahe mitawa kin en ehdepi, qa can ipatan tawapi can ipatan mitawa kin icahda, qa conkaśke miye qa iyepi otahedan wanka hena on; han, heon wowahteśni econpi kin on micaje wakan kin yuśapapi ece : Heon etanhan mitocanteptanye kin en awihnuniwicawaya.

9 Wanna wawicihaliapi econpi kin hena, qa tawicaśtayatapi tan- can tapi kin hena mitokapa tanhan yutehan iyemiciciyapi kta; kinhan miye owihanke wanin owicapeya wati kta ce.

10 Nive, wicaśta cinhintku, tipi kin he Îsrael tiyohnaka kin wicakipazo wo; hecen iye walitanipi kin on iśtecapi kta: qa okagapi kin he ito iyutapi kta.

11 Hehan taku econpi kin owasin on iśtecapi kinhan, tipi okagapi kin he wicakipazo wo, qa tokenken ehnakapi, qa oenape kin hena, qa ohna hiyupi ece kin, qa okaġapi kin ocowasin, qa tawokagge owasin, qa okagapi kin iyulipa, qa toope kin ocowasin; qa iye iśta itokam hena owa wo, hecen okagiapi kin ocowasin yuhapi kta, qa tawokagie kin owasin, qa hena ecen econpi. kta.

12 Tipi woope kin he dee : Ḧe ipa kin ekta ihdukśan hiyeye cin owanka ocowasin wakan hince kta: Tho, tipi woope kin hee.

13 Unkan owayuśna iyutapi kin dena ee, wiciśpa eciyatanhan: wiciśpa lkin he wiciśpa qa napehdakinyan: unkan maku kin he wiciśpa wanji, qa ohdakinyan kin iś wiciśpa wanji, qa ihdukśan ihanke kin en opapun kin he napapaśdecapi wanji: owayuśna nite kin hee.

14. Qa maku kin etanhan, he maka kin, kuya oahe kin ekta, wiciśpa nonpa qa ohdakinyan wiciśpa wanjidan: qa oahe ciqadan kin etanhan oahe tanka kin ekta, wiciśpa topa, qa ohdakinyan kin wiciśpa wanjidan.

15 Hecen wohuhnage owayuśna kin he wiciśpa topa lkta; qa wohuhnagge owayuśna kin etanhan qa wankantu, he topa yukan.

16 Unkan wohuhnage owayuśna ohanske kin wiciśpa akenonpa, ohdakinyan kin iśs akenonpa, to- 


\section{EZEKIEL TAWOWAPI,}

pa omdotonyan hecen omdotonyan' wanke kta.

17 Unkan oahe kin he ohanske wiciśua aketopa, qa ohdakinyan kin iś aketopa, topa omdotonyan wanka; qa opapun kin he wicispa hanke; qa cetete kin he wiciśpa wanjidan ihdukśanyan wanke: unkan iyadipi ite kin wiyohiyanpatakiya yanke kta.

18 Hehan iye hemakiya; Wicaśta cinhintku, Jehowa Itancan kin he hecen eya ce; Owayuśna wokagge tawa kin dena ee, anpetu kin en kagapi kinhan, akan wohuhnagge wośnapi kin wayuśnapi kta, qa akan we amnimnipi kta.

19 Unkan wawayuśna, Lewi etanhan, Zadok wicowazi etanhan, omakiyapi kta mikiyedan upi ece kin hena tatanka pte cinca wanji woahtani on wośnapi kta e wicayaqu kta, Jehowa Itancan kin eya :

20 Qa hetanhan we kin iyacu kta, qa he topa kin akan eyahnake kta, qa oahe oise topa kin akan, qa opapun ihdukśan wanke cin he akan: hecen duska kta qa ayakahpe kta.

21 Hehan woahtani on wośnapi tatanka kin he iyacu kta, qa tipi wakan kin itankan, tipi ohna cajeyatapi kin hen huhnahye kta.

22 Unkan anpetu inonpa kin en tatokadan cinca ecetu hinca wan woahtani on wośnapi kta he waduśna kta : unkan owayuśna kin yuskapi kta, tatanka on yuskapi qon iyececa.

23 Tohan yuskapi duśtan kinhan, hehan tatanka wan pte cinca kin ecetu hinca, qa optaye kin etanhan tamdoka wan ecetu hirlca kin hena waduśna kta :

$24 \mathrm{Qa}$ Jehowa itokam hena waduśna kta, qa wawayuśna kin hena miniskuya akadapi kta; 430 hecen woliulinagge wośnapi on hena Jehowa wakiyuśnapi kta. 25 Anpetu śakowin anpetu iyohi, tatokadan wan woahtani on wośnapi yakagie kta: Nakun ta tanka pte cinca wan qa optaye etanhan tamdoka ecetu hinca wan econpi kta.

26 Anipetu śalowin owayuśna kin akahpapi kta qa yuskapi kta; nakun iye ihduśtanpi kta.

27 Unkan anpetu kin hena ihuniyanpi hehan kaketu $\mathrm{kta}$, anpetu iśahdogan qa hetanhan tokata wawayuśna kin hena wohuhnag̉e wośna nitawapi kin owayuśna kin akan econpi $k t a$, qa wookiye wośnapi nitawapi: Unkan iyokipi mayayapi kta ce, Jehowa Itancan kin eya.

\section{WICOWOYAKE 44.}

1 Hehan tipi wakan tankantu tiyopa wiyohiyanpatakiya oenape kin he canku kin ekta amahdi : unkan he natakapi.

2 . Hehan Jehowa hemakiya; Tiyopa kin de natag he kta; yuhdokapi kte śni, qa ohna tuwedan tin hiyu kte śni: Jelowa Israel Taku Wakan tawa kin hee ohna hiyu kin heon natag un kta.

3 Wicaśtayatapi kin he tawa; wicaśtayatapi kin'he de ohna Jehowa itokam aguyapi yun iyotanke kta: tiyopa ohanzi hdepi canku kin he eciyatanhan hiyu kta, qa he canku kin ohna ake kihde kta.

4 Hehan tipi kin itokamtu, waziyata tiyopa canku kin en hiyumayan: unkan watonwan, qa iho, Jehowa towitan Jehowa ti kin ojudan: hehan ite makipusdiya i wahpamda.

5 Unkan Jehowa hemakiya; Wicaśta cinhintku, nicante ekta 


\section{WICOWOYAKE 44.}

yeya wo, qa niiśta on wanyaka wo, qa Jehowa ti tawokonze kin owasin on, qa toope kin owasin on taku eciciye kte cin hena iyuhpa ninoge on nahon wo: qa tipi ohiyupi kin he nicante ekta yeya wo: qa tipi wakan etanhan oena. pe owasin ekta.

6 Unkan wawakipajin kin he, Israel tiyohnaka kin heyakiye kta; Jehowa Itancan kin hecen eya ce; Israel tiyohnaka, wowaliteśni nitawapi owasin wanna niciotapi :

\% Wicaśta tokeca cinca, cante bakihdaye śni, qa cehpi bakihdaye śni kin hena tin liyuwicayayapi, tipi wakan mitawa ohna unpi kta, yuśapapi kta, tipi mitawa ohna woyute mitawa, waśin qa we kin waduśnapi eca; unkan wowahteśni nitawapi owasin on wicotakuye mitawa kin yujujupi.

8 Qa taku mitawa wakan kin hena niye awandakapi śni: tuka niyepi on tipi wakan mitawa ohna wowaśi mitawa awanyakapi kte cin heca ewicayahnakapi ece.

9 Jehowa Itancan kin hecen eya; Wicaśta tokeca cinca, cante en bakilidaye śni, qa celipi en bakilidaye śni, tuwedan tipi wakan mitawa ohna hiyu kte śni, oyate tokeca cinca owasin Israel cinca wicehna unpi kin hena.

10 Nakun Lewi wicaśta mitehan iyayapi qon, Israel nunipi qehan, wakagiga tawapi ihakam mitantanhan nuni yapi qehan, hena eqe wahtanipi kiçinpi kta.

.11 Tuka hena e tipi wakan mitawa ohna waokiya unpi kta, tipi tiyopa kin yulidokapi ecee kta, qa tipi en waokiya unpi kta: hena wohuhnage wośnapi qa wośnapi kin oyate wicakiktepi kta, qa hena wicitokam inajinpi kta, owicakiyapi kta e heon.

12 Wakağapi tawapi itokam owicakiyapi, qa Israel tiyohnaka wahtani kiyapi qon, heon etanhan miye minape wicawakiyugate, Jehowa Itancan kin eya; hecen iye wahtanipi kin kiçinpi kta.

13 Heon wawayuśna mitawa kta on mikiyedan upi kte śni, qa tipi wakan hinca ohna taku mitawa wakan kin owasin ikiyedan upi kte śni : tuka wowiśtece hduhapi kta, qa wowahteśni econpi qon hena.

14. Tuka tipi tawowaśi awanyakapi kin heca ewicawahnake kta, wokicanye owasin on, qa taku ohna econpi kte cin iyuhpa on.

15 Tuka wawayuśna, Lewi wicaśta, Zadok cinca kin, tipi wakan mitawa tawowaśi awanyakapi qon, Israel cinca mitantanhan nunipi qehan, hena e omakiyapi kta mikiyedan hiyupi kta, qa hena mitokam najinpi kta, waśin qa we kin wamakiyuśnapi kta e heon, Jehowa Itancan kin eya.

16 Hena eqe tipi wakan mitawa kin en tin hiyupi kta, qa hena omakiyapi kta on wahna wotapi mitawa ikiyedan upi kta, qa hena e wowaśi mitawa kin awanyakapi kta ce.

17 Unkan kaketu kta, fohan hocoka mahentu tiyopa kin ohna tin hiyupi eca miniliuha wokoyake unpi ecee kta; qa tahinca hin kin en wicau kte śni, tohanyan hocoka mahentu tiyopa kin ohna qa imahen waokiya econpi kinhan.

18 Minihuha wapaha pa akan unpi kta, qa minihuha onzeoge nite akan unpi kta; taku on temniyapi kta ipiyag kitonpi kte sni. 


\section{EZEKIEL TAWOWAPI,}

19 Qa tohan tankan hocoka kin ekta hdapi kinhan, tankan hocoka oyate kin ekta, wokoyake un waokiya unpi ecee kin hena hduśdokapi kta, qa tipi cistinna wakan kin mahen ekihnakapi kta, qa wokoyake tokeca kicunpi kta: hecen wokoyake tawapi on oyate kin wicayuwakanpi kte śni.

20 Nakun pa hdasanpi kte śni, qa sonpi hanska icahkiyapi kte śni; yuśdapi on hduśdapi ecee kta.

21 Qa wawayuśna kin hocoka mahentu kin en yapi kinhan, tuwedan miniśa yatke kte śni.

$22 \mathrm{Qa}$ wiwazica qa tuwe elipeyapi kin hena winohinca wicayuzapi kte śni: tuka Israel tiyohnaka oicage etanhan witanśna unpi, qa iś wawayuśna yuze ciqon wiwazica kin, hena wicayuzapi ece kta.

23 Hecen mitaoyate kin taku wakan qa taku ikceka otahedan onspewicakiyapi kta, qa taku śapa qa ska kin kinukankiya sdonyewicakiyapi kta.

$24 \mathrm{Qa}$ woakinica kin cn hena wayaco najinpi kta ; mitawoyaco kin eciyatanhan wayacopi ecee kta: nakun omniciye mitawa owasin en mitawoahope qa mitoope kin hena ahopapi kta; qa wookilipe mitawa kin hena wakandapi kta.

25 Unkan wicaśta te cin en hipi kte śni, on ihduśapapi kta; tuka atkuku on, qa hunku on, qa cinhintku on, qa cunwintku on, qa sunkaku on, qa tawinohitin hihna ton śni, hena on ihduśapapi kta.

26 Unkan ihduska kinhan, hehan anpetu sakowin kiciyawapi kta.

27 Qa tipi wakan kin en, hocoka mahentu ekta, tipi wakan kin ohna waokiya ye cinhan, anpetu 432 kin he en woalitani wośna kin wahduśna kta, Jehowa Itancan kin eya.

28 Unkan he qe tawayapi kte cin ee kta; tawayapi kte cin he miye hinca: hecen maga yuhapi kte cin Israel ehna wicayaqupi kte śni: taku yuhapi kte cin he miye ce.

29 Woyute wośnapi qa woahtani wośnapi qa wayuśnapi wośnapi kin hena e yutapi ecee kta; qa Israel en talku hduwakanpi kin hena owasin tawapi kta.

$30 \mathrm{Qa}$ taku owasin etanhan taku tokaheya icağe cin hena, qa taku owasin etanhan woahi kin iyuhpa, niye woahi nitawapi kin iyuhpa, hena wawayuśna tawa kta: nakun wotpanpi nitawapi etanhanhan wawayuśna kin yaqupi ecee kta; hecen yati kin ohna wowaśte ahinhekiye kta.

31 Taku iye cinka ta, qa yahdelidecapi kin owasin, wahupakoza qa woteca, etanhan wawayuśna kin yutapi kte śni.

\section{WICOWOYAKE 45.}

1 Hehan makoce kin tawayapi kta e oeconna on yeciduśpapi kinhan, wośna wan Jehowa wayakiduśnapi kta, makoce ośpe wakan kin hee kta; ohanske kin he kektopawinge wikcemna nonpa sanpa zaptan, qa ohdakinyan kin iś cedi keptopawinge wikcemna: De wakan kta, ihanke ihdukśan hiyeye cin owasin en.

2 Hetanhan opawing gaptan ohanska qa opawinge zaptan ohdakinyan ihdukśan omdotonyan wanke kta, he tipi wakan kin on ; qa he ihdukśanyan opapun wanke cin wiciśpa wikcemna zaptan.

3 Qa wiyutapi kin de etanhan, ohanska kektopawinge wikce- 


\section{WICOWOYAKE 45.}

mna nonpa sanpa zaptan, qa ohdakinyan kin kektopawinge wikcemna idute kta: unkan he tipi wakan kin on, wakan hince kte cin hee.

4 Makoce wakan kin he wawayuśna tawapi kta, tipi wakan taokiye, tona Jehowa okiya ikiyedan upi ecee Ista hena on: Unkan he ohna tipi kaggapi kta, qa tipi wakan kin on owanka wakan kta.

5 Unkan ohanske kektopawinge wikcemna nonpa sanpa zaptan, qa ohdakinyan kin iś kektopawinge wikcemna kin he Lcwi wicaśta, tipi taokiye kin hena e hduhapi kta, tipi cistinna wikcema nonpa kta on tawayapi kta.

6 Unkan otonwe tawa kte cin he ohdakinyan kek topawinge zaptan, qa ohanske kektopawinge wikcemna nonpa sanpa zaptan duśtanpi kta, wośna wakan kin iyotakonza wanke kta; he qe Israel tiyohnaka ocowasin kin hena on.

7 Hehan wicaśtayatapi kin he tawa kta, wośna wakan kin he qa otonwe tawa kte cin ideciyatanhan qa iheciyatanhan, wośna wakan kin itokam, qa otonwe tawa kte cin he itokam, wiyohpeyata etanhan wiyohpeyatakiya, qa wiyohiyanpa tanhan wiyohiyanpatakiya : unkan ohanske kin he ośpe wanji iyotakonza kta, wiyohpeyata ihanke kin etanhan wiyohiyanpata ihanke kin hehanyan.

8 Maknce kin ohna Israel ehna taku tawa kta: unkan hetanhan wicaśtayatapi mitawa icimana mitaoyate kin kakiświcayapi kte śni : Unkan makoce kin Israel tiyohnaka kin wicaqupi kta, wicowazi tawapi kin eciyatanhan.

9 Jehowa Itancan kin hecen eya; Israel wicaśtayatapi, wan- na iyenihantupi nunwe; wokipi qa wamanonpi kin yutokan iyeya po, qa woyaco woowotanna ko econ po, mitaoyate hakiświcayapi kin ayuśtan po, Jehowa Itancan kin eya.

10 On aspeyetonpi kin owotanna duhapi kta, qa epha (wiyutapi) owotanna, qa bath (wiyutapi) owotarna.

11 Epha qa bath hena wiyutapi okonwanjidan, hecen bath he homer (wiyutapi) kiyuśpapi iwikcemna wanji kipi kta, qa epha iś nakun homer kiyuśpapi iwikcemna wanji kipi kta; wiyutapi kin he homer eciyatanhan kta.

12 Unkan śekel (mazaska tkeutapi) he gerah (omnica) wikcemna nonpa: śekel wikcemna nonpa, sekel wikcemna nonpa sanpa zaptan, śekel ake zaptan, hecen maneh (tkeutapi) nitawapi kta.

13 Woahi waduśnapi kte cin he dee kta, ag̉uyapi su homer wanji etanhan epha kiyuśpapi iśakpe wanji, qa barle homer wanji śakpe kiyuśpapi wanjidan yaqupi kta.

14 Unkan wihdi woope, wihdi bath wanjidan, kor etanhan batl okiyuśpe wikccmna etanhan wanji nunpi kta; kor he homer wanjidan bath wikcemna kipi ; bath wikcemna hecen homer nakaeś.

$15 \mathrm{Qa}$ optaye etanhan tacinca wanjidan, opawinge nonpa etanhan, Israel owihan waśte kin etanhan; woyute wośnapi, qa wohulinage wośnapi, qa wookiye wośnapi kta on, waawicakahpe kta e heon, Jehowa Itancan kin eya.

16 Makoce kin ohna oyate ocowasin Israel en wicaśtayatapi kin he on woahi kin de qupi kta. 17 Unkan wicaśtayatapi tawa 433 


\section{EZEKIEL TAWOWAPI,}

kte cin, wohuhinag̉e wośnapi qa woyute wośnapi, qa woyatke wośnapi econ kte, wohanpi kin en, qa wi teca en, qa wookilipe kin en, Israel tiyohnaka omniciye wakan kin owasin en: Iye hinca woahtani wośnapi kin ode kta, qa woyute wośnapi, qa wohulinage wośnapi, qa wookiye wośnapi, Israel tiyohnaka waawicakahpe kta e heon.

18 Jehowa Itancan kin hecen eya.; Wi tokaheya en, wiyawapi anpetu tokaheya en, tatanka, pte cinca ecetu hinca wan iyacu kta, qa tipi wakan kin duska kta:

19 Unkan wawayuśna kin he woahtani wośnapi we kin etanhan icu kta, qa tipi can ipatan kin en, qa owayuśna oahe oise topa kin akan amnimni kta, qa mahentu hocoka tiyopa can ipatan kin akan.

20 Unkan wiyawapi anpetu iśakowin kin en he iyecen ecanon kta, tuwe nuni kin on, qa ksape śni kin on: hecen tipi kin waayakahpapi kta.

$21 \mathrm{Wi}$ tokaheya en, wiyawapi anpetu iaketopa kin en woacakśin duhapi kta, anpetu śakowin wohanpi; agguyapi napoliye śni yutapi kta.

22 Unkan anpetu kin he en wicaśtayatapi kin econ kta, iye hinca on, qa makoce oyate ocowasin on, tatanka wan woahtani on wośnapi kta.

23 Unkan wohanpi anpetu śakowin kin en wohuhnage wośnapi wan Jehowa wakiyuśna kta, tatanka śakowin qa tamdoka śakowin ecetu hinca, anpetu śakowin anpetu iyohi hecen econ kta: qa woahtani wośnapi kta on tatokadan cinca wan anpetu otoiyohi.

24 Unkan woyute wośnapí econ kta, tatanka otoiyohi on epha wanjidan, qa tamdoka otriyohi on epha wanjidan, qa epha otoiyohi wihdi etanhan hin (wiyutapi) wanjidan.

$25 \mathrm{Wi}$ iśakowin kin en, wiyawapi anpetu iakezaptan en, iś eya iyecen econ kta, anpetu śakowin wohanpi kin icunhan, woahtani wośnapi lin iyececa, wohuhnagie wośnapi kin iyececa, qa woyute wośnapi kin iyececa, qa wihdi kin iyecece $\mathrm{kta}$.

\section{WICOWOYAKE 46.}

1 Jehowa Itancan kin hecen eya; Mahentu hocoka tiyopa wiyohiyanpata etonwe cin he anpetu śakpe wicohtani econpi kin hena en natakaji kta; tuka anpetu wakan hehan yuhdokapi kta, qa wi teca anpetu kin he en yuhidokapi kta.

2 Unkan wicaśtayatapi kin he tiyopa kin he ohanzi hdepi tankantu canku kin ohna tin hiyu kta, qa tiyopa can ipatan kin icahda najin kta, unkan woahtani wośna qa wookiye wośna tawa kin hena wawayuśna kin ecakiconpi kta, unkan tiyopa oahe kin en patuś yanke kta ; hehan tankan hde kta; tuka htayetu hehanyan tiyopa kin natakapi kte śni.

3 Nakun makoce oyate kin tiyopa kin de oenape kin en Jehowa itokam patuś inajinpi kta, anpetu wakan eca qa wi teca kin en.

4. Unkan anpetu wakan kinhan wicaśtayatapi wohuhnagge wośnapi Jehowa wakiyuśna kte cin he, tacinca ecetu hinca śakpe, qa tamdoka ecetu hinca wanjidan.

5 Qa woyute wośna kin he tamdoka wanji on epha wanjidan kta, qa tacinca kin on wnyute wośna kin he token econ okihi

434 
kta, qa epha wanji on wihdi hin wanjidan kta.

6 Qa wi teca anpetu kin he en, tatanka pte cinca ecetu hinca wanjidan, qa tacinca śakpe, qa tamdoka wanjidan kta; hena ecetu hinca Irta.

7 Unkan tatanka on epha wanjidan, qa tamdoka on epha wanjidan, hecen woyute wośna econ kta, qa tacinca kin on token nape okihi kin iyececa, qa epha wanjidan on wihdi hin wanjidan ecee.

8 Unkan wicaśtayatapi kin tin hiyu eca tiyopa ohanzi hdepi kin he mahen hiyu ecee kta, qa canku kin he ohna ake hde kta.

9 Tuka makoce oyate kin hena tohan, wakan mniciyapi kin en, Jehowa itokam hiyupi eca, tuwe waziyata tiyopa canku kin ohnayan patuś un kta tin hiyu kinhan, he itokaga tiyopa canku kin ohnayan hde kta; qa tuwe itokagiga tiyopa canku kin ohna tin hiyu kinhan, he waziyata tiyopa canku kin ohna linihde kta: tiyopa canku ohna tin hiyu kin he ohna hnihde kte śni, tuka he iyotakonza ohnayan kinanpe kita.

10 Unkan hena mahen yapi eca wicaśtayatapi kin iś iyehan en ye kta, qa hninanpapi eca iś eya hehan hninaanpe kta.

11 Unkan wohanpi kin en, qa wakan mniciyapi kin en, woyute wośnapi kin he tatanka on epha wanjidan, qa tamdoka on epha wanjidan, qa tacinca on token econ okihi, qa epha wanjidan on wihdi hin wanjidan ecee kta.

12 Unkan tohan wicaśtayatapi kin he iye tawacin eciyatanhan wohuhnagge wośnapi qa wookiye wośnapi kin iye cinka Jehowa ecakicon kta hecinhan, hehan tiyopa wiyohiyanpata etonwe cin he kiyuhdokapi kta, qa anpetu wakan cn econ ece qon he iyecen wohuhnage wośna qa woolaiye wośna kin econ kta: hehan tankan hnihde kta: unkan tankan kihda hehan tiyopa kin natakapi kta.

13 Anpetu iyohi tacinca ecetu hinca waniyetu wanjidan, he wohulinagge wośna Jehowa ecayecon kta: hanhanna otoiyohi ecanon lita.

14 Qa hanlianna otoiyohi woyute wośna wan yecage kta, epha okiyuśpe śakpe etanhan wanjidan kta, qa wihdi hin okiyuśpe yamni. etanhan wanjidan kta, mdu kin hpanyc kta : he ohinniy an woyute wośnapi Jehowa tawa, woope owihanke wanica eciyatanhan.

15 Hecen hanhianna otoiyohi tacinca kin econpi kta, qa woyute wośnapi, qa wihdi kin, wohuhnage wośnapi owihanke wanice kta.

16 Jehowa Itancan kin hecen eya; Wicaśtayatapi kin he iye cinhintku wanji taku qu kinhan, he cinhintku tawaye kte cin ee kta; tawayapi on hduhapi kta.

17 Tuka iye taku tawaye cin etanhan tawowidake rvan taku qu kinhan, hehan he ihduhapi waniyetu kin hehanyan yuhe kta; he iyohakarn wicaśtayatapi kin en hdi kta: tuka makoce tawaye cin he iye cinca tawapi ecee kta.

18 Nakurı wicaśtayatapi kin he wokakiśye on oyate makoce tawayapi kin icu kte śni, taku tawayapi kin etanhan heyata iyewicaye kta: iye makoce tawa kin etanhan cinca wayuhewicakiya ecee lita: hecen mitaoyate wicaśta otoiyohi iye makoce ta-. wapi kin etanhan wicayuśpapi kte śni.

19 Hehan oenape tiyopa icahda wanke cin he ohna hiyumayan, 435 


\section{EZEKIEL TAWOWAPI,}

tipi cistinna wakan waziyatakiya etonwan, wawayuśna tawapi kin hena ekta: unkan iho, wiyohpeyata ihanke kin ekta owanka wan wanka.

20 Hehan iye hemakiya; Owanka kin de ohna wawayuśna kin hena wayuśnapi wośnapi qa woahitani wośnapi kin ohanpi kta, qa woyute wośnapi kin he den śpanyanpi kta: hecen oyate wicayuwakanpi kta on hena tankan hocoka kin ekta ayapi kte śni.

21 Hehan tankan hocoka kin en amahi, qa hocoka olatimin topa kin ekta hiyaye mayan: unkan iho, hocoka okahmin otoiyohi en hocoka yukan.

22 Hocoka okalimin topa kin ohna hocoka icikoyagyapi yukan, ohanska wilkcemna topa qa ohdakinyan wikcemna yamni: Okahmin topa kin dena wiyutapi wanjidan.

23 Unkan hena en ihdukśan conkaśke wan wanka, hena topa ihdukśan; unkan ihdukśan conkaśke kin ihukuya ohna wohanpi ecee kin hena kaġapi.

24. Hehan iye hemakiya; Tona wohan econpi ecee kin hena owanka kin de tawapi, tipi tawowidake kin hena den oyate tawośnapi kin owicakicihanpi ecee kta ce.

\section{WICOWOYAKE $4 \%$.}

1 He iyohakam ake tipi oenape kin en amahi; unkan iho, tipi oahe kin ihukuyatanhan wiyohiyanpatakiya mini hiyaya: tipi ite kin wiyohiyanpata wanka nakaeś; unkan tipi etapatanhan ihukuyatanhan mini kin hinanpa, owayuśna kin itokag̉atanhan.

2 Hehan waziyata tiyopa canku kin ohna hinanpe mayan, qa tankan canku kin ohna ohomni yus arnayan, tankan tiyopa kin ekta, canku wiyohiyanpatakiya etonwe cin he ohna: unkan iho, he etapatanhan mini kadus hiyaya.

3 Unkan wicaśta nape ohna ikan liduhe ciqon wiyohiyanpatakiya iyaya qa wiciśpa kektopawinge iyuta, hehan mini kin iyuweh makiya; mini kin iślkahu hehanyan.

4 Ake kektopawing e iyuta hehan mini kin iyuweh makiya; mini kin hupahu kin hehanyan. Akeś kektopawinge iyuta, qa ohna hiyumayan; mini kin wicanite kin heharyan hiyeya.

5 Nakun kektopawinge iyuta; wakpa inıduwegge kta owakihi śni : mini kin minitan aya, mini ohna niwanpi kta, wakpa iyuwehpica śni nakaeś.

6 Unkan iye hemakiya; Wicaśta cinhintku, wandaka he. $\mathrm{He}$ han amahiyu qa wakpa hute kin ekta hdicumayan.

7 Wanna en wahdi hehan iho, wakpa hute icahda can ota hinca, deciyatanhan qa heciyatanhan.

8 Hehan iye hemakiya; Mini kin dena wiyohiyanpata ohomni wanke cin ektakiya hiyu, qa Arabah ekta hiyaya, qa mini tanka kin en iyohpaya: mini tanka kin iyahde hehan mini kin yuwaśtepi kta.

9 Unkan kaketu kta, taku ni un Kin owasin, tukten wakpa kin hiyu kte cin owancaya, en śkanśkanpi kin hena ni $k$ ta: unkan hoggan ota hinca kta, mini kin dena hen hiyu kta nakaeś: hena yuwaśtepi kta; qa tukten wakpa kin hiyu kte cin hen taku owasin ni kta.

10 Unkan kaketu kta, hopsicapi kin hena Engedi etanhan Eneglaim hehanyan en najinpi kta; ho ayumdayapi ecee yuke kta; 
hogan tawapi oicage kin hena miniwanca hogan kin iyecece kta, nina ota hinca kta.

11 Tuka upśija qa tukten hidihdidan kin hena yuwaśtepi kte śni; hena miniskuya on qupi kta.

12 Unkan wakpicahda, hute kin en deciyatanhan qa heciyatanhan, waskuyeca can owasin icagge kta, ape tawa kin śnije kte śni, qa tawaskuyeca lin owihanke kte śni; wi kin en waskuyeca teca icahya ecee kta, mini tawa kin hena tipi wakan kin etanhan hiyu nakaeś: unkan waskuyeca tawa kin he woyute kta, qa ape kin hena pejihuta yapi kta.

13 Jehowa Itancan kin hecen eya; Israel wicowazi akenonpa kin eciyatanhan makoce kin tawayayapi kta opapun ihanke kin he dee. Joseph wiyutapi nom yuhe kta.

14. Unkan otoiyohi tawayayapi kta; niyatepi wicawaqu kta on nape wahdugate ciqon he eciyatanhan: hecen makoce kin tawayayapi kta on yecipamnipi kta.

15 Unkan waziyata ihanke ekta, miniwanca tanka kin etanhan, Hethlon canku kin ohna, Zedad ekta yapi ecee kin he opapun kin ee:

16 Hamat, Berotha, Sibraim, he qe Damasek opapun qa Hamat opapun okitahedan; Hazor cokaya kin he Hauran opapun kin icahda.

17 Unkan miniwanca kin etanhan opapun lin he Hazor minihoka ee kta, Damasek opapun, qa waziyata waziyatakiya, qa Hamat opapun. Waziyata ihanke kin hee.

18 Unkan wiyohiyanpata ihanke kin, Hauran otahedan, qa Damasek ohna, qa Gilead ohna, qa Israel makoce kin otahedan,

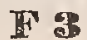

Jordan ee, opapun kin ohna widutapi kta. Unkan wiyohiyanpata ihanke kin dee.

19 Unkan itokagata ihanke kin itokahkiya, Tamar etanhan okiciğe mini kin ekta Kadeś en, wakpa kin etanhan miniwanca tanka lin ekta. Unkan itokah ihanke i tokahkiya wanke cin hee. 20 Unkan wiyohpeyata ihanke kin he miniwanca tanka opapun kin ohnayan, Hamat iyotakons ipi kin hehanyan. Wiyolipeyata ihanke kin hee.

21 Hecen Israel wicowazi kin eciyatanhan makoce kin yecipamnipi kta.

22 Unkan kaketu kta, tawayayapi kta on, niyepi qa wicaśta tokeca niyopeyapi ounyanpi kin hena koya, niyopeyapi cinca yuhapi kte cin hena, oeconna econpi kin on yecipamnipi kta. Unkan hena e makoce kin ohna Israel cinca owicapeya wicatonpi kin iyecen wicadawapi kta; hena e Israel wicowazi ehnahna niyepi om makoce tawayapi kta.

23 Unkan kaketu kta, wicowazi tukte wanji ehna wicaśta tokeca ounyan hecinhan, hen makoce tawaye kte cin yaqupi ecee $\mathrm{kta}$, Jehowa Itancan kin eya.

\section{WICUWOYAKE 48.}

1 Unkan wicowazi cajepi kin dena eepi. Waziyata ihanke etanhan hute kin ekta, Hethlon canku kin ohna, Hamat ekta yapi ecee kin, Hazor minilidoka Damasek ihanke waziyatakiya, Hamat huta kin ekta; wiyohiyanpata qa wiyohpeyata dena opapun ee; wanji Dan tawa.

2 Qa Dan ikiciyutapi kin icahda wiyohiyanpatanhan wiyoheyata ihanke ekta, wanji Aśer tawa. 


\section{EZEKIEL TAWOWAPI,}

3 Qa Aśer ikiciyutapi kin icahda wiyohiyanpatanhan wiyolipeyata ihanke ekta, wanji Naphtali tawa.

4 Qa Naphtali ikiciyutapi kin icahda, wiyohiyanpatanhan wiyohpeyata ihanke ekta, wanji Manasseh tawa.

$5 \mathrm{Qa}$ Manasseh ikiciyutapi kin icahda, wiyohiyanpatanhan wiyolipeyata ihanke kin ekta, wanji Ephraim tawa.

$6 \mathrm{Qa}$ Ephraim ikiciyutapi kin icahda, wiyohiyanpatanhan wiyolpeyata ihanke kin ekta, wanji Ruben tawa.

7 Qa Ruben ikiciyutapi kin icahda, wiyohiyanpatanhan wiyolipeyata ihanke kin ekta, wanji Juda tawa.

8 Unkan Juda ikiciyutapi kin icahda, wiyohiyanpatanhan wiyohpeyata ihanke kin ekfa, wośnapi waduśnapi kte cin ee $k$ ta, ohdakinyan cedi iyutapi kek topawinge wikcemna nonpa sanpa zaptan, qa ohanske kin he urma kiyuśpapi kin iyehankeca, wiyohiyanpatanhan wiyohpeyata ihanke kin ekta : unkan cokaya tipi wakan kin he kta.

9 Makoce wośnapi Jehowa wayakiduśnapi kte cin he ohanske kin kek topawinge wikcemna nonpa sanpa zaptan, qa ohdakinyan kektopawinge wikcemna.

10 Unkan hena on, wawayuśnapi kin hena on wośnapi wakan kin dee kta; waziyatakiya ohanske kektopa winge wikcemna nonpa sanpa zaptan, qa wiyohipeyatakiya ohdakinyan kektopawinge wikcemna, qa wiyohiyanpatakiya ohdakinyan iś kektopawinge wikcemna, qa itokahkiya ohanske kin kektopawinge wikcemna nonpa sanpa zaptan. Unkan Jehowa tipi wakan tawa kin he cokata he kta.
11 Wawayuśna ihduwakanpi Zadok cinca kin he tawapi kta; hena e wowaśi mitawa hduhapi, Israel cinca nunipi qehan hena nunipi śni, Lewi wicaśta nunipi qon iyececa.

12 Unkan makoce wośnapi wayuśnapi kin he wakan hinca hduhapi kta, Lewi wicaśta ihanke tawapi kin icahda.

$13 \mathrm{Qa}$ wawayuśna makoce tawapi kin iyotakons Lewi wicaśta kin iś kektopawinge wikcemna nonpa sanpa zaptan ohanske, qa ohdakinyan kel topawinge wikcemna yuhapi kta : ohanske ocowasin kektopawinge wikcemna nonpa sanpa zaptan qa ohdakinyan kin kektopawinge wikcemna.

14. Unkan he wiyopeyapi kte śni, qa tokiyopekiyapi kte śni, qa makoce oicage tokaheya kin hena tokan wicaqupi kte śni : Jehowa ekta wakan nakaeś.

15 Unkan kektopawinge zaptan ohdakinyan en okaptapi, kektopawinge wikcemna nonpa sanpa zaptan kir itokam wanke cin he owanka ikceka otonwe tawa kta, tipi kaġapi kta qa ibdukśan wanke kta on, qa otonwe kin he cokata yanke kta.

16 Qa decen wiyutapi kta, waziyata icagopi kin he kek topawinge topa sanpa opawinge zaptan, qa itokali icagopi kin kektopawinge topa sanpa opawinge zaptan, qa wiyohiyanpata icagopi kin kektopawinge topa sanpa opawinge zaptan, qa wiyohpeyata icagopi kin he kektopawinge topa sanpa opawinge zaptan.

17 Qa otonwe ihdukśan wanke kte cin he wariyatakiya opawinge nonpa sanpa wikcemna zaptan, qa itokahkiya opawinge nonpa sampa wikcemna zaptan, qa wiyohiyanpatakiya opawinge nonpa sanpa wikcemna zaptan, qa 


\section{WICOWOYAKE 48.}

wiyohpeyatakiya opawinge nonpa sanpa wikcemna zaptan.

18 Unkan ohanska en okaptapi kin, makoce wakan kin icahda, he wiyohiyanpatakiya kektopawinge wikcemna, qa wiyohpeyatakiya kektopawinge wikcemna kta; unkan he malroce wakan kin iyo takonza kta : unkan hetanhan oicage kin tona otonwe en waokiya unpi kin hena woyute yapi lita.

19 Unkan tona otonwe en waokiyapi kin hena Israel wicowazi iyuhpa etanhan waokiyapi ecee kta.

20 Makoce wośnapi ocowasin kin he kektopawing̀e wikcemna nonpa sanpa zaptan eceh kektopawing ge wikcemna nonpa sanpa zaptan kta: wośnapi wakan kin he topa omdotonyan waduśnapi kta, otonwe tawa kte cin ahna.

21 Hehan okaptapi kin hena wicaśtayatapi tawa kta, wośnapi wakan Kin ideciyatanhan qa iheciyatanhan, qa otonwe tawa lite cin nakun, kektopawinge wikcemna nonpa sanpa zaptan wiyohiyanpata ihanke kin iyotakonza, qa wiyohpeyatakiya kektopawinge wikcemna nonpa sanpa zaptan wiyohpeyata ilıanke kin iyotakonza, he wicaśtayatapi okiyuśpe tawa kin icahda; unkan he qe wośnapi wakan kin hee kta, qa tipi wakan kin he cokaya he kta. 22 Hehan Lewi wicaśtu makoce tawapi qa taku otonwe tawa kin etanhan, wicaśtayatapi tawa kin otahedan wanke cin, Juda ikiciyutapi qa Benjamin ikiciyutapi kin otahedan, he wicaśtayatapi tawa kta.

23 Hehan wicowazi unmapi kin on, wiyohiyanpata ihanke kin etanhan wiyohpeyata ihanke ekta, wanji Benjamin tawa.

24 Qa Benjamin ikiciyutapi kin icahda wiyohiyanpata ihanke kin etanhan wiyohpeyata ihanke ekta wanji Simeon tawa.

25 Qa Simeon ikiciyutapi kin icahda, wiyohiyanpata ihanke etanhan wiyohpeyata ihanke kin ekta, wanji Issakar tawa.

26 Qa Issakar ikiciyutapi kin icahda, wiy ohiyanpa ta ihanke kin etanhan wiyohpeyata ihanke ekta, wanji Zebulun tawa.

27 Qa Zebulun ikiciyutapi kin icahda, wiyohiyanpa ta ihanke kin etanhan wiyohpeyata ihanke kin ekta, wanji Gad tawa.

28 Qa Gad ikiciyutapi kin, itokagatanhan itokali ihanke kin he iyutapi kin, he Tamar etanhan Kadeś okiciğe mini kin hee, miniwanca tanka ektakiya wakpa kin hehanyan.

29 Israel wicowazi tawapi kta e oeconna econpi kin on yeciyuśpapi kta makoce kin he dee, qa tawapi kte cin dena ee, Jehowa Itancan kin eya.

30 Unkan otonwe etanhan oenape kin dena ee, waziyata ihanke kin wiyutapi kektopawinge topa sanpa opawinge zaptan.

31 Unkan otonwe tiyopa kin hena Israel wicowazi cajepi kin eciyatanhan lita: waziyatakiya tiyopa yamni ; tiyopa wanji Ruben tawa, tiyopa wanji Juda tawa, tiyopa wanji Lewi tawa.

32 Qa wiyohiyanpata ihanke ekta kektopawinge topa sanpa opawinge zaptan: qa tiyopa yamni; qa tiyopa wanji Joseph tawa, tiyopa wanji Benjamin tawa, tiyopa wanji Dan tawa.

33 Qa itokal ihanke kin iś wiyutapi kektopawinge topa sanpa opawinge zaptan: qa tiyopa yamni ; tiyopa wanji Simeon tawa, tiyopa wanji Issakar tawa, tiyopa wanji Zebulun tawa.

34 Nakun wiyohpeyata ihanke 439 


\section{DANIEL TAWOWAPI KIN,}

kin kektopawinge topa sanpa opawinge zaptan; tiyopa yamni nakun; tiyopa wanji Gad tawa, tiyopa wanji Aśer tawa, tiyopa wanji Napthali tawa.
35 Ihdukśan kektopawinge akeśahdogan: Unkan anpetu kin hetanhan otonwe caje kin he JEHOWA ŚMMAH (Jehowa hen un) ee kta.

\section{DANIEL TAWOWAPI KIN.}

\section{WICOWOYAKE $\dot{1}$.}

1 Jehoiakim Juda wicaśtayatapi tawaniyetu iyamni kin en, Nebukadnezzar Babel wicaśtayatapi kin he Jerusalem ekta hiyu, qa ihdukśan aonataka.

2 Unkan Itancan kin Jehoiakim Juda wicaśtayatapi kin he iye nape kin en qu, Wakantanka ti ohna wakśica kin apa nakun. Unkan hena Śinar makoce kin ekta akiyahda, iye taku wakan tawa ti kin ekta: qa wakśica kin hena taku wakan tawa mazopiye kin en ahdi.

3 Unkan wicaśtayatapi kin Aśpenaz iye yunok tawa kin wicayuhe cin he, Israel cinca kin etanhan awicaku kta keciya, wicaśtaya tapi cinca, qa wicaśta itancanpi kin etanhanhan:

4 Kośka tokeca śni unpi, tuka owanyag waśtepi, qa woksape owasin en wayupikapi, qa wo sdonye sdonyapi, qa wookahnige okahnigapi, qa tona wicaśtayatapi ti kin en najin okihipi kta; qa hena Kasdim tawowapi qa iapi koya onspewicakiyapi kta.

5 Unkan wicaśtayatapi kin, anpetu iyohi iye tawoyute etanhan hena ongege wicaqu ece, qa miniśa hdatke cin etanhan: hecen waniyetu yamni icahwicakiye
Kta, qa hena ihuniyanpi kinhan wicaśtayatapi kin itokam inajinpi kta.

6 Unkan Juda cinca kin etanhan Daniel, Hananiah, Miśael qa Azariah hena en opapi.

7 Unkan yunok unpi kin en itancan kin he hena caje wicaqu; Daniel he Belteśazzar qu, qa Hananiah, Śadrak ; qa Miśael, Meśak; qa Azariah, Abednego.

8 Tuka Daniel wicaśtayatapi tawoyute onġe on, qa miniśa hdathe cin on, iye cante mahen ihduśape kte śni kecin: Heon etanhan ihduśape kte śni e yunok unpi itancan kin kida.

9 Unkan yunok unpi kin en itancan kin he Daniel tanyan cantekiyuze ca waśtekidaka, he Wakantanka kaga.

10 Hehan yunok unpi kin en itancan kin Daniel heciya ; Itancan mitawa wicaśtayatapi wayute woyatke lso niçupi ecee kin he kowakipa : tokeca koślka obe nitawapi kin elna isanpa ite iyokiśica wanniyakapi kta he : kinhan wicaśtayatapi kin elsta pa iyaco mayakiyapi kta.

11 Hehan Daniel, yunok unpi en itancan kin, Melzar, Daniel, Hananiah, Miśael qa Azariah wicayuhekiye ciqon he heciya; 12 Ceciciya ce, wowidake nita- 


\section{WICOWOYAKE 2.}

wa anpetu wikcemna hehanyan iwicayuta ye: qa omnica etanhan unqupi kta, qa mini ece yatkeunkiyapi kta.

13 Hehan nitokam itohnake iwanunyakapi kta, qa kośka wicaśtayatapi tarvoyute ongegge yutapi kin hena iś eya itohnake wanyakapi kta: unkan iwandake cin he eciyatanhan wowidake nitawa kin ecawicakicon ye, eya.

14 Unkan wicoie kin de en anawicagioptan, qa anpetu wikcemna hehanyan iwicayukcan.

15 Unkan anpetu wikcemna owihanketa kośka owasin wicaśtayatapi tawoyute ongege yutatapi ecee kin kici iciwankiciyakapi kin iye itohnake sanpa owanyag waśte, qa celipi isanpa cepapi.

16 Hecen Melzar woyute ongege qa miniśa yatkanpi kte ciqon hena ewicakiciyaku; qa omnica ecee wicaqu.

17 Unkan kośka topapi kin dena Wakantanka wosdonye wicaqu, qa woonspe woksape ko owasin en wowiyukcan: qa Daniel wowanyake wowihanmde ko owasin olialiniga.

18 Unkan anpetu tona en awicau kta wicaśtayatapi keye ciqon hena wanna henakeca, hehan yunok unpi wicayuhe cin he hena Nebukadnezzar itokam hiyuwicaya.

$1 y$ Unkan wicaśtayatapi lin hena om wohdaka; qa iyuhpa owicapeya tuwedan Danicl, Hananiah, Miśael qa Azariah iyececa iyeyapi śni: Heon etanhan hena wicaśtayatapi kin itokam inajinpi.

20 Unkan woksape wicoie qa wowiyukcan tona wicaśtayatapi kin iwicawange cin hena iś, wicaśta ksapa owasin qa wicanhpi iwanyakapi ecee kin iye tamakoce owancaya unpi, dena wikcemna akihde isanpa waśte iyewicaya.

21 Unkan Daniel Kuros wicaśtayatapi tawaniyetu tokaheya kin hehanyan en un.

\section{WICOWOYAKE 2.}

1 Unkan Nebukadnezzar wicaśtayatapi un tawaniyetu inonpa en, Nebukadnezzar wowihanmde ihanmna, on taniya kin iliniyanyan qa iśtinbe cin akiciyuśtan.

2 Hehan wicaśtayatapi kin wicaśta ksapapi, qa wicanhpi iwanyakapi, qa wapiyapi, qa Kasdim wicaśta kin hena wicakico wicaśi, wicaśtayatapi tawowihanmde kin okiciyakapi kta. Hecen hena en upi qa wicaśtayatapi kin itokam inajinpi.

3 Unkan wicaśtayatapi kin hewicakiya; Wowihanmde wan iwahanmna, unkan mitaniya ihniyanyan, wowihanmde sdonkiye kta e heon.

4. Hehan Kasdim wicaśta kin Aram iapi kin on wicaśtayatapi kin heciyapi ; Wicaśtayatapi, ohinniyan ni un nunwe: wowidake nitawa wowihanmde kin owicakiyaka ye, kinhan ieska unkoyataninpi kta ce.

5 Wicaśtayatapi kin waayupte ca, Kasdim wicaśta kin hewicakiya; Wicoie kin tokan imakiyaya: wowihanmde kin he, qa ieska yaotaninpi kin nakun omiyeciyakapi śni kinhan, niye nicaksaksapi kta, qa yatipi kin ocesdi paha kagapi kta:

6 Tuka wowihanmde kin he qa ieska yaotaninpi kin nakun omiyeciyakapi kinhan, miye etanhan taku wicaqupi, wocinyopeyapi qa woyuonihan tanka iyacupi kta: heon etanhan wowihanmde 441 


\section{DANTEL TAWOWAPI KIN,}

qa ieska yuotaninpi kin nakun omiciyaka po.

7 Hena ake ayuptapi qa heyapi ; Wicaśtayatapi kin wowidake tawa wowihanmde kin owicakiciyake kta, kinhan ieska oyakapi kin unyaotaninpi kta ce.

8 Wicaśtayatapi kin waayupte ca heya; Anpetu yutehan wacannipi awicakehan sdonwaya, wicoie kin tokan imakiyaya wandakapi nakaeś.

9 'l'uka wowihanmde kin he omiyecidakapi śni kinhan woyaco wanjidan niciyankapi : Woitonśni qa wicoie waaśape mitokam odakapi kta yakagapi, anpetu yutokecaji kta hehanyan: Heon etanhan wowihanmde kin he omiciyaka po, kinhan ieska oyakapi kin he yaotanin oyakihipi sdonwaye kta ce.

10 Kasdim wicaśta kin wicaśtayatapi kin itokam waayuptapi qa heyapi; Wicaśta maka akan unpi tuwedan wicaśtayatapi toie kin oyaka okihi kte śni : Heon etanhan wicaśtayatapi, wicaśta itancan qa wowidake wicayuhe cin tuwedan wicaśta ksapa, wicanlipi iwanyakapi ecee kin, qa Kasdim wicaśta kin wicoie hececa wicakida śni.

11 Qa wicaśtayatapi kin taku tehike hinca wan da, qa tuwedan tokeca wicaśtayatapi kin itokam he oyake kte śni, taku wakan wicacelipi en tipi śni kin henana okihipi ce.

12 Heon etanhan wicaśtayatapi kin sinhda qa canteptanye hinca, qa Babel en ksapapi kin iyuhpa wicaktepi kta konza.

13 Unkan ksapapi kin wicaktepi kta keya wokonze kin he yaotaninpi: Unkan Daniel qa iye takodawicaye cin om wicaktepi kta e owicadepi.

14 Hehan Daniel, Ariok wica442 śtayatapi taakicita tancan, Babel en wicaśta ksapa owasin wicakte kta iyaye cin he, woksape qa wowiyukcan on ayupte:

15 Waayupte ca Ariok wicaśtayatapi taakicita tancan kin heciya; Tokeca wokonze kin wicaśtayatapi kin etanhan inahini he. Hehan Ariok wicoie kin Daniel okiyaka.

16 Hehan Daniel tin iyaye ca wicaśtayatapi kin anpetu qu kta kida, hecen ieska yaotaninpi kin he wicaśtayatapi kin kipazo kta.

17 Hehan Daniel iye ti kin ekta kihda, qa taku kin he Hananiah, Miśael qa Azariah, iye tawaśitkupi kin owicakiyaka:

18. Hena woinahbe kin de on Mahpiya Wakantanka kin itokam wowaonśida kidapi kta; hecen Daniel qa iye tawaśitkuwicaye cin Babel en wicaśta ksapa unmapi kin om ihangyapi kte śni. 19 Hehan hanyetu wowanyake wan en woinalibe kin he Daniel okiyakapi. Hehan Daniel Mahpiya Wakantanka kin yawaśte: 20 Daniel waayupte ca heya; Wakantanka caje kin he yawaśtepi kta, otokaheya wanica qa owihanke wanica; woksape qa wowaśake kin hena iye tawa nakaeś.

$21 \mathrm{Qa}$ iye omaka qa waniyetu kin yutokeca ece; wicaśtayatapi lieyata iyeya, qa wicaśtayatapi wankan ehde; ksapapi kin hena woksape wicaqu, qa tona wowiyukcan sdonyapi kin hena wosdonye wicaqu ece.

22 Tye taku temahentu qa nahmana un kin hena yuotanin: taku otpaza en un kin he sdonya, qa iyoyanpa kin he iye kici ti. 23 Atewicawaye Wakantanka tawapi, wopida eciciya qa ciyatan, woksape qa wookihi mayaqu, qa taku unnicidapi kin he 
sdonyemayaya: wicaśtayatapi toie kin he sdonyeunyakiyapi nakaeś.

24. Heon etanhan Daniel Ariok, wicaśtayatapi Babel en ksapapi kin ihangwicaye śi qon he ekta iyaya: Hkta ye ca kaken eciya; Babel en wicaśta ksapapi kin ihangwicaye śni wo: wicaśtayatapi kin itokam aınayan wo, kinhan ieska yaotaninpi kin he wicaśtayatapi kin wakipazo kta ce.

25 Hehan Ariok inalini hinca, Daniel wicaśtayatapi kin itokam ahi qa heciya; Juda eciyatanhan wayaka unpi cinca kin etanhan wicaśta wan iyewaya, he qe ieska yaotaninpi kin wicaśtayatapi kin sdonyekiye kta ce, eya.

26 Wicaśtayatapi kin waayupte ca Daniel, nakun Belteśazzar eciyapi kin he heciya; Wowihanmde wanmdake cin he omiyeciyake kta oyakihi he, nakun ieska yaotaninpi kin.

27 Daniel wicaśtayatapi kin itokam waayupte ca heya; Woinahbe wicaśtayatapi da kin he wicaśta ksapapi, wicanlipi iwanyakapi, wowapi kaġapi qa wapiyapi econpi kin hena wicaśtayatapi kin okiciyakapi kta okihipi śni :

28 Tuka mahpiya ekta Taku Wakan wanji yanka, he woinalibe yuotanin ece, qa anpetu ehake kin en taku u kte cin hena wicaśtayatapi Nebukadnezzar okiyaka. Wowihanmde nitawa qa nipa makata nunka taku wanyake ciqon dena ee:

29 Niye wicaśtayatapi, nitowinja akan, nitawacin wankan $u$, taku tokata anpetu kin en u kte cin hena; qa tuwe woinahibe yuotanin ecee kin he taku u kte cin hena sdonyeniyan.

30 Tuka miye qe, ni unpi kin owasin isanpa woksape mduhe cin on woinalibe kin de omaki- yakapi śni ; tuka ieska yaotaninpi kin he wicaśtayatapi kin okiciyakapi kta, qa nicante oyuze kin sdonyakiye kta e heon etanhan.

31 Wicaśtayatapi, niye opalita nanka, unkan inyun wakaģapi tanka wan! Wakag̉api tanka, oiyege waśte hinca he nitokam han; qa owanyake kin he wowinihan hinca.

32 Wakagapi kin de pa kin mazaskazi waśte heca; maku qa isto hena mazaska; tezi qa sican lin hena mazazi;

33 Huha kin mazasapa; siha kin onśpa mazasapa qa onśpa maka.

34 Opalita nanka ecen inyan wanji nape codan baśpapi, he wakagapi kin siha mazasapa qa maka kin en iyapa, qa hena kamdemdeca.

35 Hehan mazasapa kin, maka kin, mazazi kin, mazaska kin, qa mazaskazi kin okonwanjidan kamdemdecapi, qa mdoketu okapanpi ha kin iyececa icagga; qa tate kin hena okahbog iyeya, hecen tukten wanke kte iyeyapi śni: tuka inyan wakagapi kin iyapa qon lie he tanka icaga, qa maka ocowasin ojuya.

36 Wowihanmde kin hee: unkan ieska yaotaninpi kin he wicaśtayatapi kin itokam unkoyakapi kta.

37 Wicaśtaya tapi, niye wicaśtayatapi en wicaśtaniyatapi : Mahpiya Wakantanka kin he wokiconze wan niçu, wookihi, qa wowaśake, qa wowitan:

$38 \mathrm{Qa}$ tukte etu wicaśta cinca tipi kin, tinta woteca qa mahpiya zitkadan kin hena ninape en niçu, qa hena owasin iwankam itancan nicagga. Mazaskazi pa kin he niye.

39 Qa niye onihakam wokiconze wan tokeca nihukutu inajin kta; 443 


\section{DANIEL TAWOWAPI KIN,}

qa wokiconze tokeca wan wiciyamni kin he mazazi; he qe maka kin ocowasin iwankam ounye kta.

40 Unkan wokiconze itopa kin he mazasapa iyecen waśake kta: mazasapa taku owasin kamdemdeca qa ohiya nakaeś : qa mazasapa dena iyuhpa kamdemdece cin he iyecen iś eya wakamdemdece ça wakamdumdu kta.

$41 \mathrm{Qa}$ nakun siha qa siyukaza kin onśpaśpa maka upśija kin heca, qa onśpaśpa mazasapa wandake ciqon, wokiconze kin he kiyuśpapi kta; tuka mazasapa wowaśake kin en un kta, mazasapa maka upśija kici icicahiyapi wandake nakaeś.

42 Qa siha sipinkpa kin hena hanke mazasapa qa hanke maka heca, he iyecen wokiconze kin he hanke suta lita qa hanke wankadan kita.

43 Nakun mazasapa maka upśija kici icicahiyapi wandake ciqon, hena wicaśta akantu oicağe kin kici icicahiiçiyapi kta; tuka en askamkiciyapi kte śni, mazasapa maka upśija kin kici tanyan icicahiyapi śni nakaeś.

44 Unkan wicaśtayatapi kin de. na taanpetu kin en, Mahpiya Wakantanka kin he wokiconze wan tohinni ihangyapi kte śni kin heca yuwankan ehde kta : unkan wokiconze kin he oyate tokeca aihpewicayapi kte śni : wokiconze kin owasin kamdumdu kta qa yutakuni kte śni; tuka he qe owihanke wanin un kta.

45 Qa nakun inyan wan he kin etanhan nape codan baśpapi wandaka, qa he mazasapa lin, mazaśa kin, maka kin, mazaska kin, qa mazaskazi kin hena kamdemdeca; hecen Taku Wakan Tanka kin he taku tokata u kte cin hena wicaśtayatapi kin sdon- yekiya: unkan wowihanmde kin he wowicake, qa ieska yaotaninpi kin he wacinyepica ce.

46 Hehan Nebukadnezzar wicaśtayatapi kin ite makipusdiya ehpeiciye ca Daniel ohoda, qa wośna wan womna waśtemna iyahna wakiyuśna wicaśi.

47 Wicaśtayatapi kin Daniel ayupte ca heya; Awicakehan Taku Wakan nitawapi kin he taku wakan ehna Wakantanka hee, qa wicaśtayatapi ehna Itancan, qa woinalibe yuotanin ece kin heca, woinalibe kin de yaotanin oyakihi nakaeś.

48 Hehan wicaśtayatapi kin Daniel wicaśta tanka kaga, qa taku wicaqupi tanka ota qu, qa Babel makoce kin ocowasin en itancan kaga, qa Babel en ksapapi kin iyuhipa iye iyotan tanka.

49 Hehan Daniel wicaśtayatapi kin kida, unkan Śadrak, Meśak qa Abednego Babel makoce kin en taku econpi kin awanyay wicaśi. Tuka Daniel wicaśtayatapi tatiyopa kin en un.

\section{WICOW OYAKE 3.}

1 Nebukadnezzar wicaśtayatapi kin mazaskazi wakagiapi wan kag̉a, obosdatu kin he wiciśpa wikcemna śakpe qa ohdakinyan wiciśpa śakpe: Babel makoce Dura makomdaya kin ohna bosdan ekihde.

2 Hehan Nebukadnezzar wicaśtayatapi kin he, wicaśta ihdawapi kin, wicaśta itancanpi kin, qa akicita tancanpi kin, wayaco itancanpi kin, mazaska awanyakapi kin, woope aiapi kin, woope sdonyapi qa malroce kin en itancanpi kin iyuhpa yuritaya hiyuwicakiyapi kta ye wicaśi ; wakaǵapi Nebukadnezzar wicaśtayatapi kin bosdan eki- 


\section{WICOWOYAKE 3.}

hde kin yuwakanpi lsta ekta upi kta.

3 Hehan wicaśta ihdawapi kin, wicaśta itancanpi kin, qa akicita tancanpi, wayaco itancanpi kin, mazaska awanyakapi kin, woope aiapi kin, woope sdonyapi, qa makoce kin en wicaśta itancanpi kin owasin witaya mniciyapi, wakaġapi Nebukadnezzar wicaśtayatapi bosdan ekihde kin yuwakanpi kta elsta: unkan hena Nebukadnezzar wakaġapi bosdan ekihde kin he itokam inajinpi.

4 Hehan eyanpaha wan waśagya eyanpaha, Wicaśta, oyate, qa iapi yaunpi kin, niyepi kaken econ niśipi ce:

5 Tohan tatokadan he yajopi, cotanka, candowankiyapi, sakbut, cancega, mazayahotonpi, qa dowankiyapi ocaje owasin, hena ho kin nayahonpi kinhan, hehan mazaskazi wakagapi Nebukadnezzar wicaśtayatapi bosdan ekihde kin he en makata ehpeniçiyapi qa ohoyadapi kta.

$6 \mathrm{Qa}$ tuwe makata ehpeiciye śni qa ohoda śni hehantudan hin peta ide oceti wan cokaya ehpeyapi kta ce.

7 Heon etanhan hehantudan, oyate kin iyuhpa tatokadan he yajopi, cotanka, candowankiyapi, sakbut, cancegia, mazayahotonpi, qa dowankiyapi ocaje owasin, hena ho kin nalonpi qehan, wicaśta iyuhpa, oyate kin, qa iapi kin hena makata ehpeiciyapi, qa mazaskazi wakaġapi Nebukadnezzar wicaśtayatapi bosdan ekihde kin he ohodapi.

8 Tuka helıan Kasdim wicaśta wanjikji kiyadan upi qa Juda wicaśta kin wiyawicaonpapi.

9 Hena woyakapi qa Nebukadnezzar wicaśtayatapi kin heciyapi ; Wicaśtayatapi, ohinniyan ni un nunwe.
10 Niye, wicaśtayatapi, wokonze wan yakaga, wicaśta owasin tatokadan he yajopi, cotanka, candowankiyapi, sakbut, canceğa, mazayahotonpi qa dowankiyapi ocaje owasin hena ho kin nation kinhan, makata elpeiciye ca mazaskazi wakaggapi kin ohoda kta:

11 Qa tuwe makata elpeiçiye śni qa ohoda śni kinhan peta ide oceti wan cokaya iyohipeyapi kta ce.

12 Juda wicaśta wanjikji Babe1 en wicohan awanyagwicayakiya, Śadrak, Meśak qa Abednego; wicaśtayatapi, wicaśta dena en eniwacinpi śni : taku wakan nitawa kin en wowidagiçiyapi śni, qa mazaskazi wakaģapi bosdan eyehdc kin he ohodapi śni ece.

13 Hehan Nebukadnezzar śinhda qa canteptanyan on Śadrak, Meśak qa Abednego auwicaśi. Hecen wicaśta kin dena wicastayatapi kin itokam awicahipi.

14 Nebukadnezzar ie ca hewicakiya; He wicakapi he, Śadrak, Meśak qa Abednego, taku wakan mitawa kin hena en wowidagniciyapi śni, qa mazaskazi wakagapi bosdan ewehde kin he ohoyadapi śni he.

15 Wanna wiyeya yaunpi kinhan, tohantu tatokadan he yajopi, cotanka, candowankiyapi, salkbut, cancega, mazayahotonpi qa dowankiyapi ocaje owasin ho kin nayahonpi, hehan makata elipeniçiyapi qa wakagapi wakage cin he ohoyadapi kta: Tuka ohoyadapi śni kinhan, wihiyayedan oape kin he en peta ide oceti wan cokaya iyohpeniyanpi kta: qa Taku Wakan tukte e he minape etanhan eniyakupi kta he.

16 Śadrak, Meśak qa Abednego waayuptapi qa wicaśtayatapi kin heciyapi; Nebukadnezzar, wi445 


\section{DANIEL TAWOWAPI KIN,}

coie kin de on unkaniyuptapi kta iyecece śni.

17 He hecetu kinhan, Taku Wakan unkitawapi, en wowidagiçiya unyakonpi kin he peta ide oceti kin etanhan eunyakupi kta okihi, qa eqe, wicaśtayatapi, ninape etanhan eunyakupi kta.

18 T'uka hecon śni eśta, taku wakan nitawa en wowidagunkiciyapi kte śni, qa mazaskazi wakagapi bosdan eyehde kin he ohoundapi kte śni, wicaśtayatapi, he sdonya wo.

19 Hehan Nebukadnezzar wocanteptanye on ojudan, qa Śadrak, Meśak qa Abednego on ite tokeca hinhda: ie ca oceti kin kanyapi wanyakapi ecee qon isanpa sakowin akihde kanye wicaśi :

20 Qa iye taakicita obe kin wicaśta iyotan waśakapi kin, Śadrak, Meśak qa Abednego pawicahtapi kta, peta ide oceti kin en iyohpewicayapi kta, kewicakiya.

21 Hehan wicaśta kin hena akan unpi tawapi, taonlidolida, taśina koya, qa wokoyake tokeca ecehnana pawicalitapi, qa peta ide oceti kin cokaya iyohpewicayapi.

22 Heon etanhan wicaśtayatapi oie kir wainahini, qa oceti kin nina kata hinca, heon tona Śadrak, Meśak qa Abednego iwicacupi qon wicaśta kin hena peta ide kin wicakte.

23 Unkan dena wicaśta yamni, Śadrak, Meśak qa Abednego pawicalitapi ecen peta ide oceti kin cokaya hinhpayapi.

24. Hehan Nebukadnezzar wicaśtayatapi kin nina yuśinyaya, qa ohankoya najin hiyaya-ie ça wicaśta waaiewicakiye cin hena hewicakiya; Wicaśta yamni pahitapi peta cokaya iyohipewicunyanpi śni he. Hena wayuptapi 446 qa wicaśtayatapi kin heciyapi; Wicaśtayatapi, he hecetu ce.

25 Iye waayupte ca heya; In. yun, wicaśta topa kaśke śni unpi peta cokaya manipi wanmdaka, qa tuktedan kiunniyanpi śni : unkan itopa owanyake kin he Taku Wakan Cinhintku kin iyececa ce, eya.

26 Hehan Nebukadnezzar peta ide oceti tiyopa kin ikiyedan u ; ie ça heya; Sadrak, Meśak qa Abednego, Taku Wakan Tehanwankan taokiye, niye tankan u po, qa kuwa po. Hehan Śadrak, Meśak qa Abednego peta kin cokaya tanhan hdicupi.

27 Unkan wicaśta ihdawapi, wicaśta itancanpi, qa akicita tancanpi, qa wicaśtayatapi woope aiewicakiye cin hena witaya unpi wicaśta kin dena wanwicayakapi, tancanpi en peta takudan okihi sni, qa paha wanjidan gu śni, qa akan unpi tawapi kin yutokeca śni, qa iyepi akan peta gumna kin iwicayaye śni.

28 Nebukadnezzar ie ca heya; Șadrak, Meśak qa Abednego Taku Wakan tawapi kin he yawaśtepi nunwe; eqe taohnihde wakan kin uśi, qa wowidagwicaya wacinyanpi kin hena wicaśtayatapi oie kin yutokecapi, qa iye Taku Wakan tawapi ecedan en wowidagiciyapi, qa taku wakan tokeca ohodapi kte śni e tancan kpagganpi kin hena ewicahdaku.

29 Heon etanhan wokonze wan wakagia, Oyate owasin, wicaśta qa iapi kin, Sadrak, Meśak qa Abednego Wakantanka tawapi kin on tuwe taku śica eye cinhan, he kicaksaksapi kta, qa tipi tawapi kin ocesdi paha kagapi kta: taku wakan tokeca docen waehdaku okihi kta wanica nakaeś.

30 Hehan wicaśtayatapi kin Śa- 


\section{WICOW OYAKE 4.}

drak, Meśak qa Abednego, Babel makoce kin en itancan wicakaga.

\section{WICOWOYAKE 4.}

1 Nebukadnezzar wicaśtayatapi kin, wicaśta owasin, oyate qa iapi maka kin ocowasin en ounyanpi kin, Wookiye niciyuotapi nunwe.

2 Wowakta wowapetokeca ko Taku Wakan Tehanwankantu ecamicon kin hena mdaotanin kta iyomakipi.

3 Wowakta tawa kin hena tanka; qa wowapetokeca tawa kin hena wawokihi hinca: Wokiconze tawa kin he Wokiconze owihanke wanica, qa Wicaśtayatapi un kin he wicoicagge qa wicoicage hehanyan.

4 Nebukadnezzar miye wati ohna owanji manka, qa tipi waśte mitawa ohna icah amayan.

5 Wowihanmde wan on knpewahda kin he wanmdaka, qa mitowinja akan mitawacin qa mapa towanyake kin hena cancanmakiya.

6 Heon etanhan wokonze wan wakağa, Babel en wicaśta ksapa iyuhpa mitokam awicaupi kta, wowihanmde ieska yaotaninpi kin omiciyakapi kta heon.

7 Hehan wicaśta ksapapi kin, wicanhpi iwanyakapi kin, Kasdim wicaśta, qa wapiyapi kin hena en hiyupi. Unkan hena wicitokam wowihanmde kin owahdaka: tuka ieska yaotaninpi kin he omiciyakapi śni.

8 'Tuka unhanketa Daniel mitolkam hiyu, he nakun Belteśazzar eciyapi, taku wakan mitawa caje kin iyececa, he Taku Wakan wakan hinca Taniya kin en un: Unkan he itokam wowihanmde kin owahdaka :

9 Belteśazzar, wicaśta ksapapi itancan, Taku Wakan wakan hinca taniya kin en niun sdonwaya, qa taku woinahbe takudan nagiyeniye śni, heon wowihanmde wowanyake wanmdake cin hena omiciyaka wo, qa nakun ieska yaotaninpi kin.

10 Mitowinja akan mapa towanyake kin hena kaketu; Opahta manka, unkan iho, maka kin colraya can wan, qa obosdatu kin he tanka hinca.

11 Can kin he tanka icagge ça waśaka aya, qa ohanske cin malipiya iyapato, qa wanyakapi kin maka ocowasin ihanke kin hehanyan :

12 Ape kin hena owanyag waśte, qa waskuyeca tawa kin ota hinca, qa ohna taku owasin woyute wicakiciun: he ihukuya tinta woteca kin ohanzi yuhapi, qa mahipiya okinyanpi kin hena adetka kin ehna tipi, qa taku cehpi owasin hetanhan woyute tonpi ece.

13 Mitowinja akan mapa towanyake kin en, opahta manka, unkan iho, waawanyake wan qa taku wakan wan mahpiya kin eciyatanhan liun $u$ :

14 He waśagya eyanpaha qa kaken eya; Can kin kawanka po, qa taadetka kin kalksaksa po, ape kin kasnasna po, qa tawaskuyeca kin kahnahna po; woteca kin ihukuya tanhan yapi kte, qa taku kinyanpi kin adetka kin etanhan.

15 Tuka canpaksa hutkan kin he maka kin en ayuśtan po, qa mazasapa mazaśa ko iyuskite wan kici, tinta wato wankadan kin ehna: nakun mahpiya cu kin on spayeyapi kta, qa taku tawa kte cin he maka wato kin en woteca kin om un kta :

16 Iye cante kin wicacante etanhan yutokecapi kta, qa wo447 


\section{DANIEL TAWOWAPI KIN,}

teca cante kin qupi kta; qa omaka śakowin akan iyaye kta.

17 Wokonze kin de waawanyakapi yacopi kin eciyatanhan, qa taku kin de tona wakanpi toie kin etanhan: tona ni unpi kin Iyotan Wankan un kin he wicaśta tokiconzepi kin en wicaśtayatapi ee e sdonyapi kta, qa token cin eca wicaqu ece, qa wicaśta onśika heca yuhekiya ece.

18 Wowihanmde kin de miye, wicaśtayatapi kin, wanmdaka. Hehan niye, Belteśazzar, ieska yaotaninpi kin oyaka wo: Mitokiconze lin en tona ksapapi kin iyuhpa ieska yaotaninpi kin omiciyaka okihipi śni: tuka niye oyakihi, Taku Wakan hinca Taniya kin en niun nakaeś.

19 Hehan Daniel, he nakun Belteśazzar eciyapi, wihiyayedan oape wanjidan yuśinyaya, qa tawacin en iliniyanyan. Wicaśtayatapi kin ie ça heya; Belteśazzar, wowihanmde qa icska yaotaninpi kin unmana yuśinyeniye śni nunwe. Belteśazzar waayupte ca heya; Itancan mitawa, wowihanmde kin he tona śicenidapi, qa ieska yantaninpi kin he tona tokaniyanpi kin en wicahi nunwe.

20 Can wandake ciqon, tanka icag̉e ça waśaka aya, ohanske kin mahpiya ekta iyahde, qa maka ocowasin ihanke kin hehanyan wanyakapi ;

21 Ape kin owanyag waśteśte, qa tawaskuyeca ota hinca, qa taku owasin en woyute wicakiciyanka: ihukuya tinta woteca kin ounyanpi, qa adetka kin mahpiya okinyanpi kin en tipi qon;

22 Wicaśtayatapi, he niye, tanka inicaga qa waśaka aniyan; nitanka kin he icagge ca mahpiya ekta iyahde, qa wicaśtayatapi 448 yaun kin he maka ihanke kin ekta.

$23 \mathrm{Qa}$ nakun wicaśtayatapi kin waawanyake wan qa Wanji Wakan kin mahipiya eciyatanhan kun u wanyaka, qa he hecen eya; Can kin kawankapi qa ihangya po; tuka canpaksa hutkan kin he maka kin en kpatan po, qa mazasapa mazaśa ko iyuskite wan ahna, tinta wato wankadan kin ehna; qa malipiya cu kin on spayeyapi kta, qa taku tawa kte cin he tinta woteca kin om un kta, omaka śakowin akan iyaye kta hehanyan ce:

24 Wicaśtayatapi, ieska oyakapi kin he dee, qa Iyotan Wan. kan un tawokonze, itancan mitawa wicaśtayatapi kin akan u kte ciqon he dee :

25 Wicaśta etanhan kaliam iyeniyanpi kta, qa tinta woteca kin om ounyaye kta, qa tatanka iyecen wato ece yunniciyapi kta, qa mahpiya $\mathrm{cu}$ kin on spayeniyanpi kta, qa waniyetu śakowin akan iniyaye $\mathrm{kta}$, ecen Iyotan Wankan un kin wicaśta tokiconzepi kin en wicaśtayatapi un, qa token cin eca wicaqu ecee sdonyaye kta ce.

26 Unkan nakun canpaksa hutkan kin he kpatanpi kta keyapi, hecen nitokiconze kin wicakeyahan niciyanke kta, tohan Mahpiya kin he Itancan yanka e sdonyaye cinlian.

27 Heon etanhau, wicaśtayatapi, wowahokonkiye mitawa kin iyonicipi nunwe, qa woowotanna on wayahtani etanhan ihduśpa wo, qa taku śica ecanon kin etanhan, wah̉panicapi onśiwicakidapi kin on; okinni woozikiye nitawa niciyuhanskapi kta naceca ce.

28 Taku kin de ocowasin $\mathrm{Ne}$ bukadnezzar wicaśtayatapi kin en $u$. 


\section{WICOWOYAKE 5.}

$29 \mathrm{Wi}$ akenonpa ihuniyanpi hehan Babel wokiconze tipi waśte kin ohna mani un.

30 Wicaśtayatapi kin ie ça heya; Mitowaśake wawokihi kin on, qa mitowitan yuonihanpi on Babel tanka wakaơa, mitokiconze tipi kin he dee śni he, eya.

31 Wicoie kin he hinyahin wicaśtayatapi i kin ohna yanka icunlian, wicaho wan mahpiya eciyatanhan hiyu; Nebukadnezzar wicaśtayatapi, niye heniciyapi ce; Wokiconze kin he aniyuśtan;

32 Unkan wicaśta etanhan kaham iyeniyanpi kta, qa tinta woteca kin om ounyaye kta : tatanka iyecen wato ece yunniciyapi kta, qa waniyetu śakowin akan iniyaye $\mathrm{kta}$, ecen Tyotan Wankan un kin wicaśta tokiconzepi kin en wicaśtayatapi un, qa tuwe cin eca qu ece e sdonyaye kta ce.

33 Wihiyayedan oape kin hee en wicoie kin he Nebukadnezzar kiciyuśtanpi: Unkan wicaśta etanhan kaham iyeyapi, qa tatanka iyecen peji yuta, qa iye tancan kin mahpiya cu on spaya, ecen hin kin warımdi tawa iyececa icaga, qa sake zitkadan tawa iyececa.

34 Unkan anpetu kin hena henakeca hehan, Nebukadnezzar miye mahpiya ekta iśta yuwankan iwekcu, unkan wowakahnige ciqon lie ake en mahdi, qa Iyotan Wankarı un kin he mdawaśte, qa Tuwe ohinniyan ni un kin he mdatan qa mdaonihan, eqe wicaśtayatapi un kin wicaśtayatapi unpi heca owihanke wanica, qa tokiconze kin he wicoicage qa wicoicage hehanyan:

35 Qa maka akan ounyanpi kin owasin takuśni wicayawa: qa mahpiya ozuye kin en iye tawacin kin eciyatanhan econ ece, qa maka akan ounyanpi kin ehna: qa tuwedan nape pakam iyeya, qa, Taku ecanon he, eciye kta okihi śni.

36 Hehantudan hin wowakalinige ciqon he en mahdi, qa mitokiconze wowitan on mitoyuonihan qa mitohnake waśte kin ake en mahdi : unkan woope aiewicawakiye ciqon hena, qa wicaśta itancan mitawa qon hena omakidepi; hecen mitokiconze kin en sutaya nihduśtanpi, qa wowinihan oiyokipi hinca en akihde mayanpi.

37 Nebukadnezzar miye, wanna Mahpiya Wicaśtayatapi kin he mdatan, qa mdatanka, qa mdaonihan, iye tohan kin owasin wowicake, qa towiyukcan kin woyuecetu: qa tona wahanicidaya manipi kin hena yuhukun iyewicaye kta okihi ece.

\section{WICOWOYAKE 5.}

1 Belśazzar wicaśtayatapi kin wohanpi tanka wan wicaśta ihdawa kektopawinge wicayuhe cin wicakicaga, qa kek topawinge kin hena wicitokam miniśa yatkan.

2 Belśazzar miniśa yatkan uta icunhan, mazaskazi qa mazaska wakśica, iye tunkankiśitku Nebukadnezzar Jerusalem en Tipi Wakan etanhan ahdiyaku qon hena en au wicaśi : hecen wicaśtayatapi kin iye, qa wicaśta ihdawa wicayuhe, tawicupi qa winohinca wicayuhe cin hena om, etanhan wayatkanpi kta.

3 Hehan mazaskazi wakśica Wakantanka ti tipi wakan Jerusalem ekta yanke cin etanhan eyakupi qon hena ahipi: Unkan wicaśtayatapi iye, qa wicaśta ihdawa wicayuhe cin, tawicupi qa winohinca wicayuhe cin hena etanhanban wayatkanpi. 


\section{DANIEL TAWOWAPI KIN,}

4 Miniśa yatkanpi qa taku wakan mazaskazi, qa mazaska, mazaśa, mazasapa, can qa inyan on kagapi kin hena yatanpi.

5 Wihiyayedan oape kin hee hinca en wicanape napsukaza kin hiyu, qa petijanjan ihupa iyotakons wicaśtayatapi ti kin en tipi unnaptanyan apuspapi kin akan wowa: unkan nape inkpa wowa kin he wicaśtayatapi kin wanyaka.

6 Hehan wicaśtayatapi itohnake waśte kin tokeca hinhda, qa tawacin kin yuśinyeiçiya, qa nite ipiyake kin kiyuśkapi, qa hupahu iciyapapi.

7 Wicaśtayatapi kin nina pan, wicanlipi iwanyakapi, Kasdim wicaśta qa wapiya econpi kin hena en awicaupi kta. Wicaśtayatapi kin ie ca Babel en ksapapi kin hewicakiya; Tuwe kasta wowapi kin de yawa, qa ieska yaotaninpi kin omakiyake cinhan, wokoyake duta koyake kta, qa mazaskazi wanapin wan napin kiye kta, qa wokiconze kin en wicaśta ihdawa wiciyamni ee kta ce.

8 Hehan wicaśta ksapa wicaśtaya tapi wicayuhe cin iyuhpa en hipi; tuka wowapi kin he yawa okihipi śni, qa ieska yaotaninpi kin wicaśtayatapi kin sdonyekiyapi śni.

9 Hehan Belśazzar wicaśtayatapi kin nina yuśinyeyapi, qa itohnake tokeca hinhda, qa wicaśta ihdawa wicayuhe cin hena iś eya yuśinyayápi.

10 Wicaśtayatapi qa wicaśta ihdawa wicayuhe cin oiepi kin on wicaśtayatapi winohinea kin he woyatke tipi kin en tin hiyu : Wicaśtayatapi winohinca kin ie ca heya; Wicaśtayatapi ohinniyan ni un nunwe: nitawacin kin yuśinyeniçiye kte śni, qa 450 nitohnake tokeca hinhda śni nunwe.

11 Nitokiconze kin en wicaśta wan Taku Wakan wakan hinca Taniya kin en un : qa nitunkanśi taanpetu qon en, wosdonye, qa wookahinige, qa woksape, taku wakan toksape kin iyececa, en un iyeyapi qon; he qe nitunkanśi Nebukadnezzar wicaśtayatapi kin, wicaśtayatapi nitunkanśi he wicaśta ksapapi, wicanlipi iwanyakapi, Kasdim wicaśta wapiyapi kin en itancan kağa :

12 Unkan woniya wan iyotan waśte, qa wosdonye, qa wookahnige, wowihanmde yaotaninpi, qa wicoie tehika iyukcanpi, qa woiyakaśke jakcapi kin hena Daniel eqe en iyeyapi, heon etanhan wicaśtayatapi kin he Belteśazzar eya caśton. Wanna Daniel kicopi kte, kinhan ieska yaotaninpi kin oyake kta ce, eya. 13 Hehan Daniel wicaśtayatapi kin itokam ahipi. Wicaśtayatapi kin ie ça Daniel heciya; Juda wicaśta wayaka unpi cinca, tunkanśi wicaśtayatapi kin Juda makoce kin etanhan awicahdi qon hetanhan Daniel he niye he. 14 Niye on nawahon, taku wakan taniya kin en niun, wosdonye, qa wookahinige, qa woksape waśte hinca en niun iyeyapi keyapi:

15 Unkan nakaha ksapapi kin, wicanlipi iwanyakapi kin hena mitokam awicahipi, wowapi kin de yawapi kta, qa ieska yaotaninpi kin omakiyakapi kta e lieon: tuka wicoie kin he ieska yaotaninpi kin oyaka okihipi śni : 16 Tuka niye qe ieska yaotaninpi kin odake kta, qa woiyakaśke wicoie dakca kta oyakihi keyapi nawalion. Wanna wowapi kin de dawa, qa ieska yaotaninpi kin omayakidake kta oya- 


\section{WICOWOYAKE 6.}

kihi kinhan, wokoyake duta kodake kta, qa mazaskazi wanapin wan napin niciyapi kta, qa wokiconze kin en wicaśta ihdawa wiciyamni yaun kta ce.

17 Hehan Daniel waayupte, qa wicaśtayatapi kin itokam heya; Taku mayaqu kte cin hena niye yahduhe kta, qa woiyopeye nitawa tokan wicayaqu kta; tuka wowapi kin he wicaśtayatapi kin weciyawa kta, qa ieska yaotaninpi kin sdonyewakiye kta.

18 Wicaśtayatapi niye, Taku Wakan Iyotan Wankan un kin he wokiconze, qa wowaśake, qa wowitan, ga woyuonihan nitunkanśi Nebukadnezzar qu:

19 Qa wowaśake qu kin keon wicaśta owasin, oyate qa iapi kin hena itokam cancanpi qa inihanpi : tuwe cin eca kte ece, qa tuwe cin eca nikiya ece: tuwe cin eca yuwankan ehde, qa tuwe cin eca kun ehpeya ece.

20 Tuka cante wankan iyeiçiya, qa tawacin wahaniçidaye kta e ihdusuta qehan wicaśtayatapi toiyotanke kin etanhan kun ukiyapi, qa towitan kin he ekiciyakupi :

$21 \mathrm{Qa}$ wicaśta cinca kin etanhan kaham iyeyapi ; qa iye cante kin woteca iyececa kag̉api, qa śonśonna itu unpi kin om ounyan: tatanka iyecen peji yunkiyapi, qa tancan kin mahpiya cu kin on spayekiyapi, ecen Taku Wakan Iyotan Wankan un kin he wicaśta tokiconze kin ohna wicaśtayatapi yanka sdonya, qa tuwe cin eca he en ounyekiya ece.

22 Qa niye Belśazzar, cincaniyan, de ocowasin sdonyaya qeyaś, nicante yahduwahbadan śni; 23 Tuka Mahpiya Itancan kin itokam wankan iyeniçiya : qa iye ti kin etanhan wakśica kin hena nitolsam ahipi, qa niye, qa wicaśta ihdawa wicaduha, nitawinpi qa winohinca wicaduhe cin hena etanhan miniśa datkanpi: qa taku wakan mazaska qa mazaskazi, mazaśa, mazasapa, can qa inyan heca, wawanyake śni qa wanahon śni, qa wasdonye śni kin hena daonihan; tuka Taku Wakan nape ohna nitaniya yanka, qa nitacanku iyuhpa niciyuhe cin hee duonihan śni.

24 Hehan Iye itokapatanhan nape inkpa kin hiyuyapi; qa wowapi kin de owapi.

25 Unkan wowapi owapi qon he dee; MENE, MENE, TEKEL, UPHARSIN.

$26 \mathrm{Qa}$ wicoie ieska yaotaninpi kin he dee; MENE; Wakantanka nitokiconze kin niciyawa qa ihunnikiya.

27 TEKEL; Aspeyetonpi kin on tke iniyutapi, qa iyotpani niyawapi.

28 PERES; Nitokiconze kin he kiyuśpapi, qa Media, Perse kici wicaqupi.

29 Hehan Belśazzar econwicaśi, unkan Daniel wokoyalke duta koyagyapi, qa mazaskazi wanapin wan napinkiyapi, qa on eyanpahapi, wokiconze kîn en wicaśta wiciyamni un kta ce.

30 Hanyetu kin he en Belśazzar Kasdim oyate en wicaśtayatapi kin he ktepi.

31 Unkan Darius Media kin he wokiconze kin icu; wanna waniyetu wikcemna śakpe sanpa nonpa ecetu.

\section{WICOWOYAKE 6.}

1 Wokiconze kin en wicaśta ihdawa opawinge sanpa wikcemna nonpa Darius wicakage kta iyokipi, hena wokiconze kin ocowasin en ounyanpi kta: 


\section{DANIEL TAWOWAPI KIN,}

2 Qa dena wiciwankam itancanpi yarnni, hena en Daniel tokaheya un: hecen hena wicaśta ihdawapi kin wiwicawangapi ecee kta, qa wicaśtayatapi kin taku kitanin śni wanice kta.

3 Hehan Daniel he wicaśta itancanpi qa wicaśta ihdawapi kin wicikapeya yawapi, woniya waśte hinca en un nakaeś; unkan wicaśtayatapi kin wokiconze kin ocowasin en ounyekiye wacin.

4 Hehan wicaśta itancanpi qa wicaśta ibdawapi kin wokiconze kin eciyatanhan Daniel en taku iyaonpepica iyeye wacinpi : tuka taku on bapi lkta, qa taku iyaonpapi kta takudan iyeya okihipi śni : wacinyepica un, qa taku yuśnapi qa on bapica kin takudan en iyeyapi śni nakaeś.

5 Hehan wicaśta kin dena heyapi; Daniel he en taku iyaunpepica takudan iyeunyanpi kte śni, tuka iye Taku Wakan tawa toope kin eciyatanhan taku iyeunyanpi kta naceca ce.

6 Hehan wicaśta itancanpi qa wicaśta ihdawapi kin hena wicaśtayatapi kin ekta witaya mniciyapi, qa decen eciyapi; Darius, wicaśtayatapi ohinniyan ni un nunwe.

7 Wokiconze kin ohna wicaśta itancanpi kin iyuhpa, wicaśta waawanyakapi, qa wicaśta ihdawapi kin, woope aiewicakiyapi, qa akicita tancanpi kin hena witaya wohdakapi, wicaśtayatapi tawokonze wan yusutapi kta qa woicaśke suta wan kag̣api kta, tuwe kaśta, anpetu wikcemna yamni hehanyan, taku wakan qaiś wicaśta taku wocekiye eciye cinhan, niye, wicaśtayatapi, nicúnonpa tanhan, he mnaja tipi kin en iyohpeyapi kta ce.

8 Wanna, wicaśtayatapi, woi- hitani. caślke kin he yusuta ye, qa wowapi kin yutan ye, hecen yutokecapi kte śni, Media qa Perse woope kin yutokecapi śni ecee kin iyececa ce, eyapi.

9 Heon etanhan Darius wicaśtayatapi wowapi qa woicaśke kin yutan.

10 Unkan Daniel wowapi kin yutanpi sdonye cehan tin kihda; qa iye ti ohna Jerusalem elktakiya owanyeye kin yulidog han, anpetu eca yamni akihde canpeśka makahde inajin, qa cekiya, qa iye ta Wakantanka kin itokam wopida eya ece, he itokam econ ece qon iyececa.

11 Hehan wicaśta kin hena witaya iheyapi, qa Daniel cekiya un, qa iye Taku Wakan tawa itokam wada yanka iyeyapi.

12 Hehan ikjyedan upi qa wicaśtayatapi kin itokam wicaśtayatapi tawokonze qon on heyapi; Woicaśke wan dutan śni he, wicaśtayatapi, niye icunonpa, wicaśta otoiyoli taku wakan wanji, qa iś wicaśta akantu, anpetu wikcemna yamni hehanyan, taku kida kinhan, he mnaja tipi kin en iyohpeyapi kta ce. Wicaśtayatapi kin waayupta qa heya; Wicoie kin he hecetu, Media qa Perse woope tawapi tokan aye kte śni kin he iyececa ce.

13 Hehan hena ayuptapi qa wicaśtayatapi kin itokam heyapi; Daniel, Juda wayaka unpi cinca kin etanhan, hee, niye wicaśtayatapi, ihanikta śni, qa wokonze dutan kin he nakun, tuka anpetu eca yamni akihde wacekiya ece.

- 14 Hehan wicaśtayatapi kin wicoie kin hena nahon qehan nina śiceicidaka, qa Daniel ehdaku kta e cante ekta hduza; qa wi iyaya hehanyan ehdaku kta 


\section{WICOWOYAKE $\%$}

15 Hehan wicaśta kin dena wicaśtayatapi kin en mniciyapi, qa wicaśtayatapi kin heciyapi; Wicaśtayatapi, Media qa Perse tawonpe kin he dee, Taku woicaške qa woahope wicaśtayatapi kin yusuta kinhan he yutokecapica kte śni e he sdonya wo.

16 Hehan wicaśtayatapi kin hecon wicaśi, unkan Daniel ahipi qa mnaja tipi kin en iyohpeyapi. Wicaśtayatapi kin ie ça Daniel heciya; Taku Wakan nitawa ohinniyan htayecini kin he enihdaku kta ce.

17 Unkan inyan wan aupi qa waśun i kin akan ehnakapi. Unkan wicaśtayatapi kin he apuspa, iye wipuspe tawa, qa wicaśta ihdawapi wicayuhe wipuspe tawapi kin on, hecen Daniel on wakiconzapi qon he yutokecapi kte śni.

18 Hehan wicaśtayatapi kin hetanhan iye ti waśte kin ekta kihda, qa hanyetu kin wote śni un: nakun candowankiyapi kin heca itokam ahipi śni; qa toiśtinma elipeya ikiyaya.

19 Hehan wicaśtayatapi kin hanhanna hin najin hiyaye ca mnaja tipi kin ekta inahini iyaya :

20 Qa waśun kin ekta hi qehan hoiyokiśica on Daniel hoyekiya : wicastayatapi kin ie ca Daniel heciya; Daniel, Taku Wakan ni un tawowidake, nita Wakantanka ohinniyan htayecini kin he mnaja kin etanhan enihdaku okihi he.

21 Hehan Daniel wicaśtayatapi kin heciya; Wicaśtayatapi, ohinniyan ni yaun nunwe :

22 Wakantanka mitawa iye taohnihde kin uśi, qa mnaja ipi kin yuohmus iwicacu, hecen mnaja kin ksuwe mayanpi śni; iye itokam wiyaonpepica śni waun nakaeś; qa nakun, wica$G$; śtayatapi, niye en takudan śica ecamon śni, heon etanhan.

23 Hehan he on wicaśtayatapi kin wiyuślin binca, qa Daniel waśun kin etanhan yuwankan eyaku wicaśi. Hecen Daniel waśun kin etanhan eyakupi ; unkan en okiumniye takudan iyeyapi śni, Taku Wakan tawa wacinkiya nakaeś.

24 Hehan wicaśtayatapi kin hecon wicaśi, unkan wicaśta tona Daniel yalitakapi qon hena awicahipi qa mnaja tipi kin en iyohpewicayapi, iyepi qa cincapi qa tawicupi kin: Unkan waśun owanka kin ehan ipi śni ecen mnaja kin ohiwicayapi qa huhu iy uhpa wicakiyaweliwegapi.

25 Hehan Darius wicaśtayatapi kin oyate kin owasin, wicaśta qa iapi maka owancaya tipi kin wowapi wicakicaga; Wookiye niciyuotapi nunwe:

26 Tokaheya miye wokonze wan wakagia; Wokiconze mitawa wicaśtayatapi ounyanpi kin otoiyohi en, Daniel Taku Wakan tawa kin itokam wicaśta cancanpi qa kokipapi kta: Iye iśnana Taku Wakan ni un nakaeś, qa iye tokiconze kin he ihangyapi kte śni, qa iye wicaśtayatapi un kin he owihanke kin ekta:

27 Iye hinca wanikiya qa waehdaku, qa wowakta wowapetokeca ko econ ece, malipiya kin ekta qa maka kin akan, he qe Daniel mnaja nape kin etanhan ehdaku nakaeś.

28 Hecen Darius wicaśtayatapi un kin icunhan, qa Kuros Perse wicaśtayatapi kin hehanyan Daniel zaniyan un.

\section{WICOWOYAKE $\%$}

1 Belśazzar Babel wicaśtayatapi kin tawaniyetu tokaheya en, 453 


\section{DANIEL TAWOWAPI KIN,}

Daniel wowihanmna qa iye pa towinja akan wowanyake wan wanyaka: Hehan wowihanmde kin okiwa, wicoie kin yuptahnaka ohdaka.

2 Daniel ie ca heya; Hanhepiya mitowanyake en opahta manka, unkan iho, mahpiya tate ouye topa hena miniwanca tanka kin akan kicizapi.

3 Unkan wamanica tankinyanyan topa miniwanca kin etanhan hiyupi, hena akiyececapi śni.

4 Tokaheya kin he mnaja iyececa, qa wanmdi hupahu yuha: opalita manka ecen hupahu kin kiyujunpi, qa maka kin etanhan yuwankan icupi, qa wicaśta iyecen siha on najinkiyapi, qa wicacante wan qupi.

5 Unkan iho, wamanica tokeca wan inonpa kin he walianksica iyececa, qa sanina tanhan hduwankan iyeiciya, qa i kin ohna cutuhu yamni hi ohna yapa yan. ka: unkan kaken eciyapi, Inajin wo, cehpi ota temya wo.

$6 \mathrm{He}$ iyohakam wanmdaka, unkan iho, wanji tokeca, inmuhdeśka tanka iyececa; be qe amdo akan wahupakoza hupahu tawa topa yukan; nakun wamanica kin he pa topa; qa wokiconze wan qupi.

7 He iyohakam hanhepi wowanyake kin en opalita manka, unkan iho, wamanica itopa wan, he wowinihan, qa wohitika, qa waśake hinca; qa mazasapa hi tankinyanyan yuha: watemya qa wayamdemdeca, qa okaptapi kin siha on napanpan: qa wamanica itokam unpi qon de iś tokeca; qa he wikcemna yuha.

$8 \mathrm{He}$ kin hena awacin manka, unkan iho, hena ehna he tokeca cistinna wan uya, qa he on he tokaheya unpi kin yamni hute ekta yujunpi : unkan iho, he kin 454 de en iśta yukan, wicaśta iśta iyecera, qa i wan taku tanka eya ece.

9 Opalita manka ecen oiyotanke kin ehdepi, qa Tuwe Anpetu Wanakaja kin he en iyotanka, iye tawokoyake hin wa iyecen ska, qa paha kin talinca wanunyanpi hin ecedan kin iyececa : oiyotanke tawa kin he peta ide śaśa, qa canhdeśka tawa kin peta ide kin heca.

10 Iye itokapa tanhan peta wakpa wan hinanpa qa hiyaya: kektopawinge eceh kektopawinge htakicinipi, qa kektopawinge wikcemna ecee kektopawinge wikcemna itokam inajinpi: wayaco kin kiyotanka, qa wowapi kin yumdayapi.

11 Hehan opahta manka, he kin he wicoie tanka eya ece ho kin heon: opalita manka ecen wamanica kin ktepi, qa tancan ihangyapi, qa peta ide kin en elipeyapi.

12 Qa wamanica unmanpi qon hena wokiconze kin ewicakiciyakupi ; tuka ni unpi kin he liiciyuhanskapi, omaka qa waniyetu hehanyan.

13 Hanyetu wowanyake kin en opahta manka, unkan iho, wanji Wicaśta cinllintku kin iyececa, mahpiya śoka kin akan u, qa Tuwe Anpetu Wanakaja kin en hi; unkan he itokam kiyadan ahiyupi.

14. Unkan he wicaśtayatapi unpi, qa wowitan qa wokiconze wan qupi, hecen wicaśta iyulipa, oyate qa iapi kin hena htakicinipi kta : wicaśtayatapi oun tawa kin he wicaśtayatapi unpi owihanke wanica, he tokan aye kte śni, qa tokiconze kin he ihangyapi kte śni.

15 Miye Daniel mitaniya ojuha tawa kin ohna iyokiśica un; qa 


\section{WICOWOYARE 8.}

mapa towanyake kin hena yuśinyemayan.

16 Tona en najinpi kin wanji ikiyedan hibu, qa dena owasin on tukte wowicake kin he imunga. Hecen omakiyaka, qa dena taku kin ieska yaotaninpi kin he sdonyemakiya.

17 Wamanica tankinyanyan kin dena topapi hena wokiconze topa maka kin etanhan inanpapi kta.

18 Tuka Iyotan Wankan un wicaśta owotarna tawa kin hena wokiconze kin icupi kta, qa wokiconze kin ohinniyan yuhapi kta, han, ohinniyan owihanke wanice kta.

19 Hehan wamanica itopa kin he on wowicake kin sdonwaye kta wacin, he qe unmanpi kin iyecece sni, wolkokipe hinca, hi kin mazasapa, qa śake kin mazaśa ; watemya, wayaweliweğa, qa okaptapi kin siha on napanpali qon he :

20 Qa pa akan he wikcemia kin hena; qa wanji icag̉e ça itokum yamni hinlipaye ciqon; lian, he kin iśta yukan, qa i wan wicoie tanktanka eye cin, itohnake kin tawaśitku kin isanpa waśake cin hee.

21 Opahta manka, unkan he kin eqe wicaśta owotanna kin hena wicakiza qa ohiwicaya:

22 Ecen Tuwe Anpetu Wanakaja kin he hi, qa wicaśta owotanna Iyotan Wankan un tawa kin hena woyaco wicaqupi; qa wicaśta owotanna wokiconze kin yuhapi kta wanna iyehantu.

23 Iye kaken eye; Wamanica itopa kin he maka akan wokiconze itopa kin hee kta; eqe wokiconze owasin iyecece kte śni, qa maka ocowasin kin temye kta, qa napanpan $\mathrm{kta}$, qa namdemdece kta ce.
24. Qa wokiconze kin de etanhan he wikcemna kin wicaśtayatapi wikcemna inajinpi kte cin hena eepi: qa hena iyohakam wanji tokeca inajin $\mathrm{kta}$; qa eqe tokaheya qon hena iyecece kte śni, qa wicaśtayatapi yamni wicaktedan kta.

$25 \mathrm{Qa}$ Iyotan Wankan un kin itkom wicoie eciye kta, qa Iyotan Wankan un wicaśta owotanna tawa kin hena iyotanhan iyewicakiye kta, qa anpetu qa woope kin yutokeca wacin kta: Unkan hena iye nape kin en qupi kta, waniyetu qa waniyetu nonpa, qa waniyetu okise hehanyan.

26 Tuka wayaco kin iyotanke kta, qa wicaśtayatapi oun kin he ekiciyakıpi kta, yusote kta qa ihangye kta, owihanke kin hehanyan.

27 Unkan wokiconze qa wicastayatapi oun kin, qa mahipiya ocowasin ihukuya wokiconze tanka kin he Iyotan Wankan un wicaśta owotanna tawa oyate kin he wicaqupi kta, he qe tokiconze kin wokiconze owihanke wanica, qa wicaśtayatapi iyulipa iye htakicinipi qa anagoptanpi k ta ce. 28 Dehanyan wicoie kin owihanke. Daniel miye qe mitawacin kin nina yuśinyemayan, qa mitohnake kin tokeca mahinhda: Tuka wicoie kin he micante en hduha waun.

\section{WICOWOYYAKE 8.}

1 Belśazzar wicaśtayatapi tokiconze waniyetu iyamni en wowanyake wan wanyagmakiyapi, Daniel miye, tokaheya taku en micitanin qon he iyohakam.

2 Unkan wowanyake en wanmdaka; qa opahita manka icunhan kaketu; Śuśan tipi waśte kin ohna waun, he Elam makoce 455 


\section{DANIEL TAWOWAPI KIN,}

kin entu: unkan wowanyake kin en wanmdaka, qa Ulai wakpa kin icahda waun.

3 Hehan iśta hduwankan iwekcu qa wanmdaka, unkan iho, wakpa kin itokam tamdoka wan najin, qa he yukan: 'unkan he kin hena tehanwankantu; tuka wanji iś unma kin isanpa hanska, qa iyotan tehanwankantu kin he ehake uya.

4 Tamdoka kin he wanmdaka, wiyolipeyata, qa waziyata, qa itokahiliya wacapa yanka; hecen wamanica warijidan itokam najin okihi śni, qa iye nape kin etanhan tuwedan waehdaku okihi śni ; tuka iye tawacin kin eciyatanhan olianyan ece, qa tanka icag̉a.

5 Unkan awacin manka icunhan, iho, tatoka mdoka wan, maka itohnake ocowasin akan wiyolipeyatanhan u, qa maka en icahtake śni: qa tatoka mdoka kin iśta otahedan he tanka wanji yuha.

6 Unkan heqe tamdoka he nom yuha, wakpa itokam najin wanmdake ciqon he en lii, qa tocanniye wowaśake hduha anatan.

7 Qa tamdoka kin ikiyedan u wanmdaka; unkan nina canniyekiya, qa tamdoka kin capa, qa he nonpa kipaksa : Unkan tamdoka kin ecaca itokam najin okihi śni; tuka makata iyeya, qa ahan; qa iye nape kin etanhan tuwedan tamdoka kin eyaku okihi śni.

8 Heon etanhan tatoka mdoka kin nina tanka icaga: tuka wasaka aye cehan he tanka qon paksapi: Unkan heekiya tom wanyakapi waśte kin heca uya, mahpiya tate ouye topa kin ektakiya.

9 Unkan hena iś wanjidan etanhan he cistinna wan uya, eqe nina tanka icagia, itokahkiya qa 456 wiyohiyanpata qa makoce waśte kin ek takiya.

10 Nakun sanpa tanka icag̉a, mahpiya ozuye lin ekta, qa ozuye kin he etanhan qa wicanlipi kin etanhan wanjikśi makata ehpeya, qa hena awicahanhan.

11 Han, ozuye itancan kin ekta ihdutanka; qa iye qe ohinniyan wośnapi kin he anapta, qa tipi wakan tawa oahe kin he kun ehpeya

12 Unkan ozuye kin qupi, ohinniyan wośnapi kin akan, woahtani on etanhan; hecen wowicake kin makata elpeya: unkan waecon qa hduśtan ece.

13 Hehan wanji wakan kin ia nawahon; unkan wanji wakan tokeca wan tuwe ie ciqon he heciya; Ohinniyan wośnapi; qa woahtani wayujuju ece wowanyake kin, tipi wakan qa ozuye kin amanipi kta wicaqupi kin he tohanyan kta he.

14. Unkan iye hemakiya; Ḣtayetu hanhanna kektopawinge nonpa sanpa opawinge yamni, hehan tipi wakan kin yutecapi kta ce.

15 Unkan kaketu, miye, Daniel miye hinca, wowanyake kin wanmdaka, qa ookahiniğe kin awakite cehan, iho, tuwe wicaśta itohnake iyececa wan mitokam hinajin.

16 Unkan Ulai otahedan wicaho wan nawation, heqe pan qa heya; Gabriel, wicaśta kin de wowanyake kin okahnihkiya wo.

17 Hecen nawajin kin en ikiyedan hiyu: unkan hiyu qehan kowakipa qa ite makipusdiya ehpemiciya. Tuka iye hemakiya; Wicaśta cinhintku, wowanyake kin he owihanke ekta kta okahniga wo.

18 Unkan womakiyaka icunhan miśtinbe hinca ite makipusdiya 


\section{WTCOWOYAKE 9.}

manka: Tuka iye mayutan qa manke cin en najin makiya:

19 Qa heya; Iho, wośinhda ihanke binca ekta taku kte cin he sdonyeciciye kta ce: Tohan iyehantu kinhan owihanke kta nakaeś.

20 Tamdoka he nom yuha wandake ciqon he Media qa Perse wicaśtayatapi kin hena eepi.

$21 \mathrm{Qa}$ tatoka mdoka hin śma qon he Javan wicaśtayatapi kin hee: qa he tanka iśta otahedan yuhe cin he wicaśtayatapi tokaheya kin ee.

22 Unkan hee paksapi, qa eekiya tom icagapi qon, hecen oyate kin he etanhan wokiconze topa inajinpi kta, tuka iye towaśake qon ohna kte śni.

23 Unkan hena tokiconzepi anpetu ehake kin en, tohan wahtanipi kin ihduśtanpi kinhan, hehan wicaśtayatapi wan ite suta, qa wahnayan okahniga heca inajin kta.

$24 \mathrm{Qa}$ tookihi kin he waśake hince kta, tuka iye towaśake kin ohna kte śni. Nakun wowinihanyan waihangye kta, qa ihduśtan kta, qa waecon kta, qa oyate waśaka qa wakan kin he ihangwicaye kta.

25 Qa nakun tookahnige kin on iye nape ohna wohnaye yuśtan kiye kta; qa cante en ihdutanka kta, qa wookiye on wicota ihangwicaye kta: Nakun itancanpi en Itancan kin he itkokim inajin kta'; tuka nape codan ihangyapi kta ce.

26 Unkan htayetu qa hanlianna wowanyake oyakapi kin he wowicake: heon etanhan, niś wowanyake kin nakitaka wo; anpetu ota kta nakaeś.

27 Unkan Daniel miye qe iwahpande, qa anpetu wanjikśi wamayazanka. Hehan nawajin qa wicaśtayatapi tokicanye kin ecamon ece: qa wowanyake kin on mayuśinyaya, tuka tuwedan okahniğe śni.

\section{WICOWOYAKE 9.}

1 Darius Ahaśuerus cinhintku Media wicoicagge kin etanhan, Kasdim wokiconze kin en wicaśtayatapi kagapi qon he tawaniyetu tokaheya kin entu:

2 Waniyetu tokaheya wicaśtayatapi un qehan, Daniel miye qe wowapi eciyatanhan waniyetu tonakeca hecinhan owakahniga, Jehowa oie Jeremiah wicaśta wokcan qon en hi, Jerusalem yujujupi kin en waniyetu wikcemna śakowin yuśtan kta keye ciqon.

3 Hecen Itancan Wakantanka ekta miite ewehnaka, wote śni unpi, qa wakihdaka caliota ko en, wocekiye qa hoyekiyapi kin on awakite kta :

4 Qa Jehowa Wakantanka mitawa cewakiya, qa wowahdaka, qa hepa; Itancan, Taku Wakan tanka qa wowinihan kin, tona waśtedakapi qa tawoahope kiciyuhapi kin hena wicotakuye qa wowaonśida wicakiciyuha;

5 Unkiye waunhtanipi, qa tehiya unkohanyanpi, qa sicaya econkupi, qa wawaunkipajinpi, ban nitoope qa nitawoyaco kin hena ehpeunyanpi nakaeś.

6 Qa nakun nitaokiye wicaśta wokcan, nicaje on, wicaśtaya tapi unkitawapi, wicaśta itancan unkitawapi, qa hunkakewicunyanpi, qa makoce olna oyate owasin taku ewicakiyapi qon hena anaungoptanpi śni.

7 Itancan, niye woowotanna niciyanka, tuka unkiye ite iśtecapi, anpetu de iyececa; Juda wicaśta kin, qa Jerusalem en oun457 


\section{DANIEL TAWOWAPI KIN,}

yanpi kin, qa Israel ocowasin, kiyedan qa itehan unpi, makoce owasin elktakta enanakiya napewicayaye cin hena, taku śica econpi on wanicilitanipi kin hena on etanhan.

8 Itancan, unkiyepi en ite naśapi yukan, wicaśtayatapi unkitawapi, wicaśta itancan unkitawapi qa hunkakewicunyanpi, waunnicilitanipi nakaeś.

9 Itancan Wakantanka unkitawapi kin wowaonśida qa wokajuju hduha, unkiye waunkipajinpi eśta :

10 Qa nakun Jehowa Wakantanka unkitawapi ho kin anaungoptanpi śni, wicaśta wokcan iye taokiyc on toope unkitokam ehnake ciqon hena ohna maunnipi lita tuka.

11 Han, Israel owasin nitoope awahtanipi, qa icunonpa iyayapi, hecen niho anaggoptanpi kte śni; hcon etanhan woyaśice kin unkakaśtanpi, qa wokonze Moses Wakantanka taokiye toope kin en owapi qon, iye en waunlitanipi nakaeś.

12 Qa iye oie, unkiyepi on, qa wayaco unkitawapi unyacopi ccee kin hena on eye ciqon hena hdusuta, taku śica tanka kin de en urıaupi kin heon: taku Jerusalem ecakiconpi kin he mahpiya ocowasin ihukuya iyecen econpi śni nakaeś.

13 Moses toopc kin en owapi qon he iyecen taku śice cin de owasin unkakipapi: hececa eśta Jchowa Wakantanka unkitawapi kin itokam nape unkiyugatapi śni, waunhitanipi kin etanhan unkihduhomnipi kta, qa nitowicake unkokalinigapi kta.

14 Heon etanhan Jehowa taku sice cin atonwan qa en unkaupi : Jehowa Wakantanka unkitawapi kin iye tohan econ kin owasin en owotanna un; iye ho kin anaungoptanpi śni nakaeś.

15 Unkan wanna, Itancan Wakantanka unkitawapi napc waśaka on nitaoyate Egupta makoce kin etanhan wicayahdou, qa caje wan nicicaga, anpetu dehanyan heccca; unkiye waunlitanipi, unkiye śicaya econkupi ece.

16 Itancan ceciciya ce, nitoowotanna ocowasin eciyatanhan, Jcrusalem nitotonwe lin etanhan, the wakan nitawa kin hctanhan, nitocanniyc qa nitocanteptanye kin yuhomnipi nunwe: waunlitanipi kin hena on, qa hunkakewicunyanpi taku śica econpi kin on, Jerusalem qa nitaoyate, tona unkihdukśan unpi owasin en wowiliahayapi yakonpi nakaeś.

17 Heon etanhan nalkaha Wakantanka unkitawapi, nitaokiye tawocekiye qa hoyeye cin hena nahon ye, qa tipi wakan nitawa jujuwahe cin he niite on iyoyamkiya wo, Itancan kin on etanhan.

18 Wakantanka mitawa, ninoġe ukiye ca nalion ye; niiśta hdumdaya qa otiwita unkitawapi, qa otonwe nicaje icajcyatapi kin he wanhdaka wo: woowotanna unkitawapi on etanhan nitokam wocekiye unkeyapi śni, tuka nitowaonśida tanka kin hena on etanhan.

19 Itancan, nahon ye ; Itancan, kajuju ye; Itancan, anagoptan qa econ ye; Wakantanka mitawa, niye linca on etanhan yutehan śni ye: nitotonwe qa nitaoyate kin hena nicaje icajeyatapi nakaeś.

20 Unkan iahan waun, qa cewakiya, qa wawalitani, Israel mitaoyate wahttanipi koya owahdaka, qa Jehowa Wakantanka mi- 
tawa itokam, mita Wakantanka he wakan tawa kin on wowaonśida wakida icunhan;

21 Han, wocekiye en iahan waun icunhan, Gabriel wicaśta eqe otokahe ekta wowanyake en wanmdake ciqon, dus kinyan ukiyapi, he mayutan, litayetu wośnapi ecee kin iyehantu;

22 Qa okahinilimayan, qa mici wohdaka, qa heya; Daniel, wookaliniğe woksape ko cicu kta on wanna hibu:

23 Wocekiye toliaheya eha hehan wicole kin hiyu, ga cicipazo kta hibu; nina waśtenidakapi nakaeś: heon etanhan wicoie kin okaliniga wo, qa worvanyake kir sdonya wo.

24. Nitaoyate on, qa otonwe wakan nitawa on, wilkcemna śakowin ece śakowin konzapi, wośice anaptapi kta, qa woalitani apuspapi kta, qa taku śica èconpi kin akahpapi kta, qa woowotanna owihanke śni kin ukiyapi kta, qa wowanyake wowiyukcan ko yuśtanpi kta, qa Iyotan Wakan hinca kin he sdakiyapi kta e heon.

25 Heon etanhan sdonya wo, qa niye okahniga wo, Jerusalem yuecetupi kta qa piya kaggapi kta wicoie kin hiyu kinhan, hetanhan Messiya Mdetahunka kin ekta, śakowin ece śakowin qa wilkcemna sakpe sanpa nonpa ece śakowin kta: hocoka kin piyapi kta, qa conkaśke kin ake kagapi kta, han wokakije anpetu kin en.

26 Unkan wikcemna śakpe sanpa nonpa ece śakowin kin iyohakam Messiya kaśpapi kta, tuka iye on etanhan kte śni: Hehan mdetahunka wan u kte cin he taoyate kin otonwe qa tipi wakan kin ihangyapi kta: qa owihanke kin he minitan iyecece kta, qa okicize ihanke kin hehanyan wayujujupi ece konzapi.

27 Unkan iye anpetu wakan wanjidan wicota om wicotakuye kin wicakiciyusuta kta: qa anpetu śakowin cokaya hehan wośnapi qa minha kin ayuśtan kiye kta, qa hupahu lin akan wowaliteśni wayutakuni śni ece kin yanke kta; qa woyuśtan kta hehanyan, qa taku konzapi qon he wayujuju kin en akaśtanpi kta ce.

\section{WICOWOYAKE 10.}

1 Kuros Perse wicaśtayatapi tawaniyetu iyamni en, Daniel, caje kin Belteśazzar eciyapi kin he wicoie wanji okiyakapi : unkan wicoie kin he wicakapi, tuka okicize kin he tanka: Unkan wicoie kin he okaliniga, qa wowanyake kin on wookahnige yuha.

2 Anpetri kin hena icunhan Daniel miye qe anpetu śakowin eceli yamni hehanyan iyokiśin waun:

3 Woyute oiyokipi takndan wate śni, qa tado qa miniśa mii ohna ye śni ; nakun ecaca sdamiçiye śni, anpetu śakowin eceh̉ yamni kin ihuniyanpi śni hehanyan.

4 Unkan wi tokaheya, anpetu wikcemna nonpa sanpa itopa kin en, wakpa tanka kin Hiddekel hee icahda waun qehan;

5 Hehan iśta hduwankan iwekeu qa ewatonwan, qa iho, wicaśta wanji minihuha ska koyalsa, qa nite opta Upaz etanhan mazaskazi waśte kin ipiyag kiton:

6 Qa tancan kin topaz iyececa, qa ite kin iś wakanhdi wanyakapi kin iyececa, qa iśta peta ide śaśa iyececa, qa isto qa siha kin mazaśa pabezapi owanyake kin 459 


\section{DANIEL TAWOWAPI KIN,}

iyececa, qa oie ho kin he wicota hopi kin iyececa.

7 Unkan Daniel miye miśnana wowanyake kin wanmdaka: qa wicaśta mici unpi kin hena wanyakapi śni; tuka wonihinciye tanka wan awicahinhpaya, hecen naiçiliman najicapi.

8 Heon miśnana ehipemayanpi waun, qa wowanyake tanka kin de wanmdaka: unkan wowaśake takudan en maun śni; qa owanyag mawaśte qon he wicahwin ekta hinhda, qa wowaśake takudan mduhe śni.

9 Tuka iye oie ho kin nawahon: unkan oie ho kin nahon waun q૯han, ite akan miśtinbe liinca iwahpamde, qa miite maka akan wanke.

10 Unkan iho, wicanape wan mayutan, qa mitahupahu qa minape cokaya akan hdunajin makiya:

$11 \mathrm{Qa}$ hemakiya; Daniel wicaśta waśtedakapi, wicoie eciciye cin hena okahniga wo, qa nanke cin en inajin wo; niye ekta nakaha umaśipi nakaeś. Unkan wicoie kin de emakiya hehan cancanyan nawajin.

12 Hehan hemakiya; Daniel, kopehda śni wo, nicante wokalinige kta eyelinaka, qa Wakantanka nitawa itokam kakiśniçiye cin anpetu tokaheya kin hetanhan nioie nahonpi, qa nioie kin on etanhan miye hibu.

13 Tuka Perse wokiconze kin en mdetahunka kin he mitkokim hinajin, anpetu wikcemna nonpa sanpa wanijidan: tuka iho, Mikael itancan tokapa wanji hee omakiya $u$ : unkan hen Perse wicaśtayatapi kin ehna woohiye ecamon.

14 Wanna, anpetu ehake kin en, nitroyate taku akipapi kte cin he okahniliciye kta wahi: wow an yake kin he ehake anpetu ota kta nakaeś.

15 Unkan wicoie kin hena omakiyaka, hehan miite maka akan ewehnaka, qa ia okitpani manka.

16 Unkan iho, Adam cinca iyececa wanji miiha mayutan: Hehan i wahdukawa qa iwaa, qa tuwe mitokam najin kin hewakiya; Itancan mitawa, wowanyake kin on wayazanwahda qon ake en mihdou, qa wowaśake takudan moluhe śni.

17 Qa Itancan mitawa tawowidake kin de token Itancan mitawa kin kici wohdake kta he: miye qe ecahankeya wowaśake takudan en maun śni, qa nakun oniya en mayanke śni ce.

18 Hehan ake wicaśta owanyake iyececa wan en mahi qa mayutan, qa mayuwaśaka :

19 Qa heya; Wicaśta waśtedakapi hinca, kopehda śni wo: wookiye niciyanka nunwe; waśaka wo, han, waśaka wo. Unkan hemakiye cin on waśagmayanpi, qa hepa; Itancan mitawa ia nunwe; mayaduwaśaka nakaeś.

20 Hehan heya; Taku on en cihi sdonyaya he: Tuka ecadan Perse mdetahunka kin kici wecize kta e ekta wahde kta. Q Qa detanhan imdamda hehan, hinnakaha, Javan mdetahunka kin u kta.

21 Tuka taku Wowicake Wowapi kin en owapi kin he cicipazo kta: qa tuwedan taku kin dena en mici ihduwaśake śni, Mikael mdetahunka nitawapi kin hecedan.

\section{WICOWOYAKE 11.}

1 Unkan miye qe, Darius Media kin tawaniyetu tokaheya kin

460 


\section{WICOWOYAKE 11.}

en, mdusuta kta qa mduwaśake kta inawajin.

2 Unkan dehan wowicake kin cicipazo kta. Iho, tokata Perse en wicaśtayatapi yamni inajinpi kta, qa itopa kin he owasin isanpa wijice kte hinca, qa towijice wowaśake kin on owasin Javan wokiconze kin anatan wicaye kta.

3 Unkan wicaśtayatapi waśake hinca wan inajin kta, he qe wowaśake tanka hduha wicaśtayatapi un kta, qa iye tawacin kin ohnayan econ ecee kta.

4. Qa inajin kinhan tokiconze kin yujujupi kta, qa mahpiya ouye topa kin ektakiya kicioamnipi kta; tuka iye cinca kin ohna śni; qa wicaśtayatapi oun tawa kin en ounye cin eciyatanhan śni : iye tokiconze kin yujunpi kta nakaeś, qa hena icunonpatanhan toktokeca yuhapi kta.

5 Unkan itokah wicaśtayatapi kin he waśake kta; tuka mdetahunka wicayuhe cin wanji iye isanpa waśake kta, qa wicaśtayatapi un kta; iye wicaśtayatapi oun tawa kin he oun tanka kta.

6 Unkan waniyetu iyenakeca hehan hena takodakiciyapi kta: qa itokah wicaśtayatapi cunwintku kin he waziyata wicaśtayatapi kin kici wookiye kali u kta : tuka isto wowaśake kin hduhe kte śni; qa iye qe najin kte śni, qa isto kin nakun; tuka he qe wicaqupi kta, qa tona aupi kin hena, qa tuwe cincaye cin, ga tuwe anpetu kin hena en yuwaśake ciqon.

7 Tuka iye hutkan adetka kin etanhan wanji iye onajinye cin en inajin $\mathrm{kta}$, he qe ozuye wan hduha u kta, qa waziyata wicaśtayatapi taconkaśke kin en i kta, qa hena on econ kta qa ohiye kta.
8 Qa nakun taku wakan tawapi, wakagapi tawapi kici, wakśica waśtedakapi, mazaska qa mazaskazi nakun, hena Egupta ekta wayaka ahde kta: qa he qe waziyata wicaśtayatapi kin isanpa waniyetu ota najin kta.

9 Hecen itokah wicaśtayatapi kin wokiconze kin en hi kta, qa ake iye tamakoce kin ekta hde kta:

10 Qa unma cinhintkupi kin ozuye kagapi kta, qa wicota ozuye tanka yuwitayapi kta: qa wanji awicakehan u kta, qa apaśboke kta qa opta ye kta: hehan akeś hiyu kta, qa ozuye kagge kta, conkaśke tawa kin hehanyan.

11 Unkan itokah wicaśtayatapi kin nina śinhda kta, qa hiyu kta, qa kici kicize kta, han, waziyata wicaśtayatapi kin kici: unkan he qe wicota inajin wicakiye kta: tuka wicota kin he unma nape kin en wicaqupi kta.

12 Unkan wicota kin ewicayaku kinhan, iye cante en walianicida kta; qa kektopawing gikcemna makata ehpewicaye kta; tuka iye ihduwaśake kte śni.

13 Hehan waziyata wicaśtayatapi kin ake u kta, qa tokaheya qon isanpa wicota hinca inajin wicakiye kta, qa omaka waniyetu kin iyohakam, awicakehan ozuye tanka qa wowijice ota hduha u kta.

14. Unkan anpetu kin hena en wicota itokah wicaśtayatapi kin itkokim inajinpi kta: nakun nitaoyate etanhan waboticapi cincapi kin wowanyake kin yusutapi kta on wankan iyeiciyapi kta ; tuka hena hinhpayapi kta.

15 Hecen waziyata wicaśtayatapi kin u kta, qa paha wan kagge kta, qa otonwe acankaśkapi kin hena icu kta: tuka itokagia ozuye 461 


\section{DANIEL TAWOWAPI KIN,}

kin najinpi kte śni; qa oyate wicakalinige ciqon, qa wowaśake on najin kte cin wanice kta.

16 Tuka tuwe anatan $u$ kin he iye tawacin kin eciyatanhan econ ecee kta, qa tuwedan itokam najin lite śni : unkan iye wowaśte makoce kin ohna inajin kta, heqe iye nape kin on yusotapi kta ce.

17 Nakun iye tokiconze wowaśake ocowasin hduha en ye kta ite ekihnake kta, qa wicaśta owotanna kin om: hecen ohanye kta: qa winohinca cunwintku kin qu kta, yuśice kta heon etanhan: tuka he qe najin kte śni, qa kicica kte śni.

18 Hehan wita kin ektakiya ite hduze kta, qa ota icu kta: Tuka mdetahunka wan tawowiyopeye kin ayuśtankiye kta; iye wowiyopeye codan en hdicukiye kta.

19 Hehan iye tamakoce kin en conkaśke suta kin ekta ite hduhomni kta: tuka naśna kta, qa hinhpaye kta; qa iyeyapi kte śni.

20 Hehan iye tohe qon ohna inajin kte cin he wamnayan wan makoce waśte kin opta ye śi kta: tuka anpetu tonana kinhan ihangyapi kta, tuka wocanniye qa okicize unmana eciyatanhan śni.

21 Unkan iye tohe kin ohna wanji wahtedapi śni kin inajin kta; qa he qe wokiconze woyuonihan kin qupi kte śni ; tuka wookiye yuha en u kta, qa iapi śduśduta on wokiconze kin icu kta.

$22 \mathrm{Qa}$ he itokam apaśboka on apaśbog iyewicayapi kta, qa ihangyapi kta; han wicotakuye mdetahunka kin iś eya.

$23 \mathrm{Qa}$ wicotakuye kici kag̣api kin iyohakam wahnayan olanye kta: en u kta, qa oyate tonana on waśk ka icagge kta nakaeś.

24 Wookiye on makoce cepcepa kin en hiyu kta; qa taku iye atewicaye cin hena qa tunkanśidanwicaye cin econpi śni qon iye econ kta; wowicaki qa womanon qa wowijice kin hena wicakipamni kta ; qa conkaśke suksuta kin on tawacin kin awakicin kta, iyehantu kta hehanyan.

25 Qa itokah wicaśtayatapi kin ekta, iye towaśake qa tookihi kin ozuye tanka hduha ihduśkanśkan kta. Unkan itokah wicaśtayatapi kin iś eya ozuye tanka qa waśake hinca wan hduha kici kicize kta; tuka najin okihi kte śni : iye on wicotawacin awacinpi kta nakaeś.

$26 \mathrm{Han}$, iye tawoyute waśte kin etanhan yutapi ecee kin hena ihangyapi kta; qa ozuye tawa kin apaśbog ye kta; tuka wicota ktepi ilipaye kta.

27 Unkan wicaśtayatapi kin dena napin cante mahen śicaya econ wacinpi kta, qa wahna wotapi wanjidan en oitonpi kte śni : tuka ecetu kte śni: hececa eśta iyehantu kinhan owihanke kin tanin kta.

28 Hehan iye tamakoce kin ekta wowijice tanka yuha hdicu kta; qa wicotakuye wakan kin itkom cante yekiye kta; qa waecon kta, qa iye tamakoce kin ekta hde kta.

29 Tohan iyehantı kinhan iye ihduhomni kta, qa itokahkiya u kta; tuka tokaheya qa inonpa qon iyecece kte śni.

30 Kittim wita wata kin hena itkokim upi kta nakaeś: Heon etanhan nihinciye kta qa hdicu kta qa wicotakuye wakan kin canniyeye kta: Hecen ohanye kta; han, hdicu kta, qa tona wicotakuye wakan ayuśtanpi kin hena om okicicahnige kta.

31 Qa iye eciyatanhan ozuye wan inajin kta, qa tipi wakan 


\section{WICOWOYAKE 11.}

conkaślke.kin yuśapapi kta, qa anpetu iyohi wośnapi ecee kin yutokan iyeyapi kta, qa wowaliteśni wayutakuni śni kin he ehdepi kta.

$32 \mathrm{Qa}$ tona wicotakuye, kin en śicaya econpi kin hena iapi śduśduta on wicayuśice kta: tuka tona Taku Wakan sdonkiyapi kin hena waśakapi kta qa taku econpi kta.

33 Qa oyate etanhan tona wokahniğapi kin hena wicota waonspewicakiyapi kta: Hececa eśta, mazasagye on, qa peta ide on, wayaka unpi on, qa wawicakipi on hinhipayapi kta, anpetu ota.

34 Unkan tohan hinhpayapi kinhan waokiyapi cistinna on owicakiyapi kta: tuka iapi śduśduta yuha wicota hena en aopeiçyapi kta.

35 Unkan tona okahnigapi kin etanhan wanjikji hinhpayapi kta, hena on iyutanpi kta, qa yuecepidan kta, qa yuskapi kta, owibanke iyehantu hehanyan: iyehantu konzapi yukan nakaeś.

36 Uṇkan wicaśtayatapi kin iye tarvacin kin eciyatanhan ohanye kta, qa ihduwankantu kta, qa taku wakan owasin iwankam tanka icicage kta; qa taku wakan ehna Wakan hince cin he taku wowinihan eciye kta, qa wocanteptanye yuśtanpi kta hehanyan iyoopta ye kta; taku konzapi qon he ecen econpi kta nakaeś.

37 Qa iye atewicaya taku wakan tawapi kin he akta kte śni, winolinea waśtedakapi kin he nakun, qa taku wakan owasin akta kte śni : iye owasin iwankam tanka içicage kta nakaeś.

38 Tuka iye tohe kin en taku wakan conkaśke suta yuhe cin he yuonihan kta: qa taku wakan wan iye atewicaye cin sdonyapi śni qon he, mazaskazi on, qa mazaska on, qa inyan telike on, qa taku waśtedakapi kin on yuonihan kta.

39 Conkaśke suta hinca ohna taku wakan tokeca, iye kahnige kte cin on hecen econ kta: wowitan on icag̉e kta; qa hena wicota en ounyekiye kta, qa wokamna on makoce kin pamni kta.

40 Unkan owihanke kin iyehantu, hehan itokaga wicaśtayatapi kin he wacapa iyeye kta: Tuka waziyata wicaśtayatapi kin he tate iyumni wan iyececa, itkom hiyu kta, canpahmihma on, qa śuktanka akan yotankapi kin on, qa wita. wata ota on: qa makoce kin hena en hiyu kta, qa apaśboke kta, qa iyoopta iyaye kta.

41 Nakun makoce oiyokipi kin he en ye kta, qa makoce ota ihangyapi kta; tuka Edom, qa Moab, qa Ammon cinca tokapapi kin hena iye nape etanhan eihdakupi kta.

42 Nakun makoce kin hena ekta nape hdugate kta: qa Egupta makoce kin eihdaku kte śni. 43 Tuka iye mazaskazi qa mazaska opiye kin on waśake kta, qa Egupta en taku waśtedakapi kin iyuhpa yuhe kta: Unkan Lubin qa Kuś oyate kin hena iye owe kin en opapi kta ce.

44 Tuka wiyohiyanpa tanhan qa wariyatanhan woyakapi kin he inihanye kta: Heon etanhan wośinhda tanka hduha waihangya ye kta, qa wicota ocowasin wicayutakuni kte śni.

45 Qa iye tawakeya tipi waśteśte iyececa kin hena mini otahedan he wakan oiyokipi kin en ekihdle kta: hececa eśta iye ihangyapi kta, qa tuwedan okiye kte śni ce. 


\section{DANIEL TAWOWAPI KIN.}

\section{WICUWOYAKE .12.}

1 Unkan hehantu hin Mikael, mdetahunka tanka nitaoyate cinca kin on inajin ecee kin he inajin kta. Unkan hehan wokakije ampetu kta, oyate yukan hetanhan qa anpetu kin he hehanyan tolinni hecece śni. Unkan hehantu hin nitaoyate kin ehdakupi kta, tona wowapi kin en owicawapi iyeyapi kin hena owasir.

2 Unkan maka mdu kin en iśtinmapi kin ota kiktapi kta, dena owihanke wanin wiconi ekta, qa hena iś wowiśtece, wośicedake owihanke wanica ekta.

3 Unkan tona ksapapi kin hena okotonyan wiyatpa kin iyecen wiyatpapi kta, qa tona wicota wicayuowotanpi kin hena wicanlipi iyececapi kta, ohinniyan qa owihanke wanica.

4 Tuka niye, Daniel, wicoie kin nakitaka wo, qa wowapi kin apuspa wo, owihanke iyehantu kta hehanyan. Wicota icipaś inyankapi kta, qa wosdonye yuotapi kta ce.

5 Hehan Daniel miye ekta ewatonwan, unkan iho, nom toktokeca najinpi, wanji deciyatanhan wakpa kin icahda, qa unma kin iś kakiyatanhan wakpa kin icahda.

6 Unkan wanji wicaśta minihuha ska koyake wakpa mini kin iwankam un kin he heciya; Taku wowinihan kin dena owihanke kta tohanyan kta he.

7 Unkan wicaśta minihuha ska 464 koyaka wakpa mini kin-iwankam un, nape etapa qa catka kin mahipiya ekta hdugate ca tuwe ohinniyan ni un cajeyan konza qehan hecen eya nawahon; Omaka qa omaka nonpa qa omaka hanke hehanyan kta; qa tohan oyate wakan towaśake kin enanakiya iyeya yuśtan kinhan, hehan dena iyuhpa yuecetupi kta ce.

8 Unkan nawahon, tuka owakahnige śni : Hehan hepa; Itancan mitawa, dena owihanke kte cin tukte e he.

9 Unkan heya; Daniel, ya wo: wicoie kin natakapi, qa owihanke kte cin hehanyan puspapi.

10 Wicota wicayutecapi kta, qa wicayuskapi kta, qa wicayuecepidan kta; tuka tona śicapi kin hena śicaya econpi kta : qa śicapi kin tuwedan okahnige kte śni ; tuka ksapapi kin hena okahniğapi kta.

11 Unkan totanhan anpetu iyohi wośnapi kin yutolsan iyeyapi, qa wowaliteśni wayutakuni śni ece kin ehdepi kin hetanhan anpetu kektopawinge sanpa opawinge nonpa qa sanpa wik cemna napcinwanke kta.

12 Tuwe ape un, qa anpetu kektopawinge sanpa opawinge yamni, qa sanpa wilicemna yamni sanpa zaptan ehan i lsinhan he yawaśtepi ce.

13 Tuka niye ya wo, owihanke kin hehanyan. Niye oziniçiye kta nakaeś, qa anpetu ihanke kin ekta niowe kin ohna nayajin kta ce. 


\section{H OSEA.}

\section{WICOWOYAKE 1.}

1 Uzziah, Jotham, Ahaz qa Hezekiah, Juda wicaśtayatapi kin taanpetu kin en, qa Jeroboam Joash cinhintku Israel wicaśtayatapi taanpetu kin en, Jehowa oie Hosea Beeri cinhintku en hi kin he dee.

2 Jehowa oie Hosea etanhan tokaheya kin dee. Unkan Jehowa Hosea heciya; Ya wo, winohinca witkowinna wan yuza wo, qa wicacinca wawicihahapi etanhan: Jehowa icunonpa rnakoce kin wawicihahapi nina econ nakaeś.

3 Hecen iyaye ca Gomer Diblaim cunwintku kin he yuza: unkan he ihduśake ça hokśidan wan kiciyuha.

4 Hehan Jehowa heciya; Jezreel eya caśkiton wo; ehake cistiyedan hehan Jezreel we kin on Jehu ti kin en.wai kta, qa Israel tipi kin etanhan wokiconze kin ayuśtanwakiye kta nakaeś:

5 Qa anpetu kin he en Jezreel kaksiza kin ohna Israel tinazipe kin mduwegie kta ce.

6 Hehan ake ihduśake ca wicinca wan yuha. Unkan heciya; Jo-ruhama (onśidapi śni) eya caśkiton wo : Detanhan icimana Israel tiyohnaka kin onśiwakida kte śni nakaeś; tuka ocowasin yutokan iyewicawaye kta ce.

7 Tuka Juda tiyohnaka kin onśiwicawakida kta, qa Taku Wakan tawapi Jehowa hee on niwicawakiye kta; qa itazipe, qa mazasagye, qa okicize, qa sú ktanka, qa śunka wakan akan yotankapi kin on niwicawakiye kte śni ce.

8 Unkan Loruhama wanna azin ayuśtankiya, hehan ihduśaka qa hokśidan wan yuha.

9 Hehan Wakantanka heya; Lo-ami (mitaoyate śni) eya caśkiton wo: Oyate mitawa kin he niyepi śni nakaeś, qa nakun tawamayayapi kte śni ce.

10 Hececa eśta Israel cinca wicayawapi kin he miniwanca wiyaka iyutepica śni qa yawapica śni kin iyecece kta. Unkan kaketu kte, tukten, Mitaoyate kin niyepi śni ce, ewicakiyapi qon, hen, Wakantanka ni un cinca kin, ewicakiyapi kta.

11 Hehan Juda cinca qa Israel cinca kin yuwitayapi kta ; unkàn wicaśta itancan wanjidan hdahnigapi kta ; qa makoce kin etanhan upi kta; Jezreel taanpetu kin he tankà kta nakaeś.

\section{WICOWOYAKE 2}

1 Nihunkawanjipi Ami, qa nitawinohtinpi Ruhama, hewicakiya po:

2 Cekiya po, inayayapi kin cekiya po: he qe winohinca mitawa kin ee śni, qa nakun wicaśta tawa kin he miye śni: heon etanhan witkowinna ohanye cin hena iye iśta kin etanhan, qa wawicihahapi econ kin iye aze otahedan tanhan ehpekiye kta:

3 Okinni heyake 'yuśdogwakiye kta, qa anpetu en tonpi qon iye- 


\section{HOSEA,}

cen ewahnake kta, qa hewoskantu wan iyececa wakage kta, qa makoce puza wan iyececa ewahde kta, qa ipuzapi on tewakiye kta :

4 Qa iye cinca kin hena onśiwicawakida kte śni; hena wawicihahapi cinca kin heca nakaeś.

5 Hunkupi kin he wawicihahapi econ ece: tuwe wicayuhe cin he wawiśtenya ohanyan : Waśtemadakapi kin hena wicihakam mde kta ce, hena aguyapi mitawa, qa mini mitawa, tahinca hin mitawa qa halonta mitawa, wihdi mitawa qa miniśa mitawa maqupi ece, eya nakaeś.

6 Heon etanhar iho, canpepe kin on nitacanku kin aonawatake kta, qa acanwakaśke kta, hecen canku tawa qon hena iyekiye kte śni.

7 Qa waśtelídapi kin hena nina kuwa awicaye kta, tuka ewicakihdeg̉e kte śni ; qa owicade kta, tuka iyewicaye kte śni. Hehan heye kta; Mde ça wicaśta tokaheya mduhe ciqon he ekta wahde kta; hektam tanyan waun qon dehan iyecece śni nakaeś.

8 He miye wamnaheza, qa wihdi miniśa kici waqu, qa mazaska mazaskazi ko weciyuota he sdonkiye śni; hena Baal qupi ece.

9 Heon etanhan wahdiyaku $\mathrm{k}$ ta, qa iyehantu kinhan wamnaheza mitawa ewehdaku kta, qa miniśa mitawa tohan iyehantu kinhan, qa tahinca hin mitawa halionta ko, on tancodan ahdalipe kta tuka qon hena ake iwekcu kta.

10 Qa. Wanna waśtedakapi iśtapi itokam tawowiśtece kin mdutanin kta; unkan tuwedan minape etanhan eyaku kte śni.

11 Nakun tawowiy.uśkin kin ocowasin ayuśtan wakiye $\mathrm{kta}$, wohanpi anpetu tawa, wi teca tawa, anpetu wakan tawa, qa omniciye wakan tawa kin iyuhpa.

12 Qa hastanhanka jyuwi tawa, qa witanśna hu tawa, on, Waśtemakidapi iyunwin maqupi kin dena ee ce, eye ciqon, hena ihangwaye kta : unkan hena otehi wakage kta, qa tinta woteca kin hena yutapi kta.

13 Qa Baalim taanpetu kin hena on iyopewaye kta, lie ehan wizice izinwicakiya, qa oinpi wanapin ko on ihduwaśte, qa waśtekidapi qon wicihakam iyaya, qa miye amiktonja ce, Jehowa eya.

14. Heon etanhan iho wo, miye wicadawakiye kta, qa hopuza en awai kta, qa cante ekta owakiye kta.

15 Qa hetanhan hastanhanka ojupi kin wecu kta, qa Akor kaksiza kin he wowacinye tiyopa kta. Hehan anpetu en wikośka qon iyececa hen dowanwan kta, qa anpetu Egupta makoce kin etanhan hinanpe ciqon he iyececa.

16 Unkan anpetu kin he en, Iśi (wicaśta mitawa) emayakiye kta, qa icimana Baali (itancan mitawa) emayakiye kte śni ce, Jehowa eya.

17 Baalim cajepi kin iye i kin etanhan emdaku kta nakaeś, qa cajepi kin hena on icimana kiksuyapi kte śni.

18 Qa anpetu kin he en wicotakuye wan wicawecicagie kta, tinta woteca kin om, qa mahpiya okinyanpi kin om, qa maka asdohan unpi kin hena om: qa makoce lin etanhan itazipa, qa mazasagye, qa canbi kin hena mduweliwege kta; qa wikope-śniyan iwanke wicawaye kta ce.

19 Nakun owihanlse wanica he- 


\section{WICOWOYAKE 4.}

hanyan cihduze kta: han, woowotanna en cihduze kta, qa woyaco en, qa wawacinlta yuzapi tanka en, qa wowaonśida en:

$20 \mathrm{Han}$, wowicake en miye cihduze kta: unkan niye e Jehowa sdonyaye kta ce.

21 Unkan anpetu kin he en kaketu kta, waamdupte kta, Jehowa eya; mahpiya kin amdupte kta; qa mahipiya kin he maka kin ayupte kta :

22 Qa maka kin aguyapi ayupte kta, qa miniśa qa wihdi nakun; unkan hena e Jezreel ayupte kta. 23 Qa makoce kin en he omiçiju kta: nakun Loruhama (onśidapi śni qon) he onśiwakida kta, qa Loami, (mitaoyate śni qon) hena, Mitaoyate, ewicawakiye kta; unkan hena e, Mita Wakantanka ce, eyapi kta.

\section{WICOWOYAKE 3.}

1 Heharı Jehowa hemakiya; Ake ya wo, winohinca wan takodaku waśtekida, tuka witkowinna heca he waśtedaka wo, Jehowa Israel cinca waśtewicakidake cin iyececa; hena e taku wakan tokeca ekta etonwanpi, qa hastanhanka paskicapi kin waśtedakapi ece.

2 Hecen mazaska akezaptan on wamdulipe, qa barle homer (wiyutapi) wanjidan, qa sanpa homer hanke on :

$3 \mathrm{Qa}$ miye hewakiya; Anpetu ota mici yaun kta, wawicihahapi ecanon kte śni, qa wicaśta tokeca kici yaun kte śni : hecen miś cici waun kta ce.

4 Anpetu ota Israel cinca kin wicaśtayatapi nicapi kta, qa wicaśta itancan wanica, qa wośnapi wanica, qa wakagapi wanica, qa ephod (maku akahipe) wanica, taku wakan kaġapi koya.
5 He iyohakam Israel cinca kin hdicupi kta, qa Taku Wakan tawapi, Jehowa hee okidepi kta; qa Dawid wicaśtayatapi tawapi qon: qa anpetu ehake kin en Jehowa qa iye Towaśte kin kokipapi kta ce.

\section{WICOWOYAKE 4.}

1 Israel cinca, Jehowa oie kin nahon po: makoce en ounyanpi kin hena om Jehowa woakinica wan yuha; wowicake, qa wowaonśida, qa Wakantanka sdonyapi kin makoce kin ohna wanica nakaeś.

2 Wayaśicapi, qa itonpiśni, qa tin wicaktepi, qa wamanonpi, qa wawicihahapi econpi kin hena on waihduśicapi ; qa we we icahitaka ece.

3 Heon etanhan makoce kin ceye kta, qa en ounyanpi kin otoiyohi hanye kta, tinta woteca kin nakun, qa mahpi ya okinyanpi kin hena koya; han, miniwanca hogan kin hena nakun ihangyapi kta.

4. Tuka wicaśta tuwedan tuwe tokeca kici akinica kte śni, qa iyopeye kte śni: nitaoyate kin tona wawayuśna kin kici akinicapi kin iyececapi nakaeś.

5 Heon etanhan anpetu kin en nihinhpaye kta, qa hanyetu en wicaśta wokcan kin iś nici hinhpaye kta, unkan nihun awihnuni waye kta ce.

6 Mitaoyate wosdonye codan unpi kin on awihnunipi: Niye wosdonye ayakta śni, heon wawayuśna mici yaun kin etanhan ehpeciye kta: Taku Wakan nitawa toope kin ayektonja, heon etanhan miś eya nicinca kin awektonje kta ce.

7 Wicayuotapi kin he iyecen wamakihtanipi ecee: towitanpi 467 


\section{HOSEA,}

kin he wowiśtece wicawecicağe kta.

8 Mitaoyate wahtanipi kin hena tenya iyeyapi; qa taku śica econpi kin cante ekta yeyapi ece.

9 Heon etanhan oyate token un kin iś wawayuśna kin iyecece kta: qa iye tacankupi ohna kakiświcawaye kta, qa tảku econpi kin on wicawecicajuju kta ce.

10 Hena wotapi kta, tuka imnanpi kte śni: wiinahmanpi econpi kta tuka he on ihduotapi kte śni: Jehowa ohodapi kta he ayuśtanpi nakaeś.

11 Wiinahmanpi, qa miniśa, qa miniśa teca, hena wicacante manonpi ece.

12 Mitaoyate can okikjupi kin he wiwangapi, qa cansagye tawapi kin he wowicakiciyaka ece: wiinahmanpi oniya kin he nuniwicakiya' nakaeś, qa 'Taku Wakan tawapi kin etanhan wawiciliahaya iyayapi.

13 Ḣe ipa kin akan wawayuśnapi ece, qa paha kin akan wizice iziteyapi, utuhu can, qa waga can, qa wazi can ihukukuya, ohanzi kin waśte nakaeś: Heon etanhan nicunkśipi inahmanpi kta, qa takoświcayayapi kin wawicihahapi econpi kta.

14 Nicunkśipi inahmanpi kinhan wicawakaśtake kte śni, qa takoświcayayapi wawicihahapi econpi kinhan : iyepi qaeś wiinahimanpi kin om iyayapi, qa witkowinpi kin om wawayuśnapi ece: heon etanhan oya te okalinigge śni kin he awihnuni kta.

15 Niye, Israel, wawicilialiaya ecanon qeyaś, ihnuhan Juda wahtani kinhan: nakun niye Gilgal en upi śni po, qa Beth-aven ekta yapi śni miye, qa, Jehowa ni un ce, eya ic̣iconzapi śni po.

16 Pte heyuktanna wawakipajin kin he iyecen Israel wawa- kipajin ece: 'Tuka wanna owanka tanka ohna tacinca wan iyececa Jehowa wihanwicakiye kta ce.

17 Ephraim wakagiapi en ihdaśka : ito avuśtan wo.

18 Wayatkanpi kin he sica: wawicihahapi nina econpi ece: wicaśta itancan tawa kin hena waśtedapi, wowiśtece waśtedakapi.

19 Tate kin he iye tahupahu en opahta; hecen tawośnapi kin on iśtecapi kta tuka.

\section{WICOWOYAKE 5.}

1 Wawayuśna yaunpi, de nahon po; qa Israel tiyohnaka, anagioptan yanka po; qa wicaśtayatapi tiyohnaka, niye nahon miye; woyaco niyepi en niupi, Mizpah akan mazahtakiyapi yaunpi, qa Tabor en on-hmunkapi akahpapi kin henicapi nakaeś.

2 Unkan wicaktepi kta on woalitani temahentuya econpi; tuka miye hena iyuhipa iyopewicawaya ece.

3 Miye qe Ephraim sdonwaya, qa Israel miye etanhan naiçilibe śni: Ephraim, niye qe wanna wiinayahman, Israel ihduśapa nakaeś.

4 Taku Wakan tawspi kin ekta ihduhomnipi kta e wicohian econ wacinpi śni : wawicilahapi econpi oniya kin he wicacokaya un, qa Jehowa sdonyapi śni nakaeś.

5 Unkan Israel towahaniçida kin iye ite kin en ihdutanin: heon etanhan Israel qa Ephraim iye wahtanipi kin en hdihpayapi kta, qa Juda nakun om hinh̉paye kta.

6 Tahin wanunyanpi tatanka ko hduha Jehowa okide yapi kta, tuka iyeyapi kte śni; iye qe hena ehpeya iwicayaya. 


\section{WICOWOYAKE 6.}

7 Jehowà en hnayan olianyanpi ece; cinca tokeca icahwicayapi nakaeś: wanna wi teca kin he awihnuniwicaye kta, taku tawapi koya.

8 Gibeah en cotanka kin yajo po, mazayahotonpi tanka kin Rama entu: Beth-aven ekta śicahowaya miye, Benjamin, niye nihakamtu ce.

9 Woiyopeye anpetu kin en Ephraim otiwota wanke kta. Israel wicowazipi kin ehna taku awicakapi kלe cin he mdaotanin.

10 Juda itancanpi kin hena mag̉a icagopi yutokanpi kin iyececapi : mitocanniye kin mini iyecen awicawakaśtan kta.

11 Ephraim tehiya kuwapi, woyaco on kaśuśujapi, taku econśipi kin he iyokipiya opa nakaeś.

12 Heon etanhan miye Ephraim en wamduśkadan wayapota iyemaceca, qa Juda tiyohnaka kin en woyukuke hemaca kta.

13 Ephraim iye towayazan kin wanhdaka, qa Juda opakihte wanhdaka qehan, Ephraim Aśur ekta iyaya, qa Jareb wicaśtayatapi kin ekta ye wicaśi : tuka he qe asniniyanpi okihi śni, qa opanicilite kin okiziyan okitpani.

14 Heon miś miye Ephraim en mnaja iyemacece kta, qa Juda tiyohnaka en mnaja kośka hemaca kta; miś miye hinca mdapotpota qa imdamde kta; miye tokan emdamde kta, qa tuwedan ehdaku kte śni.

15 Miye mde kta, mitowanka kin ekta wahde kta, kakiświcayapi qa miite akitapi kte cin behanyan: iye tokakijapi kin en kohanna omadepi kta nakaeś.

\section{WICOWOYAKE 6.}

1 Kuwa miye, Jehowa ekta unhdapi kta: iye wayaśpuśpu, tuka ake okiziunyanpi kta; iye unkaśtakapi, tuka ake paunhtapi kta nakaeś.

2 Anpetu nonpa iyohakam niunkiyapi kta: anpetu iyamni en najin unkiyapi kta, unkan iye itokam unnipi kta.

3 Hehan wasdonunyanpi kta, Jehowa sdonya unkuwapi kta: iye oenape kin he anpao kin iyecen wiyeya yanka: unkan magaju iyecen en unkupi kta, ehake mağaju maka bospaya ece kin iyececa.

4 Ephraim, taku ecacicon kta he: Juda, taku ecacicon $k$ ta he : nitowaśtepi kin he hanhanna amahpiya kin iyececa nakreś, qa cu kohanna tanin śni iyaye cin he iyececa.

5 Heon etanhan wicaśta wokcan kin on bawicawaśpaśpa; mii oie kin on hena wicawakte. Unkan woyaco nitawa kin hena iyoyanpa hinanpe cin iyececa ce.

6 Wowaonśida he waśtewadaka, qa wośnapi ce śni; qa Wakantanka sdonyapi kin he wośnapi huhnahyapi kin icanpa.

7 Tuka hena e, Adam iyecen, wicotakuye kin awabitanipi; hen wahnayan omakilianyanpi ece.

8 Gilead otonwe tona woahtani econpi sa kin he tawapi ; wicawe on nakiśapapi.

9 Wamanon sa wicota wicaśta wan iyapepi kin he iyecen wawayuśna okodakiciye kin Sekem ekta canku iyahde ohna tin wicaktepi ece: hena wikikśanpi nakaeś.

10 Israel tipi kin en taku wonihinciye wanmdaka : Ephraim wiinahman kin hen yanka, Israel ihduśapapi.

11 Nakun. Juda, iye womnayan wan niciyuśtan, tohan mitaoyate way?ka unpi hdicuwicawakiye cinhan. 


\section{HOSEA,}

\section{WICOWOYAKE $\%$}

1 Israel okiziwaya icunhan Ephraim tawoahtani qa Samaria taku śica econ kin hena tanin: woitonśni econpi nakaeś : qa nakun wamanon sa kin he en u kta, waboticapi kin hena tankan wawicakipi ece.

2 Unkan taku śica econpi kin iyuhpa miye welssuya ecee he cante mahen awacinpi śni : tuka iye ohanpi kin hena aohdutewicakiya; hena miite itokam yanka.

3 Ścaya econpi kin on wicaśtayatapi kin iyuśkinkiyapi ece, qa iye itonpiśni kin on wicaśta itancanpi kin iyuśkinpi.

4 Hena owasin wiinahmanpi ece, waśpanyan wan mazaoceti ohna ceti eca, ağuyapi paținza kin he napogan śni hehanyan sanpa kanya ayuśtan lite cin he iyececa.

5 Wicaśtayatapi unkitawapi taanpetu kin en, wicaśta itancanpi kin miniśa kanyapi on wayazanka içicağapi : iye wawihahapi kin om nape hdugata.

6 Wawiyape unpi icunhan, mazaoceti wan iyecen cante ikiyedan ukiyapi nakaeś: hanyetu osan waśpanyan tawapi kin iśtinma; hanhanna eca peta itkon iyecen ide ece.

7 Hena iyuhipa katapi, mazaoceti wan iyececa, qa wayaco temwicakiyapi: wicaśtayatapi tawapi kin owasin hinlipayapi; hena etanhan tuwedan hoyemakiye śni.

8 Ephraim oyate kin ehna icicahiic̣iya: Ephraim aguyapi kagiapi yuptanyanpi śni kin heca.

9 'Towaśake kin he oyate tokeca temkiciyapi, tuka iye sdonkiye. śni: han, tuktekten pa hin skaska en un tuka sdonkiye śni. $4 \% 0$
10 Nakun Israel towahanicida kin iye ite kin en oihdake: Tuka dena owasin on etanhan Jehowa Taku Wakan tawapi kin en ihdoyapi śni, qa okidepi śni ece.

11 Nakun Ephrairn tinwakiyedan witkotkoka wan iyececa, cante nica: Egupta hoyekiyapi, Aśur ekta yapi ece.

12 Tohan yapi kinhan on-hmunkapi mitawa awicawakahpe kta: mahpiya okinyanpi kin iyececa kun ehpewicawaye kta: iye tomniciye nahonpi kin he iyecen wicawakaśtake kta ce.

13 Wotehi wicakiciyanka nunwe, hena namicijicapi nakaeś: woyutakuni śni wicakiciun nunwe, wamicihtanipi heon etanhan : hena opewicawakiton qeyaś oimatonpiśni ece.

14 Qa iye towinjapi akan śicahowayapi eśta, cante on hoyemakiyapi śni: ağuyapi qa miniśa imniciyapi, miye makipajinpi ece.

15 Nakun miye wahokonwicawakiya on isto wicaweciyuwa śaka eśta śicaya wacinmakiyuzapi ece.

16 Hdicupi eśta Iyotan Wankan un kin ekta śni : itazipa wahnaye sa wan iyececapi: wicaśta itancan wicayuhapi kin hena mazasagye on hinhpayapi kta, iye ceji wayaśicapi kin on etanhan: Decen Egupta makoce kin ohna wawihahawicayapi kta ce.

\section{WICOWOYAKE 8.}

1 Nii kin en mazayahotonpi:Wanmdi wan iyececa Jehowa ti kin takpe u kta, wicotakuye mitawa awahtanipi, qa mitoope kin kicalssapi naliaeś.

2 Miye hoyemakiyapi kta; Mita Wakantanka sdonunniyanpi ce, Israel unkiyepi. 


\section{WICOWOYAKE 9.}

3 Israel taku waśte kin dektaya: toka kin hena kuwa ayapi lita ce.

4. Wicaśtayatapi ewicahnakapi, tuka miye etanhan śni; wicaśta itancan wicakagapi, tuka sdonwaye śni : mazaska qa mazaskazi tawapi on wakagaapi içicagapi, hecen ihangyapi kta.

5 Samaria, ptejicadan nitawa kin he wowahteśni: mitocanniye kin aidewicakiyapi: tohanyan iyaonpepicaśni kin iyohiyapi kte śni he.

$6 \mathrm{He}$ nakun Israel etanhan nakaeś: mazakağa lkin he kağa; heon etanhan he Taku Wakan kin ee śni: Tuka Samaria ptejicadan tawa kin he kaksaksapi un kta.

7 Hena tate ojupi, heon etanhan tateiyumni kin mnayanpi kta: hu yuke śni; camni uye cin he aguyapi icahye kte śni : taku aicaga eśta oyate tokeca napcapi kta.

8 Israel napca iyeyapi : wanna Ikcewicaśta wicehna unpi kta, ceğa wan oiyokipi wanice cin he iyececa.

9 Aśur ekta iyryapi nakaeś, śonśonna wan iśnana un kin iyececa: Ephraim waśtedakapi kin heca opewicaton.

10 Tuka Ikcewicaśta kin ehna wiyopeiciyapi eśta, wanna mnawicawaye kta, unkan wicaśta itancanpi en wicaśtayatapi yuhapi kin on cistiyedan iyokiśiniçiyapi kta.

11 Ephraim wahtani kta on owayuśna ota kaga, heon etanhan owayuśna kin hena wahtanikiya ecee kta.

12 Mitawoalıpe taku tanka kin hena on wowapi wecagia: tuka hena taku tokeca dakapi.

13 Wośna wamakiyuśnapi, tado wayuśnapi qa yutapi ece: Jeho- wa iyowinwicakiye śni : Wanna taku śica econpi kin kiksuye kta, qa wahtanipi kin on iyopewicaye lita: Egupta ekta icicawin yapi lita ce.

14 Israel Tuwe Icahye cin he akiktonja nakaeś, qa tipi tanka icicaga: Juda nakun otonwe acankaśkapi kin hduota ece : Tuka otonwe tawa kin hena en peta yewaśi kta, unkan tipi tanka kin hena ihangkiciye kta ce.

\section{WICOWOYAKE 9.}

1 Israel, oyate kin iyecen, wowiyuśkin on wiyuślkin śni wo : nita Wakantanka ehpekiya wiinahman idada, agguyapi onapanpi otoiyohi ohna iyunwin waśteyadaka nakaeś.

2 Onapanpi qa miniśa onaskicapi kin hena wonwicayapi kte śni : qa ohna miniśa teca kin he wohnaye kta.

3 Jehowa tamakoce kin en ounyanpi kte śni : tuka Ephraim Egupta ekta hde kta, qa Aśur ohna taku śapa yutapi kta.

4. Jehowa miniśa okicaśtanpi kte śni, qa nakun iyokipi yapi kte śni : tawośnapi kin liena oiyokiśica ağuyapi kin iyececa: tona etanhan yutapi kin owasin yuśapapi kta: iye nagipi on taaguyapi kin Jehowa ti kin en u kte śni nakaeś.

5 Omniciye anpetu kin en, qa Jehowa tawośna anpetu kin en taku ecanonpi lkta he.

6 Tho, hena woyutakuniśni on iyayapi : Egupta mnawicaye kta, Memphis wicahe kta: mazaska tawapi opiye waśte kin haśbe en un kta; tawakeyapi kin ohna can pepe yuke kta.

7 Wicakiciyawapi anpetu kin wanna hiyohi; iyopewicayapi anpetu kin wanna hi: Israel 471 


\section{HOSEA,}

sdonye kta: Wicaśta wokcan kin he witkotkoka; wicaśta wakan kin iś wacinhnuni, wayalitani ota kin on, qa wicotakuniśni tanka kin on etanhan.

8 Ephraim mita Wakantanka akipe yanka: wicaśta wokcan kin iś iye tacanku owasin ohna wahmunke sa onhmunkapi tawa kin heca; iye taku wakan tawa ti kin ohna wicotakuniśni heca.

9 Ośungye ihduśicapi, Gibeah tampetu qon en iyececa: 'Taku śica econpi kin iye kiksuye kta, walitanipi kin iye wicakiciyawa kita.

10 İewotahedan hastanhanka iyagge iyececa Israel iyewaya: witanśna hu kin akan tokaheya suton kin iyececa, nihunkakepi wanwicamdaka: Tuka Baal Peor ekta iyayapi, qa wowiśtece kin he en ihduwakanpi ; qa iye waśtedakapi kin iyececa wowahteśni yukankan.

11 Heon etanhan Ephraim towitanpi kin kinyan iyaye kta, zitkadan wan iyececa; tokaheya icagge cin wanica, qa tamni etanhan, qa tonpi kin etanhan.

$12 \mathrm{Han}$, cinca icahwicakiyapi eśta cinca codan wicawakağe kta, wicaśta wanice kta: han, tohan ehpewicawaye cinhan wotehi wicakiciyanke kta.

13 Turos wanmdake ciqon iyecen Ephraim makoce waśte en ojupi: Tuka tin wicakte kin ekta Fphraim cinca hiyuwicakiye kta.

14 Jehowa, wawicaqu wo: Taku e wicayaqu kta he: Tamni hokśin yuhe śni kin he wicaqu wo, qa nakun aze asınpi wanica.

15 Wicolian śica tawapi kin iyulipa Gilgal en un: hen śicewicawakidaka nakaeś: Taku śica econpi kin on wati kin etanhan napewicawaye kta; icimana waśtewicawadake; kte śni: wicaśta itancan tawapi iyulipa wawakipajinpi.

16 Ephraim kaśtakapi, hutkan tawa kin śeca aya; waskuyeca takudan icahyapi kte śni: Han, cinca yuhapi eśta, tamnipi etanhan tona waśtedakapi kin hena wicawakte kta ce.

17 Wakantanka mitaws anagioptaupi śni, heon etanhan iye ehpewicaye kta: Unkan oyate kin ehnahna onuni unpi kta ce.

\section{WICOWOYAKE 10.}

1 Israel hastanhanka hu tankaya icagge cin heca; iye on waskuyeca icahiciya ece: tawaskuyeca ota kin he iyecen owayuśna içicaga; makoce tawa waśte kin he iyecen wakagapi bag̀opi ece.

2 Cantepi jagjata ; wanna kakiśyapi kta: Owayuśna tawapi kin hena iye pajuju kta, wakagapi tawapi kin hena ihangye kta ce.

3 Wanna heyapi kta; Jehowa kounkipapi śni, heon wicaśtayatapi unnicapi; hecen wicaśtayatapi wan taku ecaunkiconpi kta he.

4 Wicoie eyapi, wicotakuye kagapi kin en itonśni ic̣icağapi ; heon etanhan woyaco uye, maga ocanku ohnahna wato śica kin he iyececa.

5 Samaria en ounyanpi kin Bethaven ptejicadan kin hena on kopehdapi kta: hecen taoyate kin he aceye kta, qa wawayuśna on wiyuśkinpi qon hena nakun, towitan kin on, wanna ayuśtan nakaeś.

6 He nakun Aśur ekta ayapi kta, Jareb wicaśtayatapi kin qupi kta. Ephraim wowiśtece icu kta, qa Israel iye tawowahokonkiye kin on iśtece kta ce. 
7 Samaria wicaśtayatapi tawa kin he atakuniśni, mini akan carlokahpahpa wan iyececa.

8 Nakun Aven pajodan, Israel tawoahtani qon, hena ihangyapi kta: Owayuśna tawapi kin akan wapepeka qa toka hu uye kta: Hehan he kin, Unkakahpa miye, eciyapi kta; qa, Unkahinhpaya po, paha kin eciyapi kta.

9 Israel, Gibeah taanpetu kin hetanhan wayahtani ece. Hen inajinpi: Gibeah en woahtani cinca kin om okicize kin he ewicakihdeǵge śni.

10 Iyopewicawaye kita cante mduza: unkan oyate lin takpewicayapi kta, tohan walitanipi nom on ihdaśkapi kinhan.

11 Nakun Ephraim pteheyuktanna kaonspepi, wanapan wastedake cin heca: tuka miye qe tahu waśte kin alkan imdamda. Fphraim en ikoyagwaye kta: Juda womdu kta.; Jakob magga kiciyuhinhe lita ce.

12 Woowotanna on okikju po, wowaonśida eciyatanhan wamnayan po: mahteca hdumdu po: Jehowa hi kta, qa woowotanna amağaju niciyapi kta hehanyan wanna akitapi kta iyehantu nakaeś.

13 Wośice idumdupi, woahtani mnayakiyapi; woitonśni waskuyeca kin yatapi ece : Nitacanku kin he, wicaśta waśaka ota nitawa kin hena e wacinyakiya nakaeś.

14 Heon etanhan nitaoyate kin en owodntaton wan icagje kta, qa conkaśke ni tawa iyuhipa yujujupi kta, okicize anpetu kin en Salman Beth-arbel ihangye ciqon iyececa; winohinca iye cinca kin akan ihangyapi qehan.

15 He iyecen Bethel ecaniconpi kta, wicohan śica nitawapi śice hince cin hena etanhan, lianlian- na kinhan, Israel wicaśtayatapi kin ocowasin kaśpapi kta ce.

\section{WICOWOYAKE 11.}

1 Tsrael hokśiyoqopa qehan waśtewakidaka, qa micinlśsi Egupta etanhan weco.

2 Hena wicakicopi, tuka elipeya iwicayayapi : Baalirn wakiyuśnapi, qa wakagiapi bagopi kin en wizice izinkiyapi ece.

3 Nakun miye Ephraim, isto en wicamduze, maniwakiya: tuka he miye e okiziwicawakiya sdonyapi śni.

4 Wicaśta taikan kin on wicamdutitan, wowaśtedake icaśke kin on. Unkan tona cannapinpi kin tahu etanhan eyakupi kin iyececa madakapi, unkan woyute ewicawecihnaka.

5 He qe Egupta makoce kin ekta hde kte śni, tuka Aśur wicaśtayatapi kin yuhe kta; hdicupi kta wicadapi śni nakaeś.

6 Hehan iye totonwe kin hena en mazasagye kin hiyu kta, qa taakicita tancan kin ihangwicaye kta, qa temye kta, jye wahokonkiciyapi kin on etanhan.

7 Nakun mitaoyate elipemayanpi kta on nina litanipi ece: Hena Iyotan Wankan un kin elkta wicakicopi keś, tuwedan yuonihan kte śni.

8 Ephraim, token ehpeciye lita lie; Israel, token cikpagan kta he; token Adma iyecen ecilinake kta, Zeboim iyecen ecihde kta he: micante mahen ihduhomni, mitocantekiye kin okonwanjidan kaniçiya.

9 Wocanteptanye mitawa idewakiye kte śni ; Ephraim ihangwaye kta on waku kte śni ; Wakantanka he miye nakaeś, qa wicaśta hemaca śni; 'Taku Wakan Wanji nicokayapi un kin : heon 


\section{HOSEA.}

wocanteptanye yuha hibu kte sni.

10 Jehowa ihakam manipi kta: iye qe mnaja iyecen hoton kta: tohan ho hdatanin kinhan, hehan miniwanca kin etanhan wicacinca kin cancanyan upi kta.

11 Zitkadan wan iyececa Egupta etanhan cancanyan upi kita, qa tinwakiyedan wan iyecen Aśur makoce kin etanhan. Unkan miye hena tipi tawapi kin en ewicawehnake kta, Jehowa eya.

12 Lphraim woitonśni on ohomni imayaya, qa Israel tiyohnaka kin wohnaye on: Tuka Juda hinyahin Wakantanka kici itancanyan un, qa tona owotanna kin om wacinyepica un.

\section{WICOWOYAKE 12.}

1 Ephraim tate kin yun un, qa wiyohiyanpata tate kin kuwa aya: anpetu owasin woitonśni woihangye ko hduota ece: Nakun Aśur kici wicotakuye wan kagiapi kta, hecen Egupta ckta wihdi ayapi.

2 Nakun Jehowa Juda kici woakinica yuha, qa Jakob iye tacanku kin iyecen en au kta; taku econ kin he iyecen ecakicon kta.

3 He qe tamni en cinyeku siyete en yuza, qa iye towaśake on Wakantanka kici econ.

4 Han, tuwe uśipi kin he kici econ qa ohiya: ceya qa cekiya : Bethel en iyeye ciqon, unkan hen wounkiyakapi :

5 Heon Jehowa Taku Wakan ozuye yuhe cin hee; wokiksuye tawa kin he Jehowa ee ce.

6 Heon etanhan niye Taku Wakan nitawa ekta ihduhomni wo ; wowaonśida qa woyaco lipatan wo; qa nita Walkantanka ohinniyan akipe un wo.

7 Wopeton kin heca, on-aspeye474 tonpi itonśni kin nape ohna yanka: wakakiśya waśtedaka ece. 8 Tuka Ephraim heya; Awicakehan wijica imacaga; wowijice mihdamna: wicohan mitawa owasin miye en taku śica woalitani iyececa takudan iyeyapi kte śni ce, eya.

9 Tuka miye, Jehowa nita Walantanka Egupta makoce kin etanhan he miye; ake wakeya ohna ounyeciye lita, omniciye anpetu qon en iyececa.

10 Nakun wicaśta wokcan kin hena om wowahdaka: qa miye wowanyake kin mduota, qa waayate nape kin eciyatanhan wimdacin ece.

11 Iho, Gilead woahtani heca: awicakehan hena itonpiśni: Gilgal en tatanka wayuśnapi : han, owayuśna tawapi kin hena maga ocankuye ohna mahpajo kin iyececa.

12 Unkan Jakob Aram makoce kin ekta najica iyaya, qa winohinca wan on Israel wowidagiciya; han, winohinca on wawihankiya.

13 Nakun wicaśta wokcan wan on Jehowa. Israel Egupta etanhan hinanpe wicaya, qa wicaśta wokcan on iye awanyakapi ece.

14. Ephraim nina ḩin śinhdakiya: Heon etanhan Itancan tawa kin he iye we kin en ekicihnake kta, qa toiyopeye ciqon he iye en hdicuye kta ce.

\section{WICOWOYAKE 13.}

1 Ephraim kokipeyahan ie ce. han, Israel ehna wankan ihdohda; tuka Baal en walitani, hehan ta.

2 Únkan nakaha hena sanpa nina wahtanipi, qa wakagapi śdoyapi kin heca mazaska on içicagapi, wakaǵapi ige towiyukcan 
kin eciyatanhah, mazakaga he ocowasin kagia ece. Hena on heyapi ; Wicaśta wayuśnapi ece kin hena ptejicadan kin iiputakapi kta ce.

3 Heon etanhan hena hanhanna amalipiya kin iyececapi kta, qa cu kohanna tanin śni lin iyececa, ağuyapi ha owanka etanhan tate iyumni kalibog iyeye cin iyececa, qa śota oceti etanhan kin he iyececa.

4 Hececa eśta Jehowa nita Wakantanka, Egupta makoce kin etanhan, he miye, qa micunonpata taku wakan sdonyaye kte śni : micunonpa Wanikiya wanica nakaeś.

5 Ḧewoskantu miye sdonciye ciqon, makoce puze hinca ohna.

6 Wihanpi kin eciyatanhan he iyecen wipipi qon: wipipi qa cante wankan yeiçiyapi; heon etanhan amiktonjapi ece.

7 Heon mnaja wan iyececa wicawecica kta; inmuliota tanka wan iyececa canku ohna waawakite kta :

8 Wahanlssica cinca ekiciyalkupi kin iyecen itkowicawakipe kta, qa cante ogepi kin wicawakiyulidece kta; qa hen mnaja iyecen temwicawaye kta: wamanica kin wicayulidelidece kta ce.

9 Israel, niye nihdutakuni śni, tuka waoniciyapi kin he miye en un.

10 Wicaśtayatapi nitawa kin wanna tukte e he; hecen nitotonwe owasin ohna niniye kta; qa wayaco nitawa tukte epi, on, Wicaśtayatapi qa wicaśta itancan kin heca maqu wo, eha.

11 Mitocanniye en wicaśtayatapi wan ciç; mitośinhda en ewehdaku.

12 Ephraim taku śica econ kin he palitapi; woalitani tawa kin he kihnakapi.

13 Winohinca hokśiksuya wayazanhda kin hena en au lita: hokśidan ksape śni kin heca; hecece śni linhan hokśiyoqopa oyuhdecapi kin en eicihnake lkte śni tuka.

14 Hades nape etanhan ewicawehdaku kta; wiconțe etanhan opewicawakiton kta: Wiconte, woihangye nitawa kin tukte e he; Hades, woiyahipeye nitawa tukte e he: Woiyopeiciye kin miiśta e tanhan anahmanpi kta ce.'

15 Iye hunkawanjitku kin ehna waskuyeca icahya qeyaś, wiyohiyanpata tate wan uye kta, Jehowa tate tawa hewoskan tanhan u kta; q a tamniyowe kin kapuza kta; unkan minilidoka tawa kin pus aye lsta: Wakśca waśte hinca owasin ohna wakihnakapi kin hena awihnuniye kta.

16 Samaria kakiśyapi kta; Taku Wakan tawa kin kipajin nakaeś : Hena mazasagye on hinhpayapi kta, hokśiyoqopa tawapi wicakahuluggapi kta, qa winohinca ihduśakapi tawapi kin hena bawicamdazapi kta ce.

\section{WICOWOYAKE 14.}

1 Israel, Jehowa nita Wakantanka ekta ihdoku wo; wayahtani kin on nihinlipaya nakaeś. 2 Wicoie icu miye, qa Jehowa en hdi po: heciya po; Wicohan śica owasin yutokan iyeya wo, qa tanyan iyowinunkiya miye, kinhan unkihapi tawośna kin unniçupi kta ce.

3 Aśur niunkiyapi kte śni : śuktanka akan unkiyotankapi kte śni: qa detanhan icimana unnapepi taku kag่e cin, Taku wakan unkitawapi, keunkiyapi kte śni : 475 
JOEL,

niye etanhan wamdenica onśiwicadapi ecee nakaeś.

4 Hekta ihduhomnipi qon he miye okiziwicaweciciye kta, qa iyakicuya cantewicawakiye kta: mitocanniye kin he iye etanhan yuhomnipi nakaeś.

5 Miye Israel en eu kin iyemacece kta: iye mnalicalica kin iyecen namdağa $k t a$, qa hutkan icage kta, Lebanon iyececa.

6 Acincaton lin hena tankaya icage $\mathrm{kta}$, qa toiyokipi kin he wihdi can kin iyecece $\mathrm{kta}$, qa omnanpi kin Lebanon iyecece kta.

7 Tona ohanzi tawa ihukuya iyotankapi kin hena hdicupi kta, woicage kin iyecen kinipi kta, qa hastanhanka hu kin iyecen icagapi kta: hena omnanpi kin Lebanon miniśa kin iyecece kta. 8 Ephraim heye kta; Detanhan wakagapi kin hici taku micica he: Miye amdupte, qa ihawakta kta: Wazi can toto kin he iyemaceca ce: Miye etanhan waskuyeca nitawa iyeyapi ece.

9 Tuwe ksapa he, kinhan dena okahnige kta; tuwe wasdonya he, kinhan dena sdonye kta: Jehowa tacanku kin hena owotanna nakaeś, qa tona owotanpidan kin hena ohna manipi kta : tuka wawakipajinpi kin hena he ohna hicahanpi kta ce.

\section{J OE L.}

WICOWOYAKE 1.

1 Jehowa oie Joel Pethuel cinhintku en hi qon he dee.

2 Wicalincapi, de nahon po, qa makoce en ounyayapi owasin anag̉optan miye. De anpetu nitawapi kin en, qa iś niyatepi anpetu tawapi kin en hecetu he.

3 Nicincapi kin hena he owicakiyaka po, qa nicincapi kin is̉ iye cincapi kin, qa iye cincapi kin wicoicage tokeca owicakiyakapi kta.

4. Wamduśkadan taku oyapte cin he psipsicadan temya; qa psipsicadan taku oyapte cin he psipsica cinca temya; qa psipsica cinca kin taku oyapte cin he psipsica tanka kin temya ece.

5 Witkopi sa, kilkta po, qa ceya po ; qa miniśa datkanpi ecee kin iyuhpa, sicahowaya miye, miniśa teca kin on etanhan : niipi etanhan kawanicapi nakaeś.

6 Oyate wan mitamakoce kin en u nakaeś, waśake ça yawapica śni; hi kin hena mnaja hi kin heca, qa mnaja wiye hinske kin yuha.

7 Hastanhanka iyuwi kin ihangmakiya, qa witanśna hu mitawa kin micaksa; ocowasin ha kahu qa elipeya: adetka tawa kin hena kasansanpi.

8 Witanśna Wan wikośka ehan hihnaton kin on wakihdaka ipiyagkiton iyecen ceya ye.

9 Woyute wośnapi qa woyatkan wośnapi kin hena Jehowa ti kin etanhan kawanicapi ; Jehowa taokiye wawayuśna kin hena waśihdapi.

10 Mağa kin ihangyapi, makoce kin wašihda; wojupi kin ihangyapi nakaeś; miniśa teca kin pus aya, wihdi kin wanica aya ece. 


\section{WICOWOYAKE 2.}

11 Mahyumdu yaunpi, iśteca po ; hastanhanka iyuwi kicanyan yaunpi, śicahowaya po, ag̉uyapi qa barle icağe cin on: mağa oicag̉e kin ihangyapi nakaeś.

12 Hastanhanka iyuwi kin pus aya; witanśna can kin śen aya; taspantanka su ota, can bosdan he cin nakun, qa taspantanka can, mag̉a can iyulipa śeca aya: wicaśta cinca kin en wowiyuśkin śen aya nakaeś.

13 Wawayuśna yaunpi, ipiyagkitonpi qa ceya po; owayuśna en wowidake yaunpi, śicahowaya miye; u po, Wakantanka mitawa taokiye kin, hanyetu osan wakihdaka in iwanka po: woyute wośnapi qa woyatke wośnapi kin 'Taku Wakan nitawapi ti kin ipidapi nakaeś.

14 Woteśni unpi wan yawakan po, omniciye wakan wan kico po: hunkayapi, makoce en ounyanpi kin owasin Jehowa Wakantanka nitawapi ti kin en wicayuwitaya po, qa Jehowa hoyekiya miye:

15 Hehehe anpetu kin: Jehowa taanpetu kin kiyedan ihan, qa woihangye wan iyececa lyotan Waśake cin etanhan u kta.

16 Unkiśtapi itokam woyute kin kawanicapi śni he ; wowiyuśkin qa wopida Taku Wakan unkitawapi ti kin etanhan.

I7 Maka yuśpuśpupi kin ihukuya su ojupi kin ta: dotopiye kin ihangyapi, ağuyapi su opiye kin yujujupi ; wojupi kin śnija nakaeś.

18 Woteca kin comnihdazipi; wanunyanpi optaye kin hotontonpi, wilianpi takudan yuhapi śni heon: han, tahinca wanunyanpi optaye kin sotapi.

19. Jehowa, niye houciciye kta: tinta en wihanpi kin peta temya, qa maga can kin iyuhpa ide kin huhnahya nakaeś.
20 Nakun magga wanunyanpi kin hoyeniciyapi : wakpa mini kin oyahe, qa tinta ekta wihanpi kin peta hulinaga, heon etanhan.

\section{WICOWOYAKE 2.}

1 Zion en mazayahotonpi kin yajo po, qa paha wakan mitawa akan eyanpaha po: makoce en ounyanpi kin owasin cancanpi kte: Jehowa taanpetu kin u ce, wanna kiyedan ihan.

2 Otpaza anpetu qa woiyokiśica, anpetu amahpiya qa mahpiya śoka; anpao he kin akamdayapi iyececa; oyate wan tanka qa waśaka: tohinni taku iyececa yuke śni, qa nakun ohakam wanice kta, wicoicagge qa wicoicagge waniyetu kin hehanyan.

3 Wicitokam peta wan watemya iyaya; qa wicihakam ide wan itkonyan un: wicitokam makoce kin Eden wojupi qon iyececa, qa wicihakam hewoskan ehpeyapi ; han, okaptapi wanice kta.

4. Wanwicayakapi kin he śuktanka wanyakapi kin iyececa; qa śuktanka akan yotankapi kin iyecen kiinyankapi kta.

5 Canpahmihma he pajodan akan hmunhmunyan tanin kin he iyecen ipsicapi kta, peta ide peji huhnağe cin ho kin iyececa, oyate waśaka wall kiciza wiyeya ehdepi kin iyececa.

6 Hena wicitokam oyate kin nina cante śicapi kta: wicaite iyulipa naśa aye kta.

7 Wicaśta waśakapi kin iyecen inyankapi kta; ozuyc wicaśta kin iyececa conkaśke adipi kta; ya otoiy ohi iye tacanku kin ohnahna manipi kta, qa canku tawapi kin hdutokecapi kte śni.

8 Nakun wanji takodaku kici paanawam iyekiciyapi kte śni; otoiyohi iye tacanku kin ohna 477 


\section{JOEL,}

yapi kta: qa mazasagye ahinhpayapi kinhan kicaksapi kte śni.

9 Otonwe kin ohna icicawin kiinyankapi kta; conkaśke kin akan inyang yapi kta; tipi kin iyadipi kta; owanyeye kin ohna mahen yapi kta, wamanon sa wan iyececa.

10 Hena itokam maka kin cancan kta; mahpiya kin śkanśkan kta : anpetu wi qa hanyetu wi kin otpaza icu kta, qa wicanhpi kin hena oiyegge kin anaiciptapi kta.

11 Hehan Jehowa iye ozuye tawa kin wicitokam ho hdatanin kta; owanka tawa kin tanka hinca nakaeś : iye oie yuecetupi kin wicota hinca: Jehowa taanpetu kin tanka qa nina wowinihan nakaeś; qa tuwe en najin okihi kta he.

12 Nakun heon etanhan, nakaha Jehowa hecen eya; Nicantepi ocowasin on en mahdiyaku po ; qa woteśni unpi on, qa ceyapi on, qa waśihdapi on :

13 Qa nicantepi hduhdehdeca po, qa nitaśinapi ee śni ; qa Jehowa Taku Wakan nitawapi kin ekta ihdohda po: Iye qe wacantkiya, qa waonśida, qa tehan canteptanye śni, qa waśte hinca, qa taku śice cin on iyokiśiniçiya nakaeś.

14 Tuwe sdonya he, okinni hdicu kta, qa iyokiśiniçiye kta, qa ihektarn woyawaśte wan ahiehpeye kta; Jehowa Wakantanka nitawapi woyute wakiyuśnapi wan, qa woyatkan wośnapi nakun.

15 Zion en mazayahotonpi tanka kin yajo po; woteśni unpi wan yawakan po; omniciye wakan wan wicakico po:

16 Oyate kin wicayuwitaya po ; omniciye kin yuecepidan miye; hunkayapi kin u wicaśi po; ho- kśiyopa qa tona aze azinpi kin hena mnawicaya po: wakan tawicu ton kte cin he timahen tanhan hinanpe kta, qa winyan yuzapi kin he iye ohehdepi tawa kin etanhan:

17 Jehowa taokiye, wawayuśnapi kin hena, ohanzihdepi qa owayuśna kin otahedan ceyapi nunwe, qa heyapi kte; Jehowa, nitaoyate onślkida wo, qa tona nitawa kin wowiśtenyapi kin en wicaqu śni wo, Ikcewicaśta wowidagwicayapi kta e heon: tokeca oyate kin ehna, Taku Wakan tawapi kin tukten un he, eyapi kta he.

18 Hehan Jehowa iye tamakoce kin on winawizi kta, qa taoyate kin onśikida kta.

19 Han, Jehowa waayupte qa taoyate hewicakiye kta; Iho, wojupi, qa miniśa, qa wihdi hiyuciciyapi kta, unkan hena on inimnanpi kta: qa ake icimana Ikcewicaśta ehna wowiśtenyapi cicag̀api kte śni:

20 Tuka waziyata un kin he nitehanyan ehpewaye kta, qa makoce wan hewoskan qa hopuza ekta iyewaye kta ; ite kin wiyohiyanpata mini tanka kin ektakiya, qa unma ihanke kin wiyohpeyata mini tanka ektakiya wanke kta, qa iye śicamna kin hiyu kta, qa omnapi śica etanhan hiyu kta, taku tanka econ kin heon etanhan.

21 Makoce, kopehda śni wo; pida qa wiyuśkin wo: Jehowa taku tanka econ kta heon etanhan.

22 Tinta woteca, wikopapi śni po; hewotahedar makoce kin owih̉anpi icaġa nakaeś, can kin waskuyeca aicagga nakaeś, witanśna can qa hastanhanka iyuwi towijice kin hiyuya ece.

23 Hecen Zion cinca, cante 


\section{WICOWOYAKE 3.}

waśte po, qa Jehowa Taku Wakan nitawapi kin on wiyuśkin po; magiaju tokaheya kin he iwaśtedan niçupi nakaeś ; qa nakun mag̉aju kin hiy.uniciyapi kta, magiaju tokaheya qa mağaju ehake, wi tokaheya kin en.

24 Unkan onapanpi kin ag̉uyapi su ojudan kta, qa oyuśkicapi kin miniśa qa wihdi apaśboke kta.

25 Qa psipsicadan, wamduśkadan, qa psipsica cinca, qa psipsica tanka, ozuye tanka mitawa niyepi en hiyuwicawaye cin, waniyetu temyapi qon hena iyakihdeciciyapi kta.

26 Unkan wotapi en wayatapi kta, qa inimnanpi kta, qa Jehowa Taku Wakan nitawapi wowinihanyan onicilianyanpi kin he caje datanpi kta: unkan mitaoyate kin ohinniyan wiśtecapi kte śni.

$27 \mathrm{Qa}$ Israel wicacokaya waun sdonyayapi kta; qa miye e Jehowa Wakantanka nitawapi, qa tuwedan tokeca śni: unkan mitaoyate kin ohinniyan wiśtecapi kte śni ce.

28 Unkan he iyohakam kaketu kta, Mitaniya kin wicacehpi owasin awakaśtan kta; qa nieinkśipi qa nicunkśipi kin hena waayatapi kta, wicahinca nitawapi kin wowihanmna ilanmnapi kta, kośka nitawapi kin hena wowanyake wanyakapi kta :

29 Qa nakun anpetu kin hena en, wicaśta taokiye qa winyan taokiye kin hena Mitaniya awicawakaśtan kta :

$30 \mathrm{Qa}$ mahipiya en qa maka kir. akan wowapetokeca mdutanin kta, we, qa peta, qa śota bosdata. 31 Anpetu wi kin he otpaza icağe kta, qa hanyetu wi kin iś we icage kta, Jehowa taanpetu tanka qa wowiniban kin hi śni itokam.
32 Hehan kaketu kta, tuwe kaśta Jehowa caje kin hoyekiye cinhan ehdakupi kta:.Zion Paha kin akan, qa Jerusalem en woehdaku yuke kta nakaeś, Jehowa eye ciqon iyececa, qa wookapte Jehowa wicakico kte cin hena en.

\section{WICOWOYAKE 3.}

1 Iho, anpetu kin hena en, qa he iyehantu kinhan, Juda qa Jerusalem wayaka unpi kin wahdoku kta ;

2 Nakun oyate owasin wicamduwitaya kta, qa Jehośaphat taomdaye kin ekta kun awicawau kta, qa hen wicamdaco kta, mitaoyate on, qa Israel tawawakiye cin on, hena oyate kin wicehnalına enanakiya iyewicayapi, qa mitamakoce kin kicipamnipi.

3 Nakun mitaoyate on oeconna econpi ; qa hokśidan wan witkowinna on wicaqupi, qa wicinyanna wan miniśa tokiyopekiyapi, yatkanpi kta heon.

4 Qa nakun Turos, qa Zidon, qa Palestina makoce opapun ocowasin, niye miye kici taku unkicicapi he: niye miyecicajujupi kta he: qa miyecicajujupi kinhan, kohanna ohankoya wokajaju nitawapi nipapi kin en ihdoyeciciyapi kta :

5 Mazaska mitawa, qa mazaskazi mitawa iyacupi, qa taku oiyokipi waśte mitawa kin hena tipi wakan nitawapi kin en adapi nakaeś :

6 Nakun Juda cinca, qa Jerusalem cinca kin hena Javan cinca kin ekta wiyopewicayayapi, iye tamakoce kin itehan iyewicayayapi kta e heon.

\%. Heon etanhan iho, tukten wiyopewicayayapi kin hetanhan 479 


\section{JOEL.}

hiyuwicawaye kta, qa wolajuju nitawapi niye nipapi kin en ihdoyeciciyapi kta.

8 Nakun nicinkśipi qa nicunkśipi kin Juda cinca napepi kin en wiyopewicawaye kta; qa iś ito Seba wicaśta, oyate wan tehan unpi kin ekta wiyopewicayapi kta: Jehowa hecen eya nakaeś.

9 Ikcewicaśta kin ehnahna decen eyanpaha po; Wipe hduwakan po; wicaśta waśakapi wicayuhica po; okicize wicaśta owasin kiyedan hiyupi kta; upi kta.

10 Mahiyumdu nitawapi on mazasagye kag̉a po, qa isan śkopa nitawapi on wahukeza kağa po : tuwe waśake śni kin. Wamaśaka ce, eye kta.

11 Mniciya po, qa u po, Ikcewicaśta iyuhpa yaunpi, qa ihdukśan tanhan ihduwitaya miye: Jehowa, tona waśakśaka nitawa kin hena hen hiyuwicaya wo.

12 Ikcewicaśta kin ihduhicapi kta, qa Jehośaphat taomdaye kin en upi kte : heciya Ikcewicaśta ihdukśan yakonpi kin owasin wicayaco imdotanke kta nakaeś.

13 Isan śkopa kin en iyekiya po, wojupi kin suton nakaeś: u po, ekta dapi kte ; iyuśkice kin ojudan, iyohnakapi kin apaśboka ce: wicohan śica econpi kin tanka nakaeś.

14 Wicota, wicota, woyaco omdaye kin ohna: woyace omda- ye kin en Jehowa taanpetu kin kiyedan nakaeś.

15 Anpetu wi qa hanyetu wi kin otpaza icu kta, qa wicanlipi kin iś wowiyatpa eihdakupi kta. 16 Nakun Jehowa Zion etanhan ho uye kta, qa Jerusalem etanhan ho hdatanin kta: qa mahpiya qa maka kin cancan kta: 'Tuka taoyate kin Jehowa wowacinye yapi kta, qa Israel cinca he wowaśake yapi kta.

17 Hecen Jehowa Taku Wakan nitawapi, Zion Paha wakan mitawa en ounyan kin he miye e sdonyayapi kta. Hehan Jerusalem wakan kta, qa hetanhan icimana oyate tokeca tuwedan.opta ye kte śni.

18 Unkan anpetu kin he en kaketu $\mathrm{kta}$, lie kin hena miniśa teca śbuye kta, qa paha kin asanpi on kaduze kta, qa Juda kaksiza kin owasin mini ohna iyaye kta, qa Jehowa ti kin etanhan minifidoka wan uye kta, qa Śsttim omdaye kin spayeye kta.

19 Egupta otiwota elipeyapi kta, qa Edom hopuza makoce kin heca kta, Juda cinca owicakihianśunkecapi kin heon, iye tamakoce kin ohna wicawe wiyaonpepica śni kin papsonpi nakaeś.

20 Tuka Juda owihanke wanin ounye kta, qa Jerusalem wicoicagge qa wicoicage hehanyan.

21 Qa wicawe wapakinte śni qon lie wicawecipakinte kta ce : Jehowa Zion en ounyan nakaeś. 


\section{WICOWOYAKE 1.}

1 Amos oie kin, Tekoa en wanunyanpi yuhapi kin hetanhan, Uzziah Juda wicaśtayatapi taanpetu en, qa Jeroboam Joash cinhintku Israel wicaśtayatapi taanpetu kin en, maka śkanśkan itokamtu waniyetu nonpa he ehan, taku Israel on wanyake cin dena ee.

2 Unkan heya; Jehowa Zion etanhan ho hdatanin kta, qa Jerusalem etanhan ho uye lita; hecen wanunyanpi wicayuhapi en owilianwicakiyapi kin hena ceyapi kta, qa Karmel ipa kin śnije lita ce.

3 Jehowa kaken eya; Dainasek wokipajin tawa yamni qa topa on weciyuhomni kte śni ; mazasapa icapan on Gilead wicakapan, heon etallhan.

4 Tuka Hazael ti kin en peta wan yewaye kta; unkan he Benhadad tipi waśteśte tawa kin liuhnage kta.

5 Nakun Damasek inatake kin mduwege kta, qa en ounyanpi kin Aven omdaye kin etanhan ihangwicawaye $\mathrm{kta}$, qa tuwe mazasagye yuhe cin Eden tipi kin etanhan: unkan Aram oyate kin Kir ekta wayaka aye kta ce, Jehowa eya.

6 Jehowa hecen eya; Gaza wokipajin tawa yamni qa topa on weciyuhomni kte śni: wayaka unpi kin Edom en wicaqupi kta ocowasin wayaka ayapi, heon etanhan.

7 Tuka Gaza conkaśke kin en peta wan yewaye kta, qa tipi was̉tešte tawa kin huhnagie Irta:

8 Nakun en ounyanpi kin Aśdod etanhan ihangwicawaye kta, qa tuwe mazasagye yuhe cin Aśkelon etanhan; qa Ekron ekta minape wahduhomni kta; qa Philistine okaptapi kin atakuni kte śni ce, Jehowa Itancan kin eya. 9 Jehowa hecen eya; Turos wokipajin tawa yamni qa topa on weciyuhomni kte śni; wayaka ayapi kin ocowasin Edom wicaqupi, qa hunkawanjinkiciyapi wicotakuye kin he kiksuyapi śni, heon etanhan:

10 Tuka Turos conkaśke kin en peta wan yewaye kta, qa tipi waśteśte tawa kin hena liuhnage kta ce.

11 Jehowa hecen eya; Edom wokipajin tawa yamni qa topa on weciyuhomni kte śni: iye sunkaku kin mazasagye on kuwa aya, qa woçantekiye ocowasin ehpekiya, qa tocanniye kin ohinniyan wayuhdehdeca, qa tocanteptanye kin owihanke wanin hduha un kin heon etanhan:

12 Tuka Teman en peta wan yewaye kta, qa Bozrah tipi waśteśte tawa kin gi kta ce.

13 Jehowa hecen eya; Ammon cinca wokipajin tawa yamni qa topa on wicaweciyuhomni kte śni : makoce hdutankapi kta on Gilead en winohinca ihduśakapi kin hena bawicamdazapi, heon etanhan:

14 'Tulka Rabbah conkaśke kin en peta wan wakagge kta, qa tipi waštešte tawa kin gu kta; okicize anpetu kin en iyaśapi on, 


\section{AMOS,}

tateiyumni anpetu kin en icamna hinca on :

$15 \mathrm{Qa}$ wicaśtayatapi tawapi kin he wayaka ayapi kta, iye qa wicaśta iłıdawa wicayuhe cin hena koya, Jehowa eya.

\section{WICOWOYARE 2.}

1 Jehowa hecen eya; Moab wokipajin tawa yamni qa topa on weciyuhomni kte śni: Edom wicaśtayatapi huhu kin inyan acetipi iyecen guya, heon etanhan :

2 Tuka Moab en peta wan yewaye kta, qa he Qirioth tipi waśteśte kin liuhnag̉e kta: qa owodutaton kağapi, iyaśapi, mazayahotonpi tanka yajopi ko en Moab te kta.

$3 \mathrm{Qa}$ cokayatanhan wicaśta wayaco kin ihangwaye kta, qa kici wicaśta ihdawapi kin iyulipa wicawakte kta ce, Jehowa eya.

4 Jehowa hecen eya; Juda wokipajin tawa yamni qa topa on weciyuhomni kte śni: Jehowa toope kin aktapi śni, qa tawoahope kin ahopapi śni ; qa woiçihnaye tawapi, iye atewicayapi iyalina manipi qon hena nuniwicakiya nakaeś:

5 Tuka Juda en peta wan yewaye lita, qa he Jerusalem tipi waśteśte kin hulinagge kta ce.

6 Jehowa hecen eya; Israel wokipajin tawa yamni qa topa on weciyuhomni kte śni: wicaśta owotanna mazaska on wiyopeyapi, qa walipanica kin hanpa tawanji tokiyopekiyapi nakaeś.

7 Hena walipanica pa akan maka watuśekśeca kin on temniiçiyapi; qa onśiiçidapi tacanku kin icunom iyeyapi ece. Nakun wicaśta wan iye atkuku kici wikośka wanjidan en yapi, micaje wakan kin yuśapapi kta e heon:
8 Qa owayuśna otoiyohi en wokoyake ikoyagyapi kin akan iwankapi, qa wicayacopi miniśa tawapi kin he taku wakan tawapi ti kin ohna yatkanpi ece.

9 Heca eśta miye qe hena wicitokam Amori wicaśta kin ihangwaya, he qe hanske cin hanteśa can hanska iyececa, qa uskuyeca can kin iyecen waśaka; tuka wankantanhan tawaskuyeca, qa kuyatanhan hutkan tawa kin ihangweciya.

10 Nakun miye hinca Egupta makoce kin etanhan hirranpeciyapi, qa waniyetu wikcemna topa hehanyan hopuza kin en maniciyapi, Amori tamakoce kin tawayayapi kta e heon.

11 Qa nicinkśsipi etanhan wicaśta wokcan icahwicawaya, qa kośka nitawapi etanhan Nazari wicaśta heca kta. Israel cinca, he hecetu śni he, Jehowa eya.

12 Tuka Nazari wicaśta kin miniśa yatkewicayakiyapi, qa wicaśta wokcan kin, Woyakapi śni po, ewicayalkiyapi ece.

13 Wanyaka po, miye nihukuya mapaskicapi, canpahmihma wan wopalite ojudan paskicapi iyececa.

14 Heon etanhan tuwe duzahan kin he najica anaptapi kta, qa tuwe waśake cin he towaśake kin hduwaśake kte śni, qa tuwe waditake cin he iye nagi niiçiye kte śni:

15 Qa tuwe itazipa hduze cin he najin kte śni; qa tuwe siha on duzahan eśta eihdaku kte śni; qa tuwe suktanka akan iyotanke cin he nakun naggi niiçiye kte śni.

16 Tuka tuwe waśakapi kin ehna waditake cin he anpetu kin he en tancodan nape kta ce, Jebowa eya. 


\section{WICOWOYAKE 3.}

1 Israel cinca, wicowazi Egupta etanhan awau qon ocowasin, wicoie on Jehowa owaniciyepi kin de nalion po, he hecen eya:

2 Maka akan wicòwazi owasin etanhan niye niśnana sdonciyapi; heon etanhan wayahtanipi owasin on en aciyapi kta ce.

3 Tuwe nom wicakicidapi śni ehantanhan sakim mani okihipi kta he.

4. Mnaja wan takudan iyahpaye śni kinhan contanka ehna tanhan hoton kta he: mnaja kośka wan takudan icu śni kinhan śun kin etanhan ho uye kta he.

5 Tukten takudan ekionpapi śni kinhan zitkadan maka akan on-hmunkapi en ohinhipaye kta he: mazahtakiyapi ecaca takudan yuze śni kinhan, tuwe maka kin etanhan eyaku kta he.

6 Otonwe kin ohna mazayahotonpi tanka yajopi kinhan oyate kin kokipapi kte śni he : wośice kin otonwe wan en un kinhan, qa Jehowa he kag̉e śni he.

7 A wicakehan Jehowa Itancan kin takudan econ kte śni, toinalibe iye taokiye wicaśta wokcan kin wicakiyaotanin śni kinhan.

8 Mnaja kin wanna hoton, tuwe kokipe kte śni he: Jehowa Itancan kin wanna ia, tuwe he oyake kte śni he.

9 Aśdod tipi waśteśte ohna, qa Egupta makoce en tipi waśteśte ohna eyanpaha po, qa heya po ; Samaria he kin akan mniciya po, qa ohna wonihinciye tanka kin wanyaka po, qa ohna wokakiśye kin hena.

10 Tona wokamna owotanna śni qa taku.wicakipi kin tipi waśteśte ohna ekikjupi kin hena owotanna econpi kta sdonyapi śni nakaeś, Jehowa eya.
11 Heon etanhan Jehowá Itancan kin hecen eya; Toka wan, han, makoce kin ihdukśan un kta: qa iye nitowaśake kin kun elipeniciye kta, qa tipi waśteśte nitawa kin hena yucokakapi kta ce.

12 Jehowa hecen eya; Waawanyake wan mnaja $i$ kin etanhan isto nonpa qa iś nog̉e onśpa ikicicu kin he iyecen Israel cinca Samaria en ounyanpi kin owinja okise ohna ewicayakupi kta, qa Damasek etanhan ohehdepi wan ohna.

13 Niye nation po, qa Jakob ti kin ohna eyanpaha po, Jehowa Itancan, Taku Wakan ozuye yuhe cin he hecen eya :

14 Anpetu wan Israel wokipajin tawa kin en awicawai kinhan, heharl nakun Bethel owayuśna tawa kin en amde kta: unkan owayuśna he kin hena kaksapi kta, qa makata hinlipaye kta ce.

15 Hehan waniyetu tipi qa mdoketu tipi kin kici awape kta: qa huhu tipi waśteśte kin hena atakuni kte śni, qa tipi tankinyanyan kin owihanke kta ce, Jehowa eya.

\section{WICOWOYAKE 4.}

1 Baśan ptewanunyanpi, Samaria paha akan yaunpi, walipanjcapi kin kakiświcayayapi, onśikapi kin śicaya wicayakuwapi, tona itancan tawapi kin hewicayakiyapi, Au po, kinhan waunyatkanpi kta ce, ehapi ecee kin, wicoie kin de nahon po:

2. Tehowa Itancan kin iye towakan kin on iciconza, iho, anpetu kin en niupi kta, hehan iye mazaśkopa on eniyakupi kta, qa tona nihakam upi kin hinśkijupi kin on.

3 Qa yujujupi kin hena ohna 483 


\section{AMOS,}

tankan dapi kta, otoiyohi ite itoheya, qa conkaśke kin ohna iyohpeniyanpi kta ce, Jehowa eya.

4 Bethel en u po, qa wawakipajin po; Gilgal ekta wokipajin hduota po: qa hanhanna eca wośna nitawapi aku po, iwikcemnamna kin hena ornaka yamni iyohakam.

5 Nakun taku on napohyapi kin on wopida wayuśna po, qa cante waśteya paganpi kin hena yaotanin po, eyanpaha po: Israel cinca, hecen iyonicipipi nakaeś, Jehowa Itancan kin eya.

6 Unkan miśs nakun otonwe nitawapi owasin ohna hi takudan ostake śni kin ciçupi, qa ounyayapi kin iyuhpa en aguyapi wanica: tuka hececa eśta miye en nihdoupi śni, Jehowa eya.

7 Qa nakun miye magaju kin anaciciptapi, hinyahin ehake wi yamni hehan wayuksapi kta tuka: qa otonwe wanji amagajuwaya, qa otonwe tokeca wan amagajuwaye śni: hanke amagaju, qa onśpa amaġaju śni kin he śnija.

8 Hecen otonwe nonpa qa yamni otonwe warijidan ekta kacegya manipi, mini yatkanpi kta, tuka-imnanpi śni : hececa eśta miye en nihdokupi śni ce, Jehowa eya.

9 Wośnije qa aa kin on acipapi: maǵa nitawapi, qa hastanhanka iyuwi ojupi nitawapi, qa witanśna hu nitawapi, qa wihdi can nitawapi kin hena icaga hehan psipsica cinca kin temyapi: hececa eśta miye en nihdokupi śni, Jehowa eya.

10 Niyepi ehna makośica kin yewaśi, Egupta canku kin en iyececa : kośka nitawapi kin hena mazasagye on , wicawakte, nakun śuktanka nitawapi eciciyakupi ; qa wicoti nitawapi śca- mna kin he nipogepi ohna hiyuwaya: tuka hececa eśta miye en nihdokupi śni ce, Jehowa eya. 11 Niyepi etanhan ihangwicawaya, Wakantanka Sodom qa Gomorrah ihangye ciqon iyececa, unkan ide kin etanhan petuspe wan icupi kin iyenicecapi : tuka hececa eśta miye en nihdokupi śni ce, Jehowa eya.

12 Heon etanhan, Israel, hecen ecacicon kta: qa hecen ecacicon kta heon etanhan, Israel, Taku Wakan nitawa itkokipa ihduwiyeya wo.

13 Tho, tuwe he kin icaliya, qa tate kin kaga, qa wicaśta toawacin kin okiciyaka, tuwe hanhanna kin otpaza kagga, qa maka ipa kin akan mani ecee kin, Jehowa, ozuye Wakantanka, he caje kin ee.

\section{WICOWOYAKE 5.}

1 Israel tiyohnaka, wicoie kin de, niyepi on woceye iwacu kin he nahon po:

2 Hinhpaya; Israel wikośka kin ake najin kte śni: makoce tawa kin ohna ehpeyapi.; tuwedan najinkiye kte śni.

3 Jehowa Itancan kin kaken eya; Otonwe wan kektopawinge iyaye ciqon he opawinge okicaptapi kta, qa wanji opawinge iyaye cin he wikcemna okicaptapi kta, Israel tipi kin en.

4 Jehowa Israel tipi kin hecen ewicakiya; Miye omakide po, kinhan yanipi kta ce.

5 Tuka Bethel odepi śni po, qa Gilgal en yapi śni po, qa Beerśeba ekta iyoptapi 'śni miye: awicakehan Gilgal wayaka ayapi kta nakaeś, qa Bethel atakuni kte śni.

6 Jehowa ode po, kinhan yanipi kta : okinni Joseph ti kin en iyo- 


\section{WICOWOYAKE 5 .}

pta iyaye kta, ide wan iyececa, qa huhnage kta, qa Bethel ekta tuwedan kasni kte śni.

7 Tona woyaco pa hinca yakagapi, qa maka akan woowotanna aduśtanpi ece;

8 Tuwe Pleiades (Tawamnipa) qa Orion kaga, qa wiconte ohanzi kin anpao icahya, qa anpetu kin hanyetu on alianzikiya; tuwe miniw anca mini kin kipan, qa hena maka ite kin akrśtan kin hee ode po: Caje kin he Jehowa ee.

9 Tuwe waśakapi kin en wicotakuniśni wicakiyutanin ece, hecen wicotakuniśni conkaśke kin en u kta.

10 Tiyopa kin ohna tuwe wawiyopeye cin he śicedakapi, qa tuwe owotanna ie cin he wahtedapi śni ece.

11 Hecen wicaśta waśake śni kin he ayahanpi, qa aguyapi ojutonpi kin eyeciyakupi ecee, heon etanhan inyan kakanpi kin on tipi yakagiapi qeyaś ohna yatipi kte śni ; hastanhanka iyuwi ojupi oiyokipi kin heca oyajupi, tuka etanhan miniśa datkanpi kte śni.

12 Wokipajin nitawapi ota, qa. wayahtanipi tankinyanyan kin hena sdonwaya ce. Wicaśta owotanna kin śicaya kuwapi, wiyopeyapi icupi, qa otonwe tiyopa ohna wahpanica kin icunonpa iyeyapi ece.

13 Heon etanhan tuwe wasdonya kin he anpetu kin he en inina un kta; he anpetu kin sica nakaeś.

14 Taku waśte akita po, qa taku śica ee śni, hecen yanipi kta; qa heon Jehowa, ozuye en Wakantanka kin he nicipi un kta, kehapi kin iyececa.

15 Taku śice cin ścedaka po, qa taku waśte kin waśtedaka po, qa otonwe tiyopa kin ohna wo- yaco ekihde po: okinni Jehowa, ozuye en Wakantanka kin he Joseph okaptapi kin onśikida kta.

16 Heon etanhan Jehowa, ozuye en Wakantanka, Itancan kin hee hecen eya ce; Tihocoka owasin ohna, Hehehe, hehehe, eyapi kta; qa mahyumdu kin waśihdapi ikicopi kta, qa tona ceya wayupikapi kin śicahowapi kin ekta.

17. Qa hastanhanka iyuwi ojupi kin owasin ohna wicaceya yuke kta: niyepi ehna.mde kta nakaeś, Jehowa eya.

18 Tona Jehowa taanpetu cantoyakpanipi kin wotelii niciyankapi kta: he etanhan initokecapi he: Jehowa tampetu kin lie otpaza ee, qa iyoyanpa śni.

19 Wicaśta wan mnaja ite etanhan nakipa, unkan wahanksica itkokipa kin he iyececa; qa iś tipi timahen kihde ca tiunnaptanyan nape apatan, unkan wamduśka wan yahtaka kin he iyececa.

20 Jehowa taanpetu kin he otpaza kta, qa iyoyanpa kte śni he; han, otpaza hinca qa iyoyanpa takudan en un kte śni he. 21 Śicewadaka, wohanpi nitawapi kin wahtewada śni, qa omniciye nitawapi kin en womna waun kte śni.

22 Wośna hulinahyapi qa woyute wośnapi nitawapi wamayakiduśnapi eśta iyomakipi kte sni: ga woteca cepa wookiye waduśnapi kin hena nakun ekta ewatonwe kte śni.

23 Odowan nitawa ho kin tokan iyemiciciya wo : candowankiyapi nitawa ho kin nawahon kte śni nakaeś.

24 Tuka woyaco mini kin iyecen iyaye kta, qa woowotanna wakpa ohinniyan kaduze cin iyececa nuriwe. 


\section{AMOS,}

25 Israel tiyohnaka, woteca wośnapi qa woyute wośnapi kin heca waniyetu wikcemna topa hopuza en miye mayakahipi he.

26 Tuka Molek nitawapi tawakeya kin yaqinpi, qa Kiun wakagapi nitawapi, taku wakan nitawapi wicanhpi tawa kin hee, hena niye niçicağapi qon.

27 Heon etanhan Damasek akotanhan wayaka ayeciciyapi kta ce, Jehowa, ozuye Wakantanka eciyapi kin he hecen eya.

\section{WICOWOYAKE 6.}

1 Hehehe, tona Zion en owanji yankapi, qa tona Samaria paha akan wikopeśni unpi kin, oyate wicehna tokaheya ewicakiyapi, qa Israel tiyohnaka en wicahipi qon.

2 Kalne ekta unhdaka ya po, qa wanyaka po; qa hetanhan Hamath tanka kin ekta ya po; qa Gath Philistine tawa ekta kun ya miye: hena wokiconze kin dena isanpa waśte he; qa iś makoce icağopi kin niye inicağopi kin isanpa tanka he.

3 Tona anpetu sica yutehanpi, qa wokakiśye oiyotanke kin kiyedan u kiyapi :

4 Tona huhu ohehdepi kin en iwankapi, qa towinjapi akan nasonsonpi ece; tona optaye kin etanhan tahinca cinca, qa tatanka tipi etanhan ptejicadan hdutapi ecee:

5 Tona candowankiyapi ho kin on iwohdahdakapi ; Dawid iyecen on dowanpi kte cin icicagapi ece :

6 Tona miniśa iyatke kin etanhan yatkanpi, qa wipakinte iyotan on sdaiciyapi ecee; tuka Joseph ihduhdecapi kin on cante śicapi śni.
7 Heon etanhan wanna wayaka ayapi kin wicitokam hena wayaka yapi kta; qa tona nasonsonpi śicahowayapi kin tanin kte śni.

8 Jehowa Itancan kin iye hinca on iciconza, Jehowa ozuye en Wakantanka he hecen eya; Miye hinca Jakob towalianicida kin he wahtewada śni, qa tipi waśteśte tawa kin śicewadaka; heon etanhan otonwe qa taku ohna un kin icuwicawakiye kta.

9 Unkan kaketu kta, tipi wanji ohna wicaśta wikcemna okaptapi kinhan hena nakun tapi kta.

10 Qa tuwe takuye wan he icu kta, han, tuwe hulinaliye cin he, huhu kin tipi kin etanhan eyaku kta e heon; qa tuwe catkutanhan yanke cin he heciye kta; Nakun tuwe nici wanka he. Unkan iye, Wanica ce, eye kta. Hehan heye kta; Inina yanka wo; Jehowa caje kin en kilisuye unkiçiciye kte śni nakaeś.

11 İho, Jehowa wakiconza; qa tipi tanka kin he wokamdece on ape kta, qa tipi cistinna kin he wokaptuje on.

12 Sunka wakan kin imnija wan ainyankapi kta he: tuwe tatanka on he ayumdu kta he: 'Tuka niyepi woyuecetu kin he pejihuta śica yakagapi, qa woowotanna waskuyeca kin he peji pa hinca yakagapi nakaeś :

13 Tona takuśni on widuśkinpi : Wowaśake unkitawapi on he kin heca unkicupi śni he, ehapi ece.

14. Tuka Jehowa ozuye en Wakantanka kin he hecen eya; Iho, Israel tiyohnaka, oyate wan itlonicipe wicawakiye kta: qa hena kakiśniyanpi kta, Hamath en yapi kin hetanhan hopuza wakpa kin hehanyan. 


\section{WICOWOYAKE $\%$}

WICOWOYAKE $\%$

1 Jehowa Itancan kin hecen wanyagmakiya; unkan iho, peji ehake uye cin he ehan psipsicadan kaga: unkan iho, wicaśtayatapi kaśda iyohakam peji icağe cin iyehantu.

2 Unkan kaketu, makoce peji kin wanna ocowasin temyapi hehan hepa; Jehowa Itancan, ceciciya ce, kajuju ye, Jakob token najin kta he; he eistinna nakaeś.

3 De on Jehowa iyokiśiniçiya: Ecetu kte śni ce, Jehowa eya.

4 Jeliowa Itancan kin decen wanyagmakiya; unkan iho, Jehowa Itancan kin peta on wicakize kta kico: unkan he miniwanca tanka kin temya, qa maka kin liulinag̀a.

5 Hehan hepa; Jehowa Itancan ceciciya ce, ayuśtan ye : taku on Jakob najin kta he; he cistinna nakaeś.

$6 \mathrm{He}$ on Jehowa iyokiśiniciya: De nakun ecetu kte śni ce, jehowa Itancan kin eya.

7 Decen wanyagmakiya; unkan iho, Itancan kin nape ohna mazasu on iyutapi wan yuha inyan conkaślie bosdan kagapi he akan najin.

8 Hehan Jehowa hemakiya; Amos, taku wandaka he. Unkan, Mazasu on iyutapi wan, epa. Hehan Itancan kin heya; Iho, mitaoyate Israel wicacokaya mazasu on iyutapi wan ewahnake kta; ake ieimana acawicarvakśin kte śni.

9 Tuka Isaak pajodan tawa kin hena ihangyapi kta, qa Israel tipi wakan tawa kin hena awihnunipi kta: qa mazasagye yuha Jeroboam ti kin apaha nawajin kta ce.

10 Hehan Amaziah Bethel en wawayuśna kin he Jeroboam Israel wicaśtayatapi kin wahoye ca heciya; Amos Israel tipi hin cokahan niye on iẹiconza; oie iyulipa makoce kin yuha okihi lite śni:

11 Amos kaken eya ce: Jeroboam mazasagye on te kta; qa Israel wayaka ayapi on iye tamakoce kin etanhan wayaka ayapi kta ce.

12 Nakun Amariah Amos heciya; Waayate, hunkatiya wo, Juda makoce kin ekta napa wo, qa heciya aguyapi yuta wo, qa hen waayata wo:

13 Tuka ake icimana Bethel en waayate śni wo, he wicaśtayatapi tipi walran tawa, qa tipi waśte hinca wicaśtayatapi tawa hee nakaeś.

14. Hehan Amos waayupte ca Amaziah heciya; Miye waayate hemaca śni, qa wayate cinca kin hemaca śni; tuka wanunyanpi wihanwicakiye cin hemaca, qa sukamin waskuyeca wapahi ecee.

15 Unkan wanunyanpi wicihakam waun qon hetanhan Jehowa imacu; qa Jehowa hemakiya; Ya wo, Israel mitaoyate kin wowicakiyaka wo.

16 Heon etanhan niye nakaha Jehowa oie kin nation wo: Israel en waayate śni wo, qa Isaak tiyohnaka en takudan ahinhe śni wo, eha ece.

17 Heon etanhan Jehowa hecen eya; Otonwe kin ohna winohinca nitawa wawiciliahapi econ kta, qa nicinkśi qa nicunkśi kin hena mazasagye on hinhpayapi kta: qa nakun makoce nitawa hahonta on kiyuśpapi kta; qa niye makoce śapa wan ohna nite kta; qa wayaka ayapi on Israel iye tamakoce kin etanhan wayaka ayapi kta ce. 


\section{AMOS,}

WICOWOYAKE 8.

1 Jehowa Itancan kin decen wanyagmakiya: unkan iho, makanopiye wan waskuyeca suton ohna.

2 Hehan iye heya; Amos, taku wandaka he. Unkan, Makanopiye wan waskuyeca suton ohnaka, epa. Hehan Jehowa hemakiya; Mitaoyate Israel owihanke kin wanna hiyohi; ake icimana acawicawakśin k te śni.

$3 \mathrm{Qa}$ anpetu kin he en tipi wakan ohna dowanpi ece kin hena śicahowayapi kta ce, Jehowa Itancan kin eya : owanka owasin ohna wicața ota kta; inina un tankan ehpewicayapi kta ce.

4 Tona wahpanicapi kin nawicayapcapi, de nahon po, makoce en onśikapi kin ihangwicayapi kta :

5 Tohan wi teca kin henakeca $k$ ta, hecen ag̉uyapi wiyopeunyanpi kta; qa anpetu wakan kin tohan henakeca kta he, hecen aǵuyapi su taninyan eunhnakapi kta, ehapi ; wiyutapi kin cistinna yakağapi, qa iyopeye cin (śekel) dutankapi, qa onaspeyetonpi kin wohnaye on itonśniyakiyapi :

6 Hecen onślkapi kin mazaska on opewicayatonpi kta, qa wahpanicapi kin hanpa tawanji kin on; qa aguyapi su ehpeyapi kin he wiyopeyayapi ece.

7 Jakob toiyokipi kin on Jehowa iciconza! Wicolian tawapi owasin icimana awektonje kte śni.

8 De on makoce cancan kte śni he ; qa en ounyanpi kin otoiyohi iyokiśiniçiye kte śni he : unkan he ocowasin wankan u kta, wakpa wan iyececa; minitan aye kta, qa oyahe aye kta, Egupta wakpa kin iyececa.

9 Unkan anpetu kin he en kaketu kta, Jehowa Itancan kin eya; Wiyotanhan hehan wi kin isinyan iyayewaye kta, qa anpetu amahpiya śni en makoce kin aotpas wakiye kta:

$10 \mathrm{Qa}$ wonkiciyapi nitawapi kin wicocante śica wakagge kta, qa nitadowanpi owasin wicaceye kta: qa iyulipa wakihdaka ipiyagkiton wicawakiye kta; qa wicapa otoiyohi peśda kte; qa hokśincantkiyapi akiceyapi kin iyececa wakagje kta, qa owihanke kin he anpetu pa hinca iyececa.

11 Iho, anpetu kin u kta, Jehowa Itancan kin eya; wicaakilian wan makoce kin en yewaye kta; ağuyapi on akihanpi kin ee śni, qa mini on ipuzapi kin hee śni; tuka Jehowa oie nahonpi lite cin hee :

12 Unkan miniwanca kin etanhan miniwanca kin ekta yapi kta, qa waziyatanhan wiyohiyanpata ekta icimani icicawin inyang yapi kta, Jehowa oie kin odepi kta, tuka iyeyapi kte śni.

13 Anpetu kin he en wikośka waśtepi qa kośkapi kin hena ipuzapi on hanyanpi kta.

14 Tona Samaria tawoahtani on iciconzapi; qa, Dan, taku wakan nitawa ni un; qa, Beerśeba canku kin ni un ce, eyapi kin hena hinhpayapi kta, qa icimana najinpi kte śni.

\section{WICOWOYAKE 9.}

1 Itancan kin owayuśna kin akan najin wanmdaka: unkan heya; Tiyopa pa kin apa wo, hecen anokatanhan huhuzahe kta; qa hena owasin pa akan kamden ehpeya wo: unkan hena iyohakam upi kin mazasagye on wicawakte kta: tuwe hena etanhan napa eśta najice kte śni, qa tuwe hena etanhan nahmana iyaya eśta niyapi lite śni. 


\section{WICOWOYAKE 9.}

2 Hades en oqapi eśta hetanhan minape iwicacu kta; qa mahpiya ekta adipi eśta hetanhan kun awicawau kta :

3 Qa Karmel ipa kin en inahmanpi eśta, hen owicawade qa wicamduze kta; qa miniwanca śbe kin ekta miiśta etanhan analibe iciyapi eśta, hen wamduśka tanka kin econwaśi kta, unkan he wicayahtake kta.

$4 \mathrm{Qa}$ tokawicayapi wicitokam wayaka yapi eśta, hen mazasagye kin econwaśi kta, unkan wicakte kta; qa taku śica on miiśta awicawahnake kta, qa taku waśte on etanhan śni.

5 Unkan Jehowa ozuye en Itancan kin hee e maka kin yutan, unkan śdo kta; qa en ounyanpi kin iyulipa cante śicapi ece e kta; qa he wakpa wan iyecen wankan u, qa ake kun ye kta, Egupta wakpa kin iyececa.

6 Tuwe mahpiya ekta wankan tipi icicaga, qa maka akan okotonyan tawa ekihde: turve miniwanca mini kin kipan qa maka ite apapson ece; caje kin he Jehowa ee.

7 Israel cinca, miye en Kuś cinca kin iyenicecapi śni he, Jehowa eya. Israel Egupta makoce kin etanhan miye hinanpewicawaye śni he; qa Philistine oyate kin Kaphtor etanhan, qa Aram oyate kin Kir etanhan.

8 Wanyaka wo, Jehowa Itancan iśta kin wokiconze wahtani sa kin atonwan ece; qa maka ite kin etanhan ihangwaye kta : tuka Jakob ti kin ocowasin ihangwaye kte śni ce, Jehowa eya.

9 Wanyaka wo, miye econwi- cawaśi kta, qa oyate owasin ehnahna Israel tipi kin wicamducan kta, wiyucan ohna wayucanpi kin iyececa, tuka su wanjidan lseś makata hinhpaye kte śni.

10 Tuka mitaoyate etanhan wahtanipi sa, Taku śice cin unkiyahdepi kte śni, qa ahiunhdegapi kte śni ce, eyapi kin hena iyuhpa mazasagye on țapi kta ce.

11 Anpetu kin he en Dawid tawakeya hinhpaye cin he bosalan ewahde kta; qa okamdece kin hena piya wakage kta; qa yujujupi tawa qon ake najin wakiye kta, qa anpetu wanakaja kin en iyececa wakage kta.

12 Hecen Edom okaptapi kin he yuhapi kta, qa Ikcewicaśta owasin micaje on caświcatonpi kte cin hena; Jehowa hecon kin he hecen eya.

13 Iho, anpetu kin u kta, Jehowa eya; hehan mahyumdu kin he wayuksa kin ekihdege kta; qa hastanhanka naskice cin he tuwe taku su oju kin : hehan he kin miniśa teca on śbuye kta, qa paha kin owasin śdo kta.

14 Unkan Israel mitaoyate wayaka unpi kin hdicuwakiye kta ; hehan otonwe yujujupi qon hena piya kagapi qa ohna tipi lita; qa hastanhanka iyuwi ojupi kin huhdepi qa etanhan miniśa hdatkanpi kta; nakun magga kagapi kta, qa oicage kin hdutapi kta.

15 Hehan iye tamakoce kin en owicawekju kta; qa makoce wicawaqu kin hetanhan icimana wicayujunpi kte śni ce, Jehowa nita Wakantanka kin hecen eya ces 


\section{O B A D I A H.}

1 Obadiah towanyake kin. Edom on Itancan Jehowa kaken eya ce: Jehowa etanhan wicowoyake wan naunhonpi, qa wahośiye wan oyate wicehna yeśipi; Najin po, qa he kici unkicizapi kta on inaunjinpi kta ce.

2 Iho, Ikcewicaśta ehna cistinna cicağa: nina wahtenidapi śni yaun.

3 Imnija ohdoka ohna, oyanke tehanwankantu kin en yati, nicante towahanicida kin he nihnayan ece : cante mahen, Tuwe e makata ehpemaye kta he, eha ece.

4 Wamdi iyecen wankan iyeniciya, qa hohpi nitawa wicanłipi kin ehna ey ehnaka eśta, hetanhan kun ehpeciye kta ce, Jehowa eya.

5 Wamanon sa kin heca, qa iś wabotica hanyetu en nihipi kinhan; hehehe nitakuni śni ; tohanyan imuanpi hehanyan manonpi kte śni he : hastanhanka yuśpipi kin en nihipi unkanś, iyagge wanjikji okaptapi kte śni he.

6 Esau taku tawa kin kahipi hinca! taku anakilibe cin hena akitapi linca!

7 Wicaśta okodakiciye nitawa etanhan owasin heyata iyeniyanpi ; wicaśta wookiye en nici unpi kin hena nihnayanpi, niktepidan; aguyapi nitawa wohnaye ee niciyapi: wookahnige takudan en un śni.

8 Anpetu kin he en Edom etanhan wicaśta ksapa awihnuniwicawaye kte śni he, qa wowiyukcan Esau he kin etanhan, Jehowa eya.
9 Teman, wicaśta waditaka nitawa kin hena nihinciyapi kta, hecen Esau he kin etanhan wicaktepi on owasin ihangyapi kta.

10 Jakob nisunka kiunniyaye cin on etanhan wowiśtece anicahpe kta, qa ihangniyanpi kta owihanke wanica.

11 Anpetu kin en iyotakons inayajin; anpetu en tawalipaya toka kin akiyahdapi, qa wicaśta tokeca iye tatiyopa kin ohna iyayapi, qa Jerusalem on oeconna econpi qehan, hehan niye qe iyewicaceca yaun.

12 Nisunka taanpetu kin en opayakilite kte śni tuka : anpetu ell ihangyapi qon he ehan Juda cinca kin iwankam widuśkin kte śni tuka: nakun woiyokiśice anpetu kin hehan i yakapa kte śni tuka qon.

13 Anpetu en atakunipi śni qehan mitaoyate tatiyopa kin ohna idade kte śni; han, anpetu en atakunipi śni qehan niye qe kakiśyapi kin en eyatonwe kte śni; qa anpetu en atakunipi śni qehan tawowijice kin ekta nape yeyaye kte śni tuka.

14 Nakun tona etanhan najicapi qon hena ihangwicayaye kta on canku ipawege en inayajin kte śni tuka: qa woiyokiśice anpetu kin en, tona iye etanhan okaptapi kin hena hiyuwicayaye kte śni tuka.

15. Jehowa taanpetu kin Ikcewicaśta oyate owasin wicikiyedan nakaeś: niye token ecanon kin he iyecen ecaniconpi kta: 


\section{JONAH.}

niohan kin nipa kin en nihdi kta.

16 Niye lie wakan mitawa akan wadatkanpi kin he iyecen Ikcewicaśta kin iyulipa ohinniyan wayatkanpi kta; han, wayatkarpi qa wanapcapi kta, qa tohinni unpi śni iyecen unpi kta.

17 Tuka Zion he kin akan woehdaku yuke kta; unkan he wakan kta; qa Jakob tiyohnaka taku tawayapi qon hena ehdakupi kta.

18 Unkan Jakob tipi kin he peta $\mathrm{kta}$, qa Joseph ti kin he ide heca kta; qa Esau tipi kin he ag̉uyapi hu kin ee kta; unkan ehna ideyapi kta qa huhnahyapi kta; hecen Esau ti kin etanhan okaptapi wanice kta: Jehowa hecen oyaka nakaeś.

19 Hehan okağatanhan kin Esau he kin yuhapi kta, qa Philistine iś omdaye kin : Nakun Ephraim tamaga qa Samaria makoce kin yuhapi kta; qa Benjamin Gilead yuhe kta.

$20 \mathrm{Qa}$ Israel cinca wayaka unpi wicota kin de Kanaan oyate om unpi kin hena Zarephath hehanyan yuhapi kta; qa Jerusalem etanhan wayaka unpi, tona Sepharad en unpi kin hena itokagia otonwe kin yuhapi kta.

$21 \mathrm{Qa}$ wanikiya kin heca/Zion he kin ekta upi kta, Esau he kin yacopi kta: Unkan wokiconze kin he Jehowa tawa lita ce.

\section{JONAH.}

WICOWOYAKE 1.

1 Hehan Jehowa oie Jonah Amittai cinhintku en hi kin he hecen eya :

2 Najin wo, Nineveh otonwe tanka kin he ekta ya wo, qa on eyanpaha wo: wicohan śica tawapi kin mitokam u nakaeś.

3 Tuka Jonah Jehowa ite kin etanhan Tarśiśs ekta nape kta najin, qa Joppa ekta apamahde iyaya: unkan wita wata wan Tarśiś ekta ye kte cin iyeya, qa en ope kta hdajuju, qa mahen iyaya, Jehowa ite kin etanhan Tarśiś ekta om ye kta.

4. Tuka Jehowa tate tanka wan mini kin en hiyukiya; unkan miniwanca kin ohna kihanśica tanka, hecen wita wata kin kamdecapi kta seca.

5 Hehan watopapi kin nihinci- yapi, qa otoiyohi taku wakan tawapi kin hoyekiyapi, qa wita wata ohna maza kin hena minin ehpeyapi, yukapojedan kta e heon. Tuka Jonah wita wata cuwi mahen iyaya, qa iwanka, qa iśtinbe hinca.

6 Hecen wahektape cin he en ye ca heciya; Iśtinma nița, taku yaka he; najin wo, Taku Wakan nitawa hoyekiya wo ; olkinni Taku Wakan kin unkiksuyapi kta, hecen awiunhnunipi kte śni ce.

7 Hehan otoiyohi takodaku hekiciyapi; U miye, qa oeconna econkupi kta; hecen tuwe on etanhan taku śice cin de unkakipapi hecinhan sdonunkiyapi kta ce. Unkan econpidan, qa oeconna kin Jonah ahinhipaya.

8 Hehan heciyapi; Ceunniciyapi ce, taku on etanhan taku 491 


\section{JONAH,}

śice cin de en unkaupi he unkokiyaka po: Woecon nitawa kin tukte e he: Tokiyatanhan yau he : Nitamakoce tukte e he; Qa tukte oyate kin enitanhan he.

9 Unkan iye hewicakiya; Hebrew hemaca; qa Jehowa malipiya Wakantanka, tuwe miniwanca qa maka puza kagge cin he kowakipa ce.

10 Hehan wicaśta kin wokokipe tanka on kopehdapi, qa, Tokeca decen ecanon he, eciyapi. Jehowa ite kin etanhan napa wicasta kin sdonyapi, iye owicakiyaka nakaeś.

11 Unkan heciyapi; Taku ecaunniconpi $\mathrm{kta}$ he; on mini unkatajapi kin amdakedan kta: mini kin śkanśkan qa nina taja aya nakaeś.

12 Hehan iye hewicakiya ; Imacupi qa minin ehpemayan po; kinhan mini kin amdakedan iniciyayapi kta: he miye on etanhan icamna tanka kin de en niupi, he sdonwakiya ce, eya.

13 Hececa eśta wicaśta kin hutata kihunnipi kta nina watopapi : tuka okihipi śni; mini kin śkanśkan qa nina awicataja nakaeś.

14 Hehan Jehowa hoyekiyapi qa heyapi; Ceunniciyapi ce, Jehowa ceunniciyapi, wicaśta kin de nagi kin on awiunhnunipi kte śni ; qa wicawe taku iyaonpepica śni kin en unkaupi śni po; niye, Jehowa, token iyonicipi kin he ohna ecanon nakaeś.

15 Hecen Jonah icupi qa minin ehpeyapi: unkan miniwanca taja aya qon he ayuśtan.

16 Hehan wicaśta qon hena wokokipe tanka on Jehowa kokipapi, qa Jehowa wośna wakiyuśnapi, qa içiconzapi.

17 Wanna Jehowa hogan tanka wan econ śi, Jonah napce kta. 492
Unkan Jonah anpetu yamni qa hanyetu yamni hogan tezi kin mahen yanka.

\section{WICOWOYAKE 2.}

1 Hehan Jonah hogan tezi kin etanhan, Jehowa iye Taku Wakan tawa kin cekiya;

2 Qa heya;

Mitoiyokiśice on Jehowa hoyewakiya;

Unkan iye amayupta :

Hades tezi etanhan hoyewaya;

Miho kin nayahon.

3 Unkan wośbe kin en ehpemayaya, miniwanca cokaya:

Hecen wakpa kin aohdutemayan :

Minitan nitawa qa taja nitawa iyuhpa iwankam imayaya ce.

4 Hehan miye hepa;

Niiśta itokapa tanhan ehpemayanpi :

Tuka ake tipi wakan nitawa ekta ewatonwe kta ce.

5 Mini kin aomapaskica, minaği en ;

Wośbe kin aohdutemayan;

Psa kin mapa iyapemnipi :

6 He hute kin elita imdamda ;

Maka kin tatiyopa on ohinniyan aonamakitaka:

Tuka niye, Jehowa Taku Wakan mitawa,

Woha kin etanhan mitaniya hiy uyakiya.

7 Miye mahen minaği hanye cehan,

Hehan Jehowa weksuya :

Unkan wocekiye mitawa kin he en niu,

Tipi wakan nitawa kin entu.

8 'Tona woitonśni takuśni akpatanpi kin

Hena wowaonśida ehpekiyapi ece. 
9 Tuka miye qe wopida ho kin on waciciyuśna $\mathrm{kta}$ :

Taku on miciconza kin he wahduecetu kta :

Wowanikiye kin he Jehowa etanhan.

10 Hehan Jehowa hoğan qon econśi: unkan he puzata ekta ake Jonah hiyuya.

\section{WICOWOYAKE 3.}

1 Hehan Jehowa oie Jonah inonpa en hi kin hecen eya:

2 Najin wo, Nineveh otonwe tanka kin ekta ya wo, qa taku eye ciśi kin he en eyanpaha wo.

3 Hecen Jonah najin, qa Nineveh ekta iyaya, Jehowa oie kin iyececa. Unkan Nineveh otonwe tanka, Wakantanka ekta, anpetu yamni imanipi.

4 Unkan Jonah anpetu wanji imani hehanyan otonwe mahen $\mathrm{i}$, hehan eyanpaha qa heya; Ehake anpetu wikcemna topa hehan Nineveh ihangyapi kta ce.

5 Hecen Nineveh wicaśta kin Wakantanka wicadapi, qa woteśni unpi wan ieyanpahapi, qa wakihdaka oǵgekitonpi, wicatanka etanhan wicacistinna hehanyan.

6 Unkan wicoie kin de Nineveh wicaśtayatapi kin en hi, qa iś eya oiyotanke tawa kin etanhan najin hiyaya, qa taśina waśte kin ekihnaka, qa wakihdaka sihdahpa, qa cakota en iyotanka.

7 Hehan Nineveh ehna eyanpaha qa hecen oyake wicakiya, wicaśtayatapi hee qa wicaśta itancan wicayuhe tawokonzepi eciyatanhan, hecen eyapi ; Ihnuhan wicaśta qa woteca, tatanka qa tahinca wanunyanpi, taku yute cinhan; takudan yutapi kte śni qa mini yatkanpi kte śni :

8 Tuka wakihdaka ogrekitonpi kta, wicaśta qa woteca nakun; qa nina hin Wakantanka hoyekiyapi kta: han, otoiyohi iye tacanku śice cin etanhan, qa napepi ohna woyuśice kin etanhan ihduhomnipi kta:

9 T'uwe sdonya he, okinni Taku Wakan kin hdicu kta, qa iyopeiciye kta, qa tocanteptanye wohitike cin etanhan ihduhomni kta, hecen ihangunyanpi kte śni ce.

10 Unkan wicohan tawapi kin Wakantanka wanyaka, tacankupi śice cin etanhan ihduhomnipi : hecen Wakantanka iś eya taku śica ecawicakicon kta keye cin etanhan ihduhomni, qa ecen econ śni.

\section{WICOWOYAKE 4.}

1 Tuka Jonah he śicedake hinca, qa nina canteptanyan.

2 Qa Jehowa cekiye ca heya; Hehehe wanna, Jehowa, mitamakoce en waun qehan, mioie qon he dee śni he: Heon etanhan tokaheya Tarśiśs ekta nawapa: Taku Wakan canwaśte qa waon. sida, wacantkiye hinca qa wawacinkta yuza tanka, qa taku śica on iyopeiciya ecee kin herica sdonwaye ciqon:

3 Hecen wanna, Jehowa, ceciciya ce, minagi kin emiciyaku wo; mate kte cin hee waśte, wani kte cin isanpa nakaeś.

4. Unkan Jehowa heciya; Canteniptanyan kin he tanyan ecanon he.

5 Hehan Jonah otonwe kin etanhan tankan iyaye ca otonwe iwiyohiyanpatanhan iyotanka ; qa hen canwapa okeya wan icicağa, qa ohanzi kin en iyotankehan yanka; otonwe kin taku iyahde kte cin he wanyake kta.

6 Unkan Jehowa Wakantanka kikion wanji econsi, qa he Jonah iwankam icahkiciya, pa kin aohanzi kiye kta, toiyokiśice ana- 


\section{MIKA,}

kicipte kta heon etanhan. He-| ptanyan kin he waśte he. Uncen Jonah kikion kin on nina iyuśkin liinca.

7 Tuka ihanhianna anpao kta hehan Wakantanka warnduśka wan econśi, unkan he kikion ica. ge cin he kiunniya, hecen śniś aya.

8 Unkan kaketu, wihinanpa hehan wiyohiyanpa tanhan tate kata wan Wakantarka ukiya; unkan anpetu wi kin Jonah pa kin nina akanya, liccen ilipaya, qa iye nagi ekta te kta cin; qa, Mate kte cin he wani kin isanpa waśte kta ce, eya.

9 Hehan Wakantanka Jonah heciya; Kikion he on canteni- he.

kan, Mate kte cin hehanyan cantemaptanyan kin he waśte kta ce, eya.

10 Hehan Jehowa heya; Niye kikion kin, on htayani śni qa icahyakiye śni esta, tuka hanyetu wanjidan en icaga, qa hanyetu wanjidan en atakuniśni qon he onśiyakida :

11 Qa miś miye Ninereh otonwe tanka kin, ohna wicaśta nape etapa qa catka kin kinukankiya ohdahniğapi śni, kektopawinğe wikcemna eceh akenonpa sanpa yukan, qa nakun wanuyanpi ota hinca, he onśiwakida kite śni

\section{MIK A.}

WICOWOYAKE 1.

1 Jotham, Ahaz, qa Hezekiah Juda wicaśtayatapi kin taanpetu kin en, Jehowa oie, Samaria qa Jerusalem on, Mika Moraśti wicaśta en hi kin he dee.

2 Oyate iyulipa nation miye: Maka kin anagoptan kta qa toojudan koya: Qa Jehowa Itancan kin niyepi on wayaotanin kta; Itancan kin iye tipi wakan tawa kin etanhan.

3 Iho, Jehowa oyanke tawa kin etanhan u nakaeś ; kun u kta, qa maka pajodan kin en iyahe $\mathrm{kta}$.

4 Iye ihukuya he kin śloyapi kta ; qa omdaye kin hena yuptujapi kta, peta en canśin iyececa, maya etanhan mini hdihan iyeccca.

5 De ocowasin Jakob wawakipajin kin on, qa Israel tiyohnaka wahtani kin heon etanhan. Ja- kob wawakipajin kin tukte e he; Samaria hee śni he: Qa Juda pajodan tawa kin tukte e he; Jerusalem hee śni he.

$6 \mathrm{Heon}$ etanhan Samaria mag̀a en paha kagapi kin heca wakagge $\mathrm{kta}$, hastanhanka iyuwi huhdepi kin iyececa: qa inyan tawa kin kaksiza ek ta elipcwaye kta, qa taku akan he cin he mdutanin kta.

7 Qa wakağapi baǵopi tawa iyuhppa kamdecapi kta; qa wicin wicaqupi kin iyuhpa peta on hulinahyapi kta; qa wakagapi tawa kin iyuhpa mdutakuni kte śni: Hena witkowinna opetonpi kin on kamma nakaeś, unkan hena witkowinna opetonpi kin ekta hdoyapi kta ce.

8 I J eon etanhan waceye kta, qa waśicahowamde kta, sicodan qa tancodan mde kta: sunktokeca iyecen wahoton kta, qa hinhankagapi iyecen waceye kta. 


\section{WICOWOYAKE 2.}

9 Ksuweyapi kin he asniyepica śni; Juda ekta hiyohi nakaeś; he mitaoyate tiyopa kin iyahde, Jerusalem etu.

10 Gath ekta oyakapi śni po; ceyapi on ceyapi śni po: Ophra ti kin ekta maka mdu on ihdupemni wo.

11 Saphir en ounyaye cin, tancodan nitowiśtece en ako ya miye: Zaanan en ounye cin he hinanpe kte śni: Hezel tipi kin en wicaceya kin he owote tipi eniciyakupi kta.

12 Merath en ounye cin taku waśte on yazan hda, tuka taku sica Jehowa etanhan kun $\mathrm{u}$, Jerusalem tatiyopa kin en.

13 Lakiś en ounye cin, śuktanka duzahe cin he canpahmihma en ikoyagya wo: Zion cunwintku woahtani tawa tokaheya qon hee: Israel wawakipajin kin hena niye en iyeyapi nakaeś.

14. Heon etanhan kpagganpi wowapi wan Moreśeth Gath yaqu kta: Akzib tipi kin hena Israel wicaśtayatapi kin wicahnayanpi ece.

15 Tuka, Mareśa en ounyaye cin, tuwe tawaye kte cin he niye en awahi kta: Israel towitan kin he Adullam en hi kta.

16. Hduśda qa hdasan wo, hokśidan waśtewicayakidake cin hena on: tankaya ihduśda wo, huya cinca kin iyececa; hena ehpeniyan wayaka ayapi kin heon etanhan.

\section{WICOWOYAKE 2.}

1 Hehehe, tona wicohan śica nwacinpi, qa towinjapi akan taku śica kah wacinpi kin: hanhanna anpa kta hehan econpi kta, iye napepi en wowaśake yukan nakaeś.

2 Unkan mag̉a konpi qa iyahpayapi, nakun tipi kin hena, qa icu- pi : hecen wicaśta wan kakiśyapi, qa tipi tawa; han, wicaśta wan qa taku tawaye cin nakun.

3 Heon etanhan Jehowa hecen eya; Tho, wicowazi kin de taku śica wan en hiyuwicawakiya, hetanhan tahu eyehdakupi kte śni; qa wahanicidaya mayanipi kte śni; he anpetu śice hinca nakaeś.

4 Anpetu kin he en niyepi on tuwe odowan wan ahiyaye kta, qa ceyapi teliike on ceye kta: Woihangye on ihangunyanpi ce, eye kta: mitaoyate taku tawa kin iye yutokeca; yutokan iyemiciciya ce: wawakipajin wan kici maga unkitawapi kin kipamni.

5 Heon etanhan Jehowa tomniciye kin en oeconna on tuwedan hahonta on makoce iniciyute kta duhe kte śni.

6 Woyakapi śni po: tona dena on woyakapi kte śni kin hena woyakapi kta: Wowiśtece yutokanpi kte śni ce.

7 De taku iapi ka, Jakob tiyohnaka; Jehowa Taniya kin he hduptecedan he; wicohan kin dena iye tawa he; mioie kin hena tuwe owotanna mani kin yuwaśte śni he.

8 Tuka ehanna tanhan mitaoyate kin toka wan iyecen inajin : tona kicizapi cinpi śni, tona wikope śni mani hiyayapi kin hena śina okde ko wicayalipi ece.

9 Mitaoyate winyanpi kin hena tipi waśtekidapi kin etanhan tankan iyewicayayapi: iye cincapi etanhan mitowitan ewicayeciyakupi, owihanke śniyan.

10 Najin po, qa tokan ya po; oziiciyapi kte cin he detu śni nakaeś: he woaśape heon waihangye kta, qa he woihangye tehilka hinca.

11 Wicaśta wan taku śni eciyatanhan mani qa wohnaye on iton- 
śni; Miniśa qa mini wakan on wociciyake kta ce, eye cinhan, he qe oyate kin wicaśta wolkcan tawaji kta.

12 Jakob, niye ocowasin awicakehan mnaciye kta: Israel okaptapi kin yuwitayapi on wicamduwitaya kta: Bozrah tahinca wanunyanpi kin iyecen witaya ewicawahnake lata; wilianpi kin en ocokaya optaye kin iyececa: wicaśta on owodutaton tanka kta.

13 Wayujuju kin he wicitokam iyaya: hena wayujujupi, qa tiyopa kin ekta iyayapi, qa ohna tankan hinanpapi : Unkan wicastayatapi tawapi kin he wicitokam iyopte lita, qa Jehowa hee wicitokamtu kta ce.

\section{WICOWOYAKE 3.}

1 Unkan hepa; Jakob itancanpi kin, ceciciyapi, qa Israel en wicaśta way aco, nahon miye : Niye wokonze kin sdonyakiyapi kta iyecece śni he.

2 Taku waśte śicedakapi qa taku śica waśtedakapi; ha bawicakigapapi qa huhu bakicismipi kin he niyepi :

3 Nakun mitaoyate cehpi kin temyapi qa ha bawicaligapapi; huhu wicakaksaksapi, qa cegga en ohnakapi kta iyecen bawicaśpuśpupi, qa conica maza ceğa kin ohna iyececa ece.

4. Hehan Jehowa hoyekiyapi kta, tuka iye awicayupte kte śni : nakun hehan iye ite anahbewicalkiye kta, wicohan econpi kin en ihduśicapi kin heon etanhan.

5 Wicaśta wokcan tona mitaoyate nuniwicakiyapi, tona hi on wayahtakapi eca, Wookiye, eyapi ece; tuka tuwe taku $i$ en owicakicihnake śni kinhan he 496 kizapi ecee kin hena on. Jehowa hecen eya:

6 Heon etanhan hanyetu niciyankapi"kta, wowanyake wanice kta; qa otpaza niciyankapi kta, waayatapi wanice kta; qa anpetu wi kin wicaśta wokcan kin etanhan aisinyan iyaye kta, qa anpetu kin aotpaswicaye kta.

7 Hehan wawanyakapi kin iśtecapi kta, qa waayatapi kin nihinciyapi kta: han, hena iyuhpa putinhin ahdahpapi kta, Wakantanka eciyatanhan woayupte wanica nakaes.

8 Tuka miye qe wowaśake omajudan, qa woyaco wookihi ko on, Jehowa Taniya kin eciyatanhan; hecen Jakob wawakipajin kin, qa Israel woahtani tawa kin weciyaotanin kta.

9 Ceciciyapi ce, Jakob tiyohnaka itancanpi, qa Israel tipi en wayacopi kin, de nalion miye ; tona wokonze siceyadakapi, qa taku owotanna kin owasin dupemnipi ece :

10 Zion wicawe on piya kagapi, qa Jerusalem, wicolian śica on :

11 Itancanpi tawa kin hena kajujupi on wayacopi ece, qa wawayuśna tawa wiyopeyapi on waonspewicakiyapi, qa wicaśta wokcan tawa kin hena mazaska on waayatapi ece: tuka Jehowa wacinyanpi kta, qa, Jehowa unkicipi un śni he; taku śica unkakipapi kte śni ce, eyapi.

12 Heon etanhan niyepi on etanhan Zion yumdupi kta, maga iyececa, qa Jerusalem inyan paha kin heca kta, qa tipi paha kin he contanka pajodan kin hena iyecece kta ce.

\section{WICOWOYAKE 4.}

1 Tuka anpetu ehake kin en kaketu kte; Jehowa ti paha kin 


\section{WICOWOYAKE 5.}

he he ipa kin en ehdepi ktr, qa paha kin hena iwankam iyeyapi ksta; unkan oyate kin kadus en au kta ce.

2 Han, Incewicasta oyate ota upi kta qa heyapi kta; U miye, Jehowa Paha tawa kin ekta itawankanhde unyanpi kta, Jakob ta Wakantanka ti kin ekta; hecen iye tacanku kin onspeunkin yapi kta, qa ocanku tawa kin ohna maunnipi kta: Zion etanhan woope wan hinanpe kta, qa Jehowa oie kin Jerusalem etanhan kta nakaeś.

3 Unkan iye oyate ota ehnahna wayaco yanke kta, qa Ikcewicaśta waśakśaka tehan unpi kin iyopewicaye kta: hecen mazasagye on mahiyumdu isan içicağapi kta, qa wahukeza tawapi kin isan śkopa kta: Ikcewicașta oyate wan oyate tokeca kici mazasagye apahapi kte śni, qa nakun ieimana okicize onspeiciciyapi kte śni.

4 Tuka otoiyohi hastanhanka iyuwi tawapi kin ihukuya, qa suken can tawa lin ihukuya iyotankapi kta; qa tuwedan wakokipe wicakicağe kte śni: Jehowa ozuye yuhe cin hee i kin hecen eya nakaeś.

5 Oyate otoiyohi iye taku wakan tawapi caje kin eciyatanhan manipi kta; tuka unkiye Jehowa Wakantanka unkitawapi caje eciyatanhan maunnipi kta, ohinniyan qa owibanke wanica.

6 Anpetu kin he en tuwe huśte kin mnawaye lita, qa heyata iyewicayapi qon hena mduwitaya kta, qa tona kakiświcawaye ciqon, Jehowa eya.

7 Qa tuwe huśte kin he wookapte wakagie kta, qa tona tehan heyata iyeyapi qon hena oyate waśake kta: qa hena wiciwankam Jehowa Zion paha akan wicaśtayatapi un. kta, detanhan qa owihanke waniea.

8 Unkan niye, optaye conkaśke kin, Zion cunwintku pajodan tawa kin, niye en hi kta, han, iwicadake tokaheya qon he hi kta, wokiconze Jerusalem cunwintku kin en.

9 Tokeca wanna uina yaśieahowada he: Wicaśtayatapi takudan en niun śni he; waonspekiye nitawa ihangyapi he; winohinca hokśiksuye cin iyecen wayazanyahda nakaeś.

10 Wayazanhda qa hiyuya wo, Zion cunwintku, winohinca hokśiksuye cin iyececa: Wanna otonwe kin etanhan yahidu kta, qa maga kin en yati lita; qa Babel ekta de kta; heciya cinca yaton kta; heciya Jehowa tona tokaniyanpi napepi etanhan openiciton kta ce.

11 Unkan nakaha oyate ota takpe niupi ; Iho, yuśapapi kta ce, qa unkiśtapi Zion opalita un nunwe, eyapi.

12 Tuka hena Jehowa tawacin kin sdonyapi śni, qa iye tawokonze kin okahnigapi śni: hena e onapanpi kin en mnawicawaye kta, aguyapi opahte kin iyececa.

13 Najin wo, Zion cunwintku, wakapan wo; he nitawa kin he mazasapa wakag̉e kta, qa śake nitawa mazaśa wakage kta nakaeś : Unkan niye oyate ota wicayakamdemdece kta: qa miye wokamna tawapi qon Jehowa on wohduze wakage kta, qa taku yuhapi kin maka ocowasin Itancan kin he tawa kta ce.

\section{WICOWOYAKE 5.}

1 Ozuye cunwintku, wanna mniciya wo: ihdukśan acanunkaśkapi : icapsinte wan on Israel wayaco kin tapon en apapi. 
MIKA,

2 Unkan niye Bethlehem Fphratah, Juda kektópawinge kin ehna nicistinna qeyaś, niye etanhan Tuwe Israel en wawidagye un kte cin he en mahi kta, unkan iye toicage kin wanakajatanhan, anpetu otokaheya wanica etanhan.

3 Heon etanhan winohinca hokśiksuye cin cinca ton kta hehanyan wicapagan kta: hehan iye hunkawanjitku okaptapi kin ihdokupi kta, Israel cinca kin om.

4. Unkan iye najin kta, qa Jehowa towaśake on wawihankiye kta, Jehowa iye ta Wakantanka caje wowitan kin en: unkan hena owanji yakonpi kta: wanna maka ihanke kin hehanyan iye tanka kta nakaeś.

5 Unkan he qe wookiye un kta, tohan Aśur makoce unkitawapi en hiyu, qa tipi waśteśte unkitawapi kin en iyahan kinhan, hehan itkom wawihankiye śakowin, qa wicaśta sdakiyapi śahdog̣an najin wicunkiyapi kta.

6 Qa hena Aśur makoce kin ihangyapi kta, qa Nimrod tamakoce kin iye tatiyopa kin etu: hecen Aśur tohan makoce unkitawapi kin en hiyu, qa ihanke unkitawapi kin en iyahan kinhan, etanhan woehdaku yuke kta.

7 Unkan Jakob okaptapi kin hena. oyate ota ehnahna Jehowa etanhan cu kin iyecece kta ; magaju peji aśbu, wicaśta apeya un śni, qa wicaśta cinca awicakipe śni kin he iyececa.

8 Nakun Jakob okaptapi kin Ikcewicaśta ehna, oyate ota wicacokaya, contanka en woteca ehna muaja kin he iyecece kta; mnaja kośka tahin wanunyanpi optaye ehna un kin iyececa : he qe opta ye cinhan naihangye kta, qa wayapotpote kta, qa waehdaku wanice kta.
9 Tona kakiśniyanpi qon wiciwankam ninape yanke kta; qa tokaniyanpi kin iyulipa awihnunipi kta ce.

10 Unkan anpetu kin he en kaketu kta, Jehowa eya; Niye nicokaya tanhan śuktanka nitawa awihnuniwaye kta, qa canpahmihma nitawa ihangwaye kta.

11 Qa makoce nitawa en otonwe kin awihnuniwaye kta, qa conkaśke śuta nitawa mdujuju kta.

12 Qa wakan kagapi kin he ninape etanhan awihnuniwaye kta; qa wakan kagapi ece kin hena en niunpi kte śni.

13 Nakun wakagiapi bagopi, qa taku wakan yakagapi kin hena nicokaya tanhan awihnuniwaye kta; qa taku ninape kage cin icimana ohoyada kte śni.

14 Qa can wojupi nitawa nicokaya tanhan mdujun kta: hecen otonwe nitawa ihangwaye kta ce.

15 Nakun wocanniye qa wocanteptanye en Ikcewicaśta oyate waanağoptan śni unpi kin hena en towicawecicon kta ce.

\section{WICOWOYAKE 6.}

1 Wanna Jehowa taku eye cin he nation miye: Najin wo, he kin itokam wakinica wo; qa paha kin hena niho nahonpi kte.

2 Ḣe kin niye, qa maka oahe suta kin, Jehowa toakinica kin nahon miye: Jehowa iye taoyate kici woakinica wan yuha nakaeś; qa Israel om wakinica kta ce.

3 Mitaoyate, taku ecacicon he; qa taku on iyotanlian iyeciciya he, omiciyaka wo.

4 Egupta makoce kin etanhan hinanpeciya, qa wowidake tipi kin etanhan opeciciton nakaeś; 


\section{WICOWOYAKE 7.}

qa Moses, Aaron qa Miriam nitokam yewicawaśi.

5 Mitaoyate, Balak Moab wicaśtayatapi kin taku awacin gon he dehan kiksuya wo, qa Sittim etanhan Gilgal hehanyan Balaam Beor cinhintku taku ayupte ciqon: hecen Jehowa toowotanna kin oyakahnigapi kta.

6 Taku yuha Jehowa itokam hibu kta, qa Wakantanka Tehanwankantu kin itokam pamahdedan waun kta he: wohuhnahyapi wośnapi, ptejicadan waniyetu wanjidan hduha hibu kta he.

7 Tamdoka kektopawinge ece, wihdi wakpa kektopawinge wikcemna Jehowa iyokipi kta he: Micinca tokapa kin he taku śica ecamon kin on waqu kta he ; mitancan etanhan taku icage cin he minági wahtani kin on.

8 Wicaśta, iye taku waśte kin oniciyaka ce: Unkan Jehowa taku nicida kin tukte e he; wokonze ecanon kta,qa wowaonśida waśteyadake kta, qa nita Wakantanka kici ałbayedan mayani kte cin hena ee.

9 Jehowa ho kin otonwe kin en hoyekiya: Unkan wowiyukcan nicaje kin iyekiye kta: Icapsinte kin he anagoptan po, qa tuwe pazo kin he nakun.

10 Hinyahin wicaśta śica ti kin ohna wokamna śica, qa epha (wiyutapi) iyotpani wahteśni kin heca yukan he.

11 On aspeyapi śica qa wohnaye inyan wojuha ohna mduhe cinhan maska kta he.

12 Wicaśta wijica en unpi kin hena wokakiśye ojupidan, qa en ounyanpi kin hena itonpiśni ecee, qa iye ipi ohna ceji wahnayan yuhapi.

13 Heon etanhan miś eya asniyepica śni cicaśtake kta, wayahtani kin on awihnuniciye kta.
14 Niye wayate kta qa winipi kte śni, tuka wotekteyahda kin mahen niun kta; qa watoniçikśu eśta takudan eyahdaku kte śni; qa taku eyahdaku eśta mazasagye kin en waqu kta.

15 Niye woyaju kta tuka wadukse kte śni ; wihdi su kin nayapan. kta tuka wihdi on sdaniciye kte śni; hastanhanka teca kin hena, tuka miniśa datke kte śni ce.

16 Omri toope kin hena opapi nakaeś, qa Ahab tiyohnaka wicohan tawa iyuhpa; qa hena taku konzapi kin ohna mayanipi ece ; hecen otiwota elipeciye kta, qa en ounyanpi kin hena woajiji wakagge kta: Heon etanhan mitaoyate towiśtece kin he niye duhapi kta ce.

\section{WICOWOYAKE 7.}

1 Hehehe miye, mdoketu waskuyeca yuśpipi kin he iyemaceca nakaeś, hastanhanka yuśpiśpipi kin iyececa; iyagge yutapi kta wanica: suken tokaheya icage cin he minagi cantokpani tuka.

2 Tuwe waśte kin he maka kin etanhan ihangyapi; qa wicaśta ehna tuwedan owotanna śni ; iyuhpa wicawe iyapepi: on-hmunkapi kin on otoiyohi sunkakiciyapi akicitapi ece.

3 Taku śica econpi kta on way upikapi : wicaśta itancan qa wayaco kin hena wokajuju dapi, qa wicaśta tanka kin iye nagi taku sica cin kin he yaotanin ece:'hecen iciyuhmunpi.

4 Hena etanhan tuwe iyotan waśte kin he wapepeka iyececa, iyotan owotanna kin he canpepe iyececa: waawanyake nitawa taanpetu, en kakiśniyanpi kte cin he u ye : wanna wonihinciye tawapi yuke kta ce. 
5 Wicitakuye wicayecidapi kte śni; wicatakodaku wacinyakiyapi kte śni: tuwe nimaku en iwanka ece kin he nii tiyopa kin onakicitaka wo.

6 Wicacinca kin atkuku witkotkokidaka nakaeś; wicinca kin he hunku itkokim inajin, takośku kin kunkiśitku kin itkokipa ece: wicaśta tokayapi kin iye tiyohnaka wicaśta kin hena eepi ce.

7 Tuka miye qe Jehowa ekta ewatonwe kta; wowanikiye mitawa Wakantanka kin he ape waun kta: Wakantanka mitawa namakihon kta.

8 Tokamaye cin, miye on wiyuśkin śni wo: mahinhpaya eśta ake nawajin kta; otpaza en imdotanka eśta Jehowa iyoyanpa mitawa kin hee kta.

9 Jehowa tocanniye kin mduha kta, iye en wawahitani nakaeś: woakinica mitawa on imakiye kta, qa wokonze eciyatanhan ecamicon kta hehanyan iyoyanpa ekta inanpe maye kta; iye toowotanna kin wanmdake kta.

10 Hehan tuwe tokamaye ciqon he wanyake kta, qa wowiśtece akahpe kta: tuwe, Jeliowa Wakantanka nitawa tukten un he, emakiye cin he miiśta wanyake kta: wanna he qe canku upśija kin iyececa amanipi kta.

11 Anpetu kin he en conkaśke nitawa. piya kagapi kta; anpetu kin he en makoce iyutapi kin yutehanpi kta.

12 Anpetu kin he en nakun Aśur etanhan qa otonwe acankaśkapi kin etanhan niye en nihi kta, qa conkaśke kin etanhan wakpa kin ekta, qa miniwanca 500 etanhan miniwanca ekta, qa he kin etanhan he kin ekta.

13 Tuka tona en. ounyanpi kin hena on makoce kin otiwota ehpeyapi kta, iye wicohan waskuyeca kin hena on.

14 Cansagye nitawa on nitaoyate, optaye tawayakiye ciqon hena wihanwicakiya wo, iśnana ounyanpi, contanka kiı cn, Karmel cokaya : Baśan qa Gilead en wihanpi kta, anpetu wanakaja qon iyececa.

15 Egupta makoce kin etanhan yahinanpe ciqon anpetu kin he iyececa taku wowinihan wanyagwakiye kta ce.

16 Ikcewicaśta kin wanyakapi kta, qa towaśakepi kin owasin on nihinciyapi kta : nape iaputakapi kta, noge kpapi kta.

17 Maka mdu kin sdipapi kta, wanmduśka kin iyececa; maka wanmduśkadan iyececa aonaiçitakapi kin ohna cancanji kta: Jehowa Wakantanka unkitawapi kokipapi kta, qa niye nitokam kopehdapi kta ce.

18 Taku Wakan tuwe iyeniceca he, śicaya econpi kin liajuju, qa oyatc tawa okaptapi wawakipajinpi kin acakśin iyaya ece: Ohinniyan tośinhda kin hduhe śni, wowaonśida on iyuśkin nakaeś.

19 Iye ake hdicu kta, onśiunkidapi kta; taku śica econkupi kin hena ihangye kta: Unkan niye hena wahtanipi kin iyuhpa miniwanca ośbe kin en ehpeyaye kta. 20 Wowicake qon Jakob yaqu kta, wowaonśida anpetu wanakajatanhan hunkakewicunyanpi konza iwahowicayaye ciqon he Abraham ecayecon kta ce. 


\section{NAHUM.}

\section{WICOWOYAKE 1.}

1 Nineveh on woyake kin. Nahum Elkosi kin tawowanyake wowapi kin dee.

2 Taku Wakan winawizi qa watokicoa ecee kin Jehowa hee: Jehowa watokicon ya wohitika: Jehowa tona kipajinpi kin towicakicon kta, qa tona tokayapi kin wośinhda wicakiyuhe kta.

3 Jehowa wawacink ta yuza tanka, tuka waśake hinca, qa iyaonpepica śni wicayawa kte śni: Jehowa tacanku kin tateiyumni qa kihanśica ohna wanka, qa watuśekśeca iye siha askape cin mahpiya sapa kin hena ee.

4 Miniwanca kin kiśica qa kapuza, qa wakpa owasin oyaheya ece: Baśan qa Karmel śniś aya; qa Lebanon wahca kin śnija.

5 Iye itokam lie kin cancan, qa paha kin skan aya; nakun maka kin śkanśkan, iye itokapatanhan : han, maka qa en ounyarpi kin owasin koya.

6 Iye tośinhda kin itokam tuwe najin okihi kta he: qa tocanniye wohitike cin tuwe en un kta he: iye towohitike kin peta iyecen kaśtanpi, qa iye eciyatanhan imnija kamdemdecapi ece.

7 Jehowa waśte, wonihinciye anpetu kin en he wowinape yapi kin heca: qa tona wacinyanpi kin hena sdonwicakiya ece.

8 Tuka minitan apaśboka on owanka kin he ocowasin ihangye kta; qa tokawicaye cin hena otpaza kuwa awicaye kta.

9 Taku e Jehowa on awacannipi he: woihangye kag̉e kta; wokakije kin he inonpa hinanpe kte śni.

10 Wapepeka iyececa icihmunpi keś, qa miniśa tawapi on witkopi eśta, peji puze linca iyecen huhnahyapi kta ce.

11 Tuwe Jehowa on taku sica awacin, wiyukcan wicaśtaśni kin heca, he niye etanhan hinanpa.

12 Jehowa hecen eya ce; Ihduśtanpi qa decen otapi qeyaś hecen wicakaśdapi $\mathrm{kta}$, tohan iye iyopta ye cinhan. Kakiściya tuka ake icimana kakiściye kte śni.

13 Unkan nakaha iye tawanapin kin niye etanhan ciciyukse kta, qa on nicaśkapi kin mduwehwege kta ce.

14. Nakun niye on Jehowa wakiconza, nicaje etanhan icimana ojupi kte śni: Taku wakan nitawa ti kin etanhan wakagapi bagopi qa wakagapi śdoyapi kin ihangwaye kta: woha,cicicage k ta, niwahteśni nakaeś.

15 Wanyaka wo, tuwe he akan wotanin waśte au siha kin, wookiye eyanpaha: Juda, wohanpi wakan nitawa hduśtan wo; wahoyaye cin hduecetu wo: 'Tuwe wicaśtaśni kin he ake icimana en niu kte śni; he ocowasin ihangyapi nakaeś.

\section{WICOWOYAKE 2.}

1 Waihangye kin he nitkokim hiyu: Conkaśke kin acankaśka wo, canku kin awanhdaka wo, nite hduwaśaka wo, wowaśake kin he nina hdusuta wo.

2 Jehowa Jacob towitan kin tokan iyeya, Israel towitan qon iyececa: wawicaki sa kin hena 


\section{NAHUM,}

wawicakipi, qa iyuwi adetka tawapi kin ihangyapi nakaeś.

3 Wicaśta waditaka tawa tawahacanka kin śayapi, wicaśta waśakapi kin hena wokoyake duta unpi : anpetu en piiciya eca maza wiyakpakpa kin canpahmihma ikoyagyapi, qa wahukeza kin koskozapi ece.

4 Canpahmihma kin canku .ohna witkotkoya śkanpi, otonwe canku kin ohna icicawin nawankapi : wanyakapi kin petuspe seececa, wakanhdi iyecen iyoyam hinhda kta.

5 Taakicita tancan kin hena owicawa kta: hena manipi kinhan hicahanpi kta; ihdukśan conkaśke kin ekta inahni yapi kta, qa woakahpe kin ehdepi kta.

6 Wakpa tiyopa kin hena yuhokapi, qa tipi waśteśte kin hena skan aya.

7 Wanna yuśtanpi, tancodan elipeyapi, wayaka ayapi, qa wikośka tawa kin hena maku en aiçipapi wakiyedan ho kin on iyecen yus ayapi kta.

8 Anpetu wanakajatanhan Nineveh mini kiwitayapi kin iyececa. Tuka najicapi kta: Inajin po, inajin po, eyapi: Tuka tuwedan hakikta śni.

9 Mazaska kin icu po, mazaskazi kin icu po: taku mnayanpi kin yusotepica śni ; wakśica okah waśte kin owasin wopteca śni nakaeś.

10 Kaśtanpi, qa yucokapi, qa yutakunipi śni : qa wicacante kin skan aya, qa wicahupahu kin icicakog hinhdapi, qa wicanite kin otoiyohi nina yazan hda, qa wicaite owasin samya icupi ece.

11 Mnaja wamaniti kin tukten un he, qa mnaja kośka en wotapi kin, tukten mnaja, mnaja wiye, mnaja cinca ko manipi, qa tuwedan wakokipe wicakicage śni.

502
12 Mnaja kin he iye cinca on wawicakiyaśpaśpa, qa mnaja wiye tawa on wicakiyahuhuga ece, qa makolidoka tawa kin wawicakipi on ojudan kihnaka, qa waśun tawa kin taku manonpi on.

13 Iho, itkocicipe kta ce, Jehowa ozuye yuhe cin eya; qa canpahmihma tawa kin śota en huholiwaye kta; qa mazasagye kin mnaja kośka nitawa kin hena temwicaye lita: Qa maka kin etanhan taku mayanon ece kin wakaśpe kta; qa wahośi yewicayaśi ho kin ake icimana nakonpi kite śni ce.

\section{WICOWOYAKE 3.}

1 Hehehe wewe otonwe kin! wohnaye qa wicayahtahtakapi kin ojudan; wamanonpi kin ayuśtan śni ece :

2 Icapsinte ho kin, qa canhdeśka kokogya unpi, qa śuktanka nawangwankapi, qa canpahrnihma ipsipsicapi ece.

3 Sunka wakan akan iyeiciyapi, mazasagye pawiyakpapi, qa wahukeza kin wiyakpakpa: Unkan wicota wicaktepi ; qa wicaśta ța wanka ota hinca; qa wicața wanke cin wopteca śni ; wicaśta ta wankapi kin ehna naktihanhanpi ecee.

4 Witkowinna owanyag waśte wawicilialiapi ota econ kin on, wakanyan econpi itancan kin hee, wawicihahapi econ kin on oyate wiyopewicaya, qa wakanyan econ kin on wicowazi wiyopeya ecee kin hee:

5 Iho, itkocicipe kta, Jehowa ozuye yuhe cin eya; sanksanica nitawa nite elita ewahnake kta, qa tanconikadan kin he oyate kin wanyagwicawakiye kta, qa wokiconze kin nitowiśtece kin wanyakapi kta ce. 


\section{WICOWOYAKE 3.}

6 Qa taku śice hince cin aihpeciye kta, qa wahteśni cicag̀e kta, qa owanyake on ecihnake kta ce.

7 Hehan kaketu kte, tona wanniyake cin otoiyohi nanicipe kta, qa heye kta; Nineveh ihangyapi, tuwe aceye kta he; tokiyatanhan aniceyapi kte cin owade kta he.

8 No-amón (wicota) isanpa niwaśte he; he qe wakpa kin ehna iyotanka; ihdukśan mini hiyaya; towaśake kin he miniwanca kin akan yanka, conkaśke tawa kin mini tanka kin en.

9 Kuś sanpa yuwaśaka, qa E'gupta; unkan hena woptecaśni; Put qa Lubim waoniciyapi.

10 'Tuka he qe unhdalia iyaya, wayaka ayapi; nakun holśsiyopa tawa kin hena canku oise orvasin en wicakahuhugapi ; qa wicaśta okinihan tawa kin on oeconna econpi, qa wicaśta tanka tawa kin owasin maza on wicakaśkapi.

11 Niś eya winitko kta, inalibeniciye kta; niś eya tokapi kin on wowinape ayakite kta.

12 Conkaśke suta nitawa owasin suken can waskuyeca tokaheya suton kin he iyececa; yuhnapi kinhan hena tuwe yute kta i ohna hinhpaye lita.

13 Iho, nitaoyate nicokaya unpi kin hena winyanpi: makoce nitawa tiyopa kin hena tokaniyanpi kin ocowasin wicakiyulidokapi kta: inatake nitawa peta hulinage kta.

14 Onatakapi kin on mini tokikśu wo; conkaśke nitawa hdusuta wo: upśija kin en ya wo, qa maka nacoco wo, maka omodoton kin yusuta wo.

15 Hen peta temniye lita; mazasagye kin ihangniye kta; psipsica tanka kin iyececa temniye kta: Psipsica tanka kin iyecen ihduota wo; psipsicadan lin iyececa ota icicagia wo.

16 Wicaśta wopeton nitawa kin hena mahpiya wicanhipi kin isanpa yahduota: Psipsica tanka kin he watemya qa kinyan iyaya ece.

17 Wateśdake wicayecaton kin hena psipsicadan iyececapi, qa akicita tancan nitawa kin hena psipsica tanka kin iyececapi, anpetu snisni conkaśke icahda wankapi ece : wi hinanpa hehan kinyan eyaya, qa tukten unpi kin sdonyapi śni.

18 Áur wicaśtayatapi, waawanyake nitawa kin hena iśtinmapi : wicaśta itancan nitawa makan iwankapi : nitaoyate kin lie akan enanakiya iyayapi, qa tuwedan mnawicakiye śni.

19 Nicahuhugapi kin he okiziyepica śni ; anipapi kin he tehike hinca: oniyakapi kin tona nalionpi kin iyulipa niye on nape hdaskaskapapi lita: Taku śica ecanon kin ohinniyan en au śni kin he tuwe he. 


\section{HAB A K UK.}

WICOWOYAKE 1.

1 Woyake wakan Habakuk wicaśta wokcan okiyakapi qon he dee.

2 Jehowa, tohanyan hoyewaye kta, qa niye nayalion kte śni he: wośice on hoyeciciya, tuka waniyakiye śni ece.

3 Tokeca wicohan śica wanyagmayakiya, qa woiyokiśice ayatonwan he: Wuihangye qa wośice mitokam yanka: nakun kicigepi qa kicizapi wankan ihdoya ece.

4 Heon etanhan woope kin tansag aya, qa woyaco tohinni inanpe śni : taku śica wicaśta owotanna ihdukśan hiyeya; heon etanhan woyaco śkośkopa hiyaya ece.

5 Ikcewicaśta ehna tanhan wanyaka po, qa awacin po, qa yuśinyayapi on yuśinyaya po: nitaanpetu kin en wicohin wan ecamon kta; he oniciyakapi eśta wicayadapi kte śni.

6 Iho, Kasdim oyate kin icahwicawakiya, oyate wohitika qa ohanko, maka ohdakinyan omani kta, ounyanpi tawapi śni qon hena tawaye kta.

7 Hena wawinihan qa wokokipe linca: woyaco qa wowitan tawapi kin iye etanhan hiyu kta.

8 Nakun sunka wakan tawapi kin inmutanka kin isanpa duzahanpi, qa litayetu śunktokeca kin isanpa ohankopi : qa śuktanka akan yotankapi tawa kin wahanhanicidaya nawankapi ece; qa nakun śuktanka akan yotankapi tawa kin tehantanhan au kta, hena kinyan upi kta; wanmdi watemye inalini kin iyececa.

9 Ocowasin waihangya u kta; ozuye itepi kin tokatawapa yanka; qa wayaka mnawicaye kta, wiyaka iyececa.

10 Qa wicaśtayatapi iwicahaha kta, qa wicaśta itancanpi kin wowihlaha yawa kta; conkaśke suta otoiyohi on iha kta, maka mdu kin en eju, qa icu kta nakaeś.

11 Hehan hiyaye kta, tate iyececa, qa iyoopta iyaye kta, qa wan̉tani kta: towaśake kin de taku wakan tawa kecin.

12 Jehowa Wakantanka mitawa, Wanji Wakan mitawa, niye otokaheya wanica etanhan yaum śni he. Unkiye unțapi kte śni. Jehowa, he woyaco on yeconza ; qa, Imnija, he woiyopeye k ta on eyahnaka.

13 Iśta niska hinca, hecen taku śica wandake kta iyonicipi śni, qa wicolan śica ayatonwe kta iyecece śni: Tokeca wicahnayan ohanyanpi kin awicayatonwan he; wicaśta śica tuwe isanpa owotanna kin temya eśta inina nanke kta he.

14 Qa miniwanca hogian kin iyececa wicaśta wicayakaga he, maka asdohanpi kin iyececa, en itancan wanice cin hena.

15 Hena iyulipa hinśkijupi on icupi kta; ho wan on mnawicayapi kta; qa hogan icuwa kin on yuzapi kta: heon etanhan wiyuśkin kta, qa pida kta.

16 Heon etanhan ho kin wakiyuśnapi, qa hog̣an icuwa tawapi 


\section{WICOWOYAKE 2.}

kin en wizite izinyapi ece; hena on taku tawayapi kin cepa, qa woyute ota nakaeś.

17 Heon etanhan ho kin luducokaka kta, qa ohinniyan oyate kin wicakte ayuśtan kte śni he.

\section{WICOWOYAKE 2.}

1 Owanyake mitawa kin ohna nawajin kta, qa conkaśke kin akan emiçihnake kta, qa taku emakiye kta hecinhan ekta etonwan mankc kta, qa woiyopeye mitawa on token amdupte kita hecinhan.

2 Unkan Jehowa amayupte ça heya; Wowanyake kin he owa wo, qa canmdaska akan taninyan kagga wo, hecen tuwe inyanka eśta yawa kta.

3 Wowanyake kin he ehake anpetu yuśtanpi kte cin hehanyan kta nakaeś; tuka owihanke ekta inahni kta, qa itonśni wanice kta : ihdutehan kinhan ape un wo; awicakehan u kta nakaeś, hanhi kte śni ce.

4 Iho, wahanicida kin he naği owotanna śni yanka: tuka tuwe owotanna kin he iye wacinye cin on ni kta.

5 Nakun miniśa on wahanlianiçida nakaeś, wicaśta watankaicida kin heca, qa owanji yanke kte śni : hades iyececa nagi hdutanka, qa wiconte iyececa, qa tohinni imnan śni, tuka Ikcewicaśta oyate iyuhpa mnakiye, qa oyate owasin yuhe kta e wicapahi.

6 Dena iyulipa he on wiyacinpi wan, qa wowiliaha odowan wan yawankan iyeyapi kta, qa heyapi kta; Hehehe, tuwe taku tawa śni kamna ece: Tohanyan kta he: Tuwe taku icazowicakiya iye en mnakiya ece.

7 Tona niyahtakapi kte cin he- na ihnuhanna najinpi kte śni he; qa nagigeniyanpi kte cin hena kiktapi kta; qa woiyahpaye tawapi kin he niye kta ce.

8 Niye oyate ota wawicayaki ece, he iyecen oyate okaptapi kin owasin wanicipi kta: wicaśta weyapi kin on, qa woihangye makoce otonwe ko en, qa en ounyanpi kin owasin on etanhan.

9 Hehehe tuwe iye ti kin en wokamna śica wan kamna kinhan, holipi wankan eicilunake kta, taku śica nape kin etanhan eihdaku kta e heon.

10 Oyate ota ihangyapi kin on yati en taku wowiśtece wan niye niçicağa, qa ninaği en waniçihitani.

11 Hecen conkaśke etanhan inyan kin houye kta, qa can kin etanhan inatake kin ayupte $\mathrm{kta}$ ce.

12 Hehehe tuwe weyapi kin on otonwe kaga, qa otonwe tanka taku sica econpi kin on yusuta kinhan.

13 Iho, oyate kin peta linca en htanipi kta; han, takuśniśni on oyate kin mdokițe içiyapi kte cin he Jehowa ozuye yuhe cin hetanhan śni he.

14 Jehowa towitan sdonyapi kin he maka kin ojudan kta nakaeś, miniwanca mini akahipe cin iyececa.

15 Hehehe tuwe tikiyedan un wayatkekiye cinhan; janjan nitawa etanhan oyecicaśtan, qa nakun witko yakaga; hecen tancodan unpi kin ayatonwe kta.

16 Wowitan eekiya wowiśtece on winipi hinca: niś eya wayatkan wo, qa tanconikadan kin hdutanin wo: Jehowa nape etapa wiyatke kin he niye en ihdoye kta, qa nitowitan akan wowiśtece ihdepapi yuke kta. 
17 Lebanon wokakiśye tawa kin he anicahpe kta nakaeś, qa wamanica waihangye cin walkokipe wicakicaga ecee kin hena; wicaśta weyapi kin on, qa woihangye makoce qa otonwe kin ohna, qa en ounyanpi kin owasin on etanhan.

18 Wakagapi bagopi kin tuwe bago hecinhan he taku okihi kta he; wakagaapi śdoyapi, qa woitonśni onspewicakiye cin, hecen wakağapi kagie cin he wacinkiye kta he, wakaga api ia okitpani kin heca kagie kta.

19 Hehehe, tuwe can kin, Kikta wo, eciye cinhan; tuwe inyan ia okihi śni kin ihdulice śi kinhan. He waonspekiye kta he. Wanyaka wo, he mazaskazi mazaska ko on akahpapi, tuka mahen oniya ecaca takudan en un śni.

20 Tuka. Jehowa iye tawakeya wakan kin ohna yanka; iye itokam maka kin ocowasin inina un nunwe.

\section{WICOWOYAKE 3.}

1 Śigionoth on Habakuk wicaśta wokcan tawocekiye kin.

2 Jehowa, oniyakapi nawahon, kopewahda:

Jehowa, waniyetu kin ehna niohian kin piya econ wo;

Waniyetu ehna wayuotanin wo,

Wocanniye en wowaonśida kiksuya wo.

3 Teman etanhan Wakantanka hiyu;

Qa Wanji Wakan kin Paran he kin etanhan. Sela.

Iye tawootanin kin mahpiya kin akalipa;

Qa maka kin iye towitan kin on ojudan.

4 Utnkan towiyakpa kin he iyoyanpa kin iyececa: 506
Witanirin kin iye nape kin etanhan:

Qa hen towaśake kin inaliman ece.

5 Iye itokam makośica hiyaya; Qa oide wan iya siha kin etanhan hiyu ece.

6 Inajin, unkan maka kin cancan :

Ekta etonwan, unkan oyate kin nihinciyapi :

Nakun he tanina kin hena mdecahanpi,

Paha wanakaja kin hena kun elipeiçiyapi :

Iye tacanku kin otokahe wanica.

7 Knśan tawakeya kin wokakije en wanmdaka:

Midian makoce ozanhdepi kin kahuhuza.

8 Jehowa, wakpa kin canniyaya he ;

Wakpa kin en nitocanteptanyan yukan he:

Nitośinhda kin miniwanca kin en ;

Hecen śuktanka nitawa akan,

Wowanikiye canpahmihma nitawa kin ohna idada he.

9 Itazipa nitawa śdayehna taninyan yanka:

Wanhukeza śakowinwin kta, keya. Sela.

Maka kir wakpa on niye duptuptuja ece.

10 He kin hena wanniyakapi, śkanśkanpi :

Mini hinhe hinca hiyaya:

Miniśbe kin ho hiyuya.

Nape yuwankan ikikcu.

11 Anpetu wi, hanyetu wi kin iye ounyanpi kin en inajinpi :

Nitawanhinkpe iyoyanpa kin on yapi ece,

Wanhukeza nitawa ijanjan wiyakpakpa kin on.

12 Wośinhda hduha maka kin omayani ; 


\section{ZEPHANIAH.}

Wocanniye on Ikcewicaśta oyate kin wicayakaśtaka ece.

13 Nitaoyate niwicakiya on idada ;

Sdayakiye ciqon ehdakupi kta e heon:

Wicaśta śica tipi ohna pa kin yakahuliuga ;

Oahe hdepi tahu kin hehanyan yuaśdaya eyahnaka. Sela.

14 Wanhukeza tawa on taakicita tancan pa cawicayecipa:

Hena nuni makiyapi kta on tateiyumni iyecen kuwa anaupi ;

Wahpanicapi kin nahmana temyapi kta iyuśkinpi ece.

15 Suktanka nitawa om miniwanca kin ehna mayani;

Mini tanka ejupi kin ehnahna.

$16 \mathrm{He}$ nawalion, unkan mitezi śkanśkan:

Wicaho kin on iha namapapi ece :

Huhu mitawa kuka aya,

Qa mahen macancan hinca:
Tuka wokakije anpetu kin en ozimiçiye kta ;

Tohan oyate om anauntanpi kta upi kinhan.

17 Suken can kin namdag̉a śni qeyaś,

Qa hastanhanka iyuwi kin en waskuyeca wanica;

Oliwe can kicanyanpi kin he atakuniśni,

Qa maga kin woyute takudan icah̉ye śni ;

Tahin wanunyanpi tipi etanhan optaye kin ihangyapi,

Qa tatanka tipi ohna tatanka wanica qeyaś :

18 Tuka miye qe Jehowa on imduśkin kta;

Wowanikiye mitawa Wakantanka kin on iyawaśa kta.

19 Jehowa Itancan kin wowaśake mitawa kin hee;

Unkan misiha tatokadan iyececa kagie kta;

Qa paha mitawa akan manimakiye kta ce.

Candowankiyapi mitawa en itancan kin he de kicagapi.

\section{ZEPHANIAH.}

\section{WICOWOYAKE 1.}

1 Josiah Amon cinhintku Juda wicaśtayatapi taanpetu kin en, Jehowa oie Zephaniah Kuśi cinhintku, Gedaliah cinhintku, Amariah cinhintku, Hezekiya cinhintku kin en hi kin he dee.

2 Ihangyapi on makoce ite kin etanhan taku owasin ihangwaye kta ce, Jehowa eya.

3 Wicaśta qa woteca ihangwi- cawaye kta; mahpiya zitkadan qa miniwanca hoggan kin ihangwaye kta, qa taku on wahtaniwicayapi, wicohan śica econpi koya: qa maka ite kin etanhan wicaśta ihangwicawaye kta ce, Jehowa eya.

4 Nakun Juda iwankam miye nape wahdugate kta, qa Jerusalem en ounyanpi kin iyuhpa ekta; qa oyanke kin de etanhan Baal okicaptapi kin ihangwaye kta, 507 


\section{ZEPHANIAH,}

wakag̉api waliiyuśnapi cajepi qa wawayuśnapi kin hena koya :

$5 \mathrm{Qa}$ tona tiakahpe ekta mahpiya ozuye kin ohodapi; han, tona ohodapi, tona Jehowa on içiconzapi qa nakun wicaśtayatapi tawapi kin on içiconzapi ece :

6 Qa toria Jehowa etanhan namnipi, nakun tona Jehowa akitapi śni, qa on wawiwangiapi śni kin hena.

7 Jehowa Itancan kin itokam inina yanka wo: Jehowa taanpetu kin he kiyedan ihan nakaeś: Jehowa wośna wan hduwiyeya nakaeś, tona wicakico kin hena wicayuwakan.

8 Unkan Jehowa tawośna anpetu kin en kaketu kte; wicaśta ihdawapi qa wicaśtayatapi cinca kin wanyag wicawahi kta, qa tona wokoyake tokeca on ihduzapi kin hena iyuhpa.

9 Nakun anpetu kin he en, tona tiyopa oahe akan ipsicapi kin hena wanyag wicawahi kta; tona itancan tawapi tipi woihangye qa wohnaye on ojuyapi ece kin hena.

10 Unkan anpetu kin he en kaketu kte, Jehowa eya; hoggan tiyopa kin etanhan ceyapi ho yeyapi kta, qa tiyopa inonpa kin etanhan śicahowayapi kta, qa woihangye tanka wan paha kin etanhan kta ce.

11 Makteś (canwibope) en ounyanpi kin, śicahowaya po; wopeton oyate kin ocowasin ihangyapi nakaeś ; tona mazaska qinpi kin iyuhpo atakunipi śni.

12 Unkan hehan kaketu kte, petijanjan yuha Jerusalem en owakide kta, qa wicaśta cetete akan pustag iyotankapi kin hena wanyag wicawahi kta; tona cante mahen heyapi, Jehowa taku waśte econ kte śni, qa nakun taku śica econ kte śni ce, eyapi ece kin hena.

13 Heon etanhan walipaya tawapi kin wicakipi kta, qa tipi tawapi kin otiwita kta: Nakun hena e tipi kaggapi kta, tuka otipi kte śni ; qa hastanhanka iyuwi ojupi kta, tuka etanhan miniśa yatkanpi kte śni ce.

14 Jehowa taanpetu tanka kin kiyedan hinca; kiyedan qa inahni hinca: Jehowa taanpeciu ho kin : he en wicaśta waditake cin śicahowaye kta.

15 Anpetu kin he wocanniye anpetu; wonihinciye qa wicacante śica anpetu; woihangye qa woyutakuniśni anpetu ; anpetu amahpiya qa otpaza hinca:

16 Mazayahotonpi tanka qa iyaśapi anpetu, otonwe acankaśkapi akan, qa conkaśke tehanwankantu kin ekta.

17 Unkan wicaśta en wonihinciye awicawau kta, hecen iśtagongiapi iyecen manipi kta; Jehowa en wakihtanipi nakaeś: unkan iye we kin kaśtanpi kta, maka mdu iyececa, qa celipi tawapi kin tacesdi iyecece kta.

18 Mazaska tawapi qa nakun mazaskazi tawapi, Jehowa tocanniye anpetu kin en ewicahdaku okihi kte śni: 'Tuka tawowinawizi peta kin on makoce ocowasin hulinage kta: ihnuhanna woihangye wan kage kta nakaeś, maka akan ounyanpi kin owasin en.

\section{WICOWOYAKE 2 .}

1 Oyate wiśtece śni yaun, ihduwitaya wo; han, ihduwitaya wo.

2 Wokonze kin hinyahin icage śni; anpetu ,kin ağuyapi ha kin iyecen hiyaye kta; Jehowa tośinhda wohitike cin en niupi śni ito- 


\section{WICOWOYAKE 3.}

kam; Jehowa tocanniye anpetu kin en niupi śni itokam :

3 Maka akan onśihan yaunpi kin owasin, Jehowa akita po, tawoyaco ecen ecanonpi kin ; woowotanna akita po, wowahibadan akita po: okinni Jehowa tocanniye anpetu kin en anicalipapi kta ce. 4 Gaza otiwita kta, qa Aśkelon hewoskan kta: Aśdod anpecokaya hehan napewicayapi kta, qa Ekron yujun icupi kta ce.

5 Hehehe, miniwanca kahda ounyanpi; Kerethim oyate kin; Jehowa oie kin itkonicipapi : Kanaan, Philistia makoce kin, niye ihangciye kta, en ounyanpi wanice kta ce.

6 Tuka miniwanca kahda ohna wihanpi yuke kta, wihanwicakiyapi miniyowe qa optaye otipi lita.

7 Han, makoce kin lıe Juda tiyohnaka okaptapi kin yuhapi kta, he ohna wotapi kta : htayetu hehan Aślkelon tipi kin ohna iwankapi kta: Jehowa Taku Wakan tawapi kin he wanyag wicahi $k t a$, qa wayaka unpi kin hdicukiye kta nakaeś.

8 Moab waawicaie cin hena nawation, qa Ammon cinca i kapapi kin, on mitaoyate iyopewicayapi, qa makoce opapun tawapi kin en wahanhanicidapi ecee qon.

9 Heon etanhan Israel Taku Wakan tawa kin he miye ni waun, Jehowa ozuye yuhe cin he hecen eya; Awicakehan Moab Sodom iyecece kta, qa Ammon cinca kin Gomorrah iyecece kta, makoce wapepeka oicage kta, qa miniskuya oqapi yuke kta; qa owihanke wanica otiwita kta: mitaoyate okaptapi kin hena wicakipi kta, qa mitaoyate etanhan wookapte kin hena wicayuhe kta.
10 Wahanicidapi kin on decen waakipapi kta, Jehowa ozuye yuha taoyate kin i en iyewicayapi, qa en ihdatanpi kin heon etanhan.

11 Hena en Jehowa wohitike kta ; maka akan taku wakan kin iyulipa wicayuśilitin kta nakaeś. Unkan otoiyohi oyanke tawa kin etanhan iye ohodapi kta, han, Ikcewicaśta wita kin iyuhpa.

12 Nakun Kuś oyate, niyepi mazasagye mitawa on niktepi kta ce.

13 Unkan iye qe waziyatakiya nape hdugate kta, qa Aśur ihangye kta; qa Nineveh liewoskan kagge kta, hopuza iyecen puza kta.

14 Unkan he cokaya optaye kin iwankapi kta, Ikcewicaș́ta wamanica tawapi iyulipa: Nakun hoka kin, nakun pahin kin, hena wankan oinkpa kin en wankapi kta, owanyeye kin ohna hotonpi kta ; tiyopa kin ohna woyutakuni śni yuke kta; lianteśa can on kağapi kin he yutaninyan ehnake kta nakaeś.

15 Otonwe kin he dee, wiyuśkin un, wikope śni yanke ciqon, cante mahen, Miye, qa micunonpa tanhan wanica ce, eye ciqon he dee. Wanyaka wo, he otiwita icağa, wamanica owanka kin lieca; en hiyayapi kin otoiyohi ajiji kta qa nape koza kta ece.

\section{WICOWOYAKE 3.}

1 Hehehe, wawakipajin qa aśapapi kin, otonwe wawicakiśya ecee kin:

2 Wicaho kin anağoptan śni; wawiyopeyapi kin he awakicin śni: Jehowa wacinkiye śni : Taku Wakan tawa kin ikiyedan u śni ece.

3 Cokaya wicaśta ihdawa yuke 509 


\section{ZEPHANIAH.}

cin hena mnaja hotonpi kin heca ; wayaco tawa kin hena litayetu śunlktokeca kin hecapi ; hanhanna hehanyan takudan kihnakapi śni.

4 Wicaśta wokcan tawa kin hena witantanpi, wicaśta wicahuayanpi ece: wawayuśna tawa kin hena taku wakan kin yuśapapi, woope kin kicaksapi ece.

5 Jehowa owotanna un kin he cokaya yanka: He qe taku śica takudan econ kte śni. Hanlianna qa hanhanna woyaco kin iyoyanpa en ekihde ece : he qe iyotpani kte śni: tuka tuwe śice cin he wowiśtece sdonkiye śni ece.

6 Ikcewicaśta kin ihangwicawaye: conkaśke tawapi kin atakuniśni : canku tawapi kin hewotahedan ehpewaye ; hecen tuwedan olına hiyaye śni: Otonwe tawapi kin ihangyapi, hecen wicaśta wanica, en ounyanpi wanice hinca.

7 Awicakehan komayakipe kta ; wowahokonkiye iyacu kta ce: hecen en ounyanpi kin ihangkiciyapi kte śni, token waweciconze ciqon owasin eciyatanhan, epa. Tuka hankiktapi, taku econpi kin owasin hduśicapi ece.

8 Heon etanhan niye amakipe po, Jehowa eya; anpetu en wawicaki nawajin kta hehanyan: Ikcewicaśta wicamduwitaya kta miciconza; wokiconze kin hena mawicawaye kta; mitocanteptanye, mitocanniye wohitike cin ocowasin awicawakaśtan kta e heon: wowinawizi peta mitawa kin he maka kin ocowasin temye kta nakaeś.

9 Ilehan oyate kin wicaiha yutecapi wicawecu kta nakaeś; hecen Jehowa caje kin hoyekiyapi kta, wicotawacin wanji- dan on en wowidagiciyapi kta e heon.

10 Kuś wakpa kin akotanhan tona cemakiyapi kin hena, enanakiya iyewicayapi mitawa cinca kin hena ee mitawośna aupi kta ce.

11 Anpetu kin he en niohian, mayakipajin qon hena iyuhpa on iniśtece kte śni he: hehan nicokaya tanhan tona nitowahanicida on wiyuśkinpi kin hena yutokan iyewic:awaye kta nakaeś: qa he wakan mitawa kin en icimana wahannicida kte śni.

12 Nakun nicokaya oyate wan kakiśyapi qa onśika owicawakapte kta ; unkan hena e Jehowa caje kin wacinyanpi kta.

13 Israel okaptapi kin taku śica econpi kte śni, qa woitonśni eyapi kte śni, qa ipi ohna ceji wi. cahnayan yuke kte śni : tuka hena e wotapi qa iwankapi kta, qa tuwedan wakokipe wicakicage kte śni ce.

14 Zion cunwintku, dowan wo; Israel, iyaśa wo: Jerusalem cunwintku, wiyuśkin qa cante ocowasin on ipsica wo.

15 Niyacopi qon hena Jehowa eyaku; tokaniyanpi kin lıena ihangwicaya : Israel Wicaśtayatapi kin, Jehowa hee e nicokaya yanka: icimana taku śica wandake kte śni ce.

16 Anpetu kin he en Jerusalem heciyapi kta; Wakokipe śni wo : Zion, Ilınuhan nape niwankadan kinhan.

17 Jehowa Taku Wakan nitawa kin he nicokaya yanka: Wanji Waśake cin he niniye kta: wowiyuśkin on iniciyuśkin kta : towaśtedake en oziiciya un kta; dowanpi on iniciyuśtín kta.

18 Tona omniciye wakan kin on icanteśicapi kin hena mnawicawaye kta, hena niye etan- 


\section{HAGGAI.}

hanpi, woiyopeye on yuśakapi qon hena.

19 Wanyaka wo, hehan tona kakiśniyanpi kin owasin taku ecawicawecon kta; qa tuwe huśte kin he niwaye kta, qa tona napeyapi qon hena mnawaye kta ; qa makoce kin en wowiśtece yuhapi qon hena owasin en wicacaje qa wowitan wicawecage kta ce.

20 Hehan cihdoupi kta, tohan ciyuwitayapi kinhan : maka oyate kin owasin ehnahna wicacaje qa wowitan cicicagapi lita nakaeś; tohan niiśtapi itokam wayaka yaunpi kin hdicuwaye cinhan, Jehowa eya.

\section{A G GAI.}

\section{WICOWOYAKE 1 .}

1 Darius wicaśtayatapi kin tawaniyetu inonpa, wi iśakpe, anpetu tokaheya en, Haggai wicaśta wokcan nape eciyatanhan, Jehowa oie Zerubabel Śealtiel cinhintku, Juda wicaśtayatapi, qa Joshua Josedek cinhintkı wawayuśna itancan kin hena en hi, qa heya :

2 Jehowa ozuye yuha he woyake ca hecen eya; Oyate kin de kaken eyapi ece; Hinyahin iyehantu śni, tohan Jehowa tipi kagapi kte cin hinyahinke śni ce.

3 Hehan Jehowa oie Haggai wicaśta wokcan nape eciyatanhan u kin he hecen eya:

4. Niye tipi ayuco hduśtanpi kin ohna yatipi kta iyenihantupi, qa tipi kin de jujuwahan yanke kta he.

5 Heon etanhan wanna Jehowa ozuye hduhe cin he hecen eya; Nitacankupi kin awakicin po.

6 Ota oyajupi, tuka tonana ayahdipi ece: wayatapi, tuka winipipi śni ; wadatkanpi, tuka yatkanpi on inimnanpi śni ; wokoyake kodakapi, tuka tuwedan icoza śni; qa tuwe wolkamna ahtani kin he wokamna wojuha ohdoha yuke cin en ohnake kta e hitani ece.

7 Jehowa ozuye hduhe cin he. hecen eya; Nitacankupi kin awakicin po.

8 Ḣe kin ekta ya po, qa can icu po, qa tipi kin kaga po; kinhan on iyokipimiçiye kta qa mihduwitan kta ce, Jehowa eya.

9 Taku ota duhapi kta kecannipi, tuka iho, tonana: unkan ayahdipi hehan awapogan. He tokeca he, Jehowa ozuye hduhe cin eya. Tipi mitawa jujuwahan wanka heon - etanhan, qa niyepi otoiyohi tipi ekta inyang yahdapi ece.

10 Heon etanhan niwankamtu mahpiya kin cu anakipte; qa maka kin waskuyeca tawa anakipta ece.

11 Unkan miye makopuza weco, maka kin akan, qa he kin akan, qa wojupi kin akan, qa miniśa teca kin akan, qa wihdi kin akan, qa taku maka etanhan icaga ece kin akan, qa wicaśta akan, qa woteca akan, qa wicanape htani kin iyuhpa akan.

12 Hehan Zerubabel Śealtiel cinhintku, qa Joshua Josedek 


\section{HAGGAT,}

cinhintku, wawayuśna itancan kin, oyate okaptapi kin owasin koya, Jehowa Taku Wakan tawapi ho kin anagoptanpi, qa Hagyai wicasta wokcan Jehowa Taku Wakan tawapi u si oie kin hena; qa oyate kin Jehowa itokam kokipapi.

13 Hehan Haggai Jehowa u śi kin he woyake ca, Jehowa oyate taku wahowicaye cin en hecen eya; Miye cicipi waun ce, Jehowa eya.

14. Unkan Jehowa Zerubabel Sealtiel cinhintku Juda itancan taniya kin yuhica, qa Joshua .Tosedek cinhintku wawayuśna itancan taniya kin, qa oyate okaptapi owasin taniya wicayulica: Hecen upi, qa Jehowa ozuye hduha Taku Wakan tawapi tipi kin en htanipi ece :

15 Darius wicaśtayatapi kin tawaniyetu inonpa, wi iśakpe, qa anpetu wikcemna nonpa sanpa topa kin en.

\section{WICOWOYAKE \%}

$1 \mathrm{Wi}$ iśakowin, anpetu wikcemna nonpa sanpa wanjidan en, Tehowa oie Haggai wicaśta wokcan nape kin eciyatanhan u kin he hecen eya:

2 Wanna, Zerubabel Śealtiel cinhintku Juda itancan, qa Joshua Josedek cinhintku wawayuśna itancan, qa oyate okaptapi kin hena om wohdaka, hewicakiya wo:

3 Onicaptapi kin etanhan tuwe tipi kin de towitan tokaheya kin en wandakapi he: qa wanna token wandakapi he : he kici iwanyakapi niiśtapi kin en wanna takuśni iyecece sni he.

4 Tuka nakaha, Zerubabel, wasaka wo, Jehowa eya; qa Joshua Josedek cinhintku wawayu- śna itancan kin, waśaka wo; qa makoce kin en oyate ocowasin, waśaka po qa litani po; miye cicipi waun nakaeś, Jehowa ozuye hduhe cin eya.

5 Egupta etanhan yahinapapi qon he ehan, niyepi kin en mioie miçiconze cin he iyececa, Mitaniya kin nicipi un: wakokipapi śni po.

6 Jehowa ozuye hduhe cin he hecen eya ce : Ehake wancadan, wanna ecadan kta, hehan miye mahpiya kin mduśkanśkan kta, qa maka kin, qa miniwanca kin, qa hopuza kin:

7 Nakun oyate kin owasin mduśkanśkan lita, qa oyate owasin Cantiheyapi kin he u kta: Qa tipi kin de wowitan on ojuwaye kta ce, Jehowa ozuye hduhe cin eya.

8 Mazaska kin he mitawa, qa mazaskazi kin he mitawa ce, Jehowa ozuye hduhe cin eya.

9 Tipi ehake kin de wowitan tawa kin he tokaheya qon isanpa. tanka kta, Jehowa ozuye hduhe cin eya: Nakun oyanke kin de en wookiye wicawaqu lita ce, Jehowa ozuye hduhe cin eya.

$10 \mathrm{Wi}$ inapcinwanka anpetu wikcemna nonpa sanpa topa, Darius tawaniyetu inonpa en, Jehowa oie Haggai nape kin eciyatanhan $u$ kin he hecen eya : 11 Jehowa ozuye hduhe cin be hecen eya ce; Wanna woope kin on wawayuśna kin wiwicawanga qa heya wo:

12 Tuwe tado yuwakanpi kin he taśina opapun kin ohna qin aye ça, taśina on ag̉uyapi, qa iś taku ohanpi, qa miniśa, qa wihdi, qa woyute taku kaśta, kahtake cinhan he wakan kta he. Unkan wawayuśna kin ayuptapi qa, Hiya, eyapi.

13 Hehan Haggai heya; Tuwe 


\section{WICOWOYAKE 2.}

taku tá on aśape cin he taku hececa yutan kinhan iś aśape kta he. Unkan wawayuśna kin ayuptapi qa, $\mathrm{He}$ aśape kía ce, eyapi.

14 Hehan Haggai waayupta qa heya; Wicaśta kin dena hececa, qa oyate kin de mitokam hececa, Jehowa eya: qa wicohan nape on econpi kin owasin bececa, qa hen taku wayuśnapi kin hena yuśapapi ece.

15 Heon etanhan, ceciciyapi ce, anpetu kin de etanhan qa hektapa de awakicin po; Jehowa tipi tawa kin en inyan wan inyan akan ehnakapi śni qon itokamtu ;

16 Hena etanhan, tuwe paha wan wikcemna nonpa kta en hi qehan wikcemnana en un; miniśa iyuśkice en hi, iyuśkice kin etanhan wikcemna zaptan ikikcu kta, tuka wikcemna nomnana en un ece.

17 Woyuśnije, qa aa, qa wasu kin on, taku ninape econpi kin owasin en aeipapi; tuka miye en nihduhomnipi śni, Jehowa eya.

18 Wanna nicantepi en awacin po, anpetu kin de etanhan qa tokata wapa, wi inapcinwanka en anpetu wikcemna nonpa sanpa topa etanhan, Jehowa tipi 80

wakan tawa ahdehe cin ehnakapi kin hetanhan awacin po.

19 Wojupi kin hinyahin mazopiye kin ohna yanka he: han, hinyahin hastanhanka iyuwi, qa witanśna hu kin, qa taspantanka su ota, qa wihdi can kin takudan aicagge śni : anpetu kin detanhan ciyuwaśtepi kta ce.

20 Unkan wi kin en anpetu wikcemna nonpa sanpa topa kin en, Jehowa oie lrin inonpa Haggai en hi kin he hecen eya :

21 Zerubabel Juda itancar kin he kici wohdake ca heya wo; Miye mahpiya kin qa maka kin mduśkaśkan kta ;

22 Qa wokiconze oiyotanke kin mduptanye kta, qa Ikcewicaśta wokiconze wowaśake kin ihangwaye kta: qa canpahmihma kin hena mduptanye kta, tona en iyotankapi kin hena koya; qa śuktanka qa tona akan iyotankapi kin hena hinhpayapi kta, otoiyohi iye takodaku tamazasagye kin on.

23 Anpetu kin he en, Jehowa ozuye hduhe cin he hecen eya, Zerubabel mitaokiye, Ścaltiel cinhintku kin, niye icicu kta, qa woipuspe wan iyececa cicağe kta ce, Jehowa eya: Miye cicahnigga nakaeś, Jehowa ozuye hduhe cin eya. 


\section{ZEKARIAII.}

\section{WICOWOYAKE 1 .}

1 Darius tawaniyetu inonpa, wi iśahdoġan kin en, Jehowa oie Zekariah, Barakiah cinhintku, Iddo cinhintku, wicaśta wokcan kin en hi kin he hecen eya:

2 Jehowa canteptanyan, hunkakewicayayapi kin canniyewicaya :

3 Heon etanhan hewicakiya wo; Jehowa ozuye hduhe cin he kaken eya; En mahdiyaku po, Jehowa ozuye hduhe cin eya: kinhan niyepi en mihdoku kta ce, Jehowa ozuye hduhe cin eya.

4 Nihunkakepi kin iyececapi śni po: wicaśta wokcan tokaheya hena hoyewicakiyapi qa heyapi; Wanna nitacankupi śice cin etanhan, qa taku śica ecanompi kin etanhan ihdoku po, Jehowa ozuye hduhe cin eya ce. Tuka nahonpi śni qa anamagoptanpi śni, Jehowa eya.

5 Nihunkakepi kin tokiya unpi he: qa wicaśta wokcan kin hena ohinniyan ni unpi he.

6 Tuka mioie qa mitawoyaco mitaokiye wicaśta wokcan kin econwicawaśi qon hena nihunkakepi kin ewicakihdeğapi śni he: Unkan hena e ihduhomnipi qa heyapi; Unkitacankupi kin eciyatanhan, qa unkiohanpi kin eciyatanhan Jehowa ozuye yuhe cin ecaunkiconpi kta cante yuze ciqon he iyecen wanna ecaunkiconpi ce.

7 Darius tawaniyetu inonpa, wi iakewanji, wi kin Sebat eciyapi kin he en, anpetu wikcemua non- pa sanpa topa, hehan Jehowa oie Zekariah, Barakiah cinhintku, Iddo cinhintku, wicaśta wokcan kin en hi kin he liecen eya :

8 Hanyetu hehan wanmdaka, unkan iho, wicaśta wan śuktanka hin śa wan akan iyotanka, qa kaksiza ohna hadas can kin ehna inajin: qa he idazatanhan śuktanka hin śa, hin to, qa hin ska yukan.

9 Hehan hepa; Itancan mitawa, dena taku he. Unkan wahośi wakan miciwohdake cin he hemakiya; Dena taku kin cicipazo lita ce.

10 Hehan wicaśta hadas can kin ehna najin qon he waayupte, qa heya; Tona Jehowa maka kin en ohnihdeya unpi kta yewicaśi qon hena eepi.

11 Hehan hena iś Jehowa wahośi wakan tawa hadas can ehna najin kin ayuptapi qa heyapi; Maka kin en ohnihdeya unyakonpi, unkan iho, maka kin ocowasin owanji yanka qa oziiciya ce. 12 Hehan Jehowa wahośi wakan tawa kin waayupta qa heya ; Jehowa ozuye hduhe cin, Jerusalem qa Juda otonwe kin wanna waniyetu wikcemna śakow in hehanyan canniyewicayaye cin tohayan onśiwicayakida kte śni he.

13 Unkan Jehowa wahośi wakan miciwohdake cin he wicoie waśte qa wicoie oiyolsipi kin on ayupta.

14 Hehan wahośi wakan miciwohdake cin hemakiya; Eyanpaha qa heya wo; Wowinawizi tanka on Jerusalem qa Zion on 


\section{WICOWOYAKE 2.}

winawawizi ece, Jehowa ozuye hduhe cin eya:

15 Qa wocanteptanye tanka on Ikcewicaśta owanji yakonpi kin canniyewicawaya: miye cistinna cantemaptanyan, tuka heepi e wośice kin okiyapi.

16 Heon etanhan Jehowa hecen eya; Wocantekiye hduha Jerusalem en wahdiyaku: 'Tipi mitawa kin he kagapi kta, qa Jerusalem akan ikan wan yutitanpi kta ce, Jehowa ozuye hduhe cin eya.

17 Ehake eyanpaha qa heya wo; Otonwe mitawa kin he taku waśte on apaśbog un kta, qa Jehowa ehake Zion cantohnagye kta, qa ehake Jerusalem hdahinige $\mathrm{kta}$ ce, Jehowa ozuye hduhe cin eya.

18 Hehan miiśta hduwankan. iwekcu qa wanmdaka, unkan iho, he topa.

19 Unkan wahośi wakan miciwohdake cin hewakiya; Dena taku he. Unkan iye amayupta; He kin dena Juda qa Jerusalem enanakiya iyewicayapi qon hena ee.

20 Hehan Jehowa mazakağa topa makipazo.

21 Hehan hepa; Dena taku econ upi he. Unkan iye ie ca heya; Juda wicaśta enanakiya iyewicaye ciqon, hecen tuwedan pa yuwankan ikikeu śni, he kin hena ee. Tuka dena e hamwicaya hipi, Ikcewicaśta he kin ihangyapi kta, tona Juda makoce kin enanakiya iyewicayapi kta on he yuwankan ikikcupi qon hena.

\section{WICOWOYAKE 2.}

1 Hehan iśta yuwankan iwekcu qa ekta ewatonwan; unkan iho, wicaśta wan, qa nape ohna wiyutapi ikan wan.

2 Hehan hepa; Tokiya da he.
Unkan iye hemakiya; Jerusalem imdute $\mathrm{kta}$, tohanyan ohdakinyan, qa tohanyan ohanske kta he wanmdake kta ce, eya.

3 Unkan iho, wahośi wakan miciwolidake cin he iyaya, qa wahośi wakan wan tokeca itkokipa ya :

4 Qa heciya; Ekta inyang ye ca kośka kin de heciya wo; Conkiśke codan iyecen Jerusalem en ounyanpi kta, wicaśta ota qa woteca ota ohna kta nakaeś :

5 Qa miś miye ihdukśan peta conkaśke waun kta, qa cokaya wowitan waun kta ce, Jehowa eya.

$6 \mathrm{Ho}$, ho, qa waziyata makoce kin etanhan najica po, Jehowa eya : mahpiya tate ouye topa kin iyecen ciyuomdecapi nakaeś, Jehowa eya.

7 Ho, Zion, Babel cunwintku kin kici ounyaye cin, niic̣iya wo.

8 Jehowa ozuye hduhe cin he hecen eya; Wowitan ohakam, oyate wanicipi qon hena ekta yemaśi ; tuwe kiunniniyanpi kin he iye iśta su kiunniya nakaeś.

9 Iho, hena iwankam nape wakoza kta, unkan iye wowidake wicayapi kin on wawicakipi kta ; hecen Jehowa ozuye yuhe cin umaśi kin he sdonyayapi kta.

10 Dowan wo, qa wiyuśkin wo, Zion cunwintku; iho, wau qa nicokaya ounwaye kta ce, Jehowa eya.

11 Unkan anpetu kin he en oyate ota Jehowa en ikoyagiciyapi kta, qa mitanyate eepi kta: unkan nicokaya ounwaye kta, qa Jehowa ozuye yuhe cin he niye ekta umaśi kin he sdonyaye kta ce.

12 Unkan Juda makoce wakan tawa qon he Jehowa tawakiye kta, qa ake Jerusalem en iyokipiiciye kta. 


\section{ZEKARIAH,}

13 Wicacehpi owasin, Jehowa itokam inina un wo: Iye tipi wakan tawa kin etanhan yuhicapi nakaeś.

\section{WICOWOYAKE 3.}

1 Unkan iye Joshua wawayuśna itancan kin wanyagmakiya; Jehowa wahośi wakan tawa kin itokam najin: unkan iye etapa eciyatanhan Satan kipajin kta inajin.

2 Unkan Jehowa Satan heciya; Satan, Jehowa iyopeniyan nunwe; han, Jehowa Jerusalem en iyokipiiçiye cin hee iyopeniyan nunwe. Petuspe wan peta etanhan icupi kin he dee śni he.

3 Unkan Joshua wokoyake śica ece un, qa wahośi wakłn kin itokam najin.

4 Hehan iye wayupte, qa tona itokam najinpi kin hewicakiya; Wokoyake śice cin hena ekiciyaku po, eya. Hehan iye hinca heciya; Wanyaka wo, wayahtani kin yutokan iyeciciya, qa wokoyake waśte hinca koyagciciye kta ce.

5 Hehan, Wateśdake ska wan pa akan ekicihnaka po, eya. Hecen wateśdake wan teśdagkiyapi, qa wokoyake kicunkiyapi. Unkan Jehowa wahośi wakan tawa kin hen najin.

6 Unkan Jehowa wahośiye kin he Joshua wakiciyaatanin qa heya ;

7 Jehowa ozuye hduhe cin he hecen eya ce; Mitacanku kin ohna mayani kinhan, qa mitoawanyake kin he awandake cinhan, hehan nakun wati ohna wadaco ece kta, qa nakun mitahocoka kin awandake kta; qa tona den najinpi kin hena ehnahna cankuyaye kta cicu kta.

8 Heon etanhan, Joshua wawa- yuśna itancan, nahon wo, niye qa tawaśiwicayaye cin nitokam iyotankapi kin: wicaśta kin hena wowapetokeca nakaeś: Qa iho, mitaokiye ADETKa he hinanpewaye kta ce.

9 Joshua itokam inyan ewahnake cin he wanyaka wo; inyan wanji akan iśta śakowin: Ihe, bagopi kin hena bawaggo kta; qa makoce lin he woaktani kin anpetu wanjidan en yutokan iyewaye kta ce, Jehowa ozuye hduhe cin eya.

10 Anpetu kin he en otoiyohi mitakodapi hastanhanka iyuwi ihukuya, qa suiken can ihukuya yecicopi kta ce, Jehowa ozuye hduhe cin eya.

\section{WICOWOYAKE 4.}

1 Hehan wahośi wakan mici wohdake cin he ake hi, qa mayuhica, wicaśta wan iśtinma etanhan yuhicapi kin iyececa:

\& Qa hemakiya; Taku wandaka he. Unkan hepa; Watonwan, qa iho, petijanjan ihupa wan ocowasin mazaskazi, qa iwankamtu wakśica wan, qa petijanjan śakowin tawa, qa pa akan petijanjan iyahde wihdi ohna hiyaye cin śakowin ikoyaka:

3 Qa icahda wihdi can nom han, wanji iś wakśica kin etapatanhan, qa unma icatkatanhan.

4. Hehan waamdupte, qa wahośi wakan mici wohdake cin hewakiya; Itancan mitawa, dena taku he, epa.

5 Hehan wahośi wakan mici wohdake cin he waayupte, qa hemakiya; Dena taku sdonyaye śni he, eya. Unkan, Han, Itancan mitawa, epa.

6 Hehan iye wayyupte, qa womakiyake ca heya; Jehowa vie Zerubabel eciye cin he dee; Woo- 


\section{WICOWOYAKE 5 .}

kili eciyatanhan śni, qa wowaśake eciyatanhan śni, tuka Mitaniya eciyatanhan kta, Jehowa ozuye hduhe cin eya.

7 Ḧe tanka Zerubabel itokam, niś nitaku he: makomdaye $\mathrm{kta}$. Unkan iye Inyan itancan kin au kta, Woiyokipi, woiyokipi kiciun ce, eyanpahapi kta.

8 Nakun Jehowa oie en mahi kin he hecen eya;

9 Zerubabel nape tipi kin de akan he cin he ehnaka; nakun iye nape hduśtan kta ce : hecen Jehowa ozuye yuhe cin, he niyepi ekta umaśi kin he sdonyaye kta.

10 Anpetu en taku cistinna ece e kin he tuwe wahtedaśni he: Jehowa iśta śakowin maka ocowasin en ohnihdeya unpi kin hena mazasu inyan Zerubabel nape ohna wanyakapi qa iyuśkinpi kta.

11 Hehan waamdupte, qa he. wakiya; Wihdi can nom petijanjan ihupa etapatanhan qa catkatanhan kin dena taku he.

$12 \mathrm{Qa}$ inonpa waamdupte qa hewakiya; Wihdi can adetka nonpa mazaskazi oiyahde nonpa ohna mazaskazi wihdi hiyuyapi kin dena taku he.

13 Unkan iye hemakiya; Dena taku hecinhan sdonyaye śni he, eya. Unkan, Han, Itancan mitawa, epa.

14 Hehan iye heya; Wihdi cinca nonpa maka ocowasin Itancan kin icahda najinpi kin dena eepi ce.

\section{WICOWOYAKE 5.}

1 Hehan mihduhomni, qa iśta yuwankan iwekcu qa watonwan, unkan iho, wowapi wan kinyan un.

2 Unkan iye hemakiya; Taku $\mathbf{K}$ : wandaka he. Unkan amdupte; Wowapi wan kinyan un wanmdaka, ohanske cin wiciśpa wikcemna nonpa, qa ohdakinyan iś wiciśpa wikcemna, epa.

3 Hehan iye hemakiya; Woyaśice maka ite kin owancaya iyaye cin he dee. Tona wamanon kin otoiyohi pajujupi kta nakaeś, deciyatanhan un kin iyececa; qa iciconzapi otoiyohi unma eciyatanhan un kin iyecen pajujupi kta ce.

$4 \mathrm{He}$ hinanpe waye lkta ce, Jehowa ozuye hduhe cin eya; unkan tuwe wamanon ti kin en i kta, qa tuwe micaje on itonśni iciconza ti kin en: qa tipi tawa kin cokaya wanke kta, qa ihangye kta, can qa inyan koya.

5 Hehan wahośi wakan mici wohdake cin he hinanpe ca hemakiya; Wanna iśta yuwankan ikikcu qa taku hinanpe cin de wanyaka wo.

6 Unkan, He taku he, epa. Unkan iye heya; De epha wan (ohna wiyutapi) hinanpa ce. Nakun iye heya; Hena maka kin owancaya decen owanyake ece.

7 Unkan iho, mazasu hmiyanyan wan yuwankan icupi : unkan epha cokaya winohinca wan iyotankehan yanke cin he dee.

8 Hehan iye heya; Wicohan śice cin he dee. Unkan he ephakin ocokaya ehpeya; qa i kin ohna mazasu inyan kin iyohpeya.

9 Hehan iśta yuwankan iwekcu qa watonwan, unkan iho, winohinca nonpa hinanpapi, qa tate kin he hupahu tawapi ohna yanka; hena hupahu yuhapi nakaeś, pehan tanka hupahu iyececa: unkan hena epha kin maka qa mahipiya otahedan tokan ayapi. 


\section{ZEKAPIAH,}

10 Hehan wahośi wakan mici wohdake cin hewakiya; Dena epha kin tokiya ayapi he.

11 Unkan iye hemakiya; Śinar makoce kin en tipi kicagapi kta: unkan hen ehnakapi kta, qa iye tohe kin en ehdepi kta ce.

\section{WICOWOYAKE 6 .}

1 Hehan wahdicu, qa iśta yu. wankan iwekeu qa watonwan; unkan iho, he nom otahedan tanhan canpahmihma topa hiyupi; unkan lie kin hena mazaśa he kin heca.

2 Canpahmihma tokaheya kin śunka wakau śaśa; qa canpahmihma inonpa kin śunka wakan sapsapa:

3 Qa canpahmihma iyamni kin sunka wakan skaska; qa canpahmihma itopa kin en śmnka wakan hdeśkaśka dusduzahanpi.

4 Hehan waamdupte, qa wahośi wakan mici wohdake cin hewakiya; Itancan mitawa, dena taku he.

5 Unkan wahośi wakan kin waayupte, qa hemakiya; Mahpiya woniya topa kin dena ee, maka owancaya Itancan itokam najinpi kin etanhan hiyupi.

6 Śunka wakan sapsapa en unpi kin hena waziyata makoce kin elata yapi; qa hena ihakam śaśa kin hiyayapi ; qa hdeśkaśka kin hena itokah makoce kin ektakiya yapi.

$7 \mathrm{Qa}$ dusduzaharpi kin hena iyayapi, qa maka kin en ohnihdeya mani kta akitapi. Unkan iye heya; Hunktiya po, maka kin en ohnihdeya mani po. Hecen maka kin en ohnihdeya unpi.

8 Hehan iye houmakiye ça wo518 makiyake ca heya; Wanyaka wo, tona waziyata makoce kin ekta iyayapi qon hena Mitaniya waziyata makoce kin en ehnakapi ce, eya.

9 Unkan Jehowa oie en mahi kin he hecen eya:

10 Wayalsa unpi kin etanhan icu wo, Heldai etanhan, Tobijah etanhan, qa Jedaya etanhan, qa anpetu kin he en niye hinca $u$ wo, qa Josiah Zephaniah cinhintku ti, Babel etanhan en hipi kin, he en ya wo :

11 Hehan mazaska qa mazaskazi icu qa wateśdake kaġa wo, qa Joshua Josedek cinhintku wawayuśna itancan pa kin akan ehnaka wo:

12 Qa kici wohdake ca heciya wo; Jehowa ozuye hduhe cin he hecen eya ce; Wicaśta Aderka eciyapi kin he wanyaka wo; unkan iye towanko kin etanhan uye kta, qa iye Jehowa tipi kin he kicage kta ce :

13 Han, iye hinca Jehowa tipi kin kage kta; qa iye hinca wowitan kin hduhe kta; qa iye toiyotanke kin en kiyotanke kta, qa itancan yanke kta; qa iye toiyotanke kin akan wawayuśna un kta: unkan wookiye iyukcanpi kin he henaoza om un kta.

14 Unkan wateśdake kin hena Helem, qa Tobijah, qa Jedaya, qa Hen Zephaniah cinhintku kin hena tawapi kta, Jehowa tipi kin ohna wokiksuye kta e heon.

15 Hecen tona itehan unpi kin hena upi kta, qa Jehowa.tipi kin ticagapi kta; unkan Jehowa ozuye hduhe cin he niyepi ek ta umaśi kin he sdonyayapi kta. Unkan Jehowa Taku Wakan nitawapi ho kin anagoptanyan anayagoptanpi kinhan hena hecetu kta ce. 


\section{WICOWOYAKE 8.}

WICOWOYAKE 7.

1 Unkan Darius wicaśtayatapi tawaniyetu itopa kin en, Jehowa oie Zekariah en hi, anpetu itopa, wi inapcinwanka, Kislu he en:

2 Wakantanka ti kin ekta Śerezer qa Regem-melek, qa wicaśta tawapi, Jehowa itoliam cekiya yewicaśi qon he ehan :

3 Jehowa ozuye hduhe cin he ti kin ohna wawayuśna unpi, qa wicaśta wokcan unpi kin hena om wohdakapi kta, qa heyapi kta: Wi izaptan en wanna waniyetu ota ecamon ece kin iyecen woteśni un waceye kta iyececa he.

4 Hehan Jehowa ozuye hduhe cin oie kin en mahi kin hecen eya :

5 Makoce oyate ocowasin qa wawayuśnápi kin hena om wohdake ca heya wo; Wi izaptan qa iśakowin kin en wotes̉ni yaunpi qa yaceyapi, waniyetu wikcemna śakowin hehanyan, he miye, miye hinca on, woteśni yaunpi he.

6 Qa tohan wayatapi qa wadathanpi eca, he niye wayahdutapi qa wayahdatkanpi śni he.

7 Jerusalem en ounyanpi qa wookiye yuhapi, qa ihdukśan otonwe kin, qa okahi makoce makomdaye ko en tipi qehan, wicaśta wokcan tokaheya Jehowa oie eyanpahapi quon dena ee śni he.

8 Hehan Jehowa oie Zekariah en hi kin he hecen eya :

9 Jehowa ozuye hduhe cin he ie ça decen eya ce; Woyaco wowicake kin econ po; qa wowaśte wocantekiye ko wicaśta otoiyohi iye sunkaku kin en ecayeciconpi kta.

10 Nakun wiwazica qa wamdenica, oyate tokeca qa wahpanica kin hena kakiświcayapi śni po; qa tuwedarl cante mahen iye sunkaku kin śicaya canteyeciyuzapi kte śni, eya.

11 Tuka anagoptan wicadapi śni, qa hinyete kipajinyan ehnakapi, qa noge ohmus icupi, hecen nahonpi kte śni.

$12 \mathrm{Han}$, woope kin nahonpi kte śni e heon cante inyan suta icicağapi, qa wicoie Jehowa ozuye hduha iye 'Taniya on, wicaśta wokcan tokaheya eciyatanhan hiyuye ciqon hena. Heon etanhan wocanteptanye tanka wan Jehowa ozuye hduhe cin etanhan hiyu.

13 Heon etanhan wanna kaketu, iye ho uya qehan hena nation wacinpi śni, he iyecen hena iś ho uyapi kta, tuka miye nawahoon kte śni ce, Jehowa ozuye hduhe cin eya.

14 Tuka oyate owasin sdonwicayapi śni qon hena ehnahna, icamna wan on, enanakiya iyewicawaye. Heon etanhan wicihakam makoce kin hewoskan ehpeyapi, qa tuwedan en ohnihdeya un śni: makoce oiyokipi kin he otiwota kaggapi nakaeś.

\section{WICOWOYAKE 8.}

1 Akes̉ Jehowa ozuye hduhe cin he oie kin hi qa heya:

2 Jehowa ozuye hdule cin he hecen eya ce; Zion on wowinawizi tanka on winawawizi, qa wocanteptanyan tanka on inawawizi ce.

3 Jehowa hecen eya; Zion en wahdi qa Jerusalem cokaya wati kta: unkan Jerusalem Wowicake Otonwe eciyapi kta; qa Jehowa ozuye yuha lie tawa kin he Ḧe Wakan eciyapi kta ce.

4 Jehowa ozuye yuhe cin he hecen eya; Nakun wicahincapi 


\section{ZEKARIAH,}

qa wakankapi Jerusalem canku kin en iyotankapi kta, qa waniyetu otapi on wicaśta otoiyohi sagye kiton kta.

5 Qa nakun otonwe canku kin. hokśipidan qa wicinyanpidan, canku ohnahna śkatapi, ojudan lita ce.

6 Jehowa ozuye hduhe cin he hecen eya; Anpetu kin hena en oyate kin de okaptapi iśtapi kin en de wowinihan kinhan, miye miiśta en wowinihan kta iyececa he, Jehowa ozuye yuhe cin eya.

ry Jehowa ozuye hduhe cin he hecen eya; Tho, wihinanpe makoce kin etanhan qa wiiyaya makoce kin etanhan mitaoyate niwicawaye kta.

8 Qa hena awicawaku kta, unkan Jerusalem cokahan ounyanpi kta; qa hena e mitaoyate kta, qa Taku Wakan tawapi kin he miye kta, wowicake qa woowotanna en.

9 Jehowa ozuye hduhe cin he hecen eya; Tipi wakan kaģapi kta, on Jehowa ozuyc yuha he tipi oahe ehnakapi, anpetu kin cn wicaśta wokcan i eciyatanhan oiepi, tona anpetu kin dena en wicoie kin hena nayationpi, nape waniśakapi nunwe.

10 Anpetu kin dena itokamtu wicaśta htani wicakicicajujupi wanica, qa woteca wicakicicajujupi wanica nakaeś : qa tuwe tankan ye ca tin ku eśta wookiye yuhe śni, wokakije kin on etanhan; wicaśta owasin akicipaha wicawakiya nakaeś.

11 Tuka nakaha oyate kin de okaptapi kin en anpetu ehanna waun qon iyemacece kte śni, Jehowa ozuye yuhe cin eya.

12 Wojupi kin he wookiye en un kta; hastanhanka iyuwi kin waskuyeca icahye kta; qa maka 520 kin oicagie hiyuye kta, qa mahipiya kin cu wicaqu kta; qa oyate kin de okaptapi kin hena dena iyuhpa tawaye wicawaye kta ce.

13 Unkan kaketu Kte, Juda tiyohnaka qa Israel tiyohnaka, Ilkcewicaśta ahnahna woyaśice iyececa yaunpi qon, he iyecen miye niciyapi kta, qa woyawaśte yaunpi kta: Wakokipapí śni po, nape hduwaśaka po.

14 Jehowa ozuye hduhe cin he heren eya; Nihunkakepi śihdamayanpi qehan, śicaya cicuwapi kta wacanmi qon, Jehowa ozuye yuhe cin eya, qa iyopemiçiye śni ;

$15 \mathrm{He}$ iyececa, ake anpetu kin dena en Jerusalem qa Juda tipi kin tanyan ecawicawecon kta wacanmi ; wakokipapi śni po.

16 Wicoie ecanonpi kte cin dena ee: Wicaśta otoiyohi takodaku kici wowicake ecee eyeciyapi kta; wowicake qa wookiye woyaco kin nitatiyopa ohnahna hdaco po.

17 Qa tuwedan cante mahen takodaku taku śica ecakicon wacannipi kte śni, qa woitonśni wokonze kin he waśtedakapi śni po; hena orvasin taku śicewadake ciqon ee ce, Jehowa eya.

18 Hehan Jehowa ozuye yuhe cin oie en mahi kin he hecen eya :

19 Jehowa ozuye yuhe cin he hecen eya ce; Wi itopa en woteśni unpi, qa izaptan en woteśni unpi, qa iśalkowin en woteśni unpi, qa iwikcemna en woteśni unpi qon hena Juda tipi kin en wiy uśkinpi kta, qa woiyokipi kta, qa wotapi waśte kta ce. Heon etanhan wowicake qa wookiye waśtedaka po.

20 Jehowa ozuye yuhe cin he hecen eya; Ehake oyate kin upi 


\section{WICOWOYAKE 9.}

kta, qa otonwe ota en ounyanpi kin hena ;

$21 \mathrm{Qa}$ otonwe wanji en ounyanpi kin wanji tokeca ekta yapi kta qa heyapi kta; Unyanpi kta, Jehowa itokam cekiya unyanpi kta, qa Jehowa ozuye hduhe cin he unkodepi kta. Miś eya mde kta ce.

22 Han, oyate ota qa Ikcewicaśta waśalkapi kin hena upi kta, Jerusalem en Jehowa ozuye hduhe cin he akitapi kta, qa Jehowa itokam cekiyapi kta ce.

23 Jehorva ozuye hduhe cin he hecen eya ; Anpetu kin hena en, Ikcewicaśta iapi toktokeca owasin etanhan wicaśta wikcemna wiyuzapi kta; han, Juda wicaśta wanjidan taśina en yuzapi kta, qa heyapi kta; Nici unyanpi kta ce, Wakantanka nieipi un kin he naunhionpi nałłaeś.

\section{WICOWOYAKE 9.}

1 Jehowa oie Ḣadrak makoce kin en oyakapi, qa Damasek toozikiye kta ; tohan wicaśta iśta qa Israel wicowazi owasin Jehowa ektakiya yakonpi kinhan:

2 Qa nakun Hamat ikoyag yanke kta; Turos qa Zidon, he ksape hinca qeyaś.

3 Unkan Turos conkaśke suta wan içicağa, qa maka mdu iyececa mazaska eju aya, qa mazaskazi hinca, canku upśija kin iyececa.

4 Iho, Itancan kin he tankan hiyuye kta, qa towaśake miniwanca ohna kin he kaśtake kta; qa peta on hinhnahyapi kta.

5 Aśkelon he wanyake kta qa kokipe kta; Gaza nakun nina nihinciye kta; nakun Ekron, wowacinye tawa kin iśtenyapi nakaeś: Unkan Gaza etanhan wicaśtayatapi kin atakuni kte śni, qa Aśkelon en ounyanpi kte śni.

6 Qa tuwe cinca taninśni wan A.śdod en ounye kta ; qa Philistia oyate towahanicida kin he wakaśpe kta.

7 Qa iye $\mathrm{i}$ kin etanhan we kin iwacu kta, qa taku wowahteśni iye hi kin otahedan tanhan: tulia tuwe okaptapi kin, iye hinca, Taku Wakan unkitawapi kin on, en yanke kta, qa he qe Juda en wicaśtayatapi iyecece kta, qa Ekron Jebus wicaśta iyecece kta.

8 Qa tipi mitawa ihdukśan ahiwati kta, ozuye kin on etanhan, tuwe iyopta ye ca tuwe ku kin on: Qa hetanhan wakakiśye kin icimana hena opta ye kte śni; wanna miiśta on wanmdaka nakaeś.

9 Zion cunwintku, nina wiyuśkin wo; Jerusalem cunwintku, iyaśa wo ; iho, Wicaśtayatapi nitawa en niku kta; He owotanna qa wowanikiye hduha; wahba. yedan qa śonśonna wan akan iyotanka, han, śonśonna wiye cinca wan akan.

10 Unkan Ephraim etanhan ozuye canpahmihma kin ihangwaye kta, qa śuktanka kin Jerusalem etanhan, qa okicize itazipa kin kaksapi kta: Hehan iye Ikcewicaśta kin wookiye owicakiciyake kta: qa iye tokiconze kin miniwanca kin etanhan miniwanca kin elsta, qa wakpa kin etanhan maka ihanke kin hehanyan kta.

11 Nakun niye on, wicotakuye nitawa we kin eciyatanhan kaśka hnakapi nitawa kin hena woha mini codan kin hetanhan hiyuwicawaye kta ce.

12 Wowacinye yuha nicaślkapi kin, conkaśke suta kin ekta hdicu po: Anpetu kin de eyanwapaha; Nonpa akihde cicicajuju kta ce: 


\section{ZEKARIAH,}

13 Tohan Juda namiçiwinje cinhan, Ephraim itazipa kin en ewahnake kta, qa, Zion, nicinca, Javen nicinca kin itkokim inajin wicawakiye kta, qa wicaśta waditake tamazasagye kin iyececa cicagie kta ce.

14 Unkan hena wiciwankamtu Jehowa taninyan un kta, qa tiwanhinkpe kin wakanhdi iyecen iyaye kta: Qa Jehowa Itancan kin mazayahotonpi tanka kin yahoton kta, qa itokah tate iyumni kin ohna hiyaye kta.

15 Jehowa ozuye hduhe cin he awicakahpe kta: hecen hena wotapi kta, qa inyan kahoya hiyuyapi kin hena amanipi kta; qa wayatkanpi kta, miniśa on oqoyapi iyecece kta; qa wipipi kta wakśica iyececa, owayuśna oise kin iyececa.

16 Unkan anpetu kin he en, Jehowa Taku Wakan tawapi kin he niwicakiye kta, iye taoyate, optaye wan iyececa; wateśdake inyan, iye tamakoce kin en bosdan ehnakapi kin iyececapi kta nakaeś.

17 Iye towaśte kin tanka hinca, qa toiyokipi kin he wopteca śni: wojupi kin he kośka lkin icahwicaye kta, qa miniśa teca kin, wikośka kin hena.

\section{WICOWOYAKE 10.}

1 Ehake magiaju kta hehan Jehowa magiaju kida po: Jehowa wakanhdi kagge kta, qa mağaju wicaqu kta; maga en otoiyohi woicage qu kta.

2. Wakağapi kin hena takuśnisni oyakapi nakaeś, qa wakan kağapi ksin hema woitonśni wanyakapi, qa wowihanmna wicakapi śni ohdakapi ece: takuśni on wacintonhnag wicakiyapi: Heon etanhan nunipi, tahinca 522 optaye wan iyececa, waawanyake wanica heon wacin iyokiśicapi.

3 Waawanyake kin hena on mitocanniye ide, qa tamdoka kin iyopewicawaye. Tuka Jehowa ozuye yuhe cin he iye optaye tawa wanhdag wicahi, Juda tiyounaka kin hee, qa okicize en taśunke wakan oiyokipi kin iyececa wicakaga.

4 Oise kin he iye etanhan ; mazaiy oka tkuge kin he iye etanhan; okicize itazipe kin he iye etanhan; iye etanhan wawicakiśye owasin witaya upi kta.

5 Unkan wicaśta waditake okicize en canku upśija iyecen awicamanipi kin iyececapi kta: nakun kicizapi kta, Jehowa wicakiciun nakaeś, qa śuktanka akan yotankapi kin hena wacinhnunipi kta.

6 Hehan Juda tiyohnaka kin mduwaśake kta, qa Joseph tiyohnaka kin niwakiye kta, qa en ounyewicawakiye kta, onśiwicawakida nakaeś: unkan hena elipewicawakiye śni iyececapi kta; Jehowa Taku Wakan tawapi kin he miye nakaeś, becen nawicawahon kta ce.

7 Nakun Ephraim wicaśta waditaka iyececapi kta; qa cantepi wiyuśkin kta, miniśa on iyececa ; han, iye cinca kin wanyakapi kta qa wiyuśkinpi kta; hena cantepi Jehowa on iyuśkinpi kta ce.

8 Hena wicawakijojo kta, qa wicamduwitaya $\mathrm{kta}$, opewicawakiton nakaeś: unkan ihduotapi kta, ihduotapi qon iyececa.

9 Unkan oyate kin ehnahna owicawaju kta : nakun makoce tehanhan kin en miksuyapi kta; qa iye cinca kin om nipi kta, qa ake hdicupi kta.

10 Nakun Egupta makoce kin 
ctanhan awicawaku kta, "qa Aśur etanhan wicamduwitaya kta: qa ake Gilead makoce qa Lebanon en awicawahdi kta; qa owicakan kte śni.

11 Unkan iye wokakiśye yuha mini tanka kin ehna ye kta, qa miniwanca taja kin ape kta; hecen wakpa ośbe kin iyuhpa oyahe kta: qa Aśur towahaniçida kin he makata ehpeyapi kta, qa Egupta cansagye tawa kin tokan iyaye kta.

12 Qa hena Jehowa en wicamduwaśake kta ; hecen iye caje kin on hena ohnihdeya unpi kta, Jehowa eya.

\section{WICOWOYAKE 11.}

1 Lebanon, tiyopa nitawa hduhdoka wo; hecen peta kin hanteśa ni tawa liulinaliye kta.

2 Wazi can, śicahowaya wo; hanteśa kin wankahan nakaeś, suksuta kin hena awihnunipi. Baśan utuhu kin, śicahowaya po, contanka en yepica śni qon he kawankapi nakaeś.

3 Waawanyake śicahowayapi ho kin; towitanpi kin awihnuni nakaeś ; mnaja kośka hotonpi ho kin; Jordan towahanicida kin awihnuni kin heon.

4 Jehowa Wakantanka mitawa. kin he hecen eya; Optaye ktepi kte cin he wo qu wo:

5. Tona wicayuhapi kin hena wicaktepi ece, tuka śicaya econ ihdawapi śni; qa wiyopewicaya ecee kin hena heyapi; Jehowa yawaśtepi nunwe; miye wimajica nakaeś : qa waawanyake tawapi kin wicakpatanpi śni ece.

6 Miś eya ake makoce ounyanpi kin wicawapatan kte śni, Jehowa eya: tuka iho, wicaśta otoiyohi iye takodaku nape kin en iyohpaye waye kta, qa wica. śtayatapi tawa nape kin en: unkan hena makoce kin kaśtakapi kta, qa iye napepi kin etanhan ewehdaku kte śni ce.

7 Hecen optaye ktepi kte cin he wo waqu ece, awicakehan tahinca onśikapi kin. Unkan cansagye nom iwekcu; wanji, Wocantekiye, eya caśwakiton, qa unma kin iś, Woicaślke, caśwaton: hecen optaye kin wonwicawakiya ece.

8 Nakun wi wanjidan en waawanyake yamni ihangwicawaya: Qa minaği hena wahtewicada śni, qa iye nagiipi kin iś eya śicemadakapi.

9 Hehan hepa; Woyute cicupi kte śni : taku țe kte cin he țe kta; qa taku ihangyapi kte cin ihangyapi kta; qa tona okaptapi kin hena otoiyohi celipi kiciyutapi kta ce.

10 Hehan cansagye mitawa, Wocantekiye he iwacu qa wahdaksaksa, oyate owasin om wicotakuye wicawecage. ciqon he mdujuju kta heon.

11 Unkan anpetu kin he en yujujupi : Hecen tahinca onsikapi tona anamagoptanpi kin hena he Jehowa oie kin hee e sdonyapi.

12 Hehan hewicawakiya; Niiśtapi en he waśte hecinhan wokajuju maqu po; qa hecetu śni kinhan, econpi śni po. Unkan wokajuju mazaska wikcemna yamni tke imiciyutapi.

13 Hehan Jehowa hemakiya; Wakśica kağe cin he en elipeya wo; wokajuju waśte linca on imayacinpi kin hee. Unkan mazaska wikcemna yamni qon hena iwekcu, qa wakśica kage cin en elipewaya, Jehowa ti kin etu.

14 Hehan cansagye mitawa unma qon, Woicaśke he wahduksa ; Juda qa Israel kici wicotakuye 523 


\section{ZEKARIAH,}

kin he mdujuju kta e heon etanhan.

15 Unkan Jehowa hernakiya; Waawanyake witkotkoka ikicanye tawa kin ake ikikcu wo.

16 tho, makoce kin en waawanyake wan najinwakiye kta; he qe taku a takuniśni kin ekta etonwe kte śni, taku taninśni kin he okide kte śni, taku kiunniyanpi kin he okiziye kte śni, qa taku en un kin he wo qu kte śni ; tuka tona cepa cehpi kin temye kta, qa sake kin hena yuksaksa kta ce.

17 Hehehe waawanyake taku śni, optaye ehpewicaye cin he: mazasagye kin iye isto kin akan yanke kta, qa iśta etapa kin akan: isto kin ocowasin śnije kta, qa iśta etapa kin he ocowasin aotpasyapi kta.

\section{WICOWOYAKE 12.}

1 Jehowa oie Israel on oyakapi. Jehowa mahpiya kin ludumdaya, qa maka oahe kin ehna$\mathrm{ka}$, qa wicaśta mahen woniya kicaga ecee kin he hecen eya:

2 Iho, Jerusalem wiyatke iwitkopi kin heca wakage kta, oyate ihdukśan hiyeye cin owasin on ; qa nakun Juda akan yanke kta, Jerusalem onatakapi kin en.

3 Unkan anpetu kin he en oyate owasin on Jerusalem inyan yuwankan icupi kte cin heca wakagie kta: yuwankan icupi kin hena owasin kiunniiçiyapi kta, maka akan oyate hiyeye cin iyuhpa en kiwitayapi qeyaś.

4 Jehowa hecen eya; Anpetu kin he en śuktanka otoiyohi wakokipe wecagge kta, qa akan yotanke cin he wacinhnuni kta: tuka Juda tipi kin en ewatonwe kta, qa śuktanka oyate tawapi kin iyuhpa iśtag̉onge wicawakiye kta ce.

5 Hehan Juda itancanpi kin cante mahen heyapi kta; Jerusalem en ounyanpi kin Jehowa ozuye yuha Taku Wakan tawapi kin en, wowaśake mitawa kin heepi kta ce.

6 Anpetu kin he en Juda itancanpi kin hena can ihukuya peta oceti kin iyececa wicawa kage kta, qa peji opahte kin en petuspe wan iyececa: unkan etapa eciyatanhan qa catkatanhan oyate ihdukśan hiyeye cin owasin linhnahwicayapi kta. Unkan Jerusalem ake en ounyanpi kta, iye towanke kin en, Jerusalem hetu.

7 Qa nakun Jehowa tokaheya Juda tawakeya kin niwicaye kta, hecen Dawid ti towitan, qa Jerusalem en ounyanpi towitanpi kin Juda iwankam iyeiçiye kte śni.

8 Anpetu kin he en Jehowa Jerusalem en ounyanpi hin waawicakahpe kta; qa hena ehna tuwe huha suta śni kin anpetu kin he en Dawid iyecece kta; qa Dawid tiyohnaka kin Taku Wakan iyecece kta, wahośi wakan Jehowa tawa wicitokam un kin iyececa.

9 Unkan anpetu kin he en oyate Jerusalem takpe upi kin hena owasin ihangwicaya awakite kta :

10 Qa Dawid tiyohnaka qa Jerusalem en ounyanpi lsin hena wocantekiye qa wocekiye woniya kin awicawakaśtan kta: Hecen miye camapapi kin en ahimatonwanpi kta, qa iye on ceyapi kta, hokśincantkiyapi on ceyapi kin iyececa, qa on nina cante śicapi kta, tuwe cinca tokapa on nina cante śica iyececa.

11 Anpetu kin he en Jerusalem 


\section{WICOWOYATE 14.}

en wicaceya tanka kta, Megiddon kaksiza ohna Hadad-rimmon wicaceya qon iyececa.

12 Unkan makoce kin ceye kta, wicowazi otoiyohi iśnana; $\mathrm{Da}$ wid tiyohnaka wicowazi iśnanpidan, qa tawicupi iśnanpidan; Nathan tiyohnaka wicowazi iśnana, qa tawicupi iśnanpidan :

13 Levi tiyohnaka wicowazi iśnana, qa tawicupi iśnanpidan; Shimei tiyohnaka wicowazi iśnana, qa tawicupi iśnanpidan:

14 Wicowazi okaptapi kin iyuhpa, wicowazi otoiyohi iśnana, qa tawicupi kin 'iśnanpidan kta.

\section{WICUWOYAKE 13.}

1 Anpetu kin he en woahtani qa woaśape on minihidoka wan Dawid tiyohnaka qa Jerusalem en ounyanpi kin wicakiyulidokapi kta.

2 Unkan anpetu kin he en kaketu kta, Jehowa ozuye hduhe cin eya; maka kin etanhan wakağapi cajepi kin ihangwaye kta, qa lietanhan ake kiksuyapi kte śni: qa nakun waayatapi qa wośice woniya kin hena makoce kin etanhan tokan iyayewaye kta ce.

3 Unkan kaketu kta, wicaśta wanji waayate kinhan, atkuku qa hunku icahkiyapi kin hena heciyapi kta; Yani kte śni, Jehowa cajeyan itonśniyan iyaa nakaes : Hecen atkuku qa hunku icahkiyapi qon hena capapi kta, waayate kin heon.

4 Unkan anpetu kin he en waayatapi kin otoiyoli waayatapi kinlian, wowanyake tawa kin on iśtecapi kta, qa wicahnayanpi kta on icimana wokoyake hin śma kin koyakapi kte śni.

5 Tuka heye kta; Waayate hemaca śni, mahyumdu hemaca; homakśidan qehan wicaśta wan opematon nakaeś.

6 Hehan tuwe heciye kta; $\mathrm{Ni}$ nape ohna osnazi kin hena taku he. Unkan iś, Mitakoda ti kin olina ksuwemayanpi qon hena ee ce, eye kta.

7 Mazasagye, Waawanyake mitawa iwankam inajin wo, qa wicaśta mitakoda kin he iwankam, Jehowa ozuye yuha eya: Waawanyake kin he apa wo, kinhan optaye kin enanakiya iyewicayapi kta: tuka cistinpidan kin hena en nape yewakiye kta ce.

8 Unkan makoce ocowasin en kaketu kta, Jehowa eya; ohna ośpaye nonpa ihangwicayapi kta, tapi kta ; tuka ośpaye iyamni kin he ohna okaptapi kta.

9 Unkan nśpaye iyamni kin he peta ehna awicawau kta, qa mazaska yuecepidan iyecen wicamduecedan kta, qa mazaskazi iyutapi kin iyecen iwicamdute kta: Hena micaje hoyekiyapi kta, unkan awicamdupte kta: Mitaoyate hee ce, epe kta; unkan iś, Jehowa Taku Wakan mitawa ce, eyapi kta ce.

\section{WICOWOYAKE 14.}

1 Iho, Jehowa taanpetu kin $u$ kta, unkan wahpaya nitawa nicokaya pamnipi kta.

2 Oyate iyuhpa Jerusalem azuya awicawau kta nakaeśs qa otonwe kin icupi kta, qa tipi kin hena wawicakipi kta, qa winyan kin iś wicakikśanpi kta. Unkan otonwe hanke wayaka awicayapi kta; tuka wicaśta okaptapi kin hena otonwe etanhan kaśpa iyewicayapi kte śni ce.

3 Hehan Jehowa hinanpe lita, qa oyate kin hena azuwicaye kta; okicize anpetu kin en, anatanpi anpetu qon iyececa. 


\section{ZEKARIAH.}

4 Unkar anpetu kin he en iye siha Oliwe Paha kin en iyahe kta, Jerusalem itokam iwiyohiyanpa tanhan wanke cin; unkan Oliwe Paha kin wihinanpatakiya qa wiyohpeyatakiya cokaya kinaksa iyaye kta, kaksiza tanka hinca kta: qa Paha hanke waziyatakiya iyaye kta, qa hanke kin iś itokahikiya ye kta.

5 Unkan niye he mitawa kaksiza kin ekta nayapapi kta, hecaksiza kin he Azal iyahde kta nakaeś : han, nayapapi kta, Uzziah Juda wicaśtayatapi taanpetu kin en maka śkanśkan etanhan nayapapi qon iyececa. Hehan Jehowa Taku Wakan mitawa kin u kta, tona owotanna kin owasin nici unpi kta.

6 Unkan anpetu kin he en kaketu kta, iyoyanpa kin he sota kte śni, tuka cagia kta.

7 Tuka anpetu kin he wanjidan kta, Jehowa sdonye kta; anpetu śni qa hanyetu śni; tuka htayetu kinhan hehan iyoyanpa kta.

8 Unkan anpetu kin he en wiconi mini Jerusalem etanhan hiyu $\mathrm{kta}$; hanke wiyohiyanpata miniwanca kin ekta, qa hanke wiyohpeyata miniwanca kin ekta hiyaye kta; mdoketu qa waniyetu nakun hecetu kta.

9 Hehan Jehowa maka kin owancaya Wicaśtayatapi kta: Anpetu kin he en Jehowa wanjidan kta, qa iye caje kin wanjidan kta ce.

10 Makoce kin ocowasin omdaye kin iyecece kta, Geba etanhan qa Rimmon hehanyan, Jerusalem itokagatanhan; qa he qe yuwankan iyeyapi kta, qa towanke kin en ounyanpi kta, Benjamin tatiyopa etanhan tiyopa tokaheya kin ekta, okahmin tiyopa kin hehanyan; qa Hannameel conkaśke tawa kin etanhan miniśa iyuśkice wicaśtayatapi tawa kin hehanyan.

11 Unkan en ounyanpi kta, qa woyaśice icimana yuke kte śni ; tuka Jerusalem wikopeśniyan en ounyanpi kta ce.

12 Unkan oyate Jerusalem azuyapi qon owasin makośica on Jehowa wicakaśtake kte cin he dee: Siha on najinpi icunhan cehpi wicakikuke kta; qa iśta ohdoka ohna kuke kta, qa iye ipi ohna cejipi kin kuka aye kta.

13 Unkan anpetu kin he en kaketu kta, Jehowa etanhan wonihinciye tank a wan wicehna un $k$ ta hecen wicaśta otoiyohi takodaku iyakicihpayapi kta, qa takodaku nape kin itkom nape apaha najin kta.

14 Qa nakun Juda Jerusalem ekta ozuye econ kta: unkan oyate ihdukśan hiyeye cin tawowijice kin mnayanpi kta, mazaskazi, qa mazaska, qa wokoyake utkanna hinca.

15 Unkan śuktanka makośica, śonśonna, camo, qa śonśonna cistinna, qa woteca owasin ozuye owanka kin de en unpi kin he makośica kin de iyecece kta.

16 Unkan kaketu kta, tona okaptapi, oyate owasin Jerusalem takpe upi qon etanhan, hena iyuhpa omaka qa omaka eca, Wicaśtayatapi kin Jehowa ozuye yuhe cin hee e ohoda yapi kta, qa ohanzihdepi wohanpi kin en opapi kta.

17 Unkan kaketrı kte, maka akan wicowazi kin etanhan tona Jerusalem ekta Jehowa ozuyé yuha Wicaśtayatapi kin ohoda upi kte śni kin hena en magiaju wanice lita.

18 Qa Egupta wicowazi kin ekta ye śni, qa en u śni kinhan, iś eya en wanice kta: oyate ohanzihdepi wohanpi kin en opa 


\section{MALAKI.}

upi kte śni, Jehowa makośica on wicakaśtake kte cin he en un kta.

19 Egupta wahtani kin he dee, qa oyate owasin ohanzihdepi wohanpi kin en opa upi kte śni wah̉tanipi kin hee.

20 Anpetu kin he en śuktanka tamazahidahda kin akan Jehowa on Wakan ce; qa Jehowa ti kin ohna cega kin hena owayuśna itokam mazawakśica kin iyecece kta.

21 Han Jerusalem en, qa Juda en, cega otoiyohi Jehowa ozuye yuhe cin on wakan kta; qa tona wawayuśnapi kte cin hena upi kta, qa etanhan icupi kta, qa ohna wohanpi ece kta: Unkan anpetu kin he en Jehowa ozuye yuhe cin he ti kin olna Kanaan wicaśta wanice kta ce.

\section{A L A K I.}

\section{WICOWOYAKE 1.}

1 Jehowa oie Malaki nape kin eciyatanhan Israel owicakiyakapi kin dee.

2 Canteciciyapi ce, Jehowa eya: Tuka, Taku e en canteunyakiyapi he, ehapi. Esau Jakiob cincu kin hee śni he, Jehowa eya : tuka Jakob waśtewakidaka;

3 Qa Esau śicewadaka, qa he tawa kin hewoskan wakaga, qa makoce tawa hewotahedan wamduśka ounyanpi kin heca.

4 Unkiciyujujupi, tuka ake unhdapi kta qa otiswita kin piya unkaģapi kta ce", Edom eya keś, Jehowa ozuye hduhe cin hecen eya; Hena piya kagapi kta, tuka miye moujuju kta: unkan, Wośice ihanke, qa, Oyate Jehowa ohinniyan canniyewicaya, ewicakiyapi kta.

5 Tuka niiśta wanyakapi kta, qa niye hehapi kta; Jehowa yatankapi nunwe, Israel makoce ihanke kin etanhan.

6 Wicacinca wan atkuku kin ohokida, qa wowidake wan itancan tawa kin kokipa ece. Hecen miś miye atemayanpi waun kin- han ohomakidapi kin tukte e he; qa itancan mayanpi waun kinhan komakipapi kin tukte e he; wawayuśna yaunpi, micaje wahteyadapi śni kin, Jehowa ozuye yuhe cin heniciyapi ce. Tuka, Taku e en nicaje wahteundapi śni he, ehapi.

7 Owayuśna mitawa akan woyute aśapapi kin wamayakiyuśnapi ece. Tuka, Taku e en unniyuśapapi he, ehapi. Jehowa tawahnawotapi kin he wahteśni ce, ehapi kin heon.

8 Qa taku iśtağonge cin he wayaduśnapi kinhan, he śice śni he: qa taku huśte qa wayazanka kin wayaduśnapi kinhan, he śice śni he. Wanna wicaśtayatapi nitawa lxin qu wo; he iyokipiyaye kta he, qa niite yuwankan inicu kta he, Jehowa ozuye yuhe cin eya.

9 Heon nakaha, ceciciyapi, Wakantanka ite kin yuwinta po, hecen onśiunkidapi kta: Niye ninapepi kin etanhan dececa nakaeś: niitepi yuwankan inicupi kta he, Jehowa ozuye yuhe cin eya.

10 Niyepi kaeś etanhan tuwe 527 


\section{MALAKI,}

tiyopa kin ecen iyeye kta he: han, wokajuju codan owayuśna mitawa akan ceyatipi kte śni. Ecaca iyomayakipipi śni ce, Jehowa ozuye hduhe cin eya; qa ninapepi etanhan wośna wan iwacu kte śni.

11 Wihinanpe cin etanhan, qa wiiyaye cin hehanyan Ikcewicaśta oyate kin ehnahna micaje tanka kta nakaeś; qa owanka owasin en micaje on wizinye izitapi kta, qa wośnapi ska wan : Ikcewicaśta oyate kin ehnahna micaje kin tanka k ta ṇakaeś, Jehowa ozuye yuhe cin eya.

12 'Tuka niye he daśicapi, Jehowa tawahnawotapi kin yuśapapi, qa tawaskuyeca, woyute tawa kin he wahteśni ce, ehapi kin heon.

13 Nakun hehapi; Ecalie, taku on mdokițapi cee: qa apoyaśinśinpi, Jehowa ozuye yuhe cin eya. Nakun taku yahdehdecapi, qa huśte kin, qa wayazanke cin hena ayaupi ece; hecen wośna ayahipi ecee. De ninapepi etanhan iwacu kta iyececa he, Jehowa eya.

14 Tuka tuwe optaye tawa kin en mdoka wan yuha, tuka wicahnayan, qa ic̣iconze ça Itancan taku śica wan wakiyuśna kinhan, he yaśicapi kta ce: Wicaśtayatápi tanka kin he miye nakaeś, qa Ikcewicaśta oyate kin ehnahna micaje kin wowinihan hinca, Jehowa ozuye yuhe cin eya.

\section{WICOWOYAKE 2.}

1 Unkan nakaha, wawayuśna yaunpi, niyepi on wowaśi kin dee :

2 Wanayahonpi śni, qa micaje wowitan yaqupi kta cante en eniçihnakapi kte śni hecinhan, woyuśice wan en aciyapi kta, qa nakun woyuwaśte nitawapi kin mduśice kta, Jehowa ozuye yuhe cin eya: han, wanua hena mdaśica, cante en eyecihnakapi śni kin heon.

3 Iho, wojupi nitawa iyopeciciyapi kta, niitepi kin en tacesdi awakada kta, wośnapi nitawapi tacesdi kin hee; unkan he ekta aniyanpi kta.

4 Unkan woahope kin de cicahipi he sdonyakiyapi kta, wicotakuye mitawa kin he Levi kici un lita e heon, Jehowa ozuye yuhe cin eya.

5 Wicotakuye mitawa kin he wiconi qa wookiye on kici un: unkan wokokipe on hena waqu, hecen komakipe kta, qa micaje itokam nihinciye kta e heon.

6 Wowicake woope kin he iye i kin ohna yanka, qa iha en wohnaye takudan iyeyapi śni nakaeś: iye qe wookiye qa woyuecetu yuha mici mani, qa wicota woalitani etanhan wicayuhomi ce.

7 Wawayuśna iha kin wosdonye kpatan kta nakaeś, qa iye i kin etanhan woope kin akitapi kta iyececa: Jehowa ozuye yuhe cin wahośiye tawa kin hee nakaeś.

8 'Tuka niyepi canku kin icunonpa idadapi; woope kin en wieota naśnawicayakiyapi; Levi wicotakuye tawa kin he duśicapi ece, Jehowa ozuye yuhe cin eya. 9 Heon etanhan miś eya oyate owasin ehnahna wahteśni qa śica cicağapi ; mitacanku kin yapatanpi śni, tuka woope kin en wicite iwandakapi ecee kin he iyececa.

10 Owasin ateyapi wanjidan unhapi śni he; Taku Wakan wanjidan icahunyanpi śni he: hecen tokeca hunkakewicunyanpi wicotakuye tawapi yuśicapi 


\section{WICOWOYAKE 3.}

kin on, wicaśta otoiyohi iye sunkaku en sicaya unkokicilianyanpi he.

11 Juda śicaya ohanyan, qa wo wahteśni wan Israel qa Jerusalem en econpi ece; Jehowa tipi wakan waśtekidake cin be Juda yuśica, qa taku wakan tokeca cunwintku kin yuza nakaeś.

12 Wicaśta tuwe hecon kin he Jehowa ihangye kta, tuwe kikta un, qa tuwe waayupte, Jakob tawakeya kin etanhan, qa tuwe Jehowa ozuye yuhe cin wośna wan wakiciyuśna kinhan.

13 Unkan de inonpa ecanonpi, Jehowa owayuśna tawa kin iśtamnihanpe, qa ceyapi, qa śicahowayapi on ayakahpapi ; hecen wośnapi kin icimana ekta etonwe śni, qa ninapepi etanhan woiyokipi kin icu śni.

14 Tuka, Tokeca he, ehapi. Jehowa waayatanin yanka, niye qa nitawin hokśiwinna duze ciqon otahedan, lie en śicaya oyecihanyan nakaeś: Tuka he qe nitawin, qa winohinca en niçconze cin hee.

15 Unkan wanjidan kag̉e śni he: Woniya wookapte kin hduha tuka qon. Unkan tokeca wanjidan he. Wakantanka tawicoicagie kin akita heon. Heon etanhan nitaniyapi kin awanhdaka po; qa tuwedan tawicu hokśiwinna yuze cin he śicaya okicihanye kte śni.

16 Ehpekiciyapi kin he śicewadaka ce, Jehowa Israel 'Taku Wakan tawa kin eya: nakun tuwe tawicu on wośice ahdahpa, Jehowa ozuye yuhe cin eya. Heon etanhan nitaniyapi kin awanhdaka po, śicaya oyahandapi kte śni e heon.

17 Nioiepi kin on Jehowa daśihitinpi ece. Tuka, Taku e on unyaśihtinpi he, ehapi. Tohan, 81
Tuwe taku sica econ kin otoiyohi Jehowa ista kin en waśte, qa hena iyowicakipi ce, ehapi kinhan: Qa, Woyaco Wakantanka kin tukten un he, ehapi kinhan.

\section{WICOWOYAKE 3.}

1 Iho, wahośi mitawa yewaśi kta, unkan iye mitokam canku kin yuwiyeye kta: Hehan Itancan oyakidepi kin he ihnuhanna u kta, tipi wakan tawa kin ekta ; han, wicotakuye wahośiye waśteyakidapi kin hee; iho, iye hi thta ce, Jeliowa ozuye yuhe cin eya.

2 Tuka anpetu en hi kinhan he tuwe okihi kta he; qa ihdutanin kinhan tuwe najin kta he: waśdoye peta tawa kin iyececa, qa wayujaja wipajaja tawa kin iyececa nakaeś.

3 Qa mazaska śdoye ca vuecedan iyotanke kta; qa Levi cinca kin wicayuecedan kta, qa mazaskazi mazaska ko iyecen wicayucan kta; hecen woowotanna en wośna wan Jehowa wakiyuśnapi kta:

4 Hehan Juda qa Jerusalem tawośna kin Jehowa iyokipi kta, hekta anpetu kin en, qa tanihan waniyetu qon en iyececa.

5 Tuka woyaco on nikiyepidan wau kta: qa inahniyan waamdatanin kta, wakan kagapi kin en, qa wawicihahapi econpi kin en, qa tona wohnaye on içiconzapi kin en, qa tona wicaśta opetonpi, wiwazica wamdenica ko iyopeye tawapi wicakipi ece, qa ovate tokeca kin wicakiyuśepi, qa komakipapi śni kin hena en, Jehowa ozuye yuhe cin eya.

6 Jehowa he miye, mihdutokeca śni; heon etanhan, Jakob cinca, ihangniyanpi śni ce. 
7 Nihunkakepi anpetu tawapi kin ehantanhan mitawoahope etanhan icunom idadapi, qa hena yapatanpi śni ece. Miye en ihdou po; kinhan niyepi en mihdoku kta ce, Jehowa ozuye yuhe cin eya. Tuka, Taku on unkihdoupi kta he, ehapi.

8 Wicaśta wan Wakantanka wamakinon kta he. Tuka niye mayakinonpi ece. Tuka, Taku e maunnicinonpi he, ehapi. Iwikcemnamna qa wośnapi kin hena.

9 Woyaśice on niyuśsicapi, tuka wamayakinonpi ece, oyate kin de ocowasin.

10 Iwikcemnamna kin iyulipa mazopiye tipi kin en au po, hecen wati ohna woyute yuke kta, qa heon wanna imayukcan po, Jehowa ozuye yuhe cin eya; kinhan nahpiya owanyeye kin ciciyuhdokapi kta, qa woyuwaśte wan acicaśtanpi kta, yuhepica śni hehanyan.

11 Nakun niyepi on watemye kin he iyopewaye kta, hecen maka nitawapi oicage kin ihangye kte śni ; qa nitamağa en hastanhanka iyuwi kin śtunkaka elipeye kte śni, Jehowa ozuye yuhe cin eya.

12 Hehan oyate owasin niyawaśtepi kta; woiyokipi makoce kin he niyepi kta nakaeś, Jehowa ozuye yuhe cin eya.

13 Miye on nioiepi kin wohitipika hinca, Jehowa eya. Tuka, Taku e sicaya unkeniciyapi he, ehapi.

14 Wakantanka ohodapi kin he takuśni ce, ehapi : qa tawoahope unkiciyuhapi, qa Jehowa ozuye yuhe cin itokam iyokiśinya maunnipi kin etanhan wokajuju tukte e he :

$15 \mathrm{Qa}$ wanna wahaniçidapi kin hena wicunyawaśtepi ece: han, tona taku śica econpi ece kin hena icahwicayapi ; han, tona Wakantanka iyutanpi kin hena niwicayapi cee.

16 Hehan tona Jehowa kokipapi kin otoiyohi wokiciyakapi ecee: unkan Jehow a anohya yanke ça nahon, qa iye itokam wokiksuye wowapi wan kaggapi, tona Jehowa kokipapi qa iye caje awacinpi ece kin hena on.

17 Unkan hena mitawa kta ce, Jehowa ozuye yuhe cin eya; anpetu en wohdamna micicage cinhan; qa hena cantewicawakiye kta, wicaśta wan cinhintku wowidagye cin cantekiye cin iyececa.

18 Hehan yahdicupi kta, qa iwandakapi kta; wicaśta owotanna qa wicaśta śica kici, tuwe Wakantanka wowidagye, qa tuwe wowidagye śni kin otahedan.

\section{WICOWOYAKE 4.}

1 Iho, anpetu kin $u$, mazaoceti kin iyecen ide kta: unkan tona wahanicidapi qa tora śicaya econpi kin iyuhpa aguyapi hu kin heca kta; qa anpetu u kte cin he liuhnahiwicaye kta, hecen hutkan qa adetka wanin elipewicaye kta ce, Jehowa ozuye yuhe cin eya.

2 Tuka niyepi, micaje koyakipapi kin, WoowotanNa WI kin anihinanpapi kta, qa tahupahu kin en wookiziye yuke kta: hecen tankan dapi kta, qa ptejicadan tatanka tipi kin etanhan, iyecen psipsin yaunpi kta.

$3 \mathrm{Qa}$ śicapi kin hena awicayahanpi kta; hena e nisihapi sicuha ihukuya cahota kin heca kta, anpetu kin en decen ecamon kinhan, Jehowa ozuye yuhe cin eya ce.

4 Israel ocowasin on Moses mitaokiye toope Horeb he kin 


\section{WICOWOYAKE 4.}

akan econwicawaśi qon he kiksu- 6 Unkan he qe wicaatkuku wiya po, wowaśi qa woyaco kin cacinca kin ekta cante wicakihena.

5 Iho, Jehowa taanpetu tanka qa wohitike cin he u śni itokam, Elijah wicaśta wokcan kin he niyepi en uwaśi kta. yuhomni kta, qa wicacinca kin iś wicaatkuku cante en yuswicakiye kta ecee: hecece śni kinhan, wau qa maka kin woyaśice wan on awape kta ce. 
WICOWAZI OWICAWAPI.

WAKANKICIYUZAPI. 
WICOWAZI OWICAWAPI.

WICATONPI. 


\section{WICOWAZI" OWICAWAPI.}

WICATONPI. 
WICOWAZI OWICAWAPI.

WICATE CIN. 


\section{A K O T A}

\section{WOWAPI WAKAN KIN.}

\section{THE NEW TESTAMENT,}

IN THE

\section{DAKOTA LANGUAGE:}

TRANSLATED FROM THE ORIGINAL GREEK, BY STEPHEN R. RIGGS,A.M.

MISSIONARY OF THE A. B. C. F. M.

NEW YOR K :

AMERICAN BIBLE SOCIETY, INSTITUTED IN THE YEAR MDCCOXVI.

Dakuta 8vo.

$$
1887 \text {. }
$$





\section{A T T H E S}

\section{WOTANIN WAŚTE OYAKE CIN.}

\section{WICOWOYAKE 1 .}

1 Jesus Messiya, Dawid cinhintku, Abraham cinhintku, oicage wowapi kin he dee.

2 Abraham Isaak cincaya; qa Isaak Jakob cincaya; qa Jakob Judas qa hunkawanjitku ko cincawicaya :

3 Unkan Judas Phares qa Zara, Tamar etanhan, cincawicaya; qa Phares Esrom cincaya; qa Esrom Aram cincaya:

4 Qa Aram Aminadab cincaya; qa Aminadab Naasson cincaya; qa Naasson Salmon cincaya :

5 Qa Salmon, Racab etanhan, Booz cincaya; qa Booz, Ruth etanhan, Obed cincaya ; qa Obed Jesse cincaya :

6 Qa Jesse Dawid wicaśtayatapi kin cincaya; qa Dawid wicaśtayatapi kin Solomon cincaya, Urias tawicu qon etanhan.

7 Qa Solomon Roboam cincaya; qa Roboam Abia cincaya; qa Abia Asa cincaya :

8 Qa Asa Josaphat cincaya; qa Josaphat Joram cincuya; qa Joram Ozias cincaya :

9 Qa Ozias Joatham cincaya; qa Joatham Akaz cincaya; qa Âkaz Ezekias cincaya :

10 Qa Ezekias Manasses cincaya; qa Manasses Amon cincaya; qa Amon Josias cincaya:

11 Qa Josias Jekonias cincaya; hunkawanjitku hena koya, $\mathrm{Babu}$ Ion ekta awicayapi qon he ehan.

12 Unkan Babulon ekta awicaipi hehan Jekonias Salathial cincaya ; qa Salathial Zorobabel cincaya :

13 Qa Zorobabel Abiud cincaya; qa Abiud Eliakim cincaya; qa Eliakim Azor cincaya : 14 Qa Azor Sadok cincaya; qa Sadok Akim cincaya; qa Aklm Eliud cincaya :

15 Qa Eliud Eleazar cincaya; qa sileazar Matthan cincaya ; qa Matthan Jakob cincaya.

16 Unkan Jakob Joseph, Mary hihnaku kin, he cincaya; he etanhan Jesus Messiya eciyapi kin icaga.

17 Hecen wicoicage owasin, Abraham etanhan Dawid hehanyan, wicoicage ake topa; qa Dawid etanhan, Babulon ekta awicayapi qon hehanyan, wicoicage ake topa; qa Babulon ekta awicayapi etanhan, Messiya hehanyan, wicoicage ake topa.

18 Unkan Jesus Messiya icage cin he kaketu: Hunku Mary he Joseph yuze kta, tutka hinahin kici un śni, wanna Woniya Wakan kin on ihduśaka.

19 Unkan hihnaku Joseph he wicaśta owotanna, qa taninyan oyake kta tawatenye śni, heon nahmana ehpeye kta kecin.

20 Tuka hena hecen awacin un qehan, iho, Itancan taohnihde wan wowihanmde en ihdutanin qa heya ; Joseph, Dawid cinhintku, Mary winohinca nitawa kin he yahduze kta kokipe śni wo, taku itpihnake cin he Woniya Wakan kin etanhan.

$21 \mathrm{He}$ cinca ton kta, unkan 


\section{MATTHEOS.}

Jesus eya caśyaton kta ; iye taoyate kin wahtanipi kin etanhan niwicaye kta, heon etanhan.

22 Unkan dena owasin hecen econpi, Itancan oie, wicaśta wokcan oyake ciqon he yuecetupi kta; he hecen eya;

23 Iho, witanśna un wan ihduśake ca cinca ton kta; unkan Emmanuel eya caśtonpi kta; Wakantanka unkicipi un, eyapi kin he kapi.

24 Unkan Joseph iśtinma etanhan kikta, hehan Itancan taohnihde token econśi qon he ecen econ, qa tawicu hduza.

25 Tuka cinca tokapa cinca ton śni hehanyan sdonye śni ; unkan Jesus eya caśkiton.

\section{WICOWOYAKE 2.}

1 Unkan Herod wicaśtayatapi taanpetu kin he ehan, Bethlehem Juda makoce kin en Jesus tonpi, hehan iho, wiyohiyanpatanhan wicaśta ksapa Jerusalem en hipi qa heyapi ;

2 Tuwe Juda oyate kin en wicaśtayatapi kta tonpi kin he tukten un he; wicanhipi tawa kin lie wiyohiyanpata wanunyakapi qa ohoundapi kta on unhipi ce.

3 Herod wicaśtayatapi kin he nahon, unkan nina yuśinyaya, Jerusalem ocowásin nakun.

4. Unkan wośnapi kagapi owasin qa oyate kin en wowapi kagapi kin hena wicayuwitaya, hehan Messiya tukten tonpi kta hecinhan, he iwicawanga.

5 Unkan heciyapi; Juda makoce kin en Bethlehem otonwe kin hetu ce ; wicaśta wokcan kin en kaken owapi ;

6 Qa niś Be:hlehem, Juda makoce kin en, Juda itancanpi kin ehna iyotan nicistinna śni ; enitanhan wicaśtayatapi wan u kta, lie Israel mitaoyate kin wonwicaye kta.

7 Hehan Herod wicaśta ksapapi qon nahmana wicakico, qa wicanhpi kin tohanhan tanin ece, he atayedan iwicawanga.

8 Hehan Bethlehem ekta ye wicaśi qa heya; Ya po, qa hokśiyoqopa kin nina ode po; qa iyeyayapi kinhan hośimakahdi po; miś eya wau qa ohowada kta, eya.

9 Wicaśtayatapi ia nahonpi hehan tankan iyayapi ; unkan iho, wicanhipi wiyohiyanpata wanyakapi qon he wicitokam iyaye ça hokśiyoqopa wanke cin he iwankam inajin.

10 Unkan wicanhipi kin wanyakapi qehan wowiyuśkin tanka on iyuśkinpi.

11 Unkan ti mahen ipi hehan hokśiyoqopa kin wanyakapi, hunku Mary nakun, qa itokam makata ehpeiciyapi qa ohodapi : unkan wopiye hduhdokapi hehan taku qupi, mazaskazi, qa canśin pejihuta waśtemna koya.

12 Unkan wowihanmde on Wakantanka wahnwicaya, Herod ekta hdapi kte śni, hehan canku tokeca ohna iye tamakoce ekta hdapi.

13 Hena wanna kihdapi hehan, iho, Itancan taohnihde wan wowihanmde on Joseph en ihdutanin qa heya; Najin ya hokśiyoqopa hunku kici iwicacu qa Egupta ekta najica wo, qa tohan ociciyake kte cin hehanyan hen un wo: Herod hokśiyoqopa kin kte wacin on etanhan ode kta ce.

14 Hecen hanyen najin hiyaye, ca hokśiyoqopa hunku kici ewicahdaku, qa Egupta elsta iyaya:

$15 \mathrm{Qa}$ hen un, Herod țe cin hehanyan: Hecen Itancan wicaśta wokcan on taku eye ciqon 


\section{WICOWOYAKE 3.}

he yuecetupi kta ; Egupta etanhan micinkśi weco ce.

16 Wicaśta ksapapi qon Herod hnayanpi wanhdake cehan nina śihda; qa akicita ekta yewicaśi, qa Bethlehem qa makoce ihdukśan koya en, hokśiyopa owasin wicakte, tona waniyetu nonpa qa ihukuya, wicaśta ksapapi wiwicawange ciqon he iyacinyan.

17 Unkan hehan Jeremiya wicaśta wokcan oie qon yuecetupi, he kaken eya ;

18 Rama en wicaho wan nahonpi, içidowanpi, wicaceya qa waśihdapi tanka; Racel cinca awicakiceya qa wacintonknakapi kta cin śni, cinca en unpi śni nakaeś.

19 Tuka Herod wanna ta hehan, iho, Itancan taohnihde wan Egupta ekta Joseph en taniniciya;

$20 \mathrm{Qa}$ heya; Najin qa hokśiyoqopa hunku kici ewicahdaku, qa Israel makoce tawa kin ekta hda wo; tona hokśiyoqopa ța cinpi qon hena wanna tapi.

21 Unkan najin hiyaye ca hokśiyoqopa hunku kici ewicahdaku qa Israel tamakoce kin en hdi.

22 Qa Arcelaos, Juda makoce kin en, atkuku Herod tohe kin en wicaśtayatapi yanka, he nahon hehan ekta hde kta kokipa; tuka wowihanmde on Wakantanka wahoye cin on, Galile makoce kin ekta iyaya:

23 Qa otonwe wan Nazareth eciyapi kin he en hi qa hen yanka; hecen, Nazareth wicaśta eciyapi kta ce, wicaśta wokcan eye ciqon he yuecetupi.

\section{WICOWOYAKE 3.}

I Unkan anpetu kin hena en, Johannes baptem wicaqu ece kin he Juda tamakoce hewoskan ekta woyaka hi;

2 Qa heya; Ihduecetu po, mahpiya wokiconze kin wanna kiyedan u ce.

3 Isaya wicaśta wokcan cajeyate ciqon he dee, kaken eya; Wicaho hewoskan en hotanin; Itancan tacanku kin wiyeya ehnaka po, ocanku tawa kin owotanna kaga po.

4 Unkan Johannes eqe tawokoyake taku wan kamel eciyapi he hin kin on kagapi, qa tehmiso wan ipiyagkiton; unkan tawoyute kin psipsicadan qa tuhmaga canhanpi kin hee.

5 Hehan Jcrusalem qa Juda qa Jordan ihdukśan tanhan owasin en hipi :

6 Unkan Jordan en baptem wicaqu, woahtani ohdakapi.

7 Unkan Pharisee qa Saddukee wicota baptem wicaqu kin en hipi wanwicayaka, hehan hewicakiya; Wamduśka wicoicage kin, wocanniye u kte cin nayecipapi kta tuwe e wahokonniciyapi he.

8 Heon etanhan ihduecetupi kta iyececa waskuyeca icahya po :

9 Qa, Abraham ateunyanpi ce, eyeciyapi kta awacinpi śni po; miye heciciyapi, Inyan kin dena etanhan Wakantanka Abraham cinca kicage kta okihi.

10 Unkan wanna onspe kin can hute kin en ehnakapi; heon etanhan can otoiyohi waskuyeca waśte aicage śni kin he kawankapi qa.petan ehpeyapi ece.

11 Miye nihduecetupi kta on mini on baptem cicupi ; tuka wanji iyotan waśaka mihakam $\mathrm{u}$, he tahanpe kin weciyuhe kta iyemicihantu śni; he qe Woniya Wakan qa peta on baptem niçupi kta. 


\section{MATTHEOS.}

12 Icaduge nape ohna hduha, owanka tanyan hdahinte kta, qa aguyapi su kin dotopiye ohna mnakiye kta, tuka ha kin peta kasnipica śni on hulinahye kta.

13 Hehan Jesus Galile etanhan u, qa Jordan ekta Johannes en hi, baptem qupi kta e heon.

14 Tuka Johannes tehinda qa heya ; Baptem mayaqu kta iyemaceca, qa niś en mayahi he.

15 Tuka Jesus ayupte ca heciya; Dehan iyowinyan wo; decen wicoowotanna ocowasin unśtan kta iyececa. Hehan iyowinkiya.

16 Unkan Jesus baptem qupi qehan ecahankeya mini kin etanhan itawankanhde hda ; unkan iho, mahipiya kin ayuzamnipi, qa Wakantanka Taniya kin wakiyedan kahya kuntkiya $u$, qa en hiyahan, wanyaka.

17 Unkan iho, mahpiya eciyatanhan wicaho wan heya; Micinkśi waśte wakidake cin he dee, on iyomakipi hinca ce.

\section{WICOWOYAKE 4.}

1 Hehan Jesus woniya on hewoskan makoce kin ekta ayapi, Wakanśica iyutanye kta e heon. 2 Unkan wanna anpetu wikcemna topa qa hanyetu wikcemna topa wote śni un, hehan wotektehda.

3 Unkan wawiyutanyan kin en hi qa heciya; Wakantanka Cinhintku kin he niye hecinhan, inyan kin dena aguyapi icage kta keya wo.

4 Tuka iye ayupte ca heya ; Aguyapi ecedan on wicaśta ni kte śni, tuka wicoie otoiyohi Wakantanka i eciyatanhan enanpe cin hena on, hecen wowa'pi kagapi qon.

5 Hehan Wakanśica otonwe wakan kin ekta aya, qa tipi wakan oinkpa wan akan ehde;

6 Qa heciya; Wakantanka Cinhintku kin he niye hecinhan, hetanhan kun ehpeiciya wo; kaken wowapi en kagapi ce; Taohnihde kin niye on econ wicaśi kta, hecen nape ohna niyuhapi kta, inyan warl en siha ibonițo kte śni.

7 Tuka Jesus heciya; Akeś wowapi en kagapi; Itancan Wakantanka nitawa kin he iyutanyaye kte śni.

8 Hehan ake Wakanśica paha wan tehanwankantuya kin he ekta aya, qa maka akan wokiconze kin owasin wowitan ko kipazo ;

9 Qa heciya; Makata ehpeniçiye ca ohomayada kinhan, dena owasin cicu kta ce.

10 Hehan Jesus heciya ; Satan mikeyata ya wo; Itancan Wakantanka nitawa kin he ohoyada kta, qa iśnana wowidagniye kta ce, eya owapi tuka qon.

11 Hehan Wakanśica ayuśtan; unkan iho, mahpiya ohnihde kin en hipi qa okiyapi.

12 Unkan Johannes kaślkapi he nahon hehan Jesus Galile ekta iyaya:

13 Qa Nazareth elipeya iyaye ca Kapernaum en hiyanka, he mde kin icahda, Zabulon qa Nephtalim opapun kin hetu.

14 Hecen Isaya oie qon yuecetupi kta;

15 Zabulon makoce qa Nephtalim makoce, nde kahda ocanku kin, Jordan akasanpa tanhan, Galile Ikcewicaśta ounyanpi kin :

16 Oyate otpaza en iyotanke ciqon he iyoyanpa tanka wanyakapi, qa tona wiconte makoce qa ohanzi kin en iyotankapi kin hena iyoyanpa awicahinanpa ce.

17 Unkan hetanhan Jesus wo- 


\section{WICOWOYAKE 5.}

yaka aye ça heya ece; Ihduecetu po, mahpiya wokiconze kin wanna kiyedan u ce.

18 Unkan Galile mde kin icahda mani icunhan, wicaśta nom sunkakiciyapi wanwicayaka, Simon, Inyan eciyapi, qa sunkaku Andrew eciyapi, ho wan mde kin en iyeyapi ; hena hopsicapi kin hecapi :

19 Unkan hewicakiya; Miyahna u, po, kinhan wicaśta wicadupsicapi ece e kta cicagapi kta ce.

20 Unkan ecahankeya ho kin ehpeyapi qa ihakam iyayapi.

21 Unkan hetanhan iyoopta ye ca, nakun nom sunkakiciyapi wanwicayaka, Jakob Zebede cinhintku qa sunkaku Johannes, wata lin ohna atkukupi Zebede kici unpi qa lıo piyapi ; unkan hena wicakico.

22 Iś eya wata kin atkukupi ko ohankoya ehpeyapi qa ihakam iyayapi.

23 Unkan Jesus Galile owancaya iyaya, omniciye tipi yuhapi kin ohna waonspewicakiye ca, wokiconze wotanin waśte kin oyaka ece, qa oyate kị̣ en wowayazan owasin qa wicocante śica owasin asniyan ece.

24 Unkan ohan kin Suriya owancaya oyakapi; hecen tona śicaya yukanpi, qa tona wowayazan ocaje owasin on wayazanpi, qa tehiya unpi, qa tona taku wakan śica yuhapi, qa țațapike cin hena koya owasin en awicahipi; unkan asniwicaya.

25 Hecen oyate ota ihakam yapi ece, Galile etanhan, qa Dekapolis qa Jerusalern qa Juda etanhan, qa Jordan akasanpa tanhan.

\section{WICOWOYAKE 5.}

1 Unkan wicota wanwicayaka hehan paha wan ekta iyaya; qa hen iyotanka hehan waonspewicakiye cin en hipi.

2 Unkan i hdukawa qa waonspewicakiye ca heya ;

3 Tona cante mahen onśiiçidapi kin hena wicayawaśtepi ce; mahpiya wolkiconze kin he tawapi ece.

4 'Tona ceyapi kin hena wicayawaśtepi ; hena wicakihnapi kta.

5 Tona onśihanpi kin 'hena wicayawaśtepi; maka kin de tawapi kta.

6 Tona woowotanna on wotektehdapi qa ipuzapi kin hena wicayawaśtepi ce ; hena imnanpi kta.

7 Tona waonśidapi kin hena wicayawaśtepi ; hena onśiwicadapi kta.

8 Tona cante en ecepidan kin hena wicayawaśtepi ; hena Wakantanka wanyakapi kta.

9 Tona wookiye kagapi kin hena wicayawaśtepi; hena Wakantanka cinca ervicakiyapi kta.

10 Tona woowotanna econpi kin -on śicaya kuwapi kin hena wicayawaśtepi ; mahpiya wokiconze kin he tawapi ece.

11 Tohan aniiapi qa śicaya nicuwapi, qa miye on itonśniyan taku śica owasin eniciyapi kinhan, niyawaśtepi ece.

12 Wiyuśkinpi qa nina cante waśte po, mahpiya ekta ocinyopeniyanpi tanka yanka; wicaśta wokcan nitokam unpi qon hena iś eya hecen wicakuwapi qon.

13 Maka miniskuya kin he niyepi. Tuka miniskuya kin he skuye śni kinhan taku e on skuyeyapi kta he; hetanhan takudan okihi kte śni, tankan ehpeyapi kta qa wicaśta amanipi kta. 14 Oyate iyoyanpa kin he niyepi. Otonwe wan paha akan kagapi kin he anahbepica śni ece.

15 Nakun petijanjan ideyapi qa 


\section{MATTHEOS.}

koka ohdateya iyeyapi śni, tuka petijanjan ihupa wan en ośtanpi;, hecen tipi kin ohna owasin iyoyanıwicaya ece

$16 \mathrm{He}$ iyecen wicaśta itokam iyoyanpa nitawa iyojanjan kta, hecen wicohan waśte nitawa wanyakapi kta, qa mahpiya ekta ateyayapi yanke cin he yuonihanpi kta.

17 Woope qa wicaśta wokcan kin mdutakuni kte śni on wahi kecinpi śni po, ihangyapi on wahi śni tuka yuecetupi kta on.

18 Awicakehan heciciyapi ; Mahipiya qa maka kin atakuniśni eśta, oowa wanjidan qa oehnake wanjidan woope kin etanhan icupi kte śni, owasin ecetu kta.

19 Heon etanhan, tuwe woahope kin dena wanji cistinna ahope śni q qa hecen wieaśta onspewicakiye cinhan, he mahpiya wokiconze kin en iyotan cistinna yawapi kta; tuka tuwe ecen econ qa iyecen waonspewicakiye cinhan, he mahipiya wokiconze kin en tanka yawapi kta.

20 Miye heciciyapi ce; Wicoowotanna nitawapi kin, wowapi kagapi qa Pharisee tawapi kin isanpa tanka śni kinhan, mahipiya wokiconze kin en ecaca oyapapi kte śni.

21 Tuwedan yakte kte śni, hunkawicayapi kin eyapi keyapi nayahonpi; qa tuwe tin wicakte kinhan he yacopi kta ce.

22 'Tuka miś heciciyapi; Tuwe taku on etanhan śni sunkaku śicekidake cinhan he yacopi kta; qa tuwe sunkaku, Wahteśni, eciye cinhan he omniciye tanka kin en ayapi kta; qa tuwe, Winitkotkoka, eciye cinhan, he Wakanśica tapeta kin en iyolipeyapi kta iyececa.

23 Heon etanhan wośnapi nitawa owayuśna kin ekta ayahi kin- han, qa hen nisunka laku iyanionpa he yeksuya hecinhan;

24 Ito wośnapi nitawa owayuśna kin itokam ehnake ca ekta ya wo, tokaheya nisunka kici okiciciye ca hehan ku qa wahduśna wo.

25 Tuwe taku en aniu hecinhan he kohanna kici okiciyuwaśte wo, canku ohna kici yaun kin icunhan; okinni wayaco ekta aniye kta, qa wayaco kin iś aki. cita en aniye kta, qa hecen kaśka nihnakapi kta:

26 Awicakehan heciciya; Tohanyan mazaśadan ehake yahdajuju śni kinhan hetanhan tankan yaku kte śni.

27 Wawicihahapi ecanon kte śni, hunkawicayapi qon eyapi keyapi nayahonpi.

28 Tuka miś heciciyapi ; Tuwe winohinca wan en etonwe ca cantiheye cinhan he wanna cante ekta kici wawicihahapi econ. 29 Niiśta etapa eciyatanhan kin he wahtaniniye cinhan hduśdoke ca elipeya wo; niiśta wanji atakuniśni kinhan he waśte kta, qa tancan ocowasin Wakanśica ti kin en elipeniyanpi kte śni.

30 Qa ninape etapa kin wahtaniniye cinhan hdakse ça elipeya wo ; nihuha wanjidan atakuniśni kinhan he waśte kta, qa tancan ocowasin Wakanśica ti kin en iyohpeniyanpi kte śni.

31 Tuwe tawicu elipekiye kta hecinhan kpaganpi wowapi wan qu kta, keyapi qon.

32 Tuka miś heciciyapi; Tuwe tawicu elapekiya, wawicihaliapi econ kin on etanhan śni, he wawicilialiapi econkiya ece; qa tuwe winohinca ehpeyapi kin he yuze cinhan he nakun wawicihaliapi econ ece.

33 Akeś hunkawicayapi qon heyapi keyapi nayahonpi; Itonśni 


\section{WICOWOYAKE 6 .}

niçicage kte śni, tuka taku konza Itancan kin eyakiye cinhan hena yahduecetu kta ce.

34 'Tuka miś heciciyapi; 'Taku cajedate ca he namahion ce, eye śni wo; mahpiya kin he hecen cajedate kte śni, he Wakantanka oiyotanke tawa kin hee.

35 Qi nakun maka kin de, he Wakantanka siha oahe kin ee; qa nakun Jerusalem hecen cajedate kte śni, Wicaśtayatapi tanka totonwe kin hee.

$36 \mathrm{Qa}$ nakun nipa kin he caje yahdate kte śni, paha wanjidan kaeśs ska qa iś sapa yakage kta oyakihi śni, heon etanhan.

37. Tuka taku ehe cin, Han, han; Hiya, hiya, ecedan kta; taku dena sanpa kinhan he taku Sica etanhan icage kta.

38 Iśta wanji iśta wanjidan on etanhan, qa hi wanji hi wanjidan on etanhan, keyapi nayahonpi.

39 Tuka miś heciciyapi; Taku śica tokiconpi śni po; tuka tuwe tapon etapa eciyatanhan anipe cinhan unma eciyatanhan kipazo po.

$40 \mathrm{Qa}$ tuwe woope on niyaco qa onlidolida nici kta cin kinhan, nitaśina nakun tehinda śni wo.

$41 \mathrm{Qa}$ tuwe tviyutapi hanska wanji hehanyan kici yeniye l₹ta hecinhan, nom kici ya wo.

42 'Tuwe taku nicida kinhan qu wo; qa tuwe wonicidota hecinhan etanhan ihdamna śni wo.

43 Tuwe nikiyedan un kin he waśteyadake kta, qa tuwe tokaniye cin he śiceyadake kta, eyapi qon nayahonpi.

44 Tuka miś heciciyapi; Tona tokaniyanpi kin hena cante wicakiya po; qa tona niyaśicapi kin hena wicayawaśte po ; tona śicenidapi kin hena taku waśte ecawicakicon po; qa tona taku i en iyeniyanpi qa teliya nicuwapi kin hena wocekiye ewicakiciya po.

45 Hecen Ateyayapi mahpiya ekta un kin he cincaniyanpi yaunpi kta; he qe anpetu wi tawa kin wicaśta śica wicaśta waśte ko en awicahinanpeya ece, qa wicaśta owotanna owotanna śni ko awicamagajuya ece. 46 Tona waśtenidapi kin hena waśte wicayadapi kinhan wokajuju taku duhapi he; wamnayanpi kin hena eepi kaeś heconpi śni he.

47 Qa sunka wicayayapi kin henana napewicaduzapi kinhan, taku econpi ece sanpa tukte e ecanonpi he; wamnayanpi kin hena eepi kaeś heconpi śni he.

48 Heon etanhan Niyatepi mahipiya ekta un kin he owotanna hinca he iyecen niś eya owotanna hinca un po.

\section{WICOWOYAKE 6.}

1 Wicaśta itokam ihnuhan taku ituyahanpi kinhan, wanniyakapi kta heon; hecen ecanonpi kinhan Niyatepi mahpiya ekta un kin he takudan nicupi kte śni.

2 Heon etanhan tohan taku wicayaqu kta hecinhan nitokam cotanka yajowicayakiye kte śni, wanaiçihmanpi kin omniciye tipi qa canku ohna econpi ece kin iyececa, wicaśta on wicayatanpi kte cin heon; awicakehan heciciyapi; Hena wokajuju hduhapi ece.

3 Tuka niye taku wicayaqu eca ninape etapa taku econ kin he nicatka sdonye kte śni.

4 . Hecen wawicayaqu kin he nahmana un kta; qa Niyatepi taku nałmana un kin wanyaka ece kin he iye taninyan nicicajuju kta. 


\section{MATTHEOS.}

5 Qa tohan ceyakiya eca wạnaicihmanpi kin iyenicece kte śni; hena eqe omniciye tipi qa canku oise kin en najin cekiyapi waśtedakapi ece, wicaśta wanwicayakapi kta e heon; awicakehan heciciyapi ; Hena wokajuju hduhapi ece.

6 Tuka niye qe ceyakiye cinhan, tipi cistinna nitawa kin en timahen yakiyahde ca tiyopa ecen iyacu kinhan, hehan $\mathrm{Ni}$ yate nahmana un kin he cekiya wo, qa Niyate nahmana wawanyaka ece kin he taninyan nicicajuju kta.

7 Ceyakiyapi kinhan akihdehde oie kicunpi śni po, Ikcewicaśta econpi kin iyececa; hena e iapi ota unpi kin on nawicahon kta kecinpi.

8 Niye hena iyenicecapi kte śni ; hinahin yakidapi śni itokam, hena taku kin yacinpi, Niyatepi sdonya ece.

9 Heon etanhan kaken cekiya po; Ate unyanpi mahpiya kin en; Nicaje wakandapi kte;

10 Nitokiconze u kte ; Nitawacin ecen econpi nunwe, mahpiya kin en iyececa, nakun maka akan:

11 Anpetu kin de anpetu woyute unqu miye:

12 Qa waunhtanipi kin unkicicajuju po, tona waunkicilitanipi wicunkicicajujupi kin he iyececa :

13 Qa taku wawiyutanyan un kin en unkayapi śni po, tuka taku śice cin etanhan eunhdaku po: Wokiconze kin he niye nitawa, qa wowaśake kin, qa wowitan kin, owihanke wanica. Amen.

14 Niye wicaśta wahtanipi wicayecicajujupi kinhan, Niyatepi mahpiya elkta un kin he nakun niye nicicajujupi kta.
15 Tuka niye wicaśta wahtanipi kin wicayecicajujupi śni ehantanhan, nakun Niyatepi wayahtanipi kin nicicajujupi kte śni.

16 Tohan wote śni yaunpi kinhan wanaiçilmanpi kin iyecen ite śinkiyapi śni po; hena eqe ite hduśicapi ece, hecen wicaśta ekta wote śni unpi e ihdutaninpi kta; awicakehan heciciyapi, Hena wokajuju hduhapi ece.

17 Tuka niye qe wote śni yaun kinhan pa sdakiye ca ite hdujaja wo:

18 Hecen wicaśta en wote śni yaun nihdutanin kte śni, tuka Niyate nahmana un kin he en nihdutanin kta; qa Niyate nahmana wawanyake cin he taninyan nicicajuju kta.

19 Woyuha maka akan ekihnakapi śni po ; hen wamduśkadan qa gigi kin wayutakuniśni ece, qa wamanon sa wayujujupi qa wamanonpi ece.

20 Tuka woyuha mahpiya kin ekta ekihnaka po; heciya wamduśkadan qa gigi kin wayuśice cin wanica, qa wamanon sa wayujujupi śni qa wamanonpi śni.

21 Tukten woyuha niciyankapi hecinhan, nicantepi nakun hen un kta.

22 Wicista kin he wicatancan iyoyanpa kin hee; heor etanhan niiśta tokeca śni kinhan nitancan ocowasin iyoyanpa kta:

23 Tuka uiiśta śice cinhan nitancan kin ocowasin otpaze kta. Heon iyoyanpa en niun kin he otpaza hecinhan, otpaza kin he tanka hinca.

24 Tuwedan wicaśta itancan nom anawicagoptan kta olkihi śni; wanji śice kidake kta, qa unma kin iś waśte kidake kta : wanji en iyaihdaśke kta, qa unma kin iś en etonwe kte śni; 


\section{WICOWOYAKE 7.}

Wakantanka qa mammon napin anagoptan oyakihipi kte śni.

25 Heon etanhan heciciyapi ; Yanipi kin on nagiyeiçiyapi śni po, taku yatapi kta, qa taku datkanpi kta; qa nakun nitancanpi on taku kodakapi kta: Wiconi kin he woyute isanpa śni he; qa wicatancan kin iś wokoyake isanpa yawapi śni he.

26 Mahpiya okinyanpi kin hena wanwicayaka po, hena wojupi śni, qa wolksapi śni, qa mazopiye en omnayanpi śni, tuka Niyatepi malipiya ekta un kin he hena wo wicaqu ece; unkan niye, hena isanpa niyawapi śni he.

27 Niyepi etanhan wanji tukte e he awacannipi on wiciśpa wanjidan kaeś sanpa nihduhanskapi oyakihipi kta he.

$28 \mathrm{Qa}$ tokeca. wokoyake on iyokiśinniciyapi he ; tinta mnahicahca kin wanyaka po, icage cin; htani śni qa nakun wapahmun śni ;

29 'Tuka heciciyapi; Solomon wowitan tanka hduha un qon hee kiaeś de wanji iyececa wokoyake kicun śni.

30 Unkan tinta peji, dehan icage ça heyakecinhan oceti en ehpeyapi ece kin, he Wakantanka hecen koyagya hecinhan, niś niye wacinyan nicistinpidan, sanpa wakoyagniyanpi kte śni he.

31 Heon etanhan, Taku untapi, qa taku unyatkanpi, qa taku kounyakapi kta he, eya wacin iyokiśicapi śni po.

32 'Taku kin hena owasin Ikcewicaśta akitapi ece; qa Niyatepi malipiya ekta un kin he dena taku owasin yacinpi esdonya ece.

33 Tuka W akantanka tokiconze kin he tokaheya akita po, qa toowotanna nakun; kinhan dena taku owasin koya niçupi kta.

34. Heon etanhan heyakecinhan on iyolkiśiniçiyapi śni po; heyakecinhan he taku tawa kin on iyokiśica ece e kta; anpetu eca taku sica tawa kin yukan ece e kta.

\section{WICOWOYAKE $\%$}

1 Wayacopi śni po, hecen niyacopi kte śni.

2 Woyaco tukte e on wadacopi hecinhan he on niś eya niyacopi kta ; qa wiyutapi tukte e on widutapi eca hee on winiciyutapi ece e kta.

$3 \mathrm{Qa}$ nisunka iśta kin en takuśni yanka e tokeca wandaka he; qa cankaga wan niiśta ohna yanke cin he wanyahdake śni.

$4 \mathrm{Qa}$ iś token nisunka, Ito niiśta kin etanhan takuśni kin icicicu kta, eyakiye kta he; qa iho, cankaga wan niiśta obna yanka ce.

5 Wanaicihman, tokaheya cankaga iśta ohna niyanke cin he hduśdoka wo; qa hehan takuśni nisunka iśta ohna yanke cin he iyacu kta tanyan wandake kta.

6 Taku tona wakan kin hena śunka wicaqupi śni po, qa inyan tehika nitawapi kin lsukuśe wicitokam ehpeyapi śni po; okinni siha on amanipi lzta, qa akeś hdicupi qa niyahdecapi kta.

7 Da po, kinhan niçupi kta; ode po, kinhan iyeyayapi $\mathrm{kta}$; en katoto po, kinhan niciyulidokapi kta.

8 Tuwe da eca icu ece; qa tuwe ode eca iyeya ece; qa tuwe tiyopa katoto eca he kiciyuhdokapi ece.

9 . Unkan enitanhanpi wicaśta wanji cinhintlku aguyapi kida kirhan, inyan wanji qu lita he.

10 Qa hogan kida kinhan wamduśka wan qu kta he.

11 Heon etanhan niye niśicapi 


\section{MATTHEOS.}

eśta, taku waśte nicinca wicayaqupi kta onnispepi ehantanhan, Niyatepi mahpiya ekta un kin he, sam iyeya tona kidapi kin, taku waśteśte wicaqu ece e kta.

12 Heon etanhan taku tona wicaśta ecaniconpi kta yacinpi. kinhan, hena owasin ecawicakicon po; woope qa wicaśta wokcanpi kin iho hee.

13 Tiyopa ciqadan kin he ohna ya po ; Tiyopa kin tanka qa canku nakun tanka wicotakuniśni iyahde, qa ohna iyayapi kin wicota hinca.

14 Tuka tiyopa kin ciqadan qa canku nakun ocistiyedan wiconi iyahde; qa wicaśta tonana iyeyapi ece.

15 Wicaśta wokcan itonpiśni kin hena kowicakipa po; hena tahinca wanunyanpi iyecen koyag en nihipi, tuka mahen śunktokeca way apota ece kin hecapi.

16 Waskuyeca tawap1 kin on sdonwicayayapi kta. Wicaśta wapepeka etanhan hastanhanka yuśpipi he, qa toka hu kin etanhan suken waskuyeca icupi he.

17 He iyecen can waśte owasin waskuyeca waśte icahya ece; tuka can śice cin waskuyeca śica aicaga ece.

18 Can waśte kin he waskuyeca śica icahye kta ohihi śni ; qa nakun can śice cin he waskuyeca waśte icaliye kta ohihi śni.

19 Can otoiyohi waskuyeca waśte aicage śni kin he kawankapi qa petan ehpeyapi ece.

20 Heon etanhan waskuyeca tawapi on sdonwicayayapi kta.

21 Tona, Itancan, Itancan, emakiyapi kin ownsin mahpiya wokiconze kin en yapi kte śni ; tuka tuwe Atewaya mahpiya ekta un kin tawacin kin ecen econ kinhan hee en un kta.
22 Anpetu kin he en $x i$ cota hemakiyápi kta ; Itancan, I tancan, nicaje on wiunyukcanpi śni he; qa nicaje on taku wakan śica napewicunyanpi; qa nicaje on wicohan tanka ota econkupi ce.

23 Tuka hehan hewicawakiye kta; Tohinni sdonciyapi śni, wicohan śica ecanonpi kin mitantanhan iyaya po.

24 Heon etanhan tuwe mioie kin dena nation, qa ecen econ kinhan, he wicaśta ksapa e imảacin kta, he qe imnija wan akan ti kicarra.

25 Unkan nina magaju qa minitan aya; nakun tateyanpa linca, qa tipi kin he en iheya, tuka hinhipaye śni; inyan akan kagapi nakaeś.

26 Qa tuwe mioie kin dena nahon, tuka ecen econ śni kinhan, he wicaśta witkotkoka iyececa, he wiyaka akan tipi kicaga.

27 Unkan nina magaju qa mini tanka icaga. nakun tateyanpa hinca, qa tipi kin he en iheya; unkan hinhpaya; qa ihangyapi kin he tanka.

28 Unkan Jesus wicoie kin dena ihunnikiya, hehan wicota wahokonwicakiye cin on yusinyayapi.

29 Wanji wookihi yuhe cin iyecen wahokonwicakiya, qa wowapi kagapi econpi kin iyecece śni.

\section{WICOWOYAKE 8.}

1 Unkan paha kin etanhan kun ku qehan, wicota hinca ihakam unpi.

2 Unkan iho, wicaśta wan lepros ececa he en hi qa canpeśka makehde inajin qa heciya; Itancan, yacin kinhan, asnimayaye kta oyakihi. 


\section{WICOWOYAKE 8.}

3 Unkan Jesus nape ekta yekiye ca yutan, qa heciya; Wacin; hecen asni wo. Unkan ecehnana wowayazan kin ayuśtan.

4 Unkan Jesus heciya ; Ihunhan tuwe oyakidake cinhan; tuka ekta ye ca wośnapi kage cin he en ihdutanin wo, qa taku Moses econniśi qon he wayuśna wo, sdonyapi kta e heon etanhan.

5 Unkan Jesus Kapernaum en hi qehan, akicita tancan wan en u qa cekiya;

6 Qa heya; Itancan, hokśidan mitawa tiyata wanka țațaka, nina yazan.

7 Unkan Jesus heciya; Wau qa aśniwaye kta.

8 Hehan akicita opawinge wicayuhe cin he ayupte ça heya; Itancan, wati en timahen yau kta iyemacece śni; tuka oie kin ecedan eya wo, kinhan hokśidan mitawa asni kta:

9 Miś eya wicaśta itancan hemaca, qa akicita wicamduha; unkan wanji, Ya wo, ewakiya eca, ya ece ; qa wanji tokeca, U wo, ewakiya eca, u ece; qa mitaokiye, Kaken econ wo, ewakiya eca, ecen econ ece.

10 Unkan Jesus he nahon qehan yuśinyaya, qa ihakam unpi kin hewicakiya; Awicakehan heciciyapi, Israel hee kaeś en wacinyanpi hinsko tanka iyewaye śni ce.

11 Nakun heciciyapi; Wiyohiyanpa tanhan qa wiyohpeya tanhar wicota upi kta, qa Abraham qa Isaak qa Jakob om iyotankapi kta, mahipiya wokiconze kin en :

12 Tuka wokiconze cincapi kin hena tankan iyewicayapi kta, otpaze hinca ekta; heciya wicaceya hi hdakinskinzapi ko yuke kta.

13 Unkan Jesus akicita opa82 winge wicayuhe cin hecrya; Hda wo, wacinyaye cin iyecen ecaniconpi nunwe. Unkan wihiyayedan oape kin he en hokśidan tawa kin asniyanpi.

14 Unkan Jesus Inyan ti kin en tin iyaya, hehan kunku kin makata wanka wanyaka, tancan kata.

15 Unkan nape kin yutan, hehan tancan kate cin ayuśtan; unkan najin qa wowicakihan.

16 Wanna hitayetu hehan wakan śica wicayuhnaśkinyan ota en awicahipi; unkan oie kin on wakan sica napewicaya; qa tona wayazankapi kin owasin asniwicaya.

17 Hecen Tsaya wicaśta wokcan taku eye ciqon he yuecetupi kta; he kaken eya; Iye teliiya unyakonpi kin eunkiciyakupi qa waunyazanpi kin yutokan iyeunkieiciyapi ece.

18 Unkan Jesus wicota hinea ihdukśan yukanpi kin hena wanwicayaka hehan akasanpa yapi kta keya.

19 Unkan wowapi kaga wan en hi qa heciya; Waonspekiya, tokiya da eca cihakam waun ece e kta.

20 Unkan Jesus heciya ; Śungidan waśun tonpi, qa mahpiyạ okinyanpi kin hohipi yuhapi ece; tuka Wicaśta Cinhintku kin tukten pa ipahinye kta yuhe śni.

21 Hehan waonspewicakiye cin tokeca wanji heciya; Itancan, tokaheya wahde ça ate wehe kta e iyowinmakiya ye.

22 Tuka Jesus heciya; Mihakam un wo; ito tapi kin hena tona kițapi kin wicakiliapi kta. 23 Unkan wata wan en opa, hehan waonspewicakiye cin ihakam upi.

24. Unkan iho, mini kin ekta tate iyumni wan tanka; hecen 13 


\section{MATTHEOS.}

wata kin taja on akahpapi ; tuka iye iśtinma yanka.

25 Unkan waonspewicakiye cin en hipi, qa yuhicapi qa heciyapi ; I tancan, niunkiya po, unțapi kta ce.

26 Unkan hewicakiya; Cistinna wacinyayapi kin, tokeca koyakipapi he. Hehan inajin qa tate mini ko kiśica; unkan amdakedan tanka.

27 Tuka wicaśta kin hena yuśinyayapi qa heyapi; De takủ wicaśta ka hwo, hecen tate mini ko anagoptan ece.

28 Unkan akasanpa i, Gadarene makoce tawapi kin en, hehan wicaśta nom wakan śica wicayuhnaśkinye cin hena itkokipapi, wicaśta hnakapi kin etanhan upi, wohitikapi hinca, hecen tuwedan canku kin he ohna ye kta okihi śni.

29 Unkan iho, heya howayapi; Jesus Wakantanka Cinhintku, taku unkiyotahedan un he; hinahinke śni tuka itokam kakiśunyayapi kta on yahi he.

30 Unkan yukanpi kin itehan kukuśe optaye wan wo wicaqupi ece.

31 Hecen wakan śice cin hena cekiyapi qa heyapi ; Napeunyayapi kinhan kukuśe optaye kin en unkiyayapi kta iyowinunkiya miye.

32 Unkan; Ya po, ewicakiya. Hecen tankata hinanpapi hehan kukuśe optaye kin en iwicayayapi. Unkan iho, kukuśe optaye kin iyulipa maya hinca apamahde inyang naśdog iyayapi, mde kin en, qa minin țapi.

33 Unkan tona wo wicaqupi qon hena najicapi; qa otonwe en kipi, qa taku owasin oyakapi, wicaśta wakan śica wicayuhnaśkinyanpi qon, taku ecawicakiconpi kin hena koya.
34 Unkan iho, otonwe kin ocowasin Jesus itkokim upi, qa wanyakapi qehan, makoce tawapi kin etanhan hde kta icekiyapi.

\section{WICOWOYAKE 9.}

1 Hehan wata kin en okipe ça akasanpa kihde ca iye totonwe kin en ki.

2 Unkan iho, wicaśta tatake cin wan owinja akan wanka e he en ahipi. Unkan Jesus wacinyanpi kin wanyake cehan țatake cin heciya; Cinś, cante waśte wo ; wayahtani kin nicicajujupi ce.

3 Unkan iho, wowapi kagapi kin wanjikji iyakitedan hekiciyapi; Wicaśta kin de śicaya ia.

4 Unkan Jesus cantey uzapi kin wanyaka hehan heya; Tokeca cante mahen taku śica awacannipi he.

5 Wayahtani kin nicicajujupi ce, eyapi ; qa iś; Najin qa mani wo, eyapi kin, unma tukte waśakadan he.

6 Tuka Wicaśta Cinhintlku kin woahtani maka akan kajuju kta okihi e he sdonyayapi kta; hehan tatake cin heciya; Najin wo, nitowinja ehdaku qa tiyata hda wo.

7 Unkan najin hiyaye ça iye ti ekta hda.

8 Tuka wicota he wanyakapi hehan yuśinyayapi, qa Wakantanka wicaśta wookihi hinsko tanka wicaqu kin he yatanpi.

9 Unkan Jesus hetanhan iyoopta iyaya hehan wicaśta wan Mattheos eciyapi, mazaska mnayanpi kin en iyotanka he wanyaka; qa heciya; Miyahna u wo. Unkan najin hiyaye ça ihakam iyaya.

10 Unkan ti mahen wota iyo- 


\section{WICOWOYAKE 9.}

tanka yanka hehan, iho, mazaska mnayanpi wahtanipi sa ko ota en hipi, qa Jesus kici iyotankapi, waonspewicakiye cin om.

11 Unkan Pharisee kin is he wanyakapi hehan waonspewicakiye cin hewicakiyapi ; Tokeca Waonspekiye nitawapi mazaska mnayanpi wahtanipi sa ko om wota he.

12 Unkan Jesus he nahon qehan hewicakiya; Tona zanipi kin hena pejihutawicaśta cinpi śni, tuka wayazankapi kin.

13 Tuka ya po, qa de taku kapi hecinhan sdonya po; Wowaonśida iyomakipi qa wośnapi wacin śni. Wicaśta owotanna wicakico wahi śni, tuka wahtanipi sa iyopeiciyapi kta on wahi ce.

14 Hehan Johannes waonspewicakiye cin en hipi qa heciyapi ; Tokeca unkiye qa nakun Pharisee kin ijehan akihanunkiçiyapi, tuka waonspewicayakiye cin akihaniciyapi śni.

15 Unkan Jesus hewicakiya; Wakankiciyuza cincapi kin tohanyan tawicu ton kte cin om un kinhan, hehanyan token ecin iyokiśicapi kta he ; tuka anpetu u kta tawicu ton kte cin ewicakiciyakupi kta, unkan hehan akilianiçiyapi kta.

16 Tuwedan śina teca onśpa wokoyake tanika en akihdag ton śni ; kinhan onśpa teca qon he mnawahe kta qa sanpa tanka hdecahan aya ece.

17 Nakun miniśa teca ojuha tanika en okaśtanpi śni ece; kinhan ojuha kin napopa, qa miniśa kin skepa, qa ojuha kin ihangyapi ece. Tuka miniśa teca ojuha teca en okaśtanpi ece, hecen napin tanyan yuhapi.

18 Hena hecen ewicakiya icunhan, iho, wicaśta itancan wan en u qa canpeśka makehde ina- jin qa heciya; Micunkśi nakaha ța, tuka en yau qa nape on ayaputake cinhan kini kta.

19 Unkan Jesus najin qa kici hda, nakun waonspewicakiye cin.

20 Unkan iho, winohinca wan waniyetu ake nonpa wayazanka, we ece iheya, he idazatanhan en u qa taśina opapun kin yutan:

21 Taśina kin hee kaeś mdutan kinhan amasni lita ce, cante mahen eye ca hecon.

22 Tuka Jesus ihdamna, qa wanyake cehan heya; Cunś, cante waśte wo ; wacinyaye cin he asniniyan ce. Unkan wihiyayedan oape kin he en winohinca kin asni.

23 Unkan Jesus wicaśta itancan qon ti kin en $i$, qa tona cotanka yajopi, oyate ceyapi ko wanwicayaka;

24 Hehan hewicakiya; Ako iyaya po; wicinyanna kin te śni, tuka iśtinma ce. Unkan ihahiapi.

25 Tuka oyate tankan hdicuwicayapi, hehan ti mahen $i$, qa nape on yuza; unkan wicinyanna kin inajin.

26 Unkan he makoce kin owancaya oyakapi.

27 Unkan Jesus hetanhan iyoopte iyaya, hehan wicaśta nom iśtagongapi kin hena ihakam yapi, howayapi qa heyapi; Dawid Cinhintku onśiunkida miye. 28 Unkan ti mahen iyaya, hehan wicaśta iśtagongapi kin en hipi : Unkan Jesus hewicakiya ; Hecen ecamon kta owakihi wicayadapi he. Unkan, Han, Itancan, eyapi.

29: Hehan iśta en wicayutan qa heya; Wacinyayapi kin iyecen ecaniconpi nunwe.

30 Hecen iśta hdukawapi. Unkan Jesus waśagya wahokonwi- 


\section{MATTHEOS.}

cakiye ca heya; Ito túwedan sdonye kte śni

31 Tuka tankan hdapi hehan makoce kin he owancaya nina oyakapi.

32 Unkan hena iyayapi hehan iho, wicaśta wan ia okitpani, wakan śica yuhnaśkinyan, he en ahipi.

33 Unkan wakan śice cin napeyapi hehan ia okitpani qon ia; unkan oyate kin inihanpi qa heyapi ; Israel en tohinni decen wanyakapi śni tuka qon.

34 Tuka Pharisee kin heyapi ; Wakanśica itancan lkin on taku wakan śica napewicaya ece.

35 Unkan 'Jesus otonwe kin owasin, otonwe ciqadan ko iyaza un, omniciye tipi yuhapi kin ohnahna waonspekiye ca wokiconze wotanin waśte kin he oyaka ece; qa wayazankapi owasin, oyate kin en tehiya unpi ko asniwicaya ece.

36 Tuka wicota wanwicayaka hehan onśiwicakida; nina mdokitapi qa enanakiya iyayapi ece, tahinca wanunyanpi tuwedan wicayuhe śni iyececa.

37 Hehan waonspewicakiye cin hewicakiya; Awicakehan woksapi kin he tanka, tuka hitanipi kte cin hena tonana:

38 Heon etanhan woksapi en Itancan kin iye tamaga kin en -wicaśta litanipi kte cin hena hiyuwicaye kta icekiya po.

\section{WICOWOYAKE 10.}

1. Unkan waonspewicakiya akenonpapi kin hena wicakico qehan, taku wakan śica on wowaśake wicaqu, napewicayapi kta, qa nakun wowayazan śicaya unpi ko, owasin asniwicayapi kta. -2 Unkan wáhośiyapi akenonpapi kin kakenken ewicakiyapi ; tokaheya Simon he nakun Inyan eciyapi, qa Andrew iye sunkaku; Jakob Zebede cinhintku qa Johannes iye sunkaku ;

3 Philip qa Bartholomew; Thomas qa Mattheos wamnaye ciqon; Jakob Alpheus cinhintku qa Lebbeus he nakun Thaddeus eciyapi ;

4 Simon Kananite kin, qa Judas Iskariot wiyopeye kte cin hee.

5 Dena akenonpapi kin Jesus yewicaśi, wahokonwicakiye ça heya; Ikcewicaśta tacanku wan ohna yapi śni po, qa Samaria oyate otonwe tawapi kin en yapi śni po:

6 Tuka Israel ti kin etanhan tahinca wanunyanpi taninpi śni kin hena ekta ya po.

7 Qa dapi eca yaotanin po, qa ; Mahpiya wokiconze kin wanna kiyedan un ce, eya po.

8 Tona wayazankapi kin asniwicaya po, tona lepros ececapi kin ska wicakaga po, țapi kin hena kiniwicaya po, qa taku wakan śica napewicaya po ; iyunwin codan iyacupi, iyunwin codan wicaqu po.

9 Ipiyake nitawapi ohna mazaskazi, qa mazaska, qa mazaśa unmana yuhapi śni po.

$10 \mathrm{Qa}$ icimayanipi kin on wojuhadan, qa onlidolida nonpa, qa hanpa, qa cansagye, yuhapi 'śni po; tuwe htani kin he woyute qupi ece e kta iyececa.

$11 \mathrm{Qa}$ otonwe tanka otonwe ciqadan ko, wanji tukte en yaipi kinhan, tuwe iyececa hecinhan iwicawanga po, qa he kici yukan po, tohanyan etanhan yahdapi śni kinhan.

12 Qa tipi wanji en yaipi kinhan, Wookiye en un nunwe, eya po.

$13 \mathrm{Qa}$ tipi kin he iyececa hecinhan woukiye nitawapi akan 


\section{WICOWOYAKE 10.}

un kta; tuka iyecece śni kinhan wookiye niye en nihdipi kta.

$14 \mathrm{Qa}$ tuktèn iyowinniciyapi śni qa nioiepi kin nahonpi śni kinhan, tipi kin he, qa otonwe kin he, etanhan tankan yahdapi kinhan, watuśekśeca siha onitkapapi kin he natata po.

15 A wicakehan heciciyapi; Woyaco anpetu kin en otonwe kin he tehiya un kta, Sodom qa Gomorra makoce kin isanpa.

16 Tho, tahinca wanunyanpi śunktokeca wicehna iyecen yeciśipi ; heon etanhan wamduśka iyecen ksapa po, qa wakiyedan iyecen walibapidan po.

17 Tuka wicaśta iwanwicayaka po; woyaco omniciye kin en aniyanpi kta, qa omniciye tipi yuhapi kin ohna nicapsinpsintapi kta :

18 Qa wicaśta itancanpi wicaśtayatapi ko, en aniyanpi kta, miye on etanhan, hecen iyepi qa Ikcewicaśta ko wicayakiyutaninpi kta.

19 Unkan tohan hecen wicaniçupi kinhan, taku, qa token ehapi kte cin, heon iyokiśiniçiyapi śni po; wihiyayedan oape kin he en token ehapi kta he nicupi kta ce.

20 Ie kte cin he niyepi śni, tuka Niyatepi Taniya en niunpi kin he iye ie kta.

21 Hunkawanjinkiciyapi kin iś unma ktepi kta e wicaqu kta; qa wicaśta wan iye cinhintku kin nakun; qa wicacinca kin iś hunkakewicayapi itkowicakipapi qa wicakiktepi kta.

22 Qa micaje on owasin śicenidapi kta; tuka tuwe owihanke kin hehanyan sutaya un kinhan he ni.kta.

23 Truka tohan otonwe kin de en śicaya nicuwapi kinhàn, wanji Dak. tokeca ekta najica po; awica kehan heciciyapi, Israel otonwe tawapi kin iyaza yaunpi kte śni ecen Wicaśta Cinhintku kin hi kta.

24 Waonspekiyapi kin he waonspekiya tawa kakipe śni; qa tuwe wowidake un kin he yuhe cin isanpa tanka śni ece.

25 Tuka waonspekiyapi kin waonspekiya tawá kin iyececa, qa wowidake un kin yuhe cin iyececa hecinhan hecetu kta. Tipi tawa kin he Beelzebub eciyapi hecinhan, tiyohnake tawa kin iś nakun hewicakiyapi kte śni he.

26 Heon etanhan kowicakipapi śni po ; taku akahpapi qa yuzamnipi kte śni wanica, qa taku anahimanpi qa sdonyapi kte śni wanica.

27 Taku otpaza en ociciyakapi kin he anpa en daotaninpi kta; qa taku noge on nayahonpi kin he tipi akahpe kin etanhan eyanpaha odakapi kta.

28 Unkan tona wicatancan ecedan ktepi kta okihipi, qa wicanagi kte okihipi śni kin hena kowicakipapi śni po; tuka tuwe wicanagi wicatancan ko Wakanśica ti kin en ihangye kte cin hee e kokipa po.

29 Zitkadan nom mazaśa wanjidan iyopeyapi śni he; qa etanhan wanjidan kaeś Niyatepi codan makata ihpaye kte śni.

30 Tuka paha nitawapi kin hee kaeś owasin yawapi ece.

31 Heon etanhan kopehdapi śni po ; zitkadan ota isanpa niyawapi ece.

32 Heon etanhan tuwe kaśta wicaśta wicitokam miye omayake cinhan, he Ate miahpiya en un kin itokam omdake kta.

33 Tuka tuwe wicaśta wicito17 


\section{MA'T'THEOS.}

kam miye ehpemaye cinhan, he miye Atewaye mahpiya en un kin itokam elipewaye kta.

34 Wookiye maka akan wicawaqu kta on wahi kecinpi śni po; wookiye wicawaqu kta wahi śni tuka mazasgye.

35 Wicaśta wan atkuku śicekidake walkiye kta wahi, qa cunwintku iye hunku kin, qa takośku iye kunku kin śicekidake kta heon.

$36 \mathrm{Qa}$ wicaśta tona tokayapi kin iye ti en unpi kin hena eepi kta.

37 Tuwe miye isanpa atkuku qa iś hunku kin waśtekidake cinhan, he mici un kta iyecece śni; qa tuwe miye isanpa cinhintku qa iś cunwintku kin waśtekidake cinhan, he mici'un kta iyecece śni :

$38 \mathrm{Qa}$ tuwe cansusbeca tawa kin ehdaku śni qa miyahna $u$ śni kinhan, he mici un kta iyecece śni.

39 Tuwe wiconi tawa kpatan kinhan, he toki ehpelkiye kta; qa tuwe miye on etanhan wiconi tawa kpagan kinhan, he kpatan kte cin ee.

40 Tuwe iyowinniciyapi kin he iyowinmakiya; qa tuwe iyowinmakiye cin he tuwe umaśi kin he iyowinkiya ece.

41 Tuwe wicaśta wokcan, wicaśta wokcan caje on iyowinkiye cinhan, he wicaśta wokcan iyunwin tawa yuhe kta; qa tuwe wicaśta owotanna, wicaśta owotanna caje on iyowinkiye cinhan, he wicaśta owotanna iyunwin tawa kin icu kta.

42 Qa tuwe waonspekiyapi caje on, dena cikcistinpidan wanji wiyatke ohna mini sni ecedan yatkekiye cinhan, awicakehan heciciyapi, he iyunwin tawa toki ehpekiye kte śni.

\section{WICOWOYAKE 11.}

1 Unkan Jesus waonspewicakiye akenonpapi kin taku econwicaśi ayaśtan, hehan hetanhan iyaya, otonwe tawapi kin ohnahna woyake kta qa waonspekiye kta.

2 Unkan Johannes kaśka hnakapi kin en Messiya ohan kin nation qehan, iye waonspewicakiye cin nom ekta yewicaśi ;

3 Qa heciya; Tuwe u kte ciqon he niye he, qa iś tuwe tokeca wantinyakapi kta he.

4 Unkan Jesus waayupte ça hewicakiya; Hda po, qa taku tona nayahonpi qa wandakapi kin hena Johannes okiyaka po:

5 Iśtagongapi kin tonwanpi ece, huśtepi kin manipi ece, tona lepros ececapi kin ska wicakagapi ece, tapi kin kinipi ece, qa tona onśikapi kin hena wotanin waśte owicakiyakapi ece.

6 Qa tuwe miye on naśdute śni kinhan, he yawaśtepi ce, eya.

\% Hena wanna kihdapi hehan Jesus Johannes on oyate kin wowicakiyaka; Taku wandakapi kta on hewoskan yaipi he; cedi wan tateyanpa kahuhuza:

8 Tuka taku e wanyag yaipi he ; wicaśta wan wolkoyake panpanna koyake cin he; iho tona taku panpanna koyakapi lin hena wicaśtayatapi tipi ohna yakonpi ece.

9 Tuka taku e wanyag yaipi he; wicaśta wokcan kin heca he; han, eciciyapi, qa wicaśta wokcan isanpa.

10 Wowapi en kagapi qon, Iho, niite itokam wahośiya mitawa yewaśi, he nitokam canku nitawa nicage kta ce, iho hee.

11 Awicakehan heciciyapi ; Tona winohinca eciyatanhan 


\section{WICOWOYAKE 12.}

wicatonpi kin wanji Johannes baptem wicaqu ece kin sanpa tanka icage śni; tuka tuwe mahpiya wokiconze kin en iyotan cistinna kin he sanpa tanka.

12 Nakun Johannes baptem wicaqu taanpetu kin hetanhan dehanyan mahpiya wokiconze kin nina akitapi, qa nina akite cin hena iyahpayapi ece.

13 Johannes hehanyan woope qa wicaśta wokcanpi owasin woyakapi :

14. Qa niś vicada wacannipi hecinhan Elias u kte ciqon he dee.

15 Tuwe noge winalion yukan hecinhan he ito nahon kta.

16 Tuka ito wicoicage kin de taku e imdacin kta he. Hokśipidan tihocoka en iyotankapi kin hena e iyececa, takodakupi wicakipanpi,

17 Qa hewicakiyapi; Cotanke unniciyajopi tuka niye wayacipi śni; waśinunhdapi tuka niye yaceyapi śni.

18 Johannes wote śni qa wayatke śni hi; unkan, Taku wakan śica yuha ce, eyapi.

19 Wicaśta Cinhintku kin wota qa wayatkan hi; unkan heyapi; Tho, wicaśta wan wote sa qa miniśa yatkan ece, wamnayanpi qa wahtanipi sa takodawicaya ece. Tuka woksape iye cinca kin on owotanna oyakapi ece.

20 Hehan otonwe kin tona en iye ohan tanka econpi qon hella iyopewicaya, iyopeiçiyapi śni heon.

21 Hehehe IKorazin, hehehe Bethsada; wicohan tanka niyepi en econpi kin, hena Turos qa Sidon en econpi unkanś, wanakaja heyake śica cahota ko en iyopeiciyapi kta tuka.

22 Ḣeon etanhan heciciyapi; 'Woyaco anpetu kin en, tehilya yaunpi kta, qa Turos Sidon kici aopten unpi kta.

23 Qa Kapernaum niye, mahpiya ekta wankan aniyanpi, tuka wicahapi ekta ehpeniyanpi kta; wicohan tanka niye en econpi kin hena Sodom en econpi unkanś, anpetu kin dehanyan ecen un kta tuka.

24. Heon etanhan heciciyapi; Woyaco anpetu kin en teliiya yaun kta, qa Sodom makoce kin ahecece kta.

25 Anpetu kin hena en Jesus waayupte ca heya; Ate, mahpiya maka ko Itancan kin, ciyatan, dena taku kin tona lisapapi qa wasdonyapi kin anawicayakilibe ça hokśiyoqopapi owicayakidakai ece.

26 Han, Ate hecetu, hecen iyonicipi nakaeś.

27 Ato taku owasin maqu; unkan tuwedan Cinhintkuyapi kin sdonye śni, A teyapi un kin hecedan sdonkiya; nakun tuwedan Ateyapi kin sdonye śni, tuka Cinhintku kin hecedan; qa tuw\& Cinhintku kin sdonyekiye cin he nakun.

28 Tona htayanipi qa tkeya wayaqinpi kin owasin en mau po, kinhan ozikiyapi ciçupi kta.

29 Can napinpi mitawa kin he icu po, qa miye eciyatanhan onspeiciciciya po, cante elrta onśimicida qa walibayedan waun; hecen ninagipi en woozikiye duhapi kta.

30 Can napinpi mitawa kin he tehike śni, qa waqin mitawa kin he kapojedan.

\section{WICOWOYAKE 12.}

1 Anpetu kin hena en, anpetu wakan icunhan, Jesus aguyapi ojupi kin ehna iyaya; unkan waonspewicakiye cin wotekte- 


\section{MATTHEOS.}

hdapi; qa aguyapi yuksa icupi qa yutapi.

2 Unkan Pharisee kin he wanyakapi hehan heciyapi; Wanyaka wo, waonspewicayakiye cin, anpetu wakan icunhan taku econpi kte śni ece kin, hee econpi.

3 Unkan iye hewicakiya; Dawid taku econ qon he tohinni dawapi śni he; iye qa tona om un kin wotektehdapi qehan;

4 Tipi wakan kin en i, qa aguyapi taninyan ehnakapi kin yuta, he iye qa tona om un kin yutapi kte śni, tuka wośnapi kagapi kin ecedan yutapi kta tuka.

5 Qa woope kin en nakun dawapi śni, wośnapi kagapi kin tipi wakan ohna anpetu wakan ahopapi śni eśta iyaonpepica śni unpi.

6 Tuka heciciyapi; Tuwe tipi wakan kin isanpa tanka wan den un.

7 Wowaonśida wacin qa wośnapi wacin śni ce, eyapi qon he idukcanpi unkanś, tona wahtanipi śni kin hena wicadacopi kte śni tuka.

8 Qa Wicaśta Cinhintku kin he anpetu wakan Itancan kin he nakun ee.

9 Hehan hetanhan iyaye ca omniciye tipi tawapi kin en i.

10 Unkan iho, wicaśta wan nape śnija hen un; unkan wiwangapi qa heciyapi; Anpetu wakan icunhan waasniyapi kta iyececa he; he iyaonpapi kta e heyapi.

11 Unkan hewicakiya; Enitanhanpi wicaśta wanji tahinca wanunyanpi wanjidan yuhe cinhan, he anpetu wakan icunhan wolia en iyolipaya hecinhan, tancan en yuze ça ehdaku kte śni he.
12 Wicasta kin he tahinca wanunyanpi isanpa ece. Heon: etanhan anpetu wakan icunhan taku waśte econpi kta iyececa.

13 Hehan wicaśta qon heciya; Nape hdukatin wo; hecen yukatin, unkan unma kin iyecen asni icaga.

14 Unkan Pharisee kin hetanhan tankan hdapi, qa token ktepi kte cin he akiiapi.

15 Tuka Jesus he sdonye ca hetanhan tokan iyaya; unkan wicota linca ihakam unpi, qa iye hena owasin asniwicaya:

16 Qa nina oyake śni wicaśi.

17 Hecen Isaya wicaśta wokcan kin taku eye ciqon yuecetupi kta; he kaken eya ;

18 Iho, mitahokśidan wahdahnige ciqon; waśte wakidake cin on minagi iyuśkin ece; mitaniya kin waqu kta, hecen Ikcewicaśta kin woyaco owicakiyake kta.

19 Wicakize lkte śni, qa pan kte śni, qa ho kin tuwedan canku ohna nalion kte śni :

20 Cedi kaśuśujapi kin he yukse kte śni, qa hahonta ide kte cin he kasni kte śni, woyaco he woohiye ekta au śni kinhan:

21 Qa iye caje kin Ikcewicaśta wacinyanpi kta.

2:2 Hehan wanji wakan śica yuhnaśkinyan he en ahipi, iśtagonge ca ia okitpani; unkan asniyan, hecen iśtagonge ça ia okitpani kin he ia qa nakun tonwan.

23 Unkan wicaśta ota kin owasin yuśinyayapi qa heyapi ; Dawid cinhintku kin he dee śni he. 24 Tuka Pharisee kin is he nahonpi qehan heyapi; Wicaśta kin de wakan śica napewicaye cin he Beelzebub wakan sica itancan kin on hecon ece.

25 Unkan Jesus token cante- 


\section{WICOWOYAKE 12.}

yuzapi kin he sdonye ca hewicakiya; Wokiconze wan iye iyakitedan kiciza eca hinhpaya ece; nakun otonwe qa tipi otoiyohi iye iyakitedan kicizapi ehantanhan ecen he kte śni.

26 Qa Satan Satall napeye cinhan wanna iye iciciza; hecen token tokiconze kin sutaya he kta he.

27 Qa niye Beelzebub on wakan śica napewicawaya ehantanhan, nicincapi kin iś taku on napewicayapi he; heon etanhan hena niyacopi kta.

28 Tuka miye Wakantanka Taniya on wakan sica napewicawaya hecinhan, Wakantanka tokiconze kin wanna en nihipi.

29 Wicaśta waśaka ti kin en, tuwe tin iyaye cea taku tawa kin ihangye kta token okihi kta he ; tokaheya wicaśta waśake cin kaśke cinhan hehan tipi kin ihangye kta.

30 Tuwe mici un śni kinhan he makipajin ece; qa tuwe micipahi śni kinhan he yutakuni śni ece.

31 Heon etanhan heciciyapi; Woahtani owasin iapi śica ko wicaśta wicakicicajujupi kta ; tuka Woniya Wakan aiapi kin he wicaśta wicakicicajujupi kte śni.

32 Qa tuwe Wicaśta Cinhintku kin taku śica eciye cinhan, he kicicajujupi kta; tuka tuwe Woniya Wakan kin taku śica eciye cinhan, he kicicajujupi kte śni, wiconi kin de en, qa nakun wiconi u kte cin en.

33 Can kin waste kaga po, kinhan waskuyeca waśte kta; qa iś can kin śica kaga po, kinhan waskuyeca śice kta; can kin waskuyeca tawa kin on sdonyapi ece.

34 Wamduśka wicoicage, ni- śicapi hecen token taku waśte ehapi kta oyakihipi he; wicacante ojudan kin he eciyatanhan wicai kin ia ece.

35. Wicaśta waśte kin iye cante waśte ojucan kin eciyatanhan taku waśte hiyuya ece; qa nakun wicaśta śice cin iye cante śica ojudan kin etanhan taku śica hiyuya ece.

36 Tuka wicoie waśte śni otoiyohi wicaśta eyapi kin hena on woyaco anpetu kin en ohdakapi ece e kta, he miye eciciyapi.

37 Nioie kin on niyaowotanpi kta, qa nakun nioie kin on niyacopi kta.

38 Hehan wowapi kagapi wanjikji qa Pharisee kin ayuptapi qa heciyapi; Waonspekiya, wowapetokeca wan wanyagunyakiyapi kta uncinpi.

39 Tuka iye wayupte ca hewicakiya; Wicoicage śice ça wawiciliahapi econ sa kin he wowapetokeca da, tuka wow̄apetokeca wanjidan qupi kte śni, Jonas wicaśta wokcan wowapetokeca tawa kin heceedan kta.

40 Anpetu yamni qa hanyetz yamni hehanyan Jonas hogan tanka tezi kin ohna un qon, lie iyecen anpetu yamni qa hanyetu yamni Wicaśta Cinhintku kin maka cante kin en un lita.

41 Woyaco anpetu kin en Ninewe wicaśta kin inajinpi qa wicoicage kin de yacopi kta; hena e Jonas woyake cin on iyopeiçiyapi tuka; unkan iho, Jonas isanpa tanka wanji den un.

42 Itokah wicaśtayatapi winohinca qon he woyaco kin en inajin kta, qa wicoicage kin de yaco kta; eqe Solomon tolksape nation kta on maka ihanke kin etanhan u tuka; unkan iho, 


\section{MATTHEOS.}

wanji Solomon isanpa tanka den un.

43 Woniya śape cin wicaśta kin etanhan tankata hinanpa, hehan makoce puza en omani, ozikiyapi akita, tuka takudan iyeye śni; 44 Hehan heya; Tipi mitawa etanhan wahinape ciqon he ake ekta wahde kta. Unkan ekta ki, qa tuwedan ohna yanke śni, kahintapi qa ayuco yuśtanpi, hecen iyeya.

45 Hehan iyaye ca woniya tokeca śakowin iye isanpa śicapi, hena iwicacu qa om mahen iyaya, qa ohna yukanpi ; unkan wicasta kin he hetanhan tehiya un, tokaheya un qon isanpa. Wicoicage śice cin de hecece kta.

46 Unkan oyate kin hecen wowicakiyaka icunhan, iho, iye hunku qa hunkawanjitku kin tankan hinajinpi qa okiyapi kta cinpi.

47 Unkan wanji heciya; Tho, nihun qa nihunkawanji tankan najinpi qa oniciyapi kta cinpi.

48 T'uka iye waayupte ca tuwe heye cin he heciya; Tuwe inawaya he, qa mihunkawanji kin hena tuwepi he.

49 Unkan waonspewicakiye cin ektakiya nape hdugate ca heya; Iho, mihun qa mihunkawanji dena eepi ce.

50 Tuwe kaśta Ate mahpiya ekta un tawacin kin ecen econ kinhan he mihunkawanji qa mitawinohtin qa mihun ee.

\section{WICOWOYAKE 13.}

1 Unkan anpetu kin hena en Jesus tipi kin etanhan tankata iyaye ca mde kin icahda'iyotanka.

2 Unkan wicota hinca en mniciyapi, hecen iyotanke kta e wata wan en opa, qa oyate kin iyuhpa hutata najinpi.

3 Unkan wiyacinpi on taku ota owicakiyaka, qa heya; Iho, wi. caśta woju wan woju iyaya:

4 Unkan woju icunhan, apa canku icahda hinhpaya; hecen wahupakoza en hipi qa temyapi.

5 Qa apa tukten inyan ota ehna ihpaya, hen maka tonana; unkan ohankoya hinanpa, maka tonana nakaeś.

6 Tuka wi kata aya hehan owasin gu; qa hutkan nica heon etanhan śnija.

7 Unkan apa iś wapepeka ehna ihpaya; unkan wapepeka tanka icage ça hecen kte.

8 Tuka apa maka waśte en ihpaya, qa etanhan ota icaga, apa opawinge, apa wikcemna śakpe, apa wikcemna yamni.

9 Tuwe noge winahon kta yukan hecinhan, ito nalion kta.

10 Unkan waonspewicakiye cin en hipi qa heciyapi; Tokeca wiyacinpi on owawicayakiya he.

11 Unkan iye awicayupte ça heya; Mahpiya wokiconze woanahbe kin niye oyakahnigapi kta nicupi, tulka hena hecen wicaqupi śni, heon etanhan.

12 Heon tuwe taku yuhe cinhan nakun qupi kta, hecen iyakicuya yuhe kta ; tuka tuwe takudan ton śni, tona yuhe cin hee kaeś kipi ece e kta.

13 Heon etanhan wiyacinpi on wowicawakiyaka ece; hecen tonwanpi kés wanyakapi śni, qa winahonpi keś nahonpi śni, qa nakun okahnigapi śni.

14 Qa hecen Isaya wicaśta wokcan taku eye ciqon iyepi on yuecetupi ; Winahonpi on nayahonpi kta, tuka oyakalinigapi kte śni ; qa tonwanhan wandakapi kta, tuka idukcanpi kte śni ce. 


\section{WICOWOYAKE 13.}

15 Oyate kin de cantepi kin cepa aya, qa nogepi kin kitan se winahonpi, qa iśtohmuzapi; hecece śni unkanś, iśta on wanyakapi kta, qa noge on nahonpi kta, qa cante on iyukcanpi kta, qa ihduhomnipi kta, kinhan asniwicawaye kta tuka.

16 Tuka nuisśtapi kin wowaśte, on wandakapi ece; qa ninogepi kin wowaśte, on nayahonpi ece. 17 Awicakehan heciciyapi ; Wicaśta wokcan ota, qa wicaśta owotanna, taku wandakapi ece kin hena wanyakapi kta cinpi, tuka wanyakapi śni ; qa taku nayahonpi ece kin, hena nahonpi kta cinpi, tuka nahonpi śni.

18 Heon etanhan wicaśta woju qon wiyacinpi kin he ito nahon po.

19 Wicaśta otoiyohi wokiconze oie kin nahon keś, okahinige śni kinhan, he tuwe śice cin en hi, qa taku cante en ojupi qon eyaku ece; iho, canku icahda ojupi icu qon hee.

20 Unkan inyan ota en ojupi icu qon he dee; tuwe wicoie kin nahon qa ohankoya iyuśkinyan icu;

21 Tuka iye en hutkan wanica, hecen ecadan enakiya; tohan wicoie kin on wokakije qa śicaya kuwapi akipa hecinhan, hinnakaha ayuśtan iyaya ece.

22 Unkan wapepeka ehna ojupi icu qon, tuwe wicoie kin nahon kin hee; tuka wiconi kin de awacinpi qa woyuha ota wohnaye kin hena wicoie kin kte ece, hecen waskuyeca takudan aicage śni.

23 Tuka maka waśte en ojupi icu qon, he tuwe wicoie kin nahon qa okahiniga; qa hecen waskuyeca icaliya ece; apa opawinge, qa apa wikcemna śakpe, qa apa iś wikcemna yamni icaga ece.

24 Wiyacinpi tokeca wan owicakiyake ca heya; Mahpiya wokiconze kin wicaśta wan iye tamaga en su waśteśte oju kin he iyececa.

25 Tuka wiciśtinma hiyeya icunhan, toka wan en hi, qa aguyapi ehna wayahota oju, qa kihda.

26 Unkan ape kin wanna uye ca wahuwapa icage kta, hehan wayahota iś nakun tanin.

27 Unkan tipi tawa wowidakewicaye cin en hipi qa heciyapi ; Itancan, nitamaga en su waśteśte oyaju śni he; hecen wayahota kin tokiyatanhan yuha he.

28 Unkan iye hewicakiya; Wicaśta wan toka kin heca e hecon. Unkan wowidakewicaye cin hena heciyapi; Unyanpi qa unpahipi kta yacin he.

29 Tuka iye heya; Hiya; okinni wayahota kin yapahipi kinhan, nakun aguyapi koya dujunpi kta.

30 Ito woksapi kta hehanyan napin icicahiya icage kta. Unkan woksapi anpetu kin he en, wayuksapi kin hewicawakiye kta; Tokaheya wayahota pahipi qa liuhnahyapi kta on pahta po; tuka aguyapi kin he dotopiye mitawa en omnayan po.

31 Wiyacinpi tokeca wan owicakiyake ca heya; Mahpiya wokiconze kin sinape su wanji iyececa, he wicaśta wan icu qa iye tamaga kin en oju.

32 He su kin owasin iyotan cistinna; tuka icaga hehan wato kin owasin iśnana tanka; qa can iyececa icaga, hecen mahpiya okinyanpi kin en upi, qa adetka kin en ahiyahan ece.

33 Wiyacinpi tokeca wan owicakiyaka; Mahpiya|wokiconze kin on napohyapi kin iyececa, 


\section{MATTHEOS.}

he winohinca wan icu qa wotpanpi wiyutapi yamni en inahiman, hecen ocowasin napohyapi.

34 Dena taku owasin Jesus wiyacinpi on oyate kin owicakiyaka, qa wiyacinpi codan takudan o.wicakiyake śni.

35 Hecen wicaśta wokcan taku eye cigon yuecetupi, he hecen eya; Wiyacinpi on $\mathrm{i}$ wahdukawa kta; taku maka kagapi ehantanhan anahmanpi kin he omdake kta ce.

36 Hehan Jesus oyate kin hidewicaśi, qa tipi wan en tin iyaya. Unkan waonspewicakiye cin en hipi qa heciyapi; Maga en wayahota wiyacinpi kin he unkokiyaka miye.

37 Unkan iye awicayupte ca hewicakiya; Tuwe su waśteśte oju qon he Wicaśta Cinhintku kin hee.

38 Maga kin he maka ocowasin ee; su waśteśte qon he wokiconze cinca kin hena eepi; wayahota kin he tuwe śica cinca kin hena eepi :

39 Toka hena oju qon Wakanśica hee. Woksapi kin he wiconi kin de owihanke kin hee; qa wayuksapi kte cin mahpiya ohnihde kin hena eepi.

40 Heon etanhan, wayahota pahipi qa peta en hulinagapi qon he wiconi kin de owihanke kin ekta becece kta.

41 Wicaśta Cinhintku kin tona ohnihdewicaye cin hena yewicaśi kta; unkan tokiconze kin etanhan tona walitanipi qa taku śica econpi kin owasin pahipi kta :

42 Qa peta mde kin en ehpewicayapi kta; hen wicaceya hi hdakinskinzapi ko yuke kta.

43 Hehan wicaśta owotanna kin anpetu wi kin iyecen iyega- pi kta, atkukupi tokiconze kin en. Tuwe noge winahon kta yukan hecinhan, ito nahon kta. 44 Akeś mahipiya wokiconze kin he mazaska, maga wan en nalimanpi kin he iyececa, he wicaśta wan iyeya, unkan anahbe ça, wiyuśkinyan iyaye ca, taku yuhe cin owasin wiyopekiye ça, maga kin he opeton.

45 Akeś mahpiya wokiconze kin wicaśta wopeton inyan tehika akite ciqon he iyececa ye : $46 \mathrm{He}$ inyan tehika wanjidan, ota iyopeyapi kin, he iyeya, unkan iyaye ca, taku tawa kin owasin wiyopekiye ça, he opeton.

47 Akeś mahipiya wokiconze kin he ho wan, mde kin en iyohpeyapi, qa ocaje owasin etanhan manaye cin, he iyececa ;

48 He wanna ojudan hehan hutata ahdipi, en iyotankapi, qa waśteśte kin hena cega-ohna mnakiyapi, tuka śikśice cin hena ehpeyapi.

49 Maka owihanke kinhan he iyecece kta; hehan mahpiya ohnihde kin upi kta, qa tona śice cin owotanna unpi kin wiciyopeyapi kin hena iwicacupi kta ; 50 Qa peta mde kin en iyohpewicayapi kta. Heciya wicaceya hi hdakinskinzapi. ko yuke kta.

51 Jesus hewicakiya; Dena owasin oyakahnigapi he. Han, Itancan, eciyapi.

52 Hehan hewicakiya; Heon etanhan wowapi kaga otoiyohi, mahpiya wokiconze on onspekiyapi kin, he wicaśta wan tipi yuhe ca, mazopiye tawa kin etanhan taku teca tannika ko ikikcu ece kin he iyececa.

53 Unkan Jesus wiyacinpi kin dena ihunnikiya, hehan hetanhan tankan iyaya: 


\section{WICOWOYAKE 14.}

$54 \mathrm{Qa}$ iye tamakoce kin en ki qehan, omniciye tipi yuhapi kin ohna waonspewicakiya; hecen yuśinyayapi qa heyapi; Woksape kin de, qa wicolian tanka, wicaśta lin de tokiyatanhạn yuha he.

55 Cankajipa cinhintku kin he dee śni he; hunku he Mary eciyapi, qa sunkawicaye cin hena Jakob qa Joses qa Simon qa Judas:

56 Qa tawinohtin hena owasin unkiyopeyapi unpi śni he; hecen tokiyatanhan dena taku kin owasin yuha he.

57 Unkan canniyeyapi. Tuka Jesus hewicakiya; Wicaśta wokcan yuonihanpi ece, tuka iye tamakoce qa iye ti kin ohna yuonihanpi śni.

58 Unkan wicohan tanka ota hen econ śni, wicadapi śni heon etanhan.

\section{WICOWOYAKE 14.}

: 1 Unkan anpetu kin hena en Herod wicaśtayatapi kin Jesus oyakapi kin he nation;

2 Qa tahokśidan kin hewicakiya; Johannes baptem wicaqu ece kin he dee ; tapi kin etanhan kini, heon etanhan wicolian tanka econ ece.

3 Herod Johannes yuze ça kaśka, qa conkaśke en ehnaka, Herodias iye sunkaku Philip tawicu qon heon.

4 Duhe kta iyecece śni ce, Johaunes eciye ciqon.

5 Unkan heon kte kta cin, tuka oyate kin kowicakipa; hena e wicaśta wokcan heca kecinpi.

6 'Tuka Herod anpetu en tonpi qon he ake hiyohipi, hehan $\mathrm{He}$ rodias cunwintku kin wicacokaya waci, qa Herod iyokipiya.

7 Heon etanhan, taku wakan cajeyate ca, taku kida kta hecinhan, awicakehan qu kta, keciya.

8 Unkan he itokam hunku onspekiya, heon heya; Wanna Johannes baptem wicaqu ece qon he pa kin wakśica wan ohna maqu ye.

9 Unkan wicaśtayatapi kin iyokiśice hinca, tuka wakanyan wacajeyate cin heon, qa tona om wota iyotanke.cin hena on, he qu wicaśi.

10 Hecen ekta ye wicaśi, qa conkaślke mahen Johannes pa baksa.

11. Unkan pa kin he wakśica ohna akupi, qa wikośka kin qupi ; unkan iye iyoopta hunku qu. 12 Unkan waonspewicakiye cin hena en hipi, qa tancan kin eyakupi qa hapi ; hehan yapi qa Jesus okiyakapi.

13 Unkan Jesus he nation qehan, hetanhán watom iyaye ça, iśnana hewoskan makoce wan ekta i. Unkan oyate kin he nakionpi qehan, otonwe etanhanhan huinyun ihakain yapi.

14. Unkan huta ekta ihunni qehan, wicota wanwicayaka; qa onśiwicakida, qa tona tehiya unpi kin hena asniwicaya.

15 Unkan wanna hitayetu hehan waonspewicakiye cin en hipi qa heyapi; Makoce kin de hewotahedan, qa wanna hitayetn, heon oyate kin hde wicaśi wo, hecen otonwe ciqadan kin en yapi kta, qa taku yutapi opeicitonpi kta.

16 Tuka Jesus hewicakiya; Hdapi kta iyecece śni ; ito niye taku yutapi wicaqu po.

17 Unkan heciyapi; Aguyapi kagapi zaptan qa hogan nonpa, henana den unhapi ce.

18 Unkan heya; Hena makau po. 


\section{MATTHEOS.}

19 Unkan oyate kin wato en iyotanke wicaśi, qa aguyapi zap$\tan$ qa hogan nonpa nakun icu, qa mahipiya ekta etonwan, hehan yawaśte, qa yuśpaśpa qa waonspewicakiye cin wicaqu, unkan wannspewicakiye $\operatorname{cin}$ iś oyate kin wicaqupi.

20 Unkan owasin wotapi qa imnanpi; unkan oyaptapi etanhan pahipi, makanopiye akenonpa ojudan.

21 Unkan tona wotapi kin hena wicaśta kektopawinge zaptan ecetu, nakun winohinca śiceca koya.

22 Hehan ecahankeya Jesus waonspewiyakiye cin wata wan en ope wicaśi, iye itokam akasanpa yapi kta, oyate kin hde wicaśi icunhan.

23 Unkan wanna oyate kin hde wicaśi, hehan iśnana paha wan ekta cekiya iyaya. Wanna otpaza tuka iśnana ekta yanka.

24 Tuka wata kin wanna mde kin cokaya un, taja on iyotanhan iyekiyapi, tatohekiya yapi nakaeś.

25 Unkan hanyetu en itopa kiktapi hehan Jesus mini kin amani en wicaya.

26 Unkan waonspewicakiye cin mini kin amani wanyakapi qehan, yuśinyayapi qa heyapi; $\mathrm{He}$ wanagi; qa kokipapi on śicahowayapi.

27 'Tuka Jesus kohanna owicakiye ca heya; Cante waśte po; de miye ce; kopehdapi śni po.

28 Unkan Inyan ayupte ca heya; Itancan he niye hecinhan, ekta mini kin amani u maśi wo.

29 Unkan; U wo, eciya. Hecen Inyan wata kin etanhan kun iyaye ca Jesus ekta ye kta mini kin amani.
30 Tuka wohitiya tateyanpa wanyaka, hehan kokipa. Qa spaye kta iyaya, hehan śicahowaya, qa heya; Itancan, nimayan wo.

31 Unkan Jesus ecahankeya nape ekta yekiye ca yuwankan icu, qa heciya; Cistinna wacinyaya, tokeca wacetunyahda he.

32 Unkan wata kin en opapi hehan amdakedan icu.

33 Hehan wata en unpi kin en hipi, makata elipeiciyapi qa heciyapi ; Awicakehan Wakantanka Cinhintku kin he niye.

34 Unkan akasanpa ihunnipi hehan Geneseret makoce kin en hipi.

35 Unkan wicaśta makoce kin he en unpi kin hena iyekiyapi, qa ihdukśan wanke cin owancaya hośi wicakayapi. Unkan tona tehiya unpi kin owasin en awicahipi ;

$36 \mathrm{Qa}$ cekiyapi, taśina opapun heceedan kaeś yutanpi kta heon; unkan tona yutanpi kin owasin tanyan asnipi.

\section{WICOWOYAKE 15.}

1 Hehan Jerusalem etanhan wowapi kagapi qa Pharisee kin Jesus en hipi qa heyapi ;

2 Tokeca waonspewicayakiye cin hunkawicayapi woope oyakapi qon acakśinpi he; qa aguyapi yutapi kte cinhan nape hdujajapi śni.

3 Unkan iye waayupte ca hewicakiya; Qa niś nakun tokeca woope odakapi kin on Wakantanka toope kin acayakśinpi he.

4 Wakantanka heya econ wicaśi ; Niyate nihun kici wicahduonihan wo ; nakun; 'Tuwe atkuku hunku kici wicayaśice cinhan wiconte on te kta ce.

5 Tuka niye hehapi; Tuwe 
atkuku qa iś hunku kin heciye kta iyececa; Taku on ociciye kte cin he wanna wośnapi ce; qa hecen atkuku hunku kici wicahduonihan śni ece

6 Hecen woope odakapi kin on Wakantanka toope kin dutakunipiśni.

7 Wananicilimanpi, niyepi on Isaya tanyan woyake ça heye ciqon ;

8 Oyate kin de $\mathrm{i}$ on mikiyedan upi, qa iha on mayaonihanpi; tuka cantepi kin hena mitehan unpi ece.

9 Wicaśta wicoope kagapi kin hena woope keya onspewicakiyapi, qa on mayuonihanpi kte cin he takudan okihi śni ece.

10 Hehan oyate kin wicakico qa hewicakiya; Nahonpi qa okahiniga po:

11 Taku wicai kin ohna iyaye cin he wicaśta kin yuśape śni ; tuka taku wicai kin etanhan hiyu kin he wicaśta yuśape cin ee.

12 Hehan waonspewicakiye cin en hipi qa heciyapi; Wicoie kin de Pharisee kin nahonpi qa śihdapi, he sdonyaya he.

13 Unkan waayupte ca heya; Taku ojupi kin, tona Ate mahipiya elsta un kin oju śni kinhan, hena owasin yujunpi kta.

14 Awicayuśtan po; iśtagongapi iśtagongapi awicayapi kin hena hecapi. Unkan tuwe iśtagonga iśtagonga wan yus aye cinhan, napin makolidoka en ohinhipayapi lita.

15 Hehan Inyan ayupte ca heciya; Wiyacinpi kin de unkokiyaka miye.

16 Unkan Jesus heya; Niś nakun hinahin oyakahnigapi śni he,

17 Taku wicai kin ohna iyaye cin he wicatezi kin ekta i ece, qa hehan hetanhan tankan ehpe- yapi ece; he hinahin oyakalinigapi śni he

18 Tuka taku wicai kin etanhan hiyu kin hena wicacante kin eciyatanhan u ece; qa wicaśta yuśape cin hena ee.

19 Wicacante kin eciyatanhan wicotawacin śica hiyu ece ; tinwicaktepi, wawiciliahapi, wiinalimanpi, wamanonpi, woitọnśni qa wicayaśicapi kin.

20 Wicaśta yuśape cin dena ee; tuka nape hdujaja śni wotapi kin he wicaśta kin yuśape śni.

21 Hehan Jcsus hetanhan tokan iyaye ca, 'Turos qa Sidon makoce ihdukśan wanke cin he ekta i.

22 Unkan iho, Kanan winolinca wan malkoce kin hetanhan hiyu, qa hoyekiye ça heya; Itancan, Dawid Cinhintku, onśimada ye, micunkśi walkan śica yuhnaśkinyan, śicaya un.

23 Tuka iye oie wanjidan ayupte śni. Unkan waonspewicakiye cin en hipi, cekiyapi qa heyapi ; Hdeśi wo, unkihakam śicahowaya ece.

24 Tuka iye waayupte ca he. ya; Israel tiyohnaka tahinca wanunyanpi nunnipi kin henana elzta umaśipi ce.

25 Hehan winohinca qon en hi, makata elipeiçiye ca heciya; Itancan, omakiya 'we.

26 Tuka iye ayupte ca; Hokśiyopa aguyapi tawapi kin icupi qa śunka wicaqupi kin he hecetu śni ce, eya.

27 Unkan iye; Han, Itancan; tuka sunka kin iye wicayuhapi wahna wotapi tawapi kin etanhan ośnaśna hinhpaye cin hena etanhan yutapi ece, eya.

28 Hehan Jesus ayupte ca heciya; Winohinca, wacinyaye cin he tanka; token yacin kin he enicicetu nunwe. Unkan wihi- 


\section{MAT'THEOS.}

yayedan oape kin he hetanhan cunwintku kin asni.

29 Unkan Jesus hetanhan iyaye ca Galile mde kin ikiyedan $u$; qa paha wan ekta iyaye ça akan iyotanka.

30 Unkan wicaśta ota en hipi, tona huśtepi, iśtagongapi, ia okitpanipi, hu bawicaksapi, qa toktokeca ota en awicahipi, qa Jesus siha kin en ewicahnakapi ; unkan asniwicaya.

31 Hecen wicota yuśinyayapi, ia okitpanipi qon hena iapi, hu bawicaksapi qon hena tokecapi śni, huśtepi qon hena manipi, qa iśtagongapi qon hena tonwanpi wanwicayakapi, heon etanhan; qa Israel Taku Wakan tawapi kin he yatanpi.

32 Hehan Jesus waonspewicakiye cin wicakico qa hewicakiya; Oyate kin onśiwicawalkida, wanna yamni can taku yute śni mici unpi ; qa wote śni hdewicawaśi kta tawațenwaye śni, okinni tahepi ihpayapi kta.

33 Unkan waonspewicakiye cin heciyapi; Makoce hewotahedan kin de en tokiyatanhan aguyapi iyenakeca unhapi qa oyate hinsko tanka imnawicunyanpi kta he.

34 Unkan Jesus hewicakiya; Aguyapi kagapi tona duhapi he. Unkan; Sakowin qa hoganstinna tonana nakun, eyapi.

35 Unkan oyate kin makata iyotanke wicaśi ;

36 Qa aguyapi śakowin icu, hogan kin hena nakun, qa yawaśte, hehan kiyuśpaśpa qa waonspewicakiye cin wicaqu; unkan waonspewicakiye cin oyate kin wicaqupi.

37 Unkan owasin yutapi qa imnanpi; qa oyaptapi kin hena pahipi, makanopiye śakowin ojudan.
38 Wotapi kin hena wica ece kektopawinge topa, nakun winobinca śiceca koya.

39 Hehan oyate kin hdewicaśi, qa wata wan en ope ca Magdala makoce kin en hi.

\section{WICOWOYAKE 16.}

1 Unkan Pharisee qa Sadukee etanhan en hipi, qa malipiya eciyatanhan wowapetokeca wan wicakiyutanin śipi, iyutanyanpi kta.

2 Tuka iye waayupte ca hewicakiya; Tohan htayetu eca, Malipiya śaśa heon owaśtecake kta ce, ehapi ece.

3 Qa hanhanna eca, Ecin ossicecake kta, malipiya śaśa qa śapśapa, heon etanhan. Wananicihmanpi, malipiya ite kin he yukcan onnispepi, tokeca anpetu kin dena wowapetogton oyakalinigapi śni he.

4 Wicoicage śice ça wawicihahapi econ sa kin he wowapetokeca wan da; tuka wowapetokeca wanjidan qupi kte śni; Jonas wicaśta wokcan tawowapetokeca kin heceedan. Unkan ehpewicaya iyaya.

5 Unkan waonspewicalkiye cin akasanpa ipi, qa aguyapi icu akiktonjapi.

6 Hehan Jesus hewicakiya; Pharisee qa Sadukee on napohyapi tawapi kin he iwanyakapi qa kokipa po.

7 Unkan iye iyakitedan akinicapi qa heyapi; Aguyapi unkicupi śni, heon etanhan, heya ce.

8 Tuka Jesus he sdonye ça hewicakiya ; Cistinna wacinyayapi kin, tokeca niye iyakitedan ayakinicapi he, aguyapi iyacupi śni heon.

9 Hinahin oyakalinigapi śni, wicaśta kektopawinge zaptan 


\section{WICOWOYAKE 17.}

qa aguyapi zaptanna, qa makanopiye ojudan tonakeca yapahipi he yeksuyapi śni he.

10 Nakun wicaśta kektopawinge topa qa aguyapi śakowin, qa makanopiye ojudan tonakeca iyacupi he.

11 Tokeca oyakalinigapi śni he, Pharisee qa Sadukee on napohyapi tawapi kin he kokipe ciśipi, he aguyapi on heciciyapi śni.

12 Hehan aguyapi on napohyapi kin he kokipe wicaśi śni, tuka Pharisee qa Sadukee woonspe tawapi kin hee kokipapi kta, he okahinigapi.

13 Jesus Kesarea Philippi makoce kin en i qehan waonspewicakiye cin wiwicawange ca heya; Wicaśta Cinhintku kin miye, matuwe kin, wicaśta keyapi he.

14 Unkan heyapi ; Apa Johan'nes baptem wicaqu qon; qa apa iś; ; Elias; qa tok tokeca ; Jeremias, qa iś wicaśta wokcan wanji.

15. Qa niś matuwe kehapi he, ewicakiya.

16 Unkan Simon Inyan ayupte ça; Messiya Wakantanka ni un Cinhintku kin he niye, eya

17 Unkan Jesus ayupte ca heciya ; Simon Jona cinhintku niyawaśtepi ce ; wicacehipi qa wicawe kin he oniciyake śni, tuka Ate mahpiya ekta un kin he oniciyaka

18 Qa miś nakñn heciciya; Inyan he niye, qa imnija kin de akan okodakiciye mitawa wakage kta ; qa wakanśica tatiyopa kin he yujuju kte śni.

19 Unkan malipiya wokiconze iyuhdoke kin he cicu kta; hecen taku maka akan yakaśke cinhan he mahpiya ekta kaśkapi kta; qa taku maka akan yakiduśke cinhan he mah̉piya ekta kiyuśkapi kta.

20 Hehan waonspewicakiye 83 cin Jesus Messiya kin he iye, he tuwedan okiyake śni wicaśi. 21 Hetanhan Jesus waonspewicakiye cin wowicakiyaka, Jerusalem ekta ye kta iyececa, qa wicaliincapi, wośnapi kagapi, wowapi kagapi lko on taku ota kakije kta, qa ktepi kta, qa anpetu iciyamni hehan ake kini kta, hena owicakiyaka.

22 Hehan Inyan Jesus icu qa iyopeye ca heya ; Itancan, hecetu sni ; dena ayakipe kte śni.

23 'Tuka iye ihduhomni qa Inyan heciya; Satan mihektapa tanhan ya wo, tokamayaya; Wakantanka taku tawa kin awacanni śni, tuka wicaśta taku tawapi kin.

24 Hehan Jesus waonspewicakiye cin hewicakiya; Tuwe miyahna u kta cin kinhan, waipiiçida kta, qa cansusbeca, ehdaku qa mihakam un kta.

25 T'uwe kaśta wiconi tawa kpatan kinhan, he toki elipekiye kta; qa tuwe miye on wiconi tawa kin kpagan kinhan, he iyeye kta.

26 Wicaśta wan maka kin ocowasin kamna, qa nagi kin toki ehpeye cinhan he taku okihi kta he; qa wicaśta nagi kin taku iyopekiye kta he.

27 Wicaśta Cinhintku kin iye Atkuku towitan hduha taohnihdewicaye cin om u kta; hehan wicaśta otoiyohi iye ohanpi kin eciyatanhan wicaqu kta.

28 A wicakehan heciciyapi ; Tona den najinpi kin etanhan wanjikji wiconte utapi kte śni, ecen Wicaśta Cinhintku kin iye tokiconze kin en $u$ wanyakapi kta.

\section{WICOWOYAKE 17.}

1 Unkan iyohakam anpetu śakpe hehan Jesus Inyan qa 29 


\section{MATTHEOS.}

Jakob, qa iye sunkaku Johannes, hena iwicacu, qa paha wan tehanwankantu ekta awicaya;

2 Qa wicitokam yutokecapi; ite kin anperu wi kin iyecen iyega, qa tawokoyake kin iyoyanpa iyecen ska.

3 Unkan iho, Moses qa Elias en ihdutanimpi qa kici wohdakapi.

4 Hehan Inyan ayupte ça Jesus heciya; Itancan, den unyakonpi kin he waśte; yacin kinhan, den wakeya yamni ti unkagapi kta, wanji unnicagapi kta, qa Moses Elias kici wanjikji wicunkicagapi kta.

5 Iahan icunhan iho, iyoyanpa mahpiya wan aowicahanzi, qa iho, mahplya kin eciyatanhan wicaho wan heya; Micinkśi waśtewakidake ca on iyomakipi lince cin he dee ce; anagoptan po.

6 Unkan waonspewicakiye cin he nahonpi hehan makipusdiya ehpeiciyapi, qa nina kokipapi.

7 Tuka Jesus en wicahi, qa wicayutan qa heya; Inajin po, qa kokipapi śni po.

8 Unkan iśta yuwankan ikikcupi hehan, tuwedan wanyakapi śni, Jesus ecedan.

9 Unkan paha kin etanhan kun hdicupi, hehan Jesus wahokonwicakiye ca heya; Wowanyake kin he tuwedan okiyakapi śni po, Wicaśta Cinhintku kin wiconte etanhan piya ikicage śni hehanyan.

10 Unkan waonspewicakiye cin wiwangapi qa heciyapi: Wowapi kagapi kin, Klias tokaheya hi kta ce, eyapi kin, tokeca heyapi hwo.

11 Unkan Jesus waayupte ca hewicakiya; Awicakehan Elias tokaheya hi kta, qa taku owasin yuecetu kta.
12 Tuka heciciyapi; Elias wanna hi tuka iyekiyapi śni, qa token cinpi qon ecakiconpi. He iyececa Wicaśta Cinhintku kin iyepi eciyatanhan kakije kta.

13 Hehan waonspewicakiye cin okahnigapi, Johannes baptem wicaqu qon e he ke ca heon hewicakiya.

14 Unkan wicota en hdipi qehan, wicaśta wan en hi qa canpeśka makehde inajin,

15 Qa heya; Itancan, micinkśi onśimicida ye, hanyetu wi ihnaśkinyan qa śicaya un; otakiya peta en ihpaye ca otakiya mini en iyohpaya ece:

16 Qa waonspewicayakiye cin wicawakahi, tuka asniyanpi kta okihipi śni.

17 Hehan Jesus ayupte ca heya; Wicoicage wacinye śni qa wacin tehike, tohanyan cicipi waun kta he ; toharyyan iyowinciciyapi kta he; den makau po. 18 Unkan Jesus iyopeya, qa hecen wakan śice cin tankata hinanpa; unkan. wihiyayedan oape kin hetanhan hokśidan kin asniyanpi.

19 Hehan waonspewicakiye cin Jesus iśnana yanke cin en hipi qa heyapi; Tokeca unkiye he napeunyanpi kta unkokihipi śni he.

20 Unkan Jesus hewicakiya; Wacinyayapi śni heon; awicakehan heciciyapi; Sinape su wanjidan hinskokeca wacinyayapi unkanś, paha kin de, Detanhan tokan iyaya wo, eyakiyapi kta; unkan tokan iyaye kta, qa taku oyakitpanipi wanice kta.

21 Tuka taku decece cin he cekiyapi qa wote śni unpi ecedan on tankan hinanpa ece.

22 Unkan Galile en unpi icunhan Jesus bewicakiya; Wicaśta 


\section{WICOWOYAKE 18.}

Cinhintku kin wanna ecadan wicaśta napepi kin en wicaqupi kta.

23 Unkan ktepi kta, qa anpetu iciyamni kinhan ake piya ikicage kta ce, eya. Unkan nina iyolkiśicapi.

24. Hehan Kapernaum en hipi qehan, tona mazaska mnayanpi ece kin Inyan en hipi qa heyapi ; Waonspeniciyapi lin he mazaska mnayanpi en iyolipeye kta he.

25 Unkan, Han, eya. Hehan tin hdicu qehan Jesus tokaheya ie ca heciya; Simon token idukcan he; maka akan wicaśtayatapi kin tokiyatanhan mazaska mnayanpi he; iye cincapi etanhan, qa iś wicaśta tokecapi kin etanhan.

26. Wicaśta tokecapi etanhan, Inyan eya. Unkan Jesus heciya; Hehan cincapi kin wicakaśkapi śni ece :

27 Tuka śihda wicunyanpi kte śni, e heon niśs mde kin ekta ye ca hinśkijupi wan minin iyeya wo, qa hogan tokaheya hiyu kin he icu wo; he i kin dukawa kinhan ohna kangi kagapi wan iyeyaye kta; he icu qa miye qa niye on wicaqu wo:

\section{WICOWOYAKE 18.}

1 Unkan hehan waonspewicakiye cin Jesus en hipi qa heciyapi; Mahpiya wokiconze kin en tuwe iyotan tanka he.

2 Unkan Jesus hokśiyoqopa wan kico qa wicacokaya ehnaka;

3 Qa heya; Awicakehan heciciyapi; Nihduhomnipi śni, qa holsśiyoqopa iyenicecapi śni kinhan, mahpiya wokiconze kin en yaipi kte śni.

4 Tuwe ihduhukuye ca hokśiyoqopa kin de iyecen canteyuze cinhan, mahpiya wokiconze kin en iyotan tanka kin hee.

5 Qa tuwe hokśiyoqopa dececa wan, micaje on, iyowinkiye cinhan, he miye iyowinmakiya ece.

6 Qa tuwe hokślyoqopa kin dena, wacinmayanpi kin, wanji wahtanikiye cinhan, he inyan wiyutpan wan tahu en iyakaśkapi, qa iye miniwanca ośbe kin en iyohpeyapi unkanś waśte kta tuka.

7 Wahtaniwicayapi kin on oyate kin wotehi yuhapi kta; eya wahtanikiyapi yuke kta iyececa; tuka wicaśta tuwe wahtaniwicaya hecinhan, he wotehi yuhe kta.

8 Heon etanhan, ninape qa nisiha wahtaniniyanpi hecinhan, hena hdakse ca ehpeya wo; huha kaksapi wiconi en yai kta hee waśte, qa nape nonpa qa siha nonpa hduha peta owihanke wanica en iyohpeniyanpi kte cin he śica.

9 Qa niiśta wahitaniniye cinhan, hduśdoke ca elipeya wo; iśta wanjidan hduha wiconi en yai kte cin he waśte, qa iśta napin hduha peta owihanke wanica en iyohpeniyanpi kte cin he śica.

10 Ihnuhan dena cikcistinpidan wanjidan eśta śiceyadake cinhan ; heciciyapi ce ; Mahpiya ekta ohnihdewicayapi tawapi kin hena Ate mahpiya ekta un kin ite ohinniyan wanyakapi ece.

11 Wicaśta Cinhintku kin taku atakuniśni qon he niye kta on hi.

12 Hecen token idukcanpi he. Wicaśta wan tahinca wanunyanpi opawinge wicayuhe, ca etanhan wanjidan kitaninśni hecinhan, wikcemna napcinwanka sanpa napcinwanka hena owanjidan ewicahṇake ca he kin ekta iyaye ca wanji taninśni kin he okide śni he. 


\section{MATTHEOS.}

13 Qa iyeye cinhan, awicakehan heciciyapi ; hee on iyuśkin, qa wikcemna napcinwanka sanpa napcinwanka tokiya iyayapi śni kin hena on iyuśkin śni ece.

14 He iyececa, dena cikcistinpidan wanjidan eśta toki ehpeyapi kta, Niyatepi mahpiya ekta un kin lecen tawacin śni.

15 Tuka nisunka wanicihtani kinhan, ekta ye ca iye niye kiciśnana he okiciyaka ye; nanihon kinhan nisunka ake yahduhe kta.

16 Tuka ananigoptan śni kinhan, hehan wanji qa iś nonpa om de kta; hecen waayatanin nonpa, qa iś yamni ipi kin on wicoie owasin yusutapi kta.

17 Tuka hena nakun anawicagoptan śni kinhan, hehan okodakiciye kin owicakiyaka wo; unkan okodakiciye kin anawicagoptan śni kinhan, hehan Ikcewicaśta qa wamnayanpi kin iyecen yahdawa kta.

18 Awicakehan heciciyapi; Taku maka akan yakaśkapi kinhan, he mahipiya ekta kaślkapi kta; qa taku maka akan yakiduśkapi kinhan, he mahpiya ekta kiyuśkapi kta.

19 Akeś heciciyapi ; Tuwe nom maka akan taku wanjidan yadapi kta e wayeconzapi kinhan, Ate mahpiya ekta un kin he ecen ecawicakicon kta.

20 Tukten nom yamni, micaje on mniciyapi kinhan, hen wiciyopeya waun ece.

21 Hehan Inyan en hi qa heciya; Itancan, misunka tona wamicilitani qa wecicajuju kta he; śakowin hehanyan he.

22 Jesus heciya; Sakowin hehanyan kta, eciciye śni, tuka wikcemna śakowin ece śakowin.

23 Heon etanhan mahpiya wokiconze kin wicaśtayatapi wan iyececa, he wowidake wi cayuhe cin wicakiciyawa kta :

24 Unkan wicakiciyawa icunhan wanji mazaska rkeutapi tanka kektopawinge wikcemna iyohiye śni kin he ahipi.

25 Unkan on kajuju kta takudan yuhe śni, hecen yuhe cin he tancan wiyopeyapi kta, qa tawicu, qa cinca, qa taku yuhe cin owasin, qa kajujupi kta, keya.

- 26 Heon wowidake un kin he en makipusdiya elipeiciya, cekiye ca lieya ; Itancan, amakipe ye, owasin cicicajuju lita.

27 Hehan yuhe cin he wowidake tawa kin onśikida, kiyuśka qa ikicazo qon kicicajuju.

28 Tuka wowidake un kin he tankan iyaye ca om idakapi kin wanji, kaśpapidan opawinge ikicazo kin he iyeya, qa iyahpaye ca poskin yuze ca heciya; Tona imiyecazo kin micicajuju wo.

29 Hehan kici idakapi un kin he siha en ehpeiçiya, cekiye ca heya ; Amakipe ye, kinhan owasin cicicajuju kta.

30 Unkan wicada śni; tuka iyaye ça conkaśke mahen kaśkahnaka, oicazo hdajuju kta hehanyan.

31 Unkan kici wowidake unpi kin hena taku econpi kin wanyakapi qehan, nina iyokiśicapi : heon en hipi qa wicayuhe cin taku econpi kin owasin okiyakapi.

32 Hehan yuhe cin he ake kico qa heciya; Wowidake niśice hínca, icazopi hinsko tanka qon he cicicajuju, cemayakiye cin heon.

33 Hecen miye onśicida kin he iyecen kici wowidake yaun kin iś eya onśiyakida kta iyecece śni he.

34 Unkan yuhe cin śihda qa kakiśyapi kte cin en wicaqu, 
tona iyohiye śni qon ocowasin hdajuju kta hehanyan.

35 He iyecen, Ate mahpiya ekta un kin ecaniconpi kta, otoiyohi cante eciyatanhan nisunkapi tona wanicilitanipi kin wicayecicajujupi śni kinhan.

\section{WICOWOYAKE 19.}

1 Unkan Jesus wicoie kin hena heya ayaśtan, hehan Galile makoce kin etanhan iyaye ca Juda makoce, Jordan wakpa akasanpa tanhan he en hi :

2 Qa wicaśta ota hinca ihakam unpi; unkan hen asniwicaya.

3 Pharisee kin iś nakun en hipi, qa iyutanyanpi kta heciyapi ; Taku owasin on wicaśta tawicu ehpekiye kta iyececa he.

4 Unkan waayupte ca hewicakiya; Tuwe otokahe ekta wicakage cin he wica winyan ahna wicakaga, he tohinni dawapi śni he:

5 Qa heya; Heon etanhan, wicaśta atkuku hunku ko ehpewicaye kta, qa tawicu kin en iyaihdaśke kta; qa henaoza cehpi wanjidan kta.

6 Heon, hetanhan nonpapi śni, tuka wicacehpi wanjidan ece. Heon, taku Wakantanka yuokonwanjidan kin he ihnuhan wicaśta kiyuśpe cinhan.

7 Hehan heciyapi; Itancan, Moses kpaganpi wowapi wan qu kta, qa ehpeye kta, tokeca heconwicaśi hwo.

8 Unkan hewicakiya; Nicantepi suta kin heon winohinca elipewicayayapi kta, Moses iyowinniciyapi; tuka otokaheya tanhan hecetu śni.

9 Qa miś heciciyapi ce ; Tuwe, wawicitialiapi econ kin on etanhan śni, tawicu elipekiye ca wanji tokeca yuze cinhan, he wawicilialiapi econ ece; qa tuwe winyan ehpeyapi kin yuze cinhan, he nakun wawiciliahapi econ ece.

10 Unkan waonspewicakiye cin heciyapi; Wicaśta winohinca kici hecetu kinhan, tawicu tonpi kin he waśte śni.

11 Tuka hewicakiya; Wicoie kin he owasin okihipi śni, tona wicaqupi kin henana okihipi.

12 Yunokos heca yukan; hunh hunku tezi kin etanhan heca icagapi; qa hunh wicaśta on heca wicakagapi ; qa hunh mahpiya wokiconze kin on heca icicagapi. Tuwe he icu okihi kinhan he icu kta.

13 Hehan hokśiyoqopa en awicahipi, nape awicaputake ca cekiye kta e heon; unkan waonspewicakiye cin tehindapi.

14 Tuka Jesus heya; Hokśiyoqopa en mahipi kta iyowinwicakiya po, qa tehindapi śni po; mahpiya wokiconze kin he hetanhanpi ece.

15 Unkan nape awicaputake ca hetanhan tokan iyaya.

16 Unkan iho, wanji en hi qa heciya; Waonspekiye waśte, taku waśte ecamon kta, on wiconi owihanke wanica mduhe kta, tukte e he.

17 Unkan heciya; Tokeca waśte emayakiya he; tuwedan waśte śni, wanji heceedan waśte, Wakantanka hee. Tuka wiconi en yai kta yacin kinhan woahope kin hena ahopa wo.

18 Hehan heciya; Tukte e he. Unkan Jesus heya; Dena, Tinwicayakte kte śni; Wawicihahapi ecanon kte śni; Wamayanon kte śni; Woitonśni odake kte śni ;

19 Niyate nihun kici wicahduonihan wo; qa, Niye inihda33 


\section{MA'T'THEOS.}

cin nikiyedan un kin waśteyadake kta.

20 Kośka kin he heciya; Imacaga ehantanhan dena owasin ecen ecamon ece; taku hinaliin iyotpani waun he.

21 Jesus heciya; Owotanna yaun kta yacin kinhan, hde ca taku nitawa wiyopeye ca wahipanicapi kin wicaqu wo; kinhan malipiya ekta woyuha duhe kta; hehan ku qa mihakam un wo.

22 Tuka kośka kin he wicoie kin de nahon qehan iyokiśica kihda; taku ota ton kin heon etanhan.

23 Unkan Jesus waonspewicakiye cin hewicakiya; Awicakehan heciciyapi; Tuwe wijica un kin he kitan se malpiya wokiconze kin en i kta.

24 Qa ake heciciyapi ; Kamel wan tahinśpaciqadan ohdoka ohna iyaye kte cin he tehike śni, qa wicaśta wijica Wakantanka tokiconze kin en ye kte cin he tehika.

25 Waonspewicakiye $\operatorname{cin}$ he nahonpi, hehan nina yuśinyayapi qa heyapi; 'Tuwe hehan ni okihi kta lie.

26 Unkan Jesus ekta etonwe ça hewicakiya; Wicaśta ekta he okihipica śni ; tuka Wakantanka ekta taku owasin okihipica ece.

27 Hehan Inyan ayupte ca heciya; Iho, taku owasin elipeunyanpi qa nihakam unyakonpi ; hecen taku unhapi kta he.

28 Unkan Jesus hewicakiya; Awicakehan heciciyapi; Niyepi tona teca ni en wicatonpi kin de en omayapapi kin, tohan Wicaśta Cinhintku kin wowitan oiyotanke tawa kin en kiyotanke cinhan, niś eya oiyotanke akenonpa akan idotankapi kta, qa 34
Israel wicoun akenonpa wicadacopi kta ce.

29 Qa tuwe kảśta, tipi, qa hunkawanjitku, qa tawinohitin, qa atkuku, qa hunku, qa tawicu, qa cinca, qa maga, micaje on etanhan elipeye cinhan, he opawinge akihde hduhe kta, qa nakun owihanke wanin wiconi mnaiciye kta.

30 Tuka tokaheya unpi kin wicota ehake unpi kta; qa ehake unpi kin hena tokaheyapi kta.

\section{WICOWOYAKE 20.}

1 Mahpiya wokiconze kin he wicaśta wan tipi yuhe cin he iyececa, he hanhanna hinca hastanhanka iyuwi ojupi tawa kicanyanpi kte cin wicaśta opeton iyaya.

2 Unkan wicaśta anpetu eca kaśpapidan wanjidan on opewicaton, hehan hastanhanka iyuwi ojupi tawa kin en yewicaśi.

3 Unkan wihiyayedan oape yamni, hehan ake tankan iyaye ca toktokeca tihocoka en taku tokon śni najinpi wanwicayaka; 4 Qa hewicakiya; Niś eya hastanhanka iyuwi ojupi kin en ya po; kinhan token owotanna ciçupi kta ce. Unkan en iyayapi.

5 Ake oape iśakpe qa inapcinwanka hehanhan tankan iyaye ca ake iyecen econ.

6 Hehan oape iakewanji ecetu, ake tankan iyaye ca toktokeca taku tokon śni najinpi wanwicayaka, qa hewicakiya; Tokeca anpetu osan taku tokon śni nayajinpi he.

7 Unkan, Tuwedan opeuntonpi śni ce, eciyapi: Hehan hewicakiya; Niś eya hastanhanka iyuwi ojupi kin en ya po, kinhan taku owotanna iyacupi kta. 
8 Wanna litay etu hehan, hastanhanka iyuwi ojupi yuhe cin iye taokiye itancan kin heciya; Wicaśta htanipi kin wicakico qa wokajuju wicaqu wo, ehake hipi kin hena tokaheya, ecen tokaheya hipi qon wicayeciyuśtan kta ce.

9 Unkan tona oape wanjidan htanipi kin hena hipi, qa otoiyohi kaśpapidan wanji icupi.

10 Tokaheyapi kin henạ en hipi gehan, sanpa yuhapi kta kecinpi, tuka iś eya otoiyohi kaśpapidan wanji icupi.

11 He icupi hehan tipi tawa kin bapi ;

12 Qa heyapi; Ehake hipi kin dena oape wanjidan htanipi, tuka unkiye anpetu osan, wi kata eśta hitaunnipi, iyeuncecapi wicayakaga ece.

13 Unkan iye waayupte ça wanji heciya; Koda, taku śica ecacicon śni ; kaśpapidan wanjidan on htamiyecini kta kemayakiye śni he.

14 Taku nitawa kin ehdaku qa hda wo; ehake hi lin de niye ciçu kin iyecen waqu ece e kta.

15 Miye mitawa kin token wacin kin ecen ecamon kta iyecece śni he ; miye mawaśte kin heon etanhan iśta niśica he.

16 Hecen ehake unpi kin hena tokaheyapi kta; qa tokaheya unpi kin hena ehake unpi kta; wicota wicakicopi, tuka tonana wicakahnigapi ece.

17 Unkan Jesus Jerusalem ekta itanwankanhde ya, hehan waonspewicakiya akenonpa kin canku kin icunonpa iśnana awicaya, qa hewicakiya;

18 Iho, Jerusalem elsta itanwankanhde unyanpi, qa Wicaśta Cinhintku kin wośnapi kagapi wowapi kagapi ko nape en wi- caqupi lita; unkan te lita on yacopi kta,

19 Qa ihahapi kta, kapsinpsintapi lkta, qa icipaweh okatanpi kta on Ikcewicaśta iyoopta wicaqupi kta; unkan anpetu iciyamni hehan kini kta ce.

20 Hehan Zebedee cinca hunkupi kin en hi, cinhintku napin om, cekiye ça taku wanji kida.

21 Unkan iye heciya; Takı yacin he. Hehan heciya; Micinkśi kin denaoza wokiconze nitawa en, unma nietapa elita iyotanke kta, qa unma iś canitka en iyotanke lita, keya ye.

22 Tuka Jesus waayupte ca heya; Taku yadapi kin sdonyakiyapi śni. Wiyatke etanhan mdatke kte cin he etanhan yatkan oyalihipi he; qa baptem maqupi kte cin he niś eya nicupi kta oyakihipi he. Unkan, Unkokihipi ce, eciyapi.

23 Hehan hewicakiya; Awicakehan wiyatke mitawa kin etanhan datkanpi kta, qa baptem maqupi kte cin heon niś eya baptem niçupi kta; tuka ematapa qa camatka tanhan iyotankapi wicaqupi kte cin he miye mitawa śni; tuka Ate tona wiyeya wicakiciyuśtan kinhan hena tawapi kta.

24 Unkan wikcemnapi kin hena lie nahonpi qehan sunkakiciyapi nom on śihdapi.

25 Tuka Jesus wicakico qa heya; Ikcewicaśta elkta tona itancanpi kin hena oyate wicayuhapi, qa wicaśta tankinyanyanpi kin oyate wowidakewicayapi ece, he sdonyayapi.

26 Tuka niyepi ekta hecece kte śni; tuka wanji tukte tanka yaunpi kta yacinpi kinhan, he wowidake duhapi kta.

$27 \mathrm{Qa}$ tuwe niyepi en tokapa 35 


\section{MATTHEOS.}

un kta hecinhan, wowidake nitawapi kin hee kta.

28 He iyececa, Wicaśta Cinhintku wowidake wicayuhe kta on hi śni, tuka idakapi kta, qa wiconi tawa wokajuju kta wicota on wicaqu kta heon hi.

29 Unkan Jeriko etanhan iyooptapi, hehan wicota ihakam unpi. 30 Unkan iho, wicaśta iśtagonga nonpa canku icahda iyotankapi, Jesus en hiyaya nalionpi, hehan howayapi qa heyapi; Itancan, Dawid Cinhintku onśiunkida miye.

31 Unkan wicota kin tehindapi qa inina yanke wicaśipi ; tuka iś hehan heon iyotan howayapi qa heyapi ; Onśiunkida po, Itancan, Dawid Cinhintku.

32 Unkan Jesus owanji najin qa wicakico qa heya; Taku ecaciconpi kta yacinpi he.

33 Itancan iśta unhdukawapi kta ye, eciyapi.

34 Hehan Jesus onśiwicakida qa iśta wicayutan; unkan ecahankeya iśta on tonwanpi qa ihakam unpi.

\section{WICOWOYAKE 21.}

1 Unkan Jerusalem ikiyedan yapi, qa Bethpage ehan ipi, Oliwe paha kin etu, hehan Jesus waonspewicakiye cin nom yewicaśi ;

2 Qa hewicakiya; Dukanpi kin otonwe iyotakons wanke cin he ekta ya po; kinhan kohanna śonśonna wan cinca iyahna han iyeyayapi kta; kiyuśkapi qa makaku po.

3 Qa tuwe taku eniciyapi kinhan, Itancan kin hena cin ce, eya po ; kinhan kohanna awicau niśipi kta.

4 Dena owasin econpi, wicaśta wokcan oie qon yuecetupi kta, he kaken eya;
5 Zion cunwintku kin heciya po; Iho, Wicaśtayatapi nitawa en niu, walibadan qa śonśonna wan akan iyotanka, śukcinca wan, śonśonna cinca kin akan u ce.

6 Unkan waonspewicakiye cin yapi, qa Jesus econ wicaśi kin ecen econpi ;

$7 \mathrm{Qa}$ śonśonna cinca iyahna awicahipi, qa iye taśina akan ehpeyapi, qa hena iakan Jesus ehnakapi.

8 Unkan wicota canku ohna śina ehpeyapi ; qa apa canwapa kaksapi qa canku ohnahna owinśyapi.

9 Qa wicota tokata yapi, qa tona ihakam upi kin, howayapi qa heyapi; Dawid Cinhintku woohiye yuha nunwe. Tuwe Itancan caje on u kin yawaśtepi nunwe: Mahipiya ekta woohiye yuha nunwe:

10 Unkan Jerusalem en hi qehan otonwe kin ocowasin śkanśkanpi, qa heyapi; De tuwe he. 11 Unkan wicota kin heyapi; Jesus wicaśta wokcan Galile en Nazareth otonwe kin etanhan he dee.

12 Unkan Jesus tipi wakan Wakantanka tawa kin en i, qa tipi wakan ohna wiyopeyapi ece, wopetonpi ko, hena tankan iyewicaya; qa mazaska tokiyopeyapi ahna econpi kin hena yuahdapśinyan ehpeya, tona wakiyedan wiyopeyapi oiyotanke tawapi koya;

$13 \mathrm{Qa}$ hewicakiya; Tipi mitawa kin he wocekiye tipi eciyapi kta, eya wowapi en kagapi ; tuka niye wamanon tipi yakagapi.

14 Hehan iśtagongapi huśtepi ko tipi wakan kin en hipi; unkan okiziwicaya.

15 Unkan wośnapi kagapi wo- 
wapi kagapi ko taku wowapetokeca econ kin hena wanyakapi, qa hokśiyoqopapi tipi wakan kin ohna, Dawid Cinhintku kin woohiye yuha nunwe, eya howayapi, hehan nina śihdapi :

16 Qa heciyapi; Dena taku eyapi kin nayahon he. Unkan Jesus hewicakiya; Han ; Hokśiyoqopa, tona azinpi ko ipi kin etanhan wowitan duśtan ce, eyapi kin he tohinni dawapi śni he.

17 Hehan awicayuśtan, qa otonwe kin etanhan tankan iyaye ca Bethani ekta i, qa hen wanka.

18 Unkan hanhanna hinca otonwe kin ekta icicawin hda, unkan wotektehda;

19 Qa suken can wanji canku ohna han wanyake cehan, he en $i$, tuka takudan iyeye śni, ape eceedan aicaga; unkan heya; Icimana waskuyeca ainicage śni nunwe. Unkan suken can kin kohanna śnija aya.

20 Unkan waonspewicakiye cin he wanyakapi qehan yuśinyayapi qa heyapi ; Ehanqon suken can kin kohanna śnija aya.

21 Jesus waayupte ca hewicakiya; Awicakehan heciciyapi ; Wowacinye duhapi qa wacetunyahdapi śni kinhan, taku suken can kin de ecakiconpi kin heceedan ecanonpi kte śni, tuka paha kin de, Tokan iyaye ca miniwanca kin en iyohpeniyanpi nunwe, eyakiyapi kinhan, ecetu kta.

22 Qa taku tona wocekiye eya yadapi, qa wicayadapi kinhan, hena owasin duhapi ece e kta.

23 Unkan tipi wakan kin en hi, qa waonspewicakiya icunhan, wośnapi kagapi, qa oyate kin en wicaśta tankapi ko, en hipi qa heciyapi ; Wicookihi tukte e on dena ecanon he; qa tuwe wicookihi kin de niçu he.
24 Unkan Jesus waayupte ca hewicakiya; Miś eya taku wanji iciwangapi kta; he omayakidakapi kinhan, hehan wicookihi kin tukte on dena ecamon kin ociciyakapi kta.

25 Johannes baptem wicaqu qon he tokiyatanhan he; mahpiya eciyatanhan qa iś wicaśta eciyatanhan. Unkan he iyakitedan aiapi q́a hekiciyapi; $\mathrm{He}$ mahpiya eciyatanhan, unkeyapi kinhan; Tokeca he wicayadapi śni he, eye kta:

26 Tuka, He wieaśta eciyatanhan, unkeyapi kinhan, oyate kin kowicunkipapi ; owasin Johannes wicaśta wokcan heca kecinpi.

27 Unkan ayuptapi qa Jesus heciyapi; Sdonunyanpi śni ye. Unkan iś hehan hewicakiya; Miś nakun wicookihi tukte on dena ecamon kin ociciyakapi kte śni.

28 Tuka token idukcanpi he: Wicaśta wan cinhintku nonpa; unkan tokapa kin en hi qa heciya ; Cinś, anpetu kin de hastanhanka iyuwi ojupi mitawa kin en htani ya wo.

29 Unkan ayupte ca heya ; Ecamon kte śni ye. Tuka iyohakam iyopeiciye ça iyaya.

30 Unkan hakakta kin en hi, qa iyecen eciya; Unkan iye ayupte ca; Itancan, mde kta ce, eya. Tiuka ye śni.

31 Denaoza unma tukte atkukupi tawacin kin ecen econpi he. Unkan, Tokapa kin, eciyapi. Hehan Jesus hewicakiya ; Awicakehan heciciyapi; Wamnayanpi qa wawiciliahapi econpi sa niyepi nitokam Wakantanka tokiconze kin en yapi kta.

32 Johannes wicoowotanna canku kin ohna en niupi, tuka wicayadapi śni; tuka wamna- 


\section{MA'T'THEOS.}

yanpi qa wawiciliahapi econpi sa, hena wicadapi; he wandakapi eśta nakun iyohakam wicayadapi kta e on nihduhomnipi śni.

33 Wiyacinpi wan tokeca nahon po; Wicaśta wan tipi yuhe cin he hastanhanka iyuwi ojupi wan oju, qa ihdukśan natake ça ohna iyuśkice wan qe ca nakun cowahe wan en liaga; qa wicaśta kicanyanpi kta owicaqu, hehan icimani iyaya.

34 Unkan wanna waskuyeca suton kta, hehan wowidake wicayuhe cin wicaśta kicanyanpi kin ekta yewicaśi; waskuyeca etanhan icupi kte cin heon.

35 Unkan wicaśta kicanyanpi kin wowidake unpi kin hena wicayuzapi ; wanji apapi, wanji ktepi, qa wanji inyan on kininpi.

36 Akeś wowidake toktokeca ota ekta yewicaśi; unkan iś iyecen wicakuwapi.

37 Hehan ehake iye cinhintku kin ekta yeśi, qa heya; Micinkśi yuonihanpi kta。

38 Tuka maga kicanyanpi kin cinhintku wanyakapi, hehan hekiciyapi; Tawa kte cin he dee; iho po, unktepi kta, hehan taku yuhe cin he unkicupi kta.

39 Hecen yuzapi qa hastanhanka iyuwi ojupi kin etanhan tankan elipeyapi qa ktepi.

40 Hecen tohan hastanhanka iyuwi ojupi tawa kin hi kinhan kicanyanpi kin hena token ecawicakicon kta he.

41 Unkan heciyapi; Wicaśta śikśice cin hena tehiya ihangwicaye kta, qa kicanyanpi toktokeca tohan iyehantu eca waskuyeca kicupi ece e kta hena hastanhanka iyuwi ojupi kin owicaqu kta.

42 Hehan Jesus hewicakiya; Inyan wan tipi kagapi kin ehpe- yapi qon he oise pa kin icaga; he Itancan kin eciyatanhan hecetu, qa unkiśtapi en taku wowapetokeca kin hee, eyapi kin he tohinni wowapi wakan kin en dawapi śni he.

43 Heon etanhan heciciyapi; Wakantanka tokiconze kin eniciyakupi kta, qa oyate wan waskuyeca icaliyapi kte cin he wicaqupi kta.

44. Unkan tuwe inyan kin de ahinhpaye cinhan kamden elipeyapi kta ; qa tuwe he akan ilipaye cinhan tanyan kamdu kta.

45 Unkan wośnapi kagapi hena, qa Pharisee ko wiyacinpi tawa kin nahonpi qehan, iye wicaka e heya sdonyapi.

46 Qa heon yuze wacinpi, tuka oyate kin kowicakipapi ; owasin wicaśta wokcan heca kecinpi.

\section{WICOWOYAKE 22.}

1 Unkan Jesus waayupte ca ake wiyacinpi on wowicakiyake ca heya;

2 Wicaśta wan wicaśtayatapi heca cinhintku kin wakankiciyuzapi kicage cin he malipiya wokiconze kin iyececa.

3 Unkan wowidake wicayuhe cin hena yewicaśi, tona wakankiciyuzapi en wicakicopi qon hena uwicaśipi kta; tuka upi kta wicadapi śni.

4 Akeś wowidake toktokeca. ekta yewicaśi qa hewicakiya; Tona wicakicopi qon hena hewicakiya po; Wotapi mitawa wiyeya yanka ; tatanka mitawa ptejicadan ko wanna ktepi, qa taku owasin wiyeya hiyeya; iho po, wakankiciyuzapi kin en u po.

5 Tuka ilialiapi qa toki iyayapi ; wanji tamaga ekta iyaye ca, wanji iś mazopiye tawa ekta iyaya. 


\section{WICOWOYAKE 22.}

6 Qa hunh wicakico ipi kin hena wicayuzapi, qa śicaya wicakuwapi qa wicaktepi.

7 Wicaśtayatapi kin he nahon qehan nina śihda; qa taakicita ekta yewicaśi, qa tinwicaktepi kin hena ihangwicaye ça totonwepi kin hulinaliya.

8 Hehan wowidake tawa kin hewicakiya ; Wakankiciyuzapi kin wiyeya yanka, tuka tona en wicakicopi qon hena opapi kta iyececapi śni.

9 Heon etanhan canku ojate kin ektakta ya po, qa tona iyewicayayapi kin wakankiciyuzapi kin en uwicaśi po.

10 Hecen wowidake unpi kin hena canku ojate kin ektakta iyayapi, qa tona iyewicayapi, śica qa waśte ko, en awicaupi; hecen wakankiciyuzapi wicaśta. ota en opapi.

11 Unkan wicaśtayatapi kin tona wotapi kte cin hena wanwicayaka tin hiyu, qa iho, wicaśta wanji wakankiciyuzapi wokioyake kin kiçun śni hen wanyaka :

12 Qa heciya; Koda, tokeca wakankiciyuzapi wokoyake kiçun śni en hidotanka he. Unkan takudan eye śni.

13 Hehan wicaśtayatapi kin taokiyewicaye cin hewicakiya; Siha nape ko pahtapi qa detanhan aya po, qa tankan otpaza kin en elipeya po; heciya wicaceya qa hi hdakinskinzapi yuke kta.

14 Wicota wicakicopi tuka tonana wicakahnigapi ece.

15 Hehan Pharisee kin iś yapi, qa token iapi on yuśkiśkapi kta aiapi.

16 Qa iye waonspewicakiyapi kin Herodian hena om ekta yewicaśipi qa heyapi; Waonspekiye, iewicayaka sdonunyanpi, qa awicakehan Wakantanka ta- canku kin onspeunyakiyapi ece, qa tuwedan koyakipe śni; wicaśta akautu ekta eyatonwe śni nakaeś.

17 Heon token idukcan he; unkokiyalka po; Kesar mazaska qupi ece kin he owotanna he.

18 Unkan Jesus taku śica en wicaun kin he sdonya qa heya; Wananicilimanpi, tokeca iyutanmayayapi he :

19 Mazaska mnayanpi ece kin he makipazo po, eya. Unkan kaśpapidan wanji kahipi.

20 Hehan hewicakiya; Wicite qa wowapi kagapi kin de tuwe tawa he.

21 Unkan, Kesar tawa ce, eyapi. Hehan hewicakiya; Heon etanhan Kesar taku tawa kin kicu po, qa Wakantanka taku tawa kin kicu po.

22 He nahonpi hehan yuśinyayapi qa ehpeya hdicupi.

23 Unkan anpetu kin he en Sadukee kin en hipi, hena piya wicoicage kin wanica ce, eyapi ece, qa wiwangapi ;

24 Qa heciyapi; Waonspekiye, Wicaśta wan cinca yuhe śni țe cinhan, tawicu qon he iye sunkaku yuze kta, qa cincu cinca icahkiciciye kta, Moses keye ciqon.

25 Unkan unkiyepi en wicaśta śakowin sunkakiciyapi ; unkan tokapa kin he winohinca wan yuza tuka ța; qa cinca nica heon iye iyokihe cin he tawicu aihpekiya.

26 Qa icinonpa iyecen econ, qa iyamni, qa ecen śakowinpi kin. 27 Hehan ehake winohinca qon ța.

28 Hecen piya wicoicage kin en, hena sakowinpi kin wanji tukte winohinca kin he hduhapi kta he ; owasin yuzapi.

29 Jesus wayupte ca hewicakiya; Yanunipi, wowapi wakan 39 


\section{MA'T'THEOS.}

qa Wakantanka towaśake kin sdonyayapi śni.

30 Piya wicoicage kin en winohinca wicayuzapi śni, qa hihnatonpi śni, tuka mahpiya ekta Wakantanka ohnihdewicaye cin iyececapi ece.

31 Tuka wicate cin piya icagapi kin on Wakantanka taku eniciyapi lkin he dawapi śni he; he kaken eya ;

32 Abraham Wakantanka tawa, Isaak Wakantanka tawa, qa Jakob Wakantanka tawa kin he miye : Wakantanka wicaśta țapi kin tawapi śni, tuka ni unpi Wakantanka tawapi ece.

33 Unkan oyate kin hena nahonpi hehan taku onspewicakiye cin on yuśinyayapi.

34 Tuka Pharisee kin hena, Jesus Sadukee kin inina yanke wicakiya, he nahonpi hehan en mniciyapi :

35 Qa etanhan wanji woope aiekiyapi kin heca wiwange ça iyutanyan heciya;

36 Waonspekiye, woope kin en woahope kin tukte iyotan tanka he.

37 Unkan Jesus heciya; Itancan Wakantanka nitawa kin he nicante ocowasin on, qa ninagi ocowasin on, qa nitoksape ocowasin on waśtcyakidalie kta.

38 Woahope tokaheya qa tanka kin hee.

$39 \mathrm{Qa}$ inonpa kin he iyececa; Nikiyedan un kin niye inihdacin waśteyadake kta ce.

40 Woahope kin denaoza woope ocowasin wicaśta wokcan ko en ikoyaka ece.

41 Pharisee kin iś en mniciyapi icunhan Jesus wiwicawange ca heya;

42 Messiya on token idukcanpi he ; tuwe cinhintku he. Unkan, Dawid Cinhintku ce, eciyapi.
43 Hehan hewicakiya; Hecen token Dawid Woniya Wakan kin on Itancan, eciya he; qa heya;

44 Itancan kin Itancan mitawa heciya; Mietapa ekta iyotanka wo, tona tokaniyanpi kin siha oahe nitawa wicawakage kta, hehanyan.

45 Hecen Dawid, Itancan, eciya hecinhan, token ecin cinhintkuye kta he.

46 Unkan tuwedan oie wanjidan ayupte kta olkihi śni; qa anpetu kin hetanhan tuwedan ake wiwanga tawațenye śni ece.

\section{WICOWOYAKE 23.}

1 Hehan Jesus oyate kin, iye waonspewicakiye cin om wowicakiyaka :

$2 \mathrm{Qa}$ hewicakiya; Wowapi kagapi Pharisee ko Moses oiyotanke tawa kin en iyotankapi ece.

3 Heon etanhan taku tona openiśipi kin hena owasin opapi qa econ po; tuka iye ohanpi kin ohna econpi śni po ; taku eyapi, tuka iyecen econpi śni ece.

4 Waqinpi tketke qa qinpi tehika heca oheyunpi, qa wicaśta tapete akan ehnakapi ece, tuka iye qe śaśte on yutanpi kta tawațenyapi śni.

5 Qa wicohan econpi kin owasin wicaśta wanwicayakapi kta e heon econpi ece. Wateśdake tanka icicagapi, qa śina opapun hdutankapi ece.

6 Wotapi en oyanke waśteśte cinpi, qa omniciye tipi kin ohna wankan iyotankapi kte cin he waśtedakapi ece :

$7 \mathrm{Qa}$ tihocoka kin en wicayuwintapi, qa, Itancan, Itancan, wicaśta ewicakiyapi kta cinpi.

8 Tuka niye, Itancan, eniciya- 
pi kte śni; wanji mdetahunka duhapi, Messiya hee; qa niyepi owasin hunkawanjinyeciyapi.

$9 \mathrm{Qa}$ nakun maka akan tuwedan, Ate, eciyapi śni po; Wanji malipiya ekta un kin he Ateyayapi.

10 Qa nakun, Waonspekiye, eniciyapi kte śni; Wanji Waonspekiye duhapi, Messiya hee.

11 Qa tukte wanji iniyotanpi kta hecinhan, he wowidake nitawapi ee kta.

12 Tuwe yuwankan iyeiçiye kta hecinhan, he yuhukun ehpeyapi kta; qa tuwe ihduhukuya hecinhan, he yuwankan iyeyapi kta.

13 Tuka wowapi kagapi qa Pharisee kin, wananiçilimanpi, wotehi niciyankapi nunwe; wiwazica tipi tawapi ihangyayapi ece, qa wanniyakapi kta on wocekiye hanska ehapi ece; heon etanhan woyaco tanka iyahdeniciyapi kta.

14 Wowapi kagapi qa Pharisee kin, wananiçilimanpi, wotehi niciyankapi nunwe; mahpiya wokiconze kin wicaśta anawicayeciptapi, niye en dapi kte śni, qa tona en yapi kta cinpi kin teyahindapi ece.

15 Wowapi kagapi qa Pharisee kin, wananiçilimanpi, wotehi niciyankapi nunwe; miniwanca maka ko aokibeyayapi, wicaśta wanjidan duhomnipi kta ; qa ecetu kinhan, niye isanpa nonpa akihde Wakansica cinca yakagapi ece.

16 Tokakeya mani iśtagongapi kin, wotehi niciyankapi nunwe; hehapi ece; Tuwe tipi wakan kin on wakonze cinhan he taku śni; tuka tuwe tipi wakan kin en mazaskazi yuke cin, he on wakonze cinhan, he walitani ece.
17 Winitkotkokapi qa iśtani. gongapi; mazaskazi, qa is tipi wakan mazaskazi wakan kage cin unma tukte iyotan he.

18 Nakun, Tuwe owayuśna kin on wakonze cinhan he taku śni; tuka tuwe wośna owayusna akan un kin he on wakonze cinhan, he wahtani ece.

19 Winitkotkokapi qa iśtanigongapi kin ; wośnapi qa iś owayuśna wośnapi kin wakan kage cin unma tukte tanka he.

20 Heon etanhan tuwe owayuśna kin on wakonze cinhan, he owayuśna qa taku akan un kin koya on wakonza ece.

21 Qa tuwe tipi wakan kin on wakonze cinhan, he tipi wakan, qa nakun tuwe ohna ti ece kin, hee on wakonza ece.

22 Qa tuwe mahpiya kin on wakonze cinhan, he Wakantanka oiyotanke tawa, qa nakun tuwe akan iyotanke cin on wakonza ece.

23 Wowapi kagapi qa Pharisee kin, wananiçihmanpi, wotehi niciyankapi nunwe; ceyakata wahpe skuya, wacanga ko, iwikcemna kin waduśnapi ece; qa woope kin en taku tanka, woowotanna, wowaonśida qa wowacinye, hena ayaktapi śni ece; dena e ecanonpi kta, qa unma nakun econ śni yaunpi kte śni tuka.

24 Tokaheya mani iśtagongapi kin, hoponkadan puskem edakupi, qa kamel heca napca iyeyayapi ece.

25 Wowapi kagapi qa Pharisee kin, wananiçilimanpi, wotehi niciyankapi nunwe; wakśica wiyatke ko akantanhan duskapi ece, tuka mahen wamanonpi qa wicotawacin śica on ojugjudan. 26 Pharisee iśtagonge, tokaheya wiyatke wakśica ko ma41 


\section{MATTHEOS.}

hentanhan ska kaga wo, kinhan akantanhan he nakun ska kta.

27 Wowapi kagapi qa Pharisee kin, wananiçilimanpi, wotelii niciyankapi nunwe; ohıla wicahapi sanyanpi henicecapi; hena akantanhan owanyag waśte, tuka mahentanhan wicaśta huhu qa taku śica owasin on ojugjudan ece.

$28 \mathrm{He}$ iyecen niyepi wicaśta ekta akantanhan owotanna yaunpi seececa, tulka mahentanhan wanaicilimanpi qa woowotanna śni on onijupidan.

29 Wowapi kagapi qa Pharisee kin, wananiçihmanpi, wotehi niciyankapi nunwe; wicaśta wokcan ohna wicahapi kin en tipi wicayecagapi, qa wicaśta owotanna ohna wicahnakapi kin hena sanyayapi ece:

30 Qa hehapi; Atewicunyanpi ni unpi he anpetu kin en unyakonpi unkanś, wicaśta wokcan wicaktepi qon en ounpapi kte śni tuka ce.

31 Hecen tona wicaśta wokcan wicaktepi qon cincapi kin hena niyepi e onihdakapi ece.

32 Qa nakun niye niyatepi wicohan tawapi kin hena wicayeciyuśtanpi kta.

33 Wamduśka henicapi, sintelida wicoicage, token wakanśica ti iwicayacopi kin nayecipapi kta he.

34 Heon etanhan iho, wicaśta wokcan, wicaśta ksapa, wowapi kagapi hena koya, niyepi ekta yewicawaśi ; unkan etanhan apa wicayaktepi kta, qa icipaweh owicayakatanpi kta ; qa apa omniciye tipi nitawapi kin ohnahna wicayakapsinpsintapi kta; qa otonwe iyasyaza śicaya wicayakuwapi ece.e kta.

35 Hecen maka akan wicaśta owotanna wicaktepi hena we. kin ocowasin niyepi en aniupi kta ; Abel owotanna we kin hetanhan, Zakarias, Barakias cinhintku, tipi wakan qa owayuśna kin iyotahedan yaktepi qon he we kin hehanyan.

36 Awicakehan heciciyapi ; Dena owasin wicoicage kin de en awicau kta.

37 Jerusalem, Jerusalem, wicaśta wokcan wicayakte sa, qa tona niye ekta yewicaśipi qon hena inyan on wicayakinin ece qon, wahupakoza wan iye cinca hupahu ihukuya wicatpahi ece kin, he iyecen wanna ota nicinca wicawapahi kta wacin, tuka niye wicayadapi śni ece.

38 Tho, yatipi kin wanna otiwota elipeniciyapi :

39 Qa heciciyapi; Detanhan tohanyan, Tuwe Itancan caje yuha u kin he yawaśtepi nunwe, ehapi śni, hehanyan wanmayadakapi kte śni.

\section{WICOWOYAKE 24.}

1 Unkan Jesus tipi wakan kin etanhan tankan inanpe ca tokan iyaya; unkan waonspewicakiye cin en hipi qa tipi wakan token kagapi kin he wanyag śipi.

2 Unkan Jesus hewicakiya; Dena owasin waudakapi śni he; awicakehan heciciyapi; Dena inyan wanji inyan itakihna wanke kte śni, owasin yujujupi kta.

3 Unkan Oliwe paha kin akan iyotankehan yanka, hehan waonspewicakiye cin iśnana en hipi qa heciyapi ; Dena tohan ecetu kta, qa niye yahi kte ça maka ihanke kta, taku on sdonyapi kta, he ito unkokiyaka miye.

4 Unkan Jesus waayupte ca hewicakiya; Ihnuhan tuwe nihnayanpi kinhan.

5 Wicota micaje on upi kta qa, 


\section{WICOWOYAKE 24.}

Messiya he miye ce, eyapi kta; qa wicaśta ota wicahnayanpi kta.

6 Unkan wicokicize qa kicizapi oyakapi kin nayahonpi kta; ihnuhan nihinniciyapi kinhan; hena owasin hecetu kte, tuka owihanke kin hinahinke śni.

i Oyate wan oyate azuwicaye kta, qa wokiconze wokiconze anatan kta; qa tuktekten wicaakilian qa makośikśica qa maka śkanśkan yuke kta.

8 Dena owasin wicoiyokiśice tokaheya kin hee.

9. Hehan wicokakije en yeniyanpi kta qa niktepi kta ; qa micaje on oyate owasin śicenidapi kta.

10 Unkan hehan wicaśta ota śihdapi kta, qa otoiyohi kicihnayanpi kta qa śicekicidapi kta.

11 Qa wicaśta wokcan itonśni ota icagapi kta, qa wicota wicahnayanpi kta.

12 Hehan wicohian śica'ota icage kta, heon wicota waśtedake ciqon he sni aye kta.

13 Tuka tuwe owihanke hehanyan najin kinhan he ni kta.

14 Unkan wókiconze wotanin waśte kin de maka kin owancaya oyakapi kta, oyate owasin en wotanin un kta; qa hehan owihankc kta.

15 Tohan wośice woihangye kin, Daniel wicaśta wokcan cajeyata qon he tipi wakan kin en han wandakapi kinhan; tuwe yawa kinhan okahiniga nunwe ;

16 Hehan tona Juda makoce kin en unpi kin he kin.ekta napapi kta.

17 Qa tuwe tipi akan un kinhan kun ku, qa taku ti mahen tanhan ehdaku kte śni.

$18 \mathrm{Qa}$ nakun tuwe magata un kinhan, hdicu qa wokoyake ikikcu kte śni.
19 Unkan tona anpetu kin hena en ihduśakapi, qa hokśiyoqopa azinwicakiyapi kin hena wotehi yuhapi kta.

20 Tuka waniyetu, qa anpetu wakan icunhan, nayajicapi kte śni e ito cekiya po.

21 Hehan wokakije tanka kte, maka kagapi kin ehantanhan dehanyan taku hecece śni, qa nakun tohinni tokata ekta hecece kte śni.

$22 \mathrm{Qa}$ anpetu kin hena yuptecedan śni kinhan, wicaśta tuwedan ni kte śni ; tuka wicakahnigapi kin hena. on anpetu kin hena yuptecedan kta.

23 Hehan tuwe, Messiya den un ce, qa, kakiya un ce, eniciyapi eśta, wicadapi śni po.

24 Messiya itonśni, qa wicaśta wokcan itonśni kin heca icagapi kta, qa wowanyalke tanka wicolian tanka ko econpi kta, hecen okihipica unkanś wicakałinigapi kin hena eepi kaeś wicahnayanpi kta tuka.

25 Iho, itokam hena ociciyakapi.

26 Heon etanhan; Tho, hewotahedan un ce, eniciyapi eśta, ekta yapi śni po; qa, tho nałimana un ce, eniciyapi eśta, wicadapi śni po.

27 Wakanhdi wiyohiyanpa tanhan $\mathrm{u}$, qa wiyolipeyata hehanyan tanin hinhda ece, Wicaśta Cinhintku kin hi kte cin he iyecece kta.

28 Tukten taku ța wanka eca, hen wamdi kiwitayapi ece e kta. 29 Unkan wokakije anpetu kin hena ahankeya, anpetu wi kin aotpaza kta, qa hanyetu wi kin iyoyanpa kte śni, qa wicanhpi mahipiya eciyatanhan hinhpaye kta, qa mahipiya wowaśake kin yuhuhuzapi kta.

30 Unkan hehan mahpiya en, 43 


\section{MATTHEOS.}

Wicaśta Cinhintku kin wowakta tawa kin tanin kta. Hehan maka akan oyate owasin nihinciyapi kta, qa Wicaśta Cinhintku kin wowaśake qa wowitan tanka hduha, malipiya śapa akan u wanyakapi kta.

31 Unkan mazayahotonpi tanka hotanin kin on ohnihdewicaye cin yewicaśi kta, qa hena tate uya topa eciyatanhan, tona wicakahnige ciqon hena wicapahi kta, malipiya ihanke kin etanhan unma ihanke kin ekta hehanyan.

32 Wanna suken can kin etanhan wiyacinpi wan onspeiciciya po. Can intpa hinahin suta śni, qa wanna ape uya, hehan mdoketu kin wanna ikiyedan sdonyayapi ece.

33 He iyecen dena owasin ecetu wandakapi kinhan, wanna ikiyedan, tiyopa kin ehantu e sdonya po.

34 Awicakehan heciciyapi ; Wicoicage kin de ihanke kte śni, ecen dena owasin ecetu kta.

35 Mahpiya maka ko ihanke kta, tuka mioie kin owihanke kte śni.

36 Tuka anpetu kin he, qa wihiyayedan oape kin he tuwedan sdonye śni; mahipiya ohnihde kin hena sdonyapi śni ; Ate ecedan sdonya.

37 Nowa taanpetu qon hena, Wicaśta Cinhintku kin hi kte cin iyecece kta.

38 Minitan qon isanpa anpetu kin hena en, wotapi qa wayatkanpi, winohinca wicayuzapi qa wicaśta hihnawicayapi ece, Nowa wata kin en iyaye cin anpetu kin hehanyan;

39 Qa iyukcanpi śni, ecen minitan aye ca iyuhpa ihangwicaya: iho, Wicaśta Cinhintku kin u kte cin he iyecece kta.

40 Hehan wicaśta nom magata unpi kta; wanji icupi kta, qa unma kin iś okaptapi kta.

41 Winohinca nom wiyutpan on wotpan unpi kta; wanji icupi kta, qa unma kin okaptapi kta.

42 Heon etanhan waktaya un po, wihiyayedan oape tukte en Itancan nitawapi u kta sdonyayapi śni.

43 Tuka de sdonya po; wicaśta tipi tawa kin wamanon sa tohan hi kta sdonya unkanś, kikta un qa tipi tawa yuhdokapi kta iyowinwicakiye kte śni tuka. 44 Heon etanhan niś eya wiyeya un po; Wicaśta Cinhintku kin wihiyayedan oape tukte wanji en hi kta, he sdonyayapi śni.

45 Tuwe wowidake owotanna qa wayupika, itancan tawa tipi awanyagkiya, tohan iyehantu eca wo wicaqu ece e kta.

46 Wowidake kin hecen econ ece, itancan tawa en hdi qa wanhdake cinhan, he yawaśtepi ece.

47 Awicakehan heciciyapi; Taku yuhe cin owasin awanyagkiye kta.

48 Tuka wowidake sice cin he cante mahen, Itancan mitawa tehan hdi śni ce, eye cinhan;

49 Qa tona om wowidake un kin hena wicakaśtake ca, witkopi om wote ca wayatke cinhan; 50 Anpetu wan waktaya un śni, qa wihiyayedan oape wanji iye kecin śni, he en wowidake un kin yuhe cin hdi kta;

51 Qa cokaya kicakse kta, qa wanaiçihmanpi kin om taku yuhekiye kta; heciya wicaceya qa hi hdakinskinzapi yuke kta.

\section{WICOWOYAKE 25.}

1 Hehan mahpiya wokiconze kin witanśna unpi wikcemna iyacinpi kta; petijanjan ihupa 
ikikcupi qa tawicu ton kte cin he itkokim iyayapi.

2 Unkan zaptan ksapapi, qa zaptan witkotkokapi.

3 Witkotkokapi kin hena petijanjan ihupa icupi, tuka wibdi takudan yuhapi śni.

4 Tuka ksapapi kin hena cega ohna wihdi hduhapi, petijanjan ihupa iyahna.

5 Unkan tawicu ton kte cin he u śni ; hehanyan iyuhpa hbapi qa iśtinmapi.

6 Unkan hanyecokaya hehan wicaho wan tanin, Iho, tawicu ton kte cin he u ce; itkokim ya po.

7 Hehan witanśna unpi kin hena owasin iyotankapi, qa petijanjan kin piyapi.

8 Unkan witkotkokapi kin hena ksapapi kin hewicakiyapi; Wihdi nitawapi etanhan ongege unqu miye, petijanjan unkicisnipi kta.

9 Tuka ksapapi kin waayuptapi qa hewicakiyapi ; Hiya, okinni unkiye niyepi nakun iyounhipi kte śni; tuka tona wopetonpi ece kin ekta ya pe, qa opeiciton miye.

10 Unkan he opeton iyayapi, hehan tawicu ton kte cin he hi; unkan tona wiyeya unpi kin hena wakankiciyuzapi kte cin en kici iyayapi; hehan tiyopa kin ecen icupi.

11 Iyohakam witanśna unpi unmapi kin en hipi, qa heyapi; Itancan, Itancan, tiyopa unkiciyulidoka miye.

12 Tuka iye wayupte ca; Sdonciyapi śni, awicakehan eciciyapi ce, eya.

13 Heon etanhan kiktahan un po, anpetu qa wihiyayedan oape kin tukte wanji en, Wicaśta Cinhintku kin hi kte cin he sdonyayapi śni.
$14 \mathrm{He}$ iyecen wicaśta wan makoce tokeca ekta ye kta, hehan wowidake wicayuhe cin wicakico, qa woyuha tawa kin wicakipamni.

15 Unkan wanji mazaska tkeutapi tanka zaptan qu, qa wanji nom, qa wanji iś wanjidan qu; otoiyohi token okihi kta hecen wicaqu; hehan icimani iyaya.

16 Unkan tuwe tkeutapi tanka zaptan icu qon he iyaye, ca on wopeton ece econ, qa nakun tkeutapi tanka zaptan kamna.

17 Qa tuwe' nom icu qon iś eya iyecen nom nakun kamna.

18 'Tuka tuwe wanjidan icu qon he iyaye ca, maka qe ca, yuhe cin mazaska tawa kin inahima.

19 Unkan wanna tehan hehan wowidake unpi kin dena itancan tawapi kin hdi, qa wicakiciyawa.

20 Unkan tuwe theutapi tanka zaptan icu qon he zaptan toktokeca koya ahi qa heya; Itancan, tkeutapi tanka zaptan mayaqu; iho, nakun tkeutapi tanka zaptan hena awakamna, eya

21 Unkan yuhe cin héciya; Han, wowidake waśte qa wacinyepica; taku tonana on wacinyepica yaun, taku ota yuheciciye kta; niyuha towiyuśkin kin en opa wo.

22 Hehan tuwe tkeutapi tanka nom icu qon he hi, qa heya; Itancan, tkeutapi tanka nom mayaqu ; iho, nakun tkeutapi tanka nom hena awakamna.

23 Itancan tawa kin heciya; Han, wowidake waśte qa wacinyepica; taku tonana on wacinyepica yaun, ito taku ota yuheciciye kta ; niyuha towiyuśkin kin en opa wo.

24 Hehan tuwe tkeutapi tanka wanjidan icu qon he hi, qa heya; 


\section{MATTHEOS.}

Itancan, wicaśta nitehika sdonwaya, tukten woyaju śni eśta etanhan wamnayaya ece, qa tukten taku elipeyaye śni kin hetanhan wayapahi ece.

25 Qa kowakipa, heon imdamde ca mazaska tkeutapi tanka nitawa maka kin en nawahibe; iho, nitawa kin yahduha.

26 Itancan tawa kin waayupte ça heciya; Wowidake niśice ça nikuja; tukten wowaju śni kin hetanhan wamnawaya ece, qa tukten taku wakada śni hetanhan wawapahi ece e sdonyaya;

27 Heon etanhan mazaska mitawa wicaśta wopetonpi kin yuhewicayakiye kta iyececa tuka; hecen wahdi, qa mitawa oicage ko ewehdaku kta tuka.

28 Heon tkeutapi tanka kin ekiciyaku po, qa tuwe tkeutapi tanka wikcemna yuhe cin he ito qu po.

29 'Tuwe taku ota yuhe cin he nakun qupi ece e kta, hecen iyakiçuya yuhe kta; tuka tuwe takudan yuhe śni kin hetanhan taku ton kin hee kaeś ekiciyakupi ece e kta.

$30 \mathrm{Qa}$ wowidake wakamna śni kin he tankan otpaza kin en elipeya po; heciya wicaceya qa hi hdakinskinzapi yuke kta.

31 Tohan Wicaśta Cinhintku kin wowitan hduha, ohnihdewicaya wakan kin owasin om $u$ kinhan, hehan wowitan oiyotanke tarva kin en kiyotanke kta:

32 Qa itokam oyate kin iyuhpa mniciyapi kta; unkan wicayukinukan $\mathrm{kta}$, waawanhdake wan talinca wanunyanpi, tatokadan etanhan wicapahi ece kin he iyececa.

33 Qa tahinca wanunyanpi kin liena iye etapa eciyatanhan, qa tatokadan kin iye catka eciyatanhan ewicahnake kta.
34 Hehan Wicaśtayatapi kin tona etapa eciyatanhan unpi kin hena hewicakiye kta; U po, Ate eciyatanhan niyawaśtepi kin, wokiconze maka kagapi kin ehantanhan wiyeya niciyankapi kin he ito hduha po.

35 Wotektewahda, unkan wo mayaqupi ; imapuza, unkan wayatkemayakiyapi ; wicaśta matokeca waun, unkan tin hiyumayayapi :

36 Tancomakadan, unkan waamayakalipapi ; wamayazanka, unkan onśimayadapi ; makaśkapi, unkan wanyag mayahipi ece.

37 Hehan wicaśta owotanna kin hena ayuptapi qa heciyapi kta; Itancan, tohinni wotekteyahda wanunniyakapi, qa wo unnicupi he; qa inipuza qa wayatkeunniciyapi he :

38 Tohinni wicaśta tokeca yaun wanunniyakapi, qa tin hiyuunniyanpi he; qa tancodan yaun, qa wokoyake unniçupi he:

39 Tohinni waniyazanka qa kaśka nihnakapi yaun wanunniyakapi, qa en unnihipi he.

40 Unkan Wicaśtayatapi kin waayupte ca hewicakiye kta; Awicak ehan heciciyapi ; Mihunkawanji kin dena cikcistinpidan hecawicayeconpi kin he miye ecamiyeconpi ece.

41 Hehan tona catka kin eciyatanhan unpi kin hewicakiye kta ; Niyaśicapi kin, mitantanhan iyaya po, peta owihanke wanica ekta, wakanśica iye taokiyewicaye cin koya on kagapi qon.

42 Wotektewahda, tuka wo mayaqupi śni; imapuza, tuka wayatkemayakiyapi śni :

43 Wicaśta matokeca waun, tuka tin hiyumayayapi śni ; tancodan waun, tuka wokoyake mayaqupi śni; wamayazanka qa 


\section{WICOWOYAKE 26.}

kaśka mahnakapi waun, tuka onśimayadapi śni.

44 Hehan ayuptapi qa heciyapi kta; Itancan, tohinni wotekteyahda, qa inipuza, qa wicaśta tokeca yaun, qa tanconikadan, qa waniyazanka, qa kaśka nihnakapi yaun wanunniyakapi, qa ounniciyapi śni he.

45 Hehan awicayupte ca heye kta; Awicakehan heciciyapi ; Dena cikcistinpidan hecawicayeconpi śni kin he miye ecamiyeconpi śni ece.

46 Unkan dena owihanke wanin wokakije kin en yapi kta; tuka wicaśta owotanna kin hena owihanke wanin wiconi kin en yapi kta.

\section{WICOWOYAKE 26.}

1 Unkan Jesus wicoie kin dena owasin ihunnikiya, hehan waonspewicakiye cin hewicakiya;

2 Anpetu nom iyohakam woacakśin kin hehantu kta sdonyayapi ; hehan Wicaśta Cinhintku kin icipaweh okatanpi kta e wicaqupi kta.

3 Hehan wośnapi kagapi, wowapi kagapi qa oyate kin en wicaśta tankapi kin hena koya mniciyapi, wośnapi kagapi itancan, Kaiaphas eciyapi, he ti kin en.

4. Qa Jesus token nahmana icupi qa ktepi kta he aiapi.

5 Tuka wotapi anpetu kin hena icunhan śni, okinni oyate kin owodutaton lkta, eyapi.

6 Unkan Jesus Bethani en Simon lepros ecece ciqon he ti kin ohna yanka.'

7 Hehan winohinca wan inyan opiye wan wihdi waśtemna tehika ojudan he yuha en hi, qa iye iyotankehan yanka icunhan, pa kin en okaśtan.

8 Tuka waonspewicakiye cin hena he wanyakapi qehan śihdapi, qa heyapi ; 'T'okeca de awihnuniyapi he.

9 Wihdi waśtemna kin de ota iyopeyapi kta, qa wahpanica wicaqupi kta iyececa tuka ce.

10 Jesus he okalinige ca hewicakiya; Tokeca winohinca kin de iyokiśinyayapi he; wicohan waśte wan ecamicon.

11 Wahpanicapi kin ohinniyan wicaduhapi, tuka miye ohinniyan mayaduhapi śni.

12 Wihdi waśtemna kin de mitancan amakaśtan kin, mahnakapi kte cin on etanhan hecon.

13 A wicakehan heciciyapi; Maka kin owancaya wootanin waśte kin de tukten oyakapi hecinhan, winohinca kin de taku econ kin he wowitan on oyakapi ece e kta.

14 Hehan akenonpapi kin etanhan wanji, Judas Iskariot eciyapi, he wośnapi kagapi kin ekta wicai ;

15 Qa heya; He cicupi kinhan taku mayaqupi kta he. Unkan mazaska wikcemna yamni qupi kta, keciyapi.

16 Unkan hetanhan token hnayan wicaqu kta e he akita.

17 Aguyapi on napohyapi codan anpetu tokaheya, hehan waonspewicakiye cin Jesus en hipi, qa heciyapi ; Tukten woacakśin kin yate kta wiyeya unnicihnakapi kta yacin he.

18 Unkan heya; Otonwe kin en ya po, qa wicaśta kae heciya po; Wanna iyemicihantu, woacakśin kin yati en waonspewicawakiye cin om ecamon kta ce, Waonspekiye cin heya ce.

19 Unkan waonspewicakiye cin Jesus econ wicaśi kin ecen econpi, qa woacakśin kin wiyeya ehnakapi. 


\section{MATTHEOS.}

20 Wanna hitayetu hehan akenonpapi kin om en iyotanka.

$21 \mathrm{Qa}$ wotapi icunhan heya; Niyepi etanhan wanji wiyopemayayapi kta, awicakehan eciciyapi ce.

22 Unkan iyokiśicapi linca, qa otoiyohi heciyapi; Itancan, he miye he.

23 Unkan waayupte ca heya; Tuwe wakśica ohna kici nape yewaye cinhan he wiyopemaye kte cin ee.

24 Wowapi en kagapi qon he iyecen, Wicaśta Cinhintku kin ye kta; tuka wicaśta kin Wicaśta Cinhintku kin wiyopeye cinhan he wotehi kiciyanke kta; wicaśta kin he tohinni tonpi śni unkanś waśte kta tuka.

25 Unkan Judas wiyopcye kte cin he ayupte ca; Itancan, he miye he, eya. Ũnkan, Niye heha ce, eciya.

26 Unkan wotapi icunhan Jesus aguyapi icu, qa yawaśte, qa yuśpaśpa, qa waonspewicakiye cin wicaqu, qa heya; Icupi qa yuta po; mitancan kin he dee.

27 Qa wiyatke kin ehdaku, qa wopida cye ca wicaqu, qa hcya ; Owasin etanhan yatkan po.

28 Mawe kin he dee, wicotakuye teca kin en, wicota on papsonpi, woahitani kajuju kta heon.

29 Tuka heciciyapi, Detanhan hastanhanka iyuwi waskuyeca kin etanhan icimána mdatke kte śni, Ate tokiconze kin en anpetu wan teca unyatkanpi kte cin hehanyan.

30 Unkan odowan wan ahiyayapi hehan tankan iyayapi, Oliwe paha kin he ekta.

31 Hehan Jesus hewicakiya; Hanyetu kin de niyepi owasin ehpemayayapi kta. Kaken wowapi en kagapi ; Waawanlıdake kin he awape kta, unkan hetanhan tahinca wanunyanpi optaye kin enanakiya jyayapi kta.

32 Tuka ake wakini kinhan Galile ekta nitokam mde kta.

33 Hehan Inyan ayupte ca heciya; Owasin ehpeniyanpi eśta, miye tohinni ehpeciye kte śni.

34 Jesus heciya; Hanyetu kin de anpaohotonna hoton śni itokam yamni anamayakihibe kta, awicakehan eciciya.

35 Inyan heciya; Nici mata eśta anacilibe kte śni. Waonspewicakiye cin iyulipa nakun iyecen eyapi.

36 Hehan Jesus waonspewicakiye cin om can wojupi wan Gethsemane eciyapi kin he en i, qa hewicakiya; Den iyotanka po, ito kakiya cekiya mde lkta.

37 Unkan Inyan qa Zebedee cinhintku kin napin iwicacu, qa iyokiśica hinhda qa nina yuśaka: 38 Hehan hewicakiya; Minagi iyokiśice hinca, mate kta iyececa; den kiktahan mici yukan po. 39 Unkan hetanhan kitan ecinyan iyoopte iyaye ca makata ehpeiciya, cekiye ca heya; Ate, okihipica kinhan, wiyatke kin de tokan imiciyayc kta; tuka miye wacin kin hee śni, niye token yacin kin hee ecetu kte.

40 Unkan waonspewicakiye cin iśtinma liyeya en wicahdi, qa Inyan heciya; Tokeca wihiyayedan oape wanji kiktahan mici yaunpi kta oyakihipi śni he. 41 Kiktahan unpi qa cekiya po, okinni taku wawiyutanyan un kin en idadapi nun ce. Wicanagi kin he wicada, tuka wicacelipi kin waśake śni.

42 Ake inonpa ekta iyaye ca cekiye ca heya; Ate, wiyatke kin de mdatkc śni tokan imiciyaye kta okihipica śni kinhan, nitawacin ecen econpi nunwe. 


\section{WICOWOYAKE 26.}

43 Hehan ake en wicahdi, qa iśtinma hiyeya wanwicahdaka ; iśta hbapi hinca nakaeś.

44 Unkan ehpewicaye ca ake iyaye ca iyamni cekiya, oie un qon hena ake ohna ecen eya.

45 Hehan waonspewicakiye cin en wicahdi qa hewicakiya; Wanna niśtinmapi qa oziniciyapi he; iho, wanna iyehantu, qa Wicaśta Cinhintku kin wahtanipi sa napepi kin en wicaqupi.

46 Najin po, unyanpi kta; iho, tuwe wiyopemaye cin he kiyedan u ce.

47 Unkan iahan icunhan, iho, Judas, akenonpapi kin wanji ee, he hi, qa wicota wośnapi kagapi qa oyate kin en wicaśta tankinyanyanpi etanhan, mazasagye cansagye ko yuha kici hipi.

48 Unkan tuwe wiyopeye cin he iwaktawicaye ca heya; Tuwe i iwaputake cinhan hee kta; sutaya yuza po.

49 Unkan katinyan Jesus en hi qa, Iho, Itancan, eye ca i iputaka.

50 Unkan Jesus heciya; Kicuwa, taku on yahi he. Hehan en hipi qa Jesus nape ahnakapi qa yuzapi.

51 Unkan, iho, Jesus kici unpi wanji nape hdukatin, qa mazasagye ehdaku, qa on, wośnapi kagapi itancan taokiye wanji ape ça noge kaśpa.

52 Hehan Jesus heciya; Mazasagye nitawa ojuha en iyekiya wo; tona mazasagye ehdakupi kin owasin mazasagye kin on tapi kta.

53 Nakaha Ate cewakiya owakihi śni kecanni he; qa hinnakaha mahpiya ohnihde wicobe akenonpa sanpa maqu kta tuka.

54 Tuka hecetu kinhan, wowapi en kagapi, he decetu kta eyapi qon he token yuecetupi kta he.
55 Wihiyayedan oape kin he en Jesus oyate kin hewicakiya; Tokeca wamanon sa iyecen, mazasagye cansagye ko hduha takpe mayahipi he ; anpetu otoiyohi tipi wakan kin ohna waonspeciciyapi manka, tuka mayaduzapi śni.

56 Tuka dena owasin econpi, wicaśta wokcan taku owapi qon he yuecetupi kta heon. Hehan waonspewicakiye cin owasin ehpeyapi qa najicapi.

57 Unkan tona Jesus yuzapi kin hena Kaiaphas wośnapi kagapi itancan kin ekta ayapi, wowapi kagapi wicahincapi ko mniciyapi kin en.

58 Tuka Inyan itehan ihakam $u$, wośnapi kagapi itancan ti kin hehanyan, qa mahen ye ca ookiyewicayapi kin om iyotanka, owihanke kte cin he wanyake kta.

59 Unkan wośnapi kagapi qa wicahincapi kin, qa omniciye ocowasin, woitonśni wootanin oyakapi Jesus on akitapi, ktepi kte cin heon:

60 Tuka takudan iyeyapi śni; woitonśni woyakapi ota hipi, tuka takudan iyeyapi śni. Unhanketa woitonśni oyakapi nom hipi;

61 Qa heyapi; Wicaśta kin de, Tipi wakan Wakantanka tawa kin he mdujuju, qa anpetu yamni kinhan ake piya wakage kta owakihi ce, eya ce.

62 Hehan wośnapi kagapi itancan kin najin hiyaye ca heciya; Dena taku iyanionpapi kin takudan adupte śni he.

63 Tuka Jesus inina yanka. Unkan wośnapi kagapi itancan kin heciya; Wakantanka ni un kin on wacajeciciyate, Messiya Wakantanka Cinhintku kin he niye hecinhan, unkokiyaka miye. 


\section{MATTHEOS.}

64 Unkan Jesus heciya; Niye ecen eha; tuka nakun heciciyapi ; Tokata ekta Wicaśta Cinhintku kin wowaśake etapa eciyatanhan iyotanka qa mahpiya śapa akan u wandakapi kta.

65 Hehan wośnapi kagapi itancan kin śina hduhdehdece ca heya; Taku śica eya; taku on sanpa woyakapi unkakitapi kta he; iho, wanna śicaya ie cin he nayahompi :

66 Token idukcanpi he. Unkan ayuptapi qa, He te kta iyececa ce, eyapi.

67 Hehan ite atagośapi qa nape on apapi ; qa hunh kapsinpsintapi ;

68 Qa heyapi; Messiya he niye, tuwe anipe cin he ito unkokiyaka po.

69 Inyan tankan tipi kin ohna iyotankehan yanka; unkan wikośka wan en hi qa heciya; Qa niś nakun Jesus Galile etanhan kin he kici yaun qon.

70 Tuka iye owasin wicitokam anakihbe ca heya; Taku ehe cin he sdonwaye śni.

71 Unkan ohanzi hdepi kin ekta tankan iyaya, hehan wanji tokeca wanyake ca tona en unpi kin hewicakiya; De nakun Jesus Nazareth etanhan kin he kici un qon.

72 Unkan akeś anakihbe ca, Taku wakan namalion, wicaśta kin de sdonwaye śni ce, eya.

73 Hehan ake iecadan tona en najinpi kin hena hipi, qa Inyan heciyapi ; Awicakehan ewicatanhan yaun; iyae cin he oniyaka ece.

74 Hehan iapi śica ota eye ca, Taku wakan namahon, wicaśta kin he ecaca sdonwaye śni ce, eya. Unkan ecahankeya anpaohotonna kin hoton.

75 Hehan Inyan, Jesus taku 50 eciye ciqon, Anpaohotonna hoton śni kin itokam yamni anamayalkilibe kta ce, eye cin he kiksuya. Unkan tankan iyaye ca nina ceya.

\section{WICOWOYAKE 27.}

1 Unkan hanhanna hinca wośnapi kagapi kin owasin qa oyate kin en wicahincapi kin hena koya, Jesus token ktepi kta e he aiapi.

2 Unkan kaśkapi hehan ayapi, qa Pontios Pilate wicaśta itancan kin he kaipi.

3 Unkan Judas wiyopeye cin he wanna yacopi wanyaka, hehan iyopeiciye ca, mazaska wikcemna yamni kin, wośnapi kagapi wicahincapi ko ake wicakahi ;

4 Qa heya ; Wawahtani, wicawe taku iyaonpepica śni kin wiyopewaya ce. Unkan heyapi ; He etanhan unkitokecapi sni; he niś niye.

5 Unkan mazaska kin tipi wakan kin en elipeye ca kihda; qa hetanhan iyaye ca poskin icikte.

6 Unkan wośnapi kagapi kin mazaska kin hena icupi, qa heyapi ; Mazaska opiye kin en unkohnakapi kta iyecece śni, wicawe iyopeyapi kin dena ee, heon etanhan.

7. Hecen wiyukcanpi qa hena on wakśica kage cin tamaga he opetonpi ; ohna wicaśta tokeca wicahapi kta.

8 Heon etanhan maga kin he, Wicawe maga, eciyapi, anpetu kin dehanyan.

9 Hehan Jere miya wicaśta wokcan taku eye ciqon yuecetupi; he kaken eya; Unkan mazaska wikcemna yamni, tuwe iyopeyapi qon, Israel cincapi kin hecen iyacinpi qon, hena icupi, 


\section{WICOWOYAKE $2 \%$.}

$10 \mathrm{Qa}$ wakśica kage cin tamaga kin iyopeyapi, Itancan kin econmaśi iyececa.

11 Unkan Jesus wicaśta itancan kin itokam inajin: Qa wicaśta itancan kin wiwange ca heciya; Juda wicaśtayatapi kin he niye he. Unkan; Niś heha ce, Jesus eya.

12 Unkan wośnapi kagapi wicahincapi ko taku iyaonpapi, tuka takudan ayupte śni.

13 Hehan Pilate heciya; Dena taku iyanionpapi kin nayalion śni he.

14 Tuka oie wanjidan eśta ayupte śni, hecen wicaśta itancan kin nina yuśinyaya.

15 Wotapi kin de iyehantu eca wicaśta itancan kin wicakaśkapi wanji kiyuśka ece, tukte wanji oyate kin kicapi.

16 Unkan he ehan wanji tanyan sdonyapi, Barabbas eciyapi, he kaśka hnakapi.

17 Hecen en mniciyapi hehan Pilate hewicakiya; Unma tukte ciciyuśkapi kta yacinpi he, Barabbas qa iś Jesus nakun Messiya eciyapi.

18 Winawizipi on he iye en kahipi e sdonya.

19 Unkan woyaco oiyotanke kin akan kiyotanka hehan tawicu kin tuwe en usí, qa heciya; Wicaśta owotanna kin he takudan ecakicon śni we, on anpetu kin de wiwahamna en nina mayuśinyaya ce.

20 Tuka wośnapi kagapi wicahincapi ko oyate kin wahokonwicakiyapi, Barabbas kicapi kta, qa Jesus ihangyapi kta.

21 Hehan wicaśta itancan kin ake wiwicawange ca hewicakiya ; Unma tukte ciciyuśkapi kta yacinpi he. Unkan, Barabbas, eyapi.

22 Pilate hewicakiya; Jesus nakun Messiya eciyapi kin he token ecamon kta he. Unkan owasin; Icipaweli okatanpi kta, eciyapi.

23 Unkan wicaśta itancan kin heya; Tokeca, taku śica econ kin tukte e he. 'Tuka nina panpi qa; Icipaweh okatanpi kta, eyapi.

24 Hecen Pilate takudan okihi śni, qa nina owodutaton icaga he wanyaka, hehan mini icu, qa wicota wicitokam nape hdujaja, qa heya; Wicaśta owotanna kin de we kin miye en amaupi kte śni; niye ito wanyaka po.

25 Hehan oyate kin iyulipa ayuptapi qa lieyapi; He we kin unkiyepi qa unkicincapi koya en unkaupi nunwe.

26 Unkan hehan Barabbas wicakiciyuśka; qa Jesus kapsinpsinta hehan icipawel okatanpi kta e wicaqu.

27 Hehan wicaśta itancan taakicita kin Jesus ti mahen ayapi, qa wicobe ocowasin en mniciyapi.

28 Qa iye tawokoyake kiyuśdokapi, qa śina duta wan inkiyapi.

29 Qa wapepeka kazontapi on wateśdake kagapi qa teśdagkicatonpi, qa cedi wan nape etapa kin on yuskiyapi; qa itokam canpeśka makehde inajinpi, qa iliahapi, qa heyapi; Iho, Juda Wicaśtayatapi kin.

30 Qa atagośapi, qa cedi kin icupi qa pa en apapi:

31 Unkan hecen ithahapi hehan śina kin ekiciyakupi qa iye tawokoyake qon kicunkiyapi, qa icipaweh okatanpi kta ayapi.

32 Tankan ayapi hehan wicaśta wan Kurene etanhan, Simon eciyapi, he wanyakapi; unkan he cansusbeca kin kicicinkiyapi.

33 Unkan makoce wan Golgo- 


\section{MATTHEOS.}

tha eciyapi, he wicapahu makoce eyapi kin he kapi, he elkta ipi ;

34 Hehan miniśa pizi icahiyapi kin hetanhan yatkekiyapi; tuka uta hehan yatke kta wicada śni.

35 Unkan hen icipaweli okatanpi, oeconna econpi qa tawokoyake kicipamnipi. Hecen wicaśta wokcan oie qon yuecetupi; Mitawokoyake kicipamnipi qa onhdohda mitawa on oceonna econpi ce.

36 Unkan hen iyotankapi qa awanyakapi :

37 Qa wiyaonpapi kin de owapi qa pa iwankam ehnakapi ; JESUS, JUDA WICAŚSTAYATAPI KIN HE DEE.

38 Nakun wicaśta wamanon sa nom kici icipaweh owicakatanpi, unma etapa eciyatanhan, qa unma iś catka tanhan econpi.

39 Unkan tona en hiyayapi kin hena aiapi, qa apomnamnapi ;

40 Qaheyapi; Tipi wakan ihangyaye ca anpetu yamni ake piya yakage kte ciqon, niiciya wo. Wakantanka Cinhintku kin he niye hecinhan, cansusbeca kin etanhan kun ku wo.

41 He iyececa, wośnapi kagapi kin ihahapi, qa wowapi kagapi wicalincapi ko om heyapi ;

42 Wicaśta tokeca niwicaya ece, iye niiçiye kta okihi śni; Israel wicaśtayatapi tawapi hecinhan, iho, wanna cansusbeca kin etanhan kun ku kta, kinhan wicaundapi kta.

43 Wakantanka wacinkiye ciqon; tawa kta hecinhan wanna ehdaku kta; Wakantanka Cinhintku kin he miye ce, eye ciqon.

44 Nakun wicaśta wamanon sa, kici icipaweh owicakatanpi kin hena iś eya iyecen i ell hiyeyapi.

45 Unkan wihiyayedan oape śakpe hetanhan napcinwanka ape cin hehanyan makoce kin owancaya otpaza.

46 Unkan napcinwanka apa hehantu ecetu, Jesus howaye ca hotankakiya heya; Eli, Eli, lama sabakthani; Wakantanka mitawa, Wakantanka mitawa, tokeca ehpemayaya he, eyapi kin hee.

47 Unkan en najinpi kin he nahonpi qehan, apa heyapi; Elias kipan ce.

48 Unkan wanji etanhan inyang ye ca mini iyuhepe wan icu, qa miniskuya en oputkan, cedi wan icape ca yatkekiya.

49 Unmapi kin heyapi; Hinnahanka, Elias nikiya hi kta hecinhan ito wanunyakapi kta.

50 Tuka Jesus ake hotankakiya hotanin qehan, taniya kin hiyuya.

51 Unkan iho, tipi wakan cokaya ozanpi kin he okiyulidecapi, wankantanhan qa kun ihanke kin hehanyan; nakun maka kin śkanśkan qa inyan namdecapi :

$52 \mathrm{Qa}$ wicahapi kin yuhdokapi, qa wicaśta waśte iśtinmapi kin hena ota hiyupi ;

53 Qa wicahnakapi kin etanhan hninanpapi, qa otonwe wakan kin en hipi, qa wicota en taniniciyapi.

54 Ünkan akicita tancan qa tona om Jesus awanyake cin hena maka kin śkanśkan qa taku econpi ko wanyakapi qehan, nina yuśinyayapi. qa, Awicakehan Wakantanka Cinhintku kin he dee tuka ce, eyapi.

55 Unkan winoliinca ota her unpi qa itehanyan wanyakapi; tona Galile etanhan upi qa okiyapi ece qon :

56 Mary Magdalene he wanji ee, qa Mary Jakob qa Joses hunku, qa Zebede cinca hunkupi kin. 


\section{WICOWOYAKE 28.}

57 Wanna htayetu hehan Arimathea etanhan wicaśta wijica wan en hi, Joseph eciyapi, he nakun Jesus waonspewicakiye cin wanji ee :

$58 \mathrm{He}$ Pilate en i, qa Jesus tancan kin kida. Hehan Pilate tancan kin he quwicaśi.

59 Unkan Joseph tancan kin he icu qchan, minihuha ska wan opazunta ;

60 Qa ohna hnakapi tawa teca, imnija kin en kahdoke cin, he en ohnaka; qa inyan wan tanka ohna hnakapi i kin en eonpa, hehan kihda.

61 Unkan ohna hnakapi kin iyotakons, Mary Magdalene qa Mary unma qon iyotankehan yukanpi.

62 Unkan anpetu en ihduwiyeyapi ece kin he ihanlianna, hehan wośnapi kagapi qa Pharisee kin hena Pilate en hipi,

$63 \mathrm{Qa}$ heyapi ; Itancan, wicahnaye sa kin de ni un qehan, Anpetu yamni hehan wakini kta ce, eya keyapi, he unkiksuyapi.

64. Heon etanhan wicahnakapi kin natag wicaśi wo, anpetu yamni hehanyan; okinni waonspewicakiye cin hena en hipi qa tancan kin manon akiyahdapi kta, qa hehan, Wicațe cin etanhan kini ce, oyate kin ewicakiyapi kta; hecen ehake wicahnayanpi kin he tokaheya kin isanpa tanka kta.

65 Pilate liewicakiya; Akicita wicaduhapi; hdapi qa token oyakihipi sutaya nataka po.

66 Hecen kihdapi qa wicahnakapi kin sutaya natakapi ; inyan kin he apuspapi qa akicita en najinwicakiyapi.

\section{WICOWOYAKE 28.}

1 Anpetu wakan owihanke kin ekta, wanna anpetu tokaheya ayanpa kta hehan, Mary Magdalene qa Mary unma kin, wicahnakapi kin wanyag hipi:

2 Unkan iho, maka śkanśkan wan tanka; mahpiya eciyatanhan Itancan taohnihde wan kun $u$, en hi qa tiyopa kin etanhan inyan kin yuptanye ça akan iyotanka.

$3 \mathrm{He}$ ite kin wakanhdi kin iyececa, qa tawokoyake kin wa iyecen ska:

4 Unkan he kokipapi on awanyakapi kin nina cancanpi qa wicaśta tapi kin iyecen ayapi.

5. Unkan mahpiya ohnilhde kin he waayupte ca winohinca kin hewicakiya; Niye kokipapi śni po; Jesus icipaweh okatanpi qon he oyadepi sdonwaya :

6 Den un śni ; wanna ihduekicetu, heye ciqon iyececa: $\mathrm{Ku}$ wa po, Itancan kin wanke ciqon he wanyaka miye.

7 Qa kohanna hdapi qa, Wicațe cin etanhan kini ce, waonspewicakiye cin ewicakiya po ; unkan iho, Galile ekta nitokam iyaya ce, hen wandakapi kta; iho, wanna ociciyakapi.

8 Unkall wokokipe wowiyuśkin tanka ko yuha koyahanna kihdapi ; waonspewicakiye cin hośi wicakakipi kta inyang hdapi. 9 Unkan waonspewicakiye cin hośi wicakahdapi icunhan, iho, Jesus itkowicakipa qa heya; Wiyuśkin po. Unkan en hipi qa siha en yuzapi qa ohodapi.

10 Hehan hewicakiya; Kopehdapi śni po; mihunkawanji owicakiyag ya po, Galile ekta yapi kta; heciya wanmayakapi kta ce.

11 Unkan hena hdapi icunhan, akicita awanyakapi qon etanhan wanjikji otonwe kin en hipi, qa wośnapi kagapi kin taku econpi kin owasin owicakiyakapi. 


\section{MARKOS.}

12 Unkan hena witaya mnieiyapi, wicahincapi ko om, qa he akiiapi, hehan akicita mazaska ota wicaqupi ;

13 Qa heyapi ; Unkiśtinmapi icunhan waonspewicakiye cin hanyen hipi qa manon icupi ce, eya po.

14 Unkan he wicaśta itancan kin nahon kinhan, unkiye ceunkiyapi kta, qa anaunnicilś́inpi kta.

15 Hecen mazaska kin icupi, qa token onspewicakiyapi kin iyecen econpi; heon wicoie kin he Juda oyate kin en oyakapi ece, anpetu kin dehanyan.

16 Hehan waonspewicakiye cin akewanjipi, hena Galile ekta iya- yapi, paha wan Jesus cajeyate ciqon hetu.

17 Unkan wanyakapi hehan ohodapi ; tuka apa cețunhdapi.

18 Unkan Jesus en wicahi, owawicakiye ça heya; Mahpiya ekta qa maka akan wowaśake ocowasin maqupi :

19 Heon etanhan ya po, oyate kin owasin waonspewicakiya po, qa Ateyapi, Cinhintkuyapi, qa Woniya Wakan kin caje on baptem wicaqu po;

$20 \mathrm{Qa}$ taku tona econciśipi kin owasin yuhapi kta e onspewicakiya po. Unkan iho, anpetu owasin cicipi waun, maka owihanke kin hehanyan. Amen.

\section{A R KOS \\ WO'TANIN WAŚTE TAWA.}

\section{WICOWOYAKE 1.}

1 Jesus Messiya Wakantanka Cinhintku kin Wotanin Waśte tawa tokaheya kin he dee.

2 Wicaśta wokcanpi kin en owapi qon iyececa; Tho, niite kin itokam wahosi mitawa yewaśi kta, nitokam canku wiyeya enicihnake kta.

3 Wicaho wan hewotahedan hotanin kin hee, Itancan tacanku kin wiyeya ekicihnaka wo, ocanku owotanna kicaga wo.

4 Johannes hewotahedan baptem wicaqu, qa woahtani kajujupi kta, on iyopeiçiyapi baptem wicaqupi kin he oyaka ece.

5 Unkan Juda makoce kin owancaya tanhan, qa nakun Jerusalem etanhan ekta yapi ; unkan woalitani ohdaka, Jordan wakpa kin en, iye owasin baptem wicaqu.

6 Unkan Johannes kamel hin kin koyake ca tehmiso wan ipiyagkiton; qa psipsicadan tuhmaga canhanpi ahna yuta ece : 7 Qa woyake ca heya; Mihakam wanji mikapeya waśake cin he u ce, he patuś nawajin qa hankpan weciyuśdoke kta iyemicihantu śni.

8 Miś miye awicakehan mini on baptem ciçupi; tuka iye qe Woniya Wakan kin on baptem nicupi kta ce.

9 Unkan anpetu kin hena icunhan, Galile en Nazareth etanhan Jesus u, qa Jordan en Johannes baptem qu.

10 Unkan mini kin etanhan itanwankanhde ku qehan, ecahankeya malipiya kin yuzamnipi qa Woniya Wakan kin wakiye- 


\section{WICOWOYAKE 1.}

dan kahya kuntkiya u qa en hiyahan, he wanyaka.

11 Unkan malipiya eciyatanhan wicaho wan tanin, Micinkśi wastewakidake ca tanyan iyomakipi kin he niye ce.

12 Hehan ecahankeya Woniya kin hewoskan makoce kin ekta kaham aya.

13 Unkan anpetu wikcemna topa hewotahedan makoce kin en un ; qa hen Satan iyutanyan ; wamanica kin om un, unkan mahpiya ohnihde kin okiyapi ece.

14 Unkan Johannes kaśka hnakapi qehan, Jesus Galile en hi, qa Wakantanka tokiconze wotanin waśte kin oyaka:

15 Qa heya; Wanna iyehantu, Wakantanka tokiconze kin kiyedan un; iyopeiciya po, qa wotanin waśte kin wicada po.

16 Unkan Galile mde kin icahda omani, hehan Simon wanyaka, qa iye sunkaku Andrew nakun, mde kin en ho wan iyohpeyapi ; hena hopsicapi kin hecapi nakaeś.

17 Unkan. Jesus hewicakiya; Miyahna u po, kinhan wicaśta wicadupsicapi kta cicagapi kta ce. 18 Unkan ecahankeya ho kin ehpekiyapi, qa ihakam iyayapi.

19 Unkan hetanhan kitan ecinyan iyoopta ye ca, Jakob Zebede cinhintku, nakun sunkaku Johannes eciyapi, wanwicayaka; hena wata ohna ho kin piyapi.

20 Unkan ecahankeya wicakico; unkan atkukupi Zebede, qa tona wowidake wicayuhe cin hena om, wata kin en ehpewicayapi, qa ihakam iyayapi.

21 Hehan Kapernaum en yapi ; unkan anpetu wakan icunhan omniciye tipi kin katinyan en ye ça, woyaka.

22 Unkan taku oyake cin on yuśinyayapi ; wicaśta itancanyan waonspewicakiya, qa wowapi kagapi kin iyecece śni.

23 Unkan omniciye tipi kin he ohna wicaśta wan woniya śica yuha ; unkan he howaya,

24 Qa heya; Unkayuśtan po; Jesus Nazareth etanhan, taku ecaunniconpi he ; ihangunyayapi kta yahi he; nituwe kin sdonwaya, Taku Wakan Wanji Wakantanka tawa kin he niye.

25 Hehan Jesus iyopeye ca heciya; Inina yanke ca, tankata hninanpa wo.

26 Unkan woniya śice cin he wicaśta kin yuhdece ca, hotankakiya hotanin, hehan tankan hinanpa.

27 Unkan owasin inihanpi qa heya ikiciwangapi ; De talku he; de woonspe teca kin tukte e he ; woniya śice cin itancanyan owawicakiya, unkan anagoptanpi ece.

28 Unkan hetanhan Galile makoce ihdukśan owancaya olian kin oyakapi.

29 Unkan omniciye tipi kin etanhan hdicupi, hehan katinyan Simon qa Andrew tipi tawapi kin en yapi, Jakob qa Johannes nakun opapi.

30 Tuka Simon tawicu hunku kin he tancan kata on wayazanka yanka; unkan he okiyakapi.

31 Hehan en hi, qa napata yuze ca najinkiya; unkan ecahankeya tancan kata ayuśtan, qa hehan owicakiya.

32 Wanna litayetu, wi iyaya hehan, wayazankapi kin owasin yanke cin ell awicahipi, tona wakanśica wicayulınaśkinyan hena koya.

33 Hecen otonwe kin ocowasin tiyopa kin en kata iheya.

34 Unkan wowayazan toktokeca on wayazanpi kin ota asni- 


\section{MARKOS.}

wicaya, qa taku wakan sica ota nakun tankan hinanpe wicakiya; qa wakan śice cin hena ia iyowinwicakiye śni, hena iyekiyapi nakaeś.

35 Unkan ihanhanna, hinahin anpa itehan, hehan inajin, qa tankan inanpe ca, hewotahedan makoce wan ekta ye ca, hen wocekiye eya.

36 Unkan Simon tona om un kin hena koya ihakam iyayapi.

37 Qa iyeyapi hehan heciyapi; Owasin anicitapi ce.

38 Unkan hewicakiya; Otonwe ikiyedan kin hena en unyanpi kta; hen nakun womdake kta; heon etanhan wahi ce, eya.

39 Unkan Galile makoce kin owancaya, omniciye tipi kin ohna woyalke ca, wakan śica hinape wicakiya ece.

40 Unkan wicaśta wan lepros ececa, he en hi, qa cekiya, canpeśka makehde inajin qa heciya ; Yacin kinhan ska mayakage kta oyakihi.

41 Unkan Jesus onśikida, nape ekta yekiye ca, yutan qa heciya; Wacin, ska un wo.

42 Unkan heye cin hecehnana, lepros ececa qon he ayuśtan, qa ska icaga.

43 Hehan tanyan wahokonkiye ca hetanhan hdeśi;

$44 \mathrm{Qa}$ heciya; Ihnuhan tuwe taku eyakiye cinhan; tuka hde ca, wośna kage cin he en hdutanin wo, qa niyuskapi kta on taku Moses econ wicaśi qon hena wayuśna wo, hecen iyepi ekta woyutanin kta.

45 Tuka tankan hde ca, nina ohdake ca, owancaya yaotanin, hecen hetanhan Jesus otonwe kin en taninyan ye kta okihi śni, tuka tankan lewotahedan un ece: unkan owancaya tanhan yanke cin en hipi ece.

\section{WICOWOYAKE 2.}

1 Anpetu tonanà iyohakam hehan ake Kapernaum en i; unkan ti mahen yanka he oyakapi.

2 Unkan hecehnana wicota en mniciyapi, hecen tuktedan en hipi kte śni, tiyopa kin itankan tanhan ocikan śni : unkan wicoie kin owicakiyaka.

3 Unkan hehan en hipi, wicaśta wan tatake cin wicaśta tom akiyuhapi, he en aupi.

4 Unkan wicota kin on tokadan ikiyedan upi śni, hehan tipi akahpe kin yuhdokapi ; he yujujupi hehan tatake cin owinja akan yanka ecehna en yuhukun iyeyapi.

5 Unkan wacinyanpi kin he Jesus wanyake cehan, tatake cin heciya; Cinś wayahtani kin nicicajujupi ce.

6 Tuka wowapi kagapi wanjikji hen iyotankehan unpi kin hena cante mahen hecinpi;

7 Tokeca wicaśta kin de śicaya ia he : Tuwe woahtani kajuju kta okihi he, Wakantanka ecedan.

8 Unkan hena hecekcen awacinpi kin, Jesus iye tawacin ekta sdonya, hehan hewicakiya ; Tokeca hena hecekcen awacannipi he.

9 Wayahtani nicicajujupi, qa iś, Najin, owinja ehdaku qa mani wo, tatake cin eciyapi kta, unma tukte waśakadan he.

10 Tuka Wicaśta Cinhintku kin he maka akan woahtani kajuju kta okihi, he sdonyayapi kta; hehan tatake cin he heciya;

11 Najin, qa owinja ehdaku, qa yati ekta hda wo, eciciya ce, eya.

12 Unkan hecehnana najin hi. yaye ca, owinja ehdaku, qa owa, sin wicitokam tankan kihda; he. 


\section{WICOWOYAKE 2.}

cen owasin inihanpi, Wakantanka yatanpi qa heyapi; Tohinni taku dececa wanunyakapi śni.

13 Hehan ake tankan mde kahda iyaya; unkan wicota en mniciyapi; unkan waonspewicakiya.

14 En hiyaya icunhan, Lewi, Alpheus cinhintku, mazaska mnayanpi ece kin en iyotanka, he wanyake ca; Miyahna $u$ wo, eciya. Unkan najin hiyaye ça ihakam ya.

15 Unkan he ti kin ohna Jesus wota iyotanka, hehan mazaska mnayanpi wahtanipi sa ko ota Jesus kici iyotankapi, waonspewicakiye cin hena koya: wicota qa ihakam unpi ece.

16 Unkan wowapi kagapi Pharisee ko, wamnayanpi qa wahtanipi sa om wota yanka wanyakapi, hehan waonspewicakiye cin hewicakiyapi; Tokeca e wamnayanpi wahtanipi sa ko om wota qa wayatkan he.

17 Jesus he nalion, hehan hewicakiya; Tona zanipi kin hena pejihutawicaśta kin cinpi śni, tuka wayazankapi kin hena e cinpi: wicaśta owotanna kin heca on wahi śni, tuka wahtanipi sa iyopeiciyapi kta e wicakico wahi ce.

18 Johannes waonspewicakiye cin hena, qa Pharisee tawapi kin alkihaniçiyapi ece; unkan en hipi qa heciyapi ; Tokeca e Johannes waonspewicakiye cin hena, qa nakun Pharisee tawapi kin, akihaniciyapi he, tuka waonspewicayakiye cin hena akihaniçiyapi śni.

19 Unkan Jesus hewicakiya; Wakankiciyuzapi cinca kin hena tohanyan tawicu ton kte cin om un kin hehanyan akihaniciyapi kta okihipi he. Tohanyan tawicu ton kte cin yuhapi kinhan, hehanyan akihaniçiyapi kte śni.

20 Tuka anpetu kin u kta, tohan tawicu ton kte cin he ewicakiciyakupi kta, unkan anpetu kin hena en akilianiçiyapi kta.

21 Tuwedan śina teca onśpa onhdolida tanike cin en akihdagton śni; hecon kinhan onśpa teca en akagegepi kin he tanike cin etanhan namna kta, hecen oyuhdece kin sanpa tanka aya.

22 Nakun tuwedan miniśa teca ojuha tanike cin en okaśtan śni ; hecon kinhan miniśa teca kin he ojuha tanike cin kahdeca ece, hecen miniśa skepe ca ojuha kin ihangyapi; tuka miniśa teca kin ojuha teca kin en okaśtanpi kta.

23 Unkan anpetu wakan icunhan wojupi kin ehna iyaya; qa waonspewicakiye cin, yapi icunhan, wahuwapa yuksapi.

24 Hehan Pharisee kin heciyapi ; Wanyaka wo, anpetu wakan icunhan, taku econpi kta iyecece śni tokeca econpi he.

25 Unkan hewicakiya; Dawid qa tona om un qon, wotektehdapi qa cinpi qehan, token econpi qon he dawapi śni he.

26 Abiathar wośnapi kaga itancan taanpetu kin en, Wakantanka ti kin en ye ca, wayutanin aguyapi kin he yute ca, om un kin hena nakun wicaqu; he wośnapi kagapi iśnana yutapi kta tuka.

27 Unkan hehan hewicakiya; Anpetu wakan kin he wicaśta on kagapi, qa wicaśta kin iś anpetu wakan kin on kagapi śni :

28 Heon etanhan Wicaśta Cinhintku kin anpetu wakan kin en Itancan un. 


\section{MARKOS.}

\section{WICOWOYAKE 3.}

1 Hehan ake omniciye tipi kin en iyaya; unkan wicaśta wanji nape śnija hen yanka.

2 Unkan anpetu wakan icunhan asniye kta hecinhan he iawanyakapi; taku iyaonpapi kta e heon.

3 Unkan wicaśta nape śnije cin he heciya; Cokata inajin wo.

4 Hehan hewicakiya; Anpetu wakan icunhan taku waśte econpi kta iyececa, qa iś taku śica econpi kta, unma tukte he ; waniyanpi kta qa iś wațeyapi kta he. Tuka inina hiyeya.

5 Unkan icanksiya awicatonwan, cante tehipike cin on iyokiśica, hehan wicaśta kin heciya; Nape hdukatin wo. Unkan hduowotanna; hecen nape kin ocowasin yuecetupi, unma kin iyececa.

6 Hehan Pharisee kin hena iyayapi, qa ecahankeya Herodian kin om wohdakapi, token he ihangyapi kta e heon.

7 Tuka Jesus mde kin ekta hdicu, waonspewicakiye cin om ; qa Galile etanhan qa Juda makoce kin etanhan wicota hinca ihakam yapi.

8 Nakun Jerusalem etanhan, qa Idumia, qa Jordan akasanpa tanhan; qa Turos qa Sidon ihdukśan tanhan wicota, taku wicohan tanka econ nahonpi, hehan en hipi.

9 Unkan wicota aotinsyapi kta e heon, wata cistinna wan yuha waonspewicakiye cin akipepi kta, kewicakiya.

10 Wicaśta ota asniwicaya; heon tona tancan ślitinpi kin hena yutanpi kta e yuoținzapi.

11 Qa tona woniya śapa yuhapi kin hena wanyakapi, hehan itokam makata ihpayapi qa he- ya howayapi, Wakantanka Cinhintku kin he niye ye.

12 Unkan oyakapi kte śni nina kewicakiya.

13 Unkan hetanhan paha wan ckta ye ca, tona cin kin hena wicakico; unkan en hipi.

14 Unkan akenonpa wicakaliniga, ohinniyan kici unpi kta, qa woyaka yewicaśi kta ;

15 Qa wayazankapi kin asniwicayapi kta, qa wakan śica napewicayapi kta, wowaśake yuhapi kta.

16 Unkan Simon he Inyan eya caśton ;

17 Qa Jakob, Zebede cinhintku, qa Johannes Jakob sunkaku; unkan hena Boanerges ewicakiya, Wakinyan cincapi he kapi :

18 Qa Andrew, qa Philip, qa Bartholomew, qa Mattheos, qa Thomas, qa Jakob Alpheus cinhintku, qa Thaddeus, qa Simon Kananite ;

19 Qa Judas Iskariot, wiyopeye cin hee. Unkan tipi wan ti ma hen iyayapi.

20 Hehan ake wicota en mniciyapi, hecen aguyapi yuta okihipi śni.

21 Unkan iye takuwicaye cin he nahonpi qehan, yuzapi kta e ekta iyayapi; qa, Wanna wacinhnuni ce, eyapi.

22 Nakun wowapi kagapi Jerusalem etanhan hipi kin hena heyapi; He Beelzebub yuha, qa wakanśica itancan kin on wakan sica napewicaya ece.

23 Unkan iye hena wicakico qa wiyacinyan hewicakiya; Token Satan Satan napeya okihi kta he.

24. Qa wokiconze wan iye iyakitedan kicize cinhan, wokiconze kin he ecen he kte śni.

$25 \mathrm{Qa}$ tipi wanji iye iyakite- 
dan kicize cinhan, tipi kin he ecen he kte śni.

26 Nakun Satan inajin, qa iye iyakitedan kicize ça ihdunonpa kinhan, he ecen un kta okihi sni, tuka wanna owihanke kta.

27 Tuwedan wicaśta waśaka ti kin en ye ça, tawahpaya kin ihangye kte śni; wicaśta waśake cin he tokaheya kaśke cinhan, hehan tipi tawa kin ihangye kta.

28 Awicakehan heciciyapi; Wahitanipi owasin wicaśta cincapi kin wicakicicajujupi kta, qa iapi śica on wayaśicapi ece kin hena nakun;

29 Tuka tuwe Woniya Wakan kin yaśice cinhan, he icimana kicicajujupi kte śni; tuka woyaco owihanke wanica kicihe kta:

30 Woniya śapa wan yuha ce, eyapi kin heon etanhan heya.

31 Unkan hehan iye hunkawanjitkupi qa hinku kin hena en hipi, tankan hinajinpi, wahoyapi qa kicopi.

32 He icunhan wicota ihdukśan iyotankapi; unkan heciyapi ; Iho, tankan, nihun qa nihunkawanjipi anicitapi ce.

33 Unkan heya awicayıpta; Inawaye cin he tuwe, qa mihunkawanji tuwepi he.

34 Unkan tona okśan iyotankapi kin hena ekta ewicatonwe ça heya; Ina qa mihunkawanji, wanwicayaka po.

35 Tuwe Wakantanka tawacin kin ecen ecors kinhan, he mihunkawanji ee, mitawinohtin qa inawaye cin nakun.

\section{WICOWOYAKE 4.}

1 Hehan ake mde kin icahda waonspewicakiya; unkan wicota hinca en mniciyapi, hecen wata wan en ope ca, mini ekta iyotanka; unkan oyate kin owasin mde icahda maka akan unpi.

2 Unkan wiyacinpi on taku ota onspewicaliya; qa waonspewicakiya icunhan hewicakiya;

3 Nation po: Iho, wicaśta woju wan woju iyaya.

4 Unkan woju icunhan, apa canku icahda hinhpaya; unkan zitkatanka en ahiyahe ca temyapi.

5 Qa apa inyan ehna hinlipaya, hen maka tonana; unkan' maka akantuyedan heon oliankoya hinanpa.

6 Tuka wi hinanpa hehan gu; qa hutkan nice cin heon śniś aya.

7 Unkan apa wapepeka hu kin ehna hinhpaya; unkan wapepeka kin hu uye ca aotinsya, hecen waskuyeca takudan ieage śni.

8 Unkan apa maka waśte kin en hinhpaya, he waskuyeca aicaga; hinanpe ca icaga, qa suton, hunh wikcemna yamni, hunh wikcemna śakpe, qa hunh opawinge akihde aicaga ece.

9 Hehan hewicakiya; Tuwe noge wination yukan hecinhan, ito nahon kta.

10 Unkan iśnana un hehan, akenonpapi qa tona om ihdukśan unpi kin hena wiyacinpi kin he on iwangapi.

11 Unkan hewicakiya; Wakantanka tokiconze woanahbe kin hena niye sdonyayapi kta e niçupi; tuka tankan unpi kin hena taku owasin wiyacinpi kin on econpi.

12 Hecen wawanyakapi on wanyakapi kta, tuka iyukcanpi kte śni; qa winahonpi on nahonpi kta tuka okahnigapi kte śni; hecece śni kinhan okinni wicayuhomnipi kta, qa woahtani wicakicicajujupi kta. 


\section{MARKOS.}

13 Unkan hewicakiya; Wiyacinpi kin de sdonyayapi śni he, hecen token ecin wiyacinpi owasin oyakahigapi kta he.

14. Tuwe woju kin he wicoie kin oju ece.

15 Tona canku icahda qon, tukten wicoie kin ojupi, tuka he nalionpi hehan, ecahankeya $\mathrm{Wa}$ kanśica en hi, qa wicoie cantepi kin en ojupi qon he icu ece, iho, hena eepi.

16 Qa he iyececa, inyan ota en ojupi qon, tona wicoie kin naŁonpi eca, kohanna iyuśkinyan icupi ece kin hena eepi ;

17 Tuka iyepi mahen hutkan nicapi heon aśkayedan icaga; tohan wicoie kin on śicaya wicakuwapi qa śitkihdawicayapi icaga, hehan hinnahanka śihdapi.

18 Unkan tona wapepelka hu ehna ojupi qon, tona wicoie kin nahonpi ;

19 Unkan maka kin de awacinpi, qa wijicapi on wicahnayanpi, qa taku tokeca cantiheyapi kin hena en $\mathrm{u}$, qa wicoie lin yuoținza, hecen wasuton śni, hena eepi.

20 Unkan maka waśte kin en ojupi qon, tona wicoie kin nahonpi eca icupi ece, qa waskuyeca icahyapi, wikcemna yamni, wikcemna śakpe, qa opawinge akihde, iho, hena eepi.

21 Unkan hewicakiya; Petijanjan koka wan ihukuya, qa iś ohehdepi ihukuya iyeyapi kta, qa petijanjan ihupa en ośtanpi lkte śni, aupi he.

22 Taku akahpetonpi qa yutaninpi kte śni wanica; qa taku anahmanpi qa iyoyanpa en aupi kte śni wanica ce.

23 Tuwe noge winahon yukan hecinhan he nalion kta.

24 Unkan hewicakiya; Taku nayahonpi kin awacin po. Wiyutapi kin tukte on widutapi ece kin, he on ake winiciyutapi kta, qa tona anagoptan dukanpi kin sanpa niçupi ece e kta.

25 Tuwe wayuhe cin he sanpa taku qupi kta; qa tuwe takudan yuhe śni, taku yuhe cin hee kaeś kipi kta.

26 Unkan heya; Wakantanka tokiconze kin he wicaśta wan taku su kin maka kin en iyohpeya, he iyececa;

$27 \mathrm{Qa}$ iśtinma, qa hanyetu anpetu ko inajin; unkan su kin he hinanpe ca icage kta, tuka token icaga he sdonye śni.

28 Maka kin he iye cinka waicaliya ece, ape kin he tokaheya, hehan wahuwapa, qa hehan wahuwapa en tanyan wasuton ece. 29 Unkan wanna suton hehan kohanna isan śkopa kin en iyekiya, wanna kaśdapi kta iyehantu nakaeś.

30 Hehan heya; Taku e Wakantanka tokiconze kin iyececa unyawapi kta he; qa wiyacinpi kin tukte e on unkiyacinpi kta he.

31 Sinape su wan iyececa, he maka kin en ehpeyapi, hehan taku su maka en un kin owasin he iyotan cistinna;

32 Tuka maka kin en ojupi, hehan uye ca wato owasin sanpa tanka icaga; adetka tankinyanyan aicahya, hecen mahipiya okinyanpi kin ohanzi ihukuya manpi ece.

33 Unkan wiyacinpi hecekcen ota on wicoie kin owicakiyaka, token nahon okihipi kin he iyececa.

$34 \mathrm{Qa}$ wiyacinpi codan takudan owicakiyake śni. Unkan iśnana yukanpi, hehan taku owasin waonspewicakiye cin hdaheya owicakiyaka ece. 
35 Unkan anpetu kin he en, wanna litayetu hehan, hewicakiya; Akasanpa unyanpi kta.

36 Unkan wicota kin wanna hdewicaśipi, helıan ecehna wata kin en ohnakapi : qa nakun wata cikcistinna toktokeca opapi.

37 Unk'an tate tanka wan uya; qa taja wata kin apaspa, hecen wanna mini ojudan.

38 Tuka iye wahektapa tanhan ipahin wan akan iśtinma wanka. Unkan yuhicapi qa heciyapi ; Waonspekiye, unkowihankepi kta he etanhan initokeca śni he.

39 Unkan iyotanka, tate kin kiśice ça mde kin heciya ; Owanji yanka wo. Unkan tateyanpa ayuśtan qa amdakedan tanka.

40 Hehan hewicakiya; Tokeca kopeyahdapi he ; tokeca wicayadapi śni he.

41 Unkan nina kokipapi, qa iyakitedan hekiciyapi; De taku wicaśta hwo, tate kin hee kaeś, mde ko anagoptanpi ece.

\section{WICOWOYAKE 5.}

1 Unkan mde kin akasanpa ihunnipi, hehan Gadarene makoce kin en ipi.

2 Unkan wata kin etanhan inanpa, hehan ecahankeya wicaśta wan woniya śica yuha wicahnakapi etanhan itkokim hiyu:

$3 \mathrm{He}$ wicahnakapi kin en un ece; qa tuwedan kaśka okihi śni, mazaicicahilia hee kaeś on.

4 Wanna ota kaśkapi, siha on wicakaśkapi mazaicicahilia ko on; tuka mazaicicahilia kin hena yuweliwega ece, qa siha on wicakaśkapi kin yuksaksa ece; qa tuwedan wałibadan kaga okihi śni.

5 Ohinniyan, hanyetu anpetu koya, wicahnakapi kin ehna, qa he kin ekta śicahowaya un, qa inyan on kiihdaksa ece.
6 Tuka Jesus tehan tanhan wanyaka, hehan ekta inyang ye ca ohoda.

7 Qa hotankakiya hotanin qa heya; Jesus Wakantanka Tehanwankantu Cinhintku kin, taku e unkiyotahedan un he; Taku Wakan cajeyan ceciciya, kakiśmayaye kte śni.

8 Wanna, Woniya śapa, wicaśta kin etanhan hinanpa wo, eciya nakaeś.

9 Unkan, Token eniciyapi he, eya iwanga. Unkan heciya; Wicota, emakiyapi ce, wiuncotapi nakaeś.

10 Unkan makoce kin he etanhan hde wicaśi kte śni, nina cekiya.

11 Imnija he kin hen ikiyedan lukuśe optaye wan tanka wo wicaqupi.

12 Hecen wakan śicapi kin cekiyapi qa heyapi; Kukuśe kin ekta ye unśi po, mahen wicunyanpi kta ce.

13 Unkun hecehnana Jesus iyowinwicakiya. Hecen woniya śapapi kin tankan hinanpapi qa kukuśe kin mahen iwicayayapi. Unkan optaye kin ecehna maya hince cin en naśdog eyaye ca minin iyayapi; owancaya kektopawinge nonpa ecetu, qa minin tapi.

14. Unkan tona kukuśe wo wicaqupi qon hena najicapi, qa otonwe kin en makoce ihdukśan koya he oyakapi. Unkan taku econpi kiu he wanyag ipi.

15 Qa Jesus en hipi, qa wicaśta wakan śica yuhnaśkinyan, qa wicota yuhe ciqon, wanna ogekiton qa tawacin ecetu iyotankehan yanka he wanyakapi; unkan yuśinyayapi.

16 Unkan tona wanyalkapi qon hena, wicaśta wakan śica yuhnaśkinyanpi, kukuśe kin hena ko 
token ecawicakiconpi qon hena owicakiyakapi.

17 Hehan makoce tawapi kin etanhan hde kta e icekiyapi.

18 Unkan wata kin en okipa hehan tuwe wakan śica yuhe ciqon he cekiya, kici un kta heon.

19 Tuka Jesus iyowinkiye śni, qa heciya; Takuwicayaye cin ekta hda wo, qa taku tona Itancan kin ecanicon qa onśinida, hena owicakiyaka wo.

20 Hecen kihde ca Dekapolis en taku tona Jesus ecakicon kin he ohdaka ece. Unkan owasin yuśinyayapi.

21 Unkan Jesus ake watom akasanpa ki qehan, oyate ota en mniciyapi ; qa mde kin ikiyedan un.

22 Hehan iho, omniciye tipi itancanpi wanji, Jairus eciyapi, he en hi; qa wanyaka hehan siha kin en makata ehpeiçiya,

23 Qa nina cekiye ca heya; Micunkśi cistinna wanna te kta wanka ; en u qa nape on aputake ça asniya ye; hecen ni kta ce.

24 Unkan kici iyaya; qa wicaśta ota ihakam yapi qa aoținsyapi.

25 Unkan winohinca wan waniyetu ake nom hehanyan we ece iheya ;

$26 \mathrm{Qa}$ pejihutawicaśta ota on tehiya kuwapi, qa taku owasin on hdusota, qa etanhan waśte icage śni, tuka sanpa śica aya ;

27 He Jesus oyakapi nahion qehan, heyata tanhan wicota ehna hiyu, qa tawokoyake yutan.

28 Tawokoyake hee kaeś mdutan kinhan, amasni kta ce, eye ciqon.

29 Unkan hecehnana we iheye ciqon anapta; qa tancan mahen he wayazan kin on wanna akisni sdonkiya.
30 Unkan hecehnana woasni etanhan hiyu kin Jesus atayedan sdonkiya, wicota ehna ihduhomni qa heya; Mitawokoyake tuwe yutan he.

31 Unkan waonspewicakiye cin heciyapi ; Wicaśta ota aoținsniyanpi he wandaka, qa, Tuwe mayutan he, eha he.

32 Unkan tuwe hecon kin he wanyake kta e ohomni awicatonwan.

33 Tuka winohinca kin taku ecakiconpi kin sdonkiya, hecen kokipeyahan cancanyan en hi, qa itokam makata ehpeiciye ca owasin awicakehan okiyaka.

34 Unkan heciya; Cunś, wacinyaye cin he asniniyan; wookiye hda wo, qa waniyazan qon okizi un wo.

35 Unkan iahan icunhan omniciye tipi itancan ti kin eciyatanhan upi qa heyapi; Nicunkśi wanna ta; tokeca sanpa Waonspekiye cin nagiyeyaya he.

36 T'uka Jesus taku eyapi nahon qehan, hecehnana omniciye tipi itancan kin heciya; Kokipe śni wo, wicada wo ecedan.

37 Unkan tuwedan kici ye kta iyowinkiye śni, Inyan, qa Jakob, qa Johannes Jakob sunkaku, henananpidan.

38 Unkan omniciye tipi itancan ti kin he en hi, qa owodutaton kin he wanyaka, tona ceyapi qa nihinciyapi kin hena koya. 39 Unkan en i qehan hewicakiya; Tokeca owodutaton yakagapi qa yaceyapi he; wicinyanna kin te śni, tuka iśtinma ce.

40 Unkan nina ihapi. Tuka owasin tankan iyewicaya, hehan wicinyanna atkuku qa hunku, qa tona om un kin hena iwicacu, qa wicinyanna wanke cin en $\mathrm{i}$;

$41 \mathrm{Qa}$ wicinyanna kin nape yuze ça heciya; Talitha kumi, 


\section{WICOWOYAKE 6 .}

Wicinyanna najin wo, eciciya, eyapi kin he kapi.

42 Unkan ecahankeya wicinyanna kin najin qa mani ; wanna waniyetu akenonpa. Unkan nina liin yuśinyayapi.

43 Hehan nina oyake śni wicaśi ; qa taku yutapi qupi kta, kewicakiya.

\section{WICOWOYAKE 6.}

1 Unkan hetanhan iyoopta iyaye ca iye tamakoce kin ekta ki ; qa waonspewicakiye cin hena opapi.

2 Unkan wanna anpetu wakan hehan omniciye tipi kin ohna waonspewicaliya. Qa wicota nahonpi qehan yuśinyayapi qa heyapi; Tokiyatanhan dena yuha he; qa taku woksape qupi he ; qa token iye nape on wicolian tanka dececa econpi he.

3 Cankajipe cin, Mary cinhintku, qa Jakob, qa Joses, qa Judas, qa Simon cincu kin he dee śni he; qa tawinohtin kin hena owasin den unkicipi unpi śni he. Unkan he on canniyeyapi.

4 'Tuka Jesus hewicakiya; Wicaśta wokcan iye tamakoce en, qa iye takuwicaye cin ehna, qa iye ti kin ohna, ecedan yuonihanpi śni ece.

5 Unkan heciya wicolian tanka takudan econ okihi śni; tuka wayazankapi tonana nape on awicaputake ca asniwicaya.

6 Unkan wicadapi śni kin heon yuśinyaya. Qa otonwe ihdukśan wanke cin ektakta waonspewicakiya iyaya.

7 Unkan akenonpapi kin wicakico, qa nom nom yewicaśi ; qa woniya śapa on wowaśake wicaqu ;

8 Qa wahokonwicakiya, icimani yapi kte cin on takudan icupi kte śni, cansagye ecedan; wojuha, qa waneya, qa mazaśa opiye ohna hduhapi kte śni.

9 Tuka hanpokihanpi kta; qa onlidohda norn kicunpi kte śni.

10 Unkan hewicakiya; Tukten tipi wanji mahen yaipi kinhan, tohanyan hetanhan iyoopta dapi śni, hehanyan hen yukan po.

11 Qa tona iyowinniciyapi śni qa ananigoptanpi śni kinhan, tohan hetanhan dapi kinhan, owicadakapi kta e lıeon watuśekśeca siha etanhan yahdatatapi kta. Awicakehan heciciyapi; Woyaco anpetu kin en, otonwe kin he kakije kte cin Sodom qa Gomorrah ahecece kta.

12 Unkan iyayapi, qa wicaśta ihduecetupi kta e woyakapi.

13 Qa taku wakan śica ota napewicayapi, qa wayazankapi kin ota wihdi on sdawicayapi qa asniwicayapi.

14 Unkan Herod wicaśtayatapi kin hena nahon; caje kin tankaya oyakapi nakaeś; hehan heya ; Johannes baptem wicaqu qon he țapi kin etanhan kini, heon etanhan wicohan tanka econ ece.

15 Tuka toktokeca heyapi; Elias hee. Qa toktokeca iś; He wicaśta wokcan, qa iś wicaśta wokcan wanji iyececa ce, eyapi.

16 Tuka Herod nahon qehan heya; Johannes pa bawakse ciqon hee, wiconte etanhan kini ce.

17 Herod atayedan yewicaśi, qa Johannes yuze ca haśka hnaka, Herodias iye sunkaku Philip tawicu qon heon etanhan; he yuza nakaeś.

18 Unkan Johannes; Nisunka tawicu duze cin he hecetu śni ce, Herod eciya.

19 Heon etanhan Herodias can- 
niyekiye ca kte kta cin tuka okihi śni.

20 Herod Johannes kokipa, wicaśta owotanna qa waśte sdonya, heon itonpa; qa oie nahon eca taku ota ecen econ, qa iyuśkinyan nahon ece.

21 'Tuka anpetu iyehantu qehan, Herod anpetu en tonpi qon he ehan, wicaśta itancanpi wicayuhe ca, akicita tancan tankapi, qa Galilc en wicaśta tokaheya kin hena, htayetu wotapi wan wicakicaga.

22 Unkan Herodias cunwintku kin en hi, qa waci, qa Herod tona om un kin hena koya iyokipiwicaya, hehan wicaśtayatapi 'kin heciya; Taku yacin kinhan makida wo, hecen ciçu kta.

23 Nakun taku wakan cajeyan heciya; Taku mayakida kinhan cicu kta, mitokiconze hanke hehanyan.

24 Unkan tankan iyaye ca hunku heciya; Taku wakida kta he. Unkan iś, Johannes baptem wicaqu ece pa kin, eya.

25 Hehan ecahankeya inahiniyan wicaśtayatapi ekta tin hiyu qa heya kida; Johannes baptem wicaqu pa kin, wakśica ohna kohanna mayaqu kta wacin ce, eya:

26 Unkan wicaśtayatapi kin nina iyokiśica, tuka taku wakan cajeyan heye cin heon, qa tona om wota iyotanke cin hena on, he ipida kta tawatenye śni.

27 Unkan hecehnana wicaśtayatapi kin wicakte wan ekta yeśi, qa pa kin aku śi: Unkan he ekta iyaye ca, wicakaśka tipi kin ohna pa baksa;

28 Qa wakśica wan ohna pa kin ahdi, qa wikośka kin qu; unkan wikośka kin iś iyoopta hunku kin qu.

29 Unkan iye waonspewica- kiye cin hena, he nalionpi qehan, en hipi qa tancan ehdakupi, qa ohna hnakapi wan en hnakapi.

30 Unkan tona yewicaśi qon hena Jesus en hdipi, qa taku owasin okiyakapi, taku econpi qa taku oyakapi ko.

31 Hehan hewicakiya; Niye ito icunonpa hewotahedan ekta u po, qa cistiyedan oziiçiya po. Wicota upi qa hdapi ece, qa hecen wotapi kta hee kaeś okihipi śni.

32 Unkan heon hewoskan makoce wan ekta iśnana watom iyayapi.

33 Tuka yapi kin wicaśta ota wanyakapi, qa he iye iyekiyapi : qa otonwe owasin etanhan ekta inyang iyayapi, qa kawicapapi, qa en i kte cin hen mniciyapi.

34 Unkan Jesus ekta ihunni, hehan wicota wanwicayaka, qa onśiwicakida, tahinca wanunyanpi tuwedan wicayuhe śni kin iyececapi heon, qa hecen taku ota onspewicakiya.

35 Unkan wanna wi kucedan hehan, waonspewicakiye cin en hipi qa heciyapi; De hewotahedan makoce qa anpetu kin wanna owihanke :

36 Hde wicaśi wo, hecen makoce ihdukśan, qa otonwe kin ektakta yapi, qa woyute opeicitonpi kta; taku rutapi takudan yuhapi śni.

37 Tuka iye waayupte ça hewicakiya; Niś ito wo wicaqu po. Unkan heciyapi; Unyanpi qa kaśpapi opawinge nonpa aguyapi iyopeunyanpi, qa wo wicunqupi kta he.

38 Aguyapi śpanyanpi kin tona duhapi he; ito wanyaka po, ewicakiya. Unkan sdonyapi he-. han; Zaptan qa hogan nonpa, eyapi.

39 Unkan owasin wato kin 


\section{WICOWOYAKE 7.}

akan optayetonton iyotangkiye wicaśi.

40 Unkan optayeton iyotankapi, opawingege qa wikcemna zaptanptan.

41 Unkan aguyapi zaptan qa hogan nonpa hena icu, hehan malipiya ekta etonwe ça yawaśte, qa aguyapi yuśpaśpa, qa waonspewicakiye cin wicaqu, oyate kin wicaqupi kta heon; nakun hogan nonpa kin hena owasin wicakipamni.

42. Unkan iyuhpa wotapi qa imnanpi.

43 Qa oyaptapi kin etanhan makanopiye akenonpa ojudan pahipi, nakun hogan kin etanhan.

44 Unkan aguyapi yutapi kin hena kektopawinge zaptan ecetu.

45 Hehan ecahankeya waonspewicakiye cin wata kin en okipe wicaśi, qa tokaheya akasanpa Bethseda ekta yapi kta, kewicakiya; icunhan iye wicota kin hde wicaśi kta.

46 Unkan hena hde wicaśi, hehan paha wan ekta wocekiye eya iyaya.

47 Wanna htayetu hehan, wata kin mde kin cokaya un, qa iye iśnana maka akan un.

48 Unkan watopapi iyotanhan iyekiyapi wanwicayaka ; tatohekiya yapi nakaeś. Unkan hanyetu en awanyakapi itopa hehan, mini amani ekta wicaya.

49 Tuka mde kin amani wanyakapi qehan, he wanagi kecinpi, qa śicahowayapi.

50 Owasin wanyakapi qa yuśinyayapi. Unkan hecehnana owicakiye ca hewicakiya; Cante waśte po, he miye, kokipapi śni po.

51 Unkan ekta wicaya, wata kin en; hehan tate kin ayuśtan. Dak.
Hecen nina yuśinyayapi qa ihniyanyanpi.

52 Aguyapi econ qon he awacinpi śni; cantepi kin aotpasyapi nakaeś.

53 Unkan akasanpatanhan ipi, hehan Gennesaret makoce lin en yapi, qa hutata ihunnipi.

54 Unkan wata kin etanhan inanpapi, hehan hecehnana iyekiyapi ;

55 Qa makoce kin he owancaya inyang yapi, qa tukten un nahonpi kinhan, wicaśta wayazankapi kin owinja akan wicayuhapi, qa en awicayapi.

56 Unkan otonwe ciqadan, qa otonwe tanka, qa ihdukśan makoce wanke ciil, tukte en ya eca, canku ohna wayazankapi kin ahiwicahnakapi qa cekiyapi ; tawokoyake opapun hee kaeś yutanpi kta; unkan tona yutanpi kin hena asnipi ece.

\section{WICOWOYAKE 7.}

1 Hehan Pharisee qa wowapi kagapi wanjikji, Jerusalem etanhan upi qa en ahimniciya;

2 Qa iye waonspewicakiye cin wanjikji nape śapa, nape hdujajapi śni he kapi, aguyapi yutapi wanyakapi qehan wicabapi.

3 Pharisee kin Juda wicaśta ko owasin tanyan nape hdujajapi śni kinhan wotapi śni ece, qa wicahincapi tawoahope kin opapi.

4 Qa mazopiye etanhan hiyupi eca ildujajapi śni ehantanhan wotapi śni. Unkan taku hececa ota opapi kta icupi, miniyatke, qa can koka, qa cega, ohehdepi ko yujajapi ece.

5 Hehan Pharisee kin wowapi kagapi ko wiwangapi; Tokeca waonspewicayakiye cin wicahincapi tawoahope kin ahopapi 65 


\section{MARKOS.}

śni he, tuka nape hdujaja śni aguyapi yutapi ece.

6 Unkan wayupte ca hewicakiya; Wananiçihmanpi, niyepi on Isaya tanyan woyake ciqon, hecen wowapi en kagapi ; Oyate kin de ihapi kin on mayaonihanpi, tuka cantepi kin mitehanyan un ece.

7 Tuka wicaśta akantu tawoahope kin hena woonspe eekiyapi, qa oyakapi ece kin heon ohomadapi kin he taku śni.

8 Wakantanka tawoahope kin ehpeyayapi, qa wicaśta akantu toope kin duhapi, cega qa wakśica yujajapi kin; qa taku hececa ota ecanonpi ece.

9 Unkan hewicakiya; Wicaśta akantu toope duhapi kta e heon Wakantanka tawoahope kin elipeyayapi, he tanyan ecanonpi he.

10 Moses hecen eya; Niyate nihun kici wicahduonihan wo. Nakun; 'Tuwe atkuku, qa iś hunku kin hdaśice cinhan, he wiconte on te kta ce.

11 Tuka niye hehapi; Wicaśta wan atkuku, qa iś hunku; He wohduze, tokan wicaqupi he kapi, hecen on ociciye kte śni, eciye cinhan he hecetu ce.

12 Hecen atkuku qa hunku taku sanpa owicakiye kta iyoyakipi śni ;

13 Qa niye woope yakagapi qa wicayaqupi kin on Wakantanka tawoahope kin dutakunipi śni: qa taku hececa ota ecanonpi ece.

14 Unkan oyate kin owasin wicakico, hehan hewicakiya; Owasin anamagoptan po, qa okahiniga po.

15 Wicaśta tankan tanhan taku mahen iyaye cin takudan yuśica okihi śni; tuka tona mahen tanhan hinape cin wicaśta yuśice cin hena ee.
16 Tuwe noge winahon yukan hecinhan he nahon kta.

17 Unkan wicota wicehna tanhan ti mahen iyaye cehan, waonspewicakiye cin wiyacinpi kin he on wiwangapi.

18 Unkan hewicakiya; Niś eya oyakahnigapi śni he. Taku kaśta tankan tanhan wicaśta mahen iyaye cin he yuśape kta okihi śni e idukcanpi śni he.

19 Hena cante kin en i śni, tuka tezi mahen, qa hehan tankan elipeyapi, hecen woyute owasin yuecetupi.

20 Unkan heya; Taku wicaśta kin etanhan hinanpe cin he wicaśta kin yuśapa ece.

21 Mahentanhan, wicacante kin etanhan wicotawacin śica hiyu; wawiciliahapi; wiinalimanpi, tinwicaktepi,

22 Wamanonpi, waicucupikte, wośice, wohnaye, wowihaha, iśtaśica, wayašicapi, wahaniçidapi, witkotkokapi ;

23 Dena taku śice cin owasin mahentanhan hiyu, qa wicaśta yuśape cin hena ee.

24 Unkan hetanhan najin hiyaye ca, Turos qa Sidon makoce opapun kin en i, qa tipi wanji timahen iyaya; unkan tuwedan sdonye kte śni cin, tuka anahmanpi kta okihipi śni.

25 Winohinca wan cunwintku cistinna woniya śapa yuhe cin he nation qehan, en hi qa siha kin en makata elipeiciya.

$26 \mathrm{He}$ Hellenes winohinca kin heca, Surophenikiya oyate kin etanhan; unkan taku wakan śica cunwintku kin etanhan hinanpe śi kta e icekiya.

27 Tuka Jesus heciya; Wicacinca kin hena tokaheya wotapi kta; wicacinca aguyapi tawapi kin icupi, qa śunka wicaqupi kta he hecetu śni. 


\section{WICOWOYAKE 8.}

28 Unkan iye waayupte ça heciya; Han, Itancan; tuka wahna wotapi kin ihukuya hokśiyopa yuśnapi kin śunka yutapi ece. 29 Unkan heciya; Wicoie kin de on ekta hda wo, taku wakan śica nicunkśi etanhan hinanpa ce. 30 Unkan iye ti kin ekta ki, hehan taku wakan śica tankan iyaye ca, cunwintku ohehdepi kin akan wanka e wanhdaka.

31 Unkan ake Turos makoce kin ehpeye ca, Sidon opta, Dekapolis makoce kin cokaya omani, qa Galile mde kin ekta ki.

32 Unkan wicaśta wan noge tpa qa ia okitpani he en ahipi, qa nape ahnake kta icekiyapi.

33 Unkan wicota etanhan iśnana icunonpa aya, qa nape noge ohna iyeye ça, tagośa qa on ceji yutan:

34 Hehan malipiya ekta etonwe ca comnihdazi qa heciya; Ephatha, yuhdokapi nunwe, eyapi kin he kapi.

35 Unkan ecahankeya noge yuhdokapi, qa ceji ikan kin yukcapi, qa hdaheya ia.

36 Hehan he tuwedan okiyake śni wicaśi ; tuka taku ewicakiye cin on etanhan sanpa nina oyakapi cce.

37 Qa nina yuśinyayapi qa heyapi ; Taku owasin tanyan econ ece; noge tpapi kin winalionwicakiye ca, nakun ia okitpani iewicakiya ece.

\section{WICOWOYAKE 8.}

1 Unkan anpetu kin hena en nina wicota linca, qa takudan yutapi śni, hehan waonspewicakiye cin wicakico qa hewicakiya ;

2 Wicota kin onśiwicawakida, wanna yamni can mici unpi, qa taku yutapi takudan yuhapi śni.
3 Qa wote śni hde wicawaśi kinhan, okinni tahepi ihpayapi kta; hunli tehan tanhan hipi nakaeś.

4. Unkan waonspewicakiye cin ayuptapi; Makoce hewotahedan kin den, tokiya tanhan dena aguyapi imnahan yute wicakiyapi kta he.

5 Unkan, Aguyapi kagapi tona duhapi he, eya iwicawanga. Unkan iś, Śakowin, eyapi.

6 Unkan oyate kin maka akan iyotanke wicaśi ; qa hehan aguyapi śakowin qon icu, yawaśte qa yuśpaśpa qa waonspewicakiye cin wicaqu, iyoopta wicaqupi kta; unkan iś oyate kin wicakipamnipi.

7 Nakun hogan tonana yuhapi ; hena yawaśte qa wicaqupi kta, keya.

8 Hecen wotapi qa imnanpi; unkan aguyapi oyaptapi kin etanhan makanopiye śakowin pahipi.

9 Tona wotapi kin hena kektopawinge topa ecetu; hehan hde wicaśi.

10 Hehan ecahankeya wata wan en opa, waonspcwicakiye cin om, qa Dalmanutha makoce kin ekta $i$.

11 Unkan Pharisee kin en hipi, qa iyutanyan wiwangapi, qa mahiya eciyatanhan wowapetokeca kida.

12 Unkan iye cante ekta comnihdazi qa heya: Tolkeca wicoicage kin de wowapetokeca akita he. Awicakehan heciciyapi ; Wicoicage kin de wowapetokeca takudan qupi lkte śni.

13 Hehan elipewicaye ca wata kin en okipe ça akasanpa hda.

14 Unkan aguyapi icupi lkta akiktonjapi, qa wata ohna aguyapi wanjidan sanpa yuhapi śni. 15 Hehan wahokonwicakiye ça 


\section{MARKOS.}

heya; Wanyaka po, qa on napohyapi Pharisee tawapi qa Herod tawa kin he kokipa po.

16 Hecen iye iyakitedan hdokinicapi qa heyapi; Aguyapi unhapi śni, heon etanhan heya ce.

17 Jesus he sdonya hehan hewicakiya; Tokeca aguyapi duhapi śni on ayakinicapi he. Hinahin oyakahinigapi śni qa widukcanpi śni he. Hinahin cante aotpasniyanpi he.

18 Iśta niyukanpi wandakapi śni, qa noge niyukanpi eśta nayahompi śni, qa yeksuyapi śni he.

19 Aguyapi zaptan wicaśta liektopawinge zaptan wicawakipamni, hehan oyaptapi kin makanopiye ohnaka tona yapahipi he. Akenonpa, eyapi.

20 Hehan śakowin qa kektopawinge topa; hehan oyaptapi makanopiye ohnaka tona iyacupi he. Unkan, Śakowin, eyapi.

21 Hehan hewicakiya; Tokeca oyakahinigapi śni he.

22 Unkan Bethseda en hi. Hehan iśtagonga wan en ahipi, qa yutan kta e icekiyapi.

23 Unkan iśtagonge cin napata yuze ca otonwe kin tankan aya; qa iśta kin en atagośa hehan nape kin akan ehnaka, qa taku wanyaka hecinhan he iwanga.

24 Unkan wankan etonwe ca heya; Wicaśta wanwicamdaka, mani unpi, can kin iyececa.

25 Hehan ake nape kin iśta akan ehnaka, qa ake wankan etonwekiya; unkan hehan yuecetupi, qa taku owasin tanyan wanyaka.

26 Hehan iye ti ekta hde sii, qa heya; Otonwe kin en ye śni wo, qa otonwe kin en tuwedan okiyake śni wo.

27 Unkan Jesus hetanhan Ke- sareya Philippi otonwe kin hena ekta iyaya, waonspewicakiye cin om. Unkan tahepi waonspewicakiye cin heya iwicawanga; Matuwe, wicaśta keyapi he. 28 Unkan ayuptapi; Johannes baptem wicaqu kin; qa wanjikji ; Elias ; qa wanjikji ; Wicaśta wokcan wanji he niye, eyapi.

29 Unkan hewicakiya; Qa niye matuwe kehapi he. Unkan Inyan waayupte ça heciya ; Messiya he niye.

30 Unkan he tuwedan okiyake śni wicaśi.

31 Hehan wowicakiyaka, Wicaśta Cinhintku kin taku ota kakije kta; wicahincapi qa wośnapi kagapi, wowapi kagapi ko heyata iyeyapi kta, qa ktepi kta; qa anpetu yamni iyohakam kini kta.

32 Unkan hena taninyan ohdaka. Hehan Inyan icu qa iyokiśni.

33 Tuka ihduhomni qa waonspewicakiye cin awicatonwan, hehan Inyan iyopeye ça heya; Satan milieyata ya wo; taku Wakantanka tawa kin awacanni śni, tuka wicaśta akantu taku tawa kin.

34 Unkan oyate kin waonspewicakiye cin om wicakico qehan, hewicakiya; Tuwe kaśta omape kta hecinhan, waipiicida kta, qa cansusbeca kiçin kta, qa mihakam u lita.

35 Tuwe wiconi tawa tehinda kinhan he toki ehpekiye kta; tuka tuwe miye on qa wotanin waśte kin on wiconi toki ehpekiye cimban, he qe wiconi hduhe kta.

$36 \mathrm{Qa}$ wicaśta wan maka kin de ocowasin ohiya eśta, qa iye nagi kin toki ehpekiye cinhan, taku on iwaśte kta he. 
37 Qa taku e wicaśta nagi kin tokiyopekiye kta he.

38 Heon etanhan tuwe, wicoicage wiinahman qa wahtani sa kin de en, miye qa mioie kin on iśtece cinhan, tohan Wicaśta Cinhintku kin iye Atkuku towitan hduha, ohnihde wakan kin om u kinhan, wicaśta kin he on iśtece kta ce.

\section{WICOWOYAKE 9.}

1 Hehan hewicalkiya; Awicakehan heciciyapi; den najinpi etanhan wanjikji wiconte utupi śni itokam, Wakantanka tokiconze wowaśake on hi wanyakapi kta.

2 Unkan anpetu śakpe iyohakam Jesus, Inyan, qa Jakob, qa Joliannes iwicacu, qa icunonpa paha wan tehanwankantu kin ekta awicaya; qa wicitokam yutokecapi :

3 Tawokoyake kin wiyatpatpa, ska hinca, wa iyececa; maka akan wayuska kin tuwedan iyecen ska liaga okihi śni.

4 Unkan hen Elias qa Moses en ihdutaninpi ; qa hena Jesus kici wohdag yukanpi.

5 Hehan Inyan waayupte ca Jesus heciya; Itancan, den unyakonpi he waśte; ito wakeya yamni ti unkicagapi kta; wanji niye on, qa wanji Moses, qa wanji Elias unkicagapi kta.

6 Taku eye kta sdonkiye śni ; nina yuśinyayapi nakaeś.

7 Unkan mahpiya wan aohanziwicaya; qa mahpiya kin eoiyatanhan wicaho wan tanin qa heya; Micinkśi waśtewalkidake cin he dee, he anagoptan po.

8 Hehan ecahankeya ihdukśan etonwanpi qehan, wicaśta tuwedan wanyakapi śni, Jesus iśnana kici unpi.
9 Unkan paha kin etanhan apamahde kupi icunhan wahokonwicakiya, taku wanyakapi kin tuwedan okiyakapi kte śni, Wicaśta Cinhintku kin țapi etanhan kini śni hehanyan.

10 Unkan wicoie kin he awacinpi, qa țapi etanhan kini eyapi kin he taku kapi hecinhan he ikiciwangapi.

11 Unkan heya iwangapi; Tokeca e Elias tokaheya hi kta ce, wowapi kagapi kin eyapi he.

12 Unkan awicayupte ca heya; Awicakehan Elias tokaheya hi kta, qa taku owasin yuecetu kta ; qa Wicaśta Cinhintku kin token taku ota kakije kta, qa lieyata iyeyapi kta e wowapi en kagapi qon, he nakun owicakiyaka.

13 Tuka heciciyapi ce; Awicakehan Elias wanna hi; unkan token cinpi kin ecen ecakiconpi, wowapi en kagapi qon iyececa.

14 Unkan waonspewicakiye cin en hdi qehan, wicihdukśan wicota linca wanwicayaka; qa wowapi kagapi kin wiwicawangapi.

15 Unkan oyate kin iyulipa wanyakapi qehan nina yuśinyayapi, qa ekta inyang yapi qa okiyapi.

16 Unkan wowapi kagapi kin, Taku e on wiwicanungapi he, eya iwicawanga.

17 Unkan wicota etanhan wanji ayupta ; Waonspekiye, micinkśi woniya ie śni kin heca yuhe cin he cicahi.

18 Qa tukten eyaku eca yuhdehdeca ece; hecen i minitaga au, qa hi hdakinskinza, qa hanyan ece; unkan waonspewicayakiye cin hena tankan ehpeyapi kta kewicawalkiya, tuka okitpanipi.

19 Unkan waayupte ca hewicakiya; Wicoicage wicada śni, 


\section{MARKOS.}

tohanyan cicipi waun kta; tohanyan iyowinciciyapi kta he. En makau po.

20 Hehan en kahipi. Unkan wanyag iheye cin hecehna woniya kin yuhidehdeca; qa makata ehpeye ca, i minitaga au paptanptan iyeiçiya wanka.

21 Unkan atkuku kin heya iwanga; Tohantanhan hececa he. Unkan iś ; Hokśiyoqopa ehantanhan, eya.

22 Qa ota petan elpeye ça, minin ehpeya, ihangye kta e heon ; tuka niś taku oyakibi kinhan, onśiunkida po qa ounkiya po.

23 Jesus heciya; Wicada oyakihi kinhan; tuwe wicada kin he on taku owasin okihipica ce.

24 Unkan hecehnana hokśidan atkuku kin hotanin qa ceya heya; Itancan wicawada; wicawada śni kin he niye omakiya wo.

25 Jesus oyate kin en inyang hiyupi wanwicayaka, hehan woniya śapa iyopeye ca heciya; Woniya ia okitpani qa noge tpa, tankan hinanpe ca, icimana en ye śni wo, he miye e econ ciśi ce, eya.

26 Unkan hotanin qa nina yuhdehdeca, qa tankata hinanpa; unkan wicaśta ta iyececa, hecen, Wanna ța ce, wicota eyapi. 27 Tuka Jesus napata yuze ca yuwankan icu; unkan najin hiyaya.

-28 Unkan tin hiyu qehan, waonspewicakiye cin nahmana iwangapi; Tokeca unkiye tankan ehpeya unkokihipi śni he.

29 Unkan hewicakiya; Ocaje kin de wote śni cekiyapi kin ecedan on tankan hiyu kta okihi ece.

30 Hehan hetanhan yapi qa Galile iyoopta iyayapi ; qa tuwedan sdonye kte śni cin.

3.1 He icunhan waonspewica- kiye cin wowicakiyaka qa; Wicaśta Cinhintku kin wicaśta napepi kin en wicaqupi, unkan ktepi kta; qa ktepi iyohakam anpetu iciyamni hehan kini kta ce, ewicakiya.

32 Tuka wicoie kin he okahnigapi śni, qa on iwangapi kta kokipapi.

33 Unkan Kapernaum en hi; qa ti mahen yanka hehan wiwicawanga; Canku ohna taku e on ayakinicapi he.

34 'Tuka inina yukanpi ; canku ohna wanji tukte iyotan tankapi kta e heon hdokinicapi.

35 Unkan iyotanke ca akenonpapi kin wicakico qa hewicakiya; Wicaśta wan tokaheya un kta cin kinhan, hee ehake un kta, qa owasin wowidagyapi kta. 36 Hehan hokśiyoqopa wan icu, qa wicacokaya ehnaka; qa nape ohna eyaku, hehan hewicaliya ; 37 Tuwe hokśiyoqopa dececa wanji, micaje on tin hiyuye cinhan, miye tin hiyumayan ece; qa tuwe tin hiyumaye cin he miye śni, tuka tuwe u maśi kin he tin hiyuya ece.

38 Hehan Johannes ayupte ca; Waonspekiye, wicaśta wan nicaje on taku wakan śica tankan elipeya wanunyakapi, he unkihakam u śni ; unkan unkihakam u śni kin on etanhan teunhindapi ce, eya.

39 Tuka Jesus heya; Tehindapi śni po; wicaśta tuwe micaje on wicohan tanka econ kinhan, he ituya mayaśice kta okihi śni.

40 Tuwe unkizapi śni kinhan, he unkicipi un ece.

41 Tuwe micaje on miniyatke ohna mini datkanpi kta niçupi kinhan, Messiya niyuhapi kin heon, he wokajuju toki ehpekiye kte śni, awicakehan eciciyapi. 


\section{WICOWOYAKE 10.}

$42 \mathrm{Qa}$ tuwe dena cikcistinpidan wacinmayanpi kin wanji walitanikiye cinhan, tahu en inyan wiyutpan wan iyakaśkapi qa miniwanca kin en ehpeyapi unkanś, he waśte kta tuka.

43 Qa ninape wahtaniniye cinhan hdaksa wo ; nape ksa wiconi kin en yai kinhan hee waśte kta, qa nape napin hduha Wakanśica ti, peta icimana kasnipi kte śni kin en iyohpeniyanpi kte śni.

44 Hen wamduślka tawapi kin te kte śni, qa peta kin kasnipi śni ece.

45 Nakun nisiha wahtaniniye cinhan hdaksa wo; huniśte wiconi kin en yai kinhan, he waśte kta, qa siha nom hduha Wakanśica ti peta icimana kasnipi kte śni kin en iyohpeniỹanpi kte śni. 46 Hen wamduśka tawapi kin te kte śni, qa peta kin kasnipi śni ece.

47 Nakun niiśta wahtaniniye cinhan hduśdoka wo ; iśta wanjidan hduha Wakantanka tokiconze kin en de cinhan, hee waśte kta, qa iśta napin hduha Wakanśica ti peta kin en iyohpeniyanpi kte śni.

48 Hen wamduśka tawapi kin te kte śni, qa peta kin kasnipi śni ece.

49 Wicaśta otoiyohi peta on skuyeyapi kta, qa wośnapi otoiyohi miniskuya on skuyeyapi kta.

50 Miniskuya kin he waśte; tuka miniskuya kin skuye śni aye cinhan taku e on skuyeyapi kta he. Miniskuya ihduha po, qa wookiye kiciyuha po.

\section{WICOWOYAKE 10.}

1 Hetanhan najin hiyaye ca; Jordan akasanpatanhan, Juda makoce kin en hi: unkan ake oyate kin en witaya kata iheya; qa econ ece qon he iyecen ake wowicakiyaka.

2 Unkan Pharisee kin en hipi qa wiwangapi, Wicaśta tawicu elipeye kta iyececa hecinhan, he iyutanyanpi.

3 Unkan waayupte ca hewicakiya; Moses token econ niśipi he.

4 Unkan; Moses kpaganpi wowapi kage ca elpeye kta iyowinyan ce, eyapi.

5 Unkan Jesus waayupte ca hewicakiya ; Cante nitehipi kin heon Moses woope kin he nicagapi.

6 Tuka wicoicage otokaheya tanlian Wakantanka hena wica winyan ahna wicakaga:

7 Heon etanhan wicaśta wan atkuku hunku ko elpewicaye kta, qa tawicu en iyaihdaśke kta :

$8 \mathrm{Qa}$ henaoza wicacehpi wanjidan kta ce. Hecen hetanhan nonpapi śni, tuka wicacelpi wanjidan.

9 Heon taku Wakantanka yuokonwanjidan kin he ihnuhan tuwe yujuju kinhan.

10 Unkan ti mahen yukanpi, hehan waonspewicakiye cin he akta wiwangapi.

11 Unkan hewicakiya; Tuwe winohinca ehpekiye ca wanji tokeca yuze cinhan, he wawicihahapi ecakicon ece.

12 Qa winohinca wan hihnaku ehpeye ca wanji tokeca hihnaye cinhan, he nakun wawicihahapi econ ece.

13 Hehan hokśiyoqopa en awicahipi, wicayutan kta heon; tuka waonspewicakiye cin tona a wicaupi kin iyowicakipiśni.

14 Tuka Jesus he wanyaka, hehan nina iyokiśice ça hewicai1 


\section{MARKOS.}

kiya; Hokśiyoqopapi en maupi kta iyowinwicakiya po, qa tehindapi śni po; tona dececapi kin Wakantanka tokiconze kin eepi ce.

15 Awicakehan heciciyapi; Tuwe Wakantanka tokiconze kin hokśiyoqopa iyecen icu śni kinhan he mahen ye kte śni.

16 Hehan poskin wicayuza, qa nape awicaputake ça wicayawaśte.

17 Unkan canku kin ohna iyaye çehan, wanji inyang $u$, qa en canpeśka makehde inajin, qa wiwanga; Waonspekiye waśte, wiconi owihanke wanice cin he ohimiciye kta e on taku ecamon kta he.

18 Unkan Jesus heciya; Tokeca waśte emayaliya he ; tuwedan waśte śni; Wakantanka iśnana.

19 Woahope kin sdonyaya; Wawicihahapi econ śni wo, Tinwicakte śni wo, Wamanon śni wo, Woitonśni oyake śni wo, Wawicaki śni wo, Niyate nihun kici wicahduonihan wo.

20 Unkan waayupte ca heciya; Waonspekiye, dena owasin homakśiyopa ehantanhan ecamon ece.

21 Hehan Jesus atonwe celian waśtekidake ca heciya; Taku wanji ninica; hde ca taku duhe cin wiyopeya, qa walipanicapi kin wicaqu wo, kinhan mahpiya ekta wowijice duhe kta; hehan ku, can susbeca kicin, qa mihakam u wo.

22 Unkan oie kin he on iyokiśica, qa cante śica hda; taku ota yuha nakaeś.

23 Unkan Jesus ihdukśan etonrve ca waonspewicakiye cin hewicakiya; Tona watonpike cin hena Wakantanka tokiconze kin en yapi kte cin he tehika ce.
24 Unkan oie kin on waonspewicakiye cin yuśinyayapi. Tuka Jesus ake waayupte ca hewicakiya ; Hokśiyoqopa, tona wowijice wacinyanpi kin hena $\mathrm{Wa}$ kantanka tokiconze kin en yapi kte cin he tehilke hinca.

25 Wicaśta wijica Wakantanka tokiconze kin en ye kta he tehika, qa kamel wan tahinśpaciqadan olidoka ohna ye kte cin he aoptetu.

26 Unkan heon nina yuśinyayapi qa hekiciyapi; Hehan tuwe ni kta he.

27 Jesus awicatonwe ça heya ; Wicaśta ekta he okihipica śni, tuka Wakantanka ekta hecece śni ; Wakantanka ekta taku owasin okihipica ece.

28 Hehan Inyan heciya; Tho, unkiye taku owasin ehpeunyanpi, qa nihakam unyakonpi.

29 Jesus waayupte ca heya; Awicakehan heciciyapi, tuwe, miye qa wotanin waśte kin on, tipi qa hunkawanjitku, qa tawinohtin, qa atkuku, qa hunku, qa tawicu, qa cinca, qa makoce elipeye cinhan;

30 Nakaha wiconi kin de en opawinge akihde icu kta; tipi, qa hunkawanjitkupi, qa tawinohtin, qa hunkupi, qa cincapi, qa makoce ko, wośitkihdapi iyahna; qa wiconi u kte cin he en wiconi owihanke wanica yuhe kta.

31 Tuka wicota tokaheya kin hena ehake unpi kta, qa ehake unpi kin hena tokaheyapi kta.

32 Hehan canku ohna Jerusalem ekta yapi ; unkan Jesus wicitokam ya; qa iyepi qeś ihakam upi, inihanpi qa kopehdapi. Unkan akeś akenonpapi kin iwicacu, qa taku akipe kte cin hena kohan owicakiyaka :

33 Iho, Jerusalem elita itan- 


\section{WICOWOYAKE 11.}

wankanhde unyanpi; qa Wicaśta Cinhintku kin wośnapi kagapi, wowapi kagapi ko napepi kin en wicaqupi kta; unkan hena te yacopi kta, qa Ikcewicaśta kin iyoopta wicaqupi kta :

34 He qe iliahapi kta qa kapsinpsintapi kta, qa atagośapi kta, qa ktepi kta; unkan anpetu iciyamni kinhan alke kini kta.

35 Hehan Jakob qa Johannes, Zebede cinhintkupi, en hipi qa heciyapi ; Waonspekiye, taku uncinpi kin he ecen ecaunyeconpi kta uncinpi.

36 Unkan, Taku e ecaciconpi kta yacinpi he, ewicakiya.

37 Unkan heciyapi ; Nitowitan kin en, wanji nietapa qa unma nicatka tanhan unkiyotankapi kta e unqu po.

38 Tuka Jesus hewicakiya; raku yadapi kin sdonyakiyapi śni. Wiyatke etanhan mdatke kte cin he niś yatkan oyakihipi he; qa baptem miye maqupi kte cin he on niś eya niẹupi kta oyakihipi he.

39 'Unkan, Unkokihipi ce, eciyapi. Unkan Jesus hewicakiya; Awicakehan wiyatke etanhan mdatke cin niś etanhan datkanpi kta; qa baptem maqupi kin he iś nakun nicupi kta;

40 Tuka mietapa qa micatka tanhan iyotankapi kin wicaqupi kte cin he miye mitawa śni ; tuka tona wiyeya wicakicihnakapi kta.

41 Unkan wikcemna kin he nahonpi qehan, Jakob qa Johannes nina canniyewicayapi.

42 Tuka Jesus wicakico qa hewicakiya; Oyate kin ekta tona itancan unpi kin wowidagwicayapi ece; qa tona tanka unpi kin hena oyate wicayuhapi ece.

43 Tuka niyepi ekta hecece kte śni ; tuka tuwe iyotan tanka yaunpi kta hecinhan, he ookiye duhapi kta:

44 Qa tuwe tokaheya yaunpi kta hecinhan, he owasin wowidagyapi kta.

45 Wicaśta Cinhintku kin heé kaeś waokiyapi kta hi śni, tuka waowicakiye kta, qa wicota opewicakitonpi kta on wiconi tawa elpeye kta on hi.

46 Unkan Jeriko en hipi; qa Jeriko etanhan oyate ota qa waonspewicakiye cin om hdinanpa, hehan Bartimeus, Timeus cinhintlsu, iśtagonge ciqon he canku icahda wada iyotanka.

47 Unkan he Jesus Nazareth etanhan hee nahon qehan, hotanin qa heya; Jesus, Dawid Cinhintku, onśimakida wo.

48 Unkan wicota iyokipiśni, inina un kta; tuka iye iyotan hotankakiya heya; Dawid Cinhintku, onśimakida wo.

49 Unkan Jesus owanji najin qa kicopi kta, keya; hecen iśtagonge cin kicopi qa heciyapi; Cante waśte wo, najin wo, wanna nico ce.

50 Unkan iye sina elipeya najin hiyaye ça Jesus en hi.

51 Unkan Jesus waayupte ca heciya; Taku ecacicon kta yacin he. Iśtagonge cin; Itancan, watonwe kta, eciya.

52 Unkan Jesus heciya; Hda wo, wacinyaye cin he asniniyan ce. Unkan hecehnana tonwe ça canku ohna Jesus ihakam ya.

\section{WICOWOYAKE 11.}

1 Unkan wanna Jerusalem ikiyedan hipi, Bethphage qa Bethani hetu, Oliwe Paha kin en, hehan wanspewicakiye cin nom ye wicaśi ;

2 Qa hewicakiya; Otonwe iyo73 
takons yanke cin en ya po; unkan wanna en yaipi kinhan, hehan śukcinca wan, tohinni wicaśta akan iyotanke śni, he iyeyayapi kta; yukcapi qa aku po. 3 Qa tuwe, Taku on hecanonpi he, eniciyapi kinkan, Itancan kin cin ce, eya po. Unkan hecehnana au niśipi kta.

4 Unkan ekta iyayapi, qa canku nonpa ipaweh wanka, tiyopa wan en śukcinca kin kaśka najin iyeyapi ; hecen kiyukcapi.

5 Unkan hen najinpi kin wanjikji, Tokeca sukcinca kin dukcapi he, ewicakiyapi.

6 Unkan Jesus econ wicaśi qon he ohna ewicakiyapi : hecen iyowinwicakiyapi.

17 Hehan śukcinca kin Jesus kahipi ; qa tawokoyake akan ehnakapi; unkan iye akan iyotanka.

8 Unkan wicota canku ohna tawokoyake kin owinśyapi; qa apa can kin etanhan adetka kaksapi, qa canku ohna ehpeyapi.

9 Unkan tona tokaheyapi qa tona ihakam upi kin hena hotaninpi qa heyapi; Osanna, tuwe Itancan caje on u kinhan, he yawaśtepi ce.

10 Dawid ateunyanpi tokiconze Itancan caje kin on u kin he yawaśtepi: Osanna iyotan tehan wankantu.

11 Unkan Jesus Jerusalem en ye ça, tipi wakan kin en iyaya; qa wanna taku owasin ekta etonwe ca, litayetu aya, hehan akenonpapi kin om Bethani ekta kihda.

12 Unkan ihanhanna Bethani etanhan kupi, hehan wotek tehda.

$13 \mathrm{Qa}$ itehan suken can wan ape yuke cin he wanyaka, he en hi, okinni en waskuyeca iyeye kta; tuka en hi qehan takudan iyeye śni, ape ecedan; suken icage kta hinahinke śni.
14 Unkan Jesus waayupte ca heciya; Detanhan tuwedan waskuyeca enitanhan yute kte śni, owihanke wanica. Unkan waonspewicakiye cin he nalionpi.

15 Hehan Jerusalem en hipi; unkan Jesus tipi wakan kin en i, qa tona tipi wakan kin ohna wiyopeyapi qa wopetonpi kin hena tankan iyewicaya, qa mazaska tokiyopeyapi ahna econpi kin ahdapśinyan ehpeya, qa wakiyedan iyopeyapi can akan iyotankapi hena koya :

16 Qa tipi wakan kin ohna tuwe cega yuhe kta iyowinwicakiye śni.

17 Unkan wowicakiyake ca hewicakiya; Wati kin he oyate owasin on wocekiye tipi eciyapi kta ce, eya wowapi en kagapi śni he; tuka niye wamanon sa otipi kin yakagapi ce.

18 Wośnapi kagapi qa wowapi kagapi kin he nahonpi, unkan token ihangyapi kta akitapi ; kokipapi, wicaśta owasin tawoonspe kin on yuśinyayapi nakaeś.

19 Unkan wanna hitayetu hehan otonwe kin etanhan tankan iyaya.

20 Unkan ihanlianna en hiyayapi hehan suken can kin wanna hute hehanyan śnija e wanyakapi.

21 Unkan Inyan he kiksuye ca heciya; Itancan, wanyaka wo, suken can daśice ciqon he wanna śnija.

22 Unkan Jesus waayupte ca hewicakiya; Wakantanka wacinyanpi kin he yuha po.

23 Awicakehan heciciyapi ; Tuwe paha kin de, Tokan iyaye ca miniwanca kin en iyohpaya wo, eciye ca, cante kin en cețunhda śni, qa taku tona eye cin hena hecetu lata e wicada 


\section{WICOWOYAKE 12.}

kinhan; he taku eye cin hena. ecen yuhe kta.

24 Heon etanhan heciciyapi; Ceyakiyapi eca taku tona yacinpi kin hena iyacupi e wicada po, kinhan hena duhapi kta.

25 Unkan cekiya nayajinpi kinhan, tuwe taku on yeksuyapi kinhan kicicajuju po; hecen Ateyayapi malipiya ekta yanke cin he wayahtanipi kin nicicajujupi kta.

26 Qa niś wayecicajujupi śni kinhan, nakun Ateyayapi mahpiya ekta yanke cin wayahtanipi kin nicicajujupi kte śni.

27 Unkan ake Jerusalem en hdipi ; qa tipi wakan kin ohna mani un qehan, wośnapi kagapi wowapi kagapi wicahincapi koya en hipi ;

$28 \mathrm{Qa}$ heciyapi ; Taku wowaśake on dena takı kin ecanon he; qa tuwe dena econ niśi, qa hecen ecanon he.

29 Unkan Jesus waayupte ca hewicakiya; Miś eya taku wanji iciwangapi kta, amayupta po, kinhan wowaśake tukte e on dena ecamon kin ociciyakapi kta.

30 Johannes baptem wicaqu qon wicolian kin he mahpiya eciyatanhan, qa iś wicaśta eciyatanhan, unma tukte he; amayupta po.

31 Unkan hdokinicapi qa hekiciyapi; He mahpiya eciyatanhan, unkeyapi kinhan, hehan; Tokeca wicayadapi śni he, eye kta.

32 Tuka, He wicaśta akantu eciyatanhan, unkeyapi kinhan, oyate kin kowicunkipapi; wicaśta owasin Johannes wicaśta wokcan kin heca kecinpi.

33 Unkan waayuptapi qa Jesus heciyapi : Sdonunyanpi śni. Unkan Jesus waayupte ca hewicakiya; Miś eya wowaśake tukte e on dena ecamon kin he nakun ociciyakapi kte śni.

\section{WICOWOYAKE 12.}

1 Hehan wiyacinpi on wowicakiyaka; Wicaśta wan hastanhanka iyuwi wojupi wan oju, qa ohomni natake ca, miniśa iyuśkice wan en qe ça, cowahe tehan wankantu wan kaga; qa kicanyanpi kte cin owicaqu, qa makoce wan tokeca ekta icimani iyaya.

2 Qa wanna iyehantu qehan taokiye wan kicanyanpi kin ekta ye śi, kicanyanpi kin etanhan hastanhanka ojupi kin waskuyeca icu kte cin heon etanhan.

3 Unkan he yuzapi, qa apapi, qa cokadan hde śipi.

4 Unkan ake taokiye wanji tokeca ekta ye śi ; tuka e qe inyan on kininpi, qa pa kahdecapi, qa teliiya kuwapi hde śipi.

5 Unkan ake wanji tokeca ekta ye śi; qa he qe ktepi: unkan nakun wicota, hunh awicapapi qa hunh wicaktepi.

6 Hehan cinhintku wanjidan waśtekidake cin he hinahin hduha; unkan he ehake ekta ye śi, qa; Micinkśi yuonihanpi kta ce, eya.

7 Tuka kicanyanpi kin hekiciyapi; Tawa kte cin he dee; iho po, unktepi kta; hecen he unkitawapi kta ce.

8 Unkan hecen yuzapi qa ktepi, qa wojupi kin etanhan tankan ehpeyapi.

9 Heon hastanhanka ojupi yuhe cin he taku econ kta he. En hi qa kicanyanpi kin hena ihangwicaye kta, qa hastanhanka ojupi kin wicaśta tokeca owicaqu kta.

10 Wowapi kin de dawapi śni he ; Ticagapi inyan wan elipe75 


\section{MARKOS.}

yapi qon he oise en pa icaga ce.

11 He Itancan kin econ, qa unkiśtapi kin en taku wowinihan.

12 Hehan yuze wacinpi, tuka oyate kin kowicakipapi ; wiyacinpi kin de iye wicalia e heya sdonyapi. Unkan ehpeya kihdapi.

13 Hehan Pharisee qa Herodian etanhan wanjikji ekta ye wicaśipi ; taku eye cin on yuzapi kta.

14. Unkan hena en hipi qehan heciyapi; Waonspekiye, iewicayaka qa tuwedan koyakipe śni sdonunyanpi ; wicaśta tancan ekta eyatonwe śni ece, tuka awicakehan Wakantanka tacanku kin odaka ece; Kesar wamnayanpi qupi kta iyececa he.

15 Unqupi kta, qa iś unqupi kte śni he. Tuka iye wohnaye hduhapi sdonye ça hewicakiya ; Tokeca iyutanmayayapi he. Kaśpapidan wanji makau po, wanmdake kta ce.

16 Unkan kahipi. Hehan hewicakiya; Wicite qa wowapi kin de tuwe tawa he. Unkan, Kesar tawa ce, eciyapi.

17 Hehan Jesus waayupte ca; Kesar taku tawa kin kicu po; qa Wakantanka talku tawa kin kicu po, ewicakiya. Unkan heon inihanpi.

18 Hehan Saddukee kin, piya iwicacage kte cin wanica keyapi, hena etanhan en hipi ; qa wiwangapi qa heyapi ;

19 Waonspekiye, Moses wowapi unkicagapi, wicaśta wan tawicu elipeya te ca, cinca nice cinhan, sunkaku winohinca kin he hduze kta, qa cincu qon cinca kicage kta ce.

20 Hunkawanjinkiciyapi śakowin ; unkan tokapa kin winohinca wan yuze ça, cinca codan ța.
21 Hehan iyokihe kin he hduze ça nakun ța, qa cinca nica; unkan iyamni kin iś nakun.

22 Unkan ecen śakowinpi kin hduzapi, qa cinca nicapi : ehake winohinca kin iś eya ța.

23 Hecen piya iwicacage cin en inajinpi kinhan, wanji tukte tawicuyapi kta he: śakowin hduzapi tuka.

24. Unkan Jesus waayupte ca hewicakiya ; Wowapi wakan kin sdonyayapi śni, qa nakun Wakantanka towaśake kin, heon yanumipi.

25 Wiconte etanhan piya wicoicage linhan tawicu tonpi śni qa hihnaku yuhapi śni; tuka malipiya ekta ohnihde unpi kin iyececapi.

26 Unkan tona țapi kin hena piya icagapi kta, on Moses tawowapi kin en dawapi śni he; can opamna etanhan Wakantanka okiye ça heya; Abraham Wakantanka tawa, qa Isaak Wakantanka tawa, qa Jakob Wakantanka tawa kin he miye ce.

27 Wicaśta tapi kin Wakantanka tawapi śni, tuka ni unpi kin Wakantanka tawapi: heon etanhan śogya yanunipi.

28 Hehan wowapi kagapi wanji en hi, qa akinicapi kin nahon, qa tanyan awicayupta iyukcan heon etanhan, Woahope tokaheya kin tukte e he, eya iwanga.

29 Unkan Jesus ayupta; Israel nahon po, Jehowa Wakantanka unkitawapi kin he Itancan wanjidan, woahope owasin tokapa kin hee ce.

30 Unkan Jehowa Wakantanka nitawa kin he nicante ocowasin on, qa ninagi ocowasin on, qa nitawacin ocowasin on, qa nitowaśake ocowasin on, 


\section{WICOWOYAKE 13.}

waśteyakidake kta ce; woahope tokaheya kin hee.

$31 \mathrm{Qa}$ inonpa kin he he iyececa; Nikiyedan un kin he niye inihdacin waśteyadake kta. Woahope dena isanpa tanka wanica.

32 Unkan wowapi kage ein he heciya; Han, Waonspekiya, wowicake ecen eha, Taku wakan wanjidan, qa icunonpa tanhan wanica.

33 Qa wicacante ocowasin on, qa wicotawacin, ocowasin on, qa wicanagi ocowasin on, qa wicowaśake ocowasin on waśtedakapi, qa wicikiyedan unpi kin wiciye ihdacin waśtewicadapi kin, peta on wośnapi qa ikce wośnapi owasin, he isanpa tanka ece.

34 Unkan he wacinksamya ayupta Jesus wanyaka, hehan heciya; Wakantanka tokiconze kin itehan yaun śni. Unkan hetanhan tuwedan sanpa wiwanga tawațenye śni.

35 Hehan Jesus tipi wakan kin ohna wowicakiyaka icunhan waayupte ca heya; Wowapi kagapi kin Messiya he Dawid Cinhintku ce, tokeca heyapi he.

36 Dawid iye qe Woniya Wakan on heya; Itancan kin Itancan mitawa heciya; Mietapa ekta iyotanka wo, tona tokaniyanpi kin hena siha oahe nitawa kin wakage kta hehanyan.

37 Heon etanhan Dawid iye qe Itancan eciya; hecen token cincaya he. Unkan oyate ikceka kin wiyuśkinyan nahonpi.

38 Unkan wowicakiyaka icunhan hewicakiya; Wowapi kagapi kin kowicakipa po, hena wokoyake hanskaska kicun waśtedakapi, qa wopeton tipi kin ohna owicakiyapi kta nakun :

$39 \mathrm{Qa}$ omniciye tipi kin en oi- yotanke tokapapi, qa wotapi kin en oyanke waśteśte kin:

40 Hena e wiwazica tipi kin temyapi, qa ihdutaninpi on wocekiye hanska eyapi ece: hena woyaco iyotan tanka yuhapi kta.

41 Unkan Jesus mazaska opiye kin iyotakons iyotanka, qa token oyate kin mazaska opiye kin ell, mazaska elipeyapi kin he wanyaka. Unkan wicota wijicapi kin liena odota en ehpeyapi.

42 Unkan wiwazica wahpanica wan en hi, qa mazaśa onśpadan nom en ehpeya, he mazaśa wanjidan yawapi.

43 Unkan waonspewicakiye cin hena wicakico qa hewicakiya; Dena owasin mazaska opiye kin en ehpeyapi, tuka wiwazica walpanica kin de owasin isanpa en elipeya, awicakehan eciciyapi.

44. Dena owasin taku ota tompi kin eciyatanhan en ehpeyapi ece ; tuka iye qe nice cin etanhan taku yuhe cin ocowasin en ehpeya, on ni kte cin ocowasin.

\section{WICOWOYAKE 13.}

I Unkan tipi wakan kin etanhan kinanpa hehan waonspewicakiye cin wanji heciya; Waonspekiya, inyan tankinyanyan kin dena, qa tipi kagapi kin dena wanyaka wo.

2 Unkan Jesus waayupte ca heciya; Tipi tankinyanyan kin dena owasin wandaka he. Inyan wanji inyan itakihna wanke kte śni, owasin jujuwahe kta.

3 Unkan Oliwe Paha kin akan iyotanka, tipi wakan kin iyotakons, hehan Inyan qa Jakob qa Johannes qa Andrew nalimana wiwangapi ;

4 Tohán hena hecetu kta he, qa dena owasin iyecetu kta e 


\section{MARKOS.}

wowapetokeca tukte e hecinhan, unkokiyaka po.

5 Unkan Jesus waayupte ça hewicakiya; Iwanihdaka po, okinni tuwe nihnayanpi kta.

6 Wicota micaje on hipi qa; He miye ce, eyapi kta, qa wicaśta ota wicahnayanpi kta.

7 Unkan tohan wicokicize qa kicizapi kta oyakapi kin nayalionpi kinhan, nihinciyapi śni po: hena hecetu kta, tuka owihanke kin hinahinke śni.

8 Oyate wan oyate tokeca on najin kta, qa wokiconze wan wokiconze tokeca on ; qa tuktekten maka śkanśkan yuke kta, qa wicaakihan qa wicokicize yuke kta. Dena wicoiyokiśice tokaheya kin ee.

9 Tuka iwanihdaka po ; omniciye tanka kin en aniyanpi kta; qa omniciye tipi kin ohna nicaśtakapi kta; qa miye on wicaśta itancanpi wicaśtayatapi ko en aniipi kta, owicayakapi kta heon.

10 Tuka tokaheya wotanin waśte kin he oyate owasin owicakiyakapi kta.

11 Tuka tohan aniyanpi qa wicaniçupi kinhan, itokam taku ehapi kta awacinpi śni po, qa on cante śicapi śni po; tuka wihiyayedan oape kin he en taku nicupi kin he ohna eya po; eye kte cin he niyepi śni, tuka Woniya Wakan kin hee kta.

12 Hunkawanjinkiciyapi wiconțe en kicicupi kta, qa wicaśta wan iye cinca nakun; qa wicacinca inajinpi kta qa hunkakewicayapi kin țewicayapi kta.

13 Unkan miye on owasin śicenidapi kta; tuka tuwe owihanke kin hehanyan ope cinhan he ni kta.

14 Tuka tohan wośice woihangye, Daniel wicaśta wokcan cajeyate ciqon, tukten najin ktá iyecece śni, hen wandakapi kinhan, tuwe yawa kinhan okalinige kta, hehan tona Juda makoce kin en unpi kin he kin ekta najicapi kta :

15 Qa tuwe tipi akan yanke cin he kun $\mathrm{ku}$, qa timahen tanhan takudan ehdaku kte śni :

16 Qa nakun tuwe magata un kinhan, wokoyake ehdaku kta on hdicu kte śni.

17 'Tuka anpetu kin hena en tona ihduśakapi qa hokśiyoqopa azinwicakiyapi kin hena tehiya unpi kta.

18 Unkan waniyetu icunhan nayapapi kte śni e icekiya po.

19 Anpetu kin hena en wicokakije yuke kta, tokaheya Wakantanka taku kage cin ehantanhan, qa dehanyan takudan iyecece śni, qa nakun tokata ekta iyecece kte śni.

20 Unkan Itancan kin anpetu. kin hena yuptecedan śni kinhan, wicacehpi takudan ni kte śni; tuka wicakahinigapi tona wicakahinige cin hena on anpetu kin hena yuptecedan.

21 Unkan hehan tuwe; Iho, Messiya hen yanka ce, qa iś; Kan yanka ce, eniciyapi eśta, wicadapi śni po.

22 Messiya itonpiśni qa wicaśta wokcan itonpiśni kin heca icagapi kta, qa wowapetokeca taku wowinihan ko econpi kta, okihipica unkanś wicakahnigapi kin hena eepi kaeś wicahnayanpi kta tuka.

23 Tuka iwanihdaka po; iho, itokam hena"ociciyakapi.

24 Tuka anpetu kin hena en, wicokakije kin iyohakam, anpetu wi kin aotpasyapi kta, qa hanyetu wi kin iyoyanpa kte śni ;

$25 \mathrm{Qa}$ mạpiya wicanhpi kin hinihpaye kta, qa mahpiya ekta wowaśake kin yuhuhuzapi kta. 
26 Unkan hehan Wicaśta Cinhintku kin wowaśake tanka wowitan ko hduha mahpiya sapa akan u wandakapi kta.

27 Unkan hehan olnihdewicaye cin hena ye wicaśi kta, qa tate ouye topa kin etanhan, maka ihanke kin etanhan qa mahpiya ihanke kin hehanyan, wicakahnige ciqon hena witaya wicakpahi kta.

28 Suken can kin etanhan wiyacimpi kin de okahniga po: Can intpa kin hinahin wankadan, qa etanlian ape icage cinhan, hehan mdoketu wanna ikiyedan sdonyayapi ece.

29 He iyececa, niś tohan dena owasin iyecetu wandakapi kinhan, wanna ikiyedan, tiyopa kin etu, e sdonya po.

30 Awicakehan heciciyapi, wicoicage kin de tokan iyaye śni, ecen dena owasin econpi kta.

31 Mahpiya maka ko tokan iyaye kta, tuka mioie kin hena tokan iyaye kte śni.

32 Tuka anpetu kin he, qa wihiyayedan oape kin he tuwedan sdonye śni, malipiya ohnihde kin heepi kaeś, qa nakun Cinhintkuyapi kin; tuka Ateyapi kin ecedan sdonya.

33 Iwanihdaka po, wakta unpi qa cekiya po; tohan iyehantu kte cin sdonyayapi śni nakaeś.

34 Wicaśta wan icimani ye kte cin, tipi ehpeye ca taokiyewicaye cin taku econ wicaśi, otoiyohi wicohan wicaqu, qa tiawanyake cin he awanyake si, he iyececa.

35 Heon etanhan waktaya un po ; tipi ohna itancan kin tohan hdi kta sdonyayapi śni, htayetu, qa hanye cokaya, qa anpaohotonna hoton, qa iś hanlianna kinhan.

36 Okinni ihnuhanna hdi kinhan niśtinmapi iyeniyanpi kta.
37 Unkan taku eciciyapi kin he owasin ewicawakiya ece, Waktaya un po.

\section{WICOWOYAKE 14.}

1 Anpetu nonpa iyohakam he. han woacakśin qa aguyapi napohyapi śni: Unkan wośnapi kagapi wowapi kagapi ko token hnayan yuzapi kta akitapi, ktepi kta e heon.

2 Tuka heyapi; Wośnapi anpetu kin hehantu kte śni; okinni oyate kin owodutaton kta.

3 Unkan Bethani etu, Simon lepros ececa qon he ti kin en wota iyotanka, hehan winohinca wan inyan opiye wan wihdi waśtemna tehike hinca he yuha hi, qa opiye kin yulidoke ca iye pa kin akaśtan.

4 Unkan hen wanjikji cante mahen iyokipipi śni qa heyapi; Tokecà wihdi waśtemna kin hecen yutakunipi śni he.

5 Wihdi waśtemna kin de kaśpapi opawinge yamni sanpa iyopeyapi qa wahpanica wicaqupi kta tuka. Hecen winohinca qon icaptapi.

6 Unkan Jesus heya; Ayuśtan po; tokeca nagiyeyayapi he. Wicohan waśte wan ecamicon.

7 Wahpanicapi kin ohinniyan wicayahduhapi, qa tohan yacinpi kinhan tanyan ecawicayeconpi kta oyakihipi; tuka miye ohinniyan mayaduhapi śni.

8 Taku okihi kin ecen econ; mitancan hapi kte cin on itokam sdaye kta on hi.

9 Awicakehan heciciyapi; Maka kin owancaya tukten wotanin waśte kin de oyakapi kinhan, winohinca kin de nakaha taku econ kin he oyakapi kta, wokiksuye kta e heon.

10 Unkan Judas Iskariot, ake- 


\section{MARKOS.}

nonpapi kin wanji ee, wośnapi kagapi kin ekta ya, he hnayan wicaqu kta heon.

11 Unkan he nalionpi qehan wiyuśkinpi, qa mazaska qupi kta keciyapi. Unkan token tanyan hnayan wicaqu kta he akita.

12 Unkan aguyapi napohye śni anpetu tokaheya en wośna ktepi ece kin hehantu, waonspewicakiye cin heciyapi ; Tukten woacakśin wośnapi yate kta wiyeya eunhnakapi kta yacin he.

13 Unkan waonspewicakiye cin nom ye wicaśi, qa hewicakiya; Otonwe kin en ya po, kinhan wicaśta wan mini ohna wakiśkotpa wan qin itkonicipapi kta, he ihakam ya po.

14 Qa tukte en tin kihde cinhan, tipi tawa kin heciya po; Waonspekiye cin heya ce; Wankan tipi kin tukten waonspewicawakiye cin om wośnapi kin wate kta tukte e he.

15 Unkan wankan tipi wan tanka, tanyan yuśtanpi qa wiyeya yanka, nicipazopi kta; hen wiyeya eunkicihnaka po.

16 Unkan waonspewicakiye cin iyayapi, qa otonwe kin en ipi, qa token ewicakiye cin hecen iyeyapi ; unkan wośnapi kin wiyeya ehnakapi.

17 Unkan wanna litayetu hehan akenonpapi kin om en hi.

18 Unkan wota iyotankapi icunhan Jesus heya; Awicakehan heciciyapi; Mici wayatapi kin wanji wiyopemayayapi kta.

19 Hehan iyokiśica hinhdapi, qa otoiyohi heciyapi; He miye he; qa ake wanji, He miye he, eyapi.

20 Unkan hewicakiya; Akenonpapi kin etanhan wanji wakśica ohna mici oputkan kin hee ce.

21 Wicaśta Cinhintku kin awi- cakehan token wowapi en kagapi qon he iyecen iyoopta ya, tuka wicaśta kin tuwe Wicaśta Cinhintku kin wiyopeye cinhan, he wotehi yuhe kta; wicaśta kin he tohinni tonpi śni unkanś waśte kta tuka.

22 Unkan wotapi icunhan Jesus aguyapi icu, yawaśte, qa kiyuśpa, qa wicaqu, qa heya; Icupi qa yuta po; mitancan kin he dee.

23 Nakun wiyatke kin icu; qa yawaśte hehan wicaqu. Unkan owasin etanhan yatkanpi.

24 Unkan hewicakiya; Wicotakuye teca kin en, mawe kin he dee, wicota on papsonpi.

25 A wicakehan heciciyapi ; Detanhan wiyuwi waskuyeca etanhan icimana mdatke kte śni, anpetu wan en Wakantanka tokiconze kin en teca mdatke kte cin hehanyan.

26 Unkan odowan wan ahiyayapi hehan Oliwe Paha kin ekta iyayapi.

27 Hehan Jesus hewicakiya; Hanyetu kin de miye on iyuhpa niliicahanpi kta; kaken wowapi en kagapi qon, Waawanhdake kin he awape kta, hecen tahinca wanunyanpi kin mdecahanpi kta ce.

28 Tuka ake wakini iyohakam, Galile ekta nitokam imdamde kta.

29 Tuka Inyan heciya; Owasin licahanpi eśta, miye qe ecamon kte śni.

30 Unkan Jesus heciya; Awicakehan heciciya; Anpetu kin de, hanyetu kin de en, anpaohotonna nonpa hoton śni, ecen yamni akihde anamayakilibe kta.

31 Hehan iyotan nina kitan hinca ; Cicimața eśta anacicilibe kte śni. Iyuhipa nakun iyecen eyapi. 


\section{WICOWOYAKE 14.}

32 Unkan wojupi wan en ipi, Gethsemane eciyapi; hehan waonspewicakiye cin hewicakiya; Den iyotanka po, icunhan cewakiye kta.

33 Unkan Inyan qa Jakob qa Johannes hena iwicacu, hehan inihan qa nina iyokiśica hinhda;

34 Qa hewicakiya; Minagi nina iyokiśice linca, mațe kta iyececea; den yukanpi qa waktaya un po.

35 Unkan hetanhan kitan ecinyan iyoopta ye ca, makata ilipaye ca cekiya, okihipica kinhan, wihiyayedan oape kin he tokan iyaye kta.

36 Unkan heya; Abba, Ate, niye ekta taku owasin okihipica; wiyatke kin de emiciyaku wo; tuka miś taku wacin kin hee kte śni, taku yacin kin he hecetu kta.

37 Hehan en hdi, qa iśtinmapi iyewicaya, unkan Inyan heciya ; Simon niśtinma he; wihiyayedan oape wanjidan kiktahan yaun kta oyakihi śni he.

38 Kiktahan unpi qa cekiya po; okinni taku wawiyutanyan un kin en yaipi nun ce; wicanagi kin he awicakehan wicada, tuka wicacehpi kin waśake śni.

39 Unkan ake iyaye ça cekiya, qa wicoie un qon hena ake ecen eya.

40 Unkan ake en hdi qehan, ake iśtinmapi iyewicaya, iśta hbapi hinca, unkan token ayuptapi nun tanin śni.

41 Unkan iciyamni en hdi, qa hewicakiya ; Iśtinma po qa oziiciya po ; wanna henakeca, wihiyayedan oape kin wanna iyehantu; wanyaka po, Wicaśta Cinhintku kin wahtanipi sa napepi kin en hnayan wicaqupi.

42 Najin po, unyanpi kta; iho, tuwe mahnaye cin he wanna kiyedan u ce. Dak.
43 Unkan ecahankeya, iahan icunhan, Judas hi, akenonpapi kin wanji ee, qa kici wicota hinca, mazasagye can oṭoza ko yuhapi, wośnapi kagapi, wowapi kagapi, qa wicahincapi kin etanhan upi.

44 Unkan tuwe hnayan wicaqu kte cin he iwaktawicaye ca; Tuwe i iwaputake cinhan hee kta; yuzapi qa tanyan akiyahda po, eya.

45 Unkan en hi qehan, ecahankeya en ye ca, Itancan, Itancan, eciye ca, i itputaka.

46 Hehan nape ahnakapi qa yuzapi.

47 Unkan wanji en najinpi kin mazasagye ehdaku, qa wośnapi kagapi itancan taokiye wanji ape ca noge baśpa.

48 Unkan Jesus waayupte ca hewicakiya; Wamanon sa takpe hipi iyececa, mazasagye can otoza ko yuha mayaduzapi kta on yahipi he.

49 Anpetu eca tipi wakan kin ohna ocipapi qa waonspekiya waun, tuka mayaduzapi śni ; tuka wowapi wakan kin yuecetupi kta.

50 Hehan owasin ehpeya najicapi.

51 Unkan kośka wan ihakam ya, tancodan un tuka minihuha ska tancan iyakipemni. Unkan kośkapi kin hena yuzapi :

52 Hehan minihuha ska kin he ehpeya, qa tancodan kihda.

53 Unkan Jesus wośna kagapi itancan kin ekta ayapi; qa hen wośnapi kagapi, wicahincapi, wowapi kagapi ko owasin mniciyapi.

54 Unkan Inyan itehan ihakam u, qa wośna kagapi itancan ti kin en hi; qa ookiyewicayapi kin om iyotanke ça peta kin en cosic̣iya. 


\section{MARKOS.}

55 Unkan wośnapi kagapi qa omniciye ocowasin tuwe Jesus on taku oyakapi kta odepi, ktepi kta e heon, tuka takudan iyeyapi śni.

56 Wicota itonśniyan woyakapi, tuka taku oyakapi kin ocitkonze śni.

57 Hehan wanjikji inajinpi, qa itonśniyan taku iyaonpapi, qa heyapi ;

58 Unkiye, Tipi wakan nape on kagapi kin de ihangwaye kta, qa anpetu yammi hehan wanji tokeca nape codan kagapi kin he wakage kta ce, eya naunhonpi ce.

59 Tuka iś eya taku oyakapi kin ocitkonze śni.

60 Hehan woŝna kagapi itancan kin wicacokaya inajin, qa Jesus iwange ca; Dena taku iyanionpapi kin takudan adupte śni he, eya.

61 Tuka iye inina un qa takudan ayupte śni. Ake wośna kagapi itancan kin wiwange ca heciya; Messiya, Iyotan Waśte Cinhintku kin he niye he.

62 Unkan Jesus heya; He miye; qa Wicaśta Cinhintku kin wowaśake etapa eciyatanhan iyotanke ca, malipiya śapa akan u wandakapi kta ce.

63 Hehan wośna kagapi itancan kin wokoyake hdupote ca heya; Taku on woyakapi sanpa uncinpi kta he.

64 Wayaśice cin he niye nayahonpi : token idukcanpi he. Unkan owasin, te kta iyececa, yacopi.

65 Hehan wanjikji a tagośapi qa ite ogekicitonpi, qa apapi qa; Wokcan wo, eciyapi. Unkan ookiye unpi kin iś eya nape on apapi.

66 Unkan Inyan ihukuya tipi kin ohna yanka; hehan wośna kagapi itancan winyan wowidagwicaye cin wanji en hi ;

$67 \mathrm{Qa}$ Inyan petiśkan yanka wanyake cehan en etonwe ca heya; Qa niś eya Jesus Nazareth kici yaun qon.

68 Tuka anakilibe ca heya; Taku ehe cin he sdonwaye śni, qa nakun owakahinige śni ce. Hehan tankan ohanzi hdepi kin ekta iyaya: unkan anpaohotonna wan hoton.

69 Unkan ake wikośka wan wanyake ça, tona en najinpi kin hewicakiya; De iś nakun hetanhan.

70 Unkan iś ake anakihman. Hehan kitan ecinyan iyohakam tona en najinpi kin ake Inyan heciyapi; Awicakehan niś henitanhan; Galile wicaśta henica; qa iyae cin he iyececa ce.

71 Tuka iye wayaśice ca taku wakan cajeyata; Wicaśta kin de cajedatapi kin ecaca sdonwaye śni ce, eya.

72 Hehan inonpa anpaohotonna kin hoton. Unkan hehan Inyan Jesus taku eciye ciqon; Anpaohotonna nonpa hoton śni, yamni akihde anamayakihbe $\mathrm{kta}$ ce, wicoie kin he kiksuya. Unkan he awakicin hehan ceya.

\section{WICOWOYAKE 15.}

1. Unkan wanna anpao, hehan wośnapi kagapi qa wicahincapi, wowapi kagapi ko omniciye ocowasin om he aiapi, qa Jesus kaślkapi, qa ekta ayapi qa Pilate qupi.

2 Unkan Pilate wiwanga; Juda oyate Wicaśtayatapi kin he niye he. Unkan Jesus ayupte ca, Niye ecen eha ce, eya.

3 Unkan wośnapi kagapi kin taku ota iyaonpapi ; tuka takudan ayupte śni. 
4 Unkan Pilate ake wiwange ca; Takudan adupte śni he; iho, taku ota iyanionpapi ce, eya.

5 Tuka Jesus takudan ayupte śni ; hecen Pilate yuśinyaya.

6 Wośnapi kin de ekta wicakaśkapi wanji wicakiciyukca ece, wanji tukte cinpi kinhan.

7 Unkan wanji Barabbas eciyapi, he tona om inajin qon kaśkapi yanka, he inajinpi qehan nakun tinwicakte.

8 Unkan oyate kin, token econ ece qon he iyecen ecawicakicon kta, panyehan keciyapi.

- 9 Tuka Pilate awicayupte ca ; Juda Wicaśtayatapi kin he ciciyukcapi kta yacinpi he.

10 Wośnapi kagapi kin winawizipi on kahipi e sdonya.

11 'Tuka wośnapi kagapi kin oyate kin wahokonwicakiyapi, Barabbas he wicakiyukca kta e heon.

12 Unkan Pilate ake awicayupte ca; Hehan tuwe Juda Wicaśtaya tapi eyakiyapi kin he token ecamon kta yacinpi he, ewicakiya.

13 Unkan ake panyehan heyapi ; Icipaweh okatan wo.

14 Hehan Pilate hewicakiya; Tokeca, taku śica econ kin tukte e he. Unkan hehan iyotan nina; Icipaweh okatan wo, panyehan eyapi.

15 Unkan Pilate oyate kin iyokipiwicaye kta cin, heon Barabbas wicakiciyukca, qa Jesus kapsinpsinta hehan icipaweh okatanpi kta wicaqu.

16 Unkan akicita kin tipi wan tanka, Pretorium eciyapi, he ekta ayapi ; qa wicobe ocowasin wicakicopi.

17 Unkan śina duta wan inkiyapi, qa wapaha wan wapepeka on kazontapi qa unkiyapi.
18 Qa hehan okiyapi, Iho, Juda Wicaśtayatapi kin.

$19 \mathrm{Qa}$ cedi tanka wan on pa kin en apapi, qa atagośapi, qa canpeśka makehde inajinpi, qa ohodapi.

20 Unkan hecen ihahapi, hehan śina duta kin ikicicupi, qa iye tawokoyake qon ake kicunkiyapi. Hehan icipawel okatanpi kta e ekta ayapi.

21 Unkan Simon, Kurene wicaśta, en hiyaya, he Alexander qa Ruphus atkuku kin, makoce kin etanhan u kin he can susbeca tawa kin kicicinkiyapi.

22 Unkan Grolgotha owanka kin en ahipi, he, Wicapahu makoce, eyapi kin he kapi.

23 Unkan miniśa pejihuta icahiyapi kin he yatke kta e qupi ; tulka wicada śni.

24 Unkan wanna icipaweli okatanpi, hehan tawokoyake qon kicipamnipi, qa on oeconna econpi, wicaśta otoiyohi taku icupi kta. 25 Unkan wanna wihiyayedan oape yamni, hehan icipaweli okatanpi.

26 Unkan taku iyaonpapi wowapi iwankam owapi kin, JUDA WICAŚTA YATAPI KIN, hee. 27 Unkan kici wamanon sa nom icipawel owicakatanpi, wanji etapa eciyatanhan, qa unma catka eciyatanhan.

'28 Hecen wowapi kagapi qon yuecetupi; Qa walitanipi sa om yawapi ce, eya.

29 Unkan tona en hiyayapi kin hena yaśicapi, poptanptanpi qa heyapi; Iho, tipi wakan kin. ihangyaye kta, qa anpetu yamni ake piya yakage kta:

30 Ito, niiciya wo, qa cansu. sbeca kin etanhan kun ku wo.

31 Nakun wośnapi kagapi kin ihahapi, qa wowapi kagapi om iye iyakitedan hekiciyapi; Wi83 


\section{MARKOS.}

caśta tokeca niwicaya ece, tuka iye atayedan nuiçiye $\mathrm{kta}$ okihi śni.

32 Messiya Israel Wicaśtayatapi kin, ito cansusbeca kin etanhan kun hdicu kta, hecen wanunyakapi qa wicaundapi kta. Unkan tona kici icipawel owicakatanpi qon iś eya ihaliapi.

33 Unkan wihiyayedan oape iśakpe, hehan maka kin owancaya otpaza, oape inapcinwanka hehanyan.

34 Qa wihiyayedan oape inapcinwanka, hehan Jesus hotankakiya panyehan; Eloi, Eloi, lama sabakthani, eya: Wakantanka mitawa, Wakantanka mitawa, tolxeca elipemayaya he, eyapi kin he kapi.

35 Unkan en najinpi wanjikji he nalionpi qehan heyapi; Iho, Elias kipan.

36 Unkan wanji inyang ye ça, mini iyuhepe wan miniskuya en oputkan, qa can icam yatkekiye kta, qa heya; Hinnakahan po, Elias kun eyaku kta on hi kinhan wanunyakapi kta.

37 Unkan Jesus hotankakiya hotanin, qa taniya hiyuya.

38 Unkan tipi wakan cokaya ozanpi qon he owangya okinahdece ca, wankan tanhan qa kun ihanke kin aiyahdeya.

39 Unkan akicita opawinge wicayuhe cin iyotakons najin, he hecell pan qa taniya hiyuya wanyaka, hehan heya; Awicakehan wicaśta kin de Wakantanka Cinhintku kin hee.

40 Nakun winohinca itehan tanhan wanyag yukanpi; Mary Magdalene, qa Mary, Jakob cistinna qa Joses hunku kin, qa Salome, hena opapi.

41 Galile en un qon he ehan ihakam unpi qa okiyapi ece kin hena eepi, qa nakun winohinca 84 toktokeca kici Jerusalem en hipi qon.

42 Unkan wanna htayetu, Ihduwiyeyapi kta anpetu, anpetu wakan kin itokam anpetu kin hee, heon,

43 Joseph, Arimathea etanhan, woope aiekiyapi owotanna, qa nakun Wakantanka tokiconze kin ohinniyan ape un kin he $u$, qa waditagya Pilate en ye ça, Jesus tancan kin kida.

44 Unkan wanna ta hecinhan Pilate yuśinyaya; heon akicita opawinge wicayuhe cin he kico, qa wanna wanakaja tanhan ta hecinhan he iwanga.

45 Unkan akicita opawinge wicayuhe cin he ecen okiyaka, hehan tancan kin Joseph qu.

46 Unkan he miniliuha ska waśte opeton, qa tancan kin kun eyaku, qa miniliuha ska kin iyapemni, qa wicahapi ohdoka wan imnija en kagapi, he en ohnaka, qa inyan tanka wan wicaliapi olidoka i kin en eonpa.

47 Unkan Mary Magdalene qa Mary Joses hunku kin hena tukten hnakapi kin he wanyakapi.

\section{WICOWOYAKE 16.}

1 Unkan anpetu wakan kin wanna owihanke, hehan Mary Magdalene, qa Mary Jakob hunku, qa Salome hena tancan kin sdayapi kta on pejihuta waśtemna aupi : 2 Unkan anpetu tokaheya hanlianna linca, wicahapi olidoka kin en hipi, wanna wi hinanpa hehantu.

3 Unkan hekiciyapi ; Tuwe wicahapi ohidoka i kin etanhan inyan kin yutokan iyeunkiciciyapi kta he.

4 Unkan ekta etonwanpi, hehan inyun, inyan kin wanna yutokan iyeyapi; he tanka linca. 


\section{WICOWOYAKE 16.}

5 Unkan wicahapi olidoka kin mahen ipi, hehan kośka wan etapa eciyatanhan iyotanka, wokoyake ska hanska koyaka, he wanyakapi; unkan yuśinyayapi.

6 'Tuka iye hewicakiya; Thnuhan niyuśinyayapi kinhan; Jesus Nazareth etanhan, icipaweh okatanpi qon he oyadepi ; wanna ihduekicetu; den wanke śni; tukten hnakapi qon he wanyaka po.

7 Tuka niś hda po, qa waonspewicakiye cin, qa Inyan nakun, nitokam Galile ekta ye kta, heciya wanyahdakapi kta, eniciyapi qon iyececa, he owicakiyaka po.

8 Unkan hecen koyahanna hdicupi, qa wicahapi olidoka kin etanhan najica kihdapi; nina cancanpi qa yuśinyayapi ; qa tuwedan takudan eciyapi śni, inihanpi nakaeś.

9 Unkan anpetu wakan anpetu tokaheya hanhanna hinca, Jesus ihduekicetu hehan, Mary Magdalene, etanhan taku wakan śica śakowin ehpekiciye ciqon, he tokaheya en taniniciya.

10 Hehan iye hde ça, tona om un qon iyokiśicapi qa ceya yukanpi kin owicakiyaka.

11 Unkan hena, wanna kini, qa he wanyaka keya ohdaka nationpi eśta, wicadapi śni.

12 Hehan iyohakam etanhan wicaśta nom makoce ekta ici- mani yapi, hehan icunhan en taniniciya.

13 Hena unmapi kin hośi wicakakipi, tuka nakun wicadapi śni.

14 He iyohakam akewanjipi wota iyotankapi icunhan en taniniciya, qa wacețunhdapi qa cante sutapi on iyopewicaya; kini iyohakam tona wanyakapi kin heepi kaeś wicawicadapi śni heon.

15 Unkan hewicakiya; Maka kin owancaya ya po, qa wicaśta otoiyohi wotanin waśte kin owicakiyaka po.

16 Tuwe wicada qa baptem qupi kinhan he ni kta; qa tuwe wicada śni kinhan he yacopi kta.

$17 \mathrm{Qa}$ tona wicadapi kin hena wowapetokeca dena yuhapi kta; Micaje kin on taku wakan śica tankan ehpeyapi kta; wicaceji tokeca on iapi kta;

18 Sintehda yuwankan icupi kta; qa pejihuta śica yatkanpi eśta etanhan itokecapi kte śni; wayazankapi kin. nape awicahnakapi kta, kinhall asnipi kta ece.

19 Hecen Itancan kin owicakiya, hehan mahpiya ekta eyakupi, qa Wakantanka etapa eciyatanhan kiyotanka.

20 Unkan hena iyayapi, qa owancaya woyakapi; qa Itancan kin wicohan tanka econwicakiye cin on wicoie kin yuecetu ece. Amen. 


\section{U KA S}

\section{WOTANIN WAŚTE TAWA.}

\section{WICOWOYAKE 1.}

1 Taku tona cetunhdaśniyan wicaundapi kin hena wicota hdaheya oyag utapi ;

2 Tona otokahe ehantanhan iśta on wanyakapi qa wicoie oyakapi ece kin hena token unkokiyakapi qon he iyececa:

3 Heon etanhan miś eya, taku kin hena owasin otokahe hinca ehantanhan tảnyan owakahinige cin on, Taku Wakan waśtedaka iyotan waśte, hena hdaheya wowapi cicage kta iyomakipi.

4 Hecen taku onspeniciyapi qon herla wicakapi e tanyan sdonyaye kta.

5 Herod Juda wicaśtayatapi taanpetu kin en wawayuśna wan Zacariyas eciyapi, Abia optaye kin hetanhan; qa tawicu kin iś Aaron cunwintkupi kin etanhan; unkan he Elisabeth eciyapi.

6 Hena sakim Wakantanka itokam owotanpidan, qa Itancan tawoahope qa wicoope tawa kin owasin omanipi, iyaonpepica śni unpi.

7 Unkan Flisabeth hokśin yuhe śni un, qa hecen cinca nicapi; unkan sakim wanna kanpi.

8 Unkan iye optaye kin ohna wośna wicolian kin Wakantanka itokam econ eca,

9 Tipi wakan Itancan tawa kin timahen iyaya eca, waazintonpi econ śipi ece, wośna wicohan econpi kin eciyatanhan.

10 Unkan waazintonpi icunhan, oyate kin owasin itankan cekiya hiyeya.

11. Unkan Itancan taohnihde wan en taniniciya, qa wahna azintonpi kin etápa tanhan hinajin.

12 Unkan Zacariyas he wanyake cehan, wacin iyokiśice ca wakokipe hinca.

13 Tuka ohnihde wakan kin heciya; Wakokipe śni wo, Zacariyas; wocekiye nitawa kin nahonpi; qa nitawin Elisabeth hokśidan wan niciyuhe kta, unkan he Johannes eya caśyakiton kta.

$14 \mathrm{Qa}$ he on wowiyuśkin wopida ko duhe kta, qa tonpi kin on wicota iyuśkinpi lita.

15 Qa iye Itancan kin itokam tanka kta ; qa miniśa miniwakan ko takudan yatke kte śni; qa hunku ikpi kin etanhan Woniya Wakan kin on ojudan kta.

16 Unkan iye Israel cinca kin wicota Itancan Wakantanka tawapi kin ekta wicayahomni kta.

$17 \mathrm{Qa}$ Elias toksape qa towaśake kin yuha itokam ye kta, qa atewicayapi cincawicayapi kin kici cante wicayuokonwanjidan, qa wanalionpi śni kin hena owotanna unpi wicoksape kin ekta wicayuhomni kta; qa oyate wan Itancan on ihduśtanpi kin wiyeya kicihnake kta e heon etanhan.

18 Unkan Zacariyas ohnihde wakan kin heciya; Wanna wimacahinca, qa mitawin wanna kan; hecen taku on de sdonwaye kta he. 


\section{WICOWOYAKE 1.}

19 Unkan ohnihde wakan kin waayupte ca heciya; Gabriel, Wakantanka itokan najin kin he miye; qa ociciye ca, wotanin waśte kin de sdonyeciciye kta e u maśipi.

20 Unkan iho, mioie kin tohan iyehantu kinhan yuecetupi kte cin he wicayada śni kin he on, tohanyan yuecetupi śni kin hehanyan, ie śni, qa ia okitpani yaun kta ce.

21 Unkan oyate kin Zacariyas ape hiyeye, ca tehan tipi wakan kin ohna yanke cir on etanhan inihanpi.

22 Unkan tankan hdicu qehan, owicakiye kte cin okitpani : unkan namwicakicawin, qa ie śni un; on etanhan tipi wakan kin ohna taku wakan wanji wanyaka e iyukcanpi.

23 Unkan wicolian econ ece kin anpetu kin wanna ihunnikiya, hehan iye ti kin ekta kihda.

24 Unkan anpetu kin hena iyohakam tawicu Elisabeth hokśin itpihnaka; unkan wi zaptan hehanyan inalibe, ca heya;

25 Anpetu kin en, Itancan kin wicaśta kin taku i en mahdepi qon he emiciyaku kta on ahimatonwe cehan, decen ecamicon ce.

'26 Unkan wi iśakpe kin en, Gabriel ohnihde wakan kin Wakantanka etanhan u śipi ; Galile ekta, otonwe wan Nazareth eciyapi kin hetu;

27 Wikośka wan wicaśta wan Joseph eciyapi, Dawid wicowazi tawa kin etanhan, yuze kte cin he ekta; unkan wikośka kin Mary eciyapi.

28 Unkan ohnihde wakan kin he en hi qa heciya; Wiyuśkin wo, waśteya yaun kin; Itancan kin niciun, winohinca owicapeya niye niyawaśtepi ce.
29 Unkan he wanyake cehan, oie kin on inihan, qa okiyapi kin de taku kta hecinhan he awacin un.

30 Unkan ohnihde wakan kin heciya; Mary, wikope śni wo; Wakantanka ekta wowaśte iyeyaya.

$31 \mathrm{Qa}$ iho, hokśin itpiyahnake ca hokśidan wan yaton kta, qa JंEsus eya caśyakiton kta.

32 Iye tanka kta, qa Iyotan Wankantu kin Cinhintku kin eciyapi kta; qa atkuku Dawid tohe kin Wakantanka Itancan kin hduhekiye kta.

33 Qa Jakob ti kin he ohinniyan idake kta; qa wokiconze tawa kin okiciwihanke kte śni ce, eya.

34 Hehan Mary ohnihde wakan kin heciya; Wicaśta sdonye śni waun kin heon, de token on iyecetu kta he.

35 Unkan ohnihde wakan kin waayupte ca heciya; Woniya Wakan kin en niu kta, qa Iyotan Wankantu towaśake kin aohanziniye kta, qa hecen taku wakan wan yaton kte cin he Wakantanka Cinhintku kin eciyapi kta.

36 Unkan inyun, Elisabeth icepanśiyaye cin, he wakanka tuka iś eya wanna hokśin itpihnaka ce, qa hokśin yuhe sni eciyapi qon, he wanna wi kin de iśakpe.

37 Wakantanka ekta taku okihipica śni wanica ce.

38 Unkan Mary heya; Itancan ookiyemaye cin wanmayaka we ; nioie kin iyecen ecamiconpi nunwe. Hehan ohnihde kin elipeya kihda.

39 Unkan anpetu kin hena en Mary inajin, qa koyahanna hośki makoce kin, Juda otonwe wan ekta iyaya : 


\section{LUKAS.}

$40 \mathrm{Qa}$ Zacariyas ti kin en tin iyaye, ca Elisabeth okiya.

41 Unkan Elisabeth Mary ia nahon qehan, itpi mahen hokśiyoqopa kin śkehanhan; hehan Elisabeth Woniya Wakan kin ojudan :

42 Qa hotankakiya hotanin, qa heya; Winohinca opeya niye niyawaśtepi, qa niitpi kin etanhan icage kte cin he yawaśtepi ce.

43 Qa Itancan mitawa hunku kin ekta mahi kte cin de token kapi he.

44 Inyun, iyae cin noge iyohpemaye cehan, hecehnana miitpi mahen hokśiyoqopa kin wowiyuśkin on skehanhan.

45 Unkan tuwe wicada qon he yawaśtepi: Itancan kin taku eciye ciqon hena ecen yuśtanpi kta ce, eya.

46 Unkan Mary heya; Minagi kin Itancan kin yatan;

47 Qa mitaniya kin he Wakantanka Wanikiya mitawa kin on iyuśkin ece.

48 Taokiye kuya un kin ekta ahimatonwan on etanhan inyun, detanhan wicoicage kin owasin yawaśtepi emakiyapi kta ce.

49 Tuwe waśake cin he taku hinca ecamicon; unkan caje kin wakan ce.

50 Tona kokipapi kin hena wicoicage qa wicoicage kin onśiwicakida ece.

51 Iye isto kin on wowaśake hdutanin; witantanpi kin hena taku cante mahen wacinyuzapi kin en wicayuomdeca.

52 Waśakśakapi kin oyanke etanhan kun hdicuwicaye ca, kuya unpi qon hena wankan wapa awicaya.

53 Wotektehdapi kin hena taku waśteśte on imnahanwicaye, ca wijicapi kin iś cokakadan tokan yewicaśi.

54 Iye towaonśida kiksuye cin on taokiyeye cin Israel he iciya ece.

55 Hunkakewicunyanpi owicakiye ciqon iyececa, Abraham iye cinca kin om, owihanke wanica.

56 Unkan wi yamni ecetu hehanyan Mary Elisabeth kici un, qa hehan iye ti elsta kihda.

57 Elisabeth cinca ton kte cin wanna iyehantu; unkan hokșidan wan ton.

58 Unkan ikiyedan unpi kin hena, içepanwicaye cin koya, Itancan kin nina onśikida nahonpi ; hecen kici iyuśkinpi.

59 Unkan anpetu iśahdogan qehan, hokśiyoqopa kin bahidayapi kta on hipi; unkan atkuku Zacariyas caje kin he icajekiyapi.

60 Unkan hunku kin waayupte ca heya, Hiya; tuka Johannes eciyapi kta.

61 Unkan heciyapi; Takuwicayaye cin tuwedan hecen eciyapi śni ce.

62 Unkan atkuku kin iś token eya cajeyate kta hecinhan, he iyuteya iwangapi.

63 Unkan iś wowapi akan kagapi wan da, qa; Johannes he caje kin ee ce, eya owa. Unkan owasin inihanpi.

64 Unkan hecehnana i kin yukawapi, qa ceji kin kiyuśkapi; unkan ie, ca Wakantanka yatan.

65 Unkan okśan tipi kin owasin wikopapi: unkan iapi kin dena owasin Juda hośki kin owancaya yaotaninpi.

66 Unkan ton: nahonpi kin owasin cante mahen awacin unpi, qa heyapi ; De taku hokśiyoqopa kta he. Unkan Wakantanka nape kin he kici un. 


\section{WICOWOYAKE 2.}

67 Hehan atkuku Zacariyas Woniya Wakan ojudan, qa wokcan qa heya;

68 Itancan Wakantanka Israel tawa kin he taoyate kin wanna wicahiyohi, qa opewicakiton, on etanhan yawaśtepi nunwe :

69 'Taokiye Dawid ti kin en wanikiyapi he wan yuwankan eunkicihdepi ce :

70 Maka lkin tokaheya icage cin ehantanhan, wicaśta wokcan wakan tawa ipi kin eciyatanhan, oie kiton kin hena iyecetu :

71. Hecen tokaunyanpi qa unkiyuśepi kin hena napepi kin etanhan niunkiyapi kta;

72 Wowaonśida hunkakewicunyanpi cajewicakiyate ciqon, he ecen econ kta, qa wolkiyapi wakan tawa kin he kiksuye kte;

73 Abraham ateunyanpi kin he taku wakanyan eciye ciqon he hee kta ce ;

74. Decen ionśiunkidapi kta, tona tokaunyanpi nape kin etanhan unkiyuśsapi kinhan, wokokipe codan ohoundapi kta,

75 Iye itokam, wicoowotanna qa wicoecetu kin en, tohanyan unnipi kin hehanyan.

$76 \mathrm{Qa}$ niye, hokśiyoqopa, Wicaśta wokcan Iyotan Wankantu tawa kin eniciyapi kta; Itancan tacanku kin wiyeya yecage kta on ite kin itokam de kta;

77 Taoyate woahtani wicakicicajujupi kin eciyatanhan wanikiyapi sdonyapi kte cin he wicayaqu kta ;

78 Wakantanka unkitawapi canteunkiyapi kin heon etanhan; qa heon wankan tanhan anpao kin hiyounhipi ce;

79 Hecen otpaza qa wiconte ohanzi kin ehna iyotankapi kin hena iyoyamwicaye kta; qa unsihapi lkin wookiye canku kin ohna unkayapi kta ce, eya.
80 Unkan hoksiyopa kin icage, ca tawacin kin waśaka aya; unkan Israel en taniniciye lite cin hehanyan, makoskan en ece un.

\section{WICOWOYAKE 2.}

1 Unkan anpetu kin hena en, Kesar Agustus, maka kin owancaya wicaśta owicawapi kta, wakiconza.

2 Kurenios Suria en wicaśtayatapi yanke cin he ehan tokaheya owicawapi kin de yuśtanpi. 3 Unkan owasin toketken tonwanyanpi qon owicawapi kta e ektakta kipi.

4. Unkan Joseph, Dawid ti ga. wicowazi tawa kin hetanhan, heon iś eya, Galile en Nazareth otonwe kin etanhan ye ca, Bethlehem Dawid totonwe kin ekta ki ;

5 Mary tawicuye kte cin he kici owapi kta; he wanna cinca ton kta ikiyedan.

6 Unkan hen yukanpi kin icunhan, anpetu en cinca ton kte cin wanna iyehantu.

7 Hecen cinhintku tokapa kin ton, qa śina on hduskite ça, wanunyanpi en wotapi wan en ohnaka; timahen owicakan ફ́ni heon etanhan.

8 Unkan makoce kin he en tahincaska awanwicayakapi kin heca hanyen optaye tawapi kin awanwicahdakapi.

9 Unkan iho, Itancan taohnihde wan en wicahi, qa Itancan tawookitanin kin ohomni iyojanjanwicaya; unkan nina wikopapi.

10 Unkan ohnihde wakan kin hewicakiya; Wikopapi śni po ; iho, wopida tanka wootanin waste oyate kin owancaya ecen ye kte cin, he eca hosi cicahipi ce.

11 Anpe dehan Dawid totonwe 89 


\section{LUKAS.}

kin en Wanikiya wan nicitonpi, Messiya Itancan kin he hee.

$12 \mathrm{Qa}$ on sdonyayapi kte cin he dee; Hoksiyoqopa kin sina on yuskiskitapi qa wanunyanpi en wotapi wan ohna wanka iyeyayapi kta ce.

13 Unkan ihnuhanna mahpiya ekta unpi kin wicota ohnihde wakan kin kici hiyeya, Wakantanka yatanpi qa heyapi ;

14 Iyotan wankantu ekta Wakantanka wowitan yuha nunwe, maka akan wookiye qa wicaśta ekta wicokiciyuwaśte.

15 Unkan mahpiya ohnihde kin hena elipeya wicakiyahdapi qehan, wicaśta tahin caska awanwicayakapi kin hekiciyapi ; Wanna Bethlehem ekta unyanpi, qa taku hiyohi Itancan unkokiyakapi kin de wanunyakapi kta ce.

16 Hecen koyahanna upi, qa Mary Joseph kici, qa hokśíyoqopa kin wanunyanpi en wotapi wan ohna wanka iyeyapi.

17 Unkan wanyakapi qehan, hokśiyoqopa kin on iapi nahonpi qon, he owancaya yaotaninpi.

18 Unkan tahincaska awanwicayakapi taku yaotaninpi kin he tona nahonpi kin owasin yuśinyayapi.

19 Tuka Mary wicoie kin dena owasin cante mahen okihnake ca awakicin un.

$20^{\circ}$ Unkan tahincaska awanwicayakapi kin hena kihdapi, qa taku nahonpi qa wanyakapi kin on Wakantanka yaonihanpi qa yatanpi ; taku owicakiyakapi qon he iyececa.

21 Unkan wanna anpetu iśahdogan, hokśiyoqopa bahdayapi kta hehan JEsus eciyapi; nahahin itpihnakapi śni he ehan mahpiya ohnihde kin hecen caśton.
22 Unkan Moses woope kage cin iyecen, anpetu en ihdukasote kte śni hena wanna henakeca, hehan Itancan kin qupi kta e Jerusalem ekta hdoupi.

23 Itancan woope tawa kin en owapi qon iyececa; Tona tokapapi, wica eca, otoiyohi Itancan kin ekta wakan eciyapi kta ce.

24 Qa nakun wawayuśnapi kta, token Itancan toope kin en eyapi qon he iyececa; Wakiyedan tawanjidan, qa iś wakiyedan cinca nonpa ce.

25 Unkan iho, Jerusalem en wicaśta wan Simon eciyapi ; he wicaśta owotanna qa cekiya ece kin heca, ya Israel Wokicanpte kin ape un; unkàn Woniya Wakan kin kici un.

26 Unkan he te śni itokam Itancan Messiya tawa kin he wanyake kta, Woniya Wakan kin okiyaka.

$27 \mathrm{He}$ Woniya kin on tipi wakan kin en tin hiyu ; unkan hunkakewicaye cin hokśiyoqopa Jesus, wicoope kin eciyatanhan ecakiconpi kta e en hdoupi ;

28 Hehan adoksohan yuze, ca Wakantanka yawaśte, qa heya ; 29 Mayuha, nitaokiye kin wanna wookiye yuha iyayeyaye kta; 30 Wowanikiye nitawa kin he miiśta kin on wanmdaka ce ;

31 Oyate kin owasin wicitokam wiyeya yehnake cin he ;

32 Ojanjan wan oyate kin aojanjanwicaye kte cin, qa nitaoyate Israel wookitanin kin, he hee ce, eya.

33 Unkan taku eeiyapi kin hena on hunku qa Joseph yusinyayapi.

34 Ũnkan Simon wicayawaśte, qa hunku Mary heciya; Inyun, Israel en wicota hicahanpi, qa ake inajinpi kte cin on hokśiyopa kin de ehdepi, qa nakun 
WICOWOYAKE 3.

wowapetokeca ienhdepi kte cin ee kta;

35 Qa nakun mazasagye wan on nitaniya kin canipapi kte; qa hecen wicacanteoze ota yuotaninpi kta ce, eya.

36 Unkan waayate wanji Anna eciyapi, Phanuel cunwintku, qa Aser wicowazi kin etanhan; he wanna wakanka hinca, qa hihnaton kin etanhan waniyetu sakowin hehanyan hihnaku kici un :

37 Qa he wanna wiwazica, waniyetu wikcemna śahdogan sanpa topa ecetu, qa tipi wakan kin en ece un, qa wote śni unpi wocekiye eya ahna on ohoda ece.

38 Unkan he hehantudan hin en $u$, qa iś eya Itancan kin yatan, qa Jerusalem en tona opewicakitonpi kin ape unpi kin hena owasin Jesus cajewicakiyata.

39 Unkan Itancan wicoope tawa kin owasin ecekcen yuśtanpi qehan, Galile en iye otonwe tawapi Nazareth he ekta kihdapi.

40 Unkan hokśiyopa kin icage, ca woniya kin en waśaka aye, ca wicoksape kin on ojudan; unkan Wakantanka towaśte kin he kici un.

41. Woacakśin wotapi eca, hunkakewicaye cin waniyetu towanakeca Jerusalem ekta ipi ece.

42 Unkan Jesus wanña waniyetu akenonpa, hehan wotapi wicohan kin iyececa, Jerusalem ekta ipi.

43 Unkan anpetu kin yuśtanpi qehan, hdicupi, tuka hokśiyopa Jesus hekta Jerusalem en yanka ; tuka hunku Joseph kici he sdonyapi śni.

44 Tuka ptaya hdapi kin en opa kecinpi, hecen anpetu wan- jidan iyooptapi, qa takuwicayapi kici sdonkiciyapi ko wicehna okidepi.

45 Qa iyeyapi śni, hehan Jerusalem ekta ake icicawin akin ipi.

46 Unkan yamni can, hehan tipi wakan kin en wannspekiyapi kin wicacokam waanawicagoptan, qa wiwicawanh yanka iyekiyapi.

47 Unkan wacin ksape cin; qa waayupte cin tona nahonpi qon owasin inihanpi.

48 Unkan wanhdakapi qehan yuśinyayapi; qa hunlku kin heciya ; Cinś, tokeca decen unkoyakihandapi he; iho we, niyate kici wacin iyokiśinya ocide ce.

49 Unkan hewicakiya; Tokeca omayadepi he: Atewaye cin wicolian tawa kin he ito owecipe kta kecannipi śni he.

50 Unkan taku ewicakiye cin he okahnigapi śni.

51 Hecen om hde, ca Nazareth ekta ki, qa anawicakigoptan un. Unkarı hunku kin wicoie kin dena owasin cante mahen yuha un.

52 Unkan Jesus sanpa ksape ca hanska icaga ; qa Wakantanlia wicaśta ko ekta waśtedakapi.

\section{WICOWOYAKE 3.}

1 Unkan Tiberius Kesar wicaśtayatapi un waniyetu iakezaptan, Pontius Pilate Juda en itancan, Herod Galile en itancan, qa iye sunkaku Philip Itureya qa Trakonitos en itancan, qa Lusanius Abilene en itancan ;

2 Qa Annas Kaiaphas kici wośna kaga itancanpi qon he ehan, hewotahedan ekta, Johannes Zacariyas. cinhintku kin Wakantanka oie kin hiyohi. 


\section{LUKAS.}

3 Unkan he Jordan kahda makoce kin owancaya en $u$, qa woahitani kajujupi kta on iyopeiçiyapi baptem wicaqupi kin he oyaka:

4. Wicaśta wokcan Isaya oie wowapi kin en owapi qon he iyececa; Wicaho wan tuwe makotahedan elita heya niyan; Itancan tacanku kin wiyeya kicaga po, ocanku tawa kin kiciyuowotan po:

5 Kaksiza owasin ojuyapi, qa heyaka paha ko owasin kahukun iyeyapi kta, qa pakśikśan kin hena yuowotanpi, qa ocanku tahtage cin hena yumdayapi kta ce ;

6 Qa wicacelipi kin owasin Wakantanka wowanikiye kin wanyakapi kta ce.

7 Unkan wicota baptem wicaqu kte cin en ahi kin hena hewicakiya; Wamduśka wicoicage kin, tuwe wocanniye u kte cin etanhan nape niśipi he.

8 Hecen iyopeiçiyapi iyececa waskuyeca icaliya po, qa, Abraham ateunyanpi ce, cante mahen ecinpi śni po; miye heciciyapi; Wakantanka inyan kin dena etanlıan Abraham cinca kicage kta okihi.

9 Unkan iś eya onspe kin wanna can hute kin en ehnakapi; heon etanhan can kin tona waskuyeca waśte aicage śni kin hena owasin kawankapi qa pe$\tan$ ehpeyapi ece.

10 Unkan oyate kin, Hehan unkiye token econkupi kta he, eya iwangapi.

11 Waayupte ça hewicakiya; Tuwe onkdohda nonpa yuhe cinhan, he tuwe nice cin unma qu kta; qa tuwe woyute ton kinhan, iś cya ecen econ kta ce.

12 Hehan wamnayanpi kin iś nakun baptem wicaqu kta on en hipi qa heciyapi ; Waonspekiye, unkiye token econkupi kta he.

13 Unkan hewicakiya; Wakiconzapi kin isanpa kicapi śni po, eya.

14 Unkan akicita kin iś eya wiwangapi qa heciyapi ; Qa unkiś token econkupi kta he. Unkan hewicakiya; Wicaśta kin tuwedan wakokipe kicagapi śni, qa tuwedan oitonśniyan taku iyaonpapi śni po ; qa wokajuju niçupi kin he on cante waśte po.

15 Unkan oyate kin owasin wakta hiyeya, qa wicaśta owasin Johannes on awacinpi, he Messiya kin hee, qa iś hee śni hecinhan;

16 Hehan Johannes waayupte ca owasin hewicaliya; Awicakehan mini on baptem cicupi; tuka wanji mikapeya waśaka $u$, he iye tahanpe hankpan kin weciyuśke kta iyemacece śni; he qe Woniya Wakan peta ko on baptem nicupi kta.

17 He iye wicaduge nape ohna hduhe, ca owanka tawa kin tanyan hduska kta; qa aguyapi su kin he tpahi, qa canwohnaka kin en okihnake kta; tuka ha kin e peta kasnipica śni wan on hulinaliye kta ce, eya.

18 Unkan wahokonwicakiye cin en taku toktokeca nakun ota oyate kin owicakiyaka.

19 Unkan Herod wicaśta itancan kin, iye sunkaku tawicu $\mathrm{He}$ rodias hee on, qa taku śica $\mathrm{He}$ rod econ kin owasin on iyopeya; 20 Hecen taku owasin sanpa akicage ca, wicakaśka tipi kin en Johannes kaśka hnaka.

21 Unkan oyate kin owasin baptem wicaqupi, qa Jesus iś eya baptem qupi, qa cekiya un qehan, mahipiya kin yuzamnipi ;

$22 \mathrm{Qa}$ Woniya Wakan kin wakiyedan kahya tantonyan kun $u$, 


\section{WICOWOYAKE 4.}

qa en iyahan; unkan mahpiya eciyatanhan wicaho wan hiyu, qa heya; Micinkśi waśtewakidake cin he niye; niye on iyomakipi hinca.

23 Unkan Jesus iye wanna waniyetu wikcemna yamni kta, Joseph cinhintku kin hee kecinpi, he Heli etanhan,

24 He Matthat etanhan, he Lewi etanhan, he Melki etanhan, he Janna etanhan, he Joseph etanhan,

$25 \mathrm{He}$ Mattathias etanhan, he Amos etanhan, he Naum etanhan, he Esli etanhan, he Nagge etanhan,

26 He Maath etanhan, he Mattathias etanhan, he Seme etanhan, he Joseph etanhan, he Juda etanhan,

27 He Joanna etanhan, he Resa etanhan, he Zorobabel etanhan, he Salathiel etanhan, he Neri etanhan,

$28 \mathrm{He}$ Melki etanhan, he Addi etanhan, he Kosam etanhan, he Elmodam etanhan, he Er etanhan,

$29 \mathrm{He}$ Jose etanhan, he Eliezer etanhan, he Jorim etanhan, he Matthat etanhan, he Lewi etanhan,

$30 \mathrm{He}$ Simeon etanhan, he Juda etanhan, he Joseph etanhan, he Jonan etanhan, he Eliakim etanhan,

31 He Melea etanhan, he Menan etanhan, he Mattatha etanhan, he Nathan etanhan, he Dawid etanhan,

$32 \mathrm{He}$ Jesse etanhan, he Obed etanhan, he Booz etanhan, he Salmon etanhan, he Naasson etanhan,

$33 \mathrm{He}$ Aminadab etanhan, he Aram etanhan, he Esrom etanhan, he Phares etanhan, he Juda etanhan,
34 He Jakob etanhan, he Isaak etanhan, he Abraham etanhan, he Thara etanhan, he Nacor etanhan,

$35 \mathrm{He}$ Seruk etanhan, he Ragu etanhan, he Phalek etanhan, he Eber etanhan, he Sala etanhan, $36 \mathrm{He}$ Kenan etanhan, he Arphaksad etanhan, he Sem etanhan, he Nowa etanhan, he Lamek etanhan,

$37 \mathrm{He}$ Mathusala etanhan, he Fnok etanhan, he Jared etanhan, he Maleleel etanhan, he Kanan etanhan,

$38 \mathrm{He}$ Enos etanhan, he Seth etanhan, he Adam etanhan, he Wakantanka etanhan.

\section{WICOWOYAKE 4.}

1 Unkan Jesus Woniya Wakan kin ojudan, Jordan eciyatanhan hdi; qa Woniya kin makotahedan ekta iyayeya ;

2 Anpetu wikcemna topa hehanyan Wakanśica wawiyutanyan. Unkan anpetu kin hena en takudan yute śni ; tuka hena ihunniyan hehan wotektehda.

3 Hehan Wakanśica heciya; Wakantanka Cinhintku kin he niye hecinhan, inyan kin de aguyapi icage kta, keya wo.

4 Unkan Jesus waryupte ca heciya; Aguyapi ecedan on wicani kte śni ; tuka. Wakantanka oie kin owasin on wicani kta ce, eya owapi ce.

5 Hehan Wakanśica paha wan tehanwankantu ekta aye ca, wancake maka wokiconze lín owasin kipazo.

6 Unkan Wakanśica heciya; Wicowaśake kin de wicookitanin ko owasin cicu kta; hena owasin yuhemakiyapi, qa tuwe wacin kinhan waqu kta.

7 Heon etanhan niś mitokam 


\section{LUKAS.}

makata ehpeniçiye cinhan, owasin nitawa kta ce.

8 Unkan Jesus waayupte ca heciya; Satan, mitapetepa tanhan ya wo: Itancan Wakantanka nitawa kin, he iye itokam makata ehpeniciye kta, qa iye iśnana ahoyape kta ce, eya owapi ce.

9 Hehan Jerusalem ekta ahi, qa tipi wakan inkpa kin akan ehde, qa heciya; Wakantanka Cinhintku kin he niye hecinhan, hetanhan kun ehpeiciya wo.

10 Kaken wowapi en kagapi qon; Ohnihdewicaye cin hena niye oll econ wicaśi, niyuhapi kta ;

11 Qa napepi kin ohna yuwankan niyuzapi kta; qa hecen tukten inyan kin en siha ibonito lkte śni, eya owapi ce, eya.

12 Unkan Jesus waayupte ca heciya; Itancan Wakantanka nitawa kin he iyutanyaye kte śni ce, eya owapi qon.

13 Unkan Wakanśica wowiyutanye kin owasin yuśtan qehan, tona can elipeya kihda.

14 Hehan Jesus Woniya towaśake kin yuha Galile en hdi ; unkan ihdukśan makoce wanke cin owancaya he oyakapi.

15 Unkan omniciye tipi tawapi kin ohnahna waonspekiya ece, hecen owasin yuonihanpi.

16 Unkan Nazareth en icahyapi qon he ekta hdi; qa econ cce kin he iyecen, anpetu wakan icunhan, omniciye tipi kin en tin iyaye ça, wowapi yawa kta inajin.

17 Unkan Isaya wicaśta wokcan tawowapi kin qupi. Unkan wowapi kin yumdaye çehan, decen owapi kin iyeya;

18 Itancan Woniya tawa kin he akan maun; heon wahpanicapi kin wotanin waśte kin owi94 cawakiyake kta e sdamakiya; tona cante psakawahanpi kin asniwicawaye kta on u maśi ; wayaka unpi kin wicalkiyuśkapi kta, qa iśtagongapi kin ake tonwanpi kte cin omdake kta; tona kahidehdecapi kin hena wicawakiyuśke kta ;

19 Qa Itancan omaka oiyokipi tawa kin omdake kta ce.

20 Unkan wowapi kin ecen eyaku, qa ookiye kin he kicu, qa iyotanka. Unkan ommiciye tipi kin ohna hiyeye cin owasin opahitapi.

21 Unkan hehan hewicakiya; Anpetu kin de ninogepi lin en wowapi kin de yuecetupi ce.

22 Unkan owasin yaotaninpi, qa wowaonśida oie iye i kin etanhan inanpe cin on yuśinyayapi ; qa heyapi; Joseph cinhintku kin he dee śni he.

23 Unkan hewicakiya; Awicakehan iapi kin de ccen emayakiyapi kta; Niye pejihuta wicaśta kin, asniiçiya wo: Kapernaum ekta token ecanon naunhonpi kin, makoce nitawa kin den nakun ecen econ wo.

24 Unkan heya; Awicakehan heciciyapi; Wicaśta wokcan tuwedan iye tamakoce kin en iyowinkiyapi śni ece.

25 Tuka awicakehan heciciyapi ; Elias taanpetu kin en, waniyetu yamni sanpa wi śakpe hehanyan malipiya kin natakapi; qa makoce kin owancaya wicaakihan hince ciqon he ehan, Israel en wiwazica ota.

26 'Tuka hena wanjidan Elias ekta ye śipi śni; Sidon en Sarepta otonwc kin en, winohinca wiwazica wan heceedan ekta ye śipi.

27 Nakun Elisha wicaśta wokcan ni un qehan, lepros ececa wicota Israel en unpi, tuka hena 


\section{WICOWOYAKE 5.}

wanjidan yuskapi śni, Naeman Suriya wicaśta kin heceedan ce. 28 Unkan omniciye tipi ohna hiyeye ciqon hena nahonpi qehan, owasin śihdapi hinca;

29 Qa najin hiyayapi qa otonwe kin itankan iyayeyapi, qa paha akan otonwe hdepi kin he matete ekta ayapi, qa kun elipeyapi kta. 30 Tuka iye wicacokaya tanhan iyoopta iyaye ca kihda.

31 Qa Galile en Kapernaum otonwe kin he ekta hi, qa anpetu wakan eca waonspewicakiya ece.

32 Unkan waonspewicakiye cin on inihanpi ; oie kin he wowaśake kicica nakaeś.

33 Unkan omniciye tipi kin ohna wicaśta wan wakan śica śapa woniya kin yuha; qa he hotankakiya hoyeya ;

34. Qa heya; Hanta wo, Jesus Nazareth, niye qa unkiye taku unkicicapi he; ihangunyayapi kta yahi he; Wakantanka Taku Wakan Wanji tawa kin he niye e sdonciya ce.

35 Unkan Jesus kiśice ça heciya; Inina un, qa wicaśta kin etanhan tankan hinapa wo, eya. Unkan wakanśice cin wicaśta qon wicacokam ehpeye cehan, etanhan tankan hinapa; tuka ksuweye śni.

36 Unkan owasin inihanpi, qa iyakitedan hekiciyapi; De taku oie kin; wicookihi wicowaśake ko on woniya śape cin econ wicaśi eca, tankan hinanpapi ece.

37 Unkan ihdukśan makoce wanke cin owancaya he oyakapi.

38 Unkan omniciye tipi kin etanhan hdicu, qa Simon ti kin en in iyaya. Unkan Simon kunku kin he tancan wicakata ececa hinca; hecen on cekiyapi.
39 Unkan en inajin, qa tancan kata kin he kiśica; unkan asni hinhda: qa hecehnana najin hiyaye ca, owicakiya.

40 Unkan wi iyaya hehan, woyazan ocaje ota on wicayazan tona wicayuhapi kin hena en awicahipi ; unkan otoiyohi nape awicahnake ça asniwicaya.

$41 \mathrm{Qa}$ wakan śica iś eya ota wicota etanhan hinanpapi, qa heya niyanpi; Wakantanka Cinhintku Messiya kin he niye ce. Unkan iye wicakiśice ca, Messiya hee sdonyapi kin he, eyapi kta iyowicaki śni.

42 Unkan wanna anpao hinape cehan tokan iyaye, ca makotahedan ekta ya; unkan oyate kin odepi, qa yanke cin ekta ahi, qa ehpeya iwicayaye kte cin iyanaptapi.

43 Unkan hewicakiya; Wakantanka tokiconze kin otonwe toktokeca nakun ohna omdake kta; heon etanhan u maśipi ce. 44 Hecen Galile omniciye tipi kin hena ohnahna woyaka ece.

\section{WICOWOYAKE 5.}

1 Unkan oyate kin Wakantanka oie kin nahompi kta e aohduteyapi qehan, Geneseret mde kin icahda inajin.

2 Qa mde kin en wata nonpa wanka wanyaka; tuka hokuwapi kin iś wanna tokan iyayapi, qa ho kin hdujajapi.

3 Unkan wata unma Simon tawa kin he en ope ca, kitanna canan wapa iyayeye kta cin. Hehan en iyotanke ca, wata kin etanhan oyate kin waonspewicakiya.

4. Unkan wanna ayaśtan qehan Simon heciya; Mini śbe kin ekta iyaye ça ho kin minin iyohpeya wo. 
5 Unkan Simon waayupte, ca heciya; Waonspekiye cin, hanyetu osan htaunnipi, qa takudan unktepi śni; tuka nioie kin on ho kin iyohpewaye kta ce.

6 Unkan heconpi qehan, hogan utkanna yuzapi ; unkan ho kin papsakapi.

7 Unkan tawaśitkupi wata unma en opapi qon hena namwicakicawinpi, en upi qa owicakiyapi kta. Unkan en hipi qa wata napin ojukiyapi, hecen iyujimnana hiyeya.

8 Unkan Simon Inyan he wanyake cehan, Jesus hupahu kin en makata ehpeiciye ça heya; Itancan, elipeya imayaya wo, wicaśta wahtani sa hemaca ce.

$9 \mathrm{He}$ iye qa tona om un qon hena hogan yuzapi kin on etanhan owasin inihanpi.

10 Unkan Jakob qa Johannes Zebede cinhintku kin hena oza, Simon tawaśitkuwicaya, iś eya inihanpi. Unkan Jesus Simon heciya; Wikope śni wo, detanhan wicaśta kin wicaduze kta ce.

11 Unkan wata qon hutata ahdihunipi qehan, owasin elipekiyapi, qa iyahna yapi.

12 Unkan otonwe wan en un qehan, iho, wicaśta wan lepros ececa hinca, he Jesus wanyake çehan, ite makipuskin elpeiçiye ca, cekiye ca heya; Itancan, yacin kinhan mayaduska kta oyakihi.

13 Unkan nape yekiye, ça yutan, qa heya; Wacin ce: ska un wo, eya. Unkan wancake lepros ececa qon asni hinhda.

14 Unkan tuwedan okiyake sni śi t tuka wawayuśna kin ekta ye ca wanyagiciye kta, qa wayuskapi kta on token Moses econ wicaśi qon he ecen econ kta, keya; hecen wowicakiyake kta.
15 Tuka heon iyotan tankaya wicohan kin he oyakapi; hecen wicota en mniciyapi, nahonpi lita, qa wayazankapi wicayuhapi kin asniwicaye kte cin heon.

16 Hehan icunonpa makotahedan wan ekta ye ca wocekiye eya.

17 Unkan anpetu wan waonspewicakiya icunhan, Pharisee qa wicoope onspekiye cin hena, Galile otonwe kin owasin, qa Juda qa Jerusalem etanhan, en ahi kin hena en iyotankapi; unkan Itancan towaśake kin asniwicaye kta e en un.

18 Unkan iho, wicaśta wan tatake cin he owinja ohna wicaśta yuha upi : qa timahen ayapi qa itokam ehnakapi kta akitapi.

19 'Tuka wicota kin on token en aipi kte śni wanyakapi qehan, tipi akan inajinpi, qa akahpe yuhdokapi eciyatanhan cokaya Jesus itokam kun hiyuyapi.

20 Unkan wacinyanpi kin he wanyake cehan, heciya; Wicaśta, wayahtani kin nicicajujupi ce.

21 Unkan wowapi kagapi qa Pharisee kin iś waakinicapi qa heyapi; Dé tuwe e taku sica decen eya he. Tuwe woahtani kajuju kta okihi he; Wakantanka ecedan okihi.

22 Tuka tawacinpi kin Jesus iwicayukcan, hehan waayupte ca hewicakiya; Taku e cante mahen ayakinicapi he :

23 Wayahtani kin nicicajujupi ce; qa iś, Najin "qa mani wo, eyapi kte cin unma tukte waśakadan he.

24 Tuka Wicaśta Cinhintku kin he iś maka akan woahtani kajuju kta okihi sdonyayapi kta ; hehan țatake cin he heciya; Najin qa nitowinja ehdaku qa 
WICOWOYAKE 6.

yati kin ekta hda wo, eciciya ce, eya.

25 Unkan wancake wicitokam najin hiyaye, ca akan wanke ciqon he ehdaku, qa iye ti kin ekta hde, ça Wakantanka yatan.

26 Unkan owasin inihanpi, qa Wakantanka yatanpi ; qa wikopapi hince, ca heyapi ; Wicohan nakaka toktokeca wanunyakapi ce, eyapi.

27 Unkan taku kin dena iyohakam hetanhan ye, ca wamnayanpi kin heca wanji Lewi eciyapi, wamnayanpi oyanke kin en iyotankehan yanka e wanyaka; qa, Miyahna u wo, eciya. 28 Unkan taku owasin ehpeye ça, najin hiyaye ça, ihakam iyaya.

29 Unkan Lewi iye ti kin en wohanpi tanka kicaga; unkan wamnayanpi kin iś wicota, qa toktokeca nakun en opeya wotapi kta iyotankapi.

30 Tuka wowapi kagapi wicayuhapi qa Pharisee kin hena waonspewicakiye cin wicakigepi, qa heyapi ; Tokeca e wamnayanpi qa wahtanipi sa om wayatapi qa wadatkanpi ece he.

31 Unkan Jesus waayupte ca hewicakiya; Tona zanipi kin hena pejihutawicaśta cinpi śni, tuka wayazanpi kin.

32. Owotanpidan kin hena iyopeiçiyapi kta e wicakico wahi śni, tuka wahtanipi sa.

33 Unkan heciyapi ; Tokeca e Johannes waonspewicakiye cin hena ijehan wote śni unpi qa wocekiye eyapi he, qa Pharisee tawapi kin iś eya; tuka nitawa kin wotapi qa wayatkanpi ece.

34 Unkan hewicakiya; Hihnaton ti kin cinca kin hena tawicu ton kin he iś owicapeya un kin icunhan wote śni wicayakiyapi kta oyakihipi he.

Dak.
35 Tuka anpetu kin u kta, en tawicu ton kin he ewicakiciyakupi kta; hehan anpetu kin hena en wote śni unpi kta.

36 Unkan wiyacinpi wan owicakiyaka: Wicaśta tuwe dan śina teca onśpa śina tanike cin en akihdagye śni ece ; heconpi kinhan teca qon iś yuhdeca ece, qa onśpa teca etanhan kin he tanike cin kicica śni ece.

37 Qa nakun wicaśta tuwedan miniśa teca ojuha tanike cin en okaśtan śni ece; heconpi kinhan miniśa kin skepe kta, qa ojuha kin atakuni kte śni.

38 Tuka miniśa teca kin he ito ojuha teca en ohnakapi kta; qa sakim yutehanpi ece.

39 Iś eya wicaśta tuwedan miniśa tanika wanna yatke ça, hehan hinnakaha teca cin śni; Tanike cin eeś waśte ce, eya ece.

\section{WICOWOYAKE 6.}

1 Unkan anpetu wakan inonpa tokaheya, hehan wojupi kin ehna iyaya; unkan waonspewicakiye cin is wahuwapa yuksapi, napopabagapi, qa yutapi.

2 Hehan Pharisee kin wanjikji hewicakiyapi; Tokeca e anpetu wakan kin en taku iyowinwicakiyapi śni kin he eca ecen ecanonpi he.

3 Unkan Jesus awicayupte ça heya; Dawid token econ qon hee kaeś tohinni dawapi śni he; iye qa tona om un qon wotektehdapi qehan.

4 Wakantanka tipi tawa kin en tin iyaye, ca aguyapi taninyan ehnakapi, qa wawayuśnapi kin iye iśnana hetanhan yutapi kte cin iyowinwicakiyapi qon, he icu, qa yute, ca om unpi qon hena iś eya hetanhan wicaqu.

5 Unkan hewicakiya; Wicaśta 97 


\section{LUKAS.}

Cinhintku kin iś nakun anpetu wakan kin Itancan ce.

6 Unkan anpetu wakan tokeca wan omniciye tipi kin en tiu iyaye, ca waonspekiya: unkan wicaśta wan nape etapa kin śnija e en yanka.

7 Unkan wowapi kagapi qa Pharisee kin hena anpetu wakan icunhan asniye kta hecinhan he iwanyakapi, taku iyaonpapi kta akitapi.

8 Tuka iye tawacinpi kin sdonwicaya, qa wicaśta nape śnije cin he heciya; Najin qa cokaya inajin wo. Unkan najin hiyaye ça en inajin.

9 Unkan Jesus hewicakiya; Miś ito taku wanji iciwangapi kta; Anpetu wakan icunhan ta$\mathrm{ku}$ waśte, qa iś taku śica econpi kta he ; wanikiyapi, qa iś wateyapi kta, unma tukte hecetu he, eya.

10 Unkan itanihdukśan owasin awicatonwe cehan, wicaśta qon heciya; Nape kin hdukatin wo. Unkan ecen econ; qa nape kin unina kin iyecen iyekicetu.

11 Unkan śihdapi hince, ca iye iyakitedan Jesus token ecakiconpi kta hecinhan he iwohdakapi.

12 Unkan anpetu kin hena en Jesus paha wan ekta wocekiye eya i ; qa hanyetu osan Wakantanka cekiya un.

13 Unkan wanna anpa qehan, waonspewicakiye cin wicakico, qa etanhan akenonpa wicahdahinige ça, Wahośiyapi, ewicakiya.

14 Simon he Inyan nakun eya caśton, qa he sunkaku kin Andrew, Jakob qa Johannes, Philip qa Bartholomew ;

15 Mattheos qa Thomas, Jakob Alpheus cinhintku, qa Simon nakun Zelotes eciyapi;
16 Qa Judas Jakob sunkaku, qa Judas Iskariot, nakun wiyopeye kte cin hee.

17 Hehan hena om kun hdicu. qa makomdaya en hdinajin; unkan waonspewicakiye optaye kin, qa Juda owancaya qa Jerusalem, qa mde kahdaya Turos qa Sidon, henakiya etanhan wicota hinca, hena ia nalionpi, qa tona wayazankapi kin asniwicayapi kta e en ahi :

18 Nakun tona woniya sapa on kakijapi kin hena; unkan asniwicayapi.

19 Unkan wicota kin iyulipa yutanpi kta akitapi; elanhan wowaśake hiyu qa owasin asniwicaya ece kin heon etanhan.

20 Unkan waonspewicakiye cin awicatonwe, ca heya; Niwahpanicapi kin niś niyawaśtepi ce; Wakantanka tokiconze kin he niye nita wapi.

21 Dehan wotekteyahdapi kin niś niyawaśtepi ce ; imnahanniyanpi kta. Dehan yaceyapi kin niś niyawaśtepi ce ; iyahapi kta. 22 Tohan wicaśta śicenidapi, qa yuiyog iyayeniyanpi, qa iennihdepi, qa Wicaśta Cinhintku kin on nicajepi kin taku śica iyecen tankan elipeyapi kinhan, niyawaśtepi ece.

23 Anpetu kin he on wiyuśkinpi, qa wopida on śkehanhan po ; iho, mahpiya ekta wokajuju tanka duhapi ; atewicayapi kin is eya iyecen wicaśta wokcanpi wicakuwapi qon.

24. 'Tuka winijicapi kin niś wotehi niciyankapi ece; wicocante waśte kin he wanna yahduhapi.

25 Winipipi kin niś wotehi niciyankapi ece; wotekteyahdapi kta. Dehan iyahapi kin niśs wotehi niciyankapi ece; waśinyahdapi qa yaceyapi kta. 


\section{WICOWOYAKE 6.}

26 Tohan wicaśta owasin tanyan eniciyapi kinhan, wotehi niciyankapi ece; atewicayapi kin hecen wicaśta wokcan itonśni wicakuwapi qon.

27 Tuka nakion dukanpi kin heciciyapi ce, Tokaniyanpi kin hena cantewicakiya po, qa śicenidapi kin hena tanyan ecawicakicon po;

28 Niyaśicapi kin wicayawaśte po, qa wawicanksiya nicuwapi kin hena wocekiye ewicakiciya po.

$29 \mathrm{Qa}$ tuwe iyoha sani kin en anipe cinhan unma eciyatanhan kipazo wo; qa tuwe śina inicicu kinhan, onkidohda kin nakun telinda śni wo.

30 Wicaśta otoiyohi taku nicida kin qu wo; qa tuwe woyuha nici kinhan, ake kica śni wo.

31 Qa wicaśta kin token ecaniconpi yacinpi kin, he ivecen ecawicakicon po.

32 Tona waśtenidapi kin henana waśtewicayadapi kinhan, wopida tukte e duhapi kta he: wahtanipi sa kin eepi kaeś tona cantewicakiyapi kin iś itkom cantewicakiyapi ece.

$33 \mathrm{Qa}$ tona tanyan ecaniconpi kin henana tanyan ecawicayeconpi kinhan, wopida tukte e duhapi kta he ; wahtanipi sa kin iś iyecen econpi ece.

34 Qa ake niçupi kta kecannipi kin henana owicayaqupi hecinhan, wopida tukte e duhapi kta he; wahtanipi sa kin iś wahtanipi sa owicaqupi ece, iyacinyan wicakicupi kta heon.

35 Tuka niś tona tokaniyanpi kin cantewicakiya po, taku waśte econpi qa owicaqu po, ake taku niçupi kta kecinpi śni po; kinhan wokajuju tanka duhapi kta, qa Iyotan Wankantu kin he cinca yaunpi kta: he iye tona pida śni qa śicapi kin cantewicakiya ece.

36 Hecen Niyatepi kin iś token waonśida kin niś eya he iyecen waonśida po.

37 Wayacopi śni po, kinhan niyacopi kte śni : owawicakiyepi śni po, kinhan owaniciyepi kte śni : wicakicicajuju po, kinhan nicicajujupi kta:

38 Wicaqu po, kinhan niçupi kta ; wiyutapi waśte, paoținzapi, paipuskicapi qa apaśboka, hecen wicaśta kin maku kin en niçupi kta. Wiyutapi on widutapi kin hee on winiciyutapi ece e kta.

39 Unkan wiyacinpi wan owicakiyaka: Iśtagonge cin iśtagonga napata yus aya okihi he: napin ośkokpa kin en iyolipayapi kte śni he.

40 Waonspekiyapi kin he waonspelkiye cin itokapa śni ; tuka tuwe yuśtanpi kin otoiyohi waonspekiye tawa kin iyecece kta. $41 \mathrm{Qa}$ tokeca nisunka iśta kin ohna sukaza yanke cin he wandaka; tuka niye niiśta kin ohna cankaga wanke cin he wanyahdake śni he.

42 Qa, Misunka, sukaza iśta ohna niyanke cin he ito ciciyuśdoke kta ce, token nisunka eyakiye kta he, qa icunhan niye niiśta kin ohna cankaga wanke cin he wanyahdake śni. Wanayakilibe cin, niś tokaheya cankaga iśta ohna niwanke cin he ito tokan ehpeya wo; qa hehan hinakaha nisunka iśta kin ohna sukaza yanke cin he yeciyuśdoke kta mdesya wandake kta ce. 43 Can wanji waśte kin waskuyeca śica icahye śni ; qa nakun ean wanji śice cin he waskuyeca waśte icahye śni.

44. Can kin otoiyohi waskuyeca tawa kin on sdonyapi ece : wicaśta kin taspanhu kin etanhan 99 


\section{LUKAS.}

suken pahipi śni, qa iś eya tokahu kin etanhan hastanhanka pahipi śni.

45 Wicaśta waśte kin he cante. woyuha waśte kin etanhan taku waśte icaliya ece; qa wicaśta sice cin he cante woyuha sice cin etanhan taku śice icahya ece: wicacante taku iyakicuya ohnaka kin he etanhan i kin eciyatanhan enapeya ece, eya.

46 Unkan tokeca, Itancan, Itancan, emayakiyapi ece, qa taku epe cin ecen ecanonpi śni he.

47 Tuwe ekta mahi, qa mioie nation, qa ecen econ kin he tuwe kicica hecinhan he ito ociciyakapi kta.

48 Wicaśta wan tipi kaga; unkan temahentu maka qe, ca oahehde kin imnija wan akan ehde: unkan minitan aye cehan, wakpa kin tipi kin he en nina kaduza, tuka kahuhuze kta okitpani, imnija akan ehdepi nakaeś, he iyececa.

49 Tuka tuwe nation tuka ecen econ śni kinhan, wicaśta wan oahehde codan maka akan tipi kage cin he iyececa; unkan he en wakpa kin nina kaduza, qa hecehnana hinhpaya; qa tipi kin he woatakuniśni tanka.

\section{WICOWOYAKE 7.}

1 Unkan oyate nalion hiyeye cin en iapi kin dena owasin wanna ecen yaśtan qehan, Kapernaum en $i$.

2 Unkan akicita opawinge wicayuhe cin wanji taokiye wan tehinda kin he wayazanke ca wanna te kta.

3 Unkan he wanna Jesus on nahon qehan, Juda hunkayapi kin hena ekta ye wicaśi, u kta qa taokiye kin asniye kte cin he icekiya.
4. Unkan hena Jesus ekta hipi qehan, awicakehan cekiyapi, qa, Hecakiconpi kte cin wicaśta kin he iyececa ce;

5 Unkoyatepi kin cantewicakiye ca, omniciye tipi wanji wanna unkicagapi ce, eyapi.

6 Unkan Jesus hena om hda. Unkan wanna tipi kin itehan śni qehan, akicita opawinge wicayuhe ciqon he iś kodawicaye cin hena ekta yewicaśi, qa heciya; Itancan kin, nagiyeiciye śni wo, wati kin en tin yahidu kte cin iyemacece śni ce :

7 Heon etanhan miye ekta ciu kta nakun iyececa miçida śni: tuka oic kin ecen eya wo, kinhan mitaokiye kin asni kta.

8 Miś eya wicaśta wicookihi ihukuya hnakapi kin hemaca, qa mihukuya akicita wicamduha; qa wicaśta kin de, Ya wo, ewakiya eca, ya ece; qa wanji tokeca, U wo, ewakiya eca, u ece; qa mitaokiye kin, Decon wo, ewakiya eca, ecen econ ece, eya.

9 Unkan Jesus hena nation qehan, on yuśinyaye ca, ihduhomni, qa oyate ihakam unpi kin hewicakiya; Israel hee kaeś en wowacinye hinsko tanka kin iyewaye śni, eciciyapi ce.

10 Unkan ye wicaśipi qon icicawin tiyata kipi qehan, ookiye wayazanke cin he wanna asni iyeyapi.

11 Unkan ianpetu qehan otonwe wan Nain eciyapi kin en $\mathbf{i}$; unkan waonspewicakiye cin etanhan ota qa oyate ota hena kici yapi.

12 Unkan otonwe tiyopa kin he ikiyedan wanna ehan i qehan, inyun, wicaśta wan ța tankan aupi; hunku kin wiwazica heca, qa cinhintku hecedan. Unkan otonwe kin etanhan wicota opapi. 


\section{WICOWOYAKE 7.}

13 Unkan he Itancan kin wanyake cehan, onśida qa heciya; Ceye śni wo.

14 Unkan canakiyuhapi kin en $u$, qa yutan. Unkan akiyuhapi qon iś owanji najinpi. Unkan heya; Kuśka, bosdan yanka wo, eciciya ce, eya.

15 Unkan te ciqon iyotanke, ca ia. Unkan hunku kin kicu.

16 Unkan owasin nina wikopapi, qa Wakantanka yatanpi qa lieyapi ; Waayate wanji tanka unkiyopeyapi icaga ce, qa Wakantanka taoyate kin wanna wicahiyohi ce, eyapi.

17 Unkan Juda makoce qa okśan makoce wanke cin owancaya he yaotaninpi.

18 Unkan Johannes waonspewicakiye cin dena taku kin owasin okiyakapi.

19 Hehan Johannes waonspewicakiye cin nom wicakico, qa Jesus ekta ye wicaśi, qa heya ; Tuwe u kte ciqon he niye, qa iś wanji tokeca unkapepi kta he.

20 Unkan wicaśta kin hena wanna ekta hipi qehan, heyapi ; Johannes baptem wicaqu ece qon he niye ekta unkuśipi, qa, Tuwe u kte ciqon he niye he, qa iś tuwe tokeca unkapepi kta he, eya ce.

21 Unkan hehantudan hinca wayazankapi, qa makośica ececapi, qa woniya śikśica ececapi, hena wicota asniwicaya; qa iśtagongapi kin heca ota tonwewicaya.

22 Hehan Jesus waayupte ca hewicakiya; Hda po, qa taku wandakapi qa nayalionpi kin hena Johannes okiyaka po: Iśtagongapi kin hena tonwanpi, qa huśtepi kin iś manipi, qa lepros ececapi kin iś wicayuskapi, qa nogetpapi kin iś wanahonpi, qa țapi kin iś kiniwicakiyapi, qa wahpanicapi kin iś wootanin waśte kin he owicakiyakapi.

23 Qa tuwe miye on śinhda śni kin he yawaśtepi ce.

24 Unkan Johannes wahośiyapi tawa kin wanna kihdapi, hehan Johannes on oyate kin hewicakiya; Taku e makotahedan ekta wanyag yaipi he. Cedi hu wan tate kahuhuze cin heca he.

25 Tuka taku e wanyag yaipi he. Wicaśta wan wokuyake panpanna koyake cin heca he. Iho, tona waśteya wakoyalkapi, qa tanyan nipi kin hena wicaśtayatapi tipi kin en unpi ece.

26 Tuka taku e wanyag yaipi he. Wicaśta wokcan he. Han, eciciyapi, qa wanji wicaśta wokcan isanpa tanka.

27 Iho, wahośiya mitawa kin he niite itokam ye waśi, nitokam canku wiyeya nicicage kta ce, eya owapi qon he dee.

28 Qa miye heciciyapi ; Winohinca eciyatanhan wicatonpi kin wicaśta wokcan tuwedan Johannes baptem wicaqu qon isanpa tanka śni : tuka Wakantanka tokiconze kin en tuwe iyotan cistinna kin he he kapa ce.

29 Unkan oyate kin qa wamnayanpi kin tona nalionpi owasin Wakantanka yaowotanpi, Johannes baptem wicaqu kin en opapi.

30 Tuka Pharisee kin, wicoope aiapi kin om, Wakantanka wahokonwicakiye cin en iyapațoiçiyapi, Johannes baptem wicaqu śni nakaeś.

31 Unkan Itancan kin heya; Wicaśta wicoicage kin de taku e imdacin kta he; qa taku iyececapi he.

32 Siceca iciyopekiciyapi kin en iyotankapi, qa hoyekiciyapi qa heyapi; Unniciyajopi, tuka wayacipi śni ; waśinunnicihdapi, 101 
LUKAS.

tuka yaceyapi śni ce, eyapi kin he iyececapi ce.

33 Johannes baptem wicaqu qon he aguyapi yute śni, qa miniśa yatke śni $u$; unkan, $\mathrm{He}$ taku wakan śica yuha ce, ehapi.

34 Wicaśta Cinhintku kin he wote ça wayatke hi ; unkan hehapi; Wan, wicaśta wan wote sa, qa miniśa yatke sa, wamnayanpi qa wahtanipi sa takodawicaya ece.

35 Tuka Woksape iye cinca kin owasin on yaowotanpi ece.

36 Unkan Pharisee wanji kici wote kta e cinkiya. Hecen Pharisee ti kin en tin iyaye ca, wote kta iyotanka.

37 Unkan iho, otonwe kin en winohinea wahtani sa kin heca, he, Pharisee ti kin en wota iyotanka sdonye çehan, inyan opiye ihepi ohna yuha en hi ;

38 Qa tapetepa tanhan siha kin en ceya najin, qa iśta minihanpe kin on siha kiciyujaja, qa paha kin on kicipakinta ca, silı kin ikiciputake, ca ihepi qon on sdakiciciya.

39 Unkan Pharisee kico qon he wanyake cehan, cante mahen awacin qa heya; Wicaśta kin de wicaśta wokcan unkanś, yutan kin he tuwe qa taku winohinca kin sdonye kta tuka; he wahtani sa kin heca.

40 Unkan Jesus waayupte ça heciya; Simon taku eciciye kta mduha ce. Unkan iś, Waonspekiya, katinyan eya wo, eya.

41 Wicaśta wan wicaśta nonpa oicazo wicaqu: unma kin kaśpapi opawinge zaptan iyohiye śni, qa unma kin iś wikcemna zaptan.

42 Unkan taku on hdajujupi kte cin yuhapi śni qehan, wancake sakim wicakicicajuju ce. Hecen unma tukte iyotan waśte- dake kta hecinhan, he omakiyalia wo.

43 Simon waayupte ca; Tuwe ota kicicajuju hee nace epca ce, eya. Unkan, Tanyan idukcan ce, eciya.

44 Hehan winohinca qon ekta ihduhomni, qa Simon heciya; Winohinca kin de wandaka he: Yati kin en wahi, unkan mini on siha wahdujaja kta mayaqu śni ; tuka iye kin iśta minihanpe kin on siha mayujaja, qa paha kin on pakinta.

45 I imayaputake śni; tuka winohinca kin de wahi kin ehantanhan siha imaputaka ayaśtan śni.

$46 \mathrm{~Pa}$ kin wihdi on sdamayaye śni ; tuka winohinca kin de ihepi on siha sdamayan ce.

47 Hecen on heciciya ce, Wahtani kin hena ota eśta kicicajujupi ; he nina waśtedaka nakaeś: tuka tuwe waniqadan kicicajujupi kin he iwaśtedan waśtedaka ece.

48 Hehan winyan qon heciya; Niohan śice cin hena nicicajujupi ce.

49 Unkan tona kici wota iyotankapi kin hena hehan cante mahen heyapi; De tuwe e woahtani nakun kajuju he.

50 Unkan winohinca yon heciya; Wacinyaye cin he niniyan ce; wookiye on hda wo.

\section{WICOWOYAKE 8.}

1 Unkan he iyohakam, otonwe tankinkinyan otonwe cilkciqadan ko, owasin iyaza un, qa wootanin waśte Wakantanka tokiconze ahna yaotanin. Unkan akenonpapi kin kici unpi :

$2 \mathrm{Qa}$ winohinca wanjikji taku wakan śica yuhapi qa wayazankapi, tuka asniwicayapi, Mary 


\section{WICOWOYAKE 8.}

he Magdalene eciyapi, he etanhan wakan śica śakowin hinanpapi qon hee;

3 Qa Joanna, Cuza Herod waawanyagkiye ciqon he tawicu, qa Susanna, qa nakun toktokeca ota, hena woyuha yuhapi kin on okiyapi ece.

4 Unkan wicota mniciyapi, qa otonwe otoiyohi etanhan en ahi qehan, wiyacinpi on wowicakiyaka:

5 Woju heca wan taku su kin oju iyaya. Woju, unkan apa canku icahda hinhpaya; unkan naaținzapi, qa mahpiya okinyanpi kin temyapi.

6 Unkan apa imnija wan ahinhpaya; unkan uye çehan, spaye śni on wancake śnija.

7 Unkan apa wapepeka ehnahna hinhpaya; unkan wapepeka opeya uye, ca aotinsya.

8 Unkan apa iś maka waśte ahinhpaya; unkan uye, ca opawingege suton, eya. Unkan hena hecekcen eye cehan, heya niyan; Tuwe noge winalion yukan hecinhan, ito nalion kta ce, eya.

9 Unkan waonspewicakiye cin wiwangapi, qa heciyapi ; Wiyacinpi kin de toketu he.

10 Unkan heya; Niyepi Wakantanka tokiconze woanahibe kin hena oyakahnigapi kta niçupi ; tuka tokan kin iś wiyacinpi ece : hecen etonwanpi keś wanyakapi kte śni, qa wanahonpi keś okahnigapi kte śni ce.

11 Wiyacinpi kin he dee: $\mathrm{Su}$ kin he Wakantanka oie kin ee.

12 Canku icahda qon he tona nahonpi kin heepi; hehan wakan śice cin en hi, qa wicoie kin cantepi kin etanhan eyaku ece, awacinpi qa niwicayapi kte śni heon.

13 Tona wicoie nahonpi eca iyuśkinyan icupi ece kin hena imnija akan un qon hena ee; hena hutkan nicapi, qa cistiyedan wicadapi, tuka taku iyutanwicayapi hehan ayuśtanpi ece.

14 Qa tona wanna nahonpi, qa hehan tokiya yapi, qa wiconi kin de woawacin kin, qa wowijice, qa wowiyuśkin kin, hena on aoținzapi, qa hecen tanyan sutonpi śni kin hena wapepeka ehna hinhpaye ciqon eepi ce.

15 Tuka tona wanna wicoie nahonpi eca, cante waśte qa owotanna mahen yuha unpi, qa wacintankaya sutonpi kin hena maka waśte akan un qon hena eepi ce, eya.

16 Wicaśta kin tuwedan petijanjan wan ideye, ça wakśica wan iyahdapśinyan elipeye śni, qa nakun owinja wan ohdateya ehnake śni ece; tuka petijanjan ihupa akan ehde ece: hecen tona en ipi kinhan, ijanjan kin wanyakapi kta.

17 'Taku anahmanpi qa yuotanimpi kte śni wanica; qa nakun taku yutaninśniyan hnakapi qa yutaninyan eyakupi kte śni wanica ce.

18 Heon token nayahonpi hecinhan itonpa po; tuwe wayuhe cin he nakun qupi kta; qa tuwe wayuhe śni kin he taku yuha kecin kin hee ikicicupi kta ce, eya.

19 Hehan hunku qa hunkawanjitku kin hena en hipi, qa wicota kin on ikiyedan upi kta okihipi śni.

20 Unkan okiyakapi qa heyapi; Nihun qa nihunkawanji tankan najinpi, qa wannihdake kta cinpi ce.

21 Unkan waayupte, ca hewicakiya ; Wakantanka oie nationpi, qa ecen econpi kin dena ina qa mihunkawanji eepi ce, eya. 


\section{LUKAS.}

22 Unkan anpetu kin hena wanji en, waionspewicakiye cin om wata wan en opa; qa hewicakiya; Mde kin akasanpa unyanpi kta ce. Hecen canan eyaya.

23 Tuka sina watopekiyapi icunhan iye iśtinma : unkan tate iyumni wan mde kin en u; qa mini ojudan yakonpi, hecen tapi kta kolkipapi.

24 Hehan en hipi qa yuhicapi qu heyapi; Itancan, Itancan, untakunipi śni. Unkan najin hiyaye ca, tate qa mini taja ko kiśica: hecen ayuśtan, qa amdakedan tanka.

25 Unkan hewicalkiya; Wacinyayapi kin tukte e he. Unkan iś wikopapi, inihanpi qa hekiciyapi ; De taku wicaśta he ; tate mini kici ee kaeś okiya eca, anagoptan ece.

26 Unkan Galile itakasanpa Gadarene tamakocepi kin en ipi. 27 Unkan hen ihe cehan, wicaśta wannakaja tanhan wakanśica yuhe, ca wokoyake koyake śni, qa tuktedan tipi oti śni, tuka wicaśta hnakapi kin en ece un kin, heca wan otonwe kin eciyatanhan itkokipa.

$28 \mathrm{He}$ Jesus wanyake cehan, hoyeye ça itokam makata ehpeiçiye ca hotankakiya heya; Jesus Wakantanka Iyotan Wankantu Cinhintku kin, token unyakon kta he. Ceciciya ce, Kakiśmaye śni wo.

29 Taku wakan śape cin wicaśta kin etanhan hinanpe śi heon etanhan. He ijehan yuza ece ; unkan mazaicicahilia wicaśke ko on kaśka hnakapi; tuka wicaśke kin yupsapsake ça, wakanśice makotahedan ekta iyayeya ece.

30 Unkan Jesus wiwange ca heya; 'Token eniciyapi he.
Unkan, Wicota, eya: taku wakan śica ota tan mahen ipi kin heon etanhan.

31 Unkan ośbe kin ekta ye wicaśi kte śni, keya icekiyapi.

32 Unkan he kin en kukuśe ota optaye wan won unpi ; hecen en iwicayayapi kte cin he iyowinwicakiye kta keya cekiyapi ; unkan iyowinwicakiya.

33 Hecen wakanśice cin wicaśta kin etanhan tankan hinapapi, qa kukuśe kin en iwicayayapi; unkan optaye maya hinca wan en apamahde nina hin naśdog iyayapi, qa mde kin en ivolipeiciyapi, qa minin țapi.

34 Unkan taku econpi kin he kukuśe wo wicaqupi qon wanyakapi qehan, nakipapi, qa otonwe qa makoce kin ekta ohdag kipi.

35 Unkan taku econpi qon he wanyag ai, qa Jesus ekta ahi, qa wicaśta wakanśica etanhan hinapapi qon he ogeton, qa tawacin ekicetu, qa Jesus siha kin en iyotankahan yanka wanyakapi ; unkan wikopapi.

36 Tona wanyakapi qon iś eya wicaśta wakan śica yuhe ciqon token asniyanpi kin he owicakiyakapi.

37 Hehan ihdukśan Gadarene tamakocepi kin owancaya taku econpi qon he nahonpi qehan, owasin nina wikopapi on elanhan cekiyapi, qa tokan yeśipi. Unkan, wata kin en okipe, ca icicawin kihda.

38 Unkan wicaśta etanhan wakan śice cin hinanpapi qon he kici un kta keya cekiya. Tuka Jesus hde śi, qa heya;

39 Niye yati kin ekta hde, ca Wakantanka taku hinca ecanicon kin he yaotanin wo, eya. Unkan kihde, ca Jesus taku hinca ecakicon qon he otonwe owancaya ohdaka. 


\section{WICOWOYAKE 9.}

40 Unkan Jesus hdi qehan, ape hiyeya nakaeś.

41 Unkan iho, wicaśta wan Jairus eciyapi kin he en $\mathrm{u}$, omniciye tipi itancan kin wanji hee; unkan he Jesus siha kin en makata elipeiçiye cea, iye ti kin ekta u kta icekiya.

42 He cunwintku wanjidan, wanna waniyetu akenonpa ecetu; unkan iś wanna te kte wanka. Tuka elkta ye cin hepiya oyate kin aohduteyapi.

43 Unkan winolinea wan waniyetu alienonpa hehanyan we au, qa taku yuha owasin pejihutawicaśta on wanna hdusota; tulka hecen tuwedan asniye kta okihi śni ;

44. Hee tapetepa tanhan u, qa tawokoyake opapun kin yutan: unkan hecehnana we au qon he anapta.

45 Unkan Jesus heya; Tuwe mayutan he. Unkan owasin anakihmanpi qehan, Inyan qa tona kici unpi qon hena heyapi ; Waonspekiye cin, wicota kin aohduteniyanpi, qa aoţinsniyanpi ; heca eśta, Tuwe mayutan he, eha ce.

46 Unlkan Jesus heya; Tuwe mayutan; wowa秥ke ematanhan hiyu kin he sdonwakiye ce.

47 Unkan winohinca qon wanna inalibe śni e wanhdake cehan, cancanyan $u$, qa itokam makata ehpeiçiye, ça oyate kin owasin wicitokam, taku on yutan, qa token wancake asniyanpi kin he okiyaka.

48 Unkan heciya; Cunś, cante waśte wo; wacinyaye cin he asniniyan ce: wookiye on hda wo.

49 Unkan Jesus iahan icunhan, omniciye tipi idaka ti kin eciyatanhan tuwe $\mathrm{u}$, qa heciya; Wa- onspekiye cin nagiyeye śni wo; nicunkśi wanna ţa ce, eya.

50 Tuka Jesus he nation qehan, waayupte ca heciya; Wikope śni wo; awicakehan wicada wo, lzinhan niyanpi kta ce.

51 Unkan tipi kin en tin hiyu qehan, tuwedan tin ye kta iyowinkiye śni ; Inyan, qa Jakob, qa Johannes, qa wiliośka atkuku hunku kici henana en ipi.

52 Unkan owasin aceyapi qa waśinhda enapeyapi ece. Tuka heya ; Ceyapi śni po ; te śni, tuka iśtinma ce.

53 Unkan wanna ța sdonyapi kin heon wowihayapi.

54 Unkan owasin tankan iyayewicaye, ca napata yuze, ca kipan qa heya; Wikośka najin wo, eya.

55 Unkan nagi kin kiyolipaya, qa hecehnana najin hiyaya: hehan wo qu wicaśi.

56 Unkan hunkakelku kin inihanpi: tulia taku econ kin he tuwedan okiyake śni wicaśi.

\section{WICOWOYAKE 9.}

1 Unkan waonspewicakiya akenonpapi kin hena wicakico, qa wowaśake wookihi ko, wakanśica owasin on, qa wowayazan asniyanpi kta hecen wicaqu.

2 Qa Wakantanka tokiconze kin oyakapi kta, qa wayazankapi kin asniwicayapi kta ye wicaśi.

3 Qa hewicakiya; Icimayanipi kte cin on cansagye, qa wojuhadan, qa waneya, qa mazaska takudan eyakupi śni po; qa nakun onlidohida nomnom yuhapi śni po. 4 Qa tukte tipi wan en yaipi kinhan, hen ece yukan po, qa hetanhan iyoopta ya po.

5 Qa tuwe kaśta iyowinniciyapi śni kinhan, otonwe kin he inayapapi kinhan, nisihapi watuśe- 


\section{LUKAS.}

kśeca onistakapi kin hee kaeś katata po, he owicayake kta ce. 6 Unkan iyayapi, qa otonwe iyaza yapi, qa wootanin waśtr, oyakapi, qa owancaya waasniyanpi.

7 Unkan taku econ kin owasin, Herod wicaśtayatapi kin nahon; qa hehan token cante yuza nun tanin śni ; apa Johannes wiconte kin etanhan kini keyapi kin heon etanhan:

8 Qa apa iś, Elias hi ce, eyapi; qa apa tokeca iś, Wannakaja waayatapi qon hena etanhan wanji kini ce, eyapi.

9 Unkan Herod heya, Johannes pa bawaksa ce : tuka de tuwe e on taku decekceca nawahon he. Unkan wanyake kta cin.

10 Unkan wahośiyapi kin hena wanna hdipi qehan, taku token econpi kin owasin okiyakapi. Unkan ewicahdaku qa nalimanna icunonpa makotahedan wan ekta i, he otonwe wan Bethsaida eciyapi kin ahankeya.

11 Unkan oyate kin sdonyapi qehan, ihakam eyaya: unkan iyowinwicakiye ca, Wakantanka tokiconze kin he iwowicakiyake ca, tona asniyanpi cinpi kin hena asniwicaya.

12 Unkan wanna hitayetu aye cehan, akenonpapi kin upi, qa heciyapi, Wicota kin tokan yewicaśi wo; hecen otonwe qa ihdukśan makoce wanke cin hena ektakta yapi, qa taku yutapi oiçidepi, qa iwankapi kta ce; den makotahedan unyakonpi heon etanhan.

13 Tuka hewicakiya; Niye wo wicaqu po. Unkan heyapi ; Aguyapi zaptan qa hogan nonpa henana unhapi ; oyate denakeca woyute opewicakiciton unyanpi śni kinhan.

14 Wicaśta kektopawinge zaptan ecetupi. Unkan waonspe106 wicakiye cin hewicakiya; Wikcemna zaptanptan ptaptaya iyotang wicakiya po, eya.

15 Unkan ecen econpi, qa owasin iyotang wicakiyapi.

16 Hehan aguyapi zaptan qa hogan nonpa qon hena icu; qa malipiya ekta etonwan, qa yawaśte, qa yuśpaśpa, qa waonspewicakiye cin wicaqu; qa iye oyate kin wicitokam ewicakicihnakapi kta.

17 Unkan wotapi qa owasin wipipi ; unkan onśpaśpa iwicaḱiciyaye cin hena pahipi, makanopiye akenonpa.

18 Unkan iśnana woceliye eya un qehan, waonspewicakiye cin hena kici unpi : unkan wiwicawange ca heya; Miye matuwe oyate kin keyapi he.

19 Unkan waayuptapi qa, Johannes baptem wicaqu qon; qa apa iś, Elias; qa apa tokeca iś ; Wanakaja waayatapi qon hena etanhan wanji kini ce, eyapi ce, eyapi.

20 Unkan hewicakiya; Tuka niye matuwe kehapi he. Unkan Inyan waayupte ca heya; Wakantanka etanhan Messiya kin.

21 Unkan nina owicakiye, ça wicaśta kin tuwedan okiyake śni wicaśi ;

22 Qa heya; Wicaśta Cinhintku kin taku otakiya on ito iyotanhan iyekiye kta, qa wicaśta tokapapi, qa wawayuśnapi itancanpi, qa wowapi kagapi kin hena heyata iyeyapi, qa teyapi kta ce : unkan anpetu iyamni kinhan kini kta ce, eya.

23 Unkan owasin hewicakiya; Tuwe miyahna u wacin kinhan, waipiicida, qa anpetu otoiyohi cansusbeca kin kicin, qa miyahna u lita.

24 Tuwe kaśta wiconi kin hduhe wacin kinhan, togehpekiye 


\section{WICOWOYAKE 9.}

kta ce; tulka tuwe kaśta miye on wiconi kin togehpekiye cinhan, hee hduhe kta ce. .

25 Wicaśta togelipeiciya, qa iś tokan ehpeyapi hecinhan, maka kin ocowasin ohiiciya eśta, taku ecin on tanyan un kta he.

26 Tuwc miye qa mioie kin on iśtece cinhan, hce on Wicaśta Cinhintku kin iśtece kta, tohan iye towitan, qa Atkuku tawa qa taohnihde wakan tawapi kin hduha u kinhan.

27 Tuka awicakehan heciciyapi ; Den najiupi kin apa Wakantanka tokiconze kin tohanyan wanyakapi śni kin hehanyan tapi kie śni.

28 Unkan wicoie kin dena iyohakam anpetu śahdogan ecetu, hehan Inyan, qa Johannes, qa Jakob, hena ewicayaku, qa cekiye kta paha wan ekta i.

29 Unkan cekiya icunhan ite kin tokeca hinhda, qa tawokoyake kin ska qa wiyatpatpa.

30 Unkan iho, wicaśta nonpa kici wohdakapi, Moses qa Elias hena eepi.

31 Hena wokitaninyan hinajinpi, qa iye iyaye $\mathrm{kte}$ cin, Jerusalem ekta hduśtan kte cin he iwohdakapi.

32 Tuka Inyan qa om un kin hena nina iśtinmapi; unkan kiktapi qehan wookitanin tawa kin he wanyakapi, qa nakun wicaśta nonpa kici najinpi kin hena.

33 Unkan hena ehpcya kihdapi icunhan, Inyan Jesus heciya; Itancan, den unkanpi kte cin he waśte; ito wakcya yamni unkagapi kta, wanji niye, qa wanji Moses, qa wanji Elias, hecen unnicicagapi kta; taku eye cin he sdonkiye śni.

34 Hena hecen eya icunhan, mahpiya śoka wan $u$, qa aohanziwicaya. Unkan mahpiya śoka kin en hiyayapi hehan nina wikopapi.

35 Unkan mahpiya qon etanhan wicaho wan hinape, ca heya ; Micinkśi waśte wakidake cin he dee ce: hc anagoptan po.

36 Unkan wicaho qon yaśtan qehan, Jesus iśnana en najin. Unkan iye inina unpi, qa taku wanyakapi qon anpetu kin hena en wicaśta kin tuwedan okiyakapi śni.

37 Unkan ianpetu qehan, paha qon eciyatanhan wanna en hdipi qehan, oyate ota itkokipapi.

38 Unkan iho, wicota kin etanhan wicaśta wanji hoyekiye ca heya; Waonspekiye cin, ceciciya ce, micinkśi kin atonwan wo; micinca hecedan :

39 Unkan ihn, woniya wan yuza eca, ihnuhana śicalıowaya ece; qa yuhidehdeca, qa heccn minitaga apaśdiya, qa onśiya kuwa, qa kitan se ayuśtan ece.

40 Unkan waonspewicayakiye cin cewicawakiye, ca napeye wicawaśi ; tuka okitpanipi, eya. 41 Unkan Jesus waayupte ca heya; Wicoicage wicada śni qa tawacin tehika, tohanyan cicipi waun kta, qa iyowinciciyapi kta he : nicinkśi kin den au wo.

42 Unkan u kin hepiya, wakanśice cin makata ehpeye, ca yuhdehdeca. Unkan Jesus woniya śape cin kiśicc ca, hokśidan kin asniye ca, atkuku kin kicu.

43 Unkan Wakantanka towaśake hince cin on owasin inihanpi. Tuka Jesus taku token econ kin on owasin inihanpi icunhan, waonspewicakiye cin hewicakiya;

44 Wicoie kin dena ninogepi kin en iyohpayapi kte; Wicaśta Cinbintku kin wicaśta napepi kin en wicaqupi kta. 


\section{LUKAS.}

45 Tuka iapi kin he okahnigapi śni, qa anawicakihmanpi, hecen iyukcanpi śni: unkan wicoie kin on iwangapi kte cin itonpapi.

46 Unkan hehan wanji tukte iyotan tankapi kte cin he hdokinicapi.

47 Unkan cante elita hdokinicapi kin he Jesus wanyake cehan, hokśiyoqopa wan icu qa iye iyokihe ehde;

$48 \mathrm{Qa}$ hewicakiya; 'Tuwe kaśta hokśiyopa kin de micaje on eyaku kinhan, he miye e emayaku; qa tuwe kaśta miye emayaku kinhan, he umaśi kin hee eyaku ece; hecen niyepi owasin wanji tukte nicistinpidan kinhan, hee tanka kta ce, eya.

49 Unkan Johannes waayupte ca heya; Itancan, tuwe nicaje on taku wakan śica napewicaya wanunyakapi, qa den ounpapi śni kin on etanhan teunhindapi.

50 Unkan Jesus heciya; Tehindapi śni po: tuwe unkipajinpi śni kin he unkicicapi ece.

51 Unkan anpetu en wankan eyakupi kte cin wanna kiyedan aya, hehan Jerusalem elita ye kita e ite kin hdusuta;

52 Qa wahosiyapi kin heca tokata ye wicaśi. Unkan iyayapi, qa taku wiyeya kicihnakapi kta e Samariya wicaśta tonwanyanpi kin wanji en ipi.

53 Unkan Jerusalem ekta ye kta sece cin on etanhan iyowinkiyapi śni.

54 Unkan waonspewicakiye cin, Jakob qa Johannes he wanyakapi qehan, heyapi; Itancan, Elias econ qon he iyecen unkiye, mahipiya eciyatanhan peta kun $u$, qa huhnahwicaye unśipi kta yacin he.

55 Tuka ihduhomni qa wica108 kiśice, ca heya; Tawacin toniketupi kin sdonyakiyapi śni ce.

56 Wicaśta Cinhintku kin wicaśta tewicaye kta on hi śni, tuka niwicaye kta heon hi ce, eya. Unkan otonwe wan tokeca ekta iyayapi.

57 Unkan canku ohna yapi icunhan, tuwe heciya; Itancan kin, tokiya kaśta de cinhan ciyahna mde kta ce, eya.

58 Unkan Jesus heciya; Śungidan kin waśun tonpi, qua mahpiya okinyanpi kin holipi yuhapi, tuka Wicaśta Cinhintku kin iye pa kin tukten iwanke kte cin ee kaeś hduhe śni ce.

59 Unkan wanji tokeca heciya; Miyahna u wo. Tuka heya; Itancan, tokaheya ate wehe mde kte cin he iyowinmakiya ye.

60 Jesus heciya; Tona țapi kin ta wicayuhapi kin hena ito wicakiliapi kta; tuka niye qe ye ca Wakantanka tokiconze kin he oyaka wo.

61 Unkan wanji tokeca nakun heya; Itancan, ciyahna waun kta; tuka ito tokaheya wahde, ca wati kin ohna un kin tanyan wehnake kte cin he iyowinmakiya wo.

62 Unkan Jesus heciya; Wicaśta kin tuwe mahiyumdu wanna yuze, ca hehan hinakaha hakikta kinhan, he Wakantanka tokiconze kin en ope kta iyecece śni ce.

\section{WICOWOYAKE 10.}

1 Unkan taku kin hena iyohakam, Itancan kin toktokeca wikcemna śakowin cajewicayate, ca iye otonwe tona ekta ye kte cin, qa tokiya kaśta ekta ye kte cin, hena kohan ektakta nomnom yewicaśi.

2 Qa hecen ewicakiya; Awicakehan woksapi kin tanka, tuka 
htanipi kin e tonana ce; he on etanhan woksapi Itancan kin, he iye htanipi kin heca woksapi kin en yewicaśi kte cin he icekiya po.

3 Ya po ; iho, tahincaska śunktokeca ehna unpi he iyecen ye ciśipi.

4 Mazaska opiye, qa wojuhadan, qa hanpa hena hduhapi śni po: qa tahepi wicaśta tuwedan okiyapi śni po.

5 Qa tukten tipi wan en tin idadapi kinhan, tokaheya, Woolkiye tipi kin den un nunwe, eya po.

6 Unkan wookiye cinhintku kin en un kinhan wookiye nitawapi kin en iyahe kta: tuka hecece śni kinhan, ake en nihdipi kta.

7 Qa tipi kin he en ece un po, taku nicupi kin yuta qa yatkan dukanpi kta; tuwe htani kin he wokajuju kicupi ece e kta: Tipi iyaza yapi śni po.

8 Qa tukten otonwe wanji en yaipi, qa iyowinniciyapi kinhan, taku nitokam enicihnakapi kin he ece yuta po.

9 Qa wayazanka en unpi kin hena asniwicaya po, qa, Wakantanka tokiconze kin he kiyedan nihiyohipi ce, ewicakiya po.

$10 \mathrm{Qa}$ tukte otonwe wanji en yaipi qa iyowinniciyapi śni kinhan, otonwe kin he canku kin en hdicupi qa heya po;

11 Nitotonwepi watuśekśeca ountkapapi kin hee kaeś itkom unnicicatatapi ce; tuka Wakantanka tokiconze kin he kiyedan nihiyohipi kin sdonya po.

12 Tuka heciciyapi ce, Anpetu kin he en otonwe kin he tehiya un kte cin he Sodom aoptenya un lita ce, eya.

13 Korazin wotehi niciyanka ce; Bethsaida wotehi niciyanka ce; niyepi kin en wicolian tanka econpi kin hena Turos qa Sidon en econpi unkanś, wanakaja wahinske ojuha cahota ahna en iyotanka iyopeiçiyapi k ta tuka.

14 Tuka wayacopi kin ekta niye tehiya yaunpi kte cin he Turos Sidon kici aoptenya unpi kta.

15 Qa niye Kapernaum, yuwankan malipiya ekta aniyanpi kin, kuya wakanśica ti kin ekta iyaye niyanpi kta ce, eya.

16 Tuwe ananigoptanpi kin, he miye e anamagoptan; qa tuwe wahtenidapi śni kin, he miye e wahtemada śni; qa miś tuwe wahtemada śni kin, he umaśi lin hee wahteda śni ece, eya.

17 Unkan wikcemna śakowinpi qon wopidaya hdipi, qa heyapi; Itancan, nicaje kin eciyatanhan wakanśicapi lkin iyepi kaeś anáungoptanpi ece.

18 Unkan hewicakiya; Mahpiya kin eciyatanhan wakanhdi iyecen Satan hinhpaya wanmdaka ce.

19 Iho, wowaśake ciçupi, hecen wamduśka sintehida ko ayahanpi kta, qa toka token waśakapi eśta isanpa yaunpi kta; hecen takudan ksuweniyanpi kte śni.

20 Tuka wakan śice cin hena ananigoptanpi kin heon wiyuśkinpi śni po; tuka mahpiya ekta caje oniwapi kin hee on wiyuśkin po, eya.

21 Unkan he ehan Jesus cante mahen iyuśkin, qa heya; Ate, mahpiya maka ahna on Itancan, niye taku kin dena ksapapi, qa wayupikapi kin hena anawicayakihbe, ca hokśiyoqopa kin heca sdonyewicayakiye cin, he pidamayakiya ce; han, Ate ; niye hecen iyonicipi kin heon etanhan.

22 A tervaye cin he taku owasin yuhemakiya; qa Cinhintkuyapi 109 
LUKAS.

kin he tuwe kin tuwedan sdonye sni, Ateyapi kin heceyedan; qa Ateyapi kin iś tuwe kin, Cinhintkuyapi kin iye qa tona owicakiyake kte cin henana sdonyapi ece.

23 Unkan waonspewicakiye cin ekta ihduhomni, qa nahmana heya; Taku wandakapi kin hena wiciśta tona wanyakapi kin hena yawaśtepi ece.

24 Qa heciciyapi; Waayatapi kin wicaśtayatapi ko ota taku wandakapi kin hena wanyag cinpi, tuka wanyakạpi śni; qa taku nayalionpi kin he nation cinpi, tuka nalionpi śni, eya.

25 Unkan inyun, wicoope aiapi kin heca wanji najin hiyaye, ca wawiyutanye, ca heciya; Waonspekiye cin, token ecamon qa owilianke wanin wiconi ohimiciye kta he.

26 Unkan heciya; Wicoope kin en token owapi he; token dawa ece he.

27 Unkan waayupte, ca heya; Itancan Wakantanka nitawa kin he nicante kin ocowasin, qa ninagi ocowasin, qa nitowaśake ocowasin, qa nitawacin ocowasin on waśteyadake kta; qa niye inihdacin kin he iyecen nikiyedan un kin waśteyadake kta ce.

28 Unkan heciya; Tanyan wáadupta; hecen econ wo, kinhan yani kta ce.

29. Tuka iye ihdaowotanna wacin, qa Jesus heciya; Unkan mikiyedan un kin he tuwe he.

30 Unkan Jesus ayupte ca heya; Wicaśta wan Jerusalem etanhan Jeriko ekta iyaya; qa wamanonpi sa awicakipa, hena tawokoyake kin kipi, qa apapi, qa te icakiś elipeya kihdapi.

31. Unkan ehantudan wawayuśna wanji canku kin he ohna hiyaya; qa he wanyake cehan iyoopta iyaya.

32 Unkan Lewite heca wanji iś eya ehan i qehan, atonwe ca iyoopta iyaya.

33 Unkan Samariya wicaśta wanji icimani un, he wanke cin en hi; qa wanyake cehan onśida;

34 Qa en i, qa kaśujapi kin pahite ca wihdi miniśa ko en okaśtan; hehan iye taśsunke kin akan yankekiye ca, owote tipi wan en ahi, qa awanyaka.

35 Unkan ihanlianna iyoopta ye kta, hehan kaśpapidan nom ehdaku, qa tipi tawa kin qu, qa heciya; Tanyan yuha wo, qa dena sanpa tona on dusote cinhan, tohan waku kinhan ciçu kta ce.

36 Iho, hena yamnipi kin, wamanonpi sa awicakipe ciqon wanji tukte ikiyidan un idukcan he.

37 Unkan, Wanji onśida qon hee ce, eya. Hehan Jesus heciya; Ye ca, iyecen econ wo.

38 Unkan hetanhan iyoopta iyayapi, hehan otonwe wan en $i$; unkan winohinca wan Martha eciyapi, he iye ti kin en kico.

39 Unkan he tankaku kin, Mary eciyapi kin he Jesus siha kin en iyotanke ça, oie kin nation ece.

40 Tuka Martha wicohan ota on token cante yuza tanin śni; heon en hi qa heya; Itancan, mitanka ehpemaye ca miśnana taku ota ecamon ece kin niś ekta ewacanni sni he; heon etanhan omakiye kta keciya ye.

41 Tuka Jesus waayupte ça heciya; Martha, Martha, taku ota yakicanda wacanni, qa on nagiyeniciya ece :

42 Tuka taku wanjidan cinpi- 


\section{WICOWOYAKE 11.}

ca; unkan Mary taku waśte kin he kahniga, he icimana kipi kte śni ce.

\section{WICOWOYAKE 11.}

1 Unkan tukten cekiya un, qa ayaśtan qehan waonspewicakiye cin wanji heciya; Itancan, wocekiye eya onspeunkiya po, Johannes waonspewicakiye cin onspewicakiye ciqon he iyececa.

2 Unkan hewicakiya; Ceyakiyapi kinhan kaken eya po; Ateunyanpi mahpiya ekta nanke cin, nicaje wakandapi nunwe : Nitokiconze kin u kte: Mahpiya ekta nitawacin econpi kin he iyecen maka akan econpi nunwe.

3 Anpetu otoiyohi anpetu woyute unqu po.

4. Qa waunhtanipi kin unkicicajuju miye, unkiś tona śicaya ecaunkiconpi wicunkicicajujupi kin he iyececa. Qa taku wawiyutanyan un kin en unkayapi śni po ; tuka taku śice cin etanhan eunhdaku po.

5 Unkan hewicakiya; Niyepi kin wanji tuwe kodayayapi, qa hanye cokaya ekta yaipi, qa heyakiyapi ; Koda, aguyapi yamni omaqu wo :

6 Mitakoda wanji icimani hi, tuka taku itokam ewahnake kta takudan mduhe śni ce.

7 Hehan iye timahen tanhan waayupte, ça heye kta; Nagiyemaye śni wo; tiyopa wanna natakapi, qa micinca om mahen imunka; hecen nawajin qa cicu kta owakitpani-ce.

8 Heciciyapi; He kodaya on etanhan najin qa qu kte śni qeyaś, nina kitan kin heon etanhan, najin qa tona cin kinhan qu kta ce.

9 Nakun heciciyapi; Da po, kinhan niçupi kta; akita kinhan iyeyapi kta; katoto po, kinhan niciyuhdokapi ece e kta. 10 Tuwe da eca he icu ece; qa tuwe akita eca he iyeya ece; qa tuwe katoto eca he kiciyulidokapi ece e kta.

11 Cinca niyukanpi kin, wanji tukte cinhintku aguyapi kida kinhan, inyan wan qu kta he; qa iś hogan wan da kinhan, hogan on wamduśka wan qu kta he.

$12 \mathrm{Qa}$ iś witka wanji da kinhan sintelida wan qu kta he.

13 Hecen niś niśicapi kin, nicincapi taku waśteśte wicayaqupi kte cin he onnispepi ehantanhan, iś iyotan mahipiya Ateyayapi kin.tona Woniya Wakan kidapi kinhan wicaqu kta ce, eya.

14. Hehan wakan śica wanji tankan iyayeya, unkan ia okitpani. Unkan wakan śice cin wanna tankan hinape cehan, ia okitpani qon hehan ia; hecen oyate kin inihanpi.

15 Tuka apa heyapi; Beelzebub wakan śica itancan kin he eciyatanhan wakan śica napewicaya ece.

16 Qa apa toktokeca iś iyutanyanpi kta on mahpiya eciyatanhan wowapetokeca kidapi.

17 Tuka tawacinpi kin sdonwicaye ca hewicalkiya; Wokiconze kin tona iye iyakitedan kicipajinpi kin hena atakuni śni ece; qa tipi wanji iye icipajin kinhan he jujuwahan ece.

18 Qa Satan iś iye ic̣ipajin kinhan tokiconze kin he token ecin ecen he kta he. Beelzebub eciyatanhan wakan śica napewicawaya ece, kehapi kin heon etanhan.

19 Unkan miye Beelzebub eciyatanhan wakan śica napewicawaya ehantanhan, niye nicinca- 


\section{LUKAS.}

pi kin hena tuwe eciyatanhan napewicayapi he; hecen iyepi kin niciyukcanpi kta.

20 Tuka miye Wakantanka napsukaza on wakan śica napewicawaya ehantanhan, Wakantanka tokiconze kin awicakehan nihiyohipi ce.

21 Wicaśta wan waśake ca wipe ton ti awanhdake cinhan, hecen woyuha tawa kin tanyan hiyeya ece.

22 Tuka wanji ikapeya waśake cin he takpe hi, qa ktedan kinhan, tawipe wacinkiye ciqon he owasin ekiciyaku, hehan taku tawa qon pamni ece.

23 T'uwe micica śni kin he makipajin; qa tuwe miciwapahi śni kin he wayumdeca ece.

24. Woniya śapa kin wicaśta wan etanhan hinanpa eca makoce puze cin en ece un, qa oziiciye kta akita; tuka takudan iyeye śni kinhan, hehan heya; Wati etanhan wahinawape ciqon he ake ekta wahde kta ce.

25 Unkan en hdi eca, wanna kahintapi qa ayuco yuśtanpi iyekiya ece.

26 Hecen tokiya ye ça, woniya toktokeca iye kin isanpa wicaśtapiśni śakowin ewicayaku, qa hena en yapi, qa otipi: hecen wicaśta kin he otokahe kin isanpa oehake kin he śica ece.

27 Unkan hena hecekcen eya icunhan, wicota kin etanhan winohinca wan ho wankan yeye ca heciya; Wicitpi etanhan inicage cin he, qa aze dazoke cin hena yawaśtepi ce.

28 Tuka iye heya; Han, tuka tona Wakantanka oie kin nahonpi, qa ecen econpi kin hena iś iyotan wicayawaśtepi ce.

29 Unkan oyate kin wanna en himniciyapi qehan, hewicakiya; Wicoicage kin de śica; wowa- petokeca akitapi, tuka wowapetokeca takudan wicaqupi kte śni; Jonas waayate ciqon wowapetokeca tawa kin heceedan. 30 Ninewe oyate kin Jonas wowapetokeca yuhapi qon, he iyecen wicoicage kin de Wicaśta Cinhintku kin wowapetokeca yuhapi kta.

31 Woyaco kin ekta itokaga wicaśtayatapi winolinca qon he wicoicage kin de itkom nawicajin, qa wicayaco kta; he iye maka owihanke tanhan Solomon toksape kin nation hi; unkan iho, wanji Solomon isanpa tanka den un ce.

32 Woyaco kin ekta Ninewe wicaśta kin hena wicoicage kin de on inajinpi kta, qa yacopi kta; he iye Jonas wowicakiyalke cin on iyopeiciyapi; unkan inyun, wanji Jonas isanpa tanka den un ce.

33 Tuwedan petijanjan wan ideya eca nahmana ehde śni, qa iś ohna wiyutapi kin iyahdapśinyan hnake śni ; tuka petijanjan ihupa wan akan ehde ece; qa hecen tona en hipi kinhan ojanjan kin wanyakapi kte.

34 Wicatancan iyoyanpa kin wiciśta kin hee: heon etanhan niiśta kin hecetu kinhan, nitancan kin iś eya iyoyanpa ojudan ece; tuka niiiśta kin he śica eca, nitancan kin iś eya ocowasin otpaza ojudan ece.

35 Hecen iyoyanpa en niun kin he otpaze kte śni e wakta wo.

36 Heon nitancan kin ocowasin iyoyanpa ojudan, qa tuktedan otpaze śni ehantanhan, petijanjan wan yehya ide iyoyamniyan kin he iyecen ocowasin iyoyanpa ojudan kta ce.

37 Unkan heya icunhan Pharisee wan kico: hecen en $i$, qa wote k ta iyotanka. 
38 Unkan wote śni itokam ihdujaja śni kin he Pharisee qon wanyake cehan, inihan.

39 Unkan Itancan kin heciya; Niye Pharisee kin, miniyatkan wakśica ko akapatanhan duskapi ece; tuka mahen tanhan wawicakipi wicohan śica ko onijupidan ece.

40 Winitkotkopike cin, akapatanhan un kin he tuwe kaga hecinhan, he iś mahen un kin nakun kage śni he.

41 Tuka taku duhapi kin etanhanhan wicaqu po; kinhan taku owasin niciskapi kta ece.

42 Tuka Pharisee kin niyepi wotehi niciyankapi ece; ceyakata, wacanga, wahpe waśtemna ko owasin etanhan iwikcemnamna wicayaqupi ece ; tuka wicohan owotanna Wakantanka waśtedakapi ko, hena acayakśinpi ece; dena e iś ecen ecanonpi kta, qa unma qon oyakaptapi kte śni tuka.

43 Pharisee kin niyepi wotehi niciyankapi ece; omniciye tipi kin en oyanke waśteśte kin hena waśteyadakapi ece, nakun wopeton tipi kin ekta yaonihanyan oniciyapi kin.

44 Wowapi kagapi qa Pharisee, wanaicilimanpi kin, wotehi niciyankapi ece; wicaśta hnakapi tanin śni hiyeye ca wicaśta kin 'sdonye śni amanipi kin henicecapi ece.

45 Unkan hehan wicoope aiapi kin heca wanji waayupte, ca heciya; Waonspekiye cin, hecen eha eca, unkiśs eya ienunyahdepi ece.

46 Unkan heya; Wicoope aiapi kin niś eya wotehi niciyankapi ece; waqinpi qinpi tehika wicaśta qinwicayakiyapi ece qa niyepi kin napsukaza wanjidan on waqinpi kin dutanpi kte śni.

Dak.
47 Wotehi niciyankapi ece; wicaśta wokcan wicahnakapi kin hena niye yakagapi, qa niyatepi kin hena wicaktepi qon.

48 Atewicayayapi ohanyanpi qon iyowinwicayakiyapi e awicakehan nihduotaninpi; he iye hena wicaktepi e wicakapi, qa niye wicaśta hnakapi kin wicayecagapi ece.

49 Heon iś eya Wakantanka toksape kin heya; Waayatapi qa wahośiyapi heca ekta yewicawaśi kta ce ; unkan apa wicaktepi, qa onśiya wicakuwapi kta;

50 Hecen maka kagapi kin ehantanhan wicaśta wokcanpi we papsonpi kin he owasin wicoicage kin de iwicawangapi kta;

51 Abel we kin hetanhan, qa Zacariyas tipi wakan walna wośnapi kin okitahedan awihnuni qon he we kin iyahdeya: Awicakehan heciciyapi, He wicoicage kin de etanhan iwicawangapi kta ce.

52 Niye wicoope aiapi kin wotehi niciyankapi ece;' niś wosdonye iyuhdoka yutokan edakupi, qa niye ohna idadapi śni, qa tona ohna iyayapi kte cin hena anawicayaptapi ece.

53 Unkan hena hecekcen ewicakiva icunhan, wowapi kagapi qa Pharisee kin taku ota eyekiyapi kta e nina hin nagiyeyapi : 54 Taku iyaonpapi kta akitapi, heon taku i kin etanhan inanpe kta on hmunkapi kta iyapepi.

\section{WICOWOYAKE 12.}

1 Unkan wicota hinca en ahimniciya, hecen akicihanpi ece, hehan waonspewicakiye cin hewicakiya; Tokaheya Pharisee kin on napohyapi tawapi kin he 113 


\section{LUKAS.}

itonpa po, he wanaiçihmanpi kin hee ce.

2 Taku akalipetonpi qa yuzamnipi kte śni wanica; qa nakun taku anahmanpi qa yuotaninpi kte śni wanica ce.

3 Hecen otpaza ehna taku token ehapi kin he anposkantuya nahonpi kta ; qa onalibe tipi kin ohna wicanoge kin en token ehapi kin he tipi akan ieyanpahapi kta.

4 Qa kodamayayapi kin, niś heciciyapi; Wicatancan ktepi qa sanpa takudan okihipi śni kin hena kowicakipapi śni po.

5 Tuka tuwe koyakipapi kte cin he ito kanyehan ociciyakapi kte: Tuwe wicakte, qa hehan wakanśica tipi kin en ehpewicaya okihi kin he eca kokipa po; han, Hee kokipa po, eciciyapi ce.

6 Zitkadan zaptan mazaśadan nonpa iyopewicayapi śni he : heca eśta Wakantanka hena wanjidan kaeś akiktonje śni.

7 Tuka niyepi kin paha ee kaeś owasin niyawapi ece. Heon etanhan wikopapi śni po ; zitkadan ota isanpa niyawapi ece.

$8 \mathrm{Qa}$ nakun heciciyapi ce; Tuwe kaśta wicaśta kin wicitokam miye mayaotanin kinhan, Wicaśta Cinhintku kin Wakantanka taohnibde kin hena itokam he yaotanin kta.

9 Tuka tuwe wicaśta kin wicitokam amakta śni kinhan, Wakantanka taohnihde kin hena itokam, he aktapi kte śni.

10 Qa tuwe kaśta Wicaśta Cinhintku kin itkom wicoie wanji eciye cinhan, kicicajujupi kte; tuka tuwe Woniya Wakan waośtehda kinhan, kicicajujupi kte śni.

11 Tohan omniciye tipi kin en anihipi kinhan, qa wicaśtayatapi 114 wowaśake ko ekta, taku qa token aduptapi kta, qa taku ehapi kte cin awacinpi śni po.

12 Woniya Wakan kin he iye iyehantudan hin taku ehapi kta iyececa he onspeniciyapi kta ce. 13 Unkan wicota kin etanhan wanji heciya; Waonspekiye cin, misunka woyuha hanke micu kta, keciya wo.

14 Unkan heciya; Wicaśta kin, niwankam wiyukcan qa wapamni kte cin tuwe makaga he.

15 Unkan hewicakiya; Iwanihdaka po, qa wakonpi kin kokipa po ; wicaśta nipi kin he taku iyakiçuya tonpi kin he en un śni ece.

16 Hehan wiyacinpi wan owicakiyake ca heya; Wicaśta wijica wan tamaga kin taku ota icahya.

17 Unkan cante mahen he awacin qa heya; Token ecamon kta he; waskuyeca mitawa kin tukten wehnake kte cin mduhe śni ce.

18 Hehan heya; Kaken ecamon kta; wopiye wahdujuju kta, qa tankinkinyan wakage kta; qa hena ohna taku imicicaga woyuha mitawa ko owasin ewaju kta.

19 Qa minagi kin hewakiye kta; Minagi, taku ota yehnake cin he waniyetu ota oiyahde kta ce ; ito oziiçiye, ca wote, ça wayatke, ça wiyuśkin wo, eya.

20 Tuka Wakantanka heciya; Winitkotkoke cin, hanyetu kin de ninagi kin inicicupi kta; hecen wayehnake cin hena hehan tuwe tawa kta he.

21 'Tuwe woyuha kihnaka, tuka Wakantanka ekta wijice śni kin he he kicica ce, eya.

22 Unkan waonspewicakiye cin hewicakiya; Hecen on hecici- 


\section{WICOWOYAKE 12.}

yapi ce, Yanipi kin on taku yatapi kte cin, qa iś tancan kin taku kodakapi kite cin, hena on nagiyeiciyapi śni po.

23 Wicani kin he woyute kin isanpa ece; qa wicatancan kin iś wokoyake isanpa ece.

24 Kangi kin hena iwicayukcan po ; he iye wojupi śni qa woksapi śni, qa dotopiye woha ko' nicapi : unkan Wakantanka hena wo wicaqu ece. Wahupakoza kin isanpa niyawapi śni he.

25 Qa niyepi wanji awacannipi kin on wiciśpa wanjidan kaeś nihduhanskapi oyakihipi he.

26 Hecen taku iyotan cistinna kin he oyakihipi śni ehantanhan, unma kin on tokeca ecin nagiyeniciyapi he.

27 Mnalicahica kin he token icaga ece kin he iyukcan po; htani śni qa nakun wakahmun śni ; tuka heciciyapi ce, Solomon token okitanin eśta, dena wanji iyecen wakoyake śni.

28 Hecen Wakantanka peji anpedehan magata hiyeya, qa heyakecinlıan petan ehpcyapi kin hee kaeś wokoyake qu ehantanhan, kitanna wicayadapi kin, niś iyotan wokoyake niçupi kte śni be.

29 Qa taku yatapi qa datkanpi kte cin he ihnihdapi śni po ; qa nakun wacețunhdaya wacin yuzapi śni po.

30 Maka oyate kin hena owasin hecen ihnihdapi ece; qa niye taku kin hena yacinpi kin Ateyayapi kin sdonya ece.

31 Tuka Wakantanka tokiconze kin hee tokaheya ihnihda po, kinhan dena owasin koya nicupi kta.

32 Optaye cistinna kin, wikopapi śni po; wokiconze kin hee nicupi kta e Ateyayapi kin iyokipi ece.
33 Taku yatonpi kin wiyopekiya po, qa wicaqu po. Wojuha kukaka aye kte śni, malipiya ekta woyuha owihanke kte śni hena icicaga po ; heciya wamanon sa kiyedan u śni, qa wamduśkadan wayapote śni ece.

34 Woyuha tukten niciyankapi hecinhan, iś eya nicantepi kin en un ece e kta.

35 Ipiyag kiton yaunpi kta, qa petijanjan nitawapi ideyahan un kta ;

36 Qa niś wicaśta wicayuhe cin kiciyuzapi kin eciyatanhan hdi kta ape hiyeye cin hena iyecen un po ; tohan hdi qa tiyopa hdato to kinhan wancake kiciyulidokapi kta.

37 Wicayuhe cin hdi kinhan, ookiye kin tona wakta unpi iyewicakiye cin, hena wicayawaśtepi; awicakehan heciciyapi ce, Wicayuhe cin iye ipiyagkiton, qa ookiye kin hena wote kta iyotangwicakiye, ca u, qa owicakiye kta ce.

38 Hecen inonpa waktapi kin en, qa iś iyamni waktapi kin iyehan hdi, qa ecen iyewicaye cinhan, ookiye kin hena wicayawaśtepi ece.

39 Qa de sdonya po, tipi tawa kin wamanon sa tohan hi kta sdonya unkanś, wakta un qa tipi kin kiciyuldokapi kte cin anapte kta tuka.

40 Heon etanhan niś eya wiyeya un po; Wicaśta Cinhintku kin tohan awacannipi śni kinhan hehan u kta ce:

41 Unkan Inyan hehan heciya; Itancan, wiyacinpi kin de unkiśnana unkoyakidakapi, qa iś owasin wicayaka he.

42 Unkan Itancan kin heya; Ookiye wanji waawanyagkiyapi kin he wayupike, ca okiksape cinhan, yuhe cin tiwahe kin yu115 


\section{LUKAS.}

hekiye kta, qa hecen iyehanyan wo wicaqu ece e kte cin he tuwe he.

43 Itancan tawa kin $\mathrm{ku}$, qa taokiye wanji hecen econ yanka wanhdake cinhan, hee yawaśtepi ece.

44 Awicakehan heciciyapi ; Taku token tawaye cin he owasin yuhekiye kta ce.

45 Tuka ookiye kin he cante mahen, Itancan kin tehas hdi kte śni ecin; qa wicaookiye qa winyanookiye kin hena awicape, ca wote, ca wayatke, ça witkoiciye cinhan,

46 Ookiye kin he anpetu wan yuhe cin hdi ape śni, qa sdonkiye śni hehan hdi, qa kicakse, ça wacetunhdapi kin hena owicapeya ounyekiye kta.

$47 \mathrm{Qa}$ ookiye wanji yuhe cin tawacin kin sdonya, tuka wiyeya icihnake śni, qa tawacin kin okicipe śni kinhan, he ota apapi kta.

48 Tuka tuwe sdonye śni kinhan, he iś apapi kte cin iyecen ohanyan eśta tonana apapi kta ce. 'Tuwe taku ota qupi kinhan, hee taku ota iwangapi kta; qa wicaśta kin tuwe taku ota yuhekiyapi ca, he iyotan ota kicapi ece e kta.

49 Maka akan peta iyayewaye kta wahi; qa token wacanmi he, wauna ideyapi eśta.

50 Tuka baptem wanji on baptem maqupi $k$ ta; qa he tohanyan yuśtanpi śni hehanyan aotinsmayanpi ce.

51 Maka akan wookiye wicaqu wahi kecannipi he. Miya, tuka wicayuomdecapi kin iś ee kta, eciciyapi ce.

52 Detanhan tipi wanjidan ohna zaptan yukanpi kta, qa yuomdecapi kta, yamni nonpa om, qa nonpa yamni om kicipajinpi kta.
53 Wicaśta wan iye cinhintku kin kipajin kta, qa cinhintku kin iś a tkuku kin; hunku kin cunwintku kin kipajin kta, qa cunwintku kin iś hunku kin; nakun kunku kin takośku kin, qa takośku kin iś kunku kin kipajin ece e kta, eya.

54 Unkan nakun oyate kin hewicakiya; Wiyolipeyata tanhan mahpiya wanji wankan u wandakapi eca, wancake, Magaju kta ce, ehapi : unkan ecetu ece.

55 Qa itokaga tate uya eca, Odidita kta ce, ehapi : unkan ecen hiyohi ece.

56 Wanaiçihmanpi kin, niś mahpiya ite kin maka ko iyukcan oyakihipi ; tuka tokeca e nakaha kin idukcanpi śni he.

57 Han, niye cinka tokeca e taku owotanna kin idukcanpi śni he.

58 Tohan tuwe icazoniciye cin kici wicoope awanyake cin ekta de cinhan, tahepi niyuśkapi kte cin akite hinca wo: okinni he wayaco kin ekta aniye kta, qa wayaco kin iś akicita kin ekta nicu kta, qa hecen kaśka nihnakapi kta.

59 Mazaśadan ehake lince cin he tohanyan yecu śni hehanyan hetanhan yahdicu kte śni, eciciya ce, eya.

\section{WICOWOYAKE 13.}

1 Unkan hehan en opapi kin wanjikji, Pilate token Galile wicaśta heca we kin iye wośnapi tawapi kin kici icicahiye ciqon, he okiyakapi.

2 Unkan Jesus waayupte ca hewicakiya; Galile wicaśta kin decen ecawicaonpi kin heon etanhan Galile wicaśta owasin isanpa hena wahtanipi sa kecannipi he. 


\section{WICOWOYAKE 13.}

3 Hiya; tuka niye nihduecetupi śni ehantanhan, niś eya owasin iyecen nitakunipi kte śni, eciciyapi ce.

$4 \mathrm{Qa}$ iś Siloam conkaśke akeśahdogan awicahinlipaye, ca wicakte qon, wicaśta owasin Jerusalem en unpi qon henana iyotan wicohan śicapi, kecannipi he.

5 Hiya; tuka niye nihduecetupi śni ehantanhan, niś eya owasin iyecen nitakunipi kte śni, eciciyapi ce, eya.

6 Unkan wiyacinpi kin de nakun owicakiyaka; Wicaśta wan hastanhanka iyuwi maga tawa kin en suken can wanji oju; unkan en waskuyeca ode hi, tuka takudan iyeye śni.

7 Hehan hastanhanka iyuwi maga kicanye cin he heciya; Can kin de ekta omaka yamni wanna waskuyeca ode wahi, tuka ongedan iyewaye śni ece; kawanka wo; tokeca ecin maka yuśagya han he.

8 Unkan waayupte, ça heciya; Itancan kin, omaka kin de nakun ayuśtan wo, ecen ohomni maka waqe, ca tacesdi en ewahnake kta ;

9 Okinni waskuyeca icaliye kta; tuka wanice cinhan, hinnakaha hehan yahdawanke kta ce.

10 Unkan anpetu wakan icunhan omniciye tipi wan ohna waonspewicakiya yanka :

11 Unkan iho, winohinea wan waniyetu ake śahdogan hehanyan woniya waśake śni kin yuha, tancan kin wanna pako icu, qa tokadan ihduowotanna śni.

12 Jesus he wanyaka, unkan kico qa heciya; Winohinca waniyazanke cin etanhan niciyuśkapi ce.

13 Hehan nape kin ahnaka, un- kan wancake owotanna icu, qa Wakantanka yaonihan.

14 Unkan anpetu wakan icunhan Jesus waasniyan kin on etanhan omniciye tipi idake cin he canteptanyan; hecen waayupte, ca oyate kin hewicaliya; Wicaśta kin litanipi kte cin anpetu śakpe yukan ce; hecen anpetu kin hena en u po, qa asniniyanpi kta ce; tuka anpetu wakan icunhan upi śni po, eya.

15 Unkan Itancan kin waayupte ca heciya ; Wanaiçilibe cin, niyepi otoiyohi, anpetu wakan, tatanka qa iś śonśonna nitawapi kin yakiduśkapi qa miniyatkekiya adapi śni he.

16 Unkan winolinea kin de Abraham cunwintkuwicaye cin wanji ee, Satan iho, waniyetu ake śahdogan hehanyan kaślka hnaka, he iś anpetu wakan icunhan kiyuśkapi kte śni iyececa he.

17 Unkan hena hecen eye cehan, kipajinpi qon owasin iśtecapi ; unkan wokitaninyan taku econ qon hena owasin on oyate owasin iyuśkinpi.

18 Hehan heya; Wakantanka tokiconze kin he taku iyececa he; qa taku e imdacin kta he.

19 Sinape sulkaza wanji iyececa, he wicaśta wan icu, qa maga tawa kin en iyohpeya; unkan icage, ca can tanka aya; unkan mahpiya okinyanpi kin adetka kin en iyahanpi ece.

20 Unkan ake heya; Wakantanka tokiconze kin he taku e imdacin kta he.

21 On napohyapi kin he iyececa, he winolinca wan icu, qa wotpanpi wiyutapi yamni en anahman, hecen ocowasin napogan ce.

22 Unkan otonwe qa otonwe ciqadan iyaza ye ca, waonspekiya; qa Jerusalem etkiya ya. 


\section{LUKAS.}

23 Unkan tuwe heciya; Itancan, niwicayapi kte cin hena tonananpidan he. Unkan hewicakiya ;

24 Tiyopa cistiyedan kin he ohna dapi kta nina akita po: wicota ohna yapi akitapi kta, tuka okihipi kte śni, eciciyapi ce.

25 Tipi tawa kin tohan wanna najin hiyaye, ca tiyopa kin ecen ikikcu, qa itankan nayajinpi, qa tiyopa yakatotopi, qa ; Itancan, Itancan, unkiciyuhdoka miye, ehapi ; qa iye waayupte ca, 'Tonitanhanpi kin sdonwaye śni ce, eniciyapi kta ;

26 Hehan niś hehapi kta; Nanke cin en wauntapi, qa waunyatkanpi ece; qa niś ocanku unkitawapi kin ohnahna waonspeyakiye ciqon.

27 Tuka iye heye kta; Tonitanhanpi kin sdonwaye śni, eciciyapi ce; woowotanna śni ecanonpi ece kin owasin mitantanhan iyaya po.

28 Abraham, qa İsaak, qa Jakob, qa wicaśta wokcan owasin Wakantanka tokiconze kin en opapi tohan wandakapi, qa niyepi kin tankan iyayeniyanpi kinhan, wicaceya hihdakokokapi ko yuke kta.

29 Wiyohiyanpata, wiyohpeyata, waziyata, itokaga, henakiya eciyatanhan au, qa Wakantanka tokiconze kin en iyotankapi kta ce.

30 Unkan iho, ehake yakonpi kin hena tokaheyapi kta; qa tokaheyapi kin hena iś ehake yakonpi kta ce, eya.

31 Unkan anpetu kin he en Pharisee kin wanjikji ekta hipi qa heciyapi; Detanhan ye ca tokan iyaya wo; Herod nikte kta cin.

32 Unkan hewicakiya; Yapi 118 qa śungidan kin he heciya po; Iho, anpetu kin de qa nakun heyakecinhan, wakan śica napewicawaye ca, wayazankapi kin asniwicawaye kta, qa anpetu iciyamni kinhan mayuśtanpi kta ce.

33 Takomni anpetu kin de, qa heyakecinhan, nakun iyokihe kin he en mawani kta iyececa; ecaeś Jerusalem itankan wicaśta wokcan wanji te kte pica śni.

34 Jerusalem, Jerusalem, wicaśta wokcan kin hena wicayakte, qa niye ekta u wicaśipi qon hena inyan on wicayakininpi ece ; eca ijehan anpaohotonna wan hupahu ohdateya cinca wicatpahi ece kin he iyecen niye nicinca kin wicacicipahi kta, tuka yacinpi śni.

35 Tho, yatipi kin otiwota ehpeniciyapi : qa, Tohanyan tuwe Itancan caje on u kin he yawaśtepi nunwe, ehapi śni hehanyan wanmayadakapi kte śni, awicakehan eciciyapi ce.

\section{WICOWOYAKE 14.}

1 Unkan Pharisee itancan wanji ti kin en anpetu wakan icunhan wote kta tin iyaya; unkan Pharisee kin awanyag kuwapi.

2 Unkan iho, wicaśta wan dropsi ececa kin he itokam yanka.

3 Hehan Jesus waayupte ça, wicoope aiapi kin, qa Pharisee kin hena hewicakiya; Anpetu wakan icunhan waasniyanpi kte cin iyowinwicakiyapi he.

4 Tuka inina unpi. Hehan wicaśta qon eyaku, qa asniye, ça hdeśi ;

5 Qa waayupte, ca hewicakiya ; Niyepi kin wanji tatanka qa iś śonśonna yatonpi, qa anpetu wakan icunhan makohidoka wan 


\section{WICOWOYAKE 14.}

ohinhpaye cinhan, wancake hdicuyakiyapi śni naceca he.

6 Unkan hena on ayuptapi kta okitpanipi.

7 Unkan wicakicopi kin wiyacinpi wan owicakiyaka, oyanke tokapa ece kahnigapi kin he wanyake cehan; qa hewicakiya ;

8 Tuwe tohan kiciyuzapi kin ekta nicopi kinhan, oyanke tokapa kin en iyotanke śni wo; okinni nikapeya kinihanpi wanji kicopi kta;

9 Kinhan, sakim nicopi kin he u, qa, Wicaśta kin de liyukan wo, eniciye cinhan, hehan hinakaha wowiśtenya oyanke hakakta kin hee ekta idotanke kta ce.

10 Tuka nicopi kinhan ye, ca oyanke hakakta kin en iyotanka wo; hecen nico kin he tohan u kinhan, Koda, wankan wapa ya wo, eniciye kta; hecen om wota idotanke cin hena niyuonihanpi kta.

11 Tuwe kaśta ihduwankantu kinhan, hee yuhukun iyayeyapi kta ce; qa tuwe ihduhukuye cinhan, hee yuwankantuya ayapi ece e kta.

12 Unkan hehan kico qon he heciya; Tohan wiyotanhan wotapi, qa iś hitayetu wotapi yakage cinhan, kodawicayaye, ca nihunkawanji, qa takuwicayaye cin, qa nikiyedan wijinya unpi kin, hena wicakico śni wo; iś ake okinni nicopi, qa hecen nicicajujupi kta.

13 Tuka wotapi wan yakage cinhan, wahpanicapi, qa huha ksawahanpi, qả huśtepi, qa iśtagongapi kin, hena wicakico wo ; 14 Kinhan niyawaśtepi kta ce; hena nicicajujupi kta okitpanipi nakaeś, owotanpidan kinipi kte cin ekta nicicajujupi kta ce, eya.

15 Unkan opeya wota yankapi kin etanhan wanji hena hecen eya nation qehan, heciya; Wakankanka tolkiconze kin en tuwe aguyapi yute kta hecinhan hee yaw.aśtepi ce.

16 Unkan hehan heciya; Wicaśta wan htayetu wotapi wan tanka kage, ca wicota wicakico:

$17 \mathrm{Qa}$ wotapi kta wanna iyehantu, hehan taokiye wan wicakicopi qon hewicakiye kta ye śi ; U po, wanna taku owasin wiyeya hiyeya ce.

18 Unkan owasin okonwanjidan ihdatokanpi. Tokaheya kin he heciya; Makoce onśpa opewaton, qa he wanhdag mde kta iyececa; ceciciya ce, micunni wo.

19 Unkan wanji tokeca heya; Tatanka tazaptan opewaton, qa iwicahdute mde kta; ceciciya ce, micunni wo.

20 Unkan wanji tokeca heya; Winohinca wan mduza, hecen wau owakitpani ce.

21 Unkan hecen ookiye qon he ku, qa heyapi kin yuhe cin ecen okiyaka. Unkan hinakaha tipi tawa kin śihda, qa taokiye qon heciya; Koyahan wo, qa otonwe canku kin ekta ye, ca wahpanicapi kin, huha ksawahanpi, huśtepi, iśtagongapi kin, hena den awicau wo, eya.

22 Unkan ookiye qon heya; Itancan kin, ehe cin he wanna ecen econpi, tuka nahahin okan ce, eya.

23 Unkan Itancan kin ookiye qon heciya; Ocanku hince cin, qa mahinatake ektakta ye, ca uwicakiya wo, hecen wati kín ojudan kta.

24 Heciciya ce; Wicakicopi qon wanjidan kaeś wowahe cin etanhan onśpadan yutapi kte śni ce, eya.

25 Unkan wicota hinca kici 119 


\section{LUKAS.}

yapi ; hehan ihduhomni qa hewicakiya ;

26 'Tuwe ekta mahi, qa atkuku, hunku, tawicu, cinca, sunka$\mathrm{ku}$, tawinolitin kin, hena, qa iye ni kin heeś koya śicekida śni ehantanhan, waonspewicawakiye cin wanji ee kta okitpani ce.

$27 \mathrm{Qa}$ tuwe kaśta cansusbeca kin kiçin, qa miyahna u śni ehantanhan, waonspewicawakiye cin wanji ee kta okitpani ce.

28 Niyepi kin wanji conkaśke yakagapi kta kecannipi ehantanhan, ito tokaheya idotankapi, qa yahduśtanpi kte cin iyena yatonpi hecinhan, he iyahdukcanpi śni he.

29 Hecanonpi śni kinhan, okinni oahehde kin he wanna eyahnakapi, qa yahduśtanpi kte cin oyakitpanipi kinhan, tona wanyakapi kinhan owasin inihapi, qa heyapi kta;

30 Wicaśta kin de taku kage kta, tuka hduśtan kta okihi śni ce.

31 Qa nakun wicaśtayatapi wan wicaśtayatapi tokeca azuye kte cinhan, ito tokaheya iyotanke, ça iye kektopawinge wikcemna wicayuhe cin hena on, tuwe kektopawinge wikcemna nonpa yuha takpe u kin he itkokipa okihi kta hẻcinhan, he ihdukcan śni naceca he.

32 Qa iś, unma kin hinahin itehan un, tuwe ekta ye śi, qa wokiyapi kida naceca.

33 tho, he iyecen niyepi kin tuwe taku yuhe cin owasin tpagan śni ehantanhan, waonspewicawakiye cin wanji ee kta okitpani ce.

34 Miniskuya he waśte; tuka miniskuya woskuye kin en un śni ehantanhan, taku ecin on skuya kagapi kta he.

35 Maga qa watuśekśeca paha kin unmana on waśte śni ; tuka tankan ehpeyapi ece. Tuwe noge wination yukan hecinhan, nahon kta ce.

\section{WICOWOYAKE 15.}

1 Unkan hehan wamnayanpi qa wahtanipi sa, hena owasin nahonpi kta e on en ahi.

2 Unkan Pharisee kin wowapi kagapi lro ikapapi qa heyapi; Wicaśta kin de wahtanipi sa iyowinwicakiye ca om wota ece. 3 Hehan wiyacinpi kin de owicakiyake ca heya;

4 Niyepi kin etanhan wicaśta wanji tahinca wanunyanpi opawinge wicayuhe ça, wanjidan kitanin śni kinhan, wikcemna napcinwanka sanpa napcinwanka kin hena makotahedan en awicayuśtan, qa tanin śni qon he tohanyan iyeye śni hehanyan okide śni naceca he.

$5 \mathrm{Qa}$ tohan iyeye cinhan, wiyuśkinyan hiyete akan akionpa ece.

6 Qa wanna tiyata ki eca, kodawicaye ça, ikiyedan tipi kin hena witaya wicakico, qa hewicakiya; Micilyuśkin po, tahinca wanunyanpi wan makitanin śni qon he wanna iyewakiya ce.

7 Heciciyapi ce; he iyececa, wahtanipi sa wanjidan iyopeiciya eca, mahpiya ekta wiyuśkinpi ece e kta, wicaśta owotanna qa woahtani on iyopeiciyapi kta iyececapi śni wilkcemna napcinwanka sanpa napcinwanka on iyecen wiyuśkinpi kte śni.

$8 \mathrm{Qa}$ nakun winohinca tuwe kaśpapidan wikcemna yuhe, ca wanji togehpekiye cinhan, hecen petijanjan ideye, ca tipi kin kahinte, ca tohan iyekiye śni kin hehanyan okide śni naceca he. 
9 Qa tohan wanna iyeye cinhan, kodawicaye cin, qa ikiyedan tipi kin hena witaya wicakico qa hewicakiya; Miciiyuśkin pe, kaśpapidan toki elipervakiye ciqon he wanna iyewakiya ce.

10 He iyececa wahtanipi sa wanjidan iyopeiciya eca, on Wa-

- kantanka taohnihde kin wicitokam wiyuśkinpi ece, eciciyapi ce.

11 Unkan heya; Wicaśta wan cinhintku nonpa.

12 Unkan hakakta kin he atkuku kin heciya; Ate, woyuha mitawa kte cin he micu wo. Unkan woyuha kin akipam wicaqu.

13 Unkan iyohakam anpetu tonana hehan cinhintku hakakta qon he taku owasin witaya tpahi, qa itehanyan makoce wan ekta icimani iyaya: qa hen śicaya ohanyanpi kin on taku yuhe cin hdutakuni śni.

14 Unkan wanna owasin hdusote cehan, makoce kin he en wicaakihan tanka icaga; hehan iye wicakiś un.

15 Qa makoce kin hen unpi Kkin wanji ekta ye ca kici yanka : unkan he kukuśe wo wicaqu kta e maga kin ekta ye śi.

16 Unkan omnica kukuśe yutapi kin hee etanhan wipiiciye wacin; tuka tuwedan takudan qu śni.

17 Unkan içiksuye cẹehan heya ; Ookiye opetonpi heca aguyapi iyakiçuya yuhapi kin tona ate wicayuha hwo; qa miye e wotektehdapi on atakuni śni amayan ce.

18 Ito nawajin qa ate elita wahde kta, qa hewakiye kta ; Ate, mahpiya kin en, qa niye nakun nitokam wawahtani :

$19 \mathrm{Qa}$ detanhan cincamayaye kta iyemacece śni ; wicaśta opewicayaton kin he iś wanji ijececa makaga wo, epe kta ce.

20 Unkan najin hiyaye ça atlžnku kin ekta hda. 'Tuka nahahiz itehan atkuku wanhdake ca onśikida, qa ekta inyang ye ça, poskin hduze ca i itputaka.

21 Unkan cinhintku kin heciya; A te, mahpiya kin en qa niye nitokam wawahtani; qa detanhan cincamayaye kta iyemacece śni ce.

22 Tuka atkuku taokiye kin hewicakiya; Śina iyotan waśte kin he aupi qa inkiya po; qa mazanapcupe wan nape kin en iy ekiya po, qa hanpa ohekiya po : $23 \mathrm{Qa}$ ptejicadan cemyapi kin he den aupi qa kte po; wauntapi qa unkiyuśkinpi kta ce:

24 Micinkśi kin de ța, tuka lkini ; tanin śni, tuka iyeyapi ce, eya. Unkan hinnakaha wiyuśkinpi.

25 Tuka cinhintku tokapa qon he magata un; unkan ti kiyedan ku hehan dowanpi qa wacipi nahon.

26 Unkan ookiye wanji kipan, qa token he kapi hecinhan he iwanga.

27 Unkan heciya; Nisunka hdi; unkan ni un, qa zaniyan hdi kin on etanhan niyate ptejicadan cemyapi qon he kikte ce, eya.

28 Unkan hecen śihda, qa tin kihde wacin śni: hehan atkuku kin tankan hiyu, qa cekiya.

29 Unkan waayupte ca atkuku kin heciya; Wanyaka wo, wanna waniyetu ota ociciye ca tohinni nioie kawape śni ; hececa eśta kodawicarvaye cin om wimduśkin kta e tacincadan wan tohinni mayaqu śni.

30 Tuka nicinkśi witkowinpi kin om woyuha nitawa kin tem- 


\section{LUKAS.}

niciye cin de hdi ca, wancake ptejicadan cemyapi kin he yecicața ce, eya.

31 Unkan heciya; Cinś, ohinniyan mici yaun, qa taku mitawa kin he iyulipa nitawa.

32 Nisunka kin de ta, unkan kini; tanin śni, unkan iyeyapi kin, on etanhan ito cante unwaśtepi, qa unkiyuślkinpi kte cin he hecetu ce.

\section{WICOWOYAKE 16.}

1 Hehan waonspewicakiye cin hewicakiya; Wicaśta wijica wanji waawanyake wan yuha; unkan he yuhe cin woyuha tawa yutakuni śni ce, keya okiyakapi.

2 Hehan kico qa heciya; Taku eniciyapi kin de toketu he; waawandake cin ito ohdaka wo ; wanna waawandake cin aduśtan kta ce.

3 Unkan waawanyake cin cante mahen heya; Token ecamon kta he; waawanmdake cin he mayuhe cin imicicu; mahiapi kin owakitpani, qa timatayapi kin he imaśteca.

4 Taku ecamon kte cin he sdonwakiya, heon tohan waawanmdake cin he etanhan heyata iyemayanpi kinhan, tipi kin en tin hiyumayanpi kta ce.

5 Unkan hecen yuhe cin tona ikicazopi qon owasin wicakico, qa tokaheya kin he heciya; $\mathrm{Ma}$ yuhe cin tona nahahin yecu śni he.

6 Unkan, Wihdi iyutapi opawinge ce, eya. Unkan heciya; Koyahanna wowapi nitawa kin ehdaku, qa iyotanke, ca wikcemna zaptan e okiwa wo.

7 Unkan wanji tokeca hehan heciya; Qa niś tona nahahin yecu śni he. Unkan, Aguyapisu iyutapi opawinge ce, eya. Unkan heciya; Wowapi nitawa kin ehdaku, qa wikcemna śahdogan e okiwa wo.

8 Unkan yuhe cin waawanyake owotanna śni kin yaonihan, okiksamya econ kin heon etanhan: maka kin de cincapi kin iwicacage cin en iyoyanpa cinca kin isanpa ksapapi ece.

9 Unkan miś heciciyapi; Woyuha owotanna śni kin on tawaśitku içicaga po; hecen tohan niye oniçihipi śni kinhan, iye tipi owihanke kte śni en tin hiyuniciyapi kta ce.

10 Tuwe taku iyotan cistinna on wicaka hecinhan, hee taku ota nakun on wicaka ece; qa tuwe taku iyotan cistinna kin on owotanna śni hecinhan, hee taku ota kin nakun on owotanna śni ece.

11 Hecen woyuha owotanna śni kin he on wicayakapi śni ehantanhan, wicake cin he tuwe ecin yuheniciyapi kta he.

$12 \mathrm{Qa}$ wicaśta tokeca taku tawa kin on wicayakapi śni ehantanhan, niye nitawapi kin hee tuwe ecin nicupi kta he.

13 Ookiye kin tuwedan yuhe cin nonpa en wowidagiciye kta okihi śni; wanji śicedake kta, qa unma iś waśtedake kta; qa iś wanji en iyaihdaśke kta, qa unma kin iś ekta ewacin kte śni. Wakantanka qa mammon napin en wowidagniçiyapi kta oyakihipi śni ce.

14 Unkan Pharisee kin wakonpi kin, hena owasin nahonpi ; qa wowihayapi.

15 Unkan hewicakiya; Wicaśta kin wicitokam ihdaowotanpidan kin he niyepi ; tuka Wakantanka nicante ozepi kin he sdonniyanpi ce: ecaeś wicaśta ekta taku takudapi hince cin hee $\mathrm{Wa}$ kantanka wahteda śni ece. 
16 Woope qa wicaśta wokcall kin hena Johannes hehanyan; tuka hetanhan Wakantanka tokiconze kin oyakapi ece, qa owasin en opapi kte hinca.

17 Mahpiya rnaka ko tokan -iyaye kte cin he aoptetu, qa woope oowa wanjidan kaeś yuecetupi kte śni kin hee telika ce.

18 Tuwe tawicu ehpekiye ça wanji tokeca yuze cinhan, hee wawicihahapi econ ece: qa hihnaku ehpeye ciqon he tuwe yuze cinhan he wawicihahapi econ ece.

19 Wicaśta wanji wijica, he wokoyake stan qa minithuha zimzipedan ece koyaka, qa anpetu otoiyohi wiyuśkinyan un.

20 Nakun wicaśta wahpanica wan Lazaros eciyapi, he tatiyopa kin en ahionpapi, tancan owancaya hidilidi;

$21 \mathrm{Qa}$ wicaśta wijica wahna wotapi tawa kin etanhan ośnaśna hinhpaye cin hena yunkiyapi kta cin. Tuka śunka kin en ahi, qa hdiłidi kin sdipapi.

22 Unkan wahpanica kin he ta; qa malipiya ohnihde kin Abraham maku kin ekta ayapi. Wicaśta wijica qon iś eya ța, qa hapi.

23 Unkan wakanśica tipi kin en kakiś yanke cehan, wankan etonwe, ca tehan tanhan Abraham wanyaka; qa maku kin ohna Lazaros yanka.

24 Unkan heya niyan; Ate Abraham, onśimakida qa Lazaros u śi wo, napsukaza inkpa kin mini en oputkan qa ceji makasni kta; oide kin de ohna makakija ce.

25 Tuka Abraham heya; Cinś, yani qon he ehan taku waśteśte yahduha, qa Lazaros taku śikśica yuha, he kiksuya wo; tuka nakaha iye kicanptapi qa niye kakiśniyanpi.

26 Qa nakun unkiyotahedan kaksiza wan tanka yanka; hecen tona deciya tanhan niye ekta ye wacinpi keś okitpanipi ece; qa nakun heciya tanhan den ekta unhipi kta okitpanipi ece.

27 Hehan heya; Heon ate, ceciciya ce, ate ti kin ekta ye yaśi kta;

28 Misunka zaptan, hena wowicakiyake kta; iś eya okinni wokakije kin de en upi nun ce.

29 Abraham heciya; Moses qa wicaśta wokcan kin hena yuhapi; hena iś anawicagoptanpi eśta śni.

30 Tuka heya; Hiya, ate Abraham : tuka tapi kin eciyatanhan wanji ekta wicai unkanś, ihduecetupi kta tuka.

31 Unkan heciya; Moses qa wicaśta wokcan kin hena anawicagoptanpi śni ehantanhan, tapi kin eciyatanhan wanji kini qeyaś, nakun wicadapi kte śni ce, eya.

\section{WICOWOYAKE 17.}

1 Hehan wronspewicakiye cin hewicakiya; Wahtaniyapi kin u kte śni pica śni ; tuka tuwe eciyatanhan hena u kinlıan, hee wotehi kiciyanka ece.

2 Dena cikcistinpidan kin tuwe wanji wahtaniye cinhan he iny an wiyukpan wanji tahu kin en napinkiyapi, qa miniyowanca kin oiyohpeyapi unkanś, eeś waș́te kta tuka.

3 Iwanihdaka po. Nisunka śicaya ecanicon kinhan kiśica wo, qa iye iyopeiçiye cinhan, kicicajuju wo.

4 Qa śakowin akihde anpetu wanjidan śicaya ecanicon, qa śakowin akihde anpetu wanji- 


\section{LUKAS.}

dan niye ekta ihduhomni, qa, Iyopemiciya ce, eniciye cinhan, hecen yecicajuju kta ce, eya.

5 Unkan wahoślyapi kin Itancan kin heciyapi ; Wacinunyanpi kin unkiciyusanpa miye.

6 Unkan Itancan kin heya; Sinape sukaza wan iyecen wacinyayapi kinhan, sukamin can kin de, Hute ihdamna qa miniwanca kịn en huicihde wo, eyakiyapi kta, kinhan ananigoptanpi kta tuka.

7 Tuka niyepi kin wanji tukte taokiye wan yuha, maliyumdu qa iś wanunyanpi wilianwicakiya un, qa tokeśta maga kin eciyatanhan hdi kinhan, Iho wo, ye ca wota iyotanka wo, eciye kta he.

$8 \mathrm{Qa}$ iś kaken, Woyute wiyeya micihnake ça, ipiyagkiton qa omakiya wo; qa miś tohan wawate ça wamdatke cinhan, iyohakam niś ito wayate ca wadatke kta ce, eciye kte śni he.

9 Hecen ookiye kin he taku econ śipi kin ecen econ kin, on etanhan wopida eciye kta he. Hepce śni ce.

10 Niś eya iyecen taku token econ niśipi kin, owasin ecen duśtampi kinhan, heya po; Ookiye wakamna śni kin heuncapi ; taku econkupi kta iyecece cin heceedan econkupi ece.

11 Unkan Jerusalem ekta ye cehan, Samaria qa Galile cokaya iyoopta iyaya.

$12 \mathrm{Qa}$ otonwe wan en i qehan, wicaśta wikcemna lepros ececapi itkokipapi, qa itehan hinajinpi :

$13 \mathrm{Qa}$ ho wankan iyeyapi qa heyapi ; Jesus, Itancan, onśiunkida miye.

14 Unkan wanwicayake cehan, hewicakiya; Wawayuśnapi kin elsta wicaya po, qa wan124 yagiciya po. Unkan ekta yapi icunhan akisnipi.

15 Unkan wanji wanna asni sdotkiye cehan, ihdamna, qa hotankakiya Wakantanka yaonihan ;

16 Qa siha kin en ite makipuskin elipeiciye ca, wopida eciya: unkan he Samaria wicaśta kin heca.

17 Unkan Jesus waayupte ca heya; Wikcemna asniwicayapi śni he: tuka napcinwanka kin hena tokiya unpi he.

18 Wakantanka yaonihan kta hdipi kin tuwedan iyeyapi śni, oyate tokeca etanhan kin de iśnana ce.

19 Hehan heciya; Najin qa hda wo; wicayada kin he asniniyan ce.

20 Unkan Pharisee kin iś Wakantanka tokiconze kin he tohan hiyohi kta hecinhan, he iwangapi qehan, waayupte ca hewicakiya; Wakantanka tokiconze kin he wowanyake on hi kte śni.

21 Nakun, Tho, dee ce, qa iho, kae ce, eyapi kte śni : Wanyaka po, Wakantanka tokiconze kin he mahen niunpi ece.

22 Hehan waonspewicakiye cin hewicakiya; Anpetu wan hiyohi kta, Wicaśta Cinhintku kin anpetu tawa kin wanji wandakapi kta yacinpi kta, tuka wandakapi kte śni.

$23 \mathrm{Qa}$, Tho dee, qa iho kae ce, eniciyapi kta; tuka wiciyahna yapi śni po, qa owicapapi śni po. 24. Wakanhdi mahpiya ihukuya tokiyatanhan wiyatpa $u$, qa malipiya ihukuya unma ek ta iyahde ece kin he Wicaśta Cinhintku anpetu tawa kin en iyecece kta.

25 Tuka ito tokaheya taku ota on iyotanhan iyekiye kta, qa 
wicoicage kin de on lieyata iyeyapi kta ce.

26 Unkan Nowa taanpetu qon en tolien unpi qon, Wicaśta Cinhintku taanpetu kin en he iyecece kta.

27 Nowa wata kin en okipe ciqon anpetu kin hehanyan wotapi, qa wayatkanpi, tawicutonpi, qa hihnatonpi ece; unkan minitan $u$, qa owasin owihankewicaya.

$28 \mathrm{Qa}$ nakun Lot anpetu tawa qon en iś eya iyececa, wotapi, qa wayatkanpi, wopetonpi qa wiyopeyapi, wojupi qa ticagapi ece :

29 Tuka Lot Sodom etanhan tankan hinape ciqon anpetu kin hee hinca en mahpiya kin eciyatanhan peta, mazalian noge iyuwintapi kin ahna hinhe, ça owasin owihankewicaya.

30 Wicaśta Cinhintku kin yuotaninpi kte cin he iyecece lita ce.

31 Anpetu kin he en tuwe tipi akan yanke ca tawahpaya timahen hiyeye cinhan, kun ku qa ehdaku kte śni; qa tuwe magata un kinhan, iś eya taku hekta un kin ekta ihdamna kte śni.

32 Lot tawicu qon he kiksuya po.

33 Tuwe wiconi tawa kpatan cin kinhan, he toli ehpekiye kta ; qa tuwe wiconi tawa toki elipekiye cinhan, hee hduhe kta.

34 Heciciyapi ce; Hanyetu kin he en wicaśta nom owinja wanjidan akan wankapi kta; wanji icupi kta, qa unma hin iś ehpeyapi kta.

35 Winyan nonpa akiptan wotpan unpi kta; wanji icupi kta, qa unma kin iś ehpeyapi kta.

36 Wicaśta nom magata unpi kta; wanji icupi lita, qa unma kin iś ehpeyapi kta ce.
37 Unkan waayuptapi qa hec1yapi; Itancan, tukte etu he. Unkan hewicakiya; Tukten wicatancan wanka eca, hen wamdi kin kawitaya imniciyapi ece e lkta.

\section{WICOWOYAKE 18.}

1 Unkan wicaśta kin ohinniyan wocekiye eyapi kta, qa iyakicunnipi kte śni e on wiyacinpi wan owicaliyalka;

2 Qa heya; Otonwe wan en wiyukcan wanji Wakantanka kokipe śni, qa nakun wicaśta wicakinihan śni.

3 Unkan otonwe kin he en wiwazica wan, he wiyukcan kin ekta hi qa, Makipajin kin he tomicicon ye, eya.

4. Uंnkan tokaheya econ wacin śni; tuka ocim cante mahen heya; Wakantanka kowakipe śni, qa nakun wicaśta kin wicawakinihan śni qeyaś ;

5 Wiwazica kin de nagiyemaye cin on etanhan ito towecicon kta ; okinni ohinni hecetu u kinhan wacin iyolkiśinmaye kta naceca ce.

6 Unkan Itancan kin heya; Wiyukcan owotanna śni ie cin he nalion po.

7 Unkan Wakantanka tona wicakahnige, ca anpetu hanyetu ko celkiyapi kin, hena tehan towicakiciçon śni qeyaś, ocim econ kte śni he.

8 Ihnuhanna towicakicicon kta, eciciyapi ce. Tuka Wicaśta Cinhintku kin he tohan hi kinhan, maka akan wacinyanpi iyeye lita he.

9 Unkan apa iye ohan owotanna içidapi, qa tokan kin wahtewicadapi śni kin, hena wiyacinpi kin de owicakiyaka.

10 Wicaśtia nonpa tipi wakan kin ekta cekiya ipi; unma kin 


\section{LUKAS.}

Pharisee heca, qa unrna iś wamnayanpi kin heca.

11 Unkan Pharisee kin iśnana najin, qa kaken wocekiye eya; Wakantanka, wicasta tokeca iyemacece śni, wawicakipi sa, ohan owotanpidan śni, wawicihahapi econpi sa, qa wamnaye cin dee kaeś iyemacece śni heon wopida eciciya.

12 Anpetu wakan okitahedan nonpa akihanmiciye ca taku mduhe cin owasin etanhan iwikcemnamna kin wicawaqu ece.

13 Unkan wamnaye cin iś itehanyan inajin, qa iśta ee kaeś wankan malipiya kin ekta ikikcu śni ; tuka maku kin ohna aicipe, ca heya; Wakantanka onśimakida wo, wawahitani sa.

14 Wicaśta kin de yuowotanpidan tiyata kihda, qa unma qon hee śni, eciciyapi ce : Qa turve ihduwankantuya kinhan, he yuhukun iyeyapi kta: qa tuwe ihduhukuye cinhan, hee yuwankan ayapi lita ce.

15 Unkaı hokśiyoqopa kin nakun wicayutan kta e en awicahipi tuka waonspewicakiye cin he wanyakapi qehan, wicakiśicapi.

16 Tuka Jesus wicakico, qa heya; Hokśiyoqopa kin ekta mahipi kte cin iyowinwicakiya po, qa tehindapi śni po ; Wakantanka tokiconze kin he hececapi etanhan ece.

17 Wowicake eciyatanhan heciciyapi ; Tuwe hokśíy oqopa iyececa Wakantanka tokiconze kin icu śni kinhan, he tolkadan en ope kte śni ce.

18 Unkan wicaśta ihdawa wanji wiwange ça heya; Waonspekiye waśte, token ecamon, qa owihanke wanin wiconi ohimiciye kta he.

19 Unkan Jesus heciya ; Toke- ca e waśte emayakiya he; tu wedan waśte śni ; Wakantanka hecedan waśte.

20 Woahope kin hena onnispe ; Wawicihahapi ecanon kte śni; Tin wicayakte kte śni ; Wamayanon kte śni; Woitonśniyan wodake kte śni; Niyate nihun kici wicahduonihan wo.

21 Unkan heya; Macistina ehantanhan hena owasin ahowapa ce.

22 Unkan Jesus hena nahon qehan heciya; Nahanhin taku wanji iyotpani yaun; taku yaton kin owasin wiyopekiye ca wahpanicapi kin wicakipamni wo, kinhan mahpiya ekta woyuha duhe kta ce; hehan u qa mihakam un wo.

23 Unkan he nalion qehan nina iyokiśica; wijice hinca nakaeś. 24 Unkan nina wacin iyokiśice cin he Jesus wanyake cehan, heya; Wowijice tonpi kin hena Wakantanka tokiconze kin en yapi kte cin he tehike linca.

25 Wicaśta wijica wan Wakantanka tokiconze kin en ye kte cin he tehika, qa kamel heca wanji tahinśpaciqadan olidoka kin ohna ye kte cin hee kaeś aoptetu ce.

26 Unkan tona he nahonpi kin hena heyapi; Hehan tuwe ni kta he.

27 Unkan heya; Wicaśta kin ekta taku econpica śni kin, he Wakantanka ekta econpica ece. 28 Unkan Inyan heya; Iho, unkiś taku owasin untpaganpi, qa niyahna unyakonpi ce.

29 Unkan hewicalkiya; Awicakehan heciciyapi ce, Wicaśta kin tuwe ti kin, qa hunkakewicaye cin, qa hunkawanjitku, qa tawicu, qa cinca, bena wanji Wakantanka tokiconze kin on kpagan kinhan, 30 Hee dehan nakaha taku

126 


\section{WICOWOYAKE 19.}

sanpa ota yuhe kta, qa wiconi u kte cin he en wiconi owihanke wanica yuhe lkta ce.

31 Unkan akenonpapi kin ewicayaku qa hewicakiya; Iho, Jerusalem ekta unyanpi, qa wicaśta wokcan Wicaśta Cinhintku kin on token owapi quon owasin yuecetupi kta.

32 Oyate tokeca napepi kin en wicaqupi kta; hecen iśtenyapi, qa wawicanksiya kuwapi, qa atagośapi kta;

33 Qa kapsinpsintapi qa țeyapi kte; unkan anpetu iyamni kinhan kini kta ce, eya.

34 Unkan ecaca okahnigapi śni, qa oie kin de anawicakihmanpi, qa taku oyakapi kin sdonyapi śni.

35 Unkan Jeriko ikiyedan wanna u qehan, wicaśta wan iśtagonge canku icahda wada yanka,

36 Unkan wicota ahiyaye cin he nation qehan, he tọen kapi hecinhan he iwicawanga.

37 Unkan, Jesus Nazareth etanhan kin he hiyaya ce, eya okiyakapi.

38 Unkan hotankakiya heya; Jesus Dawid Cinhintku kin onśimakida wo.

39 Unkan tokahanpi kin hena iyokipi śni, inina yanke kta ; tuka heon iyotan, hotankakiya heya; Jesus Dawid Cinhintku kin onśimakida wo.

40 Unkan Jesus inajin qa aupi kta kewicakiya. Unkan wanna kiyedan u qehan, wiwange ca,

41 Token ecacicon kta yacin he, eya. Unkan iye, Itancan, watonwe kta, eya.

42 Unkan Jesus heciya; Tonwan wo, wacinyaye cin he niniyan ce.

43. Unkan wancake tonwe ca iyahna hiyu, qa Wakantanka yaonihan: unkan nyate kin he wanyakapi qehan, owasin Wakantanka yatanpi.

\section{WICOWOYAKE 19.}

1 Unkan Jeriko en i, qa iyoopte iyaya.

2 Unkan iho, wicaśta wan Zakeus eciyapi, wamnayanpi itancan kin wanji hee, qa wijica.

3 Unkan Jesus tuwe kin hecinhan he wanyag akita ; tuka tancan ptecedan, hecen wicota kin on tokadan okihi śni.

4 Unkan tokata inyang ye ca sukamin can wanji adi, wanyake kta e heon, hen hiyaye kta nakaeś.

5 Unkan Jesus wanna ehan i qehan, wankan etonwe ça wanyaka, qa heciya, Zakeus koyahanna kun hdicu wo, anpetu kin de yati kin en ito manke kta ce.

6 Unkan koyahanna kun ku, qa iyuśkinyan iyowinkiya.

7 Unkan he wanyakapi gehan owasin ikapapi qa heyapi, Wicaśta wan wahtani sa he kici wote kta iyaya ce.

8 Unkan Zakeus najinhan najin qa Itancan kin heciya; Itancan wanyaka wo, woyuha mitawa kin hanke wahpanicapi kin wicawaqu ece; qa tuwe oitonśniyan taku iwecicu kinhan, topa akihde wecu kta ce.

9 Unkan Jesus heciya; Anpetu kin de wanikiyapi tipi kin de hiyohi; Abraham cincaye cin wanji hee nakaeś.

10 Wicaśta Cinhintku kin taku atakuni śni qon, he akite ça niye kta e heon hi ce, eya.

11 Unkan hena nahonpi qehan nakun wiyacinpi wan owicakiyaka; wanna Jerusalem ikiyedan un, qa Wakantanka toki127 


\section{LUKAS.}

conze kin ecadan u kta kecinpi kin heon etanhan:

12 Qa heya; Wicaśta ihdawa wan makoce itehan wan ekta iyaya, wokiconze icu qa ku kta.

13 Unkan taokiye wikcemna wicayuhe cin, hena wicakico, qa mazaska tkeutapi wikcemna wicaqu, qa hewicakiya; Tohanyan wahdi śni hehanyan un po.

14 Tuka taoyate kin wahtedapi śni, qa tuwe iyahna yeśipi, qa heyapi ; Wicaśta kin de unkidakapi kta uncinpi śni ce.

15 Unkan wokiconze kin icu qa hdi .qehan, taokiye mazaska wicaqu qon hena vicakicopi kta keya; wopetonpi kin on tona wanna hdamnanpi hecinhan, he sdonye kta.

16 Unkan tokaheya kin he u, qa heya; Itancan kin, mazaska nitawa qon, he wanna mazaska wikcemna kamna ce.

17 Unkan heciya; Han, ookiye niwaśte ; taku tonana on wacinyepica yaun, heon etanhan ito otonwe wikcemna idaka wo.

18 Unkan iyokihe kin he $u$, qa heya; Itancan kin, mazaska nitawa qon, he wanna mazaska zaptan kamna ce.

19 Unkan iś eya heciya; Niś otonwe zaptan idaka wo.

20 Unkan wanji tokeca $u$, qa heya; Itancan kin, wanyaka wo, mazaska nitawa wanapin ohna yuha waun, he dee:

21 Wicaśta niśake cin lieon kocicipa ce; taku eyahnake śni kin, he ece edaku; qa woyaju śni kin he ece duksa ce, eya.

22 Unkan.heciya: Nii kin eciyatanhan ciyaco kta, ookiye winicaśtaśni; wicaśta maśake cin he sdonyaya; taku ewehnake śni kin he ece emdaku, qa wowaju śni kin hee mduksa ece.

23 Hecen tokeca mazaska mi- tawa kin he iciyopekiciyapi kin en ade śni he; lkinhan wahdi kin ekta mitawa kin oicage ahna weca kta tuka ce.

24 Hehan hen najinpi kin hena hewicakiya; Mazaska kin he ikicicupi qa tuwe mazaska wikcemna yuhe cin hee qu po.

25 Unkan heciyapi; Itancan kin, he wanna mazaska wikcemna yuha ce.

26 Tona taku yuhapi kin hena orvasin nakun wicaqupi ece e kta; qa tuwe taku yuhe śni kinhan, taku yuhe cin hee kaeś ekiciyakupi kta ece, eciciyapi ce.

27 'Tuka tokamayanpi iwicawadake kta cinpi śni qon hena den awicaupi qa mitokam wicakte po, eya ce.

28 Unkan hena hecen eyc cehan, tokata ye ca Jcrusalem ekta itawankanhde iyaya.

$29 \mathrm{Qa}$. Bethphage qa Bethani, paha wan Oliwe eciyapi kin, he wanna ikiyedan ehan i qehan, waonspewicakiye cin etanhan nonpa ye wicaśi ;

30 Qa heya; Otonwe iyotakons wanke cin he elkta ya po; qa tokaheya en yaipi kinhan śuk cincadan wan iyeyayapi kta, wicaśta tuwedan tohinni akan iyotanke śni; he kiyuśkapi qa aku po.

$31 \mathrm{Qa}$, Tokeca yakiduśkapi he, tuwe eya iniwangapi kinhan, niś hehan, Itancan kin cin ce, eyakiyapi kta.

32 Unkan ye wicaśi qon hena iyayapi, qa token ewicakiye cin ecen iyeyapi.

33 Ünkan śukcincadan kiyuśkapi icunhan, tuwe tarvapi kin hena hewicakiyapi ; Tokeca yakiduśkapi he.

34 Unkan, Itancan kin cin ce, eyapi. 
35 Unkan Jesus kahdipi; qa wokoyake tawapi kin śukcinca kin ailipeyapi, qa Jesus akan yankekiyapi.

36 Qa ye cin tahepi canku ohna wokoyake kin lidumdayapi.

37 Unkan ikiyedan Oliwe paha kin apamahde iyayapi kin hehan wanna i qehan, waonspe wicakiya wicota owasin, wicowaśake wicolian wanyakapi qon owasin on etanhan hinakaha iyuśkinpi, qa hotankakiya Wakantanka yatanpi,

$38 \mathrm{Qa}$ heyapi ; Wicaśtayatapi tuwe Itancan caje kin on u kin he yawaśtepi ce; mahpiya ekta wookiye, qa iyotan wankantu ekta wowitan un nunwe.

39 Unkan Pliarisee wicota en opapi qon apa heciyapi ; Waonspekiye cin, waonspewicayakiye cin wicakiśica wo.

40 Unkan waayupte ca hewicakiya; Dena inina unpi kinhan. inyan kin wancake howaye kta ce, eciciyapi ce.

41 Unkan wanna ikiyedan u, qa otonwe wanyake cehan, aceye, ça heya;

42 Niye kin anpetu nitawa kin de en taku on wookiye duhe kte cin sdonyakiya unkanś: tuka wanna icimana iśta on wanyahdake kte śni.

43 Anpetu kin hiyonihipi kta, tona tokaniyanpi kin nihdukśan maka qapi, qa okśan niyankapi kta, qa ohomni ohinniyan anapte nanijinpi kta:

44 Qa makata elipeniyanpi kta, nicinca en niunpi kin hena koya; qa inyan nonpa icitakihna wanke śni ehpeniyanpi kta; anpetu en taku waśte nihiyohipi kin he sdonyakiye śni heon etanhan.

45 Unkan tipi wakan kin en tin iyaye, ca tona ohna wiyopeDak. yapi, qa wopetonpi qon, hena tankan elipewicaya;

$46 \mathrm{Qa}$ hewicakiya; Tipi mitawa kin he wocekiye tipi, eya owapi qon; tuka niye owamanonpi kin heca yakagapi ce.

47 Unkan anpetu iyohi tipi wakan kin ohna waonspekiya. Tuka wawayuśnapi itancanpi, qa wowapi kagapi, qa oyate kin en wicaśta ihdawapi kin, hena teyapi kta akitapi;

48 Tuka token econpi kta takudan iyeyapi śni; oyate kin owasin oie kin nahonpi kta cinpi ece.

\section{WICOWOYAKE 20.}

1 Unkan anpetu lin hella wanji en tipi wakan kin ohna oyate kin waonspewicakiye, ca wootanin waśte kin he oyake cehan, wawayuśnapi itancanpi, qa wowapi kagapi, qa wicahincapi kin, hena ekta ahi,

2 Qa okiyapi, qa heciyapi; Tukte wicookihi on dena decen ecanon he; qa wicookihi kin de tuwe e niçu hecinhan, unkokiyaka po.

3 Unkan waayupte ça hewicakiya; Miś eya taku wanji iciwangapi kta; he amayupta po:

4 Johannes baptem wicaqu qon he mahipiya eciyatanhan, qa iś wicaśta kin eciyatanhan, unma tukte he.

5 Unkan iye iyakitedan iapi, qa heyapi ; Mahpiya kin eciyatanhan ce, unkeyapi kinhan, Tokeca wicayadapi śni he, eye kta : 6 Tuka, Wicaśta kin eciyatanhan, unkeyapi kinhan, oyate kin inyan on unkininpi kta; Johannes wicaśta wokcan kin heca kecinpi.

7 Unkan ayuptapi, qa tokiyatanhan un kin sdonyapi śni, ke-

yapi. 
8 Unkan Jesus hewicakiya; qon he token kapi he; Tipi kaMiś eya wicookihi tukte on dena ecamon kin nakun ociciyakapi kte śni ce.

9 Hehan wiyacinpi kin de oyate kin owicakiyaka: Wicaśta wan hastanhanka iyuwi maga wan oju, qa mahkicanyanpi kin heca owicaqu, qa makoce itehan wan ekta tehan yanka.

10 Unkan wanna iyehantu qehan, taokiye wanji hastanhanka iyuwi maga waskuyeca kin etanhan qupi kta e, mahkicanyanpi qon ekta yeśi ; tuka mahkicanyanpi qon kaśtakapi, qa cokadan hdeśipi.

11 Unkan ake taokiye wanji tokeca yeśi ; unkan iś eya kaśtakapi, qa śikśicaya kuwapi, qa cokadan lideśipi.

12 Unkan akeś iyamni wanji yeśi ; unkan iś eya taopi, qa tankan elipeyapi.

13 Hehan hastanhanka iyuwi maga tawa kin heya; Token ecamon kta he. Micinkśi waśtewalkidake cin, hee yewaśi kta ce; okinni he wanyakapi kinhan yuonihanpi kta.

14 Tuka makikicanyanpi kin he wanyakapi qehan, iye iyakitedan iapi, qa heyapi ; Tawaye kte cin he dee ce; iho po, unktepi kta; hecen unkiye tawaunyanpi kta ce.

15 Hecen hastanhanka iyuwi maga itankan ehpeyapi, qa ktepi. Heon etanhan hastanhanka iyuwi maga tawa kin token ecawicakicon kta he.

16 Ito ku kta, qa mahkicanyanpi kin hena owihankewicaye, ca hastanhanka iyuwi maga kin he tokan wicaqu kta ce, eya. Unkan he nahonpi qehan, Hecetu śni ce, eyapi.

17 Unkan awicatonwe cehan heya; Hecen wowapi en kagapi gapi kin inyan heyata iyeyapi qon hee wanna oise en itancan icaga ce :

18 Qa tuwe inyan kin he abinhpaye cinhan kahuliugapi kta; qa iś inyan kin tuwe ahinhpaye cinhan, hec pamdu kta ce.

19 Unkan wawayuśnapi itancanpi, qa wowapi kagapi kin, hena he ehan iyahpayapi kta cinpi ; tuka oyate kin kowicakipapi ; wiyacinpi oyake cin he iye wicaka e iyukcanpi.

20 Unkan awanyag kuwapi, qa wanjikji iye owotanna konzapi kin hena iwanyakapi kta e ekta ye wicaśipi; hecen oie kin iyahpayapi, qa wicaśta itancan towaśake qa tawacin kin en qupi lita.

21 Unkan hena wiwangapi, qa heyapi; Waonspekiye cin, niye tanyan iyae, ca waonspeyakiya ece; qa tuwedan en eyatonwe śni ; tuka Wakantanka ocanksu tawa kin he awicakehan onspewicayakiya e sdonunniyanpi ce: 22 Iho, Kesar wamnayanpi kin unqupi, qa iśs unqupi kte śni, unma tukte hecetu he.

23 Unkan wayupiya hnaye wacinpi kin he iwicayukcan, qa hewicakiya ; Tokeca iyutanmayayapi he.

24 Kaśpapidan wanji makipazo po. Akan owapi qa wakagapi kin de tuwe tawa he. Unkan ayuptapi qa; Kesar tawa ce, eyapi.

25 Unkan hewicakiya; Heon Kesar taku tawa kin hena Kesar kicu po; qa Wakantanka taku tawa kin Wakantanka kicu po.

26 Unkan oyate kin wicitokam oie kin iyahpayapi kte cin okitpanipi, qa waayupte cin he on inihanpi, qa inina hiyeya.

27 Hehan Sadukee ake wica130 


\section{WICOWOYAKE 21.}

kini kta wanica keyapi kin hena wanjikji en hipi ; wiwangapi,

$28 \mathrm{Qa}$ heyapi; Waonspekiye cin, Moses kaken wowapi unkicagapi ; Tuwe cincu tawicu ton qa cinca nica ecen te cinhan, iye sunkaku tawicu qon hduze ça cincu cinca icahkiciciye kta ce.

29 Unkan hecen huukawanjin.kiciyapi śakowin: unkan tokapa kin tawicu ton, qa cinca nica ecen ta.

30 Unkan iyokihe qon he helian hduza; tuka cinca nica ecen ta.

31 Unkan iyamni qon hduza; qa śakowinpi qon owasin hecen hduzapi, qa ecen tapi ; unkan cinca nicapi.

32 Unkan ehake winohinca iś eya ta.

33 Iho, hecen wicakini kte cin ekta śakowin hduzapi qon, hena tukte wanji tawapi kta he, eyapi.

34 Unkan Jesus wayyupte, ca hewicakiya; Maka kin de cinca kin tawicutonpi, qa hihnatonpi :

35 Tuka tona makoce kin he en opapi kte cin, qa wicațe cin etanhan kinipi kta iyececa wicadakapi kin hena tawicu tonpi śni, qa hihnatonpi śni ece.

36 Qa nakun ake tapi kta okihipi śni; tuka hena mahpiya ohnihde kin om akiyececapi ece, qa wicakini kin he hena cinca kin on etanhan Wakantanka cincawicaya ece.

37 Unkan wicate cin hena kiniwicakiyapi kta, Moses hee kaeś can yuhaka ekta niciyaotaninpi; Abraham Wakantanka tawa, qa Isaak Wakantanka tawa, qa Jakob Wakantanka tawa, Itancan kin eciye ciqon he ehan.

" 38 Tona tapi kin hena Wakantanka tawapi śni, tuka ni unpi kin hena: owasin iye ekta ni unpi ece.
39 Unkan wowapi kagapi kin wanjikśi hehan heciyapi; Waonspekiye cin, tanyan eha ce.

40 He iyohakam tuwedan sanpa wiwanga tawatenye śni.

41 Unkan hewicakiya; Token on Messiya Dawid Cinhintku kin eciyapi he.

42 Odowan wowapi kin en $\mathrm{Da}$ wid iye linca heya; Itancan kin Itancan mitawa kin heciya; Mietapa kin ekta iyotanka wo,

43 Ecen tokaniyanpi kin hena nisiha oahe wicawakąge kta ce. 44 Hecen Dawid Itancan eciya hecinhan, token on cinhintku kta he.

45 Unkan hehan oyate owasin nation hiyeye cin en, waonspewicakiye cin hewicakiya;

46 Wowapi kagapi kin itonwicapa po; he iye śina hanskaska in omanipi, qa iciyopekiciyapi kin en owicalkiyapi, qa omuiciye tipi kin oyanke tokapa, qa wotapi kin en ohehdepi tokapa kin, hena hecelicen cinpi :

47 Qa wiwazica tipi tawapi kin temyapi; qa ihdutaninpi kta on wocekiye hanska eyapi ece ; hena iś iyotan woyaco tanka iyahdeiçiyapi kta ce.

\section{WICOWOYAKE 21.}

1 Unkan wankan etonwe, ca wicaśta wijicapi kin womnaye opiye kin en taku wicaqupi kin ehpeya ayapi wanyaka.

2 Unkan wiwazica wanji wahpanica kin iś mazaśadan nonpa en elipeya e wanyaka.

3 Unkan heya; Awicakehan heciciyapi, Wiwazica wahpanica lrin de iśnana ota en ehipeya ce.

4 Dena owasin taku iwicakiciyaye cin hee Wakantanka taku qupi kin en elipekiyapi ece; 131 


\section{LUKAS.}

tuka iye taku ton śni, etanhan taku on ni kte cin ocowasin en elipeya ce.

5 Unkan apa iś tipi wakan kin inyan waśteśte, qa taku wicaqupi kin on ayucopi kin, he cajeyatapi qehan, heya;

6 Anpetu hiyohi kta, en taku wandakapi kin dena inyan nonpa icitakihna wanke śni elipeyapi kta ce.

7 Hehan wiwangapi, qa heyapi ; Waonspekiye cin, tohan kinhan hena hecetu kta he; qa hena hecetu kte cin wanna iyehantu kinhan, taku on sdonyapi kta he.

8 Unkan heya; Ihnuhan nihnayanpi kinhan; wicota micaje kin on upi qa, He miye ce, qa wanna ecadan iyehantu kta ce, eyapi kta: tuka wicihakam yapi śni po.

9 Tuka okicize owodutatonpi ko cajeyatapi nayahonpi kinhan, nihinciyapi śni po ; ito tokaheya hena hecen hiyohi kta iyececa, tuka owihanke kin hinyahinke kte śni ce.

10 Hehan hewicakiya; Oyate wan oyate tokeca azuye kta, qa wokiconze wan wokiconze tokeca on inajin kta :

$11 \mathrm{Qa}$ otakiya maka kin nina śkanśkan, qa wicaakilian, qa makośikśice, qa wowanyake wokokipe, qa malipiya kin eciyatanhan wowapetoktokeca, hena hecekcen yuke kta ce.

12 Tuka taku kin dena owasin itokaptu, micaje kin on etanhan iyanihpayapi, qa śicaya nicuwapi, qa omniciye tipi, kaśka wicahnakapi tipi ko en aniyanpi, qa wicaśtayatapi wicaśta iwicadakapi kin ko wicitokam aniyanpi kta ce :

13 Unkan hecen on oniyakapi ece e kta.
14 Hecen icantekicun po; token waaduptapi kte cin he kanyehan awacinpi śni po :

15 Wicai wicoksape ahna cicupi kta, hecen tokaniyanpi kin tuwedan taku. iennihdepi kte śni, qa iyakapeniyanpi kte śni.

16 'Tuka hunkake wicayayapi, qa hunkawanjin wicayayapi, qa takuwicayayapi, qa koda wicayayapi kin, hena e wiyopeniyanpi kta ; qa apa teniyanpi kagapi kta ce :

$17 \mathrm{Qa}$ micaje kin on etanhan owasin niciy uśepi kta.

18 Tuka paha wanjidan kaeś awinitukapi kte śni ce.

19 Wacinnitankapi kin on nicantepi kin hduha po.

20 Jerusalem ihdukśan ozuye yankapi wandakapi kinhan, ihangyapi kte cin he wanna kiyadan e sdonya po.

21 Hehan tona Juda makoce kin en unpi kinhan, he kin ekta najicapi kta; qa tona cokaya en unpi kinhan tankan inapapi kta; qa okśan makoce wanke cin tona en yakonpi kinhan, ekta hdicupi kte śni.

22 Tokiconpi anpetu kin hena ee; hecen taku token owapi qon hena owasin ecen yuśtanpi kta ce.

23 Tuka anpetu kin hena en tona ihduśakapi, qa tona hokśin azinwicakiyapi kin hena wotehi wicakiciyanke kta; maka kin akan wokakije tanka kta, qa wocanniye oyate kin de en awicaun kta.

$24 \mathrm{Qa}$ mazasagye ope kin on wankahanpi kta; qa oyate kin owasin ektakta wayaka awicahdapi kta; qa Ikcewicaśta kin Jerusalem naatinzapi kta, ecen Ikcewicasta kin taku iyewicakicihantu kta ce.

25 Anpetu wi, qa hanyetu wi, 


\section{WICOWOYAKE 22.}

qa wicanhpi kin hena ekta wowapetokeca yuke kta; qa maka akan oyate kin yazanhdapi kta, qa wicotoketu tanin śni ; qa miniwanca otaja ko sa wanke kta.

26 Wicaśta kin kopa, qa maka akan taku hiyohi kte cin he ape hiyeye cin, hena on cante toki wicayanka tanin kte śni ece; malipiya wowaśake kin hena huhuzahe kta heon.

27 Hehan Wicaśta Cinhintku kin mahpiya śapa wan akan, wowaśake qa wookitanin tanka hduha u wandakapi kta.

28 Unkan dena decen aye cinhan, hehan wankan etonwanpi, qa pa yuwankan icu po; openicitonpi kin he wanna kiyadan u ce, eya.

29 Unkan wiyacinpi wan owicakiyaka: Suken can, qa can kin owasin, hena wanyaka po ;

30 Canwapa palia eca, mdoketu wanna ikiyedan, niye cinka wandakapi, qa sdonyayapi ece.

31 Tho he iyececa, taku kin dena iyecetu wandakapi kinhan, Wakantanka tokiconze kin he wanna ikiyedan un e sdonya po.

32 Awicakehan heciciyapi, Wicoicage kin de tokan iyaye śni, ecen dena owasin iyecetu kta ce.

33 Mahpiya kin maka ahna tokan iyaye kta, tuka mioie kin e tokan iyaye kte śni ce.

34 Unkan itoniçipa po; okinni tukten wotapi, qa witkopi, qa wiconi kin de awacinpi kin, hena on nicantepi kin niyuśakapi kta naceca; qa hecen sdonyakiyapi śni ecen anpetu kin he nihiyohipi kte.

35 Maka ite kin akan yakonpi kin owasin wohmuke wan iyecen wicahiyohi kta ce.

36 Heon ohinniyan wakta po, qa cekiya po; hecen taku hiyohi kte cin dena owasin icunom ida- dapi, qa Wicaśta Cinhintku kin itokam nayajinpi kta iyececa niyawapi kta ce.

37 Unkan anpetu icunhan tipi wakan kin ohna. waonspekiya un; qa hanyetu hehan tankan hdicu, qa paha wan Oliwe eciyapi kin he en yanka.

38 Unkan hanhanna hinca oyate kin owasin oie nahonpi kta e tipi wakan kin en ahi.

\section{WICOWOYAKE 22.}

1 Unkan aguyapi napohyapi śni yutapi woacakśin eciyapi kin, he wanna ecadan iyehantu kte.

2 Unkan wawayuśnapi itancanpi, qa wowapi kagapi kin, hena token econpi, qa teyapi kte cin he akitapi ; tuka oyate kin kowicakipapi.

3 Unkan akenonpapi kin etanhan, wanji Judas Iskariot eciyapi kin he Satan tancan mahen iyaya.

4 Unkan he ekta ye ca, wawayuśna itancanpi, qa akicita itancanpi kin hena om wohdaka, token econ qa wicaqu kte cin heon.

5 Unkan iyuśkinpi, qa mazaska qupi kta keciyapi.

6 Hecen wicada, qa wicota kin en unpi śni icunhan wicaqu kta akita.

7 Unkan aguyapi napohyapi śni anpetu en woacakśin ktepi kte cin wanna hehantu.

8 Hehan Inyan qa Johannes ye wicaśi qa heya; Ya po, woacakśin untapi kte cin he wiyeya unkicihnaka po.

9 Unkan heciyapi; Tukten wiyeya unhnakapi kta yacin he.

10 Unkan hewicakiya; Otonwe kin en yaipi kinhan, wicaśta wan wakiśkokpa mini ohnaka yuha itkonicipapi kta; iho, iye 


\section{LUKAS.}

tukten tin kihde cinhan, iyahna ya po.

11 Qa tipi tawa kin heciya po; Waonspekiye cin heniciya ce; Wotapi tipi ohna woacakśin kin he waonspewicawakiye cin om wate kte cin lie tukte e he.

12 Kinhan, wankan tipi wan tankaya, qa ayucopi e nicipazopi kta; hen wiyeya hnaka po, eya.

13 Unkan iyayapi, qa token ewicakiye ciqon ecen iyeyapi; qa woacakśin wiyeya hnakapi.

14. Unkan wanna iyehantu qehan, en iyotanka, qa wahośiyapi akenonpapi kin nakun.

15 Unkan hewicakiya; Makakije kte cin he itokamya woacakśin kin de untapi kte cin nina wacin qon.

16 Qa heciciyapi ce; Tohan Wakantanka tokiconze kin ekta yuecetupi śni kin, hehanyan detanhan ake wate kte śni ce, eya.

17 Unkan miniyatkan kin he icu, qa wopida eye ca heya; De icupi qa kicipamni po:

18 Qa heciciyapi ce; Wakantanka tokiconze kin he tohan hiyoli śni kin, hehanyan hastanhanka iyuwi waskuyeca kin etanhan mdatke kte śni ce, eya.

19 Unkan aguyapi kin icu, qa wopida eye, ça yuśpaśpa, qa wicaqu, qa heya; Mitancan niyepi on qupi kin he dee ce; decen miksuya econ po.

20 Unkan miniyatkan kin iś eya wotapi iyohakamya wicaqu, qa heya; Mawe niyepi kin on papsonpi kin, en okodakiciye teca kin, miniyatkan kin he dee ce.

21 Tuka iho, wiyopemaye kte cin he nape kin wahna wotapi kin akan miciun.

22 Unkan Wicaśta Cinhintku kin token kiconzapi qon ecen ye kta e hecetu; tuka tuwe he wiyopeya hecinhan he wicaśta kin wotehi kiciyanka ce.

23 Unkan hinakaha iye iyakitedan tukte wanji hecon kte cin he ikiciwanh yeyapi.

24. Unkan tukte wanji iyotan yawapi kte cin he nakun hdokinicapi.

25 Unkan hewicakiya; Oyate kin wicaśtayatapi wicayuhapi kin hena iś iwicadakapi, qa tona wicookihiya owicakilanyanpi kin hena ohanwaśtepi, ewicakiyapi ece.

26 Tuka niś henicecapi kte śni; tuka niyepi kin ekta tukte wanji tokapa kinhan, hee hakakta kin iyecece kta ce.

27 Wota yanke cin, qa wayutankiyapi kin, hena unma tukte iyotan tanka he. Tuwe wota yanke cin hee śni he. Tuka miś wayutankiyapi kin he iyecen cicipi waun ce.

28 Wawiyutanmayanpi kin en kici maunpi kin he niyepi :

29 Heon Atewaye cin he wokiconze wan maqu kin he iyecen ciçupi :

30 Qa hecen wokiconze mitawa kin en, wahna wotapi mitawa kin elsta wayatapi, qa wadatkanpi kta; qa wicaśtayatapi oyanke kin heca akan idotankapi kta, qa Israel wicoun akenonpapi kin wicadacopi kta ce. 31 Hehan Itancan kin heya; Simon, Simon, iho, Satan niyuhe ca, aguyapi su iyecen niyucan kta e cin tuka ce.

32 Tuka wacinyaye cin he iyotpani kte śni e wocekiye eciciya; qa tohan niś niyuhomnipi kinhan, nihunkawanji wicahduwaśaka wo, eya.

33 Unkan heciya; Itancan, wicokaśke wiconțe ko en nici mde kta wiyeya waun ce. 
34 Unkan heya; Simon, anpetu kin de anpaohotonna hoton śni, ecen yamni akihde sdonmayaye cin he anayakilibe kta, eciciya ce.

35 Unkan hewicakiya; Mazaska ojuha, qa wojuhadan, qa hanpa, hena codan yeciśipi qon he ehan, taku wanjidan kaeś iniciyotpanipi he. Unkan, Takudan śni ce, eyapi.

36 Hehan hewicakiya; Tuka nakaha tuwe mazaska ojuha ton kinhan, ehdaku kta; qa wojuhadan nakun: qa tuwe mazasagye nice cinhan, wokoyake tawa kin wiyopekiye, ça wanji opeton kta.

37 Taku wowapi en kagapi qon, Wicolian śica econpi kin om yawapi ce, eyapi kin he miye en yuecetupi kta, eciciyapi : Unkan dena miye on ecen econpi kta ce.

38 Unkan heciyapi; Itancan, wanyaka wo, den mazasagye nonpa ce. Unkan, Henakeca ce, ewicakiya.

39 Unkan tankan hdicu, qa Oliwe paha kin ekta i ece qon, he ake ekta ya ; unkan waonspewicakiye cin iś iyahna yapi.

40 Unkan wanna ehan i qehan, hewicakiya;. Wowiyutanye kin en idadapi kte śni e cekiya po.

41 Hehan wicicunonpa inyan elrta ehpeyapi kin hehanyan ecen i, qa canpeśka makehde inajin qa celkiya,

42 Qa heya; Ate hecen nitawacin kinhan, miniyatkan lin de tokan imiciyaye kta; tuka miye mitawacin kin hee śni, niye nitawacin kin hee ecen econpi nunwe.

43 Hehan mahpiya eciyatanhan ohnihde wan en hi qa yuwaśaka.

44 Unkan nina hin yazanhda qehan, iyotan wokitanyan cekiya; qa temni kin he we ośbuye tankinkinyan makata hinhpaya se ececa.

45 Unkan cekiye cin hetanhan wanna najin hiyaye, ca waonspewicakiye cin en wicahdi qehan, wacin iyokiśicapi kin on iśtinmapi iyewicaya.

46 Qa hewicakiya ; Tokeca niśtinmapi he: najinpi qa cekiya po; hecen wowiyutanye kin en yaipi kte śni.

47 Hena hecen eya icunhan, iho, wicota, qa akenonpapi kin etanhan wanji Judas eciyapi kin, he wicitokam u, qa Jesus i iputake kta e ikiyedan hiyu.

48 'Tuka Jesus heciya; Judas, Wicaśta Cinhintku kin i iputakapi wan on wicayaqu he.

49 Unkan kici unpi qon hena, taku toketu kte cin wanna wanyakapi qehan heciyapi ; Itancan, mazasagye on waaunpapi kta he.

50 Unkan wanji wawayuśna itancan taokiye wanji ape, ca etapa kin eciyatanhan noge kin kaśpa.

51 Unkan Jesus waayupte ça, Hehanyan iyawinmakiya wo, eye ca noge yutan, qa asniyan.

52 Hehan Jesus wawayuśna itancanpi, qa tipi wakan kin en itancanpi, qa tokapapi en au qon, hena hewicakiya; Mazasagye can ko yuha wamanon sa wan tatpe yapi se iyecen yahipi he.

53 Anpetu iyohi tipi wakan kin ohna opeya ciunpi qon ehan, tuwedan nape kin itlom hiyumayalkiyapi śni ; tuka dehan nakaha kin he niye nitawapi, qa otpaza wowaśake kin, eya.

54 Hehan yuzapi qa ayapi, qa wawayuśna itancan ti kin elita aipi. Unkan Inyan itehan ihakam u. 


\section{LUKAS.}

55 Unkan itankan tipi kin en cokaya cetipi, qa ptaya iyotankapi qehan, Inyan iś eya wicehna iyotanka.

56 Tuka petkahda iyotankehan yanke cin, hehan wikośka wan wanyake ca, opahte ca heya; Wicaśta kin de iś eya he kici un tuka ce, cya.

57 Unkan anakilibe, ca, Winohinca, he tuwe kin sdonwaye śni ce, eya.

58 Unkan iecadan wanji tokeca wanyake ça heya; Niś eya henitanhan ce. Unkan Inyan heya; Wicaśta, hematanhan śni ce.

59 Unkan iyohakam wihiyayedan oape wanji ecetu, hehan wanji tokeca yaatinze ca heya; Galile wicaśta kin de heca, on etanhan awicakehan iś eya he kici un tuka ce.

60 Unkan Inyan heya; Wicaśta, token ehe cin he sdonwaye śni ce. Unkan hecehnana, iahan icunhan, anpaohotonna kin hoton.

61 Unkan Itancan kin ihduhomni, qa Inyan atonwan. Hehan Itancan kin, Anpaohotonna hoton śni kin itokam yarnni akihde anamayakihbe kta ce, eye ciqon, oie kin he Inyan kiksuya.

62 Hehan Inyan tankan kihde ca nina hin ceya.

63 Unkan wicaśta Jesus yus unpi kin hena ihahapi qa apapi.

64 Qa ite kin akahpetonpi hehan, ite kin ohna apapi, qa heya iwangapi ; Tuwe anipa hecinhan ito iyukcan wo.

65 Qa taku tok tokeca ota itkom waośtehdaya eciyapi.

66 Unkan wanna anpao qehan, oyate kin en tona tokapapi, qa wawayuśna itancanpi, qa wowapi kagapi kin, hena mniciyapi, qa omniciye kin en aupi;

$$
136
$$

67 Qa heyapi; Messiya he niye hecinhan unkokiyaka po. Un. kan hewicakiya; Ociciyakapi eśta wicayadapi kte śni.

$68 \mathrm{Qa}$ wiciwangapi eśta amayaduptapi kte śni, qa amayaduśtanpi kte śni.

69 De iyohakam Wicaśta Cinhintku kin Wakantanka towaśake etapa kin eciyatanhan iyotanke kta ce, eya.

70 Unkan owasin heyapi ; Hecen Wakantanka Cinhintku kin he niye he. Unkan, He miye kehapi ce, cwicakiya.

71 Unkan heyapi; Iye i kin eciyatanhan unkiyepi hinca wanna naunhonpi ce; hecen tokeca ecin sanpa wayaotaninpi unkodepi kta he.

\section{WICOWOYAKE 23.}

1 Unkan wicota kin owasin najin hiyayapi, qa Pilate kayapi.

2 Hehan hinnakaha wiyaonpapi, qa heyapi; De oyate kin owicayuśice, ca Kesar wamnayanpi qupi kin he tehinda iyeunyanpi; qa iye Messiya Wicaśtayatapi kin heca keiciya ce, eyapi.

3 Unkan Pilate wiwange ca heya; Juda Wicaśtayatapi kín he niye he. Unkan ayupte, ca, Niye ecen eha ce, eya.

4 Hehan Pilate wawayuśna itancanpi qa oyate kin hena hewicakiya; Wicaśta kin de on taku śica iyewaye śni ce.

5 Unkan hecen iyotan wohitipike ca heyapi; Oyate kin owodutatonwicaya ece, qa Galile etanhan Juda makoce kin owancaya dehan niyahdeya waonspekiya ece.

6 Unkan Pilate Galile eyapi nalion qehan, wicaśta kin he 


\section{WICOWOYAKE 23.}

Galile wicaśta kin heca hecinhan he iwieawanga.

7 Unkan Herod taoyate kin hetanhan e Pilate sdonya, hehan Herod ekta iyayeya; he qe wanna Jerusalem en un.

8 Herod Jesus wanyake cehun nina iyuśkin; taku ota on nation kin heon wanakajatanhan wanyaka cin; qa wowapetokeca wanji econ wanyake kta kecin.

9 Hehan iapi ota 'un wiwanga ; tuka takudan ayupte śni.

10 Unkan wawayuśna itancanpi, qa wowapi kagapi kin, hena inajinpi, qa wohitiya wiyaonpapi.

11 Unkan Herod ozuye wicaśta wicayuhe cin om takuda śni, qa ihalia kuwa, qa śina wan ayucopi in kiye, ça ake Pilate ekta iyayeya.

12 Unkan anpetu kin he en Herod Pilate kici kiciyuwaśtepi ; he itokamya tokakiciyapi.

13 Unkan Pilate wawayuśna itancanpi, qa itancanwicakiyapi, qa oyate kin hena witaya wicakico qehan, hewicakiya ;

14 Wicaśta kin de oyate kin owicayuśice cin wan iyecen mayakahipi; unkan iho nitokam iwanmdaka, tuka taku iyayaonpapi kin hena on, taku śica wicaśta kin de en takudan iyewaye śni.

15 Qa nakun Herod hee kaeś, ekta aye ciśipi; unkan iho, țe kte cin iyecece cin takudan ecakiconpi śni.

16 Hecen wakapsinpsinte, ca wakimduśke k ta ce, eya.

17 Wotapi kin he icunhan wicaśta wanji wicakiciyuśke kta e heon.

18 Unkan owasin okonwanjidan heya niyanpi; De tokan aya wo ; qa Barabbas hee unkiciyuśka miye.

$19 \mathrm{He}$ qe otonwe kin en woki- pajin lage, ca tinwicakte on etanhan kaślka wicahnakapi tipi kin en ohnakapi.

20 Pilate Jesus kiyuśke wacin kin heon ake iyecen ewicakiya.

21. Tuka howayapi qa heyapi; Icipaweh olkatan wo, icipaweh okatan wo.

22 Unkan iyamni hewicakiya; Tokeca, tukte ecin taku sica econ he. On etanhan te kte cin iyececa takudan iyewaye śni; hecen wakapsinpsinte, ça wakimduśke kta ce, eya.

23 Unkan hotankakiya kitanpi, icipaweh okatanpi kta e he kapi. Unkan iye hopi kin, wa: wayuśna itancaupi kin om iyakapeyapi.

24. Hecen token cinpi kin he iyecen Pilate kiconza.

$25 \mathrm{Qa}$ tuwe cinpi kin wokipajin kage, ca tinwicakte qon, hee wicakiciyuśke ; tuka iye tawacinpi kin en Jesus wicaqu.

26 Unkan tokan yus ayapi qehan, Kurene wicaśta wan Simon eciyapi makoce kin eciyatanhan u kin he yuzapi, qa cansusbeca kin he Jesus ihakam qin kta e ailipeyapi.

27 Unkan oyate kin wicota hinca winolinca ko iyahna yapi, qa ivaśihda aceyapi.

28 Tuka Jesus ekta ihduhomni qa hewicakiya; Jerusalem cunwintkupi kin, miye amaceyapi śni po; tuka niyepi qa nicincapi kin aiciceya po.

29 Tho, anpetu hiyohi kte cin hena en heyapi kta; Hokśin yuhapi śni, qa wicitpi tohinni cincaton śni, qa aze tohinni azinpi śni kin hena yawaśtepi ce.

30 Hehan hinnakaha he kin, Unkahinhipaya po, qa paha kin, Unkahipa po, eciyapi ece e kta.

31 Qa can teca kin en decen 137 
LUKAS.

econpi kinhan, can śeca kin en token econpi kta he, eya.

32 Unkan wicaśta tokeca nonpa, olian śicapi kin, hena wicaktepi kta e kici awicayapi.

33 Unkan tukten Wicapahu eciyapi kin wanna ehan ipi qehan, hen icipaweh okatanpi, qa nakun wicolian śica econpi qon hena, unma iye etapa eciyatanhan, qa unma kin iś catka tanhan.

34 Hehan Jesus heya; Ate, wicakicicajuju wo; taku tokonpi kin sdonkiyapi śni ce. Unkan tawokoyalke kin kicipamnipi, qa oeconna econpi.

35 Unkan oyate lsin opahta najin hiyeya: Qa itancanwicalkiyapi kin iś eya hena om ihahapi qa heyapi ; Wicaśta tokeca niwicaya ece qon; iye atayedan niiçiya eśta śni, Messiya Wakantanka hdahnige cin hee hecinhan.

36 Unkan akicita kin iś eya ihahapi, en au, qa miniskuya kipazopi ;

37 Qa heyapi ; Juda wicaśtayatapi kin he niye hecinhan, niiciya wo.

38 Unkan iwankam wowapi kin de, Helenes qa Roma qa Hebrew iapi henakiya en owapi; JUDA WICAŚTAYATAPI KIN HE DEE CE.

39 Unkan ohan śicapi en owicakatanpi qon wanji śicaya owakiye ca heya; Messiya he niye hecinhan niiciya wo, qa unkiś nakun.

40 Tuka unma kin waayupte ca kiśice ça heya; Wakantanka koyakipe śni he; wicayacopi okonwanjidan kici en yaun :

$41 \mathrm{Qa}$ unkiye kin en he owotanná; taku econku eciyatanhan unkakipa ece ; tuka iye qe taku śica takudan econ śni ce.

42 Unkan hehan Jesus heciya
Itancan, wokiconze nitawa kin en yaku kinhan, miksuya wo.

43 Unkan Jesus heciya; Anpetu kin de en wowaśte makoce lin en mici yaun kta ce, awicakehan eciciya.

44 Wanna wihiyayedan oape śakpe hehantu; unkan makoce kin owancaya aotpaza, napcinwanka apa hehanyan.

$45 \mathrm{Qa}$ anpetu wi kin otpaza icu, qa tipi wakan kin en minihuha ozanzan hiyeye cin he cokaya okinalideca.

46 Unkan Jesus hotankakiya hoyekiye cehan, hehan heya; Ate, ninape kin en minagi kin owehnaka ce. Unkan hecen eye cehan ța iyaya.

47 Ünkan akicita opawinge wicayuhe cin he token econpi qon he wanyake cehan, Wakantanka yaonihan, qa heya; Awicakehan wicaśta owotanna he de heca ce. 48 Unkan oyate kin witaya he wanyag ahi qon, hena owasin token econpi qon liena wanyakapi qehan, maku kin ohnahna aicipapi, qa kihdapi.

49 Unkan tona sdonyapi qon hena owasin itehan inajinpi, qa winohinca Galile etanhan ihakam upi qon hena taku kin dena wanyakapi.

50 Unkan iho, wicaśta wan Joseph eciyapi, wahokonwicakiya ece kin heca, wicaśta waśte qa owotanna;

51 He iye kin wakiconzapi qa ohanpi qon wicawicada sni: Arimathea, Juda totonwepi kin wanji hee etanhan; is eya Wakantanka tokiconze kin he ape un.

$52 \mathrm{He}$ Pilate ekta ye ca Jesus tancan kin kida.

53 Unkan kun eyaku, qa minihuha ska opazunte, ca imnija kalidokapi wicaśta hnakapi wan 


\section{WICOWOYAKE 24.}

en ohnaka; he itokam tuwedan en ohnakapi śni.

54. Unkan anpetu en ihduwiyeyapi ece kin he hee, qa anpetu wakan kin wanna ikiyedan.

55 Unkan winohinca Galile etanhan kici upi qon hena ihakam iyayapi, ohna hnakapi kin he, qa tancan kin token hnakapi kin hena wanyakapi.

56 Qa hetanhan kihdapi, qa pejihuta waśtemna ihepi ko wiyeya ehnakapi. Hehan woahope kin eciyatanhan anpetu wakan kin okihpapi.

\section{WICOWOYAKE 24.}

1 Unkan anpetu wakan en anpetu tokaheya, hanhanna hinca, hehan wicaśta hnakapi kin ekta, pejihuta waśtemna wiyeya ehnakapi qon hena yuha en upi ; qa toktokeca nakun owicapapi.

2 Unkan wicaśta hnakapi kin etanhan inyan kin wanna tokan iyeyapi e wanyakapi :

3 Qa mahen ipi, tuka Jesus Itancan tancan kin he iyeyapi śni.

4 Unkan token iyukcanpi nun tanin śni qehan, iho, wicaśta nonpa wokoyake wiyatpatpa unpi icahda nawicajinpi.

5 Unkan kokipapi, qa ite kin makipuskin elipeiciyapi qehan, hewicakiyapi; Tokeca e tapi kin wicehna ni un kin ayakitapi he.

6 Den un śni; tuka kini ce. Nahanliin Galile en un qon ehan token eniciyapi qon he kiksuya po:

7 Wicaśta Cinhintku kin wicaśta śica napepi hin en wicaqupi kta, qa icipaweh okatanpi kta; tuka anpetu iyamni kinhan kini kta ce, eya ce.

8 Unkan hecen eye ciqon he kiksuyapi.

9 Unkan wvicaśta hnakapi kin etanhan kihdapi, qa akewanjipidan unmapi ko hena owasin owicakiyakapi.

10 Unkan wahośiyapi kin hena hecen owicakiyakapi qon, Mary Magdalene, qa Joanna, qa Mary Jakob hunku kin, qa toktokeca om unpi qon hena eepi.

11 Unkan oiepi kin ikcekceya hitunkakanpi kin iyececa dakapi, qa wicawicadapi śni.

12 Hehan Inyan najin hiyaye ca wicaśta hnakapi kin ekta inyang iyaya; qa en eyokasin qehan minihuha wokoyake kin iśnana ehnakapi wanyaka; hehan hdicu qa cante mahen taku econpi kin on inihanyan awacin un.

13 Unkan iho, anpetu kin he en, iyepi kin etanhan wicaśta nonpa otonwe wan Emmaus eciyapi kin he ekta yapi, Jerusalem etanhan maka iyutapi wikcemna śakpe ecetu.

14. Unkan taku hiyohi kin dena ow'asin on wohdakapi.

15 Unkan wohdakapi, qa iyukcan awacinpi icunhan, Jesus iye hinca kiyedan $u$, qa om wicaya.

16 Tuka iśta on iyekiyapi kte śni wicayapi.

17 Unkan hewicakiya; Wicoie kin dena tukte e he, mayanipi icunhan woyahdakapi qa iyokiśin yaunpi kin.

18 Unkan unma Kleophas eciyapi kin he wayupte ca heciya; Jerusalem en yaun śni ece, dehan en taku hiyohi kin dena sdonyaye śni he.

19 Unkan hewicakiya; Hena taku he. Unkan heciyapi; Jesus Nazareth etanhan kin on, he wicaśta wokcan, wicohan wicoie ko on waśaka, Wakantanka qa oyate kin owasin wicitokam.

$20 \mathrm{He}$ wawayuśna itancanpi qa 
itancanwicunkiyapi kin hena te kta kiconzapi qa icipaweh okatanpi.

21 Tuka Israel opewicakiton kte cin hee unkiś unkecinpi tuka; unkan heconpi kin ehantanhan wanna anpetu kin de iyammi.

22 Nakun unkanpi kin etanhan winohinca wanjikji hanhanna hinca wicaśta hnakapi kin ekta ipi, qa inihanunyanpi :

23 Iye tancan kin iyeyapi śni qehan, hdicupi qa ohnihde wakan kin heca wanwicayakapi, qa hena he ni un keyapi ce, eya unkokiyakapi.

24 Hehan om unkanpi kin wanjikji wicaśta hnakapi kin ekta ipi, qa winohinca oyakapi qon iyececa hinca iyeyapi : tuka iye kin wanyakapi śni ce.

25 Unkan hewicakiya; Witkotkokapi qa wicaśta wokcan taku oyakapi qon hena owasin wicada cante hunkapi śni kin:

26 Messiya dena decekcen ito kakije ça wowitan tawa kin en hde kte cin he hecetu śni he.

27 Unkan hecen Moses e tokaheya, qa hehan wicaśta wokcan owasin, taku iye kin on wowapi en kagapi qon hena owasin owicakiyaka.

28 Unkan otonwe ekta yapi qon he wanna ikiyedan ehan ipi qehan, iye sanpa ye kta se ececa. 29 Tuka iyakapeyapi, qa heyapi ; Unkicipi un wo, wanna litayetu aya, qa anpetu kin wanna owihanke kta. Unkan om un kta e ti mahen iyaya.

30 Unkan om wota yanke cehan, aguyapi eyaku, qa yawaśte, qa yuśpaśpa, qa wicaqu.

31 Hehan iśta kin wicakiciyukawapi, qa iyekiyapi: unkan atanin śni iyaya.

32 Unkan hekiciyapi; Canku kin ohna wounkiyalkapi qa wo. wapi wakan kin unkiciyuzamnipi qon he ehan cante unkata śni he. 33 Unkan wihiyayedan oape kin he en najin hiyayapi, qa Jerusalem ekta hdapi, qa akewanji tona om unpi ko hena witaya yukanpi iyewicayapi ;

34 Qa heyapi ; Ehanqon Itancan kin kini, qa Simon en tanin. iciya ce.

35 Hehan iye canku kin ohna tokenketu, qa aguyapi yuśpaśpa kin on iyekiyapi qon, hena he: cekcen owicakiyakapi.

36 Unkan hena hecen eyapi icunhan, Jesus iye hinca wicacokaya hinajin qa hewicakiya; Wookiye nicipi un nunwe.

37 Unkan inihanpi, qa kokipapi, qa wanagi wanyakapi kecinpi.

38 Unkan hewicakiya; Tokeca e iyoniciśicapi he; qa tokeca cante mahen taku cețunyahdapi he.

39 Minape misiha ko, de miye hinca e wanmayaka po ; mayutanpi qa iyukcan po; cehpi huhu waton wandakapi kin wanagi kin iyecen ton śni ece.

40 Unkan hecen eye cehan, nape siha ko wicakipazo.

41 Unkan wowiyuśkin on wicadapi śni, qa hinyahin inihanpi, hehan hewicakiya; Den taku yutapi duhapi lie.

42 Unkan hogan pasnonpi onśpa tulimaga canhanpi ahna qupi.

43 Unkan icu, qa wicitokam yuta.

44 Qa hewicakiya; Nahahin om ciunpi qon ehan, wicoie ociciyakapi qon he dee ce; Moses wicoope tawa, qa wicaśta wokcan, qa odowan kin, henakiya en miye on taku token owap. qon owasin ecen yuśtanpi kta iyececa ce, eya. 


\section{WICOWOYAKE 1.}

45 Unkan hehan tawacinpi kin wicakiciyuzamni, qa hecen wowapi kin okalinigapi kte.

46 Unkan hewicakiya; Hecen owapi, qa Messiya hecen kakije ca, anpetu iyamni kinhan ake kini kte ciqon, he hecetu :

47 Qa hecen iye caje kin on ihduecetupi qa woahtani kajujupi kin, oyate kin owasin en oyakapi kta, Jerusalem en tokaheya kta.

$48 \mathrm{Qa}$ taku kin dena oyakapi kte cin he niyepi ce.

49 Unkan iho, Ate taku iwahowicaye ciqon he niyepi kin en uwakiye kta; tuka tohanyan wankantanhan wowaśake yuhe- niciyapi śni kin hehanyan Jerusalem otonwe kin en ece yukan po.

50 Hehan tankan awicaya, Bethani hehanyan; unkan nape wicakiyuwinta qa wicayawaśte.

51 Unkan wicayawaśte icunhan, yutokan ewicakiciyakupi, qa wankan malipiya kin ekta ayapi.

52 Unkan iye ohodapi, qa wowiyuśkin tanka yuha Jerusalem ekta kipi :

53 Qa ohinniyan tipi wakan kin ohna ece yukanpi, Wakantanka yatanpi qa yawaśtepi ece. Amen.

\section{J OHANNES}

\section{WOTANIN WAŚTE TAWA.}

\section{WICOWOYAKE 1.}

1 Otokahe ekta Wicoie kin hee; Wicoie kin he Wakantanka kici un, qa Wicoie kin he Wakantanka kin ee.

2 He otokahe ekta Wakantanka kici un.

3 Iye eciyatanhan taku owasin kagapi; qa taku kin tokan tanhan takudan kagapi śni.

4 Iye kin en wiconi; qa wiconi kin he wicaśta iyoyamwicaye cin hee.

5 Iyoyanpa kin hee otpaze cin en omdesya un, tuka otpaze cin he iyowinkiye śni.

6 Wicaśta wan Wakantanka eciyatanlian u śipi, he Johannes eciyapi.

7 He wayaotanin hi, Iyoyanpa kin oyake kta; hecen iye eciyatanhan owasin wicadapi kta.
8 Iyoyanpa kin he iye śni, tuka iyoyanpa kin he yaotanin kta $e$ u śipi.

9 Iyoyanpa wicakapi hince cin hee, wicaśta otoiyohi wicoicage kin en u iyoyamye cin hee.

$10 \mathrm{He}$ wicoicage kin en un, qa iye wicoicage kin kaga, tuka wicoicage kin sdonyapi śni.

11 Tona tawa kin hena ekta wicahi, tuka tawawicaye cin hena iyowinkiyapi śni.

12 'Tuka tona iyowinkiyapi kin hena Wakantanka cinca wicaya yakonpi kta e okihi wicaya, tona iye caje wicadapi kin hena.

13 Hena wicawe eciyatanhan śni, qa wicacehpi tawacin kin eciyatanhan śni, qa nakun wicaśta tawacin kin eciyatanhan śni, tuka Wakantanka eciyatanhan wicatonpi.

14 Unkan Wicoie kin he wica.

141 


\section{JOHANNES.}

cehpi kagapi, qa unkiyepi kin en ounyan; qa wootanin tawa kin wanunyakapi, wootanin kin he Atkuku eciyatanhan iśnana icaga tawa kin he iyececa; wowaonśida wowicake ko ojudan.

15 Johannes he yaotanin, qa heya niyan; Tuwe mihakam u kte cin he mitokam yawapi ce, epe ciqon he dee; he mitokam un nakaeś.

16 Unkan woojudan tawa kin etanhan unkiye owasin unkicupi, qa he wowaśte wicowaśte kin on.

17 Woope kin he Moses wicaqu; tuka wicowaśte wowicake ko hena Jesus Messiya eciyatanhan $\mathrm{u}$.

18 Tuwedan tohinni Wakantanka wanyake-śni ; tuka Cinhintku iśnana icaga Atkuku maku ohna un kin he sdonye unkiyapi.

19 Unkan Johannes woyake ciqon he dee; Jerusalem etanhan Juda oyate Wośnapi kagapi Lewi wicaśta ko ekta ye wicaśipi qa, Tuwe niye he, eciyapi.

20 Tuka Johannes ohdake ca anakihbe śni, tuka ohdaka; Messiya kin he miye śni ce.

21 Unkan wiwangapi; Nituwe he; Eliyas he niye he. Unkan, He miye śni ce, eya. Wicaśta wokcan kin he niye he, eciyapi. Tuka, Hiya, eya.

22 Hehan, Ecin tuwe niye he, eciyapi: tona deciya unkuśipi hecinhan hośi wicunkakipi kta e heunniciyapi; Token onihdaka he.

23 Unkan heya; Jehowa tacanku kin owotanna kicaga po, tuwe liewoskan eyanpalia un kin he miye ce, Isaya wicaśta wokcan eye ciqon iyececa.

24 Unkan tona en u wicaśipi qon hena Pharisee etanhanpi.
25 Unkan wiwangapi qa heciyapi; Hecen tokeca e baptem wicayaqu he; Messiya he niye śni, qa Eliyas he niye śni, qa wicaśta wolkcan kin he niye śni hecinhan.

26 Johannes awicayupte ca heya; Miye mini on baptem wicawaqu ece : tuka wanji nayajinpi kin cokaya najin tulka sdonyayapi śni ;

27 Tuwe mihektam u kte ciqon, tuka mitokam yawapi kin hee; tahanpe kin wakiyuśdoke kta eśta owalíhi śni ce.

28 Hena taku kin Bethabara, Jordan akasanpatanhan, econpi, he en Johannes baptem wicaqu.

29 Anpetu iyokihe hehan Jesus etkiya u kin Johannes wanyake ca heya; Tacinca Wakantanka tawa, oyate wahtanipi kin tokan elipeye kte cin he wanyaka po.

30 Tuwe on hepe ciqon he dee; Wicaśta wan mihakam u kte cin he mitokam yawapi ; he mitokam un nakaeś.

31 Qa miś eya he sdonwaye śni; tuka Israel oyate kin ekta yuotaninpi kta e heon mini on baptem wicawaqu wahi ce.

32 Unkan Johannes way aotanin qa heya; Woniya kin he wakiyedan kahya mahpiya eciyatanhan kuntkiya u wanmdaka, unkan he en hiyanka.

33 Unkan he tuwe kin sdonwaye śni, tuka mini on baptem wicaqu maśi qon he omakiyaka; Tohan mahpiya kin eciyatanhan Woniya kin kuntkiya ye ca, tuwe iyahde wandake cinhan ho iye Woniya Wakan on baptern wicaqu kta.

$34 \mathrm{He}$ wanmdaka e on mdaotanin; Wakantanka Cinhintku kin hee. 


\section{WICOWOYAKE 2.}

35 Ake ihanhanna hehan Johannes waonspewicakiye cin nom om enl najin:

$36 \mathrm{Qa}$ Jesus omani wanyake cehan heya; Iho, Tacinca Wakantanka tawa kin he dee ce.

37 Unkan waonspewicakiya nom ie cin he nahonpi, qa Jesus ihakam yapi.

38 Hehan Jesus ihdamna, qa ihakam upi wanwicayake ca hewicakiya; Taku ayakitapi he. Unkan, Itancan, Waonspekiye eyapi kin he kapi, tukten yati he, eciyapi.

39 Upi qa wanyaka po, ewicakiya. Unkan kici hdapi, qa tukte en ounye cin he wanyakapi, qa anpetu ihunniyan kici yukanpi : wanna oape wikcemna hehantu.

40 Nom Johannes ia nahonpi qa Jesus ihakam yapi qon, Andrew Simon Inyan sunkaku kin he unma ee.

$41 \mathrm{He}$ cincu Simon tokaheya iyeye ca heciya; Messiya, he Sdayapi eyapi kin, iyeunyanpi ce :

42 Qa Jesus ekta ai.. Unkan Jesus wanyake cehan heya; Simon Jona cinhintku kin he niye: Kephas eniciyapi kta, he Inyan eyapi kin hee.

43 Ihanhanna kin hehan Jesus Galile heciya ya, unkan Philip wanyake ca heciya; Mihakam u wo.

44 Philip Bethsada hetanhan, nakun Andrew Inyan kici he otonwe tawapi.

45 Philip Nathanael akipa, qa heciya; Moses woope en owa qon, qa wicaśta wokcanpi kin nakun, he wanna iyeunyanpi, Jesus Nazareth etanhan, Joseph cinhintku kin hee.

46 Unkan Nathanael heciya; Nazareth etanhan taku waśte $u$ okihi kta he. U qa wanyaka wo, Philip eciya.

47 Jesus Nathanael en $u$ wanyake ca he on heya; Wanyaka po, Israel wicaśta hinca wan he dee, wicahnaye wanin un ce.

48 Nathanael heciya; Tokiyatanhan sdonmayaya he. Jesus ayupte ca heciya; Philip nico qon he itokam can ihukuya nayajin qon hen wanciyaka.

49 Nathanael ayupte ca heciya; Itancan, Wakantanka Cinhintku, Israel oyate Wicaśtayatapi kin he niye.

50 Unkan Jesus ayupte ca heciya; Can ihukuya nayajin wanciyaka epa, unkan heon wicayada he. Dena taku isanpa tanka wandake kta ce.

51 Unkan heciya; Wowicake, wowicake eciyatanhan heciciyapi, Tokata mahpiya kin yuzanınipi, qa Wakantanka taokiye kin wankantkiya yapi, qa ake kuntkiya upi, qa Wicaśta Cinhintku kin en himniciyapi wandakapi kta ce.

\section{WICOWOYAKE 2.}

1 Anpetu iciyamni kin hehan Galile makoce en otonwe wan Kana eciyapi hen kiciyuzapi omniciye kagapi; unkan Jesus hunku kin en opa.

2 Jesus nakun waonspewicakiye cin on kiciyuzapi kin en kicopi.

3 Unkan miniśa wanna henakeca hehan, Jesus hunku kin heciya; Miniśa takudan yuhapi śni ye.

4 Unkan Jesus heciya; Winohinca hetanhan iwamayatokiya he; nahanhin iyemicihantu śni ce.

5 Unkan hunku kin wayutan wicakiyapi, He tokehin eniciya- 


\section{JOHANNES.}

pi owasin ecen ecom, ewicakiya.

6 Inyan wakiśkokpa śakpe en han, ohna Juda oyate ihdujajapi kta e hdepi; otoiyohi wiyutapi nom yamni kipi.

7 Wakiśkokpa kin mini ojudan okaśtan po, ewicakiya. Unkan ojugjudan okaśtanpi.

8 Hehan, Onge etanhan icupi qa omniciye itancan kin he kaya po, Jesus ewicakiya. Unkan kayapi.

9 Unkan omniciye kin en itancan kin onge yatkan uta, he mini tuka miniśa icahyapi, qa he tokiyatanhan kin sdonye śni, tuka wayutan wicakiyapi mini akupi qon hena sdonyapi, unkan itancan kin tawicu ton qon kico ;

10 Qa heciya, Wicaśta eca miniśa waśte tokaheya yatke wicakiya ece; qa tohan wicaśta wipipi hehan taku aoptetu kin; tuka niye miniśa waśte hinca dehanyan yehnaka ce, eya.

11 Galile makoce kin hen, Kana otonwe he en, Jesus toka taku wapetokeca econ, qa towitan hdutanin; unkan becen waonspewicakiye cin wicadapi.

$12 \mathrm{He}$ iyohakam Kapernaum ekta apamahde iyaya, iye qa hunku qa sunkaku qa waonspewicakiye cin hena koya om; unkan anpetu tonana hen yakonpi.

13 Unkan Juda oyate woacakśin wośnapi tawapi kin wanna ikiyedan; heon Jesus Jerusalem ekta itanwankanhde iyaya.

14 Unkan tipi wakan kin en wicaśta kin eya, tatanka, tahinca, wakiyedan ko wiyopewicakiyapi, qa maza ska tokiyopekiciyapi kiu en iyotankapi e wanwicayaka ;

15 Qa icapsinte cikciqadan yu- gaga wan kage cehan, tipi wakan kin etanhan owasin tankan iyewicaya, tahinca tatanka ko; qa mazaska tokiyopekiciyapi qon iś kada iyeya, qa can wahna wotapi kin he nakun paahdapśinyan ehpeya.

$16 \mathrm{Qa}$ wakiyedan wiyopeyapi kin iś, Dena owasin tankan iyeya po, qa, Ate ti kin de wopeton tipi kagapi śni po, ewicakiya.

17 Unkan waonspewicakiye cin wowapi en kagapi qon he kilksuyapi, Yati owakiye cin he mayapota ce.

18 Hehan Juda oyate ayuptapi qa heciyapi; Tokiya tanhan he oyakihi qa hecanon he.

19 Unkan Jesus waayupte ca, Tipi kin de ihangya po, qa anpetu iciyamni kinhan ake ekicetuwaye kta, ewicakiya.

20 Waniyetu wikcemna topa qa sam śakpe hehanyan tipi kin de kagapi qa yuśtanpi qon, niye nakaha anpetu iyamnina ekicetu yaye kta he, Juda oyate kin eciyapi.

21 Tuka tipi eye cin he iye tancan kin he ka e heon etanhan heya.

22 Heon wiconte etanhan ihduekicetu, hehan hecen ewicakiye ciqon he waonspewicakiye cin kiksuyapi; unkan wowapi wakan qa Jesus taku ewicakiye cin hena koya wicadapi.

23 Unkan Jerusalem en woacakśin wośnapi kin icunhan, taku wapetokeca econ kin hena wicota wanyakapi qehan iye caje kin on wicadapi.

24 Tuka Jesus owasin sdonwicaye cin heon etanhan wacinwicaye śni.

25 Qa wicaśta on tuwedan wayaotanin kta cin śni ; iye atayedan wicaśta taku en un kin sdonya, heon etanhan. 


\section{WICOWOYAKE 3.}

1 Wicaśta wan Pharisee etanhan Nikodemos eciyapi, Juda oyate itancanpi kin he wanji ee;

2 Hanyetu wan Jesus yanke cin en i qa heciya; Itancan, waonspekiye Wakantanka eciyatanhan u kin henica sdonunniyanpi; taku wapetokeca ecanon ece kin tuwedan hecen okihi śni, Wakantanka kici un śni kinhan.

3 Unkan Jesus ayupte ca heciya; Wowicake, wowicake eciyatanhan heciciya, Wicaśta kin wankantanhan teca nien tonpi śni kinhan Wakantanka tokiconze kin wanyaka okihi kte śni.

4. Wicaśta kin kan ehantanhan token ecin teca ni en tonpi kta he. Ake hunku tezi kin mahen kihde ca ake teca ni en tonpi kta he token okihi kta he, Nikodemos eciya.

5 Unkan Jesus ayupte; Wowicake, wowicake eciyatanhan heciciya, Wicaśta kin mini qa Woniya kin on tonpi śni kinhan Wakantanka tokiconze kin en tin iyaya okihi kte śni ce, eya.

6 Tuwe wicacehpi on tonpi kin he wicacehpi, qa tuwe Woniya kin eciyatanhan tonpi kin he woniya.

7 Wankantanhan nitonpi kta ce, eciciye cin heon ihuuhan niyuśinyaye cin.

8 Tateyanpa kin tokiyatanhan cin eca eciyatanhan ipogan ece, qa oqo kin he nayahon, tuku tokiyatanhan $u$, qa tokiya ye cin he sdonyaye śni. Wicaśta Woniya kin eciyatanhan tonpi kin owasin hecetu.

9 Nikodemos ayupte ca heciya; Hena token okihipica he.

10 Jesus. ayupte ca heciya; Israel en waonspekiye cin heniDak.

10 ca, tuka dena oyakahinige śni he.

11 Wowicake, wowicake eciyatanhan heciciya; Taku sdonunyanpi kin hena unkeyapi ece, qa taku wanunyakapi kin dena unkoyataninpi, tuka wounyataninpi kin ayaktapi śni.

12 Taku maka kin detanhan ociciyakapi kin wicayadapi śni ehantanhan, mahpiya kin ekta taku ociciyakapi kinhan hee token wicayadapi kta he.

13 Nahahin tuwedan mahpiya kin ekta i śni, tuwe malipiya kin eciyatanhan kuntkiya $u$, qa hi kin he Wicaśta Cinhintku kin hee, nahahin nakun mahpiya kin ekta yanka.

14 Nakun hewoskan wanmduśka Moses wankan ehde qon he iyecen Wicaśta Cinhintku kin wankan ehdepi kta.

15 Heon tuwe awacin kinhan owihanke kte śni, qa owihanke wanin wiconi yuhe kta.

16 Wakantanka oyate kin cantewicakiya, heon Cinhintku iśnana icage cin wicaqu, qa tuwe awacin kinhan owihanke kte śni, tuka owihanke wanin wiconi yuhe kta.

17 Wakantanka Cinhintku kin wicoicage kin en u śi kin, heon oyate kin wicayaco kta e hecon śni ; tuka iye on oyate kin nipi kta e hecon.

18 Tuwe he wacinye cinhan he yacopi kte śni; tuka tuwe wacinye śni kinhan he wanna yacopi ; Wakantanka Cinhintku iśnana icage cin he caje kin wacinye śni kin heon etanhan.

.19 Wicayacopi kin he kaketu; Oyate kin iyoyanpa en wicahiyohi, tuka wicaśta kin otpaza e waśtedakapi, qa iyoyanpa e cinpi śni, wicohan śicapi kin heon.

20 Tuwe taku śica econ kin he 145 


\section{JOHANNES.}

iyoyanpa śice daka, qa iyoyanpa ikiyedan u śni, ohan iyopeyapi kte cin heon.

21 Tuka tuwe wowicake eciya tanhan ohanye cin he iyoyanpa kin en $\mathrm{u}$, ohan yuotaninpi kta, Wakantanka eciyatanhan oh̉anye cin heon.

22 Hena iyohakam Jesus waonspewicakiye cin om Juda makoce kin en i; qa en om un, qa baptem wicaqu.

23 Unkan he icunhan Johannes iś eya Enon Salim ikiyedan baptem wicaqu, her mini ota kin he etanhan. Unkan baptem wicaqupi kta e etkiya aye.

24 Hehanyan hinyahin Johannes kaśkapi śni.

25 Hehan taku hdokinicapi, Johannes waonspewicakiye cin wanjikji qa Juda wicaśta om, wicayujajapi kin he icahtagya.

26 Unkan Johannes ekta ipi qa heciyapi; Itancan, Jordan wakpa akasanpa tanhan tuwe kici yaun qa daotanin qon he, iho, wanna baptem wicaqu, unkan owasin en ece iyoptapi.

27 Unkan Johannes waayupte ca heya; Wicaśta kin mah̉piya eciyatanhan taku qupi śni ehantanhan takudan iye cinka icu okihi kte śni ece.

28 Messiya kin he miye śni, tuka itokam u maśipi ce, epe ciqon he niye sdonyayapi.

29 Tuwe tawicu ton kin be hihna yanpi kin hee, tuka hihna yanpi takodaku kin en taninyan anagoptan najin, qa hihna yanpi ho kin nahon kin heon iyuśkin ece. Heon etanhan wowiyuśkin mitawa kin wanna yuecetupi ce.

30 Iye kin nina sanpa icage kta, tuka miye yuhukun amaye kta.

31 Tuwe wankan tanhan hi kin he taku owasin iwankam ounye. Tuwe maka etanhan hi kin he maka etanhan, qa maka kin iyecenya oie kiton. Tuwe rnahpiya kin eciyatanhan hi kin he taku owasin on iyotan.

32 Qa taku wanyake ca taku nahoon kin he owasin yaotanin ece; tuka taku yaotanin kin tuwedan wicada śni.

33 Taku yaotanin kin he tuwe wicada kinhan Wakantanka wicake cin he yutanin ece.

34 Wakantanka tuwe u si kin he Wakantanka oie oyaka; Wakantanka Taniya kin iyuta qu śni, ocowasin qu.

35 Atkuku kin Cinhintku waśtekidake ça, taku owasin iye nape kin en qu :

36 Hecen tuwe Cinhintkuyapi kin wacinye cinhan owihanke wanin wiconi kin wanna yuha; tuka tuwe wacinye śni kinhan, he wiconi wanyake kte śni, tuka Wakantanka tocanniye kin wanna akan un.

\section{WICOWOYAKE 4.}

1 Jesus waonspewicakiya ota icicage ca baptem wicaqu, Johannes econ qon sam iyeya, Pharisee kin hecen nahonpi, he Itancan kin sdonya.

2 Tuka Jesus iye atayedan baptem wicaqu śni, waonspewicakiye cin hena heconpi.

3 Hehan Juda makoce kin ayuśtan, ga Galile heciya ake ekta hda.

4 Qa Samariya he en acankuye kta iyececa.

5 Hecen otonwe wan Sukar eciyapi Samariya makoce en, Joseph en ounye kta e Jakob atkuku qu qon he ikiyedan, he ekta hi.

6 Jakob miniyowe tawa kin he

146 


\section{WICOWOYAKE 4.}

etu; Jesus mdokite hda, qa miniyowe kin he ahankeya iyotanka. Anpetu kin he en wiyotanhe cin hehantu.

7 Samariya oyate etanhan winohinca wan mini huwe hi ; unkan Jesus, Mini maqu wo, eciya.

8 He icunhan waonspewicakiye cin otonwe kin ekta taku yutapi opeton iyayapi.

9 Winolinca Samariya oyate etanhan qon hecen eya, Juda wicaśta kin henica, Samariya oyate kin hematanhan, he tokeca e mini mayakida he. Juda oyate Samariya oyate kici takudan ikicitukapi wanice ciqon.

10 Jesus ayupte ça heciya; Wakantanka taku wicaqu kin he, qa, Mini maqu wo, eniciye cin he tuwe kin sdonyaya unkanś, niye yakida kta, kinhan mini wiconi kin niẹu kta tuka ce.

11 Itancan, mini kin de temahentuya hiyeya qa takudan on edaku kte śni ; tokiya tanhan mini wiconi kin duha he, winohinca kin eciya.

12 Jakob ateunyanpi miniyowe kin de unqupi, qa etanhan iye mini yatkan, qa cinca qa tawanunyanpi ko, he hecon tuka niye iniyotan he.

13 Unkan Jesus ayupte ca heciya; Tuwe mini kin de etanhan yatke cin nakun ipuza kta ;

14 Qa tuwe mini waqu kte cin etanhan yatke cin icimana ipuza kte śni. Tuka mini waqu kte cin he owihanke wanin wiconi iyahdeya kaduze kta, eya.

15 Unkan winohinca kin heciya; Itancan, mini kin he etanhan maqu ye, hecen imapuza kte śni, qa nakun icimana mini kin de huwe wahi kte śni, eya.

16 Unkan, Nihihna kico ya wo, qa den kici hi wo, Jesus eciya.

17 Tuka winolinca kin waayupte ça heciya; Mihihna kin wanica ce. Nihihna wanica kehe cin he hecetu e ecen eha ce;

18 Nihihna zaptan, tuka nakaha hihnayaye cin de nitawa śni; hecen ehe cin he wicayaka ce, Jesus eciya.

19 Hehan winohinca kin heciya; Itancan, wicaśta wokcan kin henica imdukcan ;

20 Hunkake wicunyanpi paha kin de en ohodapi ece; tuka niye, Jerusalem he en wicaśta ohodapi ece e kta, kehapi ce.

21 Unkan Jesus heciya; Winohinca, wicamada wo, anpetu wan u ce, paha kin de en, qa Jerusalem nakun en, Ateyapi kin ohoyadapi kte śni.

22 Niye taku ohoyadapi kin sdonyayapi śni; unkiye taku ohoundapi kin sdonunyanpi ece. Juda oyate kin eciyatanhan wanikiyapi kin u ce.

23 Tuka anpetu u kin he wanna hiyohi, tona wowicake eciyatanhan ohodapi kin hena woksape wowicake eciyatanhan Ateyapi kin ohodapi kta. Ateyapi kin he tona hecen ohodapi kte cin akita ece.

24 Woksape kin he Wakantanka kin ee; qa tona ohoda kinhan hena woksape wowicake eciyatanhan ohoda kta.

25 Hehan winohinca kin heciya; Messiya Sdayapi eyapi kin hi kta, tohan hi kinhan taku kin owasin unkokiyakapi kta e sdonwaya.

26 He miye e ociciya ce, Jesus eciya.

$27 \mathrm{He}$ icunhan waonspewicakiye cin en hdipi, qa winohinca kin kici okiciciya un kin heon yuśinyayapi. Tuka wanjidan ; 


\section{JOHANNES.}

Taku ayakita he; qa, Tokeca kici iyaa he, eyapi śni.

28 Hehan winohinca lkin wakiślkokpa ehpeya kihde ca, otonwe kin ekta ki, qa wicaśta kin hewicakiya ;

29 Wicaśta wan taku ecamon qon owasin omiciyake cin he ito wanyag u miye. He Messiya kin ee śni he.

30 Hehan otonwe kin etanhan enanpa, qa yanke cin en ai.

31 He icunhan waonspewicakiye cin cekiyapi чa, Itancan, wota wo, eciyapi.

32 'Tuka iye hewicakiya; Taku yutapi sdonyayapi śni kin heca wate kta e mduha ce.

33 Heon, Tuwe taku yutapi kahi he, wonspewicakiye cin ekiciyapi.

34 Tuka Jesus hewicalkiya; Tuwe u maśi kin he tawacin kin ecen ecamon kta, qa iye tohan kin weciyuśtan kte cin he taku wate cin ee.

35 Ehake wi topa kinhan taku mnaunyanpi kta ce, ehapi. Tuka miś kaken eciciyapi; Wankan etonwanpi qa maga kin wanyaka po, wanna owasin ska qa mnayanpi kin wanna iyehantu.

$36 \mathrm{Qa}$ tuwe taku mnaye cin he wolkajuju icu ece, qa owihanke wanin wiconi waskuyeca mnayan ece; hecen on tona woju, qa tona mnaye cin napin wiyuśkinpi kta.

37 Wanji woju qa wanji mnayan, eyapi qon dee e wicakapi.

38 Niye htayanipi śni tuka wamnayanpi he econ ciśipi. Wicaśta tokeca htanipi unkan he htanipi kin en niye oyapapi.

39 Winohinca kin, 'Token ecamon gon owasin omiciyaka ce, eye ciqon heon wicaśta Samariya oyate otonwe kin he en ota Messiya hee kin wicadapi.
40 Heon Samariya oyate Jesus en hipi qa cekiyapi, iye tipi kin en un śipi. Unkan nonpa can hen un.

41 Unkan ia nahonpi kin hehan wicota wicadapi.

42 Qa, Taku odake cin he etanhan wicaundapi kin hee śni, unkiś eya naunhonpi, Messiya hee qa oyate wanikiye kte cin hee e sdonunyanpi, winohinca kin eciyapi.

43 Anpetu nonpa iyohakam hehan hetanhan ye ca Galile heciya hda.

44 Jesus iye a tayedan hdaotanin, wicaśta wokcan kin heca iye tamakoce kin en yuonihanpi śni ece.

45 Unkan Galile elita ki, hehan Galile wicaśta kin iyowinkiyapi, Jerusalem ekta wośnapi kin icunhan taku econ qon owasin wanyakapi kin heon etanhan; iś eya wośnapi kin ekta ipi nakaeś.

46 Unkan Galile en Kana otonwe kin, mini ikceka miniśa icaliye ciqon he ake en hdi. Unkan Kapernaum ekta wicaśta itancan wanji cinhintku wayazanka:

$47 \mathrm{He}$ Jesus Juda makoce kin hetanhan Galile en hi, nation kin heon ekta ye ca celiya, cinhintku kin asniye kta e ekta u kta; wanna te kta ikiyedan.

48 Hehan Jesus heciya; 'Taku wowanyake wowapetokeca ko wandakapi śni keś wicayadapi kte śni ce.

49 Unkan wicaśta itancan kin heciya; Itancan, micinkśi țe śni itokam kun u wo.

50 'Tuka Jesus heciya; Hunktiya wo, nicinkśi ni ce. Unkan wicaśta kin Jesus ie cin wicada, qa ekta hda.

51 Tiyatakiya hda, unkan wi- 


\section{WICOWOYAKE 5.}

caśta wowidake wicayuhe cin awicakipa, unkan, Nicinkśi kin ni ce, eya okiciyakapi.

52 Wi kin tohan yanka hehan asni aya he, eya iwicawanga. Unkan, Ḣtanihan wiyotanhan kitanna inaśdoka, hetanhan tancan kata ayuśtan ce, eyapi.

53 Unkan atkuku kin tohan Jesus, Nicinkśi ni ce, eciye ciqon hehantu e kiksuya. Unkan iye qa tiyohnaka tawa koya wicadapi.

54 Jesus Juda makoce etanhan Galile icicawin en hdi, wowapetokeca econ kin icinonpa kin he dee

\section{WICOWOYAKE 5.}

1 Hehan iyohakam Juda oyate omniciye wan kagapi he icunhan Jesus Jerusalem he en $i$.

2 Jerusalem en tahinca wanunyanpi tiyopa kin he en ikiyadan, mini kiwitayapi, Hebrew iapi Bethesda eciyapi, zaptankiya aohanziya hdepi.

3 Hena ohna wicaśta wayazanka ota, huśte, iśta gonga, țaṭaka ko ota en makan hiyeya, mini śkanśkan ape hiyeya.

4 'Tohan iyehantu eca, mahpiya ohnihde wan mini kin en hi qa śkanśkanya ece. Tokiya yazan kin owasin tohan mini kin he śkanśkan eca tuwe tokaheya en iyohpeiçiya eca asni ece.

5 Wicaśta wan he en wanka, waniyetu wikcemna yamni sanpa śahdogan hehanyan wayazanka.

6 Wicaśta kin he makata wanka, wanakaja tanhan wayazanka Jesus wanyaka, qa, Anisni kta yacin he, eciya.

7 Wicaśta wayazanke cin heciya; Itancan, mini kin śkanśkan keś tuwedan en iyohpemaye śni; en mde kta keś tuwe tokeca mitokam en iyeiçiya ece.

8 Najin, owinja ehdaku qa mani wo, Jesus eciya.

9 Unkan ecahankeya wicaśta kin alkisni, qa owinja kin ehdaku, qa mani. Unkan anpetu kin he anpetu wakan.

10 Heon etanhan Juda oyate kin wicaśta asniyanpi qon heciyapi; Nakaha anpetu wakan; owinja yeçin kin he hecetu śni ce.

11 Tuwe asnimaye cin he, Owinja ehdaku qa mani wo, emakiya ce, ewicakiya.

12 Hehan, Wicaśta kin, Owinja ehdaku qa mani wo, eniciye cin he tuwe he, eya iwangapi.

13 Tuka wicaśta asniyanpi kin he tuwe kin sdonye śni : he icunhan wicota hen unpi hecen Jesus icunonpa iyaya.

14 Hehan iyohakam tipi wakan en wicaśta lkin he Jesus wanyaka, unkan, Wanyaka ye, wanna anisni; icimana wahtani śni wo; okinni ake taku wanji śica sanpa tanka iyanihde kta ce, eciya.

15 Unkan wicaśta kin he kihde ca, Tuwe asniye ciqon he Jesus ee, Juda oyate owicakiyaka.

16 Heon etanhan Juda oyate Jesus kuwa ayapi, qa anpetu wakan kin icunhan hena econ kin heon țeyapi kta e akitapi.

17 Unkan, Ate nahahin hitani he etanhan miś eya htawani, Jesus ewicakiya.

18 Unkan Juda oyate hehan iyotan Jesus teyapi kta sanpa akitapi, anpetu wakan botica, qa nakun Wakantanka atayedan Ateya keiciye cin, Wakantanka kici akiyecen ihdawa kin, heon etanhan.

19 Unkan Jesus waayupte ça 149 


\section{JOHANNES.}

hewicakiya; Wowicake, wowicake eciyatanhan heciciyapi, Cinhintkuyapi kin takudan iye cinka econ kta okihi śni; Ateye cin taku econ wanyaka eca, hehan Cinhintku kin iś eya iyecen econ ece.

20 Ateyapi kin Cinhintku waśte kidake cin heon taku econ kin hena owasin onspekiya; qa nakun eeś wicolian dena sanpa tanka onspekiye kta, hecen ininihanpi kta.

21 Ateyapi kin tuwe ța keś niye ca wiconi wicaqu ece; he iyecen Cinhintku lkin iś tona cin kinhan wiconi wicaqu ece.

22 Nakun A teyapi kin tuwedan yaco śni, tuka woyaco owasin Cinhintku kin qu.

23 Heon etanhan owasin Ateyapi kin token ohodapi hecinhan he iyecen Cinhintku kin ohodapi kta. Tuwe Cinhintku kin ohoda śni kin he Atkuku u śi kin he nakun ohoda śni.

24 Wowicake, wowicake eciyatanhan heciciyapi, Tuwe mioie kin anagoptan, qa u maśi kin he awacin kinhan, owihanke wanin wiconi yuhe kta; qa woyaco en i kte śni, wanna wiconțe etanhan wiconi ekta e i.

25 Wowicake, wowicake éciyatanhan heciciyapi, Anpetu wan u qon wanna hi, wicaśta ta tona Wakantanka Cinhintku ho kin nahon kta; qa tona nalion kinhan hena ni kta.

26 Ateyapi kin iye cinka wiconi hduha, he etanhan Cinhintku kin iś iye cinka wiconi hduhe lita e qu.

27 Qa nakun wowaśake woyaco kin he nakun Cinhintku qu, Wicaśta Cinhintku kin e,heon etanhan.

28 Ihnulıan hena ininihanpi kin 150 do ; anpetu wan hi kta ce, wicaśta wicaliapi kin owasin iye ho kin nahonpi kta;

29 Qa hninanpapi kta, tona waśte econpi kin hena wiconi woekicetu ekta; qa tona taku śica econpi kin hena woyaco woekicetu ekta hiyupi kta.

30 Miye cinka taku ecamon owakitpani; taku mdaco kin hena taku nawahon kin heciya tanhan; qa taku mdaco kin hena hecetu. Miye mitawacin he owakide śni, tuwe u maśi kin he tawacin owade.

31 Miye mihdaotanin kinhan, taku mdaotanin kin he wowicake śni.

32 Wanji tokeca mayaotanin ece; unkan wayaotanin iye mayaotanin kin he wowicake e sdonwakiya.

33 Johannes ekta ye wicayaśipi ; unkan taku yaotanin kin wowicake kin hee.

34 Tuka wicaśta akantu wayaotaninpi kin jwacu śni; tuka dena on yanipi kta e heciciyapi. $35 \mathrm{He}$ peta ijanjan iyege ca okitanin; unkan iyoyanpa tawa kin on kohanna iyuśkin wacannipi.

36 Tuka Johannes sam iyeya tanka wayaotanin mduha; wicohan ecamon kta Ate maqu qon hena e ecamon ece; Ate umaśi e yuotanin kin hena ee.

37 Qa Ateyapi umaśi qon he nakun mahduotanin: He tohinni ho kin nayahonpi śni, qa itohnake wandakapi śni:

38 Qa oie kin en niunpi śni, tuwe $u$ śi kin he wicayadapi śni, heon etanhan.

39 Wowapi wakan kin en akita po; heciyatanhan wiconi owihanke wanica duhapi kecannipi ; unkan omayake cin hena ee.

40 Tuka owihanke wanin wi- 
WICOWOYAKE 6 .

coni duhapi kta e on miye en mayaupi yacinpi śni.

41 Wicaśta ekta mitawootanin kin awecite śni.

42 Tuka Wakantanka waśtedakapi kin he en niunpi śni e sdonciyapi.

43 A te cajeyan wahi, tuka iyowinmayakiyapi śni; tuwe iye caje atayedan hduha hi kin hee iyowinyakiyapi kta.

44 Niye iyakitedan nitawootaninpi kin ayecitapi, qa Wakantanka eciyatanhan wootanin kin ayakitapi śni, he token on wicayadapi kta he.

45 Ate en aciyapi kta e kecanmakinpi śni po; Moses he wacinyayapi qon he iye taku iyanionpapi ce.

46 Moses wicayadapi unkanś miś eya wicamayadapi kta tuka. He miye on wowapi kaga.

47 Tuka iye wowapi kage cin hena wicayadapi śni kinhan, ecin token mioie kin wicayadapi kta he:

\section{WICOWOYAKE 6.}

1 Hena iyohakam Jesus Galile mde kin, he nakun Tiberias mde kin ee, he akasanpa iyaya.

2 Unkan oyate ota ihakam yapi, wicaśta wayazanpika en wapetogya olianyan wanyakapi qon heon etanhan.

3 Unkan Jesus paha wan ekta iyaya, qa waonspewicakiye cin om akan iyotanka.

4 Unkan woacakśin, Juda oyate wośnapi tawapi wan, he wanna ikiyedan ihan.

5 Jesus iśta yuwankan ikikcu, qa wicota iye yanke cin en au wanwicayake cehan, Philip heciya; Aguyapi dena yutapi kte cin tokiyatanhan opeuntonpi kta he.

6 He yukcan kta on etanhan heciya; token econ kte cin he sdonkiya tuka.

7 Hehan Philip ayupte; Kaśpapidan opawinge nonpa aguyapi iyopeyapi, qa otoiyohi cikcistinna icupi eśta, nakun iyowicahi kte śni ce, eya.

8 Hehan waonspewicakiye cin wanji, Simon Inyan sunkaku, Andrew eciyapi, he nakun heciya;.

y Psin ska aguyapi zaptan qa hogan nom hena den hokśidan wan yuha: tuka wicota qa henana on token hanpica he.

10 Unkan, Wicaśta kin iyotanke wicaśi po, Jesus eya. He en peji ota. Wicaśta kin hena iyotankapi, unkan kektopawinge zaptan iyecetu.

11 Hehan Jesus aguyapi kin hena icu qa yawakan, qa waonspewicakiye cin wicaqu ; unkan waonspewicakiye cin iyotang hiyeye cin wicakipamnipi ; qa nakun hogan tohanyan cinpi kin.

12 Unkan imnanpi hehan waonspewicakiye cin hewicakiya, Oyaptapi kin hena pahi.po, hecen takudan atakuni kte śni.

13 Unkan psin ska aguyapi oyaptapi qon he etanhan makanopiye ohnaka ake nonpa pahipi ; wotapi etanhan iwicakiciyaye cin hena ee.

14 Taku wapetogya Jesus econ kin oyate kin wanyakapi, qa heon heyapi, Wicaśta wokcan itancan oyate en hi kta keyapi qon he wanna dee.

15 Oyate kin Jesus icupi, qa wicaśtayatapi kah̉ wacinpi e sdonkiya, qa paha kin icunonpa akan iśnana iyaya.

16 Unkan wanna htayetu hehan waonspewicakiye cin mde kin ektakiya yapi ;

17 Qa wata wan en opapi qa. 151 


\section{JOHANNES.}

mde kin he opta yapi, Kapernaum heciya $\mathrm{i}$ wacinpi. Unkan otpaza tuka nahanhin Jesus ekta wicahi śni.

18 Unkan tateyanpa hinca, on etanhan mde kin nina taja aya.

19 Unkan wiyutapi wikcemna nonpa sam zaptan, qa iś wikcemna yamni hehanyan watopapi, hehan wata kin ikiyedan Jesus mini kin amani u wanyakapi ; unkan yuśinyayapi.

20 Tuka, He miye ce, ihnuhan koyakipapi kin do, ewicakiya.

21 Hehan iyokipiya wata kin en iyowinkiyapi ; unkan tokiya yapi qon, wata kin kohanna he en ihunni.

22 Ihanhanna hehan oyate mde kin icahda yukanpi kin, hen wata wanica, wanji wannspewicakiye cin en opapi qon heceyedan, qa Jesus waonspewicakiye cin om wata kin en ope śni, tuka waonspewicakiye cin iśnana iyayapi, he wanyakapi :

23 'Tuka Jesus aguyapi yawakan qa yutapi qon he en ikiyadan Tiberias eciyatanhan wata toktokeca en hipi.

24 Oyate kin Jesus waonspewicakiye cin om he en yukanpi śni wanyakapi, unkan oyate kin wata kin hena en opapi qa mde kin opta yapi, Jesus Kapernaum heci un kin he akin yapi.

25 Unkan mde kin akasanpa hen iyeyapi qehan, heciyapi ; Itancan tohinni den yahi he.

26 Jesus awicayupte ça heya; Wowicake, wowicake eciyatanhan heciciyapi, Omayadepi kin he taku wapetokeca wandakapi kin heon hecanonpi śni, aguyapi imnahan yatapi qon e heon.

27 Taku yutapi on wicatakuni śni heon hitanipi śni po ; tuka taku yutapi owihanke wanin wiconi.hehanyan kte cin hee on litani po, he Wicaśta Cinhintku kin niçupi kta; Wakantanka Ateyapi kin wanna lie askamton. 28 Hehan heciyapi ; Token econkupi kta, on Wakantanka tolian kin unkolianyánpi kta he. 29 Jesus waayupte ça hewicakiya; Wakantanka wicohan tawa kin he dee, tuwe u śi kin he wicayadapi kta.

30 Heon etanhan heciyapi; Taku wapetokeca ecanon kin tukte e heon, wanunyakapi qa wicaunnidapi kta ; taku yakaga he.

31 Hunkake wicunyanpi kin eya wanna hewoskan manna yutapi qon; Mahpiya eciyatanhan aguyapi yutapi kta e wicaqu ce; eya owapi qon he iyececa.

32 Unkan Jesus hewicakiya; Wowicake, wowicake eciyatanhan heciciyapi; Moses aguyapi kin he mahpiya kin eciyatanhan niçupi śni; tuka Atewaye cin he aguyapi wowicake kin malipiya eciyatanhan nicupi.

33 Aguyapi Wakantanka tawa kin he tuwe mahpiya eciyatanhan kuntkiya $u$, qa oyate wiconi wicaqu kin hee.

34 Unkan, Eca Itancan, aguyapi kin he ohinniyan unqu po, eciyapi.

35 Tuka Jesus hewicakiya; Aguyapi wiconi kin he miye ce. Tuwe en mau kinhan wotektehda śni un kta; qa tuwe wicamada kinhan ipuza śni un kta.

36 Eya wanna wanmayadakapi, tuka wicamayadapi śni e, eciciyapi qon.

37 Ate tona maqu kin owasin miye en mau kta; qa tuwe en mau kinhan tankan iyewaye kte śni.

38 Mahpiya eciyatanhan wahi kin, he mitawacin owape kte śni, tuwe u maśi kin he tawacin owecipe kta. 


\section{WICOWOYAKE 6.}

39 Atewaya u maśi kin he tawacin kin he dee, tona maqu kin wanjidan toki ehpewaye śni, ecen anpetu ihankeya kin piya icaliwaye kta.

40 Tuwe u maśi kin he tawacin kin he dee, tona Cinhintkuyapi kin he wanyake ca wicada kin hena owihanke wanin wiconi yuhe kta, qa anpetu ihankeya kin he en piya icaliwaye kta.

41 Heon Juda oyate kin ajijipi ; Aguyapi mahipiya eciyatanhan kun u kin he miye ce, eye ciqon heon etanhan.

42 Qa heyapi; Jesus Joseph cinhintku qon he dee śni he, atkuku hunku ko sdonwicunyanpi ce : hecen token, Malipiya eciyatanhan wahi ce, eya okihi he.

43 Heon Jesus waayupte ca hewicakiya; Niye iyakitedan waajijipi śni po.

44. 'Tuwedan iye cinka en mau kte śni, Ate u maśi qon tuwedan en au śni kinhan, qa anpetu ihankeya kin en piya icaliwaye kta.

45 Unkan owasin Wakantanka eciyatanhan onspewicaliyapi kta ce, wicaśta wolkcan kin en eya owapi qon. Heon tona Ate waonspewicakiye ça anagoptanpi kin hena owasin en maupi kta.

46 Tuwedan Ateyapi kin tohinni wanyake śni, tuwe Wakantanka etanhan u kin hecedan Atkuku wanhdaka.

47 Wowicake, wowicake eciyatanhan heciciyapi, 'Tuwe miye wicamada kinhan, he owihanke wanin wiconi yuhe kta.

48 Aguyapi wiconi he miye.

49 Nihunkakepi kin liewoskan manna yutapi, tuka tapi.

50 Mahpiya eciyatanhan aguyapi hi kin he dee, tuwe etanhan yute cinhan țe kte śni.
51 Aguyapi ni un kin he miye, malipiya eciyatanhan wahi; tuwe etanhan yute cinhan owihanke wanin ni kta. Aguyapi wicawaqu kte cin he micelipi kin ee, he oyate wicani kta e wicawaqu ce, eya.

52 Wicaśta kin de iye cehpi etanhan unqupi qa untapi kta heye cin, he token okihi kta e heya he, Juda oyate iyakitedan eya hdokinicapi.

53 Hehan Jesus hewicakiya; Wowicake, wowicake eciyatanhan heciciyapi ; Wicaśta Cinhintku kin cehpi etanhan yatapi śni, qa we kin datkanpi śni kinhan wiconi takudan en niunpi kte śni.

54 Tuwe micehpi etanhan yute ca mawe yatke cinhan owihanke wanin wiconi yuha ece, qa anpetu ihankeya kin en piya icahwaye kta.

55 Micehpi kin he woyute otancanke, qa mawe kin he woyatke otancanke.

56 Tuwe micehipi yute ca mawe yatke cin he mici un, qa miś kici waun.

57 Ate u maśi kin he ni un, qa Ate on ni waun, he etanhan tuwe mayute cinhan miye on ni un kta.

58 Aguyapi mahipiya eciyatanhan hi kin he dee. Nihunkakepi manna yutapi qon de iyecece śni, he yutapi tuka tapi. Tuwe aguyapi kin de etanhan yute cinhan owihanke wanin ni kta ce, eya.

59 Kapernaum en omniciye tipi kin he ohna waonspekiya icunhan hena hecen eya.

60 Heon etanhan waonspewicakiye cin ota he nationpi qehan, Wicoie kin de tehika ce, tuwe e nahon okihi kta he, eyapi.

61 Unkan Jesus waonspewica153 


\section{JOHANNES.}

kiye cin hena heya ajijipi kin, iye atayedan sdonye ca hewicakiya; Tokeca de iyanipatopi he.

62 Wicaśta Cinhintku kin wankan un qon ake ekta kihde ca, wandakapi kinhan, tokeca kta he.

63 Woniya kin he wiconi kaga ece, wicacehpi kin takudan okihi śni. Wicoie eciciyapi kin hena woniya qa wiconi kin hee.

64 Tuka wanjikji he wicayadapi śni. Otokahe ekta tanhan tona wicadapi kte śni, qa nakun tuwe wiyopeye kte cin hena Jesus sdonva.

85 Unkan heya; He etanhan heciciyapi qon, Tuwedan iye cinka en mau okihi kte śni, tuwe Atewaye cin he qu kinhan heceyedan okihi kta.

66 Hecetu, unkan heon waonspewicakiye cin ota ayuśtanpi, qa icimana ihakam yapi śni.

67 Hehan Jesus akenonpapi kin, Niś eya yạhdapi kta he, ewicakiya.

68 Unkan Simon Inyan ayupte; Itancan, tuwe ekta unyanpi kta he; owihanke wanin wiconi wicoie duhe cin;

$69 \mathrm{Qa}$ Messiya Wakantanka ni un Cinhintku kin he niye e wicaundapi qa sdonunyanpi ye, eya.

70 Unkan Jesus awicayupte; Akeninonpapi kin miye cicalinigapi śni he ; tuka wanji wakansica yaunpi ce, eya.

71 Simon cinhintku Judas Iskariyot he ke ca hecen eya. Ake nonpapi kin he etanhan tuka he wiyopeye kte cin ee.

WICOWOYAKF $\%$

1 Hena iyohakam Jesus Galile en un: Jưda oyate te yapi kta akítapi heon Juda makoce en un wacin śni.

2 Juda oyate wakeya ohna wotapi ece kin he wanna kiyedan aya.

3 Heon etanhan iye sunkawicaye cin heciyapi ; Detanhan ya wo, qa Juda makoce kin en un wo, hecen waonspewicayakiye cin niolian ecanon ece kin hena wanyakapi kta.

4 Tuwe ihdutanin cin kinhan, taku nalimana econ śni ece. Dena ecanon kta hecinhan, iho oyate kin en ihdutanin wo.

5 Sunkawicaye cin iyepi nakun wicadapi śni.

6 Heon Jesus hewicakiya; Miye anpetu kin hinyanhin iyemicihantu śni; tuka niye qe anpetu kin ohinniyan wiyeya niciyankapi.

7 Oyate kin śicenidapi okihipi śni, tuka miye e śicemadapi ; wicolian tawapi kin hena śica $\mathrm{e}$ mdaotanin ece kin heon etanhan. 8 Niye qe wośnapi kte cin ekta ya po. Miye qe nahahin anpetu iyemicihantu śni, heon wośnapi kin he ekta mde kte śni ce.

9 Hena hewicakiye ça hehan Galile en un.

10 Tuka sunkaku iyayapi kin iyohakam hehan, iś wośnapi kte cin elsta ya, taninyan ye śni, tuka nahmana ya.

11 Wośnapi kin icunhan Juda oyate odepi qa, Tokiya un he, eyapi.

12 Qa oyate kin iapi ota on aiapi. Apa, He wicaśta waśte ce, eyapi : qa toktokeca iś, Hiya, oyate kin wicahnayan ce, eyapi. 13 Juda oyate kowicakipapi, heon etanhan tuwedan taku ataninyan eye śni.

14 Wośnapi kin cokaya hdoipi, unkan Jesus tipi wakan ohna inajin, qa wowicakiyaka. 


\section{WICOWOYAKE 7.}

15 Unkan Juda oyate kin inihanpi qa heyapi; Wicaśta kin de tokiya tanhan wowapi kin onspe he; tohinni onspekiyapi śni qon.

16 Unkan Jesus awicayupte ca heya; Wociciyakapi kin de miye etanhan śni, tuwe u maśi kin he iye etanhan.

17 Tuwe iye tawacin ecen econ wacin kinhan, woyakapi kin de Wakantanka eciyatanhan hecinhan, qa iś miye einka hena epa hecinhan, sdonye kta.

18 Tuwe iye en oie iciye cinhan he iye towitan okide ece; tuka tuwe iś, tuwe uśi kin he towitan okieide kinhan, he iye wowicake, qa wicowicaśtaśni takudan en un śni.

19 Moses woope kin nicupi śni he; tuka tuwedan woope kin ecen ecanonpi śni; taku on țemayayapi kta e ayakitapi he.

20 Oyate kin ayuptapi qa heyapi ; Wakan śica niyuhnaśkinyan; tuwe e teniyan akita he.

21 Hehan Jesus wayupte ca hewicakiya; Wicohan wanji eeamon, unkan owasin niyuśinyayapi.

22 Moses bahdayapi wicohan kin nieupi; he Mioses etanhan śni, tuka hunkakewicayapi kin etanhan; unkan anpetu wakan eca wieaśta wan bayecihidayapi ece.

23 Heeen anpetu wakan eca wieaśta wan bakicilidayapi hecinhan, on Moses woope kage ciqon yujujupi kte śni ; wieaśta wan anpetu wakan en ocowasin okiziwaye ein heon cantamayahdepi he.

24 Wiyacinyan wayacopi śni po, wokonze e eeiyatanhan wayaco po.

25 Hehan Jerusalem etanhan wanjikji heyapi; Tuwe țeyan akitapi kin he dee śni he.
26 Unkan iho, kagi śni ia tuka tuwedan taku eciye śni. Wicaśta itancanpi kin awicakehan Messiya kin he dee e sdonyapi he.

27 Tuka wicaśta kin de tokiyatanhan u kin sdonunyanpi; tohan Messiya hi kinhan, tokiyatanhan u kin tuwedan sdonye kte śni, eyapi.

28 Hehan Jesus tipi wakan kin ohna waonspekiya icunhan hotankakiya heya; Tuwe miye kin sdonmayayapi, qa tokiya tanhan wau kin he nakun: qa miye einka wahi śni; tuka tuwe u maśi kin he wicaka, eqe sdonyayapi śni.

29 Tuka miye he sdonwakiya, he iye etanhan wahi, qa u maśi kin hee.

30 Unkan heon tinsa yuze wacinpi, tuka nahahin iyehantu śni kin heon tuwedan nape on yutanpi śni.

31 Unkan oyate kin etanhan wicota he iye kin wieadapi qa heyapi ; Tohan Messiya hi kinhan, de taku wapetogya econ kin, he sam iyeya hecon kta he, eyapi.

32 Oyate kin iyakitedan hekiciyapi he Pharisee kin nationpi ; unkan wośna kagapi Pharisee ko, yuzapi kta e on akieita ekta ye wieaśipi.

33 Hehan Jesus hewicakiya; Ehalze tokata cistiyedan ocipapi waun kta, helıan tuwe u maśi kinhan heciya wahde kta.

34 Omayadepi kta, tuka iyemayayapi kte śni; qa tokiya waun kin ekta yaupi kta cśta, oyakitpanipi kta.

35 Hehan Juda oyate kin iyakitedan hekieiyapi; Tokiya ye kta he, qa iyeunyanpi unkokihipi kte śni: Helenes oyate kin ehna enanakiya iyayapi kin ekta 


\section{JOHANNES.}

ye ca, Helenes wowicakiyake kta he.

36 Omayadepi kta tuka iyemayayapi kte śni, qa tokiya waun kin ekta yaupi kta eśta, oyakitpanipi kta ce, eye cin wicoie kin he toketu he, eyapi.

37 Wośnapi anpetu ehake qa tanka kin en, Jesus najin qa hotankakiya heya; Tuwe ipuza kinhan en mau qa mini yatke kta.

38 Tuwe wicamada kinhan, wowapi wakan eye cin iyececa, iye tanmahen tanhan wiconi nini wakpadan kaduze kta ce.

39 'Tuka Woniya, tona iye wacinyanpi kin icupi kte cin hee on hecen eya: he ehan nahahin Woniya Wakan kin wicaqupi śni, nahahin Jesus wowitan ehan i śni.

40 Oyate kin etanhan wicota wicoie kin de nalionpi qehan, Awicakehan wicaśta wolkcan kin he dee ce, eyapi.

41 Toktokeca iś, Messiya kin he dee ce, eyapi. 'Tuka apa iś, Messiya Galile etanhan u kta he, eyapi.

42 Dawid wicoicage tawa kin etanhan Messiya hinanpe kta, qa Bethlehem otonwe Dawid en un qon hetanhan u kta ce, wowapi wakan eye śni he.

43 Hetanhan oyate kin akipam wacinkiyuzapi.

44 Qa hunh yuze wacinpi, tuka tuwedan nape on yutan śni.

45 Hehan akicita kin, wośna kagapi Pharisee ko ekta icicawin wicakipi; unkan, Tokeca e ayahipi śni he, ewicaliyapi.

46 Akicita kin awicayuptapi; Wicaśta kin tuwedan tohinni wicaśta kin de iyecen oie ye śni ce, eyapi.

47 Helian Pharisee kin iś awicayuptapi, Niś nakun nihnayanpi he.
48 Wicaśta itancanpi kin wan: jikji qa Pharisee ko he wicadapi he.

49 Tuka oyate kin de, woope yukcanpi śni kin hena walitepi śni ce, eyapi.

50 Nikodemos hanyetu ehan Jesus yanke cin en i qoll, he itancanpi kin wanji ee, hewicakiya;

51 Woope unkitawapi kin, wicaśta token eye cin nahon śni, qa taku econ kin atayedan sdonye śni itokam, yaco he.

52 Unkan ayuptapi qa heciyapi; Niś Galile henitanhan he: Wawiwange ca wanyaka wo ; wicaśta wokcan tuwedan Galile etanhan u śni ce.

53 Hehan otoiyohi iye tipi kin ekta kihdapi.

\section{WICOWOYAKE 8.}

1 Jesus Oliwe Paha kin ekta i. 2 Qa ihanhanna anpao hehan tipi wakan kin en ki, unkan oyate kin owasin en ahi; unkan en iyotanke ça wowicakiyaka.

3 Ưnkan wośna kagapi Pharisee ko winohinca wan nahma ihduśaka e en kahipi, qa cokata ehdepi ;

4 Qa heciyapi, Waonspekiye, winohinca kin de wawicihahapi econ wanka icunhan iyeyapi.

5 Unkan Moses, woope kin en, tona hececa kin inyan on wicakininpi kta, unkekiciyapi qon: tuka niś token ehe kta he.

6 Taku iyaonpapi kte cin he akitapi e heon etanhan he iyutanyan heciyapi. Tuka Jesus patuś inajin, qa nape on maka kin en owa.

7 Unkan kitanyan wiwangapi, hehan Jesus owotanna inajin, qa hewicakiya; Wanji tukte woahtani wanin yaunpi hecinhan, 


\section{WICOWOYAKE 8.}

he tokaheya inyan on kinin kite.

8 Hehan ake patuś inajin qa ake maka kin en owa.

9 He nahonpi, unkan iye tawacin on ihdacopi, heon wanjikjidan tankata kinanpapi, tokaheya wicaśta tanka unpi, qa ecen hakaktapi koya owasin; qa Jesus iśnana un ehpeyapi, winohinca cokata hdepi qon he koya.

10 Unkan Jesus ihduowotanna, qa tuwedan wanyake śni, winolinca ecedan ecen najin, unkan heciya, Winohinca, wiyanionpapi qon owasin toki iyayapi he; tuwedan niyaco śni he.

11 Han, Itancan, tuwedan śni, eya. Miś eya ciyaco śni, hunktiya wo, tokata yeye cin icimana walitani śni wo, Jesus eciya.

12 Hehan ake Jesus owicakiye ça heya; Oyate iyoyamwicaye cin he miye. Tuwe mihakam'u kin he otpaza ehna mani kte śni, iyoyanpa wiconi hee tawa kta.

13 Hehan Pharisee kin heciyapi ; Niye atayedan nihdaotanin, heon wadaotanin kin he wowicake śni.

14 Jesus waayupte ça hewicakiya; Miye atayedan mihdaotanin qeyaś mihdaotanin kin he wowicake; tokiya tanhan wahi kin he sdonwakiya, qa nakun tokiya mde kte cin he; qa niyepi kin tokiya tanhan wau, qa tokiya mde cin hena sdonyayapi śni.

15 Wicacehpi eciyatanhan wadacopi; tuka miye qe tuwedan mdaco śni.

16 Tuka nakun wamdaco kinhan, wamdaco kin he wowicake kta; miśnana waun śni, tuka Ateyapi u maśi kin he miciun ece.

17 Wicaśta nom waayataninpi D1 kin he wowicake ce, woope duhapi kin en owapi qon.

18 Miye atayedan mihdaotanin, qa Ate u maśi kin he nakun mayaotanin.

19 Unkan, Niyate tukte e he, eciyapi. Jesus iś awicayupte, Sdonmayayapi śni, qa nakun Atewaye cin sdonyayapi śni: Miye kin sdonmayayapi unkanś, Ate iś nakun sdonyayapi kta tuka.

20 Tipi wakan kin en mazaska opiye he cin he en, Jesus waonspewicakiya icunhan hena hewicakiya. Heca tuka tuwedan Jesus otan wacinpi śni, anpetu kin nahahin kicihi śni heon.

21 Hehan Jesus ake hewicakiya; Wahde kta, qa omayadepi ecen woahtani ehna nițapi kta; qa tokiya wahde cin heciya dapi kta eśta oyakitpanipi kta.

22 Unkan Juda oyate kin heyapi ; Iye icikte lita he. Tokiya mde cin heciya dapi oyakitpanipi kta ce, eye cin.

23 Hehan iye hewicakiya; Niye kuya tanhan yaunpi; qa miye e wankan tanhan waun; maka kin detanhan yaunpi, tuka miye maka kin dematanhan śni.

24. He etanhan wayahtanipi kin en nițapi kta ce, eciciyapi. He miye kin wicayadapi śni kinhan wayahtanipi kin ehna nitapi kta ee.

25 Unkan, Tuwe niye he, eciyapi. Tokag ehan eciciyapi qon he dee, Jesus ewicakiya.

26 Taku ota eciciyapi, qa ciyacopi kta e mduha; tuka tuwe u maśi kin he wowicake; qa taku emakiye cin owasin oyate kin owicawakiyaka ce.

27 Iye Atkuku kin on hena hewicakiye cin he okalinigapi śni.

28 Hehan Jesus hewicakiya; 


\section{JOHANNES.}

Tohan Wicaśta Cinhintku kin wankan eyahdepi kinhan, hehan he miye kin śdonyayapi kta, qa miye cinka takudan ecamon śni; tuka A te taku onspemakiye cin hena ecedan ecen omdaka ece.

29 Tuwe u maśi kin he mici un; Ate miśnana amahduśtan śni; taku iyokipi ecen ecamon ece, heon etanhan, eya.

30 Hewicakiya icunhan wicota wanna wicadapi.

31 Heon Juda oyate kin etanhan tona Jesus wieadapi kin hena hewicakiya; Mioie kin ohinniyan oyapapi kinhan, awicakehan waonspewicawakiye cin he niyepi kta;

32 Kinhan wowicake kin sdonyayapi kta; qa wowicake kin he niciyuśkapi kta ce.

33 Hehan ayuptapi; Abraham towicoun kin unketanhanpi, qa tohinni tuwedan wowidag unyanpi śni; hecen, Niciyuśkapi kta ce, ehe cin he token heha he.

34 Jesus awicayupte; Wowicake, wowicake on heciciyapi, Tuwe woalitani econ kin he woahtani en wowidake un ece.

35 Qa wowidake un kin he ohinniyan tipi kin ohna un śni ece; tuka Cinhintku kin hee ohinniyan timahen ounyan.

36 Heon Cinhintkuyapi kin niciyuśkapi hecinhan, awicakehan tawaniciyapi kta.

37 Abraham towicoun kin enitanhanpi sdonwaya; tuka țe mayayapi yacinpi, mioie kin en niunpi śni, heon etanhan.

38 'Taku Ate ekta wamdake cin hena omdaka ece; qa niś niyate ekta taku wandakapi kin hee ecen ecanonpi ece.

39 Hehan ayuptapi qa heciyapi ; Abraham he ateunyanpi kin ee. Unkan Jesus hewicakiya ;
Abraham cinca kin he niyepi unkanś, Abraham ohanye cin he ecen ecanonpi kta tuka.

40 'Tuka nakaha temayan ayakitapi, wicaśta wan wowicake Wakantanka eciyatanhan nawahon kin he ociciyakapi kin he miye tuka: Abraham e qe hecen econ śni qon.

41 Niyatepi ohan kin hee ecen ecanonpi ece, eya. Hehan heciyapi ; Tuwe cinca tanin śni kin heuncapi śni ; ate unyanpi wanjidan unhapi, Wakantanka kin hee.

42 Heon Jesus hewicakiya; Wakantanka he ateyayapi unkanś waśte mayadakapi kta tuka; miye kin Wakantanka kin hetanhan wahinape ca wau; qa miye cinka wahi śni, iye kin u maśi.

43 He tokeca e iwae cin oyakahnigapi śni he ; mioie kin anagoptan wacannipi śni kin heon etanhan.

44 Wakanśica ateyayapi kin henitanhanpi, qa niyatepi tawacin kin ecen ecanonpi yacinpi ece. He otokahe etanhan tinwicakte kin heca, qa wowicake kin en najin śni, wowicake takudan en un śni nakaeś. Tohan woitonśni oyaka eca, he iye cinka ohdaka ece ; iye kin woitonśni sa, qa woitonśni atkuku kin hee.

45 Tuka miye wowicake eciciyapi kin, heon etanhan wicamayadapi śni.

46 Niyepi kin wanji tukte he wawahtani e duwicakapi he. Qa wowicake epe cinhan, tokeca e wicamavadapi śni he.

47 Tuwe Wakantanka etanhan kin he Wakantanka oie anagoptan. Niye Wakantanka anayagoptanpi śni ece, heon etanhan henitanhanpi śni. 


\section{WICOWOYAKE 9.}

48 Hehan Juda oyate kin ayuptapi qa heciyapi ; Samariya oyate henitanhan, qa Wakanśica niyuhnaśkinyan ce, unkeniciyapi qon he wicaunkapi ce.

49 Jesus ayupte; Wakanśica mayuhnaślkinye śni; tuka Ate wahduwitan, qa niye wow iśtenmayayapi.

50 Miye mitowitan awecite śni ; tuka tuwe waakite ça wayaco yukan ce.

51 Wowicake, wowicake eciyatanhan heciciyapi, Tuwe mi= oie kin de yuhe cinhan, tohinni wiconte wanyake kte śni, eya.

52 Hehan Juda oyate kin heciyapi ; Wakanśica niyuhnaśkinyan e dehan iyotan sdonunyanpi. Abraham hee kaeś ta, qa wokcanpi kin hena nakun tapi; tuka niye, Tuwe mioie yuhe cinhan tohinni wiconte ute kte śni ce, eha ce.

53 Abraham ateunyanpi kin hee kaeś te cin, niye e iniyotan he. Wokcanpi kin nakun heepi kaeś tapi; qa niye nituwe e nicicaga he, eyapi.

54. Unkan Jesus waayupte ; Miye cinka mihduonihan kinhan, mitowitan kin he taku kte śni ; tuka Atewaye cin he mahduonihan ece; unkan he Wakantanka nitawapi, kehapi.

55 Heca eśta tohinni sdonyayapi śni ; tuka miye e sdonwakiya. Qa he sdonwaye śni ce, epe cinhan, miś eya niyepi iyecen iwaton kte śni ; tuka miye sdonwaya, heon etanhan oie kin tanyan weciyuha.

56 Abraham ateyayapi qon mitaanpetu kin wanyake kta cin hinca, unkan he wanyake ca iyuśkin ce, eya.

57. Hehan Juda oyate kin heciyapi ; Nahahin waniyetu wikce- mna nizaptan śni, tuka Abraham wandaka he.

58 Jesus hewicakiya; Wowicake, wowicake eciyatanhan heciciyapi; Abraham un qon he itokam wanna waun ce, eya.

59 Hececa unkan inyan icupi, qa on kininpi kta ; tuka Jesus naiçilibe ca, tipi wakan etanhan wicehna tanhan tankata inanpe ca, etoopteya iyaya.

\section{WICOWOYAKE 9.}

1 Jesus ye cin tahepi, wicaśta wan toka tonpi ehantanhan tonwe śni un e he wanyaka.

2 Unkan waonspewicakiye cin wiwangapi qa heyapi ; Itancan, tuwe wahtani he, wicaśta kin de atkuku, hunku, iyeka, wanji tukte wahitani he, on iśta gonga tonpi he.

3 Jesus waayupte; $\mathrm{He}$ iye, qa atkuku, hunku, wanji walitanipi on hecece śni; tuka Wakantanka ohan kin e he ayutaninpi kta e heon.

4 Anpetu icunhan, tuwe u maśi wicohan tawa kin ecen ecamon kta iyececa; hanyetu kin he hi $k t a$, he en tuwedan wicolian econ okihi kte śni.

5 Tohanyan wicaśta opeya waun kin, oyate iyoyamwicawaya ece, eya.

6 Hena heye ca hehan makata tagośa, qa tage on upśija kage ca, iśtagonge cin iśta kin en upśija ikiciun;

7 Qa heciya: Siloam miniyowe, yeśipi eyapi kin he kapi, he ekta ye ça en ihdujaja wo. Unkan ekta i, qa on ihdujaja qa hdi, unkan wawanyaka.

8 Heon itan anog tipi; qa tona wicaśta iśtagonge cin wanyakapi ece qon hena, Tuwe timata iyotang un qon he dee se, eyapi. 


\section{JOHANNES.}

9 Wanjikji, He dee ce, eyapi : tonpi kehapi he; qa tokiyatanqa toktokeça iś, He de iyececa ce : tuka iye kin, He miye ce, eya.

10 Unkan, Tokiya tanhan de on niiśta kin dumdaya he, eciyapi.

11 Unkan iye wayupte ça heya; Wicaśta wan Jesus eciyapi kin he upśija kage ça, iśta anokatanhan imiciun, qa, Siloam mininwe kin ekta ye ca, mini on ihdujaja wo, emakiya qehan, ekta wai, qa mihdujaja, unkan watonwan, eya.

12 Unkan, Wicaśta kin he tukte. e he, eciyapi. Sdonwaye śni ce, eya.

13 Wicaśta iśtagonge ciqon he Pharisee kin en wicakaipi.

14 Unkan anpetu wakan icunhan, Jesus upśija kage ça on wicaśta kin he iśta yukawakiya.

15 Hehan Pharisee kin iś ake, token on iśta yukawapi hecinhan he iwangapi. Unkan, Upsija e iśta kin en imaun qa mihdujaja, unkan watonwan, ewicakiya.

16 Unkan Pharisee kin wanjikji; Wicaśta kin he anpetu wakan awacin śni, heon etanhan. Wakantanka lietanhan śni, eyapi. Unkan apa, Wicaśta wan wahtani sa hecinhan, wowapetokeca dececa token econ okihi kta he, eyapi. Hecen on akipam wacinhnakapi.

17 Ake wicaśta iśtagonge ciqon heciyapi ; Qa niś token eyakiya he, iśta tonweniye cin. Unkan, He wicaśta wokcan kin heca ce, eya.

18 Wicaśta kin he iśta gonga tuka ihnuhanna tonwe cin he Juda oyate kin wicadapi śni, heon tuwe iśta tonweyeyapi kin atkuku hunku ko wicakicopi ;

$19 \mathrm{Qa}$ wiwicawangapi qa heyapi ; De nicincapi qa tonwe śni han nakaha tonwan he.

20 Atkuku hunku ko waayuptapi qa heyapi ; De unkicincapi tonwe śni tonpi he sdonunkiyapi ;

21 Tuka nakaha tokiya tanhan on tonwe cin de sdonunyanpi śni. Qa iśta yukawa kin de nakun sdonunyanpi śni; iś eya hokśike śni kin, iye iwanga po, toketu kin he ecen eye kta ce.

22 Juda oyate kowicakipapi, qa heon etanhan atkuku hunku kici hecen eyapi. Tuwe, Messiya kin hee, taninyan eye cinhan, he omniciye tipi kin etarnan tankan iyeyapi kta, Juda oyate kin wanna wakiconzapi.

$23 \mathrm{He}$ etanhan, Iye eś hokśike. śni kin, iye atayedan winungapi śni, atkuku hunku kici eyapi.

24 Hehan ake icinonpa wicaśta iśtagonge ciqon he wiwangapi qa heciyapi; Wakantanka woyatan qu wo; wicaśta kin he wahtani sa sdonunyanpi ce.

25 Iye waayupte ca heya; He wahtani sa hecinhan sdonwaye śni ; tuka taku wanji sdonwaya ; iśtamagonga tuka nakaha watonwe cin he.

26 Unkan, Taku tokanicon qa on iśta kin niyukawa.he, ake eciyapi.

27 Unkan awicayupte; Wanna eya keś ociciyakapi, tuka nayałonpi śni; ake icinonpa nayahonpi yacinpi he; niś eya waonspewicakiye cin hen ope nihdawapi kta he, eya.

28 Hehan iwahtedapi śni qa heyapi; Waonspewicakiye cin he wanji niye ; tuka Moses waonspewicakiye cin he unkiyepi.

29 Wakantanka Moses he okiya sdonunyanpi, tuka wicaśta kin de tokiyatanhan u kin sdonunyanpi śni ce. 160 


\section{WICOWOYAKE 10.}

30 Unkan wicaśta kin he waayupte ca hewicakiya; Taku wowinihan kin he dee; naka iśta may umdaya, tuka tokiyatanhan u kin sdonyayapi śni.

31 Wahtanipi sa kin hena Wakantanka anawicagoptan śni ece, tuka tuwe Wakantanka yuonihan, qa tawacin okicipe cin, hee Wakantanka anakigoptan e sdonunyanpi.

32 Otokaheya tanhan tuwe wicaśta tonwe śni tonpi iśta kiyukawa oyakapi kin tuwedan nahon śni ce.

33 Wicaśta kin de Wakantanka eciyatanhan śni unkanś takudan okihi kte śni ce, eya.

34 Unkan waayuptapi qa, Woahtani ocowasin ehna nitonpi, tuka waonspeunyakiyapi kta kecanni he, eciyapi; qa tankan iyeyapi.

35 Tankan iyeyapi kin he Jesus nahon; qa akipa, unkan, Wakantanka Cinhintku kin wicayada he, eciya.

36 Iye waayupte ca, $\mathrm{He}$ tuwe he, Itancan, wicawada kta ce, eya.

37 Wandake ca he iye e oniciya, Jesus eya.

38 Unkan, Itancan wicawada, eyaya itokam canpeślka makehde inajin.

39 Unkan Jesus heya; Oyate kin de ekta wicawahi, wicaśta tona tonwe śni kin hena tonwanpi kta, qa tona tonwe cin hena iśtagongapi kta, he woyaco kin hduha wahi ce.

10 Unkan Pharisee kicicapi kin hena nahonpi, unkan, Unkiś eya iśtaungongapi he, eciyapi.

41 Iśtanigongapi unkanś woalitani wanin yaunpi kta; tuka nakaha, Untonwanpi ce, ehapi ; heon woahtani niyukanpi, Jesus ewicakiya.

Dak.

\section{WICOWOYAKE 10.}

1 Wowicake, wowicake eciyatanhan heciciyapi; Tuwe tahinca tipi tiyopa ohna tin iyaye śni, tiyopa icunonpa tanhan ti iyohpaye cin he wabotice ca wamanon kin heca.

2 Tuka tuwe e tiyopa eciyatanhan tin iyaye cin hee tahinca tawa wicaye cin ee.

3 Qa iye tiyopa awanyake cin tiyopa kiciyugan ece, unkan tahinca kin he ho kin nahonpi ece; tahinca tawa kin otoiyohi cajeyan wicakico, qa tankan wicahdoya ece.

4 Unkan tahinca tawa kin tankan awicau eca, wicitokam ya ece; unkan tahinca kin' iś ihakam yapi ece, ho kin iyekiyapi nakaeś.

5 Qa tuwe tokeca kinhan he ihakam yapi kte śni, tuka nakicipapi kta; tuwe tokeca ho kin iyekiyapi śni, lieon etanhan.

6 Wiyacinpi kin de Jesus ecen ewicakiya; tuka taku owicakiyake cin hena okahnigapi śni.

7 Hehan ake Jesus hewicakiya; Wowicake, wowicake on heciciyapi, Tahinca tipi tiyopa kin he miye ce.

8 Tona mitokam hipi kin hena owasin waboticapi qa wamanonpi kin hecapi ; tuka tahinca kin anawicagoptanpi śni.

9 Tiyopa kin he miye; tuwe miye eciyatanhan ti iyohpaye cinhan ni kta; qa mahen ye ça tankata inanpa eca wato tanyan iyeye kta.

10 Wabotice cin he wamanonpi, tin wicaktepi, waihangýapi henakiya on hi ece; tuka wiconi yuhapi kta, qa takudan icakije śni unpi kta e heon miye wahi.

11 Waawanhdake waśte kin he miye. Waawanhdake waśte kin 
he tahinca'kin on wiconi tawa ehpekiya.

12 Tuka tuwe odotapi un, qa waawanhdake kin ee śni, qa tahinca tawa śni kin he śunktokeca en u wanyaka eca, tahinca kin elpewicaye ca najica ece; unkan śunk tokeca iyawicahpaye ca ihangwicaya ece.

13 Odotapi un kin he wodotapi un, qa tahinca kin ihawicakta śni, heon etanhan napa ece.

14 Waawanhdake waśte kin he miye, qa tahinca mitawa kin hena sdonwicawakiya, qa mitawa kin iś nakun sdonmakiyapi ece.

15 Ate token sdonmakiye cin he iyecen miś Ate sdonwakiya; qa talinca kin hena on wiconi mitawa kin ehpewakiya.

16 Qa tahinca toktokeca nakun wicamduha, tahinca tipi kin den un śni : hena nakun awicawahi kta, hecen miho kin nahonpi kta ; hetanhan tahinca tipi wanjidan kta, qa waawanhdake wanjidan kta.

17 Wiconi mitawa ehpewakiye ca, ake ewehdaku kte cin heon A te waśte makidaka.

18 Tuwedan he maki kte śni; qa miye cinka he wicawaqu; he amduśtan kte cin owakihi, qa ewehdaku kte cin nakun owakihi; Ate hecen econ maśi ce, eya.

19 Akeś wicoie kin dena on Juda oyate kin akipam tawacinpi.

20 De taku wakan śica yuha, qa he ihnaśkinyan, tokeca e nayahonpi he, wicota eyapi.

21 Tuka apa iś, Tuwe wakan sica yuhe cin decen oieye śni ece; taku wakan śice cin he iśta gongapi iśta wicakiyukawa okihi kta he, eyapi.

22 Wanna Jerusalem en yuwo- hduze tonpi omniciye kagapi ece qon hehantu; unkan waniyetu.

23 Unkan icunhan tipi wakan ohna, Solomon ohanzi hdepi tawa qon he en Jesus omani.

24 Hehan Juda oyate itan ihdukśan himniciyapi qa heciyapi ; Tohanyan wacin akipam yusunyakiyapi he; Messiya kin he niye hecinhan taninyan unkokiyaka po.

25 Jesus awicayupta; Wanna ociciyakapi tuka wicamayadapi śni qon ; Ate caje kin eciyatanhan wicohan ecamon kin hena omayake cin ee.

26 Tahinca tawa wicawaye cin he oyapapi śni, he etanhan wicamayadapi śni, eciciyapi qon he iyececa.

27 Tahinca mitawa kin miho kin nahonpi, qa hena sdonwicawakiya, qa mihakam unpi.

$28 \mathrm{Qa}$ owihanke wanin wiconi wicawaqu ; qa icimana owihankepi kte śni, qa minape kin etanhan tuwedan wicayuśpe kte śni. 29 Ate hena maqu kin he taku owasin sam iyeya tanka; qa Ate nape kin etanhan tuwedan wicayuśpa okihi śni.

30 Miye, qa Atewaye cin unwanjipidan, eya.

31 Hehan Juda oyate ake inyan icupi, on kininpi kta e heconpi.

32 Unkan Jesus awicayupta; Ate eciyatanhan wicohian waśte ota cicipazopi; hena tukte wanji on nakaha inyan on mayakininpi kta he, eya.

33 Juda oyate ayuptapi qa heyapi ; Wicohan waśte on unnicininpi kte śni, tuka iapi śica on, qa winicaśta tuka Wakantanka nicicage cin heon etanhan. 34 Jesus awicayupte; Taku wakan kin henicapi, eciciyapi ce, he woope nitawapi kin en hecen kagapi śni he. 


\section{WICOWOYAKE 11.}

35 Hecen tona Wakantanka oie kin en wicahiyohi kin hena taku wakanpi ewicakiya hecinhan, qa wowapi wakan kin he yujujupica śni ;

36 Hecen tuwe Ateyapi kin hduwakan qa makata u śi kin he, Wakantanka Cinhintku kin he miye ce, epe ciqon, heon, 'Taku śica eha ce, token eyalkiyapi kta he.

37 A te ohan kin hena ecen ecamon śni kinhan, wicamadapi śni po.

38 Tuka hecen écamon kinhan, miye wicamayadapi śni eśta, wicohan kin hena wicada po; hecen Atewaye cin micica, qa miye he wecica, heciyatanhan sdonyayapi qa wicayadapi kta ce, eya.

39 Heon etanhan nakun ake tinsa yuze wacinpi; tuka napepi kin etanhan ihduśpa.

$40 \mathrm{Qa}$ ake hetanhan Jordan wakpa kin he en, Johannes baptem wicaqu ece qon he en i, qa en ounyan.

41 Unkan wicota en hipi qa heyapi; Johannes takudan wapetogya ecèn econ śni, tuka Johannes wicaśta kin de etanhan tona oyake cin owasin wowicake.

42 Unkan hen wicota wicadapi.

\section{WICOWOYAKE 11.}

1 Unkan wicaśta wan wayazanka, Lazarus eciyapi, Bethani hetanhan, Mary qa cunku Martha totonwepi kin hee.

2 Mary wihdi waśtemna on Itancan kin sdaye ca, paha kin on siha kin kipakinta, Lazarus he hunkawanjitku wayazanke cin hee.

3 Unkan tawinohtinpi kin, Itancan, wicaśta wan waśteyadake ciqon he wayazanka, eya hośi kaipi.

4. Jesus nahon unkan hecen eya, Wowayazan kin he wiconte ekta śni, tuka he Wakantanka towitan kin ee, qa heon Wakantanka Cinhintku kin yuwitanpi kta.

5 Martha iye tankaku, Lazarus kici, Jesus waśte wica daka.

6 Wayazanke cin nahon, tuka anpetu nonpa ekta ye śni yanka.

7 Hehan Jesus waonspewicakiye cin liewicakiya; Juda makoce kin ekta unhdapi kta.

8 Unkan waonspewicakiye cin heciyapi; Itancan, nahanhin aśkatudan Juda oyate kin inyan on nicininpi akitapi, qa ake ekta hde wacanni he.

9 Jesus waayupte; $\Lambda$ npetu wanjidan lieś, wihiyayedan oape akenonpa śni he; tuwe anpetu icunhan mani kinhan naśna śni ece; maka akan iyoyanpa kin he wanyaka heon.

10 Tuka tuwe hanyen mani kinhan hee naśna kta, iyoyanpa takudan en un śni kin heon.

11 Hena hecen eya; qa hehan iyohakam hewicakiya; Lazarus koda unyanpi qon iśtinma, ekta mde ca mduhice kta ce.

12 Hehan waonspewicakiye cin, Itancan, iśtinma hecinhan he hecetu kta ce, eyapi.

13 He wanna ta e Jesus heya; tuka iśtinmapi on oziiciya e heya kecinpi.

14. Unkan hehan Jesus taninyan hewicakiya; Lazarus wanna ta ce :

$15 \mathrm{Qa}$ he icunhan hen waun śni kin heon niyepi en wimduśkin, hecen on wicayadapi kta. Ho po, ekta unyanpi kta.

16 - Hehan Thomas Didumos eciyapi kin he waonspewicakiye unmapi kin hewicakiya; Ekta unyanpi, qa kici unțapi kta ce. 


\section{JOHANNES.}

17 Unkan Jesus en u qehan, hapi etanhan wanna topa can he sdonya.

18 Jerusalem Bethani ikiyedan, wiyutapi akezaptan ecetu hehanyan.

19 Unkan Martha Mary kici yukanpi en Juda oyate wicota magagaye wicaipi, hunkawanjitkupi kin heon.

20 Jesus en u Martha nahon, unkan itkokim ya; tuka Mary e timahen iyotanka yanka.

21 Hehan Martha Jesus heciya ; Itancan, den yaun unkanś, mihunkawanji țe kte śni tuka ;

22 Tuka detanhan taku Wakantanka yakida kinhan, Wakantanka nicu kta e sdonwaya ce.

23 Nihunkawanji ekicetu kta, Jesus eciya.

24 Eya woekicetu anpetu ihankeya kin hehan ekicetu kta e sdonwaya, Martha eya.

25 Unkan Jesus heciya; Woekicetu qa wiconi kin he miye, tuwe wicamada kinhan toke hin ța eśta ni kta.

26 Qa tuwe ni un, qa wicamada kinhan icimana te kte śni. He wicayada he.

27 Han, Itancan; Messiya Wakantanka Cinhintku makata hi kte.ciqon he niye e wicawada ce, eciya.

28 Unkan hena hecen eya, hehan hde ca, tawinohitin Mary anahbeyahan kico, qa heciya; Itancan kin den un, qa nico ce.

$29 \mathrm{He}$ nation iheya, unkan ohankoya najin hiyaye ça ekta ya.

30 Nahanhin Jesus otonwe kin ehan i śni, tuka Martha itkokipe ciqon he en un.

31 Hehan Juda oyate en yukanpi, qa magagayapi, he icunhan Mary ohankoya najin hiyaye cin wanyakapi qehan, ihakam iya- yapi qa, Wicaśta hnakapi ekta ceye kta e ekta ya, eyapi.

32 Jesus najin kin Mary ehan i, qa wanyake cehan, ihukuya canpeśka makehde ehpeiciye ça, Itancan, den yaun unkanś, mihunkawanji țe kte śni tuka, eciya.

33 Mary ceye cin he Jesus wanyake ça, Juda wicaśta kici ipi kin hena nakun ceyapi ; unkan iye atayedan comnihdazi, qa iliniyanyan.

34 Qa tokiya eyahnakapi he, eya. Unkan, Itancan, ekta u qa wanyaka ye, eciyapi.

35 Jesus ceya.

36 Hehan Juda oyate kin heyapi; Wanyaka po, ehan qon waśte dake hinca ce.

37 Qa wicaśta wanjikji, Wicaśta iśta aohduta ee kaeś yukawa, wicaśta kin de te śni unkiya okihi kta naceca ce, eyapi.

38 Ake Jesus iye atayedan comnihdazi, qa wicaśta hnakapi kin en ya. He imnija olidoka ohna hnakapi, qa inyan wan tanka aokatinzapi.

39 Inyan kin tokan iyeya po, Jesus eya. Wicaśta te cin tawinohitin Martha heciya, Itancan, wanna topa can yanka e śicamna.

40 Wicayada kinhan, Wakantanka towitan wandake kta ce, eciciye śni he, Jesus eciya.

41. Hehan inyan kin tokan iyeyapi ; wicaśta ta wanke cin etanhan. Unkan Jesus iśta yuwankan ikikcu, qa heya; Ate ciyawaśte, namayahon kin heon ;

$42 \mathrm{Qa}$ ohinniyan namayation kin he sdonwakiya; tuka wicaśta hnakapi kin de en mitan okśan najinpi kin de on, he niye u mayaśi kin wicadapi kta e on hepe. 43 Hecen eye ça hehan, Lazarus nunke cin hetanhan tankata 


\section{WICOWOYAKE 12.}

hninanpa wo, awitukadan hoyekiya qa eya.

44 Unkan wicaśta țe cin tankata hninanpa, siha nape ko pahtapi, qa ite opemni tonpi kin hena ecehna. Kiyuśkapi qa ayuśtan po, iyaye kta, Jesus ewicakiya.

4.5 Hehan Juda wicaśta Mary kici ipi qon, hena Jesus taku econ kin he wanyakapi, unkan wicota wicadapi.

46 Tuka wanjikji Pharisee kin ekta wicakipi, qa Jesus taku econ kin owicakiyakapi.

47 Hehan wośna kagapi Pharisee ko mniciyapi qa, Token econkupi he ; wicaśta kin de taku wapetokeca ota econ kin, eyapi.

48 Iyowinunkiyapi kinhan wicaśta owasin wicadapi kta ; kinhan Roma oyate kin den upi kta, qa otonwe kin de unkasotapi, qa nakun unkitaoyatepi kin hena ko.

49 Hehan wanji Kaiaphas eciyapi waniyetu kin he en wośna kagapi itancan kin hee hewicakiya; Takudan oyakahnigapi śni.

$50 \mathrm{Qa}$ nakun awacannipi śni, wicaśta wanjidan oyate on te cinhan, hecen on oyate kin wicațe kte śni, he unkiyepi kin on hecetu kta ce, eya.

51 Iye etanhan on hecen eye śni, tuka omaka kin he en wośna kagapi itancan kin heon, Jesus oyate kin on țe kte cin he iyukcanyan heya.

52 Qa oyate kin heceedan śni, tuka Wakantanka cinca omdecahe cin hena owasin wanjidankiya kiwitaye kta.

53 Hehan anpetu kin hetanhan witaya akiiapi, teyapi kte cin heon.

54 Heon etanhan Jesus Juda oyate kin wicehna taninyan omani śni, tuka makoce wan hewoskan ikiyedan wanke, otonwe wan Ephrairn eciyapi kin he ekta ya, qa waonspewicakiye cin om he en un.

55 Unkan woacakśin Juda oyate wośnapi kagapi wanna ikiyedan aya; unkan wanna kayehan oyate ota Jerusalem en kata iheya aya, woacakśin kin itokam piicilyapi kta.

56 Hehan Jesus akitapi, qa tipi wakan kin ohna najinpi icunhan iyakitedan hekiciyapi; Token idukcanpi he; wośnapi kin en u kte śni he.

57 Wośna kagapi tankapi qa Pharisee lio wanna wakiconzapi, tuwe Jesus tukten yanka sdonye cinlian, he oyake kta, hecen yuzapi kta.

\section{WICOWOYAKE 12.}

1 Woacakśin kin itokam śakpe can, hehan Jesus Bethani en i, Lazarus wicaśta ta, tuka ekicetuyapi en un qon otonwe kin hee.

2 Unkan hen hitayetu wotapi wan kicagapi, qa Martha e wapamni ; tuka kici iyotang wotapi kin Lazarus wanji hee.

3 Hehan Mary wihdi waśtemna qa taku ota iyopeyapi, tke utapi wanjidan, he icu qa on, Jesus siha kin sdakiye ça, iye paha kin on siha kipakinta; unkan ecamna kin tipi kin ojudan.

4 Hehan Simon cinhintku, Judas Iskariot eciyapi, waonspewicakiye cin wanji hee, wiyopeye kte cin hee hecen eya;

$5 \mathrm{He}$ tokeca wihdi kin he kaśpapidan opawinge yamni iyopeyapi, qa wahpanicapi kin wicaqupi śni he.

$6 \mathrm{He}$ wamanon heca, qa mazaska opiye yuhe ca, ohna mazaska omnayan, heon hecen eya; wo165 


\section{JOHANNES.}

wahpanica kin incantowicahnake cin heon heye śni.

7 Hehan Jesus heya; Nagiyeye śni wo; anpetu wan mahnakapi kte cin he en amayuhe cin hee ce.

8 Tokeśta wowahpanica ohinni wicaduhapi kta; tuka miye e ohinniyan mayaduhapi kte śni, eya.

$9 \mathrm{He}$ icunhan hen un kin Juda oyate wicota sdonyapi; unkan Jesus ecedan on en hipi śni, tuka Lazarus, wiconțe etanhan najinkiye ciqon, he wanyakapi kta on etanhan.

10 Unkan wośna kagapi tankapi Lazarus nakun țeyapi kta akitapi :

11 Hee nakun on Juda oyate ota hduheyapapi, qa Jesus wicadapi.

12 Ihanhanna wicaśta ota wośnapi kin en hipi kin hena, Jesus Jerusalem etkiya $u$ nahonpi hehan,

13 Canwapa tanka etanhan canhaka icupi, qa itkokim yapi, qa panyanhan heyapi ; Hosanna, tuwe Israel Wicaśtayatapi, Jehowa caje kin on u kinhan, he yawaśtepi nunwe.

14 Unkan Jesus śonśonna cinca wan iyeya, hehan akan iyotanka; hecen wowapi kagapi qon;

15 Zion cunwintku ihnuhan koyakipe cin; iho, Wicaśtayatapi nitawa śunka śonśona cinca wan akan yanka u ce.

16 Dena taku kin tokaheya waonspewicakiye cin okahnigapi śni ; tuka Jesus yutanpi hehan hena hecen wowapi en kagapi qon, qa nakun hena ecen ecakiconpi kin, hehan kiksuyapi.

17 Heon oyate kicicapi kin, Lazarus hnakapi tuka kipan, qa wiconte etanhan ekicetuye ciqon, hena he yaotaninpi.
$18 \mathrm{Qa}$ heon oyate kin itkokipapi, taku wapetokeca tanka kin de econ nationpi kin heon.

19 Unkan heon etanhan Pharisee kin iyakitedan hekiciyapi; Wanyaka po, takudan oyakihipi śni ; iho, wicaśta owasin he ihakam iyayapi.

20 Helenes oyate kin etanhan wanjikji wośnapi kin icunhan en ohodapi kta e ékta itanwankanhde upi ;

21 Hena eepi Philip, Galile makoce Bethsada otonwe kin etanhan, he en ipi, qa, Itancan, Jesus wanunyakapi uncinpi ce, eciyapi.

22 Philip u, qa Andrew okiyaka; qa hehan Philip Andrew kici Jesus okiyakapi.

23 Unkan Jesus awicayupte ca heya; Anpetu wan en Wicaśta Cinhintku kin yutanpi kte cin wanna hiyohi.

24 Wowicake, wowicake eciyatanhan heciciyapi; Aguyapi su kin maka ekta ehpeyapi, țe śni kinhan, iśnana un kta ; tuka te cinhan ota icahye kta.

25 Tuwe wiconi kin de waśte kida kinhan, toki ehpeye kta; qa tuwe maka kin den wiconi śice kida kinhan, hee owihanke wanin wiconi ekta akpatan kta.

26 Tuwe omakiye lita cin kinhan mihakam un kta; qa tukten waun hecinhan mitaokiye kin is nakun hen un kta; nakun tuwe omakiye lita hecinhan, Ate wicaśta kin he yuonihan kta.

27 Wanna minagi kin nagiyeyapi, hecen token epe kta he. Ate, anpetu kin de etanhan emahdaku wo. Tuka heon anpetu kin de en wahi ce.

28 Ate nicaje kin hdutan wo. Unkan mahpiya kin eciyatanhan wicaho wan u qa; Wanna eya 


\section{WICOWOYAKE 12.}

micaje kin wahdutan, nakun wahdutan kta, eya.

29 Unkan wicaśta en najinpi kin he nalionpi qa, He walinyan hoton, eyapi. Mahpiya ohnihde heca e okiya ce, apa eyapi.

30 Unkan Jesus waayupte ca heya; Wicaho kin de miye make śni, he niye nicapi.

31 Wanna oyate kin wicayacopi ; qa wanna maka akan itancan kin tankan ehpeyapi.

32 Qa tohan maka kin detanhan wankan emahdepi kinhan, wicaśta kin owasin miye en iwicawacu kta, eya.

33 Wiconte kin tukte on țe kte cin he ka e hecen eya.

34 Oyate kin ayuptapi; Woope kin eciyatanhan, Messiya owihanke wanin un kta ce, eyapi naunhonpi; hecen, Wicaśta Cinhintku kin wankan ehdepi kța ce, token on hecen eha he; Wicaśta Cinhintku kin he ture he.

35 Hehan Jesus hewicakiya; Iyoyanpa kin ehake cistiyedan nicipi un; iyoyanpa duhapi kin icunhan en omani po; otpaze cin iyapaśtag niyanpi nun ce; tuwe otpaza icunhan omani kin he tokiya ye cin sdonye śni.

36 Iyoyanpa duhapi kin en iyoyanpa kin he wicada po, hecen on iyoyanpa cinca yaunpi kta ce. Jesus hena hecen eye ca, hehan iyaye ca inalibe wicakiya.

37 Taku wapetokeca ota econ, qa wanyagwicaya, tuka wicadapi śni.

38 Hecen Isaya wicaśta wokcan taku eye ciqon wanna iyecetu; Itancan, tuwe wounyakapi kin wicada he; qa tuwe en Jehowa hupahu kin yutaninpi he.

$39 \mathrm{Qa}$ heon etanhan wicadapi kta okihipi śni; heon Isaya ake hecen eya ;

40 Iśta gonge wicaye ça, cante kin ekta nakun wacinton śni wicaya; hecen iśta on wiwanyakapi kte śni, qa cante on takudan yukcanpi kte śni, qa ihduecetupi kte śni, qa hecen wokiziwicawaye śni.

41 Towitan kin he Isaya wanyake ciqon he ehan hena hecen ekiciya.

42 Hececa tuka itancanpi etanhan wicota wicadapi; tuka Pharisee kin hena on etanhan yaotaninpi śni, omniciye tipi kin etanhan tankan iyewicayapi kta ikopapi heon.

43 Wicaśta akantu yaonihanpi kin he iyotan dapi, qa Wakantanka wicayaonihan kin he iś iyotan dapi śni.

44 Hehan Jesus panyanhan heya; Tuwe wicamada kinhan, he miye wicamada śni, tuka tuwe u maśi kin hee wicada ece. $45 \mathrm{Qa}$ tuwe wanmayake cin he nakun tuwe u maśi kin he wanyaka.

46 Miye maka akan iyoyanpa wahi; hecen tuwe wicamada kinhan he otpaza en omani kte śni.

$47 \mathrm{Qa}$ tuwe mioie kin nahon, qa wicada śni eśta mdaco śni; wicaśta wicayacopi kin heon wahi śni, tuka waniyapi kin hee on wahi.

48 Tuwe amaktaśni, qa mioie kin icu śni kinhan he tuwe yaco kte cin hduha; wicoie omdake cin anpetu ihankeya kin en yaco kte cin hee.

$49 \mathrm{He}$ miye cinka hecen oiewaye śni ; tuka Ate u maśi kin he iye econ maśi, taku epe lite ca taku omdake kte cin.

$50 \mathrm{Qa}$ toope kin he owihanke wanin wiconi e sdonwaya. Token epe cin hena, Ate hena hecen emakiya, heon etanhan hecen epa ece, eya. 


\section{JOHANNES.}

WICOWOYAKE 13.

1 Anpetu en wośnapi ece kin itokam, anpetu qon wanna hiyohi, he en maka kin detanhan iyaye kta, Atkuku ektakiya hde kta, Jesus sdonkiya, tona maka akan tawa kin waśtewicadake cin hena owihanketa waśtewicakida.

2 Wotapi ayaśtanpi hehantu; Judas Iskariot Simon cinhintliu kin hee, Jesus wiyopeye kte cin, Wakanśica wanna hecen cante ozekiya:

3 Hehan Jesus Atkuku taku owasin tawa kiye ciq on he sdonkiya un, Wakantanka eciyatanhan hi, qa ake Wakantanka ekta hde kta.

4 Hecen wotapi kin etanhan najin, qa śina ekihnaka; qa napipakinte wan icu, qa ipiyaka.

$5 \mathrm{Qa}$ hehan mini wakśica en okaśtan, qa waonspewicakiye cin siha wicakiyujaja, qa napipakinte wan ipiyake ciqon heon siha kin wicakipakinta.

6 Simon Inyan ehan ahi; unkan, Itancan, niye siha mayakidujaja kta he, eciya.

7 Unkan Jesus ayupte ca, Taku ecamon kin de nakaha sdonyaye śni, tuka ihakamya sdonyaye kta, eciya.

8 Icimana siha mayakidujaja kte śni, ake Inyan eciya. Hehan Jesus ayupte; Ciciyujaja śni kinhan takudan on miyecica kte śni, eya.

9 Hehan Simon Inyan heciya; Itancan, siha ecedan śni, tuka minape, mapa koya.

10 Unkan Jesus heciya; T'uwe wanna ihdujaja kin he takudan sanpa cin śni, siha ecedan yujajapi kta, eya wanna ocowasin ska; unkan niye niskapi, tuka iyulipapi śni.
11 Tuwe wiyopeye kte cin he sdonya, heon etanhan, owasin niskapi śni ce, eya.

12 Unkan siha wicakiyujaja yuśtan kin hehan śina ehdaku qa hdowin qa iyotanke ca, Taku tokaciconpi kin de sdonyayapi he, ewicakiya.

13 Waonspekiya qa Itancan, emayakiyapi ece; he tanyan ehapi ; he miye nakaeś.

14 Heon etanhan mis miye Waonspekiya qa Itancan mayaduhapi kin, siha ciciyujajapi kinhan, niś eya otoiyohi siha yeciyujajapi kta iyececa.

15 Waonspeciciyapi kin he niś he iyecen ecanonpi kta e hecaciconpi.

16 Ookiye unpi kin he Itancan kin iyakapa śni ; qa tuwe u śipi kin he tuwe u śi hecinhan, he iś iye kapa śni, wowicake, wowicake eciyatanhan eciciyapi.

17 Taku kin dena sdonyayapi hecinhan, ecen ecanonpi kinhan waśteya yaunpi kta.

18 Taku epe cin de niye iyuhpa heciciyapi śni ; tona wicawakalinige cin hena sdonwicawakiya ; tuka wowapi en kagapi qon yuecetu kta; Tuwe kici aguyapi wata ece kin he miye on siha yuwankan ehdaku ce.

19 Taku kin dena ecetu śni itokam ociciyakapi; hecen tohan iyecetu kinhan, he miye e wicayadapi kta.

20 Tuwe tokiya yewakiye cin tuwe iyowinkiye cinhan, he miye e iyowinmaye; qa tuwe iyowinmaye cinhan, he tuwe u maśi kin he iyowinkiya, wowicake, wowicake eciyatanhan eciciyapi.

21 Jesus hena hecen eye ca hehan toksape kin ekta iyahdeiciya, hdaotanin qa heya; De dukanpi kin etanhan wanji wi- 


\section{WICOWOYAKE 14}

yopemayayapi kta, wowicake, wowicake on eciciyapi ce.

22 Hehan. waonspewicakiye cin opakicilita yukanpi, wanji tukte e on heye cin sdonyapi śni.

23 Unkan Jesus waonspewicakiye cin wanji nina waśte kidake ciqon, he eca maku kin en makan iwanka.

24. Heon Simon Inyan he wikiyuta, qa wanji tukte he on heye cin he iwange śi.

25 Heham he Jesus maku kin en iwanke ca, Itancan, he tuwe he, eya.

26 Jesus ayupte; Wanji tukte hpanyanpi onśpa waqu kinhan hee kta, eya. Hecen onśpa hipanye ça, Judas Iskariot eciyapi Simon cinhintku he qu.

27 Unkan Judas hpanyanpi kin icu, hehan Satan mahen iyaya. Hecen Jesus heciya; Taku ecanon kte cin kohanna econ wo.

28 Wahna wotapi kin ihdukśan yukanpi kin, taku on heye cin tuwedan okahnigapi śni.

29 Judas mazaska opiye yuhe cin heon, Jesus wośnapi kta on taku cinpi kin he opeton śi ; qa iś, wah̀panicapi kin taku wicaqu śi, apa kecinpi.

30 Unkan lipanyanpi qon he icu qehan, hecehnana tankan iyaya; wanna hanyetu hehantu.

31 He tankan iyaya, hehan Jesus heya; Wanna Wicaśta Cinhintku kin yutanpi, qa nakun iye eciyatanhan Wakantanka iś yutanpi. 32 Qa iye eciyatanhan:Wakantanka yutanpi hecinhan, hehan Wakantanka iś iye kin on hdutan kta, nakun kohanna hdutan kta.

33. Hokśiyoqopa ehake ptenyedan ocipapi kta. Amayakitapi kta, qa Juda oyate ewicawakiye ciqon; Tokiya mde cin ekta yaipi kta oyakihipi śni ce; he iyecen nakaha eciciyapi.
34. Woahope teca wan cicupi, otoiyohi waśteyecidapi kta; waśtecicidapi kin he iyecen waśteyecidapi kta.

35 Heon waonspeciciyapi yaunpi kin wicaśta owasin sdonyapi kta, otoiyohi waśteyecidapi kinhan.

36 Itancan, tokiya de kta he, Simon Inyan eciya. Jesus ayupte; Tokiya mde cin ekta de kta eśta nakaha oyakihi kte śni, tuka ihakamya mihektam yau kta, eya.

37 Unkan Inyan heciya; Itancan, tokeca nakaha cihakam waun kta owakihi śni he; niye on wiconi mduhe cin elipewaye kta, eya.

38 Jesus ayupte; Miye on wiconi nitawa ehpeyaye kta he. Wowicake, wowicake on heciciya; Anpaohotonna kin hoton śni itokam yamni akihde sdonmayaye śni, kehe kta ce, eya.

\section{WICOWOYAKE 14 .}

1 Ihnuhan cante niśicapi kinhan; Wakantanka wicayadapi, qa miś nakun wicamayadapi.

2 Ate ti kin en ounyanpi kte cin ota yanka; he hecece śni unkanś ociciyakapi kta tuka; ekta wahde ca oyanke kin ciciyuśtanpi kta.

3 Ekta mde ça oyanke ciciyuśtanpi kinhan, hehan ake wau qa acihdapi kta; hecen miś waun kin he en niśs nakun yaunpi kta.

4 Unkan tokiya mde cin he sdonyayapi, qa canku, kin he nakun sdonyayapi.

5 Itancan, tokiya de cin sdonunyanpi.śni, tokiya tanhan. canku kin he sdonunyanpi kta he, Thomas eciya.

6 Unkan Jesus heciya; Canku, qa wowicake, wiconi ko he mi169 
ye; tuwedan Ateyapi kin en u śni, miye eciyatanhan ecedan en u ece.

7 Sdonmayayapi unkanś nakun Atewaye cin sdonyayapi kta tuka; qa detanhan sdonyayapi qa wandakapi ce.

8 Itancan, Ateyaye cin wanyag unyan po, hecen iunmnanpi kta, Philip eciya.

9 Hehan Jesus heciya; Philip, wanna wanakajatanhan cicipi waun, tuka nahanhin sdonmayaye śni he ; tuwe wanmayake cin he Ateyapi kin wanyaka; hecen tokeca, Ateyapi kin wanyag unyan miye, eha he.

10 Atewaye cin he wecica qa Atewaye cin he micica kin he wicayada śni he. Wicoie eciciyapi kin dena miye cinka eciciyapi śni; Atewaye micica kin he wicolian kin hena iye econ.

11 Atewaye cin he wecica qa Atewaye cin he micica he wicamada po; qa iś wicohan kin lıena e on wicamada po.

12 Wowicake, wowicake on heciciyapi; Tuwe wicamada kin he wicolian ecamon kin hena iś iyecen econ kta, nakun eeś sanpa tanka econ kta; Ate ekta wahde kte cin heon etanhan.

13 Qa micaje kin on taku yadapi kinhan, ecen ecamon kta; Ateyapi kin Cinhintku kin on yutanpi kta e heon.

14 Taku wanji micaje on yadapi kinhan, ecen ecamon kta.

15 Waśte mayadapika hecinhan, mitawoahope kin tanyan yuha po.

16 Hehan Ate cewakiye kta, unkan wicakicanpte wan tokeca niçupi kta, he owihanke wanin nicipi un kta.

17 Wowicake Woniya kin hee, oyate kin he icu okihipi śni, tohinni wanyakapi śni qa sdonya- pi śni; tuka niye he sdonyayapi, he nicipi un qa en niunpi kta.

18 Wanidenica ehpeciyapi kte śni; ake cihdiyohipi kta.

I9 Wanna ptenyedan kinhan oyate wanmayakapi kte śni, tuka niye wanmayadakapi kta; wani waun, qa niś yani yaunpi kte cin heon.

20 Anpetu kin he en, Atewaye cin he wecica, qa niś miyecicapi, qa miś ocicipapi kin he sdonyayapi kta.

21 Tuwe mitawoahope yuhe ca, liena ope cinhan he waśtemadake cin ee; qa tuwe waśtemadake cinhan, Atewaye cin he waśtedake kta, qa miś nakun waśtewadake kita, qa en mihdutanin kta ce.

22 Hehan Judas, Iskariot hee śni, he heciya; He tokeca Itancan, unkiśnana sdonniye unyayapi kta he, qa oyate kin sdonniyanpi kte śni.

23 Jesus waayupte ca heciya; Thwe waśtemadake cinhan mioie kin yuhe kta; qa Atewaye cin waśtedake kta, qa tukten un kinhan en unhipi kta, qa ti kin en kici unyakonpi kta.

24 Tuwe waśtemadake śni kin he mioie kin yuhe śni. Wicoie nayahonpi kin de mitawa śni, Atewaya umaśi kin he iye tawa.

25 Ocipapi kin en taku kin hena heciciyapi.

26 Tuka Wicakicanpte, Woniya Wakan kin hee, Atewaye cin micaje on uśi kte cin he, taku owasin onspeniciyapi kta, qa taku eciciyapi kin owasin kiksuyeniciyapi kta.

27 Wokiyapi ailipeciyapi; wookiye mitawa cicupi: wicaśta akantu kicicupi he iyecen cicupi śni. Thnuhan cante niśicapi qa kopehda yaunpi kinhan.

28 Wahde ca ake en ciupi kta 


\section{WICOWOYAKE 15.}

eciciyapi kin he wanna nayahonpi. Waśtc mayadapi kinhan iduśkinpi kta; Atewaye cin ekta wahde lkta epe cin he; Atewaye cin he iye mikapeya tanka.

29 Qa nakaha hena heciciyapi, taku kin itokam; tohan he hiyohi kinhan hehan wicayadapi kta. 30 Detanhan taku ota eciciyapi kte śni; maka akan itancan kin wanna u, tuka miye kin en takudan tawa śni.

31 Tuka Atewaye cin waśtewakida; qa Ate taku emakiye cin owasin ecen ecamon ece, he oyate kin sdonyapi kta. Najin po, detanhan icunonpa unyanpi kta.

\section{WICOWOYAKE 15}

1 Hastanhanka iyuwi wowicake kin be miye, qa Atewaye cin he kicanye cin ee.

2 Adetka tona miye on waskuyeca icaliye śni kin hena yupśun; qa adetka tona waskuyeca icahye cin hena pakinta, hecen on waskuyeca ota icalye kta.

3 Eya wanna niskapi, wicoie ociciyakapi kin heon.

4 Mici un po, hecen miś cicipi waun kta. Hastanhanka iyuwi adetka wiyuwi kin en ikoyake śni kinhan waskuyeca icaliya okihi śni ece; he iyecen miyeci yaunpi śni ehantanhan, niś eya oyakihipi ktc śni.

5 Hastanbanka iyuwi kin he miye, adetka kin he niyepi. 'Tuwe mici un qa miś kici waun kin he waskuyeca ota icaliya; miye kin en icunonpa yaunpi kinhan takudan oyakibipi kte śni.

6 'Tuwe mici un śni kinhan adetka iyecen tankan ehpeyapi, hecen śnija aya; unkan hena wicaśta pahipi qa petan ehpeyapi, hecen hulinaga ece.

7 Miyeci yaunpi qa mioie kin ciqon he sdonyayapi. he nicipi un kinhan, taku tona yacinpi kin hena yadapi kta, unkan ccen ecaniconpi kta.

8 Waskuyeca ota icahyayapi kinhan Atewaye cin nina yutanpi kta; qa heciya tanban waonspeciciyapi yaunpi kta.

9 Atewaye cin token waśte makida kin he iyecen waśte cicidapi; mitowaśte kin he kici un po.

10 Mitawoahope kin duhapi kinhan, mitowaśte kin he kici yaunpi kta; Ate tawoahope mduhe cin heon towaśte kin kici waun kin he iyececa.

11 Taku eciciyapi kin dena on mitowiyuśkin kin nicipi un kta e, qa nitowiyuśkinpi kin he ecetu niciciyapi kta.

12 Mitawoahope kin he dee, waśtecicidapi kin he iyecen waśteyecidapi kta.

13 Tuwe takuwicaye cin on wiconi ehpekiye cinhan, he wowaśte kin tuwedan kapeye śni.

14 Taku econ ciśipi kin owasin ecen ecanonpi kinhan takuciyapi yaunpi.

15 Ookiye wicayapi wanna eciciyapi śni; ookiye yapi un kin he Itancan ye cin taku econ keś sdonye śni. Tuka takuciyapi eciciyapi; Atewaye cin tona nahonmaye cin owasin sdonye ciciyapi kin heon.

16 Niye he mayakahnigapi śni, tuka miye e cicalinigapi qa ciyusutapi ; hecen tokiya dapi qa waskuyeca icahyayapi kta; qa waskuyeca nitawapi kin ohinniyan un kta; hecen micaje on Atewaye cin taku yakidapi kinhan nicupi kta ce.

17 Otoiyohi waśte kicida po, he iwahokonciciyapi ce.

18 Oyate kin śice nidapi eśta, he itokam miye śice madapike 171 


\section{JOHANNES.}

19 Oyate kin enitanhanpi unkanś oyate kin taku iye tawapi waśte kidapi kta; tuka oyate kin henitanhanpi śni, miye e oyate kin etanhan cicahnigapi kin heon oyate kin śice nidapi.

20 Wicoie wan eciciyapi qon he yeksuyapi; Ookiye yapi un kin he Itancan yuhe cin liakipe ca iyotan tanka śni. Sicaya makuwapi hecinhan, niś oyate kin sicaya nicuwapi kta; qa mioie yuhapi hecinhan, niśs nioie kin niciyuhapi kta.

21 Tuka micaje kin on hena owasin ecen ecaniconpi kta; tuwe u maśi kin he sdonyapi śni heon etanhan.

22 Wahi śni qa owicawakiye śni kinhan, woalitani nicapi kta tuka; tuka detanhan woahtani woakahpe nicapi.

23 Tuwe śice madake cin he nakun Atewaye cin śice daka.

24. Wicolian tuwedan hecen econ śni iyecen ecawicawecon śni unkanś, woahtani nicapi kta tuka; tuka wanna Atewaye cin kici wanmayakapi, qa napin śice undakapi.

25 Tuka woope tawapi kin en wicole kagapi qon he wanna iyecetu; Takudan on etanhan śni śice madakapi ce.

26 Tuka Wicakicanpte, Atewaye cin etanhan uwaśi kte cin he, Wowicake Woniya kin hee, tohan hi kinkan, he iye Atewaye cin etanhan u kta, qa omayake kte cin hee.

27 Qa niś nakun omayadakapi kta, toka ehantanhan miyahna yaunpi qon heon.

\section{WICOWOYAKE 16.}

1 Wayahtanipi kte śni e heon dena taku kin ociciyakapi.

2 Omniciye tipi kin etanhan 172 tankan iyeniyanpi kta; nakun anpetu wan u kta, hehan tuwe kaśta niktepi kinhan, he Wakantanka iyokipiya kecin kta.

3 Atewaye cin sdonyapi śni, qa miś nakun sdonmayanpi śni, he etanhan henakiya hecen ecanionpi kta.

4. Tuka dena ociciyakapi, hecen tohan iyehantu kinhan, dena wanna eciciyapi kin he yeksuyapi kta. Qa dena otokahe ekta eciciyapi śni, hinyahin cicipi waun kin heon etanhan.

5 Tuka wanna tuwe umaśi kin he ekta wahde kta; qa wanjidan, Tokiya de kta he, emayakiyapi śni.

6 Tuka taku kin dena ociciyakapi, heon nicantepi kin ekta iyoniyakapi.

7 Tuka wowicake ece ociciyakapi; wahde cinhan heon tanyan yaunpi lita, qa wahde śni kinhạn Wicakicanpte kin en nihipi kte śni; tuka wahde cinhan niyepi elsta uwaśi kta.

8 Unkan he tohan hi kinahan, woalitani, woowotanna qa woyaco kin on oyate kin sdonyewicaye kta :

9 Woahtani kin, wicamadapi śni kin heon:

10 Woowotanna kin, Atewaye cin ekta wahde kta, qa icimana wanmayadakapi kte śni, heon :

11 Woyaco kin, oyate kin de itancan un kin he wanna yacopi, heon etanhan.

12 Nakun taku ota eciciyapi lata mduha, tuka hena e qe nahanliin yuha oyakihipi śni.

13 Tuka tohan Wowicake Woniya kin he iye hi kinhan, wowicake ocowasin en aniyanpi $\mathrm{kta}$; iye atayedan on ie kte śni, tuka taku nalion kin hena oyake kta, qa taku tokata ekta hena oniciyakapi kta. 
14 Mayutan kte cin hee, taku mitawa kin hena icu, qa oniciyakapi kta.

15 Taku Ate tawa kin hena owasin mitawa; he etanhan, Tona mitawa kin hena icu, qa oniciyakapi kta ce, eciciyapi.

16 Wanna aśkayedan hehan wanmayadakapi kte śni; hehan akeś aśkadan ake wanmayadakapi kta, Ate ekta wahde kte cin heon.

17 Hehan waonspewicakiye cin iyakitedan hekiciyapi; Unkekiciyapi kin he taku hwo; Wanna aśkayedan wanmayadakapi kte śni, qa hehan aśkadan ake wanmayadakapi kta; qa, Ate ekta wahde kte cin heon.

18 Heon heyapi; Askayedan eye cin he taku he; taku eye cin sdonunyanpi śni ce.

19 Wiwangapi cinpi kin he Jesus sdonya, unkan heon hewicakiya; Wanna aśkayedan wanmayadakapi kte śni, qa hen ikiyedan wanmayadakapi kta, epe cin he, he token kapi hwo, otoiyohi eyeciyapi he.

20 Wowicake, wowieake on heciciyapi; Nihinniçiyapi qa yaceyapi kta, tuka oyate kin iyuśkinpi kta ; iyoniciśicapi kta, tuka iyoniciśicapi kin he wowiyuśkin wan en un kta:

21 Winohinca cinca ton kta eca yazan hda, wanna iyekicihantu kin heon; tuka tohan hokśiyoqopa ton eca, yazan hda qon he kiksuye śni, wicaśta oyate kin den tonpi eca wowiyuśkin ye cin heon.

$22 \mathrm{He}$ iyecen nakaha iyokiśin dukanpi, tuka ake wanciyakapi kta, kinhan nicantepi kin wiy uśkin kta, qa widuśkinpi kte cin he tuwedan nicipi kte śni.

23 Unkan anpetu kin he en takudan imayanungapi kte śni.
Wowicake, wowicake on heciciyapi; 'Taku micaje on Atewaye cin yakidapi kinhan niçupi kta.

24 Nahahin dehanyan micaje on takudan yadapi śni. Da po, iyacupi kta, hecen wowiyuśkin ojudanniciyapi kta.

25 Hena taku iyacinyan heciciyapi ; tuka anpetu wan u kta, hehan wiyacinyan takudan eciciyapi kte śni, tuka taninyan Ateyapi kin on ociciyakapi kta. 26 Tohan iyehantu kinhan micaje on taku yadapi kta, tuka Atewaye cin wocekiye eciciyapi kta, epe śni.

27 Ate iye atayedan waśte nidapika, waśte mayadapike ca Wakantanka eciyatanhan wahi kin he wicayadapi kin heon.

28 Atewaye cin eciyatanhan wau, qa oyate kin de en wicawahi Ake oyate kin ehpewicawaye kta qa Ate ekta wahde. kta.

29 Wanna wiyacinyan iyae śni, ataninyan iyaa ce, waonspewicakiye cin eciyapi.

30 Taku owasin sdonyaye ça, tuwe winiwange $\mathrm{kta}$ iyecece śni yaun e wanna sdonunyanpi ; heon etanhan Wakantanka eciyatanhan yahi kin he wicaundapi, eyapi.

31 Jesus awicayupte; Wanna wicayadapi he.

32 Anpetu wan u kta qa wanna hiyohi, enanakiya otoiyohi yahdapi kta, qa miśnana ehpemayayapi kta; tuka nakun miśnana waun śni, Atewaye cin he mici un.

33 Wookiye amayaduhapi kta heon etanhan hena heciciyapi. Oyate kin de en wokakije duhapi kta; tuka wiyuśkin po, miye oyate kin ohiwicawaya ce. 


\section{JOHANNES.}

\section{WICOWOYAKE 17.}

1 Jesus hena hecen eye ca hehan iśta yuwankan icu, qa mahipiya kin ekta etonwan qa, Ate wanna anpetu kin hiyohi, Nicinkśi kin hdutan wo, hecen on Nicinkśi kin nihdutan kta ce.

2 Wicacelipi owasin on wowaśake yaqu qon, hecen tona yaqu kin owasin owihanke wanin wiconi wicaqu kta.

3 Unkan owihanke wanin wiconi kin he dee, wowicake Wakantanka niye e sdonniyanpi kta, qa Jesus Messiya uyaśi qon.

4 Maka kin akan ciyutan; qa wicokicanye mayaqu qon wanna owasin wahduśtan.

5 Unkan nakaha, Ate niye kin on miye mahdutan wo, wicoicage wanice cin he itokam wowitan niyeci hduha waun qon heon.

6 Oyate kin den wicaśta tona mayaqu kin hena en nicaje mdaotanin; hena nitawa, tuka hena mayaqu; unkan hena nioie qon niciyuhapi.

7 Taku mayaqu kin owasin he niye etanhan $u$, wanna sdonyapi.

8 Nioie mayaqu qon he wanna wicawaqu ; unkan icupi, qa niye eciyatanhan wahi kin he tanyan sdonyapi, qa niye e umayaśi kin he wicadapi.

9 Hena on wocekiye ewicaweciya, maka akan wicaśta kin hena on wocekiye eciciye śni, tuka tona mayaqu kin hena on wocekiye eciciye, hena nitawa kin he etanhan.

10 Taku mitawa kin hena owasin nitawa, qa niś taku nitawa kin hena mitawa, qa hena on wowitan waun.

11 Wanna oyate kin dematanhan śni, tuka iye e oyate kin en opeya ni unpi, qa miye wanna nitankiyadan waku lita. Ate wakan, nicaje kin on dena mayaqu qon hduha wo, hecen unwanjidan qon iś iyecen wanjidan kta.

12 Oyate kin den om waun kin he icunhan nicaje kin on wicawahduha. Mayaqu qon hena e wicawahduha, qa owasin elpekiyapi śni, wicaśta wayutakuni śni cinhintku kin hecedan ehpekiyapi, hecen wowapi en un qon wanna iyecetu.

13 Wanna nitankiyadan waku kta, oyate kin den opeya waun kin en ehake hecen epa, hecen on mitowiyuśkin kin iyepi en wicakiyuśtanpi kta.

14. Nioie wicawaqu, qa 'oyate kin śice wicadapika, oyate kin hetanhanpi śni heon etanhan hececa, oyate dematanhan śni he iyecen.

15 Oyate kin detanhan ewicayahdaku kta e heon wocekiye eciciye śni, tuka taku śice cin he en anawicayecipte kta e heon.

16 Oyate liin de ematanhan śni kin he iyecen iś oyate kin de etanhanpi śni.

17 Wowicake nitawa kin he on wicayuwakan wo; nioie kin he wowicake.

18 Oyate kin deci u mayaśi qon, lie iyecen iś oyate kin ecen ye wicawaśi.

19 Qa iyepi on miye mihduwakan, hecen on wowicake eciyatanhan wicayuwalkanpi kta.

20 Qa denana on wocekiye ewicaweciye śni, nakun tona wicoie oyakapi eciyatanhan wicamadapi kin hena koya.

21 Hecen on owasin wanjipidan kta, niye kin iyecen, Ate, miyecica, qa miś cicica; qa hecen iś unkicicapi kta; qa oyate kin niye u mayaśi kin he wicadapi kta. 
22 Wowitan mayaqu qon he wanna wicawaqu; hecen on unwanjidan kin iyecen wanjipidan kta.

23 Miś wicakici waưn, qa niś mici yaun, hecen wanjidan en wicayuśtanpi kta; qa hecen niye umayaśi kin he oyate kin sdonyapi kta; qa waśtemayakida kin he iyecen waśtewicawakida ece.

24 Ate, tona mayaqu kin hena, tokiya waun kin hen mici unpi kta wacin; hecen wowitan mayaqu qon he wanyakapi kta, wicoicage kin de itokam waśtemayakida kin heon etanhan.

25 Ate owotanna, oyate kin sdonniyanpi śni ye, tuka miye sdonciye ciqon, qa dena iś niye e u mayaśi kin he sdonyapi.

26 Unkan nicaje kin he sdonye wicawakiya qa nakun sdonye wicawakiye kta; hecen wawacinkta duza on waśtemayakida qon he dena en un kta, qa miś nakun owicawape kta.

\section{WICOWOYAKE 18.}

1 Jesus hena hecen eya, hehan waonspewicakiye cin om Kedron wakpadan kin akasanpa iyaya, hen can wojupi wan, unkan he en i, waonspewicakiye cin om.

2 Unkan Judas wiyopeye cin he iś nakun makoce kin he sdonya, Jesus hen waonspewicakiye cin om emniciya ece qon heon.

3 Heon Judas akicita wicoun wan icu, qa akicita tancan ko, wośna kagapi qa Pharisee kin etanhan, om wipe yuhapi, qa petijanjan can itkonya ko yuha en yapi.

4 Jesus taku hiyahde kte cin owasin sdonkiya, itkowicakipe ca, Tuwe e oyadepi he, ewicakiya.
5 Jesus Nazareth etanhan, eya ayuptapi. Unkan Jesus, He miye ce, eya. Unkan Judas he wiyopeye ciqon ee en opa.

6 Unkan Jesus, He miye ce, ewicakiya hehan icicawin kihdapi, qa makata ihpayapi.

7 Heon etanhan ake wiwicawanga; Tuwe ayakitapi he, eya. Unkan, Jesus Nazareth etanhan, eyapi.

8 Jesus waayupte; He miye ce, eciciyapi qon; hecen miye e omayadepi hecinhan dena ito kihdapi kta.

9 Wicoie wan eye ciqon he iyecetu kta, Tona mayaqu kin wanjidan ehpewakiye śni ce.

10 Unkan Inyan mazasagye wan yuhe cin ehdaku, qa on wośna kagapi itancan ookiye wicaya wan noge etapa eciyatanhan ape ca kaśpa iyeya, ookiye unna kin he Malkos eciyapi.

11 Hehan Jesus Inyan heciya; Mazasagye nitawa ojuha en iyekiya wo. Wiyatke Ate maqu kiin he mdatke kte.śni he.

12 Juda oyate akicita tancan, akicita eyanpaha, akicita ikcedan ko Jesus yuzapi, qa pahtapi.

13 Qa tokaheya Annas kaipi; Kaiaphas omaka kin he en wośna kagapi itancan kin he tunkanku kin hee.

14 Wicaśta wanjidan oyate kin on te kte cin he hecetu kta ce, Juda oyate iwalıokonwicakiye ciqon Kaiaphas ee.

15 Unkan Simon Inyan Jesus ihakam ya, nakun waonspewicakiye cin tokeca wan; unkan waonspewicakiye cin tokeca kin he wośna kagapi itancan kin sdonya qon, heon hee wośna kagapi itancan tihocoka kin en Jesus kici iyaya.

16 Tuka Inyan e tankan tiyopa kin en najin. Hehan waon- 


\section{JOHANNES.}

spewicakiye cin unma, wośna kagapi itancan sdonya qon, he tankan hiyu, qa tiyopa awanyake cin he okiye ca, Inyan tin hiyuya.

17 Hehan wikośka tiyopa awanyake cin he Inyan heciya; Wicaśta kin de waonspewicakiye cin wanji niye he. Unkan, Hemaca śni ce, eya.

18 Akicita eyanpaha wowidag wicayapi ko hen najinpi, sni hdapi qa cetipi; unkan he en petiśkanpi : unkan Inyan iś owicapeya inajin, qa petiśkan.

19 Hehan wośna kagapi itancan kin Jesus wiwanga, waonspewicakiye cin heon, qa jye woonspe tawa kin he nakun.

20 Jesus ayupte; Oyate kin en taninyan womdaka ece; omniciye tipi etu, qa tipi wakan ko en, Juda oyate mniciyapi ece kin en ohimniyan waonspekiya waun, qa takudan anahbeyahan epe śni ce.

21 Taku on wimayanunga he; token ewicawakiye cin tona nahonpi kin hena e wiwicawanga wo, token epe cin he sdonyapi ce.

22 Hena hecen eya, unkan akicita eyanpaha wan en najin kin he Jesus apa, qa heya; Wośna kagapi itancan kin hecen adupta he.

23 Unkan Jesus ayupte ; Śicaya iwaa hecinhan taku śica epe cin he yaotanin wo; tuka tanyan epa hecinhan, tokeca amayapa he.

-24 Annas Kaiaphas wośna kagapi itancan kin pahtapi ecen ekta aye wicakiye ciqon.

$25 \mathrm{He}$ icunhan Simon Inyan petiśkan najin. Heon heciyapi; Waonspewicakiye cin he wanji niye he. Tuka anakilibe ça, Hemaca śni ce, eyą.
26 Wośna lxagapi itancan kin wowidake tawa wan, Inyan noge kaśpe ciqon he takuya, Wojupi kin en kici yaun wanciyake śni he, eciya.

27 Tuka ake Inyan anakiliman; unkan he icunhan anpa ohotonna wan hoton.

28 Hehan Kaiaphas etanhan woyaco tipi kin en Jesus aipi ; unkan wanna anpa. Ihduśapapi kte śni e heon woyaco tipi kin en ipi śni, wośnapi kin hdutapi lita e heon.

29 Unkan Pilate tankata hinanpe ca, en wicau qa, Wicaśta kin de taku e iyayaonpapi he, ewicakiya.

30 Waayuptapi qa heciyapi : Wicaśta kin de ohan śice ślui unkanś unnicahipi kte śni tuka, eyapi.

31 Hehan Pilate hewicakiya; Niye ito eyaku po, qa wayeconzapi kin eciyatanhan yaco po. Hehan, Wicaśta teyapi unkiye unkokihipi śni ye, Juda oyate eciyapi.

32 Hecen Jesus oie qon ecetu $k$ ta, token wiconte on te kta eye ciqon he.

33 Hehan woyaco tipi timahen Pilate kihde ca, Jesus en au wicakiye ça, Juda oyate wicaśtayatapi qon he niye he, eciya.

34 Jesus ayupta ; He niye cinka heha he; qa iś tuwe tokeca miye on hecen oniciyaka he.

35 Pilate ayupte; Juda wicaśta hemaca he; nitaoyatepi kin hena, qa wośna kagapi tankapi kin he iye miye en anihipi. Token oyahanda he.

36 Jesus ayupte; Wokiconze mitawa kin he maka kin detanhan śni; wokiconze mitawa kin maka kin detanhan unkanś, mitaokiye kin kis unpi kta, qa Juda oyate kin makaślkapi kte śni 
tuka. Tuka nakaha wokiconze mitawa kin detanhan śni.

37 Hehan Pilate heciya; Wicaśtayatapi kin henica he. Unkan Jesus ayupte; Wicaśtayatapi hemaca e ecen eha ; hemaca kta e on matonpi, qa heon makata wahi, wowicake mdaotanin kta e heon. Tuwe wowicake eciyatanhan un kinhan he miho kin nahon ece.

38 Wowicake kin he taku he, Pilate eciya. Hena hecen oie ya, unkan Pilate tankata inanpe ca, Juda oyate en wicaye ca, Wicaśta kin he taku śica econ takudan iyewaye śni, ewicakiya.

39 Tuka wicohan duhapi kin heciyatanhan, woacakśin anpetu ehan unkipi eca, tuwe kaśka hnakapi wanji wakiyuśka ece qon. Juda oyate wicaśtayatapi kin de wakiyuśka yacinpi he, eya.

40 Unkan ake owasin panyehan howayapi qa heyapi ; Wicaśta kin dee kte śni, tuka Barabbas e hee kta. Unkan Barabbas e qe wawiicaki sa kin heca.

\section{WICOWOYAKE 19.}

1 Unkan hehan Pilate Jesus icu qa kapsinpsinta.

2 Unkan akicita wapepeka wapaha wan kazontapi qa wapaha kiyapi, qa sina to wan in kiyapi. 3 Qa, iho, Juda Wicaśtayatapi kin, eciyapi, qa nape on apapi.

4 Pilate ake tankan inanpe ca, Iho, wicaśta kin dee e tankan cicaupi, hecen on taku śica takudan en iyewaye śni e sdonyayapi kta, ewicakiya.

5 Hehan Jesus wapepeka wapaha kin un, qa sina to kin in, tankata inanpa. Unkan, Wanyaka po, wicaśta kin dee ce, ewicakiya.

Dak.

且2
6 Unkan wośna kagapi tankapi qa akicita tancanpi kin, he wanyag iheyapi hehan, panyehan heyapi, Icipaweh okatan wo, icipaweh okatan wo. Niśnana icupi qa icipaweh okatan po, miye qe taku śica econ takudan iyewaye śni, Pilate ewicakiya.

7 Wowakiconze wan unhapi, wowakiconze unhapi kin eciyatanhan te kta iyececa, Wakantanka Cinhintku keiciye cin heon etanhan, Juda oyate kin eya ayuptapi.

8. Unkan Pilate iapi kin he nahon qehan, iyotan inihan;

9 Qa woyaco tipi kin timahen kihde ca, Nitokiya tanhan he, Jesus eciya. Tuka Jesus ayupte śni.

10 Hehan Pilate heciya ; Amayadupte śni he. Icipaweh onicatanpi owakihi; qa niciyuśkapi nakun owakihi, he sdonyaye śni he.

11 Hehan Jesus ayupte; Wankan tanhan taku kin de niçupi śni unkanś takudan on omayakihi kte śni tuka; heon tuwe niye en amahi kin he iye woahitani tanka.

12 Hetanhan Pilate kiyuśkapi akita. Tuka, Wicaśta kin de yakiduśke cinhan Kesar takuyaye śni ; tuwe wicaśtayatapi içicage cinhan Kesar i en hiy eya ece, Juda oyate kin panyehan eyapi.

13 Pilate iapi kin he nation, unkan Jesus tankan yuha inanpa, qa oiyotanke tawa kin he ohna kiyotanka, inyan mdaya omanipi kin en, he Hebrew iapi kin etanhan Gabbatha eciyapi.

14 Woacakśin itokam anpetu piiciyapi ece kin hetu, qa wiyotanhe cin hehantu; Wicaśtayatapi nitawapi kin wanyaka po, Pilate Juda oyate kin ewicaliya. 15 Tuka, Icunonpa, icursonpa 


\section{JOHANNES.}

iyeye ça icipaweh okatan wo, panyehan eyapi. Wicaśtayatapi nitawapi kin de icipaweh̀ owakatan kta he, Pilate ewicakiya. Unkan wośna kagapi tankapi kin ayuptapi ; Kesar ecedan wicaśtayatapi unhapi ce.

16 Hehan icipaweh okatanpi kta e wicaqu. Unkan Jesus icupi qa tokan ayapi.

17 Unkan Jesus can susbeca kicin, qa makoce wan Wicapahu eciyapi, he Hebrew iapi on Golgotha eciyapi, he ekta aya.

18 Hen icipaweli okatanpi, qa wicaśta toktokeca nom itan anokatanhan ewicahdepi, qa. Jesus okitahedan.

19 Unkan Pilate wowapi wan kage ca, can susbeca inkpa kin en ehnaka; JESUS NAZARETH ETANHAN, JUDA OYATE WICASTAYATAPI KIN.

20 Wowapi kin de Juda wicaśta ota yawapi ; makoce kin Jesus en icipaweli okatanpi kin he otonwe kin ikiyedan, qa he Hebrew, qa Helenes, qa Roma iapi henakiya wicoie kin on owapi.

21 Hehan Juda oyate etanhan wośna kagapi tankapi kin Pilate heciyapi; Juda oyate Wicaśtayatapi kin, eya owa śni wo ; tula, Juda oyate Wicaśtayatapi kin he miye ce, eiciye cin, hee e ecen owa wo.

22 Tuka Pilate wayupte; Taku owawa kin he wanna owawa ce, eya.

23 A kicita Jesus icipaw eli okatanpi, hehan tawokoyake icupi, qa wopamni tom kagapi, akicita otoiyohi kicipamnipi ; qa nakun taśina icupi ; śina kin he okagege wanica, wankan tanhan kun ihankeya kin hehanyan okagege codan kagapi :
24 Heon etanhan iye iyakitedan hekiciyapi ; Śina kin he unyuhidecapi kte śni, econkupidan qa yeunkiyapi kta, hecen tuwe ohiye cinhan yuhe kta. Hecen wowapi en kagapi qon he iyecetu; Mitawokoyake kicipamnipi, qa mitaśina kin he oeconna en yekiyapi ce. Unkan akicita kin hena hecen econpi.

25 Unkan Jesus hunku, qa tankaku kicica, Mary Kleopas tawicu, qa Mary Magdalene, hena can susbeca kin icahda najinpi.

26 Jesus hunku wanhdaka, qa en icunonpa ikiyadan waonspewicakiye cin wanji iyotan kidake ciqon wanhdaka, unkan, Winohinca, nieinkśi kin hee ce, hunku kin eciya.

27 Qa waonspekiyapi kin he iś, Wanyaka wo, nihun lin hee ce, eciya. Unkan waonspekiyapi kin he anpetu kin hetanhan iye ti kin ekta aki.

28 Wanna taku kin owasin ecetu Jesus wanyaka, qa wowapi en kagapi qon iyecetu kta e heon, Imapuza ce, eya.

29 Unkan mini śkumna wakśica ojudan en icunhan han; mini śkumna icupi, qa nakun mini iyuliepe wan en oputkanpi, qa peji hota hu wan icam yeyapi, qa i kin en qupi.

30 Unkan Jesus mini śkumna icu qehan, Wanna yuśtanpi ce, eya; hehan pa makata iyeye ça taniya kin hiyuya.

31 Hehan Juda oyate kin Pilate cekiyapi, hu kawegapi qa etanlıan icupi kta; hecen anpetu wakan icunhan, tancan kin can susbeca kin akan un kte śni, anpetu en piiçiyapi kin wanna hehantu, qa anpetu wakan kin he anpetu tanka, heon.

32 Unkan akicita en hipi, qa tokaheya kin hu kawegapi, qa 


\section{WICOWOYAKE 20.}

nakun unma kici icipaweli okatanki qon.

33 Hehan Jesus ehan ipi, unkan wanna ța wanyakapi, heon hu kin kawegapi śni.

34 Tuka akicita wanji wahukeza wan on cuwi kin en capa; unkan we mini ko au.

35 'Tuwe wanyake ca yaotanin kin he wayaotanin kin he wowicake. Wowicake eye cin he sdonkiya, qa hecen on wicayadapi kta.

36 Hena hecetu, unkan wicowoyake wowapi en kagapi qon iyecetu; $\mathrm{Hu}$ kin wanjidan kawegapi kte śni ce.

37 Qa nakun wowapi icinonpa hecen eya; Tuwe pahdokapi kin he wanyakapi kta.

38 Hehan ihakam Joseph Arimathea etanhan Pilate cekiya, Jesus tancan kin icu kta e heon; unkan iś eya Jesus waonspewicakiye cin wanji ee, tuka anahibeya, Juda oyate kowicakipe cin heon; unkan Pilate ayupta. He en u, qa Jesus tancan kin hdokiyahda.

39 Unkan Nikodemos, tuwe tokaheya hanyen Jesus en hi qon hee, nakun en hi, qa pejihuta waśtemna noin icicahiyapi, tkeutapi opawinge ecetu, yuha hi.

$40 \mathrm{Hehan}$ Jesus tancan kin icupi, qa minihuha ska iyapemnipi, pejihuta waśtemna iyahna, Juda oyate wicaśta hnakapi ece kin he iyececa.

41 Unkan icipaweh okatanpi qon he en ikiyadan wojupi wan han, wojupi he cin he en ohna wicaśta hnakapi wan iyuśtan yanka, tuwedan he ohna oonpapi śni.

42 Juda oyate piiciyapi anpetu kin he icunhan, obna wicaśta hnakapi en ikiyadan yanke cin heon Jesus tancan kin en ohna kapi.

\section{WICOWOYAKE 20.}

1 Anpetu wakan kin en, anpe. tu tokaheya hanhanna hinca, nahanhin otpaza, hehan Mary Magdalene hnakapi qon ekta i, qa inyan kin hnakapi etanhan icunonpa iyeyapi e wanyaka.

2 Hehan inyang hde ca Simon Inyan hee, qa waonspervicakiye cin unma Jesus waśtekidake ciqon, hena en hi qa hewicakiya; Itancan kin hnakapi kin etanhan eyakupi, qa tukten hnakapi kin sdonunyanpi śni ye.

3 Unkan Inyan waonspewicakiye cin unma qon kici tankan inanpapi, qa en hnakapi qon ekta yapi.

4 Napin inyang yapi; qa waonspewicakiye cin unma qon hee duzahe ca Inyan kapa, qa iye tokaheya ehan i ;

5 Patuś inajin, qa hnakapi kin aokasin, miniliuha ccedan wanyaka, tuka mahen iyaye śni.

6 Hehan iś Simon Inyan iyohi, unkan katinyan mahen iyaya, miniliuha ecedan makata yanka wanyaka.

7 Minihuha pa akan ehnakapi kin he, minilinha umanpi qon en ope śni, he iś aiyog pehan yanka.

8 Hehan waonspewicakiye cin unma tokaheya hi qon he iś hnakapi kin mahen iyaya, qa iś eya wanyake ça wicada.

9 He wiconte etanhan ekicetu kta, eyapi, wowapi en kagapi qon he hinyahin tanyan sdonyapi śni.

10 Hehan waonspewicakiye cin hena iye tipi ekta icicawin hdapi.

11 Tuka hnakapi kin itankan Mary e ecen najin, qa ceya. 


\section{JOHANNES.}

Unkan ceyaya patuś inajin, qa hnakapi kin en aokasin.

$12 \mathrm{Qa}$ mahpiya ohnihde nom wokoyake ska ece koyakapi kin hena wanwicayaka, Jesus tancan wanke ciqon itan anokatanhan, unma pa wanke ciqon eciyatanhan, qa unma iś siha qon eciyatanhan yukanpi.

13 Unkan, Winohinca, taku on yaceya he, eciyapi. Unkan iś, Itancan mitawa tancan kin icupi, qa toki ehnakapi kin sdonwaye śni ce, ewicakiya.

14 Heye ca hehan ihdamna unkan Jesus en najin wanyaka, tuka Jesus hee kin sdonye śni.

15 Unkan Jesus heciya, Winolinca taku on yaceya he; tuwe ayakita he. Unkan iś he wakicanye hee kecin, qa heon, Itancan, he niye iyacu hecinhan tokiya eyahnake cin omakiyaka ye, kinhan ewehdaku lita ce, eciya.

16 Unkan Jesus heciya, Mary. Unkan iye ihdamna, qa, Rabboni, eciya; he Waonspekiye eyapi.

17 Unkan Jesus heciya; Ihnuhan omayadutan kin; nahanhin Ate ekta wahde śni ce. 'Tuka mihunkawanji ekta wicaye ca hewicakiya wo, Ate ekta wahde kta, he ate yayapi kin ee, he Wakantanka mitawa kin ee, ga niś he Wakantanka nitawapi kin ee ce, eya.

18 Hehan Mary Magdalene ku qa, Itancan kin wanhdake ca hena hecen eciye cin, waonspewicakiye cin owicakiyaka.

19 Anpetu kin he anpetu tokaheya kin ee, ihtayetu kin he en waonspewicakiye cin, Juda oyate kowicakipa, qa aonaicitag yukanpi, en Jesus wicacokaya inajin, qa, Wookiye nicipi un kte, ewicakiya.
20 Hecen eye ca hehan nape cuwi ko wicakipazo. Waonspewicakiye cin Itancan kin wanyakapi, unkan wiyuśkinpi tanka.

21 Wookiye nicipi un nunwe, ake Jesus ewicakiya. Ate u maśi kin he iyecen miś ye ciśipi.

22 Hecen eye ca hehan awicaniya qa, Woniya Wakan icu po, ewicakiya.

23 Tona woalitani wicayecicajujupi kinhan, hena wicakicicajujupi kta; qa tona wicayakipaganpi śni kinhan, hena wicakipaganpi kte śni.

24 Ake nonpapi kin etanhan Thomas Didumos eciyapi he Jesus hi kin he icunhan en ope śni.

25 Itancan kin wanunyakapi, waonspewicakiye cin unmapi kin eciyapi. Tuka iye kin hewicakiya ; Maza on nape en okatanpi qon he wanmdake śni, qa napsukaza maza okatanpi kin en omdutan śni, qa cuwi nakun en nape yewaye śni kinhan, wicawada kte śni ce, eya.

26 Unkan anpetu śahdogan iyohakam, hehan ake waonspewicakiye cin mahen yukanpi, qa Thomas owicapeya un. Hehan Jesus en hi, tiyopa onatag han, qa wicacokaya inajin, qa, Wookiye nicipi un nunwe, ewicakiya.

27 Hehan 'I'homas heciya ; Ninapsukaza uye ca minape kin wanyaka wo; qa ninape kin uye qa micuwi kin en oputkan wo, qa wacețunhda śni wicada wo.

28 Unkan Thomas ayupte ca heciya; Itancan mitawa, qa Wakantanka mitawa.

29 Jesus heciya; Thomas, wanmayadake cin heon wicayada; tuka tona wanmayakapi śni eśta wicadapi kinhan, hena wicayawaśtepi ce.

30 Unkan waonspewicakiye cin wanyakapi en taku tokeca ota 


\section{WICOWOYAKE 21.}

wapetokeca Jesus econ, tuka hena eqe wowapi kin de en kagapi śni.

31 Tuka dena e owapi, heon Jesus he Messiya Wakantanka Cinhintku kin hee e wicayadapi kta; qa wicayadapi lin on, iye caje kin eciyatanhan, wiconi duhapi kta.

\section{WICOWOYAKE 21.}

- 1 Hena iyohakam. Jesus ake waonspewicakiye cin en ihdutanin, Tiberias mde kin etu; unkan ihdutanin kin he kaketu:

2 Simon Inyan, qa Thomas Didumos eciyapi, qa Nathanael, Kana Galile makoce kin hetanhan, qa Zebedee cinhintku napin, qa waonspewicakiye cin tokeca nonpa, hena witayapi etu.

3 Ho wakuwa kta ce, Simon Inyan ewicakiya. Niyahna unyanpi kta ce, eciyapi. Hecehna yapi, qa wata wan en opapi, tuka hanyetu kin he takudan ktepi śni.

4 Ihanlianna qehan wicihuta ekta Jesus najin; tuka waonspewicakiye cin Jesus hee kin sdonyapi śni.

5 Unkan Jesus hewicakiya, Hokśiyopa, taku yutapi duhapi he. Unkan, Hiya, eyapi.

6 Unkan hewicakiya; Ho kin he wata etapa kin eciyatanhan ehpeya po, etanhan iyeyayapi kta ce. Unkan ecen iyohpeyapi, tuka ehaeś hogan kin ota kin heon ehdakupi olkitpanipi.

$\tau$ Hehan waonspekiyapi wan Jesus waśtedake ciqon he Inyan heciya; Itancan kin hee ce. Simon Inyan, Itancan kin hee, eya nahon qehan, tancodan un kin heon onhdohda kicun qa minin ehpeiçiya.

8 Unkan waonspewicakiye cin unmapi kin wata cistinna wan ohna upi, huta kin icannan yakonpi, wiciśpa opawinge nom hehanyan, qa ho kin hogan oju. dan akupi.

9 Wanna hutata kihunnipi, hehan petaga itkon wanyakapi, qa hogan aguyapi ko akan yanka.

10 Unkan Jẹsus hewicakiya, Hogan nakaha iyacupi kin etanhan aku po.

11 Simon Inyan ekta ye ca ho kin heyata hiyuya, hogan tankinyanyan ece opawinge qa sanpa wikcemna zaptan qa sam yamni; hogan kin ota ho kin ohnaka tuka iyulidece śni.

12 Upi qa de yuta po, Jesus ewicakiya. Unkan waonspewicakiye cin etanhan, Tuwe niye he, eyapi kta tuka tuwedan tawatenye śni; Itancan hee kin he sdonyapi kin he etanhan.

13 Hehan Jesus en ye ca aguyapi icu, qa wicaqu, hogan nakun iyecen econ.

14 Piya ekicetu kin etanhan, de iyamni Jesus waonspewicakiye cin en ihdutanin.

15 Unkan wotapi ayaśtanpi, hehan Jesus Simon Inyan heciya; Simon Jona cinhintku, dena eqe sam iyeya waśte mayadaka he. Han, Itancan, waśte cidaka e sdonyakiye ciqon, eya. Tahincadan mitarya kin taku yutapi wicaqu wo, eciya.

16 Ake icinonpa, Simon Jona cinhintku waśte mayadaka he, eciya. Han, Itancan, waśte cidaka e sdonyakiya, eya. Tahinca mitawa kin awanyaka wo, eciya.

17 Ake iciyamni, Simon Jona cinhintku waśte mayadaka he, eciya. Yamni akihde, Waśte mayadaka he, eya iwange cin heon Inyan iyokiśica; unkan heciya, Itancan, taku owasin sdonyaya; waśtecidake cin he 181 


\section{OḦANYANPI QON.}

sdonyaya. Hehan Jesus, Tahinca mitawa kin wo wicaqu wo, eciya.

18 Wowicake, wowicake on heciciya; Koniśka qehan niye cinka ipiyag yeton qa tokiya yacin eca ekta da ece, tuka tohan winicahinca kinhan wicaśta tokeca wan ekta nape yeyakiye kta, kinhan ipiyag nicaton qa tokiya yacin śni eśta ekta aniye kta ce, eya.

19 Wiconte tukte e on Wakantanka yutan kta e he kiciyaotanin kta heon hecen eya. Hecen eye cin hehan, Miyahna u -wo, eciya.

20 Hehan Inyan hakikta, qa waonspekiyapi wan Jesus iyotan kidake ciqon hee wicihektam u e wanyaka, htayetu wotapi icunhan maku kin ipahin wanke ca, Itancan, tuwe e wiyopeniye kta he, eye ciqon hee.
21 Inyan he wanyaka unkan Jesus heciya, Itancan, de iś taku e akipe kta he.

22 Ake tohan wahi kte cin hehanyan decen un kta wacin eśta, he etanhan initokeca he; niye miyahna u wo, Jesus eciya.

23 Heon etanhan wicoie kin de hunkawanjinkiciyapi hin wicehna iyaya; waonspekiyapi kin de te kte śni, eyapi kin. Tuka Jesus, He te kte śni ce, eciye śni; tuka, Wahi kte cin hehanyan decen un kta, wacin eśta, he etanhan initokeca he.

24 Taku kin hena waonspekiyapi kin he yaotanin qa wowapi en kaga; qa taku yaotanin kin he wowicake kin e sdonunyanpi.

25 Nakun taku ota Jesus econ, tuka nakun hena owasin otoiyohi kagapi eśta, oyate hiyeye cin wowapi kagapi kte cin he yuhapi kta epce śni. Amen.

\section{YEWICAŚIPI KIN \\ OHA N Y A P I Q O N.}

\section{WICOWOYAKE 1.}

1 Theophile, wicoie tokaheya wakage cin he en Jesus tokaheya taku econ qa waonspekiye cin omda7a;

2 Tona wicakahnige ca yewicaśi qon hena Woniya Wakan kin eciyatanhan wahokonwicakiye cin iyohakam, anpetu wan en wankan eyakupi kin hehanyan.

3 Iye kakije cin iyohakam hena eqe en ni un taniniçiya, woyuotanin ota on, anpetu wikcemna topa hehanyan wanyagiciya, qa Wakantanka tokiconze taku ta. wa kin cájehdata ece ;
4 Qa mniciyapi kin en owicapeya un qehan, Jerusalem etanhan ye śni wicaśi, qa Ateyapi kin wahowicaye ciqon he apepi kta; He miye eciyatanhan nayahonpi ce;

5 Awicakehan Johannes mini on baptem wicaqu, tuka tokata anpetu tonana ihan, hehan Woniya Wakan on baptem niçupi kta ce, eya.

6 Unkan hena witaya yukanpi hehan, Itancan, wanna dehantu Israel oyate wokiconze kin piya wicayaqu kta he, eya iwangapi.

7 Unkan hewicakiya; Tohanyan qa tohantu kin, Ate iye to- 


\section{WICOWOYAKE 1.}

waśake kin en ekihnake cin hena sdonyayapi kta iyecece śni ;

8'Tuka Woniya Wakan kin en nihipi kinhan, wowaśake dulıapi kta; hehan Jèrusalem en, qa Juda makoce kin owancaya, qa Samaria qa maka ihanke kin hehanyan mayadaotaninpi kta ce.

9 Unkan hena hecen eye ça, wanhdakapi icunhan, yuwankan icupi; qa wanyakapi kin etanhan mahipiya śapa wan eyaku.

10 Unkan he wankan iyaye cin, mahpiya ekta etonwan yukanpi kin he icunhan, iho, wicaśta nom ska ihduzapi en wicikiyadan najinpi ;

11 Qa, Galile wicaśta, tokeca e mahpiya ekta etonwan nayajinpi he. Jesus e qe niyepi etanhan mahpiya ekta eyakupi kin, he mahpiya ekta wankan iyaya wandakapi kin he iyecen ake $u$ kta, ewicakiyapi.

12 Hehan Oliwe paha eciyapi kin hetanhan Jerusalem ekta icicawin hdapi; he Jerusalem ikiyedan, anpetu wakan oicimani wanji ecetu.

13 En hdipi qa wankan tipi wanji tin iyayapi qa hen iyukanpi, Inyan, qa Jakob, qa Johannes, qa Andrew, Philip, qa Thomas, Bartholomew, qa Mattheos, Jakob Alpheus cinhintku, qa Simon Zelotes, qa Judas Jakob sunkaku :

14 Hena owasin tawacin wanjidan wocekiye eyapi qa kida yukanpi, winohinça kin hena om, qa Mary Jesus hunku, qa iye hunkawanjinwicaye cin hena koya.

15 Unkan anpetu kin hena en Inyan ookiye unpi kin wicacokaya najin, (wicacaje owasin opawinge sanpa wilkcemna nom wicayawapi;)

16 Qa heya; Wicaśta hunka- wanjinciyapi, Judas tona Jesus iyalipayapi qon en mdetahunka kin he on, ehanna Woniya Wakan, Dawid i kin eciyatanhan, ie ciqon, wowapi en kagapi kin, he ecetuyapi kta hunśte.

17 He iye unkiyopeyapi yawapi, qa wicohtani kin de en opa tuka.

18 Unkan wicaśta kin lie woahtani iyunwin kin maga wan iyopekiye ca, ehna makata ihpaya, unkan tancan kin kamdas ilipaye ça, śupe kin owasin tankan hiyu. 19 Tona Jerusalem en yakonpi sa owasin he sdonyapi; qa heor. maga kin he iye iapi kin eciyatanhan, Akeldama eciyapi, he We maga, eyapi.

20 Odowan wowapi kin en kaken kagapi; He tukten ti qon liewoskan yanke ca, tuwedan ohna ti śni nunwe; qa, Awanhdakapi wicolian yuhe ciqon he tuwe tokeca icu kta.

21 Heon etanhan wicaśta kin dena ohinniyan om unyakonpi, Jesus Itancan kin unkopapi, ti mahen i, qa tankan ye cin,

22 Tokaheya Johannes baptem wicaqu qon hetanhan, anpetu kin en unkiyepi etanhan wankan eyakupi kin hehanyan, hena etanhan, piya ilkicage cin, wanji unkiyopeyapi oyaka ece e kta, eya.

23 Unkan nom najinwicakiyapi, Joseph Barsabas eciyapi, he, Owotanna, eya caśtonpi, qa Matthias.

24 Hehan cekiyapi qa heyapi; Itancan niye wicacante owasin sdonya nanka, wicaśta kin dena unma tukte yakahnige cin he yutanin wo;

25 Ookiye wicolian qa yewicaśipi kin de en ope kta, Judas iye oyanke tawa kin elita hde kta e etanhan hinhipaye cin he. 


\section{OHANYANPI QON.}

26 Hehan woohiye ehpekiyapi, unkan woohiye kin Matthias ahinhpaya; qa hecen yewicaśipi akewanjipidan kin owicapeya yawapi.

\section{WICOWOYAKE 2.}

1 Anpetu iwikcemna zaptan kin wanna iyehantu, unkan owasin tawacin wanjidan witaya yukanpi.

2 Hekan ihnuhanna, tate wan waśagya uye cin he iyecen, oqo wan mahpiya kin eciyatanhan hiyu, qa tipi ohna yukanpi kin ocowasin ojudan.

3 Unkan wicaceji, peta se ececa, en wicatanin, qa otoiyohi kicipamnipi kin en awicahan.

4 Unkan owasin Woniya Wakan kin on ojupidan qa wicaceji toktokeca on iapi, Woniya Wakan ie wicakiye cin he iyecen.

$5 \mathrm{He}$ ehan wicaśta owotanna Juda wicaśta kin hecapi, mahpiya ihukuya oyate hiyeye cin etanhan Jerusalem en tipi.

6 Wicaho kin de otanin, unkan wicota en mniciyapi qa inihanpi, otoiyohi iye iapi tawapi kin on, hena ia yukanpi he nakitionpi kin heon.

7 Owasin inihanpi qa yuśinyayapi qa otoiyohi hekiciyapi; Tona ia yukanpi kin hena owasin Galile wicaśta kin hecapi śni he.

8 Token on otoiyohi iapi kin yuha untonpi kin hena ia nawicunhonpi he.

9 Parthe qa Mede qa Elamite, qa Mesopotamia en tipi qon, Juda makoce kin en, qa Kappadokia en, Pontos qa Asia en ;

10 Phrugia qa Pamphulia en, Egupta qa Libue makoce kin en, Kurene ihdukśan, Roma oyate kin etanhan, Juda wicaśta, qa en opewicakiyapi qon,

11 Krete qa Arabe kin heun. 184 capi, Wakantanka taku tanka econ kin, unkiye unkiapi kin eciyatanhan, hena ia oyakapi kin naunhonpi ce, eyapi.

12 Owasin inihanpi, qa yuśinyayapi, qa otoiyohi hekiciyapi ; De taku kapi hwo.

13 Qa wanjikśi ihahapi qa; Dena miniśa skuya on imnanpi ce, eyapi.

14 Tuka Inyan ake wanjipidan kin om najin, ho yuwankan icu, qa hewicakiya; Juda wicaśta, tona Jerusalem en dukanipi ko, owasin he de sdonyapi, qa mioie kin anagoptan po.

15 Niye hecannipi kin hecetu śni, wanna anpetu kin en yamni ape cin hehantu, heon wicaśta kin dena witkopi śni.

16 Tuka Joel wicaśta wokcan oyake ciqon he dee.

17 Unkan anpetu ihankeya kin en, (Wakantanka eya,) mitaniya kin wicacelipi owasin awicawakaśtan kta; unkan nicinkśipi nicunkśipi ko wokcanpi kta, qa kośka nitawapi kin wowanyake kin wanyakapi kta, qa wicahinca nitawapi kin wowihamde ihamnanpi kta ce.

18 Anpetu kin hena en wicaśta taokiye, qa winyan taokiye mitawa kin, hena en mitaniya awicawakaśtan kta, qa hena e wokcanpi kta.

19 Unkan wankan mahpiya kin ekta taku on yuśinyayapi wicawaqu kta, qa kuya maka kin akan wowapetokeca kin, we qa peta qa śotoju.

20 Itancan taanpetu tanka wowinihan kin he hi śni itokam, anpetu wi kin otpaza icu kta, qa hanyetu wi kin iś we icage kta.

21 Unkan hehan tuwe Itancan caje kin hoyekiye cinhan he nikiyapi kta ce. 
22 Israel wicaśta, wicoie kin de nahon po; Jesus Nazareth etanhan qon, wicasta wan niyepi kin ekta, Wakantanka hdutanin qon, wicowaśake, taku on inihanpi, qa wowapetokeca niyepi cokaya Wakantanka econ kiye ciqon hena e niye sdonyayapi.

23 He qe Wakantanka atayedan wakiconze ca, iye osdonye kin eciyatanhan qupi qon, he iyacupi, qa nape śikśica on icipaweh oyakatanpi, qa yaktepi.

24. Hee Wakantanka ekicetu ye ca, wiconțe icaśke kin kiyuśka, en yuhapi kta okihipica śni nakaeś.

25 Dawid he ke ca, kaken eya; Ohinniyan mitokam Jehowa wanmdaka, mietapa kin ekta yanke, heon pahoho śni waun lita.

26 Heon micante kin iyuśkin, qa miceji kin ipsica; qa micehpi kin woape en wanke kta.

27 Minagi kin he hades ekta elipemayakiye śni, qa Wanji Wakan nitawa kin he wicaliwin wanyake kta e on yaqu kte śni.

28 Wiconi canku kin sdonye mayaye kta; qa niite kin etanhan wowiyuśkin on imnamayaye kta.

29 Wicaśta hunka wanjinciyapi, Dawid hunkakeyapi un kin he eciyatanhan taninyan ociciyakapi kta; he te ça hapi, qa anpetu lxin dehanyan ohna hnakapi kin unkicipi wanka.

$30 \mathrm{He}$ wicaśta wokcan kin heca, qa Wakantanka wokonze on konza, wicacelipi eciyatanhan iye tancan aicage kte cin he etanhan Messiya, iye oiyotanke kin akan iyotanke kta e icahye kta he sdonya.

31 Hecen tokaheya tanhan he wanyake ca Messiya ekicetuya- pi kin he cajeyata, nagi kin hades ekta ehpekiyapi kte śni, qa cehpi kin wicaliwin wanyake kte śni.

32 Jesus iye qe Wakantanka ekicetuye cin he unkiyepi owasin unyaotaninpi ece.

33 He Wakantanka etapa kin ekta yuwankan icupi, qa Atkulku kin Woniya Wakan iwahoye ciqon he icu, heon nakaha taku. wandakapi qa nayahonpi kin he akaśtan.

34 Dawid e qe mahpiya ekta wankan iyaye śni, tuka kaken eya; Jehowa Itancan mitawa kin kaken eciya, Mietapa kin eciyatanhan iy otanka wo,

35 Tona toka niye cin hena nisiha oahe kin ewahnake kte cin hehanyan.

36 Heon etanhan, Israel tiyohnaka owasin, de tanyan sdonya wo, Jesus icipaweh oyakatanpi qon, hee Wakantanka Itancan qa Messiya kaga ce.

37 He nahonpi unkan cante kin ekta iyoyakapi, qa Inyan qa yewicaśipi unmapi kin om, Wicaśta hunkawanjin unniyanpi token econkupi kta he, ewicakiyapi.

38 Hehan Inyan hewicakiya; Ihduecetu po, qa woahitani nicicajujupi kta e on Jesus Messiya caje kin on baptem nicupi kta ; kinhan Woniya Wakan itunicihanpi kin he iyacupi kta.

39 Wahoyapi kin de niye nitawapi, qa nicincapi, qa tona itehanyan yukanpi kin owasin, tona Itancan unkita Wakantankapi kin wicakico kte cin hena tawapi ce, eya.

$40 \mathrm{Qa}$ wicoie tokeca ota on wicakiyatanin, qa wahokonwicakiye ça heya ; Wicoicage śice cin de etanhan niiciya po.

41 Unkan tona oie kin iyuśkin- 


\section{OHANYANPI QON.}

yan icupi kin hena baptem wicaqupi; hecen anpetu kin he en wicanagi kektopawinge yamni en opapi.

42 Qa yewicaśipi kin taku onspewicakiyapi kin en katinyan opapi ece, qa om taku yuhapi, aguyapi kiyuśpapi qa wocekiye eyapi kin en ece unpi.

43 Unkan wicaśta owasin nina yuśinyayapi ; unkan yewicaśipi kin taku wakanyan econpi qa wowapetokeca ota econpi ece.

44 Unkan tona wicadapi kin hena owasin witaya yukanpi, qa taku owasin ptaya yuhapi.

$45 \mathrm{Qa}$ tona maga qa woyuha yuhapi kin hena e wiyopekiyapi, qa otoiyohi cinpi kin iyecen owasin wicakipamnipi.

$46 \mathrm{Qa}$ anpetu otoiyohi, tawacin wanjidan, tipi wakan kin ohna yukanpi, qa tipi iyaza aguyapi kiyuśpapi, wowiyuśkin cante okonwanjidan ko yuha taku yutapi icupi.

47 Wakantanka yatanpi, qa oyate kin owasin en wowaśte yuhapi. Unkan Itancan kin tona nipi kte cin heca, anpetu otoiyohi, okodakiciye kin en ope wicakiya.

\section{WICOWOYAKE 3.}

1 Unkan hehan Inyan qa Johannes kici, tipi wakan kin ekta kaitawankanhde yapi, napcinwanka ape cin, wocekiye eyapi ece kin hehantu.

2 Unkan wicaśta wan tonpi kin ehantanhan huśte un kin he yuha ahipi, anpetu otoiyohi tipi wakan tiyopa wan, Waśte eciyapi kin he en ehdepi, tona tipi wakan tin yapi kte cin hena taku wicakida kte cin heon.

3 Hee Inyan Johannes kici tipi wakan kin timahen yapi kta wanwicayake ca, taku wicakida.

4 Unkan Inyan opahta, qa Joliannes kici, qa, Ekta unkatonwan po, eya.

5 Taku okini kta kecin qa hecen anawicagoptan yanka.

6 Hehan Inyan; Mazaska mazaskazi ko takudan mduhe sni, tuka taku mduhe cin cicukta, Jesus Messiya Nazareth etanhan, he caje on najin, qa mani wo, eciya.

7 Qa nape etapa kin en yuze ça najin kiya; unkan ihnuhanna siha iśkahu ko waśag hinhda.

8 Hehan iye kin psin iyaye ca najin, qa mani, qa om tipi wakan kin timahen iyaya, mani, qa psipsica, qa Wakantanka idowan.

9 He mani qa Wakantanka idowan kin oyate kin iyuhpa wanyakapi ;

10 Qa wicaśta tipi wakan, tiyopa Waśte eciyapi, kin en hiyotanke ca taku da ece qon he dee sdonyapi ; qa taku ecakiconpi kin on etanhan nina inihanpi, qa yuśinyayapi.

11 Unkan, wicaśta huśte qon wanna okizi kin he Inyan Johannes kici wicayus najin, hena en oyate owasin kiwitaya inyang iheyapi, qa nina yuśinyayapi, omanipi Solomon tawa kin hetu. 12 Unkan Inyan he wanyake cehan, oyate kin hewicakiya; İsrael wicaśta, tokeca he on niyuśinyayapi, qa tokeca opaunhitapi nayajinpi he; unkiye wowaśake qa wowaśte unhduhapi kin heon wicaśta kin de mani unyanpi kecanunyakinpi seca.

13 Abraham, qa Isaak, qa Jakob Wakantanka tawapi; hunkake wicunyanpi Wakantanka tawapi kin he Cinhintlku Jesus wanna hdutan; he niyepi e wi- 


\section{WICOWOYAKE 4.}

cayaqupi, qa Pilate itokam yakipajinpi, he iye kiyuśke kte hinca tuka.

14 Tuka Wanji Wakan qa Owotanna un kin he niye yakipajinpi, qa wicakte sa wan kiyuśkapi yaciupi.

$15 \mathrm{Qa}$ Wiconi Itancan kin he yaktepi; he qe Wakantanka wicate cin etanhan najinkiye cin unkiye unkoyakapi ece.

16 Qa iye caje kin, caje wicadapi kin heon, wicaśta kin de wandakapi qa sdonyayapi kin he yuwaśaka; han, iye wacinyanpi kin he wicaśta kin de tanyan okiziya, niyepi owasin en.

17 Unkan nakaha mihunkawanji, iyukcan śni hecanonpi, qa wicaśta itancan wicaduhapi kin hena nakun, he sdonwaya.

18 Tuka Wakantanka Messiya token kakije kte cin, wicaśta wokcan kin owasin i kin eciyatanhan, oyake ciqon hena he en hduecetu.

19 Heon induecetupi, qa ihduhomni po; hecen wayahtanipi kin nicicajujupi kta ce; tohan anpetu yuecetupi kin Itancan itohnake kin eciyatanhan u kinhan ;

20 Qa Jesus Messiya oniciyakapi qon he uśi kta.

21 He qe malipiya kin elkta eyakupi kta, taku owasin ekicetuyapi kta anpetu kin hehanyan, Wakantanka maka icage cin hetanhan wicaśta wokcan wakan wicahduhe cin owasin i kin eciyatanhan oyake ciqon hee.

22 Moses iye qe hunkakeyapi kin hewicakiya; Nihunkawanjipi kin etanhan wicaśta wokcan wanji, miye iyemaceca, Jehowa Wakantanka nitawapi kin icaliniciciyapi kta; he taku eniciyapi kte cin owasin anayagoptanpi kta.
23 Qa wicanagi otoiyohi, wicaśta wokcan kin he anagoptan śni kinhan, he oyate kin etanhan ihangyapi kta ce.

24 Unkan wicaśta wokcan owasin, Samuel hetanhan, tona iyohakam woyakapi qon anpetu kin dena cajeyatapi.

25 Wicaśta wokcan cincapi kin he niyepi, qa wicoun Wakantanka hunkake wicunyanpi wicakicage ciqon, he qe Abraham heciya; Unkan nicinca kin on etanhan wicowazi maka akan un kin owasin yawaśtepi kta ce. 26 Wakantanka iye Cinhintku Jesus najinkiye ça niyawaśtepi kta e on niyepi tokaheya en u śi, otoiyohi wayahtanipi kin etanhan ihduhomni niyanpi kta e heon.

\section{WICOWOYAKE 4.}

1 Unkan hena hecen oyate kin ewicakiyapi kin icunhan, wośna kagapi, qa tipi wakan en itancan kin, Saddukee ko en wicahipi ;

2 Oyate kin waonspewicakiyapi, qa Jesus eciyatanhan wiconte etanhan woelkicetu kin he oyakapi kin heon śihdapi ;

3 Qa nape on iyawicahpayapi, qa wicakaśka tipi kin en iyewicayapi, ihanlianna kte cin hehanyan; wanna hitayetu nakaeś. 4 Tuka wicoie nahonpi qon hena wicota wicadapi; unkan wicaśta kektopawinge zaptan ecetu.

5 Unkan ihanlianna hehan, wicaśta itancanpi, hunkawicayapi kin, wowapi kagapi ko;

$6 \mathrm{Qa}$ Annas wośna kagapi itancan, qa Kaiaphas, qa Johannes, qa Aleksandros, qa tona wośna kagapi itancan takuwicaye cin hena koyá Jerusalem en mniciyapi.

7 Unkan wicacokaya ewica187 


\section{OHANYANPI QON.}

hdepi, qa wiwicawangapi ; Taku. wowaśake, qa tuwe caje kin on hecanonpi he, eyapi.

8 Hehan Inyan Woniya Wakan on ojudan, hecen ewicalsiya; Oyate en wicaśta itancanpi, qa Israel hunkáwicayapi kin ;

9 Anpetu kin de wicaśta huśte qon tanyan ecakiconpi, qa token on okizi kin, he on wiunyanungapi hecinhan;

10 Niyepi owasin, qa Israel oyate kin owasin de sdonya po, Jesus Messiya Nazareth etanhan, icipaweli oyakatanpi qon, Wakantanka wicate cin etanhan ekicetuye cin, he caje on wicaśta kin de nitokam okizi najin.

11 Inyan kin de ticagapi yaunpi kin ayaktapi śni, tuka he oise en itancan kin ee.

$12 \mathrm{Qa}$ tuwe tokeca eciyatanhan wanikiyapi kin yuke śni; qa wicacaje tokeca małpiya kin ihukuya wicaśta wicaqupi, on unnipi kte cin wanica ce.

13 Unkan Inyan qa Johannes waditakapi kin he wanyakapi, qa taku ota onspeiciciyapi śni qa wicaśta ikceka kin hecapi e sdonyapi qehan, nina yuśinyayapi, qa hena Jesus kici unpi qon he iwicayukcanpi.

14 Qa wicaśta okiziyapi qon he wiciyopeya najin wanyakapi ; unkan taku awicayuptapi kte cin takudan yuhapi śni.

15 Tuka omniciye kin etanhan tankan ye wicaśipi, hehan he akiiapi ;

16 Qa iyakitedan hekiciyapi; Wicaśta kin dena token ecawicunkiconpi kta hwo; wowapetokeca tanka kin de econpi kin he tona Jerusalem en yakonpi kin owasin sdonyapi, qa anaunhmanpi kta unkokihipi śni.

17 Tuka he oyate kin en ana188 ptapi kta e heon nina wakokipe wicunkicagapi kta, qa caje kin de on tohinni wicaśta wowicakiyakapi kte śni, unkeyapi kta ce. 18 Unkan hehan wicalicopi, qa Jesus caje kin on takudan ie śni, qa waonspekiye śni wicaśipi.

19 Tuka Inyan Johannes kici awicayuptapi qa heyapi; Wakantanka itokam, niyepi anaunnigoptanpi kta, qa iś Wakantanlia anaungoptanpi kta, unma tukte owotanna kin, niś iyukcan po.

20 Taku sdonunyanpi qa naunhonpi qon hena oyake śni unyakonpi kta e unkokihipi śni.

21 Hehan ake wakokipe wicakicagapi tamwicalkiyapi, qa hde wicaśipi, taku on taku iyawicaonpapi kta takudan jyeyapi śni, oyate kin on etanhan; taku econpi kin heon owasin Wakantanka yatanpi.

22 Wicaśta wookizi wowapetokeca kin he en econpi qon he wamma waniyetu wikcemna topa sam iyeya.

23 Unkan kihdewicayapi, hehan iye takodawicayapi kin ekta hdapi, qa wośna lkagapi, hunkawicayapi kin ko, taku token ewicakiyapi qon owasin ohdakapi.

24 Unkan hena nalionpi qehan, witaya Waliantanka hoyekiyapi qa heyapi ; Itancan Wakantanka he niye, mahpiya, maka, miniwanca qa taku ohnaka ko owasin yakaga.

25 Dawid nitaokiye kin i kin eciyatanhan kaken ehe cin ; Tokeca e Ikcewicaśta kin oqoyapi, qa oyate kin taku ecinśniyan yukcanpi he.

26 Malka wicaśtayatapi kin najin hiyaye ca, wicaśta itancanpi kin witaya mniciyapi, Itancan 


\section{WICOWOYAKE 5.}

kin en, qa Sdakize ciqon he nakun.

$2 \%$ Awicakehan Jesus Nicinkśi wakan sdayakiye ciqon he en, Herod, qa Pontiyos Pilate, Ikcewicaśta, Israel oyate ko mniciyapi ;

28 Ehanna taku, ninape nitawacin ko on, econ yakonze ciqon, he ecen econpi kta heon etanhan.

29 Unkan nakaha, Itancan, token wakokipe unkicagapi kta tamunkiyapi kin he wanyaka wo; qa nitaokiye kin nioie nina waditagya oyakapi kta $e$ wicaqu wo ;

30 Wawokiziya on ninape kin yahdugate cin heon; qa Jesus Nicinkśi wakan caje kin on taku wapetokeca, qa on yuśinyayapi kte cin hena econpi kta.

31 Unkan wocekiye eyapi, hehan tukten witaya yukanpi kin he yuhuhuzapi, qa owasin Woniya Wakan kin on ojupidan, qa Wakantanka oie kin waditagya oyakapi.

32 Unkan wicota wicadapi kin hena wicacante wanjidan wicanagi wanjidan ko yuhapi; qa taku tonpi kin tuwedan, De mitawa ce, eye śni; tuka taku owasin witaya yuhapi.

33- Unkan yewicaśipi kin hena wowaśake tanka on Jesus Itancan piya ikicage cin he oyakapi ; unkan wowaśte tanka owasin en un.

34 Unkan hena tuwedan takudan icakije śni unpi : tuka tona maga, qa tipi yuhapi qon hena wiyopekiyapi, qa taku wiyopeyapi kin on taku icupi kin he ahipi,

35 Qa yewicaśipi kin siha hdepi kin en ehnakapi: unkan wicaśta otoiyohi taku token cinpi kin hecen pamni wicaqupi ece.
36 Unkan Joses, he yewicaśipi kin Barnabas, eya cajeyatapi qon, Wicakicanpte cinhintku kin, eyapi kin he kapi, Lewi wicowazi qa Kupros makoce kin etanhan ;

37 Hee makoce onśpa hduhe cin wiyopekiye ca mazaska kin hdohi, qa yewicaśipi siha hdepi kin en ehnaka.

\section{WICOWOYAKE 5 .}

1 Tuka wicaśta wan Ananias eciyapi, tawicu Sapphira kici, maga wan wiyopekiya;

2 Qa mazaska apa anakilibe, tawicu kin iś nakun sdotkiya; unkan apa ahi, qa yewicaśipi kìn sihapi kin en ehnaka.

3 Tuka Inyan heciya; Ananias, tokeca e Woniya Wakan kin oiyaton kte śni e Satan nicante kin en ocowasin iyohpaya, qa maga iyopeyapi kin apa anayakihman he;

4 Nahahin ecen un qon he ehan yahduhe śni he ; qa wiyopekiyapi kin he ehan nakun nitawa śni he. Tokeca nicante ekta hecen econ wacani he. Wicaśta akantu kin hee śni, tuka Wakantanka en iyatonśni ce.

5 Unkan Ananias hena oie kin nahon qehan, hinhpaye ça ța iyaya. Unkan tona hena taku kin nahonpi kin owasin nina wikopapi.

6 Unkan kośka kin najinpi, qa opazuntapi, qa tankan ayapi, qa hapi.

$7 \mathrm{He}$ iyohakam wihiyayedan oape yamni, hehan tawicu kin taku econpi qon sdonye śni ecen tin hiyu.

8 Unkan Inyan heciya; Kana on maga iyopeyakiyapi he, omakiyaka wo. Unkan iś; Hản, kana on, eya. 


\section{OḦANYANPI QON.}

9 Unkan Inyan; Token on sakim Itancan Taniya kin iyutanyayapi kta ecen wacinduzapi he. Wanyaka wo, tona nihihna hapi kin hena sihapi kin tiyopa kin en najinpi, qa niye nakun tankan aniyanpi kta, eciya.

10 Hehan iś eya hecehnana iye siha kin ekta hinhpaye ca ta iyaya. Unkan kośkapi qon en hiyupi, qa wanna ta e wanyakapi, hehan iś eya tankan ayapi, qa hihnaku kin kici hapi.

11 Unkan okodakiciye kin ocowasin, qa tona hena taku kin nahonpi owasin nina wikopapi.

12 Unkan yewicaśipi kin napepi kin on oyate kin en wowinihan wicohan qa wowapetokeca ota econpi. Unkan owasin wicacante wanjidan yuha Solomon omanipi tawa kin ohna yukanpi.

13 Qa wicaśta tokeca tuwedan en owicapa okihi śni, tuka oyate kın wicakinihanpi.

$14 \mathrm{Qa}$ tona wicadapi kin sanpa ota Itancan kin en opapi, wica winyan ko wicota.

15 Hecen tona wicayazan kin hena tankan awicaupi, qa canku otoiyohi ohna, ohehdepi qa owinja ko akan ahiwicahnakapi, Inyan hen hiyaye cinhan hunli ohanzi wicaye kte cin heon.

16 Unkan, otonwe itan ihdukśan kin hena etanhan wicota Jerusalem en hipi, qa tona wayazanpi, tona taku wakan śica wicayuhnaśkinyanpi ko en awicahipi ; unkan owasin asnipi.

17 Hehan wośna kagapi itancan kin najin hiyaye ca, tona om un kin, Saddukee wicowazi kin etanhanpi, hena winawizipi on ojupidan ;

$18 \mathrm{Qa}$ nape on yewicaśipi kin iyawicahpayapi, qa wicakaśka tipi ikceka kin ohna ewicahnakapi.

19 Tuka Itancan taohnihde ye cin he hanyen wicakaśka tipi tiyopa kin yuzamni, qa tankan awicau qa heya;

20 Hunktiya po, tipi wakan kin ohua inajinpi qa wiconi kin de wicoie kin owasin oyate kin owicakiyaka po.

21 He nahonpi, unkan hanhanna hin tipi wakan kin timahen yapi, qa wowicakiyakapi. Hehan wośna kagapi itancan, qa tona om. un kin hena witaya iheyapi, qa omniciye tanka kin mniciye wicaśi, Israel cinca hunkawicayapi kin owasin koya; unkan wicakaśka tipi kin ekta wicahuweye wicaśipi.

22 Tuka akicita kin wicakaśka tipi kin en hipi, qa iyewicayapi śni, hehan hośi hdapi ;

23 Qa heyapi ; Awicakehan wicakaśka tipi kin sutaya onatakapi ecen iyeunyanpi, qa tiawanyag wicakiyapi kin tiyopa kin itokam najinpi; tuka unyuhdokapi qehan, tuwedan en wanunyakapi śni.

24 Unkan wośna kagapi itancan, qa tipi wakan en itancan kin, wośna kagapi kin hena koya, hena wicoie kin nahonpi qehan, he toketu kta hecinhan iyukcanpi śni.

25 Hehan wanji en hi qa; Iho, wicaśta wicakaśka tipi kin en ewicayahnakapi qon hena tipi wakan kin ohna inajinpi qa oyate kin waonspewicakiyapi ce, eya owicakiyaka.

26 . Hehan akicita tancan kin akicita ko ekta yapi ya iwaśtedan awicaupi, oyate kin inyan on wicakininpi kta e kokipapi lieon etanhan.

27 En awicahipi qa omiciye kin wicacokaya najin wicakiya- 


\section{WICOWOYAKE 6.}

pi ; unkan wośna kagapi itancan kin wiwicawanga,

$28 \mathrm{Qa}$ heya; Wicacaje kin de on wowicayakidakapi kte śni, nina unkeniciyapi śni he; unkar iho, woonspe nitawapi kin on Jerusalem ojudan yayapi, qa wicaśta kin de we kin en unkayaupi kta wacannipi.

29 Hehan Inyan, yewicaśipi kin om, awicayupte ca heya; Wicaśta akantu hee śni, tuka Wakantanka hee e anaungoptanpi kta iyececa.

30 Jesus yaktepi qa can akan otkeyayapi qon he atewicunyanpi ta Wakantankapi kin hdueceta :

31 Hee kin Wakantanka wankan ehdaku, iye nape etapa kin ekta Itancan qa Wanikiya un kta, Israel ihduecetupi qa woahitani kajujupi kin wicaqu kta e heon.

32 Unkan unkiye, iye on, wicoie kin hena unkoyakapi ece, qa Woniya Wakan tona Wakantanka anagoptanpi wicaqu kin, he iś eya hena yuotanin ece.

33 He nahonpi qehan canteptanyanpi, qa țewicayapi kta e akiiapi.

34 Hehan Pharisee wan Gamaliel eciyapi, woope waonspekiya, qa oyate kin en okinihan, he omniciye kin en najin, qa yewicaśipi kin cistiyedan tankun aye wicaśi :

$35 \mathrm{Qa}$ hehan hewicakiya; Israel wicaśta, wicaśta kin dena taku ecawicakicon wacannipi kin he itonpa po.

36 Anpetu kin dena itokam Thudas icaga, he taku wicaśta keiciya; unkan wicaśta opawinge topa ecetu ihakam yapi ; tuka he iye ktepi, qa tona wicadapi qon owasin enanakiya iyewicayapi qa takuni śni aya.
37 Qa he iyohakam Judas Galile etanhan, owicawapi anpetu kin he ehan inajin, qa oyate ota ihakam awicaya; he nakun ihangyapi, qa tona wicadapi qon owasin enanakiya eyaya.

38 Heon nakaha heciciyapi; Wicaśta kin dena wicilieyata najinpi, qa awicayuśtan po; wokonze qa wicohan kin de wicaśta akantu kin etanhan hecinhan atakuni kte śni ;

39 Tuka Wakantanka eciyatanhan un kinahan, yujuju oyakihipi śni ; okinni Wakantanka kici yeciza dukanpi kta naceca, eya. 40 Unkan he anagoptanpi, qa yewicaśipi kin wicakipanpi, qa wicakapsinpsintapi qelian, Jesus caje kin on woyake śni wicaśipi, qa wicakiyuśkapi.

41 Unkan iye omniciye kin etanhan hdapi, qa Jesus caje kin on wowiśtece en awicaupi iyececa wicayawapi kin heon wiyuśkinpi.

42 Qa anpetu otoiyohi tipi wakan kin ohna, qa tipi iyaza wahokonwicakiyapi, qa Jesus Messiya oyakapi ayaśtanpi śni.

\section{WICOWOYAKE 6.}

1 Unkan anpetu kin hena en, waonspewicakiyapi kin wanna wicota aya qehan, Helenes $\mathrm{He}$ brew oyate kin wicabapi, anpetu otoiyohi wapamnipi kin en wiwazica wicayuhapi kin hena awicatonwanpi śni kin heon etanhan.

2 Hehan alienonpapi kin waonspewicakiyapi kin owasin wicakicopi qa hewicakiyapi; Wakantanka oie kin unkayuśtanpi, qa wahna wotapi wiyeya eunhnakapi kte cin hecetu śni.

3 Heon hunkawanjin unniyanpi enitanhanpi wicaśta owotanna 191 


\section{OḦANYANPI QON.}

yawapi, qa Woniya Wakan wicoksape ko on ojupidan śakowin wicakahniga po, wicohan kin de yuhe wicunkiyapi kta.

4 Tuka unkiye qe cekiyapi qa wicoie oyakapi kin en ohinniyan ye unkiçiyapi kta ce.

5 Unkan wicoie kin he oyate kin owasin iyokipipi; qa Stephanos, wicaśta wan wacinyanpi Woniya Wakan ko ojudan, kin he kahnigapi, qa Philip, qa Procoros, qa Nikanor, qa Timon, qa Parmenas, qa Nikolas Antiyoka ekta en opekiyapi qon.

6 Hena yewicaśipi kin wicacokaya ewicahdepi ; unkan wocekiye eyapi, hehan nape on awicaputakapi.

7 Unkan Wakantanka oie kin icage ca Jerusalem en waonspewicakiyapi kin nina ota aya; qa wośna kagapi kin ota nakun wacinyanpi kin en opapi.

8 Unkan Stephanos wowacinye wowaśake ko on ojudan, taku on yuśinyayapi, qa wapetokeca tanka econ, oyate kin en.

9 Unkan wicaśta wanjikji omniciye tipi wan, Wicakiyuśkapi tawapi eciyapi kin hetanhan, qa Kurene qa Aleksandre wicaśta kin, qa Kilikia qa Asia etanhanpi, hena en inajinpi qa Stephanos kici hdokinicapi.

10 Tuka Woksape Woniya ko on ie cin he okihipi śni.

11 Hehan wicaśta opewicatonpi, unkan hena e, Wicaśta kin de Moses qa Wakantanka nakun wicoie śica ewicakiya, naunhonpi ce, eyapi.

12 Hecen oyate kin, qa hunkawicayapi, wowapi kagapi ko iyowicapaśtakapi ; unkan anatan hipi, qa yuzapi, qa omniciye lin en ahipi.

13 Qa oitonśni waayatanin kin heca najin wicakiyapi; hena iś 192 heyapi; Wicaśta kin de tipi wakan kin de wicoope ko on taku śica eye cin ayaśtan śni.

14 Jesus Nazareth etanhan qon he tipi kin de ihangye ca, wicohan Moses unqupi qon hena yutokeca kta ce, eya naunlionpi ce.

15 Unkan omniciye kin en iyotankapi kin owasin opahta yukanpi, qa ite kin he malipiya ohnihde wan ite kin iyececa wanyakapi.

\section{WICOWOYAKE 7.}

1 Hehan wośna kagapi itancan kin heya; Hena hecetu he.

2 Unkan iye hehan heya; Wicaśta hunkawanjinciyapi, ateciyapi ko anamagoptan po. Wowitan Wakantanka kin, Abraham ateunyanpi Mesopotamia en ounye ciqon, Carran en ahiti kin he itokam, en ikpazo;

3 Qa heciya; Nita makoce qa nitakuye kin etanhan ya wo, qa makoce wan cicipazo kte cin he ekta u wo, eciya.

4 Hehan Kaldeya makoce kin etanhan hiyu qa Carran en ahi ti. Hen atkuku kin ța, unkan hetanhan makoce kin en nakaha oununyanpi kin den ahi ti.

5 Unkan tawa kte cin siha oahe kin hinskokeca qu śni, tuka he yuhe kta qa iyohakam cinca kin yuhapi kta e qu kta iwahoya; nahabin cinca wanica.

6 Unkan Wakantanka kaken eya; He cinca kin makoce tokeca en unhdaka unpi kta; unkan hen wowidake wicayuhapi, qa waniyetu opawinge topa hehanyan śicaya wicakuwapi kta.

7 Qa oyate kin hena wowidag wicayuhapi kte cin he wicamdaco kta; qa he iyohakam etanhan hiyupi kta qa makoce kin 


\section{WICOWOYAKE $\%$}

den ohomadapi kta ce, Wakantanka eya.

8 Hehan bakilidayapi wicoope kin he qu. Unkan hecen Isaak cincaya, qa anpetu iśahdogan hehan bakihdaya. Isaak Jakob cincaya; qa Jakob hunkakewicayapi akenonpapi qon cineawicaya.

9 Unkan hunkakewicayapi qon Joseph inakiwizipi, qa Egupta ekta wiyopekiyapi. Tuka Wakantanka kici un;

$10 \mathrm{Qa}$ wokakije kin owasin etanhan ehdaku, qa Pharo Egupta wicaśtayatapi kin itokam wowaonśida woksape ko qu; unkan Egupta en wicaśta itancan kaga, qa iye ti kin ocowasin en.

11 Hehan Egupta makoce Kanan ko owancaya wicaakihan, qa nina wicakakija; unkan hunkake wicunyanpi kin taku yutapi iyeyapi śni.

12 Tuka hehan Egupta heciya wamnaheza yukan, Jakob nahon, unkan hunkake wicunyanpi kin tokaheya ekta ye wicaśi.

13 Unkan inonpa hehan, Joseph hunkawanjinwicaye cin sdonkiyewicakiye, ca hehan Joseph otakuye kin Pharo en oyakapi.

14 Hehan Joseph atkuku kin wahoye ca kico, qa takuwicaye cin owasin nakun, wicanagi wikcemna śakowin sanpa zaptan.

15 Hecen Jakob Egupta ekta apamahde iyaye ca hen ta, iye qa nakun hunkake wicunyanpi kin :

16 Unkan Sucem ekta awicayapi, qa wicahnakapi wan, Abraharn Sucem atkuku Emmor he cinca kin, mazaska on, opewicalkicaton qon he en wicahnakapi.

17 Tuka anpetu wahoyapi, Wakantanka Abraham konza iwa- hoye ciqon he wanna kiyadan $\mathrm{u}$, hehan oyate kin icage ça Egupta en ihduotapi.

18 Hehan wicaśtayatapi tokeca wan Joseph sdonye śni kin he icaga.

19 Unkan he qe takuwicunyanpi kin wicahnaye ça, hunkake wicunyanpi kin śicaya ecawicakicon, hecen hokśiyoqopa kin nipi kte śni e tankan ehpewicakiyapi qon.

20 He ehan Moses tonpi, he qe hokśiyopa owanyag waśte hinca; unkan wi yamni hehanyan atkuku ti kin ohna icahikiyapi.

21 Qa tankan ehpeyapi, hehan Pharo cunwintku kin eyaku, qa iye cinca kin hecen icaliya.

22 Unkan Moses Egupta oyate wicoksape kin owasin onspekiyapi, qa wicoie, wicohan ko on waśaka.

23 Unkan wanna waniyetu wikcemna topa, hehan hunkawanjitku Israel cinca kin wanwicahdag ye kta wacinyuza.

24 Qa wanji śicaya ecakiconpi kin he wanhdake ceehan, okiye ca śicaya ecakiconpi qon he tokiciçon, qa Egupta wicaśta kin kaśtaka.

25 Hunkawanjitku kin, iye nape kin on Wakantanka wiconi wicaqu kte cin he iyukcanpi kta kecin, tuka okahnigapi śni.

26 Ihanhanna hehan ake kicizapi kin en taniniciye ca wookiye wicakicage kta wacin qa heya; Wicaśta hunkawanjin yeciyapi, tokeca śicaya ecayeciconpi he.

27 Tuka tuwe takodaku kin śicaya ecakicon kin he paha iyeye ca, Tuwe unkiyepi en wicaśta itancan qa wayaco nicaga he. 28 Egupta wicaśta hitanihan yakte qon he iyecen mayakte kta he, eya. 


\section{OHANYANPI QON.}

29 Wicoie kin de on Moses nape ca Madiyan makoce kin en hewotahedan un, qa hen hokśidan nom cinca wicaya.

30 Unkan wanna waniyetu wikcemna topa ihunniyan, hehan hewoskan makoce kin en Sina Paha kin hetu, can yuhaha wan ohna peta ide kin en, Itancan taohnihde wan taniniçiya.

31 Unkan Moses he wanyake cehan, wowanyake kin on yuśinyaya; qa tanyan wanyake $\mathrm{kta}$ e on kiyedan ya, hehan Itancan ho kin en tanin;

32 Qa, Nihunkake Wakantanka tawapi kin he miye; Abraham ta Wakantanka, Isaak ta Wakantanka, qa Jakob ta Wakantanka kin, eya. Unkan Moses cancan qa ekta etonwan okihi śni.

33 Unkan Itancan kin heciya; Nitahanpe kin hduśdoka wo, tukten nayajin kin he maka wakan ce.

34 Ekta ewatonwe ca, Egupta en mitaoyate token kakijapi kin he. wanmdake ca comnihdazipi kin nawahon, qa wicawakiyuśke kta e on kun hibu; unkan nakaha u wo, Egupta ekta ye ciśi kta.

35 Moses aktapi śni qa; Tuwe wicaśta itancan qa wayaco nicaga he, eciyapi qon he Wakantanka wicaśta itancan wanikiya ko kage ça ye śi, mahpiya olmihde can yutiaha kin en taniniçiye cin he nape kin on.

36 Unkan hee tankan awicau, qa taku on yuśinyayapi wapetokeca ko, Egupta makoce kin en, Mde śa ekta, qa liewoskan makoce kin etu, waniyetu wikcemna topa hehanyan econ.

37 Moses Israel cinca kin; Hunkawanjin wicayayapi etanhan wicaśta wokcan wan miye iyemaceca, Itancan Wankantanka nitawapi kin icahniciciyapi $\mathrm{kta}$, he anayagoptanpi kta ce, ewicakiye ciqon he dee.

$38 \mathrm{Qa}$ hewoskan makoce kin ekta okodakiciye kin kici un qon hee, Sina paha kin etu, mahpiya ohnihde kin okiye ca nakun hunkake wicunyanpi kin ; qa he wiconi oie kin unqupi kta $e$ icu.

39 Unkan hee kin hunkake wicunyanpi kin anagoptonpi cinpi śni, tuka heyata iyeyapi, qa cantepi kin en Egupta ekta hdapi.

40 Qa Aaroll heciyapi; Taku wakan unkitokam yapi kte cin unkicaga po ; Moses Egupta makoce kin etanhan unkaupi qon he tokiya iyaya sdonunyanpi śni ce.

41 Unkan anpetu kin hena en ptejicadan wan kagapi, qa wakagapi kin he taku wakiyuśnapi, qa iye nape kagapi kin on wiyuśkinpi.

42 Hehan Wakantanka ihduhomni, qa mahpiya ohnaka kin ohodapi kta e awicayuśtan ; wicaśta wokcan tawowapi en kagapi kin he iyececa; Israel ti kin woteca ktepi wośnapi ko, hewoskan makoce kin en, waniyetu wikcemna - topa hehanyan mayaqupi he.

43 Unkan ito Molok tawakeya kin, qa Remphan taku wakan yadapi wicanlipi tawa kin he iyacupi ; hena wakagapi kin itokam canpeśka makehde inayajinpi kta e yakagapi : Unkan ito Babulon akotanhan aciyapi kta ce.

44 Hunkake wicunyanpi kir hewoskan makoce kin en waaya. tanin wakeya kin yuhapi ; tuwe Moses okiye ça, token wanyake cin he iyecen kage kta keciye ciqon, hee yuśtan qon iyececa. 


\section{WICOWOYAKE 8.}

45 He hunkake wicunyanpi kin icupi, qa Joshua kici Ikcewicaśta tamakoce kin en ahipi, hena e Wakantanka hunkake wicunyanpi itepi kin etanhan lieyata iyaye wicaya, Dawid taanpetu kin hehanyan;

$46 \mathrm{He}$ Wakantanka itokam wowaonśida iyeye ca, Jakob ta Wakantanka kin tipi wan iyekiciciye kta cin.

47 Tuka Solomon tipi wan kicaga.

48 Hececa tuka, Iyotan Wankan un kin tipi wicanape on kagapi kin ohna ti śni; wicaśta wokcan hecen eye ciqon;

49 Malipiya kin he oiyotanke mitawa kin ee, qa maka kin he misiha oahe kin hee; ecin tukte tipi miyecagapi kta he, qa tukten ozimiciye kta he.

50 Minape kin taku henana owasin kage śni he, Itancan kin eya ce.

51 Tahu nisutapi, qa cante noge ko banicilidayapi śni kin, ohinniyan Woniya Wakan kin yakipajinpi, nihunkakepi econpi qon he niye iyenicecapi.

52 Wicaśta wokcan kin tukte wanji e nihunkakepi kin śicaya kuwapi śni he. Wanji Owotanna un kin he u kte cin tona oyakapi qon hena wicaktepi; qa he qe niś niyepi wanna iyopeyayapi qa yaktepi.

53 Mahpiya ohnihde ahipi kin he eciyatanhan woope kin iyacupi, tuka tanyan yeciyuhapi śni ce, eya.

54 Unkan hena taku kin nahonpi hehan, cante kin ekta nina iyoyakapi, qa hi ahdakokokapi.

55 Tuka iye Woniya Wakan kin ojudan malipiya ekta opalita yanke ca, Wakantanka towitan kin, qa Jesus Wakantanka etapa kin eciyatanhan najin e he wanyaka ;

$56 \mathrm{Qa}$ heya; Wanyaka po, malipiya kin yuzamnipi, qa Wicaśta Cinhintliu kin Wakantanka etapa kin eciyatanhan najin e wanmdaka ce, eya.

57 Hehan hotankakiya hotaninpi, qa nogepi kin ohmus hduzapi, qa tawacin wanjidan on iyahpayapi ;

58 Qa otonwe kin tankan ehpeyapi, qa inyan on kininpi. Unkan waayataninpi kin wokoyake kin kośka wan, Salos eciyapi, he siha kin en ekihnakapi.

59 Unkan Stephanos inyan on kininpi, he icunhan cekiye ca heya, Jesus Itancan, minagi kin ehdaku wo.

60 Hehan canpeśka makehde inajin qa hotankakiya hoyekiya; Itancan woalitani kin de iyepi kin en awicau śni wo. Hena hecen eye ça hehan iśtinma iyaya.

\section{WICOWOYAKE 8.}

1 Unkan he te cin Salos iyowinkiya. Unkan anpetu kin he en okodakiciye Jerusalem en un kin śicaya wicakuwapi tanka. Qa owasin Juda makoce qa Samaria ekta enanakiya iyewicayapi, yewicaśipi kin henana yapi śni.

2 Unkan wicaśta awacin unpi kin heca Stephanos yuha ayapi, qa nina akiceyapi.

3 Tuka Sialos okodakiciye kin yutakuni śni wicakuwa, tipi iyaza tin iyaye ça, wica winyan ko wicayuze ca, wicakaśka tipi kin en iyewicaya.

4 Heon etanhan tona enanaki. ya iyayapi qon hena owancaya iyayapi, qa wicoie kin oyakapi ece.

5 Hehan Philip Samaria oton195 


\section{OHANYANPI QON.}

we kin ekta apamahde iyaye ca, Messiya owicakiyaka.

6 Unkan oyate kin Philip taku wapetokeca econ kin nahonpi qa wanyakapi qehan, taku tona oyake cin cante wanjidan on anagoptanpi.

y Taku wakan śica hotankakiya hotaninyan tona wicayuhnaśkinyanpi kin etanhan inanpapi, qa tona tatapike cin huśtepi ko ota okizipi.

8 Unkan otonwe kin he en wiyuśkinpi tanka.

9 Unkan wicaśta wan Simon eciyapi, otonwe kin he en wanakaja tanhan wapiyapi econ, qa Samaria oyate kin yuśinyewicaye ca, iye wicaśta tanka keiciya.

10 He owasin anagoptanpi, cistinpidan tankinkinyan ko, qa; Wakantanka towaśake tanka kin he dee ce, eyapi.

11 Wanakaja tanhan wapiyapi econ kin on yuśinyewicaye cin heon he anagoptanpi.

12 'Tuka Wakantanka tokiconze kin, qa Jesus Messiya caje kin eciyatanhain taku Philip oyake cin hena wicadapi qehan baptem wicaqupi, wica winyan ko.

$13 \mathrm{Qa}$ Simon iś eya wicada, qa baptem qupi; hehan Philip kici un, qa wowakta taku wapetokeca tanka ko wanyake cin heon yuśinyaya.

14 Unkan Jerusalem ekta yewicaśipi kin, Samaria Wakantanka oie kin icupi kin he nahonpi qehan, Inyan qa Johannes kici ekta ye wicaśipi.

15 Hena e ekta apamahde hipi, qa Woniya Wakan icupi kta heun wocekiye ewicakiciyapi.

16 He nahahin tuwedan ahinhe śni, Jesus I tancan caje kin on baptem wicaqupi kin hecedan.
17 Hehan nape on awicaputakapi, unkan Woniya Wakan kin icupi.

18 Unkan yewicaśipi kin nape on awicaputakapi kin he eciyatanhan Woniya Wakan wicaqupi kin he Simon wanyaka, hehan mazaska wicakahi ;

19 Qa heya; Tuwe nape on awaputake cinhan he Woniya Wakan icu kta e wowaśake kin he maqu po.

20 Tuka Inyan heciya; Mazaska nitawa kin niye kici atakuni śni nunwe. Taku Wakantanka wicaqu ece kin he mazaska on opetonpi kta kecanni kin heon etanhan.

21 Wicoie kin de en oyape śni qa takudan nitawa śni ; Wakantanka itokamya nicante kin owotanna śni.

22 Heon etanhan taku śice cin de on iyopeiciye ca, Wakantanka cekiya wo, nicante taku awacin kin nicicajujupi nun ce.

23 Nahanliin pizi pa hinca, qa woahtani icaśke kin en yaun e wanmdaka ce.

24 Hehan Simon ayupte ca heya; Taku ehapi kin takudan mahiyahde kte śni heon niś ito miye on Itancan kin cekiya po.

25 Unkan wanna yaotaninpi, qa Itancan oie kin oyakapi qehan, Jerusalem ekta icicawin hdapi, qa Samaria otonwe ota kin en wotanin waśte kin oyakapi.

26 Unkan Itancan taohnihde ye cin Philip okiye ca heciya; Najin qa itokahkiya, canku wan Jerusalem hetainhan iyaye ça Gaza en iyolipaye cin he en i wo, he hewoskan kin ee.

27 Hehan iye najin, qa iyaya. Unkan iho, Ethiopa wicaśta wan yunokos heca, Ethiopa wicaśta- 


\section{WICOWOYAKE 9.}

yatapi winohinca, Kandake eciyapi, he ihukuya wicaśta tanka, qa woyuha tawa kin owasin kiciyuha un kin, he Jerusalem ekta cekiye kta e i.

$28 \mathrm{Qa}$ he wanna hde ca canpahmihma ohna kiyotanke ca, Isaya wicaśta wokcan kin he yawa yanka.

29 Unkan Woniya Wakan kin Philip heciya; Ekta ye ca canpahmihma kin de kici ya wo.

30 Hehan Philip ekta inyang ye ca Isaya wicaśta wokcan kin yawa yanke cin he nahion qa; Taku dawa kin he oyakahinga he, eciya.

31 Unkan; Tuwedan onspemakiye śni ecin token owakihi kta he, eye ca, Philip en u qa kici iyotanke kta, keya.

32 Wowapi yawa yanke cin iapi kin he dee; Tahinca wan ktepi kte cin en aipi, qa tacincadan hin wicayuśda kin itokam inina yanke cin, he iyecen iś iye i hdukawa śni.

33 Wicawalipanica en un qehan, yacopi kin he ekiciyakupi ; qa wicoicage tawa "kin tuwe oyake kta he; wiconi tawa kin maka kin etanhan ayapi ce.

34 Hehan yunokos kin Philip ayupte ca heciya; Ceciciya ce, tuwe on wicaśta wokcan kin hena hecen eya he, iye içica qa iś wicaśta tokeca ka.

35 Hehan Philip i hdukawa qa wowapi kin he etanhan ie ca Jesus e okiyaka.

36 Unkan canku kin ohna hdapi, qa mini yuke cin wan iyohipi. Hehan yunokos kin; Mini wanyaka wo, baptem maqupi kta e taku tehinda kta he, eya.

37 Unkan Philip, Nicante kin ocowasin on wicayada kinhan enicicetu kta, eciya. Hehan iś ayupte ça; Jesus Messiya he
Wakantanka Cinhintku kin ee wicawada ce, eya.

38 Hehan canpahmihma kin owanji yanke śi ; qa mini kin ekta kun iyayapi, Philip qa yunokos kin; unkan baptem qu.

39 Unkan mini kin etanhan hdicupi qehan, Itancan 'Taniya kin. Philip eyaku, qa yunokos kin ake wanyake śni ; unkan canku kin ohna iyuśkiny an hda. 40 Tuka Philip Azotos ekta iyekiyapi ; qa otonwe kin owasin opta ye ca wotanin waśte kin oyaka, ecen Kesareya ek ta iyohi.

\section{WICOWOYAKE 9.}

1 Unkan Salos waaiapi tin wicaktepi ko Itancan waonspewicakiye cin awicapogan, wośna kagapi itancan kin en i;

2 Qa Damaskos en omniciye tipi kin ekta wowapi da; hecen canku kin de ohna yakonpi kin tona iyewicaye kte cin, wica winyan ko, Jerusalem ekta kaśka awicahdi kta e heon.

3 Unkan icimani ye cin Damaskos ikiyedan ya; unkan ihnuhanna ojanjan wan mahpiya eciyatanhan ihdukśan iyoyanpa. 4 Hehan makata hinhpaye cehan, wicaho wan nahon, Salos, Salos, tokeca śicaya mayakuwa he, eciya.

5 Unkan iś ; Itancan nituwe he, eya. Hehan Itancan kin iś; Jesus śicaya yakuwa kin he miye ; can pesto kin nayalitake cin he tehika ce, eya.

6 He cancan qa yuśinyaye ca ; Itancan taku ecamon yacin he, eya. Unkan Itancan kin; $\mathrm{Na}$ jin qa otonwe kin ekta ya wo, token ecanon kte cin oniciyakapi kta ce, eciya.

7 Unkan wicaśta om icimani kin yuśinyaya najinpi, wicaho 197 


\section{OHANYANPI QON.}

kin nahonpi tuka tuwedan wanyakapi śni.

8 Unkan Salos maka kin etanhan najin qa iśta kamdaya hehan, tuwedan wanyake śni ; unkan nape on yus ayapi, qa Damaskos ekta aipi.

9 Unkan anpetu yamni wawanyake śni un; qa takudan yute śni qa yatke śni.

10 Unkan Damaskos en waonspekiyapi wan, Ananias eciyapi, he wowihanmde en Itancan kin; Ananias, eciya. Unkan iś ; Itancan, de miye ce, eya.

11. Hehan Itancan kin heciya; Najin qa canku wan Owotanna eciyapi kin he ekta ye ca Judas ti kin en Salos eciyapi, Tarsos etanhan he akita wo; wanna cekiya un;

12 Qa wowihanmde wan en wicaśta wan Ananias eciyapi tin hiyu, qa tonwe kta e on nape on aputake cin he wanyaka ce.

13 Hehan Ananias ayupta; Itancan, wicota etanhan wicaśta kin he Jerusalem ekta, tona ow otanna wicaduhe cin taku śica ecawicakicon kin hena nawahon;

14 Qa deciya nakun wośna kagapi kin eciyatanhan wowaśake yuha un, tona nicaje hoyekiyapi kin hena owasin wicakaśke kta ce, eya.

15 Tuka Itancan kin iś heciya; Hunk tiya wo, wakśica wakahinige cin he wanji ee, micaje kin Ikcewicaśta, qa wicaśtayatapi kin Israel cinca ko itokam yuha un kta :

16 Qa micaje kin on taku token kakije kte cin he wakipazo kta ce, eya.

17 Hehan Ananias ye ca, tipi kin timahen iyaye ca, nape on aputake ca heya; Salos mihunkawanji, yatonwe ca Woniya
Wakan on onijudan kta e Itancan kin u maśi ; Jesus canku ohna yau kin en taniniciye ci-. qon hee.

18 Unkan ihnuhanna taku hoceśpu kin iyececa iśta kin etanhan hinhpaya; unkan ecahankeya tonwe ca najin, qa baptem qupi.

19 Unkan taku yutapi icu qehan, waśaka aya. Unkan Salos anpetu tonana waonspewicakiyapi kin, Damaskos en yakonpi, hena om un.

20 Qa kohanna omniciye tipi kin ohna Messiya he Wakantanka Cinhintku kin ee ce, eya oyaka.

21 Unkan tona nalionpi kin owasin yuśinyayapi qa heyapi; Jerusalem ekta tona wicacaje kin de hoyekiyapi kin śicaya wicakuwa, qa nakaha wicakaśke ca, wośna kagapi kin ekta awicaye kta e on den hi kin he dee śni he.

22 Tuka Salos sanpa waśaka icage ca Juda wicaśta Damaskos ekta yakonpi kin hena inina yanke wicakiye ca, He Messiya kin ee e yawicaka.

23 Warna anpetu ota hehan Juda oyate kin he te yapi lita e akiiapi.

24 'Tuka hecen konzapi kin he Salos sdonya. Unkan ktepi kta e anpetu hanyetu ko otonwe tiyopa kin awanhdakapi.

25 Hehan waonspewicakiyapi kin hanyen icupi, qa makanopiye wan ohna otonwe conkaśke kin etanhan kun iyeyapi.

26 Unkan Salos Jerusalem en hdi qehan, waonspewicakiyapi kin om un kta cin; tuka owasin kokipapi, qa wanna waonspekiyapi kin heca e wicadapi śni.

27 Tuka Barnabas he icu, qa yewicaśipi kin en ahi, qa token 
tahepi Itancan kin wanyake ça, he okiye ça, token Damaskos ekta Jesus caje kin on waditagya oyake cin hena owicakiyaka.

28 Unkan Jerusalem ekta om un, qa timahen u qa tankan ya ece; qa Jesus Itancan kin on waśagya woyaka.

29 Qa Helenes oyate kin om hdokinica. Tuka hena eqe he ktepi kta akitapi.

30 Hunkaw anjin kiciyapi kin he sdonyapi, unkan Kesareya ekta aipi, qa Tarsos heciya hde śipi.

31 Hehan okodakiciye kin Juda makoce kin owancaya, qa Galile, qa Samaria ekta wookiye yuhapi, qa icagapi; qa Itancan kin kokipeyahan manipi, qa Woniya Wakan wicakicanpte cin en un$p i$, qa hecen ihduotapi.

32 Unkan Inyan makoce kin owasin opta iyaye cehan, Ludda ekta wicaśta owotanna yukanpi kin hena en wicahiyohi.

33 Qa wicaśta wan Lneas eciyapi hen wanyaka; he waniyetu śahdogan makan wanka, țațaka ececa.

34 Unkan Inyan; Eneas Jesus Messiya asniniyan, najin qa owinja hdatata wo, eciya. Unkan ihnuhanna najin hiyaya.

35 Unkan tona Ludda qa Saron en yakonpi kin owasin he wanyakapi, qa Itancan kin ekta ihduhomnipi.

36 Unkan Joppa ekta waonspekiyapi wan Tabitha eciyapi, he Tatokadan eyapi kin he kapi; winohinca kin he ohan waśte qa taku wacantkiya econ kin ojudan:

37 Unkan he anpetu kin hena en wayazanka, qa ta iyaya. He yujajapi qehan, wankan tipi wan ekta ehnakapi.

38 Unkan Ludda Joppa ikiyedan, qa Inyan hen un kin waon- spewicakiyapi kin nahonpi qon, heon wicaśta nom ekta ye wicaśipi, qa ecadan en wicau kta e iwahoyapi.

39 Hehan Inyan najin qa hena om hda. Ekta i, unkan wankan tipi kin en aipi, unkan wiwazica kin owasin en najinpi, qa ohde wokoyake ko, 'l'abitha ni un qehan, kage ciqon hena pazo yankapi, qa ceyapi ece.

40 T'uka Inyan hena, owasin tankan iyewicaye ça, canpeśka makehde inajin qa wocekiye eya, hehan tancan wanke cin ekta ihdamna qa; Tabitha, najin wo, eya. Unkan iśta kamdaye ca Inyan wanyake cechan iyotanka.

41 Unkan nape yekiye ça najinkiya ; qa wicaśta owotanna wiwazica ko wicakico qehan, he ni un e wicakipazo.

42 Unkan Joppa owancaya he otanin, qa wicota Itancan kin wacinyanpi.

43 Unkan Inyan anpetu ota Joppa en, wicaśta wakpanyan wan Simon eciyapi, he kici yanka.

\section{WICOWOYAKE 10.}

1 Unkan Kesareya en wicaśta wan Kornelios eciyapi, akicita opawinge obe wanjidan, Italike eciyapi, kin he en itancan kin hee ;

2 Wicaśta wakinihan, qa Wakantanka kokipeyahan un, tiyohnaka kici; qa oyate kin nina cantewicakiya, qa ohinniyan Wakantanka cekiya un ece.

3 He qe anpetu wan en, napcinwanka apa hehantu, wowanyake wan en, Wakantanka taohnihde wan en hi, qa, Kornelios, eciye cin he taninyan wanyaka. 1 Unkan he opalita yanke ẹa inihan qa; Itancan taku he, eya. 


\section{OHANYANPI QON.}

Unkan is ito heciya; Wocekiye nitawa qa wacantkiya oyahande cin he Wakantanka itokam kiksuyapi.

5 Heon nakaha Joppa ekta wicaśta ye wicaśi, qa Simon Inyan eciyapi kin he kico wo.

6 Wicaśta wakpanyan-wan Simon eciyapi ti kin miniwanca kahda han, he kici yanka. He token ecanon kte cin oniciyake kta ce.

7 Unkan malipiya ohnihde Kornelios olkiye cin he wanna kihda, hehan tiawanyag wicakiye cin nom, qa akicita waśte ohinniyan tankiyadan wicahduhe cin wanjidan, hena wicakico ;

8 Qa hena taku kin owasin owicakiyake cehan, Joppa ekta ye wicaśi.

9 Unkan icimanipi, qa ihanhanna wanna otonwe kin ikiyadan, hehan Inyan tipi kin akan wocekiye eya iyaya, wanna wiyotanhe cin hehantu.

10 Nina wotektehda, qa wote kta cin, tuka taku yutapi wiyeya ehnakapi kin he icunhan wokiksuye śni wan ahinhpaya.

11 Unkan malipiya kin yuzamnipi e wanyaka, qa heciyatanhan taku wan miniliuha ska tanka iyececa, oise topa kin iciyakaśkapi he kutkiya u, qa maka kin ahe kiyapi.

$12 \mathrm{He}$ ohna taku maka akan wahutopa ocaje owasin, qa woteca, qa watutka, qa malipiya okinyanpi kin.

13 Unkan wicaho wan tanin qa; Inyan, najin, qa kte, qa yuta wo, eciya.

14 Tuka iś; Itancan, hecetu śni, tohinni taku ikceka qa aśape cin wate śni ce, eya.

15 Unkan ake icinonpa wicaho kin tanin qa; 'Taku Wakantan200 ka pakinte cin he ikceka eciye śni wo, eya.

16 Yamni akihde hecen econpi, qa hehan taku kin he mahpiya kin ekta akiyahdapi.

17 Unkan Inyan wowanyake wanyake cin he taku kin iyukcan śni un, he icunhan, ito wicaśta Kornelios u wicaśi qon hena Simon ti kin akitapi, qa wanna tiyopa kin itokam en hinajinpi ;

18 Qa panpi qa; Simon Inyan eciyapi den yanka he, eya iwicawangapi.

19 Wowanyake kin he Inyan awakicin un kin he icunhan, Woniya Wakan kin heciya; Wanyaka wo, wicaśta yamni onidepi.

20 Heon najin qa kun hde ça, takudan cetunhda śni om ya wo, hena u wicawaśi ce, eya.

21 Hehan Inyan wicaśta Kornelios u wicaśi qon hena ekta kun wicai, qa; Tuwe ayakitapi kin he miye ce; taku on yahipi he, ewicakiya.

22 Unkan iś heyapi; Kornelios akicita opawinge wicayuhe cin, wicaśta owotanna, qa Wakantanka kokipeyahan un he Juda oyate kin iyulipa oyakapi, hee mahpiya ohnihde wakan wan okiye ça, tuwe nihuwe u wicaśi, qa iye ti kin ohna nioie kin nahon kta, keya ce, eyapi.

23 Hehan tin u wicaśi qa won wicaya. Unkan ihanhanna Inyan hena om hda, unkan Joppa etanhan hunkawanjinkiciyapi kin wanjikji opapi.

24 Unkan ihanhanna qehan Kesareya iyohipi. Unkan Kornelios tona takuwicaye ca koda wicaye cin hena wicakico, qa om ape yanka.

25 Unkan Inyan en $\mathrm{u}$, hehan Kornelios itkokim ye ça, siha 
kin en makata elipeiçiye ça cekiya.

26 Tuka Inyan iś najin kiye ca ; Najin wo, miś eya wimacaśta ce, eya.

27 Qa kici wohdaka ecen tipi kin timahen i, qa wicota mniciyapi kin wanwicayaka.

28 Hehan hewicakiya; Tuwe Juda wicaśta kin heca e oyatt tokeca etanhan wan kici un, qa en hi kin he hecetu śni e sdonyayapi, tuka tuwedan wicaśta ikceka qa aśape cin ewakiye kte sni he Wakantanka sdonye makiya.

29 Heon etanhan mahuwe ipi kin ecen wacețunhda śni hibu, heon taku on miyecopi hecinhan he iciwangapi, eya.

30 Unkan Kornelios heya; Wanna ehantanhan anpetu topa he ehan, qa nakaha oape kin dehantu, wote śni waun, qa napcinwanka ape cin hehan wati kin en cekiya waun ; unkan wicaśta wan wokoyake wiyatpa koyake cin he en mahinajin ;

$31 \mathrm{Qa}$, Kornelios wocekiye nitawa kin he nahonpi, qa taku wacantkiya ecanon kin he Wakantanka itokam kiksuyapi ce.

32 Heon Joppa ekta tuwe ye śi, qa Simon Inyan eciyapi kin he kico wo ; he wicaśta wakpanyan wan, Simon eciyapi, ti kin miniwanca kahda he cin he ohna yanka. He hi kinhan taku eniciye kta ce, eya.

33 Heon kohanna wahociya; qa yahi kin he tanyan ecanon. Heon nakaha unkiyepi kin owasin Wakantanka itokam unkanpi, taku Wakantanka eye niśi kin owasin naunhonpi kta ce

34 Hehan' Inyan i hdukawa qa heya; Awicakehan Wakantanka wicaśta itohnake kin iwanyake śni e imdukcan.
35 Tuka oyate otoiyohi en, tuwe kokipeyahan un, qa owotanna olianye cin he waśtedaka ece.

36 Jesus Messiya kin, owasin en Itancan kin hee, he eciyatanhan wicoie Israel cinca kin wookiye iwahowicayapi qon.

37 Wicoie kin he sdonyayapi, Juda makoce kin owancaya oyakapi, Galile etanhan, Johannes baptem oyake cin hehan tanhan. 38 Jesus Nazareth etanhan kin he Wakantanka sdakiya, Woniya Wakan wowaśake lio on ; qa he qe taku waśte econ iyaya ece, qa tona taku wakan śica wicayuhnaśkinyan kin hena okiziwicaya ece, Wakantanka kici un kin heon.

39 Qa taku Juda oyate tamakoce, qa Jerusalem ekta econ qon owasin unyaotaninpi ece. He iye kin ktepi, qa can wan akan otkeyapi qon.

40 Tuka anpetu iciyamni qehan Wakantanka piya icahkiye ca, taninyan wicakipazo.

41 Oyate kin iyuhpa śni, tuka tona otokaheya ekta Wakantanka wicakahinige ciqon hena en, waayataninpi kin unkiyepi, wiconțe etanhan piya ikicage cin iyohakam kici wauntapi qa waunyatkanpi ece.

42 Unkan oyate kin wahokonwicakiye unśipi qa nipi țapi ko en wayaco Wakantanka kage cin he iye ce, eya oyake unsiipi. 43 . He wicaśta wokcan kin owasin oyakapi : iye caje kin eciyatanhan tuwe wicada kin. han woahtani wokajuju kin yuhe kta ce.

44 Wicoie kin dena Inyan ecen eye cin he icunhan, tona oie kin nahonpi owasin Woniya Wakan kin awicahinhpaya.

45 Unkan bakihdayapi kin etan201 


\section{OHANYANPI QON.}

hanpi tona wicadapi qon, tona Inyan kici hipi kin hena yuśinyayapi, Woniya Wakan wicaqupi ece kin he Ikcewicaśta iyepi kaeś awicakaśtanpi kin heon etanhan.

46 Wicaceji tokeca on iapi, qa Wakantanka yatanpi kin he nahonpi. Hehan Inyan waayupte ca ;

47 Tuwe mini tehinda okihi, qa hena baptem wicaqupi kte śni he; hena eqe unkiyepi kin iyecen Woniya Wakan kin icupi ce, eya.

48 Hehan Itancan caje kin on baptem wicaqu wicaśi. Hehan anpetu ota en yanke kta e icekiyapi.

\section{WICOWOYAKE 11.}

1 Unkan yewicaśipi kin hunkawanjinkiciyapi ko, Juda makoce kin en yakonpi qon, Ikcewicaśta Wakantanka oie icupi kin he nalionpi.

2 Unkan Inyan Jerusalem en hdi kin, hehan tona bakilidayapi kin etanhanpi qon he kici akinicapi ;

3 Qa heyapi, Wicaśta bakihdayapi śni kin heca en wicayai, qa om wayata ce.

4 Hehan Inyan wohdake ça owasin ecekcen owicakiyake ca heya;

5 Joppa otonwe kin en, wocekiye eya waun, unkan wokiksuye śni wan en taku wowanyake wanmdaka, taku wan miniihuha ska tanka iyececa, oise topa kin iciyakaśkapi mahipiya kin eciyatanhan kun aupi, qa miye ekta mahiyohi.

6 He opahta manke ca awacin waun, unkan maka akan taku wahutopa, qa wamanica, qa watutka, qa malipiya okinyanpi kin wanmdaka.
7 Unkan wicaho wan; Inyan najin, qa kte, qa yuta wo, emakiye cin he nawation.

8 Tuka miś; Itancan hecetu śni, taku ikceka qa aśape cin tohinni mii kin ohna iyaye śni, epa.

9 'Tuka mahpiya kin eciyatanhan wicaho kin ake amayupta; Taku Wakantanka pakinte cin he ikceka eciye śni wo, eya.

10 Yamni akihde hecen econpi, qa hehan mahpiya kin ekta owasin hdokiyahdapi.

11 Unkan ito wicaśta yamni, Kesareya etanhan miye ekta mahiyu śipi qon, hena wanna tipi ohna waun kin itokam hinajinpi.

12 Hehan Woniya Wakan kin iś ; Takudan cețunwicahda śni hena om yahde kta ce, emakiya. Unkan hunkawanjinkiciyapi kin dena śakpe om imdamde ca wicaśta qon he ti kin en unkipi.

13 Hehan iye, token mahipiya ohnihde wan iye ti kin en hinajin wanyake ciqon he unkokiyakapi; hee kin kaken eciya; Joppa ekta wicaśta ye wicaśi, qa Simon Inyan eciyapi kin he u śi wo.

14 He taku eniciye kte cin on yani kta, qa nakun tiyohnaka nitawa kin owasin, eya ce, eya.

15 Unkan miś tokaheya iwae cin, hehan Woniya Wakan kin awicahinhpaya, tokag ehan unkiyepi kin en hi qon iyececa.

16 Hehan Itancan oie qon weksuya; Awicakehan Johannes mini on baptem wicaqu, tuka niyepi kin Woniya Wakan on baptem niçupi kta ce, eye ciqon he.

17 Hecen unkiye Jesus Messiya Itancan kin wicaundapi, Wakantanka taku unqupi qon he iyecen wicaqu kinhan, miś 


\section{WICOWOYAKE 12.}

matuwe he, Wakantanka anawapte kta owakihi he.

18 Hena oie kin nahonpi unkan inina yukanpi qa Wakantanka yatanpi qa heyapi ; Awicakehan Ikcewicaśta on nipi kta e ihduecetupi kin Wakantanka wicaqu ce.

19 Unkan Stephanos țe cin on sicaya wicakuwapi qon, heon enanakiya iyewicayapi kin hena Phenike, qa Kupros, qa Antiyoka ekta-ipi, qa wicoie kin Juda oyate kin ecedan owicakiyakapi.

20 Unkan hena wanjikji $\mathrm{Ku}$ pros qa Kurene wicaśta kin heca, hena Antiyoka en hipi qehan, Helenes wicaśta kin wowicakiyakapi, qa Jesus Itancan kin oyakapi.

21 Unkan I tancan nape kin hena om un, qa wicota wicadapi, qa Itancan kin ekta ihdubomnipi.

22 Hena taku kin okodakiciye Jerusalem en un kin nogepi kin en otanin, hehan Barnabas Antiyoka ekta i kta e ye śipi.

23 He ekta i, unkan Wakantanka towaonśida kin wanyake celhan iyuśkin, qa cante kin ocowasin on Itancan kin opapi kta e owasin iwahokonwicakiya.

$24 \mathrm{He}$ wicaśta waśte, qa Woniya Wakan wacinyanpi ko on ojudan. Unkan wicota I tancan kin opapi.

25 Hehan Barnabas Salos akite kta e Tarsos ekta iyaya. He iyeya, unkan Antiyoka en ahdi.

$26 \mathrm{Qa}$ waniyetu mdoketu ahna, tipi wakan kin en mniciyapi, qa oyate ota waonspewicakiyapi; unkan Antiyoka ekta, waonspewicakiyapi kin tokaheya Kristian ewicakiyapi.

27 Unkan anpetu kin hena en, wicaśta wokcan Jerusalem etanhan Antiyoka ekta hipi.
28 Hena wanji, $\Lambda$ gabos eciyapi kin he inajin, qa maka kin owancaya wicaakihan wan tanka $u$ kta e Woniya Wakan kin eciyatanhan oyaka. Unkan he Kladios Kesar taanpetu kin en ecetu.

29 Unkan hehan waonspewicakiyapi kin otoiyohi, token okihipi kin, hecen hunkawanjitkupi Juda makoce kin en yakonpi kin, wawokiyapi kin wicaqupi kta e konzapi.

30 Hecen econpi, qa Barnabas Salos kici napepi kin on hunka wicayapi kin wicakai wicaśipi.

\section{WICOWOYAKE 12.}

1 Unkan hehan Herod wicaśtayatapi kin okodakiciye kin wicakiyuśe kta e nape yekiya ;

$2 \mathrm{Qa}$ Jakob Johannes cincu qon he mazasagye on kte.

3 Qa he Juda oyate kin iyokipipi e wanyake cehan, Inyan nakun yuze kta aya; aguyapi on napoliyapi codan anpetu kin he ehan.

4 Unkan he iyahpaye cehan, wicakaśka tipi kin en ehnake ça akicita ake śakpe awanyag wicaśi, wośnapi kin enakiyapi kinhan oyate kin ekta tankan au kta kecin.

5 Hecen Inyan wicakaśka tipi kin ohna awanyakapi ; unkan on okodakiciye kin Wakantanka nina cekiyapi.

6 Unkan Herod wanna tankan au kta hehan, hanyetu kin he en Inyan akicita nom, unma itan anokatanhan iśtinma wánke ça, maza icicahika nom on iyakaśkapi, qa tiawanyag kiyâpi kin hena tiyopa kin itokam wicakaśka tipi kin awanyakapi.

7 Unkan inyun, Itancan taohnihdeye cin en hi, qa ojanjan wan 203 


\section{OHANYANPI QON.}

wicakaśka tipi kin en iyoyanpa ; unkan Inyan cuwi kin en ape ça najin kiye ca heya; Kohanna najin wo. Únkan maza icicahiha kin nape kin etanhan hinhpaya.

8 Hehan malipiya ohnihde kin; Ipihdag kiton qa han pokihan wo, eciya. Unkan iś ecen econ. Hehan ; Śna hdowin qa miyahna u wo, eciya.

9 Hehan tankan ya; unkan iś eya ihakam ye ca, mahipiya ohnihde taku ecakicon kin he wicakapi kin sdonye śni ; tuka wowanyake wan wanyaka kecin.

10 Unkan wicakaśka tipi tokaheya qa iyokihe kin etanhan hinanpapi, hehan maza tiyopa kin en iyohipi, he otonwe kin ekta iyahde, he iye cinka wicakiyulidog iyaya. Unkan tankan yapi, qa canku wanjidan ihunnipi, hehan malpiya ohnihde kin elipeya kihda.

11 Unkan Inyan kiksuya hinhda qa heya; Nakaha awicakehan Itancan kin ohnihdc tawa kin u śi, qa Herod nape kin, Juda oyate apepi ko, owasin etanhan emahdakú e sdonwakiya ce.

12 Unkan he awakicin qehan, Johannes Markos eciyapi kin, he hunku Mary ti kin ekta i, hen wicota mniciyapi, qa cekiya yukanpi.

13 Unkan Inyan tipi tiyopa kin kabubu yanke cin he icunhan, wicinyanna wan Rhoda eciyapi, he ekta wanation $\mathrm{i}$ :

$14 \mathrm{Qa}$ Inyan ho kin iyekiye cehan, wowiyuśkin on tiyopa yuŁdoke śni, tuka inyang hdicu qa, Inyan tiyopa kin itokam najin e oyaka:

15 Unkan, Niyuhnaśkinyanpi ce, eciyapi. Tuka iś hecen eya kitan. Hehan, Mahpiya ohnihde tawa kin hee ce, eyapi. 204
16 Tuka Inyan katinyan tiyopa kin kabubu yanka. Unkan yuhdokapi qa wanyakapi hehan yuśinyayapi.

17 Tuka inina yukanpi kta e namwicakicawin, qa token on Itancan kin wicakaśka tipi kin etanhan tankan hiyu kiye cin he owicakiyaka. Qa heya, Jakob qa hunkawanjinkiciyapi kin hena oie kin owicakiyaka po. Hehan tankan kinape ça tokan iyaya.

18 Unkan anpa kamdeze cin hehan Inyan toki iyaye cin he akicita kin nina aoqoyapi.

19 Unkan Herod akita, tuka iyeye śui hehan, tiawanyag wicakiyapi kin hena wiwicawange ca, wicaktepi kta e konza. Qa hehan Juda makoce kin etanhan apamahde iyaye ça Kesareya en ounyan.

20 Unkan Herod Turos qa Sidon oyatepi kin wicakize wacin ; tuka hena e wicocante wanjidan en hipi, qa Blastos wicaśtayatapi ohehdepi tipi tawa kin awanyake cin he yuwaśtepi qehan, wookiye dapi; iye tamakocepi kin wicaśtayatapi tawa kin on icahyapi kin heon etanhan.

21 Unkan anpètu wan cajeyatapi qon he en Herod wicaśtayatapi ihduze ca, woyaco oiyotanke kin akan kiyotanke ca, wowicakiyaka.

22 Hehan oyate kin hotankakiya hotaninpi qa; He wicaho śni, Wakantanka ho kin hee ce, eyapi.

23 Unkan ihnuhanna Itancan taohnihde ye cin he kaśtaka, Wakantanka wowitan qu śni kin heon etanhan. Unkan wamduśkadan yutapi qa hecen ța iyaya.

24 Tuka Wakantanka oie kin icage ça tankaya aya. 


\section{WICOWOYAKE 13.}

25 Unkan Barnabas Salos kici wawokiyapi qon hduśtanpi qehan, Jerusalem etanhan hdicupi, qa Johannes Markos eciyapi qon he yuha hdapi.

\section{WICOWOXAKE 13.}

1 Unkan Antiyoka ekta okodakiciye kin en wicaśta wokcan waonspekiya ko wanjikji yukan; Barnabas, qa Simeon he nakun Niger eciyapi, qa Lukios Kurene etanhan, qa Manaen, Herod wicaśta ihdawa qon kici icage cin hee, qa Salos.

2 Hehan Itancan kin cekiyapi qa wote śni unpi kin icunhan, Woniya Wakan kin heya; Barnabas Salos kici wokicanye iwicaweco kin heon ewicamicihde po, eya.

3 Unkan hehan takudan yute śni wocekiye eyapi, qa nape awicaputakapi, hecen ye wicaśipi.

4 Hena Woniya Wakan tokiya ye wicaśi, unkan Selukiya ekta iyohipi, qa hetanhan Kupros ektakiya watom yapi.

5 Qa Salamis en iyukanpi hehan, omniciye tipi Juda oyate tawapi kin ohna Wakantanka oie kin oyakapi, qa Johannes he ookiye yuhapi.

6 Unkan wita kin opta yapi, qa Paphos ekta iyohipi qehan, wicaśta wapiyapi econ kin, wicaśta wokcan itonśni, Juda wicaśta kin heca wan, Barjesus eciyapi he wanyakapi :

7 He Sergios Palos, wicaśta ksapa, makoce kin en itancan yanke cin he kici un. He qe Barnabas qa Salos kici wicalkico, qa Wakantanka oie kin nalion cin.

8 Tuka Elumas wapiye cin, caje kin hecen kapi, he wicakipajin, qa wicaśta itancan kin D4 wacinyanpi kin etanhan yuhomni kta e akita.

9 Hehan Salos, iye nakun $\mathrm{Pa}-$ los eciyapi, Woniya Wakan on ojudan he opahta najin,

10 Qa lieya; 'Taku wohnaye owasin on ojudan, qa wicohan śica owasin, Wakan śica cinca niye ca, taku owotanna owasin toka yaye cin, Itancan tacanku owotanna kin kaśeyaye cin he aduśtan kte śni he.

11 Hecen dehan inyun, Itancan nape kin iyahdeniyan; unkan anpetu ota iśta nigonge ca anpetu wi kin wandake kte śni, eciya. Unkan ihnuhanna opo qa otpaza wan ahinhpaya; qa tuwe nape yus aye kta e akin iyaya.

12 Hehan taku econpi kin wicaśta itancan kin wanyake ceehan wicada, qa Itancan tawoonspe kin on yuśinyaya.

13 Unkan Palos tona om un kin hena Paphos etanhan pacanan iyeyapi, qa Pampuliya ekta Perge en iyohipi. Hehan Johannes awicayuśtan qa Jerusalem ekta icicawin hda.

14 Hehan Perge etanhan inanpapi, qa Antiyoka Pisidiya en, he ekta ipi, qa anpetu wakan hehan omniciye tipi kin en tin iyayapi, qa iyotankapi.

15 Unkan woope, qa wicaśta wokcan tawowapi kin, hena yawapi enakiyapi qehan, omniciye tipi kin en wicaśta itancan wicakiyapi kin iś wicakicopi qa, Wicaśta hunkawanjin unniyanpi wicakicanpte oie wanji duhapi kinhan oyate kin owicakiyaka po, ewicakiyapi.

16 Hehan Palos najin, qa namwicakicawin qa heya, Israel wicaśta, qa tona Wakantanka kokipapi kin anagoptan po.

17 Israel oyate kin de Wakan205 


\section{OHANYANPI QON.}

tunka tawapi kin he hunkake wicunyanpi kin wicakahnige ca, oyate kin Egupta makoce kin en yakonpi kin he icunhan yuwankan iwicacu, qa isto hduwankan iyeye cin on tankan awicau.

18 Qa waniyetu wikcemna topa hehanyan liewoskan makoce kin en won wicakiya.

19 Qa oyate śakowinpi Kanan makoce kin en, ihang wicaye eehan, makoce kin woohiye eciyatanhan kicipamni wicakiya.

$20 \mathrm{Qa}$ he iyohakam, wicaśta wayaco kin heca wicaqu, waniyetu opawinge topa sanpa wikcemna zaptan hehanyan, ecen Samuel wicaśta wokcan qon $i c a-$ ga.

21 Unkan hehan wicaśtayatapi wan cinpi ; qa Wakantanka Saul, Kiś cinhintku, Benjamin wicoun kin hetanhan, wicaśta kin he wicaqu, waniyetu wikcemna topa hehanyan.

22 Qa he heyata iyeye cehan, Dawid icahwicakiciciye ça wicaśtayatapi kaga; he oyake ca heya, Dawid Jesse cinhintku kin he iyewakiya, wicaśta waśte wakidake cin, he mitawacin kin ocowasin ecen econ kta ce.

23 Wakantanka token eye ciqon he eciyatanhan, wicaśta kin de cinca kin etanhan, Jesus Wanikiya kin, Israel oyate kin icahwicakiciciya.

$24 \mathrm{He}$ ihdutanin śni qon itokam, Johannes baptem on ihduecetupi kte cin he Israel oyate kin iyulipa en eyanpaha owicakiyaka.

25 Unkan Johannes oinyanke kin ilumniye kte cin, hehan hecen eya, Miś matuwe kecannipi he : He miye śni; tuka iho, wanji mihektam $u$ kin he tahanpe siha kin etanhan kiyuśka owakihi śni ce.
26 Wicaśta hunkawanjin ciyapi kin, Abraham cinca wicaye cin, qa tona Wakantanka kokipapi kin, niś niyepi wiconi oie kin de oniciyakapi.

27 Tona Jerusalem en yakonpi, wicaśta itancan wicayuhapi ko, he iyekiyapi śni, qa wicaśta wokcan oiepi, anpetu wakan eca yawapi ece kin he nakun; hecen he yacopi kin on hena ecetuyapi.

28 Qa taku on te kte cin takudan iyeyapi śni qeyaś, he ktepi kta e Pilate icekiyapi.

29 Qa on taku wowapi en kagapi qon owasin ecetuyapi qehan, can kin etanhan eyakupi, qa ohna hnakapi wan en ohnakapi.

30 Tuka te cin etanhan Wakantanka najin kiya.

$31^{\prime}$ Unkan tona Galile etanhan Jerusalem ekta om hi qon hena anpetu ota wanhdlakapi, qa hena eepi dehan oyate kin wicakiyaotaninpi ece.

32 Unkan unkiye wotanin waśte unkoniciyakapi, hunkake wicunyanpi taku iwahowicaye ciqon,

33 He cincawicayapi unkiyepi kin en, Wakantanka ecetukiya, Jesus piya icahikiye cin hee on; hecen odowan icinonpa kin en kaken owapi qon, Micinkśi kin he niye, anpe dehan cinca cicaga ce.

34 Qa wicate cin etanhan najin kiye ca, wicaliwin kin ekta i kte śni, heon kaken eya, Dawid towaonsida wicakapi kin he cicupi kta ce.

35 Heon etanhan wanji tolzeca en hecen eya; Wanji Owotanna nitawa kin he wicaliwin wanyake kta e iyowinyakiye kte śni.

36 Dawid wicoicage tawa kin 


\section{WICOWOYAKE 14.}

tanyan owicakicilian, Wakantanka tawacin kin eciyatanhan, hehan iśtinma iyaye ca, hunkake wicaye cin om hnakapi, qa wicakwin wanyaka.

37 Tuka tuwe Wakantanka najin kiye cin he wicahwin wanyake śni.

38 Heon wicaśta hunkawarjin ciyapi, wicaśta kin de eciyatanhan, woahtani kajujupi kin oniciyakapi e sdonya po.

39 Qa taku owasin, Moses tawoahope kin niyuowotanpidan kta e okitpani kin hena ee kaeś etanhan, tuwe wicada kinhan iye on owotanna kagapi kta.

40 Heon itonicipa po, okinni taku wicaśta wokcan kin en cajeyatapi qon he en nihiyahdepi kta :

41 Tona ayaktapi śni kin, wawanyakapi qa inihanpi qa yutakuni śni iyeiçiya po ; anpetu nitawapi kin en wicohan wanji ecamon kta, qa wicohan kin he tuwe oniciyakapi eśta wicayadapi kte śni ce.

42 Unkan Juda wicaśta kin omniciye tipi kin etanhan tankan hdicupi, hehan wicoie kin hena anpetu wakan hepiya, owicakiyakapi kta e icewicakiyapi.

43 Unkan omniciye kin wanna enakiyapi, hehan Juda wicaśta qa oyate tokeca etanhan he en opapi qon, cekiya unpi kin hena wicota Palos qa Barnabas kici owicapapi. Unkan wowicakiyakapi, qa Wakantanka towaonsida kin en unpi kta e iwahokonwicakiyapi.

44 Unkan ake anpetu wakan, hehān Wakantanka oie nalionpi kta e otonwe kin iyulipa se en kiwitaya iheyapi.

45 Tuka Juda wicaśta kin hena wicota kin wanyakapi qehan, winawizipi on ojupidan, qa $\mathrm{Pa}-$ los taku eye cin he akinicapi qa aiapi.

46 Hehan Palos Barnabas kici waditake içicagapi qa heyapi, Wakantanlia oie kin niyepi tokaheya oniciyakapi kta e hecetu; tuka he ayaktapi śni, qa owihanke wanin wiconi kin iyenihantupi śni nihdukcanpi kin heon, iho, Ikcewicaśta kin ekta unkihdamnanpi.

47 Hecen Itancan kin iwa hounyanpi ; Ikcewicaśta iyoyanpa kin ecihnaka, maka ihanke kin hehanyan niwicayakiye kte cin heon.

48 Unkan Ikcewicaśta kin, hena oie kin nahonpi qehan, nina iyuśkinpi, qa Itancan oie kin yatanpi. Unkan tona owihanke wanin wiconi yuhapi kta e wicakahnigapi qon hena wicadapi. 49 Unkan Itancan oie kin makoce kin he owancaya oyakapi.

50 Tuka Juda wicaśta kin iś, winohinca okinihan cekiya unpi kin hena iyowicapaśtakapi, qa otonwe kin en wicaśta itancanpi kin nakun, hecen Palos Barnabas kici śicaya wicakuwapi, qa makoce kin he etanhan hdicu wicayapi.

51 Tuka iś iyepi kin, hena en, siha watuśekśeca askape cin he hdatatapi, qa Ikonium ekta ipi.

52 Unkan waonspewicakiyapi kin wowiyuśkin Woniya Wakan ko on ojupidan.

\section{WICOWOYAKE 14.}

1 Unkan Ikonium ekta, sakim omniciye tipi, Juda oyate tawapi kin he en timahen yapi, qa iyecen iapi, hecen Juda wicaśta Helenes ko ota wicadapi.

2 Tuka Juda wicaśta tona wicadapi śni kin hena Ikcewicaśta kin iyowicapaśtakapi, qa hun207 


\section{OHANYANPI QON.}

kawanjin kiciyapi kin sicaya wacinwicakiyus wicakiyapi.

3 Unkan tehan en yukanpi, qa Itancan kin on waditagya iapi, he qe wowaonśida oie kin hdaotanin, qa wowapetokeca wakanyan econpi ko econ wicakiya.

4 Tuka otonwe kin oyate kin akipam iyeyapi; apa Juda wicaśta kin om tipidan, qa apa iś yewicaśipi kin hena owicapapi.

.5 Unkan Ikcewicaśta, qa Juda oyate kin, tona itancan wicayuhapi kin hena koya, hena anawicatanpi, śicaya wicakuwapi qa inyan on wicakininpi kta ;

6 He iye sdonkiyapi, qa Lustra qa Derbe, Lukaoniya en otonwe kin, makoce ihdukśan ko en onapapi.

7 Qa lien wotanin waśte kin oyakapi.

8 Unkan Lustra en wicaśta wan siha on okitpani iyotankehan yanka, tonpi kin ehantanhan huśte, qa tohinni mani śni.

$9 \mathrm{He}$ Palos ie cin nation; unkan he opahta yanke ca, wacinyampi on ni kte cin yuha e wanyaka,

10 Hehan hotankakiya, Nisiha on bosdan najin wo, eya. Unkan iś psin iyaye ca mani.

11 Unkan Palos taku econ kin he oyate kin wanyakapi qehan ho yuwankan icupi qa Lukaoniya iapi kin eciyatanhan, Taku wakan kin wicaśta ihduza unkiyepi en kun unhiyupi ce, eyapi.

12 Qa Barnabas Jupiter eya caśtonpi; qa Palos iś, Hermes eciyapi, iapi on itancan kin hee, heon etanhan.

13 Hehan Jupiter otonwe itokam yanke cin he wośna kagapi tawa kin he tatanka wateśdake ko, tiyopa kin en ahi, qa oyate kin om wośna kta tuka. 208
$14 \mathrm{He}$ yewicaśipi kin, Barnabas Palos kici, nahonpi qehan, wokoyake aihdupotapi, qa oyate kin ekta inyang yapi, hotaninpi, 15 Qa heyapi, Wicaśta kin, tokeca e hecanonpi he; niye yaunpi kin iyecen, wicaśta akantu kin heuncapi, qa hena takuśniśni kin aduśtanpi qa Wakantanka ni un kin ekta nihduhominipi kta e iwahokonunniciyapi; he mahpiya, maka, qa miniwanca, taku ohnaka ko, owasin kage cin hee.

$16 \mathrm{He}$ wicoicage hekpata un kin en, oyate kin owasin canku tawapi kin ohna manipi kta e iyowinwicakiya.

17 Hececa eśta tanyan econ, qa mahpiya eciyatanhan magaju wicaqu, makoncage taku ota icahye cin hena ko, qa woyute wowiyuśkin ko on cante imnaunyanpi qon, he eciyatanhan ohinniyan ihdutanin ce.

18 Unkan rvicoie kin hena on wawicakiyuśnapi kte cin oyate kin kitan se ayuśtan wicayapi.

19 Hehan Antiyoka qa Ikonium etanhan Juda wicaśta wanjikji en hipi qa oyate kin iyowicapaśtakapi; hecen Palos inyan on kininpi qa otonwe kin tankan yusdohan ayapi, wanna ta kecinpi.

20 Tuka waonspewicakiyapi kin ihdukśan hinajin yukanpi kin icunhan, iye najin hiyaye ca otonwe kin en i. Unkan ihanhanna qehan Barnabas kici Derbe ekta iyaya.

21 Unkan otonwe kin he en wotanin waśte kin oyakapi, qa wicota waonspewicakiyapi qehan, hehan Lustra, qa Ikonium, qa Antiyoka ekta icicawin hdapi. $22 \mathrm{Qa}$ waonspewicakiyapi nagipi kin waśag wicakiyapi, qa wacinyanpi kin en kitanyan unpi 


\section{WICOWOYAKE 15.}

kta e iwahokonwicakiyapi, qa wokakije ota iyoopteya Wakantanka tokiconze kin en unkipi kta ce.

23 Unkan okodakiciye otoiyohi en hunka wicayapi kin wicakagapi, qa wote śni wocekiye eyapi qehan, Itancan wicadapi qon he awanwicahdake kta e icekiyapi.

24 Unkan Pisidia opta yapi hehan Pampulia en kiyohipi.

25 Qa Perge en wicoie kin oyakapi qehan, Atalia ekta apamahde iyayapi.

26 Qa hetanhan Antiyoka ekta watom hdapi, wicohtani wanna hduśtanpi kin heon, Wakantanka towaonśida kin yuhapi kta e icekiyapi qon he hetu.

27 Hen hdipi qa okodakiciye kin mniciye wicaśipi, qa Wakantanka token econ wicakiye cin hena owasin owicakiyakapi, qa wacinyanpi tiyopa wan Ikcewicaśta kin wicakiyulidoke cin he nakun.

28 Unkan hen waonspewicakiyapi kin om tehan owanji yukanpi.

\section{WICOWOYAKE 15.}

1 Unkan wicaśta wanjikji Juda makoce kin etanhan apamahde yapi, qa hunkawanjinkiciyapi kin wahokonwicakiyapi qa, Moses toope kin eciyatanhan banicilidayapi śni kinhan yanipi kte śni ce, eyapi.

2 Unkan Palos Barnabas kici hena wicakigepi, qa nina awicakinicapi, hehan wiwicawangapi kin-he on, Palos Barnabas kici, qa iyepi kin etanhan wicaśta tokeca wanjikji ko, yewicaśipi kin, qa hunkawicayapi kin, Jerusalem ekta yakonpi kin, hena en wicayapi kta e konzapi.

3 Unkan okodakiciye kin hena Dak

14 hecen yewicakiyapi qehan, Phe nike, qa Samaria opta yapi, qa Ikcewicaśta ihduhomnipi kin he oyakapi; qa hunkawanjin kiciyapi kin owasin en wowiyuśkin tanka kagapi.

4 Unkan Jerusalem ekta ipi qehan, okodakiciye kin he, qa yewicaśipi kin, hunkawicayapi kin hena ko, tin hiyu wicakiyapi; hehan Wakantanka token econ .wicakiye cin owasin ohdakapi.

5 Tuka Pharisee yuomdecapi kin etanhan wanjikji wicadapi qon hena inajinpi qa heyapi, Bawicakihdayapi qa Moses toope kin ope wicaśipi kta iyececa ce, eyapi ce.

6 Unkan wicoie kin de akiiapi kta e on yewicaśipi kin, hunkawicayapi ko witaya mniciyapi.

7 Qa nina wikiciwangapi hehan, Inyan inajin qa hewicakiya, Wicaśta hunkawanjinciyapi kin, ehanna unketanhanpi kin Wakantanka miye makahinige ça, mii kin eciyatanhan Ikcewicaśta kin wotanin waśte oie kin nahonpi, qa wicadapi kta e konza sdonyayapi.

8 Qa Wakantanka wicacante kin sdonye cin he wicayaotanin, qa Woniya Wakan unkiye unqupi qon, he iyecen wicaqu.

9 Qa takudan ocitkonze śni unkagapi, iye cantepi kin nakun wicadapi kin on wicakipakinta.

10 Heon nakaha tokeca e Wakantanka iyutanyayapi, qa can napinpi wan, hunkake wicun. yanpi qa unkiyepi kin yuha unkokihipi śni kin he waonspewicakiyapi tahupi kin en eyahnakapi kta he.

11 Tuka Jesus Messiya Itancan kin towaonśida kin on, iś iyepi kin wiconi yuhapi kte cin, he iyecen unkiś unhapi kta e wicaundapi ce. 


\section{OHANYANPI QON.}

12 Hehan omniciye kin owasin inina yukanpi, qa Barnabas Palos kici, wowapetokeca wakanyan econpi ko, Wakantanka Ikcewicaśta kin ekta econ wicakiye cin hena ecen ohdakapi kin nahonpi.

13 Unkan wanna ayaśtanpi, hehan Jakob ayupte ça heya; Wicaśta hunkawanjin ciyapi, miye namahon po.

14 Otokahe ekta token Wakantanka Ikcewicaśta kin etanhan oyate wanji, iye caje kin on, iwicacu $k$ ta e ekta wicai qon he Simon oyaka.

15 Qa he kici wicaśta wokcan oiepi qon okonwanjidan, kaken wowapi en kagapi ;

16 He iyohakam mihdamna, qa Dawid tawakeya jujuwahe cin he piya wakage kta ; qa mdecahe cin hena ake wakage ca ecen he wakiye kta.

17 Qa hecen wicaśta okaptapi kin, Ikcewicaśta owasin ko, tona micaje icajewicayatapi kin hena Jehowa akitapi kta ce, Itancan kin hena owasin econ kin he heya ce.

18 Otokaheya tanhan Wakantanka taku icahye cin owasin sdonkiya.

19 Heon etanhan miś kaken imdukcan, Ikcewicaśta kin tona Wakantanka ekta ihduhomnipi kin hena nagiyewicunyanpi kte śni.

20 Tuka wakagapi on aśapapi kin, qa wiinahmanpi kin, qa we, qa taku weye śni yutapi kin, hena itehan yeiçiyapi kta e wowapi wicunkicagapi kta.

21 Wanakaja tanhan tona Moses oyakapi kin hena otonwe otoiyohi kin en yukanpi, qa anpetu okihpapi eca, omniciye tipi kin ohna he yawapi ece, eya.

22 Hehan iś iyepi kin etanhan 210 wicaśta kahnigapi kin heca, Judas Barsabas eciyapi, qa Silas, hunkaw anjin kiciyapi kin en wicaśta okinihan, hena Palos qa Barnabas kici, Antiyoka ekta ye wicaśipi kta e, yewicaśipi kin, hunka wicayapi kin, okodakiciye kin owasin ko iyokipipi.

23 Qa heciya ayapi kta e kaken wowapi kagapi ; Yewicaśipi kin, qa hunka wicayapi, hunkawanjin kiciyapi kin hena ko, hunkawanjin kiciyapi Ikcewicaśta etanhan, Antiyoka, qa Suria, qa Kilikia en yakonpi kin, Wookiye yukan po.

24 Unkiyepi etanhan wanjikji iyayapi, qa wicoie on nagiyeniyanpi, qa ninagipi kin nipahohopi qa, Banicilidayapi, qa wicoope kin oyapapi kta ce, eniciyapi ce, naunlionpi; unkiye tohinni heye wicunśipi śni tuka:

25 Heon etanhan tawacin wanjidan hduha unwitayapi qehan, wicaśta kahinigapi kin heca e niyepi kin ekta ye wicunśipi kta e iyounkipipi, Barnabas qa Palos waśtewicunkidakapi kin hena om:

26 Hena wicaśta kin wiconi ehipekiyapi seca, Jesus Messiya Itancan unkiyapi kin heon etanhan.

27 Hecen Judas qa Silas ye wicunśipi, hena e wicoie on atayedan hecen oniciyakapi kta.

28 Woniya Wakan kici hecen iyounkipipi, waqinpi tokeca unkanihnakapi kte śni, tuka dena taku owotanna kin hecehnana; 29 Taku wakagapi wakiyuśnapi, qa we, qa taku we ye śni yutapi, qa wiinahmanpi kin hena itehan yeniçiyapi kta. Hena itehanyan yaunpi kinhan tanyan ecanonpi kta. Tanyan yaunpi nunwe.

30 Hecen hena ye wicaśipi qe- 


\section{WICOWOYAKE 16.}

han, Antiyoka ekta ipi, qa oyate kin kawitaya iheyapi, hehan wowapi kin he wicaqupi.

31 He yawapi, unkan wahokonwicakiyapi kin on nina iyuśkinpi.

32 Unkan Judas qa Silas wicaśta wokcan kin hecapi, heon hunkawanjin kiciyapi kin oie ota on wahokonwicakiyapi, qa wicayasutapi.

33 Wanna anpetu ota en yukanpi, hehan hunkawanjin kiciyapi lin hena yewicaśipi kin ekta wookiye hde wicaśipi.

34 Tuka Silas en un kta e iyokipi.

35 Palos qa Barnabas Antiyoka en unpi, wicaśta tokeca ota ko, oyate kin waonspewicalkiyapi, qa Itancan oie kin oyakapi.

36 Unkan iyohalram anpetu tonana, hehan Palos Barnabas heciya, Tukten Itancan oie kin unkoyake ciquon, ake otonwe otoiyohi elita unye ca, hunkawanjin wicunye cin wanwicunhdake ca, token .yakonpi kin sdonunye lita ce, eya.

37 Unkan Barnabas he iś, Johannes Markos eciyapi, yuha yapi kta cin.

38 Tuka he Pampulia ekta ehpewicaye ca wicohtani kin en owicape śni qon, heon etanhan Palos he yuha yapi kte cin iyokipi śni.

39 Unkan he on hdokinicapi qa hecen otoiyohi ehpekiciyapi: unkan Barnabas Markos yuha Kupros ekta watom iyaya.

40 Tuka Palos Silas kalinige ca, Wakantanka towaonśida kin kici un kta e hunkawanjinkiciyapi kin icekiyapi qehan, hehan iyaya ;

41 Qa Suria qa Kilikia opta iyaye ça, okodakiciye kin suta wicakaga.

\section{WICOWOYAKE 16.}

1 Hehan Derbe qa Lustra ekta iyohi ; unkan iho, waonspekiyapi kin wanji hen un, Timotheos eciyapi, Juda winohinca wicake cin he cinhintku, tuka atkuku kin e Helenes oyate kin etanhan. 2 Hunkawanjin kiciyapi Lustra, qa Ikonium en yukanpi kin hena, he waśte e oyakapi.

3 Hetanhan Palos kici ya cin, qa Juda wicaśta hen unpi kin hena on, he icu qa bakicihdaya; atkukil kin Helenes heca e owasin sdonyapi.

4 Unkan otonwe iyaza yapi, qa yewicaśipi kin, kunka wicayapi ko, Jerusalem en yukanipi kin woahope kagapi qon hena tanyan yuhe wicaśipi.

5 Hecen okodakiciye kin wacinyanpi kin en wicayusutapi, qa anpetu otoiyohi nina yuota aya.

6 Unkan Phrugia qa Galatia makoce kin opta iyayapi, qa Asia en wicoie kin oyakapi kte cin Woniya Wakan kin tehinda qehan ;

7 Hehan Musia ekta ipi, qa hetanhan Bithunia ekta ye wacinpi, tuka Woniya kin iyowicaki śni.

8 Unkan Musia opta iyayapi qehan, Troas en iyohipi.

9 Unkan hanyen Palos wowanyake wan wanyaka; Wicaśta wan Makedonia etanhan taninyan inajin, qa cekiye ca, Makedonia en $u$, qa ounkiya po, eya.

10 Wowanyake kin de wanyake cin heon hinnakaha Makedonia heciya unyanpi kta e uncinpi, Itancan kin hena wotanin waśte kin owicunkiyakapi lita cin heon unkicopi e unhdukcanpi. 


\section{OḢANYANPI QON.}

11 Hecen Troas etanhan pacanan iyeunyanpi, qa Samotrake ekta owotanna unyanpi, qa hetanhan ihanhanna Neapolis en unkipi.

12 Qa hetanhan Philippi en unkipi, otonwe teca qa Makedonia makoce onśpa kin he en otonwe tokapa kin hee. Qa anpetu tonana otonwe kin he en unkanpi.

13 Unkan anpetu wakan hehan, otonwe kin etanhan inaunpapi, qa wakpa wan icahda wocekiye eyapi ece qon he en unkipi; hen unkiyotankapi, qa winolinca ece en mniciyapi kin hena owicunkiyapi.

14 Unkan winohinca wan, Ludia eciyapi, Thuatira otonwe kin etanhan, wokoyake duta ece wiyopeye cin heca, Wakantanka kokipeyahan un he nation yanka: unkan cante kin Itancan kin yuzamni, on Palos oie kin anagoptan.

15 Unkan tiyohnaka kin om baptem qupi qehan, helian ceunkiyapi qa, Itancan kin on wicawaka kecanmayakinpi hecinhan, wati kin en tin upi, qa ohna yukan pe, eye ça ecen econ unkiyapi.

16 Hetanhan wocekiye eya unyanpi eca, wicinyanna wan itkounkipapi ece, he taku wakan woyaka ece kin yuhe ca, wakanyan wohdag un kin heon tawayapi kin taku ota wicakicamna.

17 He Palos unkiyepi ko unkihakam u, qa; Wicaśta kin dena Wakantanka tehan wankantuya un kin taokiye wicaye cin, wiconi canku kin unkokiyakapi kin hena eepi ce, eya hoyekiya.

$18 \mathrm{Qa}$ anpetu ota hecen econ. Tuka Palos nagiyeye cin heon hakikta qa, Jesus Messiya caje on winohinca kin de etanhan 212 tankata inanpe ciśi, taku wakan kin eciya. Unkan wihiyayedan oape kin he en tankan hiyu.

19 Unkan winohinca kin de yuhapi kin heepi, taku kamnanpi kte cin he akitakunipi śni kin he wanyakapi e etanhan, Palos Silas kici wicayuzapi, qa tipi liocoka kin ekta wicaśta tokahe wicakiyapi kin en awicayapi :

20 Qa wicaśta itancan wicakiyapi kin en wicakaipi, qa heyapi, Wicaśta kin dena Juda wicaśta kin hecapi, otonwe unkitarwapi kin nina nagiyeyapi ;

21 Qa wicohan onspewicakiyapi kin hena e, Roma wicaśta heuncapi kin, unkicupi qa unkopapi kta e iyecece śni.

22 Unkan oyate kin owasin witaya takpe wicaupi; qa wicaśta itancan wicakiyapi kin wokoyake awicayupotapi, qa wicakapsinpsinte wicaśipi.

23 Unkan ota awicapapi, hehan wicakaśka tipi kin en iyewicayapi, qa tipi awanyake cin sutaya wicayuhe śipi.

24 He hecèn econ śipi, unkan wicakaśka tipi temahentuya kin he en onawicataka, qa siha kin can on kaśkapi ece kin en sutaya kaśka wicahnaka.

25 Unkan hanye cokaya hehan, Palos Silas kici Wakantanka cekiyapi, qa yatan dowanpi; unkan wicaśta wicakaśkapi kin he nahonpi.

26 Unkan ihnuhanna maka kin nina huhuzahan, qa tipi ahe cin hena yuhuhuzapi, qa tiyopa kin owasin kazamni iyaye ça, on pawicahtapi kin owasin mdecahan hinhda.

27 Hececa, unkan wicakaśka tipi awanyag kiyapi kin kikta, qa tiyopa kin yuzamni han wanyaka, unkan wicaśta wicakaśkapi kin owasin kihdapi kecin, he- 


\section{WICOWOYAKE 17.}

on mazasagye ehdaku qa on içikte kta ;

28 Tuka Palos nina hoyekiye ca, Kiuniiciye śni wo, owasin den unkanpi ce, eya.

29 Hehan petijanjan wan da, qa tin iyaye ca, cancan Palos Silas kici siha hdepi kin en ehpeiciya ;

30 Qa tankan awicaye ça, Itancanpi wani kta e token ecamon kta he, ewicakiya.

31 Unkan, Jesus Messiya Itancan kin wacinyan wo, hecen nicinca om yani kta ce, eciyapi.

$32 \mathrm{Qa}$ Itancan oie kin okiyakapi, tona ti kin en yukanpi kin hena owasin koya.

33 Unkan lianyetu kin wihiyayedan oape kin he en, iwicacu, qa oape kin wicakiyujaja, qa hehan baptem qupi, tiyohriaka owasin ko.

34 Qa iye ti kin en awicalki qa won wicaya; qa tiyohnaka kin om wicada qa iyuśkin.

35 Unkan wanna anpa qehan, itancan wicakiyapi kin akicita eyanpaha kin elkta ye wicaśipi, qa, Wicaśta kin hena wicakiyuśka wo, eyapi.

36 Unkan wicakaśka tipi awanyake cin, hena oie kin Palos okiyake ca, Itancan wicakiyapi kin niciyuśkapi kta keya hośi hipi, heon etanhan tankan kinanpapi, qa wookiye hda po, eya.

37 Tuka Palos hewicakiya, Roma wicaśta heuncapi, tuka unyacopi śni ecen taninyan unkapsinpsintapi, qa onatag eunhnakapi, qa hinnakaha anahbeya hde unśipi he: hiya, iye atayedan upi, qa tankan unkaupi lita, eya.

38. Hehan akicita eyanpaha kin itancan wicakiyapi kin dena owicakiyakapi, unkan Roma wicaśta kin hecapi e nahonpi kin heon inihanpi.

39 Qa iye atayedan elkta ipi, qa cewicakiyapi, qa tankan a wicaupi, qa otonwe kin etanhan hdapi kta icewicakiyapi.

40 Unkan wicakaślka tipi kin etanhan tankata inanpapi, qa Ludia ti kin en ipi ; qa hunkawanjin kiciyapi kin wanwicahdakapi, hehan wicakihnapi, qa etanhan tokan iyayapi.

\section{WICOWOYAKE 17.}

1 Unkan Amphipolis qa Apolonia opta yapi kin, hehan Thesalonike en ipi; hen Juda oyate omniciye tipi kin wanji yukan.

2 Unkan Palos token econ ece kin ake ecen econ, qa timahen $i$, ya anpetu okilipapi yamni, wowapi wakan kin eciyatanhan, oyate kin wowicakiyaka.

3 Ie ca Messiya te kte ca, wiconte lin etanhan najin kta e hecetu e yaotanin, qa, Jesus ociciyakapi kin he Messiya kin ee ce, eya.

4 Unkan hunh wicadapi, qa Palos Silas kici owicapapi, Helenes wicaśta owotanna ota, qa winohinca tokapapi kin wanistinpidan śni.

5 Tuka Juda oyate wicadapi śni kin hena wohinyanpi, qa wopeton tipi hocoka kin etanhan wicaśta śica wanjikji iwicacupi, qa kiwitaya iheyapi, qa otonwe kin ocowasin oqoyeyapi, hehan Jason ti kin takpe ipi, qa oyate kin ekta tankan hiyu wicayapi kta e akitapi.

6 Qa iyewicayapi śni qehan, Jason hunkawanjin kiciyapi wanjikji om otonwe kin en wicaśta itancanpi kin ekta awicaipi, qa hotankakiya hotaninpi, Tona ma. 213 


\section{OHANYANPI QON.}

ka kin yuahdapśinyan ehpeyapi qon hena den hipi :

7 Qa Jason hena tin u wicaśi. Unkan hena owasin Kesar toope kin opapi śni, qa, Wicaśtayatapi tokeca wan Jesus hee cé, eya oyakapi ece, eyapi.

8 Unkan otonwe en wicaśta itancanpi kin oyate ko, hena nahonpi kin inihan wicayapi.

9 Unkan Jason qa unmapi kin taku iwakta wicayapi, hehan awicayuśtanpi.

10 Hehan hunkawanjin kiciyapi kin Palos Silas kici hanyen Berea ekta awicayapi. Hena ekta ipi, qa Juda oyate omniciye tipi yuhapi kin he en timahen yapi.

11 Hera iś Thesalonike oyate kin sam iyeya wacin ksapapi, wicoie kin tawacin inalini on icupi, qa hena hecetu e sdonyapi kta, heon anpetu iyohi wowapi wakan kin en akitapi ece.

12 Heon etanhan wicota wicadapi, Helenes winohinca okinihan, qa nakun wicaśta ota.

13 Tuka Berea ekta Palos Wakantanka oie kin oyake cin he, Juda wicaśta Thesalonike en un kin hena sdonyapi qehan, ekta ipi, qa wicota kin wicayaśkiślkapi.

14. Unkan hehan hunkawanjinkiciyapi kin Palos miniwanca kin elkta ye kta se tokan ye śipi ; tuka Silas qa 'Timotheos hen owanji yukanpi.

15 Unkan tona Palos ayapi qon hena Athenas ekta aipi; qa Silas Timotheos kici kohanna en upi kta e iwahowicaye cin he hośi wicakahdapi.

16 Unkan hena Athenas ekta upi kta e Palos awicape yanke cin, he icunhan, otonwe kin wakagapi ojudan e wanyake ça on wacin iyokiśica hinhda.

$$
214 .
$$

$17 \mathrm{Qa}$ heon omniciye tipi kin ohna Juda oyate, qa tona owicapapi kin hena om wohdaka, qa nakun anpetu otoiyohi wopeton tipi hocoka kin ekta tona itkowicakipe cin hena om.

18 Unkan hehan Epikureos qa Stoikos oyate kin edanhan, wicaśta woksape cinpi wanjikji. Palos itkokipapi qa, I wakan kin de token eye kta he, hunfi eyapi ; qa hunli iś, He taku wakan tokeca ehde sececa ce, eyapi; Jesus qa wiconte etanhan woekicetu kin hena owicakiyaka, heon etanhan.

$19 \mathrm{He}$ icupi, qa Areyos paha kin ekta aipi qa, Woonspe teca odake cin he taku kin sdonunyanpi kta uncinpi :

20 Taku wotanin tokeca noge on nahon unyayapi kin hena token kapi hecinhan, sdonunyanpi kta ce, eciyapi.

21 Athenas oyate, qa wicaśta tokeca en yukanpi kin owasin, taku tokeca econpi śni, taku nakaha otanin kin oyakapi, qa nahonpi kin heceyedan.

22 Hehan Palos Areyos paha kin cokaya inajin, qa heya ; Athenas wicaśta kin, taku wakan kin nina awacannipi e, taku owasin on imdukcan.

23 Naka taku wakan yadapi kin en awahimdamda, unkan iho, wahna wośnapi wan, Taku wakan sdonyapi śni un kin, akan owapi kin he iyewaye. $\mathrm{He}$ iyukcanśniyan ohoyaulapi kin hee e ociciyakapi.

24 'Taku Wakan kin tuwe maka taku ohnaka ko owasin kage ca, mahpiya maka ko Itancan kin hee, heon tipi wakan wicanape on kagapi kin ohna ti śni ;

$25 \mathrm{Qa}$ iye kin owasin wiconi, qa woniya, qa taku owasin ko wicaqu ece kin, he taku icakije 


\section{WICOWOYAKE 18.}

cin iyecen, wicaśta nape kin on okiyapi śni ece.

26 Qa wicawe wanjidan on, wicaśta oyate hiyeye cin owasin, maka kin owancaya etipi kta e wicakaga; qa tohanhan nipi, qa tuktekten tipi kte cin hena otokahe tanhan wicakiciyuśtan.

27 Heon Itancan kin akitapi kta iyececa, okinni yutantan akitapi kinhan iyeyapi kta, otoiyohi unkitehanpi śni un tuka ce.

28 Iye atayedan on unnipi, qa unśkanśkanpi, qa en unyakonpi ece : enitanhanpi wicaśta odowan lragapi ece kin hena wanjikji heyapi qon, Unkiś eya he cinca unyakonpi ce.

29 Hecen Wakantanka cinca unyakonpi kin, mazaskazi, qa mazaska, qa inyan, wicaśta wayupike wacinksape bagopi kin, 'Taku Wakan kin iyacinpi kta iyececa unkecinpi kte śni.

$30 \mathrm{Qa}$ wookahnige śni omaka kin hena, Wakantanka ek ta etonwe śni ; tuka wanna wicaśta owasin owancaya ihduecetu wicaśi.

31 Qa anpetu wan en wicaśta kin woowotanna on wicayaco kta e konza, wicaśta kahnige ciqon he on hecon lita, qa wiconte kin etanhan najin kiye cin heon he owasin sdonye wicaya ce, eya.

32 Unkan wicate cin piya icahyapi kin he nahonpi qehan, hunh ihahapi ; qa apa iś, He on ake naunnihonpi kta ce, eyapi.

33 Hecen Palos wicacokaya tanhan tokan iyaya.

34 Tuka wicaśta wanjikji opapi, qa wicadapi; Dionusius Areyos paha omniciye kin en ope ciqon he wanji ee, qa winohinca wan Damaris eciyapi, qa nakun tok tokecapi.
WICOWOYAKE 18.

1 Hena iyohakam Palos Athenas ayuśtan, qa Korinth ekta i :

2 Qa hen Juda wicaśta wan iyeya, Akula eciyapi, Pontos en tonpi, qa aśkatudan Italia etanhan hiyu, tawicu Priskila kici; Kladios Juda wicaśta kin owasin Roma ayuśtan wicaśi kin heon etanhan. Unkan hena en wicahi ;

3 Qa kici wicolitani okonwanjidan, heon om un, qa om htani, wakeya kagapi kin hecapi.

4 Qa anpetu wakan eca omniciye tipi kin ohna wowicakiyaka ece, qa Juda oyate Helenes ko cinwicakiya.

5 Unkan Silas qa Timotheos Makedonia etanhan hiyupi qa en hipi qehá, Palos nagi kin ekta iyopaśtag iciye ça, Jesus he Messiya kin ee ce, Juda oyate kin owicakiyaka.

6 Unkan hena e wakipajinpi, qa śicaya iapi kin, hehan Palos wokoyake aihdatata, qa hewicakiya, Niwe kin nipapi kin akan niunpi nunwe, miye mabapica śni waun, detanhan Ikcewicaśta kin ekta mde kta ce.

7 Unkan hetanhan tankan ye ca, wicaśta wan Wakantanka ohoda, Justos eciyapi he ti kin omniciye tipi kin ikiyadan han; unkan tipi kin he en tin iyaya.

8 Unkan Krispos, omniciye tipi kin en itancan kin, he Itancan kin wacinyan, tiyohnaka owasin om; qa Korinth oyate kin wicota nahonpi qehan wicadapi, unkan baptem wicaqupi.

9 Unkan hehan hanyen wowihamde en, Itancan kin Palos heciya, Ihnuhan taku koyakipe cin, tuka nina ie ça, inina yanke śni wo.

10 Miye cicica, qa tuwedan 215 


\section{OHANYANPI QON.}

kiuniniye lita e iyanilipaye kte śni; otonwe kin de ohna oyate ota wicamduha ce, eya.

11 Unkan hen wi ake śahdogan helianyan iyotanke ca, Wakantanka oie kin onspewicakiya.

12 Unkan Galiyo Akeya makoce kin en itancan un kin, hehan Juda oyate witaya Palos takpe ipi, qa woyaco oiyotanke kin en ahipi ;

13 Qa, Woahope kin eciyatanhan śni Wakantanka cekiyapi kta e wicaśta kin onspewicakiye cin he dee ce, eyapi.

14 Unkan Palos i hdukawa kta, hehan Galiyo Juda oyate kin hewicakiya; Juda wicaśta kin, de taku śica econpi, qa iś wicaśtaśniyan ohanyanpi kin hee unkanś, nacihonpi kta iyececa tuka :

15 Tuka wicoie, qa wicacaje, qa woope nitawapi on wiwangapi kin heca hecinhan, niś ito ekta etonwan po; taku hececa on wimdukcan kte śni ce.

16 Hehan woyaco oiyotanke kin etanhan kaliam iyewicaya.

17 Unkan Helenes wicaśta kin owasin Sosthenes, omniciye tipi kin en itancan kin he, icupi, qa woyaco oiyotanke kin itokan apapi. Tuka Galiyo hena taku kin ekta ewacin śni yanka.

18 Unkan he iyohakam $\mathrm{Pa}$ los anpetu ota hen yanke cehan, hunkawanjin kiciyapi kin awicayuśtan, qa Suria ektakiya watom iyaya, Priskila Akula kici opapi. Kenkreya ekta paha kin bakiśda, hecen içiconza kin heon.

19 Hehan Ephesos ekta iyohi, qa hen elipewicaya; tuka iye kin omniciye tipi kin en tin iyaye ca, Juda oyate kin om wohdaka.

20 Unkan en tehan owanji yanke kta e cinpi eśta wicada śni :
21 Tuka napewicayuze ca, Jerusalem ekta wośnapi u kte cin he en owape kta, tuka Wakantanka iyokipi kinhan, ake en cihdipi kta ce, eya. Hehan Ephesos etanhan watom iyaya. 22 Qa Kesareya en huta ekta ihunni, qa lien ihe ça okodakiciye kin napewicayuze cehan, Antiyoka ekta apamahde iyaya.

23 Qa anpetu ota hen un kin, hehan Galatia qa Phrugia makoce kin owancaya ye ça, waonspewicakiyapi kin owasin waśag wicakiya.

24 Unkan Juda wicaśta wan, Apolos eciyapi, Aleksandrea en tonpi, wicaśta wayapike ca wowapi wakan on waśaka, he Ephesos elita hi.

25 Wicaśta kin he Itancan tacanku kin onspe, qa nagi kata, lieon ninana ie ca, Itancan taku tawa kin onspewicakiya, Johannes baptem tawa kin hecedan sdonya tuka.

26 Hee omniciye tipi kin ohna waditagya ia; unkan Akula qa Priskila nalionpi qehan, he icupi, qa Wakantanka tacanku kin sanpa tanyan okiyakapi.

27 Unkan Akeya ekta ye wacin, hehan hunkawanjin kiciyapi kin heciya wowapi wicakicagapi, qa he iyowinkiyapi kta e iwahokonwicakiyapi. He heciya $i$, qa tona wowaonśida kin on wicadapi qon hena nina owicakiya ;

$28 \mathrm{Qa}$ Juda oyate kin omniciye en nina awacin wicaye ca, wowapi wakan kin eciyatanhan Jesus he Messiya kin ee e yatanin.

\section{WICOWOYAKE 19.}

1 Unkan Apolos Korinth en un kin icunhan, Palos iheyata makoce kin opta ye ça, Ephesos 
ekta iyohi, qa hen waonspewicakiyapi wanjikji iyewicaya:

2 Qa hewicakiya, Wicayadapi ehantanhan Woniya Wakan kin iyacupi he. Unkan iś, Woniya Wakan yukan e nahahin naunhonpi śni ce, eyapi.

3 Unkan, Taku on baptem nicupi he, ewicakiya. Unkan, Johannes baptem tawa kin hee ce, eyapi.

4 Unkan Palos, Johannes ihduecetupi kte cin on baptem wicaqu, qa oyate kin tuwe u kte cin he wicadapi kta, kewicakiya, he Jesus Messiya kin ee ce, eya.

5 He nahonpi, unkan Jesus Itancan caje kin on baptem wicaqupi.

6 Hehan Palos nape on awicaputake ca, Woniya Wakan en wicahi, unkan ceji tolreca on iapi qa wokcanpi.

7 Hena owasin wica ece wikcemna ake nonpa.

8 Unkan omniciye tipi kin tin iyaye ça, wi yamni waditagya ie ca wohdaka, qa Wakantanka tokiconze taku tawa kin onspewicakiya.

9 'Tuka wanjikji suta içicagapi qa wicadapi śni kin hena, wicota kin en, canku kin de on śicaya eyapi qehan, hena awicayuśtan, qa waonspewicakiyapi kin aiyog iyewicaye ca, anpetu otoiyohi, tuwe Turannos eciyapi, he oyawa tipi yuhe cin ohna woyaka ece.

10 Waniyetu nonpa hehanyan hecen econ, unkan tona Asia en yakonpi kin hena owasin Jesus Itancan oie kin nahonpi, Juda Helenes wicaśta ko.

11 Unkan Palos nape kin on Wakantanka wowapetokeca wakan kin econ ece.

12 Hecen iye tancan kin etan- han, napipakinte qa makuakalipe kin wayazanpi kin en akipi; unkan wowayazan kin ayuśtan iyaye ca, taku wakan śicapi kin tankan inanpapi.

13 Unkan wanjikji, Juda wicaśta wapiyapi kin heca, tona taku wakan śica yuhapi kin hena en, Jesus Itancan kin cajeyata utapi, qa, Jesus Palos oyake cin he cajeyan nauntion po, eyapi.

$14 \mathrm{Qa}$ Juda wicaśta wośna kagapi wanji, Skewa eciyapi, he cinhintku śalrowin kin hena he. conpi.

15 Tuka woniya śice cin he waayupte ca, Jesus sdonwaye ca, Palos nakun sdonwaya, tuka niśs nituwepi he, eya.

16 Unkan wicaśta taku wakan śica yuhe cin he iyawicalipaye ca, ohiwicaya, hecen tancodan kiunniyanpi ecen tipi kin etanhan tankan najicapi.

17 Unkan tona Ephesos en yukanpi kin, Juda qa Helenes oyate kin owasin he sdonyapi; qa wokokipe owasin awicahinhipaya, unkan Jesus Itancan caje kin yatanpi.

18 Unkan tona wicadapi kin etanhan wicota en ahi, qa wohdakapi, wicohan qon ohdakapi; 19 Qa tona wapiyapi econpi kin hena wicota wowapi tawapi kin en ahipi, qa owasin wicitokam huhnaliyapi ; hena iyopeyapi kin hdawapi, qa mazaska kektopawinge wikcemna zaptan iyawapi.

20 Hecen Itancan oie kin nina icage ça ohiya.

21 Unkan hena taku kin wanna enakiyapi, hehan Palos woniya eciyatanhan konza, Makedonia qa Akeya opta ye cinhan, hehan Jerusalem ekta ye lita, qa, Heciya wai kinhan hehan Roma wanmdake kta ce, eya. 


\section{OHANYANPI QON.}

22 Qa ookiye wicayuhe cin nom, 'T'imotheos qa Erastos, hena Makedonia ekta ye wicaśi, tuka iye anpetu tonana Asia en owanjidan yanka.

23 Unkan he icunhan canku kin de on nina owodutaton.

24. Tuwe Demetrios eciyapi, mazaska kage cin heca, he mazaska kokadan Diana kicaga ece, qa tona woecon kin he econpi kin hena taku ota wicakicamna.

25 Hena eepi, qa tona opeya htanipi kin hena ko wicakico qa hewicakiya, Wicaśta kin, wicohtani kin de on woyuha untonpi e sdonyakiyapi.

26 Qa nakun Ephesos ecedan śni, tuka Asia owancaya, $\mathrm{Pa}$ los kin de oyate ota wahokonwicakiye ca, wicayuhomni qa, Taku wakan nape on kagapi kin hena wakan śni ce, eya owicakiyaka e sdonyayapi qa nayahonpi.

$27 \mathrm{Qa}$ hecen taku on waunkamnanpi ece kin he wahtedapi kte śni seca, qa hecedan śni, nakun Diana taku wakan tanka tipi wakan tawa kin takudapi kte śni, qa wowitan hduhe cin yutakuni kte śni, he qe Asia owancaya, qa oyate kin iyuhpa ohodapi tuka ce, eya.

28 Unkan hena nahonpi qehan, nina canteptanyanpi qa, Diana Ephesos oyate tawapi kin he tanka ce, eyaya hotaninpi.

29 Unkan otonwe kin owancaya nina owodutaton; qa Gayos qa Aristarkos kici, Makedonia wicaśta kin, Palos kici hipi qon hena iwicacupi, qa tawacin wanjidan owanyake tipi kin en inyang yapi.

30 Unkan Palos oyate kin en wicai kta, tuka waonspewicakiyapi kin lyokipi śni :
31 Qa Asia en wicaśta tokapapi wanjikji, iye takodawicaye cin hena wahoyapi, qa owanyake tipi kin timahen iyohpaye kte śni e icekiyapi.

32 Heon hunh taku eya hotaninpi, qa hunh iś togye eyapi ; omniciye kin nina oqoyapi; qa tokeca e on mniciyapi kin ota sdonyapi śni.

33 Hehan Aleksander wicota kin etanhan ahiyupi, qa Juda wicaśta kin he cokata iyaye yapi. Unkan Aleksander namwicakicawin, qa oyate kin wowicakiyake kta.

34 Tuka he Juda wicaśta kin heca e sdonyapi, unkan wihiyayedan oape nompa hehanyan, owasin ho wanjidan hotankakiya hotaninpi, Diara Ephesos oyate tawapi kin he tanka ce, eyaya yukanpi.

35 Unkan wowapi kage cin he oyate kin wicayuinina qehan, hecen eya, Ephesos wicaśta kin, Ephesos otonwe kin de Diana taku wakan tanka he tipi wakan tawa kin awanyag un, qa wakagapi Jupiter etanhan hinhpaye ciqon he nakun, he tuwe wicaśta kin he sdonye śni he.

36 Dena taku kin cețunhdapica śni, heon inina dukanpi, qa takudan inahniyan ecanonpi kte śni tuka.

37 Wicaśta kin dena tipi wakan kin etanhan takudan manonpi śni, qa taku wakan nitawapi kin yaśicapi śni, tuka den awicayahipi.

38 Demetrios qa tona om hitani kin hena tuwe en taku aupi cinpi kinhan, woyaco anpetu yukan, qa nakun wicaśta wayacopi kin ; otoiyohi wiyakicionpapi kta.

39 Qa niś taku tokeca on winungapi hecinhan, omniciye wi- 
coope kin eciyatanhan un kin he en yacopi kta.

40 Anpesu kin de owodutaton kin on wiunwangapi kta naceca ; omniciye kin de on etanhan taku unkeyapi kte cin takudan unhapi śni ce, eya.

41 Unkan hena hecen eye cehan, hehan omniciye kin hide wicaśi.

\section{WICOWOYAKE 20.}

1 Owodutaton kin he henakeca, hehan Palos waonspewicakiyapi kin wicakico, qa i iwicaputaka, qa Makedonia ekta ye kta e hetanhan iyaya.

2 Unkan makoce kin hena opta iyaye ca, oie ota on iwaliokonwicakiye celıan, Helenes makoce kin en iyohi :

$3 \mathrm{Qa}$ wi yarnni hen owanji yanka. Unkan Suria ekta watom ye kta, hehan Juda wicaśta kin nahmana iyapepi kin heon Makedonia opta icicawin hde kta e iciconza.

4 Unkan Sopater Berea etanhan, qa Thesalonike etanhan Aristarkos Sekundos kici, qa Gayos Derbe etanhan, ga Timotheos, qa Asia wicaśta, 'Pucikos qa Trophimos, hena Asia ekta Palos kici yapi.

5 Hcna e tokata yapi, qa Troas en unkapepi.

6 Unkan aguyapi on napoliyapi codan anpetu kin iyohakam, Philippi etanhan watounpapi, qa anpetu zaptan hehan Troas en wicunkihdegapi, qa hen ánpetu śakowin unkokilipapi.

7 Unkan anpetu tokaheya kin he en waonspewicakiyapi kin aguyapi kiyuśpa imniciyapi, hehan Palos wowicakiyaka, hanlianna hetanhan hde kta, hecen hanye cukaya hehanyan wahokonwicakiya yanka.
8 Unkan wankan tipi ohna mniciya yukanpi kin he en petijanjan ota hdepi.

9 Unkan kośka wan, Yutikos eciyapi kin he owanyeye kin en iyotankehan yanke ca, iśtinbe hinca: unkan Palos tehan woyake cin icunhan, iśtinma iwanke ca, owanka iciyamini kin hetanhan hinhpaye ça ța ecen eyakupi.

10 Hehan Palos kun ye ca akan elpeiciye ça, poskin yuze ca, Ihnuhan yaceyapi kin, taniya kin nahahin mahen un ce, eya.

11 Qa ake wankan ye ca, aguyapi kiyuśpe ca, yute cạ, tehan ia yanke cin, anpa kamdeze cin hehanyan, hehan hetanhan kihda.

12 Unkan kośka qon ni ikikeupi qa nina pidapi.

13 Unkan unkiye tokaheya wita wata kin ekta unyanpi, qa Asos ekta watom unyanpi, heciyatanhan Palos en ope unśipi kta unkecinpi ; iye qe hehanyan mani cin, qa heon hecon unśipi.

14 Unkan Asos elkta eunkihdegapi qehan, hehan en ope unkiyapi, qa Mitulene en unhipi.

15 Unkan hetanhan iyoopta watom unyanpi, qa ihanhanna qehan Kios en iyotakons unyanpi ; qa ake iharihanna qehan Samos iyounhipi, qa 'l'rogulios en owanji unkanpi; qa ake ihanhanna qehan Miletos ekta unkipi.

16 Palos Ephesos en icunom watom iyaye wacin, Asia en okilipe kte śni, qa okihi kinhan anpetu iwikcemna zaptan kin he en Jerusalem en un kta cin, qa heon inahini.

17 Unkan Miletos etanhan ye wicaśi, qa Ephesos en okodakiciye hunkawicayapi kin wicakico. 


\section{OHANYANPI QON.}

18 Unkan hena en hipi, hehan hewicakiya; Asia en wahi qon anpetu tokaheya hehantanhan, token ohinniyan cicipi waun kin sdonyayapi.

19 Tawacin ocowasin walibayedan waun, Itancan kin ohowada, iśtamnihanpe ota, qa taku wawiyutanyan un kin, Juda oyate nahmana iyamapepi kin on mahiyahde kin hena koya.

20 Qa taku on tanyan yaunpi kte cin takudan ipicidapi śni, tuka omniciyc kin en, qa tipi iyaza wociciyakapi qa waonspeciciyapi ece.

21 Wakantanka ckta ihduecetupi, qa Jesus Messiya Itancan unkiyapi wacinyanpi kin hena, Juda Helcnes oyate ko en mdaotanin ece.

22 Unkan nakaha iho, Woniya kin on makaśkapi ecen Jerusalem ekta mda, qa heciya taku mahiyahde kte cin sdonwakiye śni.

23 Tuka otonwe otoiyohi en Woniya Wakan mayaotanin qa, On kaśkapi qa wokakije miciun, keya cc.

24 'Tuka hena takuwada śni, qa wiconi mitawa kin telike wakida śni, iyuśkinyan ihunniyan waimnanke kta, qa wicohan Jesus Itancan maqu kin, Wakantanka towaonśida wotanin waśte omdake kte cin hee tanyan mduśtan kinhan.

$25 \mathrm{Qa}$ nakaha iho, niyepi kin Wakantanka tokiconze kin ociciyag ciipi qon owasin ake miite kin wanmayadakapi kte śni e sdonwakiya.

26 Heon anpetu kin de waayatanin ciciyapi, wicaśta owasin we kin on aśape śni waun.

27 Wakantanka tawacin kin ocowasin ociciyakapi qa takudan anawalibe śni.
28 Heon tanyan piiciyapi, qa optaye owasin en, Woniya Wakan waawanhdake nicagapi kin hena koya, qa Wakantanka taokodakiciye kin, iye we kin on opekiton qon he awanhdaka po.

29 Miye imdamde cinhan, hehan sunktokeca ocin śicapi kin niyepi en niipi kta, qa tahinca kin itonwicapapi kte śni he sdonwaya.

30 Qa niyepi enitanhanpi wicaśta icagapi kta, qa iś iyepi ihakam waonspewicakiyapi kin u wicakiyapi kta e nina yaśkiśkapi kta.

31 Heon kiktahan un po, qa waniyetu yamni, anpetu hanyetu ko, iśtamnihanpe amau, qa otoiyohi wahokonciciyapi amdaśtan śni, he kiksuya po.

32 Hunkawanjinciyapi, nakaha Wakantanka iś iye, qa towaonśida oie kin en aciupi; he icaliniyanpi, qa tona ska wicakagapi kin owasin om taku yuhe niciyapi kta e okihi.

33 Tuwe mazaska, qa mazaskazi, qa wokoyakc tawa kin wakon śni.

34 Han, minape kin dena on taku wacin kin mihdamma, qa tona om waun kin hena wicawecamna qon he niye sdonyayapi.

35 Hena owasin en waonspeciciyapi, heccn htayanipi, qa tona waśake śni un kin owicayakiyapi kta, qa Jesus Itancan oie qon yeksuyapi kta, Wicaqupi kin hee wowaśte, qa icupi kin hee aoptetu, eye ciqon he.

36 Hena hecen eya, unkan hehan canpeśka makehde inajin, qa owasin om cekiya.

37 Unkan owasin nina ceyapi, qa Palos poskin yuzapi, qa i iputakapi.

38 Miite kin ake tohinni wanmayadakapi kte śni eye ciqon, oie 
WICOWOYAKE 21 .

kin de on iyotan nina iyokiśicapi. Unkan wita wata kin ekta kici yapi.

\section{WICOWOYAKE 21.}

1 Unkan hena ehpewicunyanpi, qa pacanan iyeunyanpi, hehan Kos ekta owotanna unkupi, qa ihanhianna hehan Rodos ekta, qa hetanhan Patara en iyounhipi.

2 Qa hen wita wata wan Phenike ekta watom ye kte cin iye-unyanpi, qa he en unkopapi, qa hetanhan unyanpi.

3 Qa Kupros taninyan wanunyakapi, hehan catka tanhan elipeya unhiyupi, qa Suria ekta watom unkupi, qa Turos en unhdihunipi, hen wata taku ohnaka kin wahetajupi kta.

4 Unkan waonspewicakiyapi kin iyewicunyanpi, qa hen anpetu śakowin unkokihipapi; hena e qe Woniya Wakan eciyatanhan Palos Jerusalem ekta ye kte śni, keciyapi.

5 Tuka anpetu kin hena wanna unkihunnipi, hehan hetanhan inaunpapi, qa hena iś tawicupi śiceca ko owasin opapi, otonwe itankata hehanyan, qa huta kin ekta canpeśka makehde inaunjinpi, qa ptaya ceunkiyapi.

6 Unkan hehan nape unkiciyuzapi, qa unkiś wata kin en unkopapi, tuka iyepi kin ekta hdapi.

7 Unkan Turos etanhan watom unkupi kin he ihunni unkiyapi, hehan Ptolemais ekta unhipi ; qa hunkawanjin kiciyapi kin nape wicunyuzapi, qa anpetu wanjidan om unkanpi.

8. Unkan ihanhanna qehan, tona Palos kici unyakonpi kin, hetanhan inaunpapi, qa Kesarea en iyounhipi; qa Philip wotanin waśte oyake cin he ti kin en unyanpi, śakowinpi qon he wanji ee, qa he kici unyakonpi.

$$
95
$$

9 Unkan he cunwintku topa witanśna unpi, hena wokcanpi ece.

10 Unkan hen anpetu ota owanji unkanpi kin icunhan, wicaśta wokcan wan Agabos eciyapi, Juda makoce kin hetanhan apamahde hi.

11 Qa en unhiyupi qehan, Palos ipiyaka tawa kin icu, qa on siha nape ko iyaihdaśke ça, Woniya Wakan kin heya ce, Wicaśta tuwe ipiyaka kin de tawa hecinhan, he Juda wicaśta, Jerusalem ekta, hecen kaśkapi kta, qa Ikcewicaśta kin nape kin en wicaqupi kta ce, eya.

12 Unkan he naunlionpi qehan, tona en tipi kin hena om, ceunkiyapi, Jerusalem ekta ye kte śni. 13 Tuka Palos, Token ecanonpi qa yaceyapi, qa hecen cante mayadutakunipi śni he, Jesus Itancan caje kin on Jerusalem ekta makaśkapi, qa nakun mațe kta e wiyeya manka ce, eya.

14 Unkan wicada śni qehan, unkayaśtanpi qa, Itancan tawacin kin ecen econpi nunwe, unkeyapi.

15 Unkan anpetu kin hena iyohakam owasin piunkiciyapi, qa Jerusalem ekta itawankanhde unyanpi.

16 Nakun Kesarea etanhan waonspewicakiyapi kin wanjikji unkopapi, qa wanji Mnason eciyapi kin he aupi, he Kupros etanhan, wanakaja waonspekiyapi kin heca, he ti kin en unyakonpi kta.

17 Unkan Jerusalem ekta iyounhipi, hehan hunkawanjinkiciyapi kin iyuśkinyan tin unkicopi.

18 Unkan ihanlianna kin hehan, Palos kici Jakob ekta unyanpi; unkan hunkawicayapi kin owasin en yukanpi. 


\section{OḦANYANPI QON.}

19 Hena nape wicayuze ca, hehan Ikcewicaśta kin ekta iye woyake cin on token Wakantanka econ qon owasin ecekcen owicakiyaka.

20 Unkan hena nationpi qehan, Itancan kin idowanpi qa Palos heciyapi, Cinye, Juda wicaśta kektopawinge ota wicadapi, qa owasin wicoope kin sutaya awakicinpi kin he wandaka.

21 Qa niye, Juda oyate Ilkcewicaśta ehna yakonpi kin hena owasin Moses toope kin ahduśtanpi kta e onspewicayakiye ca, cinca bawicakicihdayapi kte śni, qa wicohan kin hena eciyatanhan manipi kte śni, keha keyapi e nalionpi.

22 Heon toketu kta he. Awicakehan wicota kin kawitaya iheyapi kte. Wanna yahi kin he nationpi.

23 Hecen token unkeniciyapi kin de ecen econ wo. Wicaśta tom token içiconzapi kin hena om unyakonpi.

24 Hena owicape ca, om ihduska, qa mazaska on owicakiya wo, hecen paha kin hduśdapi kta. Unkan hecen token oniyakapi nahonpi qon hena taku śni, qa niś eya owotanna mayani, qa wicoope kin opeya yaun kin he owasin sdonyapi kta.

25 Tuka Ikcewicaśta, tona wicadapi kin hena wowapi wicunkicagapi, qa wicohan kin dena takudan opapi kte śni unkeyapi qon, tuka taku wakagapi wakiyuśnapi, qa we, qa taku we ye śni yuțapi kin, qa wiinalimanpi kin hena en ihdoipi kte śni ce, hecedan unkeyapi.

26 Hehan Palos wicaśta kin hena owicape ca, ihanhanna kin hehan om ihduska, qa ihduskapi anpetu kin wanna henakeca kte cin he yuotanin kta e tipi wa- kan kin tin iyaya; taku qupi wan otoiyohi on wośnapi kta hehantu.

27 Unkan anpetu śakowin qon wanna henakeca kte hehan Ju. da wicaśta, Asia etanhan upi qon hena tipi wakan kin en un wanyakapi qehan, oyate kin owasin iyowicapaśtakapi qa $P a-$ los iyahpayapi ;

$28 \mathrm{Qa}$ hotaninpi, Israel wicaśta kin, ounkiya po; wicaśta kin de oyate kin en, qa wicoope kin, qa nakun tipi kin de aie ça, owancaya hecen onspewicakiya; qa nakun Helenes wicaśta kin tipi wakan kin en awicahi, qa hecen tipi iyotan waśte kin de aśamya ce, eyapi.

$29 \mathrm{He}$ itokam Trophimos, Ephesos wicaśta kin heca, e otonwe kin en kici un qon he wanyakapi, unkan he Palos tipi wakan kin en ahi, kecinpi.

30 Unkan otonwe kin ocowasin nina oqoyapi, oyate kin kawitaya iheyapi, qa Palos icupi, qa tipi wakan kin etanhan tankan yusdohan ayapi, unkan ecahankeya tiyopa kin ecen iyeyapi.

31 Wanna ktepi kta e akitapi, hehan akicita tancan wicobe yuhe cin he, Jerusalem owancaya owodutaton ce, eya okiyakapi kin he nation;

32. Qa kohanna akicita, akicita tancan ko iwicacu, qa inyang ye ca ekta wicai. Unkan akicita tancan akicita ko wanwicayakapi qehan, Palos apapi kin ayuśtanpi.

33 Hehan akicita tancan kin en ye ca, icu, qa maza icicaliitia nom on lasśke wicaśi; qa he tuwe kin, qa token econ kin he, eya iwicawanga.

34 Tuka oyate kin hunh taku eya hotaninpi, qa hunli iś togye eyapi. Unkan owodutaton kin 
on wowicake kin sdonya okitpani, heon conkaśke kin mahen aye wicaśi.

35 Unkan can iyadipi kin en hdipi, hehan akicita kin yuha ayapi, oyate kin aoțins upi kin heon etanhan.

36 Oyate kin iyulipa ihakam yapi qa, Yutokan aya po, eya hotaninpi.

37 Unkan conkaśke kin mahen ayapi kta, hehan Palos akicita tancan kin heciya, Taku eciciye kta tuka ce, iyowinmayakiye kta he. Unkan iś, Helenes iapi kin onnispe he, eya.

38 Egupta wicaśta anpetu kin dena itokam icage ca, wicaśta wabotica kin hecapi kektopawinge topa ihakam hewoskan makoce kin ekta awicaye ciqon he niye śni he.

39 Unkan Palos, Juda wicaśta Kilikia en, Tarsos otonwe kin hetanhan waun, otonwe sice śni en imacaga. - Ceciciya ce, oyate kin taku ewicawakiye kta, iyowinmakiya wo, eya.

40 Hecen iyowinkiya; unkan Palos can iyadipi kin akan inajin, qa oyate kin namwicakicawin. Unkan inina yukanpi qehan, Hebrew iapi kin on ie ça, hewicakiya ;

\section{WICOWOYAKE 22.}

1 Wicaśta hunkawanjinciyapi qa hunkakeciyapi kin, nakaha niyepi en wowahdake cin namahon po.

2 Unkan Hebrew iapi un wowicakiyake cin he nahonpi qehan, iyotan inina yukanpi.

3 Unkan hecen eya; Juda wicaśta kin hemaca, Kilikia ekta Tarsos en matonpi, qa otonwe kin de en icalimayanpi, qa Gamaliel siha kin ekta, hunkake wicayapi wicoope yuhapi kin tanyan onspemakiyapi, qa Wakantanka on nina inawalini, niyepi kin owasin nakaha yaunpi kin iyececa.

4 Qa canku kin de wiconte aiyahdeya śicaya wakuwa, wicawakaśke ça, wicakaśka tipi kin en iyewicawaya, wica winyan ko.

5 Hecen wośna kagapi itancar, qa hunka wicayapi kin owasin mayaotaninpi ece. Hena eepi hunkawanjinkiciyapi kin wowapi wicakicagapi qa máqupi qon, hecen Damaskos ekta imdamde, heciya tona yukanpi kin hena wicakaśka Jerusalem ekta wicakaśtakapi kta e awicawau kta, heon etanhan.

6 Ohnihde waun, qa Damaskos wanna ikiyadan, unkan wiyotanhe cin hehan, iho, ihnuhanna mahipiya kin eciyatanhan iyoyanpa tanka wan aohdute mayan.

7 Hehan makata mahinhpaye ca, wicaho wan nawahon, Salos, Salos, tokeca e sicaya mayakuwa he, emakiya.

8 Unkan miś amdupte ça, Itancan nituwe he, epa. Hehan iś, Jesus Nazareth etanhan śicaya yakuwa kin he miye ce, emakiya. 9 Unkan tona om waun kin ojanjan kin wanyakapi, qa nina inihanpi, tuka wicaho omakiye cin he nahonpi śni.

10 Hehan miś, Itancan token ecamon kta he, epa. Unkan Itancan kin, Najin, qa Damaskos ekta ya wo, heciya token ecanon kte cin owasin oniciyakapi kta ce; emakiya.

11 Unkan iyoyanpa wiyatpa kin on wawanmdake śni, hecen tona om waun kin hena minape kin yus amayanpi, qa Damaskos en wai. 


\section{OHANYANPI QON.}

$12 \mathrm{Qa}$ wicaśta wan, Ananias eciyapi, wicoope kin eciyatanhan owotanna, Juda oyate hen yakonpi kin owasin he oyakapi ;

13 He en mahi, qa najin, qa hemakiya, Salos, misunka tonwan wo. Unkan wihiyayedan oape kin he en ekta ewatonwan.

14 Hehan iye heya; Hunkake wicunyanpi Wakantanka tawapi kin nicahniga, iye tawacin kin sdonyaye kta, qa Wanji Owotanna kin wandake ça, he i kin eciyatanhan ho kin nayahon kta;

15 Qa iye on taku wandake ca, nayahon kin wicaśta owasin owicayakidake kta heon.

16 Unkan nakaha taku e ayape he. Najin wo, baptem niçupi kta, Itancan caje kin hoyeyakiye kta, hecen wayahtani kin yakpakinte kta ce, eya.

17 Unkan ake Jerusalem ekta icicawin wahdi, qa tipi wakan kin ohna cekiya waun, hehan woakiktonje wan mahiyahde ;

18 Qa Itancan kin wanmdaka; he kaken emakiya; Inahni, qa kohanna Jcrusalem etanhan inanpa wo, mayadaotanin kin he wicadapi kte śni ce, eya.

19 Unkan hepa; Itancan, tona wacinniyanpi kin hena wicawakaska, qa omniciye tipi kin ohna wicawakaśtaka ece qon he sdonyapi :

$20 \mathrm{Qa}$ Stephanos waayatanin nitawa kin we papsonpi qehan, hen nawajin, qa he iyowinwicawakiye ca, tona ktepi taśina awanwicaweciyaka qon.

21 Hehan, Hunktiya wo, detanhan tehan ye ciśi, Ikcewicaśta kin ekta,. emakiya ce.

22 Unkan wicoie kin de hehanyan nalion yukanpi, hehan nina hotaninpi qa, Wicaśta kin de ma- ka kin etanhan aya po, ni kta e iyecece śni ce, eyapi.

23 Unkan hotankakiya hotaninpi, qa śina elipekiyapi, qa watuśekśeca wankan yeyapi kin;

24 Hehan akicita tancan kin, conkaśke mahen aupi, qa kapsinpsintapi kin on wiwangapi kta, keya; hecen tokeca on oyate kin nina aoqoyapi kin he sdonye kta.

25 Unkan tehmiso on kaśkapi icunhan, Palos akicita tancan wan en najin kin heciya, Roma wicaśta kin heca, qa nahaliin yacopi śni, tuka yakapsinpsintapi kta oyalkihipi he.

26 Akicita tancan kin he nahon, unkan akicita tancan tanka kin hośi hde ça heya; 'Taku ecanon kte cin he itonpa wo, wicaśta kin he Roma kin heca.

27 Hehan akicita tancan tanka kin en hi, qa heciya, Roma wicaśta kin henica he, omakiyaka wo. Unkan, Han, eya.

28 Unkan akicita tancan qon heya, Ihduhapi kin de ota iyopewakiya, eya. 'Tuka miś hecen matonpi ce, Palos eya.

29 Heon kohanna tona Palos wiwangapi kte cin hena ayuśtan iyayapi, qa akicita tancan tanka kin nina kopehda; he kaśka tuka Roma wicaśta kin heca e sdonye cin he etanhan.

30 Unkan ihanhanna qehan, Juda oyate taku iyaonpapi hecinhan, he atayedan sdonye kta, heon icaślke kin etanhan kiyuśke ca, wośna kagapi, hunkawicayapi ko owasin mniciye wicaśi, qa hehan en ahi, qa wicacokaya ehde.

WICOWOYAKE 23.

1 Unkan Palos omniciye kin opawicalita yanke ça, Wicaśta

224 


\section{WICOWOYAKE 23.}

hunkawanjin ciyapi, Wakantanka itokam mitawacin ocowasin waśte, anpetu kin dehan wani, eya.

2 Unkan Ananias wośna kagapi itancan kin, tona ikiyadan najinpi kin Palos i kin ohna ape wicaśi.

3 Hehan Palos heciya, Conkaśke skayapi kin, Wakantanka anipe kta ce; wicoope kin eciyatanhan mayadaco kta e yahidotanka tuka wicoope kaśeya amape wicayaśi.

4 Unkan tona en najinpi kin, Wakantanka wawayuśna itancan tawa kin he śicaya owayakiya he, eyapi.

5 Unkan Palos, Hunkawanjinciyapi, he wawayuśna itancan kin ee sdonwaye śni, eya; Wowapi en kaken kagapi, Nitaoyate kin en wicaśta itancan kin daśice kte śni ce.

6 Tuka apa Saddukee, qa apa iś Pharisee kin hecapi e Palos iyukcan qehan, hehan omniciye kin en hotankakiya heya; Pharisee kin hemaca, qa nakun Pharisee cinhintku kin, qa wicate cin piya ikicagapi kte cin ape waun kin heon etanhan nakaha mayacopi ce.

7 Unkan hecen eye çehan, Pharisee Saddukee kin om hdokinicapi, qa omniciye kin akipam iyeyapi.

8 Piya ikicagapi kin wanica, qa mahpiya ohnihde, wanagi ko wanica ce, Saddukee kin eyapi ece; tuka Pharisee kin, Napin yukan ce, eyapi ece.

9 Hecen nina owodutaton, qa wowapi kagapi Pharisee etanhanpi kin hena inajinpi, qa wicakigepi, qa heyapi, Wicaśta kin de en taku śica takndan iyeunyanpi śni ; tuka wanagi, qa malipiya ohnihde wan taku okiyake Dak. cin he hecetu kinhan, Wakantanka kici unkicizapi kte śni.

10 Nina hdokinicapi, unkan Palos yuśpaśpa icupi kta e akicita tancan tanka kin kokipe ca, heon akicita kin kun ye wicaśi, hena wicacokaya tanhan icupi, qa conkaśke kin mahen akupi lkta.

11 Unkan he ihtayetu, hehan Itancan kin en hinajin qa, Palos cante waśte wo, Jerusalem en mayadaotanin kin he iyecen Roma ekta mayadaotanin kta ce, eciya.

12 Unkan anpa kamdeze cin, hehan Juda wicaśta wanjikji okodakiciye wan kagapi, qa witaya içiconzapi, takudan yutapi kte śni, qa takudan yatkanpi kte śni, Palos ktepi śni kin hehanyan kta, keyapi.

13 Wakiconzapi kin hena wicaśta wikcemna topa aktonpi.

14 Unkan hena wawayuśna tankapi, qa hunka wicayapi ko en wicayapi, qa hcyapi; Palos unktepi śni kin hehanyan, takudan untapi kte śni e wokonze on unkiconzapi.

15 Heon etanhan hanhanna, niye omniciye kin owasin om akicita tancan tanka kin he au yaśipi kta, taku sanpa atayedan inungapi kta seca e heon; qa unkiś he ikiyadan aupi śni, hehan unktepi kta e wiyeya unkanpi kta ce, eyapi.

16 Unkan hena nahmana iyape yukanpi kin he Palos tonśkaku kin nahon qehan, hehan ekta ye ca conkaśke kin timahen i, qa Palos okiyaka.

17 Hehan Palos akicita tancan wanji kico qa, Kośka kin de akicita tancan tanka kin ekta aya wo, taku okiyake kta ce, eya.

18 Unkan heon he icu, qa akicita tancan tanka kin ekta ai qa, 


\section{OḦANYANPI QON.}

Palos kaśkapi un kin he mico, qa kośka kin de cicahi kta e econ maśi, taku oniciyake kta keya ce, eya.

19 Hehan akicita tancan tanka he nape yuze ca kiciśnana icunom iyaye ca, Taku omayakidake kta he, eya iwanga.

20 Unkan, Heyakecinhan Juda wicaśta kin omniciye kin en $\mathrm{Pa}$ los au niśipi kta wanna konzapi, taku sanpa atayedan iwangapi kta seca e heon heyapi.

21 Tuka niś awicayupte śni wo. Wicaśta wikcemna tom aktonpi kin wokonze on wakiconzapi, Palos ktepi śni hehanyan takudan yutapi kte śni qa takudan yatkanpi kte śni, hena nakaha wiyeya yukanpi qa niśs awicadupte kte cin he ape yukanpi, eya.

22 Hehan akicita tancan tanka kośka qon hdicu ye ça, Hena omayakidake cin he tuwedan sdonye ye śni wo, eciya.

23 Qa hehan akicita tancan nom wicakico qa, Akicita opawinge nom taku owasin on wicayuwiyeya po, qa nakun śuktanka akan yotankapi kin wikcemna śakowin, qa wahukeza yuhapi kin opawinge nom, hanyetu kin oape iyamni, hehan Kesarea ekta yapi kta ce.

24 Nakun suktanka wiyeya ehnaka po, Palos akan yankekiyapi kta, qa Phelika wicaśta itancan yanke cin he en tanyan aipi kta, ewicakiya.

25 Hehan wowapi wan kaken kaga :

26 Kladios Lusias, Phelika wicaśta itancan iyotan waśte kin wowapi kicaga ce. Wookiye.

27 Wicaśta kin de Juda wicaśta kin icupi, qa wanna ktepi kta hehan akicita hduha en wai, qa etanhan iwacu, he Roma wica- śta kin heca e nawahon kin heon.

28 Qa taku iyaonpapi kin he tanyan sdonwaye kta wacin, heon iye omniciye yuhapi kin en awai ;

29 Qa iye wicoope hduhapi kin eciyatanhan wiwangapi kin iyaonpapi wanmdaka, tuka taku on ktepi, qa kaśkapi kta e iyaonpapi kin takudan iyewaye śni.

30 Qa wicaśta kin de Juda wicaśta nahmana iyape yukanpi kin he omakiyakapi qehan, kohanna niye ekta aye wicawaśi, qa tona taku en aupi kte cin hena hecen iyaonpeya eniciye wicawaśi. Tanyan yaun nunwe.

31 Hehan akicita iś econ wicaśi qon iyecen Palos hanyen icupi, qa Antipatris en aipi ;

32 Qa hanhanna hehan suktanka akan yotankapi kin hena hetanhan ayapi kta e ehpewicayapi, qa conkaśke kin ekta hdicupi. 33 Unkan hena iś Kesarea ekta ipi, qa wicaśta itancan wowapi qon qupi qehan, hehan Palos itokam ehdepi.

34 Unkan iye he yawa, qa maknce kin tukte e etanhan un hecinhan wiwanga; qa Kilikia etanhan un kin he sdonya;

35 Hehan, Tohan tona taku iyanionpapi kin hena nakun hipi kinhan, hehan miś eya nacihon kta ce, eya; qa Herod woyaco tipi tawa qon he ohna awanyag wicaśi.

\section{WICOWOYAKE 24.}

1 Unkan hetanhan anpetu zaptan, hehan Ananias wawayuśna itancan kin hee, qa hunkawicayapi kin om, ekta apamahde ya, nakun wicaśta ieksapa wan, Tertulos eciyapi, hena wicaśta itancan kin itokam Palos taku iyaonpapi kta. 
2 Unkan en kicopi qehan, Tertulos taku iyaonpe ça heya;

3 Niye enitanhan wookiye tanka unhapi ce, qa waa wandake cin eciyatanhan oyate kin de en wicohan waśte econpi ece kin he ohinniyan qa owancaya unkicupi, qa on, Phelika iyotan waśte, wopida unkeniciyapi ce.

4 Tuka sanpa nagiyeciye kte śni, heon ceciciya ce, nitowaonśida kin on wicoie wanjikji naunyahompi kta.

5 Wicaśta kin de makośice, qa maka kin owancaya Juda oyate cante okicuninwicaye cin, qa yuomdecapi wan Nazareth etanhanpi, ewicakiyapi kin he en mdetahunkapi kin he wanji dee e iyeunyanpi ce.

$6 \mathrm{He}$ tipi wakan kin yusape kta; unkan hehan unkiś unkicupi, qa wicoope unkitawapi kin eciyatanhan unyacopi kta ;

7 Tuka Lusias akicita tancan tanka kin ekta i, qa wicowaśake tanka on unnapepi kin etanhan eyaku.

8 Qa tona taku iyaonpeya eyapi kin hena niye kin ekta $u$ wicaśi. Hena wiwicanunge cinhan taku iyaunkonpapi kin owasin atayedan sdonyaye kta ce.

9 Unkan Juda wicaśta kin iś waayuptapi qa, Hena hecetu ce, eyapi.

10 Hehan wicaśta itancan kin Palos ie kta e namkicawin, lehan waayupte; Oyate kin de en waniyetu ota wicaśta wayaco nanka e sdonwaya, heon etanhan nakaha iyuśkinyan wowahdaka.

11 Hecen Jerusalem ekta cekiya imdamde cin, hehantanhan wanna anpetu ake nomnana e sdonyaye kta oyakihi.

12 Qa tipi wakan kin ohna tuwe kici awakinica ecen wanma- yakapi śni, qa omniciye tipi kin ohna, qa otonwe kin en, oyate kin wicayuomdeca waun śni.

13 Qa nakaha taku iyamaonpapi kin hena yasutapi kta e okihipi śni.

14 Tuka de ociciyaka, yuomdecapi kin cajeyatapi qon he canku kin olina hunkake wicawaye cin Wakantanka tawapi kin ohowada, qa wicoope, qa wicaśta wokcan taku owapi qon hena owasin wicawada :

15 Qa Wakantanka wacinwaye, qa wicate cin, waśte śica ko, ake woekicetu kte cin he ape waun, he iś iyepi nakun hecen wicadapi.

16 Heon Wakantanka, qa nakun wicaśta kin en tawacin takudan iyaonpepica śni waun kta e ohinniyan opimiçiya ce.

17 Unkan nakaha waniyetu ota iyohakam, mitaoyate kin taku qupi, wośnapi ko wicawecicau kta e wahdi.

18 Qa hecen tipi wakan kin ohna mihduska waun, wicota qa owodutaton kin unmana en owape śni, ecen Juda wicaśta Asia etanhan wanjikji wanmayakapi qon.

19 Hena eepi kin niye en nihiyupi, qa taku yuhapi kinhan iyamaonpapi kta tuka.

20 Qa dena iś, omniciye kin en nawajin kin, he icunhan taku śica ecamon kin taku sdonyapi kinhan oyakapi kta.

.21 Tuka wicacokaya nawajin qehan, wicoie wanjidan taniny an epa, Anpetu kin de wicațe cin woekicetu kte cin heon mayadacopi, epe ciqon hee, eya.

22 Unkan Phelika hena nahon qehan, qa canku kin de on sanpa tanyan sdonye kta cin kin heon, hde wicaśi qa, Tohan Lusias akicita tancan tanka hi kinhan, 227 


\section{OḢANYANPI QON.}

niyepi kin on taku owasin sdonwaye kta ce, eya.

23 Qa akicita tancan wan $\mathrm{Pa}$ los awanyag kiye ca, woozi yuhe kta, qa iye takuwicaye cin tuwe en hi qa okiye kta cin kinhan tehinda kte śni, keya.

24 Unkan anpetu tonana iyohakam, Phelika, qa tawicu Drusila eciyapi, Juda winohinca kin heca, he kici hi, hehan Palos kico, qa Messiya wacinyanpi kin on nation.

25 Unkan Palos wicoowotanna, qa iyatahde içiyapi śni, qa woyaco u lite cin hena oyake cin, he icunhan Phelika cancan, qa, Nakaha ekta hda wo, tohan tanyan iyomakipi kinhan ake cico kta ce, eya.

26 Palos kiyuśke kta e on mazaska qupi kta kecin, heon kico, qa kici wohdaka ece.

27 Tuka wanna waniyetu nonpa, hehan Phelika yanke cin en Porkios Phestos hiyotanka. Unkan Phelika Juda oyate kin iyokipi wicaye kta cin, qa heon Palos kaśkapi ecen elipeya kihda.

\section{WICOWOYAKE 25.}

1 Unkan Phestos makoce kin he en hiyotanke cin, iyohakam anpetu yamni, hehan Kesarea etanhan Jerusalem ekta itawankanhde iyaya.

2 Unkan wawayuśna itancan qa Juda wicaśta tokapapi kin, Palos on okiyakapi qa cekiyapi.;

3 Cinkiyapi, Jerusalem elkta Palos au wicakiye kta, qa iyepi kin nahmana ktepi kta e tahepi iyapepi kta.

4 Tuka Phestos, Palos Kesarea ekta awanyakapi kta, qa iye kin ecadan ekta hde kta, keya.

5 Qa niyepi kin etanhan tona 228 waśakapi kinhan, apamahde om mde kta, qa wicaśta kin he taku en un kinhan wiyaonpapi kta ce, eya.

6 Unkan anpetu śahdogan, qa iś wikcemna hena om un kin, hehan Kesarea ekta lida, qa ihanhanna qehan woyaco oiyotanke kin akan kiyotanke cin, hehan Palos en au wicaśi.

7 He en hi, unkan hehan Juda wicaśta Jerusalem etanhan hipi qon hena ihdukśan najinpi, qa wiyaonpapi tanka ota Palos en aupi, tuka yaecetupi okihipi śni. 8 Hehan iye wohdaka; Juda oyate wicoope hduhapi, qa tipi wakan kin en, qa nakun Kesar en takudan wawalitani śni ce, eya.

9 Tuka Phestos Juda oyate kin iyokipi wicaya cin, heon Palos ayupte ca heciya; Jerusalem ekta de ça, heciya mitokam dena on niyacopi kta tawațenyaya he, eya.

10 Hehan Palos, Kesar woyaco oiyotanke tawa kin en nawajin, hen mayacopi kta iyececa; Juda oyate kin taku śice cin takudan ecawicawecon śni e tanyan sdonyaya.

11 Wawahtani, qa taku śica on maktepi kta iyecece cin he ecamon kinhan, mate kta tawatenwaya tuka; tuka dena taku iyamaonpapi kin taku śni kinhan, tuwedan hena mayuhe wicakiye kte śni. Kesar cajemdata ce, eya.

12 Hehan Phestos, tona owicapeya wayaco iyotanke cin hena om wohdaka, hehan ayupta; Kesar cajedata, Kesar elita de kta ce, eya.

13 Unkan anpetu tonana iyohakam, Agrippa wicaśtayatapi kin Bernilke kici, Phestos nape yuzapi kta e on Kesarea en hipi. 


\section{WICOWÖYAKE 26.}

14. Qa anpetu ota hen yukanpi, hehan Phestos wicaśtayatapi kin Palos on okiyake ca heya, Wicaśta wan Phelika kaśka ehnake ciqon he nahanhin ecen yanka.

15 Jerusalem ekta wai qehan, wawayuśna tankapi, qa Juda hunka wicayapi kin hena he kapi, qa omakiyakapi, qa yacopi kta e cinpi.

16 Hena hecen awicamdupte ca, Wicaśta wan taku iyaonpapi kinhan, tona taku iyaonpeya eyapi kin wicitokam wiyaonpapi kin en waayupte iyowinkiyapi śni kinhan, teyapi yacopi kin he Roma wicolian śni ce, epa.

17 Heon hena den hipi, unkan mdutehan śni, tuka ihanhanna hehan, woyaco oiyotanke . kin akan wakimdotanke ca, wicaśta kin he en au wicawaśi.

18 Hehan tona taku iyaonpapi kin hena najinpi, tuka token wacami qon he iyecen takudan iyaonpapi śni.

19 Tuka iyepi wocekiye eyapi kin eciyatanhan wiwicawangapi kin wanjikji he en aupi, qa nakun wanji Jesus eciyapi kin he ța, tuka ake kini kin, Palos keya ece.

20 Unkan wiwicawangapi heca kin imdukcan śni heon, Jerusalem ekta de ca heciya dena on niyacopi kta tawatenyaya he, eya imunga.

21 Tuka Palos Sebastos cajeyate ca, he itokam yacopi kta keye cehan, Kesar ekta aye wicawakiye kta hehanyan awanyag wicawaśi.

22 Hehan, Miś eya wicaśta kin de nawahon kta wacin ce, Agrippa Phestos eciya. Unkan iś, Heyakecinhan nayahon kta ce, eya.

23 Unkan ihanlianna qehan,
Agrippa Bernike kici wokoyake waśteśte kicun hipi, qa wanalion tipi kin en tin ipi ; qa nakun akicita tancanpi kin, qa otonwe en wicaśta tokapapi kin hena ko; hehan Phestos econwicaśi kin on Palos en ahipi.

24 Unkan Phestos heya, Agrippa wicaśtayatapi kin, qa wicaśta tona den om unkanpi kin, wicaśta kin on Jerusalem ekta, qa deciya nakun, Juda oyate kin owasin cemalkiyapi qa, Sanpa ni kta e hecetu śni ce, eya hotaninpi qon, he dee wandakapi.

$25 \mathrm{He}$ taku śica econ kin, on te kte cin, takudan iyewaye śni, qa iś iye Sabastos cajeyate cin, heon ekta ayapi kta e wakonza. 26 Tuka he on, mayuhe cin taku wecage kte cin atayedan takudan mduhe śni. He etanhan nakaha en cicahipi, wicaśtayatapi kin niye iniyotan, hecen tohan tanyan wiwangapi kinhan, token wakage kte cin taku mduhe kta.

27 Wicaśta wan kaśkapi kin he heciya aye śipi, qa wiyaonpapi kin takudan kagapi śni kinhan, he hecetu śni imdukcan ce, eya.

\section{WICOWOYAKE 26.}

1 Hehan Agrippa Palos heciya, Wanna woyahdake kte cin iyowinniciyapi ce. Unkan hehan Palos nape kin hdugate ca wohdaka.

2 Agrippa wicaśtayatapi kin, Juda oyate taku iyamaonpapi kin owasin nakaha nitokan wowahdake kte cin heon imduśkin.

3 Juda wicohan kin wiwangapi ko owasin tanyan hdukcan nanka sdonwaya, heon etanhan. Qa hecen ceciciya ce, wacin tanka on namahon wo.

4 Tokaheya tanhan Jerusalem 


\section{OHANYANPI QON.}

ekta mitaoyate kin om, homakśidan ehantanhan, token ohanyan waun qon Juda wicaśta kin owasin sdonyapi.

5 'Token' ohoundapi ece kin owotanna lince cin en opeya waun, Pharisee hemaca, hena e otokaheya tanhan sdonmayanpi, oyakapi cinpi unkanś.

6 Qa nakaha Wakantanka hunkake wicunyanpi kin iwahowicaye ciqon he apepi kin on, den mayacopi kin ecen nawajin.

7 De ekta wicoun unkitawapi ake nonpapi kin iyohipi kta e ape yukanpi, qa anpetu hanyetu ko cekiyapi ece. Agrippa wicaśtayatapi kin, woape kin de on Juda wicaśta wimawangapi qon.

8 Wakantanka wicațe cin ake ekicetu wicaye cin he tokeca e he taku wicadapica śni kecanipi he.

9 Miś eya Jesus Nazareth etanhan caje kin on, taku ota kipajinyan ecamon kta iyececa kepce ciqon.

10 Jerusalem ekta hena hecen ecamon qon; qa wawayuśna tankapi kin wowaśake maqupi kin on, wicaśta owotanna kin ota wicakaśka tipi kin en iyewicawaye ca, țe yapi kta wicayacopi qehan, miś eya iyecen epa ece.

11 Qa omniciye tipi kin iyaza otakiya wicawakaśtake ca, waośtehda wicawakiye ca, nina canniye wicawaye cin heon otonwe tokeca ekta śicaya wicawakuwa.

12 He icunhan wawayuśna tankapi kin wowaśake wowapi ko maqupi kin, he yuha Damaskos ek ta imdamda.

13 Unkan tahepi iho, wicaśtayatapi, anpe cokaya kin hehantu, iyoyanpa wan anpetu wi kin sam iyeya wiyatpa kin he wan- mdaka, he ihdukśan iyoyanpa maye ca tona om mawani kin hena nakun.

14 Unkan owasin makata elipeunkiçiyapi, hehan wicaho wan nawalion, Hebrew iapi on hecen emakiya, Salos, Salos, tokeca śicaya mayakuwa he, can pesto kin nayalitake cin he tehika ce.

15 Unkan miś, Itancan, nituwe he, epa. Unkan, Jesus śicaya yakuwa kin he miye ce, eya.

16 Tuka inajin, qa nisiha kin on najin wo; token. wandake ca, tolkata taku wanyag ciciye kte cin hena en waayatanin, qa ookiye kin cicage kta e heon nakaha wanmayag ciciya.

17 Oyate kin etanhan ecihdaku kta, Ikcewicaśta kin nakun, hena e ekta nakaha ye ciśi.

18 Iśta wicadumdaye ça, otpaza etanhan iyoyanpa ekta, qa Satan towaśake kin etanhan Wakantanka ekta wicaduhomni kta; qa hecen wacinmayanpi kin on walitanipi wicakicicajujupi kin, qa tona ska wicakagapi kin hena om woyuha yuhapi kta ce.

19 Hecen on, Agrippa wicaśtayatapi kin, mahpiya wowanyake kin he cetunwahda śni.

20 Tuka tokaheya Damaskos en yakonpi, qa Jerusalem, qa Juda makoce kin owancaya, qa nakun Ikcewicaśta kin, ihduecetupi, qa Wakantanka ekta ihduhomnipi kta, qa ihduecetupi wicohan kin econpi kta hena hecen owicawakiyaka ece.

21 Hena on etanhan, Juda wicaśta kin tipi wakan kin ohna mayuzapi, qa maktepi kta tuka. 22 Tuka Wakantanka omakiye cin heon anpetu kin dehanyan wani, qa tona ciqapidan tankinyanyan ko, wicawakiyantanin, 


\section{WICOWOYAKE 27.}

qa wicaśta wokcan kin Moses kici taku u kte cin oyakapi qon henana owicawakiyaka ece.

23 Messiya kakije kte ca iye tokaheya wicate cin etanhan najin kta, qa oyate kin Ikcewicaśta ko iyoyam wicaye kte cin.

24 Hena hecen eya, unkan Phestos hotankakiya ie ca, Palos niyuhnaśkinyan, wowapi ota onspeniciciye cin he wicayuhnaśkinyan en iyeniyan ce, eya.

25 Tuka iye, Phestos iyotan waśte kin, mayuhnaśkinye śni, tuka wowicake wicowahbadan oie kin epa ce, eya.

$26 \mathrm{Qa}$ wicaśtayatapi kin iś hena tanyan sdonya, heon itokam waditagya wowahdaka, hena taku kin iye kin anakihmanpi śni e mdukcan, okahmin en econpi śni nakaeś.

27 Agrippa wicaśtayatapi kin, wicaśta wokcan kin hena wicayada he. Wicayada e sdonwaya. 28 Hehan Agrippa Palos heciya; Kitan ecinyan Kristian hemaca kta e awacinmayaya ce.

29 Unkan Palos heya, Wakantanka cewakiya ce, niye niśnana śni, tuka tona anpetu kin de namahonpi kin owasin, kitan ecinyan hee śni, tuka ocowasin miś waun kin iyecen yaunpi kta, tuka icaślke kin dena ope kte śni.

30 Hena hecen eya, unkan hehan wicaśtayatapi, qa wicaśta itancan kin, Bernike kici, qa tona om iyotankapi kin hena ko najinpi ;

31 Qa icunom yapi qa, Wicaśta kin de taku on țe kte ça, kaśkapi kte cin takudan econ śni ce, iyakitedan ekiciyapi.

32 Hehan, Wicaśta kin de Kesar cajeyate śni unkanś kiyuśkapi kta tuka, Agrippa Phestos eciya.
WICOWOYAKE $2 \%$.

1 Unkan Italia ekta watom unyanpi kta e wanna konzapi, hehan Palos qa wicakaśkapi tokeca kin, akicita tancan wan, Sebastos taobe kin etanhan, Julios eciyapi kin, he wicayuhekiyapi.

2 Unkan wita wata wan Adramutium etanhan, Asia makoce kin ekta tuktekten oihunni kte cin he en unkopapi, qa pacanan iyeunyanpi, qa Aristarkos Makedonos, Thesalonike etanhan, he kici unvanpi.

3 Unkan ihanhanna qehan, Sidon en unkihunnipi. Unkan Julios Palos tanyan okicihan, takuwicaye cin ekta wicai, qa hena etanhan taku yuhe kta e iyowinkiya.

4 Unkan hetanhan pacanan iyeunyanpi, qa Kupros ihukuya watounpapi, tatoheya unyanpi kin heon.

5 Unkan Kilikia qa Pamphulia miniwanca kin unkihunnipi qehan, Lukia en Mura eciyapi kin he ekta unhipi.

6 Unkan hen wita wata wan Aleksandria etanhan, Italia ekta watom ye kte cin, he akicita tancan kin wanyake ca, he en ope unyanpi.

7 Unkan anpetu ota iwaśtedan watounpapi qa kitan se Knidos en iyotakons unkipi, tatoheya unyanpi nakaeś, hehan Krete ihukuya, Salmone iyotakons watounpapi.

8 Qa he kitan se kapeya unyanpi, hehan makoce wan Oihunni waśte eciyapi kin he en unkipi, he Lasea otonwe kin ikiyadan.

9 Wanna anpetu ota, qa watopapi kin okokipe aya, hamdepi tanka kin wanna enakiyapi, hehan Palos wahokonwicaliya; 231 


\section{OḢANYANPI QON.}

10 Qa hewicakiya, Wicaśta kin, watounpapi kte cin de on wita wata kin taku ohnaka ko y.utakunipi kte śni, qa nakun unkiyepi kin iyotanhan iyeunkiyapi kta e imdukcan ce, eya.

11 Tuka akicita tancan kin, wahektape cin qa wita wata tawa kin hena anawicakicigoptan, qa Palos ie cin he wicada śni.

12 Unkan oihunni kin he en waniyetu osan yukanpi kte cin he waśte śni, heon hetanhan yapi, qa okihipi kinhan, Phenike ekta watom ipi, qa hen waniyetu owanji yukanpi kta, wicota keyapi; Krete en oihunni wan itokagatanhan, wiyohpeyata ohna waziyata etkiya huta kin yuśkomya wanke cin hee.

13 Unkan okaga tanhan tate kin iwaśtedan hiyu, qa hecen token wacinpi qon wanna ecetu kecinpi, hehan kiyuśkapi qa Krete ikiyedan watopapi.

14 Tuka iecadan, tateyanpa wan ohitike cin he en iyapa hiyu, he Tate-taja eciyapi.

15 Unkan wita wata kin nina iyapa, hecen tatoheya yapi okihipi śni, hehan kaha iyeunyanpi iyowinunkiyapi.

16 Unkan wita wan Klauda eciyapi, he ikiyadan unyanpi, hehan kitan hin wata cistinna kin icu unkokihipi.

17 He yuwankan ehdakupi, qa icaśke kin unpi, qa wita wata kin opta yuskiskitapi, hehan wiyaka śice cin en iyohpeyapi kta kokipapi, qa heon śina on watopapi kin pahpapi, qa hecen tate on kaha iyewicayapi.

$18 \mathrm{Qa}$ nina unkakilianśicapi, heon ihanlianna, hehan wata kin etanhan taku tankan ehpeyapi.

19 Qa anpetu iciyamni hehan, unnapepi kin on, wita wata kin 232 en, taku wowinyunyanpi kin minin ehpeunyanpi.

20 Unkán anpetu ota, anpetu wi wicanhpi ko tanin śni un, qa nina unkakihanśicapi, hehan unnipi kta unkecinpi qon he wanna unkay uśtanpi.

21 Tuka tehan takudan yute śni unpi kin, hehan Palos wicacokaya najin, qa, Wicașta kin, anamayagoptanpi qa Krete etanhan pacanan iyeyayapi kte śni iyececa, hecen taku śice ca wicakakije cin de nihiyahdepi kte śni tuka.

.22 Qa nakaha ceciciyapi ce, cante waśte po ; tuwedan nițapi kte śni, tuka wita wata kin hecedan.

23 Wakantanka ohowada, qa iye mayuhe cin he taohnihde ye cin hinhan en mahinajin.

24 Qa, Palos kokipe śni wo; Kesar itokam inayajin kta, unkan tona om watoyape cin owasin Wakantanka nicu ce, eya ce. 25 Heon etanhan, wicaśta kin, cante waśte po; Walkantanka wicawada, token emakiye cin he ecetu kte.

26 Tuka wita wan en iyeunyanpi kta ce, eya.

27 Unkan otpaza iaketopa kin, hehan Adria miniwanca kiul ohna kaha iyeunyanpi kin icunhan, hanye cokaya hehan watope wicakiyapi kin makoce wan ikiyadan upi kecinpi.

28 Qa hehan mazasu hahonta ikoyake cin minin iyeyapi, qa akatinpi wikcemna nonpa e iyeyapi. Hetanhan kitanna kapeya yapi, hehan ake econpi, unkan wanna akatinpi ake zaptan.

29 Unkan imnija kin en iyewicayapi kta e kokipapi, heon wahektapa kin etanhan maza aspeiçiyapi tom minin iyeyapi, qa anpao kta e cinpi hinca. 


\section{WICOWOYAKE 28.}

30 Unkan watope wicakiyapi kin wita wata kin etanhan najicapi kta akitapi, qa wata cistina qon he mini kin ekta yuhukun iyeyapi, watokapa tanhan maza aspeiçiyapi minin iyeya konzapi.

31 Unkan Palos alkicita tancan kin akicita ko hewicakiya; Dena wita wata kin ohna yukanpi śni kinhan, yanipi oyakihipi kte śni ce.

32 Hehan akicita kin wata cistina hahonta ikoyake cin bapsakapi, qa kun iyeyapi.

$33 \mathrm{~W}$ anna anpao kta hehan $\mathrm{Pa}-$ los owasin taku yutapi icu wicaśi, qa heya, Nakaha takudan yute śni yaunpi anpetu iake topa kin he dee, hehanyan takudan iyacupi śni.

34 Heon ceciciyapi ce, taku yutapi icu po, on waniśakapi kta ce, paha nitawapi sukaza wanjidan hinhipaye kte śni ce.

35 Hena hecen eya hehan aguyapi icu, qa owasin wicitokam Wakantanka cekiye ça, kiyuśpe ça yuta.

36 Hehan owasin cante waśtepi, qa woyute icupi.

37 Unkan wita wata kin ohna, wicanagi owasin opawinge nom sanpa wikcemna śakowin sañpa śakpe unyakonpi.

38 Unkan taku yutapi on imnanpi hehan wita wata kin yukapojedanpi, qa aguyapi su kin minin ehpeyapi.

39 Unkan wanna anpa kamdeze cehan, makoce lin iyekiyapi śni ; tuka kalimin wan huta oihunni waśte kin he wanyakapi, qa okihipi kinhan, he en wita wata kin aipi kta, keyapi.

40 Hehan maza aspeiciyapi kin bapsag iyeyapi, qa minin ehpeyapi, qa iyupse yuza icaśke kin kiyuśkapi ; hehan sina watope- kiyapi tanka kin yuwankan lye. yapi, qa huta kin ekta yapi.

41 Tuka tukten miniwanca nom kokijuya hiyu kin he en iyolipayapi, qa hen wita wata kin azi yapi. Unkan watokapatanhan kin he sutaya ihan, tuka wahektapatanhan kin taja on kamden iyeya.

42 Unkan akicita kin wicakaślkapi kin hena wicaktepi kta e konzapi, okinni wanjikji huta kin ekta niwanpi, qa najicapi kta, keyapi.

43 Tuka akicita tancan kin iś Palos nikiye kta cin kin, lreon taku econpi kte cin iyowicaki śni ; qa hehan tona niwan okibipi kin hena tokaheya minin elipeiciyapi qa huta kin ekta niwanpi kta, keya.

44. Hehan tona nahahin en un kin hena, hunli canmdaska akan, qa hunli iś wita wata etanhan onśpaśpadan akan iyayapi. Unkan hecen owasin huta kin ekta tanyan iyohipi.

\section{WICOWOYAKE 28.}

1 Unkan ekta tanyan iyohipi hehan wita kin he Melite eciyapi e sdonyapi.

2 Unkan Ikcewicaśta kin nina taku waśte ecaunkiconpi, cetipi qa otoiyohi en unkicopi, nina magaju qa osni kin heon etanhan.

3 Unkan Palos can cikcistina ota pahi, qa peta en aonpa hehan, wamduśkadan wan iyokatapi kin etanhan hiyu, qa Palos nape kin en ikoyag içiya.

4 Unkan nape kin en taku ocinśice cin de ikoyake cin he Ikcewicaśta kin wanyakapi qehan, iyakitedan hekiciyapi; Awicakehan wicaśta kin de tin wicakte kin heca, miniwanca kin 


\section{OHANYANPI QON.}

etanhan ni hiyu eśta, taku owotanna kin he ni kta e iyowinkiye śni ce.

5 T'uka wamduskadan qon nape kin etanhan peta kin en hdatata ehpeye ça tuktedan kiunniye śni.

6 Tuka kapo kta, qa is ihnuhanna ta iyaye kta kecinpi. Qa tehan ekta etonwan yukanpi qa tuktedan kiunniye śni un kin wanyakapi, hehan tawacin kin tokeca hinhdapi qa, De taku wakan kin hee ce, eyapi.

7 Unkan hen ikiyedan, wita kin ohna wicaśta tokapa, Publios eciyapi kin he makoce onśpa yuha; inkan he tin hiyu unśipi, qa anpetu yamni hehanyan tanyan wo unqupi.

8 Unkan Publios atkuku kin wayazanka, tancan kate ca we ece iheya. Palos he en i, qa celiiye ca, nape on aputake ca asniyan.

9 Hecen econ, unkan hehan wita kin en tona wowayazan yuhapi kin hena en hipi, qa asni wicayapi.

10 Heon etanhan nina unkinihanpi, qa hetanhan unyanpi kte cin, hehan taku uncinpi kin owasin unqupi.

11 Unkan wi yamni, hehan wita wata wan Aleksandrea etanhan, he wita kin hen waniyetu wanke cin, he wiyokiyedan yuke cin, Jupiter cekpapi tawa kin hee, unkan he en unkopapi.

$12 \mathrm{Qa}$ Surakusa ekta unkihunnipi, qa anpetu yamni unyakonpi:

13 Unkan hetanhan ohomni unyanpi, qa Regium ekta unhipi. Qa anpetu wanjidan iyohakam, tate itokaga tanhan uya, qa anpetu inonpa hehan Puteoli en unkipi.

14 Hen hunkawanjin kiciyapi kin wanjikji iyewicunyanpi, qa anpetu śakowin om unyakonpi kta e cinpi. Hehan Roma ektakiya unyanpi.

15 Unkan heciyatanhan hunkawanjin kiciyapi kin unkiyepi eciyalanhan nahionpi, qa itkounkipapi au, Appiiphorum qa Owote tipi yamni kin hehanyan. Hena Palos wanwicayaka, unkan Wakantanka wopida eciye ça wakiśag içiya.

16 Unkan Roma ekta unkipi, hehan akicita tancan qon wicakaśke cin hena wicaśtayatapi taakicita tancan kin qu, tuka Palos akicita wanjidan awanyag un kin he kiciśnana yanke kta e iyowinkiyapi.

17 Unkan anpetu yamni iyohakam, Palos Juda wicaśta tokapapi kin wicakico. Qa en mniciyapi hehan hewicakiya, Wicaśta hunkawanjinciyapi, atewicunyanpi oyate qa wicohan kin en taku śica takudan ecamon śni eśta, Jerusalem ekta makaślkapi ecen Roma oyate napepi kin en iyemayanpi.

18 Hena iś wimawangapi qehan makiyuśkapi kta, miye en taku on mațe kte cin takudan iyeyapi śni.

19 Tuka Juda wicaśta kin nina tehindapi kin heon, Kesar caje mdate kta iyececa wadaka, mitaoyate kin taku iyawicawaonpe kte cin takudan muluhe śni tuka qon,

20 Heon etanhan nakaka cicopi, wanciyakapi qa wociciyakapi kta, Israel oyate awacinpi kin he on maza icicahilia kin de on makaśkapi ce, eya.

21 Hehan iś eya heciyapi, Juda makoce kin etanhan niye on wowapi unkahipi śni, qa hunkawanjin kiciyapi heciyatanhan hipi kin tuwedan taku śica iyanionpe ca oyake śni.

22 Tuka niś token nitawacin 


\section{WICOWOYAKE 1.}

kin naunnilionpi kta uncinpi, yuomdecapi kin de owancaya yasicapi e sdonunyanpi ce.

23 Unkan anpetu wan cajeyatapi kin he en wicota Palos yanke cin en hipi; unkan iś Wakantanka tokiconze kin yaotanin, qa onspewicakiye ça, Moses toope kin wicaśta wokcan ko, etanhan Jesus on wahokonwicakiya, anpao kin etanhan otpaze cin hehanyan.

24 Unkan hunli taku oyakapi kin wicadapi, qa hunli iś wicadapi śni.

25 Unkan okonwanjidan awakicinpi śni kin, hehan kihdapi, Palos wicoie wanjidan oyake cin iyohakam; Woniya Wakan kin Isaya wicaśta wokcan kin en, hunkake wicunyanpi kin tanyan wowicakiyaka;

26 Qa heya, Oyate kin de ekta wicai, qa heya wo; Wanahonpi kin on nayahonpi kta tuka oyakalinigapi kte śni, qa wawanya- kapi kin on wandakapi kta tuka widukcanpi kte sni :

27 Oyate kin de cantepi kin cepa aye ca nogepi kin on kitan se wanahonpi, ya iśtapi kin olimus icupi ; iśta kin on wawanyakapi kte śni, qa noge kin on wanahompi kte śni, qa cante kin on okahnigapi kte śni, qa ihduecetupi kte śni, qa miś okizi wicawaye kte śni heon etanhan.

28 Hecen on he sdonya po, Wakantanka wiconi tawa kin Ikcewicaśta kin wicaqupi, unkan hena iś nahonpi kta ce.

29 Hena hecen eya, unkan Juda wicaśta kin kihdapi, qa nina hdokinicapi.

30 Unkan Palos waniyetu nom tipi iyunwin ton odote cin he ohra yanke ca, tona en hipi kin owasin tin u wicaśi.

31 Wakantanka tokiconze kin yaotanin, qa Jesus Messiya Itancan taku tawa kin waditagya oyaka ece, tuwedan tehinda śni.

\section{PALOS, ROMA OYATE}

\section{WOWAPI WICAKICAGE CIN.}

\section{WICOWOYAKE 1.}

1 Palos Jesus Messiya taokiyje, yewicaśipi kin en kicopi, Wakantanka tawootanin waśte on kahnigapi ;

2 Ehanna wowapi wakan kin en wicaśta wokcan oyakapi qon hee; 3 Iye Cinhintku Jesus Messiya Itancan unyanpi kin heon etanhan; he qe wicacelpi eciyatanhan Dawid cinca kin hetanhan icaga ;
4 Qa wowaśake on Wakantanka Cinhintlku kin hee e yuotaninpi, Woniya Wakan kin eciyatanhan, wiconte etanhan piya ikicage cin he en;

5 Iye kin eciyatanhan wowaśte unkicupi, qa oyate owasin wacinyanpi kin anagoptanpi kte cin heon yewicaśipi wicohan kin he nakun, iye caje kin on:

6 Hena ehna Jesus Messiya wicakico kin he niyepi.

7 Tona Roma elkta un kin owa235 
sin, Waikantanka waśte wicakida, yaowotanpidan kte cin on wicakico kin hena, wowapi cicagapi. Wowaonśida, wookiye ko, Wakantanka ateunyanpi, qa Jesus Messiya Itancan kin etanhan, nicipi un nunwe.

8 Tokaheya, Jesus Messiy a eciyatanhan, niyepi owasin on etanhan, Wakantanka mitawa kin wopida ewakiya ece, niye wacinyayapi kin he maka kin owancaya cajeyatapi kin heon.

9 Wakantanka minagi kin eciyatanhan ohowada, iye Cinhintku tawootanin waśte kin en, he sdonmayan, ayaśtan śni wocekiye epa eca, ohinniyan cajeciyatapi ece;

10 Qa nakaha Wakantanka tawacin kin eciyatanhan ek ta ciupi owakihi kte cin heon cewalriya ece.

11 Wanciyakapi nina wacin, woniya etanhan taku wicaqupi wan cicupi kta, on niyusutapi kte cin heon etanhan.

12 Niyepi kin on iyuśkinmayanpi kte cin he waka, niś niye qa miś miye napin wacinunyanpi kin on etanhan.

13 Mihunkawanji, he de sdonye śni dukanpi kta wacin śni, wanna ota ekta ciupi kta kepca, tuka dehanyan iyomalkipi śni, niyepi ekta waskuyeca wanjikji mduhe kta wacin, oyate toktokeca kin en mduhe cin he iyececa.

14 Helenes, Ikcewicaśta ko, ksapapi, wacintonpi śni ko, hena iyohi wicaweciye śni waun.

15 Hecen token owakihi kin, niyepi nakun Roma ekta yaunpi kin, wootanin waśte kin ociciyakapi kta wacin.

16 Messiya tawootanin waśte kin on imaśtece śni ; he niwicaye kte cin on Wakantanka to. 236 waśake kin hee, tona wicadapi kin hena en, Juda wicaśta kin he tokaheya, qa hehan Helenes wicaśta kin hena.

17 Heon etanhan Wakantanka owotanua ohanye cin he wacinyanpi kin etanhan wacinyanpi ekta yuotaninpi; wowapi qon iyececa, 'Tuwe owotanna kin he wacinyanpi on ni kta ce.

$18^{\circ}$ Malipiya kin etanhan Wakantanka tocanniye kin yuotaninpi, woaktaśni owasin qa wicaśta woahitani econpi kin en, tona woaktani on wowicake kin anaptapi kin hena en.

19 Hena on Wakantanka token sdonyapi kte cin taninyan un; Wakantanka sdonye wicakiya nakaeś.

20 Maka kagapi kin hetanhan Wakantanka towakan qa towaśake otokahe wanice cin hena tanin, hena wanyagpica śni eśta, taku kage cin on etanhan sdonyapi ece; hecen on woanahbe yuhapi kte śni.

21 Qa hecen Wakantanka sdonyapi, tuka Wakantanka iyecen yutanpi śni, qa pidapi śni; tuka tawacinpi kin ekta wahianlianiçida ayapi, qa iye cantepi wacintonśni kin otpas aya.

22 Ksapeiçidapi kin en icunhan witkotkoka icah ayapi.

23 Qa Wakantanka tepica śni towitan kin he wicaśta te kte cin ouncage kin iyecen yutokecapi, qa zitkadan, wahutopa, watutka kin hena koya.

24. Heon iye cantiheyapi śice cin en Wakantanka awicayuśtan, ihduśapapi kte ca, iye tancanpi kin kiciyuśilitinpi kte cin heon.

25 Hena Wakantanka wowicake tawa kin woitonśni kagapi, qa taku icaliyapi kin he yuonihanpi qa ohodapi, waicah- 


\section{WICOWOYAKE 2.}

ye cin he isanpa, he qe owihanke wanin yawaśtepi nunwe.

26 Heon etanhan wocantiheye śice cin en Wakantanka awicayuśtan; hecen winohinca wicayuhapi kin bena e wicohan owotanna kin yutokecapi, qa uwotanna śni econpi ece.

27 Qa wicaśta kin iś eya winyan yuhapi kin he ayuśtanpi, qa iś iyepi otoiyohi winktapi on kicicinpi, wica kin wica kici wowiśtece okicikianyanpi, qa iye tancan mahen wahtanipi kin taku iyohi kte cin he yuhapi.

$28 \mathrm{Qa}$ Wakantanka wacin en yuze wacinpi śni kin he iyecen, Wakantanka iś eya wicotawacin wahte śni kin en awicayuśtan, hecen taku wowiśtece kin hduśtampi lita.

29 Hena e woahtani owasin, wiinahmanpi, wicośice, waicucupi kte cin, qa olinyanpi on iyatahdepi; winawizipi, tin wicaktepi, wakinicapi, wohnaye, qa wocanniye on ojupidan.

30 Waajijipi sa, waaiapi sa, Wakantanka śice dapika, wahanicidapi, wamnaicidapi, ihdatanpi sa, taku śica kagapi sa, hunkakeyapi kin anawicagoptanpi śni ;

31 Wacintonpi śni, woope kicaksapi, wacantkiyapi śni, wacin tankapi śni, qa waonśidapi śni.

32 Hena Wakantanka toope kin sdonyapi ; (tona hecen e conpi kin hena wiconțe iyahdeiçiyapi,) tuka iś iye hecen econpi qa tona hecompi kin hena on iyokipipi ece.

\section{WICOWOYAKE 2.}

1 Heon etanhan wicaśta kin nituwe kaśta, wadaco kinhan iyaonpepica śni yaun kte śni. Taku on wicastta tokeca daco kinhan he en niye nihdaco, wadaco tuka niś eya he kici taku okonwanjidan ecanon ece.

2 Tona wicohan hecen econpi kin hena Wakantanka wowicake eciyatanhan wicayaco kin he sdonunyanpi.

3 Qa wicaśta kin, niś tona heconpi kin wicadaco, qa iyecen ecanon kinhan, Wakantanka wicayaco kin he nayecipe kta kecanni he.

$4 \mathrm{Qa}$ iś iye towaśte wowijice kin ayakta śni he, wacintanka qa wawacinkta yuza tanka koya; qa Wakantanka towaśte kin nihduecetu kta aniye cin hee e sdonyaye śni he.

5 Tuka cante nitehika, qa nihduecetu śni kin eciyatanhan, wocanniye anpetu, qa Wakantanka owotanna wicayaco kin yutaninpi iyehantu kte cin en, wocantiyahde amnayaya he.

$6 \mathrm{He}$ wicaśta otoiyohi iye ohan kin eciyatanhan wicakicu ece e kta :

7 Tona wicolian waśte en ape yukanpi, qa wowitan, woyuonihan, qa tepica śni kin akitapi ece kin hena wiconi owihanke wanice kta :

8 Tuka tona wakinin unpi, qa wowicake kin anagoptanpi śni, tuka woahtani awacinpi kin hena, wośihda, qa wocanniye,

9 Wośitkihda, qa wokakije, wicaśta otoiyohi taku śica econ kin wicanagi kin kiciun kta, Juda wicaśta kin he tokaheya, qa hehan Helenes hee kta.

10 Tuka wowitan, woyuonihan, wookiye ko, tona waśteya ohanye cin hena kiciun kta, Juda wicaśta kin he tokaheya, qa hehan Helenes hee kta.

11 Wakantanka wicaśta itohnake ekta etonwe śni ece.

12 Tona woope codan waita237 
nipi kin hena woope codan yutakunipi kte śni, qa tona woope kin en wahtanipi kin hena woope kin eciyatanhan wicayacopi kta.

13 Wakantanka ekta tona woope nahonpi kin hena owotanna kill eepi śni, tuka tona woope kin ecen econpi kin hena owotanna wicayawapi kta.

14 'Tohan Ikcewicaśta woope yuhapi śni kin hena iye cinka woope wicohan kin ecen econpi kinhan, woope yuhapi śni eśta, iś iye woope ihduhapi ece.

15 Hena iś iye cantepi kin ekta woope wicohan owapi kin he hdutaninpi, iye tawiyukcan kin nakun he yaotanin, qa tawacinpi kin otoiyohi tuktekten iyakicionpapi, qa akeś anakilimanpi ece.

16 Anpetu wan en, Wakantanka wotanin waśte mitawa kin eciyatanhan, Jesus Messiya on, wicaśta taku nahmana awacinpi kin yaco kinhan.

1.7 Iho, Juda wicaśta eniciyapi, qa woope kin awacin nanke ca Wakantanka on nihdatan,

18 Qa iye tawacin kin sdonyaya, qa taku tona waśte kin idukcan, woope kin tanyan onnispe nakaeś ;

19 Qa tona iśta gongapi kin tanyan yewicayaye ca, otpaza ehna un kin iyoyanwicaye cin he niye kecanniçin ;

$20 \mathrm{Qa}$ wacinton śni kin hena waonspekiya niyuhapi, qa hokśiyoqopa kin onspewicayakiya ece, qa woope kin en wosdonye wowicake ko ouncage kin yuha yaun.

21 Heon etanhan wicaśta tokeca onspeyakiye cin niś niye onspeniçiciye śni he. Wamanonpi kte śni keya odake cin, niśs niye wamayanon he.
22 Wawicihiahapi econpi kte śni kehe cin, niś niye tuwe wawiyakihaha he. Wakagapi kin wahiteyada śni kin niś niye tipi wakan kin etanhan wamayanon he.

23 Niś woope kin en iniwinkta kin, woope kicaksapi kin on Wakantanka wowiśtenyaya he. 24 Niyepi eciyatanhan Ikcewicaśta kin Wakantanka caje kin ośtehdapi ece ; wowapi en kagapi qon iyececa;

25 Woope kin oyape cinhan, awicakehan bakilidayapi kin taku okihi ece; tuka woope yakaksa ece kinhan, banicildayapi kin he bakihdayapi śni icaga.

26 Heon bakilidayapi śni kin he woope woowotanna kin tanyan ope cinhan, he bakilidayapi śni kin bakihdayapi kiciyawapi kte śni he.

27 Qa bakihdayapi śni ece kin he woope kin ope cinhan, he, niye oowa qa bakihdayapi kin eciyatanhan woope yecakse cin, niyaco kte śni he.

28 Tuwe akan tanhan ecedan hecece cin, he Juda wicaśta kin heca śni; qa bakihdayapi akan tanban qa wicacelipi ecedan en un kin he hee śni ;

29 Tuka tuwe mahen tanhan hecece cin he Juda wicaśta kin hee, qa bakihdayapi kin he oowa kin en he śni, tuka wicanagi kin en un kin hee; he wowitan kin wicaśta akan tu eciyatanhan śni, tuka Wakantanka eciyataulan un.

\section{WICOWOYAKE 3.}

1 Hecen Juda wicaśta kin token iyotan un he, qa bakihdayapi kin he taku okihi he.

2 Taku owasin on iyotan, tuka tokaheya Wakantanka oie kin wicaqupi qon he. 


\section{WICOW OYAKE 3.}

3 Qa wanjikji wicadapi śni eśta, hecen tokeca kta he. Hena wicadapi śni kin he Wakantanka wacinyanpi kin ecetu śni ye kta he.

4. Hiya, hecetu śni; Wakantanka wowicake kta, qa wicaśta otoiyohi iton kte śni; wowapi en kagapi qon iyececa; Nioie kin on nihdaowotanna kta, qa niyacopi kin en ohiyaye kta ce.

5 Tuka waunhtanipi kin hena Wakantanka toowotanna yutanin kinhan token unkeyapi kta he; Wakantanka kakiświcaye cin he owotanna śni he ; (wicaśta akantu kin iyecen iwaa ;)

6 Hiya hecetu śni ; hecetu kinhan token Wakantanka wicoicage kin wicayaco kta he.

7 Oiwaton śni kin on etanhan Wakantanka towicake kin he iye towitan kin hduotanin kinhan, token on etanhan wahtani sa iyecen mayacopi he.

8 Qa tokeca taku waśte u kte cin heon taku śica econkupi kte śni he, unkakicagapi qa wanjikji, unkeyapi ce, keyapi kin iyececa; hena wicayacopi kin he owotanna.

9 He etanhan tokeca kta; unkiye iyotan unwaśtepi he. Hiya, takuśnina on. Wanna Juda Helenes wicaśta ko, owasin woahtani ihukuya yukanpi kin he unyaotaninpi qon.

10 Wowapi en kagapi qon iyececa; Tuwedan owotanna un śni ;

11 Tuwedan okahnige śni ; tuwedan Wakantanka akite śni ;

12 Owasin icunonpa iyayapi, ptaya ihduśicapi ; tuwedan taku waśte econ śni, wanjidan eśta.

13 Dotepi kin wicahnakapi yuhdokapi kin hee; cejipi kin on wicahnayanpi ece, ihapi kin en sintehda tage yukan:
14 Ipi kin wicayaśicapi qa wicoie pa hinca ko on ojudan:

15 Sihapi kin iś weyapi kta e duzahanpi ;

16 Tacankupi kin ohna wicotakuni śni wicokakije ko yukan; 17 Qa wookiye canku kin he sdonyapi śni.

18 Qa iśtapi kin itokam Wakantanka kokipapi kin wanica ce.

19 Woope kin taku tona eye cinhan, tona woope ihukuya un kin hena hewicakiya ece e sdonunyanpi. Hecen wicai otoiyohi iohmus icupi kta, qa wicoicage owasin Wakantanka itokam wicayacopi kta.

20 Heon etanhan iye itokam, woope wicohan kin on, wicacehpi takudan yaowotanpi kte śni; woope kin eciyatanhan woahtani sdonkiyapi ece.

21 Tuka nakaha woope codan Wakantanka toowotanna .kin yutaninpi ; woope qa wicaśta wokcanpi kin he yaotaninpi ece.

22 Wakantanka toowotanna kin, Jesus Messiya wacinyanpi kin eciyatanhan $\mathrm{u}$ kin hee, tona wicadapi kin owasin en, qa owasin akan un, qa owasin akiyececapi.

23 Owasin hin wahtanipi, qa Wakantanka towitan kin iyohi śni unpi.

24 Qa iye towaonśida kin on iyunwin codan owotanna wicayawapi, wopekitonpi Jesus Messiya en un kin he eciyatanhan.

$25 \mathrm{He}$ Wakantanka toka qehan ehde, wokajuju kta, iye we kin wacinyanpi kin eciyatanhan, iye toowotanna hduotanin kte, woahtani ehanna econpi qon hena kajujupi kin on etanhan.

26 Wakantanka tehan ape un kin en, nakaha iye toowotanna 


\section{ROMA.}

kin hdutanin kta e heon; hecen iye kin owotanna un kta, qa nakun tuwe Jesus wacinye cinhan, he yaowotan kta.

27 Hehan ihdatanpi kin toki un he. He anaptapi. Woope kin tukte e on; wicohan kin hee he. Hiya, wacinyanpi woope kin hee on etanhan.

28 Heon woope wicohan codan, wacinyanpi on etanhan, wicaśta kin owotanna yawapi e he unkiyukcanpi.

29 Juda oyate iśnana Wakan-tanka tawapi he; qa Ikcewicaśta tawapi śni he. Hiya, nakun Ikcewicaśta tawapi.

30 Tuwe wacinyanpi on bakihdayapi kin yaowotanna kte, qa wacinyanpi eciyatanhan bakihidayapi śni kin owotanna yawa kte cin he Wakantanka wanjidan.

31 Hecen wacinyanpi kin on woope kin ecetu śni unyanpi he. Hiya, hecetu śni, tuka woope kin unyusutapi.

\section{WICOWOYAKE 4.}

1 Heon, Abraham ate unyanpi kin, wicacehpi eciyatanhan taku iyeye ciqon tukte e he, unkeyapi kta he.

2 Abraham wicohan on ihduowotanna kinhan taku iwinkta kte cin hduha, tuka Wakantanka itokamya śni.

3 Wowapi wakan kin token eya he. Abraham Wakantanka wacinyan, qa woowotanna kiciyawapi qon.

4 Tuwe htani kin he wokajuju kin wowaonśida iyecen kiciyawapi śni, tuka wopetonpi kin he iyececa.

5 Tuka tuwe ohanye śni, qa tuwe tona wahtanipi kin wicayaowotanna kin he wacinye cin- han, wacinyanpi kin he wicoowotanna kiciyawapi ece.

6 Wicaśta kin tuwe wicolian codan Wakantanka wicoowotanna kiciyawa kin wowaśte yuhe cin he Dawid oyake ciqon iyececa :

7 Tona taku śica econpi qon wicalsicicajujupi, qa wahtanipi kin yutokan iyewicakiciciyapi kin hena wicayawaśtepi ece.

8 Wicaśta kin tuwe Itancan kin woahtani kiciyawa śni kin he yawaśtepi ce.

9 Unkan wowaśte kin de bakihdayapi kin ecedan en au he; qa is̉ bakilidayapi śni kin nakun en au he. Wacinyanpi kin he Abraham woowotanna on kiciyawapi ce, unkeyapi qon.

10 'Token he on kiciyawapi he; bakihdayapi kin en un, qa iś bakilidayapi śni en. Bakilidayapi en un śni, tuka balkihdayapi śni kin en icunhan.

11 Qa nahanhin balzihdayapi śni un kin en icunhan, bakihdayapi kin he wowapetogton, wowacinye woowotanna ipuspe kin hee icu; hecen tona wacinyanpi kin owasin, bawicahdayapi śni eśta, he ateyapi kta, qa nakun hena e wicoowotanna wicakiciyawapi kta.

12 Qa tona bakilidayapi kin heceepidan śni, nakun Abraham ateunyanpi, hinahin bakihdaye śni, he ehan wacinye ciqon, tona he oye lin ohna manipi kinhan, hena iś eya bakihdayapi kin en ateyapi kte cin heon.

13 Maka kin tawaye kte cin, Abraham iye cinca kin om, iwahoyapi qon he woope kin eciyatanhan śni, tuka wacinyanpi on woowotanna kin eciyatanhan.

14 Tona woope kin eciyatanhanpi kin hena tawayapi kte cin eepi hecinhan, wacinyanpi kin 
ecetuśniyapi, qa wahoyapi qon he nakun takudan okihi śni.

15 Woope kin he wocanniye kaga ; tukten woope wanica hecinhan hen woahtani nakun wanica.

16 Heon etanhan, he wacinyanpi kin on, wowaonśida eciyatanhan kte cin heon, qa wahoyapi qon cincapi kin owasin en wicakiciyusutapi kta, tona woope eciyatanhan un kin heceedan śni, tuka tona Abraham, unkiye owasin ateunyanpi kin, wacinye ciqon en opapi kin hena koya.

17 Wowapi qon iyececa; Ilkcewicaśta oyate ota ateniyanpi kta e ecihde ce ; Wakantanka wicate cin ake ni wicaye ca, taku tona un śni kin hena taku un kin iyecen cajeyata ece kin he wacinyan kin heon etanhan.

18 Oyate ota ateyapi kte cin he apepica śni, tuka wacinyan un kin heon ape, taku eyapi qon iyececa; Nicinca iyenaka kta ce.

19 Qa waśagya wacinye cin heon iye tancan kin wanna kan he awakicin śni, wanna waniyetu opawinge ikiyedan, qa Sara tamni kin nakun wanna ecece śni tuka.

$20 \mathrm{Qa}$ Wakantanka wahoye cin he cețunhda kin on kaktihanhan śni ; tuka wacinyanpi on wakiśaka un, qa Wakantanka yatan.

21 Qa taku iwahoye cin he ecen econ kta okihi e he nina wicada.

22 Heon etanhan he wicoowotanna kiciyawapi.

23 Qa he hecen kiciyawapi kin he iye iśnana on wowapi kin en kagapi śni ;

24 Tuka unkiyepi on, he unkiciyawapi kte cin heon etanhan, tuwe Jesus Messiya Itancan unkiyapi kin wiconțe etanhan naDak. jin kiye ciqon he wacinunyanpi kinhan.

25 Iye waunlitanipi kin on wicaqupi, qa owotanna unyawapi kte cin on ake najinkiyapi qon.

\section{WICOWOYAKE 5.}

1 Hecen wacinyanpi on owotanna unyawapi kin, heon etanhan Wakantanka ekta wookiye unhapi, Jesus Messiya Itancan unkiyapi kin eciyatanhan.

2 Qa he iye eciyatanhan en unhiyupi, wowaonśida en ahan naunjinpi kin en, wacinyanpi kin on etanhan, qa Wakantanka towitan kin ape unkiyuśkinpi ece.

$3 \mathrm{Qa}$ hecedan śni, nakun wokakije on unkiyuśkinpi ece; wokakije kin he wacin tankapi kaga e sdonunyanpi;

4 Qa. wacin tankapi kin he wiyukcanpi, qa wiyukcanpi kin he woape;

5 Qa woape kin he iśten wicaye śni, Woniya Wakan unqupi kin he eciyatanhan, Wakantanka towaśte uncantepi kin en unkokicicaśtanpi kin he etanhan.

6 Takudan unkokihipi śni kin he icunhan, wanna iyehantu qehan Messiya wahtanipi sa kin on ta.

7 Tuwedan wicaśta owotanna kin on țe kte śni naceca; tuka okinni wicaśta waśte on tuwe te kta tawatenye kta nace.

8 Tuka wahtanipi sa heuncapi kin he icunhan, Messiya unkiyepi on țe cin he en, Wakantanka token canteunkiyapi kin hduotanin.

9 Hecen sam iyeya, nakaha iye we kin on owotanna unyawapi kin, iye eciyatanhan wocanniye kin etanhan eunhdakupi kta.

10 Toka unyakonpi qehan he 241 
icunhan, iye Cinhintku tc ein eciyatanhan, Wakantanka kici okiciciye unyanpi hecinhan, he sam iyeya kici okiciciya unyakonpi kin, iye ni un kin eciyatanhan ni unyanpi kta.

11 Qa hecedan śni, tuka nakun Wakantanka kin en unkiyuśkinpi, Jesus Messiya Itancan unkiyapi kin eciyatanhan, he etanhan nakaha wookiye unhapi.

12 Heon etanhan wicaśta wanjidan eciyatanhan woahtani wicoicage kin wicehna hiyu, qa woahtani etanhan wiconte, qa hecen wiconte wicaśta owasin akan iwicayaya, owasin wahtanipi nakaeś.

13 Woope kin itokam woahtani wicaśta kin ehna un; tuka tukten woope wanice cinhan hen woahtani wicakiciyawapi śni ece.

14 Hececa eśta, Adam qa Moses iyotahedan wiconte ounyan, Adam tuwe u kte cin oowa kin hee wahtani kin tona iyecen wahitanipi śnj kin hena eepi kaeś en ounyan.

15 Tuka woahtani qon he kici wowaonśida kin akidecece śni. Wicaśta wanjidan wahtani qon he on wicota tapi hecinhan, he sam iyeya Wakantanka towaonsida, qa wowaonśida on ituwicakihanpi kin he wicaśta wanjidan, Jesus Messiya kin hee on wicota en wicakiciyuota kta.

$16 \mathrm{Qa}$ wicaśta wanjidan walitani qon eciyatanhan, wowaonsida on ituwicakihanpi kin he iyecece śni. Wanjidan on etanhan wiconțe iwicayacopi ; tuka wowaonśida on itulianpi kin he woahtani ota etanhan wicayaowotanna kta.

17 Wicaśta wanjidan wahtani kin on etanhan wanjidan eciyatanhan wiconte ounyan hecin242 han, he sam iyeya tona wowaonśida untkana, qa wicoowotanna wicaqupi kin icupi.kin hena, wanjidan, Jesus Messiya kin hee, e eciyatanhan wiconi kin en ounyanpi kta.

18 Heon etanhan woahtani wanjidan eciyatanhan, wicaśta owasin en wiconte iwicayacopi kin aupi; he iyecen woowotanna wanjidan on etanhan wiconi iwicayaowotanna kin he wicaśta owasin en aupi.

19 Wicaśta wanjidan waanagoptan śni un qon he etanhan wicota wahtani sa wicakagapi kin, he iyecen wanji waanagoptan un kin eciyatanhan wicota owotanna wicakagapi kta.

20 Woahtani ihduota kte cin heon woope kin hi, tuka tukten woahtani yuota ikicage ciqon hen wowaonsida nina sam iyeya ihduota.

21 Hecen wiconte en woahtani ounye ciqon he iyecen wiconi owihanke wanica en wowaonśida ounye kta, Jesus Messiya Itancan unkiyapi kin eciyatanhan.

\section{WICOWOYAKE 6.}

1 Hecen taku unkeyapi kta he. Wowaonśida yuotapi kte cin heon woahtani en unkitanpi kta he.

2 Hiya hecetu śni. Tona woalitani ekta unțapi kin, token he en nakun unnipi kta he.

3 Tona Jesus Messiya en baptem wicaqupi kin hena iye te cin en baptem wicaqupi kin he sdonyayapi śni he.

4 Heon etanhan baptem eciyatanhan he kici unhnakapi, wiconte kin en, hecen iye Atkuku towitan kin Messiya wicate cin etanhan ekicetu ye ciqon he iyecen unkiś eya wiconi teca kin en maunnipi kta. 


\section{WICOWOYAKE \%.}

5 Qa iye te cin iyacinpi kin en kici huunhdepi hecinhan, nakun he piya ikicage cin en iyecen unyakonpi kta.

6 Qa wicaśta tanina unhapi kin he iye kici icipaweh okatanpi kin he sdonunkiyapi, hecen woalitani tancan kin he ihangyapi kta, qa hetanhan woahtani wowidag unyanpi kte śni.

7 Tuwe te cinhan, he wanna woahtani etanhan kiyuśkapi.

8 Hecen Messiya kici unțapi hecinhan, kici unnipi kta e wa. cinunyanpi.

9 Qa Messiya wicațe cin etanhan ekicetuyapi qon he ake icimana te kte śni e sdonunyanpi ; tokata wiconte tohinni yuha okihi kte śni.

10 He te ciqon wancadan woahtani on ta ; qa he kini kin $\mathrm{Wa}$ kantanka on ni un.

11 He iyecen niś eya woahtani on te nihdawapi, tuka Wakantanka ekta ni yaunpi, Jesus Mesciya Itancan unkiyapi kin eciyatanhan.

12 Heon nitancan te kte cin en woalitani ounye śni nunwe, hecen wocantiheye śice cin anayagoptanpi kte śni.

13 Qa nihuhapi kin hena wicohan śica en woahtani wowinyunye kta e qupi śni po, tuka wicate cin etanhan ni un kin iyecen Wakantanka icicu po, qa nihuhapi kin wicoowotanna en Wakantanka wowinyunye kiya po.

14 Woahtani icimana inidakapi kte śni. Woope kin ihulruya yaunpi śni tuka wowaonśida kin ihuknya.

15 Hecen tokeca kta; woope kin ihukuya unyakonpi śni, tuka wowaonśida ihukuya unyakonpi kin heon etanhan waunhtanipi kta he. Hiya hecetu śni.
16 Tuwe anayagoptanpi kta inidake niciyapi kin the anayagoptanpi kin on wowidake niyanpi kin he sdonyayapi śni he; he woalitani wiconte aiyahdeye cin hee, qa iś waanagoptanpi kin on wicoowotanna kta.

17 Tuka Wakantanka wopida kiciun nunwe, woahtani inidakapi tuka qon; tuka woonspe ecedan en yeniyanpi qon he cante eciyatanhan oyapapi.

18 Qa woahtani etanhan enihdakupi kin, heon wicoowotanna wowidake niyan yaunpi.

19 Wicaśta akantu kin iyecen iwaa ce, nicehpipi waśake śni kin heoll etanhan. Wicośice en nihuhapi kin aśapapi qa woahtani wowinyunniyanpi kta e iyowinyakiyapi qon, he iyecen nakaha wicayuecedan kin en nihuhapi kin wicoowotanna inidakapi kta e iyowinkiya po.

20 Woaktani wowidake niyanpi qehan, wicoowotanna inidakapi śni.

21. Hehan taku nakaha on iniśtecapi kin hena en taku waskuyeca duhapi qon he tukte e he; hena e ihanke kin he wiconte ee. 22 Tuka nakaha woalitani etanhan enihdakupi, qa Wakantanka wowidake niyanpi, heon wicayuecedan on waskuyeca duhapi, qa he ihanke kin owihanke wanin wiconi kin hee.

23 Woalitani wokajuju kin he wiconte ee; tuka Wakantanka taku ituwicakilian kin he, Jesus Messiya Itancan unkiyapi kin eciyatanhan, owihanke wanin wiconi kin hee.

\section{WICOWOYAKE 7.}

1 Mihunkawanji, (tona woope sdonyapi kin hena owicawakiya); woope kin wicaśta kin wo243 
ROMA.

widag ya, tohanyan ni un kin hehanyan, he sdonyayapi śni he.

2 Winohinea kin tuwe hihna ton kinhan, hihnaku ni un kin hehanyan, toope kin on kaśkapi ; tuka hihnaku kin wanna te cinhan hehan hihnaku toope kin etanhan kiyuśkapi.

3 Hecen hihnaku ni un kin icunhan, wicaśta tokeca hihnaye cinhan, wawicihahaji econ eciyapi kta; tuka hihnaku te cinhan hehan woope qon etanhan kiyuśkapi qa wicaśta tokeca hihnayan eśta he wawiciliahapi econ śni.

4 Heon etanhan, mihunkawanji, niś eya Messiya tancan kin eciyatanhan woope kin ekta nitapi kin; hecen tuwe tokeca hihnayayapi kta, tuwe wicate cin etanhan ekicetuyapi qon he hee; hecen Wakantanka on waskuyeca icahunyanpi kta.

5 Wicacehpi kin en unyakonpi qehan, woalitani wocantiheye kin, woope kin eciyatanhan un kin, hena waskuyeca wiconțe icahkiciciye kta e heon unhuhapi kin en ohanyan.

6 Tuka nakaha woope kin etanhan unkiyuśkapi, taku on unkaśkapi qon he elkta untapi kin; hecen oowa tanina kin en wowidag unyanpi kte śni, tuka woniya teca kin en.

7 Hecece cinhan token unkeyapi kta he: Woope kin he woahtani kin ee he : Hiya, hecetu śni ; woope eciyatanhan śni unkanś, woahtani sdonwakiye kte śni tuka qon. Woope kin, Tokan tawa yacin kte śni ce, eye śni unkanśs, wocantiheye śice cin sdonwaye ktè śni tuka.

8 Hehan woahtani woahope kin wowinyunye ca, miye mahen wocantiheye śice cin owasin mi- caga. Woope codan woạhtani ța wanka.

9 Ehanna woope codan ni waun; tuka woahope kin he hị qehan, woahtani kini, qa miye mața.

10 Qa woahope kin wiconi kta e on yuśtanpi qon he wiconte kin ee imicicaga ce.

11 Woahtani woahope kin wowinyunyan, hecen mahnaye ça, on makte.

12 Hecen woope kin he wakan; qa woahope kin he nakun wakan, owotanna qa waśte.

13 Hecen taku waśte kin he wiconte imicicaga he. Hiya hecetu śni. Tuka woahtani kin he woahtani hee e tanin kta, heon taku waśte on etanhan wiconte icali miciciya; hecen woahope kin eciyatanhan woahtani kin iyotan śice lita.

14 Woope kin he wakan sdonunyanpi ; tuka miye qe wicacehipi kin hemaca, qa woalitani ihukuya wiyopemayanpi.

15 'Taku ecamon ece kin he iyowinwakiye śni. Taku wacin kin he ecen ecamon śni; tuka taku śice wadake cin he ecen ecamon ece.

16 Taku wacin śni kin he ecen ecamon kinhan, woope kin he waśte e induotanin.

17 Qa hecen tuwe becon kin he miye śni, tuka woahtani miye mahen un kin hee.

18 Miye en, micehpi kin he waka, taku waśte en maun śni e sdonwakiya. Ieiconzapi kin he iyemicihantu, túka token taku waśte ecamon lite cin iyewakiye śni.

19 Taku waśte wacin kin he ecen ecamon śni ; tuka taku șica wacin śni kin hee ecen ecamon ece.

20 Hecen taku wacin śni kin 


\section{WICOWOYAKE 8.}

he ecen ecamon kinhan, tuwe hecon kin he miye śni, tuka woahtani miye mahen un kin he hecon.

21 Hecen woope wanji iyewakiya, taku waśte ecamon wacin eca, taku śica miye en miciun ece.

22 Wicaśta mahentu kin eciyatanhan Wakantanka toope kin on imduślkin :

23 'Tuka mihuha kin en woope tokeca wan wanmdaka, he mitawacin toope kin kici kicize ca, woahtani woope mihuha kin en un kin he en wayaka amahda.

24 Wicaśta nina iyolkiśice cin he miye; tuwe wiconte tancan kin de etanhan emahdaku kta he.

25 Wakantanka wopida ewakiya ece, Jesus Messiya Itancan unkiyapi kin hee on etanhan. Hecen miye mitawacin kin on Wakan tanka toope kin wowidag mayan, tuka wicacehipi eciyatauhan woalitani woope kin he imadaka.

\section{WICOWOYAKE 8.}

1 Heon etanhan, nakaha tona Jesus Messiya en un kin, hena wiconte iwicayacopi wanin unpi, wicacehpi eciyatanhan manipi śni, tuka Woniya kin eciyatanhan.

2 Wiconi Woniya toope kin Jesus Messiya en un kin, he woahtani wiconte ko woope kin etanhan makiyuśka.

3 Woope kin wicacehipi eciyatanhan waśake śni un qon he taku okihi śni kin hee Wakantanka econ, iye Cinhintku wicacehpi wahtani ouncage kin en hiyuya, woahtani on, qa wicacehpi kin en woahtani yaco.

4 Hecen tona wicacelipi kin eciyatanhan maunnipi-śni, tuka
Woniya eciyatanhan, unkiyepi en woope wicoowotanna kin ecetu kta.

5 Tona wicacehpi eciyatanhan un kin hena wicacehpi taku tawa kin awacinpi; qa tona Woniya kin eciyatanhan un kin hena taku Woniya tawa kin awacinpi.

6 Wicacehpi awacinpi kin he wiconte kin ee; tuka Woniya awacinpi kin he wiconi qa wookiye kin hee.

7 Wicacelipi wicotawacin kin he Wakantanka toka ya. He Wakantanka toope kin ope śni, qa nakun ecaca okihi śni.

8 Hecen tolla wicacelipi kin en un kin hena Wakantanka iyokipi yapi kta okitpanipi.

9 Tuka niyepi wicacelipi kin en yaunpi śni, Woniya kin en yaunpi, Wakantanka Taniya kin niyepi kin en ounye cinhan. Qa tuwe Messiya Taniya kin yuhe śni kinhan he tawa śni.

10 Qa Messiya en niunpi kinhan, wicatancan kin he woalitani eciyatanhan ta, tuka wicanagi kin he wiconi un, wicoowotanna eciyatanhan.

11 Tuwe Jesus wicate cin etanhan najin kiye ciqon he Taniya kin niyepi en ounye cinhan, tuwe Messiya wicate cin etanhan najin kiye ciqon hee nitancan tapi kte cin ekicetu ye kta, iye Taniya Wakan niyepi en ounye cin he eciyatanhan.

12 Heon etanhan, mihunkawanji, wicacehpi kin takudan ikicazo śni unyakonpi, on etanhan wicacehpi kin eciyatanhan unnipi kta.

13 Wicacélipi kin eciyatanhan yanipi kinhan nitapi kta; tuka Woniya kin eciyatanhan wicatancan wicohan kin țe yakiyapi kinhan yanipi kta. 


\section{ROMA.}

14 Wakantanka Taniya kin tona yus awicaye cin hena Wakantanka cinca wicaye cin eepi.

15 Ake wokokipe kta e on ookiyeyapi woniya kin iyacupi śni, tuka cinhintkuyapi woniya kin he iyacupi, on Abba, Ate, eya hoy eunkiy api ece.

$16 \mathrm{Qa}$ Wakantanka cinca kin heuncapi e unnagipi kin kici Woniya kin e unyuotaninpi.

17 Unkan uncincapi kinhan tawayapi kte cin heuncapi ; Wakantanka tawayapi ; Messiya kici tawayapi kte cin; kici unkakijapi kinhan, nakun kici wowitan unhapi kta ce.

18 De nakaha wicokakije kin he, wowitan unkiyepi en ecadan yutaninpi kte cin kici akiyecen yawapi kta e iyecece śni wadaka.

19 Wakantanka cinca wicayutaninpi kte cin on taku kagapi kin cantokpaniyan ape yanka.

20 Taku kagapi kin he woecetu śni kin en ihukuya ye kta cin śni, tuka tuwe woape on he wowidagye cin hee on etanhan.

21 Qa taku kagapi kin hee kaeś wicahwin wowidagyapi kin etanhan kiyuśkapi kta, qa Wakantanka cincawicaye cin ihduhapi wowitan kin en yeyapi kta.

22 Taku icage cin owasin dehanyan witaya comnihdazi, qa hokśiksuya un e sdonunyanpi.

$23 \mathrm{Qa}$ hecedan śni, tuka unkiś eya Woniya kin taku tokaheya icahya unhapi kin, unkiyepi qe comniunhdazipi, qa atayedan cinca yapi kte cin unkapepi, unkitancanpi ekicetu ye kte cin hee.

24 Woape kin on niunyanpi; tuka woape wanyakapi kin he woape kin ee śni, tuwe taku wanyake cinhan tokeca e nahahin ape yanka he.

25 Tuka taku wanunyakapi śni kin he unkapepi hecinhan, hehan wacintankapi on unkicupi kta e ape unyakonpi ece.

26 Qa nakun Woniya kin iś waunśakapi śni kin en icunhan ounkiyapi ece. Token wocekiye unkeyapi kte cin sdonunkiyapi śni, tuka Woniya kin e qe unkiyepi on wocekiye eya, howayapi oyagpica śni kin on.

27 Qa tuwe wicacante iyukcan kin he Woniya kin token wacin yuze cin sdonya, lse Wakantanka tawacin kin eciyatanhan tona owotanna un kin hena on wocekiye eya ece.

28 Unkan Walkantanka waśte dakapi kin hena taku owasin tanyan owicakihan ece e sdonunyanpi, tona iye tawacin kin eciyatanhan wicakicopi kin hena.

29 Tona otokaheya tanhan sdonwicakiye ciqon hena wicakiconza, iye Cinhintku ouncage kin en icagàpi kte cin heon, qa hecen he hunkawanjitku ota ehna tokapa kta.

$30 \mathrm{Qa}$ tona wicakiconze ciqon hena wicakico; qa tona wicakico qon hena wicayaowotanna; qa tona wicayaowotanna qon hena iś eya wicayutan.

31 Heon etanhan hena taku kin en taku unkeyapi kta he. Wakantanka unkicipi un kinhan, tuwe kaśeunyanpi lkta he.

32 Tuwe iye Cinhintku kin kpatan śni, tuka unkiyepi owasin on kpagan qon, he iye kici taku owasin iyakiçuya unqupi kte śni he.

33 'Tona Wakantanka wicakahnige cin hena tuwe taku iyawicaonpe kta he. Wicayaowotanna kin he Wakantanka kin ee ce.

34 Tuwe wayaco kta he. Tuwe te ciqon he Messiya ee, qa ake

246 


\section{WICOWOYAKE 9.}

piya ikicage cin hee, Wakantanka etapa kin eciyatanhan yanke ca, unkiyepi on wocekiye eciya. 35 Tuwe Messiya towaśte kin etanhan unyuśpapi kta he. Wicokakije, wośitkihda, wicokicize, wicaakilian, tancowicakadan, wokokipe, qa maza sagye okihi kta he.

36 (Owapi qon he hecetu, Niye kin on anpetu ohinniyan unktepi unyakonpi, tahinca ktepi kte cin iyecen unyawapi ce.)

37 Tuka hena taku kin owasin en, tuwe canteunkiyapi qoul he eciyatanhan, tanyan ohiye unyakonpi.

38 Heon, wiconte, qa wiconi, qa mahpiya ohnihde cin hena", qa wokiconze kin, qa wicowaśake kin, qa taku nakaha un kin taku u kte cin ko;

39 Qa taku wankantuya un kin, qa taku mahentuya un kin, qa taku icage cin tokeca, takudan Wakantanka towaśte, Jesus Messiya Itancan unkiyapi en un kin, he etanhan unyuśpapi kte śni e sdonwaye linca.

\section{WICOWOYAKE 9.}

1 Messiya eciyatanhan wowicake epe, itonśni mawanica, minagi kin hee e Woniya Wakan kin kici mahdutanin;

2 Nina iyomakiśice ca micante ekta ohinniyan iyokiśin waun.

3 Mihunkawanji qa tona wicacehpi eciyatanhan takuwicawaye cin hena on, Messiya etanhan mayacopi tawatenwaya owakihi tuka.

4 Hena Israel wicaśta kin hecapi, qa atayedan cinkśi wicaye cin hena eepi, qa wowitan, qa wicotakuye, qa woope wicaqupi kin, qa wawokiyapi kin, qa wahoyapi kin hena tawapi.
5 Qa hunkake wicayapi kin etanhanpi kin hena eepi, qa hena etanhan wicacelipi eciyatanhan Messiya inapa, he owasin iwankam Wakantanka kin ee, owihanke wanin wowaśte yuha nunwe.

6 Wakantanka oie kin ecetu śni aye cin he wake śni. Tona Israel etanhanpi kin hena owasin Israel hecapi śni.

7 Qa Abraham etanhan icagapi kin heon owasin cincapi kin hecapi śni. Tuka, Isaak etanhanpi kin hena nicinca ewicakiyapi kta ce.

8 He kaketu, tona Wakan tanka cinca wicaye cin hena wicacehpi eciyatanhan cinca wicayawapi qon heon etanhan śni, tuka tona cinca wahoyapi qon hena e wicowazi kin ee iyawapi.

9 Wahoyapi wicoie kin he decetu, Omaka dehantu kinhan wau kta, qa Sara cinhintku wan ton kta ce.

10 Qa heceyedan śni, tuka Rebeka nakun wanjidān on, Isaak ateunyanpi.kin hee on, ihduśake cehan,

11 Nahanhin tonpi śni, taku waśte taku śica ko unmana nahanliin econpi śni, Wakantanka tawacin kin wicakalinigapi kin en sutaya un kte cin heon, wicohan kin eciyatanhan śni, tuka tuwe wicakico kin he eciyatanhan ;

12 Hehan heciyapi, Hakakta kin he tokapa kin wowidag ye kta ce.

13 Owapi qon he kaketu, Jakob waśte wadaka, tuka Esau śice wadaka ce.

14 Hecen token unkeyapi kta he. Wakantanka owotanna śni econ he. Hiya, hecetu śni.

$15 \mathrm{He}$ Moses heriya; Tuwe onśiwakida kte cin he onśiwaki- 
da kta, qa tuwe wacin en mduze kte cin he wacin en mduze kta ce.

16 Heon etanhan tuwe cin kin eciyatanhan śni, qa tuwe inyanke cin he nakun eciyatanhan śni, tuka Wakantanla onśiwicakida kin he eciyatanhan ece.

17 Wowapi wakan kin he Pharo heciya; He dee on etanhan icahciya, niye en mitowaśake kin wahduotanin kta, qa maka owancaya micaje kin oyakapi kte cin heon.

18 Heon etanhan tuwe kahnige cinhan, he onśikida ece; qa tuwe kahnige cinhan he yutehi ece.

19 Hecen hemayakiye kta nace; Tokeca e nahanhin wicaba he; tuwe e iye tawacin kin ecetuśniya he.

20 Hiya, wicaśta kin, niś nituwe he, hecen Wakantanka i en hiyeyaya he. Taku kagapi kin he tuwe kage cin, Tokeca hecen mayakaga he, eciye kta he.

21 Maka wakśica kage cin heca maka kin okiłi śni he, upśija omnaye wanjidan etanhan waksica wan woyuonihan, qa wanji iś wowiśtece on lkage kte śni he.

22 Hecen Wakantanka wocanniye kin hdutanin kta cin, qa towaśake kin sdonye unkiyapi kta e on wocanniye wakśica wicotakuni śni kicagapi qon hena wawacinkta yuza tanka on wicakuwa kinhan;

23 Qa tona wowaonśida wakśica kin otokaheya tanhan wowitan on wiyeya ehnakapi qon, hena en iye towitan wowijice kin hduotanin kta.

$24 \mathrm{He}$ wicakico kin hena unkiyepi, Juda oyate etanhanpi kin hecedan śni, tuka nakun Ikcewicaśta etanhanpi.

25 Hose en heye ciqon iyececa; 248
Tona mitaoyate śni kin hena mitaoyate ewicawakiye kta, qa waśte dakapi śni qon he waśte dakapi kin ewakiye kta.

26 Qa tukten, Mitaoyate kin he niyepi śni ce, ewicakiyapi qon, hen, Wakantanka ni un cinca kin ewicakiyapi kta ce, eya.

27 Isaya iś eya Israel oyate kin on hotanin; Israel cincapi kin miniwanca wiyaka sukaza iyecen ota yawapi eśta, tona okaptapi kin henana nipi kta ce, eya.

28 Wayawapi yuptecedan kta qa wicoowotanna en hduśtan kta; maka akan Itancan kin wayawapi ptecedan wan kage kta.

- 29 Qa he itokam Isaya heye ciqon; Sabaoth Itancan kin wicowazi wan unkolkicicaptapi śni unkanś, Sodom iyecen unyakonpi kta, qa Gomorra en unkiyoptapi kta tuka.

30 Hecen token unkeyapi kta he. Ikcewicaśta kin wicoowotanna iyeyapi ce, wacinyanpi kin eciyatanhan wicoowotanna kin hee.

31 Tuka Israel wicoowotanna woope odepi qon hena wicoowotanna woope kin iyohipi śni.

32 'Tokeca he. Wacinyanpi kin eciyatanhan śni, tuka woope wicolian kin eciyatanhan odepi kin, heon etanhan. Inyan ibotopi kin de on siha ibotopi.

33 Wowapi kagapi qon iyececa; Wanyaka wo, Zion en inyan ibotopi, qa imnija on hicahanpi wan ewahde; qa tuwe he wacinye cinhan iniban kte śni.

\section{WICOOWOYAKE 10.}

1 Mihunkawanji, micante cantiheye ca taku Wakantanka icewakiye cin, Israel oyate kin wicani kte cin hee. 


\section{WICOWOYAKE 11.}

2 Hena wicaweciyaotanin, Wakantanka wacin en yuzapi tuka he wosdonye eciyatanhan śni.

3 Wakantanka toowotanna kin sdonyapi śni, qa iye wiconwotanna tawapi kin hdusutapi akitapi, qa Wakantanka toowotanna kin he ihukuya iyeiciyapi śni.

4 Tona wicadapi kin owasin en Messiya kin he wicoowotanna woope woyuśtan kin hee.

5 Woowotanna woope kin eciyatanhan kin he on Moses kaken owa qon; Wicaśta tuwe hena taku kin econ kinhan, hee hena on ni kta ce.

6 Tuka, wacinyanpi eciyatanhan wicoowotanna un kin he kaken eya, Nicante kin mahen, Messiya kun ahi lite cin heon tuwe mahpiya ekta wankan ye kta he;

7 Qa, Wicate cin etanhan Messiya yuwankan au kte cin heon tuwe wośbe kin ekta ye kta he, eye śni wo.

8 Tuka taku eya he; Wicoie kin he nilkiyedan un, nii lin ohna, qa nicante kin en un, wacinyanpi wicoie unkoyalkapi kin he hee.

9 Nii kin on Jesus Itancan kin yahdaotanin, qa he wicate cin etanhan Wakantanka ekicetu ye cin he, nicante lain eciyatanhan wicayada kinhan, yani kta.

10 Wicoowotanna kta e wicacante on wicadapi, qa wiconi kta e wicai kin on wohdakapi ece.

11 Wowapi wakan kin he heya, Tuwe he wacinye cinhan, he wiśtece kte śni ce.

12 Juda qa Helenes oyate kin kici ocikpanipi wanica. Tuwe owasin en Itancan kin he tona hoyekiyapi, kin hena owasin en wijinya un.

13 Tona Itancan caje kin ho. yekiyapi kinhan hena otoiyohi nipi kta.

14 Tuka tuwe kin wacinyanpi śni kinhan token on he hoyekiyapi kta he; qa he nahahin nahonpi śni kinhan token wacinyanpi kta he ; qa tuwedan oyake śni kinhan token nahonpi kta he.

$15 \mathrm{Qa}$ ekta ye wicaśipi śni kinhan token oyakapi kta he. Owapi qon he hecetu; Tona wookiye wotanin waśte kin oyakapi, qa taku waśte en wotanin waśte oyakapi kin hena sihapi kin iyotan waśte ce.

16 Tuka owasin wotanin waśte kin anagoptanpi śni. Isaya heye ciqon; Itancan, tuwe unkoyakapi kin wicada he.

17 Heon etanhan wanahonpi kın eciyatanhan wicadapi kin $u$, qa wanahonpi kin he Wakantanka oie kin eciyatanhan.

18 Unkan miś, Hena nahonpi śni he, epe. Hiya, hena oqo kin makoce owasin ekta iyaye ca wicoie kin maka ihanke kin hehanyan i.

19 Qa Israel oyate kin he sdonyapi śni he. Tokaheya Moses heya, Tona oyate sni se un kin hena on iyocipaśtakapi kta, qa ikce oyate wacinton sni wan on śinhdaciyapi lita ce.

20 Tuka Isaya nina waditake ca heya; Tona omadepi śni qon hena e iyemayanpi, qa tona amakitapi śni qon hena en mihdutanin ce.

21 Qa Israel oyate kin hewicakiya, Anpetu osan oyate wanahon śni qa waceţunhdapi kin he nape wicawakiyugata ce.

\section{WICOWOYAKE 11.}

1 Heon hepa, Wakantanka taoyate kin ehpewicakiya he. Hiya hecetu śni. Israel wica- 
ROMA.

śta kin hemaca, Abraham cinca, qa Benjamin wicoun kin hematanhan.

2 Wakantanka taoyate kin tona otokaheya tanhan sdonwicakiye ciqon hena ehpewicakiye śni. Wowapi wakan Elijah on token eye cin sdonyayapi śni he ; Wakantanka cekiye ca, Israel oyate kin cajeyata qa heya;

3 Itancan, wicaśta wokcan nitawa kin hena wicaktepi, qa wahna wośnapi nitawa kin yujujupi, qa miye miśnana omakaptapi, unkan te mayanpi kta akitapi ce.

4 Tuka Taku Wakan kin token eya ayupta he; Nahahin Baal en canpeśka makehde inajinpi śni kin wicaśta kektopawinge śakowin wicawahduha ce.

5 He iyccen nakaha wowaonśida wicakahnigapi kin eciyatanhan hunh okaptapi.

$6 \mathrm{Qa}$ he wowaonsida eciyatanhan kinhan hehan wicohan eciyatanhan śni; hecetu śni kinhan, wowaonśida kin wanna wowaonśida heca śni. Qa wicolian eciyatanhan kinhan, hehan wowaonśida eciyatanhan śni; hecece śni kinhan, wicohan kin wanna wicohan heca śni.

7 Hecen tokctu kta he; Israel taku akite ciqon he iyeye śni, tuka tona wicakahnigapi kin hena e iyeyapi, qa unmapi kin iśta gongc wicayapi.

8 Wowapi qon iyececa; Wicahba wicacante kin Wakantanka wicaqu, iśta on wiwanyakapi kte śni, qa noge on winahonpi kte śni, anpetu kin dchanyan.

9 Qa Dawid iś heya; Wahna wotapi tawapi kin he mazahtakiyapi, qa wihmunke, qa wonahnaye, qa iyunwin yuhapi kin hee kta ce.

10 Iśta kin aotpaswicayapi kte, 250 heon wawanyakapi kte śni; qa cankahu ohinniyan patuś inajinpi nunwc.

11 Heon hepe; Hinhpayapi kta on hicahanpi he. Hiya, hecetu śni ; tuka hicahanpi kin on etanhan Ikcewicaśta kin wiconi iyowicahi, hena iś eya iyowicapaśtakapi kta e heon.

12 Hena e hicahanpi kin he wicoicage kin en wowijice kin hee, qa hena wicayuanptetu kin he Ikcewicaśta kin en wowijice kin hee hccinhan, wicayuecetupi kin he sanpa hince kta.

13 Ikcewicaśta henicapi kin hena hecen eciciyapi; Ikcewicaśta kin ekta yemaśipi waun, qa heon mitohtani kin wahdutan.

14 Hecen tona micehipi etanhanpi kin hena inahini wicawaye kta, kinhan wanjikji ni wicawaye kta.

15 Hena ehpewicayapi kin he wicoicage kin en wookiye kin hee hecinhan, hena ake wicayuecetupi kinhan he taku kta he; wiconte etanhan wiconi kin hee kta.

16 Taku tokaheya suton kin he wakan kinhan, ocowasin hecece kta; qa can huta kin he wakan kinhan, can adetka kin hena nakun hecece kta.

17 Unkan can adetka kin hena wanjikji yuksapi, qa niś can wihdi hu ikceka henica, tuka can adetka qon ehna can kin en icahniyanpi, qa can wihdi cepa can huta kin etanhan, en opeya yaun kinhan;

18 Can adetka qon on ihdatan śni wo. Nihdatan keś can huta kin he duhe śni tuka can huta kin hee niyuha.

19 Hehan, Hen emahdepi kta on can adetka qon yuksapi ce, ehe kta naceca.

$20 \mathrm{Han}$, hecetu; wicadapi śni 


\section{WICOWOYAKE 12.}

kin heon hena yuksapi, qa niye wacinyanpi on ecen nayajin ece. Wahaniçida śni qa kokipa wo.

21 Can adetka tawa qon hena Wakantanka kpatan śni hecinhan, okinni niś eya nikpatan kte śni.

22 Wakantanka towaonśida tocantiyahde ko wanyaka po ; tona hinlipayapi qon hena en wocantiyahde, qa niye en wowaonśida kin, wowaonśida kin he en nayajin kinhan, tuka hecanon śni kinhan niś eya nicaksapi kta. 23 Qa hena cețunhdapi ecen unpi śni kinhan, iś eya ake can kin en iyekiyapi kta. Ake can kin en Wakantanka icaliwicaya okihi.

24 Qa niye can wihdi ikceya icage ciqon etanhan nicaksapi, qa inicage cin eciyatanhan śni, can wihdi waśte kin en iyeniyanpi kinhan, tona can kin he aicage ciqon hena iyotan ake can wihdi tawapi kin en iyeyapi kta.

25 Mihunkawanji, wowiyukcan kin de sdonye śni dukanpi kta wacin śni, okinni ksape niçidapi kta; Israel oyate kin apa iśta gonge aya, Ikcewicaśta kin ocowasin en hiyu kte cin hehanyan. $26 \mathrm{Qa}$ hecen Israel oyate kin orvasin nipi kta. Wowapi en kagapi qon iyecetu; Zion etanhan Wanikiya wan $u$, qa woahitani Jakob yutokan iyekiciciye kta.

27 Qa woahtani yutokan iyewicaweciciye cinhan hehan wicotakuye wicawaqu kte cin hee ce.

28 Wotanin waśte kin ekta, hena niyepi kin on etanhan toka wicayawapi, tuka wicakahinigapi kin ekta, hena e hunkakepi kin on etanhan waśte wicakidapi.
29 Wakantanka taku wicaqu qa wicakico kin hena iyopeiçiyapi wanin un.

30 Unkan niś niyepi kin ehanna Wakantanka anayagoptanpi śni, tuka nakaha hena wicadapi śni kin on wowaonśida niçupi.

$31 \mathrm{He}$ iyecen nakaha hena iś eya anagoptanpi śni kin, niye nitowaonśida kin on etanhan onśiwicadapi kta.

32 Hena owasin witaya wicadapi śni kin en Wakantanka onawicataka, iyulipa onśiwicada kta heon etanhan.

33 Wakantanka toksape qa wosdonye tawa wowijica ośbe kin he tanka hinca. Woyaco tawa kin okahnilipica śni, qa tacanku kin iyeyepica śni.

34 'Tuwe Itancan tawacin kin sdonya he; qa tuwe okiya un he.

35 Qa tuwe he tokaheya taku qu he ; kinhan kicicajujupi kta.

36 Iye etanhan, qa iye eciyatanhan, qa iye ohna taku owasin un; owihanke wanin wowitan kiciun nunwe.

\section{WICOWOYAKE 12.}

1 Heon mihunkawanji, Wakantanka wacantohnake cin on etanhan eciciyapi ce, nitancanpi kin wośnapi ni un, wakan, qa taku Wakantanka iyokipi kin, hena hecen yaqupi kta, he wawoyalkiyapi kte cin hecetu hinca.

2 Qa wicoicage kin de en iyecen awacanipi kte śni, tuka nitawacinpi yuecepidan kte cin on nihdutokecapi nunwe; hecen Wakantanka tawacin waśte, oiyokipi, qa hduśtanpi kin he tukte e idukcanpi kta.

3 Wowaonśida maqupi kin he eciyatanhan, tona niyepi ekta un kinotoiyohi hecen eciciyapi; Tu- 
wedan token ihdukcan kte cin he isanpa ihdawa kste śni, tuka wacinksamya ihdukcan kta, Wakantanka otoiyohi wacinyanpi I iyuta wicaqu kin he eciyatanlian.

4 Wicatancan wanjidan en wicahuha ota unhapi, qa huha kin hena owasin okonwanjidan olianye śni :

5 He iyecen unkiye unkotapi, tuka Messiya en tancan unwanjipidan, qa otoiyohi huba unkiciyapi.

6 Hecen wowaonśida otoiyohi yukinukanyan unqupi kin eciyatanhan wicookihi ociptetu unhapi; he wokcanpi kte cin hee hecinhan, wowacinye iyutapi kin on unkiyukcanpi ece e kta.

7 Qa waowicakiyapi kin hee hecinhan, waowicakiyapi kin en unyakonpi kta; qa tuwe waonspekiya okihi kinhan, he waonspekiyapi kin en un kta.

8 Tuwe wahokonwicakiye kte cin he wahokonwicakiyapi kin en un kte; tuwe taku wicaqu kte cin he olianpiya econ kte; tuwe oyate wicayuhe cinhan he mnihenya econ kta; qa tuwe onśiwicadake cinhan iyokipiya econ kte.

9 Wacantkiyapi kin he wohnaye wanin un nunwe. Taku śice cin he sice dakapi, qa taku waśte kin he en iyaihdaśka po.

10 Hunkawanjin kiciyapi waste kicidakapi kin he on otoiyohi cante en kiciyuza po, qa woyuonihan on otoiyohi iyotan kicidaka po.

11 Wicohtani kin en kujapi śni, woniya on aiciciyapi, Itancan kin okiya po.

12 Woape en wiyuślkinpi ; kakijapi kin en icunhan wacintankapi; qa wocekiye eya yukan po.
13 Tona owotanna un kin taku icakijapi kinhan owicakiya po. Wicaśta icimanipi kin ohanpiya ecawicakicon po.

14 Tona śicaya nicuwapi kin hena wicayawaśte po ; wayawaśte po, qa wayaśicapi śni po.

15 Tona wiyuśkinpi kin hena om wiyuśkin po; qa tona ceyapi kin hena om ceya po.

16 Otoiyohi okonwanjidan arwakicicin po. Taku wankan un kin hena ekta ewacinpi śni po; tuka tona kun ihdawa kin hena en opa po. Wacinksapeicidapi śni po.

17 Tuwedan taku sica on itkom śicaya econpi śni po. Wicaśta owasin itokamya taku owotanna ecedan kamnan po.

18 Tohanyan oyakihipi kinhan, wicaśta owasin om wookiye yakon po.

19 Waśte cicidapi kin, ihnuhan niye cinka watoyeconpi kin, tuka wocanniye nakicipa po. Hecen wowapi en kagapi, Tokiconpi kin he miye mitawa, wicawecu kta ce, Itancan kin eya. 20 Heon tuwe toka niye cin he wotektehda kinhan wo qu wo; qa ipuza kinhan mini qu wo; hecen ecanon kinhan, petaga kin he pa kin en eju ade kta.

21 Ihnuhan taku śica on ohiniyanpi kin, tuka taku waśte e on taku sice cin ktepidan po.

\section{WICOWOYAKE 13.}

1 Wicanagi otoiyohi wicowaśake itancan kin hena ihukun iyeiciye kte. Wicowaśake Wakantanka etanhan un kin hecedan yukan. Wicowaśake un kin hena Wakantanka kaga.

2 Heon etanhan tuwe wicowaśake kin kipajin kinhan he Wakantanka toope kin kipajin, 
WICOWOYAKE 14.

qa tona wawakipajin kin hena wicayacopi kta.

3 Wicaśtayatapi kin hena wicohian waśte kin en wakokipe wicakicagapi śni, tuka wicohan śice cin en. Hecen wicowaśake kin he koyakipe kte śni he. Taku waśte e econ wo, kinhan on niyatanpi kta ce.

$4 \mathrm{He}$ taku waśte on niye ekta Wakantanka taokiye kin hee. Tuka taku śica ecanon kinhan kokipa wo. Hc mazasagye ituh yuhe śni; tuka Wakantanka taokiye kin heca, tuwe taku śica econ kinhan tokicon kta, wocanniye kin heon.

5 Heon etanhan anagoptan yaunpi kta, wocanniye kin hecedan on etanhan śni, tuka nakun wiyukcanpi kin heon.

6 Heon etanhan mazaska mnakiyapi kin en oyapapi ece : hena e Wakantanka taokiyepi kin ohinniyan taku kin de econ yukanpi.

7. Heon etanhan, owasin taku token wicaqupi kta iyecece cin wicaqu po: Tona iye taoyate kin etanhan mazaska mnayanpi kin he ecen wicaqu po; qa tona oyate tokeca etanhan mnayanpi kin he nakun ecen vicaqu po. Tona kinihanpi kte cin hena wicakinihan po, qa tona yuonihanpi kte cin hena wicayuonihan po.

8 Tuwedan takudan ikicazo śni un po, otoiyohi waśte yecidakapi kte cin hecedan. Tuwe wicaśta tokeca waśte wicadake cin he woahope kin tanyan yuha.

9 He decétu; Wawicihahapi ecanon kte śni; Tin wicayakte kte śni; Wamayanon kte śni; Tuwedan en oitonśniyan wodake kte śni ; Taku tokan tawapi kin yacin kte śni; qa woahope tokeca yuke cinhan wicoie kin de en yuwitayapi ; Wicaśta tokeca niye inihdacin waśte yadake kta ce.

10 Waśtewicadakapi kin he wicaśta tokeca taku śica takudan ecakicon śni, heon waśtewicadakapi kin he woahope yaecetupi kin hee.

11. Qa nakun kaketu, anpetu kin sdonunyanpi, woiśtinma etanhan unkiktapi kte cin wanna iyehantu; nakaha eunhdakupi kte cin tokaheya wicaundapi qon he isanpa ikiyadan ihan;

12 Hanyetu kin wanna ecadan unkihunipi kta, anpetu kin kohanna u kta, heon etanhan otpaza wicolian kin elipeunyanpi, qa iyoyanpa wipe kin kounyakapi kta.

13 Qa iyokipiya maunnipi kta, anpetu kin en iyececa. Hanyetu wacipi qa witkopi kin en unkopapi kte śni; wicawihomnipi qa wicinpi, wakinicapi qa winawizipi kin hena en ounpapi kte śni.

14 Tuka niye Jesus Messiya Itancan kin he koyaka po, qa wicacehpi wocantiheye śice cin ecetu yapi kta e on takudan kicamnanpi śni po.

\section{WICOWOYAKE 14.}

1 Tuwe wicada kinhan waśake śni eśta iyowinkiya po, tuka akipam waakinicapi kin elta śni.

2 Wicaśta wanjidan taku owasin yuta okihi awacin, qa wicaśta tokeca waśake śni kin he wahpe ece yuta.

3 Tuwe wote cinhan he tuwe wote śni kin iliaha kte śni; qa tuwe wote sni kinhan he tuwe wote cin yaco kte śni; Wakantanka he iyowinkiya.

4 Nituwe he wicaśta tokeca taokiye kin daco he ; he iye yu- 
he cin en najin kta qa iś hinhpaye kta. Qa he ecen najin kiyapi kta, Wakantanka najin kiye kta okihi.

5 Wicaśta wanji anpetu wanji iyotandaka, qa wicaśta tokeca wan anpetu owasin akiyecen yawa ece. Otoiyohi iye tawacin ekta sutaya awacin nunwe.

6 'Tuwe anpetu wan awacin kinhan he Itancan kin on awacin ; qa tuwe anpetu kin awacin śni kinhan, Itancan kin ekta awacin śni. Tuwe wote cinhan, he Itancan kin on wota, qa Wakantanka wopida eciya; qa tuwe wote śni kinhan, Itancan kin on wote śni, qa Wakantanka wopida eciya ece.

7 Unkiyepi kin tuwedan iye hinca on ni śni, qa tuwedan iye linca on te śni.

8 Unnipi kinhan Itancan kin on unnipi, qa untapi kinhan Itancan kin on unțapi. Hecen unnipi, qa unțapi unma tukte hecinhan, Itancan kin tawa unyanpi.

9 Hecen on Messiya te ca ake kini, wicate ca wicani kin heniyoza en Itancan kta e heon.

10 Tokeca nihunkawanji daco he; qa tokeca nihunkawanji iyakihaha he. Owasin Messiya tawoyaco oiyotanke kin itokam inaunjinpi kta.

11. Hecen wowapi en kagapi; Miye wani kin, heon hupahu otoiyohi miye en canpeśka makehde inajin kta, qa wicaceji otoiyohi Wakantanka en wohdake kta, Itancan kin eya.

12 Heon etanhan unkiyepi otoiyohi Wakantanka kin en wounhdakapi kta.

13 Hecen on, detanhan otoiyohi unkiciyacopi kte śni, tuka kaken e iyotan wakonza po, tuwedan taku en siha ibotopi, qa on hinhpaye kte cin he hunkawanjitku kin itokam ehde kte śni.

14 Miś sdonwaye ça Jesus Itancan kin en awacami, takudan atayedan śape śni; tuka tuwe taku śapa kecin kinhan, he taku kin iye elkta śapa ece.

15 Qa woyute kin on etanhan nihunkawanji iyokiśin yaye cinhan wowaśtedake eciyatanhan mayani śni. Messiya tuwe on te ciqon he woyute nitawa kin on ihang ye śni wo.

16 Ihnuhan taku waśte duhapi kin he yaśicapi kinhan.

17 Woyute qa woyatke kin Wakantanka tokiconze kin hee śni ; tuka wicoowotanna wookiye qa Woniya Wakan kin en wowiyuśkin kin hena ee.

18 Tuwe hena taku kin en Messiya wowidag ye cinhan, he Wakantanka iyokipi ye ca, wicaśta kin on waśte dakapi.

19 Heon etanhan taku tona wookiye kage cin hena unkakitapi kta qa nakun taku on otoiyohi icali unkiciciyapi kta.

20 Woyute kin on etanhan Wakantanka taku kage cin he ihang ye śni wo. Awicakehan taku owasin waśte; tuka tuwe taku yute ca on wahtani wicaye cinhan, he śica ece.

21 Waconica yutapi śni, qa mini śa yatkanpi śni, qa taku tokeca on etanhan nihunk awanji hicahe ca, wahtani, qa waśake śni aye cin, hena econpi śni kinhan he waśte.

22 Wowacinye duha he: Niś niye Wakantanka itokamya hduha wo. Tuwe taku iyowinkiye cin on ihdaco śni kinhan, he yuwaśtepi ece.

23 Qa tuwe wicada śni kinhan he yute cinluan wanna yacopi, wacinyanpi kin on hecon śni, 


\section{WICOWOYAKE 15.}

heon etanhan. Taku owasin wacinyanpi eciyatanhan śni kin hena woahtani.

\section{WICOWOYAKE 15.}

1 Unkiye waunśakapi kin tona waśake śni un sutaya wacinyanpi śni kin on wacinuntankapi kta, qa iyokipiunkiciyapi kte śni.

2 Otoiyohi wicaśta tokeca iyokipi unyanpi kta, wowaśte en icah yapi kte cin heon.

3 Messiya iye kaeś iyokipi içiye śni, tuka.wowapi en kagapi qon iyecen, Tona aniiapi kin waaiapi kin he miye ailipemayanpi qon.

4 Taku tona wowapi en kagapi kin hena onspeunkiyapi kte cin heon kagapi, hecen wicowahbadan, qa wowapi wakan kin en wicakicanpte cin eciyatanhan woape unhapi kta.

5 Wakantanka wicowahbadan, wicakicanpte ko yuhe cin he Jesus Messiya eciyatanhan, otoiyohi okonwanjidan wacin en kiciyus niyanpi nunwe.

$6 \mathrm{Qa}$ hecen wicotawacin wanjidan, qa wicai wanjidan on Wakantanka Jesus Messiya Itancan unkiyapi he Atkuku kin datanpi kta.

7 Heon etanhan otoiyohi iyowinkiciciya po, Wakantanka yutanpi kte cin hcon Messiya iyowinunkiyapi qon iyececa.

8 Miye kin kaken epe; Jesus Messiya bakilidayapi wicohan kin en ookiye ikicaga, Wakantanka towicake kin heon, qa hunkakepi kin wahowicayapi qon he hduecetu kte cin heon etanhan.

$9 \mathrm{Qa}$ hecen Ikcewicaśta kin Wakantanka yatanpi kta, iye towaonśida kin on; wowapi en kagapi qon iyececa, Heon etan- han Ikcewicaśta ehna ociyake ca nicaje kin iwadowan kta.

$10 \mathrm{Qa}$ ake hecen eya, Ikcewi-. caśta kin iyuśkin po, iye taoyate kin kici.

$11 \mathrm{Qa}$ ake, Ikcewicaśta kin owasin Itancan kin idowanpi, qa oyate kin owasin he yatan po.

12 Ake Isaya hecen eya, Jesse hutkan wanjidan qa tuwe Ikcewicaśta en wicaśtayatapi un kte cin he icage kta; he Ikcewicaśta kin wacinyanpi kta.

13 Hehan woape 'Wakantanka kin he wicayadapi kin eciyatanhan wowiyuśkin owasin wookiye ko on imna niyanpi nunwe, Woniya Wakan towaśake kin eciyatanhan woape en nina inicagapi kte cin heon.

14 Mihunkawanji niyepi on awacin manka, wowaśte onijupidan, qa wosdonye owasin on oju niyanpi, hecen otoiyohi wahokonyeciciyapi kta oyakihipi.

15 Tuka mihunkawanji, heccca eśta waditagya wowapi cicagapi, hecen wicoie wanjikji kiksuye ciyapi kta, Wakantanka towaonsida maqupi kin he eciyatanhan ;

16 Ikcewicaśta ehna Jesus Messiya taokiye kin wanji he miye kta, Wakantanka tawootanin waśte kin on litawani, qa hecen Ikcewicaśta wahduśnapi kin he woiyokipi $\mathrm{kta}$, Woniya Wakan kin on yuwakanpi kin heon.

17 Heon etanhan Jesus Messiya en taku Wakantanka tawa kin on wowinkta mduha.

18 Wicoie wicohian ko on Ikcewicaśta anagoptanpi kta e, miye eciyatanhan śni, Messiya taku econ qon hena cajemdate kte śni :

19 Tuka wowapetokeca tanka, 255 


\section{ROMA.}

qa woyuśin yaye econpi, Wakantanka Taniya Wakan towaśake kin eciyatanhan, hecen Jerusalem etanhan, qa ohomniyan Tlurikon ekta Messiya tawootanin waśte kin omdaka ece.

$20 \mathrm{Qa}$ hecen wotanin waśte kin aiciciya oyag uwate, tukten Messiya cajeyatapi kin hetu śni, okinni wicaśta tokeca taku ahde kin akan ti wakage kta naceca.

21 Tuka hecen wowapi en kagapi qon; 'Tona en cajeyatapi śni kin hena wanyakapi kta, qa tona nahonpi śni qon hena iyukcanpi kta.

$22 \mathrm{Qa}$ hecen on otakiya ekta ciupi kte cin okitpani mayanpi :

23 Tuka nakaha makoce kin dena en tuktedan omakan śni qa wanna waniyetu ota ekta ciupi kta nina wacin;

24 Heon tohan Spania ekta mde cinhan hehan ekta ciupi kta. Heciya icimani mde cinhan tahepi wanciyakapi, qa ek ta ye mayayapi kta awacin manka, tokaheya niyepi kin on cistiyedan imamdeze cinhàn.

25 Tuka nakaha Jerusalem ekta mda, tona owotanna un kin hena owicawakiye kte cin heon.

26 Tona Makedonia qa Akeya en yukanpi kin hena, tona walipanica wacinyanpi Jerusalem ekta yakonpi kin hena taku wicaqupi kta e iyokipipi.

27 Hecon iyokipipi ; taku iwicakicazopi kin iyecen unpi nakaeś. Hena taku wakan yuhapi qon en Ikcewicaśta opapi hecinhan, taku wicacehpi ekta un kin hena on itkom owicaliyapi kta iyececa.

28 Heon etanhan tohan he mduśtan qa, waskuyeca kin de hena en awicawecipuspe cin- han, hehan niyepi iyoopteya Spania ekta imdamde kta.

29 Qa ekta ciupi kinhan, Messiya tawootanin waśte woyuwaśte woojudan kin yuha wau kta sdonwakiya.

30 Hehan nakaha mihunkawanji ceciciyapi ce, Jesus Messiya Itancan kin caje on, qa Woniya Wakan towaśtedake kin on, miye kici Wakantanka niua cemiyeciciyapi kte cin he.

31 Tona Juda makoce kin ekta anagoptanpi śni kin hena etanhan emahdakupi kta, qa Jerusalem ekta wicohtani mitawa kin tona owotanna un kin iyokipi wicaye kte cin heon.

32 Qa hecen Wakantanka tawacin kin eciyatanhan wowiyuśkin yuha ekta ciupi, qa niyepi on imagaga miciye kta.

33 Wookiye Wakantanka kin niyepi owasin en nicipi un nunwe.

\section{WICOWOYAKE 16.}

1 Phebe tawinohtinunyanpi, Kenkrea ekta okodakiciye kin en ookiye wanji hee cantohnake ciśipi.

2 He Itancan kin on iyowinyakiyapi kta, tona owotanna un kin iyececa, qa taku on i kin he en token ecayeconpi cin kinhan ecen okiya po. Iye kin wicota owicakiye ca miye nakun omakiya ece.

3 Priskula Akula kici, Jesus Messiya en mitawaśipi kin hena napewicayuza po.

4 Hena e minagi kin on iye tahupi kin ehnakapi, qa hena miye miśnana pidamakiyapi śni, tuka Ikcewicaśta ekta okodakiciye kin owasin pidawicayapi.

5 Qa iye tipi kin ohna okodakiciye kin napewicayuza po. Epinetus waśtewadake cin he 


\section{WICOWOYAKE 16.}

napeyuza po; Akeya ekta Messiya en un qon tokaheya kin hee.

6 Mary nina ounkiyapi qon he napeyuza po.

7 Andronikus Junia kici mitakuye, qa om makaśkapi qon hena napewicayuza po; yewicaśipi kin owicapeya yuonihanpi, qa mitokapa tanhan Messiya en un qon hena.

8 Amplias Itancan kin en waste wadake cin he napeyuza po.

9 Urbane Messiya en unkitawaśipi kin, qa Stacus waśte wakidake cin, hena napewicayuza po.

10 Apelles Messiya en yuecepidan kin he napeyuza po. Aristobulus takuwicaye cin hena napewicayuza po.

11 Herodian mitakuye kin napeyuza po. Narkisus takuwicaye cin Itancan en un kin hena napewicayuza po.

12 Truphena Truphosa kici Itancan kin on htanipi kill hena napewicayuza po. Persis waśte dakapi kin Itancan kin on nina htani kin he napeyuza po.

13 Ruphus Itancan kin on kahinigapi kin, qa iye hunku, nakun mitawa kin, hena napewicayuza po.

14 Asunkritus, Plegon, Ermas, Patrobas, Ermes, hena, qa tona om unpi hunkawanjin kiciyapi kin hena ko; napewicayuza po.

15 Philologus, Julia, Nereus, iye tawinohitin kici, Olumpas, qa hena om tona owotanna un kin hena owasin napewicayuza po.

16 Otoiyohi iiputakapi wakan kin on napekiciyuza po. Messiya taokodakiciye kin napeniyuzapi.

17 Mihunkawanji ceciciyajpi ce, tona-woonspe onspeniçiciyapi Dak. 17 qon eciyatanhan śni yuomdecapi, qa wahtani wicayapi kin hena iwanwicayakapi, qa nawicakicipa po.

18 Tona hececapi kin Jesus Messiya Itancan unkiyapi kin wowidag wicaye śni, tuka iye tezipi kin hee, qa wicoie waśte, iapi iyokipi se ececa ko, on wicaśta wacin ks̀ape śni kin wicahnayanpi.

19 Niye waanayagoptanpi kin he wicaśta orvasin sdonyapi. Heon niyepi kin on imduśkin. Tuka taku waśte e on yaksapapi kta, qa taku śica on wadupipi kte śni wacin.

20 Unkan kohanna Wookiye Wakantanka kin niye nisihapi kin ihukuya Satan napan kta. Jesus Messiya Itancan unkiyapi towaonśida kin niyepi en nicipi un nunwe.

21 Timotheos mitawaśi, qa Lukius, Jason qa Sosipater mitakuye kin, hena napeniyuzapi.

22 'Tertius wowapi kin de owa kin he miye, Itancan kin on napeciyuzapi.

23 Gayos wonmakiye ca, okodakiciye owasin hecawicakicon kin, he napeniyuzapi. Erastus otonwe kin en wicaśta itancan wan, qa Kuartus hunkawanjin kiciyapi wan, hena napeniyuzapi.

24 Jesus Messiya Itancan unkiyapi towaonśida kin niyepi owasin en nicipi un nunwe.

25 Tuwe wootanin waśte mitawa qa. Jesus Messiya woyake cin he eciyatanhan niyusutapi kta okihi, wowiyukcan nakaha yuotaninpi kin eciyatanhan, he maka icage cin ehantanhan wicoicage kin en anahmanpi yon; 26 Tuka nakaha yuotaninpi, wicaśta wokcan tawowapi wakan kin heon, Wakantanka owikan kin heon, Wakar 


\section{KORIN'TH.}

hanke wanin un, tawoahope kin eciyatanhan, qa oyate owasin wacinyan anagoptanpi kte cin heon oyakapi;
27 Jesus Messiya on etanhan, Wakantanka ecedan ksape cin hee wowitan owihanke wanin kicihan nunwe.

\section{PA L O S KORINTH OYATE W OWAPI WICAKICAGE CIN:}

TOKAHEYA KIN.

\section{WICOWOYAKE 1.}

1 Palos Wakantanka tawacin kin eciyatanhan, Jesus yewicaśi kin heca e kahinigapi kin he, qa Sosthenes hunkawanjinunyanpi kici,

2 Wakantanka taokodakiciye Korinth ekta un qa Jesus Messiya on ecepidan kta, wakan wicakalinigapi kin hena eepi, qa tona makoce otoiyohi en Jesus Messiya iś iyepi kin Itancan kiyapi, qa unkiś eya Itancan unkiyapi caje kin hoyeyakiyapi kin wowapi unnicagapi.

3 Wowaonśida, wookiye ko, Wakantanka Ateunyanpi, qa Jesus Messiya Itancan kin etanhan niyepi en nicipi un nunwe.

4 Ohinniyan niyepi kin on Wakantanka mitawà wopida ewakiya, Wakantanka towaonśida Jesus Messiya eciyatanhan nicupi kin heon;

5 Taku henana owasin on, iye en, wijica nicagapi, wicoie owasin qa wosdonye owasir on.

6 Hecen niyepi kin en Messiya tawoyaatanin kin yusutapi.

7 Qa hecen wowaśte wanjidan aokpaniyan yaunpi śni, qa Jesus Messiya Itancan unkiyapi 258 ihdutanin kte cin he ape dukanpi.

8 He owihanketa hehanyan iyanionpepica śni niy usutapi ktą, Jesus Messiya Itancan unkiyapi taanpetu kin etu.

9 Wakantanka wasinyepica, iye Cinhintku Jesus Messiya Itancan unkiyapi kin takodakiciyapi tawa kin en nicopi.

10 Mihunkawanji, Jesus Messiya Itancan unkiyapi cajeyan ceciciyapi ce; owasin okonwanjidan oie yetonpi, qa yuomdecapi wanin yaunpi kta, qa wicotawacin eca wanjidan wiyukcanpi ko wanjidan tanyan onspe yaunpi kte.

11 Mihunkawanji, Kloe etanhanpi kin hena omakiyakapi, niyepi kin en woakinica yuke cin he.

12 Hecen kaken epe; Niyepi otoiyohi, Palos opeya waun, qa, Apolos opeya waun, qa, Inyan opeya waun, qa Messiya opeya waun ce, ehapi ece.

13 Messiya yukinukan ehnakapi he; niyepi kin on Palos cansusbeca kin en okatanpi he; qa iś Palos caje on baptem nicupi he. 14 Wakantanka wopida ewakiya, enitanhanpi tuwedan ba- 


\section{WICOWOYAKE 2.}

ptem waqu śni, tuka Krispos qa Gayos heniyoza:

15 Tuwedan, miye micaje on baptem wicawaqu, keye kte śni heon.

16 Qa nakun Stephanas tiyohnaka kin baptem wicawaqu, qa tuwe tokeca baptem waqu kinhan sdonwaye śni.

17 Baptem wicawaqu kta e on Messiya ye maśi śni, tuka wotanin waśte omdake kte cin heon; wicoksape iapi kin ohna śni, okinni Messiya cansusbeca tawa kin taku śni yapi kta.

18 Cansusbeca oyakapi kin he tona ihdutakunipi śni kin en witkotkoya iapi kin hee, tuka unkiyepi tona ni unyanpi kin en Wakantanka towaśake kin hee.

19 Kaken wowapi en kagapi; Tona wacin ksapa woksape tawa kin taku śni waye kta, qa tona okahnigapi kin hena wookahnige tawa kin mdutakuni kte śni ce.

20 Wacin ksape cin tokiya un he ; wowapi kage cin heca tokiya un he; wiconi kin de en wiyukcan kin tokiya un he; Wakantanka wicoicage kin de wicoksape kin yuwitkotko śni he.

21 Hecen Wakantanka toksape kin on, wicoicage kirı de wicoksape eciyatanhan Wakantanka sdonyapi śni qehan, wowahokonkiye wowitkotkoke cin on, tona wacinyanpi kinhan hena ni wicaye kta Wakantanka iyokipi.

22 Juda oyate kin wowapetokeca dapi, qa Helenes oyate kin wicoksape akitapi ece.

23 Tuka unkiyepi kin Messiya cansusbeca en okatanpi kin he unkoyakapi; he Juda wicaśta kin ekta wonahnaye qa Helenes wicaśta kin ekta witkotkoya iapi kin hee.

24 Tuka tona wicakahnigapi,
Juda qa Helenes wicaśta kin hena ekta, Messiya Wakantanka towaśake qa Wakantanka toksape kin hee.

25 Wakantanka taku tawa witkotkoke cin he wicaśta kin isanpa woksape ; qa Wakantanka towaśake śni kin he wicaśta kin isanpa wowaśake.

26 Mihunkawanji, nicopi kin he wandakapi, wicacehpi eciyatanhan wacin ksapa ota śni, waśaka ota śni, qa wicaśta okinihan ota śni.

27 Tuka wicoicage kin en taku witkotkoke cin he Wakantanka kahniga, on taku ksape cin wiśten ye kta; qa wicoicage kin en taku waśake śni kin hena Wakantanka kahiniga, on taku waśake cin wiśten ye kta.

28. Qa taku wicoicage kin en okinihan śni un kin he Wakantanka kahniga, qa taku un śni kin hena ko, on taku un kin yutakuni kte śni.

29 Hecen iye itokam wicacehpi owasin ihdatan kte śni

30 Tuka iye eciyatanhan Jesus Messiya en unyakonpi; he unkiyepi on Wakantanka eciyatanhan woksape, qa woowotanna, qa woyuecedan, qa wokajuju ikicaga.

31 Hecen wowapi qon iyececa; Tuwe iwinkta kinhan Itancan kin on iwinkta kta.

\section{WICOWOYAKE 2.}

1 Unkan mihunkawanji, ekta ciipi qehan, wicoie qa wicolssape oiyokipi kin yuha wai śni, tuka Wakantanka tawoyatanin kin ociciyakapi.

2 Ňiyepi kin ekta takudan sdonwaye kte śni e miciconza, Jesus Messiya hecedan, qa he cansusbeca kin en okatanpi. 


\section{KORINTH.}

3-Unkan waśake śni, wokoki- peya nina macancan cicipi waun.

4 Qa mioie, qa womdake cin heṇa wicaśta toksape wicoie oiyokipi kin en un śni, tuka Woniya wayuotanin, qa wowaśake kin en un.

5 Hecen wicayadapi kin he wicaśta wicoksape tawa kin en ahe kte śni, tuka Wakantanka towaśake kin en.

6 Tuka tona ksapapi kin hena ekta woksape unkoyakapi ece ; tuka wicoicage kin de en wicoksape kin hee śni, qa wicoicage kin de en wicaśtayatapi toksape kin hee śni, hena atakuni śni aya.

7 Tuka wowiyukcan en Wakantanka toksape kin he unkoyakapi ecè; eqe nalimanpi qon, woicage śni itokam wowitan unkitawapi kte cin heon, Wakantanka wakiconze ciqon.

$8 \mathrm{He}$ wicoicage kin de en wicaśta itancanpi kin tuwedan sdonye śni; sdonyapi unkanś Wowitan Itancan kin cansusbeca én okatanpi kte śni tuka.

9 Tuka wowapi qon iyececa; Tona Wakantanka waśtedakapi kin taku wicakiciyuśtan kin he wiciśta kin tohinni wanyake śni, qa wicanoge on nalionpi śni, qa wicaśta cante kin mahen iyohpaye śni.

10 Tuka hena Wakantanka iye Taniya kin eciyatanhan unkokiyakapi; Woniya kin he taku owasin iyukcan, Wakantanka wośbe tawa kin sdonya.

11 Wicaśta kin ekta tuwe taku wicaśta tawa kin sdonya he, wicaśta taniya iye mahen un kin hee sdonkiya. He iyecen taku Wakantanka tawa kin tuwedan sdonye śni, tuka Wakantanka Taniya kin hecedan.

12 Unkan unkiye wicoicage 260 kin de en wicoksape kin he unkicupi śni; tuka Wakantanka eciyatanhan Woniya Wakan kin he unkicupi, hecen taku Wakantanka iyunwin codan unqupi kin hena sdonunyanpi kta.

13 Qa hena unkoyakapi, wicaśta wicoksape woonspe wicoie kin eciyatanhan śni, tuka Woniya Wakan woonspe tawa kin eciyatanhan, hecen wicoie wakan kin wicaśta wakan iyukcanwicunyanpi ece.

14 Tuka wicacehpi wicaśta kin he Wakantanka Taniya taku tawa kin icu śni, hena taku witkotkoke dake ça okaliniga okihi śni, hena wakanyan iyukcanpi nakaeś.

15 Tuka tuwe wakanyan un kin he taku owasin iyukcan, tuka iye kin tuwedan on yukcanpi śni.

16 Itancan tawacin kin tuwe he iyukcan he, hecen onspekiye kta. Tuka unkiye Messiya tawacin kin unhapi.

\section{WICOWOYAKE 3.}

1 Unkan mihunkawanji, miś wicaśta wakanpi kin iyecen ocjciyapi kta owakihi śni, tuka wicacelipi wicaśta kin heca, qa Messiya en hokśiyopa kin iyececa.

2 Pteasanpi yatke ciciyapi, qa waconica kin he cicupi śni; he ehan nahahin he oyakihipi śni, qa dehan nahalin nakun oyakihipi śni.

3 Nahahin wicacehipi wicaśta kin henicapi. Niyepi ekta winawizipi, qa wakinicapi, qa yuomdecapi yukan hecinhan, wicacelipi kin henicapi, qa wicaśta akantu iyecen mayanipi śni he.

4 Wanji, Palos opeya waun, 


\section{WICOWOYAKE 4.}

qa wanji iś, Apolos opeya waun, eye cinhan, wicacehpi wicaśta kin henicapi śni he.

5 Palos he tuwe, qa Apolos he tuwe he; wowidake unpi kin hecapi, on wicayadapi, otoiyohi Itancan kin wicaqu kin iyececa. 6 Miye wowaju, Apolos mini akaśtan, qa Wakantanka icaliya.

7 Tuwe woju kin he taku śni, qa tuwe mini akaśtan kin kin he nakun, tuka Wakantanka waicaliye cir hee tanka.

8 Tuwe woju qa tuwe mini akaśtan kin hena okonwanjipidan; otoiyohi iye tohtani kin iyacinyan iyunwin icupi lita.

9 Wakantanka kici hitanipi kin hena unkiyepi; Walkantanka tamaga, qa Wakantanka tipi kage cin he niyepi.

10 Wakantanka towaonśida maqupi kin eciyatanhan wicaśta ticaga ksape cin iyecen, taku ahehde kin ewahde, qa he akan wicaśta tokeca tipi kaga; tuka otoiyohi token ticage cin he on waktaya un kte.

11 Tuka ahehde kin tokeca tuwedan ehde kta okihi śni, taku ehdepi kin hecedan, Jesus Messiya hee.

12 Unkan tuwe ahehde kin de akan mazaskazi, qa mazaska, qa inyan okitanin, qa can, qa peji, qa cedi en kage cinhan,

13 Otoiyohi olian kin atanin kta; anpetu kin he yuotanin kta, peta on yuotaninyan aye kta; qa peta kin otoiyohi ohan kin he taku kin iyukcan kta.

14. Tuwe ticage cin en olian kin sutaya un kinhan he wokajuju icu kta.

15 Qa tuwe ohan kin huhnage cinhan he iwahpanice kta, tuka iye qe peta kin etanhan iyecen niyanpi kta.

16 Wakantanka tipi tawa kin he niyepi, qa Wakantanka Taniya kin onitipi kin he sdonyakiyapi śni he.

17 Tuwe Wakantanka ti kin aśamye cinhan he Wakantanka ihangye kta. Wakantanka ti kin lie wakan, qa he niyepi.

18 Ihnuhan tuwe icihnaye cinhan. Tuwe niyepi ekta wicoicage kin de en ksapeicida kin he witkotkoke içicaga nunwe; hecen ksape kta.

19 Wicoicage kin de en taku woksape kin he Wakantanka witkotkoke daka. Kaken wowapi en kagapi ; Wicaśta ksape cin hena iye wohnaye tawapi kin on wicayuza ece.

$20 \mathrm{Qa}$ ake, Wicaśta ksape cin tawacinpi kin hena taku śni e, Itancan kin sdonya ce.

21 Hecen tuwedan wicaśta kin on iwinkta kte śni. Taku owasin nitawapi.

22 Palos, qa Apolos, qa Inyan, qa wicoicage kin, qa wiconi, qa wiconte, qa taku nakaha un kin, qa taku u kte cin hena owasin nitawapi ;

$23 \mathrm{Qa}$ Messiya tawa niyanpi, qa Wakantanka Messiya tawa ya.

\section{WICOWOYAKE 4.}

1 Wicaśta kin kaken ecanunkinpi kta, Messiya iwicadake cin qa Wakantanka tawowiyukean awanyakapi kin heuncapi.

2 Nakun tona waawanyakapi un kin hena owotanna olianyanpi kta iyececa wicadalkapi ece.

3. Tuka mayadacopi, qa wicaśta alsantu mayacopi esta, he taku śni wadaku; qa nakun mihdaco śni.

4 Miye cinka takudan sdonwakiye śni, tuka heon owotanna mihdawa śni ; tuka tuwe mayukcan kin Itancan kin hee. 


\section{KORINTH.}

5. Hecen iyehantu śni kin itokam takudan yacopi śni po, Itancan kin he hi śni kin hehanyan; he iye kin taku otpaza en nahmanpi qon aiyoyam ye kta, qa wicocante awacinpi kin yuatanin kta; unkan hehan otoiyohi Wakantanka eciyatanhan idowanpi kta.

6 Mihunkawanji, niyepi on etanhan hena hecen Apolos kici miye imihdacin; hecen unkiyepi kin on wowapi en kagapi kin isanpa kecanwicayakinpi kte śni onnispepi kta, qa hecen otoiyohi on wahannicidapi kte śni.

7 Tuwe hecen iyotan nicaga he; qa taku nicupi śni kin tukte e dulia he. Qa niçupi kinhan tokeca niçupi śni kin iyecen on iniwinkta he.

8 Nakaha winipipi ; nakaha winijicapi ; unkiyepi unkicunonpa tanhan wicaśtayatapi yaunpi : Unkan wicaśtayatapi yaunpi wacin, hecen niyepi kicj wicaśtayatapi unyakonpi kta tuka.

9 Miś kaken wacin mduza; Wakantanka yewicaśipi unkiyepi kin ehake taninyan eunhdepi, wiconte iyacopi kin iyececa; hecen wicoicage qa mahpiya ohnihde cin, qa wicaśta kin en woiw anyake kin he unkiyepikta.

10 Messiya on wiuntkotkopika, tuka niye Messiya en yalisapapi. Unkiye waunśakapi śni, tuka niye waniśakapi. Unkiye unyuonihanpi śni, tuka niye nicinihanpi.

11 Qa nakun anpe dehan wotekteunhdapi, qa iunpuzapi, qa tancounkapidan, qa unkaśtakapi, qa tuktedan tinsadan unyakonpi śni ;

$12 \mathrm{Qa}$ hununkițapi, unnapepi kin on htaunnipi. Unkaiapi keś wicunyawaśtepi ; śicaya unkuwapi keś wacin untankapi ; 262
13 Unyaśicapi keś ceunkiyapi ece. Wicoicage en watuśekśeca kin iyecen unkagapi, qa anpe dehanyan taku owasin etanhan taku kahin ehpeyapi kin hecen unyawapi ece.

14 Iśtenciyapi kta heon hena hecen wowapi wakage śni, tuka micinca waśte wicawakidake cin iyecen wahokonciciyapi.

15 Messiya en waonspekiyapi kektopawinge wikcemna duhapi eśta, a teyapi ota duhapi śni ; Jesus Messiya en wotanin waśte on cinca cicagapi.

16 Heon etanhan ceciciyapi ce, ecen omicipa po.

17 Heon niyepi kin ekta 'Timotheos ye waśi, he nakun micinca hokśincantkiyapi, qa I tancan kin en wacinyepica, he mitacanku Messiya en un kin kilksuye niyanpi kta, ohinniyan okodakiciye otoiyohi en waonspewakiye cin iyececa.

18 Ekta ciupi kte śni se ececa, heon wanjikśi wahanhaniçidapi.

19 Tuka ecadan elkta ciupi kta, Itancan kin iyokipi kinhan, qa tona wahanicidapi token eyapi kin hee śni, tuka taku okihipi kin he sdonwaye kta.

20 Wakantanka tokiconze kin he wicoie en ahe śni, tuka wowaśake en han.

21 Cansakadan yuha ekta ciupi kta, qa iś wacantkiyapi cante ahbayedan ko hduha wau kta, unma tukte yacinpi he.

\section{WICOWOYAKE 5.}

1 Niyepi ekta wawicihahapi yukan keyapi ; qa wawicihahapi kin he iyececa Ikcewicaśta kin ekta cajeyatapi śni, wanji iye atkuku tawicu kin yuze kte cin. 2 Unkan niye wahanniçidapi; on iyoniciśicapi kta tuka; hecen 


\section{WICOWOYAKE 6.}

tuwe hecon kin niyepi etanhan iyaye yapi kta.

3 Miye mitancan on ekta opeya ciunpi śni, tuka micante on en waun seca, heon en waun kin iyecen wanna mduśtan; tuwe hecon kin,

4 Mniniciyapi qa mitoksape duhapi kinhan, Jesus Messiya Itancan unkiyapi caje kin on, qa Jesus Messiya Itancan unkiyapi towaśake kin yuha,

5 Wicaśta kin he Satan yaqupi kta, celipi yutakuni kte śni, hecen Jesus Itancan kin taanpetu kin en nagi kin ni kta.

6 Iniwinktapi kin he waśte śni. Taku on napohyapi kin waniqadan aguyapi ocowasin napoliya ece e sdonyayapi śni he.

7 On napoliyapi tannike cin ehpeya po; hecen aguyapi teca qa napoliye śni yaunpi kta. Messiya wohduze unkitawapi kin he iye kaeś unkiyepi on wośnapi.

8 Heon etanhan wohduze kin en unkopapi $\mathrm{kta}$, on napohyapi wanakaja qa wocanniye wicośice ko on napohyapi kin he unha$p i$ kte śni, tuka wicoowotanna wowicake ko on napolyapi kin hee unkunpi kta.

9 Wowapi en kaken cicagapi ; Wiinahmanpi kin om mayanipi kte śni.

10 Tuka wicoicage kin de en wiinahmanpi, qa tona waicucupi kte cin, qa wawicaki sa, qa tona wakagapi ohodapi kin hena e wicawake śni ; unkanś wicoicage kin de etanhan tankan dapi kta tuka.

11 Tuka nakaha kaken wowapi cicagapi, tuwe hunkawanjin kiciyapi eciyapi kin he wiinaliman, qa waicucukte cin, qa wakagapi ohoda, qa waaie sa, qa witko sa, qa wawicaki sa heca kinhan, kici yaunpi kte śni, ihnuhan kici wayatapi kinhan.

12 Tona tankan unpi kin hena token ecin wicamdaco kta he; tona timahen un kin hena wicadacopi śni he.

13 Tuka tona tankan un kin hena Wakantanka wicayaco ece. Hecen wawicilialiapi econ qon he niyepi kin etanhan tankan iyeya po.

\section{WICOWOYAKE 6.}

1 Wicaśta wan taku icanśin niyanpi kinhan token ecin owotanna olianye śni unpi kin en yukcanpi kta e ayaipi he, qa wicaśta wacinyan unpi kin en ayaipi śni.

2 Tona wacinyan unpi kin hena wicoicage kin yacopi kta e sdonyayapi śni he. Unkan niyepi wicoicage kin dacopi kta hecinhan, taku iyotan cistinna kin hena iyukcan iyenicecapi śni he.

3 Mahpiya ohnihde kin hena eepi kaeś wicunyukcanpi kta e sdonyayapi śni he. Hecen wiconi kin de en taku hiyeye cin sam iyeya unkokihipi.

4 Heon etanhan wiconi kin de en taku iyukcanpi kte cin duhapi kinhan, tona okodakiciye kin en yuonihanpi śni kin hena iyukcan wicaśi po.

5 Iniśtecapi kte cin heon hepa. Niyepi ekta wicaśta ksape ca tuwe hunkawanjitkupi kin wiyukcan okihi kte cin wanica he.

6 Tuka hunkawanjinkiciyapi kin taku iyakicionpapi ece, qa he nakun wacinyanpi śni kin wicitokam.

7 Hecen taku iyayecionpapi kin he śicaya ecanonpi ece. Tokeca e śicaya ecaniconpi kin ayatpaspapi śni he. Tokeca ta263 


\section{KORINTH.}

ku nicipi kinhan wacin tanka yeçunpi śni he.

8 "Tuka niye śicaya ecanonpi, qa wawicayakipi ece, qa he nihunkawanjipi kin.

9 Tona owotanna śni un kin hena Wakantanka tolkiconze kin tawapi kte śni e sdonyayapi śni he. Içihnayanpi śni po: wiinahmanpi, qa wakagapi ohodapi sa, qa wawicihahapi econpi sa, qa winy an içidapi kin, qa iwicahu sa,

10 Qa wamanonpi sa, qa waicucukte cin, qa witkopi sa, qa wawicakipi sa, henakiya Wakantanka tokiconze kin tawapi kte śni.

11 Qa niś niyepi kin hunh henicecapi tuka, tuka niyujajapi ; tuka niyuwakanpi ; tuka niyuowotanpidan, Jesus Itancan kin cajeyan qa Wakantanka unkitawapi Taniya kin on.

12 Taku owasin écamon kta e iyowinmakiyapi, tuka taku owasin ecamon kta iyecece śni ; taku owasin ecamon kta e iyowinmakiyapi, tuka takudan imadake kte śni wacin.

13 Woyute kin he wicatezi kin kicagapi, qa wicatezi kin iś woyute kicagapi, tuka henioza Wakantanlka iliang ye kta. Unkan wicatancan kin he wiinalimanpi on kagapi śni, tuka he Itancan kin kicagapi, qa Itancan kin he iś wicatancan kin tawa kta.

14 Unkan Wakantanka wanna Itancan kin najin kiye ça, nakun iye torvaśake kin on najin unkiyapi kta.

15 Nitancanpi kin hena Messiya huha kin ee sdonyayapi śni he. Hecen Messiya huha kin iwacu, qa witkowinna wan huha walkiye kta he. Hiya, hecetu śni.

16 Tuwe witkowinna wan en kici iyaihdaśke cin he kici tan- can wanjidan, sdonyayapi śni he. Henioza cehpi wanjidan kta ce, eye ciqon.

17 'Tuka tuwe Itancan kin en kici iyaihdaśke cinhan he iye kici woniya wanjidan.

18 Wiinahmanpi kin nakicipa po. Woahtani wicaśta econ kin owasin wicatancan kin itankan un, tuka tuwe wiinahman kinhan he iye tancan kin en waicilitani.

19 Tokeca, nitancanpi kin hena Woniya Wakan Wakantanka niçupi, qa niyepi en un kin he tipi tawa kin hee, qa hecen tawa nihdawapi śni e sdonyayapi śni he.

20 Taku tanka iyopeniyanpi, heon nitancanpi ninagipi ko on Wakantanka yatan po, hena Wakantanka tawa.

\section{WICOWOYAKE 7.}

1 Wowapi en miyecagapi kin he icalitagya, wicaśta kin winohinca yutan śni kin he waśte.

2 Tuka wiinahmanpi kte śni e heon etanhan wicaśta otoiyohi winohinca tawa hduhe kta, qa winohinca kin iś otoiyohi wicaśta hduha nunwe.

3 Unkan wicaśta kin iye tawicu kin wowaśte ecakicon kta, qa winohinca kin iś iye hihnaku kin nakun ecen ecakicon nunwe. 4 Winohinca kin iś iye tancan kin hduhe śni, tuka hihnaku kin he yuha, qa nakun wicaśta kin iś iye tancan kin hduhe śni, tuka tawicu kin he yuha.

5 Otoiyohi tancan ehpekiciyapi śni po, pteccdan hehanyan, napin wicayadapi kinhan heceedan, takudan yute śni qa wocekiye eyapi kin en ocowasin yeniçiyapi kte cin heon, kinhan ake napin yahdapi kta, unmana

264 


\section{WICOWOYAKE $\%$}

kinhan oicihipi śni kin on Satan iyutanniyanpi kta naceca.

6 Hena hecon ciśipi kin e on hepe śni, tuka wahokonciciyapi kin heon.

7 Wicaśta owasin miye waun kin iyccen unpi kta wacin, tuka otoiyohi Wakantanka etanhan wicowaśake hduha un, wanji decetu, qa wanji iś kaketu.

8 'Tuka tona tanśna un qa tona wiwazicapi kin hena, miye waun kin iyecen unpi kte cin he waśte kta, kewicarvakiya.

9 Tuka oicihipi śni kinhan kiciyuzapi kta; wakan kiciyuzapi kin he waśte qa wacin itkon kin he sica.

10 Unkan tona kiciyuzapi kin hena kaken wahokouwicawakiya, qa he miye cinka epe śni, I tancan kin he heya; Winolinca iye hihnaku kin ahduśtan kte śni.

11 Tuka ahduśtan kinhan tanśna un kta, qa iś ake hihnaku qon okiciye kta; qa wicaśta kin iye tawicu kin ihnuhan elipekiye cinhan.

12 Unkan ehake, Itancan kin hee śni, miye cinka hecen epe kta ; Hunkawanjin kiciyapi wan winohinca wicada śni kin heca yuhe ça, he kici un iyokipi kinhan, he ihnuhan elipekiye cinhan.

13 Qa winohinca wan wicaśta wicada sni kin heca yuhe ca, he kici un iyokipi kinhan, he iś nakun ehpekiye kte śni.

14 Wicaśta wicada śni kin he iye tawicu kin on yuwakanpi, qa winoliinca wicada śni un kin he nakun iye hihnaku on yuwakan kagapi. Hecece śni unkanś nicincapi kin aśapapi kta, tuka nakaha hena è wakan.

15 'Tuka wicada śni un kin he unma kpagan kinhan hecen kpa- gan kta. Hena hecece cin en hunkawanjin kiciyapi, qa tawinolitin kiciyapi kin idakapi śni. Wakantanka wookiye en unkic opi.

16 Winohinca, niś taku sdonyaya he, okinni nihihna niyakiye kta. Qa wicaśta kin, niś token sdonyakiya he, okinni nitawin niyakiye kta.

17 Tuka otoiyohi token Wakantanka wicaqu qa Itancan kin otoiyohi wicakico kin he iyecen mani nunwe. Hecen okodakiciye owasin en econ wicawaśi ece.

18 Tuwe bakilidayapi ecen kicopi hecinhan, bakilidayapi śni kin akite kte śni. Qa tuwe bakihidayapi śni ecen kicopi hecinhan, he bakilidaye kte śni.

19 Bakilidayapi kin he taku śni, qa bakilidayapi śni kin he nakun taku śni, tuka Wakantanka tawoahope opapi kin he tanka.

20 Otoiyohi wicohtani en kicopi kin he en un kta.

21 Wowidake un kin henica ecen nicopi kinhan he ekta ewacin śni wo; tuka tawa niciye kta e oyakihi kinhan he en oyahan de kta.

22 Tuwe wowidake un kin he Itancan kico kinhan, hee. Itancan kin on tawa iciya; qa nakun. tuwe tawa iciye ein hecen kicopi kinhan he Messiya wowidake tawa kin hee.

23 Teliiya openitonpi, heon wicaśta akantu wowidag niyanpi śni nunwe.

24 Mihunkawanji, otoiyohi taku en un hecen kicopi kin he en Wakantanka kici un nunwe.

25 Unkan hokśiwinpidan icahtagya, Itancan kin eciyatanhan woope takudan nuduhe śni. Tuka miye owotanna waun kta 


\section{KORINTH.}

Itancan kin ionsimakida, hecen token wacin mduze cin owahdake kta.

26 Nakaha wicokakije kin on etanhan de waśte kepce, wicaśta kin ecen un kte cin he waśte.

27 Winohinca en iyanihdaśka he ; etanhan nihduśke kta akite śni wo. Qa winolinca en iyanihdaśke śni he; winolinca wan akite śni wo.

28 Tuka winolinca duza eśta wayahitani śni, qa hokśiwinna wan hihnaton eśta wahtani śni ; tuka hena e wicacehpi ekta wicokakije yuhapi kta; hececa eśta ito itoncipapi.

29 Tuka mihunkawanji kaken epe kta ; Wanna tokata ptenyedan; tona winohinca yubapi kin hena winohinca tonpi śni kin iyecen unpi kte.

30 Tona ceyapi kin hena ceyapi śni kin iyececapi kte; tora iyuśkinpi kin hena iyuśkinpi śni kin iyececapi kta; qa tona wopetonpi taku yuhapi śni kin iyececapi kta.

$31 \mathrm{Qa}$ tona maka kin de wowinyunyanpi kin śicaya yuhapi kin iyececapi kte śni ; wicoicage kin de ouncage kin atakuni śni aya.

32 Tuka takudan icante śice śni yaunpi kta wacin. Tuwe tawicu ton śni kin he Itancan taku tawa kin awacin yanka, token Itancan iyokipi ye lkta.

33 Tuka tuwe tawicu ton kin he wicoicage kin en taku awacin yanka, token tawicu kin iyokipi ye kta.

34 Qa nakun winohinca hihna ton qa witanśna un kin hena kici akidedece śni. Hihna ton śni kin he Itancan taku tawa kin awacin yanka, tancan nagi ko wakan un kta heon. Tuka hihna ton kin he wicoicage en ta- ku un kin awacin yanka, token hịhnaku kin iyokipi ye kta.

35 Tanyan yaunpi kta heon hena hepa. Taku on hmunkapi lin nitokam ewahnake kta e hee śni ; tuka wacinktonja wanin, qa wiciyokipi kin en Itancan kin oyapapi kta e heon.

36 Tuka tuwe iye cunwintku tanśna un kin tanyan ecalkicon śni kecin, qa wanna wikośka hecinhan, qa he iyecetu kinhan, token cin kinhan ecen econ eśta, wahitani kte śni ; wakan kiciyuzapi kte.

37 'Tuka tuwe iye cante kin en sutaya un qa tokan tarihan hecon kiyapi śni, qa iye tawacin kin oicihi, qa cunwintku tanśna un hduhe kta e cante mahen iciconze cinhan he tanyan econ.

38 Hecen tuwe kiciyuzapi kin en wicaqu kinhan he tanyan econ, qa tuwe kiciyuzapi kin en wicaqu śni kin he sanpa tanyan econ ece.

39 Winohinca kin tohanyan hihnaku ni un kin hehanyan wicoope kin on kaśkapi; tuka hihnaku kin te cinhan hehan tawaiciya, tuwe tokeca cin kinhan he hihnaye kta okihi, Itancan kin en un kin hecedan.

40 Tuka ecen yanke cinhan he iyotan waśteya un kta imdukcan, qa Wakantanka Taniya kin he mduha kepce.

\section{WICOWOYAKE 8.}

1. Unkan taku wakagapi walkiyuśnapi kin icahtake, owasin wookahnige unhapi sdonunkiyapi. Wookahnige kin he tankaicidapi kaga, tuka wacantkiyapi kin he tanka icahya.

2 Tuwe taku sdonya kecin kinhan he nahahiin sdonye kte cin iyecen takudan sdonye śni. 


\section{WICOWOYAKE 9.}

3 Tuka tuwe Wakantanka waśte dake cinhan Wakantanka he iye sdonya.

4. Taku wakagapi wakiyuśnapi kin yutapi kin he icalitake, wakagapi maka akan un kin he taku śni sdonunyanpi, qa Taku Wakan wanjidan, hecedan yukan.

5 Taku wakan eciyapi kin mahpiya ekta qa maka akan yukan eśta ; taku wakan ota, qa itancan kiyapi kin nakun ota keyapi ece :

6 Tuka unkiye, Taku Wakan wanjidan Ateyapi kin hee unhapi, he etanhan taku owasin $u$, qa he en unkiye unyakonpi; qa Jesus Messiya Itancan kin wanjidan, he on taku owasin un qa he eciyatanhan unkiyepi.

7 Tuka owasin hecen okahinigapi śni. Wanjikji anpetu dehanyan wakagapi sdonyapi, taku wakagapi wakiyuśnapi kin iyacinyan yutapi ece; heccn nagi suta śni kin hena aśamyapi.

8 Taku untapi kin eciyatanhan Wakantanka iyokipi unyanpi śni; wauntapi kinhan heon etanhan sanpa unwaśtepi śni, qa wauntapi śni kinhan heon sampa unśicapi śni.

9 Tuka ihnuhan wawoyakihipi kin de tona waśake śni un kin hena en wonahnaye kte cin.

10 Niye osdonya yaun kin, wakagapi tipi kin en wota idotanke cin tuwe wanniyake cinhan, wicaśta nagi waśake śni un kin he taku wakagapi wakiyuśnapi kin yuta onspeyakiye kte śni he.

11 Hecen nihunkawanji waśake śni un kin, on Messiya țe cin he ihangyapi kta, niye wasdonyaye cin heon etanhan.

12 Tuka hunkawanjin kiciyapi kin en hecen wayahtanpi, qa iye nagipi kin waśake śni kin nagiyeyayapi eca, Messiya en wayahtanipi ece.

13 Heon etanhan woyute kin mihunkawanji wahtaniye cinhan, ohinniyan tado wate śni waun kta, okinni mihunkawanji wahtaniwaye kta.

\section{WICOWOYAKE 9.}

1 Yewicaśipi kin hemaca śni he; tawa miçiye śni he; Jesus Messiya Itancan unkiyapi he wanmdake śni he; Itancan kin en miohan kin he niyepi śni he.

2 Wicaśta tokeca ekta yewicaśipi kin hemaca śni eśta, niyepi kin ekta hemaca. Yewicaśipi kin en opeya waun kin ipuspe kin he niyepi, Itancan kin en.

3 Tona wimawangapi kin hena kaken awicamdupta ece :

4 Unkiye wauntapi qa waunyatkanpi unkokihipi śni he.

5 Yewicaśipi kin tokeca, qa Itancan hunkawanjinwicaye cin, qa Inyan iyececa, unkiye tankśiwicunyanpi wanji hdus unkayapi unkokihipi śni he.

6 Qa iś, miś miye Barnabas kiciśnana, wicohan ayuśtan owakihi śni he.

7 Tohantu kaśta tuwe iyunwin codan zuya iyaya he ; tuwc hastanhanka iyuwi kin huhde qa etanhan waskuyeca yute śni he; qa tuwe tahinca optaye wan hduhe ca optaye kin etanhan asanpi yute śni he.

8 Wicaśta akantu eciyatanhan herra hecen epa he; qa woope kin he hena hecen eye śni he.

9 Moses toope kin en kaken kagapi, Tatanka aguyapi napan kin he iohmus icu yaye kte śni ce. Wakantanka tatanka ihawicakta he ;

$10 \mathrm{Qa}$ iś unkiyepi kin on hena 


\section{KORINTH.}

hecen eya he. Unkiyepi kin on he wowapi en kagapi; hecen turve makyumidu kinhan woape en maliyumdu kta, qa tuwe woape yuha aguyapi kapan kinhan he kici woape en okicipe kta.

11 Unkiye ninagipi kin on taku unkonicijupi hecinhan, taku wicacelipi kin nitawapi kin he mnaunyanpi kte cin he taku tanka he.

12 Wicaśta tokeca niyepi ekta wookihi kin de en okicipapi kinhan, unkiye unkiyotanpi śni he. Tuka wookihi kin he unkunpi śni; taku owasin unkapaspapi, Messiya tawootanin waśte kin anaunptapi kte śni kin heon.

13 Tona tipi wakan kin en kicanyanpi kin hena tipi wakan kin etanhan nipi ece sdonyayapi śni he; qa tona wahna wośnapi kin ekta ohanyanpi kin hena wośnapi kin etanhan wotapi ece.

14 Hecen nakun Itancan kin woope laga; tona wotanin waste oyakapi kin hena. wotanin waśte kin on nipi kta.

15 Tuka hena taku kin takudan iwacu śni, qa hecen ecamiconpi kte cin heon hena hecen wowapi wakage śni ; miye mațe kte cin hee waśte, qa tuwe imawinkta kin de ecetu śni miciciye kte cin he sica.

16 Wotanin waśte kin omdaka keś, he wowinkta wahdawa śni; waecon makiyapi, qa wotanin waśte omdake śni ehantanhan wokakije micihan.

17 Qa he iyokipiya ecamon hinhan on iyunwin mduhe kta, tuka iyomakipi śni eśta taku econmakiyapi wan maqupi.

18 Hecen taku mduhe kta he. Wotanin waśte omdake cinhan, Messiya tawootanin waśte kin iyunwin codan ewahde, qa he 268 cen wotanin waśte kin en wowakihi kin tanyan mduhe kta.

19 Wicaśta owasin elkta wowidake śni waun tuka owasin wowidake mayuhe wicawakiya, wanjikśi okihiwicawaye kte cin heon hecamon.

20 Juda oyate kin wicehna, Juda wicaśta kin hemaca, Juda oyate kin owicawakihi kte cin heon. 'Tona woope kin ihukuya un kin hena ekta woope yuha unpi kin hemaca, tona woope yuhapi kin hena owicawakihi kta.

21 Qa tona woope nicapi kin hena ekta woope codan unpi kin hemaca ; - Wakantanka ekta woope codan waun śni tuka Messiya on woope yuha waun; tona woope nicapi kin hena owicawakihi kta.

22 'Tona waśake śni kin hena en waśake śni se emaceca, tona waśake śni kin hena owicawakihi kta. Wicaśta owasin en taku owasin un kin hemaceca, wanjikji ni wicawaye kte cin heon.

23 Wotanin waśte kin he on hecamon ece; hecen he en miś eya owape k.ta.

$24 \mathrm{He}$ de sdonyayapi śni he; Tona oinyanke kin en inyankapi kin hena owasin inyankapi, tuka wicaśta wanjidan oqipe kin yekiya ece : Niś yeyakiyapi kta e iyecen inyanka po.

25 Tuwe kaśta kici econ kte cinhan taku owasin iyatahde içiye śni un. Hena wateśdake atakuni kte śni kin yekiyapi kta, tuka unkiye wateśdake ohinniyan un kte cin he unkakitapi.

26 Heon ctanhan miś hecen waimnanka, toketu tanin śni kin he iyecece śni; hecen nape on econ waun, tuwe okaduza ape cin iyecece śni ; 
27 Tuka mitancan kin suta micicage ca tinsmiciya; okinni wicaśta tokeca wotanin waśte kin owicawakiyaka eśta, miye qe lieyata iyemayanpi kte cin he kowakipa.

\section{WICOWOYAKE 10.}

1 Mihunkawanji he de sdonye śni yaunpi kta wacin sni, hunkake wicunyanpi kin owasin mahpiya śapa kin ihukuya yukanpi, qa owasin miniwanca kin opta hiyupi.

2 Qa owasin małipiya śapa qa miniwanca kin en Moses baptem wicaqu.

3 Qa owasin woyute wakan wanjidan etanhan yutapi.

4. Qa owasin woyatke wakan wanjidan etanhan yatkanpi. Imnija wakan kin wicihakam iyaye ciqon he etanhan yatkanpi. Imnija kin he Messiya hee.

5 Tuka hena wicota Wakantanka iwicayuśkin śni, hecen makoskan ilipayapi.

6 Unkan hena e waonspekiya unkitawapi kin eepi, hecen taku śica cantiheunyanpi kte śni, iś iye cantiheyapi qon iyececa.

7 Qa wakagapi ohoyadapi kte śni, iś iyepi wanjikji heconpi qon iyececa. Kaken wowapi en kagapi, Oyate kin wota qa wayatke iyotankapi, qa śkan-najin hiyayapi.

8 Qa wiinahmanpi kin econkupi kte śni, iś iyepi wanjikji econpi qon ryececa; qa anpetu wanjidan en kektopawinge wikcemna nonpa sanpa kektopawinge yamni ilipayapi.

9 Qa Messiya iyutan unyanpi kte śni, hena wanjikji iyutan yanpi qon iyececa; unkan wamduśka ihangwicayapi.

10 Qa wawiyahnupi kte śni, iś 98 iyepi wanjikji wawihnupi qon iyececa, qa waihangye cin on yutakunipi śni.

11 Hena taku kin owasin waonspekiyapi on en wicahiyahde, qa unkiyepi wicoicage owihanketa unyakonpi kin wahokonunkiyapi kte cin heon wowapi en kagapi.

12 Hecen tuwe tinsa najin kecin kinhan, he wakta un nunwe, okinni ilipaye kta.

13 Wowiyutanyan wan wicaśta sdonyapi śni ece kin en aniupi śni. Wakantanka wacin yepica, hecen wawoyakihipi kin isanpa iyutanniyanpi kta iyowinye kte śni, tuka wowiyutanyan kin he enakiye kta, hecen oyakihipi kta. 14 Heon etanhan waśte cicidapi kin, wakagapi ohodapi kin nakicipa po.

15 Wicaśta wacin ksape cin hena becen ewicawakiya, token epe cin niś iyukcan po.

16 Woyawaśte wiyatke unyawaśtepi kin he Messiya we kin en kodakiciyapi kin hee śni he. Aguyapi unkiyuśpapi kin he Messiya tancan kin en kodakiciyapi kin hee śni he.

17 Unkiye unkotapi, tuka aguyapi unwanjipidan, qa tancan unwanjipidan; unkiye owasin aguyapi wanjidan en akiptan unkopapi.

18 Wicacehpi eciyatanhan Israel oyate kin ekta ewicatonwan po. Tona wośnapi kin etanhan yutapi kin hena wahna wośnapi kin en opapi śni he.

19 Heon token epe kta he: Wakagapi kin he taku, qa iś taku wakagapi wakiyuśnapi kin he taku tanka he : Hiya.

20 Tuka taku Ikcewicaśta kin wayuśnapi ece kin hena Wakan śica wakiyuśnapi, qa Wakantanka wakiyuśnapi śni. Unkan 269 


\section{KORINTH.}

taku wakan śicapi kin en oyecipapi kta wacin śni.

21 Itancan tawoyatke qa nakun taku wakan śicapi tawoyatke kin yatkan oyạkihipi śni. Itancan kin wahna wotapi tawa kin en oyapapi, qa nakun taku wakan śicapi wahna wotapi tawapi kin en oyapapi kta oyakihipi śni。

22 Itancan kin šihda unyanpi kta he. Tye sam iyeya waunśakapi he.

23 Taku owasin iyemicihantu tuka owasin taku waśte icaliye śni. Taku owasin iyemicihantu tuka owasin waonspekiye śni.

24 'Tuwedan iśnana taku amnaiciye kte śni, tuka otoiyohi taku tokan tawa kte cin he akicicite kta.

25 Taku owasin tihocoka lkin ekta wiyopeyapi kin he yuta po, qa wiyukcanpi kin on takudan iwangapi śni po.

26 Maka lin de taku ohnaka ko Itancan kin tawa.

27 Wicaśta wicadapi śni kin wanji nicopi, qa ekta dapi tawatenyayapi kinhan, taku nitokam ehdepi kin he yuta po, qa wiyukcanpi on wiwangapi śni po.

28 Tuka tuwe, De wakagapi wakiyuuśnapi ce, eniciyapi kinhan, yutapi śni po, tuwe oniciyakapi qa wiyukcanpi kin hena on. Maka kin de taku ohnaka ko Itancan kin tawa.

29 Wiyukcanpi kin cajemdata, niye nitawa śni tuka tokan tawa kin he waka. Tokeca tawa miciye cin he wicaśta tokeca tawiyukcan kin on mayacopi kta he.

30 Wowaśte on en owape cinhan, tokeca e taku on wopida epe cin he on maraśicapi he.

31 Heon wayatapi qa wadatkanpi, qa taku kaśta ecanonpi kin owasin Wakantanka yatanpi kta e on econ po.

32 Juda oyate, qa Helenes oyate, qa Wakantanka taokodakiciye tuwedan icanśinyayapi kte śni.

$33 \mathrm{Qa}$ miye taku owasin on owasin iyolipi wicawaye cin he iyececa, taku mduhe kte cin he awakite śni, tuka taku wicota yuhapi kte cin, hecen nipi kta.

\section{WICOWOYAKE 11.}

1 Miye omicipa po, Messiya opeya waun kin iyececa.

2 Mihunkawanji, ciyatanpi ce, taku owasin on miyeksuyapi, qa woope cicupi qon ecehin duhapi kin heon etanhan.

3 Tuka he de sdonyayapi kta wacin; Wicaśta otoiyohi en pa kin he Messiya ee ; qa winohinca pa kin he wicaśta kin ee; qa Messiya pa kin he Wakantanka ee.

4 Wicaśta otoiyohi pa akahpe ton cekiye ça wiyukcan kinhan, he iye pa kin wowiśtenya ece.

5 Tuka winohinca otoiyohi pa akahpe ton śni cekiye ca, wiyukcan kinhan, he iye pa kin wowiśtenya; he paha yuśdapi kin kici akidececa.

6 Winolinca iś pa akahpe ton śni kinhan paha yuśdapi kta. Tuka winohinca paha yuśdapi, qa iś hdasanpi kin he wowiśtece kinhan, pa akalipe ton un kte.

7 Wicaśta kin iś pa akalipe ton un kin he hecetu śni, he Wakantanka touncage qa towitan kin hee; qa winohinca kin wicaśta towitan kin hee.

8 Wicaśta kin he winohinca kin etanhan śni ; tuka winohinca kin he wicaśta kin etanhan un.

9 Qa wicaśta kin he winolinca 


\section{WICOWOYAKE 11.}

kicagapi śni, tuka winohinca kin iś wicaśta kin kicagapi.

10 Heon winohinca kin pa kin akan wowaśake hduhe kta, mahipiya ohnihde cin hena on etanhan.

11 Tuka nakun wicaśta kin winohinca codan un śni, qa winohinca kin is wicaśta codan un śni, Itancan kin en.

12 Unkan winoliinca kin he wicaśta kin etanhan un kin, he iyeren wicaśta kin iś winohinca kin eciyatanhan $u$; qa taku owasin Wakantanka etanhan un.

13 Niś niyepi kin he iyukcan po; winohinca pa akahpe ton śni Wakantanka cekiye cinhan he hecetu he.

14 Taku oiyokipi kin hee kaeś he onspeniciyapi śni he; wicasta kin paha hanskaska hecinhan he wowiśtece.

15 Tuka winohinca kin iś paha hanskaska koyake cinhan he wowitan kin ee, paha kin he woakalipe qupi:

16 Tuka tuwe waakinin un kinhan, wicolian kin de iyececa takudan unhapi śni, qa nakun Wakantanka taokodakiciye kin.

17 Unkan he de omdake ca ciyatanpi śni ; taku sanpa waśte kin on mniniciyapi śni; tuka taku aoptetu kin heon etanhan.

18 Tokaheya okodakiciye mniniciyapi eca yuomdecapi dukanpi keyapi nawalion; qa onśpa wicawada.

19 Waakinicapi niyepi en un kta, hecen tona owotanna iniyukcanpi kin tanin kta.

20 Heon witaya mniniciyapi eca, he hitayetu wotapi Itancan tawa kin yutapi kte cin hee śni ;

21 Wotapi kin en otoiyohi taku yute kte cin tokaheya icu ece; unkan wanji wotektehda qa wanji iś witko ece.
22 Tokeca, tipi ohna wayatapi, qa wadatkanpi kte cin yahduhapi śni he. Wakantanka taokodakiciye kin ayaktapi śni, qa tona taku yuhapi śni kin hena iśtenwicayayapi he. Token eciciyapi kta he. Heon ciyatanpi kta he. Hiya, ciyatanpi śni.

23 Miye taku Itancan maqu qon he ciçupi, Jesus Itancan kin, hanyetu wan iyopeyapi qon he en, aguyapi icu ;

$24 \mathrm{Qa}$ wanna wopida eye cin hehan kiyuśpe ca heya; Icupi qa yuta po; mitancan kin niyepi on kiyuśpapi kin he dee; decen miksuya econ po.

25 Nakun iś eya iyecen wanna yatkan qehan, wiyatke kin icu qa heya; Mawe kin en wicotakuye teca kin he dee ce; decen econ po, tohanhan datkanpi eca, miksuya po.

26 Hecen tohan aguyapi kin de yatapi, qa wiyatke kin de dathanpi kinhan, henakiya Itancan te cin lie duotaninpi ece, tohanyan hi śni kin hehanyan.

27 Heon etanhan, tuwe aguyapi kin de iyacin śni yute ca, Itancan tawiyatke kin de yatke cinhan, he Itancan kin tancan, we ko, on yacopi.

28 Tuka wicaśta kin wihdukcan kta, hecen aguyapi kin de yute ca, wiyatke kin de etanhan yatke kta.

29 Tuwe iyacin śni yute ça yatke cinhan, he woyaco hdute ça hdatkan, Itancan tancan kin iyukcan śni kin heon.

30 Heon etanhan niyepi ekta wicota waśakapi śni, qa wayazanpi sa, qa hunli iśtinmapi.

31 Unkiye -unkihdukcanpi kinhan, tokan tanhan unkiyukcanpi kte śni.

$32 \mathrm{Qa}$ unkiyukcanpi kinhan, 271 


\section{KORINTH.}

Itancan kin wahokonunkiyapi, hecen wicoicage kin om unyacopi kte śni.

33 Hecen mihunkawanji tohan wota mniniciyapi kinhan, otoiyohi akicipe po.

$34 \mathrm{Qa}$ tuwe wotektehda kinhan, he tiyata wote kta; hecen woyaco en witaya yaipi kte śni. Qa taku nahahin ihe cin hena tohan wau kinhan, wiyeya ewahnake kta.

\section{WICOWOYAKE 12}

1 Mihunkawanji, taku wakanyan wicaqupi kin iyukcan śni yaunpi kta wacin śni.

2 Ikcewicaśta kin henicapi, wakagapi iapi okitpani kin en aniyanpi, ye niyanpi qon iyececa, he sdonyakiyapi.

3 Heon he sdonye ciciyapi; Tuwedan Wakantanka Taniya kin eciyatanhan ie ca, Jesus yaśice kte śni ; qa nakun tuwedan Jesus e Itancan eciye kta okihi śni, tuka Woniya Wakan ecedan eciyatanhan okihi ece.

4 Unkan taku wicaqupi kin hena okonwanjidan śni, tuka Woniya kin e wanjidan.

5 Qa waeconpi kin okonwanjidan śni, tuka Itancan kin e wanjidan.

6 Qa wicohan toktokeca; tuka Wakantanka kin e okonwanjidan, iye owasin en taku owasin owicakicilian.

7 Qa otoiyohi on iyopta ye kte cin heon Woniya yuotaninpi kin wicaqupi ece.

8 Woniya kin wicaśta wan woksape wicoie kin qu ece; qa wanji iś wosdonye wicoie kin, hena Woniya wanjidan etanhan.

9 Qa Woniya kin he wanji tokeca wowacinye qu ece; qa wanji tokeca iś wawokiziyapi qu ece, qa hena Woniya wanjidan etanhan.

$10 \mathrm{Qa}$ wicaśta wan wowapetokeca econpi, qa wanji tokeca wiyukcanpi, qa wanji tokeca taku wakan iyukcanpi, qa wanji tokeca iapi ocaje ota, qa wanji tokeca iapi ieska oyakapi kin hecekcen wicaqupi ece.

11 Tuka hena owasin Woniya wanjidan qa okonwanjidan un lkin he olianye ca, token cin kin hecen wicaśta otoiyohi kipamni wicaqu ece.

12 Wicatancan kin he wanjidan tuka wicahuha ota yukan; qa tancan kin en huha kin hena ota qeyaś tancan wanjidan ; Messiya kin iś he iyececa.

13 Woniya wanjidan on, unkiye owasin wicatancan wanjidan kta e baptem unqupi, Juda qa Helenes oyate, wowidake un kin, tona tawa iciyapi kin hena koya ; qa owasin Woniya wanjidan kin he en wayatke unkiyapi.

14 Wicatancan kin he huha wanjidan śni, tuka ota.

15 Hehan wicasiha kin he, Wicanape kin lie miye śni heon wicatancan kin en opeya waun śni ce, eye cinhan, heon etanhan wicatancan kin en ope śni he.

16 Qa wicanoge kin he, Wicaiśta kin he miye śni qa heon wicatancan kin en opeya waun śni ce, eye cinhan, ehantanhan wicatancan kin en ope śni he.

17 Wicatancan kin ocowasin iśta kin ee unkanś, winahonpi kin tokiya un kta he; qa ocowasin winalionpi kin ee unkanś, waomnapi kin tokiya un kta he.

18 Tuka nakaha Wakantanka token iyokipi kin hecen wicahuha kin otoiyohi wicatancan kin en ehde. 


\section{WICOWOYAKE 13.}

19 Qa hena iyulipa wicahuha wanjidan unkanś, tancan kin tokiya un kta he.

20 Tuka nakaha wicahuha ota eśta, tancan wanjidan.

21. Hecen iśta kin he, Cicin śni ce, nape kin eciya okihi śni ; qa nakun pa kin he, Cicin śni ce, siha kin eciye kte śni.

22 Qa nakun sanpa, wicatancan en wicahuha kin tona waśake śni se un kin hena iyotan.

23 Qa wicatancan ekta tona yuonihan śni undakapi kin hena iyotan unhduonihanpi ece; qa tona owanyag śice cin hena iyo$\tan$ woiyokipi ece.

24 Tona waśte unyukanpi kin hena takudan sanpa cinpi śni ; tuka Wakantanka wicatancan kin icikoyagya kage ca, tukten iyokpaniyan un kin he en yuonihanpi tanka kaga.

25 Hecen wicatancan kin en yuomdecapi wanice kta; qa wicahuha kin hena otoiyohi awakicicinpi kta.

$26 \mathrm{Qa}$ hecen huha wanjidan iyotanhan iyekiye cinhan, he kici huha kin iyuhpa iyotanhan iyekiyapi kta; qa huha wanjidan yuonihanpi kinhan he kici huha kin iyuhpa iyuśkinpi kta.

27 Messiya tancan kin he niyepi, qa otoiyohi huha yecidukanpi.

28 Unkan okodakiciye kin en Wakantanka kakenken ewicahde, tokaheya yewicaśipi kin hena, qa iyokihe wokcanpi, qa iciyamni waonspekiyapi; hehan wicowaśake, hehan waasniyanpi, waokiyapi, itancanpi, qa ceji toktokeca.

29 Owasin yewicaśipi kin hecapi he; owasin wokcanpi he; owasin waonspekiyapi he ; owasin wicowaśake kin heca he:

300 wasin waasniyanpi okihipi Dak. he; owasin ceji tokeca on iapi he ; owasin ieskapi he.

31 Wookihi iyotan waśte kin hena nina akita po. Tuka hena isanpa canku waśte wan cicipazopi kta.

\section{WICOWOYAKE 13.}

1 Wicaśta akantu, qa mahpiya ohnihde cejipi kin on iwaa eśta, wacanwakiye śni ehantanhan maza. śa snasna, qa taku ituya sna kin he iyemaceca.

$2 \mathrm{Qa}$ wowiyukcan mduhe ca, taku anahbeya un kin owasin, wookahnige owasin ko, sdonwaye ca, wowacinye owasin mduha, on he kin yutokan iyewaye kta owakihi eśta, wacanwakiye śni ehantanhan mataku śni.

3 Qa taku mitawa kin owasin won wicayapi kin en wahdusote ca, mitancan kin hee kaeś huhnage kta e waqu eśta, wacanwakiye śni ehantanhan takudan iciyopteya waun śni.

4 Wacantkiyapi kin he wicotawacin tanka qa wowaśte ocowasin. Wacantkiyapi kin he wawinawizi śni. Wacantkiyapi kin he wahanhaniçida śni, qa ihdatan śni ece ;

5 Wawiśtenya econ śni, qa iśnana takudan amnaiciye śni, wacinko śni, qa taku śica iyawicaonpe śni ;

6 Woahitani en iyuśkin śni, tuka wowicake kin en iyuśkin;

7 Taku owasin kajuju; taku owasin wicada; taku owasin ape; qa taku owasin iyowinyan.

8 Wacantkiyapi kin he tohinni owihanke śni. Wokcanpi kin hena enakiyapi kta; ceji tokeca kin hena ayuśtan aye kta; qa wookahnige kin hee kaeś atakuni kte śni. 


\section{KORINTH.}

9 Apadan sdonunyanpi, qa apadan unkiyulkcanpi.

10 Tuka tohan woyuśtan kin he hi kinhan tona woyuśtan śni kin hena ihanke kta.

11 Homakśiyoqopa qehan, hokśiyoqopa iyecen iwae ca, hokśiyogopa iyecen wimdukcan, qa hokśiyoqopa iyecen awacin waun; tuka wicaśta imacaga hehan taku hokśiyoqopa tawa kin amduśtan.

12 Dehan ihdiyomdasin en iyecen aotpasya wawanunyakapi ece ; tuka eqe hehan anog itohnake icitkokim wanunkiciyakapi kta. Nakaha taku kin tanyan sdonwaye śni; tuka e qe tokata sdonmayanpi kin iyecen tanyan sdonwaye kta e imicihan.

13 Unkan nakaha hena yamni en ounyan, wacinyanpi, qa apepi, qa wacantkiyapi ; tuka wacantkiyapi kin he iyotan tanka.

\section{WICOWOYAKE 14.}

1 Wacantkiyapi kin he okipa po, qa taku wakanyan wicaqupi kin hena cin po; tuka widukcanpi kte cin he iyotan.

2 Tuwe ceji tokeca on ie cin he wicaśta kin takudan owicakiyake śni, tuka Wakantanka taku eciya; tuwedan nahon śni kin heon: hececa eśta Woniya kin eciyatanhan taku woanahbe kin oyaka tuka.

3 Tuka tuwe wiyukcan oyake cin he wicaśta kin wowicakiyaka, on icahyapi qa wahokonkiyapi qa kicanptapi.

4 Tuwe ceji tokeca on ie cin he iye ksamiciya; tuka tuwe wiyukcan oyake cinhan he okodakiciye kin ksamwicaya ece.

5 Niyepi kin owasin ceji toktokeca on iyaapi kta wacin, 274 tuka widukcanpi kłe cin he iyotan wacin. Tuwe wiyukcan kin he tanka qa tuwe ceji tokeca on ie cin he ihukuya, ieska oyake śni kinhan, hecen okodakiciye kin icahyapi lkta tulka.

6 Unkan nalkaba mihunkawanji, ceji tokeca on iwaa en ciupi kinhan, he token oniciyapi kta he; yaotaninpi, qa wookahinige, qa wiyukcanpi, qa woonspe kin unmana eciyatanhan eciciyapi śni kinhan.

7 Unkan taku ni un śni kin hena, cotanka qa is candowankiyapi kin hotanin kinhan, ho toktokeca śni kinhan, he taku on etanhan tukte e yajopi, qa tukte e dowankiyapi kin sdonyapi kta he.

8 Maza yahotonpi tanka kin ho okonwanjidan śni yahotonpi kinhan, tuwe zuyapi kta e wiyeya ic̣icage kta he.

9 Ḣe iyecen niś niyepi, ceji on wicoie okahnih waśteśte iyaapi śni kinhan, token on etanhan taku oyakapi kin he taku ee sdonyapi kta he; okaduza kin en iyaapi kta.

10 Maka kin akan ho ocaje tokeca kanakiya naceca, qa owasin taku kapi.

11 Tuka miś ho kin taku kapi kin sdonwaye śni kinhan, tuwe ie cin he Ikcewicaśta kin kecanmakin kta, qa miś eya tuwe ie cin he Ikcewicaśta kin heca wadake kta.

12 Hecen wicohan wakan nina yacinpi kinhan, okodakiciye kin icahyapi kta e wadupipilke kte cin he akita po.

13 Heon tuwe ceji tokeca on ie cinhan, he ieska oyake kta e icekiye $\mathrm{kta}$.

14 Miye śaia cewakiye cinhan, minagi kin he cekiya; tuka mitawacin e qe takudan icaliye sni. 


\section{WICOWOYAKE 14.}

15 Hecen toketu he. Miye minagi kin eciyatanhan cewakiye kta, qa nakun mitawacin kin eciyatanhan cewakiyc kta; minagi kin on wadowan kta, qa nakun mitawacin kin on wadowan kta.

16 He hecece śni kinhan, ninagi on wopida eha eca, tuwe onspe śni en iyotanke cin he token, wopida ehe cin en, Amen eye kta he, taku ehe cin sdonyc śni nakaeś.

17 Wopida tanyan eha, tuka iye kin okahnige śni.

18 Wakantanka mitawa wopida ewakiya ce, niyepi kin owasin sam iyeya ceji tokeca on iwaa ece.

19 Tuka okodakiciye kin en mitawacin kin eciyatanhan wicoie zaptanna iwae kta, on wicaśta tokeca onpsewicawakiye kte cin he iyotan waśte, qa ceji tokcca on wicoie kektopawinge wikcemna iwae kte cin he aoptctu.

20 Mihunkawanji, wookahnige cn hokśiyoqopa unpi śni po ; tuka wicotawacin śice cin en hokśiyoqopa po, qa wookahnige kin en wicaśta tanka un po.

21 Woope kin en kaken kagapi ; Ceji tokeca, iha tokeca lio on oyate kin de owicaweciye kta; tuka hececa eśta, namahonpi kte śni, Itancan kin eya.

22 Hecen ceji tokeca kin hena wowakta kin hee, tona wicadapi śni kin hena eepi śni, tuka tona wicadapi kin hena on wowapetokeca kin hee.

23 Okodakiciye kin ocowasin witaya mniciyapi, qa owasin ceji tokeca on iapi kinhan, qa tona wacinton śni, wicada śni ko en hipi kinhan, winitkotkopika kecannicinpi ktc śni he.

24 "Tuka owasin wiyukcanpi, qa tuwe wicada śni wacinton śni un kin tin hiyu kinhan, he owasin on onspekiyapi, qa owasin on yacopi kta.

$25 \mathrm{Qa}$ hecen iye cante kin ekta taku anahbe cin yutaninpi kta; hehan makipusdiya elipeiciye ca Wakantanka ohoda kta, qa Wakantanka niyepi en nicipi un kin oyake kta.

26 Heon mihunkawanji toketu he: Mniniciyapi eca niyepi otoiyohi odowan duhapi, qa woonspe duhapi, qa ceji tolkeca, qa yaotaninpi wan, qa ieska oyakapi wan duhapi ece. Taku owasin waonspekiyapi k ta e on econpi nunwe.

27 Tuwe ceji tokeca on ie cinhan, wancadan wicaśta nomnom yamnimni, qa hena wanji itok to econpi kta, qa wanji ieska kiyapi kta.

28 'Tuka tuwe ieska kiyapi kte cin wanice cinhan, okodakiciye kin en inina yanke kta; iś iye oiçiciye ça Wakantanka okiye lita.

29 Qa wicaśta wokcan kin hena nomnom qa yamnimni oyakapi kta, qa unmanpi kin wiyukcan unpi kta.

30 Qa tuwc ikiycdan iyotanke cin he taku wakanyan okiyakapi kinhan, tokaheya kill he inina yanke kta.

31 Owasin wanji itokto widukcanpi kin odakapi kta oyakihipi ; hecen owasin onspelkiyapi, qa owasin iwicakiyapi kta.

32 Qa wicaśta wokcanpi toksapepi kin wicaśta wokcanpi kin anawicakigoptanpi ece.

33 Wakantanka kin he oqoyapi kin kage śni, tuka wookiye kin he tawa, oyate wakan okodakiciye kin owasin en un kin iyeccca.

34 Unkan winohinca nitawapi 275 


\section{KORINTH.}

kin okodakiciye kin ekta inina yankapi kta. Hena ie kta e iyowinyanpi śni, tuka anagoptan yukanpi kta, woope heye cin iyecen.

$35 \mathrm{Qa}$ taku onspepi kta cinpi kinhan iye tipi ekta hihnakupi kin iwicawangapi kta. Okodakiciye kin en winolinca ie cin he wowiśtece.

36 Tokeca, niyepi kin etanhan Wakantanka oie kin hinanpa he; qa niyepi niśnanpidan ekta nihipi he.

$37^{2}$ Tuwe wicaśta wokcan, qa iś wicaśta wakan kin heca kecaniçin kinhan, he taku wowapi en cicagapi kin hena Itancan tawoahope kin hee e yaotanin kta. 38 Qa tuwe iyukcan śni un kinhan, he iyukcan śni un nunwe.

39 Hecen mihunkawanji widukcanpi kte cin he akita po, qa ceji tokeca on iapi kte cin tehindapi śni po.

$40 \mathrm{Qa}$ taku owasin iyokipiya owotanna econpi nunwe.

\section{WICOWOY AKE 15.}

1 Tuka, mihunkawanji, wotanin waśte unkoniciyakapi, qa iyacupi qon en ayahanpi kin he sdonye ciciyapi.

$2 \mathrm{He}$ eciyatanhan nakun yanipi kta, wicoie unkoniciyakapi kin on, he ținsa duhapi kinhan, qa ecinśniyan awacanipi śni kinhan.

3 Otokaheya ekta taku iwacu qon he ciçupi ; Waunhtanipi kin on Messiya te cin, wowapi wakan eye cin ecetu;

- 4 Qa hnakapi, qa anpetu iciyamni kin piya ikicage cin, wowapi wakan eye cin ecetu.

5 Qa Inyan wanhdake ca, hehan ake nonpapi kin wanhdakapi.
6 Helıan he iyohakam wancadan hunkawanjin kiciyapi opawinge zaptan wanyakapi, hena wicota nahahin ni unpi, tuka wanjikji iśtinmapi.

7 Qa he iyohalkam Jakob wanhdaka; hehan yewicaśipi kin owasin wanhdakapi.

8 Qa eliake miś miye wanmdaka, okaśkan tonpi ikin iyemaceca.

9 Yewicaśipi kin miye iyotan macistinna, qa Wakantanka taokodakiciye kin śicaya wakuwa qon heon yeśipi emakiyapi kte cin iyemacece śni.

10 Tuka tomakece cin Wakantanka towaonśida kin on hemaceca. Qa iye towaonśida mici un kin he taku śni wanica, tuka hena owasin iyakapeya nina litawani; qa he miye śni, Wakantanka towaonśida mici un kin hee.

11 Heon, he miś miye, qa iś iyepi kin, hecen unyaotaninpi, qa nakun hecen wicayadapi qon. 12 Unkan Messiya wiconte kin etanhan piya ikicage cin he oyakapi hecinhan, token on niyepi wanjikji, Wiconte etanhan piya wicoicage wanica ce, ehapi he.

13 Wicate cin piya wicoicage wanica hecinhan, Messiya piya ikicage śni.

14 Qa Messiya piya ikicage śni hecinhan, hehan unkoyakapi kin he taku śni qa wacinyayapi kin he nakun taku śni.

$15 \mathrm{Qa}$ Wakantanka en unkitonpi śni kin; Wakantanka Messiya piya najin kiye cin he unkoyakapi; tuka he najin kiye śni, wicațe cin ake najinpi śni kinhan.

- 16 Wicate cin piya najin kiyapi kte śni kinhan, hehan Messiya nakun piya najin kiyapi śni. $17 \mathrm{Qa}$ Messiya piya ikicage 


\section{WICOWOYAKE 15.}

śni hecinhan, wacinyayapi kin he takudan okihi śni, qa nahahin wayahtanipi kin ehna yaunpi.

18 Hehan tona Messiya on iśtinma iyayapi qon hena nakun takunipi śni.

19 Wiconi kin de en ecedan Messiya on ape unyakonpi hecinhan, wicaśta owasin unkiye iyotan iyotanhan iyeunkiyapi ece.

20 Tuka wanna Messiya wiconte etanhan piya ikicaga, qa tona iśtinmapi qon hena en taku tokaheya icage cin hee.

21 Wicaśta kin eciyatanhan wiconte u kin, he iyecen wicaśta kin eciyatanhan wiconțe etanhan piya wicoicage kin $u$ ce.

22 Adam en owasin tapi kin, he iyecen Messiya en owasin piya ni yapi kta.

23 Tuka otoiyohi tohan iyehantu kinhan; Messiya e tokaheya, qa hehan tona tawa kin hena, Messiya ake hi kinhan.

24. Qa hehan owihanke kta, tohan wokiconze kin Wakantanka Ateyapi kin kicu kta; wokiconze owasin, qa wicowaśake owasin, qa wookihi kin ihangye cinhan.

25 Tona toka yapi kin hena owasin iye siha kin ihukun iyewicaye kte cin hehanyan ito wicaśtayatapi yankie kta.

$26 \mathrm{Qa}$ toka ehake ihangye kte cin he wiconțe kin ee.

$27 \mathrm{He}$ siha kin ihukuya taku owasin ekihnaka. 'Tuka tohan, He ihukuya taku owasin ehnakapi kin, eye cehan, tuwe he ihukuya taku owasin ehnake cin he okaptapi e tanin.

$28 \mathrm{Qa}$ tohan taku owasin he ihukun iyeyapi kinhan, hehan Cinhintku kin eqe tuwe taku owasin iye ihukun iyeye cin he ihukun un kta, hecen Wakantanka owasin en ocowasin un kta.

29 Wicate cin ecaca piya ikicagapi kte śni hecinhan, tona wicate cin on baptem wicaqupi kin hena taku tokonpi kta he ; qa tokeca e wicate cin on baptem wicaqupi he.

$30 \mathrm{Qa}$ tokeca anpetu iyohi ta ikopeya unyakonpi he.

31 Jesus Messiya Itancan unkiyapi kin en widuśkinpi kin en owape cin he cajemdate ca, Anpetu iyohi mața ce, epa.

32 Wicaśta akantu iyecen, Ephesos ekta wamanica kici weciza eśta, on taku iyomapte kta he, wicate cin piya wicoicage śni kinhan. Wauntapi, qua waunyatkanpi kta, heyakecinhan unțapi lita ce.

33 Içihnayanpi śni po; kodakiciyapi śice cin hena wicohan waśte yuśica ece.

34 Wicolian owotanna on ihduhicapi, qa wahtanipi śni po. Wanjikji Wakantanka sdonyapi śni. Winiśtecapi kte cin heon hena hecen epe.

35 Tuka okinni tuwe heye kta; Wicate cin,token piya icahyapi, qa taku tancan kin yuha hiyupi he.

36 Winitkotkoka, taku oyaju kin he țe śni kinhan, icage śni ece.

37 Qa taku oyaju kin he tancan icage kte cin he oyaju śni, tuka su ecedan, aguyapi qa iś taku toktokeca naceca.

38 Tuka Wakantanka token iyokipi kin hecen tancan qu, qa su ocaje otoiyohi tancan tawa kin kicu ece.

39 Cehipi owasin celipi okonwanjidan śni, tuka wicacehpi kin he wanji ee, qa woteca cehpi kin wanji hee, qa hogan ce277 


\section{KORINTH.}

hpi kin wanji hee, qa zitkadan cehpi kin wanji hee.

40 Unkan mahpiyata tancan, qa makata tancan kin heca yukan. Tuka malipiyata un kin he towitan kin wanjidan, qa makata un kin he towitan kin tokeca.

.41 Anpetu wi towitan kin wanjidan, qa hanyetu wi towitan kin he tokeca, qa wicanhipi towitan kin he nakun tokeca; qa wicanh̉pi wanji wicanhipi tokeca kici wowitan en akidecece śni.

42 He iyecen wicate cin piya wicoicage. Tancan hwin ojupi, tuka hwin kte śni ekicetu yapi.

43 Wowihahaya ojupi, tuka wowitan ekicetu yapi. Wowaśake śni yan ojupi, tuka wowaśagya ekicetu yapi.

44 Wicacelipi tancan ojupi, tuka wowakan tancan ekicetu yapi. Wicacehpi tancan yukan, qa wowakan tancan kin yukan.

45 Kaken wowapi en kagapi qon, Adam wicaśta tokaheya kin he wicanagi ni un kin heca kagapi, qa Adam ehake un kin he Woniya Wanikiye cin hee.

46 Tuka taku wakan un kin he tokaheya śni, tuka taku cehpi kin hee, qa iyohakam taku wakan kin.

47 Wicaśta tokaheya kin he maka etanhan un, qa maka kin heca; Wicaśta iyokihe kin he Itancan mahpiya eciyatanhan un kin hee.

48 Maka kin heca un qon, tona maka hecapi kin hena hececapi ; qa mahpiya tanhan un qon, tona mahipiya tanhan un kin hena hececapi.

49 Unkan makata un kin touncage kin unhapi kin, he iye278 cen mahpiya tanhan un kin touncage kin unhapi $\mathrm{kta}$.

50 Mihunkawanji kaken epa; Wicacehpi qa wicawe kin Wakantanka tokiconze kin tawapi kta okihipi śni, qa nakun wicahwin wicaliwin kte śni kin tawa kte śni.

51 Wanyaka po, wowiyukcan wan ociciyakapi; owasin unkiśtinmapi kte śni, tuka owașin unyutokecapi kta.

52 Ihnuhanna, iśta kakpapi se en maza yahotonpi tanka ehake kin tanin kinhan; maza yahotonpi tanka kin he yahotonpi kta, qa wicate cin hwin śni yan najin wicakiyapi kta, qa unkiye unyutokecapi kta.

53 Taku liwin kte cin de wicahwin śni koyake kta, qa te kte cin de tepica śni koyake kita.

54 Qa tohan taku hwin kte cin de wicaliwin śni koyake ça, tancan wiconte kin de wiconi kin ogeton kinhan, hehan wicoie kin wowapi en kagapi qon ecetu kta; Wiconte kin he woohiye kin e ocowasin iocokaya.

55 Wiconte, wicape nitawa kin tokiya un he. Wicahnalkapi, woohiye nitawa kin tokiya un he.

56 Wiconte icape kin he woahitani ee, qa woahtani wowaśake kin he woahope kin ee.

57 Tuka Wakantanka woohiye unqupi, Jesus Messiya Itancan unkiyapi kin eciyatanhan, he wopida yuha nunwe.

58 Hecen mihunkawanji waśte cicidapi kin, sutaya yahanpi, qa pahoho śni yaunpi nunwe; qa ohinniyan Itancan ohan kin en aiçiciya po, Itancan kin on htayanipi kin he taku śni wanice kta sdonyayapi kin heon etanhan. 


\section{WICOWOYAKE 16.}

WICOWOYAKE 16.

1 Wicaśta owotanna un kin hena taku wicakicamnanpi kte cin, token Galatia ekta okodakisiye kin econ wicawaśi qon, he iyecen niś econ po.

2 Anpetu tokaheya kin en niyepi otoiyohi token oyakihipi kin, iyacinyan eyahnakapi kta, hecen wau kinhan, wamnayanpi wanice kta.

3 Qa wau kinhan, tona wowapi on wicayakahnigapi kin, hena wicaqupi nitawapi lin he Jerusalem ekta aye wicawaśi kta.

4 Qa miye elita mde kte cin he waśte $k$ ta naceca hecinhan hena om mde kta.

5 Unkan Makedonia opta mde cinhan; hehan ekta ciupi kta: qa Makedonia opta mde kte cin he hecetu.

6 Qa okinni cicipi waun kta, han, waniyetu ihunniwaye kta naceca; hecen hetanhan tokiya mde cinhan niye amayadapi $\mathrm{kta}$.

7 Nakaha tahepi wanciyakapi kte śni, tuka Itancan kin iyokipi kinhan, cicipi owanji manke kta wacanmi.

8 Tuka anpetu iwikcemna zaptan kin hehanyan Ephesos en owanjidan manke kta.

9 Tiyopa tanka wawokihi kin makiyuhdokapi, qa tona wakinicapi kin hena ota.

10 Unkan Timotheos ekta i kinhan, kokipeśniyan en niunpi kta e akita po: He nakun miye ecamon kin iyecen Itancan tohtani kin econ ece.

11 Heon tuwedan ihaha kte śni ; tuka wookiye yuha au po, ekta mahiyu kta; he hunkawanjin kiciyapi kin om u kta ape manka.

12 Apolos mihunkawanji, he hunkawanjin kiciyapi kin om ni- yepi elsta niipi kta e nina cinwakiya; tuka iye dehan ekta ye lita ecaca cin śni, tuka tohan cin kinhan elsta i kta.

13 Kiktahan un po, wowacinye en sutaya han po, wicaśta iyecen ohanyan po, waśalka po.

14 Taku nitawapi kin owasin wacantkiyapi on econpi nunwe.

15 Mihunkawanji, ceciciyapi ce; Stephanas tiyohnaka kin sdonyayapi, he Akeya en waskuyeca tokaheya icage cin hee, qa wicaśta owotanna owicakiyapi kin en ye iciyapi ece lsin;

16 Tona hececapi, qa tona wawokiyapi, qa htanipi kin hena owasin wicihukuya ye niçiyapi kta.

17 Stephanas qa Phortunatus qa Akekus hipi kin heon imduśkin; hena e taku ecamiyeconpi śni kin he ecetu miciciyapi.

$18 \mathrm{Qa}$ minagi lin magaga mayanpi, qa nitawapi nakun. Heon etanhan tona hececapi kin hena wicayuonihan po.

19 Asia ekta okodakiciye kin hena nape niyuzapi. Akula qa Priskila Itancan lin on sutaya nape niyuzapi, qa okodakiciye iye tipi ohna un kin hena koya.

20 Hunkawanjin kiciyapi lin owasin nape niyuzapi. Iiputakapi wakan kin on otoiyohi i ikiciputaka po.

21 Palos he miye nape kiciyuzapi kin de miye minape kin on voakaga.

22 Tuwe Jesus Messiya Itancan kin waśtedake śni kinhan, he anathema maran-atha un nunwe.

23 Jesus Messiya Itancan unyanpi towaonśida kin nicipi un nunwe.

24 Jesus Messiya on wacanwakiye cin niyepi owasin en nicipi un nunwe. Amen. 


\section{PAL O S \\ KORINTH OYATE}

W OWAPI WICAKICAGE CIN;

INONPA KIN.

WICOWOYAKE 1.

1 Palos, Wakantanka tawacin kin eciyatanhan, Jesus Messiya yeśi qon he, qa Timotheos hunkawanjinkiciyapi wan kici, Korinth ekta Wakantanka taokodakiciye kin, qa Akeya owancaya tona owotanna un kin hena koya, wowapi unnicagapi.

2 Wowaonśida, wookiye ko, Wakantanka Ateunyanpi, qa Jesus Messiya Itancan kin etanhan, nicipi un nunwe.

3 Wakantanka Jesus Messiya Itancan unkiyapi he Atkuku, qa waonśidapi en ateyapi, qa Wakantanka owasin wacintonhnag wicaye cin he wowaśte yuha nunwe.

4 He unkakijapi owasin en wacintonhnag unyanpi, hecen tona wokakije owasin ehna un kin hena iwicunkiyapi unkokihipi kta, wacintonhnagyapi on Wakantanka unkikiyapi kin he eciyatanhan.

5 Hecen Messiya tokakije kin unkiyepi en unkiciyuotapi kin, he iyecen Messiya eciyatanhan wacintonhnag unyanpi kin he nakun unkiciyuotapi kta.

6 Kakiśunyanpi eca he wacintonhnag niyanpi, qa ni niyanpi kte cin heon; he wokakije on kakiśunyanpi kin hena yuha okihi wicaye kta e ohanyan ece; qa wacintonhnag unyanpi hecin280 han, he wacintonhnake niyanpi, qa ni niyanpi kte cin heon.

ry Unkan niyepi kin on sutaya wacinunyanpi, wokakije kin en opeya yaunpi kin he iyecen wacintonhnakeyapi kin en oyapapi kta, sdonuny anpi.

8 Mihunkaw anji, A sia en token wokakije unhiyahdepi qon he sdonye śni yaunpi kta uncinpi śni, iyotan nina unkakijapi, unkokihipi kin isanpa, hecen unnipi kta unkecinpi śni.

9 Tuka unkiyepi kin mahen wiconte woyaco kin unhapi, hecen takidan wacinunkiçiyapi kte śni, tuka Wakantarika wicațe cin ekicetu wicaye cin he wacinunyanpi kta :

10 Iye wiconte hinsko tanka etanhan eunhdakupi, qa nakaha ehdaku ece; qa eeś nakun eunhdakupi kta wacinunyanpi :

$11 \mathrm{Qa}$ niś eya, wocekiye on ounyakiyapi kta, hecen wicaśta ota etanhan, taku unqupi qon he on, unkiyepi on etanhan wicota wopida eyapi kta.

12 Unkiyuśkinpi kin he unnagipi hdaotanin kin hee, wowicake wowakan ko en okonwanjidan, wicacehpi woksape yuhe śni, tuka Wakantanka towaonśida yuha, wicoicage kin ehna unnipi, qa niyepi kin ekta iyotan hececa.

13 Taku dawapi, qa sdonyayapi kin hecedan wowapi en un- 


\section{WICOWOYAKE 2.}

nicagapi; qa owihanke kin hehanyan wicayadapi kta kepce.

14. Onśpa sdonunyayapi, unkiyuśkinpi kin he niyepi, he iyecen wowitan nitawapi kin he unkiyepi, Jesus Itancan taanpetu kin en.

15 Hecen wacinmduza, tokaheya niyepi kin ekta ciupi kta tuka, on inonpa wowaśte duhapi kte cin heon.

16 Qa niyepi kin etanhan iyoopta Makedonia ekta mde ça, ake Makedonia etanhan niyepi kin ekta icicawin wahdi kta, qa Juda makoce kin ekta ye mayayapi kta wacin.

17 Hecer wacin mduze cehan, hehan iyowikan wacin mduza he; qa token miçiconze cin he wicacehpi eciyatanhan miciconze ca hecen, Han, han, hiya, hiya, eya waun he.

18 Wakantanka wacinyepica, wicoie unkeniciyapi qon he, han qa hiya, hee śni.

19 Miye, qa Șiluanos, qa Timotheos, Jesus Messiya Wakantanka Cinhintku kin unkoniciyakapi qon he, han, qa hiya, hee śni, tuka iye kin on, han ecedan.

20 Wakantanka iwahounyanpi kin hena owasin iye $\in n$, Han hee, qa iye en Amen, unkiyepi kin etanhan Wakantanka yatanpi kte cin heon.

21 Tuwe niyepi kici Messiya en unyusutapi, qa sdaunyanpi kin he Wakantanka kin ee.

22 Qa he unkapuspapi, qa uncantepi kin ekta Woniya tokaheya icupi ece kin he unqupi.

23 Unkan nakaha minagi kin ekta Wakantanka mayaotanin kta e cewakiya; Itoncipapi kta e on nahahin Korinth ekta wai śni.

24. Wacinyayapi kin on wowi- dag unniyanpi śni, tuka widu. śkinpi kin en ounniciyapi kta. Wacinyanpi on sutaya nayajinpi ece.

\section{WICOWOYAKE 2.}

I Miye qe hecen mihdukcan, ake iyokiśnya ekta ciupi kte śni.

2 Miye iyokiśinciyapi kinhan, tuwe iyuśkinmaye kta he; iyokiśinwaye cin hee kta.

3 Hecen on he wowapi cicagapi, ekta wau kinhan tona on imduśkin kte cin hena on etanhan iyokiśin waun kte śni. Qa niyepi owasin wacinciyapi, mitowiyuśkin kin he en niyepi owasin oyapapi kta.

4 Wicokakije tanka, qa wicocanteśica, qa iśtamnihanpe ota ehna wowapi cicagapi qon, iyokiśinniyanpi lite cin heon hecamon śni ; tuka nina canteciciyapi kin he sdonyayapi kte cin heon.

5 Tuwe iyokiśicapi kage ciqon he miye iyokiśinmaye śni ; tuka niye nihunhinanpidan, owasin cibapi kte śni.

6 He tuwe kin hecen yacopi qon, wicota econpi kin hecehnana kta.

7 Heon nakaha wicaśta kin he iyuśkinyayapi, ya yecanptapi $\mathrm{kta}$, okinni nina iyokiśice cin on ktepidan kta.

8 Heon ceciciyapi ce, he cante en duzapi kin hduotanin po.

9 Taku owasin on waanagoptan yaunpi hecinhan, iciyukcanpi kte cin heon wowapi cicagapi qon.

10 Tuwe taku yecicajujupi kinhan, miiś eya hecamon, qa tuwe taku wecicajuju kin he niyepi kin on wecicajuju, Messiya itokam.

11 Hecen Satan ohiunyanpi 281 


\section{KORINTH.}

kte śni; iye token içiconze cin sdonuny anpi.

12 'Troas ekta Messiya tawootanin waśte yuha wahi, qa Itancan kin tiyopa wan makiyuzamni ;

13 Hehan minagi ekta cante waśteya waun śni, 'Titos mihunkawanji kin hen iyewaye śni kin heon; hecen hena nape wicamduze ca, hetanhan Makedonia ekta imdamda.

14 Wakantanka, ohinniyan Messiya on ohiye unyanpi, qa ohinniyan unkiyepi kin on tawosdonye woomna yaotanin kin, hee wopida yuha nunwe.

15 Wakantanka ekta, Messiya on woomna waśte kin he unkiyepi, tona wiconi yuhapi kta, qa nakun tona yutakunipi kte śni kin hena en.

16 Dena iś țapi kta e wiconte oomna kin he unkiyepi, qa hena e nipi kta e wiconi oomna kin he unkiyepi; qa tuwe hena taku kin okihi he.

17 Wicota Wakantanka oie kin hnayan kuwapi kin hena iyeuncecapi śni ; tuka wowicake eciyatanhan, tuka Wakantanka eciyatanhan, qa Wakantanka itokam, Messiya unkoyakapi ece.

\section{WICOWOYAKE 3.}

1 Ake unkihdatanpi unkayapi he; qa wicaśta wanjikji iyecen waayatanin wowapi nicagaji kte cin heca uncinpi he; qa iś waayatanin wowapi unyecagapi kta uncinp $i$ he.

2 Wowapi unkitawapi unkicantepi kin ekta owapi kin he niyepi, wicaśta owasin sdonyapi qa yawapi ;

3 Messiya tawowapi taninyan oyakapi unkiye unkagapi kin ; mini sapa on kagapi śni, tuka 282
Wakantanka ni un kin Taniya kin on owapi ; inyan mdaska kin en un śni, tuka wicacante conica kin he en.

4 Unkan Wakantanka ekta Messiya eciyatanhan woawacin kin de unhapi.

5 Unkiye cinka taku unkiyukcanpi kta unkokitpanipi, unkiyepi atayedan, taku unkokihipi. kin he Wakantanka eciyatanhan.

6 Iye wicotakuye teca kin en wowidake waokihi unkagapi, oowa kin he en un śni, woniya kin hee en; oowa kin he wateya, tuka woniya kin he waniya ece.

7 Wiconte wawokiyapi kin he owapi, qa inyan akan pagopi qon he wowitan yuhe cin, on Israel cinca kin Moses itohnake wiyatpa kin he opalita yukanpi kta okihipi śni hecinhan, wowitan kin he enakiyapi tuka;

8 Hecen Woniya wawokiyapi kin he sam iyeya nina wowitan kte śni he.

9 Woyaco wawokiyapi kin he wowitan hecinhan, wicoowotanna wawokiyapi kin he sanpa nina wowitan kta.

10 Qa taku yuwitanpi qon he taku wanji on wowitan śni, taku iyakapeya wowitan kin hee on etanhan.

$11 \mathrm{Qa}$ taku enakiyapi qon he wowitan kin hee hecinhan, taku ecen he cin he iyotan wowitan kin ee.

12 Woape hececa unhapi kin heon nina wadiuntakapi ece.

13 Unkan Moses ite akalipe wan itohnake kin akalipe kiton kin he iyecece śni, taku enakiyapi kin owihanke kin hehanyan Israel cincapi kin ekta etonwan okihipi śni kin heon etanhan.

14 Tuka iye tawacinpi kin ao- 


\section{WICOWOYAKE 4.}

tpasyapi : qa anpetu kin dehanyan Wowapi Wakan tanina kin yawapi eca, ite akahpe kin he eyakupi śni ecen un; he Messiya eciyatanhan eyakupi tuka.

15 Tuka anpetu kin dehanyan, Moses yawapi eca, ite akahpe kin he iye cantepi kin akalipa.

16 Tuka tohan Itancan kin ekta yuhomnipi kinhan, hehan ite akahpe kin he yuzamnipi kta.

17 Woniya kin he Itancan kin ee, qa tukten Itancan taniya kin un kin, hen tawa içiyapi yukan.

18 Tuka unkiye owasin itohnake kin en taku unkakalipapi śni, ihdiyomdasin en wawanyakapi kin iyecen Itancan towitan kin wanuuyakapi, qa iye ouncage kin iyecen unkagapi, wowitan sanpa wowitan kin en, Itancan Taniya kin on etanhan iyececa.

\section{WICOWOYAKE 4.}

1 Heon etanhan wawokiyapi kin de unhapi kin, wowaonśida unkicupi kin heon wacin ibounśakapi śni.

2 Tuka taku wowiśtece nahmana un kin hena elipeunyanpi, qa wicahnayanpi kin en maunnipi śni, qa wohnaye yuha Wakantanka oie kin unkiciyuhapi śni, tuka wowicake yaotaninpi kin on wicaśta owasin wiyukcanpi kin ekta unhdaotaninpi, Wakantanka itokam.

3 Wootanin waśte unkitawapi kin he anahmanpi hecinhan, tona takunipi śni kin hena anawicakihmanpi.

4 Hena ekta wicoicage kin de taku wakan tawa kin tona wicadapi śni wicotawacin kin wacinton śni wicakaga; Messiya Wakantanka ouncage kin hee, tawootanin waśte wowitan iyoyan- pa kin he iyoyamwicaye kte śni heon etanhan.

5 Unkiye unkihdaotaninpi śni, tuka Messiya Jesus Itancan kin he unyaotaninpi ece; qa unkiye Jesus on ookiyewicayayapi kin.

6 Wakantanka iyoyanpa kin otpaza etanhan yege si qon he uncantepi kin iyoyamunyanpi, Jesus Messiya itohnake kin eciyatanhan, Wakantanka towitan wosdonye iyoyanpa kin unqupi kte cin heon.

7 Tuka woyuha kin de maka cega ohna unhapi, hecen wowaśake tanka kin Wakantanka etanhan un kta, qa unketanhanpi kte śni.

8 Ihdukśantanhan aotinsunyanpi, tuka unkahdaskicapi śni : wacinhnuni unyanpi, tuka takudan wacinye śni kin heuncecapi śni.

9 Ścaya unkuwapi, tuka ehpeunyanpi unyakonpi śni: makata ehpeunyanpi, tuka ihang unyanpi śni.

10 Ohinniyan untancanpi kin en Jesus Itancan te cin he yuha unkanpi, hecen Jesus wiconi tawa kin untancanpi kin en taninyan un kta.

11 Unkiye unnipi kin Jesus on ohinniyan wiconțe en iyaye unyanpi, Jesus wiconi tawa kin uncehpipi te kte cin en atanin kte cin heon.

12 Hecen unkiyepi kin en wiconte olianyan un, tuka niyepi kin en wiconi.

13 Unkiye wowacinye woniya kin de unhapi, wowapi en kagapi qon iyececa; Wicawada kin heon iwaa ce; unkiś eya wicaundapi kin heon unkiapi ece.

14. Qa tuwe Jesus Itancan kin piya ekicetu ye ciqon, he Jesus eciyatanhan, ake ekicetu unyanpi kta, qa niyepi kin om sutaya he unkiyapi kta e sdonunyanpi. 


\section{KORINTH.}

15 Niyepi kin on etanhan taku owasin ecen un, hecen wowaonśida tanka kin, wicota wopida eyapi kin on sanpa ota aye kta, Wakantanka towitan kin on.

16 Heon wacin ibounśakapi śni, tuka wicaśta akantanhan unkitawapi kin he takuni śni aya eśta, wicaśta mahen tanhan un kin he anpetu iyohi yutecapi.

17 Unkakijapi cistinna, qa ptecedan kin he wowitan ota hinca, ota linca, owihanke wanin tke linca unkicagapi kta.

18 Icunhan taku wanyakapi kin hena ekta unketonwanpi śni, tuka taku tona wanyakapi śni kin hena ekta eivauncinpi. "Taku tona wanyakapi kin hena ihanke kta, qa taku tona wanyakapi śni un kin hena owihanke wanica.

\section{WICOWOYAKE 5.}

1 Makata wakeya unkitawapi kin de yujujupi kinhan, Wakantanka ticage cin tipi nape codan kagapi kin, mahpiya ekta, owikanke wanin yanke cin he unhapi e sdonunyanpi.

2 Qa de ohna comniunhdazipi, qa tipi unkitawapi mahpiya eciyatanhan un kin he kounyakapi kta e cantounkpanipi.

3 He kounyakapi kinhan, tancodan unyakonpi kte śni.

4 Wakeya kin de ohna unkanpi kin hehanyan comniunhdazipi, unśakapi kin hcon. Wokoyake unhduśdokapi kin he uncinpi śni, tuka kounyakapi kta: Hecen wiconi e wiconte ocowasin napce kta.

5 Tuwe he en icaliunyanpi kin he Wakantanka ee; qa he Woniya tokaheya kin wanna unqupi.

6 Heon ohinniyan cante un284 waśtepi, qa tohanyan wicatancan kin ohna unkanpi kin hehanyan Itancan kin itehanyan unyakonpi kin he sdonunyanpi.

7 Wacinyanpi eciyatanhan maunnipi, qa wawanyakapi kin eciyatanhan śni.

8 Cante unwaśtepi, tuka tancan kin de ohna unkanpi śni, qa Itancan kin kici unyakonpi kta e he iyotan uncinpi ece.

$9 \mathrm{He}$ de aiçiciya unkakitapi, ekta kici unyakonpi, qa iś den unkanpi, unma tukte kaśta, iyolipiuny anpi kte cin he.

10 Owasin Messiya tawoyaco oiyotanke kin itokam taninyan inaunjinpi kta, otoiyohi taku iye tancan kin ohna ohanye cin hena icu kta, token econ qon eciyatanhan, he waśte qa śica unma tukte kaśta.

11 Itancan wohitike cin he sdonunyanpi kin, heon wicaśta cin wicunkiyapi; Wakantanka en unkihdaotaninpi, qa nakun widukcanpi kin en unkihdaotaninpi wacanmi.

12 Ake niyepi en unkihdatanpi śni, tuka unkiyepi on iniwinktapi kta e okihi unniyanpi; hecen tona cante kin eciyatanhan śni, tuka itohnake kin on iwinktapi kin hena ekta, taku on iniwinktapi kte cin duhapi kta.

13 Wacinunhnunipi hecinhan, he Wakantanka on etanhan; qa wacinunksapapi hecirhan, he niyepi kin on etanhan.

14 Messiya wacantkiye cin he iyounpaśtakapi ece.

15 Qa he de unkiyukcanpi, wanji owasin on te cinhan hehan owasin tapi tuka; qa owasin on te cin, heon tona nipi kin hena iś iyepi on nipi kte śni, tuka tuwe hena on te ca ake kini kin hee on nipi kta.

16 Heon etanhan, detanhan wi- 


\section{WICOWOYAKE 6.}

cacelipi eciyatanhan tuwedan sdonunyanpi śni ; han, Messiya hee wicacelipi eciyatanhan sdonunyanpi eśta, nakaha detanhan sdonunyanpi śni.

17 Hecen tuwe Messiya en un kiu he wanna wicaśta teca; taku tannike cin hena enakiyapi; iho, taku owasin teca icaga.

18 Qa taku owasin Wakantanka etanhan un, he iye kici okiciciye unkiyapi, Jesus Messiya eciyatanhan, qa wookiye wawokiyapi kin he unqupi.

19 Hecen Wakantanka Messiya on, wicoicage kin, iye kici, okiciciye wicaye ca, wahtanipi kin wicakiciyawa śni; qa wookiye wicoie kin he yuhe unkiyapi.

20 Heon Messiya on wawiciyapi kin unkiyepi, unkiyepi eciyatanhan Wakantanka ceniciyapi kin iyececa, Messiya caje on ceunniciyapi, Wakantanka kici okiciciya po.

21 Tuwe woahtani sdonkiye śni un qon he, unkiyepi on woalitani kagapi ; hecen iye en Wakantanka toowotanna unkicagapi kta.

\section{WICOWOYAKE 6.}

1 Heon iye kici htaunnipi iyecen, niyepi nakun ceunniciyapi ce, ituh Wakantanka towaonśida kin iyacupi kte śni.

2 He iye kaken eya, Omaka oiyokipi kin en nacihon qa wiconi anpetu kin en ociciya: Tho nakaha omaka oiyokipi kin hee; nakaha wiconi anpetu kin he dee.

3 Takudan on tuwedan ibotounyanpi śni, hecen wawokiyapi kin he bapi kte śni :

4. Tuka Wakantanka taokiye unyanpi kin he taku owasin on unkihduotaninpi ece, wacintan- kapi kin en, wokakije en, wahpaya unnicapi kin en, woiyolziśice en ;

5 Apapi kin en, kaśka hnakapi kin en, yuomdecapi kin en, wicolitani kin en, kiktahan unpi kin en, wotektehdapi kin en;

6 Ecedan unpi kin on, wosdonye kin on, tehan apepi kin on, wacantkiyapi kin on, Woniya Wakan kin on, awicakehan waśtedakapi kin on ;

7 Wowicake oie kin on, Wakantanka towaśake kin on, wicoowotanna wipe, etapa qa catkatanhan unpi kin on ;

8 Wowitan qa wowiśtece kin ohna; waaiapi qa yaonihanpi kin ohna; wicahnayanpi kin iyececa, tuka wicakapi ;

9 Sdonyapi śni un kin iyeuncecapi, tuka tankaya sdonunyanpi ; tapi se iyecen unyakonpi, tuka ito unnipi; unkaśtakapi, tuka nahanhin unktepi śni ;

10 Iyokiśicapi iyeuncecapi, tuka ohimniyan wiunyuśkinpi ; wahpanicapi kin iyeuncecapi, tuka wicota watonka wicunkagapi ; takudan yuhapi śni kin iyeuncecapi, tuka taku owasin untonpi.

11 Korinth oyate kin, niyepi on i unhdukawapi, uncantepi kin tanka aya.

12 Unkiyepi en takudan aoțins niyanpi śni, tuka niye nicantepi kin en oțins niçiyapi.

13 Hehan iyunwin kin de mayaqupi kta ; micinca kin iyecen ociciyapi ; niś eya tankaya nicicagapi nunwe.

14 Ihnuhan tona awacin śni un kin hena en ecinśniyan iyanihdaśkapi kinhan. Token wicoowotanna woahtani kici tidan kta he; qa token iyoyanpa kin otpaza kici un kta he:

15 Qa Messiya Belial kici token okonwanjidan cante yuzapi 285 


\section{KORINTH.}

he; qa tuwe wicada kin he wicada śni un kin kici taku akiptan tawapi kta he ;

16 Qa tipi wakan Wakantanka tawa kin he wakagapi kin kici token un kta he. Wakantanka ni un tipi wakan tawa kin he niyepi. Wakantanka heye ciqon he iyececa; Hena om wati kta, qa om mawani kta. Hena Wakantanka mayanpi kta, qa mitaoyate kin hena eepi kta ce.

17 Heon etanhan hena cokaya tanhan tankan upi, qa icunonpa un po, Itancan kin eya, qa taku aśape cin oyutanpi śni po, kinhan miś tawa ciyapi kta ;

18 Niye ate mayayapi kta, qa miye cinkśi ciyapi qa cunkśi ciyapi kta ce, Itancan Iyotan Waśake cin he hena hecen eya.

\section{WICOWOYAKE 7 .}

1 Heon waśtecicidapi kin, wahoyapi kin dena unhapi kin heon wicacehpi wicanagi ko taku aśape cin etanhan unhduecepidan, qa Wakantanka kokipeyahan wicoowotanna kin tanyan unhduśtanpi kta.

2 Anaungoptan po; unkiye tuwedan śicaya ecarvicunkiconpi śni, tuwedan wicunyuśicapi śni, tuwedan taku icakiś wicunyanpi śni.

$3 \mathrm{He}$ wayaco hepe śni ; cante en unniyuzapi, ptaya unțapi qa iś unnipi kta ce, epe ciqon.

4 Niyepi on wadimatake hinca, niyepi on nina imawinkta; wocantohnake omajudan, unkakijapi owasin en nina imduśkin.

5 Makedonia en unhipi qehan, uncehpipi kin takudan oziiciye śni, tuka taku owasin on iyounkiśicapi; tankan tanhan wicokicize, qa mahen tanhan wokokipe.
6 Tuka Wakantanka tona iyokiśicapi iwicakiye cin he cantohnag mayan, Titos hen hdi kin heon:

$7 \mathrm{Qa}$ he hdi kin hecedan śni, tuka nakun niye cantohnagyayapi kin heon; nina wacin en yeyayapi, qa iyoniciśicapi, qa token cante en unyakiduzapi kin hena unkokiyakapi qehan, nina imduśkin.

8 Wowapi wan on iyokiśinciyapi eśta, heon nakaha iyopemiciye śni, iyopemiçiya tuka qon. He wowapi kin ptenyedan iyokiśinniyanpi wanmdaka.

9 Nakaha imduśkin, iyokiśinniyanpi kin heon etanhan śni, tuka nihduecetupi kta e on iyoniciśicapi kin heon. Wakantanka eciyatanhan iyokiśinniçiyapi, hecen takudan icakiś unniyanpi śni.

10 Wakantanka eciyatanhan iyowicakiśice cin he ihduecetupi on wiconi kta, on tohinni iyopeiciyapi śni kin he kaga; tuka wicoicage kin de en iyowicakiśice cin he wiconte icaliya.

11 Wanyaka po, Wakantanka eciyatanhan iyoniciśicapi kin he itonpeya nicagapi, waayuptapi, qa wośihda, qa wokokipe, qa cante en hiyeyapi, qa winawizipi, qa hdajujupi kin hena niyepi en icahniciyapi ; taku owasin on, he econpi qon en, takudan iyanionpapi śni yaunpi e nihduotaninpi.

12 Heon wowapi cicagapi, tuwe śicaya econ qon he on etanhan śni, qa tuwe śicaya ecakiconpi qon he on etanhan śni, tuka Wakantanka itokamya token wacin en unniyuzapi kin he niyepi en yutaninpi kta.

13 Heon etanhan iniciyapi kin on unkikiyapi ; qa 'Titos iyuśkin kin heon miś eya nina imduśkin, 


\section{WICOWOYAKE 8.}

iye nagi kin niyepi owasin eciyatanhan magagayapi kin heon etanhan.

14. Heon ciyatanpi qa owakiyaka eśta, on imaśtece śni ; tuka taku owasin eciyatanhan eciciyapi qon, he iyecen Titos en ciyatanpi kin he nakun wowicake.

15 Unkan niye owasin token anayagoptanpi, qa wokokipeya, cancanyan iyowinyakiyapi qon he kiksuya eca, iye iyotan cante en niyuzapi.

16 Heon etanhan, taku owasin on wicacidapi kin heon miiś eya imduśkin.

\section{WICOWOYAKE 8.}

1 Mihunkawanji, Wakantanka towaonśida Makedonia okodakiciye kin en yutaninpi qon he sdonyeciciyapi.

2 Hena wokakije tanka en nina iyuśkinpi, qa iyotan wahpanica unpi kin he etanhan taku ota iyokipiya wicaqupi.

3 Okihipi kin iyacinyan, (miś mdaotanin,) qa okihipi kin kapeya, iye cinka wicaqu wacinpi.

4 Qa wocekiye ota on ceunkivapi, taku wicaqupi kin he, qa tona ecedan un kin wicakipamnipi wawokiyapi kin he nakun unkicupi kte.

$5 \mathrm{Qa}$ unkecinpi qon iyecece śni, tuka tokaheya iye tancanpi kin Itancan kin içiçupi, qa nakun Wakantanka tawacin kin eciyatanhan unkiyepi kin en ic̣içupi.

6 Hecen Titos ceunkiyapi, niyepi en wanna tokaheya hecon kin, he iyecen wowaonśida kin de nakun niciyuśtanpi kta.

7 Hean taku owasin on winijicapi, wacinyanpi, qa iapi, qa wosdonye, qa wicamniheca owasin, qa waśteunyakidapi ko, he iyecen wowaśte kin de on nakun winijicapi kta.

8. Wicoope eciyatanhan hena hepe śni, tuka wicaśta tokeca aiciciyapi kin heon; qa wacanyakiyapi kin he wowicake kinhan imdute kta.

9 Jesus Messiya Itancan unkiyapi towaonśida kin he sdonyayapi, watonka tuka niyepi on wahpaniiciya, hecen iye wahpanica kin on winijicapi kta.

10 Unkan he de on wahokonciciyapi ; niye decanonpi kta iyececa, wanihan sanpa hecanonpi kta e niçiconzapi, qa wiyeya yaunpi kin heon etanhan.

11 Nakaha woecon kin he hduśtan po, kohanna wicayadapi qon he iyecen taku duhapi kin etanhan ecen ecanonpi kta.

12 Tokaheya wicadapi yuke cinhan, wicaśta taku yuhe cin he eciyatanhan iyokipiya icupi ece, qa taku yuhe śni kin eciyatanhan sni.

13 Wicaśta tokeca oziiciyapi kta, qa niye duśakapi kte cin hee śni; tuka akiyecen unpi kta; heon nakaha wijinya yaunpi kin he hena taku iwicakakije cin en un kta;

$14 \mathrm{Qa}$ iś iyepi nakun wijicapi kinhan, wicakiśya yaunpi kin en oniciyapi kta ; hecen'akiyececapi yuke kta.

15 Wowapi en kagapi qon iyececa; Tuwe ota pahi kin he takudan ohdapte'śni, qa tuwe waniqadan pahi kin he takudan icakiś un śni ce.

16 Tuka Wakantanka wopida yuha nunwe, he niyepi on Titos hecen cante yuskiya.

17 Awicakehan wahokonkiyapi kin anagoptan; tuka iye hinca inalini, qa kohanna niyepi kin ekta ye wacin. 


\section{KORINTH.}

18 Unkan he kici hunkawanjinkiciyapi wan, wotanin waśte on okodakiciye owasin en yatanpi kin hee ekta ye unśipi.

$19 \mathrm{Qa}$ hecedan śni, tuka kici ohnihde unyakonpi kta e he okodakiciye kin kahinigapi, Itancan kin yatanpi kta, qa unkiye de iyokipiya econkupi kta e heon taku ituhanpi kin de en ounkiyapi kta.

20 Qa taku ota unpamnipi kin de on tuwedan unbapi kte śni e he unkakitapi.

21 Taku waśte ece unkihnipi kta, Itancan kin itokam, qa nakun wicaśta kin en.

22 Unkan hena om hunkawanjinunyanpi kin yeunśipi, he wanna ota unkiyukcanpi, owotanna olianyan ece, qa nakaha iyotan aiçiciya, tanyan wacinniyanpi nakaeś.

23 Hecen Titos he kapi hecinhan, he mitawaśi qa niyepi on omakiye cin hee; qa hunkawanjinwicunyanpi kin hena eepi kinhan, okodakiciye yewicaśipi qa Messiya towitan kin hena eepi ce.

24 Heon etanhan, hena en, qa okodakiciye kin wicitokam, wacanyakiyapi kin, qa unniyatanpi qon he nakun wicakipazo po.

\section{WICOWOYAKE 9.}

1 Wicaśta owotanna owicakiyapi kte cin on wowapi cicagapi kta wanna iyecece śni.

2 Token wacin duzapi kin he sdonwaya, heon Makedonia etanhanpi kin hena en yaonihanyan cajeciyatapi, wanna waniyetu wanjidan hehanyan Alkeya wiyeya yanka ce, qa inayahinipi kin he wicaśta ota iyowicapaśtaka.

3 Tuka hunkawanjin wicawa- ye cin hena ekta yewicawaśi, unniyatanpi qon he ecetu kta, qa epe ciqon iyecen wiyeya nankapi kta e heon.

4 Okinni Makedonia etanhan upi kin hena om ekta wai, qa wiyeya yaunpi śni ecen wanunniyakapi kinhan, unkiye, niyepi epe śni, sutaya wacinyus unniyatanpi qon he on unkiśtecapi kta.

5 Heon hunkawanjin kiciyapi kin cewicawakiye kta wacami qon, tokaheya niyepi ekta ipi, qa wowaonśida nitawapi ehanna iwahoniyanpi qon he wiyeya ehnakapi kta, hecen awicakehan wowaoriśida kta, qa watehindapi kin eciyatanhan kte śni. 6 'l'uka de; Tuwe waniqadan oju lin he waniqadan mnaye kta; qa tuwe iyakicuya oju kin he iyakicuya mnaye kta ce.

7 Otoiyohi iye cante kin elkta iciconze cin eciyatanhan qu kta, woiyokiśice on qa econ śipi kin on etanhan śni ; iyuśkinyan wicaqu kin he Wakantanka waśte daka.

8 Wakantanka wowaonśida owasin niyepi en niciyuotapi kta okihi; hecen taku owasin ota duhapi kin on wicohan waśte kin wadupipike kta.

9 Wowapi en kagapi qon iyecetu; Taku elipeya, wahpaninica kin taku wicaqu ece kin he toowotanna kin ohinniyan un kta.

10 Tuwe woju kin ojupi yuhekiya ece kin he aguyapi woyute yayapi kte cin nicupi, qa taku oyajupi kin icah niciyapi, qa nitoowotanna waskuyeca kin niciyuotapi nunwe.

11 Qa taku owasin en wijinya yaunpi kta on iyotan ohansnipipi kta, heon unkiye Wakantanka wopida unkekiciyapi. 
12 Wapamnipi wawokiyapi kin de tona owotamna un kin taku icakijapi kin enakiye kte ca, nakun Wakantanka wopida nina eciyapi kta e kaga.

13 Messiya tawootanin waśte kin en oyapapi e daotaninpi, qa hena taku ota wicayaqupi, qa owasin taku wicayaqupi kin he on wawokiyapi utapi kin de on etanhan Wakantanka yaonihanpi.

14 Qa niyepi on wocekiye eniciyapi kin heon nina cantonikpanipi, Wakantanka towaonśida tanka nicipi un kin heon etanhan.

15 Wakantanka taku yawapica śni unqupi kin he on wopida kiciun nunwe.

\section{WICOWOYAKE 10.}

1 Palos he miye, Messiya walibayedan qa wacintanka heon ceciciyapi ce, niyepi ekta onśihanyan waun, tuka en waun śni ehantanhan, niyepi on wadimataka ;

2 Tuka ceciciyapi, en waun kinhan, wanjikji wicacelipi kin eciyatanhan maunnipi kecanunkinpi kin, hena en waditagya waun kta wacanmi kin he iyecen wadimatake kte śni.

3 Wicacelipi kin en maunnipi eśta, wicacehpi eciyatanhan unkicizapi śni.

4 Wipe unkunpi kin hena wicacehpi kin heca śni, tuka waśaka, Wakantanka on, inatake suta kin yujuju ece :

5 Wacinyuzapi kin kun ehpeya, qa taku tehan wankantuya un Wakantanka sdonyapi kin en wankan iyeiciye cin hena owasin, qa wicotawacin iyuhpa Messiya anagoptanpi kin en wayaka ai ece.

Dak.
6 Qa wanahoṇpi śni kin tounkiçonpi kta e wiyeya unkanpi ; tohan anayagoptanpi kin hduśtanpi kinhan.

7 Wicaśta itohnake kin hecedan iwandakapi he. Tuwe Messiya tawa kecaniçin kinhan, he ake kaken awacin kta; iś iye Messiya tawa kin heca he iyecen unkiś unkiyepi Messiya tawa unyanpi.

8 Wookihi Itancan unqupi kin, on icahunniyanpi kta, qa on ihangunniyanpi kte śni, heorl sanpa mihdatan eśta, imaśtece kte śni.

9 Wowapi on wakokipe cicagapi kta wacanmi śni.

$10 \mathrm{He}$ wowapi kage cin hena suta qa waśaka, tuka tancan en un kin he waśake śni qa ie cin he wowilia ce, eyapi.

11 Tuwe hecece cin he kaken awacin kta, en unkanpi śni wowapi wicoie kin on tounkecapi kin, he tohan en unkanpi kinhan, wicolian kin on heuncecapi kta.

12 Tona ihdatanpi kin hena unkihdacinpi, qa opeya unkihdawapi kta tawațenunyanpi śni; hena $\mathrm{e}$ iś iye on wihdutapi, qa iyepi on ihdukcanpi, qa hecen okahnigapi śni.

13 Unkiye wiunhdutapi kin isanpa unkihdatanpi kte śni; tuka wicohan iyutapi Wakantanka unqupi kin he eciyatanhan, iyutapi kin niyepi kin iyahde niyanpi.

14 Eikta iyahde unniyanpi kta e sanpa unkihdu titanpi śni. Tuka Messiya tawootanin waśte kin en niyepi kaeś ekta unniupi.

15 Wiunhdutapi kin isanpa unkihdatanpi śni, wicaśta tokeca wicohtani kin en ; tuka wicayadapi kin he icage cinhan, niyepi 289 


\section{KORINTH.}

on wiyutapi unhapi kin eciyatanhan sanpa unyuonihanpi kta unkapepi.

16 Hecen niye dukanpi kin akowapa wotanin waśte kin unkoyakapi kta, qa tuwe tokeca taku tawa wiyeya yanke cin en unkiwinktapi kte śni.

17 Tuka tuwe iwinkta kinhan Itancan kin on iwinkta nunwe.

18 'Tuwe ihdaonihan kin he ecetudakapi kin ee śni, tuka Itancan kin tuwe yaonihan kin hee kta.

\section{WICOWOYAKE 11.}

1 Witkotkoya iwae cin cistiyedan iyowinmayakiyapi kta wacin. He iyowinmayakiyapi nakaeś.

2 Wakantanka winawizi kin iyecen inaciwizipi, wicaśta wanjidan kiciyus ciyapi, hokśiwinna ecedan un kin Messiya ekta aciipi kta heon.

3 Tuka he kowakipa, wamduska wohnaye on Ewe hnaye ciqon he iyecen nitawacinpi kin yuśicapi kta, qa woyuecedan Messiya en un kin etanhan iyaye niyanpi kta naceca.

4 Tuwc en niupi kin he Jesus tokeca wan unkiye unkoyakapi śni kin he oyaka, qa Woniya tokeca, iyacupi śni qon, he nakaha iyacupi, qa wotanin waśte tokeca, anayagoptanpi śni gon he oniciy alsapi kinhan, iyowiny akiyapi kta.

5 Miye yewicaśipi iyotan tanka kin takudan ihukuya waun śni, imdukcan.

6 Ho magahan eśta, wosdonye kin on waksapa ; tuka niyepi kin en taku owasin on tanyan unkihdaotaninpi.

7 Wakantanka tawootanin waśte kin iyunwin codan ociciyakapi, qa wankantuya iyeniyanpi kta e on mihduhukuya kin he wawahtani he.

8 Okodakiciye tokeca kin taku wicawaki, qa opemicatonpi kin iwacu, ociciyapi kte cin heon; qa cicipi waun qa taku imakakije cehan, taku nitawapi hin mun śni :

9 Taku iyokpani waun qon he hunkawanjin kiciyapi Makedonia etanhan hipi kin maqupi, qa ohinniyan takudan inagiyeciyapi śni waun, qa eeś nakun hecen waun kta.

10 Messiya wowicake tawa miciun kin heon Akeya makoce kin en imawinkta kin de ecetu śni makiyapi kte śni.

11 Tokeca he; waśte cicidapi śni kin heon etanhan he. Wakantanka sdonya.

12 Tuka taku ecamon kin he nakun ecamon kta, hecen tona wiyaonpapi akitapi kin hena etanhan wiyaonpapi kin emdaku kta, qa en iwinktapi kin he unkiyepi kin iyecen unpi kta.

13 Hena yewicaśipi itonśni kin hecapi, wohnaye ohanyanpi, qa Messiya yewicaśi qon hena iyecen ihduzapi.

14 Qa he taku wowinihan śni, Satan iye kaeś iyoyanpa ohnihde kin iy ecen ihduza.

15 Heon etanhan, iye taokiye kin hena wicoowotanna ookiye kin iyecen ihduzapi kte cin he taku tanka śni, hena iye wicohan kin eciyatanhan ihang yapi kta.

16 Ake hecen epa; Tuwedan witkotkoke madake kte śni. Tuka hecon kinhan witkotkoke cin iyecen iyowinmakiye $\mathrm{kta}$, cistiyedan mihdatan kta.

17 'Taku epe cin hena Itancan kin eciyatanhan epe śni, tuka nina ihdatanpi kin he on witkoya ie cin iyemaceca. 


\section{WICOWOYAKE 12.}

18 Wicota wicacehpi kin on ihdatanpi kin he iyecen miś eya mihdatan kta.

19 Witkotkopike cin hena iyokipiya iyowinwicayakiyapi ece, niye yaksapapi nakaeś.

20 Tuwe wowidag niyanpi, tuwe temniyanpi, tuwe wanicipi, tuwe wahanicida, turve ite ohna anipapi hecinhan, iyowinwicayakiyapi ece.

21 Waośtehdapi kin he waka, waunśakapi śni kin heon. Tuka taku on tuwe waditake cinhan, witkotkoya iwaa ce, he on miś eya wadimataka.

22 Hena Hebrew wicaśta kin hecapi he. Miś eya hemaca. Hena Israel etanhanpi he. Miś eya. Hena Abraham cinca he. Miś eya.

23 Hena e Messiya taokiye kin hecapi he; witkotkoke cin iyecen iwaa, miś eya imayotan. Wicohtani kin en imayotan; apapi kin en wopteca śni waun; kaślka hnakapi kin en imayotan, qa wiconte kin en otakiya waun. 24 Juda oyate zaptan akihde, apapi wikcemna topa wanjidan iyokpani maqupi.

25 Yamni akihde cansakadan on amapapi; wancadall inyan on makininpi; yamni akihde wita wata micamdecapi; anpetu wanjidan hanyetu iyahna ośbe kin mahen waun;

26 Nina icimawani, mini ota wokokipe kin en waun, wakipi sa okokipe kin en, mitaoyate on wokokipe kin en, Ikcewicaśta on wokokipe en, otonwe ekta wokokipe en, hewoskantuya wokokipe en, miniwanca ekta wokokipe en, hunkawanjin kiciyapi itonpi śni kin hena ekta wokokipe en ;

27 Mdowakiti qa nina hitawani kin on, ota kiktahan waun kin on, wotektewahda qa imapuza on, ijehan amakitian kin on, macuwita qa tancodan waun kin on; $28 \mathrm{Qa}$ tankan tanhan anpetu iyohi taku amaupi kin, okodakiciye kin owasin awanhdakapi kin he nakun.

29 'Tuwe waśake śni un, 'qa miye wamaśake śni he; tuwe aiapi un, qa miye sinwahda śni he. 30 'Tuka imawink ta k ta iyecece cinhan, wamaśake śni waun kin heon imawinkta kta.

31 Jesus Messiya Itancan unkiyapi he Wakantanka tawa, qa Atkuku kin, owihanke wanin wowaśte yuhe cin he sdonmayan, itonśni mawanica.

32 Damaskos en, Aretas wicaśtaya tapi yanke cin ihukuya, wicaśta itancan kin akicita ota wicayuha, Damask os oyate otonwe tawapi kin awanhdake ça, maktepi lita akita.

33 Hehan conkaślke owanyeye wan etanhan, makanyankapi wan ohna, kun hiyumayanpi ; qa iye nape kin etanhan nawajica.

\section{WICOWOYAKE 12.}

1 Imawinkta kte cin he iyemicihantu śni, wowihanmde qa Itancan woyakapi tawa kin ekta wau kta.

2 Ehanna waniyetu ake topa sam iyeya, wicaśta wan Messiya en un kin he sdonwaya; (wicatancan kin ohna un kin sdonwaye śni, qa tanton śni un kinhan nakun sdonwaye śni, Wakantanka he sdonya;) wicaśta kin he mahpiya iciyamni kin ekta eyalkupi ;

3 Wicaśta kin he sdonwaya, (wicatancan kin ohna un sdonwaye śni, qa tanton śni un kinhan nakun sdonwaye śni, Wakantanka he sdonya;) 


\section{KORINTH.}

4 He Wakantanka ti kin ekta eyakupi, unkan wicoie oyagpica śni kin nałion, hena wicaśta oyake kta eśta okitpani kta.

5 Wicaśta kin hecece cin on imawinkta kta, qa miye qe on imawinkta kte śni, tuka wamaśake śni waun kin heceedan on.

6 Tuka imawinkta wacanmi keś wimatkotkoke kte śni, wowicake epe kta; tuka nakaha hecamon kte śni, tuwe wanmayake ca, token waun nahon kin he isanpa tanka kecanmakin kta he kowakipa.

7 Unkan woyakapi tanka kin on etanhan wahanmicida kte śni heon taku pepe wan micehpi kin en maqupi, Satan taokiye wanji hee, śicaya makuwa kta heon, wahanmiçida kte śni heon etanhan.

$8 \mathrm{Qa}$ heon Itancan kin yamni wocekiye ewakiya, he amayuśtan kte cin heon.

9 Hehan, Mitowaonśida kin iyonihi kta, qa mitowaśake kin he wowaśake śni kin en hduśtanpi ce, emakiya. Hecen Messiya towaśake kin miye en miciun kte cin, heon makakije cin on iyuśkinyan imawinkta kta.

10 Heon etanhan wowayazan kin en imduśkin ece, qa waaiapi, qa iwicakakije, qa śicaya wicakuwapi, qa Messiya on wicokakije kin henakiya en; tohan wamaśake śni eca taku owakihi e.ce.

11 Iwinktapi kin on witkotkoka imacaga, niye hecon mayakiyapi, mayadaotaninpi kta tuka qon; yewicaśipi iyotan tankapi kin takudan en wicihukuya waun śni, mataku śni eśta.

12 Awicakehan niyepi ekta yewicaśipi wowapetokeca tawapi kin econkupi, wacintankapi 292 owasin en, wapetogtokeca, taku wowinihan, qa waśagya wicohan kin hena on.

13 Taku e on okodakiciye tokeca kin ihukuya yaunpi he; taku nitawápi kin iwacu śni kin hee naceca. Heon wawahtani kin he micicajuju po.

14 Wanyaka po, iciyamni ekta ciupi kta wiyeya manka, qa nakun taku nitawapi kin iwacu kte śni. Taku yatonpi kin he awakite śni, tuka niyepi atayedan. Cinca yapi kin hunkakepi kin taku wicakihnakapi kin he hecetu śni, tuka hunkake yapi kin hena hokśiyoqopa kin on taku ekicihnakapi kta.

15 Ninagipi kin on htawani, qa mihdusote kte cin he iyomakipi; tuka iyotan canteciciyapi eśta, aoptetuya waśtemadakapi ece.

16 Tuka he hecetu, taku nitawapi kin iwacu śni; hececa eśta wamdupike cin heon wohnaye on ciyuzapi, keyapi.

17 Tona niyepi ekta ye wicawaśi qon hena eciyatanhan, ta$\mathrm{ku}$ mihdamna he.

18 Titos cewakiye ca kici hunkawanjitku wan ekta ye waśi. Niyepi etanhan Titos taku kamna he. Wicoksape okonwanjidan en maunnipi śni he; oye okonwanjidan ohna maunnipi śni he.

19 Ake niyepi en unkilhduwicakapi kecannipi he. Wakantanka itokamya Messiya kin en unkiapi ece. Waśtecicidapi kin, tanyan icahniyanpi kte cin heon taku owasin econkupi.

20 Ekta ciupi kinhan, niyepi token wacin kin hececa iy eciyapi kte śni, qa miye nakun token yacinpi śni kin hecen iyemayayapi kta kowakipa. Wakinicapi kin, winawizipi, canniyekici- 


\section{WICOWOYAKE 13.}

yapi, wicokicize, waaiapi, waajijipi, walianicidapi qa owodutaton kin henakiya en un kta kowakipa.

21 Qa okinni ekta wau kinhan, niyepi kin en Wakantanka mitawa kin iyokiśin maye kta, qa tona wanna woahtani econpi, qa taku aśape cin, wiinahmanpi, qa wicawihomnipi econpi kin on iyopeiçyapi śni kin hena awicawakiceye kta naceca, he kowakipa.

\section{WICOWOYAKE 13.}

1 De iciyamni ekta ciupi ; waayatanin nonpa qa yamni ipi kin on wicoie owasin yasutapi kta.

2 Ociciyakapi qon he ake nakaha ociciyakapi, icinompa ekta waun kin iyececa; qa nakaha en waun śni, tona toka wahtanipi, wicaśta tokeca ko owasin, wowapi wicawecaga, ake ekta wai kinhan itonwicawape kte śni.

3 Miye mahen tanhan Messiya ie cin on wowapetokeca ayakitapi kin heon etanhan; he niyepi ekta taku okitpani śni, tuka niyepi kin en waśake hinca.

4 He iye wowaśake śni on can susbeca kin en okatanpi eśta, Wakantanka towaśake kin on ni un. Heon unkiśs eya waunśakapi śni, tuka niyepi kin ekta Wakantanka towaśake kin on kici unnipi kta.

5 Niś niyepi ihdukcan po, wacinyanpi kin en yaunpi hecinhan; tanyan wihduta po. Elipeniyanpi śni kinhan, Jesus
Messiya niyepi kin mahen un, he sdonyakiyapi śni he.

6 Tuka ehpewicayapi kin heuncapi śni e sdonyayapi kta imdukcan.

7 Taku śica takudan ecanonpi kte śni he Wakantanka icewakiya; unkiye unwaśtepi e unyaotaninpi kte cin hee śni, tuka wahtepi śni kin iyeuncecapi kta eśta, niye taku waśte ecanonpi kte cin hee wacin.

8 Taku wowicake kaśeye cin takudan unkokihipi śni, tuka wowicake kin on etanhan.

9 Unkiye waunśakapi śni, qa niye waniśakapi eca unkiyuśkinpi ece. Qa tanyan onihduśtanpi kte cin he uncinpi.

10 Heon etanhan en waun śni icunhan, hena wowapi en wakaga, okinni ekta waun kinhan yaśinya iapi kin ohna iwae kta naceca; wowaśake Itancan maqu kin eciyatanhan, he waicahyapi kin on maqupi, qa waihangyapi kin on etanhan śni.

11 Ehake, hunkawanjin ciyapi kin, wiyuśkin po ; oihduśtan un po, cante wuśte po, okonwanjidan awacin po, wokiyapi kin en un po : qa wowaśte, wookiye ko Wakantanka kin nicipi un nunwe.

12 Otoiyohi iiputakapi wakan kin on i ikiciputaka po. Wicaśta owotanna un kin owasin i iniputakapi.

13 Jesus Messiya Itancan towaonśida kin, Wakantanka towaśtedake kin, qa Woniya Wakan iwicakiye cin niyepi owasin en nicipi unpi nunwe. Amen. 


\section{GALATIA OYATE KIN}

\section{WOWAPI WICAKICAGE CIN.}

\section{WICOWOYAKE 1.}

1 Palos yewicaśipi kin heca, wicaśta akantu kin etanhan śni, qa wicaśta on kagapi śni, tuka Jesus Messiya etanhan, qa Wakantanka Ateyapi kin, he wiconte etanhan najin kiye cin he nakun etanhan;

2 Qa hunkawanjin kiciyapi mici unpi kin owasin ko, Galatia ekta okodakiciye kin wowapi unnicagapi.

3 Wowaonśida, wookiye ko, Wakantanka Ateyapi kin, qa Jesus Messiya Itancan unkiyapi kin etanhan, nicipi un nunwe.

4 He iye waunhtanipi kin on icicu, wicoicage śice cin de etanhan eunhdakupi kta, Wakantanka Ateunyanpi tawacin kin eciyatanhan:

5 He ohinniyan owihanke wanin wowitan kicihan nunwe. Amen.

6 Tuwe Messiya towaonśida kin inicopi kin kohanna aduśtanpi, qa wotanin waśte tokeca en oyapapi kin, heon imanihan manka.

$7 \mathrm{He}$ nakun tokeca śni, tuka wicaśta wanjikji nagiyeniyanpi, qa Messiya tawootanin waśte kin ayuśtan niyanpi kta tuka.

8 Tuka he unkiś unkiyepi, qa iś ohnihde wan mahpiya kin eciyatanhan kin, wotanin waśte unkoniciyakapi qon he ohna śni, tuka tokeca oniciyakapi kinhan, wośnapi un nunwe.
9 Unkeyapi qon hecen ake nakaha epe, tuwe wotanin waśte iyacupi qon kici okonwanjidan śni kin oniciyakapi kinhan, he wośnapi un kte.

10 Wicaśta qa Wakantanka, unma tukte cinwicawakiya he; qa wicaśta kin iyokipiwicawaya awakita he. Wicaśta kin iyokipiwicawaya unkanś, Messiya wowidagmaye kte śni tuka. i1 Mihunkawanji he de ociciyakapi, wotanin waśte omdake ciqon he wicaśta akantu kagapi śni ;

12 Qa vicaśta kin etanhan iwacu śni, qa iye omakiyakapi śni, tuka Jesus Messiya oyake cin eciyatanhan onmaspe.

13 Juda wicohan en opeya waun qehan, token owahanmde cin nayahonpi; Wakantanka taokodakiciye kin nina śicaya wakuwa, qa mdujuju.

$14 \mathrm{Qa}$ mitaoyate lin en tona om akinimasìrokeca kin hena ota Juda wicohan kin en kawicawape ca, mihunkakepi wohdakapi qon iyotan nina tewahinda.

15 Tuka Wakantanka ina tezi kin etanhan imacu, qa iye towaonśida kin on mico kin he,

16 Iye Cinhintku kin sdonye mayan iyokipi qehan, lkcewicaśta wotanin waśte kin owicawakiyake kte cin heon, kohanna wicacehpi, wicawe ko, kici wowahdake śni :

$17 \mathrm{Qa}$ Jerusalem ekta tona 


\section{WICOWOYAKE 2.}

mitokapa tanhan yewicaśipi qon hena ekta wicawai śni, tuka Arabia ekta imdamde ca, ake Damaskos ekta icicawin wahdi.

18 Hehan waniyetu yamni iyohakam Inyan kici wowahdake kta e Jerusalem ekta wai, qa anpetu ake zaptan kici manka.

19 Tuka yewicaśipi kin tokeca tuwedan wanmdake śni, Jakob Itancan sunkaku kin heceedan.

20 Unkan wicoie wowapi en cicagapi kin de, iho, Wakantanka itokam itonśni mawanica.

21 He iyohakam Suria, qa Kilikia makoce kin en wahi.

22 Qa Juda makoce kin en okodakiciye kin Messiya en un kin, hena ekta ite kin sdonmayanpi śni waun.

23 Tuka, Tuwe śicaya unkuwapi qon he nakaha wowacinye ehanna yujuju qon he oyaka ce, hecedan nahonpi.

24 Unkan miye on Wakantanka yatanpi.

\section{WICOWOYAKE 2.}

$1 \mathrm{He}$ iyohakam waniyetu ake topa, hehan ake 'Titos yuha, Barnabas kici Jerusalem ekta itawankanhde mda.

2 Woyakapi oll ekta mde ca, Ikcewicaśta ekta wotanin waśte omdake ciqon he hena owicawakiyaka, qa tona okinihanpi kin hena iśnaśnana owicawakiyaka; ituya waimnanke śni, qa taku śni on waimnanke kte śni heon.

3 Tuka Titos mici un kin he Helenes heca keś bakih.dayapi kta keyapi śni.

$4 \mathrm{Qa}$ he nakun hunkawanjinkiciyapi itonpiśni kin heca, hena unkiye token Jesus Messiya on tawa unkiciyapi kin he iwanya- kapi kta e en hipi, wowidag unyanpi kte cin heon.

5 Tuka hena wihiyayedan oape wanjidan hehanyan wicihukuya unyalkonpi śui, wotanin waśte wowicake kin nicipi un kte cin heon.

6 Unkan tona wicaśta wicakinihanpi seca, qa takupi kaśta he etanhan tokeca śni, Wakantanka wicaśta itohnake kin iwanyake śni, hena wicakinihanpi seca, tuka wicoie kin en takudan omakiyapi śni.

7 Tuka hececa eśta, tohan bakilidayapi śni wotanin waśte kin he maqupi e wanyakapi qehan, bakilidayapi wotanin waśte Inyan qupi qon he iyececa;

8 Tuwe bakilidayapi kin on yewicaśipi kin en Inyan okihiye cin hee Ikcewicaśta ekta okihimayan ;

9 Qa Jakob, Inyan qa Johannes kici, ipatanhdepi kin hecapi seca, wowaonśida maqupi kin he wanyakapi, hehan takodakiciyapi on Barnabas kici nape mayuzapi, unkiś Ikcewicaśta ekta unyanpi kta, qa iyepi kin bakilidayapi kin ekta yapi kta. 10 Tuka decedan, tona wahpanicapi kin wicunkiksuyapi kta keyapi, unkan miś nakun hecamon tawatenwaya.

11 Unkan Inyan Antiyoka ekta hi qehan, kici taninyan awakinica, iye iyaonpepica nakaeś.

12 Jakob etanhan wanjikji hipi śni kin he itokam Ikcewicaśta kin om wota ece; tuka wanna en hipi, hehan tona bakilidayapi qon hena kowicakipe ça, tokan iyaye ca ihdonica.

13 Qa he opeya Juda wicaśta tokeca kin iyecen anahbeya econpi, hecen hena wohnaye kin on Barnabas nakun opeya yeyapi. 
GALATIA.

14 Tuka wotanin waśte wowicake kin eciyatanhan owotanna manipi śni, he wanmdaka hehan owasin wicitokam Inyan hewakiya; Juda wicaśta henica, tuka Ikcewicaśta kin iyecen yani kinhan, qa Juda wicaśta kin iyecece śni, tokeca e Ikcewicaśta kin Juda wicohan kin en ope wicayaśi he.

15 Unkiyc wicacehpi eciyatanhan Juda wicaśta kin heuncapi, qa Ikcewicaśta wahtanipi sa heuncapi śni ;

16 Wicaśta kin woope wicohan kin eciyatanhan yaowotanpi śni ece, tuka Jesus Messiya wacinyanpi kin on, he sdonunyanpi kin heon unkiś eya Jesus Messiya wacinunyanpi, Messiya wicadapi kin on unyaowotanpi kta e heon, qa woope opapi kin on etanhan śni; woope wicohan kin eciyatanhan wicacehpi owasin tuwedan yaowotanpi kte śni.

17 Tuka Messiya on unyaowotanpi kta unkakitapi kin he icunhan, wahtanipi sa heuncapi hecinhan, heon Messiya woahtani wowidake kin heca he. Hiya hecetu śni.

18 Taku mdujuju qon he ake piya wakage cinhan, wawahtani e mihdutanin.

19 Wakantanka on wani kta e heon, woope eciyatanhan, woope kin ekta mata ce.

20 Messiya kici icipaweh omakatanpi ; tuka nahahin wani ; qa he miye śni tuka miye mahen Messiya ni un kin hee; qa wicacehpi kin en wani kin he Wakantanka Cinhintku wacinyanpi kin eciyatanhan wani, he iye cantemakiye ça miye on iye içiçu. 21 Wakantanka towaonśida kin mdujuju śni ; woope kin eciyatanhan wicoowotanna u kinhan, hehan Messiya ituya ța. $296^{\circ}$

\section{WICOWOYAKE 3.}

1 Galatia wicaśta wacin tonpi śni kin, tuwe niyuhnaśkinyanpi, qa hecen wowicake kin anayagoptanpi kte śni he; niyepi kin en Jesus Messiya icipaweh okatanpi kin he niiśtapi kin itokam yuotaninpi.

2 Decedan omayakidakapi kta wacin, woope wicohan kin on, qa wacinyan anagoptanpi kin, unma tukte eciyatanhan Woniya kin iyacupi he.

3 Tokaheya Woniya kin on ecanonpi, qa ehake wicacehpi kin on nihduśtanpi kta he, qa wacinyatonpi kte śni.

4 Kana owasin taku śni on iyotanhan iyeyakiyapi he; he taku śni on etanhan hecinhan.

5 Tuwe Woniya kin yuhe niciyapi, qa niyepi en tankaya olianye cin he woope wicolian kin on, qa wacinyan anagoptanpi kin unma tukte eciyatanhan he.

6 Hecen Abraham Wakantanka wicada, unkan he woowotanna kiciyawapi qon.

7 Heon etanhan, tona wacinyanpi kin en opapi kin hena Abraham cincawicaye cin eepi, he sdonya po.

8 Wacinyanpi kin on Wakantanka Ikcewicaśta kin wicayaowotanna kte cin, he Wowapi wakan otokaheya tanhan wanyakc ça, hecen tokaheya Abraham wotanin waśte kin okiyaka; Niye en oyate kin owasin wicayawaśtepi kta ce.

9 Hecen tona wacinyanpi kin hena Abraham wacinye ciqon kici wowaśte yuhapi.

10 Tona woope wicohan kin etanhanpi kin hena woyaco kin en unpi. Hecen wowapi en kagapi; Tona taku woope wowapi kin en kagapi kin owasin 


\section{WICOWOYAKE 3.}

opeya unpi śni, qa ecen econpi śni kin hena otoiyohi wanna wicayacopi ce.

11 Unkan woope kin eciyatanhan tuwedan Wakantanka itokam yaowotanpi śni e sdonunyanpi: Tona owotanna un kin hena wacinyanpi eciyatanhan nipi kta ce.

12 Unkan woope kin he wacinyanpi kin eciyatanhan śni; tuka, Wicaśta kin tuwe hena econ kinhan, hena on ni kta ce.

13 Woope woyaco kin etanhan Messiya eunhdakupi, unkiyepi on iye woyaco ikicaga. Wowapi en hecen kagapi, Tona can en otkeyapi kin hena owasin yacopi ce.

14 Hecen Jesus Messiya eciyatanhan Abraham wowaśte tawa kin he Ikcewicaśta kin en awicau kta; hecen wacinyanpi kin on Woniya iwahounyanpi kin he unkicupi kta.

15 Mihunkawanji, wicaśta akantu iyecen iwaa. Wicaśta akantu wicotakuye tawa kin hee kaeś, wanna hduśtanpi kinhan, tuwedan hdujuju śni, qa taku en akage śni ece.

16 Abraham iye cinca kici wahoyapi; Cincapi kin eye śni, hehan ota kapi kta, tuka wanjidan, qa, Nicinkśi kin, he Messiya kin ee.

17 Unkan miś kaken epe kta; Otokahe ekta wicotakuye Messiya en Wakantanka hdusuta kin he, iyohakam waniyetu opawinge topa sanpa wikcemna yamni hehan woope $u$ kin he tokaheya kin yujuju, qa hecen wahoyapi qon ecetuśniye kta okitpani.

18 Taku tawapi kte cin he woope eciyatanhan un unkanś, wahoyapi kin eciyatanhan śni; tuka he Wakantanka Abraham iwahoya.
19 Hehan tokeca e woope kin yukan he. He woahtani on kagapi, cinca iwahoyapi qon u śni kin hehanyan, qa ohnihdewicayapi kin on yusutapi, iyotahedan un wan nape kin ohna.

20 Iyotahedan un kin he wanjidan eciyatanhan śni, tuka Wakantanka eqe wanjidan.

21 Heon woope kin he Wakantanka taku iwahowicaye cin he kaśeya he. Hiya hecetu śni. Woope wiconi kaga okihi unkanś, awicakehar woope kin eciyatanhan wicoowotanna $u$ kta tuka.

22 Tuka Wowapi Wakan kin he owasin woahtani ohdateya un wicayawa, qa hecen tona wicadapi kin hena, Jesus Messiya wacinyanpi wahoyapi qon he wicaqupi kta.

23 Wowacinye kin hi śni itokam woope kin on unkaśkapi; qa wowacinye yuotaninpi kte cin en onauntakapi.

24 Hecen woopc kin he wayeunkiyapi kin hee, Messiya en unkahipi kta, hecen wowacinye on unyaowotanpi kta e heon.

25 Tuka wowacinye kin wanna hiyohi, hecen wanna wayekiyapi kin ihukuya unyakonpi śni.

26 Jesus Messiya wacinyanpi kin eciyatanhan owasin Wakantanka cinca kin heuncapi.

27 Tona Messiya caje on baptem niçupi kin hena Messiya kodakapi.

28 He en Juda qa Helenes wicaśta ko wanica; wowidake un tawaiçiya ko wanica; wica winyan ko wanica; tuka Jesus Messiya ekta owasin okonniwanjipidan.

29 Messiya tawa niyanpi hecinhan, Abraham cinca kin henicapi, qa wahoyapi kin eciyatanhan tawayapi kte cin. 


\section{GALATIA.}

\section{WICOWOYAKE 4.}

1 Unkan kaken epa; Tawaye kte cin tohanyan hokśiyopa un kin hehanyan wowidake kin takudan ocitpani śni, taku owasin on itancan un eśta.

2 Tuka tohan Atkuku ke cin hehanyan waonspekiye ca tipi awanyag wicakiyapi kin hena he yuhapi.

3 He iyecen unkiś eya hounkśiyopapi qehan, wicoicage woonspe tokaheya kin ihukuya unyakonpi.

4 Tuka wanna anpetu iyehantu qehan, Wakantanka iye Cinhintku kin u śi, winohinca wan etanhan icage ca woope kin olidateya kagapi.

5 Hecen tona woope kin ihukuya un kin hena opewicakiton kta, atayedan cinhintkuyapi kin unhapi kte cin heon etanhan.

6 Unkan cinkśiniyanpi kin heon Wakantanka iye Cinhintku Taniya kin nicantepi kin en niu śipi, he, Abba, Ate, eya howaya ece.

7 Hecen wowidake kin henica śni, tuka cinhintku kin henica. Qa cinhintku hecinhan, Messiya eciyatanhan Wakantanka ekta tawaye kte cin heca.

8 Tuka Wakantanka sdonyayapi śni qehan, taku wakan śni kin hena wowidag niyanpi.

9 Unkan nakaha Wakantanka sdonyayapi, qa iś Wakantanka sdonniyanpi yaunpi kin, hecen token ake taku tokaheya hunkeśni qa takudan okihi śni un kin ekta nihdohdapi, qa hena ake wowidag niyanpi kta yacinpi he.

10 Anpetu qa wi kin, omaka waniyetu ko awacanipi.

11 Kocicipapi, taku śni on niyepi kin litacicinipi epca, heon etanhan.
12 Mihunkawanji, ceciciyapi ce; Miś waun kin iyecen un po; niye yaunpi kin iyecen waun, taku śica takudan ecamiyeconpi śni.

13 Tokaheya ekta wicacehpi waśake śni on wotanin waśte kin ociciyakapi kin he sdonyayapi.

14 Qa micehpi en taku iyutanmaye cin he śiceyadapi śni, qa paha iyeyayapi śni, tuka.Wakantanka ohnihde ye cin iyecen, qa Jesus Messiya iyecen tin ye mavaśipi.

15 Hecen wowaśte duhapi qon tukte e he. Kaken ciyaotaninpi, okihipica unkanś niiśtapi kin yahduśdokapi qa mayaqupi kta wicayadapi kta tuka.

16 Wowicake ociciyakapi kin heon toka mayayapi he.

17 Hena e tanyan canteniciyuzapi seca, tuka he taku waśte on etanhan śni, lieyata iyeunyanpi kta cinpi, hecen niye tanyan cantewicayakiyuzapi kta.

18 Tuka ohinniyan taku waśte on tanyan canteyuzapi kin he waśte, qa niyepi ekta waun kin hecedan śni.

19 Micinca, niyepi kin en Messiya icahyapi kte cin heon ake hokśiksuya waun.

20 Niyepi kin on, tolken wacin mduza tanin śni, heon nakaha ekta cicipi waun qa miho kin wahdatokeca kta wacin.

21 Tona woope ihukuya yaunpi yacinpi kin, woope kin nayahonpi śni hecinhan omakiyaka po.

22 Wowapi en hecen kagapi ; Abraham cinhintku nonpa, unma wowidake winohinca etanhan, qa unma iś winohinca tawaiciye cin etanhan.

23 Tuka wowidake winohinca etanhan un kin he wicacehpi 


\section{WICOWOYAKE 5.}

eciyatanhan torpi, qa tawaiçiye cin etanhan un kin wahoyapi kin on tonpi.

24 Hena e wiyacinpi wan ee; qa wicotakuye nonpa kin heepi. Unma Sina he kin etanhan $u$, he wowidag yapi kaga, Hagar hee. 25 Qa Hagar he Arabia ekta Sina he kin hee, qa Jerusalem wanna he cin kici akidecen un, qa cinca kici wowidake un.

26 Tuka Jerusalem wankan tanhạ $u$ kin he tawaiçiya, he owasin ina unyanpi kin ee.

27 Hecen wowapi en kagapi; Cinca oyakitpani qa cinca ton śni yaun kin iyuśkin wo ; tohinni hokśinyaksuye śni kin panpan qa dowan wo; tuwe iśnana un kin he cinca ota, qa hihnaton kin he cinca tonana.

28 Mihunkawanji, Isaak iyecen wahoyapi cinca kin heuncapi.

29 'Tuka he ehan tuwe wicacelipi eciyatanhan tonpi kin he Woniya eciyatanhan un kin he śicaya kuwa qon, iśs eya dehan iyececá.

30 'íuka Wowapi wakan kin token eya he ; Winohinca wowidake un kin cinca kici tankan iyeya wo; wowidake un cinca kin he tawaiciya cinca kin kici akidecen tawaye kte śni.

31 Hecen mihunkawariji, wowidake un cinca kin ee sni, tuka tawaiçiya cinca kin unkiyepi.

\section{WICOWOYAKE 5.}

1 Hecen tawaiciyapi kin on Messiya tawaiciye unyanpi kin he en tinsadan un po, qa ake wowidake yapi wanapin kin on iyaihdaśkapi śni po.

2 Wanyaka po, Palos he miye e kaken eciciyapi; Banicilidayapi kinhan Messiya takudan on oniciyapi kte śni ce.
3 Wicaśta bakilidayapi kin otoiyohi kaken ewakiya ece; Woope kin ocowasin econ kita iyececa tuka ce.

4 Tona woope kin on niyaowotanpidan keniçyapi kin wanna Messiya elipeyayapi, qa wowaonśida etanhan nihinhipayapi kin.

5 Unkiye Woniya kin eciyatanhan wicoowotanna woape kin wacinyanpi on unkapepi ece.

6 Jesus Messiya en bakilidayapi kin he takudan okihi śni, qa nakun bakilidayapi śni kin; tuka wacinyanpi wowaśte en olianye cin he taku okihi ece.

7 Tanyan yainankapi; tuwe iyoncipi śni kin, hecen wowicake kin wicayadapi kte śni he.

8 Woawacin kin de tuwe nicopi kin eciyatanhan u śni.

9 On napohyapi cistinna kin he aguyapi ocowasin napoliya.

10 Itancan kin eciyatanhan wacinciyapi, takudan tokeca awacanipi kte sni; qa tuwe kaśta nagiyeniyanpi kinhan he woyaco hduhe kta.

11 Mihunkawanji, miś miye bakilidayapi kin ieyanwapaha kinhan tokeca e śicaya makuwapi he; kinhan, can susbeca iwośihda kin he enaliyapi tuka.

12 Tokin tona cante okicunin niyanpi kin hena yuśpa iyewicayapin.

13 Mihunkawanji, tawaiçiyapi kin en nicopi, tuka tawaiçiyapi kin he wicacelipi iyokipi kta e wowinyunyanpi śni po; tuka wowaśte on otoiyohi okiciciya po.

14 Woahope kin ocowasin wicoie wanjidan en ecetu, he dee, Niś niye inihdacinyan wicaśta aiyog yaun kin canteyakiye kta ce.

15. Tuka yecidahitakapi qa tem299 


\section{GALATIA.}

yeciyapi kinhan, on wakta po, okinni ihangyeciyapi kta naceca. 16 Miye kaken epe; Woniya kin on mani po, hecen wicacehpi on cantiheye cin yahduśtanpi kte śni.

17 Wicacehpi kin he Woniya kin inakiwizi, qa Woniya kin iś wicacehpi kin inakiwizi, qa henaozakiya anokatanhan kicizapi, hecen taku token yacinpi śni kin hena ecanonpi ece.

18 Tuka Woniya kin yus aniyanpi hecinhan, woope kin ihukuya yaunpi śni.

19 Wicacelipi wicolian kin taninyan un ; Wawicihahapi, wiinahmanpi, waaśapapi, wicaśtapi śni ;

- 20 Wakagapi kin ohodapi, wapiyapi, śice kicidapi, wakinicapi, wawihnupi, .wacantahdepi, wicokicize, wawakipajinpi, yuomdecapi,

21 Winawizipi, tin wicaktepi, witkopi, qa witkoya wacipi, qa taku tona hecece cin hena ee; wanakaja ociciyakapi kin he iyecen nakaha eciciyapi, Tona taku hececa econpi kin hena Wakantanka tokiconze kin tawapi kte śni.

22 Tuka Woniya kin waskuyeca tawa kin he, wowaśtedake, wowiyuśkin, wookiye, wacintankapi, wicowalibayedan, wowaśte, wowacinye ;

23 Wicotawacin waśte, qa iyatahde içiyapi śni hena ee; qa taku hecece cin woope kin tuktedan iyamya un śni.

24. Unkan tona Messiya tawa wicaye cin hena wicacelipi kin icipaweli okatanpi, qa wacinyuzapi cantiheyapi koya.

25 Woniya kin unkicinipi kinhan, Woniya kin unkopapi kta.

26 Otniyohi śihdakiciyapi, qa winakiciwizipi, qa ecinśniyan 300 iwinkta içiyapi wanin unyakonpi nunwe.

WICOWOYAKE 6 .

1 Mihunkawanji, wicaśta wan ihnuhanna taku śica en iyohpaye cinhan, niye tona owotanna yaunpi kin woksape wowalibayedan yuha wicaśta kin he ake piya opeya maniya po; qa awanihdaka wo, okinni taku wawiyutanyan un kin en niu nun ce.

2 Otoiyohi waqinpi kin kicicin po, hecen Messiya toope kin tanyan ecetu yayapi lita.

3 Tuwe taku śni un eśta, taku içida kinhan, he içihnayan.

4 Tuka otoiyohi iye ohan kin awakicin $\mathrm{kta}$, hecen iye qe eciyatanhan, qa tokan tanhan śni, iyuśkin kta.

5 Otoiyohi waqinpi tawa kin kicin kta.

6 Tuwe wicoie kin eciyatanhan onspekiyapi kinhan, he waonspekiye cin taku waśte kin owasin etanhan okinikiya nunwe.

7 Ihnuhan nihnayanpi kin; Wakantanka uncapi kte śni ce. Wicaśta kin taku oju kinhan, he yulise kta ce.

8 Tuwe iye celhpi kin wokiciju kinhan, he wicacehipi kin etanhan wicotakuni śni mnaye kta; qa tuwe Woniya kin wokiciju kinhan, he Woniya kin eciyatanhan wiconi owihanke wanica mnaye lita.

9 Taku waśte econ unkapinpi śni nunwe; hu unstakapi śni kinhan tohantu kte cin mnaunyanpi kta.

10 Heon tohanyan unkokihipi kinhan, wicaśta owasin taku waśte ecawicunkiconpi kta, qa wacinyanpi tiyohnaka kin hena iyotan. 


\section{WICOWOYAKE 1.}

11 Wowapi hinsko tanka miye minape on cicagapi e wandakapi.

12 Tona wicacehipi ekta waśte ihdutaninpi cinpi kin hena baniçilidayapi kta cinniciyapi, Messiya can susbeca tawa kin on śicaya kuwapi kte śni kin heon heconpi.

13 'Tona bakihdayapi kin hena e qe nakun woope kin tanyan yuhapi śni, tuka baniçilidayapi kta cimpi, nicehpipi kin on iwinktapi kta heon.

14 Tuka takudan on imawinkta śni nunwe, Jesus Miessiya Itancan unkiyapi can susbeca tawa kin hecedan on, he on miye ekta wicoicage kin icipaweli okatanpi, qa wicoicage kin ekta icipaweh omakatanpi.

15 Jesus Messiya en bakihdayapi kin he takudan okihi śni, qa bakilidayapi śni kin he nakun, tuka wicaśta teca kin.

16 Tona woopé kin de eciyatanhan manipi, Israel Wakantanka tawa wicaye cin hena ko, wookiye, wowaonśida ko, wicakici unpi nunwe.

17 Detanhan tuwedan nagiyemaye śni nunwe; Jesus Messiya towapetogton kin mitancan kin en yuha waun.

18 Mihunkawanji, Jesus Messiya Itancan unkiyapi towaonśida kin ninagipi kin kici un nunwe. Amen.

\section{P A L O S EPHESOS OYATE KIN}

WOWAPI WICAKICAGE CIN.

WICOWOYAKE 1.

1 Palos, Wakantanka tawacin kin eciyatanhan, Jesus Messiya yeśi qon hee, Ephesos ekta tona owotanna un, qa Jesus Messiya wacinyanpi kin hena wowapi cicagapi:

2 Wowaonśida, wookiye ko, Wakantanka Ateunyanpi kin etanhan, qa Jesus Messiya Itancan unkiyapi kin etanhan niyepi en nicipi un nunwe.

3 Jesus Messiya Itancan unkiyapi Wakantanka tawa, qa Atkuku kin yawaśtepi nunwe; he iye Messiya en taku mahpiya tanhan un kin wowaśte wakan ocaje owasin on unyuwaśtepi :
$4 \mathrm{He}$ en maka kagapi kin itokam unkahnigapi qon iyececa, unwakanpi kta qa iye itokam wowaśte en iyaonpepica śni unyakonpi kte cin heon:

5 Qa iye en, Jesus Messiya eciyatanhan cinca unyanpi, iye tawacin oiyokipi kin eciyatanhan:

6 Iye towaonśida wowitan yatanpi kte cin on, he iye Waśtekidake cin en waśteundakapi :

$7 \mathrm{He}$ on wopekitonpi kin unhapi, iye we kin on, woahtani kajujupi kin hee, iye towaonśida tanka kin eciyatanhan:

8 He iye unkiciyuotapi, wicoksape owasin qa wookahnige ko on :

$9 \mathrm{Qa}$ iye toiyokipi kin eciyatanhan, iye tawacin wowiyukcan 301 


\section{EPHESOS.}

kin sdonyeunkiyapi, he iye en iciconze ciqon he iyecen:

10 Hecen tohan iyehantu kinhan, wokonze kin eciyatanhan taku owasin Messiya en witaya mnaye kta, taku mahpiya ekta un, qa taku maka akan un kin hena, iye en.

11 Qa tuwe iye tawacin wokonze kin eciyatanhan, taku owasin lage cin he otokaheya tanhan unkahnigapi kin, he iye en woaihpeye kin unhapi.

12 Hecen unkiye tokaheya Messiya wacinunyanpi qon, iye towitan kin yatan unyakonpi kte cin heon.

13 He niś niyepi nakun, wowicake oie kin nayahonpi qehan, wotanin waśte on ni niyanpi kte cin hee, he iye wacinyayapi, unkan Woniya wahoyapi kin he on wapetognitonpi :

14 He taku unhapi kte cin tokaheya wicaqu ece kin hee, taku opetonpi hdamnanpi kin $u$ kte cin hehanyan, iye towitan yatanpi kte cin heon.

15 Hecen miś eya, Jesus Messiya wacinyayapi kin he, qa tona owotanna un kin owasin waśte wicayadakapi kin nawalion kin,

16 Ehantanhan niyepi on wopida eya amdaśtan śni, qa wocekiye epa eca, ciksuyapi ece :

17 Jesus Messiya Itancan unkiyapi Wakantanka tawa, qa wowitan Ateyapi kin hee woksape wowiyukcan ko oniya kin niçupi $k \mathrm{ta}$, he iye sdonyayapi kta e heon:

18 Nitaw acinpi iśta kin iyoyam niyanpi kta, hecen nicopi wowacinye kin he taku kin e sdonyayapi lita, qa tona owotanna un kin taku tawapi kte cin wowitan wijica kin he taku;

19 Qa tona wicaundapi kin en iye towaśake tanka hinca woptecaśni kin he taku kin nakun, iye towaśake waśagya olianye cin eciyatanhan.

20 He Messiya okicihan, wiconțe etanhan najin kiye cehan, qa mahpiya ekta iye etapa kin en ekihde:

21 Wokiconze owasin, qa wowaśake, qa wookihi, qa itancankiyapi, qa wicacaje caje yatapi kin owasin, wiconi kin de en hecedan śni, wiconi u kte cin he nakun, hena iwankam tehan wankantuya elsihde:

22 Qa iye siha kin ihukuya taku owasin ekihnaka, qa taku hiyeye cin owasin iwankam olsodakiciye kin en he pa kin kaga ;

23 He iye tancan kin hee, tuwe taku owasin on owasin ojuye cin woojudan kin hee.

\section{WICOWOYAKE 2.}

1 Unkan niś niyepi kin woạhtani wicohan śica ko en nițapi :

2 Hena ehna ehanna mayanipi, wicoicage kin de wiconi kin eciyatanhan, qa okotonyan wowaśake kin itancan kin eciyatanhan, he taku wakan woakta śni cinca kin en ohanye cin hee.

3 Hena om, unkiyepi owasin ehanna unnipi, uncehpipi wacin yuze cin en, wicacehpi wicotawacin ko wacinpi kin ecetu unyanpi, qa unmanpi kin iyecen wocantiyahde cinca kin heuncapi.

4 Tuka Wakantanka wowaonśida kill on wijica kin he towaśtedake tanka kin on waśte undakapi kin heon;

5 Unkiye wicolian śica ehna unțapi qehan, Messiya kici niunkiyapi ; wowaonśida on wiconi duhapi ece : 


\section{WICOWOYAKE 3.}

6 Qa Jesus Messiya en witaya najin unkiyapi, ya mahpiya kin ekta kici kiyotang unkiyapi ;

7 Hecen wiconi u kte cin en, Jesus Messiya on cantounhnakapi kin on, towaonśida woyuha wopteca śni kin hduotanin kta.

8 Wowaonśida kin on yanipi, wacinyanpi kin eciyatanhan, qa he niyepi kin etanhan śni, Wakantanka taku niçupi kin hee.

9 Wicohan kin eciyatanhan śni, okinni tuwe ihdatan kta tuka.

10 Iye taku kage cin he unkiyepi, Jesus Messiya en wicohan waśte aicali unyanpi, hena ohna maunnipi kte cin heon otokaheya tanhan Wakantanka wiyeya ehnaka.

11 Hecen ehanna wicacehpi ekta Ikcewicaśta henicapi kin he kiksuya po, qa wicacehpi bahdayapi eyapi, nape on econpi kin he bakiłidayapi śni eniciyapi qon :

$12 \mathrm{He}$ ehan Messiya yuhe śni yaunpi; Israel wokiconze kin iyenicihantupi śni, qa wahoyapi wicotakuye kin sdonyayapi śni, wowacinye ninicapi, qa wicoicage kin en Wakantanka codan yaunpi.

13 Tuka nakaha Jesus Messiya en, niś niyepi ehanna itehanyan yaunpi qon, wanna Messiya we kin on kiyadan anihipi.

14 Unkan iye wookiye unkitawapi kin hee, iye qe napin yuwanjidan, qa cokahnagya ehnakapi qon he yujuju;

15 Qa iye cehpi kin en, tokakiciyapi kin woahope woope kin econ wicaśipi qon he yutakuni śni ; - iś iye en nonpa etanhan wicaśta wanjidan teca icaliye kta, hecen wookiye kage kte cin heon etanhan.

16 Qa tancan wanjidan on, can susbeca kin eciyatanhan, hena napin Wakantanka kici okiciciye wicakiye ca, heon tokakiciyapi kin kte.

$17 \mathrm{Qa}$ tona tehan dukanpi qon kiyadan un kin hena ko wookiye oniciyakapi hi.

18 He eciyatanhan Woniya wanjidan on, napin Ateunyanpi kin ekta kiyedan ipi kin he unhapi.

19 Heon etanhan, detanhan togkicihdapi, qa oyate tokeca kin henicapi śni; tuka tona owotanna unpi kin hena om yatipi, qa Wakantanka tiyohnaka tawa kin he niyepi :

20 Qa yewicaśipi wicaśta wokcan ko taku ahehde tawapi kin akan tinicagapi, Jesus Messiya he oise en otancanke kin hee.

21 Iye ohna tipi kin ocowasin ayucoco ehnakapi, qa Itancan lin en tipi wakan icaga.

22 He ohna niyepi nakun ptaya tinicagapi, Woniya kin eciyatanhan, Wakantanka tipi ye kte cin heon.

\section{WICOWOYAKE 3.}

1. Heon Ikcewicaśta kin niyepi on etanhan, Palos, Jesus Messiya on kaśka hnakapi kin he miye.

2 Niyepi on Wakantanka towaonśida wicolitani maqupi kin he nayahonpi hecinhan;

3 Token woyakapi kin on wowiyukcan kin he sdonye makiya; he wanna wicoie tonana on wakaga:

4 He dawapi kin ehantanhan Messiya tawowiyukcan kin token imdukcan kin sdonyayapi kta.

$5 \mathrm{He}$ wicoicage tokeca kin en wicaśta cinca kin owicakiyakapi śni, tuka nakaha Woniya kin eciyatanhan, yewicaśipi owotanna qa wicaśta wokcan tawa303 


\section{EPHESOS.}

wicaye cin hena owicakiyakapi kin iyecen :

6 Hecen Ilkcewicaśta kin nakun kici tawayapi kte ca, kici tancan wanjipidan kta, qa Messiya tawotanin waśte kin eciyatanhan wahoyapi qon he en opapi kita.

$7 \mathrm{He}$ on ookiye makagapi, Wakantanka towaonśida nıaqupi kin he eciyatanhan, iye towaśake olianye cin on.

8 Miye tona owotanna un kin owasin en iyotan macistinna, tuka wowaonśida kin de maqupi, Ikcewicaśta kin ekta Messiya tawoyuha okahinilipica śni kin he omdake lite cin hee.

9 Qa wowiyukcan kin otokahe wanin ehantanhan Wakantanka, taku owasin Jesus Messiya on lrage cin, he en nalimanpi qon hee takodakiciyapi kin he owasin sdonye wicawakiye kta.

10 Hecen nakaha okodakiciye kin eciyatanhan, wokiconze wowaśake ko, mahipiya ekta un kin en, Wakantanka toksape wopteca śni kin atanin kta.

11 Wokonze otokahe wanin ehantanhan lage ciqon he eciyatanhan, Jesus Messiya Itancan unkiyapi kin en;

12 Iye wacinunyanpi kin eciyatanhan, kokipeśniyan ekta unkipi, qa waditagya unkiapi ece.

13 Heon etanhan niyepi lzin on kakiś mayanpi kin heon canwannikapi kte śni wacin.

$14 \mathrm{Qa}$ heon Jesus Messiya Itancan unkiyapi he Atkuku kin en, anpetu iyohi canpeśka makehde inawajin.

$15 \mathrm{He}$ eciyatanhan wicowazi mahpiya ekta un, qa maka akan un kin, ocowasin caśtonpi.

16 Hecen iye towitan woyuha kin eciyatanhan talsu nicupi kta, iye Taniya kin eciyatanhan, wo- waśake on wicaśta mahen tanhan waśagniyanpi kta.

17 Hecen wacinyanpi on nicantepi kin mahen Messiya ounye kta ;

18 Hecen wowaśtedake on hutkan niyusutapi, qa sutaya hu nihdepi kta; qa tona owotanna un kin owasin om, ohdakinyan qa ohanske cin, ornahentuya qa obosdatu kin he taku kin iyu.lican oyakihipi kta ;

19 Qa Messiya towaśte okahnilipica śni kin he sdonyayapi kte, hecen Wakantanka toojudan lrin ocowasin ojuniyanpi kte.

20 Tuwe nina waśagya econ okihi, unkiś unkidapi qa awauncinpi kin isanpa, wowaśake kin on onicilianyanpi kin he eciyatanhan;

$21 \mathrm{He}$ iye olkodakiciye kin en, Jesus Messiya on, ohinniyan owihanke wanin wowitan kicihan nunwe.

\section{WICOWOYAKE' 4.}

1 Heon etanhan miś miye Itancan caje on makaśk api, ceciciyapi ce, Wicakicopi on nicopi kin he iyacinyan mayanipi kte.

2 Wicotawacin waśte ocowasin qa wicowahbadan, wacin tankapi ko yuha, wowaśtedake en otoiyohi iyowinyeciciyapi kta :

3 Qa wookiye icaśke kin on Woniya okonwanjidan kin he yahduhapi kta e aiçiciya po.

4 Wicatancan wanjidan qa Woniya nakun wanjidan, nicopi kin en wowacinye wanjidan inicopi kin he iyececa;

5 Itancan wanjidan, wowacinye wanjidan, baptem wanjidan, 6 Taku Wakan wanjidan, he owasin Ateyapi kin, owasin 
iwankam un, qa owasin opta un, qa niyepi owasin en niunpi kin.

6 Tuka Messiya iyunwin codan wicaqu iyutapi kin eciyatanhan unkiyepi otoiyohi wowaonśida unqupi.

8 Heon kaken eya; Wakantkiya kihde cehan, wayaka ahdapi qon he ocowasin ahde ca wicaśta kin taku wicaqu ce.

9 Wankan kihde cin he taku he; tokaheya maka mahentuya kin iyaye cin hee.

10 Tuwe kun hi qon he taku owasin ojuye kte cin heon, he malipiya kin ako sanpa tehan wankantuya kihde cin.

11 Unkan apa yewicaśipi kin heca wicaqu, qa wicaśta wokcan wanjikji, qa wotanin waśte oyakapi kte cin wanjikji, qa waawanhdakapi waonspekiya ko w anjikji ;

12 Tona owotanna un kin hena wicayuecedan kta, wawokiyapi wicohan kin on, qa Messiya tancan icahyapi kte cin heon.

13 Tohan owasin okonwanjidan wacinyanpi, qa Wakantanka Cinhintku sdonyapi kin ekta, qa wicaśta tanka Messiya toojudan kin iyehankeca iyutapi kin ekta iyounhipi kte cin hehanvan.

14 Hecen detanhan hokśiyoqopa aptanptan iyeyapi, qa woonspe tate owasin on kaha iyeyapi kin heuncecapi kte śni, wicaśta ośkiśkeya ohanyanpi, qa wohnaye on wicahnayanpi wicohan kin eciyatanhan;

15 Tuka wowaśtedake en iewicaunkapi kta, hecen tuwe wicapa kin ee, Messiya hee en taku owasin on unkicagapi kta.

16 Iye eciyatanhan tancan kin ocowasin wayupiya iciyakaśkapi, qa okihe kin owasin wawokiyapi on icicazontapi, huha kin Dak. otoiyohi iyacinyan icage ein he iyecen tancan kin icąhyapi, wowaśtedake en icage kte cin heon.

17 Heon kaken epe ça Itancan kin on mdaotanin; Ilicewicaśta tokeca wicotawacin witkotkopi kin en manipi kin he iyecen mayanipi kte śni.

18 Hena wicotawacin aotpasyapi, qa Wakantanka wiconi tawa kin itehanyan unpi, wosdonye śni iye tanmahen un kin eciyatanhan, wicocante tehika yuhapi kin heon;

19 Hena iyasaka icah ayapi, qa wicaśtapi śni kin en iyohipeiçiyapi, taku aśapapi kin owasin wohitiya econpi kte cin heon.

20 Tuka niyepi e qe hecen Messiya kin onspeniciciyapi śni: 21 He nayahonpi, qa he onspeniciyapi hecinhan, Jesus en wowicake kin iyececa.

22 Wicohan tokaheya kin en, wicaśta tannike cin, wohnaye wocantiheye kin on hwin kin hee yahduśdokapi kta ;

23 Qa nitawacinpi woksape kin en niyutecapi kta;

24 Qa wicaśta teca woowotanna, qa.wowicake wakan kin en, Wakantanka eciyatanhan icahyapi kin he kodakapi kta.

25 Heon etanhan, itonpi śni kin ayaśtanpi, qa otoiyohi wicaśta tokeca kici wowicake ece ohdaka po; otoiyohi huha yeciciyapi kin heon.

26 Sinyahdapi eśta, wahtanipi śni po. Canniniyanpi ecen wi iyaye śni nunwe.

27 Qa Wakanśicá kiyukanpi śni po:

28 Tuwe wamanon kin he ake manon kte śni, tuka htani kta, nape on taku waśte econ kta, hecen wahpanica kin he taku wicaqu kte cin yuhe kta. 305 


\section{EPHESOS.}

29 Wicoie śice cin owasin takudan niipi kin etanhan hinanpe śni nunwe, tuka taku waśte, on icah yapi kta, tona nahompi kinhan wowaonśida wicaqu kte cin he ecedan.

30 Qa Wakantanka 'Taniya Wakan kin iyokiśinyapi śni po; he on wopekitonpi anpetu kin aiyahdeya askam niyanpi.

31 Wicokige owasin, qa wocantiyahde, qa wośihda, qa iwaśicunpi, qa waaiapi canniyekiciyapi ko owasin ehpeyayapi nunwe.

32 Qa otoiyohi okiciciyapi, qa cantekiciyapi, qa otoiyohi kicicajuju po, Wakantanka Messiya on nicicajujupi kin he iyecen.

\section{WICOWOYAKE 5.}

1 Heon hokśiyopa cantekiyapi kin iyecen Wakantanka opa po.

2 Qa wacantkiyapi kin en mani po; Messiya canteunkiyapi, qa unkiyepi on Wakantanka en içicu, qa waihduśna, woomna iyokipi kin he iyececa.

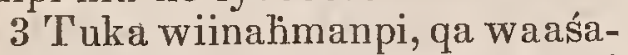
papi, qa waicucupilk te cin, niyepi ekta caje yatapi śni nunwe, tuka tona owotanna un taku iyokipi wicaye cin hena.

4 Qa wawiśtenyapi, qa wicoie ecinśniyan kin, qa iapi śica hena hecetu śni ; tuka wopida eyapi kin le waśte.

5 He de sdonyayapi, tuwe wawiciliahapi econ, qa tuwe waaśape cin, qa tuwe waicucukte cin, he wakagapi cekiya ece, hena wanjidan eśta Messiya qa Wakantanka kici tokiconze kin en takudan tawapi kte śni.

6 Iapi ecinśniyan on ihnuhan tuwe nihnayanpi kin; wicohan kin hena on Wakantanka tocan- niye kin woakta śni cincapi kin en awicau kta.

7 Heon etanhan hena en opeya unpi śni po.

8 Ehanna otpaze cin henicapi, tuka wanna Itancan kin en iyoyanpa kin henicapi; iyoyanpa cinca kin iyecen mani po:

9 Woniya tawaskuyeca kin he wowaśte owasin, qa wicoowotanna, qa wowicake kin en un:

10 Qa Itancan kin taku iyokipiye kte cin he akita po.

11 Qa otpaza wicohan, on taku waśte icage śni kin hena en okicipapi śni po, tuka hena iyopeya po.

12 Hena taku nabmana econpi kin caje yatapi kin he wowiśtece.

13 Tuka taku tona iyopeyapi kin hena owasin iyoyanpa kin yuotanin; qa taku owasin yuotanin kin he iyoyanpa kin ee.

14 Heon etanhan kaken eya; Tuwe iśtinbe cin kikta, qa wiconte etanhan najin wo, Messiya iyoyamniye kta ce.

15 Hecen on wakta po, itonpeya mayanipi kta, witkotkoke cin iyecece śni, tuka wicaśta wacin ksape cin iyececa.

16 Qa omaka kin tanyan hduha po, anpetu kin śice cin heon etanhan.

17 Heon etanhan wacin ksapa po, qa Itancan token tawacin kin sdonya po.

18 Qa miniśa on witkopi śni po, he on iyatahdepi ece; tuka Woniya kin on ojudan un po.

19 Qa Psalm, qa odowan, qa wakan dowanpi kin on wahokonkiciciya po ; ahiyayapi qa nicantepi kin ekta Itancan kin idowan po.

$20 \mathrm{Qa}$ ohinniyan, taku owasin on, Wakantanka Ateyapi kin wopida eciya po, Jesus Messiya Itancan unkiyapi caje kin on: 
21 Qa Wakantanka kokipeyahan otoiyohi tokan ihulkun iyeiciya po.

22 Winohinca, nihihnapi kin wicihukun iyeiçiya po ; Itancan kin en iyececa.

23 Wicaśta kin he iye tawicu pa kin hee, Messiya okodakiciye pa kin hee he iyececa; qa he iye wicatancan kin wanikiye cin hee.

24 Heon okodakiciye kin Messiya ihukuya yanke cin he iyecen winohinca kin iye hihnakupi kin taku owasin on ihukun unpi kta.

25 Wicaśta, winohinca nitawapi kin cantewicakiya po, Messiya okodakiciye kin waśte kidake ça, on iye ic̣içu kin he iyecen ;

26 Hecen iye oie kin eciyatanhan, mini on hduecedan, qa hduska kta;

27 Qa hecen iye ekta ehdaku kta, wowitan okodakiciye kin heca, woaśape qa yuśkipi, qa taku hececa wanica; hecen wakan, qa waaśape śni un kta.

28 He iyecen, wicaśta kin iye tancanpi kin iyecen tawicupi kin waśte wicakidakapi kta; tuwe tawicu kin waśte kidake cinhan he waśte icidaka.

$29 \mathrm{Qa}$ tohinni tuwedan iye cehpi kin śice kidake śni, tuka icahikiye cea, tanyan hduha, Messiya okodakiciye hduhe cin iyececa.

$30 \mathrm{He}$ tancan, qa cehpi, qa huhu kin en, huha kin he unkiyepi.

31 Heon etanhan wicaśta kin, atkuku, hunku ko elipewicakiye ca, tawicu kin en iyaihdaśke kta, qa heniyos wicacelipi wanjidan kta.

$32 \mathrm{He}$ wowiyukcan wan tanka, tuka Messiya qa okodakiciye kin hena wicawaka.
33 Heon niś niyepi otoiyohi niye inihdacin nitawin waśte yakidake kta, qa winohinca kin iś iye hihnaku kin kinihan kte.

\section{WICOWOYAKE 6 .}

1 Hokśiyoqopa, nihunkakepi kin anawicakigoptan po, Itancan kin en, he owotanna.

2 Niyate nihun kici wicahduonihan wo; woahope on taku wahoyapi tokaheya kin hee;

3 Hecen tanyan yaun, qa maka akan tehan yani kta.

4 Qa ateniyanpi kin, nicincapi kin wacinko wicakiyapi śni po, tuka Itancan waicaliye ca woonspe tawa kin en icahwicakiya po.

5 Qa wowidake yaunpi kin, tona wicacelipi ekta niyuhapi kin wokokipeya cancaniçiya anawicakigoptan po, Messiya kin iyececa, nicantepi okonwanjidan on:

6 Wanniyakapi ecedan śni, wicaśta iyokipiwicayapi kin iyececa; tuka Messiya taokiye kin iyececa, nagi kin eciyatanhan, Wakantanka tawacin kin ecen ecanonpi lita.

7 Iyokipiya wawokiya po, Itancan kin ekta hecetu, qa wicaśta kin en iyecece śni.

8 Qa tuwe taku waśte econ kinhan, he on Itancan kin eciyatanhan wayuhe kta, wowidake un, qa iś tawaiçiya un kin, unma tukte kaśta, he sdonyayapi.

9 Qa tona itancan yaunpi kin, niś eya he iyecen ecawicayeconpi kta, qa wakokipe wicayecagapi kte śni. Mahpiya kin ekta iś iyepi qa niś niyepi nakun Itancan yakiyapi kin yanke ca, he ekta wicaśta itohnake yuonihanpi wanica, he sdonyayapi. 10 Unkan ehake mihunkawanji, 307 


\section{PHILIPPI.}

Itancan kin en waśagya un po, iye towaśake wicookihi kin on.

11 Wakantanka tawipe kin ocowasin un po, hecen Wakansica wohnaye ohanye cin itkokim inajin oyakihipi kta.

12 Wicawe, qa wicacehpi kin kici unkicizapi śni, tuka wokiconze, qa wicowaśake, qa wiconi kin de en otpaza itancanpi kin, qa taku wakan śicapi wankantuya yukanpi kin hena om.

13 Heon etanhan Wakantanka tawipe kin ocowasin icu po, hecen anpetu śice cin en najin oyakihipi kta, qa taku owasin hduśtan nayajinpi kta.

14 Heon wowicake ipiyag kitonpi ecen najin po, qa wicoowotanna maza maku akahpe kin koyaka po.

15 Qa nisihapi kin en wookiye wotanin waśte ohduśtan kin okihan po.

16 Qa owasin akapa tanhan wowacinye wahacanka kin icu po, he on wicaśta śica tunwan- hinkpe ide kin owasin y usni oyakihipi kta.

17 Qa wiconi maza wapaha kin he icu po, qa nakun Woniya tamazasagye kin, Wakantanka oie kin hee :

18 Wocekiye qa wokidapi owa- sin on Woniya kin en, ohinniyan tona owotanna un kin on cekiya po, qa heon woape owasin wokidapi ko yuha kiktahan un po: 19 Qa nakun miye on, iapi owakihi kte cin heon, hecen waditagya i wahdukawa, qa wotanin waśte wowiyukcan kin omdake kta. 20 Heon wahośiya un wan kaśka hnakapi kin hemaca, hecen on token iwae kte cin he iyecen waditagya iwae kta.

21 Tuka taku mitawa kin, token waun kin he nakun, sdonyayapi kta e heon Tucikos hunkawanjin kiciyapi wan waśte dakapi, qa Itancan kin en ookiye owotanna kin he taku kin owasin oniciyakapi kta:

22 Heon etanhan niyepi ekta ye waśi, unkiyepi ekta taku kin sdonyayapi kta, qa he nicantepi kin wacintonhnag niyanpi kte cin heon.

23 Hunkawanjin kiciyapi kin en wookiye un nunwe, qa wowaśte, wowacinye ko, Wakantanka Ateyapi, qa Jesus Messiya Itancan kin eciyatanhan.

24 Tona awicakehan Jesus Messiya Itancan unkiyapi waśte dakapi kin hena owasin en, wowaonśida wicakici un nunwe. Amen.

\section{PAL O S

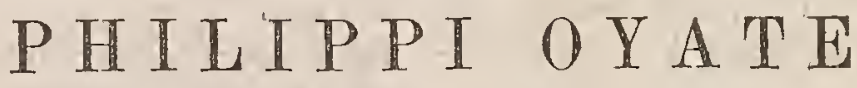

WOWAPI WICAKICAGE CIN.

WICOWOYAKE 1.

1 Palos qa Timotheos, Jesus Messiya taokiyewicaye cin, tona Philippi ekta Jesus Messiya en owotanna un kin hena, qa waawanhdake cin hena ookiye unpi ko, wowapi unnicagapi:

2 Wakantanka Ateunyanpi, qa Jesus Messiya Itancan unki308 


\section{WICOWOYAKE 1.}

yapi kin etanhan, wowaonśida, wookiye ko niyepi kin en nicipi un nunwe.

3 Ciksuyapi eca, Wakantanka mitawa wopida ewakiya ece.

4. Ohimniyan mitawocekiye otoiyohi en, niyepi owasin on iyuśkinyan cewakiya ece :

5 Anpetu tokaheya kin ehantanhan, qa dehanyan, wotanin waśte kin en kodayeciyapi kin heon.

6 Unkan he sdonwaya; tuwe tokaheya ohan waśte nicicagapi kin he niciyuśtanpi kta, Jesus Messiya anpetu tawa kin hehanyan.

7 Hecen niyepi owasin wacin en ciyuzapi kte cin he hecetu, cante en mayaduzapi kin heon; makaśkapi kin, qa wotanin waśte omdake ca mdasuta kin he en, qa nakun wowaśte mitawa kin en niyepi owasin oyapapi ece.

8 Wakantanka sdonmayan, Jesus Messiya cante kin on owasin cantocikpanipi.

9 Qa he de icewakiya, waśte yadakapi kin he wosdonye wiyukcanpi ko owasin en, sanpa qa sanpa tankaya aye kta:

10 Kinhan, taku waśte kin hena idukcanpi kta, hecen okonwanjidan hicahe ș́ni yaunpi kta, Messiya anpetu tawa kin en ;

11 Qa wicoowotanna waskuyeca kin on ojudan yaunpi nunwe, hena Jesus Messiya on Wakantanka woyatan qa wowitan tawa kin ee.

12_Mihunkawanji, taku token ecamiconpi kin he on wotanin waśte kin sanpa otanin aye cin he sdonyayapi kta wacin.

13 Hecen wicaśtayatapi tahocoka kin ekta, qa owancaya Messiya on makaśkapi kin he otanin.
14 Qa Itancan kin en, hunkawanjin kiciyapi kin ota, miye makaśkapi kin on, sanpa nina waditakapi, qa kokipeśniyan wicoie kin taninyan oyakapi ece.

15 Hunh waakinicapi qa winawizipi kin on, qa hunh iś waśtedakapi kin on Messiya oyakapi ece.

16 Hena e waakinicapi kin on, wowicake eciyatanhan śni Messiya kin oyakapi, qa makaśkapi kin en wokakije kokijuya aupi lita kecinpi ;

$17 \mathrm{Qa}$ unmapi kin iś waśtekidapi kin on etanhan, wotanin waśte mdusuta kta e on emahdepi kin sdonyapi.

18 Ecin to : toketu kaśta, wohnaye on etanhan, qa iś awicakehan, unma tukte kakeś, oyakapi kin he on imduśkin, qa eeś nakun imduśkin kta.

19 Nitawocekiyepi, qa Jesus Meșsiya Taniya wawokiye cin on, he wiconi emicicetu kta sdonwaya.

20 Qa nina awacanmi qa ape manka, hecen takudan on imaśtece kte śni, tuka ohinniyan waditagya waun kin he iyecen nakaha mitancan kin on Messiya yuonihanpi kte, wani qa mate kte cin unma tukte kaśta on etanhan.

21 Wani kin he Messiya ee, qa mate cinhan sanpa tanyan waun kita.

22 Wicacehpi kin en opeya wani kinhan, miohan waskuyeca kin hee, tuka unma tukte wacin nun tanin śni.

23 Taku nom aotins mayanpi; ekta mde ça Messiya kici waun kte hinca, he iyotan waśte.

24 Tuka wicacehpi kin en opeya waun kin he niyepi on wawokiyapi kin hee.

25 Hecen wahdukcan, qa heon 309 


\section{PHILIPPI.}

wani, qa niyepi owasin om waun kta sdonwakiya, sanpa inicagapi qa wacinyan iduśkinpi kte cin heorl.

$26 \mathrm{Qa}$ hecen akeś ekta ciupi kinhan miye on, Jesus Messiya en sanpa nina iduśkinpi kta.

27 Tuka Messiya tawootanin waśte kin eciyatanhan yanipi nunwe; hecen wanciyakapi wau kinhan, qa iś wau śni, unma tukte kaśta, niohanpi kin nawahon kta, wicotawacin wanjidan en sutaya yaunpi, qa wicanagi wanjidan yuha wotanin waśte kin wacinyan oyecipapi kin.

$28 \mathrm{Qa}$ tona toka niyanpi kin hena on, ihnuhan taku ininihanpi kin: hee hena en wicotakuni śni au kta yuotanin, tuka heon niyepi kin en wiconi Wakantanka etanhan au lita otanin.

29 Messiya lie ayuco niçupi, iye wacinyayapi kte ça, nakun iye on kakiśniyanpi kte cin.

30 Qa makakije cin wanmayadakapi qon, qa nakaha en mau nayahonpi kin, he iyecen wokakije duhapi kta.

\section{WICOWOYAKE 2.}

1 Heon Messiya on iwicakiyapi yuke cinhan, qa wowaśtedake en imagagaiciyapi, qa Woniya kin en kodaliciciyapi yuke cinhan, qa wacantkiyapi wowaonśida ko yuke cinhan,

2 Mitowiyuśkin kin miciyuśtan po, akiyecen awacannipi, qa wowaśte okonwanjidan duhapi, qa wicotawacin wanjidan yaunpi kta.

3 Waakinicapi qa ihdatanpi kin on takudan ecanonpi kte śni, tuka wahbayedan yaunpi, qa otoiyohi niye isanpa tokan waśte yecidakapi kta.

4 Otoiyohi wicitawa kin ece- dan elsta etonwanpi śni po, tuka nakun otoiyohi tokan tawa kin ekta.

5 Jesus Messiya token tawacin qon he iyecen wacin duzapi lita. $6 \mathrm{He}$ Wakantanka ouncage kin en un, qa Wakantanka kici akidecen yanka keiciye cin he wawicakipi śni kecin.

7 Tuka ihduśdoke ca wowidake un kin ouncage kin icu, qa wicaśta kin iyecen ihdus icaga; $8 \mathrm{Qa}$ wicaśta ouncage kin en un qehan, ihduhukuya qa wiconțe ekta aiyahdeya wanahon yanka, can susbeca en te cin he ehan.

9 Heon etanhan Wakantanka he tehan wankantuya hduwankan icu, qa caje wan wicacaje owasin isanpa waśte kin he qu ; 10 Hecen Jesus caje kin on, hupahu kin owasin canpeśka makehde enajin kta, malipiya ekta un, qa maka akan un, qa maka kin ihukuya un kin henakiya.

$11 \mathrm{Qa}$ Wakantanka Ateyapi kin yatanpi kte cin on, Jesus Messiya he Itancan kin ee ce; wicaceji owasin eya oyakapi kta.

12 Heon waśte cicidapi kin, ohinniyan nayahonpi kin he iyecen, en cicipi waun kin hecedan śni, tuka nakaha en waun śni eśta, sanpa wokokipeya cancaniçiya yanipi kte cin hduśtan po.

13 Tuwe cinniciyapi, qa econniciyapi kin he Wakantanka ee, iye toiyokipi kin eciyatanhan niyepi kin en ohanyan.

14 Wihnupi qa waakinicapi wanin taku owasin econ po.

15 Hecen iyaonpepica śni, qa owotanna, wicoicage wan pemni, qa yukśankśanyan un kin ehna Wakantanka cinca ecedan 


\section{WICOWOYAKE 3.}

yaunpi kta; hena en maka petijanjan iyecen iyoyanpa yaunpi ;

16 Qa wiconi wicoie kin pazo yaunpi: Hecen Messiya anpetu tawa kin en taku on imawinkta kin he dee, taku śni on waimnanke śni, qa taku śni on hitawani śni kin hee.

17 Unkan wacinyayapi wośnapi wawokiyapi kin en, amihdapson eśta nakun imaduśkin, qa niyepi owasin om imduśkin kta.

18 Heon niś niyepi nakun iduśkinpi qa miyeci iniwinktapi ece.

19 Tuka niyepi kin ekta 'Timotheos kohanna yewaśi kta wacảnmi, Jesus Messiya Itancan kin on, hecen tohan token yaunpi kin sdonwaye cinhan, hehan miś nakun iyokipi waun kta.

20 Tuwe iyecen wacin yuze ca iye cinka taku nitawapi kin ihakta kte cin mduhe śni.

21 Owasin wicitawa kin akitapi, qa taku Jesus Messiya tawa kin akitapi śni.

22 Tuka he iyutapi kin sdonyayapi, hokśidan wan atkuku kici un kin he iyecen wotanin waśte kin en micica.

23 Iye kohanna ye waśi kta, tohan token waun kte cin sdonwakiya.

24 Qa miś eya ecadan wau kta e Itancan kin wacinwaya.

25 Tuka Epaphroditos misunka qa mitawaśi, qa kici akicita waun, tuwe u yaśipi, qa tuwe taku imakakije cin omakiye cin, lie niyepi ekta hde waśi kta iyececa epca.

26 He niyepi owasin cantonikpanipi, qa iyokiśica un, wayazanke cin nayakilionpi kin heon.

27 He qeś wayazanke ça wan- na te kta ikiyedan, tuka Wakantanka onśikida, qa he iśnana śni, tuka miye nakun, hecén woiyokiśice icitakihna mduhe kte śni e heon.

$28 \mathrm{Qa}$ heon itonpeyahan hde waśi, ake wandakapi kinhan iduśkinpi kta, qa miś aopten iyokiśica amaye kta.

$29 \mathrm{He}$ Itancan kin on etanhan wopida owasin yulıa tin u śi po, qa tona hececapi kin wicayuonihan po.

$30 \mathrm{He}$ Messiya wicolitani tawa kin on wanna aśkadan te kta tuka, wiconi tawa kin itonkipe śni, miye en wawokiyapi aokpaniyan ecanonpi kin he niciyuśtanpi kte cin heon etanhan.

\section{WICOWOYAKE 3.}

1 Ehake mihunkawanji, Itancan kin en iyuśkin po. 'Taku kin dena on wowapi cicagapi kin he miye telike wadake śni, qa niyepi kin on waśte.

2 Sunka kin on waktaya un po; tona śicaya econpi kin on wakta po; wayuśpapi kin on waktaya un po.

3 'Tona bakihdayapi, qa wicocante on Wakantanka ohodapi, qa Jesus Messiya en iwinktapi, qa wicacelipi wacinyanpi śni kin heuncapi.

4. Miś nakun, taku on wicacèhipi kin wacinwaye kte cin mduha tuka. 'Tuwe wicacehpi wacinyan okihi kecin kinhan he isanpa owakihi.

5 Anpetu iśahdogan hehan bamakilidayapi, Israel oyate qa Benjamin tawicoun kin hematanhan, Hebrew etanhan Hebrew kin, qa woope kin eciyatanhan Pharisee kin hemaca.

6 Ohodapi kin ecivatanhan okodakiciye kin śicaya wakuwa, 


\section{PHILIPPI.}

qa woope woowotanna kin he eciyatanhan takudan iyaonpepica śni waun.

7 Tuka taku tona mihdamna qon hena Messiya on takuśni wadake :

8 Han, awicakehan taku owasin taku śni wadake, Jesus Messiya Itancan mitawa kin wosdonye oiyokipi kin on, iye on taku owasin toki elipewaya, qa hena tacesdi ece mdawa, Messiya iyowahi kte cin heon;

$9 \mathrm{Qa}$ he en waun kta, mitoowotanna wicoope kin eciyatanhan un kin he wahduhe śni, tuka taku Messiya wacinyanpi eciyatanhan un kin, Wakantanka toowotanna wacinyanpi kin on icage cin hee wacin.

10 Hecen he iye sdonwaye kta, qa piya ikicage cin wowaśake kin, qa iye kakije cin okicipapi kin hena ko, iye te cin ouncage kin en imacage kta :

11 Hecinhan, wiconte etanhan woekicetu kin en iyowahi kte hinca.

12 Wanna dehan iyowahi, qa wanna mayuśtanpi kin ee śni ; tuka kuwa amde, okinni taku on Jesus Messiya mayuze cin hee mduze kta.

13 Mihunkawanji, nahanliin mduze mihdawa śni ;

14. Tuka taku wanji ecamon, taku hekta un kin hena akiktonś waun, qa taku tokata un kin hena ekta nape yewakiya ece ; hecen oinajinta awaimnanka, Jesus Messiya on Wakantanka wankantuya wicakico kin en oqipe kin yewakiye kte cin heon etan. han.

15 Heon tona unyuśtanpi kin -hecen awauncinpi kta, qa taku on togye wacin duzapi hecinhan, he nakun Wakantanka oniciyakapi kta.
16 Tuka tohan iyounhipi kin he en woope wanjidan eciyatanhan maunnipi, qa okonwanjidan awauncinpi kte.

17 Hunkawanjin ciyapi kin, omicipa po, qa tona hecen manipi kin hena iwanwicayaka po, waonspekiya unyaduhapi kin he iyececa.

18 Wanna ota ociciyakapi, qa nakaha ake ceya omdake, wicaśta ota Messiya can susbeca tawa kin tokaye cin iyecen manipi ece.

19 Hena owihanke kin he wicotakuniśni ; iye tezipi kin Wakantanka yapi, wowiśtece kin en iwinktapi, qa taku makata un kin awacinpi ece.

20 Tuka okodakiciye unkitawapi kin he malipiya kin ekta un, qa hetanhan Wanikiya Jesus Messiya Itancan kin hi kta unkapepi.

21 Iye untancanpi hanye cin he yutokeca kta; qa iye tancan wakan kin ouncage kin en icahye kta, towaśake on taku owasin ohiye kta okihi kin heon etanhan.

\section{WICOWOYAKE 4.}

1 Heon etanhan mihunkawanji waśte cicidapi, qa cantocikpanipi kin, wowiyuśkin mitawa qa wateśdake mitawa kin, Itancan kin en sutaya najin po, waśte cicidapi.

2 Yuodiyas cewakiye ca, Suntuce cewakiya, Itancan kin en okonwanjidan awacinpi kta.

3 Qa mitawaśi wicake cin ceciciya ce, winohinca tona wotanin waśte kin en mici ohanye cin hena owicakiya wo, qa Klement, qa mitawaśi unmapi, cajepi kin wiconi wowapi kin en un kin hena koya.

4 Ohinniyan Itancan kin en 


\section{WICOWOYAKE 4.}

iyuślkin po; qa ake, Iyuśkin po, epe.

5 Niwahbapidan kin he wicaśta owasin sdonyapi kta. Itancan kin kiyadan un.

6 Takudan iyokiśinya awacinpi śni po, tuka taku yacinpi kin owasin on, wocekiye, wokidapi qa wopida eyapi ko on Wakantanka oyakidakapi kta.

$7 \mathrm{Qa}$ Wakantanka tawookiye okahnihpica śni kiı he nicantepi qa nitawacinpi kin Jesus Messiya en niyuhapi kte.

8 Unkan ehake mihunkawanji, taku wicakapi kin, taku yuonihanpi kin, taku owotanna kin, taku wakan kin, taku waśte dapica kin, taku waśte eyapi kin, wowaśte qa wowitan yuke cinhan, hena awacin po.

- 9 Taku tona ornispepi, qa iyacupi, qa nayahonpi, qa miye en wandakapi kin hena econ po, qa Wookiye Wakantanka kin niyepi kin en nicipi un nunwe.

10 Itancan kin en nina imduśkin, nakaha unhanketa awamayacinpi kin he piya lica aya heon. He de en ihamayaktapi, tuka token on ecamiyeconpi nun tanin śni.

11 Taku imakakije cin he wake śni; taku en micihe cin hena on iyokipiya waun kta e onspemiciciya.

12 Token wahpaniya waun kte cin he sdonwakiya, qa token wijinya waun kte cin he nakun sdonwakiya : ohinniyan qa taku owasin on, wimapi, qa wotektewahda kta, wimajica qa mawahpanica kte cin onspemakiyapi.

13 Messiya waśagmaye cin he eciyatanhan taku owasin owakihi.

14 Tuka makakije cin en omayakiyapi kin he tanyan ecanonpi.

15 Philippi wicaśta, he de sdonya po, wotanin waśte otokahe ekta, Makedonia etanhan imdamde cehan, waqupi qa icupi kin. icahtagya okodaliciye kin niye niśnana omayakiyapi.

16 Thessalonike elkta waun qon he icunhan, taku imakakije cin on wancadan qa nonpa taku mayakaipi.

17 Taku maqupi kta wacin kin hee śni, tuka waskuyeca niyepi on sanpa niciyuotapi kte cin he wacin.

18 Tuka owasin mduhe ca wijica waun; niyepi etanhan taku Epaphroditos maqu kin hena iwacu, taku waśtemna wośna waśte, qa Wakantanka iyokipi kin heca he iwamaśeca.

19 Taku inicakijapi kin owasin Wakantanka mitawa niçupi kta, iye woyuha wowitan kin en un kin hetanhan, Jesus Messiya eciyatanhan.

20 Wakantanka Ate unyanpi kin wowitan owihanke wanim kicihan nunwe. Amen.

21 Tona Messiya en owotanna un kin hena nape wicayuza po. Hunkawanjin kiciyapi om waun kin hena nape niyuzapi.

22 'Tona owotanna un kin hena owasin nape niyuzapi, Kesar tiyohnaka kin hena iyotan.

23 Jesus Messiya Itancan unkiyapi towaonśida kin niyepi owasin en nicipi un nunwe. Amen. 


\section{PALOS \\ K OL O S S E O Y A T E}

WOWAPI WICAKICAGE CIN.

\section{WICOWOYAKE 1.}

1 Palos, Wakantanka tawacin kin eciyatanhan, Jesus Messiya yeśi qon he, qa Timotheos hunkawanjin unyanpi kin kici,

2 Kolosse ekta tona owotanna un, qa hunkawanjin kiciyapi Messiya wacinyanpi kin hena, vowapi cicagapi. Wowaonśida wookiye ko, Wakantanka Ate unyanpi, qa Jèsus Messiya Itancan kin etanhan, niyepi kin en nicipi un nunwe.

3 Ohinniyan wocekiye unkeniciyapi, qa on Wakantanka Jesus Messiya Itancan unkiyapi Atkuku kin wopida unkekiciyapi.

4 Jesus Messiya wacinyayapi, qa tona owotanna un kin owasin waśte wicayadakapi kin he naunhonpi ;

5 Woape mahpiya kin ekta enicihnakapi kin on, he ehanna wotanin waśte wicoie wicakapi kin en nayahonpi kin;

6 He en nihipi, maka kin owancaya iyaye cin he iyececa, qa waskuyeca aicaga, niyepi kin en nakun, anpetu kin en nayahonpi, qa awicakehan Wakantanka towaonśida iyacupi qon ehantanhan.

7 Epaphras unkitawaśipi waśte, qa niyepi on Messiya taokiye wicake cin he hena hecen onspeniciyapi ;

$8 \mathrm{Qa}$ Woniya kin en wacanyakiyapi kin he nakun unkokiyakapi.
9 Heon anpetu kin he naunhonpi kin ehantanhan niyepi on cekiya unkayaśtanpi śni, qa woksape owasin, wookahnige ko en, iye tawacin sdonyapi kin on, onijupidan kte cin he unkidapi ece.

10 Hecen taku iyokipi kin owasin on, Itancan kin en tanyan mayanipi kta, wicohan waśte owasin en, waskuyeca icahyayapi, qa Wakantanka sdonyapi kin en sanpa inicagapi kta. 11 Iye towitan wowaśake kin eciyatanhan, wicookihi kin owasin on waśagniyanpi kta, wadiwicatake cin owasin on etanhan, qa wacin tankapi, wiyuśkinpi kici :

$12 \mathrm{Qa}$ Ateyapi kin wopida eyakiyapi kta, he iyoyanpa ekta tona owotanna un kin woaihpeye tawapi kte cin en ounpapi kta e iyehantu unyanpi :

13 He otpaza wowaśake kin etanhan unkiyuśpapi, qa iye Cinhintku waśte kidake cin tokiconze kin en ounye unkiyapi :

14 He en, iye we kin eciyatanhan, wopekitonpi unhapi, woahtani kajujupi kin hee:

15 Wakantanka wanyagpica śni un kin ouncage kin hee, qa taku kagapi kin owasin en tokapa kin hee:

16 Iye eciyatanhan taku owasin kagapi, mahpiya ekta un qa maka akan un kin hena, taku wanyakapi qa taku wanyagpica śni, oiyotanke kïn, wokiconze 


\section{WICOWOYAKE 2.}

kin, wicośkanśkan kin, qa wicowaśake kin ; taku owasin iye on icahyapi kin hena iye içicaga:

17 Qa taku owasin itokatam un kin he iye, qa he on taku owasin ecen han:

$18 \mathrm{Qa}$ iye tancan kin okodakiciye kin hee, qa pa kin he iye, qa otokahe kin, wiconte etanhan tokaheya tonpi kin hee, hecen iye taku owasin en tokapa un kta.

19 Iye ohna taku ocowasin ounye kte cin he Atkuku kin iyokipi.

20 Qa iye can susbeca tve kin eciyatanhan wookiye kage ca, heon etanhan taku owasin iye kici okiciciye wicaye kta, taku maka akan un, qa taku mahpiya ekta un kin hena, iye on.

21 Qa niś niyepi, ehanna oyate nitokecapi, qa nitawacinpi kin en toka kin henicapi, wicolian śice cin on, tuka nakaha he kici wokiyeniyan nicagapi ;

22 Iye cehpi tancan kin en țe cin eciyatanhan, hecen iye itokam owotanna, qa waaśapapi śni qa takudan iyaonpepica śni, inajin niyanpi kta :

23 Wacinyayapi kin en nayajinpi kinhan, sutaya yaunpi, qa ținsa nayajinpi, qa wotanin waśte woape nayahonpi kin etanhan nihinlipayapi śni kinhan; he mahpiya kin ihukuya wicaśta hiyeye cin owasin owicakiyakapi, qa he en Palos he miye ookiye makagapi :

24 Nakaha niyepi kin ôn etanhan makakije cin heon imduśkin, qa Messiya wokakije tawa, taku micehpi kin en yuśtanpi śni kin hena iye tancan kin, okodakiciye kin hee, on weciyuśtan kta.

$25 \mathrm{He}$ en ookiye makagapi, Wakantanka wokonze kin eci- yatanhan, he niyepi on maqupi, Wakantanka oie kin mduecetu kte cin heon.

26 Taku oyakapi śni kin, wicoicage qa wicoun ota kin ehantanhan analimanpi kin, he nakaha tona owotanna iye tawa wicaye cin hena owicakiyaka.

27 Ikcewicaśta kin ekta taku otanin śni kin de wowitan woyuha kin tinskokeca kin, he Wakantanka hena sdonye wicakiye kta, he niyepi kin en Messiya wowitan woape kin hee.

$28 \mathrm{He}$ unkiye unyaotaninpi, wicaśta kin owasin wahokonwicunkiyapi qa wicaśta owasin onspewicunkiyapi ecc, woksape owasin on ; hecen Jcsus Messiya en wicaśta otoiyohi owotanna inajin wicunkiyapi kta.

29 Heon miś eya hitawani, iye ohan kin miye en waśagya ohanye $\operatorname{cin}$ he eciyatanhan inawahini.

\section{WICOW OYAKE 2 .}

1 Niyepi kin on, qa Laodikia ekta un kin hena, qa tona wicacehpi on miite kin wanmayakapi śni kin on token hitawani kin he sdonyayapi kta wacin :

2 Hecen iye cantepi kin kicanptapi kta, qa wacantkiyapi kin on kicicazontapi, qa wosdonye tanyan okahnigapi kta wowijice kin owasin on, qa Wakantanka towiyukcan sdonyapi kte cin on, Ateyapi qa Messiya tawa kin hee.

3 Iye en woksape, qa wookahinige woyuha kin owasin nalimanpi.

4. Tuwedan wicoie skuya kin on nihnayanpi kte śni heon hena hepa.

5 Wicacelipi on, ekta waun śni eśta, woksape kin on cicipi waun, imduśkin, niohanpi owo- 


\section{KOLOSSE.}

tanna kin, qa Messiya sutaya wacinyayapi kin he wanyag waun.

6 Token Jesus Messiya Itancan kin iyacupi qon he iyecen ohna mani po.

7 Iye en sutaya hu nihdepi, qa en tinicagapi, qa wowacinye kin ținsa ayahanpi kta, onspeniciyapi qon he iyececa, qa en wopida eyapi kin sanpa ota ecanonpi kta.

8 Ihnuhan wicoksape eyapi kin on, qa ikce wohnaye kin on tuwe nihnayanpi kinhan, wicaśta hitunkakanpi oyakapi kin on, qa wicoicage en woonspe tokaheya eciyatanhan, qa Messiya eciyatanhan śni :

9 Iye kin ohna tancanyan Taku Wakan kin ocowasin ounyan.

10 Qa iye en niś niyepi kin yuecetu yaunpi, qa he wokiconze wowaśake ko owasin Itancan kin hee.

11 Qa he en banicihdayapi, bakilidayapi nape codan econpi kin he on, Messiya bakihidayapi tawa kin eciyatanhan, wicacelipi woahtani tancan kin ehpekiyapi kte cin heon.

12 Baptem on iye kici nihnakapi, qa nakun kici ekicetu niyanpi, Wakantanka wicate cin etanhan najin kiye cin he wowaśake kin wicayadapi kin heon etanhan.

13 Qa niyepi ehanna wayahtanipi, qa nicelipi banicilidayapi śni kin en nițapi qón, wanna wayahtanipi kin owasin nicicajujupi qa niniyanpi.

14 Qa wicoope kin taku nape on owapi qon, unkiyuśepi qa kaśeunyanpi kin he pajuju, qa can susbeca tawa kin en okatan, qa hecen yutokan iyeya.

15 Qa wokiconze, wicowaśake 316 ko yutakuni śni iyeye çehan, taninyan wicakipazo, qa iye hinca on iwakte hdi.

16 Heon etanhan, woyute, qa woyatke, qa omniciye wakan, qa wi teca, qa anpetu okihpapi kin hena on ihnuhan tuwe niyacopi kin :

17 Hena e taku u kte ciqon ohanzi kin hee, tuka tancan kin he Messiya etanhan.

18 Tuwe wahpaniiciye ca, mahpiya ohnihde kin ohowicada kin ihnuhan he nihnayanpi kin; he taku wanyake śni kin en yeiçiye ca, iye celipi tawacin kin on ecinśniyan ihdatan;

19 Qa Pa kin he yuze śni; he on tancan kin ocowasin okihe en iyakaśkapi kin on woyute oiyahdeyapi, qa iciyakaśkapi, qa hecen Wakantanka oicage kin on icaga ece.

20 Heon etanhan, wicoicage kin en woonspe tokaheya kin ekta Messiya kici nițapi hecinhan, tokeca e wicoicage kin en yanipi kin iyecen wicoope kin oyapapi he :

21. Oyutanpi śni, utapi śni, qa nape on yuzapi śni po, eyapi ece : 22 Hena owasin uupi kin on yasotapi ece; wicaśta akantu wicoope qa woonspe kin eciyatanhan.

23 Wicohan kin he wicotawacin ohodapi kin en taku woksape iyecen yuhe ça, wicowahbadan, qa wicatancan itonkipapi śni kin hena en; tuka wicacehpi iyokipiyapi kin he woyuonihan śni ece.

\section{WICOWOYAKE 3.}

1 Heon etanhan, Messiya kici piya inicagapi hecinhan, taku wankantuya Wakantanka etapa kin eciyatanhan, Messiya 


\section{WICOWOYAKE 3.}

kiyotanke cin hen, un kin hena akita po.

2 Taku wankan un kin hena awacin po, qa taku makata un kin hena awacinpi śni po.

3 Nițapi, qa nitowiconi kin he Messiya kici, Wakantanka en nakimanpi.

4 Tohan Messiya wiconi unkitawapi kin taninyan biyu kinhan, hehan wowitan en, kici niyuotaninpi kta.

5 Heon etanhan, nihuhapi makata un kin hena kikte po: wiinalimanpi, waaśapapi, wawihnupi, tawacin śicapi, waicucupikte cin, he wakagapi ohodapi kin hee.

6 Hena on etanhan Wakantanka tocanniye kin woakta śni cincapi kin en awicau ece.

7 Ehanna hena ehna yanipi qehan, opeya mayanipi.

8 Tuka nakaha hena owasin ayuśtan po; wocanniye, wośihda, wocantiyahdepi, waakagapi, qa iapi s̉ice cin niipi kin etanhan.

9 Ihnuhan oìyecitonpi śni kin; wicaśta tannike cin iye wicolian ko yahduśdokapi ;

$10 \mathrm{Qa}$ wicaśta teca kin he wosdonye kin on yutecapi, waicahya ouncage kin eciyatanhan, he kodakapi.

$11 \mathrm{He}$ en, Helenes, qa Juda wicaśta wanica; bakilidayapi qa balkilidayapi śni kin wanica; Ikcewicaśta qa Skuthes wicaśta kin wanica; wowidake un kin heca qa tawaiciyapi kin wanica, tuka Messiya he ocowasin, qa owasin en un.

12 Heon etanhan, owotanna yaunpi qa waśtenidakapi kin, Wakantanka wicakahinige cin iyecen, wocantekiye koyaka po, qa wowaonśida, wahaniçidapi śni, wicowalibadan, qa wacintankapi kin hena ko.
13 Otoiyohi iyowinyeciciyapi, qa otoiyohi yecicajujupi kta, tuwe wicaśta tokeca on taku śibda kinhan, Messiya kin nicicajujupi kin he iyecen niś econ po.

14 Qa taku owasin akantanhan wocantekiye kicun po, he wicoowotanna iyakaśke cin ee.

15 Qa Wakantanka tawookiye kin nicantepi kin en waniconzapi nunwe, he en wicatancan wanjidan en nicopi kin pida un po.

16 Messiya oie kin wijinya en niunpi nunwe; woksape owasin on, Psalm, qa odowan, qa wakan dowanpi kin en, otoiyohi wahokonyeciciyapi, qa onspeyeciciyapi lita, qa nicantepi kin en wowaonśida yuha Itancan kin iyadowanpi kta.

17 Qa taku ecanonpi kinhan, wicoie qa wicohan kin unma tukte kaśta, Jesus Itancan kin caje on owasin econ po, qa on Wakantanka Ateyapi kin wopida eciya po.

18 Qa winohinca kin, nihihnapi kin wicihukuya un po, Itancan kin en hecetu kin he iyececa.

19 Wicaśta kin, nitawinpi kin waśte wicakida po, qa wicakigepi śni po.

20 Śiceca kin, nihunkakepi kin taku owasin anawicakigoptan po, he Itancan kin iyokipi.

21 Qa ateyapi kin, nicincapi kin śihdawicayapi śni po, okinni wacin ibośakapi kte.

22 Wowidake yaunpi kin, tona wicacehpi eciyatanhan niyuhapi kin anawicakigoptan po; wicaśta iyokipiwicayapi kin iyecen, iśtapi kin itokam wawokiyapi kin hee śni, tuka nicantepi ocowasin on Wakantanka kokipa po. $23 \mathrm{Qa}$ taku ecanonpi kin owasin nicantepi kin eciyatanhan econ 317 


\section{KOLOSSE.}

po, Itancan kin on etanhan, qa wicaśta kin on etanhan śni.

24 Itancan kin etanhan woaihpeye iyunwin kin iyacnpi kta he sdonyayapi ; Messiya Itancan kin wowidake niyanpi nakaeś.

25 'Tuka tuwe śicaya econ kinhan, he eciyatanhan icu kta, qa wicaśta itohnake iwanyakapi kin wanica.

\section{WICOWOYAKE 4.}

1 Unkan, itancan yaunpi kin, tona wowidake wicaduhapi kin hena, taku owotanna qa iyecetu kin wicaqu po; mahpiya ekta wanji Itancan yayapi yanke cin he sdonyayapi.

2 Ohinniyan cekiya un po, qa he en wopida eya wakta po.

3 Qa unkiye on wocekiye unkeyeciyapi kta, Wakantanka iapi tiyopa wan unkiciyulidokapi kta, Messiya tawowiyukcan kin unkoyakapi kta, on makaśkapi kin hee :

4 Hecen on, taku token epe kte cin ecen mdaotanin kta.

5 Tona tankan unpi kin hena on ksamyahan mani po, qa anpetu kin opekiton po.

6 Ohinniyan iyaapi kin wowaonśida en un, qa miniskuya on skuyeyapi kta, hecen wicaśta otoiyohi token awicaduptapi kte ein sdonyayapi kta.

7 Tucikos hunkawanjin kiciyapi waśtedakapi, qa waawanhdake owotanna, mici Itancan taokiye kin hee token waun kin owasin oniciyakapi kta.

8 Heon etanhan niyepi kin ekta ye waśi, token yaunpi kin he sdonye ca, nicantepi kin iyuśkin niyanpi kta;

9 Qa he kici Onesimos ye waśi, he hunkawanjin kiciyapi owo318 tanna, qa waśte enitanhanpi kin. Heniyoza taku owasin den un kin oniciyakapi kta.

10 Aristarkos kici makaśkapi kin he nape niyuzapi, qa Markos Barnabas tonśkaku nakun. He iwahoniyanpi, niyepi ekta niipi kinhan ti mahen u śi po:

11 Qa Jesus, he nakun Justus eciyapi kin; hena e bakihdayapi kin etanhanpi. Henana Wakantanka tokiconze kin en tawaśi wicawaye ça, hena iyuśkin mayanpi.

12 Epaphras enitanhanpi kin, Messiya taokiye kin hee nape niyuzapi ; he ohinniyan wocekiye en, niyepi on nina cekiya, Wakantanka tawacin kin owasil en, owotanna, qa ecedan nayajinpi kte cin heon.

13 Qa he omdaka, niyepi on, tona Laodikia ekta un, qa tona Hierapolis ekta un kin, hena koya on nina htaniiciya.

14 Lukas, pejihuta wicaśta waśte kin, Demas kici, nape niyuzapi.

15 Hunkanwanjin kiciyapi Laodikia ekta unpi kin hena nape wicayuza po, qa Numphas, qa iye ti kin ohna okodakiciye kin he nakun.

16 Wowapi kin de niyepi ekta yawapi kinhan, okodakiciye Laodikia ekta un kin hena nakun yawa wicakiya po, qa niś niyepi kin wowapi Laodikia etanhan kin he nakun yawa po.

17 Qa Arcippos kaken eciya po, Nitohtani Itancan kin etanhan iyac1 qon he awaticin wo, yahduśtan kta ce.

18 Palos he miye, nape kiciyuzapi kin de minape kin on wakaga. Makaśkapi kin kiksuya po. Wowaonśida niyepi en nicipi un nunwe. Amen. 


\title{
PAL O S \\ THESSALONIKE OYATE
}

WOWAPI WICAKICAGE CIN;

\author{
TOKAHEYA KIN.
}

WICOWOYAKE 1.

1 Palos, qa Siluanos, qa Timotheos, Thessalonike ekta okodakiciye kin, Wakantanka Ateyapi kin en, qa Jesus Messiya Itancan kin en un kin, wowapi usicakicagapi: Wowaonśida, wookiye ko, Wakantanka A teunyanpi etanhan, qa Jesus Messiya Itancan kin nakun, niyepi en nicipi un nunwe.

2 Niyepi owasin on Wakantanka ohinniyan wopida unkekiciyapi, qa wocekiye unkeyapi kin en caje unniyatapi ece.

$3 \mathrm{Qa}$ wowacinye wicohan nitawapi kin, qa wacantkiyapi en htayanipi kin, qa Walkantanka Ateunyanpi kin itokam, Jesus Messiya Itancan unkiyapi kin en ape dukanpi kin hena ohinniyan unkiksuyapi.

4 Mihunkaw anji waśte, Wakantanka nicahnigapi kin he sdonunyanpi.

5 Wotanin waśte unkitawapi en niipi kin he wicoie ecedan en un śni, tuka wowaśake nakun en, qa Woniya Wakan, qa tanyan sdonyapi kin en; niyepi ehna, qa niyepi on etanhan wicasta tounkecapi kin sdonyayapi.

6 Wicokakije ota ehna, qa Woniya Wakan wowiyuśkin kin yuha wicoie kin iyacupi, hecen Itancan kin oyapapi, qa nakun unkiyepi.
7 Hecen Makedonia qa Akeya en, tona wacinyanpi kin owasin waonspekiye niyuhapi :

8 Qa niyepi kin etanhan Itancan oie kin oyakapi, Makedonia qa Akeya ekta, qa hecedan śni, tuka owancaya Wakantanka wacinyayapi kin he ieyanpahapi, qa hecen taku unkeyapi kta e iyehantu śni.

9 Hena e qe niye nicapi, qa niyepi ekta tukten canku kin ohna unkiyohipayapi kin he oyakapi, qa token wakagapi kin etanhan Wakantanka ekta nihduhomnipi, Wakantanka ni un qa wicake cin ohoyadapi kte cin heon :

10 Qa iye Cinhintku kin mahpiya eciyatanhan u ayapepi kta, he wiconte etanhan najin kiya, Jesus wocanniye u kte cin etanhan eunhdakupi kin hee.

\section{WICOWOYAKE 2.}

1 Mihunkawanji, niyepi ekta token unkipi kin niye e sdonyayapi, ituya unkipi śni.

2 Tuka Philippi ekta kakiśunyanpi, qa unkihahapike cin niye sdonyayapi; qa he iyohakam Wakantanka unkitawapi kin on wadiuntakapi, qa waakinicapi ota ehna wotanin waśte kin unkoniciyakapi.

3 Qa wowahokonkiye unkitawapi kin he wohnuni, qa woaśa319 


\section{THESSALONIKE.}

pe eciyatanhan śni, qa wohnaye en un śni ;

4 Tuka token wotanin waśte kin unhapi kta e Wakantanka iyokipi kin he iyecen unkiapi ece ; wicaśta iyokipirvicayapi kin iyecece śni, tuka Wakantanka cante unkiyukcanpi kin he.

5 Tohinni iskuya wicoie kin unkeyapi śni e niye sdonyayapi, qa waicucupikte cin śina unkinpi śni e Wakantanka sdonya.

6 Qa wicaśta kin etanhan wowitan unkakitapi śni, niycpi, qa wicaśta tokeca nakun etanhan śni, Messiya yewicaśi kin iyecen waeconwicunkiyapi kta iyececa tuka.

7 'Tuka niyepi cokaya wahbadan unkanpi, azinkiya wan cinca icahwicakiye cin he iyecen.

8 Hecen nina cante en unniyuzapi, qa waśteunnidakapi kin heon Wakantanka tawootanin waśte kin hee, qa unnagipi kin hena ko unnicupi kta tawatenunyanpi tuka.

9 Mihunkawanji, unkohinyanpi qa htaunnipi kin yeksuyapi, hanyetu anpetu ko htaunnipi, wotanin waśte Wakantanka tawa unkoniciyakapi kin he icunhan, tuwedan tkeya waqinunniciyapi kte śni uncinpi kin heon etanhan.

10 Niye sdonyayapi, qa Wakantanka nakun, tona wicayadapi kin en, wakanyan, owotanna, qa iyaonpepica śni unyakonpi.

11 Qa wicaśta cinca wahokonkiye cin he iyecen, niyepi otoiyohi wahokonunniciyapi, qa token unnicihnapi qa econ unniśipi kin he sdonyayapi;

12 Wakantanka iye tokiconze, qa towitan kin en nicopi kin, he iyokipiya mayanipi kte cin hcon.

13 Qa heon ohinniyan Wakantanka wopida unkekiciyapi ; 320
Wakantanka oie kin unkiyepi etanhan nayalonpi, qa iyacupi qchan, wicaśta oie kin iyecen iyacupi śni, tuka awicakehan Wakantanka oie kin hee, niye tona wicayadapi kin en olanyan ece kin iyececa.

14 Mihunkawanji, niś niyepi kin Wakantanka taokodakiciye, Juda makoce kin ekta, Jesus Messiya en un kin hena owicay ecipapi ; niś niye takuwicayayapi kin eciyatanhan kakiśniyanpi kin, iś iye Juda oyate kin eciyatanhan kakiświcayapi qon iyececa :

15 Hena e qe Jesus Itancan kin ktepi, qa wicaśta wokcan wicayuhapi qon hena nakun, qa unkiye śicaya unkuwapi, Wakantanka iyokipiyapi śni, qa wicaśta owasin kaśewicayapi :

16 Qa Ikcewicaśta nipi kte cin iwahokonwicunkiyapi kta he tehindapi, qa hecen ohinniyan wahtanipi kin hduśtanpi kta. Wocantiyahde owihanke aiyahdeya wanna en awicau.

17 Tuka mihunkawanji, unkiś niyepi kin etanhan ptecedan eunyalkupi, itohnake kin on, cante kin he wake śni, heon nitohnake wanunniyakapi kta nina cantokpaniyan unkakitapi.

18 Heon etanhan ekta unnikupi kta uncinpi, Palos miye linca, wancadan qa nonpa, tuka Satan iyounkipi śni.

19 Woape, qa wowiyuśkin, qa wowinkta wateśdakc unkitawapi kin he taku he; he niś niyepi śni he ; Jesus Messiya Itancan unkiyapi hi kinhan he itokam.

20 Wowitan qa wowiyuśkin unkitawapi kin he niyepi.

\section{WICOWOYAKE 3.}

1 Heon etanhan sanpa tinsiciya unkokihipi śni qehan, $\dot{A}$ - 
WICOWOYAKE 4.

thenas ekta unkiśnana unyakonpi kta e iyounkipipi :

2 Qa 'T'imotheos hunkawanjin unyanpi, Wakantanka taokiye, qa Messiya tawootanin waśte kin en unkitawaśipi kin hee, ye unśipi, sutaya ican̉niyanpi, qa wacinyayapi kin eciyatanhan wahokonniciyapi kte cin heon.

3 Qa hecen wicokakije kin dena on tuwedan pahohopi kte śni, hena ehna eunhdepi kin niye sdonyayapi.

4 Unkan niyepi kin opeya unyakonpi qehan, wokakije unhapi kta unkoniciyakapi, qa he ecetu kin sdonyayapi.

5. Heon etanhan ținsmiciye kta owakitpani, hehan token wacinyayapi kin sdonwaye kta e on he ekta ye waśi, okinni taku wawiyutanyan un kin iniyutanpi naceca, qa hecen htaunnipi kin taku śni ye kta.

6 Tuka nakaha Timotheos niyepi kin etanhan en unhdipi, qa wacinyayapi wacanyakiyapi ko on wotanin waśte unkahipi, qa nakun ohinniyan waśte unyadakapi kin heon wanunyadakapi kte hinca, unkiś wanurniyakapi kte cin iyececa;

7 Heon etanhan, mihunkawanji, wokakije wicocante śica ko unhapi kin owasin ehna niyepi on unkicicanptapi, wacinyayapi kin heon.

8 Nakaha unnipi, niś niyepi kin Itancan en sutaya yaunpi kinhan.

9 Unkan niyepi kin on, Wakantanka unkitawapi kin itokam, wowiyuśkin owasin on unkiyuśkinpi kin he on, ake niyepi on, taku wopida Wakantanka eciya unkokihipi kta he ;

10 Hanyetu anpetu ko nina cennkiyapi, nitohnake kin wanunniyakapi kta, qa wacinyayapi

Dak. kin en taku nahahin ocowasin śni un kin he tanyan unniciyuśtanpi kta.

11 Wakantanka iś iye, Ateunyanpi kin, qa Jesus Messiya Itancan unkiyapi kin, niyepi ekta canku kin ohna tanyan ye unyanpi nunwe.

12 Qa otoiyohi waśteyecidakapi, qa owasin waśtewicayadakapi kin he en, Itancan kin icahniyanpi, qa niciyuotapi nunwe, unkiś waśteunnicidakapi kin he iyececa.

$13 \mathrm{Qa}$ heon wowakan en nicantepi kin iyaonpepica śni niciyusutapi kta, Wakantanka Ateunyanpi kin itokam, tohan Jesus Messiya Itancan unkiyapi kin tona wicayuwakan kin owasin om hi kinhan.

\section{WICOWOYAKE 4.}

1 Unkan mihunkawanji, Jesus Itancan kin on etanhan cinunniciyapi qa ceunniciyapi, token mayanipi, qa Wakantanka iyokipiyayapi kte cin, unkiyepi etanhan iyacupi qon he iyecen sanpa iyoniptapi kte.

2 Jesus Itancan kin etanhan woahope kin tona unniçupi kin sdonyayapi.

3 Wakantanka niyuecepidan kin he tawacin kin he dee, wiinahmanpi kin en nihdoyapi kte śni ;

4 Tuka otoiyohi nitancanpi kin yuecepidan, qa yuonihanpi kin en, yahduhapi kte cin sdonyakiyapi kta.

$5 \mathrm{Qa}$ wicotawacin śica cantiheyapi kin he en unpi kte śni; Ikcewicaśta Wakantanka sdonyapi śni kin hena iyececapi.

6 Taku en tuwedan hunkawanjitku kin kape ca hnaye kte śni ; tona heconpi kin owasin 321 


\section{THESSALONIKE.}

Itancan kin tokicon ece, unkoniciyakapi qa unniciyaotaninpi qon iyececa.

7 Waaśapapi kin ekta Wakantanka unkicopi śni, tuka unyuecepidan kte cin heon.

8 Hecen tuwe waaktaśni kinhan, he wicaśta paha iyewicaye śni, tuka Wakantanka iye Taniya Wakan unqupi kin hee aktaśni.

9 Hunkawanjinkiciyapi waśtekicidakapi kin on wowapi cicagapi kta iyecece śni. Otoiyohi waśte yecidakapi kta he niś niye Wakantanka etanhan onnispepi.

$10 \mathrm{Qa}$ Makedonia owancaya hunkawanjinkiciyapi kin owasin hecawicayeconpi ece. Tuka mihunkawanji, ceunniciyapi ce, nakun sanpa nina ecanonpi kte.

11 Ito owanji dukanpi kta, qa taku tin nicibe cin he yahduśtanpi, qa niye ninapepi kin on htayanipi kta e aiciciya po, econ unniśipi qon iyecen;

12 Hecen tona tankan unpi kin hena itokam owotanna mayanipi kta, qa takudan icakije śni yaunpi kta.

13 Tuka mihunkawanji, tona iśtinmapi kin hena on sdonye śni dukanpi kta, qa iyoniciśicapi kta, wicaśta tokeca wowacinye nicapi kin iyececa, e he wacin śni.

14 Jesus te ca ake piya ikicage cin he wicaundapi kinhan, he iyecen tona Jesus en iśtinmapi kin hena iye kici Wakantanka uwicakiye lkta.

15 Unkan Itancan oie kin eciyatanhan he de unkoniciyakapi, unkiye tona unnipi, qa Itancan hi kte cin iyounhipi kinhan, tona iśtinmapi kin hena wicitokam unyanpi kte śni.

16 Iyaśapi wan qa malipiya 322 ohnihde itancan wan ho kin, qa Wakantanka maza yahotonpi tanka tawa ko Itancan kin hduha, mahpiya kin eciyatanhan kun u kta ; unkan tona Messiya en tapi qon hena tokaheya najinpi kta.

17 Hehan unkiye tona unnipi, qa he iyounhipi kinhan, hena om mahpiya śapa ekta eunhdakupi kta, okotonyan kin ehna Itancan kin itkounkipapi kta; qa hecen ohinniyan Itancan lkin kici unyakonpi kta.

18 Wicoie kin hena on otoiyohi wahokonkiciciya po.

\section{WICOWOYAKE 5.}

1 Mihunkawanji, omaka qa makoncage kin on wowapi cicagapi kta yacinpi śni ;

2 Hanyetu en wamanon sa kin he iyecen Itancan taanpetu kin $\mathrm{u}$, niś niyepi kin tanyan sdonyayapi.

3 Tohan, Wokiyapi qa tanyan yukanpi ce, eyapi kinhan, hehan ihnuhanna wicotakuni śni en awicau kta, winohinca cinca ton kte cin yazan hinhde cin he iyececa, qa najicapi kte śni.

4 Tuka mihunkawanji, niś niyepi kin otpaza ehna yaunpi śni, qa hecen anpetu kin he wamanon sa iyecen en nihipi kte śni.

5 Niyepi owasin, iyoyanpa cinca kin henicapi qa anpetu cincapi kin. Unkiyepi hanyetu otpaza kici unketanhanpi śni.

6 Heon etanhan wicaśta tokeca iyecen unkiśtinmapi kte śni; tuka kiktahan witko śni unyakonpi kta.

7 'Tona iśtinmapi kinhan, hena hanyetu icunhan iśtinmapi ; qa tona witkopi kinhan, hena hanyetu en witko unpi ece. 


\section{WICOWOYAKE 5.}

8 Tuka unkiye anpetu kin unketanhanpi, qa heon witko śni unyakonpi kta, wowacinye wacantkiyapi ko maku akahpe kin unkiçunpi kta, qa wiconi apepi kin he maza wapaha unyanpi kta.

9 Wakantanka wocanteptanye en eunhdepi śni, tuka Jesus Messiya Itancan unkiyapi kin eciyatanhan wiconi unkicupi kte cin.

10 He iye, unkiyepi on ța, hecen kiktahan unyakonpi, qa iś unkiśtinmapi, unma tukte kaśta, kici unnipi kta.

11 Heon etanhan otoiyohi wahokonkiciciyapi, qa onspekiciciya po, ecanonpi kin hececa.

12 Hunkawanjin unniyanpi kin, ceunniciyapi ce ; tona niyepi en litanipi, qa Itancan kin on awanniyakapi, qa wahokonniciyapi kin hena sdonwicaya po.

$13 \mathrm{Qa}$ wicohan yuhapi kin on etanhan, wacantkiyapi on sutaya cante en wicayuza po. Okiciciya yakon po.

14 Hunkawanjin unniyanpi kin, ceunniciyapi ce; tona yuśkiśkeya unpi kin hena iyopewicaya po, tona wacin cistinna kin hena wicakihna po, tona waśake śni un kin hena owicakiya po, qa wicaśta owasin on wacin tanka po.

15 Ihnuhan tuwe taku śica on itkom taku śica econ kinhan, tuka ohinniyan niś niyepi kin otoiyohi on, qa wicaśta owasin on taku waśte ecedan akita po.

16 Ohinniyan wiyuśkin po.

17 Ayaśtan śni cekiya po.

18 Taku owasin on wopida eya po. He niyepi on Jesus Messiya en Wakantanka tawacin kin hee.

19 Woniya kin kasnipi śni po.

20 Wiyukcanpi kin ihahapi śni po.

21 Taku owasin iyukcanpi, qa taku waśte kin he tinsa yuha po. 22 Taku śica ocaje owasin nakicipa po.

23 Qa wookiye Wakantanka kin niyepi ocowasin niyuecepidan nunwe; hecen ninagipi kin ocowasin, qa nitawacinpi, qa nitancanpi kin iyaonpepica śni niyuhapi kta, Jesus Messiya Itancan unkiyapi kin hi kte cin hehanyan.

24 Tuwe nicopi kin he wacinyepica, qa ecen econ lita.

25 Mihunkawanji, unkiyepi kin on cekiya po.

26 liputakaji wakan kin on hunkawanjin kiciyapi kin owasin i iwicaputaka po.

27 Itancan kin on hecon ciśipi, hunkawanjin kiciyapi wakan kin owasin ekta wowapi kin de yawapi kta.

28 Jesus Messiya I tancan unkiyapi kin towaonśida kin nicipi un nunwe. Amen. 


\section{PALOS \\ THESSALONIKE OYATE \\ WOWAPI WICAKICAGE CIN,}

INONPA KIN.

\section{WICOWOYAKE 1 .}

1 Palos, qa Siluanos, qa Timotheos, Thessalonike ekta okodakiciye Wakantanka Ateunyanpi, qa Jesus Messiya Itancan kin en un kin hena, wowapi wicakicagapi;

2 Wowaonśida, wookiye ko Wakantanka Ateunyanpi kin, qa Jesus Messiya Itancan kin etanhan nicipi un nunwe.

3 Mihunkawanji, wacinyayapi kin he nina icage ca, wacanyakiyapi kin otoiyohi en nina niciyuotapi kin, heon ohinniyan niyepi on, Wakantanka wopida unkekiciyapi kte cin he hecetu. 4 Hecen niyepi on, unkiye $\mathrm{Wa}$ kantanka okodakiciye tawa kin en unkiwinktapi ece ; śicaya nicuwapi kin owasin, qa wokakije duhapi kin en, wacinyan'wakiśagya yaunpi kin heon.

5 Wakantanka tawoyaco owotanna wowapetukeca kin he dee, nicakijapi kin heon Wakantanka tokiconze kin iy ehantu niyawapi kta.

6 Tona kakiśniyanpi kin hena itkom Wakantanka wokakije wicaqu kte cin he owotanna.

7 Qa tona kakiśya yaunpi kin, niś niyepi kin oziiçiya unkici yaunpi kta ; tohan Jesus Itancan kin towaśake ohnihde wicaye cin om mahpiya kin eciyatanhan ihdutaninyan u kinhan, 324
8 Peta ide kin en, tona Wakantanka sdonyapi śni, qa Jesus Messiya Itancan unkiyapi tawotanin waśte anagoptanpi śni kin hena wośitkihda wicaqu kta ;

9 Hena e Itancan itohnake kin etanhan, wicotakuni śni owihanke wanica on kakiświcayapi lita.

10 Tohan oyate owotanna tawa kin en ihduwitan kta, qa tona iye wacinyanpi kin hena owasin on yatanpi kta e on hi kinhan; anpetu kin he en taku unniciyaotaninpi qon he wicayadapi kin heon.

11 Qa heon etanhan ohinniyan niyepi on ceunkiyapi, Wakantanka wicakico kin de iyehantu niyawapi kta, qa niyepi en iye towaśte oiyokipi kin ocowasin, qa wowaśake on wacinyanpi wicohan kin he nakun hdustan kta.

12. Hecen Jesus Messiya Itancan unkiyapi caje kin niyepi on yuonihanpi kta, qa iye on, niś eya niyuonihanpi kta, Wakantanka unkitawapi, qa Jesus Messiya Itancan towaonśida kin eciyatanhan.

\section{WICOWOYAKE 2.}

1 Mihunkawanji, Jesus Messiya Itancan unkiyapi u kte cin he, qa en mniunkiciyapi kte cin hena on ceunniciyapi ce; 


\section{WICOWOYAKE 3.}

2 Ihnuhan wicanagi qa wicoie ga wowapi unnicagapi kin on ihnuhanna nitawacinpi ekta nihuhuzapi qa ininihanpi kin, Messiya taanpetu kin kiyadan u kin hececa.

3 Ihnuhan tuwe taku on nihnayanpi kin; woayuśtan wan tokaheya u kta, qa woahitani wicaśta kin wicotakuni śni cinhintku kin hee e yutaninpi kta.

4 He iye taku Wakan eyapi kin, taku ohodapi ko owasin iwankam yeiciye ça kici kiciza, hecen iye. tipi wakan Wakantanka tawa kin en, Wakantanka iyecen iyotanke ça Wakantanka keiciya oihdaka.

5 Cicipi waun qehan hena ociciyakapi qon he yeksuyapi śni he.

6 Unkan nakaha taku iyowicaki śni ece kin he sdonyayapi; hecen tohantu kinhan taninyan hiyu kta.

7 Woope aktaśni wowiyukcan kin he wanna olianyan ece, tuka tuwe he iyoki śni kin he, tohanyan tokan iyeyapi śni kin, hehanyan iyowicaki kte śni.

8 Unkan hehan woope aktaśni kin he tanin kta, Jesus Itancan kin Taniya, iye i kin etanhan hiyu kin on, qa ihdutanin wiyatpa kin on, he ihangye kta.

9 Tuwe Satan ohan kin eciyatanhan wicookihi owasin, qa wowapetokeca, qa wowinihan wicohan itonśni kin yuha u,

10 Qa tona awihnuni kin hena en woahtani wohnaye owasin koya; hena wowicake waśte dakapi kin on nipi kte cin he aktapi śni, heon etanhan.

$11 \mathrm{Qa}$ heon etanhan hena en Wakantanka wohnaye wawokihi kin awicau kta, hecen woitonśni kin wicadapi kta.

12 Qa hecen tona wowicake wicadapi śni, qa woalitani en iyuśkinpi kin hena owasin wicayacopi kta.

13 Tuka mihunkawanji, Itancan waśtenidakapi kin, niyepi on unkiye ohinniyan Wakantanka wopida unkekiciyapi kta, otokaheya tanhan Woniya wicayuecedan, qa wowicake wicadapi kin on, Wakantanka yanipi kta e on nicalinigapi kin heon etanhan.

$14 \mathrm{Qa}$ he en nicopi, wotanin waśte unlkitawapi kin on, hecen Jesus Messiya Itancan unkiyapi towitan kin iyacupi kta.

15 Heon etanhan, hunkawanjinciyapi kin, sutaya najin po, qa woope oyakapi wicoie, qa wowapi unkitawapi kin eciyatanhan onspeniciyapi kin hena tinsaya yuha po.

$16 \mathrm{Qa}$ Jesus Messiya Itancan unkiyapi kin hee, qa Wakantanka Ateunyanpi kin iye waśte undakapi, qa wicimdeza owihanke wanice cin wowaonśida eciyatanhan woape waśte ko unqupi kin,

17 He nicantepi kin mdesniyanpi, qa wicoie, wicohan ko waśte kin owasin en niyusutapi nunwe.

\section{WICOWOYAKE 3.}

1 Unkan ehake mihunkawanji, unkiyepi on cekiya po, Itancan oie kin inyanke ca, wowitan kta, niyepi kin ehna iyececa.

$2 \mathrm{Qa}$ wicaśta śice ca wicaśtapi śni kin etanhan eunhdalzupi kta; owasin wowacinye yuhapi śni kin heon.

3 Tuka Itancan kin he wacinyepica, he niyusutapi, qa taku śica etanhan enihdakupi kta.

4 Itancan kin en niyepi on kaken awauncinpi, token econ un- 


\section{TIMOTHEOS.}

niśipi qon ecen ecanonpi, qa eeś nakun ecanonpi kta.

5 Qa Itancan kin nicantepi kin Wakantanka waśtedakapi, qa Messiya wacintanka kin he en ope niyanpi nunwe.

6 Unkan mihunkawanji, Jesus Messiya Itancan unkiyapi caje kin on ceunniciyapi ce, hunkawanjin kiciyapi wan ecinśniyan mani, qa wicoope unnicupi qon eciyatanhan śni kinhan, he nakicipa po.

7 'Token unkoyecipapi kte cin niye sdonyayapi ; niyepi en ośkiśkeya maunnipi śni.

$8 \mathrm{Qa}$ tuwedan aguyapi tawa iyunwin codan untapi śni, tuka wicohtani, wicokakije ko ehna, hanyetu, anpetu ko htaunnipi, tuwedan takudan unkinicazopi kte śni heon.

9 Unkokihipi śni kin heon etanhan śni ; tuka unkiye waonspekiya yuheunniciyapi, qa unkoyapapi kte cin heon.

10 Nicipi unyakonpi qehan, he de unkoniciyakapi, 'Tuwe htanipi tawațenye śni kinhan, he takudan yute kte śni ce.

11 Enitanhanpi wanjikji ecinśniyan manipi, qa ecaca htanipi śni, tuka waaie sa hecapi kin he naunlionpi.

12 Tona hececapi kin hena Jesus Messiya Itancan unkiyapi kin etanhan wahokonwicunkiyapi, qa econ wicunśipi, ainina litanipi, qa aguyapi tawapi kin ecedan hdutapi lita.

13 Unkan mihunkawanji, niś niyepi kin taku waśte econpi kin econ kapinpi śni po.

$14 \mathrm{Qa}$ tuwe wowapi kin de en, unkoiepi kin anaungoptanpi śni kinhan, he iwanyakapi, qa lkici okiciciyapi śni po, hecen iśtece kta.

15 Tokayapi śni po, tuka hunkawanjinkiciyapi kin iyecen wahokonkiya po.

$16 \mathrm{Qa}$ ohinniyan, taku owasin on etanhan wookiye Itancan kin wookiye niçupi nunwe. I tancan kin niyepi owasin en nicipi un nunwe.

17 Palos he miye, napekiciyuzapi kin de minape on owawa, he wowapi otoiyohi en wowapetokeca kin hee, hecen wakaga ece.

18 Jesus Messiya Itancan unkiyapi kin towaonśida kin niyepi owasin en nicipi un nunwe.

\section{PAL O S TIMOTHEOS WOWAPI KICAGA;}

T OKAHEYA KIN.

\section{WICOW OYAKE 1.}

1 Palos Jesus Messiya yeśi qon, Wakantanka Wanikiya unkitawapi, qa Jesus Messiya Itancan wacinunyanpi kin he toope kin eciyatanhan,
2. Timotheos, wacinyanpi kin eciyatanhan micinkśi kin hee, wowaśte, wowaonśida, wookiye ko, Wakantanka Ateunyanpi, qa Jesus Messiya Itancan unkiyapi kin hena etanhan kiciun nunwe. 
3 Makedonia ekta mde cehan; Ephesus en owanji yanke ciśi, wanjikji woonspe tokeca oyakapi kte śni e iwahokonwicayakiye kte cin heon;

4 Qa hitunkakanpi, wicoicage owihanke śni oyakapi ko awacinpi kte sni; lıena taku kin wiwangapi eceedan okihi, qa on Wakantanka wacinyanpi kin en icahyapi śni.

5 Wicacante ecedall, wicanagi waśte, qa wacinyanpi wicakapi kin etanhan warantkiyapi kin he woahope ecetuyapi kin hee.

6 Tona he icunonpa yapi kin hena takuśniśni akinicapi kin en yeiçiyapi.

7 Woope kin tokan onspewicakiyapi kta cinpi; tuka taku eyapi, qa taku waditagya oyakapi kin he iyulkcanpi śni.

8 Woope kin he waśte sdonunyanpi, tuwe woope kin iyecen yuhe cinhan.

9 Qa he de sdonunyanpi, woope kin he wicaśta owotanna kicagapi śni, tuka tona woope opapi śni, qa anagoptanpi śni lin hena wicakicagapi, tona Taku Wakan ohodapi śni, qa wahtanipi sa, waonśidapi śni qa wayaśicapi, atkuku hunku kici wicakiktepi kin, qa wicaśta wicakațapi kin hena,

10 Wawicihahapi econpi, waihuhupi sa, wicaśta wiyopewicaye cin hena, itonpiśni qa woope kicaksapi kin hena on woope kagapi ece; qa taku tokeca woonspe zani hin kaśeye cinhan he nakun:

11 Wakantanka wacantkiya wotanin waśte wowitan yuhe maśi kin he eciyatanhan.

12 Unkan Jesus Messiya Itancan unkiyapi he okihimaye ca, wacinyepica madake ça, wico- htani kin de en opemaye ciqon he wopida ewakiya ece.

13 He itokam waośtewahda, qa śicaya wicawakuwa, qa wahanmicida; tuka wicawada śni icunhan hena iyukcan śni ecamon kin heon onśimadapi.

14 Qa Itancan unkiyapi towaonśida kin he wacinyanpi qa wacantkiyapi Jesus Messiya en nina yuotapi.

15 Wicoie kin de wacinyepica, qa owancaya icupi kta iyececa, Jesus Messiya wahtanipi sa niwicaye kta e on makata hi ; hena en miye imayotan.

16 Tuka heon etanhan onśimadapi, hecen miye en tokaheya Jesus Messiya wawacinkta yuza tanka owasin hdutanin kta, wicani kta e on wicadapi kte cin hena waonspewicawakiye kta e heon. 17 Hecen Wicaśtayatapi owihanke wanica, tepica śni, qa wanyakepica śni un kin, Taku Wakan ecedan ksape cin hee, woyuonihan, wowitan ko, owihanke wanin kicihan nunwe.

18 Timotheos micinkśi, woope kin de cicu, niye on wokcanpi tokaheya ekta un qon hena eciyatanhan, hecen hena on ozuye waśte en akicita oyape kta;

19 Wowacinye qa wicanagi waśte sutaya yahduhe kte cin heon. Wanjikśi hena elipeyapi qa' on wacinyanpi ekta kamden iyeiciyapi.

20 Yumeneos qa Aleksander kici, hena hececapi, hena Satan waqu, waośtehdapi kte śni onspeiçiciyapi kte cin heon.

\section{WICOWOYAKE 2.}

1 Heon, taku owasin itokam, wicaśta kin owasin on, wokidapi, wocekiye, waiciyapi wicoie, wopida ko eyapi kta wacin. 


\section{TTMOTHEOS.}

2 Wicaśtayatapi kin hena on, qa tona itancan unpi kin owasin on, hecen woolodupi owasin qa wicohan owotanna kin en, owanjidan unkanpi qa wikope śni unnipi kta.

3 He waśte, qa Wakantanka Wanikiya unkitawapi kin itokam woiyolkipi kin hee.

4 He iye wicaśta owasin nipi, qa wowicake sdonyapi kin en hipi kte cin he cin.

5 Taku Wakan wanjidan, qa Taku Wakan qa wicaśta kici wiciyotahedan un kin wanjidan, Jesus Messiya wicaśta kin hee.

6 He iyc atayedan owasin opewicakiton kta e icicu, anpetu tawa kin waayatanin kte cin heon.

7 He en eyanpaha qa yeśipi kin heca makagapi; Messiya en wowicake epa, itonśni mawanica; wowacinye wowicake ko Ikcewicaśta onspe wicawakiye kte cin heon.

8 Heon, wicaśta kin owancaya, wocanniye, waakinicapi ko wanin nape aśape śni kiyugan cekiyapi kta wacin.

9 Qa winohinca kin iś eya iyecell wokoyake oiyokipi kin kiçunpi kta, qa tawacin waśte, wacin tankapi koya; qa paha sonpi, mazaskazi, inyan okitanin kin, qa wokoyake taku ota iyopeyapi kin hena ko unpi kte śni;

10 Tuka wicohan waśte kin hena, taku winohinca tona $\mathrm{Wa}$ kantanka awacinpi kin iyokipipi kin hee.

$11 \mathrm{Qa}$ winolinca kin inina un, qa taku owasin en wanalion yanke ca on onspeiciciye kta.

12 Tuka winohinca kin iś waonspekiye ca wicaśta kin iwankam un kta e iyowinwakiye śni, he inina yanke kta.

13 Adam he tokaheya kagapi, qa hehan Ewe.
14. Qa Adam hnayanpi śni, tuka winolinca kin iye hnayanpi, qa hecen woahtani hiyahdeya.

15 Tuka iś eya cinca tonpi kin en niyanpi kta, wacinyanpi, wacantkiyapi, wicohan waśte qa wacintankapi kin hduha yukanpi kinhan.

\section{WICOWOYAKE 3.}

1 Iapi kin he wowicake; tuwe waawanhdake unpi cin kinhan he wicohan waśte wan cin.

2 Tuka waawanhdake cin he iyaonpepica śni un kta, winobinca wanjidan yuze kta, waktaya un kta, wacinksapa, wahibayedan, ohanpi, wowicakiyaka ;

3 Miniśa en iyeiçiye śni, waawicape śni, mazaska nina akite śni; tuka wacintanka, wacinko śni, waicucu wacin śni ;

4 Iye tiyohnaka kin tanyan hduhe kta, qa wicowahbadan owasin on cinca kin anagoptanwicakiye kta.

5 Tuwe tiyohnaka tawa kin tanyan hduha okihi śni kinhan, ecin token Wakantanka taokodakiciye kin tanyan yuhe kta he.

6 Aśkatudan en opapi kin hecece kte śni, he heca kinhan, okinni wahanicida kin on Wakanśica tawoyaco lxin ekta iyaye kta.

7 Qa tona itankan yakonpi kin hena tanyan oyakapi un kta, he hecetu śni kinhan, wowiliahaya un kta, qa Wakanśica wihmunke tawa kin en iyohpaye kta.

8 Iś eya ookiye unpi kin hena nakun wacinksapapi kta, eeji jatapi śni, miniśa en iyeiçiyapi śni, qa mazaska nina akitapi kte śni : 9 Wicanagi ecedan ohna wowacinye wowiyukcan kin yuhapi kta. 


\section{WICOWOYAKE 4.}

10 Hena e tokaheya wicayukcanpi kta, qa heban takudan iyaonpepica śni kinhan, ookiye unpi kin en iyeyapi kta.

11 Nakun iś tawicupi kin wahbapidan kta, waaie śni unpi kta, waktaya unfi kta, taku owasin on owotanpidan.

12 Ookiye unpi kin iś tawicu wanjidan kta, cinca wicayapi qa tiyohnalia tawapi kin tanyan hduhapi kta.

13 'T'ona ookiye unpi wicohan kin tanyan yuhapi kin hena wowitan waśte hdamnanpi, qa Jesus Messiya wacinyanpi kin en waditaka icicagapi.

14 Dena hecen wowapi cicaga, kohanna niye en ciu lita wacin.

15 Tuka tehan wai śni kinban, deciya tanhan on token Wakantanka ti kin ohna opiniçiye kta sdonyaye kta, he okodakiciye Wakantanka ni un tawa kin ee, wowicake ihupa qa taku ahe cin hee.

16 Unkan he taku aiepica śni, Wakantanka awacinpi kin he wowiyukcan tanka; Wakantanka wicacehpi en ihdutanin qon, Woniya kin on yaowotanna kagapi, mahpiya ohnihde kin wanyakapi, Ikcewicaśta kin elita oyakapi, wicoicage kin en wicadapi, qa wowitan kin ekta wankan ehdakupi.

\section{WICOWOYAKE 4.}

1 Woniya kin atayedan heya, Anpetu ihankeya kin en, wanjikśi wacinyanpi kin ayuśtanpi kta, qa woniya śapa wahnaye sa, qa taku wakan śica tawoonspe ko anagoptanpi kta.

2 Wicahnayanpi on itonśni iapi kta, nagipi kin maza kata on guguyapi kin heon.

3 Winolinca wicayuzapi kin he tehindapi, qa woyute, tona wowicake wicadapi, qa sdonyapi kin hena wopida eya icupi kta e Wakantanka kaga, hee yute śni wicaśipi lata.

4 Taku Wakantanka kage cin he owasin waśte, qa wopida yuha icupi kinhan, takudan olinyanpi kte śni.

5 He Wakantanka oie, wocekiye ko on yuwakanpi.

6 Hena taku kin hunkawanjinkiciyapi kin kiksuyewicayaye cinhan, Jesus Messiya taokiye waśte yaun kta, wacinyanpi, wicoie, qa woonspe waśte ekta iyohiyaye cin hena en tanyan icahniyanpi lita.

7 Tuka iapi śice cin, wakanka hitunkakanpi yuhapi ko nakicipe ca, Wakantanka awacinpi kin he amniheiciya wo.

8 Wicatancan yeiciyapi kin he taku cistinna okihi; tuka Wakantanka awacinpi kin he taku owasin okihi, wiconi kin de, qa wanji u kte cin iwahoyapi kin en un.

9 Wicoie kin he wowicake, qa owancaya anagoptanpi kta iyececa ;

10 Wakantanka ni un wicaśta owasin Wanikiya tawapi, qa iyotan tona wicadapi kin hena, he wacinunyanpi kin heon litaunnipi, qa ośtehdapi unyakonpi.

11 Hena taku kin iwahokonwicakiye ça onspewicakiya wo.

12 Koniśka yaun kin heon tuwedan iwahtenida kte śni ; tuka tona wicadapi kin hena waonspewicakiya wo, wicoic kin en, wicohan kin en, wacantkiyapi kin en, woksape kin en, wacinyanpi kin en, woyuecedan kin en.

13 Wowapi yawapt, qa wahokonwicakiyapi, waonspewicakiyapi ko, hena econ wo, en wai śni kin hehanyan. 


\section{TIMOTHEOS.}

14 Taku wawokihi en niun kin, wokcanpi, qa waawanhdake unpi, nape aniputakapi kin on nicupi qon he akiktonje śni wo.

15 Hena taku kin awacin, qa ocowasin en yeiciya wo, hecen onspeniciciye cin owasin sdonyapi kta.

I6 Atayedan awaicicin, qa woonspe nitawa kin awakicin wo, he hduha wo. Hecanon kinhan niniçiye ca, tona nanihonpi kin hena nakun niwicayaye kta.

\section{WICOWOYAKE 5.}

1 Hunkayapi wan iyopeye śni wo, tuka ateyapi un kin iyecen wahokonkiya wo, qa tona hakaktapi kin hena nihunkawanji iyececapi kta;

2 Winohinca tankapi kin hena iś inawicayaye cin iyecen, qa tona aśkatudan unpi kin hena tawinohtinwicayaye cin iyececapi kta, woyuecedan owasin en.

3 Wiwazicapi kin, tona awicakehan wiwazicapi un kin hena wicayuonihan wo.

4 Tuka wiwazica wan cinca wicaye cin, qa takojakpaku yuke cinhan, hena tokaheya wicowazi tawapi kin en wowaśte econ onspeiciciyapi kta, qa hunkake wicayapi kin iyunwin wicakicupi kta; taku waśte qa Wakantanka itokam oiyokipi kin hee.

5 Tuwe awicakehan wiwazica un kin. he iśnana ehpeyapi un, Wakantanka wacinye ça ohinniyan, hanyetu anpetu ko, wocekiye eyapi, qa hoyekiyapi kin en un.

6 Tuka tuwe iyokipi iciya un kinhan, he ni un icunhan wanna ta.

7 Hena hecen iwahokonwica- kiya wo, hecen iyaonpepica śni unpi kta.

8 Qa tuwe tona wicayuhe cin, qa iyotan tiyohnaka tawa kin, taku wicakicamna śni kinhan, he wacinyanpi kin wanna ayustan, qa waawacin śni kin sam iyeya wicaśta śica.

9 Wiwazica waniyetu wikcemna śakpe ihukuya un kin he kahnigapi kte śni. He wicaśta wanjidan hihnaye ciqon,

10 Wicohan waśte on tanyan oyakapi, cinca icahwicakiya, oicimani kin wonwicaya, tona owotanna un siha wicakiyujaja, tona kakijapi kin owicalkiya, qa wicohan waśte owasin amniheiçiya en opa hecinhan.

i1 Tuka wiwazica tona aśkatudan wotapi kin hena wicakahnige śni wo; tohan Messiya en śkehanhan aye cinhan ake hihna tonpi kta;

$12 \mathrm{Qa}$ tokaheya wacinyanpi qon he ayuśtanpi kin heon woyaco aihduhapi kta.

13 Qa nakun kujapi, qa ti iyaza yakonpi ; qa liujapi hecedan śni, nakun taku oyakapi sa, qa waaiapi sa, taku eyapi kte śni kin hena eyapi ece.

14 Heon, tona nahahin wikośkapi kin hena hihna tonpi kta, cinca tonpi kta, qa tiyohnaka hduhapi kta wacin, hecen toka kin taku iyawicaonpe kta okihi śni kagapi kta.

15 Wanna wanjikji icunonpa Satan ihakam iyayapi.

16 Wicaśta wanji, qa iś winohinca wanji wacinyan un kin, he wiwazica hduhe cinhan okiye kta; hecen okodakiciye kin tkeya qinpi kte śni, qa tona awicakehan wiwazica unpi kin hena ece owicakiyapi kta.

17 Waawanhdake un kin, tona tanyan awanhdakapi kinhan, he- 


\section{WICOWOYAKE 6.}

na wowitan icitakihna wicakiciyawapi kta, tona wicoie, waonspekiyapi ko, en htanipi kin hena iyotan.

18 Wowapi wakan kin hecen eya, Tatanka aguyapi napan kin he iohmus sutaya iyacu kte śni. Qa ake, Tuwe htani kin he taku on opetonpi qon iyohi ece.

19 Waayatanin nonpa, qa yamni duhe śni kinhan, hunka yapi un kin wanji en wiyaonpapi aupi kin anagoptan śni wo.

20 Tona walitanipi kinhan hena owasin wicitokam taninyan iyopewicaya wo, hecen unmapi kin kokipapi kta.

21 Wakantanka itokam, qa Jesus Messiya Itancan kin, mahpiya ohnihde wicakahnigapi kin hena ko. wicitokam wahokonciciya, dena taku kin ecinśniyan wiyukcanpi wanin ecanon kta, qa wicaśta iwanyakapi kte cin on etanhan takudan ecanon kte śni.

22 Oliankoya tuwedan nape aputake śni wo; qa wicaśta tokeca wahtanipi kin en ope śni wo. Ecedan ihduha wo.

23 Tokata mini ecedan yatke śni wo, nitezi kin on, qa waniyazan sa kin heon, miniśa waniqadan yatkan wo.

24 Wicaśta wanjikji wahtanipi kin taninyan han, qa itokam woyaco ekta awicaya; qa hunh wicihakam tanin ece.

25 Qa he iyecen wicolian waśte wanjikśi taninyan un, qa tona hecece śni eśta anahbepica śni.

\section{WICOWOYAKE 6 .}

1 Wowidake un kin tona can napinpi kin ihukuya yukanpi kin hena itancan wicayawapi kin wicakinihanpi owasin okihi wicahdawapi kta, hecen Wa- kantanka caje qa tawoonspe kin ośtehdapi kte śni.

$2 \mathrm{Qa}$ tona itancan wacinyan unpi kin heca ihukuya unpi kinhan, hena śicewicakidapi kte śni, om hunkaw anjinkiciyapi kin heon: tuka hena wacinyan unpi, qa waśtewicadakapi, qa taku waśte kin en owicakicipapi kin heon sanpa owicakiyapi kta. Hena hecen onspewicakiye ca wahokonwicakiya wo.

3 'Tuwe wicoie waśte, Jesus Messiya Itancan unkiyapi oie kin, wicohan ecedan kin eciyatanhan un kin hena wicada śni kinhan, qa togye waonspewicakiye cinhan,

$4 \mathrm{He}$ wahianicida, qa takudan sdonye śni un, tuka wakinicapi wiwangapi wicoie kin en cante kin ocowasin iyeiçiya; hena etanhan winawizipi, wakinicapi, waośtehdapi, woawacin śica ko icaga.

5 Qa wicaśta tawacin śicapi kin ośkiśkeya hdokinicapi, wowicake yuhapi śni, qa taku kamnanpi kinhan, he Wakantanka ohodapi kin ee kecinpi. Tona hececapi kin hena awicayuśtan wo.

6 Wakantanka ohodapi kin woiyokipi kici he woyuha tanka.

7 Maka kin de en takudan unkahipi śni, qa awicakehan hetanhan takudan unkahdapi kte śni.

8 Hecen woyute, wokoyake ko unhapi kinhan, hena iyounkipipi kte.

9 Tona watonpika cinpi kinhan, hena taku wawiyutanyan un, qa mazahtakiyapi en iyolipayapi, qa witkotkoya cantiheyapi śica ota on kiuniyanpi ece kin hena en, hena e waihangyapi, wicotakuni śni ko mahen wica- 


\section{TIMOTHEOS.}

sta kin ocowasin iyohpewicayapi ece.

10 Taku śica owasin hutkan kin he mazaska waśtedakapi kin hee; he wanjikji inahinipi, qa on wacinyanpi kin etanhan iyaye yapi, qa wicokakije ota on caicipapi.

11 Tuka Wakantanka wicaśta tawa kin he niye, hena taku kin nakicipa wo; wicoowotanna, Wakantanka ohodapi, wacinyanpi, wacantkiyapi, wacintankapi qa wowalibadan, hena akita wo.

12 Wowacinye okicize waśte kin he en econ wo, owihanke wanin wiconi kin he icu wo, he en nicopi qa waayataninpi ota itokam wolddakapi waśte ecen oyahdike ciqon.

13 Wakantanka taku owasin nikiye cin he itokam, qa Jesus Messiya Pontios Pilate itokam owotanna wohdake ciqon he on ceciciya ce ;

14 Aśape śni qa iyaonpepica śni, woahope kin de duhe kta, Jesus Messiya Itancan unkiyapi taninyan u kte cin hehanyan.

15 He tohan iyehantu kinhan, tuwe yawaśtepi, qa ecedan Wawokihi kin he taninyan hiyuye kta, wicaśtayatapi kin en Wi- caśtayatapi, qa itancanpi kin en Itancan kin hee.

$16 \mathrm{He}$ iśnana wiconi hduhe ca, iyoyanpa en hiyohipica śni kin he en ounyan, wicaśta kin tuwedan he wanyake śni, qa nakur wanyaka okihi kte śni; he wowitan, qa wowaśake owihanke wanin kiciun nunwe.

17 Tona maka kin den watonpike cin wahokonwicakiya wo, watankaicidapi kte śni, qa wo.. yuha atakuni śni aya ece kin wacinyanpi kte śni, tuka Wakantanka ni un taku iyounkipipi kta e iyakicuya unqupi kin hee; 18 Taku waśte ece econpi kta, wicohan waśte ijicapi kta, wapamnipi, qa wawicaqupi tawatenyapi kta;

19 'T'aku tokata ihe cin he elsta ahehde waśte wan içihnakapi kta, hecen wiconi owihanke wanica yuhapi kta.

20 Timotheos, taku yuheciciye cin hena tanyan yuha wo, qa ikcekceya ecinśniyan wakinicapi kin he nakicipa wo, wosdonye woitonśni alkinicapi kin he nakun.

21 Wanjikji he en opapi, qa wacinyanpi kin icunonpa iyayapi. Wowaonśida niciun nunwe. Amen.

\section{P A L O S}

\section{TIMOTHEOS WOWAPI KICAGA,}

\section{NONPA KIN.}

\section{WICOWOYAKE 1.}

1 Palos, Wakantanka tawacin kin on, Jesus Messiya yeśi qon, Jesus Messiya wiconi iwahounyanpi quon he eciyatanhan,
2 Timotheos, hokśincantkiyapi mitawa kin, wowapi cicaga. Wowaonśida, wowaste, wookiye ko, Wakantanka A.teyapi kin etanhan, qa Jesus Messiya Itancan unkiyapi kin etanhan. 


\section{WICOWOYAKE 2.}

3 Wakantanka, mihunkake kin etanhan nagi ska hduha ohowada kin, he wopida ewakiya, anpetu, hanyetu ko wocekiye epa eca, ayaśtan śni ciksuya waun ;

4 Wanciyaka nina wacin, iśtamnihanpe ota aniu qon hena weksuya, hecen wowiyuśkin omajudan kta ;

5 Tohan wowacinye anahbepica śni niye en niun kin he weksuye cinhan, he tokaheya nikunśi Lowis en un, qa nakun nihun Yunike en un, qa he niye en niun kin sdonwaya.

6 Heon etanhan kiksuyeciye kta, Wakantanka taku niçu kin, nape aciputake cin eciyatanhan, he amniheniciye kta.

7 Wakantanka wokokipe woniya kin unqupi śni; tuka wowaśake, wacantkiyapi, qa wacinksapapi woniya kin.

8 Hecen Itancan unkiyapi tawootanin kin on iśtece śni wo, qa nakun miye makaśkapi tawa waun kin; tuka Wakantanka towaśake kin eciyatanhan wotanin waśte en wokakije kin en okicipa wo :

9 He iye ni unyanpi, qa wicakicopi wakan kin on unkicopi, unkohanpi kin eciyatanhan śni, tuka iye tawacin, qa towaonśida, maka icage cin itokam Jesus Messiya on unqupi qon he eciyatanhan :

10 Tuka wanna hdutanin, Jesus Messiya Wanikiya unkitawapi taniniciye cin on, he wiconțe ihangye ca, wotanin waśte kin en, wiconi qa țepica śni unpi kin iyoyanpa en au.

11 Heon eyanpaha qa yeśipi kin heca makagapi, Ikcewicaśta wowicawakiyake kte cin heon.

$12 \mathrm{Qa}$ be etanhan hena taku on iyotanhan iyewakiya; tuka 102 imaśtece śni. 'Tuwe wacinwakiye cin he sdonwakiye ca, taku ehnake waśi kin hena anpetu wan u kte cin hehanyan miciyuha okihi sdonwaya.

13 Wicoie on zaniyan unpi nahonciye ciqon, wowacinye, wowaśte ko, Jesus Messiya en un kin he tinsa yuza wo.

14 Woniya Wakan unkicipi un kin eciyatanhan, wicohan waśte niçupi qon he tanyan yuha wo.

15 Tona Asia en un kin owasin amayuśtanpi kin he sdonyaya; Phugellos qa Hermogenes he en opapi.

16 Onesiphoros tiyohnaka tawa kin Wakantanka onśikida nunwe ; iye ota micanpte ca makaśkapi kin on iśtece śni.

17 Qa Roma ckta hi qehan, nina omade qa iyemayan.

$18 \mathrm{He}$ anpetu kin he en Itancan kin etanhan wowaonsida iyeye kta e Itancan okihikiya nunwe; Ephesos ekta taku tona on omakiye ciqon he tanyan sdonyaya.

\section{WICOWOYAKE 2.}

1 He etanhan, micinkśi, Jesus Messiya towaonśida kin he en wakiśaka wo.

2 Qa miye etanhan taku nayahon, wicota yaotaninpi qon, hena wicaśta wacinyepica, tona tokan onspewicakiya okihipi kin, hena wicaqu wo.

3 Qa niye nakun Jesus Messiya taakicita waśte kin iyecen taku tehilka en waditaka wo.

4 Tuwe ozuye econ kinhan, he taku wiconi kin de wicohan kin en ihdupemni śni, tuwe takkicitaye cin he iyokipiye kte cin heon.

$5 \mathrm{Qa}$ tuwe ohiye wacin econ kinhan, qa wakiconzapi liin ecen 333 


\section{TIMOTHEOS.}

econ śni kinhan, he watcśdagkicatonpi śni ece.

6 Wicaśta wakicanye cin he htani kinhan, iye tokaheya taku icage cin etanhan yutc kta.

7 Taku epe cin he awacin wo. Qa Itancan kin taku owasin okahnihniyan nunwe.

8 Wotanin waśte mitawa kin eciyatanhan, Jesus Messiya, Dawid wicowazi tawa kin etanhan, he wiconte etanhan ekicetuyapi kin he kiksuya wo.

9 Qa iye on wicaśta wabotice cin iyecen kakiśmayanpi, makaśkapi lkin he en; tuka Wakantanka oie kin he kaśkapi śni.

$10 \mathrm{He}$ etanhan tona wicakahinigapi qon hena on taku owasin iyowinwaya, hena e wiconi Jesus Messiya en un kin he yuhapi kta, qa nakun owihanke wanin wowitan kin.

11 Wicoie kin de wicakapi; Iye kici unțapi kinhan, nakun kici unnipi kta;

12 Iye on unkakijapi kinhan, kici wicaśtayatapi unyakonpi kta. Qa unkiye chpeunyanpi kinhan, iś eya elipeunyanpi kta.

13 Qa wacinunyanpi śni cśta, iye wacinyepica un, ihduecinśniyan kta okihi śni ce.

$14 \mathrm{Hcna}$ taku kin kiksuyewicaye ca, Itancan kin itokam, wicoie wawokihi śni, tona nahonpi kin wicalnaye cin hena on akinicapi kte śni e iwahokonwicakiya wo.

15 Wakantanka iyokipiyaye kta, wicaśta wakage cin iśtece kta iyecece śni kin heca e nihdutanin kta, qa wowicake wicoie kin owotanna yapamni kta e aiciciya wo.

-16 Tuka iapi śica ccinśniyan kin he nakicipa wo, he iyotan wicośice ekta icah aye kta.

17 Unkan wicoie tawapi kin 334 śiyaka śica wan iyecen waihangye kta; Yumeneos qa Philetos hena hececapi ;

18 Hena wowicake kin icunonpa iyayapi qa, Woekicetu kin wanna yuśtanpi ce, eyapi, qa heon wanjikji wacinyanpi kin etanhan wicayahomnipi.

19 Hececa eśta, Wakantanka ahehde tawa kin sutaya he ca ipuspe kin de en un; Itancan kin tona tawa wicaye cin hena sdonwicakiya. Qa nakun, Tuwe Messiya caje kin hoyekiye cinhan, he woahtani ayuśtan kta ce.

20 Tuka tipi tanka wanji ohna mazaskazi, qa mazask a wakśica hecedan śni, nakun can, qa maka wakśica ko yukan, hunli taku waśte, qa hunh taku śica on yuhapi.

21 Hecen on, tuwe hena taku kin etanhan itpakinte cinhan, he wakśica waśte kin heca kta, ecedan, qa Jtancan kin wowinyunye kta e iyokipi, qa wicohan waśte owasin on yuśtanpi.

22 Kośka cantihcyapi śice cin hena nakicipa wo; tuka wicoowotanna, wowacinye, wacantkiyapi, wookiye ko, henakiya tona cante ecedan on Itancan cekiyapi kin hena om en opa wo.

23 Tuka wiwangapi okahnihpica śni ecinśniyan kin hena en yeiçiyc śni wo, hena wicokicize kaga e sdonyaya.

24 Unkan Itancan taokiye kin he wicakis un kte śni; tuka owasin en wahbayedan un kta, waonspekiye ca, wawacinkta yuza tanka kta :

25 Qa tona tokaiciya unpi kin hena iwahnana wahokonwicakiye kta, okinni Wakantanka ihduecetupi wicaqu kta, hecen wowicake kin iyukcanpi kta.

$26 \mathrm{Qa}$ hecen, tona Wakanśica 


\section{WICOWOYAKE 4.}

tohan cin eca, wayaka awicahda ece kin hena mazahtakiyapi tawa kin etanhan ihduśpapi kta.

\section{WICOWOYAKE 3.}

$1 \mathrm{He}$ de sdonya wo, anpetu ihankeya kin en taku tehika e u kta.

2 Hehan wicaśta kin waśteicidapi kta, mazaska waśtedakapi, wamnaicidapi, wahanicidapi, hunkakeyapi kin anawicakigoptanpi śni, wapidapi śni, owotanpidan śni ;

3 Cinca cantekiyapi śni, woope kicaksapi, waaiapi sa, iyatahdeiçiyapi sa, ohitiiçidapi, qa taku waśte śicedapi ;

4 Wicahnayanpi sa, wacinkopi, watankaiçidapi, magagaiciyapi kin he iyotandapi, qa Wakantanka iyotandapi śni.

5 Wakantanka awacinpi kin wiyacinpi kin yuhapi, tuka wowaśake kin he wicadapi śni ; tona hececapi kin hena etanhan ihdamna wo.

6 Hena hececapi kin tipi nahmana tin ipi, qa winohinca wacintonpi śni, woahtani hduśakapi, qa śicaya wacin yuzapi on icunonpa ayapi ;

7 Ohinniyan waonspeiciciyapi keś wowicake sdonyapi kin ehan ipi okihipi śni kin wayaka awicayapi ece.

8 Unkan, Jannes qa Jambres hena Moses kici akinicapi qon he iyecen, dena iś eya wowicake kin en ibotopi, wicaśta tawacin śicapi, qa wacinyanpi kin ayuśtanpi.

9 Tuka dena e sanpa iyoopta aye kte śni, witkotkopike cin owasin en tanin kta, hena e qe econpi qon iyececa.

10 Tuka niye wowaonspekiye mitawa kin tanyan sdonyaya, miohan kin, token miciconze cin, wacinwaye cin, wawacinkta mduza tanka kin, wacanwakiye cin, wahbayedan awape kin,

11 'Tehiya makuwapi kin, makakije cin, tona mahiyahde kin, Antiyoka ekta, Ikoniyon ekta, Lustra ekta, hena śicaya makuwapi kin mahiyahde; unkan owasin etanhan Itancan kin emahdaku.

12 Qa tona Jesus Messiya en ow otanna ohanyan cinpi kin hena owasin śicaya wacakuwapi kta.

13 Tuka wicaśta śica, wicahnayanpi sa ko, hena sanpa śicapi kta, wicahnayanpi qa nakun hnayanpi kta.

14 Hececa tuka niye qe taku onnispe, qa wicayada kin hena en un wo, tokiya tanhan onnispe kin he sdonyaya.

15 Qa honikśiyoqopa kin ehantanhan Wowapi wakan sdonyaya, he niniyan on ksamniye kta okihi, Jesus Messiya wacinyanpi kin eciyatanhan.

16 Wowapi wakan ocowasin Wakantanka Taniya kin eciyatanhan, qa waonspekiyapi, wiyopeyapi, owotanna kagapi, qa wicohan waśte en onspewicakiye cin he okihi.

17 Hecen Wakantanka wicaśta tawa kin ecedan un kta, qa wicohan waśte owasin on hduśtanpi kta.

\section{WICOWOYAKE 4.}

1 Heon, Wakantanka itokam, qa Jesus Messiya Itancan kin, tona nipi tapi ko wicayaco kta, tohan wokiconze hduha hi kinhan, he nakun itokam wahokonciciya ;

2 Wicoie kin oyaka wo, tohan 335 


\section{TIMOTHEOS.}

oiyokipi, qa nakun oiyokipi śni eśta, handitaiciya, wo. Owotanna wicakage wacin, iyopewicaya, wahokonwicakiya wo, woonspe qa wawacinkta yuzapi tanka kin on.

3 Anpetu wan $\mathrm{u}$ kte cin he tohan hi kinhan, woonspe waśte kin aktapi kte śni, tuka iye wicotawacin śice cin eciyatanhan waonspekiyapi kin awicakitapi kta, noge yaśpuyapi se iyececa heon etanhan.

4 Qa nogepi kin wowicake kin etanhan hduhomnipi, qa hitunkakanpi kin ekta ihdoyapi kta.

5 Tuka niye qe taku owasin en wakta yaun kta, wicokakije en waditaka wo; wotanin waśte oyakapi wicohan kin ecen econ wo; wicolian duhe cin he hduśtan wo.

6 Wanna wamihduśna kta iyemicihantu, qa wahde kte cin he wanna kiyadan ihan.

7 Okicize waśte kin ecamon, woiny anke kin ihuniwakiya, wacinyanpi kin he hduha waun ;

8 Qa tokata, woowotanna wateśdake wan mihnakapi, he Itancan wayaco owotanna kin maqu kta, anpetu kin he en; qa miye miśnana śni, tuka tona iye taniniciye kte cin waśtedakapi kin hena owasin koya.

9 Kohanna en mayahikta nina aciciya wo.

io Demas he amayuśtan, wiconi kin de waśtedake ca Thessalonike ekta kihda, Kreskes Galatia ekta, qa Titos Dalmatia ekta.

11 Lukas kiciśnana waun; Markos icu qa kici u wo, he iye wicohan kin de en omakiya ece. 336
12 Tucikos Ephesos ekta ye waśi.

13 Yau kinhan, Troas ekta Karpos śina emicihnake waśi qon he au wo, qa nakun wowapi kin hena, tahasaka owapi kin hena iyotan.

14 Aleksander mazazi kage cin he taku śica ota iyamaonpa ; iye ohan kin on Itancan kin kicicajuju nunwe.

$15 \mathrm{He}$ on waktaya un wo; wicoie unyaotaninpi qon he nina kipajin.

16 Tokaheya wowahdake ciqon he ehan tuwedan micica śni, qa owasin inamatanpi, he wicakiciyawapi śni nunwe.

17 Tuka hececa eśta, Itancan kin mici inajin, qa waśagmaye, ca hecen miye on woyakapi kin tanyan sdonyapi kta, qa lkcewicaśta kin owasin nahonpi kta; qa mnaja i kin etanhan emahdakupi.

18 Nakun Itancan kin wicohan śica owasin etanhan emahdaku kta, qa wokiconze malipiya ekta un kin he en nimaye kta. He iye wowitan owihanke wanin kiciun nunwe.

19 Priskila qa Akula napewicayuza wo, qa nakun Onesiphoros tiyohnaka tawa kin.

20 Erastos Korinth elkta yanka. Miletos ekta Trophimos wayazanka ehpeya wahdicu.

21 Nahahin waniyetu śni u kte hinca wo. Yubulos nape niyuza, qa nakun Pudens, qa Linos, qa Klauda, qa hunkawanjin kiciyapi kin owasin.

22 Jesus Messiya Itancan kin ninagi kici un nunwe. Wowaonśida nicipi un nunwe. Amen. 


\section{TITOS WOWAPI KICAGE CIN.}

\section{WICOWOYAKE 1.}

1 Palos Wakantanka taokiye, qa Jesus Messiya yeśi qon, tona Wakantanka wicakahniga, wacinyanpi kte cin heon, qa wowicake wicohan waśte en un kin sdonyapi kte cin heon;

2 Qa owihanke wanin wiconi opapi kte cin, Wakantanka itonśni okitpani, maka kagapi kin itokam iwahounyanpi qon he on ;

3 'Tuka wanna iyehantu qehan, eyanpahapi kin on oie kin hdaotanin, he niye maqupi, Wakantanka Wanikiya unkitawapi kin he eciyatanhan;

4 Titos, witaya wacinyanpi kin he eciyatanhan cinkśiwaye cin; Wowaśte, wowaonśida, wookiye ko, Wakantanka Ateyapi kin e tanhan, qa Jesus Messiya Itancan Wanikiya unhapi kin eciyatanhan kiciun nunwe.

$5 \mathrm{He}$ etanhan Krete en yanke ciśi, taku tona yuśtanpi śni kin hena wiyeya eyahnake kta, qa otonwe otoiyohi en hunkayapi wicayalage kta e on; token econ ciśi qon iyececa.

6 Tuwe iyaonpepica śni kinhan, wicaśta tawicu wanjidan, qa cinca wacinyanpi wicahduhe cin, wicakis unpi ewicakiyapi qa wanahonpi śni kin hececapi śni :

7 Waawanhdake cin he takudan iyaonpepica śni un kta, he Wakantanka taokiye kin ee; iśnana wacin en ihduze śni, waDak. cinko śni,miniśa en iyeiçiye śni, ohitiicida śni, qa mazaska nina akite kte śni ;

8 Tuka oicimani kin onśiwicada kta, qa taku waśte kin waśtedake kta, wacin ksapa un kta, qa owotanna, wacantkiya, qa iyatahdeiçiye śni un kta;

$9 \mathrm{Qa}$ token onspekiyapi qon he iyecen wicoie oyakapi kin sutaya hduhe kta, hecen woonspe ecedan kin on wahokonwicakiya okihi kta, qa tona kipajinic̣iyapi kin hena iyopewicaye kta.

10 Wicaśta wicaśtapi śni, qa witkoya iapi, qa wicahnayanpi kin heca ota, tona bakilidayapi etanhanpi kin hena iyotanpi.

11 Hena iohmus wicayapi kta iyececa; hena e qe tiyolnaka ocowasin yaptanyan iyewicayapi, qa mazaska wahteśni kin on taku iyecetu śni kin onspewicakiyapi ece.

12 Iyepi kin etanhan waayate wan heye ciqon; Krete oyate kin ohinniyan itonpiśni, wamanica ocinśice cin, qa wicatezi kuja kin hecapi ce.

13 Wayaotanin kin he wowicake. He etanhan nina iyopewicaya wo, hecen wacinyanpi kin en ecedan unpi kta:

14 Qa hecen Juda oyate hitunkakanpi yuhapi kin, qa wicaśta akantu woope kagapi kin wowicake kaśeye cin hena awacinpi kte śni.

15 Tona ecedan unpi kin hena taku owasin ecedan yuhapi, qa tona aśapapi qa wicadapi śni kin 337 


\section{TITOS.}

hena taku ecedan kin takudan yuhapi śni, tuka tawacinpi nagipi ko hena ee kaeś aśapapi.

16 Hena iś Wakantanka sdonyapi keyapi, tuka wicohan on aktapi śni, wahtepi śni, wanahonpi śni, qa wicohan waśte owasin en wacintonpi śni.

\section{WICOWOYAKE 2.}

1 Tuka niye qe taku woonspe ecedan en iyokipi kin hena ecen oie ya wo.

2 Wicaśta tankapi kin hena waktaya unpi kta, mdesahan wacin ksamya unpi kta, wacinyanpi, wacantkiyapi, wacintankapi ko en ecedan unpi kta.

3 Qa winohinca tankapi kin iś eya winohinca waśte iyecen ohanyanpi kta, waaiapi kte śni, miniśa ota en iyeiçiyapi kte śni, qa taku waśte onspe wicakiyapi kta :

4 Hecen wikośka kin ksamwicayapi kta, wicaśta yuhapi cinca ko waśte wicakidapi kta ;

5 Wacin ksapapi kta, ecepidan, tipi awanhdakapi kta, waśteya unpi kta, hihnakupi kin anawicakigoptanpi kta; hecen Wakantanka oie kin yaśicapi kte śni.

6 Kośka kin iś nakun wacin ksapapi kte cin iwahokonwicakiya wo.

$7 \mathrm{Qa}$ taku owasin on wicohan waśte kin en waonspekiya nihdutanin kta; woonspe kin en wayuśice śni, wacinksapa, owotanna;

8 Qa iapi ecedan qa iyaonpepica śni kin he nun kta; hecen tuwe itkopatanhan un kinhan, he iśtece kta, taku śica takudan aniie k ta okihi śni kin heon.

9 'Tona wowidake un kin hena itancan wicayuhapi kin anawi338 cakigoptanpi kta, qa taku owasin wakinicapi wanin iyokipı wicayapi kta;

10 Takudan mahimana icupi śni, qa wacinyanpi waśte ocowasin en ihdutaninpi kta. Hecen taku owasin on, Wakantanka Wanikiya unhapi kin tawoonspe kin he tanyan yuhapi kta.

11 Wakan tanka towaonśida wicaśta owasin wiconi wicakahi kin he wanna tanin;

12 Wakantanka aktapi śni, qa wicoicage cantiheyapi kin hena elpeunyanpi kta, qa nakaha wiconi kin en, wacinksamya, owotanna, wakanyan unnipi kta e onspeunkiyapi.

13 Qa wacinyanpi waśte ape unyakonpi kta, Wakantanka iyotan tanka, qa Jesus Messiya Wanikiya unhapi kin he wowitan hduha taniniciye kte cin hee.

14 He unkiyepi on ic̣içu, woahtani owasin etanhan opeunkitonpi kta, qa oyate tawawicaye kte cin wicohan waśte nina hin akitapi kte cin hena wicahduska kta e heon.

15 Hena wicoie kin hecen oie ye ça, wahokonwicakiye ça iyopewicaya wo. Ihnuhan tuwe śicenidake cinhan.

\section{WICOWOYAKE 3.}

1 He kiksuyewicaya wo, taku itancanpi qa wicowaśake kin hena ihukun iyeiçiyapi kta, wicaśtayatapi kin anawicagoptanpi kta, qa wicohan waśte owasin econpi kta, on wiyeya yukanpi kta.

2 Tuwedan yaśicapi kte śni, qa wicakizapi kte-śni, tuka wahbayedan unpi, qa wicaśta owasin on wacin tankapi kta.

3 Ehanna unkiś eya wacin untonpi śni, qa waanaungoptanpi 


\section{PHILEMON.}

s̊ni, unhnayanpi, qa cantiheyapi śica ota, qa iyokipiiciyapi kin en wowidake unyakonpi, woeanniye, icekinpi ko en unnipi, wahite śni unyakonpi, qa otoiyohi śiceunkicidakapi.

4 Tuka hehan Wakantanka Wunikiya unkitawapi kin he towaśte, qa wacantkiye cin wicaśta kin en yutaninpi qehan;

5 Wicohan owotanna econkupi kin eciyatanhan śni, tuka iye towaonśida kin eciyatanhan niunyanpi; teca wicatonpi woyujaja kin on, qa Woniya Wakan wicayuteca kin heon etanhan;

6 He Jesus Messiya Wanikiya unkitawapi kin eciyatanhan iyakiçuya unkakaśtanpi kin.

7 Hecen iye towaonśida kin on etanhan unyaowotanpidan kinhan, wiconi owihanke wanica unkapepi kin eciyatanhan, taku iye tawa kin he tawaunyanpi kta.

8 Iapi kin he wowicake; qa heon hena taku kin ohinniyan yasutaya iyae kta wacin; tona Wakantanka wicadapi kin hena wicohan waśte wacin ksamya opapi kta. Hena taku waśte, qa wicaśta kin en wawokihi.

9 Tuka witkoya wiwangapi, qa wicoicage oyakapi, qa wawakipajinpi, qa woope akinicapi kin hena okamnayan ya wo; hena takudan okihi śni qa ecinśniyan un. 10 Wicaśta waakinica un kin he wancadan, qa inonpa iyopeyapi kin, ihakamya lieyata iyeya wo.

11 Tuwe hecece cinhan, he wanna yuptanyanpi, qa woahtani econ, qa iye atayedan ihdaco kin he sdonyaya.

12 Tohan niye ekta Artemas, qa iś Tucikos ye waśi kinhan, kohanna Nikopolis ekta en mahi kite hinca wo; hen waniyetu waun kta miciconza.

13 Zenas woope aie kiyapi kin he, qa Apollos icimani ipi kinhan, takudan icakije śni tanyan iyoopteya yewicakiya wo.

14 Qa tona unkicicapi kin hena wicohan waśte aiciciya econpi kta, wicakijapi kin owicakiyapi kta, qa hecen waskuyeca icahye śni yukanpi kte śni.

15 Tona micicapi kin hena owasin nape niyuzapi. Tona wacinyanpi kin eciyatanhan waśteundakapi kin hena nape wicayuza wo. Wowaonśida niyepi owasin en nicipi un nunwe. Amen.

\section{PAL O S}

\section{PHILEMON WOWAPI KICAGE CIN.}

1 Palos, Jesus Messiya on, kaśka hnakapi kin he, qa 'Timotheos sunkaunyanpi kici, Philemon waśte unkidapi qa ounkiyapi ece kin,

2 Qa nakun Apphia waśteundakapi kin, Arcippos kici ama- kicita kin he kici, qa yati ohna okodakiciye kin; witaya wowapi unnicagapi :

3 Wowaonśida, wookiye ko, Wakantanka Ateunyanpi, qa Jesus Messiya Itancan kin etanhan, nicipi un nunwe. 


\section{PHILEMON.}

4 Wocekiye epa eca, ohinniyan ciksuye ca, on Wakantanka wopida ewakiya ece :

5 Jesus Itancan kin wacinyaye ca waśte yadaka, nakun tona owotanna un kin owasin, he nawahon kin heon;

6 Hecen wacinyaye cin owicayaqu kin he sanpa waśaka aye kta, on taku waśte owasin, Jesus Messiya eciyatanhan, unkiyepi en un kin he yutaninpi kta.

7 Mihunkawanji, wacanyakiye cin lıeon nina unkiyuśkinpi, qa unkicanptapi, tona owotanna un kin hena cantepi kin iyuśkinwicayaye cin heon etariban.

8 Qa heon taku iyokipi kin Messiya en itancanyan econ ciśi kta owakihi :

9 Tuka wacantkiyapi kin eciyatanhan ceciciya ce, Palos he miye, wanna wimacalinca, qa nakaha Jesus Messiya on kaśka mahnakapi waun.

10 Hecen Onesimos micinkśi, makaśkapi kin icunhan micinca wakage cin hee on ceciciya.

11 He ehanna takudan nicamna śni, tuka nakaha miye omakiye ca nakun niye oniciya okihi. He nakaha hde waśi.

12 Niye he iyowinkiya wo, minagi kin hee kaeś iyececa.

$13 \mathrm{He}$ yuha waun kta wacin, wotanin waśte kin on etanhan makaślzapi icunhan niye eekiya omakiye kte cin heon.

14 Tuka token yacin kin sdonye śni waun takudan ecamon kte śni ; taku waśte econ niśipi kin he iyecen ecanon kte śni, tuka niye cinka econ wacani kta he wacin.

$15 \mathrm{He}$ iye anpetu tonana ani340 yuśtan, ake ohinniyan yahduhe kta heon etanhan hecon naceca.

16 Wanna wowidake unpi kin iyecece śni, tuka wowidake kin ikapeya waśte, hunkawanjinkiciyapi waśtekidapi kin iyecen ; miś hecen wacin wakiyuze cin, niye iyotan hecen wacin yakiduze kta, wicacelipi qa Itancan kin nakun eciyatanhan hunkawanjinyaye kta.

17 Kodayapi iyecen mayaduha hecinhan, he miye iyecen ake ehdaku wo.

18 Taku icakiśniye ça, taku iyohiniciciye śni hecinhan, he miciyawa wo.

19 Palos he miye, minape kin on de owawa, he miye wakajuju kta. Qa taku miyecicajuju śni, niye atayedan ocowasin yaun kin he caje mdate śni.

$20 \mathrm{Han}$, mihunkawanji, Itancan kin en niye on imduśkin kta; Itancan kin en micante kin iyuśkinmayan wo.

21 Waanayagoptan kta imdukcan, heon wowapi cicaga; qa epe cin sam iyeya ecanon kta sdonwaya.

22 'Tipi tukten manke kte cin he nakun wiyeya emicihnaka wo; wocekiye ehapi kin on etanhan niyepi on makiyuślkapi kta epca waun.

23 Epaphras, Jesus Messiya on, kici makaśkapi kin he nape niyuza ;

24 Qa Markos, Aristarkos, Demas, qa Likas micihtanipi kin hena nakun.

25 Jesus Messiya Itancan unkiyapi towaonśida kin ninagi kin kici un nunwe. Amen. 


\section{PAL O S \\ H E B R E W O Y A T E}

\section{WOWAPI WICAKICAGE CIN.}

\section{WICOWOYAKE 1.}

I Ehanna, Wakantanka toktogye, otakiya wicaśta wokcan kin eciyatanhan hunkake wicunyanpi kin wowicakiyake ciqon, he, anpetu ehake kin dena icunhan, iye Cinhintku kin eciyatanhan wounkiyakapi ;

$2 \mathrm{He}$ on woicage kin owasin kage ca, he taku owasin tawaye kta e ehde :

3 He iye towitan okitanin, qa ouncage okagapi hince cin hee, iye towaśake oie kin on taku owasin liduha yanka, he is iye eciyatanhan waunhtanipi wopakinte kage cehan, Taku iyotan tanka wankan yanke cin he etapa kin en kiyotanka.

$4 \mathrm{He}$ iye caje wan mahpiya ohnihde kin isanpa waśte ailipeyapi qa yuhe cin, he iyecen sam iyeya waśte.

5 Micinkśi kin he niye, anpetu kin de cinca cicaga ce, mahipiya ohnihde kin tukte wanji eciya he. $\mathrm{Qa}$ ake, He atemaye kta, qa miye cinkśi waye kta ce.

6 Unkan, tokapa kin he wicoicage kin ekta hiyuye cehan hecen eya,. Wakantanka ohnihde wicaye cin owasin he itokam canpeśka makehde enajin kta ce.

7 Qa malipiya ohnihde kin hena on kaken eya, He tateyanpa kin ohnihdeye ca, peta ide kin wowidakeya ece.

8 Tuka Cinhintku kin heciya,
Wakantanka, oiyotanke nitawa kin he owihanke wanica; nitokiconze mazasagye kin he mazasagye owotanna;

9 Woowotanna waśteyadake cin heon Wakantanka, nita Wakantanka kin, tona nitawaśi kin hena isanpa wowiyuśkin wihdi on sdaniyan ce.

$10 \mathrm{Qa}$, Itancan, otokahe ekta maka ahe cin eyahde, qa ninape kage cin mahpiya kin hee;

11 Hena yutakuni śni aye kta, tuka niye ecen yaun; owasin onliolida wan iyecen kuke kta;

$12 \mathrm{Qa}$ sina wan iyecen pehan eyahnake ca, hecen yutokecapi kta; tuka niye okonniwanjidan, qa waniyetu nitawa kin owihanke kte śni ce.

13 Tuka ohnihdewicayc cin tukte wanji e, Mietapa kin en iyotanka wo, tona toka niyanpi kin hena nisiha woahe kin en ewicawahnake kta ce, eciya he.

14 Hena owasin taku wakan wawokiya, tona wiconi ailipewicayapi, qa tawapi kte cin hena owicakiyapi kta e u wicaśipi qon hena eepi śni he.

\section{WICOWOYAKE 2.}

1 Heon etanhan taku naunhonpi kin hena tohinni unkikusepi kte śni e on sutaya awauncinpi kta.

2 Wicoie mahpiya ohnihde oyakapi qon he suta, qa tona anagoptan śni, qa he kaśeye cin 341 


\section{HEBREW.}

hena owasin iyacinyan woyaco owotanna icupi hecinhan ;

3 Unkiye wiconi hinsko tanka kin unkaktapi śni kinhan, token naunpapi kta he. He tokaheya Itancan kin oyake ca, tona nahonpi kin hena atayedan unkokiyakapi :

4 Wakantanka iś eya, iye tawacin kin eciyatanhan, wicakiciyaotanin, wowapetokeca taku on yuśinyewicaye cin hena ko, waśagya econpi ota, qa Woniya Wakan wicakipamni kin hena on etanhan.

5 Wicoicage u kte cin cajeunyatapi kin he malipiya ohnihde kin yuhewicakiye śni.

6 Tuka wanji tukten yaotanin qa heya, Wicaśta kin he taku he, on yeksuye kta he; qa wicaśta cinhintku kin, hecen awanyahdaka he :

7 Mahpiya ohnihde kin kitanna ihukuya yakage ca, wowitan, woyuonihan ko wateśdake yecaton, qa taku nape on yakage cin hena yuheyakiya:

8 Qa iye siha kin ihukuya taku owasin eyahnaka. Taku owasin iye ihukuya ehnake cin, hecen taku ihukuya ehnakapi śni kin takudan okapte śni. Tuka nakaha nahahin taku owasin ihukuya ehnakapi kin wanunyakapi śni.

9 Tuka Jesus wiconte kakijapi kin on, mahpiya ohnihde kin kitanna ihukuya kagapi kin he wowitan, woyuonihan ko wateśdag kiton kin he wanunyakapi, hecen iye, Wakantanka towaonśida kin eciyatanhan, wicaśta kin owasin on wiconte sdonye kta.

10 Tuwe iye tan tanhan taku owasin un, qa iye on taku owasin un kin he cinca ota wowitan ekta wicahdoye kte cin on, wi342 coni tawapi kte cin mdetahunka kin he wokakije on ecedan kage kta e iyokipi.

11 Hecen tuwe wicayuecedan, qa tona yuecepidan kin hena owasin okonwanjipidan; heon etanhan hena hunkawanjin wicakiya kewicakiye kta iśtece śni ;

12 Qa hecen eya, Nicaje kin mihunkawanji owicawakiyake kta, qa okodakiciye kin cokata icidowan kta ce.

13 Qa ake, He wacinwaye kta ce. Qa ake, Iho, miye, qa cinca Wakantanka maqu kin hena.

14 Cinca kin hena wicacehpi, qa wicawe kin en opapi kin heon iś iye hena en opa; hecen tuwe wiconte wowaśake yuhe cin, Wakanśica hee, e ihangye kta;

$15 \mathrm{Qa}$ tona tohanyan ni unpi kin hehanyan wiconțe ikopapi kin on wowidake unpi kin hena ewicahdaku kta.

16 Awicakehan mahpiya ohnihde kin he koyake śni, tuka Abraham cinca kin hecen ihduza.

17 Heon etanhan taku owasin en, iye hunkawanjinwicaye cin iyecen ikicage kte cin he hecetu; hecen taku Wakantanka tawa kin en, Wawayuśna Itancan waonśida, qa wicake kta, qa oyate wahtanipi kin on wookiye wicakicage kta.

18 Iye, iyutanyanpi kin on, atayedan kakije cin, heon etanhan tona iyutanwicayapi kin hena ewicahdaku kta okihi.

\section{WICOWOYAKE 3.}

1 Heon, mihunkawanji wakan, mahpiya tanhan wicakico kin en oyapapi kin, wounhdakapi kin on Jesus Messiya yeśipi qa Wa- 


\section{WICOWOYAKE 4.}

wayuśna Itancan kin he awacin po.

2 Moses tipi ocowasin ohna owotanna un kin, he iyecen iye qe tuwe econ śi qon owotanna ecakicon.

3 Tuwe ticage cin he tipi kin sam iyeya yuonihanpi ece kin, he iyecen he qe Moses kapeya wowitan tanka yuha.

4 Tipi otoiyohi tuwe kaga ; tuka tuwe taku owasin kage cin he Wakantanka ee.

5 Moses wowidake un kin heca, tipi tawa ocowasin ohna wacinyepica un, taku oyakapi kte cin hena yaotanin kte cin heon.

6 Tuka Messiya, iye ti kin ocowasin ohna, Cinhintkuyapi kin iyececa; tipi tawa kin he unkiyepi, waditagya wounhdakapi, qa wowiyusikinyan wacinunyanpi kin he owihanketa tinsa unhapi kinhan.

7 Heon etanhan, Woniya Wakan kin kaken eya, Anpe dehan iye ho kin nayahonpi kta hecinhan;

8 Cante ihdutehipi śni po, hepuza en, anpetu wawiyutanyan un kin en, wawakipajinpi qon iyecen ;

9 Nihunkakepi iyutanmayanpi, qa mayukcanpi, qa waniyetu wikcemna topa hehanyan miohan kin wanyakapi ce.

10 Heon etanhan wicoicage kin he on iyomayake ca, hepa, Cantepi kin ekta ohinniyan nunipi, qa mitacanku kin sdonyapi śni ce.

11. Hecen śinwahda qa, Okihpapi mitawa kin en yapi kte sni ce, eya wakonza.

12 Mihunkawanji, wakta po, okinni cante wicada śni, qa śice cin en niunpi, on Wakantanka ni un kin aduśtanpi kta.
13 Tuka anpetu otoiyohi wahokonkiciciya po, anpe dehan eyapi kin hehanyan; okinni woahtani wohnaye kin on wanji tukte niyutehipi kta.

14 Tokaheya wicaundapi kin he owihanketa sutaya unhapi kinhan, Messiya en ounpapi.

15 Anpe delian, iye ho kin nayahonpi kinhan, cante hdutehipi śni po, wawakipajinpi qon en iyececa ce, eyapi kin hehanyan. 16 Tona nahonpi qon hena kipajinpi he: tuka Moses tona Egupta etanhan awicau qon hena owasin śni he.

17 Tona waniyetu wikcemna topa hehanyan iyoyakeyapi qon hena tuwepi he; tona wahtanipi, qa liepuza en tancan ilipayapi qon hena eepi śni he.

18 Qa okihpapi tawa kin en yapi kte śni, konza kewicakiye ciqon hena tuwepi he ; tona wicadapi śni qon hena eepi śni he.

19 Hecen wicadapi śni kin heon en yapi kta okihipi śni e wanunyakapi.

\section{WICOWOYAKE 4.}

1 Hecen okihpapi kin de en unkopapi kta e iwahounyanpi kin, heon niyepi kin wanjikśi iyoyahipi lte śni se ececa e ikounpapi kta.

2 Wotanin waśte kin unkokiyakapi, iś iyepi kin iyececa; tuka wicoie nationpi qon he owicakiye śni, tona nahonpi kin wowacinye icicahiyapi śni kin heon etanhan.

3 Tuka tona wicaundapi kin okihpapi kin en ounpapi kta ; heye ciqun iyececa; Śnwahda on okihpapi mitawa kin en opapi kte śni ce, epa ce; maka icage cin hehantanhan wicohan kin yuśtanpi tuka. 


\section{HEBREW.}

4 Tukten anpetu iśakowin kin he ke ca hecen eya, Anpetu iśakowin kin he Wakantanka okilipa, taku kage cin owasin etanhan.

5 Qa hen ake, Okihipapi mitawa kin en opapi kte śni.

6 Heon etanhan, hunh en opapi kte cin he tokata ihan, qa tona tokaheya wotanin waśte owicakiyakapi qon hena wicadapi śni kin heon en opapi śni.

7 Ake anpetu wan ke ca Dawid en heya, Anpe dehan, iye ho kin nayahonpi kinhan, cante hdutehipi śni po.

8 Jośuwa okilipe wicakiya unkanś, he iyohakam anpetu tokeca caje yate kte śni tuka.

9 Hecen Wakantanka taoyate kin okilipapi wan wicakicihan.

10 Tuwe okilipapi en ope cin he wanna tohtani kin ayuśtan, Wakantanka iye tawa ayuśtan qon iyececa.

11 Heon etanhan wookihpe kin he en unkopapi kta e amniheunkiçiyapi kta, okinni wicadapi śni qon he iyecen tuwe ihpaye kta naceca.

12 Wakantanka oie kin he ni un, wawokihi, qa mazasagye anog ope kin he isanpa pe hinca, wicanagi, wicaniya kici iyotahedan capa iyaye ca, okihepi cupe ko kicakse ça, wicotawacin wicacante wacin yuze cin hena koya iyukcan ece.

13 Qa taku kagapi kin takudan iye iśta kin en analibepica śni ; tuwe oicazo unqupi kin he iśta kin en taku owasin tancodan qa śdayehnahan yanka.

14 Heon Wawayuśna Itancan tanka wan, Jesus Wakantanka Cinhintku, mahpiya kin ekta iyaye cin hee unhapi kin heon wounhdakapi kin he sutaya unhduzapi kta.
15 Wawayuśna itancan kin, unkiye unkakijapi kin en unkicanptapi kta okihi śni kin heca unhapi śni, tuka iye taku owasin on iyutanyanpi, unkiye iyeuncecapi, tuka woahtani codan un.

16 Heon etanhan wowaśte oiyotanke kin en waditagya unkupi kta, hecen wowaonśida unkicupi kta, qa tohan uncinpi eca wowaśte wawokihi kin iyeunyanpi ece e kta.

\section{WICOWOYAKE 5.}

1 Wawayuśna itancan otoiyohi, wicaśta etanhan icupi kin, he Wakantanka taku tawa kin en, wicaśta on etanhan ehdepi, taku kicicupi, woahtani on wośnapi kin hena ko wayuśna kta e heon.

2 Tona onspepi śni, qa canku icunom yapi kin hena onśiwicada kta okihi, iś iye wookihi śni aohduteyapi nakaeś.

3 Qa heon oyate kin on wośna ece kin, he iyecen iś iye woahtani econ kin on taku wayuśna ece kta.

4. Qa tuwedan iye cinka wowitan kin de icu śni, tuka, Aaron iyecen, Wakantanka tuwe kico kin hecedan.

5 He iyecen, Messiya iś eya Wawayuśna itancan kta e ihdutan śni ; tuka tuwe, Micinkśi kin he niye, anpe dehan cinca cicaga ce, eciye ciqon hee hecon.

$6 \mathrm{Qa}$ nakun tokan en kaken eya; Melkizedel ouncage kin iyecen Wawayuśna owihanke śni kin henica ce.

$7 \mathrm{He}$ qe anpetu wicacehpi en un qehan, woceliye, wokidapi ko eye ça, iśta mnigaga nina hoyekiye ca, tuwe wiconțe etanhan ehdaku kta okihi kin he ce- 


\section{WICOWOYAKE 6 .}

kiye ca, kokipeyahan un kin, heon nalionpi.

$8 \mathrm{Qa}$.Cinhintku kin hee kaeś, taku token kakije cin on woanagoptan onspeiçiciya.

9 Qa iye yuśtanpi kin heon tona anagoptanpi kin owasin owihanke wanin wiconi kin wicakicaga.

10 Melkizedek ouncage kin iyecen, Wawayuśna Itancan, Wakantanka keciye cin.

11 Wicaśta kin he on taku ota unkoniciyakapi kta, tuka oyakapi tehika, wanahon yahunkapi śni nakaeś.

12 Hinnakaha waonspekiya henicapi kta, tuka nahahin tuwe Wakantanka oie oowa tokaheya kin hena akta onspeniciyapi kta e iyenihantupi, qa tona asanpi ece cinpi, qa waconica yun okihipi śni kin hee en iyoniptapi.

13 Tuwe kaśta asanpi ece yute cinhan, he wicoowotanna wicoie kin en wayupike śni, nahahin hokśiyoqopa nakaeś.

14 Tuka tona tankapi, qa wanna taku utapi on tanyan ihduśtanpi, taku waśte, taku śica ko iyukcanpi kin, hena waconica yutapi ece.

\section{WICOWOYAKE 6 .}

1 Heon etanhan Messiya woonspe tokaheya tawa kin he hekta elipeunkiyapi, qa woyuśtan ekta unyanpi kta; wiconte wicohan on iyopeiciyapi, qa Wakantanka wacinyanpi kin taku ahe cin akta eunhdepi kte śni ;

2 Baptem eyapi woonspe kin, qa nape on awicaputakapi, qa wicate cin ekicetuwicayapi, qa woyaco owihanke wanice cin hena koya.

3 Unkan Wakantanka iyowin- unkiyapi kinhan, hecen econkupi kta.

4 Tona wancadan iyoyanpapi, qa mahpiya tanhan taku wicaqupi kin he utapi, qa Woniya Wakan kin etanhan okinipi ;

5 Qa Wakantanka oie waśte kin he utapi, wiconi u kte cin wowaśake kin nakun;

6 Hena ayuśtanpi hecinhan, ake piya iyopeiciye wicakiyapi kte cin he okihipica śni; iye atayedan Wakantanka Cinhintku can susbeca en piya okatanpi, qa taninyan wowiśtenyapi kin heon etanhan.

7 Maka kin ota amagaju kin he yuhepe ca, tona kicanyanpi kin hena on taku peji iyecetuya aicage cin he Wakantanka yuwaśte.

8 Tuka taku takanheca hu, qa wapepelka aicage cin he ehpeyapi, qa yaśicapi kte cin kiyadan ihan, he owihanketa hulinage kta.

9 Tuka, waśtecicidapi kin, hena hecen unkeyapi eśta, niyepi kin on taku sanpa waśte qa wiconi en ope cin hena en niunpi e sdonunyanpi.

10 Wakantanka owotanna, qa heon wicohtani, qa wowaśte wokicanye nitawapi, iye caje kin on ecanonpi, tona owotanna un owicayakiyapi, qa nahahin owicakiya dukanpi kin he akitonje kte śni.

11 Unkan niyepi otoiyohi owihanketa, woape woyuśtan kte cin hehanyan iyecen amniheniciyapi kta uncinpi.

12 Qa nikujapi kte śni, tuka tona wicadapi, qa wacintankapi on, taku iwahowicayapi qon wanna yuhapi kin, hena owicayapapi kta.

13 Wakantanka Abraham taku iwahoye çehan, taku sanpa tan345 


\section{HEBREW.}

ka cajeyate kta wanica, heon iye atayedan cajeihdata ;

$14 \mathrm{Qa}$ heya, Awicakehan wowaśte on ciyawaśte kta, qa yuotapi kin on yuotaciye kta ce.

15 Unkan wahbayedan ape yanke cin he iyohakam taku iwahoyapi qon ekicicetu.

16 Wicaśta akantu taku iyotan tanka cajeyatapi ece; qa wokonze woyusuta kte cin he waakinicapi owasin en woanapte kin hee.

$17 \mathrm{He}$ en, Wakantanka, tona taku iwahoyapi qon tawapi te cin hena en, iye tawacin yuhohopica śni kin he iyotan sdonye wicakiye kta cin, qa heon wokonze on hdusuta.

18 Heon taku nom yutokecapica śni, en Wakantanka itonśni okihipica śni kin hena taku kin on etanhan, tona woape unkitokam ehdepi kin en onaunpapi kin wicakicanpte wan waśaka unhapi kta.

$19 \mathrm{He}$ unhapi, wicanagi taku on aspeiçiya, wicakapi qa suta kin hee, taku tipi cokaya hnakapi kin mahen tanhan un kin he en aspeiçiya.

20 Heciya Jesus kahin tokam ye cin unkiyepi on timahen iyaya, he Melkizedek ouncage kin iyecen Wawayuśna Itancan kin heca kagapi.

\section{WICOWOYAKE 7.}

1 Melkizedek, Salem Wicaśtayatapi, qa Wawayuśna Wakantanka Iyotan wankantu kin he tawa, hee, Abraham, wicaśtayatapi wicakaśtake cin, etanhan hdicu kin he itkokipe ça yawaśte.

2 Unkan Abraham taku owasin etanhan iwikcemna kin he qu. Wicaśta kin he tokaheya caje oyakapi kin on, Woowotanna wicaśtayatapi kin hee, qa hehan, Salem wicaśtayatapi kin, he Wookiye wicaśtayatapi kin hee. 3 Atkuku wanica, hunku wanica, qa wicoicage oyakapi kin wanica, anpetu tokaheya wanice ca wiconi owihanke wanica, Wakantanka Cinhintku kin iyecen icahyapi, qa Wawayuśna ohinniyan yanka.

. Wicaśta tanka kin de wanyaka po, Abraham, hunkakeyapi un kin hee kaeś, taku iwakte ahdi kin etanhan iwikcemna kin he qu.

5 Tona Lewi cinca kin etanhanpi, wośnapi wicohan yuhapi kin hena, wicoope kin eciyatanhan iye hunkawanjitkupi oyate kin etanhan taku icupi kta e iwahowicayapi; hena Abraham nite kin etanhan inanpapi tuka heconpi.

6 Tuka tuwe hena etanhan wicoicage hdawa śni kin he Abraham etanhan taku iwikcemna kin icu, qa wahoyapi kin yuhe ciqon he yawaśte.

7 Unkan he de akinicapi śni, tuwe ihukuya un kin he iyotan waśte kin on yawaśtepi ece.

8 Qa deciya wicaśta țapi kte cin hena taku iwikcemna kin icupi ece ; tuka heciya, he ni un e yaotaninpi.

9 Unkan he de heyepica; Lewi taku iwikcemna kin icu ece kin, he iś eya Abraham eciyatanhan taku iwikcemna kin wicaqu ;

10 Melkizedek itkokipe cehan he nahahin atkuku nite kin mahen un.

11 Heon etanhan, Lewi wośnapi wicohan yuhe cin eciyatanhan woyuśtan en au unkanś ; he en oyate kin wicoope yuhapi ; tokiyatanhan wawayuśna 
tokeca wan icage kta, Mellkizedek ouncage kin eciyatanhan, qa Aaron ouncage kin eciyatanhan caje yatapi kte śni he.

12 Wośnapi wicolian kin he yutokecapi kinhan, heon etanhan wicoope kin nakun yutokecapi kta.

13 Qa tuwe on hena hecen eyapi qon he wicoun tokeca etanhan inanpa; he etanhan tuwedan wahna wośnapi kin ekta ohanye śni.

14 Itancan unkitawapi kin he Juda wicoun kin etanhan icaga e sdonunyanpi; qa wicoun kin he wośnapi kagapi lita e Moses takudan eye śni.

15 Qa de iyotan atanin, Melkizedek ouncage kin iyecen, Wawayuśna tokeca wan icage kta; $16 \mathrm{He}$ wicacelipi wicoie woope kin eciyatanhan śni, tuka wiconi owihanke wanica wowaśake kin eciyatanhan icahyapi.

17 Melkizedek ouncage kin iyecen, Wawayuśna ohinniyan nanka ce, eya yaotaninpi qon.

18 Unkan nakun woahope tokaheya ye cin he yutokan iyeyapi, waśake śni qa taku okihipica śni kin heon etanhan.

19 Woope kin he takudan yuśtan śni, tuka wowacinye iyotan waśte kin he en au; qa heon Wakantanka kin en ikiyedan unkupi.

20 Iye wolkonze oie kin codan wawayuśna kin kagapi śni ; dena e wokonze oie codan wawayuśna wicakagapi ;

21 Tuka he qe wokonze wicoie kin eciyatanhan; tuwe, Melkizedek ouncage kin iyecen Wawayuśna ohinniyan nanka ce, Itancan kin heye ca iyopeiciye kte śni ce, eciye ciqon hee hecon.

$22 \mathrm{He}$ iyecen wicotakuye iyo- tan waśte kin en Jesus wayuecetu wan kagapi.

23 Wiconte kin on, ohinniyan en un okitpanipi kin, heon hena wawayuśna kin otapi.

24 Tuka he qe owihanke. wanin yanke cin, heon wośnapi wicohan yutokecapica śni wan yuha.

$25 \mathrm{Qa}$ hecen tona iye eciyatanhan Wakantanka en upi kin hena owasin niwicaye kta olihi, hena wocekiye ewicakiciye kta e ohinniyan ni un kin heon.

26 Wawayuśna Itancan kin hececa he iyounkipipi, wakan, iyaonpepica śni, waaśape śni, qa wahtanipi sa wicicunonpa un, qa mahpiya kin sanpa wankantuya icaliyapi.

27 He iye, wawayuśna kin hena iyecen, anpetu iyohi, tokaheya iye wahtani kin on, qa hehan oyate wahtanipi kin on etanhan wośna lite cin he iyecece śni; wancadan hecon, iye atayedan waihduśna qon he ehan. 28 Woope kin he wicaśta waśakapi śni kin hena wawayuśna wicakaga ece; tuka wokonze wicoie kin, woope iyohakam un kin, he Cinhintkuyapi, owihanke wanin yawaśtepi kin he kaga.

\section{WICOWOYAKE 8.}

1 Taku nakaha unkeyapi yuptahnakapi kin he dee; Wawayuśna Itancan kin hececa unhapi, mahpiya ekta Otancanke oiyotanke etapa kin en kiyotanka;

2 Tipi walkan kin he, qa wakeya wicakapi kin, Itancan ticaga qa wicaśta akantu econpi śni, kin he en ookiye kin hee.

3 Wawayuśna otoiyohi taku kiciçupi, wośnapi ko wayuśna kta e kagapi ; heon wicaśta kin 347 


\section{HEBREW.}

de iś eyạ taku wayuśna hduhe kta e hecetu.

4 Maka alkan un unkanś, Wawayuśna kin heca lite śni ; wawayuśna woope kin eciyatanhan taku kiciçupi kin wayuśnapi ece kin hena yukanpi kin heon.

5 Hena oowa, qa taku mahipiyata un kin ohanzi kin en ohanyanpi ece; Moses wakeya qon kage kta hehan Wakantanka okiye ca, Awacin wo, he kin ekta token wanyag niciyapi qon he iyecen owasin yaliage kta ce, eciya.

6 'Tuka nakaha iye wawokiyapi iyotan waśte wan yuha, wicotakuye waśte hinca, wahoyapi iyotan waśte kin en ahe cin he en wiciyotahedan un kin, heon etanhan.

7 Wicotakuye tokaheya kin he iyaonpepica śni unkanś, iyokihe kin he tuktedan kiyukanpi kte śni tuka.

8 Hena taku iyawicaonpe ça heya, Wanyaka wo, anpetu kin u kta, hena en Israel tiyohnaka, qa Juda tipi kin wicotakuye teca wicawecage kta, Itancan kin eya :

9 Egupta makoce kin etanhan awicawau kta e hena hunkakewicayapi kin nape wicamduze ciqon anpetu kin he en, wicotakuye wicawecage ciqon he iyecece śni; wicotakuye mitawa kin he miciyuhapi śni; qa heon miś ihawicawakta śni ce, Itancan kin eya.

10 Anpetu kin hena iyohakam wicotakuye wicawecage kte cin he dee; Hena wicotawacin kin en mitoope kin wicawaqu kta, qa cantepi kin akan owawa kta, qa miye Wakantanka mayanpi kta, qa miś hena mitaoyate wicawaye kta;

$11 \mathrm{Qa}$ wicaśta otoiyohi tuwe ikiyadan ti, qa otoiyohi hunkawanjitku kin onspewicakiyapi, qa, Itancan kin sdonya wo, eyapi kte śni; tuka owasin sdonmayanpi lkta, wohakak ta tankinkinyanpi ko:

12 Taku ecinśniyan econpi kin hena onśiwicawada kta, qa wahitanipi, wicolian śica econpi ko, icimana wicaweciksuye kte śni ce, Itancan kin eya.

13 Taku teca cajeyate cin he tokaheya kin yutanina kin heon heya. Unkan taku tanina, qa takuni śni aye cin, he tanin śni iyaye kta kiyadan ihan.

\section{WICOWOYAKE 9.}

1 Hehan awicakehan tokaheya qon he en woohoda wicohan kin yukan, qa nakun makata tipi wakan.

2 Wakeya wan kagapi, tokaheya kin he ohna petijanjan ihupa, qa wahna wotapi, qa aguyapi taninyan ehnakapi kin, he tipi wakan eciyapi.

3 Qa ti cokahnakapi icinonpa mahen tanhan, he wakeya kin iyotan wakan eciyapi :

4. Hen mazaskazi oizinyapi kin, qa wicotalkuye can koka kin akapatanhan owancaya mazaskazi akahpeton, hee ohna mazaskazi cega manna ohnakapi kin, qa can sakadan Aaron tawa kin hica aye ciqon, qa wicotakuye inyan mdaska kin hena. 5 Qa he iwankapatanhan, wowitan Cerubin wowaonśida ohe kin aohanziyapi ; hena on nakaha atayedan taku unkeyapi kte śni.

6 Hena taku kin hecen yuśtanpi qehan, wawayuśnapi kin wakeya tokaheya kin en yapi, qa ohodapi wicohan kin econpi ece. 7 'Tuka icinonpa kın he en $\mathrm{Wa}$

348 


\section{WICOWOYAKE 9.}

wayuśna itancan kin ecedan, waniyetu otoiyohi wancadan mahen i, qa we codan i śni, he iś iye atayedan on, qa oyate taku ecinśniyan econpi ko on en ai.

8 Heon Woniya Wakan kin hecen oyaka, Wakeya tokaheya kin nahahin ecen he cin icunhan, tipi iyotan wakan kin ekta canku kin nahaliin yuotaninpi śni :

$9 \mathrm{He}$ ito kayehan wiyacinpi un, qa en taku wicaqupi wośnapi ko aipi, tuka hena e tuwe hecon kin nagi kin yuecedan kta okihi śni.

10 Hena e woyuecetu lite anpetu kin hehanyan, woyute, qa woyatke, qa woyujaja ota, econ wicaśipi kin.

11. Tuka Messiya, taku waśte u kte cin en, Wawayuśna I tancan ihdutanin, wakeya iyotan waśte qa yuśtanpi, nape on kagapi śni, wicoicage kin de etanhan śni, kin he ohna;

12 Tatokadan qa ptejicadan we kin yuhe śni, tuka wopekitonpi owihanke wanin kage ca, iye we kin hduha wancadan tipi iyotan wakan kin timahen iyaya.

13 Hecen tatanka qa tatokadan we kin, qa pte heyuktanna ca. hota amnimnipi kin, tona waaśape cin wicayuecedan, qa wicacehpi yuska kta e okihi hecinhan;

14 Sam iyeya Messiya, Woniya owihanke wanice cin eciyatanhan, Wakantanka en iyaonpepica śni waihduśna qon, he iye we kin, wiconte wicolian kin etanhan nagi nipakintapi kta, Wakantanka ni un kin wowidag niyanpi kte cin heon.

15 Qa heon etanhan, Wicotakuye Teca kin en Iyotahedan un kin he iye, hecen wicntakuye tokaheya ihulkuya wahtanipi qon hena kajuju kta e on te cin, he eciyatanhan tona wicakico kin owihanke wanin taku tawapi kte cin iwahowicayapi qon he yuhapi kta.

16 Tukten wicotakuye wanji yukan hecinhan, hen wicotakuye liage cin he wanna ta e yutaninpi.

17 Taku tapi kin hena on wicotakuye wowapi kin suta ece; tuka wicotakuye kage cin nahanhin ni un kinhan, he takudan okihi śni.

18 Unkan heon wicotakuye tokaheya qon he we codan yuecepidan śni.

19 Woope kin eciyatanhan, Moses woahope kin owasin oyate lin owicakiyaka yaśtan qehan, ptejicadan, qa tatokadan we kin icu, qa mini, tahinca hin duta, peji hota ko, qa wowapi kin oyate kin owasin ko, awicamnimimi ;

$20 \mathrm{Qa}$ heya, Wicotakuye Wakantanka econ niśipi kin we kin he dee ce.

21 Qa nakun wakeya kin, taku waliśica wowinyunyanpi kte cin owasin ko we amnimni.

22 Woope kin eciyatanhan taku owasin se we on pakintapi; qa we papsonpi śni ehantanhan wokajuja wanica.

23 Heon etanhan, hena taku kin on, taku mahpiya ekta un iyacinpi kin pakintapi kta e hecetu; tuka taku mahpiya ekta un kin hena e qe taku sanpa waśte wośnapi kin on.

24. Messiya tipi wakan nape on kagapi kin he mahen i śni, tipi wakan hinca iyacinpi kin hena ee ; tuka malipiya kin e qe mahen, qa heciya unkiyepi on Wakantanka itokam ihdutanin kta.

25 Qa wawayuśna itancan kin he owanka wakan kin en, taku 349 


\section{HEBREW.}

tokeca we kin yuha, waniyetu otoiyohi wancadan mahen i ece kin he iyecen ota akihde waihduśna kta iyecece śni ;

$26 \mathrm{He}$ iyececa unkanś, maka liagapi kin ehantanhun, wanna ota akihde kakije kta tuka ; tuka nakaha woicage ihanke kin en, iye waihduśna kin eciyatanhan, woahtani yutokan iyeye kta e on taniniçiya.

27 Unkan wicaśta kin wancadan tapi kte cin he iwahowicayapi; qa he iyohakam woyaco kta :

$28 \mathrm{He}$ iyecen Messiya, wicota walitanipi kin yuhe kta e wancadan wayuśnapi; unkan, tona he wanyakapi kta ape yukanpi kin hena niwicaye kta e, woalitani codan, inonpa ibdutanin kta.

\section{WICOWOYAKE 10.}

1 Taku waśte u kte cin ohanzi kin he woope kin en un, qa hena atayedan taku kin ouncage kin hee śni ; heon etanhan, waniyetu otoiyohi wośnapi ohinniyan aipi kin he tona en hipi kin wicayuecedan kta okihi śni.

2 He okihi unkanś hena taku kin wayuśnapi ayuśtaupi kte śni he. Tona en opapi wancadan pakintapi kinhan icimana woalitani sdonkiyapi kte śni tuka.

3 Tuka hena on waniyetu otoiyohi woahtani kiksuyapi ece.

4 Tatanka tatokadan kici hena we kin woahtani yutokan iyeye kta okihipica śni.

5 Heon etanhan, makata hi qehan, Wośnapi, taku wicaqupi ko yacin śni, qa tancan wan miyecaga ce, eya.

6 Peta wośnapi, qa woahtani on wośnapi kin hena iyonicipi śni ;

7 Hehan, Ito wau, wowapi tanka en miye on hecen owapi ce ; Wakantanka, nitawacin kin ecen ecamon kta ce, epa.

8 Wankan, Wośnapi, taku wicaqupi, peta wośnapi, qa woahtani on wośnapi kin; woope eciyatanhan ahi wayuśnapi kin; hena yacin śni, qa iyonicipi śni, eye cehan ;

9 Ḣehan nakun, Wakantanka, nitawacin kin ecen ecamon kta wau ce, eye cin. Tokaheya kin he yutokan iyeya, icinonpa kin he hdusuta kte cin heon.

$10 \mathrm{He}$ iye tawacin kin ee on unyuecepidan, Jesus Messiya tancan wancadan wayuśnapi lin he eciyatanhan.

11 Wawayuśna otoiyohi anpetu iyohi, en ohoda inajin, qa ohinniyan taku wośnapi ece kin hena ake ecekcen wayuśna, hena woahtani kajuju kta tokadan okihi śni.

12 'I'uka wicaśta kin de, woahtani on wośna wanjidan wahduśna, hehan Wakantanka etapa kin eciyatanhan owihanke wanin kiyotanka;

13 Qa hetanhan tona toka yapi kin hena owasin iye siha kin ihukun iyewicayapi kta ape yanka.

14 Wośnapi wanjidan on etanhan tona wicayuecepidan kin hena owihanke wanin wicahduśtan.

15 Woniya Wakan kin he nakun unkiciyaotaninpi ; tokaheya eye ciqon he iyohakam;

16 Anpetu kin hena iyohakam, wicotakuye wicawecage $k$ te cin he dee kta, Itancan kin eya; Mitoope kin hena iye cantepi kin en wicawaqu kta, qa tawacinpi kin en owakiwa kta ;

17 Qa iye wahtanipi, taku ecinśniyan econpi k̇o, icimana weksuye kte śni. 


\section{WICOWOYAKE 10.}

18 Hena owasin kajujupi kinhan, woah̆tani on wośnapi kin wanice kta.

19 Heon, mihunkawanji, Jesus we kin eciyatanhan tipi iyotan wakan kin en waditagya unyanpi kte ;

20 Canku wan teca qa ni un, ti cokaya hnakapi, iye cehpi kin hee, ohna unkicagapi kin he eciyatanhan.

21 Qa Wakantanka ti kin ohna Wawayuśna Itancan wan unhapi ;

22 Heon cante wicake hinca hduha śogya wacinunyanpi qa ikiyedan unkupi kta, wicanagi śice cin etanhan uncantepi kin unkamnimnipi ;

23 Qa mini ska kin on untancanpi kin unyujajapi ; qa wacinunyanpi unhdaotaninpi kin he yuhohopi śni unhduhapi kta; tuwe wahounyanpi kin he wacinyepica :

24 Qa otoiyohi awaunkicicinpi kte, wacantkiyapi, qa wicohan waśte en iyounkicipaśtakapi kte cin heon.

$25 \mathrm{Qa}$ wanjikji econpi kin iyecen mniunkiciyapi ece kin he unkayuśtanpi kte śni; tuka wahokonunkiciciyapi kta; qa anpetu kin he kiyadan u wandakapi kinhan, sanpa nina ecanonpi kta.

26 Wowicake sdonyapi kin unkicupi kin he iyohaham iyokipiya waunhtanipi kinhan, woahtani on wośnapi kte cin wanica.

27 Tuka woyaco inihanyan apepi kin he, qa wocanniye ide kin, tona tokayapi kin hena ihangwicaye kta.

28 Tuwe Moses toope kin akta śni, nonpa qa iś yamni yaotaninpi kinhan, he onśidapi śni ta ece ;
29 Hecen tuwe Wakantanka Cinhintku we kin amani, qa wicotakuye we kin on yuecepidan qon le wakan śni dake ça, Wowaśte Woniya kin he taku $i$ en hiyeye cinhan, he wokakije iyotan tanka hiyahde kte śni kecannipi he.

30 Tokiçonpi kin he mitawa, towicawecicon kta ce, Itancan kin eya ce, tuwe eye ciqon he sdonunyanpi. Qa ake, Itancan taoyate kin wicayaco kta ce.

31 Wakantanka ni un nape kin en ohinhpayapi kin he wokokipe.

32 Anpetu tokaheya kin kiksuya po, hena en iyoyamniyanpi, qa hehan wicokakije okicize tanka wan iyahdeniciyapi.

$33 \mathrm{He}$ icunhan waaiapi, wicokakije ko on iwanniyakapi kta enihdepi ; qa nakun tona hecawicakiconpi kin hena tawaśi wicayayapi.

34 Miye makaśkapi kin icunhan onśimayakidapi, qa woyuha duhapi qon nicipi kin he on widuśkinpi, mahpiya ekta woyuha iyotan waśte ohinniyan ye kte cin he duhapi sdonyakiyapi kin heon etanhan.

35 Wadinitakapi qon he ayuśtanpi śni po, he woyuha tanka okihi kta.

36 Wacinnitankapi kta iyececa; hecen Wakantanka tawacin kin ecen ecanonpi kinhan, taku iwahounyanpi kin he iyacupi kta.

37 Wanna aśkadan tuwe u kte cin he hi kta, qa yutehan kte śni.

38 Tuwe owotanna un kin he wacinyan un kin on ni kta. Tuka tuwe namni kinhan he minagi kin iyokipi kte śni ce.

39 Tuka tona wicotakuni śni ekta icicawin hdapi kin heunca- 
pi śni ; tona wacanagi ni kta e on wicadapi kin hena unkiyepi.

\section{WICOWOYAKE 11.}

1 Wacinyanpi kin he taku apepi oahe kin ee, qa taku wanyakapi śni un yuotanin kin hee.

$2 \mathrm{He}$ on hunka wicayapi kin yuonihanyan ihdaotaninpi qon.

3 Wacinyanpi kin eciyatanhan, Wakantanka oie kin on woicage kin icahyapi kin he sdonunyanpi, taku wanyakapi un kin hena taku tanin kin etanhan kagapi śni.

4 Wacinyanpi kin eciyatarıan Abel Qain kapc ca, wośnapi iyotan waśte wan Wakantanka wakiyuśna qon he on owotanna e hduotanin; Wakantanka nakun hecen yaotanin, taku qu kin heon, qa he eciyatanhan ta keś nahahin ia ece.

5 Wacinyanpi kin eciyatanhan Henok wiconte wanyake kte śni e tokan ayapi, qa tuktedan iyeyapi śni, Wakantanka tokan aye cin heon. Tokan ayapi śni itokam Wakantanka iyokipiye cin he okiyakapi.

6 Tuka wacinyanpi codan tuwedan iyokipiye kta okihi śni. 'Tuwe en u kinhan he Wakantanka ni un, qa tona aiçiciya akitapi kin hena iyunwin wicaqu ece kin he wicada kta.

7 Wacinyanpi kin eciyatanharı Nowa Wakantanka ihamna, taku. nahahin wanyakapi śni kin hena, qa itonkipa un kin heon tiyohnaka tawa ni kte cin on wata tanka wan kaga; qa iye ohan kin on oyate kin wicayaco, qa hecen woowotanna wacinyanpi eciyatanhan un kin he tawa kta e icaga.

8 Wacinyanpi kin eciyatanhan Abraham, makoce wan yuhe kte 352 cin he ekta ye śipi qehan, anagoptan, qa tokiya ye kte cin tanyan sdonkiye śni iyaya.

9 Wacinyanpi kin eciyatanhan makoce iwahoyapi qon he en ounyan, makoce tawa śni kin en iyececa, Isaak qa Jakob taku. iwahoyapi qon om tawaye kte cin hena om wakeya ohna ti ece.

10 Otonwe wan taku ahde kin ahe cin he ape yanka, ticage ca icaliye cin he Wakantanka kin ee.

11 Wacinyanpi kin eciyatanhan, Sara iye qe cinca yuhe kta e wowaśake icu, qa wanna waniyetu ece kin sanpa hiyu tuka cinca ton, tuwe iwahoye ciqon he wicaka e awacin yanke cin heon.

12 Heon wanjidan etanhan, qa he ta nun seca, tuka he etanhan wicuta icaga, mahpiya wicanhipi kin iyenaka, qa miniwanca kahda wiyaka sukaza kin iyecen yawapica śni.

13 Dena owasin wacinyan tapi, taku iwahowicayapi qon nahahin icupi śni, tuka tehan tanhan wanyakapi, qa wicadapi, qa adoksohan icupi, qa maka akan oyate tokeca qa unhdaka unpi kin heca ihdaotaninpi.

14 Tona taku hececa eyapi kin hena makoce wanji akitapi e taninyan ohdakapi.

15 Unkan awicakehan makoce kin etanhan hiyupi qon he wacin en yuzapi unkanś, heciya ake ekta hdapi kta okihipi tuka.

16 Tuka: nakaha wanji iyotan waśte mahpiya ekta wanke cin hee akitapi. Heon etanhan Wakantanka hena Wakantanka tawapi kin eciyapi kta iśtece śni, qa otonwe wan wiyeya ewicakicihnaka.

17 Wacinyanpi kin eciyatan- 


\section{WICOWOYAKE 11.}

han, Abraham, iyutanyanpi qehan, Isaak wahduśna, qa tuwe taku iwahoyapi qon wicada kin he cinhintku ecedan kin wahduśna.

18 Isaak etanhan wicoicage nitawa kin cajeyatapi kta ce, eciyapi tuka qon.

19 Wiconte ee kaeś etanhan Wakantanka ekicetuya okihi he wicada; qa hetanhan nakun wiyacinpi on ehdaku.

20 Wacinyanpi kin eciyatanhan Isaak, Jakob qa Esa wicahdawaśte, taku u kte cin heon.

21 Wacinyanpi kin eciyatanhan Jakob, wanna te kta hehan, Joseph cinhintku napin wicahdawaśte, qa cansagye oinkpa kin akan wocekiye eya.

22 Wacinyanpi kin eciyatanhan Joseph, wanna te kta hehan, Israel cincapi kin hetanhan hdapi kte cin he caje yate ça, iye huhu kin aye wicaśi.

23 Wacinyanpi kin eciyatanhan, Moses tonpi kin, hehan hunkakepi kin wi yamni hehanyan anakihmanpi, hokśidan waśte e wanhdakapi, qa wicaśtaya: tapi toope kin kokipapi śni.

24. Wacinyanpi kin eciyatanhan Moses wanna tanka jeage cehan, Pharo cunwintku cinca eciyapi kta wicada śni ;

25 Wakantanka taoyate kin om kakija un kte cin he hdahniga, qa woahitani woiyokipi kin he ptenyedan yuhe kta e cin śni ;

26 Messiya on aiapi kin he, woyuha Egupta en un kin sam iyeya wowijice tanka daka; wokajuju iyunwin kin he awacin kin heon etanhan.

27 Wacinyanpi kin eciyatanhan Egupta makoce kin ayuśtan, qa wicaśtaya tapi tocanniye kin kokipe śni. Tuwe wanyagDak. pica śni kin he wanyaka se ape yanka.

28 Wacinyanpi kin eciyatanhan wośnapi wohduze, qa we amnimnipi kin hena kaga, tuwe cinca tokapapi kin ihangwicaye cin he iye owicayutan kte sni heon.

29 Wacinyanpi kin on Mde-śa kin he opta iyayapi, puze cin iyecen. Unkan Egupta oyate kin hecon utapi qehan, minin țapi.

30 Wacinyanpi kin eciyatanhan Jeriko conkaśke kin makata ihpaya, anpetu śakowin ohomni unpi qehan.

31 Wacinyanpi kin on, Rahab witkowinna kin, tona anagoptanpi śni kin om ihangyapi śni, makoce iwanyag hipi kin hena wookiye on iyowinwicakiye cehan. 32 Qa taku sanpa epe kta he; Gideon, qa Barak, qa Samson, qa Jeptha, qa Dawid, qa Samuel, qa wicaśta wokcanpi kin owasin owicamdake kta anpetu kin iyehankeca śni.

33 Hena wacinyanpi kin eciyatanhan wokiconze kin ohiyapi, wicohan owotanna ohanyanpi, wahoyapi kin icupi, mnaja kin iohmusyapi ;

34 Peta wohitike cin kasnipí, maza sagye ope kin nakicipapi, wowaśake śni etanhan waśagiciyapi, okicize en waditaka icicagapi, qa Ikcewicaśta ozuye kin napewicayapi.

35 Winohinca kin cinca kitapi kin ekicetuyapi ewicahdakupi. Qa wanjikji nina kakiśy api, tuka etanhán ehdakupi kta cinpi śni, woekicetu iyotan waśte kin yuhapi kte cin heon etanhan.

$36 \mathrm{Qa}$ wanjikji waaiapi, qa nina wicakaśtakapi kin on iyutanpi, qa nakun maza icicahihia, kaśka wicahnakapi ko on.

$$
353
$$




\section{HEBREW.}

37 Inyan on wicakiniupi, canibakse on bawicaksapi, iyutanwicayapi, mazasagye on wicaktepi ; talinca ha qa tatokadan ha loyag manin unpi; taku owasin icakijapi, kakijapi un qa śicaya wicakuwapi.

38 Hena maka kin de iyewicakicihantu śni; hewoskan manin unpi, he kin akan, taku itu unpi otipi, qa makolidoka kin ohna.

39 Hena owasin wacinyanpi kin eciyatanhan tanyan ihdutaninpi, qa taku wahoyapi kin ocowasin icupi śni.

40 Wakantanka taku sam iyeya waśte unkiyepi on ehnaka, hecen hena e unkicunonpa tanhan wicahduśtanpi kte śni.

\section{WICOWOYAKE 12.}

1 Heon etanhan waayataninpi mahpiya śoka wan hinsko tanka aohdute unyanpi kin, hecen taku tkeya qinpi kin owasin eunhnakapi kta, woahtani ohiunyanpi ece kin he koya, qa oinyanke unkitokam wanke cin he wacin tankaya unkinyankapi kta.

$2 \mathrm{Qa}$ Jesus wacinunyanpi kin toka kage ca hduśtan kin hee ekta euntonwanpi kta. He iye, wowiyuśkin itokam ehdepi qon he on, can susbeca kin hee kaeś iyowinkiye ca, wowiśtece kin he taku da śni, qa Wakantanka oiyotanke etapa kin eciyatanhan kiyotanka.

3 Tuwe wahtanipi sa taku i en hiyeyapi kin he iye en walibayedan iyowinye ciqon he awacin po, hecen nitawacinpi kin ekta iconimnipi kte śni, qa wacin iboyaśakapi kte śni.

4 Woahtani kici yecizapi kin en nahahin we kin ekta aiyahdeya ecanonpi śni.
5 Qa wowahokonkiye cinca iyecen oniciyapi kin he ayektonjapi he; Micinkśi, Itancan wicakapsinpsinte cin he śice dake śni wo, qa iyopeniye cinhan wacin ibośake śni wo, eye cin.

6 Itancan kin wicaśta waśtekida kinhan, he iyopekiye ça, cinca iyowinwicakiye cin otoiyohi hdapsinpsinta ece.

7. Wiyopeniy anpi kinhan, cinca kin iyecen Wakantanka ecaniconpi; tukte cinca kin he atkuku iyopekiye śni he.

8 Tuka owasin en opapi ece kin iyecen iyopeniyanpi śni kinhan, tuwe cinca tanin śni kin henicapi, qa cinhintkuyapi un kin henicapi śni.

9 Unkan, wicacelipi eciyatanhan atewicunyanpi kin hena iyopeunkiyapi ece, unkan wicunhduonihanpi hecinhan, sam iyeya wicanagi Ateyapi kin he anaungoptanpi kte ca on unnipi kta. 10 Hena e anpetu tonana hehanyan, token iyokipipi kin hecen iyopeunkiyapi; tuka he qe unwaśtepi kte cin he on, hecen iye towakan kin en ounpapi kta.

11 Wiyopewicayapi kin owasin en icunhan woiyokipi śni, tuka woiyokiśice; tuka ihakam tona hecawicakiconpi kin en wicoowotanna waskuyeca wookiye kin icahwicakiya ece.

12 Heon etanhan wicanape kaozezeya un kin héna yuwankan icu po, qa hupahu waśake śni kin hena koya;

13 Qa nisihapi canku mdaya kicaga po, taku huśte kin he icunonpa iyeyapi kte śni, tuka okiziyapi kte cin heon.

14 Owasin en wookiye akita po, qa nakun wowakan kin, he tuwe yuhe śni kinhan Itancan kin wanyake kte śni.

$15 \mathrm{Qa}$ tuwe Wakantanka to- 
waonśida kin iyohi kte śni naceca, heon aiciciya iwanihdaka po, okinni can hute paza icage ca, nagiyeniyanpi kta, qa hecen wicota aśamyapi kta.

16 Okinni wicawihomni wan yuke kta, qa taku wakan ohöda śni, Esa iyececa, he watokapa kin taku yutapi onśpadan iyopekiya.

17 Qa iyohakam woyawaśte kin hduhe kta, tuka lieyata iyeyapi, he sdonyayapi, qa token tawacin yutokeca kte cin he iyeye śni, iśtamnihanpe on nina akita tuka.

18 Paha oyutanpica, qa peta on ide qon he elta yahipi śni, qa taku iyotan samya wanke cin, qa otpaza, qa nina icamna kin;

$19 \mathrm{Qa}$ nakun mazayahotonpi tanka lioton, wicoie ho kin hena koya; he tona nahonpi qon wicoie kin he akta owicaliiyakapi kte śni e icekiyapi.

20 Taku econ wicaśipi qon he okitpanipi; Woteca wan hee kaeś paha kin yutan kinhan he inyan on kininpi kta, qa iś wanhinkpe on. liatpa iyeyapi kta ce.

21 Unkan he wanyakapi kin nina wowinihan, qa heon Moses, Nina mahniyanyan qa macancan ce, eya.

22 Tuka Zion Paha kin ekta yahipi, Wakantanka ni un otonwe tawa kin, Jerusalem mahipiya tanhan $u$ kin, qa ohnihde unpi kin kektopawinge ota ekta;

23 Omniciye tanka, qa tokaheya wicatonpi okodakiciye kin, mahpiya ekta caje owicawapi kin hena, qa Wakantanka owasin wicayaco kin he, qa wicaśta owotanna yuśtanpi nagipi kin hena ekta;
$24 \mathrm{Qa}$ Jesus wicotakuye teca kin en iyotahedan un kin hee ekta, qa we amnimnipi kte cin, Abel sam iyeya taku waśte eye cin he ekta.

25 Ihnuhan tuwe ie cin anayagoptanpi śni kinhan; tona tuwe maka akan ie ciqon he anagoptanpi śni qon liena najicapi śni hecinhan, sam iyeya unkiye naunjicapi kte śni, tuwe mahpiya tanhan ie cin ihaunktapi śni kinhan.

26 Iye ho kin he ehan maka kin yahuhuza, tuka nakaha wahounyanpi qa heya, Ake wancadan maka ecedan mdahuhuza kte śni, tuka nakun mahpiya kin.

27 Unkan, Ake wancadan, eye cin he taku tona yahuhuzapi kte cin hena taku kagapi kin iyecen yutokan iyeyapi kta, hecen taku tona yahuhuzapica śni kin hena ecen he kta, he kapi.

28 Heon etanhan wokiconze yuhohopica śni kin unkicupi, wowaonśida unhapi kta, hecen woyuonihan, wokokipe ko yuha Wakantanka iyokipiya ohoundapi kta.

29 Wakantanka unkitawapi kin he peta wahulinahye cin heca.

\section{WICOWOYAKE 13.}

1 Hunkawanjinkiciyapi waśtekicidapi kin he ecen un nunwe. 2 Oicimani kin wonwicaya akiktonjapi śni po ; heconpi kin on wanjikśi mahpiya ohnihde kin sdonwicaye śni won wicayapi.

3 Tona kaśka wicahnakapi kin hena om nicaśkapi kin iyecen wicakiksuya po; qa tona kakiśyapi un kin hena koya, wicatancan kin ohna dukanpi kin heon. 


\section{HEBREW .}

4 Owasin en wakan kiciyuzapi kin he woyuonihan, qa ohehdepi aśamyapi śni kin; tuka wicawihomnipi qa wawicihahapi econpi kin hena Wakantanka wicayaco kta.

5 Waicucupikte cin wanin oyahandapi kta, qa taku duhapi kin hena on iyonicipipi nunwe. 'Tohinni aciyuśtan kte śni qa icinana ehpeciye kte śni, eye ciqon heon etanhan.

6 Heon, Itancan kin omakiye cin hee, qa he etanhan taku wicaśta akantu ecamiconpi kte cin kowakipe kte śni ce, waditagya unkeyapi kta.

7 Tona awannihdakapi, Wakantanka oie kin oniciyakapi kin hena wicakiksuya po, hena wicohan ihanke kin he awacin po, qa wacinyanpi qon he en opa po:

8 Jesus Messiya, litanihan qa makaha okonwanjidan, qa owihanke wanice kta.

9 Ihnuhan woonspe otakiya qa toktokeca on yutokan iyeniyanpi kinhan; woyute tona he awacinpi qon takudan okihiwicaye śni kin he wicacante kin yusuta śni, tuka wowaonśida kin on yusutapi kin he waśte.

10 Wahna wośnapi wan unhapi kin he etanhan tona wakeya qon ohna ohanyanpi kin hena yutapi kta iyececapi śni.

11 Woteca, tona we kin woahtani on, wawayuśna itancan kin tipi wakan kin timahen ai qon, hena tancanpi kin tihocoka kin itankan hulinahyapi ece.

$12 \mathrm{Heon}$ Jesus iś eya, iye we kin on oyate kin wicayuecedan kta e otonwe tiyopa kin itankan kakiśyapi qon.

13 Hecen iye on aiapi qon aihpeunyanpi kin yuha ekta wicoti kin tankan unyanpi kta.
14 Deciya otonwe ohiuniyan ecen he cir unhapi śni, tuka wanji $u$ kte cin he unkakitapi.

15 Heon etanhan, iye caje on, ohinniyan Wakantanka en wowitản wośnapi kin unkaupi kta, unkihapi etanhan waskuyeca, iye caje kin on, wounhdakapi kin hee.

16 Taku waśte econpi, qa wacantkiyapi kin hena akiktonjapi śni po, liena wośnapi kin Wakantanka iyokipi ece.

17 Tona wahokonniciyapi kin hena anawicakigoptan po, qa wicihukuya yeiçiya po, hena ninagipi kin on awanniyakapi, ohdakapi kte cin he iyecen; hecen wowiyuśkinyan econpi kta, qa woiyolisśnya econpi kte śni; he niyepi kin on waśte.

18 Wocekiye unkekiciya po; wicanagi waśte unhapi unkecinpi, taku owasin en owotanna unkohanyanpi kta uncinpi.

19 Tuka hecanonpi kta e iyotan ceciciyapi, kohanna niyepi ekta u mayanpi kte cin heon.

20 Unkan, Wookiye Wakantanka kin, Jesus Itancan unkiyapi, tahinca awanwicahdake tanka kin he, wiconte etanhan ake hiyuye ciqon he wicotakuye owihanke wanica we kin eciyatanhan,

21 Iye tawacin kin ecen ecanonpi kta e, wicohan waśte owasin en niyusutapi kte, qa taku iye iśta kin en oiyokipi kin ecaniconpi kta, Jesus Messiya eciyatanhan; he wowitan owihanke wanica kicihan nuwwe.

22 Mihunkawanji, ceciciyapi ce, wowahokonkiye wicoie kin iyowinkiya po, wicoie tonana on wowapi cicagapi.

23 Timotheos hunkawanjin unyanpi kin wanna kiyuśkapi e 


\section{WICOWOYAKE 1.}

sdonya po, he ecadan u kinhan kici wanciyakapi kta.

24 Tona niyepi en itancanpi kin hena owasin, qa tona owotanna un kin owasin uape wica- yuza po. Italia etanhanpi kin hena nape niyuzapi.

.25 Wowaonśida kin niyepi owasin en nicipi un nunwe. Amen.

\section{J A K O B}

\section{TA W OW A PI KIN .}

\section{WICOWOYAKE 1.}

1 Jakob, Wakantanka taokiye, qa Jesus Messiya Itancan tawa kin he, wicowazi akenonpapi enanakiya eyaye cin hena wowapi wicakicaga; wookiye.

2 Mihunkawanji, taku wawiyutanyan un kin ota ayakipapi kinhan, he wowiyuśkin ocowasin hdawa po:

3 Wacinyayapi iyutanpi kin he wacintankapi kaga e sdonyayapi.

4 Tuka wacintankapi kin he tohan kin tanyan hduśtan kte; hecen niyuśtanpi qa ocowasin yaunpi kta, qa takudan iyonitpanipi kte śni.

5 Niyepi etanhan tuwe woksape nice cinhan, Wakantanka kida kta, iye owasin iyakicuya wicaqu ece, qa iyopewicaye śni ; unkan qupi kta.

6 Tuka takudan cețunhda śni wacinyan kida kta ; tuwe wacetunhda kin he miniwanca taja kin iyececa, tateyanpa kaśkanśkan qa kahoya ehpeye cin.

7 Wicaśta kin he Itancan kin etanhan taku icu kta kecin kta iyecece śni.

8 Wicaśta tawacin nonpa kin he tacanku owasin ohna kaktihanhon un ece.

9 Hunkawanjinkiciyapi wahpa- nica kin yuwankan iyeyapi kinhan, heon iyuśkin kta.

10 Tuka wijica un kin yuwahpanicapi kinhan, on iyuśkin kta ; peji hica lkin he iyecen tokan aye kte cin heon.

11 Anpetu wi kin hinanpe ca kata aya eca, wato kin śniśya ece, qa wahca ihpaye ca owanyake waśte kin he atakuni śni ece: he iyecen wicaśta wijica kin iye tolian kin en awihnuni kta.

12 Wicaśta iyutanyanpi kin he yawaśtepi ece; tohan tanyan yukcanpi kinhan, hehan wiconi wateśdake, Itancan kin tona waśtedakapi iwahowicaye ciqon, hee icu kta.

13 Tuwe iyutanyanpi kinhan, Wakantanka iyutanmayan ce, eye kte śni: Wakantanka taku śica on iyutanyanpi kta okihi śni, qa nakun tuwedan iyutanye śni.

14 Tuka wicaśta otoiyohi iye cantiheye śice cin on iyutanpi qa iyakapeyapi ece.

15 Hehan wocantiheye śice cin icage cinhan woahtani kaga ; qa woahtani yuśtanpi eca, wiconte icahya ece.

16 Mihunkawanji waśte, ic̣ihnayanpi śni po.

17 Taku wicaqupi waśte qa yuśtanpi kin owasin wankantan- 


\section{JAKOB.}

han un, qa iyoyanpa A teyapi kin eciyatanhan kun $u$ ece ; iye qe tokeca śni, qa yuhomnipica śni hinca.

18 Iye tawacin kin eciyatanhan, wowicake oie kin on cinca unkagapi, hecen taku kage cin ehna unkiye waskuyeca tokaheya iyeuncecapi kta.

19 Heon etanhan, mihunkawanji waśte, wicaśta otoiyohi wanahon ohanko kta, ie kapin kta, qa wacintanka kte:

20 Wicaśta śinhdapi kin he Wakantanka toowotanna kin icahye śni.

21 Heon etanhan, wicowahteśni kin owasin, qa taku śica iyatahdepi kin ehpeya po; qa wicoie ninagipi niye kta okihi kin he onśliçiya icu po.

22 Tuka wicoie kin ecen econ po, qa iye icihnayanpi, nahonpi ecedan, unpi śni po.

23 Tuwe wicoie nahion eśta ecen econ śni kinhan, he wicaśta wan ihdiyomdasin on ite iwanihdake cin iyececa;

24 Iwanihdake ca tankan iyaya, unkan hehan hinnakaha ite tokeca kin he akiktonja ece.

25 Tuka tuwe wicoope on tawaiçiyapi yuśtanpi kin he opahta yanke ça, en un kinhan, tuwe nahon qa akiktonje cin heca śni, tuka wicohan econ kin heca, hee e taku econ kin en yawaśtepi kta.

26 Tuwe niyepi kin etanhan woohodapi kin en opa se ececa hecinha19, qa ceji hdaśke śni, tuka iye cante içihnaye cinhan, he woohodapi ope cin he taku śni.

27 Wakantanka qa Ateyapi kin itokam woohodapi opapi ecedan qa aśape śni kin he dee; Wamdenica qa wiwazica kakijapi eca en wicahipi, qa wicoi358 cage kin en taku iyaonpepica śni ihduhapi kin hee.

\section{WICOWOYAKE 2.}

1 Mihunkawanji, Jesus Messiya, wowitan Itancan wacinyanpi kin, on wicaśta iwandakapi kte cin he yuhapi śni po.

2 Nitomniciyepi kin en, wicaśta wan mazaskazi napcupe yuhe ca wokoyake waśte kiçun kin en hi kinhan; qa nakun wicaśta wahpanica wan heyake śica un kin en hi kinhan;

3 Qa tuwe wokoyake waśte kiçun kin he tanyan ayatonwanpi, qa heyakiyapi, Oiyotanke waśte kin de en hiyotanka wo ; qa wicaśta wahpanica gon, Hen najin wo, qa iś, siha wahde kin ihukuya hiyotanka wo, eyakiyapi kinhan ;

4. Otoiyohi tanyan canteyeciyuzapi śni, qa wicotawacin śica eciyatanhan widukcanpi śni he.

5 Nahon po, mihunkawanji waśte: Wakantanka maka akan wahpanicapi kin hena wicakahniga he, wacinyanpi on wijicapi, qa tona iye waśtedakapi wokiconze iwahowicaye ciqon he tawayapi kte cin.

6 Tuka niye wahpanicapi kin wahtewicayadapi śni. Wijicapi kin hena iyotanhan iyeniciyapi śni, qa woyaco oiyotanke kin en aniyanpi śni he.

7 Wicacaje waśte on cajeniyatapi ece kin he yaśicapi śni he.

8 Wowapi kin eciyatanhan, woope iyotan waśte, Nikiyedan un kin niye inihdacin waśteyadake kta ce, eyapi kin he ecen ecanonpi kinhan, tanyan ecanonpi kta.

9 Tuka wicaśta token ihduze cin ekta eyatonwanpi kinhan, woalitani ecanonpi, qa woope 


\section{WICOWOYAKE 3.}

kin on śicaya econ oniyakapi ece.

10 Tuwe woahope owasin yuha eśta, wanjidan kicakse cinhan, he ocowasin on yacopi.

11 'Tuwe, Wawiciliahapi ecanon kte śni ce, eye ciqon he is nakun, Wamayanon kte śni ce, eya. Unkan wawicihahapi takudan ecanon śni eśta, wamayanon kinhan, wanna woope kin kiyecaksa.

12 Tona woope on tawaiçiyapi kin on wicayacopi kte cin hena iyecen iapi, qa econ po.

13 Tuwe waonśida śni kin he wowaonśida wanin woyaco ecedan qupi kta; qa wowaonśida woyaco kin kapeya iyuśkin ece.

14 Mihunkawanji, tuwe wacinyan keya eśta, iyecen wicohian yuhe śni kinhan, he taku iyokihi kta he. Wacinyan un kin he niyan okihi he.

15 Nibunkawanji qa nitawinohtin tancokapidan, qa anpetu iyohi woyute nicapi kinhan;

16 Qa wanji hewicayakiyapi, Wookiye on hdapo, cosiciyapi qa wipiiciya po; tuka taku wicatancan icakije cin hena wicayaqupi śni ehantanhan, taku iwaśtepi kta he.

17 He iyecen wacinyanpi kin, wicohan codan kinhan, he wanna ța, iśnana un kin heon.

18 Han, tuwe heye kta; Niye wacinyan yaun, qa miye wicohan mduha; hecen wacinyaye cin he niohan codan makipazo wo, kinhan miohan kin ou wacinwaye cin he cicipazo kta ce.

19 Taku Wakan kin wanjidan he wicayada; he tanyan ecanon; taku wakan śicapi kin iś eya wicadapi qa cancanpi ece.

20 Tuka, wicaśta wacinton śni kin, wacinyanpi wicohan codan kin he ta e sdonyaye kta he.
21 Abraham ateunyanpi kin he, cinhintku Isaak wahna wośnapi alkan wahduśna qon he ehan, wicohian on yaowotanpi śni he.

22 Qa iye ohan kin kici wacinye cin token ohanye ca, wicohan on wacinye ciqon he yuśtanpi e wandaka he.

23 Unkan hecen wowapi kin, Abraham Wakantanka wicada, unkan he woowotanna kiciyawapi, qa he Wakantanka takicuwa eciyapi ce, eyapi qon he yuecetupi.

24 Heon, wacinyanpi ecedan on etanhan śni, tuka wicohian kin on wicaśta owotanna yawapi ece he wandakapi.

25 Nakun Rahab witkowinna kin ohnihde unpi qon hena iyowinwicakiye ca canku tokeca ohna hde wicaśi qehan, iś eya wicohan on owotanna yawapi śni he.

26 Wicatancan kin woniya codan un kin he ta ece, he iyecen wacinyanpi kin wicohian codan kinhan, he nakun ța ece.

\section{WICOWOYAKE 3.}

1 Mihunkawanji, wicota waonspekiya unpi śni po; woyaco iyotan tanka unkicupi kta e sdonyayapi.

2 Owasin taku ota on waunhtanipi ece. Tuwe oie on wahtani śni kinhan, he wicaśta yuśtanpi qa tancan ocowasin hdaśke kta okihi.

3 Wanyaka po, śuktanka anaungoptanpi kta e heon iikiyuwi i kin en iyewicunkiciyapi; qa tancanpi ocowasin wicunyuhomnipi ece.

4 Wita wata kin hena nakun wanyaka po, tankinkinyan qa tate ohitika on kaha iyeyapi eśta, iyupse yuza cistinna on 359 
token itancan kin cin eca, yuhomnipi ece.

5 He iyecen wicaceji kin taku cistinna, tuka tanka icida ece. Iho, peta cistinna keś can tanka ideya ece.

6 Wicaceji kin he peta, qa woahtani iyatahdepi ; hecen wicaceji unhuhapi kin ehna un, wicatancan kin ocowasin aśamya, qa wicoicage ohomniyan aideye ca, iś eya wakanśica ti kin etanhan ideiciya.

7 Woteca ocaje owasin, qa taku kinyan unpi, taku sdohan unpi qa miniwanca mahen unpi kin, henakiya etanhan wicaśta wanunyanpi wicakage ca wicayuha :

8 Tuka wicaceji kin he tuwedan yuwalibaka okihi śni; he wośice wicaśta śni, pejihuta śica on wicata ece kin he ojudan.

9 He on Wakantanka Ateyapi kin unyawaśtepi; qa he on wicaśta akantu, Wakantanka ouncage iyecen kagapi kin hena wicunyaśicapi ece.

10 Wicai wanjidan etanhan wayawaśtepi qa wayaśicapi kin hinanpa ece. Mihunkawanji, hena hecetu śni.

11 Miniyowe wan oenape wanjidan etanhan, mini waśte qa nakun mini pa hinca hiyuya he.

12 Mihunkawanji, suken can wan Oliwe waskuyeca aicaga, qa iś hastanyanka iyuwi wan suken waskuyeca okihi he; he iyecen miniyowe wan mini waśte qa nakun mini pa hinca hiyuye śni ece.

13 Enitanhanpi tuwe wicaśta ksape ça wiyukcan un he; woksape wowahbadan on tanyan aihduhe cin eciyatanhan iye ohan waśte hdutanin kte.

14 Tuka winawizipi pa hinca, qa wakinicapi nicantepi kin en duhapi kinhan, ihnuhan widuśkinpi qa wowicake kin on iystonpi śni kin.

15 Wicoksape kin he wankantanhan u śni; tuka maka kin etanhan, wicacehpi etanhan, qa wakanśica iyececa.

16 Tukten winawizipi qa wakinicapi yuke cinhan, wicotoketu tanin śni qa wicohan śica owasin hen un ece.

17 Tuka woksape wankantanhan un kin he tokaheya ecedan, hehan wokiyapi kaga, wahbadan, waanagoptan, wowaonśida qa waskuyeca waśte on ojudan, owotanna wiyukcan qa owotanna wohdaka ece.

18 Unkan tona wookiye kagapi kin hena woowotanna waskuyeca kin wookiye en owicakicijupi ece.

\section{WICOWOYAKE 4.}

1 Niyepi ekta wicokicize qa wakinicapi kin tokiyatanhan u he; cantiheyayapi śica nihuhapi en wakis un kin hena eciyatanhan śni he.

2 Cantiheyayapi tuka duhapi śni; wicayaktepi qa yuhe wacannipi, tuka icu oyakihipi śni ; wicayakizapi qa zuya dapi, tuka taku duhapi śni, yadapi śni kin heon etanhan.

3 Yadapi tuka iyacupi śni ece, ecinśniyan yadapi kin on, cantiheyayapi śica on dusotapi kte cin heon.

4 Wiinayahmanpi qa wawicihahapi ecanonpi kin, wicoicage kin de waśtedapi kin he Wakantanka śicedaka e sdonyayapi śni he. Heon tuwe wicoicage kin de wotakuye wacin kinhan, he Wakantanka tokaya.

5 Wowapi wakan kin, Woniya en unyakonpi kin he winawizipi 


\section{WICOWOYAKE 5 .}

cantiheya ce, ituya eya idukcanpi he.

6 Tuka sanpa wowaonśida wicaqu ece; heon heya, Wakantanka walianiçidapi kin wicakipajin, tuka tona onśikihanpi kin hena wowaonśida wicaqu ece.

7 Heon etanhan, Wakantanka ihukuya iyeiciya po. Wakanśica kipajin po, kinhan nanicipapi kta.

8 Wakantanka ikiyedan u po, hecen is nikiyepidan u kta. Wahtanipi sa, nape hdujaja po; qa wacin ninonpapi kin, cante hduecepidan po.

9 lyokiśicapi, waśihdapi qa ceya po; iyahapi kin he wicaceya ee kta, qa widuśkinpi kin he woiyolkišice kta.

10 Itancan kin itokam makata elipeiciya po, kinhan yuwankan inicupi kta.

1I Mihunkaw anji, otoiyohi akiciiapi śni po. Tuwe hunkawanjitku aie ça hunkawanjitku hdaco kinhan, he woope kin aie ca woope kin yaco ; tuka woope kin daco kinhan, woope kin ecen econpi kin henica śni, tuka wayaco kin henica.

12 Woope kage cin he Wanjidan, he wanikiye ca nakun waihangya okihi. Wicaśta tokeca daco kin niś nituwe he.

13 Tho po, nakaha tona hehapi ; Dehan, qa iś heyakecinhan, otonwe lin kae ekta unyanpi qa waniyetu wanji en unyakonpi kta, wopeuntonpi qa wiyopeunyanpi qa taku unkamnanpi kta ce.

14 Tuka heyakecinhan taku u kte cin sdonyayapi śni; yanipi kin he taku he, opo wan cistiyedan tanin qa hehan atanin śni kin he heca.

15 Kaken ehapi kta iyececa; Itancan kin iyowinunkiyapi qa unnipi kinhan, decen qa iś kaken econkupi kta ce.

16 Tuka nakaha wahannicidapi kin on iduśkinpi; hecen wiyuśkinpi kin owasin śica.

17 Heon etanhan, tuwe taku waśte econ kta sdonkiya tuka econ śni eca, he woahtani içicaga ece.

\section{WICOWOYAKE 5.}

I Tho po, tona wijica yaunpi kin, wokakije nihiyahdepi kte cin hena on ceyapi qa śicahowaya po.

2 Woyuha nitawapi kin kuka, qa nitawokoyake kin wamduśkadan yapotapi.

3 Mazaskazi qa mazaska nitawapi kin gigi aya; qa gigi kin he niyutaninpi kta, qa nicehpipi kin ihangye kta, peta iyececa. Woyuha anpetu ehake kin amnaniçiyapi.

4 Wanyaka po, tona maga nitawapi abaksapi wokajuju hnaye ayanicapi kin he howaya; qa tona aguyapi baniciksapi qon hoyeyapi kin he Sabaoth Itancan noge kin en hiyohipayá.

5 Maka akan woiyokipi imnahan yaunpi qa tanyan wayatapi ece; wapatapi anpetu kin en iyecen cante cemyakiyapi.

6 Wicaśta owotanna kin he dacopi qa yaktepi ; tuka nicipajinpi śni.

7 Heon etanhan, mihunkawanji, Itancan kin hi kte cin hehanyan wacintanka po. Wanyaka po, wicaśta woju ece kin he maka waskuyeca waśte aicage cin hena ape yanke ca, on tehan wacintanka, magaju tokaheya qa nakun ehake kin ahinhe kte cin hehanyan.

8 Niś eya wacintanka po; cante hdusuta po; Itancan kin $u$ kte cin lie wanna kiyedan ihan. 


\section{INYAN.}

9 Mihunkawanji, otoiyohi okicihinyanpi śni po, okinni niyacopi kta. Wanyalka po, Wayaco kin he tiyopa kin itokam inajin. 10 Mihunkawanji, wicaśta wokcan Itancan caje kin on iapi qon hena kakijapi qa wacintankapi on waonspekiya wicayuha po.

11 Wanyaka po, tona wacintankaya unpi kin hena waśte kecanwicunkinpi ece. Job token wacintanka qon he nayahonpi, qa Itancan owihankeye cin he wandakapi; Itancan kin waonśida qa wawacinkta yuza tanka.

12 Tuka mihunkawanji, taku owasin isanpa, Taku namahon ce, eyapi śni po, mahipiya kin he, qa maka kin de, qa taku tokeca cajeyatapi ece kin nakun; tuka, han, ehapi kin he han ecedan kta, qa, hiya, ehapi kin he hiya ecedan kta; okinni woyaco kin en iyoyahppadapi nun ce.

13 Niyepi kin etanhan wanji kakija he; wocekiye eye kta. Wanji wiyuśkin he; odowan ahiyaye kta.

14 Niyepi kin ekta wanji wayazanka he; okodakiciye kin en hunkawicayapi kin wicakico kta ; on cekiyapi qa Itancan caje kin on wihdi on sdayapi kta.

15 Unkan wacinyan cekiyapi kin he wayazanke cin asniye kta; qa Itancan kin he najinkiye kta; qa woahtani econ hecinhan, hena kicicajujupi kta.

16 Wayahtanipi kin otoiyohi okiciciyakapi qa otoiyohi wocekiye ekiciciya po, hecen anisnipi kta. Wicaśta owotanna nina waśagya cekiye cin he taku tanka okihi ece.

17 Elijah wicaśta wacinyuza iyeuncecapi, qa wocekiye on magaju kte śni e icekiya ; unkan waniyetu yamni sanpa wi śakpe hehanyan maka kin ahinhe śni. - 18 Hehan ake wocekiye eya, unkan mahpiya kin magaju hiyuye ça, maka kin waskuyeca icaliya.

19 Mihunkawanji, wanji enitanhanpi wowicake kin etanhan nuni, qa tuwe he ake ekta yuhomni kinhan,

20 Tuwe wicaśta wahtani sa wan canku onuni kin etanhan yuhomni kinhan, he wicanagi wan wiconte etanhan eyaku kta, qa woahtani ota akahpe kta e he sdonkiye lita.

\section{N Y A N}

\section{TAWOWAPI TOKAHEYA KIN.}

\section{WICOWOYAKE 1 .}

1 Inyan, Jesus Messiya yeśi qon, wicaśta toktokeca enanakiya unpi, Pontus, Galatia, Kappadokia, Asia qa Bithunia ekta, 2 Wakantanka A teyapi kin otokaheya tanhan sdonwicaye cin 362 eciyatanhan, qa Woniya wicayuecedan kta on wicakahniga, anagoptanpi kta, qa Jesus we kin awicamnimni kta e on, hena wowapi wicakicaga: Wowaonśida en niunpi, qa wookiye niciyuotapi nunwe.

3 Wakantanka, Jesus Messiya 


\section{WICOWOYAKE 1.}

Itancan unyanpi Atkuku kin he yawastepi nunwe ; iye towaonśida ota eciyatanhan Jesus Messiya wicațe cin etanhan kinikiye ciqon he on wowacinyan ni un kin en piya icahunyanpi ;

4 Woailipeye wan hinpica śni, aśapapi śni, qa ohinniyan un kta, mahpiya ekta enicihnakapi kin on ;

5 Wacinyanpi eciyatanhan Wakantanka towaśake kin on wiconi anikpatanpi, eqe anpetu ehake kin en yuotaninpi kta.

6 Heon nina iduśkinpi ece, tuka nakaha ptenyedan, he hecetu naceca, taku wawiyutanyan un kin ota on iyoniciśicapi :

7 Hecen wacinyayapi iyutanpi kin, he mazaskazi peta ece on śdoyapi keś atakuni śni ece, sam iyeya nina tehike cin he woyaonihan, wicakinihanpi qa wowitan on tanin kta, tohan Jesus Messiya ihdutanin kinhan.

8 He wandakapi śni eśta waśteyadakapi ; qa nakaha wanyake śni yaunpi keś wacinyayapi kin on iduśkinpi, wowiyuśkin oyagpica śni qa wowitan ojudan kin on :

9 Wacinyayapi ihanke kin iyacupi, ninagipi ni kte cin hee.

10 Wiconi kin he on, wicaśta wokcan wowaonśida en niunpi kin he oyakapi qehan, aiciciya akitapi qa wiwangapi ;

11 Messiya Taniya iyepi en un kin, tohantu qa anpetu kin tukte e ka e iwangapi, Messiya kakije kte ca wowitan ihakam un kte cin henaitokam oyake ciqon he ehan.

12 Unkan, iś iyepi kte sni, tuka tona wotanin waśte, Woniya Wakan malipiya eciyatanhan kun u śipi kin iyahna sdonyeniyanpi lkin eqe nakaha taku oniciyakapi kin hena unkiyepi on yuhapi e owicakiyakapi; taku kin hena mahpiya ohnihde kin en eyokasin wacinpi.

13 Heon etanhan, nitawacin nisehu kin opta ipiyagkiton po, waktaya un po, qa Jesus Messiya ihdutanin kinhan wowaśte nicaupi kte cin he ape yukan po, owihanke kin hehanyan.

14 Wicacinca waanagoptanpi kin iyenicecapi kta, qa ehanna wasdonye śni yaunpi qehan cantiheyayapi śica ake iyecen niçicagapi kte śni.

15 Tuka tuwe nicopi kin he wakan, he iyecen niś eya oyahandapi kin ocowasin en niwakanpi nunwe.

16 Heon hecen owapi qon; Wakanyan un po, miye mawakan kin heon etanhan.

17 Qa Ateyapi kin wicaśta itohnake iwanyake śni wicaśta otoiyohi iye ohan kin eciyatanhan wicayukcan ece kin he hoyeyakiyapi kinhan, tohanyan den unhdaka yaunpi kin kokipeyahan un po.

18 Witkotkoya oyahandapi kin, nihunkakepi wohdakapi eciyatanhan duhapi qon he etanhan, taku atakuniśni ece, mazaskazi qa mazaska on openicitonpi śni e sdonyakiyapi ;

19) Tuka Messiya we telike cin he on, talin wanunyanpi cincadan, taku iyaonpepica śni qa ecedan un kin iyececa.

20 Iye qe maka kin de kagapi śni itokam wakiconzapi, tuka anpetu ihankeya kin dena en yutaninpi, niyepi kin on ;

21 Wakantanka wicate cin etanhan najinkiye ca wowitan qu qon he wicayadapi, iye eciyatanhan; hecen wicayadapi qa wacinyayapi kin he Wakantanka en un kta.

22 Woniya kin eciyatanhan wowicake anayagoptanpi kin 363 


\section{INYAN.}

heon nagi nihduskapi, hunkawanjinkiciyapi kin awicakehan waśtewicayadakapi kta, heon cante ecedan on otoiyohi nina waśtekicidaka po.

23 Piya icahniyanpi, oicage kuke kte cin etanhan śni, tuka kukepica śni kin on, Wakantanka oie kin ni un qa owihanke wanice kte cin hee on.

24. Wicacehpi owasin peji iyececa, qa wicaśta towitan kin owasin peji lica kin iyececa. Peji kin he śniś aye ça walica kin hinhpaya ece;

25 Tuka Itancan oie kin he owihanke wanin un kta. Unkan wotanin waśte oniciyakapi kin wicoie kin he hee.

\section{WICOWOYAKE 2.}

1 Heon etanhan, wocanniye owasin, qa wohnaye ocowasin, qa woanakilibe, qa wowinawizi, qa iapi śica iyuhipa elipeya po ;

2 Qa hokśiyoqopa nakaha tonpi kin iyecen, wicoie asanpi wohnaye wanin un kin he cin po, hecen on inicagapi kta:

3 Itancan kin wacantkiya e uyatapi hecinhan.

$4 \mathrm{He}$ en yahipi, inyan wan ni un kin iyececa, wicaśta akantu elipeyapi, tuka Wakantanka e kahnige ca teliike daka;

5 Unkan niś eya, inyan ni un kin iyececa, tipi wakan wan en icahniyanpi, wawayuśnapi wakan kin, hecen wośnapi wakan qa Jesus Messiya eciyatanhan Wakantanka iyokipi kin waduśnapi kta.

6 Heon etanhan nakun wowapi en kagapi qon, Wanyaka po, Zion en inyan wan oise pa hinca ewahde, kahnigapi, tehila; unkan tuwe he wacinye cinhan wiśtece kte śni ce.
7 Niye wacinyayapi kin he tehilke y adapi; tuka tona waanagoptanpi śni kin hena, inyan tipi kagapi ehpeyapi qon he oise pa hinca icaga, inyan on siha ibotopi qa imnija on śinhapapi ece lkin hee ;

8 Tona wicoie kin on śinhdapi qa waanagoptan śni unpi kin hena on; heon hecen ewicahdepi. 9 Tuka wicoicage kahnigapi, wawayuśnapi wicaśtayatapi, wicoun wakan, qa oyate opewicakitonpi kin he niyepi ; hecen tuwe otpaza etanhan, iye iyoyanpa wakan tawa kin en nicopi kin he ohan waśte kin odakapi kta.

10 Ehanna oyate henicapi śni, tuka nakaha Wakantanka taoyate yaunpi ; he ehan onsinidapi śni, tuka wanna wowaonśida iyoyahipi.

11 Waśtecicidapi, ceciciyapice, oyate tokeca qa unhdaka unpi kin iyecen wicacehpi cantiheyapi kin, wicanagi kin kici kicize cin, hena ayuśtan po:

$12 \mathrm{Qa} \mathrm{Ikcewicaśta} \mathrm{ehna} \mathrm{owo-}$ tanna ohanyan po; hecen śicaya econ keniciyapi keś, wiwicawangapi anpetu kin en, niohanpi waśte wanyakapi kte cin hena on Wakantanka yaonihanpi kita.

13 Itancan kin on etanhan, wicaśta akantu wakonzapi kin owasin anagoptan po; wicaśtayatapi lkin he iyotan tanka;

14 Qa wicaśta itancanpi kin iś tona śicaya ohanyảnpi śitkihdawicayapi kta, qa tona tanyan econpi wicayaonihanpi kta e on u wicaśi kin hena.

15 Hecen Wakantanka tawacin, tanyan oyahandapi kin on wicaśta witkotkoka wiyukcan śni kin hena inina yankewicayakiyapi kta. 


\section{WICOWOYAKE 3.}

16 Nihduhapi, tuka tawaniciyapi kin he wocanniye onhohda iyecen yecunpi kte śni, tuka Wakantanka tawowidake kin iyececa.

17 Owasin wicayuonihan po. Hunkawanjinkiciyapi kin waśtekida po. Wakantanka kokipa po. Wicaśtayatapi kin yuonihan po.

18 Wowidake yaunpi kin, tona niyuhapi kin ocowasin kokipeyahan anawicagoptan po, tona waśte qa wahbadan kin hecedan śni, tuka tona ksizece cin hena nakun.

19 Tuwe Wakantanka awacin un kin on, hecetu śni eśta kakiśyapi qa woiyoliśice yuha un kinhan, he wowaśte.

20 Wayahtanipi kin on anipapi, qa wacinnitankapi kinhan taku iyokihi kta he ; tuka tanyan ecanonpi kin on kakiśniyanpi kinhan, wacinnitankapi hecinhan, he Wakantanka iyokipi.

21 Unkan he on nicopi ; Messiya unkiyepi on kakije ca woonspe aihpeunkiyapi kin he iyecen niś eya iye owe kin en opa dapi kta.

22 Iye qe woahtani takudan econ śni, qa i kin ohna wohnaye takudan iycyapi śni ;

23 Kigepi qehan itkom wicakige śni; kakiśyapi he ehan owawicakiye śni; tuka tuwe owotanna wiyukcan ece kin he en ihdoya.

24 lye hinca can akan un qehan, iye tancan kin en wauntitanipi kin yuha; hecen unkiye woahtani elipeunyanpi woowotanna en unnipi kta: Iye apapi qon on asniniyanpi ce.

25 Tahin wanunyanpi nunipi kin iyenicecapi; tuka wanna tuwe wonniyanpi qa nagi awanniyakapi kin he ekta yahdipi.
WICOWOYAKE 3.

1 He iyecen, winohincapi kin, nihihnapi wicihukun un po; hecen tona wicoie kin anagoptanpi śni kin hena, wicoie codan eśta, iye tawicupi olianpi kin on iyakapewicayapi kta ;

2 Niohanpi waśte wokokipe iyahna wanyakapi kin icunhan.

3 Thduzapi kin he akantanhan, paha kisonpi, qa mazaskazi oinpi, qa wokoyake unpi kin hee kte śni :

4. Tuka wicaśta mahentanhan cante kin ekta, taku hwinpica śni kin, tawacin wahbadan qa inina un, he Wakantanka itokam taku tehike cin ee.

5 Iś eya, wanakaja, winohinca waśteśte Wakantanka wacinyanpi qon hena e hccen kiçunpi, qa hihnakupi kin wicihukun unpi.

6 Hecen Sara Abraham anakigoptan, qa, Itancan, eciya ece; he cunkśiwicaye cin hena niyepi, tanyan ecanonpi qa wokokipe takudan on niyuśinyayapi śni kinhan.

7 Nakun wicaśta yaunpi kin, wosdonye eciyatanhan om yukan po, nitawinpi wakśica wankadan iyececa, qa om wiconi wowaśte kin tawaniçiyapi kta iyecen wicahduonihan po; hecen wocekiye nitawapi kin kagipi kte śni.

8 Ehake, owasin cante wanjidan hduwitaya onśikicida po; hunkawanjinkiciyapi kin iyecen waśtekicida po, waonśidapi qa wacantkiya po.

9 Taku śica on itkom taku śica econpi śni po; qa nicigepi eśta wicakigepi śni po; tuka itkopatanhan wayawaśte po; heon nicopi, hecen woyawaśte tawayayapi kta e sdonya po. 


\section{INYAN.}

10 Tuwe wiconi waśtedake ça anpetu waśte wanyaka cin kinhan, iye ceji kin taku śica en yeye kte śni, qa iha kin wohnaye takudan ie kte śni.

11 Taku śice cin okamna kta, qa taku waśte e econ kta; wookiye akite ca kuwa aye kta ce.

12 Jehowa iśta kin wicaśta owotanna awicatonwan, qa wocekiye eyapi kin he anoliwicakiciya ; tuka tona śicaya econpi kin Jehowa itohnake kin itkowicakipa ece.

13 Unkan taku waśte kin pasi yaunpi kinhan, tuwe e kiunniniyanpi kta he.

14. Tuka owotanna ohanyanpi kin on śicaya nicuwapi kinhan, he wowaśte; hecen wokokipe tawapi kin kołipapi śni, qa cante hahayedan yankapi śni po :

15 'Tuka nicantepi kin en Wakantanka Itancan kin wakanda po; qa tuwe wowacinye en niunpi kin on iniwangapi kinhan, wahbayedan kokipeyahan aduptapi kta e ohinniyan wiyeya yanka po ;

16 Wawiyukcan waśte hduha po; hecen śicaya ohanyanpi iyecen tona aniiapi kin hena iśtecapi kta, Messiya on niolianpi waśte kin itonśniyan oniyakapi kin.

17 Wakantanka hecen tawacin hecinhan, taku śica econpi kin hee śni, tuka taku waśte econpi kin on kakiśniyanpi kinhan hee waśte kta.

18 Messiya iś eya wancadan woahtani on kakija, owotanna un kin owotanpidan śni kin hena on, Wakantanka ekta unkaupi kta e heon, wicacehpi kicun ktepi, tuka Woniya kin on kiniyanpi.

19 Nakun he on ekta ye ca wi- canagi wicakaślka tipi ohna unpi kin hena wowicakiyaka;

20 Hena e ehanna waanagoptampi śni, Wakantanka wawacinkta yuza tanka tehan awicape, Nowa taanpetu kin en, wita wata kagapi kin icunhan, he ohna tonana, wicanagi śahdoganna mini on nipi.

21 Qa wiyacinpi kin he iyececa, baptem nakaha niunyanpi ece; wicacehpi aśape cin yutokall iyeyapi. kin hee śni, tuka Wakantanka ekta wawiyukcan waśte waayupte cin hee, Jesus Messiya ihduekicetu kin heon etanhan;

22 Iye qe malipiya kin ekta kihde ça Wakantanka etapa kin eciyatanhan yanka; mahpiya ohnihde, qa wicookihi, qa wowaśake kin owasin iye ihukun iyewicayapi.

\section{WICOWOYAKE 4.}

1 Heon etanhan, Messiya wicacehpi en unkiyepi on kakije cin lieon, niś eya iyecen tawacin kiçun po: túwe wicacehpi kin en kakije cin he wanna woahtani ayuśtan :

2 Hecen, hetanhan icimana wicacehpi eciyatanhan ni kte śni, wicaśta taku śica cantiheyapi kin en, tuka Wakantanka tawacin kin eciyatanhan.

3 Hekta unnipi kin, Ikcewicaśta tawacinpi kin ecen econkupi kin he ota, wicohan śica, wocantiheye śica, miniśa ota, wakan wacipi, witkopi, qa wakagapi wakandapi śice cin hena omaunnipi qehan.

4. He en iś iye witkoya ślkanpi kin on iyecen iyatahdeniçiyapi śni kin heon tognihdapi qa niyaśicapi ece ;

5 Hena e tuwe ni unpi țapi ko- 


\section{WICOWOYAKE 5.}

ya wicayaco kta wiyeya yanke cin hee itokam wohdakapi kta.

6 Heon etanhan, nakun tona tapi kin hena wotanin waśte owicakiyakapi qon, hecen wicaśta wicacehpi en un kin iyecen wicayacopi eśta woniya en Wakantanka eciyatanhan nipi kta.

7 Tuka taku owasin ecadan owihanke kta. Heon etanhan wacinksapa po, qa wocekiye on waktaya un po.

8 Qa taku owasin isanpa niye iyakitedan nina cantekiciya po ; wacantkiyapi kin he woahtani ota akalipe kta.

9 Iapi śica wanin otoiyohi wonkiciya po.

10 Taku wicaqupi kin wicaśta otoiyohi icu kin he iyecen iyakitedan okinikiciciya po, tona Wakantanka towaonśida ocaje ota tanyan yuhapi kin iyececa.

11 Tuwe ie cinhan Wakantanka oie kin iyecece kta; qa tuwe waokiya hecinhan wookihi Wakantanka qu kin he eciyatanhan kte; hecen taku owasin on Wakantanka yatanpi kta, Jesus Messiya eciyatanhan; iye qe woyatan qa wookihi owihanke wanin kiciun nunwe. Amen.

12 Waśtecicidapi kin, peta on iyutanpi kin on iniyutanpi kte cin he on yuśinyayapi śni po, taku tokeca ayatipapi iyececa.

13 Tuka Messiya kakije ciqon en oyapapi kin heon iyuśkin po; hecen tohan towitan tanin kinhan nina iduślkinpi kta.

14 Messiya caje kin on niyaśicapi kinhan, niyuwaśtcpi ece; wowitan qa Wakantanka Taniya kin en niunpi kin heon. Hena e eciyatanhan ośtehdapi, tuka niye eciyatanhan yatanpi ece.

15 Tuka ihnuhan wanji tin wicakte sa, qa wamanon sa, qa taku śica econ sa, qa tokan tawa i en iyewicakiciciye cin iyecen kakiśniyanpi kinhan.

16 Hcceca eśta tuwe Messiya tawa kin on kakiśyapi kinhan iśtece kte śni ; tuka heon Wakantanka yatan kta.

17 Wakantanka tiyohnaka tawa kin wicayukcanpi kte cin wanna iyehantu. Unkan he unkiyepi etanhan aye cinhan, tona Wakantanka tawootanin waśte wicadapi śni kin hena token owihankepi kta he.

$18 \mathrm{Qa}$ wicaśta owotanna kin kitan se ni kinhan, tuwe śicaya econ qa wahtani sa kin hena tukten yákonpi kta he.

19 Heon etanhan, tona Wakantanka eciyatanhan kakijapi kin hena, waśte ece ecompi kin en, Wawicaliye wacinyepica kin iyecen iye nagipi kin yuhekiyapi kte.

\section{WICOWOYAKE 5.}

1 Miye hunkayapi kin hemaca, qa Messiya kakije ciqon wanmdake ca, wowitan yutáninpi kte cin he en owapa, tona hunkayapi yaunpi kin ceciciyapi ce ; 2 Wakantanka optaye tawa ehna yaunpi kin he wonwicaya po; econ niciyapi kin iyecece śni, tuka iyokipiya awanwicadakapi kta; woyuha śica kin on etanhan śni, tuka tawacin waśte on ecanonpi kta :

3 Wakantanka taku tawa hince cin cn itancanpi kin iyenicecapi kte śni, tuka optaye kin en waonspekiya yaunpi kta.

4 Hecen Waawanhdake Itancan kin tohan ihdutanin kinhan, hehan wowitan wateśdake wan śnije kte śni kin he iyacupi kta.

5 Nakun, tona aśkatudan yaunpi kin, hunkawicayapi kin anawicagoptan po: Han,owasin 367 


\section{INYAN.}

otoiyohi anakicigoptan po, qa wowalibadan koyaka po. Tona wahaniçidapi kin hena Wakantanka wicakipajin, tuka tona onśikihanpi kin hena wowaonśida wicaqu ece.

6 Heon etanhan, Wakantanka nape waśake cin ihukuya onśikilian po ; hecen tohan iyehantu kinhan yuwankan inicupi kta:

7 Wacin akipam duzapi kin owasin iye en ailipeya po; iye qe awanicinpi ece.

8 Witkopi śni po, waktaya un po; Wakanśica tokaniyanpi kin he mnaja hoton ece kin iyecen omani un, tuwe yapote kte cin he alkita ece.

9 Sutaya wacinyayapi kin on he kipajin po; nihunkawanjipi maka akan unpi kin hena en wokakije kin dena iyececa yuśtanpi ece e sdonyayapi.

10 Tuka Wakantanka wowaonśida ocowasin hduhe cin, Je- sus Messiya eciyatanhan, wowitan owihanke wanica iye tawa kin en unkicopi kin he, tohan cistiyedan nicakijapi kinhan, niyuśtanpi kte, pahohośni enihnakapi, niyuwaśakapi, qa sutaya nibdepi nunwe.

11 Iye qe wowitan qa wokiconze kin owihanke wanin tawa nunwe. Amen.

12 Siluanos nihunkawanjipi wan wacinyepica wadake cin on wowapi ptecedan cicagapi ; wahokonciciyapi qa wociciyakapi. Wakantanka towaśte wicakapi en nayajinipi kin he dee ce.

13 Babulon ekta tona om nicahnigapi kin hena nape niyuzapi, qa nakun Markos micinkśi kin.

14. Wacantkiyapi iiputakapi kin on otoiyohi nape kiciyuza po. Tona Jesus Messiya en yaunpi kin owasin wookiye nicipi un nunwe. Amen.

\section{N Y A N}

\section{'TAWOWAPI INONPA KIN.}

\section{WICOWOYAKE 1.}

1 Simon Inyan, Jesus Messiya tawowidake qa yeśi qon he, tona Wakantanka unkitawapi toowotanna kin on, qa Jesus Messiya Wanikiye cin eciyatanhan, unkiye unhapi kin iyecen wowacinye tehika yuhapi kin hena wowapi wicakicaga.

2 Wowaonśida, wookiye ko, Wakantanka sdonyapi kin en, qa Jesus Itancan unkiyapi kin on niciyuotapi nunwe.

3 Iye towaśake wakan kin he taku on wiconi qa woohodapi 368 kte cin owasin unqupi kin he iyececa, tuwe wowitan. qa wookihi on unkicopi kin he sdonyapi kin eciyatanhan.

4 Hena on taku tanka hinca, qa taku tehike hinca iwahounyanpi ; hecen hena on Taku Wakan ouncage kin en oyapapi kta, wiconi kin de en wocantiheye śica on wicośice nayecipapi kin.

5 Qa nakun he on nina mniheiciya po, wacinyayapi kin en waditakapi kin ikoyagya po ; qa waditakapi kin en wosdonye ;

$6 \mathrm{Qa}$ wosdonye kin en iyatahdeiciyapi śni ; qa iyatahdeiçi- 


\section{WICOWOYAKE 2.}

yapi śni kin en wacintankapi ; qa wacintankapi kin en taku wakan iyececapi ;

7 Qa taku wakan iyececapi kin en waśtekicidapi ; qa waśtekicidapi kin en wacantkiyapi ikoyagya po.

8 Hena taku kin en niunpi qa niciyuotapi kinhan, Jesus Messiya Itancan unkiyapi sdonyapi kin en taku icalye ça waskuyeca aicage cin henicapi kta e nicagapi.

9 Tuka tuwe dena yuhe śni kinhan, he iśtagonge ca tehan wawanyaka okihi śni, qa wahtani qon hena kipakintapi kin he akiktonja.

10 Heon etanhan, mihunkawanji, nicopi qa nicahnigapi kin aiciciya hdusuta po; hena hecen ecanonpi kinhan icimana nihinhpayapi kte śni.

11 Qa nakun heon Jesus Messiya Itancan qa Wanikiya unkitawapi tokiconze owihanke wanice cin en yaipi kte cin wijinya niçupi kta.

12 Heon etanhan taku hececa ohinniyan kiksuyeciciyapi kta awektonje kte śni, hena niye hinca sdonyayapi, qa nakaha wowicake kin de en sutaya nihdepi eśta.

13 Tohanyan wakeya kin de ohna waun kin hehanyan kiksuyeciciyapi kin on iyocipaśtakapi kte cin he hecetu wadake :

14 Wakeya mitawa kin de aśkadan wehnake kta sdonwakiya, Jesus Messiya Itancan unkiyapi omakiyake ciqon iyececa.

15 'Tuka nakun detanhan imdamde cin iyohakam, taku kin dena ohinniyan yeksuya oyakihipi kta e awakite kta.

16 Jesus Messiya Itancan unkiyapi towaśake qa hi kte cin hena unkoniciyakapi qehan, hiDak. tunkakanpi ksamya kagapi kin unkunpi śni, tuka iye tanka hince cin he iśta on wanunyakapi.

17 Wakantanka Ateye cin eci. yatanhan woyuonihan wowitan ko icu, wowitan waśte kin etanhan wicaho kin de hiyu qehan, Micinkśi waśtewakidake cin he dee, on iyomakipi hinca ce.

18 Unkan wicaho kin he mahpiya eciyatanhan $u$ kin he naunhonpi, paha wakan kin akan kici unyakonpi qehan.

19 Tuka wokcanpi oie iyotan suta wan unhapi; he qe anayagoptanpi kinhan tanyan ecanonpi kta, petijanjan tukten otpaze cin en ijanjan kin iyececa, nicantepi kin ekta anpao kamdeze ca, en anpao wicanhipi kin hinanpe kte cin hehanyan.

20 Qa de tokaheya sdonya po, wowapi wakan kin en wokcanpi kin owasin tuwedan iye cinka oyake śni.

21 Wokcanpi kin wanakajatanhan wicaśta tawacin kin eciyatanhan u śni ; tuka wicaśta wakan Wakantanka tawa Woniya Wakan kin token iewicakiye ciqon hena hecen eyapi ece.

\section{WICOWOYAKE 2.}

1 Tuka he ehan oyate kin ehna wicaśta wokcan itonpi śni yukan qon, he iyecen niyepi kin ehna waonspekiya itonpi śni kin heca yuke kta, nahniana wohnuni woihangye kin en aupi kta, Itancan opewicakiton qon he ehpeyapi, qa wicotakuniśni olianko amnaiciyapi kta.

2 Qa wicohan śica econpi kin en wicota opapi kta; hena on wowicake canku kin yaśicapi ece e kta.

3 Qa waicu wacinpi kin eciya369 


\section{INYAN.}

tanhan wicoie skuya on wiyopeniyanpi kta; hena e wicayacopi kin wanakajatanhan en awicau, qa ihangwicayapi kte cin he liba śni.

4 Wakantanka mahipiya ohnihde walitanipi gon hena wicakpatan śni, tuka wakanśica ti kin ekta iyayewicaya, qa woyaco kte cin hehanyan wicayuhapi kta e otpaza maza icicahilia on wicakaśka hecinhan ;

5 Qa maka tannike cin kpatan śni, tuka Nowa wicaśta wiciśahdogan wicoowotanna oyake cin he kpatan, qa wicoicage wahtanipi sa amnitanwicaya;

6 Qa Sodom qa Gomorra otonwe kin cahota kaliya elipewicaye, woihangye on wicayaco, qa tona tokata wahtani sa unpi kte cin hena woonspe wicakicaga;

7 Qa Lot owo tamna un, wicaśta wahtepi śni ohan śicapi kin wacin iyowicakisica ece kin he ehdaku :

8 Wicaśta owotanna kin he hena wicehna ti, qa taku wanyake ca nation kin on, anpetu eca iye nagi owotanna ekta wacin iyowicakiśica ece, śicaya ohanyanpi kin on :

9 Itancan kin wicaśta waśte wowiyutanye kin etanhan token ewicahdaku kta sdonya, qa nakun wicaśta owotanna śni kin woyaco anpetu kin hehanyan wicayuhe kta, śitkihdawicayapi kta e heon :

10 'Tuka tona woaśa mye cantiheyapi kin en wicacehpi eciyatanhan manipi, qa wokiconze wahtedapi śni kin hena iyotan: hena walianicidapi qa wamnaicidapi ece ; qa tona tankapi kin wicayaśicapi kokipapi śni.

11 Malipiya ohnihde kin, wookihi qa wowaśake on iyotanpi qeyaś, Itancan kin itokam wa370 yaśicapi woyaco kin en awica. yapi śni ece.

12 Tuka dena iś, woteca iyececa, wicayuzapi qa ihangwicayapi kta e on wicakágapi lin, taku okahinigapi śni keś he yaśicapi ece; qa wicotakuniśni tawapi kin en ihangiciyapi kta ;

13 Qa anpetu icunhan tanyan wotapi kin he woiyokipi dakapi kin heon woalitani iyunwin kin icupi kta. Hena om wayatapi icunhan wohnayeiciyapi kin on iyuśkinpi, woaśape qa taku samya wanke cin hecapi ;

14 Iśta yukanpi wiinahmanpi kin on ojudan qa woalitani ayuśtanpica śni ; wicanagi kacegya unpi kin hena wicahnayanpi ece; cante wawicakipi e ecewakta kin heca yuhapi, wicotakuniśni cincapi kin :

15 Canku owotanna kin ayuśtanpi, qa onuniyata unpi, Balaam Bosor cinhintku woahtani iyunwin waśtedake ciqon he tacanku kin en opapi :

16 Iye taku śica econ qon on iyopeyapi ; śonśonna kin ia okitpani ece wicaho on ie ca, wicaśta wokcan witkotkoya olianye cin he kiśica.

17 Miniyowe mini wanica, mahipiya śapa tate iyumni on toke cincin eyaye cin hena hecapi ; hena on otpaza sape hinca owihanke wanica wicakicilnnakapi.

18 Wahanhaniçidaya takuśniśni eyapi eca, wicacehpi cantiheyapi kin eciyatanhan, witkoya olianyanpi kin on, tona wohnaye en ounyanpi kin kitan ecinyan nawicakicipapi qon hena iyakapewicayapi ece.

19 Tawaiciyapi kin wicaqupi kta keyapi, tuka iyepi kaeś wicotakuniśni iwicadaka. Taku on tuwe iyakapeyapi kinhan, he on wowidagyapi ece. 


\section{WICOWOYAKE 3.}

20 Itancan qa Wanikiya Jesus Messiya sdonyapi kin eciyatanhan, wicoicage kin de en woaśape kin nakipapi eśta, ake hena on iyakapeyapi qa en ihdaśkapi kinhan, hena otokahe ekta waśte qa owihankepi kin he śica ece.

21 Woowotanna canku kin he sdonyapi śni unkanś he waśte kta tuka, qa he sdonyapi qa woahope wakan wicaqupi kin ayuśtanpi kin he śice hinca.

22 Tuka wiyacinpi eyapi wicakapi kin he iyecen waakipapi; Śunka taku hiyuye cin he ake hduta ce ;' qa, Kukuśe yujajapi qon he ake upśija en iwanka ce.

\section{WICOWOYAKE 3.}

1 Waśtecicidapi kin, de nakaha wowapi inonpa cicagapi ; hena en nitawacinpi mdesahan kiksuyapi on iyocipaśtakapi.

2 Hecen wicaśta wokcan wakan token oieyapi qon, qa nakun unkiye Itancan qa Wanikiya yeunśipi qon token econ unniśipi kin hena yeksuyapi kta.

3 Qa de tokaheya sdonya po, anpetu ehake kin en waitiahapi, iye cantiheyapi śica eciyatanhan manipi kin heca hipi kta;

$4 \mathrm{Qa}$ heyapi kta; Hi kta keyapi qon he tukte e he; wicahunkake iśtinma ihpayapi ehantanhan otokaheya tanhan taku owasin tokeca śni wanka ce.

5 Tuka he de sdonyapi śni, Wakantanka oie kin eciyatanhan malipiya kin ehanna un, qa maka kin mini mahen qa nakun mini akan han;

6 Qa nakun he eciyatanhan, maka ehanna un qon he mini apaśbog hiyaye ca ihangya.

7 Tuka mahipiya qa maka nakaha un kin hena iye oie kin on kihnakapi, peta on ayuhapi, wo- yaco anpetu qa wicaśta śica. śitkihdawicayapi kte cin hehantu.

8 Tuka, waśtecicidapi kin, he de sḍonye śni yukanpi śni po, Itancan kin ekta anpetu wanjidan waniyetu kektopawinge iyececa, qa waniyetu kektopawinge anpetu wanjidan iyececa ece.

9 Itancan kin taku wahowicaye cin yutehan śni, wicaśta wanjikśi yutehanpi eyapi kin iyececa; tuka unkiyepi on wawacinkta yuza tanka, tuwedan awihnuniiciye kte śni, tuka owasin woiyopeiciye en ihdoupi kta cin.

10 Tuka Itancan taanpetu kin wamanon sa wan lianyen hi ece $\mathrm{kin}$ he iyecen u kta, hehan mahpiya kin limunlimunyan hinhda on tokan iyaye kta, qa taku kin peta hinca on skan kta; qa maka kin wicohan ohna un kin hena hulinage kta.

11. Hena taku kin owasin hecen skan kta hecinhan, wicotian waśte qa Taku Wakan iyececapi kin en taku wicaśta yaunpi kta iyececa he :

12 Wakantanka taanpetu u kte cin he ayapepi qa on inayahinipi kta; he en mahpiya kin aide ecen atakuni kte śni, qa taku kin peta tanka hinca on skan kta.

13 Hececa eśta, unkiye, iye wahounyanpi kin eciyatanhan, mahpiya teca qa maka teca en woowotanna ounye cin he wanunyakapi kta e unkapepi.

14 Heon etanhan, waśtecicidapi kin, taku hececa ayapepi kin heon aiciciya po, hecen iye wookiye en aśape śni qa iyaonpepicaśni iyeniyanpi kta.

$15 \mathrm{Qa}$ Itancan wawacinkta yuza tanka kin he wiconi kecankin po; Palos, hunkawanjinun- 


\section{JOHANNES.}

yanpi waśte kin, iś eya woksape qupi kin eciyatanhan, wowapi nicagapi kin iyececa;

16 He wowapi kage cin owasin en taku hececa cajeyata ece; hena wanjikśi okahnili tehika, tona onspepi śni qa kaktihanhan unpi kin yatokecapi, wowapi unma kin iyececa, iye ihdutakunipi kte śni heon.

17 Heon etanhan, waśtecici- dapi kin, niś niyepi hená itokam sdonyayapi, heon ihnuhan wicaśta śica wohnaye kagapi kin nihnayanpi, qa sutaya nihdepi kin etanhan nihinhpayapi kinhan.

18 Tuka wowaśte kin en, qa nakun Itancan unyanpi Wanikiya Jesus Messiya sdonyapi kin en icaga po. Tye kin wowitan nakaha qa owihanke wanica kiciun nunwe. Amen.

\section{J O H A N NES}

\section{TAWOWAPI TOKAHEYA KIN.}

\section{WICOWOYAKE 1.}

1 Taku otokaheya tanhan un, taku naunlionpi, qa iśta on wanunyakapi, opaunlitapi qa nape on unzapi, Wiconi Oie kin hee.

2 Wiconi kin he ihdutanin; unkan Wiconi Owihanke Wanica Ateyapi kin kici un, qa unkiyepi kin en ihdutanin qon he wanunyakapi, qa unyaotaninpi qa unkoniciyakapi.

3 Taku wanunyakapi qa naunhonpi kin he unkoniciyakapi, hecen niye unyecicapi kta; unkan awicakehan Ateyapi kin kici okiciciya unyakonpi, qa nakun iye Cinhintku Jesus Messiya kici.

4 Unkan nitowiyuśkinpi kin yucopi kta e heon dena decen wowapi unnicagapi.

5 Hehan wotanin waśte iye eciyatanhan naunhonpi qa unkoniciyakapi kin, Wakantanka he iyoyanpa, qa otpaza takudan en un śni kin he hee.

6 Iye kici okiciciya mnakonpi ce, unkeyapi qa otpaza kin oma$3 \% 2$ unnipi kinhan, unkitonpiśni qa wowicake kin econkupi śni ece.

7 Tuka iye iyoyanpa en un kin he iyecen iyoyanpa kin en maunnipi kinhan, otoiy ohi okiciciya unyakonpi, qa iye Cinhintku Jesus Messiya we kin he woahtani owasin unkipakintapi kta. 8 Woahtani unnicapi ce, unkeyapi kinhan, unkiçihnayanpi "qa wowicake kin unkiyepi en un śni.

9 Tuka waunlitanipi kin unkohdakapi kinhan, iye kin wacinyepica qa owotanna un, hecen woahtani yutokan iyeunkiciciyapi kta, qa taku śica owasin unkipakintapi kta.

10 Eca waunlitanipi śni ce, unkeyapi kinhan, iye itonśni undakapi, qa iye oie kin unkiyepi en un śni ece.

\section{WICOWOYAKE 2.}

1 Micinca cikcistinpidan, wayahtanipi kte śni e heon dena decen wowapi cicagapi. Unkan tuwe wahtani kinhan Ateyapi kin ekta Wawiciya wan unhapi, 


\section{WICOWOYAKE 2.}

Jesus Messiya owotanna kin hee.

2 Unkan waunhtanipi wokajuju kin he iye; qa unkiye unkitawapi kin hecedan śni, tuka maka kin owancaya woahtani econpi kin hena.

3 Unkan deciyatanhan iye kin wanna sdonunyanpi e sdonunkiyapi, tawoahope unkokicipapi kinhan.

4. 'Tuwe, He sdonwaya ce, eye ca tawoahope okicipe śni kin he itonśni, qa wowicake kin en un śni.

5 Tuka tuwe iye oie kin okicipe cinhan, awicakehan he en Wakantanka waśtedake cin yuecetupi. Heciyatanhan iye kin en unyakonpi kin sdonunkiyapi ece.

6 Tuwe he kici un keye cinhan, iye token omani qon iś iyecen omani kta iyececa.

7 Mihunkawanji, woahope teca wan cicagapi śni, tuka woahope tanina, otokaheya tanhan duhapi qon hee. Woahope tanina kin wicoie otokahe ekta nayahonpi qon he hee.

8 Hehan akeś woahope teca wan cicagapi; he iye kin en wowicake, qa nakun niyepi kin en; otpaze cin he wanna henakeca, qa iyoyanpa wicake cin he wanna tanin kin heon etanhan.

9 Tuwe iyoyanpa kin en un keiciye ca, hunkawanjitku kin sicekidake cin he dehantu otpaza kin en un.

10 'Tuwe hunkawanjitku waśteliidake cin he iyoyanpa kin en un ece, qa wokaśeye takudan en un śni.

11 Tuka tuwe hunkawanjitku śicekidake cin he otpaza en un, qa otpaza omani, qa tokiya ye cin sdonkiye śni, iśta kin otpaza kaśeya, heon etanhan.
12 Hokśiyopa cikcistinpidan, iye caje kin on wayahtanipi kin nicicajujupi kin heon wowapi cicagapi.

13 Hunkakeniyanpi kin, tuwe otokaheya tanhan un kin he sdonyayapi kin heon wowapi cicagapi. Kośkapi kin, tuwe śice cin he ohiyayapi kin heon wowapi cicagapi.

14 Hokśiyopa cikcistinpidan, Ateyapi kin sdonyayapi kin he etanhan wowapi cicagapi. Hunkakeyapi kin tuwe otokaheya tanhan kin he iye sdonyayapi kin heon wowapi cicagapi. Kośkapi kin, waniśakapi, qa Wakantanka oie kin en niunpi, qa tuwe sice cin he yaktepidan kin he etanhan wowapi cicagapi.

15 Wicoicage kin de waśtedapi śni po, qa taku wicoicage kin ekta un kin hena nakun. 'Tuwe wicoicage kin de waśtedake cinhan, Ateyapi kin waśtedake cin en un śni.

16 Taku wicoicage en un kin owasin, wicacelipi cantiheye cin, wicaiśta cantiheye cin, qa wiconi kin den wahaniçidapi kin, hena Ateyapi kin etanhan śni, tuka wicoicage kin de etanhan.

17 Unkan wicoicage kin de atakuni kte śni, qa wocantiheye kin nakun; tuka tuwe Wakantanka tawacin kin yuhe cinhan, he owihanke wanin ounye kta.

18 Hokśiyopa cikcistinpidan, anpetu ihankeya kin wanna hiyohi ; unkan, Messi ya kipajin kin he $\mathrm{u}$ kta ce, nayahonpi qon he iyecen Messiya kipajinpi kin ota wanna hipi; heon de anpetu ehake kin sdonunyanpi.

19 Unkiyepi kin etanhan inan. papi, tuka hcna unkicicapi śni. Hena unkicicapi unkanś, unkici. 


\section{JOHANNES.}

pi un wacinpi kta: tuka owasin unketanhanpi śni tanin kta. e heon etanhan hececa.

20 Tuka Wanji Wakan kin he niye sdaniyanpi, qa heon taku owasin sdonyayapi.

21 Wowicake kin sdonyayapi śni kin heon wowapi cicagapi śni ; tuka he sdonyayapi, qa woitonśni takudan wowicake kin eciyatanhan u śni, heon etanhan.

22 Tuwc itonśni he ; tuwe Jesus he Messiya kin ee śni, keye cin hee; Messiya kipajin kin hee, Ateyapi qa nakun Cinhintku kin anawicakilibe cin hee.

23 Tuwc Cinhintkuyapi kin wicada śni kin he Ateyapi kin yuhe śni : tuka tuwe Cinhintkuyapi kin oyake cinhan, he Ateyapi kin nakun yuha ece.

24. Taku otokaheya tanhan nayalionpi qon he yuhą po. Taku otokahe ekta nayahonpi qon en niunpi kinhan, Cinhintkuyapi kin en yaunpi kta, qa nakun Ateyapi kin en.

25 Unkan wahoyapi qon taka iwahounyanpi kin, owihanke wanin wiconi kin hee.

26 Tona nihnayanpi kta cinpi kin hena on decen wowapi cicagapi.

27 Tuka sdaniyanpi, iye eciyatanhan duhapi kin he nicipi un; qa tuwe waonspeniciyapi lita iyenicecapi śni ; tuka sdaniyanpi kin he taku owasin onspeniciyapi, he wowicake qa woitonśni wanica; he taku onspeniciyapi kin iyecen, iye kin en un po.

28 Unkan dehan, hokśiyopa cikcistinpidan, iye kici un po ; hecen tohan iye ihdutanin kinhan wacinumyanpi kta, qa taninyan hinajin kinhan, itokam unkiśtecapi kte śni.

29 Iye owotanna un sdonyaya- pi kinhan, tuwe woowotanna econ kin he iye kin eciya tanhan wanna teca nien tonpi e nakun sdonya po.

\section{WICOWOYAKE 3.}

1 Wanyaka po, Ateyapi kin wocantekiye hinsko tanka unqupi kin, Wakantanka cinca unkekiciyapi kta: lieon etanhan wicoicage kin sdonunyanpi śni, iye kin sdonyapi śni qon iyececa.

2 Waśtecicidapi kin, wanna Wakantanka cinca kin heuncapi ; qa tounkecapi kte cin hinalin tanin śni : tuka iye kin ihdutanin kinhan, iyeuncecapi kta e sdonunkiyapi; he token un kin wanunyakapi kta nakaeś.

3 Unkan tuwe hecen wacinyan canteyuze cinhan ihduecedan ece, iyc kin ecedan un kin iyecen.

4. Tuwe woalitani econ kin he woope kin kicaksa ece; woahtani he woope kicaksapi kin hee.

5 Unkan iye ihdutanin qon, waunhtanipi kin yutokan iyeye kta e heon, he sdonyáyapi; qa iye kin woalitani takudan en un śni.

6 Tuwe iye en un kin he wahtani śni ; tuwe wahtani ece kin he iye kin tohinni wanyake śni, qa nakun sdonye śni.

7 Hokśiyopa cikcistinpidan, ihnuhan tuwe nihnayanpi kinhan; tuwe taku owotanna econ ece kin he owotanna, iye kin owotanna un kin iyececa.

8 'Tuwe woahtani econ ece' kin he wakanśica eciyatanhan un; otokaheya tanhan wakansica kin wahtani ece. Heon etanhan Wakantanka Cinhintku kin ihdutanin, wakanśica ohan kin ihangye kte cin heon.

9 Tuwe Wakantanka eciyatan- 


\section{WICOWOYAKE 4.}

han teca nien tonpi kin he woahitani econ śni, taku on icahye cin he en un kin heon; unkan wahitani okihi śni, Wakantanka eciyatanhan teca nien tonpi kin he etanhan.

10 Detanhan Wakantanka cinca kin sdonwicayapi, qa nakun wakanśica cinca kin ; tuwe taku owotanna ece econ śni kin he Wakantanka eciyatanhan śni, qa nakun tuwe hunkawanjitku tanyan cante kiyuze śni kin.

11 Otokaheya tanhan taku iwahokonunkiciyapi nayahonpi qon he dee, otoiyohi waśteunkicidakapi kte cin.

12 Qain taku śice cin eciyatanhan un, qa iye sunkaku kikte qon iyecece śni. Unkan taku on kikte he. Iye kin ohan śica, qa sunkaku kin waśte kin heon etanhan.

13 Mihunkawanji, wicoicage kin śicenidapi eśta inihanpi śni po.

14 Hunkawanjinkiciyapi waśtewicunkidapi kin heon wiconte etanhan wiconi e ekta unkiyohipi sdonunkiyapi ; tuwe hunkawanjitku waśtekida śni kin he wiconte ehna un.

15 'Tuwe hunkawanjitku śicekidake cin he tinwicakte kin heca; unkan tuwe tinwicakte kin he wiconi owihanke wanica aihduhe śni e sdonyayapi.

16 Deciyatanhan wacantkiyapi kin sdonunyanpi ; iye kin unkiyepi on wiconi ehpekiye cin heon; hecen unkiś eya hunkawanjinkiciyapi kin on wiconi ehpeunkiyapi kta iyececa.

17 Tuka tuwe maka akan woyuha ton, qa hunkawanjitku wahpanica wanhdake ça, cantekiye cin anakipte cinhan, token Wakantanka waśtedake cin en un kta he.
18 Micinca cikcistinpidan, wicoie qa wicaceji ecedan on wacanunkiyapi kte śni, tuka wicohan qa wowicake kin on.

19 Unkan deciyatanhan wowicake eciyatanhan unyakonpi, qa iye itohnake kin en cante unhduținzapi kta e sdonunkiyapi.

20 Uncantepi kin unhdacopi kinhan, Wakantanka uncantepi kin sam iyeya tanka, qa taku owasin sdonya un.

21 Waśtecicidapi kin, uncantepi kin unhdacopi śni kinhan, Wakantanka ekta wowaditake kin unhapi :

22 Qa taku unkidapi kin owasin unkicupi ece, tawoahope kin unkiciyuhapi, qa taku iye iśta kin en iyokipi kin he econkupi, heon etanhan.

23 Unkan tawoahope kin he dee, Iye Cinhintku Jesus Messiya caje kin wacinunyanpi, qa otoiyohi waśteunkicidapi kta, econ unśipi qon iyececa.

24 Tuwe tawoahope kin opecinhan, he Wakantanka kici un, qa iś iye kin en un; unkan Woniya unqupi kin he eciyatanhan iye unkicipi un kin he sdonunyanpi ece.

\section{WICOWOYAKE 4.}

1 Waśtecicidapi kin, ihnuhan woniya owasin wicayadapi kinhan; tuka woniya kin wicayukcan po, Wakantanka etanhan unpi kinhan; wicaśta wokcan itonpiśni ota wanna wicoicage kin ehna iyayapi.

2 Deciyatanhan Wakantanka Taniya kin sdonyayapi kta; woniya kin tona Jesus Messiya wicacehipi un hi oyake cin hena Wakantanka eciyatanhanpi ece.

3 Qa woniya kin tona Jesus Messiya wicacelipi un hi oyake śni kin hena Wakantanka eciya375 


\section{JOHANNES.}

tanhanpi śni; tuka Messiya kipajin u kta nayahonpi qon he dee, wanna wicoicage kin en un.

4 Hokśiyopa cikcistinpidan, Wakantanka eciyatanhan yaunpi, qa hena ohiwicayayapi; tuwe en niunpi kin he tuwe wicoicage en un kin isanpa tanka.

5 Hena e wicoicage kin etanhanpi; heon wicoicage kin iyecen iapi, unkan wicoicage kin anawicagoptan ece.

6 Unkiye Wakantanka unketanhanpi; tuwe Wakantanka sdonye cin he unkiye anaungoptanpi ece; qa tuwe Wakantanka eciyatanhan śni kin he anaungoptanpi śni. Dcciyatanhan wowicake woniya qa wohnaye woniya kin napin s'donunyanpi.

7 Waśtecicidapi kin, otoiyohi canteunkiciciyapi kte ; wacantkiyapi kin he Wakantanka eciyatanhan un; qa tuwe wacantkiye cin lie Wakantanka eciyatanhan tonpi, qa Wakantanka sdonya.

8 'Tuwe wacantkiye śni kin he Wakantanka sdonye śni; Wakantanka he wacantkiyapi kin hee.

9 Wakantanka canteunkiyapi kin he deciyatanhan tanin, Wakantanka iye Cinhintku iśnana icage cin he makata uśi, heciyatanhan unnipi kta e heon.

10 Wacantkiyapi kin he deciyatanhan, unkiye Wakantanka waśteundakapi kin hee śni, tuka iye canteunkiyapi, qa Cinhintku waunhtanipi yutokan iyeye kta e on u si qon hee.

11 Waśtecicidapi kin, Wakantanka hecen canteunkiyapi kinhan, unkiś eya otoiyohi canteunkiciciyapi kta iyececa.

12 Tuwedan tohinni Wakantanka wanyake śni. Otoiyohi canteunkiciciyapi kinhan Wa- kantanka unkicipi un, qa iye canteunkiyapi kin unkiyepi en tanyan yuśtanpi ece.

13 Heciyatanhan unkiye kici unyakonpi, qa iye unkicipi un kin sdonunyanpi ece, iye Taniya unqupi kin heon.

14 Unkan wanunyakapi, qa Ateyapi kin Cinhintku ukiya, wicoicage kin ekta, Wanikiya hee kta e he unyaotaninpi.

15 Tuwe Jesus he Wakantanka Cinhintku kin hee e oyake cin he kici Wakantanka un, qa iś eya Wakantanka en un ece.

16 Wakantanka canteunkiyapi kin he sdonunyanpi qa wicaundapi. Wakantanka wacantkiyapi kin hee : qa tuwe wacantkiyapi en un kin he Wakantanka kici un, qa Wakantanka iś nakun iye en un ece.

17 Deciyatanhan wocantekiye unkiyepi en unkiciyuśtanpi ece, hecen woyaco anpetu kin en wowaditake unhapi kta : iye un kin unkiś iyecen wicoicage kin den unyakonpi ece.

18 Wacantkiyapi kin en wokokipe wanica, tuka wacantkiyapi yuśtanpi kin he wokokipe tankan ehpeya ece; wolkokipe kin he wicocante sica yuha ece; tuwe wakokipe cin he nahantiin wacantkiyapi kin en yuśtanpi śni.

19 Iye tokaheya canteunkiyapi kin heon unkiye Wakantanka waśteundakapi.

20 Tuwe, Wakantanka waśtewadaka ce, eye ça hunkawanjitku śicekidake cinhan, he itonśni. Tuwe hunkawanjitku wanhdake cin he waśtekidake śni kinhan, token ecin Wakantanka wanyake śni kin waśtedaka okihi kta he.

21 Unkan iye etanhan woahope kin de unhapi; tuwe Wakan- 


\section{WICOWOYAKE 5.}

tanka waśtedake cin he hunkawanjitku kin iś nakun waśtekidake kta ce.

\section{WICOWOYAKE 5.}

1 Tuwe Jesus he Messiya kin ee e wicada kin he Wakantanka eciyatanhan tonpi ; qa tuwe waicahye cin waśtedake cinhan, he tuwe iye eciyatanhan teca ni en tonpi kin he nakun waśtedaka ece.

2 Deciyatanhan Wakantanka cinca kin waśtewirundakapi kin sdonunkiyapi, Wakantanka waśteundakapi qa tawoahope kin tanyan unkiciyuhapi kinhan.

3 Wakantanka waśtedakapi kin he dee, tawoahope kin tanyan ounpapi kin he; unkan tawoahope kin wośitkihda śni.

4 'Tuwe Wakantanka eciyatanhan tonpi kin he wicoicage kin ohiya ece; unkan woohiye wicoicage ohiye cin he dee, wacinunyanpi kin hee.

5 Wicoicage ohiya ece kin he tuwe he; tuwe Jesus he Wakantanka Cinhintku kin ee e wicada kin hee.

6 Tuwe mini qa we eciyatanhan hi qon he Jesus Messiya ee; mini ecedan on hi śni, tuka mini we ahna. Unkan wayaotanin kin he Woniya kin hee; Woniya kin he wowicake, heon etanhan.

7 Mahpiya kin ekta yamni wayaotaninpi ece, A teyapi kin, Wicoie kin, qa Woniya Wakan kin; unkan hena yamni wanjipidan.

8 Nakun maka akan taku yamni wayaotanin ece, Woniya kin, qa mini kin, qa we kin; unkan hena yamni wanjidan en un.

9 Wicaśta akantu taku yaotaninpi kin he unkicupi kinhan, Wakantanka taku yaotanin kin he iyotan tanka; Wakantanka taku yaotanin kin he dee, iye Cinhintku hdaotanin qon hee.

10 Tuwe Wakantanka Cinhintku kin wicada kin he wayaotanin iye atayedan yuha un. 'Tuwe Wakantanka wicada śni kin he itonśni daka ece; wayaotanin kin on Wakantanka iye Cinhintku hdaotanin qon he wicada śni kin heon.

11 Unkan wayaotanin qon he dee, Wakantanka wiconi owihanke wanica unqupi kin he; unkan wiconi kin he iye Cinhintku kin en un.

12 Tuwe Cinhintkuyapi kin yuhe cin he wiconi yuha; qa tu.we Wakantanka Cinhintku kin yuhe śni kin he wiconi yuhe śni. 13 Wakantanka Cinhintku caje kin wacinyayapi kin dena wowapi cicagapi kin; wiconi owihanke wanica duhapi e sdonyakiyapi kta, qa Wakantanka Cinhintku caje kin wacinyayapi kta e heon.

14 Unkan iye ekta wowaditake unhapi kin he dee, Iye tawacin kin eciyatanhan taku unkidapi eca naunkihonpi ece :

15 Qa taku unkidapi eca naunkihonpi ece e sdonunkiyapi kinhan, taku tona unkidapi kin hena unhapi e nakun sdonunkiyapi ece.

16 Tuwe hunkawanjitku wahtani wanhdake cinhan, woahtani kin he wiconte ekta śni kinhan, wocekiye ekiciye kta, unkan Wakantanka wiconi qu kta, tona wahtanipi wiconte ekta iyahde śni hena on. Woahtani wanji wiconte ekta; he on wocekiye eye kta epe śni.

17 Taku śica econpi kin owasin woahtani; unkan woahtani wiconțe iyohi śni kin heca yukan.

18 Tuwe Wakantanka eciyatanhan tonpi kin he wahtani śni 377 


\section{JOHANNES.}

ece e sdonunyanpi; tuka tuwe Wakantanka eciyatanhan icage cin he tanyeh ihduhe ça hecen taku śice cin he oyutan śni ece.

19 Wakantanka eciyatanhan unyakonpi kiı he sdonunkiyapi; qa wicoicage kin ocowasin woahtani en wanka.

20 Unkan Wakantanka Cinhintku kin he hi, qa wicoksape unqupi, on tuwe wicake cin iyeunkiyapi kta e sdonunyanpi; unkan tuwe wicake cin he en unyakonpi, iye Cinhintku Jesus Messiya hee. Wowicake Wakantanka qa owihanke wanin wiconi kin hee.

21 Hokśiyopa cikcistinpidan, taku wakagapi kin itehan ihduha po. Amien.

\section{JOHAN NES}

\section{TAWOWAPI INONPA KIN.}

1 Hunkayapi un kin, Kuria kahnigapi qon wowapi kicaga; iye cinca kin, wowicake eciyatanhan waśtewicawadake cin hena om, qa miśnana śni, tuka nakun tona wowicake sdonyapi kin hena owasin;

2 Wowicake kin en unyakonpi, qa owihanke wanin unkicipi un kte cin heon etanhan.

3 Wowaśte, wowaonśida, wookiye ko, Wakantanka Ateyapi kin eciyatanhan, qa nakun Jesus Messiya Itancan, Ateyapi lin he Cinhintku kin eciyatanhan, wowicake wacantkiyapi ko en, nicipi un nunwe.

4 Ateyapi kin woahope unqupi qon iyecen, nicinca wowicalie eciyatanhan manipi iyewicawakiye cehan nina inıduśkin.

5 Unkan nakaha, Kuria, ceciya ce, woahope teca wan cicage cin iyecece śni, tuka wanji otokahe ekta unhapi qon, otoiyohi canteunkiciciyapi kte cin hee.

$6 \mathrm{Qa}$ wacantkiyapi kin he dee, tawoahope kin eciyatanhan maunnipi kte cin hee. Woahope kin he dee, Otokahe ekta taku nayahonpi qon he ohna mayanipi kte cin.
7 Wanna wicahnaye sa ota wicoicage kin ehna iyayapi, hena Jesus Messiya wicacehpi un hi qon oyakapi śni. He wicahnaye sa qa Messiya kipajin kin heca.

8 Iwanihdaka po, hecen talku unkamnanpi kin toki elipeunyanpi kte śni, tuka wokajuju iyakicuya unkicupi kta.

9 Tuwe walitani qa Messiya tawoonspe kin en un śni kin he Wakantanka yuhe śni. Tuwe Messiya tawoonspe kin en un kin he Ateyapi kin yuhe ça nakun Cinhintku kin.

10 Tuwe en niipi qa woonspe kin de yuhe śni kinhan, tin u śipi śni po, qa wóokiye eciyapi śni po.

11 Tuwe wookiye eciye cin he iye ohan śice cin en opa.

12 Taku ota wowapi cicagapi kta mduha eśta, minihuha minisapa ko on ecamon kte śni : tuka en ciupi qa i eciyatanhan ociciyakapi kta e ecin cante mduza; hecen wowiyuśkin unkitawapi kin ojudan kta.

13 Nitanka kahnigapi qon cincawicaye cin hena nape niyuzapi. Amen. 
1 Hunkayapi waun kin, Gayos waśtedakapi kin, wowicake en waśtewadale cin he, wowapi cicagat.

2 Waśtecicida, taku owasin isanpa, tanyan iyoopte de kta qa zaniyan yaun kta e cewakiya ece, ninagi iyoopta ye cin ivececa.

3 Hunkawanjinkiciyapi kin den hipi, qa wowicake en niun kin he oyakapi qehan, wowicake eciyatanhan mayani kin heun nina imduśkin.

4 Micinca wowicake kin eciyatanhan manipi nawahon kin heon wowiyuślin iyotan tanka mduha, takudan kape śni.

5 Waśtecicida, taku hunkawanjinkiciyapi kin, qa nakun wicaśta toktokeca ecawicayecon kin he tanyeh ecanon:

6 Hena e okodakiciye kin en wacanyakiye cin tanyan oyakapi.: hena icimanipi en, Taku Wakan iyecen, owicayakiye cinhan. tanyan ecanon kta.

7 Iye caje kin on iyayapi, qa Ikcewicaśta kin etanhan takudan icupi śni, heon etanhan.

8 Heon tona hececapi kin hena iyowinwicunkiyapi kta iyececa ; hecen wowicake kin ounkiyapi kta.

9 Okodakiciye kin wowapi wicawecaga; tuka hena ehna Diotrephes itancan icida kin he iyowinunkiyapi śni.

10 Heon etanhan wau kintıan, iye ohan kin, oie śica on unkaiapi ece kin hena weksuyc kta. Unkan he on imnan śni, tuka iye hinca hunkawanjinkiciyapi kin iyowinwicakiye śni, qa tona hecon wacinpi kin iyowicaki śni, qa okodakiciye kin etanhan tankan iy ayewicaya ece.

11 Waśtecicida,taku śice cin he en ope śni wo, tuka taku waśte kin. Tuwe taku waśte ccon kin he Wakantanka eciyatanhan un, tuka tuwe taku śica econ kin he Wakantanka wanyake śni.

12 Demetrios owasin on tanyan oyakapi, qa wowicake kin nakun eciyatanhan; unkan unkiś eya he unyaotaninpi, qa waunyaotaninpi kin he wowicake e sdonyayapi.

13 Taku ota ociciwa kta mduha tuka, tuka minisapa wiyaka ko on hena wowapi cicage kte śni : 14 Tuka ecadan wanciyake kta, qa i eciyatanhan unkokiciciye kta wacin.

15 Wookiye niye en niciun nunwe. Takukiciyapi kin hena nape niyuzapi. Takukiciyapi kin cajeyan nape wicayuza wo. 379 


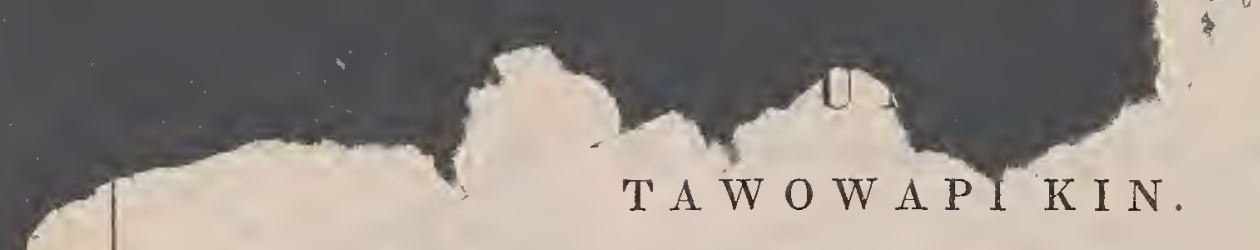

1 Judas, Jesus Messiya tawowidake kin, qa Jakob sunkaku kin, tona Wakantanka Ateyapi kin en wicayuecepidan, qa Jesus Messiya en wicakpatanpi, qa wicakicopi kin hena wowapi wicakicaga.

2 Wowaonśida, qa wookiye, wacantkiyapi ko niyepi en niciyuotapi nunwe.

3 Waśtecicidapi kin, wiconi ptaya unhapi kin on aiçiciya wowapi cicagapi eca, wowacinye ehanna wicaśta wakan wicaqupi qon he nina yakitanpi kta e on wowapi cicagapi, qa wahokonciciyapi kta iyececa.

4 Wicaśta wanjikśi nalimana en opapi, wanakajatanhan woyaco kin de on owicawapi ; hena Taku Wakan iyececapi śni, qa Wakantanka unkitawapi towaonśida kin he wicowicaśtaśni kagapi, qa Wakantanka ecedan Itancan kin he anahmanpi, qa nakun Jesus Messiya Itancan unyanpi kin.

5 Heon etanhan, taku, ehanna sdonyayapi eśta, he ake kiksuyeciciyapi kta wacin, Itancan kin oyate kin Egupta etanhan ehdaku, qa iyohakam tona wicadapi śni kin hena ihangwicaye cin.

$6 \mathrm{Qa}$ nakun mahpiya ohnihde otokahe unpi kin kpatanpi śni, tuka iye tipi ehpekiyapi qon, hena otpaza ihukuya, owihanke wanin mazaicicahilia kin on, anpetu tanka woyaco kin he en awicayuha.

7 Sodom qa Gomorra iyececa, 380 qa otonwe hena ihdukśan wanke cin, hena iś eya iyecen wiinahmanpi kin en içicupi, qa vicacelipi toktokeca akitapi ece qon hena e woonspe on ehdepi, qa peta owihanke wanica on wositkihda en unpi.

$8 \mathrm{He}$ iyececa, wihamnanpi sa kin dena wicacehpi kin aśamyapi, qa wokiconze wahtedapi śni, qa taku tanka yaśicapi ece.

9 Hececa, tuka Mikael mahpiya ohnihde itancan kin he wakanśica kin kici econ, qa Moses tancan kin on akinicapi qehan, woośtehda woiyaonpe wan en aya tawatenye śni, tuka, Itancan kin iyopeniyan nunwe, eciya.

10 Tuka dena e qe taku sdonyapi śni kin hena yaśicapi ece: tuka iye icagapi kin eciyatanhan taku sdonyapi kin hena on ihdusicapi, woteca ia okitpanipi kin iyececa.

11 Wotehi wicakiciun nunwe; Qain tancanku kin ohna yapi, qa wokajuju on, Balaam tawohnaye kin nina ainyankapi, qa Kore wicakipajin qon en ihangiciyapi.

12 Hena woaśape kin heca, wacantkiya wayatapi kin en opeya wotapi, qa wikopeśniyan cemiçiyapi ; mahpiya śapa mini wanica tate on ayapi ece kin; can kin ptanyetu eca śeca aya, waskuyeca codan, inonpa śeca, qa hute eciyatanhan yujunpi kin hena hececapi.

13 Miniwanca taja ohitika, iye wowiśtece tawapi kin minitaga 


\section{WICOWOYAKE 1.}

iyecen hiyuyapi ece; wicanlipi onuniyata unpi, on otpaza sape hinca owihanke wanin wicakicihnakapi.

14 Henok Adam etanhan wicaśta iśakowin qon he itokam hena owicayake ca heya; Wanyaka po, Itancan kin wicaśta waśte wicayuhe cin woyawa tanka om u ce ;

15 Owasin wicayaco kta, qa tona Taku Wakan ohodaśni kin hena wicohan śikśica owasin ohodaśniyan econpi qon hena sdonkiyewicaye kta, qa wicoie canksiksi owasin wahtanipi sa Tạku Wakan ohodapi śni oie kicatonpi ece qon hena nakun.

16 Hena e wihnupi sa, wawiyaonpapi sa, iyc cantiheyapi kin eciyatanhan manipi ece; qa i eciyatanhan wahanhanicidaya iapi, qa taku on etanhan wicaśta itohnake kin waśtedakapi ece.

17 Tuka waśtecicidapi kin, niyepi, Jesus Messiya Itancan un. yanpi yewicaśi qon hena oiepi ehanna oyakapi qon hena kiksuya po ;

18 Anpetu ihankeya kin en wicaśta wawilialiapi kin yuke kta, iye cantiheyapi śice cin eciya- tanhan manipi kin, he oniciyakapi qon.

19 Ihdutokanpi kin dena eepi, witantanpi, qa Woniya kin yuhapi śni.

20 Tuka waśtecicidapi kin, niś niyepi wowacinye iyotan wakan nitawapi kin he ohna icahiciyapi, qa Woniya Wakan kin eciyatanhan wocekiye eya po ;

21 Wakantanka waśtedakapi kin en ihduha po ; qa Jesus Messiya Itancan unyanpi towaonśida wiconi owihanke wanica iyahde kte cin he ape yukan po.

22 Unkan hunh wicayukcanyan onśiwicada po ;

$23 \mathrm{Qa}$ hunh iś wokokipe on niwicaya po, peta etanhan iwicacupi kin iyececa ; qa wokoyake wicacehpi on aśapapi kin hena ee kaeś śicedaka po.

24 Unkan tuwe woalitani econ śni niyuhapi kta okihi, qa wowiyuśkin yuha iye towitan kin en iyaonpepica śni enihdepi kte cin,

25 Wakantanka ecedan ksapa, Wanikiya unkitawapi kin hee, Jesus Messiya Itancan unyanpi kin eciyatanhan, wowitan, woyaonihan, wookihi qa wokiconze, dehantu qa wicoicage owasin hehanyan, tawa nunwe. Amen.

\section{JOHA N NES}

\section{WAYUOTANIN TAWA KIN.}

WICOWOYAKE 1.

1 Jesus Messiya wayuotanin tawa, taku ecadan u kta e he tawowidake kin sdonyewicakiye kta Wakantanka qu qon he dee; unkan taohnihde wan $u$ śi, qa tawowidake Johannes he okiyaka:

$2 \mathrm{He}$ Wakantanka oie kin, qa Jesus Messiya wohdake cin, taku tona wanyake cin hena yaotanin.

3 Tuwe wokcan oie kin de ya-

381 


\section{WAYUOTANIN.}

wa, qa tona nahonpi, qa taku en kagapi kin anagoptanpi kin, hena wowaśte yuhapi. Wanna kiyadan ihan.

4 Johannes, Asia ekta okodakiciye śakowinpi kin wowapi wicakicaga. Wowaonśida, wookiye ko, tuwe un, qa un qon, u kte cin hetanhan niyepi en nicipi un nunwc; qa Woniya śakowinpi oiyotanke tawa kin itokam unpi kin hena eciyatanhan;

$5 \mathrm{Qa}$ Jesus Messiya etanhan, he waayatanin wicaka, wiconte etanhan tokaheya tonpi, qa maka wicaśtayatapi kin Itancan kin hec. Tuwe waśte unkidapi, qa waunhtanipi kin etanhan iye wc kin en unyujajapi,

6 Qa Atkuku Wakantanka ekta wicaśtayatapi, wośna kagapi ko unkagapi kin hee, wowitan, wowaśake ko o wihanke wanin tawa nunwe. Amen.

7 Wanyaka po, mahpiya śapa kin akan $\mathrm{u}$; unkan wiciśta owasin wanyakapi kta, qa tona he capapi qon hena nakun, qa iyc on oyate maka ohnaka kin owasin aicipapi kta. Hecetu nunwe. Àmen.

8 Alpha qa Omega, otokahe qa owihanke kin lie miye ce; Itancan un, qa un qon, u kta, iyotan waśake cin he hena liecen eya.

9 Johannes hunkawanjinyayapi, wokakije, qa wokiconze, wowahbadan ko, Jesus Messiya tawa kin en, tawaśi yayapi kin he miye; Wakantanka oie qa Jesus Messiya wohdake cin on etanhan, wita wan, Patmos eciyapi, hen waun.

10 Itancan taanpetu kin en Woniya kin kici waun; unkan mihektapa tanhan wicaho wan tanka, maza yahotonpi tanka wan iyececa, nawation;
$11 \mathrm{He}$ kaken eya, Alpha qa Omega, tokaheya qa ehake kin he miye ce. 'Taku wandake cin wowapi ecen kage ca, $\Lambda$ șia ekta okodakiciye kin iwahowicaya wo; Ephesos, qa Smurna, qa Pergamos, qa Thuatira, qa Sardis, qa Philadelphia, qa Laodikia. 12 Unkan wicaho omakiye cin he wanmdake kta e ekta mihdamna. Unkan mihdamna qehan mazaskazi petijanjan ihupa śakowin wanmdaka.

13 Qa petijanjan ihupa śakowin kin cokaya Wanji Wicaśta Cinhintku kin iyececa, tawokoyake kin siha kin ekta iyahdeya, qa maku kin opta mazaskazi ihduskita.

14. Qa pa kin paha ko ska, tahinca wanuyanpi hin kin iyecen ska, qa wa iyececa, qa iśta kin peta ide kin iyececa;

$15 \mathrm{Qa}$ siha kin iś mazazi ecedan iyececa, peta tanka en itkonyahe seca; qa ho kin be mini ota ihaha kin iyececa.

16 Qa nape etapa kin ohna wicanlipi śakowin hduhe ca, i kin eciyatanhan maza sagye anog ope kin heca wan hiyu, qa itohnake kin he anpetu wi nina iyege cin iyececa.

$17 \mathrm{He}$ wanmdaka, unkan ta wanke cin iyecen siha hde kin en mahinlipaya. Hehan iye nape etapa kin on omayutan qa, Ihnuhan koyakipe cin, emakiya; Tokaheya qa ehake kin he miye ;

18 Tuwe te ca ake kini, qa ito owihanke wanin ni waun; Amen; qa Wakanśica ti kin wiconte ko tiyopa iyuhdoke kin yuha manka ce.

19 Taku wandake cin he wowapi ecen kaga wo, taku nakaha un qa dena iyohakam taku u kte cin hena. 


\section{WICOWOYAKE 2.}

20 Wicanhpi śakowin minape stapa kin ohna wandake ciqon wowiyukcan kin hee, qa mazaskazi petijanjan ihupa kin hena nakun. Wicanhipi śakowin qon okodakiciye śakowinpi ohnihde yuhapi kin hena eepi ; qa petijanjan ihupa śakowin wandake cin okodakiciye śakowinpi kin hena eepi.

\section{WICOWOYAKE 2.}

1 Ephesos ekta okodakiciye ohnihde yuhapi kin he ecen wowapi kicaga wo; Tuwe wicanhipi śakowin nape etapa kin ohna hduhe ca, mazaskazi petijanjan ihupa śakowin cokaya omani kin he hecen eya;

2 Niohan, qa nitohtani, qa wacinnitanka kin he sdonwaya; qa tona śicapi kin hena iyowinwicakiya oyakihi śni; qa tona yewicaśipi kin hecapi keiciyapi kin hena wicadukcan qa itonpiśni kin heca iyewicayaya.

3 Wacinnitanka, qa ayape, qa micaje kin on htayani, qa oyakite śni.

4 Tuka taku cistinna iyacionpa, tokaheya waśteyadake cin he aduśtan.

5 Heon tokiya tanhan nihinhpaye cin he kilksuye, ça ihduecetu, qa niohan tokaheya kin hduśtan wo. Hecanon śni kinhan kohanna ekta ciu, qa petijanjan nitawa kin yutokan iyeciciye kta, nihduecetu śni kinhan.

6 Tuka he duha, Nikoleton wicolian kin śiceyadake cin, hena miś eya śicewadaka.

7 Tuwe noge yukan hecinhan, taku Woniya kin okodakiciye kin ewicakiye cin he nahon kta. Tuwe ohiye cinhan he can wiconi, Wakantanka tamaga co- kaya he cin, hetanhan yun wakiye kta.

8 Unkan Smurna ekta okodakiciye ohnihde yuhapi kin he ecen wowapi kicaga wo; Tuwe tokaheya qa ehake un kin, te ca ake kini kin hee hecen eya ;

9 Niohan kin sdonwaya, wokakije wowalipanica ko nitawa kin, (tuka winijica;) qa tona Juda wicaśta keiciyapi qa hecapi śni, tuka Satan omniciye tawa kin etanhanpi, hena waaiapi kin nakun sdonwaya.

10 Token nicakije kte cin ihnuhan taku koyakipe cin. Iho, Wakanśica niyepi wanjikji wicakaśka tipi kin en iyeniyanpi kta, iniyukcanpi kta e heon; unkan anpetu wikcemra hehanyan wokakije duhapi kta; tuka wicate cin hehanyan wicaka wo, kinhan wiconi wateśdake wan ciçu kta.

11 Tuwe noge yukan hecinhan, taku Woniya kin okodakiciye kin ewicakiye cin he nahon kta. Tuwe ohiye cinhan he wiconte icinonpa kin on kiuniyanpi kte śni.

12 Unkan Pergamos ekta okodakiciye ohnihde yuhapi kin he ecen wowapi kicaga wo; Tuwe maza sagye anog ope kin hduhe cin hee hecen eya ;

13 Niohan kin sdonwaya, qa tukten Satan oiyotanke tawa yanke cin hen yati; qa micaje kin yuha yaun, qa wacinmayanpi kin aduśtan śni, anpetu kin Antipas waayatanin wicaka mitawa kin niyepi kin en, tukten Satan ti kin, hen ktepi qon he ehan.

14 Tuka taku wanjikjidan iyacionpa; Balaam hee Balak Israel cinca kin taku on wahtani iciyapi kte cin wicitokam ehde 383 


\section{WAYUOTANIN.}

kin he onspekiye ca, taku wakagapi wakiyuśnapi kin yutapi: qa wiinahmanpi econpi kta, he tawoonspe tona yuhapi kin hena wicaduha ;

15 Qa nakun Nikoleton tawoonspe yuhapi kin hena wicaduha, he śicewadaka tuka.

16 Ihduecetu wo; hecanon śni kinhan kohanna ekta ciu, qa mii maza sagye kin on hena kici wecize lita.

17 Tuwe noge yılkan hecinhan, taku Woniya kin ok odakiciye kin ewicakiye cin he nation kta. Tuwe ohiye cinhan he manna kihnakapi qon he etanhan yunwakiye ça inyan ska wan waqu kta, inyan lkin he en wicacaje teca wan kagapi kin he tuwedan sdonye śni, tuka tuwe icu kte cin hecedan.

18 Unkan Thuatira ekta okodakiciye ohnihde yuhapi kin he ecen wowapi kicaga wo; Wakantanka Cinhintku, iśta peta ide kin iyecen hduhe ca, siha kin mazazi ecedan iyececa hee hecen eya ;

19 Niohan kin sdonwaya, wacanyakiye, ca htayani, qa wicayada, qa ayape, qa niohan kin, qa ehake kin hena tokaheya kin sam iyeya ota.

20 Tuka taku tonana iyacionpa, winohinca wan Jezebel eciyapi, winon̉inca wokcanka keiçiye cin he mitaokiye kin wicahnaye ca, wiinahmanpi econpi, qa taku wakagapi wakiyuśnapi kin yutapi kta e onspe wicakiye cin hee iyowinyakiya.

21 Unkan he wawicihahapi econ kin on iyopeiciye kta e anpetu waqu, tuka iyopeiçiye śni.

22 Ito, owinja wan akan ewaonpe kta, qa tona kici wawicihahapi econpi kin hena nakun, wo- kakije tanka en; wicohan kin on iyopeiçiyapi śni kinhan.

23 Qa iye cinca kin wiconte on wicawakte kta; qa okodakiciye kin owasin, tuwe wicapakśin wicacante ko iyukcan kin he miye e sdonyapi kta. Qa niyepi kin otoiyohi niohanpi kin eciyatanhan cicupi kta.

24 Tuka niyepi, qa tona Thuatira ekta woonspe kin he yuhapi śni, qa Satan ośbe tawa eyapi kin sdonye śni yaunpi kin kaken eciciyapi ; Waqinpi tokeca acihnakapi kte śni ;

25 Tuka taku duhapi kin he tinsa hduha po, hibu kte cin hehanyan.

$26 \mathrm{Qa}$ tuwe ohiye ca owihanke kin iyahdeya miohian kin yuha un kinhan, oyate kin en wowaśake waqu kta.

$27 \mathrm{Qa}$ maza icapsinte wan on wicayuhe ca maka wakśica iyecen wicakamdece kta ce; hecen A te etanhan hduha waun.

$28 \mathrm{Qa}$ anpao wicanlipi kin he waqu kta.

29 Tuwe noge yukan hecinhan taku. Woniya kin okodakiciye lin ewicakiye cin he nahon kta.

\section{WICOWOYAKE 3.}

1. Unkan Sardis ekta okodakiciye ohnihde yuhapi kin he ecen wowapi kicaga wo; 'Tuwe Wakantanka Taniya śakowin kin hena, qa wicanhipi śakowin hduhe cin he hecen eya; Niolian kin sdonwaya, caje wan duha, yani kin hee, tuka nita.

2 Kiktahan un, qa taku tona nahahin en un qa te kte cin hena hduwaśaka wo; Wakantanka itokam niohan kin owotanna e iyewaye śni.

3 Heon token iyacu, qa nayahon kin kiksuye ca, ținsa yuze 


\section{WICOWOYAKE 3.}

ça, ihduecetu wo. Kiktahan yaun śni kinhan wamanon sa iyecen ekta ciu kta, qa tohan ekta cihi kte cin he sdonyakiye kte śni.

4 Tuka Sardis ekta wicacaje tonana duha, hena e tawokoyake kin hduśapapi śni ; qa ska ihduzapi ecen mici manipi kta; he iy ehantupi nakaeś.

5 Tuwe ohiye cinhan he wokoyake ska koyake kta, qa iye caje kin wiconi wowapi kin etanhan wapajuju kte śni, tuka he caje kin Ate itokam, qa ohnihde wicaye cin hena wicitokam omdake kta.

6 Tuwe noge yukan hecinhan taku Woniya kin okodakiciye kin ewicakiye cin he nalion kta.

7 Unkan Philadelphia ekta okodakiciye ohnihde yuhapi kin he ecen wowapi kicaga wo; Tuwe wakan qa wicaka un, qa Dawid tiyopa iyuhdoke kin yuhe ca, yulidoka eca tuwedan ecen iyeye śni, qa ecen icu eca tuwedan yulidoke śni ece kin hee hecen eya;

8 Niohan kin sdonwaya, tiyopa wan yulidokapi ecen he cin he nitokam ewahde, qa tuwedan ecen iyeya okihi śni ; wowaśake cistinna duhe ca mioie kin yuha yaun, qa micaje kin ehpemayaye śni.

9 Ito, Satan omniciye tawa kin etanhanpi Juda wicaśta keiciyapi, tuka hecapi śni, qa itonpi śni kin, hena iho, upi, qa nisiha kin itokam canpeśka makehde inajin wicawakiye kta, qa waśtecicida e sdonyapi kta.

10 Woape oie mitawa kin he awandake cin, heon tohan taku wawiyutanyan un kin tona maka owancaya unpi kin iyutanwicaye kta u kinhan, hehan awanciyake kta. Dak.
11 Iho ecadan wau kta; taku duhe cin he tinsa yuza wo, hecen wateśdake nitawa kin tuwedan nici kte śni.

12 Tuwe ohiye cinhan, he tipi wakan mita Wakantanka tawa kin ohna can ihupa wan wakage kta, qa icimana tankan ye kte śni ; qa he akan mita Wakantanka caje kin owawa kta, qa mita Wakantanka otonwe tawa caje kin, Jerusalem teca kin hee, mahpiya kin etanhan Wakantanka mitawa kin eciyatanhan u kin hee, qa nakun micaje teca kin.

13 'Tuwe noge yukan hecinhan, taku Woniya kin okodakiciye kin ewicakiye cin he nation kta.

14 Unkan Laodikia ekta okodakiciye ohnihde yuhapi kin he ecen wowapi kicaga wo; Tuwe Amen eciyapi, waayatanin owotanna, qa wicaka, Wakantanka woicage tawa otokahe kin hee hecen eya;

15 Niohan kin sdonwaya, sni qa ipiga unmana ecen yaun śni, sni qa ipiga unma tukte e ecen yaun kta wacin;

16 Tuka initeca, qa sni ipiga kici unmana ecen yaun śni, heon mii kin etanhan icihdepe kta.

17 Wimajica, qa woyuha ota waton, qa takudan imakakije śni, keha ce; qa inicakije ça, onniśike ça, niwahpanica, qa iśta nigonge ca, tanconikadan e sdonyakiye śni.

18 Kaken wahokonciciya ce, mazaskazi peta on yuecedan kagapi kin he opemicaton wo, winijica kta ce; qa wokoyake ska, kodake kta e heon, hecen tanconikadan on winiśtece cin he tanin kte śni; qa wiciśta wihdi kin, niiśta iyakiun kta, hecen wawandake kta.

19 Tona cantewicawakiye cin 


\section{WAYUOTANIN.}

hena wahokonwicarvakiye ça, iyopewicawakiya ece. Heon mniheiçiye ça ihduecetu wo.

20 Ito, tiyopa kin en nawajin qa wakabubu ece; tuwe miho kin nahon, qa tiyopa hduhdoke cinhan, he ekta tin hibu, qa kici wawate kta, qà iś eya mici wote kta.

21 Tuwe ohiye cinhan he oiyotanke mitawa kin akan mici iyotanke wakiye kta, miye ohiwaye ca Ate oiyotanke tawa kin akan weci imdotanke cin he iyecen.

22 Tuwe noge yukan hecinhan, taku Woniya kin okodakiciye kin ewicakiye cin he nalion kta.

\section{WICOW OYAKE 4.}

1 Hena iyohakanı wanmdake ca ito makipiya kin ekta tiyopa wan yuhdokapi; qa wicaho tokaheya nawahon kin he maza yahotonpi tanka kin iyececa, he omakiye ça heya, Deciya u wo, dena iyohakam taku u kte cin hena wanyagciciye kta ce.

2 Unkan kohanna Woniya kin en waun; qa ito, mahpiya kin ekta oiyotanke wan ecen hdepi, qa tuwe akan iyotankehan yanka.

3 Tuwe akan iyotanke cin he iwanyakapi kin inyan telika, iyaspis qa salidinos iyececa; qa oiyotanke kin ihdukśan wihmunke wan hmihbeya yanka, smahagdos inyan kin iyececa.

$4 \mathrm{Qa}$ oiyotanke kin ihdukśan oyanke wikcemna nonpa sam topa wanka; qa oyanke kin hena en hunkawicayapi wikcemna nonpa sam topa iyotankapi, qa wokoyake ska koyakapi e wanmdaka; qa pa kin en mazaskazi teśdakapi.
5 Unkan oiyotanke kin etanhan wakanhdi qa wakinyan hotonpi qa wicaho hiyu; qa oiyotanke kin itokam petijanjan śakowin peta ece ideyapi, hena Wakantanka taniya śakowin kin heepi.

6 Unkan oiyotanke kin itokam mde wan wanka janjan seca, cahtowata iyecen kohdi ; qa oiyotanke kin cokaya, qa oiyotanke kin ihdukśan, taku ni un topa kin yukanpi, hena e tokapatanhan qa hektapatanhan ko iśta ojupidan.

7 Unkan taku ni un tokaheya kin he mnaja ouncage kin iyececa; qa taku ni un iyokihe kin he tatanka ouncage kin iyececa ; qa taku ni un iciyamni kin he wicaśta itohnake kin iyecen yuha; qa taku ni un icitopa kin he wanmdi kinyan un ouncage kin iyececa.

8 Qa taku nj un topa kin otoiyohi hupahu śakpekpe yuhapi, qa ihdukśan, qa mahen tanhan iśta ojupidan; qa anpetu hanyetu ko ayaśtan śni hecen eyapi, Wakan, Wakan, Wakan, Itancan Wakantanka Iyotan waśaka, tuwe un, qa un qon, u kte cin hee ce.

9 Qa tohan taku ni un topa kin, tuwe oiyotanke kin akan kiyotanke ca owihanke wanin ni un kin he wowitan, qa wootanin, qa wopida qupi kinhan;

10 Hehan hunkawicayapi wikcemna nonpa sam topa kin hena, tuwe oiyotanke kin akan kiyotanke cin he itokam makata ehpeiciyapi, qa tuwe ohinniyan ni un kin ohodapi, qa wateśdake tawapi kin oiyotanke kin itokam ehpekiyapi, qa hecen eyapi;

11 Itancan, wowitan, qa wootanin, qa wowaśake iyacu kta e iyenihantu, taku owasin yaka- 
ge ca nitoiyokipi kin on owasin kagapi qa ecen han.

\section{WICOWOYAKE 5.}

1 Unkan tuwe oiyotanke kin akan kiyotanke cin he etapa kin eciyatanhan wowapi wan mahen tanhan qa akapatanhan owapi, qa ipuspe śakowin on apuspapi kin he wanmdaka.

2 Qa mahipiya ohnihde waśaka wan wanmdaka, he hotankakiya hotanin qa, Wowapi kin he tuwe yumdaye ca ipuspe śakowin kin yulidoke kta okihi he, eya.

3 Unkan mah̉piya kin ekta, qa maka kin akan, qa maka kin ihukuya tanhan tuwedan wowapi kin he yumdaye ça, en wanyaka okihi śni. .

4 Hehan nina waceya, tuwe wowapi kin yumdaye ca yawa, qa en wanyake kta iyekicihantu kin tuwedan iyeyapi śni kin heon etanhan.

5 Unkan hunkawicayapi kin wanji hemakiya; Ceye śni wo, ito Juda wicoun kin etanhan, mnaja kin, Dawid hutkan kin hee wowapi kin yumdaye ca, ipuspe śakowin kin yulidoke kita okihi.

6 Hehan wanmdake ca, iho, oiyotanke kin cokaya, qa taku ni un topa, hunkawicayapi ko wicacokaya Amnos wan najin, wośnapi iyececa, he śakowin iśta śakowin ko yukan, Wakantanka taniya śakowin maka kin owancaya ye wicayapi kin hena eepi.

7 He en hi, qa tuwe oiyotanke kin akan kiyotanke cin nape etapa kin etanhan wowapi qon icu.

8 Unkan wowapi kin he icu qehan, taku ni un topa kin, qa hunkawicayapi wikcemna ronpa sam topa kin hena Amnos kin itokam makata ehpeiciyapi, otoiyohi candowankiyapi hduhapi, qa nakun mazaskazi wiyatke taku waśtemna on ojudan, wicaśta waśte wocekiye tawapi kin hee:

9 Qa odowan teca wan ahiyayapi, qa heyapi; Wowapi kin iyacu, qa ipuspe kin dulidoke kta e iyenihantu ce, waniyuśnapi qa Wakantanka ekta niwe kin on opeunyakitonpi, wicoun otoiyohi etanhan, qa iapi kin, qa wicowazi kin, qa oyate kin otoiyobi etanhan;

10 Qa Wakantanka ekta wicaśtaya tapi wawayuśnapi ko unyakagapi ; unkan maka kin oununyanpi kta ce.

11 Unkan wanmdake ca, oiyotanke kin ihdukśan, qa taku ni unpi kin hunkawicayapi ko wicihdukśan, mal̉piya ohnihde woyawa tanka ota, qa kektopawinge ece kektopawinge, hena hopi kin nawahon ;

12 Hotankakiya heyapi, Amnos wośnapi qon he wowaśake, qa woyuha, qa woksape, qa wicookihi, qa wootanin, qa wowitan, qa wowaśte henakiya icu kta okihi ce.

13 Unkan taku mahpiya. ekta un, qa taku maka akan un, qa taku maka ihukuya tanhan un, qa taku miniwanca mahen un, hena taku ohnaka ko owasin kaken eyapi nawahon; Tuwe oiyotanke kin akan kiyotanke cin Amnos kin kici wowaśte kin, wootanin kin, wowitan kin, qa wowaśake kin henakiya owihanke wanin tawapi nunwe.

14 Unkan taku ni un topa lsin hena, Hecetu nunwe, eyapi; qa hunkawicayapi wikcemna nonpa sam topa kin hena makata elipeiciyapi, qa tuwe ohinniyan ni un kin he ohodapi. 


\section{WAYUOTANIN.}

\section{WICOWOYAKE 6 .}

1 Unkan Amnos kin ipuspe tokaheya yuhdoke ceehan wanmdaka; unkan taku ni un topa kin wanji, wakinyan hotonpi kin iyecen hotanin qa, U qa wanyaka wo, eya nawation.

2 Unkan wanmdake ca, ito, suktanka ska wan tuwe akan iyotanke cin he itazipa wan yuha; qa wateśdake wan qupi ; unkan ohiye ca, ohiye kta e iyaya.

3 Unkan ipuspe inonpa yuhidoke cehan, taku ni un icinonpa kin he, U qa wanyaka wo, eya nawahon.

4 Unkan śuktanka wan tokeca hin śa kin he hinanpa; unkan tuwe akan iyotanke cin he maka kin etanhan wookiye icu kta e qupi, hecen otoiyohi kiciktepi kta; qa nakun maza sagye wan tanka qupi.

5. Unkan ipuspe iyamni kin yuh̊doke cehan, taku ni un wiciyamni kin he, U qa wanyaka wo, eya nawahon. Unkan wanmdake ca ito śuktanka sapa wan; qa tuwe akan iyotanke cin he nape ohna taku on tke utapi wanji yuha.

6 Unkan taku ni un topa kin cokaya tanhan wicaho wan nawahon, Aguyapi iyutapi wanji he kaśpapidan wanjidan, qa śuktanka tawote iyutapi nonpa he kaśpapidan wanjidan kta; qa wihdi miniśa ko ihnuhan kiuniyaye cin, eya.

7 Unkan ipuspe itopa kin yulidoke cehan, taku ni un icitopa kin he ho kin nawahon; U qa wanyaka wo, eya.

8 Unkan wanmdake ca ito śuktanka wan hin san; tuwe akan iyotanke cin he Wiconte eciyapi, qa Wicahapi kin he ihakam iyaya. Unkan maka hanke ito- pa kin hehanyan maza sagye, qa wicaakihian, qa wiconte, qa wamanica maka akan un kin hena on wicaśta wicakte kta e wowaśake qupi.

9 Unkan ipuspe izaptan kin yulidoke cehan, wahna wośnapi kin ihukuya tona Wakantanka oie, qa iye waayataninpi kin he on wicaktepi qon hena nagipi kin wanwicamdaka.

10 Hena hotankakiya hotaninpi qa heyapi, Itancan wakan, qa wicaka, tohanyan tona maka kin akan yukanpi kin wicadaco śni qa we unkitawapi kin on toyecon śni he.

11 Unkan hena otoiyohi wokoyake ska wicaqupi, qa ptecedan ape yukanpi kta, tona om taokiye unpi qon, qa iye hunkawanjitkupi kin, iś iyepi iyecen wicaktepi kte cin he yuśtanpi kta hehanyan, kewicakiyapi.

12 Unkan ipuspe iśakpe kin yuhdoke çchan, wanmdake ca ito maka śkanśkan tanka, qa anpetu wi kin sapa aya, wahinske ojuha kin iyececa, qa hanyetu wi kin iś we iyecen icaga.

13 Qa mahpiya wicanlipi kin makata hinhpayapi, witanśna hu wan tateyanpa tanka kahuhuza eca waskuyeca śtunkadan keś pahpa ece kin he iyececa.

14. Qa wowapi pehan ehnakapi kin he iyecen malipiya kin tanin śni iyaye ca, he otoiyohi, wita otoiyohi ko yutokan iyeyapi.

15 Qa maka wicaśtayatapi, qa wicaśta tankinkinyanpi, qa wicaśta watonpika, qa wicaśta itancanpi, qa wicaśta waśaks̉akapi, qa wicaśta wowidake unpi kin otoiyohi, qa ihduhapi kin otoiyohi, makohdoka qa lie imnija kin ehna naiçihmanpi ;

$16 \mathrm{Qa}$ inyan he imnija ko hena heciyapi, Unkahinhpayapi, qa tu-

388 


\section{WICOWOYAKE $\%$}

we oiyotanke kin akan kiyotanke cin itohnake kin etanhan, qa Amnos kin wocanniye tawa kin etanhan anaunhman po:

$17 \mathrm{He}$ wośihda tawa anpetu tanka kin wanna hi ; unkan tuwe najin okihi kta he.

\section{WICOWOYAKE 7.}

I Unkan hena iyohatram mahpiya ohnihde topa maka oise topa kin en inajinpi kin wanwicamdaka, maka tate ouye topa kin yuhapi, hecen maka qa miniwanca qa can hiyeye cin wanjidan a tateyanpa kte śni.

2 Hehan mahpiya ohnihde tokeca wan wiyohiyanpa tanhan wankantkiya $u$ kin wanmdaka, he Wakantanka ni un ipuspe tawa kin yuhe ca mahpiya ohnihde topa maka miniwanca ko kiuniyanpi kta e wicaqupi qon hena hotankakiya hoyewicakiye ;

3 Qa heya, Maka, qa miniwanca, qa can hiyeye cin kiuniyanpi śni po, Wakantanka unkitawapi taokiye wicaye cin itepi kin en wapetog wicuntonpi śni kin hehanyan.

4 Unkan tona wapetog wicatonpi wicayawapi kin nawahon, Israel cincapi wicoun owasin etanhan kektopawinge opawinge sam kektopawinge wikcemna topa sanpa kektopawinge topa wapetog wicatonpi.

5 Juda wicoun kin etanhan kektopawinge ake nom wapetog wicatonpi; qa Ruben wicoun kin etanhan kektopawinge ake nom wapetog wicatonpi; qa Gad wicoun kin etanhan kektopawinge ake nom wapetog wicatonpi ;

6 Aser wicoun kin etanhan kektopawinge ake nom wapetog wicatonpi; qa Nepthalim wicoun kin etanhan kektopawinge akenonpa wapetog wicatonpi ; qa Manasse wicoun kin etanhan kektopawinge ake nom wapetog wicatonpi ;

7 Sumeon wicoun kin etanhan kektopawinge ake nom wapetog wicatonpi ; qa Lewi wicoun kin etanhan kektopawinge ake nom wapetog wicatonpi; qa Isakar wicoun kin etanhan kelitopawinge ake nom wapetog wicatonpi ;

8 Zabulon wicoun kin etanhan kektopawinge ake nom wapetog wicatonpi ; qa Joseph wicoun kin etanhan kektopawinge ake nom wapetog wicatonpi; qa Benjamin wicoun kin etanhan kektopawinge ake nom wapetog wicatonpi.

9 Hena taku kin iyohakam wanmdake ca, iho, wicota hinca, wicayawa kta tuwedan okihi śni, oyate hiyeye cin, qa wicoun kin, wicowazi kin, iapi ko owasin otoiyohi etanhanpi, oiyotanke kin itokam, qa Amnos kin itokam najinpi, wokoyake ska ece koyakapi, qa can wapa nape ohna yuhapi ;

10 Qa hotankakiya hotaninpi qa heyapi, Wakantanka unkitawapi oiyotanke kin akan kiyotanke cin hee, Amnos kin kici, niwicaye yuha nunwe.

11 Unlkan mahpiya ohnihde owasin oiyotanke kin okśan, qa hunkawicayapi taku ni un topa kin hena ko wicihdukśan inajinpi, qa oiyotanke kin itokam ite makipusdiya ehpeiciyapi, qa Wakantanka ohodapi ;

12 Qa heyapi, Amen; Wowaśte, qa wowitan, qa wolsape, qa wopida, qa woyuonihan, qa wowaśake, qa wicookihi henakiya Wakantanka unkitawapi kin 389 


\section{WAYUOTANIN.}

owihanke wanin yuha nunwe. tawapi kin ahna, mazaskazi waAmen.

13 Hehan hunkawicayapi kin etanhan wanji waayupte ça, Wokoyake ska koyakapi kin hena tuwepi, qa tokiya tanhan upi he, emakiya.

14 Unkan, Itancan, niye sdonyaya ce, epa. Unkan hemakiya; Wicokakije tanka etanhan upi qon dena eepi, unkan wokoyake hdujajapi, qa Amnos we kin on hduskapi.

15 Heon etanhan Wakantanka oiyotanke kin itokam yakonpi, qa tipi wakan iye tawa lin ohna anpetu hanyetu ko ohodapi ece ; qa tuwe oiyotanke kin akan kiyotanke cin he hena wicacokaya ounye kta.

$16 \mathrm{Qa}$ tohinni wotektehdapi kte śni, qa ipuzapi kte śni, qa anpetu wi kin qa taku kata aspanwicaye kte śni.

17 Tuka. Amnos kin, oiyotanke cokaya un kin he, hena wonwicaye ca, minilidoka ni un kin icahda yus awicaye kta : qa hena iśtapi kin etanhan Wakantanka iśtamnihanpe kin owasin wicakipakinte $\mathrm{k}$ ta.

\section{WICOWOYAKE 8.}

1 Unkan ipuspe iśakowin kin yuhdoke çehan, mahpiya ekta wihiyayedan wancadan ape cin hanke hehanyan inina yukanpi.

2 Unkan mahpiya ohnihde śakowin Wakantanka itokam najinpi kin wanwicamdaka; qa maza yahotonpi tanka śakowin wicaqupi.

3 Hehan mahpiya ohnihde wan tokeca u qa wahna wośnapi kin ekta hinajin, mazaskazi oizinye wan yuha: Unkan taku waśtemna ota qupi kin he, tona owotanna un kin owasin wocekiye hna wośnapi kin oiyotanke kin itokam wanke cin he akan wośna kta e heon.

4 Unkan mahpiya ohnihde nape kin etanhan śota izite cin, tona owotanna un wocekiye tawapi kin hena ko, Wakantanka itokam wankantkiya aya.

5 Unkan mahpiya ohnihde kin he oizinye kin icu, qa wahna wośnapi peta kin etanhan oju, qa maka kin elita ehpeya; unkan iho, wicaho, qa wakinyan hotonpi, qa wakanhdi, qqa maka śkanśkan.

6 Unkan mahpiya ohnihde śakowinpi maza yahotonpi tanka yuhapi kin hena yahotonpi kta e hduwiyeyapi.

7 Unkan mahpiya ohnihde tokaheya kin yahoton, qa wasu peta ko we icicahiyapi maka kin ahinhe: Qa can iyamnimni kin hulinaga, qa wato kin iyuhpa huhnaga.

8 Unkan mahpiya ohnihde iyokihe kin he yahoton, qa taku he wan tanka iyececa peta on itkonyahe cin he miniwanca kin en iyohpeyapi : Qa.miniwanca kin hanke iyamni we icaga:

$9 \mathrm{Qa}$ taku miniwanca oicage ni un kin hanke iyamni țapi, qa wita wata kin iyamnimni kin owihanke yapi.

10 Unkan mahpiya ohnihde iciyamni kin he yahoton, qa wicanlipi wan tanka ideyapi petijanjan iyececa, mahpiya kin eciyatanhan hinhpaye ca wakpa iyamnimni kin ahinhpaye ça mini hdoka kin en.

11 Wicanhipi kin he, Yatkepicaśni, eciyapi. Unkan mini yatkepica śni icage ca wicaśta ota mini kin on tapi, pa icage cin heon.

12 Unkan mahpiya ohnihde 390 


\section{WICOWOYAKE 9.}

icitopa kin he yahoton; unkan anpetu wi hanke iyamni, qa hanyetu wi hanke iyamni, qa wicanhipi iyamnimni kin apapi, qa hecen hanke iyamni otpaza icu, qa anpetu kin hanke iyamni hehanyan iyoyanpa śni un, qa hanyetu kin nakun iyececa.

13 Hehan wanmdake ca nawahon, makpiya obnihde wan mahipiya cokaya tanhan kinyan iyaye ca hotankakiya heya, Wicokakije, wicokakije, wicokakije, tona maka ounyanpi kin hena en, maza yahotonpi tanka hotonpi kin mahpiya ohnihde yamni yahotonpi kte cin heon etanhan.

\section{WICOWOYAKE 9 .}

1 Unkan mahpiya ohnihde icizaptan kin he yahoton, qa iho, wacanlipi mahpiya kin eciyatanhan maka kin ahinlipaya wanmdaka; unkan he makolidoka ceteta wanica tiyopa iyulidoke kin qupi.

2 Qa makohdoka ceteta wanica he tiyopa kin yuhdoka, unkan makolidoka kin etanhan śota hiyu, peta on maza śdoyapi tanka hinca etanhan śota uye cin iyececa; qa wośbe etanhan śota kin he on anpetu wi kin okotonyan kici aotpaza.

3 Unkan śota kin etanhan psipsicadan au, maka kin ekta, qa wicowaśake wicaqupi, wamduślka maka akan un kin wicowaśake yuhe cin he iyececa.

$4 \mathrm{Qa}$ wato maka aicage cin, taku toya un, qa can kin owasin kiuniye śni wicaśipi, tuka wicaśta kin tona itepi kin en Wakantanka tawowapetogton yuhapi śni kin henana.

5 Qa hena wicaktepi kta e wicaqupi śni, tuka wi zaptan hehanyan kakiświcaye kta e wi- caqupi. Unkan kakiśyapi kin he wamduśka wicaśta cawicape cinhan kiuniyanpi kin he iyececa.

6 Unkan anpetu kin hena en wicaśta wiconte akitapi kta, tuka iyeyapi kte śni, qa țapi cinpi kta, tuka wiconțe e nawicakicipe kta.

7 Psipsicadan kin hena ouncage kin suktanka ozuye on wiyeya ehnag najinpi kin he iyececa; qa pa akan mazaskazi wateśdake iyececa wapaha kitonpi, qa itepi kin wicaśta ite kin iyececa.

8 Qa paha kin he winohinca paha iyecen yuhapi, qa hi kin hena mnaja hi kin iyececa.

9 Qa maza sapa maku akahipe iyececa maku akahpe tonpi ; qa hupahu hmuhmunyan he ozuye canpahmihma, qa śuktanka ota ozuye ekta nawang yapi kin he iyececa.

10 Wamduśka kin iyecen sinte yuhapi, qa sinte kin en icape yuke ca, wi zaptan hehanyan wicaśta kin kiuniwicaye kta okihipi.

11 Unkan wicaśtayatapi wan yuhapi, wośbe ceteta wanica etanhan ohnihde, Hebrew iapi kin eciyatanhan Abaddon eciyapi, qa Helenes iapi kin eciyatanhan Apoluon eciyapi kin hee.

12 Wicokakije kin wanji wanna henakeca, qa ito he iyohakam wicokakije nom u kta ce.

13 Unkan hehan malipiya ohnihde iciśakpe kin yahoton, qa mazaskiazi wahna wośnapi Wakantanka itokam wanke cin he he topa kin etanhan wicaho wan taninyan nawation:

14 He mahpiya ohnihde iciśakpe maza yahotonpi tanka yuhe cin he heciya; Malipiya ohnihde 391 


\section{WAYUOTANIN.}

topa wakpa tanka Yuphrate kin ekta wicakaśkapi kin hena wicakiyuśka wo.

15 Hehan malipiya ohnihde topa kin wicalkiyuśkapi; hena e wancadan ape cin, qa anpetu wanji, qa wi wanji, qa omaka wanjidan hehanyan wiyeya ehnag unpi, wicaśta iciyamnimni kin wicaktepi kta e heon.

16 Unkan ozuye kin śuktanka akan iyotankapi kin hena kektopawinge kektopawinge opawinge nonpa; hena wicayawapi kin nawahon.

$17 \mathrm{Qu}$ wowanyake kin en śuktanka kin hecen wanwicamdaka, qa wicaśta akan iyotankapi kin hena maku akahpe śaśa, toto, qa ziżi yuhapi. Unkan śuktanka pa kin he mnaja pa kin iyececa, qa ipi kin etanhan peta, qa śota, qa calidi on kagapi kin hiyu.

18 Unkan hena yamni, peta, qa śota, qa cahidi on kagapi, hena ipi kin etanhan hiyu qon he on wicaśta iciyamnimni kin wicaktepi.

19 Wowaśake yuhapi kin he ipi kin ohna qa sintepi kin ohna; sintepi kin hena wamduśka kin iyececa, qa pa yukan ece, qa hena on wakiuniyapi ece.

20 Unkan wicaśta tona wicokakije kin hena on wicaktepi śni kin hena iye napepi wicohan kin on iyopeiciyapi śni, hecén taku wakan śicapi kin ohowicadapi, qa mazaskazi, qa mazaska, qa mazazi, qa inyan, qa can wakagapi ohodapi ece kin ayuśtanpi śni; hena wawanyake śni, qa winalion śni qa mani okihi śni.

21 Qa nakun tinwicaktepi, qa wapiyapi, qa wiinalimanpi, qa wamanonpi econpi kin on iyopeiçiyapi śni.

\section{WICOWOYAKE 10.}

1 Unkan hehan mahpiya ohnihde wan tokeca waśake hinca mahpiya kin eciyatanhan kunthiya $u$, malipiya śapa hdowin kin he wanmdaka; wihmunke wan wapaha kiye ça, ite kin he anpetu wi kin iyececa, qa siha kin peta wankantkiya ide kin iyececa.

2 Qa nape kin on wowapi wan cistinna yumdayeya yuha. Qa siha etapa kin miniwanca ahekiye ca, sicatka kin iś maka kin akan.

$3 \mathrm{Qa}$ hotankaliya hotanin, mnaja wan hoton kin iyececa. Unkan hotanin hehan wakinyan śakowin hotonpi.

4 Unkan wakinyan śakowin kin hotonpi hehan wowapi wakage kta, tuka wicaho wan nawahon, mahpiya kin eciyatanhan hemakiya, Taku wakinyan śakowin eyapi kin he sutaya apuspa wo, qa wowapi en kage śni wo.

5 Unkan mahpiya ohnihde miniwanca maka ko akan najin wanmdake ciqon he nape lin mahpiya kin ekta hdugate;

6 Qa tuwe ohinniyan ni un, qa mahpiya kage ça, taku ohnaka ko, maka qa taku ohnaka ko, miniwanca qa taku ohnaka ko kage cin hee on konza, Anpetu kin wanna henakeca kta;

7 Tuka mahpiya ohnihde iciśakowin yahoton kinhan, anpetu kin hena en Wakantanka tawowiyukcan henakeca kte cin hehanyan, iye taokiye, wicaśta wokcan kin owicakiyake ciqon he iyecetu ce.

8 Unkan wicaho mahpiya kin eciyatanhan tanin qon he ake hoyemakiye ca heya, Malipiya ohnihde miniwanca maka ko akan najin kin he ekta ye ca, 


\section{WICOWOYAKE 11.}

wowapi cistinna yumdayapi kin nape en un kin he icu wo.

9 Hehan malipiya ohnihde kin he en wai qa hewakiya, Wowapi cistinna kin he maqu wo. Unkan, Icu qa yuta wo, tezi kin pa niye kta, tuka nii kin ohna tuhmaga canhanpi kin iyecen skuye lita ce, emakiya.

10 Unkan wowapi cistinna kin malpiya ohnihde nape kin etanhan iwacu, qa temwaya; qa mii kin en tuhmaga canhanpi kin iyecen skuya, tuka nawapca hehan tezi kin pa mayan.

11 Hehan, Oyatc, qa Ikcewicaśta, qa iapi lkin, qa wicaśtayatapi ota en wicayakidukcan lita ce, emakiya.

\section{WICOWOYAKE 11.}

1 Unkan cedi wan cansakadan iyececa he maqupi; unkan mahipiya ohnihde tin najinhan najin qa heya; Najin, qa tipi wakan Wakantanka tawa kin iyuta wo, qa wahna wośnapi, qa tona en cekiyapi ece kin hena nakun.

2 'T'uka hocoka kin, tipi wakan itankan, he tankan iyeye ca iyute śni wo; he Ilicewicaśta kin wicaqupi ; unkan otonwe wakan kin amanipi kta, wi wikcemna topa sam nonpa hehanyan.

3 Unkan waayataninpi nom mitawa kin wahinske ojuha oihdugepi waayatapi kta e wicawaqu kta, anpetu kektopawinge sanpa opawinge nonpa sanpa wikcemna śakpe hehanyan.

4 Hena e Oliwe can nonpa qa petijanjan nom, Wakantanka maka yuhe cin itokam he cin hena eepi.

5 Unkan tuwe hena kiuniwi.. caye kta cin kinhan, ipi kin etanhan peta hiyu, qa toka wi- cayapi kin ihang wicaye kta: Tuwe kiuniwicaya cin kinhan he hecen litepi lkta.

6 Hena e malipiya kin onataka okihipi, hecen magaju kte śni, waayatapi anpetu kin icunhan, qa mini kin we icaliyapi kta okihipi, qa tohan cinpi eca wokakije owasin on maka kin kakiśyapi ecc.

7 Unkan taku yaotaninpi kin wanna yuśtanpi kta hehan, wośbe kin etanhan wamanica wan wankantkiya hiyu, qa hena azuwicaye kta, qa ohiwicaye ca wicalite kta.

8 Unkan lıena tancan țapi kin otonwe tanka canku kin olına wanke kta, he iapi wakan kin eciyatanhan Sodom qa Egupta eciyapi, qa tukten Itancan unkitawapi kin icipaweh okatanpi qon.

9 Unkan wicaśta kin, qa wicowazi kin, qa iapi kin, qa oyate kin, hena tancan tapi kin wanwicayaliapi kta, anpetu yamni qa wanji hanke hehanyan, qa tancan tapi kin maka mahen wicaliapi kte cin iyowinwicakiyapi kte śni.

10. Unkan liena on etanhan toria makoce kin en ounyanpi kin magagaiçiyapi, qa wiyuśkinpi kta, qa taku kiciçupi kta, waayatapi nom tona maka akan ni un kin kakiświcayapi qon hena on etanhan.

11. Unkan anpetu yamni qa wanji hanke iyohakam, wiconi oniya kin Wakantanka eciyatanhan hena mahen iwicayaya; qa siha on najinpi, unkan tona wanwicayakapi kin nina yuśinyayapi.

12 Unkan hena wicaho wan tanka nalionpi, mahpiya kin eciyatanhan hewicakiya; Deciya wankan u po, eya. Unkan ma- 


\section{WAYUOTANIN.}

hipiya śapa wan akan mahpiya kin ekta iyayapi, qa tona toka wicayapi qon hena wanwicayakapi.

13 Unkan wihiyayedan ape cin he icunhan maka śkanśkan wan tanka, qa otonwe kin hankedan iwikcemnamına kin hinhpaya, qa maka śkanśkan kin on tona tapi kin hena wicaśta kektopawinge sakowin. Qa unmapi kin yusinyayapi qa mahpiya Wakantanka kin wowitan qupi.

14 Wicokakije inonpa kin wanna henakeca, qa ito wicokakije iyamni kin kohanna $\mathrm{u} k \mathrm{kta}$ ce.

15 Hehan mahpiya ohnihde iciśakowin kin yalıoton, qa mahpiya kin ekta wicaho tanka hotaninpi, qa heyapi, Itancan unkitawapi qa Messiya tawa kin, maka wokiconze kin tawaye ca, ohinniyan en wicaśtayatapi un kta ce.

16 Hehan hunkawicayapi wikcernna nonpa sanpa topa, Wakantanka itokam oiyotanke kin akan kiyotankapi kir, hena makata elipeiçiyapi, qa Wakantanka ohodapi ;

17 Qa heyapi, Itancan Wakantanka Iyotan waśake cin, tuwe un, ya un qon, u kte cin he niye ce, pidaunyayapi, nitorvaśake tanka kin iyekcu, qa wicayeconza ce.

18 Qa oyate kin śinhdapi, qa wocantiyahde nitawa kin wanna hi; qa tohan wicate cin wicayacopi kta, qa ookiye wicayaye cin wicaśta wokcan, qa owotanna, qa tona nicaje kin kokipapi, cistinpidan tankinkinyan ko, taku wicayaqu $\mathrm{kta}$, qa tona maka napiśtanyanpi kin hena napiśtanwicayaye kte cin.

19 Hehan mahipiya kin ekta tipi wakan Wakantanka tawa kin yulidokapi, qa tipi wakan 394 kin en wicotakuye can koka kin wanyakapi. Unkan ito wakanhdi, qa wicaho, qa wakinyan hotonpi, qa maka śkanślian, qa wasu tanka.

\section{WICOWOYAKE 12.}

1 Unkan mahpiya kin ekta wowapetokeca tanka wan tanin : Winohinca wan anpetu wi kin koyake ca, hanyetu wi kin siha kin ihukuya, qa pa kin en wicanhipi ake nonpa wapaha kiya.

2 He ihduśake ca, hokśiksuye ca howaya, cinca ton lita e wayazanka.

3 Unkan hehan mahpiya kin ekta wowapetokeca tokeca wan tanin; wamduślia duta tanka wan, he pa śakowin, qa he wikcemna yula, qa pa śakowin kin en wateśdake śakowin teśdaka.

4. Qa sinte kin on mahpiya wicanhpi iyamnimni kin iwicacu, qa maka kin ekta ehpewicaya. Unkan wamduśka kin he winohinca hokśiksuye cin itokam najin, cinca ton kinhan temye kta.

5 Hehan cinca ton, wica kin, oyate hiyeye cin owasin maza icapsinte wan on wicayuhe kte cin hee. Unkan hokśiyoqopa kin he Wakantanka, qa iye oiyotanke kin ekta eyalkupi.

6 Unkan winohinca kin he hewoskan makoce kin ekta napa, heciya Wakantanka taku wiyeya ekicihnaka, qa hen anpetu kektopawinge sanpa opawinge nonpa sam wikcemna sakpe hehanyan wonyapi kta.

7 Hehan mahpiya kin ek ta ozuye kagapi; Mikael qa iye taokiye kin wamduśka kin kici kicizapi. Unkan wamduśka kin qa iye taokiye kin kicizapi ;

8 Qa ohiwicayapi śni; hecen 
WICOWOYAKE 13.

hetanhan mahipiya kin ekta tuktedan wicakiyukanpi śni.

9 Unkan wamduśka tanka kin, wamduśka wanakaja tanhan un kin hee, Wakanśica qa Satan eciyapi, wicaśta hiyeye cin owasin wicahnaye cin hee, makata ehpeyapi, qa tona ookiye wicaye cin hena nakun kici tankan iyewicayapi.

10 Únkan mahpiya kin eciyatanhan wicaho wan tanka nawalion, hecen eya, Wanna unkita Vrakantankapi wiconi tawa, qa towaśake qa tokiconze kin $u$; qa Messiya wicookihi tawa kin nakun; tuwe hunkawanjin wicunkiyapi kin taku iyawicaonpe cin, Wakantanka unkitawapi kin itokam, anpetu hanyetu ko awicaie cin hee kun ehpeyapi kin heon etanhan.

11 Unkan hena Amnos we kin he on, qa wayataniopi oie tawapi kin he on ohiyapi, qa wiconte hehanyau wiconi tawapi kin waśte kidapi śni.

12 Heon etanhan, malpiya kin iyuśkin po, ga tona ohna sipi kin. Tuka tona maka kin miniwanca ko ekta yakonpi kin hena wicokakije yuhapi kta; niyepi kin ekta Wakansica kun iyaye ça wośihda tanka yuha, aślayedan kta e sdonkiye cin heon etanhan.

13 Unkan wamduśka kin maka kin elita ehpeyapi kin he wanhdaka, hehan winolinea cinca ton qun he śicaya kuwa.

11 Unkan winohinca kin he wanmdi tanka hupahu tawa nom qupi, on liewoskan makoce tukten ti kte cin heci kinyan ivaye lita, heciya waniyetu yamni qa wanji hanke hehanyan wonyapi kta, wamduśka itohnake kin itehanyan.

15 Unkan wamduśka kin iye i kin etanhan mini hiyuya, wakpa wan iyececa, ga winohinca kin ihakam hiyayeya, ninin teye kta e heon.

16 Unkan maka kin winohinca kin he okiye ea, i hdukawa, ga wakpa wamduśka i kin etanhan hiyuye cin he yaliepa.

17 Unkan wamduska kin he winohinca kin on śinhda, qa winohinca cinca wicaye cin, tona Wakantanka tawoahope kin ahopapi, qa Jesus Messiya wootanin tawa yuhapi kin hena azuwicaya.

\section{WICOWOYAKE 13.}

1 Unkan hehan miniwanca kahda wiyaka kin en nawajin. Qa miniwanca kin etanhan wamanica wan hiyu wanmdaka, pa śakowin, qa he wikcernna yuha, qa he kin akan wacinhe wikcemna, qa pa kin akan waośtehdapi caje kin.

2 Unkan wamanica wanmdake cin he inmu tanka iyececa, qa siha kin hena walianksica siha kin iyececa, ga i kin maja i kin iyececa. Unkan wamduślxa qon towaśake kin he qu, qa oiyotan. ke tawa kin, qa wicookiti ka.

3 Unkan wanmdake ca kin wanji kiuniyanpi, on tuka; unkan kiuniyano tekte cin he okizi, kin owasin wamay yuśinyayapi.

\section{Qa wamduśka} kin wamanica qu dapi, qa wamanical ohodapi, qa heyar manica kin iyeced

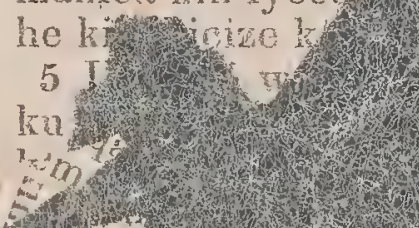




\section{WAYUOTANIN.}

hanyan, oruye econ kte cin heon.

6 Unkan i hdukawa qa Wakantanka yaśica, caje, qa wakeya tawa kin, qa tona mahpiya kin ekta etipi kin hena taku awicakicaga.

7 Qa tona owotanna un kin hena azuwicaye ca wicaktcdan kta e qupi, qa wicowazi, qa iapi kin, qa oyate kin owasin wicayuhe kta e wowaśake qupi.

8 Unkan tona maka akan unpi cajepi kin wiconi wowapi Amnos, maka kagapi kin hehantanhan wośnapi qon, he tawa kin en owapi śni kin hena owasin wamanica kin ohodapi.

9 Tuwe noge yukan hecinhan, he nalion kta.

10 Tuwe wayaka awicahdi kinhan he wayaka ayapi kta, qa tuwe maza sagye on wicakte kin he maza sagye on ktepi kta ce. He en wicaśta owotanna apepi qa wacinyanpi kin tanin.

11 Unkan wamanica wan tokeca maka kin etanhan hiyu kin he wanmdaka; he he nom yuha talin wanuyanpi cincadan iyececa, qa wamduśka iyecen

Unkan wamanica tokaheya he towaśakc kin ncowasin qa maka kin, tona akan Gena ko wamanica tokakiuniyanpi, qa on tc kizi kin he ohodawi-wapetokeca tanka 1. wicitokam mahipiatanhan peta maka e ya.

maka akan unpi okeca - n kta ra ona sica qon he iyacinpi wan kagapi kta e iwahokonwicakiya.

$15 \mathrm{Qa}$ wamanica iyacinpi kin he oniya qu okihi, hecen on wamanica iyacinpi kin ie kta, qa tona iyacinpi kin ohodapi śni kin hena wicakte kta okihi.

16 Unkan owasin, cistinpidan tankinkinyanpi ko, wijicapi qa wahpanicapi, tona ihduhapi, wowidake unpi kin hena ko, nape etapa kin en, qa iś itepi kin en wowapetogton tawa kin yuhe wicakiya.

17 Unkan tuwedan wopeton kte śni, tuka tona wamanica towapetogton, caje kin, qa caje ihdawa kin he wanji tukte e yuhe cin henana.

18 De en woksape yukan. Tuwe ksape cin he wamanica tona ihdawa kin he yawa kta. He wicaśta iyawapi kin hee, ihdawa kin he opawinge śakpo sanpa .wilkcemna śakpe sanpa śakpe.

\section{WICOWOYAKE 14.}

1 Hehan wanmdalic ca, iho, Amnos wan Zion Paha kin akan najin, qa kektopawinge opawinge sanpa kektopawinge wikcemna topa sam kektopawinge topa kici najinpi, iye Atkuku caje kin itepi lin en owapi qon.

2 Unkan mahpiya kin eciyatanhan wicaho wan nawation, mini ota ihaha kin iyececa, qa wakinyan tanka hoton kin iyececa. Qa dowankiyapi sa candowankiyapi on dowanpi wicahotanin nawahon.

3 Qa oiyotanke kin itokam, qa taku ni un topa kin, qa hunkawicayapi kin wicitokam odowan teca se ahiyayapi. Odowan kin he tuwedan onspe kta olkihi śni, tuka lektopawinge opawinge sam kektopawinge wikcemna 


\section{WICOWOYAKE 14.}

topa sam kektopawinge topa maka kin etanhan opewicatonpi qon hena.

4. Winohinca on aśamwicayapi śni kin hena eepi, tanśna unpi nakaeś. Tona Amnos kin tokiya ye cinhan iyahna yapi kin hena eepi. Wicaśta kin etanhan Wakantanka qa Amnos kin elsta opewicatonpi tokaheya kin hena eepi

5 Qa hena ipi kin en wohnaye takudan iyeyapi śni; qa Wakantanka oiyotanke kin itokam takudan iyaonpepica śni unpi.

6 Hehan malipiya ohnibde tokeca wan mahpiya cokaya kinyan iyaye cin he wanmdaka, wotanin waśte owihanke wanin un kin, tona maka akan unpi kin, wicaśta kin, qa wicowazi, qa iapi, qa oyate hiyeye cin owasin ieyanpaha owicakiyake kta yuha iyaya.

7. Qa hotankakiya heya, Wakantarka kinihanpi qa wowitan qu po; woyaco anpetu kin wanna hi ce; qa tuwe mahpiya, maka, miniwanca, qa wakoniya kin kage cin he itokam canpeśka makehde inajin po.

8 Unkan malipiya ohnihde icinonpa kin he ihakam ye ca heya, Hinhpaya ce, Babulon otonwe tanka kin he hinlipaya; wawicihaliapi wocantiyahde mini sa tawa kin etanhan oyate hiyeye cin owasin yatke wicakiye cin he dee.

9 Unkan mahpiya ohnihde iciyamni kin he hena wicihakam ye ca hotankakiya heya, Tuwe wamanica, qa iyacinpi kin ohoda, qa wowapetogton tawa kin ite, qa iś nape kin en yuhe cinhan;

$10 \mathrm{He}$ Wakantanka wocantiyahde miniśa tawa kin wocanteptanye miniyatke tawa kin en okaśtan kin hetanhan yatke kta, qa mahpiya ohnihde owotanna un kin hena wicitokam, qa Amnos kin itokam, peta, cahdi ko en kakiśyapi kta.

11 Qa kakiświcayapi śota kin owihanke wanin wankan iyaya ece ; qa tona wamanica iye iyacinpi ko ohodapi, qa tuwe he caje wapetogtonpi yuhe cin hena anpetu hanyetu ko oziyapi wanin unpi.

12 Wicaśta owotanna apepi kin he de en un, qa tona Wakantanka tawoahope opapi qa Jesus wacinyanpi kin hena.

13 Hehan mahpiya kin eciyatanban wicaho wan nawalion, hecen emakiya, Wowapi ecen kaga wo; Detanhan wicate cin tona Itancan kin en tapi kin hena wicayawaśtepi ece. Han, Woniya kin eya, Wicohtani kin ayuśtanpi kta, qa wicohan kin wiciyahna iyaya ece.

14 Hehan wanmdake ca, iho, mahpiya ska wan, qa wanji Wicaśta Cinhintku kin iyececa akan iyotanka, he maza wapaha wan wapaha nape etapa kin on isar hinca yuha.

15 Unkán mahpiy tokeca tran tipi wal to pa han $u, \quad-0 m$ te kta akan iy kin on heciya; + to cra wicaśta en iyek yica kin on wo. Mr iyehantu wanna śec

16 Unka iyotanke kin $m$ makaci kn

17 Unkan 1 wal tanka, kin wo

106 


\section{WAYUOTANIN.}

18 Tinkan mahpiya ohnihde tokeca wan wahna wośnapi kin etanhan $u$, he peta on wowaśake yuha. Qa he tuwe isan śkopa pe hinca yuhe cin he panyanhan hoyekiye ca heya, Isan \$kopa pe hinca nitawa kin ekta yekiye ca maka hastanhanka kin mnayan wo: hastanhanka iyage kin wanna sapa ce.

19 Unkan mahpiya ohnihde kin he isan śkopa tawa kin maka ckta yekiye ca, maka hastanhanka iyuwi kin mnaye ca, Wakantanka wocantiyahde miniśa iyuśkice tawa tanka kin he en iyohpeya.

20 Unkan otonwe kin itankan mini śa iyuśkice kin napanpi, qa mini śa iyuśkice kin etanhan we hiyu, suktanka 'i iyuwi kin behanyan, stadiya kektopawinge sam opawinge śakpe hehanan.

\section{WICOWOYAKE 15.}

Unkan makpiya kin ekta woapetokeca anka, qa wowinioretranmdaka; malpiya ohni-

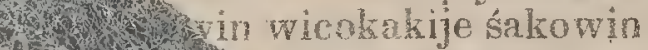
1. 1 - yuhapi, hena on Wa1. H t. Ecantiyahde tawakin $1 x^{3}+x$ in

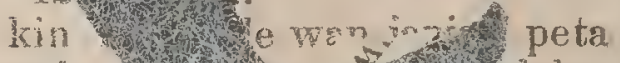
yuha, w un kin 1.62.t. heya kins -

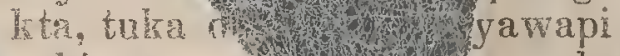
cklciyq. Wy an mde 13 Qa wd nd kantanacon . . H ka taon kin heecot. IQa $10-$ pi kin he niye ce, nitacanku kin owntanna qa wicaka.

4 Itancan, tuwe konicipe kte śni, qa nicaje kin inidowan kte śni he; niśnalia oniowotanna; qa oyate hiyeye cin owasin upi, qa nitokam canpeśka makehde enajin kta; woyaco nitawa kin wanna tanin kin heon etanhan.

5 Unkan he iyohakam wanmdake ca, iho, mahpiya kin ekta waayataninpi wakeya. wakan kin he yuzamni han.

6 Qa malipiya ohnihde śakow in wicokakije śakowin yuhapi kin hena tipi wakan kin etanhan inanpapi. miniliuha ska wiyatpa kin heca koyakapi, qa maraskazi on maku opta ihduskitapi.

7 Unkan taku ni un topa kin wanji mahpiya ohnihde śakowin kin mazaskazi wiyatke kin heca śakowin wicaqu; hena Wakantanka ohinniyan ni un wocantiyahde tawa kin on ojudan.

8 Unkan Wakantanka towitan, qุa towaśake kin eciyatanhan tipi wakan kin śota ojudan. Qa tipi wakan kin tuwedan timahen ye kta okihi śni, wicokakije śakowin mahpiya ohnihde śakowin yuhapi kin henakeca kte śni hehanyan.

\section{WICOWOYAKE 16.}

1 Unkan tipi wakan kin etanhan wicaho wan tanka nawation, mahpiya ohnihde śakowinpi gon hewicakiya, Yapi; qa wiyatke Wakantanka wocantiyahde. tawa kin hena maka kin en akaśtan po, eya.

2 Hehan mabipiya ohnihde tokaheya kin $u, q a$ wiyatke tawa kin maka kin en akaśtan. Unkan wicaśta tona wamanica wo wapetogton tawa kin yuhapi, qa ìacinpi kin ohodapi kin he- 


\section{WICOWOYAKE 16.}

na en śiyaka o tanka qa śica awicahinlipaya.

3 Unkan mahpiya ohnihde icinonpa kin wiyatke tawa kin miniwanca kin en akaśtan; unkan he we icaga, wicate cin we kin iyececa, qa miniwanca kiru en taku niyake un kin owasin tapi.

4 Unkan mahpiya ohnihde iciyamni kin wiyatke tawa kin wakpa qa wakoniya kin hena en akaśtan; unkan hena we icaga.

5 Hehan mahpiya ohnihde wan mini kin yuhe cin he kaken eya, nawahon; Itancan, tuwe un, qa un qon, u kte cin he niye, oniowotanna, hecen wicadaco:

6 Wicaśta owotanna, qa wokcanpi kin hena we kin wicakipapsonpi; qa hecen we yatke wicayakiya, he iyekicihantupi nakaeś.

7 Unkan wanji tokeca wahna wośnapi kin eciyatanhan kaken eya, nawahon; Itancan, Wakantanka Iyotan waśaka, wadaco kin he ohinniyan owotanna qa wicaka ce.

8 Hehan mahpiya ohnihde icitopa kin wiyatke tawa kin anpetu wi kin en akaśtan. Unkan he wicaśta kin peta on wicagu kta e qupi.

9 Qa iyokatapi tanka kin wicaśta wicagu, qa hecen Wakantanka wicokakije hena yuhe cin he caje kin ośtehdapi, qa wowitan qupi kta on ihduecetupi śni.

10 Unkan mahpiya ohnihde icizaptan kin wiyatke tawa kin wamanica oyanke tawa kin en akaśtan; unkan wokiconze tawa kin otpaza ojudan, qa wayazanpi on cejipi kin hdalitalitakapi.

$11 \mathrm{Qa}$ wicokakije qa śiyaka o kin on etanhan malipiya Wakantanka kin yaśicapi, qa iye olianpi kin on iyopeiciyapi śni.

12 Unkan mahipiya ohnihde iciśakpe kin wiyatke tawa wakpa tanka kin Yuphrate, he en akaśtan; unkan mini kin puza aya, hecen wicaśtayatapi wiyohiyanpa tanhan au kin canku kin wicakiciyumdayapi kta.

13 Unkan wamduśka i kin etanhan, qa wamanica i kin etanhan, qa woitonśni wokean kin he i kin etanhan, taku wakan sica yamni, hnaśka iyececa, hena hiyu wanmdaka.

14 Hena taku wakan śica taniyapi kin hecapi, wowapetokeca econpi, qa maka sitomniyan wicaśtayatapi kin, qa wicoicage ocowasin ekta yapi, Wakantanka Iyotan waśake cin anpetu tawa tanka kin en zuya awicaupi kta e heon.

15 Tho, wamanon sa wan iyecen wau ce. Tuwe kiktahan un, qa wokoyake kpatan kin he yawaśtepi ece, hecen tancodan mani- kte śni, qa wiśtece cin wanyakapi kte śni.

16 Unkan Hebrew iapi kin eciyatanhan tukten Armagedon eciyapi, hen witaya u wicaya.

17 Hehan malipiya ohnihde iciśakowin kin wiyatke tawa kin okaduze cin en akaśtan. Unkan mahpiya kin ekta tipi wakan kin etanhan, qa oiyotanke kin etanhan, wicaho tanka wan tanin, qa heya, Wanna henakeca.

18 Unkan iho wicaho taninpi, qa wakinyan hotonpi, qa wakanhdi tanin, qa maka śkanśkan wan tanka, wicaśta kin maka akan iwicacage cin ehantanhan maka śkanśkan iyecen tanka wanica.

$19 \mathrm{Qa}$ otonwe tanka kin he yamni kiyuśpapi; qa otonwe Ikcewicaśta tawapi kin hena hinhpayapi. Qa Babulon tanka kin he Wakantanka itokam kiksuyapi, wocanniye ohitike (in 399 


\section{WAYUOTANIN.}

miniśa wiyatke kin qu kta heon.

20 Unkan wita kin owasin najica, qa he kin hena tuktedan iyeyapi śni.

21 Unkan mahpiya kin eciyatanhan wasu tanka wicaśta kin awicahinhe, otoiyohi taku tke utapi opawinge wanjidan inskokeca. Unkan wasu wicokakije kin on wicaśta kin Wakantanka yaśicapi ece, he wokakije iyotan tanka kin heon.

\section{WICOWOYAKE 17.}

1 Hehan mahpiya ohnihde śakowin wiyatke śakowin yuhapi qon etanhan wanji $u$, qa omakiye ça hemakiya, Deciya u wo, wawicihahapi econ sa tanka mini ota akan iyotanke cin he token yacopi kin cicipazo kta ce.

2 He kici wicaśtayatapi maka akan unpi kin wawicihahapi econpi ece, qa tona maka akan unpi kin wawiciliahapi tawa miniśa kin on witkopi ce.

3 Hehan Woniya kin on hewoskan makoce ekta amayan. Unkan winohinca wan wamanica duta wan akan iyotanke cin he wanmdaka; he waośtehdapi wicacaje kin ojudan, qa pa śakowin, he wikcemna ko ikoyaka.

4 Unkan winohinca kin he taku stan duta ko koyake ca, mazaskazi, inyan teliika, oinpidan ko hena on wiyatpa un, qa nape kin ohna mazaskazi wiyatke wan yuha waośtehdapi, wawicihahapi ko aśamyapi kin on ojudan.

5 Qa ite kin en caje wan owapi, Woanahbe kin, Babulon tanka, maka kin akan wawicihahapi, qa wayaśicapi hunku kin hee.

6 Unkan wicaśta owotanna we kin winohinca kin he iwitko wanmdaka, qa tona Jesus yaotaninpi kin hena we kin on. $\mathrm{He}$ wanmdake ça nina imanihan waun.

7 Hehan mahpiya ohnihde "kin he, Tokeca e ininihan he, emakiya; Winohinca woanahbe kin he ociciyake kta, qa wamanica akan iyotanke cin, pa śakowin, qa he wikcemna hduhe cin he nakun.

8 Wamanica wandake cin he un qon, qa un śni kin; qa wośbe cetete wanica etanhan hiyu kta, qa wicotakuni śni ekta hde kta. Qa tona maka akan unpi, maka kagapi kin ehantanhan, cajepi kin wiconi wowapi kin en owapi śni, hena wamanica kin wanyakapi kinhan yuśinyayapi kta, he un qon, qa un śni, qa hinaliin un kin heon etanhan.

9 Unkan wicotawacin wicoksape yuhe cin he den un. Pa śakowin kin hena paha śakowin winohinca kin akan iyotanke cin hee :

$10 \mathrm{Qa}$ wicaśtayatapi śakowin kin heepi, zaptan wanna hinhpayapi, qa wanji nahahin en yanka, qa wanji iśs hinahin hi śni; he hi kinhan ptecedan he kta.

$11 \mathrm{Qa}$ wamanica wandake ciqon he un qon, qa un śni kin, he iciśahdogan kin ee, śakowinpi kin he etanhan, qa wicotakuni śni ekta hde kta.

$12 \mathrm{Qa}$ he wikcemna wandake ciqon hena wicaśtayatapi wikcemna kin eepi, nahahin wokiconze yuhapi śni, tuka wihiyayedan wancadan ape cin wicaśtayatapi iyecen wamánica kin kici wicowaśake icupi kta.

13 Hena wicotawacin wanjidan yuhapi, qa wicowaśake wicookihi ko tawapi kin wamanica kin qupi.

14 Qa hena Amnos kin kici ki-

400 


\section{WICOWOYAKE 18.}

cizapi kta, tuka Amnos kin wicaktedan kta, he itancanpi kin Itancan, qa wicaśtayatapi kin en Wicaśtayatapi kin hee, qa tona om un kin hena wicakicopi, qa wicakahnigapi, qa wicakapi.

15 Hehan hecen emakiya, Mini wandake ciqon tukten wawicihaliapi econ sa iyotanke cin he oyate, qa wicota, qa wicaśta, qa iapi kin eepi.

16 Qa he wikcemna wandake ciqon, wantanica ikoyake cin hena, wawicihahapi econ sa kin sice kidakapi kta, qa hewoskantuya tancodan iyaye yapi kta, cehpi kin temyapi, qa peta on huhnałyapi kta.

17 Hena \&akantanka tawacin kin ecen econpi kta, qa wicotawacin wanjidan unpi $\mathrm{kta}$, qa wokiconze tawapi kin wamanica qupi kta e wacin yus wicakiya, Wakantanka oie kin yuecetu kte cin hehanyan.

$18 \mathrm{Qa}$ winohinca wandake cigon he otonwe tanka kin makata wicaśtayatapi kin iwicadake cin hee.

\section{WICOWOYAKE 18.}

1 Unkan hena taku kin iyohakam mahpiya ohnihde wan mahpiya kin eciyatanhan kitkiya u wanmdaka, wicowaśake tanka yuha: qa he towitan kin on maka kin iyoyanpa.

2 Unkar he wasagya hotankakiya hotanin, qa heya, Hinhpaya ce, Babulon tanka kin he hinhpaya; qa taku wakan śicapi en ounyanpi, qa wanagi aśape cin owasin he otipi, qa zitkadan śice cin śicedapi kin owasin he hohpi yapi ce.

3 Wawicihahapi wocantiyahde miniśa tawa kin hetauhan oyate hiyeye cin owasin yatlanpi; qa Dak he kici wicaśtaya tapi maka akan unpi kin wawicinhahapi econpi, qa taku tehika ota yuhe cin on wopeton maka akan unpi kin wijiniciyapi ce.

4 Hehan malipiya eciyatanhan wicaho. wan tokeca nawation, kaken eya, Mitaoyate kin tankata inanpa po, hecen woahtani tawa kin ehna yaunpi kte śni, qa wicokakije tawa kin en oyapapik kte śni.

5 He walitani kin malipiya kin elta iyahdeya, qa talku śica econ kin leena Wakantanka kiksuya un.

6 Token ecanicompi qon he iyecen ecakicon po, qa iye ohan kin etarhan nonpa akihde kicu po, wiyatke ojudan ye cin he obna nonpa akihde okicicaśtan po.

7 Token wahanicida qa takudan icakije śni un qon he iyecen wicokakije, qa iyokiśicapi hin qu po. Iye canté kin ekta kaken eja; Wicaśtayatapi winohinea hera iyotankelian waun, qa wiwazica hemaca sni, qa iyokiśicapi kin icimana wanmdake kte sini ce.

8 Heon etanhan anpetu wanjidan er wicokakije tawa kin hiyalide kta, wiconte, qa iyokisicapi, qa wicaakilian, qa ocowasin neta on hulnage kta; tuwe yaco kin Itancan kin Wakantanka hee waśaka ce, heon etanhan.

9 Unkan wicaśtayatapi naka ohnaka kin kici wawiciliahapi econpi, qa takudan icakije śni unpi kin hena he aceyapi kta, qa nihinciyapi kta, he hulnage cin śota kin wanyakapi kinhan;

10 Wicokakije kin ikopapi kin on itehanyan inajinpi, qa heyapi $\mathrm{kta}$, Hehehe, hehehe, Babulon otonwe tanka kin, otonwe waśake cin, ihnuhanna niyacopi kin anihinlipaya ce. 


\section{WAYUOTANIN.}

$11 \mathrm{Qa}$ heon wopeton maka "akan unpi kin nihinciyapi, qa ceyapi kta, hetanhan maza tawapi kin tuwedan opewicakicaton kte śni :

12 Maza kin he mazaskazi, qa mazaska, qa inyan tehika, qa oinpidan, qa minihuha waśte, qa śina to, qa minihuha zipzipedan, qa śina śa, qa can waśtemna ocaje owasin, qa huhu wakśica owasin, qa can tehika, qa nıazazi, qa mazasapa, qa inyan ska wakśica;

13 Qa canha śa, qa taku waśtemna, qa pejihuta pa, qa canśin, qa miniśa, qa wihdi, qa aguyapi mdu, qa woteca, qa tahin wanuyanpi, qa śuktanka, qa canpahmihma, qa wicatancan, wicanagi ko henakiya.

14 Waskuyeca kin ninagi waśte dake cin he wanna henakeca, qa woyute napin qa taku wicimdeza, hena owasin aniyuśtan, qa hena ake tohinni iyeyaye kte śni.

15 Unkan wopeton tona taku hececa wiyopeyapi ece, qa on wijiniciyapi kin hena itehanyan inajinpi kta, he wokakije kin ikopapi, nihinciyapi, qa ceyapi ;

16. Qa heyapi; Hehehe, hehehe, otonwe tanka kin miniliuha waśte, śa stan, śa ko koyake ça, niazaskazi, inyan tehika oinpidan ko kohdaka; qa ihnuhanna wiwicajica tanka kin he yutakuni śni.

17 Unkan tona wita wata iyupse yuzapi, qa tona ohna yapi, qa tona watopapi, qa tona miniwanca ohna wopetonpi ece kin hena owasin itehanyan inajinpi ;

18 Qa he huhnage cin sota kin wanyakapi qehan, hotaninpi qa heyapi; Otonwe kin tukte wanji e otonwe tanka kin he iyececa he.
19 Qa pa kin akan maka ahdatapi, qa hotaninyan nihinciyapi, qa ceyapi, qa heyapi; Hehehe, hehehe, otonwe tanka kin he eciyatanhan tona mini wanca kin ohna wita wata yuhapi kin hena owasin watonpika, taku tehika opeton qon heon, he ihnuhanna liewoskan kagapi ce.

20 Heon, mahpiya kin, iyuśkin wo, qa ohnihde owotanna yaunpi, qa wokcanpi kin nakun, niyepi kin on Wakantanka tokicon kin he etanhan.

21 Hehan mahpiya ohnihde waśake linca wan, inyan wan, inyan wiyutpan tanka iyececa, he icu, qa miniwanca kin en ehpeye ca heya, Hecen wowaśake on Babulon otonwe tanka kin jujuwahan ehpeyapi kta, qa tohinni iyeyapi kte śni ce.

22 Unkan niye kin en candowankiyapi sa, qa dowanpi sa, qa cotanka yajopi sa, qa maza yahotonpi sa wicaho kin tohinni nahonpi kte śni; qa takı kage sa, ocaje owasin, niye kin en iyeyapi kte śni, qa wiyutpan hmun kin niye en hetanhan tohinni nalionpi kte śni.

23 Qa petijanjan ojanjan kin icimana iyoyamniye kte śni, qa niye en hihnayanpi qa tawicuyapi wicaho kin tohinni nahonpi kte śni. Wicaśta wopeton nitawa kin hena maka akan wicaśta itancanpi kin hecapi; qa wicayahmunge cin on oyate kin owasin wicayahnayan.

24 Unkan he ohna wicaśta wokcan wicaśta owotanna ko we kin iyeyapi, qa tona maka akan ktepi kin hena nakun.

\section{WICOWOYAKE 19.}

1 Unkan hena iyohakam malipiya kin ekta wicota hotanka- 
kiya hotaninpi nawahon, kaken eyapi, Jehowa yatan po, niwicaye ca, wowitan, qa wootanin, qa wowaśake, Itancan Wakantanka unkitawapi kin he tawa nunwe.

2 Wayaco kin owotanna qa wicaka; witkowin tanka, wawicihahapi econ kin oll maka kin yuśice cin he yaco, qa taokiye kin hena we kin he nape kin en tokicon.

3 Hehan inonpa heyapi, Jehowa yatan po. Unkan he śota kin owihanke wanin wankantkiya iyaya.

4 Hehan hunkawicayapi wikcemna nonpa sanpa topa, qa taku ni un topa kin hena makata ehpeiçiyapi, qa Wakantanka oiyotanke kin akan kiyotanke cin he ohodapi, qa heyapi, Amen, Jehowa yatan po.

5 Hehan oiyotanke kin etanhan wicaho wan taninyan heya, Taokiye niyanpi kin owasin, qa toula cekiyapi ece, cistinpidan tankinkinyanpi ko, Wakantanka nitawapi kin yatan po.

6 Unkan nawahon, wicota hotaninpi kin iyececa, qa mini ota ihaha kin iyececa, qa wakinyan tanka hotonpi kin iyececa, kaken eyapi, Jehowa yatan po: Itancan Wakantanka Iyotan Waśake cin he Wicaśtayatapi un.

7 Heon etanhah piundapi, qa unkiyuśkinpi kta, qa wowitan unqupi kta; Amnos kin tohan tawicu ton kte cin wanna iyehantu, qa winohinca kin taku owasin wiyeya ekihnaka.

8 Unkan he minihuha ska wiyatpa kin heca koyake kta e qupi; miniliuha ska kin he tona waśte woowotanna yuhapi kin hee.

9 Hehan hecen emakiya, Ka- ken wowapi kaga wo, Tona Amnos kin winohinca yuze lita omniciye kin en wicakicopi kin hena wicayawaśtepi ce. Hehan ake hecen enıkiya, Wakantanka oie wicake cin hena ee.

10 Unkan hehan he siha hdepi kin en makata ehpemiciye ca ohowada kta; tuka iye hemakiya, Ihnuhan hecanon kin, miś cici ookiye waun, qa nihunkawanji Jesus yaotanin yuhapi kin hemaca; Wakantanka ohnda wo. Jesus yaotanin kin he wokcanpi woniya kin hee.

11 Unkan mahpiya kin yuzamnipi e wanmdaka, qa ito śuktanka ska wan, qa tuwe akan iyotanke cin he Wicalse ca Owotanna eciyapi, he owotanna wicayaco qa ozuye econ ece.

12 Iśta kin peta ide kin iyececa, qa pa kin akan wateśdake ota yukan; qa caje kin owapi, tuka he tuwedan sdonye śni, iye iśnana sdonkiya.

13 Qa wokoyake we en oputkanpi kin heca koyaka: Qa Wakantanka Oie kin eciyapi.

14 Unkan mahpiya wicobe kin owasin he ihakam yapi, śuktanka ska akan iyotankapi qa minihuha waśte, ska, qa wakaśote śni kin heca koyakapi.

15 Qa iye i kin etanhan maza sagye anog ope kin hiyu, heon oyate kin awicape kta, qa maza icapsinte wan on wicayuhe kta ; qa Wakantanka Iyotan Waśake cin he wocantiyahde ohitike cin miniśa iyuśkice kin he naśkica.

$16 \mathrm{Qa}$ onholida ceca sani ko akan caje kin owapi, Wicaśtayatapi kin en Wicaśtayatapi, qa itancanpi kin Itancan kin he dee.

17 Hehan mahpiya ohnihde wan anpetu wi kin en najin kin he wanmdaka; he hotankakiya 403 
hotanin, qa taku kinyanpi kin owasin, okotonyan kin en kinyan unpi kin hena hewicakiya; Upi qa Wakantanka he wotapi tanka tawa kin en mniciya po;

18 Wicaśtayatapi cehpi kin yatapi kta, qa wicaśta itancanpi cehpi kin, qa tona waśakśakapi cehpi kin he, qa śuktanka celipi, qa tona akan iyotankapi kin, wicacehpi ocaje owasin, wowidake unpi, qa ihduhapi kin, cistinpidan tankinkinyanpi koya.

19 Unkan wamanica kin wanmdaka, qa wicaśtayatapi maka akan unpi kin akicita wicayuhapi ko witaya mniciyapi, qa tuwe suktanka akan iyotanke cin akicita wicayuhe cin ko, kici kicizapi kte cin heon.

20 Hehan wamanica kin he niyake yuzapi, qa woitonśni wokcan kin he nakun, he wamanica kin itokam wowapetokeca econ, qa on tona wamanica wowapetogton tawa yuhapi, qa iyacinpi kin ohodapi kin hena wicahnaye cin hee. Unkan hena napin niyake peta mde wan inyan zi on itkonyahe cin he en iyohpewicayapi.

21 Unkan unmanpi kin owasin tuwe suktanka akan iyotanke cin he maza sagye tawa kin on wicalitepi, maza sagye he $\mathrm{i}$ kin etanhan hiyu qon hee on. Unkan hena celipi.kin on taku kinyan un kin owasin imnanpi.

\section{WICOWOYAKE 20 .}

1 Hehan mahpiya ohnihde wan mahpiya kin eciyatanhan kun u wanmdaka, he wośbe ceteta wanica tiyopa iyulidoke kin yuhe ça, nape ohna maza icicahiha wan tanka:

$2 \mathrm{Qa}$ he wamduśka kin iyahpaya, sintehda wanakaja tanhan 404 un kin, Wakanśica qa Satan hee, qa kaśka ehnaka, waniyetu kektopawinge hehanyan;

3 Qa wośbe ceteta wanica he en ehpeye ça onataka, qa ipuspe wan on apuspa, hecen oyate kin wicahnaye kte śni, waniyetu kektopawinge kin ihuniyanpi śni kin hehanyan. Unkan he iyohakam ptenyedan kiyuśkapi kta. 4 Unkan oiyotanke kin heca wanmdaka, qa tona akan iyotankapi kin hena woyaco yuhapi. Unkan tona Jesus oyakapi kin on, qa Wakantanka oie kin on pa bawicaksapi qon, wamanica kin wakagapi ko ohodapi śni, qa wowapetogton tawa kin itepi, qa napepi kin en yuhapi śni, hena nagipi kin wanwicamdaka, ake kinipi qa Messiya kin kici ounyanpi, waniyetu kektopawinge hehanyan.

5 Tuka wicate cin unmanpi kin ake kinipi śni, waniyetu kektopawinge kin henakeca śni kin hehanyan. Piya iwicacage tokaheya kin hee.

6 Tuwe piya iwicacage tokaheya kin en ope cinhan he yawaśtepi qa owotanna un. Hena wiconte inonpa kin iyowicahi kte śni, tuka Wakantanka qa Messiya kin ekta wawayuśnapi kin heca wicayawapi kta, qa kici ounyanpi kta, waniyetu kektopawinge hehanyan.

7 Unkan waniyetu kektopawinge kin henakeca kinhan, Satan wicakaśka tipi kin etanhan kiyuśkapi kta.

8 Qa oyate kin wicahnaye kta e makata tate ouye topa kin ektakiya ye kta, qa Gog Magog kici zuya u wicaśi kta; hena miniwanca wiyaka sukaza kin iyecen wicota.

9 Unkan maka ohdakinyan ohna yapi, qa wicaśta owotanna 


\section{WICOWOYAKE 21.}

ewanke cin ihdukśan hinajinpi, qa otonwe wakan kin nakun. Unkan mahpiya kin etanhan Wakantanka eciyatanhan peta hiyu, qa huhnahwicaya.

10 Unkan Wakanśica, hena wicahnaye cin he peta qa inyanzi mde kin en iyolipeyapi, heciya wamanica qa woitonśni wokcan kin unpi, qa anpetu han yetu ko owihanke wanin kakijapi kta.

11 Hehan oiyotanke ska tanka wan wanmdaka, qa tuwe akan iyotanke cin he ite kin etanhan maka mahpiya ko najicapi ; qa tukten wanke kte cin iyeyapi śni.

$12 \mathrm{Qa}$ wicate ciqon, cistinpidan tankinkinyanpi ko, hena Wakantanka itokam najinpi, wanmdaka. Unkan wowapi kin yumdayapi; qa wowapi tokeca wan yumdayapi, wiconi wowapi kin hee: Qa wicate ciqon token wowapi kin en kagapi kin he iyecen wicayacopi, iye wicohan kin eciyatanhan.

13 Unkan miniwanca kin wicate cin tona en un kin hena hiyuwicaya, qa wiconte Hades ko wicate cin tona en unpi kin hena hiyuwicayapi. Qa iye wicohan kin eciyatanhan otoiyohi wicayacopi.

14 Unkan wiconte qa Hades kin hena peta mde kin en iyohpewicayapi. Wiconțe inonpa kill hee.

15 Unkan tuwe wiconi wowapi kin en owapi iyeyapi śni kin he peta inde kin en iyohpeyapi ece.

\section{WICOWOYAKE 21.}

1 Hehan mahpiya teca qa maka teca wan wanmdaka. Mahpiya tokaheya qa maka tokaheya kin hena yutokan iyeyapi, qa miniwanca wanica.
2 Unkan Johannes he miye e otonwe wakan kin wamdaka, Jerusalem teca kin hee mahpiya kin etanhan, Wakantanka eciyatanhan kun $u$, winohinca wan wicaśta hihna ton kte cin on wiyeya un kin he iyececa.

3 Unkan mahpiya kin eciyatanhan wicaho wan tanka nawahon, kaken eya, Wanyaka wo, Wakantanka wakeya tawa kin wicaśta kin ehna han, qa iye hena om ti kta, qa hena e oyate tawawicaye kta, qa Wakantanka hince cin hena om un kta, qa Wakantanka tawapi kta. 4 Qa wiciśta kin etanhan Wakantanka iśtamnihanpe owasin wicakipakinte kta, qa hetanhan wiconte wanice kta, wicocante śica, wicaceya, wicokakije ko wanice kta, taku tokaheya un kin wanna henakeca.

5 Unkan tuwe oiyotanke kin akan kiyotanke cin he, Ito taku owasin teca wakaga ce, eya. Hehan, Wowapi ecen kaga wo, hena oie kin wicake ça owotanna, emakiya.

6 Qa ake kaken emakiya, Wanna henakeca. Alpha qa Omega, otokahe qa owihanke kin he miye ce. Tuwe ipuza kinhan he wiconi mini lidoka kin etanhan iyunwin codan yatke wakiye kta.

7 Tuwe ohiye cinhan he taku owasin tawaye kta, qa iye Wakantanka maye kta, qa miś he cinkśiwaye kta.

8 Tuka tona wikopapi, qa wicadapi śni, qa wahtepi śni, qa tin wicaktepi, qa wawicilialiapi econpi sa, qa wapiyapi, qa wakagapi ohodapi sa, qa oitonpiśni kin hena owasin mde wan peta qa inyan zi on itkonyahe cin he ohna taku tawapi kta, wicont inonpa kin hee. 
9 Hehan mahipiya ohnihde śakowin wiyatke śakowin wicokakije ehake śakowin kin on ojudan yuhapi qon hena etanhan wanji hi, qa omakiye ca heya, $\mathrm{U}$ wo, winohinca wan Amnos kin tawicuye kte cin he cicipazo kita ce.

10 Unkan Woniya kin on paha wan tanka tehan wankantuya kin ekta amaye ca, otonwe tanka kin, Jerusalem wakan, mahpiya kin etanhan Wakantanka eciyatanhan kutkiya u kin he makipazo;

11 Wakantanka wowitan tawa kin yuha, qa wiyatpa kin he inyan tehika iyececa, inyan wan acaliśdaya iyececa :

12 Qa ihdukśan aconkaśkapi tanka qa tehan wankantu kin, qa tiyopa ake nonpa yukan, qa tiyopa kin hena en mahpiya ohnihde ake nonpa yukanpi, qa akan 'wicacaje owapi, Israel cincapi wicoun ake nonpa kin hena eepi.

13 Wiyohiyanpa tanhan tiyopa yamni; qa waziyapa tanhan tiyopa yamni; qa itokaga tanhan tiyopa yamni; qa wiyohpeya tanhan tiyopa yamni.

$14 \mathrm{Qa}$ otonwe conkaśke kin taku akan lıe cin hena ake nonpa, qa Amnos kin yewicaśi ake nonpa cajepi kin hena en un.

15 Unkan tuwe omakiye sin he mazaskazi cedihu wan yuha, on otonwe, qa tiyopa kin, conkaśke ko iyute kta.

16 Otonwe kin oise tom yukan, qa ohdakinyan kin ohanske cin kici akidehankeca. Unkan cedihu kin on otonwe kin iyuta, wiyu tapi kek topawinge ake nom; ohdakinyan ohanske cin obosdatu ko akidecen han.

17 Qa conkaśke kin he iyuta, iciśpa opawinge sanpa wikce406 mna topa sam topa, wicaśta ihduta, malipiya ohnihde ihdute cin hee.

18 Conkaśke kin he iyaspis inyan telika on kagapi, qa otonwe kin he mazaskazi ecedan, janjan ecedan iyececa.

19 Qa otonwe conkaśke kin taku akan he cin he inyan tehika ocaje owasin en un. Taku akan he cin tokaheya kin he iyaspis ; inonpa kin he saphiros ; iyamni kin he kalkedon; itopa kin he smaragdos;

$20 \mathrm{Qa}$ izaptan kin he sardonis ; iśakpe kin he sardius; iśakowin kin he krusolitos; iśahdogan kin he berulos; inapcinwanka kin he topaz; iwikcemna kin he krusophrasos; iakewanji kiu he huakinthos; qa iakenonpa kin he amathustos.

21 Tiyopa ake nonpa kin hena inyan tehika ocaje ake nom, tiyopa otoiyohi inyan tehika wanjidan; qa otonwe ocanku kin he mazaskazi ecedan janjan kin iyecen wiyatpa.

22 Qa he en tipi wakan wanica; Itancan Wakantanka Iyotan Waśake cin, qa Amnos kin hena tipi wakan kin eepi.

$23 \mathrm{Qa}$ otonwe kin he anpetu wi, hanyetu wi ko en iyoyanpapi kta cinpi śni; Wakantanka wowitan tawa kin iyoyanpa, qa Amnos kin he petijanjan kin hee.

24 Qa oyate kin tona ni wicayapi kin hena iyoyanpa kin he en manipi kta; qa wicaśtayatapi maka akan unpi kin hena wowitan qa wootanin tawapi kin en ahipi kta.

$25 \mathrm{Qa}$ tiyopa kin hena anpetu icunhan ecen iyeyapi kte śni ; qa heciya hanyetu wanica.

26 Oyate hiyeye cin wowitan, qa wootanin kin en ahipi kta. 


\section{WICOI}

27 Qa taku wiśamye aśamy cin he en i kte śni, qa taku śicaya econ, qa itonśni kin; tuka tona cajepi kin wiconi wowapi Amnos tawa kin en owicawapi kin henanapidan.

\section{WICOWOYAKE 22.}

1 Hehan wakpa wan wiconi mini ska kin, calitowata iyecen ska, he makipazo, he Wakantanka qa Amnos oiyotanke tawa kin etanhan kaduza.

2 Unkan canku cok wakpa kin anokatanhan wiconi can kin icaga, he waskuyeca ocaje ake nonpa aicaga, wi otoiyohi waskuyeca aicaliya ece; qa can wapa kin hena oyate kin okizi wicaya ece,

3 Unkan heciya wicayuśice wanice kta; uka Wakantanka oiyotank tawa kin he, qa Amnos tawa kin hen he kta, qa taokiye kin hena tawoahope kin ecen econpi kta:

$4 \mathrm{Qa}$ itohnake kin wanyakapi kta, qa caje kin iye itepi kin en yuhapi kta.

5 Qa heciya hanyetu wanice kta; qa petijanjan qa anpetu wi iyoyanpa kin he cinpi śni; Itancan Wakantanka iyoyamwicaya ece; qa ohinniyan owihanke wanin wicaśtayatapi ounyanpi kta.

6 Hehan hecen. emakiya, Wicoie kin dena wacinyepica qa wicakapi. Qa Itancan Wakantanka wicaśta wokcan wakan tawapi kin hee, taku ecadan u kte cin hena taokiye kin owicakiyake kta e on ohnihde tawa kin u śi.

7 Iho ecadan waukta. Tuwe wowapi kin de wowiyukcan oie kin tanyan yuhe cinhan he yawaśtepi ce.
1.

clome.

caśta wo.

makiya, Ihnuhan miś eya ookiye nihunkawanji wii kin etanhan waun, qa ton hapi kin de oie yuhapi kin hena owicawapa; Wakantanka ohoda wo.

10 Hehan ake hemakiya, Wowapi kin de wowiyukcan oie kin hena sutaya apuspe śni wo. Wanna ecadan kta ce.

11 Tuwe owotanna śni kin ohinniyan owotanna kte śni, qa tuwe aśape cin he ohinniyan aśapa un nunwe; qa tuwe owotanna kin he ohinniyan owotanna kta, qa tuwe ecedan kin he ohinniyan ecedan un nunwe.

12 Unkan iho, kohanna wau kta, qa taku mitawa kin hduha waun, otoiyohi iye wicolian kin eciyatanhan wicawaqu kta.

13 Alpha qa Omega, tokapa qa hakakta, otokahe qa owihanke kin he miye ce.

14 Tona tawoahope kin ecen econpi kin hena wicayawaśtepi, hecen wiconi can kin en ya okihipi kta, qa tiyopa kin ohna otonwe kin timahen yapi kta.

15 Tuka sunka, qa tona wapiyapi sa, qa wiinalimanpi sa, qa wawicihahiapi econpi sa, qa wakagapi ohodapi sa, qa tuwe itonśni waśtedake ca econ kin hena tankan yakonpi ece.

16 Jesus he miye ce, okodakiciye kin ekta niyepi kin en hena oniciyakapi kta e heon ohnihde mitawa kin u waśi. Dawid can hutkan adetka ko he miye, qa anpao wicanhpi nina iyege cin. 
NIN.

Wapi oie kin dena yuaoptetu kinhan, he taku tawa kte cin wiconi wowapi kin etanhan Wakantanka icu kta, qa otonwe wakan kin etanhan, qa taku tona wowapi kin de en kagapi kin he etanhan.

20 Tuwe hena yaotanin kin he kaken eya, Tho, kohanna wau kta ce. Amen. Itancan Jesus hecen yau nunwe.

21 Jesru kitay 今 f̂e towaonśida kin niye vasin en nicipi un kta. pi kin do en cajeyatapi kin Waika qu kta:

19 Qa tuwe wowiyukcan wo /Ami 408

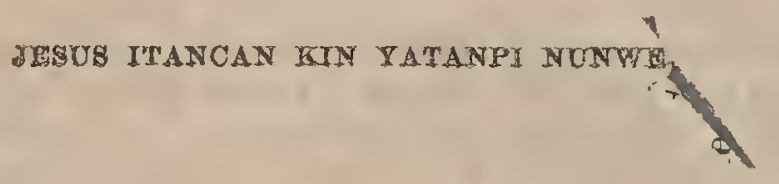

Microlarme ay

Provervolises

Samizs:

mira ${ }^{c} 6561.01$

$$
21 \mathrm{Nov} 95
$$




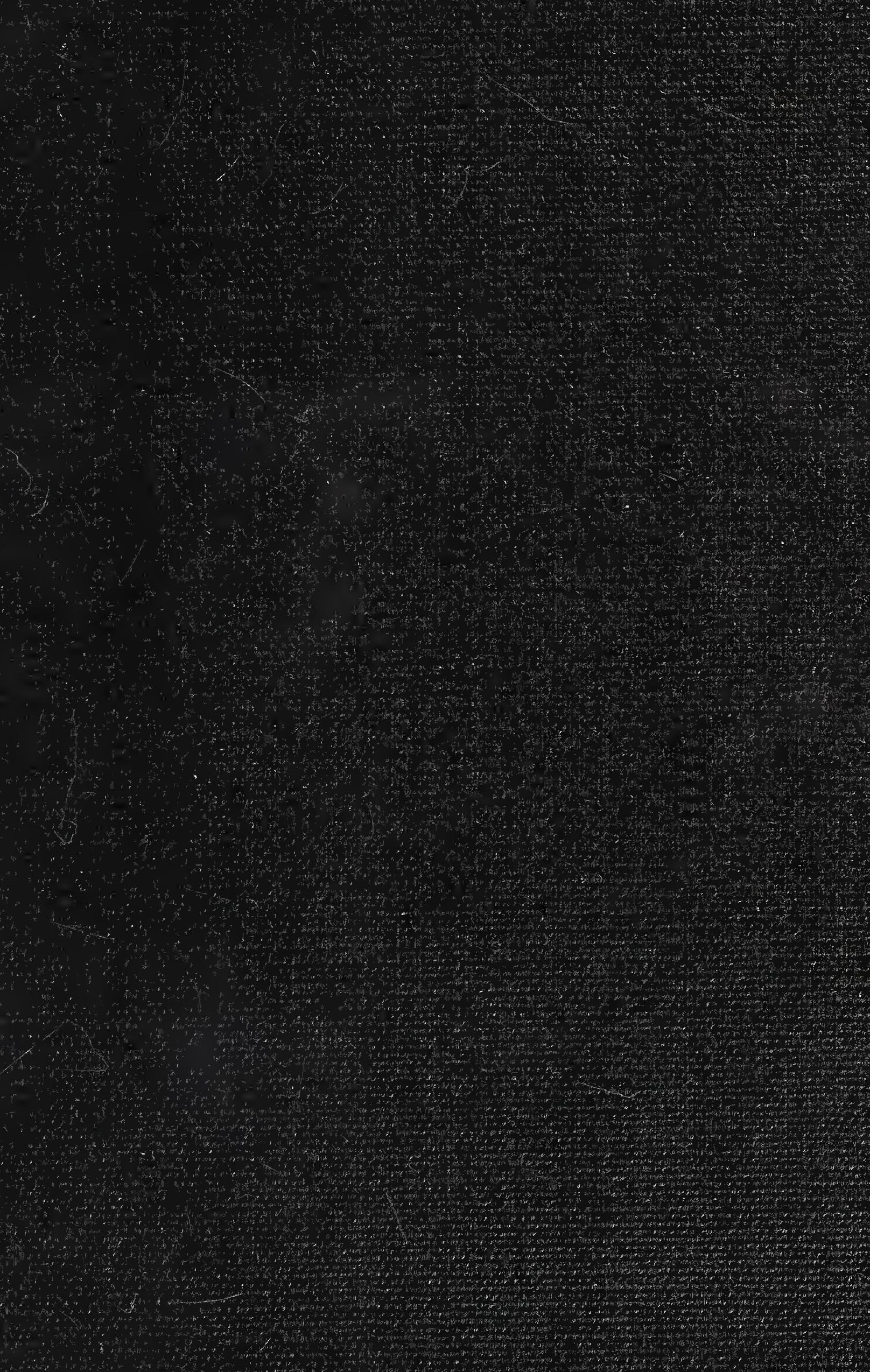


